\title{
Chemical, Geologic, and Hydrologic Data from the Little Colorado River Basin, Arizona and New Mexico, 1988-91
}

By GREGORY G. FISK, SHERYL A. FERGUSON, DALE R. RANKIN, and LAURIE WIRT

U.S. GEOLOGICAL SURVEY

Open-File Report 94-356

Prepared in cooperation with the

OFFICE OF NAVAJO AND HOPI INDIAN RELOCATION, U.S. BUREAU OF INDIAN AFFAIRS,

ARIZONA DEPARTMENT OF ENVIRONMENTAL QUALITY, ARIZONA DEPARTMENT OF WATER RESOURCES, NAVAJO NATION, and

NEW MEXICO ENVIRONMENT DEPARTMENT 


\title{
U.S. DEPARTMENT OF THE INTERIOR BRUCE BABBITT, Secretary
}

\author{
U.S. GEOLOGICAL SURVEY \\ Gordon P. Eaton, Director
}

Any use of trade, product, or firm names in this publication is for descriptive purposes only and does not constitute endorsement by the U.S. Government.

For additional information write to:

District Chief

U.S. Geological Survey

Water Resources Division

375 South Euclid Avenue

Tucson, AZ 85719-6644
Copies of this report can be purchased from:

U.S. Geological Survey

Earth Science Information Center

Open-File Reports Section

Box 25286, MS 517

Denver Federal Center

Denver, CO 80225 


\section{CONTENTS}

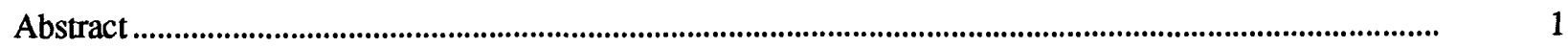

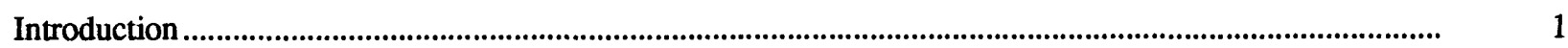

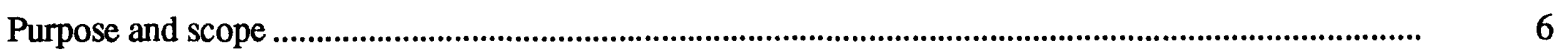

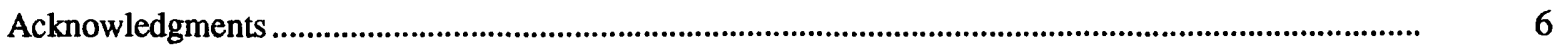

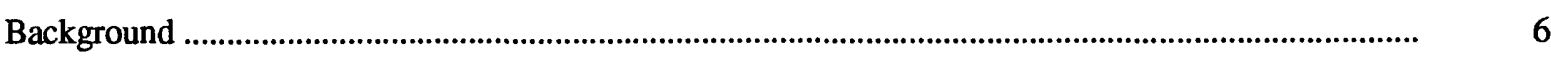

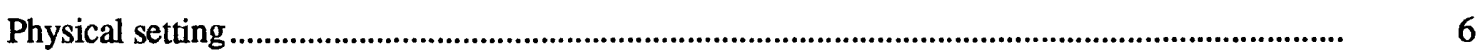

Hydrogeologic setting ..................................................................................................................

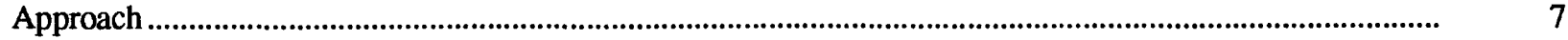

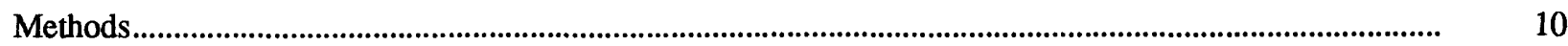

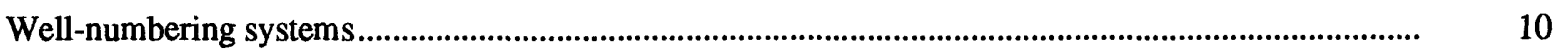

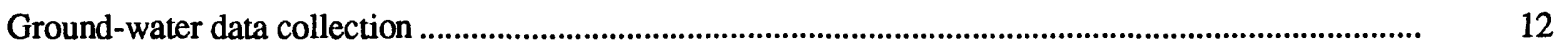

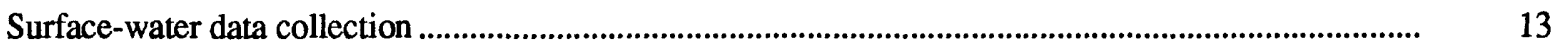

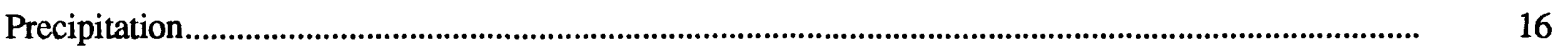

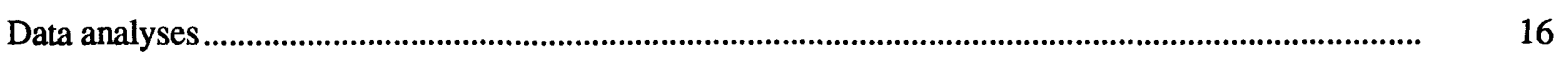

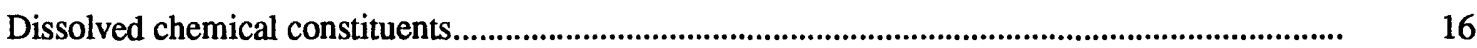

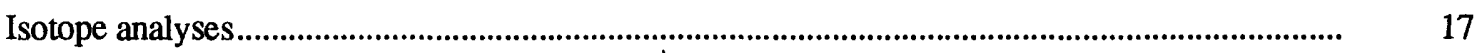

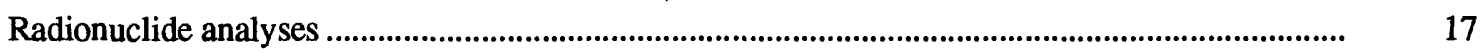

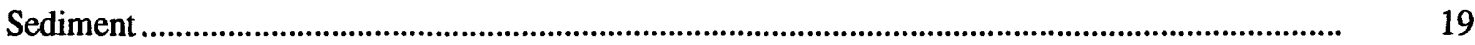

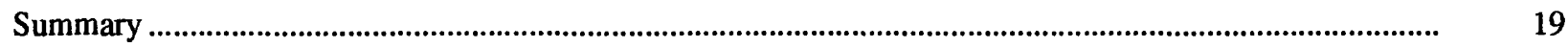

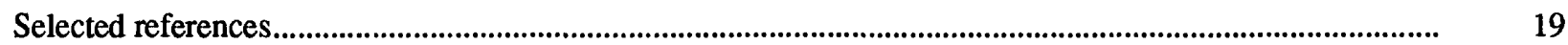

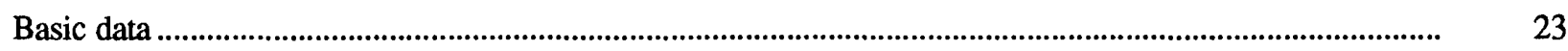

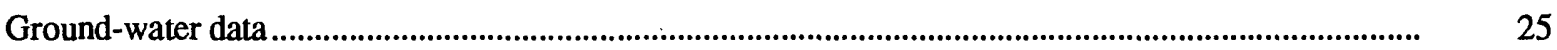

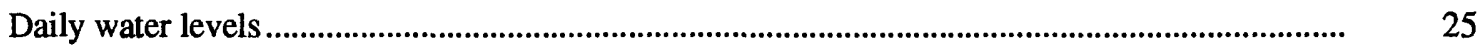

Discrete water levels................................................................................................................ 54

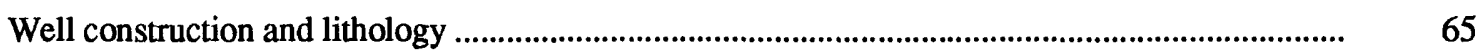

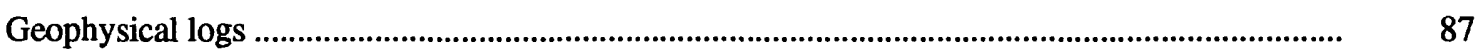

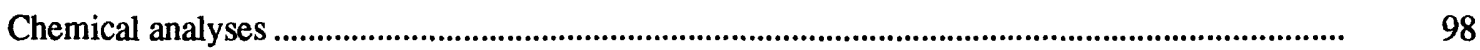

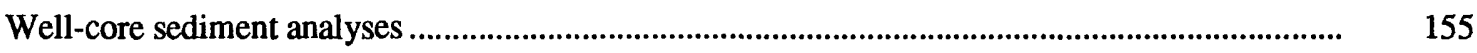

Radionuclide analyses ....................................................................................... 155

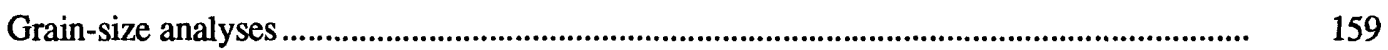

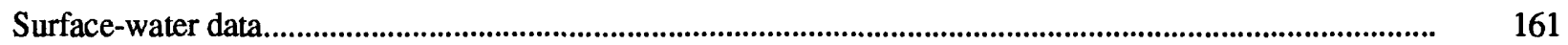

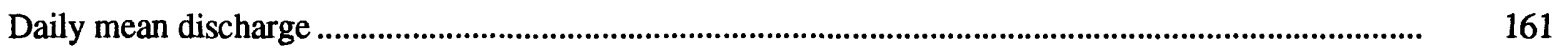

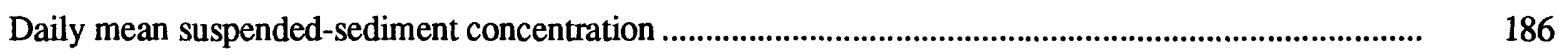

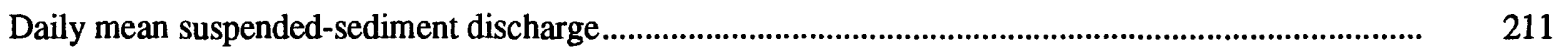

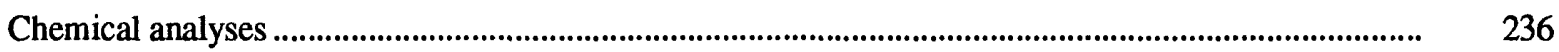

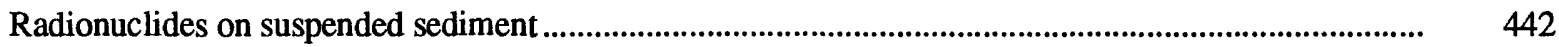

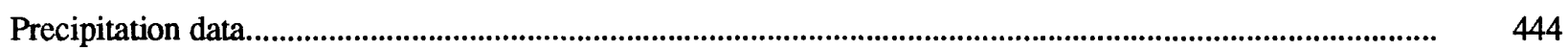




\section{FIGURES}

1.-2. Maps showing:

1. Little Colorado River basin in the Colorado Plateau region of Arizona and New Mexico, and locations of streamflow-gaging stations and selected uranium mines

2. Well clusters, temporary hand-driven wells, private wells, and spring

3.-6. Sketch showing:

3. Well-numbering system in Arizona

4. Well-numbering system in New Mexico

5. Surface-water samples collected using a continual-record streamflow-gaging station and an automatic water sampler.

6. Passive single-stage sampler, which collects water from near the surface during rising stages

\section{TABLES}

1. Continual-record and partial-record streamflow-gaging stations used to monitor the occurrence of radionuclides and suspended-sediment transport in the Little Colorado River basin, Arizona and New Mexico.

2. Summary of well-completion data for selected wells, Puerco River basin, Arizona and New Mexico.

3. Number of flow events sampled and samples collected at continual-record streamflow-gaging stations in the Little Colorado River basin, Arizona and New Mexico, water years 1989-91

4. Agencies that analyzed samples from the Little Colorado River basin,

Arizona and New Mexico.

\section{CONVERSION FACTORS}

\begin{tabular}{lll}
\hline \multicolumn{1}{c}{ Multiply } & By & \multicolumn{1}{c}{ To obtain } \\
\hline millimeter $(\mathrm{mm})$ & 0.03937 & inch \\
centimeter $(\mathrm{cm})$ & 0.3937 & inch \\
meter $(\mathrm{m})$ & 3.281 & foot \\
kilometer $(\mathrm{km})$ & 0.6214 & mile \\
square kilometer $\left(\mathrm{km}^{2}\right)$ & 0.3861 & square mile \\
cubic meter per second $\left(\mathrm{m}^{3} / \mathrm{s}\right)$ & 35.3107 & cubic foot per second \\
liter per second $(\mathrm{L} / \mathrm{s})$ & 15.85 & gallon per minute \\
megagram $(\mathrm{Mg})$ & 1.102 & ton, short $(2,000$ pounds $)$ \\
\hline
\end{tabular}

Air temperatures are given in degrees Celsius $\left({ }^{\circ} \mathrm{C}\right)$, which can be converted to degrees Fahrenheit $\left({ }^{\circ} \mathrm{F}\right)$ by the following equation:

$$
{ }^{\circ} \mathrm{F}=1.8\left({ }^{\circ} \mathrm{C}\right)+32
$$




\section{ABBREVIATED WATER-QUALITY UNITS}

Chemical concentration and water temperature are given only in metric units. Chemical concentration in water is given in milligrams per liter $(\mathrm{mg} / \mathrm{L})$ or micrograms per liter $(\mu \mathrm{g} / \mathrm{L})$. Milligrams per liter is a unit expressing the solute per unit volume (liter) of water. One thousand micrograms per liter is equivalent to 1 milligram per liter. For concentrations less than 7,000 milligrams per liter, the numerical value is about the same as for concentrations in parts per million. Specific conductance is given in microsiemens per centimeter $(\mu \mathrm{S} / \mathrm{cm})$ at 25 degrees Celsius. Radioactivity is expressed in picocuries per liter $(\mathrm{pCi} / \mathrm{L})$ or picocuries per gram $(\mathrm{pCi} / \mathrm{g})$, which is the amount of radioactive decay producing 2.2 disintegrations per minute in a unit volume (liter) of water or volume (gram) of sediment, respectively. Chemical concentration in material from core samples is given in grams per kilogram $(\mathrm{g} / \mathrm{kg})$ or micrograms per gram $(\mu \mathrm{g} / \mathrm{g})$. Micrograms per gram is equivalent to parts per million.

\section{VERTICAL DATUM}

Sea Level: In this report, "sea level" refers to the National Geodetic Vertical Datum of 1929-A geodetic datum derived from a general adjustment of the first-order level nets of the United States and Canada, formerly called Sea Level Datum of 1929. 


\title{
Chemical, Geologic, and Hydrologic Data from the Little Colorado River Basin, Arizona and New Mexico, 1988-91
}

\author{
By Gregory G. Fisk, Sheryl A. Ferguson, Dale R. Rankin, and Laurie Wirt
}

\section{Abstract}

In June 1988, the U.S. Geological Survey began a 4-year study of the occurrence and movement of radionuclides and other chemical constituents in ground water and surface water in the Little Colorado River basin in Arizona and New Mexico. Radionuclides and other chemical constituents occur naturally in water, rock, and sediment throughout the region; however, discharge of mine-dewatering effluents released by mining operations increased the quantity of radionuclides and other chemical contaminants. Additionally, in 1979, the failure of a tailingspond dike resulted in the largest known single release of water contaminated by uranium tailings in the United States. Ground-water and surface-water data were collected from July 1988 through September 1991. Sixty-nine wells were sampled, and collected data include well-construction information, lithologic logs, water levels, and chemical analysis of water samples. These wells include 31 wells drilled by the U.S. Geological Survey, 7 wells drilled by the New Mexico Environment Department, 11 private wells, and 20 temporary hand-driven wells; in addition, 1 spring was sampled. Data from the spring include flow rate and chemical analysis. Data from nine continual-record and five partial-record streamflow-gaging stations include daily mean discharge, daily mean suspended-sediment concentration and discharge, and chemical analysis for discrete water and sediment samples. Precipitation data also were collected at the nine continual-record stations.

\section{INTRODUCTION}

In June 1988, the U.S. Geological Survey (USGS) began collecting chemical, geologic, and hydrologic data in a 4-year study of the occurrence and movement of radionuclides and other chemical constituents in ground water and surface water in the Little Colorado River basin in northeastern Arizona and northwestern New Mexico (fig. 1; table 1). The Little Colorado River originates in the White Mountains of Arizona and New Mexico and has a drainage area of $69,800 \mathrm{~km}^{2}$ at its confluence with the Colorado River in the Grand Canyon. The Puerco River, a major tributary of the Little Colorado River, drains the west flank of the Chuska Mountains and the western part of the Grants Mineral Belt in New Mexico (fig. 2).
Uranium was mined in the upper Puerco River basin near Church Rock, New Mexico, from the 1950's until 1963 and from 1967 to 1986 . Uranium milling also took place near Church Rock from 1977 to 1986. Radionuclides and other chemical constituents occur naturally in water, rock, and sediments throughout the region; however, discharge of dewatering effluents released by mining operations increased the quantity of radionuclides and other chemical contaminants. During mining operations, water was pumped from mine shafts and discharged to Pipeline Arroyo, a tributary of the Puerco River (fig. 1). Water was pumped from the Church Rock Mine at a rate of less than $0.03 \mathrm{~m}^{3} / \mathrm{s}$ from 1960 until the mine was 


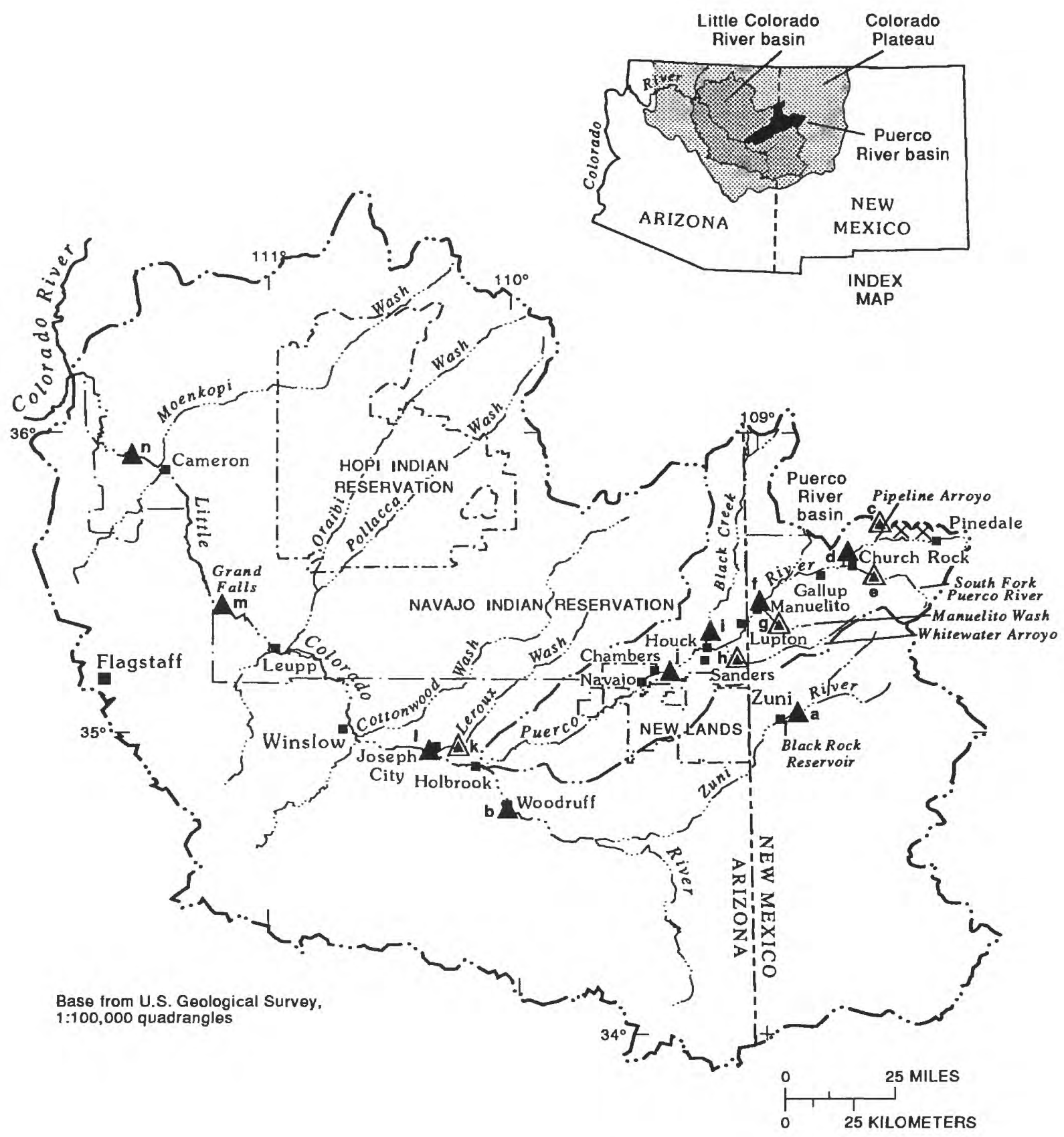

EXPLANATION

bA CONTINUOUS-RECORD STREAMFLOW-GAGING AND PRECIPITATION STATION-Letter, b, refers to station identification in table 1

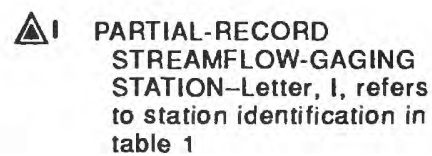

$\triangle 1 \quad$ PARTIAL-RECORD
STREAMFLOW-GAGING

to station identification in table 1

\section{\& URANIUM MINE}

URANIUM MINE

Figure 1. Little Colorado River basin in the Colorado Plateau region of Arizona and New Mexico and locations of streamflow-gaging stations and selected uranium mines. Samples were collected at streamflow-gaging stations to determine the amount of water, sediment, and chemical constituents transported in various parts of the basin. 
Table 1. Continual-record and partial-record streamflow-gaging stations used to monitor the occurrence of radionuclides and suspended-sediment transport in the Little Colorado River basin, Arizona and New Mexico

[C, continual-record streamflow-gaging station; $P$, partial-record streamflow-gaging station]

\begin{tabular}{|c|c|c|c|c|c|}
\hline Station number & $\begin{array}{c}\text { Station } \\
\text { number } \\
\text { as } \\
\text { shown in } \\
\text { flgure } 1\end{array}$ & Station name & $\begin{array}{c}\text { Station } \\
\text { type }\end{array}$ & $\begin{array}{l}\text { Drainage } \\
\text { area, in } \\
\text { square } \\
\text { kilometers }\end{array}$ & $\begin{array}{c}\text { Approximate } \\
\text { distance } \\
\text { downstream } \\
\text { from Church } \\
\text { Rock Mining } \\
\text { District, in } \\
\text { kilometers }\end{array}$ \\
\hline 09386950 & a & $\begin{array}{l}\text { Zuni River above Black Rock Reservoir, New } \\
\text { Mexico }\end{array}$ & C & 2,196 & (1) \\
\hline 09394500 & b & Little Colorado River at Woodruff, Arizona & c & 20,906 & $\left({ }^{1}\right)$ \\
\hline 353727108312001 & c & Pipeline Arroyo near Pinedale, New Mexico & $\mathbf{P}$ & 28 & 3 \\
\hline 09395350 & $\mathrm{~d}$ & Puerco River near Church Rock, New Mexico & C & 500 & 13 \\
\hline 353156108362301 & e & $\begin{array}{l}\text { South Fork Puerco River at Church Rock, New } \\
\text { Mexico }\end{array}$ & $\mathbf{P}$ & 2750 & $\left({ }^{1}\right)$ \\
\hline 09395630 & f & Puerco River near Manuelito, New Mexico & C & 2,176 & 62 \\
\hline 352450108592401 & $\mathbf{g}$ & Manuelito Wash near Manuelito, New Mexico & $\mathbf{P}$ & 250 & (1) \\
\hline 351515109072101 & h & Whitewater Arroyo near Allentown, Arizona & $\mathbf{P}$ & 378 & $\left({ }^{1}\right)$ \\
\hline 09395990 & i & $\begin{array}{l}\text { Black Creek below West Fork Black Creek near } \\
\text { Houck, Arizona }\end{array}$ & C & ${ }^{2} 1,680$ & $\left({ }^{l}\right)$ \\
\hline 09396100 & $\mathbf{j}$ & Puerco River near Chambers, Arizona & C & 5,584 & 119 \\
\hline 09397100 & $\mathbf{k}$ & Leroux Wash near Holbrook, Arizona & $\mathbf{P}$ & 2,077 & $\left({ }^{1}\right)$ \\
\hline 09397300 & 1 & Little Colorado River near Joseph City, Arizona & C & 32,075 & 215 \\
\hline 09401000 & $\mathrm{~m}$ & Little Colorado River at Grand Falls, Arizona & C & 54,908 & 355 \\
\hline 09402000 & $\mathbf{n}$ & Little Colorado River near Cameron, Arizona & C & 68,529 & 415 \\
\hline
\end{tabular}

${ }^{1}$ Not downstream from Church Rock Mining District.

${ }^{2}$ Approximate.

abandoned in 1963 (Hearne, 1977; Perkins and Goad, 1980). Mining resumed in 1967, and from 1967 to 1986 , dewatering discharges ranged from about 0.14 to $0.38 \mathrm{~m}^{3} / \mathrm{s}$ (Gallaher and Cary, 1986; New Mexico Water Quality Control Commission, 1988; Perkins and Goad, 1980).

In addition, the failure of a tailings-pond dike in 1979 resulted in the largest known single release of water contaminated by uranium mill-processing water and tailings in the United States. After the tailings-pond dike failure, public concern about the quality of surface water and ground water in the Puerco River basin increased, particularly in the
Navajo Tribal Trust Lands referred to as the New Lands area near Sanders, Arizona (fig. 1).

In 1985, the Office of Navajo and Hopi Indian Relocation (NHIR) requested that the USGS study the distribution of radionuclides in the water and sediment. Webb and others (1987) made a reconnaissance-level study of the ground-water chemistry in the Puerco River basin. Radionuclide activities in 5 of 14 wells were at or above the Federal and State of Arizona maximum contaminant level for drinking water of $15 \mathrm{pCi} / \mathrm{L}$ of gross alpha minus the sum of activity of uranium and radon (McClennan, 1984; U.S. Environmental Protection Agency, 1993). 


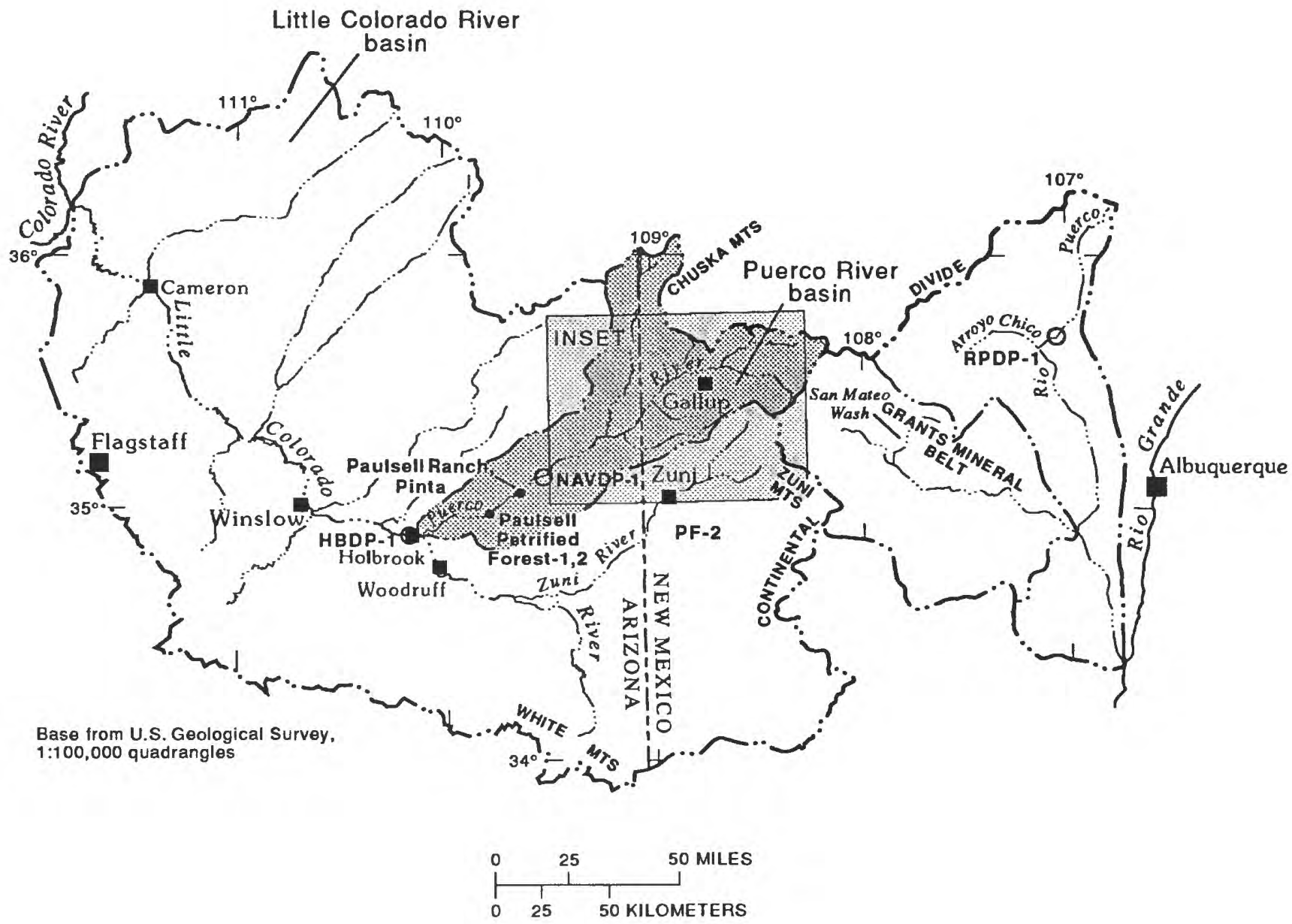

\title{
EXPLANATION
}

\author{
QRDP-1O TEMPORARY HAND-DRIVEN WELL AND \\ NAME FROM TABLE 2 \\ BLM-1U NEW MEXICO ENVIRONMENT DEPARTMENT \\ WELL CLUSTER AND INDIVIDUAL WELL NAME \\ - Codar Point U.S. GEOLOGICAL SURVEY WELl Cluster \\ (CP-1 to CP-8) AND INDIVIDUAL WELL NAME \\ - Paulsell PRIVATE WELL AND WELL NAME \\ Petrified \\ Forest-1,2 \\ Waterfall spring SPRING AND SPRING NAME
}

Figure 2. Well clusters, temporary hand-driven wells, private wells, and spring used for collection of data. 

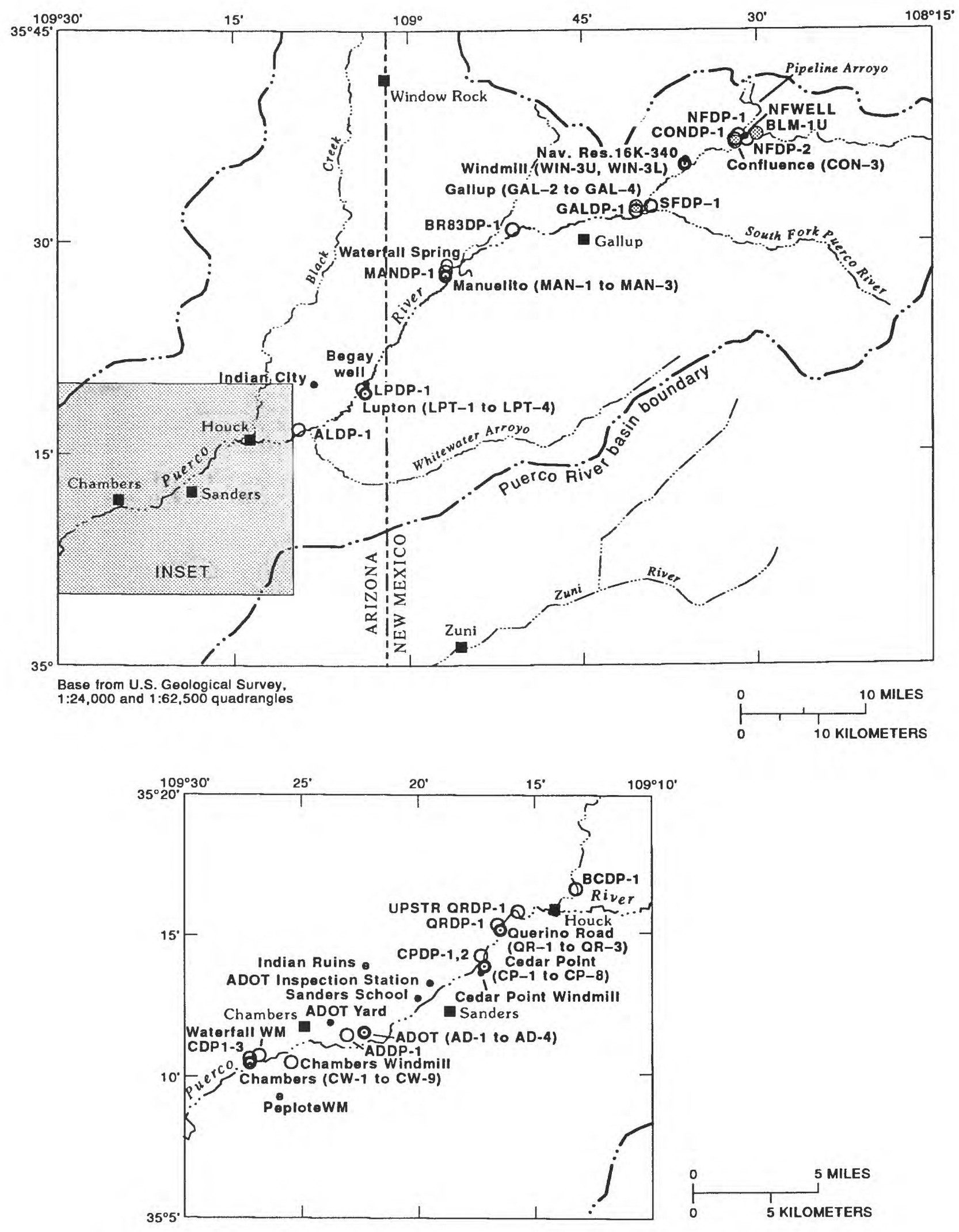

Figure 2. Continued. 
In 1988, the USGS began a more detailed study of the occurrence and movement of radionuclides and other chemical constituents in the Puerco and Little Colorado River basins in cooperation with the NHIR, U.S. Bureau of Indian Affairs (BIA), Arizona Department of Environmental Quality (ADEQ), Arizona Department of Water Resources (ADWR), the Navajo Nation, and New Mexico Environment Department (NMED).

\section{Purpose and Scope}

The purpose of this report is to present chemical, geologic, and hydrologic data for the Little Colorado River basin collected from June 1, 1988, to September 30, 1991. Types of data collected include ground-water levels, groundwater and well-core samples, surface-water discharge, surface-water and suspended-sediment samples, and precipitation data. Ground-water data include well-construction information, lithologic logs, water levels, and chemical analysis including analysis of radionuclides. Sixty-nine wells were sampled-31 wells drilled by the USGS, 7 wells drilled by the NMED, 11 private wells, and 20 temporary hand-driven wells-in addition, 1 spring was sampled. Data from the spring include flow rate and chemical analysis. Surfacewater data for nine continual-record and five partial-record streamflow-gaging stations include daily mean values for streamflow discharge, suspended-sediment concentration and discharge, and laboratory analysis of selected radionuclides and chemical constituents. Daily precipitation data are presented for the nine continual-record streamflow-gaging stations.

\section{Acknowledgments}

Wayne Lynch, Toby Martinez, and the Navajo Nation granted permission to install and access monitor wells. The Petrified Forest National Park, the Arizona Department of Transportation Maintenance Yard and Inspection Station, Sanders Public School, Indian City and Indian Ruins Trading Posts, and the Paulsell Ranch Trust gave permission for wells on their properties to be sampled. The State of New Mexico Highway Department granted permission to sample from the Interstate 40 bridge at Manuelito, New Mexico. The Atchison, Topeka, and Santa Fe Railroad Company granted permission to install a continual-record streamflow-gaging station near Chambers, Arizona.

\section{Background}

\section{Physical Setting}

The Little Colorado River basin of northeastern Arizona and northwestern New Mexico has a drainage area of $68,529 \mathrm{~km}^{2}$ upstream from the USGS streamflow-gaging station near Cameron, Arizona, which is $72 \mathrm{~km}$ upstream from the confluence with the Colorado River in northern Arizona. The Little Colorado River originates in the White Mountains of eastern Arizona and western New Mexico and flows $573 \mathrm{~km}$ to the northwest to its confluence with the Colorado River (fig. 2). Streamflow in the Little Colorado River generally is perennial upstream and ephemeral downstream from Joseph City, Arizona, and has steadily decreased in the last 100 years because of the construction of dams in the upper basin, which created lakes for recreation and provided storage for irrigation diversions.

The Puerco River drains about $7,800 \mathrm{~km}^{2}$ of the Little Colorado River basin (fig. 2). The headwaters of the Puerco River are in northwestern New Mexico, north of the Zuni Mountains and south of the Chuska Mountains in the southeastem part of the Colorado Plateau. The river flows $170 \mathrm{~km}$ southwest through Gallup, New Mexico, and west-southwest to the Little Colorado River near Holbrook, Arizona. The Puerco River is ephemeral along most of its length and is characterized by long periods of no flow. Peak runoff typically occurs in March and April from snowmelt and rainfall or in July and August from rainfall from thunderstorms (U.S. Department of Agriculture, 1981). Streamflow in some reaches of the Puerco River has become perennial as a result of effluent discharge from the municipal sewage-treatment plant at Gallup, New Mexico (Gallaher and Cary, 1986; Perkins and Goad, 1980).

Climate in the Little Colorado River basin is arid in the lower elevations and semiarid to 
subhumid in the mountainous regions. The mean annual precipitation ranges from about $200 \mathrm{~mm}$ near Cameron, Arizona, to about $800 \mathrm{~mm}$ at the basin divide south of Winslow, Arizona. Average daily temperatures in the basin range from $-3^{\circ}$ to $27^{\circ} \mathrm{C}$.

\section{Hydrogeologlc SettIng}

The Little Colorado River and Puerco River channels are cut into older alluvium that fills valleys eroded in the Quaternary Period (Leopold and Snyder, 1951; Mann and Nemecek, 1983). The valley fill varies in thickness from zero to about $45 \mathrm{~m}$ and in width from about $100 \mathrm{~m}$ to about $6 \mathrm{~km}$ (Mann and Nemecek, 1983). Graf (1990) found that the uppermost $48 \mathrm{~km}$ of the Puerco River channel could be divided into reaches underlain by thick alluvial-fill material separated by reaches where bedrock constrains the channel laterally or vertically.

The thickness of the alluvial aquifer along the Puerco and Little Colorado Rivers generally is unknown. Bedrock was found at 20,32, and $41 \mathrm{~m}$ below land surface during the drilling of monitor wells CP-7, CW-1, and CP-1, respectively (table 2) in the Chambers (CW) and Cedar Point (CP) well clusters (fig. 2). Bedrock was not found in a fourth well, $A D-1$, drilled to a depth of $59 \mathrm{~m}$ at the Arizona Department of Transportation cluster (ADOT) on the Lynch Ranch near Sanders, Arizona. In most places, the alluvial aquifer of the Puerco River is underlain by the nearly impermeable siltstone of the Chinle Formation of Triassic age, which impedes downward movement of water. In some areas, such as in tributary channels of the Puerco River near Navajo, Arizona, the alluvium overlies both the permeable sandstone of the Bidahochi Formation of Tertiary age and the sandstone beds of the Chinle Formation. In these areas the alluvium is hydraulically connected to the underlying unit. Most wells that penetrate these formations provide water for livestock and domestic supplies (Wirt and others, 1991).

When mining was active near Church Rock, New Mexico, water was pumped from deep mine shafts and discharged into Pipeline Arroyo. Discharge from mine-dewatering effluent from the Church Rock Mine ranged from 0.03 to $0.37 \mathrm{~m}^{3} / \mathrm{s}$ during mining operations (Hearne, 1977; Perkins and Goad, 1980; and Gallaher and Carey, 1986). In 1958, the City of Gallup, New Mexico, began operation of the sewage-treatment facility and has gradually increased effluent discharges. The facility typically discharges about $0.15 \mathrm{~m}^{3} / \mathrm{s}$ into the Puerco River (Albert Jackson, Wastewater System Superintendent, Water Maintenance and Repair, City of Gallup, New Mexico, written commun., 1990). Effluent discharged from the sewagetreatment plant in Gallup and from mine dewatering near Church Rock resulted in perennial flow in the Puerco River as far downstream as $24 \mathrm{~km}$ west of the Arizona-New Mexico border (Arizona Department of Health Services, 1983). Although mine dewatering ceased in 1986, discharges from the sewage-treatment facility in Gallup maintained perennial flow from Gallup to beyond the ArizonaNew Mexico border.

\section{APPROACH}

Radionuclides and other chemical constituents have a strong tendency to sorb to fine-grained sediment under most natural surface-water conditions (Ames and Rai, 1978; Horowitz, 1985; Horowitz and Elrick, 1987; Hsi and Langmuir, 1985; Langmuir, 1978). The high percentage of silt and clay-sized sediment in the Puerco and Little Colorado Rivers and the corresponding largeparticle surface area gives these sediments a high potential for sorption of chemical constituents. Radioactivity of unfiltered samples of storm runoff from the Puerco River has been measured as 2 to 3 orders of magnitude larger than in filtered water samples (Gallaher and Cary, 1986, p. 45-51; Gray and Webb, 1991). Sorbed chemical constituents on suspended sediment are easily transported by runoff. Because of the importance of sediment in transporting radionuclides and other constituents of concern in the Puerco and Little Colorado Rivers, the sampling-site network was designed for collection of data for computation of suspendedsediment loads and loads of chemical constituents carried with the sediment. Because most sediment is carried during brief, infrequent periods of runoff and sample sites are in remote locations, automatic suspended-sediment samplers were the primary mechanism for sample collection. 
Table 2. Summary of well-completion data for selected wells, Puerco River basin, Arizona and New Mexico

[Dashes indicate that data is not available]

\begin{tabular}{|c|c|c|c|c|c|c|c|c|c|}
\hline \multirow[b]{2}{*}{ Well name } & \multirow{2}{*}{$\begin{array}{c}\text { Site } \\
\text { Identification }\end{array}$} & \multirow{2}{*}{$\begin{array}{l}\text { Land- } \\
\text { surface } \\
\text { altitude, } \\
\text { In } \\
\text { meters } \\
\text { above } \\
\text { sea level }\end{array}$} & \multirow{2}{*}{$\begin{array}{l}\text { Hole } \\
\text { depth, } \\
\text { in } \\
\text { meters }\end{array}$} & \multirow{2}{*}{$\begin{array}{l}\text { Casing } \\
\text { depth, } \\
\text { in } \\
\text { meters }\end{array}$} & \multicolumn{2}{|c|}{$\begin{array}{l}\text { Screened } \\
\text { interval, } \\
\text { in meters }\end{array}$} & \multirow{2}{*}{$\begin{array}{c}\text { Uthologic } \\
\text { unit }\end{array}$} & \multirow{2}{*}{$\begin{array}{c}\text { Water } \\
\text { level } \\
\text { below } \\
\text { land } \\
\text { surface, } \\
\text { in } \\
\text { meters }\end{array}$} & \multirow{2}{*}{$\begin{array}{c}\text { Date } \\
\text { measured }\end{array}$} \\
\hline & & & & & From & To & & & \\
\hline $\mathrm{CW}-1$ & 351043109270301 & $1,744.22$ & 32.0 & 32.0 & 27.4 & 29.0 & Bedrock & 4.7 & $09-27-88$ \\
\hline$C W-2$ & 351043109270302 & $1,743.85$ & 25.0 & 25.0 & 14.3 & 15.8 & Alluvium & 3.6 & $09-27-88$ \\
\hline $\mathrm{CW}-3$ & 351043109270303 & $1,744.31$ & 11.7 & 11.7 & 4.6 & 6.1 & Alluvium & 4.2 & $09-27-88$ \\
\hline $\mathrm{CW}-4$ & 351038109270801 & $1,743.09$ & 30.5 & 30.5 & 27.4 & 29.0 & Alluvium & 3.4 & $09-27-88$ \\
\hline CW-5 & 351038109270802 & $1,743.02$ & 19.8 & 19.8 & 16.8 & 18.3 & Alluvium & 3.4 & $09-27-88$ \\
\hline $\mathrm{CW}-6$ & 351038109270803 & $1,743.14$ & 9.1 & 9.1 & 4.6 & 7.6 & Alluvium & 3.6 & $09-28-88$ \\
\hline $\mathrm{CW}-7$ & 351039109270001 & $1,748.75$ & 30.0 & 30.0 & 24.4 & 26.0 & Alluvium & 8.9 & $09-30-88$ \\
\hline $\mathrm{CW}-8$ & 351039109270002 & $1,748.88$ & 21.2 & 21.2 & 18.3 & 19.8 & Alluvium & 8.9 & $09-30-88$ \\
\hline CW-9 & 351039109270003 & $1,748.81$ & 16.5 & 16.5 & 11.6 & 14.6 & Alluvium & 8.8 & $09-30-88$ \\
\hline CDP-1 & 351044109270501 & ${ }^{1} 1,740$ & --.--.. & -.....- & $\ldots$ & -..-- & Alluvium & .7 & $01-16-89$ \\
\hline CDP-2 & 351044109270502 & ${ }^{1} 1,740$ & ----- & ------ & ------ & ----- & Alluvium & ---- & ---.---. \\
\hline CDP-3 & 351044109270503 & ${ }^{1} 1,740$ & 4.7 & -.---. & ----- & -..--- & Alluvium & .3 & $04-04-89$ \\
\hline CDP-4 & 351045109270601 & $1,740.87$ & ------- & ---.-- & ------ & ------ & Alluvium & $-\cdots--$ & -------- \\
\hline $\mathrm{AD}-1$ & 351140109220901 & $1,766.01$ & 59.1 & 57.9 & 36.6 & 39.6 & Alluvium & 5.3 & $06-20-89$ \\
\hline $\mathrm{AD}-3$ & 351140109220403 & $1,765.97$ & 12.2 & 10.1 & 5.5 & 8.5 & Alluvium & 6.1 & $06-22-89$ \\
\hline $\mathrm{AD}-4$ & 351144109220701 & $1,765.23$ & 12.2 & 11.6 & 5.5 & 8.5 & Alluvium & 7.6 & $06-28-89$ \\
\hline$A D-5$ & 351139109221301 & $1,765.44$ & 11.1 & 9.9 & 5.3 & 8.4 & Alluvium & 3.8 & $06-23-89$ \\
\hline ADDP-1 & 351135109225001 & ${ }^{1} 1,760$ & 11.0 & -.-- & ----- & ----- & Alluvium & .7 & $05-15-90$ \\
\hline CP-1 & 351411109170701 & $1,792.23$ & 41.0 & 33.2 & 26.8 & 28.3 & Bedrock & 6.6 & $06-15-89$ \\
\hline CP-2 & 351411109170702 & $1,792.30$ & 18.1 & 18.1 & 15.4 & 16.9 & Alluvium & 6.1 & $06-28-89$ \\
\hline CP-3 & 351411109170703 & $1,792.17$ & 8.1 & 8.1 & 6.2 & 7.8 & Alluvium & 6.0 & $06-28-89$ \\
\hline $\mathrm{CP}-4$ & 351415109170201 & $1,792.11$ & 8.1 & 8.1 & 5.8 & 7.3 & Alluvium & 5.7 & $06-28-89$ \\
\hline CP-5 & 351410109170201 & $1,791.71$ & 8.1 & 8.1 & 5.3 & 7.8 & Alluvium & 5.4 & $06-19-89$ \\
\hline $\mathrm{CP}-6$ & 351407109165801 & $1,791.48$ & 7.9 & 7.7 & 4.9 & 7.6 & Alluvium & 6.9 & $06-19-89$ \\
\hline $\mathrm{CP}-7$ & 351407109165601 & ${ }^{1} 1,800$ & 20.4 & 20.4 & 15.8 & 18.9 & Bedrock & 5.8 & $07-26-90$ \\
\hline CP-8 & 351407109165602 & ${ }^{1} 1,800$ & 39.6 & 39.6 & 35.1 & 38.1 & Bedrock & 5.8 & $07-26-90$ \\
\hline CPDP-1 & 351419109165901 & ${ }^{1} 1,790$ & 17.0 & ------- & 1.3 & 1.6 & Alluvium & .7 & $11-17-89$ \\
\hline CPDP-2 & 351419109165902 & ${ }^{1} 1,790$ & 13.0 & ------- & ----- & $\cdots$ & Alluvium & .5 & $05-16-90$ \\
\hline QR-1 & 351519109161501 & $1,796.55$ & 48.3 & 34.7 & 31.7 & 33.2 & Alluvium & 4.0 & $06-30-89$ \\
\hline QR-2 & 351519109161502 & $1,796.61$ & 9.1 & 9.0 & 4.3 & 7.5 & Alluvium & 3.8 & $06-27-89$ \\
\hline
\end{tabular}

See the footnotes at the end of the table. 
Table 2. Summary of well-completion data for selected wells, Puerco River basin, Arizona and New Mexico-Continued

\begin{tabular}{|c|c|c|c|c|c|c|c|c|c|}
\hline \multirow[b]{2}{*}{ Well name } & \multirow{2}{*}{$\begin{array}{c}\text { Site } \\
\text { Identlification }\end{array}$} & \multirow{2}{*}{$\begin{array}{l}\text { Land- } \\
\text { surface } \\
\text { altitude, } \\
\text { In } \\
\text { meters } \\
\text { above } \\
\text { sea level }\end{array}$} & \multirow{2}{*}{$\begin{array}{c}\text { Hole } \\
\text { depth, } \\
\text { In } \\
\text { meters }\end{array}$} & \multirow{2}{*}{$\begin{array}{c}\text { Casing } \\
\text { depth, } \\
\text { in } \\
\text { meters }\end{array}$} & \multicolumn{2}{|c|}{$\begin{array}{l}\text { Screened } \\
\text { Interval, } \\
\text { In meters }\end{array}$} & \multirow{2}{*}{$\begin{array}{l}\text { Lithologlc } \\
\text { unlt }\end{array}$} & \multirow{2}{*}{$\begin{array}{l}\text { Water } \\
\text { lovel } \\
\text { below } \\
\text { land } \\
\text { surface, } \\
\text { In } \\
\text { meters }\end{array}$} & \multirow{2}{*}{$\begin{array}{c}\text { Date } \\
\text { measured }\end{array}$} \\
\hline & & & & & From & To & & & \\
\hline QR-3 & 351519109161801 & $1,794.39$ & 9.1 & 8.8 & 4.3 & 7.3 & Alluvium & 1.4 & $06-27-89$ \\
\hline QRDP-1 & 351527109161901 & ${ }^{1} 1,790$ & 16.0 & -.---- & ----- & ------ & Alluvium & 1.6 & $06-07-89$ \\
\hline UPSTR QRDP-1 & 351620109152101 & ${ }^{1} 1,790$ & --.--- & -....- & .8 & 1.1 & Alluvium & 1.9 & $06-08-89$ \\
\hline LPT-1 & 351928109042601 & $1,888.52$ & 21.6 & 21.6 & 14.0 & 15.5 & Alluvium & 1.1 & $10-11-90$ \\
\hline LPT-2 & 351928109042602 & $1,888.76$ & 6.1 & 6.1 & 3.0 & 4.6 & Alluvium & 1.4 & $10-11-90$ \\
\hline LPT-3 & 351929109042401 & ${ }^{1} 1,890$ & 8.1 & 8.1 & 1.8 & 5.0 & Alluvium & 2.1 & $10-12-90$ \\
\hline LPT-4 & 351930109042701 & ${ }^{1} 1,890$ & 9.1 & 9.0 & 2.9 & 5.9 & Alluvium & 2.2 & $10-11-90$ \\
\hline LPDP-1 & 351942109041401 & ${ }^{1} 1,880$ & ------ & ----- & 1.1 & 1.4 & Alluvium & 2.6 & $06-11-90$ \\
\hline MAN-1 & 352742108563301 & ${ }^{1} 1,910$ & 24.8 & 24.8 & 21.8 & 23.3 & Alluvium & 6.5 & $10-10-90$ \\
\hline MAN-2 & 352742108563302 & ${ }^{1} 1,910$ & 13.7 & 13.7 & 7.6 & 10.7 & Alluvium & 7.9 & $06-06-90$ \\
\hline MAN-3 & 352743108563401 & ${ }^{1} 1,910$ & 15.7 & 15.7 & 9.6 & 14.2 & Alluvium & 7.9 & $10-06-90$ \\
\hline MANDP-1 & 352743108563201 & ${ }^{1} 1,900$ & -..-- & ----- & 0.7 & 1.0 & Alluvium & 2.1 & $10-16-90$ \\
\hline GAL-2 & 353219108400301 & ${ }^{1} 2,000$ & 12.2 & 12.2 & 9.1 & 12.2 & Alluvium & 4.1 & $10-24-90$ \\
\hline GAL -3 & 353218108400303 & ${ }^{1} 2,000$ & 3.7 & 3.7 & 2.8 & 3.7 & Alluvium & 4.2 & $10-24-90$ \\
\hline GAL-4 & 353218108400304 & ${ }^{1} 2,000$ & 7.4 & 7.4 & 6.5 & 7.4 & Alluvium & 4.0 & $10-24-90$ \\
\hline GALDP-1 & 353215108400401 & ${ }^{1} 1,980$ & 3.1 & ----- & ----- & ---- & Alluvium & 2.5 & $05-02-90$ \\
\hline WIN-3U & 353535108355003 & ${ }^{1} 2,040$ & 11.5 & 11.5 & 5.5 & 8.5 & Alluvium & 5.6 & $10-24-90$ \\
\hline WIN-3L & 353535108355004 & ${ }^{1} 2,040$ & 13.7 & 13.7 & $-\cdots--$ & ----- & Alluvium & 6.1 & $10-24-90$ \\
\hline $\mathrm{CON}-3$ & 353710108312803 & ${ }^{1}, 080$ & 13.1 & 13.1 & 8.5 & 11.6 & Alluvium & 10.0 & $01-11-88$ \\
\hline CONDP-1 & 353717108312801 & ${ }^{1} 2,070$ & 14.0 & ----- & .7 & 1.0 & Alluvium & .6 & $10-18-90$ \\
\hline BLM-1U & 353742108293601 & ${ }^{1} 2,090$ & 16.8 & 16.8 & 10.7 & 13.7 & Alluvium & 8.8 & $01-10-89$ \\
\hline NF WELL & 353726108303702 & ${ }^{1} 2,085$ & ------ & ----- & ---- & ----- & Alluvium & -..-- & --------- \\
\hline NFDP-1 & 353727108311501 & ${ }^{1} 2,090$ & ------- & ----- & ---- & ----- & Alluvium & ---- & --------- \\
\hline NFDP-2 & 353726108303701 & ${ }^{1} 2,085$ & -......- & $\cdots$ & ----- & ----- & Alluvium & .5 & $11-18-89$ \\
\hline $\begin{array}{l}\text { Paulsell Ranch, } \\
\text { Petrified Forest }\end{array}$ & 345757109482001 & ${ }^{1} 1,620$ & 13.7 & 13.7 & ----- & ----- & Alluvium & 4.4 & $07-14-89$ \\
\hline Petrified Forestfl2 & 345850109475001 & ${ }^{1} 1,620$ & 33.5 & 33.5 & .0 & 33.2 & Alluvium & 4.0 & $09-26-75$ \\
\hline Paulsell Ranch, Pinta & 350338109384801 & ${ }^{1} 1,670$ & 16.8 & 16.8 & ----- & $-\cdots$ & Alluvium & 4.2 & $12-05-86$ \\
\hline Waterfall Windmill & 351044109265401 & ${ }^{1} 1,750$ & 11.3 & 11.3 & ----- & $-\cdots$ & Alluvium & 9.5 & $08-21-75$ \\
\hline Chambers Windmill & 351039109251301 & ${ }^{1} 1,820$ & ------ & ------ & ----- & -.--- & -..--..-- & ------ & --.---n- \\
\hline Peplote Windmill & 350925109254201 & ${ }^{1} 1,850$ & 61.0 & 61.0 & ---- & ----- & -------- & 56.8 & $08-20-75$ \\
\hline
\end{tabular}

See the footnotes at the end of the table. 
Table 2. Summary of well-completion data for selected wells, Puerco River basin, Arizona and New Mexico—Continued

\begin{tabular}{|c|c|c|c|c|c|c|c|c|c|}
\hline \multirow[b]{2}{*}{ Well name } & \multirow{2}{*}{$\begin{array}{c}\text { Shie } \\
\text { Identificatlon }\end{array}$} & \multirow{2}{*}{$\begin{array}{c}\text { Land- } \\
\text { surface } \\
\text { altitude, } \\
\text { In } \\
\text { meters } \\
\text { above } \\
\text { sea level }\end{array}$} & \multirow{2}{*}{$\begin{array}{l}\text { Hole } \\
\text { depth, } \\
\text { in } \\
\text { meters }\end{array}$} & \multirow{2}{*}{$\begin{array}{l}\text { Casing } \\
\text { depth, } \\
\text { in } \\
\text { meters }\end{array}$} & \multicolumn{2}{|c|}{$\begin{array}{l}\text { Screened } \\
\text { Interval, } \\
\text { in meters }\end{array}$} & \multirow{2}{*}{$\begin{array}{l}\text { Wthologic } \\
\text { unlt }\end{array}$} & \multirow{2}{*}{$\begin{array}{c}\text { Water } \\
\text { level } \\
\text { below } \\
\text { land } \\
\text { surface, } \\
\text { In } \\
\text { meters }\end{array}$} & \multirow{2}{*}{$\begin{array}{c}\text { Date } \\
\text { measured }\end{array}$} \\
\hline & & & & & From & To & & & \\
\hline ADOT Yard & 351202109233001 & ${ }_{1}^{1,760}$ & -..-- & …..- & -..-- & -...- & 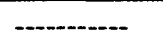 & -...-- & ------ \\
\hline Cedar Point Windmill & 351311109183701 & ${ }^{1} 1,800$ & 39.6 & 22.9 & 0.0 & 22.2 & Bedrock & 9.1 & $12-11-75$ \\
\hline Sanders School & 351254109194501 & $1_{1,770}$ & 48.8 & 48.8 & -.-- & $\cdots$ & Alluvium & 36.6 & --.-- \\
\hline $\begin{array}{l}\text { ADOT Inspection } \\
\text { Station }\end{array}$ & 351325109191601 & ${ }^{1} 1,790$ & ----- & ------ & ----- & -.-- & ------ & -..--.- & --o- \\
\hline Indian Ruins & 351400109220001 & ${ }^{1} 1,870$ & ------ & ------ & ----- & $-\cdots--$ & Bedrock & --.-- & --.--n- \\
\hline Indian City & 352000109075001 & $1_{2,010}$ & …-. & -.....- & $-\cdots$ & -.-- & -......- & -...-. & -......... \\
\hline Begay Well & 351933109041701 & ${ }^{1} 1,860$ & 3.07 & 3.07 & $-\cdots$ & $\ldots$ & Alluvium & 2.1 & $12-03-86$ \\
\hline Navajo Res. $16 \mathrm{~K}-340$ & 353535108355005 & ${ }^{1} 2,040$ & 43.0 & 43.0 & $-\cdots$ & $-\cdots$ & (n) & 11.3 & $06-22-54$ \\
\hline $\begin{array}{l}\text { Holbrook DP } \\
\text { (HBDP-1) }\end{array}$ & 345351110094401 & -....... & ------ & - & ---- & ---- & - & ----- & -.------ \\
\hline $\begin{array}{l}\text { Navajo DP } \\
\text { (NAVDP-1) }\end{array}$ & 350719109320801 & ${ }^{1} 1,710$ & 1.46 & $\cdots$ & $\cdots$ & $\cdots$ & $\cdots$ & $\cdots$ & $\cdots$ \\
\hline $\begin{array}{l}\text { Allentown DP } \\
\text { (ALDP-1) }\end{array}$ & 351650109064801 & ${ }^{1} 1,830$ & 1.46 & ------ & ----- & ----- & & .49 & $06-12-91$ \\
\hline $\begin{array}{l}\text { Black Creek DP } \\
\text { (BCDP-1) }\end{array}$ & 351645109130001 & ${ }^{1} 1,840$ & 1.22 & 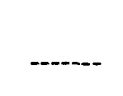 & ----- & ----- & (n.......- & .35 & $05-16-90$ \\
\hline $\begin{array}{l}\text { South Fork DP } \\
\text { (SFDP-1) }\end{array}$ & 353232108384801 & ${ }^{1} 2,010$ & 1.46 & ----- & ----- & ---- & ---o--- & ---- & -...-.- \\
\hline $\begin{array}{l}\text { Bridge-83 DP } \\
\text { (BR83DP-1) }\end{array}$ & 350356108504401 & ${ }^{1} 1,930$ & 1.46 & $\cdots$ & $\cdots$ & ---- & -.... & .061 & $10-16-90$ \\
\hline $\begin{array}{l}\text { Rio Puerco DP } \\
\text { (RPDP-1) }\end{array}$ & 354020107043301 & ${ }^{1} 1,800$ & 1.22 & -..-- & ---- & ---- & - & ----- & - \\
\hline
\end{tabular}

${ }^{1}$ Elevation measured from topographic map.

${ }^{2}$ Water level measured below streambed.

\section{METHODS}

Most of the data in this report were collected using standard USGS methods. Methods for collection, examination, and computation of records of discharge, sediment, water chemistry, and other hydrologic data; definition of downstream order; and methods of identifying data-collection sites are described by Boner and others (1992, p. 6-37), except as noted.

\section{Well-Numbering Systems}

The well numbers used by the USGS in Arizona are in accordance with the Bureau of Land Management's system of land subdivision. The land survey in Arizona is based on the Gila and Salt River Meridian and Base Line, which divides the State into four quadrants (fig. 3). These quadrants are designated counterclockwise by the capital letter-A, B, C, and D. All land north and east of the point of origin is in A quadrant, that north and 
R.28 E.

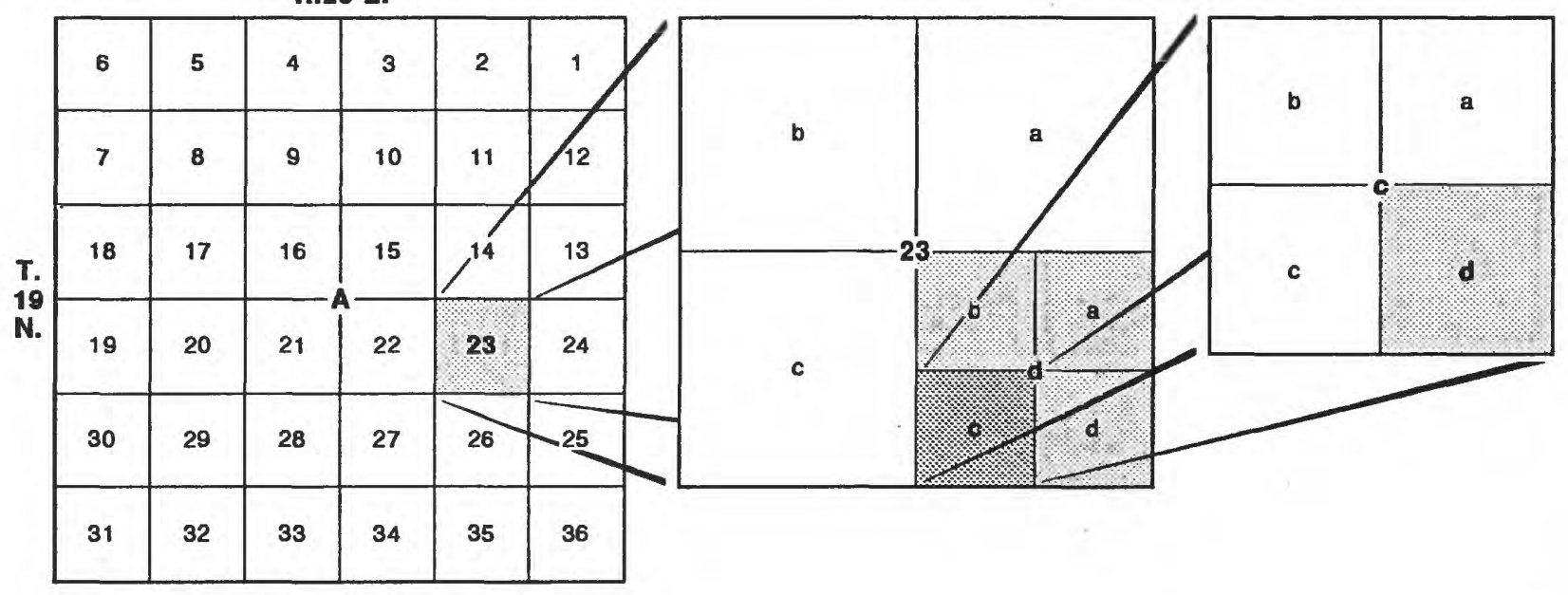

Quadrant A, Township 19 North, Range 28 East, section 23, quarter section d, quarter section $\mathrm{c}$, quarter section $\mathrm{d}$

Figure 3. Well-numbering system in Arizona. Wells are numbered according to a system that uses numbers and letters to identify the location of wells (Smith and others, 1992).

west in B quadrant, that south and west in C quadrant, and that south and east in D quadrant. The first digit of a well number indicates the township, the second the range, and the third the section in which the well is situated. The lower case letters $a, b, c$, and $d$ after the section number indicate the subsections. The first letter denotes the first quarter section, the second the quarter section of the first quarter section, and the third the quarter section of the second quarter section. These letters also are assigned in a counterclockwise direction, beginning in the northeast quarter. Lowercase letters are assigned only to known subsections; for example, if the well location within the third subsection is not known, then there will be only two lowercase letters. The well number (A-19-28)23dcd designates the well as being in quadrant A, Township 19 North, Range 28 East, section 23, subsection d, subsection c, subsection d (fig. 3). The well is in the $\mathrm{SE}_{\frac{1}{4}} \mathrm{SW}_{\frac{1}{4}} \mathrm{SE}_{\frac{1}{4}}^{1} ; \mathrm{sec} .23$, T. 19 N., R. $28 \mathrm{E}$. Where there is more than one well within a subsection, consecutive numbers beginning with 1 are added as suffixes.

In New Mexico, the State identification number locates the well site to the nearest 10 -acre tract in the land network (fig. 4). The site number is divided into four segments. The first segment denotes the township north or south of the New Mexico Base Line; the second segment denotes the range east or west of the New Mexico Principal Meridian; the third segment denotes the section. The fourth segment, consisting of three digits, denotes the 160-, 40-, and 10-acre tracts, respectively, in which the site is situated. The section is divided into four quarters, numbered 1, 2, 3, and 4, clockwise, for the northwest, northeast, southeast, and southwest quarters, respectively. The first digit of the fourth segment gives the quarter section, which is a tract of 160 acres. Similarly, the quarter section is divided into four 40 -acre tracts numbered in the same manner, the second digit denotes the 40-acre tract. Finally, the 40-acre tract is divided into four 10-acre tracts; the third digit denotes the 10-acre tract. Thus, site T.16N., R.16W.,17.214 is in the $\mathrm{SE}_{\frac{1}{4}} \mathrm{NW}_{\frac{1}{4}} \mathrm{NE}_{\frac{1}{4}}$, section 17 , Township 16 North, Range 16 West. If the site cannot be located accurately within a 10-acre tract, the third digit is absent; if it cannot be located accurately within a 40-acre tract, both the second and third digits are absent. If the site cannot be located more closely 
R.16 W.

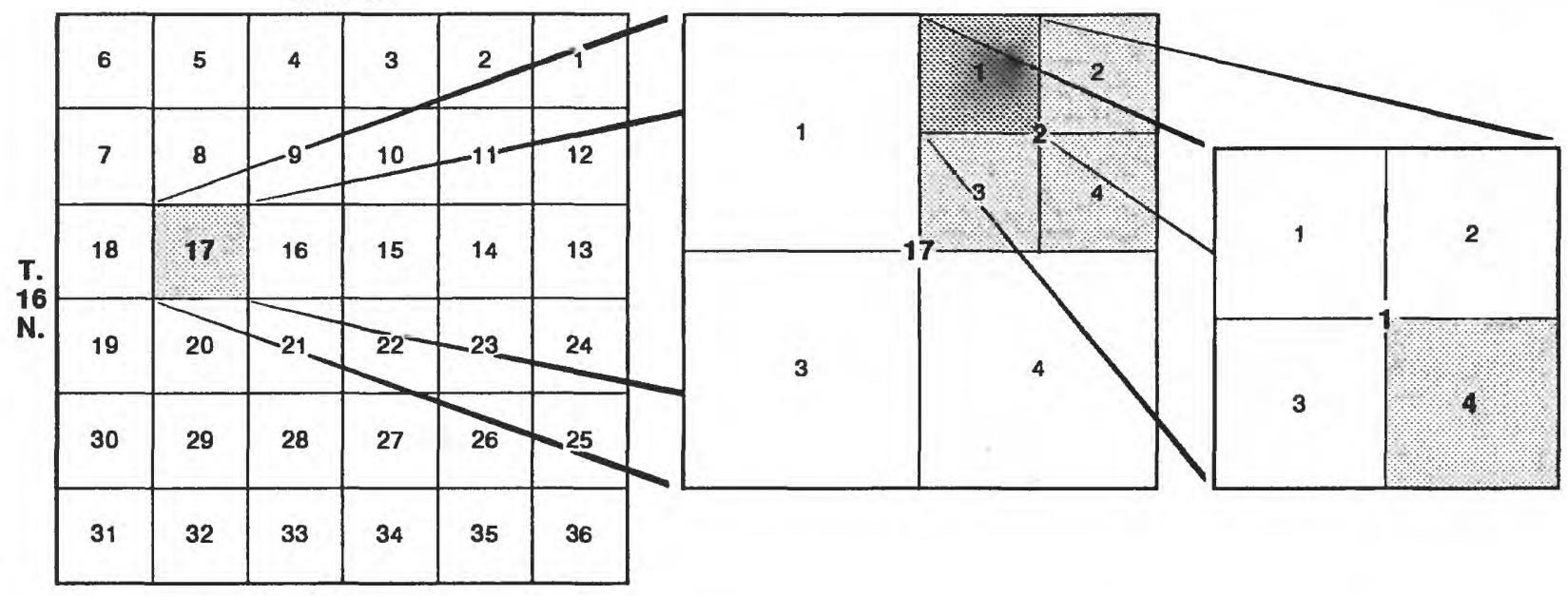

Township 16 North, Range 16 West, section 17, quarter section 2, quarter section 1, quarter section 4

Flgure 4. Well-numbering system in New Mexico. The well-numbering system for New Mexico is similar to that in Arizona, but uses numbers rather than letters (Gallaher and Cary, 1986).

than a section, the entire fourth segment of the number is omitted (Gallaher and Cary, 1986).

\section{Ground-Water Data Collection}

The USGS drilled 33 wells at 6 different sites, referred to as clusters that had 3 to 9 wells each. Thirty-one wells had sufficient flow to monitor water levels and to sample for chemical constituents. The six USGS well clusters (fig. 2) are: (1) near Manuelito, New Mexico; (2) near Lupton, Arizona; (3) downstream from Querino Road near Houck, Arizona; (4) at Cedar Point, Arizona; (5) near the Arizona Department of Transportation (ADOT) maintenance yard near Chambers, Arizona (referred to as the ADOT Cluster); and (6) near Chambers, Arizona. Monitor wells were constructed of 51-millimeter-diameter polyvinylchloride (PVC) pipe with a 0.25-millimeter screen that was 1.6 to $3.0 \mathrm{~m}$ in length. Twenty-seven of the 31 wells were drilled into the alluvium and four were drilled into the bedrock below the alluvium. Ten wells-four at Chambers Cluster (CW-2, CW-3, CW-6, and CW-9); two at ADOT Cluster
(AD-3 and AD-5); one at Querino Road Cluster $(\mathrm{QR}-2)$; and three at Cedar Point Cluster (CP-2, $\mathrm{CP}-3$, and $\mathrm{CP}-4$ ) were equipped with continual water-level recorders (table 2). Water levels were recorded at 15 -minute intervals. The remaining wells were inspected and water levels were measured monthly. Thirty-one wells were sampled at least once, and selected wells were measured biannually to determine temporal variations. Water samples were collected from monitor wells using a submersible pump. Dissolved-oxygen concentration, specific conductance, water temperature, and $\mathrm{pH}$ were monitored continually during pumping to ensure that the conditions in the well had stabilized before samples were collected.

Temporary shallow wells were placed at 20 locations in the Puerco River streambed. The wells were hand driven into the streambed to a depth where the screen was below the water table. Well casings were constructed of 32-millimeterdiameter stainless-steel pipe with a 0.25 -millimeter screen that was $61 \mathrm{~cm}$ in length. Water samples were collected with a peristaltic pump.

In addition to wells installed by the USGS, 18 existing wells also were sampled. The New Mexico Environment Department (NMED) granted access 
to 7 wells in 4 NMED clusters between Pipeline Arroyo and Gallup, New Mexico (fig. 2). Eleven private wells also were sampled. These samples were collected from a spigot or with a submersible pump. The spring was sampled using a peristaltic pump to pump water from the spring opening directly to the churn splitter.

\section{Surface-Water Data Collection}

Data were collected at nine continual-record and five partial-record streamflow-gaging stations (table 1). The continual-record streamflow-gaging stations had five principal components: (1) a datacollection platform (DCP), (2) a stage sensor, (3) a rain gage, (4) an automatic water sampler, and (5) an auxiliary pump (fig. 5). The DCP's were programmed to: (1) receive and store input from the stage sensor and rain gage, (2) trigger as many as 24 automatic water samples, (3) record individual water-sample numbers and their corresponding times, and (4) transmit data every 4 hours to a USGS computer by satellite.

The automatic water-sampling system had two subcomponents - a Manning Environmental

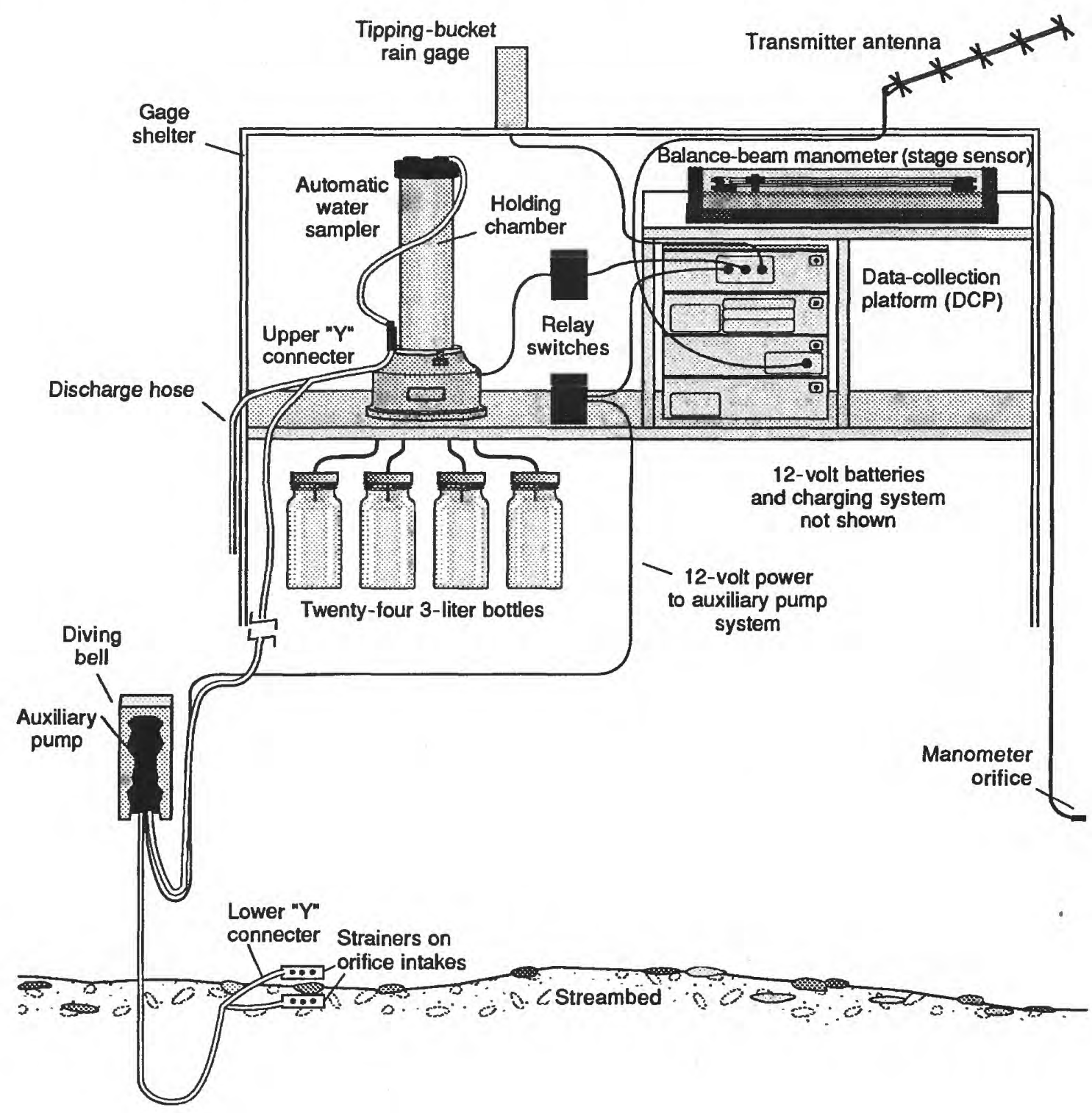

Figure 5. Surface-water samples collected using a continual-record streamflow-gaging station and an automatic water sampler. 
Corporation Model S-4050 automatic water sampler and an auxiliary pump (fig. 5). All automatic water-sampling system parts that contacted water samples were nonmetallic. The auxiliary pumps were near the channel and pumped water from the stream to the automatic samplers. The automatic samplers collected as many as 24 individual 3-liter samples and distributed them to sample bottles. The DCP's were programmed to activate the automatic sampler and auxiliary pump when stage, change-in-stage, and change-in-time criteria were met. The automatic water-sampling system resulted in the sampling of 6 to 19 flow events at the nine continual-record streamflow-gaging stations (table 3).

The five partial-record streamflow-gaging stations consisted of a bank of as many as eight passive single-stage samplers and a peak-stage indicator. The samplers collected water samples from near the water surface during rising stages (fig. 6). Samplers designed for this study were a modification of the U-59 series single-stage sampler developed by the Subcommittee on Sedimentation (1961).

Continual-record and partial-record streamflow-gaging stations were visited during runoff, when possible, or soon after runoff occurred. Water samples were removed and prepared for processing and analysis. During runoff, water discharge was measured using methods described by Rantz and others (1982) and flow-integrated samples were collected using methods described by Edwards and Glysson (1988).

Water samples collected manually and with automatic water samplers typically had high concentrations of sediment, which made filtering difficult. Consequently, samples were transported to field offices in Flagstaff, Arizona, or Albuquerque, New Mexico, for processing. Water samples were processed either as individual discrete samples to obtain an instantaneous value, or as a flow-weighted composite, to obtain a value representative of a period of runoff, using the following equation

where

$$
S_{i}=\frac{T_{i} Q_{i} \sum_{i=1}^{n} S_{i}}{\sum_{i=1}^{n} T_{i} Q_{i}}
$$

$S i=$ volume of the individual sample, representing the interval T;

Table 3. Number of flow events sampled and samples collected at continual-record streamflow-gaging stations in the Little Colorado River basin, Arizona and New Mexico, water years 1989-91.

\begin{tabular}{llcccc}
\hline $\begin{array}{c}\text { Station } \\
\text { number }\end{array}$ & \multicolumn{1}{c}{ Station name } & $\begin{array}{c}\text { Number } \\
\text { of } \\
\text { flow } \\
\text { ovents } \\
\text { sampled }\end{array}$ & $\begin{array}{c}\text { Number } \\
\text { of } \\
\text { samples } \\
\text { collected }\end{array}$ & $\begin{array}{c}\text { Number of } \\
\text { composite } \\
\text { samples }\end{array}$ & $\begin{array}{c}\text { Number } \\
\text { of } \\
\text { flow- } \\
\text { Integrated } \\
\text { samples }\end{array}$ \\
\hline 09386950 & Zuni River above Black Rock Reservoir, New Mexico & 13 & 27 & 0 & 3 \\
09394500 & Little Colorado River at Woodruff, Arizona & 13 & 79 & 5 & 2 \\
09395350 & Puerco River near Church Rock, New Mexico & 11 & 32 & 0 & 3 \\
09395630 & Puerco River near Manuelito, New Mexico & 14 & 35 & 0 & 2 \\
09395990 & Black Creek near Houck, Arizona & 6 & 22 & 0 & 2 \\
09396100 & Puerco River near Chambers, Arizona & 15 & 37 & 2 & 2 \\
09397300 & Little Colorado River near Joseph City, Arizona & 16 & 78 & 2 & 3 \\
0940100 & Little Colorado River at Grand Falls, Arizona & 14 & 90 & 7 & 8 \\
09402000 & Little Colorado River near Cameron, Arizona & 19 & 33 & 3 & 11 \\
\hline
\end{tabular}




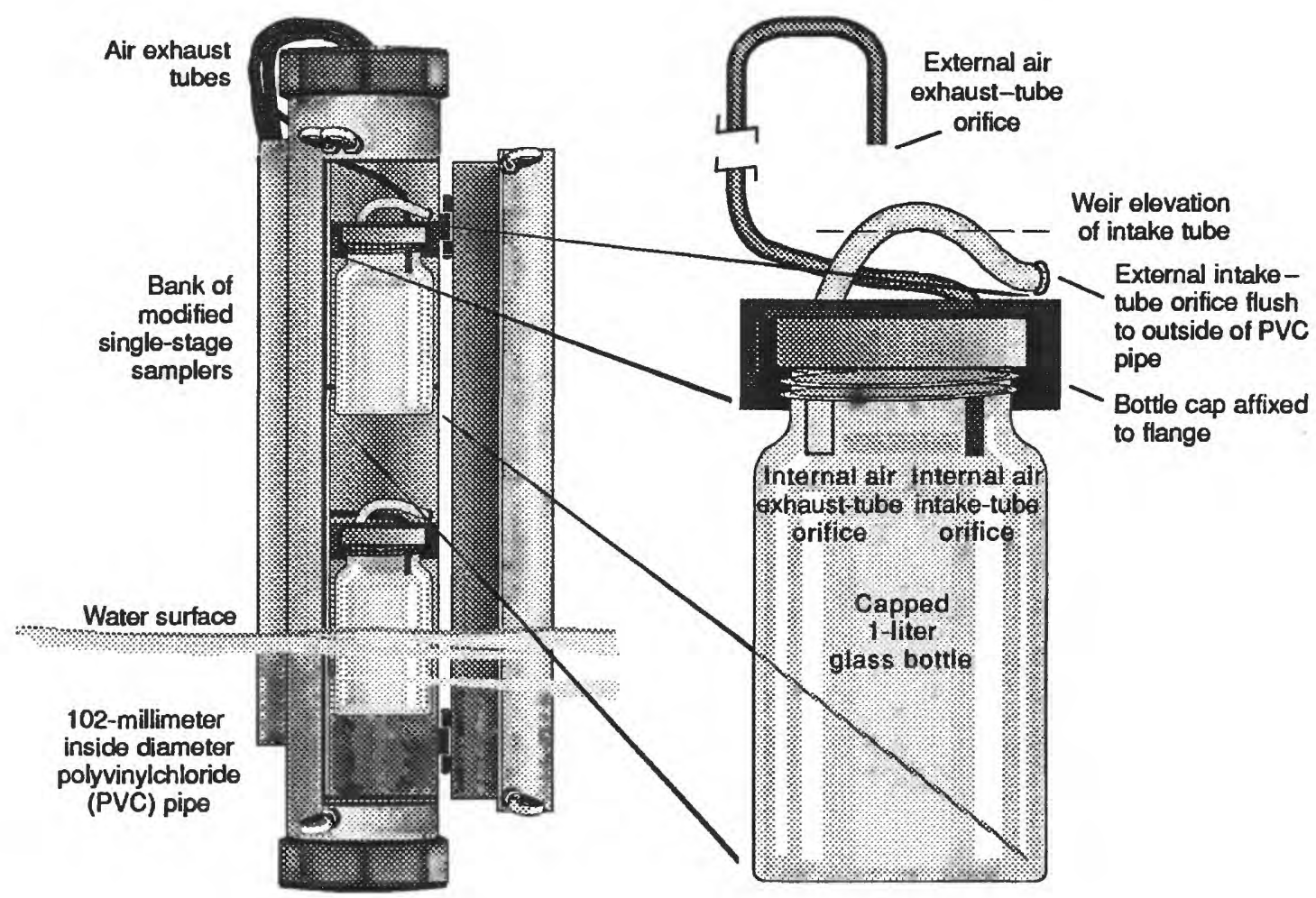

Figure 6. Passive single-stage sampler, which collects water from near the surface during rising stages (Gray and Fisk, 1992).

$T i=$ interval time, in minutes, from the start of the event to the midpoint between the first and second sample, or from the midpoints between the following samples, and from the midpoint before the last sample to the end of the event;

$Q i=$ mean discharge during the sample interval; and

$n=$ number of intervals.

Flow-weighted composite samples, which require a single laboratory analysis for constituent concentration to represent an entire runoff period, were used to reduce the number and cost of analyses. A representative aliquot from each discrete sample that was proportional to the volume of runoff event was obtained using a cone-splitter.
The composite sample was processed using standard methods. All individual samples of the runoff event were processed and analyzed for sediment concentration.

Because suspended-sediment samples from the Little Colorado River basin normally contained large amounts (5-20 percent sediment by weight) of fine-grained $(<0.062 \mathrm{~mm})$ sediment, special techniques were required to separate sediment from water for chemical analysis of dissolved constituents. Samples for dissolved-constituent analyses usually were centrifuged before filtering to remove the large concentrations of sediment from suspension. Disposable high-surface area $(0.45 \mu \mathrm{m})$ cartridge filters were used to filter the centrifuged water. Filters were rinsed before use with about $200 \mathrm{~mL}$ of deionized water and about $100 \mathrm{~mL}$ of sample water. Because large amounts of colloidal material in the water quickly clogged the filter, only $100 \mathrm{~mL}$ of sample water were used to rinse the filter. The sediment obtained from the centrifuge was oven dried at $80^{\circ} \mathrm{C}$ and then 
processed for the analysis of suspended constituents.

Because certain dissolved gases, such as carbon dioxide $\left(\mathrm{CO}_{2}\right)$ in streamflow, are volatile and escape rapidly to the atmosphere, the chemistry of the streamflow samples may have changed between collection, processing, and preservation. A change in the chemistry would account for high concentrations of dissolved iron, dissolved manganese, dissolved copper, and dissolved zinc that were determined in some automated and manual samples. Manually collected cross-section samples could have been contaminated by samplers used for collection of integrated samples (David A. Rickert, hydrologist, U.S. Geological Survey, oral commun., 1992). Sampler contamination has been shown to cause high concentrations of arsenic, cadmium, chromium, copper, iron, lead, zinc, and beryllium in the dissolved phase. In this study, the dissolved chemistry of manually collected samples was not significantly different from the chemistry of automated (Manning) samples; therefore, sampler contamination was not evident.

\section{Precipitation}

Precipitation data were collected at the nine continual-record surface-water sites with tippingbucket gages. The precipitation gages recorded in increments of $0.25 \mathrm{~mm}$ per tip, and data were compiled as daily totals.

\section{Data Analyses}

Chemical analyses were made by the USGS National Water Quality Laboratory (NWQL), Arvada, Colorado, except as noted. All non-USGS laboratories that analyzed samples were inspected and approved by the NWQL before use. Analyses not made by the NWQL are identified by numeric or letter codes in the data tables. Most samples were shipped to the NWQL and then to laboratories subcontracted by the NWQL; however, some samples were shipped directly to other USGS laboratories and to the New Mexico Health and Environment Department Scientific Laboratory Division (NMSLD; table 4, this report). Most of the column headings in tables containing results of chemical analysis include a five-digit parameter code used by the USGS computer system, WATSTORE, to uniquely identify a constituent.

\section{Dissolved Chemlcal Constltuents}

Analyses for dissolved chemical constituents were made by NWQL, which performed analyses using standard methods described by Fishman and Friedman (1989). An ionic balance was computed as part of the review of laboratory results for dissolved constituents (Hem, 1985, p. 164). The balance was computed as:

$$
\frac{\text { cations - anions }}{\text { cations }+ \text { anions }} \times 100 \text {, }
$$

where

$$
\begin{aligned}
\text { cations }= & \begin{array}{l}
\text { sum of the concentrations of } \\
\text { all positively charged ions, } \\
\text { in milliequivalents per liter; } \\
\text { and }
\end{array} \\
\text { anions }= & \begin{array}{l}
\text { sum of the concentrations of } \\
\text { all negatively charged ions, } \\
\text { in milliequivalents per liter. }
\end{array}
\end{aligned}
$$

All major ionic species determined in the analysis were included in the computation. If the result of the equation was less than 8 percent, the numerical values for each chemical constituent were accepted. Balances greater than 8 percent could have been the result of a rapid change in the water chemistry between time of collection and processing and analysis. Laboratory reruns of analyses were requested when results exceeded 8 percent, providing additional water samples were available.

Analyses of chemical constituents on suspended sediment were done by the USGS Branch of Mineral Resources Laboratory, Denver, Colorado. The method involved the complete digestion of dried sediment in mixed acids before analysis by induction-coupled plasma atomicemission spectrometry (Fishman and Friedman, 1989). Duplicate analyses on selected samples were made by the USGS Sediment Partitioning 
Table 4. Agencies that analyzed samples from the Little Colorado River basin, Arizona and New Mexico

\begin{tabular}{|c|c|c|}
\hline Type of analyals & Date & Analyzlng agency and laboratory \\
\hline Field measurements & 1988-91 & $\begin{array}{l}\text { U.S. Geological Survey, Water Resources } \\
\text { Division, Arizona District }\end{array}$ \\
\hline Dissolved and total ions, trace metals, and nutrients & $1988-91$ & $\begin{array}{l}\text { U.S. Geological Survey, Water Resources } \\
\text { Division, National Water Quality } \\
\text { Laboratory, Arvada, Colorado }\end{array}$ \\
\hline${ }^{18} \mathrm{Oxygen} /{ }^{16}$ oxygen, deuterium/protium & $1988-91$ & $\begin{array}{l}\text { U.S. Geological Survey, Water Resources } \\
\text { Division, Reston, Virginia }\end{array}$ \\
\hline Sulfur isotopes $\left({ }^{34} \mathrm{~S} /{ }^{32} \mathrm{~S}\right)$ & $1988-91$ & $\begin{array}{l}\text { U.S. Geological Survey, Geologic Division, } \\
\text { Denver, Colorado }\end{array}$ \\
\hline Solid-phase trace metals & 1988-91 & $\begin{array}{l}\text { U.S. Geological Survey, Geologic Division, } \\
\text { Denver, Colorado }\end{array}$ \\
\hline $\begin{array}{l}\text { Solid-phase radiochemicals: } \\
\text { Gross alpha, gross beta, uranium-234, } \\
\text { uranium-235, uranium-238, radium-226, } \\
\text { radium-228, thorium-230, thorium- } 232\end{array}$ & $1988-89$ & $\begin{array}{l}\text { New Mexico Health and Environment } \\
\text { Department Scientific Laboratory Division, } \\
\text { Albuquerque, New Mexico }\end{array}$ \\
\hline \multirow{3}{*}{$\begin{array}{l}\text { Dissolved and total radiochemicals: } \\
\text { Gross alpha, gross beta, uranium-234, } \\
\text { uranium-235, uranium-238, polonium-210, } \\
\text { lead-210, radium-226, radium-228, } \\
\text { thorium-230, thorium-232, tritium }\end{array}$} & 1988 & \multirow{2}{*}{$\begin{array}{l}\text { U.S. Testing, Richland, Washington } \\
\text { International Technology Corporation, Oak } \\
\text { Ridge, Tennessee }\end{array}$} \\
\hline & 1989 & \\
\hline & $1990-91$ & $\begin{array}{l}\text { International Technology } \\
\text { Richland, Washington }\end{array}$ \\
\hline Cesium-137 & $1989-91$ & $\begin{array}{l}\text { U.S. Geological Survey, National Research } \\
\text { Program, Menlo Park, California }\end{array}$ \\
\hline \multirow[t]{3}{*}{ Grain size and sediment concentration } & $1988-90$ & $\begin{array}{l}\text { U.S. Geological Survey, Sediment Laboratory, } \\
\text { Iowa City, Iowa }\end{array}$ \\
\hline & $1990-92$ & $\begin{array}{l}\text { U.S. Geological Survey, Cascades Volcanic } \\
\text { Observatory, Washington }\end{array}$ \\
\hline & 1992 & $\begin{array}{l}\text { U.S. Geological Survey, Arizona District } \\
\text { Sediment Laboratory }\end{array}$ \\
\hline
\end{tabular}

Research Project Laboratory in Doraville, Georgia (Fishman and Friedman, 1989, p. 535-545).

\section{isotope Analyses}

Selected ground-water and surface-water samples were analyzed for isotopes of hydrogen (protium, deuterium, and tritium), oxygen $\left({ }^{18} \mathrm{O} /{ }^{16} \mathrm{O}\right)$, and sulfur $\left({ }^{34} \mathrm{~S} /{ }^{32} \mathrm{~S}\right)$. Analyses of samples for isotopes of oxygen and hydrogen were made at the USGS Isotope Fractionation Laboratory in Reston, Virginia. Sulfur isotope ratios $\left({ }^{34} S /{ }^{32} S\right)$ for dissolved samples and suspended sediment were measured by the USGS, Geologic Division, Denver, Colorado. Thirty suspended-sediment samples were analyzed for cesium-137 at the USGS National Research Laboratory in Menlo Park, California.

\section{Radionuclide Analyses}

Several laboratories were subcontracted by the NWQL to analyze samples for radionuclide activity during the 4-year collection period. The NWQL subcontracted radionuclide analysis of water and sediment to three laboratories in the private sector: U.S. Testing, Richland, Washington, in 1988; International Technology Corporation (IT), Oak Ridge, Tennessee, in 1989; and IT, Richland, Washington (formerly U.S. Testing), in 1990 and 1991. In 
addition, NMSLD analyzed suspended sediment and well-core material for radionuclides from June 1988 to September 1990 . Analytical methods and quality-assurance procedures varied among the Oak Ridge, Richland, and NMSLD laboratories. At all three laboratories, concentrations of radioactive isotopes in the suspended phase were reported in picocuries per gram.

Measurements of uranium-series radionuclides followed standard methods described by U.S. Environmental Protection Agency (USEPA), USGS, and American Society for Testing and Materials (ASTM). Dissolved isotopic uranium $\left({ }^{238} \mathrm{U},{ }^{234} \mathrm{U}\right.$, and $\left.{ }^{235} \mathrm{U}\right)$ was measured using ASTM method D 3972-90, through an alpha spectrometer (American Society for Testing and Materials, 1992). For solid-phase isotopic uranium, the uranium is separated from sediment using wetchemical extraction techniques before the radioactivity of the individual uranium isotopes is measured. Chemical-extraction techniques also are used for solid-phase radium and thorium isotope measurements. Elemental uranium concentration, in micrograms per liter, is determined by the standard fluorometric technique (USGS $\mathrm{R}-1180-76)$ described in Thatcher and others (1977, p. 89-92). Radioactivity of radium $\left({ }^{226} \mathrm{Ra}\right.$ and $\left.{ }^{228} \mathrm{Ra}\right)$ was measured by radon- $222\left({ }^{222} \mathrm{Rn}\right) \mathrm{de}-$ emanation using a scintillation counter according to USEPA methods 903.1 and 904.0, respectively (U.S. Environmental Protection Agency, 1980). Measurements of ${ }^{232} \mathrm{Th}$ and ${ }^{230} \mathrm{Th}$ activities were made using the ASTM method D 3084-89 and an alpha spectrometer (American Society for Testing and Materials, 1992). The chemical separation and precipitation method (USGS R-1130-76) was used for ${ }^{210} \mathrm{~Pb}$ (Thatcher and others, 1977, p. 33-37). Gross-alpha and gross-beta radioactivities were measured according to EPA method 900.0, using a thin end-window proportional counter (U.S. Environmental Protection Agency, 1980). The NMSLD also followed approved EPA methods. Concentration of ${ }^{226} \mathrm{Ra}$ was measured by counting the ${ }^{222} \mathrm{Rn}$ progeny by gas-phase scintillation using a Lucas cell. Radioactivities of ${ }^{210} \mathrm{~Pb}$ and ${ }^{228} \mathrm{Ra}$ were measured by beta counting of the bismuth- 210 and actinium-228 daughters, respectively (Loren Berge, radiochemist, New Mexico Health and Environment Department Scientific Laboratory Division, oral commun., 1990).
Gross-alpha and gross-beta analyses were affected by several types of analytical errors in addition to those normally inherent in procedures for other chemical constituents. The degree of error for gross alpha and gross beta was observed to vary significantly between duplicate samples and between samples analyzed by different laboratories. Other possible sources of error include interferences caused by uneven particle surfaces (for unfiltered samples) and ingrowth of radionuclides between the time of collection and analysis. In many instances, the measured uncertainty of gross-alpha and gross-beta radioactivity is more than half of the numerical value determined, as indicated by reported counting and precision errors. Analytical procedures used by the NWQL contract laboratory were not documented and in many instances reruns were not possible because there were inadequate volumes of sample remaining.

In addition to these measurement errors, a study of radionuclides in ground water in the Carson River basin of Nevada (Thomas and others, 1993), found that gross-beta activity in the dissolved phase was derived in part from decay of potassium-40 and ingrowth of ${ }^{238} \mathrm{U}$ progeny. Ingrowth occurred in the sample between the time it was collected and the time it was analyzed. The gross-beta activity in water samples was found to increase proportionally in relation to sample-storage time. In this study, it is presumed that ingrowth during sample storage may have affected the accuracy of total gross-alpha and total gross-beta results.

Although data for total gross-alpha and total gross-beta radioactivities from unfiltered water samples are included in this report, they are considered poor values and are flagged accordingly in the tables. Most of the total gross-alpha and gross-beta analyses are from the first year of the study. Subsequently, a different method was used. Quality-assurance checks on gross-alpha analyses of sample splits showed that analyses of dried sediment (reported in picocuries per gram), were more precise than sample splits for whole samples, reported in picocuries per liter. Differences in the analytical values for replicate analyses on unfiltered samples were probably caused by nonrepresentative sample-splitting techniques used by the laboratory. Subsequent to this finding, all analyses for total radioactivity were made on dried 
suspended sediment rather than whole-water samples. Values of total or suspended-phase radionuclides reported in this study were converted from picocuries per gram to picocuries per liter. Although this method of analyzing samples is more precise and therefore more accurate, the sample analyses should not be compared with data collected by other agencies before this study because of differences in sample-collection and laboratory procedures.

\section{Sediment}

Suspended-sediment and bed-material samples were analyzed by USGS sediment laboratories in Iowa City, Iowa, and Vancouver, Washington. Suspended-sediment samples were analyzed for sediment concentration and grain-size distribution, and bed-material samples were analyzed for grainsize distribution using methods described by Guy (1969).

Daily suspended-sediment concentration and sediment discharge were calculated from values of streamflow discharge collected at 10-minute intervals (discharge unit values) and discrete suspended-sediment concentrations using methods described by Porterfield (1972) and a computer program (SEDCALC) to calculate sedimentdischarge records (J.R. Gray, hydrologist, U.S. Geological Survey, written commun., 1990).

Two SEDCALC subroutines were used to calculate unit and daily suspended-sediment concentration and discharge: (1) linear interpolation using an uneven time interval and (2) transport curve. Measured suspended-sediment concentrations were used in conjunction with concentrations extrapolated from a transport curve to develop a plot of suspended-sediment concentration with time for each runoff event. Linear interpolation then was used to calculate 10-minute suspended-sediment concentration unit values, which were used with discharge-unit values to calculate suspended-sediment discharge. The transport-curve method calculates suspendedsediment discharge by utilizing suspendedsediment concentrations from samples and the corresponding discharge in a linear regression on the logarithms of both variables. The results of the regression were a $\log$ offset and a slope of the sediment-discharge line, which were used with discharge unit values to calculate suspended-sediment discharge.

\section{SUMMARY}

During 1988-91, chemical, geologic, and hydrologic data were collected in the Little Colorado River basin in Arizona and New Mexico to determine the distribution and movement of radionuclides and other chemical constituents in ground water and surface water. Sixty-nine groundwater wells were sampled-31 wells drilled by the USGS, 7 wells drilled by the NMED, 11 private wells, and 20 temporary hand-driven wells-in addition, 1 spring was sampled. Data from wells include well-construction information, lithologic logs, water levels, and chemical data for discrete samples. Data from the spring include flow rate and chemical analysis. Surface-water data were collected from nine continual-record and five partial-record streamflow-gaging stations. Data from streamflow-gaging stations include dailymean discharge, daily-mean suspended-sediment concentration and discharge, and chemical data for discrete samples. Precipitation data also were collected at the continual-record streamflow-gaging stations.

\section{SELECTED REFERENCES}

American Society for Testing and Materials, 1992, Annual book of ASTM standards, Water and Atmospheric Analysis: American Society for Testing and Materials, v. 11.02, Philadelphia, Pennsylvania, p. 420-424.

Ames, L.L, and Rai, Dhanpat, 1978, Radionuclide interactions with soil and rock media, volume 1 , Processes influencing radionuclide mobility and retention, element chemistry and geochemistry, and conclusions and evaluation: Las Vegas, Nevada, U.S. Environmental Protection Agency Report EPA 520/6-78-007-A, 330 p.

Arizona Department of Health Services, 1983, Statement by Division of Environmental Health before U.S. Environmental Protection Agency Public Hearing, July 27, 1983, Gallup, New Mexico: Phoenix, Arizona, Arizona Department of Health Services AWQR 512.120, $10 \mathrm{p}$. 
Boner, F.C., Davis, R.G., and Duet, N.R., 1992, WaterResources Data, Arizona, 1991: U.S. Geological Survey Water-Data Report AZ-91-1,411 p.

Edwards, T.K., and Glysson, G.D., 1988, Field methods for measurement of fluvial sediment: U.S. Geological Survey Open-File Report 86-531, 118 p.

Fishman, M.J., and Friedman, L.C., 1989, Methods for determination of inorganic substances in water and fluvial sediments: U.S. Geological Survey Techniques of Water-Resources Investigations book 5 , chap. A1, $545 \mathrm{p}$.

Gallaher, B.M., and Cary, S.J., 1986, Impacts of uranium mining on surface and shallow ground waters, Grants Mineral Belt, New Mexico: Santa Fe, New Mexico Environmental Improvement Division Report, EID/GWH-86/2, 152 p.

Graf, W.L., 1990, Fluvial dynamics of thorium-230 in the Church Rock event, Puerco River, New Mexico: Annual Association of American Geographers, v. 80 , no. 3, p. 327-342.

Gray, J.R., and Webb, R.H., 1991, Radionuclides in the Puerco and Lower Little Colorado River basins, New Mexico and Arizona, before 1987, in Gundersen, L.C.S., and Wanty, R.B., eds., Field Studies of Radon in Rocks, Soils, and Water: U.S. Geological Survey Bulletin 1971, p. 297-311.

Gray, J.R., and Fisk, G.G., 1992, Monitoring of radionuclide and suspended-sediment transport in the Little Colorado River Basin, Arizona and New Mexico, in Bogen, J., Walling, D.E., and Day, T.J., eds., Erosion and Sediment Transport Monitoring Programmes in River Basins: International Association of Hydrological Sciences, Publication 210, p. 505-516.

Gray, J.R., and McElhone, T.J., 1990, A computer program to calculate sediment discharge records [abs.], in Balthrop, B.H., and Baker, E.G., compilers, U.S. Geological Survey National Computer Technology Meeting-Programs and Abstracts, May 7-11, 1990: U.S. Geological Survey Open-File Report 90-161, p. 12.

Guy, H.P., 1969, Laboratory theory and methods for sediment analysis: U.S. Geological Survey Techniques of Water-Resources Investigations, book 5, chap. $\mathrm{Cl}, 58 \mathrm{p}$.

Hearne, G.A., 1977, Evaluation of a potential well field near Church Rock as a water supply for Gallup, New Mexico: U.S. Geological Survey Water-Resources Investigations Report 77-8, $21 \mathrm{p}$.

Hem, J.D., 1985, Study and interpretation of the chemical characteristics of natural water, 3rd ed: U.S. Geological Survey Water-Supply Paper 2254, $263 \mathrm{p}$.
Horowitz, A.J., 1985, A primer on trace metal-sediment chemistry: U.S. Geological Survey Water-Supply Paper 2277, $67 \mathrm{p}$.

Horowitz, A.J., and Elrick, K.A., 1987, The relation of stream sediment surface area, grain size, and composition to trace element chemistry: Applied Geochemistry, v. 2, no. 4, p. 437-451.

Hsi, C.D., and Langmuir, Donald, 1985, Adsorption of uranyl onto ferric oxyhydroxides: Application of the surface complexation site-binding model: Geochimica et Cosmochimica Acta, v. 49, p. 1931-1941.

Langmuir, Donald, 1978, Uranium solution-mineral equilibrium at low temperatures with applications to sedimentary ore deposits: Geochimica et Cosmochimica Acta, v. 42, no. 6, p. 547-569.

Leopold, L.B., and Snyder, C.T., 1951, Alluvial fills near Gallup, New Mexico: U.S. Geological Survey Water-Supply Paper 1110-A, 19 p.

Mann, L.J., and Nemecek, E.A., 1983, Geohydrology and water use in southern Apache County, Arizona: Phoenix, Arizona Department of Water Resources Bulletin 1,86 p.

McClennan, J.J., 1984, Official compilation of administrative rules and regulations: Phoenix, Arizona, State of Arizona report, Supplement 84-3, p. 68-84.

New Mexico Water Quality Control Commission, 1988, Water quality and water pollution control in New Mexico, 1988: Santa Fe, New Mexico Water Quality Control Commission report, 212 p. [published annually].

Perkins, B.L., and Goad, M.S., 1980, Water quality data for discharge from New Mexico uranium mines and mills: Santa Fe, New Mexico Health and Environment Department, New Mexico Environmental Improvement Division report, $87 \mathrm{p}$.

Porterfield, George, 1972, Computation of fluvialsediment records: U.S. Geological Survey, Techniques of Water-Resources Investigations, book 3, chap. C3, $66 \mathrm{p}$.

Rantz, S.E. and others, 1982, Measurement and computation of streamflow: U.S. Geological Survey Water-Supply Paper 2175, v.1 and 2, 631 p.

Smith, C.F., Boner, F.C., Davis, R.G., Duet, N.R., Rigas, P.D., Water-Resources Data, Arizona, 1992: U.S. Geological Survey Water-Data Report AZ-92-1, p. 9.

Subcommittee on Sedimentation, 1961, The single-stage sampler for suspended sediment: Interagency Committee on Water-Resources Report 13, 105 p.

Thatcher, L.L., Janzer, V.J., and Edwards, K.W., 1977, Methods for determination of radioactive substances in water and fluvial sediments: U.S. 
Geological Survey Techniques of Water-Resources Investigations, book 5, chap. A5, $95 \mathrm{p}$.

Thomas, J.M., Welch, A.H., Lico, M.S., Hughes, J.H., and Whitney, Rita, 1993, Radionuclides in ground water of the Carson River Basin, western Nevada and eastern California, U.S.A: Applied Geochemistry, v. 8, no. 5, p. 447-469.

U.S. Department of Agriculture, 1981, Little Colorado River basin, Arizona and New Mexico, Summary report and four appendices: U.S. Department of Agriculture report, v.p.

U.S. Environmental Protection Agency, 1980, Prescribed procedures for measurement of radioactivity in drinking water: Cincinnati, Ohio,
Environmental Monitoring and Support Laboratory, EPA-600/4-80-032, $133 \mathrm{p}$.

1993, Drinking water regulations and health advisories: Washington, D.C., U.S. Environmental Protection Agency report, $13 \mathrm{p}$.

Webb, R.H., Rink, G.R., and Favor, B.O., 1987, Distribution of radionuclide and trace elements in ground water, grasses, and surficial sediments associated with the alluvial aquifer along the Puerco River, northeastern Arizona-A reconnaissance sampling program: U.S. Geological Survey Open-File Report 87-206, 108 p.

Wirt, Laurie, Van Metre, P.C., and Favor, B.O., 1991, Historical water-quality data, Puerco River basin, Arizona and New Mexico: U.S. Geological Survey Open-File Report 91-196, 339 p. 


\section{BASIC DATA}

Basic Data 23

(page 25 follows) 
GROMD-MATER DATA

DAILY UATER LEVELS

ChaMbers Well Cluster

STATION MUBER-351063109270302

STATION MAME-CH-2

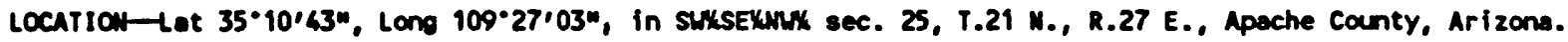

ARIZOMA WELL MUBER-(A-21-27)35bodc2.

LAD SURFACE ALTITUDE-1743.58 meters above mean sea level.

MATER LEVEL, In METERS ABOVE MEAN SEA LEVEL, NOVEMBER 1989 TO SEPTEMBER 1990 DAILY MEAN VALUES

\begin{tabular}{|c|c|c|c|c|c|c|c|c|c|c|c|c|}
\hline AY & C & NOW & DEC & JAN & FEB & MAR & APR & MAY & JUN & JUL & AUG & SEP \\
\hline $\begin{array}{l}1 \\
2 \\
3 \\
4 \\
5\end{array}$ & $\begin{array}{l}\ldots \\
\ldots \\
\ldots \\
\ldots\end{array}$ & $\begin{array}{l}\ldots \\
\ldots \\
\ldots- \\
\ldots \\
\ldots\end{array}$ & $\begin{array}{l}1740.14 \\
1740.13 \\
1740.14 \\
1740.15 \\
1740.15\end{array}$ & $\begin{array}{l}1740.17 \\
1740.19 \\
1740.18 \\
1740.17 \\
1740.16\end{array}$ & $\begin{array}{l}-.- \\
\cdots- \\
\cdots- \\
\cdots-\end{array}$ & $\begin{array}{l}1740.27 \\
1740.27 \\
1740.28 \\
1740.28 \\
1740.28\end{array}$ & $\begin{array}{l}1740.21 \\
1740.21 \\
1740.21 \\
1740.21 \\
1740.22\end{array}$ & $\begin{array}{l}0.15 \\
0.15 \\
0.16 \\
0.17 \\
0.19\end{array}$ & $\begin{array}{l}1740 \\
1740 \\
1740 \\
1740 \\
1740\end{array}$ & $\begin{array}{l}1739.96 \\
1739.96 \\
1739.96 \\
1739.96 \\
1739.95\end{array}$ & $\begin{array}{l}1739.76 \\
1739.74 \\
1739.74 \\
1739.73 \\
1739.72\end{array}$ & $\begin{array}{l}1739.67 \\
1739.68 \\
1739.71 \\
1739.71 \\
1739.70\end{array}$ \\
\hline $\begin{array}{r}6 \\
7 \\
8 \\
9 \\
10\end{array}$ & $\begin{array}{l}\ldots- \\
\ldots- \\
-\ldots \\
-\ldots\end{array}$ & $\begin{array}{l}\ldots \\
\ldots \\
\ldots- \\
\ldots- \\
\ldots\end{array}$ & $\begin{array}{l}1740.16 \\
1740.15 \\
1740.15 \\
1740.16 \\
1740.17\end{array}$ & $\begin{array}{l}1740.15 \\
1740.16 \\
1740.17 \\
1740.15 \\
1740.17\end{array}$ & $\begin{array}{r}1740.23 \\
1740.22 \\
1740.23\end{array}$ & $\begin{array}{l}1740.26 \\
1740.24 \\
1740.24 \\
1740.24 \\
1740.26\end{array}$ & $\begin{array}{l}740.22 \\
740.21 \\
740.22 \\
740.20 \\
740.19\end{array}$ & $\begin{array}{l}740.19 \\
740.19 \\
740.17 \\
740.14 \\
740.15\end{array}$ & $\begin{array}{l}1740.04 \\
1740.03 \\
1740.03 \\
1740.03 \\
1740.03\end{array}$ & & $\begin{array}{l}1739.71 \\
1739.71 \\
1739.73 \\
1739.72 \\
1739.71\end{array}$ & $\begin{array}{l}1739.83 \\
1739.81 \\
1739.78 \\
1739.77 \\
1739.78\end{array}$ \\
\hline $\begin{array}{l}11 \\
12 \\
13 \\
14 \\
15\end{array}$ & $\begin{array}{l}\ldots \\
\ldots \\
\ldots- \\
\ldots\end{array}$ & $\begin{array}{l}\ldots- \\
\ldots- \\
\ldots- \\
\ldots- \\
-.-\end{array}$ & $\begin{array}{l}1740.15 \\
1740.15 \\
1740.15 \\
1740.15 \\
1740.15\end{array}$ & $\begin{array}{l}\ldots . \\
\ldots- \\
\cdots- \\
\cdots \\
\cdots\end{array}$ & $\begin{array}{l}1740.23 \\
1740.26 \\
1740.26 \\
1740.27 \\
1740.24\end{array}$ & $\begin{array}{l}17 \\
17 \\
17 \\
17 \\
17\end{array}$ & $\begin{array}{l}1740.19 \\
1740.19 \\
1740.18 \\
1740.17 \\
1740.18\end{array}$ & $\begin{array}{l}1740.14 \\
1740.13 \\
1740.13 \\
1740.13 \\
1740.12\end{array}$ & $\begin{array}{l}17 \\
17 \\
17 \\
17 \\
17\end{array}$ & $\begin{array}{l}17 \\
17 \\
17 \\
17 \\
17\end{array}$ & $\begin{array}{l}1739.70 \\
1739.69 \\
1739.70 \\
1739.76 \\
1739.94\end{array}$ & $\begin{array}{l}1739.74 \\
1739.72 \\
1739.69 \\
1739.68 \\
1739.67\end{array}$ \\
\hline $\begin{array}{l}16 \\
17 \\
18 \\
19 \\
20\end{array}$ & $\begin{array}{l}\ldots \\
\ldots \\
\ldots- \\
\ldots- \\
\ldots\end{array}$ & $\begin{array}{l}1740.14 \\
1740.16 \\
1740.13 \\
1740.13 \\
1740.14\end{array}$ & $\begin{array}{l}1740 \\
1740 \\
1740 \\
1740 \\
1740\end{array}$ & $\begin{array}{l}\ldots- \\
\cdots- \\
\cdots- \\
\cdots-\end{array}$ & $\begin{array}{l}.22 \\
.23 \\
.23 \\
.23 \\
.23\end{array}$ & $\begin{array}{l}17 \\
17 \\
17 \\
17 \\
17\end{array}$ & $\begin{array}{l}0.18 \\
0.17 \\
0.17 \\
0.17 \\
0.17\end{array}$ & $\begin{array}{l}0.11 \\
0.12 \\
\ldots . . \\
\ldots . . \\
\ldots\end{array}$ & $\begin{array}{l}17 \\
17 \\
17 \\
17 \\
17\end{array}$ & & & $\begin{array}{l}.67 \\
.68 \\
.69 \\
.69 \\
.72\end{array}$ \\
\hline $\begin{array}{l}21 \\
22 \\
23 \\
24 \\
25\end{array}$ & $\begin{array}{l}\ldots \\
\ldots \\
\ldots \\
\ldots \\
\ldots\end{array}$ & $\begin{array}{l}1740.15 \\
1740.14 \\
1740.15 \\
1740.15 \\
1740.15\end{array}$ & $\begin{array}{l}1740.15 \\
1740.15 \\
1740.15 \\
1740.15 \\
1740.15\end{array}$ & $\begin{array}{l}\ldots \\
\cdots \\
\cdots \\
\cdots \\
\cdots\end{array}$ & $\begin{array}{l}1740.24 \\
1740.24 \\
1740.24 \\
1740.24 \\
1740.25\end{array}$ & $\begin{array}{l}1740 . \\
1740 . \\
1740 . \\
1740 . \\
1740 .\end{array}$ & $\begin{array}{l}1740.17 \\
1740.17 \\
1740.18 \\
1740.19 \\
1740.19\end{array}$ & $\begin{array}{l}1740.09 \\
1740.09 \\
1740.09 \\
1740.08\end{array}$ & $\begin{array}{l}1739.99 \\
1739.99 \\
1739.98 \\
1739.98 \\
1739.98\end{array}$ & $\begin{array}{l}1739.86 \\
1739.84 \\
1739.83 \\
1739.84 \\
1739.83\end{array}$ & $\begin{array}{l}1739.84 \\
1739.82 \\
1739.78 \\
1739.75 \\
1739.72\end{array}$ & $\begin{array}{l}1739.76 \\
1739.77 \\
1739.83 \\
1739.81 \\
1739.77\end{array}$ \\
\hline $\begin{array}{l}26 \\
27 \\
28 \\
29 \\
30 \\
31\end{array}$ & ... & $\begin{array}{r}1740.15 \\
1740.14 \\
1740.13 \\
1740.13 \\
1740.14\end{array}$ & $\begin{array}{l}1740.17 \\
1740.17 \\
1740.18 \\
1740.19 \\
1740.18 \\
1740.16\end{array}$ & $\begin{array}{l}\ldots . \\
\ldots- \\
\ldots- \\
\cdots \\
\cdots-\end{array}$ & $\begin{array}{r}1740.25 \\
1740.25 \\
1740.25 \\
\ldots \\
\ldots . \\
\ldots\end{array}$ & $\begin{array}{l}1740.21 \\
1740.22 \\
1740.22 \\
1740.22 \\
1740.22 \\
1740.21\end{array}$ & $\begin{array}{r}1740.19 \\
1740.17 \\
1740.16 \\
1740.16 \\
1740.15\end{array}$ & $\begin{array}{l}1740.08 \\
1740.08 \\
1740.08 \\
1740.08 \\
1740.07 \\
1740.07\end{array}$ & $\begin{array}{r}1739.98 \\
1739.98 \\
1739.97 \\
1739.96 \\
1739.96 \\
.\end{array}$ & $\begin{array}{l}1739.81 \\
1739.80 \\
1739.78 \\
1739.76 \\
1739.76 \\
1739.76\end{array}$ & $\begin{array}{l}1739.71 \\
1739.70 \\
1739.69 \\
1739.69 \\
1739.68 \\
1739.67\end{array}$ & $\begin{array}{r}1739.74 \\
1739.73 \\
1739.71 \\
1739.69 \\
1739.69 \\
\ldots . .\end{array}$ \\
\hline
\end{tabular}




$$
\begin{aligned}
& \text { GROUMD-WATER DATA-Continued } \\
& \text { DAILY WATER LEVELS-Continued } \\
& \text { CHAMBERS WELL CLUSTER-Continued }
\end{aligned}
$$

STATION MUMBER 351043109270302 (CW-2)-Continued

\begin{tabular}{|c|c|c|c|c|c|c|c|c|c|c|c|c|}
\hline DAY & OCT & MON & DEC & JAN & FEB & MAR & APR & maY & JUN & JUL & AUG & SEP \\
\hline $\begin{array}{l}1 \\
2 \\
3 \\
4 \\
5\end{array}$ & $\begin{array}{l}1739.70 \\
1739.71 \\
1739.71 \\
1739.69 \\
1739.69\end{array}$ & $\begin{array}{l}1739.64 \\
1739.69 \\
1739.70 \\
1739.69 \\
1739.71\end{array}$ & $\begin{array}{l}1739.64 \\
1739.63 \\
1739.62 \\
1739.63 \\
1739.64\end{array}$ & $\begin{array}{l}1739.66 \\
1739.66 \\
1739.67 \\
1739.71 \\
1739.71\end{array}$ & $\begin{array}{l}1739.74 \\
1739.76 \\
1739.76 \\
1739.76 \\
1739.79\end{array}$ & $\begin{array}{l}1739.87 \\
1739.94 \\
1739.96 \\
1739.92 \\
1739.91\end{array}$ & $\begin{array}{l}1739.96 \\
1739.95 \\
1739.96 \\
1739.95 \\
1739.96\end{array}$ & $\begin{array}{l}1739.82 \\
1739.81 \\
1739.80 \\
1739.78 \\
1739.78\end{array}$ & $\begin{array}{r}1739.70 \\
1739.71 \\
1739.70 \\
1739.70 \\
\ldots\end{array}$ & $\begin{array}{l}\ldots \\
\cdots \\
\cdots \\
\cdots\end{array}$ & $\begin{array}{l}\cdots \\
\cdots \\
\cdots \\
\cdots \\
\cdots\end{array}$ & $\begin{array}{l}\ldots \\
\ldots \\
\ldots \\
\ldots \\
\ldots\end{array}$ \\
\hline $\begin{array}{r}6 \\
7 \\
8 \\
9 \\
10\end{array}$ & $\begin{array}{l}1739.68 \\
1739.67 \\
1739.66 \\
1739.65 \\
1739.66\end{array}$ & $\begin{array}{l}1739.70 \\
1739.70 \\
1739.68 \\
1739.68 \\
1739.68\end{array}$ & $\begin{array}{l}1739.63 \\
1739.63 \\
1739.63 \\
1739.63 \\
1739.63\end{array}$ & $\begin{array}{l}1739.73 \\
1739.79 \\
1739.81 \\
1739.82 \\
1739.83\end{array}$ & $\begin{array}{l}1739.79 \\
1739.79 \\
1739.82 \\
1739.87 \\
1739.88\end{array}$ & $\begin{array}{l}1739.97 \\
1739.97 \\
1739.94 \\
1739.91 \\
1739.90\end{array}$ & $\begin{array}{l}1739.96 \\
1739.97 \\
1739.95 \\
1739.94 \\
1739.94\end{array}$ & $\begin{array}{l}1739.79 \\
1739.78 \\
1739.77 \\
1739.77 \\
1739.76\end{array}$ & $\begin{array}{l}\cdots \\
\ldots \\
\cdots \\
\cdots \\
\cdots\end{array}$ & $\begin{array}{l}\ldots \\
\ldots \\
\cdots \\
\cdots \\
\ldots\end{array}$ & $\begin{array}{l}\ldots \\
\ldots \\
\cdots \\
\cdots \\
\cdots\end{array}$ & $\begin{array}{l}\ldots \\
\ldots \\
\ldots \\
\ldots \\
\ldots\end{array}$ \\
\hline $\begin{array}{l}11 \\
12 \\
13 \\
14 \\
15\end{array}$ & $\begin{array}{l}1739.66 \\
1739.65 \\
1739.65 \\
1739.64 \\
1739.64\end{array}$ & $\begin{array}{l}1739.67 \\
1739.67 \\
1739.67 \\
1739.66 \\
1739.65\end{array}$ & $\begin{array}{l}1739.64 \\
1739.64 \\
1739.68 \\
1739.70 \\
1739.71\end{array}$ & $\begin{array}{l}1739.81 \\
1739.82 \\
1739.82 \\
1739.82 \\
1739.83\end{array}$ & $\begin{array}{l}1739.91 \\
1739.93 \\
1739.95 \\
1739.94 \\
1739.89\end{array}$ & $\begin{array}{l}1739.89 \\
1739.86 \\
1739.86 \\
1739.88 \\
1739.88\end{array}$ & $\begin{array}{l}1739.92 \\
1739.90 \\
1739.92 \\
1739.92 \\
1739.90\end{array}$ & $\begin{array}{l}1739.74 \\
1739.73 \\
1739.74 \\
1739.74 \\
1739.73\end{array}$ & $\begin{array}{l}\cdots \\
\cdots \\
\cdots \\
\cdots \\
\cdots\end{array}$ & $\begin{array}{l}\ldots \\
\ldots \\
\cdots \\
\cdots \\
\cdots\end{array}$ & $\begin{array}{l}\cdots \\
\cdots \\
\cdots \\
\cdots \\
\cdots\end{array}$ & $\begin{array}{l}\ldots \\
\ldots \\
\cdots \\
\cdots \\
\cdots\end{array}$ \\
\hline $\begin{array}{l}16 \\
17 \\
18 \\
19 \\
20\end{array}$ & $\begin{array}{l}1739.64 \\
1739.63 \\
1739.63 \\
1739.66 \\
1739.85\end{array}$ & $\begin{array}{l}1739.64 \\
1739.65 \\
1739.66 \\
1739.66 \\
1739.65\end{array}$ & $\begin{array}{l}1739.75 \\
1739.70 \\
1739.69 \\
1739.70 \\
1739.70\end{array}$ & $\begin{array}{l}1739.82 \\
1739.80 \\
1739.80 \\
1739.81 \\
1739.80\end{array}$ & $\begin{array}{l}1739.89 \\
1739.90 \\
1739.89 \\
1739.84 \\
1739.83\end{array}$ & $\begin{array}{l}1739.89 \\
1739.88 \\
1739.89 \\
1739.90 \\
1739.89\end{array}$ & $\begin{array}{l}1739.87 \\
1739.86 \\
1739.87 \\
1739.90 \\
1739.91\end{array}$ & $\begin{array}{l}1739.73 \\
1739.73 \\
1739.72 \\
1739.71 \\
1739.72\end{array}$ & $\begin{array}{l}\cdots \\
\cdots \\
\cdots \\
\cdots\end{array}$ & $\begin{array}{l}\cdots \\
\cdots \\
\cdots \\
\cdots \\
\cdots\end{array}$ & $\begin{array}{l}\ldots \\
\cdots \\
\cdots \\
\cdots \\
\cdots\end{array}$ & $\begin{array}{l}\ldots \\
\ldots \\
\ldots \\
\ldots \\
\ldots\end{array}$ \\
\hline $\begin{array}{l}21 \\
22 \\
23 \\
24 \\
25\end{array}$ & $\begin{array}{l}1739.80 \\
1739.76 \\
1739.73 \\
1739.71 \\
1739.69\end{array}$ & $\begin{array}{l}1739.63 \\
1739.63 \\
1739.63 \\
1739.63 \\
1739.64\end{array}$ & $\begin{array}{l}1739.68 \\
1739.67 \\
1739.64 \\
1739.65 \\
1739.66\end{array}$ & $\begin{array}{l}1739.80 \\
1739.80 \\
1739.79 \\
1739.79 \\
1739.77\end{array}$ & $\begin{array}{l}1739.83 \\
1739.83 \\
1739.82 \\
1739.81 \\
1739.79\end{array}$ & $\begin{array}{l}1739.90 \\
1739.88 \\
1739.89 \\
1739.91 \\
1739.90\end{array}$ & $\begin{array}{l}1739.91 \\
1739.90 \\
1739.90 \\
1739.89 \\
1739.88\end{array}$ & $\begin{array}{l}1739.73 \\
1739.71 \\
1739.70 \\
1739.71 \\
1739.71\end{array}$ & $\begin{array}{l}\ldots \\
\cdots \\
\cdots \\
\cdots \\
\cdots\end{array}$ & $\begin{array}{l}\cdots \\
\cdots \\
\cdots \\
\cdots \\
\cdots\end{array}$ & $\begin{array}{l}\ldots \\
\ldots \\
\cdots \\
\cdots \\
\cdots\end{array}$ & $\begin{array}{l}\ldots \\
\ldots \\
\ldots \\
\cdots \\
\cdots\end{array}$ \\
\hline $\begin{array}{l}26 \\
27 \\
28 \\
29 \\
30 \\
31\end{array}$ & $\begin{array}{l}1739.68 \\
1739.67 \\
1739.66 \\
1739.66 \\
1739.64 \\
1739.64\end{array}$ & $\begin{array}{r}1739.69 \\
1739.66 \\
1739.63 \\
1739.63 \\
1739.65 \\
\ldots\end{array}$ & $\begin{array}{l}1739.66 \\
1739.65 \\
1739.68 \\
1739.70 \\
1739.68 \\
1739.66\end{array}$ & $\begin{array}{l}1739.77 \\
1739.78 \\
1739.79 \\
1739.78 \\
1739.75 \\
1739.74\end{array}$ & $\begin{array}{r}1739.80 \\
1739.80 \\
1739.83 \\
\ldots \\
\ldots . \\
\ldots\end{array}$ & $\begin{array}{l}1739.90 \\
1739.90 \\
1739.94 \\
1739.95 \\
1739.96 \\
1739.94\end{array}$ & $\begin{array}{c}1739.87 \\
1739.86 \\
1739.84 \\
1739.83 \\
1739.82 \\
\ldots\end{array}$ & $\begin{array}{l}1739.71 \\
1739.70 \\
1739.69 \\
1739.69 \\
1739.70 \\
1739.69\end{array}$ & $\begin{array}{l}\cdots \\
\cdots \\
\cdots \\
\cdots \\
\cdots\end{array}$ & $\begin{array}{l}\cdots \\
\cdots \\
\cdots \\
\cdots \\
\cdots \\
\cdots\end{array}$ & $\begin{array}{l}\ldots \\
\cdots \\
\cdots \\
\cdots \\
\cdots \\
\cdots\end{array}$ & $\begin{array}{l}\ldots \\
\ldots \\
\ldots \\
\ldots \\
\ldots \\
\ldots\end{array}$ \\
\hline
\end{tabular}

WATER LEVEL, In MEters abOVE MEAK SEA LEVEL, OCTOBER 1990 to JUNE 1991 DAILY MEAN VALUES 


\section{GROUND-MATER DATA-Cont inued \\ DAILY MATER LEVELS-Continued \\ CHAMBERS MELL CLUSTER-Cont inued}

STATION MUAER-351043109270303

STATION MAME-CW-3

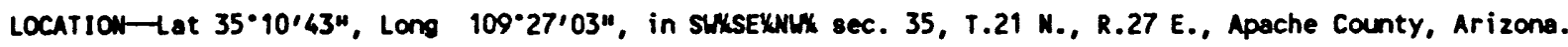

ARIZONA WELL MUMBER-(A-21-27)35bdc3.

LAND SURFACE ALTITUDE-1743.78 meters above mean sea level.

WATER LEVEL, IN METERS ABOVE MEAN SEA LEVEL, JULY 1989 TO SEPTEMBER 1989 DAILY MEAN VALUES

\begin{tabular}{|c|c|c|c|c|c|c|c|c|c|c|c|c|}
\hline DAY & OCt & NOV & DEC & JAN & FEB & MAR & APR & MYY & JUN & JUL & AUG & SEP \\
\hline $\begin{array}{l}1 \\
2 \\
3 \\
4 \\
5\end{array}$ & $\begin{array}{l}\ldots \\
\ldots \\
\ldots \\
\ldots \\
\ldots\end{array}$ & $\begin{array}{l}\cdots \\
\cdots \\
\cdots \\
\cdots \\
\cdots\end{array}$ & $\begin{array}{l}\ldots \\
\ldots \\
\ldots- \\
\ldots \\
\ldots\end{array}$ & $\begin{array}{l}\cdots \\
\cdots \\
\cdots- \\
\cdots \\
\cdots\end{array}$ & $\begin{array}{l}\ldots \\
\ldots \\
\ldots \\
\ldots \\
\ldots\end{array}$ & $\begin{array}{l}-\cdots \\
\cdots \\
\cdots \\
\cdots \\
\cdots\end{array}$ & $\begin{array}{l}\ldots \\
\ldots \\
\ldots \\
\ldots \\
\cdots\end{array}$ & $\begin{array}{l}\ldots- \\
\ldots- \\
\ldots- \\
\cdots \\
\ldots-\end{array}$ & $\begin{array}{l}\ldots \\
\cdots- \\
\cdots \\
\cdots \\
\cdots\end{array}$ & $\begin{array}{l}\ldots . \\
\ldots \\
\ldots \\
\ldots \\
\cdots\end{array}$ & $\begin{array}{l}\ldots \\
\ldots \\
\ldots \\
\cdots \\
\cdots\end{array}$ & $\begin{array}{l}1740.07 \\
1740.06 \\
1740.06 \\
1740.07 \\
1740.06\end{array}$ \\
\hline $\begin{array}{r}6 \\
7 \\
8 \\
9 \\
10\end{array}$ & $\begin{array}{l}\ldots \\
\ldots \\
\ldots \\
\ldots \\
\ldots\end{array}$ & $\begin{array}{l}\ldots \\
\ldots \\
\cdots \\
\ldots \\
\cdots\end{array}$ & $\begin{array}{l}\ldots \\
\ldots \\
\ldots \\
\ldots \\
\ldots\end{array}$ & $\begin{array}{l}\ldots \\
\ldots \\
\ldots \\
\ldots \\
\cdots\end{array}$ & $\begin{array}{l}\ldots \\
\ldots \\
\ldots \\
\ldots \\
\ldots\end{array}$ & $\begin{array}{l}\cdots \\
\cdots \\
\cdots \\
\cdots \\
\cdots\end{array}$ & $\begin{array}{l}\ldots \\
\ldots \\
\ldots \\
\cdots \\
\cdots\end{array}$ & $\begin{array}{l}\cdots- \\
\ldots- \\
\ldots- \\
\cdots \\
\cdots\end{array}$ & $\begin{array}{l}\ldots- \\
\ldots- \\
\cdots \\
\cdots- \\
\cdots\end{array}$ & $\begin{array}{l}\ldots \\
\ldots \\
\cdots \\
\cdots \\
\cdots\end{array}$ & $\begin{array}{l}\cdots \\
\cdots \\
\cdots \\
\cdots \\
\cdots\end{array}$ & $\begin{array}{l}1740.09 \\
1740.15 \\
1740.15 \\
1740.13 \\
1740.12\end{array}$ \\
\hline $\begin{array}{l}11 \\
12 \\
13 \\
14 \\
15\end{array}$ & $\begin{array}{l}\ldots \\
\ldots \\
\ldots \\
\ldots \\
\cdots\end{array}$ & $\begin{array}{l}\cdots \\
\ldots \\
\cdots \\
\cdots \\
\cdots\end{array}$ & $\begin{array}{l}\ldots \\
\ldots \\
\ldots \\
\ldots \\
\cdots\end{array}$ & $\begin{array}{l}\cdots \\
\ldots \\
\ldots \\
\ldots \\
\cdots\end{array}$ & $\begin{array}{l}\ldots \\
\ldots \\
\ldots \\
\ldots \\
\ldots\end{array}$ & $\begin{array}{l}\cdots \\
\cdots \\
\cdots \\
\cdots \\
\cdots\end{array}$ & $\begin{array}{l}\ldots \\
\ldots \\
\cdots \\
\cdots \\
\cdots\end{array}$ & $\begin{array}{l}\ldots \\
\ldots \\
\ldots- \\
\ldots \\
\ldots\end{array}$ & $\begin{array}{l}\ldots . \\
\ldots- \\
\cdots \\
\ldots- \\
\cdots\end{array}$ & $\begin{array}{l}\ldots . \\
\ldots- \\
\ldots- \\
\cdots \\
\cdots\end{array}$ & $\begin{array}{l}\ldots . \\
\ldots- \\
\ldots- \\
\ldots \\
\cdots\end{array}$ & $\begin{array}{l}1740.10 \\
1740.09 \\
1740.07 \\
1740.06 \\
1740.06\end{array}$ \\
\hline $\begin{array}{l}16 \\
17 \\
18 \\
19 \\
20\end{array}$ & $\begin{array}{l}\ldots \\
\ldots \\
\ldots \\
\ldots \\
\ldots\end{array}$ & $\begin{array}{l}\cdots \\
\cdots \\
\ldots \\
\cdots \\
\cdots\end{array}$ & $\begin{array}{l}\ldots- \\
\ldots \\
\ldots \\
\ldots \\
\ldots\end{array}$ & $\begin{array}{l}\ldots \\
\ldots \\
\ldots \\
\ldots \\
\ldots\end{array}$ & $\begin{array}{l}\ldots \\
\ldots \\
\ldots \\
\ldots \\
\ldots\end{array}$ & $\begin{array}{l}\ldots . \\
\ldots \\
\ldots- \\
\cdots \\
\cdots\end{array}$ & $\begin{array}{l}\ldots \\
\ldots \\
\ldots \\
\ldots \\
\ldots\end{array}$ & $\begin{array}{l}\ldots- \\
\ldots- \\
\ldots- \\
\ldots \\
\ldots\end{array}$ & $\begin{array}{l}\ldots . \\
\ldots- \\
\ldots- \\
\ldots- \\
\ldots\end{array}$ & $\begin{array}{l}\ldots- \\
\ldots- \\
\ldots- \\
\cdots \\
\cdots\end{array}$ & $\begin{array}{l}\ldots \\
\ldots \\
\ldots \\
\cdots \\
\cdots\end{array}$ & $\begin{array}{l}1740.06 \\
1740.06 \\
1740.06 \\
1740.05 \\
1740.04\end{array}$ \\
\hline $\begin{array}{l}21 \\
22 \\
23 \\
24 \\
25\end{array}$ & $\begin{array}{l}\ldots- \\
\ldots \\
\ldots \\
\ldots \\
\ldots\end{array}$ & $\begin{array}{l}\ldots \\
\cdots \\
\ldots \\
\cdots \\
\cdots\end{array}$ & $\begin{array}{l}\ldots \\
\ldots \\
\ldots \\
\ldots \\
\ldots\end{array}$ & $\begin{array}{l}\cdots \\
\ldots \\
\ldots \\
\ldots \\
\ldots\end{array}$ & $\begin{array}{l}\ldots \\
\ldots \\
\ldots \\
\ldots \\
\ldots\end{array}$ & $\begin{array}{l}\ldots \\
\ldots \\
\cdots \\
\cdots \\
\cdots\end{array}$ & $\begin{array}{l}\ldots \\
\ldots \\
\cdots \\
\cdots \\
\cdots\end{array}$ & $\begin{array}{l}\ldots \\
\ldots \\
\ldots \\
\ldots \\
\cdots\end{array}$ & $\begin{array}{l}\ldots \\
\ldots \\
\ldots \\
\ldots \\
\ldots\end{array}$ & $\begin{array}{l}\ldots . \\
\ldots \\
\cdots \\
\cdots \\
\cdots\end{array}$ & $\begin{array}{r}\ldots \\
1740.19 \\
1740.16 \\
1740.15 \\
1740.13\end{array}$ & $\begin{array}{l}1740.04 \\
1740.04 \\
1740.04 \\
1740.04 \\
1740.03\end{array}$ \\
\hline $\begin{array}{l}26 \\
27 \\
28 \\
29 \\
30 \\
31\end{array}$ & $\begin{array}{l}\ldots \\
\ldots \\
\ldots \\
\ldots \\
\ldots \\
\ldots\end{array}$ & $\begin{array}{l}\ldots \\
\ldots \\
\ldots \\
\ldots \\
\ldots \\
\ldots\end{array}$ & $\begin{array}{l}\ldots- \\
\ldots \\
\ldots- \\
\ldots \\
\ldots \\
\ldots\end{array}$ & $\begin{array}{l}\ldots \\
\ldots \\
\ldots \\
\ldots \\
\ldots \\
\ldots\end{array}$ & $\begin{array}{l}\ldots \\
\ldots \\
\ldots \\
\ldots \\
\ldots \\
\ldots\end{array}$ & $\begin{array}{l}\ldots \\
\cdots \\
\cdots \\
\cdots \\
\cdots \\
\cdots\end{array}$ & $\begin{array}{l}\ldots \\
\ldots \\
\ldots \\
\ldots \\
\ldots \\
\ldots\end{array}$ & $\begin{array}{l}\ldots \\
\ldots \\
\ldots \\
\ldots \\
\ldots \\
\ldots\end{array}$ & $\begin{array}{l}\ldots \\
\ldots \\
\ldots \\
\ldots \\
\ldots- \\
\ldots\end{array}$ & $\begin{array}{r}\ldots \\
1740.43 \\
\ldots \\
\ldots \\
\ldots\end{array}$ & $\begin{array}{l}1740.11 \\
1740.10 \\
1740.09 \\
1740.09 \\
1740.09 \\
1740.08\end{array}$ & $\begin{array}{r}1740.03 \\
1740.03 \\
1740.02 \\
1740.02 \\
1740.03 \\
\ldots . .\end{array}$ \\
\hline
\end{tabular}


GROUND-MATER DATA-Cont inued

DAILY WATER LEVELS-Continued

CHAMBERS WELL CLUSTER-Continued

STATION MUMBER 351043109270303 (CW-3)-Continued

WATER LEVEL, IN METERS ABOVE MEAN SEA LEVEL, OCTOBER 1989 TO SEPTEMBER 1990

daily mean values

\begin{tabular}{|c|c|c|c|c|c|c|c|c|c|c|c|c|}
\hline DAY & OCT & NOV & DEC & JAN & FEB & MAR & APR & MAY & JUN & JUL & AUG & SEP \\
\hline $\begin{array}{l}1 \\
2 \\
3 \\
4 \\
5\end{array}$ & $\begin{array}{l}1740.03 \\
1740.03 \\
1740.03 \\
1740.06 \\
1740.09\end{array}$ & $\begin{array}{l}\ldots \\
\ldots \\
\ldots \\
\ldots \\
\cdots\end{array}$ & $\begin{array}{l}1740.12 \\
1740.11 \\
1740.11 \\
1740.12 \\
1740.13\end{array}$ & $\begin{array}{l}1740.14 \\
1740.15 \\
1740.14 \\
1740.14 \\
1740.13\end{array}$ & $\begin{array}{l}1740.19 \\
1740.19 \\
1740.16 \\
1740.18 \\
1740.19\end{array}$ & $\begin{array}{l}1740.24 \\
1740.24 \\
1740.25 \\
1740.25 \\
1740.25\end{array}$ & $\begin{array}{l}1740.18 \\
1740.18 \\
1740.17 \\
1740.18 \\
1740.19\end{array}$ & $\begin{array}{l}1740.12 \\
1740.12 \\
1740.13 \\
1740.14 \\
1740.15\end{array}$ & $\begin{array}{l}\ldots- \\
\ldots \\
\ldots \\
\ldots \\
\ldots\end{array}$ & $\begin{array}{l}\ldots- \\
\ldots- \\
\cdots \\
\ldots- \\
\cdots\end{array}$ & $\begin{array}{l}1739.72 \\
1739.71 \\
1739.70 \\
1739.70 \\
1739.69\end{array}$ & $\begin{array}{l}1739.64 \\
1739.64 \\
1739.67 \\
1739.68 \\
1739.67\end{array}$ \\
\hline $\begin{array}{r}6 \\
7 \\
8 \\
9 \\
10\end{array}$ & $\begin{array}{l}1740.08 \\
1740.08 \\
1740.08 \\
1740.07 \\
1740.06\end{array}$ & $\begin{array}{l}\ldots \\
\ldots \\
\cdots \\
\cdots \\
\cdots\end{array}$ & $\begin{array}{l}1740.13 \\
1740.12 \\
1740.12 \\
1740.13 \\
1740.14\end{array}$ & $\begin{array}{l}1740.12 \\
1740.13 \\
1740.13 \\
1740.12 \\
1740.13\end{array}$ & $\begin{array}{l}1740.18 \\
1740.19 \\
1740.20 \\
1740.19 \\
1740.19\end{array}$ & $\begin{array}{l}1740.23 \\
1740.21 \\
1740.21 \\
1740.21 \\
1740.22\end{array}$ & $\begin{array}{l}1740.18 \\
1740.18 \\
1740.19 \\
1740.17 \\
1740.15\end{array}$ & $\begin{array}{l}1740.16 \\
1740.15 \\
1740.13 \\
1740.11 \\
1740.12\end{array}$ & $\begin{array}{l}\ldots \\
\ldots \\
\ldots \\
\ldots \\
\ldots\end{array}$ & $\begin{array}{l}\ldots \\
\ldots \\
\cdots \\
\cdots \\
\cdots\end{array}$ & $\begin{array}{l}1739.68 \\
1739.68 \\
1739.70 \\
1739.69 \\
1739.68\end{array}$ & $\begin{array}{l}1739.80 \\
1739.78 \\
1739.75 \\
1739.74 \\
1739.75\end{array}$ \\
\hline $\begin{array}{l}11 \\
12 \\
13 \\
16 \\
15\end{array}$ & $\begin{array}{l}1740.06 \\
1740.06 \\
1740.06 \\
1740.07 \\
1740.08\end{array}$ & $\begin{array}{l}\ldots \\
\ldots \\
\ldots \\
\ldots \\
\cdots\end{array}$ & $\begin{array}{l}1740.12 \\
1740.12 \\
1740.12 \\
1740.12 \\
1740.12\end{array}$ & $\begin{array}{l}1740.14 \\
1740.15 \\
1740.15 \\
1740.15 \\
1740.16\end{array}$ & $\begin{array}{l}1740.20 \\
1740.22 \\
1740.22 \\
1740.24 \\
1740.21\end{array}$ & $\begin{array}{l}1740.24 \\
1740.24 \\
1740.25 \\
1740.25 \\
1740.25\end{array}$ & $\begin{array}{l}1740.16 \\
1740.16 \\
1740.15 \\
1740.16 \\
1740.15\end{array}$ & $\begin{array}{l}1740.11 \\
1740.10 \\
1740.09 \\
1740.09 \\
1740.09\end{array}$ & $\begin{array}{l}\ldots \\
\ldots \\
\ldots \\
\ldots \\
\ldots\end{array}$ & $\begin{array}{l}\cdots \\
\cdots \\
\cdots \\
\cdots \\
\cdots\end{array}$ & $\begin{array}{l}1739.66 \\
1739.65 \\
1739.67 \\
1739.72 \\
1739.90\end{array}$ & $\begin{array}{l}1739.71 \\
1739.68 \\
1739.66 \\
1739.64 \\
1739.64\end{array}$ \\
\hline $\begin{array}{l}16 \\
17 \\
18 \\
19 \\
20\end{array}$ & $\begin{array}{l}1740.06 \\
1740.05 \\
1740.05 \\
1740.05 \\
1740.07\end{array}$ & $\begin{array}{l}1740.12 \\
1740.11 \\
1740.10 \\
1740.10 \\
1740.11\end{array}$ & $\begin{array}{l}1740.14 \\
1740.14 \\
1740.14 \\
1740.12 \\
1740.12\end{array}$ & $\begin{array}{l}1740.16 \\
1740.17 \\
1740.17 \\
1740.17 \\
1740.16\end{array}$ & $\begin{array}{l}1740.19 \\
1740.19 \\
1740.19 \\
1740.19 \\
1740.19\end{array}$ & $\begin{array}{l}1740.22 \\
1740.22 \\
1740.22 \\
1740.20 \\
1740.20\end{array}$ & $\begin{array}{l}1740.15 \\
1740.14 \\
1740.14 \\
1740.13 \\
1740.13\end{array}$ & $\begin{array}{r}1740.08 \\
1740.08 \\
\ldots \\
\ldots\end{array}$ & $\begin{array}{l}\ldots \\
\ldots \\
\ldots \\
\ldots \\
\ldots\end{array}$ & $\begin{array}{l}\ldots . \\
\cdots \\
\cdots \\
\cdots \\
\cdots\end{array}$ & $\begin{array}{l}1739.84 \\
1739.96 \\
1739.87 \\
1739.80 \\
1739.76\end{array}$ & $\begin{array}{l}1739.64 \\
1739.64 \\
1739.66 \\
1739.66 \\
1739.68\end{array}$ \\
\hline $\begin{array}{l}21 \\
22 \\
23 \\
26 \\
25\end{array}$ & $\begin{array}{l}1740.09 \\
1740.09 \\
1740.09 \\
1740.10 \\
1740.11\end{array}$ & $\begin{array}{l}1740.12 \\
1740.11 \\
1740.12 \\
1740.13 \\
1740.12\end{array}$ & $\begin{array}{l}1740.13 \\
1740.12 \\
1740.12 \\
1740.12 \\
1740.12\end{array}$ & $\begin{array}{l}1740.15 \\
1740.16 \\
1740.17 \\
1740.16 \\
1740.16\end{array}$ & $\begin{array}{l}1740.20 \\
1740.21 \\
1740.20 \\
1740.21 \\
1740.22\end{array}$ & $\begin{array}{l}1740.20 \\
1740.19 \\
1740.19 \\
1740.19 \\
1740.17\end{array}$ & $\begin{array}{l}1740.13 \\
1740.13 \\
1740.14 \\
1740.15 \\
1740.15\end{array}$ & $\begin{array}{l}\ldots \\
\cdots \\
\cdots \\
\cdots \\
\cdots\end{array}$ & $\begin{array}{l}\ldots \\
\ldots \\
\ldots \\
\ldots \\
\ldots\end{array}$ & $\begin{array}{l}\ldots . \\
\ldots \\
\ldots \\
\cdots\end{array}$ & $\begin{array}{l}1739.81 \\
1739.79 \\
1739.75 \\
1739.71 \\
1739.69\end{array}$ & $\begin{array}{l}1739.73 \\
1739.74 \\
1739.80 \\
1739.78 \\
1739.74\end{array}$ \\
\hline $\begin{array}{l}26 \\
27 \\
28 \\
29 \\
30 \\
31\end{array}$ & $\begin{array}{c}1740.09 \\
1740.10 \\
\ldots \\
\ldots \\
\ldots\end{array}$ & $\begin{array}{r}1740.12 \\
1740.12 \\
1740.10 \\
1740.10 \\
1740.12 \\
\ldots\end{array}$ & $\begin{array}{l}1740.14 \\
1740.14 \\
1740.15 \\
1740.15 \\
1740.14 \\
1740.12\end{array}$ & $\begin{array}{l}1740.18 \\
1740.17 \\
1740.17 \\
1740.18 \\
1740.19 \\
1740.19\end{array}$ & $\begin{array}{r}1740.22 \\
1740.22 \\
1740.22 \\
\ldots . \\
\ldots \\
\ldots\end{array}$ & $\begin{array}{l}1740.17 \\
1740.19 \\
1740.18 \\
1740.18 \\
1740.18 \\
1740.18\end{array}$ & $\begin{array}{r}1740.15 \\
1740.13 \\
1740.13 \\
1740.12 \\
1740.12 \\
\ldots\end{array}$ & $\begin{array}{l}\ldots . \\
\cdots \\
\cdots \\
\cdots \\
\cdots \\
\cdots\end{array}$ & $\begin{array}{l}\ldots \\
\ldots \\
\ldots \\
\ldots \\
\ldots \\
\ldots\end{array}$ & $\begin{array}{l}\ldots \\
1739.76 \\
1739.75 \\
1739.73 \\
1739.72 \\
1739.72\end{array}$ & $\begin{array}{l}1739.67 \\
1739.66 \\
1739.66 \\
1739.66 \\
1739.65 \\
1739.64\end{array}$ & $\begin{array}{r}1739.71 \\
1739.70 \\
1739.68 \\
1739.66 \\
1739.66 \\
\ldots\end{array}$ \\
\hline
\end{tabular}




\author{
GROUND-WATER DATA-Cont inued \\ DAILY WATER LEVELS-Continued \\ ChaMBers WELL CLUSTER-Continued
}

STATION MUMBER 351043109270303 (CW-3)-Continued

mater level, in meters above mean sea leVel, OCtober 1990 to June 1991 DAILY MEAN VALUES

\begin{tabular}{|c|c|c|c|c|c|c|c|c|c|c|c|c|}
\hline DAY & OCT & NOV & DEC & JAK & FEB & MAR & APR & MAY & JUN & JUL & AUG & SEP \\
\hline $\begin{array}{l}1 \\
2 \\
3 \\
4 \\
5\end{array}$ & $\begin{array}{l}1739.66 \\
1739.67 \\
1739.67 \\
1739.66 \\
1739.66\end{array}$ & $\begin{array}{l}1739.61 \\
1739.65 \\
1739.67 \\
1739.66 \\
1739.68\end{array}$ & $\begin{array}{l}1739.61 \\
1739.60 \\
1739.59 \\
1739.59 \\
1739.60\end{array}$ & $\begin{array}{l}1739.63 \\
1739.62 \\
1739.64 \\
1739.67 \\
1739.68\end{array}$ & $\begin{array}{l}1739.70 \\
1739.72 \\
1739.73 \\
1739.72 \\
1739.75\end{array}$ & $\begin{array}{l}1739.84 \\
1739.91 \\
1739.93 \\
1739.89 \\
1739.87\end{array}$ & $\begin{array}{l}1739.93 \\
1739.91 \\
1739.92 \\
1739.92 \\
1739.93\end{array}$ & $\begin{array}{l}1739.78 \\
1739.77 \\
1739.75 \\
1739.74 \\
1739.73\end{array}$ & $\begin{array}{r}1739.66 \\
1739.67 \\
1739.66 \\
1739.66 \\
\ldots\end{array}$ & $\begin{array}{l}\ldots \\
\ldots \\
\ldots \\
\ldots \\
\cdots\end{array}$ & $\begin{array}{l}\cdots \\
\cdots \\
\cdots \\
\cdots \\
\cdots\end{array}$ & $\begin{array}{l}\ldots- \\
\ldots- \\
\ldots- \\
\cdots \\
\cdots\end{array}$ \\
\hline $\begin{array}{r}6 \\
7 \\
8 \\
9 \\
10\end{array}$ & $\begin{array}{l}1739.65 \\
1739.64 \\
1739.62 \\
1739.62 \\
1739.62\end{array}$ & $\begin{array}{l}1739.67 \\
1739.67 \\
1739.64 \\
1739.65 \\
1739.64\end{array}$ & $\begin{array}{l}1739.59 \\
1739.59 \\
1739.60 \\
1739.59 \\
1739.60\end{array}$ & $\begin{array}{l}1739.69 \\
1739.75 \\
1739.78 \\
1739.79 \\
1739.80\end{array}$ & $\begin{array}{l}1739.75 \\
1739.75 \\
1739.78 \\
1739.83 \\
1739.84\end{array}$ & $\begin{array}{l}1739.94 \\
1739.94 \\
1739.91 \\
1739.88 \\
1739.86\end{array}$ & $\begin{array}{l}1739.93 \\
1739.93 \\
1739.91 \\
1739.91 \\
1739.91\end{array}$ & $\begin{array}{l}1739.75 \\
1739.74 \\
1739.73 \\
1739.73 \\
1739.72\end{array}$ & $\begin{array}{l}\ldots \\
\ldots \\
\ldots \\
\ldots \\
\ldots\end{array}$ & $\begin{array}{l}\ldots \\
\ldots \\
\ldots \\
\cdots \\
\cdots\end{array}$ & $\begin{array}{l}\ldots \\
\ldots \\
\ldots \\
\ldots \\
\cdots\end{array}$ & $\begin{array}{l}\ldots- \\
\ldots \\
\ldots \\
\cdots \\
\cdots\end{array}$ \\
\hline $\begin{array}{l}11 \\
12 \\
13 \\
14 \\
15\end{array}$ & $\begin{array}{l}1739.62 \\
1739.61 \\
1739.62 \\
1739.61 \\
1739.60\end{array}$ & $\begin{array}{l}1739.63 \\
1739.63 \\
1739.63 \\
1739.63 \\
1739.61\end{array}$ & $\begin{array}{l}1739.60 \\
1739.61 \\
1739.65 \\
1739.66 \\
1739.67\end{array}$ & $\begin{array}{l}1739.77 \\
1739.79 \\
1739.79 \\
1739.78 \\
1739.79\end{array}$ & $\begin{array}{l}1739.88 \\
1739.90 \\
1739.91 \\
1739.91 \\
1739.86\end{array}$ & $\begin{array}{l}1739.85 \\
1739.83 \\
1739.83 \\
1739.84 \\
1739.85\end{array}$ & $\begin{array}{l}1739.88 \\
1739.87 \\
1739.89 \\
1739.88 \\
1739.87\end{array}$ & $\begin{array}{l}1739.70 \\
1739.70 \\
1739.70 \\
1739.70 \\
1739.69\end{array}$ & $\begin{array}{l}\ldots \\
\ldots \\
\ldots \\
\ldots \\
\ldots\end{array}$ & $\begin{array}{l}\ldots \\
\ldots \\
\cdots \\
\cdots \\
\cdots\end{array}$ & $\begin{array}{l}\ldots \\
\cdots \\
\ldots \\
\ldots \\
\cdots\end{array}$ & $\begin{array}{l}\ldots \\
\ldots \\
\ldots \\
\ldots \\
\ldots\end{array}$ \\
\hline $\begin{array}{l}16 \\
17 \\
18 \\
19 \\
20\end{array}$ & $\begin{array}{l}1739.60 \\
1739.59 \\
1739.60 \\
1739.62 \\
1739.82\end{array}$ & $\begin{array}{l}1739.60 \\
1739.62 \\
1739.62 \\
1739.62 \\
1739.62\end{array}$ & $\begin{array}{l}1739.72 \\
1739.66 \\
1739.66 \\
1739.67 \\
1739.66\end{array}$ & $\begin{array}{l}1739.78 \\
1739.77 \\
1739.77 \\
1739.77 \\
1739.76\end{array}$ & $\begin{array}{l}1739.85 \\
1739.87 \\
1739.85 \\
1739.81 \\
1739.80\end{array}$ & $\begin{array}{l}1739.85 \\
1739.84 \\
1739.86 \\
1739.86 \\
1739.85\end{array}$ & $\begin{array}{l}1739.84 \\
1739.82 \\
1739.83 \\
1739.86 \\
1739.87\end{array}$ & $\begin{array}{l}1739.69 \\
1739.69 \\
1739.68 \\
1739.67 \\
1739.68\end{array}$ & $\begin{array}{l}\cdots \\
\ldots \\
\cdots \\
\cdots \\
\cdots\end{array}$ & $\begin{array}{l}\cdots \\
\ldots \\
\cdots \\
\cdots \\
\cdots\end{array}$ & $\begin{array}{l}\ldots \\
\ldots \\
\ldots \\
\cdots \\
\cdots\end{array}$ & $\begin{array}{l}\ldots \\
\ldots \\
\ldots \\
\cdots \\
\cdots\end{array}$ \\
\hline $\begin{array}{l}21 \\
22 \\
23 \\
24 \\
25\end{array}$ & $\begin{array}{l}1739.77 \\
1739.73 \\
1739.70 \\
1739.67 \\
1739.66\end{array}$ & $\begin{array}{l}1739.60 \\
1739.59 \\
1739.59 \\
1739.60 \\
1739.61\end{array}$ & $\begin{array}{l}1739.64 \\
1739.63 \\
1739.60 \\
1739.61 \\
1739.62\end{array}$ & $\begin{array}{l}1739.77 \\
1739.77 \\
1739.76 \\
1739.76 \\
1739.74\end{array}$ & $\begin{array}{l}1739.79 \\
1739.79 \\
1739.79 \\
1739.77 \\
1739.76\end{array}$ & $\begin{array}{l}1739.87 \\
1739.84 \\
1739.86 \\
1739.88 \\
1739.87\end{array}$ & $\begin{array}{l}1739.87 \\
1739.87 \\
1739.86 \\
1739.86 \\
1739.84\end{array}$ & $\begin{array}{l}1739.68 \\
1739.67 \\
1739.66 \\
1739.67 \\
1739.67\end{array}$ & $\begin{array}{l}\ldots \\
\ldots \\
\cdots \\
\cdots \\
\cdots\end{array}$ & $\begin{array}{l}\ldots \\
\ldots \\
\ldots \\
\cdots \\
\cdots\end{array}$ & $\begin{array}{l}\ldots \\
\ldots \\
\cdots \\
\cdots \\
\cdots\end{array}$ & $\begin{array}{l}\ldots \\
\ldots \\
\ldots \\
\ldots \\
\ldots\end{array}$ \\
\hline $\begin{array}{l}26 \\
27 \\
28 \\
29 \\
30 \\
31\end{array}$ & $\begin{array}{l}1739.65 \\
1739.63 \\
1739.62 \\
1739.61 \\
1739.60 \\
1739.60\end{array}$ & $\begin{array}{c}1739.65 \\
1739.62 \\
1739.59 \\
1739.59 \\
1739.61 \\
. . .\end{array}$ & $\begin{array}{l}1739.62 \\
1739.62 \\
1739.65 \\
1739.66 \\
1739.64 \\
1739.63\end{array}$ & $\begin{array}{l}1739.73 \\
1739.75 \\
1739.75 \\
1739.74 \\
1739.71 \\
1739.70\end{array}$ & $\begin{array}{r}1739.76 \\
1739.76 \\
1739.79 \\
\ldots . \\
\ldots .\end{array}$ & $\begin{array}{l}1739.87 \\
1739.86 \\
1739.90 \\
1739.92 \\
1739.92 \\
1739.91\end{array}$ & $\begin{array}{r}1739.83 \\
1739.83 \\
1739.81 \\
1739.80 \\
1739.78 \\
\ldots .\end{array}$ & $\begin{array}{l}1739.67 \\
1739.66 \\
1739.65 \\
1739.65 \\
1739.66 \\
1739.66\end{array}$ & $\begin{array}{l}\ldots- \\
\ldots- \\
\ldots- \\
\ldots- \\
\ldots \\
\ldots\end{array}$ & $\begin{array}{l}\ldots \\
\ldots \\
\ldots \\
\ldots \\
\ldots \\
\ldots\end{array}$ & $\begin{array}{l}\ldots \\
\ldots \\
\cdots \\
\cdots \\
\cdots \\
\cdots\end{array}$ & $\begin{array}{l}\ldots \\
\ldots \\
\ldots \\
\ldots \\
\ldots \\
\ldots\end{array}$ \\
\hline
\end{tabular}




\author{
GROND-UATER DATA-Continued \\ DAILY UATER LEVELS-Continued \\ CHAMBERS MELL CLUSTER-Continued
}

STATION MUBER-351038109270803

STATION MAME-CW-6

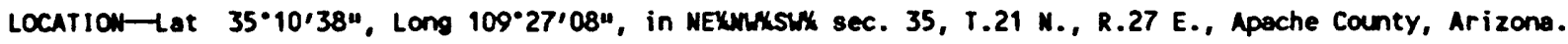

ARIZONA MELL MUMBER-(A-21-27)35cba3.

LAND SURFACE ALTITUDE-1742.78 meters above mean sea level.

WATER LEVEL, IN METERS ABOVE MEAN SEA LEVEL, JULY 1989 TO SEPTEMBER 1989 DAILY MEAH VALUES

\begin{tabular}{|c|c|c|c|c|c|c|c|c|c|c|c|c|}
\hline DAY & OCT & NON & DEC & JAN & FEB & MAR & APR & MAY & JuN & JUL & AUG & SEP \\
\hline $\begin{array}{l}1 \\
2 \\
3 \\
4 \\
5\end{array}$ & $\begin{array}{l}\ldots \\
\ldots \\
\ldots \\
\ldots \\
\ldots\end{array}$ & $\begin{array}{l}\ldots \\
\ldots \\
\ldots \\
\ldots \\
\ldots\end{array}$ & $\begin{array}{l}\ldots \\
\ldots \\
\ldots \\
\ldots \\
\ldots\end{array}$ & $\begin{array}{l}\ldots \\
\ldots \\
\ldots \\
\ldots \\
\ldots\end{array}$ & $\begin{array}{l}\ldots \\
\cdots \\
\cdots \\
\cdots \\
\cdots\end{array}$ & $\begin{array}{l}\ldots \\
\ldots \\
\ldots \\
\ldots\end{array}$ & $\begin{array}{l}\ldots \\
\ldots \\
\ldots \\
\ldots \\
\ldots\end{array}$ & $\begin{array}{l}\ldots \\
\ldots \\
\ldots \\
\ldots \\
\ldots\end{array}$ & $\begin{array}{l}\ldots \\
\cdots \\
\cdots \\
\cdots \\
\cdots\end{array}$ & $\begin{array}{l}\cdots \\
\cdots \\
\cdots \\
\cdots \\
\cdots\end{array}$ & $\begin{array}{l}\ldots \\
\ldots \\
\ldots \\
\ldots \\
\ldots\end{array}$ & $\begin{array}{l}1739.37 \\
1739.37 \\
1739.36 \\
1739.37 \\
1739.36\end{array}$ \\
\hline $\begin{array}{r}6 \\
7 \\
8 \\
9 \\
10\end{array}$ & $\begin{array}{l}\ldots \\
\ldots \\
\ldots \\
\ldots \\
\ldots\end{array}$ & $\begin{array}{l}\ldots \\
\ldots \\
\ldots \\
\ldots \\
\ldots\end{array}$ & $\begin{array}{l}\ldots \\
\ldots \\
\ldots \\
\ldots \\
\ldots\end{array}$ & $\begin{array}{l}\ldots \\
\ldots \\
\ldots \\
\ldots \\
\ldots\end{array}$ & $\begin{array}{l}\ldots \\
\ldots \\
\ldots \\
\ldots \\
\ldots\end{array}$ & $\begin{array}{l}\ldots \\
\ldots \\
\ldots \\
\ldots\end{array}$ & $\begin{array}{l}\ldots \\
\ldots \\
\ldots \\
\ldots \\
\ldots\end{array}$ & $\begin{array}{l}\ldots \\
\ldots \\
\ldots \\
\ldots \\
\ldots\end{array}$ & $\begin{array}{l}\ldots \\
\cdots \\
\cdots \\
\cdots \\
\cdots\end{array}$ & $\begin{array}{l}\ldots \\
\ldots \\
\cdots \\
\ldots \\
\ldots\end{array}$ & $\begin{array}{l}\ldots \\
\ldots \\
\ldots \\
\ldots \\
\ldots\end{array}$ & $\begin{array}{l}1739.39 \\
1739.46 \\
1739.45 \\
1739.44 \\
1739.43\end{array}$ \\
\hline $\begin{array}{l}11 \\
12 \\
13 \\
14 \\
15\end{array}$ & $\begin{array}{l}\ldots \\
\ldots \\
\ldots \\
\ldots \\
\ldots\end{array}$ & $\begin{array}{l}\ldots \\
\ldots \\
\ldots \\
\ldots \\
\ldots\end{array}$ & $\begin{array}{l}\ldots \\
\ldots \\
\ldots \\
\ldots \\
\ldots\end{array}$ & $\begin{array}{l}\ldots \\
\ldots \\
\ldots \\
\ldots \\
\ldots\end{array}$ & $\begin{array}{l}\ldots \\
\ldots \\
\ldots \\
\ldots \\
\ldots\end{array}$ & $\begin{array}{l}\ldots \\
\ldots \\
\ldots \\
\ldots \\
\ldots\end{array}$ & $\begin{array}{l}\ldots \\
\ldots \\
\ldots \\
\ldots \\
\ldots\end{array}$ & $\begin{array}{l}\ldots \\
\ldots \\
\ldots \\
\ldots \\
\ldots\end{array}$ & $\begin{array}{l}\ldots \\
\cdots \\
\cdots \\
\cdots \\
\cdots\end{array}$ & $\begin{array}{l}\ldots \\
\ldots \\
\ldots \\
\ldots \\
\cdots\end{array}$ & $\begin{array}{l}\ldots \\
\ldots \\
\ldots \\
\ldots \\
\ldots\end{array}$ & $\begin{array}{l}1739.41 \\
1739.40 \\
1739.38 \\
1739.37 \\
1739.37\end{array}$ \\
\hline $\begin{array}{l}16 \\
17 \\
18 \\
19 \\
20\end{array}$ & $\begin{array}{l}\ldots \\
\ldots \\
\cdots \\
\cdots \\
\cdots\end{array}$ & $\begin{array}{l}\ldots \\
\cdots \\
\cdots \\
\cdots \\
\cdots\end{array}$ & $\begin{array}{l}\ldots \\
\ldots \\
\cdots \\
\cdots \\
\cdots\end{array}$ & $\begin{array}{l}\cdots \\
\cdots \\
\cdots \\
\cdots \\
\cdots\end{array}$ & $\begin{array}{l}\cdots \\
\cdots \\
\cdots \\
\cdots \\
\cdots\end{array}$ & $\begin{array}{l}\ldots \\
\ldots \\
\ldots \\
\ldots \\
\ldots\end{array}$ & $\begin{array}{l}\ldots \\
\ldots \\
\ldots \\
\ldots \\
\ldots\end{array}$ & $\begin{array}{l}\ldots \\
\ldots \\
\ldots \\
\ldots \\
\ldots\end{array}$ & $\begin{array}{l}\ldots \\
\ldots \\
\cdots \\
\cdots \\
\cdots\end{array}$ & $\begin{array}{l}\ldots \\
\ldots \\
\ldots \\
\ldots \\
\ldots\end{array}$ & $\begin{array}{l}\ldots \\
\ldots \\
\ldots \\
\ldots \\
\ldots\end{array}$ & $\begin{array}{l}1739.37 \\
1739.37 \\
1739.36 \\
1739.36 \\
1739.34\end{array}$ \\
\hline $\begin{array}{l}21 \\
22 \\
23 \\
26 \\
25\end{array}$ & $\begin{array}{l}\ldots \\
\ldots \\
\ldots \\
\ldots \\
\ldots\end{array}$ & $\begin{array}{l}\ldots \\
\ldots \\
\ldots \\
\ldots \\
\ldots\end{array}$ & $\begin{array}{l}\ldots \\
\ldots \\
\ldots \\
\ldots \\
\ldots\end{array}$ & $\begin{array}{l}\ldots \\
\ldots \\
\ldots \\
\ldots\end{array}$ & $\begin{array}{l}\cdots \\
\ldots \\
\cdots \\
\ldots \\
\cdots\end{array}$ & $\begin{array}{l}\ldots \\
\ldots \\
\ldots \\
\ldots \\
\ldots\end{array}$ & $\begin{array}{l}\ldots \\
\ldots \\
\ldots \\
\cdots \\
\ldots\end{array}$ & $\begin{array}{l}\ldots \\
\ldots \\
\ldots \\
\ldots \\
\ldots\end{array}$ & $\begin{array}{l}\ldots \\
\cdots \\
\cdots \\
\cdots \\
\cdots\end{array}$ & $\begin{array}{l}\ldots \\
\ldots \\
\cdots \\
\ldots \\
\cdots\end{array}$ & $\begin{array}{l}1739.54 \\
1739.51 \\
1739.48 \\
1739.47 \\
1739.44\end{array}$ & $\begin{array}{l}1739.34 \\
1739.34 \\
1739.33 \\
1739.34 \\
1739.33\end{array}$ \\
\hline $\begin{array}{l}26 \\
27 \\
28 \\
29 \\
30 \\
31\end{array}$ & $\begin{array}{l}\ldots \\
\ldots \\
\ldots \\
\ldots \\
\ldots \\
\ldots\end{array}$ & $\begin{array}{l}\cdots \\
\ldots \\
\ldots \\
\ldots \\
\ldots \\
\ldots\end{array}$ & $\begin{array}{l}\ldots \\
\ldots \\
\ldots \\
\ldots \\
\ldots\end{array}$ & $\begin{array}{l}\ldots \\
\ldots \\
\ldots \\
\ldots \\
\ldots \\
\ldots\end{array}$ & $\begin{array}{l}\cdots \\
\ldots \\
\cdots \\
\cdots \\
\cdots \\
\cdots\end{array}$ & $\begin{array}{l}\ldots \\
\ldots \\
\ldots \\
\ldots \\
\ldots\end{array}$ & $\begin{array}{l}\ldots \\
\ldots \\
\ldots \\
\ldots \\
\cdots \\
\ldots\end{array}$ & $\begin{array}{l}\ldots \\
\ldots \\
\ldots \\
\ldots \\
\ldots \\
\ldots\end{array}$ & $\begin{array}{l}\ldots \\
\ldots \\
\ldots \\
\ldots \\
\ldots \\
\ldots\end{array}$ & $\begin{array}{r}1739.31 \\
1739.41 \\
1739.57 \\
\ldots . \\
\ldots .\end{array}$ & $\begin{array}{l}1739.43 \\
1739.42 \\
1739.41 \\
1739.41 \\
1739.40 \\
1739.39\end{array}$ & $\begin{array}{r}1739.33 \\
1739.33 \\
1739.33 \\
1739.33 \\
1739.33 \\
\ldots\end{array}$ \\
\hline
\end{tabular}




\author{
GROUMD-WATER DATA-Continued \\ DAILY MATER LEVELS-Continued \\ CHAMBERS WELL CLUSTER - Cont inued
}

STATION MUMBER $351038109270803(\mathrm{CW}-6)$-Cont inued

WATER LEVEL, In METERS ABOVE MEAN SEA LEVEL, OCTOBER 1989 TO SEPTEMBER 1990 DAILY MEAN VALUES

\begin{tabular}{|c|c|c|c|c|c|c|c|c|c|c|c|c|}
\hline DAY & OCT & NOV & DEC & JAN & FEB & MAR & APR & MaY & JUN & JUL & AUG & SEP \\
\hline $\begin{array}{l}1 \\
2 \\
3 \\
4 \\
5\end{array}$ & $\begin{array}{l}1739.33 \\
1739.32 \\
1739.32 \\
1739.34 \\
1739.37\end{array}$ & $\begin{array}{l}1739.38 \\
1739.38 \\
1739.39 \\
1739.40 \\
1739.39\end{array}$ & $\begin{array}{l}1739.41 \\
1739.41 \\
1739.41 \\
1739.42 \\
1739.43\end{array}$ & $\begin{array}{l}\ldots \\
\ldots \\
\ldots \\
\ldots \\
\ldots\end{array}$ & $\begin{array}{l}1739.50 \\
1739.50 \\
1739.48 \\
1739.49 \\
1739.50\end{array}$ & $\begin{array}{l}1739.54 \\
1739.55 \\
1739.55 \\
1739.56 \\
1739.57\end{array}$ & $\begin{array}{l}1739.50 \\
1739.49 \\
1739.50 \\
1739.50 \\
1739.51\end{array}$ & $\begin{array}{l}1739.44 \\
1739.44 \\
1739.44 \\
1739.45 \\
1739.47\end{array}$ & $\begin{array}{l}\ldots \\
\ldots \\
\ldots \\
\ldots \\
\ldots\end{array}$ & $\begin{array}{l}\ldots \\
\cdots \\
\cdots \\
\cdots \\
\cdots\end{array}$ & $\begin{array}{l}1739.05 \\
1739.05 \\
1739.04 \\
1739.04 \\
1739.03\end{array}$ & $\begin{array}{l}\cdots \\
\cdots \\
\cdots \\
\cdots \\
\cdots\end{array}$ \\
\hline $\begin{array}{r}6 \\
7 \\
8 \\
9 \\
10\end{array}$ & $\begin{array}{l}1739.37 \\
1739.37 \\
1739.36 \\
1739.36 \\
1739.36\end{array}$ & $\begin{array}{l}1739.39 \\
1739.40 \\
1739.39 \\
1739.39 \\
1739.40\end{array}$ & $\begin{array}{r}1739.44 \\
1739.43 \\
\ldots \\
\ldots \\
\ldots\end{array}$ & $\begin{array}{l}\ldots \\
\ldots \\
\ldots \\
\ldots \\
\ldots\end{array}$ & $\begin{array}{l}1739.49 \\
1739.50 \\
1739.51 \\
1739.51 \\
1739.51\end{array}$ & $\begin{array}{l}1739.55 \\
1739.54 \\
1739.53 \\
1739.53 \\
1739.54\end{array}$ & $\begin{array}{l}1739.50 \\
1739.50 \\
1739.50 \\
1739.49 \\
1739.48\end{array}$ & $\begin{array}{l}1739.47 \\
1739.47 \\
1739.46 \\
1739.44 \\
1739.44\end{array}$ & $\begin{array}{l}\cdots \\
\ldots \\
\ldots \\
\ldots \\
\ldots\end{array}$ & $\begin{array}{l}\ldots \\
\cdots \\
\cdots \\
\cdots \\
\cdots\end{array}$ & $\begin{array}{l}1739.01 \\
1739.01 \\
1739.03 \\
1739.02 \\
1739.01\end{array}$ & $\begin{array}{l}1739.10 \\
1739.06 \\
1739.05 \\
1739.05 \\
1739.05\end{array}$ \\
\hline $\begin{array}{l}11 \\
12 \\
13 \\
14 \\
15\end{array}$ & $\begin{array}{l}1739.35 \\
1739.35 \\
1739.35 \\
1739.36 \\
1739.36\end{array}$ & $\begin{array}{l}1739.40 \\
1739.41 \\
1739.41 \\
1739.41 \\
1739.40\end{array}$ & $\begin{array}{l}\ldots . \\
\ldots- \\
\cdots \\
\cdots \\
\cdots\end{array}$ & $\begin{array}{l}1739.45 \\
1739.45 \\
1739.46 \\
1739.46 \\
1739.47\end{array}$ & $\begin{array}{l}1739.51 \\
1739.53 \\
1739.54 \\
1739.55 \\
1739.53\end{array}$ & $\begin{array}{l}1739.55 \\
1739.55 \\
1739.55 \\
1739.56 \\
1739.56\end{array}$ & $\begin{array}{l}1739.49 \\
1739.48 \\
1739.47 \\
1739.47 \\
1739.47\end{array}$ & $\begin{array}{l}1739.44 \\
1739.43 \\
1739.42 \\
1739.42 \\
1739.41\end{array}$ & $\begin{array}{l}\ldots \\
\ldots \\
\ldots \\
\ldots \\
\ldots\end{array}$ & $\begin{array}{l}\ldots \\
\ldots \\
\cdots \\
\cdots \\
\cdots\end{array}$ & $\begin{array}{l}1739.00 \\
1738.99 \\
1738.99 \\
1739.03 \\
1739.16\end{array}$ & $\begin{array}{l}1739.02 \\
1739.00 \\
1738.98 \\
1738.97 \\
1738.96\end{array}$ \\
\hline $\begin{array}{l}16 \\
17 \\
18 \\
19 \\
20\end{array}$ & $\begin{array}{l}1739.35 \\
1739.34 \\
1739.34 \\
1739.34 \\
1739.35\end{array}$ & $\begin{array}{l}1739.41 \\
1739.41 \\
1739.41 \\
1739.40 \\
1739.41\end{array}$ & $\begin{array}{l}\ldots \\
\cdots \\
\cdots \\
\cdots \\
\cdots\end{array}$ & $\begin{array}{l}1739.47 \\
1739.47 \\
1739.48 \\
1739.48 \\
1739.47\end{array}$ & $\begin{array}{l}1739.51 \\
1739.52 \\
1739.52 \\
1739.51 \\
1739.51\end{array}$ & $\begin{array}{l}1739.55 \\
1739.55 \\
1739.54 \\
1739.53 \\
1739.53\end{array}$ & $\begin{array}{l}1739.47 \\
1739.47 \\
1739.46 \\
1739.45 \\
1739.45\end{array}$ & $\begin{array}{r}1739.40 \\
1739.41 \\
\ldots \\
\ldots \\
\ldots\end{array}$ & $\begin{array}{l}\ldots \\
\ldots \\
\ldots \\
\ldots \\
\cdots\end{array}$ & $\begin{array}{l}\ldots \\
\cdots \\
\cdots \\
\cdots \\
\cdots\end{array}$ & $\begin{array}{r}1739.14 \\
1739.19 \\
\ldots \\
\ldots \\
\ldots\end{array}$ & $\begin{array}{l}1738.96 \\
1738.95 \\
1738.96 \\
1738.97 \\
1738.98\end{array}$ \\
\hline $\begin{array}{l}21 \\
22 \\
23 \\
24 \\
25\end{array}$ & $\begin{array}{l}1739.37 \\
1739.38 \\
1739.39 \\
1739.39 \\
1739.40\end{array}$ & $\begin{array}{l}1739.42 \\
1739.42 \\
1739.42 \\
1739.43 \\
1739.43\end{array}$ & $\begin{array}{l}\ldots \\
\cdots \\
\cdots \\
\cdots \\
\cdots\end{array}$ & $\begin{array}{l}1739.47 \\
1739.48 \\
1739.49 \\
1739.48 \\
1739.47\end{array}$ & $\begin{array}{l}1739.52 \\
1739.52 \\
1739.52 \\
1739.53 \\
1739.54\end{array}$ & $\begin{array}{l}1739.53 \\
1739.52 \\
1739.52 \\
1739.51 \\
1739.51\end{array}$ & $\begin{array}{l}1739.45 \\
1739.45 \\
1739.46 \\
1739.46 \\
1739.46\end{array}$ & $\begin{array}{l}\ldots \\
\ldots \\
\cdots \\
\ldots \\
\ldots\end{array}$ & $\begin{array}{l}\ldots \\
\ldots \\
\ldots \\
\ldots \\
\ldots\end{array}$ & $\begin{array}{l}\ldots \\
\ldots \\
\ldots \\
\ldots \\
\cdots\end{array}$ & $\begin{array}{l}\cdots \\
\ldots \\
\cdots \\
\cdots \\
\cdots\end{array}$ & $\begin{array}{l}1739.03 \\
1739.04 \\
1739.08 \\
1739.08 \\
1739.05\end{array}$ \\
\hline $\begin{array}{l}26 \\
27 \\
28 \\
29 \\
30 \\
31\end{array}$ & $\begin{array}{l}1739.38 \\
1739.39 \\
1739.39 \\
1739.38 \\
1739.37 \\
1739.39\end{array}$ & $\begin{array}{r}1739.43 \\
1739.42 \\
1739.41 \\
1739.41 \\
1739.41 \\
\ldots .\end{array}$ & $\begin{array}{l}\ldots . \\
\ldots \\
\cdots \\
\cdots \\
\cdots \\
\cdots\end{array}$ & $\begin{array}{l}1739.49 \\
1739.48 \\
1739.47 \\
1739.49 \\
1739.50 \\
1739.50\end{array}$ & $\begin{array}{r}1739.53 \\
1739.54 \\
1739.53 \\
\ldots \\
\ldots . \\
\ldots\end{array}$ & $\begin{array}{l}1739.50 \\
1739.51 \\
1739.51 \\
1739.51 \\
1739.50 \\
1739.50\end{array}$ & $\begin{array}{r}1739.47 \\
1739.45 \\
1739.45 \\
1739.44 \\
1739.44 \\
\ldots .\end{array}$ & $\begin{array}{l}\ldots \\
\ldots \\
\ldots \\
\ldots \\
\ldots \\
\ldots\end{array}$ & $\begin{array}{l}\ldots \\
\ldots \\
\ldots \\
\ldots \\
\ldots \\
\ldots\end{array}$ & $\begin{array}{r}\ldots \\
1739.11 \\
1739.09 \\
1739.08 \\
1739.06 \\
1739.06\end{array}$ & $\begin{array}{l}\cdots \\
\ldots \\
\cdots \\
\ldots \\
\cdots \\
\cdots\end{array}$ & $\begin{array}{r}1739.03 \\
1739.02 \\
1739.00 \\
1738.98 \\
1738.97 \\
\ldots\end{array}$ \\
\hline
\end{tabular}




\author{
GROUNO-HATER DATA-Continued \\ DAILY MATER LEVELS-Continued \\ CHAMBERS MELL CLUSTER-Continued
}

STATION MUMBER 351038109270803 (CH-6)-Continued

wATER LEVEL, IN METERS ABOVE MEAN SEA LEVEL, OCTOBER 1990 TO JUNE 1991 DAILY MEAN VALUES

\begin{tabular}{|c|c|c|c|c|c|c|c|c|c|c|c|c|}
\hline DAY & OCT & NOV & DEC & JAN & FEB & MAR & APR & MAY & JUN & JUL & AUG & SEP \\
\hline $\begin{array}{l}1 \\
2 \\
3 \\
4 \\
5\end{array}$ & $\begin{array}{l}1738.97 \\
1738.98 \\
1738.99 \\
1738.97 \\
1738.97\end{array}$ & $\begin{array}{l}1738.92 \\
1738.94 \\
1738.97 \\
1738.97 \\
1738.99\end{array}$ & $\begin{array}{l}1738.92 \\
1738.91 \\
1738.90 \\
1738.91 \\
1738.91\end{array}$ & $\begin{array}{l}1738.94 \\
1738.94 \\
1738.94 \\
1738.97 \\
1738.97\end{array}$ & $\begin{array}{l}1738.99 \\
1739.00 \\
1739.01 \\
1739.01 \\
1739.04\end{array}$ & $\begin{array}{l}1739.11 \\
1739.14 \\
1739.15 \\
1739.16 \\
1739.16\end{array}$ & $\begin{array}{l}1739.19 \\
1739.18 \\
1739.19 \\
1739.19 \\
1739.19\end{array}$ & $\begin{array}{l}1739.06 \\
1739.06 \\
1739.04 \\
1739.02 \\
1739.01\end{array}$ & $\begin{array}{r}1738.94 \\
1738.94 \\
1738.94 \\
1738.94 \\
\ldots .\end{array}$ & $\begin{array}{l}\ldots \\
\ldots \\
\ldots \\
\ldots \\
\ldots\end{array}$ & $\begin{array}{l}\ldots \\
\ldots \\
\ldots \\
\ldots \\
\ldots\end{array}$ & $\begin{array}{l}\ldots \\
\ldots \\
\ldots \\
\ldots\end{array}$ \\
\hline $\begin{array}{r}6 \\
7 \\
8 \\
9 \\
10\end{array}$ & $\begin{array}{l}1738.97 \\
1738.95 \\
1738.94 \\
1738.94 \\
1738.94\end{array}$ & $\begin{array}{l}1738.98 \\
1738.97 \\
1738.95 \\
1738.95 \\
1738.96\end{array}$ & $\begin{array}{l}1738.91 \\
1738.91 \\
1738.91 \\
1738.91 \\
1738.91\end{array}$ & $\begin{array}{l}1738.98 \\
1739.02 \\
1739.04 \\
1739.05 \\
1739.06\end{array}$ & $\begin{array}{l}1739.03 \\
1739.04 \\
1739.06 \\
1739.08 \\
1739.10\end{array}$ & $\begin{array}{l}1739.17 \\
1739.19 \\
1739.18 \\
1739.16 \\
1739.16\end{array}$ & $\begin{array}{l}1739.20 \\
1739.21 \\
1739.20 \\
1739.19 \\
1739.20\end{array}$ & $\begin{array}{l}1739.02 \\
1739.02 \\
1739.01 \\
1739.01 \\
1739.01\end{array}$ & $\begin{array}{l}\ldots \\
\ldots \\
\cdots \\
\cdots \\
\cdots\end{array}$ & $\begin{array}{l}\ldots \\
\ldots \\
\ldots \\
\ldots \\
\ldots\end{array}$ & $\begin{array}{l}\ldots \\
\ldots \\
\cdots \\
\cdots \\
\cdots\end{array}$ & $\begin{array}{l}\ldots \\
\ldots \\
\ldots \\
\ldots \\
\ldots\end{array}$ \\
\hline $\begin{array}{l}11 \\
12 \\
13 \\
14 \\
15\end{array}$ & $\begin{array}{l}1738.94 \\
1738.94 \\
1738.94 \\
1738.92 \\
1738.92\end{array}$ & $\begin{array}{l}1738.95 \\
1738.95 \\
1738.95 \\
1738.94 \\
1738.93\end{array}$ & $\begin{array}{l}1738.91 \\
1738.91 \\
1738.94 \\
1738.96 \\
1738.96\end{array}$ & $\begin{array}{l}1739.05 \\
1739.06 \\
1739.07 \\
1739.07 \\
1739.07\end{array}$ & $\begin{array}{l}1739.12 \\
1739.14 \\
1739.15 \\
1739.15 \\
1739.14\end{array}$ & $\begin{array}{l}1739.15 \\
1739.12 \\
1739.13 \\
1739.13 \\
1739.14\end{array}$ & $\begin{array}{l}1739.18 \\
1739.15 \\
1739.16 \\
1739.17 \\
1739.17\end{array}$ & $\begin{array}{l}1738.99 \\
1738.98 \\
1738.99 \\
1738.99 \\
1738.98\end{array}$ & $\begin{array}{l}\ldots . \\
\ldots \\
\cdots \\
\cdots \\
\cdots\end{array}$ & $\begin{array}{l}\ldots \\
\ldots \\
\cdots \\
\cdots \\
\cdots\end{array}$ & $\begin{array}{l}\ldots \\
\cdots \\
\cdots \\
\cdots \\
\cdots\end{array}$ & $\begin{array}{l}\ldots \\
\ldots \\
\ldots \\
\ldots \\
\ldots\end{array}$ \\
\hline $\begin{array}{l}16 \\
17 \\
18 \\
19 \\
20\end{array}$ & $\begin{array}{l}1738.92 \\
1738.91 \\
1738.91 \\
1738.93 \\
1739.05\end{array}$ & $\begin{array}{l}1738.92 \\
1738.93 \\
1738.93 \\
1738.93 \\
1738.93\end{array}$ & $\begin{array}{l}1739.00 \\
1738.97 \\
1738.96 \\
1738.97 \\
1738.96\end{array}$ & $\begin{array}{l}1739.07 \\
1739.05 \\
1739.05 \\
1739.06 \\
1739.05\end{array}$ & $\begin{array}{l}1739.14 \\
1739.16 \\
1739.15 \\
1739.11 \\
1739.10\end{array}$ & $\begin{array}{l}1739.14 \\
1739.12 \\
1739.14 \\
1739.15 \\
1739.14\end{array}$ & $\begin{array}{l}1739.14 \\
1739.11 \\
1739.10 \\
1739.13 \\
1739.15\end{array}$ & $\begin{array}{l}1738.97 \\
1738.97 \\
1738.97 \\
1738.96 \\
1738.96\end{array}$ & $\begin{array}{l}\cdots \\
\cdots \\
\cdots \\
\cdots \\
\cdots\end{array}$ & $\begin{array}{l}\ldots \\
\ldots \\
\ldots \\
\ldots \\
\cdots\end{array}$ & $\begin{array}{l}\ldots \\
\ldots \\
\cdots \\
\cdots \\
\cdots\end{array}$ & $\begin{array}{l}\ldots \\
\ldots \\
\ldots \\
\ldots \\
\ldots\end{array}$ \\
\hline $\begin{array}{l}21 \\
22 \\
23 \\
24 \\
25\end{array}$ & $\begin{array}{l}1739.05 \\
1739.03 \\
1739.01 \\
1738.98 \\
1738.97\end{array}$ & $\begin{array}{l}1738.91 \\
1738.91 \\
1738.91 \\
1738.91 \\
1738.92\end{array}$ & $\begin{array}{l}1738.95 \\
1738.93 \\
1738.91 \\
1738.91 \\
1738.92\end{array}$ & $\begin{array}{l}1739.05 \\
1739.05 \\
1739.04 \\
1739.04 \\
1739.02\end{array}$ & $\begin{array}{l}1739.09 \\
1739.09 \\
1739.09 \\
1739.08 \\
1739.06\end{array}$ & $\begin{array}{l}1739.15 \\
1739.13 \\
1739.13 \\
1739.15 \\
1739.15\end{array}$ & $\begin{array}{l}1739.16 \\
1739.15 \\
1739.15 \\
1739.14 \\
1739.13\end{array}$ & $\begin{array}{l}1738.97 \\
1738.96 \\
1738.95 \\
1738.95 \\
1738.96\end{array}$ & $\begin{array}{l}\ldots \\
\ldots \\
\cdots \\
\cdots \\
\cdots\end{array}$ & $\begin{array}{l}\ldots \\
\ldots \\
\ldots \\
\ldots \\
\ldots\end{array}$ & $\begin{array}{l}\ldots \\
\ldots \\
\ldots \\
\cdots \\
\cdots\end{array}$ & $\begin{array}{l}\ldots \\
\ldots \\
\ldots \\
\ldots \\
\ldots\end{array}$ \\
\hline $\begin{array}{l}26 \\
27 \\
28 \\
29 \\
30 \\
31\end{array}$ & $\begin{array}{l}1738.95 \\
1738.94 \\
1738.93 \\
1738.92 \\
1738.92 \\
1738.92\end{array}$ & $\begin{array}{r}1738.95 \\
1738.93 \\
1738.91 \\
1738.91 \\
1738.92 \\
\ldots\end{array}$ & $\begin{array}{l}1738.92 \\
1738.92 \\
1738.95 \\
1738.95 \\
1738.94 \\
1738.93\end{array}$ & $\begin{array}{l}1739.02 \\
1739.03 \\
1739.04 \\
1739.03 \\
1738.99 \\
1738.99\end{array}$ & $\begin{array}{r}1739.07 \\
1739.06 \\
1739.08 \\
\ldots \\
\ldots \\
\ldots\end{array}$ & $\begin{array}{l}1739.15 \\
1739.13 \\
1739.16 \\
1739.17 \\
1739.18 \\
1739.17\end{array}$ & $\begin{array}{r}1739.12 \\
1739.11 \\
1739.09 \\
1739.08 \\
1739.06 \\
\ldots\end{array}$ & $\begin{array}{l}1738.95 \\
1738.94 \\
1738.94 \\
1738.94 \\
1738.95 \\
1738.95\end{array}$ & $\begin{array}{l}\ldots \\
\cdots \\
\cdots \\
\cdots \\
\cdots \\
\cdots\end{array}$ & $\begin{array}{l}\ldots \\
\ldots \\
\cdots \\
\cdots \\
\cdots \\
\cdots\end{array}$ & $\begin{array}{l}\cdots \\
\ldots \\
\cdots \\
\cdots \\
\cdots \\
\cdots\end{array}$ & $\begin{array}{l}\ldots \\
\ldots \\
\ldots \\
\ldots \\
\ldots \\
\ldots\end{array}$ \\
\hline
\end{tabular}


GROUND-MATER DATA-Cont inued

DAILY MATER LEVELS- Continued

CHAMBERS WELL ClUSTER-Continued

STATION MUMBER-351039109270003

STATION MAME-CW-9

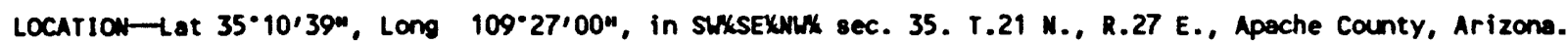

ARIZONA WELL NUMBER-(A-21-27)35bode3.

LAND SURFACE ALTITUDE-1748.52 meters above mean sea level.

WATER LeVel, IN MEters abOVE MeAN SEA LEVEL, JULY 1989 to SEPTEMBER 1989 DAILY MEAN VALUES

\begin{tabular}{|c|c|c|c|c|c|c|c|c|c|c|c|c|}
\hline DAY & OCT & NON & DEC & JAN & FEB & MAR & APR & MaY & JUN & JUL & AUG & SEP \\
\hline $\begin{array}{l}1 \\
2 \\
3 \\
4 \\
5\end{array}$ & $\begin{array}{l}\ldots \\
\ldots \\
\ldots \\
\ldots \\
\ldots\end{array}$ & $\begin{array}{l}\ldots \\
\ldots \\
\ldots \\
\cdots \\
\cdots\end{array}$ & $\begin{array}{l}\ldots \\
\ldots \\
\ldots \\
\ldots \\
\ldots\end{array}$ & $\begin{array}{l}\ldots \\
\ldots \\
\ldots \\
\ldots \\
\ldots\end{array}$ & $\begin{array}{l}\ldots \\
\ldots \\
\ldots \\
\ldots \\
\ldots\end{array}$ & $\begin{array}{l}\ldots \\
\ldots \\
\ldots \\
\cdots \\
\cdots\end{array}$ & $\begin{array}{l}\ldots \\
\cdots \\
\cdots \\
\cdots \\
\cdots\end{array}$ & $\begin{array}{l}\ldots \\
\ldots \\
\ldots \\
\ldots \\
\ldots\end{array}$ & $\begin{array}{l}\cdots \\
\cdots \\
\cdots \\
\cdots \\
\cdots\end{array}$ & $\begin{array}{l}\cdots \\
\cdots \\
\cdots \\
\cdots \\
\cdots\end{array}$ & $\begin{array}{l}\ldots \\
\ldots \\
\ldots \\
\cdots \\
\cdots\end{array}$ & $\begin{array}{l}1739.67 \\
1739.67 \\
1739.66 \\
1739.67 \\
1739.66\end{array}$ \\
\hline $\begin{array}{r}6 \\
7 \\
8 \\
9 \\
10\end{array}$ & $\begin{array}{l}\ldots \\
\ldots \\
\ldots \\
\ldots\end{array}$ & $\begin{array}{l}\ldots \\
\ldots \\
\ldots \\
\ldots \\
\cdots\end{array}$ & $\begin{array}{l}\ldots . \\
\cdots \\
\cdots \\
\cdots \\
\cdots\end{array}$ & $\begin{array}{l}\ldots \\
\ldots \\
\ldots \\
\ldots \\
\ldots\end{array}$ & $\begin{array}{l}\ldots \\
\ldots \\
\cdots \\
\ldots \\
\cdots\end{array}$ & $\begin{array}{l}\ldots \\
\ldots \\
\ldots \\
\ldots \\
\cdots\end{array}$ & $\begin{array}{l}\ldots \\
\ldots \\
\ldots \\
\ldots \\
\cdots\end{array}$ & $\begin{array}{l}\ldots \\
\ldots \\
\ldots \\
\ldots \\
\ldots\end{array}$ & $\begin{array}{l}\ldots \\
\cdots \\
\cdots \\
\cdots \\
\cdots\end{array}$ & $\begin{array}{l}\cdots \\
\ldots \\
\cdots \\
\cdots \\
\cdots\end{array}$ & $\begin{array}{l}\ldots \\
\ldots \\
\cdots \\
\cdots \\
\cdots\end{array}$ & $\begin{array}{l}1739.68 \\
1739.75 \\
1739.75 \\
1739.73 \\
1739.72\end{array}$ \\
\hline $\begin{array}{l}11 \\
12 \\
13 \\
14 \\
15\end{array}$ & $\begin{array}{l}\ldots \\
\ldots \\
\ldots \\
\ldots\end{array}$ & $\begin{array}{l}\ldots \\
\cdots \\
\cdots \\
\cdots \\
\cdots\end{array}$ & $\begin{array}{l}\ldots \\
\ldots \\
\ldots \\
\ldots \\
\cdots\end{array}$ & $\begin{array}{l}\ldots \\
\ldots \\
\ldots \\
\ldots \\
\ldots\end{array}$ & $\begin{array}{l}\ldots \\
\cdots \\
\cdots \\
\cdots \\
\cdots\end{array}$ & $\begin{array}{l}\ldots \\
\ldots \\
\ldots \\
\cdots \\
\cdots\end{array}$ & $\begin{array}{l}\ldots \\
\ldots \\
\ldots \\
\ldots \\
\ldots\end{array}$ & $\begin{array}{l}\ldots \\
\ldots \\
\ldots \\
\ldots \\
\ldots\end{array}$ & $\begin{array}{l}\ldots \\
\ldots \\
\ldots \\
\cdots \\
\cdots\end{array}$ & $\begin{array}{l}\ldots \\
\ldots \\
\ldots \\
\ldots \\
\ldots\end{array}$ & $\begin{array}{l}\ldots . \\
\ldots \\
\ldots \\
\ldots \\
\ldots\end{array}$ & $\begin{array}{l}1739.71 \\
1739.69 \\
1739.67 \\
1739.67 \\
1739.67\end{array}$ \\
\hline $\begin{array}{l}16 \\
17 \\
18 \\
19 \\
20\end{array}$ & $\begin{array}{l}\ldots \\
\ldots \\
\ldots \\
\ldots \\
\ldots\end{array}$ & $\begin{array}{l}\ldots \\
\ldots \\
\cdots \\
\ldots \\
\cdots\end{array}$ & $\begin{array}{l}\ldots \\
\ldots \\
\ldots \\
\ldots \\
\ldots\end{array}$ & $\begin{array}{l}\ldots \\
\ldots \\
\ldots \\
\ldots \\
\ldots\end{array}$ & $\begin{array}{l}\ldots \\
\ldots \\
\ldots \\
\ldots \\
\ldots\end{array}$ & $\begin{array}{l}\ldots \\
\ldots \\
\ldots \\
\ldots \\
\ldots\end{array}$ & $\begin{array}{l}\ldots \\
\ldots \\
\ldots \\
\ldots \\
\cdots\end{array}$ & $\begin{array}{l}\ldots \\
\ldots \\
\ldots \\
\ldots \\
\ldots\end{array}$ & $\begin{array}{l}\ldots \\
\ldots \\
\ldots \\
\cdots \\
\cdots\end{array}$ & $\begin{array}{l}\ldots \\
\ldots \\
\ldots \\
\ldots \\
\ldots\end{array}$ & $\begin{array}{l}\ldots . \\
\ldots \\
\ldots \\
\ldots \\
\ldots\end{array}$ & $\begin{array}{l}1739.67 \\
1739.67 \\
1739.67 \\
1739.66 \\
1739.65\end{array}$ \\
\hline $\begin{array}{l}21 \\
22 \\
23 \\
24 \\
25\end{array}$ & $\begin{array}{l}\ldots \\
\ldots \\
\ldots \\
\ldots \\
\ldots\end{array}$ & $\begin{array}{l}\ldots \\
\cdots \\
\cdots \\
\cdots \\
\cdots\end{array}$ & $\begin{array}{l}\ldots . \\
\cdots \\
\cdots \\
\cdots \\
\cdots\end{array}$ & $\begin{array}{l}\ldots \\
\cdots \\
\cdots \\
\cdots \\
\cdots\end{array}$ & $\begin{array}{l}\ldots \\
\cdots \\
\cdots \\
\cdots\end{array}$ & $\begin{array}{l}\ldots . \\
\cdots \\
\cdots \\
\cdots \\
\cdots\end{array}$ & $\begin{array}{l}\ldots \\
\ldots \\
\cdots \\
\ldots \\
\cdots\end{array}$ & $\begin{array}{l}\ldots \\
\ldots \\
\ldots \\
\ldots \\
\ldots\end{array}$ & $\begin{array}{l}\ldots . \\
\cdots \\
\cdots \\
\cdots\end{array}$ & $\begin{array}{l}\cdots \\
\cdots \\
\cdots \\
\cdots \\
\cdots\end{array}$ & $\begin{array}{r}1739.80 \\
1739.79 \\
1739.78 \\
1739.76\end{array}$ & $\begin{array}{l}1739.64 \\
1739.64 \\
1739.63 \\
1739.64 \\
1739.63\end{array}$ \\
\hline $\begin{array}{l}26 \\
27 \\
28 \\
29 \\
30 \\
31\end{array}$ & $\begin{array}{l}\ldots \\
\ldots \\
\ldots \\
\ldots \\
\ldots \\
\ldots\end{array}$ & $\begin{array}{l}\ldots . \\
\ldots \\
\ldots \\
\ldots \\
\ldots \\
\ldots\end{array}$ & $\begin{array}{l}\ldots \\
\ldots \\
\ldots \\
\ldots \\
\ldots\end{array}$ & $\begin{array}{l}\ldots \\
\ldots \\
\ldots \\
\ldots \\
\ldots \\
\ldots\end{array}$ & $\begin{array}{l}\ldots \\
\ldots \\
\ldots \\
\ldots \\
\ldots \\
\ldots\end{array}$ & $\begin{array}{l}\ldots \\
\ldots \\
\ldots \\
\ldots \\
\ldots \\
\ldots\end{array}$ & $\begin{array}{l}\ldots \\
\ldots \\
\ldots \\
\ldots \\
\ldots \\
\ldots\end{array}$ & $\begin{array}{l}\ldots \\
\ldots \\
\ldots \\
\ldots \\
\ldots \\
\ldots\end{array}$ & $\begin{array}{l}\ldots \\
\ldots \\
\ldots \\
\ldots \\
\ldots \\
\ldots\end{array}$ & $\begin{array}{r}1739.62 \\
1739.74 \\
1739.89 \\
\ldots \\
\ldots . .\end{array}$ & $\begin{array}{l}1739.74 \\
1739.73 \\
1739.71 \\
1739.70 \\
1739.69 \\
1739.68\end{array}$ & $\begin{array}{r}1739.63 \\
1739.63 \\
1739.63 \\
1739.63 \\
1739.63 \\
\ldots . .\end{array}$ \\
\hline
\end{tabular}




\author{
GROUND-WATER DATA-Continued \\ DAILY WATER LEVELS-Continued \\ CHAMBERS MELL CLUSTER-Continued
}

STATION MUMBER 351039109270003 (CH-9)-Continued

mater level, in meters above mean SEA LeVEL, OCtOBer 1989 to SePtember 1990 DAILY MEAN VALUES

\begin{tabular}{|c|c|c|c|c|c|c|c|c|c|c|c|c|}
\hline $\mathbf{A Y}$ & OCT & NOV & DEC & JAN & FEB & MAR & APR & MaY & JUN & JUL & AUG & SEP \\
\hline $\begin{array}{l}1 \\
2 \\
3 \\
4 \\
5\end{array}$ & $\begin{array}{l}1739.63 \\
1739.63 \\
1739.62 \\
1739.66 \\
1739.68\end{array}$ & $\begin{array}{l}1739.69 \\
1739.70 \\
1739.70 \\
1739.71 \\
1739.70\end{array}$ & $\begin{array}{l}1739.72 \\
1739.71 \\
1739.72 \\
1739.73 \\
1739.74\end{array}$ & $\begin{array}{l}1739.76 \\
1739.78 \\
1739.75 \\
1739.75 \\
1739.74\end{array}$ & $\begin{array}{l}\ldots \\
\ldots \\
\ldots \\
\ldots \\
\cdots\end{array}$ & $\begin{array}{l}1739.85 \\
1739.85 \\
1739.86 \\
1739.86 \\
1739.87\end{array}$ & $\begin{array}{l}1739.80 \\
1739.79 \\
1739.79 \\
1739.80 \\
1739.81\end{array}$ & $\begin{array}{l}1739.73 \\
1739.73 \\
1739.74 \\
1739.75 \\
1739.76\end{array}$ & $\begin{array}{l}\ldots \\
\ldots \\
\ldots \\
\cdots \\
\cdots\end{array}$ & $\begin{array}{l}\ldots \\
\ldots \\
\ldots \\
\ldots \\
\ldots\end{array}$ & $\begin{array}{l}1739.36 \\
1739.35 \\
1739.34 \\
1739.34 \\
1739.32\end{array}$ & $\begin{array}{l}1739.27 \\
1739.27 \\
1739.30 \\
1739.30 \\
1739.29\end{array}$ \\
\hline $\begin{array}{r}6 \\
7 \\
8 \\
9 \\
10\end{array}$ & $\begin{array}{l}1739.67 \\
1739.67 \\
1739.67 \\
1739.67 \\
1739.66\end{array}$ & $\begin{array}{l}1739.70 \\
1739.71 \\
1739.70 \\
1739.69 \\
1739.70\end{array}$ & $\begin{array}{l}1739.75 \\
1739.72 \\
1739.72 \\
1739.75 \\
1739.76\end{array}$ & $\begin{array}{l}1739.74 \\
1739.75 \\
1739.75 \\
1739.74 \\
1739.75\end{array}$ & $\begin{array}{r}\ldots \\
\ldots \\
1739.81 \\
1739.81\end{array}$ & $\begin{array}{l}1739.84 \\
1739.83 \\
1739.83 \\
1739.83 \\
1739.84\end{array}$ & $\begin{array}{l}1739.80 \\
1739.80 \\
1739.80 \\
1739.78 \\
1739.77\end{array}$ & $\begin{array}{l}1739.77 \\
1739.77 \\
1739.76 \\
1739.73 \\
1739.74\end{array}$ & $\begin{array}{l}\ldots \\
\ldots \\
\ldots \\
\ldots- \\
\cdots\end{array}$ & $\begin{array}{l}\ldots \\
\ldots \\
\ldots \\
\ldots \\
\cdots\end{array}$ & $\begin{array}{l}1739.32 \\
1739.31 \\
1739.33 \\
1739.32 \\
1739.31\end{array}$ & $\begin{array}{l}1739.38 \\
1739.39 \\
1739.36 \\
1739.35 \\
1739.36\end{array}$ \\
\hline $\begin{array}{l}11 \\
12 \\
13 \\
14 \\
15\end{array}$ & $\begin{array}{l}1739.66 \\
1739.66 \\
1739.66 \\
1739.67 \\
1739.68\end{array}$ & $\begin{array}{l}1739.71 \\
1739.72 \\
1739.72 \\
1739.71 \\
1739.69\end{array}$ & $\begin{array}{l}1739.73 \\
1739.73 \\
1739.73 \\
1739.73 \\
1739.74\end{array}$ & $\begin{array}{r}1739.76 \\
\ldots \\
\ldots \\
\ldots \\
\ldots\end{array}$ & $\begin{array}{l}1739.82 \\
1739.84 \\
1739.85 \\
1739.86 \\
1739.83\end{array}$ & $\begin{array}{l}1739.86 \\
1739.85 \\
1739.86 \\
1739.86 \\
1739.86\end{array}$ & $\begin{array}{l}1739.79 \\
1739.78 \\
1739.76 \\
1739.76 \\
1739.77\end{array}$ & $\begin{array}{l}1739.73 \\
1739.72 \\
1739.72 \\
1739.72 \\
1739.71\end{array}$ & $\begin{array}{l}\ldots \\
\ldots \\
\ldots \\
\ldots \\
\ldots\end{array}$ & $\begin{array}{l}\ldots \\
\ldots \\
\cdots \\
\ldots \\
\cdots\end{array}$ & $\begin{array}{l}1739.30 \\
1739.29 \\
1739.30 \\
1739.34 \\
1739.47\end{array}$ & $\begin{array}{l}1739.33 \\
1739.31 \\
1739.29 \\
1739.28 \\
1739.27\end{array}$ \\
\hline $\begin{array}{l}16 \\
17 \\
18 \\
19 \\
20\end{array}$ & $\begin{array}{l}1739.66 \\
1739.65 \\
1739.65 \\
1739.65 \\
1739.67\end{array}$ & $\begin{array}{l}1739.73 \\
1739.72 \\
1739.71 \\
1739.71 \\
1739.72\end{array}$ & $\begin{array}{l}1739.75 \\
1739.75 \\
1739.75 \\
1739.73 \\
1739.73\end{array}$ & $\begin{array}{l}\ldots \\
\ldots \\
\ldots \\
\ldots \\
\ldots\end{array}$ & $\begin{array}{l}1739.81 \\
1739.82 \\
1739.82 \\
1739.82 \\
1739.81\end{array}$ & $\begin{array}{l}1739.83 \\
1739.84 \\
1739.84 \\
1739.82 \\
1739.82\end{array}$ & $\begin{array}{l}1739.76 \\
1739.76 \\
1739.76 \\
1739.75 \\
1739.75\end{array}$ & $\begin{array}{r}1739.69 \\
1739.71 \\
\ldots . \\
\ldots \\
\ldots\end{array}$ & $\begin{array}{l}\ldots \\
\ldots \\
\ldots \\
\ldots\end{array}$ & $\begin{array}{l}\ldots \\
\ldots \\
\ldots \\
\ldots \\
\ldots\end{array}$ & $\begin{array}{l}1739.45 \\
1739.51 \\
1739.48 \\
1739.42 \\
1739.39\end{array}$ & $\begin{array}{l}1739.27 \\
1739.26 \\
1739.27 \\
1739.28 \\
1739.29\end{array}$ \\
\hline $\begin{array}{l}21 \\
22 \\
23 \\
24 \\
25\end{array}$ & $\begin{array}{l}1739.69 \\
1739.69 \\
1739.69 \\
1739.70 \\
1739.71\end{array}$ & $\begin{array}{l}1739.73 \\
1739.72 \\
1739.73 \\
1739.74 \\
1739.73\end{array}$ & $\begin{array}{l}1739.74 \\
1739.72 \\
1739.72 \\
1739.73 \\
1739.74\end{array}$ & $\begin{array}{l}\ldots \\
\ldots \\
\ldots \\
\ldots \\
\ldots\end{array}$ & $\begin{array}{l}1739.82 \\
1739.82 \\
1739.82 \\
1739.83 \\
1739.83\end{array}$ & $\begin{array}{l}1739.83 \\
1739.82 \\
1739.81 \\
1739.81 \\
1739.80\end{array}$ & $\begin{array}{l}1739.76 \\
1739.76 \\
1739.76 \\
1739.77 \\
1739.76\end{array}$ & $\begin{array}{l}\ldots- \\
\ldots \\
\ldots \\
\ldots \\
\ldots\end{array}$ & $\begin{array}{l}\ldots \\
\ldots \\
\cdots \\
\cdots \\
\cdots\end{array}$ & $\begin{array}{l}\ldots \\
\ldots \\
\cdots \\
\cdots \\
\cdots\end{array}$ & $\begin{array}{l}1739.41 \\
1739.41 \\
1739.38 \\
1739.34 \\
1739.32\end{array}$ & $\begin{array}{l}1739.33 \\
1739.34 \\
1739.39 \\
1739.39 \\
1739.36\end{array}$ \\
\hline $\begin{array}{l}26 \\
27 \\
28 \\
29 \\
30 \\
31\end{array}$ & $\begin{array}{l}1739.69 \\
1739.70 \\
1739.69 \\
1739.68 \\
1739.69 \\
1739.69\end{array}$ & $\begin{array}{r}1739.74 \\
1739.72 \\
1739.71 \\
1739.71 \\
1739.72 \\
. . .\end{array}$ & $\begin{array}{l}1739.75 \\
1739.76 \\
1739.76 \\
1739.77 \\
1739.76 \\
1739.73\end{array}$ & $\begin{array}{l}\ldots \\
\ldots \\
\ldots \\
\ldots \\
\ldots \\
\ldots\end{array}$ & $\begin{array}{r}1739.83 \\
1739.83 \\
1739.83 \\
\ldots . \\
\ldots \\
\ldots\end{array}$ & $\begin{array}{l}1739.80 \\
1739.81 \\
1739.81 \\
1739.80 \\
1739.80 \\
1739.80\end{array}$ & $\begin{array}{r}1739.76 \\
1739.75 \\
1739.76 \\
1739.75 \\
1739.73 \\
\ldots\end{array}$ & $\begin{array}{l}\ldots \\
\ldots \\
\ldots \\
\ldots \\
\ldots \\
\ldots\end{array}$ & $\begin{array}{l}\ldots \\
\ldots \\
\ldots \\
\ldots \\
\ldots \\
\ldots\end{array}$ & $\begin{array}{r}. .- \\
1739.41 \\
1739.39 \\
1739.37 \\
1739.36 \\
1739.37\end{array}$ & $\begin{array}{l}1739.31 \\
1739.29 \\
1739.29 \\
1739.29 \\
1739.28 \\
1739.27\end{array}$ & $\begin{array}{r}1739.34 \\
1739.33 \\
1739.31 \\
1739.29 \\
1739.27 \\
\ldots . .\end{array}$ \\
\hline
\end{tabular}




$$
\begin{aligned}
& \text { GROUND-WATER DATA-Continued } \\
& \text { OAILY WATER LEVELS-Continued } \\
& \text { CHAMBERS WELL CLUSTER-Continued }
\end{aligned}
$$

STATION MUABER 351039109270003 (CH-9)-Cont inued

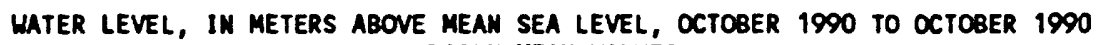
DAILY MEAN VALUES

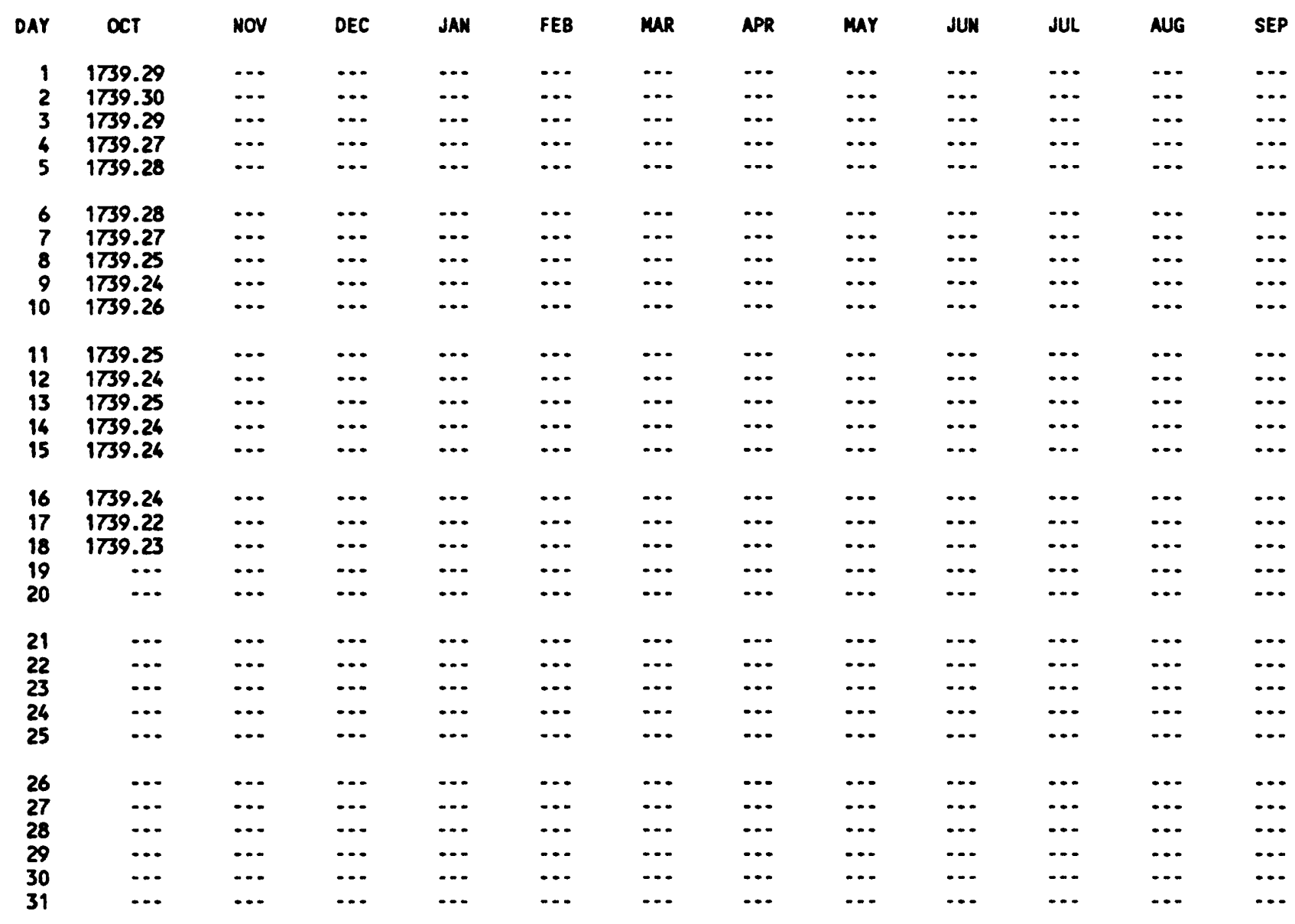


GROUND-WATER DATA-Cont inued

DAILY WATER LEVELS-continued

ADOT WELL CLUSTER

\section{STATION MUABER-351140109220403}

STATION NAME $\rightarrow$ AO-3

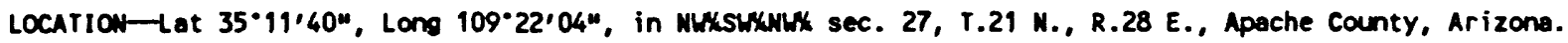

AR1ZOWA WELL MUMBER-(A-21-28)27bCb.

LAND SURFACE ALTITUDE-1765.97 meters above mean sea level.

MATER LEVEL, IN METERS ABOVE MEAN SEA LEVEL, JULY 1989 TO SEPTEMBER 1989 DAILY MEAN VALUES

\begin{tabular}{|c|c|c|c|c|c|c|c|c|c|c|c|c|}
\hline DAY & OCT & NOV & DEC & JAN & FEB & MAR & APR & MAY & JUN & JUL & AUG & SEP \\
\hline $\begin{array}{l}1 \\
2 \\
3 \\
4 \\
5\end{array}$ & $\begin{array}{l}\ldots \\
\ldots \\
\ldots \\
\ldots \\
\ldots\end{array}$ & $\begin{array}{l}\ldots \\
\ldots \\
\ldots \\
\ldots \\
\cdots\end{array}$ & $\begin{array}{l}\ldots \\
\cdots \\
\ldots \\
\cdots \\
\cdots\end{array}$ & $\begin{array}{l}\ldots \\
\ldots \\
\ldots \\
\ldots \\
\ldots\end{array}$ & $\begin{array}{l}\ldots \\
\ldots \\
\ldots \\
\ldots \\
\ldots\end{array}$ & $\begin{array}{l}\cdots \\
\cdots \\
\cdots \\
\cdots \\
\cdots\end{array}$ & $\begin{array}{l}\ldots \\
\ldots \\
\ldots \\
\ldots \\
\cdots\end{array}$ & $\begin{array}{l}\ldots \\
\ldots \\
\ldots \\
\ldots \\
\ldots\end{array}$ & $\begin{array}{l}\ldots \\
\ldots \\
\ldots \\
\ldots\end{array}$ & $\begin{array}{l}\ldots \\
\ldots \\
\ldots \\
\cdots \\
\cdots\end{array}$ & $\begin{array}{l}1761.30 \\
1761.36 \\
1761.41 \\
1761.46 \\
1761.46\end{array}$ & $\begin{array}{r}1761.47 \\
1761.45 \\
1761.45 \\
\ldots . \\
\ldots\end{array}$ \\
\hline $\begin{array}{r}6 \\
7 \\
8 \\
9 \\
10\end{array}$ & $\begin{array}{l}\ldots \\
\ldots \\
\ldots \\
\ldots \\
\ldots\end{array}$ & $\begin{array}{l}\ldots \\
\ldots \\
\ldots \\
\ldots \\
\ldots\end{array}$ & $\begin{array}{l}\ldots \\
\ldots \\
\ldots \\
\ldots \\
\ldots\end{array}$ & $\begin{array}{l}\ldots \\
\ldots \\
\ldots \\
\ldots \\
\ldots\end{array}$ & $\begin{array}{l}\ldots \\
\ldots \\
\ldots \\
\ldots \\
\ldots\end{array}$ & $\begin{array}{l}\ldots \\
\ldots \\
\ldots \\
\ldots \\
\ldots\end{array}$ & $\begin{array}{l}\ldots . \\
\ldots \\
\cdots \\
\cdots \\
\cdots\end{array}$ & $\begin{array}{l}\ldots \\
\ldots \\
\ldots \\
\ldots \\
\ldots\end{array}$ & $\begin{array}{l}\ldots \\
\ldots \\
\ldots \\
\cdots \\
\cdots\end{array}$ & $\begin{array}{l}\ldots . \\
\ldots \\
\ldots \\
\ldots \\
\cdots\end{array}$ & $\begin{array}{l}1761.47 \\
1761.48 \\
1761.48 \\
1761.48 \\
1761.48\end{array}$ & $\begin{array}{l}\ldots \\
\ldots \\
\ldots \\
\ldots \\
\ldots\end{array}$ \\
\hline $\begin{array}{l}11 \\
12 \\
13 \\
16 \\
15\end{array}$ & $\begin{array}{l}\ldots \\
\ldots \\
\ldots \\
\ldots \\
\ldots\end{array}$ & $\begin{array}{l}\ldots \\
\ldots \\
\ldots \\
\ldots \\
\cdots\end{array}$ & $\begin{array}{l}\ldots . \\
\ldots \\
\ldots \\
\ldots \\
\ldots\end{array}$ & $\begin{array}{l}\ldots \\
\ldots \\
\ldots \\
\ldots \\
\ldots\end{array}$ & $\begin{array}{l}\ldots \\
\ldots \\
\ldots \\
\ldots \\
\ldots\end{array}$ & $\begin{array}{l}\ldots \\
\ldots \\
\ldots \\
\ldots \\
\ldots\end{array}$ & $\begin{array}{l}\cdots \\
\cdots \\
\cdots \\
\cdots \\
\cdots\end{array}$ & $\begin{array}{l}\ldots \\
\ldots \\
\cdots \\
\ldots \\
\cdots\end{array}$ & $\begin{array}{l}\cdots \\
\ldots \\
\cdots \\
\cdots \\
\ldots\end{array}$ & $\begin{array}{l}\ldots . \\
\ldots \\
\cdots \\
\cdots \\
\cdots\end{array}$ & $\begin{array}{l}1761.47 \\
1761.47 \\
1761.47 \\
1761.47 \\
1761.47\end{array}$ & $\begin{array}{l}\ldots . \\
\cdots \\
\cdots \\
\cdots \\
\cdots\end{array}$ \\
\hline $\begin{array}{l}16 \\
17 \\
18 \\
19 \\
20\end{array}$ & $\begin{array}{l}\ldots \\
\ldots \\
\ldots \\
\ldots \\
\ldots\end{array}$ & $\begin{array}{l}\ldots \\
\ldots \\
\ldots \\
\ldots \\
\ldots\end{array}$ & $\begin{array}{l}\ldots . \\
\ldots \\
\ldots \\
\ldots \\
\ldots\end{array}$ & $\begin{array}{l}\ldots \\
\ldots \\
\ldots \\
\ldots \\
\ldots\end{array}$ & $\begin{array}{l}\ldots \\
\ldots \\
\ldots \\
\ldots \\
\ldots\end{array}$ & $\begin{array}{l}\ldots \\
\ldots \\
\ldots \\
\ldots \\
\ldots\end{array}$ & $\begin{array}{l}\ldots \\
\ldots \\
\ldots \\
\ldots \\
\cdots\end{array}$ & $\begin{array}{l}\ldots \\
\ldots \\
\ldots \\
\ldots \\
\ldots\end{array}$ & $\begin{array}{l}\ldots \\
\ldots \\
\ldots \\
\ldots \\
\ldots\end{array}$ & $\begin{array}{l}\ldots . \\
\ldots \\
\ldots- \\
\ldots \\
\ldots\end{array}$ & $\begin{array}{l}1761.46 \\
1761.45 \\
1761.43 \\
1761.44 \\
1761.48\end{array}$ & $\begin{array}{l}\ldots . \\
\ldots \\
\cdots \\
\ldots \\
\cdots\end{array}$ \\
\hline $\begin{array}{l}21 \\
22 \\
23 \\
24 \\
25\end{array}$ & $\begin{array}{l}\ldots \\
\ldots \\
\ldots \\
\ldots \\
\ldots\end{array}$ & $\begin{array}{l}\ldots \\
\cdots \\
\cdots \\
\cdots \\
\cdots\end{array}$ & $\begin{array}{l}\cdots \\
\cdots \\
\cdots \\
\cdots \\
\cdots\end{array}$ & $\begin{array}{l}\ldots \\
\ldots \\
\ldots \\
\ldots \\
\ldots\end{array}$ & $\begin{array}{l}\ldots \\
\ldots \\
\cdots \\
\cdots \\
\cdots\end{array}$ & $\begin{array}{l}\ldots \\
\ldots \\
\ldots \\
\ldots \\
\ldots\end{array}$ & $\begin{array}{l}\cdots \\
\cdots \\
\cdots \\
\cdots \\
\cdots\end{array}$ & $\begin{array}{l}\ldots \\
\ldots \\
\ldots \\
\ldots \\
\ldots\end{array}$ & $\begin{array}{l}\ldots . \\
\ldots- \\
\ldots \\
\ldots \\
\ldots\end{array}$ & $\begin{array}{l}\ldots \\
\cdots \\
\cdots \\
\cdots \\
\cdots\end{array}$ & $\begin{array}{l}1761.50 \\
1761.51 \\
1761.52 \\
1761.54 \\
1761.53\end{array}$ & $\begin{array}{l}\ldots \\
\ldots \\
\cdots \\
\cdots \\
\cdots\end{array}$ \\
\hline $\begin{array}{l}26 \\
27 \\
28 \\
29 \\
30 \\
31\end{array}$ & $\begin{array}{l}\ldots \\
\ldots \\
\ldots \\
\ldots \\
\ldots \\
\ldots\end{array}$ & $\begin{array}{l}\ldots \\
\ldots \\
\ldots \\
\ldots \\
\ldots \\
\ldots\end{array}$ & $\begin{array}{l}\cdots \\
\cdots \\
\cdots \\
\cdots \\
\cdots \\
\cdots\end{array}$ & $\begin{array}{l}\ldots \\
\ldots \\
\ldots \\
\ldots \\
\ldots \\
\ldots\end{array}$ & $\begin{array}{l}\ldots \\
\ldots \\
\ldots \\
\ldots \\
\ldots \\
\ldots\end{array}$ & $\begin{array}{l}\ldots \\
\ldots \\
\ldots \\
\ldots \\
\ldots \\
\ldots\end{array}$ & $\begin{array}{l}\ldots \\
\cdots \\
\cdots \\
\cdots \\
\cdots \\
\cdots\end{array}$ & $\begin{array}{l}\ldots \\
\ldots \\
\ldots \\
\ldots \\
\ldots \\
\ldots\end{array}$ & $\begin{array}{l}\ldots \\
\ldots \\
\cdots \\
\cdots \\
\ldots \\
\cdots\end{array}$ & $\begin{array}{r}\ldots \\
1761.23 \\
1761.24 \\
1761.25 \\
1761.27\end{array}$ & $\begin{array}{l}1761.52 \\
1761.51 \\
1761.50 \\
1761.50 \\
1761.51 \\
1761.49\end{array}$ & $\begin{array}{l}\ldots \\
\ldots \\
\ldots \\
\ldots \\
\ldots \\
\ldots\end{array}$ \\
\hline
\end{tabular}


GROUND-MATER DATA-Cont inued

DAILY MATER LEVELS - Continued

ADOT WELL CLUSTER-Continued

STATION MUABER 351140109220403 (AD-3)-Continued

WATER LeVEL, IN METERS ABOVE MEAN SEA LEVEL, OCTOBER 1989 TO SEPTEMBER 1990 DaILY MEAN VALUES

\begin{tabular}{|c|c|c|c|c|c|c|c|c|c|c|c|c|}
\hline DAY & OCT & NOV & DEC & JAN & FEB & MAR & APR & MaY & JUN & JUL & AUG & SEP \\
\hline $\begin{array}{l}1 \\
2 \\
3 \\
4 \\
5\end{array}$ & $\begin{array}{l}\ldots \\
\ldots \\
\cdots \\
\cdots \\
\cdots\end{array}$ & $\begin{array}{l}\ldots . \\
\ldots \\
\ldots \\
\ldots \\
\cdots\end{array}$ & $\begin{array}{l}1760.96 \\
1760.97 \\
1760.99 \\
1761.00\end{array}$ & $\begin{array}{l}1760.94 \\
1760.91 \\
1760.87 \\
1760.87\end{array}$ & $\begin{array}{l}1760.94 \\
1760.93 \\
1760.86 \\
1760.91 \\
1760.92\end{array}$ & $\begin{array}{l}1760.98 \\
1760.99 \\
1761.00 \\
1761.03 \\
1761.05\end{array}$ & $\begin{array}{l}176 \\
176 \\
176 \\
176\end{array}$ & $\begin{array}{l}17 \\
17 \\
17 \\
17\end{array}$ & $\begin{array}{l}17 \\
17 \\
17 \\
17\end{array}$ & $\begin{array}{l}176 \\
176 \\
170 \\
176 \\
170\end{array}$ & $\begin{array}{l}.80 \\
.79 \\
.78 \\
.77 \\
.75\end{array}$ & 17 \\
\hline $\begin{array}{r}6 \\
7 \\
8 \\
9 \\
10\end{array}$ & $\begin{array}{l}\cdots \\
\cdots \\
\cdots \\
\cdots \\
\cdots\end{array}$ & $\begin{array}{l}\ldots \\
\ldots \\
\cdots \\
\cdots \\
\cdots\end{array}$ & $\begin{array}{l}.02 \\
.97 \\
.95 \\
.98 \\
.00\end{array}$ & $\begin{array}{l}170 \\
170 \\
170 \\
170\end{array}$ & $\begin{array}{l}1760.89 \\
1760.91 \\
1760.92 \\
1760.89 \\
1760.88\end{array}$ & $\begin{array}{l}17 \\
17 \\
17 \\
17\end{array}$ & $\begin{array}{l}.94 \\
.93 \\
.93 \\
.91 \\
.88\end{array}$ & $\begin{array}{l}17 \\
17 \\
17 \\
17\end{array}$ & $\begin{array}{l}17 \\
17 \\
17 \\
17\end{array}$ & $\begin{array}{l}9 \\
9 \\
8 \\
7 \\
7\end{array}$ & $\begin{array}{l}17 \\
17 \\
17 \\
17\end{array}$ & $\begin{array}{l}11 \\
17 \\
17 \\
17\end{array}$ \\
\hline $\begin{array}{l}11 \\
12 \\
13 \\
14 \\
15\end{array}$ & $\begin{array}{l}\ldots . \\
\cdots \\
\cdots \\
\cdots \\
\cdots\end{array}$ & $\begin{array}{l}\ldots \\
\ldots \\
\ldots \\
\ldots \\
\cdots\end{array}$ & $\begin{array}{l}1760.97 \\
1760.95 \\
1760.96 \\
1760.95 \\
1760.97\end{array}$ & $\begin{array}{l}1760.86 \\
1760.87 \\
1760.88 \\
1760.87\end{array}$ & $\begin{array}{l}1760.88 \\
1760.94 \\
1760.97 \\
1761.00 \\
1760.97\end{array}$ & $\begin{array}{l}1761.05 \\
1761.04 \\
1761.04 \\
1761.03 \\
1761.03\end{array}$ & $\begin{array}{l}1760.91 \\
1760.92 \\
1760.89 \\
1760.88 \\
1760.89\end{array}$ & $\begin{array}{l}1760.81 \\
1760.77 \\
1760.77 \\
1760.77 \\
1760.77\end{array}$ & $\begin{array}{l}1760 . \\
1760 . \\
1760 . \\
1760 .\end{array}$ & & $\begin{array}{l}1760.76 \\
1760.76 \\
1760.76 \\
1760.76 \\
1760.77\end{array}$ & $\begin{array}{l}1761 . \\
1761 . \\
1761 . \\
1761 .\end{array}$ \\
\hline $\begin{array}{l}16 \\
17 \\
18 \\
19 \\
20\end{array}$ & $\begin{array}{l}\ldots . \\
\cdots \\
\cdots \\
\cdots \\
\cdots\end{array}$ & $\begin{array}{r}\ldots \\
\ldots \\
1761.04 \\
1761.03 \\
1761.04\end{array}$ & $\begin{array}{l}1760.98 \\
1760.98 \\
1760.97 \\
1760.92 \\
1760.92\end{array}$ & $\begin{array}{l}176 \\
176 \\
176 \\
176\end{array}$ & $\begin{array}{l}1760.93 \\
1760.95 \\
1760.96 \\
1760.97 \\
1760.95\end{array}$ & $\begin{array}{l}1760.99 \\
1761.01 \\
1761.01 \\
1760.98 \\
1760.99\end{array}$ & $\begin{array}{l}17 \\
17 \\
17 \\
17 \\
17\end{array}$ & $\begin{array}{l}17 \\
17 \\
17 \\
17\end{array}$ & $\begin{array}{l}17 \\
17 \\
17 \\
17 \\
17\end{array}$ & $\begin{array}{l}.67 \\
.68 \\
.71 \\
.73 \\
.75\end{array}$ & $\begin{array}{l}17 \\
17 \\
17 \\
17 \\
17\end{array}$ & $\begin{array}{l}176 \\
176 \\
176 \\
176\end{array}$ \\
\hline $\begin{array}{l}21 \\
22 \\
23 \\
24 \\
25\end{array}$ & $\begin{array}{l}\ldots . \\
\cdots \\
\cdots \\
\cdots \\
\cdots\end{array}$ & $\begin{array}{l}1761.06 \\
1761.03 \\
1761.04 \\
1761.06 \\
1761.04\end{array}$ & $\begin{array}{l}1760.91 \\
1760.88 \\
1760.88 \\
1760.88 \\
1760.88\end{array}$ & $\begin{array}{l}1760.83 \\
1760.85 \\
1760.87 \\
1760.85 \\
1760.83\end{array}$ & $\begin{array}{l}1760.95 \\
1760.94 \\
1760.92 \\
1760.93 \\
1760.95\end{array}$ & $\begin{array}{l}1761.01 \\
1761.01 \\
1761.01 \\
1761.02 \\
1761.00\end{array}$ & $\begin{array}{l}1760.86 \\
1760.86 \\
1760.88 \\
1760.90 \\
1760.85\end{array}$ & $\begin{array}{l}1760.73 \\
1760.73 \\
1760.74 \\
1760.75 \\
1760.73\end{array}$ & $\begin{array}{l}1760.64 \\
1760.63 \\
1760.63 \\
1760.63 \\
1760.62\end{array}$ & $\begin{array}{l}1760.76 \\
1760.77 \\
1760.78 \\
1760.79 \\
1760.79\end{array}$ & $\begin{array}{l}176 \\
176 \\
176 \\
17 t \\
176\end{array}$ & $\begin{array}{l}176 \\
176 \\
176 \\
176\end{array}$ \\
\hline $\begin{array}{l}26 \\
27 \\
28 \\
29 \\
30 \\
29\end{array}$ & $\begin{array}{l}\cdots \\
\cdots \\
\cdots \\
\cdots \\
\cdots \\
\cdots\end{array}$ & $\begin{array}{r}1761.04 \\
1761.01 \\
1760.99 \\
1760.99 \\
1761.00 \\
\ldots . .\end{array}$ & $\begin{array}{l}1760.90 \\
1760.91 \\
1760.94 \\
1760.95 \\
1760.92 \\
1760.88\end{array}$ & $\begin{array}{l}1760.89 \\
1760.87 \\
1760.85 \\
1760.90 \\
1760.93 \\
1760.94\end{array}$ & $\begin{array}{r}1760.97 \\
1760.97 \\
1760.97 \\
\ldots . \\
\ldots .\end{array}$ & $\begin{array}{l}1760.99 \\
1761.02 \\
1761.03 \\
1761.03 \\
1761.00 \\
1760.98\end{array}$ & $\begin{array}{r}1760.84 \\
1760.83 \\
1760.85 \\
1760.86 \\
1760.84 \\
\ldots .\end{array}$ & $\begin{array}{l}1760.73 \\
1760.73 \\
1760.75 \\
1760.72 \\
1760.72 \\
1760.72\end{array}$ & $\begin{array}{l}1760.62 \\
1760.63 \\
1760.63 \\
1760.61 \\
1760.60\end{array}$ & $\begin{array}{l}1760.79 \\
1760.80 \\
1760.81 \\
1760.80 \\
1760.79 \\
1760.79\end{array}$ & $\begin{array}{l}1760.96 \\
1760.95 \\
1760.95 \\
1760.95 \\
1760.95 \\
1760.93\end{array}$ & $\begin{array}{l}1761.0 \\
1761.0 \\
1761.0 \\
1761.0 \\
1761.0\end{array}$ \\
\hline
\end{tabular}


GROUND-WATER DATA-Continued

DAILY WATER LEVELS-Continued

ADOT MELL CLUSTER-Continued

STATION MUMBER 351140109220403 (ND-3)-Continued

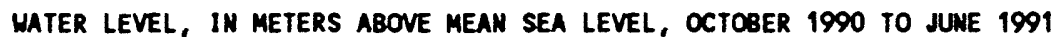
DAILY MEAN VALUES

\begin{tabular}{|c|c|c|c|c|c|c|c|c|c|c|c|c|}
\hline DAY & OCT & NOV & DEC & JAN & FEB & MAR & APR & mar & Jur & JUL & AUG & SEP \\
\hline $\begin{array}{l}1 \\
2 \\
3 \\
4 \\
5\end{array}$ & $\begin{array}{l}1761.04 \\
1761.07 \\
1761.03 \\
1761.00 \\
1761.03\end{array}$ & $\begin{array}{l}1761.04 \\
1761.05 \\
1761.01 \\
1760.98 \\
1761.04\end{array}$ & $\begin{array}{l}1760.98 \\
1760.96 \\
1760.92 \\
1760.92 \\
1760.95\end{array}$ & $\begin{array}{l}1760.85 \\
1760.84 \\
1760.85 \\
1760.88 \\
1760.85\end{array}$ & $\begin{array}{l}1761.10 \\
1761.12 \\
1761.14 \\
1761.13 \\
1761.15\end{array}$ & $\begin{array}{l}1761.35 \\
1761.30 \\
1761.30 \\
1761.38 \\
1761.43\end{array}$ & $\begin{array}{l}1761.62 \\
1761.63 \\
1761.64 \\
1761.65 \\
1761.67\end{array}$ & $\begin{array}{l}1761.47 \\
1761.47 \\
1761.43 \\
1761.39 \\
1761.36\end{array}$ & $\begin{array}{r}1761.13 \\
1761.12 \\
1761.10 \\
\ldots \\
\ldots\end{array}$ & $\begin{array}{l}\ldots . \\
\ldots \\
\cdots \\
\cdots \\
\cdots\end{array}$ & $\begin{array}{l}\ldots . \\
\ldots \\
\ldots \\
\ldots \\
\cdots\end{array}$ & $\begin{array}{l}\ldots \\
\ldots \\
\cdots \\
\cdots \\
\cdots\end{array}$ \\
\hline $\begin{array}{r}6 \\
7 \\
8 \\
9 \\
10\end{array}$ & $\begin{array}{l}1761.05 \\
1761.04 \\
1761.00 \\
1760.97 \\
1761.00\end{array}$ & $\begin{array}{l}1761.06 \\
1761.03 \\
1761.01 \\
1760.99 \\
1760.99\end{array}$ & $\begin{array}{l}1760.93 \\
1760.92 \\
1760.92 \\
1760.91 \\
1760.92\end{array}$ & $\begin{array}{l}1760.82 \\
1760.82 \\
1760.85 \\
1760.89 \\
1760.89\end{array}$ & $\begin{array}{l}1761.15 \\
1761.15 \\
1761.18 \\
1761.18 \\
1761.21\end{array}$ & $\begin{array}{l}1761.46 \\
1761.47 \\
1761.47 \\
1761.48 \\
1761.52\end{array}$ & $\begin{array}{l}1761.70 \\
1761.73 \\
1761.69 \\
1761.67 \\
1761.73\end{array}$ & $\begin{array}{l}1761.38 \\
1761.37 \\
1761.36 \\
1761.38 \\
1761.36\end{array}$ & $\begin{array}{l}\ldots . \\
\cdots \\
\cdots \\
\cdots \\
\cdots\end{array}$ & $\begin{array}{l}\ldots . \\
\cdots \\
\cdots \\
\cdots \\
\cdots\end{array}$ & $\begin{array}{l}\ldots \\
\ldots \\
\cdots \\
\cdots \\
\cdots\end{array}$ & $\begin{array}{l}\ldots \\
\cdots \\
\cdots \\
\cdots \\
\cdots\end{array}$ \\
\hline $\begin{array}{l}11 \\
12 \\
13 \\
14 \\
15\end{array}$ & $\begin{array}{l}1761.00 \\
1760.98 \\
1760.99 \\
1760.97 \\
1760.96\end{array}$ & $\begin{array}{l}1760.99 \\
1761.00 \\
1761.02 \\
1761.03 \\
1761.01\end{array}$ & $\begin{array}{l}1760.93 \\
1760.92 \\
1760.93 \\
1760.94 \\
1760.96\end{array}$ & $\begin{array}{l}1760.89 \\
1760.92 \\
1760.96 \\
1760.99 \\
1761.03\end{array}$ & $\begin{array}{l}1761.21 \\
1761.24 \\
1761.25 \\
1761.25 \\
1761.27\end{array}$ & $\begin{array}{l}1761.54 \\
1761.49 \\
1761.51 \\
1761.53 \\
1761.52\end{array}$ & $\begin{array}{l}1761.70 \\
1761.64 \\
1761.62 \\
1761.60 \\
1761.62\end{array}$ & $\begin{array}{l}1761.31 \\
1761.29 \\
1761.30 \\
1761.31 \\
1761.29\end{array}$ & $\begin{array}{l}\ldots . \\
\cdots \\
\cdots \\
\cdots \\
\cdots\end{array}$ & $\begin{array}{l}\ldots \\
\cdots \\
\cdots \\
\cdots \\
\cdots\end{array}$ & $\begin{array}{l}\ldots \\
\ldots \\
\cdots \\
\cdots \\
\cdots\end{array}$ & $\begin{array}{l}\ldots \\
\cdots \\
\cdots \\
\cdots\end{array}$ \\
\hline $\begin{array}{l}16 \\
17 \\
18 \\
19 \\
20\end{array}$ & $\begin{array}{l}1760.96 \\
1760.92 \\
1760.92 \\
1760.96 \\
1760.92\end{array}$ & $\begin{array}{l}1761.00 \\
1761.02 \\
1761.04 \\
1761.05 \\
1761.05\end{array}$ & $\begin{array}{l}1761.00 \\
1760.99 \\
1761.00 \\
1761.05 \\
1761.06\end{array}$ & $\begin{array}{l}1761.04 \\
1761.03 \\
1761.05 \\
1761.07 \\
1761.08\end{array}$ & $\begin{array}{l}1761.31 \\
1761.34 \\
1761.33 \\
1761.29 \\
1761.29\end{array}$ & $\begin{array}{l}1761.49 \\
1761.46 \\
1761.49 \\
1761.54 \\
1761.53\end{array}$ & $\begin{array}{l}1761.59 \\
1761.59 \\
1761.57 \\
1761.55 \\
1761.56\end{array}$ & $\begin{array}{l}1761.27 \\
1761.26 \\
1761.25 \\
1761.23 \\
1761.24\end{array}$ & $\begin{array}{l}\ldots . \\
\cdots \\
\cdots \\
\cdots \\
\cdots\end{array}$ & $\begin{array}{l}\ldots \\
\ldots \\
\ldots \\
\ldots \\
\cdots\end{array}$ & $\begin{array}{l}\ldots \\
\ldots \\
\ldots \\
\ldots \\
\cdots\end{array}$ & $\begin{array}{l}\ldots \\
\ldots \\
\cdots \\
\cdots \\
\cdots\end{array}$ \\
\hline $\begin{array}{l}21 \\
22 \\
23 \\
24 \\
25\end{array}$ & $\begin{array}{l}1760.92 \\
1760.98 \\
1760.99 \\
1760.99 \\
1761.01\end{array}$ & $\begin{array}{l}1761.00 \\
1760.97 \\
1760.97 \\
1760.98 \\
1761.01\end{array}$ & $\begin{array}{l}1761.04 \\
1761.01 \\
1760.93 \\
1760.93 \\
1760.95\end{array}$ & $\begin{array}{l}1761.08 \\
1761.09 \\
1761.10 \\
1761.08 \\
1761.09\end{array}$ & $\begin{array}{l}1761.30 \\
1761.32 \\
1761.33 \\
1761.32 \\
1761.28\end{array}$ & $\begin{array}{l}1761.53 \\
1761.46 \\
1761.47 \\
1761.51 \\
1761.53\end{array}$ & $\begin{array}{l}1761.57 \\
1761.56 \\
1761.55 \\
1761.54 \\
1761.55\end{array}$ & $\begin{array}{l}1761.23 \\
1761.21 \\
1761.19 \\
1761.18 \\
1761.19\end{array}$ & $\begin{array}{l}\ldots \\
\cdots \\
\cdots \\
\cdots \\
\cdots\end{array}$ & $\begin{array}{l}\ldots . \\
\cdots \\
\cdots \\
\cdots \\
\cdots\end{array}$ & $\begin{array}{l}\cdots \\
\cdots \\
\cdots \\
\cdots \\
\cdots\end{array}$ & $\begin{array}{l}\ldots . \\
\cdots \\
\cdots \\
\cdots \\
\cdots\end{array}$ \\
\hline $\begin{array}{l}26 \\
27 \\
28 \\
29 \\
30 \\
31\end{array}$ & $\begin{array}{l}1761.02 \\
1761.00 \\
1761.01 \\
1761.02 \\
1761.01 \\
1761.02\end{array}$ & $\begin{array}{r}1761.07 \\
1761.00 \\
1760.94 \\
1760.93 \\
1760.98 \\
\ldots . .\end{array}$ & $\begin{array}{l}1760.94 \\
1760.93 \\
1760.97 \\
1760.95 \\
1760.86 \\
1760.85\end{array}$ & $\begin{array}{l}1761.11 \\
1761.13 \\
1761.16 \\
1761.15 \\
1761.08 \\
1761.08\end{array}$ & $\begin{array}{r}1761.30 \\
1761.32 \\
1761.35 \\
\ldots . \\
\ldots \\
\ldots .\end{array}$ & $\begin{array}{l}1761.54 \\
1761.51 \\
1761.52 \\
1761.52 \\
1761.52 \\
1761.55\end{array}$ & $\begin{array}{r}1761.53 \\
1761.52 \\
1761.49 \\
1761.48 \\
1761.44 \\
\ldots\end{array}$ & $\begin{array}{l}1761.19 \\
1761.16 \\
1761.15 \\
1761.15 \\
1761.19 \\
1761.17\end{array}$ & $\begin{array}{l}\ldots \\
\ldots \\
\cdots \\
\cdots \\
\cdots \\
\cdots\end{array}$ & $\begin{array}{l}\ldots \\
\ldots \\
\cdots \\
\cdots \\
\cdots \\
\ldots\end{array}$ & $\begin{array}{l}\ldots \\
\ldots \\
\cdots \\
\ldots \\
\ldots \\
\ldots\end{array}$ & $\begin{array}{c}\ldots \\
\ldots \\
\ldots \\
\ldots\end{array}$ \\
\hline
\end{tabular}




\section{GROUND-MATER DATA-Cont inued \\ DAILY MATER LEVELS-Continued \\ ADOT WELL CLUSTER-Continued}

STATION MUMBER-351139109221301

STATION MAME $\rightarrow A D-5$

LOCATION-Lat 35'11'39", Long 109.22'13", in NEXSEXNEX sec. 28, T.21 E., R.28 E., Apache County, Arizona. ARIZONA WELL NUMBER-(A-21-28)28ada.

LAND SURFACE ALTITUDE-1765.43 meters above mean sea level

WATER LEVEL, IN METERS ABOVE MEAN SEA LEVEL, JULY 1989 TO SEPTEMBER 1989 DAILY MEAN VALUES

\begin{tabular}{|c|c|c|c|c|c|c|c|c|c|c|c|c|}
\hline DAY & OCT & NOV & DEC & JAN & FEB & MAR & APR & MaY & JUN & JUL & AUG & SEP \\
\hline 1 & $\ldots$ & $\ldots$ & $\ldots$ & $\ldots$ & $\cdots$ & $\cdots$ & $\ldots$ & $\ldots$ & $\ldots$ & $\ldots$ & $\ldots$ & $\ldots$ \\
\hline 2 & $\ldots$ & $\cdots$ & $\ldots$ & $\ldots$ & $\cdots$ & $\ldots$ & $\ldots$ & $\cdots$ & $\ldots$ & $\ldots$ & $\ldots$ & $\ldots$ \\
\hline 3 & $\ldots$ & $\ldots$ & $\ldots$ & $\ldots$ & $\ldots$ & $\cdots$ & $\ldots$ & $\ldots$ & $\ldots$ & $\ldots$ & $\ldots$ & $\ldots$ \\
\hline 4 & $\ldots$ & $\cdots$ & $\cdots$ & $\ldots$ & $\ldots$ & $\ldots$ & $\ldots$ & $\ldots$ & $\ldots$ & $\ldots$ & $\ldots$ & $\ldots$ \\
\hline 5 & $\cdots$ & $\cdots$ & $\cdots$ & $\cdots$ & $\cdots$ & $\cdots$ & $\cdots$ & $\cdots$ & $\cdots$ & $\cdots$ & $\cdots$ & $\cdots$ \\
\hline 6 & $\cdots$ & $\cdots$ & $\cdots$ & $\cdots$ & $\cdots$ & $\cdots$ & $\cdots$ & $\cdots$ & $\cdots$ & $\cdots$ & $\cdots$ & $\cdots$ \\
\hline 7 & $\cdots$ & $\cdots$ & $\cdots$ & $\cdots$ & $\cdots$ & $\cdots$ & $\cdots$ & $\cdots$ & $\cdots$ & $\cdots$ & $\cdots$ & $\cdots$ \\
\hline 8 & $\ldots$ & $\ldots$ & $\cdots$ & $\cdots$ & $\cdots$ & $\cdots$ & $\cdots$ & $\cdots$ & $\cdots$ & $\cdots$ & $\cdots$ & $\cdots$ \\
\hline 9 & $\cdots$ & $\cdots$ & $\cdots$ & $\cdots$ & $\cdots$ & $\cdots$ & $\cdots$ & $\cdots$ & $\cdots$ & $\cdots$ & $\cdots$ & $\cdots$ \\
\hline 10 & $\cdots$ & $\cdots$ & $\cdots$ & $\cdots$ & $\cdots$ & $\cdots$ & $\cdots$ & $\cdots$ & $\cdots$ & $\cdots$ & $\cdots$ & $\cdots$ \\
\hline 11 & $\cdots$ & $\cdots$ & $\cdots$ & $\cdots$ & $\cdots$ & $\cdots$ & $\cdots$ & $\cdots$ & $\cdots$ & $\ldots$ & $\cdots$ & $\cdots$ \\
\hline 12 & $\cdots$ & $\cdots$ & $\cdots$ & $\cdots$ & $\cdots$ & $\cdots$ & $\cdots$ & $\cdots$ & $\cdots$ & $\cdots$ & $\cdots$ & $\cdots$ \\
\hline 13 & $\ldots$ & $\ldots$ & $\cdots$ & $\cdots$ & $\cdots$ & $\cdots$ & $\cdots$ & $\cdots$ & $\cdots$ & $\cdots$ & $\cdots$ & $\cdots$ \\
\hline 14 & $\cdots$ & $\cdots$ & $\cdots$ & $\cdots$ & $\cdots$ & $\cdots$ & $\cdots$ & $\cdots$ & $\cdots$ & $\cdots$ & $\cdots$ & $\cdots$ \\
\hline 15 & $\cdots$ & $\cdots$ & $\cdots$ & $\cdots$ & $\cdots$ & $\cdots$ & $\cdots$ & $\cdots$ & $\cdots$ & $\cdots$ & $\cdots$ & $\cdots$ \\
\hline 16 & $\cdots$ & $\cdots$ & $\cdots$ & -- & $\cdots$ & $\cdots$ & $\cdots$ & $\cdots$ & $\ldots$ & $\cdots$ & $\cdots$ & $\cdots$ \\
\hline 17 & $\cdots$ & $\cdots$ & $\cdots$ & $\cdots$ & $\cdots$ & $\cdots$ & $\cdots$ & $\cdots$ & $\cdots$ & $\cdots$ & $\cdots$ & $\cdots$ \\
\hline 18 & $\cdots$ & $\cdots$ & $\cdots$ & $\cdots$ & $\cdots$ & $\cdots$ & $\cdots$ & $\cdots$ & $\cdots$ & $\cdots$ & $\cdots$ & $\cdots$ \\
\hline 19 & $\cdots$ & $\cdots$ & $\cdots$ & $\cdots$ & $\cdots$ & $\cdots$ & $\cdots$ & $\cdots$ & $\cdots$ & $\cdots$ & $\cdots$ & $\cdots$ \\
\hline 20 & $\cdots$ & $\cdots$ & $\cdots$ & $\cdots$ & $\cdots$ & $\cdots$ & $\cdots$ & $\cdots$ & $\cdots$ & $\cdots$ & $\cdots$ & $\cdots$ \\
\hline 21 & $\cdots$ & $\cdots$ & $\cdots$ & $\cdots$ & $\cdots$ & $\cdots$ & $\cdots$ & $\cdots$ & $\cdots$ & ... & $\ldots$ & $\cdots$ \\
\hline 22 & $\cdots$ & $\cdots$ & $\cdots$ & $\cdots$ & $\cdots$ & $\cdots$ & $\cdots$ & $\cdots$ & $\cdots$ & -- & $\cdots$ & $\cdots$ \\
\hline 23 & $\ldots$ & $\ldots$ & $\cdots$ & $\cdots$ & $\cdots$ & $\cdots$ & $\cdots$ & $\cdots$ & $\cdots$ & $\cdots$ & 1761.20 & $\cdots$ \\
\hline 24 & $\cdots$ & $\cdots$ & $\cdots$ & $\cdots$ & $\cdots$ & $\cdots$ & -- & $\cdots$ & $\cdots$ & $\cdots$ & 1761.23 & $\cdots$ \\
\hline 25 & $\cdots$ & $\cdots$ & $\cdots$ & $\cdots$ & $\cdots$ & $\cdots$ & $\cdots$ & $\cdots$ & $\cdots$ & $\cdots$ & 1761.22 & $\cdots$ \\
\hline 26 & $\cdots$ & $\cdots$ & $\cdots$ & $\cdots$ & $\cdots$ & $\cdots$ & $\cdots$ & $\cdots$ & $\cdots$ & $\cdots$ & 1761.21 & $\cdots$ \\
\hline 27 & $\cdots$ & $\cdots$ & $\cdots$ & $\cdots$ & $\cdots$ & $\cdots$ & $\cdots$ & $\cdots$ & $\cdots$ & 1760.95 & 1761.21 & $\cdots$ \\
\hline 28 & $\cdots$ & $\cdots$ & $\cdots$ & $\cdots$ & $\cdots$ & $\cdots$ & $\cdots$ & $\cdots$ & $\cdots$ & 1760.96 & 1761.21 & \\
\hline 29 & $\cdots$ & $\cdots$ & $\cdots$ & $\cdots$ & $\cdots$ & $-\infty$ & $\cdots$ & $\cdots$ & $\cdots$ & $\cdots$ & 1761.21 & $\cdots$ \\
\hline 30 & $\cdots$ & $\cdots$ & $\cdots$ & -- & $\cdots$ & $\cdots$ & $\cdots$ & $\cdots$ & $\cdots$ & $\cdots$ & 1761.22 & $\cdots$ \\
\hline 31 & $\cdots$ & $\cdots$ & $\cdots$ & $\cdots$ & $\cdots$ & $\cdots$ & $\cdots$ & $\cdots$ & $\cdots$ & $\cdots$ & 1761.20 & \\
\hline
\end{tabular}


GROUND-WATER DATA-Cont inued

DAILY MATER LEVELS-Cont inued

NDOT MELL CLUSTER-Continued

STATION MUMBER 351139109221301 (AD-5)-Cont inued

WATER LEVEL, IN METERS ABOVE MEAN SEA LEVEL, OCTOBER 1989 TO SEPTEMBER 1990 DAILY MEAN VALUES

\begin{tabular}{|c|c|c|c|c|c|c|c|c|c|c|c|c|}
\hline AY & CT & NOV & DEC & JAN & FEB & MAR & APR & MaY & JUN & JUL & AUG & SEP \\
\hline $\begin{array}{l}1 \\
2 \\
3 \\
4 \\
5\end{array}$ & $\begin{array}{l}\ldots \\
\ldots \\
\ldots- \\
\ldots \\
\ldots\end{array}$ & $\begin{array}{r}1760.87 \\
1760.88 \\
1760.87\end{array}$ & $\begin{array}{l}1760.72 \\
1760.69 \\
1760.70 \\
1760.72 \\
1760.74\end{array}$ & $\begin{array}{l}1760.62 \\
1760.67 \\
1760.64 \\
1760.60 \\
1760.60\end{array}$ & $\begin{array}{l}1760.65 \\
1760.64 \\
1760.57 \\
1760.62 \\
1760.63\end{array}$ & $\begin{array}{l}1760.69 \\
1760.69 \\
1760.71 \\
1760.74 \\
1760.76\end{array}$ & $\begin{array}{l}1760.69 \\
1760.67 \\
1760.67 \\
1760.69 \\
1760.69\end{array}$ & $\begin{array}{l}1760.57 \\
1760.56 \\
1760.53 \\
1760.51 \\
1760.51\end{array}$ & $\begin{array}{l}1760.46 \\
1760.43 \\
1760.43 \\
1760.44 \\
1760.45\end{array}$ & $\begin{array}{l}1760.36 \\
1760.36 \\
1760.35 \\
1760.34 \\
1760.34\end{array}$ & $\begin{array}{l}1760.52 \\
1760.52 \\
1760.51 \\
1760.51 \\
1760.49\end{array}$ & $\begin{array}{l}760.6 \\
760.6 \\
760.6\end{array}$ \\
\hline $\begin{array}{r}6 \\
7 \\
8 \\
9 \\
10\end{array}$ & $\begin{array}{l}\ldots \\
\ldots \\
\ldots \\
\ldots \\
\ldots\end{array}$ & $\begin{array}{l}1760.86 \\
1760.87 \\
1760.83 \\
1760.82 \\
1760.82\end{array}$ & $\begin{array}{l}1760.76 \\
1760.70 \\
1760.69 \\
1760.72 \\
1760.74\end{array}$ & $\begin{array}{l}1760 . \\
1760 . \\
1760 . \\
1760 .\end{array}$ & $\begin{array}{l}.61 \\
.63 \\
.63 \\
.61 \\
.60\end{array}$ & $\begin{array}{l}1760.74 \\
1760.71 \\
1760.72 \\
1760.73 \\
1760.75\end{array}$ & $\begin{array}{l}1760.67 \\
1760.67 \\
1760.67 \\
1760.64 \\
1760.62\end{array}$ & $\begin{array}{l}17 \\
17 \\
17 \\
17\end{array}$ & $\begin{array}{l}1760.44 \\
1760.43 \\
1760.43 \\
1760.42 \\
1760.42\end{array}$ & $\begin{array}{l}.34 \\
.34 \\
.33 \\
.32 \\
.32\end{array}$ & $\begin{array}{l}17 \\
17 \\
17 \\
17\end{array}$ & $\begin{array}{l}1 \\
1\end{array}$ \\
\hline $\begin{array}{l}11 \\
12 \\
13 \\
14 \\
15\end{array}$ & $\begin{array}{l}\ldots \\
\ldots \\
\ldots \\
\ldots \\
\ldots\end{array}$ & $\begin{array}{l}1760.82 \\
1760.83 \\
1760.83 \\
1760.82 \\
1760.78\end{array}$ & $\begin{array}{l}1760.70 \\
1760.69 \\
1760.69 \\
1760.69 \\
1760.70\end{array}$ & $\begin{array}{l}1760.58 \\
1760.59 \\
1760.61 \\
1760.61 \\
1760.61\end{array}$ & $\begin{array}{l}1760.60 \\
1760.65 \\
1760.68 \\
1760.71 \\
1760.67\end{array}$ & $\begin{array}{l}1760.76 \\
1760.76 \\
1760.76 \\
1760.75 \\
1760.74\end{array}$ & $\begin{array}{l}1760.64 \\
1760.65 \\
1760.62 \\
1760.61 \\
1760.63\end{array}$ & $\begin{array}{l}1760.5 \\
1760.5 \\
1760.5 \\
1760.5\end{array}$ & $\begin{array}{l}17 \\
17 \\
17 \\
17 \\
17\end{array}$ & $\begin{array}{l}0.31 \\
0.31 \\
0.31 \\
0.35 \\
0.36\end{array}$ & & $\begin{array}{l}17 \\
17 \\
17 \\
17\end{array}$ \\
\hline $\begin{array}{l}16 \\
17 \\
18 \\
19 \\
20\end{array}$ & $\begin{array}{l}\ldots \\
\ldots \\
\ldots \\
\ldots \\
\ldots\end{array}$ & $\begin{array}{l}1760.81 \\
1760.82 \\
1760.77 \\
1760.76 \\
1760.78\end{array}$ & $\begin{array}{l}1760.72 \\
1760.72 \\
1760.71 \\
1760.66 \\
1760.65\end{array}$ & $\begin{array}{l}1760.61 \\
1760.61 \\
1760.63 \\
1760.62 \\
1760.58\end{array}$ & $\begin{array}{l}1760.64 \\
1760.65 \\
1760.66 \\
1760.68 \\
1760.66\end{array}$ & $\begin{array}{l}1760.70 \\
1760.72 \\
1760.72 \\
1760.69 \\
1760.70\end{array}$ & $\begin{array}{l}1760.64 \\
1760.64 \\
1760.62 \\
1760.60 \\
1760.59\end{array}$ & $\begin{array}{l}1760 . \\
1760 . \\
1760 . \\
1760 .\end{array}$ & $\begin{array}{l}1760.41 \\
1760.39 \\
1760.39 \\
1760.40 \\
1760.39\end{array}$ & $\begin{array}{l}0.36 \\
0.37 \\
0.40 \\
0.42 \\
0.43\end{array}$ & & $\begin{array}{l}1760.7 \\
1760.7 \\
1760.7 \\
1760.7\end{array}$ \\
\hline $\begin{array}{l}21 \\
22 \\
23 \\
24 \\
25\end{array}$ & $\begin{array}{l}\ldots- \\
\ldots- \\
\ldots- \\
\ldots-\end{array}$ & $\begin{array}{l}1760.80 \\
1760.77 \\
1760.78 \\
1760.80 \\
1760.78\end{array}$ & $\begin{array}{l}1760.65 \\
1760.61 \\
1760.61 \\
1760.62 \\
1760.62\end{array}$ & $\begin{array}{l}1760.55 \\
1760.58 \\
1760.59 \\
1760.57 \\
1760.55\end{array}$ & $\begin{array}{l}1760.66 \\
1760.64 \\
1760.63 \\
1760.63 \\
1760.66\end{array}$ & $\begin{array}{l}1760.72 \\
1760.72 \\
1760.73 \\
1760.73 \\
1760.72\end{array}$ & $\begin{array}{l}1760.60 \\
1760.60 \\
1760.62 \\
1760.64 \\
1760.59\end{array}$ & $\begin{array}{l}1760.48 \\
1760.48 \\
1760.49 \\
1760.50 \\
1760.48\end{array}$ & $\begin{array}{l}1760.39 \\
1760.38 \\
1760.38 \\
1760.37 \\
1760.37\end{array}$ & $\begin{array}{l}1760.44 \\
1760.46 \\
1760.47 \\
1760.48 \\
1760.49\end{array}$ & $\begin{array}{l}1760.59 \\
1760.62 \\
1760.64 \\
1760.65 \\
1760.66\end{array}$ & $\begin{array}{l}1760.6 \\
1760.6 \\
1760.7 \\
1760.7\end{array}$ \\
\hline $\begin{array}{l}26 \\
27 \\
28 \\
29 \\
30\end{array}$ & $\begin{array}{l}\ldots \\
\ldots- \\
\ldots- \\
\ldots \\
\ldots \\
\ldots\end{array}$ & $\begin{array}{r}1760.78 \\
1760.74 \\
1760.71 \\
1760.72 \\
1760.74 \\
. .\end{array}$ & $\begin{array}{l}1760.63 \\
1760.65 \\
1760.68 \\
1760.68 \\
1760.65 \\
1760.61\end{array}$ & $\begin{array}{l}1760.61 \\
1760.59 \\
1760.57 \\
1760.62 \\
1760.64 \\
1760.65\end{array}$ & $\begin{array}{r}1760.67 \\
1760.67 \\
1760.67 \\
\ldots . \\
\ldots \\
\ldots\end{array}$ & $\begin{array}{l}1760.71 \\
1760.74 \\
1760.75 \\
1760.75 \\
1760.73 \\
1760.71\end{array}$ & $\begin{array}{r}1760.58 \\
1760.57 \\
1760.59 \\
1760.60 \\
1760.58 \\
.\end{array}$ & $\begin{array}{l}1760.48 \\
1760.49 \\
1760.51 \\
1760.48 \\
1760.46 \\
1760.47\end{array}$ & $\begin{array}{r}1760.37 \\
1760.37 \\
1760.37 \\
1760.36 \\
1760.35 \\
.\end{array}$ & $\begin{array}{l}1760.49 \\
1760.50 \\
1760.51 \\
1760.51 \\
1760.51 \\
1760.52\end{array}$ & $\begin{array}{l}1760.66 \\
1760.66 \\
1760.67 \\
1760.67 \\
1760.67 \\
1760.67\end{array}$ & $\begin{array}{l}1760.7 \\
1760.7 \\
1760.7 \\
1760.7 \\
1760.7\end{array}$ \\
\hline
\end{tabular}


GROUND-WATER DATA-Contimued

DAILY WATER LEVELS-Continued

ADOT WELL CLUSTER-Continued

STATION MUMBER 351139109221301 (AD-5)-Continued

mater leVel, in meters above mean SEA LeVEL, OCtOBer 1990 to JUNe 1991 DAILY MEAN VALUES

\begin{tabular}{|c|c|c|c|c|c|c|c|c|c|c|c|}
\hline DAY & OCT & NOV & DEC & JAN & FEB & MAR & APR & MAY & JUN & JUL & AUG \\
\hline $\begin{array}{l}1 \\
2 \\
3 \\
4 \\
5\end{array}$ & $\begin{array}{l}1760.77 \\
1760.80 \\
1760.76 \\
1760.72 \\
1760.75\end{array}$ & $\begin{array}{l}1760.78 \\
1760.79 \\
1760.75 \\
1760.72 \\
1760.77\end{array}$ & $\begin{array}{l}1760.72 \\
1760.70 \\
1760.66 \\
1760.66 \\
1760.69\end{array}$ & $\begin{array}{l}1760.60 \\
1760.60 \\
1760.61 \\
1760.64 \\
1760.61\end{array}$ & $\begin{array}{l}1760.81 \\
1760.82 \\
1760.84 \\
1760.83 \\
1760.85\end{array}$ & $\begin{array}{l}1761.09 \\
1761.02 \\
1760.99 \\
1761.06 \\
1761.10\end{array}$ & $\begin{array}{l}\cdots \\
\cdots \\
\cdots \\
\cdots \\
\cdots\end{array}$ & $\begin{array}{l}1761.14 \\
1761.13 \\
1761.11 \\
1761.10 \\
1761.09\end{array}$ & $\begin{array}{r}1760.88 \\
1760.87 \\
1760.87 \\
1760.87 \\
\ldots \ldots\end{array}$ & $\begin{array}{l}\ldots- \\
\ldots \\
\ldots \\
\cdots \\
\cdots\end{array}$ & $\begin{array}{l}\ldots- \\
\ldots- \\
-- \\
\cdots \\
\cdots\end{array}$ \\
\hline $\begin{array}{r}6 \\
7 \\
8 \\
9 \\
10\end{array}$ & $\begin{array}{l}1760.77 \\
1760.77 \\
1760.73 \\
1760.71 \\
1760.74\end{array}$ & $\begin{array}{l}1760.78 \\
1760.75 \\
1760.73 \\
1760.71 \\
1760.71\end{array}$ & $\begin{array}{l}1760.67 \\
1760.66 \\
1760.66 \\
1760.66 \\
1760.66\end{array}$ & $\begin{array}{l}1760.58 \\
1760.58 \\
1760.61 \\
1760.63 \\
1760.62\end{array}$ & $\begin{array}{l}1760.85 \\
1760.86 \\
1760.87 \\
1760.88 \\
1760.90\end{array}$ & $\begin{array}{r}1761.12 \\
\ldots \\
\ldots \\
\ldots \\
\ldots\end{array}$ & $\begin{array}{l}\cdots \\
\cdots \\
\cdots \\
\cdots \\
\cdots\end{array}$ & $\begin{array}{l}1761.08 \\
1761.07 \\
1761.06 \\
1761.06 \\
1761.05\end{array}$ & $\begin{array}{l}\ldots \\
\ldots \\
\ldots \\
\ldots \\
\ldots\end{array}$ & $\begin{array}{l}\ldots \\
\ldots \\
\ldots \\
\ldots \\
\ldots\end{array}$ & $\begin{array}{l}-.- \\
\ldots- \\
-.- \\
-.-\end{array}$ \\
\hline $\begin{array}{l}11 \\
12 \\
13 \\
14 \\
15\end{array}$ & $\begin{array}{l}1760.75 \\
1760.73 \\
1760.74 \\
1760.72 \\
1760.71\end{array}$ & $\begin{array}{l}1760.71 \\
1760.71 \\
1760.74 \\
1760.76 \\
1760.74\end{array}$ & $\begin{array}{l}1760.68 \\
1760.68 \\
1760.68 \\
1760.68 \\
1760.68\end{array}$ & $\begin{array}{l}1760.60 \\
1760.62 \\
1760.67 \\
1760.69 \\
1760.73\end{array}$ & $\begin{array}{l}1760.91 \\
1760.94 \\
1760.94 \\
1760.94 \\
1760.97\end{array}$ & $\begin{array}{l}\ldots . \\
\cdots \\
\cdots \\
\cdots- \\
\cdots\end{array}$ & $\begin{array}{l}1761.27 \\
1761.25 \\
1761.25 \\
1761.24 \\
1761.24\end{array}$ & $\begin{array}{l}1761.03 \\
1761.03 \\
1761.02 \\
1761.01 \\
1761.00\end{array}$ & $\begin{array}{l}\ldots- \\
\ldots- \\
\ldots \\
\ldots \\
\ldots\end{array}$ & $\begin{array}{l}\ldots- \\
\ldots- \\
\cdots \\
\cdots \\
\cdots\end{array}$ & $\begin{array}{l}-.- \\
\cdots- \\
\cdots- \\
-.-\end{array}$ \\
\hline $\begin{array}{l}16 \\
17 \\
18 \\
19 \\
20\end{array}$ & $\begin{array}{l}1760.71 \\
1760.67 \\
1760.67 \\
1760.72 \\
1760.68\end{array}$ & $\begin{array}{l}1760.73 \\
1760.75 \\
1760.77 \\
1760.78 \\
1760.79\end{array}$ & $\begin{array}{l}1760.72 \\
1760.71 \\
1760.71 \\
1760.77 \\
1760.78\end{array}$ & $\begin{array}{l}1760.74 \\
1760.73 \\
1760.75 \\
1760.78 \\
1760.79\end{array}$ & $\begin{array}{l}1761.00 \\
1761.03 \\
1761.02 \\
1760.97 \\
1760.98\end{array}$ & $\begin{array}{l}\cdots \\
\cdots \\
\cdots- \\
\cdots- \\
\cdots\end{array}$ & $\begin{array}{l}1761.23 \\
1761.22 \\
1761.22 \\
1761.22 \\
1761.22\end{array}$ & $\begin{array}{l}1760.99 \\
1760.98 \\
1760.98 \\
1760.96 \\
1760.96\end{array}$ & $\begin{array}{l}\ldots \\
\ldots \\
\ldots \\
\ldots \\
\ldots\end{array}$ & $\begin{array}{l}\cdots \\
\cdots \\
\cdots- \\
\cdots \\
\cdots\end{array}$ & $\begin{array}{l}\ldots- \\
\ldots- \\
\ldots- \\
\ldots\end{array}$ \\
\hline $\begin{array}{l}21 \\
22 \\
23 \\
24 \\
25\end{array}$ & $\begin{array}{l}1760.65 \\
1760.68 \\
1760.69 \\
1760.68 \\
1760.70\end{array}$ & $\begin{array}{l}1760.74 \\
1760.71 \\
1760.70 \\
1760.72 \\
1760.75\end{array}$ & $\begin{array}{l}1760.76 \\
1760.73 \\
1760.65 \\
1760.66 \\
1760.68\end{array}$ & $\begin{array}{l}1760.79 \\
1760.81 \\
1760.81 \\
1760.81 \\
1760.81\end{array}$ & $\begin{array}{l}1761.00 \\
1761.03 \\
1761.05 \\
1761.04 \\
1761.01\end{array}$ & $\begin{array}{l}\ldots- \\
\cdots \\
\cdots \\
\cdots- \\
\cdots\end{array}$ & $\begin{array}{l}1761.21 \\
1761.21 \\
1761.20 \\
1761.19 \\
1761.19\end{array}$ & $\begin{array}{l}1760.95 \\
1760.95 \\
1760.94 \\
1760.93 \\
1760.93\end{array}$ & $\begin{array}{l}\ldots- \\
\ldots \\
\ldots \\
\ldots \\
\ldots\end{array}$ & $\begin{array}{l}\cdots- \\
\cdots- \\
\cdots- \\
\cdots- \\
\cdots\end{array}$ & $\begin{array}{l}\ldots \\
\ldots \\
\ldots \\
\ldots \\
\ldots\end{array}$ \\
\hline $\begin{array}{l}26 \\
27 \\
28 \\
29 \\
30 \\
31\end{array}$ & $\begin{array}{l}1760.72 \\
1760.72 \\
1760.72 \\
1760.73 \\
1760.73 \\
1760.75\end{array}$ & $\begin{array}{r}1760.81 \\
1760.73 \\
1760.67 \\
1760.67 \\
1760.71 \\
\ldots .\end{array}$ & $\begin{array}{l}1760.68 \\
1760.67 \\
1760.73 \\
1760.71 \\
1760.61 \\
1760.60\end{array}$ & $\begin{array}{l}1760.82 \\
1760.85 \\
1760.87 \\
1760.86 \\
1760.79 \\
1760.79\end{array}$ & $\begin{array}{r}1761.03 \\
1761.06 \\
1761.09 \\
\ldots \\
\ldots . \\
\ldots\end{array}$ & $\begin{array}{l}\cdots \\
\cdots \\
\cdots \\
\cdots \\
\cdots \\
\cdots\end{array}$ & $\begin{array}{r}1761.19 \\
1761.18 \\
1761.18 \\
1761.17 \\
1761.15 \\
\ldots\end{array}$ & $\begin{array}{l}1760.92 \\
1760.92 \\
1760.90 \\
1760.90 \\
1760.90 \\
1760.89\end{array}$ & $\begin{array}{l}\ldots- \\
\ldots- \\
\ldots- \\
\ldots \\
\ldots\end{array}$ & $\begin{array}{l}\cdots \\
\cdots \\
\cdots \\
\cdots \\
\cdots \\
\cdots\end{array}$ & $\begin{array}{l}\ldots \\
\ldots \\
\ldots \\
\ldots \\
\ldots \\
\ldots\end{array}$ \\
\hline
\end{tabular}




\section{GROUND-HATER DATA-Contimued \\ DAILY MATER LEVELS-Cont inued \\ CEDAR POINT WELL CLUSTER}

\section{STATION MUMBER-351411109170703}

STATION MAME-CP-3

LOCATIOW-Lat 35.14'11", Long 109.17'07", in SEXNWXNEX sec.8, T.21 N., 29 E., Apache County, Arizons. ARIZONA WELL MUMBER-(A-21-29)08abc3.

LAND SURFACE ALTITUDE-1792.17 meters above mean sea level.

mater leVel, In meters above meAn SEA LeVEL, JULY 1989 to SEPTEMBer 1989 dAILY MEAN VALUES

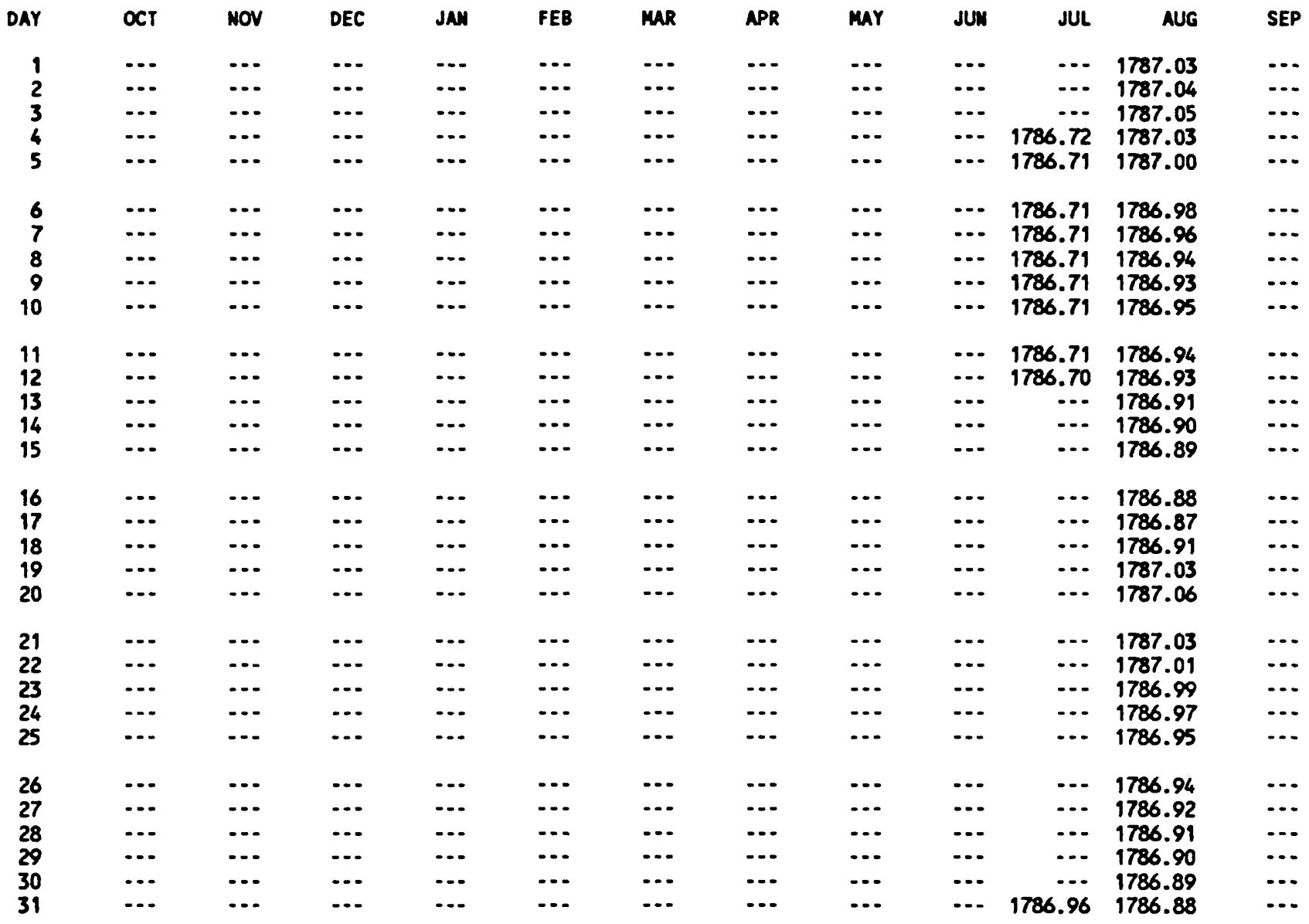


GROUND-WATER DATA-Continued

DAILY WATER LEVELS-Continued

CEDAR POINT MELL CLUSTER-Continued

STATION MUMBER 351411109170703 (CP-3)-Continued

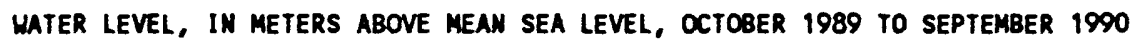
DAILY MEAN VALUES

\begin{tabular}{|c|c|c|c|c|c|c|c|c|c|c|c|c|}
\hline DAY & OCT & NOV & DEC & JAN & FEB & MAR & APR & MAY & JUN & JUL & AUG & SEP \\
\hline $\begin{array}{l}1 \\
2 \\
3 \\
4 \\
5\end{array}$ & $\begin{array}{l}\ldots \\
\ldots \\
\ldots \\
\ldots \\
\ldots\end{array}$ & $\begin{array}{l}\ldots \\
\cdots \\
\cdots \\
\cdots \\
\cdots\end{array}$ & $\begin{array}{l}1786.78 \\
1786.77 \\
1786.77 \\
1786.77 \\
1786.78\end{array}$ & $\begin{array}{l}1786.85 \\
1786.86 \\
1786.86 \\
1786.86 \\
1786.86\end{array}$ & $\begin{array}{l}1786.94 \\
1786.94 \\
1786.94 \\
1786.94 \\
1786.94\end{array}$ & $\begin{array}{l}1787.04 \\
1787.05 \\
1787.05 \\
1787.06 \\
1787.06\end{array}$ & $\begin{array}{l}1786.93 \\
1786.92 \\
1786.92 \\
1786.92 \\
1786.95\end{array}$ & $\begin{array}{l}1786.84 \\
1786.84 \\
1786.85 \\
1786.89 \\
1786.89\end{array}$ & $\begin{array}{l}\ldots \\
\ldots \\
\ldots \\
\ldots \\
\ldots\end{array}$ & $\begin{array}{l}\cdots \\
\cdots \\
\cdots \\
\cdots \\
\cdots\end{array}$ & $\begin{array}{l}1786.77 \\
1786.76 \\
1786.76 \\
1786.76 \\
1786.75\end{array}$ & $\begin{array}{l}1786.75 \\
1786.75 \\
1786.78 \\
1786.80 \\
1786.79\end{array}$ \\
\hline $\begin{array}{r}6 \\
7 \\
8 \\
9 \\
10\end{array}$ & $\begin{array}{l}\ldots \\
\ldots \\
\ldots \\
\ldots \\
\ldots\end{array}$ & $\begin{array}{l}\ldots \\
\ldots \\
\cdots \\
\cdots \\
\cdots\end{array}$ & $\begin{array}{l}1786.79 \\
1786.80 \\
1786.80 \\
1786.80 \\
1786.80\end{array}$ & $\begin{array}{l}1786.86 \\
1786.85 \\
1786.84 \\
1786.84 \\
1786.84\end{array}$ & $\begin{array}{l}1786.95 \\
1786.96 \\
1786.96 \\
1786.96 \\
1786.97\end{array}$ & $\begin{array}{l}1787.05 \\
1787.05 \\
1787.05 \\
1787.04 \\
1787.05\end{array}$ & $\begin{array}{l}1786.96 \\
1786.97 \\
1786.97 \\
1786.97 \\
1786.97\end{array}$ & $\begin{array}{l}1786.90 \\
1786.90 \\
1786.89 \\
1786.87 \\
1786.86\end{array}$ & $\begin{array}{l}\ldots \\
\ldots \\
\ldots \\
\ldots \\
\ldots\end{array}$ & $\begin{array}{l}\cdots \\
\cdots \\
\cdots \\
\cdots\end{array}$ & $\begin{array}{l}1786.75 \\
1786.74 \\
1786.74 \\
1786.73 \\
1786.73\end{array}$ & $\begin{array}{l}1786.84 \\
1786.86 \\
1786.85 \\
1786.86 \\
1786.87\end{array}$ \\
\hline $\begin{array}{l}11 \\
12 \\
13 \\
14 \\
15\end{array}$ & $\begin{array}{l}\ldots \\
\ldots \\
\ldots \\
\ldots \\
\ldots\end{array}$ & $\begin{array}{l}\cdots \\
\cdots \\
\cdots \\
\cdots \\
\cdots\end{array}$ & $\begin{array}{l}1786.80 \\
1786.80 \\
1786.80 \\
1786.80 \\
1786.80\end{array}$ & $\begin{array}{l}1786.86 \\
1786.86 \\
1786.87 \\
1786.88 \\
1786.89\end{array}$ & $\begin{array}{l}1786.98 \\
1786.99 \\
1787.00 \\
1787.00 \\
1787.00\end{array}$ & $\begin{array}{l}1787.07 \\
1787.07 \\
1787.08 \\
1787.07 \\
1787.07\end{array}$ & $\begin{array}{l}1786.96 \\
1786.95 \\
1786.93 \\
1786.92 \\
1786.91\end{array}$ & $\begin{array}{l}1786.84 \\
1786.84 \\
1786.84 \\
1786.83 \\
1786.83\end{array}$ & $\begin{array}{l}\ldots \\
\ldots \\
\ldots \\
\ldots \\
\ldots\end{array}$ & $\begin{array}{l}\ldots \\
\ldots \\
\cdots \\
\cdots \\
\cdots\end{array}$ & $\begin{array}{l}1786.73 \\
1786.72 \\
1786.72 \\
1786.74 \\
1786.82\end{array}$ & $\begin{array}{l}1786.86 \\
1786.84 \\
1786.83 \\
1786.81 \\
1786.79\end{array}$ \\
\hline $\begin{array}{l}16 \\
17 \\
18 \\
19 \\
20\end{array}$ & $\begin{array}{l}\ldots \\
\ldots \\
\ldots \\
\ldots \\
\ldots\end{array}$ & $\begin{array}{l}1786.77 \\
1786.77 \\
1786.76 \\
1786.77 \\
1786.77\end{array}$ & $\begin{array}{l}1786.81 \\
1786.81 \\
1786.81 \\
1786.81 \\
1786.81\end{array}$ & $\begin{array}{l}1786.89 \\
1786.89 \\
1786.90 \\
1786.90 \\
1786.90\end{array}$ & $\begin{array}{l}1786.99 \\
1787.00 \\
1787.00 \\
1787.00 \\
1787.01\end{array}$ & $\begin{array}{l}1787.06 \\
1787.06 \\
1787.07 \\
1787.06 \\
1787.05\end{array}$ & $\begin{array}{l}1786.90 \\
1786.90 \\
1786.89 \\
1786.88 \\
1786.87\end{array}$ & $\begin{array}{l}\ldots \\
\ldots \\
\ldots \\
\ldots \\
\cdots\end{array}$ & $\begin{array}{l}\ldots \\
\ldots \\
\ldots \\
\ldots \\
\ldots\end{array}$ & $\begin{array}{l}\ldots \\
\ldots \\
\ldots \\
\ldots \\
\cdots\end{array}$ & $\begin{array}{l}1786.85 \\
1786.88 \\
1786.88 \\
1786.87 \\
1786.85\end{array}$ & $\begin{array}{l}1786.77 \\
1786.76 \\
1786.78 \\
1786.80 \\
1786.83\end{array}$ \\
\hline $\begin{array}{l}21 \\
22 \\
23 \\
24 \\
25\end{array}$ & $\begin{array}{l}\ldots \\
\ldots \\
\ldots \\
\ldots \\
\ldots\end{array}$ & $\begin{array}{l}1786.77 \\
1786.77 \\
1786.78 \\
1786.78 \\
1786.78\end{array}$ & $\begin{array}{l}1786.81 \\
1786.81 \\
1786.83 \\
1786.83 \\
1786.83\end{array}$ & $\begin{array}{l}1786.90 \\
1786.90 \\
1786.90 \\
1786.91 \\
1786.91\end{array}$ & $\begin{array}{l}1787.02 \\
1787.02 \\
1787.02 \\
1787.02 \\
1787.03\end{array}$ & $\begin{array}{l}1787.05 \\
1787.04 \\
1787.02 \\
1787.01 \\
1786.99\end{array}$ & $\begin{array}{l}1786.87 \\
1786.87 \\
1786.86 \\
1786.86 \\
1786.85\end{array}$ & $\begin{array}{l}\ldots \\
\ldots \\
\ldots \\
\cdots \\
\cdots\end{array}$ & $\begin{array}{l}\ldots \\
\ldots \\
\ldots \\
\ldots \\
\ldots\end{array}$ & $\begin{array}{l}\ldots \\
\ldots \\
\ldots \\
\ldots \\
\ldots\end{array}$ & $\begin{array}{l}1786.88 \\
1786.88 \\
1786.86 \\
1786.84 \\
1786.82\end{array}$ & $\begin{array}{l}1786.87 \\
1786.89 \\
1786.92 \\
1786.93 \\
1786.91\end{array}$ \\
\hline $\begin{array}{l}26 \\
27 \\
28 \\
29 \\
30 \\
31\end{array}$ & $\begin{array}{l}\ldots \\
\ldots \\
\ldots \\
\ldots \\
\ldots \\
\ldots\end{array}$ & $\begin{array}{r}1786.80 \\
1786.80 \\
1786.79 \\
1786.79 \\
1786.78 \\
\ldots\end{array}$ & $\begin{array}{l}1786.83 \\
1786.84 \\
1786.84 \\
1786.84 \\
1786.84 \\
1786.84\end{array}$ & $\begin{array}{l}1786.92 \\
1786.92 \\
1786.93 \\
1786.93 \\
1786.93 \\
1786.93\end{array}$ & $\begin{array}{r}1787.03 \\
1787.03 \\
1787.03 \\
\ldots \\
\ldots \\
\ldots\end{array}$ & $\begin{array}{l}1786.98 \\
1786.97 \\
1786.96 \\
1786.95 \\
1786.94 \\
1786.94\end{array}$ & $\begin{array}{r}1786.84 \\
1786.86 \\
1786.87 \\
1786.87 \\
1786.86 \\
. .\end{array}$ & $\begin{array}{l}\ldots . \\
\ldots \\
\ldots \\
\ldots \\
\ldots\end{array}$ & $\begin{array}{l}\ldots . \\
\cdots \\
\cdots \\
\cdots \\
\cdots \\
\cdots\end{array}$ & $\begin{array}{r}1786.81 \\
1786.80 \\
1786.79 \\
1786.78 \\
1786.78\end{array}$ & $\begin{array}{l}1786.81 \\
1786.80 \\
1786.78 \\
1786.78 \\
1786.77 \\
1786.76\end{array}$ & $\begin{array}{r}1786.91 \\
1786.90 \\
1786.89 \\
1786.88 \\
1786.87 \\
\ldots . .\end{array}$ \\
\hline
\end{tabular}


GROUND-WATER DATA-Cont inued

DAILY WATER LEVELS- Continued

CEDAR POINT MELL CLUSTER-Continued

STATION MUMBER 351411109170703 (CP-3)-Continued

WATER LEVEL, IN METERS ABOVE MEAN SEA LEVEL, OCTOBER 1990 TO JUNE 1991 DAILY MEAN VALUES

\begin{tabular}{|c|c|c|c|c|c|c|c|c|c|c|c|c|}
\hline DAY & OCT & NOV & DEC & JAN & FEB & MAR & APR & MaY & JUN & JUL & AUG & SEP \\
\hline $\begin{array}{l}1 \\
2 \\
3 \\
4 \\
5\end{array}$ & $\begin{array}{l}1786.88 \\
1786.90 \\
1786.91 \\
1786.90 \\
1786.88\end{array}$ & $\begin{array}{l}1786.93 \\
1786.97 \\
1787.01 \\
1786.99 \\
1786.99\end{array}$ & $\begin{array}{l}1786.96 \\
1786.97 \\
1786.98 \\
1786.99 \\
1786.99\end{array}$ & $\begin{array}{l}1787.03 \\
1787.02 \\
1787.02 \\
1787.05 \\
1787.11\end{array}$ & $\begin{array}{l}1787.17 \\
1787.17 \\
1787.17 \\
1787.17 \\
1787.18\end{array}$ & $\begin{array}{l}1787.20 \\
1787.24 \\
1787.24 \\
1787.23 \\
1787.24\end{array}$ & $\begin{array}{l}1787.21 \\
1787.20 \\
1787.21 \\
1787.20 \\
1787.21\end{array}$ & $\begin{array}{l}1786.95 \\
1786.94 \\
1786.91 \\
1786.90 \\
1786.89\end{array}$ & $\begin{array}{r}1786.73 \\
1786.73 \\
1786.72 \\
\ldots \\
\ldots . .\end{array}$ & $\begin{array}{l}\ldots- \\
\ldots \\
\ldots- \\
\ldots-\end{array}$ & $\begin{array}{l}\ldots- \\
\ldots- \\
-. . \\
-. .\end{array}$ & $\begin{array}{l}\ldots \\
\ldots \\
\ldots \\
\ldots \\
\ldots\end{array}$ \\
\hline $\begin{array}{r}6 \\
7 \\
8 \\
9 \\
10\end{array}$ & $\begin{array}{l}1786.87 \\
1786.87 \\
1786.85 \\
1786.84 \\
1786.83\end{array}$ & $\begin{array}{l}1786.98 \\
1787.01 \\
1787.00 \\
1787.01 \\
1787.00\end{array}$ & $\begin{array}{l}1786.98 \\
1786.98 \\
1786.98 \\
1786.97 \\
1786.97\end{array}$ & $\begin{array}{l}1787.14 \\
1787.19 \\
1787.20 \\
1787.20 \\
1787.19\end{array}$ & $\begin{array}{l}1787.17 \\
1787.19 \\
1787.20 \\
1787.21 \\
1787.22\end{array}$ & $\begin{array}{l}1787.26 \\
1787.24 \\
1787.20 \\
1787.20 \\
1787.20\end{array}$ & $\begin{array}{l}1787.21 \\
1787.20 \\
1787.18 \\
1787.17 \\
1787.16\end{array}$ & $\begin{array}{l}1786.88 \\
1786.87 \\
1786.86 \\
1786.85 \\
1786.84\end{array}$ & $\begin{array}{l}\ldots \\
\ldots \\
\ldots- \\
\ldots\end{array}$ & $\begin{array}{l}\ldots \\
\ldots \\
\ldots- \\
\ldots\end{array}$ & $\begin{array}{l}\cdots \\
\cdots \\
\cdots- \\
\cdots\end{array}$ & $\begin{array}{l}\ldots \\
\ldots \\
\ldots \\
\ldots \\
\ldots\end{array}$ \\
\hline $\begin{array}{l}11 \\
12 \\
13 \\
14 \\
15\end{array}$ & $\begin{array}{l}1786.82 \\
1786.81 \\
1786.81 \\
1786.80 \\
1786.79\end{array}$ & $\begin{array}{l}1787.00 \\
1786.99 \\
1786.98 \\
1786.98 \\
1786.96\end{array}$ & $\begin{array}{l}1786.99 \\
1786.99 \\
1787.03 \\
1787.03 \\
1787.03\end{array}$ & $\begin{array}{l}1787.18 \\
1787.18 \\
1787.18 \\
1787.19 \\
1787.19\end{array}$ & $\begin{array}{l}1787.23 \\
1787.23 \\
1787.23 \\
1787.23 \\
1787.22\end{array}$ & $\begin{array}{l}1787.19 \\
1787.17 \\
1787.17 \\
1787.19 \\
1787.19\end{array}$ & $\begin{array}{l}1787.14 \\
1787.16 \\
1787.15 \\
1787.14 \\
1787.12\end{array}$ & $\begin{array}{l}1786.83 \\
1786.82 \\
1786.81 \\
1786.81 \\
1786.80\end{array}$ & $\begin{array}{l}-.- \\
\cdots- \\
\cdots- \\
\cdots\end{array}$ & $\begin{array}{l}\ldots \\
\ldots \\
\ldots \\
\ldots- \\
\ldots\end{array}$ & $\begin{array}{l}\ldots- \\
\ldots- \\
\ldots- \\
-.-\end{array}$ & $\begin{array}{l}\ldots \\
\ldots \\
\ldots \\
\ldots \\
\ldots\end{array}$ \\
\hline $\begin{array}{l}16 \\
17 \\
18 \\
19 \\
20\end{array}$ & $\begin{array}{l}1786.78 \\
1786.77 \\
1786.76 \\
1786.76 \\
1786.91\end{array}$ & $\begin{array}{l}1786.96 \\
1786.95 \\
1786.94 \\
1786.94 \\
1786.94\end{array}$ & $\begin{array}{l}1787.08 \\
1787.06 \\
1787.05 \\
1787.04 \\
1787.04\end{array}$ & $\begin{array}{l}1787.18 \\
1787.18 \\
1787.17 \\
1787.18 \\
1787.19\end{array}$ & $\begin{array}{l}1787.21 \\
1787.23 \\
1787.23 \\
1787.19 \\
1787.19\end{array}$ & $\begin{array}{l}1787.20 \\
1787.19 \\
1787.19 \\
1787.19 \\
1787.19\end{array}$ & $\begin{array}{l}1787.10 \\
1787.11 \\
1787.13 \\
1787.13 \\
1787.13\end{array}$ & $\begin{array}{l}1786.80 \\
1786.79 \\
1786.78 \\
1786.78 \\
1786.77\end{array}$ & $\begin{array}{l}\ldots \\
\ldots \\
\ldots \\
\ldots \\
\ldots\end{array}$ & $\begin{array}{l}\ldots- \\
\ldots- \\
\ldots- \\
\ldots-\end{array}$ & $\begin{array}{l}\ldots- \\
\ldots- \\
\ldots- \\
\ldots-\end{array}$ & $\begin{array}{l}\ldots \\
\ldots \\
\ldots- \\
\cdots \\
\ldots\end{array}$ \\
\hline $\begin{array}{l}21 \\
22 \\
23 \\
24 \\
25\end{array}$ & $\begin{array}{l}1786.99 \\
1786.99 \\
1786.99 \\
1786.98 \\
1786.97\end{array}$ & $\begin{array}{l}1786.94 \\
1786.93 \\
1786.94 \\
1786.94 \\
1786.95\end{array}$ & $\begin{array}{l}1787.03 \\
1787.03 \\
1787.02 \\
1787.03 \\
1787.03\end{array}$ & $\begin{array}{l}1787.19 \\
1787.18 \\
1787.17 \\
1787.18 \\
1787.18\end{array}$ & $\begin{array}{l}1787.17 \\
1787.17 \\
1787.17 \\
1787.16 \\
1787.15\end{array}$ & $\begin{array}{l}1787.20 \\
1787.20 \\
1787.20 \\
1787.19 \\
1787.18\end{array}$ & $\begin{array}{l}1787.13 \\
1787.12 \\
1787.12 \\
1787.11 \\
1787.11\end{array}$ & $\begin{array}{l}1786.77 \\
1786.76 \\
1786.76 \\
1786.75 \\
1786.75\end{array}$ & $\begin{array}{l}\ldots \\
\ldots \\
\ldots \\
\ldots \\
\ldots\end{array}$ & $\begin{array}{l}\ldots- \\
\ldots- \\
-\ldots \\
-. . \\
-.\end{array}$ & $\begin{array}{l}\ldots \\
-.- \\
\ldots- \\
-. .\end{array}$ & $\begin{array}{l}\ldots- \\
\ldots \\
\ldots- \\
-. . \\
-.\end{array}$ \\
\hline $\begin{array}{l}26 \\
27 \\
28 \\
29 \\
30 \\
31\end{array}$ & $\begin{array}{l}1786.96 \\
1786.95 \\
1786.94 \\
1786.94 \\
1786.94 \\
1786.94\end{array}$ & $\begin{array}{r}1786.97 \\
1786.98 \\
1786.97 \\
1786.97 \\
1786.97 \\
\ldots\end{array}$ & $\begin{array}{l}1787.02 \\
1787.02 \\
1787.02 \\
1787.03 \\
1787.06 \\
1787.04\end{array}$ & $\begin{array}{l}1787.18 \\
1787.18 \\
1787.18 \\
1787.17 \\
1787.16 \\
1787.17\end{array}$ & $\begin{array}{r}1787.15 \\
1787.14 \\
1787.17 \\
\ldots . \\
\ldots \\
\ldots\end{array}$ & $\begin{array}{l}1787.18 \\
1787.19 \\
1787.21 \\
1787.23 \\
1787.24 \\
1787.22\end{array}$ & $\begin{array}{r}1787.10 \\
1787.10 \\
1787.08 \\
1787.05 \\
1786.98 \\
\ldots\end{array}$ & $\begin{array}{l}1786.75 \\
1786.74 \\
1786.74 \\
1786.73 \\
1786.73 \\
1786.73\end{array}$ & $\begin{array}{l}\cdots \\
\cdots \\
\cdots \\
\cdots \\
\cdots \\
\cdots\end{array}$ & $\begin{array}{l}\ldots \\
\ldots- \\
\ldots \\
\ldots \\
\ldots \\
\ldots\end{array}$ & $\begin{array}{l}\ldots . \\
\ldots- \\
\ldots- \\
\ldots- \\
\ldots\end{array}$ & $\begin{array}{l}\ldots \\
\ldots \\
\ldots \\
\ldots \\
\ldots \\
\ldots\end{array}$ \\
\hline
\end{tabular}




\section{GROND-MATER DATA-Continued}

DAILY MATER LEVELS-Continued

CEDAR POINT MELL CLUSTER-Continued

STATION MUMBER-351415109170201

STATION MAME-CP-4

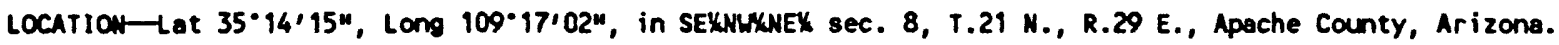

ARIZONA WELL NUMBER-(A-21-29)8abC4.

LAMD SURFACE ALTITUDE-1792.11 meters above mean sea level.

MATER LEVEL, IN METERS ABOVE MEAN SEA LEVEL, JULY 1989 TO SEPTEMBER 1989

DAILY MEAN VALUES

\begin{tabular}{|c|c|c|c|c|c|c|c|c|c|c|c|c|}
\hline DAY & OCT & NOV & DEC & JNH & FEB & MAR & APR & MAY & JUN & JUL & AUG & SEP \\
\hline $\begin{array}{l}1 \\
2 \\
3 \\
4 \\
5\end{array}$ & $\begin{array}{l}\ldots- \\
\ldots \\
\ldots \\
\ldots \\
\ldots\end{array}$ & $\begin{array}{l}\ldots \\
\ldots \\
\ldots \\
\ldots \\
\ldots\end{array}$ & $\begin{array}{l}\cdots \\
\cdots \\
\cdots \\
\cdots \\
\cdots\end{array}$ & $\begin{array}{l}\ldots \\
\cdots \\
\cdots \\
\cdots \\
\cdots\end{array}$ & $\begin{array}{l}\ldots \\
\ldots \\
\ldots \\
\ldots \\
\cdots\end{array}$ & $\begin{array}{l}\ldots \\
\ldots \\
\ldots \\
\cdots \\
\cdots\end{array}$ & $\begin{array}{l}\ldots \\
\ldots \\
\ldots \\
\ldots \\
\ldots\end{array}$ & $\begin{array}{l}\ldots \\
\ldots \\
\ldots \\
\ldots \\
\ldots\end{array}$ & $\begin{array}{l}\ldots \\
\ldots \\
\cdots \\
\cdots\end{array}$ & $\begin{array}{r}\ldots \\
\ldots \\
1786.93 \\
1786.92\end{array}$ & $\begin{array}{l}\cdots \\
\cdots \\
\ldots \\
\cdots \\
\cdots\end{array}$ & $\begin{array}{l}1787.05 \\
1787.04 \\
1787.04 \\
1787.04 \\
1787.03\end{array}$ \\
\hline $\begin{array}{r}6 \\
7 \\
8 \\
9 \\
10\end{array}$ & $\begin{array}{l}\ldots \\
\ldots \\
\ldots \\
\ldots \\
\ldots\end{array}$ & $\begin{array}{l}\ldots \\
\ldots \\
\ldots \\
\ldots \\
\ldots\end{array}$ & $\begin{array}{l}\ldots \\
\ldots \\
\ldots \\
\ldots \\
\ldots\end{array}$ & $\begin{array}{l}\ldots \\
\ldots \\
\ldots \\
\ldots \\
\ldots\end{array}$ & $\begin{array}{l}\ldots \\
\ldots \\
\ldots \\
\ldots \\
\ldots\end{array}$ & $\begin{array}{l}\ldots \\
\ldots \\
\ldots \\
\ldots \\
\cdots\end{array}$ & $\begin{array}{l}\ldots \\
\ldots \\
\ldots \\
\ldots \\
\ldots\end{array}$ & $\begin{array}{l}\ldots \\
\ldots \\
\ldots \\
\ldots \\
\ldots\end{array}$ & $\begin{array}{l}\ldots \\
\ldots \\
\cdots \\
\cdots \\
\cdots\end{array}$ & $\begin{array}{l}1786.92 \\
1786.91 \\
1786.91 \\
1786.91 \\
1786.91\end{array}$ & $\begin{array}{l}\ldots . \\
\ldots \\
\ldots . \\
\ldots \\
\ldots\end{array}$ & $\begin{array}{l}1787.06 \\
1787.08 \\
1787.07 \\
1787.06 \\
1787.06\end{array}$ \\
\hline $\begin{array}{l}11 \\
12 \\
13 \\
14 \\
15\end{array}$ & $\begin{array}{l}\ldots \\
\ldots \\
\ldots \\
\ldots \\
\ldots\end{array}$ & $\begin{array}{l}\ldots \\
\ldots \\
\ldots \\
\ldots \\
\ldots\end{array}$ & $\begin{array}{l}\cdots \\
\cdots \\
\cdots \\
\cdots \\
\cdots\end{array}$ & $\begin{array}{l}\ldots \\
\cdots \\
\cdots \\
\cdots \\
\cdots\end{array}$ & $\begin{array}{l}\cdots \\
\ldots \\
\cdots \\
\cdots \\
\cdots\end{array}$ & $\begin{array}{l}\ldots \\
\cdots \\
\cdots \\
\cdots \\
\cdots\end{array}$ & $\begin{array}{l}\cdots \\
\ldots \\
\ldots \\
\ldots \\
\cdots\end{array}$ & $\begin{array}{l}\cdots \\
\cdots \\
\cdots \\
\cdots \\
\cdots\end{array}$ & $\begin{array}{l}\ldots \\
\ldots \\
\ldots \\
\ldots \\
\cdots\end{array}$ & $\begin{array}{r}1786.90 \\
1786.90 \\
\ldots \\
\ldots\end{array}$ & $\begin{array}{l}\ldots \\
\ldots \\
\ldots \\
\cdots \\
\cdots\end{array}$ & $\begin{array}{l}1787.04 \\
1787.06 \\
1787.03 \\
1787.02 \\
1787.01\end{array}$ \\
\hline $\begin{array}{l}16 \\
17 \\
18 \\
19 \\
20\end{array}$ & $\begin{array}{l}\ldots \\
\ldots \\
\ldots \\
\ldots \\
\ldots\end{array}$ & $\begin{array}{l}\ldots \\
\ldots \\
\ldots \\
\ldots \\
\ldots\end{array}$ & $\begin{array}{l}\cdots \\
\cdots \\
\cdots \\
\cdots \\
\cdots\end{array}$ & $\begin{array}{l}\ldots \\
\ldots \\
\cdots \\
\cdots \\
\cdots\end{array}$ & $\begin{array}{l}\cdots \\
\cdots \\
\cdots \\
\cdots \\
\cdots\end{array}$ & $\begin{array}{l}\cdots \\
\cdots \\
\cdots \\
\cdots \\
\cdots\end{array}$ & $\begin{array}{l}\ldots \\
\ldots \\
\ldots \\
\ldots \\
\ldots\end{array}$ & $\begin{array}{l}\cdots \\
\cdots \\
\cdots \\
\cdots \\
\cdots\end{array}$ & $\begin{array}{l}\ldots \\
\ldots \\
\cdots \\
\cdots \\
\cdots\end{array}$ & $\begin{array}{l}\ldots \\
\ldots \\
\cdots \\
\cdots \\
\cdots\end{array}$ & $\begin{array}{l}\cdots \\
\cdots \\
\cdots \\
\cdots \\
\cdots\end{array}$ & $\begin{array}{l}1787.01 \\
1787.01 \\
1787.00 \\
1787.00 \\
1786.99\end{array}$ \\
\hline $\begin{array}{l}21 \\
22 \\
23 \\
24 \\
25\end{array}$ & $\begin{array}{l}\ldots \\
\ldots \\
\ldots \\
\ldots \\
\ldots\end{array}$ & $\begin{array}{l}\ldots \\
\ldots \\
\ldots \\
\ldots \\
\ldots\end{array}$ & $\begin{array}{l}\ldots \\
\cdots \\
\cdots \\
\cdots \\
\cdots\end{array}$ & $\begin{array}{l}\ldots \\
\ldots \\
\ldots \\
\ldots \\
\cdots\end{array}$ & $\begin{array}{l}\ldots \\
\ldots \\
\ldots \\
\ldots \\
\ldots\end{array}$ & $\begin{array}{l}\ldots \\
\ldots \\
\ldots \\
\ldots \\
\ldots\end{array}$ & $\begin{array}{l}\ldots \\
\ldots \\
\ldots \\
\ldots \\
\ldots\end{array}$ & $\begin{array}{l}\ldots \\
\ldots \\
\ldots \\
\ldots \\
\ldots\end{array}$ & $\begin{array}{l}\ldots \\
\ldots \\
\ldots \\
\ldots \\
\ldots\end{array}$ & $\begin{array}{l}\ldots \\
\ldots \\
\ldots \\
\ldots \\
\ldots\end{array}$ & $\begin{array}{r}\ldots \\
1787.14 \\
1787.13 \\
1787.12\end{array}$ & $\begin{array}{l}1786.99 \\
1786.98 \\
1786.97 \\
1786.97 \\
1786.97\end{array}$ \\
\hline $\begin{array}{l}26 \\
27 \\
28 \\
29 \\
30 \\
31\end{array}$ & $\begin{array}{l}\ldots \\
\ldots \\
\ldots \\
\ldots \\
\ldots \\
\ldots\end{array}$ & $\begin{array}{l}\ldots \\
\ldots \\
\ldots \\
\ldots \\
\ldots \\
\ldots\end{array}$ & $\begin{array}{l}\cdots \\
\ldots \\
\ldots \\
\ldots \\
\ldots \\
\ldots\end{array}$ & $\begin{array}{l}\cdots \\
\ldots \\
\cdots \\
\cdots \\
\cdots \\
\cdots\end{array}$ & $\begin{array}{l}\ldots \\
\ldots \\
\ldots \\
\ldots \\
\ldots \\
\ldots\end{array}$ & $\begin{array}{l}\cdots \\
\ldots \\
\ldots \\
\ldots \\
\ldots \\
\ldots\end{array}$ & $\begin{array}{l}\ldots \\
\ldots \\
\ldots \\
\ldots \\
\ldots \\
\ldots\end{array}$ & $\begin{array}{l}\ldots \\
\ldots \\
\ldots \\
\ldots \\
\ldots \\
\ldots\end{array}$ & $\begin{array}{l}\ldots \\
\ldots \\
\ldots \\
\ldots \\
\ldots \\
\ldots\end{array}$ & $\begin{array}{l}\ldots \\
\ldots \\
\cdots \\
\cdots \\
\cdots \\
\cdots\end{array}$ & $\begin{array}{l}1787.10 \\
1787.09 \\
1787.09 \\
1787.07 \\
1787.07 \\
1787.06\end{array}$ & $\begin{array}{l}1786.96 \\
1786.96 \\
1786.96 \\
1786.96 \\
1786.95\end{array}$ \\
\hline
\end{tabular}


GROUND-WATER DATA-Continued

DAILY WATER LEVELS-Cont inued

CEDAR POINT WELL CLUSTER-Continued

STATION NUMBER 351415109170201 (CP-4)-Cont inued

WATER LEVEL, IN METERS ABOVE MEAN SEA LEVEL, OCTOBER 1989 TO SEPTEMBER 1990 DAILY MEAK VALUES

\begin{tabular}{|c|c|c|c|c|c|c|c|c|c|c|c|c|}
\hline DAY & oCt & nov & DEC & JAN & FEB & MAR & APR & MAY & JUN & JUL & AUG & SEP \\
\hline $\begin{array}{l}1 \\
2 \\
3 \\
4 \\
5\end{array}$ & $\begin{array}{l}1786.94 \\
1786.94 \\
1786.94 \\
1786.94 \\
1786.94\end{array}$ & $\begin{array}{r}1786.90 \\
\ldots \\
\ldots \\
\ldots\end{array}$ & $\begin{array}{l}1786.93 \\
1786.93 \\
1786.92 \\
1786.93 \\
1786.93\end{array}$ & $\begin{array}{l}1786.97 \\
1786.97 \\
1786.97 \\
1786.97 \\
1786.97\end{array}$ & $\begin{array}{l}1787.03 \\
1787.04 \\
1787.04 \\
1787.04 \\
1787.04\end{array}$ & $\begin{array}{l}1787.12 \\
1787.12 \\
1787.12 \\
1787.13 \\
1787.13\end{array}$ & $\begin{array}{l}1787.07 \\
1787.06 \\
1787.06 \\
1787.06 \\
1787.07\end{array}$ & $\begin{array}{l}1787.00 \\
1786.99 \\
1787.00 \\
1787.00 \\
1787.01\end{array}$ & $\begin{array}{l}1786.93 \\
1786.91 \\
1786.91 \\
1786.91 \\
1786.91\end{array}$ & $\begin{array}{l}1786.84 \\
1786.84 \\
1786.84 \\
1786.83 \\
1786.83\end{array}$ & $\begin{array}{l}1786.99 \\
1786.98 \\
1786.97 \\
1786.97 \\
1786.96\end{array}$ & $\begin{array}{l}1786.94 \\
1786.94 \\
1786.96 \\
1786.96 \\
1786.96\end{array}$ \\
\hline $\begin{array}{r}6 \\
7 \\
8 \\
9 \\
10\end{array}$ & $\begin{array}{l}1786.93 \\
1786.93 \\
1786.93 \\
1786.93 \\
1786.93\end{array}$ & $\begin{array}{l}\ldots \\
\ldots \\
\ldots \\
\ldots \\
\ldots\end{array}$ & $\begin{array}{l}1786.93 \\
1786.93 \\
1786.93 \\
1786.93 \\
1786.94\end{array}$ & $\begin{array}{l}1786.97 \\
1786.97 \\
1786.97 \\
1786.97 \\
1786.97\end{array}$ & $\begin{array}{l}1787.04 \\
1787.05 \\
1787.05 \\
1787.05 \\
1787.06\end{array}$ & $\begin{array}{l}1787.13 \\
1787.13 \\
1787.13 \\
1787.13 \\
1787.13\end{array}$ & $\begin{array}{l}1787.07 \\
1787.07 \\
1787.08 \\
1787.08 \\
1787.08\end{array}$ & $\begin{array}{l}1787.02 \\
1787.02 \\
1787.01 \\
1787.01 \\
1787.00\end{array}$ & $\begin{array}{l}1786.90 \\
1786.90 \\
1786.90 \\
1786.90 \\
1786.89\end{array}$ & $\begin{array}{l}1786.83 \\
1786.83 \\
1786.83 \\
1786.86 \\
1786.87\end{array}$ & $\begin{array}{l}1786.96 \\
1786.96 \\
1786.95 \\
1786.94 \\
1786.94\end{array}$ & $\begin{array}{l}1786.98 \\
1787.00 \\
1787.00 \\
1787.02 \\
1787.02\end{array}$ \\
\hline $\begin{array}{l}11 \\
12 \\
13 \\
14 \\
15\end{array}$ & $\begin{array}{l}1786.93 \\
1786.93 \\
1786.93 \\
1786.93 \\
1786.93\end{array}$ & $\begin{array}{l}\ldots \\
\ldots \\
\ldots \\
\ldots \\
\ldots\end{array}$ & $\begin{array}{l}1786.94 \\
1786.94 \\
1786.94 \\
1786.94 \\
1786.94\end{array}$ & $\begin{array}{l}1786.97 \\
1786.98 \\
1786.99 \\
1786.99 \\
1786.99\end{array}$ & $\begin{array}{l}1787.07 \\
1787.07 \\
1787.08 \\
1787.09 \\
1787.09\end{array}$ & $\begin{array}{l}178 \\
178 \\
178 \\
178 \\
178\end{array}$ & $\begin{array}{l}1787.08 \\
1787.07 \\
1787.07 \\
1787.06 \\
1787.05\end{array}$ & $\begin{array}{l}1787.00 \\
1786.99 \\
1786.99 \\
1786.99 \\
1786.98\end{array}$ & $\begin{array}{l}1786.89 \\
1786.89 \\
1786.89 \\
1786.88 \\
1786.88\end{array}$ & $\begin{array}{l}1786.90 \\
1786.92 \\
1786.94 \\
1786.99 \\
1787.00\end{array}$ & $\begin{array}{l}1786.94 \\
1786.93 \\
1786.93 \\
1786.93 \\
1786.96\end{array}$ & $\begin{array}{l}178 \\
17 \\
178 \\
17\end{array}$ \\
\hline $\begin{array}{l}16 \\
17 \\
18 \\
19 \\
20\end{array}$ & $\begin{array}{l}1786.92 \\
1786.91 \\
1786.91 \\
1786.91 \\
1786.90\end{array}$ & $\begin{array}{r}\ldots \\
\ldots \\
1786.91 \\
1786.91 \\
1786.92\end{array}$ & $\begin{array}{l}1786.94 \\
1786.94 \\
1786.94 \\
1786.94 \\
1786.94\end{array}$ & $\begin{array}{l}1787.00 \\
1787.00 \\
1787.00 \\
1787.00 \\
1787.00\end{array}$ & $\begin{array}{l}1787.08 \\
1787.09 \\
1787.09 \\
1787.09 \\
1787.09\end{array}$ & $\begin{array}{l}178 \\
178 \\
178 \\
178 \\
178\end{array}$ & $\begin{array}{l}1787.05 \\
1787.04 \\
1787.04 \\
1787.03 \\
1787.03\end{array}$ & $\begin{array}{l}178 \\
178 \\
178 \\
178 \\
178\end{array}$ & $\begin{array}{l}1786.87 \\
1786.87 \\
1786.87 \\
1786.87 \\
1786.86\end{array}$ & $\begin{array}{l}178 \\
178 \\
178 \\
178 \\
178\end{array}$ & $\begin{array}{l}5.99 \\
7.01 \\
7.02 \\
7.02 \\
7.01\end{array}$ & $\begin{array}{l}.97 \\
.96 \\
.96 \\
.96 \\
.98\end{array}$ \\
\hline $\begin{array}{l}21 \\
22 \\
23 \\
24 \\
25\end{array}$ & $\begin{array}{l}1786.90 \\
1786.90 \\
1786.91 \\
1786.91 \\
1786.91\end{array}$ & $\begin{array}{l}1786.92 \\
1786.92 \\
1786.93 \\
1786.93 \\
1786.93\end{array}$ & $\begin{array}{l}1786.94 \\
1786.94 \\
1786.95 \\
1786.96 \\
1786.96\end{array}$ & $\begin{array}{l}1787.01 \\
1787.01 \\
1787.02 \\
1787.02 \\
1787.02\end{array}$ & $\begin{array}{l}1787.09 \\
1787.10 \\
1787.10 \\
1787.10 \\
1787.10\end{array}$ & $\begin{array}{l}1787.14 \\
1787.13 \\
1787.13 \\
1787.12 \\
1787.11\end{array}$ & $\begin{array}{l}1787.02 \\
1787.02 \\
1787.02 \\
1787.01 \\
1787.01\end{array}$ & $\begin{array}{l}1786.96 \\
1786.96 \\
1786.96 \\
1786.94 \\
1786.94\end{array}$ & $\begin{array}{l}1786.86 \\
1786.86 \\
1786.86 \\
1786.86 \\
1786.86\end{array}$ & $\begin{array}{l}1787.06 \\
1787.06 \\
1787.05 \\
1787.05 \\
1787.05\end{array}$ & $\begin{array}{l}1787.02 \\
1787.04 \\
1787.03 \\
1787.02 \\
1787.01\end{array}$ & $\begin{array}{l}1787.02 \\
1787.05 \\
1787.06 \\
1787.06\end{array}$ \\
\hline $\begin{array}{l}26 \\
27 \\
28 \\
29 \\
30\end{array}$ & $\begin{array}{r}1786.91 \\
\ldots \\
\ldots \\
1786.91 \\
1786.90 \\
1786.90\end{array}$ & $\begin{array}{r}1786.93 \\
1786.93 \\
1786.93 \\
1786.93 \\
1786.93 \\
\ldots\end{array}$ & $\begin{array}{l}1786.96 \\
1786.96 \\
1786.96 \\
1786.97 \\
1786.97 \\
1786.97\end{array}$ & $\begin{array}{l}1787.02 \\
1787.02 \\
1787.02 \\
1787.02 \\
1787.03 \\
1787.03\end{array}$ & $\begin{array}{r}1787.10 \\
1787.11 \\
1787.12 \\
\ldots \\
\ldots \\
\ldots\end{array}$ & $\begin{array}{l}1787.10 \\
1787.10 \\
1787.09 \\
1787.09 \\
1787.07 \\
1787.07\end{array}$ & $\begin{array}{r}1787.01 \\
1787.00 \\
1787.01 \\
1787.01 \\
1787.00 \\
\ldots\end{array}$ & $\begin{array}{l}1786.94 \\
1786.94 \\
1786.94 \\
1786.93 \\
1786.93 \\
1786.93\end{array}$ & $\begin{array}{r}1786.86 \\
1786.84 \\
1786.84 \\
1786.84 \\
1786.84 \\
\ldots\end{array}$ & $\begin{array}{l}1787.04 \\
1787.03 \\
1787.02 \\
1787.01 \\
1787.00 \\
1786.99\end{array}$ & $\begin{array}{l}1787.00 \\
1786.98 \\
1786.98 \\
1786.97 \\
1786.96 \\
1786.95\end{array}$ & $\begin{array}{l}1787.06 \\
1787.06 \\
1787.06 \\
1787.04 \\
1787.04\end{array}$ \\
\hline
\end{tabular}


GROUND-WATER DATA-Continued

DAILY WATER LEVELS-Continued

CEDAR POINT WELL CLUSTER-cont inued

STATION MUMBER $351415109170201(\mathrm{CP}-4)$-Cont inued

water leVel, IN meters above meAN SEA LEVEL, OCTOBER 1990 TO JUNE 1991 DAILY MEAN VALUES

\begin{tabular}{|c|c|c|c|c|c|c|c|c|c|c|c|c|}
\hline DAY & OCT & NOV & DEC & JAN & FEB & MAR & APR & MAY & JUN & JUL & AUG & SEP \\
\hline $\begin{array}{l}1 \\
2 \\
3 \\
4 \\
5\end{array}$ & $\begin{array}{l}1787.04 \\
1787.05 \\
1787.06 \\
1787.05 \\
1787.05\end{array}$ & $\begin{array}{l}1787.05 \\
1787.07 \\
1787.10 \\
1787.09 \\
1787.09\end{array}$ & $\begin{array}{l}1787.07 \\
1787.08 \\
1787.09 \\
1787.09 \\
1787.09\end{array}$ & $\begin{array}{l}1787.15 \\
1787.14 \\
1787.13 \\
1787.15 \\
1787.18\end{array}$ & $\begin{array}{l}1787.29 \\
1787.29 \\
1787.29 \\
1787.29 \\
1787.30\end{array}$ & $\begin{array}{l}1787.32 \\
1787.35 \\
1787.35 \\
1787.35 \\
1787.36\end{array}$ & $\begin{array}{l}1787.35 \\
1787.34 \\
1787.34 \\
1787.33 \\
1787.33\end{array}$ & $\begin{array}{l}1787.15 \\
1787.13 \\
1787.11 \\
1787.10 \\
1787.09\end{array}$ & $\begin{array}{r}1786.94 \\
1786.94 \\
1786.93 \\
\ldots \\
\ldots .\end{array}$ & $\begin{array}{l}\ldots \\
\ldots \\
\cdots \\
\ldots \\
\cdots\end{array}$ & $\begin{array}{l}\cdots \\
\cdots \\
\cdots \\
\cdots \\
\cdots\end{array}$ & $\begin{array}{l}\cdots \\
\cdots \\
\cdots \\
\cdots \\
\cdots\end{array}$ \\
\hline $\begin{array}{r}6 \\
7 \\
8 \\
9 \\
10\end{array}$ & $\begin{array}{l}1787.04 \\
1787.03 \\
1787.01 \\
1787.01 \\
1787.00\end{array}$ & $\begin{array}{l}1787.09 \\
1787.10 \\
1787.10 \\
1787.11 \\
1787.11\end{array}$ & $\begin{array}{l}1787.09 \\
1787.09 \\
1787.09 \\
1787.09 \\
1787.09\end{array}$ & $\begin{array}{l}1787.21 \\
1787.25 \\
1787.27 \\
1787.28 \\
1787.29\end{array}$ & $\begin{array}{l}1787.30 \\
1787.31 \\
1787.32 \\
1787.33 \\
1787.33\end{array}$ & $\begin{array}{l}1787.37 \\
1787.36 \\
1787.34 \\
1787.33 \\
1787.33\end{array}$ & $\begin{array}{l}1787.33 \\
1787.33 \\
1787.31 \\
1787.29 \\
1787.29\end{array}$ & $\begin{array}{l}1787.08 \\
1787.07 \\
1787.07 \\
1787.06 \\
1787.05\end{array}$ & $\begin{array}{l}\ldots \\
\ldots \\
\ldots \\
\ldots- \\
\cdots\end{array}$ & $\begin{array}{l}\ldots . \\
\ldots \\
\cdots \\
\cdots \\
\cdots\end{array}$ & $\begin{array}{l}\ldots . \\
\cdots \\
\cdots \\
\cdots \\
\cdots\end{array}$ & $\begin{array}{l}\ldots \\
\ldots \\
\cdots \\
\cdots \\
-.-\end{array}$ \\
\hline $\begin{array}{l}11 \\
12 \\
13 \\
14 \\
15\end{array}$ & $\begin{array}{l}1786.99 \\
1786.98 \\
1786.98 \\
1786.97 \\
1786.96\end{array}$ & $\begin{array}{l}1787.10 \\
1787.10 \\
1787.10 \\
1787.09 \\
1787.09\end{array}$ & $\begin{array}{l}1787.09 \\
1787.09 \\
1787.12 \\
1787.13 \\
1787.13\end{array}$ & $\begin{array}{l}1787.29 \\
1787.29 \\
1787.29 \\
1787.30 \\
1787.30\end{array}$ & $\begin{array}{l}1787.33 \\
1787.34 \\
1787.33 \\
1787.35 \\
1787.35\end{array}$ & $\begin{array}{l}1787.32 \\
1787.30 \\
1787.30 \\
1787.31 \\
1787.31\end{array}$ & $\begin{array}{l}1787.27 \\
1787.26 \\
1787.26 \\
1787.25 \\
1787.24\end{array}$ & $\begin{array}{l}1787.04 \\
1787.03 \\
1787.03 \\
1787.02 \\
1787.01\end{array}$ & $\begin{array}{l}\ldots \\
\ldots \\
\ldots \\
\ldots \\
\cdots\end{array}$ & $\begin{array}{l}\ldots \\
\ldots \\
\ldots \\
\ldots \\
\ldots\end{array}$ & $\begin{array}{l}\ldots . \\
\ldots- \\
\cdots \\
\ldots- \\
\cdots\end{array}$ & $\begin{array}{l}\ldots \\
\ldots \\
\ldots \\
\ldots \\
\cdots\end{array}$ \\
\hline $\begin{array}{l}16 \\
17 \\
18 \\
19 \\
20\end{array}$ & $\begin{array}{l}1786.96 \\
1786.95 \\
1786.94 \\
1786.94 \\
1787.02\end{array}$ & $\begin{array}{l}1787.08 \\
1787.07 \\
1787.07 \\
1787.07 \\
1787.07\end{array}$ & $\begin{array}{l}1787.16 \\
1787.16 \\
1787.15 \\
1787.15 \\
1787.15\end{array}$ & $\begin{array}{l}1787.30 \\
1787.30 \\
1787.30 \\
1787.30 \\
1787.30\end{array}$ & $\begin{array}{l}1787.34 \\
1787.35 \\
1787.34 \\
1787.32 \\
1787.32\end{array}$ & $\begin{array}{l}1787.32 \\
1787.31 \\
1787.32 \\
1787.32 \\
1787.32\end{array}$ & $\begin{array}{l}1787.23 \\
1787.22 \\
1787.23 \\
1787.23 \\
1787.24\end{array}$ & $\begin{array}{l}1787.01 \\
1787.00 \\
1786.99 \\
1786.99 \\
1786.99\end{array}$ & $\begin{array}{l}-.- \\
\ldots- \\
\ldots- \\
\ldots- \\
-.-\end{array}$ & $\begin{array}{l}\ldots- \\
\cdots \\
\ldots \\
\cdots \\
\cdots\end{array}$ & $\begin{array}{l}\ldots . \\
\cdots \\
\cdots \\
\cdots \\
\cdots\end{array}$ & $\begin{array}{l}\ldots- \\
\ldots- \\
\cdots \\
\cdots \\
\cdots\end{array}$ \\
\hline $\begin{array}{l}21 \\
22 \\
23 \\
24 \\
25\end{array}$ & $\begin{array}{l}1787.08 \\
1787.09 \\
1787.09 \\
1787.08 \\
1787.07\end{array}$ & $\begin{array}{l}1787.06 \\
1787.05 \\
1787.06 \\
1787.06 \\
1787.06\end{array}$ & $\begin{array}{l}1787.14 \\
1787.14 \\
1787.13 \\
1787.14 \\
1787.14\end{array}$ & $\begin{array}{l}1787.30 \\
1787.30 \\
1787.29 \\
1787.29 \\
1787.30\end{array}$ & $\begin{array}{l}1787.31 \\
1787.30 \\
1787.30 \\
1787.29 \\
1787.28\end{array}$ & $\begin{array}{l}1787.32 \\
1787.32 \\
1787.33 \\
1787.32 \\
1787.32\end{array}$ & $\begin{array}{l}1787.24 \\
1787.23 \\
1787.23 \\
1787.22 \\
1787.22\end{array}$ & $\begin{array}{l}1786.98 \\
1786.97 \\
1786.97 \\
1786.97 \\
1786.96\end{array}$ & $\begin{array}{l}\ldots . \\
\ldots- \\
\ldots \\
\ldots \\
\ldots\end{array}$ & $\begin{array}{l}\ldots . \\
\ldots- \\
\cdots \\
\ldots \\
\cdots\end{array}$ & $\begin{array}{l}\ldots . \\
\cdots \\
\cdots \\
\cdots \\
\cdots\end{array}$ & $\begin{array}{l}\ldots \\
\ldots \\
\cdots \\
\cdots \\
\cdots\end{array}$ \\
\hline $\begin{array}{l}26 \\
27 \\
28 \\
29 \\
30 \\
31\end{array}$ & $\begin{array}{l}1787.07 \\
1787.07 \\
1787.06 \\
1787.06 \\
1787.06 \\
1787.05\end{array}$ & $\begin{array}{r}1787.08 \\
1787.09 \\
1787.09 \\
1787.09 \\
1787.08 \\
\ldots\end{array}$ & $\begin{array}{l}1787.14 \\
1787.13 \\
1787.13 \\
1787.14 \\
1787.16 \\
1787.16\end{array}$ & $\begin{array}{l}1787.30 \\
1787.30 \\
1787.30 \\
1787.29 \\
1787.28 \\
1787.28\end{array}$ & $\begin{array}{r}1787.28 \\
1787.28 \\
1787.29 \\
\ldots \\
\ldots \\
\ldots .\end{array}$ & $\begin{array}{l}1787.32 \\
1787.31 \\
1787.33 \\
1787.35 \\
1787.35 \\
1787.35\end{array}$ & $\begin{array}{r}1787.22 \\
1787.21 \\
1787.20 \\
1787.18 \\
1787.16 \\
\ldots\end{array}$ & $\begin{array}{l}1786.96 \\
1786.96 \\
1786.95 \\
1786.94 \\
1786.94 \\
1786.94\end{array}$ & $\begin{array}{l}\ldots . \\
\ldots \\
\ldots \\
\ldots \\
\ldots \\
\ldots\end{array}$ & $\begin{array}{l}\ldots . \\
\ldots \\
\ldots \\
\ldots \\
\ldots \\
\ldots\end{array}$ & $\begin{array}{l}\ldots . \\
\ldots \\
\cdots \\
\cdots \\
\cdots \\
\cdots\end{array}$ & $\begin{array}{l}\ldots \\
\ldots \\
\ldots \\
\ldots \\
\ldots \\
\ldots\end{array}$ \\
\hline
\end{tabular}




\section{GROUND-WATER DATA-Continued \\ DAILY WATER LEVELS-Continued}

CEDAR POINT WELL CLUSTER-Continued

STATION MUMER-351410109170201

STATION WAME-CP-5

LOCATION-Lat 35'14'01' Long 109.17'02", in SEXSEXNEX sec. 8, T.21 N., R.29 E., Apache County, Arizona.

ARIZONA WELL MUMBER-(A-21-29)8add1.

LAND SURFACE ALTITUDE-1791.71 meters above mean sea level.

mater level, In meters abOVE MEAN SEA LEVEL, JULY 1989 TO SEPTEMBER 1989 DAILY MEAN VALUES

\begin{tabular}{|c|c|c|c|c|c|c|c|c|c|c|c|c|}
\hline DAY & OCT & MOV & DEC & JAN & FEB & MAR & $A P R$ & MAY & JuN & JUL & NUG & SEP \\
\hline $\begin{array}{l}1 \\
2 \\
3 \\
4 \\
5\end{array}$ & $\begin{array}{l}\ldots \\
\ldots \\
\ldots \\
\ldots\end{array}$ & $\begin{array}{l}\ldots- \\
\ldots- \\
\ldots- \\
\ldots \\
\ldots\end{array}$ & $\begin{array}{l}\ldots \\
\ldots \\
\ldots \\
\ldots \\
\ldots-\end{array}$ & $\begin{array}{l}\ldots . \\
\ldots- \\
\ldots- \\
\ldots-\end{array}$ & $\begin{array}{l}\ldots- \\
\ldots \\
\ldots- \\
\ldots \\
\ldots\end{array}$ & $\begin{array}{l}\ldots- \\
\ldots- \\
\ldots- \\
\cdots \\
\cdots\end{array}$ & $\begin{array}{l}\ldots . \\
\ldots- \\
\ldots- \\
\ldots- \\
\ldots\end{array}$ & $\begin{array}{l}\ldots \\
\ldots \\
\ldots \\
\ldots \\
\ldots\end{array}$ & $\begin{array}{l}\ldots- \\
\ldots- \\
\ldots- \\
\ldots \\
\cdots\end{array}$ & $\begin{array}{r}\ldots \\
1786.67 \\
1786.67\end{array}$ & $\begin{array}{l}\ldots \\
\ldots- \\
\ldots \\
\ldots \\
\ldots\end{array}$ & $\begin{array}{l}1786.71 \\
1786.71 \\
1786.70 \\
1786.70 \\
1786.70\end{array}$ \\
\hline $\begin{array}{r}6 \\
7 \\
8 \\
9 \\
10\end{array}$ & $\begin{array}{l}\ldots \\
\cdots \\
\cdots \\
\cdots \\
\cdots\end{array}$ & $\begin{array}{l}\ldots- \\
\ldots \\
\ldots \\
\ldots \\
\ldots\end{array}$ & $\begin{array}{l}\ldots \\
\ldots \\
\ldots \\
\ldots \\
\ldots\end{array}$ & $\begin{array}{l}\ldots \\
\ldots \\
\ldots- \\
\ldots \\
\ldots-\end{array}$ & $\begin{array}{l}\ldots- \\
\ldots- \\
\ldots- \\
\ldots\end{array}$ & $\begin{array}{l}\ldots \\
\ldots \\
\ldots- \\
\ldots \\
\ldots\end{array}$ & $\begin{array}{l}\ldots \\
\ldots \\
\ldots- \\
\ldots \\
\ldots\end{array}$ & $\begin{array}{l}\ldots \\
\ldots \\
\ldots \\
\ldots \\
\ldots\end{array}$ & $\begin{array}{l}\ldots \\
\ldots \\
\ldots \\
\ldots \\
\ldots\end{array}$ & $\begin{array}{l}1786.66 \\
1786.66 \\
1786.66 \\
1786.65 \\
1786.65\end{array}$ & $\begin{array}{l}\ldots \\
\ldots \\
\ldots \\
\ldots \\
\ldots\end{array}$ & $\begin{array}{l}1786.70 \\
1786.70 \\
1786.71 \\
1786.71 \\
1786.71\end{array}$ \\
\hline $\begin{array}{l}11 \\
12 \\
13 \\
14 \\
15\end{array}$ & $\begin{array}{l}\ldots \\
\ldots \\
\ldots \\
\ldots \\
\ldots\end{array}$ & $\begin{array}{l}\ldots \\
\ldots \\
\ldots \\
\ldots \\
\ldots\end{array}$ & $\begin{array}{l}\ldots \\
\ldots \\
\ldots \\
\ldots \\
\ldots\end{array}$ & $\begin{array}{l}\ldots . \\
\ldots \\
\ldots- \\
\ldots \\
\ldots\end{array}$ & $\begin{array}{l}\ldots- \\
\ldots- \\
\ldots \\
\ldots- \\
\ldots\end{array}$ & $\begin{array}{l}\ldots \\
\ldots \\
\ldots \\
\ldots \\
\ldots\end{array}$ & $\begin{array}{l}\ldots . \\
\ldots- \\
\ldots- \\
\ldots- \\
\ldots\end{array}$ & $\begin{array}{l}\ldots \\
\ldots \\
\ldots- \\
\ldots \\
\ldots\end{array}$ & $\begin{array}{l}\ldots \\
\ldots \\
\ldots \\
\ldots \\
\ldots\end{array}$ & $\begin{array}{l}1786.65 \\
1786.65 \\
1786.65 \\
1786.65 \\
1786.65\end{array}$ & $\begin{array}{l}\ldots \\
\ldots \\
\ldots \\
\ldots \\
\ldots\end{array}$ & $\begin{array}{l}1786.71 \\
1786.70 \\
1786.70 \\
1786.69 \\
1786.68\end{array}$ \\
\hline $\begin{array}{l}16 \\
17 \\
18 \\
19 \\
20\end{array}$ & $\begin{array}{l}\ldots \\
\cdots \\
\cdots \\
\cdots \\
\cdots\end{array}$ & $\begin{array}{l}\ldots \\
\ldots \\
\ldots \\
\ldots \\
\ldots\end{array}$ & $\begin{array}{l}\ldots \\
\ldots \\
\ldots \\
\ldots \\
\ldots\end{array}$ & $\begin{array}{l}\ldots \\
\ldots \\
\ldots- \\
\cdots \\
\cdots\end{array}$ & $\begin{array}{l}\ldots \\
\ldots \\
\ldots \\
\ldots \\
\ldots\end{array}$ & $\begin{array}{l}\cdots \\
\ldots \\
\cdots \\
\cdots \\
\cdots\end{array}$ & $\begin{array}{l}\ldots \\
\cdots \\
\cdots \\
\cdots \\
\cdots\end{array}$ & $\begin{array}{l}\ldots \\
\ldots \\
\ldots \\
\ldots \\
\ldots\end{array}$ & $\begin{array}{l}\ldots \\
\cdots \\
\cdots \\
\cdots \\
\cdots\end{array}$ & $\begin{array}{l}1786.64 \\
1786.64 \\
1786.64 \\
1786.63 \\
1786.63\end{array}$ & $\begin{array}{l}\ldots \\
\ldots \\
\ldots \\
\cdots\end{array}$ & $\begin{array}{r}1786.68 \\
1786.68 \\
1786.68 \\
1786.68 \\
. .\end{array}$ \\
\hline $\begin{array}{l}21 \\
22 \\
23 \\
24 \\
25\end{array}$ & $\begin{array}{l}\ldots \\
\cdots \\
\cdots \\
\cdots \\
\cdots\end{array}$ & $\begin{array}{l}\ldots \\
\ldots \\
\ldots \\
\ldots \\
\ldots\end{array}$ & $\begin{array}{l}\ldots \\
\ldots \\
\ldots \\
\ldots \\
\ldots\end{array}$ & $\begin{array}{l}\ldots \\
\ldots \\
\ldots \\
\cdots \\
\cdots\end{array}$ & $\begin{array}{l}\ldots- \\
\ldots \\
\ldots \\
\ldots \\
\ldots\end{array}$ & $\begin{array}{l}\ldots \\
\ldots \\
\cdots \\
\cdots \\
\cdots\end{array}$ & $\begin{array}{l}\ldots \\
\ldots \\
\ldots \\
\ldots \\
\cdots\end{array}$ & $\begin{array}{l}\ldots \\
\ldots \\
\ldots \\
\ldots \\
\ldots\end{array}$ & $\begin{array}{l}\ldots \\
\cdots \\
\cdots \\
\cdots \\
\cdots\end{array}$ & $\begin{array}{l}\cdots \\
\cdots \\
\cdots \\
\cdots \\
\cdots\end{array}$ & $\begin{array}{l}1786.76 \\
1786.76 \\
1786.76 \\
1786.76\end{array}$ & $\begin{array}{l}1786.67 \\
1786.67 \\
1786.67 \\
1786.66 \\
1786.66\end{array}$ \\
\hline $\begin{array}{l}26 \\
27 \\
28 \\
29 \\
30 \\
31\end{array}$ & $\begin{array}{l}\ldots \\
\ldots \\
\ldots \\
\ldots \\
\ldots\end{array}$ & $\begin{array}{l}\ldots \\
\ldots \\
\cdots \\
\ldots \\
\cdots \\
\ldots\end{array}$ & $\begin{array}{l}\ldots- \\
\ldots \\
\ldots \\
\ldots \\
\ldots \\
\ldots\end{array}$ & $\begin{array}{l}\ldots . \\
\ldots \\
\ldots \\
\ldots \\
\ldots \\
\ldots\end{array}$ & $\begin{array}{l}\ldots \\
\ldots \\
\ldots \\
\ldots \\
\ldots \\
\ldots\end{array}$ & $\begin{array}{l}\ldots \\
\ldots \\
\ldots- \\
\ldots \\
\ldots \\
\ldots\end{array}$ & $\begin{array}{l}\ldots \\
\ldots \\
\ldots \\
\ldots \\
\ldots \\
\ldots\end{array}$ & $\begin{array}{l}\ldots \\
\ldots \\
\ldots \\
\ldots \\
\ldots \\
\ldots\end{array}$ & $\begin{array}{l}\ldots \\
\ldots \\
\ldots \\
\ldots \\
\ldots \\
\ldots\end{array}$ & $\begin{array}{l}\cdots \\
\cdots \\
\cdots \\
\cdots \\
\cdots \\
\cdots\end{array}$ & $\begin{array}{l}1786.75 \\
1786.74 \\
1786.74 \\
1786.73 \\
1786.73 \\
1786.72\end{array}$ & $\begin{array}{r}1786.65 \\
1786.65 \\
1786.65 \\
1786.65 \\
1786.65 \\
-\end{array}$ \\
\hline
\end{tabular}


GROUND-WATER DATA-Continued

DAILY WATER LEVELS-Cont inued

CEDAR POINT WELL Cluster-Continued

STATION MUMBER 351410109170201 (CP-5)-Continued

WATER LeVEL, IN Meters ABOVE MEAN SEA LeVEL, OCtOBER 1989 TO SEPTEMBer 1990 DAILY MEAN VALUES

\begin{tabular}{|c|c|c|c|c|c|c|c|c|c|c|c|c|}
\hline AY & OCT & NOV & DEC & JAN & FEB & MAR & APR & MAY & JUN & JUL & AUG & SEP \\
\hline $\begin{array}{l}1 \\
2 \\
3 \\
4 \\
5\end{array}$ & $\begin{array}{l}786.65 \\
786.65 \\
786.64 \\
786.64 \\
786.64\end{array}$ & $\begin{array}{l}\cdots \\
\cdots \\
\cdots \\
\cdots \\
\cdots\end{array}$ & $\begin{array}{l}1786 . \\
1786 . \\
1786 . \\
1786 . \\
1786 .\end{array}$ & $\begin{array}{l}1786.78 \\
1786.78 \\
1786.78 \\
1786.78 \\
1786.79\end{array}$ & $\begin{array}{l}6.71 \\
6.71 \\
6.71 \\
6.73 \\
6.73\end{array}$ & $\begin{array}{l}\ldots \\
\ldots \\
\cdots \\
\cdots \\
\cdots\end{array}$ & $\begin{array}{c}86.76 \\
86.76 \\
\ldots . . \\
\ldots . \\
\ldots\end{array}$ & $\begin{array}{r}\ldots \\
\ldots \\
\ldots \\
786.71 \\
786.72\end{array}$ & $\begin{array}{l}178 \\
178 \\
178 \\
178 \\
178\end{array}$ & $\begin{array}{l}1786 \\
1786 \\
1786 \\
1786 \\
1786\end{array}$ & $\begin{array}{l}1786.61 \\
1786.60 \\
1786.60 \\
1786.60 \\
1786.60\end{array}$ & $\begin{array}{l}1786.60 \\
1786.60 \\
1786.60 \\
1786.60 \\
1786.60\end{array}$ \\
\hline $\begin{array}{r}6 \\
7 \\
8 \\
9 \\
10\end{array}$ & $\begin{array}{l}1786.63 \\
1786.63 \\
1786.63 \\
1786.63\end{array}$ & $\begin{array}{l}\cdots \\
\cdots \\
\cdots \\
\cdots \\
\cdots\end{array}$ & $\begin{array}{l}178 \\
178 \\
178 \\
17\end{array}$ & $\begin{array}{l}1786.80 \\
1786.80 \\
1786.81 \\
1786.82 \\
1786.83\end{array}$ & $\begin{array}{l}\ldots \\
\ldots \\
\cdots \\
\cdots\end{array}$ & $\begin{array}{l}1786.80 \\
1786.80 \\
1786.81 \\
1786.81\end{array}$ & $\begin{array}{l}\ldots \\
\ldots \\
\ldots \\
\cdots \\
\cdots\end{array}$ & $\begin{array}{l}.73 \\
0.73 \\
.73 \\
.72 \\
0.71\end{array}$ & $\begin{array}{l}1786.63 \\
1786.63 \\
1786.62 \\
1786.62 \\
1786.62\end{array}$ & & $\begin{array}{l}1786.59 \\
1786.58 \\
1786.58 \\
1786.58 \\
1786.58\end{array}$ & $\begin{array}{l}1786.61 \\
1786.62 \\
1786.63 \\
1786.63 \\
1786.63\end{array}$ \\
\hline 11 & $\begin{array}{l}786.63 \\
786.63 \\
786.63 \\
786.63 \\
786.63\end{array}$ & $\begin{array}{l}\ldots \\
\cdots \\
\cdots \\
\cdots \\
\cdots\end{array}$ & $\begin{array}{l}1786.63 \\
1786.63 \\
1786.63 \\
1786.64 \\
1786.65\end{array}$ & $\begin{array}{l}1786.83 \\
1786.83 \\
1786.84 \\
1786.84 \\
1786.84\end{array}$ & $\begin{array}{l}\ldots \\
\ldots \\
\ldots \\
\cdots \\
\cdots\end{array}$ & $\begin{array}{l}1786.81 \\
1786.81 \\
1786.81 \\
1786.81 \\
1786.81\end{array}$ & $\begin{array}{l}\ldots \\
\ldots \\
\ldots \\
\ldots \\
\ldots\end{array}$ & $\begin{array}{l}.71 \\
.71 \\
.71 \\
.70 \\
.70\end{array}$ & $\begin{array}{l}1786.61 \\
1786.61 \\
1786.61 \\
1786.60 \\
1786.60\end{array}$ & $\begin{array}{l}17 \\
17 \\
17 \\
17 \\
17\end{array}$ & $\begin{array}{l}58 \\
58 \\
58 \\
58 \\
58\end{array}$ & $\begin{array}{l}.63 \\
.64 \\
.63 \\
.63 \\
.62\end{array}$ \\
\hline $\begin{array}{l}10 \\
19 \\
20\end{array}$ & $\begin{array}{l}1786.63 \\
1786.63 \\
1786.62 \\
1786.62 \\
1786.62\end{array}$ & $\begin{array}{r}\ldots \\
\ldots \\
1786.62 \\
1786.63 \\
1786.63\end{array}$ & $\begin{array}{l}1786.65 \\
1786.65 \\
1786.65 \\
1786.65 \\
1786.65\end{array}$ & $\begin{array}{l}1786.84 \\
1786.76 \\
1786.68 \\
1786.68 \\
1786.68\end{array}$ & $\begin{array}{l}\cdots \\
\cdots \\
\cdots \\
\cdots \\
\cdots\end{array}$ & $\begin{array}{l}1786.81 \\
1786.82 \\
1786.83 \\
1786.82 \\
1786.83\end{array}$ & $\begin{array}{l}\ldots \\
\ldots \\
\ldots \\
\ldots\end{array}$ & $\begin{array}{l}1786.70 \\
1786.70 \\
1786.69 \\
1786.68 \\
1786.68\end{array}$ & $\begin{array}{l}1786.60 \\
1786.60 \\
1786.60 \\
1786.60 \\
1786.60\end{array}$ & $\begin{array}{l}1786.63 \\
1786.63 \\
1786.63 \\
1786.63 \\
1786.63\end{array}$ & $\begin{array}{l}1786.60 \\
1786.61 \\
1786.62 \\
1786.63 \\
1786.63\end{array}$ & $\begin{array}{l}1786.62 \\
1786.61 \\
1786.61 \\
1786.61 \\
1786.61\end{array}$ \\
\hline $\begin{array}{l}21 \\
22 \\
23 \\
24 \\
25\end{array}$ & $\begin{array}{l}1786.62 \\
1786.62 \\
1786.62 \\
1786.62 \\
1786.63\end{array}$ & $\begin{array}{l}1786.63 \\
1786.63 \\
1786.63 \\
1786.63 \\
1786.63\end{array}$ & $\begin{array}{l}1786.65 \\
1786.65 \\
1786.65 \\
1786.65 \\
1786.66\end{array}$ & $\begin{array}{l}1786.69 \\
1786.70 \\
1786.70 \\
1786.70 \\
1786.70\end{array}$ & $\begin{array}{l}\ldots \\
\cdots \\
\cdots \\
\cdots \\
\cdots\end{array}$ & $\begin{array}{l}17 \\
17 \\
17 \\
17\end{array}$ & $\begin{array}{l}\cdots \\
\ldots \\
\cdots \\
\ldots \\
\cdots\end{array}$ & $\begin{array}{l}.68 \\
.68 \\
.67 \\
.67 \\
.67\end{array}$ & $\begin{array}{l}17 \\
17 \\
17 \\
17 \\
17\end{array}$ & $\begin{array}{l}1786.63 \\
1786.64 \\
1786.64 \\
1786.63 \\
1786.63\end{array}$ & $\begin{array}{l}1786.63 \\
1786.64 \\
1786.65 \\
1786.65 \\
1786.64\end{array}$ & $\begin{array}{l}1786.62 \\
1786.63 \\
1786.64 \\
1786.65 \\
1786.65\end{array}$ \\
\hline $\begin{array}{l}26 \\
27 \\
28 \\
29\end{array}$ & $\begin{array}{c}786.62 \\
\ldots \\
\ldots \\
\ldots \\
\ldots \\
\ldots\end{array}$ & $\begin{array}{l}1786.63 \\
1786.63 \\
1786.63 \\
1786.63 \\
1786 .\end{array}$ & $\begin{array}{l}1786.66 \\
1786.66 \\
1786.66 \\
1786.67 \\
1786.67 \\
1786.67\end{array}$ & $\begin{array}{l}1786.70 \\
1786.70 \\
1786.71 \\
1786.71 \\
1786.71 \\
1786.71\end{array}$ & $\begin{array}{l}\ldots \\
\ldots \\
\ldots \\
\ldots \\
\ldots \\
\cdots\end{array}$ & $\begin{array}{l}1786.80 \\
1786.80 \\
1786.79 \\
1786.78 \\
1786.78 \\
1786.77\end{array}$ & $\begin{array}{l}\ldots \\
\ldots \\
\ldots \\
\ldots \\
\ldots\end{array}$ & $\begin{array}{l}1786.66 \\
1786.66 \\
1786.66 \\
1786.65 \\
1786.65 \\
1786.65\end{array}$ & $\begin{array}{l}58 \\
58 \\
58 \\
57 \\
57 \\
--\end{array}$ & $\begin{array}{l}1786.63 \\
1786.63 \\
1786.63 \\
1786.62 \\
1786.62 \\
1786.61\end{array}$ & $\begin{array}{l}1786.64 \\
1786.63 \\
1786.62 \\
1786.62 \\
1786.61 \\
1786.61\end{array}$ & $\begin{array}{l}1786.66 \\
1786.66 \\
1786.66 \\
1786.66 \\
1786.66\end{array}$ \\
\hline
\end{tabular}


GROUND-HATER DATA-Cont inued

DAILY UATER LEVELS-Cont inued

CEOAR POINT MELL CLUSTER-Continued

STATION MUMBER 351410109170201 (CP-5)-Cont inued

WATER LEVEL, IN METERS ABOVE MEAN SEA LEVEL, OCTOBER 1990 TO JUNE 1991 DAILY MEAN VALUES

\begin{tabular}{|c|c|c|c|c|c|c|c|c|c|c|c|c|}
\hline DAY & OCT & NOV & DEC & JAN & FEB & MAR & APR & MAr & JUN & JUL & NUG & SEP \\
\hline $\begin{array}{l}1 \\
2 \\
3 \\
4 \\
5\end{array}$ & $\begin{array}{l}1786.66 \\
1786.66 \\
1786.66 \\
1786.67 \\
1786.67\end{array}$ & $\begin{array}{r}\ldots \\
1786.70 \\
1786.70\end{array}$ & $\begin{array}{l}1786.71 \\
1786.71 \\
1786.71 \\
1786.71 \\
1786.71\end{array}$ & $\begin{array}{l}1786.76 \\
1786.76 \\
1786.76 \\
1786.76 \\
1786.77\end{array}$ & $\begin{array}{l}1786.86 \\
1786.86 \\
1786.86 \\
1786.86 \\
1786.86\end{array}$ & $\begin{array}{l}1786.89 \\
1786.89 \\
1786.89 \\
1786.90 \\
1786.90\end{array}$ & $\begin{array}{l}1786.91 \\
1786.91 \\
1786.91 \\
1786.91 \\
1786.92\end{array}$ & $\begin{array}{l}\cdots \\
\cdots \\
\cdots \\
\cdots \\
\cdots\end{array}$ & $\begin{array}{l}\ldots \\
\ldots \\
\ldots \\
\ldots \\
\ldots\end{array}$ & $\begin{array}{l}\ldots \\
\ldots \\
\cdots \\
\cdots \\
\cdots\end{array}$ & $\begin{array}{l}\ldots \\
\ldots \\
\ldots \\
\ldots \\
\cdots\end{array}$ & $\begin{array}{l}\ldots \\
\ldots \\
\cdots \\
\cdots \\
\cdots\end{array}$ \\
\hline $\begin{array}{r}6 \\
7 \\
8 \\
9 \\
10\end{array}$ & $\begin{array}{l}1786.67 \\
1786.67 \\
1786.66 \\
1786.65 \\
1786.65\end{array}$ & $\begin{array}{l}1786.70 \\
1786.71 \\
1786.71 \\
1786.71 \\
1786.71\end{array}$ & $\begin{array}{l}1786.72 \\
1786.73 \\
1786.73 \\
1786.73 \\
1786.73\end{array}$ & $\begin{array}{l}1786.77 \\
1786.78 \\
1786.80 \\
1786.80 \\
1786.81\end{array}$ & $\begin{array}{l}1786.86 \\
1786.86 \\
1786.86 \\
1786.87 \\
1786.87\end{array}$ & $\begin{array}{l}1786.90 \\
1786.90 \\
1786.90 \\
1786.90 \\
1786.90\end{array}$ & $\begin{array}{l}1786.92 \\
1786.92 \\
1786.91 \\
1786.90 \\
1786.91\end{array}$ & $\begin{array}{l}\cdots \\
\cdots \\
\cdots \\
\cdots \\
\cdots\end{array}$ & $\begin{array}{l}\ldots \\
\ldots \\
\ldots \\
\ldots \\
\ldots\end{array}$ & $\begin{array}{l}\ldots \\
\ldots \\
\cdots \\
\cdots \\
\cdots\end{array}$ & $\begin{array}{l}\ldots \\
\ldots \\
\ldots \\
\ldots \\
\ldots\end{array}$ & $\begin{array}{l}\cdots \\
\cdots \\
\cdots \\
\cdots \\
\cdots\end{array}$ \\
\hline $\begin{array}{l}11 \\
12 \\
13 \\
14 \\
15\end{array}$ & $\begin{array}{l}1786.65 \\
1786.65 \\
1786.65 \\
1786.64 \\
1786.63\end{array}$ & $\begin{array}{l}1786.71 \\
1786.71 \\
1786.71 \\
1786.71 \\
1786.71\end{array}$ & $\begin{array}{l}1786.73 \\
1786.73 \\
1786.73 \\
1786.73 \\
1786.73\end{array}$ & $\begin{array}{l}1786.81 \\
1786.81 \\
1786.83 \\
1786.83 \\
1786.83\end{array}$ & $\begin{array}{l}1786.87 \\
1786.87 \\
1786.88 \\
1786.89 \\
1786.89\end{array}$ & $\begin{array}{l}1786.90 \\
1786.90 \\
1786.90 \\
1786.90 \\
1786.90\end{array}$ & $\begin{array}{l}\ldots \\
\ldots \\
\ldots \\
\ldots \\
\ldots\end{array}$ & $\begin{array}{l}\cdots \\
\cdots \\
\cdots \\
\cdots \\
\cdots\end{array}$ & $\begin{array}{l}\cdots \\
\ldots \\
\cdots \\
\cdots \\
\cdots\end{array}$ & $\begin{array}{l}\ldots \\
\ldots \\
\ldots \\
\ldots \\
\ldots\end{array}$ & $\begin{array}{l}\ldots \\
\ldots \\
\ldots \\
\ldots \\
\ldots\end{array}$ & $\begin{array}{l}\cdots \\
\cdots \\
\cdots \\
\cdots \\
\cdots\end{array}$ \\
\hline $\begin{array}{l}16 \\
17 \\
18 \\
19 \\
20\end{array}$ & $\begin{array}{r}1786.63 \\
\ldots \\
\ldots \\
\ldots \\
\ldots\end{array}$ & $\begin{array}{l}1786.71 \\
1786.71 \\
1786.71 \\
1786.71 \\
1786.71\end{array}$ & $\begin{array}{l}1786.74 \\
1786.74 \\
1786.75 \\
1786.75 \\
1786.75\end{array}$ & $\begin{array}{l}1786.83 \\
1786.83 \\
1786.84 \\
1786.84 \\
1786.84\end{array}$ & $\begin{array}{l}1786.89 \\
1786.89 \\
1786.89 \\
1786.89 \\
1786.89\end{array}$ & $\begin{array}{l}1786.90 \\
1786.90 \\
1786.90 \\
1786.90 \\
1786.90\end{array}$ & $\begin{array}{l}\ldots \\
\ldots- \\
\ldots \\
\ldots \\
\cdots\end{array}$ & $\begin{array}{l}\cdots \\
\cdots \\
\cdots \\
\cdots \\
\cdots\end{array}$ & $\begin{array}{l}\cdots \\
\cdots \\
\cdots \\
\cdots \\
\cdots\end{array}$ & $\begin{array}{l}\ldots \\
\ldots \\
\ldots \\
\cdots \\
\cdots\end{array}$ & $\begin{array}{l}\cdots \\
\cdots \\
\cdots \\
\cdots \\
\cdots\end{array}$ & $\begin{array}{l}\cdots \\
\cdots \\
\cdots \\
\cdots \\
\cdots\end{array}$ \\
\hline $\begin{array}{l}21 \\
22 \\
23 \\
24 \\
25\end{array}$ & $\begin{array}{l}\ldots \\
\ldots \\
\ldots \\
\ldots \\
\ldots\end{array}$ & $\begin{array}{l}1786.71 \\
1786.71 \\
1786.71 \\
1786.71 \\
1786.71\end{array}$ & $\begin{array}{l}1786.75 \\
1786.76 \\
1786.75 \\
1786.76 \\
1786.76\end{array}$ & $\begin{array}{l}1786.84 \\
1786.84 \\
1786.84 \\
1786.84 \\
1786.84\end{array}$ & $\begin{array}{l}1786.89 \\
1786.89 \\
1786.89 \\
1786.88 \\
1786.87\end{array}$ & $\begin{array}{l}1786.90 \\
1786.90 \\
1786.90 \\
1786.90 \\
1786.90\end{array}$ & $\begin{array}{l}\ldots \\
\ldots \\
\cdots \\
\cdots \\
\cdots\end{array}$ & $\begin{array}{l}\cdots \\
\cdots \\
\cdots \\
\cdots \\
\cdots\end{array}$ & $\begin{array}{l}\cdots \\
\ldots \\
\cdots \\
\cdots \\
\cdots\end{array}$ & $\begin{array}{l}\ldots \\
\ldots \\
\cdots \\
\cdots \\
\cdots\end{array}$ & $\begin{array}{l}\cdots \\
\cdots \\
\cdots \\
\cdots \\
\cdots\end{array}$ & $\begin{array}{l}\cdots \\
\cdots \\
\cdots \\
\cdots \\
\cdots\end{array}$ \\
\hline $\begin{array}{l}26 \\
27 \\
28 \\
29 \\
30 \\
31\end{array}$ & $\begin{array}{l}\cdots \\
\ldots \\
\cdots \\
\ldots \\
\ldots \\
\ldots\end{array}$ & $\begin{array}{r}1786.71 \\
1786.71 \\
1786.71 \\
1786.71 \\
1786.71 \\
\ldots .\end{array}$ & $\begin{array}{l}1786.76 \\
1786.76 \\
1786.76 \\
1786.76 \\
1786.76 \\
1786.76\end{array}$ & $\begin{array}{l}1786.85 \\
1786.86 \\
1786.86 \\
1786.86 \\
1786.85 \\
1786.86\end{array}$ & $\begin{array}{r}1786.87 \\
1786.87 \\
1786.87 \\
\ldots . . \\
\ldots .\end{array}$ & $\begin{array}{l}1786.90 \\
1786.90 \\
1786.90 \\
1786.91 \\
1786.91 \\
1786.91\end{array}$ & $\begin{array}{l}\ldots . \\
\ldots \\
\cdots \\
\cdots \\
\cdots \\
\cdots\end{array}$ & $\begin{array}{l}\cdots \\
\cdots \\
\cdots \\
\ldots \\
\cdots \\
\cdots\end{array}$ & $\begin{array}{l}\ldots \\
\ldots \\
\ldots \\
\ldots \\
\ldots \\
\ldots\end{array}$ & $\begin{array}{l}\ldots \\
\ldots \\
\cdots \\
\ldots \\
\ldots \\
\cdots\end{array}$ & $\begin{array}{l}\cdots \\
\cdots \\
\cdots \\
\cdots \\
\cdots \\
\cdots\end{array}$ & $\begin{array}{l}\cdots \\
\cdots \\
\cdots \\
\cdots\end{array}$ \\
\hline
\end{tabular}




\section{GROUND-WATER DATA-Continued \\ DAILY WATER LEVELS-Continued \\ QUERINO ROAD MELL CLUSTER}

\section{STATION MUMBER-351519109161502}

STATION MAME-OR-2

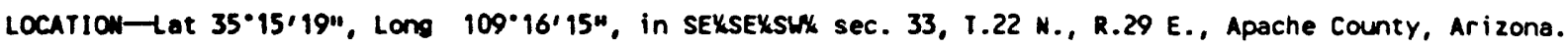
ARIZONA WELL NUMBER-(A-22-29)33COCR.

LAND SURFACE ALTITLE-1796.61 meters above mean sea level.

MATER LEVEL, IN METERS ABOVE MEAN SEA LEVEL, JULY 1989 TO SEPTEMBER 1989 DALLY MEAN VALUES

\begin{tabular}{|c|c|c|c|c|c|c|c|c|c|c|c|c|}
\hline DAY & OCt & NOW & DEC & JAN & FEB & MAR & APR & MAY & JUN & JUL & AUG & SEP \\
\hline $\begin{array}{l}1 \\
2 \\
3 \\
4 \\
5\end{array}$ & $\begin{array}{l}\ldots \\
\ldots \\
\ldots \\
\ldots\end{array}$ & $\begin{array}{l}\ldots \\
\ldots \\
\ldots \\
\ldots \\
\cdots\end{array}$ & $\begin{array}{l}\ldots \\
\ldots \\
\ldots \\
\ldots \\
\ldots\end{array}$ & $\begin{array}{l}\cdots \\
\ldots \\
\ldots \\
\cdots \\
\cdots\end{array}$ & $\begin{array}{l}\ldots \\
\ldots \\
\ldots \\
\ldots \\
\cdots\end{array}$ & $\begin{array}{l}\ldots \\
\ldots \\
\ldots \\
\ldots \\
\ldots\end{array}$ & $\begin{array}{l}\cdots \\
\ldots \\
\cdots \\
\cdots \\
\cdots\end{array}$ & $\begin{array}{l}\ldots \\
\ldots \\
\ldots \\
\ldots \\
\ldots\end{array}$ & $\begin{array}{l}\ldots \\
\ldots \\
\ldots \\
\ldots \\
\ldots\end{array}$ & $\begin{array}{r}\ldots \\
1793.26 \\
1793.25 \\
1793.25 \\
1793.24\end{array}$ & $\begin{array}{l}\ldots \\
\ldots \\
\ldots \\
\ldots \\
\ldots\end{array}$ & $\begin{array}{l}1793.46 \\
1793.45 \\
1793.46 \\
1793.43 \\
1793.43\end{array}$ \\
\hline $\begin{array}{r}6 \\
7 \\
8 \\
9 \\
10\end{array}$ & $\begin{array}{l}\ldots \\
\ldots \\
\ldots \\
\ldots\end{array}$ & $\begin{array}{l}\ldots \\
\ldots \\
\ldots \\
\ldots\end{array}$ & $\begin{array}{l}\ldots \\
\ldots \\
\ldots \\
\ldots \\
\ldots\end{array}$ & $\begin{array}{l}\cdots \\
\cdots \\
\cdots \\
\cdots \\
\cdots\end{array}$ & $\begin{array}{l}\ldots \\
\ldots \\
\ldots \\
\ldots\end{array}$ & $\begin{array}{l}\ldots \\
\ldots \\
\ldots \\
\ldots\end{array}$ & $\begin{array}{l}\ldots \\
\ldots \\
\ldots \\
\cdots\end{array}$ & $\begin{array}{l}\ldots \\
\ldots \\
\ldots \\
\ldots \\
\ldots\end{array}$ & $\begin{array}{l}\ldots \\
\ldots \\
\ldots \\
\ldots \\
\ldots\end{array}$ & $\begin{array}{r}1793.25 \\
1793.24 \\
1793.24 \\
1793.24 \\
\ldots\end{array}$ & $\begin{array}{l}\ldots \\
\ldots \\
\ldots \\
\ldots \\
\ldots\end{array}$ & $\begin{array}{l}1793.51 \\
1793.59 \\
1793.60 \\
1793.59 \\
1793.57\end{array}$ \\
\hline $\begin{array}{l}11 \\
12 \\
13 \\
14 \\
15\end{array}$ & $\begin{array}{l}\ldots \\
\ldots \\
\cdots \\
\cdots \\
\cdots\end{array}$ & $\begin{array}{l}\ldots \\
\ldots \\
\ldots \\
\ldots \\
\ldots\end{array}$ & $\begin{array}{l}\ldots \\
\ldots \\
\ldots \\
\ldots \\
\cdots\end{array}$ & $\begin{array}{l}\ldots \\
\ldots \\
\ldots \\
\cdots \\
\cdots\end{array}$ & $\begin{array}{l}\ldots \\
\ldots \\
\ldots \\
\ldots \\
\ldots\end{array}$ & $\begin{array}{l}\cdots \\
\cdots \\
\cdots \\
\cdots\end{array}$ & $\begin{array}{l}\ldots \\
\ldots \\
\ldots \\
\ldots\end{array}$ & $\begin{array}{l}\ldots \\
\ldots \\
\ldots \\
\ldots \\
\ldots\end{array}$ & $\begin{array}{l}\ldots \\
\ldots \\
\ldots \\
\ldots \\
\cdots\end{array}$ & $\begin{array}{l}\ldots \\
\cdots \\
\cdots \\
\cdots \\
\cdots\end{array}$ & $\begin{array}{l}\ldots \\
\ldots \\
\ldots \\
\ldots \\
\cdots\end{array}$ & $\begin{array}{l}1793.55 \\
1793.52 \\
1793.50 \\
1793.48 \\
1793.46\end{array}$ \\
\hline $\begin{array}{l}16 \\
17 \\
18 \\
19 \\
20\end{array}$ & $\begin{array}{l}\ldots \\
\ldots \\
\ldots \\
\ldots \\
\cdots\end{array}$ & $\begin{array}{l}\ldots \\
\ldots \\
\ldots \\
\ldots \\
\cdots\end{array}$ & $\begin{array}{l}\ldots \\
\ldots \\
\ldots \\
\ldots \\
\ldots\end{array}$ & $\begin{array}{l}\ldots \\
\cdots \\
\cdots \\
\cdots \\
\cdots\end{array}$ & $\begin{array}{l}\ldots \\
\ldots \\
\cdots \\
\cdots \\
\cdots\end{array}$ & $\begin{array}{l}\ldots \\
\ldots \\
\cdots \\
\cdots \\
\cdots\end{array}$ & $\begin{array}{l}\ldots . \\
\ldots \\
\cdots \\
\cdots \\
\cdots\end{array}$ & $\begin{array}{l}\ldots \\
\ldots \\
\ldots \\
\ldots \\
\cdots\end{array}$ & $\begin{array}{l}\ldots \\
\ldots \\
\ldots \\
\ldots \\
\ldots\end{array}$ & $\begin{array}{l}\ldots \\
\cdots \\
\cdots \\
\cdots \\
\cdots\end{array}$ & $\begin{array}{l}\ldots \\
\ldots \\
\cdots \\
\cdots \\
\ldots\end{array}$ & $\begin{array}{l}1793.45 \\
1793.44 \\
1793.43 \\
1793.43 \\
1793.41\end{array}$ \\
\hline $\begin{array}{l}21 \\
22 \\
23 \\
24 \\
25\end{array}$ & $\begin{array}{l}\cdots \\
\cdots \\
\cdots \\
\cdots \\
\cdots\end{array}$ & $\begin{array}{l}\ldots \\
\ldots \\
\ldots \\
\ldots \\
\ldots\end{array}$ & $\begin{array}{l}\cdots \\
\ldots \\
\cdots \\
\ldots \\
\ldots\end{array}$ & $\begin{array}{l}\cdots \\
\ldots \\
\cdots \\
\cdots \\
\cdots\end{array}$ & $\begin{array}{l}\ldots \\
\ldots \\
\cdots \\
\cdots\end{array}$ & $\begin{array}{l}\cdots \\
\cdots \\
\cdots \\
\cdots\end{array}$ & $\begin{array}{l}\ldots \\
\ldots \\
\cdots \\
\cdots \\
\cdots\end{array}$ & $\begin{array}{l}\ldots \\
\ldots \\
\ldots \\
\ldots \\
\cdots\end{array}$ & $\begin{array}{l}\ldots \\
\ldots \\
\ldots \\
\cdots \\
\cdots\end{array}$ & $\begin{array}{l}\cdots \\
\cdots \\
\cdots \\
\cdots \\
\cdots\end{array}$ & $\begin{array}{r}\ldots \\
\ldots \\
1793.65 \\
1793.62 \\
1793.59\end{array}$ & $\begin{array}{l}1793.41 \\
1793.40 \\
1793.39 \\
1793.39 \\
1793.38\end{array}$ \\
\hline $\begin{array}{l}26 \\
27 \\
28 \\
29 \\
30 \\
31\end{array}$ & $\begin{array}{l}\cdots \\
\cdots \\
\cdots \\
\cdots \\
\cdots \\
\cdots\end{array}$ & $\begin{array}{l}\ldots \\
\ldots \\
\ldots \\
\ldots \\
\ldots\end{array}$ & $\begin{array}{l}\ldots \\
\ldots \\
\ldots \\
\ldots \\
\ldots \\
\ldots\end{array}$ & $\begin{array}{l}\ldots \\
\ldots \\
\ldots \\
\ldots \\
\ldots \\
\ldots\end{array}$ & $\begin{array}{l}\ldots \\
\ldots \\
\ldots \\
\ldots \\
\ldots \\
\ldots\end{array}$ & $\begin{array}{l}\cdots \\
\cdots \\
\cdots \\
\cdots \\
\cdots\end{array}$ & $\begin{array}{l}\ldots \\
\ldots \\
\ldots \\
\ldots \\
\ldots \\
\ldots\end{array}$ & $\begin{array}{l}\ldots \\
\ldots \\
\ldots \\
\ldots \\
\ldots \\
\ldots\end{array}$ & $\begin{array}{l}\ldots \\
\ldots \\
\ldots \\
\ldots \\
\ldots \\
\ldots\end{array}$ & $\begin{array}{l}\ldots \\
\ldots \\
\ldots \\
\ldots \\
\ldots \\
\ldots\end{array}$ & $\begin{array}{l}1793.56 \\
1793.54 \\
1793.52 \\
1793.50 \\
1793.49 \\
1793.48\end{array}$ & $\begin{array}{r}1793.38 \\
1793.37 \\
1793.36 \\
1793.36 \\
1793.35 \\
\ldots\end{array}$ \\
\hline
\end{tabular}


GROUMD-WATER DATA-Cont Inued

DAILY MATER LEVELS-Contínued

OUERINO ROAD WELL CLUSTER-CONt inued

STATION MUABER 351519109161502 (OR-2)-Continued

UATER LEVEL, IN METERS ABOVE MEAN SEA LEVEL, OCTOBER 1989 TO SEPTEMBER 1990 DAILY MEAN VALUES

\begin{tabular}{|c|c|c|c|c|c|c|c|c|c|c|c|c|}
\hline ir & OCT & NOV & DEC & JAN & FEB & MuR & APR & MAY & JUK & JUL & AUG & SEP \\
\hline $\begin{array}{l}1 \\
2 \\
3 \\
6 \\
5\end{array}$ & $\begin{array}{l}1793.35 \\
1793.34 \\
1793.34 \\
1793.34 \\
1793.34\end{array}$ & $\begin{array}{l}1793.52 \\
1793.53 \\
1793.53 \\
1793.53 \\
1793.53\end{array}$ & $\begin{array}{l}1793.59 \\
1793.59 \\
1793.59 \\
1793.59 \\
1793.60\end{array}$ & $\begin{array}{l}1793.72 \\
1793.72 \\
1793.72 \\
1793.72 \\
1793.72\end{array}$ & $\begin{array}{l}1793.79 \\
1793.79 \\
1793.78 \\
1793.80 \\
1793.80\end{array}$ & $\begin{array}{l}1793.85 \\
1793.85 \\
1793.86 \\
1793.85 \\
1793.84\end{array}$ & 1793.69 & $\begin{array}{l}1793.54 \\
1793.53 \\
1793.57 \\
1793.62 \\
1793.64\end{array}$ & $\begin{array}{l}1793.37 \\
1793.36 \\
1793.36 \\
1793.35 \\
1793.35\end{array}$ & $\begin{array}{l}175 \\
17 \\
17 \\
175 \\
17\end{array}$ & $\begin{array}{l}\ldots \\
\ldots \\
\cdots \\
\cdots \\
\cdots\end{array}$ & $\begin{array}{l}\cdots \\
\cdots \\
\cdots \\
\cdots \\
\cdots\end{array}$ \\
\hline $\begin{array}{r}6 \\
7 \\
8 \\
9 \\
10\end{array}$ & $\begin{array}{l}1793.38 \\
1793.42 \\
1793.44 \\
1793.44 \\
1793.46\end{array}$ & $\begin{array}{l}1793.54 \\
1793.54 \\
1793.54 \\
1793.54 \\
1793.55\end{array}$ & $\begin{array}{l}1793.62 \\
1793.62 \\
1793.62 \\
1793.64 \\
1793.64\end{array}$ & $\begin{array}{l}1793.71 \\
1793.71 \\
1793.71 \\
1793.70 \\
1793.71\end{array}$ & $\begin{array}{l}179 \\
179 \\
179 \\
179 \\
179\end{array}$ & $\begin{array}{l}\ldots \\
\ldots \\
\cdots \\
\cdots \\
\cdots\end{array}$ & $\begin{array}{l}1793.73 \\
1793.72 \\
1793.74 \\
1793.73 \\
1793.71\end{array}$ & $\begin{array}{l}1793 \\
1793 \\
1793 \\
1793 \\
1793\end{array}$ & $\begin{array}{l}1793.34 \\
1793.34 \\
1793.33 \\
1793.33 \\
1793.33\end{array}$ & $\begin{array}{l}17 \\
17 \\
17 \\
17 \\
17\end{array}$ & $\begin{array}{l}\cdots \\
\cdots \\
\cdots \\
\cdots \\
\cdots\end{array}$ & $\begin{array}{r}\ldots \\
1793.30 \\
1793.31 \\
1793.32\end{array}$ \\
\hline $\begin{array}{l}11 \\
12 \\
13 \\
14 \\
15\end{array}$ & $\begin{array}{l}1793.46 \\
1793.46 \\
1793.46 \\
1793.47 \\
1793.47\end{array}$ & $\begin{array}{r}1793.56 \\
1793.56 \\
1793.56 \\
1793.56 \\
\ldots \ldots\end{array}$ & $\begin{array}{l}1793.64 \\
1793.64 \\
1793.65 \\
1793.65 \\
1793.66\end{array}$ & $\begin{array}{l}1793.72 \\
1793.73 \\
1793.73 \\
1793.74 \\
1793.74\end{array}$ & $\begin{array}{l}179 \\
179 \\
179 \\
179 \\
179\end{array}$ & $\begin{array}{l}\ldots \\
\cdots \\
\cdots \\
\cdots \\
\cdots\end{array}$ & $\begin{array}{l}1793.70 \\
1793.69 \\
1793.65 \\
1793.63 \\
1793.61\end{array}$ & $\begin{array}{l}1793.53 \\
1793.51 \\
1793.50 \\
1793.49 \\
1793.48\end{array}$ & $\begin{array}{l}1793.32 \\
1793.35 \\
1793.37 \\
1793.37 \\
1793.35\end{array}$ & $\begin{array}{l}17 \\
17 \\
17 \\
17 \\
17\end{array}$ & $\begin{array}{l}\cdots \\
\cdots \\
\cdots \\
\cdots \\
\cdots\end{array}$ & $\begin{array}{l}1793.29 \\
1793.25 \\
1793.22 \\
1793.19 \\
1793.16\end{array}$ \\
\hline $\begin{array}{l}16 \\
17 \\
18 \\
19 \\
20\end{array}$ & $\begin{array}{l}1793.46 \\
1793.45 \\
1793.43 \\
1793.44 \\
1793.46\end{array}$ & $\begin{array}{l}1793.56 \\
1793.57 \\
1793.57 \\
1793.57 \\
1793.57\end{array}$ & $\begin{array}{l}1793.66 \\
1793.66 \\
1793.67 \\
1793.66 \\
1793.67\end{array}$ & $\begin{array}{l}.74 \\
.75 \\
.75 \\
.75\end{array}$ & $\begin{array}{l}17 \\
17 \\
17 \\
17 \\
17\end{array}$ & $\begin{array}{l}\ldots \\
\ldots \\
\ldots \\
\cdots \\
\cdots\end{array}$ & $\begin{array}{l}1793.60 \\
1793.58 \\
1793.57 \\
1793.56 \\
1793.54\end{array}$ & $\begin{array}{l}17 \\
17 \\
17 \\
17 \\
17\end{array}$ & $\begin{array}{l}17 \\
17 \\
17 \\
17 \\
17\end{array}$ & $\begin{array}{l}17 \\
17 \\
17 \\
17 \\
17\end{array}$ & $\begin{array}{l}\ldots \\
\ldots \\
\cdots \\
\cdots \\
\cdots\end{array}$ & $\begin{array}{l}1793.14 \\
1793.15 \\
1793.18 \\
1793.21 \\
1793.26\end{array}$ \\
\hline $\begin{array}{l}21 \\
22 \\
23 \\
24 \\
25\end{array}$ & $\begin{array}{l}1793.47 \\
1793.49 \\
1793.49 \\
1793.50 \\
1793.51\end{array}$ & $\begin{array}{l}1793.57 \\
1793.57 \\
1793.59 \\
1793.59 \\
1793.59\end{array}$ & $\begin{array}{l}1793.67 \\
1793.68 \\
1793.69 \\
1793.69 \\
1793.70\end{array}$ & $\begin{array}{l}.75 \\
.76 \\
.77 \\
.77 \\
.77\end{array}$ & $\begin{array}{l}1793.85 \\
1793.85 \\
1793.84 \\
1793.83 \\
1793.83\end{array}$ & $\begin{array}{l}\ldots \\
\ldots \\
\ldots \\
\ldots \\
\cdots\end{array}$ & $\begin{array}{l}.54 \\
.53 \\
.52 \\
.51 \\
.51\end{array}$ & $\begin{array}{l}179 \\
179 \\
179 \\
179 \\
179\end{array}$ & $\begin{array}{l}179 \\
179 \\
179 \\
179 \\
179\end{array}$ & $\begin{array}{l}1793.19 \\
1793.17 \\
1793.14 \\
1793.17 \\
1793.15\end{array}$ & $\begin{array}{l}\cdots \\
\cdots \\
\cdots \\
\cdots \\
\cdots\end{array}$ & $\begin{array}{l}1793.32 \\
1793.32 \\
1793.37 \\
1793.34 \\
1793.29\end{array}$ \\
\hline $\begin{array}{l}26 \\
27 \\
28 \\
29 \\
30 \\
31\end{array}$ & $\begin{array}{r}1793.51 \\
\ldots . . \\
1793.51 \\
1793.51 \\
1793.52 \\
1793.52\end{array}$ & $\begin{array}{c}1793.59 \\
1793.59 \\
1793.58 \\
1793.58 \\
1793.59 \\
\ldots\end{array}$ & $\begin{array}{l}1793.70 \\
1793.70 \\
1793.71 \\
1793.72 \\
1793.72 \\
1793.72\end{array}$ & $\begin{array}{l}1793.77 \\
1793.77 \\
1793.78 \\
1793.78 \\
1793.78 \\
1793.79\end{array}$ & $\begin{array}{r}1793.83 \\
1793.83 \\
1793.83 \\
\ldots \\
\ldots . \\
\ldots\end{array}$ & $\begin{array}{l}\ldots \\
\ldots \\
\ldots \\
\ldots \\
\ldots \\
\ldots\end{array}$ & $\begin{array}{r}1793.51 \\
1793.56 \\
1793.60 \\
1793.59 \\
1793.57 \\
\ldots\end{array}$ & $\begin{array}{l}1793.40 \\
1793.40 \\
1793.39 \\
1793.38 \\
1793.38 \\
1793.38\end{array}$ & $\begin{array}{r}1793.28 \\
1793.28 \\
1793.27 \\
1793.27 \\
1793.27 \\
\ldots\end{array}$ & $\begin{array}{l}\ldots \\
\ldots \\
\ldots \\
\ldots \\
\ldots \\
\ldots\end{array}$ & $\begin{array}{l}\ldots \\
\cdots \\
\cdots \\
\cdots \\
\cdots \\
\cdots\end{array}$ & $\begin{array}{r}1793.25 \\
1793.23 \\
1793.21 \\
1793.20 \\
1793.19 \\
\ldots\end{array}$ \\
\hline
\end{tabular}




\author{
GROND-HATER DATA-Continued \\ DAILY MATER LEVELS-Cont inued \\ QUERINO ROAD WELL CLUSTER-Continued \\ STATION NUMBER 351519109161502 (OR-2)-Continued
}

WATER LeVEL, In Meters ABOVE MEAN SEA LEVEL, OCTOBER 1990 TO JUNE 1991 DAILY MEAN VALUES

\begin{tabular}{|c|c|c|c|c|c|c|c|c|c|c|c|c|}
\hline DAY & OCr & NOV & DEC & JAN & FEB & MAR & APR & MaY & JUN & JUL & AUG & SEP \\
\hline $\begin{array}{l}1 \\
2 \\
3 \\
4 \\
5\end{array}$ & $\begin{array}{l}1793.20 \\
1793.22 \\
1793.24 \\
1793.21 \\
1793.19\end{array}$ & $\begin{array}{l}1793.27 \\
1793.31 \\
1793.35 \\
1793.34 \\
1793.35\end{array}$ & $\begin{array}{l}1793.31 \\
1793.31 \\
1793.31 \\
1793.31 \\
1793.31\end{array}$ & $\begin{array}{l}1793.41 \\
1793.40 \\
1793.40 \\
1793.43 \\
1793.46\end{array}$ & $\begin{array}{l}1793.45 \\
1793.44 \\
1793.43 \\
1793.43 \\
1793.43\end{array}$ & $\begin{array}{l}1793.46 \\
1793.53 \\
1793.56 \\
1793.52 \\
1793.50\end{array}$ & $\begin{array}{l}1793.46 \\
1793.45 \\
1793.46 \\
1793.46 \\
1793.46\end{array}$ & $\begin{array}{l}1793.25 \\
1793.23 \\
1793.20 \\
1793.18 \\
1793.16\end{array}$ & $\begin{array}{r}1792.91 \\
1792.91 \\
1792.91 \\
\ldots \\
\ldots\end{array}$ & $\begin{array}{l}\ldots . \\
\ldots \\
\ldots . \\
\ldots- \\
\ldots\end{array}$ & $\begin{array}{l}\ldots \\
\ldots \\
\ldots \\
\ldots \\
\ldots\end{array}$ & $\begin{array}{l}\ldots \\
\ldots \\
\ldots \\
\ldots \\
\ldots\end{array}$ \\
\hline $\begin{array}{r}6 \\
7 \\
8 \\
9 \\
10\end{array}$ & $\begin{array}{l}1793.17 \\
1793.17 \\
1793.16 \\
1793.14 \\
1793.14\end{array}$ & $\begin{array}{l}1793.34 \\
1793.37 \\
1793.35 \\
1793.34 \\
1793.34\end{array}$ & $\begin{array}{l}1793.31 \\
1793.31 \\
1793.31 \\
1793.31 \\
1793.31\end{array}$ & $\begin{array}{l}1793.53 \\
1793.67 \\
1793.68 \\
1793.66 \\
1793.63\end{array}$ & $\begin{array}{l}1793.43 \\
1793.45 \\
1793.48 \\
1793.51 \\
1793.52\end{array}$ & $\begin{array}{l}1793.56 \\
1793.54 \\
1793.50 \\
1793.47 \\
1793.44\end{array}$ & $\begin{array}{l}1793.44 \\
1793.43 \\
1793.42 \\
1793.41 \\
1793.39\end{array}$ & $\begin{array}{l}1793.15 \\
1793.13 \\
1793.12 \\
1793.10 \\
1793.09\end{array}$ & $\begin{array}{l}\cdots \\
\ldots \\
\ldots \\
\ldots \\
\cdots\end{array}$ & $\begin{array}{l}\ldots . \\
\ldots . \\
\cdots \\
\cdots \\
\cdots\end{array}$ & $\begin{array}{l}\ldots \\
\ldots \\
\ldots \\
\ldots \\
\ldots\end{array}$ & $\begin{array}{l}\ldots \\
\ldots \\
\ldots \\
\ldots \\
\ldots\end{array}$ \\
\hline $\begin{array}{l}11 \\
12 \\
13 \\
14 \\
15\end{array}$ & $\begin{array}{l}1793.13 \\
1793.12 \\
1793.12 \\
1793.11 \\
1793.10\end{array}$ & $\begin{array}{l}1793.33 \\
1793.32 \\
1793.31 \\
1793.30 \\
1793.30\end{array}$ & $\begin{array}{l}1793.31 \\
1793.32 \\
1793.37 \\
1793.37 \\
1793.37\end{array}$ & $\begin{array}{l}1793.59 \\
1793.55 \\
1793.53 \\
1793.51 \\
1793.50\end{array}$ & $\begin{array}{l}1793.53 \\
1793.53 \\
1793.56 \\
1793.60 \\
1793.58\end{array}$ & $\begin{array}{l}1793.42 \\
1793.40 \\
1793.40 \\
1793.41 \\
1793.42\end{array}$ & $\begin{array}{l}1793.37 \\
1793.38 \\
1793.38 \\
1793.37 \\
1793.35\end{array}$ & $\begin{array}{l}1793.07 \\
1793.05 \\
1793.05 \\
1793.03 \\
1793.02\end{array}$ & $\begin{array}{l}\ldots \\
\ldots \\
\cdots \\
\cdots \\
\cdots\end{array}$ & $\begin{array}{l}\ldots \\
\cdots \\
\cdots \\
\cdots \\
\cdots\end{array}$ & $\begin{array}{l}\ldots \\
\ldots \\
\cdots \\
\ldots \\
\cdots\end{array}$ & $\begin{array}{l}\ldots \\
\ldots \\
\cdots \\
\cdots\end{array}$ \\
\hline $\begin{array}{l}16 \\
17 \\
18 \\
19 \\
20\end{array}$ & $\begin{array}{l}1793.10 \\
1793.08 \\
1793.07 \\
1793.08 \\
1793.38\end{array}$ & $\begin{array}{l}1793.29 \\
1793.28 \\
1793.28 \\
1793.28 \\
1793.28\end{array}$ & $\begin{array}{l}1793.42 \\
1793.39 \\
1793.38 \\
1793.37 \\
1793.38\end{array}$ & $\begin{array}{l}1793.49 \\
1793.47 \\
1793.45 \\
1793.45 \\
1793.45\end{array}$ & $\begin{array}{l}1793.54 \\
1793.57 \\
1793.53 \\
1793.47 \\
1793.45\end{array}$ & $\begin{array}{l}1793.42 \\
1793.40 \\
1793.40 \\
1793.41 \\
1793.41\end{array}$ & $\begin{array}{l}1793.33 \\
1793.34 \\
1793.37 \\
1793.39 \\
1793.39\end{array}$ & $\begin{array}{l}1793.01 \\
1793.01 \\
1792.99 \\
1792.99 \\
1792.98\end{array}$ & $\begin{array}{l}\ldots \\
\ldots \\
\cdots \\
\ldots \\
\cdots\end{array}$ & $\begin{array}{l}\ldots . \\
\ldots \\
\cdots \\
\cdots \\
\cdots\end{array}$ & $\begin{array}{l}\ldots \\
\ldots \\
\cdots \\
\ldots \\
\ldots\end{array}$ & . \\
\hline $\begin{array}{l}21 \\
22 \\
23 \\
24 \\
25\end{array}$ & $\begin{array}{l}1793.43 \\
1793.38 \\
1793.36 \\
1793.34 \\
1793.32\end{array}$ & $\begin{array}{l}1793.28 \\
1793.28 \\
1793.28 \\
1793.28 \\
1793.29\end{array}$ & $\begin{array}{l}1793.38 \\
1793.38 \\
1793.38 \\
1793.38 \\
1793.38\end{array}$ & $\begin{array}{l}1793.44 \\
1793.44 \\
1793.44 \\
1793.43 \\
1793.44\end{array}$ & $\begin{array}{l}1793.42 \\
1793.41 \\
1793.40 \\
1793.38 \\
1793.37\end{array}$ & $\begin{array}{l}1793.42 \\
1793.43 \\
1793.43 \\
1793.42 \\
1793.40\end{array}$ & $\begin{array}{l}1793.38 \\
1793.38 \\
1793.37 \\
1793.36 \\
1793.35\end{array}$ & $\begin{array}{l}1792.97 \\
1792.96 \\
1792.96 \\
1792.95 \\
1792.94\end{array}$ & $\begin{array}{l}\ldots \\
\ldots \\
\cdots \\
\cdots \\
\cdots\end{array}$ & $\begin{array}{l}\ldots . \\
\cdots \\
\cdots \\
\cdots \\
\cdots\end{array}$ & $\begin{array}{l}\ldots . \\
\ldots \\
\cdots \\
\ldots \\
\cdots\end{array}$ & $\begin{array}{l}- \\
- \\
- \\
\cdots \\
-.\end{array}$ \\
\hline $\begin{array}{l}26 \\
27 \\
28 \\
29 \\
30 \\
31\end{array}$ & $\begin{array}{l}1793.31 \\
1793.30 \\
1793.28 \\
1793.28 \\
1793.27 \\
1793.27\end{array}$ & $\begin{array}{r}1793.32 \\
1793.32 \\
1793.31 \\
1793.31 \\
1793.31 \\
\ldots\end{array}$ & $\begin{array}{l}1793.39 \\
1793.39 \\
1793.39 \\
1793.42 \\
1793.42 \\
1793.41\end{array}$ & $\begin{array}{l}1793.44 \\
1793.44 \\
1793.45 \\
1793.47 \\
1793.44 \\
1793.45\end{array}$ & $\begin{array}{r}1793.36 \\
1793.35 \\
1793.39 \\
\ldots . \\
\ldots\end{array}$ & $\begin{array}{l}1793.40 \\
1793.42 \\
1793.45 \\
1793.48 \\
1793.49 \\
1793.47\end{array}$ & $\begin{array}{c}1793.35 \\
1793.34 \\
1793.32 \\
1793.31 \\
1793.28 \\
\ldots\end{array}$ & $\begin{array}{l}1792.94 \\
1792.94 \\
1792.92 \\
1792.92 \\
1792.92 \\
1792.91\end{array}$ & $\begin{array}{l}\cdots \\
\ldots \\
\cdots \\
\cdots \\
\cdots \\
\cdots\end{array}$ & $\begin{array}{l}\cdots \\
\cdots \\
\cdots \\
\cdots \\
\cdots \\
--\end{array}$ & $\begin{array}{l}\ldots . \\
\ldots \\
\cdots \\
\ldots \\
\cdots \\
\cdots\end{array}$ & 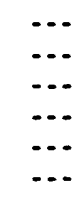 \\
\hline
\end{tabular}


GRound-WATER DATA-Continued

DISCRETE mATER LEVELS

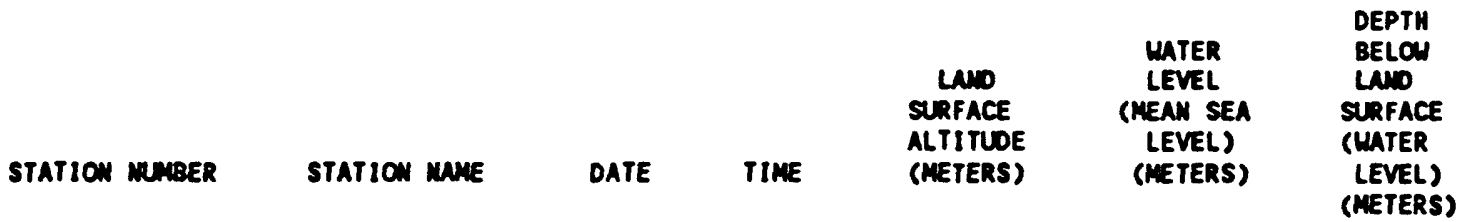

CHAMBERS WELL CLUSTER

\begin{tabular}{|c|c|c|c|c|c|c|}
\hline 351063109270301 & $C W-1$ & $\begin{array}{l}09-30-88 \\
10-28-88 \\
10-29-88 \\
06-07-89 \\
09-01-89 \\
09-11-89 \\
11-02-89 \\
11-16-89 \\
01-11-90 \\
02-07-90 \\
03-07-90 \\
04-04-90 \\
05-02-90 \\
07-27-90 \\
09-06-90 \\
10-30-90 \\
12-05-90 \\
01-16-91 \\
03-04-91 \\
04-11-91 \\
06-05-91\end{array}$ & $\begin{array}{c}\cdots \\
\cdots \\
\cdots \\
\cdots \\
1610 \\
1400 \\
1400 \\
\cdots \\
1015 \\
1225 \\
1545 \\
1010 \\
0935 \\
1400 \\
1130 \\
1530 \\
1005 \\
1615 \\
1225 \\
1715 \\
0900\end{array}$ & 1744.22 & $\begin{array}{l}1739.81 \\
1739.80 \\
1739.80 \\
1739.79 \\
1739.73 \\
1739.75 \\
1739.74 \\
1739.74 \\
1739.77 \\
1739.83 \\
1739.85 \\
1739.84 \\
1739.80 \\
1739.42 \\
1739.31 \\
1739.25 \\
1739.24 \\
1739.33 \\
1739.40 \\
1739.48 \\
1739.32\end{array}$ & $\begin{array}{l}4.41 \\
4.42 \\
4.42 \\
4.43 \\
4.49 \\
4.47 \\
4.48 \\
4.48 \\
4.45 \\
4.39 \\
4.36 \\
4.38 \\
4.42 \\
4.80 \\
4.91 \\
4.97 \\
4.97 \\
4.89 \\
4.82 \\
4.74 \\
4.90\end{array}$ \\
\hline 351043109270302 & $C W-2$ & $\begin{array}{l}07-29-89 \\
09-01-89 \\
09-11-89 \\
11-02-89 \\
11-16-89 \\
12-07-89 \\
01-11-90 \\
02-07-90 \\
03-07-90 \\
04-04-90 \\
05-02-90 \\
05-17-90 \\
07-27-90 \\
09-06-90 \\
10-30-90 \\
12-05-90 \\
01-16-91 \\
03-04-91 \\
04-11-91 \\
06-05-91\end{array}$ & $\begin{array}{c}1400 \\
1600 \\
\cdots \\
1500 \\
0945 \\
1355 \\
1020 \\
1205 \\
1655 \\
1045 \\
1230 \\
1215 \\
1530 \\
1320 \\
1630 \\
1015 \\
1705 \\
1235 \\
1545 \\
0850\end{array}$ & $\begin{array}{l}1743.88 \\
1743.85\end{array}$ & $\begin{array}{l}1740.43 \\
1740.10 \\
1740.13 \\
1740.13 \\
1740.13 \\
1740.16 \\
1740.17 \\
1740.22 \\
1740.25 \\
1740.22 \\
1740.17 \\
1740.12 \\
1739.79 \\
1739.86 \\
1739.65 \\
1739.66 \\
1739.82 \\
1739.93 \\
1739.92 \\
1739.70\end{array}$ & $\begin{array}{l}3.45 \\
3.75 \\
3.72 \\
3.72 \\
3.72 \\
3.69 \\
3.68 \\
3.63 \\
3.60 \\
3.63 \\
3.68 \\
3.73 \\
4.06 \\
3.99 \\
4.20 \\
4.19 \\
4.03 \\
3.92 \\
3.93 \\
4.15\end{array}$ \\
\hline 351043109270303 & CW-3 & $\begin{array}{l}07-02-89 \\
09-01-89 \\
09-11-89 \\
11-11-89 \\
11-15-89 \\
11-16-89 \\
12-07-89 \\
01-11-90 \\
02-07-90 \\
03-07-90 \\
06-04-90 \\
05-02-90 \\
05-17-90 \\
07-27-90\end{array}$ & $\begin{array}{l}1147 \\
1605 \\
\ldots \\
1500 \\
1445 \\
1538 \\
1400 \\
1305 \\
1240 \\
1545 \\
1020 \\
1430 \\
1130 \\
1400\end{array}$ & $\begin{array}{l}1746.35 \\
1746.31 \\
1746.35 \\
1743.87\end{array}$ & $\begin{array}{l}1740.43 \\
1740.06 \\
1740.10 \\
1740.09 \\
1740.10 \\
1740.16 \\
1740.12 \\
1740.14 \\
1740.20 \\
1740.22 \\
1740.19 \\
1740.14 \\
1740.07 \\
1739.78\end{array}$ & $\begin{array}{l}3.92 \\
4.25 \\
4.21 \\
4.22 \\
4.21 \\
4.19 \\
3.75 \\
3.73 \\
3.67 \\
3.65 \\
3.68 \\
3.73 \\
3.80 \\
4.09\end{array}$ \\
\hline
\end{tabular}


GROUND-WATER DATA-Contimued

DISCRETE WATER LEVELS- Cont inued

\begin{tabular}{|c|c|c|c|c|c|c|}
\hline STATION MUMBER & STATION NAME & DATE & TIME & $\begin{array}{l}\text { LAND } \\
\text { SURFACE } \\
\text { ALTITUDE } \\
\text { (METERS) }\end{array}$ & $\begin{array}{c}\text { WMTER } \\
\text { LEVEL } \\
\text { (MEN SEA } \\
\text { LEVEL) } \\
\text { (METERS) }\end{array}$ & $\begin{array}{l}\text { DEPTH } \\
\text { BELOH } \\
\text { LANO } \\
\text { SURFACE } \\
\text { (UATER } \\
\text { LEVEL) } \\
\text { (METERS) }\end{array}$ \\
\hline
\end{tabular}

CHAMBERS WELL CLUSTER-Contimued

\begin{tabular}{|c|c|c|c|c|c|c|}
\hline $\begin{array}{c}351043109270303 \\
\text { (Cont inued) }\end{array}$ & CW-3 & $\begin{array}{l}09-06-90 \\
10-30-90 \\
12-05-90 \\
01-16-91 \\
03-06-91 \\
06-11-91 \\
06-05-91\end{array}$ & $\begin{array}{l}1130 \\
1530 \\
1000 \\
1630 \\
1305 \\
1730 \\
0900\end{array}$ & & $\begin{array}{l}1739.83 \\
1739.64 \\
1739.62 \\
1739.80 \\
1739.90 \\
1739.88 \\
1739.66\end{array}$ & $\begin{array}{l}4.04 \\
4.23 \\
4.25 \\
4.07 \\
3.97 \\
3.99 \\
4.21\end{array}$ \\
\hline 351038109270801 & CW-6 & $\begin{array}{l}09-30-88 \\
10-29-88 \\
12-07-88 \\
06-07-89 \\
09-01-89 \\
09-11-89 \\
11-02-89 \\
11-15-89 \\
12-07-89 \\
01-11-90 \\
02-07-90 \\
03-07-90 \\
04-04-90 \\
05-02-90 \\
07-27-90 \\
09-06-90 \\
10-30-90 \\
10-31-90 \\
12-05-90 \\
01-16-91 \\
03-04-91 \\
04-11-91 \\
06-05-91\end{array}$ & $\begin{array}{c}. . \\
. \\
\cdots \\
\therefore \\
1545 \\
\cdots \\
1500 \\
\cdots \\
1305 \\
1005 \\
1150 \\
1530 \\
0910 \\
1510 \\
1400 \\
1130 \\
1530 \\
. \\
1045 \\
1735 \\
1345 \\
1705 \\
0920\end{array}$ & 1743.09 & $\begin{array}{l}1739.69 \\
1739.65 \\
1739.74 \\
1739.66 \\
1739.59 \\
1739.61 \\
1739.61 \\
1739.59 \\
1739.63 \\
1739.66 \\
1739.69 \\
1739.71 \\
1739.70 \\
1739.66 \\
1738.56 \\
1738.58 \\
1738.61 \\
1738.61 \\
1738.94 \\
1739.02 \\
1739.11 \\
1739.18 \\
1739.16\end{array}$ & $\begin{array}{l}3.40 \\
3.45 \\
3.36 \\
3.44 \\
3.51 \\
3.48 \\
3.48 \\
3.51 \\
3.47 \\
3.43 \\
3.40 \\
3.38 \\
3.39 \\
3.43 \\
4.53 \\
4.52 \\
4.48 \\
4.49 \\
4.16 \\
4.08 \\
3.98 \\
3.92 \\
3.93\end{array}$ \\
\hline 351038109270802 & CW-5 & $\begin{array}{l}09-30-88 \\
10-29-88 \\
12-07-88 \\
06-07-89 \\
09-01-89 \\
09-11-89 \\
11-02-89 \\
11-15-89 \\
12-07-89 \\
01-11-90 \\
02-07-90 \\
03-07-90 \\
04-04-90 \\
05-02-90 \\
07-27-90 \\
09-06-90 \\
10-30-90 \\
10-31-90 \\
12-05-90 \\
01-16-91 \\
03-04-91 \\
04-11-91 \\
06-05-91\end{array}$ & $\begin{array}{l}.- \\
\ldots \\
. \\
. . \\
1550 \\
1400 \\
1500 \\
1245 \\
1330 \\
1000 \\
1145 \\
1530 \\
0915 \\
1500 \\
1400 \\
1130 \\
1530 \\
1350 \\
1050 \\
1740 \\
1345 \\
1710 \\
0925\end{array}$ & 1743.02 & $\begin{array}{l}1739.57 \\
1739.52 \\
1739.64 \\
1739.44 \\
1739.43 \\
1739.47 \\
1739.45 \\
1739.45 \\
1739.48 \\
1739.50 \\
1739.57 \\
1739.59 \\
1739.55 \\
1739.49 \\
-0 \\
1739.15 \\
1738.97 \\
1738.97 \\
1738.96 \\
1739.11 \\
1739.22 \\
1739.23 \\
1738.97\end{array}$ & $\begin{array}{l}3.46 \\
3.51 \\
3.38 \\
3.58 \\
3.59 \\
3.55 \\
3.57 \\
3.57 \\
3.54 \\
3.52 \\
3.46 \\
3.43 \\
3.47 \\
3.53 \\
. . \\
3.88 \\
4.05 \\
4.05 \\
4.06 \\
3.91 \\
3.80 \\
3.79 \\
4.05\end{array}$ \\
\hline
\end{tabular}


CROUND-WATER DATA-Cont inued

DISCRETE WATER LEVELS-Cont inued

\begin{tabular}{|c|c|c|c|c|c|c|}
\hline TATION MUABER & STATION NAME & DATE & TIME & $\begin{array}{l}\text { LAND } \\
\text { SURFACE } \\
\text { ALTITUDE } \\
\text { (METERS) }\end{array}$ & $\begin{array}{l}\text { WATER } \\
\text { LEVEL } \\
\text { (MEAN SEA } \\
\text { LEVEL) } \\
\text { (METERS) }\end{array}$ & $\begin{array}{l}\text { BELOU } \\
\text { LAND } \\
\text { SURFACE } \\
\text { (WATER } \\
\text { LEVEL) } \\
\text { (METERS }\end{array}$ \\
\hline
\end{tabular}

CHAMBERS WELL CLUSTER-continued

\begin{tabular}{|c|c|c|c|c|c|c|}
\hline 351038109270803 & CW-6 & $\begin{array}{l}07-02-89 \\
07-27-89 \\
09-01-89 \\
09-11-89 \\
11-02-89 \\
11-16-89 \\
12-07-89 \\
01-11-90 \\
02-07-90 \\
03-07-90 \\
04-04-90 \\
05-02-90 \\
05-17-90 \\
07-27-90 \\
09-06-90 \\
10-30-90 \\
12-05-90 \\
01-16-91 \\
03-04-91 \\
04-11-91 \\
06-05-91\end{array}$ & $\begin{array}{c}\cdots \\
1056 \\
1555 \\
\cdots \\
1500 \\
1144 \\
1315 \\
0955 \\
1120 \\
1530 \\
0925 \\
1505 \\
1315 \\
1600 \\
1130 \\
1530 \\
1115 \\
1745 \\
1350 \\
1815 \\
0935\end{array}$ & 1743.14 & $\begin{array}{c}1739.32 \\
1739.31 \\
1739.39 \\
1739.43 \\
1739.40 \\
1739.41 \\
1739.43 \\
1739.45 \\
1739.51 \\
1739.55 \\
1739.51 \\
1739.44 \\
-. \\
1739.11 \\
1739.10 \\
1738.92 \\
1738.98 \\
1739.06 \\
1739.17 \\
1739.18 \\
1738.92\end{array}$ & $\begin{array}{l}3.82 \\
3.83 \\
3.75 \\
3.72 \\
3.75 \\
3.73 \\
3.72 \\
3.69 \\
3.63 \\
3.60 \\
3.63 \\
3.70 \\
. . \\
4.03 \\
4.04 \\
4.22 \\
4.17 \\
4.08 \\
3.97 \\
3.97 \\
4.22\end{array}$ \\
\hline 351039109270001 & $\mathrm{CW}-7$ & $\begin{array}{l}09-30-88 \\
10-28-88 \\
10-29-88 \\
06-07-89 \\
09-01-89 \\
09-11-89 \\
11-02-89 \\
11-14-89 \\
12-07-89 \\
01-11-90 \\
02-07-90 \\
03-07-90 \\
04-04-90 \\
05-02-90 \\
07-27-90 \\
09-06-90 \\
10-30-90 \\
11-01-90 \\
12-05-90 \\
01-16-91 \\
03-04-91 \\
04-11-91 \\
06-05-91\end{array}$ & $\begin{array}{c}\cdots \\
\ldots \\
\cdots \\
\cdots \\
1515 \\
\cdots \\
1500 \\
1710 \\
1140 \\
0930 \\
1020 \\
1515 \\
0810 \\
1600 \\
1400 \\
1130 \\
1530 \\
1150 \\
1150 \\
1610 \\
1330 \\
1700 \\
0940\end{array}$ & 1748.75 & $\begin{array}{l}1739.83 \\
1739.80 \\
1739.83 \\
1739.74 \\
1739.70 \\
1739.75 \\
1739.74 \\
1739.76 \\
1739.76 \\
1739.78 \\
1739.83 \\
1739.87 \\
1739.84 \\
1739.77 \\
1739.43 \\
1739.44 \\
1737.27 \\
1739.27 \\
1739.57 \\
1739.61 \\
1739.52 \\
1739.52 \\
1739.28\end{array}$ & $\begin{array}{l}8.91 \\
8.95 \\
8.95 \\
9.00 \\
9.04 \\
9.00 \\
9.01 \\
8.99 \\
8.99 \\
8.96 \\
8.91 \\
8.88 \\
8.90 \\
8.98 \\
9.32 \\
9.31 \\
9.48 \\
9.48 \\
9.18 \\
9.33 \\
9.23 \\
9.32 \\
9.46\end{array}$ \\
\hline 351039109270002 & $C H-8$ & $\begin{array}{l}09-30-88 \\
10-28-88 \\
10-29-88 \\
06-07-89 \\
09-01-89 \\
09-11-89 \\
11-02-89 \\
11-14-89 \\
12-07-89 \\
01-11-90 \\
02-07-90 \\
03-07-90\end{array}$ & $\begin{array}{c}. . \\
. . \\
\therefore \\
\therefore \\
1520 \\
-. \\
1500 \\
1600 \\
1150 \\
0925 \\
1015 \\
1515\end{array}$ & 1748.88 & $\begin{array}{l}1739.84 \\
1739.83 \\
1739.79 \\
1739.75 \\
1739.72 \\
1739.76 \\
1739.74 \\
1739.76 \\
1740.07 \\
1739.78 \\
1738.62 \\
1739.87\end{array}$ & $\begin{array}{r}9.04 \\
9.05 \\
9.09 \\
9.13 \\
9.16 \\
9.12 \\
9.16 \\
9.11 \\
8.81 \\
9.10 \\
10.26 \\
9.01\end{array}$ \\
\hline
\end{tabular}


GROUND-WATER DATA-Continued

DISCRETE WATER LEVELS-Continued

\begin{tabular}{|c|c|c|c|c|c|c|}
\hline STATION MABER & STATION MAME & DATE & TIME & $\begin{array}{c}\text { LAND } \\
\text { SIRFACE } \\
\text { ALTITUDE } \\
\text { (METERS) }\end{array}$ & $\begin{array}{c}\text { WATER } \\
\text { LEVEL } \\
\text { (MEAN SEA } \\
\text { LEVEL) } \\
\text { (METERS) }\end{array}$ & $\begin{array}{l}\text { DEPTH } \\
\text { BELOW } \\
\text { LAMO } \\
\text { SURFACE } \\
\text { (WATER } \\
\text { LEVEL) } \\
\text { (METERS) }\end{array}$ \\
\hline & \multicolumn{6}{|c|}{ CHAMBERS WELL CLUSTER-Cont inued } \\
\hline $\begin{array}{l}351039109270002 \\
\text { (Cont inved) }\end{array}$ & $\mathrm{CH}-8$ & $\begin{array}{l}04-04-90 \\
05-02-90 \\
07-27-90 \\
09-06-90 \\
10-18-90 \\
11-01-90 \\
12-05-90 \\
01-16-91 \\
03-04-91 \\
04-11-91 \\
06-05-91\end{array}$ & $\begin{array}{l}0820 \\
1615 \\
1400 \\
1130 \\
1600 \\
1800 \\
1210 \\
1605 \\
1335 \\
1655 \\
0945\end{array}$ & & $\begin{array}{l}1739.83 \\
1739.78 \\
1739.44 \\
1739.44 \\
1739.76 \\
1739.44 \\
1739.88 \\
1739.41 \\
1739.52 \\
1739.53 \\
1739.29\end{array}$ & $\begin{array}{l}9.04 \\
9.10 \\
9.44 \\
9.44 \\
9.11 \\
9.60 \\
9.00 \\
9.47 \\
9.36 \\
9.35 \\
9.59\end{array}$ \\
\hline 351039109270003 & CW-9 & $\begin{array}{l}07-27-89 \\
09-01-89 \\
09-11-89 \\
11-02-89 \\
11-15-89 \\
11-16-89 \\
12-07-89 \\
01-11-90 \\
02-07-90 \\
02-09-90 \\
03-07-90 \\
04-04-90 \\
05-02-90 \\
05-17-90 \\
07-27-90 \\
09-06-90 \\
10-18-90 \\
11-01-90 \\
12-05-90 \\
01-16-91 \\
03-04-91 \\
04-11-91 \\
06-05-91\end{array}$ & $\begin{array}{l}1250 \\
1530 \\
\cdots \\
1500 \\
0940 \\
1330 \\
1130 \\
1040 \\
1100 \\
1300 \\
1615 \\
0830 \\
1800 \\
1615 \\
1430 \\
1445 \\
1445 \\
1800 \\
1215 \\
1600 \\
1340 \\
1650 \\
0950\end{array}$ & 1748.81 & $\begin{array}{c}1739.62 \\
1739.69 \\
1739.72 \\
1739.71 \\
\ldots \\
\ldots \\
1739.73 \\
1739.76 \\
\ldots \\
\cdots \\
\ldots \\
\ldots \\
\cdots \\
\cdots \\
\cdots \\
\cdots \\
1739.24 \\
1739.24 \\
1739.24 \\
1739.38 \\
1739.49 \\
1739.80 \\
1739.26\end{array}$ & $\begin{array}{c}9.19 \\
9.12 \\
9.09 \\
9.10 \\
\ldots \\
\ldots . \\
9.07 \\
9.04 \\
. . \\
\ldots \\
. . \\
. . \\
. . \\
. . \\
. . \\
. . \\
9.57 \\
9.57 \\
9.57 \\
9.43 \\
9.32 \\
9.01 \\
9.55\end{array}$ \\
\hline
\end{tabular}

ADOT WELL CLUSTER

\begin{tabular}{|c|c|c|c|c|c|c|}
\hline 351140109220901 & $10-1$ & $\begin{array}{l}06-29-89 \\
09-01-89 \\
09-11-89 \\
11-02-89 \\
11-14-89 \\
12-07-89 \\
01-10-90 \\
02-06-90 \\
03-08-90 \\
04-03-90 \\
05-01-90 \\
07-27-90 \\
09-05-90 \\
10-13-90 \\
11-03-90 \\
12-04-90 \\
01-17-91 \\
03-04-91 \\
04-11-91 \\
06-04-91\end{array}$ & $\begin{array}{c}\cdots \\
1340 \\
1330 \\
1400 \\
\cdots \\
1600 \\
1635 \\
1755 \\
0915 \\
1805 \\
1630 \\
1030 \\
1500 \\
\cdots \\
1430 \\
1315 \\
1425 \\
1815 \\
1420 \\
1550\end{array}$ & 1766.23 & $\begin{array}{l}1761.01 \\
1761.35 \\
1761.36 \\
1761.06 \\
1761.03 \\
1760.93 \\
1760.81 \\
1760.84 \\
1760.81 \\
1760.87 \\
1760.77 \\
1760.67 \\
1760.79 \\
1760.87 \\
1760.89 \\
1761.10 \\
1760.87 \\
1761.15 \\
1761.46 \\
1761.00\end{array}$ & $\begin{array}{l}5.22 \\
4.88 \\
4.88 \\
5.18 \\
5.20 \\
5.30 \\
5.43 \\
5.39 \\
5.33 \\
5.36 \\
5.46 \\
5.56 \\
5.44 \\
5.36 \\
5.34 \\
5.44 \\
5.36 \\
5.08 \\
4.77 \\
5.23\end{array}$ \\
\hline
\end{tabular}


DISCRETE HATER LEVELS-Continued

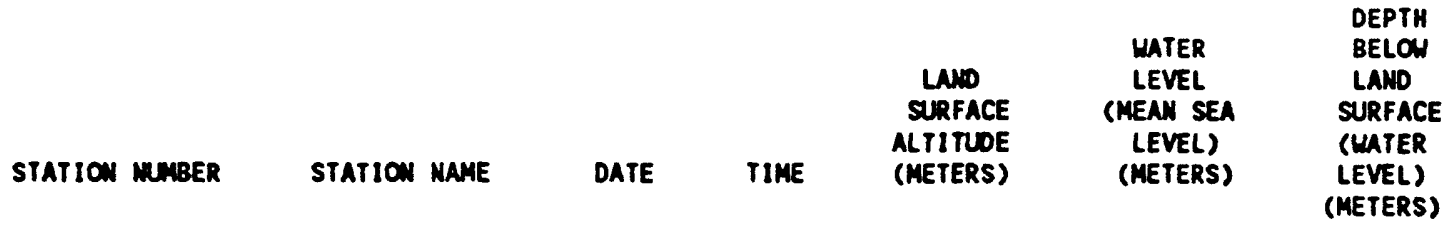

ADOT WELL CLUSTER-Contimued

\begin{tabular}{|c|c|c|c|c|c|c|}
\hline 351140109220403 & $\mathbf{A D}-\mathbf{3}$ & $\begin{array}{l}06-29-89 \\
07-13-89 \\
07-27-89 \\
09-01-89 \\
09-11-89 \\
09-22-89 \\
11-02-89 \\
11-17-89 \\
12-07-89 \\
01-10-90 \\
02-07-90 \\
03-08-90 \\
04-03-90 \\
05-01-90 \\
06-08-90 \\
07-27-90 \\
09-05-90 \\
10-19-90 \\
11-03-90 \\
12-04-90 \\
01-17-91 \\
03-04-91 \\
04-11-91 \\
06-04-91\end{array}$ & $\begin{array}{l}\cdots \\
1130 \\
1324 \\
1350 \\
1300 \\
1020 \\
1400 \\
1545 \\
1600 \\
1640 \\
0750 \\
1115 \\
1800 \\
1550 \\
0940 \\
1130 \\
1530 \\
0930 \\
1530 \\
1350 \\
1500 \\
1820 \\
1435 \\
1600\end{array}$ & 1766.15 & $\begin{array}{l}1761.37 \\
1760.60 \\
1761.23 \\
1761.47 \\
1761.49 \\
1761.36 \\
1761.14 \\
1761.10 \\
1760.97 \\
1760.85 \\
1760.91 \\
1761.00 \\
1760.97 \\
1760.84 \\
1760.70 \\
1761.11 \\
1760.93 \\
1760.97 \\
1761.02 \\
1760.94 \\
1761.06 \\
1761.41 \\
1761.73 \\
1761.12\end{array}$ & $\begin{array}{l}4.78 \\
5.55 \\
4.92 \\
4.68 \\
4.66 \\
4.79 \\
5.01 \\
5.05 \\
5.18 \\
5.18 \\
5.24 \\
5.15 \\
5.18 \\
5.31 \\
5.44 \\
5.04 \\
5.22 \\
5.18 \\
5.13 \\
5.21 \\
5.09 \\
4.74 \\
4.41 \\
5.03\end{array}$ \\
\hline 351144109220701 & AD-4 & $\begin{array}{l}06-29-89 \\
09-01-89 \\
09-11-89 \\
09-22-89 \\
11-02-89 \\
12-07-89 \\
01-10-90 \\
02-06-90 \\
03-08-90 \\
04-03-90 \\
05-01-90 \\
07-27-90 \\
09-05-90 \\
10-13-90 \\
11-03-90 \\
12-04-90 \\
01-17-91 \\
03-04-91 \\
04-11-91 \\
06-04-91\end{array}$ & 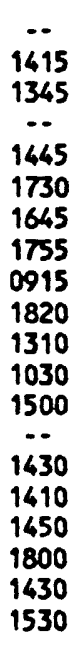 & 1765.51 & $\begin{array}{l}1760.98 \\
1761.32 \\
1761.33 \\
1761.27 \\
1761.07 \\
1760.90 \\
1760.79 \\
1760.80 \\
1760.85 \\
1760.84 \\
1760.74 \\
1760.63 \\
1760.76 \\
1760.83 \\
1760.85 \\
1760.78 \\
1760.83 \\
1761.11 \\
1761.40 \\
1761.01\end{array}$ & $\begin{array}{l}4.53 \\
4.19 \\
4.18 \\
4.24 \\
4.44 \\
4.61 \\
4.73 \\
4.72 \\
4.66 \\
4.67 \\
4.77 \\
4.88 \\
4.75 \\
4.68 \\
4.67 \\
4.74 \\
4.69 \\
4.40 \\
4.11 \\
4.51\end{array}$ \\
\hline 351139109221301 & ND-5 & $\begin{array}{l}07-13-89 \\
07-26-89 \\
09-01-89 \\
09-11-89 \\
11-02-89 \\
11-13-89 \\
11-14-89 \\
11-15-89 \\
12-07-89 \\
01-10-90\end{array}$ & $\begin{array}{c}1600 \\
1145 \\
1350 \\
\ldots \\
1400 \\
1800 \\
0900 \\
1615 \\
1655 \\
1615\end{array}$ & $\begin{array}{l}1766.04 \\
1765.72 \\
1766.04\end{array}$ & $\begin{array}{l}1761.04 \\
1760.96 \\
1761.05 \\
1761.21 \\
1760.87 \\
1760.86 \\
1760.86 \\
1760.80 \\
1760.70 \\
1760.59\end{array}$ & $\begin{array}{l}5.00 \\
5.08 \\
4.67 \\
4.51 \\
4.85 \\
5.18 \\
5.18 \\
5.24 \\
5.03 \\
5.13\end{array}$ \\
\hline
\end{tabular}


GROAND-WATER DATA-Continued

DISCRETE MATER LEVELS-continued

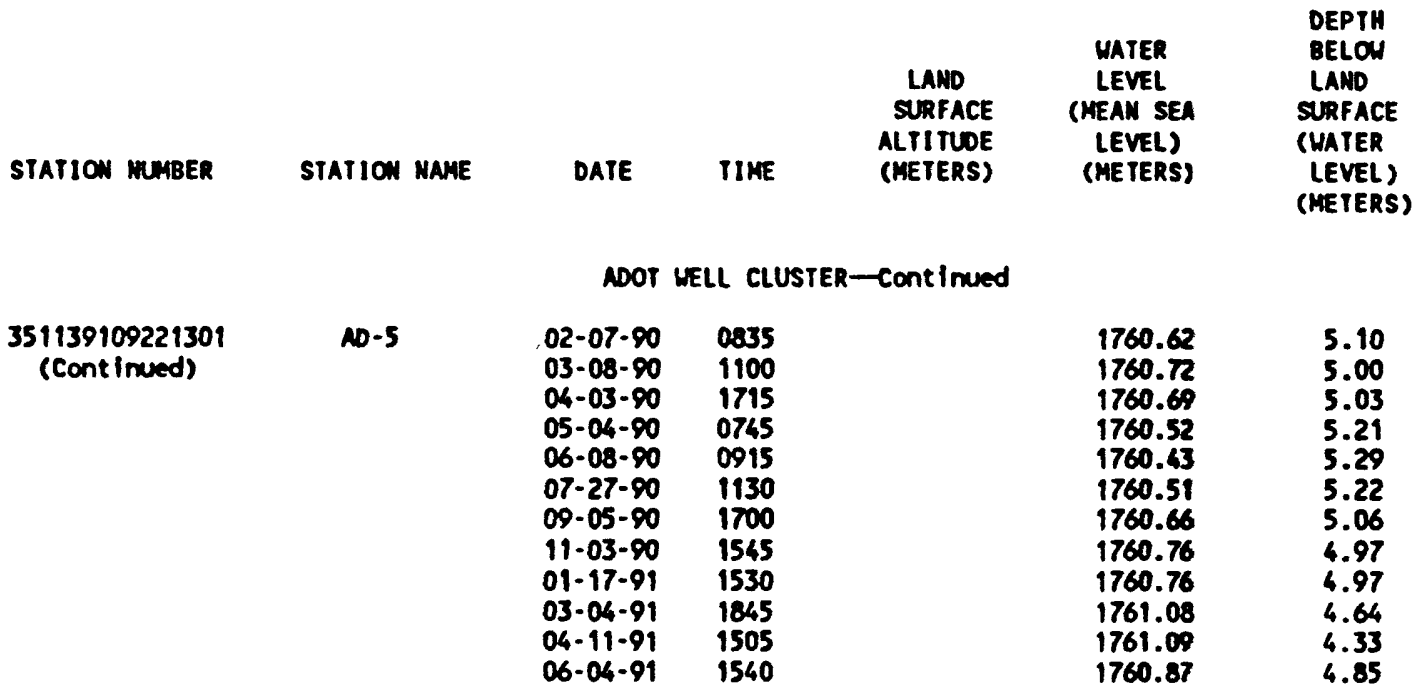

CEDAR SURFACE WELL CLUSTER

\begin{tabular}{|c|c|c|c|c|c|c|}
\hline 351411109170701 & $C P-1$ & $\begin{array}{l}06-28-89 \\
09-01-89 \\
09-11-89 \\
09-21-89 \\
11-02-89 \\
12-08-89 \\
01-10-90 \\
02-06-90 \\
03-06-90 \\
04-03-90 \\
05-03-90 \\
07-26-90 \\
09-06-90 \\
10-12-90 \\
11-03-90 \\
12-05-90 \\
01-17-91 \\
03-04-91 \\
04-11-91 \\
06-04-91\end{array}$ & $\begin{array}{c}-. \\
1235 \\
-- \\
-- \\
1300 \\
1135 \\
1335 \\
1540 \\
1330 \\
1505 \\
0840 \\
1400 \\
1600 \\
\cdots- \\
1200 \\
1335 \\
1115 \\
1525 \\
1155 \\
1330\end{array}$ & 1792.75 & $\begin{array}{l}1786.50 \\
1786.73 \\
1786.76 \\
1786.66 \\
1786.65 \\
1786.75 \\
1786.81 \\
1786.97 \\
1787.09 \\
1786.86 \\
1786.76 \\
1786.66 \\
1786.09 \\
1786.69 \\
1786.93 \\
1786.91 \\
1787.06 \\
1787.13 \\
1786.96 \\
1786.60\end{array}$ & $\begin{array}{l}6.17 \\
6.03 \\
5.99 \\
6.08 \\
6.10 \\
6.00 \\
5.93 \\
5.78 \\
5.65 \\
5.89 \\
5.98 \\
6.09 \\
5.94 \\
6.05 \\
5.82 \\
5.84 \\
5.68 \\
5.61 \\
5.79 \\
6.15\end{array}$ \\
\hline 351411109170702 & CP-2 & $\begin{array}{l}06-28-89 \\
09-01-89 \\
09-11-89 \\
09-21-89 \\
11-02-89 \\
12-08-89 \\
01-10-90 \\
02-06-90 \\
03-06-90 \\
04-03-90 \\
05-03-90 \\
07-26-90 \\
09-06-90 \\
10-12-90 \\
11-03-90 \\
12-05-90 \\
01-17-91 \\
03-04-91 \\
04-11-91 \\
06-04-91\end{array}$ & $\begin{array}{c}\ldots \\
1240 \\
\cdots \\
\cdots \\
1300 \\
1130 \\
1330 \\
1545 \\
1330 \\
1510 \\
0840 \\
1400 \\
1600 \\
\cdots \\
1200 \\
1345 \\
1120 \\
1530 \\
1200 \\
1335\end{array}$ & 1792.80 & $\begin{array}{l}1786.74 \\
1786.87 \\
1786.87 \\
1786.81 \\
1786.75 \\
1786.81 \\
1786.86 \\
1786.97 \\
1787.07 \\
1786.93 \\
1786.85 \\
1786.82 \\
1786.87 \\
1786.82 \\
1787.03 \\
1787.00 \\
1786.88 \\
1787.25 \\
1787.16 \\
1786.13\end{array}$ & $\begin{array}{l}6.06 \\
5.93 \\
5.92 \\
5.99 \\
6.06 \\
5.99 \\
5.94 \\
5.83 \\
5.73 \\
5.87 \\
5.95 \\
5.98 \\
5.93 \\
5.98 \\
5.77 \\
5.80 \\
5.92 \\
5.55 \\
5.65 \\
6.07\end{array}$ \\
\hline
\end{tabular}


GROUND-WATER DATA-COnt InUEd

DISCRETE WATER LEVELS-Cont Inued

\begin{tabular}{|c|c|c|c|c|c|c|}
\hline STATION MUABER & STATION NAME & DATE & TIME & $\begin{array}{c}\text { LAND } \\
\text { SURFACE } \\
\text { ALTITUDE } \\
\text { (METERS) }\end{array}$ & $\begin{array}{c}\text { WATER } \\
\text { LEVEL } \\
\text { (MEAN SEA } \\
\text { LEVEL) } \\
\text { (METERS) }\end{array}$ & $\begin{array}{l}\text { OEPTH } \\
\text { BELON } \\
\text { LAND } \\
\text { SURFACE } \\
\text { (WATER } \\
\text { LEVEL) } \\
\text { (METERS) }\end{array}$ \\
\hline
\end{tabular}

\begin{tabular}{|c|c|c|c|c|c|c|}
\hline 351411109170703 & $C P-3$ & $\begin{array}{l}07-03-89 \\
07-30-89 \\
09-01-89 \\
09-11-89 \\
09-21-89 \\
11-02-89 \\
11-15-89 \\
12-08-89 \\
01-10-90 \\
02-06-90 \\
03-06-90 \\
04-03-90 \\
05-03-90 \\
05-16-90 \\
07-26-90 \\
09-06-90 \\
11-03-90 \\
12-05-90 \\
01-17-91 \\
03-04-91 \\
04-11-91\end{array}$ & $\begin{array}{c}1100 \\
1448 \\
1245 \\
\cdots \\
1615 \\
1300 \\
1400 \\
1120 \\
1330 \\
1550 \\
1430 \\
1520 \\
1125 \\
1530 \\
1600 \\
1700 \\
1300 \\
1330 \\
1235 \\
1535 \\
1220\end{array}$ & $\begin{array}{l}1792.72 \\
1792.43\end{array}$ & $\begin{array}{l}1786.73 \\
1786.94 \\
1786.87 \\
1786.88 \\
1786.81 \\
1786.75 \\
1786.79 \\
1786.80 \\
1786.87 \\
1786.97 \\
1787.06 \\
1786.94 \\
1786.86 \\
1786.83 \\
1786.84 \\
1786.85 \\
1787.01 \\
1787.00 \\
1787.19 \\
1787.25\end{array}$ & $\begin{array}{l}5.99 \\
5.78 \\
5.85 \\
5.84 \\
5.91 \\
5.97 \\
5.93 \\
5.62 \\
5.56 \\
5.45 \\
5.36 \\
5.48 \\
5.57 \\
5.60 \\
5.59 \\
5.57 \\
5.41 \\
5.43 \\
5.24 \\
5.17\end{array}$ \\
\hline 351615109170201 & CP-4 & $\begin{array}{l}07-03-89 \\
07-30-89 \\
09-01-89 \\
09-11-89 \\
09-21-89 \\
11-02-89 \\
11-17-89 \\
12-08-89 \\
01-10-90 \\
02-06-90 \\
03-10-90 \\
04-03-90 \\
05-03-90 \\
06-07-90 \\
07-26-90 \\
09-06-90 \\
10-17-90 \\
11-03-90 \\
12-05-90 \\
01-17-91 \\
03-04-91 \\
04-11-91 \\
06-04-91\end{array}$ & $\begin{array}{c}1230 \\
1642 \\
1255 \\
\cdots \\
1020 \\
1300 \\
0949 \\
1030 \\
1300 \\
1640 \\
1430 \\
1555 \\
1500 \\
1845 \\
1600 \\
1715 \\
0830 \\
1315 \\
1405 \\
1305 \\
1600 \\
1245 \\
1350\end{array}$ & $\begin{array}{l}1792.67 \\
1792.30\end{array}$ & $\begin{array}{r}1786.94 \\
1787.07 \\
1787.05 \\
1787.04 \\
1786.98 \\
1786.91 \\
1786.93 \\
1786.93 \\
1786.99 \\
1787.05 \\
1787.13 \\
1787.07 \\
1787.01 \\
1786.91 \\
1787.05 \\
1786.99 \\
\cdots .9 \\
1787.10 \\
1787.10 \\
1878.30 \\
1787.37 \\
1787.28 \\
1786.94\end{array}$ & $\begin{array}{l}5.73 \\
5.60 \\
5.62 \\
5.63 \\
5.69 \\
5.76 \\
5.74 \\
5.37 \\
5.32 \\
5.25 \\
5.17 \\
5.23 \\
5.29 \\
5.39 \\
5.25 \\
5.31 \\
5.10 \\
5.20 \\
5.20 \\
5.00 \\
4.94 \\
5.02 \\
5.36\end{array}$ \\
\hline 351610109170201 & CP-5 & $\begin{array}{l}07-03-89 \\
07-30-89 \\
09-01-89 \\
09-11-89 \\
09-20-89 \\
11-02-89 \\
11-17-89 \\
12-08-89 \\
01-10-90 \\
02-06-90\end{array}$ & $\begin{array}{l}1420 \\
1300 \\
1305 \\
190 \\
1630 \\
1300 \\
1122 \\
1100 \\
1150 \\
1500\end{array}$ & $\begin{array}{l}1792.25 \\
1791.88\end{array}$ & $\begin{array}{l}1786.68 \\
1786.71 \\
1786.73 \\
1786.71 \\
1786.77 \\
1786.63 \\
1786.65 \\
1786.64 \\
1786.68 \\
1786.74\end{array}$ & $\begin{array}{l}5.58 \\
5.55 \\
5.53 \\
5.54 \\
5.49 \\
5.62 \\
5.61 \\
5.24 \\
5.20 \\
5.14\end{array}$ \\
\hline
\end{tabular}


OISCRETE WATER LEVELS-cont inued

\begin{tabular}{|c|c|c|c|c|c|c|}
\hline STATION MUAER & STATION NAME & DATE & TIME & $\begin{array}{c}\text { LAND } \\
\text { SURFACE } \\
\text { ALTITLDE } \\
\text { (METERS) }\end{array}$ & $\begin{array}{c}\text { WATER } \\
\text { LEVEL } \\
\text { (MEAN SEA } \\
\text { LEVEL) } \\
\text { (METERS) }\end{array}$ & $\begin{array}{l}\text { DEPTH } \\
\text { BELOH } \\
\text { LAND } \\
\text { SURFACE } \\
\text { (UATER } \\
\text { LEVEL) } \\
\text { (METERS) }\end{array}$ \\
\hline $\begin{array}{l}351610109170201 \\
\text { (Cont Inved) }\end{array}$ & $C P-5$ & $\begin{array}{l}03-06-90 \\
04-03-90 \\
05-03-90 \\
05-07-90 \\
06-07-90 \\
07-26-90 \\
09-06-90 \\
10-17-90 \\
11-03-90 \\
12-05-90 \\
01-17-91 \\
03-04-91 \\
04-11-91 \\
06-04-91\end{array}$ & $\begin{array}{l}1330 \\
1430 \\
1700 \\
1610 \\
1900 \\
1630 \\
1730 \\
1143 \\
1330 \\
1415 \\
1205 \\
1625 \\
1305 \\
1415\end{array}$ & & $\begin{array}{l}1786.81 \\
1786.77 \\
1786.71 \\
1786.71 \\
1786.62 \\
1786.64 \\
1786.61 \\
1786.64 \\
1786.70 \\
1786.73 \\
1786.84 \\
1786.91 \\
1786.92 \\
1786.67\end{array}$ & $\begin{array}{l}5.07 \\
5.11 \\
5.17 \\
5.17 \\
5.26 \\
5.24 \\
5.27 \\
5.24 \\
5.18 \\
5.15 \\
5.04 \\
4.97 \\
4.96 \\
5.21\end{array}$ \\
\hline 351607109165801 & $C P-6$ & $\begin{array}{l}06-28-89 \\
09-01-89 \\
09-11-89 \\
09-20-89 \\
11-02-89 \\
12-08-89 \\
01-10-90 \\
02-06-90 \\
03-06-90 \\
04-03-90 \\
05-03-90 \\
07-26-90 \\
09-06-90 \\
11-03-90 \\
12-05-90 \\
01-17-91 \\
03-04-91 \\
04-11-91 \\
06-04-91\end{array}$ & $\begin{array}{c}1315 \\
\ldots \\
\cdots \\
1300 \\
1020 \\
1130 \\
1445 \\
1330 \\
1420 \\
1540 \\
1400 \\
1600 \\
1200 \\
1450 \\
1100 \\
1515 \\
1150 \\
1435\end{array}$ & 1792.02 & $\begin{array}{l}1786.56 \\
1786.50 \\
1786.48 \\
1786.48 \\
1786.44 \\
1786.44 \\
1786.45 \\
1786.48 \\
1786.51 \\
1786.53 \\
1786.51 \\
1786.40 \\
1786.38 \\
1786.41 \\
1786.44 \\
1786.49 \\
1786.55 \\
1786.59 \\
1786.50\end{array}$ & $\begin{array}{l}5.66 \\
5.52 \\
5.54 \\
5.54 \\
5.57 \\
5.57 \\
5.57 \\
5.54 \\
5.51 \\
5.49 \\
5.51 \\
5.62 \\
5.64 \\
5.61 \\
5.57 \\
5.53 \\
5.47 \\
5.43 \\
5.51\end{array}$ \\
\hline 351407109165601 & $C P-7$ & $\begin{array}{l}07-26-90 \\
09-06-90 \\
11-03-90 \\
12-05-90 \\
01-17-91 \\
03-04-91 \\
04-11-91 \\
06-04-91\end{array}$ & $\begin{array}{l}1400 \\
1600 \\
-- \\
1455 \\
1110 \\
1505 \\
1145 \\
1445\end{array}$ & 1792.42 & $\begin{array}{l}1786.59 \\
1786.58 \\
1786.63 \\
1786.67 \\
1786.75 \\
1786.81 \\
1786.84 \\
1786.66\end{array}$ & $\begin{array}{l}5.82 \\
5.84 \\
5.78 \\
5.75 \\
5.67 \\
5.60 \\
5.57 \\
5.75\end{array}$ \\
\hline 351407109165602 & $C P-8$ & $\begin{array}{l}06-07-90 \\
07-26-90 \\
09-06-90 \\
10-17-90 \\
11-03-90 \\
12-05-90 \\
01-17-91 \\
03-04-91 \\
04-11-91 \\
06-04-91\end{array}$ & $\begin{array}{c}-1 \\
1400 \\
1100 \\
\because- \\
1200 \\
1500 \\
1105 \\
1510 \\
1140 \\
1440\end{array}$ & 1792.46 & $\begin{array}{l}1786.04 \\
1786.10 \\
1786.13 \\
1786.09 \\
1786.24 \\
1786.28 \\
1786.41 \\
1786.45 \\
1786.42 \\
1786.07\end{array}$ & $\begin{array}{l}6.42 \\
6.36 \\
6.34 \\
6.37 \\
6.22 \\
6.18 \\
6.05 \\
6.01 \\
6.04 \\
6.39\end{array}$ \\
\hline 351311109183701 & CP HINDMILL & $\begin{array}{l}02-06-90 \\
04-03-90\end{array}$ & $\begin{array}{l}1550 \\
1400\end{array}$ & 1796.16 & $\begin{array}{l}1786.11 \\
1786.14\end{array}$ & $\begin{array}{l}10.05 \\
10.02\end{array}$ \\
\hline
\end{tabular}


CROUND-WATER DATA-Continued

DISCRETE HATER LEVELS-Continued

\begin{tabular}{|c|c|c|c|c|c|c|}
\hline STATION MUBER & STATION NAME & DATE & TIME & $\begin{array}{l}\text { LAND } \\
\text { SURFACE } \\
\text { ALTITUDE } \\
\text { (METERS) }\end{array}$ & $\begin{array}{l}\text { WATER } \\
\text { LEVEL } \\
\text { (MEAN SEA } \\
\text { LEVEL) } \\
\text { (METERS) }\end{array}$ & $\begin{array}{l}\text { DEPTH } \\
\text { BELCH } \\
\text { LAND } \\
\text { SURFACE } \\
\text { (WATER } \\
\text { LEVEL) } \\
\text { (METERS) }\end{array}$ \\
\hline
\end{tabular}

\begin{tabular}{|c|c|c|c|c|c|c|}
\hline 351519109161501 & $O R-1$ & $\begin{array}{l}06-30-89 \\
09-01-89 \\
09-11-89 \\
09-19-89 \\
11-02-89 \\
12-08-89 \\
01-10-90 \\
02-06-90 \\
03-06-90 \\
04-03-90 \\
04-30-90 \\
07-26-90 \\
09-07-90 \\
11-03-90 \\
12-04-90 \\
01-18-91 \\
03-04-91 \\
04-11-91 \\
06-04-91\end{array}$ & $\begin{array}{c}10 \\
1205 \\
1200 \\
\cdots \\
1600 \\
0820 \\
1650 \\
1220 \\
1130 \\
1220 \\
1640 \\
1700 \\
1615 \\
1045 \\
1655 \\
1335 \\
1710 \\
1035 \\
1225\end{array}$ & 1797.32 & $\begin{array}{l}1793.27 \\
1793.46 \\
1793.55 \\
1793.43 \\
1793.53 \\
1793.64 \\
1793.72 \\
1793.80 \\
1793.85 \\
1793.70 \\
1793.56 \\
1793.00 \\
1793.31 \\
1793.36 \\
1793.32 \\
1793.46 \\
1793.51 \\
1793.39 \\
1793.91\end{array}$ & $\begin{array}{l}4.05 \\
3.86 \\
3.77 \\
3.89 \\
3.79 \\
3.68 \\
3.59 \\
3.52 \\
3.46 \\
3.62 \\
3.76 \\
4.23 \\
4.01 \\
3.96 \\
4.00 \\
3.86 \\
3.81 \\
3.93 \\
4.40\end{array}$ \\
\hline 351519109161502 & $Q R-2$ & $\begin{array}{l}07-01-89 \\
07-11-89 \\
07-30-89 \\
09-01-89 \\
09-11-89 \\
09-20-89 \\
11-02-89 \\
11-15-89 \\
12-08-89 \\
01-10-90 \\
02-06-90 \\
03-06-90 \\
04-03-90 \\
05-01-90 \\
06-07-90 \\
07-27-90 \\
09-07-90 \\
11-03-90 \\
12-04-90 \\
01-18-91 \\
03-04-91 \\
04-11-91 \\
06-04-91\end{array}$ & $\begin{array}{c}1300 \\
1030 \\
1230 \\
1210 \\
\cdots \\
1030 \\
1200 \\
1200 \\
0830 \\
1500 \\
1240 \\
1130 \\
1300 \\
0915 \\
1410 \\
1730 \\
1045 \\
1115 \\
1650 \\
1400 \\
1715 \\
1065 \\
1220\end{array}$ & 1797.12 & $\begin{array}{l}1793.27 \\
1793.04 \\
1793.54 \\
1793.46 \\
1793.56 \\
1793.26 \\
1793.52 \\
1793.57 \\
1793.63 \\
1793.72 \\
1793.79 \\
1793.85 \\
1793.68 \\
1793.55 \\
1793.34 \\
1793.11 \\
1793.32 \\
1793.37 \\
1793.32 \\
1793.48 \\
1793.52 \\
1793.61 \\
1792.92\end{array}$ & $\begin{array}{l}3.85 \\
4.08 \\
3.58 \\
3.66 \\
3.56 \\
3.86 \\
3.60 \\
3.55 \\
3.47 \\
3.40 \\
3.33 \\
3.27 \\
3.44 \\
3.57 \\
3.78 \\
4.01 \\
3.80 \\
3.75 \\
3.80 \\
3.64 \\
3.60 \\
3.71 \\
4.20\end{array}$ \\
\hline 351519109161801 & $a R-3$ & $\begin{array}{l}06-27-89 \\
07-11-89 \\
09-01-89 \\
09-11-89 \\
09-20-89 \\
11-02-89 \\
12-08-89 \\
01-10-90 \\
02-06-90 \\
03-06-90 \\
04-03-90 \\
04-30-90\end{array}$ & $\begin{array}{c}\ldots \\
\ldots \\
1200 \\
\ldots \\
\ldots \\
1200 \\
0815 \\
1510 \\
1200 \\
1130 \\
1210 \\
1445\end{array}$ & 1794.63 & $\begin{array}{l}1793.26 \\
1793.22 \\
1793.45 \\
1793.54 \\
1793.41 \\
1793.52 \\
1793.63 \\
1793.71 \\
1793.79 \\
1793.85 \\
1793.67 \\
1793.55\end{array}$ & $\begin{array}{l}1.37 \\
1.41 \\
1.19 \\
1.10 \\
1.22 \\
1.11 \\
1.01 \\
0.93 \\
0.84 \\
0.79 \\
0.96 \\
1.09\end{array}$ \\
\hline
\end{tabular}


GROUND-UATER DATA-Continued

DISCRETE WATER LEVELS-Contimued

\begin{tabular}{|c|c|c|c|c|c|c|}
\hline STATION MUABER & STATION NAME & DATE & TIME & $\begin{array}{c}\text { LAND } \\
\text { SURFACE } \\
\text { ALTITUDE } \\
\text { (METERS) }\end{array}$ & $\begin{array}{l}\text { WATER } \\
\text { LEVEL } \\
\text { (MEAN SEA } \\
\text { LEVEL) } \\
\text { (METERS) }\end{array}$ & $\begin{array}{l}\text { DEPTH } \\
\text { BELOW } \\
\text { LAND } \\
\text { SURFACE } \\
\text { (WATER } \\
\text { LEVEL) } \\
\text { (METERS) }\end{array}$ \\
\hline \multirow[t]{2}{*}{$\begin{array}{l}351519109161801 \\
\text { (Cont inued) }\end{array}$} & OR-3 & $\begin{array}{l}12-04-90 \\
01-18-91 \\
03-04-91 \\
04-11-91 \\
06-04-91\end{array}$ & $\begin{array}{l}1730 \\
1345 \\
1730 \\
1030 \\
1240\end{array}$ & & $\begin{array}{l}1793.31 \\
1793.47 \\
1793.51 \\
1793.38 \\
1792.91\end{array}$ & $\begin{array}{l}1.32 \\
1.17 \\
1.13 \\
1.26 \\
1.73\end{array}$ \\
\hline & \multicolumn{6}{|c|}{ LUPTON WELL CLUSTER } \\
\hline 351928109042601 & LPT-1 & $\begin{array}{l}07-26-90 \\
09-07-90 \\
10-11-90 \\
11-03-90 \\
12-05-90 \\
01-16-91 \\
03-05-91 \\
04-11-91 \\
06-04-91\end{array}$ & $\begin{array}{c}1800 \\
1230 \\
\cdots \\
0930 \\
0825 \\
1000 \\
0755 \\
0740 \\
0845\end{array}$ & 1858.04 & $\begin{array}{l}1856.52 \\
1856.74 \\
1856.93 \\
1856.99 \\
1856.79 \\
1857.01 \\
1857.03 \\
1857.00 \\
1856.77\end{array}$ & $\begin{array}{l}1.52 \\
1.30 \\
1.11 \\
1.05 \\
1.25 \\
1.03 \\
1.01 \\
1.04 \\
1.26\end{array}$ \\
\hline 351928109042602 & LPT-2 & $\begin{array}{l}07-26-90 \\
09-07-90 \\
10-11-90 \\
11-03-90 \\
12-05-90 \\
01-16-91 \\
03-05-91 \\
04-11-91 \\
06-04-91\end{array}$ & $\begin{array}{c}1800 \\
1230 \\
\cdots \\
0930 \\
0830 \\
0955 \\
0800 \\
0745 \\
0850\end{array}$ & 1858.29 & $\begin{array}{l}1857.07 \\
1857.20 \\
1856.91 \\
1857.00 \\
1857.26 \\
1857.40 \\
1857.47 \\
1857.48 \\
1857.31\end{array}$ & $\begin{array}{l}1.22 \\
1.09 \\
1.38 \\
1.29 \\
1.03 \\
0.89 \\
0.82 \\
0.81 \\
0.98\end{array}$ \\
\hline 351929109042401 & LPT-3 & $\begin{array}{l}09-07-90 \\
10-12-90 \\
11-03-90 \\
12-05-90 \\
01-16-91 \\
03-05-91 \\
04-11-91 \\
06-04-91\end{array}$ & $\begin{array}{c}1230 \\
\cdots \\
0930 \\
0835 \\
0930 \\
0810 \\
0850 \\
0855\end{array}$ & 1858.87 & $\begin{array}{l}1856.84 \\
1856.80 \\
1856.90 \\
1856.93 \\
1857.05 \\
1857.13 \\
1857.13 \\
1856.96\end{array}$ & $\begin{array}{l}2.03 \\
2.07 \\
1.96 \\
1.94 \\
1.81 \\
1.74 \\
1.74 \\
1.91\end{array}$ \\
\hline 351930109042701 & LPT -4 & $\begin{array}{l}07-26-90 \\
09-07-90 \\
10-11-90 \\
11-03-90 \\
12-05-90 \\
01-16-91 \\
03-05-91 \\
04-11-91 \\
06-04-91\end{array}$ & $\begin{array}{c}1800 \\
1230 \\
\cdots \\
0930 \\
0840 \\
0945 \\
0805 \\
0800 \\
0900\end{array}$ & 1858.53 & $\begin{array}{l}1856.23 \\
1856.41 \\
1856.37 \\
1856.46 \\
1856.49 \\
1856.69 \\
1856.74 \\
1856.73 \\
1856.53\end{array}$ & $\begin{array}{l}2.30 \\
2.11 \\
2.16 \\
2.07 \\
2.03 \\
1.84 \\
1.79 \\
1.80 \\
2.00\end{array}$ \\
\hline
\end{tabular}


GROUND-WATER DATA-Cont inued

DISCRETE HATER LEVELS-Cont inued

\begin{tabular}{|c|c|c|c|c|c|c|}
\hline STATION MUABER & STATION NAME & DATE & TIME & $\begin{array}{l}\text { LAND } \\
\text { SURFACE } \\
\text { ALTITLDE } \\
\text { (METERS) }\end{array}$ & $\begin{array}{l}\text { WATER } \\
\text { LEVEL } \\
\text { (MEAN SEA } \\
\text { LEVEL) } \\
\text { (METERS) }\end{array}$ & $\begin{array}{l}\text { DEPTH } \\
\text { BELON } \\
\text { LAND } \\
\text { SURFACE } \\
\text { (WATER } \\
\text { LEVEL) } \\
\text { (METERS }\end{array}$ \\
\hline & \multicolumn{6}{|c|}{ MANUELITO MELL CLUSTER } \\
\hline 352742108563301 & MAN-1 & $\begin{array}{l}06-06-90 \\
07-27-90 \\
09-07-90 \\
10-10-90 \\
11-03-90 \\
12-05-90 \\
01-16-91 \\
03-05-91 \\
04-10-91 \\
06-03-91\end{array}$ & $\begin{array}{c}\cdots \\
0900 \\
0820 \\
\cdots \\
0815 \\
0745 \\
0800 \\
0705 \\
1835 \\
1635\end{array}$ & 1919.13 & $\begin{array}{l}1912.67 \\
1912.63 \\
1912.60 \\
1912.60 \\
1912.63 \\
1912.64 \\
1912.72 \\
1912.73 \\
1912.74 \\
1912.71\end{array}$ & $\begin{array}{l}6.45 \\
6.50 \\
6.53 \\
6.52 \\
6.50 \\
6.49 \\
6.40 \\
6.39 \\
6.39 \\
6.41\end{array}$ \\
\hline 352742108563302 & MN-2 & $\begin{array}{l}06-06-90 \\
07-27-90 \\
09-07-90 \\
10-10-90 \\
12-05-90 \\
01-16-91 \\
03-05-91 \\
04-10-91 \\
06-03-91\end{array}$ & $\begin{array}{c}\cdots \\
0900 \\
0820 \\
\cdots \\
0740 \\
0825 \\
0710 \\
1840 \\
1640\end{array}$ & 1919.12 & $\begin{array}{l}1911.20 \\
1911.21 \\
1911.19 \\
1911.20 \\
1911.21 \\
1911.33 \\
1911.37 \\
1911.39 \\
1911.35\end{array}$ & $\begin{array}{l}7.93 \\
7.91 \\
7.93 \\
7.92 \\
7.91 \\
7.80 \\
7.75 \\
7.73 \\
7.77\end{array}$ \\
\hline 352743108563401 & MAN-3 & $\begin{array}{l}06-06-90 \\
09-07-90 \\
10-11-90 \\
11-03-90 \\
12-05-90 \\
03-05-91 \\
04-10-91 \\
06-03-91\end{array}$ & $\begin{array}{l}\cdots \\
0830 \\
\ddot{0815} \\
0730 \\
0720 \\
1845 \\
1645\end{array}$ & 1919.21 & $\begin{array}{l}1911.29 \\
1911.29 \\
1911.59 \\
1911.34 \\
1911.34 \\
1919.52 \\
1911.57 \\
1919.49\end{array}$ & $\begin{array}{l}7.92 \\
7.92 \\
7.62 \\
7.87 \\
7.87 \\
7.69 \\
7.64 \\
7.72\end{array}$ \\
\hline
\end{tabular}


GROUND-WATER DATA-Cont inUEd

WELL CONSTRUCTION AND LITHOLOGY

CHAMBERS WELL CLUSTER

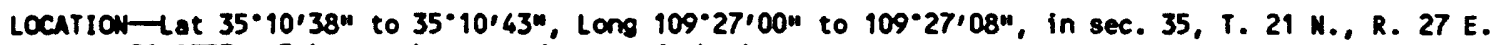
(A 21-2735), $3 \mathrm{~km}$ southwest and east of Chambers.

Landowner: New lands

LAND SURFACE DATUM-See table belou.

DRILLIMG AND WELL CONSTRUCTION

The wells are cased with nominal 5-centimeter dianeter, schedule 40, polwinyl-chloride pipe. Each well is screened with a length of slotted, 5-centimeter dianeter, schedule 42, polyinyl-chloride pipe as the well screen. Each screen has 1,470 factory-cut slots $3.6 \mathrm{~cm}$ long by $0.64 \mathrm{~mm}$ wide for a total open area of $339 \mathrm{~cm}$. The borehole anulus around the screen is filled with sand. A bentonite seal was placed in the annulus from approximately 0.5 to $1.5 \mathrm{~m}$ above the screen. The wells were developed by jetting high-pressure air horizontally through the screen to agitate the formation and air-lift water and sediment until no further visible sediment was removed.

LOGS: G, geologist; GA, gamma; GG, gamma-ganma; N, neutron; --, no dato

\begin{tabular}{|c|c|c|c|c|c|c|c|c|c|}
\hline WELL & $\begin{array}{c}\text { DATE } \\
\text { COMPLETED }\end{array}$ & DRILLING METHOO & $\begin{array}{l}\text { LANO } \\
\text { SURFACE } \\
\text { ALTITUDE } \\
\text { (meters) }\end{array}$ & $\begin{array}{c}\text { HOLE } \\
\text { DEPTH } \\
\text { (meters) }\end{array}$ & $\begin{array}{c}\text { WELL } \\
\text { OEPTH } \\
\text { (meters) }\end{array}$ & $\begin{array}{l}\text { SCREENED } \\
\text { INTERVAL } \\
\text { (meters) }\end{array}$ & $\begin{array}{c}\text { GEOLOGIC } \\
\text { UNIT }\end{array}$ & $\begin{array}{l}\text { BOTTOM } \\
\text { OF SEAL } \\
\text { (meters) }\end{array}$ & $\begin{array}{c}\text { LOGS } \\
\text { AVAILABLE }\end{array}$ \\
\hline $\begin{array}{l}\text { CH-1 } \\
\text { CH-2 } \\
\text { CH-3 } \\
\text { CH-4 } \\
\text { CH-5 } \\
\text { CH-6 } \\
\text { CH-7 } \\
\text { CH-8 } \\
\text { CH-9 }\end{array}$ & $\begin{array}{l}09-27-88 \\
09-27-88 \\
09-27-88 \\
09-27-88 \\
09-27-88 \\
09-28-88 \\
09-30-88 \\
09-30-88 \\
09-30-88\end{array}$ & $\begin{array}{l}\text { Holl low-stem auger } \\
\text { Holl low-stem auger } \\
\text { Holl low-stem auger } \\
\text { Holl } \text { ow-stem auger } \\
\text { Hol low-stem auger } \\
\text { Holl low-stem auger } \\
\text { Holl ow-stem auger } \\
\text { Holl low-stem auger } \\
\text { Holl low-stem auger }\end{array}$ & $\begin{array}{l}1.744 .22 \\
1.743 .85 \\
1.744 .31 \\
1.743 .09 \\
1.743 .02 \\
1.743 .14 \\
1.748 .75 \\
1.748 .88 \\
1.748 .81\end{array}$ & $\begin{array}{r}32.0 \\
25.0 \\
19.7 \\
30.5 \\
19.8 \\
9.1 \\
30.0 \\
21.2 \\
16.5\end{array}$ & $\begin{array}{r}32.0 \\
25.0 \\
11.7 \\
30.5 \\
19.8 \\
9.1 \\
30.0 \\
21.2 \\
16.5\end{array}$ & $\begin{array}{r}27.4-29.0 \\
14.3-15.8 \\
4.6-6.1 \\
27.4-29.0 \\
16.8-18.3 \\
4.6-7.6 \\
24.4-26.0 \\
18.3-19.8 \\
11.6-14.6\end{array}$ & $\begin{array}{l}\text { Chinle } \\
\text { Alluvium } \\
\text { Alluvium } \\
\text { Alluvium } \\
\text { Alluvium } \\
\text { Alluvium } \\
\text { Alluvium } \\
\text { Alluvium } \\
\text { Alluvium }\end{array}$ & $\begin{array}{l}\cdots \\
\cdots \\
\cdots \\
\cdots \\
\cdots \\
\cdots \\
\cdots \\
\cdots\end{array}$ & $\begin{array}{l}G, G A, G G, N \\
G \\
G \\
G, G A, G G, N \\
G \\
G \\
G, G A, G G, N \\
G \\
G\end{array}$ \\
\hline
\end{tabular}




\begin{tabular}{|c|c|c|}
\hline Sumbry of geologist log: & $\begin{array}{l}\text { Thickness } \\
\text { (m) }\end{array}$ & $\begin{array}{r}\text { Inter } \\
(m\end{array}$ \\
\hline \multicolumn{3}{|l|}{ CH-1: } \\
\hline 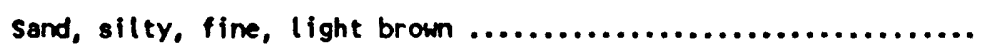 & 1.0 & 1.0 \\
\hline 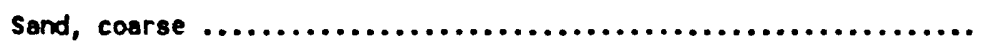 & .2 & 1.2 \\
\hline Sand, nedium to coarse with clay layer $\ldots . . . \ldots \ldots \ldots \ldots \ldots . . . . . .$. & .1 & 1.3 \\
\hline $\ldots \ldots \ldots \ldots \ldots \ldots \ldots \ldots \ldots \ldots \ldots \ldots \ldots$ & .2 & 1.5 \\
\hline 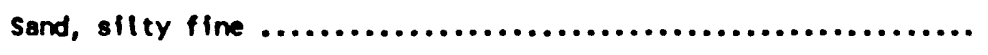 & .6 & 2.1 \\
\hline 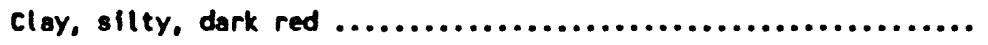 & .5 & 2.6 \\
\hline 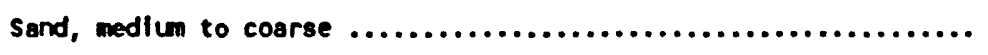 & .2 & 2.8 \\
\hline 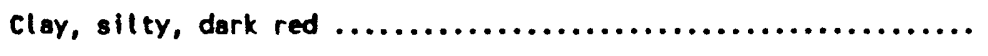 & 1.5 & 4.3 \\
\hline 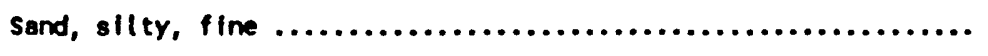 & .1 & 4.4 \\
\hline 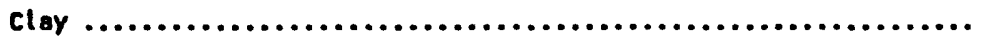 & .2 & 4.6 \\
\hline 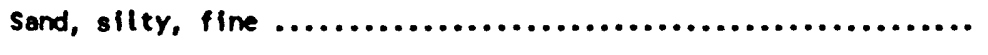 & .1 & 4.7 \\
\hline clay $\ldots \ldots \ldots \ldots \ldots \ldots \ldots \ldots \ldots \ldots \ldots \ldots \ldots \ldots \ldots \ldots \ldots \ldots \ldots \ldots \ldots \ldots$ & .2 & 4.9 \\
\hline 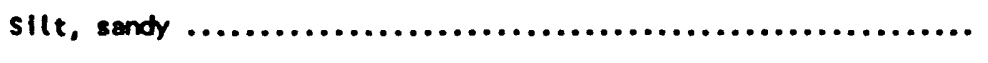 & .3 & 5.2 \\
\hline 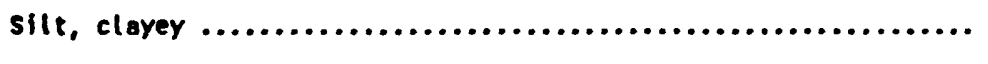 & .6 & 5.8 \\
\hline 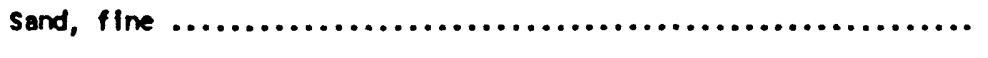 & .6 & 6.4 \\
\hline 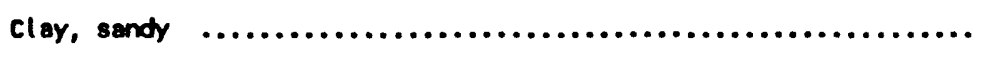 & .3 & 6.7 \\
\hline No return...... & .1 & 6.8 \\
\hline clay, red $\ldots \ldots \ldots \ldots \ldots \ldots \ldots \ldots \ldots \ldots \ldots \ldots \ldots \ldots \ldots \ldots \ldots \ldots \ldots \ldots$ & .4 & 7.2 \\
\hline 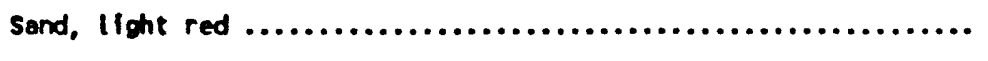 & .4 & 7.6 \\
\hline 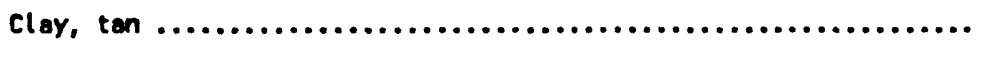 & .3 & 7.9 \\
\hline 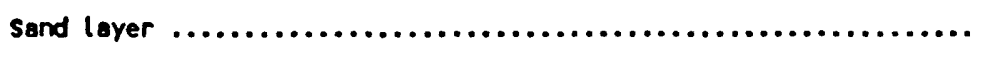 & .9 & 8.8 \\
\hline clay layer...$\ldots \ldots \ldots \ldots \ldots \ldots \ldots$ & .2 & 9.0 \\
\hline Sand layer $\ldots \ldots \ldots \ldots \ldots$. & 3.5 & 12.5 \\
\hline Sand, clayey, mediun to coarse $\ldots \ldots \ldots \ldots \ldots \ldots \ldots \ldots \ldots \ldots \ldots$ & .5 & 13.0 \\
\hline 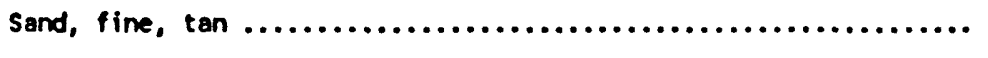 & .5 & 13.5 \\
\hline 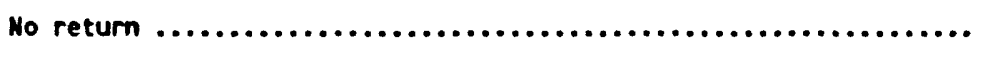 & 8.1 & 21.6 \\
\hline 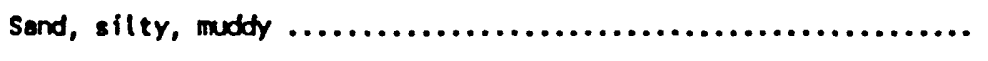 & 3.1 & 24.7 \\
\hline 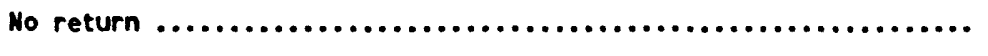 & .6 & 25.3 \\
\hline silt $\ldots \ldots \ldots \ldots \ldots \ldots \ldots \ldots \ldots \ldots \ldots \ldots \ldots \ldots \ldots \ldots \ldots \ldots \ldots \ldots \ldots \ldots \ldots$ & .8 & 26.1 \\
\hline 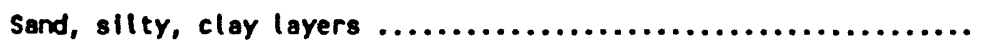 & 2.9 & 29.0 \\
\hline
\end{tabular}


cu-1-cont inued:

Cu-2:

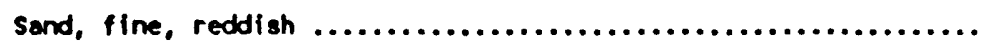

clay, sandy, darker red

sand, red, with clay layers

No return

sand, silty, fine

clay, silty

CH-3:

Sand, silty, medium dark brown $\ldots \ldots \ldots \ldots \ldots \ldots \ldots \ldots \ldots \ldots \ldots \ldots$

Send, silty, lighter brown

cley

No return

clay, reddish 
MELL CONSTRUCTION AND LITHOLOGY-Cont inued

CHAMBERS MELL CLUSTER-Continued

Summary of geologist log:

Thickness

(m)

4.6

.1

Clay layer

CW-4:

silt $\tan . \ldots \ldots \ldots \ldots \ldots \ldots \ldots \ldots \ldots \ldots \ldots \ldots \ldots \ldots \ldots \ldots \ldots \ldots \ldots \ldots . . \ldots \ldots \ldots$

Sand, fine, light brown

Sand, fine, $\tan$

Sand, medium, reddish

Sand, red with silty clay layers

Sand, coarse, red

clay, red

No return

Sand, silty, fine, brown

Sand, medium

clay, purple

CH-5:

Sand, fine, $\tan . \ldots \ldots \ldots \ldots \ldots \ldots \ldots \ldots \ldots \ldots \ldots \ldots \ldots \ldots \ldots \ldots \ldots \ldots \ldots$

Sand, medium, light $\tan . \ldots \ldots \ldots \ldots \ldots \ldots \ldots \ldots \ldots \ldots \ldots \ldots \ldots . . . \ldots \ldots$

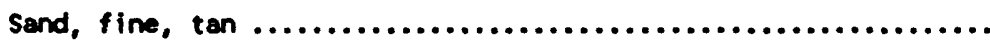

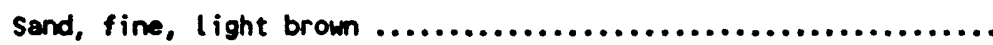

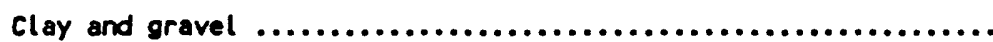

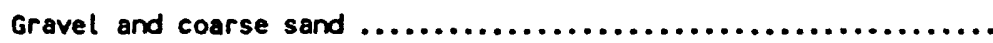

Clay and coarse sand

Sand with clay

No return

Sand and clay layers

Sand, silty, fine

Clay
.3

.3

.6

1.8

1.3

.3

.3

6.1

15.5

3.0

1.0

.3

.6

.6

1.5

.9

.6

.3

.3

6.6

3.2

4.1

.8
Botton of depth interval

(m)

11.6

11.7

.3

.6

1.2

3.0

4.3

4.6

4.9

11.0

26.5

29.5

30.5

.3

.9

1.5

3.0

3.9

4.5

4.8

5.1

11.7

14.9

19.0

19.8 
Thickness

ch-6:

silt, brown $\ldots \ldots \ldots \ldots \ldots \ldots \ldots \ldots \ldots \ldots \ldots \ldots \ldots \ldots \ldots \ldots \ldots \ldots \ldots \ldots$

Sand, fine, light tan.

Sand, gravelly, fline, $\tan \ldots . . \ldots \ldots \ldots \ldots \ldots \ldots \ldots \ldots \ldots \ldots \ldots \ldots$

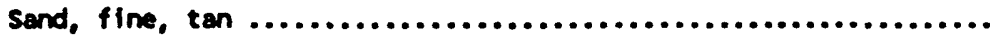

Sand, clayey, fine, $\tan . \ldots \ldots \ldots \ldots \ldots \ldots \ldots \ldots \ldots \ldots \ldots \ldots \ldots \ldots \ldots$

Sand, gravelly, fine, $\tan . \ldots \ldots \ldots \ldots \ldots \ldots \ldots \ldots \ldots \ldots \ldots \ldots \ldots \ldots$

Sand, fine, reddish, with gravel and clay ......................

Sand, clayey, fine, reddish

Sand, fine, reddish

Clay, sandy, red

No return

clay, reddish

Cr-7:

Sand, silty, fine, red

sand, silty, red to tan

Sand, fine, tan

Sand, silty, fine, reddish

Sand, coarse; with clay layer

Sand, fine, tan

Sand, fine to coarse, tan

Sand, coarse to fine, $\tan$

Sand, fine, tan, slightly reddish

Sand, fine, dark brown; with clay layer

Sand, fine, tan

Sand, coarse, red; with gravel

Clay, sandy, reddish; with gravel

clay, silty, red; with fine sand layers

Clay, reddish; fine sand layers, tan (m)

Botton of depth interval

(m)

$$
.3
$$

.3

.6

.9

.6

1.5

.6

2.1

.6

2.7

.3

3.0

.7

3.7

.3

4.0

.3

4.3

.1

4.4

4.4

8.8

.3

9.1

.6

.6

.6

1.2

.6

1.8

.5

2.3

.1

2.4

.6

3.0

.6

3.6

.6

4.2

.6

4.8

.6

5.4

.1

5.5

.5

6.0

.6

6.6

.6

7.2

.6 
Thickness

cW-7-Cont inued:

clay, red.

Clay, little sand

Sand, fine; clay layer

Sand and silty clay

No return

Sand, silty

No return

Grovel

No return

CW-8:

Sand, silty, fine, reddish

Sand, silty, light tan

Sand, fine, $\tan$

Sand, fine, reddish

Clay, sandy, reodish

$\mathrm{Clay}$, sandy, reddish-orange

Clay, sandy, reddish

No return

CW-9:

Sand, silty, fine

Sand, fine, light tan

No return

Clay layer

Clay, sandy, dark red (m)

3.7

2.4

1.8

.3

3.1

1.2

1.5

7.2

Botton of depth interval

(m)

.6

8.4

.6

9.0

1.8

10.8

.6

11.4

.6

12.0

9.9

21.9

.8

22.7

4.6

27.3

2.1

29.4

.6

30.0

3.7

6.1

7.9

8.2

11.3

12.5

14.0

21.2

5.2

5.2

.6

5.8

1.5

7.3

4.3

11.6

4.9

16.5 
WELL CONSTRUCTION AND LITHOLOGY-Continued

NDOT WELL CLUSTER

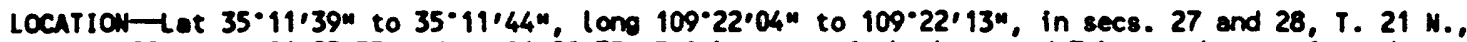
R. 28 E. (A-21-27) 35 and (A-21-28)35, 3.0 km east of Chambers and $7 \mathrm{~km}$ southwest of Sanders. Lendowner: Wayme Lynch

LAMD SURFACE DATUH-See table below.

\section{DRILLING AND WELL CONSTRUCTION}

The wells are cased with nominal 5-centimeter diameter, schedule 40, polwinyl-chloride pipe. Each well is screened with a single length of slotted, 5-centimeter diameter, schedule 42, polyvinylchloride pipe. Each screen has 1,470 factory-cut slots $3.6 \mathrm{~cm}$ long by $0.64 \mathrm{~mm}$ wide for a total apen area of $339 \mathrm{~cm}$. The borehole amulus around the screen is filled with sand. The wells were developed by jetting high-pressure air horizontally through the screen to agitate the formation and air-lift water and sediment until no further visible sediment was removed.

LOGS: G, geologist; GA, gamma; GG, gamna-gama; H, neutron

\begin{tabular}{|c|c|c|c|c|c|c|c|c|c|}
\hline WELL & $\begin{array}{c}\text { DATE } \\
\text { COMPLETED }\end{array}$ & DRILLING METHOO & $\begin{array}{l}\text { LAND } \\
\text { SURFACE } \\
\text { ALTITLE } \\
\text { (meters) }\end{array}$ & $\begin{array}{l}\text { HOLE } \\
\text { DEPTH } \\
\text { (meters) }\end{array}$ & $\begin{array}{l}\text { WELL } \\
\text { DEPTH } \\
\text { (meters) }\end{array}$ & $\begin{array}{l}\text { SCREENED } \\
\text { INTERVAL } \\
\text { (meters) }\end{array}$ & $\begin{array}{l}\text { GEOLOGIC } \\
\text { UNIT }\end{array}$ & $\begin{array}{l}\text { BOTTOM } \\
\text { OF SEAL } \\
\text { (meters) }\end{array}$ & $\begin{array}{l}\text { LOGS } \\
\text { AVAILABLE }\end{array}$ \\
\hline $\begin{array}{l}N D-1 \\
N-2 \\
N-3 \\
N D-4 \\
N D-5\end{array}$ & $\begin{array}{l}06-20-89 \\
06-21-89 \\
06-23-89 \\
06-23-89 \\
06-23-89\end{array}$ & $\begin{array}{l}\text { Holl low-stem auger } \\
\text { Holl low-stem auger } \\
\text { Hol low-stem auger } \\
\text { Holl low-stem auger } \\
\text { Holl low-stem auger }\end{array}$ & $\begin{array}{l}1.766 .01 \\
1.765 \\
1.765 .97 \\
1.765 .23 \\
1.765 .44\end{array}$ & $\begin{array}{l}59.1 \\
24.5 \\
12.2 \\
12.2 \\
11.1\end{array}$ & $\begin{array}{r}57.9 \\
23.5 \\
10.1 \\
11.6 \\
9.9\end{array}$ & $\begin{array}{r}36.6-39.6 \\
18.0-19.5 \\
5.5-8.5 \\
5.5-8.5 \\
5.3-8.5\end{array}$ & $\begin{array}{l}\text { Alluviun } \\
\text { Alluvium } \\
\text { Alluviun } \\
\text { Alluvium } \\
\text { All loviun }\end{array}$ & $\begin{array}{l}3.0 \\
4.6 \\
4.6 \\
4.6 \\
4.3\end{array}$ & $\begin{array}{l}G, G A, G G, N \\
G \\
G \\
G, G A, G G, N \\
G, G A, G G, N\end{array}$ \\
\hline
\end{tabular}


GROUND-MATER DATA-Continued

WELL CONSTRUCTION AND LITHOLOGY-Continued

ADOT WELL CLUSTER-Continued

Summary of geologist $\log$ :

Thickness

Silt, $\tan$

silt, sandy, reddish-orange brown

Sand and silt, clayey, reddish-brown; forms $1 / 2$ inch bolls ........

silt, clayey, grayish-brown; higher clay fraction

Clay and silt, sancty

Clay, firm, 5YR $3 / 4$

Sand, silty

Sand, silty, $5 Y R 3 / 4$ to $5 Y R 4 / 4$

No return

Sand, silty, 5YR $3 / 4$

Sand, silty, reddish-brown

Sand, silty, less red, slightly grayish-brown .................

Sand, silty, increase in silt fraction; reddish-brown to slightly orangish-brown ..............................

Sand, sllty, reddish-brown..$\ldots \ldots \ldots \ldots \ldots \ldots \ldots \ldots \ldots \ldots \ldots \ldots \ldots$

Sand, silty, reddish-brom, stightly grayish

Sand, silty, slightly yellowish-brom

Sand, silty, less yellow

Sand, silty, slightly yellowish-brown

Sand, silty, slightly yellowish-brown to grayish-brown

Sand, silty, dull yellowish-brown to brownish-gray

Sand, silty, slightly grayish-brown to yellowish-brown

AD-2:

silt, sandy, reddish-orange brown $\ldots \ldots \ldots \ldots \ldots \ldots \ldots \ldots \ldots \ldots \ldots . . . \ldots$

Silt, sandy and clayey, reddish-brown; forms 1 inch clay balls ...

Clay, silty, 5YR 3/4; crumbles with moderate pressure ............

No return

Sand, silty, moderate brown (m)

.3

3.0

Bottom of depth interval

(m)

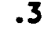

3.3

3.5

4.4

4.8

5.3

5.4

6.3

5.9

12.2

1.5

13.7

3.1

16.8

1.5

18.3

9.1

27.4

7.6

35.0

3.1

38.1

1.5

39.6

1.5

41.1

4.6

45.7

6.1

51.8

6.1

57.9

1.2

59.1

3.6

3.6 
GROUND-HATER DATA-Continued

MELL CONSTRUCTION AND LITHOLOGY-Cont inued

ADOT WELL CLUSTER-Continued

Sumary of geologist log:

$\begin{array}{cc}\text { Bottom } \\ \text { of depth } \\ \text { Thickness } & \begin{array}{c}\text { interval } \\ (m)\end{array} \\ \text { (m) }\end{array}$

AD-3:

silt, $\tan \ldots \ldots \ldots \ldots \ldots \ldots \ldots \ldots \ldots \ldots \ldots \ldots \ldots \ldots \ldots \ldots \ldots \ldots \ldots \ldots$

silt, light red.

2.1

2.3

Sand, silty, reddish brown; with winor clay

1.8

4.1

Clay, dark red, 5YR 3/4, with winor silt

2.0

6.1

Sand, red

1.8

7.9

No return

3.7

11.6

Sand, red

ND-4:

Sand, silty, light brown; sand and clay balls

sand, with clay

No return

Sand, clayey, silty; clay is 5YR 3/4

AD-5:

silt, $\tan \ldots \ldots \ldots \ldots \ldots \ldots \ldots \ldots \ldots \ldots \ldots \ldots \ldots \ldots \ldots \ldots \ldots \ldots \ldots \ldots \ldots$

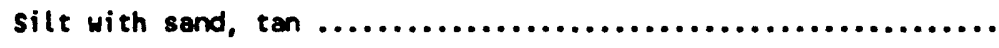

silt, sandy, brown $\ldots \ldots \ldots \ldots \ldots \ldots \ldots \ldots \ldots \ldots \ldots \ldots \ldots \ldots \ldots \ldots$

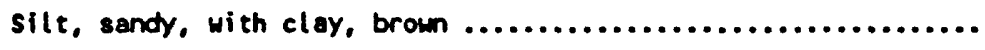

Sand, silty with clay, brown; predominantly clay balls

$$
(.6 \text { to } 1.3 \mathrm{~cm})
$$

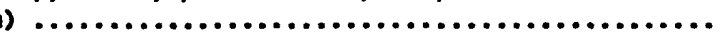

Sand, silty

Clay, brownish-red, 5YR 3/4, dense

Sand, red .

Clay, sandy, dark red 
LOCATION-Lat $35^{\circ} 14^{\prime} 07^{\prime \prime}$ to $35^{\circ} 14^{\prime} 15^{\prime \prime}$, long $109^{\circ} 16^{\prime} 56^{\prime \prime}$ to $109^{\circ} 17^{\prime} 07^{\prime \prime}$, in secs. 8, T. 21 N., R. 29 E. $(A-21-29) 08,3 \mathrm{~km}$ northeast of Sanders. Landowner: Mew Lands

LAND SURFACE DATUM-See table belon.

\section{DRILLING AND MELL CONSTRUCTION}

The wells are cased with nominal 5-centimeter diameter, schedule 40, polyvinyl-chloride pipe. Each well is screened with a single length of slotted, 5-centimeter diameter, schedule 42, polyvinylchloride pipe. Each screen has 1,470 factory-cut slots $3.6 \mathrm{~cm}$ long by 0.64 wide for a total open area of $339 \mathrm{~cm}$. The borehole annulus around the sereen is filled with sand. The wells were developed by jetting high-pressure air horizontally through the screen to agitate the formation and air-lift water and sediment until no further visible sediment was removed.

LOGS: G, geologist; GA, gamma; GG, gamma-gamma; N, neutron; --, no data

\begin{tabular}{|c|c|c|c|c|c|c|c|c|c|}
\hline :LL & $\begin{array}{c}\text { DATE } \\
\text { COMPLETED }\end{array}$ & DRILLING METHOD & $\begin{array}{l}\text { LAND } \\
\text { SURFACE } \\
\text { ALTITUDE } \\
\text { (meters) }\end{array}$ & $\begin{array}{l}\text { HOLE } \\
\text { DEPTH } \\
\text { (meters) }\end{array}$ & $\begin{array}{l}\text { WELL } \\
\text { DEPTH } \\
\text { (meters) }\end{array}$ & $\begin{array}{l}\text { SCREENED } \\
\text { INTERVAL } \\
\text { (meters) }\end{array}$ & $\begin{array}{l}\text { GEOLOGIC } \\
\text { UNIT }\end{array}$ & $\begin{array}{l}\text { BOTTOM } \\
\text { OF SEAL } \\
\text { (meters) }\end{array}$ & $\begin{array}{c}\text { LOGS } \\
\text { AVAILABLE }\end{array}$ \\
\hline $\begin{array}{l}C P-1 \\
C P-2 \\
C P-3 \\
C P-4 \\
C P-5 \\
C P-6 \\
C P-7 \\
C P-8\end{array}$ & $\begin{array}{l}06-16-89 \\
06-17-89 \\
06-17-89 \\
06-19-89 \\
06-19-89 \\
06-19-89 \\
05-18-90 \\
05-18-90\end{array}$ & $\begin{array}{l}\text { Holl low-stem auger } \\
\text { Holl low-stem auger } \\
\text { Hol low-sten auger } \\
\text { Holl low-sten auger } \\
\text { Holl low-sten auger } \\
\text { Holl low-sten auger } \\
\text { Reverse rotary } \\
\text { Reverse rotary }\end{array}$ & $\begin{array}{l}1,792.23 \\
1.792 .30 \\
1.792 .17 \\
1.792 .11 \\
1.791 .71 \\
1,791.48 \\
1,800 \\
1,800\end{array}$ & $\begin{array}{r}41.0 \\
18.1 \\
8.1 \\
8.1 \\
8.1 \\
7.9 \\
20.4 \\
39.6\end{array}$ & $\begin{array}{r}33.2 \\
18.1 \\
8.1 \\
8.1 \\
8.0 \\
7.7 \\
20.4 \\
39.6\end{array}$ & $\begin{array}{r}26.8-28.3 \\
15.4-16.9 \\
6.2-7.8 \\
5.8-7.3 \\
5.1-7.7 \\
4.9-7.6 \\
15.8-18.9 \\
35.1-38.1\end{array}$ & $\begin{array}{l}\text { Chinle } \\
\text { Alluvium } \\
\text { Alluvium } \\
\text { Alluvium } \\
\text { Alluvium } \\
\text { Alluvium } \\
\text { Chinle } \\
\text { Chinle }\end{array}$ & $\begin{array}{r}2.4 \\
.9 \\
1.8 \\
4.0 \\
4.6 \\
4.0 \\
32.0\end{array}$ & $\begin{array}{l}G, G A, G G, N \\
G \\
G \\
G \\
G \\
G \\
- \\
G\end{array}$ \\
\hline
\end{tabular}


CP-1:

Sand, silty, very fine, light brown; loose ....................

silt, clayey, broun; moderately dense

1.6

2.9

silt, brown

.1

3.0

Sand, silty, medium, brown

1

3.1

Clay, silty, fine, brown, moderately dense; layers of silty sand ..

Sand, silty, fine, red-brown; sandy silt with clay

\section{.5}

3.6

.9

4.5

Clay, silty, brown, dense, low to moderate plasticity; coarse

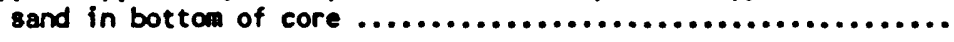

No return .

Sand, mediun to coarse, brown, loose, some silt

No return

Sand, silty, coarse $\ldots \ldots \ldots \ldots \ldots \ldots \ldots \ldots \ldots \ldots \ldots \ldots \ldots \ldots \ldots \ldots \ldots$

Sand, silty, coarse, red-brown; some $2-3$ millimeters fragments ....

Sand, silty, medium

clay, sandy

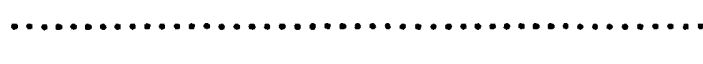

silty, sandy mud; medium sand, some fine and coarse-grained .......

Sand, silty, clayey, mediun to coarse-grained ..................

No return

Sand, clayey, medium to coarse-grained 
WELL CONSTRUCTION AND LITHOLOGY-Continued

CEDAR POINT WELL CLUSTER-Continued

Sumary of geologist log:

Thickness

(m)

3.5

2.1

.9

1.6

2.0

3.5

.5

2.1

2.9

.6

1.5

.4

.1

.3

.2

1.2

.3

.5

.1
Bottom of depth interval

(m)

3.5

5.6

6.5

8.1

Sand, fine

Clay, sandy, fine

No return

Clay, sandy, very fine

Sand, medium brown; several cobbles; purple sandstone at bottom ...

No return

2.0

5.5

6.0

8.1 
Thickness

Sand, fine, mall, hard clay chunks; silt balls

Clay balls

No return

Clay bolls

Sand

CP-8:.

Sand, medium, some fine, brown

Clay balls

Sand, coarse

Sand, clayey, coarse, brown

Sand, coarse to pebble fragments, angular, brown

Clay, purple, with sandy layers

Sand, coarse, brown

Clay, purple, with sand

Clay, brown

Clay, purple

Clay, brown

Clay, purplish-brown

Clay with sand, 1-2 millimeters grains; clay chips, purple

Clay, sandy, purple

Clay, sandy, purple and gray

Clay, sandy, brown and gray, less purple (m)

2.0

1.5

Bottom of depth

(m)

2.0

3.5

.9

4.4

.8

5.2

1.2

6.4

1.5

7.9

1.8

1.8

1.5

3.3

.9

4.2

2.8

7.0

.6

7.6

.5

8.1

.3

8.4

.6

9.0

.5

9.5

1.4

10.9

.3

11.2

1.2

12.4

1.5

13.9

4.0

17.9

2.5

20.4

1.2

21.6 
WELL CONSTRUCTION AND LITHOLOGY-Continued CEDAR POINT WELL CLUSTER-Continued

Thickness

(m)

1.2

2.2

.8

3.5

.3

.8

.5

.3

3.4

3.1

3.1
Bottom of depth interval (m)

21.6

23.8

24.6

28.1

28.4

29.2

29.7

30.0

Sand, medium; some clay

33.4

Sand, medium; sandstone chips, gray, with same clay

36.5

Sand, medium; some clay; sandstone fragments

39.6 
GROND-WATER DATA-Continued

MELL CONSTRUCTION AND LITHOLOGY-Continued

QUERINO ROND WELL CLUSTER

LOCATIOW-lat 35*15'19", lono 109.16'15", in sec. 33, T. 22 N., R. 29 E. (A-22-29)33cdd, $11 \mathrm{~km}$ southwest of Sanders on Querino Road.

Landouner: Navajo Indian Reservation

LAND SURFACE DATUH-See table below.

\section{DRILLING AND MELL CONSTRUCTION}

The wells are cased with nominal 5-centimeter dianeter, schedule 40, polwimyl-chloride pipe. Each well is screened with a single length of slotted, 5-centimeter dianeter, schedule 42, polyvinyl-chloride pipe. Each screen has 1,470 factory-cut slots $3.6 \mathrm{~cm}$ long by $0.64 \mathrm{~mm}$ wide for a total open area of $339 \mathrm{~cm}$. The borehole anulus around the screen is filled with sand. The wells were developed by jetting high-pressure air horizontally through the screen to agitate the formation and air-lift water and sediment until no further visible sediment was removed.

LOGS: G, geologist; GA, gamma; GG, gamma-gamma; W, neutron

\begin{tabular}{|c|c|c|c|c|c|c|c|c|c|}
\hline WELL & $\begin{array}{l}\text { DATE } \\
\text { COMPLETED }\end{array}$ & DRILLING METHOO & $\begin{array}{l}\text { SURFACE } \\
\text { ALTITUDE } \\
\text { (meters) }\end{array}$ & $\begin{array}{l}\text { HOLE } \\
\text { DEPTH } \\
\text { (meters) }\end{array}$ & $\begin{array}{c}\text { WELL } \\
\text { DEPTH } \\
\text { (meters) }\end{array}$ & $\begin{array}{l}\text { SCREENED } \\
\text { (NTERVAL } \\
\text { (meters) }\end{array}$ & $\begin{array}{c}\text { GEOLOGIC } \\
\text { UNIT }\end{array}$ & $\begin{array}{l}\text { BotTOM } \\
\text { Of SEAL } \\
\text { (meters) }\end{array}$ & $\begin{array}{c}\text { LOGS } \\
\text { AVAILABLE }\end{array}$ \\
\hline-2 & $\begin{array}{l}06-14-89 \\
06-14-89 \\
06-14-89\end{array}$ & $\begin{array}{l}\text { Holl low-stem auger } \\
\text { Hollow-stem auger } \\
\text { Holl low-sten auger }\end{array}$ & $\begin{array}{l}1.796 .55 \\
1.796 .61 \\
1.794 .39\end{array}$ & $\begin{array}{r}48.3 \\
9.1 \\
9.1\end{array}$ & $\begin{array}{r}34.7 \\
9.0 \\
8.8\end{array}$ & $\begin{array}{r}31.7-33.2 \\
4.3-7.5 \\
4.3-7.5\end{array}$ & $\begin{array}{l}\text { Alluvium } \\
\text { Alluvium } \\
\text { Alluvium }\end{array}$ & $\begin{array}{l}3.4 \\
2.4 \\
1.2\end{array}$ & $\begin{array}{l}G, G A, G C \\
G \\
G\end{array}$ \\
\hline
\end{tabular}


Thickness

(in)

Botton of depth interval

(m)

ar-1:

Sand, fine, $\tan \ldots \ldots \ldots \ldots \ldots \ldots \ldots \ldots \ldots \ldots \ldots \ldots \ldots \ldots \ldots \ldots \ldots \ldots \ldots$

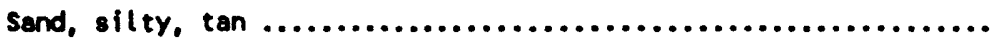

Sand, silty, fine, reddish orange $\ldots \ldots \ldots \ldots \ldots \ldots \ldots \ldots \ldots \ldots \ldots$

send, silty, fine; clay bolls, few pebbles

silt, tan; sand, fine, red; clay, brown

Sand, fine to medium, tan; clay, dense, red with minor brownyellowish clay streaks; contains small rock fragments and one pebble $(4 \mathrm{~cm})$, base of sample red fine to coarse sand $(8 \mathrm{~cm})$...............................................

No return

Silt, sandy, brownish-red ...............................

Sand, gravely, clayey, reddish-brown .......................

silt, sandy, reddish-brown; some clay

Sand, silty, slightly reddish-brown to brown ..................

Sand, silty, brown to grayish brown ........................

No return

Sandstone, quartz, tan, well sorted

Sandstone, silty, pale red

Note: Upper $9 \mathrm{~cm}$ consists of gravel to cobble size rocks (angular to rounded, chert, mudstone and tan sandstone).

Sandstone, pale red and reddish orange to dusky red .............

Sandstone, tan, contains mineralized fracture bisecting piece

$18 \mathrm{~cm}$ in length at 47.0 to $47.2 \mathrm{a}$, yell owish-brown stain

at top of fractured section about $2.5 \mathrm{~cm}$ inch deep............

Note: Upper $15 \mathrm{~cm}$ of core barrel contained sand to cobble size material, disaggregated; gravel size consists of angular to subangular fragments of chert, sandstone and siltstone; pebble and cobble size rocks subrounded to rounded, well indurated mudstone (which wake up about 40X of sample; gravel-size rocks and chips comprise another 40\%). Sand is loose, subangular to subrounded quartz and makes up remaining $20 \%$ of sample. Tan sandstone chips (gravel size) make up about $40 \%$ of gravel.

$\begin{array}{rr}.6 & .6 \\ .6 & 1.2 \\ 1.5 & 2.7 \\ .9 & 3.6 \\ .6 & 4.2 \\ & \\ .8 & 5.0 \\ 1.1 & 6.1 \\ 2.7 & 8.8 \\ 7.9 & 16.7 \\ 18.3 & 35.0 \\ 3.1 & 38.1 \\ 2.4 & 40.5 \\ 3.2 & 43.7 \\ .7 & 44.4 \\ .7 & 45.1\end{array}$

$1.4 \quad 46.5$

$.8 \quad 47.3$ 
WELL CONSTRUCTION AND LITHOLOGY-Continued

QUERIMO ROND WELL CLUSTER-Continued

Sumary of geologist log:

Thickness

(a)

.9

Sandstone, tan, less fractured; tighter

Sandatone, clay, light gray to greenish-white; sand and sandstone fragments

OR-2:

Sand, silty, mediun

Sand, silty, medium, red-brown

Sand, coarse

No return

Cley, silty, brown

Sand, clayey, red-brown

No return

QR-3:

Sand, silty, medium, tan

sand, silty, coarse, brom

Sand, silty, coarse; with gravel

No return

Sand, silty, coarse, with gravel
.8

5.0

.9

.9

1.5
48.2

(a)

48.3

$\begin{array}{rr}.6 & .6 \\ 1.8 & 2.4 \\ .9 & 3.3 \\ .3 & 3.6 \\ .6 & 4.2 \\ .6 & 4.8 \\ 4.3 & 9.1\end{array}$

.6

2.4

3.3

3.6

.2

9.1 
LOCATIOH-Lat $35^{\circ} 19^{\prime} 28^{\prime \prime}$ to $35^{\circ} 19^{\prime} 30^{\prime \prime}$, tong $109^{\circ} 04^{\prime 2} 24^{\prime \prime}$ to $109^{\circ} 04^{\prime} 27^{\prime \prime}$, in sec. 8, T. 22 N., R. 31 E. (A-22-31)08, $30 \mathrm{~km}$ southwest of Gallup.

Landowner: New Lands

LANO SURFACE DATUK- See table below.

\section{DRILLING AND WELL CONSTRUCTION}

The wells are cased with nominal 5-centimeter diameter, schedule 40, polwinyl-chloride pipe. Each well is screened with a single length of slotted, 5-centimeter diameter, schedule 42, polyvinyl-chloride pipe. Each screen has 1,470 factory-cut slots $3.6 \mathrm{~cm}$ long by $0.64 \mathrm{~mm}$ wide for a total open area of $339 \mathrm{~cm}$. The borehole anmulus around the screen is filled with sand. The wells were developed by jetting high-pressure air horizontally through the screen to agitate the formation and air-lift water and sediment until no further visible sediment was removed.

LOGS: G, geologist; GA, gamma; GG, gamma-gamma; N, neutron

$\begin{array}{lc}\text { DATE } & \text { COMPLETED } \\ \text { WELL } & \\ & \\ \text { LPT }-1 & 05-14-90 \\ \text { LPT }-2 & 05-14-90 \\ \text { LPT }-3 & 05-15-90\end{array}$

LPT $-4 \quad 05-15-90$
ORILLING METHOO

Hollow-stem auger Hollow-stem auger Hollow-stem auger Hollow-stem auger

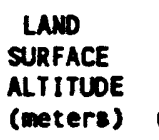

(meters)

$1,788.52$

21.6

1,860

1,860
HOLE
DEPTH
(meters)

MELL

DEPTH

SCREENED

(meters)

(NTERVAL
21.6

6.1

8.1

9.0
$14.0-15.5$

$3.0-4.6$

1.8- 5.0

2.9- 5.9

\section{GEOLOGIC} UNIT

8.1

9.1

\section{Alluvium}

Alluvium

Alluvium

Alluvium
BOTTOM

OF SEAL (meters)

LOGS

$\begin{array}{ll}1.5 & 6 \\ 0.6 & G \\ 0.9 & G \\ 0.9 & G\end{array}$


Thickness

(m)

Lupton-1:

Sand, fine, reddish-brown

Sand, fine, grayish; some silt or mud

sand, fine, grayish-black

sand, fine, grayish-brown

Clay lumps, dark greenish-gray; fine sand

Clay, green-gray; $2.5 \mathrm{~cm}$ lumps

clay, dark greenish-gray; sand; medium-fine

Sond, dark greenish-gray

Sond, brounish, slightly purple

sand, medium; reddish-brown

Lupton-2:

Sand, medium, broun $\ldots \ldots \ldots \ldots \ldots \ldots \ldots \ldots \ldots \ldots \ldots \ldots \ldots \ldots \ldots \ldots \ldots \ldots \ldots$

Sond, medium, broun to greenish-gray

Sand, greenish

Lupton-4:

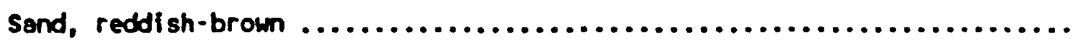

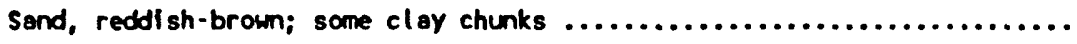

Clay, reddish

Clay, greenish

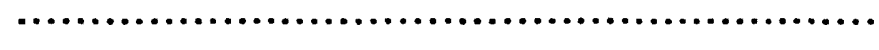

Sand, fine to mediun; light brown

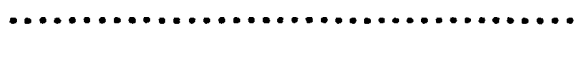

No return

Sand, greenish

Sand, fine, greenish-brown

Sand, medium to fine, some clay; dark greenish 
GROUND-WATER DATA-COnt inued

WELL CONSTRUCTION AND LITHOLOGY-Cont inued

MANUELITO WELL CLUSTER

LOCATIOH-Lat $35^{\circ} 27^{\prime} 42^{\prime \prime}$ to $35^{\circ} 27^{\prime} 43^{\prime \prime}$, long $108^{\circ} 56^{\prime 3} 33^{\prime \prime}$ to $108^{\circ} 56^{\prime 3} 34^{\prime \prime}$, in sec. 10, T. 14 N., R. $20 \mathrm{~W}$., $20 \mathrm{~km}$ southwest of Gallup. Landowner: Toby Martinez

LAND SURFACE DATUM-See table below.

\section{DRILLING AND WELL CONSTRUCTION}

The wells are cased with nominal 5-centimeter dianeter, schedule 40, polyvinyl-chloride pipe. Each well is screened with : length of slotted, 5-centimeter diameter, schedule 42, polyvinyl-chloride pipe. Each screen has 1,470 factory-cut 8 lots $3.6 \mathrm{~cm}$ long by $0.64 \mathrm{~mm}$ wide for total open area of $339 \mathrm{~cm}$. The borehole annulus around the screen is filled with sand. The wells were developed by jetting high-pressure air horizontally through the screen to agitate the formation and air-lift water and sediment until no further visible sediment was removed.

LOGS: G, geologist; GA, gamma; GG, gamma-gamma; N, neutron; --, no data

\begin{tabular}{|c|c|c|c|c|c|c|c|c|c|}
\hline WELL & $\begin{array}{c}\text { DATE } \\
\text { CONPLETED }\end{array}$ & DRILLING METHOO & $\begin{array}{c}\text { LAND } \\
\text { SURFACE } \\
\text { ALTITUDE } \\
\text { (meters) }\end{array}$ & $\begin{array}{l}\text { HOLE } \\
\text { DEPTH } \\
\text { (meters) }\end{array}$ & $\begin{array}{l}\text { WELL } \\
\text { DEPTH } \\
\text { (meters) }\end{array}$ & $\begin{array}{l}\text { SCREENED } \\
\text { INTERVAL } \\
\text { (meters) }\end{array}$ & $\begin{array}{l}\text { GEOLOGIC } \\
\text { UNIT }\end{array}$ & $\begin{array}{l}\text { BOTTOM } \\
\text { OF SEAL } \\
\text { (meters) }\end{array}$ & $\begin{array}{c}\text { LOGS } \\
\text { AVAILABLE }\end{array}$ \\
\hline $\begin{array}{l}\text { MN-1 } \\
\text { MAN-2 } \\
\text { MNH-3 }\end{array}$ & $\begin{array}{l}05-23-90 \\
05-24-90 \\
05-23-90\end{array}$ & $\begin{array}{l}\text { Holl low-stem auger } \\
\text { Holl low-stern auger } \\
\text { Holl low-sten suger }\end{array}$ & $\begin{array}{l}1.910 \\
1.910 \\
1.910\end{array}$ & $\begin{array}{l}24.8 \\
13.7 \\
15.7\end{array}$ & $\begin{array}{l}24.8 \\
13.7 \\
15.7\end{array}$ & $\begin{array}{r}21.8-23.3 \\
7.6-10.7 \\
9.6-14.2\end{array}$ & $\begin{array}{l}\text { Alluvium } \\
\text { Alluvium } \\
\text { Alluvium }\end{array}$ & $\begin{array}{l}7.0 \\
7.0 \\
5.5\end{array}$ & $\ddot{G}$ \\
\hline
\end{tabular}


WELL CONSTRUCTION AND LITHOLOGY-Continued

MANUELITO WELL CLUSTER-Continued

Sumary of geologist log:

Thickness

MN-1:

silt, sandy, clayey, brown, poorly sorted .....................

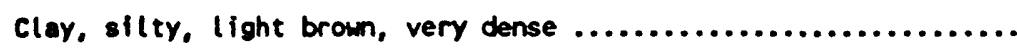

Clay, silty, dark brown, very dense $\ldots \ldots \ldots \ldots \ldots \ldots \ldots \ldots \ldots \ldots$

Sand, silty, fine, poorly sorted, golden brown ..................

Clay, dark brown

Sand, silty, fine, poorly sorted, light brow; with silty

layers; gradation into clay above ........................

silt, sendy, fine, laminations, brownish-orange, $1 / 2$ to $1 \mathrm{~cm} \ldots . .$.

Sand, silty, fine to medium, moderately well sorted, brown .........

Clay, dark brown, slightly fat, with laminations

Sand, clayey, medium, poorly sorted, brown; with pieces of

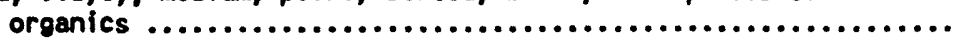

clay, brown, moderately fat

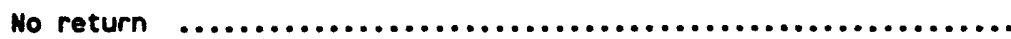

Clay, broun $\ldots \ldots \ldots \ldots \ldots \ldots \ldots \ldots \ldots \ldots \ldots \ldots \ldots \ldots \ldots \ldots \ldots \ldots \ldots \ldots \ldots$

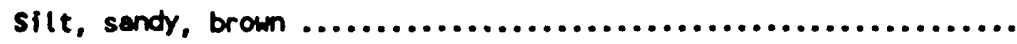

Interbedded mud, clay and sand, brown (m)

.5

.9

.8

.5

1.1

2.0

.6

1.1

.3

.9

1.8

5.8

1.3

Bottom of depth interval

(m) 
MANUELITO WELL CLUSTER-Contínued

\section{Sumsary of geologist log:}

MN-3:

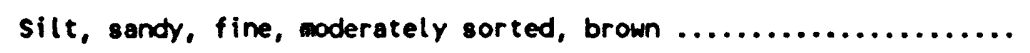

Clay, silty, very lean; appears gradational to silt above; brown ..

Clay, silty, more clay, less silt $\ldots \ldots \ldots \ldots \ldots \ldots \ldots \ldots \ldots \ldots \ldots \ldots$

silt, sendy, very fine; moderately sorted, brown; appears

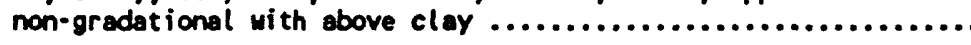

Sand, silty, very fine to fine; moderately well sorted; brown .....

Clay, silty, lean; brown $\ldots \ldots \ldots \ldots \ldots \ldots \ldots \ldots \ldots \ldots \ldots \ldots \ldots \ldots$

Sand, silty, fine to medium, moderately well sorted, brom ........

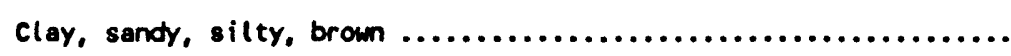

Sand, clayey, silty; fine and sandy clay, poorly sorted, brown ....

clay, silty, brown $\ldots \ldots \ldots \ldots \ldots \ldots \ldots \ldots \ldots \ldots \ldots \ldots \ldots \ldots \ldots \ldots \ldots$

clay

No return

clay
Thickness

(m)

$\begin{array}{rr}1.4 & 1.4 \\ 1.7 & 3.1 \\ 1.8 & 4.9 \\ 1.2 & 6.1 \\ 1.5 & 7.6 \\ .8 & 8.4 \\ .3 & 8.7 \\ .6 & 9.3 \\ .5 & 9.8 \\ 1.2 & 11.0 \\ .5 & 11.5 \\ 3.5 & 15.0 \\ .7 & 15.7\end{array}$

Botton of depth interval

(m) 


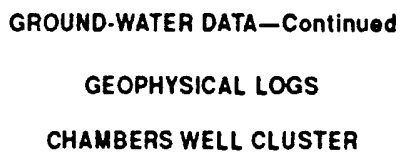

STATION NUMBER 351043109270301 (CW-1)

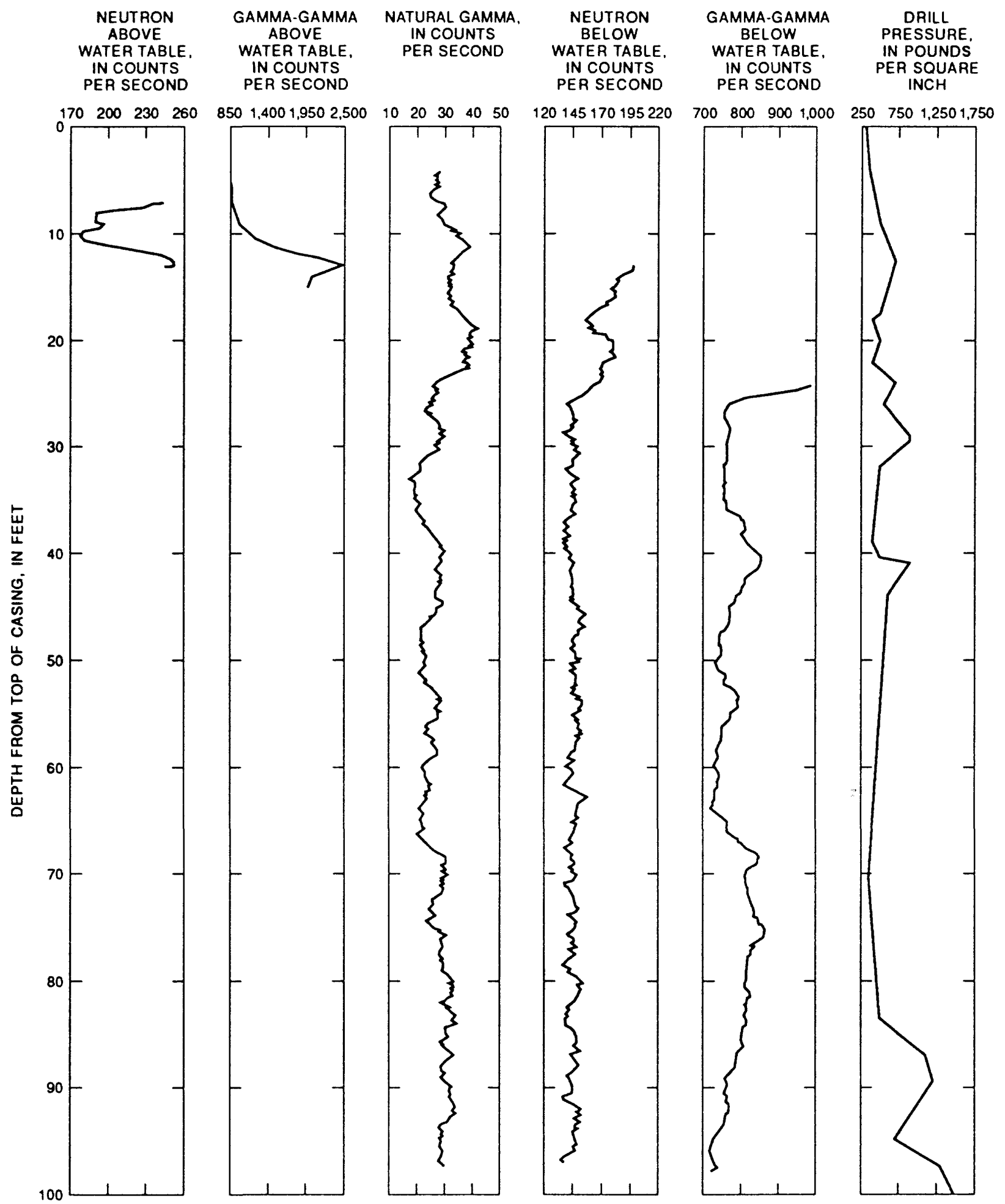


GROUND-WATER DATA-Continued

GEOPHYSICAL LOGS-COntinued

CHAMBERS WELL CLUSTER-Continued

STATION NUMBER 351038109270801 (CW-4)

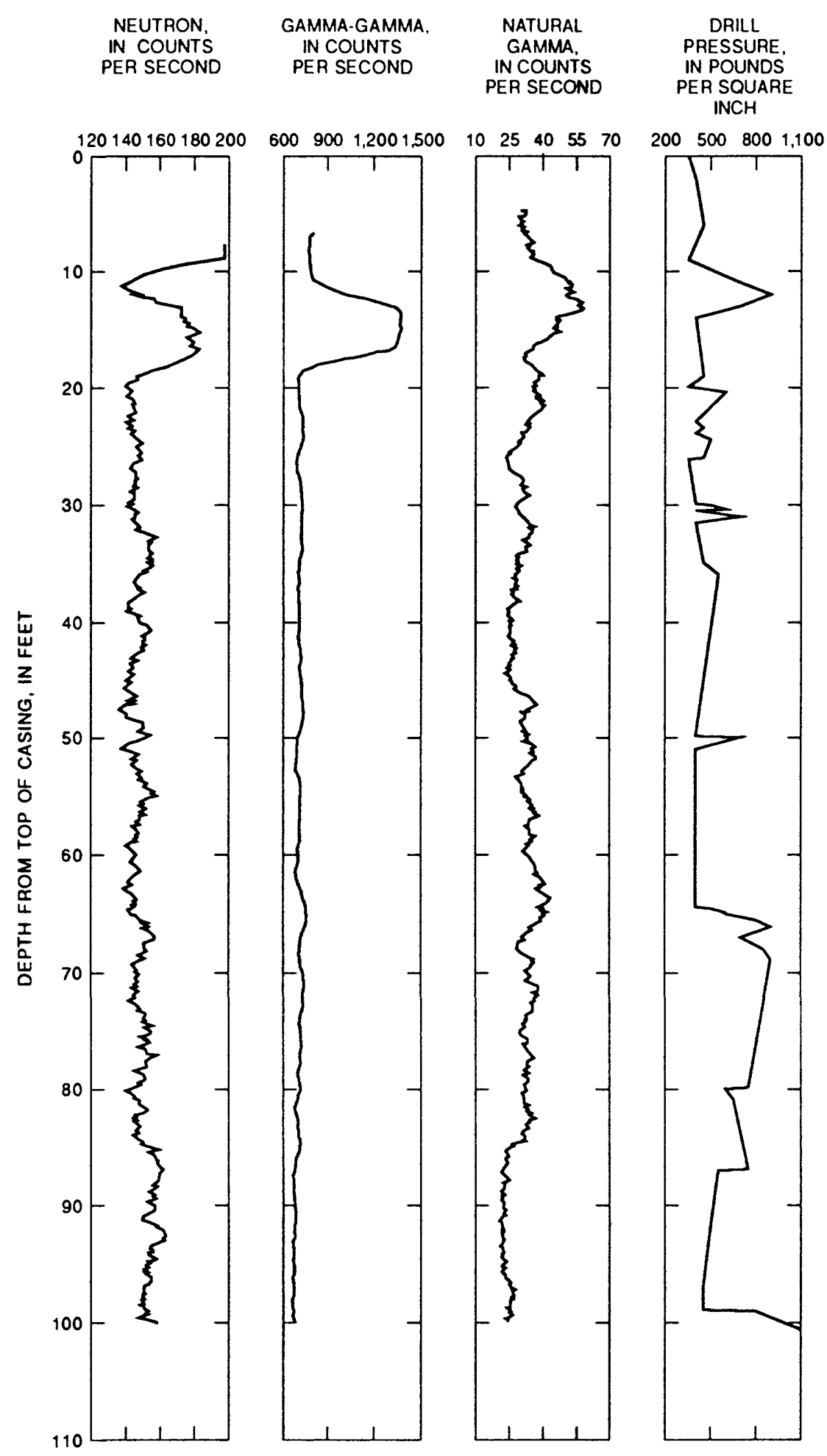


GROUND.WATER DATA-Continued

GEOPHYSICAL LOGS-Continued

CHAMBERS WELL CLUSTER-Continued

STATION NUMBER 351039109270001 (CW-7)

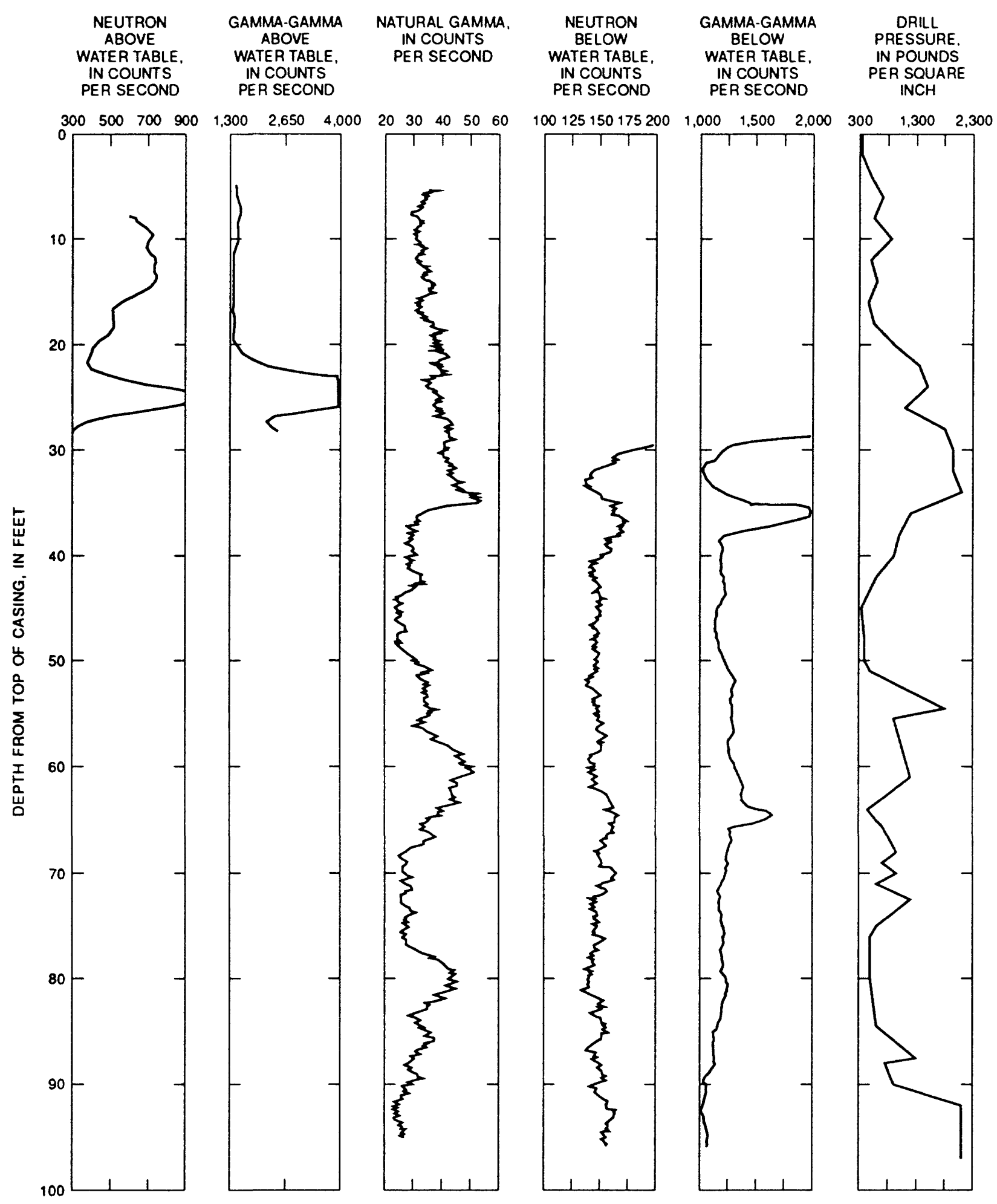




\section{GROUND-WATER DATA-Continued}

GEOPHYSICAL LOGS-CONIinUOd

ADOT WELL CLUSTER

STATION NUMBER 351140109220901 (AD-1)

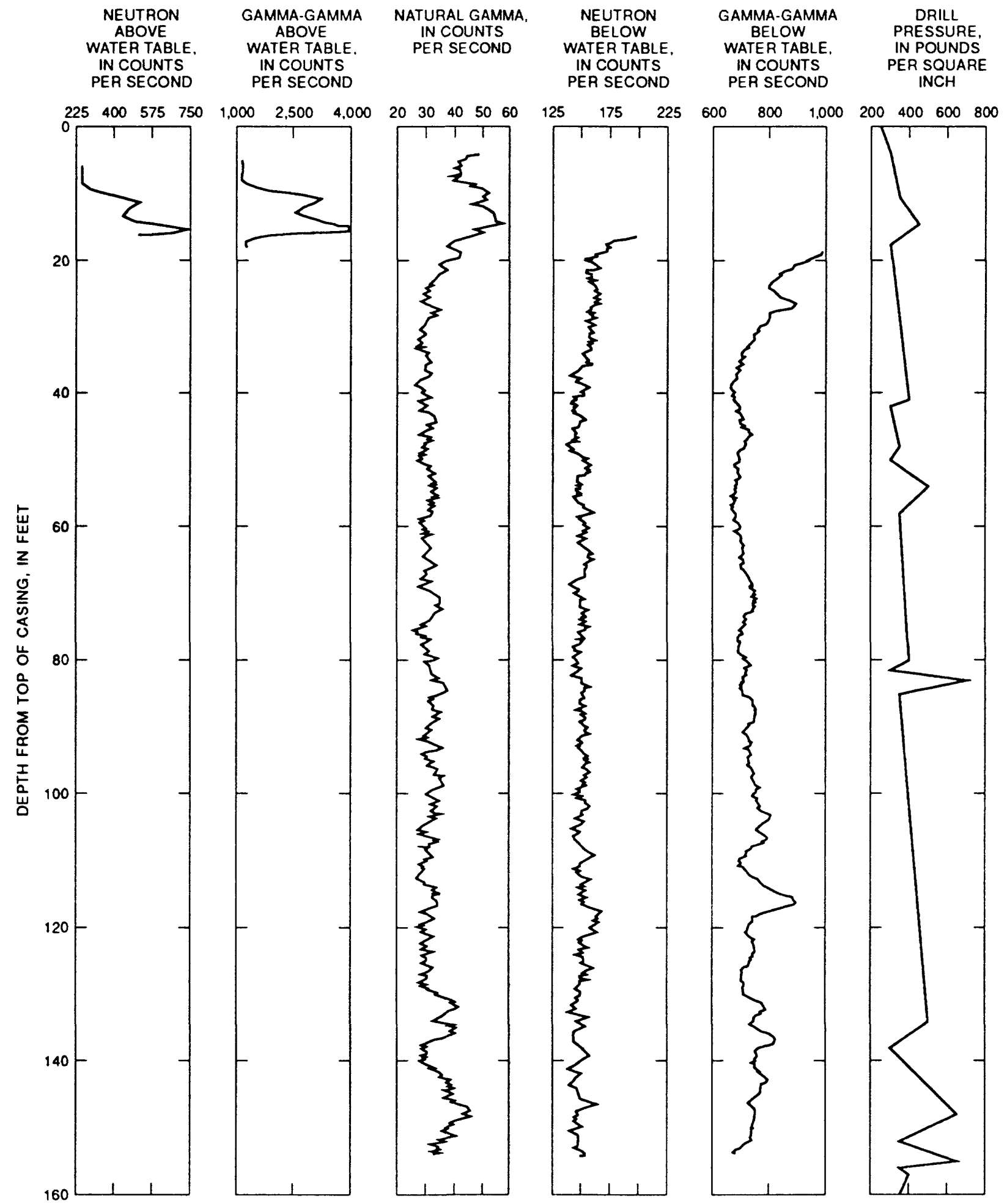




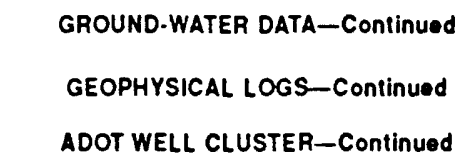

STATION NUMBER 351144109220701 (AD-4)

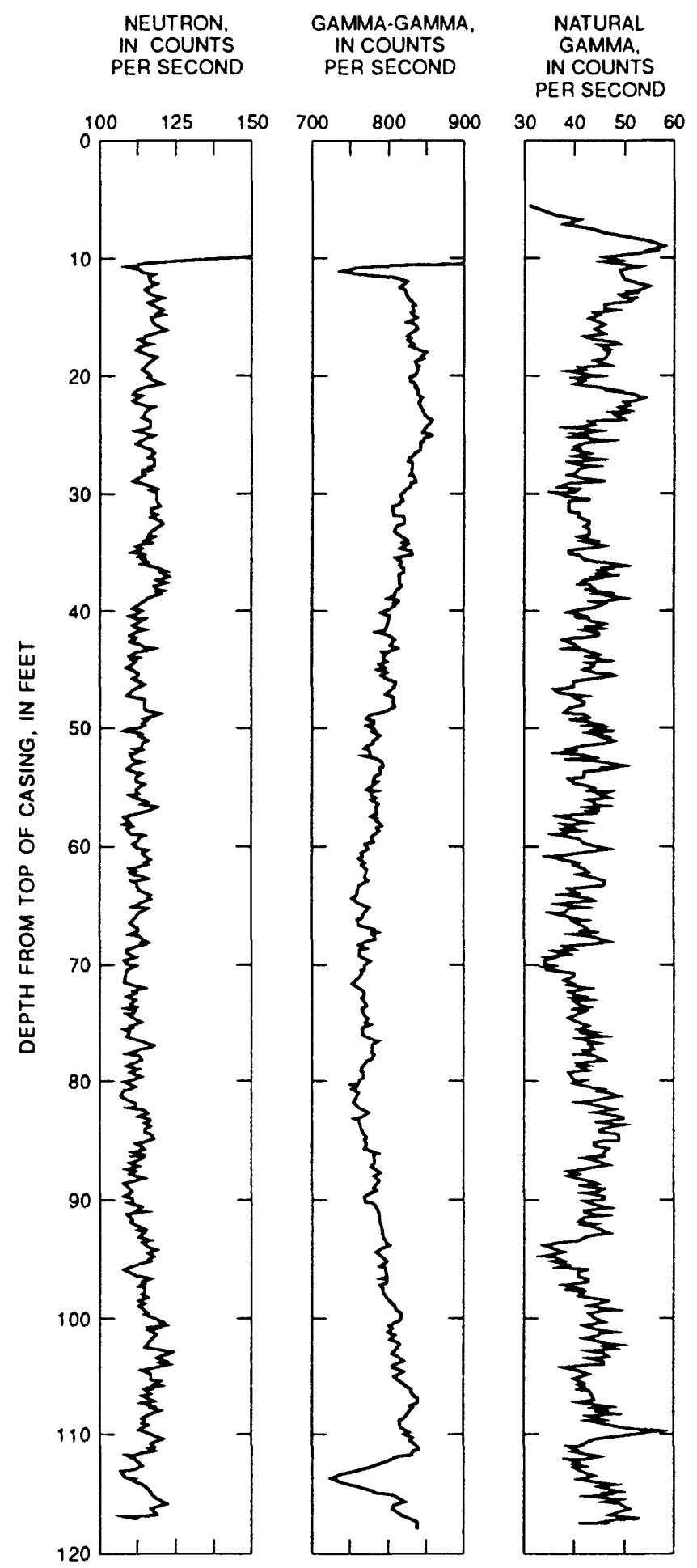


GROUND-WATER DATA-Continued

GEOPHYSICAL LOGS-Continued

CEDAR POINT WELL CLUSTER

STATION NUMBER 351411109170701 (CP-1)

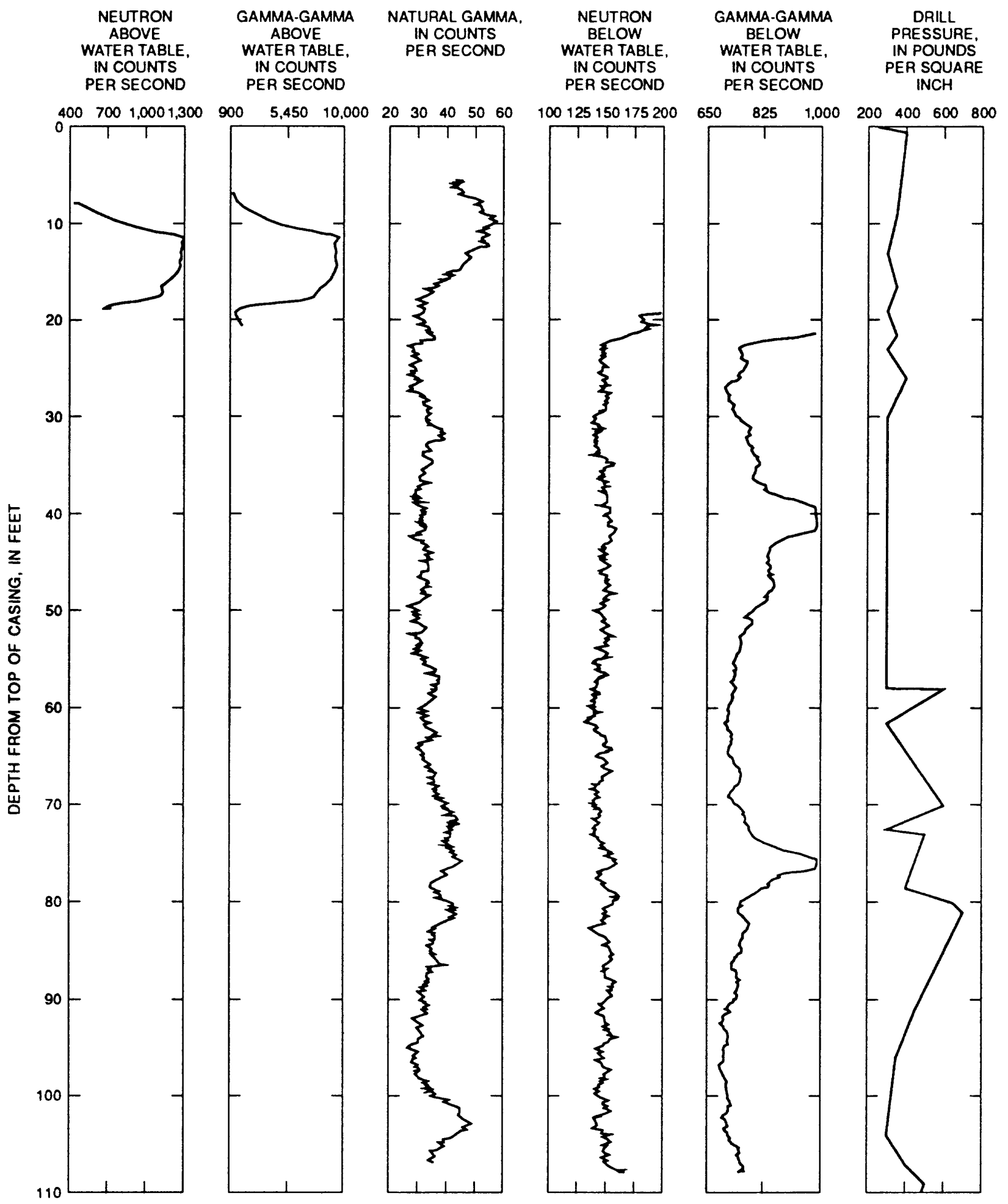




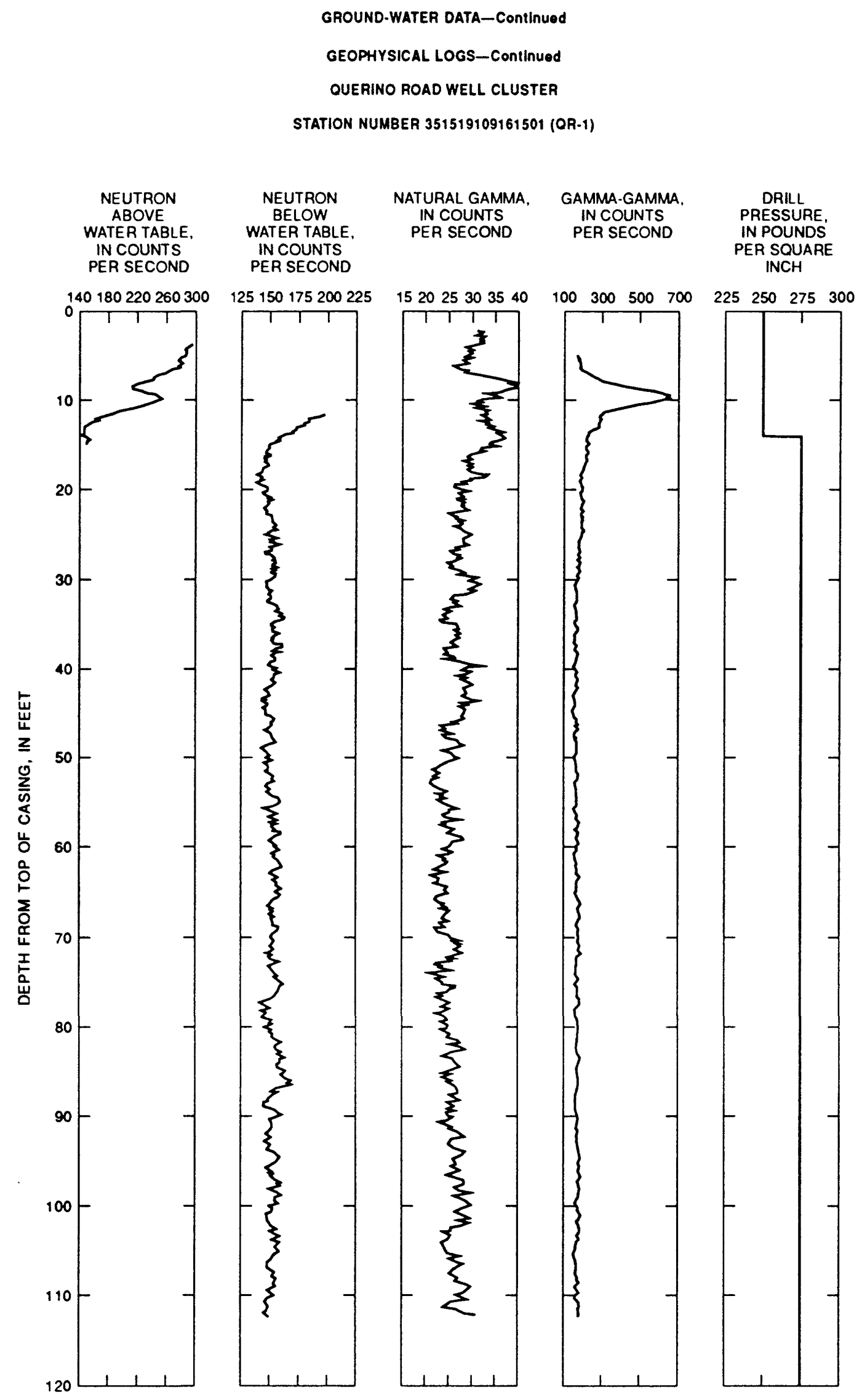




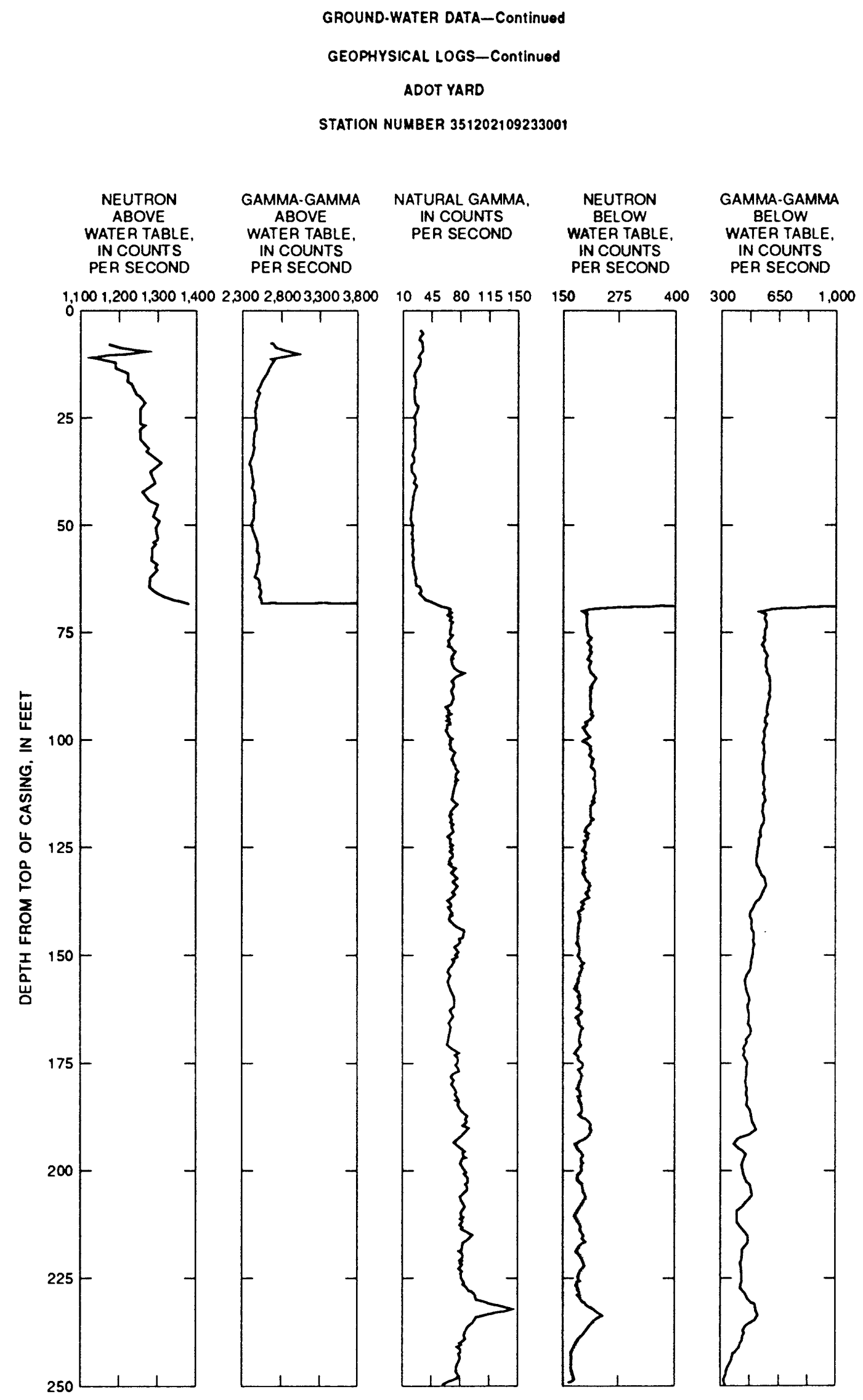




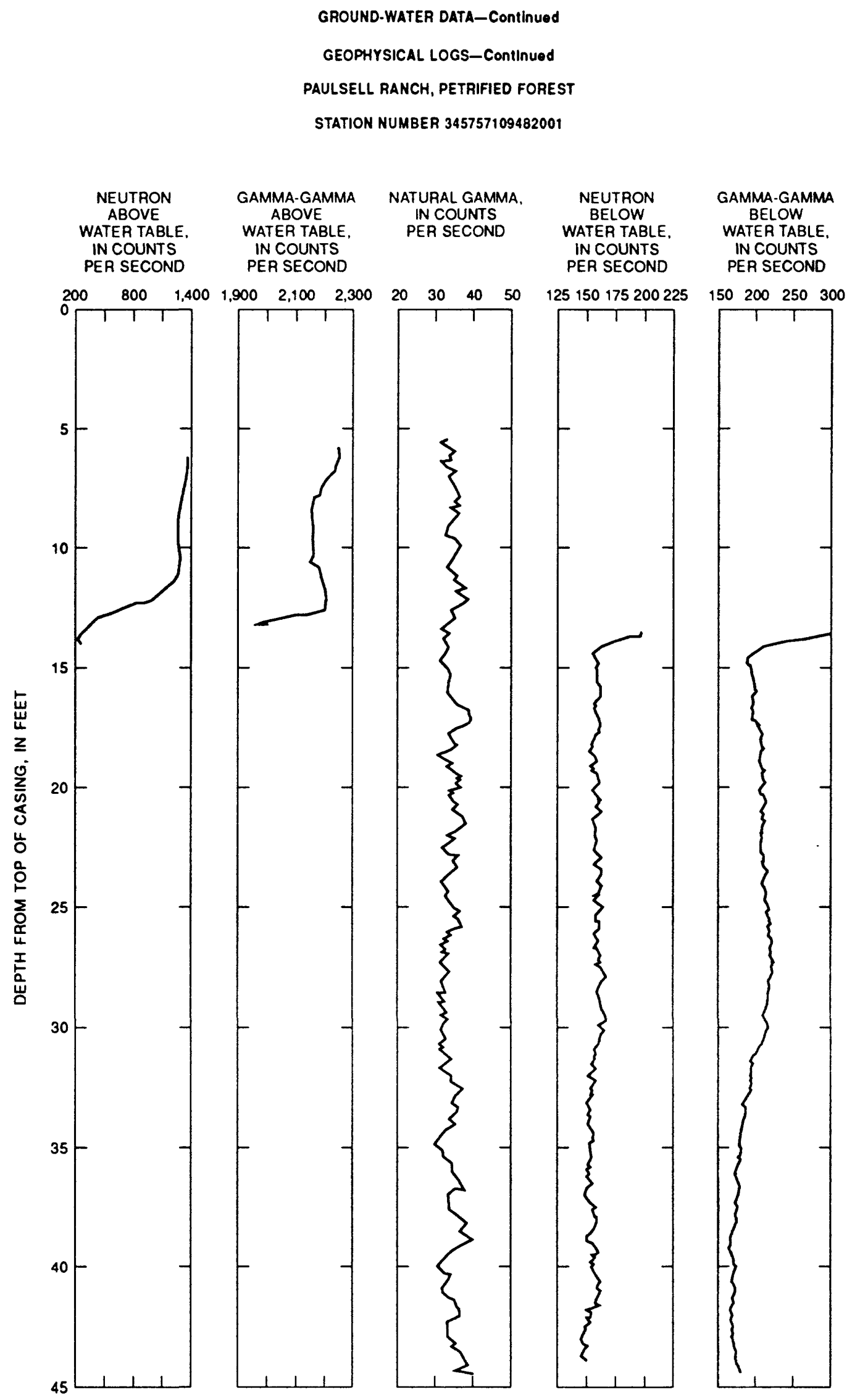




$$
\begin{aligned}
& \text { GROUND-WATER DATA-Continued } \\
& \text { GEOPHYSICAL LOGS-Continued } \\
& \text { PAULSELL RANCH, PINTA }
\end{aligned}
$$

STATION NUMBER 350338109384801

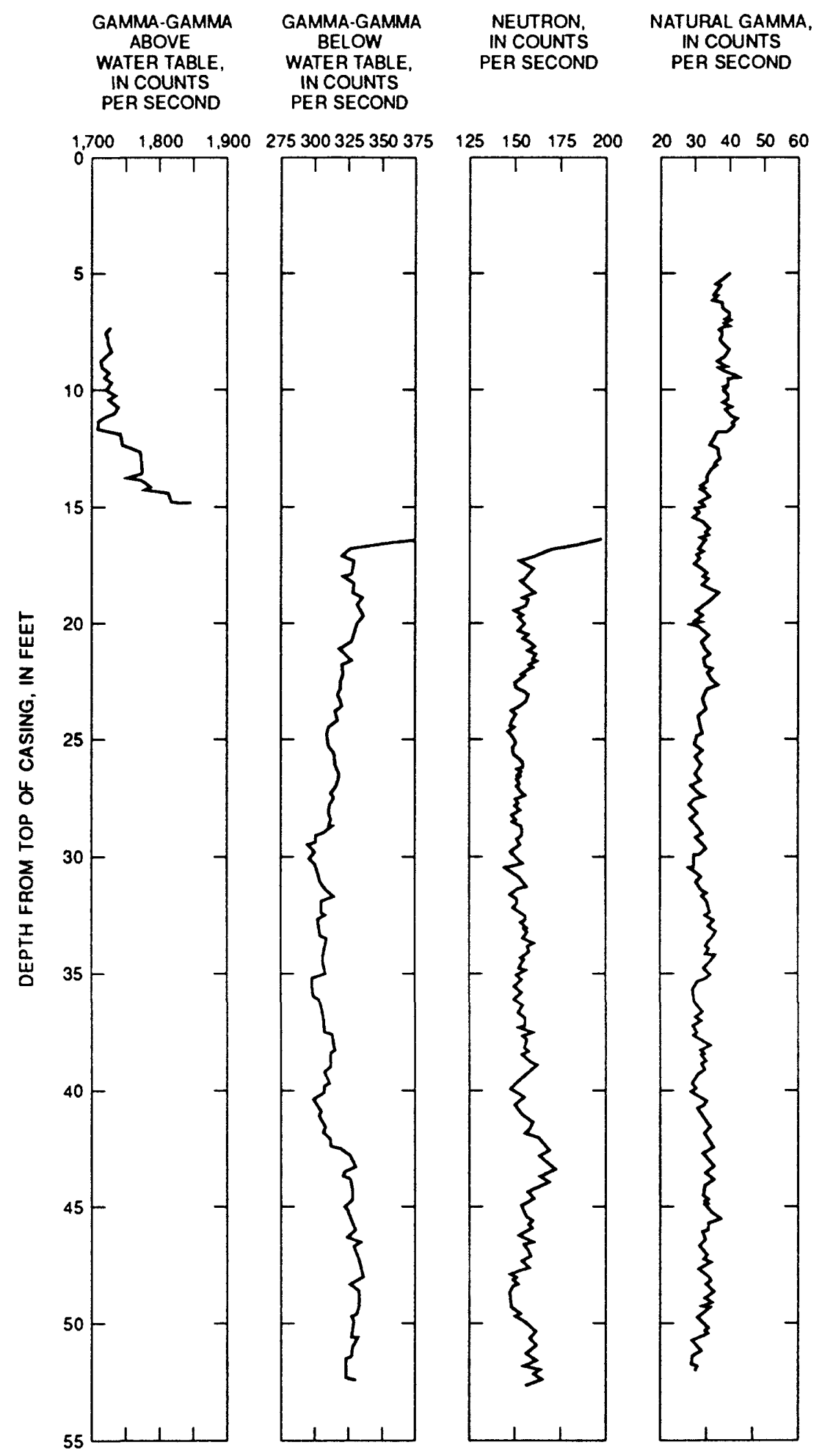


GROUND-WATER DATA-Continued

GEOPHYSICAL LOGS-Continued

SANOERS SCHOOL

STATION NUMBER 351254109194501

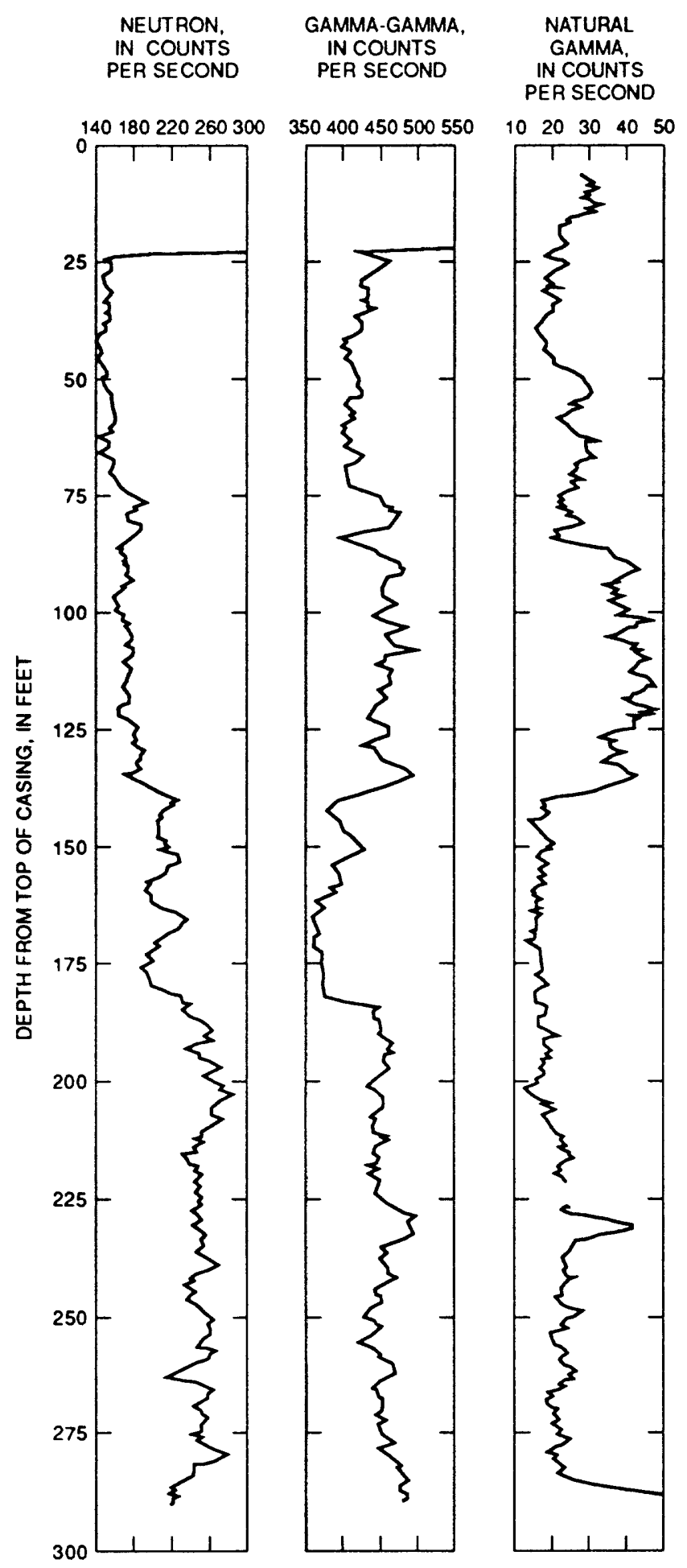


IMD, not detected; dashes, no data; E, estimated; <, less than; 'C, degrees Celsius; MGVD, Mational Geodectic Vertical Datum; $\mathrm{m}^{3} / \mathrm{s}$, cubic meters per second, $\mu \mathrm{S} / \mathrm{cm}$, microsiemens per centimeter; ac-ft, ocre-feet; mo/L, milligrans per liter; $\mu g / L$, micrograms per liter; pci/L, picocuries per liter; $\mathrm{PCi} / G$, picocuries per gram; NTU, nephelometric-turbdity units; mV, millivolt; DS, dry sieve; $P$, volue exceeds USEPA Maximum Contaminant Level; $\&$, value exceeds USEPA Secondary Maximum Contaninant Level; *, value considered poor; i, indeterminate value].

\begin{tabular}{|c|c|c|c|c|c|}
\hline $\begin{array}{l}\text { STATION } \\
\text { MAME }\end{array}$ & STATION MUMBER & DATE & TIME & LATITUDE & LONGI TUDE \\
\hline \multicolumn{6}{|c|}{ CKAMBERS WELL CLUSTER } \\
\hline $\begin{array}{l}C W-1 \\
C H-1 \\
C W-1 \\
C H-1\end{array}$ & 351043109270301 & $\begin{array}{l}12-09-88 \\
11-16-89 \\
05-02-90 \\
05-02-90\end{array}$ & $\begin{array}{l}1000 \\
1100 \\
1110 \\
1210\end{array}$ & $35 \cdot 10^{\prime} 43^{m N}$ & $109^{\circ} 27^{\prime} 03^{m y}$ \\
\hline $\begin{array}{l}C H-2 \\
C H-2 \\
C H-2 \\
C H-2 \\
C H-2\end{array}$ & 351043109270302 & $\begin{array}{l}12-09-88 \\
12-09-88 \\
11-16-89 \\
05-02-90 \\
05-02-90\end{array}$ & $\begin{array}{l}1030 \\
1200 \\
1100 \\
1400 \\
1530\end{array}$ & $35 \cdot 10^{\prime} 43^{m N}$ & $109 \cdot 27 \cdot 03$ 'и \\
\hline $\begin{array}{l}C H-3 \\
C H-3 \\
C H-3\end{array}$ & 351043109270303 & $\begin{array}{l}12-09-88 \\
11-15-89 \\
05-02-90\end{array}$ & $\begin{array}{l}1600 \\
1445 \\
1530\end{array}$ & $35 \cdot 10 \cdot 43^{m N}$ & $109^{\circ} 27^{m 03 m y}$ \\
\hline $\begin{array}{l}\text { CW-4 } \\
\text { CW-4 } \\
\text { CW-4 }\end{array}$ & 351038109270801 & $\begin{array}{l}12-07-88 \\
11-15-89 \\
05-02-90\end{array}$ & $\begin{array}{l}1623 \\
1130 \\
1715\end{array}$ & $35 \cdot 10 \cdot 38 m N$ & $109 \cdot 27 \cdot 08 \mathrm{my}$ \\
\hline $\begin{array}{l}C H-5 \\
C H-5 \\
C H-5\end{array}$ & 351038109270802 & $\begin{array}{l}12-08-88 \\
11-15-89 \\
10-31-90\end{array}$ & $\begin{array}{l}1300 \\
1245 \\
1350\end{array}$ & $35 \cdot 10 \cdot 38 m$ & $109 \cdot 27 \cdot 08 \mathrm{mu}$ \\
\hline $\begin{array}{l}\text { CH-6 } \\
\text { CH-6 } \\
\text { CH-6 }\end{array}$ & 351038109270803 & $\begin{array}{l}12-08-88 \\
11-15-89 \\
10-31-90\end{array}$ & $\begin{array}{l}1603 \\
1415 \\
1720\end{array}$ & $35 \cdot 10 \prime 38 w N$ & $109^{\circ} 27^{\prime} 08^{\mathrm{my}}$ \\
\hline $\begin{array}{l}\mathrm{CH}-7 \\
\mathrm{CH}-7 \\
\mathrm{CH}-7\end{array}$ & 351039109270001 & $\begin{array}{l}12-06-88 \\
11-14-89 \\
11-01-90\end{array}$ & $\begin{array}{l}1100 \\
1710 \\
1150\end{array}$ & $35 \cdot 10 \cdot 39$ mN & $109 \cdot 27 \cdot 00 \mathrm{my}$ \\
\hline $\begin{array}{l}C H-8 \\
C H-8 \\
C H-8\end{array}$ & 351039109270002 & $\begin{array}{l}12-06-88 \\
11-14-89 \\
10-18-90\end{array}$ & $\begin{array}{l}1632 \\
1600 \\
1455\end{array}$ & $35 \cdot 10 \cdot 39$ m & $109 \cdot 27 \cdot 00 \mathrm{~ms}$ \\
\hline $\begin{array}{l}\text { CH-9 } \\
\text { CH-9 } \\
\text { CH-9 } \\
\text { CH-9 }\end{array}$ & 351039109270003 & $\begin{array}{l}12-06-88 \\
11-15-89 \\
10-18-90 \\
10-18-90\end{array}$ & $\begin{array}{l}1130 \\
0940 \\
1545 \\
1600\end{array}$ & $35 \cdot 10 \cdot 39$ "N & $109^{\circ} 27^{\prime} 00^{\prime \prime W}$ \\
\hline $\begin{array}{l}\text { CDP-01 } \\
\text { CDP-01 } \\
\text { CDP-01 } \\
\text { CDP-01 }\end{array}$ & 351044109270501 & $\begin{array}{l}08-11-88 \\
12-07-88 \\
11-16-89 \\
10-17-90\end{array}$ & $\begin{array}{l}1400 \\
1215 \\
1430 \\
1310\end{array}$ & $35 \cdot 10 \cdot 44 \mathrm{NN}$ & $109 \cdot 27 \cdot 05^{m}$ \\
\hline $\begin{array}{l}\text { CDP-02 } \\
\text { CDP-02 }\end{array}$ & 351044109270502 & $\begin{array}{l}08-11-88 \\
11-16-89\end{array}$ & $\begin{array}{l}1630 \\
1610\end{array}$ & $35^{\circ} 10^{\prime} 44^{m} \mathrm{~N}$ & $109^{\circ} 27^{\prime} 05^{\mathrm{my}}$ \\
\hline $\begin{array}{l}\text { CDP-03 } \\
\text { CDP-03 }\end{array}$ & 351044109270503 & $\begin{array}{l}12-08-88 \\
04-04-89\end{array}$ & $\begin{array}{l}1400 \\
1045\end{array}$ & $35 \cdot 10 \cdot 44 \times N$ & $109^{\circ} 27^{\prime} 05^{\mathrm{mm}}$ \\
\hline CDP -04 & 351045109270601 & $08-11-88$ & 1800 & $35 * 10 \cdot 45 * N$ & $109^{\circ} 27^{\prime} 06^{\prime \prime} \mathrm{H}$ \\
\hline
\end{tabular}


GROUND-WATER DATA-Continued

CHEMICAL AMALYSES-Continued

\begin{tabular}{|c|c|c|c|c|c|c|c|c|c|c|}
\hline $\begin{array}{l}\text { STATION } \\
\text { MAME }\end{array}$ & DATE & $\begin{array}{l}\text { ALTITUDE } \\
\text { OF LAND } \\
\text { SURFACE } \\
\text { DATUM } \\
\text { (METERS } \\
\text { ABOVE } \\
\text { NGVD) } \\
\text { (72000) }\end{array}$ & $\begin{array}{l}\text { DEPTH } \\
\text { OF } \\
\text { LELL, } \\
\text { TOTAL } \\
\text { (METERS) } \\
\text { (T2OOB) }\end{array}$ & $\begin{array}{l}\text { DEPTH } \\
\text { BELOW } \\
\text { LAND } \\
\text { SURFACE } \\
\text { (WATER } \\
\text { LEVEL) } \\
\text { (METERS } \\
\text { (72019) }\end{array}$ & $\begin{array}{l}\text { PUMP } \\
\text { OR FLON } \\
\text { PERIOD } \\
\text { PRIOR } \\
\text { TO SAN- } \\
\text { PLING } \\
\text { (MIN) } \\
\text { (72004) }\end{array}$ & $\begin{array}{l}\text { FLOH, } \\
\text { RATE } \\
\text { INSTAN- } \\
\text { TANEOUS } \\
\left(\pi^{3} / 8\right) \\
(00059)\end{array}$ & $\begin{array}{l}\text { TENPER- } \\
\text { ATURE } \\
\text { HATER } \\
\left({ }^{\circ} \mathrm{C}\right) \\
(00010)\end{array}$ & $\begin{array}{l}\text { TUR- } \\
\text { BID- } \\
\text { ITY } \\
\text { (NTU) } \\
\text { (00076) }\end{array}$ & $\begin{array}{l}\text { OXID- } \\
\text { ATION } \\
\text { RED- } \\
\text { UCTION } \\
\text { POTEN- } \\
\text { TIAL } \\
(\mathrm{mV}) \\
(00090)\end{array}$ & $\begin{array}{l}\text { SPE- } \\
\text { CIFIC } \\
\text { CON- } \\
\text { DUCT- } \\
\text { ANCE } \\
(\mu S / \mathrm{cm}) \\
(00095)\end{array}$ \\
\hline \multicolumn{11}{|c|}{ CHAMBERS WELL CLUSTER-Cont inued } \\
\hline CW-1 & $\begin{array}{l}12-09-88 \\
11-16-89 \\
05-02-90 \\
05-02-90\end{array}$ & 1744.22 & 32.0 & $\begin{array}{l}. . \\
4.28 \\
4.21 \\
4.21\end{array}$ & $\begin{array}{l}-- \\
40 \\
45 \\
45\end{array}$ & $\begin{array}{c}\text { ND } \\
.0004 \\
.0027 \\
.0027\end{array}$ & $\begin{array}{r}12.0 \\
9.0 \\
13.0 \\
13.0\end{array}$ & $\begin{array}{l}\cdots \\
\cdots \\
\cdots \\
\cdots\end{array}$ & $\begin{array}{r}-105 \\
213 \\
22 \\
\cdots\end{array}$ & $\begin{array}{l}\cdots \\
1510 \\
1510\end{array}$ \\
\hline $\mathrm{CH}-2$ & $\begin{array}{l}12-09-88 \\
12-09-88 \\
11-16-89 \\
05-02-90 \\
05-02-90\end{array}$ & 1743.85 & 25.0 & $\begin{array}{c}\ldots \\
\ldots \\
3.41 \\
\ldots\end{array}$ & $\begin{array}{l}-. \\
40 \\
30 \\
\cdots\end{array}$ & $\begin{array}{c}.0038 \\
.0004 \\
-- \\
.0027 \\
-.\end{array}$ & $\begin{array}{c}12.5 \\
9.0 \\
\therefore- \\
12.5 \\
-.\end{array}$ & $\begin{array}{l}\ldots \\
\cdots \\
-- \\
\cdots \\
--\end{array}$ & $\begin{array}{c}77 \\
\therefore \\
-\therefore \\
162 \\
--\end{array}$ & $\begin{array}{l}1030 \\
-- \\
-- \\
982 \\
\ldots\end{array}$ \\
\hline $\mathrm{CH}-3$ & $\begin{array}{l}12-09-88 \\
11-15-89 \\
05-02-90\end{array}$ & 1744.31 & 11.7 & $\begin{array}{l}.- \\
3.68 \\
3.64\end{array}$ & $\begin{array}{l}-2 \\
30 \\
45\end{array}$ & $\begin{array}{l}.0038 \\
.0011 \\
.0027\end{array}$ & $\begin{array}{l}12.5 \\
12.5 \\
12.0\end{array}$ & $\begin{array}{l}\cdots \\
\cdots \\
\cdots\end{array}$ & $\begin{array}{r}217 \\
37 \\
166\end{array}$ & $\begin{array}{r}1100 \\
969 \\
1080\end{array}$ \\
\hline $\mathrm{CH}-4$ & $\begin{array}{l}12-07-88 \\
11-15-89 \\
05-02-90\end{array}$ & 1743.09 & 30.5 & $\begin{array}{l}-. \\
3.20 \\
3.12\end{array}$ & $\begin{array}{l}\cdots \\
28 \\
45\end{array}$ & $\begin{array}{c}. . \\
.0019 \\
.0027\end{array}$ & $\begin{array}{l}14.5 \\
14.5 \\
14.0\end{array}$ & $\begin{array}{l}-- \\
\cdots\end{array}$ & $\begin{array}{r}21 \\
-52 \\
44\end{array}$ & $\begin{array}{l}999 \\
927 \\
988\end{array}$ \\
\hline $\mathrm{CH}-5$ & $\begin{array}{l}12-08-88 \\
11-15-89 \\
10-31-90\end{array}$ & 1743.02 & 19.8 & $\begin{array}{l}.- \\
3.25 \\
4.05\end{array}$ & $\begin{array}{l}-- \\
24 \\
52\end{array}$ & $\begin{array}{c}0019 \\
. .\end{array}$ & $\begin{array}{l}14.0 \\
13.5 \\
15.0\end{array}$ & $\begin{array}{l}\cdots \\
\cdots \\
\cdots\end{array}$ & $\begin{array}{r}98 \\
6 \\
145\end{array}$ & $\begin{array}{l}956 \\
888 \\
951\end{array}$ \\
\hline $\mathrm{CH}-6$ & $\begin{array}{l}12-08-88 \\
11-15-89 \\
10-31-90\end{array}$ & 1743.14 & 9.1 & $\begin{array}{l}-. \\
3.38 \\
3.86\end{array}$ & $\begin{array}{l}-. \\
52 \\
55\end{array}$ & $\begin{array}{c}0 \\
.0019 \\
--\end{array}$ & $\begin{array}{l}14.5 \\
15.0 \\
15.0\end{array}$ & $\begin{array}{l}-- \\
\cdots \\
\cdots\end{array}$ & $\begin{array}{r}278 \\
40 \\
190\end{array}$ & $\begin{array}{l}1370 \\
1140 \\
1120\end{array}$ \\
\hline $\mathrm{CH}-7$ & $\begin{array}{l}12-06-88 \\
11-14-89 \\
11-01-90\end{array}$ & 1748.75 & 30.0 & $\begin{array}{l}-. \\
8.68 \\
9.16\end{array}$ & $\begin{array}{l}\cdots \\
20\end{array}$ & $\begin{array}{c}\ldots \\
.0030 \\
\ldots\end{array}$ & $\begin{array}{l}14.0 \\
14.0 \\
14.0\end{array}$ & $\begin{array}{c}1.0 \\
\ldots \\
\cdots\end{array}$ & $\begin{array}{r}160 \\
11 \\
110\end{array}$ & $\begin{array}{r}967 \\
1040 \\
1080\end{array}$ \\
\hline $\mathrm{CH}-8$ & $\begin{array}{l}12-06-88 \\
19-14-89 \\
10-18-90\end{array}$ & 1748.88 & 21.2 & $\begin{array}{l}8.81 \\
9.30\end{array}$ & $\begin{array}{l}-2 \\
60 \\
34\end{array}$ & $\begin{array}{l}.0038 \\
.0019 \\
.0023\end{array}$ & $\begin{array}{l}13.5 \\
14.0 \\
15.5\end{array}$ & $\begin{array}{c}1.4 \\
\cdots \\
\cdots\end{array}$ & $\begin{array}{l}244 \\
168 \\
212\end{array}$ & $\begin{array}{r}980 \\
1040 \\
1040\end{array}$ \\
\hline CW-9 & $\begin{array}{l}12-06-88 \\
11-15-89 \\
10-18-90 \\
10-18-90\end{array}$ & 1748.81 & 16.5 & $\begin{array}{c}\ldots \\
\ldots \\
9.28 \\
9.28\end{array}$ & $\begin{array}{l}\cdots \\
30 \\
27 \\
27\end{array}$ & $\begin{array}{l}.0038 \\
.0019 \\
.0030 \\
.0030\end{array}$ & $\begin{array}{l}14.0 \\
13.5 \\
15.0 \\
15.0\end{array}$ & $\begin{array}{c}1.2 \\
\cdots \\
\cdots \\
\cdots\end{array}$ & $\begin{array}{l}282 \\
140 \\
209 \\
209\end{array}$ & $\begin{array}{l}1210 \\
1160 \\
1180 \\
1180\end{array}$ \\
\hline CDP-01 & $\begin{array}{l}08-11-88 \\
12-07-88 \\
11-16-89 \\
10-17-90\end{array}$ & 1740 & $\begin{array}{l}\ldots \\
\ldots \\
. \\
.\end{array}$ & $\begin{array}{l}\cdots \\
. \\
.69\end{array}$ & $\begin{array}{l}\cdots \\
\cdots 5 \\
\cdots\end{array}$ & $\begin{array}{c}\cdots \\
.0 \\
.0004 \\
.0011\end{array}$ & $\begin{array}{r}20.0 \\
7.0 \\
14.0 \\
16.5\end{array}$ & $\begin{array}{c}6.0 \\
\cdots \\
\cdots \\
\cdots\end{array}$ & $\begin{array}{r}78 \\
126 \\
138 \\
120\end{array}$ & $\begin{array}{l}1100 \\
1060 \\
1070 \\
1290\end{array}$ \\
\hline CDP-02 & $\begin{array}{l}08-11-88 \\
11-16-89\end{array}$ & 1740 & $\begin{array}{l}-- \\
\cdots\end{array}$ & $\begin{array}{l}-. \\
.67\end{array}$ & 52 & .0008 & $\ddot{10.5}$ & $\ddot{--}$ & 129 & 1340 \\
\hline $\operatorname{COP}-03$ & $\begin{array}{l}12-08-88 \\
04-04-89\end{array}$ & 1740 & 4.7 & $\begin{array}{l}-- \\
\therefore-\end{array}$ & $\because-$ & $\begin{array}{l}-- \\
--\end{array}$ & $\begin{array}{l}13.0 \\
11.0\end{array}$ & $\begin{array}{l}. . \\
.20\end{array}$ & $\begin{array}{l}209 \\
113\end{array}$ & $\begin{array}{l}1010 \\
1050\end{array}$ \\
\hline CDP- 04 & $08-11-88$ & 1740.87 & -- & -- & -- & -- & 20.0 & -- & -. & 1260 \\
\hline
\end{tabular}


GROUND-WATER DATA-Cont inued

CHEMICAL ANALYSES-Continued

\section{STATION}

MAME

DATE

12-09-88

$11-16-89$

05-02-90

$05-02 \cdot 90$

CW-2

12-09-88

12-09-88

$11-16-89$

05-02-90

05-02-90

CW-3

12-09-88

$11-15-89$

05-02-90

Cu-4

12-07-88

$11-15-89$

05-02-90

cw-5

12-08-88

$11-15-89$

$10-31-90$

CW-6

12-08-88

$11-15-89$

$10-31-90$

CW-7

12-06-88

$11-16-89$

$11-01-90$

CW-8

12-06-88

$11-16-89$

10-18-90

CW-9

12-06-88

$11-15-89$

$10-18-90$

$10-18-90$

CDP-01

08- $11-88$

12-07-88

$11-16-89$

$10-17-90$

CDP-02

08-11-88

$11-16-89$

CDP- 03

12-08-88

04-04-89

08-11-88

CDP- 04

SPE-
CIFIC
CON-
DUCT-
ANCE
LAB
$(\mu S / \mathrm{cm})$
$(90095)$

$\begin{array}{cl} & \begin{array}{c}\text { OXYGEN } \\ \text { DEMAND, } \\ \text { CHEM- }\end{array} \\ \text { OXYGEN, } & \text { ICAL } \\ \text { DIS- } & \text { (HIGH } \\ \text { SOLVEO } & \text { LEVEL) } \\ (\mathrm{mg} / \mathrm{L}) & (\mathrm{mg} / \mathrm{L}) \\ (00300) & (00340)\end{array}$

$\begin{array}{cc}\text { PH } & \text { PH } \\ \text { WATER } & \text { MATER } \\ \text { MHOLE } & \text { MHOLE } \\ \text { FIELD } & \text { LAB } \\ \text { (STAND- } & \text { (STAND- } \\ \text { ARD } & \text { ARD } \\ \text { UNITS) } & \text { UNITS) } \\ \text { (00400) } & \text { (00403) }\end{array}$

ALKA-
LINITY
WAT DIS
FIX END
FIELD
CaCO3
$(\mathrm{mg} / \mathrm{L})$
$(39036)$

ALKa-

AINITY ALKA-

WAT DIS LINITY

TOT IT

FIELD

$\mathrm{mg} / \mathrm{L}$ as

(39086) (90410)

ChAMBERS WELL CLUSTER-Continued

$\begin{array}{lcccccc}5.6 & 120 & 7.7 & 8.1 & 970 & 992 & 959 \\ 8.5 & \ldots & 7.7 & 8.3 & 860 & 869 & \ldots \\ \ldots & \ldots & 7.5 & 8.0 & 810 & 812 & \ldots \\ .1 & \ldots & 7.5 & 7.9 & \ldots & 812 & \ldots\end{array}$

1760
1720
1570
1570

.1

\begin{tabular}{lc}
972 & ND \\
965 & 8.5 \\
\hdashline- & $\therefore$ \\
962 & $\therefore 1$ \\
$\therefore$ & $\therefore$
\end{tabular}

$10 \quad 7.5$

8.0

219

-. 213

$11 \quad 7.7$

8.0

870

$\because 7.5$

7.9

200

$1040 \quad \cdots$

$\cdots$

1050

$16 \quad 7.4$

-.

-.

976

291

.03

-.

7.4

7.8

238

$7.8 \quad 230$

$\cdots$

203

203

..

No
.03

117

7.3
7.2

$7.8 \quad 231$

$\begin{array}{llll}1 & 7.3 & 7.8 & 231 \\ & 7.2 & 7.6 & 230\end{array}$

.03

-.

7.3

7.7

220

242

230

232

$\begin{array}{llllll}940 & \text { ND } & <10 & 7.2 & 8.3 & 233\end{array}$

$\begin{array}{lll}940 & \text { ND } & <10 \\ 948 & .04 & \\ 945 & .4 & -0\end{array}$

$<10$
$\cdots$
$\cdots$

7.2

$\begin{array}{ll}8.3 & 233 \\ 7.8 & 230\end{array}$

7.1

7.7

240

233

233

236

1360

1360

$2.9<10 \quad 7.3$

$\begin{array}{ll}7.3 & 7.9 \\ 7.2 & 7.7\end{array}$

$7.9 \quad 255$

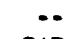

1120

-.

7.1

7.7

240

243

258

1020

ND $\quad 46 \quad 7.4$

1040

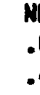

7.4

$7.9 \quad 238$

1060

.03

-.

7.4

7.

1040

1040

.

$\ldots$

7.4

7.7

230

240

247

1050

.1
.1

$\because$.

7.2

8.12210

22

234

1200
1180
1190
1190
1090
1100
977
1250

ND 11

6.9

$7.9 \quad 210$

$$
\text { - }
$$

-. 214

$\begin{array}{ll}212 & \cdots \\ 219 & 217\end{array}$

4.

\section{2}

7

220

-. 308

$\begin{array}{rrr}7.2 & 8.2 & 303 \\ -\quad 7.2 & 7.8 & 300\end{array}$

6.8

7.8

300

$\begin{array}{ll}305 & 308 \\ 382 & 296\end{array}$

$\begin{array}{lllll}.1 & \cdots & 6.8 & 7.7 & 380 \\ .1 & \cdots & 6.8 & 7.7 & 380\end{array}$

382

296

$\begin{array}{ll}.2 & \\ \text { ND } & 53 \\ .5 & - \\ .7 & \end{array}$

$53 \quad 7.3$

7.3
7.6

$\begin{array}{ll}7.6 & 213 \\ 7.9 & 230\end{array}$

$213 \quad 215$

-. $\quad 7.4$

230

215
222

1250

- 6.9

8.3

210

205

262

$\begin{array}{ccc}\cdots & \cdots & -\end{array}$

-. $\quad$ -

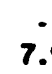

1090

1060

14

\section{7}

7.8

$\cdots \quad 7.6$

-.


GROUND-MATER DATA-Cont inued

CHEMICAL AHALYSES-Cont inued

STATION

MAME

DATE

$12-09-88$
$11-16-89$
$05-02-90$

05-02-90

Cu-2

12-09-88

$12-09-88$

$11-16-89$

$05-02-90$

05-02-90

Cu-3

12-09-88

$11-15-89$

$05-02-90$

CW-4

12-07-88

$11-15-89$

$05-02-90$

CW-5

12-08-88

$19-15 \cdot 89$

$10-31-90$

Cu-6

12-08-88

$11-15-89$

10-31-90

Cu-7

12-06-88

$11-16-89$

$11-01-90$

CW-8

12-06-88

$11-14-89$

$10-18-90$

CW-9

12-06-88

$11-15-89$

$10-18-90$

$10-18-90$

$\operatorname{CDP}-01$

$08-11-88$

$12-07-88$

$11-16-89$

$10-17-90$

CDP-02 08-19-88

$11-16-89$

$\operatorname{CDP}-03$

$12-08-88$

$04-04-89$

CDP-04 08-11-88

BICAR-
BONATE
WATER
OIS IT
FIELD
moll 88
HCO3
$(00453)$

SOLIOS, SOLIOS,

RESIDUE SUN OF

AT 180 CONSTI-

- $C$ TUENTS,

DIs-

SOLVED

( $\mathrm{mg} / \mathrm{L}$ )

Dis-

SOLVED

$(m o / L)$

(70301)
MITRO- NITRO- NITRO-

GEN, GEN, GEN,AM- PHOS-

AMHONIA NO2+MO3 MONIA + PHORUS PHOS-

OIS- DIS- ORGANIC DIS- PHORUS

SOLVED SOLVED TOTAL SOLVED TOTAL

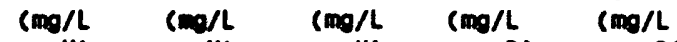

as $\mathrm{N}$ ) as $\mathrm{N}$ ) as $\mathrm{N}$ ) as P) as P)

$\begin{array}{llll}(00608) & (00631) & (00625) & (00666)\end{array}$

(00665)

CHAKBERS UELL CLUSTER-Continued

\begin{tabular}{|c|c|c|c|c|c|c|c|c|}
\hline $\begin{array}{c}1210 \\
1060 \\
990 \\
\cdots\end{array}$ & $\begin{array}{c}1180 \\
\cdots \\
\cdots \\
\cdots\end{array}$ & $\begin{array}{r}1070 \\
1010 \\
992 \\
976\end{array}$ & $\begin{array}{l}1.60 \\
1.37 \\
1.35 \\
1.33\end{array}$ & $\begin{array}{c}1.60 \\
\ldots \\
\ldots \\
\ldots\end{array}$ & $\begin{array}{r}<.100 \\
<.100 \\
<.100 \\
.100\end{array}$ & $\begin{array}{l}\because \\
\cdots \\
\cdots\end{array}$ & $\begin{array}{l}.640 \\
\therefore- \\
\cdots \\
\therefore\end{array}$ & $\begin{array}{l}\cdots \\
\cdots \\
\cdots\end{array}$ \\
\hline 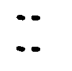 & $\begin{array}{l}646 \\
632\end{array}$ & $\begin{array}{l}630 \\
626\end{array}$ & $\begin{array}{l}.88 \\
.86\end{array}$ & $\begin{array}{l}.030 \\
.030\end{array}$ & $\begin{array}{l}.550 \\
.570\end{array}$ & 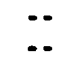 & $\begin{array}{l}.010 \\
.020\end{array}$ & $\begin{array}{l}\cdots \\
\cdots\end{array}$ \\
\hline$\ddot{n}$ & $\cdots$ & $\because$ & $\because$ & $\cdots$ & 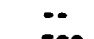 & $\cdots$ & - & $\cdots$ \\
\hline 248 & $\cdots$ & 575 & .78 & $\cdots$ & .500 & $\because$ & $\cdots$ & $\cdots$ \\
\hline$\cdots$ & $\cdots$ & $\cdots$ & $\cdots$ & $\cdots$ & $\cdots$ & $\cdots$ & $\cdots$ & $\cdots$ \\
\hline $\begin{array}{l}293 \\
295 \\
281\end{array}$ & $\begin{array}{l}\ldots \\
\cdots\end{array}$ & $\begin{array}{l}\cdots \\
659 \\
634\end{array}$ & $\begin{array}{l}.9 \\
.90 \\
.86\end{array}$ & $\begin{array}{c}.060 \\
\ldots \\
\ldots\end{array}$ & $\begin{array}{r}.230 \\
<.100 \\
.300\end{array}$ & $\begin{array}{l}\cdots \\
\cdots\end{array}$ & $\begin{array}{l}.020 \\
-. \\
\cdots\end{array}$ & $\begin{array}{l}\cdots \\
\cdots \\
\cdots\end{array}$ \\
\hline $\begin{array}{l}\ddot{283} \\
268\end{array}$ & $\begin{array}{l}629 \\
\cdots \\
\cdots\end{array}$ & $\begin{array}{l}633 \\
627 \\
557\end{array}$ & $\begin{array}{l}.86 \\
.85 \\
.76\end{array}$ & $\begin{array}{l}.690 \\
\cdots \\
\cdots\end{array}$ & $\begin{array}{r}.260 \\
.650 \\
\times .100\end{array}$ & $\begin{array}{c}1.0 \\
\cdots \\
\cdots\end{array}$ & $\begin{array}{l}.010 \\
\cdots \\
-\cdot\end{array}$ & $\begin{array}{c}.050 \\
\cdots \\
\cdots\end{array}$ \\
\hline $\begin{array}{l}284 \\
284 \\
290\end{array}$ & $\begin{array}{l}604 \\
\therefore \\
606\end{array}$ & $\begin{array}{l}598 \\
\cdots \\
616\end{array}$ & $\begin{array}{l}.82 \\
. .82 \\
.82\end{array}$ & $\begin{array}{l}.200 \\
\cdots \\
\cdots\end{array}$ & $\begin{array}{r}<.100 \\
<.100 \\
.015\end{array}$ & $\begin{array}{l}\cdots \\
\cdots \\
\cdots\end{array}$ & $\begin{array}{c}<.010 \\
\ldots \\
.012\end{array}$ & $\begin{array}{l}\cdots \\
\cdots \\
\cdots\end{array}$ \\
\hline $\begin{array}{l}315 \\
296 \\
293\end{array}$ & $\begin{array}{l}933 \\
\cdots \\
710\end{array}$ & $\begin{array}{l}911 \\
759 \\
732\end{array}$ & $\begin{array}{r}1.27 \\
1.03 \\
.97\end{array}$ & $\begin{array}{l}.020 \\
\ldots \\
\cdots\end{array}$ & $\begin{array}{r}.110 \\
.190 \\
.189\end{array}$ & $\begin{array}{l}\because \\
\cdots \\
\cdots\end{array}$ & $\begin{array}{c}.010 \\
\ldots \\
.014\end{array}$ & $\begin{array}{l}\cdots \\
\cdots\end{array}$ \\
\hline $\begin{array}{l}290 \\
279 \\
288\end{array}$ & $\begin{array}{l}684 \\
\cdots \\
682\end{array}$ & $\begin{array}{l}697 \\
654 \\
689\end{array}$ & $\begin{array}{l}.93 \\
.89 \\
.93\end{array}$ & $\begin{array}{l}\cdots \\
\cdots\end{array}$ & $\begin{array}{l}. .170 \\
.222\end{array}$ & $\begin{array}{l}<.20 \\
\cdots \\
\cdots\end{array}$ & $\begin{array}{l}\ldots \\
.018\end{array}$ & $\begin{array}{l}.010 \\
\cdots \\
\cdots\end{array}$ \\
\hline $\begin{array}{l}261 \\
259 \\
267\end{array}$ & $\begin{array}{l}692 \\
-- \\
694\end{array}$ & $\begin{array}{l}691 \\
676 \\
707\end{array}$ & $\begin{array}{l}.94 \\
.92 \\
.94\end{array}$ & $\begin{array}{l}.030 \\
\cdots \\
\cdots\end{array}$ & $\begin{array}{r}<.100 \\
.800 \\
.833\end{array}$ & $\begin{array}{l}<.20 \\
\because . \\
-.\end{array}$ & $\begin{array}{c}<.010 \\
-. \\
.012\end{array}$ & $\begin{array}{c}<.010 \\
\ldots \\
\ldots\end{array}$ \\
\hline $\begin{array}{l}376 \\
372 \\
466 \\
466\end{array}$ & \begin{tabular}{l}
789 \\
\hdashline- \\
774 \\
768
\end{tabular} & $\begin{array}{l}799 \\
766 \\
836 \\
842\end{array}$ & $\begin{array}{l}1.07 \\
1.04 \\
1.05 \\
1.04\end{array}$ & $\begin{array}{l}\cdots \\
\cdots \\
\cdots\end{array}$ & $\begin{array}{c}-. \\
<.100 \\
-. \\
.014\end{array}$ & $\begin{array}{l}<.20 \\
\cdots \\
\cdots \\
\cdots\end{array}$ & $\begin{array}{l}\ldots \\
\ldots \\
.011\end{array}$ & $\begin{array}{c}<.010 \\
\ldots \\
\ldots \\
\ldots\end{array}$ \\
\hline $\begin{array}{l}260 \\
279 \\
250 \\
320\end{array}$ & $\begin{array}{l}717 \\
736 \\
\cdots \\
882\end{array}$ & $\begin{array}{l}727 \\
746 \\
721 \\
846\end{array}$ & $\begin{array}{r}.98 \\
1.00 \\
.98 \\
1.20\end{array}$ & $\begin{array}{c}.480 \\
.380 \\
.- \\
.-\end{array}$ & $\begin{array}{c}<.100 \\
<.100 \\
-. \\
.397\end{array}$ & $\begin{array}{l}.90 \\
\because- \\
\cdots \\
\cdots\end{array}$ & $\begin{array}{c}.040 \\
.030 \\
.0 \\
.034\end{array}$ & $\begin{array}{l}.040 \\
\cdots \\
\cdots \\
\cdots\end{array}$ \\
\hline$\ddot{262}$ & $\because$ & 875 & 1.19 & 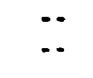 &. .220 & $\ddot{-\cdot}$ & $\because \cdot$ & $\because$ \\
\hline $\begin{array}{l}279 \\
273\end{array}$ & $\begin{array}{l}717 \\
691\end{array}$ & $\begin{array}{l}714 \\
699\end{array}$ & $\begin{array}{l}.98 \\
.94\end{array}$ & $\begin{array}{r}<.010 \\
.010\end{array}$ & $\begin{array}{l}<.100 \\
<.100\end{array}$ & .30 & $\begin{array}{r}.020 \\
<.010\end{array}$ & .010 \\
\hline
\end{tabular}


STATION

MAME

DATE
PHOS- PHOS-

PHORUS PHATE, CARBON, MARD-
ORTHO, ORTHO, ORGANIC CARBON, MESS CALCIUM SIUH, SOOIUN, SODIUM

DIS- DIS- DIS- CRGANIC TOTAL DIS- DIS- DIS- AD-

SOLVED SOLVED SOLVED TOTAL (mg/L SOLVED SOLVED SOLVED SORP-

$(\mathrm{mg} / \mathrm{L} \quad(\mathrm{mg} / \mathrm{L} \quad(\mathrm{mg} / \mathrm{L} \quad(\mathrm{mg} / \mathrm{L}$ as $(\mathrm{mg} / \mathrm{L} \quad(\mathrm{mg} / \mathrm{L} \quad(\mathrm{mg} / \mathrm{L}$ TION SOOIUN

as P) as PO4) as () as () CaCO3) as (a) as $\mathrm{Mg}$ ) as $\mathrm{Na}$ ) RATIO PERCENT

(00671) (00660) (00681) (00680) (00900) (00915) (00925) (00930) (00931) (00932)

CHAMBERS WELL CLUSTER-Cont inued

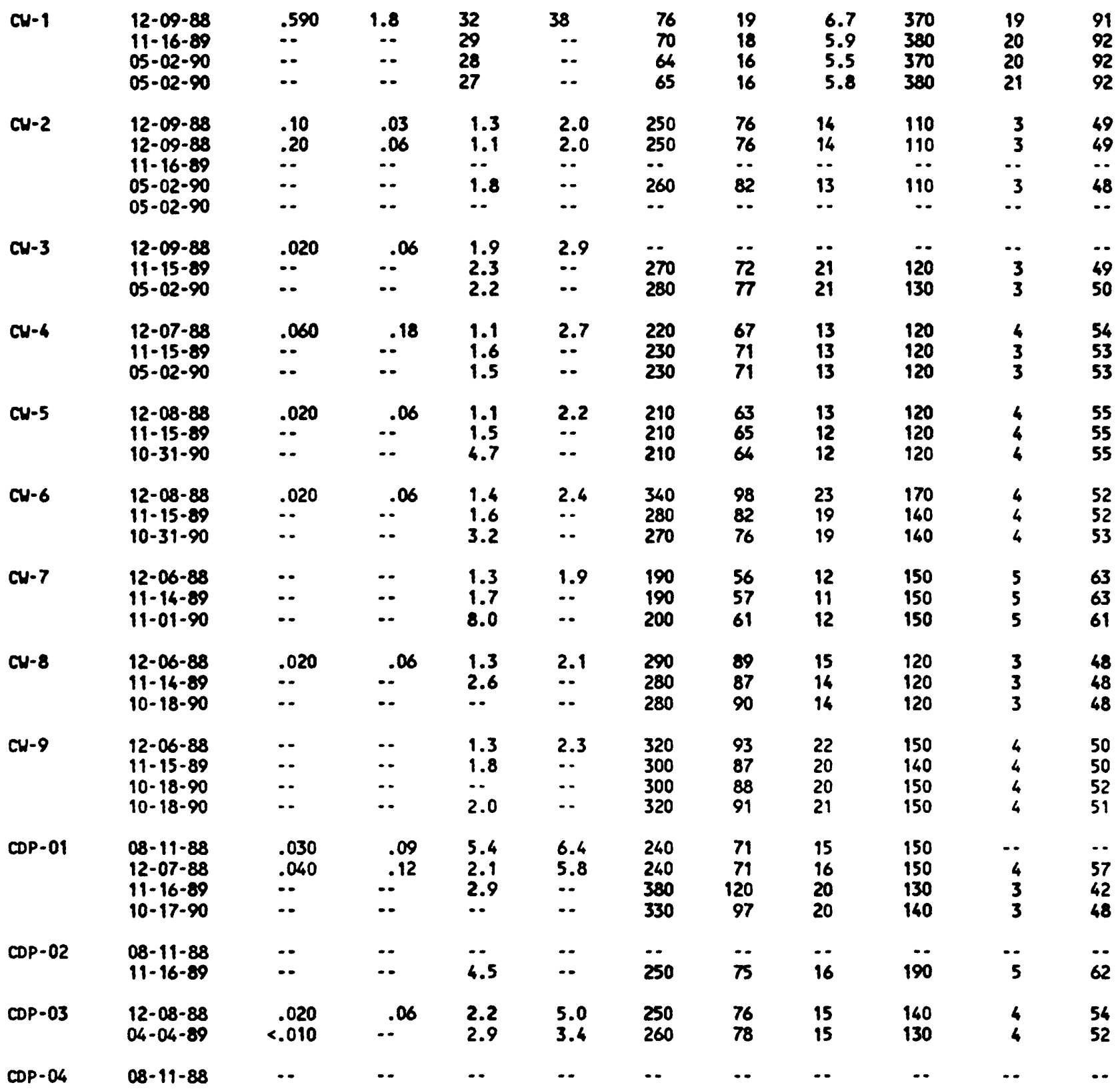


GROAND-WATER DATA-Continued

CHEMICAL AMALYSES-continued

STATION

MAME

DATE

\begin{tabular}{|c|c|c|c|c|c|c|c|c|c|c|}
\hline $\mathbf{E}$ & $\begin{array}{l}\text { POTAS- } \\
\text { SIUA, } \\
\text { DIS- } \\
\text { SOLVED } \\
(m g / L \\
\text { As K) }\end{array}$ & $\begin{array}{l}\text { CHLO- } \\
\text { RIDE, } \\
\text { DIS- } \\
\text { SOLVED } \\
\text { (mo/l } \\
\text { as Cl) }\end{array}$ & $\begin{array}{c}\text { BRONIDE } \\
\text { DIS- } \\
\text { SOLVED } \\
\text { (mo/L } \\
\text { as Br) } \\
(71870)\end{array}$ & $\begin{array}{l}\text { FLUO- } \\
\text { RIDE, } \\
\text { DIS- } \\
\text { SOLVED } \\
(\mathrm{mg} / \mathrm{L} \\
\text { as F) } \\
(00950)\end{array}$ & $\begin{array}{l}\text { SILICA, } \\
\text { DIS- } \\
\text { SOLVED } \\
\text { (mg/L } \\
\text { as } \\
\text { sio2 } \\
(00955)\end{array}$ & $\begin{array}{c}\text { SULFATE } \\
\text { DIS- } \\
\text { SOLVED } \\
\text { (mo/L } \\
\text { as so4) } \\
\text { (00945) }\end{array}$ & $\begin{array}{c}\text { ARSENIC } \\
\text { DIS- } \\
\text { SOLVED } \\
(\mu g / L \\
\text { as As) } \\
(0100 S 0)\end{array}$ & $\begin{array}{l}\text { BARIUA, } \\
\text { DIS- } \\
\text { SOLVED } \\
(\mu g / L \\
\text { as Ba) } \\
\text { (01005) }\end{array}$ & $\begin{array}{l}\text { BERYL- } \\
\text { LIUA, } \\
\text { DIS- } \\
\text { SOLVED } \\
\text { (ug/L } \\
\text { os Be) } \\
(01010)\end{array}$ & $\begin{array}{c}\text { BORON, } \\
\text { DIS- } \\
\text { SOL VED } \\
(\mu \mathcal{L} / \\
\text { as B) } \\
(01020)\end{array}$ \\
\hline
\end{tabular}

CHAMBERS WELL CLUSTER-Continued

\begin{tabular}{|c|c|c|c|c|c|c|c|c|c|c|c|}
\hline CN-1 & $\begin{array}{l}12-09-88 \\
11-16-89 \\
05-02-90 \\
05-02-90\end{array}$ & $\begin{array}{l}2.8 \\
2.5 \\
3.0 \\
2.8\end{array}$ & $\begin{array}{l}32 \\
33 \\
38 \\
37\end{array}$ & $\begin{array}{l}.16 \\
.20 \\
.070 \\
.090\end{array}$ & $\begin{array}{l}.60 \\
.70 \\
.60 \\
.50\end{array}$ & $\begin{array}{l}15 \\
15 \\
15 \\
15\end{array}$ & $\begin{array}{l}25 \\
28 \\
55 \\
30\end{array}$ & $\begin{array}{l}5 \\
\cdots \\
\cdots \\
\cdots\end{array}$ & $\begin{array}{l}800 \\
610 \\
660 \\
660\end{array}$ & $\begin{array}{l}\cdots \\
<.5 \\
<.5 \\
<.5\end{array}$ & $\begin{array}{l}920 \\
-- \\
-- \\
--\end{array}$ \\
\hline \multirow[t]{3}{*}{ CU-2 } & $\begin{array}{l}12 \cdot 09-88 \\
12-09-88\end{array}$ & $\begin{array}{l}2.2 \\
2.1\end{array}$ & $\begin{array}{l}40 \\
39\end{array}$ & $\begin{array}{l}.13 \\
.14\end{array}$ & $\begin{array}{l}.60 \\
.60\end{array}$ & $\begin{array}{l}12 \\
12\end{array}$ & $\begin{array}{l}240 \\
240\end{array}$ & $<1$ & $\begin{array}{l}<100 \\
<100\end{array}$ & 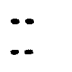 & $\begin{array}{l}170 \\
170\end{array}$ \\
\hline & $\begin{array}{l}11-16-89 \\
05-02.90\end{array}$ & $\ddot{2.0}$ & $\ddot{40}$ & $\because 15$ & .60 & $\ddot{12}$ & $\ddot{190}$ & $\ddot{\cdots}$ & $\ddot{57}$ & $\ddot{5}$ & $\cdots$ \\
\hline & $05-02-90$ & $\cdots$ & -. & $\therefore$ & $\cdots$ & 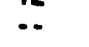 & .. & $\cdots$ & 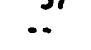 & $\begin{array}{l}2.3 \\
\cdots\end{array}$ & $\ldots$ \\
\hline $\mathrm{CH}-3$ & $\begin{array}{l}12-09 \cdot 88 \\
11-15-89 \\
05-02 \cdot 90\end{array}$ & $\begin{array}{l}-2 \\
1.4 \\
1.1\end{array}$ & $\begin{array}{l}-\cdot \\
51\end{array}$ & $\begin{array}{l}.32 \\
.16 \\
.19\end{array}$ & $\begin{array}{l}. . \\
.70 \\
.30\end{array}$ & $\begin{array}{l}\cdots \\
13 \\
12\end{array}$ & $\begin{array}{l}240 \\
200\end{array}$ & $\begin{array}{l}1 \\
\therefore \\
\cdots\end{array}$ & $\begin{array}{r}<100 \\
42 \\
48\end{array}$ & $\begin{array}{l}\ddot{<} \\
<.5 \\
<.5\end{array}$ & $\begin{array}{l}200 \\
\cdots \\
\cdots\end{array}$ \\
\hline $\mathrm{CN}-4$ & $\begin{array}{l}12-07-88 \\
11-15-89 \\
05-02-90\end{array}$ & $\begin{array}{l}3.6 \\
3.8 \\
3.4\end{array}$ & $\begin{array}{l}40 \\
38 \\
40\end{array}$ & $\begin{array}{l}.22 \\
.15 \\
.16\end{array}$ & $\begin{array}{l}.50 \\
.50 \\
.20\end{array}$ & $\begin{array}{l}15 \\
16 \\
15\end{array}$ & $\begin{array}{l}230 \\
220 \\
160\end{array}$ & $\begin{array}{l}<1 \\
\cdots \\
\cdots\end{array}$ & $\begin{array}{r}<100 \\
61 \\
65\end{array}$ & $\begin{array}{l}<. \\
<.5 \\
<.5\end{array}$ & $\begin{array}{l}190 \\
\cdots \\
\cdots\end{array}$ \\
\hline$C W-5$ & $\begin{array}{l}12-08-88 \\
11-15-89 \\
10-31-90\end{array}$ & $\begin{array}{l}2.3 \\
2.1 \\
2.2\end{array}$ & $\begin{array}{l}43 \\
34 \\
39\end{array}$ & $\begin{array}{l}.17 \\
.18 \\
.18\end{array}$ & $\begin{array}{l}.70 \\
.70 \\
.50\end{array}$ & $\begin{array}{l}14 \\
14 \\
14\end{array}$ & $\begin{array}{l}200 \\
210 \\
220\end{array}$ & $\begin{array}{l}2 \\
\cdots \\
1\end{array}$ & $\begin{array}{r}<100 \\
32 \\
34\end{array}$ & $\begin{array}{l}<. \\
<.5 \\
<.5\end{array}$ & $\begin{array}{l}180 \\
\cdots \\
200\end{array}$ \\
\hline $\mathrm{CH}-6$ & $\begin{array}{l}12-08-88 \\
11-15-89 \\
10-31-90\end{array}$ & $\begin{array}{l}.90 \\
.60 \\
.40\end{array}$ & $\begin{array}{l}75 \\
52 \\
54\end{array}$ & $\begin{array}{l}.29 \\
.17 \\
.22\end{array}$ & $\begin{array}{l}.70 \\
.90 \\
.70\end{array}$ & $\begin{array}{l}16 \\
16 \\
15\end{array}$ & $\begin{array}{l}370 \\
300 \\
280\end{array}$ & $\begin{array}{l}1 \\
-- \\
<1\end{array}$ & $\begin{array}{r}<100 \\
19 \\
22\end{array}$ & $\begin{array}{l}\cdots . \\
<.5 \\
<.5\end{array}$ & $\begin{array}{l}300 \\
\cdots \\
290\end{array}$ \\
\hline CN-7 & $\begin{array}{l}12-06-88 \\
11-14-89 \\
11-01-90\end{array}$ & $\begin{array}{l}3.1 \\
3.1 \\
2.9\end{array}$ & $\begin{array}{l}49 \\
41 \\
46\end{array}$ & $\begin{array}{l}.16 \\
.13 \\
.17\end{array}$ & $\begin{array}{l}.60 \\
.70 \\
.40\end{array}$ & $\begin{array}{l}12 \\
12 \\
12\end{array}$ & $\begin{array}{l}270 \$ \\
240 \$ \\
260 \$\end{array}$ & $\begin{array}{l}<1 \\
\therefore< \\
<1\end{array}$ & $\begin{array}{l}59 \\
52 \\
55\end{array}$ & $\begin{array}{l}\cdots . \\
<.5 \\
<.5\end{array}$ & $\begin{array}{l}170 \\
\cdots \\
210\end{array}$ \\
\hline$C N-8$ & $\begin{array}{l}12-06-88 \\
11-14-89 \\
10-18-90\end{array}$ & $\begin{array}{l}2.5 \\
2.2 \\
2.4\end{array}$ & $\begin{array}{l}50 \\
46 \\
51\end{array}$ & $\begin{array}{l}.16 \\
.16 \\
.17\end{array}$ & $\begin{array}{l}.60 \\
.60 \\
.40\end{array}$ & $\begin{array}{l}13 \\
13 \\
12\end{array}$ & $\begin{array}{l}270 \$ \\
260 \$ \\
280 \$\end{array}$ & $\begin{array}{l}<1 \\
\therefore \\
<1\end{array}$ & $\begin{array}{l}50 \\
49 \\
53\end{array}$ & $\begin{array}{l}\cdots \\
<.5 \\
<.5\end{array}$ & $\begin{array}{l}170 \\
\cdots \\
170\end{array}$ \\
\hline $\mathrm{CH} \cdot 9$ & $\begin{array}{l}12-06-88 \\
11-15-89 \\
10-18-90 \\
10-18-90\end{array}$ & $\begin{array}{l}2.0 \\
1.9 \\
1.9 \\
1.9\end{array}$ & $\begin{array}{l}50 \\
47 \\
51 \\
52\end{array}$ & $\begin{array}{l}.22 \\
.18 \\
.23 \\
.24\end{array}$ & $\begin{array}{l}.50 \\
.50 \\
.30 \\
.20\end{array}$ & $\begin{array}{l}15 \\
15 \\
14 \\
15\end{array}$ & $\begin{array}{l}280 \ddagger \\
270 \ddagger \\
280 \ddagger \\
280\end{array}$ & $\begin{array}{l}<1 \\
\therefore< \\
<1\end{array}$ & $\begin{array}{l}43 \\
40 \\
42 \\
46\end{array}$ & $\begin{array}{l}-. \\
<.5 \\
<.5 \\
<.5\end{array}$ & $\begin{array}{l}200 \\
\cdots \\
210 \\
200\end{array}$ \\
\hline CDP-01 & $\begin{array}{l}08-11-88 \\
12-07-88 \\
11-16-89 \\
10-17-90\end{array}$ & $\begin{array}{l}3.9 \\
3.2 \\
3.7 \\
4.2\end{array}$ & $\begin{array}{l}61 \\
53 \\
54 \\
36\end{array}$ & $\begin{array}{l}. \\
.15 \\
. \\
.070\end{array}$ & $\begin{array}{c}.60 \\
.40 \\
1.1 \\
.10\end{array}$ & $\begin{array}{c}12 \\
9.1 \\
5.5 \\
12\end{array}$ & $\begin{array}{l}280 \ddagger \\
300 \$ \\
260 \$ \\
370 \$\end{array}$ & $\begin{array}{r}3 \\
4 \\
-\therefore \\
2\end{array}$ & $\begin{array}{r}120 \\
100 \\
42 \\
170\end{array}$ & 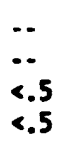 & $\begin{array}{l}190 \\
120 \\
\because- \\
180\end{array}$ \\
\hline CDP.02 & $\begin{array}{l}08-11-88 \\
11-16-89\end{array}$ & 3.6 & $\ddot{76}$ & $\ddot{-.}$ & $\begin{array}{l}-. \\
.20\end{array}$ & 9.8 & $\ddot{370}$ & $\ddot{-}$ & $\ddot{110}$ & $\ddot{<.5}$ & $\ddot{-.}$ \\
\hline CDP-03 & $\begin{array}{l}12-08-88 \\
04-04-89\end{array}$ & $\begin{array}{l}3.6 \\
3.3\end{array}$ & $\begin{array}{l}49 \\
46\end{array}$ & .14 & $\begin{array}{l}.70 \\
.70\end{array}$ & $\begin{array}{l}11 \\
10\end{array}$ & $\begin{array}{l}280 \notin \\
280 \notin\end{array}$ & $\begin{array}{l}1 \\
1\end{array}$ & $\begin{array}{l}100 \\
\therefore\end{array}$ & $\ddot{-}$ & $\begin{array}{l}170 \\
150\end{array}$ \\
\hline
\end{tabular}




\begin{tabular}{|c|c|c|c|c|c|c|c|c|c|c|c|}
\hline $\begin{array}{l}\text { STATION } \\
\text { MANE }\end{array}$ & DATE & $\begin{array}{c}\text { CADMIUA } \\
\text { DIS- } \\
\text { SOLVED } \\
\text { ( } \mu \mathrm{g} / \mathrm{L} \\
\text { as Cd) } \\
(01025)\end{array}$ & $\begin{array}{l}\text { CHRO- } \\
\text { MIUH, } \\
\text { DIS- } \\
\text { SOLVED } \\
\text { ( } \mu Q / L \\
\text { as Cr) } \\
(01030)\end{array}$ & $\begin{array}{c}\text { CHRO- } \\
\text { MIUH, } \\
\text { HEXA- } \\
\text { VALENT, } \\
\text { DIS. } \\
\text { ( } \mu g / L \\
\text { as Cr) } \\
\text { (01032) }\end{array}$ & $\begin{array}{c}\text { COBALT, } \\
\text { DIS- } \\
\text { SOAVED } \\
(\mu g / L \\
\text { As Co) } \\
(01035)\end{array}$ & $\begin{array}{l}\text { COPPER, } \\
\text { DIS- } \\
\text { SOLVED } \\
\text { ( } \mu g / L \\
\text { as Cu) } \\
(01040)\end{array}$ & $\begin{array}{l}\text { IRON, } \\
\text { DIS- } \\
\text { SOLVED } \\
\text { ( } \mu 9 / L \\
\text { as Fe) } \\
(01046)\end{array}$ & $\begin{array}{l}\text { LEAD, } \\
\text { DIS- } \\
\text { SOLVED } \\
\text { ( } \mu Q / L \\
\text { AS Pb) } \\
(01049)\end{array}$ & $\begin{array}{l}\text { MANGA- } \\
\text { NESE, } \\
\text { DIS- } \\
\text { SOLVED } \\
\text { ( } \mu \mathrm{g} / \mathrm{L} \\
\text { as Mn) } \\
(01056)\end{array}$ & $\begin{array}{c}\text { MERCURY } \\
\text { DIS- } \\
\text { SOLVED } \\
\text { ( } \mu \mathrm{g} / \mathrm{L} \\
\text { as } \mathrm{Hg}) \\
(71890)\end{array}$ & $\begin{array}{c}\text { MOLYB- } \\
\text { DEMUM, } \\
\text { DIS- } \\
\text { SOLVED } \\
(\mu g / L \\
\text { as Mo) } \\
(01060)\end{array}$ \\
\hline
\end{tabular}

cu-1

CN-2

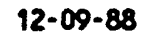

$11-16-89$

$05-02-90$

05-02-90

12-09-88

$12-09-88$

$11-16-89$

05-02-90

05- 02-90

CH-3

12-09-88

$11-15-89$

05-02-90

CW-6

12-07-88

$11-15-89$

05-02-90

CW-5

$12-08-88$

$11-15-89$

$10 \cdot 31-90$

CH-6

12-08-88

$11-15-89$

$10-31-90$

CW-7

$12-06-88$

$11-14-89$

$11-01-90$

CW-8

$12-06-88$

$11-14-89$

$10-18-90$

CW-9

12-06-88

$11-15-89$

$10-18-90$

10- $18-90$

CDP-01

08-11-88

12-07-88

$11-16-89$

$10-17-90$

CDP-02

08-11-88

$11-16-89$

CDP -03

12-08-88

$04-04-89$

CDP -04

$08-11-88$

CHNBEERS IELL CLUSTER-continued

$<1.0$
$<1.0$
$<1.0$
2.0

$<1.0 \quad \cdots$

$<1.0$ -

..

$<1.0 \quad \ldots \quad<1$

$<1.0$

$<1.0 \quad \cdots$

2.0

2.0

$<1.0$

$<1.0$

1.0
$<1.0$

$<1.0$

2.0
$<1.0$

$<1.0$

$\begin{array}{rl}2.0 & <.0 \\ <1.0 & 5\end{array}$

$<1.0$

2.0
$<1.0$

$<1.0$

$<1.0$

$\begin{array}{rr}1.0 & \ldots \\ 1.0 & \ldots \\ <1.0 & <5 \\ <1.0 & <5\end{array}$

1
$<1$
$\cdots$

$\begin{array}{ll}<1.0 & \ldots \\ <1.0 & \end{array}$

$<1$
$\ldots$
$\ldots$

1

$-$

-. $\because 0$

$\because 0$

$<1.0$

$<1$
$\cdots$
$\cdots$

$<1$
$<3$
$<3$

1
$<10$
$<10$
$<10$

6604

480

950

$<5$
$<101$
$<10$

$<10 i$
$<10 i$

$\begin{array}{ll}30 & <5 \\ 30 & <5 \\ -. & \quad- \\ 19 & <10 i \\ .- & -.\end{array}$

1

3
$\cdots$
$\cdots$

1
$\cdots$
$\cdots$

$\begin{array}{ll}1 & <1 \\ . & <3 \\ . & <3\end{array}$

$<1$
$<3$

3
$<10$

20

13
15

$<5$

$<10 i$

$<1 \quad<1$

1200

9901
1200

$<5$

$<10 i$

290
150

$<1 \quad 2$

2
$<10$
$<10$

$<5$
$<10 i$

$<10 i$

$20<$

$<5$
$<10$

$<10 i$

17
100

$<5$

$<10 i$

$\begin{array}{rrr}1 & 1\end{array}$

$\begin{array}{lll}\ldots & <3 & <10 \\ \cdots & <3 & <10\end{array}$

$\begin{array}{rrr}1 & <1 & 1 \\ -. & <3 & <10\end{array}$

$<3$

$<3$

$<10$
$<10$

$<1.0$
9
20

$<$

$<10$

$<10$

$\begin{array}{rr}7 & <5 \\ 14 & <10 i \\ 7 & <10 i\end{array}$

$<10 i$

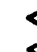

$<5 \quad 3300$ \& $<.1 \quad 20$

$<5 \quad 3200$ \& $\quad .6 \quad 11$

$<10 i \quad 2300 ; \quad \cdots \quad<10$

$340 \div<10 i \quad 5000$

$<10 i$

3200

$100 \leqslant<.1 \quad 11$ 
Chemical AHALYSES-Cont inued

STATION

MAME
DATE

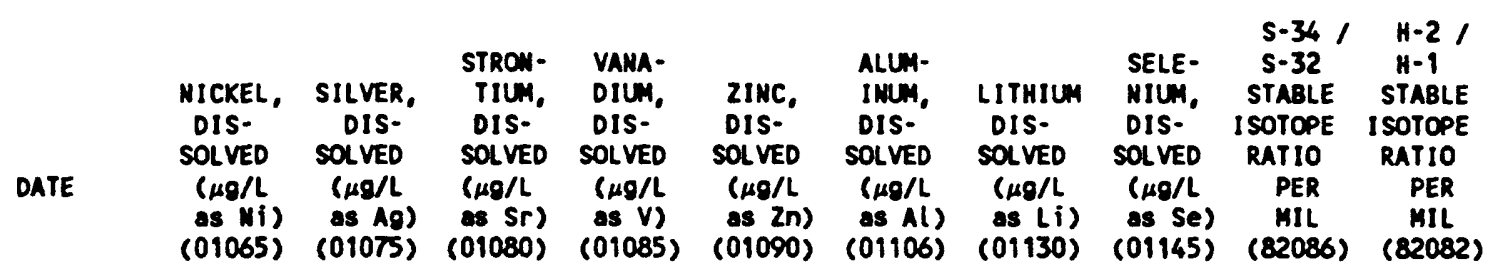

CHAMBERS WELL CLUSTER-Continued

\begin{tabular}{|c|c|c|c|c|c|c|c|c|c|c|c|}
\hline CU-1 & $\begin{array}{l}12-09-88 \\
11-16-89 \\
05-02-90 \\
05-02-90\end{array}$ & $\begin{array}{r}2 \\
<10 \\
<10 \\
10\end{array}$ & $\begin{array}{r}<1.0 \\
<1.0 \\
2.0\end{array}$ & $\begin{array}{l}520 \\
480 \\
450 \\
460\end{array}$ & $\begin{array}{l}13 \\
46 \\
46 \\
46\end{array}$ & $\begin{array}{r}<10 \\
<3 \\
E 17 \\
E 11\end{array}$ & $\begin{array}{l}30 \\
\cdots \\
\cdots\end{array}$ & $\begin{array}{l}\because 9 \\
110 \\
110 \\
110\end{array}$ & $\begin{array}{l}<1 \\
\therefore \\
\therefore\end{array}$ & $\begin{array}{l}\cdots \\
\cdots \\
\cdots\end{array}$ & $\begin{array}{c}-76.5 \\
\ldots \\
\ldots \\
\ldots\end{array}$ \\
\hline $\mathrm{Cu}-2$ & $\begin{array}{l}12-09-88 \\
12-09-88 \\
11-16-89 \\
05-02-90 \\
05-02-90\end{array}$ & $\begin{array}{r}2 \\
1 \\
\cdots \\
0 \\
0\end{array}$ & $\begin{array}{c}-. \\
\therefore \\
\therefore \\
<1.0 \\
\cdots\end{array}$ & $\begin{array}{l}100 \\
970 \\
\cdots \\
980 \\
\cdots\end{array}$ & $\begin{array}{l}<1 \\
<1 \\
\therefore< \\
\therefore<\end{array}$ & $\begin{array}{l}<10 \\
<10 \\
\cdots \\
\cdots\end{array}$ & $\begin{array}{l}<10 \\
<10 \\
\therefore \\
\cdots \\
--\end{array}$ & $\begin{array}{l}\cdots \\
\cdots \\
\cdots \\
36 \\
\cdots\end{array}$ & $\begin{array}{l}<1 \\
<1 \\
\cdots \\
\cdots\end{array}$ & $\begin{array}{c}-4.10 \\
-3.90 \\
\ldots \\
\cdots \\
\cdots\end{array}$ & $\begin{array}{c}-74.5 \\
-74.0 \\
. . \\
. . \\
.-\end{array}$ \\
\hline $\mathrm{CH}-3$ & $\begin{array}{l}12-09-88 \\
11-15-89 \\
05-02-90\end{array}$ & $\begin{array}{r}2 \\
<10 \\
<10\end{array}$ & $\begin{array}{r}<1.0 \\
2.0\end{array}$ & $\begin{array}{l}1300 \\
1600 \\
1400\end{array}$ & $\begin{array}{l}<1 \\
46 \\
46\end{array}$ & $\begin{array}{r}<10 \\
5 \\
<3\end{array}$ & $\begin{array}{l}<10 \\
\cdots \\
\cdots\end{array}$ & $\begin{array}{l}\cdots \\
42 \\
37\end{array}$ & $\begin{array}{l}<1 \\
\cdots \\
\cdots\end{array}$ & $\begin{array}{c}-2.70 \\
\cdots \\
\cdots\end{array}$ & $\begin{array}{c}-77.0 \\
\cdots \\
\cdots\end{array}$ \\
\hline CH- 6 & $\begin{array}{l}12-07-88 \\
11-15-89 \\
05-02-90\end{array}$ & $\begin{array}{r}<1 \\
<10 \\
20\end{array}$ & $\begin{array}{r}0 \\
<1.0 \\
2.0\end{array}$ & $\begin{array}{l}920 \\
950 \\
930\end{array}$ & $\begin{array}{l}<1 \\
46 \\
46\end{array}$ & $\begin{array}{r}<10 \\
<3 \\
6\end{array}$ & $\begin{array}{l}<10 \\
\cdots \\
\cdots\end{array}$ & $\begin{array}{l}\cdots \\
52 \\
47\end{array}$ & $\begin{array}{l}<1 \\
\therefore\end{array}$ & $\begin{array}{c}-2.60 \\
\cdots \\
-.\end{array}$ & $\begin{array}{c}\ldots \\
-70.0\end{array}$ \\
\hline$C H-5$ & $\begin{array}{l}12-08-88 \\
11-15-89 \\
10-31-90\end{array}$ & $\begin{array}{r}6 \\
<10 \\
<10\end{array}$ & $\begin{array}{l}-\ddot{0} \\
<1.0\end{array}$ & $\begin{array}{l}700 \\
710 \\
700\end{array}$ & $\begin{array}{l}<1 \\
46 \\
66\end{array}$ & $\begin{array}{r}10 \\
<3 \\
4\end{array}$ & $\begin{array}{l}<10 \\
\cdots \\
\cdots\end{array}$ & $\begin{array}{l}\cdots \\
30 \\
30\end{array}$ & $\begin{array}{l}<1 \\
\therefore<3\end{array}$ & $\begin{array}{c}-1.70 \\
\cdots \\
\cdots\end{array}$ & $\begin{array}{c}-71.5 \\
\ldots \\
\ldots\end{array}$ \\
\hline CH-6 & $\begin{array}{l}12-08-88 \\
11-15-89 \\
10-31-90\end{array}$ & $\begin{array}{r}5 \\
<10 \\
<10\end{array}$ & $\begin{array}{l}\because 1.0 \\
<1.0\end{array}$ & $\begin{array}{l}1700 \\
1400 \\
1400\end{array}$ & $\begin{array}{l}7 \\
8 \\
7\end{array}$ & $\begin{array}{r}<10 \\
4 \\
5\end{array}$ & $\begin{array}{l}<10 \\
\cdots \\
\cdots\end{array}$ & $\begin{array}{l}\cdots \\
48 \\
47\end{array}$ & $\begin{array}{l}1 \\
<3\end{array}$ & $\begin{array}{c}-3.90 \\
\cdots \\
-.\end{array}$ & $\begin{array}{c}-70.0 \\
\cdots \\
-.\end{array}$ \\
\hline $\mathrm{CH}-7$ & $\begin{array}{l}12-06-88 \\
11-14-89 \\
11-01-90\end{array}$ & $\begin{array}{l}<1 \\
<10 \\
<10\end{array}$ & $\begin{array}{l}<1.0 \\
<1.0\end{array}$ & $\begin{array}{l}810 \\
800 \\
840\end{array}$ & $\begin{array}{l}<1 \\
46 \\
46\end{array}$ & $\begin{array}{r}6 \\
<3 \\
7\end{array}$ & $\begin{array}{l}<10 \\
\cdots \\
\cdots\end{array}$ & $\begin{array}{l}- \\
51 \\
48\end{array}$ & $\begin{array}{l}<1 \\
<1\end{array}$ & $\begin{array}{c}-3.40 \\
\cdots \\
\cdots\end{array}$ & $\begin{array}{c}-72.5 \\
\cdots \\
\cdots\end{array}$ \\
\hline $\mathrm{CH}-8$ & $\begin{array}{l}12-06-88 \\
11-14-89 \\
10-18-90\end{array}$ & $\begin{array}{r}3 \\
<10 \\
<10\end{array}$ & $\begin{array}{l}\cdots 1.0 \\
<1.0\end{array}$ & $\begin{array}{l}1100 \\
1100 \\
1100\end{array}$ & $\begin{array}{l}<1 \\
<6 \\
<6\end{array}$ & $\begin{array}{l}33 \\
<3 \\
63\end{array}$ & $\begin{array}{l}<10 \\
\cdots \\
\cdots\end{array}$ & $\begin{array}{l}\cdots \\
33 \\
33\end{array}$ & $\begin{array}{l}<1 \\
\therefore 1\end{array}$ & $\begin{array}{c}-4.10 \\
\ldots \\
-.\end{array}$ & $\begin{array}{c}-74.5 \\
\ldots \\
\ldots\end{array}$ \\
\hline CW-9 & $\begin{array}{l}12-06-88 \\
11-15-89 \\
10-18-90 \\
10-18-90\end{array}$ & $\begin{array}{r}2 \\
<10 \\
<10 \\
<10\end{array}$ & $\begin{array}{r}\cdots \\
<1.0 \\
<1.0 \\
2.0\end{array}$ & $\begin{array}{l}1300 \\
1200 \\
1200 \\
1300\end{array}$ & $\begin{array}{l}<1 \\
<6 \\
<6 \\
<6\end{array}$ & $\begin{array}{r}5 \\
3 \\
<3 \\
3\end{array}$ & $\begin{array}{l}<10 \\
\cdots \\
\cdots \\
\cdots\end{array}$ & $\begin{array}{l}\cdots \\
33 \\
34 \\
35\end{array}$ & $\begin{array}{l}<1 \\
\therefore<1 \\
<1\end{array}$ & $\begin{array}{c}-2.36 \\
-. \\
\ldots \\
-.\end{array}$ & $\begin{array}{c}-73.5 \\
-. \\
\ldots \\
\ldots\end{array}$ \\
\hline CDP-01 & $\begin{array}{l}08-11-88 \\
12-07-88 \\
11-16-89 \\
10-17-90\end{array}$ & $\begin{array}{r}3 \\
3 \\
10 \\
<10\end{array}$ & $\begin{array}{c}<1.0 \\
\therefore< \\
<1.0 \\
1.0\end{array}$ & $\begin{array}{l}1000 \\
1000 \\
1600 \\
1300\end{array}$ & $\begin{array}{l}<1 \\
<1 \\
46 \\
46\end{array}$ & $\begin{array}{r}19 \\
20 \\
210 \\
80\end{array}$ & $\begin{array}{l}<10 \\
<10 \\
\cdots \\
\cdots\end{array}$ & $\begin{array}{l}\cdots \\
\cdots \\
15 \\
22\end{array}$ & $\begin{array}{l}<1 \\
<1 \\
<1\end{array}$ & $\begin{array}{c}-. \\
-3.40 \\
\cdots\end{array}$ & $\begin{array}{l}-81.0 \\
-71.0 \\
-69.4 \\
. .\end{array}$ \\
\hline CDP-02 & $\begin{array}{l}08-11-88 \\
11-16-89\end{array}$ & $\begin{array}{l}\ddot{10} \\
<10\end{array}$ & $<1.0$ & $\ddot{1100}$ & 46 & 9 & -. & 21 & $\cdots$ & -4.00 & $\begin{array}{l}-71.5 \\
-67.0\end{array}$ \\
\hline CDP.03 & $\begin{array}{l}12-08-88 \\
04-04-89\end{array}$ & $\begin{array}{l}3 \\
1\end{array}$ & 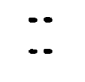 & $\begin{array}{l}1100 \\
1100\end{array}$ & ${ }^{3}$ & $\begin{array}{r}20 \\
8\end{array}$ & $\begin{array}{l}<10 \\
<10\end{array}$ & $\cdots$ & $\begin{array}{l}<1 \\
<1\end{array}$ & $\begin{array}{l}-4.00 \\
-3.40\end{array}$ & $\begin{array}{l}-72.0 \\
-71.5\end{array}$ \\
\hline CDP -04 & $08-11-88$ & $\cdots$ & $\cdots$ & $\because$ & $\cdots$ & -- & $\cdots$ & $\cdots$ & $\cdots$ & .. & $\cdots$ \\
\hline
\end{tabular}


GROUND-WATER DATA-Cont inued

ChEmICAL AMALYSES-Cont inued

STATION

MAME

DATE

\begin{tabular}{|c|c|c|c|c|c|c|c|c|c|c|}
\hline & $\begin{array}{c}0.18 / \\
0.16 \\
\text { STABLE } \\
\text { ISOTOPE } \\
\text { RATIO } \\
\text { PER } \\
\text { MIL } \\
(82085)\end{array}$ & $\begin{array}{l}\text { TRITIUA } \\
\text { TOTAL } \\
\text { (PCI/L) } \\
(07000)\end{array}$ & $\begin{array}{l}\text { GROSS } \\
\text { ALPHA, } \\
\text { DIS- } \\
\text { SOLVED } \\
\text { ( } \mu g / L \\
\text { as } \\
\text { U-nat) } \\
(80030)\end{array}$ & $\begin{array}{l}\text { ALPHA, } \\
\text { COUNT, } \\
2 \text { SIGM } \\
\text { WAT DIS } \\
\text { ( } \mu g / L \\
\text { as } \\
\text { U-nat) } \\
\text { (75986) }\end{array}$ & $\begin{array}{l}\text { GROSS } \\
\text { ALPHA, } \\
\text { SUSP. } \\
\text { TOTAL } \\
\text { ( } \mu 9 / L \\
\text { as } \\
\text { U*nat) } \\
(80040)\end{array}$ & $\begin{array}{c}\text { GROSS } \\
\text { BETA, } \\
\text { DIS- } \\
\text { SOLVED } \\
\text { (pCi/L } \\
\text { os } \\
\text { Cs-137) } \\
(03515)\end{array}$ & $\begin{array}{c}\text { BETA, } \\
2 \text { SIGA } \\
\text { UATER, } \\
\text { OISS, } \\
\text { (pCi/L } \\
\text { as } \\
\text { Cs-137) } \\
(75989)\end{array}$ & $\begin{array}{c}\text { GROSS } \\
\text { BETA, } \\
\text { SUSP. } \\
\text { TOTAL } \\
\text { (pCi/L } \\
\text { as } \\
\text { C8-137) } \\
(03516)\end{array}$ & $\begin{array}{c}\text { GROSS } \\
\text { BETA, } \\
\text { DISS. } \\
\text { (PCi/L } \\
\text { as } \\
\text { Sr-90/ } \\
\text { Y-90) } \\
(80050)\end{array}$ & $\begin{array}{l}\text { BETA, } \\
2 \text { SICYA } \\
\text { UATER, } \\
\text { DISS. } \\
\text { (pCI/L } \\
\text { as } \\
\text { Sr-90/ } \\
Y-90) \\
(75988)\end{array}$ \\
\hline
\end{tabular}

\section{ChaMBERS WELL CLUSTER-Continued}

\begin{tabular}{|c|c|c|c|c|c|c|c|c|c|c|}
\hline CW-1 & $\begin{array}{l}12-09-88 \\
11-16-89 \\
05-02-90 \\
05-02-90\end{array}$ & $\begin{array}{c}-10.00 \\
- \\
- \\
-\end{array}$ & $\begin{array}{l}<2.5 \\
\therefore \\
\ldots \\
\ldots\end{array}$ & $\begin{array}{l}.5 \\
<.4 \\
1.2 \\
1.2\end{array}$ & $\begin{array}{l}\cdots \\
\cdots \\
.80 \\
\cdots\end{array}$ & $\begin{array}{l}6.4^{\star} \\
\therefore \\
-. \\
-.\end{array}$ & $\begin{array}{l}3.6 \\
5.2 \\
4.8 \\
4.8\end{array}$ & $\begin{array}{l}\because . \\
2.7 \\
\cdots\end{array}$ & $\begin{array}{l}5.4 \\
\cdots \\
\cdots \\
\therefore\end{array}$ & $\begin{array}{l}2.5 \\
4.6 \\
4.6 \\
4.6\end{array}$ \\
\hline $\mathrm{CW}-2$ & $\begin{array}{l}12-09-88 \\
12-09-88 \\
11-16-89 \\
05-02-90 \\
05-02-90\end{array}$ & $\begin{array}{c}-10.20 \\
-10.15 \\
\ldots \\
\ldots \\
\ldots\end{array}$ & $\begin{array}{l}77 \\
78 \\
\cdots \\
\cdots \\
\cdots\end{array}$ & $\begin{array}{c}11 \% \\
9.4 \\
<.6 \\
5.9 \\
167\end{array}$ & $\begin{array}{l}\ldots \\
\therefore \\
.60 \\
1.7 \\
3.0\end{array}$ & $\begin{array}{l}1.0^{*} \\
<.4^{\star} \\
\ldots \\
\ldots \\
\cdots\end{array}$ & $\begin{array}{l}5.3 \\
5.5 \\
5.2 \\
6.4 \\
10\end{array}$ & $\begin{array}{l}\cdots \\
\cdots \\
1.9 \\
1.8 \\
2.4\end{array}$ & $\begin{array}{l}.8 \star \\
1.2^{\star} \\
\therefore \\
-. \\
\cdots\end{array}$ & $\begin{array}{l}3.7 \\
3.8 \\
4.6 \\
4.8 \\
7.6\end{array}$ \\
\hline CW-3 & $\begin{array}{l}12-09-88 \\
11-15-89 \\
05-02-90\end{array}$ & $\begin{array}{c}-10.20 \\
\ldots \\
\ldots\end{array}$ & $\begin{array}{l}59 \\
\cdots \\
\ldots\end{array}$ & $\begin{array}{c}\cdots .7 \\
16\}\end{array}$ & $\ddot{1.4}$ & $\begin{array}{l}\cdots \\
\cdots \\
\cdots\end{array}$ & 7.3 & $\begin{array}{l}\cdots \\
1.4 \\
\cdots\end{array}$ & $\begin{array}{l}\cdots \\
\cdots \\
\cdots\end{array}$ & $\begin{array}{l}\cdots \\
6.7 \\
7.6\end{array}$ \\
\hline CW-4 & $\begin{array}{l}12-07-88 \\
11-15-89 \\
05-02-90\end{array}$ & $\begin{array}{l}\cdots \\
-9.60\end{array}$ & $\begin{array}{c}120 \\
\ldots \\
\ldots\end{array}$ & $\begin{array}{r}.7 \\
<.6 \\
1.4\end{array}$ & $\begin{array}{l}. .60 \\
.90\end{array}$ & $\begin{array}{l}<.4 \\
\therefore \\
\cdots\end{array}$ & $\begin{array}{l}5.7 \\
4.7 \\
5.2\end{array}$ & $\begin{array}{l}0.1 \\
1.7\end{array}$ & $\begin{array}{l}<.4 \\
\cdots \\
-\end{array}$ & $\begin{array}{l}3.9 \\
4.1 \\
3.9\end{array}$ \\
\hline $\mathrm{CW}-5$ & $\begin{array}{l}12-08-88 \\
11-15-89 \\
10-31-90\end{array}$ & $\begin{array}{l}-9.75 \\
\cdots \\
\cdots\end{array}$ & $\begin{array}{l}61 \\
\cdots \\
\cdots\end{array}$ & $\begin{array}{l}6.7 \\
3.1 \\
5.4\end{array}$ & $\begin{array}{l}.90 \\
1.5\end{array}$ & $\begin{array}{l}<.4 * \\
\cdots \\
\cdots\end{array}$ & $\begin{array}{l}4.9 \\
5.4 \\
4.3\end{array}$ & $\begin{array}{l}9.2 \\
1.7\end{array}$ & $\begin{array}{l}.9 \\
\therefore \\
\therefore\end{array}$ & $\begin{array}{l}3.4 \\
4.7 \\
3.3\end{array}$ \\
\hline CW-6 & $\begin{array}{l}12-08-88 \\
11-15-89 \\
10-31-90\end{array}$ & $\begin{array}{l}-9.35 \\
\ldots \\
\cdots\end{array}$ & $\begin{array}{l}71 \\
\cdots \\
\cdots\end{array}$ & $\begin{array}{c}14 f \\
4.9 \\
10\end{array}$ & $\begin{array}{l}\cdots \\
1.1 \\
2.2\end{array}$ & $\begin{array}{l}<.4^{\star} \\
\cdots \\
\cdots\end{array}$ & $\begin{array}{l}7.0 \\
7.0 \\
5.1\end{array}$ & $\begin{array}{l}\ddot{1} \\
1.4\end{array}$ & $\begin{array}{l}.8 \\
\therefore- \\
\cdots\end{array}$ & $\begin{array}{l}4.5 \\
6.3 \\
3.9\end{array}$ \\
\hline CW-7 & $\begin{array}{l}12-06-88 \\
11-14-89 \\
11-01-90\end{array}$ & $\begin{array}{l}-9.95 \\
\ldots \\
\ldots\end{array}$ & $\begin{array}{c}100 \\
\ldots \\
\ldots\end{array}$ & $\begin{array}{l}10 \\
4.8 \\
8.3\end{array}$ & $\begin{array}{l}\cdots \\
1.1 \\
1.9\end{array}$ & $\begin{array}{l}<.4 \\
\cdots \\
\cdots\end{array}$ & $\begin{array}{l}5.8 \\
8.7 \\
7.1\end{array}$ & $\begin{array}{l}\because . \\
1.6 \\
2.2\end{array}$ & $\begin{array}{l}.8^{\star} \\
\cdots\end{array}$ & $\begin{array}{l}4.0 \\
7.7 \\
5.4\end{array}$ \\
\hline CW- 8 & $\begin{array}{l}12-06-88 \\
11-14-89 \\
10-18-90\end{array}$ & $\begin{array}{c}-10.20 \\
\ldots \\
\ldots\end{array}$ & $\begin{array}{l}94 \\
\ldots \\
\ldots\end{array}$ & $\begin{array}{c}121 \\
5.1 \\
8.9\end{array}$ & $\begin{array}{l}-. \\
1.1 \\
1.9\end{array}$ & $\begin{array}{l}<.4^{\star} \\
\cdots \\
\cdots\end{array}$ & $\begin{array}{l}6.3 \\
9.7 \\
7.0\end{array}$ & $\begin{array}{l}\cdots \\
1.7 \\
2.2\end{array}$ & $\begin{array}{l}.8^{\star} \\
\therefore \\
\therefore\end{array}$ & $\begin{array}{l}4.4 \\
8.6 \\
5.3\end{array}$ \\
\hline $\mathrm{CW}-9$ & $\begin{array}{l}12-06-88 \\
11-15-89 \\
10-18-90 \\
10-18-90\end{array}$ & $\begin{array}{l}-9.95 \\
\ldots \\
\cdots \\
\cdots\end{array}$ & $\begin{array}{l}98 \\
\ldots \\
\ldots \\
\cdots\end{array}$ & $\begin{array}{l}17 \nmid \\
5.6 \\
-- \\
14 \uparrow\end{array}$ & $\begin{array}{l}\ddot{1.9} \\
2.5\end{array}$ & $\begin{array}{l}<.4 * \\
\therefore \\
- \\
\therefore\end{array}$ & $\begin{array}{l}9.5 \\
9.8 \\
-. \\
8.0\end{array}$ & $\begin{array}{l}\ddot{1.7} \\
-. \\
2.5\end{array}$ & $\begin{array}{l}1.2^{\star} \\
\therefore \\
-. \\
-.\end{array}$ & $\begin{array}{c}6.4 \\
9.0 \\
-6 \\
6.2\end{array}$ \\
\hline CDP-01 & $\begin{array}{l}08-11-88 \\
12-07-88 \\
11-16-89 \\
10-17-90\end{array}$ & $\begin{array}{c}-10.10 \\
-9.35 \\
-9.15 \\
-.\end{array}$ & $\begin{array}{l}40 \\
56 \\
96 \\
\cdots\end{array}$ & $\begin{array}{l}20 \nmid \\
19 \uparrow \\
8.2 \\
31 \uparrow\end{array}$ & $\begin{array}{l}\ldots \\
1 . . \\
4.3\end{array}$ & $\begin{array}{l}8.2^{\star} \\
<.4^{\star} \\
\cdots \\
\cdots\end{array}$ & $\begin{array}{l}12 \\
11 \\
12 \\
24\end{array}$ & $\begin{array}{l}\cdots \\
2.0 \\
4.6\end{array}$ & $\begin{array}{l}4.7 \\
5.8^{*} \\
\therefore- \\
-.\end{array}$ & $\begin{array}{c}8.2 \\
7.8 \\
11 \\
18\end{array}$ \\
\hline CDP-02 & $\begin{array}{l}08-11-88 \\
11-16-89\end{array}$ & $\begin{array}{l}-9.60 \\
-8.35\end{array}$ & $\begin{array}{l}45 \\
53\end{array}$ & $\ddot{121}$ & 1.7 & 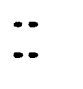 & $\ddot{12}$ & 2.1 & $\cdots$ & $\ddot{11}$ \\
\hline CDP-03 & $\begin{array}{l}12-08-88 \\
04-04-89\end{array}$ & $\begin{array}{l}-9.60 \\
-9.50\end{array}$ & $\begin{array}{l}81 \\
71\end{array}$ & $\begin{array}{l}23 t \\
21 t\end{array}$ & 3.5 & $\begin{array}{l}<.4^{*} \\
<.6^{*}\end{array}$ & $\begin{array}{r}14 \\
9.7\end{array}$ & $\ddot{2.1}$ & $\begin{array}{l}1.0^{\star} \\
2.6^{\star}\end{array}$ & $\begin{array}{l}9.5 \\
6.7\end{array}$ \\
\hline CDP. 04 & $08 \cdot 11 \cdot 88$ & $\cdots$ & $\cdots$ & $15 f$ & $\cdots$ & $7.1 *$ & 13 & $-\cdot$ & $11 *$ & 8.6 \\
\hline
\end{tabular}


GROUND-WATER DATA-Cont inued

CHEMICAL ANALYSES-Cont inued

STATION

NAME

DATE

\begin{tabular}{|c|c|c|c|c|c|c|c|c|}
\hline $\begin{array}{l}\text { GROSS } \\
\text { BETA. } \\
\text { SUSP. } \\
\text { TOTAL } \\
\text { (PCi/L } \\
\text { As } \\
\text { Sr-90/ } \\
Y-90 \text { ) } \\
80060 \text { ) }\end{array}$ & $\begin{array}{l}\text { BETA, } \\
2 \text { SIGUA } \\
\text { SED, SUSP. } \\
\text { TOT DRY } \\
\text { (PCI/G } \\
\text { \&s } \\
\text { Sr-90/ } \\
Y-90) \\
(76005)\end{array}$ & $\begin{array}{l}\text { Ra-226, } \\
\text { DIS- } \\
\text { SOLVED, } \\
\text { PLAN- } \\
\text { CHET } \\
\text { COUNT } \\
(\text { PCi/L) } \\
(09510)\end{array}$ & $\begin{array}{l}\text { Ra-226 } \\
2 \text { SICMA } \\
\text { WATER, } \\
\text { DISS, } \\
\text { (pCi/L) } \\
\text { (76001) }\end{array}$ & $\begin{array}{l}\text { RADIU, } \\
\text {-226, } \\
\text { DIS- } \\
\text { SOLVED, } \\
\text { RADON } \\
\text { METHCD } \\
\text { (PCi/L) } \\
\text { (OSS11) }\end{array}$ & $\begin{array}{l}\text { RADIUA } \\
\text {-228 } \\
\text { DIS- } \\
\text { SOLVED } \\
\text { (pCi/L } \\
\text { os } \\
\text { Ra-228) } \\
(81366)\end{array}$ & $\begin{array}{l}\text { RADON } \\
\text {-222 } \\
\text { TOTAL } \\
\text { (pCi/L) } \\
\text { (82303) }\end{array}$ & $\begin{array}{l}\text { Rn-222 } \\
2 \text { SIGMA } \\
\text { HATER, } \\
\text { HHOLE, } \\
\text { TOTAL, } \\
\text { (pCi/L) } \\
\text { (76002) }\end{array}$ & $\begin{array}{l}\text { LEAD } \\
-210 \\
\text { DIS- } \\
\text { SOLVED } \\
\text { (pCi/L) } \\
\text { (17503) }\end{array}$ \\
\hline
\end{tabular}

CHAMBERS WELL CLUSTER-Continued

\begin{tabular}{|c|c|c|c|c|c|c|c|c|c|c|}
\hline CH-1 & $\begin{array}{l}12-09-88 \\
11-16-89 \\
05-02-90 \\
05-02-90\end{array}$ & $\begin{array}{c}4.9 \\
\ldots \\
\ldots\end{array}$ & $\begin{array}{l}\ldots \\
\ldots \\
\ldots \\
\ldots\end{array}$ & $\begin{array}{l}\cdots \\
\cdots \\
\cdots\end{array}$ & $\begin{array}{l}\cdots \\
\cdots \\
\cdots \\
\cdots\end{array}$ & $\begin{array}{l}.15 \\
\cdots \\
\cdots\end{array}$ & $\begin{array}{c}<1.0 \\
\therefore \\
\therefore \\
\cdots\end{array}$ & $\begin{array}{l}<80 \\
- \\
<80 \\
140\end{array}$ & $\begin{array}{l}66 \\
\because 34 \\
74\end{array}$ & $\begin{array}{c}<1.5 \\
\cdots \\
\therefore \\
\cdots\end{array}$ \\
\hline $\mathrm{CH}-2$ & $\begin{array}{l}12-09-88 \\
12-09-88 \\
11-16-89 \\
05-02-90 \\
05-02-90\end{array}$ & $\begin{array}{c}.8^{*} \\
1.2^{*} \\
\cdots \\
\cdots\end{array}$ & $\begin{array}{l}\ldots \\
\cdots \\
\cdots \\
\cdots \\
\cdots\end{array}$ & $\begin{array}{l}\ldots \\
\cdots \\
\cdots \\
\ldots\end{array}$ & $\begin{array}{l}\cdots \\
\cdots \\
\cdots \\
\cdots\end{array}$ & $\begin{array}{l}.08 \\
.06 \\
\cdots \\
\cdots \\
\cdots\end{array}$ & $\begin{array}{c}<1.0 \\
<1.0 \\
\ldots \\
\ldots \\
\cdots\end{array}$ & $\begin{array}{c}140 \\
137 \\
\cdots \\
170 \\
300 \dagger\end{array}$ & $\begin{array}{l}\cdots \\
44 \\
-\therefore \\
48 \\
49\end{array}$ & $\begin{array}{c}<1.5 \\
<1.5 \\
\ldots \\
-. \\
-.\end{array}$ \\
\hline$C H-3$ & $\begin{array}{l}12-09-88 \\
11-15-89 \\
05-02-90\end{array}$ & $\cdots$ & $\begin{array}{l}\cdots \\
\cdots\end{array}$ & $\begin{array}{l}\cdots \\
\cdots\end{array}$ & $\cdots$ & $\begin{array}{l}.05 \\
\cdots \\
\cdots\end{array}$ & $\begin{array}{c}<1.0 \\
\cdots \\
\cdots\end{array}$ & $\begin{array}{l}340\} \\
530\} \\
300\}\end{array}$ & $\begin{array}{l}46 \\
88 \\
\cdots\end{array}$ & $\begin{array}{c}<1.5 \\
\cdots \\
\cdots\end{array}$ \\
\hline$C U-4$ & $\begin{array}{l}12-07-88 \\
11-15-89 \\
05-02-90\end{array}$ & $\begin{array}{c}<.4 \\
\ldots \\
\ldots\end{array}$ & $\begin{array}{l}\cdots \\
\cdots \\
\cdots\end{array}$ & $\begin{array}{l}\cdots \\
\cdots\end{array}$ & $\ddot{-\infty}$ & $\begin{array}{l}.10 \\
\cdots \\
\cdots\end{array}$ & $\begin{array}{l}<1.0 \\
\ldots \\
\ldots\end{array}$ & $\begin{array}{l}<80 \\
110 \\
140\end{array}$ & $\begin{array}{l}55 \\
80 \\
49\end{array}$ & $\begin{array}{c}<1.5 \\
\cdots \\
-.\end{array}$ \\
\hline CU-5 & $\begin{array}{l}12-08-88 \\
11-15-89 \\
10-31-90\end{array}$ & $\begin{array}{l}.8 \\
\cdots \\
\cdots\end{array}$ & $\begin{array}{l}\ldots \\
\cdots \\
\cdots\end{array}$ & $\begin{array}{l}\ldots \\
<-1\end{array}$ & $\begin{array}{l}\cdots \\
\cdots 0\end{array}$ & $\begin{array}{l}.07 \\
\cdots \\
\cdots\end{array}$ & $\begin{array}{c}<1.0 \\
\ldots \\
\ldots\end{array}$ & $\begin{array}{c}160 \\
220 \\
\cdots\end{array}$ & $\begin{array}{r}135 \\
87 \\
\cdots\end{array}$ & $\begin{array}{c}<1.5 \\
\cdots \\
\cdots\end{array}$ \\
\hline CU-6 & $\begin{array}{l}12-08-88 \\
11-15-89 \\
10-31-90\end{array}$ & $\begin{array}{l}.8 \\
\cdots \\
\cdots\end{array}$ & $\begin{array}{l}\cdots \\
\cdots \\
\cdots\end{array}$ & $\begin{array}{c}\ldots \\
< \\
<.1\end{array}$ & $\ddot{0}$ & $\begin{array}{l}.10 \\
\therefore \\
\cdots\end{array}$ & $\begin{array}{l}<1.0 \\
\ldots \\
\ldots\end{array}$ & $\begin{array}{c}520\} \\
4801 \\
\ldots\end{array}$ & $\begin{array}{l}93 \\
95 \\
\cdots\end{array}$ & $\begin{array}{c}<1.5 \\
\cdots \\
\cdots\end{array}$ \\
\hline CH-7 & $\begin{array}{l}12-06-88 \\
11-14-89 \\
11-01-90\end{array}$ & $\begin{array}{l}.8 \\
-. \\
-.\end{array}$ & $\begin{array}{l}\cdots \\
\cdots \\
\cdots\end{array}$ & $\begin{array}{l}. . \\
. \\
.1\end{array}$ & .100 & $\begin{array}{l}.10 \\
\therefore- \\
-.\end{array}$ & $\begin{array}{c}<1.0 \\
\ldots \\
\cdots\end{array}$ & $\begin{array}{c}180 \\
260 \\
-\cdot\end{array}$ & $\begin{array}{r}44 \\
120 \\
\cdots\end{array}$ & $\begin{array}{l}\cdots \\
\cdots\end{array}$ \\
\hline CU- 8 & $\begin{array}{l}12-06-88 \\
11-14-89 \\
10-18-90\end{array}$ & $\begin{array}{l}.8 \\
\cdots \\
--\end{array}$ & $\begin{array}{l}\cdots \\
\cdots \\
\cdots\end{array}$ & $\begin{array}{l}\cdots \\
\therefore \\
-.\end{array}$ & $\begin{array}{l}\ldots \\
\cdots\end{array}$ & $\begin{array}{l}.15 \\
\cdots \\
\cdots\end{array}$ & $\begin{array}{c}<1.0 \\
\therefore \\
\therefore\end{array}$ & $\begin{array}{c}91 \\
5401 \\
\ldots\end{array}$ & $\begin{array}{r}41 \\
120 \\
\ldots\end{array}$ & $\begin{array}{l}\cdots \\
\cdots \\
\cdots\end{array}$ \\
\hline CH-9 & $\begin{array}{l}12-06-88 \\
11-15-89 \\
10-18-90 \\
10-18-90\end{array}$ & $\begin{array}{c}1.2 \\
\cdots \\
\cdots \\
\cdots\end{array}$ & $\begin{array}{l}\cdots \\
\cdots \\
\cdots \\
\cdots\end{array}$ & $\begin{array}{l}\cdots \\
\cdots \\
\cdots\end{array}$ & $\begin{array}{l}-- \\
\cdots \\
\cdots\end{array}$ & $\begin{array}{l}.05 \\
\cdots \\
\cdots \\
\cdots\end{array}$ & $\begin{array}{l}<1.0 \\
\cdots \\
\cdots \\
\cdots\end{array}$ & $\begin{array}{c}170 \\
\therefore \\
\cdots \\
\cdots\end{array}$ & $\begin{array}{l}35 \\
\cdots \\
\cdots \\
\cdots\end{array}$ & $\begin{array}{l}\cdots \\
\cdots \\
\cdots\end{array}$ \\
\hline CDP-01 & $\begin{array}{l}08-11-88 \\
12-07-88 \\
11-16-89 \\
10-17-90\end{array}$ & $\begin{array}{c}4.5^{\star} \\
6.0^{\star} \\
\cdots \\
\cdots\end{array}$ & $\begin{array}{l}\cdots \\
\cdots \\
\cdots \\
\cdots\end{array}$ & $\begin{array}{l}\cdots \\
\cdots \\
\cdots \\
.2\end{array}$ & $\begin{array}{l}\cdots \\
\ldots \\
. \\
.100\end{array}$ & $\begin{array}{l}.15 \\
.17 \\
\therefore- \\
\cdots\end{array}$ & $\begin{array}{l}<1.0 \\
<1.0 \\
\ldots \\
\cdots\end{array}$ & $\begin{array}{c}\cdots \\
370+ \\
\cdots\end{array}$ & $\begin{array}{l}\ddot{59} \\
\cdots \\
\cdots\end{array}$ & $\begin{array}{c}\ddot{1.5} \\
\ddot{\cdots}\end{array}$ \\
\hline CDP-02 & $\begin{array}{l}08-11-88 \\
11-16-89\end{array}$ & $\cdots$ & $\cdots$ & $\cdots$ & $\cdots$ & $\ddot{\cdots}$ & $\because$ & $\ddot{-.}$ & 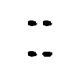 & $\ddot{-}$ \\
\hline CDP.03 & $\begin{array}{l}12-08-88 \\
04-04-89\end{array}$ & $\begin{array}{l}1.0 * \\
2.6^{*}\end{array}$ & .80 & $\cdots$ & 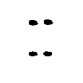 & .07 & $\begin{array}{c}<1.0 \\
\therefore\end{array}$ & $\begin{array}{l}3901 \\
4201\end{array}$ & $\begin{array}{l}91 \\
72\end{array}$ & $<1.5$ \\
\hline CDP-O4 & $08-11-88$ & $9.6^{*}$ & $\cdots$ & -. & $\cdots$ & $\cdots$ & $\cdots$ & $\cdots$ & $\cdots$ & $\cdots$ \\
\hline
\end{tabular}


GROUND-WATER DATA-Continued

CHEMICAL ANALYSES-Cont inued

\begin{tabular}{|c|c|c|c|c|c|c|c|c|c|c|}
\hline $\begin{array}{l}\text { STATIOU } \\
\text { WAME }\end{array}$ & DATE & $\begin{array}{l}\text { POLO- } \\
\text { NIUA } \\
210 \\
\text { DIS- } \\
\text { SOLVED } \\
\text { (pCi/L) } \\
\text { (19503) }\end{array}$ & $\begin{array}{l}\text { URANIUN } \\
\text {-234 } \\
\text { WATER } \\
\text { DISSOLY } \\
\text { (PCI/L) } \\
\text { (22610) }\end{array}$ & $\begin{array}{l}\text { U-234 } \\
2 \text { SIGMA } \\
\text { WATER. } \\
\text { DISS, } \\
\text { (pCi/L) } \\
\text { (75992) }\end{array}$ & $\begin{array}{l}\text { URANIUA } \\
\text {-235 } \\
\text { WATER, } \\
\text { DISS } \\
\text { (pCI/L) } \\
\text { (22620) }\end{array}$ & $\begin{array}{l}\text { U-235 } \\
2 \text { SICH } \\
\text { UATER, } \\
\text { DISS, } \\
\text { (pCi/L) } \\
\text { (75994) }\end{array}$ & $\begin{array}{l}\text { URANIUA } \\
\text { - } 238 \\
\text { WATER } \\
\text { DISSOLY } \\
\text { (pCI/L) } \\
\text { (22603) }\end{array}$ & $\begin{array}{c}\text { U-238 } \\
2 \text { SIGA } \\
\text { WATER, } \\
\text { DISS, } \\
\text { (pCi/L) } \\
\text { (75991) }\end{array}$ & $\begin{array}{c}\text { URANIUM } \\
\text { MATURAL } \\
\text { DIS- } \\
\text { SOLVED } \\
\text { ( } \mu \mathrm{g} / \mathrm{L} \\
\text { as U) } \\
(22703)\end{array}$ & $\begin{array}{c}\text { THORIUA } \\
230 \\
\text { DIS- } \\
\text { SOLVED } \\
\text { (pCI/L) } \\
\text { (26503) }\end{array}$ \\
\hline & \multicolumn{10}{|c|}{ CHAMBERS WELL CLUSTER-Cont inued } \\
\hline CN-1 & $\begin{array}{l}12-09-88 \\
11-16-89 \\
05-02-90 \\
05-02-90\end{array}$ & $\begin{array}{c}<1.0 \\
\ldots \\
\ldots \\
-.\end{array}$ & $\begin{array}{l}<.10 \\
.90 \\
.10 \\
.12\end{array}$ & $\begin{array}{c}\ldots \\
\ldots \\
.-\end{array}$ & $\begin{array}{l}-. \\
<.1 \\
<.1 \\
10\end{array}$ & $\begin{array}{l}\ldots \\
\ldots \\
.10 \\
\ldots\end{array}$ & $\begin{array}{r}<.10 \\
.20 \\
<.10 \\
10\end{array}$ & $\begin{array}{l}\ldots \\
\ldots \\
.20\end{array}$ & $\begin{array}{r}<.40 \\
<1.0 \\
<1.0 \\
.33\end{array}$ & $\begin{array}{r}<1.0 \\
\ldots \\
\ldots \\
\ldots\end{array}$ \\
\hline cu-2 & $\begin{array}{l}12-09-88 \\
12-09-88 \\
11-16-89 \\
05-02-90 \\
05-02-90\end{array}$ & $\begin{array}{r}<1.0 \\
<1.0 \\
\ldots \\
\ldots \\
\ldots\end{array}$ & $\begin{array}{l}3.5 \\
4.0 \\
.90 \\
4.1 \\
7.3\end{array}$ & $\begin{array}{r}-. \\
.-3 \\
.7 \\
1.1\end{array}$ & $\begin{array}{l}-. \\
-. \\
<.1 \\
<.1 \\
.3\end{array}$ & $\begin{array}{l}.- \\
. \\
.20 \\
N 0 \\
.20\end{array}$ & $\begin{array}{l}2.2 \\
2.4 \\
.20 \\
2.7 \\
4.0\end{array}$ & $\begin{array}{l}\ldots \\
.20 \\
.50 \\
.70\end{array}$ & $\begin{array}{r}6.6 \\
6.7 \\
<1.0 \\
7.6 \\
15\end{array}$ & $\begin{array}{r}<1.0 \\
<1.0 \\
\ldots \\
\ldots \\
\ldots\end{array}$ \\
\hline ad-3 & $\begin{array}{l}12-09-88 \\
11-15-89 \\
05-02-90\end{array}$ & $\begin{array}{r}<1.0 \\
\ldots \\
\ldots\end{array}$ & $\begin{array}{l}5.8 \\
5.6 \\
7.3\end{array}$ & .9 & $\begin{array}{r}.3 \\
.3\end{array}$ & $\begin{array}{l}\cdots \\
.20 \\
-.\end{array}$ & $\begin{array}{l}4.3 \\
3.6 \\
4.0\end{array}$ & .60 & ${ }_{15}^{13}$ & $\begin{array}{r}<1.0 \\
\ldots \\
.-\end{array}$ \\
\hline CN-6 & $\begin{array}{l}12-07-88 \\
11-15-89 \\
05-02-90\end{array}$ & $\begin{array}{r}<1.0 \\
\ldots \\
\ldots\end{array}$ & $\begin{array}{r}.10 \\
<.10 \\
<.10\end{array}$ & $\begin{array}{r}. \\
.1 \\
.1\end{array}$ & $\begin{array}{l}-. \\
<.1 \\
<.1\end{array}$ & $\begin{array}{l}.- \\
.10\end{array}$ & $\begin{array}{r}.10 \\
<.10 \\
.20\end{array}$ & $\begin{array}{l}. . \\
.10 \\
.20\end{array}$ & $\begin{array}{l}<.40 \\
<1.0 \\
<1.0\end{array}$ & $\begin{array}{l}\cdots \\
\cdots \\
\cdots\end{array}$ \\
\hline cu-5 & $\begin{array}{l}12-08-88 \\
11-15-89 \\
10-31-90\end{array}$ & $\begin{array}{c}<1.0 \\
\ldots \\
\ldots\end{array}$ & $\begin{array}{l}2.2 \\
2.2 \\
2.3\end{array}$ & .4 & $\begin{array}{r}. . \\
.2 \\
<.1\end{array}$ & iD & $\begin{array}{l}1.6 \\
1.5 \\
1.6\end{array}$ & $\begin{array}{l}.2 \\
.30 \\
.20\end{array}$ & $\begin{array}{l}4.2 \\
1.8 \\
4.6\end{array}$ & $\begin{array}{r}<1.0 \\
\ldots \\
\ldots\end{array}$ \\
\hline CN-6 & $\begin{array}{l}12-08-88 \\
11-15-89 \\
10-31-90\end{array}$ & $\begin{array}{r}<1.0 \\
\ldots \\
\ldots\end{array}$ & $\begin{array}{l}5.0 \\
4.1 \\
4.8\end{array}$ & $\begin{array}{r}.7 \\
.7 \\
.5\end{array}$ & $\begin{array}{r}. . \\
.1\end{array}$ & .20 & $\begin{array}{l}3.6 \\
2.9 \\
3.1\end{array}$ & $\begin{array}{l}. . \\
.60 \\
.60\end{array}$ & $\begin{array}{r}10 \\
5.5 \\
8.8\end{array}$ & $\begin{array}{r}<1.0 \\
\ldots \\
\ldots\end{array}$ \\
\hline Cx-7 & $\begin{array}{l}12-06-88 \\
11-14-89 \\
11-01-90\end{array}$ & $\begin{array}{l}\cdots \\
\cdots \\
\cdots\end{array}$ & $\begin{array}{l}3.7 \\
3.7 \\
3.6\end{array}$ & $\begin{array}{r}\ldots \\
.7 \\
.4\end{array}$ & $\begin{array}{r}-. \\
<.1 \\
.1\end{array}$ & $\begin{array}{l}\cdots \\
\text { NO }\end{array}$ & $\begin{array}{l}2.3 \\
2.1 \\
2.4\end{array}$ & $\begin{array}{l}\ldots \\
.50 \\
.30\end{array}$ & $\begin{array}{l}7.2 \\
2.2 \\
6.6\end{array}$ & $\begin{array}{l}\cdots \\
\cdots \\
\cdots\end{array}$ \\
\hline Cu- 8 & $\begin{array}{l}12-06-88 \\
11-14-89 \\
10-18-90\end{array}$ & $\begin{array}{l}\cdots \\
\cdots\end{array}$ & $\begin{array}{l}4.1 \\
3.7 \\
3.9\end{array}$ & $\begin{array}{l}.6 \\
.6\end{array}$ & $\begin{array}{r}. .3 \\
<.1\end{array}$ & .20 & $\begin{array}{l}2.5 \\
2.3 \\
2.6\end{array}$ & $\begin{array}{l}.- \\
.50 \\
.30\end{array}$ & $\begin{array}{l}7.3 \\
3.3 \\
6.7\end{array}$ & $\begin{array}{l}\cdots \\
\cdots\end{array}$ \\
\hline Cu- 9 & $\begin{array}{l}12-06-88 \\
11-15-89 \\
10-18-90 \\
10-18-90\end{array}$ & $\begin{array}{l}\ldots \\
\ldots \\
\ldots\end{array}$ & $\begin{array}{l}6.7 \\
6.2 \\
\ldots \\
6.0\end{array}$ & $\begin{array}{c}.0 \\
.9 \\
.6\end{array}$ & $\begin{array}{c}. . \\
.2 \\
.1\end{array}$ & $\begin{array}{l}\ldots \\
.20 \\
\cdots \\
\text { ND }\end{array}$ & $\begin{array}{r}4.6 \\
4.3 \\
-. \\
3.8\end{array}$ & $\begin{array}{l}\ldots \\
.70 \\
\ldots \\
.40\end{array}$ & $\begin{array}{c}13 \\
7.3 \\
\cdots \\
12\end{array}$ & $\begin{array}{l}\cdots \\
\cdots \\
\cdots\end{array}$ \\
\hline CDP-01 & $\begin{array}{r}08-11-88 \\
12-07-88 \\
11-16-89 \\
10-17-90\end{array}$ & $\begin{array}{r}\ldots \\
<1.0 \\
\ldots \\
\ldots\end{array}$ & $\begin{array}{c}6.8 \\
7.1 \\
6.8 \\
12\end{array}$ & $\begin{array}{l}-. \\
-. \\
1.1 \\
1.2\end{array}$ & $\begin{array}{l}\ldots \\
. . \\
.2 \\
.4\end{array}$ & $\begin{array}{l}\ldots \\
.20 \\
10\end{array}$ & $\begin{array}{l}6.3 \\
7.3 \\
5.2 \\
11\end{array}$ & $\begin{array}{c}\ldots \\
. .90 \\
1.9\end{array}$ & $\begin{array}{c}19 \\
19 \\
7.2 \\
201\end{array}$ & $\begin{array}{r}\ldots \\
<1.0 \\
\ldots \\
\ldots\end{array}$ \\
\hline CDP-02 & $\begin{array}{l}08-11-88 \\
11-16-89\end{array}$ & $\cdots$ & 6.7 & $\because 1$ & .4 & .20 & 6.6 & 1.1 & 11 & $\cdots$ \\
\hline COP-03 & $\begin{array}{l}12-08-88 \\
04-04-89\end{array}$ & $<1.0$ & 9.9 & $\cdots$ & $\cdots$ & $\cdots$ & $\begin{array}{r}7.2 \\
\ldots\end{array}$ & $\cdots$ & 19 & $\begin{array}{c}<1.0 \\
\ldots\end{array}$ \\
\hline CDP-04 & $08-11-88$ & $\cdots$ & -- & $\cdots$ & $\cdots$ & $-\infty$ & $\cdots$ & $\cdots$ & $\cdots$ & $\cdots$ \\
\hline
\end{tabular}


GROUND-WATER DATA-Cont Inued

CHEMICAL ANALYSES-Cont Inued

STATION
NAME STATION MUMBER DATE TIME

ARIZOMA DEPARTMENT OF TRANSPORTATION WELL CLUSTER

\begin{tabular}{|c|c|c|c|c|c|}
\hline$A D-1$ & 351140109220901 & $\begin{array}{l}11-14-89 \\
05-01-90 \\
10-13-90\end{array}$ & $\begin{array}{l}1215 \\
1730 \\
1101\end{array}$ & $35 * 11 \cdot 40 \mathrm{mn}$ & $109^{\circ} 22^{\prime} 09^{\text {an }}$ \\
\hline$A D-3$ & 351140109220403 & $\begin{array}{l}07-13-89 \\
07-13-89 \\
09-22-89 \\
05-01-90 \\
10-19-90\end{array}$ & $\begin{array}{l}1130 \\
1131 \\
1020 \\
1605 \\
0930\end{array}$ & $35 \cdot 11 \cdot 40 \mathrm{mn}$ & $109^{\circ} 22^{\prime} 04^{\circ} \mathrm{cu}$ \\
\hline$A D-4$ & 351144109220701 & $\begin{array}{l}09-22-89 \\
10-13-90 \\
05-01-90\end{array}$ & $\begin{array}{l}1145 \\
0845 \\
1400\end{array}$ & $35 \cdot 11 \cdot 44 \mathrm{mN}$ & $109 \cdot 22 \cdot 07 \cdot 4$ \\
\hline$A D-5$ & 351139109221301 & $\begin{array}{l}07-13-89 \\
11-13-89 \\
11-14-89 \\
05-04-90 \\
10-19-90\end{array}$ & $\begin{array}{l}1600 \\
1800 \\
0900 \\
0845 \\
0800\end{array}$ & $35 \cdot 11 \cdot 39 \mathrm{~mm}$ & $109^{\circ} 22^{\prime} 13^{\mathrm{m}}$ \\
\hline ADDP-1 & 351135109225001 & $\begin{array}{l}05-15-90 \\
06-13-91\end{array}$ & $\begin{array}{l}1600 \\
1230\end{array}$ & $35 * 11 \cdot 35 \mathrm{NN}$ & $109 \cdot 22 \cdot 50$ ' \\
\hline
\end{tabular}

CEDAR POINT MELL CLUSTER

\begin{tabular}{|c|c|c|c|c|c|}
\hline$C P-1$ & 351411109170701 & $\begin{array}{l}09-21-89 \\
05-03-90 \\
05-03-90 \\
10-12-90\end{array}$ & $\begin{array}{l}1230 \\
1030 \\
0955 \\
1245\end{array}$ & $35 \cdot 16 \cdot 11 \mathrm{mN}$ & $109 \cdot 17 \cdot 07 \mathrm{my}$ \\
\hline CP-2 & 351411109170702 & $\begin{array}{l}09-21-89 \\
05-03-90 \\
10-12-90\end{array}$ & $\begin{array}{l}1425 \\
1250 \\
1100\end{array}$ & $35 \cdot 14 \cdot 11$ WN & $109 \cdot 17 \cdot 07$ in \\
\hline CP-3 & 351411109170703 & $\begin{array}{l}09-21-89 \\
05-03-90 \\
10-17-90\end{array}$ & $\begin{array}{l}1615 \\
1400 \\
1005\end{array}$ & $35^{\circ} 14^{\prime} 11 \mathrm{mN}$ & $109 \cdot 17^{\prime} 07^{\prime \prime H}$ \\
\hline$C P-4$ & 351415109170201 & $\begin{array}{l}09-21-89 \\
10-17-90 \\
05-03-90\end{array}$ & $\begin{array}{l}1020 \\
0830 \\
1600\end{array}$ & $35^{\circ} 14^{\prime} 15^{\prime \prime N}$ & $109^{\circ} 17^{\prime} 02^{\prime \prime W}$ \\
\hline$C P-5$ & 351610109170201 & $\begin{array}{l}09-20-89 \\
05-07-90 \\
10-17-90\end{array}$ & $\begin{array}{l}1630 \\
1610 \\
1143\end{array}$ & $35 \cdot 16 \cdot 10^{m N}$ & $109^{\circ} 17 \cdot 02^{14}$ \\
\hline CP-6 & 351407109165801 & $\begin{array}{l}09-20-89 \\
06-16-90 \\
10-12-90\end{array}$ & $\begin{array}{l}1440 \\
1200 \\
1445\end{array}$ & $35 \cdot 14 \cdot 07 \mathrm{mn}$ & $109 \cdot 16 \cdot 5814 \mathrm{y}$ \\
\hline$C P-8$ & 351407109165602 & $\begin{array}{l}06-07-90 \\
10-17-90\end{array}$ & $\begin{array}{l}1620 \\
1400\end{array}$ & $35 \cdot 14^{\prime} 07^{m N}$ & $109 \cdot 16^{\prime} 56^{\mathrm{cm}}$ \\
\hline CPOP-1 & 351419109165901 & $\begin{array}{l}11-17-89 \\
10-16-90\end{array}$ & $\begin{array}{l}1300 \\
1530\end{array}$ & $35^{\circ} 14^{\prime} 19 \mathrm{WN}$ & $109 \cdot 16 \cdot 59 \cdot 4$ \\
\hline CPOP-2 & 351419109165902 & $05-16-90$ & 0830 & $35^{\circ} 14^{\prime} 194 N$ & $109 \cdot 16 \cdot 59 \cdot 4$ \\
\hline
\end{tabular}


GROUND-WATER DATA-Continued

CHEMICAL AHALYSES-Cont inued

STATION

MAME

DATE

$11-14-89$

05-01-90

10-13-90

AD-3

AD- 5

07-13-89

07-13-89

09-22-89

05-01-90

10-19-90

10-4 09-22-89

05-01-90

10-13-90

07-13-89

$11-13-89$

$11-14-89$

05-04-90

10-19-90

05-15-90

06-13-91

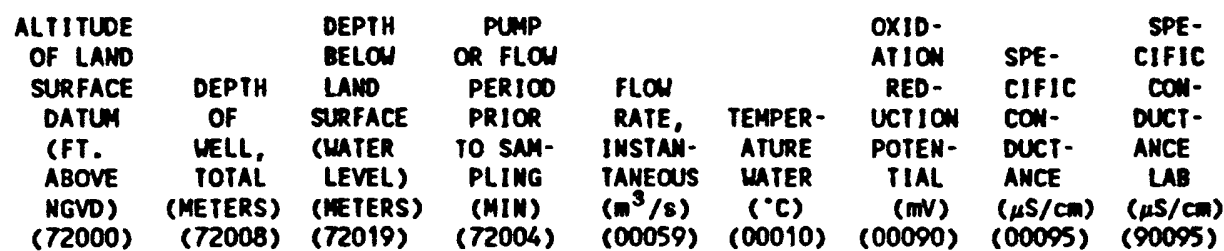

ARIZONA DEPARTIENT OF TRAMSPORTATION MELL CLUSTER-Continued

\begin{tabular}{|c|c|c|c|c|c|c|c|c|}
\hline 1766.01 & 57.9 & $\begin{array}{l}5.0 \\
5.2 \\
5.2\end{array}$ & $\begin{array}{l}60 \\
40 \\
-.\end{array}$ & $\begin{array}{c}.0019 \\
.0027 \\
\ldots\end{array}$ & $\begin{array}{l}12.0 \\
12.0 \\
12.0\end{array}$ & $\begin{array}{r}85 \\
57 \\
103\end{array}$ & $\begin{array}{l}1080 \\
1090 \\
1110\end{array}$ & $\begin{array}{l}1090 \\
1100 \\
1110\end{array}$ \\
\hline 1765.97 & 10.1 & $\begin{array}{l}4.9 \\
4.9 \\
4.6 \\
5.1 \\
5.0\end{array}$ & $\begin{array}{l}\ldots- \\
\ldots \\
50 \\
25 \\
15\end{array}$ & $\begin{array}{c}.0015 \\
- \\
.0011 \\
.0027 \\
.0023\end{array}$ & $\begin{array}{c}16.0 \\
\ldots 0 \\
13.0 \\
12.5 \\
13.0\end{array}$ & $\begin{array}{r}\ldots \\
304 \\
213 \\
230\end{array}$ & $\begin{array}{l}860 \\
\cdots \\
909 \\
921 \\
954\end{array}$ & $\begin{array}{l}848 \\
-0 \\
916 \\
949 \\
963\end{array}$ \\
\hline 1765.23 & 11.6 & $\begin{array}{l}4.0 \\
4.5 \\
4.4\end{array}$ & $\begin{array}{l}40 \\
20 \\
\cdots\end{array}$ & $\begin{array}{c}.0011 \\
.0027 \\
\ldots\end{array}$ & $\begin{array}{l}14.5 \\
13.5 \\
12.5\end{array}$ & $\begin{array}{l}286 \\
220 \\
319\end{array}$ & $\begin{array}{l}1270 \\
1310 \\
1620\end{array}$ & $\begin{array}{l}1300 \\
1300 \\
1450\end{array}$ \\
\hline 1765.44 & 9.9 & $\begin{array}{l}4.4 \\
4.6 \\
4.6 \\
4.9 \\
4.7\end{array}$ & $\begin{array}{l}\cdots \\
60 \\
35 \\
65 \\
55\end{array}$ & $\begin{array}{l}.0038 \\
.0019 \\
.0019 \\
.0027 \\
.0023\end{array}$ & $\begin{array}{l}17.0 \\
12.5 \\
12.5 \\
13.0 \\
13.0\end{array}$ & $\begin{array}{l}\ldots \\
270 \\
304 \\
215 \\
288\end{array}$ & $\begin{array}{l}1140 \\
1180 \\
1200 \\
1200 \\
1350\end{array}$ & $\begin{array}{c}1080 \\
1240 \\
\therefore \\
1160 \\
1370\end{array}$ \\
\hline 1762 & $\begin{array}{l}1.07 \\
1.46\end{array}$ & $\therefore 7$ & $\ddot{35}$ & .0004 & $\begin{array}{l}20.5 \\
13.5\end{array}$ & $\begin{array}{l}278 \\
263\end{array}$ & $\begin{array}{r}1510 \\
893\end{array}$ & $\ddot{876}$ \\
\hline
\end{tabular}

\section{CEDAR POINT MELL CLUSTER-Continued}

\begin{tabular}{|c|c|c|c|c|c|c|c|c|c|c|}
\hline CP-1 & $\begin{array}{l}09-21-89 \\
05-03-90 \\
05-03-90 \\
10-12-90\end{array}$ & 1792.23 & 33.2 & $\begin{array}{l}5.6 \\
5.5 \\
5.5 \\
5.5\end{array}$ & $\begin{array}{l}65 \\
65 \\
65 \\
\cdots\end{array}$ & $\begin{array}{c}.0011 \\
.0027 \\
.0027 \\
\ldots\end{array}$ & $\begin{array}{l}13.0 \\
12.5 \\
12.5 \\
12.5\end{array}$ & $\begin{array}{l}58 \\
27 \\
27 \\
62\end{array}$ & $\begin{array}{l}808 \\
775 \\
775 \\
728\end{array}$ & $\begin{array}{l}800 \\
770 \\
779 \\
811\end{array}$ \\
\hline $\mathrm{CP}-2$ & $\begin{array}{l}09-21-89 \\
05-03-90 \\
10-12-90\end{array}$ & 1792.30 & 18.1 & $\begin{array}{l}5.5 \\
5.4 \\
5.5\end{array}$ & $\begin{array}{l}85 \\
45 \\
--\end{array}$ & $\begin{array}{c}.0011 \\
.0027 \\
.-\end{array}$ & $\begin{array}{l}18.0 \\
13.0 \\
12.5\end{array}$ & $\begin{array}{l}242 \\
166 \\
210\end{array}$ & $\begin{array}{l}1200 \\
1100 \\
1160\end{array}$ & $\begin{array}{l}1200 \\
1150 \\
1070\end{array}$ \\
\hline$C P-3$ & $\begin{array}{l}09-21-89 \\
05-03-90 \\
10-17-90\end{array}$ & 1792.17 & 8.1 & $\begin{array}{l}5.4 \\
5.3 \\
5.4\end{array}$ & $\begin{array}{l}65 \\
55 \\
30\end{array}$ & $\begin{array}{l}.0004 \\
.0011 \\
.0008\end{array}$ & $\begin{array}{l}19.0 \\
11.5 \\
16.0\end{array}$ & $\begin{array}{l}175 \\
101 \\
226\end{array}$ & $\begin{array}{l}1200 \\
1100 \\
1200\end{array}$ & $\begin{array}{l}1200 \\
1110 \\
1210\end{array}$ \\
\hline CP- 4 & $\begin{array}{l}09-21-89 \\
05-03-90 \\
10-17-90\end{array}$ & 1792.11 & 8.1 & $\begin{array}{l}5.7 \\
5.1 \\
5.2\end{array}$ & $\begin{array}{l}- \\
50 \\
50\end{array}$ & $\begin{array}{r}\text { E.0004 } \\
.0015 \\
.0008\end{array}$ & $\begin{array}{l}17.5 \\
11.0 \\
16.0\end{array}$ & $\begin{array}{r}261 \\
89 \\
138\end{array}$ & $\begin{array}{l}1080 \\
1170 \\
1180\end{array}$ & $\begin{array}{l}1180 \\
1180\end{array}$ \\
\hline$C P-5$ & $\begin{array}{l}09-20-89 \\
05-07-90 \\
10-17-90\end{array}$ & 1791.71 & 8.1 & $\begin{array}{l}5.0 \\
5.0 \\
5.2\end{array}$ & $\begin{array}{l}45 \\
50 \\
18\end{array}$ & $\begin{array}{l}.0011 \\
.0027 \\
.0011\end{array}$ & $\begin{array}{l}15.0 \\
14.5 \\
15.0\end{array}$ & $\begin{array}{l}215 \\
170 \\
177\end{array}$ & $\begin{array}{l}1250 \\
1230 \\
1190\end{array}$ & $\begin{array}{l}1200 \\
1170 \\
1200\end{array}$ \\
\hline CP-6 & $\begin{array}{l}09-20-89 \\
06-16-90 \\
10-12-90\end{array}$ & 1791.48 & 7.7 & $\begin{array}{l}5.0 \\
\therefore- \\
5.1\end{array}$ & $\begin{array}{l}60 \\
\cdots \\
\cdots\end{array}$ & $\begin{array}{c}.0011 \\
\ldots \\
\cdots\end{array}$ & $\begin{array}{l}17.0 \\
\therefore \\
16.0\end{array}$ & $\begin{array}{c}201 \\
\cdots \\
222\end{array}$ & $\begin{array}{c}1320 \\
\cdots \\
1230\end{array}$ & $\begin{array}{c}1270 \\
\therefore- \\
1240\end{array}$ \\
\hline CP- 8 & $\begin{array}{l}06-07-90 \\
10-17-90\end{array}$ & 1800 & 39.6 & $\begin{array}{l}5.9 \\
5.8\end{array}$ & $\begin{array}{l}70 \\
30\end{array}$ & $\begin{array}{l}.0008 \\
.0011\end{array}$ & $\begin{array}{l}16.0 \\
16.0\end{array}$ & $\begin{array}{r}128 \\
13\end{array}$ & $\begin{array}{l}657 \\
649\end{array}$ & $\begin{array}{l}644 \\
647\end{array}$ \\
\hline CPDP-1 & $\begin{array}{l}11-17-89 \\
10-16-90\end{array}$ & 1790 & $\begin{array}{l}\cdots \\
-.\end{array}$ & $\ddot{1.0}$ & $\begin{array}{l}45 \\
25\end{array}$ & $\begin{array}{l}.0008 \\
.0011\end{array}$ & $\begin{array}{l}11.0 \\
19.0\end{array}$ & $\begin{array}{l}175 \\
167\end{array}$ & $\begin{array}{l}1670 \\
2090\end{array}$ & $\begin{array}{l}1390 \\
1990\end{array}$ \\
\hline CPOP-2 & $05-16-90$ & 1790 & 1.28 & .5 & - & -. & 16.5 & 82 & 1430 & 1280 \\
\hline
\end{tabular}


GROND-WATER DATA-Cont inued

CHEMICAL ANALYSES-Cont inued

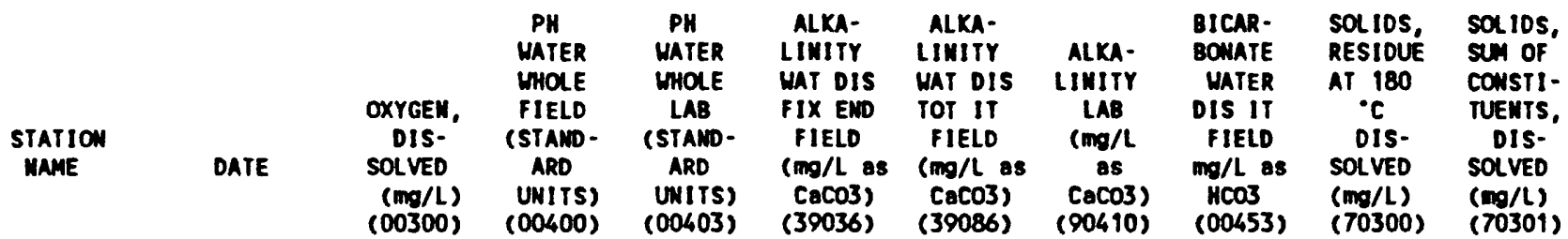

ARIZONA DEPARTMENT OF TRANSPORTATION WELL CLUSTER-Continued

\begin{tabular}{|c|c|c|c|c|c|c|c|c|c|c|}
\hline $10-1$ & $\begin{array}{l}11-14-89 \\
05-01-90 \\
10-13-90\end{array}$ & $\begin{array}{l}\text { No } \\
.1 \\
.3\end{array}$ & $\begin{array}{l}7.1 \\
7.1 \\
7.2\end{array}$ & $\begin{array}{l}7.7 \\
7.6 \\
7.5\end{array}$ & $\begin{array}{l}330 \\
400 \\
380\end{array}$ & $\begin{array}{l}333 \\
-\because \\
372\end{array}$ & $\begin{array}{l}\cdots \\
375\end{array}$ & $\begin{array}{l}406 \\
482 \\
454\end{array}$ & $\begin{array}{l}-. \\
-\therefore \\
696\end{array}$ & $\begin{array}{l}698 \\
679 \\
710\end{array}$ \\
\hline $10-3$ & $\begin{array}{l}07-13-89 \\
07-13-89 \\
09-22-89 \\
05-01-90 \\
10-19-90\end{array}$ & $\begin{array}{l}.5 \\
-. \\
.1 \\
.1 \\
.2\end{array}$ & $\begin{array}{l}7.6 \\
-. \\
7.8 \\
7.2 \\
7.1\end{array}$ & $\begin{array}{r}8.0 \\
. . \\
7.9 \\
7.8 \\
7.8\end{array}$ & $\begin{array}{r}210 \\
\cdots \\
200 \\
230 \\
230\end{array}$ & $\begin{array}{l}216 \\
\cdots \\
206 \\
234 \\
230\end{array}$ & $\begin{array}{c}- \\
-- \\
- \\
- \\
222\end{array}$ & $\begin{array}{l}264 \\
\cdots \\
251 \\
286 \\
281\end{array}$ & $\begin{array}{l}\ldots \\
\cdots \\
\cdots \\
620\end{array}$ & $\begin{array}{l}\cdots \\
-. \\
553 \\
572 \\
635\end{array}$ \\
\hline$A D-4$ & $\begin{array}{l}09-22-89 \\
05-01-90 \\
10-13-90\end{array}$ & $\begin{array}{l}.8 \\
\text { 10 } \\
.7\end{array}$ & $\begin{array}{l}7.7 \\
7.4 \\
7.5\end{array}$ & $\begin{array}{l}7.9 \\
7.8 \\
7.6\end{array}$ & $\begin{array}{l}230 \\
220 \\
240\end{array}$ & $\begin{array}{l}-. \\
223 \\
238\end{array}$ & $\begin{array}{l}-. \\
225\end{array}$ & $\begin{array}{l}288 \\
272 \\
290\end{array}$ & $\begin{array}{l}-. \\
-\therefore \\
974\end{array}$ & $\begin{array}{l}822 \\
815 \\
926\end{array}$ \\
\hline $10-5$ & $\begin{array}{l}07-13-89 \\
11-13-89 \\
11-14-89 \\
05-04-90 \\
10-19-90\end{array}$ & $\begin{array}{l}3.3 \\
2.8 \\
2.8 \\
1.5 \\
.9\end{array}$ & $\begin{array}{l}7.6 \\
7.4 \\
7.3 \\
7.5 \\
7.1\end{array}$ & $\begin{array}{r}7.9 \\
8.4 \\
-. . \\
7.9 \\
7.8\end{array}$ & $\begin{array}{r}240 \\
240 \\
-0 \\
230 \\
290\end{array}$ & $\begin{array}{l}240 \\
239 \\
\cdots- \\
234 \\
296\end{array}$ & $\begin{array}{l}-- \\
-- \\
- \\
-- \\
249\end{array}$ & $\begin{array}{l}293 \\
292 \\
\cdots- \\
286 \\
361\end{array}$ & $\begin{array}{l}\cdots \\
\cdots \\
\cdots \\
904\end{array}$ & $\begin{array}{l}\because- \\
-- \\
\cdots \\
703 \\
907\end{array}$ \\
\hline ADDP-1 & $\begin{array}{l}05-15-90 \\
06-13-91\end{array}$ & $\begin{array}{l}3.6 \\
2.0\end{array}$ & $\begin{array}{l}7.3 \\
7.4\end{array}$ & $\begin{array}{l}7.6 \\
7.8\end{array}$ & $\begin{array}{l}636 \\
200\end{array}$ & 200 & $\begin{array}{r}222 \\
--\end{array}$ & $\ddot{244}$ & $\overline{545}$ & $\begin{array}{r}1100 \\
532\end{array}$ \\
\hline
\end{tabular}

CEDAR POINT WELL CLUSTER-Cont inued

\begin{tabular}{|c|c|c|c|c|c|c|c|c|c|c|}
\hline$C P-1$ & $\begin{array}{l}09-21-89 \\
05-03-90 \\
05-03-90 \\
10-12-90\end{array}$ & $\begin{array}{l}.1 \\
\text { nD } \\
\text { No } \\
.2\end{array}$ & $\begin{array}{l}7.5 \\
7.2 \\
7.2 \\
7.2\end{array}$ & $\begin{array}{l}7.9 \\
7.4 \\
7.7 \\
7.5\end{array}$ & $\begin{array}{l}340 \\
340 \\
340 \\
330\end{array}$ & $\begin{array}{l}420 \\
342 \\
342 \\
336\end{array}$ & $\begin{array}{l}\ldots \\
\ldots \\
317\end{array}$ & $\begin{array}{l}-. \\
417 \\
\because- \\
410\end{array}$ & $\begin{array}{l}\cdots \\
\cdots \\
\angle- \\
488\end{array}$ & $\begin{array}{l}466 \\
468 \\
472 \\
504\end{array}$ \\
\hline$C P-2$ & $\begin{array}{l}09-21-89 \\
05-03-90 \\
10-12-90\end{array}$ & $\begin{array}{l}.6 \\
.1 \\
.3\end{array}$ & $\begin{array}{l}7.7 \\
7.4 \\
7.3\end{array}$ & $\begin{array}{l}7.9 \\
7.7 \\
7.6\end{array}$ & $\begin{array}{l}210 \\
220 \\
230\end{array}$ & $\begin{array}{l}-\because \\
220 \\
228\end{array}$ & $\begin{array}{l}-. \\
147\end{array}$ & $\begin{array}{l}264 \\
270 \\
278\end{array}$ & $\begin{array}{l}\because- \\
\ddot{770}\end{array}$ & $\begin{array}{l}755 \\
690 \\
781\end{array}$ \\
\hline$C P-3$ & $\begin{array}{l}09-21-89 \\
05-03-90 \\
10-17-90\end{array}$ & $\begin{array}{l}.1 \\
.1 \\
.-\end{array}$ & $\begin{array}{l}7.5 \\
7.4 \\
7.4\end{array}$ & $\begin{array}{l}8.1 \\
7.8 \\
7.8\end{array}$ & $\begin{array}{l}250 \\
240 \\
220\end{array}$ & $\begin{array}{l}\cdots \\
240 \\
\cdots\end{array}$ & $\begin{array}{c}\ldots \\
-\cdots \\
222\end{array}$ & $\begin{array}{l}308 \\
293 \\
270\end{array}$ & $\begin{array}{l}-- \\
\cdots \\
778\end{array}$ & $\begin{array}{l}757 \\
679 \\
807\end{array}$ \\
\hline CP-4 & $\begin{array}{l}09-21-89 \\
05-03-90 \\
10-17-90\end{array}$ & $\begin{array}{l}1.1 \\
.1 \\
.4\end{array}$ & $\begin{array}{l}7.9 \\
7.6 \\
7.3\end{array}$ & $\begin{array}{l}-. \\
7.9 \\
7.8\end{array}$ & $\begin{array}{l}\cdots \\
230 \\
240\end{array}$ & $\begin{array}{l}-. \\
240 \\
--\end{array}$ & $\begin{array}{c}-- \\
233\end{array}$ & $\begin{array}{l}-- \\
293 \\
290\end{array}$ & $\begin{array}{l}\because . \\
\therefore \\
770\end{array}$ & $\begin{array}{l}717 \\
784\end{array}$ \\
\hline$C P-5$ & $\begin{array}{l}09-20-89 \\
05-07-90 \\
10-17-90\end{array}$ & $\begin{array}{l}.3 \\
.5 \\
.4\end{array}$ & $\begin{array}{l}7.5 \\
7.4 \\
7.0\end{array}$ & $\begin{array}{l}8.0 \\
7.8 \\
7.8\end{array}$ & $\begin{array}{l}240 \\
240 \\
240\end{array}$ & $\begin{array}{l}-- \\
243 \\
--\end{array}$ & $\begin{array}{r}\ddot{2} \\
245\end{array}$ & $\begin{array}{l}286 \\
297 \\
300\end{array}$ & $\begin{array}{l}\ddot{-} \\
\ddot{808}\end{array}$ & $\begin{array}{l}799 \\
767 \\
806\end{array}$ \\
\hline$C P-6$ & $\begin{array}{l}09-20-89 \\
06-16-90 \\
10-12-90\end{array}$ & $\begin{array}{l}.1 \\
\because . \\
.4\end{array}$ & $\begin{array}{c}7.5 \\
\therefore .1 \\
7.1\end{array}$ & $\begin{array}{c}8.0 \\
\cdots \\
7.5\end{array}$ & $\begin{array}{r}250 \\
-- \\
250\end{array}$ & $\begin{array}{l}259 \\
-- \\
264\end{array}$ & $\begin{array}{c}\ldots \\
249\end{array}$ & $\begin{array}{l}306 \\
-- \\
322\end{array}$ & $\begin{array}{l}\ldots \\
\therefore \\
856\end{array}$ & $\begin{array}{l}856 \\
-- \\
842\end{array}$ \\
\hline CP-8 & $\begin{array}{l}06-07-90 \\
10-17-90\end{array}$ & $\begin{array}{l}.2 \\
.2\end{array}$ & $\begin{array}{l}7.2 \\
7.0\end{array}$ & $\begin{array}{l}7.5 \\
7.8\end{array}$ & 270 & $\begin{array}{l}287 \\
\cdots\end{array}$ & $\begin{array}{l}273 \\
276\end{array}$ & 330 & $\ddot{361}$ & $\begin{array}{l}371 \\
381\end{array}$ \\
\hline CPDP- 1 & $\begin{array}{l}11-17-89 \\
10-16-90\end{array}$ & 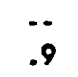 & $\begin{array}{l}7.0 \\
6.9\end{array}$ & $\begin{array}{l}7.9 \\
8.1\end{array}$ & $\begin{array}{l}320 \\
410\end{array}$ & $\begin{array}{l}322 \\
\cdots\end{array}$ & 399 & $\begin{array}{l}392 \\
500\end{array}$ & $\ddot{1390}$ & 1430 \\
\hline CPOP-2 & $05-16-90$ & 1.1 & 7.2 & 8.0 & 280 & 285 & 199 & 348 & -- & 852 \\
\hline
\end{tabular}


CHEMICAL AMALYSES-Cont inued

STATION
NAME

DATE

$11-14-89$

$05-01-90$

$10-13-90$

$A D-3$

$07-13-89$

$07-13-89$

09-22-89

05-01-90

10-19-90

$A D-6$

$09-22-89$

05-01-90

10-13-90

AD-5

07-13-89

$11-13-89$

$11-14-89$

$05-04-90$

10-19-90

ADOP-1

05-15-90

$06-13-91$

\begin{tabular}{|c|c|c|c|c|c|c|c|c|c|}
\hline $\begin{array}{l}\text { SOLIDS, } \\
\text { DIS } \\
\text { SOLVED } \\
\text { (tons } \\
\text { per } \\
\text { ac-ft) } \\
(70303 \text { ) }\end{array}$ & $\begin{array}{l}\text { NIIRO- } \\
\text { GEN, } \\
\text { NWONIA } \\
\text { DIS- } \\
\text { SOLVEO } \\
\text { (mo/L } \\
\text { OS N) } \\
\text { (00608) }\end{array}$ & $\begin{array}{l}\text { NITRO- } \\
\text { GEN, } \\
\text { NITRITE } \\
\text { OIS- } \\
\text { SOLVEO } \\
\text { (mg/L } \\
\text { as N) } \\
(00613)\end{array}$ & $\begin{array}{l}\text { NITRO- } \\
\text { GEN, } \\
\text { NITRATE } \\
\text { DIS- } \\
\text { SOL VED } \\
\text { (mg/L } \\
\text { as N) } \\
\text { (00618) }\end{array}$ & $\begin{array}{c}\text { NITRO- } \\
\text { GEN, } \\
\text { NO2+NO3 } \\
\text { DIS- } \\
\text { SOLVED } \\
\text { (mg/L } \\
\text { OS N) } \\
(00631)\end{array}$ & $\begin{array}{l}\text { MITRO- } \\
\text { GEN, } \\
\text { NITRATE } \\
\text { DIS- } \\
\text { SOLVED } \\
\text { (mo/L } \\
\text { OS NO3) } \\
\text { (71851) }\end{array}$ & $\begin{array}{l}\text { MIIRO- } \\
\text { GEN, } \\
\text { MITRITE } \\
\text { OIS- } \\
\text { SOLVED } \\
\text { (mo/L } \\
\text { OS NO2) } \\
\text { (71856) }\end{array}$ & $\begin{array}{c}\text { PHOS- } \\
\text { PHORUS } \\
\text { OIS- } \\
\text { SOLVED } \\
\text { (mg/l } \\
\text { as P) } \\
(00666)\end{array}$ & $\begin{array}{l}\text { PHOS- } \\
\text { PHORUS } \\
\text { ORIHO, } \\
\text { DIS- } \\
\text { SOLVEO } \\
\text { (mg/L } \\
\text { OS P } \\
\text { (00671) }\end{array}$ & $\begin{array}{c}\text { PHOS- } \\
\text { PHATE, } \\
\text { ORTHO, } \\
\text { OIS- } \\
\text { SOLVED } \\
(m g / L \\
\text { as PO4) } \\
(00660)\end{array}$ \\
\hline
\end{tabular}

ARIZONA DEPARTMENT OF IRAMSPORTATION WELL CLUSTER-COnt inued

\begin{tabular}{|c|c|c|c|c|c|c|c|c|c|}
\hline $\begin{array}{l}.95 \\
.92 \\
.95\end{array}$ & $\begin{array}{l}-. \\
\therefore \\
\therefore\end{array}$ & 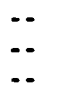 & $\begin{array}{l}\cdots \\
\cdots \\
\cdots\end{array}$ & $\begin{array}{l}. . \\
.400 \\
.415\end{array}$ & $\begin{array}{l}\cdots \\
\cdots \\
\cdots\end{array}$ & $\begin{array}{l}-- \\
\cdots \\
\cdots\end{array}$ & $\begin{array}{l}\cdots \\
\ddot{.0} \\
.075\end{array}$ & $\begin{array}{l}\cdots \\
\because-\end{array}$ & 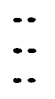 \\
\hline$\cdots$ & - & -. & $\cdots$ & 1.90 & $\cdots$ & $\cdots$ & - & $\cdots$ & $\cdots$ \\
\hline -. & $\cdots$ & $\cdots$ & -. & -. & -. & $\cdots$ & $\cdots$ & -. & $\cdots$ \\
\hline $\begin{array}{l}.75 \\
.78\end{array}$ & $\begin{array}{l}\cdots \\
\cdots\end{array}$ & $\begin{array}{l}\cdots \\
\cdots\end{array}$ & -. & $\begin{array}{l}2.50 \\
2.50\end{array}$ & $\begin{array}{l}\cdots \\
\cdots\end{array}$ & $\begin{array}{l}\cdots \\
\cdots\end{array}$ & $\begin{array}{l}\cdots \\
\cdots\end{array}$ & -. & 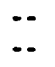 \\
\hline .84 & $\cdots$ & $\cdots$ & $\cdots$ & 2.10 & $\cdots$ & $\cdots$ & .022 & $\cdots$ & -- \\
\hline 1.12 & $\cdots$ & -. & $\cdots$ & 6.10 & -. & -. & -. & .. & $\cdots$ \\
\hline 1.11 & $\cdots$ & -. & $\cdots$ & 7.20 & -. & $\cdots$ & -. & -. & -. \\
\hline 1.32 & $\cdots$ & $\cdots$ & $\cdots$ & .018 & - & -- & .014 & $\cdots$ & $\cdots$ \\
\hline - & $\cdots$ & $\cdots$ & -. & 3.00 & -. & -. & - & .. & $\ldots$ \\
\hline-- & $\cdots$ & $\cdots$ & -. & 3.20 & $\cdots$ & -. & $\cdots$ & $\cdots$ & $\cdots$ \\
\hline -. & $\cdots$ & $\cdots$ & -. & - & -. & -- & $\cdots$ & -. & -. \\
\hline .96 & $\cdots$ & - & $\cdots$ & 3.00 & $\cdots$ & $\cdots$ & $\cdots$ & $\cdots$ & -- \\
\hline 1.23 & $\cdots$ & $\cdot-$ & $\cdot-$ & 3.80 & $\cdots$ & $\cdots$ & .033 & $\cdots$ & $\cdots$ \\
\hline 1.50 & .018 & .003 & 2.30 & 2.30 & 10 & .01 & -- & .016 & .05 \\
\hline .74 & & & - & .659 & $\cdots$ & -. & .109 & $\cdots$ & -. \\
\hline
\end{tabular}

CEDAR POINT MELL CLUSTER-Continued

\begin{tabular}{|c|c|c|c|c|c|c|c|c|c|c|c|}
\hline$C P-1$ & $\begin{array}{l}09-21-89 \\
05-03-90 \\
05-03-90 \\
10-12-90\end{array}$ & $\begin{array}{l}.63 \\
.64 \\
.64 \\
.66\end{array}$ & $\begin{array}{l}-- \\
\ldots \\
-- \\
-\end{array}$ & $\begin{array}{l}\cdots \\
\cdots \\
-- \\
-\end{array}$ & $\begin{array}{l}\cdots \\
\cdots \\
\cdots \\
\cdots\end{array}$ & $\begin{array}{l}<.100 \\
<.100 \\
<.100 \\
<.010\end{array}$ & $\begin{array}{l}\cdots \\
\cdots \\
\cdots \\
\cdots\end{array}$ & $\begin{array}{l}\ldots \\
\cdots \\
\ldots \\
\ldots\end{array}$ & $\begin{array}{l}\ldots \\
\ldots \\
\cdots \\
.021\end{array}$ & $\begin{array}{l}-. \\
\cdots \\
\cdots \\
--\end{array}$ & $\begin{array}{l}\cdots \\
\cdots \\
\cdots \\
\cdots\end{array}$ \\
\hline$C P-2$ & $\begin{array}{l}09-21-89 \\
05-03-90 \\
10-12-90\end{array}$ & $\begin{array}{r}1.03 \\
.94 \\
1.05\end{array}$ & $\begin{array}{l}-- \\
-- \\
--\end{array}$ & $\begin{array}{l}\cdots \\
\cdots \\
\cdots\end{array}$ & $\begin{array}{l}\cdots \\
\cdots \\
\cdots\end{array}$ & $\begin{array}{l}<.100 \\
<.100 \\
<.010\end{array}$ & $\begin{array}{l}\cdots \\
\cdots \\
\cdots\end{array}$ & $\begin{array}{l}\cdots \\
\cdots \\
\cdots\end{array}$ & $\begin{array}{l}\cdots \\
. \\
.009\end{array}$ & $\begin{array}{l}\cdots \\
\cdots \\
\cdots\end{array}$ & $\begin{array}{l}\cdots \\
\cdots \\
\cdots\end{array}$ \\
\hline$C P-3$ & $\begin{array}{l}09-21-89 \\
05-03-90 \\
10-17-90\end{array}$ & $\begin{array}{r}1.03 \\
.92 \\
1.06\end{array}$ & $\begin{array}{l}-- \\
-- \\
--\end{array}$ & $\begin{array}{l}-. \\
\cdots \\
\cdots\end{array}$ & $\begin{array}{l}-- \\
\cdots \\
--\end{array}$ & $\begin{array}{l}<.100 \\
<.100 \\
.047\end{array}$ & $\begin{array}{l}-. \\
\cdots \\
\cdots\end{array}$ & $\begin{array}{l}\cdots \\
\cdots \\
\cdots\end{array}$ & $\begin{array}{l}\ldots \\
.037\end{array}$ & $\begin{array}{l}\cdots \\
\cdots \\
\cdots\end{array}$ & $\begin{array}{l}-\cdot \\
\cdots \\
\cdots\end{array}$ \\
\hline$C P-4$ & $\begin{array}{l}09-21-89 \\
05-03-90 \\
10-17-90\end{array}$ & $\begin{array}{r}.9 \\
1.98 \\
1.05\end{array}$ & $\begin{array}{l}-. \\
- \\
-\end{array}$ & $\begin{array}{l}\cdots \\
\cdots \\
\cdots\end{array}$ & $\begin{array}{l}-. \\
\cdots \\
--\end{array}$ & $\begin{array}{l}-. \\
<.100 \\
.075\end{array}$ & $\begin{array}{l}-\cdot \\
--\end{array}$ & $\begin{array}{l}-. \\
\cdots \\
\cdots\end{array}$ & $\begin{array}{l}. . \\
.024 \\
.024\end{array}$ & $\begin{array}{l}\cdots \\
\cdots\end{array}$ & $\begin{array}{l}-\cdot \\
-\cdot \\
\cdots\end{array}$ \\
\hline $\mathrm{CP}-5$ & $\begin{array}{l}09-20-89 \\
05-07-90 \\
10-17-90\end{array}$ & $\begin{array}{l}1.09 \\
1.04 \\
1.10\end{array}$ & $\begin{array}{l}\cdots \\
\cdots \\
\cdots\end{array}$ & $\begin{array}{l}\cdots \\
\cdots \\
\cdots\end{array}$ & $\begin{array}{l}\cdots \\
\cdots \\
\cdots\end{array}$ & $\begin{array}{r}<.100 \\
<.100 \\
.036\end{array}$ & $\begin{array}{l}\cdots \\
\cdots \\
\cdots\end{array}$ & $\begin{array}{l}\cdots \\
\cdots \\
\cdots\end{array}$ & $\begin{array}{l}\ldots \\
.013\end{array}$ & $\begin{array}{l}-. \\
\cdots \\
--\end{array}$ & $\begin{array}{l}\cdots \\
\cdots \\
\cdots\end{array}$ \\
\hline$C P-6$ & $\begin{array}{l}09-20-89 \\
06-16-90 \\
10-12-90\end{array}$ & $\begin{array}{l}1.16 \\
-0 \\
1.16\end{array}$ & $\begin{array}{l}-. \\
\cdots \\
-.\end{array}$ & $\begin{array}{l}\cdots \\
\cdots \\
\cdots\end{array}$ & $\begin{array}{l}-. \\
-- \\
--\end{array}$ & $\begin{array}{l}<.100 \\
-. \\
.011\end{array}$ & $\begin{array}{l}-\cdot \\
\cdots \\
--\end{array}$ & $\begin{array}{l}\cdots \\
\cdots \\
\cdots\end{array}$ & $\begin{array}{l}. \\
.0 \\
.016\end{array}$ & $\begin{array}{l}-\cdot \\
\cdots \\
--\end{array}$ & $\begin{array}{l}-. \\
-. \\
-\cdot\end{array}$ \\
\hline$C P-8$ & $\begin{array}{l}06-07-90 \\
10-17-90\end{array}$ & $\begin{array}{l}.50 \\
.49\end{array}$ & $\begin{array}{l}.053 \\
--\end{array}$ & .003 & 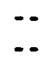 & $\begin{array}{r}<.010 \\
.016\end{array}$ & $\begin{array}{l}-- \\
\cdots\end{array}$ & .01 & $\begin{array}{l}-. \\
.002\end{array}$ & $\begin{array}{l}.001 \\
\therefore-\end{array}$ & ND \\
\hline CPDP-1 & $\begin{array}{l}11-17-89 \\
10-16-90\end{array}$ & 1.89 & $\cdots$ & $\cdots$ & -- & .055 & -- & -- & .045 & $\because \cdot$ & 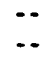 \\
\hline-2 & $05-16-90$ & 1.16 & .735 & .001 &.- & $<.010$ & $-\cdot$ & ND & $\cdots$ & .008 & .02 \\
\hline
\end{tabular}




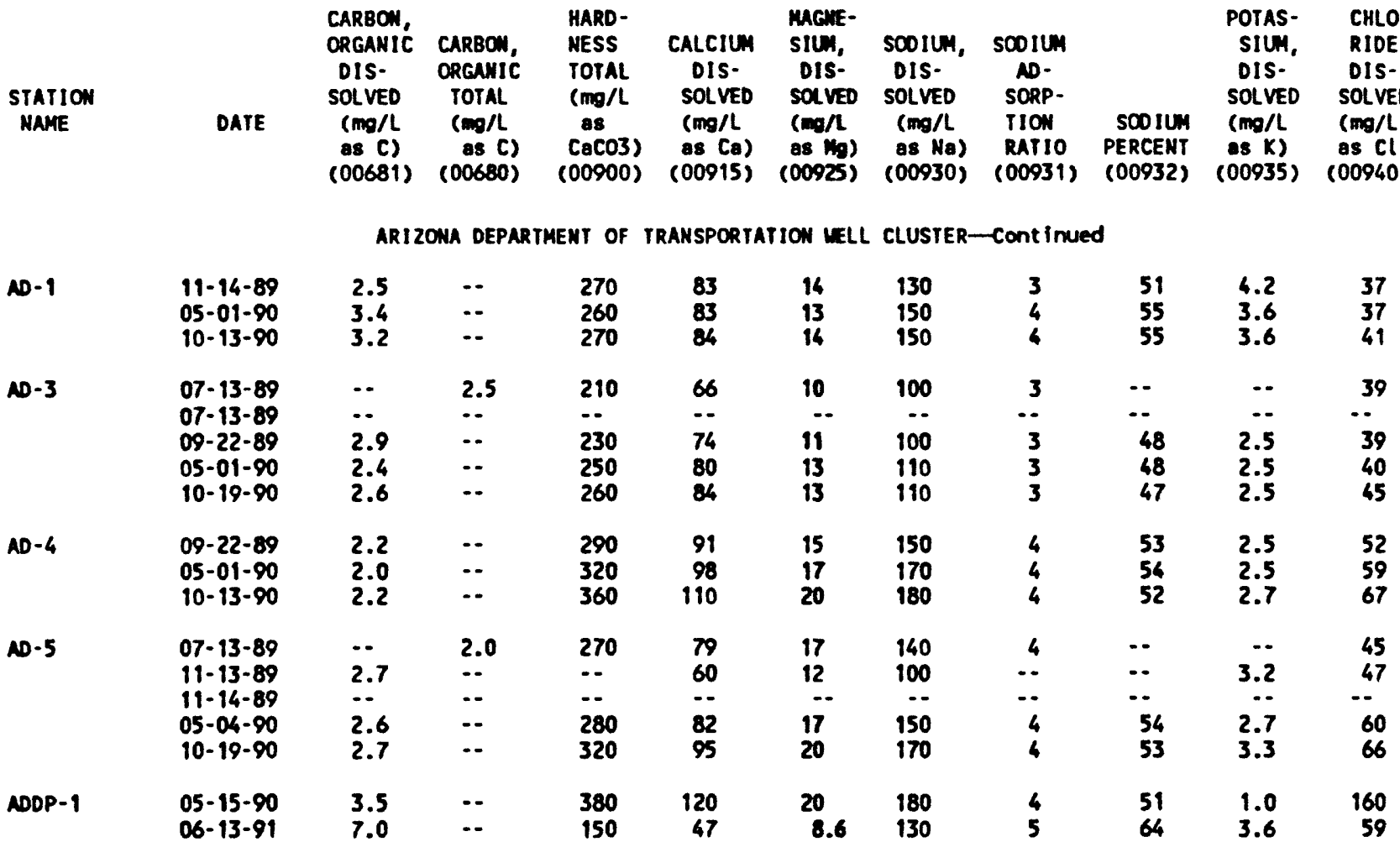

CEDAR POINT WELL CLUSTER-Continued

\begin{tabular}{|c|c|c|c|c|c|c|c|c|c|c|c|}
\hline$C P-1$ & $\begin{array}{l}09-21-89 \\
05-03-90 \\
05-03-90 \\
10-12-90\end{array}$ & $\begin{array}{l}2.6 \\
2.5 \\
2.7 \\
2.7\end{array}$ & $\begin{array}{l}-. \\
\cdots \\
\cdots \\
\cdots\end{array}$ & $\begin{array}{l}290 \\
290 \\
290 \\
290\end{array}$ & $\begin{array}{l}79 \\
80 \\
80 \\
81\end{array}$ & $\begin{array}{l}21 \\
21 \\
22 \\
22\end{array}$ & $\begin{array}{l}55 \\
56 \\
58 \\
57\end{array}$ & $\begin{array}{l}1 \\
1 \\
1 \\
1\end{array}$ & $\begin{array}{l}29 \\
30 \\
30 \\
29\end{array}$ & $\begin{array}{l}2.9 \\
3.1 \\
2.8 \\
2.9\end{array}$ & $\begin{array}{l}24 \\
27 \\
27 \\
35\end{array}$ \\
\hline$C P-2$ & $\begin{array}{l}09-21-89 \\
05-03-90 \\
10-12-90\end{array}$ & $\begin{array}{l}3.3 \\
2.6 \\
3.3\end{array}$ & $\begin{array}{l}\cdots \\
\cdots \\
\cdots\end{array}$ & $\begin{array}{l}320 \\
310 \\
310\end{array}$ & $\begin{array}{l}99 \\
96 \\
96\end{array}$ & $\begin{array}{l}17 \\
16 \\
16\end{array}$ & $\begin{array}{l}130 \\
140 \\
140\end{array}$ & $\begin{array}{l}3 \\
3 \\
3\end{array}$ & $\begin{array}{l}47 \\
50 \\
50\end{array}$ & $\begin{array}{l}3.6 \\
3.1 \\
3.2\end{array}$ & $\begin{array}{l}63 \\
61 \\
67\end{array}$ \\
\hline $\mathrm{CP}-3$ & $\begin{array}{l}09-21-89 \\
05-03-90 \\
10-17-90\end{array}$ & $\begin{array}{l}3.8 \\
3.0 \\
3.7\end{array}$ & $\begin{array}{l}\cdots \\
\cdots \\
\cdots\end{array}$ & $\begin{array}{l}300 \\
280 \\
290\end{array}$ & $\begin{array}{l}96 \\
88 \\
90\end{array}$ & $\begin{array}{l}15 \\
14 \\
15\end{array}$ & $\begin{array}{l}140 \\
140 \\
150\end{array}$ & $\begin{array}{l}4 \\
4 \\
4\end{array}$ & $\begin{array}{l}50 \\
52 \\
53\end{array}$ & $\begin{array}{l}2.8 \\
2.4 \\
2.6\end{array}$ & $\begin{array}{l}49 \\
59 \\
74\end{array}$ \\
\hline$C P-4$ & $\begin{array}{l}09-21-89 \\
05-03-90 \\
10-17-90\end{array}$ & $\begin{array}{l}\cdots \\
3.5 \\
3.7\end{array}$ & $\begin{array}{l}- \\
\cdots \\
--\end{array}$ & $\begin{array}{l}-- \\
250 \\
250\end{array}$ & $\begin{array}{l}\cdots \\
77 \\
77\end{array}$ & $\begin{array}{l}-- \\
14\end{array}$ & $\begin{array}{r}-- \\
160 \\
160\end{array}$ & $\begin{array}{l}\cdots \\
4\end{array}$ & $\begin{array}{l}\cdots \\
58 \\
58\end{array}$ & $\begin{array}{l}-. \\
2.3 \\
2.4\end{array}$ & $\begin{array}{l}\cdots \\
67 \\
65\end{array}$ \\
\hline$C P-5$ & $\begin{array}{l}09-20-89 \\
05-07-90 \\
10-17-90\end{array}$ & $\begin{array}{l}2.6 \\
2.3 \\
2.3\end{array}$ & $\begin{array}{l}\cdots \\
\cdots \\
--\end{array}$ & $\begin{array}{l}380 \\
360 \\
350\end{array}$ & $\begin{array}{l}120 \\
110 \\
110\end{array}$ & $\begin{array}{l}20 \\
20 \\
19\end{array}$ & $\begin{array}{l}120 \\
130 \\
130\end{array}$ & $\begin{array}{l}3 \\
3 \\
3\end{array}$ & $\begin{array}{l}40 \\
44 \\
44\end{array}$ & $\begin{array}{l}1.8 \\
1.7 \\
1.7\end{array}$ & $\begin{array}{l}52 \\
46 \\
53\end{array}$ \\
\hline CP-6 & $\begin{array}{l}09-20-89 \\
06-16-90 \\
10-12-90\end{array}$ & $\begin{array}{l}2.6 \\
\therefore . \\
1.8\end{array}$ & $\begin{array}{l}\cdots \\
\cdots\end{array}$ & $\begin{array}{l}420 \\
\ldots \\
390\end{array}$ & $\begin{array}{r}130 \\
\cdots \\
120\end{array}$ & $\begin{array}{c}22 \\
21\end{array}$ & $\begin{array}{r}120 \\
\cdots \\
120\end{array}$ & $\begin{array}{r}3 \\
-\therefore \\
3\end{array}$ & $\begin{array}{c}39 \\
\cdots \\
40\end{array}$ & $\begin{array}{c}1.4 \\
\cdots \\
1.3\end{array}$ & $\begin{array}{c}56 \\
-- \\
56\end{array}$ \\
\hline$C P-8$ & $\begin{array}{l}06-07-90 \\
10-17-90\end{array}$ & $\begin{array}{r}1.1 \\
.6\end{array}$ & $\begin{array}{l}-\cdot \\
--\end{array}$ & $\begin{array}{l}260 \\
270\end{array}$ & $\begin{array}{l}71 \\
74\end{array}$ & $\begin{array}{l}20 \\
21\end{array}$ & $\begin{array}{l}37 \\
37\end{array}$ & $\begin{array}{l}1 \\
1\end{array}$ & $\begin{array}{l}23 \\
22\end{array}$ & $\begin{array}{l}5.6 \\
5.4\end{array}$ & $\begin{array}{l}22 \\
23\end{array}$ \\
\hline CPDP-1 & $\begin{array}{l}11-17-89 \\
10-16-90\end{array}$ & $\begin{array}{l}6.4 \\
8.9\end{array}$ & $\begin{array}{l}-. \\
\cdots\end{array}$ & $\begin{array}{l}470 \\
430\end{array}$ & $\begin{array}{l}140 \\
130\end{array}$ & $\begin{array}{l}29 \\
25\end{array}$ & $\begin{array}{l}150 \\
330\end{array}$ & $\begin{array}{l}3 \\
7\end{array}$ & $\begin{array}{l}41 \\
62\end{array}$ & $\begin{array}{l}4.9 \\
6.0\end{array}$ & 80 \\
\hline CPDP-2 & $05-16-90$ & 4.1 & $\cdots$ & 350 & 100 & 23 & 150 & 4 & 48 & 3.5 & 63 \\
\hline
\end{tabular}


STATION

MAME

DATE

ARIZONA DEPARTMENT OF TRANSPORTATION WELL CLUSTER-Continued

\begin{tabular}{|c|c|c|c|c|c|c|c|c|c|c|}
\hline$A D-1$ & $\begin{array}{l}11-14-89 \\
05-01-90 \\
10-13-90\end{array}$ & $\begin{array}{l}.18 \\
.13 \\
.16\end{array}$ & $\begin{array}{l}.50 \\
.20 \\
.40\end{array}$ & $\begin{array}{l}17 \\
20 \\
19\end{array}$ & $\begin{array}{l}210 \\
130 \\
170\end{array}$ & $\begin{array}{l}\cdots \\
-2 \\
<1\end{array}$ & $\begin{array}{l}330 \\
280 \\
250\end{array}$ & $\begin{array}{l}<.5 \\
<.5 \\
<.5\end{array}$ & $\begin{array}{l}\cdots \\
180\end{array}$ & $\begin{array}{r}<1.0 \\
3.0 \\
<1.0\end{array}$ \\
\hline$A D-3$ & $\begin{array}{l}07-13-89 \\
07-13-89 \\
09-22-89 \\
05-01-90 \\
10-19-90\end{array}$ & $\begin{array}{l}.17 \\
. . \\
.15 \\
.15 \\
.15\end{array}$ & $\begin{array}{l}.40 \\
. . \\
.40 \\
1.1 \\
.20\end{array}$ & $\begin{array}{l}12 \\
\because- \\
11 \\
13 \\
12\end{array}$ & $\begin{array}{c}170 \\
\cdots \\
180 \\
160 \\
220\end{array}$ & $\begin{array}{l}-- \\
-- \\
\cdots \\
- \\
1\end{array}$ & $\begin{array}{r}36 \\
\therefore \\
37 \\
<100 \\
45\end{array}$ & $\begin{array}{c}<.5 \\
-- \\
<.5 \\
<10 \quad \mid \\
<.5\end{array}$ & $\begin{array}{l}-. \\
-. \\
\cdots \\
160\end{array}$ & $\begin{array}{l}<1.0 \\
-8 \\
<1.0 \\
<1.0 \\
2.0\end{array}$ \\
\hline$A D-4$ & $\begin{array}{l}09-22-89 \\
05-01-90 \\
10-13-90\end{array}$ & $\begin{array}{l}.29 \\
.35 \\
.38\end{array}$ & $\begin{array}{l}.70 \\
.30 \\
.50\end{array}$ & $\begin{array}{l}11 \\
11 \\
11\end{array}$ & $\begin{array}{l}330 \$ \\
290 \$ \\
390\end{array}$ & $\begin{array}{l}\because- \\
\ddot{<1}\end{array}$ & $\begin{array}{l}26 \\
31 \\
33\end{array}$ & $\begin{array}{l}<.5 \\
<.5 \\
<.5\end{array}$ & $\ddot{300}$ & $\begin{array}{l}<1.0 \\
<1.0 \\
<1.0\end{array}$ \\
\hline$A D-5$ & $\begin{array}{l}07-13-89 \\
11-13-89 \\
11-14-89 \\
05-04-90 \\
10-19-90\end{array}$ & $\begin{array}{l}.050 \\
.29 \\
. . \\
.28 \\
.35\end{array}$ & $\begin{array}{r}.70 \\
.80 \\
. . \\
.60 \\
.80\end{array}$ & $\begin{array}{l}16 \\
12 \\
-\therefore \\
16 \\
16\end{array}$ & $\begin{array}{c}270 \$ \\
320 \\
-- \\
220 \\
340\end{array}$ & $\begin{array}{l}\cdots \\
\cdots \\
\cdots \\
\cdots \\
1\end{array}$ & $\begin{array}{l}28 \\
26 \\
-- \\
32 \\
29\end{array}$ & $\begin{array}{l}<.5 \\
<.5 \\
-\therefore \\
<.5 \\
<.5\end{array}$ & $\begin{array}{l}\cdots \\
\cdots \\
\cdots \\
280\end{array}$ & $\begin{array}{l}<1.0 \\
3.0 \\
-1 \\
2.0 \\
<1.0\end{array}$ \\
\hline ADOP-1 & $\begin{array}{l}05-15-90 \\
06-13-91\end{array}$ & $\begin{array}{l}.20 \\
.55\end{array}$ & $\begin{array}{r}<.10 \\
.70\end{array}$ & $\begin{array}{l}11 \\
8.9\end{array}$ & $\begin{array}{l}220 \\
150\end{array}$ & -- & $\begin{array}{l}61 \\
57\end{array}$ & $<2{ }^{<} 1$ & $\begin{array}{l}-. \\
-\cdot\end{array}$ & $\begin{array}{l}<3.0 \\
<1.0\end{array}$ \\
\hline
\end{tabular}

CEDAR POINT WELL CLUSTER-Continued

\begin{tabular}{|c|c|c|c|c|c|c|c|c|c|c|}
\hline$C P-1$ & $\begin{array}{l}09-21-89 \\
05-03-90 \\
05-03-90 \\
10-12-90\end{array}$ & $\begin{array}{l}.16 \\
.12 \\
.13 \\
.16\end{array}$ & $\begin{array}{l}.70 \\
.20 \\
.60 \\
.80\end{array}$ & $\begin{array}{l}17 \\
17 \\
17 \\
17\end{array}$ & $\begin{array}{l}57 \\
53 \\
54 \\
81\end{array}$ & $\begin{array}{l}-. \\
\cdots \\
\therefore\end{array}$ & $\begin{array}{l}500 \\
580 \\
570 \\
550\end{array}$ & $\begin{array}{l}<.5 \\
<.5 \\
<.5 \\
<.5\end{array}$ & $\begin{array}{l}\ldots \\
\ldots \\
250\end{array}$ & $\begin{array}{l}<1.0 \\
<1.0 \\
<1.0 \\
<1.0\end{array}$ \\
\hline$C P-2$ & $\begin{array}{l}09-21-89 \\
05-03-90 \\
10-12-90\end{array}$ & $\begin{array}{l}.19 \\
.19 \\
.20\end{array}$ & $\begin{array}{l}.50 \\
.20 \\
.30\end{array}$ & $\begin{array}{l}11 \\
10 \\
10\end{array}$ & $\begin{array}{l}3001 \\
230 \\
3101\end{array}$ & $\begin{array}{l}\cdots \\
\therefore 1\end{array}$ & $\begin{array}{l}40 \\
47 \\
38\end{array}$ & $\begin{array}{l}<.5 \\
<.5 \\
<.5\end{array}$ & $\begin{array}{l}\cdots \\
140\end{array}$ & $\begin{array}{l}<1.0 \\
<1.0 \\
<1.0\end{array}$ \\
\hline CP-3 & $\begin{array}{l}09-21-89 \\
05-03-90 \\
10-17-90\end{array}$ & $\begin{array}{l}.15 \\
.17 \\
.36\end{array}$ & $\begin{array}{l}.60 \\
.30 \\
.40\end{array}$ & $\begin{array}{l}9.4 \\
8.8 \\
9.0\end{array}$ & $\begin{array}{l}2901 \\
220 \\
3301\end{array}$ & $\begin{array}{l}\cdots \\
\cdots 1\end{array}$ & $\begin{array}{l}47 \\
53 \\
51\end{array}$ & $\begin{array}{l}<.5 \\
<.5 \\
<.5\end{array}$ & $\begin{array}{l}\cdots \\
180\end{array}$ & $\begin{array}{r}<1.0 \\
1.0 \\
<1.0\end{array}$ \\
\hline$C P-4$ & $\begin{array}{l}09-21-89 \\
05-03-90 \\
10-17-90\end{array}$ & $\begin{array}{l}. . \\
.15 \\
.17\end{array}$ & $\begin{array}{l}.30 \\
.40\end{array}$ & $\begin{array}{l}9.6 \\
9.6\end{array}$ & $\begin{array}{l}\cdots \\
240 \\
3101\end{array}$ & $\begin{array}{l}\cdots \\
-- \\
<1\end{array}$ & $\begin{array}{l}-. \\
58 \\
53\end{array}$ & $\begin{array}{l}<. \\
<.5 \\
<.5\end{array}$ & $\begin{array}{l}\ldots \\
\cdots \\
180\end{array}$ & $\begin{array}{r}10 \\
<1.0\end{array}$ \\
\hline$C P-5$ & $\begin{array}{l}09-20-89 \\
05-07-90 \\
10-17-90\end{array}$ & $\begin{array}{l}.19 \\
.19 \\
.21\end{array}$ & $\begin{array}{l}.60 \\
.30 \\
.40\end{array}$ & $\begin{array}{l}12 \\
11 \\
12\end{array}$ & $\begin{array}{l}330 \& \\
300 \\
330\end{array}$ & $\begin{array}{l}-- \\
-- \\
<1\end{array}$ & $\begin{array}{l}38 \\
38 \\
47\end{array}$ & $\begin{array}{l}<.5 \\
<.5 \\
<.5\end{array}$ & $\begin{array}{l}\cdots \\
\cdots \\
170\end{array}$ & $\begin{array}{l}<1.0 \\
<1.0 \\
<1.0\end{array}$ \\
\hline$C P-6$ & $\begin{array}{l}09-20-89 \\
06-16-90 \\
10-12-90\end{array}$ & $\begin{array}{l}.22 \\
-. \\
.25\end{array}$ & $\begin{array}{l}.50 \\
.60\end{array}$ & $\begin{array}{l}14 \\
-2 \\
13\end{array}$ & $\begin{array}{c}3601 \\
\cdots \\
3504\end{array}$ & $\begin{array}{l}\cdots \\
<1\end{array}$ & $\begin{array}{c}31 \\
- \\
29\end{array}$ & $\begin{array}{l}<.5 \\
-- \\
<.5\end{array}$ & $\begin{array}{l}\ldots \\
\cdots \\
170\end{array}$ & $\begin{array}{l}<1.0 \\
<1.0\end{array}$ \\
\hline$C P-8$ & $\begin{array}{l}06-07-90 \\
10-17-90\end{array}$ & $\begin{array}{l}.26 \\
.27\end{array}$ & $\begin{array}{l}1.7 \\
1.5\end{array}$ & $\begin{array}{l}8.0 \\
8.0\end{array}$ & $\begin{array}{l}39 \\
46\end{array}$ & $\begin{array}{l}8 \\
7\end{array}$ & $\begin{array}{l}56 \\
60\end{array}$ & $\begin{array}{l}<.5 \\
<.5\end{array}$ & $\begin{array}{l}830 \\
790\end{array}$ & $\begin{array}{l}<1.0 \\
<1.0\end{array}$ \\
\hline CPOP-1 & $\begin{array}{l}11-17-89 \\
10-16-90\end{array}$ &. .17 & $\begin{array}{r}<.10 \\
.40\end{array}$ & $\begin{array}{l}13 \\
11\end{array}$ & $\begin{array}{l}3901 \\
6001\end{array}$ & $-\infty$ & $\begin{array}{l}140 \\
190\end{array}$ & $\begin{array}{l}<.5 \\
<.5\end{array}$ & 300 & $\begin{array}{l}<1.0 \\
<1.0\end{array}$ \\
\hline CPOP-2 & $05-16-90$ & .23 & .30 & 13 & $320 \&$ & $\cdots$ & 120 & $<.5$ & $\cdots$ & $<1.0$ \\
\hline
\end{tabular}


STATIOA

NAME

oATE

11-14-89

05-01-90

10-13-90

ND-3

07-13-89

07-13-89

09-22-89

05-01-90

10-19-90

ND-6

09-22-89

05-01-90

10-13-90

ND-5

$11-13-89$

$11-14-89$

05-04-90

10-19-90

NOOP-1

05- $15-90$

06-13-91
07-13-89

\begin{tabular}{|c|c|c|c|c|c|c|c|}
\hline $\begin{array}{l}\text { COBALT, } \\
\text { DIS- } \\
\text { SOLVED } \\
(\mu g / L \\
\text { as Co) } \\
(01035)\end{array}$ & $\begin{array}{l}\text { COPPER, } \\
\text { DIS- } \\
\text { SOLVED } \\
\text { ( } \mu g / L \\
\text { as Cu) } \\
\text { (010/0) }\end{array}$ & $\begin{array}{l}\text { IRON, } \\
\text { DIS- } \\
\text { SOLVED } \\
\text { ( } \mu g / L \\
\text { os Fe) } \\
\text { (010/6) }\end{array}$ & $\begin{array}{l}\text { LEAD, } \\
\text { DIS- } \\
\text { SOLVED } \\
\text { ( } \mu g / L \\
\text { AS Pb) } \\
\text { (01049) }\end{array}$ & $\begin{array}{l}\text { MMGA- } \\
\text { MESE, } \\
\text { DIS- } \\
\text { SOL VED } \\
\text { ( } \mu g / L \\
\text { es Mn) } \\
\text { (01056) }\end{array}$ & $\begin{array}{l}\text { MOLYB- } \\
\text { DENUA, } \\
\text { DIS- } \\
\text { SOL VEO } \\
(\mu g / L \\
\text { OS MO) } \\
(01060)\end{array}$ & $\begin{array}{l}\text { NICKEL, } \\
\text { DIS- } \\
\text { SOLVED } \\
\text { ( } \mu g / L \\
\text { os Ni) } \\
(01065)\end{array}$ & $\begin{array}{l}\text { SILVER, } \\
\text { DIS- } \\
\text { solveo } \\
\text { (ag/l } \\
\text { as Ag) } \\
\text { (atoT) }\end{array}$ \\
\hline
\end{tabular}

ARIZONA DEPARTMENT OF TRAHSPORTATION WELL CLUSTER-Continued

\begin{tabular}{|c|c|c|c|c|c|c|c|}
\hline $\begin{array}{l}<3 \\
<3 \\
<3\end{array}$ & $\begin{array}{l}<10 \\
<10 \\
<10\end{array}$ & $\begin{array}{r}910 \$ \\
1500 \mid \\
1500 \$\end{array}$ & $\begin{array}{l}<101 \\
<101 \\
<101\end{array}$ & $\begin{array}{l}330 \$ \\
370 \$ \\
390 \$\end{array}$ & $\begin{array}{r}<10 \\
<10 \\
<2\end{array}$ & $\begin{array}{l}<10 \\
<10 \\
<10\end{array}$ & $\begin{array}{r}<1.0 \\
2.0 \\
<1.0\end{array}$ \\
\hline$<3$ & $<10$ & 9 & $<101$ & 5 & $<10$ & $<10$ & $<1.0$ \\
\hline.- & - & $\cdots$ & - & $\cdots$ & $\cdots$ & -. & $\cdots$ \\
\hline $\begin{array}{l}<3 \\
<1\end{array}$ & $\begin{array}{r}<10 \\
1\end{array}$ & $\begin{array}{l}11 \\
30\end{array}$ & $<101$ & $\begin{array}{r}8 \\
20 \\
19\end{array}$ & $\begin{array}{r}<10 \\
-- \\
3\end{array}$ & $\begin{array}{r}<10 \\
1 \\
<10\end{array}$ & $\begin{array}{r}1.0 \\
<.0 \\
1.0\end{array}$ \\
\hline $\begin{array}{l}<3 \\
<3 \\
3\end{array}$ & $\begin{array}{l}<10 \\
<10 \\
<10\end{array}$ & $\begin{array}{r}3 \\
28 \\
12\end{array}$ & $\begin{array}{l}<10 i \\
<10 i \\
<10 i\end{array}$ & $\begin{array}{r}<1 \\
2 \\
2\end{array}$ & $\begin{array}{r}<10 \\
10 \\
1\end{array}$ & $\begin{array}{l}<10 \\
<10 \\
<10\end{array}$ & $\begin{array}{r}1.0 \\
2.0 \\
1.0\end{array}$ \\
\hline $\begin{array}{l}<3 \\
10\end{array}$ & $\begin{array}{r}<10 \\
10\end{array}$ & $\begin{array}{r}5 \\
35\end{array}$ & $\begin{array}{r}<10 i \\
70 \dagger\end{array}$ & $\begin{array}{l}<1 \\
17\end{array}$ & $\begin{array}{r}<10 \\
10\end{array}$ & $\begin{array}{r}<10 \\
10\end{array}$ & $\begin{array}{l}<1.0 \\
19\end{array}$ \\
\hline- & - & $=$ & - & $\cdots$ & $\cdots$ & - & -. \\
\hline $\begin{array}{l}<3 \\
<3\end{array}$ & $\begin{array}{l}<10 \\
<10\end{array}$ & $\begin{array}{r}12 \\
3\end{array}$ & $\begin{array}{l}<10 i \\
<10 i\end{array}$ & $\begin{array}{r}6 \\
<1\end{array}$ & $\begin{array}{r}<10 \\
4\end{array}$ & $\begin{array}{l}<10 \\
<10\end{array}$ & $\begin{array}{r}2.0 \\
<1.0\end{array}$ \\
\hline $\begin{array}{l}8 \\
<3\end{array}$ & $\begin{array}{l}<30 \\
<10\end{array}$ & $\begin{array}{r}25 \\
5\end{array}$ & $\begin{array}{l}<30 i \\
10 f\end{array}$ & 9 & $\begin{array}{r}<30 \\
10\end{array}$ & $\begin{array}{l}<30 \\
<10\end{array}$ & $\begin{array}{l}3.0 \\
<1.0\end{array}$ \\
\hline
\end{tabular}

CEDAR POIMT WELL CLUSTER-Continued

\begin{tabular}{|c|c|c|c|c|c|c|c|c|c|c|}
\hline$C P-1$ & $\begin{array}{l}09-21-89 \\
05-03-90 \\
05-03-90 \\
10-12-90\end{array}$ & $\begin{array}{l}<3 \\
<3 \\
<3 \\
<3\end{array}$ & $\begin{array}{l}<10 \\
<10 \\
<10 \\
<10\end{array}$ & $\begin{array}{l}24001 \\
29001 \\
28001 \\
28001\end{array}$ & $\begin{array}{l}<101 \\
<101 \\
<101 \\
<101\end{array}$ & $\begin{array}{l}570: \\
650: \\
650: \\
700:\end{array}$ & $\begin{array}{r}<10 \\
<10 \\
10 \\
<1\end{array}$ & $\begin{array}{r}<10 \\
<10 \\
10 \\
<10\end{array}$ & $\begin{array}{r}<1.0 \\
<1.0 \\
1.0 \\
1.0\end{array}$ & $\begin{array}{l}900 \\
910 \\
960 \\
930\end{array}$ \\
\hline$c p-2$ & $\begin{array}{l}09-21-89 \\
05-03-90 \\
10-12-90\end{array}$ & $\begin{array}{l}<3 \\
<3 \\
<3\end{array}$ & $\begin{array}{l}<10 \\
<10 \\
<10\end{array}$ & $\begin{array}{l}13 \\
16 \\
12\end{array}$ & $\begin{array}{l}<101 \\
<101 \\
<101\end{array}$ & $\begin{array}{l}270 \$ \\
260 \$ \\
240 \$\end{array}$ & $\begin{array}{r}<10 \\
20 \\
3\end{array}$ & $\begin{array}{l}<10 \\
<10 \\
<10\end{array}$ & $\begin{array}{r}<1.0 \\
2.0 \\
1.0\end{array}$ & $\begin{array}{l}900 \\
860 \\
850\end{array}$ \\
\hline$C P-3$ & $\begin{array}{l}09-21-89 \\
05-03-90 \\
10-17-90\end{array}$ & $\begin{array}{l}<3 \\
<3 \\
<3\end{array}$ & $\begin{array}{l}<10 \\
<10 \\
<10\end{array}$ & $\begin{array}{l}38 \\
67 \\
28\end{array}$ & $\begin{array}{l}<10 i \\
<10 i \\
<10 i\end{array}$ & $\begin{array}{l}1300 \\
1000 \\
1000\end{array}$ & $\begin{array}{l}20 \\
20 \\
10\end{array}$ & $\begin{array}{r}<10 \\
10 \\
<10\end{array}$ & $\begin{array}{l}<1.0 \\
<1.0 \\
<1.0\end{array}$ & $\begin{array}{r}1000 \\
920 \\
960\end{array}$ \\
\hline$C P-4$ & $\begin{array}{l}09-21-89 \\
05-03-90 \\
10-17-90\end{array}$ & $\begin{array}{l}-8 \\
<3 \\
3\end{array}$ & $\begin{array}{l}-2 \\
<10 \\
<10\end{array}$ & $\begin{array}{r}\cdots \\
120 \\
110\end{array}$ & $\begin{array}{l}\because \ddot{10 i} \\
<10 i\end{array}$ & $\begin{array}{c}\cdots \\
1600 \\
1400\end{array}$ & $\begin{array}{l}40 \\
24\end{array}$ & $\begin{array}{r}\ddot{10} \\
<10\end{array}$ & $\begin{array}{r}\ddot{1.0} \\
<1.0\end{array}$ & $\begin{array}{l}\ddot{750} \\
740\end{array}$ \\
\hline$C P-5$ & $\begin{array}{l}09-20-89 \\
05-07-90 \\
10-17-90\end{array}$ & $\begin{array}{l}<3 \\
<3 \\
<3\end{array}$ & $\begin{array}{l}<10 \\
<10 \\
<10\end{array}$ & $\begin{array}{l}12 \\
30 \\
42\end{array}$ & $\begin{array}{l}<101 \\
<101 \\
<101\end{array}$ & $\begin{array}{l}6001 \\
3101 \\
4201\end{array}$ & $\begin{array}{r}10 \\
10 \\
7\end{array}$ & $\begin{array}{l}<10 \\
<10 \\
<10\end{array}$ & $\begin{array}{r}<1.0 \\
<1.0 \\
1.0\end{array}$ & $\begin{array}{l}1100 \\
1100 \\
1100\end{array}$ \\
\hline$c p-6$ & $\begin{array}{l}09-20-89 \\
06-16-90 \\
10-12-90\end{array}$ & $\begin{array}{l}<3 \\
\cdots \\
<3\end{array}$ & $\begin{array}{r}<10 \\
-- \\
<10\end{array}$ & $\begin{array}{l}7 \\
-- \\
15\end{array}$ & $\begin{array}{c}<10 i \\
\therefore \\
<10 i\end{array}$ & $\begin{array}{c}3101 \\
\ldots \\
881\end{array}$ & $\begin{array}{r}<10 \\
-. \\
2\end{array}$ & $\begin{array}{r}<10 \\
+- \\
<10\end{array}$ & $\begin{array}{r}1.0 \\
\cdots \\
\times 1.0\end{array}$ & $\begin{array}{r}1300 \\
1300\end{array}$ \\
\hline$C P-8$ & $\begin{array}{l}06-07-90 \\
10-17-90\end{array}$ & $\begin{array}{l}<3 \\
<3\end{array}$ & $\begin{array}{l}<10 \\
<10\end{array}$ & $\begin{array}{r}80 \\
190\end{array}$ & $\begin{array}{l}<10 i \\
<10 i\end{array}$ & $\begin{array}{l}911 \\
1301\end{array}$ & $\begin{array}{r}<10 \\
2\end{array}$ & $\begin{array}{l}<10 \\
<10\end{array}$ & $\begin{array}{l}<1.0 \\
<1.0\end{array}$ & $\begin{array}{l}1400 \\
1500\end{array}$ \\
\hline CPOP-1 & $\begin{array}{l}11-17-89 \\
10-16-90\end{array}$ & $\begin{array}{r}5 \\
<3\end{array}$ & $\begin{array}{l}<10 \\
<10\end{array}$ & $\begin{array}{c}850 \\
50\end{array}$ & $\begin{array}{l}<101 \\
<101\end{array}$ & $\begin{array}{r}4600 \\
890\end{array}$ & $\begin{array}{r}<10 \\
11\end{array}$ & $\begin{array}{r}10 \\
<10\end{array}$ & $\begin{array}{l}<1.0 \\
1.0\end{array}$ & $\begin{array}{l}1900 \\
1800\end{array}$ \\
\hline CPOP-2 & $05-16-90$ & 4 & $<10$ & $1800\}$ & $<10 i$ & 38001 & 10 & $<10$ & 2.0 & 1400 \\
\hline
\end{tabular}


STATION

MAME

DATE

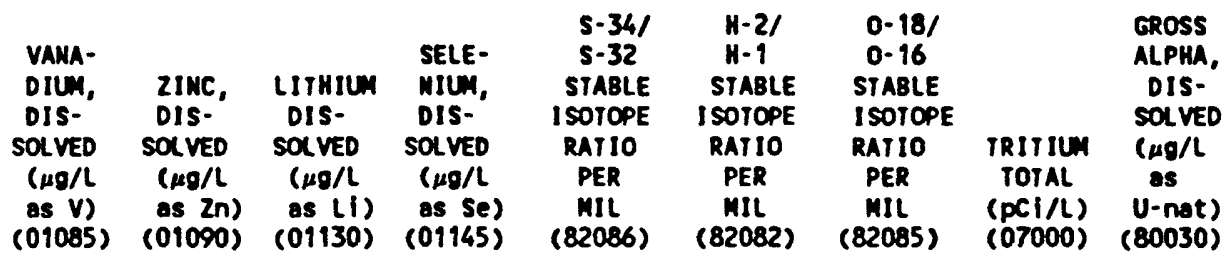

ARIZONA DEPARTMENT OF TRANSPORTATION WELL CLUSTER-Continued

\begin{tabular}{|c|c|c|c|c|c|c|c|c|c|c|}
\hline$A D-1$ & $\begin{array}{l}11-14-89 \\
05-01-90 \\
10-13-90\end{array}$ & $\begin{array}{l}<6 \\
<6 \\
<6\end{array}$ & $\begin{array}{l}<3 \\
<3 \\
4\end{array}$ & $\begin{array}{l}44 \\
43 \\
44\end{array}$ & $\begin{array}{l}\cdots \\
<1\end{array}$ & $\begin{array}{l}1.20 \\
\cdots \\
\cdots\end{array}$ & $\begin{array}{l}-77.0 \\
\cdots \\
\cdots\end{array}$ & $\begin{array}{c}-10.30 \\
\ldots \\
\ldots\end{array}$ & $\begin{array}{l}38 \\
\cdots \\
--\end{array}$ & $\begin{array}{l}11 f \\
12 f \\
12 f\end{array}$ \\
\hline$A D-3$ & $\begin{array}{l}07-13-89 \\
07-13-89 \\
09-22-89 \\
05-01-90 \\
10-19-90\end{array}$ & $\begin{array}{l}<6 \\
\cdots \\
<6 \\
2 \\
<6\end{array}$ & $\begin{array}{r}6 \\
-7 \\
7 \\
<10 \\
5\end{array}$ & $\begin{array}{l}20 \\
\cdots \\
19 \\
20 \\
24\end{array}$ & $\begin{array}{l}\cdots \\
\cdots \\
\cdots \\
<1\end{array}$ & $\begin{array}{l}-3.40 \\
\ldots \\
-. \\
-. \\
-\end{array}$ & $\begin{array}{l}-83.5 \\
\ldots \\
\cdots \\
\cdots \\
\cdots\end{array}$ & $\begin{array}{c}-10.45 \\
\ldots \\
\ldots \\
\ldots \\
\ldots\end{array}$ & $\begin{array}{l}32 \\
\ldots \\
\ldots \\
\ldots \\
\ldots\end{array}$ & $\begin{array}{l}30\} \\
25 f \\
29 f \\
66 f \\
41 f\end{array}$ \\
\hline $10-4$ & $\begin{array}{l}09-22-89 \\
05-01-90 \\
10-13-90\end{array}$ & $\begin{array}{l}46 \\
46 \\
46\end{array}$ & $\begin{array}{l}9 \\
3 \\
3\end{array}$ & $\begin{array}{l}25 \\
29 \\
34\end{array}$ & 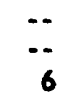 & $\begin{array}{l}\cdots \\
\cdots\end{array}$ & $\begin{array}{l}\cdots \\
\cdots\end{array}$ & $\begin{array}{l}\cdots \\
\cdots\end{array}$ & $\begin{array}{l}\cdots \\
\cdots \\
\cdots\end{array}$ & $\begin{array}{c}4.8 \\
12\} \\
8.1\end{array}$ \\
\hline$A D-5$ & $\begin{array}{l}07-13-89 \\
11-13-89 \\
11-14-89 \\
05-04-90 \\
10-19-90\end{array}$ & $\begin{array}{l}<6 \\
16 \\
\cdots \\
<6 \\
<6\end{array}$ & $\begin{array}{c}3 \\
<3 \\
\cdots \\
5 \\
4\end{array}$ & $\begin{array}{l}35 \\
30 \\
\cdots \\
35 \\
49\end{array}$ & $\begin{array}{c}-. \\
\cdots \\
\cdots \\
\angle 10\end{array}$ & $\begin{array}{l}-2.80 \\
-\therefore \\
-2.70 \\
\cdots \\
\cdots\end{array}$ & $\begin{array}{l}-80.0 \\
-79.0 \\
-. \\
\cdots \\
\cdots\end{array}$ & $\begin{array}{c}-10.25 \\
-10.20 \\
\ldots \\
\ldots \\
\ldots\end{array}$ & $\begin{array}{l}\cdots \\
30 \\
\cdots \\
\cdots \\
\cdots\end{array}$ & $\begin{array}{l}6.4 \\
-9 \\
10 \\
111\end{array}$ \\
\hline ADDP-1 & $\begin{array}{l}05-15-90 \\
06-13-91\end{array}$ & $\begin{array}{r}<18 \\
<6\end{array}$ & $\begin{array}{l}11 \\
10\end{array}$ & $\begin{array}{l}28 \\
13\end{array}$ & $\because$ & $\begin{array}{r}-4.60 \\
1.60\end{array}$ & $\begin{array}{l}-78.5 \\
--\end{array}$ & $\begin{array}{l}-9.95 \\
-.\end{array}$ & $\begin{array}{l}17 \\
--\end{array}$ & $\begin{array}{l}98\} \\
10\end{array}$ \\
\hline
\end{tabular}

CEDAR POINT WELL CLUSTER-Continued

\begin{tabular}{|c|c|c|c|c|c|c|c|c|c|c|}
\hline$C P-1$ & $\begin{array}{l}09-21-89 \\
05-03-90 \\
05-03-90 \\
10-12-90\end{array}$ & $\begin{array}{l}<6 \\
<6 \\
<6 \\
<6\end{array}$ & $\begin{array}{r}3 \\
4 \\
5 \\
3\end{array}$ & $\begin{array}{l}43 \\
43 \\
43 \\
46\end{array}$ & $\begin{array}{l}\cdots \\
\cdots \\
\therefore\end{array}$ & $\begin{array}{l}\ldots \\
\ldots \\
\ldots \\
\cdots\end{array}$ & $\begin{array}{l}-81.0 \\
-. \\
-. \\
-.\end{array}$ & $\begin{array}{c}-10.55 \\
\ldots \\
\ldots \\
-\end{array}$ & $\begin{array}{l}2.9 \\
\therefore- \\
\cdots \\
\cdots\end{array}$ & $\begin{array}{c}2.0 \\
3.8 \\
-\therefore \\
1.5\end{array}$ \\
\hline$C P-2$ & $\begin{array}{l}09-21-89 \\
05-03-90 \\
10-12-90\end{array}$ & $\begin{array}{l}<6 \\
<6 \\
46\end{array}$ & $\begin{array}{l}4 \\
7 \\
4\end{array}$ & $\begin{array}{l}24 \\
22 \\
24\end{array}$ & $\begin{array}{l}\cdots \\
<1\end{array}$ & $\begin{array}{l}-4.30 \\
\cdots \\
\cdots\end{array}$ & $\begin{array}{l}-69.0 \\
\cdots \\
\cdots\end{array}$ & $\begin{array}{c}-8.30 \\
\cdots \\
\cdots\end{array}$ & $\begin{array}{l}33 \\
\cdots \\
\cdots\end{array}$ & $\begin{array}{l}111 \\
8.1 \\
5.3\end{array}$ \\
\hline$C P-3$ & $\begin{array}{l}09-21-89 \\
05-03-90 \\
10-17-90\end{array}$ & $\begin{array}{l}46 \\
46 \\
46\end{array}$ & $\begin{array}{r}5 \\
10 \\
4\end{array}$ & $\begin{array}{l}20 \\
17 \\
19\end{array}$ & $\begin{array}{l}\cdots \\
\cdots \\
<1\end{array}$ & $\begin{array}{l}-4.20 \\
-. \\
-.\end{array}$ & $\begin{array}{l}-65.0 \\
\cdots \\
-.\end{array}$ & $\begin{array}{l}-9.35 \\
-. \\
-.\end{array}$ & $\begin{array}{l}\cdots \\
\cdots \\
--\end{array}$ & $\begin{array}{l}111 \\
7.2 \\
5.6\end{array}$ \\
\hline CP-4 & $\begin{array}{l}09-21-89 \\
05-03-90 \\
10-17-90\end{array}$ & $\begin{array}{l}26 \\
26\end{array}$ & $\begin{array}{r}\cdots \\
5 \\
3\end{array}$ & $\begin{array}{l}\ddot{.} \\
18 \\
20\end{array}$ & 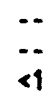 & $\begin{array}{l}\because . \\
\cdots\end{array}$ & 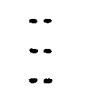 & $\begin{array}{l}-. \\
-.\end{array}$ & $\begin{array}{l}-- \\
-- \\
--\end{array}$ & $\begin{array}{l}13 f \\
30 \% \\
211\end{array}$ \\
\hline$C P-5$ & $\begin{array}{l}09-20-89 \\
05-07-90 \\
10-17-90\end{array}$ & $\begin{array}{l}46 \\
46 \\
46\end{array}$ & $\begin{array}{r}4 \\
4 \\
11\end{array}$ & $\begin{array}{l}47 \\
48 \\
48\end{array}$ & $\begin{array}{l}\cdots \\
-1\end{array}$ & $\begin{array}{l}-4.40 \\
-. \\
-.\end{array}$ & $\begin{array}{l}-74.5 \\
-. \\
\cdots\end{array}$ & $\begin{array}{l}-9.40 \\
\cdots \\
\cdots\end{array}$ & $\begin{array}{l}44 \\
\cdots \\
\cdots\end{array}$ & $\begin{array}{l}4.1 \\
9.2 \\
8.6\end{array}$ \\
\hline$C P-6$ & $\begin{array}{l}09-20-89 \\
06-16-90 \\
10-12-90\end{array}$ & $\begin{array}{l}46 \\
-6 \\
46\end{array}$ & $\begin{array}{l}19 \\
-3\end{array}$ & $\begin{array}{l}52 \\
56\end{array}$ & $\begin{array}{l}\ldots \\
\therefore 1\end{array}$ & $\begin{array}{l}-4.30 \\
-. \\
-.\end{array}$ & $\begin{array}{l}-72.5 \\
-. \\
--\end{array}$ & $\begin{array}{l}-9.20 \\
-. \\
--\end{array}$ & $\begin{array}{l}53 \\
\ldots \\
\ldots\end{array}$ & $\begin{array}{c}4.5 \\
\therefore 7.6\end{array}$ \\
\hline$C P-8$ & $\begin{array}{l}06-07-90 \\
10-17-90\end{array}$ & $\begin{array}{l}<6 \\
<6\end{array}$ & $\begin{array}{r}12 \\
6\end{array}$ & $\begin{array}{l}140 \\
140\end{array}$ & $\begin{array}{l}<1 \\
<1\end{array}$ & $\begin{array}{c}-3.70 \\
-.\end{array}$ & $\begin{array}{l}-78.0 \\
-.\end{array}$ & $\begin{array}{c}-10.20 \\
-.\end{array}$ & $\begin{array}{l}<2.5 \\
\cdots\end{array}$ & $\begin{array}{l}8.6 \\
5.6\end{array}$ \\
\hline CPDP- 1 & $\begin{array}{l}11-17-89 \\
10-16-90\end{array}$ & $\begin{array}{l}<6 \\
<6\end{array}$ & $\begin{array}{r}270 \\
11\end{array}$ & $\begin{array}{l}22 \\
37\end{array}$ & $\ddot{4}$ & $\begin{array}{c}-3.20 \\
-.\end{array}$ & $\begin{array}{l}-68.0 \\
-.\end{array}$ & $\begin{array}{l}-9.00 \\
-.\end{array}$ & $\begin{array}{l}38 \\
-.\end{array}$ & $\begin{array}{l}111 \\
46 f\end{array}$ \\
\hline CPDP-2 & $05-16-90$ & $<6$ & 4 & 17 & $\cdots$ & -4.40 & -71.9 & -9.60 & 30 & 211 \\
\hline
\end{tabular}


GROUND-WATER DATA-Cont inued

CHEMICAL AMALYSES- Cont InUEd

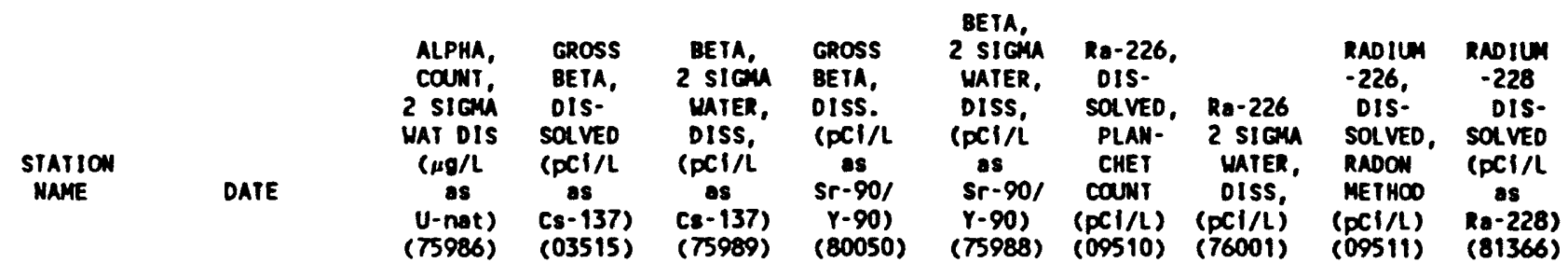

ARIZONA OEPARTMENT OF IRANSPORTATION WELL CLUSTER-Cont InUEA

\begin{tabular}{|c|c|c|c|c|c|c|c|c|c|c|}
\hline$A D-1$ & $\begin{array}{l}11-16-89 \\
05-01-90 \\
10-13-90\end{array}$ & $\begin{array}{l}1.8 \\
4.4 \\
2.4\end{array}$ & $\begin{array}{c}12 \\
9.1 \\
7.3\end{array}$ & $\begin{array}{l}1.9 \\
2.6 \\
2.4\end{array}$ & $\begin{array}{l}11 \\
6.9 \\
5.6\end{array}$ & $\begin{array}{l}1.7 \\
1.8 \\
1.8\end{array}$ & $\begin{array}{l}\cdots \\
\cdots \\
\cdots\end{array}$ & $\begin{array}{l}\cdots \\
\cdots \\
\cdots\end{array}$ & $\begin{array}{l}\cdots \\
\cdots \\
\cdots\end{array}$ & $\begin{array}{l}<1.0 \\
\therefore \\
. .\end{array}$ \\
\hline ND-3 & $\begin{array}{l}07-13-89 \\
07-13-89 \\
09-22-89 \\
05-01-90 \\
10-19-90\end{array}$ & $\begin{array}{c}3.9 \\
3.4 \\
3.3 \\
16 \\
5.5\end{array}$ & $\begin{array}{l}23 \\
22 \\
23 \\
39 \\
32\end{array}$ & $\begin{array}{l}4.1 \\
3.9 \\
3.0 \\
5.5 \\
5.0\end{array}$ & $\begin{array}{l}18 \\
17 \\
21 \\
29 \\
24\end{array}$ & $\begin{array}{l}3.3 \\
3.1 \\
2.7 \\
5.5 \\
3.7\end{array}$ & $\begin{array}{l}\ldots \\
\ldots \\
\ldots \\
\ldots \\
<.1\end{array}$ & $\begin{array}{l}.030 \\
.030 \\
\ldots \\
. . \\
.0\end{array}$ & $\begin{array}{l}.12 \\
.13 \\
\ldots \\
\ldots \\
\ldots\end{array}$ & $\begin{array}{l}<1.0 \\
<1.0 \\
<1.0 \\
\cdots \\
-.\end{array}$ \\
\hline AD-4 & $\begin{array}{l}09-22-89 \\
05-01-90 \\
10-13-90\end{array}$ & $\begin{array}{l}.90 \\
3.1 \\
1.8\end{array}$ & $\begin{array}{l}6.7 \\
8.5 \\
7.6\end{array}$ & $\begin{array}{l}2.3 \\
2.4 \\
2.7\end{array}$ & $\begin{array}{l}5.2 \\
6.4 \\
5.7\end{array}$ & $\begin{array}{l}2.1 \\
1.8 \\
2.0\end{array}$ & $\begin{array}{l}\cdots \\
\cdots \\
\cdots\end{array}$ & $\begin{array}{l}\cdots \\
\cdots \\
\cdots\end{array}$ & $\begin{array}{l}\cdots \\
\cdots \\
\cdots\end{array}$ & $\begin{array}{c}<1.0 \\
\because- \\
\because-\end{array}$ \\
\hline $10-5$ & $\begin{array}{l}07-13-89 \\
11-13-89 \\
11-16-89 \\
05-04-90 \\
10-19-90\end{array}$ & $\begin{array}{l}1.3 \\
\because . \\
1.2 \\
2.6 \\
2.2\end{array}$ & $\begin{array}{l}5.0 \\
\ldots \\
9.0 \\
8.1 \\
9.6\end{array}$ & \begin{tabular}{l}
2.7 \\
\hdashline- \\
1.7 \\
2.3 \\
2.9
\end{tabular} & $\begin{array}{l}4.0 \\
.6 \\
8.3 \\
6.0 \\
7.2\end{array}$ & $\begin{array}{l}2.2 \\
\because \therefore \\
1.6 \\
1.7 \\
2.2\end{array}$ & $\begin{array}{l}\ldots \\
\cdots \\
\cdots \\
\cdots \\
<.1\end{array}$ & $\begin{array}{l}.020 \\
\ldots \\
\ldots \\
\ldots \\
\text { NO }\end{array}$ & $\begin{array}{l}.10 \\
\therefore \\
\ldots \\
\ldots \\
\ldots\end{array}$ & $\begin{array}{c}<1.0 \\
\therefore 1.0 \\
\therefore \\
\therefore\end{array}$ \\
\hline ADOP-1 & $\begin{array}{l}05-15-90 \\
06-13-91\end{array}$ & $\begin{array}{l}17 \\
2.1\end{array}$ & $\begin{array}{l}58 \\
11\end{array}$ & $\begin{array}{l}8.2 \\
2.2\end{array}$ & $\begin{array}{l}44 \\
7.9\end{array}$ & $\begin{array}{l}6.2 \\
1.7\end{array}$ & $\begin{array}{l}\cdots \\
\cdots\end{array}$ & $\begin{array}{l}-- \\
\cdots\end{array}$ & -- & $\begin{array}{c}<1.0 \\
\therefore\end{array}$ \\
\hline
\end{tabular}

CEDAR POINT MELL CLUSTER-Contimued

\begin{tabular}{|c|c|c|c|c|c|c|c|c|c|c|}
\hline$C P-1$ & $\begin{array}{l}09-21-89 \\
05-03-90 \\
05-03-90 \\
10-12-90\end{array}$ & $\begin{array}{l}.50 \\
1.6 \\
\therefore .80\end{array}$ & $\begin{array}{c}3.6 \\
5.2 \\
-. \\
5.7\end{array}$ & \begin{tabular}{l}
1.5 \\
1.8 \\
\hdashline- \\
2.0
\end{tabular} & \begin{tabular}{c}
3.0 \\
4.0 \\
\hdashline- \\
4.3
\end{tabular} & $\begin{array}{l}1.3 \\
1.4 \\
\therefore .5 \\
1.5\end{array}$ & $\begin{array}{l}\ldots \\
\ldots \\
\cdots\end{array}$ & $\begin{array}{l}\cdots \\
\cdots \\
\cdots \\
\cdots\end{array}$ & $\begin{array}{l}\ldots \\
\cdots \\
\cdots\end{array}$ & $\begin{array}{l}<1.0 \\
\ldots \\
\ldots\end{array}$ \\
\hline$C P-2$ & $\begin{array}{l}09-21-89 \\
05-03-90 \\
10-12-90\end{array}$ & $\begin{array}{l}2.1 \\
2.0 \\
1.3\end{array}$ & $\begin{array}{l}6.7 \\
7.6 \\
8.3\end{array}$ & $\begin{array}{l}2.1 \\
2.1 \\
2.6\end{array}$ & $\begin{array}{l}6.0 \\
5.6 \\
6.3\end{array}$ & $\begin{array}{l}1.8 \\
1.6 \\
2.0\end{array}$ & $\begin{array}{l}\cdots \\
\cdots \\
\cdots\end{array}$ & $\begin{array}{l}\cdots \\
\cdots \\
\cdots\end{array}$ & $\begin{array}{l}\cdots \\
\cdots \\
\cdots\end{array}$ & $\begin{array}{c}<1.0 \\
\cdots \\
\cdots\end{array}$ \\
\hline$C P-3$ & $\begin{array}{l}09-21-89 \\
05-03-90 \\
10-17-90\end{array}$ & $\begin{array}{l}2.0 \\
2.2 \\
1.5\end{array}$ & $\begin{array}{l}3.9 \\
6.8 \\
7.0\end{array}$ & $\begin{array}{l}1.8 \\
2.1 \\
2.4\end{array}$ & $\begin{array}{l}3.6 \\
5.1 \\
5.3\end{array}$ & $\begin{array}{l}1.6 \\
1.5 \\
1.8\end{array}$ & $\begin{array}{l}-. \\
-- \\
<.1\end{array}$ & $\begin{array}{l}-. \\
\text { no }\end{array}$ & $\begin{array}{l}\cdots \\
\cdots \\
-.\end{array}$ & $\begin{array}{l}<1.0 \\
\cdots \\
\cdots\end{array}$ \\
\hline CP- 4 & $\begin{array}{l}09-21-89 \\
05-03-90 \\
10-17-90\end{array}$ & $\begin{array}{l}1.7 \\
6.0 \\
3.2\end{array}$ & $\begin{array}{l}22 \\
16 \\
139\end{array}$ & $\begin{array}{l}3.1 \\
3.2 \\
3.0\end{array}$ & $\begin{array}{c}21 \\
12 \\
9.7\end{array}$ & $\begin{array}{l}2.9 \\
2.4 \\
2.3\end{array}$ & $\begin{array}{l}-. \\
-. \\
.1\end{array}$ & $\begin{array}{l}. . \\
. \\
.100\end{array}$ & $\begin{array}{l}-. \\
-- \\
-.\end{array}$ & $\begin{array}{l}<1.0 \\
\cdots \\
\cdots\end{array}$ \\
\hline CP. 5 & $\begin{array}{l}09-20-89 \\
05-07-90 \\
10-17-90\end{array}$ & $\begin{array}{l}.80 \\
1.9 \\
1.9\end{array}$ & $\begin{array}{c}5.0 \\
20 \\
5.3\end{array}$ & $\begin{array}{l}1.8 \\
3.9 \\
2.3\end{array}$ & $\begin{array}{c}4.4 \\
15 \\
4.0\end{array}$ & $\begin{array}{l}1.6 \\
3.0 \\
1.7\end{array}$ & $\begin{array}{l}\ldots \\
\ldots \\
<.1\end{array}$ & $\begin{array}{l}. . \\
.0 \\
.100\end{array}$ & $\begin{array}{l}\cdots \\
\cdots \\
\cdots\end{array}$ & $\begin{array}{c}<1.0 \\
\cdots \\
\cdots\end{array}$ \\
\hline$C P-6$ & $\begin{array}{l}09-20-89 \\
06-16-90 \\
10-12-90\end{array}$ & $\begin{array}{l}.80 \\
.- \\
1.8\end{array}$ & $\begin{array}{c}6.5 \\
-\therefore \\
5.2\end{array}$ & \begin{tabular}{l}
2.0 \\
\hdashline- \\
2.2
\end{tabular} & $\begin{array}{l}5.9 \\
\therefore \\
3.9\end{array}$ & $\begin{array}{l}1.8 \\
1 . \\
1.7\end{array}$ & $\begin{array}{l}\cdots \\
\cdots \\
\cdots\end{array}$ & $\begin{array}{l}\because- \\
\because- \\
-\end{array}$ & $\begin{array}{l}\cdots \\
\cdots \\
\cdots\end{array}$ & $\begin{array}{l}1.9 \\
\cdots \\
\cdots\end{array}$ \\
\hline$C P-8$ & $\begin{array}{l}06-07-90 \\
10-17-90\end{array}$ & $\begin{array}{l}2.3 \\
1.5\end{array}$ & $\begin{array}{r}11 \\
7.6\end{array}$ & $\begin{array}{l}2.7 \\
1.9\end{array}$ & $\begin{array}{l}7.8 \\
5.7\end{array}$ & $\begin{array}{l}1.6 \\
1.5\end{array}$ & .6 & .200 & 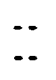 & 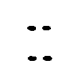 \\
\hline CPDP-1 & $\begin{array}{l}11-17-89 \\
10-16-90\end{array}$ & $\begin{array}{l}1.7 \\
5.9\end{array}$ & $\begin{array}{l}18 \\
32\end{array}$ & $\begin{array}{l}3.6 \\
6.7\end{array}$ & $\begin{array}{l}16 \\
26\end{array}$ & $\begin{array}{l}3.3 \\
5.0\end{array}$ & 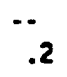 & .100 & $\begin{array}{l}-- \\
--\end{array}$ & $\begin{array}{l}\cdots \\
\cdots\end{array}$ \\
\hline CPOP-2 & $05-16-90$ & 3.3 & 19 & 3.7 & 14 & 2.8 & -. & - & .. & $<1.0$ \\
\hline
\end{tabular}


GROND-WATER DATA-Cont Inued

CHEMICAL AMALYSES-Continued

\begin{tabular}{|c|c|c|c|c|c|c|c|c|c|c|}
\hline $\begin{array}{l}\text { STATION } \\
\text { MAME }\end{array}$ & DATE & $\begin{array}{l}\text { RADON } \\
\text {-222 } \\
\text { TOTAL } \\
\text { (PCI/L) } \\
\text { (82303) }\end{array}$ & $\begin{array}{l}\text { Rn-222 } \\
2 \text { SIGM } \\
\text { HATER, } \\
\text { WHOLE, } \\
\text { TOTAL, } \\
\text { (PCI/L) } \\
(76002)\end{array}$ & $\begin{array}{l}\text { URANIUN } \\
\text {-234 } \\
\text { WATER } \\
\text { DISSOLV } \\
\text { (PCI/L) } \\
\text { (22610) }\end{array}$ & $\begin{array}{l}\text { U-234 } \\
2 \text { SIENA } \\
\text { WATER, } \\
\text { DISS, } \\
\text { (PCI/L) } \\
\text { (75992) }\end{array}$ & $\begin{array}{l}\text { URANIUN } \\
\text { - } 235 \\
\text { WATER, } \\
\text { DISS } \\
\text { (pCi/L) } \\
\text { (22620) }\end{array}$ & $\begin{array}{l}\text { U-235 } \\
2 \text { SIEA } \\
\text { WATER, } \\
\text { DISS, } \\
\text { (pcifi) } \\
\text { ( } 75994 \text { ) }\end{array}$ & $\begin{array}{l}\text { URANIUH } \\
\text {-238 } \\
\text { WATER } \\
\text { OISSOLY } \\
\text { (PCI/L) } \\
\text { (22603) }\end{array}$ & $\begin{array}{c}\text { U-238 } \\
2 \text { SIGU } \\
\text { WATER, } \\
\text { DISS, } \\
\text { (PCI/L) } \\
\text { (75991) }\end{array}$ & $\begin{array}{l}\text { URANIUN } \\
\text { MATURAL } \\
\text { DIS- } \\
\text { SOLVEO } \\
\text { ( } \mu \sigma / L \\
\text { Os U) } \\
(22703)\end{array}$ \\
\hline
\end{tabular}

ARIZONA DEPARTMENT OF IRANSPORTATION WELL CLUSTER-cont inued

\begin{tabular}{|c|c|c|c|c|c|c|c|c|c|c|}
\hline$A D-1$ & $\begin{array}{l}11-14-89 \\
05-01-90 \\
10-13-90\end{array}$ & $\begin{array}{c}330\} \\
<80 \\
--\end{array}$ & $\begin{array}{r}110 \\
34 \\
\cdots\end{array}$ & $\begin{array}{l}7.7 \\
5.8 \\
4.3\end{array}$ & $\begin{array}{l}1.1 \\
1.0 \\
.4\end{array}$ & $\begin{array}{r}.3 \\
1.0 \\
.1\end{array}$ & $\begin{array}{r}.20 \\
.60 \\
10\end{array}$ & $\begin{array}{l}5.0 \\
3.3 \\
2.6\end{array}$ & $\begin{array}{l}.80 \\
.70 \\
.30\end{array}$ & $\begin{array}{l}6.2 \\
8.9 \\
7.2\end{array}$ \\
\hline$A D-6$ & $\begin{array}{l}07-13-89 \\
07-13-89 \\
09-22-89 \\
05-01-90 \\
10-19-90 \\
09-22-89 \\
05-01-90 \\
10-13-90\end{array}$ & $\begin{array}{l}210 \\
210 \\
330 \nmid \\
270 \\
-. \\
340\} \\
310 \uparrow \\
-.\end{array}$ & $\begin{array}{l}-. \\
42 \\
40 \\
40 \\
-. \\
46 \\
39 \\
-.\end{array}$ & $\begin{array}{l}16 \\
11 \\
17 \\
22 \\
20 \\
3.3 \\
3.3 \\
3.4\end{array}$ & $\begin{array}{l}1.7 \\
1.2 \\
2.4 \\
2.7 \\
2.1 \\
.6 \\
.6 \\
.6\end{array}$ & $\begin{array}{r}1.6 \\
1.0 \\
.4 \\
1.6 \\
.5 \\
.1 \\
.3 \\
e .1\end{array}$ & $\begin{array}{l}.20 \\
.20 \\
.20 \\
.40 \\
.20 \\
.10 \\
.20 \\
\omega\end{array}$ & $\begin{array}{c}16 \\
8.9 \\
16 \\
20 \\
18 \\
1.7 \\
1.5 \\
2.2\end{array}$ & $\begin{array}{l}1.7 \\
1.0 \\
2.3 \\
2.5 \\
1.9 \\
.40 \\
.40 \\
.20\end{array}$ & $\begin{array}{c}-. \\
-. \\
-\therefore \\
491 \\
471 \\
\ddot{4.4} \\
7.2\end{array}$ \\
\hline$A D-5$ & $\begin{array}{l}07-13-89 \\
11-13-89 \\
11-14-89 \\
05-04-90 \\
10-19-90\end{array}$ & $\begin{array}{c}\ldots \\
200 \\
290 \\
\cdots\end{array}$ & $\begin{array}{c}\ldots \\
98 \\
\cdots \\
\ldots \\
\ldots\end{array}$ & $\begin{array}{l}4.1 \\
4.0 \\
-. \\
4.0 \\
4.3\end{array}$ & $\begin{array}{c}.7 \\
.7 \\
-.7 \\
.7 \\
.4\end{array}$ & $\begin{array}{r}.1 \\
.2 \\
-. \\
.2 \\
<.1\end{array}$ & $\begin{array}{l}.20 \\
.10 \\
-. \\
.20 \\
10\end{array}$ & $\begin{array}{l}2.7 \\
2.5 \\
-. \\
2.4 \\
2.8\end{array}$ & $\begin{array}{l}.60 \\
.50 \\
. . \\
.50 \\
.30\end{array}$ & $\begin{array}{l}-2 \\
7.0 \\
-. \\
7.0 \\
8.3\end{array}$ \\
\hline$A D D P-1$ & $\begin{array}{l}05-15-90 \\
06-13-91\end{array}$ & $\ldots$ & -. & $\begin{array}{l}32 \\
5.9\end{array}$ & $\begin{array}{r}3.5 \\
.6\end{array}$ & $\begin{array}{r}1.5 \\
.2\end{array}$ & .60 & $\begin{array}{l}29 \\
4.9\end{array}$ & $\begin{array}{c}3.2 \\
.50\end{array}$ & $\begin{array}{l}68 f \\
13\end{array}$ \\
\hline
\end{tabular}

CEDAR POIKT WELL CLUSTER-Continued

\begin{tabular}{|c|c|c|c|c|c|c|c|c|c|c|}
\hline$C P \cdot 1$ & $\begin{array}{l}09-21-89 \\
05-03-90 \\
05-03-90 \\
10-12-90\end{array}$ & $\begin{array}{r}260 \\
220 \\
200 \\
\ldots\end{array}$ & $\begin{array}{l}47 \\
48 \\
51 \\
\cdots\end{array}$ & $\begin{array}{l}.20 \\
.20 \\
\therefore . \\
<.10\end{array}$ & $\begin{array}{c}.1 \\
.2 \\
\therefore\end{array}$ & $\begin{array}{l}<.1 \\
<.1 \\
\therefore .1 \\
<.1\end{array}$ & $\begin{array}{l}m \\
\cdots \\
m\end{array}$ & $\begin{array}{c}<.10 \\
.10 \\
\therefore . \\
<.10\end{array}$ & $\begin{array}{l}\text { No } \\
.10 \\
\because- \\
m\end{array}$ & $\begin{array}{c}\ddot{1.0} \\
\ddot{<} \\
<1.0\end{array}$ \\
\hline$C P-2$ & $\begin{array}{l}09-21-89 \\
05-03-90 \\
10-12-90\end{array}$ & $\begin{array}{c}390 f \\
500 f \\
\cdots\end{array}$ & $\begin{array}{l}53 \\
50 \\
\cdots\end{array}$ & $\begin{array}{l}2.6 \\
2.5 \\
3.2\end{array}$ & $\begin{array}{l}.5 \\
.5 \\
.3\end{array}$ & $\begin{array}{r}.2 \\
.3 \\
<.1\end{array}$ & $\begin{array}{l}.10 \\
.20 \\
10\end{array}$ & $\begin{array}{l}1.4 \\
1.6 \\
1.9\end{array}$ & $\begin{array}{l}.30 \\
.40 \\
.20\end{array}$ & $\begin{array}{l}-. \\
6.9 \\
6.0\end{array}$ \\
\hline$C P-3$ & $\begin{array}{l}09-21-89 \\
05-03-90 \\
10-17-90\end{array}$ & $\begin{array}{c}810 \uparrow \\
860 \uparrow \\
\ldots-\end{array}$ & $\begin{array}{l}50 \\
49 \\
\cdots\end{array}$ & $\begin{array}{l}3.2 \\
2.9\end{array}$ & $\begin{array}{c}.6 \\
. .3\end{array}$ & $\begin{array}{l}.3 \\
\therefore .1 \\
<.1\end{array}$ & $\begin{array}{l}.20 \\
\because 0\end{array}$ & $\begin{array}{l}2.1 \\
1.8\end{array}$ & $\begin{array}{l}.50 \\
-. \\
.20\end{array}$ & 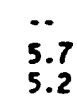 \\
\hline$C P-4$ & $\begin{array}{l}09-21-89 \\
05-03-90 \\
10-17-90\end{array}$ & 6404 & $\begin{array}{l}\cdots \\
50 \\
\cdots\end{array}$ & $\begin{array}{c}8.3 \\
12 \\
9.2\end{array}$ & $\begin{array}{l}1.1 \\
1.6 \\
1.0\end{array}$ & $\begin{array}{r}.2 \\
1.6 \\
.3\end{array}$ & $\begin{array}{l}.10 \\
.30 \\
10\end{array}$ & $\begin{array}{l}7.1 \\
7.3 \\
7.9\end{array}$ & $\begin{array}{l}1.0 \\
1.0 \\
.80\end{array}$ & $\begin{array}{l}\ddot{211} \\
211\end{array}$ \\
\hline$C P-5$ & $\begin{array}{l}09-20-89 \\
05-07-90 \\
10-17-90\end{array}$ & $\begin{array}{c}520\} \\
350\} \\
\ldots\end{array}$ & $\begin{array}{l}54 \\
75 \\
\cdots\end{array}$ & $\begin{array}{l}3.3 \\
3.3 \\
3.5\end{array}$ & $\begin{array}{l}.6 \\
.3 \\
.4\end{array}$ & $\begin{array}{l}.2 \\
<.1 \\
<.1\end{array}$ & $\begin{array}{r}.20 \\
10 \\
m\end{array}$ & $\begin{array}{l}1.9 \\
2.1 \\
2.2\end{array}$ & $\begin{array}{l}.40 \\
.20 \\
.30\end{array}$ & $\begin{array}{l}-. \\
4.2 \\
6.1\end{array}$ \\
\hline$C P-6$ & $\begin{array}{l}09-20-89 \\
06-16-90 \\
10-12-90\end{array}$ & $\begin{array}{c}850 \nmid \\
\ldots \\
\ldots\end{array}$ & $\begin{array}{l}68 \\
\ldots \\
\ldots\end{array}$ & $\begin{array}{l}3.6 \\
\ddot{3.0}\end{array}$ & $\begin{array}{c}.6 \\
. .3\end{array}$ & $\begin{array}{l}.3 \\
\therefore .1 \\
<.1\end{array}$ & $\begin{array}{l}.20 \\
-. \\
10\end{array}$ & $\begin{array}{l}2.1 \\
\therefore .8 \\
1.8\end{array}$ & $\begin{array}{l}.40 \\
. . \\
.20\end{array}$ & $\begin{array}{l}-. \\
0.7\end{array}$ \\
\hline$C P-8$ & $\begin{array}{l}06-07-90 \\
10-17-90\end{array}$ & 6001 & $\begin{array}{l}48 \\
\cdots\end{array}$ & $\begin{array}{l}1.6 \\
1.5\end{array}$ & $\begin{array}{l}.2 \\
.2\end{array}$ & $\begin{array}{l}<.1 \\
<.1\end{array}$ & $m$ & $\begin{array}{l}.40 \\
.40\end{array}$ & $\mathbf{M D}_{\text {ND }}$ & $\begin{array}{r}<1.0 \\
1.6\end{array}$ \\
\hline CPDP- 1 & $\begin{array}{l}11-17-89 \\
10-16-90\end{array}$ & -. & $\begin{array}{l}-. \\
\cdots\end{array}$ & $\begin{array}{l}10 \\
19\end{array}$ & $\begin{array}{l}1.4 \\
2.0\end{array}$ & $\begin{array}{l}.7 \\
.5\end{array}$ & $\begin{array}{l}.20 \\
.10\end{array}$ & 14.9 & $\begin{array}{l}1.2 \\
1.5\end{array}$ & $\begin{array}{l}18 \\
361\end{array}$ \\
\hline CPOP-2 & $05-16-90$ & $\cdots$ & .. & 8.7 & 1.0 & .3 & .10 & 7.7 & .90 & $20\}$ \\
\hline
\end{tabular}


GROUND-WATER DATA-Cont inued

CHEMICAL AMALYSES- Continued

STATION

NAME

ar-1

QR-2

QR-3

351519109161801

QRDP-1

351527109161901

UPSTR ARDP

351620109152101

351519109161501

351519109161502

$$
1415
$$

$09-20-89 \quad 1235$

$04-30-90 \quad 1550$

$04-04-89 \quad 1545$

$06-07-89$

06-07-89 1300

06-08-89 1700

$06-08-89 \quad 1730$

LUPTON WELL CLUSTER

LPT $-1 \quad 351928109042601$

$06-05-90$ 10-11-90

1450

$06-05-90-1045$
LPT-2

351928109042602

LPT-3

351929109042401

LPT-4

351930109042701

LPDP-1

351942109041401

$\begin{array}{ll}06-05-90 & 1045 \\ 10-11-90 & 1345\end{array}$

06-05-90 1820

10-12-90 0800

06-07-90 $\quad 1130$ $10-11-90 \quad 1410$

$11-17-89 \quad 1700$

$10-16-90 \quad 1220$ $06-11-91 \quad 1500$

MANUELITO WELL CLUSTER

$\begin{array}{llll}\text { MAN-1 } & 352742108563301 & 06-06-90 & 1200 \\ & & 10-10-90 & 1400 \\ \text { MAN-2 } & 352742108563302 & 06-06-90 & 1450 \\ & & 10-10-90 & 1650 \\ \text { MAN-3 } & 352743108563401 & 06-06-90 & 1810 \\ & & 10-11-90 & 0800 \\ \text { MANDP-1 } & 352743108563201 & 04-05-89 & 1130 \\ & & 10-16-90 & 1010 \\ & & 06-11-91 & 0845\end{array}$

LATITUDE LONGITUDE

\begin{tabular}{|c|c|}
\hline $35 \cdot 15 \cdot 194 \mathrm{~N}$ & $109^{\circ} 16 \cdot 15^{44}$ \\
\hline $35 \cdot 15 \cdot 19 \cdot 1 \mathrm{~N}$ & $109 \cdot 16 \cdot 15 \mathrm{my}$ \\
\hline $35 \cdot 15 \cdot 194 x$ & $109^{\circ} 16^{\prime} 18^{\prime \prime 4}$ \\
\hline $35^{\circ} 15^{\prime} 27 \mathrm{WN}$ & $109^{\circ} 16^{\prime} 1944$ \\
\hline $35 \cdot 16 \cdot 20 \times 1$ & $109^{\circ} 15 \cdot 21 \mathrm{my}$ \\
\hline
\end{tabular}

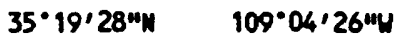

$35 \cdot 19^{\prime 29 \text { mW }} \quad 109^{\circ} 04 \cdot 26^{\text {in }}$

$35 \cdot 19 \cdot 29$ wN $\quad 109 \cdot 04 \cdot 24$ "4

$35 \cdot 19 \cdot 30$ WN $109 \cdot 04 \cdot 27$ WH

$35^{\circ} 19^{\prime} 42^{\prime \prime N} \quad 109^{\circ} 04^{\prime} 14^{\prime \prime H}$

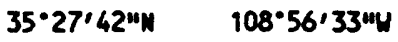

$35 \cdot 27 \cdot 42^{m N} \quad 108 \cdot 56 \cdot 33^{\cdots W}$

$35^{\circ} 27^{\prime} 43^{\circ} \mathrm{N} \quad 108^{\circ} 56^{\prime} 34^{\prime \prime K}$

$35 \cdot 27 \cdot 43^{\prime \prime N} \quad 108 \cdot 56 \cdot 32^{114}$ 
GROUND-WATER DATA-Cont inued

CHEMICAL AMALYSES-Continued

\begin{tabular}{|c|c|c|c|c|c|c|c|c|c|c|}
\hline $\begin{array}{l}\text { STATION } \\
\text { NAME }\end{array}$ & DATE & $\begin{array}{l}\text { ALTIITUDE } \\
\text { OF LAND } \\
\text { SURFACE } \\
\text { DATUM } \\
\text { (METERS } \\
\text { ABOVE } \\
\text { NGVD) } \\
\text { (72000) }\end{array}$ & $\begin{array}{l}\text { DEPTH } \\
\text { OF } \\
\text { UELL, } \\
\text { TOTAL } \\
\text { (METERS) } \\
\text { (72008) }\end{array}$ & $\begin{array}{l}\text { DEPTH } \\
\text { BELOW } \\
\text { LAND } \\
\text { SURFACE } \\
\text { (WATER } \\
\text { LEVEL) } \\
\text { (METERS) } \\
\text { (72019) }\end{array}$ & $\begin{array}{l}\text { PUMP } \\
\text { OR FLON } \\
\text { PERIOD } \\
\text { PRIOR } \\
\text { TO SAM- } \\
\text { PLING } \\
\text { (MIN) } \\
\text { (72004) }\end{array}$ & $\begin{array}{l}\text { FLOW } \\
\text { RATE } \\
\text { INSTAN- } \\
\text { TANEOUS } \\
\left(m^{3} / s\right) \\
(00059)\end{array}$ & $\begin{array}{l}\text { TEMPER- } \\
\text { ATURE } \\
\text { WATER } \\
\left({ }^{\circ} \mathrm{C}\right) \\
(00010)\end{array}$ & $\begin{array}{l}\text { TUR- } \\
\text { BID- } \\
\text { ITY } \\
\text { (NTU) } \\
\text { (00076) }\end{array}$ & $\begin{array}{l}\text { OXID- } \\
\text { ATION } \\
\text { RED- } \\
\text { UCTION } \\
\text { POTEN- } \\
\text { TIAL } \\
\text { (mV) } \\
(00090)\end{array}$ & $\begin{array}{l}\text { SPE- } \\
\text { CIFIC } \\
\text { CON- } \\
\text { DUCT- } \\
\text { ANCE } \\
(\mu S / C \mathrm{~m}) \\
(00095)\end{array}$ \\
\hline \multicolumn{11}{|c|}{ QUERINO ROND WELL CLUSTER-Continued } \\
\hline$Q R-1$ & $\begin{array}{l}09-19-89 \\
04-30-90\end{array}$ & 1796.55 & 34.75 & $\begin{array}{l}3.12 \\
2.98\end{array}$ & $\begin{array}{l}45 \\
35\end{array}$ & $\begin{array}{l}.0011 \\
.0038\end{array}$ & $\begin{array}{l}18.5 \\
13.5\end{array}$ & $\cdots$ & $\begin{array}{l}55 \\
56\end{array}$ & $\begin{array}{l}1190 \\
1190\end{array}$ \\
\hline$Q R-2$ & $\begin{array}{l}07-11-89 \\
09-20-89 \\
05-01-90\end{array}$ & 1796.61 & 8.99 & $\begin{array}{r}4.08 \\
.14 \\
3.06\end{array}$ & $\begin{array}{l}\cdots \\
38 \\
35\end{array}$ & $\begin{array}{l}.0019 \\
.0004 \\
.0027\end{array}$ & $\begin{array}{l}18.5 \\
16.5 \\
13.5\end{array}$ & $\begin{array}{l}\cdots \\
\cdots\end{array}$ & $\begin{array}{r}\cdots \\
207 \\
138\end{array}$ & $\begin{array}{l}1280 \\
1280 \\
1130\end{array}$ \\
\hline$Q R-3$ & $\begin{array}{l}07-11-89 \\
09-20-89 \\
04-30-90\end{array}$ & 1794.39 & 8.84 & $\begin{array}{r}1.17 \\
.98 \\
.85\end{array}$ & $\begin{array}{l}-- \\
50 \\
55\end{array}$ & $\begin{array}{l}.0011 \\
.0004 \\
.0030\end{array}$ & $\begin{array}{l}16.5 \\
18.0 \\
13.4\end{array}$ & $\begin{array}{l}\cdots \\
\cdots \\
\cdots\end{array}$ & $\begin{array}{l}\cdots \\
168 \\
376\end{array}$ & $\begin{array}{l}1170 \\
1160 \\
1110\end{array}$ \\
\hline QRDP - 1 & $\begin{array}{l}04-04-89 \\
06-07-89 \\
06-07-89\end{array}$ & 1790 & $\begin{array}{l}1.65 \\
1.07 \\
1.07\end{array}$ & $\begin{array}{l}. . \\
.57 \\
.57\end{array}$ & $\begin{array}{l}\cdots \\
\cdots \\
\cdots\end{array}$ & $\begin{array}{l}\cdots \\
\cdots\end{array}$ & $\begin{array}{r}9.0 \\
21.0 \\
21.0\end{array}$ & $\begin{array}{l}14 \\
\cdots \\
\cdots\end{array}$ & $\begin{array}{l}96 \\
89 \\
89\end{array}$ & $\begin{array}{l}1100 \\
1230 \\
1230\end{array}$ \\
\hline UPSTR QRDP & $\begin{array}{l}06-08-89 \\
06-08-89\end{array}$ & 1790 & $\begin{array}{c}1.07 \\
\ldots\end{array}$ & $\because$ & $\because-$ & $\because-$ & $\begin{array}{c}16.5 \\
\cdots\end{array}$ & $\because-$ & $\begin{array}{l}81 \\
--\end{array}$ & $\begin{array}{c}1250 \\
\ldots\end{array}$ \\
\hline
\end{tabular}

LUPTON UELL CLUSTER-Continued

\begin{tabular}{|c|c|c|c|c|c|c|c|c|c|c|}
\hline LPT-1 & $\begin{array}{l}06-05-90 \\
10-11-90\end{array}$ & 1888.52 & 21.64 & 1.0 & $\begin{array}{l}87 \\
--\end{array}$ & $\begin{array}{c}.0019 \\
\cdots\end{array}$ & $\begin{array}{l}14.5 \\
13.5\end{array}$ & $\because$ & $\begin{array}{l}28 \\
50\end{array}$ & $\begin{array}{l}2160 \\
2130\end{array}$ \\
\hline LPT -2 & $\begin{array}{l}06-05-90 \\
10-11-90\end{array}$ & 1888.76 & 6.10 & $\begin{array}{l}1.01 \\
1.08\end{array}$ & $\begin{array}{l}72 \\
\cdots\end{array}$ & $\begin{array}{c}.0027 \\
\ldots\end{array}$ & $\begin{array}{l}16.5 \\
17.0\end{array}$ & 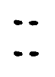 & $\frac{46}{73}$ & $\begin{array}{l}2270 \\
2210\end{array}$ \\
\hline LPT -3 & $\begin{array}{l}06-05-90 \\
10-12-90\end{array}$ & 1890 & 8.08 & 2.07 & $\begin{array}{l}88 \\
--\end{array}$ & $\begin{array}{c}.0027 \\
\ldots\end{array}$ & $\begin{array}{l}13.5 \\
14.0\end{array}$ & $\because$ & $\begin{array}{l}28 \\
69\end{array}$ & $\begin{array}{l}2370 \\
2290\end{array}$ \\
\hline LPT -4 & $\begin{array}{l}06-07-90 \\
10-11-90\end{array}$ & 1890 & 8.99 & $\begin{array}{l}1.70 \\
1.78\end{array}$ & $\begin{array}{l}73 \\
\cdots\end{array}$ & $\begin{array}{c}.0027 \\
\cdots\end{array}$ & $\begin{array}{l}15.5 \\
15.0\end{array}$ & $\because$ & $\begin{array}{l}57 \\
77\end{array}$ & $\begin{array}{l}2540 \\
2420\end{array}$ \\
\hline LPDP- 1 & $\begin{array}{l}11-17-89 \\
10-16-90 \\
06-11-91\end{array}$ & 1880 & $\begin{array}{l}\cdots \\
\cdots \\
1.46\end{array}$ & $\begin{array}{l}.32 \\
.61 \\
.15\end{array}$ & $\begin{array}{l}34 \\
25\end{array}$ & $\begin{array}{l}.0008 \\
.0011 \\
.0004\end{array}$ & $\begin{array}{r}6.5 \\
16.0 \\
15.5\end{array}$ & $\begin{array}{l}-- \\
-- \\
--\end{array}$ & $\begin{array}{l}245 \\
136 \\
122\end{array}$ & $\begin{array}{l}2530 \\
1890 \\
3920\end{array}$ \\
\hline
\end{tabular}

MANUELITO WELL CLUSTER-Cont inued

\begin{tabular}{|c|c|c|c|c|c|c|c|c|c|c|}
\hline MAN-1 & $\begin{array}{l}06-06-90 \\
10-10-90\end{array}$ & 1910 & 24.84 & $\begin{array}{l}6.22 \\
6.29\end{array}$ & $\begin{array}{l}65 \\
\therefore\end{array}$ & $\begin{array}{c}.0008 \\
\cdots\end{array}$ & $\begin{array}{l}18.5 \\
13.0\end{array}$ & $\begin{array}{l}-. \\
-\cdot\end{array}$ & $\begin{array}{r}-14 \\
4\end{array}$ & $\begin{array}{l}863 \\
850\end{array}$ \\
\hline MAN-2 & $\begin{array}{l}06-06-90 \\
10-10-90\end{array}$ & 1910 & 13.72 & $\begin{array}{l}7.73 \\
7.72\end{array}$ & 90 & $\begin{array}{c}.0008 \\
\ldots\end{array}$ & $\begin{array}{l}19.0 \\
14.0\end{array}$ & 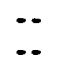 & $\begin{array}{l}272 \\
241\end{array}$ & $\begin{array}{l}2030 \\
2250\end{array}$ \\
\hline MAN-3 & $\begin{array}{l}06-06-90 \\
10-11-90\end{array}$ & 1910 & 15.70 & $\begin{array}{l}7.72 \\
7.88\end{array}$ & 90 & $\begin{array}{c}.0004 \\
\ldots\end{array}$ & $\begin{array}{l}18.5 \\
12.0\end{array}$ & -. & $\begin{array}{l}182 \\
165\end{array}$ & $\begin{array}{l}2890 \\
2450\end{array}$ \\
\hline MANDP-1 & $\begin{array}{l}04-05-89 \\
10-16-90 \\
06-11-91\end{array}$ & 1900 & $\begin{array}{c}1.95 \\
\ldots \\
\ldots\end{array}$ & $\begin{array}{c}. . \\
.03 \\
1.46\end{array}$ & $\begin{array}{l}- \\
10 \\
-.\end{array}$ & .0011 & $\begin{array}{r}8.0 \\
17.0 \\
15.5\end{array}$ & $\begin{array}{l}1.9 \\
-. \\
-.\end{array}$ & $\begin{array}{r}178 \\
80 \\
105\end{array}$ & $\begin{array}{l}1760 \\
1420 \\
2000\end{array}$ \\
\hline
\end{tabular}


GROUND-UATER DATA-Continued

CHEMICAL ANALYSES-Continued

\section{STATION}

NAME

SPE-
CIFIC
CON-
DUCT-
ANCE
LAB
$(\mu S / C \mathrm{Cm})$
$(90095)$

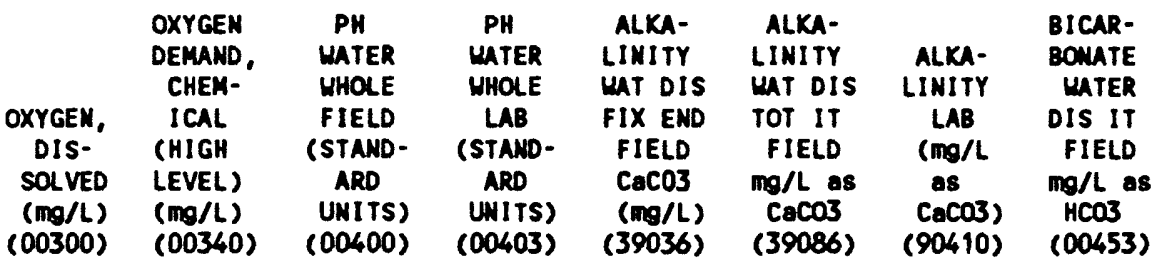

QUERIMO ROAD WELL CLUSTER-CONtinued

\begin{tabular}{|c|c|c|c|c|c|c|c|c|c|c|}
\hline$Q R-1$ & $\begin{array}{l}09-19-89 \\
04-30-90\end{array}$ & $\ddot{1150}$ & $\begin{array}{l}.3 \\
.1\end{array}$ & -- & $\begin{array}{l}7.5 \\
7.5\end{array}$ & $\begin{array}{l}8.1 \\
7.7\end{array}$ & $\begin{array}{r}260 \\
\cdots\end{array}$ & $\ddot{260}$ & -. & $\begin{array}{l}327 \\
317\end{array}$ \\
\hline QR-2 & $\begin{array}{l}07-11-89 \\
09-20-89 \\
05-01-90\end{array}$ & $\begin{array}{c}1260 \\
-- \\
1190\end{array}$ & $\begin{array}{l}1.7 \\
1.5 \\
1.2\end{array}$ & $\begin{array}{l}-- \\
-- \\
--\end{array}$ & $\begin{array}{l}7.6 \\
7.4 \\
7.2\end{array}$ & $\begin{array}{l}8.0 \\
8.0 \\
7.7\end{array}$ & $\begin{array}{r}-. \\
260 \\
-.\end{array}$ & $\begin{array}{l}268 \\
-- \\
259\end{array}$ & $\begin{array}{l}-- \\
-- \\
--\end{array}$ & $\begin{array}{l}327 \\
317 \\
316\end{array}$ \\
\hline$Q R-3$ & $\begin{array}{l}07-11-89 \\
09-20-89 \\
04-30-90\end{array}$ & $\begin{array}{l}1150 \\
1160 \\
1060\end{array}$ & $\begin{array}{r}1.5 \\
.2 \\
1.2\end{array}$ & $\begin{array}{l}-. \\
-- \\
--\end{array}$ & $\begin{array}{l}7.6 \\
7.5 \\
7.6\end{array}$ & $\begin{array}{l}8.1 \\
8.0 \\
7.8\end{array}$ & $\begin{array}{l}240 \\
230\end{array}$ & $\begin{array}{l}234 \\
-- \\
227\end{array}$ & $\begin{array}{l}-. \\
-. \\
-.\end{array}$ & $\begin{array}{l}286 \\
293 \\
277\end{array}$ \\
\hline ORDP-1 & $\begin{array}{l}04-04-89 \\
06-07-89 \\
06-07-89\end{array}$ & $\begin{array}{l}1110 \\
\cdots \\
\cdots\end{array}$ & $\begin{array}{l}.3 \\
.8 \\
.8\end{array}$ & $\begin{array}{l}23 \\
\cdots \\
-.\end{array}$ & $\begin{array}{l}7.4 \\
7.4 \\
7.4\end{array}$ & $\begin{array}{l}7.8 \\
-. \\
-.\end{array}$ & $\begin{array}{l}260 \\
240 \\
240\end{array}$ & $\begin{array}{l}256 \\
242 \\
242\end{array}$ & $\begin{array}{c}233 \\
-. \\
--\end{array}$ & $\begin{array}{l}312 \\
295 \\
295\end{array}$ \\
\hline UPSTR ORDP & $\begin{array}{l}06-08-89 \\
06-08-89\end{array}$ & $\because-$ &. .5 & $\ddot{-.}$ & 7.3 & $\ddot{--}$ & 320 & 325 & $=$ & 397 \\
\hline
\end{tabular}

LUPTON WELL CLUSTER-Continued

\begin{tabular}{|c|c|c|c|c|c|c|c|c|c|c|}
\hline LPT-1 & $\begin{array}{l}06-05-90 \\
10-11-90\end{array}$ & $\begin{array}{l}2140 \\
2160\end{array}$ & $\begin{array}{l}.1 \\
.3\end{array}$ & 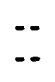 & $\begin{array}{l}7.4 \\
7.4\end{array}$ & $\begin{array}{l}7.6 \\
7.6\end{array}$ & $\begin{array}{l}460 \\
470\end{array}$ & $\begin{array}{l}480 \\
480\end{array}$ & $\begin{array}{l}460 \\
429\end{array}$ & $\begin{array}{l}573 \\
586\end{array}$ \\
\hline LPT-2 & $\begin{array}{l}06-05-90 \\
10-11-90\end{array}$ & $\begin{array}{l}2240 \\
2250\end{array}$ & .1 & $=$ & $\begin{array}{l}7.3 \\
7.2\end{array}$ & $\begin{array}{l}7.6 \\
7.5\end{array}$ & $\begin{array}{l}480 \\
480\end{array}$ & $\begin{array}{l}480 \\
485\end{array}$ & $\begin{array}{l}463 \\
464\end{array}$ & $\begin{array}{l}586 \\
592\end{array}$ \\
\hline LPT -3 & $\begin{array}{l}06-05-90 \\
10-12-90\end{array}$ & $\begin{array}{l}2550 \\
2350\end{array}$ & $\begin{array}{l}0 \\
.3\end{array}$ & $\begin{array}{l}-- \\
--\end{array}$ & $\begin{array}{l}7.4 \\
7.4\end{array}$ & $\begin{array}{l}7.5 \\
7.5\end{array}$ & $\begin{array}{l}490 \\
496\end{array}$ & $\begin{array}{l}489 \\
502\end{array}$ & $\begin{array}{l}474 \\
464\end{array}$ & $\begin{array}{l}597 \\
613\end{array}$ \\
\hline LPT-4 & $\begin{array}{l}06-07-90 \\
10-11-90\end{array}$ & $\begin{array}{l}2830 \\
2470\end{array}$ & $\begin{array}{l}0 \\
.3\end{array}$ & -- & $\begin{array}{l}7.2 \\
7.1\end{array}$ & $\begin{array}{l}7.3 \\
7.5\end{array}$ & $\begin{array}{l}490 \\
480\end{array}$ & $\begin{array}{l}496 \\
484\end{array}$ & $\begin{array}{l}790 \\
470\end{array}$ & $\begin{array}{l}605 \\
591\end{array}$ \\
\hline LPDP-1 & $\begin{array}{l}11-17-89 \\
10-16-90 \\
06-11-91\end{array}$ & $\begin{array}{l}2270 \\
1940 \\
3910\end{array}$ & $\begin{array}{l}3.7 \\
.6 \\
1.0\end{array}$ & $\begin{array}{l}\because- \\
\because-\end{array}$ & $\begin{array}{l}7.0 \\
6.8 \\
6.9\end{array}$ & $\begin{array}{l}8.0 \\
7.6 \\
7.3\end{array}$ & $\begin{array}{l}320 \\
454 \\
500\end{array}$ & $\begin{array}{l}325 \\
454 \\
502\end{array}$ & $\ddot{436}$ & $\begin{array}{l}397 \\
555 \\
613\end{array}$ \\
\hline
\end{tabular}

MANUELITO WELL CLUSTER-Continued

\begin{tabular}{|c|c|c|c|c|c|c|c|c|c|c|}
\hline MAN-1 & $\begin{array}{l}06-06-90 \\
10-10-90\end{array}$ & $\begin{array}{l}848 \\
804\end{array}$ & $\begin{array}{l}0 \\
.3\end{array}$ & $\because-$ & $\begin{array}{l}7.5 \\
7.6\end{array}$ & $\begin{array}{l}7.7 \\
7.6\end{array}$ & $\begin{array}{l}440 \\
449\end{array}$ & $\begin{array}{l}443 \\
450\end{array}$ & $\begin{array}{l}448 \\
458\end{array}$ & $\begin{array}{l}541 \\
549\end{array}$ \\
\hline MAN-2 & $\begin{array}{l}06-06-90 \\
10-10-90\end{array}$ & $\begin{array}{l}2120 \\
2300\end{array}$ & $\begin{array}{l}2.0 \\
7.0\end{array}$ & $\begin{array}{l}-- \\
--\end{array}$ & $\begin{array}{l}7.1 \\
7.2\end{array}$ & $\begin{array}{l}7.5 \\
7.4\end{array}$ & $\begin{array}{l}620 \\
738\end{array}$ & $\begin{array}{l}636 \\
747\end{array}$ & $\begin{array}{l}575 \\
742\end{array}$ & $\begin{array}{l}775 \\
912\end{array}$ \\
\hline MAN-3 & $\begin{array}{l}06-06-90 \\
10-11-90\end{array}$ & $\begin{array}{l}2340 \\
2590\end{array}$ & $\begin{array}{l}2.2 \\
4.9\end{array}$ & -- & $\begin{array}{l}6.9 \\
7.1\end{array}$ & $\begin{array}{l}7.6 \\
7.3\end{array}$ & $\begin{array}{c}798 \\
-.\end{array}$ & $\begin{array}{l}804 \\
810\end{array}$ & $\begin{array}{l}459 \\
641\end{array}$ & $\begin{array}{l}981 \\
988\end{array}$ \\
\hline MANDP-1 & $\begin{array}{l}04-05-89 \\
10-16-90 \\
06-11-91\end{array}$ & $\begin{array}{l}1830 \\
1430 \\
1990\end{array}$ & $\begin{array}{l}.2 \\
1.2 \\
1.0\end{array}$ & $\begin{array}{l}35 \\
-- \\
--\end{array}$ & $\begin{array}{l}6.9 \\
6.7 \\
7.8\end{array}$ & $\begin{array}{l}7.6 \\
7.4 \\
7.5\end{array}$ & $\begin{array}{l}520 \\
440 \\
380\end{array}$ & $\begin{array}{l}538 \\
-- \\
387\end{array}$ & $\begin{array}{r}415 \\
402 \\
\ldots\end{array}$ & $\begin{array}{l}656 \\
540 \\
472\end{array}$ \\
\hline
\end{tabular}




\section{GROUND-MATER DATA-Continued}

CHEMICAL AMALYSES-Continued

STATION

MAME

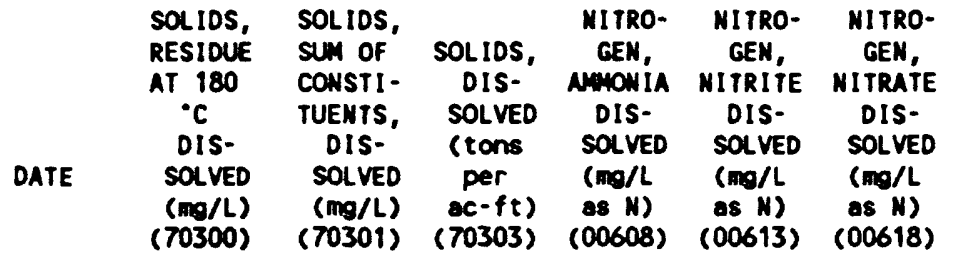

QUERIMO ROAD WELL CLUSTER-Continued

\begin{tabular}{|c|c|c|c|c|c|c|c|c|c|c|c|}
\hline QR-1 & $\begin{array}{l}09-19-89 \\
04-30-90\end{array}$ & $\because$ & $\begin{array}{l}726 \\
684\end{array}$ & $\begin{array}{l}.99 \\
.93\end{array}$ & $\ddot{a}$ & $\ddot{a}$ & $\because$ & $\begin{array}{l}<.100 \\
<.100\end{array}$ & $\because$ & $\because-$ & $\because$ \\
\hline QR-2 & $\begin{array}{l}07-11-89 \\
09-20-89 \\
05-01-90\end{array}$ & $\begin{array}{l}-. \\
\cdots \\
-\end{array}$ & $\begin{array}{l}806 \\
741\end{array}$ & $\begin{array}{l}\cdots \\
1.10 \\
1.01\end{array}$ & $\begin{array}{l}\because- \\
-. \\
-\end{array}$ & $\begin{array}{l}\because- \\
\therefore \\
\cdots\end{array}$ & 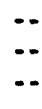 & $\begin{array}{l}<.100 \\
<.100 \\
<.100\end{array}$ & $\begin{array}{l}\because . \\
\cdots\end{array}$ & $\begin{array}{l}-. \\
\cdots \\
\cdots\end{array}$ & $\begin{array}{l}\because \\
\therefore\end{array}$ \\
\hline$Q R-3$ & $\begin{array}{l}07-11-89 \\
09-20-89 \\
04-30-90\end{array}$ & $\begin{array}{l}-. \\
\cdots\end{array}$ & $\begin{array}{l}\ddot{724} \\
633\end{array}$ & $\begin{array}{l}. . \\
.99 \\
.86\end{array}$ & 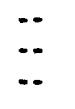 & $\begin{array}{l}\because- \\
\cdots \\
\cdots\end{array}$ & $\begin{array}{l}\because \\
\cdots\end{array}$ & $\begin{array}{l}<.100 \\
<.100 \\
<.100\end{array}$ & $\begin{array}{l}-. \\
-\end{array}$ & $\begin{array}{l}\cdots \\
\cdots \\
\cdots\end{array}$ & $\ddot{-}$ \\
\hline QRDP - 1 & $\begin{array}{l}04-04-89 \\
06-07-89 \\
06-07-89\end{array}$ & $\begin{array}{l}708 \\
\cdots \\
\cdots\end{array}$ & $\begin{array}{l}718 \\
\because- \\
\cdots\end{array}$ & $\begin{array}{l}.96 \\
\because- \\
-.\end{array}$ & $\begin{array}{l}.770 \\
\because- \\
-.\end{array}$ & 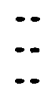 & $\begin{array}{l}\because \\
\because-\end{array}$ & $\begin{array}{c}<.100 \\
-. \\
-.\end{array}$ & $\begin{array}{l}-. \\
\cdots\end{array}$ & $\begin{array}{l}-. \\
-.\end{array}$ & $\begin{array}{l}1.0 \\
-. \\
-.\end{array}$ \\
\hline UPSTR ORDP & $\begin{array}{l}06-08-89 \\
06-08-89\end{array}$ & $\cdots$ & 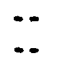 & 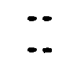 & $\ddot{-.}$ & $\because$ & $\because$ & 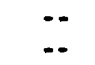 & 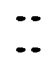 & $\ddot{-.}$ & $\begin{array}{l}. \\
-.\end{array}$ \\
\hline
\end{tabular}

LUPTON WELL CLUSTER-Continued

\begin{tabular}{|c|c|c|c|c|c|c|c|c|c|c|c|}
\hline LPT-1 & $\begin{array}{l}06-05-90 \\
10-11-90\end{array}$ & 1380 & $\begin{array}{l}1420 \\
1380\end{array}$ & $\begin{array}{l}1.93 \\
1.88\end{array}$ & 2.20 & $\begin{array}{l}.004 \\
\therefore\end{array}$ & .013 & $\begin{array}{l}.017 \\
<.010\end{array}$ & .06 & .01 & .. \\
\hline LPT -2 & $\begin{array}{l}06-05-90 \\
10-11-90\end{array}$ & $\ddot{1460}$ & $\begin{array}{l}1520 \\
1490\end{array}$ & $\begin{array}{l}2.07 \\
1.99\end{array}$ & $\begin{array}{l}1.50 \\
-.\end{array}$ & $\begin{array}{l}.003 \\
\therefore\end{array}$ & $\begin{array}{l}.009 \\
\therefore\end{array}$ & $\begin{array}{r}.012 \\
<.010\end{array}$ & .04 & .01 & $\begin{array}{l}. \\
-.\end{array}$ \\
\hline LPT -3 & $\begin{array}{l}06-05-90 \\
10-12-90\end{array}$ & 1530 & $\begin{array}{l}1700 \\
1540\end{array}$ & $\begin{array}{l}2.32 \\
2.08\end{array}$ & $\begin{array}{c}2.10 \\
\cdots\end{array}$ & $\begin{array}{l}<.001 \\
\therefore .\end{array}$ & -. & $\begin{array}{l}.011 \\
<.010\end{array}$ & 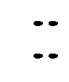 & $\begin{array}{l}-\cdot \\
\cdots\end{array}$ & -. \\
\hline LPT -4 & $\begin{array}{l}06-07-90 \\
10-11-90\end{array}$ & $\begin{array}{c}1650 \\
0\end{array}$ & $\begin{array}{l}1720 \\
1630\end{array}$ & $\begin{array}{l}2.33 \\
2.24\end{array}$ & $\begin{array}{c}1.40 \\
-.\end{array}$ & .005 & .006 & $\begin{array}{l}.011 \\
.020\end{array}$ & .03 & .02 & $\ddot{-.}$ \\
\hline LPDP-9 & $\begin{array}{l}11-17-89 \\
10-16-90 \\
06-11-91\end{array}$ & $\begin{array}{c}\cdots \\
1240 \\
2640\end{array}$ & $\begin{array}{l}1800 \\
1240 \\
1690\end{array}$ & $\begin{array}{l}2.45 \\
1.69 \\
3.59\end{array}$ & $\begin{array}{l}\cdots \\
-. \\
-.\end{array}$ & $\begin{array}{l}-. \\
-- \\
--\end{array}$ & $\begin{array}{l}-. \\
\because- \\
-.\end{array}$ & $\begin{array}{c}-. \\
<.010 \\
<.005\end{array}$ & $\begin{array}{l}-. \\
-- \\
-\end{array}$ & $\begin{array}{l}- \\
- \\
-\end{array}$ & -. \\
\hline
\end{tabular}

MANUELITO MELL ClUSTER-Continued

\begin{tabular}{|c|c|c|c|c|c|c|c|c|c|c|c|}
\hline MAN-1 & $\begin{array}{l}06-06-90 \\
10-10-90\end{array}$ & $\begin{array}{l}-. \\
519\end{array}$ & $\ddot{515}$ & .79 & $\begin{array}{l}1.40 \\
-.\end{array}$ & .002 & $\begin{array}{l}\cdots \\
\cdots\end{array}$ & $\begin{array}{l}<.010 \\
<.010\end{array}$ & -. & $\begin{array}{l}.01 \\
. .\end{array}$ & $\begin{array}{l}. \\
\therefore\end{array}$ \\
\hline MAN-2 & $\begin{array}{l}06-06-90 \\
10-10-90\end{array}$ & $\ddot{1570}$ & $\begin{array}{l}1500 \\
1650\end{array}$ & $\begin{array}{l}2.05 \\
2.14\end{array}$ & $\begin{array}{l}.056 \\
\therefore\end{array}$ & $\begin{array}{l}.005 \\
\therefore\end{array}$ & $\begin{array}{l}.040 \\
\therefore\end{array}$ & $\begin{array}{r}.045 \\
<.010\end{array}$ & $\begin{array}{l}.18 \\
-.\end{array}$ & $\begin{array}{l}.02 \\
.-\end{array}$ & $\begin{array}{l}. \\
\therefore\end{array}$ \\
\hline MAN-3 & $\begin{array}{l}06-06-90 \\
10-11-90\end{array}$ & $\ddot{1740}$ & $\begin{array}{l}1670 \\
1770\end{array}$ & $\begin{array}{l}2.27 \\
2.37\end{array}$ & .402 & $<.001$ & 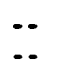 & $\begin{array}{l}<.010 \\
<.010\end{array}$ & $\begin{array}{l}-\cdot \\
-\cdot\end{array}$ & $\begin{array}{l}-. \\
--\end{array}$ & $\because$ \\
\hline MAMDP-1 & $\begin{array}{l}04-05-89 \\
10-16-90 \\
06-11-91\end{array}$ & $\begin{array}{r}1290 \\
964 \\
1300\end{array}$ & $\begin{array}{l}1270 \\
1020 \\
1240\end{array}$ & $\begin{array}{l}1.75 \\
1.31 \\
1.77\end{array}$ & $\begin{array}{l}.720 \\
\therefore \\
\therefore\end{array}$ & $\begin{array}{l}\cdots \\
\cdots \\
\cdots\end{array}$ & $\begin{array}{l}\cdots \\
\cdots \\
-\end{array}$ & $\begin{array}{r}<.100 \\
.034 \\
.007\end{array}$ & $\begin{array}{l}-- \\
-- \\
--\end{array}$ & $\begin{array}{l}-- \\
- \\
--\end{array}$ & $\begin{array}{l}1.0 \\
-. \\
-.\end{array}$ \\
\hline
\end{tabular}


GROUND-MATER DATA-Cont inued

CHEMICAL ANALYSES-Continued

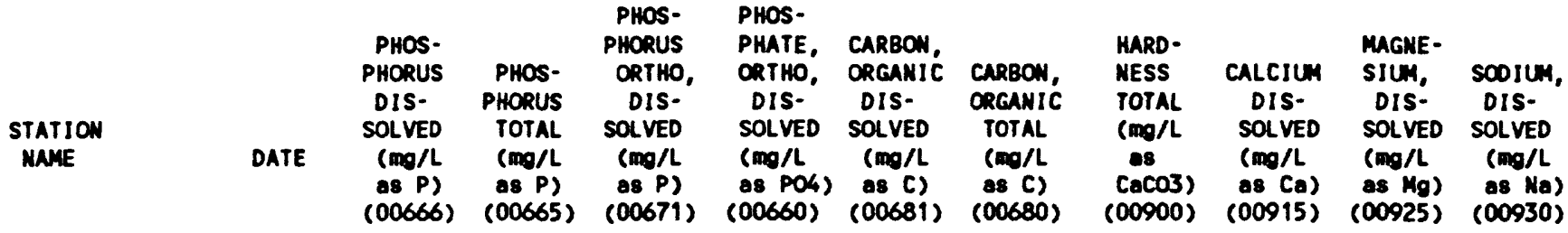

QUERINO ROND WELL CLUSTER-COntinued

\begin{tabular}{|c|c|c|c|c|c|c|c|c|c|c|}
\hline$Q R-1$ & $\begin{array}{l}09-19-89 \\
04-30-90\end{array}$ & 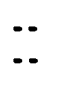 & -- & $\begin{array}{l}\cdots \\
\cdots\end{array}$ & $\begin{array}{l}\cdots \\
--\end{array}$ & $\begin{array}{l}2.1 \\
1.6\end{array}$ & $\begin{array}{l}-. \\
--\end{array}$ & $\begin{array}{l}310 \\
340\end{array}$ & $\begin{array}{r}91 \\
100\end{array}$ & $\begin{array}{l}20 \\
22\end{array}$ \\
\hline OR-2 & $\begin{array}{l}07-11-89 \\
09-20-89 \\
05-01-90\end{array}$ & $\begin{array}{l}-- \\
--\end{array}$ & $\begin{array}{l}-- \\
-- \\
--\end{array}$ & $\begin{array}{l}\cdots \\
\cdots \\
\cdots\end{array}$ & $\begin{array}{l}\cdots \\
\cdots \\
\cdots\end{array}$ & $\begin{array}{l}-. \\
2.6 \\
2.2\end{array}$ & $\begin{array}{l}\cdots \\
\cdots \\
--\end{array}$ & $\begin{array}{l}350 \\
350 \\
350\end{array}$ & $\begin{array}{l}110 \\
110 \\
110\end{array}$ & $\begin{array}{l}19 \\
18 \\
18\end{array}$ \\
\hline QR-3 & $\begin{array}{l}07-11-89 \\
09-20-89 \\
04-30-90\end{array}$ & $\begin{array}{l}\cdots \\
\cdots \\
\cdots\end{array}$ & $\begin{array}{l}\cdots \\
\cdots \\
\cdots\end{array}$ & $\begin{array}{l}\cdots \\
\cdots \\
\cdots\end{array}$ & $\begin{array}{l}\cdots \\
\cdots \\
\cdots\end{array}$ & $\begin{array}{l}-. \\
3.8 \\
3.2\end{array}$ & $\begin{array}{l}\cdots \\
\because- \\
--\end{array}$ & $\begin{array}{l}260 \\
250 \\
230\end{array}$ & $\begin{array}{l}81 \\
79 \\
73\end{array}$ & $\begin{array}{l}13 \\
12 \\
11\end{array}$ \\
\hline ORDP-1 & $\begin{array}{l}06-06-89 \\
06-07-89 \\
06-07-89\end{array}$ & \begin{tabular}{l}
.090 \\
\hdashline- \\
--
\end{tabular} & $\begin{array}{l}.080 \\
-- \\
\cdots\end{array}$ & $\begin{array}{l}.060 \\
-- \\
--\end{array}$ & $\begin{array}{l}.18 \\
\therefore\end{array}$ & $\begin{array}{l}6.1 \\
\ldots \\
\ldots\end{array}$ & $\begin{array}{l}6.1 \\
\cdots \\
\cdots\end{array}$ & $\begin{array}{l}160 \\
270 \\
270\end{array}$ & $\begin{array}{l}48 \\
80 \\
79\end{array}$ & $\begin{array}{l}9.6 \\
17 \\
17\end{array}$ \\
\hline UPSTR ORDP & $\begin{array}{l}06-08-89 \\
06-08-89\end{array}$ & 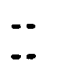 & $\because$ & -. & $\ldots$ & 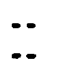 & -. & $\begin{array}{l}250 \\
260\end{array}$ & $\begin{array}{l}74 \\
76\end{array}$ & $\begin{array}{l}16 \\
16\end{array}$ \\
\hline
\end{tabular}

LUPTON MELL CLUSTER-Continued

\begin{tabular}{|c|c|c|c|c|c|c|c|c|c|c|}
\hline LPT - 1 & $\begin{array}{l}06-05-90 \\
10-11-90\end{array}$ & .100 & $\cdots$ & $\begin{array}{l}.188 \\
--\end{array}$ & $\begin{array}{l}.58 \\
-.\end{array}$ & $\begin{array}{l}4.4 \\
4.5\end{array}$ & -- & $\begin{array}{l}320 \\
320\end{array}$ & $\begin{array}{l}92 \\
88\end{array}$ & $\begin{array}{l}22 \\
23\end{array}$ \\
\hline LPT -2 & $\begin{array}{l}06-05-90 \\
10-11-90\end{array}$ & .002 & $\begin{array}{l}-. \\
-.\end{array}$ & $\begin{array}{l}.002 \\
-.\end{array}$ & $\therefore 01$ & $\begin{array}{l}4.5 \\
4.5\end{array}$ & $\begin{array}{l}-. \\
-.\end{array}$ & $\begin{array}{l}370 \\
340\end{array}$ & $\begin{array}{r}100 \\
94\end{array}$ & $\begin{array}{l}390 \\
370\end{array}$ \\
\hline LPT -3 & $\begin{array}{l}06-05-90 \\
10-12-90\end{array}$ & .069 & $\begin{array}{l}-- \\
--\end{array}$ & $\begin{array}{l}.147 \\
--\end{array}$ &. .45 & $\begin{array}{l}4.9 \\
4.9\end{array}$ & $\ddot{-\cdot}$ & $\begin{array}{l}440 \\
360\end{array}$ & $\begin{array}{l}120 \\
100\end{array}$ & $\begin{array}{l}430 \\
390\end{array}$ \\
\hline LPT -4 & $\begin{array}{l}06-07-90 \\
10-11-90\end{array}$ & .006 & $\begin{array}{l}-. \\
--\end{array}$ & $\begin{array}{l}.022 \\
-.\end{array}$ & $\therefore .07$ & $\begin{array}{l}4.2 \\
4.2\end{array}$ & $\because-$ & $\begin{array}{l}340 \\
410\end{array}$ & $\begin{array}{r}73 \\
110\end{array}$ & $\begin{array}{l}530 \\
400\end{array}$ \\
\hline LPDP-1 & $\begin{array}{l}11-17-89 \\
10-16-90 \\
06-11-91\end{array}$ & $\begin{array}{l}. . \\
.049 \\
.035\end{array}$ & $\begin{array}{l}-. \\
-. \\
-.\end{array}$ & $\begin{array}{l}\cdots \\
\cdots \\
\cdots\end{array}$ & $\begin{array}{l}-- \\
-. \\
--\end{array}$ & $\begin{array}{l}6.4 \\
4.6 \\
6.8\end{array}$ & $\begin{array}{l}- \\
-. \\
--\end{array}$ & $\begin{array}{l}790 \\
260 \\
870\end{array}$ & $\begin{array}{r}250 \\
74 \\
240\end{array}$ & $\begin{array}{l}270 \\
330 \\
680\end{array}$ \\
\hline
\end{tabular}

MANUELITO WELL CLUSTER-Continued

\begin{tabular}{|c|c|c|c|c|c|c|c|c|c|c|}
\hline MaK-1 & $\begin{array}{l}06-06-90 \\
10-10-90\end{array}$ & $\begin{array}{l}. . \\
.535\end{array}$ & $\begin{array}{l}\cdots \\
--\end{array}$ & $\begin{array}{l}.588 \\
-.\end{array}$ & $\begin{array}{l}1.8 \\
--\end{array}$ & $\begin{array}{l}9.6 \\
9.9\end{array}$ & -- & $\begin{array}{l}140 \\
150\end{array}$ & $\begin{array}{l}31 \\
33\end{array}$ & $\begin{array}{l}15 \\
16\end{array}$ \\
\hline MaK-2 & $\begin{array}{l}06-06-90 \\
10-10-90\end{array}$ & .013 & $\because$ & $\begin{array}{l}.008 \\
\therefore\end{array}$ & $\therefore .02$ & $\begin{array}{l}5.1 \\
5.8\end{array}$ & $\begin{array}{l}-- \\
--\end{array}$ & $\begin{array}{l}260 \\
330\end{array}$ & $\begin{array}{l}46 \\
65\end{array}$ & $\begin{array}{l}35 \\
40\end{array}$ \\
\hline MAN-3 & $\begin{array}{l}06-06-90 \\
10-11-90\end{array}$ & .021 & $\because-$ & $\begin{array}{l}.006 \\
\therefore\end{array}$ & $\therefore 01$ & $\begin{array}{l}7.8 \\
8.2\end{array}$ & -. & $\begin{array}{l}360 \\
310\end{array}$ & $\begin{array}{r}100 \\
67\end{array}$ & $\begin{array}{l}26 \\
35\end{array}$ \\
\hline МАКDP-1 & $\begin{array}{l}04-05-89 \\
10-16-90 \\
06-11-91\end{array}$ & $\begin{array}{l}.030 \\
.042 \\
. .\end{array}$ & $\begin{array}{l}.030 \\
\cdots \\
\cdots\end{array}$ & $\begin{array}{l}.020 \\
-. \\
-.\end{array}$ & $\begin{array}{l}.06 \\
\therefore \\
\therefore\end{array}$ & $\begin{array}{l}5.6 \\
8.0 \\
17\end{array}$ & $\begin{array}{l}5.6 \\
\cdots \\
-.\end{array}$ & $\begin{array}{r}440 \\
390 \\
95\end{array}$ & $\begin{array}{r}130 \\
110 \\
28\end{array}$ & $\begin{array}{l}27 \\
27 \\
6.0\end{array}$ \\
\hline
\end{tabular}


STATION

NAME

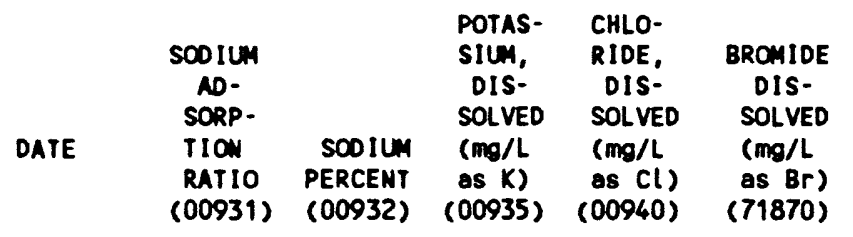

QUERINO ROND WELL CLUSTER-COntinued

\begin{tabular}{|c|c|c|c|c|c|c|c|c|c|c|}
\hline$Q R-1$ & $\begin{array}{l}09-19-89 \\
04-30-90\end{array}$ & $\begin{array}{l}3 \\
3\end{array}$ & $\begin{array}{l}45 \\
43\end{array}$ & $\begin{array}{l}2.8 \\
2.5\end{array}$ & $\begin{array}{l}75 \\
87\end{array}$ & $\begin{array}{l}.46 \\
\therefore\end{array}$ & $\begin{array}{l}.60 \\
.20\end{array}$ & $\begin{array}{l}14 \\
14\end{array}$ & $\begin{array}{l}240 \\
180\end{array}$ & $\begin{array}{l}-. \\
-\cdot\end{array}$ \\
\hline$Q R-2$ & $\begin{array}{l}07-11-89 \\
09-20-89 \\
05-01-90\end{array}$ & $\begin{array}{l}3 \\
3 \\
3\end{array}$ & $\begin{array}{l}\cdots \\
46 \\
46\end{array}$ & $\begin{array}{l}\ddot{-} \\
4.3 \\
3.3\end{array}$ & $\begin{array}{l}62 \\
53 \\
51\end{array}$ & $\begin{array}{l}.22 \\
.18 \\
.19\end{array}$ & $\begin{array}{l}.50 \\
.50 \\
.10\end{array}$ & $\begin{array}{l}12 \\
12 \\
11\end{array}$ & $\begin{array}{l}330 \ddagger \\
310 \ddagger \\
250 \$\end{array}$ & $\begin{array}{l}-. \\
\cdots \\
--\end{array}$ \\
\hline$Q R-3$ & $\begin{array}{l}07-11-89 \\
09-20-89 \\
04-30-90\end{array}$ & $\begin{array}{l}4 \\
4 \\
4\end{array}$ & $\begin{array}{l}- \\
57 \\
59\end{array}$ & $\begin{array}{l}-2 \\
3.1 \\
2.6\end{array}$ & $\begin{array}{l}57 \\
53 \\
58\end{array}$ & $\begin{array}{l}.17 \\
.15 \\
.17\end{array}$ & $\begin{array}{l}.60 \\
.60 \\
.60\end{array}$ & $\begin{array}{l}10 \\
11 \\
10\end{array}$ & $\begin{array}{l}290 \$ \\
270 \$ \\
190\end{array}$ & $\begin{array}{l}\cdots \\
\cdots \\
\cdots\end{array}$ \\
\hline QRDP - 1 & $\begin{array}{l}04-04-89 \\
06-07-89 \\
06-07-89\end{array}$ & $\begin{array}{l}6 \\
5 \\
5\end{array}$ & $\begin{array}{l}71 \\
\ldots \\
\ldots\end{array}$ & $\begin{array}{l}3.2 \\
\cdots \\
\cdots\end{array}$ & $\begin{array}{l}53 \\
\cdots \\
\cdots\end{array}$ & $\begin{array}{l}\cdots \\
\cdots\end{array}$ & $\begin{array}{l}.70 \\
\therefore \\
.-\end{array}$ & $\begin{array}{l}7.8 \\
11 \\
11\end{array}$ & $\begin{array}{r}260 \xi \\
\cdots \\
\cdots\end{array}$ & ${ }^{2}$ \\
\hline UPSTR ORDP & $\begin{array}{l}06-08-89 \\
06-08-89\end{array}$ & $\begin{array}{l}4 \\
5\end{array}$ & $\ddot{-.}$ & $\begin{array}{l}-- \\
-.\end{array}$ & 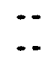 & -. & $\begin{array}{l}\cdots \\
\cdots\end{array}$ & $\begin{array}{l}10 \\
10\end{array}$ & -. & $\begin{array}{l}-- \\
-\end{array}$ \\
\hline
\end{tabular}

LUPTON WELL CLUSTER-Continued

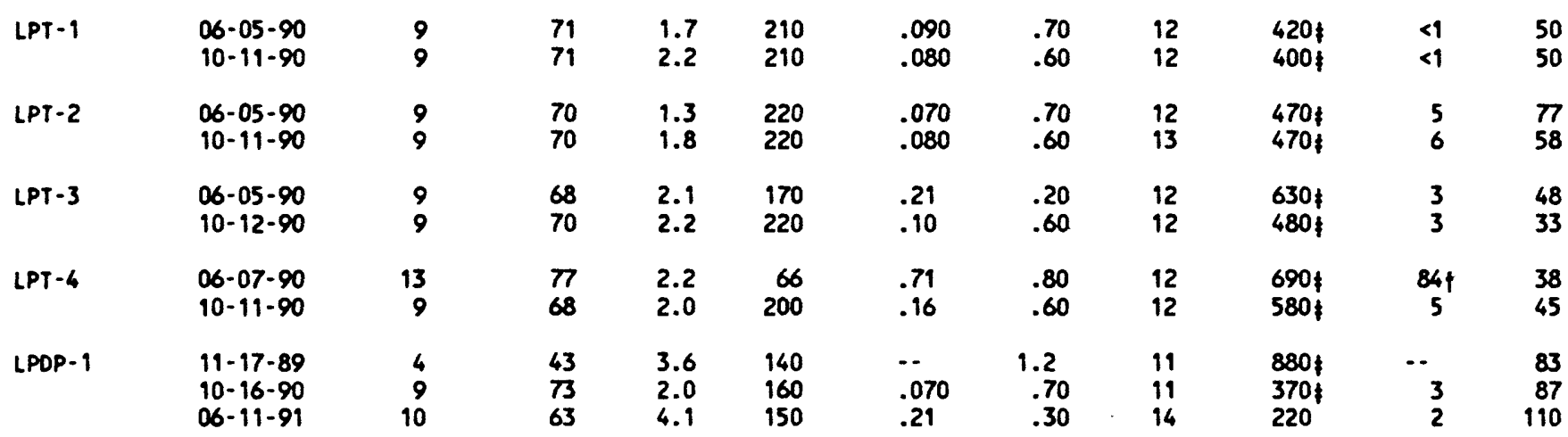

MANUELITO MELL CLUSTER-Continued

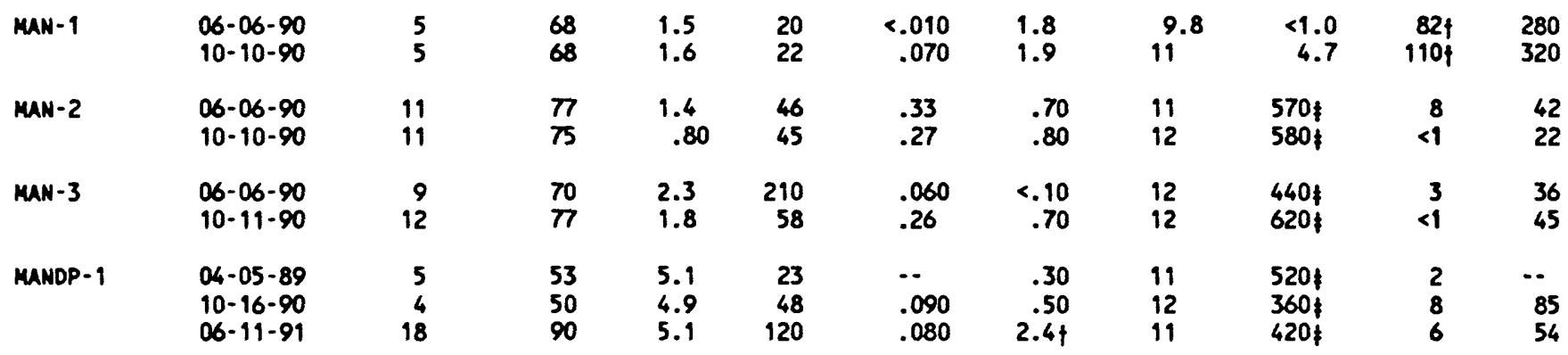


STATION

NAME

DATE

\begin{tabular}{|c|c|c|c|c|c|c|c|c|c|}
\hline $\begin{array}{l}\text { LIUM, } \\
\text { DIS- } \\
\text { SOLVED } \\
\text { ( } \mu \mathrm{g} / \mathrm{L} \\
\text { as } \mathrm{Be})\end{array}$ & $\begin{array}{l}\text { BORON, } \\
\text { DIS- } \\
\text { SOLVED } \\
(\mu g / L \\
\text { OS B) } \\
(01020)\end{array}$ & $\begin{array}{l}\text { CADHILH } \\
\text { DIS- } \\
\text { SOLVED } \\
\text { ( } \mu g / L \\
\text { as Cd) } \\
(01025)\end{array}$ & $\begin{array}{c}\text { CHRO- } \\
\text { MIUH, } \\
\text { DIS- } \\
\text { SOLVED } \\
\text { ( } \mu g / L \\
\text { os Cr) } \\
(01030)\end{array}$ & $\begin{array}{l}\text { CHRO- } \\
\text { MIUH, } \\
\text { HEXA- } \\
\text { VALENT, } \\
\text { DIS. } \\
(\mu g / L \\
\text { as Cr) } \\
(01032)\end{array}$ & $\begin{array}{l}\text { COBALT, } \\
\text { DIS- } \\
\text { SOLVED } \\
(\mu g / L \\
\text { os Co }) \\
(01035)\end{array}$ & $\begin{array}{c}\text { COPPER, } \\
\text { DIS- } \\
\text { SOLVED } \\
(\mu g / L \\
\text { as Cu) } \\
(01040)\end{array}$ & $\begin{array}{l}\text { IRO } \\
\text { DIS } \\
\text { SOLV } \\
\text { C } \mu g / \\
\text { as F } \\
\text { CO10 }\end{array}$ & $\begin{array}{l}\text { LEAD, } \\
\text { DIS- } \\
\text { SOLVED } \\
(\mu g / L \\
\text { SS Pb) } \\
(01049)\end{array}$ & $\begin{array}{l}\text { NE } \\
\text { DI } \\
\text { SOLV } \\
(\mu 8 \\
\text { as } \\
\text { co10 }\end{array}$ \\
\hline
\end{tabular}

QUERINO ROAD WELL CLUSTER-Continued

\begin{tabular}{|c|c|c|c|c|c|c|c|c|c|c|c|}
\hline$Q R-1$ & $\begin{array}{l}09-19-89 \\
04-30-90\end{array}$ & $\begin{array}{l}<.5 \\
<.5\end{array}$ & -- & $\begin{array}{l}<1.0 \\
<1.0\end{array}$ & $\begin{array}{l}<5 \\
<5\end{array}$ & $\cdots$ & $\begin{array}{l}<3 \\
<3\end{array}$ & $\begin{array}{l}<10 \\
<10\end{array}$ & $\begin{array}{l}310 \\
670\end{array}$ & $\begin{array}{l}<10 i \\
<10 i\end{array}$ & $\begin{array}{l}350 \$ \\
410 \$\end{array}$ \\
\hline$Q R-2$ & $\begin{array}{l}07-11-89 \\
09-20-89 \\
05-01-90\end{array}$ & $\begin{array}{l}<.5 \\
<.5 \\
<.5\end{array}$ & $\begin{array}{l}\cdots \\
\cdots \\
--\end{array}$ & $\begin{array}{r}<1.0 \\
<1.0 \\
3.0\end{array}$ & $\begin{array}{l}<5 \\
<5 \\
<5\end{array}$ & $\begin{array}{l}- \\
\cdots \\
\cdots\end{array}$ & $\begin{array}{l}<3 \\
<3 \\
<3\end{array}$ & $\begin{array}{l}<10 \\
<10 \\
<10\end{array}$ & $\begin{array}{r}7 \\
36 \\
78\end{array}$ & $\begin{array}{l}<10 i \\
<10 i \\
<10 i\end{array}$ & $\begin{array}{l}610 \\
910 \\
980\end{array}$ \\
\hline$Q R-3$ & $\begin{array}{l}07-11-89 \\
09-20-89 \\
04-30-90\end{array}$ & $\begin{array}{l}<.5 \\
<.5 \\
<.5\end{array}$ & $\begin{array}{l}\cdots \\
\cdots \\
\cdots\end{array}$ & $\begin{array}{l}<1.0 \\
<1.0 \\
<1.0\end{array}$ & $\begin{array}{l}<5 \\
<5 \\
<5\end{array}$ & $\begin{array}{l}\cdots \\
\cdots \\
\cdots\end{array}$ & $\begin{array}{l}<3 \\
<3 \\
<3\end{array}$ & $\begin{array}{l}<10 \\
<10 \\
<10\end{array}$ & $\begin{array}{l}13 \\
20 \\
12\end{array}$ & $\begin{array}{r}<10 i \\
104 \\
<10 i\end{array}$ & $\begin{array}{l}280 \\
460 \$ \\
260\end{array}$ \\
\hline QRDP-1 & $\begin{array}{l}04-04-89 \\
06-07-89 \\
06-07-89\end{array}$ & $\begin{array}{l}<. \\
<.5 \\
<.5\end{array}$ & $\begin{array}{l}170 \\
-. \\
\therefore\end{array}$ & $\begin{array}{l}<1.0 \\
<1.0 \\
<1.0\end{array}$ & $\begin{array}{l}-8 \\
<5 \\
<5\end{array}$ & $\begin{array}{l}1 \\
-\therefore \\
--\end{array}$ & $\begin{array}{l}3 \\
<3 \\
<3\end{array}$ & $\begin{array}{r}7 \\
<10 \\
<10\end{array}$ & $\begin{array}{l}730 \\
750\end{array}$ & $\begin{array}{l}<5 \\
10 \dagger \\
<10 i\end{array}$ & $\begin{array}{l}- \\
2900 \\
3000\end{array}$ \\
\hline UPSTR QRDP & $\begin{array}{l}06-08-89 \\
06-08-89\end{array}$ & $\begin{array}{l}<.5 \\
<.5\end{array}$ & -. & $\begin{array}{r}<1.0 \\
2.0\end{array}$ & $\begin{array}{r}5 \\
<5\end{array}$ & $\because-$ & $\begin{array}{l}<3 \\
<3\end{array}$ & $\begin{array}{r}20 \\
<10\end{array}$ & $\begin{array}{l}660\} \\
640\}\end{array}$ & $\begin{array}{r}<10 i \\
10 i\end{array}$ & $\begin{array}{l}730 \\
740\end{array}$ \\
\hline LPT-1 & $\begin{array}{l}06-05-90 \\
10-11-90\end{array}$ & $\begin{array}{l}<2 i \\
<2 i\end{array}$ & $\begin{array}{l}560 \\
550\end{array}$ & $\begin{array}{r}3.0 \\
<3.0\end{array}$ & $\begin{array}{l}<20 \\
<20\end{array}$ & $\because$ & 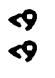 & $\begin{array}{l}<30 \\
<30\end{array}$ & $\begin{array}{l}1900 \$ \\
2000 \$\end{array}$ & $\begin{array}{l}<30 i \\
<30 i\end{array}$ & $\begin{array}{l}590 \ddagger \\
620 \notin\end{array}$ \\
\hline LPT-2 & $\begin{array}{l}06-05-90 \\
10-11-90\end{array}$ & $\begin{array}{l}<2 i \\
<2 i\end{array}$ & $\begin{array}{l}500 \\
580\end{array}$ & $\begin{array}{l}264 \\
<3.0\end{array}$ & $\begin{array}{l}<20 \\
<20\end{array}$ & -. & $\infty$ & $\begin{array}{l}<30 \\
<30\end{array}$ & $\begin{array}{l}2400 \$ \\
2800 \xi\end{array}$ & $\begin{array}{l}<30 i \\
<30 i\end{array}$ & $\begin{array}{r}1000 \ddagger \\
880 \ddagger\end{array}$ \\
\hline LPT -3 & $\begin{array}{l}06-05-90 \\
10-12-90\end{array}$ & $\begin{array}{l}<2 i \\
<2 i\end{array}$ & $\begin{array}{l}520 \\
560\end{array}$ & $\begin{array}{l}6.0 \dagger \\
<3.0\end{array}$ & $\begin{array}{l}<20 \\
<20\end{array}$ & $\because-$ & $\begin{array}{l}9 \\
9\end{array}$ & $\begin{array}{l}<30 \\
<30\end{array}$ & $\begin{array}{l}2500 \$ \\
2600 \ddagger\end{array}$ & $\begin{array}{r}30 \uparrow \\
<30 i\end{array}$ & $\begin{array}{r}1200 \$ \\
790 \$\end{array}$ \\
\hline LPT -4 & $\begin{array}{l}06-07-90 \\
10-11-90\end{array}$ & $\begin{array}{l}<2 i \\
<2 i\end{array}$ & $\begin{array}{l}400 \\
530\end{array}$ & $\begin{array}{l}8.0 \nmid \\
<3.0\end{array}$ & $\begin{array}{l}<20 \\
<20\end{array}$ & $\cdots$ & $\infty$ & $\begin{array}{l}<30 \\
<30\end{array}$ & $\begin{array}{c}270 \\
2900\end{array}$ & $\begin{array}{r}40 i \\
<30 i\end{array}$ & $\begin{array}{r}970 \$ \\
1100 \$\end{array}$ \\
\hline LPDP-1 & $\begin{array}{l}11-17-89 \\
10-16-90 \\
06-11-91\end{array}$ & $\begin{array}{l}<1 \\
<.5 \\
<2 i\end{array}$ & $\begin{array}{l}\cdots \\
600 \\
\cdots\end{array}$ & $\begin{array}{l}<2.0 \\
<1.0 \\
<3.0\end{array}$ & $\begin{array}{l}<10 \\
<5 \\
<20\end{array}$ & $\begin{array}{l}\cdots \\
\cdots \\
--\end{array}$ & $\begin{array}{l}7 \\
<3 \\
9\end{array}$ & $\begin{array}{l}<20 \\
<10 \\
<30\end{array}$ & $\begin{array}{l}150 \\
520 \\
490\end{array}$ & $\begin{array}{l}<20 i \\
<10 i \\
<30 i\end{array}$ & $\begin{array}{l}4500 \ddagger \\
1800 \ddagger \\
6900 \notin\end{array}$ \\
\hline
\end{tabular}

MANUELITO WELL CLUSTER-Continued

\begin{tabular}{|c|c|c|c|c|c|c|c|c|c|c|c|}
\hline MAN-1 & $\begin{array}{l}06-06-90 \\
10-10-90\end{array}$ & $\begin{array}{l}<.5 \\
<.5\end{array}$ & $\begin{array}{l}210 \\
200\end{array}$ & $\begin{array}{r}2.0 \\
<1.0\end{array}$ & $\begin{array}{l}<5 \\
<5\end{array}$ & -. & $\begin{array}{l}<3 \\
<3\end{array}$ & $\begin{array}{r}10 \\
<10\end{array}$ & $\begin{array}{l}2000 \\
3100\end{array}$ & $\begin{array}{l}<10 i \\
<10 i\end{array}$ & $\begin{array}{l}120 \$ \\
150 \$\end{array}$ \\
\hline MAN-2 & $\begin{array}{l}06-06-90 \\
10-10-90\end{array}$ & $\begin{array}{l}<2 i \\
<2 i\end{array}$ & $\begin{array}{l}300 \\
330\end{array}$ & $\begin{array}{l}311 \\
<3.0\end{array}$ & $\begin{array}{l}<20 \\
<20\end{array}$ & $\cdots$ & $\begin{array}{l}< \\
<9\end{array}$ & $\begin{array}{l}<30 \\
<30\end{array}$ & $\begin{array}{l}19 \\
21\end{array}$ & $\begin{array}{l}<30 i \\
<30 i\end{array}$ & $\begin{array}{r}400 \$ \\
1000 \$\end{array}$ \\
\hline MAN-3 & $\begin{array}{l}06-06-90 \\
10-11-90\end{array}$ & $\begin{array}{l}<2 i \\
<2 i\end{array}$ & $\begin{array}{l}520 \\
370\end{array}$ & $\begin{array}{l}7.0 \dagger \\
<3.0\end{array}$ & $\begin{array}{l}<20 \\
<20\end{array}$ & $\begin{array}{l}- \\
-.\end{array}$ & 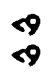 & $\begin{array}{l}<30 \\
<30\end{array}$ & $\begin{array}{r}2000 \\
660\end{array}$ & $\begin{array}{l}<30 i \\
<30 i\end{array}$ & $\begin{array}{l}810 \$ \\
900 \$\end{array}$ \\
\hline
\end{tabular}




\section{GROUNO-WATER DATA-Cont inued \\ CHEMICAL ANALYSES - Cont inued}

\begin{tabular}{|c|c|c|c|c|c|c|c|c|c|c|c|}
\hline $\begin{array}{l}\text { STATION } \\
\text { NAME }\end{array}$ & DATE & $\begin{array}{c}\text { MERCURY } \\
\text { OIS- } \\
\text { SOLVED } \\
(\mu g / L \\
\text { as Hg) } \\
(71890)\end{array}$ & $\begin{array}{l}\text { MOLYB- } \\
\text { DENUH, } \\
\text { OIS- } \\
\text { SOLVED } \\
(\mu \sigma / L \\
\text { as Ho) } \\
(01060)\end{array}$ & $\begin{array}{c}\text { NICKEL, } \\
\text { DIS- } \\
\text { SOL VED } \\
(\mu g / L \\
\text { es Ni) } \\
(01065)\end{array}$ & $\begin{array}{l}\text { SILVER, } \\
\text { OIS- } \\
\text { SOLVED } \\
\text { ( } \mu \sigma / L \\
\text { as Ag) } \\
(01075)\end{array}$ & $\begin{array}{c}\text { STRON- } \\
\text { TIUN, } \\
\text { OIS- } \\
\text { SOLVED } \\
\text { ( } \mu g / L \\
\text { as Sr) } \\
\text { (01080) }\end{array}$ & $\begin{array}{l}\text { VANA- } \\
\text { DIUA, } \\
\text { DIS- } \\
\text { SOLVED } \\
\text { ( } \mu 9 / L \\
\text { as V) } \\
(01085)\end{array}$ & $\begin{array}{l}\text { ZINC, } \\
\text { OIS- } \\
\text { SOLVED } \\
(\mu g / L \\
\text { as Zn) } \\
(01090)\end{array}$ & $\begin{array}{l}\text { ALUA- } \\
\text { INUM, } \\
\text { DIS- } \\
\text { SOLVED } \\
\text { ( } \mu g / L \\
\text { as Al) } \\
(01106)\end{array}$ & $\begin{array}{c}\text { LITHIUN } \\
\text { DIS- } \\
\text { SOLVED } \\
(\mu g / L \\
\text { os Li) } \\
(01130)\end{array}$ & $\begin{array}{c}\text { SELE- } \\
\text { NIUH, } \\
\text { DIS- } \\
\text { SOLVED } \\
\text { ( } \mu \sigma / L \\
\text { as SE) } \\
\text { (01145) }\end{array}$ \\
\hline
\end{tabular}

\begin{tabular}{|c|c|c|c|c|c|c|}
\hline$Q R-1$ & $\begin{array}{l}09-19-89 \\
04-30-90\end{array}$ & $\begin{array}{l}-. \\
. .\end{array}$ & $\begin{array}{r}<10 \\
10\end{array}$ & $\begin{array}{l}<10 \\
<10\end{array}$ & $\begin{array}{r}<1.0 \\
2.0\end{array}$ & $\begin{array}{r}930 \\
1000\end{array}$ \\
\hline$Q R-2$ & $\begin{array}{l}07-11-89 \\
09-20-89 \\
05-01-90\end{array}$ & $\begin{array}{l}-. \\
-. \\
-.\end{array}$ & $\begin{array}{l}20 \\
20 \\
20\end{array}$ & $\begin{array}{l}<10 \\
<10 \\
<10\end{array}$ & $\begin{array}{r}<1.0 \\
2.0 \\
2.0\end{array}$ & $\begin{array}{l}1100 \\
1100 \\
1100\end{array}$ \\
\hline$Q R-3$ & $\begin{array}{l}07-11-89 \\
09-20-89 \\
04-30-90\end{array}$ & $\begin{array}{l}-. \\
\cdots \\
-.\end{array}$ & $\begin{array}{l}20 \\
20 \\
20\end{array}$ & $\begin{array}{r}<10 \\
10 \\
10\end{array}$ & $\begin{array}{r}1.0 \\
<1.0 \\
1.0\end{array}$ & $\begin{array}{l}820 \\
800 \\
730\end{array}$ \\
\hline QROP-1 & $\begin{array}{l}04-04-89 \\
06-07-89 \\
06-07-89\end{array}$ & $\begin{array}{l}<.1 \\
\therefore- \\
-.\end{array}$ & $\begin{array}{l}\cdots \\
10 \\
10\end{array}$ & $\begin{array}{r}7 \\
<10 \\
<10\end{array}$ & $\begin{array}{l}<- \\
<1.0 \\
<1.0\end{array}$ & $\begin{array}{r}660 \\
1100 \\
1100\end{array}$ \\
\hline UPSTR ORDP & $\begin{array}{l}06-08-89 \\
06-08-89\end{array}$ & - & $\begin{array}{l}<10 \\
<10\end{array}$ & $\begin{array}{l}<10 \\
<10\end{array}$ & $\begin{array}{l}<1.0 \\
<1.0\end{array}$ & $\begin{array}{r}990 \\
1000\end{array}$ \\
\hline
\end{tabular}

LUPTON WELL CLUSTER-Continued

\begin{tabular}{|c|c|c|c|c|c|c|c|c|c|c|c|}
\hline LPT-1 & $\begin{array}{l}06-05-90 \\
10-11-90\end{array}$ & $\because-$ & $\begin{array}{r}<30 \\
2\end{array}$ & $\begin{array}{l}<30 \\
<30\end{array}$ & $\begin{array}{l}<3.0 \\
<3.0\end{array}$ & $\begin{array}{l}1900 \\
1800\end{array}$ & $\begin{array}{l}<18 \\
<18\end{array}$ & $\begin{array}{l}23 \\
69\end{array}$ & $\because-$ & $\begin{array}{l}27 \\
25\end{array}$ & $\begin{array}{l}<1 \\
<1\end{array}$ \\
\hline LPT-2 & $\begin{array}{l}06-05-90 \\
10-11-90\end{array}$ & $\begin{array}{l}-- \\
--\end{array}$ & $\begin{array}{l}<30 \\
<4\end{array}$ & $\begin{array}{l}<30 \\
<30\end{array}$ & $\begin{array}{r}4.0 \\
3.0\end{array}$ & $\begin{array}{l}2300 \\
2100\end{array}$ & $\begin{array}{l}<18 \\
<18\end{array}$ & $<$ & 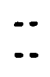 & $\begin{array}{l}23 \\
24\end{array}$ & $\begin{array}{l}<1 \\
<1\end{array}$ \\
\hline LPT -3 & $\begin{array}{l}06-05-90 \\
10-12-90\end{array}$ & $\cdots$ & $\begin{array}{r}<30 \\
1\end{array}$ & $\begin{array}{l}<30 \\
<30\end{array}$ & $\begin{array}{r}5.0 \\
3.0\end{array}$ & $\begin{array}{l}2600 \\
1900\end{array}$ & $\begin{array}{l}<18 \\
<18\end{array}$ & $\begin{array}{l}10 \\
<9\end{array}$ & -. & $\begin{array}{l}31 \\
25\end{array}$ & $<1$ \\
\hline LPDP - 1 & $\begin{array}{l}11-17-89 \\
10-16-90 \\
06-19-91\end{array}$ & $\begin{array}{l}\cdots \\
\cdots \\
\cdots\end{array}$ & $\begin{array}{r}<20 \\
6 \\
<30\end{array}$ & $\begin{array}{r}30 \\
<10 \\
<30\end{array}$ & $\begin{array}{l}<2.0 \\
<1.0 \\
<3.0\end{array}$ & $\begin{array}{l}3200 \\
1500 \\
4800\end{array}$ & $\begin{array}{r}<12 \\
<6 \\
<18\end{array}$ & $\begin{array}{r}420 \\
4 \\
72\end{array}$ & $\begin{array}{l}\cdots \\
\cdots \\
\cdots\end{array}$ & $\begin{array}{l}31 \\
23 \\
40\end{array}$ & $\begin{array}{l}-. \\
<1 \\
<1\end{array}$ \\
\hline
\end{tabular}

MANUELITO WELL CLUSTER-Continued

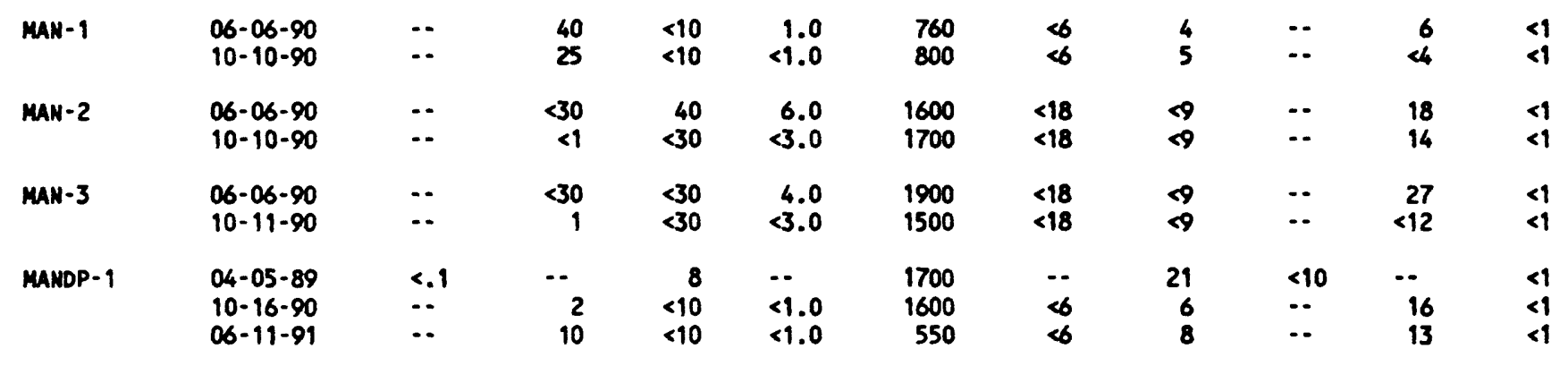


GROUND-MATER DATA-Cont inued

CHEMICAL AMALYSES-Cont inued

\begin{tabular}{|c|c|c|c|c|c|c|c|c|c|c|}
\hline $\begin{array}{l}\text { STATION } \\
\text { MAME }\end{array}$ & DATE & $\begin{array}{l}\text { S-34/ } \\
\text { S-32 } \\
\text { STABLE } \\
\text { ISOTOPE } \\
\text { RATIO } \\
\text { PER } \\
\text { MIL } \\
(82086)\end{array}$ & $\begin{array}{l}\text { H-2/ } \\
\text { H-1 } \\
\text { STABLE } \\
\text { I SOTOPE } \\
\text { RATIO } \\
\text { PER } \\
\text { MIL } \\
\text { (82082) }\end{array}$ & $\begin{array}{l}0-18 / \\
0-16 \\
\text { STABLE } \\
\text { I SOTOPE } \\
\text { RATIO } \\
\text { PER } \\
\text { MIL } \\
(82085)\end{array}$ & $\begin{array}{l}\text { TRITIUM } \\
\text { TOTAL } \\
\text { (PCiLL) } \\
(07000)\end{array}$ & $\begin{array}{l}\text { GROSS } \\
\text { ALPHA, } \\
\text { DIS- } \\
\text { SOLVED } \\
(\mu g / L \\
\text { os } \\
U \text {-nat) } \\
(80030)\end{array}$ & 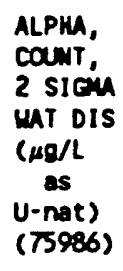 & $\begin{array}{l}\text { GROSS } \\
\text { ALPHA, } \\
\text { SUSP. } \\
\text { TOTAL } \\
\text { ( } \mu g / L \\
\text { os } \\
U-n a t) \\
(80040)\end{array}$ & $\begin{array}{c}\text { GROSS } \\
\text { BETA, } \\
\text { DIS- } \\
\text { SOLVED } \\
\text { (PCi/L } \\
\text { Bs } \\
\text { CS-137) } \\
(03515)\end{array}$ & $\begin{array}{c}\text { BETA, } \\
2 \text { SIGIA } \\
\text { WATER, } \\
\text { DISS, } \\
\text { (PCi/L } \\
\text { os } \\
\text { Cs-137) } \\
(75989)\end{array}$ \\
\hline \multicolumn{11}{|c|}{ QUERINO ROND MELL CLUSTER-Continued } \\
\hline QR-1 & $\begin{array}{l}09-19-89 \\
04-30-90\end{array}$ & $\ddot{-\cdot}$ & $\because-$ & $\because$ & 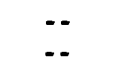 & $\begin{array}{l}3.9 \\
4.9\end{array}$ & $\begin{array}{l}0.80 \\
1.6\end{array}$ & $\begin{array}{l}\cdots \\
\cdots\end{array}$ & $\begin{array}{l}5.8 \\
6.1\end{array}$ & $\begin{array}{l}1.8 \\
2.1\end{array}$ \\
\hline QR-2 & $\begin{array}{l}07-11-89 \\
09-20-89 \\
05-01-90\end{array}$ & $\begin{array}{l}-4.70 \\
-. \\
-.\end{array}$ & $\begin{array}{l}-80.0 \\
-. \\
-.\end{array}$ & $\begin{array}{l}-9.85 \\
-\therefore \\
-.\end{array}$ & $\begin{array}{l}39 \\
\cdots \\
\cdots\end{array}$ & $\begin{array}{l}9.5 \\
5.7 \\
7.6\end{array}$ & $\begin{array}{l}1.7 \\
1.0 \\
1.9\end{array}$ & $\begin{array}{l}-. \\
\cdots\end{array}$ & $\begin{array}{c}1.6 \\
26 \\
9.4\end{array}$ & $\begin{array}{l}3.4 \\
3.9 \\
2.5\end{array}$ \\
\hline QR-3 & $\begin{array}{l}07-11-89 \\
09-20-89 \\
04-30-90\end{array}$ & $\begin{array}{l}-3.30 \\
\therefore . \\
-.\end{array}$ & $\begin{array}{l}-74.0 \\
\because- \\
--\end{array}$ & $\begin{array}{l}-9.50 \\
\therefore- \\
-\end{array}$ & $\begin{array}{l}35 \\
\therefore- \\
\cdots\end{array}$ & $\begin{array}{c}4.8 \\
15 \uparrow \\
5.2\end{array}$ & $\begin{array}{l}1.1 \\
2.4 \\
1.5\end{array}$ & $\ddot{-}$ & $\begin{array}{c}4.2 \\
10 \\
9.6\end{array}$ & $\begin{array}{l}3.6 \\
3.3 \\
2.3\end{array}$ \\
\hline QRDP - 1 & $\begin{array}{l}04-04-89 \\
06-07-89 \\
06-07-89\end{array}$ & $\begin{array}{l}-5.10 \\
\therefore . \\
-.\end{array}$ & $\begin{array}{l}-84.0 \\
\because- \\
-.\end{array}$ & $\begin{array}{c}-11.25 \\
\cdots \\
-.\end{array}$ & $\begin{array}{l}28 \\
\cdots \\
\cdots\end{array}$ & $\begin{array}{c}161 \\
8.3 \\
7.1\end{array}$ & $\begin{array}{l}2.8 \\
1.3 \\
1.1\end{array}$ & $\begin{array}{l}3.4 * \\
\because- \\
-.\end{array}$ & $\begin{array}{l}9.2 \\
12 \\
<10\end{array}$ & $\begin{array}{r}2.1 \\
2.2 \\
\text { NO }\end{array}$ \\
\hline UPSTR QRDP & $\begin{array}{l}06-08-89 \\
06-08-89\end{array}$ & $\ddot{-.}$ & 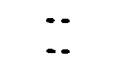 & 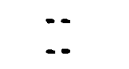 & $\because \cdot$ & $\begin{array}{l}29 f \\
-.\end{array}$ & $\begin{array}{l}3.3 \\
. .\end{array}$ & 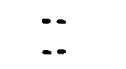 & $<29$ & $\begin{array}{l}4.8 \\
-.\end{array}$ \\
\hline
\end{tabular}

LUPTON VELL CLUSTER-Continued

\begin{tabular}{|c|c|c|c|c|c|c|c|c|c|}
\hline LPT-1 & $\begin{array}{l}06-05-90 \\
10-11-90\end{array}$ & 13.30 & $\begin{array}{l}-90.4 \\
-.\end{array}$ & $\begin{array}{c}-12.20 \\
\ldots\end{array}$ & $\ddot{-.}$ & $\begin{array}{l}6.4 \\
1.8\end{array}$ & $\begin{array}{l}2.6 \\
.90\end{array}$ & $\ddot{a}$ & $\begin{array}{l}6.3 \\
4.6\end{array}$ \\
\hline LPT -2 & $\begin{array}{l}06-05-90 \\
10-11-90\end{array}$ & 12.70 & -91.0 & $\begin{array}{c}-12.15 \\
. .\end{array}$ & $\begin{array}{l}<2.5 \\
\cdots\end{array}$ & $\begin{array}{l}9.3 \\
4.9\end{array}$ & $\begin{array}{l}3.1 \\
1.4\end{array}$ & 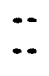 & $\begin{array}{l}6.9 \\
5.9\end{array}$ \\
\hline LPT - 3 & $\begin{array}{l}06-05-90 \\
10-12-90\end{array}$ & -4.40 & -88.0 & $\begin{array}{c}-11.75 \\
. .\end{array}$ & $<2.5$ & $\begin{array}{l}9.7 \\
1.8\end{array}$ & $\begin{array}{l}3.3 \\
.80\end{array}$ & $\because$ & $\begin{array}{l}8.1 \\
4.9\end{array}$ \\
\hline LPT -4 & $\begin{array}{l}06-07-90 \\
10-11-90\end{array}$ & 4.10 & -92.5 & $\begin{array}{c}-12.35 \\
\ldots\end{array}$ & $<2.5$ & $\begin{array}{c}22 \nmid \\
3.1\end{array}$ & $\begin{array}{l}6.5 \\
1.2\end{array}$ & $\cdots$ & $\begin{array}{l}11 \\
4.9\end{array}$ \\
\hline LPDP-1 & $\begin{array}{l}11-17-89 \\
10-16-90 \\
06-11-91\end{array}$ & $\begin{array}{c}-2.00 \\
-\because 3.10\end{array}$ & $\begin{array}{l}-68.5 \\
-. \\
-.\end{array}$ & $\begin{array}{l}-8.55 \\
\because . \\
-.\end{array}$ & $\begin{array}{l}24 \\
-- \\
--\end{array}$ & $\begin{array}{r}12 \dagger \\
5.9 \\
8.6\end{array}$ & $\begin{array}{l}1.9 \\
1.6 \\
1.9\end{array}$ & $\begin{array}{l}\ddot{-} \\
\ddot{-}\end{array}$ & $\begin{array}{l}17 \\
5.8 \\
14\end{array}$ \\
\hline
\end{tabular}

mMUELITO MELL CLUSTER-Continued

\begin{tabular}{|c|c|c|c|c|c|c|c|c|c|}
\hline MNN-1 & $\begin{array}{l}06-06-90 \\
10-10-90\end{array}$ & $\because-$ & $\begin{array}{c}-106.0 \\
. .\end{array}$ & $\begin{array}{c}-14.05 \\
. .\end{array}$ & $\ddot{~}$ & $\begin{array}{l}1.6 \\
1.0\end{array}$ & $\begin{array}{l}1.0 \\
.70\end{array}$ & 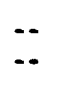 & $\begin{array}{l}2.9 \\
1.8\end{array}$ \\
\hline MAN-2 & $\begin{array}{l}06-06-90 \\
10-10-90\end{array}$ & $\begin{array}{l}3.30 \\
-\cdot\end{array}$ & $\begin{array}{l}-84.0 \\
-.\end{array}$ & $\begin{array}{c}-11.30 \\
. .\end{array}$ & $\begin{array}{l}14 \\
\cdots\end{array}$ & $\begin{array}{c}32 \uparrow \\
8.7\end{array}$ & ${ }^{10} 1.9$ & $\because-$ & $1^{9.3}$ \\
\hline MAN-3 & $\begin{array}{l}06-06-90 \\
10-19-90\end{array}$ & 12.50 & -92.0 & $\begin{array}{c}-12.20 \\
. .\end{array}$ & $<2.5$ & 19.7 & $\begin{array}{l}1.8 \\
4.0\end{array}$ & $\ddot{-}$ & $11^{4.0}$ \\
\hline MANDP-1 & $\begin{array}{l}04-05-89 \\
10-16-90 \\
06-11-91\end{array}$ & $\begin{array}{l}5.90 \\
-1.10\end{array}$ & $\begin{array}{l}-94.5 \\
-. \\
--\end{array}$ & $\begin{array}{c}-12.85 \\
\ldots \\
\ldots\end{array}$ & $\begin{array}{l}2.9 \\
\therefore- \\
\therefore-\end{array}$ & $\begin{array}{c}120 \uparrow \\
2.3 \\
11 \uparrow\end{array}$ & $\begin{array}{l}12 \\
1.0 \\
2.1\end{array}$ & $\begin{array}{l}1.5^{*} \\
\cdots \\
\ldots\end{array}$ & $\begin{array}{l}32 \\
7.9\end{array}$ \\
\hline
\end{tabular}


GROUND-MATER DATA-Continued

CHEMICAL ANALYSES-Cont inued

STATION

MAME

DATE

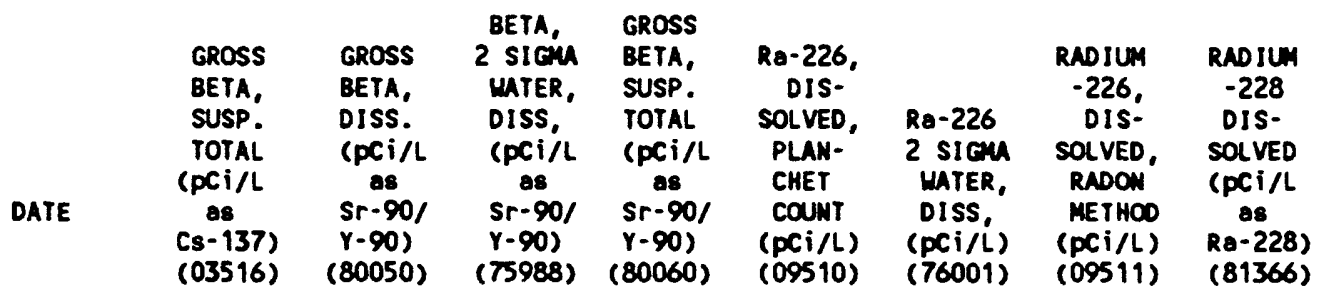

QUERINO ROAD WELL CLUSTER-Continued

\begin{tabular}{|c|c|c|c|c|c|c|c|c|c|}
\hline$Q R-1$ & $\begin{array}{l}09-19-89 \\
04-30-90\end{array}$ & -. & $\begin{array}{l}5.2 \\
4.6\end{array}$ & $\begin{array}{l}1.6 \\
1.6\end{array}$ & $\begin{array}{l}\cdots \\
\cdots\end{array}$ & $\begin{array}{l}-. \\
\cdots\end{array}$ & $\begin{array}{l}-. \\
\cdots\end{array}$ & -. & $<1.0$ \\
\hline$Q R-2$ & $\begin{array}{l}07-11-89 \\
09-20-89 \\
05-01-90\end{array}$ & $\begin{array}{l}\cdots \\
\cdots \\
\ldots\end{array}$ & $\begin{array}{c}1.3 \\
24 \\
7.0\end{array}$ & $\begin{array}{l}2.7 \\
3.5 \\
1.9\end{array}$ & $\begin{array}{l}\cdots \\
\cdots \\
-.\end{array}$ & $\begin{array}{l}\cdots \\
\cdots \\
\cdots\end{array}$ & $\begin{array}{l}.020 \\
\cdots \\
--\end{array}$ & $\begin{array}{l}.08 \\
\cdots \\
\cdots\end{array}$ & $\begin{array}{l}<1.0 \\
<1.0 \\
\cdots\end{array}$ \\
\hline$Q R-3$ & $\begin{array}{l}07-11-89 \\
09-20-89 \\
04-30-90\end{array}$ & $\begin{array}{l}-. \\
-- \\
--\end{array}$ & $\begin{array}{l}3.3 \\
9.0 \\
7.3\end{array}$ & $\begin{array}{l}2.8 \\
2.9 \\
1.8\end{array}$ & $\begin{array}{l}-. \\
\because- \\
-\end{array}$ & $\begin{array}{l}-- \\
-- \\
--\end{array}$ & $\begin{array}{l}.030 \\
-- \\
--\end{array}$ & $\begin{array}{l}.17 \\
-. \\
--\end{array}$ & $\begin{array}{r}1.2 \\
<1.0 \\
-.\end{array}$ \\
\hline ORDP-1 & $\begin{array}{l}04-04-89 \\
06-07-89 \\
06-07-89\end{array}$ & $\begin{array}{l}4.0^{\circ} \\
-- \\
--\end{array}$ & $\begin{array}{l}6.3 \\
10 \\
<.1\end{array}$ & $\begin{array}{l}1.4 \\
1.9 \\
1.6\end{array}$ & $\begin{array}{l}3.6^{\star} \\
\cdots \\
--\end{array}$ & $\begin{array}{l}\cdots \\
\cdots \\
\cdots\end{array}$ & $\begin{array}{l}-- \\
-- \\
--\end{array}$ & $\begin{array}{l}\cdots \\
\cdots \\
\cdots\end{array}$ & $\begin{array}{l}- \\
- \\
-\end{array}$ \\
\hline UPSTR QRDP & $\begin{array}{l}06-08-89 \\
06-08-89\end{array}$ & -. & $<23$ & $\begin{array}{l}3.9 \\
\ldots\end{array}$ & -- & $\begin{array}{l}\cdots \\
\cdots\end{array}$ & -. & 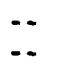 & -- \\
\hline
\end{tabular}

LUPTON MELL CLUSTER-Continued

\begin{tabular}{|c|c|c|c|c|c|c|c|c|c|}
\hline LPT-1 & $\begin{array}{l}06-05-90 \\
10-11-90\end{array}$ & $\begin{array}{l}-. \\
--\end{array}$ & $\begin{array}{l}4.7 \\
3.5\end{array}$ & $\begin{array}{l}2.3 \\
2.3\end{array}$ & $\begin{array}{l}-. \\
--\end{array}$ & $\begin{array}{l}-- \\
--\end{array}$ & $\begin{array}{l}-. \\
--\end{array}$ & -. & -. \\
\hline LPT -2 & $\begin{array}{l}06-05-90 \\
10-11-90\end{array}$ & -. & $\begin{array}{l}5.2 \\
4.5\end{array}$ & $\begin{array}{l}2.4 \\
2.6\end{array}$ & $\begin{array}{l}-- \\
--\end{array}$ & $\begin{array}{l}\cdots \\
\cdots\end{array}$ & $\begin{array}{l}-- \\
--\end{array}$ & 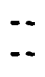 & -. \\
\hline LPT -3 & $\begin{array}{l}06-05-90 \\
10-12-90\end{array}$ & -. & $\begin{array}{l}6.0 \\
3.7\end{array}$ & $\begin{array}{l}2.8 \\
2.7\end{array}$ & $\begin{array}{l}-- \\
--\end{array}$ & $\begin{array}{l}\cdots \\
\cdots\end{array}$ & $\begin{array}{l}-- \\
--\end{array}$ & $\cdots$ & -- \\
\hline LPT-4 & $\begin{array}{l}06-07-90 \\
10-11-90\end{array}$ & $\begin{array}{l}-- \\
--\end{array}$ & $\begin{array}{l}8.2 \\
3.7\end{array}$ & $\begin{array}{l}3.4 \\
2.8\end{array}$ & $\begin{array}{l}-- \\
--\end{array}$ & $\begin{array}{l}-. \\
\therefore\end{array}$ & $\begin{array}{l}-- \\
--\end{array}$ & $\because$ & -. \\
\hline LPDP - 1 & $\begin{array}{l}11-17-89 \\
10-16-90 \\
06-11-91\end{array}$ & $\begin{array}{l}\cdots \\
\cdots \\
\cdots\end{array}$ & $\begin{array}{c}15 \\
4.5 \\
10\end{array}$ & $\begin{array}{l}3.0 \\
2.4 \\
4.5\end{array}$ & $\begin{array}{l}\because- \\
\cdots \\
\cdots\end{array}$ & $\begin{array}{l}-. \\
<.1 \\
-.\end{array}$ & $\begin{array}{l}-- \\
\text { ND } \\
-.\end{array}$ & $\begin{array}{l}\cdots \\
\cdots\end{array}$ & $\begin{array}{l}-. \\
\cdots\end{array}$ \\
\hline
\end{tabular}

\begin{tabular}{|c|c|c|c|c|c|c|c|c|c|}
\hline mN-1 & $\begin{array}{l}06-06-90 \\
10-10-90\end{array}$ & -- & $\begin{array}{l}2.2 \\
1.4\end{array}$ & $\begin{array}{l}1.1 \\
1.1\end{array}$ & -- & $\cdot$. & .0 & $\because-$ & $\because-$ \\
\hline MAN-2 & $\begin{array}{l}06-06-90 \\
10-10-90\end{array}$ & $\cdots$ & $\begin{array}{l}6.9 \\
8.1\end{array}$ & $\begin{array}{l}2.6 \\
3.3\end{array}$ & $\cdots$ & .1 & .100 & 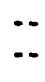 & 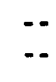 \\
\hline MaN-3 & $\begin{array}{l}06-06-90 \\
10-11-90\end{array}$ & $\because-$ & $\begin{array}{l}3.0 \\
8.3\end{array}$ & $\begin{array}{l}2.2 \\
3.6\end{array}$ & -. &.. &..-100 & -. & -. \\
\hline MANDP - 1 & $\begin{array}{l}04-05-89 \\
10-16-90 \\
06-11-91\end{array}$ & $\begin{array}{r}22 * \\
\cdots \\
--\end{array}$ & $\begin{array}{l}21 \\
6.1 \\
8.6\end{array}$ & $\begin{array}{l}3.4 \\
2.0 \\
2.6\end{array}$ & $\begin{array}{l}20^{*} \\
-- \\
-\cdot\end{array}$ & $\begin{array}{c}-. \\
.-\end{array}$ & $\begin{array}{l}-. \\
.100 \\
--\end{array}$ & $\begin{array}{l}\cdots \\
\cdots \\
\cdots\end{array}$ & $\begin{array}{l}- \\
--\end{array}$ \\
\hline
\end{tabular}


GROUND-WATER DATA-Cont inued

CHEMICAL ANALYSES-Cont inued

STATION

NAME

DATE

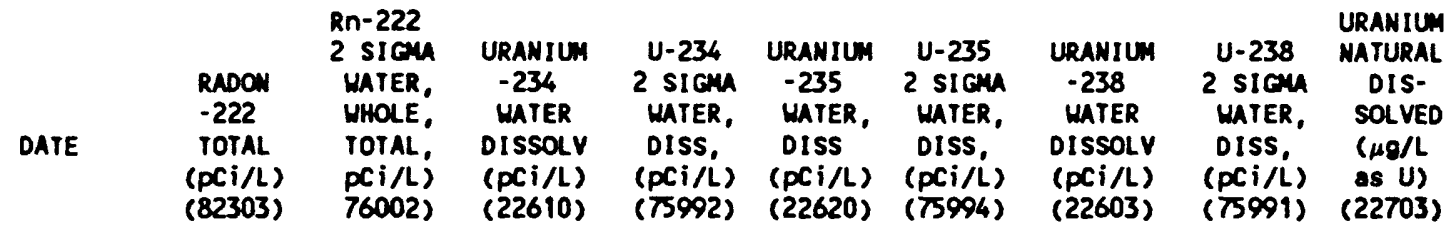

QUERIMO ROND WELL CLUSTER-CONtinued

\begin{tabular}{|c|c|c|c|c|c|c|c|c|c|c|}
\hline$Q R-1$ & $\begin{array}{l}09-19-89 \\
04-30-90\end{array}$ & $\begin{array}{l}360 \uparrow \\
210\end{array}$ & $\begin{array}{l}31 \\
48\end{array}$ & $\begin{array}{l}2.4 \\
2.4\end{array}$ & $\begin{array}{l}.6 \\
.5\end{array}$ & $\begin{array}{l}.3 \\
.1\end{array}$ & $\begin{array}{l}.20 \\
.20\end{array}$ & $\begin{array}{l}2.1 \\
1.5\end{array}$ & $\begin{array}{l}.50 \\
.40\end{array}$ & $\ddot{3.3}$ \\
\hline$Q R-2$ & $\begin{array}{l}07-11-89 \\
09-20-89 \\
05-01-90\end{array}$ & $\begin{array}{l}490\} \\
590 \uparrow \\
480 \uparrow\end{array}$ & $\begin{array}{l}61 \\
55 \\
39\end{array}$ & $\begin{array}{l}4.7 \\
3.9 \\
4.4\end{array}$ & $\begin{array}{l}.5 \\
.7 \\
.7\end{array}$ & $\begin{array}{l}.4 \\
.3 \\
.3\end{array}$ & $\begin{array}{l}\text { ND } \\
.20 \\
.20\end{array}$ & $\begin{array}{l}2.3 \\
2.8 \\
2.8\end{array}$ & $\begin{array}{l}.30 \\
.60 \\
.50\end{array}$ & $\begin{array}{l}-- \\
-- \\
5.8\end{array}$ \\
\hline$Q R-3$ & $\begin{array}{l}07-11-89 \\
09-20-89 \\
04-30-90\end{array}$ & $\begin{array}{l}390 \dagger \\
490 \phi \\
500 \dagger\end{array}$ & $\begin{array}{l}42 \\
52 \\
48\end{array}$ & $\begin{array}{l}3.7 \\
2.3 \\
3.4\end{array}$ & $\begin{array}{l}.4 \\
.4 \\
.7\end{array}$ & $\begin{array}{r}.8 \\
<.1 \\
.2\end{array}$ & $\begin{array}{l}. . \\
\text { ND } \\
.20\end{array}$ & $\begin{array}{l}2.6 \\
1.4 \\
2.8\end{array}$ & $\begin{array}{l}.30 \\
.30 \\
.60\end{array}$ & $\begin{array}{l}\cdots \\
4.3\end{array}$ \\
\hline QRDP-1 & $\begin{array}{l}04-04-89 \\
06-07-89 \\
06-07-89\end{array}$ & $\begin{array}{c}270 \\
-- \\
--\end{array}$ & $\begin{array}{l}67 \\
-- \\
--\end{array}$ & $\begin{array}{l}14 \\
=- \\
\end{array}$ & $\begin{array}{l}1.6 \\
-- \\
--\end{array}$ & $\begin{array}{l}.2 \\
\therefore-\end{array}$ & $\begin{array}{l}\text { ND } \\
-- \\
--\end{array}$ & $\begin{array}{l}1.5 \\
-- \\
--\end{array}$ & $\begin{array}{l}.30 \\
\therefore- \\
\therefore-\end{array}$ & $\begin{array}{l}-\cdot \\
-- \\
--\end{array}$ \\
\hline UPSTR ARDP & $\begin{array}{l}06-08-89 \\
06-08-89\end{array}$ & -- & $\begin{array}{l}-- \\
--\end{array}$ & $\because$ & $\because$ & -- & -- & -- & $\because-$ & $\because-$ \\
\hline \multicolumn{11}{|c|}{ LUPTON WELL CLUSTER-Continued } \\
\hline LPT-1 & $\begin{array}{l}06-05-90 \\
10-11-90\end{array}$ & $\begin{array}{l}130 \\
--\end{array}$ & $\begin{array}{l}36 \\
--\end{array}$ & $\begin{array}{l}.20 \\
.20\end{array}$ & $\begin{array}{l}\text { ND } \\
\text { ND }\end{array}$ & $\begin{array}{l}<.1 \\
<.1\end{array}$ & $\begin{array}{l}\text { MD } \\
\text { ND }\end{array}$ & $\begin{array}{l}.10 \\
.10\end{array}$ & $\begin{array}{l}\text { NO } \\
\text { NO }\end{array}$ & $\begin{array}{l}<1.0 \\
<1.0\end{array}$ \\
\hline LPT -2 & $\begin{array}{l}06-05-90 \\
10-11-90\end{array}$ & $380 f$ & $\begin{array}{l}54 \\
--\end{array}$ & $\begin{array}{l}2.0 \\
1.8\end{array}$ & $\begin{array}{l}.2 \\
.2\end{array}$ & $\begin{array}{l}<.1 \\
<.1\end{array}$ & $\begin{array}{l}\text { NO } \\
\text { NO }\end{array}$ & $\begin{array}{l}1.4 \\
1.2\end{array}$ & $\begin{array}{l}.20 \\
.20\end{array}$ & $\begin{array}{l}2.9 \\
4.0\end{array}$ \\
\hline LPT-3 & $\begin{array}{l}06-05-90 \\
10-12-90\end{array}$ & 290 & $\begin{array}{l}56 \\
--\end{array}$ & $\begin{array}{l}.60 \\
.40\end{array}$ & $\begin{array}{l}\text { MD } \\
\text { ND }\end{array}$ & $\begin{array}{l}<.1 \\
<.1\end{array}$ & $\begin{array}{l}\text { NO } \\
\text { NO }\end{array}$ & $\begin{array}{l}.40 \\
.30\end{array}$ & $\begin{array}{l}\text { MO } \\
\text { MD }\end{array}$ & $\begin{array}{r}3.2 \\
<1.0\end{array}$ \\
\hline LPT -4 & $\begin{array}{l}06-07-90 \\
10-11-90\end{array}$ & $\begin{array}{c}230 \\
--\end{array}$ & $\begin{array}{l}51 \\
\cdots\end{array}$ & $\begin{array}{l}1.9 \\
1.5\end{array}$ & $\begin{array}{l}.2 \\
.2\end{array}$ & $\begin{array}{l}<.1 \\
<.1\end{array}$ & $\begin{array}{l}\text { NO } \\
\text { NO }\end{array}$ & $\begin{array}{l}1.3 \\
.90\end{array}$ & $\begin{array}{l}.20 \\
.10\end{array}$ & $\begin{array}{l}6.6 \\
3.0\end{array}$ \\
\hline LPDP - 1 & $\begin{array}{l}11-17-89 \\
10-16-90 \\
06-11-91\end{array}$ & $\begin{array}{l}-. \\
\cdots \\
-.\end{array}$ & $\begin{array}{l}-- \\
-- \\
-.\end{array}$ & $\begin{array}{l}9.4 \\
2.7 \\
7.8\end{array}$ & $\begin{array}{r}1.3 \\
.3 \\
.8\end{array}$ & $\begin{array}{r}.6 \\
<.1 \\
.2\end{array}$ & $\begin{array}{l}.20 \\
\text { NO } \\
\text { ND }\end{array}$ & $\begin{array}{l}7.7 \\
1.9 \\
6.1\end{array}$ & $\begin{array}{l}1.1 \\
.20 \\
.60\end{array}$ & $\begin{array}{l}11 \\
7.8 \\
7.6\end{array}$ \\
\hline
\end{tabular}

\section{MAMUELITO WELL CLUSTER-Cont inued}

\begin{tabular}{|c|c|c|c|c|c|c|c|c|c|c|}
\hline$M N-1$ & $\begin{array}{l}06-06-90 \\
10-10-90\end{array}$ & $\begin{array}{c}370 \phi \\
--\end{array}$ & $\begin{array}{l}52 \\
-.\end{array}$ & $\begin{array}{l}<.10 \\
<.10\end{array}$ & $\begin{array}{l}\text { MD } \\
\text { MD }\end{array}$ & $\begin{array}{l}<.1 \\
<.1\end{array}$ & $\begin{array}{l}\text { ND } \\
\text { ND }\end{array}$ & $\begin{array}{l}<.10 \\
<.10\end{array}$ & $\begin{array}{l}\text { MD } \\
\text { ND }\end{array}$ & $\begin{array}{l}<1.0 \\
<1.0\end{array}$ \\
\hline MAN-2 & $\begin{array}{l}06-06-90 \\
10-10-90\end{array}$ & $\begin{array}{c}540 \uparrow \\
--\end{array}$ & $\begin{array}{l}50 \\
-.\end{array}$ & $\begin{array}{l}7.3 \\
7.5\end{array}$ & $\begin{array}{l}.8 \\
.8\end{array}$ & $\begin{array}{l}.2 \\
.2\end{array}$ & $\begin{array}{l}\text { NO } \\
\text { NO }\end{array}$ & $\begin{array}{l}4.5 \\
4.5\end{array}$ & $\begin{array}{l}.50 \\
.50\end{array}$ & $\begin{array}{l}8.8 \\
13\end{array}$ \\
\hline MAN-3 & $\begin{array}{l}06-06-90 \\
10-11-90\end{array}$ & $\begin{array}{c}4901 \\
=-\end{array}$ & $\begin{array}{l}51 \\
--\end{array}$ & $\begin{array}{l}6.4 \\
6.1\end{array}$ & $\begin{array}{l}.7 \\
.6\end{array}$ & $\begin{array}{l}.2 \\
.1\end{array}$ & $\begin{array}{l}\text { ND } \\
\text { ND }\end{array}$ & $\begin{array}{l}3.7 \\
3.6\end{array}$ & $\begin{array}{l}.40 \\
.40\end{array}$ & $\begin{array}{r}<1.0 \\
9.4\end{array}$ \\
\hline MANDP-1 & $\begin{array}{l}04-05-89 \\
10-16-90 \\
06-11-91\end{array}$ & $\begin{array}{c}440 \uparrow \\
\cdots \\
-\end{array}$ & $\begin{array}{l}62 \\
-- \\
--\end{array}$ & $\begin{array}{l}51 \\
.60 \\
5.9\end{array}$ & $\begin{array}{r}6.8 \\
\text { ND } \\
.6\end{array}$ & $\begin{array}{r}2.4 \\
<.1 \\
.2\end{array}$ & $\begin{array}{l}.70 \\
\text { ND } \\
.-\end{array}$ & $\begin{array}{c}43 \\
.50 \\
4.4\end{array}$ & $\begin{array}{l}5.8 \\
\text { NO } \\
.50\end{array}$ & $\begin{array}{c}2.3 \\
10\end{array}$ \\
\hline
\end{tabular}


GROUND-WATER DATA-Cont inued

CHEMICAL ANALYSES-Cont inued

STATION

NAME

GAL-2

GAL-3

GAL-4

GALDP-1

HIN-3L

$\infty N-3$

CONDP- 1

BLM-IU

NF MELL

NFDP-1

NFDP - 2
STATION NUMBER

DATE

TIME

LATITUDE

LONGI TUDE

GALLP WELL CLUSTER

$$
353219108400301
$$

353218108400303

353218108400304

353215108400401
$05-17-90 \quad 1130$ $10-15-90$

$10-24-90 \quad 1820$

$01-12-89 \quad 1600$ $10-24-90 \quad 1700$

$01-12-89 \quad 1730$ $10-24-90 \quad 1530$ 1620 $35^{\circ} 32^{\prime} 19$ N $\quad 108^{\circ} 40^{\prime} 03^{\prime \prime}$

$35^{\circ} 32^{\prime} 18^{n N} \quad 108^{\circ} 40 \cdot 03^{n H}$

$35^{\circ} 32^{\prime} 18^{m N} \quad 108^{\circ} 40^{\prime} 03^{\prime \prime} \mathrm{H}$

$35^{\circ} 32^{\prime} 15$ mN $\quad 108^{\circ} 40^{\prime} 04^{\prime \prime} \mathrm{W}$

NORTH FORK PUERCO RIVER WELLS AND DRIVE POINTS

\begin{tabular}{|c|c|c|c|c|}
\hline 353535108355003 & $\begin{array}{l}01-11-89 \\
10-24-90\end{array}$ & $\begin{array}{l}1430 \\
1040\end{array}$ & $35 \cdot 35 \cdot 35$ mN & $108 \cdot 35 \cdot 50^{\circ 4}$ \\
\hline 353535108355004 & $\begin{array}{l}01-11-89 \\
10-24-90\end{array}$ & $\begin{array}{l}1510 \\
1250\end{array}$ & $35 \cdot 35 \cdot 35$ mN & $108 \cdot 35 \cdot 50^{\circ} \mathrm{y}$ \\
\hline 353710108312803 & $01-11-89$ & 1115 & $35 \cdot 37 \cdot 10^{m N}$ & $108^{\circ} 31 \cdot 28 * 4$ \\
\hline 353717108312801 & $\begin{array}{l}03-30-89 \\
10-18-90 \\
06-10-91\end{array}$ & $\begin{array}{l}1130 \\
0835 \\
1745\end{array}$ & $35^{\circ} 37^{\prime} 17 \mathrm{~m}_{\mathrm{N}}$ & $108^{\circ} 31^{\prime} 28^{\prime \prime} y$ \\
\hline 353742108293601 & $01-10-89$ & 1600 & $35^{\circ} 37^{\prime} 42^{m} \mathrm{~N}$ & $108^{\circ} 29^{\prime} 36^{\prime 4}$ \\
\hline 353726108303702 & $11-18-89$ & 1100 & $35 \cdot 37 \cdot 26$ mu & $108 \cdot 30 \cdot 3744$ \\
\hline 353727108311501 & $03-30-89$ & 1705 & $35 \cdot 37 \cdot 27 m N$ & $108^{\circ} 31 \cdot 15^{m}$ \\
\hline 353726108303701 & $11-18-89$ & 1100 & $35^{\circ} 37 \cdot 26^{m n}$ & $108^{\circ} 30^{\prime} 37^{\prime \prime} \mathrm{W}$ \\
\hline
\end{tabular}


GROUND-MATER DATA-Cont inued

CHEMICAL ANALYSES-Cont inued

$\begin{array}{cc}\text { STATION } & \text { (METERS } \\ \text { NAME } & \text { DATE } \\ & \text { NGVD) } \\ & (72000)\end{array}$

\begin{tabular}{|c|c|c|c|c|c|c|c|}
\hline $\begin{array}{l}\text { ALTITTDE } \\
\text { OF LAND } \\
\text { SURFACE } \\
\text { DATUN } \\
\text { (METERS } \\
\text { ABOVE } \\
\text { NGVD) } \\
\text { (72000) }\end{array}$ & $\begin{array}{l}\text { DEPTH } \\
\text { OF } \\
\text { WELL, } \\
\text { TOTAL } \\
\text { (meters) } \\
\text { (72008) }\end{array}$ & $\begin{array}{l}\text { DEPTH } \\
\text { BELOW } \\
\text { LAND } \\
\text { SURFACE } \\
\text { (WATER } \\
\text { LEVEL) } \\
\text { (meters) } \\
\text { (72019) }\end{array}$ & $\begin{array}{l}\text { PUNP } \\
\text { OR FLON } \\
\text { PERIOD } \\
\text { PRIOR } \\
\text { TO SAM- } \\
\text { PLING } \\
\text { (Din) } \\
(72004)\end{array}$ & $\begin{array}{l}\text { FLON } \\
\text { RATE, } \\
\text { INSTAN- } \\
\text { TANEOUS } \\
\left(\pi^{3} / 8\right) \\
(00059)\end{array}$ & $\begin{array}{c}\text { TEMPER- } \\
\text { ATURE } \\
\text { WATER } \\
\left({ }^{\circ} \mathrm{C}\right) \\
(00010)\end{array}$ & $\begin{array}{l}\text { TUR- } \\
\text { BID- } \\
\text { ITY } \\
\text { (NTU) } \\
\text { (00076) }\end{array}$ & $\begin{array}{l}\text { OXID- } \\
\text { ATION } \\
\text { RED- } \\
\text { UCTION } \\
\text { POTEN- } \\
\text { TIAL } \\
\text { (DN) } \\
\text { (OOOSO) }\end{array}$ \\
\hline
\end{tabular}

GALLUP UELL CLUSTER-Continued

\begin{tabular}{|c|c|c|c|c|c|c|c|c|}
\hline GAL-2 & $10-24-90$ & 2000 & 12.2 & 4.17 & $\cdots$ & .6 & 13.0 & $\cdots$ \\
\hline GAL-3 & $\begin{array}{l}01-12-89 \\
10-24-90\end{array}$ & 2000 & 3.7 & $\begin{array}{l}3.77 \\
4.21\end{array}$ & $\ddot{60}$ & .0 & $\begin{array}{l}10.0 \\
13.5\end{array}$ & $\begin{array}{l}30 \\
-\cdot\end{array}$ \\
\hline GAL - 4 & $\begin{array}{l}01-12-89 \\
10-24-90\end{array}$ & 2000 & 7.4 & $\begin{array}{l}4.05 \\
4.05\end{array}$ & 49 & $\ddot{1.0}$ & $\begin{array}{r}9.5 \\
12.0\end{array}$ & 1.2 \\
\hline GALDP-1 & $\begin{array}{l}05-17-90 \\
10-15-90\end{array}$ & 1980 & $\therefore 94$ & .58 & $\ddot{8}$ & .1 & $\begin{array}{l}17.5 \\
14.0\end{array}$ & $\ddot{-}$ \\
\hline
\end{tabular}

NORTH FORK PUERCO RIVER WELLS AND DRIVE POINTS-Cont inued

\begin{tabular}{|c|c|c|c|c|c|c|c|c|c|}
\hline WIN-3U & $\begin{array}{l}01-11-89 \\
10-24-90\end{array}$ & 2040 & 11.5 & $\begin{array}{l}5.85 \\
5.55\end{array}$ & $\ddot{64}$ & .3 & $\begin{array}{r}8.0 \\
14.5\end{array}$ & $\begin{array}{l}78 \\
\cdots\end{array}$ & $\begin{array}{l}405 \\
362\end{array}$ \\
\hline $\begin{array}{l}H 1 N-3 L \\
\cos -3\end{array}$ & $\begin{array}{l}01-11-89 \\
10-24-90 \\
01-11-89\end{array}$ & $\begin{array}{l}2040 \\
2080\end{array}$ & $\begin{array}{l}13.7 \\
13.1\end{array}$ & $\begin{array}{l}6.16 \\
6.07 \\
9.97\end{array}$ & $\begin{array}{l}\cdots \\
74 \\
\cdots\end{array}$ &.. & $\begin{array}{r}6.0 \\
18.5 \\
9.0\end{array}$ & $\begin{array}{l}40 \\
\therefore \\
730\end{array}$ & $\begin{array}{l}127 \\
137 \\
393\end{array}$ \\
\hline CONDP-1 & $\begin{array}{l}03-30-89 \\
10-18-90 \\
06-10-91\end{array}$ & 2070 & $\begin{array}{l}\cdots \\
1.46\end{array}$ & $\begin{array}{l}. . \\
.61 \\
.76\end{array}$ & $\begin{array}{l}\cdots \\
22 \\
26\end{array}$ & $\begin{array}{l}. . \\
.2 \\
.1\end{array}$ & $\begin{array}{l}10.5 \\
12.0 \\
15.0\end{array}$ & $\begin{array}{l}1.0 \\
\therefore \\
\therefore\end{array}$ & $\begin{array}{l}114 \\
213 \\
375\end{array}$ \\
\hline BLK-IU & $01-10-89$ & 2090 & 16.8 & 8.83 & $\cdots$ & $\cdots$ & 10.0 & 190 & 246 \\
\hline MF VELL & $11-18-89$ & 2085 & $\cdots$ & -. & -. & -- & - & - & $\cdots$ \\
\hline NFDP-1 & $03-30-89$ & 2090 & -. & $\cdots$ & $\cdots$ & $\cdots$ & 9.5 & 12 & 200 \\
\hline MFDP-2 & $11-18-89$ & 2085 & .. & .51 & 60 & .2 & 9.0 & $\cdots$ & 315 \\
\hline
\end{tabular}


GROUND-WATER DATA-Cont inued

CHEMICAL AHALYSES-Cont inued

STATION

MNAE

DATE

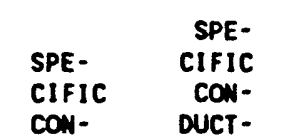

CON- DUCT-

DUCT - ANCE

ANCE LAB

$(\mu \mathrm{S} / \mathrm{cm}) \quad(\mu \mathrm{S} / \mathrm{cm})$

(00095)

$\begin{array}{ccc} & \text { OXYGEN } & \text { PH } \\ & \begin{array}{c}\text { PEMAND, } \\ \text { CHEM- }\end{array} & \begin{array}{c}\text { WATER } \\ \text { WHOLE }\end{array} \\ \text { OXYGEN, } & \text { ICAL } & \text { FIELD } \\ \text { DIS- } & \text { (HIGH } & \text { (STAND- } \\ \text { SOLVED } & \text { LEVEL) } & \text { NRD } \\ (m 9 / L) & (M G / L) & \text { UNITS) } \\ (00300) & (00340) & (00400)\end{array}$

PH WATER WHOLE

LAB

(STAND-

ARD

(NITS)

(00403)
ALKA- ALKA-

LINITY LINITY

WAT DIS WAT DIS

FIX END TOT IT

FIELD FIELD

$\mathrm{CaCO3} \mathrm{mg} / \mathrm{L}$ os

(mg/L) CaCO3

(39036) (39086)

GALLUP MELL CLUSTER-Continued

$\begin{array}{lrrrrrrrrr}\text { GAL-2 } & 10-24-90 & 1340 & 1370 & .3 & \ldots & 7.0 & 7.6 & 480 & \ldots \\ \text { GAL-3 } & 01-12-89 & \text { E1800 } & 1890 & .3 & 25 & 7.6 & 7.6 & 360 & 359 \\ & 10-24-90 & 2030 & 2070 & .8 & \ldots & 6.9 & 7.5 & 380 & \ldots \\ \text { GAL-4 } & 01-12-89 & 752 & 1640 & 0 & 19 & 7.1 & 7.3 & 432 & \ldots \\ & 10-24-90 & 1590 & 1630 & .3 & \ldots & 6.8 & 7.3 & 450 & \ldots \\ \text { GALDP-1 } & 05-17-90 & 4910 & 5330 & 1.2 & \ldots & 7.3 & 8.1 & 230 & 233 \\ & 10-15-90 & 1490 & 1610 & .7 & \ldots & 7.2 & 7.7 & 480 & \ldots\end{array}$

MORTH FORK PUERCO RIVER WELLS AND DRIVE POINTS- Continued

\begin{tabular}{|c|c|c|c|c|c|c|c|c|}
\hline MIN-3U & $\begin{array}{l}01-11-89 \\
10-24-90\end{array}$ & 3430 & $\begin{array}{l}3790 \\
3430\end{array}$ & 1.3 & 19 & $\begin{array}{l}7.2 \\
7.1\end{array}$ & $\begin{array}{l}7.5 \\
7.6\end{array}$ & $\begin{array}{l}301 \\
280\end{array}$ \\
\hline HIN-3L & $\begin{array}{l}01-11-89 \\
10-24-90\end{array}$ & $\ddot{9240}$ & $\begin{array}{l}8060 \\
8490\end{array}$ & $\begin{array}{r}90.0 \\
4.1\end{array}$ & $\begin{array}{l}-\cdot \\
\cdots\end{array}$ & $\begin{array}{l}7.1 \\
6.8\end{array}$ & $\begin{array}{l}7.4 \\
7.3\end{array}$ & $\begin{array}{l}757 \\
790\end{array}$ \\
\hline CON-3 & $01-11-89$ & 384 & 947 & $\cdots$ & 17 & 7.5 & 7.7 & 213 \\
\hline CONDP-1 & $\begin{array}{l}03-30-89 \\
10-18-90 \\
06-10-91\end{array}$ & $\begin{array}{r}1320 \\
652 \\
469\end{array}$ & $\begin{array}{r}1330 \\
663 \\
450\end{array}$ & $\begin{array}{l}.2 \\
3.4 \\
3.3\end{array}$ & $\begin{array}{l}-- \\
\cdots \\
\cdots\end{array}$ & $\begin{array}{l}7.1 \\
7.3 \\
7.3\end{array}$ & $\begin{array}{l}7.8 \\
7.8 \\
7.8\end{array}$ & $\begin{array}{l}240 \\
110 \\
160\end{array}$ \\
\hline BLH-IU & $01-10-89$ & $\cdots$ & 1140 & .3 & $<10$ & 7.0 & 7.6 & 190 \\
\hline NF WELL & $11-18-89$ & $\cdots$ & $\cdots$ & $\cdots$ & $\cdots$ & $\cdots$ & $\cdots$ & $\cdots$ \\
\hline NFDP-1 & $03-30-89$ & 902 & 903 & .1 & $\cdots$ & 7.1 & 7.7 & 210 \\
\hline NFDP - 2 & $11-18-89$ & 981 & 965 & 3.8 & -- & 7.1 & 7.4 & 150 \\
\hline
\end{tabular}


GROUND-MATER DATA-Continued

CHEMICAL ANALYSES-Cont inued

STATION

NAME

DATE

\begin{tabular}{|c|c|c|c|c|c|c|c|c|}
\hline $\begin{array}{l}\text { ALKA- } \\
\text { LINITY } \\
\text { LAB } \\
\text { (mo/L } \\
\text { as } \\
\text { CaCO3) } \\
(90410)\end{array}$ & $\begin{array}{l}\text { BICAR- } \\
\text { BONATE } \\
\text { WATER } \\
\text { OIS IT } \\
\text { FIELD } \\
\text { H/L os } \\
\text { HCO3 } \\
(00453)\end{array}$ & $\begin{array}{l}\text { SOLIDS, } \\
\text { RESIDUE } \\
\text { AT } 180 \\
\text { C } \\
\text { DIS- } \\
\text { SOLVED } \\
(m g / L) \\
(70300)\end{array}$ & $\begin{array}{l}\text { SOLIDS, } \\
\text { SUM OF } \\
\text { CONSTI- } \\
\text { TUENTS, } \\
\text { DIS- } \\
\text { SOLVED } \\
\text { (mo/L) } \\
(70301)\end{array}$ & $\begin{array}{l}\text { SOLIDS, } \\
\text { DIS- } \\
\text { SOLVED } \\
\text { (tons } \\
\text { per } \\
\text { ac- ft) } \\
(70303)\end{array}$ & $\begin{array}{l}\text { MITRO- } \\
\text { GEN, } \\
\text { MAMONIA } \\
\text { DIS- } \\
\text { SOLVED } \\
\text { (mG/L } \\
\text { AS N) } \\
\text { (OOSOB) }\end{array}$ & $\begin{array}{l}\text { NITRO- } \\
\text { GEN, } \\
\text { NITRITE } \\
\text { DIS- } \\
\text { SOLVED } \\
\text { (MO/L } \\
\text { OS N) } \\
(00613)\end{array}$ & $\begin{array}{l}\text { NITRO- } \\
\text { GEN, } \\
\text { NITRATE } \\
\text { DIS- } \\
\text { SOLVED } \\
\text { (MO/L } \\
\text { OS N) } \\
\text { (00618) }\end{array}$ & $\begin{array}{c}\text { NITRO- } \\
\text { GEN, } \\
\text { NO2+NO3 } \\
\text { OIS- } \\
\text { SOLVED } \\
\text { (mg/L } \\
\text { as N) } \\
(00631)\end{array}$ \\
\hline
\end{tabular}

GALLUP MELL CLUSTER-Continued

$\begin{array}{lllllllllll}\text { GAL-2 } & 10-24-90 & 488 & 588 & 858 & 861 & 1.17 & \ldots & \ldots & . . & .040 \\ \text { GAL-3 } & 01-12-89 & 380 & 438 & 1280 & 1660 & 1.74 & .140 & \ldots & \ldots & .130 \\ & 10-24-90 & 389 & 470 & 1480 & 1430 & 2.01 & \ldots & \ldots & \ldots & .158 \\ \text { GAL-4 } & 01-12-89 & 445 & 535 & 1100 & 1120 & 1.50 & 1.40 & \ldots & \ldots & <.100 \\ & 10-24-90 & 447 & 550 & 1100 & 1110 & 1.50 & \ldots & \ldots & \ldots & <.010 \\ \text { GALDP-1 } & 05-17-90 & 109 & 284 & \ldots & 4110 & 5.58 & .825 & .005 & .008 & .013 \\ & 10-15-90 & 471 & 590 & 1060 & 1140 & 1.44 & \ldots & \ldots & \ldots & .035\end{array}$

MORTH FORK PUERCO RIVER WELLS AMO DRIVE POINTS-Continued

\begin{tabular}{|c|c|c|c|c|c|c|c|c|c|c|}
\hline HIN-3U & $\begin{array}{l}01-11-89 \\
10-24-90\end{array}$ & $\begin{array}{l}316 \\
172\end{array}$ & $\begin{array}{l}369 \\
340\end{array}$ & $\begin{array}{l}3680 \\
3080\end{array}$ & $\begin{array}{l}3470 \\
3060\end{array}$ & $\begin{array}{l}5.00 \\
4.19\end{array}$ & $\begin{array}{l}.120 \\
\cdots\end{array}$ & $\begin{array}{c}.160 \\
\ldots\end{array}$ & $\cdots$ & $\begin{array}{l}1.20 \\
.086\end{array}$ \\
\hline HIN-3L & $\begin{array}{l}01-11-89 \\
10-24-90\end{array}$ & $\begin{array}{l}754 \\
768\end{array}$ & $\begin{array}{l}918 \\
979\end{array}$ & $\begin{array}{l}7040 \\
5480\end{array}$ & $\begin{array}{l}7050 \\
7530\end{array}$ & $\begin{array}{l}9.57 \\
7.45\end{array}$ & $\begin{array}{l}-. \\
-.\end{array}$ & $\because$ & 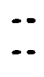 & .010 \\
\hline $\operatorname{con}-3$ & $01-11-89$ & 199 & 262 & 613 & 632 & .83 & .060 & $\cdots$ & -. & 5.60 \\
\hline CONDP-1 & $\begin{array}{l}03-30-89 \\
10-18-90 \\
06-10-91\end{array}$ & $\begin{array}{r}229 \\
104 \\
--\end{array}$ & $\begin{array}{l}292 \\
130 \\
194\end{array}$ & $\begin{array}{r}1020 \\
463 \\
273\end{array}$ & $\begin{array}{l}986 \\
435 \\
282\end{array}$ & $\begin{array}{r}1.39 \\
.63 \\
.37\end{array}$ & $\begin{array}{l}.020 \\
\cdots \\
\cdots\end{array}$ & $\begin{array}{l}-. \\
\cdots \\
\cdots\end{array}$ & $\begin{array}{l}\cdots \\
\cdots\end{array}$ & $\begin{array}{l}<.100 \\
1.00 \\
1.20\end{array}$ \\
\hline BLM-IU & $01-10-89$ & 192 & 242 & 874 & 845 & 1.19 & .110 & - & $\cdots$ & .270 \\
\hline NF MELL & $11-18-89$ & -. & $\cdots$ & $\cdots$ & -. & -. & $\cdots$ & -. & $\cdots$ & $\cdots$ \\
\hline NFDP-1 & $03-30-89$ & 188 & 256 & 654 & 650 & .89 & .510 & - & -. & $<.100$ \\
\hline NFDP-2 & $11-18-89$ & .. & 185 & $\cdots$ & 681 & .93 & $\cdots$ & -. & $\cdots$ & $<.100$ \\
\hline
\end{tabular}


GROUND-UATER DATA-Continued

CHEMICAL ANALYSES-continued

STATION

MAME

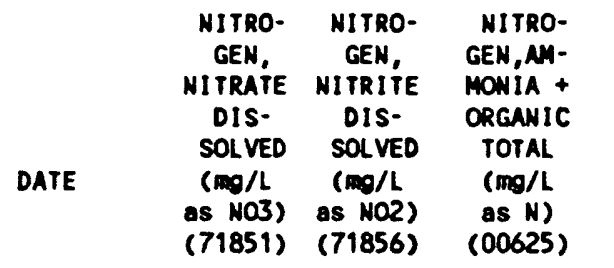

PHos-
PHOnels
DIS-
SOLVED
$($ mo/l
as P)
$(00666)$

PHOS-
PHORUS
TOTAL
$(m / L$
as P)
$(00665)$

PHOS- PHOS-

PHORUS PHATE, CARBON,

HARD-

ORTHO, ORTHO, ORGANIC CARBON, NESS

DIS- DIS- DIS- ORGANIC TOTAL

SOLVED SOLVED SOLVED TOTAL (m/L

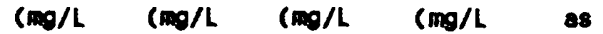

as P) as PO4) as ( ) as (C) (aco3)

(00671) (00660) (00681) (00680) (00900)

GALLUP MELL CLUSTER-Cont inued

\begin{tabular}{|c|c|c|c|c|c|c|c|c|c|c|c|}
\hline GAL -2 & $10-24-90$ & $-\cdot$ & $\cdots$ & $\cdot-$ & .010 & $\cdots$ & $\cdots$ & -. & 2.3 & $\cdots$ & 190 \\
\hline GAL -3 & $\begin{array}{l}01-12-89 \\
10-24-90\end{array}$ & $\ddot{-.}$ & $\ddot{-}$ & .30 & $\begin{array}{r}<.010 \\
.001\end{array}$ & .010 & $<.010$ & $\because \cdot$ & $\ddot{2.5}$ & $\begin{array}{l}1.9 \\
.-\end{array}$ & $\begin{array}{l}360 \\
460\end{array}$ \\
\hline GAL -4 & $\begin{array}{l}01-12-89 \\
10-24-90\end{array}$ & $\because$ & $\because$ & $\begin{array}{l}1.5 \\
. .\end{array}$ & $\begin{array}{r}<.010 \\
.008\end{array}$ & $<.010$ & .010 & .03 & 3.5 & $\begin{array}{l}3.4 \\
-.\end{array}$ & $\begin{array}{l}360 \\
330\end{array}$ \\
\hline GALDP-1 & $\begin{array}{l}05-17-90 \\
10-15-90\end{array}$ & .03 & $\begin{array}{l}.02 \\
\therefore-\end{array}$ & $\begin{array}{l}-. \\
-.\end{array}$ & .008 & $\because$ & .010 & .03 & $\begin{array}{l}6.9 \\
4.3\end{array}$ & 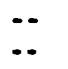 & $\begin{array}{l}970 \\
260\end{array}$ \\
\hline
\end{tabular}

NORTH FORK PUERCO RIVER WELLS ND DRIVE POINTS-Continued

\begin{tabular}{|c|c|c|c|c|c|c|c|c|c|c|c|}
\hline WIN-3U & $\begin{array}{l}01-11-89 \\
10-24-90\end{array}$ & 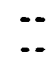 & $\ddot{-.}$ & .70 & $\begin{array}{l}.020 \\
.033\end{array}$ & .110 & .010 & .03 & $\ddot{2.7}$ & $\begin{array}{l}4.2 \\
-.\end{array}$ & $\begin{array}{l}1600 \\
1600\end{array}$ \\
\hline MIN-3L & $\begin{array}{l}01-11-89 \\
10-24-90\end{array}$ & -. & 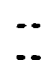 & 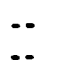 & .062 & 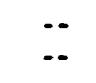 & $\because \cdot$ & $\cdots$ & 9.2 & $\begin{array}{l}18 \\
-.\end{array}$ & $\begin{array}{l}1500 \\
1700\end{array}$ \\
\hline CON-3 & $01-11-89$ & -. & $\cdots$ & .70 & .010 & .100 & .010 & .03 & $\cdots$ & 11 & 170 \\
\hline CONDP-1 & $\begin{array}{l}03-30-89 \\
10-18-90 \\
06-10-91\end{array}$ & $\begin{array}{l}- \\
- \\
-\end{array}$ & $\begin{array}{l}-. \\
\cdots \\
-.\end{array}$ & $\begin{array}{l}.50 \\
\because . \\
-\cdot\end{array}$ & $\begin{array}{l}.010 \\
.024 \\
.051\end{array}$ & $\begin{array}{l}.020 \\
\because- \\
--\end{array}$ & $\begin{array}{l}.040 \\
-. \\
-.\end{array}$ & $\begin{array}{l}.12 \\
-. \\
-.\end{array}$ & $\begin{array}{l}4.3 \\
3.4 \\
3.6\end{array}$ & $\begin{array}{l}4.4 \\
-. \\
--\end{array}$ & $\begin{array}{l}600 \\
290 \\
190\end{array}$ \\
\hline BLM-1U & $01-10-89$ & $\cdots$ & $\cdots$ & .20 & $<.010$ & $<.010$ & $<.010$ & $\cdots$ & $\cdots$ & 5.8 & 570 \\
\hline MF VELL & $11-18-89$ & $\cdots$ & $\cdots$ & $\cdot-$ & $\cdots$ & $\cdots$ & $\cdot-$ & $-\cdot$ & $\cdots$ & $\cdots$ & $-\cdot$ \\
\hline NFDP-1 & $03-30-89$ & $\cdots$ & $\cdots$ & .60 & .030 & .040 & .020 & .06 & 4.1 & 4.3 & 450 \\
\hline NFDP-2 & $11-18-89$ & $\cdots$ & $\cdots$ & .. & -. & -. & -. & -. & -. & 6.8 & 460 \\
\hline
\end{tabular}


CHEMICAL ANALYSES-Continued

STATION

NAME

DATE

\begin{tabular}{|c|c|c|}
\hline $\begin{array}{l}\text { SIUN, } \\
\text { DIS- } \\
\text { SOLVED } \\
\text { (mg/L } \\
\text { as Mg) } \\
(00925 \text { ) }\end{array}$ & $\begin{array}{l}\text { SOOIUH, } \\
\text { DIS- } \\
\text { SOLVED } \\
(m, / L \\
\text { es } \mathrm{Na}) \\
(00930)\end{array}$ & $\begin{array}{c}\text { SOOIUA } \\
\text { AD- } \\
\text { SORP- } \\
\text { TION } \\
\text { RATIO } \\
\text { (00931) }\end{array}$ \\
\hline
\end{tabular}

SOOIUN
PERCENT
(00932)

POTAS- CHLO

SIU,
DIS-

SOLVED SOLVED

( $\mathrm{mg} / \mathrm{L} \quad(\mathrm{m} / \mathrm{L} / \mathrm{L}$

os $\mathrm{K}$ )

(00935)

$(00940)$

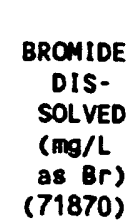

FLUO- SILICA,

RIDE, DIS-

DIS- SOLVED

SOLVED (mg/L

$(\mathrm{mg} / \mathrm{L}$ os

os F) SiO2)

(00950) (00955)

\begin{tabular}{|c|c|c|c|c|c|c|c|c|c|c|}
\hline GAL-2 & $10-24-90$ & 56 & 11 & 240 & 8 & 74 & .90 & 38 & .25 & .50 \\
\hline GALDP-1 & $\begin{array}{l}05-17-90 \\
10-15-90\end{array}$ & $\begin{array}{r}300 \\
74\end{array}$ & $\begin{array}{l}52 \\
19\end{array}$ & $\begin{array}{l}990 \\
330\end{array}$ & $\begin{array}{r}14 \\
9\end{array}$ & $\frac{69}{73}$ & $\begin{array}{l}8.8 \\
5.2\end{array}$ & $\begin{array}{c}300 \notin \\
37\end{array}$ & $\begin{array}{l}.20 \\
.22\end{array}$ & $\begin{array}{r}<.10 \\
.50\end{array}$ \\
\hline
\end{tabular}

NORTH FORK PUERCO RIVER UELLS AND DRIVE POINTS-Continued

\begin{tabular}{|c|c|c|c|c|c|c|c|c|c|c|c|}
\hline WIN-3U & $\begin{array}{l}01-11-89 \\
10-24-90\end{array}$ & $\begin{array}{l}440 \\
460\end{array}$ & $\begin{array}{l}130 \\
110\end{array}$ & $\begin{array}{l}370 \\
290\end{array}$ & 4 & $\begin{array}{l}33 \\
28\end{array}$ & $\begin{array}{l}2.4 \\
2.5\end{array}$ & $\begin{array}{l}28 \\
14\end{array}$ & $\begin{array}{l}.26 \\
.14\end{array}$ & $\begin{array}{r}.50 \\
<.10\end{array}$ & $\begin{array}{l}9.2 \\
8.6\end{array}$ \\
\hline WIN-3L & $\begin{array}{l}01-11-89 \\
10-24-90\end{array}$ & $\begin{array}{l}200 \\
210\end{array}$ & $\begin{array}{l}250 \\
280\end{array}$ & $\begin{array}{l}1600 \\
1700\end{array}$ & $\begin{array}{l}18 \\
18\end{array}$ & $\begin{array}{l}69 \\
69\end{array}$ & $\begin{array}{l}5.9 \\
8.0\end{array}$ & $\begin{array}{l}33 \\
33\end{array}$ & $\begin{array}{l}1.0 \\
1.3\end{array}$ & $\begin{array}{l}1.7 \\
1.0\end{array}$ & $\begin{array}{l}9.7 \\
8.4\end{array}$ \\
\hline $\cos -3$ & $01-11-89$ & 57 & 7.6 & 130 & 4 & 61 & 4.1 & 8.2 & .054 & .40 & 9.9 \\
\hline CONDP-1 & $\begin{array}{l}03-30-89 \\
10-18-90 \\
06-10-91\end{array}$ & $\begin{array}{r}180 \\
88 \\
59\end{array}$ & $\begin{array}{l}36 \\
18 \\
10\end{array}$ & $\begin{array}{l}68 \\
20 \\
21\end{array}$ & $\begin{array}{l}1 \\
.5 \\
.7\end{array}$ & $\begin{array}{l}20 \\
13 \\
19\end{array}$ & $\begin{array}{l}4.7 \\
5.1 \\
4.4\end{array}$ & $\begin{array}{l}13 \\
5.9 \\
2.7\end{array}$ & $\begin{array}{c}<.010 \\
.020 \\
.18\end{array}$ & $\begin{array}{l}.40 \\
.40 \\
.60\end{array}$ & $\begin{array}{r}7.9 \\
8.4 \\
11\end{array}$ \\
\hline BLM-1U & $01-10-89$ & 180 & 28 & 27 & .5 & 9 & 5.9 & 4.0 & .058 & .40 & 7.4 \\
\hline NF NELL & $11-18-89$ & $\cdots$ & $\cdots$ & $\cdots$ & -- & -- & $\cdots$ & $\cdots$ & $\cdots$ & $\cdots$ & $\cdots$ \\
\hline NFDP - 1 & $03-30-89$ & 140 & 24 & 21 & .4 & 9 & 5.9 & 13 & $<.010$ & .40 & 7.9 \\
\hline
\end{tabular}


GROUND-MATER DATA-Continued

ChEmICAL AMALYSES-Continued

STATION

NAME
DATE

\begin{tabular}{|c|c|c|c|c|c|c|}
\hline $\begin{array}{l}\text { BERYL- } \\
\text { LIUN, } \\
\text { DIS- } \\
\text { SOLVED } \\
(\mu 9 / L \\
\text { as Be) } \\
(01010)\end{array}$ & $\begin{array}{c}\text { BORON, } \\
\text { DIS- } \\
\text { SOLVED } \\
(\mu 9 / L \\
\text { OS B) } \\
(01020)\end{array}$ & $\begin{array}{l}\text { CADMIUN } \\
\text { DIS- } \\
\text { SOLVED } \\
\text { ( } \mu g / L \\
\text { as Cd) } \\
\text { (01025) }\end{array}$ & $\begin{array}{l}\text { CHRO- } \\
\text { MIUH, } \\
\text { DIS- } \\
\text { SOLVED } \\
(\mu g / L \\
\text { as Cr) } \\
(01030)\end{array}$ & $\begin{array}{l}\text { CHRO- } \\
\text { MIUH, } \\
\text { HEXA- } \\
\text { VALENT, } \\
\text { DIS. } \\
(\mu g / L \\
\text { as Cr) } \\
(01032)\end{array}$ & $\begin{array}{l}\text { COBALT, } \\
\text { DIS- } \\
\text { SOLVED } \\
\text { ( } \mu g / L \\
\text { AS CO) } \\
(01035)\end{array}$ & $\begin{array}{l}\text { COPPER, } \\
\text { DIS- } \\
\text { SOLVED } \\
\text { ( } \mu 9 / L \\
\text { as CU) } \\
(01040)\end{array}$ \\
\hline
\end{tabular}

GALLUP MELL CLUSTER-Continued

\begin{tabular}{|c|c|c|c|c|c|c|c|c|c|c|c|}
\hline GAL-2 & $10-24-90$ & 210 & $<1$ & 17 & $<.5$ & 230 & $<1.0$ & $<5$ & $\cdots$ & $<3$ & $<10$ \\
\hline GAL-3 & $\begin{array}{l}01-12-89 \\
10-24-90\end{array}$ & $\begin{array}{l}600 \$ \\
660 \$\end{array}$ & $\begin{array}{l}<1 \\
<1\end{array}$ & $\begin{array}{r}<100 \\
20\end{array}$ & $\begin{array}{l}-. \\
<.5\end{array}$ & $\begin{array}{l}250 \\
260\end{array}$ & $\begin{array}{l}<1.0 \\
<1.0\end{array}$ & $\begin{array}{l}-. \\
<5\end{array}$ & $\begin{array}{l}<1 \\
\therefore\end{array}$ & $<1$ & $\begin{array}{l}<1 \\
<10\end{array}$ \\
\hline CAL -4 & $\begin{array}{l}01-12-89 \\
10-24-90\end{array}$ & $\begin{array}{l}410 \ddagger \\
410 \neq\end{array}$ & $\begin{array}{l}<1 \\
<1\end{array}$ & $\begin{array}{r}<100 \\
21\end{array}$ & $\begin{array}{l}-. \\
<.5\end{array}$ & $\begin{array}{l}200 \\
220\end{array}$ & $\begin{array}{l}<1.0 \\
<1.0\end{array}$ & -2 & $\begin{array}{l}<1 \\
--\end{array}$ & $\begin{array}{l}<1 \\
<3\end{array}$ & $\begin{array}{r}1 \\
<10\end{array}$ \\
\hline GALOP-1 & $\begin{array}{l}05-17-90 \\
10-15-90\end{array}$ & $\begin{array}{r}2300 \$ \\
370 \$\end{array}$ & $\ddot{2}$ & $\begin{array}{l}79 \\
87\end{array}$ & $\begin{array}{l}<2 i \\
<.5\end{array}$ & $\ddot{190}$ & $\begin{array}{l}<3.0 \\
<1.0\end{array}$ & $\begin{array}{l}<20 \\
<5\end{array}$ & -. & $\begin{array}{l}9 \\
<3\end{array}$ & $\begin{array}{l}<30 \\
<10\end{array}$ \\
\hline
\end{tabular}

\begin{tabular}{|c|c|c|c|c|c|c|c|c|c|c|c|}
\hline$H I N-3 U$ & $\begin{array}{l}01-11-89 \\
10-24-90\end{array}$ & $\begin{array}{l}2300 \notin \\
2000 \notin\end{array}$ & $\begin{array}{l}<1 \\
<1\end{array}$ & $\begin{array}{r}<100 \\
24\end{array}$ & $<.5$ & $\begin{array}{l}240 \\
250\end{array}$ & $\begin{array}{l}<1.0 \\
<1.0\end{array}$ & 45 & $\begin{array}{l}<1 \\
--\end{array}$ & $\begin{array}{l}<1 \\
<3\end{array}$ & $\begin{array}{r}1 \\
<10\end{array}$ \\
\hline HIN-3L & $\begin{array}{l}01-11-89 \\
10-24-90\end{array}$ & $\begin{array}{l}4500 \$ \\
4800 \$\end{array}$ & 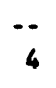 & $<100$ & $<10 i$ & 580 & $<1.0$ & $\ddot{<1}$ & $\cdots$ & - & 3 \\
\hline $\operatorname{con}-3$ & $01-11-89$ & $260 \notin$ & $<1$ & $<100$ &.- & 80 & $<1.0$ & -. & $<1$ & $<1$ & 7 \\
\hline CONDP - 1 & $\begin{array}{l}03-30-89 \\
10-18-90 \\
06-10-91\end{array}$ & $\begin{array}{c}530 \$ \\
220 \\
72\end{array}$ & $\begin{array}{r}2 \\
<1 \\
2\end{array}$ & $\begin{array}{l}\cdots \\
98 \\
35\end{array}$ & $\begin{array}{l}-- \\
<.5 \\
<.5\end{array}$ & $\begin{array}{l}70 \\
60 \\
\cdots\end{array}$ & $\begin{array}{l}<1.0 \\
<1.0 \\
<1.0\end{array}$ & $\begin{array}{l}-2 \\
<5 \\
<5\end{array}$ & $\begin{array}{l}3 \\
\therefore- \\
\therefore\end{array}$ & $\begin{array}{l}<1 \\
<3 \\
<3\end{array}$ & $\begin{array}{r}1 \\
<10 \\
10\end{array}$ \\
\hline BLM- IU & $01-10-89$ & 470 & $<1$ & 100 & -- & 100 & $<1.0$ & $\cdots$ & $<1$ & $<1$ & 2 \\
\hline MF MELL & $11-18-89$ & $\cdots$ & $\cdots$ & $\cdots$ & $\cdots$ & -. & - & -. & -- & -. & - \\
\hline NFDP-1 & $03-30-89$ & $310 \$$ & 1 & $\cdots$ & $\cdots$ & 50 & $<1.0$ & $\cdots$ & 4 & $<1$ & 2 \\
\hline MFDP-2 & $11-18-89$ & $380 \xi$ & $\cdots$ & 50 & $<.5$ & $\cdots$ & $<1.0$ & $<5$ & -. & $<3$ & $<10$ \\
\hline
\end{tabular}


GROUND-WATER DATA-Continued

CHEMICAL ANALYSES-Continued

STATION

NAME

DATE

\begin{tabular}{|c|c|c|c|c|c|c|c|c|c|c|}
\hline DTE & $\begin{array}{c}\text { IRON, } \\
\text { DIS- } \\
\text { SOLVED } \\
\text { ( } \mu g / L \\
\text { as Fe) } \\
(01046)\end{array}$ & $\begin{array}{l}\text { LEAD, } \\
\text { DIS- } \\
\text { SOLVED } \\
\text { ( } \mu \mathrm{g} / \mathrm{L} \\
\text { aS Pb) } \\
(01049)\end{array}$ & $\begin{array}{l}\text { MANGA- } \\
\text { NESE, } \\
\text { DIS- } \\
\text { SOLVED } \\
(\mu g / L \\
\text { OS Mn) } \\
(01056)\end{array}$ & $\begin{array}{c}\text { MERCURY } \\
\text { DIS- } \\
\text { SOLVED } \\
\text { ( } \mu \mathrm{g} / \mathrm{L} \\
\text { as } \mathrm{Hg}) \\
(71890)\end{array}$ & $\begin{array}{c}\text { MOLYB- } \\
\text { DENUH, } \\
\text { DIS- } \\
\text { SOLVED } \\
(\mu g / L \\
\text { as MO) } \\
(01060)\end{array}$ & $\begin{array}{l}\text { NICKEL, } \\
\text { DIS- } \\
\text { SOLVED } \\
(\mu g / L \\
\text { as Ni) } \\
(01065)\end{array}$ & $\begin{array}{c}\text { SILVER, } \\
\text { DIS- } \\
\text { SOLVED } \\
\text { ( } \mu \mathrm{g} / \mathrm{L} \\
\text { os } A g) \\
(01075)\end{array}$ & $\begin{array}{c}\text { STRON- } \\
\text { TIUM, } \\
\text { DIS- } \\
\text { SOLVED } \\
\text { ( } \mu \mathrm{g} / \mathrm{L} \\
\text { as Sr) } \\
(01080)\end{array}$ & $\begin{array}{c}\text { VAMR- } \\
\text { DIUM, } \\
\text { DIS- } \\
\text { SOLVED } \\
(\mu \mathrm{g} / \mathrm{L} \\
\text { as V) } \\
(01085)\end{array}$ & $\begin{array}{c}\text { ZINC, } \\
\text { DIS- } \\
\text { SOLVED } \\
\text { ( } \mu g / L \\
\text { os Zn) } \\
(01090)\end{array}$ \\
\hline
\end{tabular}

GALLUP WELL CLUSTER-Continued

\begin{tabular}{|c|c|c|c|c|c|c|c|c|c|c|c|}
\hline GAL-2 & $10-24-90$ & 74 & $<10 i$ & $74 \xi$ & $\cdots$ & 3 & $<10$ & $<1.0$ & 540 & $<6$ & $<3$ \\
\hline GALDP-1 & $\begin{array}{l}05-17-90 \\
10-15-90\end{array}$ & $\begin{array}{c}48 \\
510 \xi\end{array}$ & $\begin{array}{l}<30 i \\
<10 i\end{array}$ & $\begin{array}{l}3400 \xi \\
1800 \xi\end{array}$ & -- & $\begin{array}{r}<30 \\
27\end{array}$ & $\begin{array}{l}<30 \\
<10\end{array}$ & $\begin{array}{l}<3.0 \\
<1.0\end{array}$ & $\begin{array}{l}3000 \\
1500\end{array}$ & $\begin{array}{r}<18 \\
<6\end{array}$ & $\begin{array}{l}9 \\
<3\end{array}$ \\
\hline
\end{tabular}

MORTH FORK PUERCO RIVER UELLS AMD DRIVE POINTS-COntinUed

\begin{tabular}{|c|c|c|c|c|c|c|c|c|c|c|c|}
\hline HIN-3U & $\begin{array}{l}01-11-89 \\
10-24-90\end{array}$ & $\begin{array}{r}40 \\
4\end{array}$ & $\begin{array}{l}<5 \\
<10 i\end{array}$ & $\begin{array}{c}120 \$ \\
23\end{array}$ & $\begin{array}{l}<.1 \\
-.\end{array}$ & $\begin{array}{l}2 \\
4\end{array}$ & $\begin{array}{r}2 \\
<10\end{array}$ & $\ddot{<1.0}$ & $\begin{array}{l}4600 \\
4100\end{array}$ & $\begin{array}{l}<1 \\
<6\end{array}$ & $\begin{array}{r}<10 \\
9\end{array}$ \\
\hline HIN-3L & $\begin{array}{l}01-11-89 \\
10-24-90\end{array}$ & 2800 t & 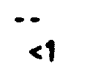 & $\ddot{1800 \mid}$ & $\begin{array}{l}-- \\
--\end{array}$ & -- & $\because 4$ & $<\ddot{1.0}$ & 5000 & $\because 6$ & $<\ddot{10}$ \\
\hline $\cos -3$ & $01-11-89$ & 160 & $<5$ & 10 & .4 & 200 & 3 & $\cdots$ & 610 & 4 & $<10$ \\
\hline CONDP-1 & $\begin{array}{l}03-30-89 \\
10-18-90 \\
06-10-91\end{array}$ & $\begin{array}{r}7 \\
34\end{array}$ & $\begin{array}{l}<5 \\
<10 i \\
<10 i\end{array}$ & $\begin{array}{l}1 \\
5\end{array}$ & $\begin{array}{c}<.1 \\
-- \\
--\end{array}$ & $\begin{array}{l}\cdots \\
50 \\
20\end{array}$ & $\begin{array}{r}3 \\
<10 \\
<10\end{array}$ & $\begin{array}{l}-- \\
<1.0 \\
<1.0\end{array}$ & $\begin{array}{r}1700 \\
740 \\
510\end{array}$ & $\begin{array}{l}-1 \\
46 \\
46\end{array}$ & $\begin{array}{r}210 \\
<3 \\
8\end{array}$ \\
\hline BLM-1U & $01-10-89$ & 160 & $<5$ & $210 \ddagger$ & $<.1$ & 1 & $<1$ & $\cdots$ & 1400 & $<1$ & 30 \\
\hline NF MELL & $11-18-89$ & -- & $\cdots$ & $\cdot-$ & $-\cdot$ & $\cdots$ & $-\cdot$ & $\cdots$ & -- & $\because$ & $\cdots$ \\
\hline NFOP- 1 & $03-30-89$ & $\cdots$ & $<5$ & -- & $<.1$ & -- & 2 & -- & 1400 & -- & 30 \\
\hline
\end{tabular}


GROUND-MATER DATA-Continued

CHEMICAL ANALYSES-Cont inued

STATION

MAME

$\begin{array}{cccc} & & & \\ & \text { ALUM- } & & \text { SELE- } \\ \text { INUN, } & \text { LITHIUN } & \text { NIUN, } \\ \text { DIS- } & \text { DIS- } & \text { DIS- } \\ & \text { SOLVED } & \text { SOLVED } & \text { SOLVED } \\ & (\mu g / L & (\mu g / L & (\mu g / L \\ \text { DATE } & \text { OS Al) } & \text { OS Li) } & \text { as Se) } \\ & (01106) & (01130) & (01145)\end{array}$

S-34/ H-2/ S-32 H-1 STABLE

ISOTOPE

STABLE

I SOTOPE

RATIO

PER

MIL

RATIO

PER

NIL

(82082)

$0-18 /$

$$
0-16
$$

STABLE

ISOTOPE

RATIO

PER

MIL

$\begin{array}{ccc} & \text { GROSS } & \text { ALPHA, } \\ & \text { ALPHA, } & \text { COUNT, } \\ \text { DIS- } & 2 \text { SIGMA } \\ & \text { SOLVED } & \text { WAT DIS } \\ \text { TRITIUN } & (\mu g / L & (\mu g / L \\ \text { TOTAL } & \text { aS } & \text { as } \\ (\text { PCi } / L) & U-n a t) & U-n a t) \\ (07000) & (80030) & (75986)\end{array}$

GALLUP WELL CLUSTER-Continued

\begin{tabular}{|c|c|c|c|c|c|c|c|c|c|c|}
\hline GAL-2 & $10-24-90$ & $\cdots$ & 24 & $<3$ & -. & $\cdots$ & $\cdots$ &.- & $27 \nmid$ & 3.8 \\
\hline GAL-3 & $\begin{array}{l}01-12-89 \\
10-24-90\end{array}$ & $\begin{array}{c}<10 \\
--\end{array}$ & --. & $\begin{array}{l}1 \\
<1\end{array}$ & $\begin{array}{c}-4.60 \\
\therefore-\end{array}$ & $\begin{array}{l}-87.0 \\
-.\end{array}$ & $\begin{array}{c}-11.70 \\
\cdots\end{array}$ & $\begin{array}{l}21 \\
-.\end{array}$ & $\begin{array}{l}47 \dagger \\
21 \uparrow\end{array}$ & $\begin{array}{l}6.2 \\
3.3\end{array}$ \\
\hline GAL -4 & $\begin{array}{l}01-12-89 \\
10-24-90\end{array}$ & $\begin{array}{l}10 \\
-.\end{array}$ & $\ddot{19}$ & $\begin{array}{l}<1 \\
<3\end{array}$ & -1.10 & $\begin{array}{l}-88.5 \\
-.\end{array}$ & $\begin{array}{c}-12.05 \\
\cdots\end{array}$ & $\begin{array}{l}<2.5 \\
-.\end{array}$ & $\begin{array}{l}18 \uparrow \\
16 \uparrow\end{array}$ & $\begin{array}{l}3.0 \\
2.8\end{array}$ \\
\hline GALDP-1 & $\begin{array}{l}05-17-90 \\
10-15-90\end{array}$ & 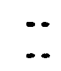 & $\begin{array}{r}110 \\
22\end{array}$ & $\because 2$ & 6.10 & $\begin{array}{c}-79.5 \\
\ldots\end{array}$ & $\begin{array}{c}-9.95 \\
--\end{array}$ & $\begin{array}{l}13 \\
--\end{array}$ & $\begin{array}{l}160 \dagger \\
110 \dagger\end{array}$ & $\begin{array}{l}43 \\
12\end{array}$ \\
\hline
\end{tabular}

NORTH FORK PUERCO RIVER WELLS AMD DRIVE POINTS-Cont inued

\begin{tabular}{|c|c|c|c|c|c|c|c|c|c|c|}
\hline HIN-3U & $\begin{array}{l}01-11-89 \\
10-24-90\end{array}$ & $\begin{array}{l}10 \\
--\end{array}$ & $\ddot{72}$ & $\begin{array}{r}1 \\
<3\end{array}$ & $\begin{array}{c}-13.00 \\
\cdots\end{array}$ & $\begin{array}{l}-83.0 \\
-.\end{array}$ & $\begin{array}{c}-11.15 \\
. .\end{array}$ & $\begin{array}{l}42 \\
-.\end{array}$ & $\begin{array}{l}140 \dagger \\
130 \dagger\end{array}$ & $\begin{array}{l}15 \\
14\end{array}$ \\
\hline WIN-3L & $\begin{array}{l}01-11-89 \\
10-24-90\end{array}$ & $\begin{array}{l}-\cdot \\
--\end{array}$ & 50 & $\ddot{<1}$ & $\begin{array}{c}-11.80 \\
-.\end{array}$ & $\begin{array}{l}-75.5 \\
-.\end{array}$ & $\begin{array}{c}-10.25 \\
-.\end{array}$ & $\begin{array}{l}<2.5 \\
--\end{array}$ & $\begin{array}{l}73 t \\
46 t\end{array}$ & $\begin{array}{l}8.5 \\
7.4\end{array}$ \\
\hline $\mathrm{CON}-3$ & $01-11-89$ & 80 & $\cdots$ & $54 p$ & -10.60 & -84.9 & -91.50 & $-\cdot$ & 7204 & 65 \\
\hline CONDP- 1 & $\begin{array}{l}03-30-89 \\
10-18-90 \\
06-10-91\end{array}$ & $\begin{array}{c}<10 \\
\ldots \\
\ldots\end{array}$ & $\begin{array}{l}\cdots \\
25 \\
21\end{array}$ & $\begin{array}{l}<1 \\
<1 \\
10\end{array}$ & $\begin{array}{l}-8.20 \\
-- \\
-6.10\end{array}$ & $\begin{array}{l}-84.0 \\
\cdots \\
\cdots\end{array}$ & $\begin{array}{c}-11.60 \\
\ldots \\
\ldots\end{array}$ & $\begin{array}{l}28 \\
\cdots \\
\cdots\end{array}$ & $\begin{array}{l}590+ \\
220 \dagger \\
110 \dagger\end{array}$ & $\begin{array}{l}58 \\
27 \\
12\end{array}$ \\
\hline BLA-IU & $01-10-89$ & 20 & -. & $<1$ & -14.90 & -86.5 & -11.55 & 73 & $12 \nmid$ & 2.3 \\
\hline MF WELL & $11-18-89$ & $\cdots$ & $\cdots$ & $\cdots$ & -- & -- & - & -- & 5.6 & -- \\
\hline NFDP-1 & $03-30-89$ & $<10$ & -. & $<1$ & -11.70 & -68.5 & -9.50 & 28 & $11 t$ & 3.3 \\
\hline NFDP-2 & $11-18-89$ & -. & 14 & -- & -11.20 & -88.0 & -12.95 & 22 & 3.7 & .90 \\
\hline
\end{tabular}


STATION

WAME

DATE
GROAND-HATER DATA-Cont inued

CHEMICAL ANALYSES-Cont inued

\begin{tabular}{|c|c|c|c|c|c|c|c|c|}
\hline \multirow[b]{2}{*}{$\begin{array}{l}\text { GROSS } \\
\text { ALPHA, } \\
\text { SUSP. } \\
\text { TOTAL } \\
\text { ( } \mu g / L \\
\text { as } \\
U-n a t) \\
(80040)\end{array}$} & \multicolumn{4}{|c|}{ CHEMICAL AMALYSES-Cont inued } & & & & \\
\hline & $\begin{array}{l}\text { CROSS } \\
\text { BETR, } \\
\text { DIS- } \\
\text { SOLVED } \\
\text { (PCi/L } \\
\text { os } \\
\text { Cs-137) } \\
(03515)\end{array}$ & $\begin{array}{c}\text { BETA, } \\
2 \text { SIGIA } \\
\text { WATER, } \\
\text { DISS, } \\
\text { (PCI/L } \\
\text { as } \\
\text { Cs-137) } \\
\text { (7S989) }\end{array}$ & $\begin{array}{c}\text { GROSS } \\
\text { BETA, } \\
\text { SUSP. } \\
\text { TOTAL } \\
\text { (pCi/L } \\
\text { as } \\
\text { Cs-137) } \\
(03516)\end{array}$ & $\begin{array}{c}\text { GROSS } \\
\text { BETA, } \\
\text { DISS. } \\
\text { (pCi/L } \\
\text { as } \\
S r-90 / \\
Y-90) \\
(80050)\end{array}$ & $\begin{array}{c}2 \text { SIGIA } \\
\text { WATER, } \\
\text { DISS, } \\
\text { (PCi/L } \\
\text { as } \\
\text { Sr-90/ } \\
Y-90) \\
(75988)\end{array}$ & $\begin{array}{c}\text { BETA, } \\
\text { SUSP. } \\
\text { TOTAL } \\
\text { (PCi/L } \\
\text { as } \\
S r-90 / \\
Y-90) \\
(80060)\end{array}$ & $\begin{array}{l}2 \text { SIGYA } \\
\text { SED, } \\
\text { SUSP, } \\
\text { TOT DRY } \\
\text { (PCi/G } \\
\text { Sr-90/ } \\
Y-90) \\
(76005)\end{array}$ & $\begin{array}{c}\text { Ra-226, } \\
\text { DIS- } \\
\text { SOLVED, } \\
\text { PLAN- } \\
\text { CHET } \\
\text { COUNT } \\
\text { (PCi/L) } \\
\text { (O9510) }\end{array}$ \\
\hline
\end{tabular}

GALLUP WELL CLUSTER-Continued

\begin{tabular}{|c|c|c|c|c|c|c|c|c|c|c|}
\hline GAL-2 & $10-24-90$ & -. & 19 & 4.1 & $\cdots$ & 15 & 3.1 & $-\cdot$ & $\cdots$ & .1 \\
\hline GAL-3 & $\begin{array}{l}01-12-89 \\
10-24-90\end{array}$ & $\begin{array}{l}<.6 \\
\therefore-\end{array}$ & $\begin{array}{l}12 \\
25\end{array}$ & $\begin{array}{l}3.1 \\
5.8\end{array}$ & $\begin{array}{l}7.5^{*} \\
\therefore-\end{array}$ & 19 & $\begin{array}{l}2.1 \\
5.0\end{array}$ & $7.4^{*}$ & $\begin{array}{l}1.3 \\
\cdots\end{array}$ & $\begin{array}{l}-. \\
.2\end{array}$ \\
\hline GAL-4 & $\begin{array}{l}01-12-89 \\
10-24-90\end{array}$ & $\therefore 7^{7 \star}$ & 115.2 & $\begin{array}{l}2.0 \\
3.4\end{array}$ & $2.6^{*}$ & $\begin{array}{l}3.4 \\
8.3\end{array}$ & $\begin{array}{l}1.3 \\
2.6\end{array}$ & $2.6^{\star}$ & $\therefore 70$ & $<$. \\
\hline GALDP-1 & $\begin{array}{l}05-17-90 \\
10-15-90\end{array}$ & $\begin{array}{l}\cdots \\
\cdots\end{array}$ & $\begin{array}{l}94 \\
77\end{array}$ & $\begin{array}{l}17 \\
11\end{array}$ & $\ddot{-.}$ & $\begin{array}{l}72 \\
58\end{array}$ & $\begin{array}{l}13 \\
8.2\end{array}$ & $\begin{array}{l}-- \\
\cdots\end{array}$ & $\ddot{-.}$ &.. \\
\hline
\end{tabular}

MORTH FORK PUERCO RIVER IELLS AND DRIVE POINTS-Cont inued

\begin{tabular}{|c|c|c|c|c|c|c|c|c|c|c|}
\hline HIN-3U & $\begin{array}{l}01-11-89 \\
10-24-90\end{array}$ & $\begin{array}{l}9.6^{\star} \\
\therefore-\end{array}$ & $\begin{array}{l}32 \\
54\end{array}$ & $19^{7.5}$ & $\begin{array}{l}37 * \\
\cdots\end{array}$ & $\begin{array}{l}21 \\
41\end{array}$ & $\begin{array}{l}5.0 \\
8.7\end{array}$ & $\begin{array}{l}32^{*} \\
-\end{array}$ & $\begin{array}{l}5.0 \\
\therefore\end{array}$ & $\begin{array}{l}* \\
<.1\end{array}$ \\
\hline HIN-3L & $\begin{array}{l}01-11-89 \\
10-24-90\end{array}$ & $\begin{array}{r}26 * \\
-.\end{array}$ & $\begin{array}{l}.31 \\
27\end{array}$ & $\begin{array}{l}14 \\
15\end{array}$ & $\begin{array}{l}27 * \\
-\cdot\end{array}$ & $\begin{array}{l}21 \\
21\end{array}$ & $\begin{array}{l}9.2 \\
12\end{array}$ & $\begin{array}{l}24 * \\
\cdots\end{array}$ & $\begin{array}{l}4.6 \\
\therefore-\end{array}$ & 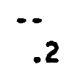 \\
\hline $\operatorname{con}-3$ & $01-11-89$ & 49 & 260 & 28 & $170 *$ & 180 & 20 & $150 *$ & 21 & -- \\
\hline CONDP-1 & $\begin{array}{l}03-30-89 \\
10-18-90 \\
06-10-91\end{array}$ & $\begin{array}{l}1.9 \\
\ldots \\
\ldots\end{array}$ & $\begin{array}{r}140 \\
150 \\
53\end{array}$ & $\begin{array}{l}16 \\
17 \\
6.4\end{array}$ & $\begin{array}{l}82 \\
\cdots \\
--\end{array}$ & $\begin{array}{r}90 \\
120 \\
39\end{array}$ & $\begin{array}{l}11 \\
13 \\
4.8\end{array}$ & $\begin{array}{l}79 \\
\cdots \\
--\end{array}$ & $\begin{array}{l}9.2 \\
\cdots \\
\cdots\end{array}$ & $\therefore 1$ \\
\hline$B L M-I U$ & $01-10-89$ & $23 *$ & 12 & 2.6 & $15 *$ & 7.7 & 1.7 & 13* & 3.2 & $\cdots$ \\
\hline NF WELL & $11-18-89$ & $\cdots$ & 9.9 & $\cdots$ & $\cdots$ & 8.6 & $\cdots$ & $\cdots$ & $\cdots$ & $-\cdot$ \\
\hline NFDP-1 & $03-30-89$ & $4.4^{\star}$ & 13 & 2.5 & $4.4 *$ & 9.2 & 1.8 & 3.9 & 1.1 & $\cdots$ \\
\hline NFDP-2 & $11-18-89$ & -. & 8. 6 & 1.5 & -. & 7.8 & 1.4 & -. & $\cdots$ & $-\cdot$ \\
\hline
\end{tabular}


GROUMD-WATER DATA-Cont inued

CHEMICAL AMALYSES-Continued

\begin{tabular}{|c|c|c|c|c|c|c|c|c|c|c|}
\hline $\begin{array}{l}\text { STATION } \\
\text { NAME }\end{array}$ & DATE & $\begin{array}{l}R a-226 \\
2 \text { SIGM } \\
\text { WATER, } \\
\text { DISS, } \\
\text { (PCi/i) } \\
\text { (76001) }\end{array}$ & $\begin{array}{l}\text { RADIUN } \\
\text {-226, } \\
\text { DIS- } \\
\text { SOLVED, } \\
\text { RADON } \\
\text { METHOD } \\
\text { (PCi/L) } \\
\text { (09511) }\end{array}$ & $\begin{array}{c}\text { RADIUA } \\
-228 \\
\text { DIS- } \\
\text { SOLVED } \\
\text { (pCi/L } \\
\text { as } \\
\text { Ra-228) } \\
(81366)\end{array}$ & $\begin{array}{l}\text { RADON } \\
-222 \\
\text { TOTAL } \\
\text { (PCi/L) } \\
(82303)\end{array}$ & $\begin{array}{l}\text { Rn-222 } \\
2 \text { SIGUA } \\
\text { WATER, } \\
\text { WHOLE, } \\
\text { TOTAL, } \\
\text { (pCi/i) } \\
\text { (76002) }\end{array}$ & $\begin{array}{l}\text { LEAD } \\
-210 \\
\text { DIS- } \\
\text { SOLVED } \\
\text { (pCi/L) } \\
(17503)\end{array}$ & $\begin{array}{l}\text { Pb-210 } \\
2 \text { SIGMA } \\
\text { WATER, } \\
\text { DISS, } \\
\text { (PCi/L) } \\
\text { (75995) }\end{array}$ & $\begin{array}{l}\text { POLO- } \\
\text { NIUM } \\
\text { - } 210 \\
\text { DIS- } \\
\text { SOLVED } \\
\text { (PCi/L) } \\
\text { (19503) }\end{array}$ & $\begin{array}{l}\text { URANIUM } \\
\text {-234 } \\
\text { UATER } \\
\text { DISSOLV } \\
\text { (PCi/L) } \\
\text { (22610) }\end{array}$ \\
\hline
\end{tabular}

\begin{tabular}{|c|c|c|c|c|c|c|c|c|c|c|}
\hline GAL-2 & $10-24-90$ & .100 & -. & -. & -. & $\cdots$ & $\cdots$ & $\cdots$ & $\cdots$ & 16 \\
\hline GAL -3 & $\begin{array}{l}01-12-89 \\
10-24-90\end{array}$ & $\begin{array}{l}.020 \\
.100\end{array}$ & .06 & $<1.0$ & 210 & $\begin{array}{l}58 \\
-\because\end{array}$ & $\ddot{-}$ & $\ddot{\prime}$ & $\ddot{-}$ & $\begin{array}{l}15 \\
15\end{array}$ \\
\hline $\mathrm{GAL}-4$ & $\begin{array}{l}01-12-89 \\
10-24-90\end{array}$ & .020 & .06 & $<1.0$ & 120 & $\begin{array}{l}78 \\
\cdots\end{array}$ & $\because \cdot$ & $\ddot{x}$ & 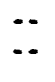 & $\begin{array}{l}7.6 \\
7.6\end{array}$ \\
\hline GALDP-1 & $\begin{array}{l}05-17-90 \\
10-15-90\end{array}$ & .00 & -. & $\begin{array}{r}<1.0 \\
\ldots\end{array}$ & $620 \uparrow$ & $\begin{array}{l}48 \\
-.\end{array}$ & $\ddot{~}$ & 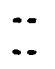 & $\ddot{-}$ & $\begin{array}{l}52 \\
46\end{array}$ \\
\hline
\end{tabular}

MORTH FORK PUERCO RIVER WELLS AND DRIVE POINTS-COntinued

\begin{tabular}{|c|c|c|c|c|c|c|c|c|c|c|}
\hline HIN-3U & $\begin{array}{l}01-11-89 \\
10-24-90\end{array}$ & $\begin{array}{r}.020 \\
10\end{array}$ & .09 & $<1.0$ & 200 & $\begin{array}{l}34 \\
\cdots\end{array}$ & $\begin{array}{l}\cdots \\
\cdots\end{array}$ & 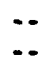 & 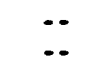 & $\begin{array}{l}67 \\
49\end{array}$ \\
\hline HIN-3L & $\begin{array}{l}01-11-89 \\
10-24-90\end{array}$ & .100 & 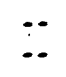 & -. & -. & 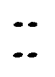 & -. & $\ddot{x}$ & 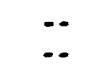 & $\ddot{19}$ \\
\hline CON-3 & $01-11-89$ & $\cdots$ & $\cdots$ & $\cdots$ & $1100 \nmid$ & 40 & .. & $\ldots$ & $\cdots$ & 320 \\
\hline CONDP-1 & $\begin{array}{l}03-30-89 \\
10-18-90 \\
06-10-91\end{array}$ & $\begin{array}{l}.040 \\
.100 \\
. .\end{array}$ & $\begin{array}{l}.21 \\
\cdots \\
\cdots\end{array}$ & $\begin{array}{r}<1.9 \\
\ldots \\
\ldots\end{array}$ & $\begin{array}{c}1100+ \\
\ldots \\
\ldots\end{array}$ & $\begin{array}{l}49 \\
\ldots \\
\ldots\end{array}$ & $\begin{array}{c}<1.5 \\
\ldots \\
\ldots\end{array}$ & $\begin{array}{l}\text { ND } \\
\cdots \\
\cdots\end{array}$ & $\begin{array}{c}<1.0 \\
\ldots \\
\cdots\end{array}$ & $\begin{array}{r}220 \\
95 \\
45\end{array}$ \\
\hline$B L M-1 U$ & $01-10-89$ & .030 & .18 & $<1.0$ & $580 \uparrow$ & 41 & $<1.5$ & ND & $<1.0$ & 4.4 \\
\hline NF MELL & $11-18-89$ & $\cdots$ & $\cdots$ & $\cdots$ & $\cdots$ & -. & -. & $\cdots$ & $\cdots$ & 5.7 \\
\hline NFDP - 1 & $03-30-89$ & .030 & .15 & $<1.2$ & $600 \uparrow$ & 46 & $<1.5$ & ND & $<1.0$ & 3.2 \\
\hline NFDP-2 & $11-18-89$ & -. & $\cdots$ & $<1.0$ & -. & $\cdots$ & $\cdots$ & $\cdots$ & $\cdots$ & 2.4 \\
\hline
\end{tabular}


GROUND-HATER DATA-Cont imued

CHEMICAL AKALYSES-Continued

STATION

MAME

GAL-2

GAL-3

GALDP-1

$10-24-90$

$01-12-89$

$10-24-90$

$01-12-89$

$10-24-90$

$05-17-90$

$10-15-90$

U-234
2 SI GMA
UATER,
DISS,
(pCi/L)
(75992)

$\begin{array}{ll}\text { URANIUM } & \text { U-235 } \\ -235 & 2 \text { SIGMA } \\ \text { UATER, } & \text { UATER, } \\ \text { DISS } & \text { DISS, } \\ \text { (PCi/L) } & (\text { PCi/L) } \\ (22620) & (75994)\end{array}$

$\begin{array}{ll}\text { URANIUN } & U-238 \\ -238 & 2 \text { SIGMA } \\ \text { WATER } & \text { WATER. }\end{array}$ DISSOLV DISS, $(\mathrm{pCi} / \mathrm{L}) \quad(\mathrm{pCi} / \mathrm{L})$ (22603) (75991)
URANIUN

MATURAL THORIUN Th-230

DIS- $-230 \quad 2$ SIGM Th-232

SOLVED DIS- MATER, MATER,

( $\mu \mathrm{g} / \mathrm{L}$ SOLVED DISS, DISS,

as U) (pCi/L) (pCi/L) (pCi/L)

$\begin{array}{llll}\text { (22703) (26503) (75997) (75976) } & \end{array}$

GALLUP WELL CLUSTER-Continued

$\begin{array}{rrrrrrrrr}1.6 & .4 & \text { ND } & 11 & 1.1 & 27 \uparrow & \ldots & \ldots & \ldots \\ 1.9 & .3 & .20 & 13 & 1.7 & \ldots & \ldots & \ldots & \ldots \\ 1.5 & .4 & \text { ND } & 12 & 1.2 & 27 \uparrow & \ldots & \ldots & \ldots \\ 1.0 & .1 & \text { NO } & 5.2 & .70 & \ldots & \ldots & \ldots & \ldots \\ .8 & .2 & \text { NO } & 5.2 & .50 & 13 \uparrow & \ldots & \ldots & \ldots \\ 5.3 & 2.1 & .50 & 50 & 5.1 & 140 \uparrow & \ldots & \ldots & \ldots \\ 0.9 & 1.0 & .10 & 41 & .90 & 140 \uparrow & \ldots & \ldots & \ldots\end{array}$

NORTK FORK PUERCO RIVER WELLS ANO DRIVE POINTS-Continued

\begin{tabular}{|c|c|c|c|c|c|c|c|c|c|c|}
\hline HIN-3U & $\begin{array}{l}01-11-89 \\
10-24-90\end{array}$ & $\begin{array}{l}8.3 \\
4.9\end{array}$ & $\begin{array}{l}1.9 \\
1.4\end{array}$ & $\begin{array}{l}.90 \\
.30\end{array}$ & $\begin{array}{l}54 \\
39\end{array}$ & $\begin{array}{l}7.0 \\
4.0\end{array}$ & 1201 & 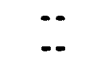 & $\because-$ & -- \\
\hline$H I N-3 L$ & $\begin{array}{l}01-11-89 \\
10-24-90\end{array}$ & $\ddot{2.0}$ &.. & 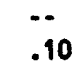 & $\ddot{13}$ & $1 . .4$ & $\ddot{401}$ & $\because-$ & $\because$ & 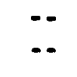 \\
\hline $\operatorname{con}-3$ & $01-11-89$ & 41 & 18 & 6.9 & 290 & 38 & $-\cdot$ & $\cdots$ & $\cdots$ & $\cdots$ \\
\hline CONDP-1 & $\begin{array}{l}03-30-89 \\
10-18-90 \\
06-10-91\end{array}$ & $\begin{array}{l}26 \\
9.8 \\
4.7\end{array}$ & $\begin{array}{r}12 \\
3.2 \\
1.5\end{array}$ & $\begin{array}{r}3.9 \\
.80 \\
.40\end{array}$ & $\begin{array}{r}220 \\
96 \\
42\end{array}$ & $\begin{array}{l}27 \\
9.9 \\
4.4\end{array}$ & $\begin{array}{l}2201 \\
1301\end{array}$ & $\begin{array}{c}<1.0 \\
\ldots \\
\ldots\end{array}$ & $\begin{array}{l}\text { No } \\
\therefore- \\
-\cdot\end{array}$ & $\begin{array}{c}<1.0 \\
\cdots \\
\cdots\end{array}$ \\
\hline$B L M-1 U$ & $01-10-89$ & .5 & .1 & NO & 2.8 & .30 & $\cdots$ & $<1.0$ & NO & $<1.0$ \\
\hline NF WELL & $11-18-89$ & $\cdots$ & .8 & $\cdots$ & 3.6 & $\cdots$ & $\cdots$ & $\cdots$ & $\cdot \cdot$ & $\cdots$ \\
\hline NFDP-1 & $03-30-89$ & .3 & $<.1$ & ND & 2.1 & .20 & $\cdots$ & $<1.0$ & No & $<1.0$ \\
\hline NFDP-2 & $11-18-89$ & .5 & .2 & .10 & 1.5 & .30 & 6.7 & $\cdots$ & -. & $\cdots$ \\
\hline
\end{tabular}


GROUND-MATER DATA-Continued

CHEMICAL ANALYSES-Continued

STATION
MAME
STATION NUMBER DATE TIME RATITUDE LOMGITUDE

MISCELLANEOUS PRIVATE WELLS, SPRINGS AND DRIVEPOINTS

\begin{tabular}{|c|c|c|c|c|c|}
\hline $\begin{array}{l}\text { PAULSELL RANCH, } \\
\text { PETRIFIED FOREST }\end{array}$ & 345757109482001 & $07-14-89$ & 1615 & $34^{\circ} 57 \cdot 57 m N$ & $109 \cdot 48 \cdot 20 \mathrm{mu}$ \\
\hline PETRIFIED FOREST-2 & 345850109475001 & $01-20-89$ & 1630 & $34 \cdot 58 \cdot 50 w N$ & $109 \cdot 47 \cdot 50$ ㅂy \\
\hline PAULSELL RANCH, PINTA & 350338109384801 & $07-12-89$ & 1200 & $35^{\circ} 03 \cdot 38 \times N$ & $109 \cdot 38 \cdot 4810 \mathrm{~W}$ \\
\hline WATERFALL WINDMILL & 351046109265401 & $05-10-90$ & 1210 & $35 \cdot 10 \cdot 44 \mathrm{WN}$ & $109 \cdot 26 \cdot 54 \mathrm{mH}$ \\
\hline CHAMBERS HIMOMILL & 351039109251301 & $05-10-90$ & 1000 & $35 \cdot 10 \cdot 39$ wN & $109 \cdot 25 \cdot 13 \mathrm{~mW}$ \\
\hline PEPLOTE MINOMILL & 350925109254201 & $05-10-90$ & 1535 & $35^{\circ} 09 \cdot 25^{\circ K}$ & $109 \cdot 25 \cdot 42$ पy \\
\hline ADOT YARD & 351202109233001 & $01-19-89$ & 1040 & $35^{\bullet} 12^{\prime} 02^{w N}$ & $109 \cdot 23 \cdot 33^{\mathrm{mW}}$ \\
\hline CEDAR POINT HINDMILL & 351311109183701 & $05-16-90$ & 1230 & $35^{\bullet} 14^{\prime} 00^{m N}$ & $109 \cdot 17 \cdot 02^{\prime 4}$ \\
\hline SAMDERS SCHOOL & 351254109194501 & $\begin{array}{l}08-04-88 \\
08-10-88 \\
08-10-88 \\
08-10-88 \\
08-10-88 \\
01-20-89 \\
05-09-90\end{array}$ & $\begin{array}{c}-. \\
1037 \\
1205 \\
1230 \\
1310 \\
1116 \\
1150\end{array}$ & $35 \cdot 12 \cdot 54^{\prime \prime} N$ & $109 \cdot 19 \cdot 45 \mathrm{~cm}$ \\
\hline NDOT INSPECTION STATION & 351325109191601 & $05-09-90$ & 1400 & $35 \cdot 13 \cdot 25$ min & $109^{\circ} 19 \cdot 16^{\mathrm{mW}}$ \\
\hline INDIAN RUINS & 351400109220001 & $\begin{array}{l}08-08-88 \\
01-18-89\end{array}$ & 1000 & $35^{\circ} 14^{\prime} 00^{\circ} \mathrm{N}$ & $109 \cdot 22 \cdot 00$ yㅐ \\
\hline INDIAN CITY & 352000109075001 & $01-18-89$ & 1700 & $355^{\circ} 20^{\prime} 00^{m} N$ & $109 \cdot 07 \cdot 50 \mathrm{MW}$ \\
\hline BEGAY MELL & 351933109041701 & $\begin{array}{l}05-08-90 \\
05-08-90\end{array}$ & $\begin{array}{l}1005 \\
1125\end{array}$ & $35^{\bullet} 19^{\prime} 33^{4 N}$ & $109^{\circ} 04^{\prime} 17^{\circ} \mathrm{W}$ \\
\hline MAVAHO RES $16 K-340$ & 353535108355005 & $10-23-90$ & 1545 & $35^{\circ} 35^{\prime} 35^{m N}$ & $108 \cdot 35 \cdot 50^{44} \mathrm{H}$ \\
\hline MATERFALL SPRING & 351047109265001 & $\begin{array}{l}08-11-88 \\
05-08-90\end{array}$ & $\begin{array}{l}1710 \\
1410\end{array}$ & $35 \cdot 10 \cdot 47 " N$ & $109^{\circ} 26^{\prime} 50^{\prime \prime W}$ \\
\hline HOLBROOK DP & 345351110094401 & $05-14-90$ & 1900 & $34 \cdot 53 \cdot 59 \cdot 1 \mathrm{~N}$ & $190.09 \cdot 44 \mathrm{WH}$ \\
\hline MAVAHO DP & 350719109320801 & $06-12-91$ & 1700 & $35^{\circ} 07^{\prime} 19 M_{N}$ & $109^{\circ} 32^{\prime} 08^{\prime \prime} \mathrm{W}$ \\
\hline ALLENTOWN DP & 351650109064801 & $06-11-91$ & 1715 & $35 \cdot 16 \cdot 50 m N$ & $109^{\circ} 09^{\prime} 15^{\mathrm{MW}}$ \\
\hline BLACK CREEK DP & 351645109130001 & $\begin{array}{l}05-16-90 \\
05-16-90\end{array}$ & $\begin{array}{l}1800 \\
1700\end{array}$ & $35 \cdot 16 \cdot 4511 N$ & $109 \cdot 13 \cdot 0014$ \\
\hline SOUTH FORK DP & 353232108384801 & $11-02-90$ & 1524 & $35 \cdot 32 \cdot 32^{\prime \prime N}$ & $108^{\circ} 38^{\prime} 48^{\prime \prime W}$ \\
\hline 8RIDGE-83 DP & 353056108504401 & $\begin{array}{l}03-29-89 \\
10-16-90\end{array}$ & 1635 & $35^{\circ} 30^{\prime} 56^{\prime \prime N}$ & $108.50 \cdot 44^{\circ} \mathrm{W}$ \\
\hline RIO PUERCO DP & 354020107043301 & $05-18-90$ & 1630 & $35 \cdot 40 \cdot 201 \mathrm{~N}$ & $107^{\circ} 04^{\prime} 33^{\prime \prime} \mathrm{W}$ \\
\hline
\end{tabular}


STATIOA

MAME
GROUND-WATER DATA-Continued

CHEMICAL AKALYSES-Continued

\begin{tabular}{|c|c|c|c|c|c|c|}
\hline $\begin{array}{l}\text { ALIIITUDE } \\
\text { OF LAND } \\
\text { SURFACE } \\
\text { DATUN } \\
\text { (METERS } \\
\text { ABOVE } \\
\text { NGVD) } \\
(72000)\end{array}$ & $\begin{array}{l}\text { DEPTH } \\
\text { OF } \\
\text { WELL, } \\
\text { TOTAL } \\
\text { (METERS } \\
\text { (72008) }\end{array}$ & $\begin{array}{l}\text { DEPTH } \\
\text { BELOH } \\
\text { LAND } \\
\text { SURFACE } \\
\text { (MATER } \\
\text { LEVEL) } \\
\text { (METERS) } \\
\text { (72019) }\end{array}$ & $\begin{array}{l}\text { PUNP } \\
\text { OR FLON } \\
\text { PERIOO } \\
\text { PRIOR } \\
\text { TO SAH- } \\
\text { PLING } \\
\text { (MIN) } \\
\text { (T2004) }\end{array}$ & $\begin{array}{l}\text { FLOW } \\
\text { RATE, } \\
\text { INSTAN- } \\
\text { TANEOUS } \\
\left(m^{3} / s\right) \\
(00059)\end{array}$ & $\begin{array}{c}\text { TEMPER- } \\
\text { ATURE } \\
\text { WATER } \\
\left({ }^{\circ} \mathrm{C}\right) \\
(00010)\end{array}$ & $\begin{array}{l}\text { TUR- } \\
\text { BID- } \\
\text { ITY } \\
\text { (NTU) } \\
(00076)\end{array}$ \\
\hline
\end{tabular}

MISCELLANEOUS PRIVATE WELLS, SPRINGS AND DRIVEPOINTS-Continued

\begin{tabular}{|c|c|c|c|c|c|c|c|c|}
\hline $\begin{array}{l}\text { PAULSELL RANCH, } \\
\text { PETRIFIEO FOREST }\end{array}$ & $07-14-89$ & 1620 & 13.7 & 4.36 & $\cdots$ & $\cdots$ & 18.0 & $\cdots$ \\
\hline PETRIFIED FOREST-2 & $01-20-89$ & 1620 & 33.5 & $\cdots$ & $\cdots$ & -. & 16.0 & 1.1 \\
\hline PAULSELL RANCH, PINTA & $07-12-89$ & 1670 & 16.8 & $\cdots$ & $\cdots$ & .0038 & 16.5 & $\cdots$ \\
\hline WATERFALL WINOMILL & $05-10-90$ & 1750 & $\cdots$ & $\cdots$ & 1 & .0019 & 15.0 & $\cdots$ \\
\hline CHAMBERS HINDMILL & $05-10-90$ & 1820 & $\cdots$ & $\cdots$ & $\cdots$ & .0019 & 17.0 & $\cdots$ \\
\hline PEPLOTE UINDMILL & $05-10-90$ & 1850 & 61.0 & $\cdots$ & $\cdots$ & $\cdots$ & 16.0 & $\cdots$ \\
\hline ADOT YARD & $01-19-89$ & 1760 & $\cdots$ & $\cdots$ & $\cdots$ & $\cdots$ & 15.5 & .70 \\
\hline CP HINOHILL & $05-16-90$ & 1800 & 22.9 & $\cdots$ & $\cdots$ & $\cdots$ & 17.5 & $\cdots$ \\
\hline SANDERS SCHOOL & $\begin{array}{l}08-04-88 \\
08-10-88 \\
08-10-88 \\
08-10-88 \\
08-10-88 \\
01-20-89 \\
05-09-90\end{array}$ & !770 & 48.8 & $\begin{array}{l}\ldots \\
\ldots \\
\ldots \\
\ldots \\
\ldots \\
\ldots\end{array}$ & $\begin{array}{c}\ldots \\
\ldots \\
\ldots \\
\ldots \\
\ldots \\
\ldots \\
155\end{array}$ & 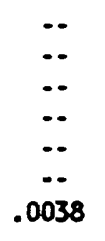 & $\begin{array}{l}\cdots \\
17.0 \\
13.5 \\
13.5 \\
13.5 \\
13.0 \\
14.0\end{array}$ & $\begin{array}{l}\ldots \\
\ldots \\
\ldots \\
.50 \\
\ldots \\
.60 \\
\ldots\end{array}$ \\
\hline ADOT INSP. STATION & $05-09-90$ & 1790 & $\cdots$ & $\cdots$ & $\cdots$ & $-\cdot$ & 14.5 & $\cdots$ \\
\hline INDIAN RUINS & $\begin{array}{l}08-08-88 \\
01-18-89\end{array}$ & 1870 & - & $\cdots$ & $\cdots$ & -. & 15.5 & $14^{\cdots}$ \\
\hline INOIAN CITY & $01-18-89$ & 2010 & $\cdots$ & $\cdots$ & $\cdots$ & $\cdots$ & 20.5 & .90 \\
\hline BEGAY IELLL & $\begin{array}{l}05-08-90 \\
05-08-90\end{array}$ & 1860 & 3.07 & $\begin{array}{l}2.1 \\
2.1\end{array}$ & $\begin{array}{l}60 \\
60\end{array}$ & $\begin{array}{l}.0038 \\
.0038\end{array}$ & $\begin{array}{l}11.5 \\
11.5\end{array}$ & $\cdots$ \\
\hline NAVAHO RES $16 \mathrm{~K}-340$ & $10-23-90$ & 2040 & 43.0 & $\cdots$ & $\cdots$ & $\cdots$ & 11.0 & $\cdots$ \\
\hline WATERFALL SPRING & $\begin{array}{l}08-10-88 \\
05-08-90\end{array}$ & 1740 & $\cdots$ & $\cdots$ & $\cdots$ & .0019 & 13.0 & $\cdots$ \\
\hline HOLBROOK OP & $05-14-90$ & $\cdots$ & $\cdots$ & $\cdots$ & $-\cdot$ & $\cdots$ & 17.0 & $\cdots$ \\
\hline MAVAHO DP & $06-12-91$ & 1710 & 1.46 & $\cdots$ & 20 & .0004 & 17.5 & $\cdots$ \\
\hline ALLENTOWN DP & $06-11-91$ & 1830 & 1.46 & .49 & 35 & .0004 & 14.0 & $\cdots$ \\
\hline BLACK CREEK DP & $\begin{array}{l}05-16-90 \\
05-16-90\end{array}$ & 1840 & $\begin{array}{l}1.22 \\
-\cdots\end{array}$ & .35 & $\cdots$ & $\cdots$ & $\begin{array}{l}12.5 \\
12.5\end{array}$ & $\begin{array}{l}\ddot{ } \\
\cdots\end{array}$ \\
\hline SOUTH FORK DP & $11-02-90$ & 2010 & $\cdots$ & $\cdots$ & 34 & $\cdots$ & 9.0 & $\cdots$ \\
\hline BRIDGE-83 DP & $\begin{array}{l}03-29-89 \\
10-16-90 \\
06-11-91\end{array}$ & 1930 & $\begin{array}{l}\ldots \\
1.46\end{array}$ & $\begin{array}{l}.061 \\
\ldots\end{array}$ & 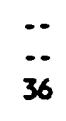 & $\begin{array}{c}. . \\
.0008 \\
.0004\end{array}$ & $\begin{array}{l}12.5 \\
10.0 \\
17.5\end{array}$ & $\begin{array}{c}3.0 \\
\cdots \\
\cdots\end{array}$ \\
\hline RIO PUERCO DP & $05-18-90$ & 1800 & 1.22 & $\cdots$ & $\cdots$ & $\cdots$ & $\cdots$ & $\cdots$ \\
\hline
\end{tabular}


ROUND-WATER OATA-Cont imued

CHEMICAL ANALYSES-Contimed

\begin{tabular}{|c|c|c|c|c|c|c|c|c|c|}
\hline $\begin{array}{l}\text { STATION } \\
\text { MAME }\end{array}$ & DATE & $\begin{array}{l}\text { OXID- } \\
\text { ATION } \\
\text { RED- } \\
\text { UCTION } \\
\text { POTEN- } \\
\text { TIAL } \\
\text { (mN) } \\
\text { (00090) }\end{array}$ & $\begin{array}{l}\text { SPE- } \\
\text { CIFIC } \\
\text { CON- } \\
\text { OUCT- } \\
\text { ANCE } \\
\text { ( } \text { SS/Cm) } \\
(00095)\end{array}$ & $\begin{array}{l}\text { SPE- } \\
\text { CIFIC } \\
\text { CON- } \\
\text { DUCT- } \\
\text { AMCE } \\
\text { LAB } \\
(\mu S / \mathrm{cm}) \\
(90095)\end{array}$ & $\begin{array}{l}\text { OXYGEN, } \\
\text { DIS- } \\
\text { SOLVEO } \\
(\mathrm{m} / \mathrm{L}) \\
(00300)\end{array}$ & $\begin{array}{l}\text { OXYGEN } \\
\text { OEMAND, } \\
\text { CHEM- } \\
\text { ICAL } \\
\text { (HIGH } \\
\text { LEVEL) } \\
\text { (mg/L) } \\
\text { (OO34O) }\end{array}$ & $\begin{array}{l}\text { PH } \\
\text { WATER } \\
\text { WHOLE } \\
\text { FIELD } \\
\text { (STAND- } \\
\text { ARD } \\
\text { UNITS) } \\
\text { (O04OO) }\end{array}$ & $\begin{array}{c}\text { PH } \\
\text { WATER } \\
\text { WHOLE } \\
\text { LAB } \\
\text { (STAND- } \\
\text { ARD } \\
\text { UN1TS) } \\
\text { (00403) }\end{array}$ & $\begin{array}{l}\text { ALKA- } \\
\text { LINITY } \\
\text { WAT OIS } \\
\text { FIX END } \\
\text { FIELO } \\
\text { CaCO3 } \\
(\text { mo/L) } \\
(39036)\end{array}$ \\
\hline
\end{tabular}

mISCELLANEOUS PRIVATE WELLS, SPRIMGS ANO ORIVEPOINTS-Continued

\begin{tabular}{|c|c|c|c|c|c|c|c|c|c|}
\hline $\begin{array}{l}\text { PAULSELL RANCH, } \\
\text { PETRIFIED FOREST }\end{array}$ & $07-14-89$ & -- & 2820 & 2790 & .3 & 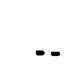 & 8.1 & 8.1 & 700 \\
\hline PETRIFIED FOREST-2 & $01-20-89$ & -5 & 1500 & 1520 & ND & $<10$ & 7.6 & 7.9 & 450 \\
\hline PAULSELL, RANCh PINTA & $07-12-89$ & -- & 1390 & 1400 & .4 & -- & 7.8 & 8.0 & 340 \\
\hline WATERFALL MIMDNILL & $05-10-90$ & 301 & 1510 & 1670 & 6.0 & -- & 8.5 & -- & 590 \\
\hline CHAMBERS HIMDMILL & $05-10-90$ & 288 & 1670 & 1630 & 4.8 & $\cdots$ & 9.0 & $\cdots$ & 590 \\
\hline PEPLOTE HIMOHILL & $05-10-90$ & 290 & 390 & 371 & 5.6 & -- & 7.8 & -- & 120 \\
\hline ADOT YARD & $01-19-89$ & -90 & 2210 & 2190 & MD & 30 & 8.6 & 8.9 & 1020 \\
\hline CP MINOHILL & $05-16-90$ & 189 & 1220 & 1200 & 1.8 & $\cdots$ & 7.4 & 7.8 & 240 \\
\hline SANDERS SCHOOL & $\begin{array}{l}08-04-88 \\
08-10-88 \\
08-10-88 \\
08-10-88 \\
08-10-88 \\
01-20-89 \\
05-09-90\end{array}$ & $\begin{array}{r}-- \\
-- \\
-- \\
229 \\
-- \\
50 \\
205\end{array}$ & $\begin{array}{l}1160 \\
1140 \\
1140 \\
1140 \\
1160 \\
1150\end{array}$ & $\begin{array}{c}1350 \\
-- \\
-- \\
1150 \\
-- \\
1150 \\
1150\end{array}$ & $\begin{array}{l}.3 \\
\text { ND } \\
-. \\
\text { ND } \\
-. \\
\text { ND } \\
.1\end{array}$ & $\begin{array}{l}-- \\
-- \\
-- \\
-- \\
-- \\
<10 \\
--\end{array}$ & $\begin{array}{l}7.6 \\
7.4 \\
7.4 \\
7.4 \\
7.4 \\
7.2 \\
7.4\end{array}$ & $\begin{array}{l}-- \\
-- \\
-- \\
7.8 \\
-. \\
7.7 \\
7.9\end{array}$ & $\begin{array}{r}\ldots \\
-. \\
-. \\
221 \\
-. \\
240 \\
230\end{array}$ \\
\hline ADOT INSP. STATION & $05-09-90$ & $\cdots$ & 1270 & 1260 & ND & -- & 7.2 & 7.6 & 230 \\
\hline INDIAN RUINS & $\begin{array}{l}08-08-88 \\
01-18-89\end{array}$ & 88 & $\ddot{862}$ & $\begin{array}{l}991 \\
863\end{array}$ & $\begin{array}{l}1.1 \\
\text { ND }\end{array}$ & $<10$ & $\begin{array}{l}7.3 \\
6.9\end{array}$ & $\overline{7.5}$ & 259 \\
\hline INDIAN CITY & $01-18-89$ & 270 & 911 & 896 & 2.7 & $<10$ & 6.8 & 7.6 & 244 \\
\hline BEGAY WELL & $\begin{array}{l}05-08-90 \\
05-08-90\end{array}$ & $\begin{array}{l}311 \\
311\end{array}$ & $\begin{array}{l}3270 \\
3270\end{array}$ & $\begin{array}{l}3210 \\
3180\end{array}$ & $\begin{array}{l}7.9 \\
7.9\end{array}$ & -- & $\begin{array}{l}8.1 \\
8.1\end{array}$ & $\begin{array}{l}8.1 \\
8.2\end{array}$ & $\begin{array}{c}350 \\
\ldots\end{array}$ \\
\hline NAVAHO RES $16 K-340$ & $10-23-90$ & 284 & 1690 & 1750 & 3.1 & -- & 7.3 & 8.0 & 580 \\
\hline WATERFALL SPRING & $\begin{array}{l}08-10-88 \\
05-08-90\end{array}$ & $\begin{aligned}-- \\
269\end{aligned}$ & $\ddot{1170}$ & $\ddot{1150}$ & $\overline{1.1}$ & $\begin{array}{l}-- \\
--\end{array}$ & $\ddot{7.7}$ & $\ddot{8.0}$ & $\begin{array}{r}220 \\
--\end{array}$ \\
\hline HOLBROOK DP & $05-14-90$ & 79 & 1700 & 1680 & 2.2 & $\cdots$ & 7.5 & 7.8 & 2000 \\
\hline MAVAMO DP & $06-12-91$ & $\pi$ & 2050 & 2040 & .7 & $\cdots$ & 7.1 & 7.5 & 460 \\
\hline ALLENTON DP & $06-11-91$ & 138 & 1450 & 1430 & 1.3 & $\cdots$ & 6.9 & 7.4 & 390 \\
\hline BLACK CREEK DP & $\begin{array}{l}05-16-90 \\
05-16-90\end{array}$ & $\begin{array}{l}22 \\
--\end{array}$ & $\begin{array}{l}916 \\
916\end{array}$ & $\begin{array}{l}909 \\
906\end{array}$ & .3 & $\begin{array}{l}-- \\
--\end{array}$ & $\begin{array}{l}7.6 \\
7.6\end{array}$ & $\begin{array}{l}7.9 \\
7.9\end{array}$ & 340 \\
\hline SOUTH FORK OP & $11-02-90$ & 272 & 508 & 487 & .3 & -- & 7.3 & 7.9 & 100 \\
\hline BR1OGE-83 OP & $\begin{array}{l}03-29-89 \\
10-16-90 \\
06-11-91\end{array}$ & $\begin{array}{r}204 \\
-\therefore \\
97\end{array}$ & $\begin{array}{l}1710 \\
2310\end{array}$ & $\begin{array}{r}475 \\
1490 \\
2280\end{array}$ & $\begin{array}{r}.4 \\
9.0 \\
.7\end{array}$ & $\begin{array}{l}48 \\
-- \\
--\end{array}$ & $\begin{array}{l}7.2 \\
8.0 \\
7.1\end{array}$ & $\begin{array}{l}7.8 \\
7.6 \\
7.4\end{array}$ & $\begin{array}{l}480 \\
230 \\
410\end{array}$ \\
\hline RIO PUERCO OP & $05-18-90$ & 86 & 2740 & 2850 & $<1$ & $\cdots$ & E7.4 & 7.4 & 380 \\
\hline
\end{tabular}


GROUND-HATER DATA-Contimed

CHEMICAL AHALYSES-Continued

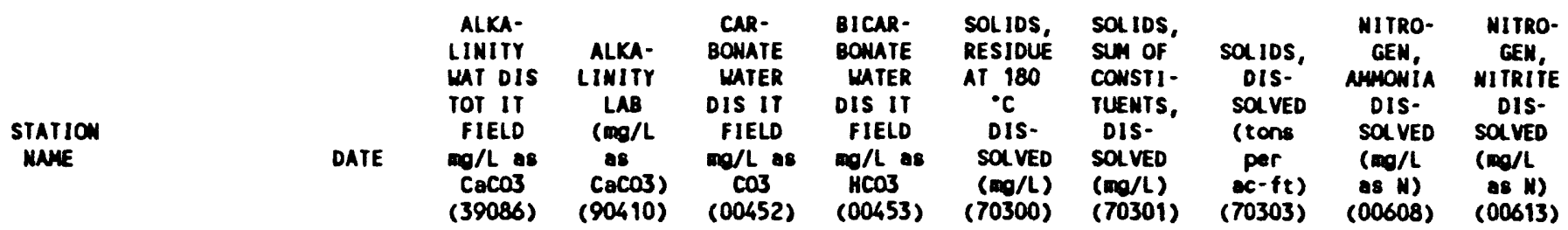

miscellakeQUS PRIVATE MELLS, SPRINGS AND DRIVEPOINTS-Continued

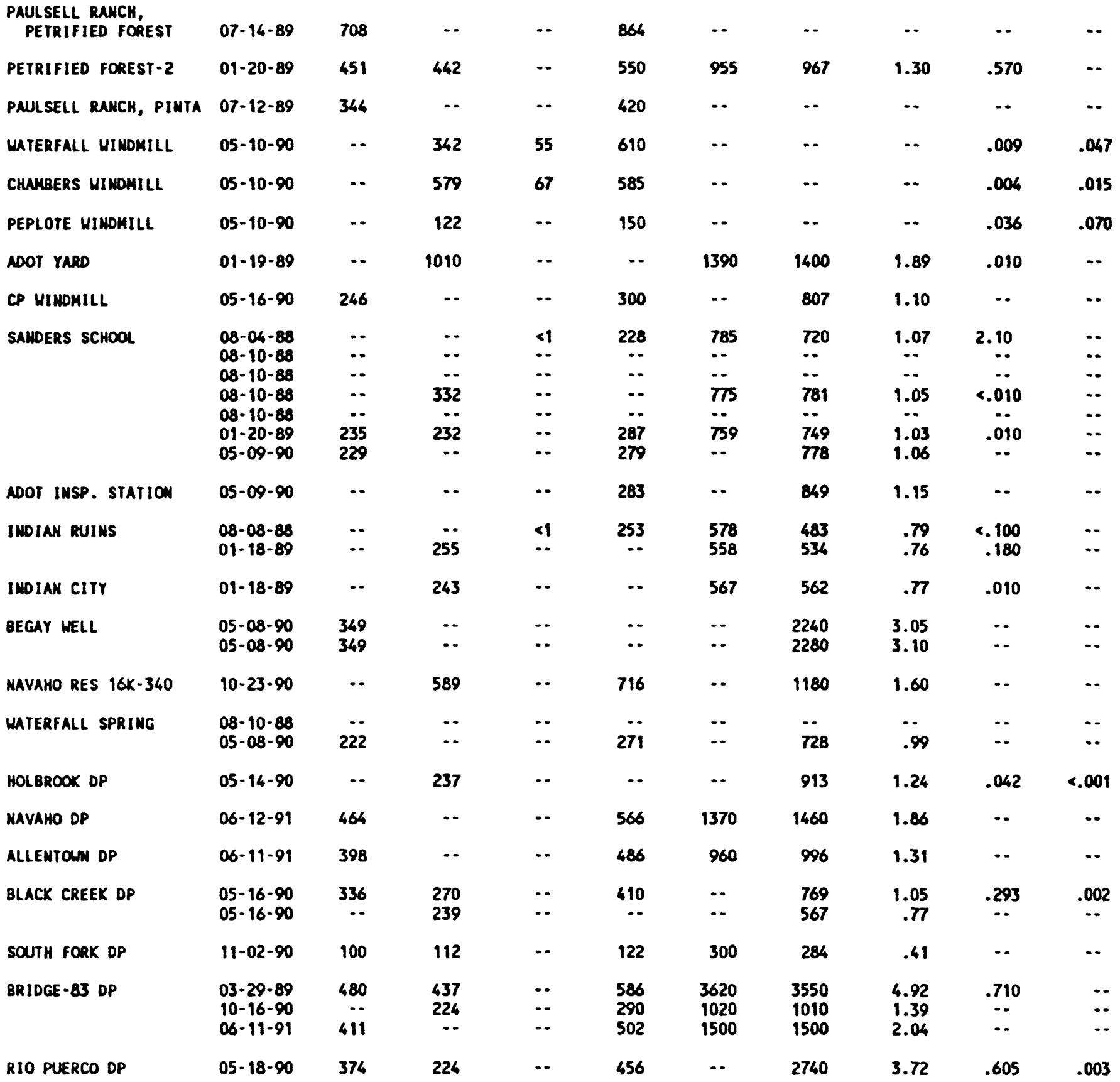


GROUND-MATER DATA-Continued

CHEMICAL AMALYSES-Continued

STATIOW

MAME

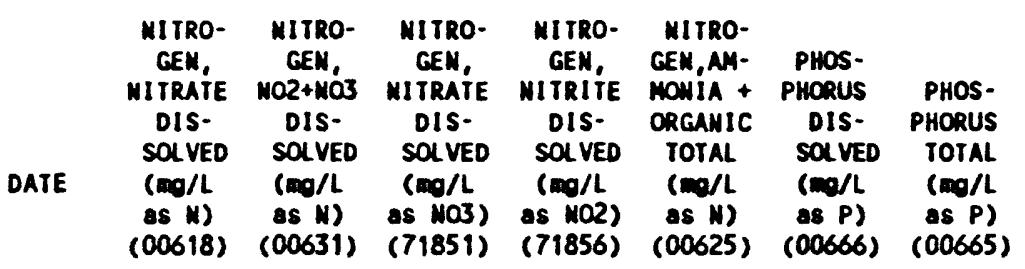

PHOS- PHOS-

PHORUS PHATE, CAR8ON,

ORTHO, ORTHO, ORGAMIC

DIS- DIS- DIS-

SOLVED SOLVED SOLVED

$(m / L) \quad(m / L / L \quad(m / L$

as P) 88 PO4) 88 C)

(00671) $(00660)(00681)$

MISCELLAMEQUS PRIVATE WELLS, SPRIMGS AMD DRIVEPOINTS-Continued

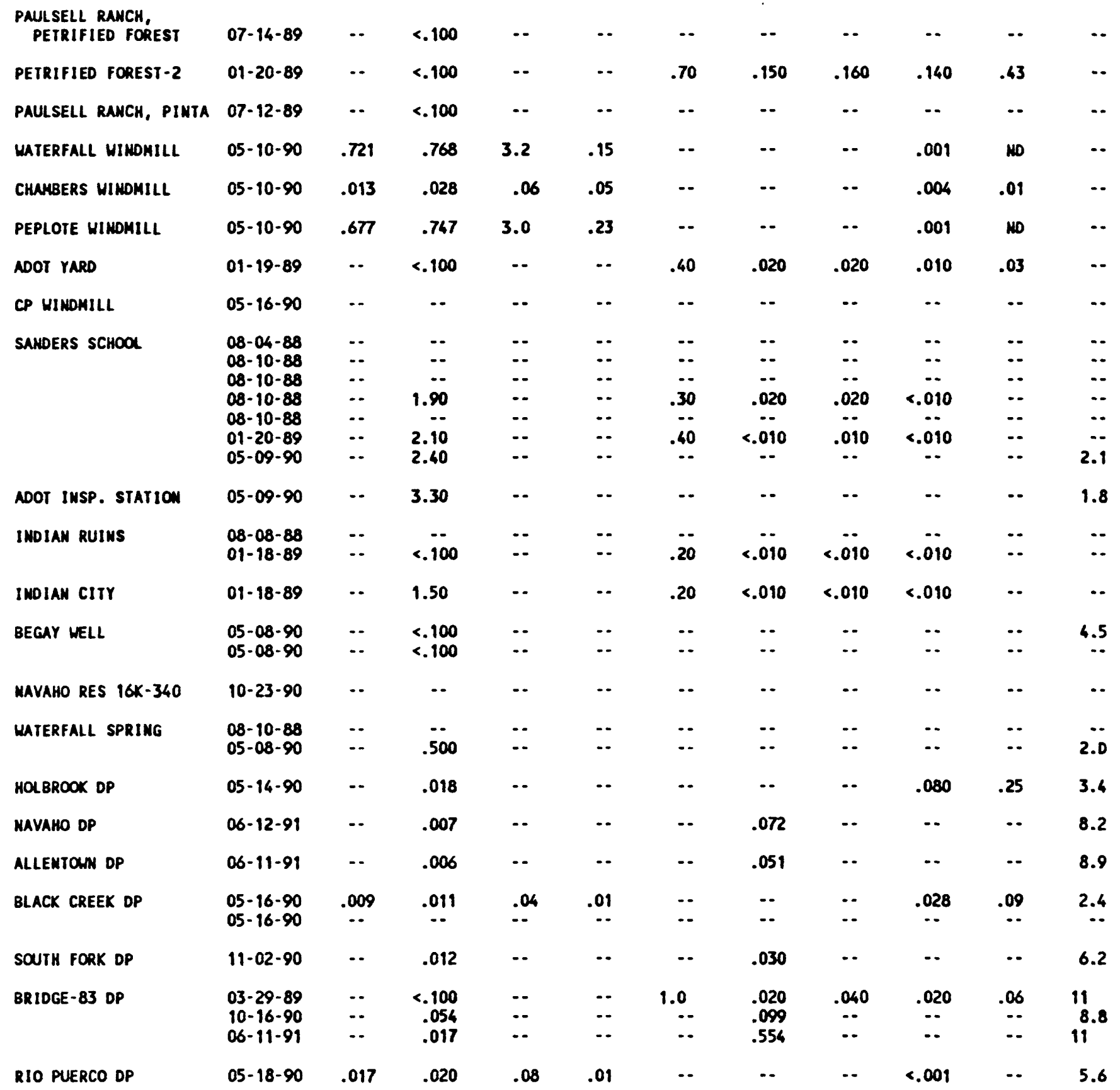


GROUND-WATER DATA-Cont irued

CHEMICAL ANALYSES-Contimued

STATION

MAME

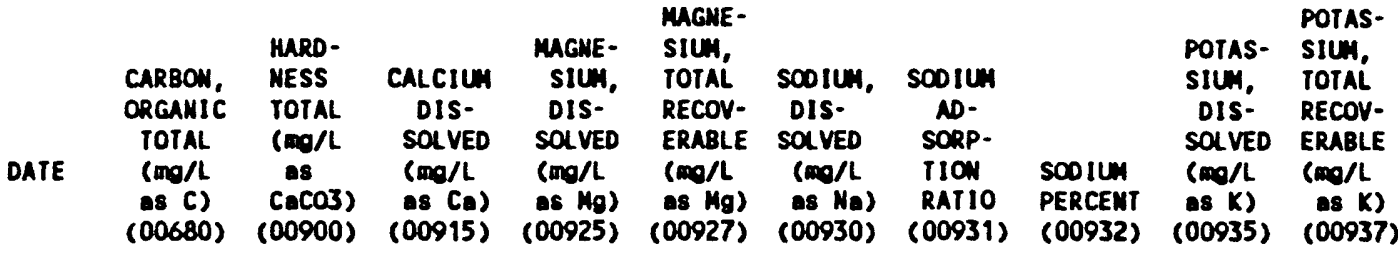

MISCELLANEOUS PRIVATE vELLS, SPRINGS AND DRIVEPOINTS-continued

\begin{tabular}{|c|c|c|c|c|c|c|c|c|c|c|c|}
\hline $\begin{array}{l}\text { PAULSELL RANCH, } \\
\text { PETRIFIED FOREST }\end{array}$ & $07-14-89$ & 4.2 & 37 & 10 & 2.7 & $\cdots$ & 620 & 45 & $\cdots$ & $\cdots$ & $\cdots$ \\
\hline PETRIFIED FOREST-2 & $01-20-89$ & 2.9 & 88 & 25 & 6.1 & $\cdots$ & 320 & 15 & 89 & 2.2 & $\cdots$ \\
\hline PAULSELL RAMCH, PIMTA & $07-12-89$ & 1.7 & 160 & 44 & 11 & $\cdots$ & 250 & 9 & $\cdots$ & $\cdots$ & $\cdots$ \\
\hline WATERFALL MIMOM & $05-10-90$ & $\cdots$ & $\cdots$ & $\cdots$ & $\cdots$ & $\cdots$ & $\cdots$ & $\cdots$ & $\cdots$ & $\cdots$ & $\cdots$ \\
\hline CHAMBERS HINONI & $05-10-90$ & $\cdots$ & $\cdots$ & $\cdots$ & $\cdots$ & $\cdots$ & $\cdots$ & $-\cdot$ & $\cdots$ & $\cdots$ & $\cdots$ \\
\hline PEPLOTE MIMONIL & $05-10-90$ & $\cdots$ & $\cdots$ & $\cdots$ & $\cdots$ & $\cdots$ & $\cdots$ & $\cdots$ & $\cdots$ & $\cdots$ & $\cdots$ \\
\hline ADOT YARD & $01-19-89$ & 20 & 7 & 2.2 & .40 & $\cdots$ & 580 & 94 & $\varphi$ & 5.8 & $\cdots$ \\
\hline CP MINDHILL & $05-16-90$ & $\cdots$ & 390 & 120 & 22 & $\cdots$ & 110 & 2 & 38 & 1.0 & -. \\
\hline SAMDERS SCHOOL & $\begin{array}{l}08-04-88 \\
08-10-88 \\
08-10-88 \\
08-10-88 \\
08-10-88 \\
01-20-89 \\
05-09-90\end{array}$ & $\begin{array}{l}\cdots \\
\cdots \\
\cdots \\
\cdots \\
\ddot{3.2} \\
\cdots\end{array}$ & $\begin{array}{c}310 \\
\ldots \\
\cdots \\
320 \\
\ddot{290} \\
300\end{array}$ & $\begin{array}{l}97 \\
\cdots \\
\cdots \\
99 \\
\cdots \\
89 \\
93\end{array}$ & $\begin{array}{l}17 \\
\cdots- \\
\cdots \\
17 \\
\therefore- \\
16 \\
16\end{array}$ & $\begin{array}{l}19 \\
\cdots \\
\ldots \\
\cdots \\
\cdots \\
\cdots \\
--\end{array}$ & $\begin{array}{c}130 \\
\ldots \\
\cdots \\
140 \\
\cdots \\
130 \\
140\end{array}$ & $\begin{array}{l}3 \\
\therefore \\
\therefore \\
3 \\
- \\
3 \\
4\end{array}$ & $\begin{array}{l}48 \\
\cdots \\
\cdots \\
49 \\
\cdots \\
49 \\
50\end{array}$ & $\begin{array}{c}2.9 \\
\because . \\
\cdots \\
1.9 \\
\because .2 \\
2.2 \\
1.9\end{array}$ & $\begin{array}{l}2.8 \\
\because- \\
\cdots \\
\cdots \\
\cdots \\
\cdots\end{array}$ \\
\hline ADOT INSP. STATION & $05-09-90$ & $\cdots$ & 490 & 130 & 39 & $\cdots$ & 90 & 2 & 29 & 4.9 & $\cdots$ \\
\hline $\begin{array}{l}\text { INDIAN RUINS } \\
\text { INOIAN CITY }\end{array}$ & $\begin{array}{l}08-08-88 \\
01-18-89 \\
01-18-89\end{array}$ & $\begin{array}{l}-. \\
4.2 \\
1.9\end{array}$ & $\begin{array}{l}370 \\
380 \\
340\end{array}$ & $\begin{array}{r}110 \\
110 \\
89\end{array}$ & $\begin{array}{l}23 \\
24 \\
29\end{array}$ & $\begin{array}{l}24 \\
-- \\
\cdots\end{array}$ & $\begin{array}{l}31 \\
33 \\
50\end{array}$ & .7 & $\begin{array}{l}15 \\
16 \\
26\end{array}$ & $\begin{array}{l}4.6 \\
4.1 \\
2.9\end{array}$ & $\begin{array}{l}4.4 \\
\cdots \\
\cdots\end{array}$ \\
\hline BEGAY MELL & $\begin{array}{l}05-08-90 \\
05-08-90\end{array}$ & $\begin{array}{l}\cdots \\
\cdots\end{array}$ & $\begin{array}{l}470 \\
480\end{array}$ & $\begin{array}{l}140 \\
140\end{array}$ & $\begin{array}{l}29 \\
30\end{array}$ & $\begin{array}{l}-- \\
--\end{array}$ & $\begin{array}{l}600 \\
620\end{array}$ & $\begin{array}{l}12 \\
12\end{array}$ & $\begin{array}{l}73 \\
74\end{array}$ & $\begin{array}{l}3.7 \\
4.5\end{array}$ & 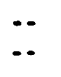 \\
\hline MAVAHO RES $16 K-340$ & $10-23-90$ & $\cdots$ & 490 & 130 & 40 & -- & 210 & 4 & 48 & 3.0 & $\cdots$ \\
\hline WATERFALL SPRING & $\begin{array}{l}08-10-88 \\
05-08-90\end{array}$ & $\cdots$ & $\ddot{190}$ & $\ddot{54}$ & $\ddot{12}$ & $\because-$ & $\ddot{180}$ & $-\overline{6}$ & 67 & $\ddot{8.4}$ & $\because$ \\
\hline HOL BROOK DP & $05-16-90$ & $\cdots$ & 290 & 83 & 20 & $\cdots$ & 230 & 6 & 63 & 3.8 & $\cdots$ \\
\hline MAVAHO DP & $06-12-91$ & $\cdots$ & 350 & 100 & 24 & $\cdots$ & 400 & 9 & 71 & 3.9 & $\cdots$ \\
\hline ALLENTONN DP & $06-11-91$ & $\cdots$ & 400 & 120 & 24 & $\cdots$ & 170 & 4 & 48 & 4.8 & $\cdots$ \\
\hline BLACK CREEK DP & $\begin{array}{l}05-16-90 \\
05-16-90\end{array}$ & $\cdots$ & $\begin{array}{l}330 \\
330\end{array}$ & $\begin{array}{l}93 \\
94\end{array}$ & $\begin{array}{l}24 \\
24\end{array}$ & 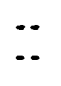 & $\begin{array}{l}69 \\
68\end{array}$ & $\begin{array}{l}2 \\
2\end{array}$ & $\begin{array}{l}31 \\
31\end{array}$ & $\begin{array}{l}2.8 \\
2.9\end{array}$ & $\ddot{*}$ \\
\hline SOUTH FORK DP & $11-02-90$ & $\cdots$ & 110 & 33 & 6.0 & $\cdots$ & 58 & 2 & 53 & 3.8 & $\cdots$ \\
\hline BRIDGE-83 DP & $\begin{array}{l}03-29-89 \\
10-16-90 \\
06-11-91\end{array}$ & $\begin{array}{l}14 \\
\cdots \\
\cdots\end{array}$ & $\begin{array}{l}670 \\
330 \\
370\end{array}$ & $\begin{array}{l}160 \\
100 \\
110\end{array}$ & $\begin{array}{l}65 \\
19 \\
23\end{array}$ & $\begin{array}{l}\cdots \\
\cdots \\
\cdots\end{array}$ & $\begin{array}{l}780 \\
190 \\
430\end{array}$ & $\begin{array}{r}13 \\
5 \\
10\end{array}$ & $\begin{array}{l}72 \\
55 \\
71\end{array}$ & $\begin{array}{l}5.6 \\
7.3 \\
7.7\end{array}$ & $\begin{array}{l}\cdots \\
\cdots \\
\cdots\end{array}$ \\
\hline RIO PUERCO DP & $05-18-90$ & $\cdots$ & 1600 & 470 & 98 & $\cdots$ & 170 & 2 & 19 & 9.3 & $\cdots$ \\
\hline
\end{tabular}


GROUHD-WATER DATA-Cont inued

CHEMICAL ARALYSES-Continued

STATION

MAME

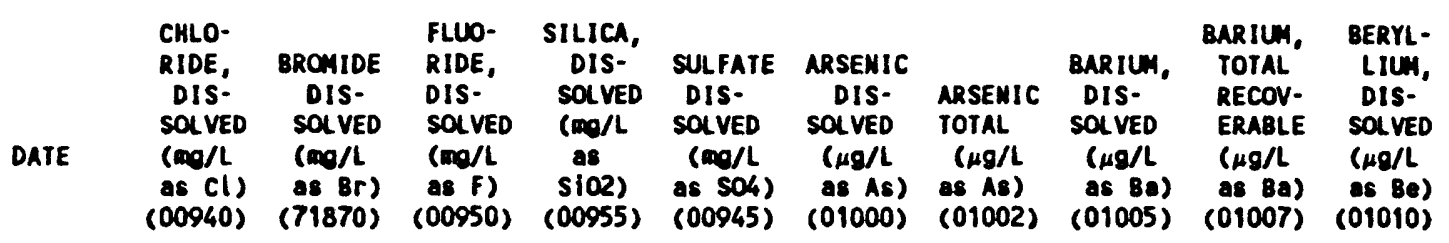

MISCELLAKEOUS PRIVATE MELLS, SPRIMGS AND DRIVEPOINTS-Continued

\begin{tabular}{|c|c|c|c|c|c|c|c|c|c|c|c|}
\hline $\begin{array}{l}\text { PAULSELL RANCH, } \\
\text { PETRIFIEO FOREST }\end{array}$ & $07-14-89$ & 3401 & .86 & 1.6 & 16 & $290 \$$ & $\cdots$ & $\cdots$ & 110 & $\cdots$ & $<.5$ \\
\hline PETRIFIED FOREST-2 & $01-20-89$ & 100 & .26 & 1.0 & 19 & 220 & $<1$ & $\cdots$ & $<100$ & $\cdots$ & $\cdots$ \\
\hline PAULSELl RANCH, PINTA & $07-12-89$ & 53 & .26 & 1.1 & 18 & $330 \xi$ & $\cdots$ & -- & 31 & $\cdots$ & $<.5$ \\
\hline MATERFALL WINDMILL & $05-10-90$ & 58 & .34 & 1.0 & $\cdots$ & $290 \$$ & $\cdots$ & $\cdots$ & $\cdots$ & $\cdots$ & $\cdots$ \\
\hline CHAMBERS HIMDKILL & $05-10-90$ & 15 & .040 & $7.9 \ddagger$ & $\cdots$ & $250 \ddagger$ & $\cdots$ & $\cdots$ & $\cdots$ & $\cdots$ & $\cdots$ \\
\hline PEPLOTE HIMDHILL & $05-10-90$ & 25 & .32 & .40 & $\cdots$ & 14 & $\cdots$ & $\cdots$ & $\cdots$ & $\cdots$ & $\cdots$ \\
\hline ADOT YARD & $01-19-89$ & 34 & .028 & $3.3 \xi$ & 10 & 150 & 1 & $\cdots$ & $<100$ & $\cdots$ & $\cdots$ \\
\hline CP HINDKILL & $05-16-90$ & 63 & .35 & .80 & 15 & $330 \neq$ & $\cdots$ & $\because$ & 30 & $\cdots$ & $<.5$ \\
\hline SAHDERS SCHOOL & $\begin{array}{l}08-04-88 \\
08-10-88 \\
08-10-88 \\
08-10-88 \\
08-10-88 \\
01-20-89 \\
05-09-90\end{array}$ & $\begin{array}{l}57 \\
\cdots \\
\cdots \\
55 \\
\therefore- \\
54 \\
54\end{array}$ & $\begin{array}{l}\ldots \\
\ldots \\
\ldots \\
\ldots \\
\ldots \\
.20 \\
.22\end{array}$ & $\begin{array}{l}.72 \\
\therefore . \\
-. \\
.60 \\
\because . \\
.70 \\
.50\end{array}$ & $\begin{array}{c}-. \\
\ldots \\
15 \\
\cdots \\
15 \\
14\end{array}$ & $\begin{array}{c}300 \$ \\
\cdots \\
310 \\
\cdots \\
290 \\
310\end{array}$ & $\begin{array}{l}9 \\
\therefore \\
\ldots \\
1 \\
\therefore-1 \\
\therefore\end{array}$ & $\begin{array}{c}12 \\
\ldots \\
\cdots \\
1 \\
\ldots \\
\cdots\end{array}$ & $\begin{array}{r}\ldots \\
\ldots \\
37 \\
\cdots \\
<100 \\
37\end{array}$ & $\begin{array}{c}\ldots \\
\ldots \\
100 \\
\ldots \\
\ldots\end{array}$ & $\begin{array}{l}\ldots \\
\ldots \\
\ldots \\
\ldots \\
\ldots \\
<.5\end{array}$ \\
\hline ADOT IMSP. STATION & $05-09-90$ & 54 & .36 & .30 & 14 & 360 & $\cdots$ & $\cdots$ & 25 & $\cdots$ & $<.5$ \\
\hline INDIAN RUINS & $\begin{array}{l}08-08-88 \\
01-18-89\end{array}$ & $\begin{array}{l}46 \\
40\end{array}$ & .39 & $\begin{array}{l}.23 \\
.20\end{array}$ & 12 & $\begin{array}{l}140 \\
150\end{array}$ & $\begin{array}{l}14 \\
10\end{array}$ & $\begin{array}{l}14 \\
\cdots\end{array}$ & $<100$ & 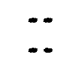 & 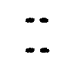 \\
\hline INDINN CITY & $01-18-89$ & 31 & .24 & 1.3 & 14 & 190 & $<1$ & $\cdots$ & $<100$ & $\cdots$ & $\cdots$ \\
\hline BEGAY MELL & $\begin{array}{l}05-08-90 \\
05-08-90\end{array}$ & $\begin{array}{l}150 \\
160\end{array}$ & $\begin{array}{l}.24 \\
.30\end{array}$ & $\begin{array}{l}.30 \\
.30\end{array}$ & $\begin{array}{l}9.0 \\
9.4\end{array}$ & $\begin{array}{l}1100\} \\
1100\}\end{array}$ & $\cdots$ & $\cdots$ & $\begin{array}{l}40 \\
37\end{array}$ & $\cdots$ & $\begin{array}{l}<2 i \\
<2 i\end{array}$ \\
\hline MAVAHO RES $16 K-340$ & $10-23-90$ & 27 & .13 & .60 & 11 & $400\}$ & $<1$ & $\cdots$ & 170 & $\cdots$ & $<.5$ \\
\hline WATERFALL SPRIMG & $\begin{array}{l}08-10-88 \\
05-08-90\end{array}$ & $\ddot{45}$ & .17 & .50 & $\ddot{11}$ & $\ddot{280}$ & $\begin{array}{l}-- \\
\cdots\end{array}$ & $\because-$ & 41 & $\because$ & $\begin{array}{l}-. \\
<.5\end{array}$ \\
\hline HOLBROOK DP & $05-14-90$ & 3304 & .040 & .50 & 14 & 83 & $\cdots$ & $\cdots$ & 240 & $\cdots$ & $<.5$ \\
\hline MAVAKO OP & $06-12-91$ & 100 & .27 & .30 & 17 & $530\}$ & 6 & $\cdots$ & 160 & $\cdots$ & $<21$ \\
\hline ALLENTON DP & $06-11-91$ & 54 & .040 & .40 & 16 & $360\}$ & 5 & $\cdots$ & 93 & $\cdots$ & $<.5$ \\
\hline BLACK CREEK DP & $\begin{array}{l}05-16-90 \\
05-16-90\end{array}$ & $\begin{array}{l}54 \\
55\end{array}$ & $\begin{array}{l}.26 \\
.29\end{array}$ & $\begin{array}{l}.30 \\
.20\end{array}$ & $\begin{array}{l}12 \\
12\end{array}$ & $\begin{array}{l}150 \\
160\end{array}$ & 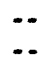 & $\ddot{-\cdot}$ & $\begin{array}{l}260 \\
250\end{array}$ & $\because$ & $\begin{array}{l}<.5 \\
<.5\end{array}$ \\
\hline SOUTH FORK DP & $11-02-90$ & 39 & .010 & .40 & 6.0 & 77 & $<1$ & $\cdots$ & 75 & $\cdots$ & $<.5$ \\
\hline BRIDGE-83 DP & $\begin{array}{l}03-29-89 \\
10-16-90 \\
06-11-91\end{array}$ & $\begin{array}{r}140 \\
43 \\
110\end{array}$ & $\begin{array}{l}.34 \\
.060 \\
.14\end{array}$ & $\begin{array}{l}.40 \\
.30 \\
.80\end{array}$ & $\begin{array}{l}9.4 \\
11^{15}\end{array}$ & $\begin{array}{r}2100 \\
490 \\
550\end{array}$ & $\begin{array}{l}1 \\
2 \\
3\end{array}$ & $\begin{array}{l}\cdots \\
\cdots \\
\cdots\end{array}$ & $\begin{array}{l}-. \\
120 \\
140\end{array}$ & $\begin{array}{l}\cdots \\
\cdots \\
\cdots\end{array}$ & $\dot{<.5}$ \\
\hline RIO PUERCO DP & $05-18-90$ & 32 & .060 & $<.10$ & 13 & $1700\}$ & $\cdots$ & $\cdots$ & 34 & $\cdots$ & $<2 \mathbf{i}$ \\
\hline
\end{tabular}


CHEMICAL AMALYSES - Continued

STATION

MAME

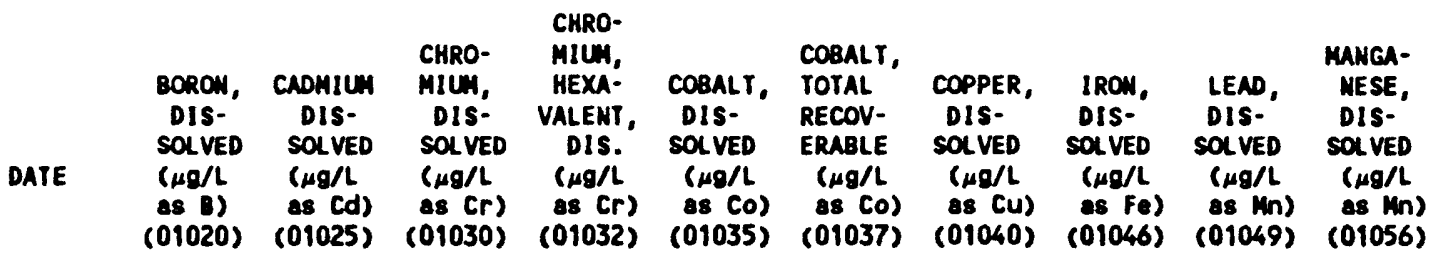

MISCELLANEQUS PRIVATE IELLS, SPRINGS AND DRIVEPOINTS-Continued

\begin{tabular}{|c|c|c|c|c|c|c|c|c|c|c|c|}
\hline $\begin{array}{l}\text { PAULSELL RANCH, } \\
\text { PETRIFIED FOREST }\end{array}$ & $07-14-89$ & $\cdots$ & $<1.0$ & $<5$ & $-\cdot$ & $<3$ & $\cdots$ & $<10$ & 150 & $<10 i$ & $210 \$$ \\
\hline PETRIFIED FOREST-2 & $01-20-89$ & 560 & $<1.0$ & $\cdots$ & 1 & $<1$ & $\cdots$ & $<1$ & $-\cdot$ & $<5$ & $240\}$ \\
\hline PAULSELL RANCH, PINTA & $07 \cdot 12 \cdot 89$ & $\cdots$ & $<1.0$ & $<5$ & $-\cdot$ & $<3$ & - & $<10$ & 3001 & $<10 i$ & $58 f$ \\
\hline WATERFALL WIHOMILL & $05-10 \cdot 90$ & $\cdots$ & $\cdots$ & $\cdots$ & $\cdots$ & -- & -- & -9, & $-\cdot$ & -- & $\cdots$ \\
\hline CHANBERS MIMDMILL & $05 \cdot 10-90$ & $\cdots$ & $\cdots$ & $\cdots$ & -- & $\cdots$ & $\cdots$ & $\cdots$ & $\cdots$ & $\cdots$ & $\cdots$ \\
\hline PEPLOTE VIMDMILL & $05-10-90$ & $\cdots$ & $\cdots$ & -. & -- & -- & $\cdots$ & $\cdots$ & $\cdots$ & $\cdots$ & -- \\
\hline NDOT YARD & $01-19-89$ & 690 & $<1.0$ & $\cdots$ & $<1$ & 1 & $\cdots$ & 2 & $-\cdot$ & $<5$ & 20 \\
\hline CP VIROKILL & $05-16-90$ & $\cdots$ & $<1.0$ & $<5$ & $\cdots$ & $<3$ & $\cdots$ & $<10$ & 60 & $<10 i$ & 2 \\
\hline SAMDERS SCHOOL & $\begin{array}{l}08-04-88 \\
08-10-88 \\
08-10-88 \\
08-10-88 \\
08-10-88 \\
01-20-89 \\
05-09-90\end{array}$ & $\begin{array}{c}-. \\
. . \\
1 . \\
190 \\
19 \\
190\end{array}$ & $\begin{array}{c}10\} \\
\cdots \\
\cdots \\
<1.0 \\
\cdots \\
<1.0 \\
<1.0\end{array}$ & $\begin{array}{l}\ldots \\
\ldots \\
\ldots \\
\ldots \\
\ldots \\
\ldots \\
<5\end{array}$ & $\begin{array}{l}-- \\
\ldots \\
\cdots \\
2 \\
-- \\
<1 \\
--\end{array}$ & $\begin{array}{l}-. \\
\ldots \\
\therefore \\
<1 \\
\therefore \\
<1 \\
<3\end{array}$ & $\begin{array}{l}-. \\
\ldots \\
-- \\
1 \\
\ldots \\
-. \\
-.\end{array}$ & $\begin{array}{c}<10 \\
\cdots- \\
\cdots \\
2 \\
\cdots \\
<1 \\
<10\end{array}$ & $\begin{array}{c}10 \\
\cdots \\
\cdots \\
9 \\
\cdots \\
\cdots \\
17\end{array}$ & $\begin{array}{c}\ldots \\
\ldots \\
\cdots \\
81 \\
\cdots \\
<5 \\
<10 i\end{array}$ & $\begin{array}{l}30 \\
\ldots \\
31 \\
31 \\
30 \\
30\end{array}$ \\
\hline ADOT INSP. STATION & $05-09-90$ & $\cdots$ & $<1.0$ & $<5$ & $\cdots$ & $<3$ & $\cdots$ & $<10$ & 3401 & $<10 i$ & 320 t \\
\hline INDIAN RUINS & $\begin{array}{l}08-08-88 \\
01-18-89\end{array}$ & $\ddot{80}$ & $\begin{array}{r}5.01 \\
<1.0\end{array}$ & 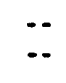 & $\ddot{3}$ & -2 & $\cdots$ & $\begin{array}{r}<10 \\
<1\end{array}$ & $\begin{array}{l}1200 \$ \\
1300\end{array}$ & $<5$ & $\begin{array}{c}160 \% \\
20\end{array}$ \\
\hline INDIAN CITY & $01-18-89$ & 80 & $<1.0$ & $\cdots$ & $<1$ & $<1$ & -- & $<1$ & $\cdots$ & $<5$ & $160\}$ \\
\hline BEGAY MELL & $\begin{array}{l}05-08-90 \\
05-08-90\end{array}$ & $\cdots$ & $\begin{array}{l}<3.0 \\
<4.0\end{array}$ & $\begin{array}{l}<20 \\
<20\end{array}$ & $\cdots$ & $\begin{array}{r}<9 \\
<10\end{array}$ & 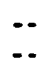 & $\begin{array}{l}<30 \\
<40\end{array}$ & $\begin{array}{l}18 \\
21\end{array}$ & $\begin{array}{l}<30 i \\
<40 i\end{array}$ & $\begin{array}{l}E 22 \\
E 54 f\end{array}$ \\
\hline MAVAHO RES $16 K-340$ & $10-23-90$ & 170 & $<1.0$ & $<5$ & $\cdots$ & $<3$ & $\cdots$ & $<10$ & 4 & $<10 i$ & $520 t$ \\
\hline UATERFALL SPRIMG & $\begin{array}{l}08-10-88 \\
05-08-90\end{array}$ & $\because \cdot$ & $\ddot{<1.0}$ & $\ddot{<5}$ & $\begin{array}{l}-. \\
-\cdot\end{array}$ & -- & $\begin{array}{l}-. \\
--\end{array}$ & $\ddot{<10}$ & ${ }^{-.}$ & $<101$ & $\ddot{<i}$ \\
\hline HOLBROOK DP & $05-14-90$ & -- & $<1.0$ & $<5$ & $\cdots$ & $<3$ & $\cdots$ & $<10$ & $2000\}$ & $<10 i$ & $2500 \$$ \\
\hline NAVAHO DP & $06-12 \cdot 91$ & $\cdots$ & $<3.0$ & $<20$ & -- & $<9$ & -- & $<30$ & $2500\}$ & $<301$ & 39004 \\
\hline ALLENTOWN DP & $06-11-91$ & $\cdots$ & $<1.0$ & $<5$ & $\cdots$ & 5 & $\cdots$ & $<10$ & $1300 \mid$ & $<10 i$ & $4200 \$$ \\
\hline BLACK CREEK DP & $\begin{array}{l}05-16-90 \\
05-16-90\end{array}$ & 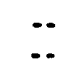 & $\begin{array}{l}<1.0 \\
<1.0\end{array}$ & $\begin{array}{l}<5 \\
<5\end{array}$ & $\begin{array}{l}-- \\
--\end{array}$ & $\begin{array}{l}<3 \\
<3\end{array}$ & $\cdots$ & $\begin{array}{l}<10 \\
<10\end{array}$ & $\begin{array}{l}1100 \$ \\
1000\end{array}$ & $\begin{array}{l}<101 \\
<101\end{array}$ & $\begin{array}{l}4700 \text { t } \\
4700 t\end{array}$ \\
\hline SOUTH FORK DP & $11-02-90$ & 90 & $<1.0$ & $<5$ & $\cdots$ & $<3$ & $\cdots$ & $<10$ & 31 & $<101$ & 1804 \\
\hline BRIDGE-83 DP & $\begin{array}{l}03-29-89 \\
10-16-90 \\
06-11-91\end{array}$ & $\begin{array}{c}190 \\
160 \\
\cdots\end{array}$ & $\begin{array}{l}<1.0 \\
<1.0 \\
<3.0\end{array}$ & $\begin{array}{r}\ldots \\
<5 \\
<20\end{array}$ & $\begin{array}{l}5 \\
-- \\
--\end{array}$ & $\begin{array}{r}9 \\
3 \\
<9\end{array}$ & $\begin{array}{l}\cdots \\
\cdots\end{array}$ & $\begin{array}{r}1 \\
<10 \\
<30\end{array}$ & $\begin{array}{l}\ldots \\
55 \\
64\end{array}$ & $\begin{array}{l}<5 \\
<10 i \\
<30 i\end{array}$ & $\begin{array}{r}920 \$ \\
2500 \$\end{array}$ \\
\hline RIO PUERCO DP & $05-18-90$ & $\cdots$ & $<3.0$ & $<20$ & -- & 20 & $\cdots$ & $<30$ & $8400\}$ & $<30 i$ & 50004 \\
\hline
\end{tabular}


GROUND-HATER DATA-Cont inued

CHEMICAL AMALYSES-Continued

STATION

MNAE

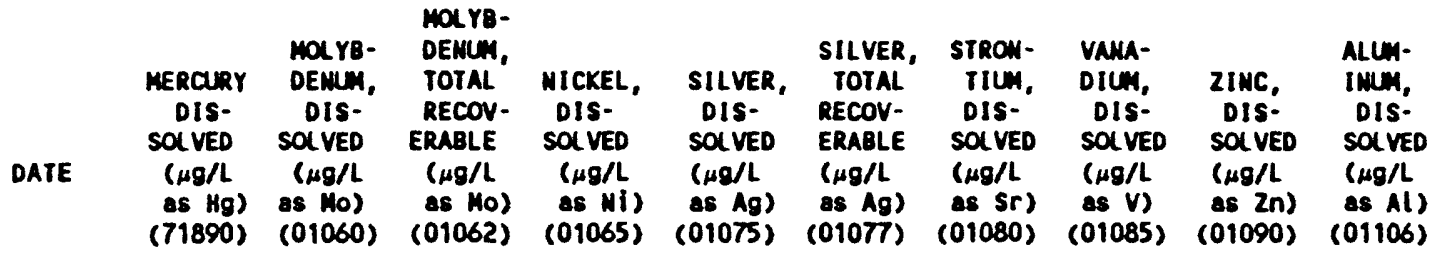

MISCELLAMEQUS PRIVATE WELLS, SPRIMGS AND DRIVEPOINTS-Continued

\begin{tabular}{|c|c|c|c|c|c|c|c|c|c|c|c|}
\hline $\begin{array}{l}\text { PAULSELL RANCH, } \\
\text { PETRIFIEO FOREST }\end{array}$ & $07-14-89$ & $\cdots$ & 60 & $\cdots$ & $<10$ & 2.0 & $\cdots$ & 510 & 18 & 15 & $\cdots$ \\
\hline PETRIFIED FOREST-2 & $01-20-89$ & $<.1$ & 18 & $\cdots$ & $<1$ & -. & -- & 600 & 3 & 10 & $<10$ \\
\hline PAULSELl RANCH, PINTA & $07-12-89$ & $\cdots$ & 40 & $\cdots$ & $<10$ & $<1.0$ & $\cdots$ & 1100 & $<6$ & 4 & $\cdots$ \\
\hline MATERFALL WIRDMILL & $05-10-90$ & $\cdots$ & $\cdots$ & $\cdots$ & $\cdots$ & $\cdots$ & $\cdots$ & -- & $\cdots$ & $\cdots$ & $\cdots$ \\
\hline CHAMBERS MIMOMILL & $05-10-90$ & -- & $\cdots$ & -- & $-\cdot$ & $-\cdot$ & $-\cdot$ & $\cdots$ & $\cdots$ & $\cdots$ &.- \\
\hline PEPLOTE HINOHILL & $05-10-90$ & -- & $\cdots$ & $\cdots$ & $\cdots$ & $\cdots$ & $\cdots$ & -- & $\cdots$ & $\cdots$ & $\cdots$ \\
\hline ADOT YARD & $01-19-89$ & $<.1$ & 15 & $\cdots$ & 3 & $\cdots$ & $\cdots$ & 100 & 51 & 10 & 10 \\
\hline CP HIMONILL & $05-16-90$ & $\cdots$ & $<10$ & $\cdots$ & $<10$ & $<1.0$ & $\cdots$ & 1200 & $<6$ & 1500 & $\cdots$ \\
\hline SANDERS SCHOOL & $\begin{array}{l}08-04-88 \\
08-10-88 \\
08-10-88 \\
08-10-88 \\
08-10-88 \\
01-20-89 \\
05-09-90\end{array}$ & $\begin{array}{l}\ldots \\
\ldots \\
\ldots \\
\ldots \\
\cdots \\
<.1 \\
\therefore\end{array}$ & $\begin{array}{c}<10 \\
\cdots \\
\ldots \\
4 \\
- \\
4 \\
10\end{array}$ & $\begin{array}{c}<10 \\
-- \\
-- \\
6 \\
\ldots \\
\therefore \\
--\end{array}$ & $\begin{array}{r}\ldots \\
\ldots \\
\ldots \\
3 \\
-\therefore \\
1 \\
<10\end{array}$ & $\begin{array}{c}\ldots \\
\ldots \\
\cdots \\
<1.0 \\
\cdots \\
2.0\end{array}$ & $\begin{array}{c}\ldots \\
\cdots \\
\cdots \\
1 \\
\ldots \\
\cdots \\
\cdots\end{array}$ & $\begin{array}{l}\ldots \\
\ldots \\
-. \\
940 \\
-. \\
900 \\
920\end{array}$ & $\begin{array}{l}\ldots \\
\ldots \\
\ldots \\
<1 \\
\ldots \\
<1 \\
<6\end{array}$ & $\begin{array}{r}\cdots \\
\cdots \\
\cdots \\
7 \\
-- \\
<10 \\
7\end{array}$ & $\begin{array}{l}\ldots \\
\ldots \\
\ddot{10} \\
\ddot{10} \\
\ddot{10} \\
. .\end{array}$ \\
\hline ADOT INSP. STATION & $05-09-90$ & $\cdots$ & $<10$ & $\cdots$ & $<10$ & $<1.0$ & $\cdots$ & 1500 & $<6$ & 96 & $\cdots$ \\
\hline IMOIAN RUINS & $\begin{array}{l}08-08-88 \\
01-18-89\end{array}$ & $<.1$ & $\begin{array}{r}<10 \\
3\end{array}$ & $\begin{array}{c}<10 \\
\cdots\end{array}$ & $\ddot{1}$ & 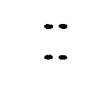 & $\cdots$ & 1300 & $\ddot{<}$ & 40 & $<10$ \\
\hline IMDIAN CITY & $01-18-89$ & $<.1$ & 2 & $\cdots$ & $<1$ & $\cdots$ & $\cdots$ & 1000 & $<1$ & 490 & $<10$ \\
\hline BEgAY MELL & $\begin{array}{l}05-08-90 \\
05-08-90\end{array}$ & 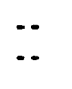 & $\begin{array}{l}<30 \\
<40\end{array}$ & $\begin{array}{l}-\cdot \\
\cdots\end{array}$ & $\begin{array}{l}<30 \\
<40\end{array}$ & $\begin{array}{r}4.0 \\
<4.0\end{array}$ & $\begin{array}{l}-- \\
--\end{array}$ & $\begin{array}{l}3000 \\
3100\end{array}$ & $\begin{array}{l}<18 \\
<24\end{array}$ & $\begin{array}{r}23 \\
<12\end{array}$ & 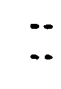 \\
\hline NAVAHO RES $16 K-340$ & $10-23-90$ & $\cdots$ & $<10$ & $\cdots$ & $<10$ & $<1.0$ & -- & 2000 & $<6$ & 120 & -. \\
\hline WATERFALL SPRING & $\begin{array}{l}08-10-88 \\
05-08-90\end{array}$ & -. & $\ddot{10}$ & -- & $<10$ & $<1.0$ & $\cdots$ & $\ddot{1300}$ & $\ddot{<6}$ & $\ddot{<}$ & $\cdots$ \\
\hline HOLBROOK DP & $05-14-90$ & $\cdots$ & $<10$ & $\cdots$ & $<10$ & 1.0 & $\cdots$ & 1600 & $<6$ & 25 & $\cdots$ \\
\hline MAVAHO DP & $06-12-91$ & $\cdots$ & $<30$ & $\cdots$ & $<30$ & 3.0 & $\cdots$ & 1500 & $<18$ & 14 & $\cdots$ \\
\hline ALLENTONN DP & $06-11-91$ & $\cdots$ & $<10$ & $\cdots$ & $<10$ & 1.0 & -. & 1600 & $<6$ & 57 & $\cdots$ \\
\hline BLACK CREEK DP & $\begin{array}{l}05-16-90 \\
05-16-90\end{array}$ & -- & $\begin{array}{l}<10 \\
<10\end{array}$ & $\cdots$ & $\begin{array}{l}<10 \\
<10\end{array}$ & $\begin{array}{r}2.0 \\
<1.0\end{array}$ & $\cdots$ & $\begin{array}{l}1000 \\
1000\end{array}$ & $\begin{array}{l}<6 \\
<6\end{array}$ & $\begin{array}{r}4 \\
<3\end{array}$ & $\cdots$ \\
\hline SOUTH FORK DP & $11-02-90$ & .. & 3 & -- & $<10$ & $<1.0$ & -. & 630 & $<6$ & 15 & $\cdots$ \\
\hline BRIDGE-83 DP & $\begin{array}{l}03-29-89 \\
10-16-90 \\
06-11-91\end{array}$ & $\begin{array}{l}.1 \\
\therefore\end{array}$ & $\begin{array}{r}-7 \\
<30\end{array}$ & $\begin{array}{l}\cdots \\
\cdots \\
\cdots\end{array}$ & $\begin{array}{r}10 \\
<10 \\
<30\end{array}$ & $\begin{array}{r}-- \\
<1.0 \\
4.0\end{array}$ & $\begin{array}{l}\cdots \\
\cdots \\
\cdots\end{array}$ & $\begin{array}{l}3700 \\
1300 \\
1400\end{array}$ & $\begin{array}{r}<6 \\
<18\end{array}$ & $\begin{array}{r}10 \\
6 \\
<18\end{array}$ & $\begin{array}{l}20 \\
\cdots \\
\cdots\end{array}$ \\
\hline RIO PUERCO DP & $05-18-90$ & $\cdots$ & $<30$ & - & $<30$ & 5.0 & $\cdots$ & 4100 & $<18$ & 11 & $\cdots$ \\
\hline
\end{tabular}


GROUND-MATER DATA-Continued

CHEMICAL AKALYSES-Continued

STATION

MNEE

\begin{tabular}{|c|c|c|c|c|c|c|c|c|c|c|}
\hline T & $\begin{array}{l}\text { ALUN- } \\
\text { INUW, } \\
\text { TOTAL } \\
\text { RECOV- } \\
\text { ERABLE } \\
(\mu g / L \\
\text { AB AL) } \\
(01105)\end{array}$ & $\begin{array}{c}\text { LITHIUA } \\
\text { OIS- } \\
\text { SOLVED } \\
\text { ( } \mu \mathrm{g} / \mathrm{L} \\
\text { es Li) } \\
(01130)\end{array}$ & $\begin{array}{c}\text { SELE- } \\
\text { NIUH, } \\
\text { OIS- } \\
\text { SOLVED } \\
\text { ( } \mu g / L \\
\text { as SE) } \\
(01145)\end{array}$ & $\begin{array}{l}\text { SELE- } \\
\text { NIUM, } \\
\text { TOTAL } \\
\text { ( } \mu \mathrm{g} / \mathrm{L} \\
\text { as Se) } \\
\text { (01147) }\end{array}$ & $\begin{array}{c}\text { S-34/ } \\
\text { S-32 } \\
\text { STABLE } \\
\text { ISOTOPE } \\
\text { RATIO } \\
\text { PER } \\
\text { MIL } \\
(82086)\end{array}$ & $\begin{array}{l}\text { H-2/ } \\
\text { H-I } \\
\text { STABLE } \\
\text { ISOTOPE } \\
\text { RATIO } \\
\text { PER } \\
\text { MIL } \\
\text { (82082) }\end{array}$ & $\begin{array}{l}0-18 / \\
0-16 \\
\text { STABLE } \\
\text { ISOTOPE } \\
\text { RAIIO } \\
\text { PER } \\
\text { MIL } \\
\text { (82085) }\end{array}$ & $\begin{array}{l}\text { TRITILA } \\
\text { TOTAL } \\
\text { (pCI/L) } \\
\text { (07000) }\end{array}$ & $\begin{array}{l}\text { GROSS } \\
\text { ALPHA, } \\
\text { DIS- } \\
\text { SOLVED } \\
\text { ( } \mu g / L \\
\text { os } \\
\text { U-nat) } \\
(80030)\end{array}$ & $\begin{array}{l}\text { ALPHA, } \\
\text { COUNT, } \\
2 \text { SIGH } \\
\text { WAT OIS } \\
\text { ( } \mu \mathrm{g} / \mathrm{L} \\
\text { as } \\
U \text {-nat) } \\
\text { (75986) }\end{array}$ \\
\hline
\end{tabular}

MISCELLAMEQUS PRIVATE WELLS, SPRINGS AND DRIVEPOINTS-cont inued

\begin{tabular}{|c|c|c|c|c|c|c|c|c|c|c|c|}
\hline $\begin{array}{l}\text { PAULSELL RAICH, } \\
\text { PETRIFIED FOREST }\end{array}$ & $07-14-89$ & $\cdots$ & 57 & $\cdots$ & $-\cdot$ & 20.20 & -79.5 & -10.25 & $\cdots$ & $18 f$ & 2.6 \\
\hline PETRIFIED FOREST-2 & $01-20-89$ & $\cdots$ & $\cdots$ & $<1$ & $\cdots$ & 11.30 & $-\pi .0$ & -10.65 & 2.6 & $<.6$ & .50 \\
\hline PAULSELL RANCH, PIHTA & $07-12-89$ & $\cdots$ & 120 & $\cdots$ & $\cdots$ & -2.80 & -70.5 & -9.45 & $\cdots$ & $24 f$ & 3.3 \\
\hline MATERFALL MIMOMILL & $05-10-90$ & $\cdots$ & $\cdots$ & $\cdots$ & $\cdots$ & $\cdots$ & $\cdots$ & $\cdots$ & $\cdots$ & 201 & 3.1 \\
\hline CHAMBERS NIMOMILL & $05-10-90$ & $\cdots$ & -- & $\cdots$ & $\cdots$ & $\cdots$ & $\cdots$ & $\cdots$ & $\cdots$ & $95 f$ & 10 \\
\hline PEPLOTE HIMDNILL & $05-10-90$ & $\cdots$ & $\cdots$ & $\cdots$ & $\cdots$ & $\cdots$ & $\cdots$ & $\cdots$ & $\cdots$ & 5.3 & 1.5 \\
\hline ADOT YARD & $01-19-89$ & -. & -- & $<1$ & $-\cdot$ & 9.10 & -89.5 & -11.75 & $<2.5$ & $380\}$ & 36 \\
\hline CP HIMONILL & $05-16-90$ & $\cdots$ & 48 & $\cdots$ & $\cdots$ & -4.40 & -74.0 & -9.80 & 49 & $14 f$ & 3.3 \\
\hline SAMOERS SCHOOL & $\begin{array}{l}08-04-88 \\
08-10-88 \\
08-10-88 \\
08-10-88 \\
08-10-88 \\
01-20-89 \\
05-09-90\end{array}$ & $\begin{array}{c}-. \\
\therefore \\
\therefore- \\
<10 \\
\therefore \\
\therefore\end{array}$ & $\begin{array}{l}\cdots \\
\cdots \\
\cdots \\
\cdots \\
\cdots \\
38\end{array}$ & $\begin{array}{c}2 \\
\ldots \\
\cdots \\
1 \\
\therefore 1 \\
\ldots\end{array}$ & $\begin{array}{l}2 \\
-- \\
\therefore- \\
<1 \\
\therefore- \\
\cdots \\
--\end{array}$ & $\begin{array}{c}\cdots \\
\cdots \\
\cdots \\
\cdots \\
\cdots \\
-3.30 \\
-11.50\end{array}$ & $\begin{array}{c}-81.0 \\
\ldots \\
\ldots \\
\ldots \\
.- \\
-78.5 \\
-81.5\end{array}$ & $\begin{array}{c}-10.80 \\
\ldots \\
\cdots \\
\cdots \\
-10.45 \\
-10.60\end{array}$ & $\begin{array}{c}-. \\
\therefore \\
50 \\
50 \\
52 \\
39\end{array}$ & $\begin{array}{l}\cdots \\
21 f \\
18 f \\
23 f \\
19 f \\
19 f \\
15 f\end{array}$ & $\begin{array}{l}-. \\
-- \\
-- \\
-. \\
-. \\
3.8 \\
2.8\end{array}$ \\
\hline ADOT INSP. STATION & $05-09-90$ & $\cdots$ & 110 & -. & $\cdots$ & $\cdots$ & -75.0 & -10.00 & 71 & $14 f$ & 2.5 \\
\hline INDIAN RUINS & $\begin{array}{l}08-08-88 \\
01-18-89\end{array}$ & $\cdots$ & 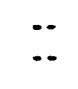 & $\begin{array}{r}5 \\
<1\end{array}$ & $\begin{array}{l}12 \\
--\end{array}$ & -12.00 & $\begin{array}{l}-80.0 \\
-79.0\end{array}$ & $\begin{array}{l}-10.80 \\
-10.40\end{array}$ & $<2.5$ & $\ddot{54 f}$ & 6.9 \\
\hline IMOINN CITY & $01-18-89$ & $\cdots$ & $\cdots$ & 3 & - & 9.10 & -82.0 & -11.05 & 9.3 & 9.3 & 2.0 \\
\hline BEGAY WELL & $\begin{array}{l}05-08-90 \\
05-08-90\end{array}$ & $\cdots$ & $\begin{array}{l}39 \\
38\end{array}$ & $\cdots$ & -- & $\begin{array}{c}6.40 \\
\cdots\end{array}$ & $\begin{array}{c}-\pi .0 \\
\cdots\end{array}$ & $\begin{array}{c}-9.00 \\
-.\end{array}$ & 25 & $\begin{array}{l}291 \\
\cdots\end{array}$ & $\begin{array}{l}4.2 \\
\cdots\end{array}$ \\
\hline MAVAHO RES $16 K-340$ & $10-23-90$ & $\cdots$ & 27 & $<10$ & $\cdots$ & $\cdots$ & $\cdots$ & $\cdots$ & $<2.5$ & 4.3 & 1.3 \\
\hline MATERFALL SPRING & $\begin{array}{l}08-10-88 \\
05-08-90\end{array}$ & $\cdots$ & 65 & $\begin{array}{l}-- \\
--\end{array}$ & -. & -11.30 & $\begin{array}{l}-77.0 \\
-78.5\end{array}$ & $\begin{array}{l}-10.80 \\
-10.25\end{array}$ & -. & $\begin{array}{l}17 t \\
121\end{array}$ & $\ddot{2.4}$ \\
\hline HOLBROOK DP & $05-14-90$ & $\cdots$ & 21 & $\cdots$ & $\cdots$ & 25.80 & -70.0 & -9.60 & 2.9 & 2.1 & .90 \\
\hline MAVAHO DP & $06-12-91$ & $\cdots$ & 41 & $<1$ & $\cdots$ & -5.80 & $\cdots$ & $\cdots$ & $\cdots$ & 131 & 2.3 \\
\hline ALLENTONN DP & $06-11-91$ & -- & 18 & $<1$ & $\cdots$ & -2.30 & $\cdots$ & - & $\cdots$ & $13\}$ & 2.4 \\
\hline BLACK CREEK DP & $\begin{array}{l}05-16-90 \\
05-16-90\end{array}$ & $\cdots$ & $\begin{array}{l}20 \\
21\end{array}$ & $\begin{array}{l}\cdots \\
\cdots\end{array}$ & - & 7.70 & $\begin{array}{c}-77.5 \\
-.\end{array}$ & $\begin{array}{c}-10.20 \\
\cdots\end{array}$ & 45 & $\begin{array}{l}2.7 \\
3.7\end{array}$ & $\begin{array}{l}1.1 \\
1.2\end{array}$ \\
\hline SOUTH FORK DP & $11-02-90$ & -- & 9 & $<1$ & $\cdots$ & 1.80 & -52.0 & -9.10 & $\cdots$ & 6.7 & 1.6 \\
\hline BRIDGE-83 DP & $\begin{array}{l}03-29-89 \\
10-16-90 \\
06-11-91\end{array}$ & $\begin{array}{l}-. \\
-- \\
-\end{array}$ & $\begin{array}{l}\ddot{18} \\
22\end{array}$ & $\begin{array}{l}1 \\
<1\end{array}$ & $\begin{array}{l}-- \\
\cdots \\
--\end{array}$ & $\begin{array}{c}7.00 \\
\cdots \\
2.60\end{array}$ & $\begin{array}{c}-88.0 \\
-. \\
--\end{array}$ & $\begin{array}{c}-12.05 \\
\ldots \\
\ldots\end{array}$ & $\begin{array}{l}22 \\
-- \\
--\end{array}$ & $\begin{array}{l}170\} \\
15\} \\
291\end{array}$ & $\begin{array}{c}17 \\
2.7 \\
4.2\end{array}$ \\
\hline RIO PUERCO DP & $05-18-90$ & $\cdots$ & 92 & $\cdots$ & $\cdots$ & -13.90 & -69.5 & -9.50 & 38 & 9.0 & 2.6 \\
\hline
\end{tabular}


STATION

MAME
GROUND-WATER DATA-Contínued

CHEMICAL AMALYSES-Continued

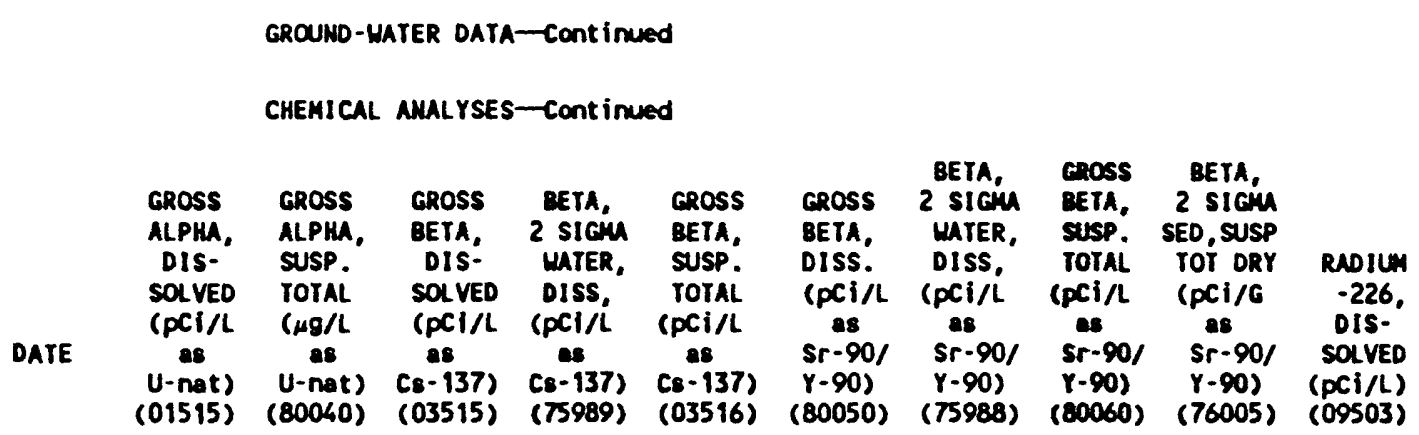

MISCELLANEOUS PRIVATE MELLS, SPRIMGS AND DRIVEPOINTS-continued

\begin{tabular}{|c|c|c|c|c|c|c|c|c|c|c|c|}
\hline $\begin{array}{l}\text { PAULSELL RUNCH, } \\
\text { PETRIFIED FOREST }\end{array}$ & $07-14-89$ & -- & $\cdots$ & 4.3 & 8.6 & $\cdots$ & 3.4 & 6.8 & -- & $\cdots$ & $\cdots$ \\
\hline PETRIFIED FOREST-2 & $01-20-89$ & $-\infty$ & $<.6 *$ & 2.6 & 1.6 & $<.6^{*}$ & 1.7 & 1.0 & $<.6^{*}$ & .40 & $\cdots$ \\
\hline PAULSELL RANCH, PINTA & $07-12-89$ & -- & -- & 16 & 5.4 & -- & 13 & 4.3 & $\cdots$ & $\cdots$ & $\cdots$ \\
\hline WATERFALL WINDMILL & $05-10-90$ & $\cdots$ & $\cdots$ & 11 & 3.1 & $\cdots$ & 8.5 & 2.4 & $-\cdot$ & $\cdots$ & $\cdots$ \\
\hline CHANBERS YIMDMILL & $05-10-90$ & $-\cdot$ & $\cdots$ & 26 & 5.1 & -- & 20 & 3.9 & $\cdots$ & $\cdots$ & $\cdots$ \\
\hline PEPLOTE HINONILL & $05-10-90$ & $\cdots$ & $\cdots$ & 5.4 & 1.5 & $\cdots$ & 4.0 & 1.4 & $\cdots$ & $\cdots$ & $\cdots$ \\
\hline ADOT YARD & $01-19-89$ & -- & $.7 *$ & 210 & 31 & $2.0 *$ & 140 & 21 & $2.0^{*}$ & .70 & $\cdots$ \\
\hline CP MIMDNILL & $05-16-90$ & -- & $\cdots$ & 5.0 & 1.9 & $\cdots$ & 3.8 & 1.5 & $\cdots$ & $\cdots$ & $\cdots$ \\
\hline SAMDERS SCHOOL & $\begin{array}{l}08-04-88 \\
08-10-88 \\
08-10-88 \\
08-10-88 \\
08-10-88 \\
01-20-89 \\
05-09-90\end{array}$ & $\begin{array}{l}1.8 \\
\ldots \\
\ldots \\
\ldots \\
\ldots \\
\ldots\end{array}$ & $\begin{array}{l}-. \\
<.4 * \\
<.4 * \\
<.4 * \\
.6 * \\
<.6 * \\
-\end{array}$ & $\begin{array}{c}4.5 \\
10 \\
2.9 \\
11 \\
9.0 \\
7.2 \\
10\end{array}$ & $\begin{array}{l}\ldots \\
\cdots \\
\cdots \\
\cdots \\
\cdots \\
1.9 \\
2.5\end{array}$ & $\begin{array}{l}\cdots .4^{*} \\
.5^{*} \\
<.4^{*} \\
.6^{*} \\
<.6^{*} \\
\cdots\end{array}$ & $\begin{array}{l}-. \\
6.9 \\
2.0 \\
7.4 \\
6.2 \\
4.8 \\
7.5\end{array}$ & $\begin{array}{l}-. \\
\cdots \\
\cdots \\
\cdots \\
\cdots \\
1.3 \\
1.9\end{array}$ & $\begin{array}{l}<. \\
<.6 * \\
.5 * \\
<.4 * \\
.6 * \\
<.6 * \\
-.\end{array}$ & $\begin{array}{l}\ldots \\
\ldots \\
\ldots \\
\ldots \\
. \\
.40\end{array}$ & $\begin{array}{l}.3 \\
\therefore \\
\cdots \\
\cdots \\
\cdots \\
\cdots\end{array}$ \\
\hline ADOT INSP. STATION & $05-09-90$ & $\cdots$ & $\cdots$ & 11 & 2.8 & $\cdots$ & 8.6 & 2.1 & $\cdots$ & $\cdots$ & $\cdots$ \\
\hline INDIAN RUINS & $\begin{array}{l}08-08-88 \\
01-18-89\end{array}$ & $\begin{array}{l}50\} \\
--\end{array}$ & $2.8 *$ & $\begin{array}{l}22 \\
19\end{array}$ & 3.2 & $\ddot{3.1 *}$ & 13 & $\ddot{2.2}$ & $\ddot{3.1 *}$ & .80 & 11 \\
\hline IMDIAN CITY & $01-18-89$ & $\cdots$ & $<.6 *$ & 5.4 & 1.6 & $<.6^{*}$ & 3.8 & 1.1 & $<.6 *$ & .40 & $\cdots$ \\
\hline BEGAY MELL & $\begin{array}{l}05-08-90 \\
05-08-90\end{array}$ & $\begin{array}{l}\cdots \\
\cdots\end{array}$ & $\cdots$ & $\begin{array}{l}19 \\
\cdots\end{array}$ & $\begin{array}{l}6.0 \\
\cdots\end{array}$ & -- & 14 & $\begin{array}{l}4.5 \\
--\end{array}$ & -. & $\cdots$ & 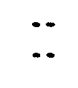 \\
\hline MAVAHO RES 16K-340 & $10-23 \cdot 90$ & $\cdots$ & $\cdots$ & 7.3 & 3.5 & -- & 5.6 & 2.7 & $\cdots$ & $\cdots$ & $\cdots$ \\
\hline MATERFALL SPRING & $\begin{array}{l}08-10-88 \\
05-08-90\end{array}$ & -. & $.9 *$ & 16.2 & 3.3 & .7 & ${ }_{12}^{2.1}$ & 2.5 & $\therefore$ & $\begin{array}{l}\cdots \\
\cdots\end{array}$ & $\begin{array}{l}-. \\
--\end{array}$ \\
\hline HOLBROOK DP & $05-14-90$ & $\cdots$ & $\cdots$ & 6.0 & 2.5 & $\cdots$ & 4.6 & 1.9 & $\cdots$ & $\cdots$ & $\cdots$ \\
\hline MAVAHO DP & $06-12-91$ & $\cdots$ & $\cdots$ & 17 & 3.8 & $\cdots$ & 12 & 2.8 & $\cdots$ & $\cdots$ & $\cdots$ \\
\hline ALLENTOMN DP & $06-11-91$ & $\cdots$ & $\cdots$ & 14 & 3.9 & $\cdots$ & 10 & 2.9 & $\cdots$ & $\cdots$ & $\cdots$ \\
\hline BLACK CREEK OP & $\begin{array}{l}05-16-90 \\
05-16-90\end{array}$ & $\cdots$ & 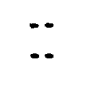 & $\begin{array}{l}6.9 \\
7.8\end{array}$ & $\begin{array}{l}2.1 \\
2.2\end{array}$ & $\cdots$ & $\begin{array}{l}5.2 \\
5.9\end{array}$ & $\begin{array}{l}1.6 \\
1.7\end{array}$ & $\because$ & $\cdots$ & $\because$ \\
\hline SOUTH FORK DP & $11-02-90$ & $\cdots$ & $\cdots$ & 8.0 & 1.6 & $\cdots$ & 6.0 & 1.2 & $\cdots$ & $\cdots$ & $\cdots$ \\
\hline BRIDGE-83 DP & $\begin{array}{l}03-29-89 \\
10-16-90 \\
06-11-91\end{array}$ & $\begin{array}{l}- \\
\cdots \\
--\end{array}$ & $\begin{array}{c}<.6 \\
\cdots \\
\cdots\end{array}$ & $\begin{array}{l}35 \\
19 \\
30\end{array}$ & $\begin{array}{l}7.4 \\
4.3 \\
6.1\end{array}$ & $\begin{array}{c}15 * \\
-\therefore \\
--\end{array}$ & $\begin{array}{l}22 \\
15 \\
22\end{array}$ & $\begin{array}{l}4.7 \\
3.2 \\
4.6\end{array}$ & $\begin{array}{c}15 * \\
\cdots \\
\cdots\end{array}$ & $\begin{array}{r}2.2 \\
\cdots \\
\cdots\end{array}$ & $\begin{array}{l}\cdots \\
\cdots \\
\cdots\end{array}$ \\
\hline RIO PUERCO OP & $05-18-90$ & $\cdots$ & $\cdots$ & 24 & 6.8 & $\cdots$ & 18 & 5.1 & $\cdots$ & $\cdots$ & $\cdots$ \\
\hline
\end{tabular}


ROUNO-WATER DATA-Continued

CHEMICAL AMALYSES-Continued

STATIOA

NAME

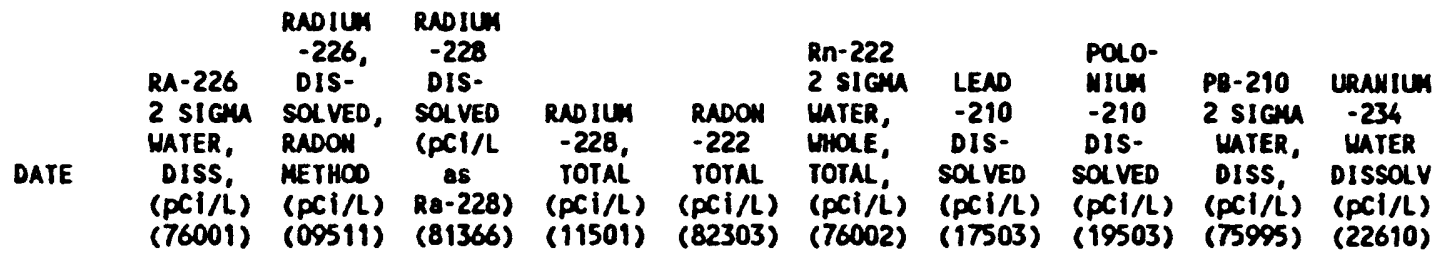

MISCELLANEQUS PRIVATE WELLS, SPRINGS AND DRIVEPOINTS-Continued

\begin{tabular}{|c|c|c|c|c|c|c|c|c|c|c|c|}
\hline $\begin{array}{l}\text { PAULSELL RANCK, } \\
\text { PETRIFIED FOREST }\end{array}$ & $07-14-89$ & .020 & .07 & 1.4 & $\cdots$ & 290 & 39 & $\cdots$ & $\cdots$ & $\cdots$ & 4.1 \\
\hline PETRIFIED FOREST-2 & $01-20-89$ & .020 & .09 & $<1.0$ & $-\cdot$ & 160 & 59 & $<1.5$ & $<1.0$ & mo & .20 \\
\hline PAULSELL RANCH, PINTA & $07-12-89$ & .020 & .07 & $<1.0$ & $\cdots$ & $360\}$ & 35 & $\cdots$ & $\cdots$ & -- & 15 \\
\hline MATERFALL MINONILL & $05-10-90$ & $\cdots$ & $\cdots$ & $\cdots$ & $-\cdot$ & $\cdots$ & $\cdots$ & $\cdots$ & $\cdots$ & $\cdots$ & $\cdots$ \\
\hline CHURBERS WIMONILL & $05-10-90$ & -. & $\cdots$ & $\cdots$ & $\cdots$ & $\cdots$ & $\cdots$ & $\cdots$ & $\cdots$ & $\cdots$ & -. \\
\hline PEPLOTE MIMONILL & $05-10-90$ & $\cdots$ & $\cdots$ & $\cdots$ & $\cdots$ & -. & $\cdots$ & $\cdots$ & $\cdots$ & $\cdots$ & $\cdots$ \\
\hline ADOT YARD & $01-19-89$ & .020 & .07 & $<1.0$ & $\cdots$ & $15000 t$ & 130 & 6.7 & $<2.5$ & 1.2 & 220 \\
\hline CP HIMDNILL & $05-16-90$ & $\cdots$ & $\cdots$ & $\cdots$ & $-\cdot$ & $\cdots$ & $\cdots$ & $\cdots$ & $\cdots$ & $\cdots$ & 4.2 \\
\hline SAMERS SCHOOL & $\begin{array}{l}08-04-88 \\
08-10-88 \\
08-10-88 \\
08-10-88 \\
08-10-88 \\
01-20-89 \\
05-09-90\end{array}$ & $\begin{array}{l}\ldots \\
\ldots \\
\ldots \\
\ldots \\
\ldots \\
.010 \\
\ldots\end{array}$ & $\begin{array}{l}\ldots \\
\ldots \\
\ldots \\
.07 \\
.05\end{array}$ & $\begin{array}{c}100 \\
\ldots \\
\cdots \\
<1.0 \\
\cdots \\
<1.0 \\
<1.0\end{array}$ & $\begin{array}{l}10 \\
\cdots \\
\cdots \\
\cdots \\
\cdots \\
\cdots\end{array}$ & $\begin{array}{c}\ldots \\
\ldots \\
\ldots \\
\ldots \\
210 \\
200\end{array}$ & $\begin{array}{l}\cdots \\
\cdots \\
\cdots \\
\cdots \\
60 \\
31\end{array}$ & $\begin{array}{c}\ldots \\
\ldots \\
\ldots \\
\ldots \\
\ldots \\
<1.5 \\
\ldots\end{array}$ & $\begin{array}{c}\ldots \\
\ldots \\
\ldots \\
\ldots \\
\cdots \\
<1.0 \\
\cdots\end{array}$ & $\begin{array}{l}\ldots \\
\cdots \\
\cdots \\
\cdots \\
\cdots \\
\cdots\end{array}$ & $\begin{array}{l}-. \\
6.5 \\
-. \\
6.3 \\
\ldots \\
6.4 \\
6.3\end{array}$ \\
\hline ADOT INSP. STATION & $05-09-90$ & $\cdots$ & $\cdots$ & $<1.0$ & $\cdots$ & $1500\}$ & 64 & $\cdots$ & $\cdots$ & $\cdots$ & 5.1 \\
\hline INDIAN RUIMS & $\begin{array}{l}08-08-88 \\
01-18-89\end{array}$ & $2 . \ddot{40}$ & $\ddot{14}$ & $\begin{array}{r}5.6 \\
<6.6\end{array}$ & $\begin{array}{l}5.8 \\
\cdots\end{array}$ & $\ddot{900 t}$ & $\ddot{64}$ & $<1.5$ & $<1.0$ & ino & $\ddot{8.0}$ \\
\hline INDIAN CITY & $01-18-89$ & .030 & .18 & $<1.0$ & $\cdots$ & 150 & 60 & $<1.5$ & $<1.0$ & mo & 4.2 \\
\hline BEGAY IELL & $\begin{array}{l}05-08-90 \\
05-08-90\end{array}$ & $\cdots$ & -. & $\begin{array}{c}<1.0 \\
\ldots\end{array}$ & -. & $\cdots$ & 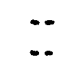 & $\cdots$ & 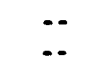 & 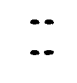 & $\begin{array}{l}13 \\
\cdots\end{array}$ \\
\hline NAVAHO RES $16 K-340$ & $10-23-90$ & $\cdots$ & $\cdots$ & $\cdots$ & $\cdots$ & $\cdots$ & $\cdots$ & $\cdots$ & -- & $-\cdot$ & $\cdots$ \\
\hline WATERFALL SPRING & $\begin{array}{l}08-10-88 \\
05-08-90\end{array}$ & $\cdots$ & $\cdots$ & $<1.0$ & $\cdots$ & $\cdots$ & $\cdots$ & 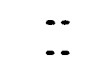 & $\ddot{--}$ & 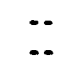 & $\ddot{5.2}$ \\
\hline HOL BROOK DP & $05-14-90$ & $\cdots$ & $\cdots$ & 1.0 & $-\cdots$ & $\cdots$ & $\cdots$ & $\cdots$ & $\cdots$ & $\cdots$ & .40 \\
\hline MAYAHO DP & $06-12-91$ & $\cdots$ & $\cdots$ & $\cdots$ & $\cdots$ & $\cdots$ & $\cdots$ & $\cdots$ & $\cdots$ & $\cdots$ & 6.8 \\
\hline ALLENTON DP & $06-11-91$ & $\cdots$ & $\cdots$ & $\cdots$ & $\cdots$ & $\cdots$ & $\cdots$ & $\cdots$ & $\cdots$ & $\cdots$ & 6.6 \\
\hline BLACK CREEK DP & $\begin{array}{l}05-16-90 \\
05-16-90\end{array}$ & $\cdots$ & $\cdots$ & $\begin{array}{r}1.1 \\
<1.0\end{array}$ & 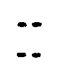 & $\begin{array}{c}300\} \\
\ldots\end{array}$ & $\begin{array}{l}54 \\
--\end{array}$ & $\ddot{-}$ & $\cdots$ & 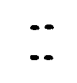 & $\begin{array}{l}.90 \\
.80\end{array}$ \\
\hline SOUTH FORK DP & $11-02-90$ & $\cdots$ & $\cdots$ & $\cdots$ & $\cdots$ & $\cdots$ & $\therefore$ & $\cdots$ & $\cdots$ & $\cdots$ & 2.2 \\
\hline BRIDGE-83 DP & $\begin{array}{l}03-29-89 \\
10-16-90 \\
06-11-91\end{array}$ & $\begin{array}{l}-. \\
.100 \\
. .\end{array}$ & $\begin{array}{l}\cdots \\
\ldots \\
\cdots\end{array}$ & $\begin{array}{l}\cdots \\
\ldots \\
\cdots\end{array}$ & $\begin{array}{l}-- \\
-. \\
-\end{array}$ & $\begin{array}{l}\cdots \\
\cdots \\
\cdots\end{array}$ & $\begin{array}{l}\cdots \\
\cdots \\
\cdots\end{array}$ & $\begin{array}{l}\cdots \\
\cdots \\
\cdots\end{array}$ & $\begin{array}{l}- \\
-- \\
--\end{array}$ & $\begin{array}{l}\cdots \\
\cdots \\
\cdots\end{array}$ & $\begin{array}{c}5.6 \\
18\end{array}$ \\
\hline RIO PUERCO OP & $05-18-90$ & $\cdots$ & $\cdots$ & $<1.0$ & -. & $\cdots$ & $\cdots$ & $\cdots$ & $\cdots$ & $\cdots$ & 7.8 \\
\hline
\end{tabular}


GROUND-WATER DATA-Continued

CHEMICAL NAALYSES-Continued

STATION

MANE

\begin{tabular}{|c|c|c|c|c|c|c|c|c|c|c|}
\hline ATE & $\begin{array}{c}\text { U-234 } \\
2 \text { SIGUA } \\
\text { WATER, } \\
\text { DISS, } \\
\text { (pCi/L) } \\
\text { (75992) }\end{array}$ & $\begin{array}{l}\text { URANIUA } \\
\text {-235 } \\
\text { UATER, } \\
\text { DISS } \\
\text { (pCI/L) } \\
(22620)\end{array}$ & $\begin{array}{l}\text { U-235 } \\
2 \text { SIGMA } \\
\text { WATER, } \\
\text { DISS, } \\
\text { (pCi/L) } \\
(75994)\end{array}$ & $\begin{array}{l}\text { URANIUH } \\
\text {-238 } \\
\text { UATER } \\
\text { DISSOLY } \\
\text { (pCi/L) } \\
(22603)\end{array}$ & $\begin{array}{l}\text { U-238 } \\
2 \text { SIGU } \\
\text { WATER, } \\
\text { DISS, } \\
\text { (pCI/L) } \\
\text { (75991) }\end{array}$ & $\begin{array}{l}\text { URANIUM } \\
\text { MATURAL } \\
\text { DIS- } \\
\text { SOLVED } \\
\text { ( } \mu g / L \\
\text { OSU) } \\
(22703)\end{array}$ & $\begin{array}{l}\text { URANIUN } \\
\text { MATURAL } \\
\text { TOTAL } \\
\text { ( } \mu g / L \\
\text { es U) } \\
\text { (28011) }\end{array}$ & $\begin{array}{l}\text { THORIUH } \\
\text { - } 230 \\
\text { DIS- } \\
\text { SOLVED } \\
\text { (pCi/L) } \\
\text { (26503) }\end{array}$ & $\begin{array}{l}\text { Th- } 230 \\
2 \text { SICMA } \\
\text { UATER, } \\
\text { DISS, } \\
\text { (pCI/L) } \\
\text { (75997) }\end{array}$ & $\begin{array}{c}\text { Th-232 } \\
\text { WATER, } \\
\text { DISS, } \\
\text { (pCI/L) } \\
\text { (TS976) }\end{array}$ \\
\hline
\end{tabular}

mISCELLANEQUS PRIVATE MELLS, SPRINGS AND DRIVEPOINTS-Continued

\begin{tabular}{|c|c|c|c|c|c|c|c|c|c|c|c|}
\hline PAULSELL RANCH, & $07-14-89$ & .5 & .3 & NO & 2.6 & .30 & $\therefore$ & $\cdots$ & $\cdots$ & $\cdots$ & $\cdots$ \\
\hline PETRIFIED FOREST-2 & $01-20-89$ & ND & $<.1$ & ND & .10 & NO & $\cdots$ & $\cdots$ & $<1.0$ & NO & $<1.0$ \\
\hline PAULSELL, PINTA & $07-12-89$ & 1.6 & 1.3 & .20 & 12 & 1.3 & $\cdots$ & $\cdots$ & $\cdots$ & $\cdots$ & $\cdots$ \\
\hline WATERFALL HIMDM & $05-10-90$ & $\cdots$ & $\cdots$ & $\cdots$ & $\cdots$ & $\cdots$ & $\cdots$ & $\cdots$ & $\cdots$ & $\cdots$ & $\cdots$ \\
\hline CHAMBERS HIMOMI & $05-10-90$ & $\cdots$ & $\cdots$ & $\cdots$ & $\cdots$ & $\cdots$ & $\cdots$ & $\cdots$ & $\cdots$ & $\cdots$ & $\cdots$ \\
\hline PEPLOTE NIMDMIL & $05-10-90$ & $\cdots$ & $\cdots$ & $\cdots$ & $\cdots$ & $\cdots$ & $\cdot-$ & $\cdots$ & $\cdots$ & $\cdots$ & $\cdots$ \\
\hline ADOT YARD & $01-19-89$ & 21 & 4.8 & .50 & 92 & 8.8 & $\cdots$ & $\cdots$ & $<1.0$ & No & $<1.0$ \\
\hline CP HINONILL & $05-16-90$ & .6 & $<.1$ & NO & 2.7 & .30 & 7.0 & $\cdots$ & $\cdots$ & $\cdots$ & $\cdots$ \\
\hline SAMDERS SCHOOL & $\begin{array}{l}08-04-88 \\
08-10-88 \\
08-10-88 \\
08-10-88 \\
08-10-88 \\
01-20-89 \\
05-09-90\end{array}$ & $\begin{array}{l}\ldots \\
\cdots \\
\ldots \\
\ldots \\
.7 \\
.6\end{array}$ & $\begin{array}{l}\ldots \\
\ldots \\
\ldots \\
\ldots \\
\ldots \\
.2 \\
.2\end{array}$ & $\begin{array}{l}\ldots \\
\ldots \\
\ldots \\
\ldots \\
\text { MO } \\
\text { ND }\end{array}$ & $\begin{array}{l}. . \\
4.3 \\
. . \\
4.4 \\
. . \\
4.5 \\
4.2\end{array}$ & $\begin{array}{l}\ldots \\
\ldots \\
\ldots \\
\ldots \\
-. \\
.50 \\
.40\end{array}$ & $\begin{array}{c}\ldots \\
13 \\
\ldots \\
13 \\
\ldots \\
\cdots \\
9.2\end{array}$ & $\begin{array}{c}17 \\
\ldots \\
\ldots \\
\ldots \\
\ldots \\
\ldots \\
\ldots\end{array}$ & $\begin{array}{l}\ldots \\
\ldots \\
\ldots \\
\ldots \\
\ldots \\
<1.0 \\
\ldots\end{array}$ & $\begin{array}{l}\ldots \\
\ldots \\
\ldots \\
\ldots \\
\ldots \\
\ldots \\
\ldots\end{array}$ & $\begin{array}{c}\ldots \\
\cdots \\
\cdots \\
\cdots \\
\ddot{-} \\
\cdots\end{array}$ \\
\hline ADOT INSP. STATION & $05-09-90$ & .5 & .1 & MD & 3.0 & .30 & 6.1 & $\cdots$ & $\cdots$ & $\cdots$ & $\cdots$ \\
\hline INOIAN RUIMS & $\begin{array}{l}08-08-88 \\
01-18-89\end{array}$ & .8 & $<.1$ & MD & 1.2 & $\begin{array}{l}\ldots \\
.20\end{array}$ & $\cdots$ & $\begin{array}{l}5.6 \\
\cdots\end{array}$ & $<1.0$ & $\ddot{M O}$ & $\ddot{1.0}$ \\
\hline INDIAN CITY & $01-18-89$ & .4 & .1 & ND & 2.2 & .30 & $\cdots$ & $\cdots$ & $<1.0$ & NO & $<1.0$ \\
\hline BEGAY MELL & $\begin{array}{l}05-08-90 \\
05-08-90\end{array}$ & 1.3 & .4 & $\begin{array}{l}\text { NO } \\
\cdots\end{array}$ & 9.1 & .90 & 261 & -. & 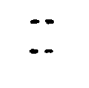 & -. & $\cdots$ \\
\hline MAVAHO RES $16 K-340$ & $10-23-90$ & $\cdots$ & $\cdots$ & $\cdots$ & $\cdots$ & $\cdots$ & 3.7 & $\cdots$ & $\cdots$ & $\cdots$ & $\cdots$ \\
\hline MATERFALL SPRIMG & $\begin{array}{l}08-10-88 \\
05-08-90\end{array}$ & $\begin{array}{l}. . \\
.5\end{array}$ &.. & NO & 3.7 & .40 & $\ddot{6.9}$ & $\cdots$ & $\because$ & $\cdots$ & $\begin{array}{l}-\cdot \\
\cdots\end{array}$ \\
\hline HOLBROOK DP & $05-14-90$ & ND & $<.1$ & NO & .30 & ND & $<1.0$ & $\cdots$ & $\cdots$ & $\cdots$ & $\cdots$ \\
\hline MAVAHO DP & $06-12-91$ & .7 & .2 & ND & 5.3 & .50 & 9.5 & $\cdots$ & $\cdots$ & $\cdots$ & $\cdots$ \\
\hline ALLENTOWN DP & $06-11-91$ & .7 & .2 & NO & 5.5 & .60 & 7.9 & $\cdots$ & $\cdots$ & $\cdots$ & $\cdots$ \\
\hline BLACK CREEK DP & $\begin{array}{l}05-16-90 \\
05-16-90\end{array}$ & .1 & $\begin{array}{l}<.1 \\
<.1\end{array}$ & $\begin{array}{l}\text { NO } \\
\text { NO }\end{array}$ & $\begin{array}{l}.60 \\
.50\end{array}$ & $\begin{array}{l}\text { NO } \\
\text { NO }\end{array}$ & $\begin{array}{l}1.3 \\
1.6\end{array}$ & -. & -. & 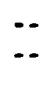 & $\therefore$ \\
\hline SOUTH FORK DP & $11-02-90$ & .3 & $<.1$ & NO & 1.7 & .20 & 4.2 & -- & $\cdots$ & -. & $\cdots$ \\
\hline BRIDGE-83 DP & $\begin{array}{l}03-29-89 \\
10-16-90 \\
06-11-91\end{array}$ & $\begin{array}{l}. . \\
1.8\end{array}$ & $\begin{array}{l}. . \\
.2 \\
.6\end{array}$ & $\begin{array}{l}\cdots \\
\text { ND }\end{array}$ & 4.3 & .10 & $\begin{array}{l}11 \\
44 f\end{array}$ & $\begin{array}{l}\cdots \\
\cdots\end{array}$ & $\begin{array}{l}\cdots \\
\cdots \\
\cdots\end{array}$ & $\begin{array}{l}\ldots \\
\cdots \\
\cdots\end{array}$ & $\begin{array}{l}\cdots \\
\cdots \\
\cdots\end{array}$ \\
\hline RIO PUERCO DP & $05-18-90$ & .8 & .1 & NO & 4.3 & .50 & 9.0 & $\cdots$ & $\cdots$ & $\cdots$ & $-\cdot$ \\
\hline
\end{tabular}




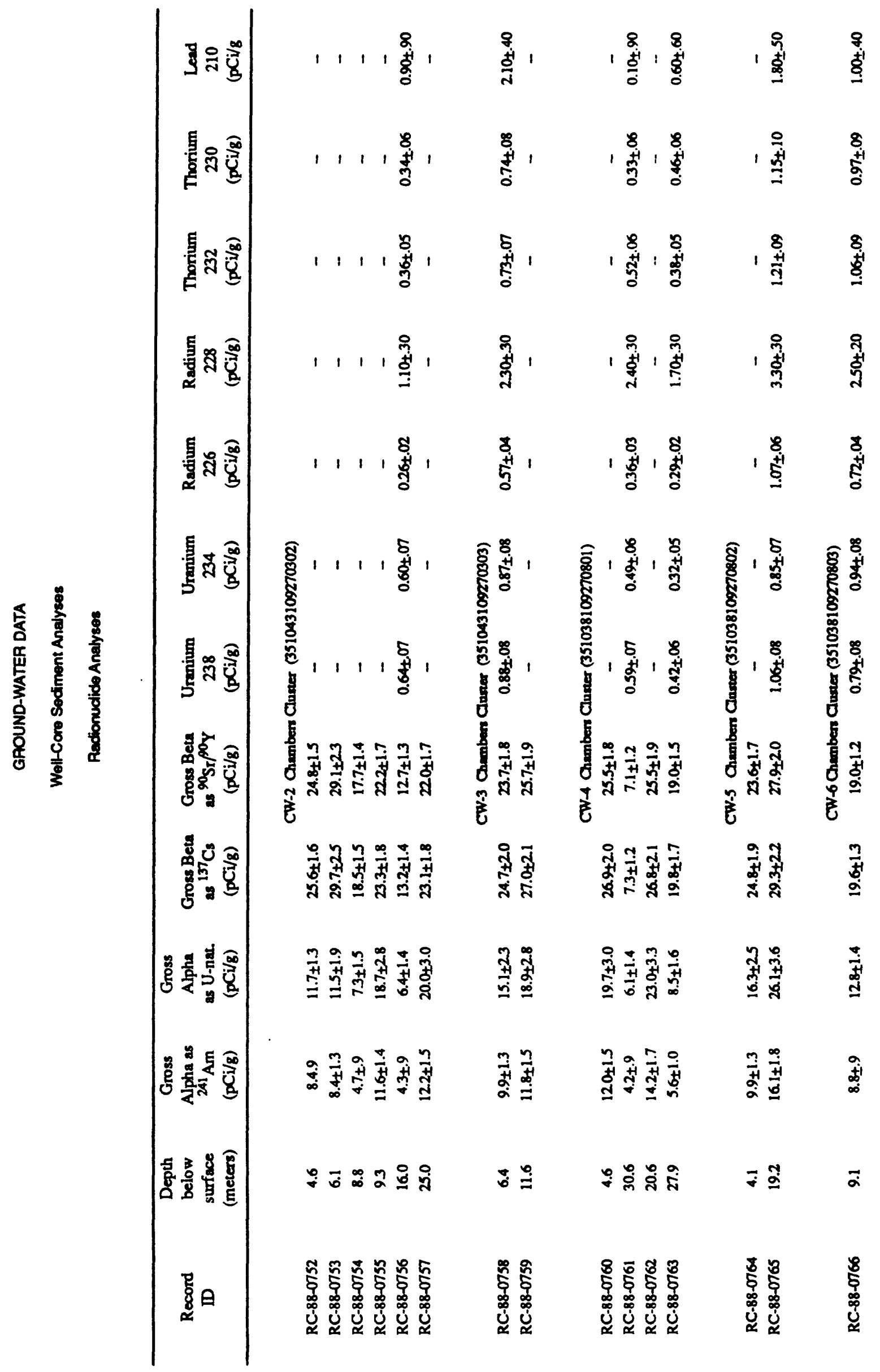




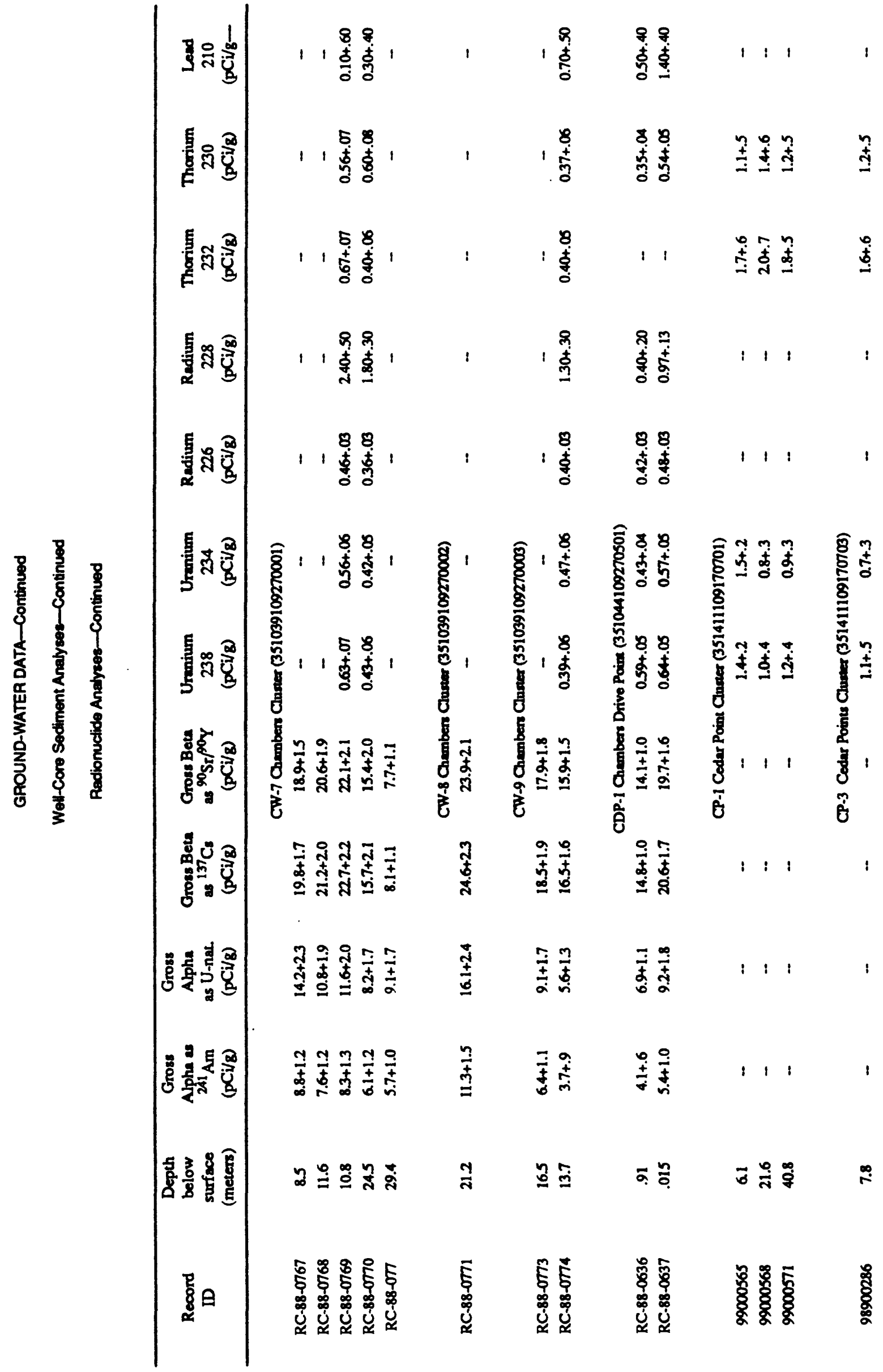




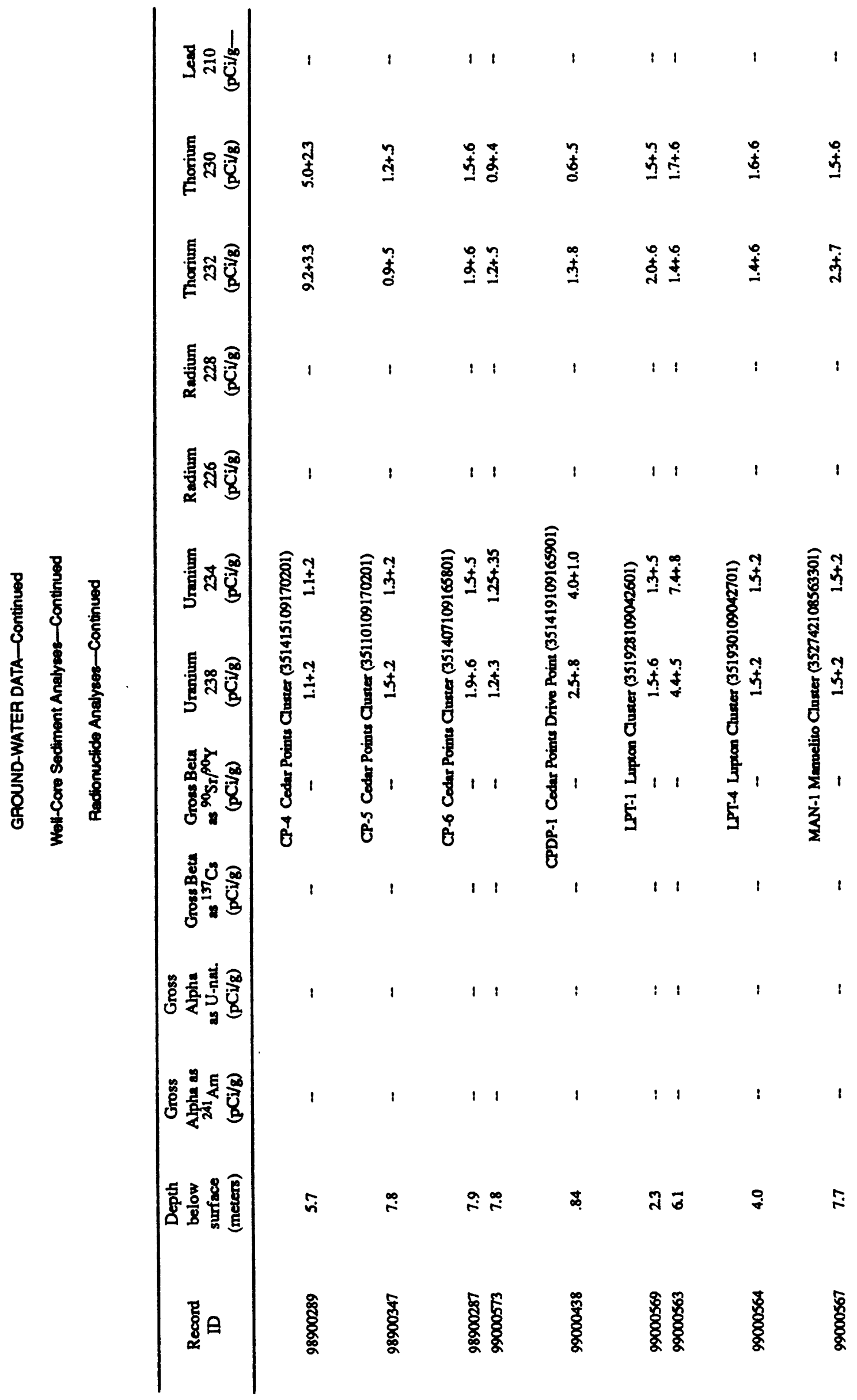




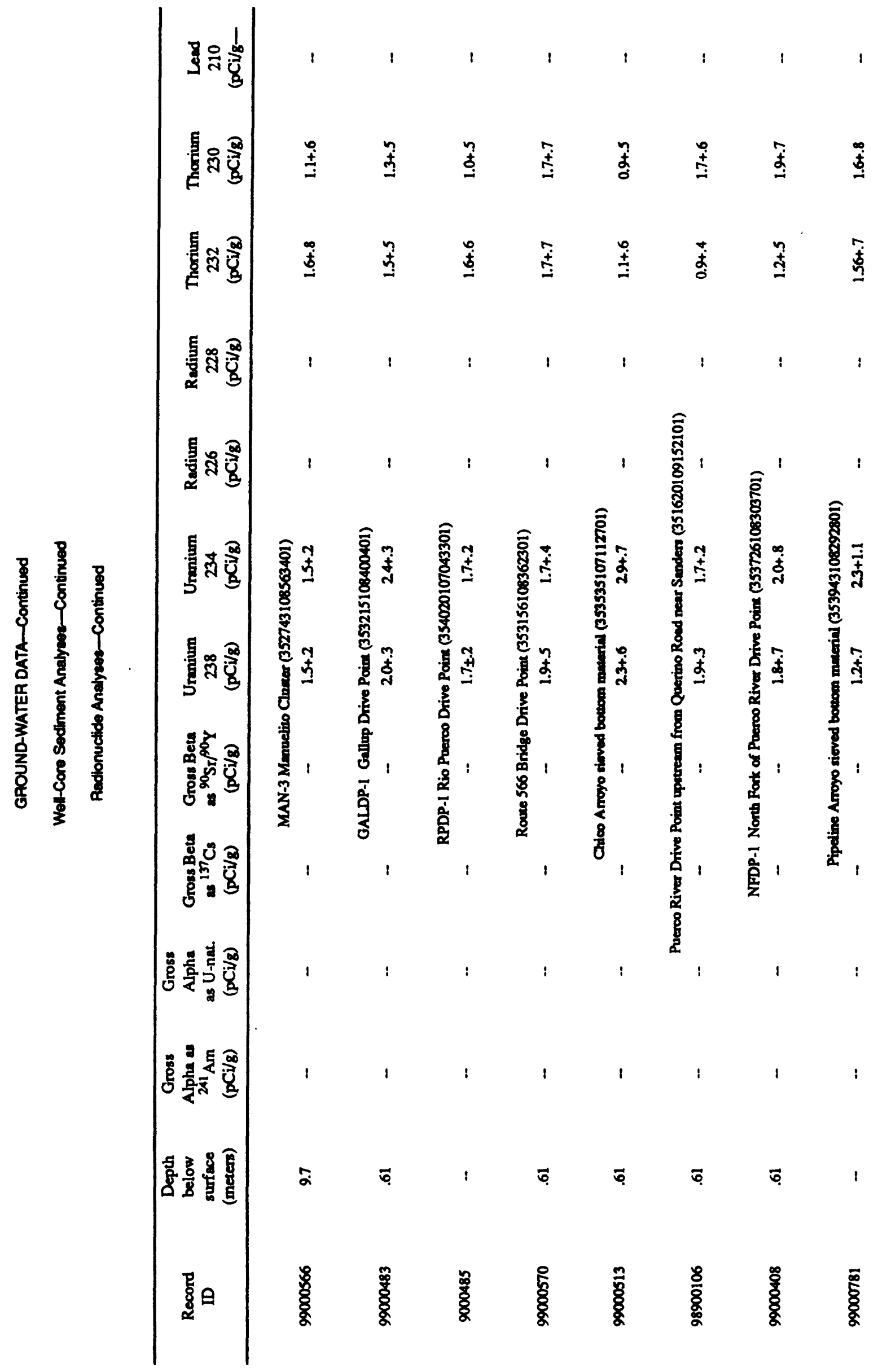




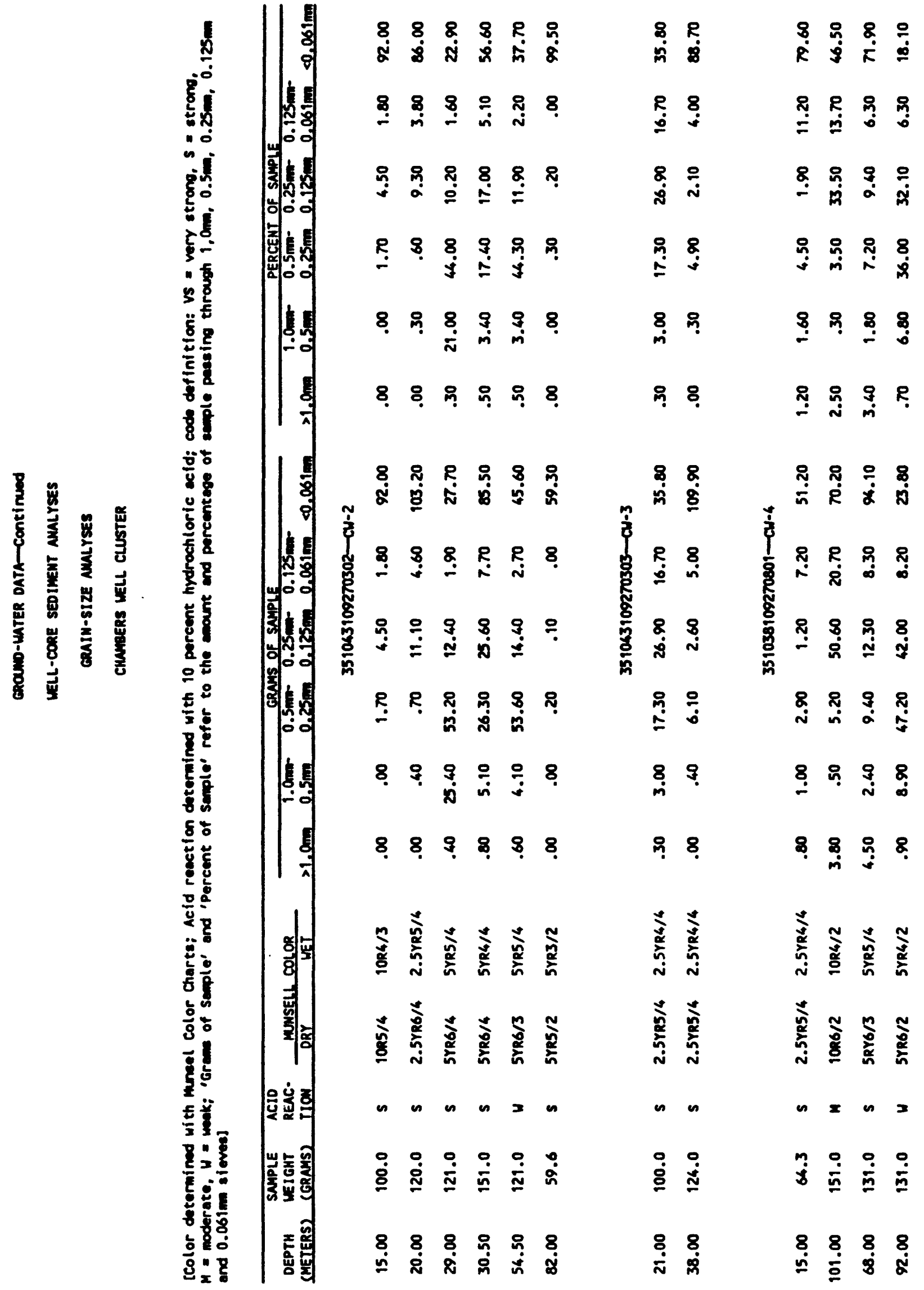




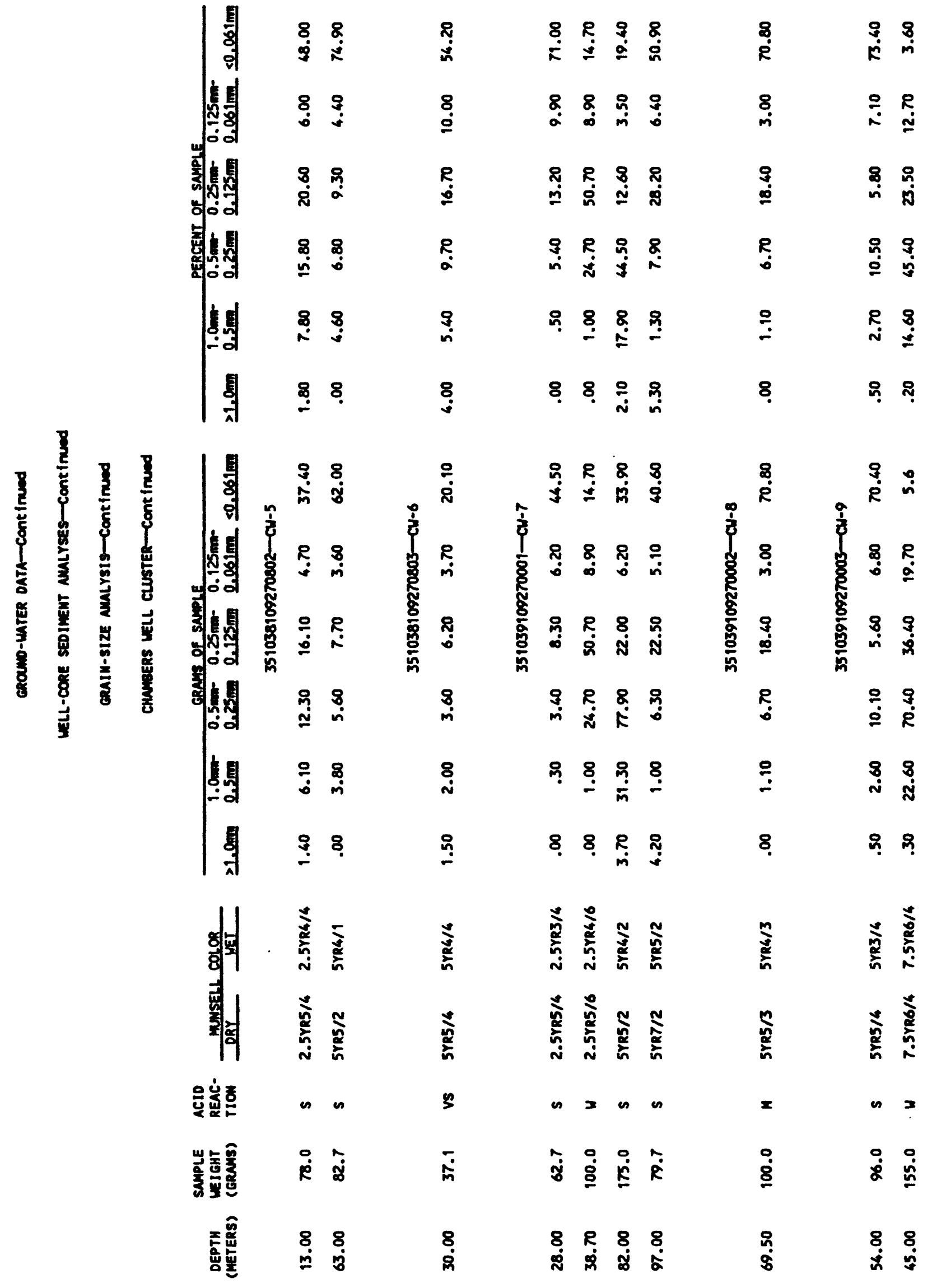




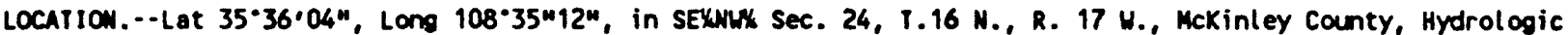
Unit 15020006, on right bank $61 \mathrm{~m}$ downstream from 32m Cic pipe bridge on dirt road $1.6 \mathrm{~m}$ northwest of State Highway 566, $4.3 \mathrm{~km}$ upstream from Hard Ground Canyon, $11.9 \mathrm{~km}$ upstream from South Fork, and $15.3 \mathrm{~km}$ northeast of Gallup.

DRAIMAGE AREA. $--531 \mathrm{~km}^{2}$.

PERIOD OF REEORD.---May 1989 to September 1991.

OTHER OATA COLLECTION AT THIS SITE.--October 1977 to September 1982.

DISCHARGE, CUBIC METERS PER SECOND, MAY 1989 TO SEPTEMBER 1989 DAILY MEAN VALUES

\begin{tabular}{|c|c|c|c|c|c|c|c|c|c|c|c|c|}
\hline DAY & OCT & NOV & DEC & JAN & FEB & MAR & APR & MAY & JUN & JUL & NUG & SEP \\
\hline $\begin{array}{l}1 \\
2 \\
3 \\
4 \\
5\end{array}$ & $\begin{array}{l}\ldots \\
\ldots \\
\ldots \\
\ldots\end{array}$ & $\begin{array}{l}\cdots \\
\ldots \\
\ldots \\
\ldots \\
\ldots\end{array}$ & $\begin{array}{l}\cdots \\
\cdots \\
\ldots \\
\cdots \\
\cdots\end{array}$ & $\begin{array}{l}\ldots \\
\ldots \\
\ldots \\
\ldots \\
\cdots\end{array}$ & $\begin{array}{l}\ldots \\
\ldots \\
\ldots \\
\ldots \\
\ldots\end{array}$ & $\begin{array}{l}\ldots \\
\ldots \\
\ldots \\
\ldots \\
\ldots\end{array}$ & $\begin{array}{l}\ldots \\
\ldots \\
\ldots \\
\ldots\end{array}$ & $\begin{array}{l}.000 \\
.000 \\
.000 \\
.000 \\
.000\end{array}$ & $\begin{array}{l}.000 \\
.000 \\
.000 \\
.000 \\
.000\end{array}$ & $\begin{array}{l}.000 \\
.000 \\
.000 \\
.000 \\
.000\end{array}$ & $\begin{array}{l}.708 \\
.821 \\
.000 \\
.000 \\
.000\end{array}$ & $\begin{array}{l}.000 \\
.000 \\
.000 \\
.000 \\
3.11\end{array}$ \\
\hline $\begin{array}{r}6 \\
7 \\
8 \\
9 \\
10\end{array}$ & $\begin{array}{l}\ldots \\
\ldots \\
\ldots \\
\ldots\end{array}$ & $\begin{array}{l}\ldots \\
\ldots \\
\ldots \\
\ldots \\
\ldots\end{array}$ & $\begin{array}{l}\ldots \\
\ldots \\
\ldots \\
\ldots\end{array}$ & $\begin{array}{l}\ldots \\
\ldots \\
\ldots \\
\ldots \\
\cdots\end{array}$ & $\begin{array}{l}\ldots \\
\ldots \\
\ldots \\
\cdots \\
\cdots\end{array}$ & $\begin{array}{l}\ldots \\
\ldots \\
\ldots \\
\ldots \\
\ldots\end{array}$ & $\begin{array}{l}\ldots \\
\ldots \\
\ldots \\
\ldots \\
\ldots\end{array}$ & $\begin{array}{l}.000 \\
.000 \\
.000 \\
.000 \\
.000\end{array}$ & $\begin{array}{l}.000 \\
.040 \\
.088 \\
.096 \\
.122\end{array}$ & $\begin{array}{l}.000 \\
.000 \\
.000 \\
.000 \\
.000\end{array}$ & $\begin{array}{l}.000 \\
.000 \\
.000 \\
.000 \\
.000\end{array}$ & $\begin{array}{l}.269 \\
.000 \\
.000 \\
.000 \\
.000\end{array}$ \\
\hline $\begin{array}{l}11 \\
12 \\
13 \\
14 \\
15\end{array}$ & $\begin{array}{l}\ldots \\
\ldots \\
\ldots \\
\ldots \\
\ldots\end{array}$ & $\begin{array}{l}\ldots \\
\ldots \\
\ldots \\
\ldots \\
\ldots\end{array}$ & $\begin{array}{l}\ldots \\
\ldots \\
\ldots \\
\ldots \\
\ldots\end{array}$ & $\begin{array}{l}\ldots \\
\ldots \\
\ldots \\
\ldots \\
\ldots\end{array}$ & $\begin{array}{l}\ldots \\
\ldots \\
\ldots \\
\ldots\end{array}$ & $\begin{array}{l}\ldots \\
\ldots \\
\ldots \\
\ldots \\
\ldots\end{array}$ & $\begin{array}{l}\ldots \\
\ldots \\
\ldots \\
\ldots \\
\ldots\end{array}$ & $\begin{array}{l}.000 \\
.000 \\
.000 \\
.000 \\
.000\end{array}$ & $\begin{array}{l}.119 \\
.116 \\
.108 \\
.076 \\
.000\end{array}$ & $\begin{array}{l}.000 \\
.000 \\
.000 \\
.000 \\
.000\end{array}$ & $\begin{array}{l}.000 \\
.000 \\
.000 \\
.000 \\
.000\end{array}$ & $\begin{array}{l}.000 \\
.000 \\
.000 \\
.000 \\
.000\end{array}$ \\
\hline $\begin{array}{l}16 \\
17 \\
18 \\
19 \\
20\end{array}$ & $\begin{array}{l}\ldots \\
\ldots \\
\ldots \\
\ldots \\
\ldots\end{array}$ & $\begin{array}{l}\ldots \\
\ldots \\
\ldots \\
\ldots\end{array}$ & $\begin{array}{l}\ldots \\
\ldots \\
\ldots \\
\ldots\end{array}$ & $\begin{array}{l}\ldots \\
\ldots \\
\ldots \\
\ldots\end{array}$ & $\begin{array}{l}\ldots \\
\ldots \\
\ldots \\
\ldots \\
\ldots\end{array}$ & $\begin{array}{l}\ldots \\
\ldots \\
\ldots \\
\ldots\end{array}$ & $\begin{array}{l}\ldots \\
\ldots \\
\ldots \\
\ldots\end{array}$ & $\begin{array}{l}.000 \\
.000 \\
.000 \\
.000 \\
.000\end{array}$ & $\begin{array}{l}.000 \\
.000 \\
.000 \\
.000 \\
.000\end{array}$ & $\begin{array}{l}.000 \\
.000 \\
.000 \\
.000 \\
.000\end{array}$ & $\begin{array}{l}.000 \\
.000 \\
.000 \\
.000 \\
.000\end{array}$ & $\begin{array}{l}.000 \\
.000 \\
.000 \\
.000 \\
.000\end{array}$ \\
\hline $\begin{array}{l}21 \\
22 \\
23 \\
24 \\
25\end{array}$ & $\begin{array}{l}\ldots \\
\ldots \\
\ldots \\
\ldots \\
\ldots\end{array}$ & $\begin{array}{l}\ldots \\
\ldots \\
\ldots \\
\ldots\end{array}$ & $\begin{array}{l}\ldots \\
\ldots \\
\ldots \\
\ldots\end{array}$ & $\begin{array}{l}\ldots \\
\ldots \\
\ldots \\
\ldots\end{array}$ & $\begin{array}{l}\ldots \\
\ldots \\
\ldots \\
\ldots\end{array}$ & $\begin{array}{l}\ldots \\
\ldots \\
\ldots \\
\ldots \\
\ldots\end{array}$ & $\begin{array}{l}\ldots \\
\ldots \\
\ldots \\
\ldots \\
\ldots\end{array}$ & $\begin{array}{l}.000 \\
.000 \\
.000 \\
.000 \\
.000\end{array}$ & $\begin{array}{l}.000 \\
.000 \\
.000 \\
.000 \\
.000\end{array}$ & $\begin{array}{l}.000 \\
.000 \\
.000 \\
.821 \\
.181\end{array}$ & $\begin{array}{l}.000 \\
.000 \\
.000 \\
.000 \\
.000\end{array}$ & $\begin{array}{l}.000 \\
.000 \\
.000 \\
.000 \\
.000\end{array}$ \\
\hline $\begin{array}{l}26 \\
27 \\
28 \\
29 \\
30 \\
31\end{array}$ & $\begin{array}{l}\ldots \\
\ldots \\
\ldots \\
\ldots \\
\ldots \\
\ldots\end{array}$ & $\begin{array}{l}\ldots \\
\ldots \\
\ldots \\
\ldots \\
\ldots\end{array}$ & $\begin{array}{l}\ldots \\
\ldots \\
\ldots \\
\ldots \\
\ldots\end{array}$ & $\begin{array}{l}\ldots \\
\ldots \\
\ldots \\
\ldots \\
\ldots \\
\ldots\end{array}$ & $\begin{array}{l}\ldots \\
\ldots \\
\ldots \\
\ldots \\
\ldots\end{array}$ & $\begin{array}{l}\ldots \\
\ldots \\
\ldots \\
\ldots \\
\ldots \\
\ldots\end{array}$ & $\begin{array}{l}\ldots \\
\ldots \\
\ldots \\
\ldots \\
\ldots \\
\ldots\end{array}$ & $\begin{array}{l}.000 \\
.000 \\
.000 \\
.000 \\
.000 \\
.000\end{array}$ & $\begin{array}{l}.000 \\
.000 \\
.000 \\
.000 \\
.000 \\
. . .\end{array}$ & $\begin{array}{l}2.61 \\
1.16 \\
2.72 \\
.159 \\
.000 \\
.000\end{array}$ & $\begin{array}{l}.000 \\
.000 \\
.000 \\
.000 \\
.000 \\
.000\end{array}$ & $\begin{array}{l}.000 \\
.000 \\
.000 \\
.000 \\
.000 \\
\ldots\end{array}$ \\
\hline
\end{tabular}


SURFACE-WATER DATA-Cont inUed

DAILY MEAN DISCHARGE-Continued

09395350 PUERCO RIVER MEAR CHURCH ROCK, NM-Continued

DISCHARGE, CUBIC METERS PER SECOND, WATER YEAR OCTOBER 1989 TO SEPTEMBER 1990 DAILY MEAN VALUES

\begin{tabular}{|c|c|c|c|c|c|c|c|c|c|c|c|}
\hline DAY & OCT & NOV & DEC & JAN & FEB & MAR & APR & Mar & JUN & JUL & AUG \\
\hline $\begin{array}{l}1 \\
2 \\
3 \\
4 \\
5\end{array}$ & $\begin{array}{l}.000 \\
.000 \\
.000 \\
.000 \\
.000\end{array}$ & $\begin{array}{l}.000 \\
.000 \\
.000 \\
.000 \\
.000\end{array}$ & $\begin{array}{l}.000 \\
.000 \\
.000 \\
.000 \\
.000\end{array}$ & $\begin{array}{l}.000 \\
.000 \\
.000 \\
.000 \\
.000\end{array}$ & $\begin{array}{l}.000 \\
.000 \\
.000 \\
.000 \\
.000\end{array}$ & $\begin{array}{l}.000 \\
.000 \\
.000 \\
.000 \\
.000\end{array}$ & $\begin{array}{l}.000 \\
.000 \\
.000 \\
.000 \\
.000\end{array}$ & $\begin{array}{l}.000 \\
.000 \\
.000 \\
.000 \\
.000\end{array}$ & $\begin{array}{l}.000 \\
.000 \\
.000 \\
.000 \\
.000\end{array}$ & $\begin{array}{l}.000 \\
.000 \\
.000 \\
.000 \\
1.47\end{array}$ & $\begin{array}{l}.000 \\
.000 \\
.000 \\
.000 \\
.311\end{array}$ \\
\hline $\begin{array}{r}6 \\
7 \\
8 \\
9 \\
10\end{array}$ & $\begin{array}{l}.000 \\
.000 \\
.000 \\
.000 \\
.000\end{array}$ & $\begin{array}{l}.000 \\
.000 \\
.000 \\
.000 \\
.000\end{array}$ & $\begin{array}{l}.000 \\
.000 \\
.000 \\
.000 \\
.000\end{array}$ & $\begin{array}{l}.000 \\
.000 \\
.000 \\
.000 \\
.000\end{array}$ & $\begin{array}{l}.000 \\
.000 \\
.000 \\
.000 \\
.000\end{array}$ & $\begin{array}{l}.000 \\
.000 \\
.000 \\
.000 \\
.000\end{array}$ & $\begin{array}{l}.000 \\
.000 \\
.000 \\
.000 \\
.000\end{array}$ & $\begin{array}{l}.000 \\
.000 \\
.000 \\
.000 \\
.000\end{array}$ & $\begin{array}{l}.000 \\
.000 \\
.000 \\
.000 \\
.000\end{array}$ & $\begin{array}{c}.850 \\
.906 \\
2.27 \\
2.21 \\
.623\end{array}$ & $\begin{array}{l}.125 \\
.000 \\
.000 \\
.000 \\
.000\end{array}$ \\
\hline $\begin{array}{l}11 \\
12 \\
13 \\
14 \\
15\end{array}$ & $\begin{array}{l}.000 \\
.000 \\
.000 \\
.000 \\
.000\end{array}$ & $\begin{array}{l}.000 \\
.000 \\
.000 \\
.000 \\
.000\end{array}$ & $\begin{array}{l}.000 \\
.000 \\
.000 \\
.000 \\
.000\end{array}$ & $\begin{array}{l}.000 \\
.000 \\
.000 \\
.000 \\
.000\end{array}$ & $\begin{array}{l}.000 \\
.000 \\
.000 \\
.000 \\
.000\end{array}$ & $\begin{array}{l}.000 \\
.000 \\
.000 \\
.000 \\
.000\end{array}$ & $\begin{array}{l}.000 \\
.000 \\
.000 \\
.000 \\
.000\end{array}$ & $\begin{array}{l}.000 \\
.000 \\
.000 \\
.000 \\
.000\end{array}$ & $\begin{array}{l}.000 \\
.000 \\
.000 \\
.000 \\
.000\end{array}$ & $\begin{array}{l}.000 \\
2.10 \\
.136 \\
.224 \\
.000\end{array}$ & $\begin{array}{l}.000 \\
.000 \\
.000 \\
.566 \\
1.33\end{array}$ \\
\hline $\begin{array}{l}16 \\
17 \\
18 \\
19 \\
20\end{array}$ & $\begin{array}{l}.000 \\
.000 \\
.000 \\
.000 \\
.000\end{array}$ & $\begin{array}{l}.000 \\
.000 \\
.000 \\
.000 \\
.000\end{array}$ & $\begin{array}{l}.000 \\
.000 \\
.000 \\
.000 \\
.000\end{array}$ & $\begin{array}{l}.000 \\
.000 \\
.000 \\
.000 \\
.000\end{array}$ & $\begin{array}{l}.000 \\
.000 \\
.000 \\
.000 \\
.000\end{array}$ & $\begin{array}{l}.000 \\
.000 \\
.000 \\
.000 \\
.000\end{array}$ & $\begin{array}{l}.000 \\
.000 \\
.000 \\
.000 \\
.000\end{array}$ & $\begin{array}{l}.000 \\
.000 \\
.000 \\
.000 \\
.000\end{array}$ & $\begin{array}{l}.000 \\
.000 \\
.000 \\
.000 \\
.000\end{array}$ & $\begin{array}{l}.000 \\
.000 \\
.034 \\
.000 \\
.000\end{array}$ & $\begin{array}{l}1.13 \\
.000 \\
.000 \\
.000 \\
.000\end{array}$ \\
\hline $\begin{array}{l}21 \\
22 \\
23 \\
24 \\
25\end{array}$ & $\begin{array}{l}.000 \\
.000 \\
.000 \\
.000 \\
.000\end{array}$ & $\begin{array}{l}.000 \\
.000 \\
.000 \\
.000 \\
.000\end{array}$ & $\begin{array}{l}.000 \\
.000 \\
.000 \\
.000 \\
.000\end{array}$ & $\begin{array}{l}.000 \\
.000 \\
.000 \\
.000 \\
.000\end{array}$ & $\begin{array}{l}.000 \\
.000 \\
.000 \\
.000 \\
.000\end{array}$ & $\begin{array}{l}.000 \\
.000 \\
.000 \\
.000 \\
.000\end{array}$ & $\begin{array}{l}.000 \\
.000 \\
.000 \\
.000 \\
.000\end{array}$ & $\begin{array}{l}.000 \\
.000 \\
.000 \\
.000 \\
.000\end{array}$ & $\begin{array}{l}.000 \\
.000 \\
.000 \\
.000 \\
.000\end{array}$ & $\begin{array}{l}.000 \\
.000 \\
.000 \\
.000 \\
.000\end{array}$ & $\begin{array}{l}.000 \\
.000 \\
.000 \\
.000 \\
.000\end{array}$ \\
\hline $\begin{array}{l}26 \\
27 \\
28 \\
29 \\
30 \\
31\end{array}$ & $\begin{array}{l}.000 \\
.000 \\
.000 \\
.000 \\
.000 \\
.000\end{array}$ & $\begin{array}{l}.000 \\
.000 \\
.000 \\
.000 \\
.000 \\
. .\end{array}$ & $\begin{array}{l}.000 \\
.000 \\
.000 \\
.000 \\
.000 \\
.000\end{array}$ & $\begin{array}{l}.000 \\
.000 \\
.000 \\
.000 \\
.000 \\
.000\end{array}$ & $\begin{array}{c}.000 \\
.000 \\
.000 \\
\ldots \\
\ldots \\
\ldots\end{array}$ & $\begin{array}{l}.000 \\
.000 \\
.000 \\
.000 \\
.000 \\
.000\end{array}$ & $\begin{array}{c}.000 \\
.000 \\
.000 \\
.000 \\
.000 \\
\ldots .\end{array}$ & $\begin{array}{l}.000 \\
.000 \\
.000 \\
.000 \\
.000 \\
.000\end{array}$ & $\begin{array}{l}.000 \\
.000 \\
.000 \\
.000 \\
.000 \\
\ldots .\end{array}$ & $\begin{array}{l}.000 \\
.000 \\
.000 \\
.000 \\
.000 \\
.000\end{array}$ & $\begin{array}{l}.000 \\
.000 \\
.000 \\
.000 \\
.000 \\
.000\end{array}$ \\
\hline
\end{tabular}


SURFACE-WATER DATA-Continued

DAILY MEAN DISCHARGE-Continued

09395350 PUERCO RIVER NEAR CHURCH ROCK, NM-Continued

DISCHARGE, CUBIC METERS PER SECOND, WATER YEAR OCTOBER 1990 TO SEPTEMBER 1991 DAILY MEAN VALUES

\begin{tabular}{|c|c|c|c|c|c|c|c|c|c|c|c|c|}
\hline DAY & OCT & NOV & DEC & JAN & FEB & MAR & APR & MAY & JUN & JUL & AUG & SEP \\
\hline $\begin{array}{l}1 \\
2 \\
3 \\
4 \\
5\end{array}$ & $\begin{array}{l}1.02 \\
.085 \\
.000 \\
.000 \\
.000\end{array}$ & $\begin{array}{l}.000 \\
.000 \\
.000 \\
.000 \\
.000\end{array}$ & $\begin{array}{l}.000 \\
.000 \\
.000 \\
.000 \\
.000\end{array}$ & $\begin{array}{l}.000 \\
.000 \\
.000 \\
.000 \\
.000\end{array}$ & $\begin{array}{l}.000 \\
.000 \\
.000 \\
.000 \\
.000\end{array}$ & $\begin{array}{l}.000 \\
.000 \\
.000 \\
.000 \\
.000\end{array}$ & $\begin{array}{l}.000 \\
.000 \\
.000 \\
.000 \\
.000\end{array}$ & $\begin{array}{l}.000 \\
.000 \\
.000 \\
.000 \\
.000\end{array}$ & $\begin{array}{l}.000 \\
.000 \\
.000 \\
.000 \\
.000\end{array}$ & $\begin{array}{l}.000 \\
.000 \\
.000 \\
.000 \\
.000\end{array}$ & $\begin{array}{l}.510 \\
2.38 \\
.142 \\
.085 \\
.000\end{array}$ & $\begin{array}{l}.000 \\
.000 \\
.000 \\
.000 \\
.000\end{array}$ \\
\hline $\begin{array}{r}6 \\
7 \\
8 \\
9 \\
10\end{array}$ & $\begin{array}{l}.000 \\
.000 \\
.000 \\
.000 \\
.000\end{array}$ & $\begin{array}{l}.000 \\
.000 \\
.000 \\
.000 \\
.000\end{array}$ & $\begin{array}{l}.000 \\
.000 \\
.000 \\
.000 \\
.000\end{array}$ & $\begin{array}{l}.000 \\
.000 \\
.000 \\
.000 \\
.000\end{array}$ & $\begin{array}{l}.000 \\
.000 \\
.000 \\
.000 \\
.000\end{array}$ & $\begin{array}{l}.000 \\
.000 \\
.000 \\
.000 \\
.000\end{array}$ & $\begin{array}{l}.000 \\
.000 \\
.000 \\
.000 \\
.000\end{array}$ & $\begin{array}{l}.000 \\
.000 \\
.000 \\
.000 \\
.000\end{array}$ & $\begin{array}{l}.000 \\
.000 \\
.000 \\
.000 \\
.000\end{array}$ & $\begin{array}{l}.000 \\
.000 \\
.000 \\
.000 \\
.000\end{array}$ & $\begin{array}{r}2.83 \\
.906 \\
.142 \\
.085 \\
.184\end{array}$ & $\begin{array}{l}.000 \\
.000 \\
.000 \\
.000 \\
.000\end{array}$ \\
\hline $\begin{array}{l}11 \\
12 \\
13 \\
14 \\
15\end{array}$ & $\begin{array}{l}.000 \\
.000 \\
.000 \\
.000 \\
.000\end{array}$ & $\begin{array}{l}.000 \\
.000 \\
.000 \\
.000 \\
.000\end{array}$ & $\begin{array}{l}.000 \\
.000 \\
.000 \\
.000 \\
.000\end{array}$ & $\begin{array}{l}.000 \\
.000 \\
.000 \\
.000 \\
.000\end{array}$ & $\begin{array}{l}.000 \\
.000 \\
.000 \\
.000 \\
.000\end{array}$ & $\begin{array}{l}.000 \\
.000 \\
.000 \\
.000 \\
.000\end{array}$ & $\begin{array}{l}.000 \\
.000 \\
.000 \\
.000 \\
.000\end{array}$ & $\begin{array}{l}.000 \\
.000 \\
.000 \\
.000 \\
.000\end{array}$ & $\begin{array}{l}.000 \\
.000 \\
.000 \\
.000 \\
.000\end{array}$ & $\begin{array}{l}.000 \\
.000 \\
.000 \\
.000 \\
.000\end{array}$ & $\begin{array}{l}.263 \\
.028 \\
.000 \\
.000 \\
.000\end{array}$ & $\begin{array}{l}.000 \\
.000 \\
.000 \\
.000 \\
.000\end{array}$ \\
\hline $\begin{array}{l}16 \\
17 \\
18 \\
19 \\
20\end{array}$ & $\begin{array}{l}.000 \\
.000 \\
.000 \\
.510 \\
5.49\end{array}$ & $\begin{array}{l}.000 \\
.000 \\
.000 \\
.000 \\
.000\end{array}$ & $\begin{array}{l}.000 \\
.000 \\
.000 \\
.000 \\
.000\end{array}$ & $\begin{array}{l}.000 \\
.000 \\
.000 \\
.000 \\
.000\end{array}$ & $\begin{array}{l}.000 \\
.000 \\
.000 \\
.000 \\
.000\end{array}$ & $\begin{array}{l}.000 \\
.000 \\
.000 \\
.000 \\
.000\end{array}$ & $\begin{array}{l}.000 \\
.000 \\
.000 \\
.000 \\
.000\end{array}$ & $\begin{array}{l}.000 \\
.000 \\
.000 \\
.000 \\
.000\end{array}$ & $\begin{array}{l}.000 \\
.000 \\
.000 \\
.000 \\
.000\end{array}$ & $\begin{array}{l}.000 \\
.000 \\
.000 \\
.000 \\
.000\end{array}$ & $\begin{array}{l}.000 \\
.000 \\
.000 \\
.000 \\
.000\end{array}$ & $\begin{array}{l}.000 \\
.000 \\
.000 \\
.000 \\
.000\end{array}$ \\
\hline $\begin{array}{l}21 \\
22 \\
23 \\
24 \\
25\end{array}$ & $\begin{array}{l}.283 \\
.142 \\
.000 \\
.000 \\
.000\end{array}$ & $\begin{array}{l}.000 \\
.000 \\
.000 \\
.000 \\
.000\end{array}$ & $\begin{array}{l}.000 \\
.000 \\
.000 \\
.000 \\
.000\end{array}$ & $\begin{array}{l}.000 \\
.000 \\
.000 \\
.000 \\
.000\end{array}$ & $\begin{array}{l}.000 \\
.000 \\
.000 \\
.000 \\
.000\end{array}$ & $\begin{array}{l}.000 \\
.000 \\
.000 \\
.000 \\
.000\end{array}$ & $\begin{array}{l}.000 \\
.000 \\
.000 \\
.000 \\
.000\end{array}$ & $\begin{array}{l}.000 \\
.000 \\
.000 \\
.000 \\
.000\end{array}$ & $\begin{array}{l}.000 \\
.000 \\
.000 \\
.000 \\
.000\end{array}$ & $\begin{array}{l}.000 \\
.000 \\
.000 \\
.000 \\
.000\end{array}$ & $\begin{array}{l}.000 \\
.000 \\
.000 \\
.000 \\
.000\end{array}$ & $\begin{array}{l}.000 \\
.000 \\
.000 \\
.000 \\
.000\end{array}$ \\
\hline $\begin{array}{l}26 \\
27 \\
28 \\
29 \\
30 \\
31\end{array}$ & $\begin{array}{l}.000 \\
.000 \\
.000 \\
.000 \\
.000 \\
.000\end{array}$ & $\begin{array}{c}.000 \\
.000 \\
.000 \\
.000 \\
.000 \\
\ldots .\end{array}$ & $\begin{array}{l}.000 \\
.000 \\
.000 \\
.000 \\
.000 \\
.000\end{array}$ & $\begin{array}{l}.000 \\
.000 \\
.000 \\
.000 \\
.000 \\
.000\end{array}$ & $\begin{array}{c}.000 \\
.000 \\
.000 \\
\ldots \\
\ldots\end{array}$ & $\begin{array}{l}.000 \\
.000 \\
.000 \\
.000 \\
.000 \\
.000\end{array}$ & $\begin{array}{c}.000 \\
.000 \\
.000 \\
.000 \\
.000 \\
\ldots .\end{array}$ & $\begin{array}{l}.000 \\
.000 \\
.000 \\
.000 \\
.000 \\
.000\end{array}$ & $\begin{array}{c}.000 \\
.000 \\
.000 \\
.000 \\
.000 \\
\ldots\end{array}$ & $\begin{array}{l}.000 \\
.000 \\
.000 \\
.000 \\
.000 \\
.000\end{array}$ & $\begin{array}{l}.000 \\
.000 \\
.000 \\
.000 \\
.000 \\
.000\end{array}$ & $\begin{array}{r}.000 \\
.000 \\
.000 \\
.000 \\
.000 \\
\ldots\end{array}$ \\
\hline
\end{tabular}


SURFACE-WATER DATA-Continued

DAILY MEAN DISCHARGE-Continued

09395630 PUERCO RIVER MEAR MANUELITO, NM

LOCATION.--Lat 35.27'42', Long 108.56'42" in SEXNWK Sec. 10, T.14 N., R.20 H., Mckinley County, Hydrologic Unit 15020006, on dounstream side of Atchison, Topeks, and Santa Fe Rail raad bridge, $60 \mathrm{~m}$ upstream from Interstate Highway 40, $1.9 \mathrm{~km}$ upstrean from Hunt ing Canyon and $20.3 \mathrm{~km}$ west of Gallup.

DRAINAGE AREA. $--1,593 \mathrm{~km}^{2}$

PERIOD OF RECORD.--MAY 1989 TO SEPTEMBER 1991.

DISCHARGE, CUBIC METERS PER SECOND, MAY 1989 TO SEPTEMBER 1989 DAILY MEAN VALUES

\begin{tabular}{|c|c|c|c|c|c|c|c|c|c|c|c|c|}
\hline DAY & OCT & NOV & DEC & JAN & FEB & MAR & APR & MAY & JUN & JUL & AUG & SEP \\
\hline $\begin{array}{l}1 \\
2 \\
3 \\
4 \\
5\end{array}$ & $\begin{array}{l}\ldots \\
\ldots \\
\ldots \\
\ldots \\
\ldots\end{array}$ & $\begin{array}{l}\ldots \\
\ldots \\
\ldots \\
\ldots \\
\cdots\end{array}$ & $\begin{array}{l}\ldots \\
\ldots \\
\cdots \\
\cdots \\
\cdots\end{array}$ & $\begin{array}{l}\cdots \\
\cdots \\
\cdots \\
\cdots\end{array}$ & $\begin{array}{l}\ldots \\
\ldots \\
\ldots \\
\cdots\end{array}$ & $\begin{array}{l}\ldots \\
\ldots \\
\ldots \\
\cdots \\
\cdots\end{array}$ & $\begin{array}{l}\ldots \\
\ldots \\
\ldots \\
\ldots\end{array}$ & $\begin{array}{l}. .2 \\
.045 \\
.045 \\
.045 \\
.045\end{array}$ & $\begin{array}{l}.045 \\
.045 \\
.045 \\
.045 \\
.045\end{array}$ & $\begin{array}{l}.045 \\
.045 \\
.045 \\
.045 \\
.045\end{array}$ & $\begin{array}{l}1.25 \\
2.94 \\
.680 \\
.045 \\
.045\end{array}$ & $\begin{array}{l}.045 \\
.045 \\
.045 \\
.045 \\
.566\end{array}$ \\
\hline $\begin{array}{r}6 \\
7 \\
8 \\
9 \\
10\end{array}$ & $\begin{array}{l}\ldots \\
\ldots \\
\ldots \\
\ldots \\
\ldots\end{array}$ & $\begin{array}{l}\ldots \\
\ldots \\
\ldots \\
\ldots\end{array}$ & $\begin{array}{l}\cdots \\
\cdots \\
\cdots \\
\cdots\end{array}$ & $\begin{array}{l}\cdots \\
\ldots \\
\cdots \\
\cdots\end{array}$ & $\begin{array}{l}\cdots \\
\cdots \\
\cdots \\
\cdots\end{array}$ & $\begin{array}{l}\ldots \\
\ldots \\
\cdots \\
\cdots \\
\cdots\end{array}$ & $\begin{array}{l}\ldots \\
\ldots \\
\ldots \\
\ldots\end{array}$ & $\begin{array}{l}.045 \\
.045 \\
.045 \\
.045 \\
.045\end{array}$ & $\begin{array}{l}.045 \\
.045 \\
.045 \\
.045 \\
.045\end{array}$ & $\begin{array}{l}.045 \\
.045 \\
.045 \\
.045 \\
.045\end{array}$ & $\begin{array}{l}.045 \\
.045 \\
.045 \\
.045 \\
.045\end{array}$ & $\begin{array}{r}14.2 \\
.045 \\
.045 \\
.045 \\
.045\end{array}$ \\
\hline $\begin{array}{l}11 \\
12 \\
13 \\
14 \\
15\end{array}$ & $\begin{array}{l}\ldots \\
\ldots \\
\ldots \\
\ldots \\
\ldots\end{array}$ & $\begin{array}{l}\ldots \\
\ldots \\
\ldots \\
\ldots \\
\ldots\end{array}$ & $\begin{array}{l}\ldots \\
\ldots \\
\ldots \\
\ldots \\
\cdots\end{array}$ & $\begin{array}{l}\ldots \\
\ldots \\
\ldots \\
\ldots \\
\cdots\end{array}$ & $\begin{array}{l}\ldots \\
\ldots \\
\ldots \\
\ldots \\
\cdots\end{array}$ & $\begin{array}{l}\ldots \\
\ldots \\
\ldots \\
\ldots \\
\ldots\end{array}$ & $\begin{array}{l}\ldots \\
\ldots \\
\ldots \\
\ldots \\
\ldots\end{array}$ & $\begin{array}{l}.045 \\
.045 \\
.045 \\
.045 \\
.045\end{array}$ & $\begin{array}{l}.045 \\
.045 \\
.045 \\
.045 \\
.045\end{array}$ & $\begin{array}{l}.045 \\
.045 \\
.045 \\
.045 \\
.045\end{array}$ & $\begin{array}{l}.045 \\
.045 \\
.045 \\
.045 \\
.045\end{array}$ & $\begin{array}{l}.045 \\
.045 \\
.045 \\
.045 \\
.045\end{array}$ \\
\hline $\begin{array}{l}16 \\
17 \\
18 \\
19 \\
20\end{array}$ & $\begin{array}{l}\ldots \\
\ldots \\
\ldots \\
\ldots \\
\ldots\end{array}$ & $\begin{array}{l}\ldots \\
\ldots \\
\ldots \\
\ldots \\
\ldots\end{array}$ & $\begin{array}{l}\ldots \\
\ldots \\
\ldots \\
\cdots\end{array}$ & $\begin{array}{l}\ldots \\
\ldots \\
\cdots \\
\cdots \\
\cdots\end{array}$ & $\begin{array}{l}\ldots \\
\ldots \\
\cdots \\
\cdots\end{array}$ & $\begin{array}{l}\ldots \\
\ldots \\
\ldots \\
\ldots \\
\ldots\end{array}$ & $\begin{array}{l}\ldots \\
\ldots \\
\ldots \\
\ldots \\
\ldots\end{array}$ & $\begin{array}{l}.045 \\
.045 \\
.045 \\
.045 \\
.045\end{array}$ & $\begin{array}{l}.045 \\
.045 \\
.045 \\
.045 \\
.045\end{array}$ & $\begin{array}{l}.045 \\
.045 \\
.045 \\
.045 \\
.045\end{array}$ & $\begin{array}{c}.045 \\
.045 \\
2.32 \\
4.22 \\
.144\end{array}$ & $\begin{array}{l}.045 \\
.045 \\
.045 \\
.368 \\
.045\end{array}$ \\
\hline $\begin{array}{l}21 \\
22 \\
23 \\
24 \\
25\end{array}$ & $\begin{array}{l}\ldots \\
\ldots \\
\ldots \\
\ldots \\
\ldots\end{array}$ & $\begin{array}{l}\ldots \\
\ldots \\
\ldots \\
\ldots \\
\ldots\end{array}$ & $\begin{array}{l}\ldots \\
\ldots \\
\ldots \\
\ldots \\
\ldots\end{array}$ & $\begin{array}{l}\ldots \\
\ldots \\
\ldots \\
\ldots\end{array}$ & $\begin{array}{l}\ldots \\
\ldots \\
\ldots \\
\ldots \\
\ldots\end{array}$ & $\begin{array}{l}\ldots \\
\ldots \\
\ldots \\
\ldots\end{array}$ & $\begin{array}{l}\ldots \\
\ldots \\
\ldots \\
\ldots \\
\ldots\end{array}$ & $\begin{array}{l}.045 \\
.045 \\
.045 \\
.045 \\
.045\end{array}$ & $\begin{array}{l}.045 \\
.045 \\
.045 \\
.045 \\
.045\end{array}$ & $\begin{array}{l}.045 \\
.045 \\
.045 \\
.566 \\
.425\end{array}$ & $\begin{array}{l}.045 \\
.045 \\
.045 \\
.045 \\
.045\end{array}$ & $\begin{array}{l}.045 \\
.045 \\
.045 \\
.045 \\
.045\end{array}$ \\
\hline $\begin{array}{l}26 \\
27 \\
28 \\
29 \\
30 \\
31\end{array}$ & $\begin{array}{l}\ldots \\
\ldots \\
\ldots \\
\ldots \\
\ldots \\
\ldots\end{array}$ & $\begin{array}{l}\ldots \\
\ldots \\
\ldots \\
\ldots \\
\ldots \\
\ldots\end{array}$ & $\begin{array}{l}\ldots \\
\ldots \\
\ldots \\
\ldots \\
\ldots \\
\ldots\end{array}$ & $\begin{array}{l}\ldots \\
\ldots \\
\ldots \\
\ldots \\
\ldots\end{array}$ & $\begin{array}{l}\ldots \\
\ldots \\
\ldots \\
\ldots \\
\ldots \\
\ldots\end{array}$ & $\begin{array}{l}\ldots \\
\ldots \\
\cdots \\
\cdots \\
\ldots \\
\ldots\end{array}$ & $\begin{array}{l}\ldots \\
\ldots \\
\ldots \\
\ldots \\
\ldots \\
\ldots\end{array}$ & $\begin{array}{l}.045 \\
.045 \\
.045 \\
.045 \\
.045 \\
.045\end{array}$ & $\begin{array}{l}.045 \\
.045 \\
.045 \\
.045 \\
.045 \\
. . .\end{array}$ & $\begin{array}{l}.12 \\
.97 \\
.52 \\
.35 \\
.25 \\
.25 \\
.44\end{array}$ & $\begin{array}{l}.045 \\
.045 \\
.045 \\
.045 \\
.045 \\
.045\end{array}$ & $\begin{array}{l}.045 \\
.045 \\
.045 \\
.045 \\
.045\end{array}$ \\
\hline
\end{tabular}


SURFACE-WATER DATA-Cont inued

DAILY MEAN DISCHARGE-Cont inued

09395630 PUERCO RIVER NEAR MANUELITO, MH-Continued

DISCHARGE, CUBIC METERS PER SECOND, WATER YEAR OCTOBER 1989 TO SEPTEMBER 1990

DAILY MEAN VALUES

\begin{tabular}{|c|c|c|c|c|c|c|c|c|c|c|c|c|}
\hline DAY & OCT & nOV & DEC & JAK & FEB & MAR & APR & MAY & JUN & JUL & AUG & SEP \\
\hline $\begin{array}{l}1 \\
2 \\
3 \\
4 \\
5\end{array}$ & $\begin{array}{l}.045 \\
.045 \\
.045 \\
.045 \\
.045\end{array}$ & $\begin{array}{l}.045 \\
.045 \\
.045 \\
.045 \\
.045\end{array}$ & $\begin{array}{l}.045 \\
.045 \\
.045 \\
.045 \\
.045\end{array}$ & $\begin{array}{l}.045 \\
.045 \\
.045 \\
.045 \\
.045\end{array}$ & $\begin{array}{l}.045 \\
.045 \\
.045 \\
.045 \\
.045\end{array}$ & $\begin{array}{l}.045 \\
.045 \\
.045 \\
.045 \\
.045\end{array}$ & $\begin{array}{l}.045 \\
.045 \\
.045 \\
.045 \\
.045\end{array}$ & $\begin{array}{l}.045 \\
.045 \\
.045 \\
.045 \\
.045\end{array}$ & $\begin{array}{l}.045 \\
.045 \\
.045 \\
.045 \\
.045\end{array}$ & $\begin{array}{l}.045 \\
.045 \\
.045 \\
.045 \\
.045\end{array}$ & $\begin{array}{l}.045 \\
.045 \\
.045 \\
.045 \\
.045\end{array}$ & $\begin{array}{l}.045 \\
1.02 \\
.045 \\
.045 \\
.051\end{array}$ \\
\hline $\begin{array}{r}6 \\
7 \\
8 \\
9 \\
10\end{array}$ & $\begin{array}{l}.045 \\
.045 \\
.045 \\
.045 \\
.045\end{array}$ & $\begin{array}{l}.045 \\
.045 \\
.045 \\
.045 \\
.045\end{array}$ & $\begin{array}{l}.045 \\
.045 \\
.045 \\
.045 \\
.045\end{array}$ & $\begin{array}{l}.045 \\
.045 \\
.045 \\
.045 \\
.045\end{array}$ & $\begin{array}{l}.045 \\
.045 \\
.045 \\
.045 \\
.045\end{array}$ & $\begin{array}{l}.045 \\
.045 \\
.045 \\
.045 \\
.045\end{array}$ & $\begin{array}{l}.045 \\
.045 \\
.045 \\
.045 \\
.045\end{array}$ & $\begin{array}{l}.045 \\
.045 \\
.045 \\
.045 \\
.045\end{array}$ & $\begin{array}{l}.045 \\
.045 \\
.045 \\
.045 \\
.045\end{array}$ & $\begin{array}{l}.651 \\
1.36 \\
1.78 \\
.045 \\
1.08\end{array}$ & $\begin{array}{l}.045 \\
2.18 \\
.045 \\
.045 \\
.045\end{array}$ & $\begin{array}{l}.045 \\
.045 \\
.045 \\
.045 \\
.045\end{array}$ \\
\hline $\begin{array}{l}11 \\
12 \\
13 \\
14 \\
15\end{array}$ & $\begin{array}{l}.045 \\
.045 \\
.045 \\
.045 \\
.045\end{array}$ & $\begin{array}{l}.045 \\
.045 \\
.045 \\
.045 \\
.045\end{array}$ & $\begin{array}{l}.045 \\
.045 \\
.045 \\
.045 \\
.045\end{array}$ & $\begin{array}{l}.045 \\
.045 \\
.045 \\
.045 \\
.045\end{array}$ & $\begin{array}{l}.045 \\
.045 \\
.045 \\
.045 \\
.045\end{array}$ & $\begin{array}{l}.045 \\
.045 \\
.045 \\
.045 \\
.045\end{array}$ & $\begin{array}{l}.045 \\
.045 \\
.045 \\
.045 \\
.045\end{array}$ & $\begin{array}{l}.045 \\
.045 \\
.045 \\
.045 \\
.045\end{array}$ & $\begin{array}{l}.045 \\
.045 \\
.045 \\
.045 \\
.045\end{array}$ & $\begin{array}{l}.045 \\
.906 \\
17.8 \\
2.18 \\
.045\end{array}$ & $\begin{array}{l}.045 \\
.045 \\
.045 \\
6.88 \\
4.84\end{array}$ & $\begin{array}{l}.045 \\
.045 \\
.045 \\
.045 \\
.045\end{array}$ \\
\hline $\begin{array}{l}16 \\
17 \\
18 \\
19 \\
20\end{array}$ & $\begin{array}{l}.045 \\
.045 \\
.045 \\
.045 \\
.045\end{array}$ & $\begin{array}{l}.045 \\
.045 \\
.045 \\
.045 \\
.045\end{array}$ & $\begin{array}{l}.045 \\
.045 \\
.045 \\
.045 \\
.045\end{array}$ & $\begin{array}{l}.045 \\
.045 \\
.045 \\
.045 \\
.045\end{array}$ & $\begin{array}{l}.045 \\
.045 \\
.045 \\
.045 \\
.045\end{array}$ & $\begin{array}{l}.045 \\
.045 \\
.045 \\
.045 \\
.045\end{array}$ & $\begin{array}{l}.045 \\
.045 \\
.045 \\
.045 \\
.045\end{array}$ & $\begin{array}{l}.045 \\
.045 \\
.045 \\
.045 \\
.045\end{array}$ & $\begin{array}{l}.045 \\
.045 \\
.045 \\
.045 \\
.045\end{array}$ & $\begin{array}{l}.045 \\
1.30 \\
.283 \\
.275 \\
.566\end{array}$ & $\begin{array}{l}6.91 \\
2.97 \\
.045 \\
.045 \\
2.49\end{array}$ & $\begin{array}{l}.653 \\
.045 \\
.045 \\
.045 \\
.510\end{array}$ \\
\hline $\begin{array}{l}21 \\
22 \\
23 \\
24 \\
25\end{array}$ & $\begin{array}{l}.045 \\
.045 \\
.045 \\
.045 \\
.045\end{array}$ & $\begin{array}{l}.045 \\
.045 \\
.045 \\
.045 \\
.045\end{array}$ & $\begin{array}{l}.045 \\
.045 \\
.045 \\
.045 \\
.045\end{array}$ & $\begin{array}{l}.045 \\
.045 \\
.045 \\
.045 \\
.045\end{array}$ & $\begin{array}{l}.045 \\
.045 \\
.045 \\
.045 \\
.045\end{array}$ & $\begin{array}{l}.045 \\
.045 \\
.045 \\
.045 \\
.045\end{array}$ & $\begin{array}{l}.045 \\
.045 \\
.045 \\
.045 \\
.045\end{array}$ & $\begin{array}{l}.045 \\
.045 \\
.045 \\
.045 \\
.045\end{array}$ & $\begin{array}{l}.045 \\
.045 \\
.045 \\
.045 \\
.045\end{array}$ & $\begin{array}{c}.045 \\
.045 \\
.963 \\
1.47 \\
.045\end{array}$ & $\begin{array}{l}2.41 \\
.045 \\
.045 \\
.045 \\
.045\end{array}$ & $\begin{array}{r}.425 \\
.368 \\
4.67 \\
2.27 \\
.991\end{array}$ \\
\hline $\begin{array}{l}26 \\
27 \\
28 \\
29 \\
30 \\
31\end{array}$ & $\begin{array}{l}.045 \\
.045 \\
.045 \\
.045 \\
.045 \\
.566\end{array}$ & $\begin{array}{l}.045 \\
.045 \\
.045 \\
.045 \\
.045 \\
. . .\end{array}$ & $\begin{array}{l}.045 \\
.045 \\
.045 \\
.045 \\
.045 \\
.045\end{array}$ & $\begin{array}{l}.045 \\
.045 \\
.045 \\
.045 \\
.045 \\
.045\end{array}$ & $\begin{array}{l}.045 \\
.045 \\
.045 \\
\ldots \\
\ldots \\
\ldots\end{array}$ & $\begin{array}{l}.045 \\
.045 \\
.045 \\
.045 \\
.045 \\
.045\end{array}$ & $\begin{array}{l}.045 \\
.045 \\
.045 \\
.045 \\
.045 \\
\cdots\end{array}$ & $\begin{array}{l}.045 \\
.045 \\
.045 \\
.045 \\
.045 \\
.045\end{array}$ & $\begin{array}{l}.045 \\
.045 \\
.045 \\
.045 \\
.045 \\
\ldots\end{array}$ & $\begin{array}{l}.045 \\
.045 \\
.045 \\
.045 \\
.045 \\
.045\end{array}$ & $\begin{array}{l}.045 \\
.045 \\
.045 \\
.045 \\
.045 \\
.045\end{array}$ & $\begin{array}{l}.045 \\
.045 \\
.045 \\
.045 \\
.045 \\
. . .\end{array}$ \\
\hline
\end{tabular}


DISCHARGe, CUBIC METERS PER SECOND, MATER YEAR OCTOBER 1990 TO SEPTEMBER 1991 DAILY MEAN VALUES

\begin{tabular}{|c|c|c|c|c|c|c|c|c|c|c|c|}
\hline DAY & OCT & NOV & DEC & JAN & FEB & MAR & APR & mur & JUN & JUL & AUG \\
\hline $\begin{array}{l}1 \\
2 \\
3 \\
4 \\
5\end{array}$ & $\begin{array}{l}.167 \\
.821 \\
.510 \\
.045 \\
.045\end{array}$ & $\begin{array}{l}.045 \\
.045 \\
.045 \\
.045 \\
.045\end{array}$ & $\begin{array}{l}.045 \\
.045 \\
.045 \\
.045 \\
.045\end{array}$ & $\begin{array}{l}.045 \\
.045 \\
.045 \\
.045 \\
.045\end{array}$ & $\begin{array}{l}.045 \\
.045 \\
.045 \\
.045 \\
.045\end{array}$ & $\begin{array}{l}.045 \\
.045 \\
.045 \\
.045 \\
.045\end{array}$ & $\begin{array}{l}.045 \\
.045 \\
.045 \\
.045 \\
1.22\end{array}$ & $\begin{array}{l}.045 \\
.045 \\
.045 \\
.045 \\
.045\end{array}$ & $\begin{array}{l}.045 \\
.045 \\
.045 \\
.045 \\
.045\end{array}$ & $\begin{array}{l}.045 \\
.045 \\
.045 \\
.045 \\
.045\end{array}$ & $\begin{array}{l}2.04 \\
5.38 \\
.793 \\
.991 \\
.133\end{array}$ \\
\hline $\begin{array}{r}6 \\
7 \\
8 \\
9 \\
10\end{array}$ & $\begin{array}{l}.045 \\
.045 \\
.045 \\
.045 \\
.045\end{array}$ & $\begin{array}{l}.045 \\
.045 \\
.045 \\
.045 \\
.045\end{array}$ & $\begin{array}{l}.045 \\
.045 \\
.045 \\
.045 \\
.045\end{array}$ & $\begin{array}{l}.045 \\
.045 \\
.045 \\
.045 \\
.045\end{array}$ & $\begin{array}{l}.045 \\
.045 \\
.045 \\
.045 \\
.045\end{array}$ & $\begin{array}{l}.045 \\
.045 \\
.045 \\
.045 \\
.045\end{array}$ & $\begin{array}{l}2.61 \\
.045 \\
1.67 \\
.045 \\
.045\end{array}$ & $\begin{array}{l}.045 \\
.045 \\
.045 \\
.045 \\
.045\end{array}$ & $\begin{array}{l}.045 \\
.045 \\
.045 \\
.045 \\
.045\end{array}$ & $\begin{array}{l}.045 \\
.045 \\
.045 \\
.045 \\
.045\end{array}$ & $\begin{array}{l}3.00 \\
3.45 \\
.045 \\
.045 \\
.045\end{array}$ \\
\hline $\begin{array}{l}11 \\
12 \\
13 \\
14 \\
15\end{array}$ & $\begin{array}{l}.045 \\
.263 \\
.045 \\
.045 \\
.045\end{array}$ & $\begin{array}{l}.045 \\
.045 \\
.045 \\
.045 \\
.045\end{array}$ & $\begin{array}{l}.045 \\
.045 \\
.045 \\
.045 \\
.045\end{array}$ & $\begin{array}{l}.045 \\
.045 \\
.045 \\
.045 \\
.045\end{array}$ & $\begin{array}{l}.045 \\
.045 \\
.045 \\
.045 \\
.045\end{array}$ & $\begin{array}{l}.045 \\
.045 \\
.045 \\
.045 \\
.045\end{array}$ & $\begin{array}{l}.045 \\
.045 \\
.045 \\
.045 \\
.045\end{array}$ & $\begin{array}{l}.045 \\
.045 \\
.045 \\
.045 \\
.045\end{array}$ & $\begin{array}{l}1.81 \\
1.67 \\
1.27 \\
1.25 \\
.045\end{array}$ & $\begin{array}{l}.045 \\
.045 \\
.045 \\
.045 \\
.045\end{array}$ & $\begin{array}{l}.566 \\
.045 \\
.045 \\
.045 \\
.045\end{array}$ \\
\hline $\begin{array}{l}16 \\
17 \\
18 \\
19 \\
20\end{array}$ & $\begin{array}{c}.045 \\
.045 \\
.045 \\
1.53 \\
20.0\end{array}$ & $\begin{array}{l}.045 \\
.045 \\
.045 \\
.045 \\
.045\end{array}$ & $\begin{array}{l}.045 \\
.045 \\
.045 \\
.045 \\
.045\end{array}$ & $\begin{array}{l}.045 \\
.045 \\
.045 \\
.045 \\
.045\end{array}$ & $\begin{array}{l}.045 \\
.045 \\
.045 \\
.045 \\
.045\end{array}$ & $\begin{array}{l}.045 \\
.045 \\
.045 \\
.045 \\
.045\end{array}$ & $\begin{array}{l}.045 \\
.045 \\
.045 \\
.045 \\
.045\end{array}$ & $\begin{array}{l}.045 \\
.045 \\
.045 \\
.045 \\
.045\end{array}$ & $\begin{array}{l}.045 \\
.045 \\
.045 \\
.045 \\
.045\end{array}$ & $\begin{array}{l}.045 \\
.045 \\
.045 \\
.045 \\
.045\end{array}$ & $\begin{array}{l}.045 \\
.045 \\
.045 \\
.045 \\
.045\end{array}$ \\
\hline $\begin{array}{l}21 \\
22 \\
23 \\
24 \\
25\end{array}$ & $\begin{array}{l}.045 \\
.045 \\
.045 \\
.045 \\
.045\end{array}$ & $\begin{array}{l}.045 \\
.045 \\
.045 \\
.045 \\
.045\end{array}$ & $\begin{array}{l}.045 \\
.045 \\
.045 \\
.045 \\
.045\end{array}$ & $\begin{array}{l}.045 \\
.045 \\
.045 \\
.045 \\
.045\end{array}$ & $\begin{array}{l}.045 \\
.045 \\
.045 \\
.045 \\
.045\end{array}$ & $\begin{array}{l}.045 \\
.045 \\
.045 \\
.045 \\
.045\end{array}$ & $\begin{array}{l}.045 \\
.045 \\
.045 \\
.045 \\
.045\end{array}$ & $\begin{array}{l}.045 \\
.045 \\
.045 \\
.045 \\
.045\end{array}$ & $\begin{array}{l}.045 \\
.045 \\
.045 \\
.045 \\
.045\end{array}$ & $\begin{array}{l}.045 \\
.045 \\
.045 \\
.045 \\
.045\end{array}$ & $\begin{array}{l}.045 \\
.045 \\
.045 \\
.045 \\
.045\end{array}$ \\
\hline $\begin{array}{l}26 \\
27 \\
28 \\
29 \\
30 \\
31\end{array}$ & $\begin{array}{l}.045 \\
.045 \\
.045 \\
.045 \\
.045 \\
.045\end{array}$ & $\begin{array}{l}.045 \\
.045 \\
.045 \\
.045 \\
.045 \\
. . .\end{array}$ & $\begin{array}{l}.045 \\
.045 \\
.045 \\
.045 \\
.045 \\
.045\end{array}$ & $\begin{array}{l}.045 \\
.045 \\
.045 \\
.045 \\
.045 \\
.045\end{array}$ & $\begin{array}{c}.045 \\
.045 \\
.045 \\
\ldots \\
\ldots \\
\ldots\end{array}$ & $\begin{array}{l}.045 \\
.045 \\
1.19 \\
.906 \\
.045 \\
.045\end{array}$ & $\begin{array}{c}.045 \\
.045 \\
.045 \\
.045 \\
.045 \\
\ldots .\end{array}$ & $\begin{array}{l}.045 \\
.045 \\
.045 \\
.045 \\
.045 \\
.045\end{array}$ & $\begin{array}{l}.045 \\
.045 \\
.045 \\
.045 \\
.045 \\
. . .\end{array}$ & $\begin{array}{l}1.33 \\
1.76 \\
.045 \\
1.05 \\
.045 \\
.045\end{array}$ & $\begin{array}{l}7.31 \\
4.11 \\
.651 \\
.207 \\
.045 \\
.045\end{array}$ \\
\hline
\end{tabular}


SURFACE-WATER DATA-Cont inued

DAILY MEAN DISChARGE-Cont inued

09395990 BLACK CREEK NEAR HOUCK, AZ

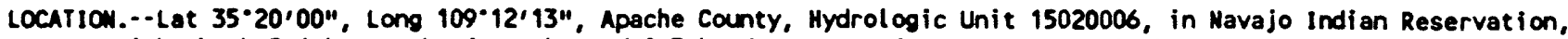
on right bank $5.6 \mathrm{~km}$ north of Houck, and $9.3 \mathrm{~km}$ downstream from West Fork Black Creek.

DRAIMAGE AREA. $--1,627 \mathrm{~km}^{2}$.

PERICO OF RECORD.--March 1989 to September 1991.

OTHER DATA COLLECTION AT THIS SITE.--August 1986 to March 1989, station operated by the Mavajo Nation (records unpubl ished).

DISCHARGE, CUBIC METERS PER SECOND, MARCH 1989 TO SEPTEMBER 1989 DAILY MEAN VALUES

\begin{tabular}{|c|c|c|c|c|c|c|c|c|c|c|c|c|}
\hline DAY & OCT & NOV & DEC & JAN & FEB & MAR & APR & MAY & JUN & JUL & AUG & SEP \\
\hline $\begin{array}{l}1 \\
2 \\
3 \\
4 \\
5\end{array}$ & $\begin{array}{l}\ldots \\
\ldots \\
\ldots \\
\ldots \\
\ldots\end{array}$ & $\begin{array}{l}\cdots \\
\ldots \\
\ldots \\
\cdots \\
\cdots\end{array}$ & $\begin{array}{l}\ldots \\
\ldots \\
\ldots \\
\cdots \\
\cdots\end{array}$ & $\begin{array}{l}\cdots \\
\cdots \\
\cdots \\
\cdots\end{array}$ & $\begin{array}{l}\ldots \\
\ldots \\
\ldots \\
\ldots \\
\cdots\end{array}$ & $\begin{array}{l}\ldots \\
\ldots \\
\ldots \\
\ldots \\
\ldots\end{array}$ & $\begin{array}{l}.193 \\
.156 \\
.136 \\
.113 \\
.082\end{array}$ & $\begin{array}{l}.000 \\
.000 \\
.000 \\
.000 \\
.000\end{array}$ & $\begin{array}{l}.000 \\
.000 \\
.000 \\
.000 \\
.000\end{array}$ & $\begin{array}{l}.000 \\
.000 \\
.000 \\
.000 \\
.000\end{array}$ & $\begin{array}{l}1.67 \\
.368 \\
.099 \\
.034 \\
.005\end{array}$ & $\begin{array}{l}.000 \\
.000 \\
.000 \\
.000 \\
.510\end{array}$ \\
\hline $\begin{array}{r}6 \\
7 \\
8 \\
9 \\
10\end{array}$ & $\begin{array}{l}\ldots \\
\ldots \\
\ldots \\
\ldots \\
\ldots\end{array}$ & $\begin{array}{l}\ldots \\
\ldots \\
\ldots \\
\ldots \\
\ldots\end{array}$ & $\begin{array}{l}\ldots . \\
\ldots \\
\ldots . \\
\ldots \\
\ldots\end{array}$ & $\begin{array}{l}\ldots \\
\ldots \\
\ldots \\
\ldots \\
\ldots\end{array}$ & $\begin{array}{l}\ldots \\
\ldots \\
\ldots \\
\ldots \\
\ldots\end{array}$ & $\begin{array}{l}\ldots \\
\ldots \\
\ldots \\
\ldots \\
\ldots\end{array}$ & $\begin{array}{l}.076 \\
.062 \\
.028 \\
.016 \\
.000\end{array}$ & $\begin{array}{l}.000 \\
.000 \\
.000 \\
.000 \\
.000\end{array}$ & $\begin{array}{l}.000 \\
.000 \\
.000 \\
.000 \\
.000\end{array}$ & $\begin{array}{l}.000 \\
.000 \\
.000 \\
.000 \\
.000\end{array}$ & $\begin{array}{l}.000 \\
.000 \\
.963 \\
.218 \\
.232\end{array}$ & $\begin{array}{r}1.16 \\
.082 \\
.020 \\
.002 \\
.000\end{array}$ \\
\hline $\begin{array}{l}11 \\
12 \\
13 \\
14 \\
15\end{array}$ & $\begin{array}{l}\ldots \\
\ldots \\
\ldots \\
\ldots \\
\ldots\end{array}$ & $\begin{array}{l}\ldots \\
\ldots \\
\ldots \\
\ldots \\
\ldots\end{array}$ & $\begin{array}{c}\ldots . \\
\ldots \\
\ldots \\
\ldots \\
\ldots\end{array}$ & $\begin{array}{l}\ldots \\
\ldots \\
\ldots \\
\ldots \\
\ldots\end{array}$ & $\begin{array}{l}\ldots \\
\ldots \\
\ldots \\
\ldots \\
\ldots\end{array}$ & $\begin{array}{l}\ldots \\
\ldots \\
\ldots \\
\ldots \\
\ldots\end{array}$ & $\begin{array}{l}.000 \\
.000 \\
.000 \\
.000 \\
.000\end{array}$ & $\begin{array}{l}.000 \\
.000 \\
.000 \\
.000 \\
.000\end{array}$ & $\begin{array}{l}.000 \\
.000 \\
.000 \\
.000 \\
.000\end{array}$ & $\begin{array}{l}.000 \\
.000 \\
.000 \\
.000 \\
.000\end{array}$ & $\begin{array}{l}.071 \\
.016 \\
.000 \\
.000 \\
.000\end{array}$ & $\begin{array}{l}.000 \\
.000 \\
.000 \\
.000 \\
.000\end{array}$ \\
\hline $\begin{array}{l}16 \\
17 \\
18 \\
19 \\
20\end{array}$ & $\begin{array}{l}\ldots . \\
\ldots \\
\ldots \\
\ldots \\
\ldots\end{array}$ & $\begin{array}{l}\ldots \\
\ldots \\
\ldots \\
\ldots \\
\ldots\end{array}$ & $\begin{array}{l}\ldots \\
\ldots \\
\ldots \\
\ldots \\
\ldots\end{array}$ & $\begin{array}{l}\ldots \\
\ldots \\
\ldots \\
\ldots \\
\ldots\end{array}$ & $\begin{array}{l}\ldots \\
\ldots \\
\ldots \\
\ldots \\
\ldots\end{array}$ & $\begin{array}{l}\ldots \\
\ldots \\
\ldots \\
\ldots \\
\ldots\end{array}$ & $\begin{array}{l}.000 \\
.000 \\
.000 \\
.000 \\
.000\end{array}$ & $\begin{array}{l}.000 \\
.000 \\
.000 \\
.000 \\
.000\end{array}$ & $\begin{array}{l}.000 \\
.000 \\
.000 \\
.000 \\
.000\end{array}$ & $\begin{array}{l}.000 \\
.000 \\
.000 \\
.000 \\
.000\end{array}$ & $\begin{array}{c}.000 \\
.000 \\
.065 \\
4.67 \\
.263\end{array}$ & $\begin{array}{l}.000 \\
.000 \\
.000 \\
.000 \\
.000\end{array}$ \\
\hline $\begin{array}{l}21 \\
22 \\
23 \\
24 \\
25\end{array}$ & $\begin{array}{l}\ldots \\
\ldots \\
\ldots \\
\ldots \\
\ldots\end{array}$ & $\begin{array}{l}\ldots \\
\ldots \\
\ldots \\
\ldots \\
\ldots\end{array}$ & $\begin{array}{l}\ldots . \\
\ldots \\
\ldots \\
\ldots \\
\ldots\end{array}$ & $\begin{array}{l}\ldots \\
\ldots \\
\ldots \\
\ldots \\
\ldots\end{array}$ & $\begin{array}{l}\ldots \\
\ldots \\
\ldots \\
\cdots \\
\cdots\end{array}$ & $\begin{array}{l}\ldots . \\
\ldots . \\
.311 \\
.283 \\
.283\end{array}$ & $\begin{array}{l}.000 \\
.000 \\
.000 \\
.000 \\
.000\end{array}$ & $\begin{array}{l}.000 \\
.000 \\
.000 \\
.000 \\
.000\end{array}$ & $\begin{array}{l}.000 \\
.000 \\
.000 \\
.000 \\
.000\end{array}$ & $\begin{array}{l}.000 \\
.000 \\
.000 \\
.000 \\
.000\end{array}$ & $\begin{array}{l}.057 \\
.022 \\
.000 \\
.000 \\
.000\end{array}$ & $\begin{array}{l}.000 \\
.000 \\
.000 \\
.000 \\
.000\end{array}$ \\
\hline $\begin{array}{l}26 \\
27 \\
28 \\
29 \\
30 \\
31\end{array}$ & $\begin{array}{l}\ldots \\
\ldots \\
\ldots \\
\ldots \\
\ldots \\
\ldots\end{array}$ & $\begin{array}{l}\ldots \\
\ldots \\
\ldots \\
\ldots \\
\ldots \\
\ldots\end{array}$ & $\begin{array}{l}\ldots \\
\ldots \\
\ldots \\
\ldots \\
\ldots \\
\ldots\end{array}$ & $\begin{array}{l}\ldots \\
\ldots \\
\ldots \\
\ldots \\
\ldots \\
\ldots\end{array}$ & $\begin{array}{l}\ldots \\
\ldots \\
\ldots \\
\ldots \\
\ldots \\
\ldots\end{array}$ & $\begin{array}{l}.425 \\
.708 \\
.425 \\
.425 \\
.425 \\
.241\end{array}$ & $\begin{array}{l}.000 \\
.000 \\
.000 \\
.000 \\
.000 \\
. . .\end{array}$ & $\begin{array}{l}.000 \\
.000 \\
.000 \\
.000 \\
.000 \\
.000\end{array}$ & $\begin{array}{l}.000 \\
.000 \\
.000 \\
.000 \\
.000 \\
. . .\end{array}$ & $\begin{array}{c}.396 \\
.065 \\
.040 \\
1.87 \\
.481 \\
1.27\end{array}$ & $\begin{array}{l}.000 \\
.000 \\
.000 \\
.000 \\
.000 \\
.000\end{array}$ & $\begin{array}{l}.000 \\
.000 \\
.000 \\
.000 \\
.000 \\
\ldots . .\end{array}$ \\
\hline
\end{tabular}


SURFACE-WATER DATA-Cont inued

DAILY MEAN DISCHARGE-Cont inued

09395990 BLACK CREEK NEAR HOUCK, AZ-Continued

DISCHARGE, CUBIC METERS PER SECOND, WATER YEAR OCTOBER 1989 TO SEPTEMBER 1990 DAILY MEAN VALUES

\begin{tabular}{|c|c|c|c|c|c|c|c|c|c|c|c|c|}
\hline DAY & OCT & NOV & DEC & JAN & FEB & MAR & APR & 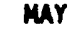 & JUN & JUL & AUG & SEP \\
\hline $\begin{array}{l}1 \\
2 \\
3 \\
4 \\
5\end{array}$ & $\begin{array}{l}.000 \\
.000 \\
.000 \\
.000 \\
.000\end{array}$ & $\begin{array}{l}.000 \\
.000 \\
.000 \\
.000 \\
.000\end{array}$ & $\begin{array}{l}.000 \\
.000 \\
.000 \\
.000 \\
.000\end{array}$ & $\begin{array}{l}.000 \\
.000 \\
.000 \\
.000 \\
.000\end{array}$ & $\begin{array}{l}.000 \\
.000 \\
.000 \\
.000 \\
.000\end{array}$ & $\begin{array}{l}.368 \\
.249 \\
.193 \\
.125 \\
.125\end{array}$ & $\begin{array}{l}.000 \\
.001 \\
.007 \\
.002 \\
.006\end{array}$ & $\begin{array}{l}.000 \\
.000 \\
.000 \\
.000 \\
.000\end{array}$ & $\begin{array}{l}.000 \\
.000 \\
.000 \\
.000 \\
.000\end{array}$ & $\begin{array}{l}.000 \\
.000 \\
.000 \\
.000 \\
.000\end{array}$ & $\begin{array}{l}.091 \\
.144 \\
.068 \\
.014 \\
.000\end{array}$ & $\begin{array}{l}.000 \\
.000 \\
.000 \\
.000 \\
.013\end{array}$ \\
\hline $\begin{array}{r}6 \\
7 \\
8 \\
9 \\
10\end{array}$ & $\begin{array}{l}.000 \\
.000 \\
.000 \\
.000 \\
.000\end{array}$ & $\begin{array}{l}.000 \\
.000 \\
.000 \\
.000 \\
.000\end{array}$ & $\begin{array}{l}.000 \\
.000 \\
.000 \\
.000 \\
.000\end{array}$ & $\begin{array}{l}.000 \\
.000 \\
.000 \\
.000 \\
.000\end{array}$ & $\begin{array}{l}.000 \\
.000 \\
.000 \\
.000 \\
.000\end{array}$ & $\begin{array}{l}.068 \\
.051 \\
.048 \\
.034 \\
.034\end{array}$ & $\begin{array}{l}.011 \\
.012 \\
.011 \\
.007 \\
.000\end{array}$ & $\begin{array}{l}.000 \\
.000 \\
.000 \\
.000 \\
.000\end{array}$ & $\begin{array}{l}.000 \\
.000 \\
.000 \\
.000 \\
.000\end{array}$ & $\begin{array}{l}.000 \\
.040 \\
.283 \\
.224 \\
.057\end{array}$ & $\begin{array}{l}.000 \\
.000 \\
.000 \\
.000 \\
.000\end{array}$ & $\begin{array}{c}1.39 \\
.934 \\
.283 \\
3.37 \\
.212\end{array}$ \\
\hline $\begin{array}{l}11 \\
12 \\
13 \\
14 \\
15\end{array}$ & $\begin{array}{l}.000 \\
.000 \\
.000 \\
.000 \\
.000\end{array}$ & $\begin{array}{l}.000 \\
.000 \\
.000 \\
.000 \\
.000\end{array}$ & $\begin{array}{l}.000 \\
.000 \\
.000 \\
.000 \\
.000\end{array}$ & $\begin{array}{l}.000 \\
.000 \\
.000 \\
.000 \\
.000\end{array}$ & $\begin{array}{l}.000 \\
.017 \\
.085 \\
.122 \\
.099\end{array}$ & $\begin{array}{l}.065 \\
.057 \\
.051 \\
.071 \\
.059\end{array}$ & $\begin{array}{l}.000 \\
.000 \\
.000 \\
.000 \\
.000\end{array}$ & $\begin{array}{l}.000 \\
.000 \\
.000 \\
.000 \\
.000\end{array}$ & $\begin{array}{l}.000 \\
.000 \\
.000 \\
.000 \\
.000\end{array}$ & $\begin{array}{c}.008 \\
.878 \\
.224 \\
1.13 \\
.906\end{array}$ & $\begin{array}{l}.000 \\
.000 \\
.000 \\
3.31 \\
5.55\end{array}$ & $\begin{array}{l}.040 \\
.003 \\
.000 \\
.000 \\
.000\end{array}$ \\
\hline $\begin{array}{l}16 \\
17 \\
18 \\
19 \\
20\end{array}$ & $\begin{array}{l}.000 \\
.000 \\
.000 \\
.000 \\
.000\end{array}$ & $\begin{array}{l}.000 \\
.000 \\
.000 \\
.000 \\
.000\end{array}$ & $\begin{array}{l}.000 \\
.000 \\
.000 \\
.000 \\
.000\end{array}$ & $\begin{array}{l}.005 \\
.013 \\
.024 \\
.054 \\
.116\end{array}$ & $\begin{array}{l}.108 \\
.108 \\
.093 \\
.082 \\
.068\end{array}$ & $\begin{array}{l}.048 \\
.037 \\
.034 \\
.025 \\
.017\end{array}$ & $\begin{array}{l}.000 \\
.000 \\
.000 \\
.000 \\
.000\end{array}$ & $\begin{array}{l}.000 \\
.000 \\
.000 \\
.000 \\
.000\end{array}$ & $\begin{array}{l}.000 \\
.000 \\
.000 \\
.000 \\
.000\end{array}$ & $\begin{array}{l}.176 \\
1.30 \\
2.38 \\
.453 \\
.263\end{array}$ & $\begin{array}{l}.623 \\
.283 \\
.071 \\
.028 \\
.001\end{array}$ & $\begin{array}{l}.000 \\
.000 \\
.019 \\
.368 \\
.368\end{array}$ \\
\hline $\begin{array}{l}21 \\
22 \\
23 \\
24 \\
25\end{array}$ & $\begin{array}{l}.000 \\
.000 \\
.000 \\
.000 \\
.000\end{array}$ & $\begin{array}{l}.000 \\
.000 \\
.000 \\
.000 \\
.000\end{array}$ & $\begin{array}{l}.000 \\
.000 \\
.000 \\
.000 \\
.000\end{array}$ & $\begin{array}{l}.054 \\
.016 \\
.004 \\
.000 \\
.000\end{array}$ & $\begin{array}{l}.059 \\
.042 \\
.051 \\
.130 \\
.224\end{array}$ & $\begin{array}{l}.012 \\
.004 \\
.000 \\
.000 \\
.000\end{array}$ & $\begin{array}{l}.000 \\
.000 \\
.000 \\
.000 \\
.000\end{array}$ & $\begin{array}{l}.000 \\
.000 \\
.000 \\
.000 \\
.000\end{array}$ & $\begin{array}{l}.000 \\
.000 \\
.000 \\
.000 \\
.000\end{array}$ & $\begin{array}{l}.184 \\
.091 \\
.008 \\
.000 \\
.000\end{array}$ & $\begin{array}{l}.481 \\
.178 \\
.054 \\
.018 \\
.000\end{array}$ & $\begin{array}{l}.963 \\
.161 \\
.396 \\
.269 \\
.071\end{array}$ \\
\hline $\begin{array}{l}26 \\
27 \\
28 \\
29 \\
30 \\
31\end{array}$ & $\begin{array}{l}.000 \\
.000 \\
.000 \\
.000 \\
.000 \\
.000\end{array}$ & $\begin{array}{l}.000 \\
.000 \\
.000 \\
.000 \\
.000 \\
. .-\end{array}$ & $\begin{array}{l}.000 \\
.000 \\
.000 \\
.000 \\
.000 \\
.000\end{array}$ & $\begin{array}{l}.002 \\
.002 \\
.002 \\
.000 \\
.000 \\
.000\end{array}$ & $\begin{array}{r}.368 \\
.269 \\
.425 \\
\ldots .- \\
. .- \\
. . .\end{array}$ & $\begin{array}{l}.000 \\
.000 \\
.000 \\
.000 \\
.000 \\
.000\end{array}$ & $\begin{array}{c}.000 \\
.000 \\
.000 \\
.000 \\
.000 \\
. . .\end{array}$ & $\begin{array}{l}.000 \\
.000 \\
.000 \\
.000 \\
.000 \\
.000\end{array}$ & $\begin{array}{c}.000 \\
.000 \\
.000 \\
.000 \\
.000 \\
. .-\end{array}$ & $\begin{array}{l}.000 \\
.000 \\
.000 \\
.000 \\
.000 \\
.000\end{array}$ & $\begin{array}{l}.000 \\
.000 \\
.000 \\
.000 \\
.000 \\
.000\end{array}$ & $\begin{array}{r}.028 \\
.007 \\
.013 \\
.001 \\
.000 \\
.-\end{array}$ \\
\hline
\end{tabular}


SURFACE-WATER DATA-Cont inued

DAILY MEAN DISCHARGE-Cont inued

09395990 BLACK CREEK NEAR hOUCK, A2-Cont inued

DISCHARGE, CUBIC METERS PER SECOND, WATER YEAR OCTOBER 1990 TO SEPTEMBER 1991 DAILY MEAK VALUES

\begin{tabular}{|c|c|c|c|c|c|c|c|c|c|c|c|c|}
\hline DAY & OCT & NOV & DEC & JAN & FEB & MAR & APR & MAY & JUN & JUL & AUG & SEP \\
\hline $\begin{array}{l}1 \\
2 \\
3 \\
4 \\
5\end{array}$ & $\begin{array}{l}.000 \\
.000 \\
.000 \\
.000 \\
.000\end{array}$ & $\begin{array}{l}.000 \\
.000 \\
.057 \\
.065 \\
.021\end{array}$ & $\begin{array}{l}.003 \\
.014 \\
.015 \\
.000 \\
.000\end{array}$ & $\begin{array}{l}.000 \\
.000 \\
.000 \\
.142 \\
1.42\end{array}$ & $\begin{array}{l}.000 \\
.000 \\
.000 \\
.000 \\
.000\end{array}$ & $\begin{array}{l}.368 \\
1.13 \\
1.22 \\
.765 \\
1.25\end{array}$ & $\begin{array}{r}1.36 \\
.878 \\
.566 \\
.368 \\
.244\end{array}$ & $\begin{array}{l}.016 \\
.012 \\
.010 \\
.008 \\
.008\end{array}$ & $\begin{array}{l}.000 \\
.000 \\
.000 \\
.000 \\
.000\end{array}$ & $\begin{array}{l}.000 \\
.000 \\
.000 \\
.000 \\
.000\end{array}$ & $\begin{array}{l}.079 \\
.110 \\
.018 \\
.079 \\
.000\end{array}$ & $\begin{array}{l}.000 \\
.000 \\
.000 \\
.000 \\
.340\end{array}$ \\
\hline $\begin{array}{r}6 \\
7 \\
8 \\
9 \\
10\end{array}$ & $\begin{array}{l}.000 \\
.000 \\
.000 \\
.000 \\
.000\end{array}$ & $\begin{array}{l}.011 \\
.020 \\
.022 \\
.051 \\
.027\end{array}$ & $\begin{array}{l}.000 \\
.001 \\
.000 \\
.000 \\
.000\end{array}$ & $\begin{array}{c}1.13 \\
.708 \\
.566 \\
.311 \\
.142\end{array}$ & $\begin{array}{l}.019 \\
.178 \\
.425 \\
.246 \\
.283\end{array}$ & $\begin{array}{l}4.05 \\
2.61 \\
.680 \\
.396 \\
.283\end{array}$ & $\begin{array}{l}.178 \\
.119 \\
.074 \\
.048 \\
.034\end{array}$ & $\begin{array}{l}.007 \\
.005 \\
.002 \\
.000 \\
.000\end{array}$ & $\begin{array}{l}.000 \\
.000 \\
.000 \\
.000 \\
.000\end{array}$ & $\begin{array}{l}.000 \\
.000 \\
.000 \\
.000 \\
.000\end{array}$ & $\begin{array}{c}.048 \\
7.11 \\
.566 \\
.178 \\
.074\end{array}$ & $\begin{array}{l}1.70 \\
.311 \\
.059 \\
.007 \\
.000\end{array}$ \\
\hline $\begin{array}{l}11 \\
12 \\
13 \\
16 \\
15\end{array}$ & $\begin{array}{l}.000 \\
.000 \\
.000 \\
.000 \\
.000\end{array}$ & $\begin{array}{l}.017 \\
.013 \\
.010 \\
.008 \\
.007\end{array}$ & $\begin{array}{l}.000 \\
.000 \\
.093 \\
.082 \\
.048\end{array}$ & $\begin{array}{l}.085 \\
.057 \\
.028 \\
.016 \\
.000\end{array}$ & $\begin{array}{l}.283 \\
.283 \\
.283 \\
.238 \\
.311\end{array}$ & $\begin{array}{l}.198 \\
.116 \\
.091 \\
.091 \\
.190\end{array}$ & $\begin{array}{l}.396 \\
.736 \\
.425 \\
.207 \\
.096\end{array}$ & $\begin{array}{l}.000 \\
.000 \\
.000 \\
.000 \\
.000\end{array}$ & $\begin{array}{l}.000 \\
.002 \\
.031 \\
.009 \\
.037\end{array}$ & $\begin{array}{l}.000 \\
.003 \\
.000 \\
.000 \\
.000\end{array}$ & $\begin{array}{l}.045 \\
.018 \\
.006 \\
.000 \\
.481\end{array}$ & $\begin{array}{l}.000 \\
.000 \\
.000 \\
.000 \\
.000\end{array}$ \\
\hline $\begin{array}{l}16 \\
17 \\
18 \\
19 \\
20\end{array}$ & $\begin{array}{l}.000 \\
.000 \\
.000 \\
.042 \\
.680\end{array}$ & $\begin{array}{l}.006 \\
.005 \\
.003 \\
.005 \\
.003\end{array}$ & $\begin{array}{l}.076 \\
.057 \\
.028 \\
.014 \\
.000\end{array}$ & $\begin{array}{l}.000 \\
.000 \\
.000 \\
.000 \\
.000\end{array}$ & $\begin{array}{l}.311 \\
.595 \\
.396 \\
.187 \\
.130\end{array}$ & $\begin{array}{l}.122 \\
.110 \\
.096 \\
.079 \\
.062\end{array}$ & $\begin{array}{l}.187 \\
.538 \\
.538 \\
.623 \\
.510\end{array}$ & $\begin{array}{l}.000 \\
.000 \\
.000 \\
.000 \\
.000\end{array}$ & $\begin{array}{l}.026 \\
.000 \\
.000 \\
.000 \\
.000\end{array}$ & $\begin{array}{l}.000 \\
.000 \\
.000 \\
.000 \\
.000\end{array}$ & $\begin{array}{r}1.59 \\
.150 \\
.040 \\
.008 \\
.000\end{array}$ & $\begin{array}{l}.000 \\
.000 \\
.000 \\
.000 \\
.000\end{array}$ \\
\hline $\begin{array}{l}21 \\
22 \\
23 \\
24 \\
25\end{array}$ & $\begin{array}{l}.110 \\
.040 \\
.014 \\
.005 \\
.000\end{array}$ & $\begin{array}{l}.011 \\
.013 \\
.008 \\
.005 \\
.001\end{array}$ & $\begin{array}{l}.000 \\
.000 \\
.000 \\
.000 \\
.000\end{array}$ & $\begin{array}{l}.000 \\
.000 \\
.000 \\
.000 \\
.000\end{array}$ & $\begin{array}{l}.079 \\
.051 \\
.034 \\
.031 \\
.034\end{array}$ & $\begin{array}{l}.085 \\
.110 \\
.108 \\
.076 \\
.059\end{array}$ & $\begin{array}{l}.311 \\
.283 \\
.227 \\
.198 \\
.144\end{array}$ & $\begin{array}{l}.000 \\
.000 \\
.000 \\
.000 \\
.000\end{array}$ & $\begin{array}{l}.000 \\
.000 \\
.000 \\
.000 \\
.000\end{array}$ & $\begin{array}{r}.000 \\
.000 \\
.000 \\
.130 \\
2.18\end{array}$ & $\begin{array}{l}.000 \\
.000 \\
.000 \\
.000 \\
.000\end{array}$ & $\begin{array}{l}.000 \\
.000 \\
.000 \\
.000 \\
.000\end{array}$ \\
\hline $\begin{array}{l}26 \\
27 \\
28 \\
29 \\
30 \\
31\end{array}$ & $\begin{array}{l}.000 \\
.000 \\
.000 \\
.000 \\
.000 \\
.000\end{array}$ & $\begin{array}{l}.008 \\
.027 \\
.024 \\
.034 \\
.059 \\
\ldots . .\end{array}$ & $\begin{array}{l}.000 \\
.000 \\
.000 \\
.000 \\
.000 \\
.000\end{array}$ & $\begin{array}{l}.000 \\
.000 \\
.000 \\
.000 \\
.000 \\
.000\end{array}$ & $\begin{array}{c}.031 \\
.024 \\
.040 \\
\ldots . . \\
\ldots \\
\ldots\end{array}$ & $\begin{array}{l}.054 \\
.062 \\
.130 \\
.510 \\
.850 \\
1.61\end{array}$ & $\begin{array}{l}.130 \\
.079 \\
.037 \\
.025 \\
.017 \\
\ldots\end{array}$ & $\begin{array}{l}.000 \\
.000 \\
.000 \\
.000 \\
.000 \\
.000\end{array}$ & $\begin{array}{l}.000 \\
.000 \\
.000 \\
.000 \\
.000 \\
. .\end{array}$ & $\begin{array}{l}.991 \\
.425 \\
.074 \\
.012 \\
.000 \\
.000\end{array}$ & $\begin{array}{l}.000 \\
.000 \\
.000 \\
.000 \\
.000 \\
.000\end{array}$ & $\begin{array}{l}.000 \\
.000 \\
.000 \\
.000 \\
.000 \\
\ldots .\end{array}$ \\
\hline
\end{tabular}


SURFACE-HATER DATA-Cont imued

DAILY MEAN DISCHARGE-Contimued

09396100 PUERCO RIVER NEAR CHAMBERS, AZ

LOCATION.---Lat 35'10'56", Long 109.26'47", in NWkHEX Sec. 35, T.21 N., R.27 E., Apache County, Hydrologic Unit 15020007 , on right bank $0.8 \mathrm{~km}$ upstream from Atchison, Topeka, and Santo Fe Railway Co. bridge, and $1.6 \mathrm{~km}$ southwest of Chambers.

DRAINAGE AREA. $-5,584 \mathrm{~km}^{2}$, of which $130 \mathrm{~km}^{2}$ is noncontributing.

PERIOD OF RECORD.---October 1988 to September 1991

OTHER DATA COLLECTION AT THIS SITE.--Records were published in Hater Resources Data for Arizona for: water years 1971-72 (annual maximums only), January 1973 to current year (daily mean discharge above $14.16 \mathrm{~m}^{3} / \mathrm{s}$ only).

REMARKS.- - Only daily mean discharges above $0.556 \mathrm{~m}^{3} / \mathrm{s}$ are published.

DISCHARGE, CUBIC METERS PER SECOND, MATER YEAR OCTOBER 1988 TO SEPTEMBER 1989

DAILY MEAN VALUES

\begin{tabular}{|c|c|c|c|c|c|c|c|c|c|c|c|c|}
\hline DAY & OCT & NOV & DEC & JAN & FEB & MAR & APR & MaY & JUW & JUL & AUE & SEP \\
\hline $\begin{array}{l}1 \\
2 \\
3 \\
4 \\
5\end{array}$ & $\begin{array}{l}\cdots \\
\cdots \\
\cdots \\
\cdots\end{array}$ & $\begin{array}{l}\ldots \\
\ldots \\
\ldots \\
\ldots \\
\ldots\end{array}$ & $\begin{array}{l}\ldots \\
\ldots \\
\ldots \\
\ldots\end{array}$ & $\begin{array}{l}\ldots \\
\ldots \\
\cdots \\
\cdots \\
\cdots\end{array}$ & $\begin{array}{l}\ldots . \\
.680 \\
1.02 \\
1.42 \\
1.19\end{array}$ & $\begin{array}{l}\ldots \\
\ldots \\
\ldots \\
\cdots\end{array}$ & $\begin{array}{l}\ldots \\
\ldots \\
\ldots \\
\ldots \\
\ldots\end{array}$ & $\begin{array}{l}\ldots \\
\cdots \\
\cdots \\
\cdots\end{array}$ & $\begin{array}{l}\ldots \\
\ldots \\
\ldots \\
\ldots\end{array}$ & $\begin{array}{l}\ldots \\
\ldots \\
\ldots \\
\cdots \\
\ldots\end{array}$ & $\begin{array}{c}12.0 \\
.651 \\
1.84 \\
\ldots \\
\ldots\end{array}$ & ‥ \\
\hline $\begin{array}{r}6 \\
7 \\
8 \\
9 \\
10\end{array}$ & $\begin{array}{l}\ldots \\
\ldots \\
\ldots \\
\ldots \\
\ldots\end{array}$ & $\begin{array}{l}\ldots \\
\ldots \\
\ldots \\
\ldots \\
\ldots\end{array}$ & $\begin{array}{l}\ldots \\
\ldots \\
\ldots \\
\ldots \\
\ldots\end{array}$ & $\begin{array}{l}\ldots . \\
\cdots \\
\cdots \\
\cdots \\
\cdots\end{array}$ & $\begin{array}{l}.566 \\
.680 \\
.623 \\
\ldots . \\
\ldots .\end{array}$ & $\begin{array}{c}.566 \\
\ldots . \\
\ldots . \\
\ldots \\
\ldots\end{array}$ & $\begin{array}{l}\ldots \\
\ldots \\
\ldots \\
\ldots \\
\ldots\end{array}$ & $\begin{array}{l}\ldots . \\
\ldots \\
\ldots \\
\ldots \\
\ldots\end{array}$ & $\begin{array}{l}\ldots . \\
\cdots \\
\cdots \\
\cdots \\
\cdots\end{array}$ & $\begin{array}{l}\ldots \\
\ldots \\
\ldots \\
\ldots \\
\ldots\end{array}$ & $\begin{array}{l}\cdots \\
\cdots \\
\cdots \\
\cdots \\
\cdots \\
\cdots\end{array}$ & $\begin{array}{c}2.58 \\
1.27 \\
\ldots \ldots \\
\ldots\end{array}$ \\
\hline $\begin{array}{l}11 \\
12 \\
13 \\
14 \\
15\end{array}$ & $\begin{array}{l}\cdots \\
\cdots \\
\cdots \\
\cdots\end{array}$ & $\begin{array}{l}\ldots \\
\ldots \\
\ldots \\
\ldots \\
\ldots\end{array}$ & $\begin{array}{l}\ldots \\
\ldots \\
\ldots \\
\ldots \\
\ldots\end{array}$ & $\begin{array}{l}\ldots . \\
\ldots \\
\cdots \\
\ldots \\
\cdots\end{array}$ & $\begin{array}{l}. \ldots \\
1.50 \\
1.87 \\
.991 \\
.821\end{array}$ & $\begin{array}{l}\ldots \\
\ldots \\
\ldots \\
\ldots \\
\ldots\end{array}$ & $\begin{array}{l}\ldots \\
\ldots \\
\ldots \\
\ldots \\
\ldots\end{array}$ & $\begin{array}{l}\ldots \\
\ldots \\
\ldots \\
\ldots \\
\cdots\end{array}$ & $\begin{array}{l}\ldots . \\
\ldots \\
\cdots \\
\cdots \\
\cdots\end{array}$ & $\begin{array}{l}\ldots \\
\ldots \\
\cdots \\
\ldots \\
\cdots\end{array}$ & $\begin{array}{l}\ldots \\
\ldots \\
\ldots \\
\ldots \\
\ldots\end{array}$ & $\begin{array}{l}\ldots \\
\ldots \\
\cdots \\
\ldots\end{array}$ \\
\hline $\begin{array}{l}16 \\
17 \\
18 \\
19 \\
20\end{array}$ & $\begin{array}{l}\ldots \\
\ldots \\
\ldots \\
\ldots\end{array}$ & $\begin{array}{l}\ldots \\
\ldots \\
\ldots \\
\ldots \\
\ldots\end{array}$ & $\begin{array}{l}\ldots \\
\ldots \\
\ldots \\
\ldots \\
\ldots\end{array}$ & $\begin{array}{l}\ldots \\
\cdots \\
\cdots \\
\cdots \\
\cdots\end{array}$ & $\begin{array}{l}.878 \\
.736 \\
.963 \\
1.10 \\
1.13\end{array}$ & $\begin{array}{l}\ldots \\
\ldots \\
\ldots \\
\ldots \\
.566\end{array}$ & $\ldots$ & $\begin{array}{l}\ldots \\
\ldots \\
\ldots \\
\ldots \\
\ldots\end{array}$ & $\begin{array}{l}\ldots \\
\ldots \\
\ldots \\
\ldots \\
\ldots\end{array}$ & $\begin{array}{l}\ldots \\
\ldots \\
\ldots \\
\ldots \\
\ldots\end{array}$ & $\begin{array}{c}\ldots \\
\ldots \\
\ldots \\
7.56 \\
2.69\end{array}$ & $\begin{array}{l}\cdots \\
\cdots \\
\cdots \\
\cdots\end{array}$ \\
\hline $\begin{array}{l}21 \\
22 \\
23 \\
24 \\
25\end{array}$ & $\begin{array}{l}\ldots \\
\ldots \\
\ldots \\
\ldots\end{array}$ & $\begin{array}{l}\ldots \\
\ldots \\
\ldots \\
\ldots\end{array}$ & $\begin{array}{l}\ldots \\
\ldots \\
\ldots \\
\ldots\end{array}$ & $\begin{array}{l}\ldots \\
\ldots \\
\ldots \\
\ldots \\
\ldots\end{array}$ & $\begin{array}{l}.595 \\
.651 \\
.708 \\
.595 \\
.566\end{array}$ & $\begin{array}{l}\ldots \\
\ldots \\
\ldots \\
\ldots \\
\ldots\end{array}$ & $\begin{array}{l}\ldots \\
\ldots \\
\ldots \\
\ldots \\
\ldots\end{array}$ & $\begin{array}{l}\ldots . \\
\ldots \\
\ldots \\
\ldots \\
\ldots\end{array}$ & $\begin{array}{l}\ldots . \\
\ldots \\
\cdots \\
\ldots \\
\cdots\end{array}$ & $\begin{array}{l}\ldots \\
\cdots \\
\cdots \\
\cdots \\
\cdots\end{array}$ & $\begin{array}{l}\ldots \\
\ldots \\
\ldots \\
\ldots \\
\ldots\end{array}$ & $\begin{array}{l}\cdots \\
\cdots \\
\cdots\end{array}$ \\
\hline $\begin{array}{l}26 \\
27 \\
28 \\
29 \\
30 \\
31\end{array}$ & $\begin{array}{l}\ldots \\
\ldots \\
\ldots \\
\ldots \\
\cdots \\
\cdots\end{array}$ & $\begin{array}{l}\ldots \\
\ldots \\
\ldots \\
\ldots \\
\ldots\end{array}$ & $\begin{array}{l}\ldots \\
\ldots \\
\ldots \\
\ldots \\
\ldots \\
\ldots\end{array}$ & $\begin{array}{l}\ldots \\
\ldots \\
\ldots \\
\ldots \\
\ldots \\
\ldots\end{array}$ & $\begin{array}{l}. . . \\
.850 \\
.595 \\
\ldots . \\
\ldots \\
\ldots .\end{array}$ & $\begin{array}{l}\ldots \\
\ldots \\
\ldots \\
\ldots \\
\ldots \\
\ldots\end{array}$ & $\begin{array}{l}\ldots \\
\ldots \\
\ldots \\
\ldots \\
\ldots \\
\ldots\end{array}$ & $\begin{array}{l}\ldots \\
\ldots \\
\ldots \\
\ldots \\
\ldots \\
\ldots\end{array}$ & $\begin{array}{l}\ldots . \\
\ldots \\
\ldots \\
\ldots \\
\ldots\end{array}$ & $\begin{array}{l}.934 \\
2.07 \\
5.58 \\
1.73 \\
2.38\end{array}$ & $\begin{array}{l}\ldots \\
\ldots \\
\ldots \\
\ldots \\
\ldots \\
\ldots\end{array}$ & $\begin{array}{l}- \\
- \\
- \\
-\end{array}$ \\
\hline
\end{tabular}


SURFACE-WATER DATA-Cont inued

DAILY MEAN DISCHARGE-Continued

09396100 PUERCO RIVER MEAR CHAMBERS, AZ-Continued

DISCHARge, CUBIC METERS PER SECOND, MATER YEAR OCTOBER 1989 TO SEPTEMBER 1990 DAILY MEAN VALUES

\begin{tabular}{|c|c|c|c|c|c|c|c|c|c|c|c|c|}
\hline DAY & OCT & NON & DEC & JAN & FEB & MAR & APR & MAY & JUN & JUL & NUG & SEP \\
\hline $\begin{array}{l}1 \\
2 \\
3 \\
4 \\
5\end{array}$ & $\begin{array}{l}\cdots \\
\cdots \\
\cdots \\
\cdots \\
\cdots\end{array}$ & $\begin{array}{l}\ldots \\
\ldots \\
\ldots \\
\ldots \\
\ldots\end{array}$ & $\begin{array}{l}\ldots \\
\ldots \\
\ldots \\
\cdots \\
\cdots\end{array}$ & $\begin{array}{l}\cdots \\
\cdots \\
\cdots \\
\cdots \\
\cdots\end{array}$ & $\begin{array}{l}\ldots \\
\cdots \\
\cdots \\
\cdots \\
\cdots\end{array}$ & $\begin{array}{l}\ldots \\
\ldots \\
\ldots \\
\ldots \\
\ldots\end{array}$ & $\begin{array}{l}\cdots \\
\cdots \\
\cdots \\
\cdots \\
\cdots\end{array}$ & $\begin{array}{l}\cdots \\
\ldots \\
\ldots \\
\cdots \\
\cdots\end{array}$ & $\begin{array}{l}\ldots \\
\ldots \\
\cdots \\
\cdots \\
\cdots\end{array}$ & $\begin{array}{l}\ldots \\
\ldots \\
\ldots \\
\ldots \\
\ldots\end{array}$ & $\begin{array}{l}\cdots \\
\ldots \\
\ldots \\
\cdots \\
\cdots\end{array}$ & $\begin{array}{l}\ldots . \\
\ldots . \\
.708 \\
.566 \\
\ldots\end{array}$ \\
\hline $\begin{array}{r}6 \\
7 \\
8 \\
9 \\
10\end{array}$ & $\begin{array}{l}\cdots \\
\cdots \\
\cdots \\
\cdots \\
\cdots\end{array}$ & $\begin{array}{l}\ldots \\
\ldots \\
\ldots \\
\ldots \\
\ldots\end{array}$ & $\begin{array}{l}\ldots \\
\ldots \\
\ldots \\
\ldots \\
\ldots\end{array}$ & $\begin{array}{l}\cdots \\
\cdots \\
\cdots \\
\cdots \\
\cdots\end{array}$ & $\begin{array}{l}\ldots \\
\ldots \\
\cdots \\
\cdots \\
\cdots\end{array}$ & $\begin{array}{l}\ldots \\
\ldots \\
\ldots \\
\ldots \\
\cdots\end{array}$ & $\begin{array}{l}\ldots \\
\ldots \\
\ldots \\
\ldots \\
\ldots\end{array}$ & $\begin{array}{l}\cdots \\
\cdots \\
\cdots \\
\cdots \\
\cdots\end{array}$ & $\begin{array}{l}\ldots \\
\ldots \\
\ldots \\
\ldots\end{array}$ & $\begin{array}{c}\ldots \\
\ldots \\
1.44 \\
2.75 \\
1.13\end{array}$ & $\begin{array}{l}\ldots \\
\ldots \\
.793 \\
\ldots \\
\ldots\end{array}$ & $\begin{array}{c}10.8 \\
1.53 \\
.963 \\
1.47 \\
.906\end{array}$ \\
\hline $\begin{array}{l}11 \\
12 \\
13 \\
14 \\
15\end{array}$ & $\begin{array}{l}\ldots \\
\ldots \\
\cdots \\
\cdots \\
\ldots\end{array}$ & $\begin{array}{l}\ldots \\
\ldots \\
\cdots \\
\cdots \\
\cdots\end{array}$ & $\begin{array}{l}\ldots \\
\cdots \\
\cdots \\
\cdots \\
\ldots\end{array}$ & $\begin{array}{l}\ldots \\
\ldots \\
\ldots \\
\ldots \\
\ldots\end{array}$ & $\begin{array}{l}\ldots . \\
.651 \\
. \ldots \\
.595 \\
\ldots .\end{array}$ & $\begin{array}{l}\ldots \\
\ldots \\
\ldots \\
\ldots \\
\ldots\end{array}$ & $\begin{array}{l}\cdots \\
\ldots \\
\ldots \\
\ldots \\
\ldots\end{array}$ & $\begin{array}{l}\cdots \\
\cdots \\
\cdots \\
\cdots \\
\cdots\end{array}$ & $\begin{array}{l}\ldots \\
\ldots \\
\cdots \\
\ldots \\
\ldots\end{array}$ & $\begin{array}{c}3.06 \\
1.30 \\
2.15 \\
28.3 \\
3.68\end{array}$ & $\begin{array}{c}\ldots \\
\ldots \\
\cdots \\
1.73 \\
21.4\end{array}$ & $\begin{array}{l}\ldots . \\
\ldots \\
\ldots . \\
\ldots\end{array}$ \\
\hline $\begin{array}{l}16 \\
17 \\
18 \\
19 \\
20\end{array}$ & $\begin{array}{l}\ldots \\
\ldots \\
\ldots \\
\ldots \\
\ldots\end{array}$ & $\begin{array}{l}\ldots \\
\ldots \\
\ldots \\
\ldots \\
\ldots\end{array}$ & $\begin{array}{l}\ldots \\
\ldots \\
\ldots \\
\ldots \\
\ldots\end{array}$ & $\begin{array}{l}\cdots \\
\cdots \\
\cdots \\
\cdots\end{array}$ & $\begin{array}{l}\ldots \\
\ldots \\
\ldots \\
\ldots \\
\ldots\end{array}$ & $\begin{array}{l}\ldots \\
\cdots \\
\cdots \\
\cdots\end{array}$ & $\begin{array}{l}\cdots \\
\ldots \\
\ldots \\
\cdots \\
\cdots\end{array}$ & $\begin{array}{l}\ldots \\
\ldots \\
\ldots \\
\ldots \\
\ldots\end{array}$ & $\begin{array}{l}\cdots \\
\cdots \\
\cdots \\
\cdots\end{array}$ & $\begin{array}{c}1.05 \\
\cdots . \\
2.86 \\
.651 \\
.623\end{array}$ & $\begin{array}{r}9.77 \\
11.4 \\
2.44 \\
\ldots \\
\ldots\end{array}$ & $\begin{array}{l}\ldots . \\
\ldots \\
\ldots \\
\ldots \\
\cdots\end{array}$ \\
\hline $\begin{array}{l}21 \\
22 \\
23 \\
24 \\
25\end{array}$ & $\begin{array}{l}\ldots \\
\ldots \\
\cdots \\
\cdots \\
\cdots\end{array}$ & $\begin{array}{l}\ldots \\
\ldots \\
\ldots \\
\ldots \\
\cdots\end{array}$ & $\begin{array}{l}\cdots \\
\cdots \\
\cdots \\
\cdots \\
\cdots\end{array}$ & $\begin{array}{l}\cdots \\
\cdots \\
\cdots \\
\cdots\end{array}$ & $\begin{array}{l}\ldots \\
\ldots \\
\ldots \\
\ldots \\
\ldots\end{array}$ & $\begin{array}{l}\ldots \\
\ldots \\
\ldots \\
\ldots \\
\ldots\end{array}$ & $\begin{array}{l}\cdots \\
\cdots \\
\cdots \\
\cdots\end{array}$ & $\begin{array}{l}\cdots \\
\ldots \\
\ldots \\
\ldots \\
\cdots\end{array}$ & $\begin{array}{l}\ldots \\
\cdots \\
\ldots \\
\ldots\end{array}$ & $\begin{array}{c}.651 \\
.651 \\
\ldots . \\
2.63 \\
1.44\end{array}$ & $\begin{array}{c}3.51 \\
1.50 \\
\ldots . \\
\ldots \\
\ldots\end{array}$ & $\begin{array}{l}\ldots \\
\ldots \\
\ldots \\
\cdots \\
\cdots\end{array}$ \\
\hline $\begin{array}{l}26 \\
27 \\
28 \\
29 \\
30\end{array}$ & $\begin{array}{l}\cdots \\
\ldots \\
\ldots \\
\ldots \\
\ldots\end{array}$ & $\begin{array}{l}\cdots \\
\ldots \\
\ldots \\
\ldots \\
\ldots\end{array}$ & $\begin{array}{l}\cdots \\
\ldots \\
\ldots \\
\ldots \\
\ldots\end{array}$ & $\begin{array}{l}\cdots \\
\ldots \\
\ldots \\
\cdots \\
\cdots\end{array}$ & $\begin{array}{l}\cdots \\
\ldots \\
\cdots \\
\cdots \\
\cdots\end{array}$ & $\begin{array}{l}\ldots \\
\ldots \\
\ldots \\
\ldots \\
\ldots \\
\ldots\end{array}$ & $\begin{array}{l}\ldots \\
\ldots \\
\ldots \\
\ldots \\
\ldots\end{array}$ & $\begin{array}{l}\cdots \\
\cdots \\
\cdots \\
\cdots \\
\cdots\end{array}$ & $\begin{array}{l}\cdots \\
\ldots \\
\cdots \\
\cdots \\
\ldots\end{array}$ & $\begin{array}{l}\ldots \\
\ldots \\
\ldots \\
\ldots \\
\ldots\end{array}$ & $\begin{array}{l}\ldots \\
\ldots \\
\ldots \\
\ldots \\
\ldots \\
\ldots\end{array}$ & $\begin{array}{l}\ldots \\
\cdots \\
\cdots \\
\cdots \\
\cdots\end{array}$ \\
\hline
\end{tabular}




\author{
SURFACE-MATER DATA-Continued \\ DAILY MEAK DISCHARGE-Continued \\ 09396100 PUERCO RIVER NEAR CHAMBERS, AZ-Continued
}

DISCHARGE, CUBIC METERS PER SECOND, MATER YEAR OCTOBER 1990 TO SEPTEMBER 1991

DAILY MEAN VALUES

\begin{tabular}{|c|c|c|c|c|c|c|c|c|c|c|c|c|}
\hline DAY & OCT & MOV & DEC & JAN & FEB & MAR & APR & mar & JUN & JUL & AUG & SEP \\
\hline $\begin{array}{l}1 \\
2 \\
3 \\
4 \\
5\end{array}$ & $\begin{array}{l}\ldots \\
\ldots \\
\cdots \\
\cdots \\
\cdots\end{array}$ & $\begin{array}{l}\ldots . \\
\ldots \\
\cdots \\
\cdots \\
\cdots\end{array}$ & $\begin{array}{l}\ldots . \\
\ldots . \\
\ldots . \\
\ldots .\end{array}$ & $\begin{array}{c}\ldots . . \\
\ldots . . \\
1.13 \\
2.83\end{array}$ & $\begin{array}{l}\ldots . \\
\ldots . \\
\cdots \\
\cdots\end{array}$ & $\begin{array}{l}7 . . \\
6.70 \\
6.99 \\
2.69 \\
2.49\end{array}$ & $\begin{array}{l}.963 \\
1.05 \\
1.44 \\
1.25 \\
.765\end{array}$ & $\begin{array}{l}\ldots . \\
\ldots . \\
\ldots . \\
\ldots .\end{array}$ & $\begin{array}{l}\ldots . \\
\cdots \\
\cdots \\
\cdots \\
\cdots\end{array}$ & $\begin{array}{l}\ldots . \\
\ldots \\
\ldots \\
\ldots \\
\ldots\end{array}$ & $\begin{array}{l}1.59 \\
4.28 \\
7.28 \\
2.27 \\
1.53\end{array}$ & $\begin{array}{c}\ldots \\
\ldots \\
\ldots \\
1.27\end{array}$ \\
\hline $\begin{array}{r}6 \\
7 \\
8 \\
9 \\
10\end{array}$ & $\begin{array}{l}\ldots \\
\cdots \\
\cdots \\
\cdots \\
\cdots\end{array}$ & $\begin{array}{l}\ldots . \\
\cdots \\
\cdots \\
\cdots \\
\cdots\end{array}$ & $\begin{array}{l}\ldots . \\
\ldots . \\
\cdots \\
\ldots .\end{array}$ & $\begin{array}{l}6.99 \\
5.38 \\
8.50 \\
2.49 \\
4.87\end{array}$ & $\begin{array}{c}\ldots \\
\ldots . \\
1.02 \\
3.48 \\
3.40\end{array}$ & $\begin{array}{c}5.52 \\
2.55 \\
1.50 \\
.736 \\
\ldots . .\end{array}$ & $\begin{array}{l}.934 \\
.821 \\
.651 \\
\ldots \ldots \\
\ldots .\end{array}$ & $\begin{array}{l}\ldots \\
\cdots \\
\cdots \\
\cdots \\
\cdots\end{array}$ & $\begin{array}{l}\cdots \\
\cdots \\
\cdots \\
\cdots \\
\cdots\end{array}$ & $\begin{array}{l}\cdots \\
\cdots \\
\cdots \\
\cdots \\
\cdots\end{array}$ & $\begin{array}{c}4.42 \\
18.5 \\
3.23 \\
\ldots \\
\ldots .\end{array}$ & $\begin{array}{c}1.36 \\
1.02 \\
\ldots . \\
\ldots . \\
\ldots .\end{array}$ \\
\hline $\begin{array}{l}11 \\
12 \\
13 \\
14 \\
15\end{array}$ & $\begin{array}{l}\ldots \\
\cdots \\
\cdots \\
\cdots \\
\cdots\end{array}$ & $\begin{array}{l}\ldots- \\
\cdots \\
\cdots \\
\cdots \\
\cdots\end{array}$ & $\begin{array}{l}\ldots . \\
\ldots \\
.623 \\
\ldots .\end{array}$ & $\begin{array}{l}2.07 \\
1.69 \\
4.47 \\
1.81 \\
.623\end{array}$ & $\begin{array}{l}7.84 \\
6.77 \\
4.56 \\
7.67 \\
5.27\end{array}$ & $\begin{array}{l}\cdots \\
\cdots \\
\cdots \\
\cdots\end{array}$ & $\begin{array}{l}\ldots \\
\ldots \\
\cdots \\
\ldots \\
\ldots\end{array}$ & $\begin{array}{l}\cdots \\
\cdots \\
\cdots \\
\cdots \\
\cdots\end{array}$ & $\begin{array}{l}\ldots . . \\
9.26 \\
6.00 \\
8.44 \\
3.03\end{array}$ & $\begin{array}{l}\ldots \\
\ldots \\
\cdots \\
\cdots \\
\cdots\end{array}$ & $\begin{array}{l}\cdots \\
\cdots \\
\cdots \\
\cdots\end{array}$ & $\begin{array}{l}\ldots \\
\ldots \\
\ldots \\
\ldots\end{array}$ \\
\hline $\begin{array}{l}16 \\
17 \\
18 \\
19 \\
20\end{array}$ & $\begin{array}{c}\ldots \\
\cdots \\
\cdots \\
\cdots \\
22.5\end{array}$ & $\begin{array}{l}\ldots . \\
\ldots \\
\cdots \\
\cdots \\
\cdots\end{array}$ & $\begin{array}{l}\ldots . \\
\ldots . \\
\ldots . \\
\ldots .\end{array}$ & $\begin{array}{c}.821 \\
\ldots . \\
\ldots \\
\ldots \\
\ldots\end{array}$ & $\begin{array}{l}5.47 \\
6.12 \\
6.77 \\
1.16 \\
\cdots . .\end{array}$ & $\begin{array}{l}\ldots . \\
.651 \\
\ldots . \\
\ldots .\end{array}$ & $\begin{array}{l}\ldots \\
\cdots \\
\cdots \\
\cdots \\
\ldots\end{array}$ & $\begin{array}{l}\ldots . \\
\cdots \\
\cdots \\
\cdots \\
\cdots\end{array}$ & $\begin{array}{l}\cdots \\
\cdots \\
\cdots \\
\cdots\end{array}$ & $\begin{array}{l}\ldots \\
\ldots . \\
\ldots . \\
\cdots\end{array}$ & $\begin{array}{c}1.27 \\
.736 \\
\ldots . \\
\ldots \\
\ldots\end{array}$ & $\begin{array}{l}\cdots . \\
\cdots \\
\cdots \\
\cdots\end{array}$ \\
\hline $\begin{array}{l}21 \\
22 \\
23 \\
24 \\
25\end{array}$ & $\begin{array}{c}3.57 \\
.850 \\
\ldots . \\
\ldots . \\
\ldots\end{array}$ & $\begin{array}{l}\ldots . \\
\cdots \\
\cdots \\
\cdots \\
\cdots\end{array}$ & $\begin{array}{l}\ldots . \\
\ldots \\
\ldots . \\
\ldots .\end{array}$ & $\begin{array}{l}\ldots . \\
\ldots \\
\cdots . \\
\cdots \\
\ldots\end{array}$ & $\begin{array}{l}\ldots . \\
\cdots \\
\cdots \\
\cdots \\
\ldots .\end{array}$ & $\begin{array}{l}\ldots \\
\cdots \\
\cdots \\
\cdots \\
\cdots\end{array}$ & $\begin{array}{l}\ldots \\
\ldots \\
\ldots \\
\ldots \\
\ldots\end{array}$ & $\begin{array}{l}\ldots . \\
\ldots \\
\cdots \\
\ldots \\
\ldots\end{array}$ & $\begin{array}{l}\cdots \\
\cdots \\
\cdots \\
\cdots \\
\cdots\end{array}$ & $\begin{array}{l}\ldots \\
\ldots . \\
\cdots \\
\cdots\end{array}$ & $\begin{array}{l}\ldots \\
\ldots \\
\ldots \\
\ldots\end{array}$ & $\begin{array}{l}\ldots \\
\ldots \\
\cdots \\
\cdots \\
\ldots\end{array}$ \\
\hline $\begin{array}{l}26 \\
27 \\
28 \\
29 \\
30 \\
31\end{array}$ & $\begin{array}{l}\ldots . \\
\ldots . \\
\ldots . \\
\cdots \\
\ldots\end{array}$ & $\begin{array}{l}\ldots . \\
\ldots \\
\ldots . \\
\ldots \\
\ldots\end{array}$ & $\begin{array}{l}\ldots . \\
\ldots \\
\ldots \\
\ldots \\
\ldots\end{array}$ & $\begin{array}{l}\ldots . \\
\ldots . \\
\cdots . \\
\ldots . \\
\ldots .\end{array}$ & $\begin{array}{l}\ldots \\
\ldots . \\
\cdots \\
\cdots \\
\ldots .\end{array}$ & $\begin{array}{c}\ldots . \\
. . \\
.623 \\
2.41 \\
2.72 \\
2.01\end{array}$ & $\begin{array}{l}\cdots \\
\cdots \\
\cdots \\
\cdots \\
\cdots \\
\cdots\end{array}$ & $\begin{array}{l}\cdots \\
\cdots \\
\cdots \\
\cdots \\
\cdots \\
\cdots\end{array}$ & $\begin{array}{l}\cdots \\
\cdots \\
\cdots \\
\cdots \\
\cdots\end{array}$ & $\begin{array}{c}1.53 \\
4.28 \\
.680 \\
.566 \\
1.50 \\
. . .\end{array}$ & $\begin{array}{c}1 . . \\
15.9 \\
1.10 \\
.906 \\
.566 \\
\ldots . .\end{array}$ & $\begin{array}{l}\ldots \\
\cdots \\
\cdots \\
\cdots \\
\cdots \\
\cdots\end{array}$ \\
\hline
\end{tabular}


SURFACE-HATER DATA-Cont inued

DAILY MEAN DISCHARGE-Continued

09386950 ZUNI RIVER ABOVE BLACK ROCK RESERVOIR, NH

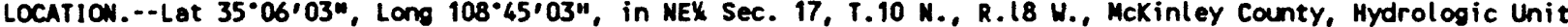
15020004, on Zuni Indian Reservation, on left bank downstream from highway bridge on State Highway 36, $1.3 \mathrm{~km}$ upstream from flow line of 8 lack Rock Reservoir, $3.7 \mathrm{~km}$ northeast of Black Rock, and $9.5 \mathrm{~km}$ northeast of Zuni Pueblo.

DRAIMAGE AREA. $--2,196 \mathrm{~km}^{2}$, of wich $34 \mathrm{~km}^{2}$ is non-contributing.

PERIO0 OF RECORD.--October 1988 to September 1991.

OTHER DATA COLLECTION AT THIS SITE.--October 1969 to current year. Prior to October 1974 published as "above Zuni Reservoir."

DISCHARGE, CUBIC METERS PER SECOND, WATER YEAR OCTOBER 1988 TO SEPTEMBER 1989 DAILY MEAN VALUES

\begin{tabular}{|c|c|c|c|c|c|c|c|c|c|c|c|c|}
\hline DAY & OCT & nov & DEC & JAN & FEB & MR & APR & MAY & JUN & JUL & AUG & SEP \\
\hline $\begin{array}{l}1 \\
2 \\
3 \\
4 \\
5\end{array}$ & $\begin{array}{l}.040 \\
.040 \\
.040 \\
.042 \\
.042\end{array}$ & $\begin{array}{l}.054 \\
.051 \\
.054 \\
.057 \\
.057\end{array}$ & $\begin{array}{l}.071 \\
.079 \\
.079 \\
.076 \\
.082\end{array}$ & $\begin{array}{l}.042 \\
.045 \\
.051 \\
.076 \\
.116\end{array}$ & $\begin{array}{l}.113 \\
.227 \\
.396 \\
.232 \\
.173\end{array}$ & $\begin{array}{l}.085 \\
.082 \\
.085 \\
.088 \\
.088\end{array}$ & $\begin{array}{l}.042 \\
.042 \\
.042 \\
.040 \\
.037\end{array}$ & $\begin{array}{l}.006 \\
.006 \\
.009 \\
.010 \\
.007\end{array}$ & $\begin{array}{l}.000 \\
.000 \\
.000 \\
.000 \\
.000\end{array}$ & $\begin{array}{l}.000 \\
.000 \\
.000 \\
.000 \\
.000\end{array}$ & $\begin{array}{l}.017 \\
.040 \\
.020 \\
.013 \\
.007\end{array}$ & $\begin{array}{l}.000 \\
.000 \\
.000 \\
.000 \\
.000\end{array}$ \\
\hline $\begin{array}{r}6 \\
7 \\
8 \\
9 \\
10\end{array}$ & $\begin{array}{l}.042 \\
.040 \\
.042 \\
.042 \\
.040\end{array}$ & $\begin{array}{l}.057 \\
.054 \\
.051 \\
.054 \\
.054\end{array}$ & $\begin{array}{l}.079 \\
.076 \\
.068 \\
.065 \\
.068\end{array}$ & $\begin{array}{l}.122 \\
.105 \\
.076 \\
.051 \\
.051\end{array}$ & $\begin{array}{l}.122 \\
.125 \\
.116 \\
.139 \\
.187\end{array}$ & $\begin{array}{l}.088 \\
.085 \\
.082 \\
.076 \\
.071\end{array}$ & $\begin{array}{l}.037 \\
.037 \\
.037 \\
.034 \\
.034\end{array}$ & $\begin{array}{l}.004 \\
.003 \\
.001 \\
.000 \\
.002\end{array}$ & $\begin{array}{l}.000 \\
.000 \\
.000 \\
.000 \\
.000\end{array}$ & $\begin{array}{l}.000 \\
.000 \\
.000 \\
.000 \\
.000\end{array}$ & $\begin{array}{l}.002 \\
.000 \\
.000 \\
.000 \\
.000\end{array}$ & $\begin{array}{l}.000 \\
.000 \\
.000 \\
.000 \\
.000\end{array}$ \\
\hline $\begin{array}{l}11 \\
12 \\
13 \\
14 \\
15\end{array}$ & $\begin{array}{l}.045 \\
.045 \\
.042 \\
.040 \\
.045\end{array}$ & $\begin{array}{l}.057 \\
.057 \\
.062 \\
.059 \\
.062\end{array}$ & $\begin{array}{l}.071 \\
.065 \\
.065 \\
.068 \\
.074\end{array}$ & $\begin{array}{l}.054 \\
.054 \\
.054 \\
.054 \\
.057\end{array}$ & $\begin{array}{l}.198 \\
.164 \\
.136 \\
.119 \\
.113\end{array}$ & $\begin{array}{l}.074 \\
.074 \\
.071 \\
.068 \\
.068\end{array}$ & $\begin{array}{l}.037 \\
.034 \\
.031 \\
.031 \\
.031\end{array}$ & $\begin{array}{l}.005 \\
.002 \\
.000 \\
.001 \\
.007\end{array}$ & $\begin{array}{l}.000 \\
.000 \\
.000 \\
.000 \\
.000\end{array}$ & $\begin{array}{l}.000 \\
.000 \\
.000 \\
.000 \\
.000\end{array}$ & $\begin{array}{l}.000 \\
.000 \\
.000 \\
.000 \\
.000\end{array}$ & $\begin{array}{l}.000 \\
.000 \\
.000 \\
.000 \\
.000\end{array}$ \\
\hline $\begin{array}{l}16 \\
17 \\
18 \\
19 \\
20\end{array}$ & $\begin{array}{l}.045 \\
.042 \\
.042 \\
.042 \\
.040\end{array}$ & $\begin{array}{l}.068 \\
.068 \\
.076 \\
.071 \\
.071\end{array}$ & $\begin{array}{l}.068 \\
.076 \\
.076 \\
.082 \\
.074\end{array}$ & $\begin{array}{l}.057 \\
.065 \\
.071 \\
.074 \\
.088\end{array}$ & $\begin{array}{l}.113 \\
.119 \\
.116 \\
.110 \\
.110\end{array}$ & $\begin{array}{l}.068 \\
.068 \\
.062 \\
.062 \\
.062\end{array}$ & $\begin{array}{l}.028 \\
.028 \\
.027 \\
.027 \\
.028\end{array}$ & $\begin{array}{l}.008 \\
.018 \\
.022 \\
.020 \\
.014\end{array}$ & $\begin{array}{l}.000 \\
.000 \\
.000 \\
.000 \\
.000\end{array}$ & $\begin{array}{l}.000 \\
.000 \\
.000 \\
.000 \\
.000\end{array}$ & $\begin{array}{l}.000 \\
.000 \\
.000 \\
.004 \\
.018\end{array}$ & $\begin{array}{l}.000 \\
.000 \\
.000 \\
.000 \\
.000\end{array}$ \\
\hline $\begin{array}{l}21 \\
22 \\
23 \\
24 \\
25\end{array}$ & $\begin{array}{l}.040 \\
.042 \\
.045 \\
.048 \\
.045\end{array}$ & $\begin{array}{l}.065 \\
.059 \\
.059 \\
.074 \\
.082\end{array}$ & $\begin{array}{l}.076 \\
.079 \\
.079 \\
.074 \\
.079\end{array}$ & $\begin{array}{l}.105 \\
.099 \\
.113 \\
.127 \\
.127\end{array}$ & $\begin{array}{l}.096 \\
.096 \\
.096 \\
.093 \\
.091\end{array}$ & $\begin{array}{l}.062 \\
.062 \\
.059 \\
.051 \\
.048\end{array}$ & $\begin{array}{l}.025 \\
.019 \\
.015 \\
.014 \\
.012\end{array}$ & $\begin{array}{l}.010 \\
.005 \\
.001 \\
.000 \\
.000\end{array}$ & $\begin{array}{l}.000 \\
.000 \\
.000 \\
.000 \\
.000\end{array}$ & $\begin{array}{l}.000 \\
.000 \\
.000 \\
.000 \\
.000\end{array}$ & $\begin{array}{l}.013 \\
.009 \\
.040 \\
.019 \\
.005\end{array}$ & $\begin{array}{l}.000 \\
.000 \\
.000 \\
.000 \\
.000\end{array}$ \\
\hline $\begin{array}{l}26 \\
27 \\
28 \\
29 \\
30 \\
31\end{array}$ & $\begin{array}{l}.045 \\
.048 \\
.048 \\
.048 \\
.051 \\
.054\end{array}$ & $\begin{array}{c}.074 \\
.071 \\
.062 \\
.062 \\
.065 \\
\ldots .\end{array}$ & $\begin{array}{l}.082 \\
.076 \\
.076 \\
.054 \\
.048 \\
.045\end{array}$ & $\begin{array}{l}.125 \\
.130 \\
.105 \\
.105 \\
.102 \\
.099\end{array}$ & $\begin{array}{l}.091 \\
.091 \\
.091 \\
. \ldots \\
\ldots . \\
\ldots .\end{array}$ & $\begin{array}{l}.048 \\
.048 \\
.048 \\
.048 \\
.045 \\
.042\end{array}$ & $\begin{array}{c}.014 \\
.010 \\
.008 \\
.007 \\
.008 \\
. .-\end{array}$ & $\begin{array}{l}.000 \\
.000 \\
.000 \\
.000 \\
.000 \\
.000\end{array}$ & $\begin{array}{c}.000 \\
.000 \\
.000 \\
.000 \\
.000 \\
\ldots . .\end{array}$ & $\begin{array}{r}2.97 \\
.210 \\
.099 \\
.082 \\
.023 \\
.017\end{array}$ & $\begin{array}{l}.000 \\
.000 \\
.000 \\
.000 \\
.000 \\
.000\end{array}$ & $\begin{array}{l}.000 \\
.000 \\
.000 \\
.000 \\
.000 \\
. . .\end{array}$ \\
\hline
\end{tabular}


DISChARge, CUBIC METERS PER SECOND, hATER YEAR OCTOBER 1989 TO SEPTEMBER 1990 DAILY MEAN VALUES

\begin{tabular}{|c|c|c|c|c|c|c|c|c|c|c|c|c|}
\hline DAY & OCT & NOV & DEC & JAN & FEB & MAR & APR & MAY & JUN & JUL & NUG & SEP \\
\hline $\begin{array}{l}1 \\
2 \\
3 \\
4 \\
5\end{array}$ & $\begin{array}{l}.000 \\
.000 \\
.000 \\
.000 \\
.000\end{array}$ & $\begin{array}{l}.003 \\
.004 \\
.003 \\
.003 \\
.004\end{array}$ & $\begin{array}{l}.002 \\
.003 \\
.006 \\
.006 \\
.006\end{array}$ & $\begin{array}{r}.008 \\
.012 \\
.013 \\
.011 \\
.010\end{array}$ & $\begin{array}{l}.031 \\
.034 \\
.028 \\
.028 \\
.031\end{array}$ & $\begin{array}{r}.059 \\
.054 \\
.048 \\
.048 \\
.048\end{array}$ & $\begin{array}{l}.040 \\
.040 \\
.040 \\
.034 \\
.034\end{array}$ & $\begin{array}{r}.000 \\
.000 \\
.027 \\
.031 \\
.019\end{array}$ & $\begin{array}{l}.000 \\
.000 \\
.000 \\
.000 \\
.000\end{array}$ & $\begin{array}{l}.000 \\
.000 \\
.000 \\
.000 \\
.000\end{array}$ & $\begin{array}{r}.000 \\
.000 \\
.000 \\
.000 \\
.000\end{array}$ & $\begin{array}{r}.000 \\
.000 \\
.000 \\
.000 \\
.000\end{array}$ \\
\hline $\begin{array}{r}6 \\
7 \\
8 \\
9 \\
10\end{array}$ & $\begin{array}{l}.016 \\
.018 \\
.009 \\
.002 \\
.000\end{array}$ & $\begin{array}{l}.005 \\
.005 \\
.003 \\
.003 \\
.004\end{array}$ & $\begin{array}{l}.007 \\
.007 \\
.007 \\
.006 \\
.006\end{array}$ & $\begin{array}{l}.009 \\
.010 \\
.017 \\
.019 \\
.021\end{array}$ & $\begin{array}{l}.034 \\
.042 \\
.042 \\
.045 \\
.045\end{array}$ & $\begin{array}{l}.048 \\
.054 \\
.051 \\
.042 \\
.048\end{array}$ & $\begin{array}{l}.034 \\
.034 \\
.037 \\
.037 \\
.034\end{array}$ & $\begin{array}{l}.012 \\
.007 \\
.003 \\
.000 \\
.000\end{array}$ & $\begin{array}{l}.000 \\
.000 \\
.000 \\
.000 \\
.000\end{array}$ & $\begin{array}{l}.000 \\
.000 \\
.000 \\
.000 \\
.000\end{array}$ & $\begin{array}{l}.000 \\
.000 \\
.000 \\
.000 \\
.000\end{array}$ & $\begin{array}{l}.074 \\
.027 \\
.017 \\
.011 \\
.000\end{array}$ \\
\hline $\begin{array}{l}11 \\
12 \\
13 \\
14 \\
15\end{array}$ & $\begin{array}{l}.000 \\
.000 \\
.000 \\
.000 \\
.000\end{array}$ & $\begin{array}{l}.005 \\
.004 \\
.004 \\
.005 \\
.005\end{array}$ & $\begin{array}{l}.006 \\
.003 \\
.000 \\
.000 \\
.001\end{array}$ & $\begin{array}{l}.026 \\
.031 \\
.040 \\
.037 \\
.034\end{array}$ & $\begin{array}{l}.048 \\
.051 \\
.040 \\
.034 \\
.031\end{array}$ & $\begin{array}{l}.085 \\
.071 \\
.054 \\
.048 \\
.048\end{array}$ & $\begin{array}{l}.031 \\
.024 \\
.019 \\
.017 \\
.016\end{array}$ & $\begin{array}{l}.000 \\
.000 \\
.000 \\
.000 \\
.000\end{array}$ & $\begin{array}{l}.000 \\
.000 \\
.000 \\
.000 \\
.000\end{array}$ & $\begin{array}{l}.000 \\
.000 \\
.000 \\
.000 \\
.000\end{array}$ & $\begin{array}{l}.000 \\
.000 \\
.000 \\
.010 \\
.002\end{array}$ & $\begin{array}{l}.000 \\
.000 \\
.000 \\
.000 \\
.000\end{array}$ \\
\hline $\begin{array}{l}16 \\
17 \\
18 \\
19 \\
20\end{array}$ & $\begin{array}{l}.000 \\
.000 \\
.000 \\
.000 \\
.001\end{array}$ & $\begin{array}{l}.004 \\
.003 \\
.003 \\
.004 \\
.005\end{array}$ & $\begin{array}{l}.003 \\
.004 \\
.006 \\
.007 \\
.006\end{array}$ & $\begin{array}{l}.028 \\
.027 \\
.028 \\
.031 \\
.037\end{array}$ & $\begin{array}{l}.028 \\
.031 \\
.048 \\
.042 \\
.031\end{array}$ & $\begin{array}{l}.042 \\
.042 \\
.040 \\
.037 \\
.037\end{array}$ & $\begin{array}{l}.015 \\
.014 \\
.010 \\
.007 \\
.007\end{array}$ & $\begin{array}{l}.000 \\
.000 \\
.000 \\
.000 \\
.000\end{array}$ & $\begin{array}{l}.000 \\
.000 \\
.000 \\
.000 \\
.000\end{array}$ & $\begin{array}{l}.000 \\
.000 \\
.000 \\
.000 \\
.000\end{array}$ & $\begin{array}{l}.000 \\
.042 \\
.161 \\
.042 \\
.010\end{array}$ & $\begin{array}{l}.000 \\
.000 \\
.000 \\
.000 \\
.000\end{array}$ \\
\hline $\begin{array}{l}21 \\
22 \\
23 \\
24 \\
25\end{array}$ & $\begin{array}{l}.007 \\
.011 \\
.008 \\
.006 \\
.005\end{array}$ & $\begin{array}{l}.006 \\
.005 \\
.002 \\
.003 \\
.007\end{array}$ & $\begin{array}{l}.005 \\
.005 \\
.004 \\
.004 \\
.004\end{array}$ & $\begin{array}{l}.037 \\
.034 \\
.037 \\
.037 \\
.034\end{array}$ & $\begin{array}{l}.042 \\
.051 \\
.054 \\
.054 \\
.054\end{array}$ & $\begin{array}{l}.037 \\
.034 \\
.037 \\
.034 \\
.034\end{array}$ & $\begin{array}{l}.004 \\
.004 \\
.003 \\
.002 \\
.004\end{array}$ & $\begin{array}{l}.000 \\
.000 \\
.000 \\
.000 \\
.000\end{array}$ & $\begin{array}{l}.000 \\
.000 \\
.000 \\
.000 \\
.000\end{array}$ & $\begin{array}{l}.000 \\
.000 \\
.000 \\
.000 \\
.000\end{array}$ & $\begin{array}{l}.229 \\
.048 \\
.013 \\
.002 \\
.000\end{array}$ & $\begin{array}{l}.000 \\
.000 \\
.028 \\
.027 \\
.008\end{array}$ \\
\hline $\begin{array}{l}26 \\
27 \\
28 \\
29 \\
30 \\
31\end{array}$ & $\begin{array}{l}.003 \\
.001 \\
.001 \\
.001 \\
.003 \\
.003\end{array}$ & $\begin{array}{c}.008 \\
.006 \\
.004 \\
.001 \\
.000 \\
. . .\end{array}$ & $\begin{array}{l}.004 \\
.005 \\
.005 \\
.006 \\
.007 \\
.007\end{array}$ & $\begin{array}{l}.028 \\
.028 \\
.028 \\
.031 \\
.034 \\
.034\end{array}$ & $\begin{array}{r}.054 \\
.056 \\
.057 \\
\ldots \\
\ldots \\
\ldots\end{array}$ & $\begin{array}{l}.031 \\
.028 \\
.031 \\
.031 \\
.037 \\
.040\end{array}$ & $\begin{array}{r}.006 \\
.003 \\
.000 \\
.000 \\
.000 \\
\ldots .\end{array}$ & $\begin{array}{l}.000 \\
.000 \\
.000 \\
.000 \\
.000 \\
.000\end{array}$ & $\begin{array}{c}.000 \\
.000 \\
.000 \\
.000 \\
.000 \\
. .\end{array}$ & $\begin{array}{l}.000 \\
.000 \\
.000 \\
.000 \\
.000 \\
.000\end{array}$ & $\begin{array}{l}.000 \\
.000 \\
.000 \\
.000 \\
.000 \\
.000\end{array}$ & $\begin{array}{r}.000 \\
.000 \\
.001 \\
.001 \\
.000 \\
. . .\end{array}$ \\
\hline
\end{tabular}


SURFACE-WATER DATA-Continued

DAILY MEAN DISCHARGE-Cont inued

09386950 ZUNI RIVER ABOVE BLACK ROCK RESERVOIR, NH-Continued

DISCharge, CUBIC meters PER SECOND, hater yeAr OCTOBER 1990 to SEPTEMBER 1991

DAILY MEAN VALUES

\begin{tabular}{|c|c|c|c|c|c|c|c|c|c|c|c|c|}
\hline DAY & OCT & NOV & DEC & JAN & FEB & MAR & APR & MAY & JUA & JUL & NUG & SEP \\
\hline $\begin{array}{l}1 \\
2 \\
3 \\
4 \\
5\end{array}$ & $\begin{array}{l}.000 \\
.001 \\
.000 \\
.000 \\
.000\end{array}$ & $\begin{array}{l}.006 \\
.010 \\
.017 \\
.018 \\
.017\end{array}$ & $\begin{array}{l}.008 \\
.010 \\
.010 \\
.009 \\
.008\end{array}$ & $\begin{array}{l}.016 \\
.019 \\
.028 \\
.031 \\
.042\end{array}$ & $\begin{array}{l}.023 \\
.025 \\
.031 \\
.040 \\
.045\end{array}$ & $\begin{array}{l}.088 \\
.127 \\
.116 \\
.079 \\
.068\end{array}$ & $\begin{array}{l}.071 \\
.065 \\
.059 \\
.935 \\
4.53\end{array}$ & $\begin{array}{l}.031 \\
.027 \\
.024 \\
.020 \\
.018\end{array}$ & $\begin{array}{l}.000 \\
.000 \\
.000 \\
.000 \\
.000\end{array}$ & $\begin{array}{l}.000 \\
.000 \\
.000 \\
.000 \\
.000\end{array}$ & $\begin{array}{l}.000 \\
.000 \\
.000 \\
.000 \\
.000\end{array}$ & $\begin{array}{l}.000 \\
.000 \\
.000 \\
.004 \\
1.08\end{array}$ \\
\hline $\begin{array}{r}6 \\
7 \\
8 \\
9 \\
10\end{array}$ & $\begin{array}{l}.000 \\
.000 \\
.000 \\
.000 \\
.000\end{array}$ & $\begin{array}{l}.014 \\
.013 \\
.015 \\
.017 \\
.017\end{array}$ & $\begin{array}{l}.011 \\
.010 \\
.010 \\
.010 \\
.012\end{array}$ & $\begin{array}{l}.037 \\
.045 \\
.054 \\
.042 \\
.040\end{array}$ & $\begin{array}{l}.054 \\
.082 \\
.127 \\
.127 \\
.150\end{array}$ & $\begin{array}{l}.093 \\
.076 \\
.057 \\
.057 \\
.054\end{array}$ & $\begin{array}{l}3.40 \\
2.55 \\
1.81 \\
1.44 \\
1.02\end{array}$ & $\begin{array}{l}.018 \\
.018 \\
.017 \\
.017 \\
.016\end{array}$ & $\begin{array}{l}.000 \\
.000 \\
.000 \\
.000 \\
.000\end{array}$ & $\begin{array}{l}.000 \\
.000 \\
.000 \\
.000 \\
.000\end{array}$ & $\begin{array}{l}.000 \\
.000 \\
.000 \\
.000 \\
.000\end{array}$ & $\begin{array}{l}.538 \\
.272 \\
.091 \\
.042 \\
.031\end{array}$ \\
\hline $\begin{array}{l}11 \\
12 \\
13 \\
14 \\
15\end{array}$ & $\begin{array}{l}.000 \\
.000 \\
.001 \\
.005 \\
.006\end{array}$ & $\begin{array}{l}.013 \\
.008 \\
.005 \\
.005 \\
.005\end{array}$ & $\begin{array}{l}.014 \\
.016 \\
.028 \\
.037 \\
.028\end{array}$ & $\begin{array}{l}.031 \\
.031 \\
.034 \\
.040 \\
.042\end{array}$ & $\begin{array}{l}.170 \\
.150 \\
.133 \\
.113 \\
.091\end{array}$ & $\begin{array}{l}.051 \\
.048 \\
.051 \\
.051 \\
.054\end{array}$ & $\begin{array}{l}.623 \\
.481 \\
.396 \\
.368 \\
.340\end{array}$ & $\begin{array}{l}.016 \\
.014 \\
.015 \\
.013 \\
.007\end{array}$ & $\begin{array}{l}.000 \\
.000 \\
.000 \\
.000 \\
.000\end{array}$ & $\begin{array}{l}.000 \\
.000 \\
.000 \\
.000 \\
.000\end{array}$ & $\begin{array}{l}.000 \\
.000 \\
.000 \\
.000 \\
.000\end{array}$ & $\begin{array}{l}.026 \\
.025 \\
.028 \\
.027 \\
.027\end{array}$ \\
\hline $\begin{array}{l}16 \\
17 \\
18 \\
19 \\
20\end{array}$ & $\begin{array}{l}.004 \\
.002 \\
.000 \\
.000 \\
.034\end{array}$ & $\begin{array}{l}.005 \\
.005 \\
.005 \\
.004 \\
.010\end{array}$ & $\begin{array}{l}.028 \\
.040 \\
.040 \\
.028 \\
.025\end{array}$ & $\begin{array}{l}.037 \\
.040 \\
.034 \\
.031 \\
.028\end{array}$ & $\begin{array}{l}.076 \\
.068 \\
.062 \\
.045 \\
.042\end{array}$ & $\begin{array}{l}.068 \\
.076 \\
.088 \\
.074 \\
.068\end{array}$ & $\begin{array}{r}.312 \\
.283 \\
.161 \\
.133 \\
.119\end{array}$ & $\begin{array}{l}.002 \\
.000 \\
.000 \\
.000 \\
.000\end{array}$ & $\begin{array}{l}.000 \\
.000 \\
.000 \\
.000 \\
.000\end{array}$ & $\begin{array}{l}.000 \\
.000 \\
.000 \\
.000 \\
.000\end{array}$ & $\begin{array}{l}.000 \\
.000 \\
.000 \\
.000 \\
.000\end{array}$ & $\begin{array}{l}.025 \\
.021 \\
.020 \\
.016 \\
.009\end{array}$ \\
\hline $\begin{array}{l}21 \\
22 \\
23 \\
24 \\
25\end{array}$ & $\begin{array}{l}.062 \\
.031 \\
.013 \\
.010 \\
.007\end{array}$ & $\begin{array}{l}.014 \\
.015 \\
.015 \\
.014 \\
.014\end{array}$ & $\begin{array}{l}.020 \\
.021 \\
.017 \\
.016 \\
.021\end{array}$ & $\begin{array}{l}.031 \\
.034 \\
.034 \\
.028 \\
.028\end{array}$ & $\begin{array}{l}.042 \\
.040 \\
.040 \\
.040 \\
.040\end{array}$ & $\begin{array}{l}.079 \\
.088 \\
.088 \\
.085 \\
.074\end{array}$ & $\begin{array}{l}.093 \\
.074 \\
.059 \\
.048 \\
.045\end{array}$ & $\begin{array}{l}.000 \\
.000 \\
.000 \\
.000 \\
.000\end{array}$ & $\begin{array}{l}.000 \\
.000 \\
.000 \\
.000 \\
.000\end{array}$ & $\begin{array}{l}.000 \\
.000 \\
.000 \\
.000 \\
.000\end{array}$ & $\begin{array}{l}.000 \\
.000 \\
.000 \\
.000 \\
.000\end{array}$ & $\begin{array}{r}.009 \\
.007 \\
.002 \\
.000 \\
.000\end{array}$ \\
\hline $\begin{array}{l}26 \\
27 \\
28 \\
29 \\
30 \\
31\end{array}$ & $\begin{array}{l}.005 \\
.005 \\
.005 \\
.005 \\
.005 \\
.006\end{array}$ & $\begin{array}{c}.017 \\
.016 \\
.013 \\
.008 \\
.006 \\
\ldots \ldots\end{array}$ & $\begin{array}{l}.024 \\
.018 \\
.017 \\
.020 \\
.022 \\
.016\end{array}$ & $\begin{array}{l}.028 \\
.028 \\
.027 \\
.027 \\
.025 \\
.023\end{array}$ & $\begin{array}{r}.037 \\
.037 \\
.042 \\
\ldots \ldots \\
\ldots \ldots \\
\ldots\end{array}$ & $\begin{array}{l}.074 \\
.091 \\
.105 \\
.133 \\
.093 \\
.079\end{array}$ & $\begin{array}{c}.051 \\
.040 \\
.040 \\
.037 \\
.034 \\
\ldots . .\end{array}$ & $\begin{array}{l}.000 \\
.000 \\
.000 \\
.000 \\
.000 \\
.000\end{array}$ & $\begin{array}{c}.000 \\
.000 \\
.000 \\
.000 \\
.000 \\
\ldots\end{array}$ & $\begin{array}{l}.000 \\
.000 \\
.000 \\
.000 \\
.000 \\
.000\end{array}$ & $\begin{array}{l}.000 \\
.000 \\
.020 \\
.037 \\
.010 \\
.001\end{array}$ & $\begin{array}{r}.000 \\
.000 \\
.000 \\
.000 \\
.000 \\
. .\end{array}$ \\
\hline
\end{tabular}




\section{SURFACE-WATER DATA-Continued \\ DAILY MEAN DISCHARGE-Continued \\ 09394500 LITTLE COLORADO RIVER AT WOODRUFF, AZ}

LOCATION.--Lat 34'46'58", Long 110'02'37\%, in NEXSWX Sec. 17, T.16 N., R.22 E., Navajo County, Hydrologic Unit 15020002, on left bank at abandoned county road bridge in Hoodruff, $6.0 \mathrm{~km}$ downstream from Silver Creek.

DRAINAGE AREA. - 20,907 $\mathrm{km}^{2}$, of which $769 \mathrm{~km}^{2}$ is noncontributing.

PERIOD OF RECORD.--October 1988 to September 1991.

OTHER DATA COLLECTION AT THIS SITE.--March to May 1905; June to July 1905 (gage heights only); August 1905 to May 1907; July 1907 to April 1908, July to October 1908, Decenber 1908, and December 1915 to September 1916 (gage heights only); October 1916 to August 1917 (monthly discharge only); September 1917 to March 1918, December 1918 to December 1919, April 1929 to Decenber 1933, Septenber 1935 to current year. Published as Mnear Woodruff" 1916-19, 1929-48.

DISCHARGE, CUBIC METERS PER SECOND, WATER YEAR OCTOBER 1988 TO SEPTEMBER 1989 DAILY MEAN VALUES

\begin{tabular}{|c|c|c|c|c|c|c|c|c|c|c|c|c|}
\hline DAY & OCT & NOV & DEC & JAN & FEB & MAR & APR & MAY & JuW & JUL & AUG & SEP \\
\hline $\begin{array}{l}1 \\
2 \\
3 \\
4 \\
5\end{array}$ & $\begin{array}{l}.232 \\
.201 \\
.187 \\
.147 \\
.212\end{array}$ & $\begin{array}{l}.065 \\
.068 \\
.065 \\
.062 \\
.045\end{array}$ & $\begin{array}{l}.178 \\
.176 \\
.181 \\
.170 \\
.173\end{array}$ & $\begin{array}{l}.133 \\
.139 \\
.139 \\
.178 \\
.187\end{array}$ & $\begin{array}{l}.226 \\
.283 \\
.261 \\
.283 \\
.181\end{array}$ & $\begin{array}{l}.085 \\
.085 \\
.091 \\
.093 \\
.093\end{array}$ & $\begin{array}{l}.048 \\
.040 \\
.051 \\
.051 \\
.028\end{array}$ & $\begin{array}{l}.091 \\
.076 \\
.054 \\
.057 \\
.054\end{array}$ & $\begin{array}{l}.023 \\
.040 \\
.048 \\
.051 \\
.045\end{array}$ & $\begin{array}{l}.062 \\
.031 \\
.040 \\
.045 \\
.068\end{array}$ & $\begin{array}{c}4.30 \\
3.51 \\
1.98 \\
1.19 \\
.453\end{array}$ & $\begin{array}{c}.045 \\
.074 \\
1.16 \\
3.68 \\
.934\end{array}$ \\
\hline $\begin{array}{r}6 \\
7 \\
8 \\
9 \\
10\end{array}$ & $\begin{array}{l}.178 \\
.187 \\
.252 \\
.198 \\
.280\end{array}$ & $\begin{array}{l}.065 \\
.065 \\
.065 \\
.068 \\
.068\end{array}$ & $\begin{array}{l}.170 \\
.176 \\
.204 \\
.201 \\
.201\end{array}$ & $\begin{array}{l}.906 \\
.340 \\
.283 \\
.147 \\
.144\end{array}$ & $\begin{array}{l}.164 \\
.139 \\
.125 \\
.142 \\
.173\end{array}$ & $\begin{array}{l}.096 \\
.085 \\
.082 \\
.082 \\
.065\end{array}$ & $\begin{array}{l}.034 \\
.048 \\
.048 \\
.042 \\
.042\end{array}$ & $\begin{array}{l}.054 \\
.048 \\
.054 \\
.057 \\
.048\end{array}$ & $\begin{array}{l}.034 \\
.015 \\
.037 \\
.031 \\
.002\end{array}$ & $\begin{array}{l}.045 \\
.042 \\
.042 \\
.042 \\
.566\end{array}$ & $\begin{array}{l}.311 \\
.221 \\
.085 \\
.062 \\
.396\end{array}$ & $\begin{array}{l}.653 \\
.238 \\
.133 \\
.105 \\
.091\end{array}$ \\
\hline $\begin{array}{l}11 \\
12 \\
13 \\
16 \\
15\end{array}$ & $\begin{array}{l}.311 \\
.311 \\
.283 \\
.396 \\
1.25\end{array}$ & $\begin{array}{l}.065 \\
.065 \\
.093 \\
.113 \\
.099\end{array}$ & $\begin{array}{l}.190 \\
.176 \\
.178 \\
.176 \\
.159\end{array}$ & $\begin{array}{l}.139 \\
.176 \\
.133 \\
.113 \\
.102\end{array}$ & $\begin{array}{l}.595 \\
.991 \\
.538 \\
.340 \\
.246\end{array}$ & $\begin{array}{l}.068 \\
.071 \\
.068 \\
.059 \\
.059\end{array}$ & $\begin{array}{l}.045 \\
.042 \\
.034 \\
.340 \\
.566\end{array}$ & $\begin{array}{l}.037 \\
.042 \\
.062 \\
.065 \\
.085\end{array}$ & $\begin{array}{l}.042 \\
.074 \\
.031 \\
.045 \\
.023\end{array}$ & $\begin{array}{l}.275 \\
.878 \\
.708 \\
.232 \\
.079\end{array}$ & $\begin{array}{l}.283 \\
.133 \\
.249 \\
.176 \\
.116\end{array}$ & $\begin{array}{l}.082 \\
.076 \\
.133 \\
.150 \\
.139\end{array}$ \\
\hline $\begin{array}{l}16 \\
17 \\
18 \\
19 \\
20\end{array}$ & $\begin{array}{l}1.05 \\
.396 \\
.170 \\
.130 \\
.133\end{array}$ & $\begin{array}{l}.093 \\
.085 \\
.088 \\
.102 \\
.133\end{array}$ & $\begin{array}{l}.113 \\
.113 \\
.102 \\
.139 \\
.139\end{array}$ & $\begin{array}{l}.108 \\
.105 \\
.122 \\
.110 \\
.125\end{array}$ & $\begin{array}{l}.201 \\
.204 \\
.178 \\
.156 \\
.150\end{array}$ & $\begin{array}{l}.057 \\
.054 \\
.051 \\
.048 \\
.048\end{array}$ & $\begin{array}{l}.210 \\
.113 \\
.099 \\
.105 \\
.099\end{array}$ & $\begin{array}{l}.071 \\
.034 \\
.082 \\
.079 \\
.142\end{array}$ & $\begin{array}{l}.042 \\
.042 \\
.037 \\
.037 \\
.022\end{array}$ & $\begin{array}{l}.011 \\
.054 \\
.091 \\
.110 \\
.065\end{array}$ & $\begin{array}{c}.102 \\
.091 \\
11.0 \\
16.6 \\
8.13\end{array}$ & $\begin{array}{l}.204 \\
.142 \\
.144 \\
.082 \\
.079\end{array}$ \\
\hline $\begin{array}{l}21 \\
22 \\
23 \\
24 \\
25\end{array}$ & $\begin{array}{l}.113 \\
.133 \\
.116 \\
.099 \\
.102\end{array}$ & $\begin{array}{l}.153 \\
.139 \\
.144 \\
.207 \\
.176\end{array}$ & $\begin{array}{l}.153 \\
.153 \\
.147 \\
.164 \\
.142\end{array}$ & $\begin{array}{l}.110 \\
.181 \\
.198 \\
.272 \\
.340\end{array}$ & $\begin{array}{l}.139 \\
.139 \\
.142 \\
.142 \\
.125\end{array}$ & $\begin{array}{l}.031 \\
.037 \\
.042 \\
.031 \\
.040\end{array}$ & $\begin{array}{l}.076 \\
.048 \\
.062 \\
.059 \\
.051\end{array}$ & $\begin{array}{l}.093 \\
.088 \\
.068 \\
.065 \\
.057\end{array}$ & $\begin{array}{l}.017 \\
.011 \\
.059 \\
.042 \\
.042\end{array}$ & $\begin{array}{c}.068 \\
.048 \\
13.4 \\
2.63 \\
1.39\end{array}$ & $\begin{array}{l}2.72 \\
1.08 \\
.340 \\
.161 \\
.142\end{array}$ & $\begin{array}{l}.085 \\
.071 \\
.054 \\
.059 \\
.142\end{array}$ \\
\hline $\begin{array}{l}26 \\
27 \\
28 \\
29 \\
30 \\
31\end{array}$ & $\begin{array}{l}.091 \\
.082 \\
.062 \\
.065 \\
.071 \\
.068\end{array}$ & $\begin{array}{l}.190 \\
.178 \\
.178 \\
.181 \\
.190 \\
. . .\end{array}$ & $\begin{array}{l}.136 \\
.136 \\
.144 \\
.133 \\
.119 \\
.133\end{array}$ & $\begin{array}{l}.227 \\
.212 \\
.167 \\
.190 \\
.167 \\
.198\end{array}$ & $\begin{array}{l}.105 \\
.093 \\
.088 \\
\ldots \\
\ldots \\
\ldots\end{array}$ & $\begin{array}{l}.091 \\
.453 \\
.125 \\
.048 \\
.048 \\
.048\end{array}$ & $\begin{array}{l}.037 \\
.034 \\
.025 \\
.059 \\
.068 \\
. . .\end{array}$ & $\begin{array}{l}.031 \\
.028 \\
.042 \\
.040 \\
.004 \\
.040\end{array}$ & $\begin{array}{l}.059 \\
.048 \\
.042 \\
.045 \\
.022 \\
\ldots\end{array}$ & $\begin{array}{l}8.78 \\
4.87 \\
2.83 \\
3.34 \\
2.55 \\
1.70\end{array}$ & $\begin{array}{l}.105 \\
.099 \\
.093 \\
.056 \\
.082 \\
.062\end{array}$ & $\begin{array}{l}.082 \\
.057 \\
.068 \\
.091 \\
.091\end{array}$ \\
\hline
\end{tabular}


SURFACE-UATER DATA-Continued

DAILY MEAN DISCHARGE-Continued

09394500 LITTLE COLORADO RIVER AT WOOORUFF, AZ-CONTINUED

DISCHARGE, CUBIC METERS PER SECOND, MATER YEAR OCTOBER 1989 TO SEPTEMBER 1990 DAILY MEAK VALUES

\begin{tabular}{|c|c|c|c|c|c|c|c|c|c|c|c|c|}
\hline DAY & OCT & NOV & DEC & JAN & FEB & MAR & APR & MAY & JUN & JUL & AUG & SEP \\
\hline $\begin{array}{l}1 \\
2 \\
3 \\
4 \\
5\end{array}$ & $\begin{array}{l}.125 \\
.116 \\
.108 \\
.093 \\
.105\end{array}$ & $\begin{array}{l}.088 \\
.096 \\
.093 \\
.108 \\
.108\end{array}$ & $\begin{array}{l}.091 \\
.088 \\
.082 \\
.082 \\
.093\end{array}$ & $\begin{array}{l}.085 \\
.096 \\
.096 \\
.079 \\
.088\end{array}$ & $\begin{array}{l}.091 \\
.093 \\
.082 \\
.085 \\
.091\end{array}$ & $\begin{array}{l}.082 \\
.079 \\
.085 \\
.082 \\
.079\end{array}$ & $\begin{array}{l}.059 \\
.057 \\
.048 \\
.025 \\
.051\end{array}$ & $\begin{array}{l}.048 \\
.034 \\
.051 \\
.051 \\
.048\end{array}$ & $\begin{array}{l}.040 \\
.045 \\
.054 \\
.045 \\
.020\end{array}$ & $\begin{array}{l}.001 \\
.241 \\
.028 \\
.031 \\
.031\end{array}$ & $\begin{array}{l}.396 \\
.113 \\
.071 \\
.161 \\
.178\end{array}$ & $\begin{array}{l}3.23 \\
4.16 \\
1.59 \\
2.26 \\
2.44\end{array}$ \\
\hline $\begin{array}{r}6 \\
7 \\
8 \\
9 \\
10\end{array}$ & $\begin{array}{l}.181 \\
.229 \\
.176 \\
.108 \\
.088\end{array}$ & $\begin{array}{l}.091 \\
.093 \\
.099 \\
.096 \\
.096\end{array}$ & $\begin{array}{l}.127 \\
.119 \\
.085 \\
.093 \\
.088\end{array}$ & $\begin{array}{l}.085 \\
.085 \\
.088 \\
.085 \\
.088\end{array}$ & $\begin{array}{l}.088 \\
.085 \\
.085 \\
.085 \\
.082\end{array}$ & $\begin{array}{l}.079 \\
.071 \\
.074 \\
.068 \\
.059\end{array}$ & $\begin{array}{l}.057 \\
.057 \\
.057 \\
.051 \\
.056\end{array}$ & $\begin{array}{l}.018 \\
.059 \\
.076 \\
.082 \\
.085\end{array}$ & $\begin{array}{l}.037 \\
.028 \\
.015 \\
.016 \\
.031\end{array}$ & $\begin{array}{c}.031 \\
6.99 \\
10.2 \\
5.64 \\
1.70\end{array}$ & $\begin{array}{l}.105 \\
.082 \\
.062 \\
.136 \\
.105\end{array}$ & $\begin{array}{l}.623 \\
1.02 \\
.425 \\
.311 \\
.261\end{array}$ \\
\hline $\begin{array}{l}11 \\
12 \\
13 \\
16 \\
15\end{array}$ & $\begin{array}{l}.096 \\
.085 \\
.071 \\
.062 \\
.059\end{array}$ & $\begin{array}{l}.096 \\
.102 \\
.113 \\
.108 \\
.102\end{array}$ & $\begin{array}{l}.079 \\
.062 \\
.082 \\
.099 \\
.085\end{array}$ & $\begin{array}{l}.085 \\
.085 \\
.088 \\
.091 \\
.091\end{array}$ & $\begin{array}{l}.085 \\
.085 \\
.085 \\
.079 \\
.085\end{array}$ & $\begin{array}{l}.065 \\
.062 \\
.062 \\
.059 \\
.045\end{array}$ & $\begin{array}{l}.037 \\
.042 \\
.054 \\
.051 \\
.051\end{array}$ & $\begin{array}{l}.085 \\
.079 \\
.062 \\
.059 \\
.037\end{array}$ & $\begin{array}{l}.040 \\
.031 \\
.031 \\
.021 \\
.028\end{array}$ & $\begin{array}{c}.850 \\
1.02 \\
.212 \\
.108 \\
1.67\end{array}$ & $\begin{array}{c}.076 \\
.065 \\
.119 \\
12.0 \\
13.8\end{array}$ & $\begin{array}{l}.181 \\
.102 \\
.116 \\
.116 \\
.178\end{array}$ \\
\hline $\begin{array}{l}16 \\
17 \\
18 \\
19 \\
20\end{array}$ & $\begin{array}{l}.059 \\
.062 \\
.059 \\
.040 \\
.065\end{array}$ & $\begin{array}{l}.119 \\
.116 \\
.108 \\
.127 \\
.125\end{array}$ & $\begin{array}{l}.085 \\
.085 \\
.113 \\
.105 \\
.105\end{array}$ & $\begin{array}{l}.091 \\
.088 \\
.085 \\
.082 \\
.082\end{array}$ & $\begin{array}{l}.082 \\
.085 \\
.088 \\
.091 \\
.091\end{array}$ & $\begin{array}{l}.051 \\
.051 \\
.054 \\
.051 \\
.051\end{array}$ & $\begin{array}{l}.048 \\
.048 \\
.048 \\
.037 \\
.048\end{array}$ & $\begin{array}{l}.045 \\
.048 \\
.042 \\
.054 \\
.057\end{array}$ & $\begin{array}{l}.016 \\
.008 \\
.025 \\
.011 \\
.026\end{array}$ & $\begin{array}{l}.595 \\
.153 \\
.425 \\
.156 \\
.133\end{array}$ & $\begin{array}{c}17.7 \\
10.6 \\
1.62 \\
.311 \\
.235\end{array}$ & $\begin{array}{l}.147 \\
.144 \\
.178 \\
.164 \\
4.19\end{array}$ \\
\hline $\begin{array}{l}21 \\
22 \\
23 \\
24 \\
25\end{array}$ & $\begin{array}{l}.065 \\
.076 \\
.068 \\
.071 \\
.065\end{array}$ & $\begin{array}{l}.113 \\
.108 \\
.102 \\
.110 \\
.105\end{array}$ & $\begin{array}{l}.119 \\
.105 \\
.096 \\
.082 \\
.079\end{array}$ & $\begin{array}{l}.074 \\
.079 \\
.105 \\
.076 \\
.071\end{array}$ & $\begin{array}{l}.085 \\
.085 \\
.085 \\
.082 \\
.082\end{array}$ & $\begin{array}{l}.051 \\
.051 \\
.045 \\
.037 \\
.057\end{array}$ & $\begin{array}{l}.051 \\
.045 \\
.051 \\
.042 \\
.054\end{array}$ & $\begin{array}{l}.051 \\
.051 \\
.057 \\
.051 \\
.045\end{array}$ & $\begin{array}{l}.027 \\
.025 \\
.017 \\
.017 \\
.015\end{array}$ & $\begin{array}{l}.076 \\
.082 \\
.079 \\
.071 \\
.057\end{array}$ & $\begin{array}{l}.190 \\
.156 \\
.156 \\
.178 \\
.178\end{array}$ & $\begin{array}{c}30.0 \\
13.6 \\
1.50 \\
1.56 \\
.991\end{array}$ \\
\hline $\begin{array}{l}26 \\
27 \\
28 \\
29 \\
30 \\
31\end{array}$ & $\begin{array}{l}.057 \\
.045 \\
.068 \\
.076 \\
.079 \\
.079\end{array}$ & $\begin{array}{l}.099 \\
.110 \\
.108 \\
.096 \\
.091 \\
\ldots\end{array}$ & $\begin{array}{l}.082 \\
.062 \\
.085 \\
.096 \\
.093 \\
.085\end{array}$ & $\begin{array}{l}.082 \\
.076 \\
.071 \\
.082 \\
.082 \\
.088\end{array}$ & $\begin{array}{l}.079 \\
.085 \\
.085 \\
\ldots . \\
\ldots \\
\ldots\end{array}$ & $\begin{array}{l}.054 \\
.057 \\
.059 \\
.056 \\
.028 \\
.059\end{array}$ & $\begin{array}{l}.054 \\
.056 \\
.040 \\
.042 \\
.045 \\
. .-\end{array}$ & $\begin{array}{l}.037 \\
.018 \\
.020 \\
.042 \\
.031 \\
.045\end{array}$ & $\begin{array}{l}.011 \\
.018 \\
.025 \\
.016 \\
.012 \\
\ldots \ldots\end{array}$ & $\begin{array}{l}.051 \\
.051 \\
.045 \\
.042 \\
.045 \\
.048\end{array}$ & $\begin{array}{l}.136 \\
.093 \\
.082 \\
.091 \\
.136 \\
.079\end{array}$ & $\begin{array}{l}.510 \\
.241 \\
.167 \\
.139 \\
.116 \\
\ldots . .\end{array}$ \\
\hline
\end{tabular}


09394500 LITTLE COLORADO RIVER AT HOODRUFF, AZ-Cont inued

DISCHARGE, CUBIC METERS PER SECOND, WATER YEAR OCTOBER 1990 TO SEPTEMBER 1991 DAILY MEAN VALUES

\begin{tabular}{|c|c|c|c|c|c|c|c|c|c|c|c|c|}
\hline DAY & OCT & NOV & DEC & JAN & FEB & MAR & APR & MAY & Ju & JUL & AUG & SEP \\
\hline $\begin{array}{l}1 \\
2 \\
3 \\
4 \\
5\end{array}$ & $\begin{array}{l}.105 \\
.170 \\
.906 \\
.396 \\
.235\end{array}$ & $\begin{array}{l}.088 \\
3.85 \\
9.80 \\
2.21 \\
1.22\end{array}$ & $\begin{array}{l}.062 \\
.065 \\
.062 \\
.059 \\
.059\end{array}$ & $\begin{array}{l}.991 \\
.510 \\
.187 \\
.368 \\
.906\end{array}$ & $\begin{array}{l}.099 \\
.099 \\
.102 \\
.116 \\
.133\end{array}$ & $\begin{array}{l}2.18 \\
21.9 \\
11.5 \\
6.68 \\
6.99\end{array}$ & $\begin{array}{c}3.28 \\
2.66 \\
1.87 \\
1.02 \\
.623\end{array}$ & $\begin{array}{l}.082 \\
.096 \\
.071 \\
.065 \\
.062\end{array}$ & $\begin{array}{l}.108 \\
.102 \\
.139 \\
.110 \\
.091\end{array}$ & $\begin{array}{l}.054 \\
.026 \\
.026 \\
.048 \\
.054\end{array}$ & $\begin{array}{l}.453 \\
1.59 \\
.311 \\
.229 \\
.204\end{array}$ & $\begin{array}{l}.510 \\
.311 \\
.232 \\
.201 \\
1.08\end{array}$ \\
\hline $\begin{array}{r}6 \\
7 \\
8 \\
9 \\
10\end{array}$ & $\begin{array}{l}.176 \\
.164 \\
.130 \\
.113 \\
.122\end{array}$ & $\begin{array}{l}.765 \\
.368 \\
.198 \\
.085 \\
.085\end{array}$ & $\begin{array}{l}.059 \\
.057 \\
.059 \\
.059 \\
.059\end{array}$ & $\begin{array}{c}18.0 \\
10.4 \\
2.58 \\
1.61 \\
1.08\end{array}$ & $\begin{array}{l}.116 \\
.110 \\
.108 \\
.105 \\
.102\end{array}$ & $\begin{array}{l}6.37 \\
3.65 \\
1.53 \\
1.10 \\
.680\end{array}$ & $\begin{array}{l}.453 \\
.272 \\
.156 \\
.085 \\
.059\end{array}$ & $\begin{array}{l}.059 \\
.071 \\
.065 \\
.178 \\
.235\end{array}$ & $\begin{array}{l}.079 \\
.076 \\
.068 \\
.091 \\
.082\end{array}$ & $\begin{array}{l}.056 \\
.368 \\
.057 \\
.065 \\
.074\end{array}$ & $\begin{array}{l}.142 \\
.091 \\
.108 \\
.110 \\
.105\end{array}$ & $\begin{array}{l}6.91 \\
3.28 \\
1.19 \\
.595 \\
.425\end{array}$ \\
\hline $\begin{array}{l}11 \\
12 \\
13 \\
14 \\
15\end{array}$ & $\begin{array}{l}.119 \\
.116 \\
.119 \\
.110 \\
.110\end{array}$ & $\begin{array}{l}.096 \\
.065 \\
.057 \\
.057 \\
.057\end{array}$ & $\begin{array}{l}.065 \\
.093 \\
.136 \\
.096 \\
.105\end{array}$ & $\begin{array}{l}.566 \\
.453 \\
.311 \\
.255 \\
.204\end{array}$ & $\begin{array}{l}.099 \\
.096 \\
.088 \\
.088 \\
.088\end{array}$ & $\begin{array}{l}.425 \\
.255 \\
.195 \\
.142 \\
.119\end{array}$ & $\begin{array}{l}.065 \\
.065 \\
.059 \\
.042 \\
.037\end{array}$ & $\begin{array}{l}.105 \\
.079 \\
.093 \\
.082 \\
.082\end{array}$ & $\begin{array}{l}.096 \\
.093 \\
.099 \\
.091 \\
.068\end{array}$ & $\begin{array}{l}.057 \\
.042 \\
.031 \\
.023 \\
.048\end{array}$ & $\begin{array}{l}.076 \\
.068 \\
.218 \\
.229 \\
.221\end{array}$ & $\begin{array}{l}.340 \\
.139 \\
.198 \\
.093 \\
.184\end{array}$ \\
\hline $\begin{array}{l}16 \\
17 \\
18 \\
19 \\
20\end{array}$ & $\begin{array}{l}.088 \\
.065 \\
.085 \\
.093 \\
.238\end{array}$ & $\begin{array}{l}.054 \\
.054 \\
.054 \\
.054 \\
.054\end{array}$ & $\begin{array}{l}.934 \\
5.32 \\
1.73 \\
.272 \\
.108\end{array}$ & $\begin{array}{l}.167 \\
.139 \\
.116 \\
.113 \\
.108\end{array}$ & $\begin{array}{l}.088 \\
.088 \\
.088 \\
.085 \\
.082\end{array}$ & $\begin{array}{l}.110 \\
.105 \\
.093 \\
.085 \\
.085\end{array}$ & $\begin{array}{l}.048 \\
.048 \\
.048 \\
.037 \\
.045\end{array}$ & $\begin{array}{l}.074 \\
.071 \\
.065 \\
.190 \\
.136\end{array}$ & $\begin{array}{l}.071 \\
.065 \\
.136 \\
.062 \\
.042\end{array}$ & $\begin{array}{l}.045 \\
.062 \\
.085 \\
.057 \\
.040\end{array}$ & $\begin{array}{l}.130 \\
.113 \\
.108 \\
.119 \\
.096\end{array}$ & $\begin{array}{l}.113 \\
.102 \\
.102 \\
.122 \\
.085\end{array}$ \\
\hline $\begin{array}{l}21 \\
22 \\
23 \\
24 \\
25\end{array}$ & $\begin{array}{l}.311 \\
.368 \\
.119 \\
.088 \\
.071\end{array}$ & $\begin{array}{l}.048 \\
.054 \\
.054 \\
.054 \\
.057\end{array}$ & $\begin{array}{l}.156 \\
.125 \\
.130 \\
.113 \\
.099\end{array}$ & $\begin{array}{l}.122 \\
.113 \\
.130 \\
.136 \\
.127\end{array}$ & $\begin{array}{l}.093 \\
.079 \\
.074 \\
.071 \\
.076\end{array}$ & $\begin{array}{l}.096 \\
.110 \\
.108 \\
.102 \\
.850\end{array}$ & $\begin{array}{l}.054 \\
.057 \\
.054 \\
.062 \\
.074\end{array}$ & $\begin{array}{l}.099 \\
.099 \\
.074 \\
.065 \\
.057\end{array}$ & $\begin{array}{l}.113 \\
.074 \\
.059 \\
.040 \\
.037\end{array}$ & $\begin{array}{l}.059 \\
.096 \\
.105 \\
.142 \\
.074\end{array}$ & $\begin{array}{l}.082 \\
.088 \\
.076 \\
1.95 \\
3.31\end{array}$ & $\begin{array}{c}.082 \\
.102 \\
2.01 \\
1.30 \\
.212\end{array}$ \\
\hline $\begin{array}{l}26 \\
27 \\
28 \\
29 \\
30 \\
31\end{array}$ & $\begin{array}{l}.054 \\
.045 \\
.068 \\
.057 \\
.048 \\
.074\end{array}$ & $\begin{array}{c}.062 \\
.068 \\
.065 \\
.062 \\
.059 \\
. . .\end{array}$ & $\begin{array}{l}.093 \\
.093 \\
.093 \\
7.45 \\
3.11 \\
1.76\end{array}$ & $\begin{array}{l}.119 \\
.127 \\
.130 \\
.113 \\
.113 \\
.113\end{array}$ & $\begin{array}{r}.076 \\
.076 \\
.082 \\
\ldots . \\
\ldots \\
\ldots\end{array}$ & $\begin{array}{l}3.60 \\
3.34 \\
2.35 \\
2.44 \\
4.16 \\
4.33\end{array}$ & $\begin{array}{r}.071 \\
.076 \\
.102 \\
.079 \\
.108 \\
\ldots . .\end{array}$ & $\begin{array}{l}.062 \\
.051 \\
.040 \\
.040 \\
.023 \\
.082\end{array}$ & $\begin{array}{l}.020 \\
.022 \\
.042 \\
.034 \\
.034 \\
\ldots . .\end{array}$ & $\begin{array}{l}.164 \\
.218 \\
.130 \\
.065 \\
.082 \\
.096\end{array}$ & $\begin{array}{r}1.39 \\
.623 \\
.878 \\
.453 \\
.244 \\
.595\end{array}$ & $\begin{array}{r}.096 \\
.065 \\
.076 \\
.122 \\
.181\end{array}$ \\
\hline
\end{tabular}


DAILY MEAN DISCHARGE-Cont inued

09397300 LITTLE COLORADO RIVER MEAR JOSEPH CITY, AZ

LOCATION. - Lat 34.54'04", Long 110.15'17", in NEXSEX Sec. 6, T.17 N., R.20 E.., Mavajo County, Hydrologic Unit 15020008, on right bank just upstream from diversion dam, $8.7 \mathrm{~km}$ west of Holbrook, $9.2 \mathrm{~km}$ southeast of Joseph City, and $13.7 \mathrm{~km}$ downstream from Puerco River.

DRAINAGE AREA.--32,075 $\mathrm{km}^{2}$, of which $899 \mathrm{~km}^{2}$ are noncontributing.

PERIOO OF RECORD.--October 1988 to September 1991.

OTHER DATA COLLCTION AT THIS SITE.-. July 1973 to current year (daily discharge only for those days on wich instantaneous discharge exceeds $\left.14.16 \mathrm{~m}^{3} / \mathrm{s}\right)$.

REMARKS. - - Only daily mean discharges above $1.42 \mathrm{~m}^{3} / \mathrm{s}$ are published.

DISCHARGe, CUBIC METERS PER SECOND, MATER YEAR OCTOBER 1988 TO SEPTEMBER 1989

DAILY MEAN VALUES

\begin{tabular}{|c|c|c|c|c|c|c|c|c|c|c|c|c|}
\hline DAY & OCT & MOV & DEC & JAN & FEB & MAR & APR & MY & JuW & JUL & AUG & SEP \\
\hline 1 & $\cdots$ & -.. & $\cdots$ & $\cdots$ & $\cdots$ & $\cdots$ & $\cdots$ & $\cdots$ & $\cdots$ & $\cdots$ & 10.6 & $\cdots$ \\
\hline 2 & $\cdots$ & -.. & $\cdots$ & $\cdots$ & $\cdots$ & $\cdots$ & $\cdots$ & $\ldots$ & $\cdots$ & $\cdots$ & 11.5 & $\cdots$ \\
\hline 3 & $\cdots$ & $\cdots$ & $\cdots$ & $\cdots$ & -.. & $\cdots$ & $\cdots$ & $\cdots$ & $\ldots$ & $\cdots$ & 8.67 & $\cdots$ \\
\hline 4 & $\cdots$ & -.. & $\cdots$ & $\cdots$ & 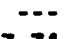 & $\cdots$ & $\cdots$ & $\cdots$ & $\cdots$ & $\cdots$ & $\cdots$ & 3.57 \\
\hline 5 & $\cdots$ & $\cdots$ & $\cdots$ & $\cdots$ & 3.31 & $\cdots$ & $\cdots$ & $\cdots$ & $\cdots$ & $\cdots$ & $\cdots$ & - \\
\hline 6 & $\ldots$ & $\cdots$ & $\cdots$ & $\cdots$ & $\cdots$ & $\cdots$ & $\cdots$ & $\cdots$ & $\cdots$ & $\cdots$ & $\cdots$ & $\cdots$ \\
\hline 7 & $\cdots$ & -.. & $\cdots$ & $\cdots$ & $\cdots$ & $\cdots$ & $\cdots$ & $\cdots$ & $\cdots$ & $\cdots$ & $\cdots$ & $\cdots$ \\
\hline 8 & $\cdots$ & $\cdots$ & $\cdots$ & $\cdots$ & $\cdots$ & $\cdots$ & $\cdots$ & $\cdots$ & $\cdots$ & $\cdots$ & $\cdots$ & $\cdots$ \\
\hline 9 & $\ldots$ & $\ldots$ & $\ldots$ & $\ldots$ & $\ldots$ & $\ldots$ & $\ldots$ & $\ldots$ & $\ldots$ & $\ldots$ & $\ldots$ & $\cdots$ \\
\hline 10 & & & & & & & & & & & $\cdots$ & 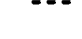 \\
\hline 11 & $\cdots$ & -.. & $\cdots$ & $\cdots$ & $\cdots$ & $\cdots$ & $\cdots$ & $\cdots$ & $\cdots$ & $\cdots$ & $\cdots$ & $\cdots$ \\
\hline 12 & $\cdots$ & $\cdots$ & $\cdots$ & $\cdots$ & -.. & $\cdots$ & $\cdots$ & $\cdots$ & $\cdots$ & $\cdots$ & 3.88 & \\
\hline 13 & ... & $\cdots$ & $\cdots$ & $\cdots$ & $\cdots$ & $\cdots$ & $\cdots$ & $\cdots$ & $\cdots$ & $\cdots$ & $\cdots$ & $\cdots$ \\
\hline 14 & $\cdots$ & -.. & $\cdots$ & $\cdots$ & -.. & $\cdots$ & $\cdots$ & $\cdots$ & $\cdots$ & $\cdots$ & $\cdots$ & $\ldots$ \\
\hline 15 & -.- & $\cdots$ & $\cdots$ & $\cdots$ & $\cdots$ & $\cdots$ & $\cdots$ & $\cdots$ & $\cdots$ & $\cdots$ & $\cdots$ & $\cdots$ \\
\hline 16 & $\cdots$ & -.. & - & ... & ... & -.. & -. & $\ldots$ & -.. & - & --. & -.. \\
\hline 17 & $\cdots$ & $\cdots$ & $\cdots$ & $\cdots$ & $\cdots$ & $\cdots$ & $\cdots$ & $\cdots$ & $\cdots$ & $\cdots$ & $\ldots$ & \\
\hline 18 & $\cdots$ & $\cdots$ & $\cdots$ & $\cdots$ & $\cdots$ & $\cdots$ & $\cdots$ & $\cdots$ & $\cdots$ & $\cdots$ & 67.7 & \\
\hline 19 & $\cdots$ & -.. & $\cdots$ & $\cdots$ & ... & $\cdots$ & $\cdots$ & $\cdots$ & $\cdots$ & -- & 31.4 & $\cdots$ \\
\hline 20 & $\cdots$ & $\cdots$ & $\cdots$ & $\cdots$ & $\cdots$ & $\cdots$ & $\cdots$ & $\cdots$ & $\cdots$ & $\cdots$ & 15.8 & $\cdots$ \\
\hline 29 & $\ldots$ & ... & -.. & -.. & ... & --. & -.. &.-- & -.. & $\ldots$ & 5.89 & $\ldots$ \\
\hline 22 & $\cdots$ & ... & $\cdots$ & $\cdots$ & -.. & ... & $\ldots$ & -.. & ... & $\ldots$ & 1.61 & \\
\hline 23 & $\cdots$ & -.. & $\cdots$ & $\cdots$ & $\cdots$ & -.. & $\cdots$ & $\cdots$ & $\cdots$ & 7.82 & $\cdots$ & $\cdots$ \\
\hline 24 & $\cdots$ & $\cdots$ & $\cdots$ & $\cdots$ & $\cdots$ & $\cdots$ & $\cdots$ & $\cdots$ & $\cdots$ & $\cdots$ & $\cdots$ & \\
\hline 25 & $\cdots$ & $\cdots$ & $\cdots$ & $\ldots$ & $\cdots$ & $\cdots$ & $\cdots$ & $\cdots$ & $\cdots$ & -- & $\cdots$ & $\cdots$ \\
\hline 26 & $\ldots$ & 1.42 & -- & ... & -.. & ... & ... & -.. & ... & 11.8 & -.. & - \\
\hline 27 & $\cdots$ & $\ldots$ & $-\cdot$ & $\cdots$ & $\cdots$ & 1.56 & $\cdots$ & $\cdots$ & $\cdots$ & 9.34 & $\cdots$ & \\
\hline 28 & $\ldots$ & $\ldots$ & $\cdots$ & $\cdots$ & $\cdots$ & $\cdots$ & $\cdots$ & $\cdots$ & $\ldots$ & 10.7 & $\cdots$ & \\
\hline 29 & $\cdots$ & $\cdots$ & $\cdots$ & -.. & $\cdots$ & $\cdots$ & $\cdots$ & $\cdots$ & $\cdots$ & 9.32 & -.. & $\because$ \\
\hline 30 & $\cdots$ & -.. & $\cdots$ & $\cdots$ & $\cdots$ & $\cdots$ & $\cdots$ & $-\cdot$ & -.. & 9.00 & $\cdots$ & - \\
\hline 31 & $\cdots$ & $\cdots$ & $\cdots$ & $\cdots$ & -.. & -.. & $\cdots$ & -.. & -.. & 4.76 & $\cdots$ & $\because$ \\
\hline
\end{tabular}




\section{SURFACE-WATER DATA-Continued \\ DAILY MEAN DISCHARGE-Cont inued}

09397300 LITTLE COLORADO RIVER NEAR JOSEPH CITY, AZ-Continued

DISCHARGE, CUBIC METERS PER SECOND, WATER YEAR OCTOBER 1989 TO SEPTEMBER 1990 DAILY MEAN VALUES

\begin{tabular}{|c|c|c|c|c|c|c|c|c|c|c|c|c|}
\hline DAY & OCT & nOV & DEC & JAK & FEB & MAR & APR & MYY & JUN & JUL & AUG & SEP \\
\hline 1 & $\ldots$ & $\ldots$ & $\cdots$ & $\ldots$ & $\cdots$ & $\ldots$ & $\ldots$ & $\ldots$ & $\ldots$ & -.. & $\ldots$ & 12.1 \\
\hline 2 & $\cdots$ & $\cdots$ & $\cdots$ & $\cdots$ & $\cdots$ & $\cdots$ & $\ldots$ & $\ldots$ & $\ldots$ & -.. & $\ldots$ & $\ldots$ \\
\hline 3 & $\ldots$ & $\cdots$ & $\cdots$ & $\cdots$ & $\cdots$ & $\cdots$ & $\cdots$ & $\ldots$ & $\ldots$ & $\ldots$ & $\ldots$ & $\ldots$ \\
\hline 4 & $\cdots$ & $\cdots$ & $\cdots$ & $\cdots$ & $\cdots$ & $\cdots$ & $\cdots$ & $\cdots$ & $\cdots$ & $\cdots$ & $\ldots$ & $\cdots$ \\
\hline 5 & $\cdots$ & $\cdots$ & $\cdots$ & $\cdots$ & $\cdots$ & $\cdots$ & $\cdots$ & $\cdots$ & $\cdots$ & $\cdots$ & $\cdots$ & 1.47 \\
\hline 6 & $\ldots$ & $\ldots$ & $\cdots$ & $\cdots$ & $\cdots$ & $\cdots$ & $\ldots$ & $\ldots$ & $\ldots$ & $\ldots$ & $\ldots$ & $\ldots$ \\
\hline 7 & $\cdots$ & $\cdots$ & $\cdots$ & $\ldots$ & $\cdots$ & $\cdots$ & $\cdots$ & $\cdots$ & $\ldots$ & $\cdots$ & $\ldots$ & 10.9 \\
\hline 8 & $\cdots$ & $\cdots$ & $\cdots$ & $\cdots$ & $\cdots$ & $\cdots$ & $\cdots$ & $\cdots$ & $\cdots$ & 27.8 & $\cdots$ & $\cdots$ \\
\hline 9 & $\ldots$ & $\cdots$ & -- & $\cdots$ & $\cdots$ & $\cdots$ & $\cdots$ & $\cdots$ & $\ldots$ & 9.88 & $\ldots$ & $\ldots$ \\
\hline 10 & $\cdots$ & $\cdots$ & $\cdots$ & $\cdots$ & $\cdots$ & $\cdots$ & $\cdots$ & $\cdots$ & $\cdots$ & 3.57 & $\cdots$ & $\cdots$ \\
\hline 11 & $\cdots$ & $\cdots$ & $\cdots$ & $\cdots$ & $\cdots$ & $\cdots$ & $\cdots$ & $\cdots$ & $\cdots$ & $\cdots$ & $\cdots$ & $\cdots$ \\
\hline 12 & $\cdots$ & $\cdots$ & $\cdots$ & $\cdots$ & $\cdots$ & $\cdots$ & $\cdots$ & $\cdots$ & $\cdots$ & 1.70 & $\cdots$ & $\cdots$ \\
\hline 13 & $\cdots$ & $\cdots$ & $\cdots$ & $\cdots$ & $\cdots$ & $\cdots$ & $\cdots$ & $\cdots$ & $\cdots$ & $\cdots$ & $\cdots$ & $\cdots$ \\
\hline 16 & $\cdots$ & $\cdots$ & $\cdots$ & $\cdots$ & $\cdots$ & $\cdots$ & $\cdots$ & $\cdots$ & $\cdots$ & 10.8 & 4.84 & $\cdots$ \\
\hline 15 & $\cdots$ & $\cdots$ & $\cdots$ & $\cdots$ & $\cdots$ & $\cdots$ & $\cdots$ & $\cdots$ & $\cdots$ & 20.6 & 25.0 & $\cdots$ \\
\hline 16 & $\cdots$ & $\cdots$ & $\cdots$ & $\cdots$ & $\ldots$ & $\cdots$ & $\cdots$ & $\cdots$ & $\cdots$ & 8.44 & 37.9 & $\cdots$ \\
\hline 17 & $\cdots$ & $\cdots$ & $\cdots$ & $\cdots$ & $\cdots$ & $\cdots$ & $\cdots$ & $\cdots$ & $\cdots$ & 1.90 & 34.5 & $\cdots$ \\
\hline 18 & $\cdots$ & $\cdots$ & $\cdots$ & $\cdots$ & $\cdots$ & $\cdots$ & $\cdots$ & $\cdots$ & $\cdots$ & 3.51 & 16.7 & $\cdots$ \\
\hline 19 & $\cdots$ & $\cdots$ & $\cdots$ & $\cdots$ & $\cdots$ & $\cdots$ & $\cdots$ & $\cdots$ & $\cdots$ & $\cdots$ & $\cdots$ & 15.7 \\
\hline 20 & $\cdots$ & $\cdots$ & $\cdots$ & $\cdots$ & $\cdots$ & $\cdots$ & $\cdots$ & $\cdots$ & $\cdots$ & $\cdots$ & $\cdots$ & 18.1 \\
\hline 21 & $\cdots$ & $\cdots$ & -- & $\cdots$ & $\cdots$ & $\cdots$ & $\cdots$ & $\cdots$ & $\cdots$ & $\cdots$ & $\cdots$ & 28.3 \\
\hline 22 & $\cdots$ & $\cdots$ & $\cdots$ & $\ldots$ & $\cdots$ & $\cdots$ & $\cdots$ & $\cdots$ & $\cdots$ & $\cdots$ & $\cdots$ & 20.5 \\
\hline 23 & $\cdots$ & $\cdots$ & $\cdots$ & $\cdots$ & $\cdots$ & $\cdots$ & $\cdots$ & $\cdots$ & $\cdots$ & $\cdots$ & $\cdots$ & 20.5 \\
\hline 24 & $\cdots$ & $\cdots$ & $\cdots$ & $\cdots$ & $\cdots$ & $\cdots$ & $\cdots$ & $\cdots$ & $\cdots$ & $\cdots$ & $\cdots$ & 16.7 \\
\hline 25 & $\cdots$ & $\cdots$ & $\cdots$ & $\cdots$ & $\cdots$ & $\cdots$ & $\cdots$ & $\cdots$ & $\cdots$ & $\cdots$ & $\cdots$ & 13.9 \\
\hline 26 & $\ldots$ & $\ldots$ & $\cdots$ & $\ldots$ & $\ldots$ & $\ldots$ & $\cdots$ & $\cdots$ & $\ldots$ & $\ldots$ & $\ldots$ & 8.50 \\
\hline 27 & $\cdots$ & $\cdots$ & $\cdots$ & $\cdots$ & $\cdots$ & $\cdots$ & $\cdots$ & $\cdots$ & $\cdots$ & $\cdots$ & $\cdots$ & $\cdots$ \\
\hline 28 & $\cdots$ & $\cdots$ & $\cdots$ & $\cdots$ & $\cdots$ & $\cdots$ & $\cdots$ & $\cdots$ & $\cdots$ & $\cdots$ & $\cdots$ & $\cdots$ \\
\hline 29 & $\cdots$ & $\cdots$ & $\cdots$ & $\cdots$ & $\cdots$ & $\cdots$ & $\cdots$ & $\cdots$ & $\cdots$ & $\cdots$ & $\cdots$ & $\cdots$ \\
\hline 30 & $\cdots$ & $\cdots$ & $\cdots$ & $\cdots$ & $\cdots$ & $\cdots$ & $\cdots$ & $\cdots$ & $\cdots$ & $\cdots$ & $\cdots$ & -- \\
\hline 31 & $\cdots$ & $\cdots$ & $\cdots$ & $\cdots$ & $\cdots$ & $\cdots$ & $\cdots$ & $\cdots$ & $\cdots$ & $\cdots$ & $\cdots$ & \\
\hline
\end{tabular}


SURFACE-HATER DATA-Continued

DAILY MEAN DISChARGE-Continued

09397300 LITTLE COLORADO RIVER MEAR JOSEPH CITY, AZ-Continued

DISCHARGE, CUBIC METERS PER SECOND, WATER YEAR OCTOBER 1990 TO SEPTEMBER 1991

DAILY MEAN VALUES

\begin{tabular}{|c|c|c|c|c|c|c|c|c|c|c|c|c|}
\hline DAY & OCT & NOV & DEC & JAN & FEB & MRR & APR & MaY & JUN & JUL & AUG & SEP \\
\hline $\begin{array}{l}1 \\
2 \\
3 \\
6 \\
5\end{array}$ & $\begin{array}{c}\ldots \\
\cdots \\
\cdots \\
\cdots\end{array}$ & $\begin{array}{c}\ldots \\
22.3 \\
5.66 \\
\ldots\end{array}$ & $\begin{array}{l}\ldots \\
\ldots \\
\cdots \\
\cdots\end{array}$ & $\begin{array}{c}\ldots \\
\ldots \\
10.6 \\
28.6\end{array}$ & $\begin{array}{l}\ldots \\
\ldots \\
\ldots \\
\ldots\end{array}$ & $\begin{array}{r}28.9 \\
36.5 \\
13.7 \\
9.32\end{array}$ & $\begin{array}{l}6.40 \\
5.44 \\
4.53 \\
3.09 \\
2.63\end{array}$ & $\begin{array}{c}\ldots \\
\ldots \\
\ldots \\
\ldots\end{array}$ & $\begin{array}{c}\cdots \\
\cdots \\
\cdots \\
\cdots\end{array}$ & $\begin{array}{c}\ldots . \\
\ldots \\
\cdots \\
\cdots\end{array}$ & $\begin{array}{c}1.76 \\
\ldots \ldots \\
3.14 \\
\ldots\end{array}$ & $\begin{array}{l}\ldots . \\
\ldots \\
\ldots \\
\ldots\end{array}$ \\
\hline $\begin{array}{r}6 \\
7 \\
8 \\
9 \\
10\end{array}$ & $\begin{array}{c}\cdots \\
\cdots \\
\cdots \\
\cdots\end{array}$ & $\begin{array}{c}\cdots \\
\cdots \\
\cdots \\
\cdots \\
\cdots\end{array}$ & $\begin{array}{l}\ldots . \\
\cdots \\
\cdots \\
\cdots \\
\cdots\end{array}$ & $\begin{array}{c}73.6 \\
30.6 \\
12.1 \\
7.76 \\
4.33\end{array}$ & $\begin{array}{l}\ldots \\
\ldots \\
\ldots \\
\ldots \\
\ldots\end{array}$ & $\begin{array}{c}7.76 \\
12.6 \\
9.32 \\
4.96 \\
1.61\end{array}$ & $\begin{array}{c}1.61 \\
\ldots \\
\ldots \\
\ldots \\
\ldots\end{array}$ & $\begin{array}{l}\cdots \\
\cdots \\
\cdots \\
\cdots \\
\cdots\end{array}$ & $\begin{array}{l}\ldots \\
\cdots \\
\cdots \\
\cdots \\
\cdots\end{array}$ & $\begin{array}{l}\ldots \\
\ldots \\
\ldots \\
\ldots \\
\ldots\end{array}$ & $\begin{array}{c}\ldots . \\
4.67 \\
\ldots\end{array}$ & $\begin{array}{c}12.2 \\
3.79 \\
2.41 \\
\ldots \\
\ldots\end{array}$ \\
\hline $\begin{array}{l}11 \\
12 \\
13 \\
16 \\
15\end{array}$ & $\begin{array}{c}\ldots \\
\ldots \\
\cdots \\
\cdots \\
\cdots\end{array}$ & $\begin{array}{c}\ldots \\
\cdots \\
\cdots \\
\cdots \\
\cdots\end{array}$ & $\begin{array}{c}\ldots \\
\cdots \\
\cdots \\
\cdots\end{array}$ & $\begin{array}{c}3.23 \\
1.90 \\
\ldots . \\
\ldots \\
\ldots\end{array}$ & $\begin{array}{l}2.61 \\
5.89 \\
6.91 \\
7.19 \\
6.91\end{array}$ & $\begin{array}{c}\ldots . \\
\cdots \\
\cdots \\
\cdots\end{array}$ & $\begin{array}{l}\ldots \\
\ldots \\
\ldots \\
\cdots \\
\cdots\end{array}$ & $\begin{array}{c}\ldots \\
\cdots \\
\cdots \\
\cdots \\
\cdots\end{array}$ & $\begin{array}{l}\ldots \\
\cdots \\
\cdots \\
\cdots \\
\cdots\end{array}$ & $\begin{array}{l}\ldots \\
\ldots \\
\ldots \\
\ldots \\
\ldots\end{array}$ & $\begin{array}{c}\ldots . \\
\cdots \\
\cdots \\
\cdots\end{array}$ & $\begin{array}{c}\ldots . \\
\cdots . \\
\cdots \\
\cdots\end{array}$ \\
\hline $\begin{array}{l}16 \\
17 \\
18 \\
19 \\
20\end{array}$ & $\begin{array}{c}\ldots . \\
\ldots . \\
\ldots \\
10.3\end{array}$ & $\begin{array}{c}\ldots \\
\cdots \\
\cdots \\
\cdots\end{array}$ & $\begin{array}{c}31.4 \\
15.8 \\
1.70 \\
\ldots \ldots \\
\ldots\end{array}$ & $\begin{array}{l}\ldots \\
\cdots \\
\cdots \\
\cdots\end{array}$ & $\begin{array}{l}6.16 \\
2.26 \\
5.30 \\
4.53 \\
1.47\end{array}$ & $\begin{array}{l}\cdots \\
\cdots \\
\cdots \\
\cdots \\
\cdots\end{array}$ & $\begin{array}{l}\ldots \\
\ldots \\
\ldots \\
\ldots\end{array}$ & $\begin{array}{l}\cdots \\
\cdots \\
\cdots \\
\cdots\end{array}$ & $\begin{array}{l}\cdots \\
\cdots \\
\cdots \\
\cdots \\
\cdots\end{array}$ & $\begin{array}{l}\ldots . \\
\ldots \\
\ldots \\
\ldots \\
\ldots\end{array}$ & $\begin{array}{c}\cdots . \\
\cdots \\
\cdots \\
\cdots\end{array}$ & $\begin{array}{l}\ldots \\
\ldots \\
\ldots \\
\ldots \\
\ldots\end{array}$ \\
\hline $\begin{array}{l}21 \\
22 \\
23 \\
24 \\
25\end{array}$ & $\begin{array}{c}20.7 \\
\ldots \\
\ldots . \\
\ldots \\
\ldots\end{array}$ & $\begin{array}{c}\cdots \\
\cdots \\
\cdots \\
\cdots\end{array}$ & $\begin{array}{l}\cdots \\
\cdots \\
\cdots \\
\cdots \\
\cdots\end{array}$ & $\begin{array}{l}\ldots \\
\cdots \\
\cdots \\
\cdots\end{array}$ & $\begin{array}{l}\ldots \\
\cdots \\
\cdots \\
\cdots\end{array}$ & $\begin{array}{c}\cdots \\
\cdots \\
\cdots \\
\cdots\end{array}$ & $\begin{array}{l}\ldots \\
\cdots \\
\cdots \\
\cdots\end{array}$ & $\begin{array}{l}\cdots \\
\cdots \\
\cdots \\
\cdots \\
\cdots\end{array}$ & $\begin{array}{l}\cdots \\
\cdots \\
\cdots \\
\cdots \\
\cdots\end{array}$ & $\begin{array}{l}\ldots \\
\ldots \\
\ldots \\
\ldots\end{array}$ & $\begin{array}{l}\cdots \\
\cdots \\
\cdots \\
\cdots\end{array}$ & $\begin{array}{l}\ldots \\
\ldots \\
\cdots \\
\cdots\end{array}$ \\
\hline $\begin{array}{l}26 \\
27 \\
28 \\
29 \\
30 \\
31\end{array}$ & $\begin{array}{l}\ldots . \\
\ldots \\
\ldots . \\
\ldots \\
\ldots\end{array}$ & $\begin{array}{c}\cdots \\
\cdots \\
\cdots \\
\cdots \\
\cdots \\
\cdots\end{array}$ & $\begin{array}{c}\ldots \\
\ldots \\
10.3 \\
10.1\end{array}$ & $\begin{array}{c}\ldots \\
\cdots \\
\cdots \\
\cdots \\
\cdots \\
\cdots\end{array}$ & $\begin{array}{c}\ldots \\
\cdots \\
\cdots \\
\cdots \\
\cdots\end{array}$ & $\begin{array}{l}3.26 \\
5.44 \\
4.33 \\
4.53 \\
4.70 \\
11.5\end{array}$ & $\begin{array}{c}\cdots \\
\cdots \\
\cdots \\
\cdots \\
\cdots\end{array}$ & $\begin{array}{c}\ldots \\
\cdots \\
\cdots . \\
\cdots \\
\ldots\end{array}$ & $\begin{array}{c}\ldots \\
\ldots . \\
\ldots . \\
\ldots . \\
\ldots .\end{array}$ & $\begin{array}{c}\cdots \\
\cdots \\
\cdots \\
\cdots \\
\cdots\end{array}$ & $\begin{array}{c}\ldots \\
8.33 \\
\ldots \\
\ldots\end{array}$ & $\begin{array}{c}\ldots . \\
\ldots . \\
\cdots \\
\cdots \\
\ldots\end{array}$ \\
\hline
\end{tabular}




\author{
SURFACE-UATER DATA-Continued \\ DAILY MEAN DISCHARGE-Continued \\ 09401000 LITTLE COLORADO RIVER AT GRAMD FALLS, AZ
}

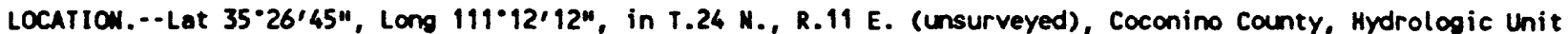
15020016, in Mavajo Indian Reservation, on left bank 305 indownstream from Grand Falls, $7.2 \mathrm{~km}$ upstream from Dimebito Wash, $48 \mathrm{~km}$ northeast of Flagstaff, and $154 \mathrm{~km}$ upstream from mouth.

DRAIMAGE AREA. $-54,566 \mathrm{~km}^{2}$, of which $953 \mathrm{~km}^{2}$ are noncontributing.

PERIOD OF RECORD.-- OCtober 1989 to September 1991.

OTHER DATA COLLECTION AT THIS SITE.--October 1925 to september 1951, October 1951 to september 1953 (peak discharges on(y), October 1953 to June 1960, October 1989 to current year.

DISCHARGE, CUBIC METERS PER SECOND, WATER YEAR OCTOBER 1989 TO SEPTEMBER 1990 DAILY MEAN VALUES

\begin{tabular}{|c|c|c|c|c|c|c|c|c|c|c|c|c|}
\hline DAY & OCT & NOV & DEC & JAN & FEB & MRR & APR & MAr & JUN & JUL & AUG & SEP \\
\hline $\begin{array}{l}1 \\
2 \\
3 \\
4 \\
5\end{array}$ & $\begin{array}{l}.000 \\
.000 \\
.000 \\
.000 \\
.000\end{array}$ & $\begin{array}{l}.000 \\
.000 \\
.000 \\
.000 \\
.000\end{array}$ & $\begin{array}{l}.000 \\
.000 \\
.000 \\
.000 \\
.000\end{array}$ & $\begin{array}{l}.000 \\
.000 \\
.000 \\
.000 \\
.000\end{array}$ & $\begin{array}{l}.000 \\
.000 \\
.000 \\
.000 \\
.000\end{array}$ & $\begin{array}{l}.000 \\
.000 \\
.000 \\
.000 \\
.000\end{array}$ & $\begin{array}{l}.000 \\
.000 \\
.000 \\
.000 \\
.000\end{array}$ & $\begin{array}{l}.000 \\
.000 \\
.000 \\
.000 \\
.000\end{array}$ & $\begin{array}{l}.000 \\
.000 \\
.000 \\
.000 \\
.000\end{array}$ & $\begin{array}{l}.000 \\
.000 \\
.000 \\
.000 \\
.000\end{array}$ & $\begin{array}{l}.000 \\
.000 \\
.000 \\
.000 \\
.000\end{array}$ & $\begin{array}{l}.142 \\
.127 \\
5.32 \\
8.69 \\
5.35\end{array}$ \\
\hline $\begin{array}{r}6 \\
7 \\
8 \\
9 \\
10\end{array}$ & $\begin{array}{l}.000 \\
.000 \\
.000 \\
.000 \\
.000\end{array}$ & $\begin{array}{l}.000 \\
.000 \\
.000 \\
.000 \\
.000\end{array}$ & $\begin{array}{l}.000 \\
.000 \\
.000 \\
.000 \\
.000\end{array}$ & $\begin{array}{l}.000 \\
.000 \\
.000 \\
.000 \\
.000\end{array}$ & $\begin{array}{l}.000 \\
.000 \\
.000 \\
.000 \\
.000\end{array}$ & $\begin{array}{l}.000 \\
.000 \\
.000 \\
.000 \\
.000\end{array}$ & $\begin{array}{l}.000 \\
.000 \\
.000 \\
.000 \\
2.18\end{array}$ & $\begin{array}{l}.000 \\
.000 \\
.000 \\
.000 \\
.000\end{array}$ & $\begin{array}{l}.000 \\
.000 \\
.000 \\
.000 \\
.000\end{array}$ & $\begin{array}{c}.000 \\
.000 \\
.000 \\
15.5 \\
8.01\end{array}$ & $\begin{array}{l}.000 \\
.000 \\
.000 \\
.000 \\
.000\end{array}$ & $\begin{array}{l}3.40 \\
3.16 \\
1.61 \\
3.94 \\
2.15\end{array}$ \\
\hline $\begin{array}{l}11 \\
12 \\
13 \\
14 \\
15\end{array}$ & $\begin{array}{l}.000 \\
.000 \\
.000 \\
.000 \\
.000\end{array}$ & $\begin{array}{l}.000 \\
.000 \\
.000 \\
.000 \\
.000\end{array}$ & $\begin{array}{l}.000 \\
.000 \\
.000 \\
.000 \\
.000\end{array}$ & $\begin{array}{l}.000 \\
.000 \\
.000 \\
.000 \\
.000\end{array}$ & $\begin{array}{l}.000 \\
.000 \\
.000 \\
.000 \\
.000\end{array}$ & $\begin{array}{l}.000 \\
.000 \\
.000 \\
.000 \\
.000\end{array}$ & $\begin{array}{l}2.58 \\
1.78 \\
1.16 \\
.821 \\
.453\end{array}$ & $\begin{array}{l}.000 \\
.000 \\
.000 \\
.000 \\
.000\end{array}$ & $\begin{array}{l}.000 \\
.000 \\
.000 \\
.000 \\
.000\end{array}$ & $\begin{array}{l}5.47 \\
2.44 \\
1.27 \\
2.21 \\
1.53\end{array}$ & $\begin{array}{l}.000 \\
.000 \\
.000 \\
.000 \\
.001\end{array}$ & $\begin{array}{l}.651 \\
.368 \\
.340 \\
.252 \\
.184\end{array}$ \\
\hline $\begin{array}{l}16 \\
17 \\
18 \\
19 \\
20\end{array}$ & $\begin{array}{l}.000 \\
.000 \\
.000 \\
.000 \\
.000\end{array}$ & $\begin{array}{l}.000 \\
.000 \\
.000 \\
.000 \\
.000\end{array}$ & $\begin{array}{l}.000 \\
.000 \\
.000 \\
.000 \\
.000\end{array}$ & $\begin{array}{l}.000 \\
.000 \\
.000 \\
.000 \\
.000\end{array}$ & $\begin{array}{l}.000 \\
.000 \\
.000 \\
.000 \\
.000\end{array}$ & $\begin{array}{l}.000 \\
.000 \\
.000 \\
.000 \\
.000\end{array}$ & $\begin{array}{l}.210 \\
.040 \\
.000 \\
.000 \\
.000\end{array}$ & $\begin{array}{l}.000 \\
.000 \\
.000 \\
.000 \\
.000\end{array}$ & $\begin{array}{l}.000 \\
.000 \\
.000 \\
.000 \\
.000\end{array}$ & $\begin{array}{c}7.45 \\
18.4 \\
4.28 \\
4.62 \\
2.89\end{array}$ & $\begin{array}{c}10.2 \\
41.1 \\
18.2 \\
13.5 \\
6.23\end{array}$ & $\begin{array}{l}.204 \\
.147 \\
.311 \\
1.33 \\
6.80\end{array}$ \\
\hline $\begin{array}{l}21 \\
22 \\
23 \\
24 \\
25\end{array}$ & $\begin{array}{l}.000 \\
.000 \\
.000 \\
.000 \\
.000\end{array}$ & $\begin{array}{l}.000 \\
.000 \\
.000 \\
.000 \\
.000\end{array}$ & $\begin{array}{l}.000 \\
.000 \\
.000 \\
.000 \\
.000\end{array}$ & $\begin{array}{l}.000 \\
.000 \\
.000 \\
.000 \\
.000\end{array}$ & $\begin{array}{l}.000 \\
.000 \\
.000 \\
.000 \\
.000\end{array}$ & $\begin{array}{l}.000 \\
.000 \\
.000 \\
.000 \\
.000\end{array}$ & $\begin{array}{l}.000 \\
.000 \\
.000 \\
.000 \\
.000\end{array}$ & $\begin{array}{l}.000 \\
.000 \\
.000 \\
.000 \\
.000\end{array}$ & $\begin{array}{l}.000 \\
.000 \\
.000 \\
.000 \\
.000\end{array}$ & $\begin{array}{l}2.04 \\
3.48 \\
1.30 \\
.623 \\
.340\end{array}$ & $\begin{array}{l}2.63 \\
1.05 \\
.510 \\
.311 \\
1.33\end{array}$ & $\begin{array}{c}3.65 \\
27.7 \\
25.2 \\
7.33 \\
5.86\end{array}$ \\
\hline $\begin{array}{l}26 \\
27 \\
28 \\
29 \\
30 \\
31\end{array}$ & $\begin{array}{l}.000 \\
.000 \\
.000 \\
.000 \\
.000 \\
.000\end{array}$ & $\begin{array}{l}.000 \\
.000 \\
.000 \\
.000 \\
.000 \\
\ldots .\end{array}$ & $\begin{array}{l}.000 \\
.000 \\
.000 \\
.000 \\
.000 \\
.000\end{array}$ & $\begin{array}{l}.000 \\
.000 \\
.000 \\
.000 \\
.000 \\
.000\end{array}$ & $\begin{array}{l}.000 \\
.000 \\
.000 \\
\ldots . \\
\ldots \\
\ldots\end{array}$ & $\begin{array}{l}.000 \\
.000 \\
.000 \\
.000 \\
.000 \\
.000\end{array}$ & $\begin{array}{l}.000 \\
.000 \\
.000 \\
.000 \\
.000 \\
\ldots .\end{array}$ & $\begin{array}{l}.000 \\
.000 \\
.000 \\
.000 \\
.000 \\
.000\end{array}$ & $\begin{array}{l}.000 \\
.000 \\
.000 \\
.000 \\
.000 \\
\ldots .\end{array}$ & $\begin{array}{l}.142 \\
.093 \\
.068 \\
.051 \\
.034 \\
.010\end{array}$ & $\begin{array}{l}.538 \\
.278 \\
.206 \\
.198 \\
.156 \\
.136\end{array}$ & $\begin{array}{r}4.47 \\
2.78 \\
1.27 \\
.850 \\
510\end{array}$ \\
\hline
\end{tabular}


SURFACE-WATER DATA-Continued

DAILY MEAN DISCHARGE-Cont inued

09401000 LITTLE COLORADO RIVER AT GRAND FALLS, AZ-Cont imued

DISCHARGE, CUBIC METERS PER SECOND, WATER YEAR OCTOBER 1990 TO SEPTEMBER 1991 DAILY MEAN VALUES

\begin{tabular}{|c|c|c|c|c|c|c|c|c|c|c|c|c|}
\hline DAY & OCT & NOV & DEC & JAN & FEB & MAR & APR & MAY & JUN & JUL & AUG & SEP \\
\hline $\begin{array}{l}1 \\
2 \\
3 \\
4 \\
5\end{array}$ & $\begin{array}{l}.368 \\
.311 \\
.269 \\
.187 \\
.110\end{array}$ & $\begin{array}{l}.057 \\
.031 \\
.027 \\
8.07 \\
5.89\end{array}$ & $\begin{array}{l}.000 \\
.000 \\
.000 \\
.000 \\
.000\end{array}$ & $\begin{array}{c}11.0 \\
9.32 \\
6.40 \\
4.81 \\
5.89\end{array}$ & $\begin{array}{l}.006 \\
.007 \\
.006 \\
.006 \\
.005\end{array}$ & $\begin{array}{l}3.17 \\
3.03 \\
36.5 \\
60.0 \\
36.5\end{array}$ & $\begin{array}{l}13.6 \\
18.5 \\
18.5 \\
26.5 \\
39.1\end{array}$ & $\begin{array}{l}6.65 \\
4.79 \\
4.30 \\
3.82 \\
3.82\end{array}$ & $\begin{array}{l}.000 \\
.000 \\
.000 \\
.000 \\
.000\end{array}$ & $\begin{array}{l}.000 \\
.000 \\
.000 \\
.000 \\
.000\end{array}$ & $\begin{array}{l}.023 \\
.014 \\
.000 \\
.000 \\
.000\end{array}$ & $\begin{array}{l}.062 \\
.170 \\
.193 \\
.283 \\
.201\end{array}$ \\
\hline $\begin{array}{r}6 \\
7 \\
8 \\
9 \\
10\end{array}$ & $\begin{array}{l}.093 \\
.074 \\
.023 \\
.003 \\
.000\end{array}$ & $\begin{array}{l}2.44 \\
1.56 \\
.538 \\
.283 \\
.159\end{array}$ & $\begin{array}{l}.000 \\
.000 \\
.000 \\
.000 \\
.000\end{array}$ & $\begin{array}{c}22.6 \\
76.7 \\
56.1 \\
16.6 \\
7.28\end{array}$ & $\begin{array}{l}.005 \\
.003 \\
.003 \\
.002 \\
.000\end{array}$ & $\begin{array}{l}25.7 \\
45.0 \\
54.1 \\
40.2 \\
22.9\end{array}$ & $\begin{array}{l}47.6 \\
55.2 \\
56.9 \\
61.4 \\
70.2\end{array}$ & $\begin{array}{l}3.34 \\
2.69 \\
2.44 \\
1.81 \\
1.67\end{array}$ & $\begin{array}{l}.000 \\
.000 \\
.000 \\
.000 \\
.000\end{array}$ & $\begin{array}{l}.000 \\
.000 \\
.000 \\
.000 \\
.000\end{array}$ & $\begin{array}{l}.028 \\
.000 \\
.000 \\
.000 \\
.000\end{array}$ & $\begin{array}{l}.176 \\
.110 \\
6.37 \\
4.96 \\
2.55\end{array}$ \\
\hline $\begin{array}{l}11 \\
12 \\
13 \\
14 \\
15\end{array}$ & $\begin{array}{l}.000 \\
.000 \\
.000 \\
.000 \\
.000\end{array}$ & $\begin{array}{l}.037 \\
.022 \\
.008 \\
.006 \\
.003\end{array}$ & $\begin{array}{l}.000 \\
.000 \\
.000 \\
.000 \\
.000\end{array}$ & $\begin{array}{l}5.47 \\
3.31 \\
2.92 \\
2.07 \\
1.42\end{array}$ & $\begin{array}{l}.000 \\
.000 \\
.000 \\
.000 \\
3.11\end{array}$ & $\begin{array}{c}14.5 \\
11.2 \\
10.3 \\
9.29 \\
7.11\end{array}$ & $\begin{array}{l}84.4 \\
85.2 \\
71.4 \\
40.5 \\
26.8\end{array}$ & $\begin{array}{l}1.39 \\
1.22 \\
1.10 \\
.991 \\
.821\end{array}$ & $\begin{array}{l}.000 \\
.000 \\
.000 \\
.000 \\
.000\end{array}$ & $\begin{array}{l}.000 \\
.000 \\
.000 \\
.000 \\
.000\end{array}$ & $\begin{array}{l}.000 \\
.765 \\
.425 \\
.340 \\
.278\end{array}$ & $\begin{array}{r}1.36 \\
.680 \\
.368 \\
.278 \\
.255\end{array}$ \\
\hline $\begin{array}{l}16 \\
17 \\
18 \\
19 \\
20\end{array}$ & $\begin{array}{l}.000 \\
.000 \\
.000 \\
.000 \\
.000\end{array}$ & $\begin{array}{l}.001 \\
.000 \\
.000 \\
.000 \\
.000\end{array}$ & $\begin{array}{l}.000 \\
16.9 \\
20.6 \\
5.35 \\
3.20\end{array}$ & $\begin{array}{l}.991 \\
.736 \\
.595 \\
.425 \\
.340\end{array}$ & $\begin{array}{l}9.15 \\
8.50 \\
6.99 \\
6.51 \\
8.33\end{array}$ & $\begin{array}{l}7.45 \\
6.80 \\
5.38 \\
4.50 \\
3.40\end{array}$ & $\begin{array}{l}19.2 \\
19.3 \\
27.7 \\
29.7 \\
27.0\end{array}$ & $\begin{array}{l}.680 \\
.453 \\
.283 \\
.159 \\
.059\end{array}$ & $\begin{array}{l}.000 \\
.000 \\
.000 \\
.000 \\
.000\end{array}$ & $\begin{array}{l}.000 \\
.000 \\
.000 \\
.000 \\
.000\end{array}$ & $\begin{array}{l}.198 \\
.159 \\
.102 \\
.068 \\
.034\end{array}$ & $\begin{array}{l}.142 \\
.028 \\
.000 \\
.000 \\
.000\end{array}$ \\
\hline $\begin{array}{l}21 \\
22 \\
23 \\
24 \\
25\end{array}$ & $\begin{array}{l}.000 \\
9.57 \\
3.96 \\
1.27 \\
.510\end{array}$ & $\begin{array}{l}.000 \\
.000 \\
.000 \\
.000 \\
.000\end{array}$ & $\begin{array}{l}.850 \\
.793 \\
.793 \\
.934 \\
.425\end{array}$ & $\begin{array}{l}.283 \\
.215 \\
.108 \\
.091 \\
.051\end{array}$ & $\begin{array}{l}5.61 \\
3.94 \\
2.92 \\
2.21 \\
1.70\end{array}$ & $\begin{array}{l}2.86 \\
3.23 \\
4.73 \\
5.15 \\
3.82\end{array}$ & $\begin{array}{l}25.0 \\
22.9 \\
22.8 \\
20.4 \\
17.4\end{array}$ & $\begin{array}{l}.010 \\
.001 \\
.000 \\
.000 \\
.000\end{array}$ & $\begin{array}{l}.000 \\
.000 \\
.000 \\
.000 \\
.000\end{array}$ & $\begin{array}{l}.000 \\
.000 \\
.000 \\
.000 \\
.000\end{array}$ & $\begin{array}{l}.014 \\
.001 \\
.000 \\
.000 \\
.000\end{array}$ & $\begin{array}{l}.000 \\
.000 \\
.000 \\
.000 \\
.000\end{array}$ \\
\hline $\begin{array}{l}26 \\
27 \\
28 \\
29 \\
30 \\
31\end{array}$ & $\begin{array}{l}.258 \\
.201 \\
.178 \\
.215 \\
.150 \\
.110\end{array}$ & $\begin{array}{l}.003 \\
.000 \\
.000 \\
.000 \\
.000 \\
\ldots .\end{array}$ & $\begin{array}{r}.108 \\
.051 \\
.068 \\
.093 \\
.396 \\
14.8\end{array}$ & $\begin{array}{l}.042 \\
.023 \\
.016 \\
.008 \\
.007 \\
.006\end{array}$ & $\begin{array}{r}1.27 \\
1.22 \\
3.11 \\
\ldots \\
\ldots\end{array}$ & $\begin{array}{c}3.23 \\
3.11 \\
9.12 \\
10.2 \\
7.11 \\
7.67\end{array}$ & $\begin{array}{r}14.8 \\
13.5 \\
13.3 \\
12.2 \\
7.67 \\
\ldots . .\end{array}$ & $\begin{array}{l}.000 \\
.000 \\
.000 \\
.000 \\
.000 \\
.000\end{array}$ & $\begin{array}{l}.000 \\
.000 \\
.000 \\
.000 \\
.000 \\
. . .\end{array}$ & $\begin{array}{l}.000 \\
.000 \\
.000 \\
.000 \\
.000 \\
.000\end{array}$ & $\begin{array}{l}.000 \\
.000 \\
.000 \\
.000 \\
.000 \\
.004\end{array}$ & $\begin{array}{l}.000 \\
.000 \\
.000 \\
.000 \\
.000 \\
\ldots . .\end{array}$ \\
\hline
\end{tabular}


SURFACE-WATER DATA-Continued

DAILY MEAN DISCHARGE-Cont inued

09402000 LITTLE COLORADO RIVER MEAR CAMERON, A2

LOCATION.-- Lat 35.55.35", Long 111.34'00", in NWK, Sec. 5, T.29 N.,R.8 E. (unsurveyed), Coconino County, Hydrologic Unit 15020016, in Navajo Indian Reservation, on left bank $4.8 \mathrm{~km}$ downstrean from Coconino dansite, $15.2 \mathrm{~km}$ downstream from Moenkopi Wash, $15.3 \mathrm{~km}$ northwest of Cameron, and $72 \mathrm{kM}$ upstream from mouth.

DRAINAGE AREA. $--68,529 \mathrm{~km}^{2}$, of which $953 \mathrm{~km}^{2}$ are noncontributing.

PERIOD OF RECORD.---October 1989 to September 1991.

OTHER DATA COLLECTION AT THIS SITE.--June 1947 to current year.

DISCHARGE, CUBIC METERS PER SECOND, WATER YEAR OCTOBER 1989 TO SEPTEMBER 1990 DAILY MEAN VALUES

\begin{tabular}{|c|c|c|c|c|c|c|c|c|c|c|c|c|}
\hline DAY & $\mathrm{OCT}$ & NOV & DEC & JAN & FEB & MAR & APR & MAY & JUN & JUL & NUG & SEP \\
\hline $\begin{array}{l}1 \\
2 \\
3 \\
4 \\
5\end{array}$ & $\begin{array}{l}.000 \\
.000 \\
.000 \\
.000 \\
.000\end{array}$ & $\begin{array}{l}.000 \\
.000 \\
.000 \\
.000 \\
.000\end{array}$ & $\begin{array}{l}.000 \\
.000 \\
.000 \\
.000 \\
.000\end{array}$ & $\begin{array}{l}.000 \\
.000 \\
.000 \\
.000 \\
.000\end{array}$ & $\begin{array}{l}.042 \\
.062 \\
.014 \\
.006 \\
.014\end{array}$ & $\begin{array}{l}.023 \\
.020 \\
.023 \\
.031 \\
.034\end{array}$ & $\begin{array}{l}.000 \\
.000 \\
.000 \\
.000 \\
.000\end{array}$ & $\begin{array}{l}.004 \\
.014 \\
.002 \\
.001 \\
.001\end{array}$ & $\begin{array}{l}.000 \\
.000 \\
.000 \\
.000 \\
.000\end{array}$ & $\begin{array}{l}.000 \\
.000 \\
.000 \\
.000 \\
.000\end{array}$ & $\begin{array}{l}.481 \\
3.34 \\
.255 \\
.017 \\
.003\end{array}$ & $\begin{array}{l}.091 \\
.076 \\
.059 \\
9.32 \\
8.58\end{array}$ \\
\hline $\begin{array}{r}6 \\
7 \\
8 \\
9 \\
10\end{array}$ & $\begin{array}{l}.538 \\
1.22 \\
.368 \\
.068 \\
.015\end{array}$ & $\begin{array}{l}.000 \\
.000 \\
.000 \\
.000 \\
.000\end{array}$ & $\begin{array}{l}.000 \\
.000 \\
.000 \\
.000 \\
.000\end{array}$ & $\begin{array}{l}.000 \\
.000 \\
.000 \\
.000 \\
.000\end{array}$ & $\begin{array}{l}.017 \\
.028 \\
.028 \\
.017 \\
.020\end{array}$ & $\begin{array}{l}.023 \\
.018 \\
.013 \\
.006 \\
.003\end{array}$ & $\begin{array}{l}.000 \\
.000 \\
.000 \\
.000 \\
.000\end{array}$ & $\begin{array}{l}.001 \\
.000 \\
.000 \\
.000 \\
.000\end{array}$ & $\begin{array}{l}.000 \\
.000 \\
.000 \\
.000 \\
.000\end{array}$ & $\begin{array}{c}.000 \\
.000 \\
11.0 \\
5.30 \\
9.77\end{array}$ & $\begin{array}{l}.000 \\
.000 \\
.000 \\
.000 \\
.000\end{array}$ & $\begin{array}{l}7.19 \\
5.66 \\
2.83 \\
1.70 \\
1.42\end{array}$ \\
\hline $\begin{array}{l}11 \\
12 \\
13 \\
14 \\
15\end{array}$ & $\begin{array}{l}.003 \\
.000 \\
.000 \\
.000 \\
.000\end{array}$ & $\begin{array}{l}.000 \\
.000 \\
.000 \\
.000 \\
.000\end{array}$ & $\begin{array}{l}.000 \\
.000 \\
.000 \\
.000 \\
.000\end{array}$ & $\begin{array}{l}.000 \\
.000 \\
.009 \\
.018 \\
.023\end{array}$ & $\begin{array}{l}.023 \\
.028 \\
.025 \\
.023 \\
.003\end{array}$ & $\begin{array}{l}.003 \\
.003 \\
.003 \\
.003 \\
.000\end{array}$ & $\begin{array}{l}.000 \\
.159 \\
.453 \\
.340 \\
.156\end{array}$ & $\begin{array}{l}.000 \\
.000 \\
.000 \\
.000 \\
.000\end{array}$ & $\begin{array}{l}.000 \\
.000 \\
.000 \\
.000 \\
.000\end{array}$ & $\begin{array}{l}4.96 \\
2.83 \\
1.70 \\
1.13 \\
6.74\end{array}$ & $\begin{array}{l}.000 \\
.000 \\
.000 \\
.000 \\
17.3\end{array}$ & $\begin{array}{l}.850 \\
.708 \\
.566 \\
.453 \\
.396\end{array}$ \\
\hline $\begin{array}{l}16 \\
17 \\
18 \\
19 \\
20\end{array}$ & $\begin{array}{l}.000 \\
.000 \\
.000 \\
.000 \\
.000\end{array}$ & $\begin{array}{l}.000 \\
.000 \\
.000 \\
.000 \\
.000\end{array}$ & $\begin{array}{l}.000 \\
.000 \\
.000 \\
.000 \\
.000\end{array}$ & $\begin{array}{l}.034 \\
.031 \\
.026 \\
.026 \\
.034\end{array}$ & $\begin{array}{l}.003 \\
.003 \\
.003 \\
.028 \\
.272\end{array}$ & $\begin{array}{l}.000 \\
.000 \\
.000 \\
.000 \\
.000\end{array}$ & $\begin{array}{l}.071 \\
.016 \\
.003 \\
.002 \\
.001\end{array}$ & $\begin{array}{l}.000 \\
.000 \\
.000 \\
.000 \\
.000\end{array}$ & $\begin{array}{l}.000 \\
.000 \\
.000 \\
.000 \\
.000\end{array}$ & $\begin{array}{c}4.22 \\
14.5 \\
11.1 \\
4.25 \\
4.25\end{array}$ & $\begin{array}{c}10.1 \\
30.0 \\
26.2 \\
17.8 \\
9.03\end{array}$ & $\begin{array}{l}.963 \\
2.46 \\
23.5 \\
47.0 \\
26.1\end{array}$ \\
\hline $\begin{array}{l}21 \\
22 \\
23 \\
24 \\
25\end{array}$ & $\begin{array}{l}.000 \\
.000 \\
.000 \\
.000 \\
.000\end{array}$ & $\begin{array}{l}.000 \\
.000 \\
.000 \\
.000 \\
.000\end{array}$ & $\begin{array}{l}.000 \\
.000 \\
.000 \\
.000 \\
.000\end{array}$ & $\begin{array}{l}.031 \\
.037 \\
.003 \\
.006 \\
.003\end{array}$ & $\begin{array}{l}2.04 \\
2.55 \\
1.25 \\
.566 \\
.170\end{array}$ & $\begin{array}{l}.000 \\
.000 \\
.000 \\
.000 \\
.000\end{array}$ & $\begin{array}{l}.001 \\
.001 \\
.000 \\
.108 \\
.396\end{array}$ & $\begin{array}{l}.000 \\
.000 \\
.000 \\
.000 \\
.000\end{array}$ & $\begin{array}{l}.000 \\
.000 \\
.000 \\
.000 \\
.000\end{array}$ & $\begin{array}{c}2.27 \\
1.42 \\
17.0 \\
5.72 \\
.651\end{array}$ & $\begin{array}{l}4.47 \\
2.01 \\
1.02 \\
.481 \\
.210\end{array}$ & $\begin{array}{c}31.4 \\
20.1 \\
32.0 \\
34.3 \\
2.24\end{array}$ \\
\hline $\begin{array}{l}26 \\
27 \\
28 \\
29 \\
30 \\
31\end{array}$ & $\begin{array}{l}.000 \\
.000 \\
.000 \\
.000 \\
.000 \\
.000\end{array}$ & $\begin{array}{l}.000 \\
.000 \\
.000 \\
.000 \\
.000 \\
. . .\end{array}$ & $\begin{array}{l}.000 \\
.000 \\
.000 \\
.000 \\
.000 \\
.000\end{array}$ & $\begin{array}{l}.003 \\
.003 \\
.003 \\
.003 \\
.003 \\
.008\end{array}$ & $\begin{array}{l}.057 \\
.037 \\
.026 \\
\ldots \ldots \\
\ldots . \\
\ldots .\end{array}$ & $\begin{array}{l}.000 \\
.000 \\
.000 \\
.000 \\
.000 \\
.000\end{array}$ & $\begin{array}{l}.133 \\
.059 \\
.022 \\
.006 \\
.003 \\
. . .\end{array}$ & $\begin{array}{l}.000 \\
.000 \\
.000 \\
.000 \\
.000 \\
.000\end{array}$ & $\begin{array}{l}.000 \\
.000 \\
.000 \\
.000 \\
.000 \\
. . .\end{array}$ & $\begin{array}{l}.258 \\
.093 \\
.031 \\
.006 \\
.002 \\
.002\end{array}$ & $\begin{array}{l}.595 \\
.595 \\
.283 \\
.184 \\
.144 \\
.113\end{array}$ & $\begin{array}{l}3.91 \\
2.86 \\
1.78 \\
1.08 \\
.623 \\
\ldots .-\end{array}$ \\
\hline
\end{tabular}


09402000 LITTLE COLORADO RIVER MEAR CAMERON, AZ-Continued

DISCHARGe, CUBIC METers PER SECOND, WATER yeAR OCTOBER 1990 TO SEPTEMBER 1991 DAILY MEAN VALUES

\begin{tabular}{|c|c|c|c|c|c|c|c|c|c|c|c|c|}
\hline DAY & OCT & NOV & DEC & JAN & FEB & MAR & APR & MAY & JUN & JUL & AUG & SEP \\
\hline $\begin{array}{l}1 \\
2 \\
3 \\
4 \\
5\end{array}$ & $\begin{array}{l}.396 \\
1.50 \\
4.30 \\
2.52 \\
.736\end{array}$ & $\begin{array}{l}.093 \\
.062 \\
.037 \\
.022 \\
10.3\end{array}$ & $\begin{array}{l}.009 \\
.008 \\
.007 \\
.006 \\
.002\end{array}$ & $\begin{array}{c}5.58 \\
6.82 \\
10.1 \\
11.8 \\
11.7\end{array}$ & $\begin{array}{l}.028 \\
.025 \\
.023 \\
.020 \\
.283\end{array}$ & $\begin{array}{l}1.90 \\
2.80 \\
8.52 \\
46.4 \\
42.5\end{array}$ & $\begin{array}{l}7.25 \\
16.4 \\
19.3 \\
21.2 \\
28.9\end{array}$ & $\begin{array}{l}7.53 \\
6.17 \\
4.56 \\
4.02 \\
3.77\end{array}$ & $\begin{array}{l}.127 \\
.031 \\
.000 \\
.000 \\
.000\end{array}$ & $\begin{array}{l}.000 \\
.000 \\
.000 \\
.000 \\
.000\end{array}$ & $\begin{array}{l}.000 \\
.340 \\
.235 \\
.116 \\
.062\end{array}$ & $\begin{array}{c}.071 \\
12.0 \\
8.10 \\
2.61 \\
.651\end{array}$ \\
\hline $\begin{array}{r}6 \\
7 \\
8 \\
9 \\
10\end{array}$ & $\begin{array}{l}.368 \\
.127 \\
.040 \\
.015 \\
.009\end{array}$ & $\begin{array}{l}4.25 \\
2.07 \\
1.50 \\
1.05 \\
.651\end{array}$ & $\begin{array}{l}.001 \\
.000 \\
.000 \\
.000 \\
.000\end{array}$ & $\begin{array}{l}9.51 \\
30.6 \\
59.7 \\
27.3 \\
11.9\end{array}$ & $\begin{array}{l}.057 \\
.048 \\
.040 \\
.040 \\
.040\end{array}$ & $\begin{array}{l}27.2 \\
30.3 \\
42.2 \\
43.0 \\
29.2\end{array}$ & $\begin{array}{l}36.8 \\
43.3 \\
47.0 \\
49.0 \\
51.3\end{array}$ & $\begin{array}{l}3.91 \\
3.62 \\
3.11 \\
2.61 \\
2.04\end{array}$ & $\begin{array}{l}.000 \\
.000 \\
.000 \\
.000 \\
.000\end{array}$ & $\begin{array}{l}.000 \\
.000 \\
.000 \\
.000 \\
.000\end{array}$ & $\begin{array}{l}.368 \\
.906 \\
.963 \\
.481 \\
.340\end{array}$ & $\begin{array}{c}8.07 \\
5.86 \\
7.08 \\
10.2 \\
6.97\end{array}$ \\
\hline $\begin{array}{l}11 \\
12 \\
13 \\
14 \\
15\end{array}$ & $\begin{array}{l}.008 \\
.007 \\
.007 \\
.004 \\
.001\end{array}$ & $\begin{array}{l}.481 \\
.340 \\
.255 \\
.195 \\
.142\end{array}$ & $\begin{array}{l}.000 \\
.000 \\
.000 \\
.000 \\
.000\end{array}$ & $\begin{array}{l}4.87 \\
2.61 \\
1.53 \\
1.56 \\
1.36\end{array}$ & $\begin{array}{l}.037 \\
.037 \\
.031 \\
.025 \\
.026\end{array}$ & $\begin{array}{c}18.0 \\
12.6 \\
10.2 \\
9.29 \\
8.18\end{array}$ & $\begin{array}{l}57.8 \\
60.6 \\
56.6 \\
45.0 \\
30.3\end{array}$ & $\begin{array}{l}1.56 \\
1.25 \\
1.02 \\
.850 \\
.651\end{array}$ & $\begin{array}{l}.000 \\
.000 \\
.000 \\
.000 \\
.000\end{array}$ & $\begin{array}{l}.000 \\
.000 \\
.000 \\
.000 \\
.000\end{array}$ & $\begin{array}{l}.261 \\
.227 \\
.510 \\
.368 \\
.283\end{array}$ & $\begin{array}{l}4.25 \\
2.83 \\
1.42 \\
.708 \\
.425\end{array}$ \\
\hline $\begin{array}{l}16 \\
17 \\
18 \\
19 \\
20\end{array}$ & $\begin{array}{l}.000 \\
.000 \\
.000 \\
.000 \\
.000\end{array}$ & $\begin{array}{l}.102 \\
.068 \\
.042 \\
.031 \\
.025\end{array}$ & $\begin{array}{c}.021 \\
.022 \\
19.8 \\
9.00 \\
3.99\end{array}$ & $\begin{array}{l}1.36 \\
1.08 \\
.963 \\
.906 \\
.765\end{array}$ & $\begin{array}{l}.027 \\
7.28 \\
6.77 \\
4.93 \\
6.37\end{array}$ & $\begin{array}{l}6.94 \\
6.48 \\
6.51 \\
5.95 \\
5.38\end{array}$ & $\begin{array}{l}22.8 \\
17.7 \\
21.8 \\
28.6 \\
28.6\end{array}$ & $\begin{array}{l}.453 \\
.368 \\
.283 \\
.142 \\
.014\end{array}$ & $\begin{array}{l}.000 \\
.000 \\
.000 \\
.000 \\
.000\end{array}$ & $\begin{array}{l}.000 \\
.000 \\
.000 \\
.000 \\
.000\end{array}$ & $\begin{array}{l}.241 \\
.130 \\
.074 \\
.042 \\
.014\end{array}$ & $\begin{array}{l}.283 \\
.057 \\
.028 \\
.014 \\
.000\end{array}$ \\
\hline $\begin{array}{l}21 \\
22 \\
23 \\
24 \\
25\end{array}$ & $\begin{array}{l}.000 \\
.000 \\
5.04 \\
4.73 \\
1.84\end{array}$ & $\begin{array}{l}.022 \\
.022 \\
.024 \\
.024 \\
.024\end{array}$ & $\begin{array}{l}2.78 \\
1.90 \\
1.25 \\
.906 \\
.708\end{array}$ & $\begin{array}{l}.623 \\
.453 \\
.368 \\
.311 \\
.224\end{array}$ & $\begin{array}{l}6.37 \\
4.19 \\
3.09 \\
2.72 \\
2.38\end{array}$ & $\begin{array}{l}4.25 \\
2.83 \\
3.96 \\
5.38 \\
5.66\end{array}$ & $\begin{array}{l}25.8 \\
24.0 \\
23.0 \\
22.8 \\
19.8\end{array}$ & $\begin{array}{l}.000 \\
.000 \\
.000 \\
.000 \\
.000\end{array}$ & $\begin{array}{l}.000 \\
.000 \\
.000 \\
.000 \\
.000\end{array}$ & $\begin{array}{l}.000 \\
.000 \\
.000 \\
.000 \\
.008\end{array}$ & $\begin{array}{l}.003 \\
.000 \\
.000 \\
.000 \\
.000\end{array}$ & $\begin{array}{l}.000 \\
.000 \\
.000 \\
.000 \\
.000\end{array}$ \\
\hline $\begin{array}{l}26 \\
27 \\
28 \\
29 \\
30 \\
31\end{array}$ & $\begin{array}{l}1.10 \\
.708 \\
.481 \\
.311 \\
.198 \\
.133\end{array}$ & $\begin{array}{l}.018 \\
.021 \\
.019 \\
.017 \\
.013 \\
\ldots . .\end{array}$ & $\begin{array}{l}.566 \\
.425 \\
.340 \\
.283 \\
.181 \\
.102\end{array}$ & $\begin{array}{l}.113 \\
.085 \\
.057 \\
.045 \\
.037 \\
.034\end{array}$ & $\begin{array}{c}2.07 \\
1.64 \\
1.27 \\
\ldots \\
\ldots \\
\ldots\end{array}$ & $\begin{array}{c}5.10 \\
4.53 \\
3.96 \\
11.6 \\
9.09 \\
7.28\end{array}$ & $\begin{array}{c}16.7 \\
13.8 \\
13.3 \\
12.5 \\
9.66 \\
\ldots . .\end{array}$ & $\begin{array}{l}.000 \\
.000 \\
.000 \\
.000 \\
.000 \\
.000\end{array}$ & $\begin{array}{l}.000 \\
.000 \\
.000 \\
.000 \\
.000 \\
\ldots . .\end{array}$ & $\begin{array}{l}.027 \\
.009 \\
.004 \\
.000 \\
.000 \\
.000\end{array}$ & $\begin{array}{l}.000 \\
2.29 \\
7.22 \\
1.02 \\
.215 \\
.113\end{array}$ & $\begin{array}{l}.000 \\
.000 \\
.000 \\
.000 \\
.000 \\
\ldots .\end{array}$ \\
\hline
\end{tabular}


SURFACE-MATER DATA-Continued

DAILY MEAN SUSPENDED-SEDIMENT CONCENTRATION

09395350 PUERCO RIVER MEAR CHURCH ROCK, MM

REMARKS.--Sediment concentration for days when the daily mean discharge was greater than $.283 \mathrm{~m}^{3} / \mathrm{s}$ are published.

SEDIMENT, SUSPENDED CONCENTRATION (MILLIGRAMS PER LITER), MAY 1989 TO SEPTEMBER 1989 DAILY MEAN VALUES

\begin{tabular}{|c|c|c|c|c|c|c|c|c|c|c|c|c|}
\hline DAY & OCT & NOV & DEC & JAN & FEB & $M R$ & $A P R$ & MAY & JUN & JUL & AUG & SEP \\
\hline 1 & $\cdots$ & $\cdots$ & $\cdots$ & $\cdots$ & $\cdots$ & $\cdots$ & $\cdots$ & $\cdots$ & $\cdots$ & $\cdots$ & 15100 & $\cdots$ \\
\hline 2 & $\cdots$ & $\cdots$ & $\cdots$ & $\cdots$ & $\cdots$ & $\cdots$ & $\cdots$ & $\cdots$ & $\cdots$ & $\cdots$ & 46600 & $\cdots$ \\
\hline 3 & $\cdots$ & $\cdots$ & $\cdots$ & $\ldots$ & $\cdots$ & $\cdots$ & $\cdots$ & $\cdots$ & $\cdots$ & $\cdots$ & $\cdots$ & $\cdots$ \\
\hline 4 & $\cdots$ & $\cdots$ & $\cdots$ & $\cdots$ & $\cdots$ & $\cdots$ & $\cdots$ & $\cdots$ & $\cdots$ & $\cdots$ & $\cdots$ & $\ddot{*}$ \\
\hline 5 & $\cdots$ & $\cdots$ & $\cdots$ & $\cdots$ & $\cdots$ & $\cdots$ & $\cdots$ & $\cdots$ & $\cdots$ & $\cdots$ & $\cdots$ & 31300 \\
\hline 6 & $\cdots$ & $\cdots$ & $\cdots$ & $\cdots$ & $\cdots$ & $\cdots$ & $\cdots$ & $\cdots$ & $\cdots$ & $\cdots$ & $\cdots$ & 38200 \\
\hline 7 & $\cdots$ & $\cdots$ & $\cdots$ & $\ldots$ & $\cdots$ & $\cdots$ & $\cdots$ & $\cdots$ & $\cdots$ & $\cdots$ & $\cdots$ & $\cdots$ \\
\hline 8 & $\cdots$ & $\cdots$ & $\cdots$ & $\cdots$ & $\cdots$ & $\cdots$ & $\cdots$ & $\cdots$ & $\cdots$ & $\cdots$ & $\cdots$ & $\cdots$ \\
\hline 9 & $\cdots$ & $\cdots$ & $\cdots$ & $\cdots$ & $\cdots$ & $\cdots$ & $\cdots$ & $\cdots$ & $\cdots$ & $\cdots$ & $\cdots$ & $\cdots$ \\
\hline 10 & $\cdots$ & $\cdots$ & $\cdots$ & $\cdots$ & $\cdots$ & $\cdots$ & $\cdots$ & $\cdots$ & $\cdots$ & $\cdots$ & $\cdots$ & $\cdots$ \\
\hline 11 & $\cdots$ & $\cdots$ & $\cdots$ & $\cdots$ & $\cdots$ & $\cdots$ & $\cdots$ & $\cdots$ & $\cdots$ & $\cdots$ & $\cdots$ & $\cdots$ \\
\hline 12 & $\cdots$ & $\cdots$ & $\cdots$ & $\cdots$ & $\cdots$ & $\cdots$ & $\cdots$ & $\cdots$ & $\cdots$ & $\cdots$ & $\cdots$ & $\cdots$ \\
\hline 13 & $\cdots$ & $\cdots$ & $\cdots$ & $\ldots$ & $\cdots$ & $\cdots$ & $\cdots$ & $\cdots$ & $\cdots$ & $\cdots$ & $\cdots$ & $\cdots$ \\
\hline 14 & $\cdots$ & $\cdots$ & $\cdots$ & $\cdots$ & $\cdots$ & $\cdots$ & $\cdots$ & $\cdots$ & $\cdots$ & $\cdots$ & $\cdots$ & $\cdots$ \\
\hline 15 & $\cdots$ & $\cdots$ & $\cdots$ & $\cdots$ & $\cdots$ & $\cdots$ & $\cdots$ & $\cdots$ & $\cdots$ & $\cdots$ & $\cdots$ & $\cdots$ \\
\hline 16 & $\cdots$ & $\cdots$ & $\cdots$ & $\cdots$ & $\cdots$ & $\cdots$ & $\cdots$ & $\cdots$ & $\cdots$ & $\cdots$ & $\cdots$ & $\cdots$ \\
\hline 17 & $\cdots$ & $\cdots$ & $\cdots$ & $\ldots$ & $\cdots$ & $\cdots$ & $\cdots$ & $\cdots$ & $\cdots$ & $\cdots$ & $\cdots$ & $\cdots$ \\
\hline 18 & $\cdots$ & $\cdots$ & $\cdots$ & $\cdots$, & $\cdots$ & $\cdots$ & $\cdots$ & $\cdots$ & $\cdots$ & $\cdots$ & $\cdots$ & $\cdots$ \\
\hline 19 & $\cdots$ & $\cdots$ & $\cdots$ & $\cdots$ & $\cdots$ & $\cdots$ & $\cdots$ & $\cdots$ & $\cdots$ & $\cdots$ & $\cdots$ & $\cdots$ \\
\hline 20 & $\cdots$ & $\cdots$ & $\cdots$ & $\cdots$ & $\cdots$ & $\cdots$ & $\cdots$ & $\cdots$ & $\cdots$ & $\cdots$ & $\cdots$ & $\cdots$ \\
\hline 21 & $\cdots$ & $\cdots$ & $\cdots$ & $\cdots$ & $\cdots$ & $\cdots$ & $\cdots$ & $\cdots$ & $\cdots$ & $\cdots$ & $\cdots$ & $\cdots$ \\
\hline 22 & $\cdots$ & $\cdots$ & $\cdots$ & $\cdots$ & $\cdots$ & $\cdots$ & $\cdots$ & $\cdots$ & $\cdots$ & $\cdots$ & $\cdots$ & $\cdots$ \\
\hline 23 & $\cdots$ & $\cdots$ & $\cdots$ & $\cdots$ & $\cdots$ & $\cdots$ & $\cdots$ & $\cdots$ & $\cdots$ & $\cdots$ & $\cdots$ & $\cdots$ \\
\hline 24 & $\cdots$ & $\cdots$ & $\cdots$ & $\cdots$ & $\cdots$ & $\cdots$ & $\cdots$ & $\cdots$ & $\cdots$ & 60700 & $\cdots$ & $\cdots$ \\
\hline 25 & $\cdots$ & $\cdots$ & $\cdots$ & $\cdots$ & $\cdots$ & $\cdots$ & $\cdots$ & $\cdots$ & $\cdots$ & 62100 & $\cdots$ & $\cdots$ \\
\hline 26 & $\cdots$ & $\cdots$ & $\cdots$ & $\cdots$ & $\cdots$ & $\cdots$ & $\cdots$ & $\cdots$ & $\cdots$ & 120000 & $\cdots$ & $\cdots$ \\
\hline 27 & $\cdots$ & $\cdots$ & $\cdots$ & $\cdots$ & $\cdots$ & $\cdots$ & $\cdots$ & $\cdots$ & $\cdots$ & 103000 & $\cdots$ & $\cdots$ \\
\hline 28 & $\cdots$ & $\cdots$ & $\cdots$ & $\ldots$ & $\cdots$ & $\cdots$ & $\cdots$ & $\cdots$ & $\cdots$ & 126000 & $\cdots$ & $\cdots$ \\
\hline 29 & $\cdots$ & $\cdots$ & $\cdots$ & $\cdots$ & $\cdots$ & $\cdots$ & $\cdots$ & $\cdots$ & $\cdots$ & 83200 & $\cdots$ & $\cdots$ \\
\hline 30 & $\cdots$ & $\cdots$ & $\cdots$ & $\cdots$ & $\cdots$ & $\cdots$ & $\cdots$ & $\cdots$ & $\cdots$ & $\cdots$ & $\cdots$ & $\cdots$ \\
\hline 31 & $\cdots$ & $\cdots$ & $\ldots$ & $\cdots$ & $\cdots$ & $\cdots$ & $\cdots$ & $\begin{array}{l}- \\
-\end{array}$ & 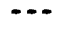 & $\cdots$ & $\cdots$ & $\cdots$ \\
\hline
\end{tabular}




\author{
SURFACE-WATER DATA-Cont inued \\ DAILY MEAN SUSPENDED-SEDIMENT CONCENTRATION-Continued \\ 09395350 PUERCO RIVER NEAR CHURCH ROCK, NM-Continued
}

SEDIMENT, SUSPENDED CONCENTRATION (MILLGRAMS PER LITER), WATER YEAR OCTOBER 1989 TO SEPTEMBER 1990 DAILY MEAN VALLUES

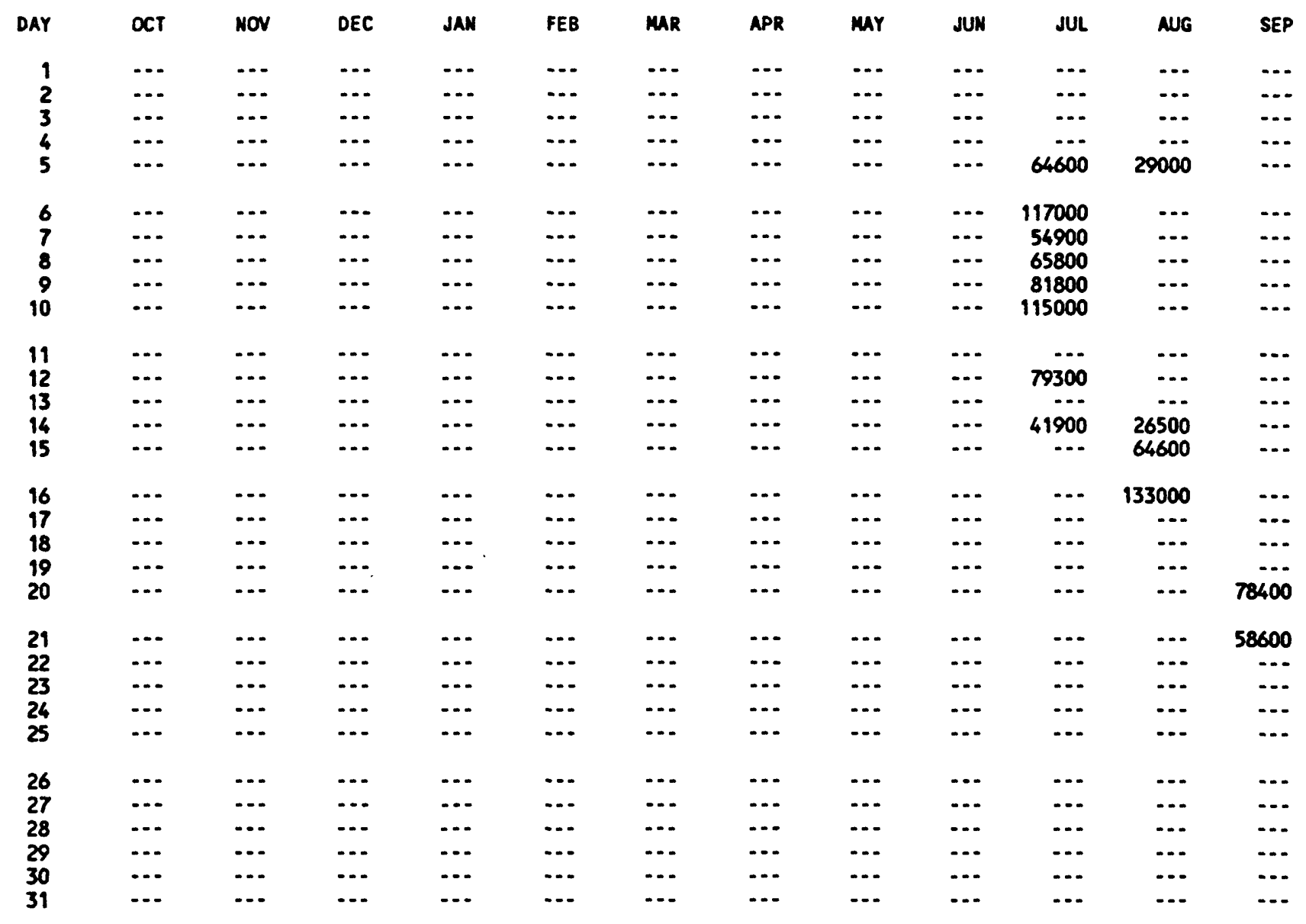


SURFACE-MATER DATA-Cont inued

DAILY MEAN SUSPENDED-SEDIMENT CONCENTRATION-Cont inUEd

09395350 PUERCO RIVER NEAR CHURCH ROCK, NH-Continued

SUSPENOED CONCENTRATION (MILLIGRAMS PER LITER), MATER YEAR OCTOBER 1990 TO SEPTEMBER 1991 DAILY MEAN VALUES

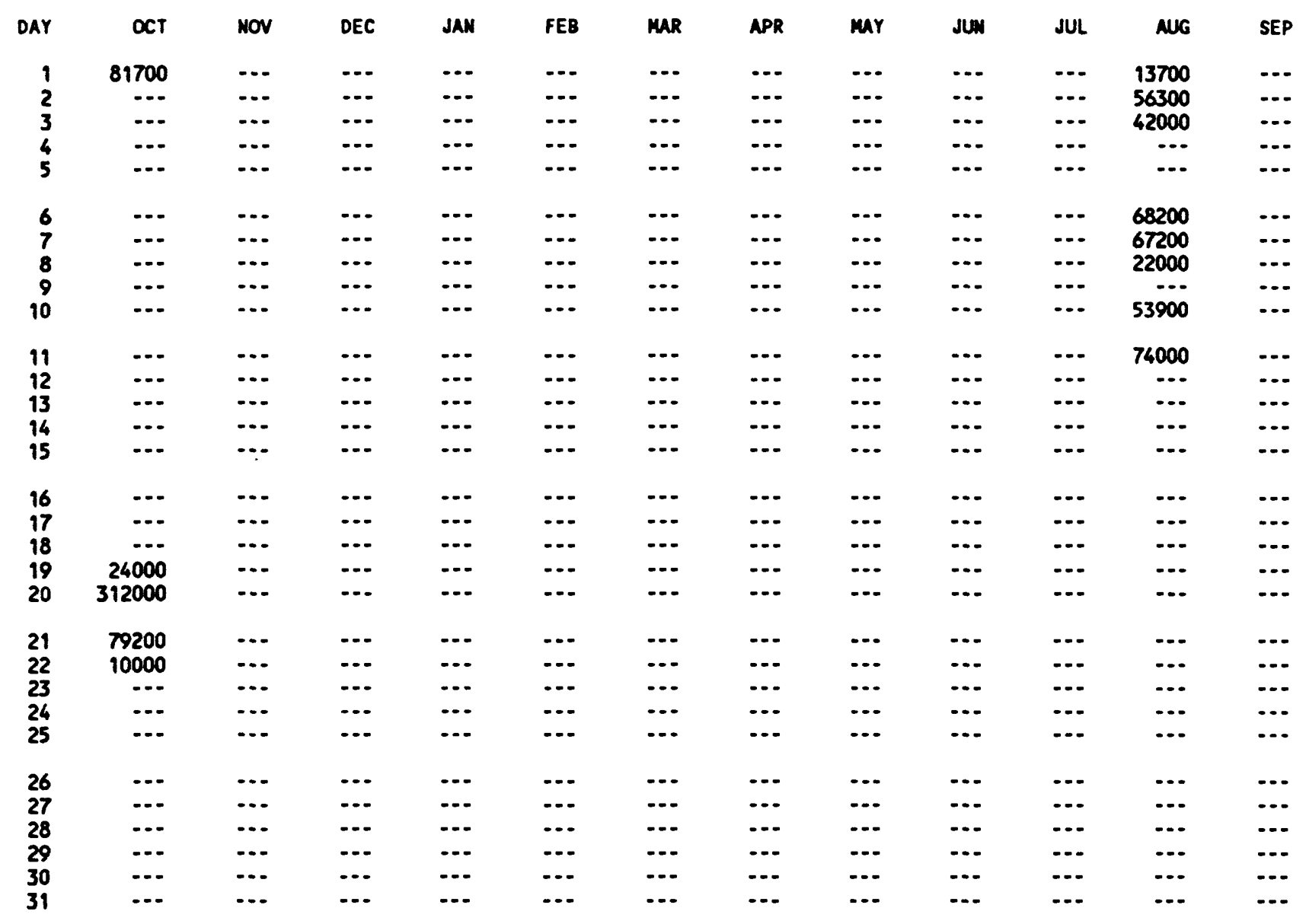


DAILY MEAN SUSPENDED-SEDIMENT CONCENTRATION-Cont inued

09395630 PUERCO RIVER NEAR MANUELITO, NM

REMARKS.--Sediment concentration for days then the daily mean discharge was greater than $1.416 \mathrm{~m}^{3} / \mathrm{s}$ are $p$ blished.

SEDIMENT, SUSPENDED CONCENTRATION (MILLIGRAMS PER LITER), MAY 1989 TO SEPTEMBER 1989 DaILY MEAN VaLUES

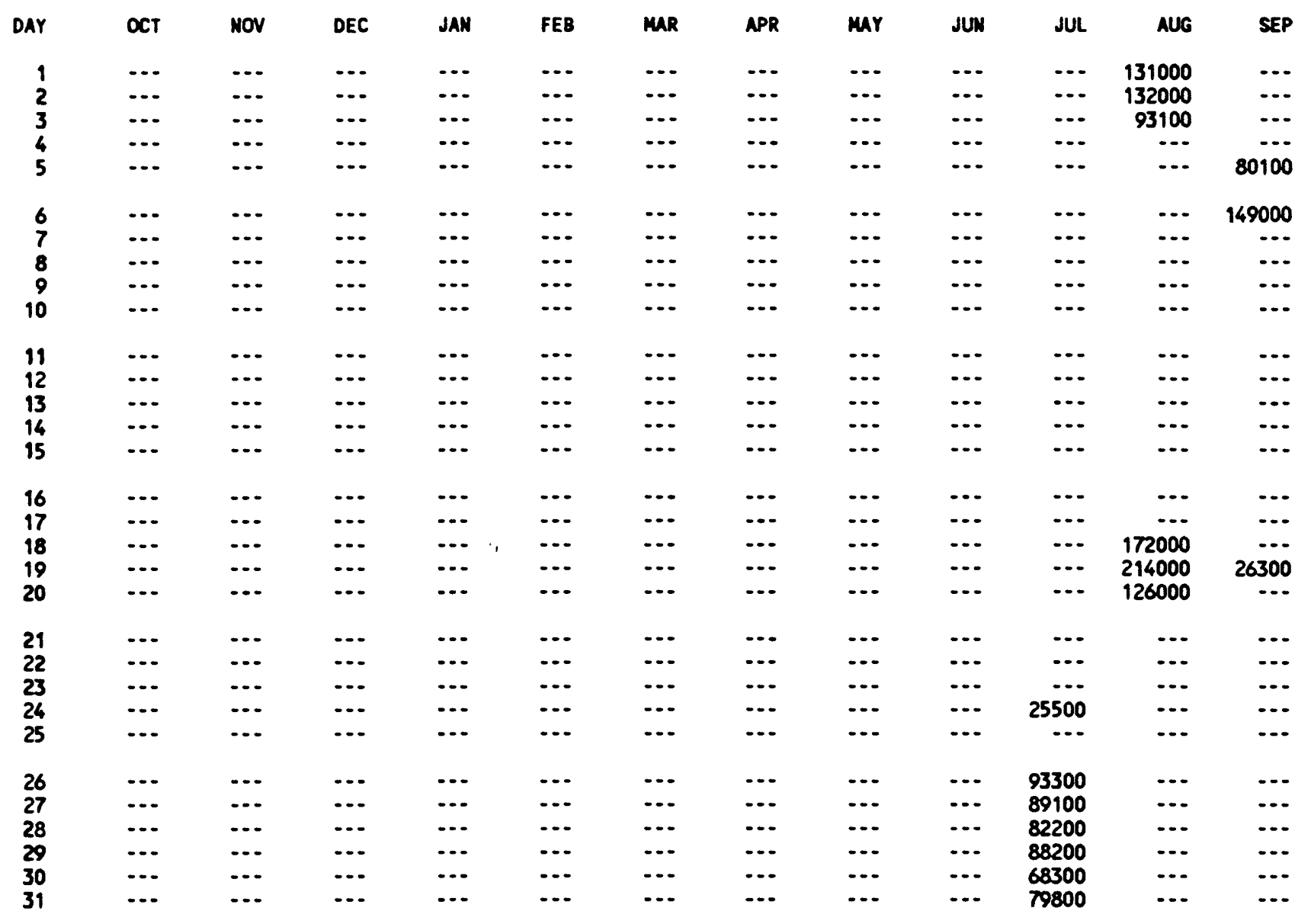


SURFACE-WATER DATA-Continued

DAILY MEAN SUSPENDED-SEDIMENT CONCENTRATION-Cont inued

09395630 PUERCO RIVER NEAR MANUELITO, MH-Continued

SEDIMENT, SUSPENDED CONCENTRATION (MILLIGRAMS PER LITER), WATER YEAR OCTOBER 1989 TO SEPTEMBER 1990 DAILY MEAN VALUES

\begin{tabular}{|c|c|c|c|c|c|c|c|c|c|c|c|c|}
\hline DAY & OCT & NOV & DEC & JAN & FEB & MAR & APR & MAY & JUN & JUL & AUG & SEP \\
\hline 1 & -.. & $\ldots$ & $\cdots$ & $\cdots$ & $\cdots$ & $\ldots$ & $\cdots$ & -.. & $\cdots$ & $\cdots$ & $\cdots$ & $\ldots$ \\
\hline 2 & ... & $\ldots$ & $\cdots$ & $\cdots$ & $\cdots$ & $\cdots$ & $\cdots$ & $\cdots$ & $\cdots$ & $\cdots$ & - . & 70500 \\
\hline 3 & -.. & $\ldots$ & $\cdots$ & $\ldots$ & $\ldots$ & $\ldots$ & $\cdots$ & $\cdots$ & $\cdots$ & -. & $\ldots$ & $\cdots$ \\
\hline 4 & $\cdots$ & $\ldots$ & $\cdots$ & $\cdots$ & $\cdots$ & $\cdots$ & $\cdots$ & $\cdots$ & $\cdots$ & $\ldots$ & $\ldots$ & ... \\
\hline 5 & $\cdots$ & $\cdots$ & $\cdots$ & $\cdots$ & $\cdots$ & $\cdots$ & $\cdots$ & $\cdots$ & $\cdots$ & $\cdots$ & $\cdots$ & 38700 \\
\hline 6 & -.. & $\ldots$ & $\cdots$ & $\ldots$ & $\cdots$ & $\ldots$ & $\cdots$ & $\ldots$ & $\ldots$ & 50100 & $\ldots$ & ... \\
\hline 7 & $\cdots$ & $\cdots$ & $\cdots$ & $\cdots$ & $\cdots$ & $\cdots$ & $\cdots$ & $\ldots$ & $\cdots$ & 58900 & 94400 & $\cdots$ \\
\hline 8 & $\cdots$ & $\cdots$ & $\cdots$ & $\cdots$ & $\cdots$ & $\cdots$ & $\cdots$ & $\cdots$ & $\cdots$ & 97100 & $\cdots$ & $\cdots$ \\
\hline 9 & $\cdots$ & $\cdots$ & $\cdots$ & $\cdots$ & $\cdots$ & $\cdots$ & $\cdots$ & $\cdots$ & $\cdots$ & $\ddot{-0}$ & $\cdots$ & $\cdots$ \\
\hline 10 & $\cdots$ & $\cdots$ & $\cdots$ & $\cdots$ & $\cdots$ & $\cdots$ & $\cdots$ & $\cdots$ & $\cdots$ & 45500 & $\cdots$ & $\cdots$ \\
\hline 11 & $\cdots$ & $\cdots$ & $\cdots$ & $\cdots$ & $\cdots$ & $\ldots$ & $\ldots$ & $\cdots$ & -- & $\cdots$ & $\cdots$ & -. \\
\hline 12 & $\cdots$ & $\cdots$ & $\cdots$ & $\cdots$ & -.. & $\cdots$ & $\cdots$ & $\ldots$ & $\cdots$ & 31800 & $\cdots$ & $\cdots$ \\
\hline 13 & ... & $\ldots$ & $\cdots$ & $\cdots$ & $\cdots$ & $\ldots$ & $\cdots$ & $\cdots$ & $\cdots$ & 27700 & $\ddot{-\infty}$ & $\cdots$ \\
\hline 14 & $\cdots$ & $\cdots$ & $\cdots$ & $\cdots$ & $\cdots$ & $\cdots$ & $\cdots$ & $\cdots$ & $\cdots$ & 14500 & 60500 & $\ldots$ \\
\hline 15 & $\cdots$ & $\cdots$ & $\cdots$ & $\cdots$ & $\cdots$ & $\cdots$ & $\cdots$ & $\cdots$ & $\cdots$ & $\cdots$ & 67900 & $\cdots$ \\
\hline 16 & $\cdots$ & $\cdots$ & $\cdots$ & $\ldots$ & $\ldots$ & $\ldots$ & $\ldots$ & $\ldots$ & ... & $\ldots$ & 74900 & $\ldots$ \\
\hline 17 & $\cdots$ & $\cdots$ & -.. & $\cdots$ & $\cdots$ & $\cdots$ & $\cdots$ & $\cdots$ & $\cdots$ & 44500 & 41600 & $\cdots$ \\
\hline 18 & $\cdots$ & $\cdots$ & $\cdots$ & $\cdots$ & $\cdots$ & $\cdots$ & $\cdots$ & $\cdots$ & $\cdots$ & $\cdots$ & $\cdots$ & $\cdots$ \\
\hline 19 & $\cdots$ & $\cdots$ & -.. & $\cdots$ & $\cdots$ & $\cdots$ & $\cdots$ & $\cdots$ & $\cdots$ & $\because-\bar{x}$ & $\cdots$ & $\cdots$ \\
\hline 20 & $\cdots$ & $\cdots$ & $\cdots$ & $\cdots$ & $\cdots$ & $\cdots$ & $\cdots$ & $\cdots$ & $\cdots$ & 49300 & 42100 & $\cdots$ \\
\hline 21 & ... & $\ldots$ & $\ldots$ & $\ldots$ & $\cdots$ & $\cdots$ & $\ldots$ & - - & ... & $\ldots$ & 108000 & -.. \\
\hline 22 & $\cdots$ & $\cdots$ & $\ldots$ & $\cdots$ & $\cdots$ & $\cdots$ & $\cdots$ & -. & $\cdots$ & $\cdots$ & $\cdots$ & $\cdots$ \\
\hline 23 & $\cdots$ & $\cdots$ & $\ldots$ & $\cdots$ & $\cdots$ & $\cdots$ & $\cdots$ & $\ldots$ & $\cdots$ & 11900 & $\cdots$ & 128000 \\
\hline 24 & $\cdots$ & $\cdots$ & $\cdots$ & $\cdots$ & $\cdots$ & $\cdots$ & $\cdots$ & $\cdots$ & $\cdots$ & 42100 & $\cdots$ & 81800 \\
\hline 25 & $\cdots$ & $\cdots$ & $\cdots$ & $\cdots$ & $\cdots$ & $\cdots$ & $\cdots$ & $\cdots$ & $\cdots$ & $\cdots$ & $\cdots$ & 34300 \\
\hline 26 & $\cdots$ & $\cdots$ & $\ldots$ & $\cdots$ & $\cdots$ & $\ldots$ & $\ldots$ & $\cdots$ & $\cdots$ & -- & $\cdots$ & ... \\
\hline 27 & $\cdots$ & $\cdots$ & ... & $\ldots$ & $\cdots$ & $\cdots$ & -.. & $\cdots$ & $\cdots$ & $\cdots$ & -. & $\ldots$ \\
\hline 28 & $\cdots$ & $\cdots$ & $\cdots$ & $\cdots$ & $\cdots$ & $\cdots$ & ... & $\cdots$ & $\cdots$ & $\cdots$ & $\cdots$ & $\cdots$ \\
\hline 29 & $\cdots$ & $\cdots$ & -.. & $\cdots$ & $\cdots$ & $\cdots$ & $\ldots$ & -.. & $\cdots$ & $\cdots$ & $\cdots$ & $\cdots$ \\
\hline 30 & $\cdots$ & $\cdots$ & $\cdots$ & $\cdots$ & $\cdots$ & $\cdots$ & $\cdots$ & $\cdots$ & $\cdots$ & $\cdots$ & $\cdots$ & $\cdots$ \\
\hline 31 & 37200 & $\cdots$ & $\cdots$ & $\cdots$ & $\cdots$ & $\cdots$ & $\cdots$ & $\cdots$ & $\cdots$ & $\cdots$ & $\cdots$ & $\cdots$ \\
\hline
\end{tabular}


SURFACE-MATER DATA-Continued

DAILY MEAN SUSPENDED-SEDIMENT CONCENTRATION-Continued

09395630 PUERCO RIVER MEAR MANUELITO, NM-Cont inued

SEDIMENT, SUSPEMDED CONCENTRATION (MILLIGRAMS PER LITER), HATER YEAR OCTOBER 1990 TO SEPTEMBER 1991 DAILY MEAN VALUES

\begin{tabular}{|c|c|c|c|c|c|c|c|c|c|c|c|c|}
\hline DAY & OCT & nOV & DEC & JAN & FEB & MAR & APR & Mur & JUN & JUL & AUG & SEP \\
\hline $\begin{array}{l}1 \\
2 \\
3 \\
4 \\
5\end{array}$ & $\begin{array}{r}6690 \\
50800 \\
\ldots \\
\ldots . \\
\cdots\end{array}$ & $\begin{array}{l}\cdots \\
\cdots \\
\cdots \\
\cdots\end{array}$ & $\begin{array}{l}\cdots \\
\cdots \\
\cdots \\
\cdots \\
\cdots\end{array}$ & $\begin{array}{l}\cdots \\
\cdots \\
\cdots \\
\cdots\end{array}$ & $\begin{array}{l}\ldots . \\
\cdots \\
\cdots \\
\cdots \\
\cdots\end{array}$ & $\begin{array}{l}\cdots \\
\cdots \\
\cdots- \\
\cdots- \\
\cdots-\end{array}$ & $\begin{array}{c}\cdots \\
\cdots \\
\cdots \\
31100\end{array}$ & $\begin{array}{c}\cdots \\
\cdots \\
\cdots . \\
\cdots \\
\cdots\end{array}$ & $\begin{array}{l}\cdots \\
\cdots \\
\cdots \\
\cdots \\
\cdots\end{array}$ & $\begin{array}{l}\cdots \\
\cdots \\
\cdots \\
\cdots\end{array}$ & $\begin{array}{r}37500 \\
127000 \\
88000 \\
47400 \\
\ldots\end{array}$ & $\begin{array}{c}\ldots . \\
\cdots \\
22700 \\
\ldots\end{array}$ \\
\hline $\begin{array}{c}6 \\
7 \\
8 \\
9 \\
10\end{array}$ & $\begin{array}{l}\cdots \\
\cdots \\
\cdots \\
\cdots\end{array}$ & $\begin{array}{l}\cdots \\
\cdots \\
\cdots \\
\cdots \\
\cdots\end{array}$ & $\begin{array}{l}\cdots \\
\cdots \\
\cdots \\
\cdots \\
\cdots\end{array}$ & $\begin{array}{l}\cdots \\
\cdots \\
\cdots \\
\cdots \\
\cdots\end{array}$ & $\begin{array}{l}\cdots \\
\cdots \\
\cdots \\
\cdots \\
\cdots\end{array}$ & $\begin{array}{l}\cdots- \\
\cdots- \\
\cdots- \\
\cdots\end{array}$ & $\begin{array}{r}74800 \\
\ldots 1100 \\
\ldots . \\
\ldots .\end{array}$ & $\begin{array}{l}\cdots \\
\cdots . \\
\cdots . \\
\cdots \\
\cdots\end{array}$ & $\begin{array}{l}\cdots \\
\cdots \\
\cdots \\
\cdots \\
\cdots\end{array}$ & $\begin{array}{l}\cdots \\
\cdots . \\
\cdots \cdot \\
\cdots\end{array}$ & $\begin{array}{r}49300 \\
81600 \\
\ldots \\
\ldots \\
\ldots\end{array}$ & $\begin{array}{l}\cdots \\
\cdots \\
\cdots \\
\cdots \\
\cdots\end{array}$ \\
\hline $\begin{array}{l}11 \\
12 \\
13 \\
14 \\
15\end{array}$ & $\begin{array}{r}\ldots . . \\
12400 \\
\ldots . \\
\ldots\end{array}$ & $\begin{array}{l}\cdots \\
\cdots \\
\cdots \\
\cdots\end{array}$ & $\begin{array}{l}\cdots \\
\cdots \\
\cdots \\
\cdots \\
\cdots\end{array}$ & $\begin{array}{l}\cdots \\
\cdots \\
\cdots \\
\cdots \\
\cdots\end{array}$ & $\begin{array}{l}\cdots \\
\cdots \\
\cdots \\
\cdots \\
\cdots\end{array}$ & $\begin{array}{l}\cdots \\
\cdots- \\
\cdots \\
\cdots \\
\cdots\end{array}$ & $\begin{array}{l}\ldots \\
\ldots \\
\ldots \\
\ldots\end{array}$ & $\begin{array}{l}\cdots \\
\cdots \\
\cdots \\
\cdots \\
\cdots\end{array}$ & $\begin{array}{r}19800 \\
62400 \\
44400 \\
44000 \\
\ldots .\end{array}$ & $\begin{array}{l}\ldots . \\
\cdots \\
\cdots . \\
\cdots\end{array}$ & $\begin{array}{c}69200 \\
\ldots \\
\ldots \\
\ldots \\
\ldots\end{array}$ & $\begin{array}{c}\cdots \\
\cdots \\
\cdots\end{array}$ \\
\hline $\begin{array}{l}16 \\
17 \\
18 \\
19 \\
20\end{array}$ & $\begin{array}{r}\ldots . \\
\ldots . \\
12500 \\
59100\end{array}$ & $\begin{array}{l}\cdots \\
\cdots \\
\cdots \\
\cdots\end{array}$ & $\begin{array}{l}\cdots \\
\cdots \\
\cdots \\
\cdots\end{array}$ & $\begin{array}{l}\cdots \\
\cdots \\
\cdots \\
\cdots \\
\cdots\end{array}$ & $\begin{array}{l}\cdots \\
\cdots \\
\cdots \\
\cdots \\
\cdots\end{array}$ & $\begin{array}{l}\cdots \\
\cdots \\
\cdots \\
\cdots\end{array}$ & $\begin{array}{l}\ldots \\
\cdots \\
\cdots \\
\cdots\end{array}$ & $\begin{array}{l}\cdots \\
\cdots . \\
\cdots \\
\cdots \\
\cdots\end{array}$ & $\begin{array}{l}\cdots \\
\cdots \\
\cdots \\
\cdots \\
\cdots\end{array}$ & $\begin{array}{l}\cdots \\
\cdots . \\
\cdots . \\
\cdots \\
\cdots\end{array}$ & $\begin{array}{l}\cdots \\
\cdots \\
\cdots \\
\cdots \\
\cdots\end{array}$ & 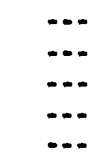 \\
\hline $\begin{array}{l}21 \\
22 \\
23 \\
24 \\
25\end{array}$ & $\begin{array}{l}\cdots \\
\cdots \\
\cdots \\
\cdots \\
\cdots\end{array}$ & $\begin{array}{l}\ldots \\
\cdots \\
\cdots \\
\cdots \\
\cdots\end{array}$ & $\begin{array}{l}\ldots . \\
\cdots \\
\cdots \\
\cdots \\
\cdots\end{array}$ & $\begin{array}{l}\cdots \\
\cdots \\
\cdots \\
\cdots\end{array}$ & $\begin{array}{l}\cdots \\
\cdots \\
\cdots \\
\cdots\end{array}$ & $\begin{array}{l}\ldots \\
\cdots \\
\cdots \\
\cdots \\
\cdots\end{array}$ & $\begin{array}{l}\ldots . \\
\cdots \\
\cdots \\
\cdots\end{array}$ & $\begin{array}{l}\cdots \\
\cdots \\
\cdots . \\
\cdots\end{array}$ & $\begin{array}{l}\ldots- \\
\cdots \\
\cdots \\
\cdots \\
\cdots\end{array}$ & $\begin{array}{l}\cdots \\
\cdots . \\
\cdots . \\
\cdots \\
\cdots .\end{array}$ & $\begin{array}{l}\cdots \\
\cdots \\
\cdots \\
\cdots \\
\cdots\end{array}$ & $\begin{array}{l}\cdots \\
\cdots \\
\cdots \\
\cdots- \\
\cdots\end{array}$ \\
\hline $\begin{array}{l}26 \\
27 \\
28 \\
29 \\
30 \\
31\end{array}$ & $\begin{array}{l}\cdots \\
\cdots \\
\cdots \cdot \\
\cdots \cdot \\
\cdots\end{array}$ & $\begin{array}{l}\cdots \\
\cdots \\
\cdots \\
\cdots \\
\cdots \\
\cdots\end{array}$ & $\begin{array}{l}\cdots \\
\cdots \\
\cdots \cdot \\
\cdots \\
\cdots\end{array}$ & $\begin{array}{l}\cdots \cdot \\
\cdots \cdot \\
\cdots \cdot \\
\cdots \\
\cdots\end{array}$ & $\begin{array}{l}\cdots \\
\cdots \\
\cdots \cdot \\
\cdots \cdot \\
\cdots\end{array}$ & $\begin{array}{r}\ldots . \\
24200 \\
34100 \\
\ldots \\
\ldots .\end{array}$ & $\begin{array}{l}\cdots \\
\cdots \\
\cdots \\
\cdots \\
\cdots\end{array}$ & $\begin{array}{l}\cdots . \\
\cdots \\
\cdots . \\
\cdots \\
\cdots\end{array}$ & $\begin{array}{l}\cdots \\
\cdots \\
\cdots \\
\cdots \\
\cdots \\
\cdots\end{array}$ & $\begin{array}{r}79500 \\
90900 \\
\ldots \\
86300 \\
\ldots . \\
\ldots .\end{array}$ & $\begin{array}{c}20000 \\
72900 \\
53800 \\
\ldots . . \\
\cdots \\
\ldots .-\end{array}$ & \\
\hline
\end{tabular}


SURFACE-WATER DATA-Continued

DAILY MEAN SUSPENDED-SEDIMENT CONCENTRATION-Continued

09395990 BLACK CREEK WEAR HOUCK, AZ

REMARKS.--Sediment concentration for days when the daily mean discharge was greater than $.142 \mathrm{~m}^{3} / 8$ are published.

SEDIMENT, SUSPEMDED CONCENTRATION (MILLIGRAMS PER LITER), MARCH 1989 TO SEPTEMBER 1989 DAILY MEAN VALUES

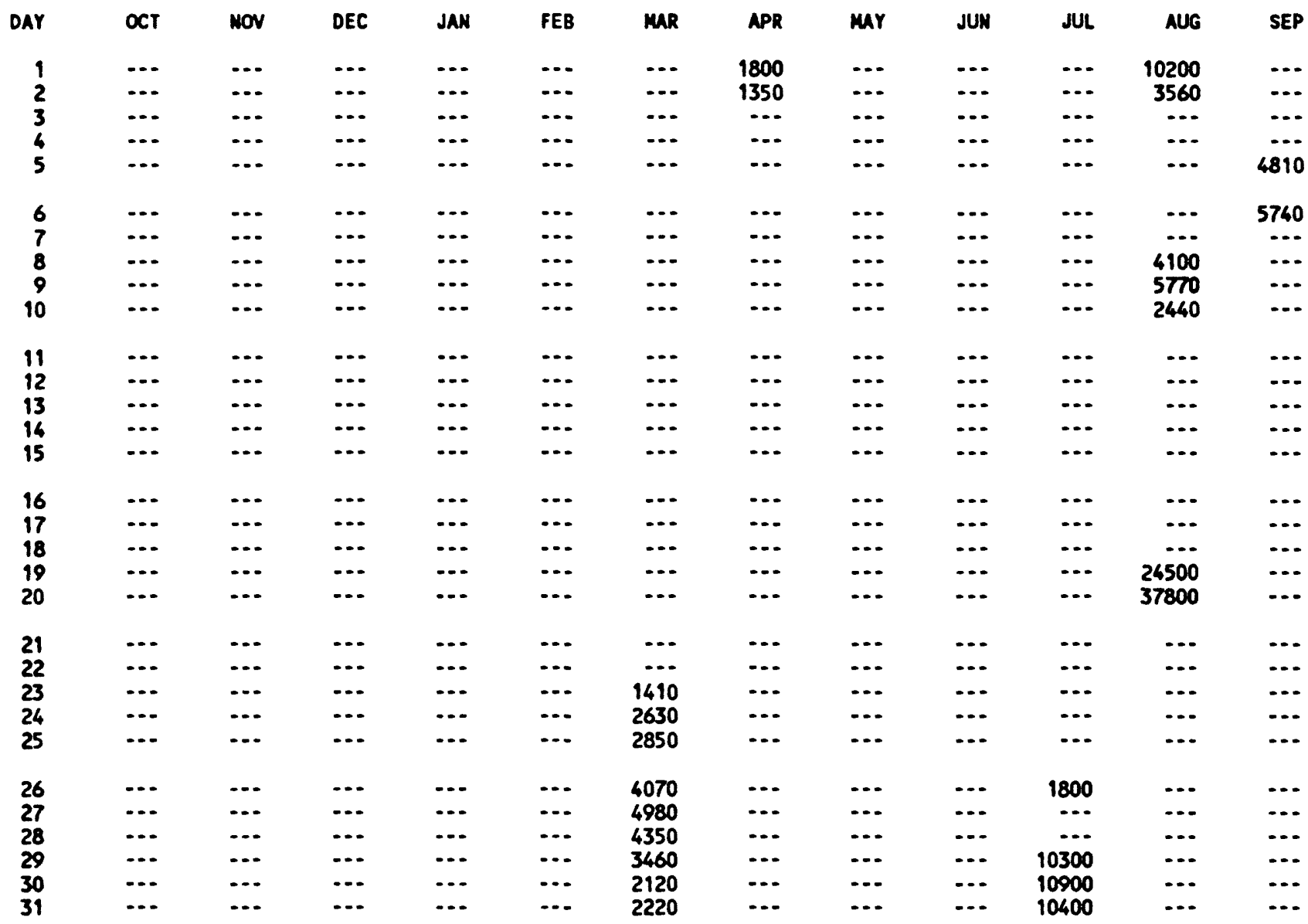


SURFACE-WATER DATA-Continued

DAILY MEAN SUSPENDED-SEDIMENT CONCENTRATION-Continued

09395990 BLACK CREEK MEAR HOUCK, AZ-Continued

SEDIMENT, SUSPENDED CONCENTRATION (MILLIGRAMS PER LITER), WATER YEAR OCTOBER 1989 TO SEPTEMBER 1990 DAILY MEAN VALUES

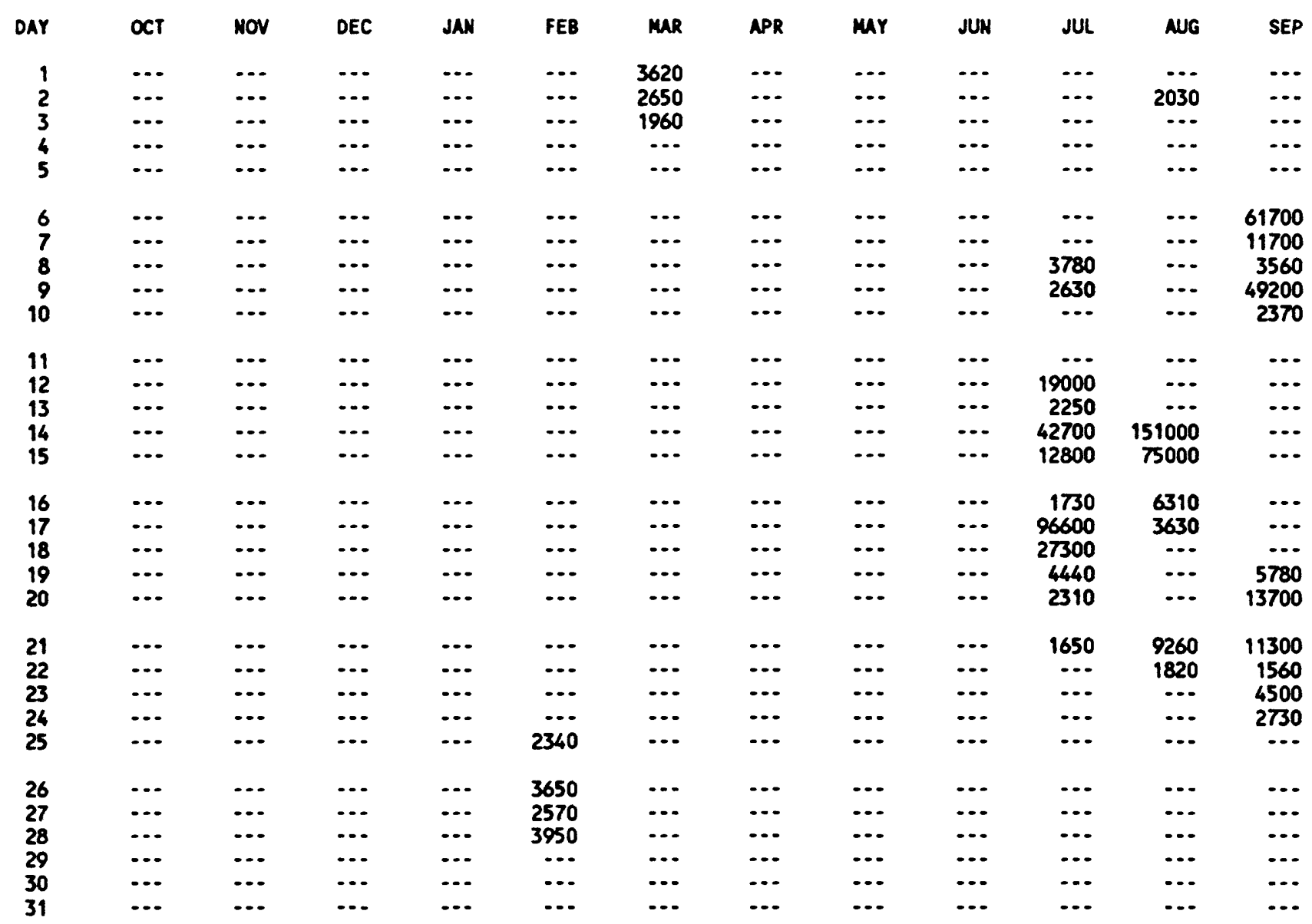


SURFACE-MATER DATA-Continued

DAILY MEAN SUSPENDED-SEDIMENT CONCENTRATION-CONTInUEd

09395990 BLACK CREEK NEAR HOUCK, AZ-COnt Inued

SEDIMENT, SUSPENDED CONCENTRATION (MILLIGRAMS PER LITER), WATER YEAR OCTOBER 1990 TO SEPTEMBER 1991 DAILY MEAN VALUES

\begin{tabular}{|c|c|c|c|c|c|c|c|c|c|c|c|c|}
\hline DAY & ост & nOV & DEC & JAN & FEB & MAR & APR & MAY & JUW & JUL & AUG & SEP \\
\hline $\begin{array}{l}1 \\
2 \\
3 \\
6 \\
5\end{array}$ & $\begin{array}{l}\ldots \\
\ldots \\
\ldots \\
\ldots \\
\cdots\end{array}$ & $\begin{array}{l}\cdots \\
\ldots \\
\cdots \\
\ldots \\
\cdots\end{array}$ & $\begin{array}{l}\ldots \\
\ldots \\
\ldots \\
\cdots \\
\cdots\end{array}$ & $\begin{array}{r}\ldots \\
\ldots \\
e 1040 \\
e 10600\end{array}$ & $\begin{array}{l}\ldots \\
\ldots \\
\ldots \\
\ldots \\
\ldots\end{array}$ & $\begin{array}{r}9290 \\
12000 \\
10800 \\
7110 \\
15500\end{array}$ & $\begin{array}{r}12500 \\
8060 \\
5590 \\
3300 \\
2150\end{array}$ & $\begin{array}{l}\ldots \\
\ldots \\
\ldots \\
\ldots \\
\ldots\end{array}$ & $\begin{array}{l}\ldots \\
\ldots \\
\ldots \\
\ldots \\
\ldots\end{array}$ & $\begin{array}{l}\ldots \\
\ldots \\
\cdots \\
\cdots \\
\cdots\end{array}$ & $\begin{array}{l}\ldots \\
\ldots \\
\ldots \\
\ldots \\
\ldots\end{array}$ & $\begin{array}{c}\ldots \\
\ldots \\
\ldots \\
6080\end{array}$ \\
\hline $\begin{array}{r}6 \\
7 \\
8 \\
9 \\
10\end{array}$ & $\begin{array}{l}\ldots \\
\ldots \\
\ldots \\
\ldots\end{array}$ & $\begin{array}{l}\ldots \\
\ldots \\
\ldots \\
\ldots \\
\ldots\end{array}$ & $\begin{array}{l}\ldots \\
\ldots \\
\ldots \\
\ldots \\
\ldots\end{array}$ & $\begin{array}{l}e 8470 \\
e 5290 \\
e 4220 \\
e 2320 \\
e 1040\end{array}$ & $\begin{array}{r}\ldots . . \\
1880 \\
2770 \\
2680 \\
2560\end{array}$ & $\begin{array}{r}32100 \\
22200 \\
11400 \\
3970 \\
2560\end{array}$ & $\begin{array}{c}1590 \\
\ldots \\
\ldots \\
\ldots \\
\ldots\end{array}$ & $\begin{array}{l}\ldots \\
\ldots \\
\ldots \\
\ldots \\
\ldots\end{array}$ & $\begin{array}{l}\ldots \\
\ldots \\
\ldots \\
\ldots \\
\ldots\end{array}$ & $\begin{array}{l}\ldots \\
\ldots \\
\ldots \\
\ldots \\
\cdots\end{array}$ & $\begin{array}{r}121000 \\
6280 \\
1650 \\
\ldots\end{array}$ & $\begin{array}{r}27800 \\
4040 \\
\ldots \\
\ldots \\
\ldots\end{array}$ \\
\hline $\begin{array}{l}11 \\
12 \\
13 \\
16 \\
15\end{array}$ & $\begin{array}{l}\ldots \\
\ldots \\
\ldots \\
\ldots \\
\ldots\end{array}$ & $\begin{array}{l}\ldots \\
\ldots \\
\ldots \\
\ldots \\
\ldots\end{array}$ & $\begin{array}{l}\ldots \\
\ldots \\
\ldots \\
\ldots \\
\ldots\end{array}$ & $\begin{array}{l}\ldots \\
\ldots \\
\ldots \\
\ldots \\
\ldots\end{array}$ & $\begin{array}{l}2670 \\
2670 \\
2520 \\
2340 \\
2530\end{array}$ & $\begin{array}{c}1750 \\
\ldots . \\
\ldots \\
\ldots \\
\ldots\end{array}$ & $\begin{array}{c}4230 \\
7080 \\
3900 \\
1880 \\
\cdots .-\end{array}$ & $\begin{array}{l}\ldots \\
\ldots \\
\ldots \\
\ldots \\
\ldots\end{array}$ & $\begin{array}{l}\ldots \\
\ldots \\
\ldots \\
\ldots \\
\ldots\end{array}$ & $\begin{array}{l}\ldots \\
\ldots \\
\ldots \\
\ldots \\
\cdots\end{array}$ & $\begin{array}{c}\ldots \\
\ldots \\
\ldots \\
\ldots 630\end{array}$ & $\begin{array}{l}\ldots \\
\ldots \\
\ldots \\
\ldots \\
\ldots\end{array}$ \\
\hline $\begin{array}{l}16 \\
17 \\
18 \\
19 \\
20\end{array}$ & $\begin{array}{r}\ldots \\
\ldots \\
\ldots \\
11900\end{array}$ & $\begin{array}{l}\ldots \\
\ldots \\
\ldots \\
\ldots \\
\ldots\end{array}$ & $\begin{array}{l}\ldots \\
\ldots \\
\ldots \\
\ldots \\
\ldots\end{array}$ & $\begin{array}{l}\ldots \\
\ldots \\
\ldots \\
\ldots \\
\ldots\end{array}$ & $\begin{array}{r}3570 \\
4300 \\
3390 \\
2020 \\
\ldots\end{array}$ & $\begin{array}{l}\ldots \\
\ldots \\
\ldots \\
\ldots \\
\ldots\end{array}$ & $\begin{array}{l}2300 \\
4970 \\
5650 \\
6230 \\
4810\end{array}$ & $\begin{array}{l}\ldots \\
\ldots \\
\ldots \\
\ldots \\
\ldots\end{array}$ & $\begin{array}{l}\ldots \\
\ldots \\
\ldots \\
\ldots \\
\ldots\end{array}$ & $\begin{array}{l}\ldots \\
\ldots \\
\ldots \\
\ldots \\
\ldots\end{array}$ & $\begin{array}{r}24700 \\
1610 \\
\ldots \\
\ldots \\
\ldots\end{array}$ & $\begin{array}{l}\ldots \\
\ldots \\
\ldots \\
\ldots\end{array}$ \\
\hline $\begin{array}{l}21 \\
22 \\
23 \\
24 \\
25\end{array}$ & $\begin{array}{l}\ldots . \\
\ldots \\
\ldots \\
\ldots \\
\ldots\end{array}$ & $\begin{array}{l}\ldots \\
\ldots \\
\ldots \\
\ldots \\
\ldots\end{array}$ & $\begin{array}{l}\ldots \\
\ldots \\
\ldots \\
\ldots \\
\cdots\end{array}$ & $\begin{array}{l}\ldots \\
\ldots \\
\ldots \\
\ldots \\
\ldots\end{array}$ & $\begin{array}{l}\ldots \\
\ldots \\
\ldots \\
\ldots \\
\ldots\end{array}$ & $\begin{array}{l}\ldots \\
\ldots \\
\ldots \\
\ldots \\
\ldots\end{array}$ & $\begin{array}{l}2830 \\
2670 \\
2040 \\
1750 \\
1310\end{array}$ & $\begin{array}{l}\ldots \\
\ldots \\
\ldots \\
\ldots \\
\ldots\end{array}$ & $\begin{array}{l}\ldots \\
\ldots \\
\ldots \\
\ldots \\
\ldots\end{array}$ & $\begin{array}{r}\ldots \\
\ldots \\
40400 \\
14200\end{array}$ & $\begin{array}{l}\ldots \\
\ldots \\
\ldots \\
\ldots \\
\ldots\end{array}$ & $\begin{array}{l}\ldots \\
\ldots \\
\ldots \\
\ldots \\
\ldots\end{array}$ \\
\hline $\begin{array}{l}26 \\
27 \\
28 \\
29 \\
30 \\
31\end{array}$ & $\begin{array}{l}\ldots . \\
\ldots \\
\ldots \\
\ldots \\
\ldots \\
\ldots\end{array}$ & $\begin{array}{l}\ldots \\
\ldots \\
\ldots \\
\ldots \\
\ldots\end{array}$ & $\begin{array}{l}\ldots \\
\ldots \\
\cdots \\
\cdots \\
\ldots \\
\ldots\end{array}$ & $\begin{array}{l}\ldots \\
\ldots \\
\ldots \\
\ldots \\
\ldots \\
\ldots\end{array}$ & $\begin{array}{l}\ldots \\
\ldots \\
\ldots \\
\ldots \\
\ldots\end{array}$ & $\begin{array}{r}\ldots \\
\ldots \\
5530 \\
7640 \\
15100\end{array}$ & $\begin{array}{l}\ldots \\
\ldots \\
\ldots \\
\ldots \\
\ldots\end{array}$ & $\begin{array}{l}\ldots \\
\ldots \\
\ldots \\
\ldots \\
\ldots \\
\ldots\end{array}$ & $\begin{array}{l}\ldots \\
\ldots \\
\ldots \\
\ldots \\
\ldots \\
\ldots\end{array}$ & $\begin{array}{c}5380 \\
\ldots \\
\ldots \\
\ldots \\
\ldots \\
\ldots\end{array}$ & $\begin{array}{l}\ldots \\
\ldots \\
\ldots \\
\ldots \\
\ldots \\
\ldots\end{array}$ & $\begin{array}{l}\ldots \\
\ldots \\
\ldots \\
\ldots \\
\ldots\end{array}$ \\
\hline
\end{tabular}

estimated 
SURFACE-MATER DATA-Continued

DAILY MEAN SUSPENDED-SEDIMENT CONCENTRATION-Continued

09396100 PUERCO RIVER NEAR CHAMBERS, AZ

REMURKS.--Sediment concentration for days when the daily mean discharge was greater than $.566 \mathrm{~m}^{3} / \mathrm{s}$ are published.

SEDIRENT, SUSPENDED CONCENTRATION (MILLLIGRAMS PER LITER), WATER YEAR OCTOBER 1988 TO SEPTEMBER 1989 DAILY MEAN VALUES

\begin{tabular}{|c|c|c|c|c|c|c|c|c|c|c|c|c|}
\hline DAY & OCT & MOV & DEC & JAN & FEB & MAR & APR & MAY & JUN & JUL & AUG & SEP \\
\hline $\begin{array}{l}1 \\
2 \\
3 \\
4 \\
5\end{array}$ & $\begin{array}{l}\ldots \\
\ldots \\
\ldots \\
\ldots \\
\ldots\end{array}$ & $\begin{array}{l}\ldots \\
\ldots \\
\ldots \\
\ldots \\
\ldots\end{array}$ & $\begin{array}{l}\ldots \\
\ldots \\
\ldots \\
\ldots \\
\ldots\end{array}$ & $\begin{array}{l}\ldots \\
\ldots \\
\ldots \\
\ldots \\
\ldots\end{array}$ & $\begin{array}{r}\ldots 100 \\
34100 \\
38400 \\
31300\end{array}$ & $\begin{array}{l}\ldots \\
\ldots \\
\ldots \\
\ldots \\
\ldots\end{array}$ & $\begin{array}{l}\ldots \\
\ldots \\
\ldots \\
\ldots \\
\ldots\end{array}$ & $\begin{array}{l}\ldots \\
\ldots \\
\ldots \\
\ldots \\
\ldots\end{array}$ & $\begin{array}{l}\ldots \\
\ldots \\
\ldots \\
\ldots \\
\ldots\end{array}$ & $\begin{array}{l}\ldots \\
\ldots \\
\ldots \\
\ldots \\
\ldots\end{array}$ & $\begin{array}{r}95800 \\
16100 \\
38600 \\
\ldots \\
\ldots\end{array}$ & $\begin{array}{l}\ldots \\
\ldots \\
\ldots \\
\ldots \\
\ldots\end{array}$ \\
\hline $\begin{array}{r}6 \\
7 \\
8 \\
9 \\
10\end{array}$ & $\begin{array}{l}\ldots \\
\ldots \\
\ldots \\
\ldots \\
\ldots\end{array}$ & $\begin{array}{l}\ldots \\
\ldots \\
\ldots \\
\ldots \\
\ldots\end{array}$ & $\begin{array}{l}\ldots \\
\ldots \\
\ldots \\
\ldots \\
\ldots\end{array}$ & $\begin{array}{l}\ldots \\
\ldots \\
\ldots \\
\ldots \\
\ldots\end{array}$ & $\begin{array}{c}16400 \\
19300 \\
19500 \\
\ldots \ldots \\
\ldots\end{array}$ & $\begin{array}{c}18000 \\
\ldots \\
\ldots \\
\ldots \\
\ldots\end{array}$ & $\begin{array}{l}\ldots \\
\ldots \\
\ldots \\
\ldots \\
\ldots\end{array}$ & $\begin{array}{l}\ldots \\
\ldots \\
\ldots \\
\ldots \\
\ldots\end{array}$ & $\begin{array}{l}\ldots \\
\ldots \\
\ldots \\
\ldots \\
\ldots\end{array}$ & $\begin{array}{l}\ldots \\
\ldots \\
\ldots \\
\ldots \\
\ldots\end{array}$ & $\begin{array}{l}\ldots \\
\ldots \\
\ldots \\
\ldots \\
\ldots\end{array}$ & $\begin{array}{r}46300 \\
15000 \\
\ldots \\
\ldots \\
\ldots\end{array}$ \\
\hline $\begin{array}{l}11 \\
12 \\
13 \\
14 \\
15\end{array}$ & $\begin{array}{l}\ldots \\
\ldots \\
\ldots \\
\cdots \\
\cdots\end{array}$ & $\begin{array}{l}\ldots \\
\ldots \\
\ldots \\
\ldots \\
\ldots\end{array}$ & $\begin{array}{l}\ldots \\
\ldots \\
\cdots \\
\cdots \\
\cdots\end{array}$ & $\begin{array}{l}\ldots \\
\ldots \\
\ldots \\
\ldots \\
\ldots\end{array}$ & $\begin{array}{r}\ldots 100 \\
46100 \\
26500 \\
17900\end{array}$ & $\begin{array}{l}\ldots \\
\ldots \\
\ldots \\
\ldots \\
\ldots\end{array}$ & $\begin{array}{l}\ldots \\
\ldots \\
\ldots \\
\ldots \\
\cdots\end{array}$ & $\begin{array}{l}\ldots \\
\ldots \\
\ldots \\
\ldots \\
\ldots\end{array}$ & $\begin{array}{l}\ldots \\
\ldots \\
\ldots \\
\ldots \\
\ldots\end{array}$ & $\begin{array}{l}\ldots \\
\ldots \\
\ldots \\
\ldots \\
\ldots\end{array}$ & $\begin{array}{l}\ldots \\
\ldots \\
\ldots \\
\ldots \\
\ldots\end{array}$ & $\begin{array}{l}\ldots . \\
\ldots \\
\ldots- \\
\ldots \\
\ldots\end{array}$ \\
\hline $\begin{array}{l}16 \\
17 \\
18 \\
19 \\
20\end{array}$ & $\begin{array}{l}\ldots \\
\ldots \\
\ldots \\
\ldots \\
\ldots\end{array}$ & $\begin{array}{l}\ldots \\
\ldots \\
\ldots \\
\ldots \\
\ldots\end{array}$ & $\begin{array}{l}\ldots \\
\ldots \\
\ldots \\
\ldots \\
\ldots\end{array}$ & $\begin{array}{l}\ldots \\
\ldots \\
\ldots \\
\ldots \\
\ldots\end{array}$ & $\begin{array}{l}24900 \\
21400 \\
28400 \\
30400 \\
37600\end{array}$ & $\begin{array}{c}\ldots \\
\ldots \\
\ldots \\
\ldots \\
18000\end{array}$ & $\begin{array}{l}\ldots \\
\ldots \\
\ldots \\
\ldots \\
\ldots\end{array}$ & $\begin{array}{l}\ldots \\
\ldots \\
\ldots \\
\ldots \\
\ldots\end{array}$ & $\begin{array}{l}\ldots \\
\ldots \\
\ldots \\
\ldots\end{array}$ & $\begin{array}{l}\ldots \\
\ldots \\
\ldots \\
\ldots \\
\ldots\end{array}$ & $\begin{array}{r}\ldots \\
\ldots \\
136000 \\
75600\end{array}$ & $\begin{array}{l}\ldots \\
\ldots \\
\ldots \\
\ldots \\
\ldots\end{array}$ \\
\hline $\begin{array}{l}21 \\
22 \\
23 \\
24 \\
25\end{array}$ & $\begin{array}{l}\ldots \\
\ldots \\
\ldots \\
\ldots \\
\ldots\end{array}$ & $\begin{array}{l}\ldots \\
\ldots \\
\cdots \\
\cdots \\
\cdots\end{array}$ & $\begin{array}{l}\ldots \\
\ldots \\
\ldots \\
\ldots\end{array}$ & $\begin{array}{l}\ldots \\
\ldots \\
\ldots \\
\ldots \\
\ldots\end{array}$ & $\begin{array}{l}17300 \\
20000 \\
21200 \\
18500 \\
16900\end{array}$ & $\begin{array}{l}\ldots \\
\ldots \\
\ldots \\
\ldots \\
\ldots\end{array}$ & $\begin{array}{l}\ldots \\
\ldots \\
\ldots \\
\ldots \\
\ldots\end{array}$ & $\begin{array}{l}\ldots \\
\ldots \\
\ldots \\
\ldots \\
\ldots\end{array}$ & $\begin{array}{l}\ldots \\
\ldots- \\
\cdots \\
\cdots \\
\cdots\end{array}$ & $\begin{array}{l}\ldots . \\
\ldots . \\
\ldots . \\
\ldots \\
\ldots\end{array}$ & $\begin{array}{l}\ldots \\
\ldots \\
\cdots \\
\cdots \\
\ldots\end{array}$ & $\begin{array}{l}\ldots . \\
\cdots \\
\cdots \\
\cdots\end{array}$ \\
\hline $\begin{array}{l}26 \\
27 \\
28\end{array}$ & $\begin{array}{l}\ldots \\
\ldots \\
\ldots \\
\ldots \\
\ldots \\
\ldots\end{array}$ & $\begin{array}{l}\ldots \\
\ldots \\
\ldots \\
\ldots \\
\cdots \\
\ldots\end{array}$ & $\begin{array}{l}\ldots \\
\ldots \\
\ldots \\
\ldots \\
\ldots \\
\ldots\end{array}$ & $\begin{array}{l}\ldots \\
\ldots \\
\ldots \\
\ldots \\
\ldots \\
\ldots\end{array}$ & $\begin{array}{c}23300 \\
19800 \\
\ldots \\
\ldots \\
\ldots\end{array}$ & $\begin{array}{l}\ldots \\
\ldots \\
\ldots \\
\ldots \\
\ldots \\
\ldots\end{array}$ & $\begin{array}{l}\ldots \\
\ldots \\
\ldots \\
\ldots \\
\ldots\end{array}$ & $\begin{array}{l}\ldots \\
\ldots \\
\ldots \\
\ldots \\
\ldots \\
\ldots\end{array}$ & $\begin{array}{l}\ldots \\
\ldots \\
\ldots \\
\ldots \\
\ldots \\
\ldots\end{array}$ & $\begin{array}{l}12100 \\
31400 \\
55500 \\
28900 \\
51000\end{array}$ & $\begin{array}{l}\cdots \\
\ldots \\
\ldots \\
\ldots \\
\ldots \\
\ldots\end{array}$ & $\begin{array}{l}\ldots \\
\ldots \\
\ldots \\
\ldots \\
\ldots\end{array}$ \\
\hline
\end{tabular}


SURFACE-WATER DATA-Continued

DAILY MEAN SUSPENDED-SEDIMENT CONCENTRATION-COnt InUEd

09396100 PUERCO RIVER MEAR CHAMBERS, AZ-Continued

SEDIMENT, SUSPENDED CONCENTRATION (MILLIGRAMS PER LITER), WATER YEAR OCTOBER 1989 TO SEPTEMBER 1990 DAILY MEAN VALUES

\begin{tabular}{|c|c|c|c|c|c|c|c|c|c|c|c|c|}
\hline DAY & OCT & NOV & DEC & JAN & FEB & MAR & APR & MY & JUN & JUL & AUG & SEP \\
\hline 1 & $\cdots$ & $\cdots$ & $\cdots$ & $\cdots$ & $\cdots$ & $\cdots$ & $\cdots$ & $\cdots$ & $\ldots$ & $\cdots$ & $\cdots$ & $\cdots$ \\
\hline 2 & $\cdots$ & $\cdots$ & $\cdots$ & $\cdots$ & $\cdots$ & $\cdots$ & $\cdots$ & $\cdots$ & ... & $\cdots$ & $\cdots$ & $\cdots$ \\
\hline 3 & $\ldots$ & $\ldots$ & $\ldots$ & $\cdots$ & $\cdots$ & $\ldots$ & $\ldots$ & $\ldots$ & $\ldots$ & $\ldots$ & $\ldots$ & 20100 \\
\hline 4 & $\ldots$ & $\cdots$ & $\cdots$ & $\cdots$ & $\ldots$ & $\cdots$ & - & $\ldots$ & $\ldots$ & $\ldots$ & $\ldots$ & 8860 \\
\hline 5 & $\cdots$ & $\cdots$ & $\cdots$ & $\cdots$ & $\cdots$ & $\cdots$ & $\cdots$ & $\cdots$ & $\cdots$ & $\cdots$ & $\cdots$ & $\cdots$ \\
\hline 6 & $\cdots$ & $\cdots$ & $\cdots$ & $\cdots$ & $\ldots$ & $\cdots$ & $\cdots$ & $\cdots$ & $\cdots$ & $\cdots$ & $\cdots$ & 66000 \\
\hline 7 & $\cdots$ & $\cdots$ & $\cdots$ & $\cdots$ & $\cdots$ & $\cdots$ & $\cdots$ & $\cdots$ & $\cdots$ & $\cdots$ & $\cdots$ & 30700 \\
\hline 8 & $\cdots$ & $\cdots$ & $\cdots$ & $\cdots$ & $\cdots$ & $\cdots$ & $\cdots$ & $\cdots$ & $\cdots$ & 26900 & 25900 & 25900 \\
\hline 9 & $\cdots$ & $\cdots$ & $\cdots$ & $\cdots$ & $\cdots$ & $\cdots$ & $\cdots$ & $\cdots$ & -- & 44000 & $\cdots$ & 28100 \\
\hline 10 & $\cdots$ & $\cdots$ & $\cdots$ & $\cdots$ & $\cdots$ & $\cdots$ & $\cdots$ & $\cdots$ & $\cdots$ & 22500 & $\cdots$ & 20900 \\
\hline 11 & $\cdots$ & $\cdots$ & $\cdots$ & $\cdots$ & $\cdots$ & $\cdots$ & $\cdots$ & $\cdots$ & $\cdots$ & 59400 & $\cdots$ & $\cdots$ \\
\hline 12 & $\cdots$ & $\cdots$ & $\cdots$ & $\cdots$ & 20200 & $\cdots$ & $\cdots$ & $\cdots$ & $\cdots$ & 29300 & $\cdots$ & $\cdots$ \\
\hline 13 & $\cdots$ & $\cdots$ & $\cdots$ & $\cdots$ & $\cdots$ & $\cdots$ & $\cdots$ & $\cdots$ & $\cdots$ & 28500 & -.. & $\cdots$ \\
\hline 14 & $\cdots$ & $\cdots$ & $\cdots$ & $\cdots$ & 19200 & $\cdots$ & $\cdots$ & $\cdots$ & $\cdots$ & 109000 & 25800 & $\cdots$ \\
\hline 15 & $\cdots$ & $\cdots$ & $\cdots$ & $\cdots$ & $\cdots$ & $\cdots$ & $\cdots$ & $\cdots$ & $\cdots$ & 48400 & 115000 & $\cdots$ \\
\hline 16 & $\cdots$ & $\cdots$ & $\cdots$ & $\cdots$ & $\cdots$ & $\cdots$ & $\cdots$ & $\cdots$ & $\cdots$ & 57100 & 40800 & $\cdots$ \\
\hline 17 & $\cdots$ & $\cdots$ & $\cdots$ & $\cdots$ & $\cdots$ & $\cdots$ & $\cdots$ & $\cdots$ & $\cdots$ & $\cdots$ & 28200 & $\cdots$ \\
\hline 18 & $\cdots$ & $\cdots$ & $\cdots$ & $\cdots$ & $\cdots$ & $\cdots$ & $\cdots$ & $\cdots$ & $\cdots$ & 43900 & 35200 & $\cdots$ \\
\hline 19 & $\cdots$ & $\cdots$ & $\cdots$ & $\cdots$ & $\cdots$ & $\cdots$ & $\cdots$ & $\cdots$ & $\cdots$ & 29300 & $\cdots$ & $\cdots$ \\
\hline 20 & $\cdots$ & $\cdots$ & $\cdots$ & $\cdots$ & $\cdots$ & $\cdots$ & $\cdots$ & $\cdots$ & $\cdots$ & 16200 & $\cdots$ & $\cdots$ \\
\hline 21 & $\cdots$ & $\cdots$ & $\ldots$ & $\cdots$ & $\cdots$ & $\cdots$ & $\ldots$ & $\cdots$ & $\ldots$ & 23400 & 39400 & $\ldots$ \\
\hline 22 & $\cdots$ & $\cdots$ & $\cdots$ & $\cdots$ & $\cdots$ & $\cdots$ & $\cdots$ & $\cdots$ & $\cdots$ & 18300 & 28400 & $\cdots$ \\
\hline 23 & $\cdots$ & $\cdots$ & $\cdots$ & $\cdots$ & $\cdots$ & $\cdots$ & $\cdots$ & $\cdots$ & $\cdots$ & 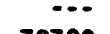 & $\cdots$ & $\cdots$ \\
\hline 24 & $\cdots$ & $\cdots$ & $\cdots$ & $\cdots$ & $\cdots$ & $\cdots$ & $\cdots$ & $\cdots$ & $\cdots$ & 38300 & $\cdots$ & $\cdots$ \\
\hline 25 & $\cdots$ & $\cdots$ & $\cdots$ & $\cdots$ & $\cdots$ & $\cdots$ & $\cdots$ & $\cdots$ & $\cdots$ & 21900 & $\cdots$ & $\cdots$ \\
\hline 26 & $\cdots$ & $\cdots$ & $\cdots$ & $\cdots$ & $\cdots$ & $\cdots$ & $\cdots$ & $\cdots$ & $\cdots$ & $\cdots$ & $\cdots$ & $\ldots$ \\
\hline 27 & $\cdots$ & $\cdots$ & $\cdots$ & $\cdots$ & $\cdots$ & $\cdots$ & $\cdots$ & $\cdots$ & $\cdots$ & $\cdots$ & $\ldots$ & $\cdots$ \\
\hline 28 & $\cdots$ & $\cdots$ & $\cdots$ & $\cdots$ & $\cdots$ & $\cdots$ & $\cdots$ & $\cdots$ & $\cdots$ & $\cdots$ & $\cdots$ & $\cdots$ \\
\hline 29 & $\cdots$ & $\cdots$ & $\cdots$ & $\cdots$ & $\cdots$ & $\cdots$ & $\cdots$ & $\cdots$ & $\cdots$ & $\cdots$ & $\cdots$ & $\cdots$ \\
\hline 30 & $\cdots$ & $\cdots$ & $\cdots$ & $\cdots$ & $\cdots$ & $\cdots$ & $\cdots$ & $\cdots$ & $\cdots$ & $\cdots$ & $\cdots$ & $\cdots$ \\
\hline 31 & $\cdots$ & $\cdots$ & $\cdots$ & $\cdots$ & $\cdots$ & $\cdots$ & $\cdots$ & $\cdots$ & $\cdots$ & $\cdots$ & $\cdots$ & $\cdots$ \\
\hline
\end{tabular}


SURFACE-HATER DATA-Continued

DAILY MEAN SUSPENDED-SEDIMENT CONCENTRATION-Continued

09396100 PUERCO RIVER MEAR CHAMBERS, AZ-Continued

SEDIMENT, SUSPENDED CONCENTRATION (MILLIGRANS PER LITER), MATER YEAR OCTOBER 1990 TO SEPTEMBER 1991 DAILY MEAN VALUES

\begin{tabular}{|c|c|c|c|c|c|c|c|c|c|c|c|c|}
\hline DAY & OCT & NOV & DEC & JAN & FEB & MAR & APR & MAY & JUN & JUL & AUG & SEP \\
\hline $\begin{array}{l}1 \\
2 \\
3 \\
4 \\
5\end{array}$ & $\begin{array}{l}\ldots \\
\ldots \\
\ldots \\
\ldots \\
\ldots\end{array}$ & $\begin{array}{l}\ldots \\
\ldots \\
\ldots \\
\cdots \\
\cdots\end{array}$ & $\begin{array}{l}\ldots \\
\ldots \\
\ldots \\
\ldots \\
\ldots\end{array}$ & $\begin{array}{r}\ldots \\
\ldots \\
e 27000 \\
e 42000\end{array}$ & $\begin{array}{l}\ldots \\
\ldots \\
\cdots \\
\cdots\end{array}$ & $\begin{array}{l}\ldots 9200 \\
64300 \\
41300 \\
39600\end{array}$ & $\begin{array}{l}27300 \\
33700 \\
37500 \\
28100 \\
21600\end{array}$ & $\begin{array}{l}\ldots \\
\ldots \\
\ldots \\
\cdots \\
\cdots\end{array}$ & $\begin{array}{l}\ldots . \\
\ldots \\
\ldots \\
\ldots \\
\ldots\end{array}$ & $\begin{array}{l}\ldots \\
\ldots \\
\ldots \\
\cdots \\
\cdots\end{array}$ & $\begin{array}{l}23200 \\
98400 \\
69400 \\
42200 \\
20600\end{array}$ & $\begin{array}{r}\ldots \\
\ldots \\
\ldots \\
15400\end{array}$ \\
\hline $\begin{array}{r}6 \\
7 \\
8 \\
9 \\
10\end{array}$ & $\begin{array}{l}\ldots \\
\ldots \\
\ldots \\
\ldots \\
\ldots\end{array}$ & $\begin{array}{l}\ldots- \\
\ldots \\
\ldots \\
\ldots \\
\ldots\end{array}$ & $\begin{array}{l}\ldots \\
\ldots \\
\ldots \\
\ldots \\
\cdots\end{array}$ & $\begin{array}{r}\text { e70000 } \\
23800 \\
73800 \\
40600 \\
56600\end{array}$ & $\begin{array}{r}\ldots \\
e 26000 \\
34000 \\
42100\end{array}$ & $\begin{array}{r}59200 \\
37900 \\
26600 \\
\ldots \\
\ldots\end{array}$ & $\begin{array}{c}23900 \\
18300 \\
19600 \\
\ldots \\
\ldots\end{array}$ & $\begin{array}{l}\ldots \\
\ldots \\
\ldots \\
\ldots \\
\ldots\end{array}$ & $\begin{array}{c}\ldots \\
\ldots \\
\ldots \\
\ldots\end{array}$ & $\begin{array}{l}\ldots . \\
\ldots- \\
\ldots \\
\ldots\end{array}$ & $\begin{array}{c}39000 \\
97900 \\
53600 \\
\ldots \\
\ldots .\end{array}$ & $\begin{array}{r}27800 \\
24900 \\
\ldots \\
\ldots \\
\ldots\end{array}$ \\
\hline $\begin{array}{l}11 \\
12 \\
13 \\
14 \\
15\end{array}$ & $\begin{array}{l}\ldots- \\
\ldots \\
\cdots \\
\cdots \\
\cdots\end{array}$ & $\begin{array}{l}\ldots \\
\ldots \\
\ldots \\
\ldots \\
\ldots\end{array}$ & $\begin{array}{r}\ldots \\
\ldots \\
21300 \\
\ldots\end{array}$ & $\begin{array}{r}37200 \\
33100 \\
35600 \\
33100 \\
\text { e20000 }\end{array}$ & $\begin{array}{l}75700 \\
77000 \\
50200 \\
63000 \\
61100\end{array}$ & $\begin{array}{l}\ldots \\
\ldots \\
\ldots \\
\cdots\end{array}$ & $\begin{array}{l}\ldots \\
\ldots \\
\ldots \\
\ldots \\
\cdots\end{array}$ & $\begin{array}{l}\ldots \\
\ldots \\
\cdots \\
\cdots \\
\cdots\end{array}$ & $\begin{array}{l}42900 \\
40700 \\
52500 \\
23600\end{array}$ & $\begin{array}{l}\ldots- \\
\ldots \\
\ldots \\
\ldots\end{array}$ & $\begin{array}{l}\ldots \\
\ldots \\
\ldots \\
\ldots \\
\ldots\end{array}$ & $\begin{array}{l}\cdots \\
\cdots \\
\cdots\end{array}$ \\
\hline $\begin{array}{l}16 \\
17 \\
18 \\
19 \\
20\end{array}$ & $\begin{array}{c}\ldots \\
\ldots \\
\cdots \\
\cdots 3400\end{array}$ & $\begin{array}{l}\ldots \\
\cdots \\
\cdots \\
\cdots \\
\cdots\end{array}$ & $\begin{array}{l}\ldots \\
\ldots \\
\ldots \\
\ldots\end{array}$ & $\begin{array}{c}7710 \\
\ldots \\
\ldots \\
\ldots \\
\ldots\end{array}$ & $\begin{array}{c}54700 \\
62100 \\
69700 \\
22300 \\
\ldots\end{array}$ & $\begin{array}{r}\ldots \\
20700 \\
\ldots \\
\ldots \\
\ldots\end{array}$ & $\begin{array}{l}\ldots \\
\ldots \\
\ldots \\
\cdots \\
\cdots\end{array}$ & $\begin{array}{l}\ldots \\
\ldots \\
\cdots \\
\cdots \\
\cdots\end{array}$ & $\begin{array}{l}\ldots \\
\ldots \\
\ldots \\
\cdots\end{array}$ & $\begin{array}{l}\ldots \\
\ldots \\
\ldots- \\
\ldots\end{array}$ & $\begin{array}{r}22400 \\
18400 \\
\ldots \\
\ldots \\
\ldots\end{array}$ & $\begin{array}{l}-- \\
\cdots \\
- \\
-\end{array}$ \\
\hline $\begin{array}{l}21 \\
22 \\
23 \\
24 \\
25\end{array}$ & $\begin{array}{r}44000 \\
23600 \\
\ldots \\
\ldots \\
\ldots\end{array}$ & $\begin{array}{l}\ldots \\
\ldots \\
\ldots \\
\ldots \\
\cdots\end{array}$ & $\begin{array}{l}\ldots \\
\ldots \\
\ldots \\
\ldots \\
\ldots\end{array}$ & $\begin{array}{l}\ldots \\
\ldots \\
\ldots \\
\ldots \\
\ldots\end{array}$ & $\begin{array}{l}\ldots \\
\ldots \\
\cdots \\
\cdots\end{array}$ & $\begin{array}{l}\cdots \\
\cdots \\
\cdots \\
\cdots\end{array}$ & $\begin{array}{l}\ldots \\
\ldots \\
\ldots \\
\ldots \\
\ldots\end{array}$ & $\begin{array}{l}\ldots \\
\ldots \\
\ldots \\
\ldots \\
\cdots\end{array}$ & $\begin{array}{l}\ldots \\
\ldots \\
\ldots \\
\ldots \\
\cdots\end{array}$ & $\begin{array}{l}\ldots \\
\ldots \\
\ldots \\
\ldots \\
\ldots\end{array}$ & $\begin{array}{l}\ldots \\
\ldots \\
\ldots \\
\ldots \\
\ldots\end{array}$ & $\because$ \\
\hline $\begin{array}{l}26 \\
27 \\
28 \\
29 \\
30 \\
31\end{array}$ & $\begin{array}{l}\ldots \\
\ldots \\
\ldots \\
\ldots \\
\ldots\end{array}$ & $\begin{array}{l}\ldots \\
\ldots \\
\ldots \\
\ldots \\
\ldots \\
\ldots\end{array}$ & $\begin{array}{l}\ldots \\
\ldots \\
\ldots \\
\ldots \\
\ldots \\
\ldots\end{array}$ & $\begin{array}{l}\ldots \\
\ldots \\
\ldots \\
\ldots \\
\ldots\end{array}$ & $\begin{array}{l}\ldots \\
\ldots \\
\ldots \\
\ldots \\
\ldots\end{array}$ & $\begin{array}{r}\ldots \\
18200 \\
34500 \\
32200 \\
28900\end{array}$ & $\begin{array}{l}\ldots \\
\ldots \\
\ldots \\
\ldots \\
\ldots\end{array}$ & $\begin{array}{l}\cdots \\
\cdots \\
\cdots \\
\ldots \\
\cdots \\
\cdots\end{array}$ & $\begin{array}{l}\ldots \\
\ldots \\
\ldots \\
\ldots \\
\ldots\end{array}$ & $\begin{array}{r}29500 \\
44500 \\
23100 \\
12500 \\
10400 \\
\ldots\end{array}$ & $\begin{array}{r}85400 \\
25100 \\
26300 \\
22400 \\
\ldots\end{array}$ & $\begin{array}{l}\cdots \\
\cdots \\
\cdots \\
\cdots \\
\cdots\end{array}$ \\
\hline
\end{tabular}

estimated 
SURFACE-HATER DATA-Continued

DAILY MEAN SUSPENDED-SEDIMENT CONCENTRATION-Continued

09386950 ZUNI RIVER ABOVE BLACK ROCK RESERVIR, MM

REMARKS.--Sediment concentration for days when the daily mean discharge was greater than $.142 \mathrm{~m}^{3} / \mathrm{s}$ are published.

SEDIMENT, SUSPENDED CONCENTRATION (MILLIGRAMS PER LITER), WATER YEAR OCTOBER 1988 TO SEPTEMBER 1989 DAILY MEAN VALUES

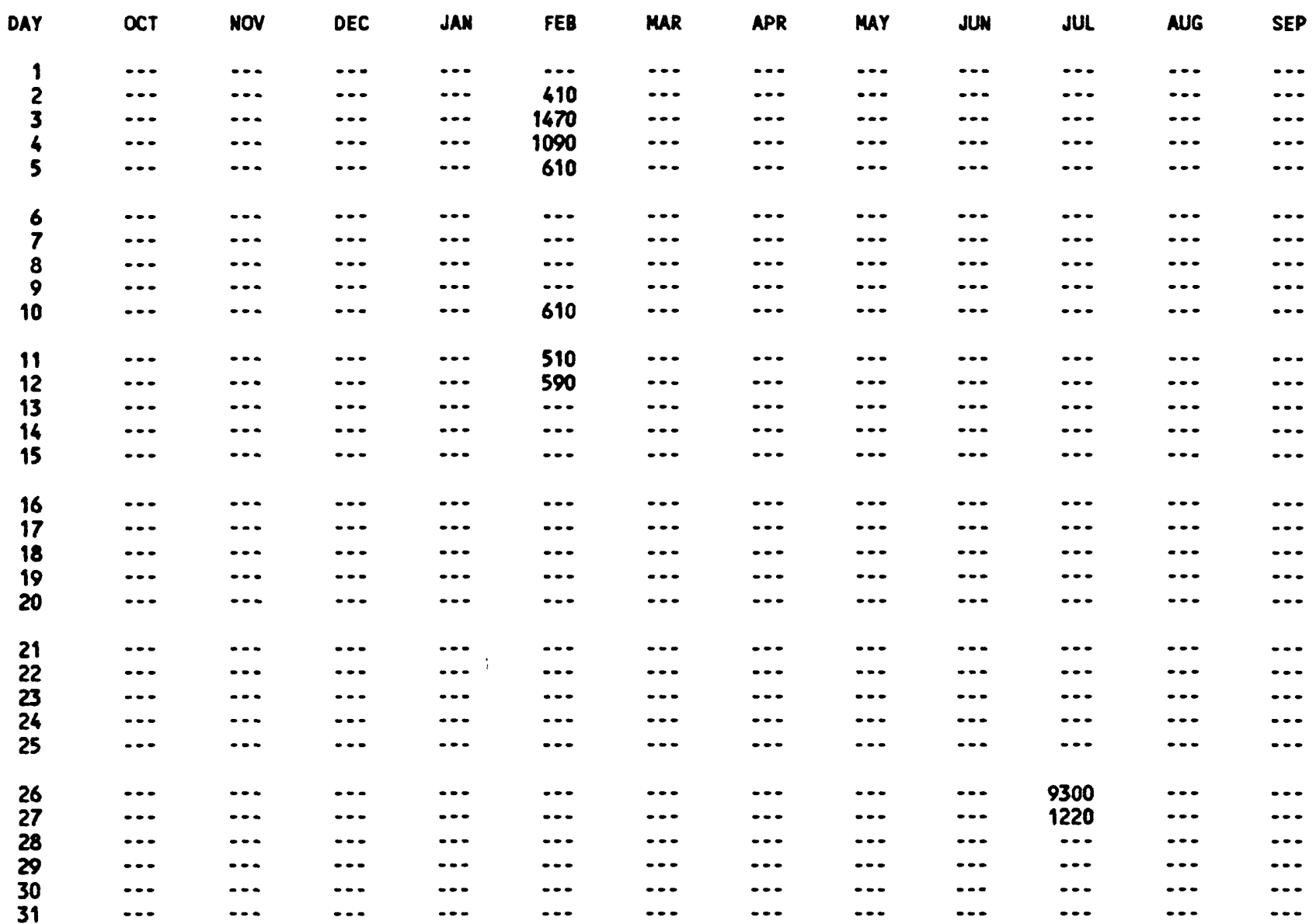


SURFACE-MATER DATA-Continued

DAILY MEAN SUSPENDED-SEDIMENT CONCENTRATION-Continued

09386950 ZUNI RIVER ABOVE BLACK ROCK RESERVOIR, NH-Continued

SEDIMENT, SUSPENDED CONCENTRATION (MILLIGRAMS PER LITER), WATER YEAR OCTOBER 1989 TO SEPTEMBER 1990 DAILY MEAN VALUES

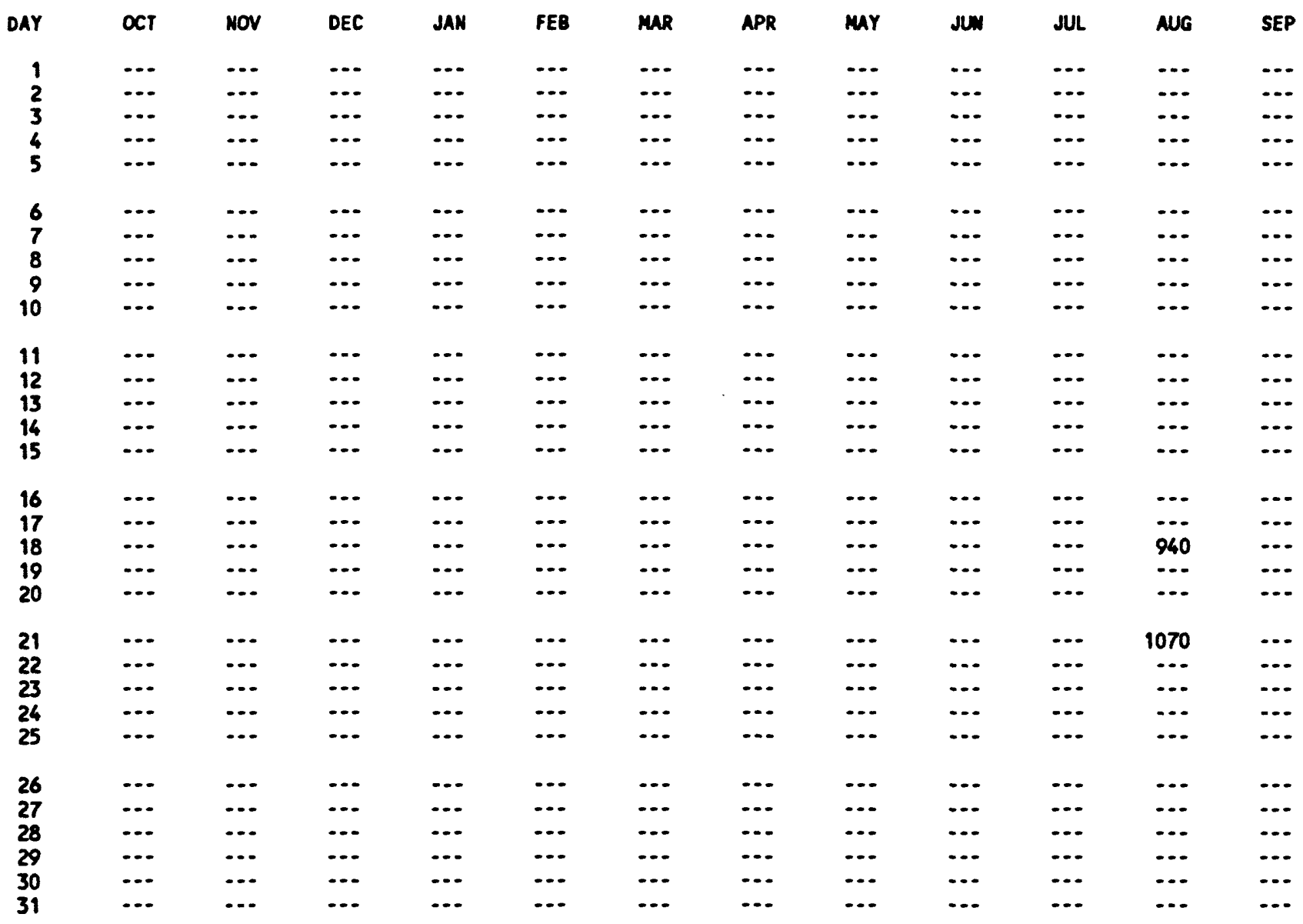


SURFACE-MATER DATA-Cont inued

DAILY MEAN SUSPENDED-SEDIMENT CONCENTRATION-Continued

09386950 ZLWI RIVER ABOVE BLACK ROCK RESERVIR, MH-Continued

SEDIMENT, SUSPENDED CONCENTRATION (MILLIGRAMS PER LITER), WATER YEAR OCTOBER 1990 TO SEPTEMBER 1991 DaILY MEAN Values

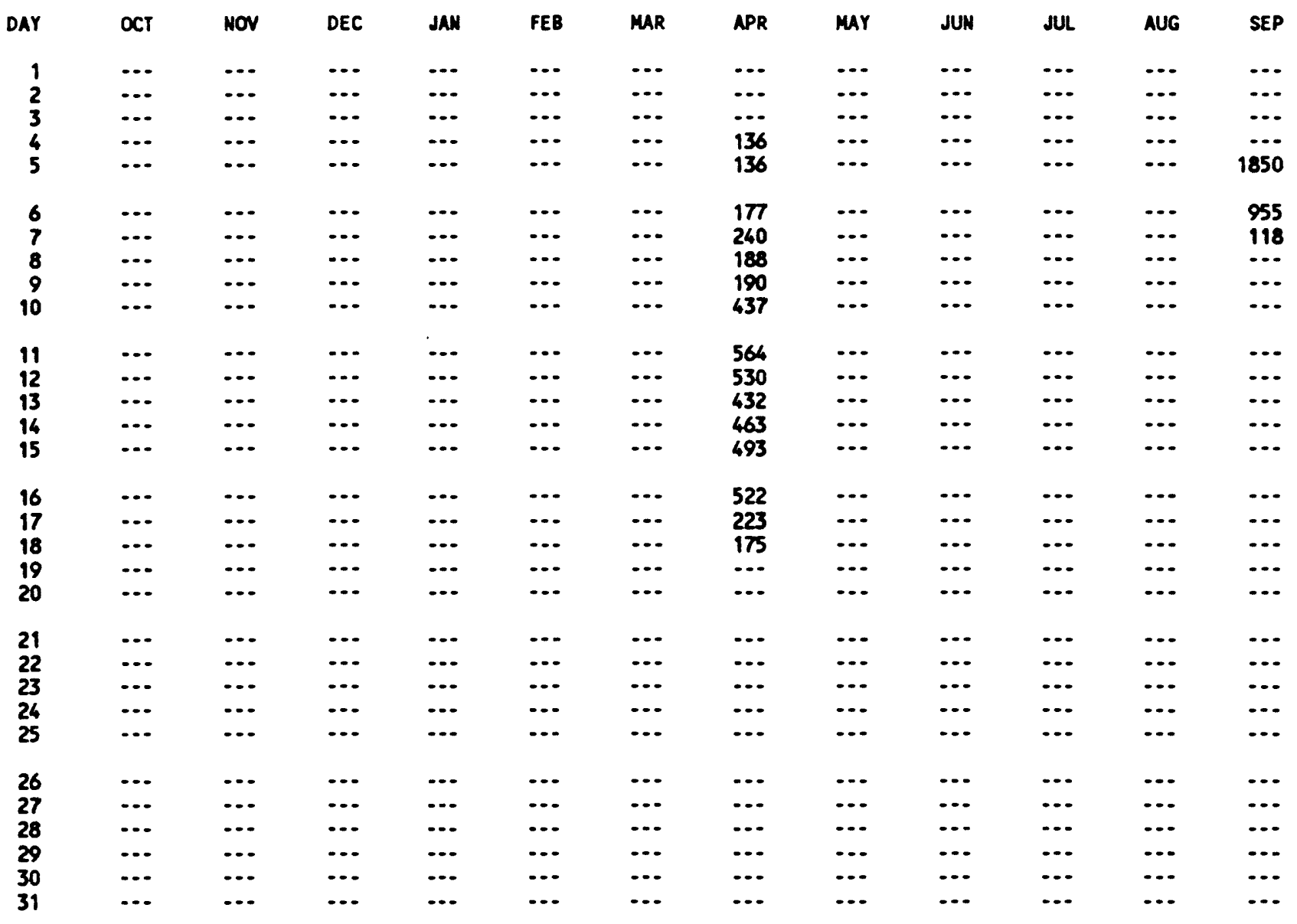


SURFACE-WATER DATA-Cont inued

DAILY MEAN SUSPENDED-SEDIMENT CONCENTRATION-Cont inued

09394500 LITTLE COLORADO RIVER AT WOOORUFF, AZ

REMARKS.---Sediment concentration for days when the daily mean discharge was greater than $.283 \mathrm{~m}^{3} / \mathrm{s}$ are published.

SEDIMENT, SUSPENDED CONCENTRATION (MILLIGRAMS PER LITER), HATER YEAR OCTOBER 1988 TO SEPTEMBER 1989 DAILY MEAN VALUES

\begin{tabular}{|c|c|c|c|c|c|c|c|c|c|c|c|c|}
\hline DAY & $O^{\prime}$ & NOV & DEC & JNN & FEB & MRR & APR & MAY & $\boldsymbol{\omega}$ & JUL & NUG & SEP \\
\hline $\begin{array}{l}1 \\
2 \\
3 \\
4 \\
5\end{array}$ & $\begin{array}{l}\ldots . \\
\ldots \\
\ldots \\
\ldots \\
\ldots\end{array}$ & $\begin{array}{l}\ldots \\
\ldots \\
\ldots \\
\ldots \\
\ldots\end{array}$ & $\begin{array}{l}\ldots \\
\ldots \\
\ldots \\
\ldots \\
\ldots\end{array}$ & $\begin{array}{l}\ldots \\
\ldots \\
\ldots \\
\ldots \\
\ldots\end{array}$ & $\begin{array}{l}\ldots \\
\ldots \\
\ldots \\
\ldots \\
\ldots\end{array}$ & $\begin{array}{l}\ldots \\
\ldots \\
\ldots \\
\ldots \\
\ldots\end{array}$ & $\begin{array}{l}\ldots \\
\ldots \\
\ldots \\
\ldots \\
\ldots\end{array}$ & $\begin{array}{l}\ldots \\
\ldots \\
\ldots \\
\ldots \\
\ldots\end{array}$ & $\begin{array}{l}\ldots \\
\ldots \\
\ldots \\
\ldots \\
\ldots\end{array}$ & $\begin{array}{l}\ldots \\
\ldots \\
\ldots \\
\ldots \\
\ldots\end{array}$ & $\begin{array}{l}6480 \\
5570 \\
3120 \\
2040 \\
1140\end{array}$ & $\begin{array}{c}\ldots \\
1590 \\
5320 \\
1580\end{array}$ \\
\hline $\begin{array}{r}6 \\
7 \\
8 \\
9 \\
10\end{array}$ & $\begin{array}{l}\ldots \\
\ldots \\
\ldots \\
\ldots \\
\ldots\end{array}$ & $\begin{array}{l}\ldots \\
\ldots \\
\ldots \\
\ldots \\
\ldots\end{array}$ & $\begin{array}{l}\ldots \\
\ldots \\
\ldots \\
\ldots \\
\ldots\end{array}$ & $\begin{array}{r}2080 \\
617 \\
\ldots . \\
\ldots \\
\ldots\end{array}$ & $\begin{array}{l}\ldots \\
\ldots \\
\ldots \\
\ldots \\
\ldots\end{array}$ & $\begin{array}{l}\ldots \\
\ldots \\
\ldots \\
\ldots \\
\ldots\end{array}$ & $\begin{array}{l}\ldots \\
\ldots \\
\ldots \\
\ldots \\
\ldots\end{array}$ & $\begin{array}{l}\ldots \\
\ldots \\
\ldots \\
\ldots \\
\ldots\end{array}$ & $\begin{array}{l}\ldots \\
\ldots \\
\ldots \\
\ldots \\
\ldots\end{array}$ & $\begin{array}{c}\ldots \\
\ldots \\
\ldots \\
1240\end{array}$ & $\begin{array}{c}630 \\
\ldots \\
\ldots \\
\ldots \\
363\end{array}$ & $\begin{array}{l}822 \\
\ldots \\
\ldots \\
\ldots \\
\ldots\end{array}$ \\
\hline $\begin{array}{l}11 \\
12 \\
13 \\
14 \\
15\end{array}$ & $\begin{array}{r}582 \\
640 \\
\ldots .- \\
847 \\
2950\end{array}$ & $\begin{array}{l}\ldots \\
\ldots \\
\ldots \\
\ldots \\
\ldots\end{array}$ & $\begin{array}{l}\ldots \\
\ldots \\
\ldots \\
\ldots \\
\ldots\end{array}$ & $\begin{array}{l}\ldots . \\
\ldots- \\
\ldots \\
\ldots \\
\ldots\end{array}$ & $\begin{array}{r}1870 \\
2060 \\
1210 \\
772 \\
\ldots .\end{array}$ & $\begin{array}{l}\ldots \\
\ldots \\
\ldots \\
\ldots \\
\ldots\end{array}$ & $\begin{array}{c}\ldots . \\
\ldots \\
1200 \\
1200\end{array}$ & $\begin{array}{l}\ldots \\
\ldots \\
\ldots \\
\ldots \\
\ldots\end{array}$ & $\begin{array}{l}\ldots \\
\ldots \\
\ldots \\
\ldots \\
\ldots\end{array}$ & $\begin{array}{r}1670 \\
1120 \\
\ldots\end{array}$ & $\begin{array}{l}\ldots \\
\ldots \\
\ldots \\
\ldots \\
\ldots\end{array}$ & $\begin{array}{l}\ldots \\
\ldots \\
\ldots \\
\ldots \\
\ldots\end{array}$ \\
\hline $\begin{array}{l}16 \\
17 \\
18 \\
19 \\
20\end{array}$ & $\begin{array}{r}2180 \\
979 \\
\ldots . \\
\ldots \\
\ldots\end{array}$ & $\begin{array}{l}\ldots \\
\ldots \\
\ldots \\
\ldots\end{array}$ & $\begin{array}{l}\ldots \\
\ldots \\
\ldots \\
\ldots \\
\ldots\end{array}$ & $\begin{array}{l}\ldots \\
\ldots \\
\ldots \\
\ldots \\
\ldots\end{array}$ & $\begin{array}{l}\ldots \\
\ldots \\
\ldots \\
\ldots\end{array}$ & $\begin{array}{l}\ldots \\
\ldots \\
\ldots \\
\ldots \\
\ldots\end{array}$ & $\begin{array}{l}\ldots \\
\ldots \\
\ldots \\
\ldots \\
\ldots\end{array}$ & $\begin{array}{l}\ldots \\
\ldots \\
\ldots \\
\ldots \\
\ldots\end{array}$ & $\begin{array}{l}\ldots \\
\ldots \\
\ldots \\
\ldots\end{array}$ & $\begin{array}{l}\ldots \\
\ldots \\
\ldots \\
\ldots \\
\ldots\end{array}$ & $\begin{array}{r}\ldots \\
20800 \\
33600 \\
11700\end{array}$ & $\begin{array}{l}\ldots \\
\ldots \\
\ldots \\
\ldots\end{array}$ \\
\hline $\begin{array}{l}29 \\
22 \\
23 \\
24 \\
25\end{array}$ & $\begin{array}{l}\ldots . \\
\ldots \\
\ldots \\
\ldots \\
\cdots\end{array}$ & $\begin{array}{l}\ldots \\
\ldots \\
\ldots \\
\ldots\end{array}$ & $\begin{array}{l}\ldots \\
\ldots \\
\ldots \\
\ldots \\
\ldots\end{array}$ & $\begin{array}{c}\ldots . \\
\ldots . \\
\ldots . \\
833\end{array}$ & $\begin{array}{l}\ldots \\
\ldots \\
\ldots \\
\ldots \\
\ldots\end{array}$ & $\begin{array}{l}\cdots \\
\cdots \\
\cdots \\
\cdots \\
\cdots\end{array}$ & $\begin{array}{l}\ldots \\
\ldots \\
\ldots \\
\ldots \\
\ldots\end{array}$ & $\begin{array}{l}\ldots \\
\ldots \\
\ldots \\
\ldots\end{array}$ & $\begin{array}{l}\ldots \\
\ldots \\
\ldots \\
\ldots\end{array}$ & $\begin{array}{r}15000 \\
4480 \\
2450\end{array}$ & $\begin{array}{r}4310 \\
1870 \\
684 \\
\ldots \\
\ldots\end{array}$ & $\ldots$ \\
\hline $\begin{array}{l}26 \\
27 \\
28 \\
29 \\
30 \\
31\end{array}$ & $\begin{array}{l}\ldots \\
\ldots \\
\ldots \\
\ldots \\
\ldots\end{array}$ & $\begin{array}{l}\ldots \\
\ldots \\
\ldots \\
\ldots \\
\ldots\end{array}$ & $\begin{array}{l}\ldots \\
\ldots \\
\ldots \\
\ldots \\
\ldots \\
\ldots\end{array}$ & $\begin{array}{l}\ldots . \\
\ldots \\
\ldots \\
\ldots \\
\ldots \\
\ldots\end{array}$ & $\begin{array}{l}\ldots \\
\ldots \\
\ldots \\
\ldots \\
\ldots \\
\ldots\end{array}$ & $\begin{array}{c}\ldots \\
1320 \\
\ldots \\
\ldots \\
\ldots \\
\ldots\end{array}$ & $\begin{array}{l}\ldots \\
\ldots \\
\ldots \\
\ldots \\
\ldots \\
\ldots\end{array}$ & $\begin{array}{l}\ldots \\
\ldots \\
\ldots \\
\ldots \\
\ldots \\
\ldots\end{array}$ & $\begin{array}{l}\ldots \\
\ldots \\
\ldots \\
\ldots \\
\ldots \\
\ldots\end{array}$ & $\begin{array}{r}11200 \\
7650 \\
5280 \\
5220 \\
4550 \\
3490\end{array}$ & $\begin{array}{l}\ldots \\
\ldots \\
\ldots \\
\ldots \\
\ldots\end{array}$ & $\begin{array}{l}\ldots \\
\ldots \\
\ldots \\
\ldots \\
\ldots \\
\ldots\end{array}$ \\
\hline
\end{tabular}


SURFACE-HATER DATA-Continued

DAILY MEAN SUSPENDED-SEDIMENT CONCENTRATION-Continued

09394500 LITTLE COLORADO RIVER AT WOOORUFF, AZ-Continued

SEDIMENT, SUSPENDED CONCENTRATION (MILLGRAMS PER LITER), WATER YEAR OCTOBER 1989 TO SEPTEMBER 1990 DAILY MEAN VALUES

\begin{tabular}{|c|c|c|c|c|c|c|c|c|c|c|c|c|}
\hline DAY & OCT & NOV & DEC & JAN & FEB & MAR & APR & MYY & JUN & JUL & AUG & SEP \\
\hline $\begin{array}{l}1 \\
2 \\
3 \\
4 \\
5\end{array}$ & $\begin{array}{l}\ldots \\
\ldots \\
\ldots \\
\ldots \\
\ldots\end{array}$ & $\begin{array}{l}\ldots \\
\ldots \\
\ldots \\
\ldots \\
\ldots\end{array}$ & $\begin{array}{l}\ldots \\
\ldots \\
\ldots \\
\ldots \\
\ldots\end{array}$ & $\begin{array}{l}\ldots \\
\ldots \\
\ldots \\
\ldots \\
\ldots\end{array}$ & $\begin{array}{l}\ldots \\
\ldots \\
\ldots \\
\ldots \\
\ldots\end{array}$ & $\begin{array}{l}\ldots \\
\ldots \\
\ldots \\
\ldots \\
\ldots\end{array}$ & $\begin{array}{l}\ldots \\
\ldots \\
\ldots \\
\ldots \\
\ldots\end{array}$ & $\begin{array}{l}\ldots \\
\ldots \\
\ldots \\
\ldots \\
\ldots\end{array}$ & $\begin{array}{l}\ldots \\
\ldots \\
\ldots \\
\ldots \\
\ldots\end{array}$ & $\begin{array}{l}\ldots . \\
\ldots \\
\cdots \\
\ldots \\
\ldots\end{array}$ & $\begin{array}{l}983 \\
\ldots \\
\ldots \\
\ldots \\
\ldots\end{array}$ & $\begin{array}{l}4210 \\
6730 \\
2870 \\
3570 \\
4280\end{array}$ \\
\hline $\begin{array}{r}6 \\
7 \\
8 \\
9 \\
10\end{array}$ & $\begin{array}{l}\ldots \\
\ldots \\
\ldots \\
\ldots \\
\ldots\end{array}$ & $\begin{array}{l}\ldots \\
\ldots \\
\ldots \\
\ldots \\
\ldots\end{array}$ & $\begin{array}{l}\ldots \\
\ldots \\
\ldots \\
\ldots \\
\ldots\end{array}$ & $\begin{array}{l}\ldots \\
\ldots \\
\ldots \\
\ldots \\
\ldots\end{array}$ & $\begin{array}{l}\ldots \\
\ldots \\
\ldots \\
\ldots \\
\ldots\end{array}$ & $\begin{array}{l}\ldots \\
\ldots \\
\ldots \\
\ldots \\
\ldots\end{array}$ & $\begin{array}{l}\ldots \\
\ldots \\
\ldots \\
\ldots \\
\ldots\end{array}$ & $\begin{array}{l}\ldots \\
\ldots \\
\ldots \\
\ldots \\
\ldots\end{array}$ & $\begin{array}{l}\ldots \\
\ldots \\
\ldots \\
\ldots \\
\ldots\end{array}$ & $\begin{array}{r}\ldots . . \\
4450 \\
9670 \\
8380 \\
2490\end{array}$ & $\begin{array}{l}\ldots \\
\ldots \\
\ldots \\
\ldots \\
\ldots\end{array}$ & $\begin{array}{r}1020 \\
1920 \\
902 \\
567 \\
\ldots .\end{array}$ \\
\hline $\begin{array}{l}11 \\
12 \\
13 \\
14 \\
15\end{array}$ & $\begin{array}{l}\ldots \\
\ldots \\
\ldots \\
\ldots \\
\ldots\end{array}$ & $\begin{array}{l}\ldots \\
\ldots \\
\ldots \\
\ldots \\
\ldots\end{array}$ & $\begin{array}{l}\ldots \\
\ldots \\
\ldots \\
\ldots \\
\ldots\end{array}$ & $\begin{array}{l}\ldots \\
\ldots \\
\ldots \\
\ldots \\
\ldots\end{array}$ & $\begin{array}{l}\ldots \\
\ldots \\
\ldots \\
\ldots \\
\ldots\end{array}$ & $\begin{array}{l}\ldots \\
\ldots \\
\ldots \\
\ldots \\
\ldots\end{array}$ & $\begin{array}{l}\ldots \\
\ldots \\
\cdots \\
\ldots \\
\ldots\end{array}$ & $\begin{array}{l}\ldots \\
\ldots \\
\ldots \\
\ldots \\
\ldots\end{array}$ & $\begin{array}{l}\ldots \\
\ldots \\
\ldots \\
\ldots \\
\ldots\end{array}$ & $\begin{array}{c}1790 \\
1410 \\
\ldots . \\
\ldots . \\
2590\end{array}$ & $\begin{array}{c}\ldots \\
\ldots \\
18000 \\
23400\end{array}$ & $\begin{array}{l}\ldots \\
\ldots \\
\ldots \\
\ldots \\
\ldots\end{array}$ \\
\hline $\begin{array}{l}16 \\
17 \\
18 \\
19 \\
20\end{array}$ & $\begin{array}{l}\ldots \\
\ldots \\
\ldots \\
\ldots \\
\ldots\end{array}$ & $\begin{array}{l}\ldots \\
\ldots \\
\ldots \\
\ldots \\
\ldots\end{array}$ & $\begin{array}{l}\ldots \\
\ldots \\
\ldots \\
\ldots \\
\ldots\end{array}$ & $\begin{array}{l}\ldots \\
\ldots \\
\ldots \\
\ldots \\
\ldots\end{array}$ & $\begin{array}{l}\ldots \\
\ldots \\
\ldots \\
\ldots \\
\ldots\end{array}$ & $\begin{array}{l}\ldots \\
\ldots \\
\ldots \\
\ldots \\
\ldots\end{array}$ & $\begin{array}{l}\cdots \\
\cdots \\
\cdots \\
\cdots \\
\cdots\end{array}$ & $\begin{array}{l}\ldots \\
\ldots \\
\ldots \\
\ldots \\
\ldots\end{array}$ & $\begin{array}{l}\ldots \\
\ldots \\
\ldots \\
\ldots \\
\ldots\end{array}$ & $\begin{array}{c}636 \\
\ldots . \\
\ldots . \\
\ldots \\
\ldots\end{array}$ & $\begin{array}{r}28100 \\
16900 \\
2790 \\
746 \\
\ldots .\end{array}$ & $\begin{array}{c}\ldots \\
\ldots \\
\ldots \\
6210\end{array}$ \\
\hline $\begin{array}{l}21 \\
22 \\
23 \\
24 \\
25\end{array}$ & $\begin{array}{l}\ldots \\
\ldots \\
\ldots \\
\ldots \\
\ldots\end{array}$ & $\begin{array}{l}\ldots \\
\ldots \\
\ldots \\
\ldots \\
\ldots\end{array}$ & $\begin{array}{l}\ldots \\
\ldots \\
\ldots \\
\ldots \\
\ldots\end{array}$ & $\begin{array}{l}\ldots \\
\ldots \\
\ldots \\
\ldots \\
\ldots\end{array}$ & $\begin{array}{l}\ldots \\
\ldots \\
\ldots \\
\ldots \\
\ldots\end{array}$ & $\begin{array}{l}\ldots \\
\ldots \\
\ldots \\
\ldots \\
\ldots\end{array}$ & $\begin{array}{l}\ldots \\
\ldots \\
\ldots \\
\ldots \\
\ldots\end{array}$ & $\begin{array}{l}\ldots \\
\ldots \\
\ldots \\
\cdots \\
\cdots\end{array}$ & $\begin{array}{l}\ldots \\
\ldots \\
\ldots \\
\ldots \\
\ldots\end{array}$ & $\begin{array}{l}\ldots . \\
\ldots \\
\ldots \\
\ldots\end{array}$ & $\begin{array}{l}\ldots \\
\ldots \\
\ldots \\
\ldots \\
\ldots\end{array}$ & $\begin{array}{r}30400 \\
17500 \\
4360 \\
2710 \\
1370\end{array}$ \\
\hline $\begin{array}{l}26 \\
27 \\
28 \\
29 \\
30 \\
31\end{array}$ & $\begin{array}{l}\ldots \\
\ldots \\
\ldots \\
\ldots \\
\ldots \\
\ldots\end{array}$ & $\begin{array}{l}\ldots \\
\ldots \\
\ldots \\
\ldots \\
\ldots \\
\ldots\end{array}$ & $\begin{array}{l}\ldots \\
\ldots \\
\ldots \\
\ldots \\
\ldots \\
\ldots\end{array}$ & $\begin{array}{l}\ldots \\
\ldots \\
\ldots \\
\ldots \\
\ldots \\
\ldots\end{array}$ & $\begin{array}{l}\ldots \\
\ldots \\
\ldots \\
\ldots \\
\ldots \\
\ldots\end{array}$ & $\begin{array}{l}\ldots \\
\ldots \\
\ldots \\
\ldots \\
\ldots \\
\ldots\end{array}$ & $\begin{array}{l}\ldots \\
\ldots \\
\ldots \\
\ldots \\
\ldots \\
\ldots\end{array}$ & $\begin{array}{l}\ldots \\
\ldots \\
\ldots \\
\ldots \\
\ldots \\
\ldots\end{array}$ & $\begin{array}{l}\ldots \\
\ldots \\
\ldots \\
\ldots \\
\ldots \\
\ldots\end{array}$ & $\begin{array}{l}\ldots \\
\ldots \\
\ldots \\
\ldots \\
\ldots \\
\ldots\end{array}$ & $\begin{array}{l}\ldots \\
\ldots \\
\ldots \\
\ldots \\
\ldots \\
\ldots\end{array}$ & $\begin{array}{l}841 \\
\ldots . \\
\ldots \\
\ldots \\
\ldots\end{array}$ \\
\hline
\end{tabular}


SURFACE-WATER DATA-Continued

DAILY MEAN SUSPENDED-SEDIMENT CONCENTRATION-Continued

09394500 LITTLE COLORADO RIVER AT WOOORUFF, AZ-Continued

SEDIMENT, SUSPENDED CONCENTRATION (MILLIGRAMS PER LITER), WATER YEAR OCTOBER 1990 TO SEPTEMBER 1991 DAILY MEAN VALUES

\begin{tabular}{|c|c|c|c|c|c|c|c|c|c|c|c|c|}
\hline DAY & $\alpha C T$ & NOV & DEC & JAN & FEB & MAR & APR & mar & JUN & JUL & NuG & SEP \\
\hline $\begin{array}{l}1 \\
2 \\
3 \\
4 \\
5\end{array}$ & $\begin{array}{r}\ldots . \\
1560 \\
753 \\
\ldots\end{array}$ & $\begin{array}{r}5690 \\
12200 \\
3930 \\
2170\end{array}$ & $\begin{array}{l}\ldots- \\
\ldots- \\
\cdots \\
\cdots \\
\cdots\end{array}$ & $\begin{array}{r}1770 \\
903 \\
\cdots \ldots \\
703 \\
1490\end{array}$ & $\begin{array}{l}\ldots \\
\ldots \\
\ldots \\
\ldots \\
\ldots\end{array}$ & $\begin{array}{r}2060 \\
29100 \\
16700 \\
10400 \\
10700\end{array}$ & $\begin{array}{l}4150 \\
4190 \\
2840 \\
1990 \\
1310\end{array}$ & $\begin{array}{l}\ldots . \\
\ldots \\
\ldots \\
\ldots\end{array}$ & $\begin{array}{l}\ldots \\
\ldots \\
\ldots \\
\ldots \\
\ldots\end{array}$ & $\begin{array}{l}\ldots \\
\ldots \\
\ldots \\
\ldots \\
\ldots\end{array}$ & $\begin{array}{r}672 \\
2740 \\
644 \\
\ldots \\
\ldots\end{array}$ & $\begin{array}{c}950 \\
622 \\
\ldots \ldots \\
1780\end{array}$ \\
\hline $\begin{array}{r}6 \\
7 \\
8 \\
9 \\
10\end{array}$ & $\begin{array}{l}\ldots \\
\ldots \\
\ldots \\
\ldots\end{array}$ & $\begin{array}{r}1420 \\
689 \\
\ldots- \\
\ldots \\
\ldots\end{array}$ & $\begin{array}{l}\ldots . \\
\ldots \\
\ldots \\
\ldots \\
\ldots\end{array}$ & $\begin{array}{r}25400 \\
36300 \\
5580 \\
2870 \\
1960\end{array}$ & $\begin{array}{l}\ldots \\
\ldots \\
\ldots \\
\ldots \\
\ldots\end{array}$ & $\begin{array}{l}9350 \\
5550 \\
2950 \\
1820 \\
1080\end{array}$ & $\begin{array}{c}850 \\
\ldots \\
\ldots \\
\ldots\end{array}$ & $\begin{array}{l}\ldots \\
\ldots \\
\ldots \\
\cdots \\
\cdots\end{array}$ & $\begin{array}{l}\ldots \\
\ldots \\
\ldots \\
\ldots \\
\ldots\end{array}$ & $\begin{array}{l}\ldots 68 \\
\ldots \\
\ldots \\
\ldots\end{array}$ & $\begin{array}{l}\ldots \\
\ldots \\
\ldots \\
\ldots\end{array}$ & $\begin{array}{r}10800 \\
4980 \\
2300 \\
1060 \\
757\end{array}$ \\
\hline $\begin{array}{l}11 \\
12 \\
13 \\
14 \\
15\end{array}$ & $\begin{array}{l}\ldots \\
\ldots \\
\ldots \\
\ldots\end{array}$ & $\begin{array}{l}\ldots \\
\ldots \\
\ldots \\
\ldots \\
\ldots\end{array}$ & $\begin{array}{l}\ldots \\
\ldots \\
\ldots \\
\ldots \\
\cdots\end{array}$ & $\begin{array}{r}1160 \\
874 \\
693 \\
\ldots \ldots \\
\ldots .\end{array}$ & $\begin{array}{l}\ldots \\
\ldots \\
\ldots \\
\ldots\end{array}$ & $\begin{array}{c}313 \\
\ldots \\
\ldots- \\
\ldots \\
\ldots\end{array}$ & $\begin{array}{l}\ldots \\
\ldots \\
\ldots \\
\ldots\end{array}$ & $\begin{array}{l}\ldots \\
\ldots \\
\ldots \\
\ldots\end{array}$ & $\begin{array}{l}\ldots \\
\ldots \\
\ldots \\
\ldots \\
\ldots\end{array}$ & $\ldots$ & $\begin{array}{l}\ldots \\
\ldots \\
\ldots \\
\ldots\end{array}$ & $\begin{array}{l}594 \\
\ldots \ldots \\
\ldots \\
\ldots\end{array}$ \\
\hline $\begin{array}{l}16 \\
17 \\
18 \\
19 \\
20\end{array}$ & $\begin{array}{l}\ldots \\
\ldots \\
\ldots \\
\ldots\end{array}$ & $\begin{array}{l}\ldots \\
\ldots \\
\ldots \\
\ldots\end{array}$ & $\begin{array}{r}748 \\
8260 \\
2960 \\
\ldots \\
\ldots\end{array}$ & $\begin{array}{l}\ldots \\
\ldots \\
\ldots \\
\ldots \\
\ldots\end{array}$ & $\begin{array}{l}\ldots \\
\ldots \\
\ldots \\
\ldots\end{array}$ & $\begin{array}{l}\ldots \\
\ldots \\
\ldots \\
\ldots\end{array}$ & $\begin{array}{l}\ldots \\
\ldots \\
\ldots \\
\ldots\end{array}$ & $\begin{array}{l}\ldots \\
\ldots \\
\ldots \\
\ldots\end{array}$ & $\begin{array}{l}\ldots \\
\ldots \\
\ldots \\
\ldots\end{array}$ & $\begin{array}{l}\ldots \\
\ldots \\
\ldots \\
\ldots\end{array}$ & $\begin{array}{l}\ldots \\
\ldots \\
\cdots \\
\cdots\end{array}$ & $\begin{array}{l}\ldots \\
\ldots \\
\ldots \\
\ldots\end{array}$ \\
\hline $\begin{array}{l}21 \\
22 \\
23 \\
24 \\
25\end{array}$ & $\begin{array}{l}662 \\
575 \\
\ldots \ldots \\
\ldots \\
\ldots\end{array}$ & $\begin{array}{l}\ldots \\
\ldots \\
\ldots \\
\ldots \\
\ldots\end{array}$ & $\begin{array}{l}\ldots \\
\ldots \\
\ldots \\
\ldots\end{array}$ & $\begin{array}{l}\ldots . \\
\ldots \\
\ldots \\
\ldots\end{array}$ & $\begin{array}{l}\ldots \\
\ldots \\
\ldots \\
\ldots \\
\ldots\end{array}$ & $\begin{array}{l}\ldots . \\
\ldots \\
\ldots 2 \\
923\end{array}$ & $\begin{array}{l}\ldots \\
\ldots \\
\ldots \\
\ldots\end{array}$ & $\begin{array}{l}\ldots \\
\ldots \\
\ldots \\
\ldots\end{array}$ & $\begin{array}{l}\ldots \\
\ldots \\
\ldots \\
\ldots \\
\ldots\end{array}$ & $\begin{array}{l}\ldots \\
\ldots \\
\ldots \\
\ldots\end{array}$ & $\begin{array}{c}\ldots \\
\ldots \\
2930 \\
5010\end{array}$ & $\begin{array}{c}\ldots . \\
2730 \\
2000 \\
\ldots\end{array}$ \\
\hline $\begin{array}{l}26 \\
27 \\
28 \\
29 \\
30 \\
31\end{array}$ & $\begin{array}{l}\ldots \\
\ldots \\
\ldots \\
\ldots\end{array}$ & $\begin{array}{l}\ldots \\
\ldots \\
\ldots \\
\ldots \\
\ldots \\
\ldots\end{array}$ & $\begin{array}{r}\ldots . \\
\ldots \\
8420 \\
5390 \\
2990\end{array}$ & $\begin{array}{l}\ldots . \\
\ldots- \\
\ldots \\
\ldots \\
\ldots \\
\ldots\end{array}$ & $\begin{array}{l}\ldots \\
\ldots \\
\ldots \\
\ldots \\
\ldots \\
\ldots\end{array}$ & $\begin{array}{l}5340 \\
4920 \\
3840 \\
3940 \\
4580 \\
4220\end{array}$ & $\begin{array}{l}\ldots \\
\ldots \\
\ldots \\
\ldots \\
\ldots\end{array}$ & $\begin{array}{l}\ldots \\
\ldots \\
\ldots \\
\ldots \\
\ldots\end{array}$ & $\begin{array}{l}\ldots \\
\ldots \\
\ldots \\
\ldots \\
\ldots \\
\ldots\end{array}$ & $\begin{array}{l}\ldots \\
\ldots \\
\ldots \\
\ldots \\
\ldots \\
\ldots\end{array}$ & $\begin{array}{r}2340 \\
1050 \\
3620 \\
1550 \\
\cdots \\
1290\end{array}$ & $\begin{array}{l}\ldots \\
\ldots \\
\ldots \\
\ldots \\
\ldots\end{array}$ \\
\hline
\end{tabular}


SURFACE-MATER DATA-Continued

DAILY MEAN SUSPENDED-SEDIMENT CONCENTRATION-CONtinued

9397300 LITTLE COLORADO RIVER MEAR JOSEPH CITY, AZ

REMARKS.--Sediment concentration for days when the daily mean discharge was greater than $1.416 \mathrm{~m}^{3} / \mathrm{s}$ are published.

SEDIMENT, SUSPENDED CONCENTRATION (MILLIGRAMS PER LITER), WATER YEAR OCTOBER 1988 TO SEPTEMBER 1989 DAILY MEAN VALUES

\begin{tabular}{|c|c|c|c|c|c|c|c|c|c|c|c|c|}
\hline DAY & OCT & NOV & DEC & JAN & FEB & MAR & APR & MAY & JUN & JUL & NuE & SEP \\
\hline $\begin{array}{l}1 \\
2 \\
3 \\
4 \\
5\end{array}$ & $\begin{array}{l}\ldots \\
\ldots \\
\ldots \\
\ldots \\
\cdots\end{array}$ & $\begin{array}{l}\ldots \\
\ldots \\
\ldots \\
\ldots \\
\cdots\end{array}$ & $\begin{array}{l}\ldots \\
\ldots \\
\ldots \\
\ldots \\
\ldots\end{array}$ & $\begin{array}{l}\ldots \\
\ldots \\
\cdots \\
\cdots \\
\cdots\end{array}$ & $\begin{array}{r}\ldots \\
\ldots \\
\ldots \\
15300\end{array}$ & $\begin{array}{l}\ldots \\
\ldots \\
\ldots \\
\cdots \\
\cdots\end{array}$ & $\begin{array}{l}\ldots \\
\ldots \\
\ldots \\
\ldots \\
\ldots\end{array}$ & $\begin{array}{l}\ldots \\
\ldots \\
\ldots \\
\ldots\end{array}$ & $\begin{array}{l}\ldots \\
\ldots \\
\ldots \\
\ldots \\
\ldots\end{array}$ & $\begin{array}{l}\ldots \\
\ldots \\
\ldots \\
\ldots \\
\ldots\end{array}$ & $\begin{array}{r}44600 \\
53000 \\
25900 \\
\ldots \\
\ldots\end{array}$ & 6990 \\
\hline $\begin{array}{r}6 \\
7 \\
8 \\
9 \\
10\end{array}$ & $\begin{array}{l}\ldots \\
\ldots \\
\ldots \\
\ldots \\
\ldots\end{array}$ & $\begin{array}{l}\ldots \\
\ldots \\
\ldots \\
\ldots \\
\cdots\end{array}$ & $\begin{array}{l}\ldots \\
\ldots \\
\ldots \\
\ldots \\
\ldots\end{array}$ & $\begin{array}{l}\ldots \\
\ldots \\
\ldots \\
\ldots \\
\ldots\end{array}$ & $\begin{array}{l}\ldots \\
\ldots \\
\ldots \\
\ldots\end{array}$ & $\begin{array}{l}\ldots . \\
\ldots \\
\ldots \\
\ldots\end{array}$ & $\begin{array}{l}\ldots \\
\ldots \\
\ldots \\
\ldots \\
\ldots\end{array}$ & $\begin{array}{l}\ldots \\
\ldots \\
\ldots \\
\ldots \\
\ldots\end{array}$ & $\begin{array}{l}\ldots \\
\ldots \\
\ldots \\
\ldots \\
\ldots\end{array}$ & $\begin{array}{l}\ldots . \\
\ldots \\
\ldots \\
\ldots \\
\cdots\end{array}$ & $\begin{array}{l}\ldots . \\
\ldots \\
\ldots- \\
\ldots-\end{array}$ & $\begin{array}{l}\ldots \\
\ldots \\
\ldots \\
\ldots\end{array}$ \\
\hline $\begin{array}{l}11 \\
12 \\
13 \\
14 \\
15\end{array}$ & $\begin{array}{l}\ldots \\
\ldots \\
\ldots \\
\ldots \\
\ldots\end{array}$ & $\begin{array}{c}\ldots . \\
\ldots \\
\ldots \\
\ldots \\
\ldots\end{array}$ & $\begin{array}{l}\ldots \\
\ldots \\
\ldots \\
\ldots \\
\ldots\end{array}$ & $\begin{array}{l}\ldots \\
\ldots \\
\ldots \\
\ldots \\
\ldots\end{array}$ & $\begin{array}{l}\ldots \\
\ldots \\
\ldots \\
\ldots \\
\ldots\end{array}$ & $\begin{array}{l}\ldots \\
\ldots \\
\ldots \\
\cdots\end{array}$ & $\begin{array}{l}\ldots- \\
\ldots \\
\ldots \\
\ldots\end{array}$ & $\begin{array}{l}\ldots \\
\ldots \\
\ldots \\
\ldots \\
\ldots\end{array}$ & $\begin{array}{l}\ldots \\
\ldots \\
\ldots \\
\ldots \\
\ldots\end{array}$ & $\begin{array}{l}\ldots . \\
\ldots \\
\ldots- \\
\ldots\end{array}$ & $\begin{array}{c}\ldots 00 \\
\ldots \\
\ldots\end{array}$ & $\begin{array}{l}\ldots \\
\ldots \\
\ldots \\
\ldots \\
\ldots\end{array}$ \\
\hline $\begin{array}{l}16 \\
17 \\
18 \\
19 \\
20\end{array}$ & $\begin{array}{l}\ldots \\
\ldots \\
\ldots \\
\ldots \\
\ldots\end{array}$ & $\begin{array}{l}\ldots \\
\ldots \\
\ldots \\
\ldots \\
\ldots\end{array}$ & $\begin{array}{l}\ldots \\
\ldots \\
\ldots \\
\ldots \\
\cdots\end{array}$ & $\begin{array}{l}\ldots \\
\ldots \\
\ldots \\
\ldots \\
\ldots\end{array}$ & $\begin{array}{l}\ldots \\
\ldots \\
\ldots \\
\ldots \\
\ldots\end{array}$ & $\begin{array}{l}\ldots \\
\ldots \\
\ldots \\
\ldots \\
\ldots\end{array}$ & $\begin{array}{l}\ldots . \\
\ldots \\
\ldots \\
\ldots \\
\ldots\end{array}$ & $\begin{array}{l}\ldots \\
\ldots \\
\ldots \\
\ldots \\
\ldots\end{array}$ & $\begin{array}{l}\ldots \\
\ldots \\
\ldots \\
\ldots \\
\ldots\end{array}$ & $\begin{array}{l}\ldots \\
\ldots \\
\ldots \\
\ldots \\
\cdots\end{array}$ & $\begin{array}{r}54600 \\
43300 \\
15800\end{array}$ & $\begin{array}{l}\ldots \\
\ldots \\
\ldots \\
\ldots\end{array}$ \\
\hline $\begin{array}{l}21 \\
22 \\
23 \\
24 \\
25\end{array}$ & $\begin{array}{l}\ldots \\
\ldots \\
\ldots \\
\ldots \\
\ldots\end{array}$ & $\begin{array}{l}\ldots \\
\ldots \\
\ldots \\
\ldots \\
\ldots\end{array}$ & $\begin{array}{l}\ldots \\
\ldots \\
\ldots \\
\ldots \\
\ldots\end{array}$ & $\begin{array}{l}\ldots \\
\ldots \\
\ldots \\
\ldots \\
\ldots\end{array}$ & $\begin{array}{l}\ldots \\
\ldots \\
\ldots \\
\ldots \\
\ldots\end{array}$ & $\begin{array}{l}\ldots . \\
\ldots \\
\ldots \\
\cdots \\
\cdots\end{array}$ & $\begin{array}{l}\ldots . \\
\ldots \\
\ldots \\
\ldots \\
\ldots\end{array}$ & $\begin{array}{l}\ldots \\
\ldots \\
\ldots \\
\ldots \\
\ldots\end{array}$ & $\begin{array}{l}\ldots \\
\ldots \\
\ldots \\
\ldots \\
\ldots\end{array}$ & $\begin{array}{r}\ldots \\
\ldots \\
\ldots \\
\ldots\end{array}$ & $\begin{array}{r}6580 \\
3440 \\
\ldots \\
\ldots \\
\ldots\end{array}$ & $\begin{array}{l}\ldots \\
\ldots \\
\ldots \\
\ldots \\
\ldots\end{array}$ \\
\hline $\begin{array}{l}26 \\
27 \\
28 \\
29 \\
30 \\
31\end{array}$ & $\begin{array}{l}\ldots \\
\ldots \\
\ldots \\
\ldots \\
\ldots \\
\ldots\end{array}$ & $\begin{array}{c}9880 \\
\ldots . \\
\ldots \\
\ldots \\
\ldots \\
\ldots .\end{array}$ & $\begin{array}{l}\ldots \\
\ldots \\
\ldots \\
\ldots \\
\ldots \\
\ldots\end{array}$ & $\begin{array}{l}\ldots \\
\ldots \\
\ldots \\
\ldots \\
\ldots \\
\ldots\end{array}$ & $\begin{array}{l}\ldots \\
\ldots \\
\ldots \\
\ldots \\
\ldots\end{array}$ & $\begin{array}{c}10800 \\
\ldots \\
\ldots \\
\ldots \\
\ldots\end{array}$ & $\begin{array}{l}\ldots \\
\ldots \\
\ldots \\
\ldots \\
\ldots\end{array}$ & $\begin{array}{l}\ldots \\
\ldots \\
\ldots \\
\ldots \\
\ldots \\
\ldots\end{array}$ & $\begin{array}{l}\ldots \\
\ldots \\
\ldots \\
\ldots \\
\ldots \\
\ldots\end{array}$ & $\begin{array}{l}36000 \\
34200 \\
22900 \\
16000 \\
23900 \\
20800\end{array}$ & $\begin{array}{l}\ldots \\
\ldots \\
\cdots \\
\cdots \\
\cdots \\
\cdots\end{array}$ & $\begin{array}{l}\ldots \\
\ldots \\
\ldots \\
\ldots \\
\ldots \\
\ldots\end{array}$ \\
\hline
\end{tabular}


SURFACE-HATER DATA-Continued

DAILY MEAN SUSPENDED-SEDIMENT CONCENTRATION-ContinUEd

09397300 LITTLE COLORADO RIVER NEAR JOSEPH CITY, AZ-Continued

SEDIMENT, SUSPENDED CONCENTRATION (MILLIGRAMS PER LITER), WATER YEAR OCTOBER 1989 TO SEPTEMBER 1990 DAILY MEAN VALUES

\begin{tabular}{|c|c|c|c|c|c|c|c|c|c|c|c|c|}
\hline DAY & OCT & Mov & DEC & JAN & FEB & MAR & APR & MAY & JUN & JUL & AUG & SEP \\
\hline 1 & $\cdots$ & $\ldots$ & $\cdots$ & $\cdots$ & $\cdots$ & $\cdots$ & ... & $\cdots$ & $\cdots$ & $\cdots$ & $\cdots$ & 11800 \\
\hline 2 & $\cdots$ & $\cdots$ & $\ldots$ & $\cdots$ & $\cdots$ & $\cdots$ & $\ldots$ & $\ldots$ & $\cdots$ & $\cdots$ & $\ldots$ & $\ldots$ \\
\hline 3 & $\cdots$ & $\cdots$ & $\cdots$ & $\cdots$ & $\cdots$ & $\cdots$ & $\cdots$ & $\cdots$ & $\cdots$ & $\cdots$ & $\cdots$ & $\cdots$ \\
\hline 4 & $\cdots$ & $\ldots$ & $\cdots$ & $\cdots$ & $\ldots$ & $\cdots$ & ... & $\cdots$ & $\cdots$ & $\cdots$ & $\cdots$ & $\cdots$ \\
\hline 5 & $\cdots$ & $\cdots$ & $\cdots$ & $\cdots$ & $\cdots$ & $\cdots$ & $\cdots$ & $\cdots$ & $\cdots$ & $\cdots$ & $\cdots$ & 23200 \\
\hline 6 & $\ldots$ & $\ldots$ & $\cdots$ & $\ldots$ & $\cdots$ & $\ldots$ & $\ldots$ & $\ldots$ & $\ldots$ & $\ldots$ & $\ldots$ & ... \\
\hline 7 & $\ldots$ & $\ldots$ & $\ldots$ & $\cdots$ & -.. & $\cdots$ & $\ldots$ & $\cdots$ & $\cdots$ & $\cdots$ & $\ldots$ & 58500 \\
\hline 8 & $\cdots$ & $\cdots$ & $\cdots$ & $\cdots$ & $\cdots$ & $\cdots$ & $\cdots$ & $\cdots$ & $\cdots$ & 26600 & $\cdots$ & ... \\
\hline 9 & $\cdots$ & $\cdots$ & $\cdots$ & $\cdots$ & $\cdots$ & $\cdots$ & $\cdots$ & $\cdots$ & $\cdots$ & 15100 & $\cdots$ & $\cdots$ \\
\hline 10 & $\cdots$ & $\cdots$ & $\cdots$ & $\cdots$ & $\cdots$ & $\cdots$ & $\cdots$ & $\cdots$ & $\cdots$ & 6980 & $\cdots$ & $\cdots$ \\
\hline 11 & $\cdots$ & $\ldots$ & $\cdots$ & $\cdots$ & $\cdots$ & $\cdots$ & $\cdots$ & $\cdots$ & $\ldots$ & $\cdots$ & $\ldots$ & $\ldots$ \\
\hline 12 & $\cdots$ & $\cdots$ & $\cdots$ & $\cdots$ & $\cdots$ & $\cdots$ & $\cdots$ & $\cdots$ & $\cdots$ & 7900 & $\cdots$ & $\cdots$ \\
\hline 13 & $\cdots$ & $\cdots$ & $\cdots$ & $\cdots$ & $\cdots$ & $\cdots$ & $\cdots$ & $\cdots$ & $\cdots$ & $\cdots$ & $\cdots$ & $\cdots$ \\
\hline 16 & $\cdots$ & $\cdots$ & $\cdots$ & $\cdots$ & $\cdots$ & $\cdots$ & $\cdots$ & $\cdots$ & $\cdots$ & 65900 & 22000 & $\cdots$ \\
\hline 15 & $\cdots$ & $\cdots$ & $\cdots$ & $\cdots$ & $\cdots$ & $\cdots$ & $\cdots$ & $\cdots$ & $\cdots$ & 103000 & 48700 & $\cdots$ \\
\hline 16 & $\cdots$ & $\cdots$ & $\cdots$ & $\cdots$ & $\cdots$ & $\ldots$ & $\cdots$ & $\cdots$ & $\cdots$ & 66000 & 66400 & $\cdots$ \\
\hline 17 & $\cdots$ & $\cdots$ & $\cdots$ & $\cdots$ & $\cdots$ & $\cdots$ & $\cdots$ & $\cdots$ & $\cdots$ & 10500 & 47900 & $\cdots$ \\
\hline 18 & $\cdots$ & $\cdots$ & $\cdots$ & $\cdots$ & $\cdots$ & $\cdots$ & $\cdots$ & $\cdots$ & $\cdots$ & 7950 & 34200 & $\cdots$ \\
\hline 19 & $\cdots$ & $\cdots$ & $\cdots$ & $\cdots$ & $\cdots$ & $\cdots$ & $\cdots$ & $\cdots$ & $\cdots$ & $\cdots$ & $\cdots$ & 30300 \\
\hline 20 & $\cdots$ & $\cdots$ & $\cdots$ & $\cdots$ & $\cdots$ & $\cdots$ & $\cdots$ & $\cdots$ & $\cdots$ & $\cdots$ & $\cdots$ & 33500 \\
\hline 21 & $\cdots$ & $\cdots$ & $\ldots$ & $\ldots$ & $\ldots$ & $\cdots$ & $\ldots$ & $\cdots$ & $\cdots$ & $\cdots$ & $\cdots$ & 46400 \\
\hline 22 & $\cdots$ & $\cdots$ & $\cdots$ & $\cdots$ & $\cdots$ & $\cdots$ & $\cdots$ & $\cdots$ & $\cdots$ & $\cdots$ & $\cdots$ & 28300 \\
\hline 23 & $\cdots$ & $\cdots$ & $\cdots$ & $\cdots$ & $\cdots$ & $\cdots$ & $\cdots$ & $\cdots$ & $\cdots$ & $\cdots$ & $\cdots$ & 29200 \\
\hline 24 & $\cdots$ & $\cdots$ & $\cdots$ & $\cdots$ & $\cdots$ & $\cdots$ & $\cdots$ & $\cdots$ & $\cdots$ & $\cdots$ & $\cdots$ & 30000 \\
\hline 25 & $\cdots$ & $\cdots$ & $\cdots$ & $\cdots$ & $\cdots$ & $\cdots$ & $\cdots$ & $\cdots$ & $\cdots$ & $\cdots$ & $\cdots$ & 27900 \\
\hline 26 & $\cdots$ & $\cdots$ & $\cdots$ & $\cdots$ & $\cdots$ & $\cdots$ & -.. & $\cdots$ & $\cdots$ & $\cdots$ & $\cdots$ & 24400 \\
\hline 27 & $\cdots$ & $\cdots$ & $\cdots$ & $\cdots$ & $\cdots$ & $\cdots$ & $\cdots$ & $\cdots$ & $\cdots$ & $\cdots$ & $\cdots$ & $\cdots$ \\
\hline 28 & $\cdots$ & $\cdots$ & $\cdots$ & $\cdots$ & $\cdots$ & $\cdots$ & $\cdots$ & $\cdots$ & $\cdots$ & $\cdots$ & $\cdots$ & $\cdots$ \\
\hline 29 & $\cdots$ & $\cdots$ & $\cdots$ & $\cdots$ & $\cdots$ & $\cdots$ & $\cdots$ & $\cdots$ & $\cdots$ & $\cdots$ & $\cdots$ & $\cdots$ \\
\hline 30 & $\cdots$ & $\cdots$ & $\cdots$ & $\cdots$ & $\cdots$ & $\cdots$ & $\cdots$ & $\cdots$ & $\cdots$ & $\cdots$ & $\cdots$ & $\cdots$ \\
\hline 31 & $\cdots$ & $\cdots$ & $\cdots$ & $\cdots$ & $\cdots$ & $\cdots$ & $\cdots$ & $\cdots$ & & $\cdots$ & $\cdots$ & $\cdots$ \\
\hline
\end{tabular}


SURFACE-HATER DATA-Cont inued

DAILY MEAN SUSPENDED-SEDIMENT CONCENTRATION-Continued

09397300 LITTLE COLORADO RIVER NEAR JOSEPH CITY, A2-Continued

SEDIMENT, SUSPENDED CONCENTRATION (MILLIGRAMS PER LITER), WATER YEAR OCTOBER 1990 TO SEPTEMBER 1991 DAILY MEAN VALUES

\begin{tabular}{|c|c|c|c|c|c|c|c|c|c|c|c|c|}
\hline DAY & OCT & MOV & DEC & JAN & FEB & MAR & APR & MAY & JUN & JUL & AUS & SEP \\
\hline $\begin{array}{l}1 \\
2 \\
3 \\
4 \\
5\end{array}$ & $\begin{array}{l}\ldots \\
\ldots \\
\ldots \\
\ldots \\
\cdots\end{array}$ & $\begin{array}{r}\ldots \\
44500 \\
15000 \\
\ldots\end{array}$ & $\begin{array}{l}\ldots \\
\ldots \\
\cdots \\
\cdots \\
\cdots\end{array}$ & $\begin{array}{r}\ldots \\
\ldots \\
14300 \\
31700\end{array}$ & $\begin{array}{l}\ldots \\
\ldots \\
\cdots \\
\cdots \\
\cdots\end{array}$ & $\begin{array}{r}\ldots 5500 \\
53700 \\
29000 \\
21400\end{array}$ & $\begin{array}{l}15100 \\
22300 \\
18100 \\
15800 \\
12800\end{array}$ & $\begin{array}{l}\ldots \\
\ldots \\
\ldots \\
\cdots \\
\cdots\end{array}$ & $\begin{array}{l}\cdots \\
\cdots \\
\cdots \\
\cdots \\
\cdots\end{array}$ & $\begin{array}{l}\cdots \\
\cdots \\
\cdots \\
\cdots \\
\cdots\end{array}$ & $\begin{array}{r}9450 \\
\ldots \\
11600 \\
\ldots\end{array}$ & $\begin{array}{l}\ldots \\
\cdots \\
\cdots \\
\cdots\end{array}$ \\
\hline $\begin{array}{r}6 \\
7 \\
8 \\
9 \\
10\end{array}$ & $\begin{array}{l}\ldots \\
\ldots \\
\ldots \\
\cdots \\
\cdots\end{array}$ & $\begin{array}{l}\cdots \\
\cdots \\
\cdots \\
\cdots\end{array}$ & $\begin{array}{l}\cdots \\
\cdots \\
\cdots \\
\cdots \\
\cdots\end{array}$ & $\begin{array}{r}85300 \\
34200 \\
9360 \\
5000 \\
2590\end{array}$ & $\begin{array}{l}\cdots \\
\cdots \\
\cdots \\
\cdots \\
\cdots\end{array}$ & $\begin{array}{r}18300 \\
30900 \\
21800 \\
13400 \\
6600\end{array}$ & $\begin{array}{c}9490 \\
\ldots \\
\ldots \\
\ldots\end{array}$ & $\begin{array}{l}\cdots \\
\cdots \\
\cdots \\
\cdots \\
\cdots\end{array}$ & $\begin{array}{l}\ldots \\
\ldots \\
\cdots \\
\cdots \\
\cdots\end{array}$ & $\begin{array}{l}\cdots \\
\cdots \\
\cdots \\
\cdots \\
\cdots\end{array}$ & $\begin{array}{c}\ldots \\
104000 \\
\ldots \\
\ldots\end{array}$ & $\begin{array}{r}28300 \\
20300 \\
16200 \\
\ldots \\
\ldots\end{array}$ \\
\hline $\begin{array}{l}11 \\
12 \\
13 \\
16 \\
15\end{array}$ & $\begin{array}{l}\ldots . \\
\ldots . \\
\cdots \\
\cdots \\
\cdots\end{array}$ & $\begin{array}{l}\cdots \\
\cdots \\
\cdots \\
\cdots \\
\cdots\end{array}$ & $\begin{array}{l}\cdots \\
\ldots \\
\cdots \\
\cdots \\
\cdots\end{array}$ & $\begin{array}{r}1510 \\
907 \\
\ldots \\
\ldots\end{array}$ & $\begin{array}{r}4320 \\
16200 \\
17700 \\
18000 \\
17700\end{array}$ & $\begin{array}{l}\ldots \\
\cdots \\
\cdots \\
\cdots\end{array}$ & $\begin{array}{c}\ldots . \\
\ldots \\
\ldots- \\
\cdots \\
\cdots\end{array}$ & $\begin{array}{l}\cdots \\
\cdots \\
\cdots \\
\cdots \\
\cdots\end{array}$ & $\begin{array}{l}\ldots \\
\ldots \\
\cdots \\
\cdots \\
\cdots\end{array}$ & $\begin{array}{l}\cdots \\
\cdots \\
\cdots \\
\cdots \\
\cdots\end{array}$ & $\begin{array}{l}\ldots . \\
\ldots \\
\ldots \\
\ldots \\
\ldots\end{array}$ & $\begin{array}{l}\ldots \\
\ldots \\
\cdots \\
\cdots \\
\cdots\end{array}$ \\
\hline $\begin{array}{l}16 \\
17 \\
18 \\
19 \\
20\end{array}$ & $\begin{array}{r}\ldots \\
\ldots \\
\ldots \\
\ldots \\
15900\end{array}$ & $\begin{array}{l}\ldots \\
\ldots \\
\ldots \\
\ldots \\
\cdots\end{array}$ & $\begin{array}{r}91600 \\
82600 \\
37100 \\
\ldots \\
\ldots\end{array}$ & $\begin{array}{l}\ldots \\
\ldots \\
\cdots \\
\cdots \\
\cdots\end{array}$ & $\begin{array}{r}14900 \\
9120 \\
14100 \\
11300 \\
5750\end{array}$ & $\begin{array}{l}\ldots \\
\ldots \\
\ldots \\
\cdots \\
\cdots\end{array}$ & $\begin{array}{l}\ldots \\
\ldots \\
\ldots \\
\ldots \\
\cdots\end{array}$ & $\begin{array}{l}\ldots \\
\cdots \\
\cdots \\
\cdots \\
\cdots\end{array}$ & $\begin{array}{l}\ldots \\
\ldots \\
\ldots \\
\cdots \\
\cdots\end{array}$ & $\begin{array}{l}\ldots \\
\ldots \\
\ldots \\
\cdots \\
\cdots\end{array}$ & $\begin{array}{l}\ldots . \\
\ldots \\
\ldots \\
\ldots \\
\ldots\end{array}$ & $\begin{array}{l}\ldots \\
\ldots \\
\ldots \\
\ldots \\
\cdots\end{array}$ \\
\hline $\begin{array}{l}21 \\
22 \\
23 \\
24 \\
25\end{array}$ & $\begin{array}{r}34600 \\
\ldots \\
\ldots \\
\ldots \\
\ldots\end{array}$ & $\begin{array}{l}\ldots \\
\cdots \\
\cdots \\
\cdots \\
\cdots\end{array}$ & $\begin{array}{l}\cdots \\
\cdots \\
\cdots \\
\cdots \\
\cdots\end{array}$ & $\begin{array}{l}\ldots \\
\cdots \\
\cdots \\
\cdots \\
\cdots\end{array}$ & $\begin{array}{l}\ldots \\
\ldots \\
\ldots \\
\ldots \\
\ldots\end{array}$ & $\begin{array}{l}\cdots \\
\cdots \\
\cdots \\
\cdots \\
\cdots\end{array}$ & $\begin{array}{l}\ldots \\
\ldots \\
\cdots \\
\cdots \\
\cdots\end{array}$ & $\begin{array}{l}\ldots \\
\ldots \\
\ldots \\
\cdots \\
\cdots\end{array}$ & $\begin{array}{l}\cdots \\
\cdots \\
\cdots \\
\cdots \\
\cdots\end{array}$ & $\begin{array}{l}\cdots \\
\cdots \\
\cdots \\
\cdots \\
\cdots\end{array}$ & $\begin{array}{l}\ldots \\
\ldots \\
\ldots \\
\ldots \\
\ldots\end{array}$ & $\begin{array}{l}\ldots \\
\ldots \\
\ldots \\
\cdots \\
\cdots\end{array}$ \\
\hline $\begin{array}{l}26 \\
27 \\
28 \\
29 \\
30 \\
31\end{array}$ & $\begin{array}{l}\ldots . \\
\ldots \\
\ldots \\
\ldots \\
\ldots \\
\ldots\end{array}$ & $\begin{array}{l}\cdots \\
\ldots \\
\cdots \\
\cdots \\
\ldots \\
\ldots\end{array}$ & $\begin{array}{c}\ldots \\
\ldots \\
17900 \\
26700 \\
\ldots\end{array}$ & $\begin{array}{l}\cdots \\
\cdots \\
\ldots \\
\cdots \\
\cdots \\
\cdots\end{array}$ & $\begin{array}{l}\ldots \\
\ldots \\
\ldots \\
\ldots \\
\ldots \\
\ldots\end{array}$ & $\begin{array}{l}11000 \\
15400 \\
12600 \\
12900 \\
13300 \\
13700\end{array}$ & $\begin{array}{l}\ldots \\
\ldots \\
\ldots \\
\ldots \\
\cdots \\
\cdots\end{array}$ & $\begin{array}{l}\cdots \\
\cdots \\
\cdots \\
\cdots \\
\cdots \\
\cdots\end{array}$ & $\begin{array}{l}\ldots \\
\ldots \\
\ldots \\
\ldots \\
\ldots \\
\ldots\end{array}$ & $\begin{array}{l}\ldots \\
\ldots \\
\ldots \\
\cdots \\
\cdots \\
\ldots\end{array}$ & $\begin{array}{r}\ldots \\
162000 \\
\ldots \\
\ldots \\
\ldots\end{array}$ & $\begin{array}{l}\cdots \\
\ldots \\
\cdots \\
\cdots \\
\cdots \\
\cdots\end{array}$ \\
\hline
\end{tabular}


SURFACE- WATER DATA-Continued

DAILY MEAN SUSPENDED-SEDIMENT CONCENTRATION-Continued

09401000 LITTLE COLORADO RIVER AT GRAND FALLS, AZ

REMARKS.--Sediment concentration for days when the daily mean discharge was greater than .566 $\mathrm{m}^{3} / \mathrm{s}$ are published.

SEDIMENT, SUSPENDED CONCENTRATION (MILLIGRAMS PER LITER), WATER YEAR OCTOBER 1989 TO SEPTEMBER 1990 DAILY MEAN VALUES

\begin{tabular}{|c|c|c|c|c|c|c|c|c|c|c|c|c|}
\hline DAY & OCT & MOV & DEC & JAN & FEB & MAR & APR & MYY & JUN & JUL & AUG & SEP \\
\hline 1 & $\ldots$ & $\ldots$ & $\ldots$ & $\ldots$ & $\ldots$ & $\ldots$ & $\ldots$ & $\ldots$ & $\ldots$ & ... & $\ldots$ & $\ldots$ \\
\hline 2 & $\cdots$ & $\cdots$ & $\cdots$ & $\cdots$ & $\cdots$ & $\cdots$ & -.. & $\cdots$ & $\ldots$ & $\cdots$ & $\cdots$ & $\ldots$ \\
\hline 3 & $\cdots$ & $\cdots$ & $\ldots$ & $\cdots$ & $\cdots$ & $\cdots$ & $\cdots$ & $\cdots$ & $\cdots$ & $\cdots$ & $\cdots$ & 36600 \\
\hline 4 & $\cdots$ & $\cdots$ & $\cdots$ & $\cdots$ & $\ldots$ & $\cdots$ & $\cdots$ & $\cdots$ & $\cdots$ & $\ldots$ & $\cdots$ & 47800 \\
\hline 5 & $\cdots$ & $\cdots$ & $\cdots$ & $\cdots$ & $\cdots$ & $\cdots$ & $\cdots$ & $\cdots$ & $\cdots$ & $\cdots$ & $\cdots$ & 42600 \\
\hline 6 & $\ldots$ & $\cdots$ & $\cdots$ & $\cdots$ & $\cdots$ & $\cdots$ & $\cdots$ & $\cdots$ & $\cdots$ & $\cdots$ & $\cdots$ & 39700 \\
\hline 7 & $\ldots$ & $\cdots$ & $\ldots$ & $\cdots$ & -. & $\cdots$ & $\ldots$ & $\ldots$ & $\cdots$ & $\ldots$ & -.. & 38800 \\
\hline 8 & $\ldots$ & $\cdots$ & $\ldots$ & $\ldots$ & $\ldots$ & $\cdots$ & $\ldots$ & $\ldots$ & $\cdots$ & $\cdots$ & ... & 33800 \\
\hline 9 & $\cdots$ & $\cdots$ & $\cdots$ & $\cdots$ & $\ldots$ & $\cdots$ & $\cdots$ & $\ldots$ & $\ldots$ & 33100 & $\cdots$ & 40400 \\
\hline 10 & $\cdots$ & $\cdots$ & $\cdots$ & $\cdots$ & $\cdots$ & $\cdots$ & 1310 & $\cdots$ & $\cdots$ & 50900 & $\cdots$ & 34700 \\
\hline 11 & $\ldots$ & $\cdots$ & $\cdots$ & $\cdots$ & $\cdots$ & $\cdots$ & 1780 & $\cdots$ & $\cdots$ & 48100 & $\cdots$ & 27300 \\
\hline 12 & $\cdots$ & $\cdots$ & $\cdots$ & $\cdots$ & $\cdots$ & $\cdots$ & 1400 & $\cdots$ & $\cdots$ & 45000 & $\cdots$ & $\cdots$ \\
\hline 13 & $\cdots$ & $\cdots$ & $\cdots$ & $\cdots$ & $\cdots$ & $\cdots$ & 1110 & $\cdots$ & $\cdots$ & 38700 & $\cdots$ & $\cdots$ \\
\hline 14 & $\cdots$ & $\cdots$ & $\cdots$ & $\cdots$ & $\cdots$ & $\cdots$ & 896 & $\cdots$ & $\cdots$ & 40400 & $\cdots$ & $\cdots$ \\
\hline 15 & $\cdots$ & $\cdots$ & $\cdots$ & $\cdots$ & $\cdots$ & $\cdots$ & $\cdots$ & $\cdots$ & $\cdots$ & 38800 & $\cdots$ & $\cdots$ \\
\hline 16 & $\ldots$ & $\ldots$ & $\ldots$ & $\ldots$ & $\ldots$ & $\cdots$ & $\ldots$ & $\ldots$ & $\ldots$ & 73200 & 29400 & $\ldots$ \\
\hline 17 & $\cdots$ & $\cdots$ & $\cdots$ & $\cdots$ & $\cdots$ & $\cdots$ & $\cdots$ & $\cdots$ & $\ldots$ & 105000 & 93200 & $\cdots$ \\
\hline 18 & $\cdots$ & $\cdots$ & $\cdots$ & $\cdots$ & $\cdots$ & $\cdots$ & $\cdots$ & $\cdots$ & $\cdots$ & 64900 & 77000 & $\cdots$ \\
\hline 19 & $\cdots$ & $\cdots$ & $\cdots$ & $\cdots$ & $\cdots$ & $\cdots$ & $\ldots$ & $\ldots$ & $\ldots$ & 65100 & 71900 & 22700 \\
\hline 20 & $\cdots$ & $\cdots$ & $\cdots$ & $\cdots$ & $\cdots$ & $\cdots$ & $\cdots$ & $\cdots$ & $\cdots$ & 56900 & 63400 & 44200 \\
\hline 21 & $\cdots$ & $\cdots$ & $\cdots$ & $\cdots$ & $\cdots$ & $\cdots$ & $\cdots$ & $\cdots$ & $\cdots$ & 52800 & 52200 & 40500 \\
\hline 22 & $\cdots$ & $\cdots$ & $\cdots$ & $\cdots$ & $\cdots$ & $\cdots$ & $\cdots$ & $\cdots$ & $\cdots$ & 59500 & 43100 & 65700 \\
\hline 23 & $\ldots$ & $\cdots$ & $\cdots$ & $\cdots$ & $\cdots$ & $\cdots$ & $\cdots$ & $\cdots$ & $\cdots$ & 44800 & $\ldots$ & 55300 \\
\hline 24 & $\cdots$ & $\cdots$ & $\cdots$ & $\cdots$ & $\cdots$ & $\cdots$ & $\cdots$ & $\cdots$ & $\ldots$ & 35700 & $\ldots$ & 42800 \\
\hline 25 & $\cdots$ & $\cdots$ & $\cdots$ & $\cdots$ & $\cdots$ & $\cdots$ & $\cdots$ & $\cdots$ & $\cdots$ & $\cdots$ & 43900 & 43300 \\
\hline 26 & $\cdots$ & $\cdots$ & $\cdots$ & $\cdots$ & $\cdots$ & $\cdots$ & $\cdots$ & $\cdots$ & $\cdots$ & $\cdots$ & $\cdots$ & 40900 \\
\hline 27 & $\cdots$ & $\cdots$ & $\cdots$ & $\cdots$ & $\cdots$ & $\cdots$ & $\cdots$ & $\cdots$ & $\cdots$ & $\cdots$ & $\cdots$ & 37300 \\
\hline 28 & $\ldots$ & $\cdots$ & $\cdots$ & $\cdots$ & $\cdots$ & $\cdots$ & $\cdots$ & $\cdots$ & $\cdots$ & $\cdots$ & $\ldots$ & 31300 \\
\hline 29 & $\cdots$ & $\cdots$ & $\cdots$ & $\cdots$ & $\cdots$ & $\cdots$ & $\cdots$ & $\cdots$ & $\cdots$ & $\cdots$ & $\cdots$ & 27100 \\
\hline 30 & $\cdots$ & $\cdots$ & $\ldots$ & $\cdots$ & $\cdots$ & $\cdots$ & $\cdots$ & $\cdots$ & $\cdots$ & $\cdots$ & $\cdots$ & $\cdots$ \\
\hline 31 & $\cdots$ & $\cdots$ & $\cdots$ & $\cdots$ & $\cdots$ & $\cdots$ & $\cdots$ & $\cdots$ & $\cdots$ & $\cdots$ & $\cdots$ & $\cdots$ \\
\hline
\end{tabular}


SURFACE-WATER DATA-Cont inued

DAILY MEAN SUSPENDED-SEDIMENT CONCENTRATION-Continued

09401000 LITTLE COLORADO RIVER AT GRAND FALLS, AZ-Continued

SEDIMENT, SUSPENDED CONCENTRATION (MILLGRMS PER LITER), WATER YEAR OCTOBER 1990 TO SEPTEMBER 1991 DAILY MEAN VALUES

\begin{tabular}{|c|c|c|c|c|c|c|c|c|c|c|c|c|}
\hline DAY & OCT & NOV & DEC & JAN & FEB & MAR & APR & MAY & JUN & JUL & AUG & SEP \\
\hline $\begin{array}{l}1 \\
2 \\
3 \\
4 \\
5\end{array}$ & $\begin{array}{l}\cdots \\
\cdots \\
\cdots \\
\cdots \\
\cdots\end{array}$ & $\begin{array}{r}\ldots \\
\ldots \\
24300 \\
44000\end{array}$ & $\begin{array}{l}\cdots \\
\cdots \\
\cdots \\
\cdots \\
\cdots\end{array}$ & $\begin{array}{l}27700 \\
26900 \\
23400 \\
22600 \\
25500\end{array}$ & $\begin{array}{l}\ldots \\
\ldots \\
\ldots \\
\ldots\end{array}$ & $\begin{array}{l}12000 \\
12000 \\
23700 \\
29400 \\
23500\end{array}$ & $\begin{array}{l}10100 \\
10600 \\
10300 \\
14700 \\
13100\end{array}$ & $\begin{array}{l}2530 \\
2210 \\
2000 \\
1800 \\
1610\end{array}$ & $\begin{array}{l}\ldots \\
\ldots \\
\ldots \\
\ldots\end{array}$ & $\begin{array}{l}\ldots \\
\ldots \\
\ldots \\
\cdots\end{array}$ & $\begin{array}{l}\ldots \\
\ldots \\
\ldots \\
\ldots\end{array}$ & $\begin{array}{l}\ldots \\
\ldots \\
\ldots \\
\ldots \\
\ldots\end{array}$ \\
\hline $\begin{array}{r}6 \\
7 \\
8 \\
9 \\
10\end{array}$ & $\begin{array}{l}\ldots \\
\ldots \\
\cdots \\
\cdots \\
\cdots\end{array}$ & $\begin{array}{r}38200 \\
34200 \\
\ldots \\
\ldots \\
\ldots\end{array}$ & $\begin{array}{l}\ldots \\
\ldots \\
\ldots \\
\cdots \\
\cdots\end{array}$ & $\begin{array}{l}29300 \\
41900 \\
40900 \\
30600 \\
25200\end{array}$ & $\begin{array}{l}\ldots \\
\ldots \\
\ldots \\
\ldots \\
\cdots\end{array}$ & $\begin{array}{l}20800 \\
22600 \\
16100 \\
15400 \\
12100\end{array}$ & $\begin{array}{r}11600 \\
15300 \\
16600 \\
11900 \\
9670\end{array}$ & $\begin{array}{l}1500 \\
1410 \\
1390 \\
1320 \\
1200\end{array}$ & $\begin{array}{l}\ldots \\
\ldots \\
\ldots \\
\cdots \\
\cdots\end{array}$ & $\begin{array}{l}\ldots \\
\ldots \\
\ldots \\
\cdots\end{array}$ & $\begin{array}{l}\ldots \\
\ldots \\
\ldots \\
\ldots\end{array}$ & $\begin{array}{r}\ldots \\
\ldots \\
58100 \\
57500 \\
53100\end{array}$ \\
\hline $\begin{array}{l}11 \\
12 \\
13 \\
14 \\
15\end{array}$ & $\begin{array}{l}\cdots \\
\cdots \\
\cdots \\
\cdots\end{array}$ & $\begin{array}{l}\ldots \\
\ldots \\
\cdots \\
\cdots\end{array}$ & $\begin{array}{l}\ldots \\
\ldots \\
\cdots \\
\cdots\end{array}$ & $\begin{array}{l}23500 \\
20300 \\
19000 \\
17900 \\
16600\end{array}$ & $\begin{array}{c}\ldots \\
\ldots \\
\ldots 5 \\
\ldots\end{array}$ & $\begin{array}{r}10500 \\
9580 \\
9200 \\
8770 \\
7880\end{array}$ & $\begin{array}{r}22800 \\
24200 \\
16400 \\
12100 \\
9170\end{array}$ & $\begin{array}{r}1100 \\
998 \\
912 \\
887 \\
798\end{array}$ & $\begin{array}{l}\cdots \\
\cdots \\
\cdots \\
\cdots \\
\cdots\end{array}$ & $\begin{array}{l}\ldots \\
\ldots \\
\ldots \\
\ldots\end{array}$ & $\begin{array}{c}\ldots \\
38100 \\
\ldots \\
\ldots \\
\ldots\end{array}$ & $\begin{array}{r}49700 \\
44900 \\
\ldots \\
\ldots \\
\ldots\end{array}$ \\
\hline $\begin{array}{l}16 \\
17 \\
18 \\
19 \\
20\end{array}$ & $\begin{array}{l}\ldots \\
\ldots \\
\ldots \\
\cdots \\
\cdots\end{array}$ & $\begin{array}{c}\ldots \\
\ldots \\
\cdots \\
\cdots\end{array}$ & $\begin{array}{r}\cdots \\
12200 \\
30700 \\
23100 \\
19000\end{array}$ & $\begin{array}{c}15900 \\
15000 \\
13800 \\
\ldots \\
\ldots\end{array}$ & $\begin{array}{l}17000 \\
16200 \\
16000 \\
16100 \\
16600\end{array}$ & $\begin{array}{l}7920 \\
7740 \\
7660 \\
7360 \\
6760\end{array}$ & $\begin{array}{l}5770 \\
5980 \\
7860 \\
8740 \\
8050\end{array}$ & $\begin{array}{l}698 \\
\ldots \\
\ldots \\
\ldots \\
\ldots\end{array}$ & $\begin{array}{l}\ldots \\
\ldots \\
\ldots \\
\ldots \\
\ldots\end{array}$ & $\begin{array}{l}\ldots \\
\ldots \\
\ldots \\
\ldots \\
\ldots\end{array}$ & $\begin{array}{l}\ldots \\
\ldots \\
\ldots \\
\ldots \\
\ldots\end{array}$ & $\begin{array}{l}\ldots \\
\ldots \\
\ldots \\
\cdots \\
\cdots\end{array}$ \\
\hline $\begin{array}{l}21 \\
22 \\
23 \\
24 \\
25\end{array}$ & $\begin{array}{r}28200 \\
43300 \\
31500 \\
\ldots\end{array}$ & $\begin{array}{l}\ldots \\
\ldots \\
\ldots \\
\cdots\end{array}$ & $\begin{array}{r}13800 \\
13900 \\
14700 \\
14900 \\
\ldots\end{array}$ & $\begin{array}{l}\ldots \\
\ldots \\
\cdots \\
\cdots \\
\cdots\end{array}$ & $\begin{array}{r}15000 \\
13000 \\
11200 \\
10400 \\
9410\end{array}$ & $\begin{array}{l}6090 \\
6170 \\
7240 \\
7470 \\
6870\end{array}$ & $\begin{array}{l}7490 \\
7120 \\
7370 \\
6920 \\
5980\end{array}$ & $\begin{array}{l}\ldots \\
\ldots \\
\ldots \\
\ldots \\
\ldots\end{array}$ & $\begin{array}{l}\cdots \\
\ldots \\
\ldots \\
\cdots\end{array}$ & $\begin{array}{l}\ldots \\
\ldots \\
\ldots \\
\ldots\end{array}$ & $\begin{array}{l}\ldots \\
\ldots \\
\ldots \\
\ldots \\
\ldots\end{array}$ & $\begin{array}{l}\ldots \\
\ldots \\
\ldots \\
\ldots \\
\ldots\end{array}$ \\
\hline $\begin{array}{l}26 \\
27 \\
28 \\
29 \\
30 \\
31\end{array}$ & $\begin{array}{l}\ldots \\
\ldots \\
\ldots \\
\ldots \\
\ldots \\
\ldots\end{array}$ & $\begin{array}{l}\ldots \\
\ldots \\
\ldots \\
\ldots \\
\cdots\end{array}$ & $\begin{array}{c}\ldots \\
\ldots \\
\ldots \\
\ldots \\
\ldots \\
30200\end{array}$ & $\begin{array}{l}\ldots \\
\ldots \\
\ldots \\
\ldots \\
\cdots\end{array}$ & $\begin{array}{r}8150 \\
8300 \\
11500 \\
\ldots \\
\ldots \\
\ldots\end{array}$ & $\begin{array}{l}6570 \\
6610 \\
8970 \\
9100 \\
9320 \\
9660\end{array}$ & $\begin{array}{c}5030 \\
4480 \\
4420 \\
3920 \\
3040 \\
\ldots . .\end{array}$ & $\begin{array}{l}\cdots \\
\cdots \\
\cdots \\
\cdots \\
\cdots \\
\cdots\end{array}$ & $\begin{array}{l}\ldots \\
\ldots \\
\ldots \\
\ldots \\
\ldots \\
\ldots\end{array}$ & $\begin{array}{l}\ldots \\
\ldots \\
\ldots \\
\ldots \\
\ldots\end{array}$ & $\begin{array}{l}\ldots \\
\ldots \\
\ldots \\
\ldots \\
\ldots \\
\ldots\end{array}$ & $\begin{array}{l}\ldots \\
\ldots \\
\ldots \\
\ldots \\
\ldots\end{array}$ \\
\hline
\end{tabular}


SURFACE-HATER DATA-Continued

DAILY MEAN SUSPENDED-SEDIMENT CONCENTRATION-Cont inued

09402000 LITTLE COLORADO RIVER NEAR CAMERON, AZ

REMARKS.--Sediment concentration for days when the dally mean discharge was greater than $.566 m^{3} / 8$ are publiahed.

SEDIMENT, SUSPENDED CONCENTRATION (MILLIGRAMS PER LITER), WATER YEAR OCTOBER 1989 TO SEPTEMBER 1990 DAILY MEAN VALUES

\begin{tabular}{|c|c|c|c|c|c|c|c|c|c|c|c|c|}
\hline DAY & OCT & NOV & DEC & JAN & FEB & MAR & APR & MAY & HUM & JUL & AUG & SEP \\
\hline $\begin{array}{l}1 \\
2 \\
3 \\
4 \\
5\end{array}$ & $\begin{array}{c}\ldots . \\
\ldots \\
5400 \\
\ldots .\end{array}$ & $\begin{array}{l}\ldots \\
\ldots \\
\ldots \\
\ldots \\
\ldots\end{array}$ & $\begin{array}{l}\ldots \\
\ldots \\
\ldots \\
\ldots \\
\cdots\end{array}$ & $\begin{array}{l}\ldots \\
\ldots \\
\ldots \\
\ldots \\
\ldots\end{array}$ & $\begin{array}{l}\ldots \\
\ldots \\
\ldots \\
\ldots \\
\cdots\end{array}$ & $\begin{array}{l}\ldots \\
\ldots \\
\ldots \\
\ldots \\
\ldots\end{array}$ & $\begin{array}{l}\ldots \\
\ldots \\
\ldots \\
\ldots \\
\ldots\end{array}$ & $\begin{array}{l}\ldots \\
\ldots \\
\ldots \\
\ldots \\
\ldots\end{array}$ & $\begin{array}{l}\ldots \\
\ldots \\
\ldots \\
\ldots \\
\ldots\end{array}$ & $\begin{array}{l}\cdots \\
\ldots \\
\cdots \\
\cdots \\
\cdots\end{array}$ & $\begin{array}{r}\ldots \\
36400 \\
\ldots \\
\ldots\end{array}$ & $\begin{array}{r}\ldots \\
69100 \\
60100\end{array}$ \\
\hline $\begin{array}{r}6 \\
7 \\
8 \\
9 \\
10\end{array}$ & $\begin{array}{l}\ldots \\
\ldots \\
\ldots \\
\ldots \\
\ldots\end{array}$ & $\begin{array}{l}\ldots \\
\cdots \\
\cdots \\
\cdots \\
\cdots\end{array}$ & $\begin{array}{l}\ldots \\
\ldots \\
\ldots \\
\ldots \\
\ldots\end{array}$ & $\begin{array}{l}\ldots \\
\ldots \\
\cdots \\
\cdots \\
\cdots\end{array}$ & $\begin{array}{l}\ldots . \\
\ldots \\
\ldots \\
\ldots \\
\ldots\end{array}$ & $\begin{array}{l}\ldots \\
\ldots . \\
\ldots . \\
\ldots \\
\ldots\end{array}$ & $\begin{array}{l}\ldots \\
\ldots \\
\ldots \\
\cdots \\
\cdots\end{array}$ & $\begin{array}{l}\ldots \\
\ldots \\
\cdots \\
\cdots \\
\cdots\end{array}$ & $\begin{array}{l}\ldots . \\
\ldots \\
\cdots \\
\cdots \\
\cdots\end{array}$ & $\begin{array}{r}\ldots \\
55200 \\
63300 \\
68500\end{array}$ & $\begin{array}{l}\ldots \\
\ldots \\
\ldots \\
\ldots\end{array}$ & $\begin{array}{l}60700 \\
59500 \\
54900 \\
49200 \\
39700\end{array}$ \\
\hline $\begin{array}{l}11 \\
12 \\
13 \\
14 \\
15\end{array}$ & $\begin{array}{l}\ldots . \\
\ldots \\
\cdots \\
\cdots\end{array}$ & $\begin{array}{l}\ldots \\
\ldots \\
\ldots \\
\ldots \\
\ldots\end{array}$ & $\begin{array}{l}\ldots \\
\ldots \\
\ldots \\
\ldots \\
\ldots\end{array}$ & $\begin{array}{l}\ldots \\
\ldots \\
\ldots \\
\ldots \\
\ldots\end{array}$ & $\begin{array}{l}\ldots \\
\ldots \\
\ldots \\
\ldots \\
\ldots\end{array}$ & $\begin{array}{l}\ldots \\
\ldots \\
\ldots \\
\ldots \\
\ldots\end{array}$ & $\begin{array}{l}\ldots \\
\ldots \\
\ldots \\
\ldots \\
\ldots\end{array}$ & $\begin{array}{l}\ldots \\
\ldots \\
\ldots \\
\ldots \\
\ldots\end{array}$ & $\begin{array}{l}\ldots \\
\ldots \\
\ldots \\
\ldots \\
\ldots\end{array}$ & $\begin{array}{l}69900 \\
66000 \\
56900 \\
52900 \\
52400\end{array}$ & $\begin{array}{c}\ldots \\
\ldots \\
\ldots \\
\ldots \\
53800\end{array}$ & $\begin{array}{r}29600 \\
20800 \\
\ldots \\
\ldots \\
\ldots\end{array}$ \\
\hline $\begin{array}{l}16 \\
17 \\
18 \\
19 \\
20\end{array}$ & $\begin{array}{l}\ldots . \\
\ldots \\
\ldots \\
\ldots \\
\ldots\end{array}$ & $\begin{array}{l}\ldots \\
\ldots \\
\ldots \\
\ldots \\
\ldots\end{array}$ & $\begin{array}{l}\ldots \\
\ldots \\
\ldots \\
\ldots \\
\ldots\end{array}$ & $\begin{array}{l}\ldots \\
\ldots \\
\ldots \\
\ldots \\
\ldots\end{array}$ & $\begin{array}{l}\ldots \\
\ldots \\
\ldots \\
\ldots \\
\ldots\end{array}$ & $\begin{array}{l}\ldots \\
\ldots \\
\ldots \\
\ldots\end{array}$ & $\begin{array}{l}\ldots \\
\ldots \\
\ldots \\
\ldots \\
\ldots\end{array}$ & $\begin{array}{l}\ldots \\
\ldots \\
\ldots \\
\ldots \\
\ldots\end{array}$ & $\begin{array}{l}\ldots \\
\ldots \\
\ldots \\
\ldots \\
\ldots\end{array}$ & $\begin{array}{r}42400 \\
45300 \\
34300 \\
9020 \\
11400\end{array}$ & $\begin{array}{l}61400 \\
76000 \\
80500 \\
77600 \\
81100\end{array}$ & $\begin{array}{r}24800 \\
53300 \\
82300 \\
96800 \\
108000\end{array}$ \\
\hline $\begin{array}{l}21 \\
22 \\
23 \\
24 \\
25\end{array}$ & $\begin{array}{l}\ldots \\
\ldots \\
\ldots- \\
\ldots \\
\ldots\end{array}$ & $\begin{array}{l}\ldots \\
\ldots \\
\ldots \\
\ldots \\
\ldots\end{array}$ & $\begin{array}{l}\ldots \\
\ldots \\
\ldots \\
\ldots \\
\ldots\end{array}$ & $\begin{array}{l}\ldots \\
\ldots \\
\ldots \\
\ldots \\
\ldots\end{array}$ & $\begin{array}{r}27200 \\
28500 \\
40600 \\
\ldots \\
\ldots\end{array}$ & $\begin{array}{l}\ldots \\
\ldots \\
\ldots \\
\ldots \\
\ldots\end{array}$ & $\begin{array}{l}\ldots \\
\ldots \\
\ldots \\
\ldots \\
\ldots\end{array}$ & $\begin{array}{l}\ldots \\
\ldots \\
\ldots \\
\ldots \\
\cdots\end{array}$ & $\begin{array}{l}\ldots \\
\ldots \\
\ldots \\
\ldots \\
\ldots\end{array}$ & $\begin{array}{r}6770 \\
8180 \\
10500 \\
17400 \\
14500\end{array}$ & $\begin{array}{r}87200 \\
88800 \\
84400 \\
\ldots \\
\ldots\end{array}$ & $\begin{array}{l}97400 \\
65900 \\
67900 \\
74400 \\
59200\end{array}$ \\
\hline $\begin{array}{l}26 \\
27 \\
28 \\
29 \\
30 \\
31\end{array}$ & $\begin{array}{l}\ldots . \\
\ldots \\
\ldots \\
\ldots \\
\ldots \\
\ldots\end{array}$ & $\begin{array}{l}\ldots \\
\ldots \\
\ldots \\
\ldots \\
\ldots \\
\ldots\end{array}$ & $\begin{array}{l}\ldots \\
\ldots \\
\ldots \\
\ldots \\
\ldots \\
\ldots\end{array}$ & $\begin{array}{l}\ldots \\
\ldots \\
\ldots \\
\ldots \\
\ldots \\
\ldots\end{array}$ & $\begin{array}{l}\ldots \\
\ldots \\
\ldots \\
\ldots \\
\ldots \\
\ldots\end{array}$ & $\begin{array}{l}\ldots \\
\ldots \\
\ldots \\
\ldots \\
\ldots\end{array}$ & $\begin{array}{l}\ldots \\
\ldots \\
\ldots \\
\ldots \\
\ldots \\
\ldots\end{array}$ & $\begin{array}{l}\ldots \\
\ldots \\
\ldots \\
\ldots \\
\ldots \\
\ldots\end{array}$ & $\begin{array}{l}\ldots \\
\ldots \\
\ldots \\
\ldots \\
\ldots\end{array}$ & $\begin{array}{l}\ldots \\
\ldots \\
\ldots \\
\ldots \\
\ldots \\
\ldots\end{array}$ & $\begin{array}{c}28600 \\
20600 \\
\ldots \\
\ldots \\
\ldots \\
\ldots\end{array}$ & $\begin{array}{r}60200 \\
58000 \\
54000 \\
45500 \\
41200\end{array}$ \\
\hline
\end{tabular}


SURFACE-WATER DATA-Cont inued

DAILY MEAN SUSPENDED-SEDIMENT CONCENTRATION-Cont inued

09402000 LITTLE COLORADO RIVER NEAR CAMERON, AZ-Continued

SEDIMENT, SUSPENDED CONCENTRATION (MILLIGRAMS PER LITER), WATER YEAR OCTOBER 1990 TO SEPTEMBER 1991 DAILY MEAN VALUES

\begin{tabular}{|c|c|c|c|c|c|c|c|c|c|c|c|c|}
\hline DAY & OCT & NOV & DEC & JAN & FEB & MAR & APR & Mar & JUN & JUL & AUG & SEP \\
\hline $\begin{array}{l}1 \\
2 \\
3 \\
4 \\
5\end{array}$ & $\begin{array}{l}34000 \\
35100 \\
59500 \\
57000 \\
49500\end{array}$ & $\begin{array}{c}\ldots \\
\ldots \\
\ldots \\
\ldots \\
44300\end{array}$ & $\begin{array}{l}\cdots \\
\cdots \\
\cdots \\
\cdots \\
\cdots\end{array}$ & $\begin{array}{l}21200 \\
24900 \\
29300 \\
30000 \\
29300\end{array}$ & $\begin{array}{l}\ldots \\
\ldots \\
\ldots \\
\ldots \\
\ldots\end{array}$ & $\begin{array}{l}13100 \\
15300 \\
22100 \\
44900 \\
47700\end{array}$ & $\begin{array}{l}27600 \\
30600 \\
32900 \\
34500 \\
36500\end{array}$ & $\begin{array}{l}4980 \\
4010 \\
3100 \\
2900 \\
2810\end{array}$ & $\begin{array}{l}\ldots \\
\ldots \\
\ldots \\
\ldots \\
\ldots\end{array}$ & $\begin{array}{l}\ldots \\
\cdots \\
\cdots \\
\cdots \\
\cdots\end{array}$ & $\begin{array}{l}\ldots \\
\ldots \\
\ldots \\
\ldots \\
\ldots\end{array}$ & $\begin{array}{r}\cdots \\
130000 \\
155000 \\
145000 \\
140000\end{array}$ \\
\hline $\begin{array}{r}6 \\
7 \\
8 \\
9 \\
10\end{array}$ & $\begin{array}{l}\ldots \\
\ldots \\
\ldots \\
\ldots \\
\ldots\end{array}$ & $\begin{array}{l}39400 \\
30500 \\
26800 \\
23100 \\
20100\end{array}$ & $\begin{array}{l}\ldots \\
\ldots \\
\cdots \\
\cdots \\
\cdots\end{array}$ & $\begin{array}{l}28700 \\
55000 \\
73200 \\
60300 \\
40700\end{array}$ & $\begin{array}{l}\ldots \\
\ldots \\
\ldots \\
\ldots \\
\cdots\end{array}$ & $\begin{array}{l}44700 \\
45900 \\
47000 \\
47300 \\
43700\end{array}$ & $\begin{array}{l}43200 \\
48600 \\
50800 \\
51600 \\
52000\end{array}$ & $\begin{array}{l}2770 \\
2600 \\
2610 \\
2300 \\
2200\end{array}$ & $\begin{array}{l}\ldots \\
\ldots \\
\ldots \\
\ldots \\
\ldots\end{array}$ & $\begin{array}{l}\ldots \\
\ldots \\
\ldots \\
\ldots \\
\ldots\end{array}$ & $\begin{array}{r}\ldots . \\
36500 \\
54300 \\
\ldots \\
\ldots\end{array}$ & $\begin{array}{r}152000 \\
130000 \\
108000 \\
88700 \\
80700\end{array}$ \\
\hline $\begin{array}{l}11 \\
12 \\
13 \\
14 \\
15\end{array}$ & $\begin{array}{l}\ldots \\
\ldots \\
\ldots \\
\ldots \\
\ldots\end{array}$ & $\begin{array}{l}\ldots \\
\ldots \\
\ldots \\
\ldots \\
\ldots\end{array}$ & $\begin{array}{l}\cdots \\
\cdots \\
\cdots \\
\cdots \\
\cdots\end{array}$ & $\begin{array}{l}30400 \\
25200 \\
22200 \\
20800 \\
19600\end{array}$ & $\begin{array}{l}\ldots \\
\ldots \\
\ldots \\
\ldots \\
\ldots\end{array}$ & $\begin{array}{l}38100 \\
33600 \\
30700 \\
29000 \\
27700\end{array}$ & $\begin{array}{l}52300 \\
52300 \\
51100 \\
47500 \\
49300\end{array}$ & $\begin{array}{r}2100 \\
1940 \\
1480 \\
973 \\
595\end{array}$ & $\begin{array}{l}\ldots \\
\ldots \\
\cdots \\
\cdots \\
\cdots\end{array}$ & $\begin{array}{l}\ldots \\
\ldots \\
\ldots \\
\ldots \\
\cdots\end{array}$ & $\begin{array}{l}\ldots \\
\ldots \\
\ldots \\
\ldots \\
\ldots\end{array}$ & $\begin{array}{r}69800 \\
60500 \\
54900 \\
51200 \\
\ldots .\end{array}$ \\
\hline $\begin{array}{l}16 \\
17 \\
18 \\
19 \\
20\end{array}$ & $\begin{array}{l}\ldots \\
\ldots \\
\cdots \\
\cdots \\
\cdots\end{array}$ & $\begin{array}{l}\ldots \\
\ldots \\
\ldots \\
\cdots \\
\cdots\end{array}$ & $\begin{array}{r}\ldots \\
38500 \\
45900 \\
38400\end{array}$ & $\begin{array}{l}21200 \\
19100 \\
17000 \\
15000 \\
13000\end{array}$ & $\begin{array}{r}\ldots . . \\
19500 \\
18300 \\
17200 \\
17700\end{array}$ & $\begin{array}{l}27200 \\
27100 \\
27000 \\
27000 \\
27000\end{array}$ & $\begin{array}{l}34300 \\
30100 \\
30000 \\
30400 \\
30200\end{array}$ & $\begin{array}{l}\ldots \\
\ldots \\
\ldots \\
\ldots \\
\ldots\end{array}$ & $\begin{array}{l}\cdots \\
\cdots \\
\cdots \\
\cdots \\
\cdots\end{array}$ & $\begin{array}{l}\ldots . \\
\ldots \\
\ldots \\
\ldots \\
\ldots\end{array}$ & $\begin{array}{l}\ldots \\
\ldots \\
\cdots \\
\ldots \\
\cdots\end{array}$ & 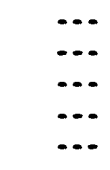 \\
\hline $\begin{array}{l}21 \\
22 \\
23 \\
24 \\
25\end{array}$ & $\begin{array}{r}\ldots . \\
28200 \\
55200 \\
47700\end{array}$ & $\begin{array}{l}\ldots \\
\ldots \\
\ldots \\
\ldots \\
\ldots\end{array}$ & $\begin{array}{l}33900 \\
29900 \\
25700 \\
22300 \\
21200\end{array}$ & $\begin{array}{c}11100 \\
\ldots \\
\ldots \\
\ldots \\
\ldots\end{array}$ & $\begin{array}{l}17000 \\
16000 \\
15000 \\
14000 \\
13500\end{array}$ & $\begin{array}{l}27000 \\
27000 \\
27000 \\
27000 \\
27000\end{array}$ & $\begin{array}{l}27700 \\
23900 \\
20200 \\
18800 \\
14000\end{array}$ & $\begin{array}{l}\ldots \\
\ldots \\
\ldots \\
\ldots \\
\ldots\end{array}$ & $\begin{array}{l}\ldots \\
\ldots \\
\ldots \\
\cdots\end{array}$ & $\begin{array}{l}\ldots \\
\ldots \\
\ldots \\
\ldots \\
\ldots\end{array}$ & $\begin{array}{l}\ldots \\
\ldots \\
\ldots \\
\ldots \\
\ldots\end{array}$ & 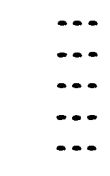 \\
\hline $\begin{array}{l}26 \\
27 \\
28 \\
29 \\
30 \\
31\end{array}$ & $\begin{array}{r}39500 \\
29600 \\
\ldots \\
\ldots \\
\ldots \\
\ldots\end{array}$ & $\begin{array}{l}\ldots \\
\ldots \\
\ldots \\
\ldots \\
\ldots \\
\ldots\end{array}$ & $\begin{array}{l}\ldots \\
\ldots \\
\ldots \\
\ldots \\
\ldots \\
\ldots\end{array}$ & $\begin{array}{l}\ldots \\
\ldots \\
\ldots \\
\ldots \\
\ldots \\
\ldots\end{array}$ & $\begin{array}{c}13000 \\
12500 \\
12200 \\
\ldots \\
\ldots \\
\ldots\end{array}$ & $\begin{array}{l}27000 \\
27000 \\
27400 \\
29500 \\
29000 \\
28000\end{array}$ & $\begin{array}{r}12000 \\
9610 \\
8090 \\
6980 \\
5980 \\
\ldots . .\end{array}$ & $\begin{array}{l}\ldots \\
\ldots \\
\ldots \\
\ldots \\
\ldots \\
\ldots\end{array}$ & $\begin{array}{l}\cdots \\
\ldots \\
\cdots \\
\cdots \\
\ldots \\
\ldots\end{array}$ & $\begin{array}{l}\ldots \\
\ldots \\
\ldots \\
\ldots \\
\ldots\end{array}$ & $\begin{array}{r}18700 \\
133000 \\
110000 \\
\ldots \\
\ldots\end{array}$ & $\because$ \\
\hline
\end{tabular}


SURFACE-MATER DATA-Continued

DAILY MEAN SUSPENDED-SEDIMENT DISCHARGE

09395350 PUERCO RIVER NEAR CHURCH ROCK, MM

REMARKS.--Sediment load for days when the daily mean discharge was greater than $.283 \mathbf{m}^{3} / \mathrm{s}$ are published.

SEDIMENT DISCHARGE, SUSPENDED (MEGAGRAMS/DAY), MAY 1989 TO SEPTEMBER 1989 DAILY MEAN VALUES

\begin{tabular}{|c|c|c|c|c|c|c|c|c|c|c|c|c|}
\hline DAY & OCT & NOV & DEC & JAN & FEB & MAR & APR & mar & JuN & JUL & AUG & SEP \\
\hline 1 & $\ldots$ & $\ldots$ & $\cdots$ & $\cdots$ & $\ldots$ & $\ldots$ & $\ldots$ & $\ldots$ & $\ldots$ & $\ldots$ & 2690 & $\ldots$ \\
\hline 2 & $\ldots$ & $\ldots$ & $\cdots$ & $\cdots$ & $\cdots$ & $\ldots$ & $\cdots$ & $\cdots$ & $\cdots$ & $\ldots$ & 7250 & $\cdots$ \\
\hline 3 & $\ldots$ & $\cdots$ & $\cdots$ & $\cdots$ & $\cdots$ & $\cdots$ & $\ldots$ & $\ldots$ & $\cdots$ & $\cdots$ & $\cdots$ & $\cdots$ \\
\hline 4 & $\ldots$ & $\ldots$ & $\ldots$ & $\cdots$ & $\ldots$ & $\cdots$ & $\ldots$ & $\cdots$ & $\cdots$ & $\cdots$ & $\ldots$ & $\ldots$ \\
\hline 5 & $\cdots$ & $\cdots$ & $\cdots$ & $\cdots$ & $\cdots$ & $\cdots$ & $\cdots$ & $\cdots$ & $\cdots$ & $\cdots$ & $\cdots$ & 49800 \\
\hline 6 & $\ldots$ & $\ldots$ & $\ldots$ & $\ldots$ & $\ldots$ & $\cdots$ & $\ldots$ & $\cdots$ & $\cdots$ & $\ldots$ & $\ldots$ & 1230 \\
\hline 7 & $\ldots$ & $\ldots$ & $\cdots$ & $\cdots$ & $\ldots$ & $\cdots$ & $\ldots$ & $\ldots$ & $\ldots$ & $\ldots$ & $\ldots$ & $\ldots$ \\
\hline 8 & $\ldots$ & $\ldots$ & $\ldots$ & $\cdots$ & $\ldots$ & $\ldots$ & $\cdots$ & $\ldots$ & $\ldots$ & $\ldots$ & $\ldots$ & $\ldots$ \\
\hline 9 & $\ldots$ & $\cdots$ & $\cdots$ & $\cdots$ & $\cdots$ & $\cdots$ & $\cdots$ & $\cdots$ & $\cdots$ & $\ldots$ & $\cdots$ & $\cdots$ \\
\hline 10 & $\cdots$ & $\cdots$ & $\cdots$ & $\cdots$ & $\cdots$ & $\cdots$ & $\cdots$ & $\cdots$ & $\cdots$ & $\cdots$ & $\cdots$ & $\cdots$ \\
\hline 11 & $\ldots$ & $\ldots$ & $\ldots$ & $\cdots$ & $\ldots$ & $\ldots$ & $\ldots$ & $\cdots$ & $\ldots$ & $\ldots$ & $\ldots$ & $\ldots$ \\
\hline 12 & $\ldots$ & $\ldots$ & $\ldots$ & $\ldots$ & $\ldots$ & $\ldots$ & $\ldots$ & $\cdots$ & $\ldots$ & $\cdots$ & $\ldots$ & $\ldots$ \\
\hline 13 & $\ldots$ & $\ldots$ & $\cdots$ & $\cdots$ & $\cdots$ & $\cdots$ & $\cdots$ & $\cdots$ & $\cdots$ & $\ldots$ & $\cdots$ & .. \\
\hline 14 & $\ldots$ & $\ldots$ & $\ldots$ & $\cdots$ & $\ldots$ & $\ldots$ & $\ldots$ & $\ldots$ & $\ldots$ & $\ldots$ & $\ldots$ & $\cdots$ \\
\hline 15 & $\cdots$ & $\cdots$ & $\cdots$ & $\cdots$ & $\cdots$ & $\cdots$ & $\cdots$ & $\cdots$ & $\cdots$ & $\cdots$ & $\cdots$ & $\cdots$ \\
\hline 16 & $\ldots$ & $\ldots$ & $\ldots$ & $\ldots$ & $\ldots$ & $\ldots$ & $\ldots$ & $\ldots$ & $\ldots$ & $\ldots$ & $\ldots$ & $\ldots$ \\
\hline 17 & $\cdots$ & $\cdots$ & $\ldots$ & $\cdots$ & $\cdots$ & $\cdots$ & $\cdots$ & $\cdots$ & $\cdots$ & $\cdots$ & $\cdots$ & $\cdots$ \\
\hline 18 & $\ldots$ & $\ldots$ & $\ldots$ & $\cdots$ & $\cdots$ & $\cdots$ & $\cdots$ & $\cdots$ & $\cdots$ & $\cdots$ & $\cdots$ & $\cdots$ \\
\hline 19 & $\cdots$ & $\ldots$ & $\ldots$ & $\cdots$ & $\cdots$ & $\cdots$ & $\cdots$ & $\cdots$ & $\cdots$ & -- & $\cdots$ & $\cdots$ \\
\hline 20 & $\cdots$ & $\cdots$ & $\cdots$ & $\cdots$ & $\cdots$ & $\cdots$ & $\cdots$ & $\cdots$ & $\cdots$ & $\cdots$ & $\cdots$ & $\cdots$ \\
\hline 21 & $\ldots$ & $\cdots$ & $\cdots$ & $\cdots$ & $\cdots$ & $\cdots$ & $\cdots$ & $\cdots$ & $\cdots$ & $\cdots$ & $\cdots$ & $\cdots$ \\
\hline 22 & $\cdots$ & $\cdots$ & $\cdots$ & $\cdots$ & $\cdots$ & $\cdots$ & $\cdots$ & $\cdots$ & $\cdots$ & $\cdots$ & $\cdots$ & $\cdots$ \\
\hline 23 & $\cdots$ & $\cdots$ & $\cdots$ & $\cdots$ & $\cdots$ & $\cdots$ & $\cdots$ & $\cdots$ & $\cdots$ & 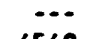 & $\cdots$ & $\cdots$ \\
\hline 24 & $\cdots$ & $\cdots$ & $\cdots$ & $\cdots$ & $\cdots$ & $\cdots$ & $\cdots$ & $\cdots$ & $\cdots$ & 4540 & $\cdots$ & $\cdots$ \\
\hline 25 & $\cdots$ & $\cdots$ & $\cdots$ & $\cdots$ & $\cdots$ & $\cdots$ & $\cdots$ & $\cdots$ & $\cdots$ & 1160 & $\cdots$ & $\cdots$ \\
\hline 26 & $\ldots$ & $\cdots$ & $\ldots$ & $\cdots$ & $\cdots$ & $\cdots$ & $\cdots$ & $\cdots$ & $\cdots$ & 53200 & $\cdots$ & -.. \\
\hline 27 & $\cdots$ & $\cdots$ & $\cdots$ & $\cdots$ & $\cdots$ & $\cdots$ & $\cdots$ & $\cdots$ & $\cdots$ & 12400 & $\cdots$ & $\cdots$ \\
\hline 28 & $\cdots$ & $\ldots$ & $\cdots$ & $\cdots$ & $\cdots$ & $\cdots$ & $\cdots$ & $\cdots$ & $\cdots$ & 65900 & $\cdots$ & $\cdots$ \\
\hline 29 & $\cdots$ & $\cdots$ & $\cdots$ & $\cdots$ & $\cdots$ & $\cdots$ & $\cdots$ & $\cdots$ & $\cdots$ & 1690 & $\cdots$ & $\cdots$ \\
\hline 30 & $\cdots$ & $\cdots$ & $\cdots$ & $\cdots$ & $\cdots$ & $\cdots$ & $\cdots$ & $\cdots$ & $\cdots$ & $\cdots$ & $\cdots$ & $\ldots$ \\
\hline 31 & $\cdots$ & $\cdots$ & $\cdots$ & $\cdots$ & $\cdots$ & $\cdots$ & $\cdots$ & $\cdots$ & $\cdots$ & $\cdots$ & $\cdots$ & \\
\hline
\end{tabular}


SURFACE-WATER DATA-Continued

DAILY MEAN SUSPENDED-SEDIMENT DISCHARGE-Cont inued

09395350 PUERCO RIVER MEAR CHURCH ROCK, HH-Continued

SEDIMENT DISCHARGE, SUSPENDED (MEGAGRAMS/DAY), WATER YEAR OCTOBER 1989 TO SEPTEMBER 1990 DAILY MEAN VALUES

\begin{tabular}{|c|c|c|c|c|c|c|c|c|c|c|c|c|}
\hline DAY & OCT & NOV & DEC & JAN & FEB & MAR & APR & MAY & JUN & JUL & AUG & SEP \\
\hline 1 & $\cdots$ & $\cdots$ & $\cdots$ & $\cdots$ & $\cdots$ & $\cdots$ & $\cdots$ & $\cdots$ & $\cdots$ & $\cdots$ & $\ldots$ & $\ldots$ \\
\hline 2 & $\ldots$ & $\cdots$ & $\ldots$ & $\cdots$ & $\cdots$ & $\ldots$ & $\cdots$ & $\ldots$ & $\cdots$ & $\ldots$ & $\cdots$ & ... \\
\hline 3 & $\cdots$ & $\cdots$ & $\cdots$ & $\cdots$ & $\cdots$ & $\cdots$ & $\cdots$ & $\cdots$ & $\cdots$ & $\cdots$ & $\cdots$ & $\cdots$ \\
\hline 4 & $\cdots$ & $\cdots$ & $\cdots$ & $\cdots$ & $\cdots$ & $\cdots$ & $\cdots$ & $\cdots$ & $\cdots$ & $\cdots$ & $\cdots$ & $\cdots$ \\
\hline 5 & $\cdots$ & $\cdots$ & $\cdots$ & $\cdots$ & $\cdots$ & $\cdots$ & $\cdots$ & $\cdots$ & $\cdots$ & 40100 & 2220 & $\cdots$ \\
\hline 6 & $\cdots$ & $\cdots$ & $\cdots$ & $\cdots$ & $\cdots$ & $\cdots$ & $\cdots$ & $\cdots$ & $\cdots$ & 14900 & $\cdots$ & $\cdots$ \\
\hline 7 & $\cdots$ & $\cdots$ & $\cdots$ & $\cdots$ & $\cdots$ & $\cdots$ & $\cdots$ & $\cdots$ & $\cdots$ & 6170 & $\cdots$ & $\cdots$ \\
\hline 8 & $\cdots$ & $\cdots$ & $\cdots$ & $\cdots$ & $\cdots$ & $\cdots$ & $\cdots$ & $\cdots$ & $\cdots$ & 18300 & $\cdots$ & $\cdots$ \\
\hline 9 & $\cdots$ & $\cdots$ & $\cdots$ & $\cdots$ & $\cdots$ & $\cdots$ & $\cdots$ & $\cdots$ & $\cdots$ & 30200 & $\cdots$ & $\cdots$ \\
\hline 10 & $\cdots$ & $\cdots$ & $\cdots$ & $\cdots$ & $\cdots$ & $\cdots$ & $\cdots$ & $\cdots$ & $\cdots$ & 7710 & $\cdots$ & $\cdots$ \\
\hline 11 & $\cdots$ & $\cdots$ & $\cdots$ & $\cdots$ & $\cdots$ & $\cdots$ & $\cdots$ & $\cdots$ & $\cdots$ & $\cdots$ & $\cdots$ & $\cdots$ \\
\hline 12 & $\cdots$ & $\cdots$ & $\cdots$ & $\cdots$ & $\cdots$ & $\cdots$ & $\cdots$ & $\cdots$ & $\cdots$ & 24300 & $\cdots$ & $\cdots$ \\
\hline 13 & $\cdots$ & $\cdots$ & $\cdots$ & $\cdots$ & $\cdots$ & $\cdots$ & $\cdots$ & $\cdots$ & $\cdots$ & $\cdots$ & $\cdots$ & $\cdots$ \\
\hline 14 & $\cdots$ & $\cdots$ & $\cdots$ & $\cdots$ & $\cdots$ & $\cdots$ & $\cdots$ & $\cdots$ & $\cdots$ & 998 & 2380 & $\cdots$ \\
\hline 15 & $\cdots$ & $\cdots$ & $\cdots$ & $\cdots$ & $\cdots$ & $\cdots$ & $\cdots$ & $\cdots$ & $\cdots$ & $\cdots$ & 11300 & $\cdots$ \\
\hline 16 & $\cdots$ & $\cdots$ & $\cdots$ & $\cdots$ & $\cdots$ & $\cdots$ & $\cdots$ & $\cdots$ & $\cdots$ & $\cdots$ & 15400 & $\cdots$ \\
\hline 17 & $\cdots$ & $\cdots$ & $\cdots$ & $\cdots$ & $\cdots$ & $\cdots$ & $\cdots$ & $\cdots$ & $\cdots$ & $\cdots$ & $\cdots$ & $\cdots$ \\
\hline 18 & $\cdots$ & $\cdots$ & $\cdots$ & $\cdots$, & $\cdots$ & $\cdots$ & $\cdots$ & $\cdots$ & $\cdots$ & $\cdots$ & $\cdots$ & $\cdots$ \\
\hline 19 & $\cdots$ & $\cdots$ & $\cdots$ & $\cdots$ & $\cdots$ & $\cdots$ & $\cdots$ & $\cdots$ & $\cdots$ & $\cdots$ & $\cdots$ & $\cdots$ \\
\hline 20 & $\cdots$ & $\cdots$ & $\cdots$ & $\cdots$ & $\cdots$ & $\cdots$ & $\cdots$ & $\cdots$ & $\cdots$ & $\cdots$ & $\cdots$ & 2330 \\
\hline 21 & $\cdots$ & $\cdots$ & $\cdots$ & $\cdots$ & $\cdots$ & $\cdots$ & $\cdots$ & $\cdots$ & $\cdots$ & $\cdots$ & $\cdots$ & 728 \\
\hline 22 & $\cdots$ & $\cdots$ & $\cdots$ & $\cdots$ & $\cdots$ & $\cdots$ & $\cdots$ & $\cdots$ & $\cdots$ & $\cdots$ & $\cdots$ & $\cdots$ \\
\hline 23 & $\cdots$ & $\cdots$ & $\cdots$ & $\cdots$ & $\cdots$ & $\cdots$ & $\cdots$ & $\cdots$ & $\cdots$ & $\cdots$ & $\cdots$ & $\cdots$ \\
\hline 24 & $\cdots$ & $\cdots$ & $\cdots$ & $\cdots$ & $\cdots$ & $\cdots$ & $\cdots$ & $\cdots$ & $\cdots$ & $\cdots$ & $\cdots$ & $\cdots$ \\
\hline 25 & $\cdots$ & $\cdots$ & $\cdots$ & $\cdots$ & $\cdots$ & $\cdots$ & $\cdots$ & $\cdots$ & $\cdots$ & $\cdots$ & $\cdots$ & $\cdots$ \\
\hline 26 & $\cdots$ & $\cdots$ & $\cdots$ & $\cdots$ & $\cdots$ & $\cdots$ & $\cdots$ & $\cdots$ & $\cdots$ & $\cdots$ & $\cdots$ & $\cdots$ \\
\hline 27 & $\cdots$ & $\cdots$ & $\cdots$ & $\cdots$ & $\cdots$ & $\cdots$ & $\cdots$ & $\cdots$ & $\cdots$ & $\cdots$ & $\cdots$ & $\cdots$ \\
\hline 28 & $\cdots$ & $\cdots$ & $\cdots$ & $\cdots$ & $\cdots$ & $\cdots$ & $\cdots$ & $\cdots$ & $\cdots$ & $\cdots$ & $\cdots$ & $\cdots$ \\
\hline 29 & $\cdots$ & $\cdots$ & $\cdots$ & $\cdots$ & $\cdots$ & $\cdots$ & $\cdots$ & $\cdots$ & $\cdots$ & $\cdots$ & $\cdots$ & $\cdots$ \\
\hline 30 & $\cdots$ & $\cdots$ & $\cdots$ & $\cdots$ & $\cdots$ & $\cdots$ & $\cdots$ & $\cdots$ & $\cdots$ & $\cdots$ & $\cdots$ & $\cdots$ \\
\hline 31 & $\cdots$ & $\cdots$ & $\cdots$ & $\cdots$ & $\cdots$ & $\cdots$ & $\cdots$ & $\cdots$ & $\cdots$ & $\cdots$ & $\cdots$ & $\cdots$ \\
\hline
\end{tabular}


SURFACE-HATER DATA-Continued

DAILY MEAN SUSPENDED-SEDIMENT DISCHARGE-Cont inued

09395350 PUERCO RIVER MEAR CHURCH ROCK, NM-Continued

SEDIMENT DISCHARGE, SUSPEMDED (MEgAGRAMS/DAY), WATER YEAR OCTOBER 1990 TO SEPTEMBER 1991 DAILY MEAN VALUES

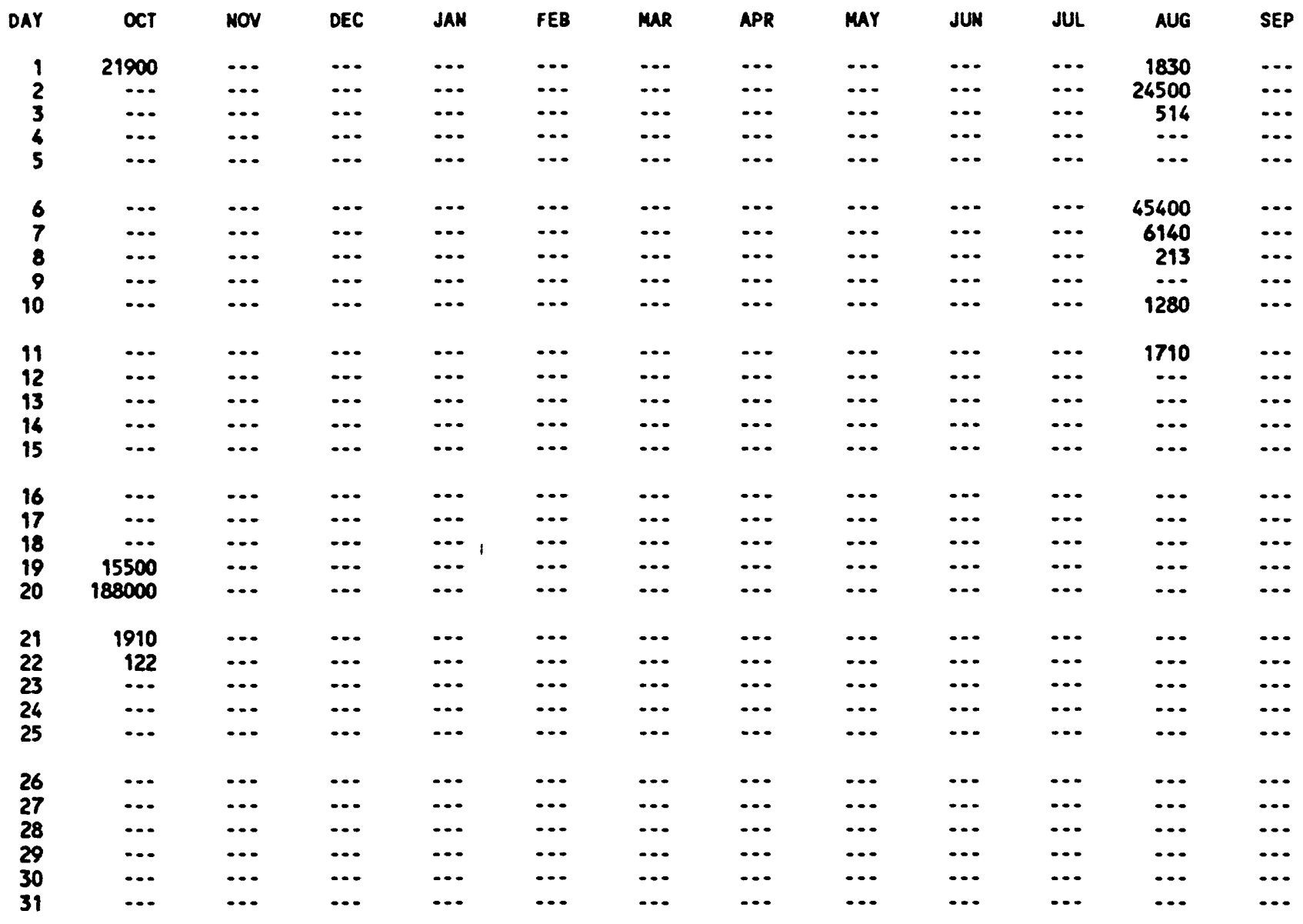


SURFACE-HATER DATA-Continued

DAILY MEAM SUSPENDED-SEDIMENT DISCHARGE-Continued

09395630 PUERCO RIVER NEAR MANUELITO, MM

REMARKS.--Sediment load for days when the daily mean discharge was greater than $1.416 \mathbf{a}^{3} / \mathrm{s}$ are published.

SEDIMENT DISCHARGE, SUSPENDED (MEGAGRAMS/DAY), MAY 1989 TO SEPTEMBER 1989 DAILY MEAN VALUES

\begin{tabular}{|c|c|c|c|c|c|c|c|c|c|c|c|c|}
\hline DAY & OCT & NOV & DEC & JAN & FEB & MAR & APR & MAY & JUN & JUL & AUG & SEP \\
\hline 1 & $\cdots$ & $\cdots$ & $\cdots$ & $\cdots$ & $\ldots$ & $\ldots$ & $\cdots$ & $\cdots$ & $\ldots$ & $\ldots$ & 15100 & $\ldots$ \\
\hline 2 & $\cdots$ & $\ldots$ & $\cdots$ & $\cdots$ & $\cdots$ & $\cdots$ & $\cdots$ & $\cdots$ & $\cdots$ & $\cdots$ & 39000 & $\cdots$ \\
\hline 3 & $\cdots$ & $\cdots$ & $\cdots$ & $\cdots$ & $\cdots$ & $\cdots$ & $\cdots$ & $\cdots$ & $\cdots$ & $\cdots$ & 5590 & $\cdots$ \\
\hline 4 & $\cdots$ & $\cdots$ & $\cdots$ & $\cdots$ & $\cdots$ & $\cdots$ & $\cdots$ & $\cdots$ & $\cdots$ & $\cdots$ & $\cdots$ & $\cdots$ \\
\hline 5 & $\cdots$ & $\cdots$ & $\cdots$ & $\cdots$ & $\cdots$ & $\cdots$ & $\cdots$ & $\cdots$ & $\cdots$ & $\cdots$ & $\cdots$ & 4140 \\
\hline 6 & $\cdots$ & $\cdots$ & $\cdots$ & $\cdots$ & $\cdots$ & $\cdots$ & $\cdots$ & $\cdots$ & $\cdots$ & $\cdots$ & -.. & 237000 \\
\hline 7 & $\cdots$ & $\cdots$ & $\cdots$ & $\cdots$ & $\cdots$ & $\cdots$ & $\cdots$ & $\cdots$ & $\cdots$ & $\cdots$ & $\cdots$ & $\cdots$ \\
\hline 8 & $\cdots$ & $\cdots$ & $\cdots$ & $\cdots$ & $\cdots$ & $\cdots$ & $\cdots$ & $\cdots$ & $\cdots$ & $\cdots$ & $\cdots$ & $\cdots$ \\
\hline 9 & $\cdots$ & $=-$ & $\cdots$ & $\cdots$ & $\cdots$ & $\cdots$ & $\cdots$ & $\cdots$ & $\cdots$ & $\cdots$ & $\cdots$ & $\cdots$ \\
\hline 10 & $\cdots$ & -- & $\cdots$ & $\cdots$ & $\cdots$ & $\cdots$ & $\cdots$ & $\cdots$ & $\cdots$ & $\cdots$ & $\cdots$ & $\cdots$ \\
\hline 11 & $\cdots$ & $\cdots$ & $\cdots$ & $\cdots \quad \vdots$ & $\ldots$ & $\cdots$ & $\cdots$ & $\cdots$ & $\cdots$ & $\cdots$ & $\ldots$ & $\cdots$ \\
\hline 12 & $\cdots$ & $\cdots$ & $\cdots$ & $\cdots$ & $\cdots$ & $\cdots$ & $\cdots$ & $\cdots$ & $\cdots$ & $\cdots$ & $\cdots$ & $\cdots$ \\
\hline 13 & $\cdots$ & $\cdots$ & $\cdots$ & $\cdots$ & $\cdots$ & $\cdots$ & $\cdots$ & $\cdots$ & $\cdots$ & $\cdots$ & $\ldots$ & $\ldots$ \\
\hline 16 & $\cdots$ & $\cdots$ & $\cdots$ & $\cdots$ & $\cdots$ & $\cdots$ & $\cdots$ & $\cdots$ & $\cdots$ & $\cdots$ & $\cdots$ & $\cdots$ \\
\hline 15 & $\cdots$ & $\cdots$ & $\cdots$ & $\cdots$ & $\cdots$ & $\cdots$ & $\cdots$ & $\cdots$ & $\cdots$ & $\cdots$ & $\cdots$ & $\cdots$ \\
\hline 16 & $\cdots$ & $\ldots$ & $\cdots$ & $\cdots$ & $\ldots$ & $\ldots$ & $\cdots$ & $\cdots$ & $\ldots$ & $\ldots$ & $\ldots$ & $\ldots$ \\
\hline 17 & $\cdots$ & $\cdots$ & -- & $\cdots$ & $\cdots$ & $\cdots$ & $\cdots$ & $\cdots$ & $\cdots$ & -.. & $\cdots$ & $\cdots$ \\
\hline 18 & $\cdots$ & $\cdots$ & $\cdots$ & $\cdots$ & $\cdots$ & $\cdots$ & $\cdots$ & $\cdots$ & $\cdots$ & $\cdots$ & 36400 & $\cdots$ \\
\hline 19 & $\cdots$ & $\ldots$ & $\cdots$ & $\cdots$ & $\cdots$ & $\ldots$ & $\cdots$ & $\cdots$ & $\cdots$ & $\cdots$ & 86100 & 1560 \\
\hline 20 & $\cdots$ & $\cdots$ & $\cdots$ & $\cdots$ & $\cdots$ & $\cdots$ & $\cdots$ & $\cdots$ & $\cdots$ & $\cdots$ & 1600 & $\cdots$ \\
\hline 21 & $\cdots$ & $\cdots$ & $\cdots$ & $\cdots$ & $\cdots$ & $\cdots$ & $\cdots$ & $\cdots$ & $\cdots$ & $\cdots$ & $\cdots$ & $\cdots$ \\
\hline 22 & $\cdots$ & $\cdots$ & $\cdots$ & $\cdots$ & $\cdots$ & $\cdots$ & $\cdots$ & $\cdots$ & $\cdots$ & $\cdots$ & $\cdots$ & $\cdots$ \\
\hline 23 & 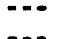 & $\cdots$ & $\cdots$ & $\cdots$ & $\because$ & $\cdots$ & $\cdots$ & $\cdots$ & $\cdots$ & 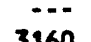 & $\cdots$ & -0 \\
\hline 24 & $\cdots$ & $\cdots$ & $\ldots$ & $\cdots$ & $\ldots$ & $\ldots$ & $\ldots$ & $\cdots$ & $\ldots$ & 3160 & $\cdots$ & $\cdots$ \\
\hline 25 & $\cdots$ & $\cdots$ & 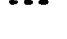 & $\cdots$ & 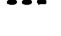 & 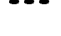 & 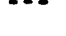 & 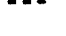 & 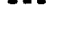 & $\cdots$ & $\cdots$ & $\cdots$ \\
\hline 26 & $\cdots$ & $\cdots$ & $=-$ & $\cdots$ & $\cdots$ & $\cdots$ & $\cdots$ & $\cdots$ & -- & 18300 & $\cdots$ & $\cdots$ \\
\hline 27 & $\cdots$ & -.. & $\cdots$ & $\ldots$ & $\cdots$ & $\cdots$ & $\cdots$ & $\cdots$ & $\cdots$ & 50500 & $\cdots$ & $\cdots$ \\
\hline 28 & $\cdots$ & $\cdots$ & $\cdots$ & $\cdots$ & $\cdots$ & $\cdots$ & $\cdots$ & $\cdots$ & $\cdots$ & 18900 & $\ldots$ & $\ldots$ \\
\hline 29 & $\cdots$ & $\cdots$ & $\cdots$ & $\cdots$ & $\cdots$ & $\cdots$ & $\cdots$ & $\cdots$ & $\cdots$ & 44000 & $\cdots$ & $\cdots$ \\
\hline 30 & $\cdots$ & $\cdots$ & $\cdots$ & $\cdots$ & $\cdots$ & $\cdots$ & $\cdots$ & $\cdots$ & 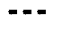 & 7410 & $\cdots$ & $\cdots$ \\
\hline 31 & $\cdots$ & $\cdots$ & $\cdots$ & $\cdots$ & $\ldots$ & $\cdots$ & $\cdots$ & $\cdots$ & $\cdots$ & 67900 & $\cdots$ & $\ldots$ \\
\hline
\end{tabular}


SURFACE-WATER DATA-Continued

DAILY MEAN SUSPENDED-SEDIMENT DISCHARGE-Cont inued

09395630 PUERCO RIVER MEAR MANUELITO, MH-Continued

SEDIMENT DISCHARGE, SUSPEMDED (MEGAGRAMS/DAY), WATER YEAR OCTOBER 1989 TO SEPTEMBER 1990 DAILY MEAN VALUES

\begin{tabular}{|c|c|c|c|c|c|c|c|c|c|c|c|c|}
\hline DAY & OCT & NOV & DEC & JAN & FEB & MAR & APR & MaY & JUN & JUL & AUG & SEP \\
\hline 1 & $\cdots$ & $\cdots$ & $\cdots$ & $\cdots$ & $\cdots$ & $\cdots$ & $\cdots$ & $\ldots$ & $\ldots$ & $\ldots$ & $\ldots$ & $\ldots$ \\
\hline 2 & $\cdots$ & $\cdots$ & $\cdots$ & $\cdots$ & $\cdots$ & $\cdots$ & $\cdots$ & $\cdots$ & $\cdots$ & $\cdots$ & $\ldots$ & 6750 \\
\hline 3 & $\cdots$ & $\cdots$ & $\cdots$ & $\cdots$ & $\cdots$ & $\cdots$ & $\cdots$ & $\cdots$ & $\cdots$ & $\cdots$ & $\cdots$ & $\cdots$ \\
\hline 4 & $\cdots$ & $\cdots$ & $\cdots$ & $\cdots$ & $\cdots$ & $\cdots$ & $\cdots$ & $\cdots$ & $\cdots$ & $\cdots$ & $\cdots$ & $\cdots$ \\
\hline 5 & $\cdots$ & $\cdots$ & $\cdots$ & $\cdots$ & $\cdots$ & $\cdots$ & $\cdots$ & $\cdots$ & $\cdots$ & $\cdots$ & $\cdots$ & 2220 \\
\hline 6 & $\cdots$ & $\cdots$ & $\cdots$ & $\cdots$ & $\cdots$ & $\cdots$ & $\cdots$ & $\cdots$ & $\cdots$ & 2900 & $\cdots$ & $\cdots$ \\
\hline 7 & $\cdots$ & $\cdots$ & $\cdots$ & $\cdots$ & $\cdots$ & $\cdots$ & $\cdots$ & $\cdots$ & $\cdots$ & 9250 & 21700 & $\cdots$ \\
\hline 8 & $\cdots$ & $\cdots$ & $\cdots$ & $\cdots$ & $\cdots$ & $\cdots$ & $\cdots$ & $\cdots$ & $\cdots$ & 16500 & $\cdots$ & $\cdots$ \\
\hline 9 & $\cdots$ & $\cdots$ & $\cdots$ & $\cdots$ & $\cdots$ & $\cdots$ & $\cdots$ & $\cdots$ & $\cdots$ & $\cdots$ & $\cdots$ & $\cdots$ \\
\hline 10 & $\cdots$ & $\cdots$ & $\cdots$ & $\cdots$ & $\cdots$ & $\cdots$ & $\cdots$ & $\cdots$ & $\cdots$ & 4960 & $\cdots$ & $\cdots$ \\
\hline 11 & $\cdots$ & $\cdots$ & $\cdots$ & $\cdots$ & $\cdots$ & $\cdots$ & $\cdots$ & $\cdots$ & $\cdots$ & $\cdots$ & $\cdots$ & $\cdots$ \\
\hline 12 & $\cdots$ & $\cdots$ & $\cdots$ & $\cdots$ & $\cdots$ & $\cdots$ & $\cdots$ & $\cdots$ & $\cdots$ & 2720 & $\cdots$ & $\cdots$ \\
\hline 13 & $\cdots$ & $\cdots$ & $\cdots$ & $\cdots$ & $\cdots$ & $\cdots$ & $\cdots$ & $\cdots$ & $\cdots$ & 144000 & $\cdots$ & $\ldots$ \\
\hline 16 & $\cdots$ & $\cdots$ & $\cdots$ & $\cdots$ & $\cdots$ & $\cdots$ & $\cdots$ & $\cdots$ & $\cdots$ & 3210 & 67600 & $\cdots$ \\
\hline 15 & $\cdots$ & $\cdots$ & $\cdots$ & $\cdots$ & $\cdots$ & $\cdots$ & $\cdots$ & $\cdots$ & $\cdots$ & $\cdots$ & 31100 & $\cdots$ \\
\hline 16 & $\cdots$ & $\ldots$ & $\cdots$ & $\cdots$ & $\cdots$ & $\cdots$ & $\cdots$ & $\cdots$ & $\cdots$ & $\cdots$ & 58200 & $\cdots$ \\
\hline 17 & $\cdots$ & $\cdots$ & $\cdots$ & $\cdots$ & $\cdots$ & $\cdots$ & $\cdots$ & $\cdots$ & $\cdots$ & 6880 & 19300 & $\cdots$ \\
\hline 18 & $\cdots$ & $\cdots$ & $\cdots$ & $\cdots$ & $\cdots$ & $\cdots$ & $\cdots$ & $\cdots$ & $\cdots$ & $\cdots$ & $\cdots$ & $\cdots$ \\
\hline 19 & $\cdots$ & $\cdots$ & $\cdots$ & $\cdots$ & $\cdots$ & $\cdots$ & $\cdots$ & $\cdots$ & $\cdots$ & $\cdots$ & $\cdots$ & $\cdots$ \\
\hline 20 & $\cdots$ & $\cdots$ & $\cdots$ & $\cdots$ & $\cdots$ & $\cdots$ & $\cdots$ & $\cdots$ & $\cdots$ & 2440 & 18100 & $\cdots$ \\
\hline 21 & $\cdots$ & $\cdots$ & $\cdots$ & $\cdots$ & $\cdots$ & $\cdots$ & $\cdots$ & $\cdots$ & $\cdots$ & $\cdots$ & 28100 & $\cdots$ \\
\hline 22 & $\cdots$ & $\cdots$ & $\cdots$ & $\cdots$ & $\cdots$ & $\cdots$ & $\cdots$ & $\cdots$ & $\cdots$ & $\cdots$ & $\cdots$ & $\cdots$ \\
\hline 23 & $\cdots$ & $\cdots$ & $\cdots$ & $\cdots$ & $\cdots$ & $\cdots$ & $\cdots$ & $\cdots$ & $\cdots$ & 1060 & $\cdots$ & 55400 \\
\hline 26 & $\cdots$ & $\cdots$ & $\cdots$ & $\cdots$ & $\cdots$ & $\cdots$ & $\cdots$ & $\cdots$ & $\cdots$ & 5950 & $\cdots$ & 16100 \\
\hline 25 & $\cdots$ & $\cdots$ & $\cdots$ & $\cdots$ & $\cdots$ & $\cdots$ & $\cdots$ & $\cdots$ & $\cdots$ & $\cdots$ & $\cdots$ & 2980 \\
\hline 26 & $\cdots$ & $\cdots$ & $\cdots$ & $\cdots$ & $\cdots$ & $\cdots$ & $\cdots$ & $\cdots$ & $\cdots$ & $\cdots$ & $\cdots$ & $\cdots$ \\
\hline 27 & $\cdots$ & $\cdots$ & $\cdots$ & $\cdots$ & $\cdots$ & $\cdots$ & $\cdots$ & $\cdots$ & $\cdots$ & $\cdots$ & $\cdots$ & $\cdots$ \\
\hline 28 & $\cdots$ & $\cdots$ & $\cdots$ & $\cdots$ & $\cdots$ & $\cdots$ & $\cdots$ & $\cdots$ & $\cdots$ & $\cdots$ & $\cdots$ & $\cdots$ \\
\hline 29 & $\cdots$ & $\cdots$ & $\cdots$ & $\cdots$ & $\cdots$ & $\cdots$ & $\cdots$ & $\cdots$ & $\cdots$ & $\cdots$ & $\cdots$ & $\cdots$ \\
\hline 30 & 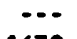 & $\cdots$ & $\cdots$ & $\cdots$ & $\cdots$ & $\cdots$ & $\cdots$ & $\cdots$ & $\cdots$ & $\cdots$ & $\cdots$ & $\cdots$ \\
\hline 31 & 1630 & $\cdots$ & $\cdots$ & $\cdots$ & $\cdots$ & $\cdots$ & $\cdots$ & $\cdots$ & $\cdots$ & $\cdots$ & $\cdots$ & $\cdots$ \\
\hline
\end{tabular}


SURFACE-UATER DATA-Continued

DAILY MEAK SUSPENDED-SEDIMEKT DISCRARGE-Cont inued

09395630 PUERCO RIVER NEAR MMUUELITO, Continued

SEDIMENT DISCHARGE, SUSPENDED (MEGAGRAMS/DAY), WATER YEAR OCTOBER 1990 TO SEPTEMBER 1991 DAILY MEAN VALUES

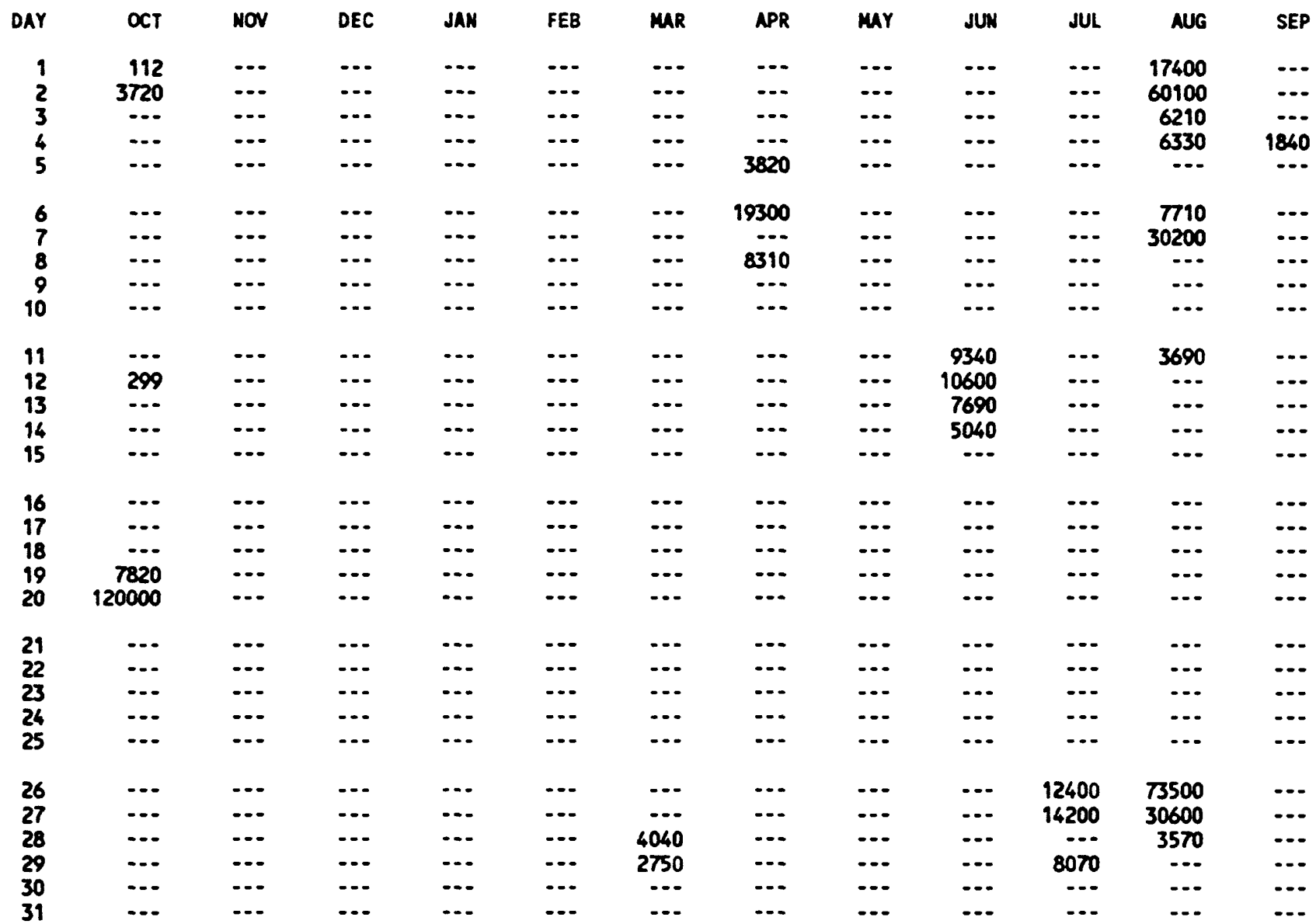


SURFACE- UATER DATA-Cont inued

DAILY MEAN SUSPENDED-SEDIMENT DISCHARGE-COnt inued

09395990 BLACK CREEK NEAR HOUCK, AZ

REMARKS.-- Sediment laad for days when the daily mean discharge was greater than $.142 \mathrm{~m}^{3} / \mathrm{s}$ are published.

SEDIMENT DISCHARGE, SUSPENDED (MEGAGRAMS/DAY), MARCH 1989 TO SEPTEMBER 1989 DAILY MEAN VALUES

\begin{tabular}{|c|c|c|c|c|c|c|c|c|c|c|c|c|}
\hline DAY & OCT & NOV & DEC & JAN & FEB & MRR & APR & MAY & JUN & JUL & NUG & SEP \\
\hline 1 & $\cdots$ & $\cdots$ & $\cdots$ & $\cdots$ & -.. & $\cdots$ & 30 & $\cdots$ & $\cdots$ & $\cdots$ & 1470 & $\cdots$ \\
\hline 2 & $\cdots$ & $\cdots$ & $\cdots$ & $\ldots$ & $\cdots$ & $\cdots$ & 18 & $\cdots$ & $\cdots$ & $\cdots$ & 113 & $\cdots$ \\
\hline 3 & $\cdots$ & $\cdots$ & $\cdots$ & $\cdots$ & $\cdots$ & $\cdots$ & $\cdots$ & $\cdots$ & $\cdots$ & -. & $\cdots$ & $\cdots$ \\
\hline 4 & $\cdots$ & $\cdots$ & $\cdots$ & $\cdots$ & $\cdots$ & $\cdots$ & $\cdots$ & $\cdots$ & $\cdots$ & $\cdots$ & $\cdots$ & 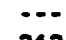 \\
\hline 5 & $\cdots$ & $\cdots$ & $\cdots$ & $\cdots$ & $\cdots$ & $\cdots$ & $\cdots$ & $\cdots$ & $\cdots$ & $\cdots$ & $\cdots$ & 212 \\
\hline 6 & $\cdots$ & $\cdots$ & $\cdots$ & $\cdots$ & $\cdots$ & $\ldots$ & $\ldots$ & $\cdots$ & $\cdots$ & -.. & $\cdots$ & 576 \\
\hline 7 & $\cdots$ & $\cdots$ & $\cdots$ & $\cdots$ & $\cdots$ & $\cdots$ & $\cdots$ & $\cdots$ & $\cdots$ & $\cdots$ & $\cdots$ & $\cdots$ \\
\hline 8 & $\cdots$ & -- & $\cdots$ & $\cdots$ & $\cdots$ & $\cdots$ & $\cdots$ & $\cdots$ & $\cdots$ & $\cdots$ & 341 & $\cdots$ \\
\hline 9 & $\cdots$ & $\cdots$ & $\cdots$ & $\cdots$ & $\cdots$ & $\cdots$ & $\cdots$ & $\cdots$ & $\cdots$ & $\cdots$ & 109 & - \\
\hline 10 & $\cdots$ & $\cdots$ & $\cdots$ & $\cdots$ & $\cdots$ & $\cdots$ & $\cdots$ & $\cdots$ & $\cdots$ & $\cdots$ & 49 & $\cdots$ \\
\hline 11 & $\cdots$ & $\cdots$ & $\cdots$ & $\cdots$ & $\cdots$ & -.. & $\cdots$ & $\cdots$ & $\cdots$ & $\cdots$ & $\cdots$ & \\
\hline 12 & $\cdots$ & -.. & $\cdots$ & $\cdots$ & $\cdots$ & -. & $\cdots$ & $\cdots$ & $\cdots$ & $\cdots$ & $\cdots$ & . \\
\hline 13 & $-\infty$ & $\cdots$ & $\cdots$ & $\cdots$ & $\cdots$ & $\cdots$ & $\cdots$ & $\cdots$ & $\cdots$ & $\cdots$ & $\cdots$ & $\cdots$ \\
\hline 14 & $\cdots$ & $\cdots$ & $\cdots$ & $\cdots$ & $-\cdot$ & $\cdots$ & $\cdots$ & $\cdots$ & $\cdots$ & $\cdots$ & $\cdots$ & $\cdots$ \\
\hline 15 & $\cdots$ & $\cdots$ & $\cdots$ & $\cdots$ & $\cdots$ & $\cdots$ & $\cdots$ & $\cdots$ & $\cdots$ & $\cdots$ & $\cdots$ & $\cdots$ \\
\hline 16 & $\cdots$ & $\cdots$ & $\cdots$ & $\cdots$ & $\cdots$ & $\cdots$ & $\cdots$ & $\cdots$ & $\cdots$ & $\cdots$ & $\cdots$ & \\
\hline 17 & $\cdots$ & $\ldots$ & $\cdots$ & $\cdots$ & $\cdots$ & $\cdots$ & $\cdots$ & $\cdots$ & $\cdots$ & $\cdots$ & $\cdots$ & \\
\hline 18 & $\cdots$ & $\cdots$ & $\cdots$ & $\cdots$ & $\cdots$ & $\cdots$ & $\cdots$ & $\cdots$ & $\cdots$ & $\cdots$ & $\cdots$ & 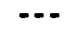 \\
\hline 19 & $\cdots$ & $\cdots$ & $\cdots$ & $\cdots$ & $\cdots$ & $\cdots$ & $\cdots$ & $\cdots$ & $\cdots$ & $\cdots$ & 9860 & 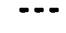 \\
\hline 20 & $\cdots$ & $\cdots$ & $\cdots$ & $\cdots$ & $\cdots$ & $\cdots$ & $\cdots$ & $\cdots$ & $\cdots$ & $\cdots$ & 862 & 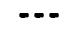 \\
\hline 21 & $\cdots$ & $=-$ & -- & $\cdots$ & $\cdots$ & 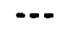 & $\cdots$ & $\cdots$ & $\cdots$ & $\cdots$ & $\cdots$ & - \\
\hline 22 & $\cdots$ & -.. & $\cdots$ & -.. & $\cdots$ & $=$ & $\cdots$ & $\ldots$ & $\cdots$ & $\cdots$ & $\cdots$ & \\
\hline 23 & $\cdots$ & $\cdots$ & $\cdots$ & $\cdots$ & $\cdots$ & 38 & $\cdots$ & $\cdots$ & $\cdots$ & $\cdots$ & $\cdots$ & 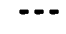 \\
\hline 24 & $\cdots$ & $\cdots$ & $\cdots$ & $\cdots$ & $\cdots$ & 64 & $\cdots$ & $\cdots$ & $\cdots$ & $\cdots$ & $\cdots$ & 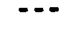 \\
\hline 25 & $\cdots$ & $\cdots$ & $\cdots$ & $\cdots$ & $\cdots$ & 70 & $\cdots$ & $\cdots$ & $\cdots$ & $\cdots$ & $\cdots$ & 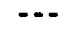 \\
\hline 26 & $\cdots$ & $\cdots$ & $\ldots$ & $\cdots$ & $\cdots$ & 150 & 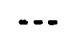 & $\cdots$ & $\cdots$ & 61 & ... & $\cdots$ \\
\hline 27 & $\cdots$ & $\cdots$ & $\cdots$ & $\cdots$ & $\cdots$ & 305 & $\ldots$ & $\cdots$ & $\cdots$ & $\cdots$ & $\cdots$ & \\
\hline 28 & $\cdots$ & $\cdots$ & $\cdots$ & $\cdots$ & $\cdots$ & 159 & $\cdots$ & $\cdots$ & $\cdots$ & $\cdots$ & $\cdots$ & \\
\hline 29 & $\cdots$ & $\cdots$ & $\cdots$ & $\cdots$ & $\cdots$ & 127 & $\cdots$ & $\cdots$ & $\cdots$ & 1670 & $\cdots$ & \\
\hline 30 & $\cdots$ & $\cdots$ & -- & $\cdots$ & $\cdots$ & 78 & $\cdots$ & $\cdots$ & $\cdots$ & 453 & -- & \\
\hline 31 & $\cdots$ & $\cdots$ & $\cdots$ & $\cdots$ & $\cdots$ & 46 & $\cdots$ & $\cdots$ & $\cdots$ & 1140 & $\cdots$ & \\
\hline
\end{tabular}


SURFACE-HATER DATA-Continued

DAILY MEAN SUSPENDED-SEDIMENT DISCHARGE-Continued

09395990 BLACK CREEK NEAR HOUCK, AZ-Cont inued

SEDIMENT DISCHARGE, SUSPENDED (MEgAGRAMS/DAY), WATER YEAR OCTOBER 1989 TO SEPTEMBER 1990 DAILY MEAN VALUES

\begin{tabular}{|c|c|c|c|c|c|c|c|c|c|c|c|c|}
\hline DAY & OCT & NOV & DEC & JAN & FEB & MAR & APR & Mar & JUN & JUL & AUG & SEP \\
\hline $\begin{array}{l}1 \\
2 \\
3 \\
4 \\
5\end{array}$ & $\begin{array}{l}\ldots \\
\ldots \\
\ldots \\
\ldots \\
\ldots\end{array}$ & $\begin{array}{l}\ldots \\
\ldots \\
\ldots \\
\ldots \\
\ldots\end{array}$ & $\begin{array}{l}\ldots \\
\ldots \\
\ldots \\
\ldots \\
\cdots\end{array}$ & $\begin{array}{l}\ldots \\
\ldots \\
\ldots \\
\ldots\end{array}$ & $\begin{array}{l}\ldots \\
\ldots \\
\ldots \\
\cdots \\
\cdots\end{array}$ & $\begin{array}{r}115 \\
57 \\
32 \\
\ldots \\
\ldots\end{array}$ & $\begin{array}{l}\ldots \\
\ldots \\
\ldots \\
\ldots \\
\ldots\end{array}$ & $\begin{array}{l}\ldots \\
\ldots \\
\ldots \\
\ldots \\
\ldots\end{array}$ & $\begin{array}{l}\ldots \\
\ldots \\
\ldots \\
\ldots \\
\ldots\end{array}$ & $\begin{array}{l}\ldots \\
\ldots \\
\cdots \\
\cdots\end{array}$ & $\begin{array}{c}\ldots \\
25 \\
\ldots \\
\ldots \\
\ldots\end{array}$ & $\begin{array}{l}\ldots \\
\ldots \\
\ldots \\
\ldots \\
\ldots\end{array}$ \\
\hline $\begin{array}{r}6 \\
7 \\
8 \\
9 \\
10\end{array}$ & $\begin{array}{l}\ldots \\
\ldots \\
\ldots \\
\ldots\end{array}$ & $\begin{array}{l}\ldots \\
\ldots \\
\ldots \\
\ldots \\
\ldots\end{array}$ & $\begin{array}{l}\ldots \\
\ldots \\
\ldots \\
\ldots \\
\ldots\end{array}$ & $\begin{array}{l}\ldots \\
\ldots \\
\ldots \\
\ldots \\
\ldots\end{array}$ & $\begin{array}{l}\ldots \\
\ldots \\
\ldots \\
\ldots \\
\ldots\end{array}$ & $\begin{array}{l}\ldots \\
\ldots \\
\ldots \\
\ldots \\
\ldots\end{array}$ & $\begin{array}{l}\ldots \\
\ldots \\
\ldots \\
\ldots \\
\ldots\end{array}$ & $\begin{array}{l}\ldots \\
\ldots \\
\ldots \\
\ldots \\
\ldots\end{array}$ & $\begin{array}{l}\ldots \\
\ldots \\
\ldots \\
\ldots \\
\ldots\end{array}$ & $\begin{array}{l}\ldots \\
\ldots \\
92 \\
51 \\
\ldots\end{array}$ & $\begin{array}{l}\ldots \\
\ldots \\
\ldots \\
\ldots \\
\cdots\end{array}$ & $\begin{array}{r}7410 \\
943 \\
87 \\
14400 \\
44\end{array}$ \\
\hline $\begin{array}{l}11 \\
12 \\
13 \\
14 \\
15\end{array}$ & $\begin{array}{l}\ldots \\
\ldots \\
\ldots \\
\ldots \\
\ldots\end{array}$ & $\begin{array}{l}\ldots \\
\ldots \\
\ldots \\
\ldots \\
\ldots\end{array}$ & $\begin{array}{l}\ldots . \\
\ldots \\
\ldots \\
\ldots \\
\cdots\end{array}$ & $\begin{array}{l}\ldots \\
\ldots \\
\ldots \\
\ldots \\
\ldots\end{array}$ & $\begin{array}{l}\ldots \\
\ldots \\
\ldots \\
\ldots \\
\cdots\end{array}$ & $\begin{array}{l}\ldots \\
\ldots \\
\ldots \\
\ldots \\
\ldots\end{array}$ & $\begin{array}{l}\ldots \\
\ldots \\
\ldots \\
\ldots \\
\ldots\end{array}$ & $\begin{array}{l}\ldots \\
\ldots \\
\ldots \\
\ldots\end{array}$ & $\begin{array}{l}\ldots \\
\ldots \\
\ldots \\
\cdots\end{array}$ & $\begin{array}{r}1440 \\
43 \\
4190 \\
1010\end{array}$ & $\begin{array}{r}\ldots \\
\ldots \\
43400 \\
36000\end{array}$ & $\begin{array}{l}\ldots \\
\ldots \\
\ldots \\
\ldots\end{array}$ \\
\hline $\begin{array}{l}16 \\
17 \\
18 \\
19 \\
20\end{array}$ & $\begin{array}{l}\ldots \\
\ldots \\
\ldots \\
\ldots \\
\ldots\end{array}$ & $\begin{array}{l}\ldots \\
\ldots \\
\ldots \\
\ldots \\
\ldots\end{array}$ & $\begin{array}{l}\ldots \\
\ldots \\
\ldots \\
\ldots \\
\ldots\end{array}$ & $\begin{array}{l}\ldots \\
\ldots \\
\ldots \\
\ldots\end{array}$ & $\begin{array}{l}\ldots \\
\ldots \\
\ldots \\
\ldots\end{array}$ & $\begin{array}{l}\ldots \\
\ldots \\
\ldots \\
\ldots \\
\ldots\end{array}$ & $\begin{array}{l}\ldots \\
\ldots \\
\ldots \\
\ldots \\
\ldots\end{array}$ & $\begin{array}{l}\ldots \\
\ldots \\
\ldots \\
\ldots \\
\ldots\end{array}$ & $\begin{array}{l}\ldots \\
\ldots \\
\ldots \\
\ldots \\
\ldots\end{array}$ & $\begin{array}{r}26 \\
10900 \\
5620 \\
174 \\
52\end{array}$ & $\begin{array}{r}341 \\
89 \\
\ldots \\
\ldots \\
\ldots\end{array}$ & $\begin{array}{l}\ldots . \\
\ldots \\
\ldots . \\
184 \\
435\end{array}$ \\
\hline $\begin{array}{l}21 \\
22 \\
23 \\
24 \\
25\end{array}$ & $\begin{array}{l}\ldots \\
\ldots \\
\ldots \\
\ldots \\
\ldots\end{array}$ & $\begin{array}{l}\ldots \\
\ldots \\
\ldots \\
\ldots \\
\ldots\end{array}$ & $\begin{array}{l}\ldots \\
\ldots \\
\ldots \\
\ldots \\
\ldots\end{array}$ & $\begin{array}{l}\ldots \\
\ldots \\
\ldots \\
\ldots \\
\ldots\end{array}$ & $\begin{array}{c}\ldots . \\
\ldots \\
\ldots \\
\ldots 5\end{array}$ & $\begin{array}{l}\ldots \\
\ldots \\
\ldots \\
\ldots \\
\ldots\end{array}$ & $\begin{array}{l}\ldots \\
\ldots \\
\ldots \\
\ldots \\
\ldots\end{array}$ & $\begin{array}{l}\ldots \\
\ldots \\
\ldots \\
\ldots \\
\ldots\end{array}$ & $\begin{array}{l}\ldots \\
\ldots \\
\ldots \\
\ldots \\
\ldots\end{array}$ & $\begin{array}{c}26 \\
\ldots \\
\cdots \\
\cdots \\
\cdots\end{array}$ & $\begin{array}{r}386 \\
28 \\
\ldots \\
\ldots\end{array}$ & $\begin{array}{r}947 \\
22 \\
154 \\
63 \\
\ldots\end{array}$ \\
\hline $\begin{array}{l}26 \\
27 \\
28 \\
29 \\
30 \\
31\end{array}$ & $\begin{array}{l}\ldots \\
\ldots \\
\ldots \\
\ldots \\
\ldots \\
\ldots\end{array}$ & $\begin{array}{l}\ldots \\
\ldots \\
\ldots \\
\ldots \\
\cdots \\
\cdots\end{array}$ & $\begin{array}{l}\ldots \\
\ldots \\
\ldots \\
\ldots \\
\ldots\end{array}$ & $\begin{array}{l}\ldots \\
\ldots \\
\ldots \\
\ldots \\
\ldots \\
\ldots\end{array}$ & $\begin{array}{r}116 \\
60 \\
145 \\
\ldots \\
\ldots\end{array}$ & $\begin{array}{l}\cdots \\
\cdots \\
\cdots \\
\cdots \\
\cdots \\
\cdots\end{array}$ & $\begin{array}{l}\cdots \\
\cdots \\
\cdots \\
\cdots \\
\cdots \\
\cdots\end{array}$ & $\begin{array}{l}\cdots \\
\ldots \\
\ldots \\
\cdots \\
\cdots \\
\cdots\end{array}$ & $\begin{array}{l}\cdots \\
\cdots \\
\cdots \\
\cdots \\
\cdots \\
\cdots\end{array}$ & $\begin{array}{l}\ldots \\
\ldots \\
\ldots \\
\ldots \\
\ldots \\
\ldots\end{array}$ & $\begin{array}{l}\ldots \\
\ldots \\
\ldots \\
\ldots \\
\ldots \\
\ldots\end{array}$ & $\begin{array}{l}\ldots \\
\ldots \\
\ldots \\
\ldots \\
\ldots\end{array}$ \\
\hline
\end{tabular}


SURFACE-MATER DATA-Continued

DAILY MEAN SUSPENDED-SEDIMENT DISCHARGE-Cont inued

09395990 BLACK CREEK NEAR HOUCK, AZ-COnt inued

SEDIMENT DISCHARGE, SUSPENDED (MEGAGRAMS/DAY), WATER YEAR OCTOBER 1990 TO SEPTEMBER 1991 DAILY MEAN VALUES

\begin{tabular}{|c|c|c|c|c|c|c|c|c|c|c|c|c|}
\hline DAY & OCT & NOV & DEC & JAN & FEB & MAR & APR & MAY & JUN & JUL & NUG & SEP \\
\hline $\begin{array}{l}1 \\
2 \\
3 \\
4 \\
5\end{array}$ & $\begin{array}{l}\cdots \\
\ldots- \\
\cdots- \\
-\ldots \\
--\end{array}$ & $\begin{array}{l}\cdots- \\
\cdots- \\
\cdots- \\
\cdots-\end{array}$ & $\begin{array}{l}-.- \\
-\ldots \\
\ldots- \\
-\ldots \\
--\end{array}$ & $\begin{array}{r}\ldots . \\
13 \\
1300\end{array}$ & $\begin{array}{l}\cdots \\
\ldots- \\
\ldots- \\
\cdots\end{array}$ & $\begin{array}{r}232 \\
1180 \\
1140 \\
470 \\
1670\end{array}$ & $\begin{array}{r}1470 \\
613 \\
274 \\
105 \\
45\end{array}$ & $\begin{array}{l}\ldots \\
\ldots \\
\ldots \\
\ldots \\
\ldots\end{array}$ & $\begin{array}{l}-.- \\
-\ldots \\
-\ldots \\
\ldots- \\
-\ldots\end{array}$ & $\begin{array}{l}\ldots- \\
\ldots \\
\ldots- \\
\cdots \\
\cdots\end{array}$ & $\begin{array}{l}\ldots . \\
\ldots- \\
\ldots- \\
\cdots-\end{array}$ & $\begin{array}{l}\ldots \\
\ldots \\
\ldots \\
179\end{array}$ \\
\hline $\begin{array}{r}6 \\
7 \\
8 \\
9 \\
10\end{array}$ & $\begin{array}{l}\ldots- \\
\ldots- \\
\ldots- \\
\ldots- \\
\ldots-\end{array}$ & $\begin{array}{l}\ldots- \\
\ldots \\
\ldots \\
\ldots- \\
\cdots\end{array}$ & $\begin{array}{l}-\ldots \\
--- \\
-\ldots \\
-\ldots \\
--\end{array}$ & $\begin{array}{r}830 \\
324 \\
207 \\
63 \\
13\end{array}$ & $\begin{array}{r}29 \\
101 \\
57 \\
63\end{array}$ & $\begin{array}{r}11300 \\
5010 \\
670 \\
136 \\
62\end{array}$ & $\begin{array}{c}24 \\
\ldots- \\
\ldots- \\
\ldots \\
-\end{array}$ & $\begin{array}{l}\ldots- \\
\ldots- \\
\ldots- \\
\ldots\end{array}$ & $\begin{array}{l}-\ldots \\
\ldots- \\
-\ldots \\
-\ldots \\
--\end{array}$ & $\begin{array}{l}-\ldots \\
-\ldots \\
--- \\
-\ldots \\
--\end{array}$ & $\begin{array}{r}74100 \\
308 \\
26 \\
\ldots\end{array}$ & $\begin{array}{r}4090 \\
109 \\
\ldots \\
\ldots- \\
\ldots-\end{array}$ \\
\hline $\begin{array}{l}11 \\
12 \\
13 \\
14 \\
15\end{array}$ & $\begin{array}{l}\cdots \\
\ldots- \\
\ldots- \\
\cdots \\
\cdots\end{array}$ & $\begin{array}{l}\ldots- \\
\ldots- \\
\ldots- \\
\ldots- \\
-.\end{array}$ & $\begin{array}{l}-\ldots \\
\ldots- \\
-\ldots \\
-\ldots \\
-\ldots\end{array}$ & $\begin{array}{l}\cdots- \\
\cdots \\
\cdots- \\
\cdots- \\
\cdots\end{array}$ & $\begin{array}{l}65 \\
65 \\
62 \\
48 \\
68\end{array}$ & $\begin{array}{c}30 \\
\ldots- \\
\ldots- \\
\ldots-\end{array}$ & $\begin{array}{r}145 \\
451 \\
144 \\
34 \\
-\end{array}$ & $\begin{array}{l}-\ldots \\
-\ldots \\
-\ldots- \\
-\ldots \\
---\end{array}$ & $\begin{array}{l}-\ldots \\
\ldots- \\
\ldots- \\
\ldots- \\
-\ldots\end{array}$ & $\begin{array}{l}\ldots- \\
\ldots- \\
\ldots- \\
\ldots- \\
\ldots-\end{array}$ & $\begin{array}{l}-. . \\
\ldots- \\
-\ldots- \\
401\end{array}$ & $\begin{array}{l}\ldots- \\
\ldots- \\
\ldots- \\
\ldots-\end{array}$ \\
\hline $\begin{array}{l}16 \\
17 \\
18 \\
19 \\
20\end{array}$ & $\begin{array}{l}\ldots- \\
\ldots- \\
\cdots \\
\cdots \\
-. \\
02\end{array}$ & $\begin{array}{l}\ldots- \\
\ldots- \\
\ldots- \\
\cdots\end{array}$ & $\begin{array}{l}-\ldots \\
\ldots- \\
-\ldots \\
-\ldots \\
-\ldots\end{array}$ & $\begin{array}{l}\ldots- \\
\ldots- \\
\ldots- \\
\ldots-\end{array}$ & $\begin{array}{r}96 \\
221 \\
116 \\
33 \\
---\end{array}$ & $\begin{array}{l}\ldots- \\
\ldots- \\
\ldots- \\
\ldots- \\
\ldots\end{array}$ & $\begin{array}{r}37 \\
232 \\
263 \\
336 \\
212\end{array}$ & $\begin{array}{l}-\ldots \\
\ldots- \\
-\ldots \\
-\ldots \\
-\ldots\end{array}$ & $\begin{array}{l}\ldots- \\
\ldots- \\
\ldots- \\
-\ldots \\
-.-\end{array}$ & $\begin{array}{l}-\ldots \\
-\ldots \\
-\ldots \\
-\ldots \\
--\end{array}$ & $\begin{array}{r}3380 \\
21 \\
-\ldots- \\
-.- \\
-. .\end{array}$ & $\begin{array}{l}\ldots \\
\ldots \\
\ldots- \\
\ldots- \\
\ldots\end{array}$ \\
\hline $\begin{array}{l}21 \\
22 \\
23 \\
24 \\
25\end{array}$ & $\begin{array}{l}\ldots- \\
\ldots- \\
\ldots- \\
\cdots\end{array}$ & $\begin{array}{l}\ldots- \\
\ldots- \\
\ldots- \\
\ldots-\end{array}$ & $\begin{array}{l}-\ldots \\
-\ldots \\
-\ldots \\
-\ldots \\
-.-\end{array}$ & $\begin{array}{l}\ldots- \\
\ldots- \\
\cdots- \\
\cdots-\end{array}$ & $\begin{array}{l}\ldots- \\
\ldots \\
\ldots- \\
\ldots- \\
\ldots\end{array}$ & $\begin{array}{l}\ldots- \\
\ldots- \\
\ldots- \\
\ldots- \\
\ldots-\end{array}$ & $\begin{array}{l}76 \\
66 \\
40 \\
30 \\
17\end{array}$ & $\begin{array}{l}\ldots \\
\ldots- \\
\ldots- \\
-\ldots \\
-\ldots\end{array}$ & $\begin{array}{l}\ldots- \\
\ldots- \\
\ldots- \\
\ldots-\end{array}$ & $\begin{array}{r}- \\
- \\
- \\
- \\
7620\end{array}$ & $\begin{array}{l}\ldots- \\
\ldots- \\
-\ldots \\
\ldots- \\
\ldots\end{array}$ & $\begin{array}{l}\ldots- \\
\ldots- \\
\ldots- \\
\ldots-\end{array}$ \\
\hline $\begin{array}{l}26 \\
27 \\
28 \\
29 \\
30 \\
31\end{array}$ & $\begin{array}{l}\ldots- \\
\ldots- \\
\ldots- \\
\ldots- \\
\ldots- \\
\ldots\end{array}$ & $\begin{array}{l}\ldots- \\
\ldots \\
\ldots \\
\ldots- \\
\ldots \\
\ldots-\end{array}$ & $\begin{array}{l}-\ldots \\
\ldots- \\
-\ldots \\
\ldots- \\
\ldots- \\
\ldots\end{array}$ & $\begin{array}{l}\ldots- \\
\cdots \\
\cdots- \\
\cdots \\
\cdots\end{array}$ & 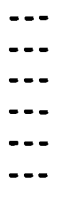 & $\begin{array}{r}\ldots . \\
\ldots . \\
244 \\
562 \\
2110\end{array}$ & $\begin{array}{l}-. \\
\ldots- \\
\ldots- \\
-\ldots \\
-\ldots \\
-.-\end{array}$ & $\begin{array}{l}-\ldots \\
-\ldots \\
-\ldots \\
\ldots- \\
-\ldots \\
\ldots-\end{array}$ & $\begin{array}{l}\ldots- \\
\ldots- \\
\ldots- \\
\ldots- \\
-.- \\
\ldots-\end{array}$ & $\begin{array}{r}1220 \\
198 \\
\ldots .- \\
\ldots \\
\ldots \\
\ldots\end{array}$ & $\begin{array}{l}\ldots- \\
\ldots- \\
\ldots- \\
\ldots- \\
\ldots- \\
\ldots\end{array}$ & $\begin{array}{l}\ldots- \\
\ldots- \\
\ldots- \\
\ldots- \\
\ldots-\end{array}$ \\
\hline
\end{tabular}


SURFACE-MATER DATA-Continued

DAILY MEAN SUSPENDED-SEDIMENT DISCHARGE-Cont inued

09396100 PUERCO RIVER MEAR CHAMBERS, AZ

REMARKS.---Sediment load for days when the daily mean discharge was greater than .566 $\mathrm{m}^{3}$ are published.

SEDIMENT DISCHARGE, SUSPENDED (MEgAGRAMS/DAY), WATER YEAR OCTOBER 1988 TO SEPTEMBER 1989 DAILY MEAN VALUES

\begin{tabular}{|c|c|c|c|c|c|c|c|c|c|c|c|c|}
\hline DAY & OCT & HOV & DEC & JAK & FEB & MAR & APR & MaY & JUN & JUL & AUG & SEP \\
\hline $\begin{array}{l}1 \\
2 \\
3 \\
4 \\
5\end{array}$ & $\begin{array}{l}-.- \\
-\ldots \\
-.- \\
-\ldots \\
--.\end{array}$ & $\begin{array}{l}\ldots- \\
\cdots \\
\cdots- \\
\cdots- \\
\cdots\end{array}$ & $\begin{array}{l}\ldots- \\
\ldots- \\
\ldots- \\
\cdots- \\
\ldots-\end{array}$ & $\begin{array}{l}\ldots- \\
\ldots \\
\ldots- \\
\ldots- \\
\ldots\end{array}$ & $\begin{array}{l}1 .- \\
1420 \\
1680 \\
2400 \\
1500\end{array}$ & $\begin{array}{l}-.- \\
\ldots- \\
-\ldots \\
-\ldots\end{array}$ & $\begin{array}{l}\ldots- \\
\ldots- \\
\ldots- \\
\ldots- \\
\ldots\end{array}$ & $\begin{array}{l}\ldots \\
\cdots \\
\cdots \\
\cdots \\
\cdots\end{array}$ & $\begin{array}{l}\ldots- \\
\ldots- \\
\ldots- \\
\ldots \\
\ldots-\end{array}$ & $\begin{array}{l}\ldots- \\
\ldots- \\
\ldots- \\
\ldots- \\
\ldots-\end{array}$ & $\begin{array}{r}121000 \\
4640 \\
18700 \\
\ldots-. \\
\ldots\end{array}$ & $\begin{array}{l}\ldots- \\
\ldots- \\
\cdots- \\
\cdots \\
\cdots\end{array}$ \\
\hline $\begin{array}{r}6 \\
7 \\
8 \\
9 \\
10\end{array}$ & $\begin{array}{l}-.- \\
-\ldots \\
-.- \\
-\ldots\end{array}$ & $\begin{array}{l}\ldots \\
\ldots \\
\ldots \\
\ldots \\
\ldots\end{array}$ & $\begin{array}{l}\ldots- \\
\ldots- \\
\ldots- \\
-\ldots \\
-\ldots\end{array}$ & $\begin{array}{l}\ldots- \\
\ldots- \\
\ldots- \\
\ldots- \\
\ldots-\end{array}$ & $\begin{array}{l}345 \\
\ldots \\
\ldots \\
\ldots \\
\ldots\end{array}$ & $\begin{array}{l}336 \\
\ldots- \\
\ldots- \\
\ldots- \\
\ldots-\end{array}$ & $\begin{array}{l}\ldots- \\
\ldots- \\
\ldots- \\
\ldots \\
\ldots\end{array}$ & $\begin{array}{l}\ldots . \\
\cdots \\
\cdots- \\
\cdots- \\
\cdots\end{array}$ & $\begin{array}{l}\ldots- \\
\ldots- \\
\ldots- \\
\ldots \\
\ldots\end{array}$ & $\begin{array}{l}\ldots- \\
\ldots \\
\ldots- \\
\ldots- \\
\ldots\end{array}$ & $\begin{array}{l}\ldots- \\
\ldots- \\
\ldots- \\
\ldots \\
\ldots\end{array}$ & $\begin{array}{r}21900 \\
4100 \\
\ldots \ldots \\
\ldots- \\
\ldots-\end{array}$ \\
\hline $\begin{array}{l}11 \\
12 \\
13 \\
14 \\
15\end{array}$ & $\begin{array}{l}-.- \\
-.- \\
-\ldots \\
-\ldots\end{array}$ & $\begin{array}{l}\ldots- \\
\cdots \\
\cdots \\
\cdots\end{array}$ & $\begin{array}{l}\ldots- \\
\ldots- \\
\ldots- \\
\ldots-\end{array}$ & $\begin{array}{l}\ldots \\
\ldots \\
\ldots- \\
\ldots\end{array}$ & $\begin{array}{r}\cdots . . \\
3310 \\
3760 \\
980 \\
744\end{array}$ & $\begin{array}{l}\ldots \\
\ldots \\
\ldots- \\
\ldots\end{array}$ & $\begin{array}{l}\cdots \\
\ldots \\
\ldots \\
\ldots \\
\ldots\end{array}$ & $\begin{array}{l}\ldots- \\
\ldots- \\
\ldots- \\
-\ldots\end{array}$ & $\begin{array}{l}\cdots \\
\ldots- \\
\ldots- \\
\cdots \\
-.-\end{array}$ & $\begin{array}{l}\ldots . \\
\ldots- \\
\ldots- \\
\ldots \\
\ldots\end{array}$ & $\begin{array}{l}\cdots \\
\cdots \\
\cdots \\
\cdots \\
\cdots\end{array}$ & $\begin{array}{l}-.- \\
\cdots \\
\cdots- \\
\cdots \\
-.\end{array}$ \\
\hline $\begin{array}{l}16 \\
17 \\
18 \\
19 \\
20\end{array}$ & $\begin{array}{l}-\ldots \\
-\ldots \\
-\ldots \\
-\ldots \\
\ldots\end{array}$ & $\begin{array}{l}\ldots- \\
\ldots- \\
\ldots \\
\ldots \\
\ldots\end{array}$ & $\begin{array}{l}\ldots \\
\ldots \\
\ldots \\
\ldots \\
\ldots\end{array}$ & $\begin{array}{l}\ldots- \\
\ldots- \\
\ldots \\
\ldots \\
\ldots\end{array}$ & $\begin{array}{r}807 \\
553 \\
1080 \\
1350 \\
1890\end{array}$ & $\begin{array}{l}\ldots . \\
\ldots \\
\ldots \\
\ldots- \\
345\end{array}$ & $\begin{array}{l}\ldots- \\
\ldots \\
\ldots \\
\ldots\end{array}$ & $\begin{array}{l}\cdots- \\
\cdots \\
\cdots \\
\cdots \\
\cdots\end{array}$ & $\begin{array}{l}\ldots- \\
\ldots \\
\ldots- \\
\ldots \\
\ldots\end{array}$ & $\begin{array}{l}\ldots- \\
\ldots- \\
\ldots- \\
\ldots-\end{array}$ & $\begin{array}{r}\ldots \\
\ldots \\
112000 \\
23200\end{array}$ & $\begin{array}{l}\ldots- \\
\cdots- \\
\cdots- \\
\cdots \\
\cdots\end{array}$ \\
\hline $\begin{array}{l}21 \\
22 \\
23 \\
24 \\
25\end{array}$ & $\begin{array}{l}\cdots \\
\cdots \\
\cdots \\
\cdots \\
\cdots\end{array}$ & $\begin{array}{l}\cdots- \\
\cdots- \\
\cdots-- \\
\cdots-\end{array}$ & $\begin{array}{l}\ldots \\
\cdots \\
\cdots \\
\cdots \\
\cdots\end{array}$ & $\begin{array}{l}\cdots \\
\cdots \\
\cdots- \\
\cdots- \\
\cdots\end{array}$ & $\begin{array}{l}345 \\
435 \\
499 \\
354 \\
299\end{array}$ & $\begin{array}{l}-\ldots \\
\ldots- \\
\cdots- \\
-\ldots \\
-\ldots\end{array}$ & $\begin{array}{l}-\cdot- \\
-\cdots \\
\cdots- \\
\cdots- \\
\cdots\end{array}$ & $\begin{array}{l}\cdots \\
\cdots \\
\cdots \\
\cdots \\
\cdots\end{array}$ & $\begin{array}{l}\cdots \\
\cdots- \\
\cdots- \\
\cdots- \\
--\end{array}$ & $\begin{array}{l}\cdots \\
\cdots \\
\cdots- \\
\cdots \\
--\end{array}$ & $\begin{array}{l}\cdots \\
\cdots \\
\cdots- \\
\cdots- \\
\cdots-\end{array}$ & $\begin{array}{l}\cdots \\
\cdots \\
\cdots- \\
\cdots- \\
\cdots-\end{array}$ \\
\hline $\begin{array}{l}26 \\
27 \\
28 \\
29 \\
30 \\
31\end{array}$ & $\begin{array}{l}\ldots \\
\ldots \\
\ldots \\
\ldots \\
\ldots \\
\ldots\end{array}$ & $\begin{array}{l}\ldots- \\
\ldots \\
\ldots- \\
\ldots- \\
\ldots \\
\ldots\end{array}$ & $\begin{array}{l}\ldots- \\
\ldots \\
-\ldots \\
\ldots- \\
\ldots \\
\ldots\end{array}$ & $\begin{array}{l}\ldots- \\
\ldots- \\
\ldots- \\
\ldots- \\
\ldots \\
\ldots\end{array}$ & $\begin{array}{l}708 \\
408 \\
\ldots . \\
\ldots \\
\ldots\end{array}$ & $\begin{array}{l}\ldots- \\
\ldots \\
\ldots \\
\ldots- \\
\ldots \\
\ldots\end{array}$ & $\begin{array}{l}\cdots \\
\cdots- \\
\cdots- \\
\cdots- \\
\cdots \\
\cdots\end{array}$ & $\begin{array}{l}\ldots . \\
\ldots \\
\ldots- \\
\ldots- \\
\ldots\end{array}$ & $\begin{array}{l}\ldots- \\
\ldots- \\
\ldots \\
\ldots- \\
\ldots \\
\ldots\end{array}$ & $\begin{array}{r}-.- \\
8720 \\
15300 \\
62900 \\
12200 \\
20200\end{array}$ & $\begin{array}{l}\ldots- \\
\ldots \\
\ldots \\
\ldots \\
\ldots \\
\ldots\end{array}$ & $\begin{array}{l}\ldots \\
\ldots- \\
\ldots- \\
\ldots- \\
\ldots- \\
\ldots\end{array}$ \\
\hline
\end{tabular}


SURFACE-WATER DATA-Cont inued

DAILY MEAN SUSPENDED-SEDIMENT DISCHARGE-Cont inuEd

09396100 PUERCO RIVER NEAR CHAMBERS, AZ-Continued

SEDIMENT DISCHARGE, SUSPENDED (MEGAGRAMS/DAY), HATER YEAR OCTOBER 1989 TO SEPTEMBER 1990 DAILY MEAN VALUES

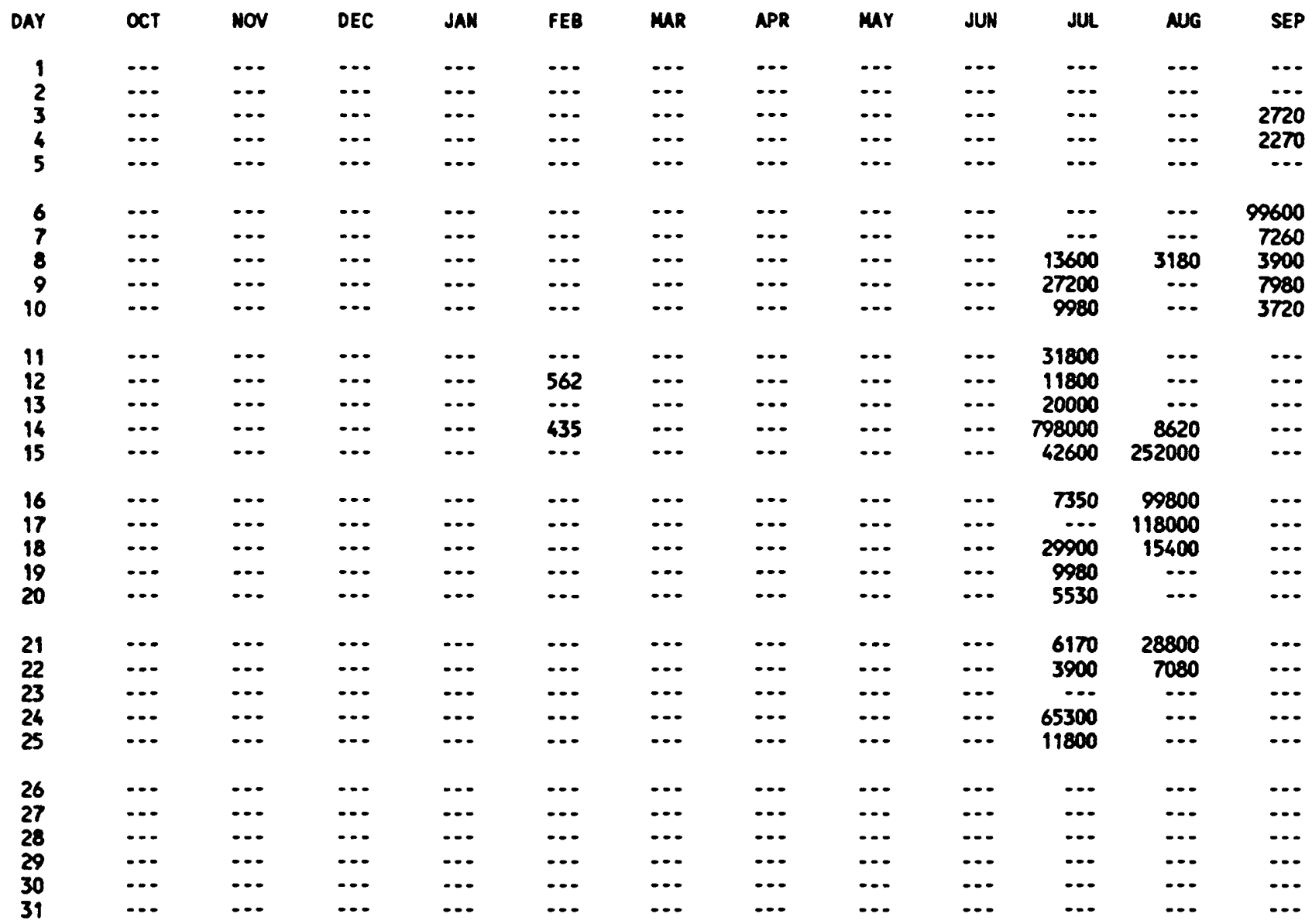


SURFACE-WATER DATA-Cont inued

DAILY MEAN SUSPENDED-SEDIMENT DISCHARGE-Cont inued

09396100 PUERCO RIVER NEAR ChAMBERS, AZ-Continued

SEDIMENT DISCHARGE, SUSPENDED (MEGAGRAMS/DAY), WATER YEAR OCTOBER 1990 TO SEPTEMBER 1991 DAILY MEAN VALUES

\begin{tabular}{|c|c|c|c|c|c|c|c|c|c|c|c|c|}
\hline DAY & OCT & NOV & DEC & JAN & FEB & MUR & APR & MYY & JuN & JUL & AUG & SEP \\
\hline 1 & $\ldots$ & $\ldots$ & $\cdots$ & $\ldots$ & $\ldots$ & $\ldots$ & 2240 & $\ldots$ & $\cdots$ & $\ldots$ & 4540 & $\cdots$ \\
\hline 2 & ... & $\cdots$ & ... & $\cdots$ & $\ldots$ & 48200 & 3070 & $\cdots$ & $\cdots$ & $\cdots$ & 40700 & ... \\
\hline 3 & $\cdots$ & $\cdots$ & $\cdots$ & $\cdots$ & $\cdots$ & 40800 & 4750 & $\cdots$ & $\cdots$ & $\cdots$ & 59600 & $\cdots$ \\
\hline 4 & $\cdots$ & $\cdots$ & $\cdots$ & 2650 & ... & 9670 & 3040 & $\cdots$ & $\cdots$ & $\cdots$ & 8240 & \\
\hline 5 & $\cdots$ & $\cdots$ & $\cdots$ & 10300 & $\cdots$ & 9210 & 1430 & $\cdots$ & $\cdots$ & $\cdots$ & 3030 & 3340 \\
\hline 6 & $\cdots$ & $\cdots$ & $\cdots$ & 42400 & $\cdots$ & 31400 & 1940 & $\ldots$ & ... & $\ldots$ & 22900 & 3510 \\
\hline 7 & $\cdots$ & $\cdots$ & $\cdots$ & 10500 & $\ldots$ & 8560 & 1290 & $\cdots$ & $\cdots$ & $\cdots$ & 211000 & 2340 \\
\hline 8 & $\cdots$ & $\cdots$ & $\cdots$ & 75200 & 2300 & 3610 & 1090 & $\cdots$ & $\cdots$ & $\cdots$ & 23000 & \\
\hline 9 & $\cdots$ & $\cdots$ & $\cdots$ & 9180 & 10700 & 1310 & $\cdots$ & $\cdots$ & $\cdots$ & $\cdots$ & $\cdots$ & $\cdots$ \\
\hline 10 & $\cdots$ & $\cdots$ & $\cdots$ & 28900 & 13400 & $\cdots$ & $\cdots$ & $\cdots$ & $\cdots$ & $\cdots$ & $\cdots$ & -. \\
\hline 11 & ... & $\cdots$ & $\cdots$ & 6820 & 57500 & -.. & ... & $\cdots$ & -.. & $\cdots$ & ... & $\cdots$ \\
\hline 12 & $\cdots$ & $\cdots$ & $\cdots$ & 4800 & 46900 & $\cdots$ & $\cdots$ & $\cdots$ & 58100 & $\cdots$ & $\cdots$ & .- \\
\hline 13 & ... & $\cdots$ & $\cdots$ & 13800 & 19500 & $\cdots$ & $\cdots$ & $\cdots$ & 24400 & $\cdots$ & $\cdots$ & $\cdots$ \\
\hline 14 & $\cdots$ & $\cdots$ & 1170 & 5320 & 48700 & $\cdots$ & $\cdots$ & $\cdots$ & 57800 & $\cdots$ & $\cdots$ & $\cdots$ \\
\hline 15 & $\cdots$ & $\cdots$ & $\cdots$ & 1080 & 29900 & $\cdots$ & $\cdots$ & $\cdots$ & 8600 & $\cdots$ & $\cdots$ & .- \\
\hline 16 & $\ldots$ & $\ldots$ & $\ldots$ & 562 & 25700 & $\ldots$ & ... & ... & $\cdots$ & -.. & 4850 & - \\
\hline 17 & $\cdots$ & $\cdots$ & $\cdots$ & $\ldots$ & 32800 & 1260 & $\cdots$ & $\cdots$ & -.. & $\cdots$ & 1340 & \\
\hline 18 & $\cdots$ & $\cdots$ & $\ldots$ & $\ldots$ & 42400 & $\cdots$ & $\cdots$ & $\cdots$ & $\cdots$ & $\cdots$ & $\cdots$ & $\cdots$ \\
\hline 19 & $\cdots$ & $\cdots$ & $\cdots$ & $\cdots$ & 3060 & $\cdots$ & $\cdots$ & $\cdots$ & $\cdots$ & $\cdots$ & $\cdots$ & \\
\hline 20 & 325000 & $\cdots$ & $\cdots$ & $\cdots$ & $\cdots$ & $\cdots$ & $\cdots$ & $\cdots$ & $\cdots$ & $\cdots$ & $\cdots$ & $\cdots$ \\
\hline 21 & 14600 & $\ldots$ & $\cdots$ & $\cdots$ & $\cdots$ & ... & ... & -.. & $\ldots$ & $\ldots$ & $\ldots$ & 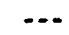 \\
\hline 22 & 1760 & $\cdots$ & $\cdots$ & $\cdots$ & $\cdots$ & $\cdots$ & $\cdots$ & $\cdots$ & $\cdots$ & $\cdots$ & $\cdots$ & \\
\hline 23 & $\cdots$ & $\cdots$ & $\cdots$ & $\cdots$ & $\cdots$ & $\cdots$ & $\cdots$ & $\cdots$ & $\cdots$ & $\cdots$ & $\cdots$ & $\cdots$ \\
\hline 24 & $\cdots$ & $\cdots$ & $\cdots$ & $\cdots$ & $\cdots$ & $\cdots$ & $\cdots$ & $\cdots$ & $\cdots$ & $\cdots$ & $\cdots$ & 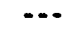 \\
\hline 25 & $\cdots$ & $\cdots$ & $\cdots$ & $\cdots$ & $\cdots$ & $\cdots$ & $\cdots$ & $\cdots$ & $\cdots$ & $\cdots$ & $\cdots$ & $\cdots$ \\
\hline 26 & $\ldots$ & $\ldots$ & $\ldots$ & $\cdots$ & $\ldots$ & $\cdots$ & ... & -.. & $\ldots$ & 4050 & $\ldots$ & -. \\
\hline 27 & $\ldots$ & $\cdots$ & $\ldots$ & $\ldots$ & $\ldots$ & $\ldots$ & ... & $\ldots$ & $\ldots$ & 20500 & 208000 & \\
\hline 28 & $\cdots$ & $\cdots$ & $\cdots$ & $\cdots$ & $\cdots$ & 980 & $\cdots$ & $\cdots$ & $\cdots$ & 1520 & 3040 & \\
\hline 29 & $\cdots$ & $\cdots$ & $\cdots$ & $\cdots$ & $\cdots$ & 9140 & -.. & $\cdots$ & $\cdots$ & 1050 & 2760 & \\
\hline 30 & $\ldots$ & $\ldots$ & $\ldots$ & $\ldots$ & $\ldots$ & 7720 & $\ldots$ & ... & $\cdots$ & 733 & 1210 & \\
\hline 31 & $\cdots$ & $\cdots$ & $\cdots$ & $\ldots$ & $\ldots$ & 5030 & $\ldots$ & $\ldots$ & -.. & $\ldots$ & -.. & \\
\hline
\end{tabular}


SURFACE-HATER DATA-Contimued

DAILY MEAN SUSPENDED-SEDIMENT DISCHARGE-Cont inued

09386950 ZUNI RIVER ABOVE BLACK ROCK RESERVOIR, MM

REMARKS.---Sediment load for days when the daily mean discharge was greater than $.142 \mathrm{~m}^{3} / \mathrm{s}$ are $p u b l i s h e d$.

SEDIMENT DISCHARGE, SUSPENDED (MEGAGRAMS/DAY), WATER YEAR OCTOBER 1988 TO SEPTEMBER 1989 DAILY MEAN VALUES

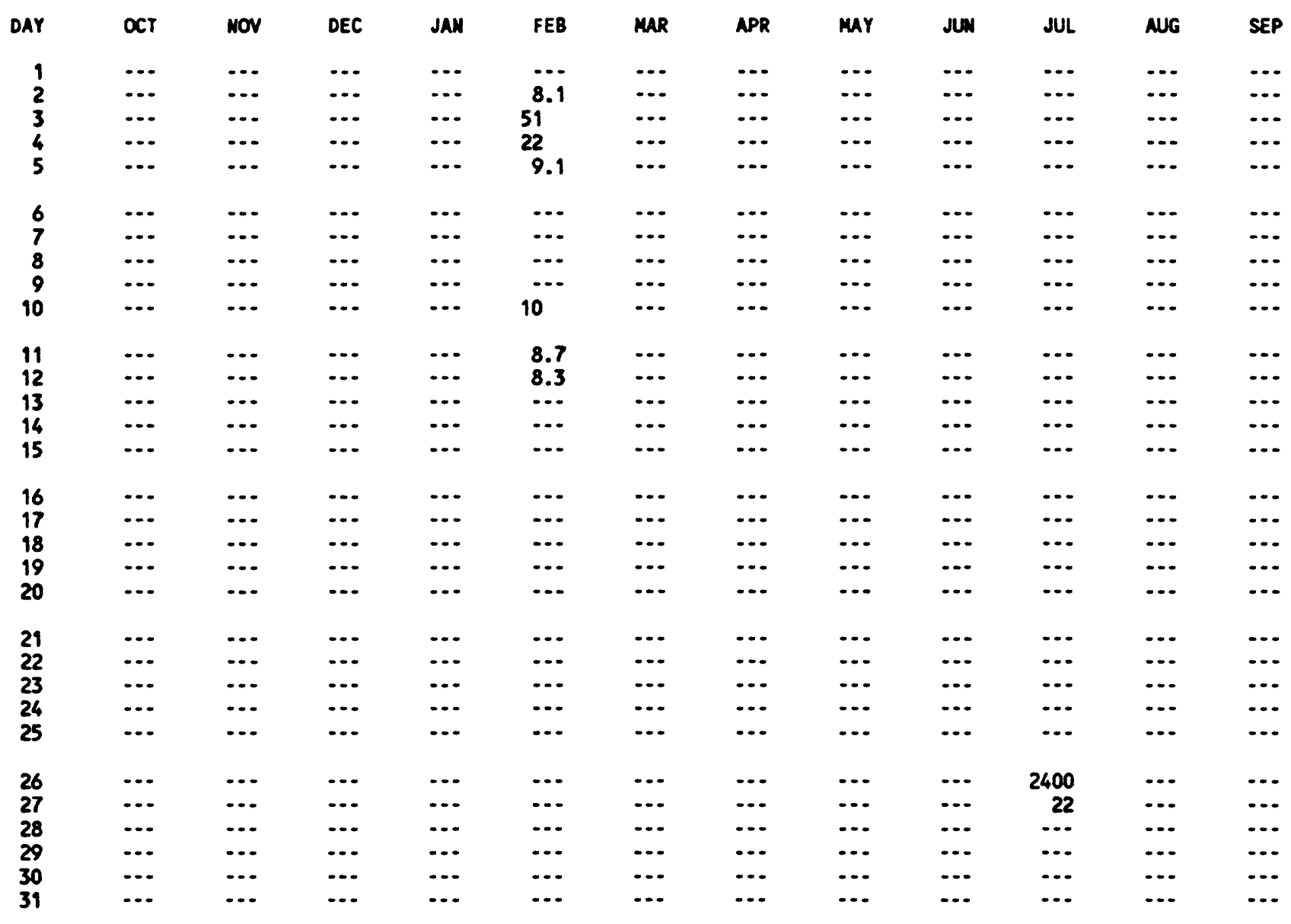


SURFACE-WATER DATA-Continued

DAILY MEAN SUSPEMDED-SEDIMENT DISCHARGE-Cont inued

09386950 ZUNI RIVER ABOVE BLACK ROCK RESERVOIR, NH-Continued

SEDIMENT DISCHARGE, SUSPENDED (MEGAGRAMS/DAY), WATER YEAR OCTOBER 1989 TO SEPTEMBER 1990 DAILY MEAN VALUES

\begin{tabular}{|c|c|c|c|c|c|c|c|c|c|c|c|c|}
\hline DAY & OCT & NOV & DEC & JAN & FEB & MAR & APR & Mar & Jun & JUL & AUG & SEP \\
\hline 1 & $\cdots$ & $\cdots$ & $\cdots$ & $\cdots$ & - & $\cdots$ & $\ldots$ & $\cdots$ & $\ldots$ & $\cdots$ & $\cdots$ & $\ldots$ \\
\hline 2 & $\ldots$ & $\ldots$ & $\ldots$ & $\ldots$ & $\ldots$ & $\ldots$ & $\ldots$ & $\cdots$ & $\ldots$ & $\cdots$ & $\ldots$ & $\ldots$ \\
\hline 3 & $\ldots$ & $\cdots$ & $\cdots$ & $\cdots$ & $\cdots$ & $\cdots$ & $\cdots$ & $\cdots$ & $\cdots$ & $\cdots$ & $\cdots$ & $\cdots$ \\
\hline 4 & $\ldots$ & $\cdots$ & $\ldots$ & $\ldots$ & $\cdots$ & $\cdots$ & $\cdots$ & $\cdots$ & $\ldots$ & $\cdots$ & $\cdots$ & $\ldots$ \\
\hline 5 & $\cdots$ & $\cdots$ & $\cdots$ & $\cdots$ & $\cdots$ & $\cdots$ & $\cdots$ & $\cdots$ & $\cdots$ & $\cdots$ & $\cdots$ & $\cdots$ \\
\hline 6 & $\cdots$ & $\cdots$ & $\cdots$ & $\cdots$ & $\cdots$ & $\cdots$ & $\cdots$ & $\cdots$ & $\cdots$ & $\cdots$ & $\cdots$ & $\cdots$ \\
\hline 7 & $\cdots$ & $\cdots$ & $\cdots$ & $\cdots$ & $\cdots$ & $\cdots$ & $\cdots$ & $\cdots$ & $\cdots$ & $\cdots$ & $\cdots$ & $\cdots$ \\
\hline 8 & $\ldots$ & $\ldots$ & $\ldots$ & $\ldots$ & $\cdots$ & $\ldots$ & $\cdots$ & $\ldots$ & $\ldots$ & $\cdots$ & $\cdots$ & $\cdots$ \\
\hline 9 & $\ldots$ & $\ldots$ & $\cdots$ & $\cdots$ & $\cdots$ & $\cdots$ & $\cdots$ & $\cdots$ & $\cdots$ & $\cdots$ & $\cdots$ & $\cdots$ \\
\hline 10 & $\cdots$ & $\cdots$ & $\cdots$ & $\cdots$ & $\cdots$ & $\cdots$ & $\cdots$ & $\cdots$ & $\cdots$ & $\cdots$ & $\cdots$ & $\cdots$ \\
\hline 11 & $\cdots$ & $\cdots$ & $\cdots$ & $\cdots$ & $\cdots$ & $\cdots$ & $\cdots$ & $\cdots$ & $\cdots$ & $\cdots$ & $\cdots$ & $\cdots$ \\
\hline 12 & $\cdots$ & $\cdots$ & $\cdots$ & $\cdots$ & $\cdots$ & $\cdots$ & $\cdots$ & $\cdots$ & $\cdots$ & $\cdots$ & $\cdots$ & $\cdots$ \\
\hline 13 & $\cdots$ & $\cdots$ & $\cdots$ & $\cdots$ & $\cdots$ & $\cdots$ & $\cdots$ & $\cdots$ & $\cdots$ & $\cdots$ & $\cdots$ & $\cdots$ \\
\hline 14 & $\cdots$ & $\cdots$ & $\cdots$ & $\cdots$ & $\cdots$ & $\cdots$ & $\cdots$ & $\cdots$ & $\cdots$ & $\cdots$ & $\cdots$ & $\cdots$ \\
\hline 15 & $\cdots$ & $\cdots$ & $\cdots$ & $\cdots$ & $\cdots$ & $\cdots$ & $\cdots$ & $\cdots$ & $\cdots$ & $\cdots$ & $\cdots$ & $\cdots$ \\
\hline 16 & $\cdots$ & $\cdots$ & $\cdots$ & $\cdots$ & -.. & $\cdots$ & $\cdots$ & $\cdots$ & $\cdots$ & $\cdots$ & $\cdots$ & $\cdots$ \\
\hline 17 & $\cdots$ & $\cdots$ & $\cdots$ & $\cdots$ & $\cdots$ & $\cdots$ & $\cdots$ & $\cdots$ & $\cdots$ & $\cdots$ & $\cdots$ & $\cdots$ \\
\hline 18 & $\cdots$ & $\cdots$ & $\cdots$ & $\cdots$ & $\cdots$ & $\cdots$ & $\cdots$ & $\cdots$ & $\cdots$ & $\cdots$ & 13 & $\cdots$ \\
\hline 19 & $\cdots$ & $\cdots$ & $\cdots$ & $\cdots$ & $\cdots$ & $\cdots$ & $\cdots$ & $\cdots$ & $\cdots$ & $\cdots$ & $\cdots$ & $\cdots$ \\
\hline 20 & $\cdots$ & $\cdots$ & $\cdots$ & $\cdots$ & $\cdots$ & $\cdots$ & $\cdots$ & $\cdots$ & $\cdots$ & $\cdots$ & $\cdots$ & $\cdots$ \\
\hline 21 & $\cdots$ & $\cdots$ & $\cdots$ & $\cdots$ & $\cdots$ & $\cdots$ & $\cdots$ & $\cdots$ & $\cdots$ & $\cdots$ & 21 & $\cdots$ \\
\hline 22 & $\cdots$ & $\cdots$ & $\cdots$ & $\cdots$ & $\cdots$ & $\cdots$ & $\cdots$ & $\cdots$ & $\cdots$ & $\cdots$ & $\cdots$ & $\cdots$ \\
\hline 23 & $\cdots$ & $\cdots$ & $\cdots$ & $\cdots$ & $\cdots$ & $\cdots$ & $\cdots$ & $\cdots$ & $\cdots$ & $\cdots$ & $\cdots$ & $\cdots$ \\
\hline 24 & $\cdots$ & $\cdots$ & $\cdots$ & $\cdots$ & $\cdots$ & $\cdots$ & $\cdots$ & $\cdots$ & $\cdots$ & $\cdots$ & $\cdots$ & 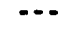 \\
\hline 25 & $\cdots$ & $\cdots$ & $\cdots$ & $\cdots$ & $\cdots$ & $\cdots$ & $\cdots$ & $\cdots$ & $\cdots$ & $\cdots$ & $\cdots$ & - \\
\hline 26 & $\cdots$ & $\cdots$ & $\cdots$ & $\cdots$ & $\cdots$ & $\cdots$ & $\cdots$ & $\cdots$ & $\cdots$ & $\cdots$ & $\cdots$ & $\cdots$ \\
\hline 27 & $\cdots$ & $\cdots$ & $\cdots$ & $\cdots$ & $\cdots$ & $\cdots$ & $\cdots$ & $\cdots$ & $\cdots$ & $\cdots$ & $\cdots$ & \\
\hline 28 & $\cdots$ & $\cdots$ & $\cdots$ & $\cdots$ & $\cdots$ & $\cdots$ & $\cdots$ & $\cdots$ & $\cdots$ & $\cdots$ & $\cdots$ & $\cdots$ \\
\hline 29 & $\cdots$ & $\cdots$ & $\cdots$ & $\cdots$ & $\cdots$ & $\cdots$ & $\cdots$ & $\cdots$ & $\cdots$ & $\cdots$ & $\cdots$ & $\cdots$ \\
\hline 30 & $\ldots$ & $\cdots$ & $\cdots$ & $\cdots$ & $\cdots$ & $\cdots$ & $\cdots$ & $\cdots$ & $\cdots$ & $\cdots$ & $\cdots$ & \\
\hline 31 & $\cdots$ & $\cdots$ & $\cdots$ & $\cdots$ & $\cdots$ & $\cdots$ & $\cdots$ & $\cdots$ & $\cdots$ & $\cdots$ & $\cdots$ & \\
\hline
\end{tabular}


SURFACE-MATER DATA-Continued

DAILY MEAN SUSPENDED-SEDIMENT DISCHARGE-Cont inued

09386950 ZUNI RIVER ABOVE BLACK ROCK RESERVOIR, MH-Continued

SEDIMENT DISCHARGE, SUSPENDED (MEGAGRAMS/DAY), WATER YEAR OCTOBER 1990 TO SEPTEMBER 1991 DAILY MEAN VALUES

\begin{tabular}{|c|c|c|c|c|c|c|c|c|c|c|c|c|}
\hline DAY & OCT & MOV & DEC & JAN & FE8 & MAR & APR & MAY & JUN & JUL & NUG & SEP \\
\hline 1 & $\cdots$ & $\cdots$ & $\cdots$ & $\cdots$ & $\cdots$ & $\cdots$ & $\cdots$ & $\cdots$ & $\cdots$ & $\cdots$ & $\cdots$ & $\cdots$ \\
\hline 2 & $\ldots$ & $\cdots$ & $\cdots$ & $\cdots$ & $\cdots$ & $\cdots$ & $\cdots$ & $\cdots$ & $\cdots$ & $\cdots$ & $\cdots$ & $\cdots$ \\
\hline 3 & $\cdots$ & $\cdots$ & $\cdots$ & $\cdots$ & $\cdots$ & $\cdots$ & $\cdots$ & $\cdots$ & $\cdots$ & $\cdots$ & $\cdots$ & $\cdots$ \\
\hline 4 & $\ldots$ & $\cdots$ & $\cdots$ & $\cdots$ & $\cdots$ & $\cdots$ & 25 & $\cdots$ & $\cdots$ & $\cdots$ & $\cdots$ & $\cdots$ \\
\hline 5 & $\ldots$ & $\cdots$ & $\cdots$ & $\cdots$ & $\cdots$ & $\cdots$ & 66 & $\cdots$ & $\cdots$ & $\cdots$ & $\cdots$ & 190 \\
\hline 6 & $\cdots$ & $\cdots$ & $\cdots$ & $\cdots$ & $\cdots$ & $\cdots$ & 111 & $\cdots$ & $\cdots$ & $\cdots$ & $\cdots$ & 46 \\
\hline 7 & $\ldots$ & $\cdots$ & $\cdots$ & $\cdots$ & $\ldots$ & $\cdots$ & 104 & $\cdots$ & $\cdots$ & $\cdots$ & $\cdots$ & 3.2 \\
\hline 8 & $\cdots$ & $\cdots$ & $\cdots$ & $\cdots$ & $\cdots$ & $\cdots$ & 59 & $\cdots$ & $\cdots$ & $\cdots$ & $\cdots$ & $\cdots$ \\
\hline 9 & $\cdots$ & $\cdots$ & $\cdots$ & $\cdots$ & $\cdots$ & $\cdots$ & 52 & $\cdots$ & $\cdots$ & $\cdots$ & $\cdots$ & $\cdots$ \\
\hline 10 & $\cdots$ & $\cdots$ & $\cdots$ & $\cdots$ & $\cdots$ & $\cdots$ & 64 & $\cdots$ & $\cdots$ & $\cdots$ & $\cdots$ & $\cdots$ \\
\hline 11 & $\ldots$ & $\cdots$ & $=-$ & $\cdots$ & $-\cdots$ & $=-$ & 40 & $\ldots$ & $\ldots$ & $\cdots$ & $\ldots$ & $\cdots$ \\
\hline 12 & $\cdots$ & $\cdots$ & $\cdots$ & $\cdots$ & $\cdots$ & $\cdots$ & 28 & $\cdots$ & $\cdots$ & $\cdots$ & $\ldots$ & $\cdots$ \\
\hline 13 & $\cdots$ & $\cdots$ & $\cdots$ & $\cdots$ & $\cdots$ & $\cdots$ & 21 & $\cdots$ & $\cdots$ & $\cdots$ & $\cdots$ & $\cdots$ \\
\hline 16 & $\cdots$ & $\cdots$ & $\cdots$ & $\cdots$ & $\cdots$ & $\cdots$ & 22 & $\cdots$ & $\cdots$ & $\cdots$ & $\cdots$ & $\cdots$ \\
\hline 15 & $\cdots$ & $\cdots$ & $\cdots$ & $\cdots$ & $\cdots$ & $\cdots$ & 23 & $\cdots$ & $\cdots$ & $\cdots$ & $\cdots$ & $\cdots$ \\
\hline 16 & $\cdots$ & $\cdots$ & $\cdots$ & $\cdots$ & $\cdots$ & $\cdots$ & 20 & $\cdots$ & $\cdots$ & $\cdots$ & $\cdots$ & $\cdots$ \\
\hline 17 & $\cdots$ & $\cdots$ & $\cdots$ & $\cdots$ & $\cdots$ & $\cdots$ & 7.1 & $\cdots$ & $\cdots$ & $\cdots$ & $\ldots$ & $\cdots$ \\
\hline 18 & $\cdots$ & $\cdots$ & $\cdots$ & $\cdots$ & $\cdots$ & $\cdots$ & 2.4 & $\cdots$ & $\cdots$ & $\cdots$ & $\cdots$ & $\cdots$ \\
\hline 19 & $\cdots$ & $\cdots$ & $\cdots$ & $\cdots$ & $\cdots$ & $\cdots$ & $\cdots$ & $\cdots$ & $\cdots$ & $\cdots$ & $\cdots$ & $\cdots$ \\
\hline 20 & $\cdots$ & $\cdots$ & $\cdots$ & $\cdots$ & $-\infty$ & $\cdots$ & $\cdots$ & $\cdots$ & $\cdots$ & $\cdots$ & $\cdots$ & $\cdots$ \\
\hline 21 & $\ldots$ & $\cdots$ & $\cdots$ & $\cdots$ & $\cdots$ & $\cdots$ & $\cdots$ & $\cdots$ & $\cdots$ & $\cdots$ & $\cdots$ & $\cdots$ \\
\hline 22 & $\cdots$ & $\cdots$ & $\cdots$ & $\cdots$ & $\cdots$ & $\cdots$ & $\cdots$ & $\cdots$ & $\cdots$ & $\cdots$ & $\cdots$ & $\cdots$ \\
\hline 23 & $\cdots$ & $\cdots$ & $\cdots$ & $\cdots$ & $\cdots$ & $\cdots$ & $\cdots$ & $\cdots$ & $\cdots$ & $\cdots$ & $\cdots$ & $\cdots$ \\
\hline 26 & $\cdots$ & $\cdots$ & $\cdots$ & $\cdots$ & $\cdots$ & $\cdots$ & $\cdots$ & $\cdots$ & $\cdots$ & $\cdots$ & $\cdots$ & $\cdots$ \\
\hline 25 & $\cdots$ & $\cdots$ & $\cdots$ & $\cdots$ & $\cdots$ & $\cdots$ & $\cdots$ & $\cdots$ & $\cdots$ & $\cdots$ & $\cdots$ & $\cdots$ \\
\hline 26 & $\cdots$ & $\cdots$ & $\cdots$ & $\cdots$ & $\cdots$ & $\cdots$ & $\cdots$ & $\cdots$ & $\cdots$ & $\cdots$ & $\cdots$ & $\cdots$ \\
\hline 27 & $\cdots$ & $\cdots$ & $\cdots$ & $\cdots$ & $\cdots$ & $\cdots$ & $\cdots$ & $\cdots$ & $\cdots$ & $\cdots$ & $\cdots$ & $\cdots$ \\
\hline 28 & $\cdots$ & $\cdots$ & $\cdots$ & $\cdots$ & $\cdots$ & $\cdots$ & $\cdots$ & $\cdots$ & $\cdots$ & $\cdots$ & $\cdots$ & $\cdots$ \\
\hline 29 & $\cdots$ & $\cdots$ & $\cdots$ & $\cdots$ & $\cdots$ & $\cdots$ & $\cdots$ & $\cdots$ & $\cdots$ & $\cdots$ & $\cdots$ & $\cdots$ \\
\hline 30 & $\cdots$ & $\cdots$ & $\cdots$ & $\cdots$ & $\cdots$ & $\cdots$ & $\cdots$ & $\cdots$ & $\cdots$ & $\cdots$ & $\cdots$ & $\cdots$ \\
\hline 31 & $\ldots$ & $\ldots$ & $\cdots$ & $\ldots$ & $\cdots$ & $\cdots$ & $\cdots$ & $\cdots$ & $\ldots$ & $\cdots$ & $\cdots$ & $\cdots$ \\
\hline
\end{tabular}


SURFACE-WATER DATA-Continued

DAILY MEAN SUSPENDED-SEDIMENT DISCHARGE-ContinUed

09394500 LITTLE COLORADO RIVER AT WOOORUFF, AZ

REMARKS.---Sediment load for days when the daily mean discharge was greater than $.283 \mathrm{~m}^{3} / \mathrm{s}$ are published.

SEDIMENT DISCHARGE, SUSPENDED (MEgAGRAMS/DAY), WATER YEAR OCTOBER 1988 TO SEPTEMBER 1989 DAILY MEAN VALUES

\begin{tabular}{|c|c|c|c|c|c|c|c|c|c|c|c|c|}
\hline DAY & OCT & NOV & DEC & JAK & FEB & MAR & APR & mar & JUW & JUL & AUG & SEP \\
\hline $\begin{array}{l}1 \\
2 \\
3 \\
4 \\
5\end{array}$ & $\begin{array}{l}\ldots \\
\ldots \\
\ldots \\
\ldots\end{array}$ & $\begin{array}{l}\ldots \\
\ldots \\
\ldots \\
\ldots\end{array}$ & $\begin{array}{l}\ldots \\
\ldots \\
\ldots \\
\ldots\end{array}$ & $\begin{array}{l}\cdots \\
\ldots \\
\cdots \\
\cdots\end{array}$ & $\begin{array}{l}\ldots \\
\ldots \\
\ldots \\
\ldots \\
\ldots\end{array}$ & $\begin{array}{l}\ldots \\
\ldots \\
\ldots \\
\ldots\end{array}$ & $\begin{array}{l}\cdots \\
\cdots \\
\cdots \\
\cdots\end{array}$ & $\begin{array}{l}\cdots \\
\ldots \\
\cdots \\
\cdots\end{array}$ & $\begin{array}{l}\ldots \\
\ldots \\
\ldots \\
\ldots\end{array}$ & $\begin{array}{l}\ldots \\
\ldots \\
\ldots \\
\ldots\end{array}$ & $\begin{array}{r}2410 \\
1790 \\
546 \\
210 \\
45\end{array}$ & $\begin{array}{r}\ldots . \\
916 \\
2890 \\
128\end{array}$ \\
\hline $\begin{array}{r}6 \\
7 \\
8 \\
9 \\
10\end{array}$ & $\begin{array}{l}\ldots \\
\ldots \\
\ldots \\
\ldots \\
\ldots\end{array}$ & $\begin{array}{l}\ldots \\
\ldots \\
\ldots \\
\ldots\end{array}$ & $\begin{array}{l}\ldots \\
\ldots \\
\ldots \\
\ldots\end{array}$ & $\begin{array}{r}163 \\
18 \\
\ldots \ldots \\
\ldots \ldots\end{array}$ & $\begin{array}{l}\ldots \\
\ldots \\
\ldots \\
\ldots\end{array}$ & $\begin{array}{l}\ldots \\
\ldots \\
\ldots \\
\ldots\end{array}$ & $\begin{array}{l}\ldots \\
\ldots \\
\ldots \\
\ldots\end{array}$ & $\begin{array}{l}\ldots . \\
\ldots \\
\ldots \\
\ldots\end{array}$ & $\begin{array}{l}\ldots \\
\ldots \\
\ldots \\
\ldots\end{array}$ & $\begin{array}{l}\ldots \\
\ldots \\
\ldots \\
\ldots \\
111\end{array}$ & $\begin{array}{c}17 \\
\ldots \ldots \\
\ldots \ldots \\
\ldots \\
36\end{array}$ & $\begin{array}{c}33 \\
\ldots \\
\ldots \\
\ldots \\
\ldots\end{array}$ \\
\hline $\begin{array}{l}11 \\
12 \\
13 \\
16 \\
15\end{array}$ & $\begin{array}{r}20 \\
17 \\
2 . \\
29 \\
318\end{array}$ & $\begin{array}{l}\ldots \\
\ldots \\
\ldots \\
\ldots\end{array}$ & $\begin{array}{l}\ldots \\
\ldots \\
\ldots \\
\ldots\end{array}$ & $\begin{array}{l}\ldots \\
\ldots \\
\ldots \\
\ldots\end{array}$ & $\begin{array}{r}96 \\
177 \\
56 \\
23 \\
\cdots\end{array}$ & $\begin{array}{l}\ldots \\
\ldots \\
\ldots \\
\ldots\end{array}$ & $\begin{array}{l}\ldots . \\
\ldots . \\
35 \\
59\end{array}$ & $\begin{array}{l}\ldots \\
\ldots \\
\ldots \\
\ldots\end{array}$ & $\begin{array}{l}\ldots \\
\ldots \\
\ldots \\
\ldots\end{array}$ & $\begin{array}{r}\ldots \\
142 \\
76 \\
\ldots \\
\ldots\end{array}$ & $\begin{array}{l}\ldots \\
\ldots \\
\ldots \\
\ldots\end{array}$ & $\begin{array}{l}\ldots \\
\ldots \\
\ldots \\
\ldots\end{array}$ \\
\hline $\begin{array}{l}16 \\
17 \\
18 \\
19 \\
20\end{array}$ & $\begin{array}{r}198 \\
34 \\
\ldots \\
\ldots\end{array}$ & $\begin{array}{l}\ldots \\
\ldots \\
\ldots \\
\ldots \\
\ldots\end{array}$ & $\begin{array}{l}\ldots \\
\ldots \\
\ldots \\
\ldots\end{array}$ & $\begin{array}{l}\ldots \\
\ldots \\
\ldots \\
\ldots\end{array}$ & $\begin{array}{l}\ldots \\
\ldots \\
\ldots \\
\ldots\end{array}$ & $\begin{array}{l}\ldots \\
\ldots \\
\ldots \\
\ldots \\
\ldots\end{array}$ & $\begin{array}{l}\ldots \\
\ldots \\
\ldots \\
\ldots\end{array}$ & $\begin{array}{l}\ldots \\
\ldots \\
\ldots \\
\ldots\end{array}$ & $\begin{array}{l}\ldots \\
\ldots \\
\ldots \\
\ldots\end{array}$ & $\begin{array}{l}\ldots \\
\ldots \\
\ldots \\
\ldots\end{array}$ & $\begin{array}{r}\ldots \\
42400 \\
47800 \\
8590\end{array}$ & $\begin{array}{l}\ldots \\
\ldots \\
\ldots \\
\ldots\end{array}$ \\
\hline $\begin{array}{l}21 \\
22 \\
23 \\
24 \\
25\end{array}$ & $\begin{array}{l}\ldots \\
\ldots \\
\ldots \\
\ldots \\
\ldots\end{array}$ & $\begin{array}{l}\ldots \\
\ldots \\
\ldots \\
\ldots \\
\ldots\end{array}$ & $\begin{array}{l}\ldots \\
\ldots \\
\ldots- \\
\ldots \\
\ldots\end{array}$ & $\begin{array}{l}\ldots \\
\cdots \\
\cdots \\
24\end{array}$ & $\begin{array}{l}\ldots \\
\ldots \\
\ldots \\
\ldots \\
\ldots\end{array}$ & $\begin{array}{l}\ldots \\
\ldots \\
\ldots \\
\ldots \\
\ldots\end{array}$ & $\begin{array}{c}\ldots \\
\ldots \\
\ldots \\
\cdots\end{array}$ & $\begin{array}{l}\ldots \\
\ldots \\
\ldots \\
\ldots \\
\ldots\end{array}$ & $\begin{array}{l}\ldots \\
\ldots \\
\ldots \\
\ldots\end{array}$ & $\begin{array}{r}\ldots \\
34800 \\
1080 \\
396\end{array}$ & $\begin{array}{r}1020 \\
176 \\
23 \\
\ldots \\
\ldots .\end{array}$ & $\begin{array}{l}\ldots \\
\ldots \\
\ldots \\
\ldots\end{array}$ \\
\hline $\begin{array}{l}26 \\
27 \\
28 \\
29 \\
30 \\
31\end{array}$ & $\begin{array}{l}\ldots \\
\ldots \\
\ldots \\
\ldots \\
\ldots\end{array}$ & $\begin{array}{l}\ldots \\
\ldots \\
\ldots \\
\ldots \\
\ldots \\
\ldots\end{array}$ & $\begin{array}{l}\cdots \\
\ldots \\
\cdots \\
\cdots \\
\cdots\end{array}$ & $\begin{array}{l}\ldots \\
\ldots \\
\ldots \\
\ldots \\
\ldots\end{array}$ & $\begin{array}{l}\ldots \\
\ldots \\
\ldots \\
\ldots \\
\ldots \\
\ldots\end{array}$ & $\begin{array}{c}\ldots . \\
52 \\
\ldots \\
\ldots \\
\ldots \\
\ldots\end{array}$ & $\begin{array}{l}\ldots \\
\ldots \\
\ldots \\
\ldots \\
\ldots\end{array}$ & $\begin{array}{l}\ldots \\
\ldots \\
\ldots \\
\ldots \\
\ldots\end{array}$ & $\begin{array}{l}\ldots \\
\ldots \\
\ldots \\
\ldots \\
\ldots\end{array}$ & $\begin{array}{r}10400 \\
3480 \\
1300 \\
1520 \\
1010 \\
513\end{array}$ & $\begin{array}{l}\ldots \\
\ldots \\
\ldots \\
\ldots \\
\ldots\end{array}$ & $\begin{array}{l}\ldots \\
\ldots \\
\ldots \\
\ldots \\
\ldots\end{array}$ \\
\hline
\end{tabular}


SURFACE-WATER DATA-Continued

DAILY MEAN SUSPENDED-SEDIMENT DISCHARGE-Continued

09394500 LITTLE COLORADO RIVER AT WOOORUFF, AZ-Continued

SEDIMENT DISCHARGE, SUSPENDED (MEGAGRAMS/DAY), WATER YEAR OCTOBER 1989 TO SEPTEMBER 1990 DAILY MEAN VALUES

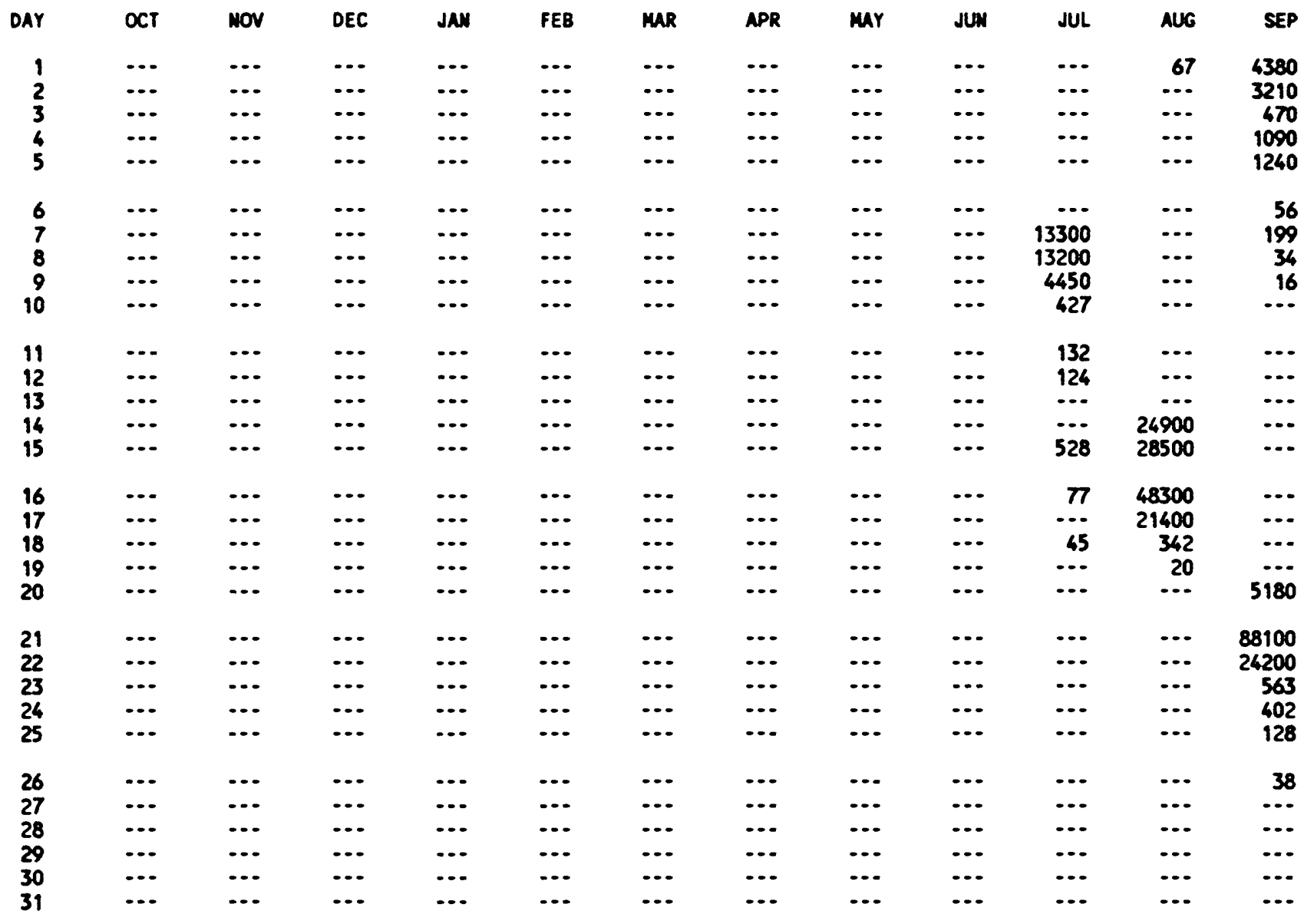


SURFACE-WATER DATA-Cont inued

DAILY MEAN SUSPENDED-SEDIMENT DISCHARGE-Contimued

09394500 LITTLE COLORADO RIVER AT HOODRUFF, AZ-Continued

SEDIMENT DISCHARGE, SUSPENDED (MEGAGRAMS/DAY), WATER YEAR OCTOBER 1990 TO SEPTEMBER 1991 DAILY MEAH VALUES

\begin{tabular}{|c|c|c|c|c|c|c|c|c|c|c|c|c|}
\hline DAY & OCT & NOV & DEC & JAK & FEB & MAR & APR & MAY & JUN & JUL & AUG & SEP \\
\hline $\begin{array}{l}1 \\
2 \\
3 \\
4 \\
5\end{array}$ & $\begin{array}{r}\ldots \\
126 \\
26 \\
\ldots\end{array}$ & $\begin{array}{r}3540 \\
11600 \\
751 \\
229\end{array}$ & $\begin{array}{l}\ldots \\
\ldots \\
\cdots \\
\cdots \\
\cdots\end{array}$ & $\begin{array}{r}152 \\
40 \\
\cdots- \\
26 \\
120\end{array}$ & $\begin{array}{l}\ldots \\
\ldots \\
\ldots \\
\ldots \\
\cdots\end{array}$ & $\begin{array}{r}2270 \\
59400 \\
17200 \\
6210 \\
7230\end{array}$ & $\begin{array}{r}1690 \\
998 \\
466 \\
180 \\
73\end{array}$ & $\begin{array}{l}\ldots \\
\ldots \\
\ldots \\
\ldots \\
\ldots\end{array}$ & $\begin{array}{l}\ldots \\
\ldots \\
\ldots \\
\ldots\end{array}$ & $\begin{array}{l}\ldots \\
\ldots \\
\ldots \\
\ldots \\
\ldots\end{array}$ & $\begin{array}{r}41 \\
666 \\
18 \\
\ldots \\
\ldots\end{array}$ & $\begin{array}{c}43 \\
17 \\
\ldots \\
252\end{array}$ \\
\hline $\begin{array}{r}6 \\
7 \\
8 \\
9 \\
10\end{array}$ & $\begin{array}{l}\ldots \\
\ldots \\
\ldots \\
\ldots \\
\ldots\end{array}$ & $\begin{array}{c}94 \\
22 \\
\ldots \\
\ldots \\
\ldots\end{array}$ & $\begin{array}{l}\ldots \\
\ldots \\
\cdots \\
\cdots \\
\cdots\end{array}$ & $\begin{array}{r}65100 \\
36900 \\
1340 \\
401 \\
182\end{array}$ & $\begin{array}{l}\ldots \\
\ldots \\
\ldots \\
\ldots\end{array}$ & $\begin{array}{r}5290 \\
1880 \\
390 \\
109 \\
36\end{array}$ & $\begin{array}{c}34 \\
\ldots \\
\ldots \\
\ldots \\
\ldots\end{array}$ & $\begin{array}{l}\ldots \\
\ldots \\
\ldots \\
\ldots \\
\ldots\end{array}$ & $\begin{array}{l}\ldots \\
\ldots \\
\ldots \\
\ldots \\
\ldots\end{array}$ & $\begin{array}{c}\ldots \\
63 \\
\cdots \\
\ldots\end{array}$ & $\begin{array}{l}\ldots \\
\ldots \\
\ldots \\
\ldots\end{array}$ & $\begin{array}{r}8110 \\
1460 \\
262 \\
55 \\
28\end{array}$ \\
\hline $\begin{array}{l}11 \\
12 \\
13 \\
14 \\
15\end{array}$ & $\begin{array}{l}\ldots \\
\ldots \\
\ldots \\
\ldots \\
\ldots\end{array}$ & $\begin{array}{l}\ldots \\
\ldots \\
\ldots \\
\ldots\end{array}$ & $\begin{array}{l}\ldots \\
\ldots \\
\ldots \\
\ldots \\
\cdots\end{array}$ & $\begin{array}{c}57 \\
34 \\
19 \\
\ldots \\
\ldots\end{array}$ & $\begin{array}{l}\ldots \\
\ldots \\
\ldots \\
\ldots \\
\ldots\end{array}$ & $\begin{array}{c}12 \\
\ldots . \\
\ldots . \\
\ldots . \\
\ldots\end{array}$ & $\begin{array}{l}\ldots . \\
\ldots \\
\cdots \\
\cdots\end{array}$ & $\begin{array}{l}\ldots \\
\ldots \\
\ldots \\
\ldots \\
\ldots\end{array}$ & $\begin{array}{l}\ldots \\
\ldots \\
\ldots \\
\ldots \\
\ldots\end{array}$ & $\begin{array}{l}\ldots \\
\ldots \\
\ldots \\
\ldots \\
\ldots\end{array}$ & $\begin{array}{l}\ldots \\
\ldots \\
\ldots \\
\ldots \\
\ldots\end{array}$ & $\begin{array}{c}18 \\
\ldots \\
\ldots \\
\ldots \\
\ldots\end{array}$ \\
\hline $\begin{array}{l}16 \\
17 \\
18 \\
19 \\
20\end{array}$ & $\begin{array}{l}\ldots \\
\ldots \\
\ldots \\
\ldots \\
\ldots\end{array}$ & $\begin{array}{l}\ldots \\
\ldots \\
\cdots \\
\cdots \\
\cdots\end{array}$ & $\begin{array}{r}234 \\
3970 \\
443 \\
\ldots . \\
\ldots\end{array}$ & $\begin{array}{l}\ldots \\
\ldots \\
\ldots \\
\ldots \\
\ldots\end{array}$ & $\begin{array}{l}\ldots \\
\ldots \\
\ldots \\
\ldots \\
\cdots\end{array}$ & $\begin{array}{l}\ldots . \\
\ldots \\
\ldots \\
\ldots \\
\ldots\end{array}$ & $\begin{array}{l}\ldots \\
\ldots \\
\ldots \\
\cdots\end{array}$ & $\begin{array}{l}\ldots \\
\ldots \\
\ldots \\
\ldots \\
\cdots\end{array}$ & $\begin{array}{l}\ldots \\
\ldots \\
\ldots \\
\ldots \\
\ldots\end{array}$ & $\begin{array}{l}\ldots \\
\ldots \\
\ldots \\
\ldots \\
\ldots\end{array}$ & $\begin{array}{l}\ldots \\
\ldots \\
\ldots \\
\ldots \\
\ldots\end{array}$ & - \\
\hline $\begin{array}{l}21 \\
22 \\
23 \\
24 \\
25\end{array}$ & $\begin{array}{r}19 \\
18 \\
\ldots \\
\ldots \\
\ldots\end{array}$ & $\begin{array}{l}\ldots \\
\ldots \\
\ldots \\
\ldots\end{array}$ & $\begin{array}{l}\ldots \\
\ldots \\
\ldots \\
\ldots\end{array}$ & $\begin{array}{l}\cdots \\
\ldots \\
\cdots \\
\cdots \\
\cdots\end{array}$ & $\begin{array}{l}\ldots \\
\ldots \\
\ldots \\
\ldots \\
\ldots\end{array}$ & $\begin{array}{l}\ldots . \\
\ldots \\
\ldots \\
382\end{array}$ & $\begin{array}{l}\ldots \\
\ldots \\
\ldots \\
\ldots\end{array}$ & $\begin{array}{l}\ldots \\
\ldots \\
\ldots \\
\cdots \\
\cdots\end{array}$ & $\begin{array}{l}\ldots \\
\ldots \\
\ldots \\
\ldots \\
\ldots\end{array}$ & $\begin{array}{l}\ldots \\
\ldots \\
\ldots \\
\ldots \\
\ldots\end{array}$ & $\begin{array}{c}\ldots . \\
\ldots . \\
837 \\
1980\end{array}$ & $\begin{array}{c}957 \\
301 \\
9.4\end{array}$ \\
\hline $\begin{array}{l}26 \\
27 \\
28 \\
29 \\
30 \\
31\end{array}$ & $\begin{array}{l}\ldots \\
\ldots \\
\ldots \\
\ldots \\
\ldots \\
\ldots\end{array}$ & $\begin{array}{l}\ldots \\
\ldots \\
\ldots \\
\ldots \\
\ldots\end{array}$ & $\begin{array}{r}\ldots . \\
\ldots 800 \\
1490 \\
464\end{array}$ & $\begin{array}{l}\ldots \\
\ldots \\
\ldots \\
\ldots \\
\ldots \\
\ldots\end{array}$ & $\begin{array}{l}\ldots \\
\ldots \\
\ldots \\
\ldots \\
\ldots \\
\ldots\end{array}$ & $\begin{array}{r}1710 \\
1450 \\
802 \\
841 \\
2980 \\
3140\end{array}$ & $\begin{array}{l}\ldots \\
\ldots \\
\ldots \\
\ldots \\
\ldots\end{array}$ & $\begin{array}{l}\ldots \\
\ldots \\
\ldots \\
\ldots \\
\ldots \\
\ldots\end{array}$ & $\begin{array}{l}\ldots \\
\ldots \\
\ldots \\
\ldots \\
\ldots \\
\ldots\end{array}$ & $\begin{array}{l}\ldots \\
\ldots \\
\ldots \\
\ldots \\
\ldots \\
\ldots\end{array}$ & $\begin{array}{r}288 \\
58 \\
457 \\
72 \\
-.- \\
82\end{array}$ & - \\
\hline
\end{tabular}


SURFACE-WATER DATA-Continued

DAILY MEAN SUSPENDED-SEDIMENT DISCHARGE-Cont inued

09397300 LITTLE COLORADO RIVER NEAR JOSEPH CITY, AZ

REMARKS.--Sediment load for days when the daily mean discharge was greater than $1.416 \mathrm{~m}^{3} / \mathrm{s}$ are published.

SEDIMENT DISCHARGE, SUSPENDED (MEGAGRAS/DAY), WATER YEAR OCTOBER 1988 TO SEPTEMBER 1989

DAILY MEAN VALUES

\begin{tabular}{|c|c|c|c|c|c|c|c|c|c|c|c|c|}
\hline DAY & OCT & NOV & DEC & JAN & FEB & MRR & APR & MAY & JUN & JUL & AUG & SEP \\
\hline 1 & $\cdots$ & $\ldots$ & $\cdots$ & $\ldots$ & $\ldots$ & $\cdots$ & $\cdots$ & $\cdots$ & $\cdots$ & $\ldots$ & 47600 & $\ldots$ \\
\hline 2 & $\cdots$ & $\ldots$ & $\ldots$ & $\cdots$ & $\cdots$ & $\cdots$ & $\cdots$ & $\cdots$ & $\cdots$ & $\cdots$ & 56500 & $\ldots$ \\
\hline 3 & $\ldots$ & $\ldots$ & $\ldots$ & $\ldots$ & $\cdots$ & $\ldots$ & $\cdots$ & $\cdots$ & $\cdots$ & $\cdots$ & 22600 & $\cdots$ \\
\hline 4 & $\cdots$ & $\ldots$ & $\ldots$ & $\cdots$ & $\cdots$ & $\ldots$ & $\ldots$ & $\cdots$ & $\cdots$ & $\cdots$ & $\ldots$ & 3830 \\
\hline 5 & $\cdots$ & $\ldots$ & $\ldots$ & $\cdots$ & 4940 & $\ldots$ & $\cdots$ & $\cdots$ & $\cdots$ & $\cdots$ & $\cdots$ & $\cdots$ \\
\hline 6 & $\ldots$ & $\ldots$ & $\ldots$ & $\ldots$ & $\ldots$ & $\ldots$ & $\cdots$ & $\cdots$ & $\cdots$ & $\cdots$ & $\ldots$ & $\cdots$ \\
\hline 7 & $\cdots$ & $\cdots$ & $\cdots$ & $\ldots$ & $\cdots$ & $\ldots$ & $\cdots$ & $\cdots$ & $\cdots$ & $\cdots$ & $\cdots$ & $\cdots$ \\
\hline 8 & $\cdots$ & $\ldots$ & $\cdots$ & $\cdots$ & $\cdots$ & $\cdots$ & $\cdots$ & $\cdots$ & $\cdots$ & $\cdots$ & $\cdots$ & $\cdots$ \\
\hline 9 & $\cdots$ & $\cdots$ & $\cdots$ & $\cdots$ & $\cdots$ & $\cdots$ & $\cdots$ & $\cdots$ & $\cdots$ & $\cdots$ & $\cdots$ & $\cdots$ \\
\hline 10 & $\cdots$ & $\cdots$ & $\cdots$ & $\cdots$ & $\cdots$ & $\cdots$ & $\cdots$ & $\cdots$ & $\cdots$ & $\cdots$ & $\cdots$ & $\cdots$ \\
\hline 11 & $\cdots$ & $\ldots$ & $\cdots$ & $\cdots$ & $\cdots$ & $\cdots$ & $\cdots$ & $\cdots$ & $\cdots$ & $\cdots$ & 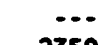 & $\cdots$ \\
\hline 12 & $\cdots$ & $\cdots$ & $\cdots$ & $\cdots$ & $\cdots$ & $\cdots$ & $\cdots$ & $\cdots$ & $\cdots$ & $\cdots$ & 2350 & $\cdots$ \\
\hline 13 & $\cdots$ & $\cdots$ & $\cdots$ & $\cdots$ & $\cdots$ & $\cdots$ & $\cdots$ & $\cdots$ & $\cdots$ & $\cdots$ & $\cdots$ & $\cdots$ \\
\hline 14 & $\cdots$ & $\cdots$ & $\cdots$ & $\cdots$ & $\cdots$ & $\cdots$ & $\cdots$ & $\cdots$ & $\cdots$ & $\cdots$ & $\cdots$ & $\cdots$ \\
\hline 15 & $\cdots$ & $\cdots$ & $\cdots$ & $\cdots$ & $\cdots$ & $\cdots$ & $\cdots$ & $\cdots$ & $\cdots$ & $\cdots$ & $\cdots$ & $\cdots$ \\
\hline 16 & $\cdots$ & $\cdots$ & $\cdots$ & $\cdots$ & $\cdots$ & $\cdots$ & $\cdots$ & $\cdots$ & $\cdots$ & $\cdots$ & $\cdots$ & $\cdots$ \\
\hline 17 & $\cdots$ & $\cdots$ & $\cdots$ & $\cdots$ & $\cdots$ & $\cdots$ & $\cdots$ & $\cdots$ & $\cdots$ & $\cdots$ & $\cdots$ & $\cdots$ \\
\hline 18 & $\cdots$ & $\cdots$ & $\cdots$ & $\cdots$ & $\cdots$ & $\cdots$ & $\cdots$ & $\cdots$ & $\cdots$ & $\cdots$ & 512000 & $\cdots$ \\
\hline 19 & $\cdots$ & $\cdots$ & $\cdots$ & $\cdots$ & $\cdots$ & $\cdots$ & $\cdots$ & $\cdots$ & $\cdots$ & $\cdots$ & 126000 & $\cdots$ \\
\hline 20 & $\cdots$ & $\cdots$ & $\cdots$ & $\cdots$ & $\cdots$ & $\cdots$ & $\cdots$ & $\cdots$ & $\cdots$ & $\cdots$ & 22500 & $\cdots$ \\
\hline 21 & $\cdots$ & $\cdots$ & $\cdots$ & $\cdots$ & $\cdots$ & $\ldots$ & $\cdots$ & $\cdots$ & $\cdots$ & $\cdots$ & 3460 & $\cdots$ \\
\hline 22 & $\cdots$ & $\cdots$ & $\cdots$ & $\cdots$ & $\cdots$ & $\cdots$ & $\cdots$ & $\cdots$ & $\cdots$ & $\cdots$ & 495 & $\cdots$ \\
\hline 23 & $\cdots$ & $\cdots$ & $\cdots$ & $\cdots$ & $\cdots$ & $\cdots$ & $\cdots$ & $\cdots$ & $\cdots$ & 28800 & $\cdots$ & $\cdots$ \\
\hline 24 & $\ldots$ & $\cdots$ & $\cdots$ & $\cdots$ & $\cdots$ & $\cdots$ & $\cdots$ & $\cdots$ & $\cdots$ & $\cdots$ & $\cdots$ & $\cdots$ \\
\hline 25 & $\cdots$ & $\cdots$ & $\cdots$ & $\cdots$ & $\cdots$ & $\cdots$ & $\cdots$ & $\cdots$ & $\cdots$ & $\cdots$ & $\cdots$ & $\cdots$ \\
\hline 26 & $\cdots$ & 1620 & $\cdots$ & $\cdots$ & $\cdots$ & $\cdots$ & $\cdots$ & $\cdots$ & $\cdots$ & 46600 & $\cdots$ & $\ldots$ \\
\hline 27 & $\cdots$ & $\cdots$ & $\cdots$ & $\cdots$ & $\cdots$ & 2460 & $\cdots$ & $\cdots$ & $\cdots$ & 31600 & $\cdots$ & $\cdots$ \\
\hline 28 & $\cdots$ & $\cdots$ & $\cdots$ & $\cdots$ & $\cdots$ & $\cdots$ & $\cdots$ & $\cdots$ & $\cdots$ & 18500 & $\cdots$ & $\cdots$ \\
\hline 29 & $\cdots$ & $\cdots$ & $\cdots$ & $\cdots$ & $\cdots$ & $\cdots$ & $\cdots$ & $\cdots$ & $\cdots$ & 12900 & $\cdots$ & $\cdots$ \\
\hline $\begin{array}{l}30 \\
31\end{array}$ & $\ldots$ & $\cdots$ & $\cdots$ & $\cdots$ & $\cdots$ & $\cdots$ & & $\cdots$ & $\cdots$ & $\begin{array}{r}20500 \\
8550\end{array}$ & $\cdots$ & $\cdots$ \\
\hline
\end{tabular}


SURFACE-HATER DATA-Cont inued

DAILY MEAN SUSPENDED-SEDIMEMT DISCHARGE-Cont inued

09397300 LITTLE COLORADO RIVER NEAR JOSEPH CITY, AZ-Continued

SEDIMENT DISCHARGE, SUSPENDED (MEgAGRAMS/DAY), WATER YEAR OCTOBER 1989 TO SEPTEMBER 1990 DAILY MENM VALUES

\begin{tabular}{|c|c|c|c|c|c|c|c|c|c|c|c|c|}
\hline DAY & OCT & MOV & DEC & JAN & FEB & MAR & APR & mar & JUN & JUL & AUG & SEP \\
\hline 1 & $\cdots$ & $\ldots$ & $\cdots$ & $\ldots$ & $\cdots$ & $\ldots$ & $\ldots$ & $\cdots$ & $\ldots$ & $\cdots$ & $\cdots$ & 43300 \\
\hline 2 & $\cdots$ & $\cdots$ & $\cdots$ & $\ldots$ & $\cdots$ & $\cdots$ & $\cdots$ & $\cdots$ & $\cdots$ & $\ldots$ & $\ldots$ & $\ldots$ \\
\hline 3 & $\cdots$ & $\cdots$ & $\cdots$ & $\cdots$ & $\ldots$ & $\cdots$ & $\cdots$ & $\cdots$ & $\cdots$ & $\cdots$ & $\cdots$ & $\cdots$ \\
\hline 4 & $\ldots$ & $\ldots$ & $\cdots$ & $\cdots$ & $\ldots$ & $\cdots$ & $\ldots$ & $\ldots$ & $\ldots$ & $\ldots$ & $\cdots$ & $\ldots$ \\
\hline 5 & $\cdots$ & $\cdots$ & $\cdots$ & $\cdots$ & $\cdots$ & $\cdots$ & $\cdots$ & $\cdots$ & $\cdots$ & $\cdots$ & $\cdots$ & 2960 \\
\hline 6 & $\ldots$ & $\cdots$ & $\ldots$ & $\ldots$ & $\cdots$ & $\ldots$ & $\ldots$ & $\ldots$ & $\ldots$ & $\ldots$ & $\ldots$ & $\cdots$ \\
\hline 7 & $\cdots$ & $\ldots$ & $\ldots$ & $\ldots$ & $\cdots$ & $\ldots$ & $\ldots$ & $\cdots$ & $\ldots$ & $\ldots$ & $\cdots$ & 53100 \\
\hline 8 & $\ldots$ & $\cdots$ & $\ldots$ & $\cdots$ & $\cdots$ & $\cdots$ & $\cdots$ & $\ldots$ & $\cdots$ & 87600 & $\cdots$ & $\ldots$ \\
\hline 9 & $\cdots$ & $\cdots$ & $\ldots$ & ... & $\cdots$ & $\ldots$ & $\cdots$ & $\cdots$ & $\cdots$ & 13200 & $\cdots$ & $\cdots$ \\
\hline 10 & $\cdots$ & $\cdots$ & $\cdots$ & $\cdots$ & $\cdots$ & $\cdots$ & $\cdots$ & $\cdots$ & $\cdots$ & 2150 & $\cdots$ & $\cdots$ \\
\hline 11 & $\cdots$ & $\cdots$ & ... & $\ldots$ & $\ldots$ & $\ldots$ & $\ldots$ & $\ldots$ & $\ldots$ & $\ldots$ & $\ldots$ & $\cdots$ \\
\hline 12 & $\ldots$ & $\ldots$ & $\ldots$ & $\ldots$ & $\ldots$ & $\ldots$ & $\ldots$ & $\cdots$ & $\ldots$ & 1160 & $\ldots$ & $\ldots$ \\
\hline 13 & $\cdots$ & $\cdots$ & $\ldots$ & $\ldots$ & $\cdots$ & $\cdots$ & $\ldots$ & $\cdots$ & $\cdots$ & $\ldots$ & $\ldots$ & \\
\hline 16 & $\cdots$ & $\cdots$ & $\cdots$ & $\cdots$ & $\cdots$ & $\cdots$ & $\cdots$ & $\ldots$ & $\ldots$ & 202000 & 9250 & $\cdots$ \\
\hline 15 & $\cdots$ & $\cdots$ & $\cdots$ & $\cdots$ & $\cdots$ & $\cdots$ & $\cdots$ & $\cdots$ & $\cdots$ & 218000 & 184000 & $\cdots$ \\
\hline 16 & $\ldots$ & $\ldots$ & $\ldots$ & $\ldots$ & $\cdots$ & $\ldots$ & $\cdots$ & $\ldots$ & $\ldots$ & 48200 & 210000 & $\cdots$ \\
\hline 17 & $\ldots$ & $\ldots$ & $\ldots$ & $\ldots$ & $\ldots$ & $\ldots$ & $\ldots$ & $\ldots$ & $\ldots$ & 1720 & 127000 & - \\
\hline 18 & $\cdots$ & $\cdots$ & $\ldots$ & $\ldots$ & $\ldots$ & $\cdots$ & $\cdots$ & $\ldots$ & $\cdots$ & 2410 & 56000 & $\ldots$ \\
\hline 19 & $\ldots$ & $\cdots$ & $\ldots$ & $\cdots$ & $\cdots$ & $\cdots$ & $\cdots$ & $\cdots$ & $\cdots$ & $\cdots$ & $\cdots$ & 41500 \\
\hline 20 & $\cdots$ & $\cdots$ & $\cdots$ & $\cdots$ & $\cdots$ & $\cdots$ & $\cdots$ & $\cdots$ & $\cdots$ & $\cdots$ & $\cdots$ & 58200 \\
\hline 21 & $\ldots$ & $\ldots$ & $\ldots$ & $\ldots$ & $\cdots$ & $\cdots$ & $\ldots$ & $\ldots$ & $\ldots$ & $\ldots$ & $\ldots$ & 132000 \\
\hline 22 & $\cdots$ & $\cdots$ & $\cdots$ & $\cdots$ & $\cdots$ & $\cdots$ & $\cdots$ & $\cdots$ & $\cdots$ & $\cdots$ & $\cdots$ & 52300 \\
\hline 23 & $\cdots$ & $\cdots$ & $\cdots$ & $\cdots$ & $\cdots$ & $\cdots$ & $\cdots$ & $\cdots$ & $\cdots$ & $\cdots$ & $\cdots$ & 51500 \\
\hline 24 & $\cdots$ & $\cdots$ & $\ldots$ & $\cdots$ & $\cdots$ & $\cdots$ & $\cdots$ & $\ldots$ & $\cdots$ & $\cdots$ & $\cdots$ & 43200 \\
\hline 25 & $\cdots$ & $\cdots$ & $\cdots$ & $\cdots$ & $\cdots$ & $\cdots$ & $\cdots$ & $\cdots$ & $\cdots$ & $\cdots$ & $\cdots$ & 33700 \\
\hline 26 & $\cdots$ & $\cdots$ & $\ldots$ & $\ldots$ & $\cdots$ & $\ldots$ & $\cdots$ & $\cdots$ & $\cdots$ & $\cdots$ & $\cdots$ & 18000 \\
\hline 27 & $\cdots$ & $\cdots$ & $\cdots$ & $\cdots$ & $\cdots$ & $\cdots$ & $\cdots$ & $\cdots$ & $\cdots$ & $\cdots$ & $\cdots$ & $\cdots$ \\
\hline 28 & $\cdots$ & $\cdots$ & $\cdots$ & $\cdots$ & $\cdots$ & $\cdots$ & $\cdots$ & $\cdots$ & $\cdots$ & $\cdots$ & $\cdots$ & $\cdots$ \\
\hline 29 & $\cdots$ & $\cdots$ & $\cdots$ & $\cdots$ & $\cdots$ & $\cdots$ & $\cdots$ & $\cdots$ & $\cdots$ & $\cdots$ & $\cdots$ & $\cdots$ \\
\hline 30 & $\cdots$ & $\cdots$ & $\cdots$ & $\cdots$ & $\cdots$ & $\cdots$ & $\cdots$ & $\cdots$ & $\cdots$ & $\cdots$ & $\cdots$ & $\cdots$ \\
\hline 31 & $\cdots$ & $\cdots$ & $\cdots$ & $\cdots$ & $\cdots$ & $\cdots$ & $\cdots$ & $\cdots$ & $\cdots$ & $\cdots$ & $\cdots$ & \\
\hline
\end{tabular}


SURFACE-MATER DATA-Continued

DAILY MEAN SUSPEIDED-SEDIMENT DISCHARGE-Continued

09397300 LITTLE COLORADO RIVER MEAR JOSEPH CITY, AZ-Cont inued

SEDIMENT DISCHARGE, SUSPENDED (MEGAGRMS/DAY), WATER YEAR OCTOBER 1990 TO SEPTEMBER 1991 DAILY MEAN VALUES

\begin{tabular}{|c|c|c|c|c|c|c|c|c|c|c|c|c|}
\hline DAY & oct & HOV & DEC & JAN & FEB & MAR & APR & MAY & Ju & JUL & AUG & SEP \\
\hline $\begin{array}{l}1 \\
2 \\
3 \\
4 \\
5\end{array}$ & $\begin{array}{l}\ldots \\
\ldots \\
\ldots \\
\ldots\end{array}$ & $\begin{array}{r}93400 \\
7350 \\
\ldots\end{array}$ & $\begin{array}{l}\ldots \\
\ldots \\
\ldots \\
\ldots\end{array}$ & $\begin{array}{r}\ldots \\
12800 \\
138000\end{array}$ & $\begin{array}{l}\ldots \\
\ldots \\
\ldots \\
\ldots\end{array}$ & $\begin{array}{r}142000 \\
178000 \\
32700 \\
17200\end{array}$ & $\begin{array}{r}8360 \\
10500 \\
7090 \\
4220 \\
2910\end{array}$ & $\begin{array}{l}\ldots \\
\ldots \\
\ldots \\
\ldots \\
\ldots\end{array}$ & $\ldots$ & $\ldots$ & $\begin{array}{c}1430 \\
\ldots \\
5620 \\
\ldots\end{array}$ & $\ldots$ \\
\hline $\begin{array}{r}6 \\
7 \\
8 \\
9 \\
10\end{array}$ & $\begin{array}{l}\ldots \\
\ldots \\
\ldots- \\
\ldots- \\
\ldots-\end{array}$ & $\begin{array}{l}\ldots \\
\ldots \\
\ldots \\
\ldots \\
\ldots-\end{array}$ & $\begin{array}{l}\ldots \\
\ldots \\
\cdots \\
\cdots \\
\cdots\end{array}$ & $\begin{array}{r}807000 \\
119000 \\
9890 \\
3360 \\
971\end{array}$ & $\begin{array}{l}\ldots \\
\ldots \\
\cdots \\
\ldots\end{array}$ & $\begin{array}{r}12200 \\
33700 \\
17600 \\
5740 \\
925\end{array}$ & $\begin{array}{c}1320 \\
\ldots \\
\ldots \\
\ldots\end{array}$ & $\begin{array}{l}\ldots \\
\ldots \\
\ldots \\
\ldots \\
\ldots\end{array}$ & $\begin{array}{l}\ldots \\
\ldots \\
\ldots \\
\ldots\end{array}$ & $\begin{array}{l}\ldots \\
\ldots \\
\ldots \\
\ldots\end{array}$ & 42000 & $\begin{array}{r}30800 \\
6920 \\
3860 \\
\ldots \\
\ldots\end{array}$ \\
\hline $\begin{array}{l}11 \\
12 \\
13 \\
14 \\
15\end{array}$ & $\begin{array}{l}\ldots \\
\ldots \\
\ldots \\
\ldots \\
\ldots\end{array}$ & $\begin{array}{l}\ldots \\
\ldots \\
\ldots \\
\ldots \\
\ldots\end{array}$ & $\begin{array}{l}\ldots \\
\ldots \\
\ldots \\
\cdots \\
\cdots\end{array}$ & $\begin{array}{l}422 \\
149 \\
\ldots \ldots \\
\ldots \\
\ldots\end{array}$ & $\begin{array}{r}971 \\
8260 \\
10600 \\
11200 \\
10600\end{array}$ & $\begin{array}{l}\ldots \\
\ldots \\
\ldots \\
\ldots\end{array}$ & $\begin{array}{l}\ldots \\
\ldots \\
\ldots \\
\ldots\end{array}$ & $\ldots$ & $\begin{array}{l}\ldots \\
\ldots \\
\ldots \\
\ldots\end{array}$ & $\begin{array}{l}\ldots \\
\ldots \\
\ldots \\
\ldots\end{array}$ & $\begin{array}{l}\ldots \\
\ldots \\
\ldots \\
\ldots \\
\ldots\end{array}$ & $\ldots$ \\
\hline $\begin{array}{l}16 \\
17 \\
18 \\
19 \\
20\end{array}$ & $\begin{array}{c}\ldots \\
\ldots \\
\ldots \\
\ldots \\
75800\end{array}$ & $\begin{array}{l}\ldots \\
\ldots \\
\ldots \\
\ldots\end{array}$ & $\begin{array}{r}343000 \\
122000 \\
5450 \\
\ldots \\
\ldots\end{array}$ & $\begin{array}{l}\ldots \\
\ldots \\
\ldots \\
\ldots\end{array}$ & $\begin{array}{l}7920 \\
1770 \\
6460 \\
4430 \\
732\end{array}$ & $\begin{array}{l}\ldots \\
\ldots \\
\ldots \\
\ldots\end{array}$ & $\begin{array}{l}\cdots \\
\ldots \\
\cdots \\
\cdots\end{array}$ & $\begin{array}{l}\ldots \\
\ldots \\
\ldots \\
\ldots\end{array}$ & $\begin{array}{l}\ldots \\
\ldots \\
\ldots \\
\ldots\end{array}$ & $\begin{array}{l}\ldots \\
\ldots \\
\ldots \\
\ldots\end{array}$ & $\ldots$ & $\begin{array}{l}\ldots \\
\ldots \\
\ldots \\
\ldots\end{array}$ \\
\hline $\begin{array}{l}21 \\
22 \\
23 \\
24 \\
25\end{array}$ & $\begin{array}{c}75800 \\
\ldots \\
\ldots \\
\ldots \\
\ldots\end{array}$ & $\begin{array}{l}\ldots \\
\ldots \\
\ldots \\
\ldots\end{array}$ & $\begin{array}{l}\ldots \\
\ldots \\
\ldots \\
\ldots\end{array}$ & $\begin{array}{l}\ldots \\
\ldots \\
\ldots \\
\ldots \\
\ldots\end{array}$ & $\ldots$ & $\begin{array}{l}\ldots \\
\ldots \\
\ldots \\
\cdots \\
\cdots\end{array}$ & $\begin{array}{l}\ldots \\
\ldots \\
\ldots \\
\ldots\end{array}$ & $\begin{array}{l}\ldots \\
\ldots \\
\ldots \\
\ldots \\
\ldots\end{array}$ & $\begin{array}{l}\ldots \\
\ldots \\
\ldots \\
\ldots \\
\ldots\end{array}$ & $\begin{array}{l}\ldots \\
\ldots \\
\ldots \\
\ldots\end{array}$ & $\begin{array}{l}\ldots \\
\ldots \\
\ldots \\
\ldots \\
\ldots\end{array}$ & $\begin{array}{l}\ldots \\
\ldots \\
\ldots \\
\ldots \\
\ldots\end{array}$ \\
\hline $\begin{array}{l}26 \\
27 \\
28 \\
29 \\
30 \\
31\end{array}$ & $\begin{array}{l}\ldots \\
\ldots \\
\ldots \\
\ldots \\
\ldots \\
\ldots\end{array}$ & $\begin{array}{l}\ldots \\
\ldots \\
\ldots \\
\ldots \\
\ldots \\
\ldots\end{array}$ & $\begin{array}{r}\ldots \\
\ldots \\
36200 \\
23200 \\
\ldots\end{array}$ & $\begin{array}{l}\ldots \\
\ldots \\
\ldots \\
\ldots \\
\ldots \\
\ldots\end{array}$ & $\begin{array}{l}\ldots \\
\ldots \\
\ldots \\
\ldots \\
\ldots\end{array}$ & $\begin{array}{r}4220 \\
7240 \\
4730 \\
5050 \\
5410 \\
13600\end{array}$ & $\begin{array}{l}\ldots \\
\ldots \\
\ldots \\
\ldots \\
\ldots \\
\ldots\end{array}$ & $\begin{array}{l}\ldots- \\
\ldots- \\
\ldots- \\
\ldots \\
\ldots \\
\ldots\end{array}$ & $\begin{array}{l}\ldots \\
\ldots \\
\ldots \\
\ldots \\
\ldots \\
\ldots\end{array}$ & $\begin{array}{l}\ldots \\
\ldots \\
\ldots \\
\ldots \\
\ldots \\
\ldots\end{array}$ & 170000 & $\begin{array}{l}\ldots \\
\ldots \\
\ldots \\
\ldots \\
\ldots \\
\ldots\end{array}$ \\
\hline
\end{tabular}




\section{SURFACE-HATER DATA-Continued \\ DAILY MEAN SUSPENDED-SEDIMENT DISCHARGE-Cont inued \\ 09401000 LITTLE COLORADO RIVER AT GRAMD FALLS, AZ}

REMARKS.--Sediment laad for days then the daily mean discharge was greater than .566 $\mathrm{m}^{3} / \mathrm{s}$ are published.

SEDIMENT DISCHARGE, SUSPENDED (MEGAGRAMS/DAY), WATER YEAR OCTOBER 1989 TO SEPTEMBER 1990 DAILY MEAN VALUES

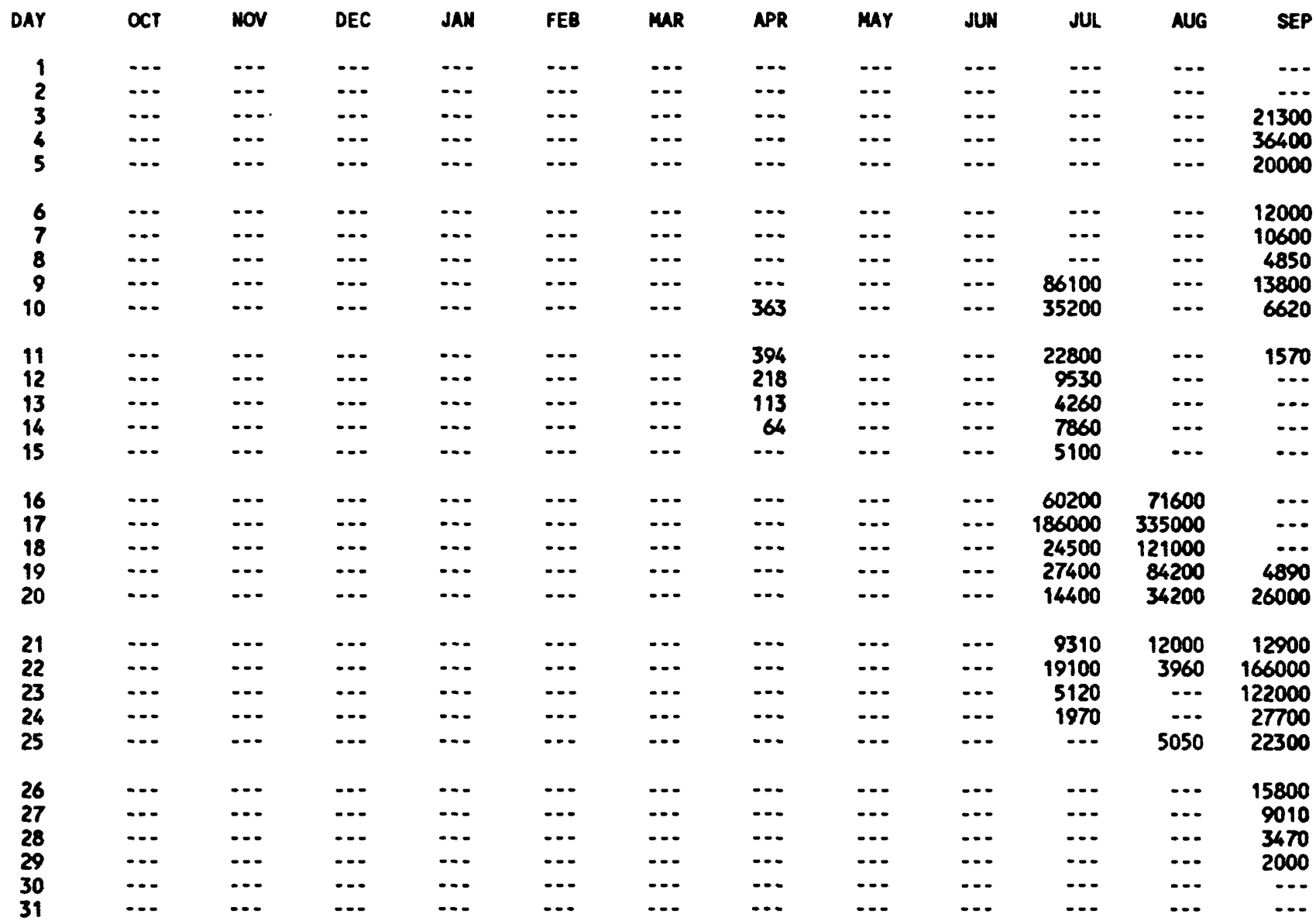


SURFACE-WATER DATA-Continued

DAILY MEAN SUSPENDED-SEDIMENT DISCHARGE-ContinuEd

09401000 LITTLE COLORADO RIVER AT GRAND FALLS, AZ-Cont inued

SEDIMENT DISCHARGE, SUSPENDED (MEGAGRAMS/OAY), WATER YEAR OCTOBER 1990 TO SEPTEMBER 1991 DAILY MEAN VALUES

\begin{tabular}{|c|c|c|c|c|c|c|c|c|c|c|c|c|}
\hline DAY & OCT & $\operatorname{mov}$ & DEC & JAM & FEB & MAR & $A P R$ & MAY & JUN & JUL & AUG & SEP \\
\hline $\begin{array}{l}1 \\
2 \\
3 \\
4 \\
5\end{array}$ & $\begin{array}{l}\ldots- \\
\ldots- \\
\ldots- \\
\ldots- \\
\ldots-\end{array}$ & $\begin{array}{r}\ldots- \\
=-- \\
=-- \\
37900 \\
22500\end{array}$ & $\begin{array}{l}\ldots \\
\ldots \\
\ldots \\
\ldots\end{array}$ & $\begin{array}{r}26500 \\
21800 \\
13000 \\
9430 \\
13100\end{array}$ & $\begin{array}{l}\ldots \\
\ldots- \\
\ldots- \\
\ldots-\end{array}$ & $\begin{array}{r}3290 \\
3150 \\
83300 \\
153000 \\
74700\end{array}$ & $\begin{array}{l}11900 \\
17000 \\
16400 \\
33700 \\
44300\end{array}$ & $\begin{array}{r}1460 \\
916 \\
745 \\
595 \\
533\end{array}$ & $\begin{array}{l}=- \\
=-- \\
=-- \\
=-- \\
=--\end{array}$ & $\begin{array}{l}\ldots- \\
=- \\
=- \\
=- \\
=-\end{array}$ & $\begin{array}{l}=-- \\
--- \\
--- \\
-\infty\end{array}$ & $\begin{array}{l}\ldots \\
\ldots \\
\ldots \\
\ldots\end{array}$ \\
\hline $\begin{array}{r}6 \\
7 \\
8 \\
9 \\
10\end{array}$ & $\begin{array}{l}\ldots- \\
\ldots- \\
\ldots- \\
\ldots- \\
\ldots-\end{array}$ & $\begin{array}{r}8050 \\
4800 \\
\ldots- \\
\ldots \\
\ldots\end{array}$ & $\begin{array}{l}\ldots \\
\ldots \\
\ldots \\
\ldots \\
\ldots\end{array}$ & $\begin{array}{r}57300 \\
281000 \\
204000 \\
44000 \\
15900\end{array}$ & $\begin{array}{l}\ldots- \\
\ldots- \\
\ldots- \\
\ldots-\end{array}$ & $\begin{array}{l}46400 \\
87800 \\
75300 \\
53500 \\
24100\end{array}$ & $\begin{array}{l}47700 \\
73600 \\
81900 \\
62900 \\
59300\end{array}$ & $\begin{array}{l}434 \\
328 \\
293 \\
207 \\
173\end{array}$ & $\begin{array}{l}-\infty \\
=- \\
--- \\
=- \\
-\infty\end{array}$ & $\begin{array}{l}=- \\
=- \\
=- \\
\ldots- \\
\ldots-\end{array}$ & $\begin{array}{l}-\infty \\
=-- \\
=-- \\
-\infty\end{array}$ & $\begin{array}{r}\ldots \\
32000 \\
25000 \\
11700\end{array}$ \\
\hline $\begin{array}{l}11 \\
12 \\
13 \\
14 \\
15\end{array}$ & $\begin{array}{l}\ldots- \\
\cdots \\
\ldots- \\
\ldots- \\
\ldots-\end{array}$ & $\begin{array}{l}=- \\
--- \\
=-- \\
=-- \\
=-\end{array}$ & $\begin{array}{l}\ldots \\
\ldots \\
\ldots \\
\ldots \\
\ldots\end{array}$ & $\begin{array}{r}11200 \\
5840 \\
4770 \\
3190 \\
2040\end{array}$ & $\begin{array}{l}\ldots . \\
\ldots \\
\ldots \\
-. . \\
3740\end{array}$ & $\begin{array}{r}13300 \\
9330 \\
8230 \\
7050 \\
4860\end{array}$ & $\begin{array}{r}170000 \\
179000 \\
102000 \\
42400 \\
21400\end{array}$ & $\begin{array}{r}132 \\
106 \\
88 \\
76 \\
57\end{array}$ & $\begin{array}{l}\ldots- \\
\ldots- \\
=-- \\
=- \\
=-\end{array}$ & $\begin{array}{l}\ldots \\
\ldots- \\
\ldots- \\
\ldots- \\
\ldots-\end{array}$ & $\begin{array}{r}\ldots \\
2700 \\
\cdots \\
\cdots\end{array}$ & $\begin{array}{r}5850 \\
2690 \\
\ldots \\
\ldots \\
\ldots\end{array}$ \\
\hline $\begin{array}{l}16 \\
17 \\
18 \\
19 \\
20\end{array}$ & $\begin{array}{l}--- \\
--- \\
=-- \\
=-- \\
=--\end{array}$ & $\begin{array}{l}--- \\
\ldots- \\
--- \\
---\end{array}$ & $\begin{array}{r}-- \\
50300 \\
58400 \\
10700 \\
5360\end{array}$ & $\begin{array}{r}1350 \\
952 \\
717 \\
-.- \\
-.-\end{array}$ & $\begin{array}{r}13600 \\
11900 \\
9640 \\
9140 \\
12000\end{array}$ & $\begin{array}{l}5110 \\
4470 \\
3570 \\
2870 \\
1990\end{array}$ & $\begin{array}{r}9640 \\
10100 \\
18900 \\
22400 \\
18800\end{array}$ & $\begin{array}{r}41 \\
\ldots \\
\ldots \\
\ldots \\
\ldots\end{array}$ & $\begin{array}{l}=-- \\
=-\infty \\
=-\infty \\
=--\end{array}$ & $\begin{array}{l}\ldots \\
\ldots \\
\ldots \\
\ldots- \\
\ldots\end{array}$ & $\begin{array}{l}--\infty \\
-\infty \\
-\infty \\
-\infty\end{array}$ & $\ldots$ \\
\hline $\begin{array}{l}21 \\
22 \\
23 \\
24 \\
25\end{array}$ & $\begin{array}{r}43300 \\
14900 \\
3510 \\
-\cdots\end{array}$ & $\begin{array}{l}\ldots- \\
\ldots \\
\ldots \\
\ldots \\
\ldots\end{array}$ & $\begin{array}{c}1040 \\
1000 \\
1020 \\
1240 \\
-\ldots\end{array}$ & $\begin{array}{l}\ldots- \\
\ldots- \\
\ldots- \\
-\ldots\end{array}$ & $\begin{array}{l}7280 \\
4420 \\
2820 \\
1980 \\
1390\end{array}$ & $\begin{array}{l}1480 \\
1720 \\
2960 \\
3330 \\
2270\end{array}$ & $\begin{array}{r}16200 \\
14100 \\
14500 \\
12200 \\
8980\end{array}$ & $\begin{array}{l}\ldots \\
\ldots \\
\ldots \\
\ldots \\
\ldots\end{array}$ & $\begin{array}{l}\ldots- \\
\ldots- \\
\ldots- \\
\cdots- \\
--\end{array}$ & $\begin{array}{l}\ldots \\
\ldots- \\
\ldots- \\
\cdots \\
\cdots-\end{array}$ & $\begin{array}{l}\ldots \\
\ldots \\
\ldots \\
\ldots \\
\ldots\end{array}$ & $\ldots$ \\
\hline $\begin{array}{l}26 \\
27 \\
28 \\
29 \\
30 \\
31\end{array}$ & $\begin{array}{l}\ldots \\
\ldots- \\
\ldots- \\
\ldots- \\
\ldots- \\
\ldots-\end{array}$ & $\begin{array}{l}\ldots \\
\ldots- \\
\ldots- \\
\ldots- \\
\ldots \\
\ldots\end{array}$ & $\begin{array}{r}\ldots \\
\ldots \\
\ldots \\
\ldots \\
\ldots \\
38600\end{array}$ & $\begin{array}{l}-. . \\
\ldots \\
\ldots- \\
\ldots- \\
\ldots \\
\ldots\end{array}$ & $\begin{array}{r}890 \\
897 \\
3130 \\
\ldots- \\
\ldots- \\
-\ldots\end{array}$ & $\begin{array}{l}1830 \\
1780 \\
7080 \\
8050 \\
5730 \\
6410\end{array}$ & $\begin{array}{c}6510 \\
5200 \\
5140 \\
4150 \\
2010 \\
\ldots . .\end{array}$ & $\begin{array}{l}-- \\
\ldots- \\
-- \\
\ldots- \\
\ldots- \\
-\ldots\end{array}$ & $\begin{array}{l}\ldots- \\
\ldots \\
\ldots- \\
\ldots- \\
\ldots \\
\ldots\end{array}$ & $\begin{array}{l}-\ldots \\
\ldots- \\
\ldots- \\
\ldots- \\
\ldots- \\
\ldots-\end{array}$ & $\begin{array}{l}-\ldots \\
\ldots- \\
=- \\
=- \\
\ldots-\end{array}$ & $\begin{array}{l}\cdots \\
\ldots- \\
\ldots \\
\ldots \\
\ldots \\
\ldots\end{array}$ \\
\hline
\end{tabular}


SURFACE-WATER DATA-Cont inued

DAILY MEAN SUSPENDED-SEDIMENT DISCHARGE-Cont inued

09402000 LITTLE COLORADO RIVER MEAR CAMERON, AZ

REMARKS.--Sediment load for days when the daily mean discharge was greater than $.566 \mathrm{~m}^{3} / \mathrm{s}$ are published.

SEDIMENT DISCHARGE, SUSPEMDED (MEGAGRAMS/DAY), WATER YEAR OCTOBER 1989 TO SEPTEMBER 1990 DAILY MEAN VALUES

\begin{tabular}{|c|c|c|c|c|c|c|c|c|c|c|c|c|}
\hline DAY & oct & NON & DEC & JAN & FEB & MAR & APR & MAY & JUN & Jur & AUG & SEP \\
\hline $\begin{array}{l}1 \\
2 \\
3 \\
4 \\
5\end{array}$ & $\begin{array}{l}\ldots \\
\ldots \\
\ldots \\
\ldots \\
\ldots\end{array}$ & $\begin{array}{l}\ldots \\
\ldots \\
\ldots \\
\cdots \\
\cdots\end{array}$ & $\begin{array}{l}\cdots \\
\cdots \\
\cdots \\
\cdots \\
\cdots\end{array}$ & $\begin{array}{l}\ldots \\
\ldots \\
\ldots \\
\ldots \\
\cdots\end{array}$ & $\begin{array}{l}\ldots \\
\cdots \\
\cdots \\
\cdots \\
\cdots\end{array}$ & $\begin{array}{l}\cdots \\
\cdots \\
\ldots \\
\ldots \\
\cdots\end{array}$ & $\begin{array}{l}\ldots \\
\ldots \\
\ldots \\
\ldots \\
\ldots\end{array}$ & $\begin{array}{l}\ldots \\
\ldots \\
\ldots \\
\ldots \\
\ldots\end{array}$ & $\begin{array}{l}\ldots \\
\ldots \\
\cdots \\
\cdots \\
\cdots\end{array}$ & $\begin{array}{l}\ldots \\
\ldots \\
\ldots \\
\ldots \\
\ldots\end{array}$ & $\begin{array}{c}18100 \\
\ldots \\
\ldots \\
\ldots\end{array}$ & $\begin{array}{r}\ldots \\
\ldots \\
\ldots \\
49900 \\
44600\end{array}$ \\
\hline $\begin{array}{r}6 \\
7 \\
8 \\
9 \\
10\end{array}$ & $\begin{array}{l}\ldots \\
569 \\
\ldots \\
\ldots \\
\ldots\end{array}$ & $\begin{array}{l}\ldots \\
\ldots \\
\ldots \\
\ldots \\
\ldots\end{array}$ & $\begin{array}{l}\ldots \\
\ldots \\
\ldots \\
\cdots \\
\cdots\end{array}$ & $\begin{array}{l}\cdots \\
\cdots \\
\cdots \\
\cdots \\
\cdots\end{array}$ & $\begin{array}{l}\ldots \\
\ldots \\
\ldots \\
\ldots \\
\cdots\end{array}$ & $\begin{array}{l}\cdots \\
\ldots \\
\ldots \\
\cdots \\
\cdots\end{array}$ & $\begin{array}{l}\ldots \\
\ldots \\
\ldots \\
\ldots \\
\ldots\end{array}$ & $\begin{array}{l}\ldots \\
\ldots \\
\ldots \\
\ldots \\
\ldots\end{array}$ & $\begin{array}{l}\ldots \\
\ldots \\
\ldots \\
\ldots \\
\cdots\end{array}$ & $\begin{array}{r}\ldots . . \\
70300 \\
29100 \\
57900\end{array}$ & $\begin{array}{l}\ldots . \\
\ldots \\
\cdots \\
\cdots \\
\cdots\end{array}$ & $\begin{array}{r}37700 \\
29100 \\
13400 \\
7230 \\
4860\end{array}$ \\
\hline $\begin{array}{l}11 \\
12 \\
13 \\
14 \\
15\end{array}$ & $\begin{array}{l}\ldots \\
\ldots \\
\ldots \\
\ldots \\
\ldots\end{array}$ & $\begin{array}{l}\ldots \\
\cdots \\
\ldots \\
\ldots \\
\cdots\end{array}$ & $\begin{array}{l}\ldots \\
\ldots \\
\ldots \\
\ldots \\
\ldots\end{array}$ & $\begin{array}{l}\ldots \\
\ldots \\
\cdots \\
\cdots \\
\cdots\end{array}$ & $\begin{array}{l}\ldots . \\
\ldots \\
\cdots \\
\cdots\end{array}$ & $\begin{array}{l}\cdots \\
\ldots \\
\cdots \\
\cdots \\
\cdots\end{array}$ & $\begin{array}{l}\ldots \\
\ldots \\
\ldots \\
\ldots \\
\ldots\end{array}$ & $\begin{array}{l}\ldots \\
\ldots \\
\ldots \\
\ldots \\
\ldots\end{array}$ & $\begin{array}{l}\cdots \\
\cdots \\
\cdots \\
\cdots \\
\cdots\end{array}$ & $\begin{array}{r}29900 \\
16100 \\
8360 \\
5180 \\
31700\end{array}$ & $\begin{array}{r}\ldots \\
\ldots \\
\ldots \\
\ldots\end{array}$ & $\begin{array}{c}2180 \\
1270 \\
\ldots \\
\ldots \\
\ldots\end{array}$ \\
\hline $\begin{array}{l}16 \\
17 \\
18 \\
19 \\
20\end{array}$ & $\begin{array}{l}\cdots \\
\cdots \\
\cdots \\
\cdots \\
\cdots\end{array}$ & $\begin{array}{l}\ldots \\
\ldots \\
\cdots \\
\cdots \\
\cdots\end{array}$ & $\begin{array}{l}\ldots \\
\cdots \\
\cdots \\
\cdots\end{array}$ & $\begin{array}{l}\cdots \\
\cdots \\
\cdots \\
\cdots \\
\cdots\end{array}$ & $\begin{array}{l}\ldots \\
\ldots \\
\cdots \\
\cdots\end{array}$ & $\begin{array}{l}\cdots \\
\cdots \\
\cdots \\
\cdots \\
\cdots\end{array}$ & $\begin{array}{l}\ldots \\
\ldots \\
\ldots \\
\ldots \\
\ldots\end{array}$ & $\begin{array}{l}\cdots \\
\cdots \\
\ldots \\
\cdots \\
\cdots\end{array}$ & $\begin{array}{l}\ldots \\
\ldots \\
\cdots \\
\cdots \\
\cdots\end{array}$ & $\begin{array}{l}15500 \\
59000 \\
36100 \\
3310 \\
4190\end{array}$ & $\begin{array}{r}53500 \\
209000 \\
182000 \\
119000 \\
62400\end{array}$ & $\begin{array}{r}3610 \\
11200 \\
241000 \\
394000 \\
244000\end{array}$ \\
\hline $\begin{array}{l}21 \\
22 \\
23 \\
24 \\
25\end{array}$ & $\begin{array}{l}\ldots \\
\ldots \\
\ldots \\
\ldots \\
\ldots\end{array}$ & $\begin{array}{l}\ldots \\
\ldots \\
\ldots \\
\ldots \\
\cdots\end{array}$ & $\begin{array}{l}\ldots \\
\ldots \\
\ldots \\
\cdots \\
\cdots\end{array}$ & $\begin{array}{l}\ldots \\
\ldots \\
\ldots \\
\cdots \\
\cdots\end{array}$ & $\begin{array}{r}9890 \\
8300 \\
10400 \\
\ldots \ldots \\
\ldots .\end{array}$ & $\begin{array}{l}\ldots \\
\ldots \\
\ldots \\
\ldots \\
\ldots\end{array}$ & $\begin{array}{l}\ldots \\
\ldots \\
\ldots \\
\ldots \\
\ldots\end{array}$ & $\begin{array}{l}\ldots \\
\cdots \\
\cdots \\
\cdots \\
\cdots\end{array}$ & $\begin{array}{l}\ldots \\
\cdots \\
\cdots \\
\cdots \\
\cdots\end{array}$ & $\begin{array}{r}1320 \\
998 \\
15400 \\
8950 \\
833\end{array}$ & $\begin{array}{r}33600 \\
15400 \\
7610 \\
\ldots \\
\ldots\end{array}$ & $\begin{array}{r}265000 \\
117000 \\
189000 \\
256000 \\
11500\end{array}$ \\
\hline $\begin{array}{l}26 \\
27 \\
28 \\
29 \\
30 \\
31\end{array}$ & $\begin{array}{l}\ldots \\
\ldots \\
\ldots \\
\ldots \\
\ldots \\
\ldots\end{array}$ & $\begin{array}{l}\cdots \\
\ldots \\
\ldots \\
\cdots \\
\cdots \\
\cdots\end{array}$ & $\begin{array}{l}\ldots \\
\ldots \\
\ldots \\
\ldots \\
\ldots\end{array}$ & $\begin{array}{l}\cdots \\
\ldots \\
\ldots \\
\ldots \\
\ldots \\
\ldots\end{array}$ & $\begin{array}{l}\ldots \\
\cdots \\
\cdots \\
\cdots \\
\cdots\end{array}$ & $\begin{array}{l}\ldots \\
\ldots \\
\ldots \\
\ldots \\
\ldots \\
\ldots\end{array}$ & $\begin{array}{l}\ldots \\
\ldots \\
\ldots \\
\ldots \\
\ldots\end{array}$ & $\begin{array}{l}\cdots \\
\cdots \\
\cdots \\
\cdots \\
\cdots\end{array}$ & $\begin{array}{l}\cdots \\
\cdots \\
\cdots \\
\cdots \\
\cdots\end{array}$ & $\begin{array}{l}\cdots \\
\cdots \\
\cdots \\
\cdots \\
\cdots\end{array}$ & $\begin{array}{c}1700 \\
1070 \\
\ldots \\
\ldots \\
\ldots\end{array}$ & $\begin{array}{r}20500 \\
14400 \\
8360 \\
4260 \\
2510\end{array}$ \\
\hline 31 & $\cdots$ & $\cdots$ & $\cdots$ & $\cdots$ & $\cdots$ & $\cdots$ & $\cdots$ & $\cdots$ & $\cdots$ & $\cdots$ & $\cdots$ & $\cdots$ \\
\hline
\end{tabular}


SURFACE-WATER DATA-Continued

DAILY MEAN SUSPENDED-SEDIMENT DISCHARGE-Cont inued

09402000 LITTLE COLORADO RIVER NEAR CAMERON, AZ-Continued

SEDIMENT DISCHARGE, SUSPENDED (MEGAGRAMS/DAY), WATER YEAR OCTOBER 1990 TO SEPTEMBER 1991 DAILY MEAN VALUES

\begin{tabular}{|c|c|c|c|c|c|c|c|c|c|c|c|c|}
\hline DAY & oct & MOV & DEC & $\mathbf{J A N}$ & FEB & MAR & APR & MAY & JU & JUL & AUS & SEP \\
\hline $\begin{array}{l}1 \\
2 \\
3 \\
4 \\
5\end{array}$ & $\begin{array}{r}1000 \\
8070 \\
22300 \\
12600 \\
3210\end{array}$ & 55200 & $\begin{array}{l}\ldots- \\
\ldots- \\
\ldots- \\
\ldots-\end{array}$ & $\begin{array}{l}10300 \\
14700 \\
25700 \\
30600 \\
29700\end{array}$ & $\begin{array}{l}\ldots \\
\ldots \\
\ldots \\
\ldots \\
\ldots\end{array}$ & $\begin{array}{r}2150 \\
3720 \\
20500 \\
182000 \\
174000\end{array}$ & $\begin{array}{l}17300 \\
43600 \\
56700 \\
63500 \\
91900\end{array}$ & $\begin{array}{r}3160 \\
2140 \\
1220 \\
1010 \\
916\end{array}$ & $\begin{array}{l}\ldots \\
\ldots \\
\ldots \\
\ldots \\
\ldots\end{array}$ & $\begin{array}{l}\ldots \\
\ldots \\
\ldots- \\
\ldots- \\
\ldots\end{array}$ & $\begin{array}{l}\ldots \\
\ldots \\
\ldots \\
\ldots \\
\ldots\end{array}$ & $\begin{array}{r}174000 \\
108000 \\
32700 \\
7880\end{array}$ \\
\hline $\begin{array}{r}6 \\
7 \\
8 \\
9 \\
10\end{array}$ & $\begin{array}{l}\cdots \\
\cdots \\
\cdots \\
\cdots \\
\ldots\end{array}$ & $\begin{array}{r}14800 \\
5490 \\
3480 \\
2090 \\
1150\end{array}$ & $\begin{array}{l}\ldots- \\
\ldots \\
\ldots \\
\ldots \\
\ldots\end{array}$ & $\begin{array}{r}23400 \\
162000 \\
379000 \\
147000 \\
41700\end{array}$ & $\begin{array}{l}\ldots \\
\ldots- \\
\ldots- \\
\ldots- \\
\ldots-\end{array}$ & $\begin{array}{l}105000 \\
121000 \\
172000 \\
177000 \\
110000\end{array}$ & $\begin{array}{l}138000 \\
182000 \\
206000 \\
218000 \\
232000\end{array}$ & $\begin{array}{l}934 \\
816 \\
650 \\
518 \\
388\end{array}$ & $\begin{array}{l}\ldots \\
\ldots \\
\ldots \\
\ldots \\
\ldots\end{array}$ & $\begin{array}{l}\ldots \\
\ldots \\
\ldots \\
\ldots \\
\ldots\end{array}$ & $\begin{array}{r}\ldots \\
4320 \\
4520 \\
\ldots . \\
\ldots\end{array}$ & $\begin{array}{r}119000 \\
73300 \\
66100 \\
78200 \\
48600\end{array}$ \\
\hline $\begin{array}{l}11 \\
12 \\
13 \\
16 \\
15\end{array}$ & $\begin{array}{l}\ldots- \\
\ldots- \\
\ldots- \\
\ldots-\end{array}$ & $\begin{array}{l}--- \\
--- \\
--- \\
-\ldots-\end{array}$ & $\begin{array}{l}\ldots \\
\ldots \\
\ldots- \\
\ldots- \\
\ldots-\end{array}$ & $\begin{array}{r}12800 \\
5680 \\
2940 \\
2800 \\
2300\end{array}$ & $\begin{array}{l}\ldots- \\
\ldots- \\
\ldots- \\
\ldots- \\
--\infty\end{array}$ & $\begin{array}{l}59600 \\
36100 \\
27100 \\
23300 \\
19600\end{array}$ & $\begin{array}{l}261000 \\
275000 \\
250000 \\
187000 \\
109000\end{array}$ & $\begin{array}{l}251 \\
191 \\
123 \\
65 \\
32\end{array}$ & $\begin{array}{l}\ldots- \\
\ldots- \\
--- \\
-\ldots \\
---\end{array}$ & $\begin{array}{l}\ldots . \\
\ldots- \\
\ldots- \\
\ldots\end{array}$ & $\begin{array}{l}--- \\
--- \\
--- \\
-\ldots\end{array}$ & $\begin{array}{r}25700 \\
14800 \\
6720 \\
3140 \\
\ldots . .\end{array}$ \\
\hline $\begin{array}{l}16 \\
17 \\
18 \\
19 \\
20\end{array}$ & $\begin{array}{l}\ldots- \\
\ldots- \\
\ldots- \\
\ldots- \\
-\infty\end{array}$ & $\begin{array}{l}\ldots- \\
\ldots- \\
\ldots- \\
\ldots-\end{array}$ & $\begin{array}{r}112000 \\
36100 \\
13300\end{array}$ & $\begin{array}{r}2490 \\
1780 \\
1430 \\
1160 \\
989\end{array}$ & $\begin{array}{r}13400 \\
10700 \\
7350 \\
9810\end{array}$ & $\begin{array}{l}16300 \\
15200 \\
15200 \\
13900 \\
12600\end{array}$ & $\begin{array}{l}67200 \\
65400 \\
60900 \\
75300 \\
75100\end{array}$ & $\begin{array}{l}--- \\
--- \\
=-- \\
--- \\
---\end{array}$ & $\begin{array}{l}--- \\
--- \\
--- \\
-\ldots- \\
-\infty\end{array}$ & $\begin{array}{l}\ldots- \\
\ldots- \\
\ldots- \\
\ldots-\end{array}$ & $\begin{array}{l}-.- \\
--- \\
--- \\
-\ldots-\end{array}$ & $\begin{array}{l}\ldots- \\
\ldots \\
\ldots- \\
\ldots- \\
\ldots-\end{array}$ \\
\hline $\begin{array}{l}21 \\
22 \\
23 \\
24 \\
25\end{array}$ & $\begin{array}{r}26700 \\
22600 \\
7610\end{array}$ & $\begin{array}{l}\ldots- \\
\ldots- \\
--- \\
-\ldots \\
-\ldots\end{array}$ & $\begin{array}{l}8080 \\
4910 \\
2770 \\
1750 \\
1300\end{array}$ & $\begin{array}{l}700 \\
\ldots- \\
\ldots- \\
\ldots- \\
\ldots-\end{array}$ & $\begin{array}{l}9340 \\
5790 \\
4000 \\
3290 \\
2780\end{array}$ & $\begin{array}{r}9890 \\
6610 \\
9250 \\
12600 \\
13200\end{array}$ & $\begin{array}{l}61400 \\
48500 \\
40100 \\
37800 \\
24000\end{array}$ & $\begin{array}{l}--- \\
--- \\
-.- \\
---\end{array}$ & $\begin{array}{l}\ldots- \\
\ldots- \\
\ldots- \\
\ldots- \\
\ldots-\end{array}$ & $\begin{array}{l}\ldots- \\
\ldots- \\
\ldots- \\
\ldots- \\
\ldots-\end{array}$ & $\begin{array}{l}\ldots- \\
\ldots-- \\
\ldots- \\
\ldots-\end{array}$ & $\begin{array}{l}\ldots \\
\ldots \\
\ldots \\
\ldots \\
\ldots\end{array}$ \\
\hline $\begin{array}{l}26 \\
27 \\
28 \\
29 \\
30 \\
31\end{array}$ & $\begin{array}{c}3760 \\
1840 \\
\ldots \\
\ldots \\
\ldots \\
\ldots\end{array}$ & $\begin{array}{l}\ldots- \\
\ldots \\
\ldots \\
\ldots \\
\ldots \\
\ldots\end{array}$ & $\begin{array}{l}\ldots \\
\ldots \\
\ldots \\
\ldots \\
\ldots \\
\ldots\end{array}$ & $\begin{array}{l}\ldots \\
\ldots \\
\ldots \\
\ldots \\
\ldots \\
\ldots\end{array}$ & $\begin{array}{r}2320 \\
1780 \\
1340 \\
\ldots . \\
\ldots \\
\ldots\end{array}$ & $\begin{array}{r}11900 \\
10600 \\
9430 \\
29500 \\
22700 \\
17600\end{array}$ & $\begin{array}{r}17300 \\
11100 \\
9130 \\
7160 \\
4940 \\
\ldots .\end{array}$ & $\begin{array}{l}\ldots- \\
\ldots- \\
\ldots- \\
\ldots \\
\ldots\end{array}$ & $\begin{array}{l}\ldots- \\
\ldots \\
\ldots- \\
\ldots- \\
\ldots\end{array}$ & $\begin{array}{l}\ldots \\
\ldots \\
\ldots \\
\ldots- \\
\ldots- \\
-\ldots\end{array}$ & $\begin{array}{r}9620 \\
83200 \\
9710 \\
\ldots\end{array}$ & $\begin{array}{l}\ldots \\
\ldots \\
\ldots \\
\ldots \\
\ldots \\
\ldots\end{array}$ \\
\hline
\end{tabular}




$\begin{array}{ll}07-24-89 & 0515 \\ 07-24-89 & 1435 \\ 07-27-89 & 1025 \\ 07-28-89 & 1830 \\ 09-05-89 & 2110 \\ 07-07-90 & 2350 \\ 07-08-90 & 0030 \\ 07-08-90 & 0800 \\ 07-08-90 & 0810 \\ 07-09-90 & 2020 \\ 07-09-90 & 2020 \\ 07-09-90 & 2040 \\ 07-09-90 & 2120 \\ 07-12-90 & 0100 \\ 07-12-90 & 0100 \\ 07-12-90 & 0140 \\ 08-15-90 & 1030 \\ 08-01-91 & 1900 \\ 08-02-91 & 0120 \\ 08-02-91 & 0130 \\ 08-02-91 & 0210 \\ 08-02-91 & 0230 \\ 08-02-91 & 0310 \\ 08-02-91 & 0350 \\ 08-02-91 & 0430 \\ 08-06-91 & 2100 \\ 08-06-91 & 2110 \\ 08-06-91 & 2140 \\ 08-06-91 & 2200 \\ 08-06-91 & 2240 \\ 08-06-91 & 2320 \\ 08-06-91 & 2350 \\ 08-07-91 & 0010\end{array}$


SURFACE-WATER DATA-Continued

CHEMICAL AMALYSES-Continued

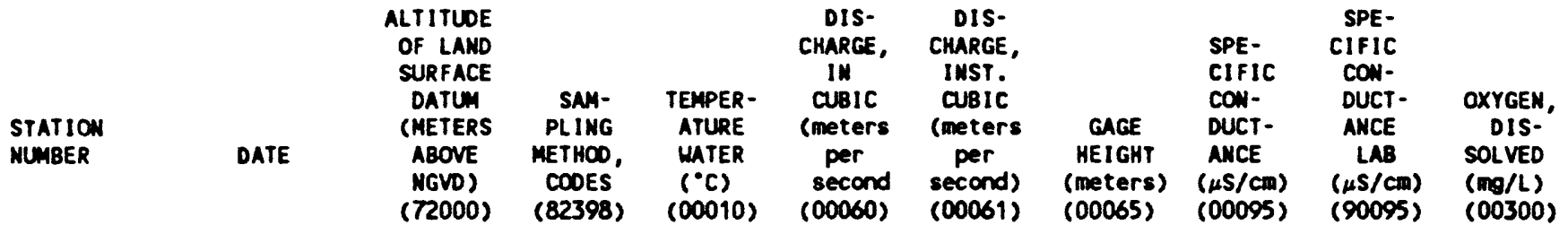

PUERCO RIVER MEAR CHURCH ROCK, Continued

$09395350 \quad \begin{aligned} & 07-24-89 \\ & 07-24-89 \\ & 07-27-89 \\ & 07-28-89 \\ & 09-05-89 \\ & 07-07-90 \\ & 07-08-90 \\ & 07-08-90 \\ & 07-08-90 \\ & 07-09-90 \\ & 07-09-90 \\ & 07-09-90 \\ & 07-09-90 \\ & 07-12-90 \\ & 07-12-90 \\ & 07-12-90 \\ & 08-15-90 \\ & 08-01-91 \\ & 08-02-91 \\ & 08-02-91 \\ & 08-02-91 \\ & 08-02-91 \\ & 08-02-91 \\ & 08-02-91 \\ & 08-02-91 \\ & 08-06-91 \\ & 08-06-91 \\ & 08-06-91 \\ & 08-06-91 \\ & 08-06-91 \\ & 08-06-91 \\ & 08-06-91 \\ & 08-07-91 \\ & \end{aligned}$

2051

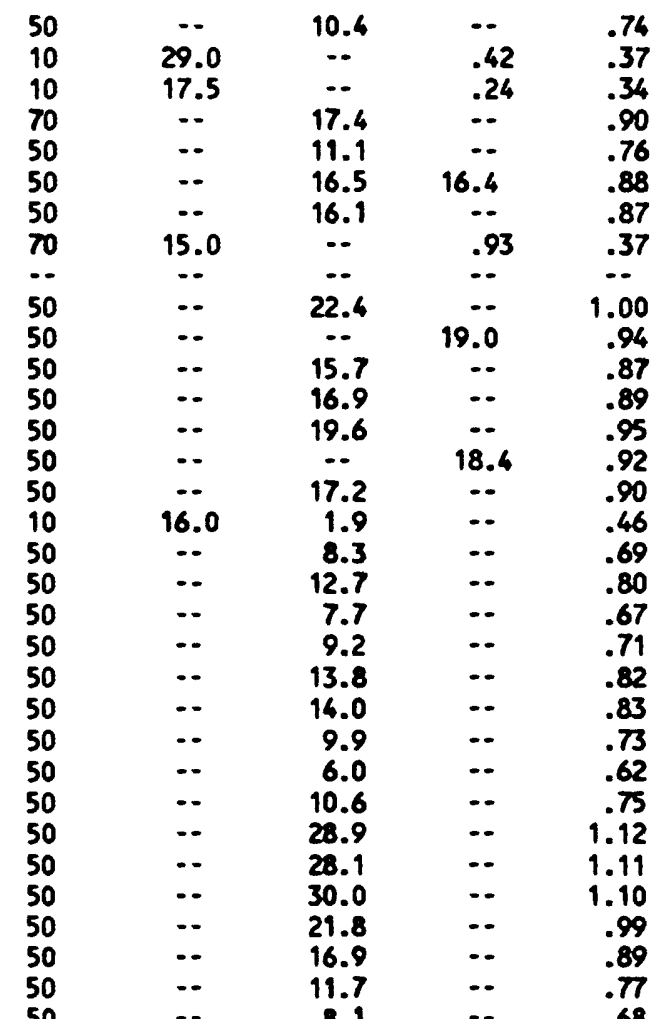

\begin{tabular}{|c|c|c|}
\hline $\begin{array}{r}1520 \\
896 \\
696\end{array}$ & $\begin{array}{r}1520 \\
896 \\
696\end{array}$ & $\begin{array}{l}-. \\
--\end{array}$ \\
\hline$\therefore$ & 969 & $\ldots$ \\
\hline -. & 661 & .. \\
\hline 1040 & 1000 & $\cdots$ \\
\hline 810 & $\cdots$ & -- \\
\hline 720 & 768 & -. \\
\hline$\cdots$ & $\cdots$ & $\cdots$ \\
\hline 515 & - & -. \\
\hline$\cdots$ & 814 & $\cdots$ \\
\hline 700 & $\cdots$ & - \\
\hline 690 & 822 & -. \\
\hline 770 & $\because$ & -. \\
\hline 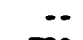 & 883 & $\cdots$ \\
\hline $\begin{array}{l}720 \\
530\end{array}$ & 044 & 7.6 \\
\hline 530 & $\cdots$ & $\cdots$ \\
\hline 990 & -. & -. \\
\hline 1120 & - & $\cdots$ \\
\hline 930 & - & $\cdots$ \\
\hline 860 & - & -. \\
\hline 820 & $\cdots$ & $\cdots$ \\
\hline 810 & -- & $\cdots$ \\
\hline 800 & 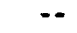 & $\cdots$ \\
\hline 930 & $\cdots$ & $\cdots$ \\
\hline 830 & $\cdots$ & $\cdots$ \\
\hline 650 & $\ldots$ & $\cdots$ \\
\hline 630 & - & $\cdots$ \\
\hline 620 & -. & $\cdots$ \\
\hline 630 & $\cdots$ & $\cdots$ \\
\hline 640 & -. & $\cdots$ \\
\hline 650 & $\cdots$ & $\cdots$ \\
\hline
\end{tabular}


SURFACE-MATER DATA-Cont inued

CHEMICAL AMALYSES-Continued

STATION

NUMBER

DATE

09395350

$07-24-89$
$07-24-89$

$07-27-89$

07-28-89

09-05-89

07-07-90

$07-08-90$

07-08-90

$07-08-90$

$07-09-90$

$07-09-90$

07-09-90

$07-09-90$

$07-12-90$

$07-12-90$

$07-12-90$

$08-15-90$

08-01-91

08-02-91

08-02-91

08-02-91

08-02-91

08-02-91

08-02-91

08-02-91

08-06-91

08-06-91

08-06-91

08-06-91

08-06-91

08-06-91

08-06-91

08-07-91
PH

MATER

WHOLE

HHOLE

FIELD

(STAND-

ARD

UNITS)

(00400)

CSTAND -

(STAND -

ARD

UNITS)

(00403)

$\begin{array}{cc}\text { ALKA- } & \text { SOLIOS, } \\ \text { LINITY } & \text { RESIDUE } \\ \text { LAB } & \text { AT } 180^{\circ} \mathrm{C} \\ \text { (mo/L } & \text { DIS- } \\ \text { as } & \text { SOLVED } \\ \text { CaCO3) } & (\mathrm{mg} / \mathrm{L}) \\ (90410) & (70300)\end{array}$

SOLIDS, SOLIDS, NITRO-

SUN OF DIS- GEN,

TUENTS, (metric DIS.

per ( $\mathrm{mo} / \mathrm{L}$

$\begin{array}{lll}(70301) & (70302) \quad(00631)\end{array}$

as

(aco3)

(00900)

PUERCO RIVER MEAR CHURCK ROCK, W-Continued

\begin{tabular}{|c|c|c|c|c|c|c|c|}
\hline-- & -- & - & -- & -- & -- & -- & -- \\
\hline-- & -- & 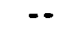 & -- & -- & - & - & - \\
\hline-- & -- & - & $=$ & -- & -. & -. & - \\
\hline -- & -- & -. & - & -- & - & $=$ & $\ldots$ \\
\hline -- & 7.8 & -- & -- & -. & - & .550 & -. \\
\hline 8.5 & 7.1 & 148 & 720 & 691 & 1016 & - & 430 \\
\hline 8.5 & -- & $\cdots$ & $\cdots$ & -- & - & - & 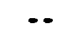 \\
\hline 7.8 & 7.2 & 113 & 526 & 508 & 41.9 & - & 320 \\
\hline$\cdots$ & -- & $\cdots$ & $\cdots$ & $\cdots$ & $\cdots$ & $\cdots$ & $\cdots$ \\
\hline 7.4 & -. & - & -- & -- & $\cdots$ & - & -. \\
\hline -. & 7.4 & 167 & 548 & 535 & 901 & $\cdots$ & 350 \\
\hline 7.5 & - & -. & $\cdots$ & -- & $\cdots$ & - & - \\
\hline 7.4 & 7.4 & - & $\cdots$ & -- & - & $\cdots$ & $\cdots$ \\
\hline 7.5 & -- & -- & $\cdots$ & - & $\cdots$ & $\cdots$ & $\cdots$ \\
\hline - & 7.4 & 82 & 615 & 601 & 980 & - & 390 \\
\hline 7.6 & $\cdots$ & $\cdots$ & $\cdots$ & $\cdots$ & $\cdots$ & $\cdots$ & $\cdots$ \\
\hline 8.6 & 8.1 & 155 & 364 & 377 & 58.9 & - & 330 \\
\hline 7.5 & -- & $\cdots$ & $\cdots$ & -- & - & $\cdots$ & - \\
\hline 7.4 & -- & $\cdots$ & $\cdots$ & 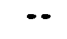 & $\cdots$ & $\cdots$ & $\cdots$ \\
\hline 7.6 & $-\cdot$ & -. & $\cdots$ & $\cdots$ & $\cdots$ & $\cdots$ & $\cdots$ \\
\hline 7.5 & $\cdots$ & $\cdots$ & $\cdots$ & $\cdots$ & $\cdots$ & 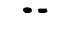 & -- \\
\hline 7.5 & -- & - & $\cdots$ & -- & $\cdots$ & -- & $\cdots$ \\
\hline 7.5 & -- & - & -. & - & $\cdots$ & - & $\cdots$ \\
\hline 7.3 & -- & - & $\cdots$ & - & $\cdots$ & $\cdots$ & $\cdots$ \\
\hline 7.4 & -- & -- & -- & -- & $\cdots$ & $\cdots$ & - \\
\hline 7.5 & -- & $\cdots$ & -- & $-\cdot$ & $\cdots$ & -- & - \\
\hline 7.4 & $\cdots$ & $-\cdot$ & -- & -- & -- & -- & - \\
\hline 7.4 & $\because$ & -- & 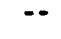 & -- & $\cdots$ & $\cdots$ & $\cdots$ \\
\hline 7.4 & $=-$ & 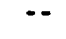 & $\cdots$ & -- & $\cdots$ & $\because$ & $\because$ \\
\hline 7. & -. & -. & - & -- & -- & $\cdots$ & $=-$ \\
\hline 7. & 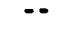 & -- & 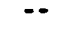 & -- & $\cdots$ & -- & -. \\
\hline 7.4 & $\because$ & -- & $\because$ & -- & $\because$ & $\cdots$ & $\cdots$ \\
\hline 7 & $=-$ & - & -- & -- & $\because$ & -- & \\
\hline
\end{tabular}


SURFACE-UATER DATA-Cont inued

CHEMICAL ANALYSES-Cont inued

STATION

NUABER
07-24-89

$07-24-89$

07-27-89

07-28-89

09-05-89

07-07-90

07-08-90

07-08-90

07-08-90

07-09-90

07-09-90

07-09-90

07-09-90

07-12-90

07-12-90

07-12-90

08-15-90

08-01-91

08-02-91

08-02-91

08-02-91

08-02-91

08-02-91

08-02-91

08-02-91

08-06-91

08-06-91

08-06-91

08-06-91

08-06-91

08-06-91

08-06-91

08-07-91

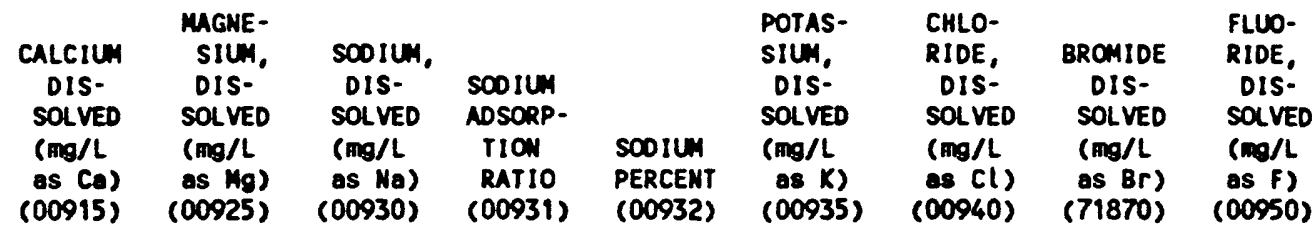

PUERCO RIVER MEAR CHURCH ROCK, MH-Continued

\begin{tabular}{|c|c|c|c|c|c|c|c|c|}
\hline-- & -. & -- & -. & $\cdots$ & $\cdots$ & $\cdots$ & - & $\cdots$ \\
\hline-- & -. & $\cdots$ &.- & $\cdots$ & $\cdots$ & -- & -- & -. \\
\hline -- & $\cdots$ & $\cdots$ & $\cdots$ & $\cdots$ & $\cdots$ & $\cdots$ & $\cdots$ & $\cdots$ \\
\hline$\cdots$ & $\cdots$ & $\cdots$ & $\cdots$ & $\cdots$ & $\cdots$ & -- & $\because$ & $\cdots$ \\
\hline$\because$ & 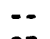 & $=$ & $\cdots$ & 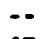 & -- & 4.0 & $<.010$ & .60 \\
\hline 130 & 25 & 30 & .6 & 13 & 9.2 & 6.5 & $<.010$ & .70 \\
\hline$\cdots$ & $\cdots$ & $\cdots$ & -. & $\cdots$ & -- & $\cdots$ & $\cdots$ & $\cdots$ \\
\hline 98 & 18 & 22 & .5 & 13 & 7.6 & 5.2 & $<.010$ & .80 \\
\hline$\cdots$ & $\cdots$ & $\cdots$ & $\cdots$ & $\cdots$ & $\cdots$ & $\cdots$ & -. & - \\
\hline$\cdots$ & -. & $=$ & $\cdots$ & $\cdots$ & $\cdots$ & $\cdots$ & - & -- \\
\hline 110 & 19 & 21 & .5 & 11 & 8.8 & 4.6 & $<.010$ & .70 \\
\hline-- & $\cdots$ & $\cdots$ & $\cdots$ & $\cdots$ & $\because$ & $\because$ & 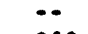 & $\because$ \\
\hline-- & $\cdots$ & $\cdots$ & -. & $\cdots$ & 7.7 & 5.0 & .010 & .60 \\
\hline-- & 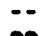 & $=$ & $\because$ & $\overline{-}$ & $\cdots$ & $\because$ & $\cdots$ & -- \\
\hline 120 & 22 & 23 & .5 & 11 & 9.2 & 6.3 & $<.010$ & .80 \\
\hline -- & $\cdots$ & $\cdots$ & $\cdots$ & $\cdots$ & $-\cdot$ & $\cdots$ & -- & -- \\
\hline 110 & 13 & 13 & .3 & 8 & 7.2 & 3.0 & $<.010$ & .60 \\
\hline-- & $\cdots$ & $\cdots$ & - & $\cdots$ & -- & $\cdots$ & - & -- \\
\hline-- & $\cdots$ & -- & -- & $\cdots$ & -- & $\cdots$ & -- & $\cdots$ \\
\hline-- & -- & $\cdots$ & -- & $\because$ & -- & -- & -- & $\cdots$ \\
\hline-- & $\cdots$ & -- & -- & $\cdots$ & -- & -- & -- & 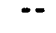 \\
\hline-- & $\cdots$ & -- & $\cdots$ & -- & -- & $\cdots$ & -- & -- \\
\hline-- & $-\cdot$ & $\cdots$ & -- & -- & -- & $\cdots$ & -- & $\cdots$ \\
\hline$=$ & $\because$ & $\ldots$ & $\cdots$ & -- & $\because$ & $\ldots$ & $=$ & $\because$ \\
\hline 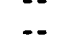 & $\ldots$ & $\ldots$ & -. & $\ldots$ & $\ldots$ & $\ldots$ &.- & 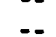 \\
\hline .- & -- & -. & -. & - & - & .- & .- & 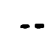 \\
\hline-- & -- & - & - & -. & -. & -. & - & - \\
\hline -- & -- & - & -- & - & -- & -- & -- & 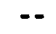 \\
\hline -- & -- & $\cdots$ & $\cdots$ & -- & -- & -- & $\cdots$ & 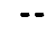 \\
\hline 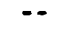 & -- & $\cdots$ & -- & -- & $\cdots$ & -- & -- & -- \\
\hline -. & $\cdots$ & $\cdots$ & $-\cdot$ & $\cdots$ & -- & -- & -- & 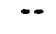 \\
\hline-- & -- & $\cdots$ & $\cdots$ & -- & -. & -- & -- & \\
\hline
\end{tabular}


CHEHICAL AHALYSES-Continued

\begin{tabular}{|c|c|c|c|c|c|c|c|c|c|c|}
\hline $\begin{array}{l}\text { STATION } \\
\text { MUMBER }\end{array}$ & DATE & $\begin{array}{l}\text { SILICA, } \\
\text { DIS- } \\
\text { SOLVED } \\
\text { (mg/L } \\
\text { as } \\
\text { si02) } \\
(00955)\end{array}$ & $\begin{array}{c}\text { SULFATE } \\
\text { DIS- } \\
\text { SOLVED } \\
\text { (mg/L. } \\
\text { as SOL) } \\
(00945)\end{array}$ & $\begin{array}{c}\text { ARSENIC } \\
\text { DIS- } \\
\text { SOLVED } \\
(\mu g / L \\
\text { as AS) } \\
(01000)\end{array}$ & $\begin{array}{l}\text { BARILA, } \\
\text { DIS- } \\
\text { SOLVED } \\
(\mu g / L \\
\text { as Ba) } \\
(01005)\end{array}$ & $\begin{array}{l}\text { BERYL- } \\
\text { LIUM, } \\
\text { DIS- } \\
\text { SOLVED } \\
\text { ( } \mu \mathrm{g} / \mathrm{L} \\
\text { aS BE) } \\
(01010)\end{array}$ & $\begin{array}{l}\text { BOPON, } \\
\text { DIS- } \\
\text { SOLVED } \\
(\mu g / L \\
\text { As B) } \\
(01020)\end{array}$ & $\begin{array}{c}\text { CADHIUM } \\
\text { DIS- } \\
\text { SOLVED } \\
\text { ( } \mu \text { g/L } \\
\text { as Cd) } \\
\text { (01025) }\end{array}$ & $\begin{array}{l}\text { CHRO- } \\
\text { MIUA, } \\
\text { DIS- } \\
\text { SOLVED } \\
\text { ( } \mu g / L \\
\text { as Cr) } \\
(01030)\end{array}$ & $\begin{array}{c}\text { COBALT, } \\
\text { DIS- } \\
\text { SOLVED } \\
(\mu \sigma / L \\
\text { as Co) } \\
(01035)\end{array}$ \\
\hline
\end{tabular}

PUERCO RIVER NEAR CHURCH ROCK, WH-Continued

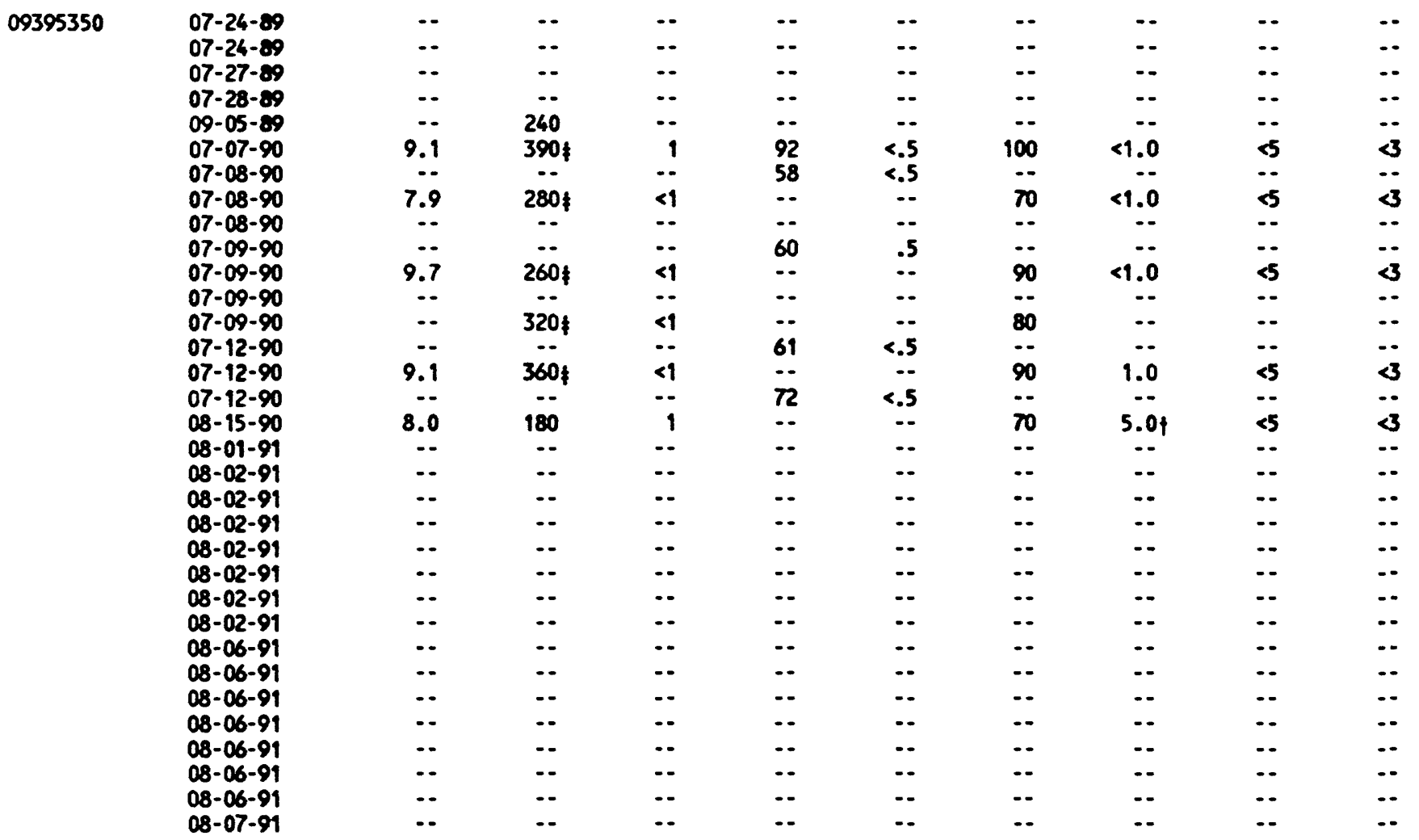


STATION

MUMBER

09395350
DATE

$07-26-89$

$07-26-89$

07-27-89

07-28-89

09-05-89

07-07-90

07-08-90

07-08-90

07-08-90

07-09-90

07-09-90

07-09-90

07-09-90

07-12-90

$07-12-90$

07-12-90

08-15-90

08-01-91

08-02-91

08-02-91

08-02-91

08-02-91

08-02-91

08-02-91

08-02-91

08-06-91

08-06-91

08-06-91

08-06-91

08-06-91

08-06-91

08-06-91

08-07-91

\begin{tabular}{|c|c|c|c|c|c|c|c|}
\hline $\begin{array}{l}\text { COPPER, } \\
\text { DIS- } \\
\text { SOLVED } \\
\text { ( } \mu g / L \\
\text { as CU) } \\
(01040)\end{array}$ & $\begin{array}{l}\text { IRON, } \\
\text { OIS- } \\
\text { SOLVED } \\
\text { ( } \mu 9 / L \\
\text { as Fe) } \\
(01046)\end{array}$ & $\begin{array}{c}\text { LEAD, } \\
\text { OIS- } \\
\text { SOLVED } \\
\text { ( } \mu g / L \\
\text { aS Pb) } \\
(01049)\end{array}$ & $\begin{array}{l}\text { MANGA- } \\
\text { NESE, } \\
\text { OIS- } \\
\text { SOLVED } \\
(\mu Q / L \\
\text { as } / n) \\
(01056)\end{array}$ & $\begin{array}{c}\text { MOLYB- } \\
\text { DENUA, } \\
\text { DIS- } \\
\text { SOLVED } \\
(\mu g / L) \\
\text { as MO) } \\
(01060)\end{array}$ & $\begin{array}{l}\text { NICKEL, } \\
\text { OIS- } \\
\text { SOLVED } \\
\text { ( } \mu g / L \\
\text { as Ni) } \\
\text { (01065) }\end{array}$ & $\begin{array}{c}\text { SILVER, } \\
\text { OIS- } \\
\text { SOLVED } \\
\text { ( } \mu g / L \\
\text { as Ag) } \\
\text { (01075) }\end{array}$ & $\begin{array}{c}\text { STRON- } \\
\text { TIUN, } \\
\text { OIS- } \\
\text { SOLVEO } \\
\text { ( } \mu g / L \\
\text { as Sr) } \\
\text { (01080) }\end{array}$ \\
\hline
\end{tabular}

PUERCO RIVER NEAR CHURCH ROCK, W-Continued

\begin{tabular}{|c|c|c|c|c|c|c|c|c|}
\hline - & -. & -- & - & -- & -- & -. & -- & $\cdots$ \\
\hline -- & - & -. & $\cdots$ & -. & $\cdots$ & $\cdots$ & $\cdots$ & - \\
\hline-- & - & - & -- & -- & - & -- & - & -. \\
\hline-- & - & - & $\cdots$ & -. & -- & - & - & -. \\
\hline -. & $\cdots$ & $\cdots$ & $\cdots$ & $\cdots$ & $\cdots$ & $\cdots$ & $\cdots$ & $\cdots$ \\
\hline$<10$ & 29 & $<10 i$ & $190\}$ & $<10$ & $<10$ & $<1.0$ & 1000 & $<6$ \\
\hline$\cdots$ & $\cdots$ & $\cdots$ & $\cdots$ & -- & $\cdots$ & $\cdots$ & $\cdots$ & -. \\
\hline$<10$ & 23 & $<10 i$ & $110\}$ & $<10$ & $<10$ & 1.0 & 700 & $<6$ \\
\hline$\cdots$ & $\cdots$ & $\cdots$ & $\cdots$ & $\cdots$ & -- & $\cdots$ & $\cdots$ & $\cdots$ \\
\hline 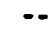 & -- & - & - & - & - & - & - & - \\
\hline$<10$ & 9 & $<10 i$ & 38 & $<10$ & $<10$ & $<1.0$ & 790 & $<6$ \\
\hline$\cdots$ & $\cdots$ & $\cdots$ & $\cdots$ & $\cdots$ & $\cdots$ & $\cdots$ & - & $\cdots$ \\
\hline$\cdots$ & $\cdots$ & -. & -- & $\cdots$ & $\cdots$ & $\cdots$ & $\cdots$ & $\cdots$ \\
\hline$\cdots$ & $\cdots$ & $\cdots$ & $\cdots$ & $\cdots$ & $\cdots$ & $\cdots$ & - & -. \\
\hline$<10$ & 10 & $<10 i$ & 45 & $<10$ & $<10$ & $<1.0$ & 860 & $<6$ \\
\hline 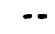 & - & $\cdots$ & -. & -. & - & $\cdots$ & -. & - \\
\hline$<10$ & 160 & $<10 i$ & $310 \$$ & $<10$ & $<10$ & $<1.0$ & 590 & $<6$ \\
\hline$\cdots$ & $\cdots$ & $\cdots$ & $\cdots$ & -- & -. & $\cdots$ & - & $\cdots$ \\
\hline$\cdots$ & $\cdots$ & $\cdots$ & $\cdots$ & $\cdots$ & $\cdots$ & $\cdots$ & $\cdots$ & $\cdots$ \\
\hline-- & $\cdots$ & $\cdots$ & -- & $\cdots$ & $\cdots$ & $\cdots$ & $\cdots$ & $\cdots$ \\
\hline - & $\cdots$ & $\cdots$ & $\cdots$ & $\because$ & -- & $\cdots$ & -- & - \\
\hline 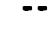 & $\cdots$ & $\cdots$ & $\cdots$ & $\cdots$ & $\cdots$ & $\cdots$ & $\cdots$ & $\cdots$ \\
\hline$\cdots$ & $\cdots$ & $\cdots$ & $\cdots$ & $\cdots$ & $\cdots$ & $\because$ & $\cdots$ & $\cdots$ \\
\hline 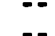 & $\because$ & 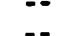 & $\because$ & $=$ & $\cdots$ & $\cdots$ & $\cdots$ & $\cdots$ \\
\hline & $\ldots$ & $\ldots$ & $\ldots$ & $\ldots$ & 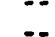 & 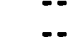 & 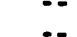 & $\cdots$ \\
\hline & $\ldots$ & $\ldots$ & $\ldots$ & -. & -. & $\ldots$ & $\ldots$ & 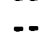 \\
\hline 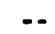 & -. & -. & -. & -. & -. & .. & $\ldots$ & . \\
\hline -. & .. & - & -. & -. & . & $=$ & - & $\ldots$ \\
\hline - & -. & -- & -- & $\cdots$ & $\cdots$ & $\because$ & $\cdots$ & 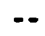 \\
\hline & $\cdots$ & $\cdots$ & -- & $\cdots$ & $\cdots$ & -- & -- & -- \\
\hline- & -- & $\cdots$ & -- & -- & $\because$ & $\cdots$ & $\cdots$ & $\cdots$ \\
\hline & - & $\cdots$ & - & - & $\cdots$ & $\cdots$ & - & \\
\hline
\end{tabular}


SURFACE-WATER DATA-Cont inued

CHEMICAL ANALYSES-Continued

STATION

MUMBER

DATE

$07-24-89$

$07-27-89$

07-28-89

$09-05-89$

$07-07-90$

$07-08-90$

$07-08-90$

$07-08-90$

$07-09-90$

$07-09-90$

$07-09-90$

$07-09-90$

$07-12-90$

$07-12-90$

$07-12-90$

$08-15-90$

08-01-91

08-02-91

08-02-91

$08-02-91$

$08-02-91$

08-02-91

$08-02-91$

$08-02-91$

08-06-91

08-06-91

$08-06-91$

08-06-91

08-06-91

08-06-91

08-06-91

08-07-91

$\begin{array}{ccc} & H-2 / & 0-18 / \\ \text { SELE- } & H-1 & 0-16 \\ \text { NIUM, } & \text { STABLE } & \text { STABLE } \\ \text { DIS- } & \text { ISOTOPE } & \text { ISOTOPE } \\ \text { SOLVED } & \text { RATIO } & \text { RATIO } \\ \text { ( } \mu g / L & \text { PER } & \text { PER } \\ \text { SS SE) } & \text { MIL } & \text { MIL } \\ (01145) & (82082) & (82085)\end{array}$

GROSS ALPHA, GROSS

ALPHA, CONT, ALPHA, DIS- 2 SIGM SUSP.

SOLVE WAT DIS TOTAL

$(\mu \mathrm{g} / \mathrm{L} \quad(\mu \mathrm{g} / \mathrm{L} \quad(\mu \mathrm{g} / \mathrm{L}$

as

U-nat) (U-nat)

(80030) (75986)

$(80040)$

CROSS

ALPHA

SED I-

MENT

(PCi/G)

(01090) (01130)

(01145)

(82085)

\section{PUERCO RIVER NEAR CHURCH ROCK, WH-Continued}

\begin{tabular}{|c|c|c|c|c|c|c|c|c|}
\hline - & - & -. & -. & $\cdots$ & -. & -. & -. & -. \\
\hline$\cdots$ & $\cdots$ & $\cdots$ & $\cdots$ & $\cdots$ & $\cdots$ & $\cdots$ & $\cdots$ & $\cdots$ \\
\hline$\cdots$ & $\cdots$ & $\cdots$ & $\cdots$ & $\cdots$ & $\cdots$ & $\cdots$ & $\cdots$ & $\cdots$ \\
\hline$\cdots$ & $\cdots$ & $\cdots$ & $\cdots$ & $\cdots$ & 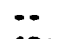 & $\cdots$ & 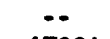 & - \\
\hline -. & -. & -. & $\cdots$ & $\cdots$ & $12 \uparrow$ & 2.2 & $1700 *$ & -. \\
\hline 6 & 22 & 1 & - & -. & 6.3 & 2.3 & $12000 *$ & $\cdots$ \\
\hline$\cdots$ & $\cdots$ & $\cdots$ & $\cdots$ & $\cdots$ & $\cdots$ & $\cdots$ & $\cdots$ & $\cdots$ \\
\hline 6 & 15 & 2 & $\cdots$ & $\cdots$ & $11\}$ & 2.7 & $2600 *$ & - \\
\hline$\cdots$ & $\cdots$ & $\cdots$ & $\cdots$ & $\cdots$ & $\cdots$ & $\cdots$ & $\cdots$ & $\cdots$ \\
\hline$\cdots$ & $\cdots$ & $\cdots$ & $\cdots$ & $\cdots$ & $\cdots$ & $\cdots$ & $\cdots$ & -. \\
\hline$<3$ & 18 & $<3$ & $\cdots$ & $\cdots$ & $14 \uparrow$ & 3.3 & $2900 *$ & 9 \\
\hline$\cdots$ & $\cdots$ & $\cdots$ & $\cdots$ & $\cdots$ & -. & -. & -. & -. \\
\hline$\cdots$ & - & $<2$ & $\cdots$ & $\cdots$ & $12\}$ & 3.0 & $5500 *$ & - \\
\hline$\cdots$ & $\cdots$ & $\cdots$ & $\cdots$ & $\cdots$ & $\cdots$ & $\cdots$ & $\cdots$ & $\cdots$ \\
\hline$<3$ & 18 & 3 & $\cdots$ & $\cdots$ & 10 & 2.7 & $8100 *$ & 11 \\
\hline$\cdots$ & $\cdots$ & $\cdots$ & $\cdots$ & $\cdots$ & $\cdots$ & $\cdots$ & $\cdots$ & - \\
\hline 1900 & 16 & $<1$ & $\because$ & $\cdots$ & - & -. & $\cdots$ & 8 \\
\hline$\cdots$ & $\cdots$ & $\cdots$ & -64.0 & -9.35 & $\cdots$ & -- & $\cdots$ & $\cdots$ \\
\hline$\cdots$ & $\cdots$ & $\cdots$ & $\cdots$ & $\cdots$ & $\cdots$ & $\cdots$ & $\cdots$ & -- \\
\hline$\cdots$ & $\cdots$ & $\cdots$ & $\cdots$ & $\cdots$ & $\cdots$ & $\cdots$ & $\cdots$ & $\cdots$ \\
\hline$\cdots$ & $\cdots$ & $\cdots$ & $\cdots$ & $\cdots$ & $\cdots$ & $\cdots$ & $\cdots$ & $\cdots$ \\
\hline$\cdots$ & $\cdots$ & $\cdots$ & $\cdots$ & $\cdots$ & $\cdots$ & $\cdots$ & $\cdots$ & -. \\
\hline .. & $\cdots$ & $\cdots$ & -84.5 & -12.35 & $\cdots$ & $\cdots$ & $\cdots$ & $\cdots$ \\
\hline$\cdots$ & $\cdots$ & $\cdots$ & $\cdots$ & $\cdots$ & $\cdots$ & -- & $\cdots$ & $\cdot$ \\
\hline -- & $\cdots$ & $\cdots$ & $\cdots$ & $\cdots$ & $\cdots$ & $\cdots$ & $\cdots$ & - \\
\hline -. & $\cdots$ & $\cdots$ & $\because$ & $\cdots$ & $\cdots$ & $\cdots$ & $\cdots$ & $=$ \\
\hline$\cdots$ & $\cdots$ & $\cdots$ & -55.5 & -9.15 & $\cdots$ & -- & $\cdots$ & - \\
\hline$\cdots$ & $\cdots$ & $\cdots$ & $\cdots$ & $\cdots$ & $\because$ & $\because$ & $\because$ & $\because$ \\
\hline$\cdots$ & $\cdots$ & $\cdots$ & $\cdots$ & $\cdots$ & $\cdots$ & $\cdots$ & $\cdots$ & 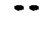 \\
\hline$\cdots$ & $\cdots$ & $\cdots$ & $\cdots$ & $\cdots$ & $\cdots$ & $\cdots$ & $\cdots$ & - \\
\hline$\cdot-$ & $\cdots$ & $\cdots$ & $\cdots$ & $\cdots$ & $\cdots$ & $\cdot-$ & $\cdots$ & - \\
\hline$\cdots$ & $\cdots$ & $\cdots$ & $\cdots$ & $\cdots$ & $\cdots$ & $\cdots$ & $\cdots$ & . \\
\hline$\cdots$ & $\cdots$ & $\cdots$ & $\cdots$ & $\cdots$ & $\cdots$ & $\cdots$ & $\cdots$ & \\
\hline
\end{tabular}




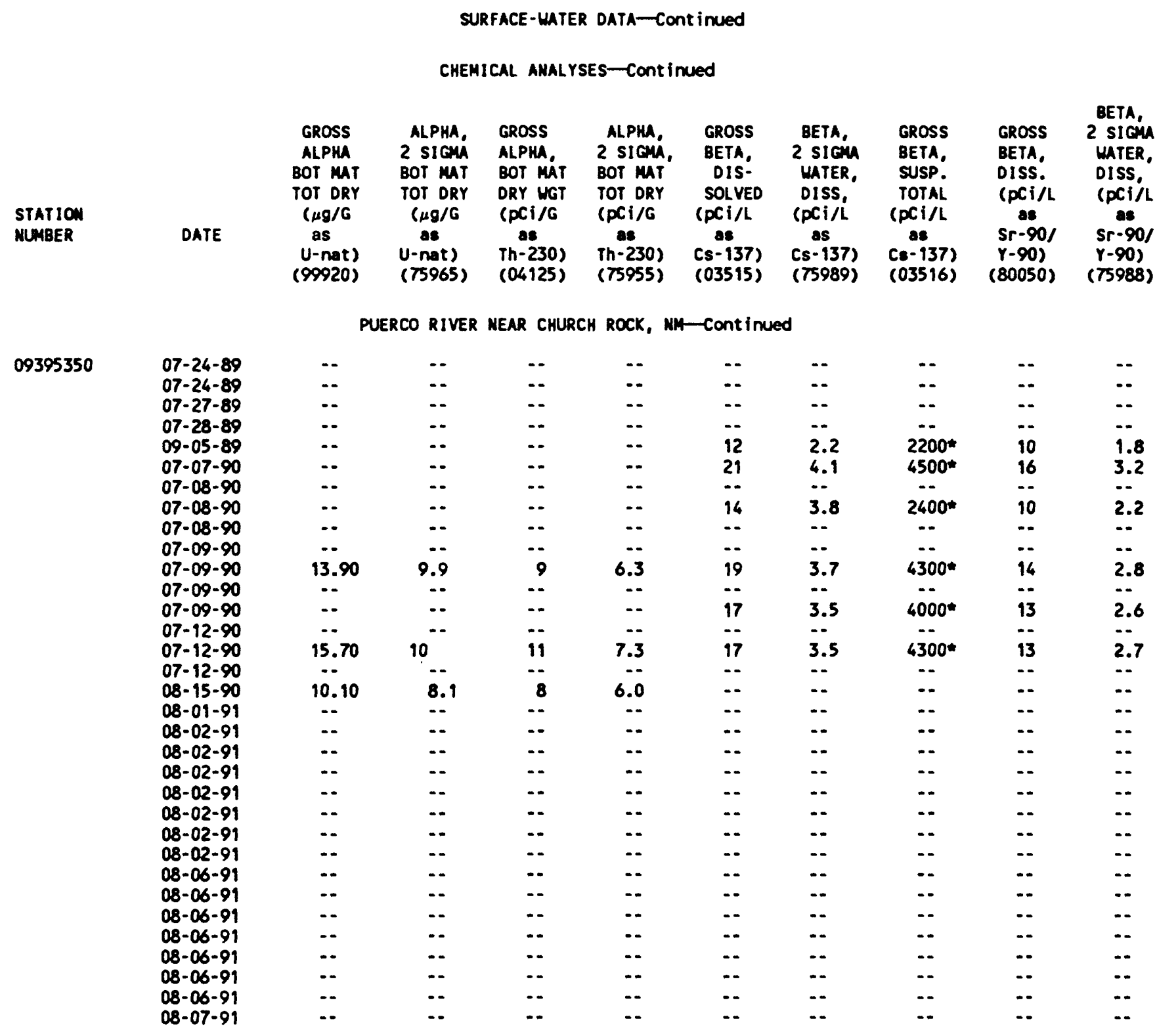


STATION

MUABER

DATE

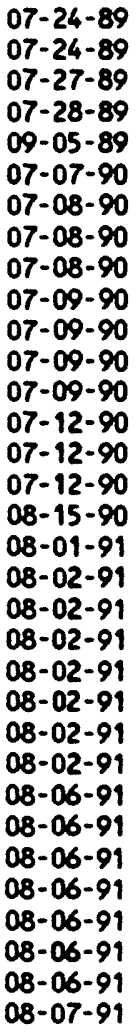

$09395350 \quad 07-24-89$
$07-24-89$
$07-27-89$
$07-28-89$
$09-05-89$
$07-07-90$
$07-08-90$
$07-08-90$
$07-08-90$
$07-09-90$
$07-09-90$
$07-09-90$
$07-09-90$
$07-12-90$
$07-12-90$
$07-12-90$
$08-15-90$
$08-01-91$
$08-02-91$
$08-02-91$
$08-02-91$
$08-02-91$
$08-02-91$
$08-02-91$
$08-02-91$
$08-06-91$
$08-06-91$
$08-06-91$
$08-06-91$
$08-06-91$
$08-06-91$
$08-06-91$
$08-07-91$

U.234

U-234 2 SIGM

$\begin{array}{ll}\text { SED, } & \text { SED, } \\ \text { SUSP, } & \text { SUSP, }\end{array}$

TOTAL, TOTAL,

DRY WGT DRY WGT

(PCi/G) (PCi/G)

(75942)

$\begin{array}{cc} & \\ \text { URANIUH } & \text { U-235 } \\ -235 & 2 \text { SIGA } \\ \text { UTER, } & \text { WATER, } \\ \text { DISS } & \text { DISS, } \\ (p C i / L) & (P C I / L) \\ (22620) & (75994)\end{array}$

U-235

U.235 2 SI CM

SED,

TOTAL.

ORY WGT

(PCi/G)

(75975)
SED.

SUSP,

DRY WGT

(PCi/G)

(75947)
URANIUH

$-238$

HATER

DISSOLV

(pci/l)

PUERCO RIVER NEAR CHURCH ROCK, W-Continued

\begin{tabular}{|c|c|c|}
\hline -. & .. & -. \\
\hline -. & -. & $\cdots$ \\
\hline$\cdots$ & - & $\cdots$ \\
\hline$\cdots$ & $\cdots$ & $\cdots$ \\
\hline$\cdots$ & $\cdots$ & $\cdots$ \\
\hline$\cdots$ & $\cdots$ & $\cdots$ \\
\hline$\cdots$ & $\cdots$ & $\cdots$ \\
\hline$\cdots$ & $\cdots$ & $\cdots$ \\
\hline$\cdots$ & $\cdots$ & $\cdots$ \\
\hline$\cdots$ & $\cdots$ & $\because$ \\
\hline$\because$ & $\cdots$ & 1.5 \\
\hline .. & $\ldots$ & 8 \\
\hline -. & - & $\ldots$ \\
\hline -. & $\ldots$ & 1.3 \\
\hline - & -- & $\cdots$ \\
\hline 1.2 & .2 & 1.3 \\
\hline - & $\cdots$ & 1.6 \\
\hline$\cdots$ & $\cdots$ & $\cdots$ \\
\hline$\cdots$ & $\cdots$ & $\cdots$ \\
\hline$\cdots$ & $\cdots$ & $\cdots$ \\
\hline$\cdots$ & $\cdots$ & $\because$ \\
\hline$\cdots$ & $\cdots$ & 1.2 \\
\hline 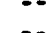 & - & $\cdots$ \\
\hline & 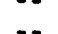 & 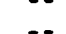 \\
\hline 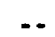 & $\ldots$ & 1.0 \\
\hline$\cdots$ & $\ldots$ & $\ldots$ \\
\hline -. & -. & $\cdots$ \\
\hline- & $\cdots$ & -. \\
\hline$\cdots$ & - & $\cdots$ \\
\hline & $\cdots$ & 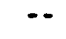 \\
\hline & $\cdots$ & $\cdots$ \\
\hline
\end{tabular}

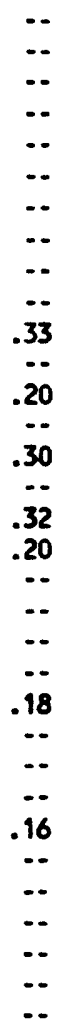

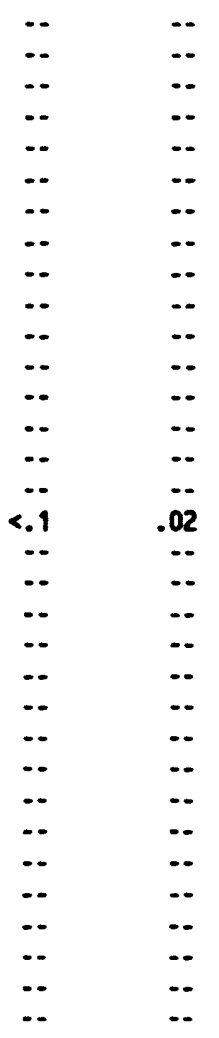

\begin{tabular}{|c|c|c|}
\hline .. & - & $\cdots$ \\
\hline -. & $\cdots$ & $\cdots$ \\
\hline$\cdots$ & 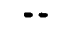 & $\cdots$ \\
\hline$\cdots$ & $-\cdot$ & $\cdots$ \\
\hline$\cdots$ & -- & $\cdots$ \\
\hline-- & -- & $\cdots$ \\
\hline$\cdots$ & 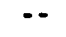 & $\cdots$ \\
\hline-- & - & $\cdots$ \\
\hline$\cdots$ & $-\cdot$ & $\cdots$ \\
\hline 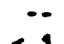 & $\ddot{\ddot{g}}$ & $\cdots$ \\
\hline$<.1$ & .05 & $\cdots$ \\
\hline$<1$ & 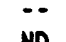 & $\because$ \\
\hline $\begin{array}{l}<1 \\
\ldots-1\end{array}$ & ND & $\cdots$ \\
\hline$\because$ & $\because$ & $\cdots$ \\
\hline$<.1$ & ND & $\cdots$ \\
\hline$<.1$ & $\overline{07}$ & 10 \\
\hline$<.1$ & . & $\begin{array}{r}1.0 \\
\ldots\end{array}$ \\
\hline-- & $\ldots$ & $\ldots$ \\
\hline - & $\ldots$ & $\ldots$ \\
\hline - & -. & .. \\
\hline -. & -. & -. \\
\hline$<.1$ & ND & $\cdots$ \\
\hline$\cdots$ & -- & $\cdots$ \\
\hline$\cdots$ & $\cdots$ & $\cdots$ \\
\hline$\cdots$ & -- & $\cdots$ \\
\hline$<.1$ & ND & $\cdots$ \\
\hline$\cdots$ & $\cdots$ & $\cdots$ \\
\hline$\cdots$ & $\cdots$ & $\cdots$ \\
\hline$\cdots$ & $\cdots$ & $\cdots$ \\
\hline$\ldots$ & $\ldots$ & $\ldots$ \\
\hline$\cdots$ & .. & $\ldots$ \\
\hline
\end{tabular}


ChEMICAL ANALYSES-Continued

STATION

MUMBER

09395350

$$
\begin{aligned}
& 07-24-89 \\
& 07-24-89 \\
& 07-27-89 \\
& 07-28-89 \\
& 09-05-89 \\
& 07-07-90 \\
& 07-08-90 \\
& 07-08-90 \\
& 07-08-90 \\
& 07-09-90 \\
& 07-09-90 \\
& 07-09-90 \\
& 07-09-90 \\
& 07-12-90 \\
& 07-12-90 \\
& 07-12-90 \\
& 08-15-90 \\
& 08-01-91 \\
& 08-02-91 \\
& 08-02-91 \\
& 08-02-91 \\
& 08-02-91 \\
& 08-02-91 \\
& 08-02-91 \\
& 08-02-91 \\
& 08-06-91 \\
& 08-06-91 \\
& 08-06-91 \\
& 08-06-91 \\
& 08-06-91 \\
& 08-06-91 \\
& 08-06-91 \\
& 08-07-91
\end{aligned}
$$

\begin{tabular}{|c|c|c|c|c|c|c|c|}
\hline & & & & & & & \\
\hline $\begin{array}{l}\text { U-238 } \\
2 \text { SIGMA } \\
\text { WATER, } \\
\text { DISS, } \\
(P C i / L) \\
(75991)\end{array}$ & $\begin{array}{c}\text { U-238 } \\
\text { SED, } \\
\text { SUSP, } \\
\text { TOTAL, } \\
\text { DRY UGT } \\
\text { (PCi/G) } \\
(75940)\end{array}$ & $\begin{array}{l}2 \text { SIGM } \\
\text { SED, } \\
\text { SUSP, } \\
\text { TOTAL, } \\
\text { ORY UGT } \\
\text { (PCI/G) } \\
\text { (04113) }\end{array}$ & $\begin{array}{l}\text { URANIUN } \\
\text { MATURAL } \\
\text { DIS- } \\
\text { SOLVED } \\
\text { ( } \mu 9 / L \\
\text { as U) } \\
(22703)\end{array}$ & $\begin{array}{l}\text { URANIUM } \\
\text { NATURAL } \\
2 \text { SIGMA } \\
\text { WATER, } \\
\text { DISS, } \\
(\mu 9 / L) \\
(75990)\end{array}$ & $\begin{array}{l}\text { Th-230 } \\
\text { SED, } \\
\text { SUSP, } \\
\text { TOTAL, } \\
\text { DRY WGT } \\
\text { (PCi/G) } \\
\text { (75939) }\end{array}$ & $\begin{array}{l}2 \text { SIGM } \\
\text { SED, } \\
\text { SUSP, } \\
\text { TOTAL, } \\
\text { DRY WGT } \\
\text { (PCi/G) } \\
\text { (75952) }\end{array}$ & $\begin{array}{l}\text { Th-232 } \\
\text { SED, } \\
\text { SUSP, } \\
\text { TOTAL, } \\
\text { DRY WGT } \\
\text { (PCi/G) } \\
\text { (75953) }\end{array}$ \\
\hline
\end{tabular}

PUERCO RIVER MEAR CHURCH ROCK, MH-CONtinued

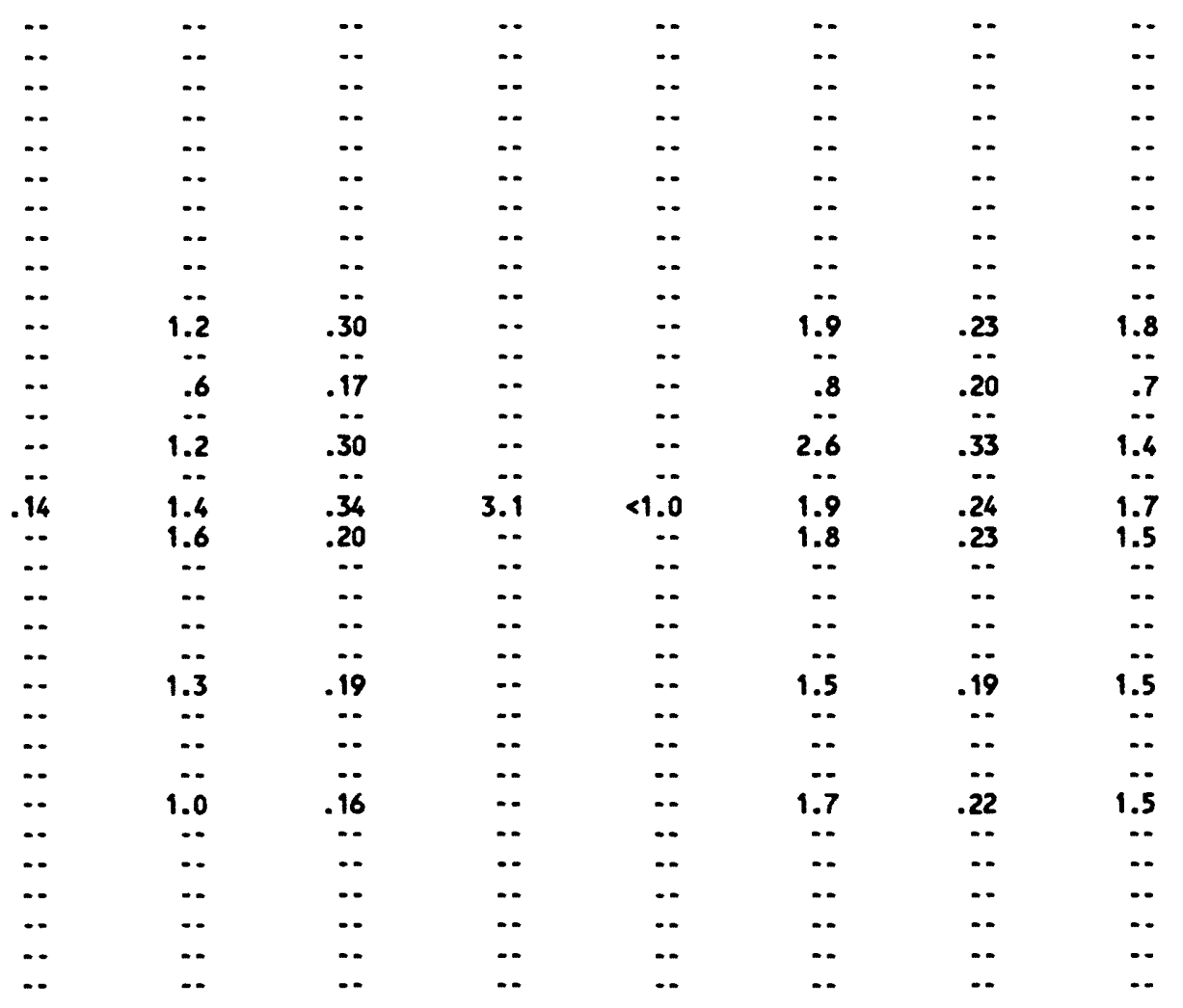


SURFACE-WATER DATA-Cont imued

CHEMICAL AMALYSES-Cont inued

\begin{tabular}{|c|c|c|c|c|c|c|c|c|c|}
\hline & & $\begin{array}{l}\text { Th- } 232 \\
2 \text { SI GNA } \\
\text { SED, }\end{array}$ & $\begin{array}{l}\text { ALUM- } \\
\text { INUM }\end{array}$ & ARSENIC & BARIUN & $\begin{array}{l}\text { BERYL- } \\
\text { LIUM }\end{array}$ & BISINTH & CADMJU & CALCIUN \\
\hline $\begin{array}{l}\text { STATION } \\
\text { NUMBER }\end{array}$ & DATE & $\begin{array}{l}\text { SUSP, } \\
\text { TOTAL, } \\
\text { DRY WGT } \\
\text { (pCi/G) } \\
\text { (75936) }\end{array}$ & $\begin{array}{l}\text { BOT MAT } \\
\angle 63_{\mu} \text { DS } \\
\text { LAB } \\
\text { PERCENT } \\
\text { (34792) }\end{array}$ & $\begin{array}{c}\text { BOT MAT } \\
\angle 63 \mu \text { DS } \\
\text { LAB } \\
(\mu 9 / G) \\
(34802)\end{array}$ & $\begin{array}{c}\text { BOT MAT } \\
\angle 63 \mu \text { DS } \\
\text { LAB } \\
(\mu g / G) \\
(34807)\end{array}$ & $\begin{array}{c}\text { BOT MAT } \\
<63 \mu \text { DS } \\
\text { LAB } \\
(\mu g / G) \\
(34812)\end{array}$ & $\begin{array}{c}\text { BOT MAT } \\
\angle 63_{\mu} \text { DS } \\
\text { LAB } \\
(\mu g / G) \\
(34817)\end{array}$ & $\begin{array}{c}\text { BOT MAT } \\
\angle 63 \mu \text { DS } \\
\text { LAB } \\
(\mu g / G) \\
(34827)\end{array}$ & $\begin{array}{l}\text { BOT MAT } \\
\angle 63 \mu \text { DS } \\
\text { LAB } \\
\text { PERCENT } \\
\text { (34832) }\end{array}$ \\
\hline
\end{tabular}

$09395350 \quad 07-24-89$
$07-24-89$
$07-27-89$
$07-28-89$
$09-05-89$
$07-07-90$
$07-08-90$
$07-08-90$
$07-08-90$
$07-09-90$
$07-09-90$
$07-09-90$
$07-09-90$
$07-12-90$
$07-12-90$
$07-12-90$
$08-15-90$
$08-01-91$
$08-02-91$
$08-02-91$
$08-02-91$
$08-02-91$
$08-02-91$
$08-02-91$
$08-02-91$
$08-06-91$
$08-06-91$
$08-08-91$
$08-06-91$
$08-06-91$
$08-06-91$
$08-06-91$
$08-07-91$
07

PUERCO RIVER NEAR CMURCH ROCK, NH-Cont inued

\begin{tabular}{|c|c|c|c|c|c|c|}
\hline .. & -. & -. & $\because-$ & .. & -. & $\cdots$ \\
\hline -. & 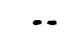 & & -. & 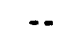 & -. &.- \\
\hline 11 & $<10$ & 450 & 2 & $<10$ & $<2$ & 1.4 \\
\hline$\cdots$ & $\cdots$ & $\because \cdot$ & -. & -. & $\cdots$ & $\cdots$ \\
\hline 76 & 10 & 500 & 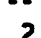 & >0 & $\Leftrightarrow$ & 90 \\
\hline$\therefore 0$ & $\ldots$ & ... & $\therefore$ & $\ldots$ & 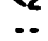 & 1.0 \\
\hline 11 & 10 & 470 & 3 & $<10$ & $<2$ & 1.5 \\
\hline$\because$ & $\because$ & 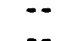 & $\because$ & $\because$ & $\cdots$ & $\because$ \\
\hline .. & $\therefore$ & $\therefore$ & $\because$ & $\therefore$ & $\therefore$ & $\because$ \\
\hline -. & .. & .. & -. & -. & $\cdots$ & . \\
\hline 7.6 & $<10$ & 510 & 2 & $<10$ & $<2$ & 1.3 \\
\hline-- & $\cdots$ & $-\cdot$ & $-\cdot$ & $\cdots$ & $\cdots$ & $\cdots$ \\
\hline .20 & $\because$ & $\because$ & $\cdots$ & $\cdots$ & $\cdots$ & - \\
\hline 8.2 & $\ddot{10}$ & $\ddot{100}$ & $\ddot{2}$ & $\ddot{0}$ & $\ddot{\theta}$ & , \\
\hline .19 & $\ldots$ & $\ldots$ & $\therefore$ & $\ldots$ & $\therefore$ & $\cdots$ \\
\hline -- & -. & -. & -. & -. & $\cdots$ & .. \\
\hline-- & $\cdots$ & $\because$ & -- & $\because$ & $\cdots$ & - \\
\hline - & -. & -. & -- & -. & $\cdots$ & -- \\
\hline -. & $\cdots$ & $\because$ & $\because$ & $\because$ & $\because-$ & $\cdots$ \\
\hline -. & .. & .. & -. & -. & -. & .. \\
\hline -- & -. & -. & -. & $-\cdot$ & $\cdots$ & -- \\
\hline 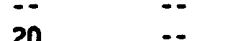 & $\because$ & 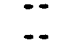 & 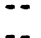 & $\cdots$ & $\because$ & $\cdots$ \\
\hline .. & .. & .. & .- & .. & -. & $\cdots$ \\
\hline . & -. & -. & -. & -- & $\cdots$ & - \\
\hline$\cdots$ & $\cdots$ & -. & $\cdots$ & $\because$ & $\cdots$ & -. \\
\hline- & $\cdots$ & $\cdots$ & $\cdots$ & $\cdots$ & $\cdots$ & \\
\hline 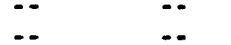 & $\because-$ & $\ddot{-}$ & 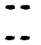 & $\because$ & $\ldots$ & $\because$ \\
\hline
\end{tabular}


SURFACE-WATER DATA-Cont inued

CHEMICAL ANALYSES-Cont inued

STATION

MUABER

DATE

$<63_{\mu}$ DS

$<63 \mu$ DS

$(\mu g / 6)$

( $\mu g / G)$

(34842)

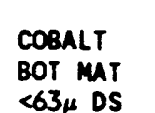

LAB

$(\mu g / G)$

(34847)

COPPER
BOT MAT
$\angle 63_{\mu}$ DS
$L A B$
$(\mu g / G)$
$(34852)$

EURO-

PIUN GALLIUN

BOT MAT

$\angle 63_{\mu}$ DS

LAB

$(\mu g / G)$

(34857)
BOT MT

$<63 \mu$ DS

LAB

$(\mu g / G)$

(34862)
COLD

BOT MAT $<63 \mu$ DS

LAB

$(\mu g / G)$

(34872)
HOLMIUA

BOT MAT $<63_{\mu}$ DS

LAB

$(\mu \mathrm{g} / \mathrm{G})$

(34877)
IRON

BOT MT

$\angle 63_{\mu}$ DS

LAB

PERCENT

(34882)

PUERCO RIVER NEAR CHURCH ROCK, MH-Continued

$09395350 \quad 07-24-89$
$07-24-89$
$07-27-89$
$07-28-89$
$09-05-89$
$07-07-90$
$07-08-90$
$07-08-90$
$07-08-90$
$07-09-90$
$07-09-90$
$07-09-90$
$07-09-90$
$07-12-90$
$07-12-90$
$07-12-90$
$08-15-90$
$08-01-91$
$08-02-91$
$08-02-91$
$08-02-91$
$08-02-91$
$08-02-91$
$08-02-91$
$08-02-91$
$08-06-91$
$08-06-91$
$08-06-91$
$08-06-91$
$08-06-91$
$08-06-91$
$08-06-91$
$08-07-91$

\begin{tabular}{|c|c|c|}
\hline$\cdots$ & -. & $\cdots$ \\
\hline$\ldots$ & $\cdots$ & -. \\
\hline 100 & 72 & 12 \\
\hline$\cdots$ & $\cdots$ & $\cdots$ \\
\hline -. & $\cdots$ & $\cdots$ \\
\hline 88 & 46 & 10 \\
\hline 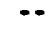 & $\cdots$ & $\because$ \\
\hline 99 & 54 & 13 \\
\hline 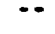 & $\cdots$ & $\cdots$ \\
\hline & $\cdots$ & $\cdots$ \\
\hline & $\cdots$ & $\cdots$ \\
\hline 76 & $\ddot{38}$ & 19 \\
\hline 10 & 38 & 11 \\
\hline & $\ldots$ & 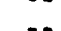 \\
\hline- & .. & $\ldots$ \\
\hline 77 & 42 & 10 \\
\hline$\cdots$ & $\cdots$ & $\cdots$ \\
\hline$\cdots$ & $\cdots$ & $\cdots$ \\
\hline$\cdots$ & $\cdots$ & $\cdots$ \\
\hline$\cdots$ & $\cdots$ & $\cdots$ \\
\hline & $\cdots$ & $\cdots$ \\
\hline & $\cdots$ & $\cdots$ \\
\hline & $\cdots$ & $\cdots$ \\
\hline & 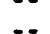 & 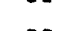 \\
\hline & $\ldots$ & . \\
\hline & .. & 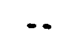 \\
\hline & .. & \\
\hline$\cdots$ & -. & $\cdots$ \\
\hline 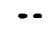 & $\cdots$ & $\cdots$ \\
\hline & $\cdots$ & $\cdots$ \\
\hline & $\cdots$ & \\
\hline
\end{tabular}

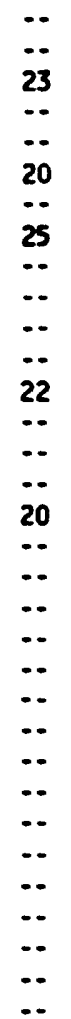

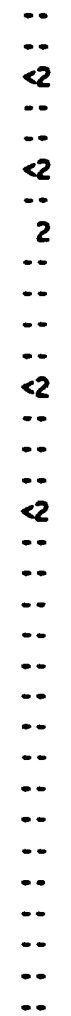

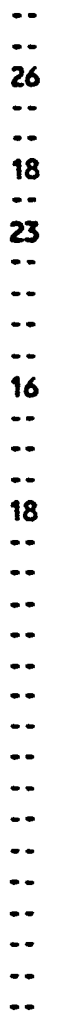

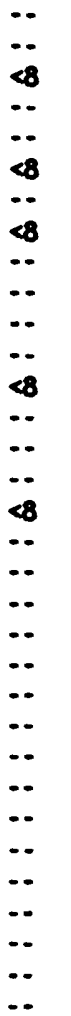

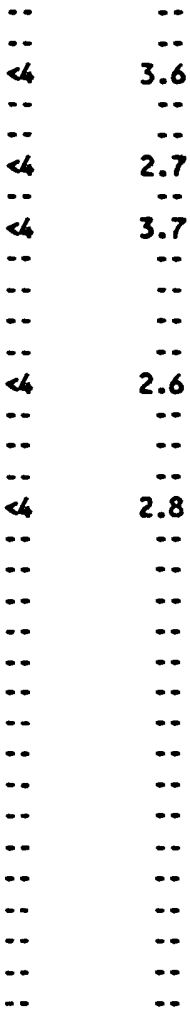


STATION

MUMBER

DATE

\begin{tabular}{|c|c|c|c|c|c|c|c|c|}
\hline $\begin{array}{c}\text { LANTHA- } \\
\text { NUN } \\
\text { BOT MAT } \\
\angle 63_{\mu} \text { DS } \\
\text { LAB } \\
(\mu g / G) \\
(34887)\end{array}$ & $\begin{array}{c}\text { LEAD } \\
\text { BOT MAT } \\
\angle 63 \mu \text { DS } \\
\text { LAB } \\
(\mu 9 / G) \\
(34892)\end{array}$ & $\begin{array}{l}\text { LITHIUM } \\
\text { BOT MAT } \\
\angle 63_{\mu} \text { DS } \\
\text { LAB } \\
(\mu 9 / G) \\
(34897)\end{array}$ & $\begin{array}{l}\text { MMGNE- } \\
\text { SIUM } \\
\text { BOT MAT } \\
\text { C63 } \mu \text { DS } \\
\text { LAB } \\
\text { PERCENT } \\
\text { (34902) }\end{array}$ & $\begin{array}{l}\text { MANGA- } \\
\text { NESE } \\
\text { BOT MAT } \\
<63_{\mu} \text { DS } \\
\text { LAB } \\
(\mu 9 / G) \\
(34907)\end{array}$ & $\begin{array}{l}\text { MOLYB- } \\
\text { DENUA } \\
\text { BOT MAT } \\
<63 \mu \text { DS } \\
\text { LAB } \\
(\mu 9 / G) \\
(34917)\end{array}$ & $\begin{array}{l}\text { NEOOYM- } \\
\text { IUM } \\
\text { BOT MAT } \\
<63 \mu \text { DS } \\
\text { LAB } \\
(\mu 9 / G) \\
(34922)\end{array}$ & $\begin{array}{l}\text { NICKEL } \\
\text { BOT MAT } \\
\angle 63 \mu \text { DS } \\
\text { LAB } \\
(\mu g / G) \\
(34927)\end{array}$ & $\begin{array}{l}\text { NIOBIUN } \\
\text { BOT MAT } \\
<63 \mu \text { DS } \\
\text { LAB } \\
(\mu 9 / G) \\
(34932)\end{array}$ \\
\hline
\end{tabular}

PUERCO RIVER NEAR CHURCW ROCK, WOATInUEd

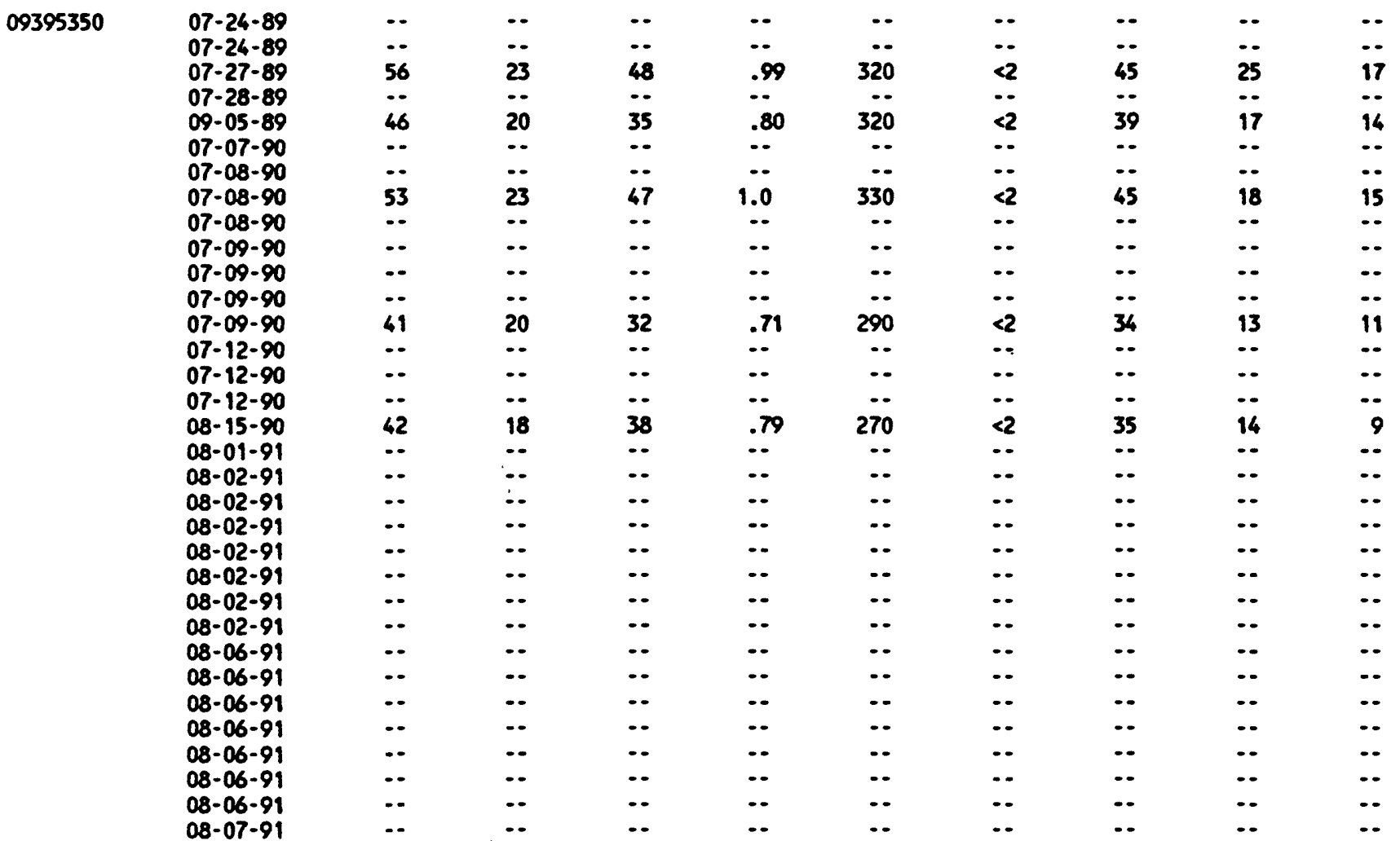


SURFACE-MATER DATA-Cont inued

CHEMICAL ANALYSES-Continued

STATION

NUMBER

DATE

\begin{tabular}{|c|c|c|c|c|c|c|c|c|c|}
\hline in & $\begin{array}{l}\text { PHOS- } \\
\text { PHORUS } \\
\text { BOT MAT } \\
\angle 63 \mu \text { DS } \\
\text { LAB } \\
\text { PERCENT } \\
\text { (34937) }\end{array}$ & $\begin{array}{l}\text { POTAS- } \\
\text { SIUA } \\
\text { BOT MAT } \\
\angle 63 \mu \text { DS } \\
\text { LAB } \\
\text { PERCENT } \\
(34942)\end{array}$ & $\begin{array}{c}\text { SCAN- } \\
\text { DIUN } \\
\text { BOT MAT } \\
\angle 63 \mu \text { DS } \\
\text { LAB } \\
(\mu g / G) \\
(34947)\end{array}$ & $\begin{array}{c}\text { SILVER } \\
\text { BOT MAT } \\
\angle 63 \mu \text { DS } \\
\text { LAB } \\
(\mu g / G) \\
(34957)\end{array}$ & $\begin{array}{l}\text { SODIUN } \\
\text { BOT MAT } \\
\angle 63 \mu \text { DS } \\
\text { LAB } \\
\text { PERCENT } \\
\text { (34962) }\end{array}$ & $\begin{array}{c}\text { STRON- } \\
\text { TIUN } \\
\text { BOT MAT } \\
\angle 63_{\mu} \text { DS } \\
\text { LAB } \\
(\mu 9 / G) \\
(34967)\end{array}$ & $\begin{array}{l}\text { TANTA- } \\
\text { LUA } \\
\text { BOT MAT } \\
\angle 63 \mu \text { OS } \\
\text { LAB } \\
(\mu g / G) \\
(34977)\end{array}$ & 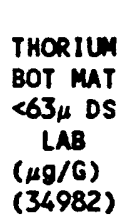 & $\begin{array}{c}\text { TIN } \\
\text { BOT MAT } \\
\text { <63 }{ }^{\prime} \text { DS } \\
\text { LAB } \\
(\mu g / G) \\
(34987)\end{array}$ \\
\hline
\end{tabular}

PUERCO RIVER MEAR CHURCH ROCK, WH-Continued

$09395350 \quad \begin{aligned} & 07-24-89 \\ & 07-24-89 \\ & 07-27-89 \\ & 07-28-89 \\ & 09-05-89 \\ & 07-07-90 \\ & 07-08-90 \\ & 07-08-90 \\ & 07-08-90 \\ & 07-09-90 \\ & 07-09-90 \\ & 07-09-90 \\ & 07-09-90 \\ & 07-12-90 \\ & 07-12-90 \\ & 07-12-90 \\ & 08-15-90 \\ & 08-01-91 \\ & 08-02-91 \\ & 08-02-91 \\ & 08-02-91 \\ & 08-02-91 \\ & 08-02-91 \\ & 08-02-91 \\ & 08-02-91 \\ & 08-06-91 \\ & 08-06-91 \\ & 08-06-91 \\ & 08-06-91 \\ & 08-06-91 \\ & 08-06-91 \\ & 08-06-91 \\ & 08-07-91\end{aligned}$

\begin{tabular}{|c|c|c|}
\hline -. & -. & . \\
\hline$\ldots$ & -. & . \\
\hline .06 & 1.9 & 15 \\
\hline . & $\ldots$ & $\ldots$ \\
\hline - & .. & $\ldots$ \\
\hline .06 & 2.0 & 11 \\
\hline$\ldots$ & $\cdots$ & $\cdots$ \\
\hline .07 & 2.1 & 15 \\
\hline$\cdots$ & $\cdots$ & $\cdots$ \\
\hline$\cdots$ & $\cdots$ & $\cdots$ \\
\hline$\cdots$ & $\because$ & $\ldots$ \\
\hline$\ddot{B r}$ & $\because$ & $\ddot{0}$ \\
\hline .05 & 2.0 & 10 \\
\hline 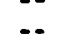 & $\because$ & 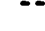 \\
\hline$\ldots$ & 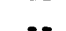 & - \\
\hline .05 & 1.9 & 12 \\
\hline$\ldots$ & $\ldots$ & $\cdots$ \\
\hline -. & - & $\cdots$ \\
\hline- & -. & - \\
\hline$\cdots$ & $\cdots$ & - \\
\hline$\cdots$ & $\cdots$ & - \\
\hline$\cdots$ & $-\cdot$ & - \\
\hline$\cdots$ & $\cdots$ & - \\
\hline$\cdots$ & $\cdots$ & - \\
\hline$\cdots$ & $\cdots$ & - \\
\hline$\cdots$ & $\cdots$ & - \\
\hline$\ldots$ & $\therefore$ & - \\
\hline & $\ldots$ & \\
\hline$\cdots$ & $\ldots$ & - \\
\hline & .- & \\
\hline$\cdots$ & 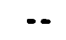 & \\
\hline
\end{tabular}

\begin{tabular}{|c|c|}
\hline - & $\cdots$ \\
\hline & \\
\hline$<4$ & .29 \\
\hline 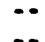 & $\cdots$ \\
\hline$\ddot{4 a}$ & $\ddot{6}$ \\
\hline$\ldots$ & .66 \\
\hline$<4$ & .34 \\
\hline -. & $\cdots$ \\
\hline - & $\ldots$ \\
\hline$\cdots$ & $\cdots$ \\
\hline$\cdots$ & 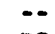 \\
\hline$<4$ & .52 \\
\hline- & $\cdots$ \\
\hline$\cdots$ & $\cdots$ \\
\hline 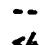 & 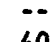 \\
\hline$<4$ & .40 \\
\hline$\ldots$ & $\ldots$ \\
\hline -. & $\cdots$ \\
\hline$\cdots$ & . \\
\hline$\cdots$ & $\cdots$ \\
\hline$\cdots$ & \\
\hline -. & 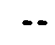 \\
\hline-- & 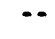 \\
\hline - & 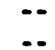 \\
\hline - & \\
\hline - & 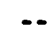 \\
\hline • & \\
\hline & \\
\hline
\end{tabular}

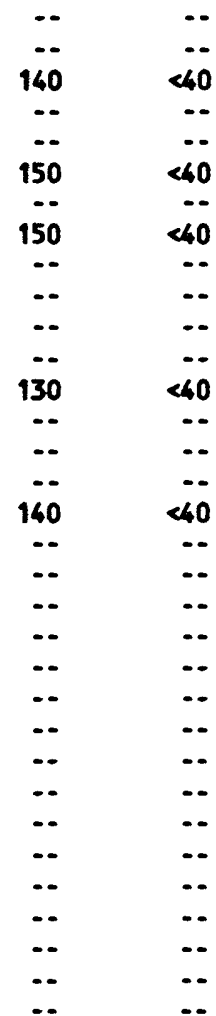

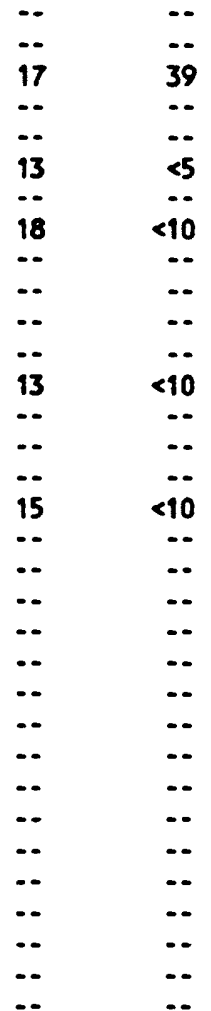


CHEMICAL ANALYSES-Cont inued

STATION

NUMBER

DATE

07-24-89

$07-24-89$

$07-27-89$

07-28-89

09-05-89

$07-07-90$

07-08-90

$07-08-90$

$07-08-90$

$07-09-90$

$07-09-90$

$07-09-90$

$07-09-90$

$07-12-90$

$07-12-90$

$07-12-90$

$08-15-90$

08-01-91

08-02-91

$08-02-91$

08-02-91

08-02-91

08-02-91

08-02-91

08-02-91

08-06-91

08-06-91

08-06-91

08-06-91

08-06-91

08-06-91

08-06-91

08-07-91

\begin{tabular}{|c|c|c|c|c|c|c|c|}
\hline $\begin{array}{l}\text { TITA- } \\
\text { NIUH } \\
\text { BOT MAT } \\
\angle 63_{\mu} \text { DS } \\
\text { LAB } \\
\text { PERCENT } \\
\text { (34992) }\end{array}$ & $\begin{array}{c}\text { URANIUN } \\
\text { BOT MAT } \\
\angle 63 \mu \text { DS } \\
\text { LAB } \\
(\mu g / G) \\
(35002)\end{array}$ & $\begin{array}{l}\text { VANA- } \\
\text { DIUNA } \\
\text { BOT MAT } \\
\angle 63 \mu \text { DS } \\
\text { LAB } \\
(\mu g / G) \\
(35007)\end{array}$ & $\begin{array}{c}\text { YTTRIUM } \\
\text { BOT MAT } \\
\angle 63 \mu \text { DS } \\
\text { LAB } \\
(\mu g / G) \\
(35012)\end{array}$ & $\begin{array}{c}\text { YITER- } \\
\text { BIUH } \\
\text { BOT MAT } \\
\angle 63_{\mu} \text { DS } \\
\text { LAB } \\
(\mu g / G) \\
(35017)\end{array}$ & $\begin{array}{c}21 N C \\
801 \text { MAT } \\
\angle 63 \mu \text { DS } \\
\text { LAB } \\
(\mu g / G) \\
(35022)\end{array}$ & $\begin{array}{l}\text { SEDI- } \\
\text { MENT, } \\
\text { SUS- } \\
\text { PENDED } \\
\text { (mo/l) } \\
(80154)\end{array}$ & $\begin{array}{c}\text { SED. } \\
\text { SUSP. } \\
\text { SIEVE } \\
\text { DINM. } \\
\times \text { FINER } \\
\text { THAN } \\
\text {.062 MH } \\
\text { (70331) }\end{array}$ \\
\hline
\end{tabular}

PUERCO RIVER NEAR CHURCH ROCK, WH-Continued

\begin{tabular}{|c|c|c|c|c|c|c|c|}
\hline & & & & & & & \\
\hline$\cdots$ & $\cdots$ & $\cdots$ & $\cdots$ & -. & $\cdots$ & 115000 & $\cdots$ \\
\hline$\ldots$ & -. & $\cdots$ & $\cdots$ & $\ldots$ & $\cdots$ & 80000 & -. \\
\hline .49 & $<100$ & 110 & 30 & 3 & $\varphi$ & 54500 & -. \\
\hline-- & $\cdots$ & 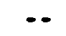 & $\cdots$ & $\ldots$ & $\ldots$ & 94300 & .. \\
\hline .. & -- & - & $\cdots$ & -. & $\cdots$ & 66800 & $\cdots$ \\
\hline .61 & $<100$ & 81 & 25 & 3 & 73 & 119000 & 55 \\
\hline$\cdots$ & $\cdots$ & $\cdots$ & $\cdots$ & $\cdots$ & $\cdots$ & 126000 & 61 \\
\hline .48 & $<100$ & 110 & 30 & 4 & 94 & 56900 & $\cdots$ \\
\hline - & $\cdots$ & $-\cdot$ & $\cdots$ & $\cdots$ & $\cdots$ & $\cdots$ & $\cdots$ \\
\hline$\cdots$ & -. & $-\cdot$ & $\cdots$ & $\cdots$ & -. & 161000 & 61 \\
\hline - & -. & -. & - & $\cdots$ & -. & $\cdots$ & $\cdots$ \\
\hline$\cdots$ & - & $\cdots$ & $\cdots$ & $\cdots$ & -. & 98900 & 74 \\
\hline .38 & $<100$ & 74 & 25 & 3 & 67 & 238000 & $\cdots$ \\
\hline -- & $\cdots$ & $\cdots$ & $\cdots$ & $\ldots$ & $\ldots$ & 213000 & 48 \\
\hline$\cdots$ & $\cdots$ & $\cdots$ & $\cdots$ & $\cdots$ & $\cdots$ & $\cdots$ & $\cdots$ \\
\hline .. & .. & $-\cdot$ & $\cdots$ & $\cdots$ & $\cdots$ & 149000 & 74 \\
\hline .38 & $<100$ & 91 & 26 & 3 & 74 & 55600 & $\cdots$ \\
\hline - & -. & $\cdots$ & $\cdots$ & $\cdots$ & -. & 73300 & $\cdots$ \\
\hline$\cdots$ & $\cdots$ & $\cdots$ & $\cdots$ & $\cdots$ & $\cdots$ & 160000 & 80 \\
\hline - & $\cdots$ & $\cdots$ & $\cdots$ & -. & $\cdots$ & 179000 & 80 \\
\hline -. & -. & - & $\cdots$ & $\cdots$ & $\cdots$ & 160000 & 81 \\
\hline$\cdots$ & $\cdots$ & $\cdots$ & $\cdots$ & $\cdots$ & $\cdots$ & 155000 & 81 \\
\hline -. & $-\cdot$ & $\cdots$ & $\cdots$ & $\cdots$ & .. & 144000 & $\cdots$ \\
\hline$\cdots$ & $\cdots$ & $\cdots$ & $\cdots$ & $\cdots$ & $\cdots$ & 161000 & 76 \\
\hline$\cdots$ & $\cdots$ & $\cdots$ & $\cdots$ & $\cdots$ & $\cdots$ & 132000 & $\pi$ \\
\hline -. & -. & -- & $\cdots$ & $\cdots$ & -. & 462000 & 46 \\
\hline$\cdots$ & $\cdots$ & 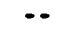 & $\cdots$ & $\cdots$ & $\cdots$ & 258000 & $\cdots$ \\
\hline$\cdots$ & $\cdots$ & $\cdots$ & $\cdots$ & $\cdots$ & $\cdots$ & 168000 & 55 \\
\hline -. & $\cdots$ & $\cdots$ & $\cdots$ & $\cdots$ & $\cdots$ & 178000 & 5 \\
\hline$\cdots$ & $-\cdot$ & $\cdots$ & $\cdots$ & $\cdots$ & $\cdots$ & 182000 & 46 \\
\hline$\cdots$ & $\cdots$ & $\cdots$ & $\cdots$ & $\cdots$ & $\cdots$ & 199000 & 42 \\
\hline$\cdots$ & -- & $-\cdot$ & $\cdots$ & $\cdots$ & $\cdots$ & 162000 & 51 \\
\hline & -. & -. & $\ldots$ & .. & $\cdots$ & 132000 & 61 \\
\hline
\end{tabular}


STATION

MUABER

DATE

\section{SURFACE-WATER DATA-Cont inued}

CHEMICAL AMALYSES-Cont inued

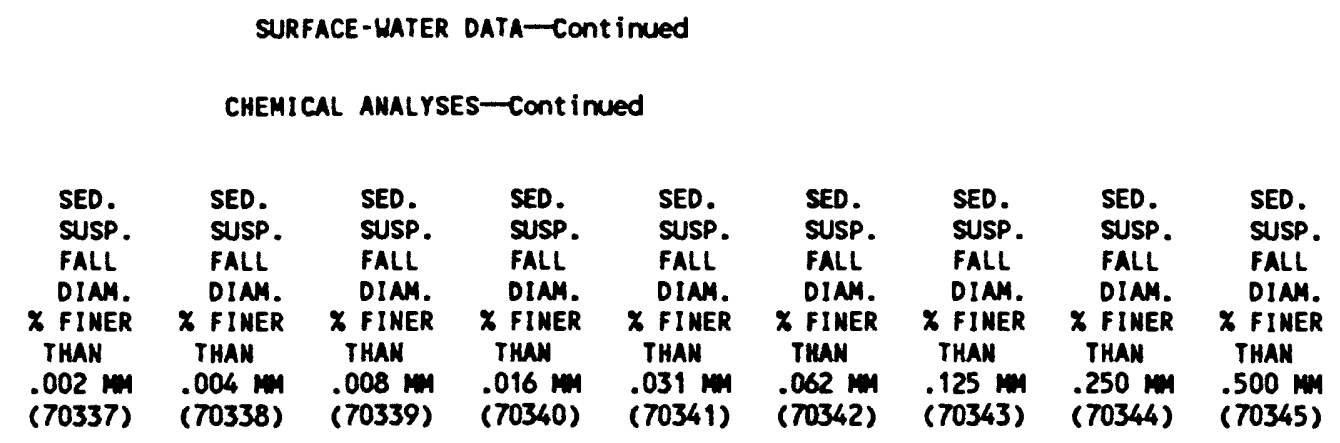

PUERCO RIVER MEAR CHURCH ROCK, MH-Continued

\begin{tabular}{|c|c|c|c|c|}
\hline $\begin{array}{l}50 \\
63 \\
59 \\
58 \\
41\end{array}$ & $\begin{array}{l}59 \\
76 \\
70 \\
69 \\
49\end{array}$ & $\begin{array}{l}80 \\
\ldots \\
\ldots- \\
\ldots \\
\ldots\end{array}$ & $\begin{array}{l}80 \\
92 \\
81 \\
88 \\
67\end{array}$ & $\begin{array}{l}-- \\
- \\
- \\
- \\
-\end{array}$ \\
\hline$\ldots$ & $\therefore$ & .. & -. & - \\
\hline - & -- & -. & -- & -. \\
\hline 62 & 76 & 83 & 90 & 94 \\
\hline-- & $\cdots$ & -. & -. & $\cdots$ \\
\hline$\cdots$ & $\cdots$ & $\cdots$ & $\cdots$ & -- \\
\hline$\cdots$ & -. & -. & -- & -- \\
\hline$\because$ & -- & 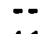 & $=$ & $\ddot{z}$ \\
\hline 43 & 46 & 46 & 59 & 68 \\
\hline$\ldots$ & 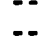 & .- & -- & $\ldots$ \\
\hline$\ldots$ & .. & -. & .. & -- \\
\hline 44 & $\begin{array}{l}53 \\
40\end{array}$ & $\begin{array}{l}59 \\
55\end{array}$ & $\begin{array}{l}65 \\
67\end{array}$ & $\begin{array}{l}71 \\
76\end{array}$ \\
\hline$\therefore$ & $\ldots$ & $\ldots$ & $\ldots$ & $\ldots$ \\
\hline -- & - & - & - & -- \\
\hline -. & $\cdots$ & - & -- & $=$ \\
\hline -. & 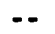 & -. & -- & -- \\
\hline 42 & 52 & 55 & 65 & 72 \\
\hline$\cdots$ & $\cdots$ & $\cdots$ & -- & -- \\
\hline -. & $\cdots$ & $\cdots$ & $\cdots$ & - \\
\hline$\ddot{z a}$ & $\ddot{3 x}$ & $\ddot{n}$ & $\ddot{\theta}$ & $\bar{c}$ \\
\hline $\begin{array}{l}100 \\
\ldots\end{array}$ & 36 & 40 & 42 & 56 \\
\hline 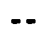 & -. & -. & -. & -. \\
\hline- & -. & - & -. & -- \\
\hline - & $\cdots$ & -. & - & -- \\
\hline - & -. & -. & -- & -- \\
\hline & & & & \\
\hline
\end{tabular}

\begin{tabular}{|c|c|c|}
\hline $\begin{array}{r}100 \\
98 \\
89 \\
100 \\
91\end{array}$ & $\begin{array}{r}100 \\
100 \\
98 \\
- \\
100\end{array}$ & $\begin{array}{r}\ddot{100} \\
100 \\
\cdots \\
100\end{array}$ \\
\hline$\ldots$ & $\ldots$ & $=$ \\
\hline -. & -- & -. \\
\hline 97 & 100 & 100 \\
\hline$\cdots$ & -- & - \\
\hline -- & $\cdots$ & $\cdots$ \\
\hline-- & - & -- \\
\hline 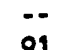 & $\ddot{96}$ & $\ddot{100}$ \\
\hline$\cdots$ & $\ldots$ & $\ldots$ \\
\hline$\cdots$ & $\cdots$ & $\cdots$ \\
\hline - & $\cdots$ & $\cdots$ \\
\hline $\begin{array}{l}84 \\
91\end{array}$ & $\begin{array}{l}96 \\
98\end{array}$ & $\begin{array}{l}100 \\
100\end{array}$ \\
\hline- & $=$ & - \\
\hline- & - & -1 \\
\hline-- & -- & $\cdots$ \\
\hline$\cdots$ & - & $\cdots$ \\
\hline 92 & 100 & - \\
\hline- & -- & $=-$ \\
\hline$\cdots$ & $\cdots$ & $\cdots$ \\
\hline$\ddot{\pi}$ & $\ddot{a z}$ & $\ddot{-}$ \\
\hline 77 & 93 & 100 \\
\hline$\infty$ & $\because$ & $\cdots$ \\
\hline 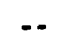 & -. & - \\
\hline$\cdots$ & -- & $\cdots$ \\
\hline 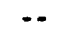 & -- & \\
\hline & & \\
\hline
\end{tabular}




$\begin{array}{ll}03-09-89 & 0815 \\ 04-05-89 & 1315 \\ 04-11-89 & 1419 \\ 07-13-89 & 1400 \\ 07-27-89 & 1400 \\ 07-27-89 & 1410 \\ 09-06-89 & 0110 \\ 09-06-89 & 0120 \\ 09-06-89 & 0130 \\ 03-08-90 & 0950 \\ 07-13-90 & 1850 \\ 07-13-90 & 1850 \\ 07-13-90 & 1900 \\ 07-13-90 & 1920 \\ 07-13-90 & 1950 \\ 07-13-90 & 1950 \\ 07-13-90 & 2010 \\ 07-13-90 & 2030 \\ 08-03-90 & -0 \\ 08-14-90 & 2035 \\ 08-15-90 & 0800 \\ 10-20-90 & 0030 \\ 10-20-90 & 0030 \\ 10-20-90 & 0100 \\ 10-20-90 & 0200 \\ 10-20-90 & 0330 \\ 10-20-90 & 0330 \\ 10-20-90 & 0410 \\ 06-11-91 & 01 \\ 06-12-91 & 0010 \\ 06-12-91 & 0800 \\ 06-13-91 & 2120 \\ 08-02-91 & 1445 \\ 08-06-91 & 0030 \\ 08-15-91 & 0800 \\ 08-26-91 & 2050 \\ 08-26-91 & 2120 \\ 08-26-91 & 2200 \\ 08-26-91 & 2240 \\ 08-26-91 & 2320 \\ 08-26-91 & 2400 \\ & \end{array}$

0030 
CHEMICAL ANALYSES-Cont inued

STATION

MUMBER

\begin{tabular}{|c|c|c|c|c|c|c|c|c|c|c|}
\hline ITE & $\begin{array}{l}\text { ALTITUDE } \\
\text { OF LAND } \\
\text { SURFACE } \\
\text { DATUN } \\
\text { (METERS } \\
\text { ABOVE } \\
\text { NGVD } \\
\text { (72000) }\end{array}$ & $\begin{array}{l}\text { SAM- } \\
\text { PLING } \\
\text { METHCO, } \\
\text { COOES } \\
(82398)\end{array}$ & $\begin{array}{l}\text { STREAM } \\
\text { WIDTH } \\
\text { (meters) } \\
\text { (00004) }\end{array}$ & $\begin{array}{l}\text { TEMPER- } \\
\text { ATURE } \\
\text { UATER } \\
\left({ }^{-} \mathrm{C}\right) \\
(00010)\end{array}$ & $\begin{array}{l}\text { DIS- } \\
\text { CHARGE, } \\
\text { IN } \\
\text { CUBIC } \\
\text { METERS } \\
\text { PER } \\
\text { SECOND } \\
(00060)\end{array}$ & $\begin{array}{l}\text { DIS- } \\
\text { CHARGE, } \\
\text { INST. } \\
\text { CUBIC } \\
\text { METERS } \\
\text { PER } \\
\text { SECOND } \\
\text { (00061) }\end{array}$ & $\begin{array}{l}\text { GAGE } \\
\text { HEIGHT } \\
\text { (meters) } \\
\text { (00065) }\end{array}$ & $\begin{array}{l}\text { TUR- } \\
\text { BID- } \\
\text { ITY } \\
\text { (NTU) } \\
\text { (00076) }\end{array}$ & $\begin{array}{l}\text { OXID- } \\
\text { ATION } \\
\text { RED- } \\
\text { UCTION } \\
\text { POTEN- } \\
\text { TIAL } \\
\text { (WV) } \\
(00090)\end{array}$ & $\begin{array}{c}\text { SPE- } \\
\text { CIFIC } \\
\text { CON- } \\
\text { OUCT- } \\
\text { ANCE } \\
(\mu S / \mathrm{Cm}) \\
(00095)\end{array}$ \\
\hline
\end{tabular}

PUERCO RIVER MNUELITO, MH-Continued

\begin{tabular}{|c|c|c|c|c|c|c|c|c|c|c|c|}
\hline 09395630 & $\begin{array}{l}03-09-89 \\
04-05-89 \\
04-11-89 \\
07-13-89 \\
07-27-89 \\
07-27-89 \\
09-06-89 \\
09-06-89 \\
09-06-89 \\
03-08-90 \\
07-13-90 \\
07-13-90 \\
07-13-90 \\
07-13-90 \\
07-13-90 \\
07-13-90 \\
07-13-90 \\
07-13-90 \\
08-03-90 \\
08-14-90 \\
08-15-90 \\
10-20-90 \\
10-20-90 \\
10-20-90 \\
10-20-90 \\
10-20-90 \\
10-20-90 \\
10-20-90 \\
06-11-91 \\
06-12-91 \\
06-12-91 \\
06-13-91 \\
08-02-91 \\
08-06-91 \\
08-15-91 \\
08-26-91 \\
08-26-91 \\
08-26-91 \\
08-26-91 \\
08-26-91 \\
08-26-91\end{array}$ & 1,890 & $\begin{array}{l}70 \\
7 \\
70 \\
70 \\
70 \\
70 \\
50 \\
50 \\
50 \\
-- \\
50 \\
50 \\
50 \\
50 \\
50 \\
50 \\
50 \\
50 \\
-. \\
70 \\
10 \\
50 \\
50 \\
50 \\
50 \\
50 \\
50 \\
50 \\
- \\
\therefore \\
70 \\
50 \\
10 \\
50 \\
30 \\
50 \\
50 \\
50 \\
50 \\
50 \\
50\end{array}$ & 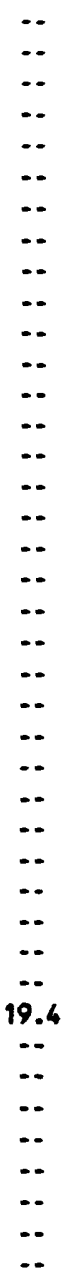 & 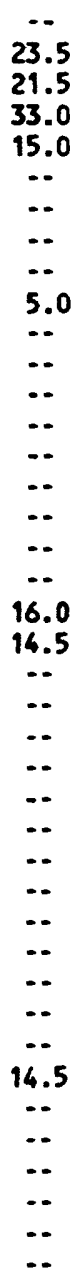 & $\begin{array}{l}\ldots \\
\ldots \\
\ldots \\
\ldots \\
\ldots \\
32 \\
\ldots \\
\ldots \\
\ldots \\
53 \\
103 \\
153 \\
\ldots \\
170 \\
140 \\
124 \\
96 \\
\ldots \\
\ldots \\
\cdots \\
32 \\
\ldots \\
36 \\
79 \\
54 \\
\ldots \\
47 \\
\ldots \\
\ldots \\
\ldots \\
36 \\
\ldots \\
42 \\
\ldots \\
35 \\
33 \\
51 \\
57 \\
41 \\
41\end{array}$ & 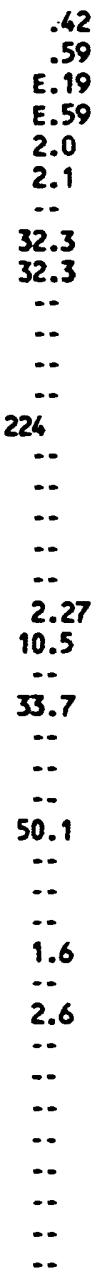 & $\begin{array}{l}1.05 \\
1.0 \\
1.06 \\
1.07 \\
1.15 \\
1.15 \\
1.68 \\
\ldots \\
\cdots \\
1 . \\
1.87 \\
2.19 \\
2.51 \\
2.82 \\
2.59 \\
2.37 \\
2.35 \\
2.18 \\
.1 . \\
1.15 \\
1.26 \\
1.68 \\
1.69 \\
1.71 \\
2.07 \\
1.88 \\
1.85 \\
1.82 \\
. .9 \\
. . \\
1.2 \\
1.71 \\
1.17 \\
1.77 \\
1 . . \\
1.70 \\
1.68 \\
1.86 \\
1.90 \\
1.76 \\
1.76\end{array}$ & 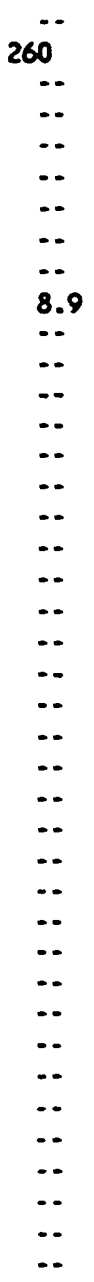 & 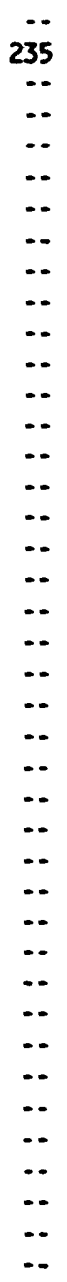 & 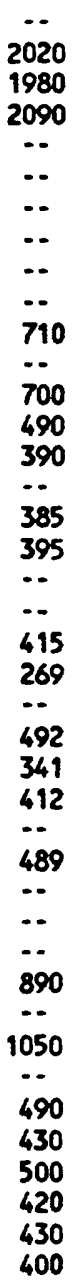 \\
\hline
\end{tabular}


CHEMICAL ANALYSES-Cont inued

STATION MUMBER

09395630

\begin{tabular}{|c|c|c|c|c|c|c|c|c|c|}
\hline ATE & $\begin{array}{l}\text { SPE- } \\
\text { CIFIC } \\
\text { CON- } \\
\text { DUCT- } \\
\text { ANCE } \\
\text { LAB } \\
(\mu S / \mathrm{Cm}) \\
(90095)\end{array}$ & $\begin{array}{c}\text { OXYGEN, } \\
\text { DIS- } \\
\text { SOLVED } \\
(\mathrm{mg} / \mathrm{L}) \\
(00300)\end{array}$ & $\begin{array}{l}\text { OXYGEN } \\
\text { DEMAND, } \\
\text { CHEM- } \\
\text { ICAL } \\
\text { (HIGH } \\
\text { LEVEL) } \\
(\mathrm{Mg} / L) \\
(00340)\end{array}$ & $\begin{array}{l}\text { PH } \\
\text { WATER } \\
\text { WHOLE } \\
\text { FIELD } \\
\text { (STAND- } \\
\text { ARD } \\
\text { UNITS) } \\
\text { (00400) }\end{array}$ & $\begin{array}{l}\text { PH } \\
\text { WATER } \\
\text { UHOLE } \\
\text { LAB } \\
\text { (STAND- } \\
\text { ARD } \\
\text { UNITS) } \\
\text { (00403) }\end{array}$ & $\begin{array}{l}\text { ALKA- } \\
\text { LINITY } \\
\text { WAT DIS } \\
\text { FIX END } \\
\text { FIELD } \\
\text { mg/L as } \\
\text { CaCO3 } \\
(39036)\end{array}$ & $\begin{array}{l}\text { ALKA- } \\
\text { LINITY } \\
\text { WAT DIS } \\
\text { TOT IT } \\
\text { FIELD } \\
\text { mg/L as } \\
\text { CaCO3 } \\
(39086)\end{array}$ & $\begin{array}{l}\text { ALKA- } \\
\text { LINITY } \\
\text { LAB } \\
\text { (mg/L } \\
\text { as } \\
\text { Caco3) } \\
(90410)\end{array}$ & $\begin{array}{c}\text { CAR- } \\
\text { BONATE } \\
\text { WATER } \\
\text { DIS IT } \\
\text { FIELD } \\
\mathrm{mg} / \mathrm{L} \text { as } \\
\text { CO3 } \\
(00452)\end{array}$ \\
\hline
\end{tabular}

PUERCO RIVER MANUELITO, Continued

\begin{tabular}{|c|c|c|c|c|c|c|c|c|c|}
\hline $\begin{array}{l}03-09-89 \\
04-05-89\end{array}$ & $\begin{array}{l}1850 \\
2070\end{array}$ & $\ddot{10.8}$ & 69 & 8.7 & 8.5 & $\ddot{4}$ & $\ddot{424}$ & $\ddot{393}$ & $\ddot{\pi}$ \\
\hline $04-11-89$ & -- & $\cdots$ & $\cdots$ & 7.8 & $\cdots$ & $\cdots$ & $\cdots$ & $\cdots$ & $\cdots$ \\
\hline $07-13-89$ & 2090 & $\cdots$ & $\cdots$ & 8.4 & $\cdots$ & $\cdots$ & -- & -- & $\cdots$ \\
\hline $07-27-89$ & 1080 & -- & $\cdots$ & - & $\cdots$ & $\cdots$ & $\cdots$ & $\cdots$ & $-\cdot$ \\
\hline $07-27-89$ & 879 & $\cdots$ & -. & $\cdots$ & -- & $\cdots$ & -- & $\cdots$ & -- \\
\hline $09-06-89$ & 1340 & -- & $\cdots$ & $\because$ & 7.8 & $\cdots$ & $\cdot-$ & $\cdots$ & $\cdots$ \\
\hline $09-06-89$ & 1200 & $\cdots$ & $\cdots$ & -- & $\cdots$ & $\cdots$ & -- & -- & $\cdots$ \\
\hline $09-06-89$ & 1080 & -- & $\cdots$ & $\cdots$ & $\because$ & $\cdots$ & $\cdots$ & 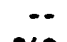 & -- \\
\hline $03-08-90$ & 1600 & -- & -- & -- & 7.4 & $\cdots$ & $\cdots$ & 249 & -- \\
\hline $07-13-90$ & $\cdots$ & $\cdots$ & -. & 7.1 & $\cdots$ & $\cdots$ & $\cdots$ & $\cdots$ & $\cdots$ \\
\hline $07-13-90$ & 935 & $\cdots$ & $\cdots$ & $\cdots$ & 7.1 & $\cdots$ & -- & 191 & $-\cdot$ \\
\hline $07-13-90$ & $\cdots$ & -- & -. & 7.3 & $\cdots$ & $\cdots$ & -- & $\cdots$ & $\cdots$ \\
\hline $07-13-90$ & 628 & $\cdots$ & $\cdots$ & 7.5 & 7.3 & $\cdots$ & -- & $\cdots$ & $\cdots$ \\
\hline $07-13-90$ & $\cdots$ & $\cdots$ & $\cdots$ & 7.6 & -- & $\cdots$ & $\cdot-$ & -- & $-\cdot$ \\
\hline $07-13-90$ & 524 & $\cdots$ & -- & $\cdots$ & 7.3 & $\cdots$ & $-\cdot$ & 219 & $\cdots$ \\
\hline $07-13-90$ & $\cdots$ & $\cdots$ & $\cdots$ & 7.6 & $\cdots$ & $\cdots$ & $\cdots$ & $\cdots$ & $\cdots$ \\
\hline $07-13-90$ & -. & $\cdots$ & -- & 7.6 & $\cdots$ & $\cdots$ & $\cdots$ & -- & - \\
\hline $08-03-90$ & 1420 & $\cdots$ &.- & -- & 7.9 & $\cdots$ & -- & 262 & $\cdots$ \\
\hline $08-14-90$ & 486 & $\cdots$ & -- & $\because$ & 7.3 & -- & $-\cdot$ & 317 & $\cdots$ \\
\hline $08-15-90$ & 565 & 7.5 & $\cdots$ & 8.8 & 8.3 & 94 & $\cdots$ & 201 & $\cdots$ \\
\hline $10-20-90$ & $\cdots$ & $\cdots$ & -- & 7.8 & -. & $\cdots$ & -. & $\cdots$ & .. \\
\hline $10-20-90$ & 456 & $\cdots$ & $\cdots$ & $\cdots$ & 7.6 & $\cdots$ & $-\cdot$ & 160 & -- \\
\hline $10-20-90$ & -- & $\cdots$ & -- & 7.6 & $\therefore$ & $\cdots$ & $\cdots$ & $\cdot-$ & -. \\
\hline $10-20-90$ & 519 & -. & -- & 7.7 & 7.7 & $\cdots$ & -. & 92 & -. \\
\hline $10-20-90$ & -- & $\cdots$ & -- & 7.8 & $\cdots$ & $\cdots$ & $-\cdot$ & $\cdots$ & $\cdots$ \\
\hline $10-20-90$ & 483 & $\cdots$ & -. & -. & 7.7 & $\cdots$ & -. & 144 & .. \\
\hline $10-20-90$ & $\cdots$ & $\cdots$ & $\cdots$ & 7.7 & -. & -. & -. & $\cdots$ & -. \\
\hline $06-11-91$ & -- & $\cdots$ & -- & $\cdots$ & $\cdots$ & $\cdots$ & $-\cdot$ & $\cdots$ & $\cdots$ \\
\hline $06-12-91$ & $\cdots$ & $\cdots$ & $\cdots$ & $\cdots$ & $\cdots$ & $\cdots$ & -- & $\cdots$ & $\cdot \cdot$ \\
\hline $06-12 \cdot 91$ & $\cdots$ & $\cdots$ & $\cdots$ & 7.6 & $\cdots$ & $\cdots$ & $\cdots$ & $\cdots$ & -- \\
\hline $06-13-91$ & $\cdots$ & $\cdots$ & $\cdots$ & 7.5 & $\cdots$ & -- & $\cdots$ & $\cdots$ & -- \\
\hline $08-02-91$ & $\cdots$ & $\cdots$ & $\cdots$ & -. & $\cdots$ & $\cdots$ & $\cdots$ & $\cdots$ & $\cdots$ \\
\hline $08-06-91$ & $\cdots$ & -. & $\cdots$ & 7.4 & $\cdots$ & $\cdots$ & $-\cdot$ & $\cdots$ & -- \\
\hline $08-15-91$ & $\cdots$ & $\cdots$ & -. & -- & $\cdots$ & $\cdots$ & $-\cdot$ & $\cdots$ & -. \\
\hline $08-26-91$ & $\cdots$ & $\cdots$ & $\cdots$ & $\cdots$ & $\cdots$ & $\cdots$ & $\cdots$ & $\cdots$ & -. \\
\hline $08-26-91$ & $\cdots$ & -. & -- & $\cdots$ & -- & $\cdots$ & $\cdots$ & $\cdots$ & $\cdots$ \\
\hline $08-26-91$ & $\cdots$ & .. & $\cdots$ & $\cdots$ & $\cdots$ & $\cdots$ & $-\cdot$ & $\cdots$ & $\cdots$ \\
\hline $08-26-91$ & $\cdots$ & $\cdots$ & $\cdots$ & 7.4 & $\cdots$ & $\cdots$ & $-\cdot$ & $\cdots$ & $\cdots$ \\
\hline $08-26-91$ & $\cdots$ & $\cdots$ & $\cdots$ & $\cdots$ & $-\cdot$ & $\cdots$ & $\cdots$ & $\cdots$ & $\cdots$ \\
\hline 91 & $\cdots$ & $\cdots$ & $\cdots$ & $\cdots$ & $\cdots$ & $\cdots$ & $\cdots$ & $\cdots$ & - \\
\hline
\end{tabular}


SURFACE-MATER DATA-Cont inued

CHEMICAL ANALYSES-Continued

STATION

MUMBER

\begin{tabular}{|c|c|c|c|c|c|c|c|c|c|}
\hline & $\begin{array}{l}\text { BICAR- } \\
\text { BONATE } \\
\text { WATER } \\
\text { OIS IT } \\
\text { FIELD } \\
\mathrm{mg} / \mathrm{L} \text { as } \\
\mathrm{HCO3} \\
(00453)\end{array}$ & $\begin{array}{l}\text { SOLIDS, } \\
\text { RESIDUE } \\
\text { AT } 180^{\circ} \mathrm{C} \\
\text { DIS- } \\
\text { SOLVED } \\
(\mathrm{mg} / \mathrm{L}) \\
(70300)\end{array}$ & $\begin{array}{l}\text { SOLIDS, } \\
\text { SUM OF } \\
\text { CONSII- } \\
\text { TUENTS, } \\
\text { DIS- } \\
\text { SOLVED } \\
\text { (mg/L) } \\
\text { (70301) }\end{array}$ & $\begin{array}{c}\text { SOLIDS, } \\
\text { DIS- } \\
\text { SOLVED } \\
\text { (metric } \\
\text { tons } \\
\text { per } \\
\text { day) } \\
(70302)\end{array}$ & $\begin{array}{l}\text { NITRO- } \\
\text { GEN, } \\
\text { NMONIA } \\
\text { DIS- } \\
\text { SOLVED } \\
\text { (Mg/L } \\
\text { OS N) } \\
(00608)\end{array}$ & $\begin{array}{l}\text { N1TRO- } \\
\text { GEN, } \\
\text { NO2+NÓ3 } \\
\text { DIS- } \\
\text { SOL VED } \\
\text { (mo/L } \\
\text { as N) } \\
\text { (00631) }\end{array}$ & $\begin{array}{l}\text { NITRO- } \\
\text { GEN,AM- } \\
\text { MONIA + } \\
\text { ORGANIC } \\
\text { TOTAL } \\
\text { (Mg/L } \\
\text { AS N) } \\
\text { (00625) }\end{array}$ & $\begin{array}{l}\text { PHOS- } \\
\text { PHORUS } \\
\text { DIS- } \\
\text { SOLVED } \\
\text { (mg/L } \\
\text { as P) } \\
(00666)\end{array}$ & $\begin{array}{l}\text { PHORUS } \\
\text { TOTAL } \\
\text { (mg/L } \\
\text { as P) } \\
\text { (00665) }\end{array}$ \\
\hline
\end{tabular}

PUERCO RIVER MANUELITO, NA-Cont inued

\begin{tabular}{|c|c|c|c|c|c|c|c|c|c|}
\hline $\begin{array}{l}03-09-89 \\
04-05-89\end{array}$ & 361 & 1320 & 1350 & $\ddot{16.1}$ & 8.80 & .830 & $\ddot{16}$ & 7.00 & 8.60 \\
\hline $04-11-89$ & $\because$ & -. & 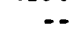 & -- & $-\cdot$ & $\cdots$ & $\cdots$ & $-\cdot$ & $\cdots$ \\
\hline $07-13-89$ & $\cdots$ & -- & -. & -- & $\cdots$ & $\cdots$ & $\cdots$ & -. & $-\cdot$ \\
\hline $07-27-89$ & -. & .. & -. & $\cdot-$ & -. & -. & .. & -. & -. \\
\hline $07-27-89$ & $\cdots$ & -. & -. & -. & -. & -. & .. & .- & -. \\
\hline $09-06-89$ & $\cdots$ & -. & -. & -. & $-\cdot$ & 1.40 & $\cdots$ & $-\cdot$ & -- \\
\hline $09-06-89$ & $\cdots$ & -. & $-\cdot$ & $\cdots$ & $-\cdot$ & -. & $\cdots$ & -. & -. \\
\hline $09-06-89$ & $\cdots$ & $\because$ & $\because-$ & -. & -. & $\cdots$ & $\cdots$ & -. & -. \\
\hline $03-08-90$ & $\cdots$ & 1080 & 1000 & $-\cdot$ & -- & -. & $\cdots$ & $-\cdot$ & -- \\
\hline $07-13-90$ & $\cdots$ & $\cdots$ & - & $-\cdot$ & $\cdots$ &.- & $\cdots$ & $-\cdot$ & -. \\
\hline $07-13-90$ & $\cdots$ & 531 & 517 & 4744 & -. & -- & -. & -. & -. \\
\hline $07-13-90$ & $\cdots$ & $\cdots$ & $\therefore$ & $\because$ & -. & -. & -. & -. & -. \\
\hline $07-13-90$ & $-\cdot$ & $\cdot-$ & $\cdots$ & -. & -. & $\cdots$ & $\cdots$ & -. & -. \\
\hline $07-13-90$ & $\cdots$ & -. & $\cdots$ & $\cdots$ & -- & -. & $\cdots$ & $\cdots$ & -- \\
\hline $07-13-90$ & $\cdots$ & 314 & 322 & 3791 & -. & -. & .. & -. & -. \\
\hline $07-13-90$ & -- & -- & -- & $\cdots$ & -- & -- & -. & -. & -. \\
\hline $07-13-90$ & -. & . & $-\cdot$ & -. & $-\cdot$ & -. & -. & -. & -. \\
\hline $08-03-90$ & -. & 906 & $-\cdot$ & $-\cdot$ & -. & -. & -. & -. & $-\cdot$ \\
\hline $08-14-90$ & -. & 317 & 357 & 62.1 &.- & -. & -. & -. & -. \\
\hline $08-15-90$ & -. & 269 & 244 & 244 & -. &.- & -. & -. & -. \\
\hline $10-20-90$ & -- & -- & -- & -. & -. &.- &.- & -. & -. \\
\hline $10-20-90$ & -. & -. & 271 & 793 & $\cdots$ & -. & $\cdots$ & -. & -. \\
\hline $10-20-90$ & $\cdots$ & $\cdots$ & $\cdots$ & $\cdots$ & $\cdots$ & 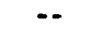 & $\cdots$ & -. & -. \\
\hline $10-20-90$ & -- & -. & 204 & 1397 & -. & -. & $\cdots$ & $-\cdot$ & -. \\
\hline $10-20-90$ & $\cdots$ & -. & $\because-$ & $\because$ & -. & -. &.- & -. & -. \\
\hline $10-20-90$ & $\cdots$ & $\cdots$ & 296 & 1279 & -. & $-\cdot$ &.- & -. & -. \\
\hline $10-20-90$ & -- & $\cdots$ & $\cdots$ & $\cdots$ & -- & -. & -- & $-\cdot$ & -. \\
\hline $06-11-91$ & -. & $\cdots$ & -. & -. & $\cdots$ & $-\cdot$ & $\cdots$ & -. & -. \\
\hline $06-12-91$ & $\cdots$ & $\cdots$ & $\cdots$ & -. & -- & -. &.- & -. & -. \\
\hline $06-12-91$ & .. & -. & -- & -. & -. & -. & -. & -. & -. \\
\hline $06-13-91$ & $\cdots$ & -. & -. & -. & -. & -. & $\cdots$ & -. & $\cdot \cdot$ \\
\hline $08-02-91$ & -. & -. & -. & .. & -- & -. & $-\cdot$ & -. & -- \\
\hline $08-06-91$ & -- & -. & -- & -. & -- & -- & $-\cdot$ & -. & -. \\
\hline $08-15-91$ & $\cdots$ & -. & $\cdots$ & -. & -. & -. & $\cdots$ & $\cdot-$ & $\cdots$ \\
\hline $08-26-91$ & $\cdots$ & -. & $\cdots$ & -. & $-\cdot$ & -. & $\cdot-$ & $-\cdot$ & $\cdots$ \\
\hline $08-26-91$ & $\cdots$ & $\cdots$ & -- & -. & -- & $\cdots$ & $\cdots$ & -. & $-\cdot$ \\
\hline $08-26-91$ & $\cdots$ & $\cdots$ & -. & -. & -. & .. & $\cdots$ & -. & -. \\
\hline $08-26-91$ &.- & -- & -- & -. & -. & -. & $-\cdot$ & $-\cdot$ & -- \\
\hline $08-26-91$ & $\cdots$ & $\cdots$ & $\cdots$ & $\cdots$ & $\cdots$ & $-\cdot$ & $\cdots$ & -. & $\cdot-$ \\
\hline $08-26-91$ & -. & $-\cdot$ & -- & -. & $\cdots$ & -. & -. & $\cdots$ & -. \\
\hline
\end{tabular}


SURFACE-MATER DATA-Cont inued

CHEMICAL AMALYSES-Cont inued

STATION

NUMBER

DATE

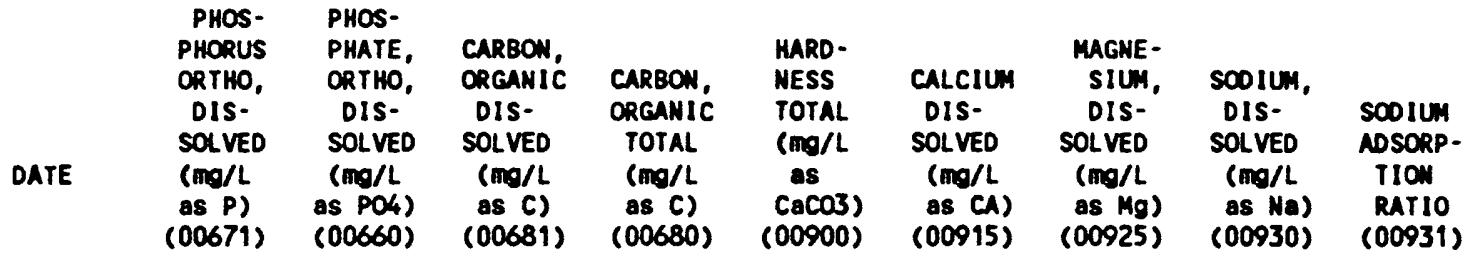

PUERCO RIVER MANUELITO, MM-Continued

09395630

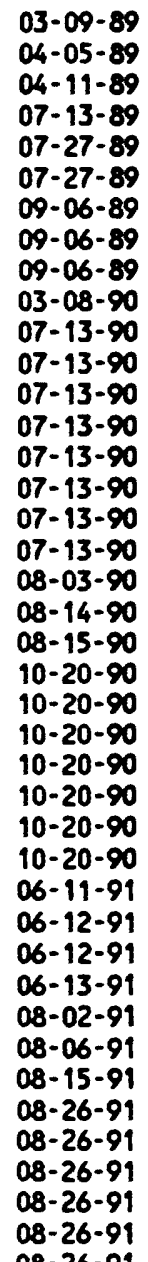

\begin{tabular}{|c|c|}
\hline .. & $\cdots$ \\
\hline 4.40 & 13 \\
\hline$\cdots$ & $\cdots$ \\
\hline$\cdots$ & $\cdots$ \\
\hline$\cdots$ & $\cdots$ \\
\hline$\cdots$ & $\cdots$ \\
\hline$\cdots$ & $\cdots$ \\
\hline$\cdots$ & $\cdots$ \\
\hline$\ldots$ & 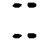 \\
\hline$\ldots$ & $\ldots$ \\
\hline -. & .. \\
\hline - & -. \\
\hline -. & $\cdots$ \\
\hline$\cdots$ & $\cdots$ \\
\hline$\cdots$ & $\cdots$ \\
\hline$\cdots$ & $\cdots$ \\
\hline$\because$ & $\cdots$ \\
\hline$\cdots$ & $\cdots$ \\
\hline - & $\cdots$ \\
\hline 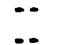 & 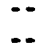 \\
\hline$\because$ & 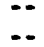 \\
\hline$\cdots$ & .. \\
\hline -. & -. \\
\hline -. & $\cdots$ \\
\hline$\cdots$ & $\cdots$ \\
\hline$\cdots$ & $\cdots$ \\
\hline$\cdots$ & $\cdots$ \\
\hline$\cdots$ & $\cdots$ \\
\hline -. & $\cdots$ \\
\hline$\cdots$ & $\cdots$ \\
\hline$\cdots$ & $\cdots$ \\
\hline - & 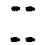 \\
\hline 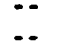 & 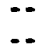 \\
\hline$\ldots$ & $\cdots$ \\
\hline$\ldots$ & -. \\
\hline$\cdots$ & $\because$ \\
\hline$\because$ & $\because$ \\
\hline
\end{tabular}

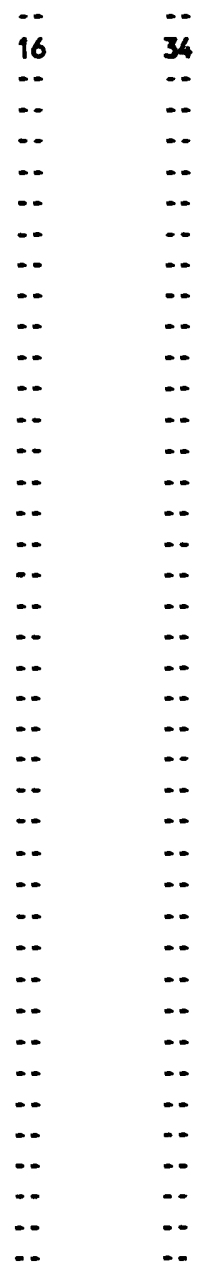

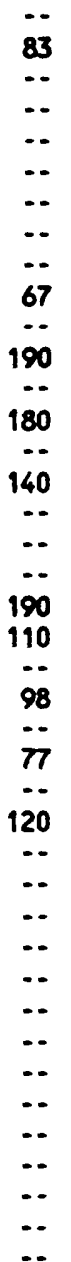

\begin{tabular}{|c|c|c|c|}
\hline$\cdots$ & - & - & $\cdots$ \\
\hline 24 & 5.6 & 420 & 20 \\
\hline$\cdots$ & $\cdots$ & $\cdots$ & $\cdots$ \\
\hline$\cdots$ & $\cdots$ & $\cdots$ & $\cdots$ \\
\hline$\cdots$ & $\cdots$ & $\therefore$ & $\cdots$ \\
\hline$\cdots$ & $\cdots$ & $\cdots$ & $\cdots$ \\
\hline- & $\cdots$ & $\cdots$ & $\cdots$ \\
\hline- & $\cdots$ & $\cdots$ & $\cdots$ \\
\hline 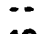 & $\because$ & $\cdots$ & $\because$ \\
\hline 19 & 4.7 & 340 & 18 \\
\hline - & $\because$ & $\cdots$ & $\because$ \\
\hline 59 & 11 & 100 & 3 \\
\hline 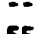 & $\ddot{0}$ & $\ddot{3}$ & , \\
\hline 55 & 9.0 & 63 & 2 \\
\hline 33 & 73 & 52 & 2 \\
\hline 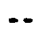 & $\ldots$ & $\ldots$ & 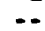 \\
\hline - & $\ldots$ & - & 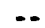 \\
\hline- & - & - & 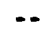 \\
\hline $\begin{array}{l}61 \\
36\end{array}$ & $\begin{array}{l}9.9 \\
5.5\end{array}$ & $\begin{array}{l}40 \\
48\end{array}$ & $\begin{array}{r}1 \\
12\end{array}$ \\
\hline$\cdots$ & $\cdots$ & $\cdots$ & $\cdots$ \\
\hline 31 & 4.9 & 52 & 2 \\
\hline$\because$ & $\cdots$ & $\cdots$ & $\cdots$ \\
\hline 24 & 4.1 & 44 & 2 \\
\hline . & $\because$ & $\because$ & $\cdots$ \\
\hline 37 & 6.4 & 43 & 2 \\
\hline$\cdots$ & $\cdots$ & $\cdots$ & $\cdots$ \\
\hline$\cdots$ & $\cdots$ & $\cdots$ & $\cdots$ \\
\hline & $\cdots$ & $\cdots$ & $\bullet$ \\
\hline & $\cdots$ & $\cdots$ & - \\
\hline & $\cdots$ & $\because$ & 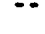 \\
\hline & $\because$ & $\because$ & $=$ \\
\hline & $\ldots$ & 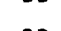 & \\
\hline & $\ldots$ & $\ldots$ & $\bullet$ \\
\hline & $\ldots$ & $\ldots$ & \\
\hline & $\ldots$ & $\ldots$ & \\
\hline & $\cdots$ & - & - \\
\hline & $\cdots$ & $\cdots$ & \\
\hline & - & & \\
\hline
\end{tabular}


SURFACE-MATER DATA-Cont inued

CHEMICAL ANALYSES-Cont inued

STATION

MUMBER

09395630

\begin{tabular}{|c|c|c|c|c|c|c|c|c|c|}
\hline DATE & $\begin{array}{l}\text { SODIUN } \\
\text { PERCENT } \\
\text { (00932) }\end{array}$ & $\begin{array}{l}\text { POTAS- } \\
\text { SIUH, } \\
\text { DIS- } \\
\text { SOLVED } \\
\text { (mg/L } \\
\text { as K) } \\
(00935)\end{array}$ & $\begin{array}{l}\text { CHLO- } \\
\text { RIDE, } \\
\text { DIS- } \\
\text { SOLVED } \\
\text { (mg/L } \\
\text { As Cl) } \\
(00940)\end{array}$ & $\begin{array}{c}\text { BROMIDE } \\
\text { OIS- } \\
\text { SOLVED } \\
\text { (mg/L } \\
\text { as Br) } \\
(71870)\end{array}$ & $\begin{array}{c}\text { FLUO- } \\
\text { RIDE, } \\
\text { DIS- } \\
\text { SOLVED } \\
\text { (mg/L } \\
\text { AS F) } \\
(00950)\end{array}$ & $\begin{array}{l}\text { SILICA, } \\
\text { DIS- } \\
\text { SOLVED } \\
\text { (mo/L } \\
\text { as } \\
\text { siO2) } \\
(00955)\end{array}$ & $\begin{array}{c}\text { SULFATE } \\
\text { DIS- } \\
\text { SOLVED } \\
\text { (mo/L } \\
\text { as SO4) } \\
(00945)\end{array}$ & $\begin{array}{c}\text { ARSENIC } \\
\text { DIS- } \\
\text { SOLVED } \\
\text { ( } \mu 9 / L \\
\text { OS AS) } \\
(01000)\end{array}$ & $\begin{array}{l}\text { BARIUM, } \\
\text { DIS- } \\
\text { SOLVED } \\
\text { ( } \mu 9 / L \\
\text { as Ba) } \\
(01005)\end{array}$ \\
\hline
\end{tabular}

PUERCO RIVER MANUELITO, Continued

\begin{tabular}{|c|c|c|c|c|c|c|c|c|c|}
\hline $03-09-89$ & $\ddot{\infty}$ & $\ddot{י}$ & $\ddot{0}$ & $-\cdot$ & $\because$ & $\ddot{2}$ & L608 & $\ddot{0}$ & $\begin{array}{l}\cdots \\
\cdots\end{array}$ \\
\hline $\begin{array}{l}04-05-89 \\
04-11-89\end{array}$ & 90 & $\begin{array}{l}12 \\
-.\end{array}$ & 120 & $\because-$ & 2.21 & $\begin{array}{l}21 \\
--\end{array}$ & $460 \mid$ & $\begin{array}{l}9 \\
\therefore-\end{array}$ & $\because \cdot$ \\
\hline $07-13-89$ & $\because$. & $\because$ & $\because$ & $\ldots$ & $\ldots$ & $\cdots$ & $\ldots$ & $\cdots$ & $\because$. \\
\hline $07-27-89$ & $-\cdot$ & -- & $-\cdot$ & -- & -. & -- & -- & $-\cdot$ & $\cdot \cdot$ \\
\hline $07-27-89$ & $\cdots$ & -. & $\because$ & $\because$ & $\because$ & -. & $\because$ & $\cdots$ & $\cdots$ \\
\hline $09-06-89$ & -- & -- & 37 & .060 & .70 & $-\cdot$ & $480 \mid$ & $\cdots$ & -. \\
\hline $09-06-89$ & $\cdots$ & -- & -- & -- & $\cdots$ & $\cdots$ & -- & $\cdots$ & $\cdots$ \\
\hline $09-06-89$ & $\cdots$ & $\cdots$ & $-\cdot$ & -- & -- & $\cdots$ & $\because-$ & $\cdots$ & $\cdots$ \\
\hline 03-08-90 & 90 & 9.5 & 110 & -- & 1.6 & 20 & $350 \&$ & $\cdots$ & $\cdots$ \\
\hline $07-13-90$ & -- & -- & -- & -- & $\ldots$ & $\cdots$ & $\ldots$ & $-\cdot$ & -. \\
\hline $07-13-90$ & 52 & 6.2 & 30 & .040 & .90 & 14 & 180 & 3 & 91 \\
\hline $07-13-90$ & $\because$ & 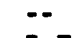 & $\because-$ & -- & $=$ & $\because$ & $\because-$ & $\cdots$ & $\cdots$ \\
\hline $07-13-90$ & 43 & 5.7 & 16 & .030 & .70 & 16 & 73 & 3 & 120 \\
\hline $07-13-90$ & $\because-$ & $\because-$ & $-\cdot$ & $\because$ & $\because-$ & $\because$ & $\because$ & $\because$ & 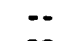 \\
\hline $07-13-90$ & 44 & 5.6 & 12 & .010 & .70 & 16 & 55 & 2 & 89 \\
\hline 07-13-90 & $\cdots$ & $\cdots$ & -- & $\cdots$ & $\cdots$ & $\cdots$ & $\cdots$ & $\cdots$ & $\cdots$ \\
\hline $07-13-90$ & $-\cdot$ & $\cdots$ & -- & $-\cdot$ & -. & $\cdots$ & -- & -. & -- \\
\hline $08-03-90$ & $\because-$ & 5.8 & 87 & .070 & 1.0 & $\cdots$ & $300 \notin$ & 5 & -- \\
\hline $\begin{array}{l}08-14-90 \\
08-15-90\end{array}$ & 30 & $\begin{array}{l}4.6 \\
4.2\end{array}$ & 7.1 & $<.010$ & $\begin{array}{r}.50 \\
60\end{array}$ & $\begin{array}{l}18 \\
10\end{array}$ & 23 & 8 & $\begin{array}{l}68 \\
50\end{array}$ \\
\hline $10-20-90$ & -. & $\therefore$ & - & $\cdots$ & 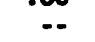 & .- & $\therefore$ & .. & $\therefore$ \\
\hline $10-20-90$ & 53 & 3.6 & 10 & .020 & .40 & 8.6 & 64 & 1 & 50 \\
\hline $10-20-90$ & $-\cdot$ & $\because$ & -- & -- & -- & -- & -- & -- & -- \\
\hline $10-20-90$ & 54 & 3.5 & 9.3 & .030 & .30 & 6.6 & 56 & $<1$ & 35 \\
\hline $10-20-90$ & 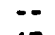 & $\because$ & -- & 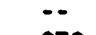 & $=$ & $=$ & $\because$ & $\because$ & 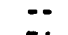 \\
\hline $10-20-90$ & 43 & 4.3 & 9.6 & .030 & .50 & 8.4 & 100 & 1 & 54 \\
\hline $10-20-90$ & $\cdots$ & $\cdots$ & -- & $-\cdot$ & $\cdot-$ & -- & $\cdots$ & -- & $\cdot-$ \\
\hline $06-11-91$ & $\cdots$ & $\cdots$ & $\cdots$ & -- & $\cdots$ & -- & -- & $\cdots$ & $-\cdot$ \\
\hline $06-12-91$ & $\cdots$ & -- & $\cdots$ & $\cdots$ & -. & $\cdots$ & -- & $\cdots$ & -- \\
\hline $06-12-91$ & $\cdots$ & -. & -. & -. & -- & -- & -- & $\cdots$ & -- \\
\hline $06-13-91$ & $\cdots$ & $-\cdot$ & $-\cdot$ & - & $\cdots$ & -- & -- & $\cdots$ & -- \\
\hline $08-02-91$ & $\cdots$ & -- & $\cdots$ & -. & $\cdots$ & -- & -- & $\cdots$ & -- \\
\hline 08-06-91 & $\because$ & $\cdots$ & -. & $\cdots$ & $\cdots$ & -. & -- & $-\cdot$ & $-\cdot$ \\
\hline $08-15-91$ & $\cdots$ & $\cdots$ & $\cdots$ & $\cdots$ & -. & $\cdot-$ & $\ldots$ & $\cdots$ & $-\cdot$ \\
\hline $08-26-91$ & $\cdots$ & -- & -- & -. & $\cdots$ & -- & -- & $\cdots$ & $\ldots$ \\
\hline $08-26-91$ & 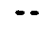 & -- & $-\cdot$ & $\cdots$ & $\cdots$ & $-\cdot$ & -- & $\cdots$ & $\cdots$ \\
\hline $08-26-91$ & - & - & $\cdots$ & $\cdots$ & $\cdots$ & $-\cdot$ & -. & $\cdots$ & $\ldots$ \\
\hline $08-26-91$ & $\cdots$ & $\cdots$ & $\cdots$ & $\cdots$ & $\cdots$ & $-\cdot$ & $\cdots$ & $\cdots$ & $\cdots$ \\
\hline$-26-91$ & - & -- & $\cdots$ & -- & -- & -- & -- & $\cdots$ & $\because$ \\
\hline $38-26-91$ & -- & -- & -- & -- & -- & -. & -- & -- & 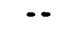 \\
\hline
\end{tabular}


CHEMICAL AMALYSES-Cont inued

STATION

MUMBER

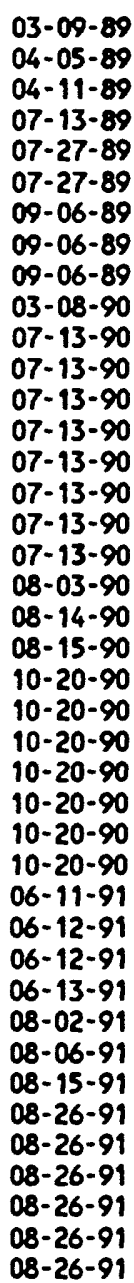

\begin{tabular}{|c|c|c|c|c|c|c|c|c|}
\hline $\begin{array}{l}\text { BERYL- } \\
\text { LIUN, } \\
\text { DIS- } \\
\text { SOLVED } \\
(\mu g / L \\
\text { As Be) } \\
(01010)\end{array}$ & $\begin{array}{l}\text { BORON, } \\
\text { DIS- } \\
\text { SOLVED } \\
(\mu g / L \\
\text { OS B) } \\
(01020)\end{array}$ & $\begin{array}{l}\text { CADHIUH } \\
\text { DIS- } \\
\text { SOLVED } \\
\text { ( } \mu g / L \\
\text { os Cd) } \\
\text { (01025) }\end{array}$ & $\begin{array}{l}\text { CHRO- } \\
\text { MIUH, } \\
\text { DIS- } \\
\text { SOLVED } \\
(\mu g / L \\
\text { OS Cr) } \\
(01030)\end{array}$ & $\begin{array}{c}\text { CHRO- } \\
\text { MIUH, } \\
\text { HEXA- } \\
\text { VALENT, } \\
\text { DIS. } \\
\text { ( } \mu g / L \\
\text { OS Cr) } \\
(01032)\end{array}$ & $\begin{array}{l}\text { COBALT, } \\
\text { DIS- } \\
\text { SOLVED } \\
\text { ( } \mu g / L \\
\text { OS Co) } \\
(01035)\end{array}$ & $\begin{array}{l}\text { COPPER, } \\
\text { DIS- } \\
\text { SOLVED } \\
(\mu g / L \\
\text { OS CU) } \\
(01040)\end{array}$ & $\begin{array}{l}\text { IRON, } \\
\text { DIS- } \\
\text { SOLVED } \\
(\mu g / L \\
\text { os Fe) } \\
(01046)\end{array}$ & $\begin{array}{l}\text { LEAD, } \\
\text { DIS- } \\
\text { SOLVED } \\
\text { ( } \mu g / L \\
\text { as Pb) } \\
(01049)\end{array}$ \\
\hline
\end{tabular}

PUERCO RIVER MANUELITO, WH-Continued

\begin{tabular}{|c|c|c|c|c|c|c|c|c|}
\hline$\cdots$ & $\cdots$ & -. & -- & -. & - & - & $\cdots$ & - \\
\hline - & 420 & $<1.0$ & $\cdots$ & $<1$ & 3 & 12 & $\cdots$ & $<5$ \\
\hline$\cdots$ & $\cdots$ & -- & -- & -- & $\cdots$ & -- & $\cdots$ & $\cdots$ \\
\hline - & -- & $\cdots$ & -- & -- & $\cdots$ & $\cdots$ & - & $\cdots$ \\
\hline$\cdots$ & $\cdots$ & $\cdots$ & -- & $\cdots$ & -. & $\cdots$ & $\cdots$ & $\cdots$ \\
\hline-- & $\cdots$ & $\cdots$ & -- & -- & $\cdots$ & $-\cdots$ & -- & - \\
\hline$\cdots$ & $\cdots$ & $\cdots$ & $\cdots$ & -- & $\cdots$ & $\cdots$ & $\cdots$ & $\cdots$ \\
\hline- & $\cdots$ & $\cdots$ & $\cdots$ & $\cdots$ & $-\cdot$ & -- & $\cdots$ & $\cdots$ \\
\hline$\cdots$ & $\cdots$ & $\cdots$ & -- & $\cdots$ & $\cdots$ & -- & $\cdots$ & $\cdots$ \\
\hline - & -- & -- & -- & -. & - & -- & $\cdots$ & -. \\
\hline$\cdots$ & $\cdots$ & $\cdots$ & - & -- & -. & $\cdots$ & - & - \\
\hline .5 & 160 & $<1.0$ & $<5$ & $\cdots$ & 5 & $<10$ & 59 & $<10 i$ \\
\hline$\cdots$ & $\because$ & -- & $\because$ & -- & $\because$ & 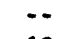 & $\because$ & -- \\
\hline$<.5$ & 140 & $<1.0$ & $<5$ & -- & $<3$ & $<10$ & 32 & $<10 i$ \\
\hline - & - & -- & -- & $\cdots$ & $\cdots$ & $\cdots$ & $\cdots$ & $\cdots$ \\
\hline$<.5$ & 110 & $<1.0$ & $<5$ & -- & $<3$ & $<10$ & 20 & $10 f$ \\
\hline - & - & -- & -- & -- & - & -- & $\cdots$ & $\ldots$ \\
\hline - & $\cdots$ & $\cdots$ & -- & -- & $\cdots$ & -- & $\cdots$ & -- \\
\hline -- & $\cdots$ & -- & $\cdots$ & $\cdots$ & $\cdots$ & -. & $\cdots$ & -- \\
\hline $\begin{array}{l}<.5 \\
<.5\end{array}$ & $\begin{array}{r}100 \\
80\end{array}$ & $\begin{array}{l}<1.0 \\
<1.0\end{array}$ & $\begin{array}{l}<5 \\
<5\end{array}$ & -. & $\begin{array}{r}3 \\
<3\end{array}$ & $\begin{array}{l}<10 \\
<10\end{array}$ & $\begin{array}{c}1100 \ddagger \\
120\end{array}$ & $\begin{array}{l}<10 i \\
<10 i\end{array}$ \\
\hline$\cdots$ & 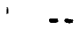 & - & -- & - & $\therefore$ & - & -. & -- \\
\hline$<.5$ & 90 & $<1.0$ & $<5$ & -- & $<3$ & $<10$ & 72 & $<10 i$ \\
\hline$\cdots$ & $\cdots$ & $\cdots$ & -- & -- & $\cdots$ & $\cdots$ & - & - \\
\hline$<.5$ & 60 & 1.0 & $<5$ & -- & $<3$ & $<10$ & 9 & $<10 i$ \\
\hline 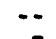 & 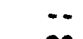 & $\because$ & $\because$ & $\cdots$ & $\because$ & $\ddot{*}$ & 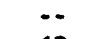 & 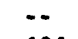 \\
\hline$<.5$ & 90 & $<1.0$ & $<5$ & -. & $<3$ & $<10$ & 62 & $<10 i$ \\
\hline$\cdots$ & $\cdots$ & $\cdots$ & -- & -- & $\cdots$ & $-\cdot$ & -- & $\cdots$ \\
\hline -- & $\cdots$ & $\cdots$ & - & -- & -- & - & -- & -. \\
\hline-- & $\cdots$ & $\cdots$ & -- & -- & $\cdots$ & -- & $\cdots$ & - \\
\hline-- & $\cdots$ & $\cdots$ & $\cdots$ & -- & $=$ & -- & -- & $\cdots$ \\
\hline- & $\cdots$ & $\cdots$ & $\cdots$ & $\cdots$ & $\cdots$ & -- & 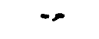 & $\cdots$ \\
\hline$\cdots$ & $\cdots$ & $\cdots$ & $\cdots$ & $\cdots$ & $\cdots$ & $-\cdot$ & $\cdots$ & $\cdots$ \\
\hline$\cdots$ & $\cdots$ & -- & $=$ & -- & -- & -- & $\cdots$ & $\cdots$ \\
\hline$\cdots$ & $\cdots$ & $\cdots$ & $\cdots$ & $\cdots$ & $\cdots$ & $\cdots$ & $\cdots$ & $\cdots$ \\
\hline$\because$ & $\because$ & $\because$ & $\because$ & $\because-$ & $\because$ & $\therefore$ & $\cdots$ & $\cdots$ \\
\hline$\cdots$ & $\because$ & $\because$ & $\therefore$ & $\because$ & $\because$ & $\cdots$ & $\cdots$ & $\cdots$ \\
\hline$\ldots$ & $\ldots$ & $\ldots$ & $\therefore$ & $\cdots$ & $\therefore$ & $\therefore$ & $\cdots$ & $\because$ \\
\hline$\ldots$ & - & - & -. & .. & .. &.- & $\ldots$ & .. \\
\hline - & - & -. & $\cdots$ & -. & $\cdots$ & -- & - & - \\
\hline
\end{tabular}


CHEMICAL AHALYSES-Cont inued

STATION

MUABER

09395630

\begin{tabular}{|c|c|c|c|c|c|c|c|c|c|}
\hline TE & $\begin{array}{l}\text { MNGGA- } \\
\text { NESE, } \\
\text { DIS- } \\
\text { SOLVED } \\
(\mu g / L \\
\text { as Nn) } \\
(01056)\end{array}$ & $\begin{array}{c}\text { MERCURY } \\
\text { DIS- } \\
\text { SOLVED } \\
\text { ( } \mu g / L \\
\text { as Hg) } \\
(71890)\end{array}$ & $\begin{array}{l}\text { MOLYB- } \\
\text { OENUM, } \\
\text { DIS- } \\
\text { SOLVED } \\
(\mu g / L \\
\text { os MO) } \\
(01060)\end{array}$ & $\begin{array}{l}\text { NICKEL, } \\
\text { OIS- } \\
\text { SOLVED } \\
\text { ( } \mu g / L \\
\text { as Ni) } \\
\text { (01065) }\end{array}$ & $\begin{array}{c}\text { SILVER, } \\
\text { DIS- } \\
\text { SOLVED } \\
\text { ( } \mu g / L \\
\text { is Ag) } \\
(01075)\end{array}$ & $\begin{array}{c}\text { STRON- } \\
\text { TIUH, } \\
\text { DIS- } \\
\text { SOLVED } \\
\text { ( } \mu g / L \\
\text { as SR) } \\
\text { (01080) }\end{array}$ & $\begin{array}{l}\text { VANA- } \\
\text { DIUH, } \\
\text { DIS- } \\
\text { SOLVED } \\
\text { ( } \mu g / L \\
\text { OS V) } \\
\text { (01085) }\end{array}$ & $\begin{array}{l}\text { ZINC, } \\
\text { DIS- } \\
\text { SOLVED } \\
(\mu g / L \\
\text { as } 2 n) \\
(01090)\end{array}$ & $\begin{array}{l}\text { ALUN- } \\
\text { IMU, } \\
\text { DIS- } \\
\text { SOLVED } \\
\text { ( } \mu g / L \\
\text { as Al) } \\
\text { (01106) }\end{array}$ \\
\hline
\end{tabular}

PUERCO RIVER MANUELITO, MH-Continued

\begin{tabular}{|c|c|c|c|c|c|c|c|c|c|}
\hline $03-09-89$ & $\cdots$ & $\cdots$ & $\cdots$ & $\because$ & $\cdots$ & $\because$ & $\cdots$ & -- & $\cdots$ \\
\hline $04-05-89$ & $\cdots$ & $<.1$ & $\cdots$ & 10 & - & 320 & $\cdots$ & 10 & 10 \\
\hline $04-11-89$ & $\cdots$ & $\therefore$ & $\cdots$ & $\cdots$ & -- & -- & $\cdots$ & -- & - \\
\hline $07-13-89$ & $\cdots$ & $\cdots$ & $\cdots$ & $\cdots$ & -- & -- & $\cdots$ & $\cdots$ & $\cdots$ \\
\hline $07-27-89$ & $\cdots$ & -. & -. & $\cdots$ & $\cdots$ & -- & -- &.- & $\because$ \\
\hline $07-27-89$ & $\cdots$ & $-\cdot$ & $\cdots$ & -- & $\cdots$ & $\cdots$ & $\cdots$ & $\cdots$ & -. \\
\hline $09-06-89$ & $\cdots$ & $\cdots$ & $\cdots$ & $\cdots$ & $\cdots$ & $\cdots$ & $\cdots$ & $\cdots$ & $\cdots$ \\
\hline $09-06-89$ & $\cdots$ & $\cdots$ & $\cdots$ & -- & $\cdots$ & -- & $\cdots$ & $\cdots$ & $-\cdot$ \\
\hline $09-06-89$ & $\cdots$ & $\cdots$ & $\cdots$ & $\cdots$ & $\cdots$ & $\cdots$ & $\cdots$ & $\cdots$ & $\cdots$ \\
\hline $03-08-90$ & $\cdots$ & $\cdots$ & $\cdots$ & $\cdots$ & -- & $-\cdot$ & $\cdots$ & -- & -- \\
\hline $07-13-90$ & $\cdots$ & $\cdots$ & $\cdots$ & $\cdots$ & $\cdots$ & - & $\cdots$ & $\cdots$ & .. \\
\hline $07-13-90$ & $750 \&$ & $\cdots$ & $<10$ & $<10$ & 1.0 & 700 & $<6$ & $<3$ & - \\
\hline $07-13-90$ & $\cdots$ & $\cdots$ & $\cdots$ & $\cdots$ & $\cdots$ & $\cdots$ & $\cdots$ & $\cdots$ & $\cdots$ \\
\hline $07-13-90$ & $190 \$$ & $-\cdot$ & $<10$ & $<10$ & 1.0 & 680 & $<6$ & $<3$ & $\cdots$ \\
\hline $07-13-90$ & $\cdots$ & -- & $\cdots$ & $\cdots$ & $\cdots$ & $\cdots$ & $\cdots$ & $\cdots$ & $\cdots$ \\
\hline $07-13-90$ & $540 \$$ & $-\cdot$ & $<10$ & $<10$ & $<1.0$ & 560 & $<6$ & 6 & $\cdots$ \\
\hline $07-13-90$ & -- & $\cdots$ & $\cdots$ & $\cdots$ & $\cdots$ & $\cdots$ & $\cdots$ & $\cdots$ & $\cdots$ \\
\hline $07-13-90$ & $\cdots$ & -- & $\cdots$ & $\cdots$ & $\cdots$ & $\cdots$ & -- &.- & $\cdots$ \\
\hline $08-03-90$ & $\cdots$ & $\cdots$ & $\cdots$ & $\cdots$ & $\cdots$ & $\cdots$ & $\cdots$ & $\cdots$ & $\cdots$ \\
\hline $\begin{array}{l}08-14-90 \\
08-15-90\end{array}$ & $\begin{array}{r}1100\} \\
82 \xi\end{array}$ & $\because$ & $\begin{array}{l}<10 \\
<10\end{array}$ & $\begin{array}{l}<10 \\
<10\end{array}$ & $\begin{array}{l}<1.0 \\
<1.0\end{array}$ & $\begin{array}{l}740 \\
420\end{array}$ & $\begin{array}{l}<6 \\
<6\end{array}$ & $\begin{array}{r}<3 \\
4\end{array}$ & -. \\
\hline $10-20-90$ & $\cdots$ & $-\cdot$ & -- & $\cdots$ & $\cdots$ & $\cdots$ & $\cdots$ & $\cdots$ & $\cdots$ \\
\hline $10-20-90$ & 3 & -- & $<10$ & $<10$ & $<1.0$ & 400 & $<6$ & 12 & $\cdots$ \\
\hline $10-20-90$ & -- & $-\cdot$ & $\cdots$ & $\cdots$ & $\cdots$ & $\cdots$ & -- & $\cdots$ & $\cdots$ \\
\hline $10-20-90$ & 4 & $\cdots$ & $<10$ & $<10$ & $<1.0$ & 310 & $<6$ & $<3$ & $\cdots$ \\
\hline $10-20-90$ & $\cdots$ & $\cdots$ & $\because$ & $\because$ & -- & $\cdots$ & $-\cdot$ & $\cdots$ & $\cdots$ \\
\hline $10-20-90$ & 3 & $-\cdot$ & $<10$ & $<10$ & $<1.0$ & 490 & $<6$ & 4 & $\cdots$ \\
\hline $10-20-90$ & $\cdots$ & $\cdots$ & $\cdots$ & -- & $\cdots$ & $\cdots$ & $\because \cdot$ & $\cdots$ & $\cdots$ \\
\hline $06-11-91$ & $\cdots$ & -- & $\cdot-$ & -- & $\cdots$ & $\cdots$ & $\cdots$ & $\cdots$ & $\cdots$ \\
\hline $06-12-91$ & $\cdots$ & -- & $\cdots$ & $\cdots$ & $\cdots$ & $\cdots$ & $\cdots$ & $\cdots$ & $\cdots$ \\
\hline $06-12-91$ & $\cdots$ & -. & $\cdots$ & -- & $\cdots$ & -- & $-\cdot$ & $\cdots$ & $\cdots$ \\
\hline $06-13-91$ & $\cdots$ & $-\cdot$ & $\cdots$ & $-\cdot$ & $\cdots$ & $\cdots$ & $\cdots$ & $\cdots$ & $\cdots$ \\
\hline $08-02-91$ & $\cdots$ & $\cdots$ & $\cdots$ & $\cdots$ & $\cdots$ & $\cdots$ & -- & $\cdots$ & - \\
\hline 08-06-91 & $\cdots$ & $\cdots$ & $\cdots$ & $\cdots$ & $\cdots$ & $\cdots$ & $\cdots$ & $\cdots$ & - \\
\hline $08-15-91$ & $\cdots$ & $\cdots$ & $\cdots$ & $\cdots$ & $\cdots$ & -- & $\cdots$ & $\cdots$ & $\cdot$ \\
\hline $08-26-91$ & $\cdots$ & $\cdots$ & $\cdots$ & $\cdots$ & -- & -- & $-\cdot$ & $\cdots$ & - \\
\hline $08-26-91$ & $\cdots$ & -- & 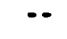 & 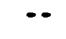 & $\cdots$ & $\cdots$ & $\cdot-$ & -- & $=$ \\
\hline $08-26-91$ & $\cdots$ & $\cdot-$ & $-\cdot$ & -- & -- & $\cdots$ & $\cdots$ & $\cdots$ & $-\cdot$ \\
\hline $08-26-91$ & $\cdots$ & -. & $\cdots$ & $\cdots$ & -- & $\cdots$ & $\cdots$ & $\cdots$ & $\cdots$ \\
\hline $08-26-91$ & $\cdots$ & $\cdots$ & $\cdots$ & $\cdots$ & -- & $\cdots$ & -- & $\cdots$ & - \\
\hline $08-26$ & $\cdots$ & $\cdots$ & $\cdots$ & -- & $\cdots$ & $\cdots$ & $\cdots$ & $\cdots$ & - \\
\hline
\end{tabular}


SURFACE-HATER DATA-Cont inued

CHEMICAL AMALYSES-Cont inued

STATION

NUMBER

09395630

\begin{tabular}{|c|c|c|c|c|c|c|c|c|c|}
\hline \multicolumn{10}{|c|}{ CHEMICAL ANALYSES-Cont inued } \\
\hline DATE & $\begin{array}{c}\text { LITHIUN } \\
\text { DIS- } \\
\text { SOLVED } \\
\text { ( } \mu g / L \\
\text { as Li) } \\
(01130)\end{array}$ & $\begin{array}{l}\text { SELE- } \\
\text { NILA, } \\
\text { DIS- } \\
\text { SOLVED } \\
\text { ( } \mu 8 / L \\
\text { as Se) } \\
\text { (01145) }\end{array}$ & $\begin{array}{l}\text { S-34/ } \\
\text { S-32 } \\
\text { STABLE } \\
\text { ISOTOPE } \\
\text { RAT1O } \\
\text { PER } \\
\text { MIL } \\
(82086)\end{array}$ & $\begin{array}{l}\text { H-2/ } \\
\text { H-1 } \\
\text { STABLE } \\
\text { I SOTOPE } \\
\text { RATIO } \\
\text { PER } \\
\text { NIL } \\
(82082)\end{array}$ & $\begin{array}{l}0-18 / \\
0-16 \\
\text { STABLE } \\
\text { ISOTOPE } \\
\text { RAT 10 } \\
\text { PER } \\
\text { HIL } \\
\text { (82085) }\end{array}$ & $\begin{array}{l}\text { GROSS } \\
\text { ALPHA, } \\
\text { DIS- } \\
\text { SOLVED } \\
\text { ( } \mu g / L \\
\text { as } \\
U-n a t) \\
(80030)\end{array}$ & $\begin{array}{l}\text { ALPHA, } \\
\text { COUNT, } \\
2 \text { SIGU } \\
\text { WAT DIS } \\
\text { ( } \mu g / L \\
\text { as } \\
\text { U-nat) } \\
\text { (75986) }\end{array}$ & $\begin{array}{l}\text { GROSS } \\
\text { ALPHA, } \\
\text { SUSP. } \\
\text { TOTAL } \\
\text { ( } \mu g / L \\
\text { as } \\
U-n a t) \\
(80040)\end{array}$ & $\begin{array}{l}\text { GROSS } \\
\text { ALPHA } \\
\text { SEDI- } \\
\text { MENT } \\
\text { (PCi/G) } \\
\text { (01507) }\end{array}$ \\
\hline
\end{tabular}

PUERCO RIVER MANUELITO, Cont inued

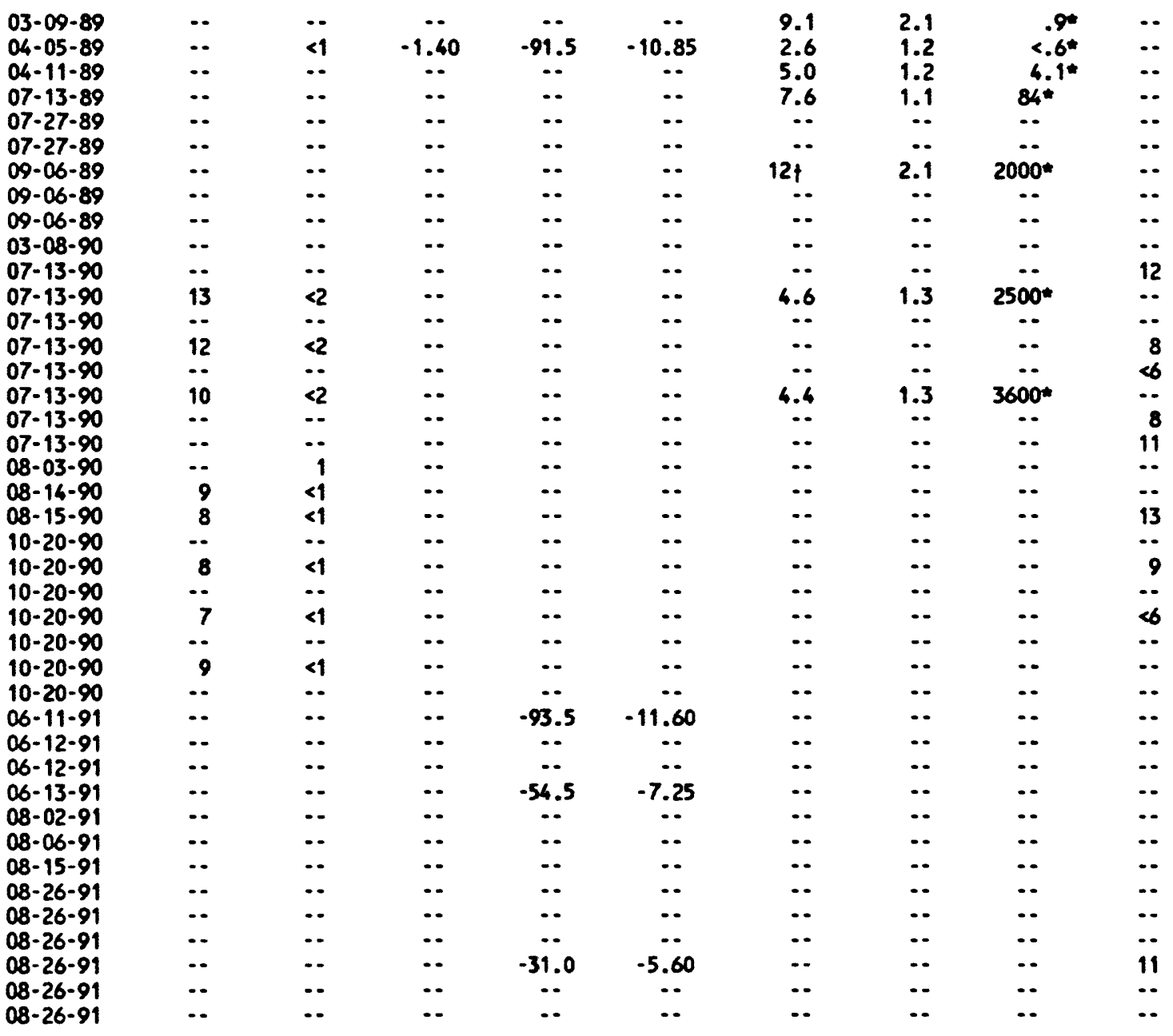




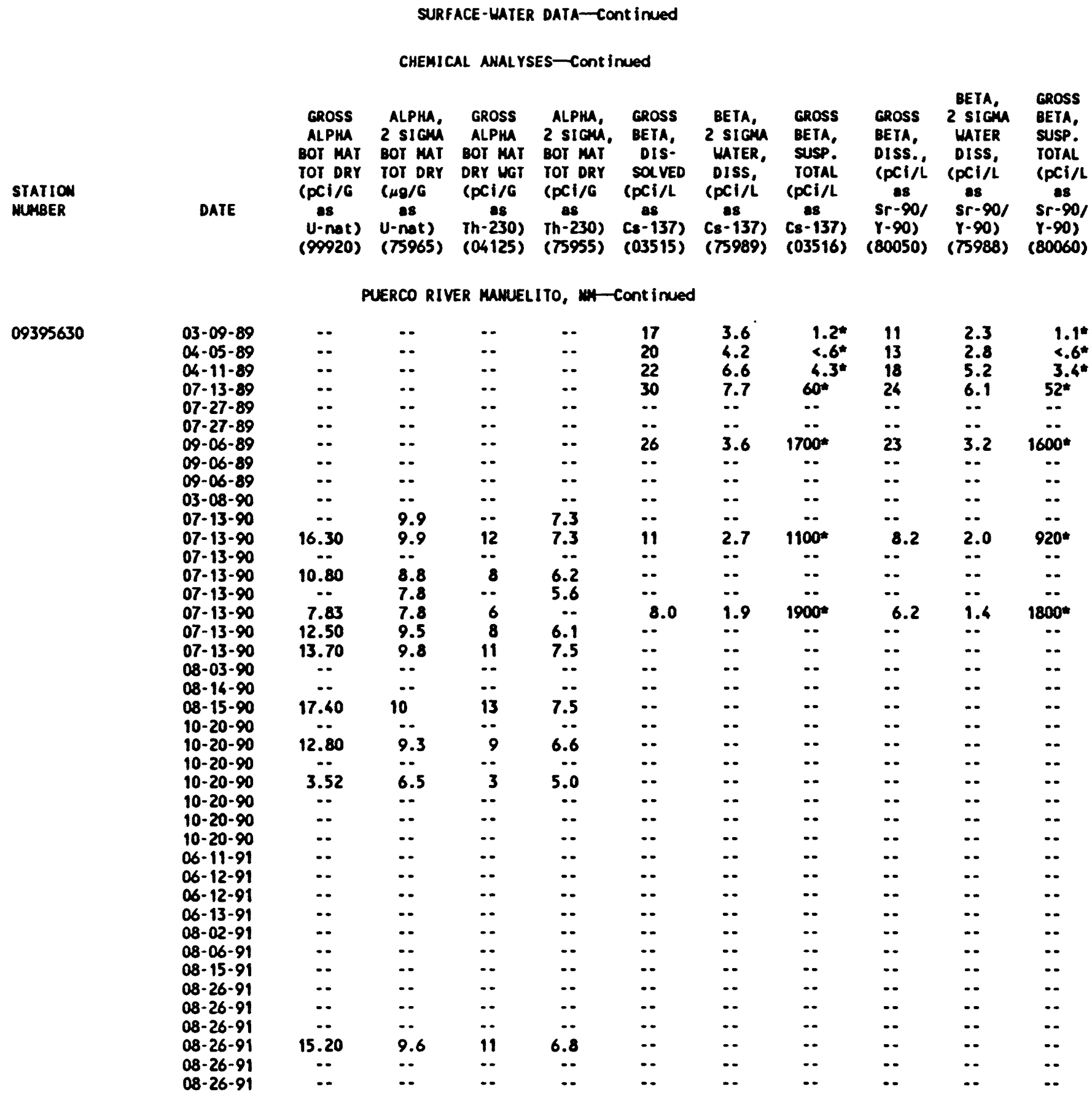


CHEHICAL AMALYSES-Cont inued

STATION

NUMBER

DATE

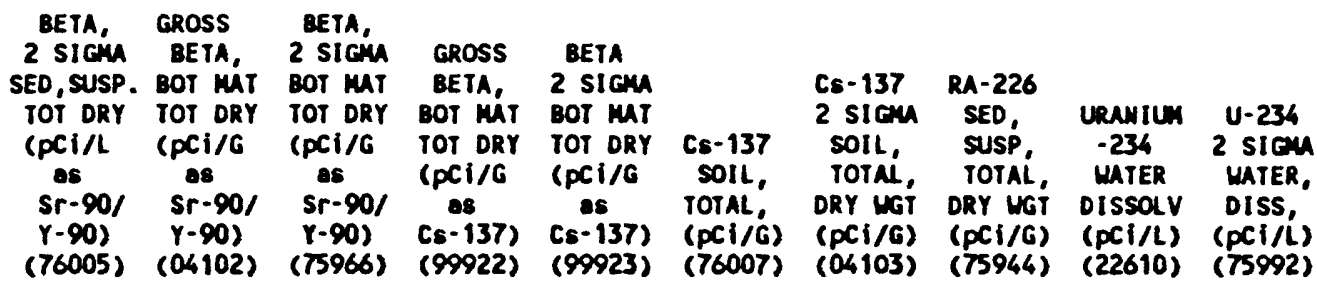

PUERCO RIVER MHUELITO, MH-Cont inued

09395630

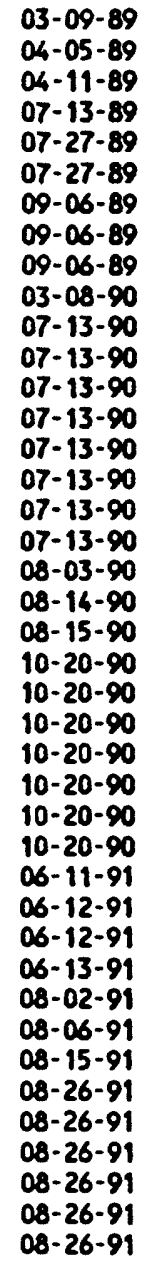

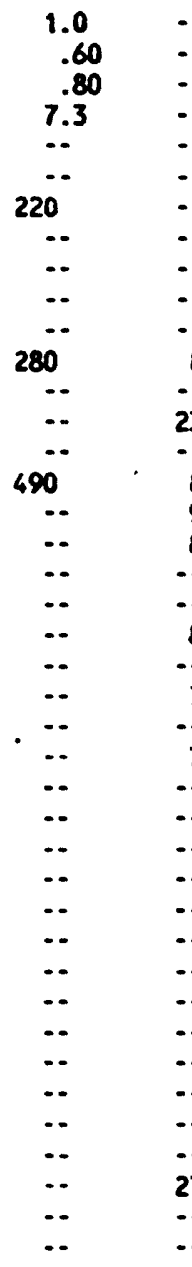

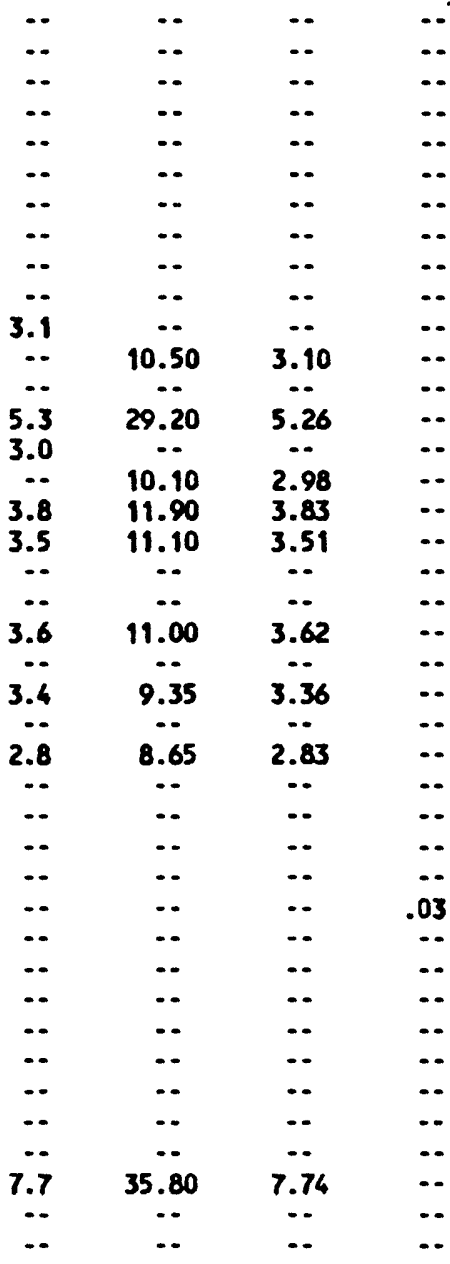

\begin{tabular}{|c|c|c|c|}
\hline -. & $\cdots$ & $\cdots$ & $\cdots$ \\
\hline$\cdots$ & $\cdots$ & 2.1 & 4.3 \\
\hline$\cdots$ & $\cdots$ & $\cdots$ & $\cdots$ \\
\hline -. & -. & $\cdots$ & -. \\
\hline$\cdots$ & $\cdots$ & $\cdots$ & - \\
\hline$\cdots$ & 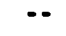 & $\cdots$ & $\cdots$ \\
\hline -. & .. & 8.5 & 1.3 \\
\hline - & $\cdots$ & -- & $\cdots$ \\
\hline$\cdots$ & $\cdots$ & $\cdots$ & $\cdots$ \\
\hline$\cdots$ & $\cdots$ & $\cdots$ & $\cdots$ \\
\hline$\cdots$ & 1.3 & $\cdots$ & $\cdots$ \\
\hline$\cdots$ & 1.3 & $\cdots$ & $\cdots$ \\
\hline - & $\therefore$ & $\cdots$ & $\cdots$ \\
\hline$\cdots$ & 1.4 & $\cdots$ & $\cdots$ \\
\hline$\cdots$ & $\cdots$ & $\cdots$ & $\cdots$ \\
\hline- & $\because$ & $\cdots$ & $\cdots$ \\
\hline$\cdots$ & 1.2 & $\cdots$ & $\cdots$ \\
\hline .. & $\ldots$ & $\ldots$ & $\cdots$ \\
\hline .. & .. & 1.5 & .2 \\
\hline$\cdots$ & 1.3 & 1.0 & .1 \\
\hline . & $\cdots$ & $\cdots$ & $\cdots$ \\
\hline - & $\cdots$ & $\cdots$ & $\cdots$ \\
\hline$\cdots$ & $\cdots$ & $\cdots$ & $\cdots$ \\
\hline$\cdots$ & $\cdots$ & $\cdots$ & $\cdots$ \\
\hline$\cdots$ & $\cdots$ & $\cdots$ & $\cdots$ \\
\hline$\cdots$ & $\cdots$ & $\cdots$ & $\cdots$ \\
\hline$\therefore$ & $\because$ & $\because$ & $\because$ \\
\hline .010 & .. & $\ldots$ & -. \\
\hline - & - & .. & .. \\
\hline$\cdots$ & $\cdots$ & -. & $\cdots$ \\
\hline -. & $\cdots$ & $\cdots$ & $\cdots$ \\
\hline$\cdots$ & $\cdots$ & $\cdots$ & 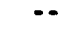 \\
\hline$\cdots$ & $\cdots$ & $\cdots$ & $\cdots$ \\
\hline$\cdots$ & $\cdots$ & $\cdots$ & $\cdots$ \\
\hline$\cdots$ & $\cdots$ & $\cdots$ & 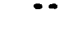 \\
\hline$\cdots$ & 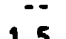 & $\because$ & - \\
\hline$\cdots$ & 1.5 & $\cdots$ & $\cdots$ \\
\hline 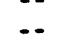 & $\ldots$ & $\cdots$ & \\
\hline
\end{tabular}


SURFACE-WATER DATA-Cont inued

STATION

MUABER

09395630

CHERICAL AMALYSES - Cont inued

\begin{tabular}{|c|c|c|c|c|c|c|c|c|c|c|}
\hline ATE & $\begin{array}{l}\text { U-234 } \\
\text { SED, } \\
\text { SUSP, } \\
\text { TOTAL, } \\
\text { ORY WGT } \\
\text { (PCi/G) } \\
\text { (TS942) }\end{array}$ & $\begin{array}{l}\text { U-234 } \\
2 \text { SIGM } \\
\text { SED, } \\
\text { SUSP, } \\
\text { TOTAL, } \\
\text { DRY WGi } \\
\text { (PCI/G) } \\
\text { (75941) }\end{array}$ & $\begin{array}{l}\text { URANIUA } \\
\text {-235 } \\
\text { WATER, } \\
\text { DISS } \\
\text { (pCI/L) } \\
\text { (22620) }\end{array}$ & $\begin{array}{l}\text { U-235 } \\
2 \text { SIGMA } \\
\text { UATER, } \\
\text { DISS, } \\
\text { (pCi/L) } \\
\text { ( } 75994)\end{array}$ & $\begin{array}{l}\text { U-235 } \\
\text { SED, } \\
\text { SUSP, } \\
\text { TOTAL, } \\
\text { ORY WGT } \\
\text { (PCi/G) } \\
\text { (75975) }\end{array}$ & $\begin{array}{l}\text { U-235 } \\
2 \text { SIGM } \\
\text { SED, } \\
\text { SUSP, } \\
\text { TOTAL, } \\
\text { ORY WGT } \\
\text { (PCI/G) } \\
\text { (75947) }\end{array}$ & $\begin{array}{l}\text { URANIUY } \\
\text {-238 } \\
\text { UATER } \\
\text { OISSOLV } \\
\text { (pCi/L) } \\
\text { (22603) }\end{array}$ & $\begin{array}{l}\text { U-238 } \\
2 \text { SIGM } \\
\text { WATER, } \\
\text { OISS, } \\
\text { (pCi/L) } \\
\text { (75991) }\end{array}$ & $\begin{array}{l}\text { U-238 } \\
\text { SED, } \\
\text { SUSP. } \\
\text { TOTAL, } \\
\text { DRY WGT } \\
\text { (PCI/G) } \\
\text { (75940) }\end{array}$ & $\begin{array}{l}\text { U-238 } \\
2 \text { SIGM } \\
\text { SED, } \\
\text { SUSP, } \\
\text { TOTAL, } \\
\text { ORY WGT } \\
\text { (PCI/G) } \\
\text { (04113) }\end{array}$ \\
\hline
\end{tabular}

PUERCO RIVER MAHELITO, NH-Continued

\begin{tabular}{|c|c|c|c|c|c|c|c|c|c|c|}
\hline 03-09-89 & -- & $\cdots$ & $\cdots$ & -. & -. & -- & $\cdots$ & $\cdots$ & $\cdots$ & $\cdots$ \\
\hline $04-05-89$ & $\cdots$ & $\cdots$ & .3 & .20 & $\cdots$ & $\cdots$ & 1.5 & .40 & $\cdots$ & $\cdots$ \\
\hline $04-11-89$ & $\cdots$ & $\cdots$ & $\cdots$ & $\cdots$ & -. & -. & $\cdots$ & -. & $\cdots$ & -- \\
\hline $07-13-89$ & $\cdots$ & $\cdots$ & $\cdots$ & $\cdots$ & -. & $\cdots$ & $\cdots$ & $\cdots$ & $\cdots$ & $\cdots$ \\
\hline $07-27-89$ & $\cdots$ & $\cdots$ & $\cdots$ & $\cdots$ & $\cdots$ & -. & $\cdots$ & - & $\cdots$ & $\cdots$ \\
\hline $07-27-89$ & $\cdots$ & $\cdots$ & $\cdots$ & $\cdots$ & $\cdots$ & - & $\cdots$ & $\cdots$ & $\cdots$ & $\cdots$ \\
\hline $09-06-89$ & $\cdots$ & $\cdots$ & .6 & .30 & $\cdots$ & $\cdots$ & 7.5 & 1.2 & $\cdots$ & $\cdots$ \\
\hline $09-06-89$ & $\cdots$ & $\cdots$ & $\cdots$ & $\cdots$ & $\therefore$ & $\cdots$ & - & $\cdots$ & $\cdots$ & $\cdots$ \\
\hline $09-06-89$ & $\cdots$ & $\cdots$ & -. & $\cdots$ & $\cdots$ & -. & -. & $\cdots$ & $\cdots$ & -. \\
\hline $03-08-90$ & $\cdots$ & $\cdots$ & $\cdots$ & $\cdots$ & $\cdots$ & $\cdots$ & $\cdots$ & $\cdots$ & $\cdots$ & $\cdots$ \\
\hline $07-13-90$ & 1.2 & .30 & $\cdots$ & $\cdots$ & $<.1$ & .06 & - & .. & 1.3 & $\cdots$ \\
\hline $07-13-90$ & 1.2 & .30 & $\cdots$ & -. & .9 & .06 & $\cdots$ & $\cdots$ & 1.3 & .31 \\
\hline $07-13-90$ & 1.3 & .20 & $\cdots$ & $\cdots$ & $<.1$ & No & $\cdots$ & $\cdots$ & 1.4 & .25 \\
\hline $07-13-90$ & 1.2 & .27 & - & -. & $<.1$ & .06 & $\cdots$ & $\cdots$ & 1.5 & .31 \\
\hline $07-13-90$ & 1.3 & .20 & $\cdots$ & $\cdots$ & $<.1$ & 10 & $\cdots$ & $\cdots$ & 1.2 & $\cdots$ \\
\hline $07-13-90$ & 1.3 & .24 & - & -. & .1 & .05 & $\cdots$ & $\cdots$ & 1.2 & .23 \\
\hline $07-13-90$ & 1.3 & .29 & $\cdots$ & $\cdots$ & $<.1$ & .05 & $\cdots$ & $\cdots$ & 1.0 & .25 \\
\hline $07-13-90$ & 1.6 & .30 & - & -- & $<.1$ & no & $\cdots$ & -. & 1.2 & .26 \\
\hline $08-03-90$ & $\cdots$ & $\cdots$ & $\cdots$ & $\cdots$ & $\cdots$ & $\cdots$ & $\cdots$ & $\cdots$ & $\cdots$ & $\cdots$ \\
\hline $08-14-90$ & $\cdots$ & $\cdots$ & $<.1$ & MD & $\cdots$ & $-\cdot$ & .90 & .10 & $\cdots$ & $\cdots$ \\
\hline $08-15-90$ & 1.3 & .40 & $<.1$ & .02 & $<.1$ & .04 & .80 & .11 & 1.4 & .30 \\
\hline $10-20-90$ & $\cdots$ & $\cdots$ & $\cdots$ & $\cdots$ & $\cdots$ & $\cdots$ & $\cdots$ & $\therefore$ & $\cdots$ & $\cdots$ \\
\hline $10-20-90$ & 1.3 & .27 & $\cdots$ & -. & $<.1$ & .05 & $\cdots$ & -. & 1.2 & .26 \\
\hline $10-20-90$ & $\cdots$ & $\cdots$ & $\cdots$ & $\cdots$ & $\cdots$ & $\cdots$ & $\cdots$ & $\cdots$ & $\cdots$ & $\cdots$ \\
\hline $10-20-90$ & 1.1 & .30 & $\cdots$ & $\cdots$ & $<.1$ & NO & $\cdots$ & $\cdots$ & 1.3 & .28 \\
\hline $10-20-90$ & $\cdots$ & $\cdots$ & $\cdots$ & $\cdots$ & $\cdots$ & $\cdots$ & $\cdots$ & $\cdots$ & $\cdots$ & $\cdots$ \\
\hline $10-20-90$ & 1.0 & .22 & $\cdots$ & $\cdots$ & $<.1$ & .04 & -- & $\cdots$ & 1.6 & .27 \\
\hline $10-20-90$ & -- & $\cdots$ & -. & - & $\cdots$ & -. & - & 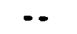 & -. & $\cdots$ \\
\hline $06-11-91$ & -. & -. & $-\cdot$ & -. & - & -. & -. & $\ldots$ & -. & $\cdots$ \\
\hline $06-12-91$ & -. & -. & $-\cdot$ & $\cdots$ & $\cdots$ & -. & $\cdots$ & $\cdots$ & - & -. \\
\hline $06-12-91$ & $\cdots$ & $\cdots$ & $\cdots$ & $\cdots$ & $\cdots$ & $\cdots$ & $\cdots$ & $\cdots$ & $\cdots$ & $\cdots$ \\
\hline $06-13-91$ & 1.2 & .16 & $\cdots$ & $\cdots$ & $<.1$ & MO & $\cdots$ & $\cdots$ & 1.2 & .16 \\
\hline $08-02-91$ & $\cdots$ & $\cdots$ & $\cdots$ & $\cdots$ & $\cdots$ & $\cdots$ & $\cdots$ & $\cdots$ & $\cdots$ & $\cdots$ \\
\hline $08-06-91$ & $\cdots$ & $-\cdot$ & $\cdots$ & $\cdots$ & $\cdots$ & $\cdots$ & $\cdots$ & $\cdots$ & $\cdots$ & $\cdots$ \\
\hline $08-15-91$ & $\cdots$ & $\cdots$ & -- & $-\cdot$ & $\cdots$ & $\cdots$ & $\cdots$ & $\cdots$ & - & $\cdots$ \\
\hline $08-26-91$ & $\cdots$ & $\cdots$ & $\cdots$ & -. & $\cdots$ & -. & $\cdots$ & -. & $\cdots$ & $\cdots$ \\
\hline $08-26-91$ & -- & $\cdots$ & $\cdots$ & - & -- & $-\cdot$ & $\cdots$ & $\cdots$ & $\cdots$ & $\cdots$ \\
\hline $08-26-91$ & 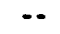 & $\cdots$ & $\cdots$ & $\cdots$ & -. & -- & $\cdots$ & 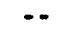 & - & $\cdots$ \\
\hline $08-26-91$ & 1.4 & .30 & -- & -. & $<.1$ & NO & -. & $\cdots$ & 1.5 & .27 \\
\hline $08-26-91$ & $\cdots$ & $\cdots$ & $\cdots$ & -. & $\cdots$ & $\cdots$ & $\cdots$ & $\cdots$ & $\cdots$ & $\cdots$ \\
\hline $08-26$ & $\cdots$ & $\cdots$ & $\cdots$ & - & $\cdots$ & $\cdots$ & - & - & $\cdots$ & $\cdots$ \\
\hline
\end{tabular}


URFACE-MATER DATA-Contínued

CHEMICAL AMALYSES-Cont irued

STATION

MLABER

09395630

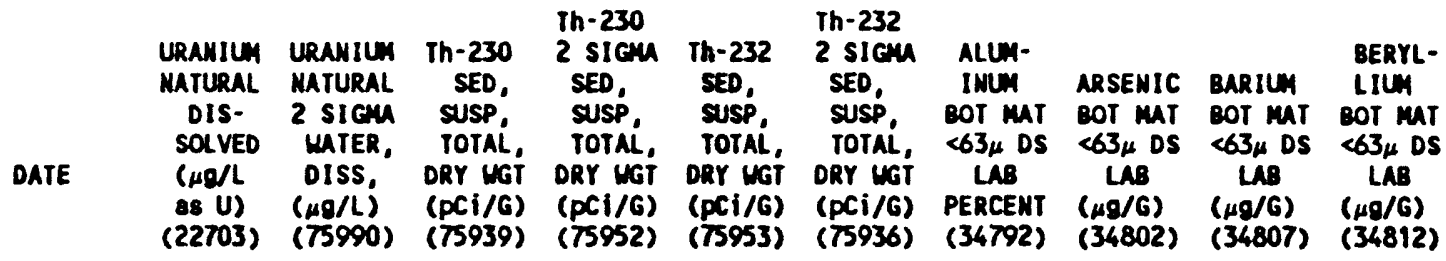

PUERCO RIVER MANUELITO, MH-Continued

\begin{tabular}{|c|c|c|}
\hline -. & $\cdots$ & $\cdots$ \\
\hline -- & $\cdots$ & $\cdots$ \\
\hline$\cdots$ & -. & $\ldots$ \\
\hline -. & -- & . \\
\hline$\cdots$ & -. & $\cdots$ \\
\hline$\cdots$ & -. & $\cdots$ \\
\hline-- & $\cdots$ & $\cdots$ \\
\hline-- & $\cdots$ & $\cdots$ \\
\hline$-\cdot$ & -. & $\cdots$ \\
\hline -. & -. & $\cdots$ \\
\hline -- & -. & 1.4 \\
\hline 4.4 & $\cdots$ & 1.4 \\
\hline$\cdots$ & $\cdots$ & $\because$ \\
\hline$-\cdot$ & - & 1.7 \\
\hline-- & -- & $\cdots$ \\
\hline-- & -- & $\because$ \\
\hline$\ddot{-.}$ & $\cdots$ & 1.3 \\
\hline$\cdots$ & $\cdots$ & 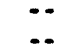 \\
\hline 1.9 & - & .. \\
\hline 2.2 & $<1.0$ & 1.5 \\
\hline-- & -- & $\because$ \\
\hline$\cdots$ & $-\cdot$ & 1.4 \\
\hline$\cdots$ & $\cdots$ & $\cdots$ \\
\hline -. & -. & 1.5 \\
\hline$-\cdot$ & $\cdots$ & 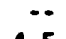 \\
\hline$\cdots$ & $\cdots$ & 1.5 \\
\hline$\cdots$ & $\cdots$ & $\because$ \\
\hline$\cdots$ & $\cdots$ & $\because$ \\
\hline$\because$ & $\cdots$ & $\cdots$ \\
\hline .. & .. & 1.4 \\
\hline -. & - & $\cdots$ \\
\hline -. & $\cdots$ & -. \\
\hline$\cdots$ & $\cdots$ & $\cdots$ \\
\hline$\cdots$ & $\cdots$ & $\cdots$ \\
\hline$\cdots$ & $\because$ & $\because$ \\
\hline 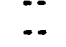 & $\therefore$ & 1.4 \\
\hline -. & $\cdots$ & \\
\hline
\end{tabular}

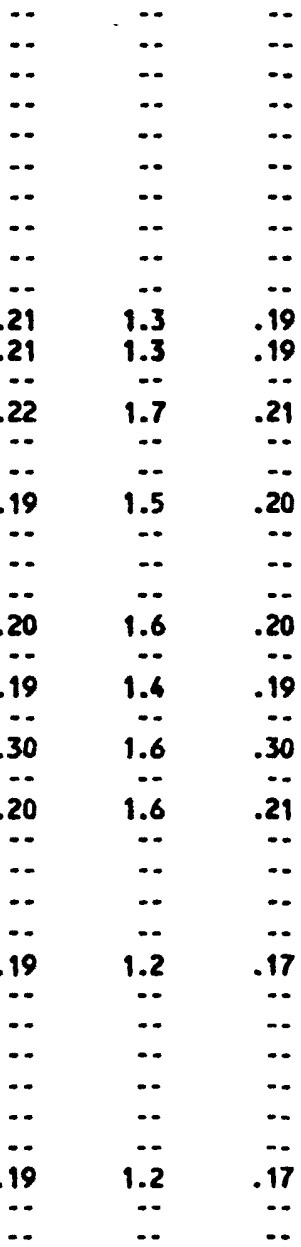

\begin{tabular}{|c|c|c|c|}
\hline -. & $\cdots$ & $\cdots$ & $\cdots$ \\
\hline - & $\cdots$ & -- & $\cdots$ \\
\hline$\cdots$ & $\cdots$ & $\cdots$ & $\cdots$ \\
\hline$\cdots$ & $\cdots$ & $\cdots$ & $\cdots$ \\
\hline-- & $\cdots$ & $\cdots$ & $\cdots$ \\
\hline - & -. & 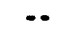 & .. \\
\hline-- & -. & - & $\cdots$ \\
\hline$-\cdot$ & -- & $\cdots$ & $\cdots$ \\
\hline$\cdots$ & $\cdots$ & $\cdots$ & $\cdots$ \\
\hline-- & -. & $\cdots$ & $\cdots$ \\
\hline$\cdots$ & 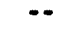 & $\cdots$ & $\cdots$ \\
\hline$\therefore$ & $\cdots$ & -- & $\cdots$ \\
\hline-- & $\cdots$ & $\cdots$ & $\cdots$ \\
\hline$\cdots$ & $\cdots$ & $\cdots$ & 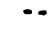 \\
\hline-- & $\because$ & $\cdots$ & 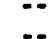 \\
\hline$\cdots$ & $\cdots$ & $\because$ & $\ldots$ \\
\hline .. & .. & $\ldots$ & $\ldots$ \\
\hline -. & .. & .. & -. \\
\hline $\begin{array}{l}8.0 \\
8.6\end{array}$ & $\begin{array}{l}<10 \\
<10\end{array}$ & $\begin{array}{l}660 \\
640\end{array}$ & $\begin{array}{l}2 \\
2\end{array}$ \\
\hline$\cdots$ & $\cdots$ & -. & $\cdots$ \\
\hline 7.2 & 10 & 670 & 2 \\
\hline$\because$ & 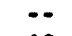 & $\cdots$ & 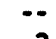 \\
\hline 6.9 & $<10$ & 670 & 2 \\
\hline 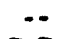 & $\ddot{B}$ & 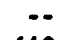 & 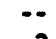 \\
\hline 7.7 & 10 & 640 & 2 \\
\hline$\cdots$ & $\cdots$ & $\cdots$ & $\cdots$ \\
\hline$\cdots$ & $\cdots$ & -- & $\cdots$ \\
\hline$\cdots$ & $\cdots$ & $\cdots$ & $\cdots$ \\
\hline$\cdots$ & $\cdots$ & $\cdots$ & $\cdots$ \\
\hline$\because$ & $\because$ & $\because$ & $\because$ \\
\hline$\therefore$ & $\therefore$ & $\therefore$ & $\ldots$ \\
\hline$\therefore$ & $\ldots$ & $\therefore$ & $\ldots$ \\
\hline -. & -. & -. & - \\
\hline$\cdots$ & $\cdots$ & $\cdots$ & $\cdots$ \\
\hline$\cdots$ & $\cdots$ & -. & $\cdots$ \\
\hline$\cdots$ & $\because$ & $-\cdot$ & $\cdots$ \\
\hline$\cdots$ & $\because$ & $\begin{array}{l}- \\
\cdots\end{array}$ & 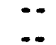 \\
\hline
\end{tabular}


CHEMICAL AMALYSES-Cont inued

STATION

MUABER

09395630
DATE

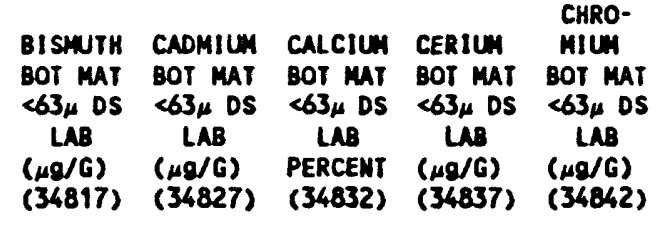

\begin{tabular}{|c|c|c|c|c|}
\hline $3 \mu$ DS & $\begin{array}{c}\angle 63 \mu \text { DS } \\
L A B \\
(\mu g / G) \\
(34852)\end{array}$ & $\begin{array}{c}\text { BOT MT } \\
663_{\mu} \text { DS } \\
\text { LAS }\end{array}$ & $\begin{array}{c}\text { GALLIUH } \\
\text { BOT MAT } \\
\angle 63 \mu \text { DS } \\
\text { LAB } \\
(\mu g / G) \\
(34862)\end{array}$ & $\begin{array}{r}<63 \\
149 \\
(34\end{array}$ \\
\hline
\end{tabular}

PUERCO RIVER MAUUELITO, WH-ContínUed

\begin{tabular}{|c|c|c|c|c|c|c|c|c|c|c|}
\hline $\begin{array}{l}03-09-89 \\
04-05-89\end{array}$ & $\begin{array}{l}\cdots \\
\cdots\end{array}$ & 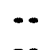 & $\begin{array}{l}\cdots \\
\cdots\end{array}$ & $\because$ & $\because$ & $\cdots$ & 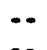 & $\cdots$ & $\cdots$ & 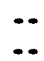 \\
\hline $\begin{array}{l}04-05-89 \\
04-11-89\end{array}$ & $\because$ & $\cdots$ & $\because$ & $\because$ & $\because$ & 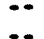 & $\because$ & $\cdots$ & $\cdots$ & \\
\hline $04-11-89$ & $\ldots$ & $\cdots$ & $\cdots$ & $\cdots$ & $\cdots$ & $\cdots$ & $\cdots$ & $\cdots$ & $\cdots$ & $\cdots$ \\
\hline $07-13-89$ & $\cdots$ & $\cdots$ & $\cdots$ & $\cdots$ & $\cdots$ & $\cdots$ & $\cdots$ & $\cdots$ & $\cdots$ & $\cdots$ \\
\hline $07-27-89$ & $\cdots$ & $\cdots$ & $\cdots$ & $\cdots$ & $\cdots$ & $\cdots$ & $\cdots$ & $\cdots$ & $\cdots$ & $\cdots$ \\
\hline $07-27-89$ & $\cdots$ & $\cdots$ & $\cdots$ & $\cdots$ & $\cdots$ & $\cdots$ & $\cdots$ & $\cdots$ & $\cdots$ & $\cdots$ \\
\hline $09-06-89$ & $\cdots$ & $\cdots$ & $\cdots$ & $\cdots$ & $\cdots$ & $\cdots$ & $\cdots$ & $\cdots$ & $\cdots$ & $\cdots$ \\
\hline $09-06-89$ & $\cdots$ & $\cdots$ & $\cdots$ & $\cdots$ & $\cdots$ & $\cdots$ & $\cdots$ & $\cdots$ & $\cdots$ & $\cdots$ \\
\hline $09-06-89$ & $\cdots$ & $\cdots$ & $\cdots$ & $\cdots$ & $\cdots$ & $\cdots$ & $\cdots$ & $\cdots$ & $\cdots$ & $\cdots$ \\
\hline $03-08-90$ & $\cdots$ & $\cdots$ & $\cdots$ & $\cdots$ & $\cdots$ & $\cdots$ & $\cdots$ & $\cdots$ & $\cdots$ & $\cdots$ \\
\hline $07-13-90$ & $\cdots$ & $\cdots$ & $\cdots$ & $\cdots$ & $\cdots$ & $\cdots$ & $\cdots$ & $\cdots$ & $\cdots$ & $\cdots$ \\
\hline $07-13-90$ & $\cdots$ & $\cdots$ & $\cdots$ & $\cdots$ & $\cdots$ & $\cdots$ & $\cdots$ & $\cdots$ & $\cdots$ & $\cdots$ \\
\hline $07-13-90$ & $\cdots$ & $\cdots$ & $\cdots$ & $\cdots$ & $\cdots$ & $\cdots$ & $\cdots$ & $\cdots$ & $\cdots$ & $\cdots$ \\
\hline $07-13-90$ & $\cdots$ & $\cdots$ & $\cdots$ & $-\cdot$ & $\cdots$ & $\cdots$ & $\cdots$ & $\cdots$ & $\cdots$ & $\cdots$ \\
\hline $07-13-90$ & -- & $\cdots$ & $\cdots$ & $\cdots$ & $\cdots$ & $\cdots$ & $\cdots$ & $\cdots$ & $\cdots$ & $\cdots$ \\
\hline $07-13-90$ & $\cdots$ & $\cdots$ & $\cdots$ & $\cdots$ & $\cdots$ & $\cdots$ & $\cdots$ & $\cdots$ & $\cdots$ & $\cdots$ \\
\hline $07-13-90$ & $\cdots$ & $\cdots$ & $\cdots$ & $\cdots$ & $\cdots$ & $\cdots$ & $\cdots$ & $\cdots$ & $\cdots$ & $\cdots$ \\
\hline $07-13-90$ & $\cdots$ & $\cdots$ & $\cdots$ & $\cdots$ & $\cdots$ & $\cdots$ & $\cdots$ & $\cdots$ & $\cdots$ & $\cdots$ \\
\hline $08-03-90$ & $\cdots$ & $\cdots$ & $\cdots$ & $\cdots$ & $-\cdot$ & $\cdots$ & $\cdots$ & $\cdots$ & $\cdots$ & $\cdots$ \\
\hline $\begin{array}{l}08-14-90 \\
08-15-90\end{array}$ & $\begin{array}{l}<10 \\
<10\end{array}$ & $\begin{array}{l}<2 \\
<2\end{array}$ & $\begin{array}{l}1.0 \\
1.1\end{array}$ & $\begin{array}{l}76 \\
78\end{array}$ & $\begin{array}{l}41 \\
44\end{array}$ & $\begin{array}{l}12 \\
12\end{array}$ & $\begin{array}{l}23 \\
23\end{array}$ & $\begin{array}{l}2 \\
<2\end{array}$ & $\begin{array}{l}17 \\
20\end{array}$ & $\begin{array}{l}8 \\
48\end{array}$ \\
\hline $10-20-90$ & $-\cdot$ & .. & $\cdots$ & $\cdots$ & $\cdots$ & $\cdots$ & $\cdots$ & $\therefore$ & $\cdots$ & -. \\
\hline $10-20-90$ & $<10$ & $<2$ & .98 & 68 & 32 & 11 & 19 & $<2$ & 17 & $\infty$ \\
\hline $10-20-90$ & $\cdots$ & $-\cdot$ & $\cdots$ & $\cdots$ & 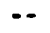 & $\cdots$ & $\cdots$ & $\cdots$ & $\cdots$ & -. \\
\hline $10-20-$ & $<10$ & $<2$ & .86 & 63 & 30 & 11 & 18 & 4 & 17 & $\infty$ \\
\hline $10-20-90$ & $\cdots$ & $\cdots$ & -. & - & $\cdots$ & $\cdots$ & $\cdots$ & $\cdots$ & $\cdots$ & -. \\
\hline $10-20-90$ & $<10$ & $<2$ & 1.1 & 69 & 35 & 11 & 20 & $<2$ & 19 & 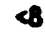 \\
\hline $10-20-90$ & $\cdots$ & $\cdots$ & $\cdots$ & $\cdots$ & $\cdots$ & $\cdots$ & $\cdots$ & $\cdots$ & $\cdots$ & $\cdots$ \\
\hline $06-11-91$ & -. & $\cdots$ & $\cdots$ & -. & $\cdots$ & -- & $\cdots$ & $\cdots$ & $\cdots$ & $\cdots$ \\
\hline $06-12-91$ & -. & $\cdots$ & $-\cdot$ & -. & $\cdots$ & $\cdots$ & $\cdots$ & $\cdots$ & $\cdots$ & $\cdots$ \\
\hline $06-12-$ & $\cdots$ & -- & $\cdots$ & $\cdots$ & $\cdots$ & $\cdots$ & $\cdots$ & $\cdots$ & $\cdots$ & $\cdots$ \\
\hline $06-13-91$ & $\cdots$ & $\cdots$ & $\cdots$ & $\cdots$ & $\cdots$ & $\cdots$ & $\cdots$ & $\cdots$ & $\cdots$ & $\cdots$ \\
\hline $08-02-91$ & -. & $\cdots$ & $\cdots$ & $\cdots$ & $\cdots$ & $\cdots$ & $\cdots$ & $\cdots$ & $\cdots$ & $\cdots$ \\
\hline $08-06-91$ & $\cdots$ & $\cdots$ & -- & $\cdots$ & $\cdots$ & $\cdots$ & $\cdots$ & $\cdots$ & $\cdots$ & $\cdots$ \\
\hline $08-15-91$ & $\cdots$ & $\cdots$ & $\cdots$ & -- & $\cdots$ & $\cdots$ & $\cdots$ & $\cdots$ & $\cdots$ & $\cdots$ \\
\hline $08-26-91$ & $\cdots$ & $\cdots$ & $\cdots$ & $\cdots$ & $\cdots$ & $\cdots$ & $\cdots$ & $\cdots$ & $\cdots$ & $\cdots$ \\
\hline $08-26$ & $\cdots$ & $\cdots$ & $\cdots$ & $\cdots$ & $\cdots$ & $\cdots$ & $\cdots$ & $\cdots$ & $\cdots$ & $\cdots$ \\
\hline $08-26-91$ & $\cdots$ & $\cdots$ & $\cdots$ & $\cdots$ & $\cdots$ & $\cdots$ & $\cdots$ & $\cdots$ & $\cdots$ & $\cdots$ \\
\hline $08-26$ & $\cdots$ & $\cdots$ & $\cdots$ & $\cdots$ & $\cdots$ & $\cdots$ & $\cdots$ & $\cdots$ & $\cdots$ & $\cdots$ \\
\hline $08-26$ & 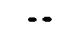 & - & $\cdots$ & .. & -. & $\cdots$ & $\cdots$ & $\cdots$ & $\cdots$ & - \\
\hline $26-91$ & $\cdots$ & -. & $\cdots$ & $\ldots$ & -. & .. & $\because$ & $\cdots$ & - & $\ldots$ \\
\hline
\end{tabular}


SURFACE-MATER DATA-Cont inued

CHEMICAL AHALYSES - Cont inued

STATION

MUMBER

09395630

\begin{tabular}{|c|c|c|c|c|c|c|c|c|c|c|}
\hline & $\begin{array}{c}\text { BOT MAT } \\
\angle 63 \mu \text { DS } \\
L A B \\
(\mu g / G) \\
(34877)\end{array}$ & $\begin{array}{l}\text { IRON } \\
\text { BOT MAT } \\
\angle 63_{\mu} \text { OS } \\
\text { LAB } \\
\text { PERCENT } \\
\text { (34882) }\end{array}$ & $\begin{array}{c}\text { LAMTMA- } \\
\text { MUA } \\
\text { BOT MAT } \\
\angle 63 \mu \text { DS } \\
\text { LAB } \\
(\mu g / G) \\
(34887)\end{array}$ & $\begin{array}{c}\text { LEAD } \\
\text { BOT MAT } \\
\angle 63 \mu \text { OS } \\
\text { LAB } \\
(\mu g / G) \\
(34892)\end{array}$ & $\begin{array}{c}\text { LITHIUM } \\
\text { BOT MAT } \\
\angle 63_{\mu} \text { DS } \\
\text { LAB } \\
(\mu 9 / G) \\
(34897)\end{array}$ & $\begin{array}{l}\text { MAGNE- } \\
\text { SIUN } \\
\text { BOT MAT } \\
\angle 63 \mu \text { DS } \\
\text { LAB } \\
\text { PERCENT } \\
\text { (34902) }\end{array}$ & $\begin{array}{l}\text { MNGA- } \\
\text { NESE } \\
\text { BOT MAT } \\
\angle 63_{\mu} \text { DS } \\
\text { LAB } \\
(\mu g / G) \\
(34907)\end{array}$ & $\begin{array}{c}\text { MLYB- } \\
\text { DENUN } \\
\text { BOT MAT } \\
\angle 63_{\mu} \text { DS } \\
\text { LAB } \\
(\mu g / G) \\
(34917)\end{array}$ & $\begin{array}{c}\text { NEOOYM- } \\
\text { IUA } \\
\text { BOT MAT } \\
\angle 63_{\mu} \text { DS } \\
L A B \\
(\mu 9 / G) \\
(34922)\end{array}$ & $\begin{array}{c}\text { NICKEL } \\
\text { BOT MAT } \\
\angle 63_{\mu} \text { DS } \\
\text { LAB } \\
(\mu g / G) \\
(34927)\end{array}$ \\
\hline
\end{tabular}

PUERCO RIVER MULELITO, Cont inued

\begin{tabular}{|c|c|c|c|c|c|c|c|c|c|c|}
\hline 03-09-89 & $\cdots$ & $\cdots$ & $\cdots$ & $\cdots$ & $\cdots$ & $\cdots$ & $\cdots$ & -- & $\cdots$ & .. \\
\hline $04-05-89$ & $\cdots$ & $\cdots$ & $\cdots$ & $\cdots$ & $\cdots$ & $\cdots$ & $\cdots$ & $\cdots$ & $\cdots$ & $\cdots$ \\
\hline $04-11-89$ & $\cdots$ & -- & $\cdots$ &.- & $\cdots$ & $\cdots$ & $\cdots$ & -. & -. & .. \\
\hline $07-13-89$ & $\cdots$ & $\cdots$ & $\cdots$ & $\cdots$ & $\cdots$ & $\cdots$ & $\cdots$ & - & -. & -. \\
\hline $07-27-89$ & $\cdots$ & $\cdots$ & $\cdots$ & $\cdots$ & $\cdots$ & $-\infty$ & $\cdots$ & - & -. & -. \\
\hline $07-27-89$ & $\cdots$ & $\cdots$ & -. & $\cdots$ & -. & $\cdots$ & $\cdots$ & -. & -. & -. \\
\hline $09-06-89$ & $\cdots$ & $\cdots$ & $\cdot-$ & $\cdots$ & $\cdots$ & $\cdots$ & $\cdots$ & $\cdots$ & $\cdots$ & -- \\
\hline $09-06-89$ & $\cdots$ & $\cdots$ & $\cdots$ & $\cdots$ & $\cdots$ & $\cdots$ & $\cdots$ & $\cdots$ & -. & -. \\
\hline $09-06-89$ & $\cdots$ & $\cdots$ & $\cdots$ & $\cdots$ & $\cdots$ & $\cdots$ & $\cdots$ & $\cdots$ & $\cdots$ & $\cdots$ \\
\hline $03-08-90$ & $\cdots$ & $\cdots$ & $\cdots$ & $\cdots$ & $\cdots$ & -- & $\cdots$ & $\cdots$ & $\cdots$ & -. \\
\hline $07-13-90$ & $\cdots$ & -. & $\cdots$ & $\cdots$ & $\cdots$ & $\cdots$ & $\cdots$ & $\cdots$ & $\cdots$ & -. \\
\hline $07-13-90$ & $\cdots$ & -. & $\cdots$ & - & $\cdots$ & -- & $\cdots$ & $\cdots$ & -. & -. \\
\hline $07-13-90$ & -. & $\cdots$ & $\cdots$ & $\cdots$ & $\cdots$ & $\cdots$ & $\cdots$ & $\cdots$ & $\cdots$ & $\cdots$ \\
\hline $07-13-90$ & $\cdots$ & $\cdots$ & - & $\cdots$ & $\cdots$ & -- & $\cdots$ & -. & -. & -. \\
\hline $07-13-90$ & $\cdots$ & $\cdots$ & $\cdots$ & $\cdots$ & $\cdots$ & $\cdots$ & $\cdots$ & $\cdots$ & $\cdots$ & $\cdots$ \\
\hline $07-13 \cdot 90$ & $\cdots$ & $\cdots$ & $\cdots$ & $\cdots$ & $\cdots$ & -- & $\cdots$ & $\cdots$ & -. & $\cdots$ \\
\hline $07-13-90$ & $\cdots$ & $\cdots$ & $\cdots$ & $\cdots$ & $\cdots$ & $\cdots$ & $\cdots$ & -- & $\cdots$ & -. \\
\hline $07-13-90$ & $\cdots$ & $\cdots$ & $\cdots$ & $\cdots$ & $\cdots$ & $\cdots$ & $\cdots$ & $\cdots$ & $\cdots$ & $\cdots$ \\
\hline $08-03-90$ & $\cdots$ & $\cdots$ & $\cdots$ & $\cdots$ & $\cdots$ & $\cdots$ & $\cdots$ & $\cdots$ & $\cdots$ & $\cdots$ \\
\hline $\begin{array}{l}08-14-90 \\
08-15-90\end{array}$ & $<4$ & $\begin{array}{l}2.8 \\
3.2\end{array}$ & $\begin{array}{l}42 \\
42\end{array}$ & $\begin{array}{l}22 \\
23\end{array}$ & $\begin{array}{l}31 \\
34\end{array}$ & .68 & $\begin{array}{l}340 \\
390\end{array}$ & $<2$ & $\begin{array}{l}34 \\
34\end{array}$ & $\begin{array}{l}14 \\
16\end{array}$ \\
\hline $10-20-90$ & $\ldots$ & -. & $\therefore$ & $\ldots$ & $\therefore$ & - & $\ldots$ & $\therefore$ & $\therefore$ & $\therefore$ \\
\hline $10-20-90$ & $<4$ & 2.5 & 37 & 22 & 27 & .61 & 340 & $<2$ & 28 & 12 \\
\hline $10-20-90$ & $\cdots$ & -. & $\cdots$ & $\cdots$ & $\cdots$ & $\cdots$ & $\cdots$ & $\cdots$ & $\cdots$ & -- \\
\hline $10-20-90$ & $<4$ & 2.4 & 35 & 17 & 25 & .57 & 340 & $<2$ & 28 & 12 \\
\hline $10-20-90$ & $\cdots$ & -. & $\cdots$ & $\cdots$ & $\cdots$ & $\cdots$ & -- & $\cdots$ & $\cdots$ & -- \\
\hline $10-20-90$ & $<4$ & 2.7 & 38 & 19 & 30 & .69 & 350 & $<2$ & 31 & 13 \\
\hline $10-20-90$ & $\cdots$ & $\cdots$ & $\cdots$ & $\cdots$ & $\cdots$ & $\cdots$ & - & $\cdots$ & -. & -- \\
\hline $06-11-91$ & $\cdots$ & - & $\cdots$ & - & $\cdots$ & $\cdots$ & $\cdots$ & $\cdots$ & $\cdots$ & $\cdots$ \\
\hline $06-12-91$ & $\cdots$ & -. & $\cdots$ & $\cdots$ & $\cdots$ & $\cdots$ & $\cdots$ & $\cdots$ & -. & -. \\
\hline $06-12-91$ & $\cdots$ & $\cdots$ & $\cdots$ & $\cdots$ & $\cdots$ & $\cdots$ & $\cdots$ & $\cdots$ & $\cdots$ & $\cdots$ \\
\hline $06-13-91$ & $\cdots$ & $\cdots$ & $\cdots$ & $\cdots$ & $\cdots$ & $\cdots$ & $\cdots$ & $\cdots$ & $\cdots$ & $\cdots$ \\
\hline $08-02-91$ & -- & $\cdots$ & $\cdots$ & $\cdots$ & $\cdots$ & -- & $\cdots$ & $\cdots$ & $\cdots$ & -- \\
\hline $08-06-91$ & $\cdots$ & $\cdots$ & $\cdots$ & $\cdots$ & $\cdots$ & $\cdots$ & -- & $\cdots$ & $\cdots$ & $\cdots$ \\
\hline $08-15-91$ & - & -- & $\cdots$ & $\cdots$ & $\cdots$ & $\cdots$ & $\cdots$ & - & - & -. \\
\hline $08-26-91$ & $\cdots$ & $\cdots$ & $\cdots$ & $\cdots$ & $\cdots$ & $\cdots$ & $\cdots$ & $\cdots$ &.- & -. \\
\hline 08 & $\cdots$ & $\cdots$ & $\cdots$ & $\cdots$ & $\cdots$ & $\cdots$ & $\cdots$ & $\cdots$ & $\cdots$ & $\cdots$ \\
\hline & $\cdots$ & $\cdots$ & $\cdots$ & $\cdots$ & $\cdots$ & $\cdots$ & $\cdots$ & $\cdots$ & - & -. \\
\hline 08 & $\cdots$ & $\cdots$ & $\cdots$ & $\cdots$ & $\cdots$ & $\cdots$ & $\cdots$ & $\cdots$ & $\cdots$ & $-\cdot$ \\
\hline-9 & -. & $\cdots$ & - & $\cdots$ & $\cdots$ & $\cdots$ & $\cdots$ & $\cdots$ &.- & -. \\
\hline & .. & -. & $\ldots$ & $\ldots$ & $\ldots$ & -. & $\ldots$ & -. & $\ldots$ & \\
\hline
\end{tabular}


SURFACE-WATER DATA-Continued

CHEMICAL AHALYSES-Contínued

STATION

MUABER

09395630

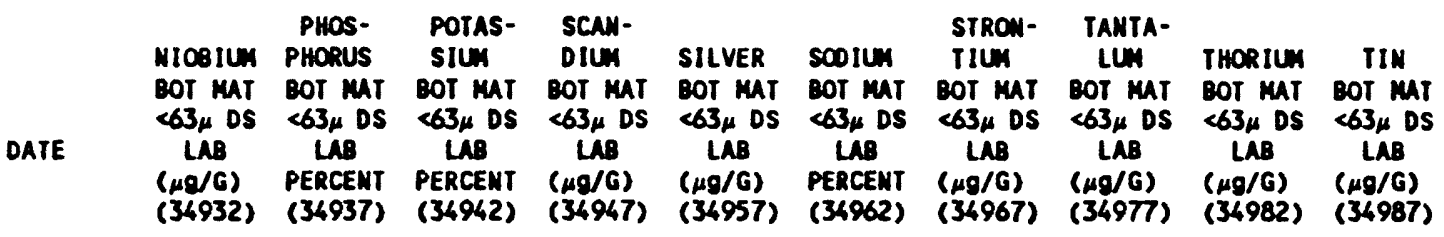

PUERCO RIVER MANUELITO, MH-Continued

\begin{tabular}{|c|c|c|c|c|c|c|c|c|c|c|}
\hline $03-09-89$ & - & $\because$ & -- & $\because$ & -- & $\because{ }^{\circ}$ & -- & 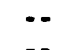 & $\cdots$ & $\because-$ \\
\hline $04-05-89$ & $\cdots$ & $-\cdot$ & $\cdots$ & $\cdots$ & $\cdots$ & -- & $\cdot-$ & $\cdots$ & -- & -- \\
\hline $04-11-89$ & -- & -- & -- & $\cdots$ & $\cdots$ & -- & $\cdots$ & $\cdots$ & -- & -- \\
\hline $07-13-89$ & -- & -- & $\cdot-$ & $\cdots$ & -- & -- & $=$ & $\cdots$ & $=$ & $-\cdot$ \\
\hline $07-27-89$ & $\cdots$ & $\cdots$ & $\cdots$ & $\cdots$ & $\cdots$ & -- & -- & $\cdots$ & -- & -- \\
\hline $07-27-89$ & $\cdots$ & -- & $\cdots$ & $\cdots$ & $\cdots$ & -- & -- & -- & -- & -- \\
\hline $09-06-89$ & $\cdots$ & -- & $\cdots$ & $\cdots$ & $\cdots$ & -- & $\cdots$ & -- & $\cdots$ & -- \\
\hline $09-06-89$ & -. & -- & $\cdots$ & $\cdots$ & $\cdots$ & -- & -- & -- & -- & -- \\
\hline $09-06-89$ & $\cdots$ & $\cdots$ & $\cdots$ & $\cdots$ & $\cdots$ & $\cdots$ & $\cdots$ & $\cdots$ & -- & -- \\
\hline $03-08-90$ & $\cdots$ & $\cdots$ & $\cdots$ & -- & $\cdots$ & -- & -- & $\cdots$ & $=$ & -- \\
\hline $07-13-90$ & $\cdots$ & -- & $\cdots$ & -- & $\cdots$ & -- & $\cdots$ & $\cdots$ & $\cdots$ & -- \\
\hline $07-13-90$ & $\cdots$ & $\cdots$ & $\cdots$ & $\cdots$ & $\cdots$ & -- & -- & $\cdots$ & - & -- \\
\hline $07-13-90$ & -- & -- & $\cdots$ & $\cdots$ & $\cdots$ & -- & -- & $\cdots$ & $\cdots$ & -- \\
\hline $07-13-90$ & $\cdots$ & - & -- & -- & -- & -- & -- & -- & -- & -- \\
\hline $07-13-90$ & $\cdots$ & $\cdots$ & $\cdots$ & -- & $\cdots$ & -- & $\cdots$ & - & $\cdots$ & -- \\
\hline $07-13-90$ & -- & $\cdots$ & $\cdots$ & -- & $\cdots$ & -- & -- & $\cdots$ & -- & -- \\
\hline $07-13-90$ & -- & $1 \quad-$. & -- & -- & $\cdots$ & -- & -- & -- & -- & -- \\
\hline $07-13-90$ & $=$ & -- & -- & -- & 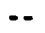 & -- & $=$ & $\ldots$ & -- & -- \\
\hline $08-03-90$ & $\cdots$ & -- & $\cdots$ & -- & $\cdot-$ & -- & $\cdots$ & $\cdots$ & -- & -- \\
\hline $08-14-90$ & 11 & .06 & 1.9 & 12 & $<4$ & 0.56 & 160 & $<40$ & 15 & $<10$ \\
\hline $08-15-90$ & 10 & .05 & 1.9 & 13 & $<4$ & 0.53 & 170 & $<40$ & 15 & $<10$ \\
\hline $10-20-90$ & -- & -- & $\cdots$ & -- & - & $\ddot{m}$ & -- & $=-$ & $\ddot{-}$ & $\because$ \\
\hline $10-20-90$ & 7 & .04 & 2.1 & 9 & $<4$ & 0.72 & 150 & $<40$ & 10 & $<5$ \\
\hline $10-20-90$ & $\cdots$ & $\cdots$ & $\cdots$ & -- & -- & -- & $-\cdot$ & -- & -. & -- \\
\hline $10-20-90$ & 6 & .04 & 2.1 & 9 & $<4$ & 0.72 & 140 & $<40$ & 12 & $<5$ \\
\hline $10-20-90$ & -- & -. & $\cdots$ & $=$ & -- & $\because$ & $\because-$ & $\cdots$ & -- & -- \\
\hline $10-20-90$ & 7 & .04 & 2.1 & 10 & $<4$ & 0.67 & 160 & $<40$ & 12 & $<5$ \\
\hline $10-20-90$ & $\cdots$ & $\cdots$ & $\cdots$ & -- & $\cdots$ & -- & $\cdots$ & -- & $=$ &.- \\
\hline $06-11-91$ & -- & $\cdots$ & $-\cdot$ & -- & -. & -- & -- & -- & -- & $=-$ \\
\hline $06-12-91$ & -. & -- & -- & -- & -- & $\cdots$ & $-\cdot$ & -- & $-\cdot$ & -- \\
\hline $06-12-91$ & -- & -- & $\cdots$ & -- & $-\cdot$ & $\cdots$ & $-\cdot$ & $\cdots$ & $\cdots$ & -- \\
\hline $06-13-91$ & $\because$ & $\cdots$ & $\cdots$ & -- & -- & -- & -- & $\cdots$ & $\because$ & -- \\
\hline $08-02-91$ & $\cdots$ & $\cdots$ & $\cdots$ & 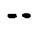 & $\cdots$ & $-\cdot$ & -- & -- & $-\cdot$ & -- \\
\hline $08-06-91$ & -- & -- & -- & $\cdots$ & -- & -- & -- & -- & $\cdots$ & -. \\
\hline $08-15-91$ & -- & $-\cdot$ & $\cdots$ & $\cdots$ & -- & -. & -- & -- & -- & -- \\
\hline $08-26-91$ & $\cdots$ & -- & -. & -- & -- & $-\cdot$ & -. & -- & $\cdots$ & $\cdots$ \\
\hline $08-26-91$ & $\cdots$ & $\cdots$ & -- & - & -- & -- &.- & -- & $\cdots$ & $-\cdot$ \\
\hline $08-26-91$ & $\cdots$ & $\cdots$ & $\cdots$ & -. & $\cdots$ & $\cdots$ & $-\cdot$ & $\cdots$ & $\cdots$ & $\cdots$ \\
\hline $08-26-91$ & -. & -- & -. & -. & -- & -- & -- & -- & -. & -. \\
\hline $08-26-91$ & $\cdots$ & -- & -- & -- & $-\cdot$ & -- & $-\cdot$ & -- & -- & $\cdots$ \\
\hline $08-26-91$ & -- & -- & - & $-\cdot$ & -- & -- & $-\cdot$ & -- & -- & -- \\
\hline
\end{tabular}


CHEMICAL AMALYSES-Continued

STATION

MUMBER

09395630
DATE

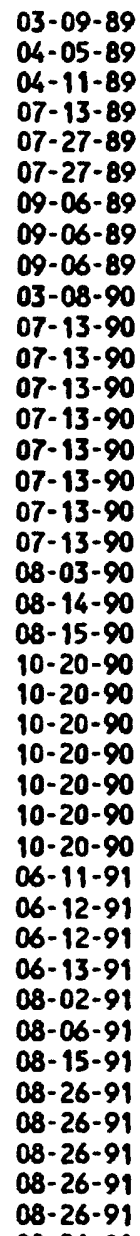

\begin{tabular}{|c|c|c|c|c|c|c|c|c|}
\hline $\begin{array}{l}\text { IITA- } \\
\text { NIUM } \\
\text { OT MAT } \\
63_{\mu} \text { DS } \\
\text { LAB } \\
\text { ERCENT } \\
\text { 34992) }\end{array}$ & $\begin{array}{l}\text { URANIUA } \\
\text { BOT MAT } \\
<63 \mu \text { DS } \\
\text { LAB } \\
(\mu 9 / G) \\
(35002)\end{array}$ & $\begin{array}{l}\text { VANA- } \\
\text { DIUA } \\
\text { BOI MAT } \\
<63 \mu \text { DS } \\
\text { LAB } \\
(\mu g / G) \\
(35007)\end{array}$ & 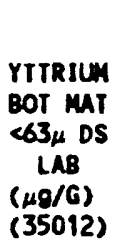 & $\begin{array}{c}\text { YITER- } \\
\text { BIUA } \\
\text { BOT MAI } \\
\angle 63_{\mu} \text { DS } \\
\text { LAB } \\
(\mu 9 / G) \\
(35017)\end{array}$ & $\begin{array}{c}21 N C \\
B 0 T M A T \\
\angle 63 \mu \mathrm{DS} \\
\text { LAB } \\
(\mu \sigma / G) \\
(35022)\end{array}$ & 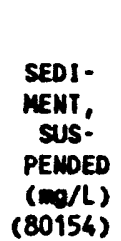 & $\begin{array}{l}\text { SED. } \\
\text { SUSP. } \\
\text { SIEVE } \\
\text { DINH. } \\
\times \text { FINER } \\
\text { THAN } \\
.062 \text { MM } \\
\text { (70331) }\end{array}$ & $\begin{array}{l}\text { SED. } \\
\text { SUSP. } \\
\text { FALL } \\
\text { DINM. } \\
\times \text { FINER } \\
\text { THAN } \\
\text {.002 MM } \\
\text { (70337) }\end{array}$ \\
\hline
\end{tabular}

PUERCO RIVER MANUELITO, M-Continued

\begin{tabular}{|c|c|c|c|c|c|c|c|c|}
\hline$\cdots$ & $\cdots$ & $\cdots$ & $\cdots$ & $\cdots$ & $\cdots$ & 1140 & $-\cdot$ & 61 \\
\hline$\cdots$ & $\cdots$ & $\cdots$ & $\cdots$ & $\cdots$ & -. & $\cdots$ & $-\cdot$ & $\cdots$ \\
\hline$\cdots$ & $\cdots$ & $\cdots$ & $\cdots$ & $\cdots$ & 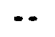 & 37 & $\cdots$ & $\cdots$ \\
\hline$\cdots$ & $\cdots$ & $\cdots$ & $\cdots$ & $-\cdot$ & $\cdots$ & 1990 & $-\cdot$ & 66 \\
\hline$\cdots$ & $\cdots$ & $\cdots$ & $\cdots$ & $\cdots$ & $\cdots$ & 79800 & $-\cdot$ & 60 \\
\hline$\cdots$ & $\cdots$ & $\cdots$ & $\cdots$ & $\cdots$ & -. & 81200 & - & 60 \\
\hline$\cdots$ & $\cdots$ & $\cdots$ & $\cdots$ & $\cdots$ & $\cdots$ & 77200 & $\cdots$ & 31 \\
\hline -- & $\cdots$ & $\cdots$ & $\cdots$ & $\cdots$ & $\cdots$ & 142000 & $\cdots$ & 36 \\
\hline$\cdots$ & $\cdots$ & $\cdots$ & $\cdots$ & $\cdots$ & $\cdots$ & 116000 & -- & 41 \\
\hline$\cdots$ & $\cdots$ & $\cdots$ & $\cdots$ & $\cdots$ & $\cdots$ & $\cdots$ & $\cdots$ & $\cdots$ \\
\hline$\cdots$ & $\cdots$ & $\cdots$ & $\cdots$ & $\cdots$ & $\cdots$ & 133000 & -- & 36 \\
\hline -. & $\cdots$ & $\cdots$ & $\cdots$ & $\cdots$ & -- & $\cdots$ & $\cdots$ & -. \\
\hline$\cdots$ & $\cdots$ & $\cdots$ & $\cdots$ & $\cdots$ & $\cdots$ & 142000 & 79 & $\cdots$ \\
\hline$\cdots$ & $\cdots$ & $\cdots$ & $\cdots$ & $\cdots$ & -. & 145000 & - & 39 \\
\hline-- & $-\cdot$ & $\cdots$ & $\cdots$ & $\cdots$ & $\cdots$ & 146000 & 60 & $\cdots$ \\
\hline-- & $\cdots$ & $\cdots$ & $\cdots$ & $\cdots$ & $\cdots$ & $\cdots$ & $\cdots$ & $\cdots$ \\
\hline 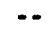 & $\cdots$ & $\cdots$ & $\cdots$ & $\cdots$ & $\cdots$ & 130000 & $\cdots$ & 32 \\
\hline$\cdots$ & $\cdots$ & $\cdots$ & $\cdots$ & $\cdots$ & $\cdots$ & 97900 & 60 & $\cdots$ \\
\hline$\cdots$ & $\because$ & $\cdots$ & 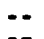 & $\cdots$ & $-\cdot$ & - & $\cdots$ & $\cdots$ \\
\hline $\begin{array}{l}.43 \\
.42\end{array}$ & $\begin{array}{l}<100 \\
<100\end{array}$ & $\begin{array}{l}86 \\
97\end{array}$ & $\begin{array}{l}25 \\
25\end{array}$ & $\begin{array}{l}3 \\
3\end{array}$ & $\begin{array}{l}79 \\
93\end{array}$ & $\begin{array}{r}111000 \\
68200\end{array}$ & $\ddot{--}$ & $\begin{array}{l}19 \\
53\end{array}$ \\
\hline$\cdots$ & - & $\cdots$ & $\cdots$ & $\cdots$ & $\cdots$ & 80200 & 55 & $\cdots$ \\
\hline .35 & $<100$ & 73 & 19 & 2 & 72 & 102000 & $\because$ & 33 \\
\hline - & -. & $\cdots$ & $\cdots$ & $\cdots$ & -. & 119000 & 50 & -. \\
\hline .32 & $<100$ & 69 & 18 & 2 & 69 & 92500 & $\cdots$ & 29 \\
\hline$\ldots$ & $\cdots$ & $\cdots$ & $\cdots$ & $\cdots$ & $\cdots$ & 69200 & 66 & .. \\
\hline .35 & $<100$ & 79 & 19 & 2 & $\pi$ & 77200 & $\cdots$ & 13 \\
\hline$\cdots$ & $\cdots$ & $\cdots$ & $\cdots$ & $\cdots$ & $\cdots$ & 57300 & 83 & $\cdots$ \\
\hline -. & -. & -. & $\cdots$ & $\cdots$ & -. & $\cdots$ & -- & -. \\
\hline$\cdots$ & $\cdots$ & $\cdots$ & $\cdots$ & $\cdots$ & $\cdots$ & $\cdots$ & $-\cdot$ & $\cdots$ \\
\hline- & $\cdots$ & - & $\cdots$ & $\cdots$ & -- & 26700 & 100 & - \\
\hline -. & $\cdots$ & -. & $\cdots$ & -. & -. & 96600 & $\cdots$ & 37 \\
\hline$-\cdot$ & $\cdots$ & $\cdots$ & $\cdots$ & $\cdots$ & -- & 130000 & -- & 58 \\
\hline$\cdots$ & $\cdots$ & $\cdots$ & $\cdots$ & $\cdots$ & $\cdots$ & 264000 & 68 & -. \\
\hline.- & $\cdots$ & $\cdots$ & $\cdots$ & $\cdots$ & -. & 66500 & $\cdots$ & 44 \\
\hline$\cdots$ & -- & $\cdots$ & $\cdots$ & $\cdots$ & -. & 211000 & 78 & -- \\
\hline$\because-$ & 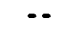 & $\cdots$ & $\cdots$ & $\cdots$ & $-\cdot$ & 197000 & 75 & $\cdots$ \\
\hline -. & $\cdots$ & $\cdots$ & $\cdots$ & $\cdots$ & $\cdots$ & 129000 & 79 & $\cdots$ \\
\hline$\cdots$ & $\cdots$ & $\cdots$ & $\cdots$ & $\cdots$ & $\cdots$ & 102000 & $\cdots$ & 46 \\
\hline$\cdots$ & $\cdots$ & $\cdots$ & $\cdots$ & $\cdots$ & - & 107000 & 74 & $\cdots$ \\
\hline$\cdots$ & $\cdots$ & $\cdots$ & $\cdots$ & $\cdots$ & $\cdots$ & 91600 & 76 & \\
\hline
\end{tabular}


SURFACE-WATER DATA-Continued

CHEMICAL ANALYSES-Cont inued

STATION

MUABER

DATE

$$
\begin{aligned}
& 03-09-89 \\
& 04-05-89 \\
& 04-11-89 \\
& 07-13-89 \\
& 07-27-89 \\
& 07-27-89 \\
& 09-06-89 \\
& 09-06-89 \\
& 09-06-89 \\
& 03-08-90 \\
& 07-13-90 \\
& 07-13-90 \\
& 07-13-90 \\
& 07-13-90 \\
& 07-13-90 \\
& 07-13-90 \\
& 07-13-90 \\
& 07-13-90 \\
& 08-03-90 \\
& 08-14-90 \\
& 08-15-90 \\
& 10-20-90 \\
& 10-20-90 \\
& 10-20-90 \\
& 10-20-90 \\
& 10-20-90 \\
& 10-20-90 \\
& 10-20-90 \\
& 06-11-91 \\
& 06-12-91 \\
& 06-12-91 \\
& 06-13-91 \\
& 08-02-91 \\
& 08-06-91 \\
& 08-15-91 \\
& 08-26-91 \\
& 08-26-91 \\
& 08-26-91 \\
& 08-26-91 \\
& 08-26-91 \\
& 08-26-91
\end{aligned}
$$

\begin{tabular}{|c|c|c|c|c|c|c|c|}
\hline $\begin{array}{l}\text { SED. } \\
\text { SUSP. } \\
\text { FALL } \\
\text { DIAM. } \\
\text { G FINER } \\
\text { THAN } \\
004 \text { M } \\
70338 \text { ) }\end{array}$ & $\begin{array}{l}\text { SED. } \\
\text { SUSP. } \\
\text { FALL } \\
\text { DIAN. } \\
\times \text { FINER } \\
\text { THAN } \\
\text {.008 } \\
\text { (70339) }\end{array}$ & $\begin{array}{l}\text { SED. } \\
\text { SUSP. } \\
\text { FALL } \\
\text { DINA. } \\
\times \text { FINER } \\
\text { THAN } \\
.016 \mathrm{~mA} \\
(70340)\end{array}$ & $\begin{array}{l}\text { SED. } \\
\text { SUSP. } \\
\text { FALL } \\
\text { DIAM. } \\
\times \text { FINER } \\
\text { THAN } \\
.031 \text { MI } \\
\text { (70341) }\end{array}$ & $\begin{array}{l}\text { SED. } \\
\text { SUSP. } \\
\text { FALL } \\
\text { DIAM. } \\
\times \text { FINER } \\
\text { THAN } \\
\text {.062 MA } \\
\text { (70342) }\end{array}$ & $\begin{array}{l}\text { SED. } \\
\text { SUSP. } \\
\text { FALL } \\
\text { DINA. } \\
\times \text { FINER } \\
\text { THAN } \\
\text {-125 MH } \\
\text { (70343) }\end{array}$ & $\begin{array}{l}\text { SED. } \\
\text { SUSP. } \\
\text { FALL } \\
\text { DIAN. } \\
\times \text { FINER } \\
\text { THAN } \\
\text {.250 } \\
\text { (70344) }\end{array}$ & $\begin{array}{l}\text { SED. } \\
\text { SUSP. } \\
\text { FALL } \\
\text { DINA. } \\
\times \text { FINER } \\
\text { THAN } \\
\text { THO } \\
\text { (70345) }\end{array}$ \\
\hline
\end{tabular}

\begin{tabular}{|c|c|c|c|c|c|c|c|}
\hline 76 & - & 92 & -. & 99 & -. & - & $\cdots$ \\
\hline-- & $\cdots$ & $\cdots$ & $\cdots$ & $\cdots$ & $\cdots$ & -- & $\cdots$ \\
\hline$\cdots$ & $\cdots$ & $\cdots$ & $\cdots$ & $\cdots$ & $\cdots$ & $\cdots$ & $\cdots$ \\
\hline 79 & - & 88 & $\cdots$ & 97 & 98 & 100 & 100 \\
\hline 71 & $\cdots$ & 90 & $\cdots$ & 97 & 100 & 100 & $\cdots$ \\
\hline 71 & 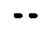 & 91 & $\cdots$ & 97 & 99 & 100 & 100 \\
\hline 37 & $\cdots$ & 51 & $\cdots$ & 71 & 84 & 99 & 100 \\
\hline 43 & $\cdots$ & 58 & $\cdots$ & 84 & 96 & 100 & 100 \\
\hline 49 & $\cdots$ & 66 & $\cdots$ & 89 & 98 & 100 & $\cdots$ \\
\hline 44 & 6 & 57 & 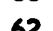 & 81 & $\ddot{0}$ & $\ddot{m}$ & in \\
\hline$\therefore$ & 40 & Jr & oc & 01 & 90 & 49 & 100 \\
\hline .. & -. & $\ldots$ & $\ldots$ & $\ldots$ & $\ldots$ & $\ldots$ & $\therefore$ \\
\hline 45 & 49 & 59 & 68 & 80 & 93 & 99 & 100 \\
\hline$\cdots$ & $\cdots$ & $\cdots$ & $\cdots$ & $\cdots$ & $\cdots$ & $\cdots$ & $\cdots$ \\
\hline$\cdots$ & $\cdots$ & $\cdots$ & $\cdots$ & $\cdots$ & $\cdots$ & $\cdots$ & $\cdots$ \\
\hline 37 & 41 & 48 & 57 & 67 & 85 & 99 & 100 \\
\hline$\cdots$ & $\cdots$ & $\cdots$ & $\cdots$ & $\cdots$ & $\cdots$ & $\cdots$ & $\cdots$ \\
\hline$\cdots$ & $\cdots$ & $\cdots$ & $\cdots$ & $\cdots$ & $\cdots$ & $\cdots$ & -- \\
\hline $\begin{array}{l}27 \\
64\end{array}$ & $\begin{array}{l}36 \\
66\end{array}$ & $\begin{array}{l}45 \\
76\end{array}$ & $\begin{array}{l}56 \\
83\end{array}$ & $\begin{array}{l}87 \\
90\end{array}$ & $\begin{array}{l}98 \\
98\end{array}$ & $\begin{array}{l}100 \\
100\end{array}$ & $\cdots$ \\
\hline$\cdots$ & $\cdots$ & $\cdots$ & $\cdots$ & $\cdots$ & $\cdots$ & $\cdots$ & $\cdots$ \\
\hline 36 & 40 & 45 & 54 & $\cdots$ & $\cdots$ & $\cdots$ & $\cdots$ \\
\hline 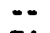 & $\cdots$ & $\cdots$ & $\cdots$ & $\cdots$ & $\cdots$ & $\cdots$ & $\cdots$ \\
\hline 36 & 39 & 45 & 54 & $\cdots$ & $\cdots$ & $\cdots$ & $\cdots$ \\
\hline 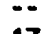 & $\ddot{m}$ & $\ddot{m}$ & $\ddot{M}$ & $\cdots$ & $\cdots$ & $\cdots$ & $\cdots$ \\
\hline 17 & 23 & 33 & 40 & $\cdots$ & $\cdots$ & $\cdots$ & $\cdots$ \\
\hline$\cdots$ & $\cdots$ & $\cdots$ & $\cdots$ & $\because$ & $\cdots$ & $\cdots$ & - \\
\hline$\cdots$ & $\cdots$ & $\cdots$ & $\cdots$ & $\because$ & $\cdots$ & $\cdots$ & $\cdots$ \\
\hline$\cdots$ & $\cdots$ & $\cdots$ & $\cdots$ & $\cdots$ & $\cdots$ & $\cdots$ & $\because$ \\
\hline$\ddot{x}$ & 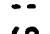 & 55 & $\overline{70}$ & 89 & 05 & $\infty$ & ח \\
\hline $\begin{array}{l}46 \\
66\end{array}$ & $\begin{array}{l}49 \\
71\end{array}$ & $\begin{array}{l}55 \\
81\end{array}$ & $\begin{array}{l}70 \\
90\end{array}$ & $\begin{array}{l}81 \\
93\end{array}$ & $\begin{array}{l}95 \\
98\end{array}$ & $\begin{array}{l}99 \\
99\end{array}$ & $\begin{array}{l}100 \\
100\end{array}$ \\
\hline$\cdots$ & 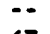 & 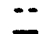 & $\ddot{-}$ & $\ddot{m}$ & $\cdots$ & $\ddot{n}$ & $\cdots$ \\
\hline 54 & 63 & 73 & 83 & 92 & 97 & 100 & $\cdots$ \\
\hline$\cdots$ & $\cdots$ & $\cdots$ & $\cdots$ & $\cdots$ & $\cdots$ & $\cdots$ & $\cdots$ \\
\hline$\cdots$ & $\cdots$ & -. & $\cdots$ & $\cdots$ & $\cdots$ & $\cdots$ & - \\
\hline$\ldots$ & $\cdots$ & $\cdots$ & $\cdots$ & $\cdots$ & $\cdots$ & $\cdots$ & - \\
\hline 48 & 53 & 59 & 70 & 78 & 93 & 99 & 100 \\
\hline$\cdots$ & $\cdots$ & $\cdots$ & $\cdots$ & $\cdots$ & $\cdots$ & $\cdots$ & $\cdots$ \\
\hline & $\cdots$ & & $\cdots$ & & & $\cdots$ & \\
\hline
\end{tabular}

PUERCO RIVER MANUELITO, Cont inued 
SURFACE-MATER DATA-COnt inued

CHEMICAL AMALYSES-Continued
STATION

NUMBER

09395990
STATION MAME

BLACK CREEK MEAR hOUCK, ARIzONA
DATE

$\begin{array}{lc}03-09-89 & 1030 \\ 08-01-89 & 1300 \\ 09-05-89 & 2020 \\ 09-05-89 & 2021 \\ 09-05-89 & 2050 \\ 09-05-89 & 2051 \\ 09-05-89 & 2200 \\ 09-05-89 & 2201 \\ 09-05-89 & 2321 \\ 09-06-89 & 2320 \\ 03-07-90 & 1005 \\ 03-07-90 & 1130 \\ 08-14-90 & 0010 \\ 03-06-91 & 0950 \\ 03-06-91 & 1100 \\ 03-06-91 & 1320 \\ 03-06-91 & 1600 \\ 07-25-91 & -. \\ 07-25-91 & 1640 \\ 07-26-91 & 1400 \\ 08-07-91 & 0010 \\ 08-07-91 & 1215 \\ 08-07-91 & 1250 \\ 08-08-91 & --\end{array}$

LATITUDE LONGITUDE

$35^{\circ} 17^{\prime} 05^{\prime \prime N} \quad 109 \cdot 12 \cdot 54 \mathrm{~m}$ 
SURFACE-MATER DATA-Cont inued

CHEMICAL ANALYSES-Continued

STATION

MUMBER

DATE

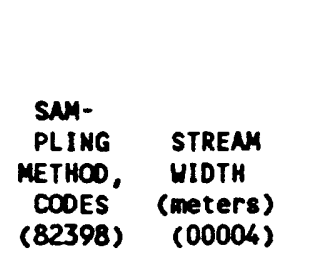
SURFACE DATUN (METERS ABOVE NGVD) $(72000)$
DISCHARGE, INST.

$\begin{array}{ccc} & \text { DIS- } & \\ & \text { CHARGE, } \\ & \\ \text { INST. } & \\ \text { TEMPER- } & \text { CUBIC } & \\ \text { ATURE } & \text { FEET } & \text { GAGE } \\ \text { UATER } & \text { PER } & \text { HEIGHT } \\ \left({ }^{\circ} \mathrm{C}\right) & \text { SECOND } & \text { (meters) } \\ (00010) & (00061) & (00065)\end{array}$

BLACK CREEK NEAR HOUCK, AZ-Continued

$09395990 \quad 03-09-89$
$08-01-89$
$09-05-89$
$09-05-89$
$09-05-89$
$09-05-89$
$09-05-89$
$09-05-89$
$09-05-89$
$09-06-89$
$03-07-90$
$03-07-90$
$08-14-90$
$03-06-91$
$03-06-91$
$03-06-91$
$03-06-91$
$07-25-91$
$07-25-91$
$07-26-91$
$08-07-91$
$08-07-91$
$08-07-91$
$08-08-91$

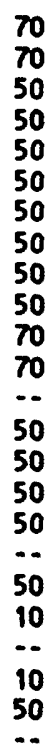

70
70
50
50
50
50
50
50
50
50
70
70
$\cdots$
50
50
50
50
$\cdots$
50
10
$\cdots$
10
50
$\cdots$

$\begin{array}{ll}\ldots & \ldots \\ \ldots & \ldots \\ \ldots & \ldots \\ \ldots & \ldots \\ \ldots & \ldots \\ \ldots & \ldots \\ \ldots & \ldots \\ \ldots & \ldots \\ \ldots & 6.0 \\ 3.5 & 6.0 \\ \ldots & \ldots \\ \ldots & \ldots \\ \ldots & \ldots \\ \ldots & \ldots \\ \ldots & \ldots \\ 10.4 & \ldots \\ \ldots & \ldots \\ \ldots & 19.5 \\ \ldots & 19.5 \\ & \ldots\end{array}$

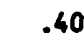

\section{1}

$$
17.5
$$$$
17.5
$$$$
5.6
$$

$$
5.6
$$

$$
4.4
$$$$
4.4
$$$$
3.7
$$$$
3.7
$$

0

6.0

.09

.09

E3.4

E4.5

E4.0

E3.7

14.3

1.2

$\because$

4.1

\begin{tabular}{|c|c|c|}
\hline$\cdots$ & $\cdots$ & $\cdots$ \\
\hline$\cdots$ & - & $\cdots$ \\
\hline$\because$ & 819 & $\ldots$ \\
\hline - & - & $\cdots$ \\
\hline$\cdots$ & 690 & $\cdots$ \\
\hline$\cdots$ & $\because$ & $\cdots$ \\
\hline - & 530 & $\cdots$ \\
\hline$\cdots$ & $\cdots$ & $\cdots$ \\
\hline$\cdots$ & 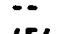 & $\cdots$ \\
\hline$\cdots$ & 454 & $\cdots$ \\
\hline$\cdots$ & $\cdots$ & $\cdots$ \\
\hline$\ldots$ & $\cdots$ & 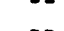 \\
\hline 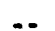 & 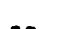 & 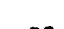 \\
\hline - & $\ldots$ & $\ldots$ \\
\hline. & -. & $\ldots$ \\
\hline -- & -. & .. \\
\hline. & $\cdots$ & - \\
\hline$\cdots$ & $\cdots$ & $\cdots$ \\
\hline 772 & 727 & $\cdots$ \\
\hline$\cdots$ & $\cdots$ & $\cdots$ \\
\hline 585 & 722 & 7.3 \\
\hline 729 & $\cdots$ & $\cdots$ \\
\hline
\end{tabular}

4.1

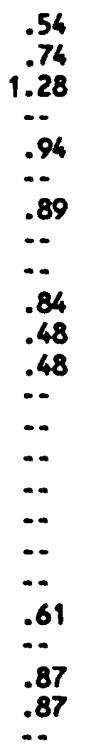


SURFACE-HATER DATA-Cont inued

CHEMICAL ANALYSES-Continued

STATION

NUMBER

DATE

$09395990 \quad \begin{aligned} & 03-09-89 \\ & 08-01-89 \\ & 09-05-89 \\ & 09-05-89 \\ & 09-05-89 \\ & 09-05-89 \\ & 09-05-89 \\ & 09-05-89 \\ & 09-05-89 \\ & 09-06-89 \\ & 03-07-90 \\ & 03-07-90 \\ & 08-14-90 \\ & 03-06-91 \\ & 03-06-91 \\ & 03-06-91 \\ & 03-06-91 \\ & 07-25-91 \\ & 07-25-91 \\ & 07-26-91 \\ & 08-07-91 \\ & 08-07-91 \\ & 08-07-91 \\ & 08-08-91\end{aligned}$

PH
WATER
WHOLE
FIELD
(SIAND-
ARD
UNITS)
(00400)

PH
HATER
MHOLE
LAB
(STAND-
ARD
UNITS)
(OO403)

ALKALINITY

WAT DIS

TOT IT

FIELD

$\mathrm{mg} / \mathrm{L}$ as

Caco3
(39086)
NITROGEN, NATONIA DISSOLVED $(\mathrm{mg} / \mathrm{L}$ (as N) (00608)

$\begin{array}{cc}\text { NITRO- } & \text { NITRO- } \\ \text { GEN, } & \text { GEN, } \\ \text { NITRITE } & \text { NITRATE } \\ \text { DIS- } & \text { DIS- } \\ \text { SOLVED } & \text { SOLVED } \\ (\mathrm{mg} / L & (\mathrm{mg} / L \\ \mathrm{as} \mathrm{N)} & \mathbf{a 8} N) \\ (00613) & (00618)\end{array}$

BLACK CREEK MEAR MOUCK, AZ-Continued

\begin{tabular}{|c|c|c|c|}
\hline . & - & .. & .. \\
\hline -- & $\cdots$ & $\cdots$ & - \\
\hline$\cdots$ & 7.7 & - & $\cdots$ \\
\hline-- & $\cdots$ & $\cdots$ & - \\
\hline - & 7.7 & -. & $\cdots$ \\
\hline -- & -- & -- & $\cdots$ \\
\hline$\cdots$ & 7.7 & -. & .. \\
\hline -- & $\because$ & $\cdots$ & - \\
\hline - & - & $\cdots$ & - \\
\hline -- & 7.7 & -. & $\cdots$ \\
\hline$\cdots$ & $\cdots$ & $\cdots$ & $\cdots$ \\
\hline$\cdots$ & $\cdots$ & $\cdots$ & $\cdots$ \\
\hline - & $\cdots$ & -- & - \\
\hline$\cdots$ & $\cdots$ & - & $\cdots$ \\
\hline$\cdots$ & " & $\cdots$ & $\cdots$ \\
\hline$\because$ & $\cdots$ & $\cdots$ & - \\
\hline$\cdots$ & $\cdots$ & $\cdots$ & $\because$ \\
\hline$\because$ & $\because$ & $\because$ & $\cdots$ \\
\hline 8.1 & 8.0 & 122 & .. \\
\hline - & -. & .. & - \\
\hline 7.6 & 7.6 & 117 & 143 \\
\hline 7.7 & $\cdots$ & -. & - \\
\hline$\cdots$ & $\cdots$ & $\cdots$ & $\cdots$ \\
\hline
\end{tabular}

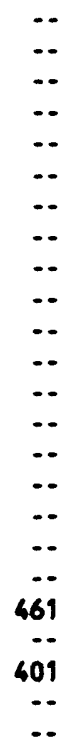

\begin{tabular}{|c|c|c|c|}
\hline$\ldots$ & $\cdots$ & - & -. \\
\hline$\cdots$ & $\cdots$ & $\cdots$ & $\cdots$ \\
\hline$\cdots$ & $\cdots$ & $\cdots$ & $\cdots$ \\
\hline$\cdots$ & $\cdots$ & $\cdots$ & $\cdots$ \\
\hline -. & $\cdots$ & $\cdots$ & $\cdots$ \\
\hline - & - & $\cdots$ & $\cdots$ \\
\hline -. & $\cdots$ & $\cdots$ & $\because-$ \\
\hline - & $\cdots$ & $\cdots$ & $\cdots$ \\
\hline - & $\cdots$ & $\cdots$ & $\cdots$ \\
\hline - & $\cdots$ & $\cdots$ & $\cdots$ \\
\hline$\ldots$ & $\cdots$ & $\because$ & $\cdots$ \\
\hline & $\because$ & $\ldots$ & $\cdots$ \\
\hline$\ldots$ & - & $\ldots$ & -. \\
\hline - & $\cdots$ & $\cdots$ & .. \\
\hline$\cdots$ & $\cdots$ & $\cdots$ & $\cdots$ \\
\hline$\cdots$ & $\cdots$ & $\cdots$ & $\because$ \\
\hline$\cdots$ & $\cdots$ & $\cdots$ & - \\
\hline 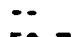 & $\because$ & 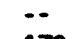 & $\because$ \\
\hline 50.7 & .450 & .170 & 1.43 \\
\hline & 340 & $\ddot{0} 0$ & pis \\
\hline & $\because 30$ & .00 & $\begin{array}{r}1 .<4 \\
\ldots\end{array}$ \\
\hline & $\ldots$ & 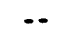 & \\
\hline
\end{tabular}


SURFACE-WATER DATA-Cont inued

CHEMICAL ANALYSES-Continued

\begin{tabular}{|c|c|c|c|c|c|c|c|c|c|c|}
\hline $\begin{array}{l}\text { TATION } \\
\text { MBERR }\end{array}$ & DATE & $\begin{array}{c}\text { NITRO- } \\
\text { GEN, } \\
\text { MO2+NÓ3 } \\
\text { D1S- } \\
\text { SOLVED } \\
\text { (mo/L } \\
\text { as N) } \\
(00631)\end{array}$ & $\begin{array}{c}\text { NITRO- } \\
\text { GEN, } \\
\text { NITRATE } \\
\text { DIS- } \\
\text { SOLVED } \\
\text { (mo/l } \\
\text { as NO3) } \\
\text { (71851) }\end{array}$ & $\begin{array}{c}\text { NITRO- } \\
\text { GEN, } \\
\text { NITRITE } \\
\text { DIS- } \\
\text { SOLVED } \\
\text { (mo/L } \\
\text { As NO2) } \\
(71856)\end{array}$ & $\begin{array}{l}\text { NITRO- } \\
\text { GEN,NM- } \\
\text { MONIA + } \\
\text { ORGANIC } \\
\text { TOTAL } \\
(\mathrm{mg} / L \\
\text { OS N) } \\
(00625)\end{array}$ & $\begin{array}{l}\text { PHOS- } \\
\text { PHORUS } \\
\text { DIS- } \\
\text { SOLVED } \\
\text { (mo/L } \\
\text { as P) } \\
(00666)\end{array}$ & $\begin{array}{c}\text { PHOS- } \\
\text { PHORUS } \\
\text { TOTAL } \\
(m 0 / L \\
\text { as P) } \\
(00665)\end{array}$ & $\begin{array}{l}\text { PHOS- } \\
\text { PHORUS } \\
\text { ORTHO, } \\
\text { DIS- } \\
\text { SOLVED } \\
\text { (ag/L } \\
\text { as P) } \\
(00671)\end{array}$ & $\begin{array}{l}\text { PHOS- } \\
\text { PHATE, } \\
\text { ORTHO, } \\
\text { DIS- } \\
\text { SOLVED } \\
(\mathrm{mg} / \mathrm{L} \\
\text { SS PO4) } \\
(00660)\end{array}$ & $\begin{array}{l}\text { HARD- } \\
\text { NESS } \\
\text { TOTAL } \\
\text { (mo/L } \\
\text { as } \\
\text { Caco3) } \\
(00900)\end{array}$ \\
\hline
\end{tabular}

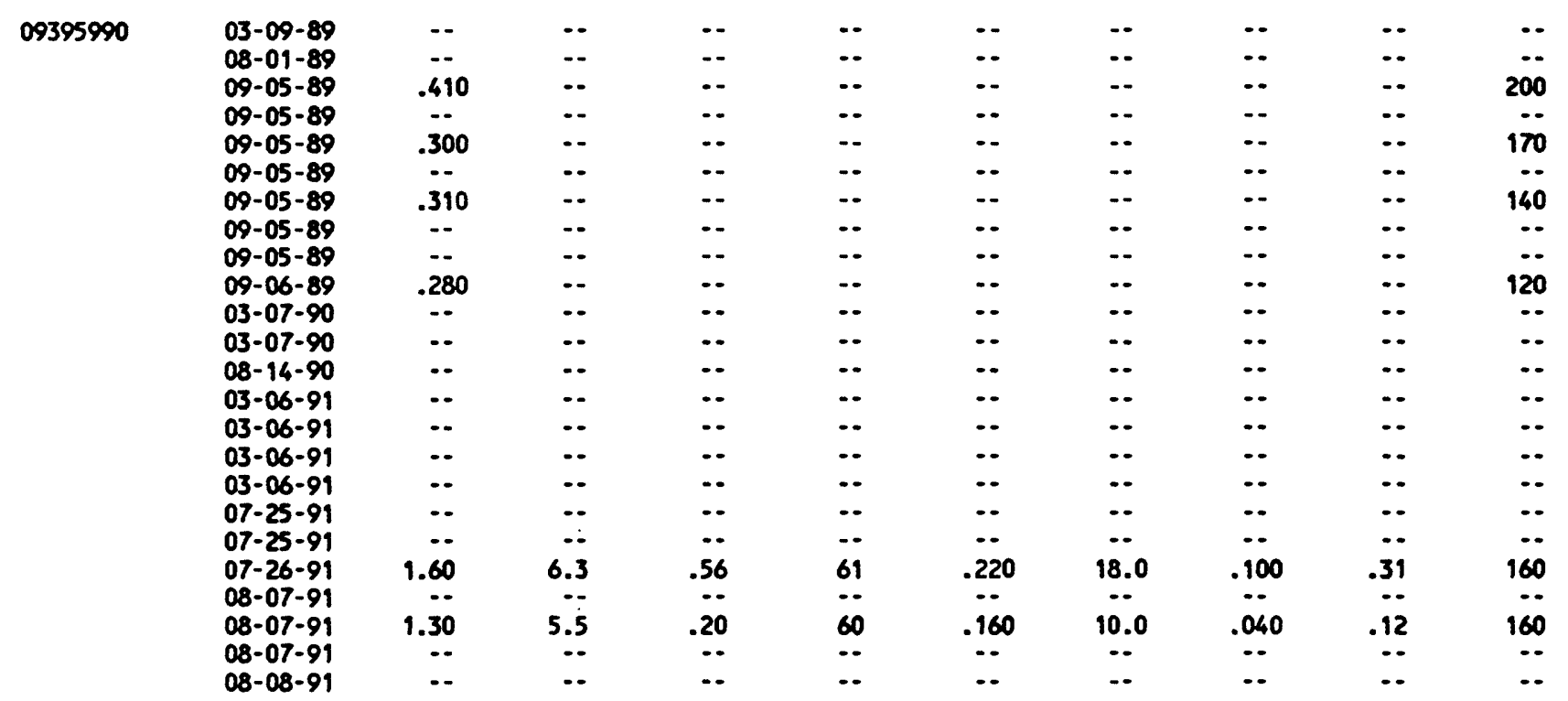


STATION

MUMBER

09395990

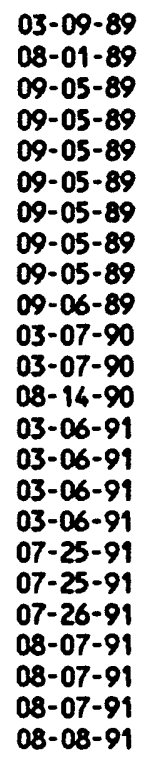

MAGNE-

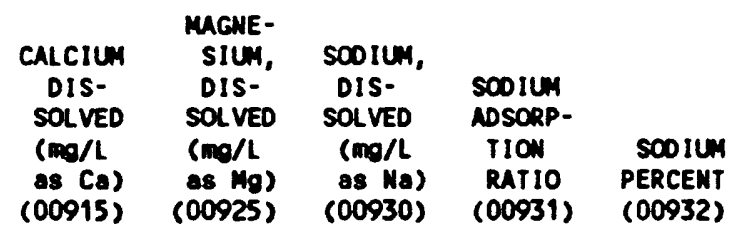

POTASSIUM, DISSOLVED (mo/l as $K$ ) $(00935)$
CHLORIDE, DISSOL VED $(\mathrm{mg} / \mathrm{L}$ $88 \mathrm{Cl}$ ) (0094D)
FLUORIDE, DIS- DISSOLVED SOLVED $(\mathrm{mg} / \mathrm{L} \quad(\mathrm{mg} / \mathrm{L}$ as $\mathrm{Br}$ ) $\quad \mathrm{s}(\mathrm{F})$ (71870) (00950)

BLACK CREEK MEAR hOUCK, AZ-Continued

\begin{tabular}{|c|c|c|c|c|c|c|c|c|}
\hline$\cdots$ & -- & -. & -. & -. & -. & $\cdots$ & -. & $\cdots$ \\
\hline . & $\ldots$ & $\cdots$ & $\cdots$ & $\cdots$ & -. & $\cdots$ & .. & -. \\
\hline 54 & 15 & 91 & 3 & 49 & 5.1 & 59 & .13 & .50 \\
\hline$\ldots$ & - & $\cdots$ & - & $\cdots$ & - & $\cdots$ & $\cdots$ & -. \\
\hline 48 & 12 & 80 & 3 & 50 & 4.9 & 46 & .11 & .50 \\
\hline$\cdots$ & $\cdots$ & $\cdots$ & $\cdots$ & $\cdots$ & . & $\because$ & $\ldots$ & $\ldots$ \\
\hline 38 & 9.6 & 62 & 2 & 49 & 4.4 & 30 & .070 & .50 \\
\hline$\cdots$ & $\cdots$ & $\cdots$ & $\cdots$ & $\cdots$ & $\cdots$ & $\cdots$ & $\cdots$ & -. \\
\hline$\cdots$ & $\cdots$ & $\cdots$ & $\cdots$ & $\cdots$ & $\cdots$ & $\cdots$ & $\cdots$ & -. \\
\hline 33 & 8.3 & 48 & 2 & 46 & 4.1 & 21 & .080 & .60 \\
\hline$\cdots$ & -- & $\cdots$ & $\cdots$ & -. & -. & $\cdots$ & $\cdots$ & $\cdots$ \\
\hline$\cdots$ & $\cdots$ & $\cdots$ & $\cdots$ & $\cdots$ & $\cdots$ & $\cdots$ & $\cdots$ & -. \\
\hline$\cdots$ & $\cdots$ & $\cdots$ & $\cdots$ & $\cdots$ & $\cdots$ & $\cdots$ & $\cdots$ & $\cdots$ \\
\hline$\cdots$ & $\cdots$ & $\cdots$ & $\cdots$ & $\cdots$ & $\cdots$ & $\cdots$ & $\cdots$ & -. \\
\hline$\cdots$ & $\cdots$ & $\cdots$ & $\cdots$ & $\cdots$ & $\cdots$ & $\cdots$ & -. & $\cdots$ \\
\hline$\cdots$ & -- & $\cdots$ & $\cdots$ & $\cdots$ & $\cdots$ & $\cdots$ & $\cdots$ & $\cdots$ \\
\hline$\cdots$ & $\cdots$ & $\cdots$ & $\cdots$ & $\cdots$ & $\cdots$ & $\cdots$ & $\cdots$ & $\cdots$ \\
\hline$\cdots$ & $\cdots$ & $\cdots$ & $\cdots$ & $\because$ & $\because$ & 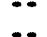 & $\because$ & $\cdots$ \\
\hline 44 & 12 & 87 & 3 & 53 & 7.4 & 48 & .64 & .50 \\
\hline 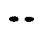 & $\because$ & $\cdots$ & $\ldots$ & $\cdots$ & $\cdots$ & -- & $\cdots$ & .. \\
\hline 45 & 11 & 68 & 2 & 47 & 6.3 & 40 & 1.7 & .50 \\
\hline$\cdots$ & $\cdots$ & $\cdots$ & $\cdots$ & $\cdots$ & $\cdots$ & $\cdots$ & - & $\cdots$ \\
\hline -. & - & $\cdots$ & $\cdots$ & $\cdots$ & $\cdots$ & $\cdots$ & $\cdots$ & \\
\hline
\end{tabular}


SURFACE-HATER DATA-Continued

CHEMICAL ANALYSES-Continued

\begin{tabular}{|c|c|c|c|c|c|c|c|c|c|c|}
\hline $\begin{array}{l}\text { STATION } \\
\text { MUNBER }\end{array}$ & DATE & $\begin{array}{l}\text { SILICA, } \\
\text { DIS- } \\
\text { SOLVED } \\
\text { (mg/L } \\
\text { as } \\
\text { sio2) } \\
(00955)\end{array}$ & $\begin{array}{c}\text { SULFATE } \\
\text { DIS- } \\
\text { SOLVED } \\
\text { (mg/L } \\
\text { as sol4) } \\
(00945 \text { ) }\end{array}$ & $\begin{array}{c}\text { ARSENIC } \\
\text { DIS- } \\
\text { SOLVED } \\
\text { ( } \mu G / L \\
\text { AS AS) } \\
(01000)\end{array}$ & $\begin{array}{l}\text { BARIUH, } \\
\text { DIS- } \\
\text { SOLVED } \\
(\mu \sigma / L \\
\text { as Ba) } \\
(01005)\end{array}$ & $\begin{array}{l}\text { BERYL- } \\
\text { LIUH, } \\
\text { DIS- } \\
\text { SOLVED } \\
\text { ( } \mu \sigma / L \\
\text { as Be) } \\
(01010)\end{array}$ & $\begin{array}{l}\text { CADHIUM } \\
\text { DIS- } \\
\text { SOLVED } \\
\text { ( } \mu g / L \\
\text { as Cd) } \\
\text { (01025) }\end{array}$ & $\begin{array}{l}\text { CHRO- } \\
\text { MIUA, } \\
\text { DIS- } \\
\text { SOLVED } \\
\text { ( } \mu g / L \\
\text { as Cr) } \\
(01030)\end{array}$ & $\begin{array}{c}\text { COBALT, } \\
\text { DIS- } \\
\text { SOLVED } \\
\text { ( } \mu g / L \\
\text { as Co) } \\
(01035)\end{array}$ & $\begin{array}{c}\text { COPPER, } \\
\text { DIS- } \\
\text { SOLVED } \\
\text { ( } \mu g / L \\
\text { as CU) } \\
(01040)\end{array}$ \\
\hline
\end{tabular}

BLACK CREEK MEAR HOUCK, A2-Continued

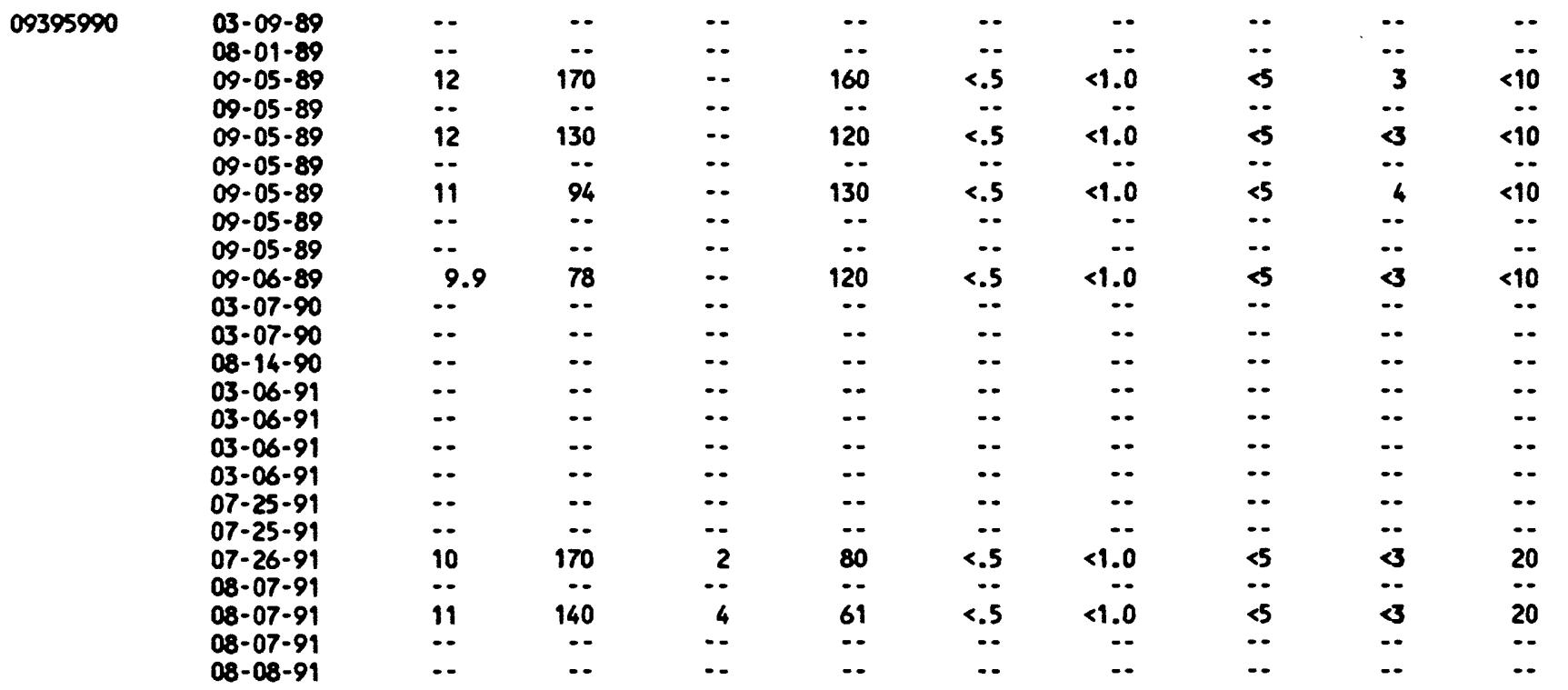


STATION

MUMER

DATE

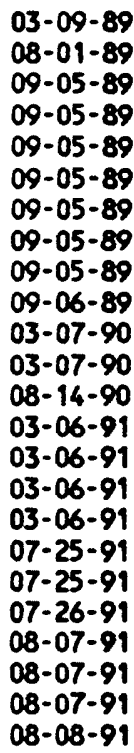

\begin{tabular}{|c|c|}
\hline 09395990 & $\begin{array}{l}03-09-89 \\
08-01-89 \\
09-05-89 \\
09-05-89 \\
09-05-89 \\
09-05-89 \\
09-05-89 \\
09-05-89 \\
09-05-89 \\
09-06-89 \\
03-07-90 \\
03-07-90 \\
08-14-90 \\
03-06-91 \\
03-06-91 \\
03-06-91 \\
03-06-91 \\
07-25-91 \\
07-25-91 \\
07-26-91 \\
08-07-91 \\
08-07-91 \\
08-07-91 \\
08-08-91\end{array}$ \\
\hline
\end{tabular}

\begin{tabular}{|c|c|c|c|c|c|c|c|c|}
\hline $\begin{array}{l}\text { IRON, } \\
\text { DIS- } \\
\text { SOLVED } \\
\text { ( } \mu g / L \\
\text { as Fe) } \\
(01046)\end{array}$ & $\begin{array}{l}\text { LEAD, } \\
\text { DIS- } \\
\text { SOLVED } \\
(\mu g / L \\
\text { as Pb) } \\
(01049)\end{array}$ & $\begin{array}{c}\text { MANGA- } \\
\text { NESE, } \\
\text { DIS- } \\
\text { SOLVED } \\
(\mu g / L) \\
\text { as } \mathrm{Nn}) \\
(01056)\end{array}$ & $\begin{array}{c}\text { MOLYB- } \\
\text { DENUN, } \\
\text { DIS- } \\
\text { SOLVED } \\
(\mu 9 / L \\
\text { as MO) } \\
(01060)\end{array}$ & $\begin{array}{l}\text { NICKEL, } \\
\text { DIS- } \\
\text { SOLVED } \\
\text { ( } \mu g / L \\
\text { as Ni) } \\
(01065)\end{array}$ & $\begin{array}{l}\text { SILVER, } \\
\text { DIS- } \\
\text { SOLVED } \\
\text { ( } \mu g / L \\
\text { as Ag) } \\
\text { (01075) }\end{array}$ & $\begin{array}{l}\text { STRON- } \\
\text { TIUA, } \\
\text { DIS- } \\
\text { SOLVED } \\
\text { ( } \mu \mathrm{g} / \mathrm{L} \\
\text { as Sr) } \\
\text { (01080) }\end{array}$ & $\begin{array}{l}\text { VANA- } \\
\text { DIUH, } \\
\text { DIS- } \\
\text { SOLVED } \\
(\mu g / L \\
\text { as V) } \\
(01085)\end{array}$ & $\begin{array}{c}\text { ZINC, } \\
\text { DIS- } \\
\text { SOLVED } \\
\text { ( } \mu g / L \\
\text { os } 2 n) \\
(01090)\end{array}$ \\
\hline
\end{tabular}

BLACK CREEK MEAR HOUCK, AZ-Continued

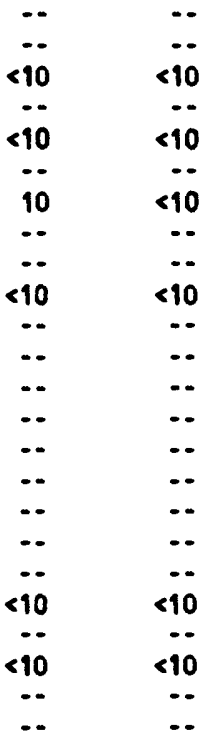

\begin{tabular}{|c|c|c|}
\hline .. & .. & .. \\
\hline 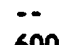 & $\cdots$ & 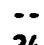 \\
\hline 600 & $<6$ & 24 \\
\hline$\cdots$ & $\cdots$ & -. \\
\hline 520 & $<6$ & 14 \\
\hline$\cdots$ & $\cdots$ & - \\
\hline 410 & $<6$ & 20 \\
\hline$\cdots$ & $\cdots$ & - \\
\hline$\cdots$ & $\cdots$ & $\cdots$ \\
\hline 350 & $<6$ & 17 \\
\hline$\cdots$ & $\cdots$ & $\cdots$ \\
\hline$\cdots$ & $\cdots$ & $\cdots$ \\
\hline 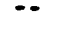 & $\cdots$ & $\cdots$ \\
\hline- & $\cdots$ & $\cdots$ \\
\hline$\because$ & $\cdots$ & $\cdots$ \\
\hline$\cdots$ & $\because$ & $\because$ \\
\hline . & $\ldots$ & $\cdots$ \\
\hline 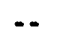 & $\ldots$ & .. \\
\hline 500 & $<6$ & 19 \\
\hline 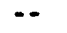 & $\cdots$ & $\cdots$ \\
\hline 480 & 7 & 8 \\
\hline 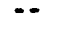 & $\cdots$ & $\cdots$ \\
\hline & $\cdots$ & \\
\hline
\end{tabular}


SURFACE-WATER DATA-Cont inued

CHEMICAL ANALYSES-Cont inued

STATION

MUAER

DATE

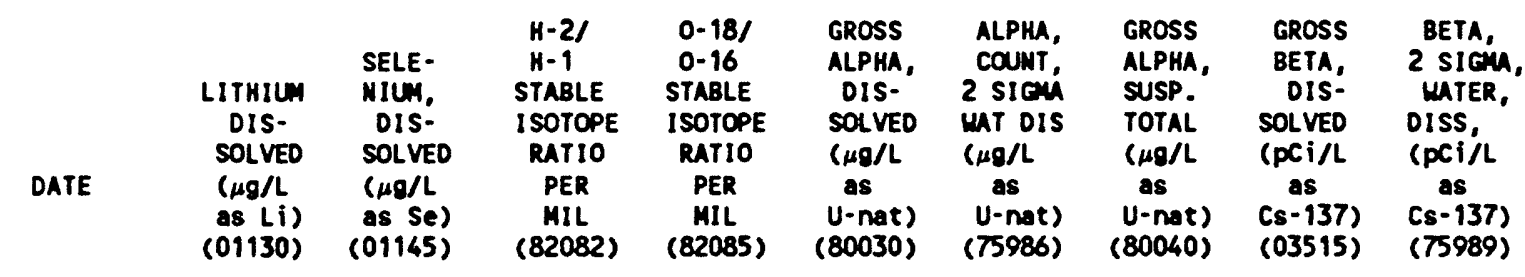

BLACK CREEK NEAR HOUCK, AZ-Cont inued

$0339590 \quad 03-09-89$
$08-01-89$
$09-05-89$
$09-05-89$
$09-05-89$
$09-05-89$
$09-05-89$
$09-05-89$
$09-05-89$
$09-06-89$
$03-07-90$
$03-07-90$
$08-14-90$
$03-06-91$
$03-06-91$
$03-06-91$
$03-06-91$
$07-25-91$
$07-25-91$
$07-26-91$
$08-07-91$
$08-07-91$
$08-07-91$
$08-08-91$

$\ldots$
$\ldots$
14
13
$\ldots$
11
$\ldots$
$\ldots$
8
$\ldots$
$\ldots$
$\ldots$
$\ldots$
$\ldots$
$\ldots$
$\ldots$
17
$\ldots$
15
$\ldots$

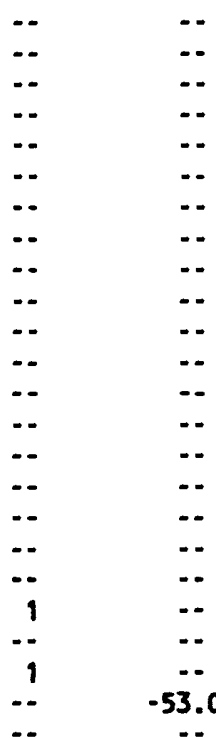

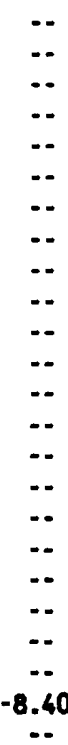

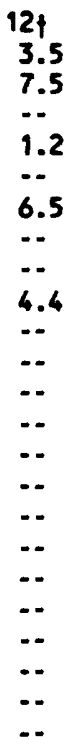

\section{2.}

\section{0}

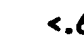

$<.6$

510* 23

590*

560

3.8

$930^{\circ}$

1.4

-.

1.2

--

$1100 *$

-..

--

-

-.

-

$-$

$-$

$-$

$-$

-

-.

--

$\because$

$\because$.

-.

$\because$.

-.

-.

$\because$

-.

-.

$-$

$-$

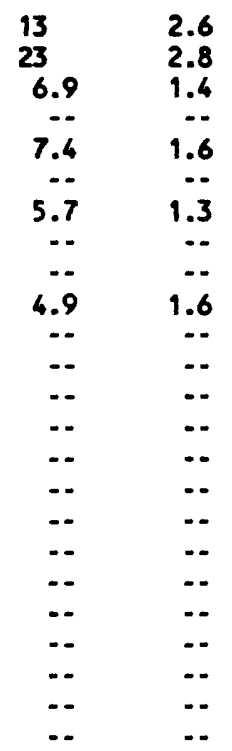




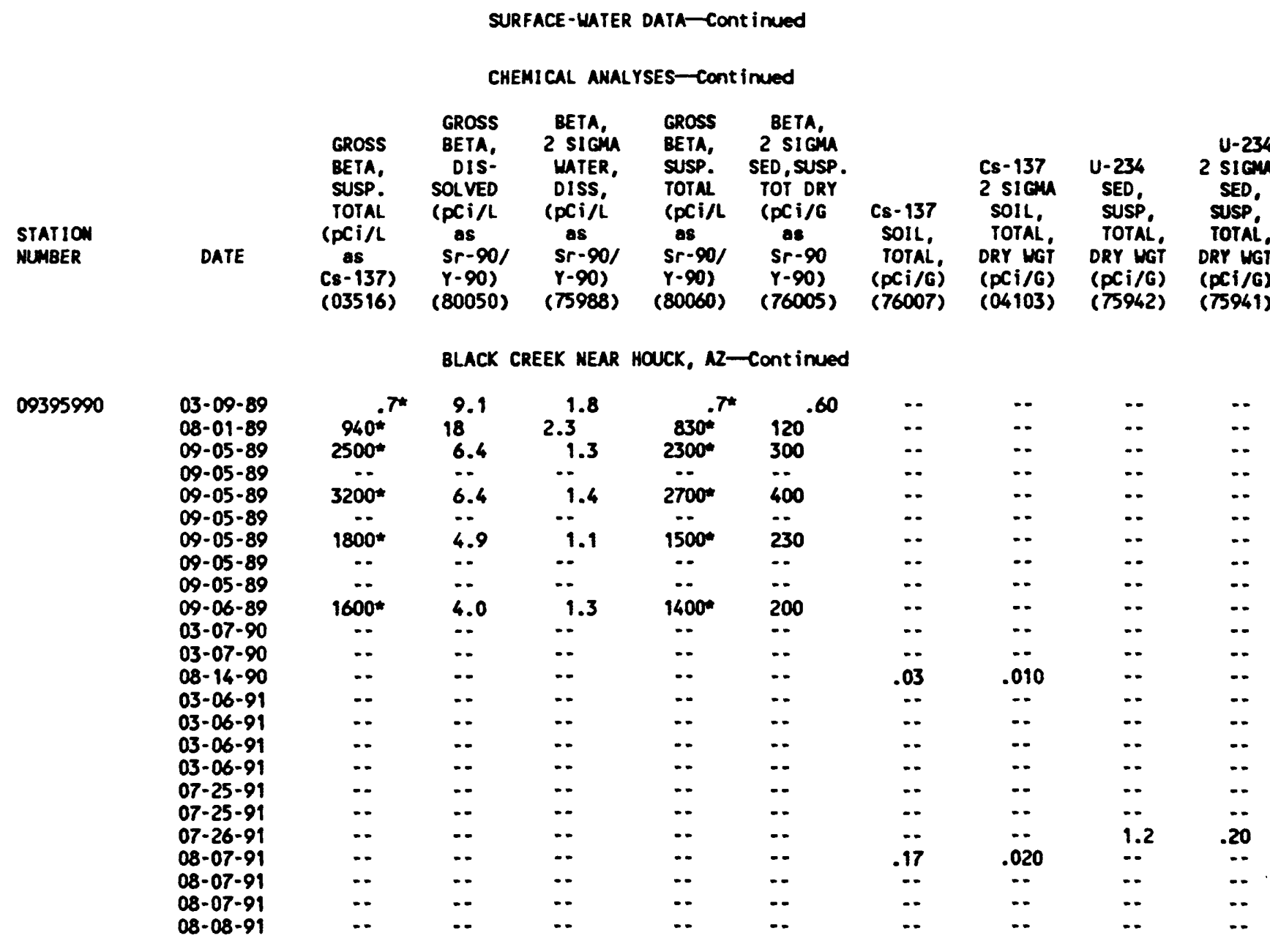


SURFACE-WATER DATA-Continued

CHEMICAL ANALYSES-Cont inued

STATION

MUABER

09395990

$$
\begin{aligned}
& 03-09-89 \\
& 08-01-89 \\
& 09-05-89 \\
& 09-05-89 \\
& 09-05-89 \\
& 09-05-89 \\
& 09-05-89 \\
& 09-05-89 \\
& 09-05-89 \\
& 09-06-89 \\
& 03-07-90 \\
& 03-07-90 \\
& 08-14-90 \\
& 03-06-91 \\
& 03-06-91 \\
& 03-06-91 \\
& 03-06-91 \\
& 07-25-91 \\
& 07-25-91 \\
& 07-26-91 \\
& 08-07-91 \\
& 08-07-91 \\
& 08-07-91 \\
& 08-08-91
\end{aligned}
$$

\begin{tabular}{|c|c|c|c|c|c|c|c|c|}
\hline $\begin{array}{l}\text { U-235 } \\
2 \text { SIGMA } \\
\text { SED, } \\
\text { SUSP, } \\
\text { TOTAL, } \\
\text { ORY WGT } \\
\text { (PCi/G) } \\
\text { (75947) }\end{array}$ & $\begin{array}{l}\text { U-235 } \\
\text { SED, } \\
\text { SUSP, } \\
\text { TOTAL, } \\
\text { DRY WGT } \\
\text { (PCi/G) } \\
\text { ( } 75975 \text { ) }\end{array}$ & $\begin{array}{c}\text { U-238 } \\
\text { SED, } \\
\text { SUSP, } \\
\text { TOTAL, } \\
\text { DRY WGT } \\
\text { (PCi/G) } \\
\text { (75940) }\end{array}$ & $\begin{array}{c}\text { U-238 } \\
2 \text { SIGMA } \\
\text { SED, } \\
\text { SUSP, } \\
\text { TOTAL, } \\
\text { DRY WGT } \\
\text { (PCi/G) } \\
\text { (041113) }\end{array}$ & $\begin{array}{l}\text { Th-230 } \\
\text { SED, } \\
\text { SUSP, } \\
\text { TOTAL, } \\
\text { DRY WGT } \\
\text { (PCi/G) } \\
\text { (TS939) }\end{array}$ & $\begin{array}{l}\text { Th-230 } \\
2 \text { SIGMA } \\
\text { SED, } \\
\text { SUSP, } \\
\text { TOTAL, } \\
\text { DRY WGT } \\
\text { (PCi/G) } \\
\text { (75952) }\end{array}$ & $\begin{array}{c}\text { Th-232 } \\
\text { SED, } \\
\text { SUSP, } \\
\text { TOTAL, } \\
\text { DRY WGT } \\
\text { (PCi } / G \text { ) } \\
\text { (75953) }\end{array}$ & $\begin{array}{l}\text { Th-232 } \\
2 \text { SIGU } \\
\text { SED, } \\
\text { SUSP, } \\
\text { TOTAL, } \\
\text { DRY WGT } \\
\text { (PCi/G) } \\
\text { (75936) }\end{array}$ & $\begin{array}{l}\text { ALUN- } \\
\text { INUN } \\
\text { BOT MAT } \\
\text { C63 DS DS } \\
\text { LAB } \\
\text { PERCENT } \\
\text { (34792) }\end{array}$ \\
\hline
\end{tabular}

\begin{tabular}{|c|c|c|c|c|c|c|c|c|}
\hline - & $\cdots$ & $\cdots$ & $\cdots$ & $\cdots$ & $\cdots$ & $\cdots$ & $\cdots$ & $\because$ \\
\hline$\cdots$ & $\cdots$ & $\cdots$ & $\cdots$ & $\cdots$ & $\cdots$ & $\cdots$ & $\therefore$ & 7.8 \\
\hline$\cdots$ & $\cdots$ & $\cdots$ & $\cdots$ & $\cdots$ & $\cdots$ & $\cdots$ & $\cdots$ & 8.6 \\
\hline$\cdots$ & -. & $\cdots$ & - & -. & - & -. & -. & $\therefore$ \\
\hline 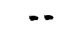 & - & $\cdots$ & $\cdots$ & $\cdots$ & $\cdots$ & $\cdots$ & -. & 8.4 \\
\hline$\cdots$ & $\cdots$ & $\cdots$ & $\cdots$ & $\cdots$ & $\cdots$ & $\cdots$ & $\cdots$ & - \\
\hline$\cdots$ & $\cdots$ & $\cdots$ & $\cdots$ & $\cdots$ & $\cdots$ & $\cdots$ & -. & 8.4 \\
\hline$\cdots$ & $\cdots$ & $\cdots$ & $\cdots$ & $\cdots$ & $\cdots$ & $\cdots$ & - & $\cdots$ \\
\hline$\cdots$ & $\cdots$ & $\cdots$ & $\cdots$ & $\cdots$ & $\cdots$ & $\cdots$ & - & $\cdots$ \\
\hline$\cdots$ & $\cdots$ & $\cdots$ & $\cdots$ & $\cdots$ & - & $\cdots$ & -. & 9.2 \\
\hline$\cdots$ & $\cdots$ & $\cdots$ & $\cdots$ & $\cdots$ & $\cdots$ & $\cdots$ & -. & $\cdots$ \\
\hline$\cdots$ & $\cdots$ & $\cdots$ & $\cdots$ & $\cdots$ & $\cdots$ & $\cdots$ & $\cdots$ & $\cdots$ \\
\hline$\because$ & $\cdots$ & $\cdots$ & $\cdots$ & $\cdots$ & $\cdots$ & $\cdots$ & .. & $\cdots$ \\
\hline$\cdots$ & $\cdots$ & $\cdots$ & $\cdots$ & $\cdots$ & $\cdots$ & $\cdots$ & -. & $\cdots$ \\
\hline$\cdots$ & $\cdots$ & $\cdots$ & $\cdots$ & $\cdots$ & $\cdots$ & $\cdots$ & $\therefore$ & $\cdots$ \\
\hline$\cdots$ & $\cdots$ & $\cdots$ & $\cdots$ & - & $\cdots$ & $\cdots$ & $\cdots$ & $\cdots$ \\
\hline$\cdots$ & $\cdots$ & $\cdots$ & $\cdots$ & $\cdots$ & $\cdots$ & $\cdots$ & - & $\cdots$ \\
\hline$\cdots$ & $\cdots$ & $\cdots$ & $\cdots$ & 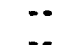 & $\cdots$ & $\because$ & - & 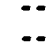 \\
\hline$\ddot{z}$ & $\cdots$ & $\because 2$ & $\because 7$ & $\because$ & $\ddot{3 n}$ & $\because$ & $\ddot{2 z}$ & $\because$ \\
\hline$<.03$ & $<.1$ & 1.3 & .17 & 1.6 & .20 & 1.6 & .23 & 9.8 \\
\hline$\cdots$ & $\cdots$ & $\cdots$ & $\cdots$ & $\cdots$ & $\cdots$ & $\cdots$ & $\cdots$ & 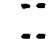 \\
\hline$\cdots$ & $\cdots$ & $\cdots$ & $\cdots$ & $\cdots$ & $\cdots$ & $\cdots$ & $\cdots$ & 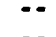 \\
\hline$\cdots$ & $\cdots$ & $\cdots$ & $\cdots$ & $\cdots$ & $\because$ & $\cdots$ & $\cdots$ & 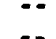 \\
\hline$\cdots$ & $\cdots$ & $\because$ & $\cdots$ & 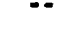 & $\cdots$ & $\cdots$ & $\because$ & \\
\hline
\end{tabular}

BLACK CREEK NEAR HOUCK, A2-Continued 
SURFACE-WATER DATA-Continued

CHEMICAL AMALYSES-Cont inued

STATION

MUABER

DATE

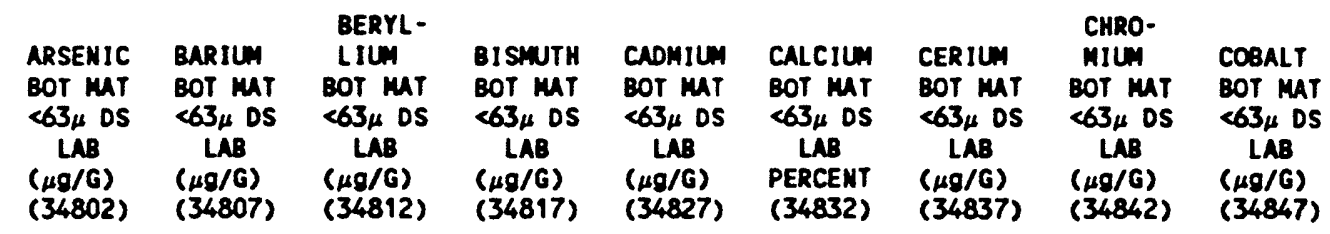

09395990

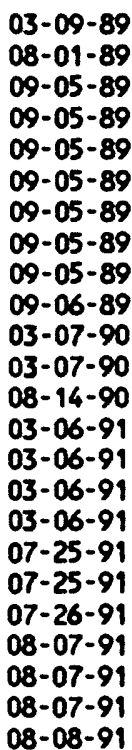

BLACK CREEK MEAR HOUCK, AZ-Continued

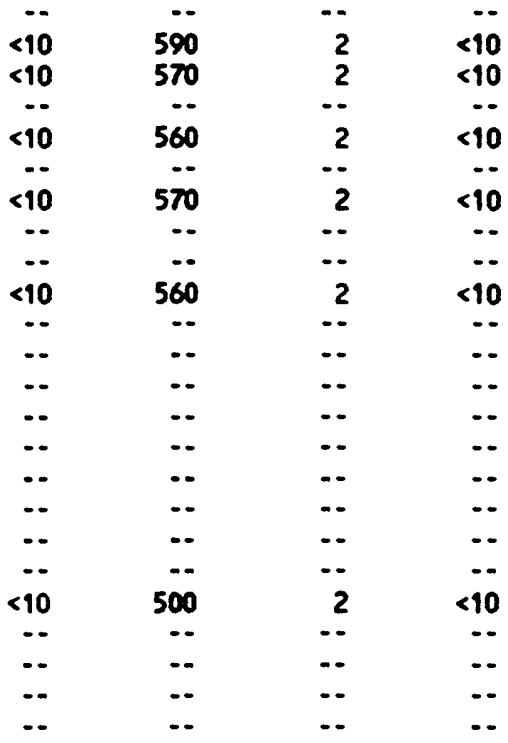

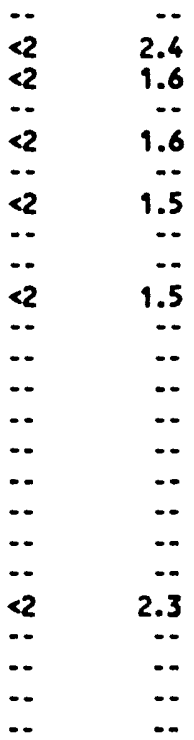

\begin{tabular}{|c|c|}
\hline$\cdots$ & $\cdots$ \\
\hline $\begin{array}{l}87 \\
83\end{array}$ & $\begin{array}{l}52 \\
50\end{array}$ \\
\hline - & $\cdots$ \\
\hline 81 & 49 \\
\hline$\cdots$ & $\cdots$ \\
\hline 80 & 46 \\
\hline$\cdots$ & $\cdots$ \\
\hline$\because$ & $\because$ \\
\hline 83 & 51 \\
\hline$\cdots$ & $\cdots$ \\
\hline$\cdots$ & $\cdots$ \\
\hline$\cdots$ & -. \\
\hline$\cdots$ & $\cdots$ \\
\hline$\cdots$ & $\cdots$ \\
\hline$\because$ & $\cdots$ \\
\hline$\cdots$ & $\cdots$ \\
\hline 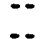 & $\because$ \\
\hline 80 & 60 \\
\hline$\cdots$ & $\cdots$ \\
\hline$\cdots$ & - \\
\hline$\cdots$ & $\cdots$ \\
\hline & $\ldots$ \\
\hline
\end{tabular}


SURFACE-WATER DATA-Cont inued

CHEMICAL ANALYSES-Cont inued

\begin{tabular}{|c|c|c|c|c|c|c|c|c|c|c|}
\hline $\begin{array}{l}\text { STATION } \\
\text { NUABER }\end{array}$ & DATE & $\begin{array}{c}\text { COPPER } \\
\text { BOT MAT } \\
\angle 63 \mu \text { DS } \\
\text { LAB } \\
(\mu g / G) \\
(34852)\end{array}$ & $\begin{array}{c}\text { EURO- } \\
\text { PIUA } \\
\text { BOT MAT } \\
\angle 63_{\mu} \text { DS } \\
\text { LAB } \\
(\mu g / G) \\
(34857)\end{array}$ & $\begin{array}{l}\text { GALLIUM } \\
\text { BOT MAT } \\
\angle 63_{\mu} \text { OS } \\
\text { LAB } \\
(\mu g / G) \\
(34862)\end{array}$ & $\begin{array}{c}\text { COLD } \\
\text { BOT MAT } \\
\angle 63 \mu \text { OS } \\
\text { LAB } \\
(\mu g / G) \\
(34872)\end{array}$ & $\begin{array}{c}\text { HOLMIUA } \\
\text { BOT MAT } \\
\angle 63_{\mu} \text { DS } \\
\text { LAB } \\
(\mu 9 / G) \\
(34877)\end{array}$ & $\begin{array}{l}\text { IRON } \\
\text { BOT MAT } \\
\angle 63 \mu \text { OS } \\
\text { LAB } \\
\text { PERCENT } \\
\text { (34882) }\end{array}$ & $\begin{array}{c}\text { LANTHA- } \\
\text { NUA } \\
\text { BOT MAT } \\
\angle 63_{\mu} \text { DS } \\
\text { LAB } \\
(\mu g / G) \\
(34887)\end{array}$ & $\begin{array}{c}\text { LEAD } \\
\text { BOT MAT } \\
\angle 63_{\mu} \text { DS } \\
\text { LAB } \\
(\mu g / G) \\
(34892)\end{array}$ & $\begin{array}{c}\text { LITHIUA } \\
\text { BOT MAT } \\
<63 \mu \text { OS } \\
\text { LAB } \\
(\mu g / G) \\
(34897)\end{array}$ \\
\hline
\end{tabular}

$09395990 \quad 03-09-89$
$08-01-89$
$09-05-89$
$09-05-89$
$09-05-89$
$09-05-89$
$09-05-89$
$09-05-89$
$09-05-89$
$09-06-89$
$03-07-90$
$03-07-90$
$08-14-90$
$03-06-91$
$03-06-91$
$03-06-91$
$03-06-91$
$07-25-91$
$07-25-91$
$07-26-91$
$08-07-91$
$08-07-91$
$08-07-91$
$08-08-91$

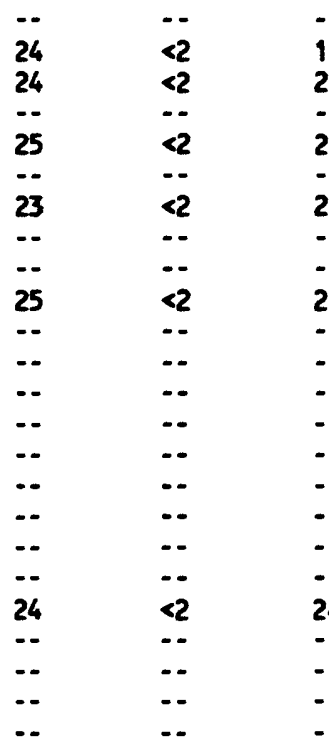

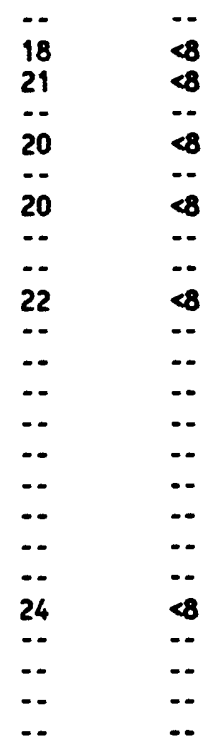

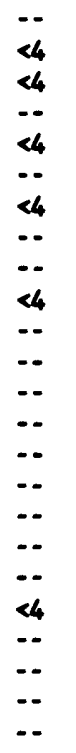

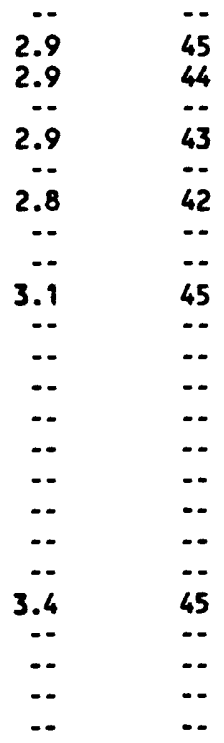

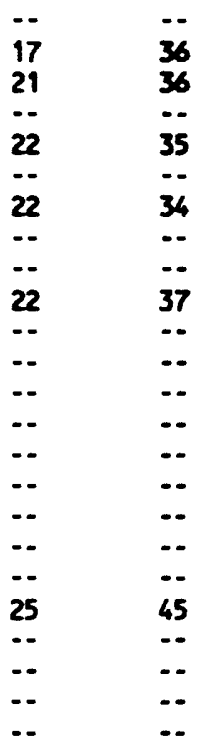




\author{
SURFACE-WATER DATA-Continued \\ ChEMICAL ANALYSES-Cont inued
}

STATION

MUMBER

DATE

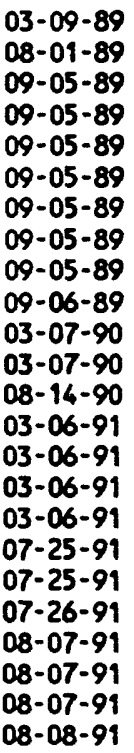

09395990
MAGNESIUA

BOT MAT

$<63 \mu$ DS

LAB

PERCENT

(34902)
MANGA- MOLYB- NEOOYM-

MESE

BOT MAT

$\angle 63_{\mu}$ DS

LAB

$(\mu g / G)$

(34907) $\angle 63 \mu$ DS

$(\mu 9 / G)$

(34922)
IUN

BOT MAT BOT MAT

$<63 \mu$ DS

LAB

( $\mu \mathrm{g} / \mathrm{G})$

(34917)

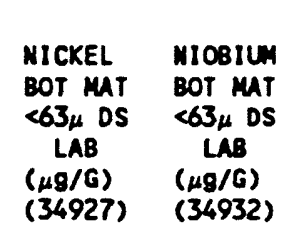

PHOSPHORUS

BOT MAT

$\angle 63 \mu$ DS

LAB

PERCENT
(34937)

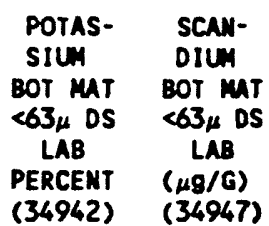

BLACK CREEK NEAR HOUCK, AZ-Continued

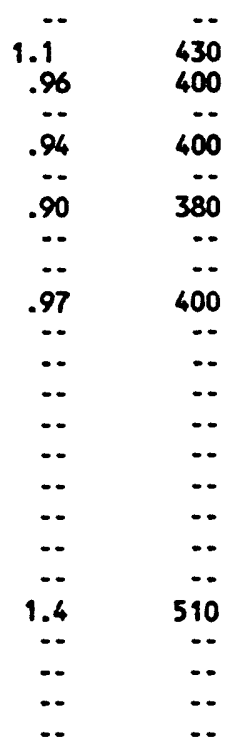

$\cdots$
$<2$
$<2$
$\cdots$
$<2$
$\cdots$
$<2$
$\cdots$
$\cdots$
$<2$
$\cdots$
$\cdots$
$\cdots$
$\cdots$
$\cdots$
$\cdots$
$\cdots$
$\cdots$
$<2$
$\cdots$
$\cdots$
$\cdots$
$\cdots$

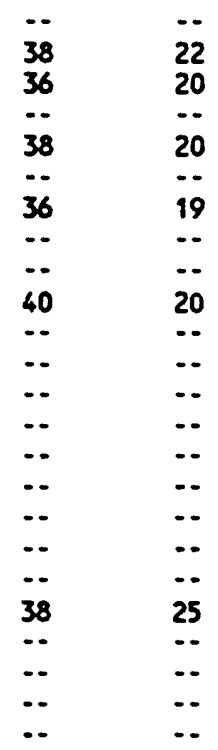

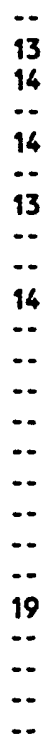

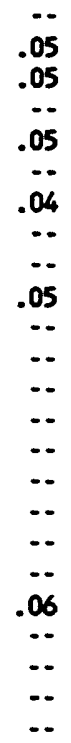

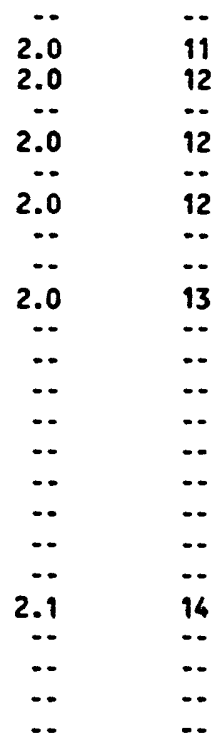




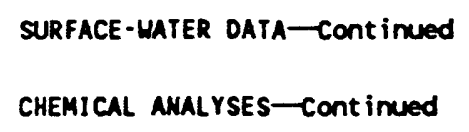

SILVER
BOT MAT
$\angle 63_{\mu}$ OS
LAB
( $\mu 9 / G)$
$(34957)$

SOOIUN
BOT MAT
$\angle 63_{\mu}$ OS
LAB
PERCENT
(34962)

STRON- TANTATIUA LUM THORIUM BOT MAT BOT MAT BOT MAT $\angle 63 \mu$ oS $\angle 63_{\mu}$ DS $\angle 63_{\mu}$ DS

$1 A B$

LAB

$(\mu g / G)$

(34967)

( $\mu g / G)$

LAB

$(\mu g / 6)$

(34982)

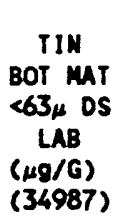

TITA-

NIUN

VARA$\angle 63_{\mu}$ DS $\angle 63 \mu$ OS $\angle 63_{\mu}$ OS

BLACK CREEK MEAR HOUCK, AZ-Continued

$09395990 \quad 03-09-89$
$08-01-89$
$09-05-89$
$09-05-89$
$09-05-89$
$09-05-89$
$09-05-89$
$09-05-89$
$09-05-89$
$09-06-89$
$03-07-90$
$03-07-90$
$08-14-90$
$03-06-91$
$03-06-91$
$03-06-91$
$03-06-91$
$07-25-91$
$07-25-91$
$07-26-91$
$08-07-91$
$08-07-91$
$08-07-91$
$08-08-91$

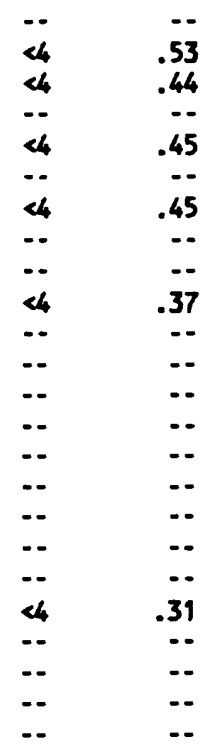

170
150
--
150
--
150
--
--
150
--
--
--
$\cdots$
--
--
--
--
--
180
--
--
--
--

$<40$

$<40$

$<40$

-.

$<40$

-.

$<40$

$<40$

$\because$

$\because$

$\because$

$\because$

$\because$

$\because$

..

$<40$

--

$--$

$-$

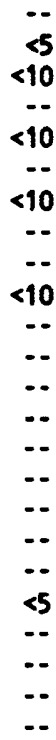

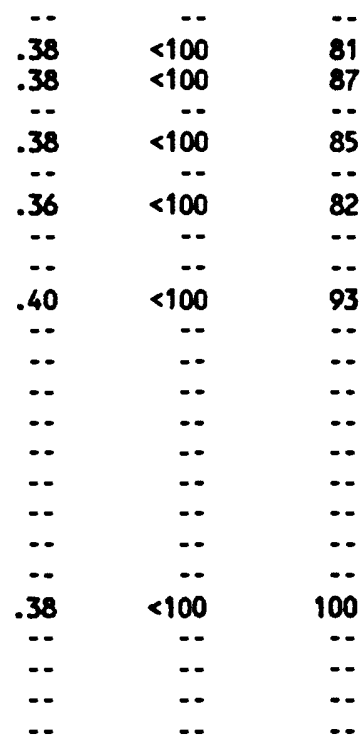




\section{SURFACE-MATER DATA-Cont inued \\ CHEMICAL AMALYSES-Continued}

STATION

NUMBER

DATE

03-09-89

08-01-89

09-05-89

09-05-89

09-05-89

09-05-89

09-05-89

09-05-89

09-05-89

09-06-89

03-07-90

03-07-90

08-14-90

03-06-91

03-06-91

03-06-91

03-06-91

07-25-91

07-25-91

07-26-91

08-07-91

08-07-91

08-07-91

08-08-91

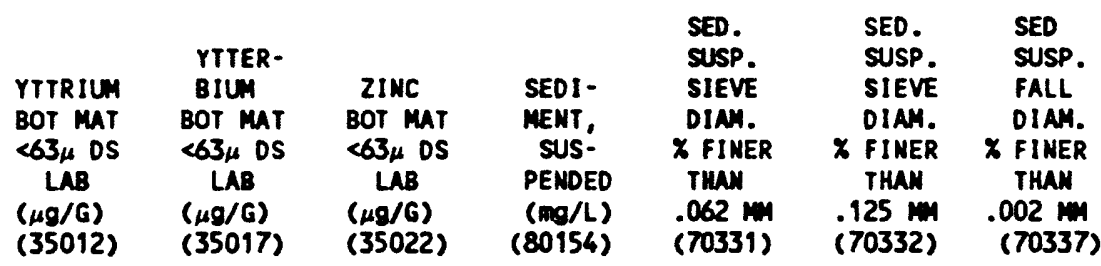

BLACK CREEK NEAR HOUCK, AZ-Continued

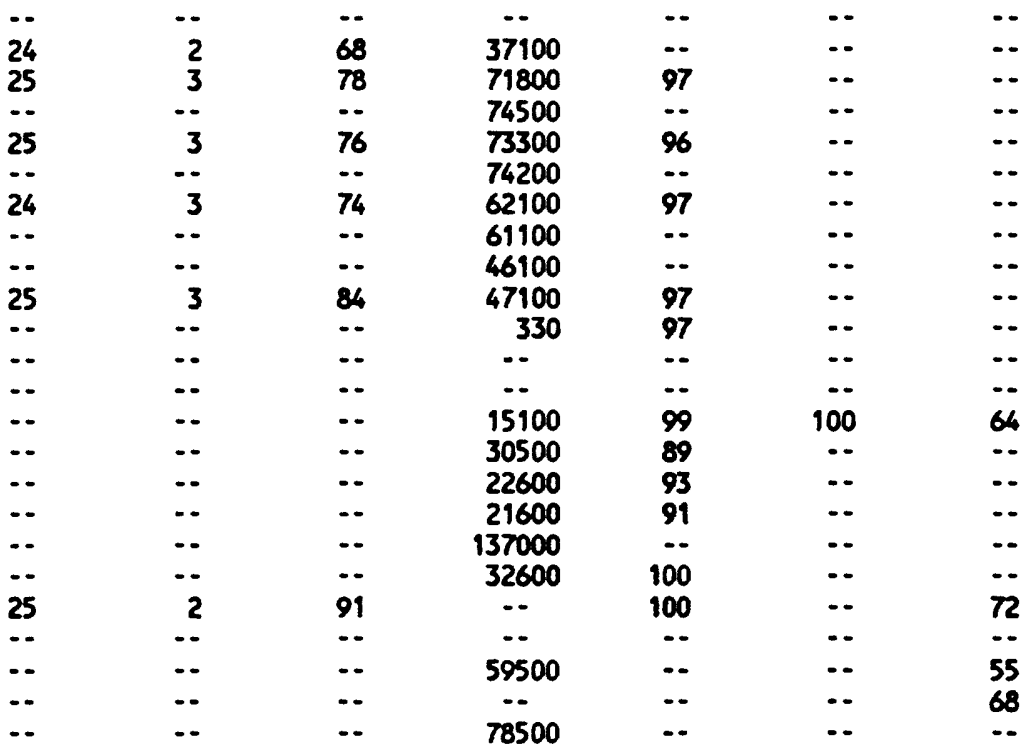




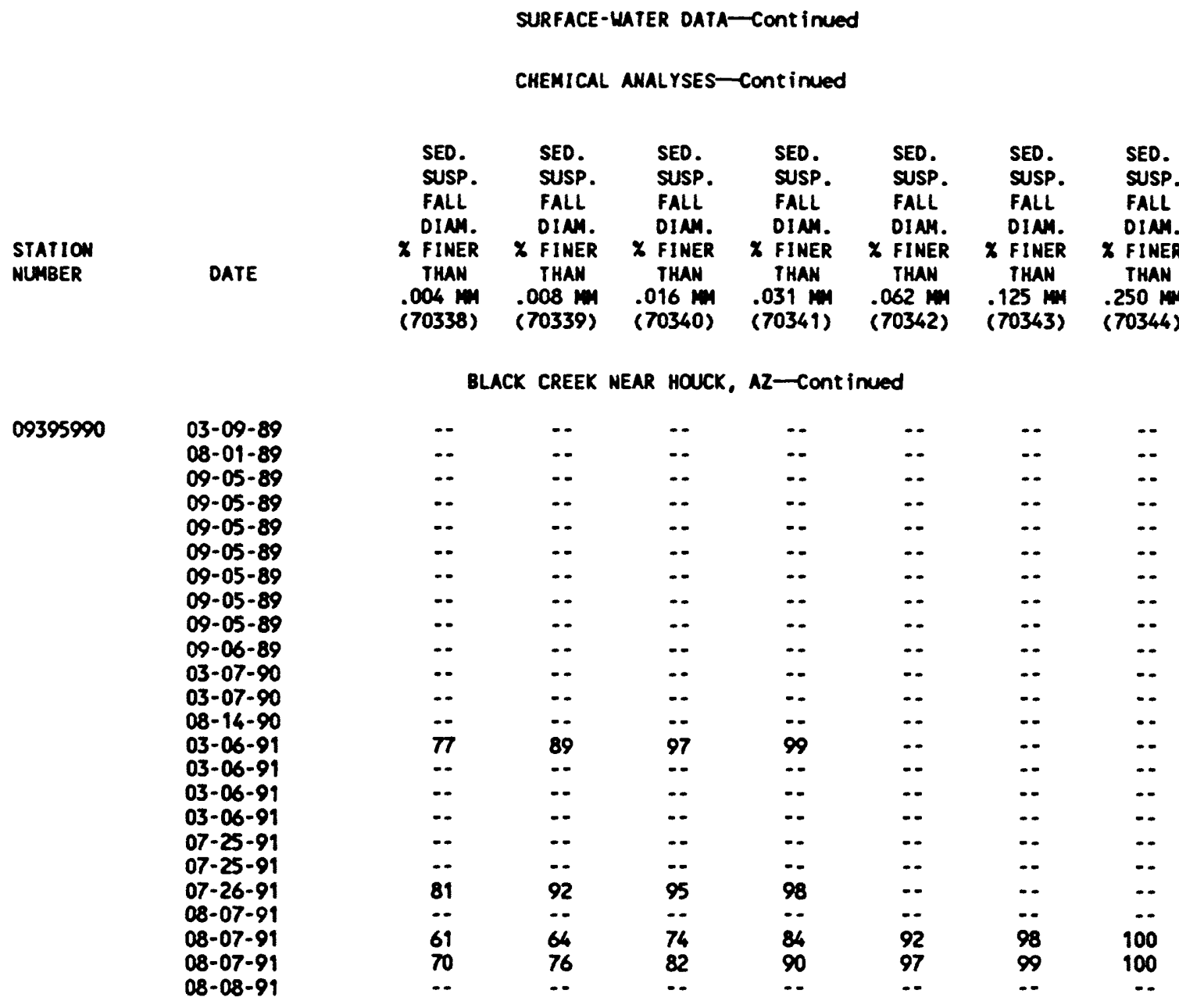


SURFACE-WATER DATA-Cont inued

CHEMICAL ANALYSES-Cont inued

\section{STATION}

MUABER

09396100
STATION MANE

PUERCO RIVER MEAR CHAMBERS, ARIZONA

$\begin{array}{ll}02-15-89 & 1400 \\ 08-01-89 & 0050 \\ 08-01-89 & 0130 \\ 08-01-89 & 0230 \\ 08-01-89 & 0710 \\ 08-01-89 & 0810 \\ 08-01-89 & 0820 \\ 08-01-89 & 1030 \\ 08-01-89 & 1320 \\ 08-01-89 & 1630 \\ 08-18-89 & 2359 \\ 08-18-89 & 2400 \\ 09-06-89 & 1440 \\ 09-06-89 & 1441 \\ 09-06-89 & 1510 \\ 09-06-89 & 1511 \\ 09-06-89 & 1515 \\ 09-06-89 & 1516 \\ 02-21-90 & 1255 \\ 03-06-90 & 0930 \\ 07-11-90 & 1300 \\ 07-11-90 & 1320 \\ 07-11-90 & 1325 \\ 07-16-90 & 1300 \\ 08-15-90 & 0250 \\ 08-15-90 & 0310 \\ 08-15-90 & 1135 \\ 08-15-90 & 1145 \\ 08-15-90 & 1820 \\ 08-16-90 & 0930 \\ 08-16-90 & 0935 \\ 09-05-90 & 1430 \\ 10-19-90 & 0010 \\ 10-20-90 & 0720 \\ 10-20-90 & 0800 \\ 01-07-91 & 1140 \\ 01-16-91 & 1415 \\ 02-09-91 & 1005 \\ 03-05-91 & 0935 \\ 06-12-91 & 1415 \\ 08-08-91 & 1015 \\ 08-27-91 & 0001 \\ 08-27-91 & 0002 \\ 08-27-91 & 1630 \\ & \end{array}$

0130

0230

1320

1630

1440

1441

1515

1516

0930

1300

1300

0250

145

1820

1430

0010

0720

40

005

015

0002

1630
LATITUDE LONGITUDE

$35^{\circ} 10^{\prime} 40^{\prime \prime N} \quad 109^{\circ} 27 \cdot 15^{m y}$ 
SURFACE-WATER DATA-Cont inued

CHEMICAL ANALYSES-Cont inued

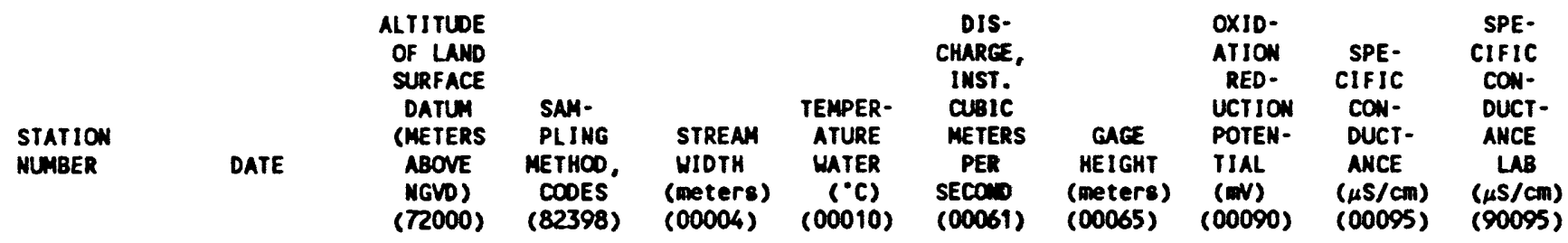

PUERCO RIVER NEAR CHAMBERS, A2-Continued

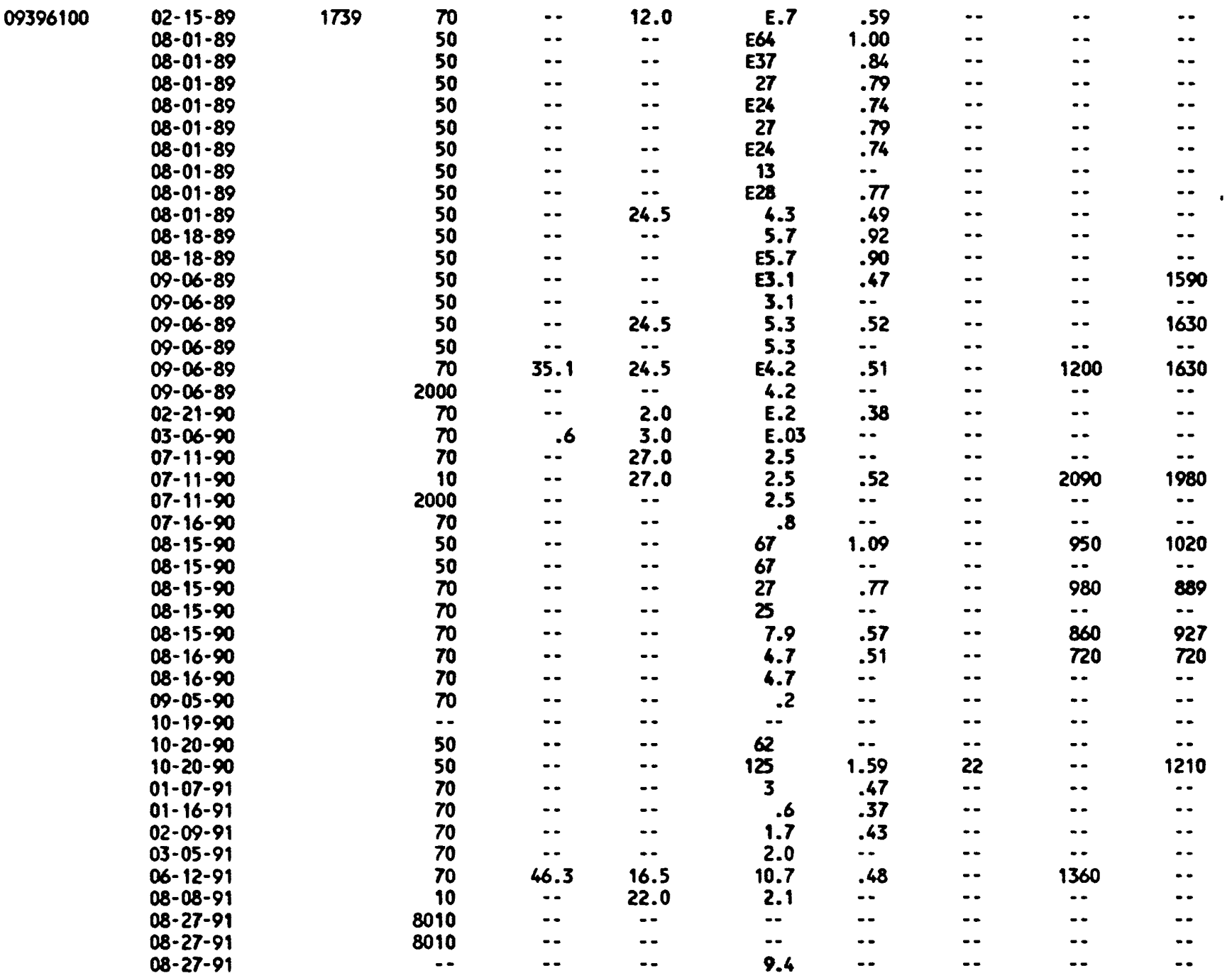


SURFACE-WATER DATA-Continued

CHEMICAL AKALYSES-Continued

\begin{tabular}{|c|c|c|c|c|c|c|c|c|c|c|}
\hline $\begin{array}{l}\text { STATION } \\
\text { MUMBER }\end{array}$ & DATE & $\begin{array}{l}\text { OXYGEN, } \\
\text { DIS- } \\
\text { SOLVED } \\
\text { (mg/L) } \\
(00300)\end{array}$ & $\begin{array}{c}\text { PH } \\
\text { WATER } \\
\text { WHOLE } \\
\text { FIELD } \\
\text { (STAND- } \\
\text { NRD } \\
\text { UNITS) } \\
\text { (00400) }\end{array}$ & $\begin{array}{l}\text { PH } \\
\text { WATER } \\
\text { WHOLE } \\
\text { LAB } \\
\text { (STAND- } \\
\text { ARD } \\
\text { UNITS) } \\
\text { (00403) }\end{array}$ & $\begin{array}{c}\text { ALKA- } \\
\text { LINITY } \\
\text { LAB } \\
\text { (mg/L } \\
\text { as } \\
\text { Caco3) } \\
(90410)\end{array}$ & $\begin{array}{l}\text { SOLIDS, } \\
\text { RESIDUE } \\
\text { AT } 180^{\circ} \mathrm{C} \\
\text { OIS- } \\
\text { SOLVED } \\
(1 / L) \\
(70300)\end{array}$ & $\begin{array}{l}\text { SOLIDS, } \\
\text { SUN OF } \\
\text { CONSTI- } \\
\text { TUENTS, } \\
\text { DIS- } \\
\text { SOLVED } \\
\text { (mg/L) } \\
\text { (70301) }\end{array}$ & $\begin{array}{c}\text { SOLIDS, } \\
\text { DIS- } \\
\text { SOLVED } \\
\text { (metric } \\
\text { tons } \\
\text { per } \\
\text { day) } \\
\text { (70302) }\end{array}$ & $\begin{array}{l}\text { NITROCEN } \\
\text { NO2+NO3 } \\
\text { DIS- } \\
\text { SOLVED } \\
\text { ( } \mathrm{ma} / L \\
\text { as N) } \\
(00631)\end{array}$ & $\begin{array}{l}\text { HARD- } \\
\text { NESS } \\
\text { TOTAL } \\
\text { (mo/L } \\
\text { as } \\
\text { Caco3) } \\
(00900)\end{array}$ \\
\hline
\end{tabular}

PUERCO RIVER MEAR CHAMBERS, AZ-Continued

$09396100 \quad 02-15-89$
$08-01-89$
$08-01-89$
$08-01-89$
$08-01-89$
$08-01-89$
$08-01-89$
$08-01-89$
$08-01-89$
$08-01-89$
$08-18-89$
$08-18-89$
$09-06-89$
$09-06-89$
$09-06-89$
$09-06-89$
$09-06-89$
$09-06-89$
$02-21-90$
$03-06-90$
$07-11-90$
$07-11-90$
$07-11-90$
$07-16-90$
$08-15-90$
$08-15-90$
$08-15-90$
$08-15-90$
$08-15-90$
$08-16-90$
$08-16-90$
$09-05-90$
$10-19-90$
$10-20-90$
$10-20-90$
$01-07-91$
$01-16-91$
$02-09-91$
$03-05-91$
$06-12-91$
$08-08-91$
$08-27-91$
$08-27-91$
$08-27-91$

\begin{tabular}{|c|c|}
\hline$\ldots$ & .. \\
\hline$\cdots$ & $\cdots$ \\
\hline - & $\cdots$ \\
\hline$\cdots$ & $\cdots$ \\
\hline$\ldots$ & $\ldots$ \\
\hline .. & $\ldots$ \\
\hline -. & $\cdots$ \\
\hline -. & - \\
\hline -. & -. \\
\hline 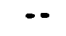 & $\cdots$ \\
\hline$\cdots$ & $\cdots$ \\
\hline$\cdots$ & $\cdots$ \\
\hline$\cdots$ & -- \\
\hline$\cdots$ & $\because$ \\
\hline$\because$ & $\cdots$ \\
\hline 4.9 & 7.9 \\
\hline - & $\cdots$ \\
\hline - & $\ldots$ \\
\hline - & $\cdots$ \\
\hline -. & $\cdots$ \\
\hline 5.3 & 7.1 \\
\hline$\cdots$ & $\cdots$ \\
\hline$\cdots$ & $\cdots$ \\
\hline$\cdots$ & 7.8 \\
\hline$\cdots$ & $\because$ \\
\hline$-\cdot$ & 8.1 \\
\hline$\because$ & $\because 8$ \\
\hline$\ldots$ & $\begin{array}{l}7.8 \\
7.6\end{array}$ \\
\hline -. & - \\
\hline - & $\cdots$ \\
\hline - & $\cdots$ \\
\hline - & - \\
\hline -. & $\cdots$ \\
\hline-- & $\cdots$ \\
\hline-- & -- \\
\hline$\cdots$ & $\cdots$ \\
\hline$\cdots$ & 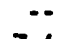 \\
\hline$\therefore$ & 7.4 \\
\hline$\ldots$ & 7.8 \\
\hline -. & 7.6 \\
\hline 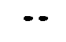 & - \\
\hline
\end{tabular}

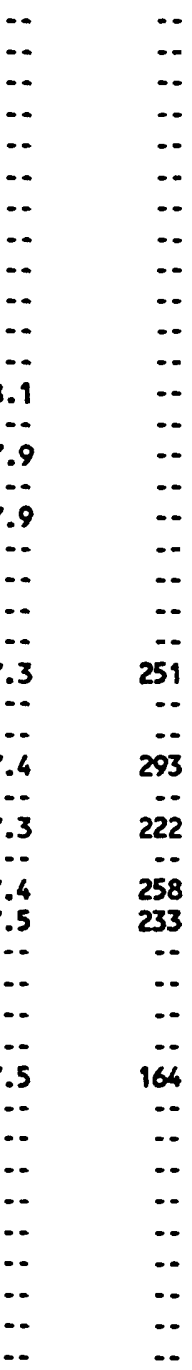

\begin{tabular}{|c|c|c|c|c|}
\hline .. & $\cdots$ & $\cdots$ & $\cdots$ & $\cdots$ \\
\hline -- & $\cdots$ & $\cdots$ & $\cdots$ & $\cdots$ \\
\hline-- & $\cdots$ & $\cdots$ & $\cdots$ & - \\
\hline$\cdots$ & $\cdots$ & -. & $\cdots$ & - \\
\hline$\cdots$ & $\cdots$ & $\cdots$ & $\cdots$ & $\cdots$ \\
\hline$\cdots$ & $\cdots$ & $\cdots$ & $\cdots$ & - \\
\hline$\cdots$ & $\cdots$ & $\cdots$ & $\cdots$ & - \\
\hline$\cdots$ & $\cdots$ & $\cdots$ & $\cdots$ & - \\
\hline$\because$ & $\cdots$ & $\cdots$ & $\cdots$ & - \\
\hline$\cdots$ & $\because$ & 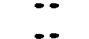 & $\because$ & - \\
\hline$\ldots$ & $\ldots$ & $\ldots$ & $\ldots$ & - \\
\hline -- & . & -. & .490 & 370 \\
\hline -. & - & - & - & - \\
\hline$\cdots$ & - & $\cdots$ & .500 & 370 \\
\hline$\cdots$ & $\cdots$ & $\cdots$ & -. & \\
\hline$\cdots$ & $\cdots$ & $\cdots$ & .370 & 370 \\
\hline$\cdots$ & $\cdots$ & $\cdots$ & $-\cdot$ & 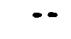 \\
\hline$\cdots$ & $\cdots$ & $\cdots$ & $\cdots$ & $\cdots$ \\
\hline$\cdots$ & $\cdots$ & $\cdots$ & $\cdots$ & $\cdots$ \\
\hline$\because$ & $\cdots$ & $\cdots$ & $\cdots$ & 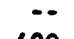 \\
\hline 1320 & 1400 & 291 & $\cdots$ & 400 \\
\hline 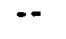 & $\cdots$ & $\ddot{--}$ & $\cdots$ & $\cdots$ \\
\hline$\ddot{s i n}$ & $\ddot{666}$ & 3491 & 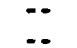 & 210 \\
\hline $\begin{array}{l}000 \\
.-\end{array}$ & 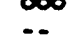 & $\ldots$ & $\ldots$ & .. \\
\hline 515 & 526 & 1188 & .. & 180 \\
\hline - & -. & $\cdots$ & $\cdots$ & - \\
\hline $\begin{array}{l}503 \\
392\end{array}$ & $\begin{array}{l}549 \\
428\end{array}$ & $\begin{array}{l}345 \\
169\end{array}$ & 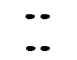 & $\begin{array}{l}190 \\
110\end{array}$ \\
\hline$\cdots$ & $\cdots$ & $\cdots$ & $\cdots$ & - \\
\hline - & -. & - & $\cdots$ & 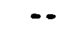 \\
\hline$\cdots$ & $\cdots$ & $\cdots$ & $\cdots$ & $\cdots$ \\
\hline -. & $\because$ & $\because$ & $\cdots$ & \\
\hline - & 755 & 8127 & $\cdots$ & 260 \\
\hline$\cdots$ & $\cdots$ & $\cdots$ & $\cdots$ & \\
\hline$\cdots$ & $\cdots$ & $\cdots$ & $\cdots$ & 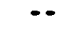 \\
\hline$\cdots$ & $\cdots$ & $\cdots$ & $\cdots$ & \\
\hline$\cdots$ & $\cdots$ & $\cdots$ & $\cdots$ & . \\
\hline$\cdots$ & $\cdots$ & $\cdots$ & $\cdots$ & . \\
\hline$\cdots$ & $\cdots$ & $\cdots$ & $\cdots$ & \\
\hline$\cdots$ & $\because$ & $\because$ & $\cdots$ & \\
\hline$\because$ & $\cdots$ & $\because$ & $\because$ & \\
\hline
\end{tabular}


CHEMICAL ANALYSES-Continued

STATION

MUMBER

DATE

\begin{tabular}{|c|c|c|c|c|c|c|c|c|c|}
\hline ATE & $\begin{array}{l}\text { CALCIUA } \\
\text { DIS- } \\
\text { SOLVED } \\
\text { (mo/L } \\
\text { As Ca) } \\
\text { (00915) }\end{array}$ & $\begin{array}{c}\text { MAGNE- } \\
\text { SIUH, } \\
\text { DIS- } \\
\text { SOLVED } \\
\text { (mo/L } \\
\text { as Mg) } \\
\text { (00925) }\end{array}$ & $\begin{array}{l}\text { SOOIU, } \\
\text { DIS- } \\
\text { SOLVED } \\
\text { (mo/L } \\
\text { as Na) } \\
(00930)\end{array}$ & $\begin{array}{l}\text { SOOIUN } \\
\text { ADSORP. } \\
\text { TION } \\
\text { RATIO } \\
\text { (00931) }\end{array}$ & $\begin{array}{l}\text { SOOIUH } \\
\text { PERCENT } \\
\text { (00932) }\end{array}$ & $\begin{array}{l}\text { POTAS- } \\
\text { SIUN, } \\
\text { DIS- } \\
\text { SOLVED } \\
\text { (mo/L } \\
\text { AS K) } \\
\text { (00935) }\end{array}$ & $\begin{array}{l}\text { CHLO- } \\
\text { RIDE, } \\
\text { DIS- } \\
\text { SOLVED } \\
\text { (mo/L } \\
\text { aS Cl) } \\
(00940)\end{array}$ & $\begin{array}{c}\text { BROMIDE } \\
\text { DIS- } \\
\text { SOLVED } \\
\text { (mo/L } \\
\text { As Br) } \\
(71870)\end{array}$ & $\begin{array}{l}\text { FLUO- } \\
\text { RIDE, } \\
\text { DIS- } \\
\text { SOLVED } \\
\text { (mo/L } \\
\text { as F) } \\
\text { (00950) }\end{array}$ \\
\hline
\end{tabular}

PUERCO RIVER NEAR CHAMBERS, AZ-Continued

\begin{tabular}{|c|c|c|c|c|c|c|c|c|c|}
\hline $02-15-89$ & $\cdots$ & -. & $\cdots$ & $\cdots$ & 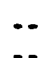 & -. & -. & $\because$. & $\ldots$ \\
\hline $\begin{array}{l}08-01-89 \\
08-01-89\end{array}$ & $\because$ & $\because-$ & 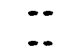 & $\ddot{-.}$ & 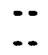 & $\begin{array}{l}-. \\
-.\end{array}$ & 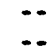 & $\ddot{-.}$ & $\ddot{-.}$ \\
\hline $08-01-89$ & $\ldots$ & $\ldots$ & $\cdots$ & $\ldots$ & $\ldots$ & 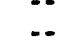 & $\cdots$ & $\therefore$ & $\cdots$ \\
\hline $08-01-89$ & $\cdots$ & $\cdots$ & -- & $\cdots$ & $\cdots$ & $\cdots$ & -. & -. & -. \\
\hline 08-01-89 & $\cdots$ & $\cdots$ & $\cdots$ & $\cdots$ & $\cdots$ & $\cdot-$ & -. & $\cdot-$ & $\cdots$ \\
\hline $08-01-89$ & $\cdots$ & $\cdots$ & $\cdots$ & $\cdots$ & $\cdots$ & $\cdot-$ & $\cdots$ & $\cdot-$ & -. \\
\hline $08-01-89$ & $\cdots$ & $\cdots$ & $\cdots$ & $\cdots$ & $\cdots$ & -. & $\cdots$ & $\cdots$ & -. \\
\hline 08-01-89 & $\cdots$ & $\cdots$ & $\cdots$ & $\cdots$ & $\cdots$ & $\cdot \cdot$ & $\cdots$ & $\cdots$ & $\cdots$ \\
\hline $08-01-89$ & $\cdots$ & $\cdots$ & -. & $\cdots$ & $\cdots$ & $\cdot \cdot$ & $\cdots$ & -. & $\cdots$ \\
\hline $08-18-89$ & $\cdots$ & $\cdots$ & $\cdots$ & $\cdots$ & $\cdots$ & $\cdots$ & -. & $\cdot-$ & $-\cdot$ \\
\hline $08-18-89$ & $\because$ & 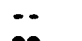 & 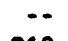 & $\because$ & $\because$ & $\because$ & $\ddot{a}$ & $\ddot{z}$ & $\ddot{m}$ \\
\hline 09-06-89 & 110 & 22 & 210 & 5 & 55 & 7.3 & 93 & .13 & .70 \\
\hline 09-06-89 & $\because$ & 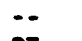 & 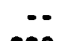 & $\because$ & $\because$ & $\because$ & $\ddot{m}$ & $\ddot{\sigma}$ & 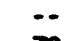 \\
\hline $09-06-89$ & 110 & 23 & 220 & 5 & 56 & 7.3 & 92 & .15 & .70 \\
\hline $09-06-89$ & $\because$ & 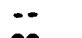 & 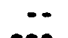 & $\because$ & $\because$ & $\because$ & $\cdots$ & $\ddot{-}$ & $\cdots$ \\
\hline $09-06-89$ & 110 & 22 & 220 & 5 & 56 & 7.2 & 94 & .13 & .80 \\
\hline $09-06-89$ & $\cdots$ & $\cdots$ & -. & $\cdots$ & -. & -. & -. & $\cdots$ & -. \\
\hline $02-21-90$ & $\cdots$ & $\cdots$ & $\cdots$ & $\cdots$ & $\cdots$ & $\cdot-$ & $\cdots$ & -. & -. \\
\hline $03-06-90$ & $\cdot-$ & $\because$ & $\cdot-$ & -. & -. & $-\cdot$ & $\cdots$ & -. & -. \\
\hline $07-11-90$ & $\cdots$ & $\therefore$ & $\because \cdot$ & $\cdots$ & $\cdots$ & $\because$ & $\cdots$ & $\because \cdot$ & -. \\
\hline $07-11-90$ & 120 & 23 & 280 & 6 & 60 & 7.3 & 96 & .11 & .80 \\
\hline $07-11-90$ & $\cdots$ & $\cdots$ & $\cdots$ & $\cdots$ & $\cdots$ & $\cdots$ & $\cdots$ & .. & $\cdots$ \\
\hline $07-16-90$ & $-\cdot$ & $\cdots$ & $\cdots$ & -. & $\cdots$ & $\cdots$ & $\because-$ & $\cdots$ & $\cdots$ \\
\hline $08-15-90$ & 62 & 13 & 120 & 4 & 55 & 5.1 & 36 & .09 & .30 \\
\hline $08-15-90$ & $\because$ & $\cdots$ & 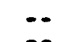 & $\cdots$ & 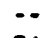 & $\cdots$ & 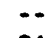 & $\ddot{-}$ & 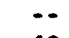 \\
\hline $08-15-90$ & 54 & 9.9 & 98 & 3 & 54 & 4.7 & 26 & .08 & .60 \\
\hline $08-15-90$ & $\because$ & $\because$ & 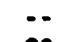 & $\because$ & 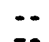 & $\because$ & 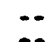 & $\ddot{-}$ & $\because-$ \\
\hline $08-15-90$ & 58 & 11 & 90 & 3 & 50 & 5.0 & 20 & .05 & .40 \\
\hline $08-16-90$ & 34 & 5.9 & 88 & 4 & 63 & 3.9 & 15 & .04 & .70 \\
\hline $08-16-90$ & $\cdots$ & $\cdots$ & $\cdots$ & $\cdots$ & $\cdots$ & $\cdots$ & $\cdots$ & $\cdots$ & $\cdots$ \\
\hline $09-05-90$ & -. & -. & $\cdots$ & -. & -. & $\cdots$ & -. & $\cdot \cdot$ & $\cdots$ \\
\hline $10-19-90$ & $\cdots$ & $\cdots$ & -. & $\cdots$ & $\cdots$ & -. & -. & $\cdots$ & $\cdots$ \\
\hline $10-20-90$ & - & .. & .. & -. & .. & -. & .. & 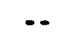 & $\cdots$ \\
\hline $10-20-90$ & 79 & 14 & 150 & 4 & 56 & 4.5 & 48 & .08 & .60 \\
\hline $01-07-91$ & -. & $\cdots$ & $\cdot-$ & -. & -. & -. & -. & $\cdots$ & $\cdots$ \\
\hline $01-16-91$ & $-\cdot$ & $\cdots$ & -. & $\cdots$ & -- & $\cdots$ & -. & $\cdots$ & $\cdots$ \\
\hline $02-09-91$ & $\because$ & -. & -. & -. & .. & -. & -. & -. & -. \\
\hline $03-05-91$ & $\cdots$ & $\cdots$ & $\cdots$ & $\cdots$ & $\cdots$ & -. & $\cdots$ & -. & $\cdot \cdot$ \\
\hline $06-12-91$ & $\cdots$ & $\cdots$ & $\cdots$ & -. & -. & -. & $\cdots$ & $\cdots$ & $\cdots$ \\
\hline $08-08-91$ & -. & -. & $\cdots$ & -- & -. & -. & -. & -. & -. \\
\hline $08-27-91$ & $\cdots$ & -. & $\cdots$ & $\cdots$ & $\cdots$ & $\cdot-$ & $\cdots$ & $\cdots$ & $\cdots$ \\
\hline $08-27-91$ & $\cdots$ & -. & $\cdots$ & -. & $\cdots$ & -- & $\cdots$ & $\cdots$ & $\cdots$ \\
\hline $08-27-91$ & $\cdots$ & -. & $\cdots$ & -. & $\cdots$ & $\cdot-$ & $\cdots$ & $\cdot \cdot$ & -. \\
\hline
\end{tabular}


SURFACE-WATER DATA-Cont inued

CHEMICAL ANALYSES-Continued

STATION

MUAER

DATE

\begin{tabular}{|c|c|c|c|c|c|c|c|c|}
\hline $\begin{array}{l}\text { SILICA, } \\
\text { DIS- } \\
\text { SOLVED } \\
\text { (ng/L } \\
\text { as } \\
\text { siO2) } \\
(00955)\end{array}$ & $\begin{array}{c}\text { SULFATE } \\
\text { DIS- } \\
\text { SOLVED } \\
\text { (mg/L } \\
\text { as SO4) } \\
\text { (00945) }\end{array}$ & $\begin{array}{l}\text { ARSENIC } \\
\text { DIS- } \\
\text { SOLVED } \\
(\mu g / L \\
\text { as AS) } \\
(01000)\end{array}$ & $\begin{array}{l}\text { BARIUM, } \\
\text { DIS- } \\
\text { SOLVED } \\
\text { ( } \mu g / L \\
\text { as Ba) } \\
\text { (01005) }\end{array}$ & $\begin{array}{l}\text { BERYL- } \\
\text { LIUH, } \\
\text { DIS- } \\
\text { SOLVED } \\
\text { ( } \mu g / L \\
\text { AS BE) } \\
(01010)\end{array}$ & $\begin{array}{c}\text { BOBON, } \\
\text { DIS- } \\
\text { SOLVED } \\
(\mu D A \\
\text { as B) } \\
(01020)\end{array}$ & $\begin{array}{c}\text { CADMIUN } \\
\text { DIS- } \\
\text { SOLVED } \\
\text { ( } \mu g / L \\
\text { as Cd) } \\
\text { (01025) }\end{array}$ & $\begin{array}{l}\text { CHRO- } \\
\text { MIUH, } \\
\text { DIS- } \\
\text { SOLVED } \\
\text { ( } \mu g / L \\
\text { as Cr) } \\
(01030)\end{array}$ & $\begin{array}{l}\text { COBALT, } \\
\text { DIS- } \\
\text { SOLVED } \\
\text { ( } \mu g / L \\
\text { as Co) } \\
(01035)\end{array}$ \\
\hline
\end{tabular}

\begin{tabular}{|c|c|c|c|c|c|c|c|c|c|c|}
\hline $093 \% 6100$ & $02-15-89$ & $\cdots$ & $\cdots$ & $\cdots$ & $\cdots$ & $\cdots$ & $\cdots$ & $\cdots$ & $\cdots$ & $\cdots$ \\
\hline & $08-01-89$ & $\cdots$ & $\cdots$ & $\infty$ & $\cdots$ & $\cdots$ & $\cdots$ & $\cdots$ & $\cdots$ & $\cdots$ \\
\hline & $08-01-89$ & $\cdots$ & $\cdots$ & $\cdots$ & $\cdots$ & $=$ & $\rightarrow$ & $\rightarrow$ & $\cdots$ & $\cdots$ \\
\hline & $08-01-89$ & $\cdots$ & $\ldots$ & $\cdots$ & $\cdots$ & $\ldots$ & $\cdots$ & $-\infty$ & $\cdots$ & $\cdots$ \\
\hline & $08-01-89$ & $\cdots$ & $\cdots$ & $\cdots$ & $\ldots$ & $\cdots$ & - & $\cdots$ & $\cdots$ & $\cdots$ \\
\hline & $08-01-89$ & $\cdots$ & $\cdots$ & $\cdots$ & $\infty$ & 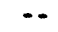 & $\cdots$ & $\cdots$ & $\cdots$ & $\cdots$ \\
\hline & $08-01-89$ & $\cdots$ & $\cdots$ & $\cdots$ & $\cdots$ & $\cdots$ & $\cdots$ & $\cdots$ & $\cdots$ & $\cdots$ \\
\hline & $08-01-89$ & $\cdots$ & $\cdots$ & $\cdots$ & $\ldots$ & - & $\cdots$ & $\infty$ & $\cdots$ & $\cdots$ \\
\hline & $08-01-89$ & $\cdots$ & $\cdots$ & $\cdots$ & $\cdots$ & $\cdots$ & $\cdots$ & $\cdots$ & $\cdots$ & $\cdots$ \\
\hline & $08-01-89$ & $\cdots$ & $\cdots$ & $\cdots$ & $\ldots$ & $\cdots$ & $\cdots$ & $\cdots$ & $\cdots$ & $\cdots$ \\
\hline & $08-18-89$ & $\cdots$ & $\cdots$ & $\cdots$ & $\cdots$ & $\ldots$ & $\cdots$ & $-\infty$ & $\cdots$ & $\cdots$ \\
\hline & $08-18-89$ & $\cdots$ & $\cdots$ & $\cdots$ & $\cdots$ & $\ldots$ & - & $\cdots$ & $\cdots$ & $\cdots$ \\
\hline & $09-06-89$ & 11 & $480\}$ & $\cdots$ & 150 & $<.5$ & $\cdots$ & $<1.0$ & $<5$ & $<3$ \\
\hline & $09-06-89$ & $\ldots$ & $\cdots$ & $\ldots$ & $\cdots$ & $\cdots$ & $\cdots$ & $\cdots$ & $\cdots$ & $\cdots$ \\
\hline & $09-06-89$ & 11 & $500 \$$ & $\cdots$ & 160 & $<.5$ & -- & $<1.0$ & $<5$ & $<3$ \\
\hline & $09-06-89$ & $-\infty$ & $\cdots$ & $\cdots$ & $\cdots$ & $\cdots$ & $\cdots$ & $\cdots$ & $\cdots$ & $\cdots$ \\
\hline & $09-06-89$ & 9.4 & $510 \$$ & $\cdots$ & 150 & $<.5$ & -- & $<1.0$ & $<5$ & $<$ \\
\hline & $09-06-89$ & $\cdots$ & $\cdots$ & $-\infty$ & $\ldots$ & $\cdots$ & $\cdots$ & $\cdots$ & $\cdots$ & $\cdots$ \\
\hline & $02-21-90$ & $\cdots$ & $\cdots$ & $\cdots$ & 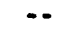 & $\infty$ & $\cdots$ & $-\infty$ & $\cdots$ & 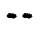 \\
\hline & $03-06-90$ & $\cdots$ & r- & $\cdots$ & $\cdots$ & $\cdots$ & $\cdots$ & $\cdots$ & $\cdots$ & $\cdots$ \\
\hline & $07-11-90$ & $\ldots$ & $\therefore$ & $\cdots$ & -- & $\cdots$ & $\cdots$ & - & $\infty$ & $-\infty$ \\
\hline & $07-11-90$ & 11 & $710 \$$ & 1 & 170 & $<.5$ & 300 & 1.0 & $<5$ & $<3$ \\
\hline & $07-11-90$ & $\cdots$ & $\ldots$ & $-\infty$ & $\cdots$ & $-\infty$ & $\cdots$ & $\cdots$ & $\cdots$ & $\cdots$ \\
\hline & $07-16-90$ & $\cdots$ & $\infty$ & $\cdots$ & $\cdots$ & $\cdots$ & $\cdots$ & $\ldots$ & $\cdots$ & $\cdots$ \\
\hline & $08-15-90$ & 12 & 240 & 2 & 160 & $<.5$ & 210 & $<1.0$ & $<5$ & $<$ \\
\hline & $08-15-90$ & $\cdots$ & $\cdots$ & 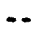 & $\ldots$ & $\cdots$ & $\cdots$ & $\cdots$ & $\cdots$ & $-\infty$ \\
\hline & $08-15-90$ & 10 & 190 & 1 & 110 & $<.5$ & 170 & $<1.0$ & $<5$ & $<3$ \\
\hline & $08-15-90$ & $\cdots$ & $\ldots$ & $\ldots$ & $\ldots$ & $\ldots$ & $\cdots$ & $-\infty$ & $\ldots$ & $\therefore$ \\
\hline & $08-15-90$ & 10 & 190 & 1 & 120 & $<.5$ & 150 & $<1.0$ & $<5$ & $<3$ \\
\hline & $08-16-90$ & 9.7 & 130 & 1 & 99 & $<.5$ & 180 & $<1.0$ & $<5$ & $<3$ \\
\hline & $08-16-90$ & $\cdots$ & $\cdots$ & 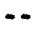 & $\cdots$ & $\cdots$ & $\rightarrow$ & $\cdots$ & $\cdots$ & $\cdots$ \\
\hline & $09-05-90$ & $\cdots$ & $\cdots$ & $-\infty$ & $\ldots$ & $\cdots$ & $\infty$ & $\cdots$ & $\cdots$ & $\ldots$ \\
\hline & $10-19-90$ & $\ldots$ & -- & $\ldots$ & $-\infty$ & $\ldots$ & $\cdots$ & $\cdots$ & $\ldots$ & $\cdots$ \\
\hline & $10-20-90$ & $\cdots$ & $\cdots$ & $\cdots$ & - & - & $\cdots$ & $\cdots$ & $\cdots$ & $\cdots$ \\
\hline & $10-20-90$ & 8.3 & 350 & 2 & 110 & $<.5$ & 170 & 3.0 & $<5$ & $<3$ \\
\hline & $01-07-91$ & $\cdots$ & $\cdots$ & $\cdots$ & 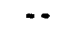 & $\cdots$ & $\cdots$ & $\cdots$ & $\cdots$ & $\cdots$ \\
\hline & $01-16-91$ & $\cdots$ & $\cdots$ & $\cdots$ & $\cdots$ & $\cdots$ & $\cdots$ & $\cdots$ & - & $\cdots$ \\
\hline & $02-09-91$ & $\ldots$ & $\cdots$ & $\cdots$ & $\cdots$ & 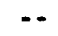 & $\cdots$ & $\ldots$ & $\cdots$ & $-\infty$ \\
\hline & $03-05-91$ & - & -. & $\cdots$ & $\cdots$ & $\ldots$ & -- & $\cdots$ & $\cdots$ & $\ldots$ \\
\hline & $06-12-91$ & $\ldots$ & $\ldots$ & $\cdots$ & $\cdots$ & $\cdots$ & $\cdots$ & $\cdots$ & $\cdots$ & $\ldots$ \\
\hline & $08-08-91$ & $\cdots$ & $\cdots$ & $\cdots$ & $\cdots$ & $\ldots$ & $\cdots$ & $\cdots$ & $\cdots$ & $\ldots$ \\
\hline & $08-27-91$ & $\cdots$ & $\cdots$ & $\ldots$ & $\ldots$ & $\cdots$ & $\cdots$ & $\cdots$ & $\cdots$ & $\cdots$ \\
\hline & $08-27-91$ & $\ldots$ & $\cdots$ & $\cdots$ & $\cdots$ & $\cdots$ & $\cdots$ & $\cdots$ & $\ldots$ & $\cdots$ \\
\hline & $08-27-91$ & $\cdots$ & $\cdots$ & $\cdots$ & $\cdots$ & $\ldots$ & $\cdots$ & $\cdots$ & $\ldots$ & - \\
\hline
\end{tabular}


SURFACE-MATER DATA-Cont inued

CHEMICAL AMALYSES-Cont inued

STATION

MUMBER

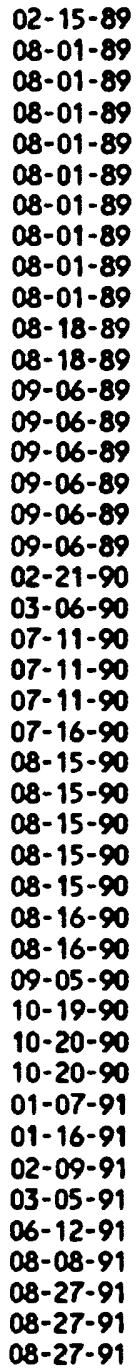

DATE

$\begin{array}{ccc}\text { COPPER, } & \text { IRON, } & \text { LEND, } \\ \text { DIS- } & \text { DIS- } & \text { DIS- } \\ \text { SOLVED } & \text { SOLVED } & \text { SOLVED } \\ (\mu g / L & (\mu g / L & (\mu g / L \\ \text { aS CU) } & \text { aS FE) } & \text { AS Pb) } \\ (01040) & (01046) & (01049)\end{array}$

MANGA- MOLYB-

$\begin{array}{cccc}\text { NICKEL, } & \text { SILVER, } & \begin{array}{c}\text { STRON- } \\ \text { TIUM, }\end{array} & \begin{array}{c}\text { VAMA- } \\ \text { DIUH, }\end{array} \\ \text { DIS- } & \text { DIS- } & \text { DIS- } & \text { DIS- } \\ \text { SOLVED } & \text { SOLVED } & \text { SOLVED } & \text { SOLVED } \\ (\mu g / L & (\mu g / L & (\mu g / L & (\mu g / L \\ \text { OS Ni) } & \text { OS Ag) } & \text { OS SR) } & \text { as V) } \\ (01065) & (01075) & (01080) & (01085)\end{array}$

PUERCO RIVER MEAR CHAMBERS, AZ-Continued

\begin{tabular}{|c|c|c|c|c|c|c|c|c|}
\hline-- & -- & $\cdots$ & -. & $\cdots$ & -- & -- & -. & -. \\
\hline-- & -- & - & -- & - & $\cdots$ & -- & - & -. \\
\hline-- & -- & -- & -- & - & - & - & - & -- \\
\hline -. & -- & -. & -. & -. & -- & -- & -- & -- \\
\hline -- & -- & -. & - & - & -- & - & -- & -- \\
\hline - & - & - & - & $\cdots$ & $\cdots$ & - & - & - \\
\hline- & -- & $\cdots$ & -- & $\cdots$ & 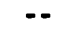 & $=$ & 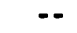 & - \\
\hline -. & -- & $\cdots$ & - & $\cdots$ & $=$ & - & -. & -. \\
\hline-- & -- & -- & $\cdots$ & $\cdots$ & $\cdots$ & $\cdots$ & -- & - \\
\hline- & -- & $\cdots$ & $\cdots$ & - & - & $\cdots$ & $\cdots$ & $\cdots$ \\
\hline -- & -- & $\cdots$ & 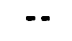 & -- & - & -- & -- & - \\
\hline 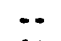 & 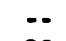 & 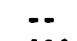 & $\cdots$ & 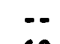 & 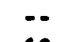 & $\cdots$ & 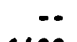 & $=$ \\
\hline$<10$ & 28 & $<10 i$ & $190\}$ & $<10$ & $<10$ & 1.0 & 1400 & $<6$ \\
\hline -- & - & -- & - & $\cdots$ & $\cdots$ & $\cdots$ & $\cdots$ & $\cdots$ \\
\hline$<10$ & 20 & $<10 i$ & $140\}$ & $<10$ & $<10$ & $<1.0$ & 1500 & $<6$ \\
\hline-- & -- & -- & -- & -- & - & -- & -- & $\cdots$ \\
\hline$<10$ & 18 & $<10 i$ & 22 & 10 & $<10$ & $<1.0$ & 1500 & $<6$ \\
\hline -- & - & $\cdots$ & - & - & $\cdots$ & 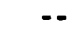 & -- & - \\
\hline$\cdots$ & $\therefore$ & -- & - & $\cdots$ & 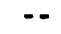 & $\cdots$ & -- & $\cdots$ \\
\hline-- & $\cdots$ & -- & $\cdots$ & $\cdots$ & - & $\cdots$ & $=$ & $\cdots$ \\
\hline-- & -- & -- & - & - & - & $\cdots$ & $=$ & $\cdots$ \\
\hline$<10$ & 260 & $<10 i$ & $270 \&$ & 10 & $<10$ & $<1.0$ & 1600 & $<6$ \\
\hline -- & -- & -- & - & $\cdots$ & $\cdots$ & -- & $=$ & $\cdots$ \\
\hline-- & 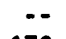 & -- & -- & -- & 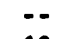 & - & 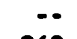 & $\because$ \\
\hline$<10$ & 130 & $<10 i$ & $600\}$ & $<10$ & $<10$ & $<1.0$ & 860 & $<6$ \\
\hline-- & - & $=$ & -- & - & -- & -- & $\because$ & -- \\
\hline$<10$ & 210 & $<101$ & $560\}$ & $<10$ & $<10$ & $<1.0$ & 730 & $<6$ \\
\hline-- & -. & - & - & -- & $\cdots$ & $\cdots$ & -- & - \\
\hline $\begin{array}{l}<10 \\
<10\end{array}$ & $\begin{array}{l}210 \\
110\end{array}$ & $\begin{array}{r}<10 i \\
201\end{array}$ & $\begin{array}{l}620 \\
160\end{array}$ & $\begin{array}{l}<10 \\
<10\end{array}$ & $\begin{array}{l}<10 \\
<10\end{array}$ & $\begin{array}{l}<1.0 \\
<1.0\end{array}$ & $\begin{array}{l}760 \\
500\end{array}$ & $\begin{array}{l}<6 \\
<6\end{array}$ \\
\hline$=$ & -. & -- & -- & $\cdots$ & - & - & $\therefore$ & $=$ \\
\hline -. & -- & $=$ & - & - & - & $\cdots$ & -- & -- \\
\hline$\cdots$ & - & -- & $\cdots$ & -- & 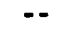 & -- & - & $\cdots$ \\
\hline - & - & -- & $\cdots$ & $\cdots$ & -- & $\cdots$ & -- & -. \\
\hline$<10$ & 38 & $<10 i$ & $290 \ddagger$ & 10 & $<10$ & 1.0 & 1100 & $<6$ \\
\hline-- & $\cdots$ & -- & $\cdots$ & -- & -- & $\because$ & - & $\cdots$ \\
\hline-- & -- & $\cdots$ & $\cdots$ & $\cdots$ & $\cdots$ & $\cdots$ & -- & $\cdots$ \\
\hline$\cdots$ & $\cdots$ & -- & $\cdots$ & -- & -- & -- & -- & $\cdots$ \\
\hline$\cdots$ & $\cdots$ & $\cdots$ & -- & -- & $\cdots$ & 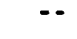 & $\cdots$ & $\cdots$ \\
\hline$\cdots$ & 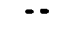 & $\cdots$ & $\cdots$ & $-\cdot$ & -- & -- & $-\cdot$ & -- \\
\hline$\cdots$ & $=$ & $\cdots$ & $\cdots$ & -- & $\cdots$ & $\cdots$ & - & $\cdots$ \\
\hline$\therefore$ & $\because$ & $\because$ & $\because$ & 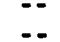 & $\ldots$ & $=$ & $\therefore$ & $\because$ \\
\hline -. & . & - & $\ldots$ & - & 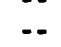 & $\therefore$ & - & $\ldots$ \\
\hline
\end{tabular}


SURFACE-MATER DATA-Cont inued

CHERICAL AMALYSES-Continued

STATION

NUMBER

09396100

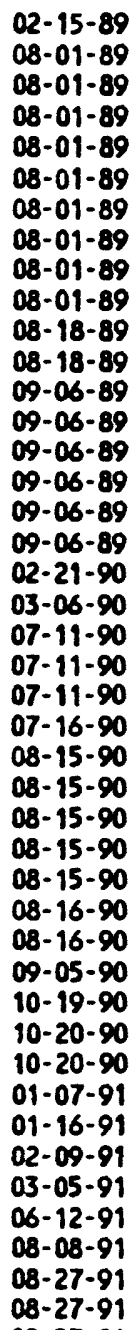

$08-27-$

PUERCO RIVER MEAR CHAMBERS, AZ-Continued

\begin{tabular}{|c|c|c|c|c|c|c|c|c|c|}
\hline .. & .- & -. & .. & -. & $7.8^{\circ}$ & 2.1 & $1.7 *$ & .. & -. \\
\hline -. & $\cdot-$ & $\cdots$ & -. & -. & $\cdots$ & $\because \cdot$ & $\cdots$ & -- & -- \\
\hline$\cdot \cdot$ & $\cdots$ & $\cdots$ & $\cdots$ & $\cdots$ & 8.0 & 1.5 & $370^{*}$ & -. & -- \\
\hline 4 & -. & $\cdot \cdot$ & -. & $\cdots$ & $\because$ & $\because$ & $\because$ & -. & -. \\
\hline -. & -. & $\cdots$ & $\cdots$ & -. & 6.9 & 1.1 & $2200 *$ & $\cdots$ & -- \\
\hline$\cdots$ & -. & $\cdots$ & - & $\cdots$ & 7.0 & 1.3 & $840^{*}$ & $\cdots$ & -- \\
\hline$\cdots$ & $\cdot-$ & $\cdots$ & -. & -- & 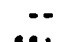 & $\therefore$ & 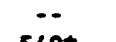 & -. & $\cdot-$ \\
\hline 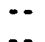 & -. & $\cdots$ & $\cdots$ & -. & 111 & 1.8 & $540 *$ & $\cdots$ & -. \\
\hline$\cdots$ & $\cdots$ & $\cdots$ & -- & $\cdots$ & 111 & 1.8 & $2200^{*}$ & $\cdots$ & •. \\
\hline -. & $\cdots$ & -. & -. & .. & 3.8 & .80 & $690^{*}$ & $\cdots$ & -. \\
\hline$\cdot \cdot$ & -. & $\cdots$ & -- & -. & $\ddot{x}$ & $\because$ & $\ddot{B}$ & $\cdots$ & $\cdot-$ \\
\hline$\ddot{5}$ & $\ddot{n}$ & $\cdots$ & $-\cdot$ & $\cdots$ & 131 & 2.4 & $1800 *$ & $\cdots$ & $\cdots$ \\
\hline 5 & 24 & 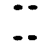 & $\because$ & $\ddot{.-}$ & 6.7 & 1.5 & $1900^{*}$ & $\because$ & $\because$ \\
\hline 17 & 23 & -. & -. & -. & 5.0 & 1.1 & $1000 *$ & .. & .. \\
\hline.- & $\cdots$ & $\cdots$ & $\cdots$ & $\cdots$ & 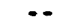 & -. & 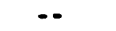 & -. & -. \\
\hline 11 & 24 & $\cdots$ & -. & -. & 6.6 & 1.3 & $230=$ & $\cdot \cdot$ & -. \\
\hline$\cdots$ & $\cdots$ & 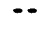 & -- & -・ & $\cdots$ & $\cdots$ & $\cdots$ & $\cdots$ & $\because \cdot$ \\
\hline -. & $\cdots$ & $\cdots$ & $\cdots$ & $\cdots$ & $\cdots$ & $\because-$ & $\cdots$ & $\cdots$ & $\because$ \\
\hline$\ddot{-}$ & -- & $\cdots$ & -- & -- & $\cdots$ & $-\cdot$ & $\cdots$ & $\cdots$ & $\cdots$ \\
\hline 39 & $\ddot{z}$ & $\ddot{s}$ & $\because-$ & $\because-$ & $\ddot{2 i t}$ & 32 & 26000 & $\cdots$ & $\because$ \\
\hline$\cdots$ & $\therefore$ & $\therefore$ & .. & .. & $\therefore$ & $\ldots$ & $\ldots$ & -. & .. \\
\hline-- & -. & -. & -- & -. & $\cdots$ & -- & -. & -. & -. \\
\hline 11 & 16 & $<1$ & -90.5 & -12.75 & -. & -. & -. & 13 & 18.90 \\
\hline$\cdots$ & $\cdots$ & $\cdots$ & $-\cdot$ & $\cdots$ & -. & $\cdots$ & $-\cdot$ & -- & -. \\
\hline 8 & 12 & $<1$ & -97.5 & -13.95 & .. & -- & -. & -- & -. \\
\hline$\cdots$ & $\cdots$ & $\cdots$ & -. & & -. & -. & -. & -- & $-\cdot$ \\
\hline 8 & 13 & $<1$ & -95.5 & -13.65 & $\cdot \cdot$ & $\cdot-$ & $\cdots$ & 7 & 10.20 \\
\hline 6 & 9 & $<1$ & $\cdots$ & -. & $\cdots$ & $\cdots$ & -. & -. & -. \\
\hline$\cdots$ & $\cdots$ & $\cdots$ & $\cdots$ & -. & $\cdots$ & $\cdot-$ & $\cdots$ & $-\cdot$ & -. \\
\hline$\cdots$ & $\cdots$ & -. & 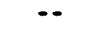 & -. & $\cdots$ & $\cdots$ & -. & -. & 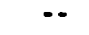 \\
\hline$\cdots$ & -. & $\cdots$ & -. & -・ & -. & $\cdot-$ & -. & $\cdots$ & $\cdots$ \\
\hline$\cdots$ & -. & -. & $\cdots$ & -. & -. & -- & -- & -. & -. \\
\hline 7 & 16 & $<1$ & -. & -. & -. & $\cdots$ & -. & $<6$ & 5.00 \\
\hline$\cdots$ & $\cdots$ & $\cdots$ & $\cdots$ & -・ & $\because$ & 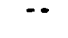 & - & $\cdots$ & $\cdots$ \\
\hline$\cdots$ & $\cdots$ & -. & $\cdots$ & $\because$ & $\cdots$ & $\cdots$ & -. & $\cdots$ & $\cdots$ \\
\hline$\cdots$ & $\cdots$ & -. & $\cdots$ & $\cdots$ & $\cdots$ & $\cdots$ & $\cdots$ & $\because$ & -. \\
\hline -. & $\cdots$ & $\cdots$ & $\cdots$ & $\cdots$ & $\cdots$ & $\because-$ & $\cdots$ & $\because$ & -. \\
\hline$\cdots$ & $\cdots$ & $\cdots$ & $\because$ & $\because$ & $\cdots$ & $\because-$ & -. & $\because$ & $-\cdot$ \\
\hline$\cdots$ & $\cdots$ & $\cdots$ & $\cdots$ & $\cdots$ & -- & -- & $\cdots$ & $\because-$ & $-\cdot$ \\
\hline & $\cdots$ & 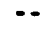 & $\cdots$ & $\cdots$ & -. & -- & $\cdots$ &.- & $\cdots$ \\
\hline .. & $\cdots$ & $\cdots$ & $\because$ & $\because$ & $\because$ & $\cdots$ & $\because$ & 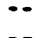 & $\cdots$ \\
\hline$\cdots$ & $\cdots$ & $\cdots$ & -- & -. & - & -. & $\cdots$ & $\because$ & - \\
\hline
\end{tabular}


SURFACE-WATER DATA-Cont inued

CHEMICAL ANALYSES-Cont inued

STATION

MUBER

09396100

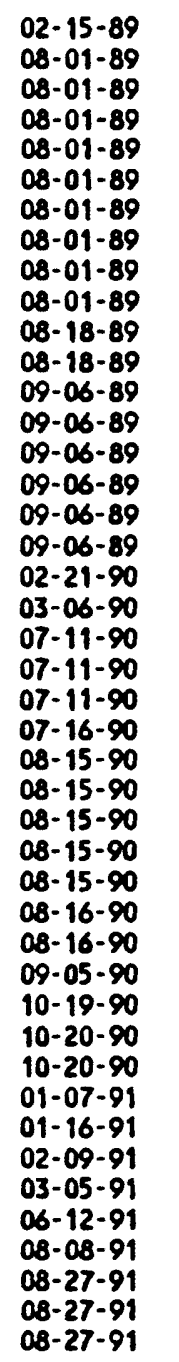

PUERCO RIVER MEAR ChaMbers, A2-Continued

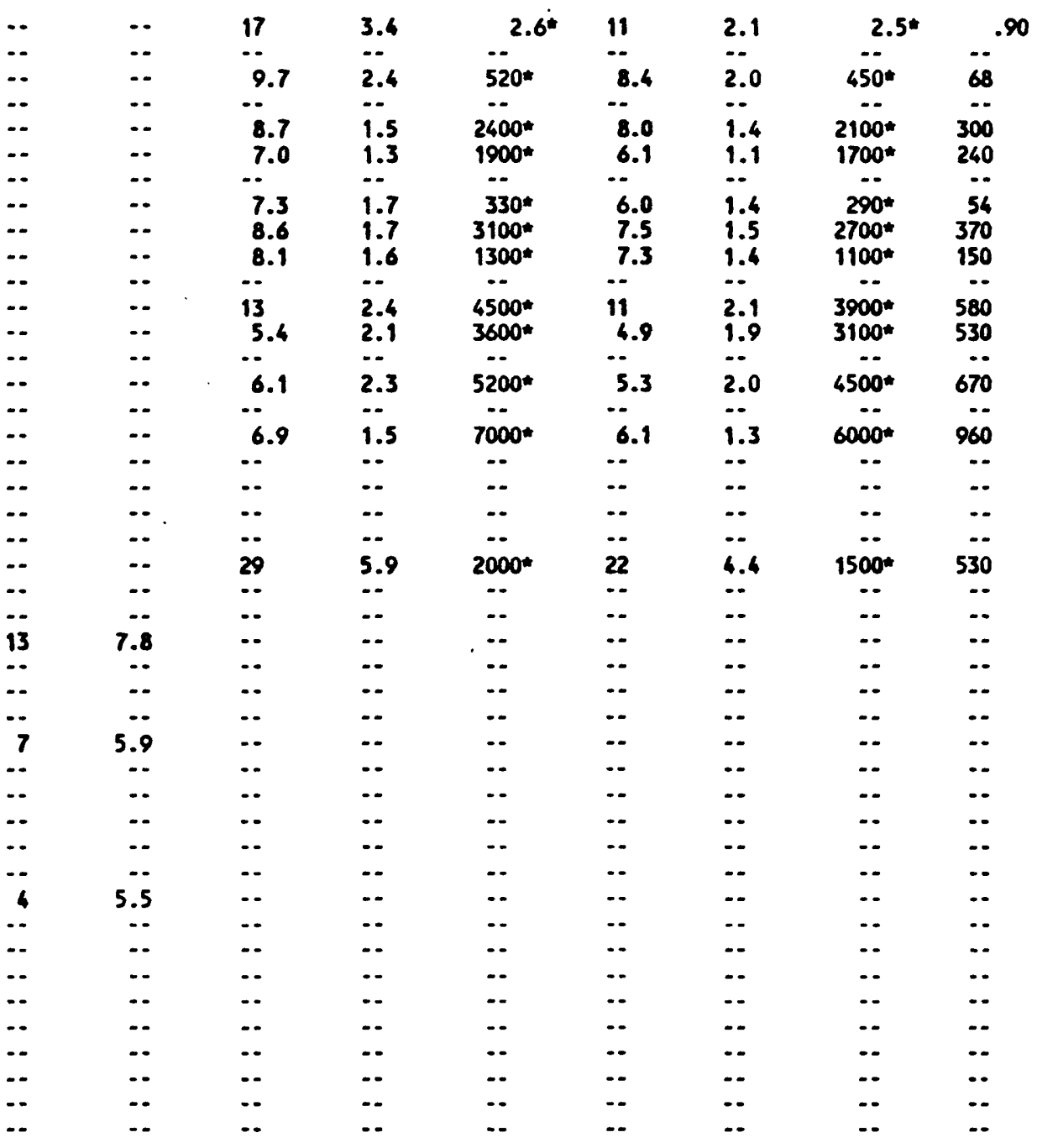


SURFACE-WATER DATA-Cont inued

CHEMICAL ANALYSES-Cont inued

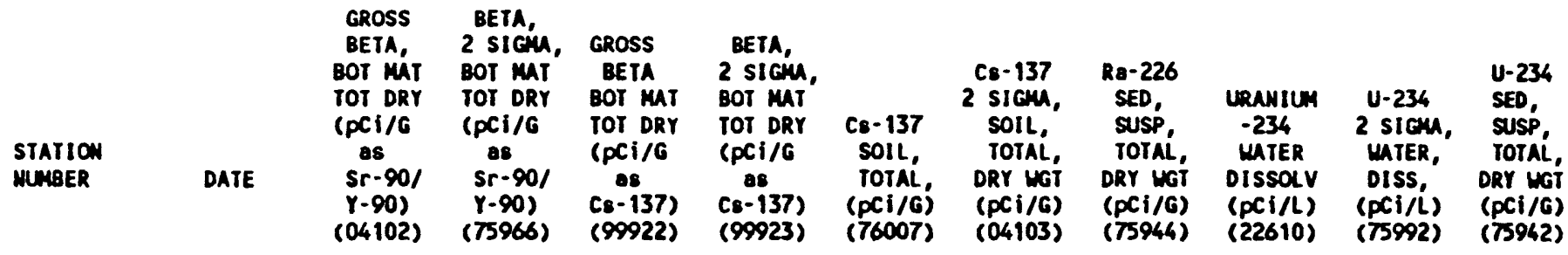

PUERCO RIVER MEAR CHAMBERS, AZ-Cont inued

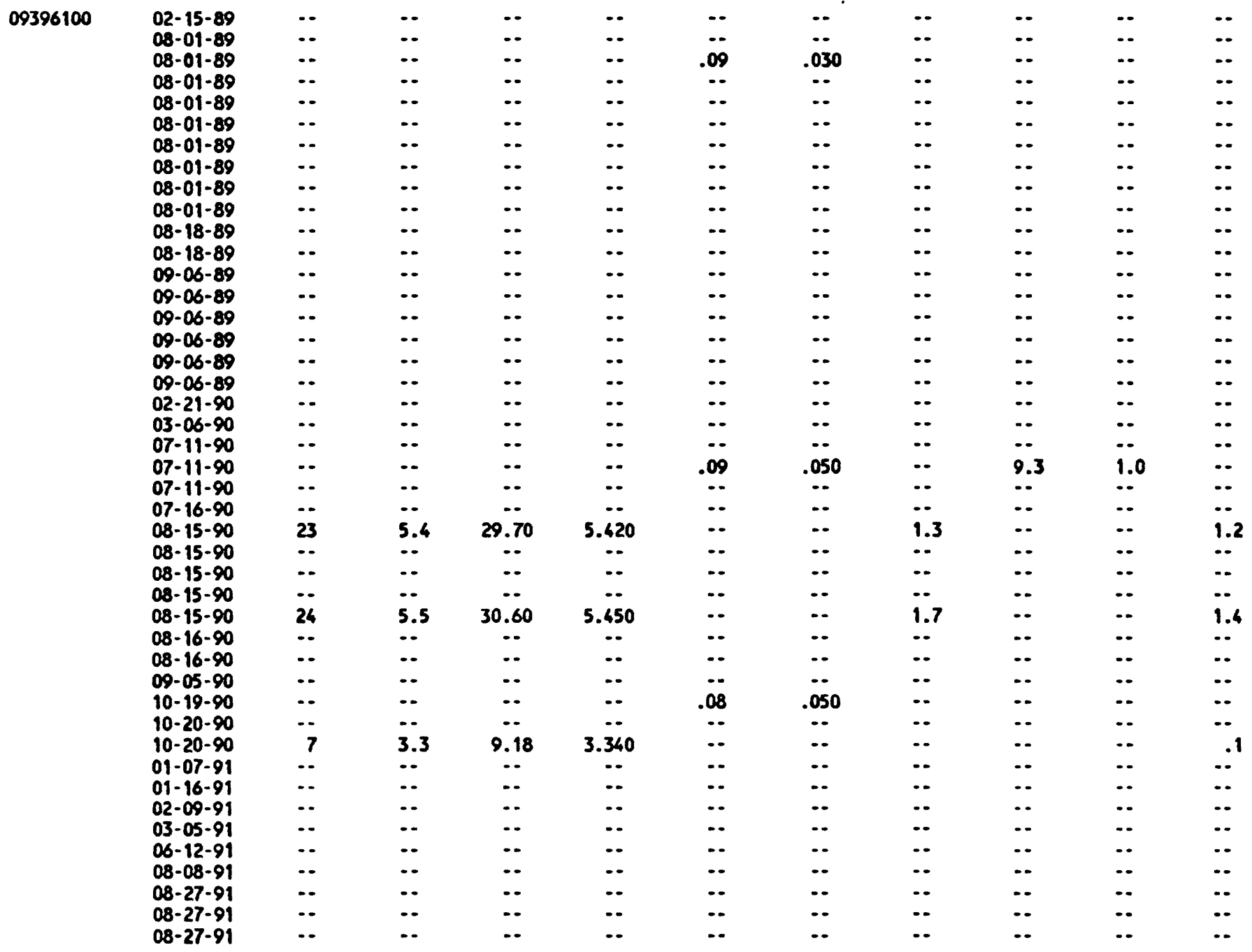


SURFACE-MATER DATA-Contínued

CHEMICAL AMALYSES-Continued

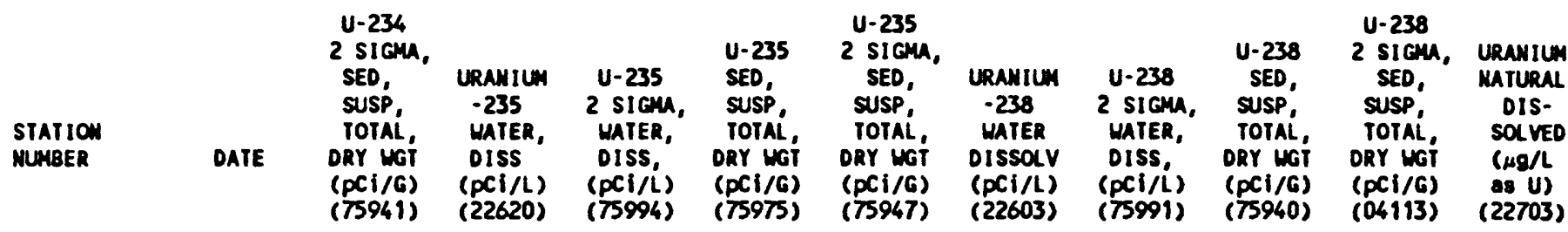

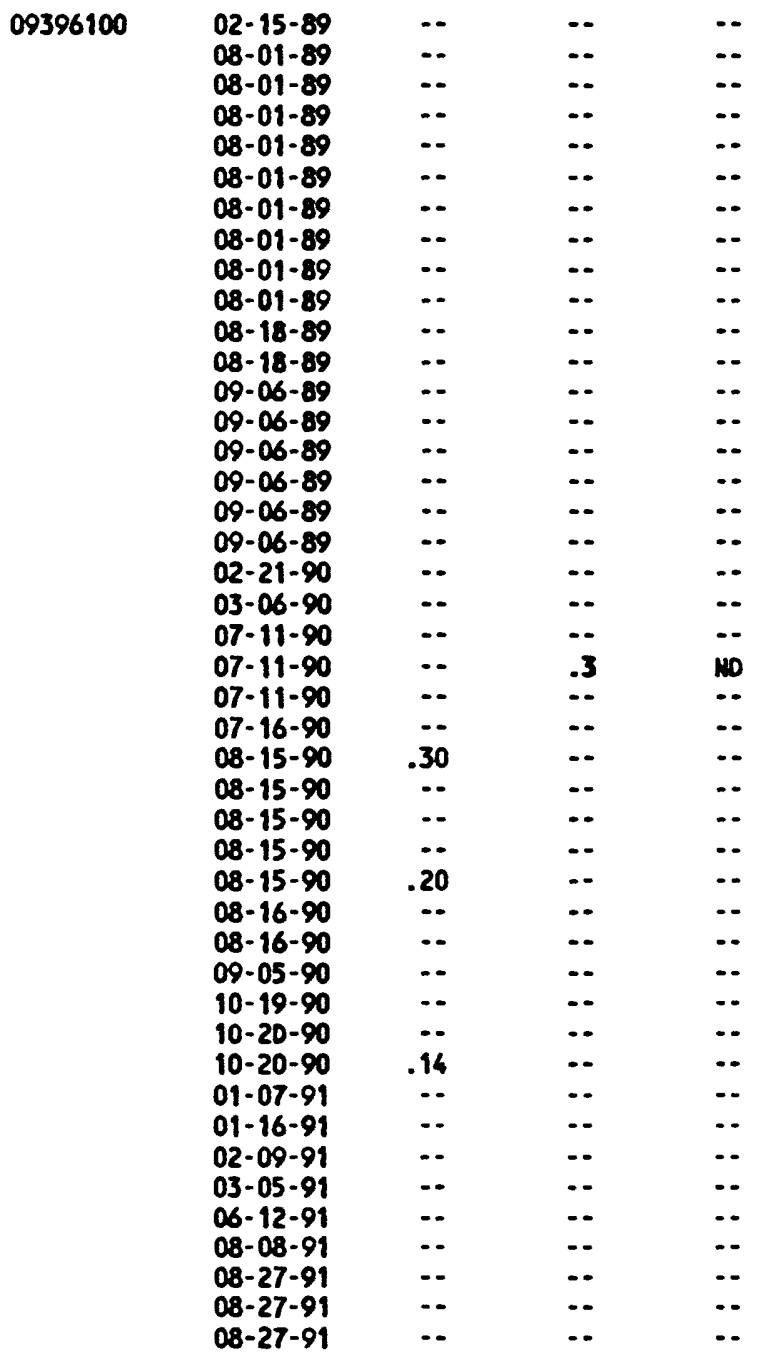

PUERCo River meAr chambers, az-Cont ínued 
SURFACE-WATER DATA-Cont inued

CHENICAL ANALYSES-Cont inued

STATION

MUABER

DATE

Th-230
SED,
SUSP,
TOTAL,
DRY WGT
(PCi/G)
(TS939)

Th- 230

2 sice

Th-232

SUSP.

TOrAL.

DRY WGT

(pCi 10 )

(Di/G)

(75852) TOTAL, DRY MGI (pCi/G) (75953)
Th-232

2 SIGU, ALUNSED, IMU SUSP. IMUM ARSENIC BOT MAT BOT MAT TOTAL, $\angle 63 \mu$ DS $\angle 63 \mu$ DS
DRY MGT

(pCi/G) (75936)
PERCENT LAB

(34792) (34802)

\begin{tabular}{|c|c|c|c|}
\hline $\begin{array}{c}\text { BARIUN } \\
\text { BOT MAT } \\
\angle 63_{\mu} \text { DS } \\
\text { LAB } \\
(\mu g / G) \\
(34807)\end{array}$ & $\begin{array}{l}\text { BERYL- } \\
\text { LIUA } \\
\text { COT MAT } \\
<63 \mu \text { DS } \\
\text { LAB } \\
(\mu 9 / G) \\
(34812)\end{array}$ & $\begin{array}{c}\text { BISIUTH } \\
\text { BOT MAT } \\
\angle 63_{\mu} \text { DS } \\
\text { LAB } \\
(\mu 9 / G) \\
(34817)\end{array}$ & $\begin{array}{l}\text { CADHIU } \\
\text { BOT MAT } \\
\angle 63_{\mu} \text { DS } \\
\text { LAB } \\
(\mu g / G) \\
(34827)\end{array}$ \\
\hline
\end{tabular}

PUERCO RIVER MEAR ChAMBERS, AZ-Continued

\begin{tabular}{|c|c|c|c|c|c|c|c|c|c|c|c|}
\hline 09396100 & $\begin{array}{l}02-15-89 \\
08-01-89\end{array}$ & $\begin{array}{l}\cdots \\
\cdots\end{array}$ & 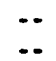 & 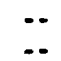 & 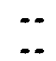 & 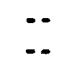 & $\begin{array}{l}-. \\
\cdots\end{array}$ & -. & 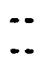 & $\begin{array}{l}-. \\
-\end{array}$ & -. \\
\hline & $\begin{array}{l}08-01-89 \\
08-01-89\end{array}$ & $\cdots$ & $\because$ & $\because$ & $\because$ & $\because$ & $\cdots$ & $\because$ & $\cdots$ & $\ldots$ & $\cdots$ \\
\hline & $\begin{array}{l}08-01-89 \\
08-01-89\end{array}$ & & & & $\ldots$ & $\ldots$ & $\ldots$ & 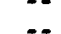 & -0 & $\cdots$ & $\because$ \\
\hline & $08-01-89$ & $\ldots$ & $\cdots$ & $\because$ & $\ldots$ & 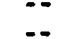 & $\because$ & $\cdots$ & $\cdots$ & -- & $\cdots$ \\
\hline & 08-01-89 & $\because$ & $\cdots$ & 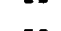 & $\cdots$ & $\cdots$ & $\cdots$ & $\because$ & $\cdots$ & $\cdots$ & $\cdots$ \\
\hline & $08-01-89$ & $\cdots$ & $\cdots$ & $\cdots$ & $\cdots$ & -- & -- & $\cdots$ & $\cdots$ & $\cdots$ & $\cdots$ \\
\hline & $08-01-89$ & $\cdots$ & $\cdots$ & -- & $\cdots$ & $\cdots$ & $\cdots$ & $-\cdot$ & $\cdots$ & $\cdots$ & $\cdots$ \\
\hline & $08-01-89$ & $\cdots$ & -- & $\cdots$ & $\cdots$ & -- & $\cdots$ & $\cdots$ & $\cdots$ & $\cdots$ & $\cdots$ \\
\hline & $08-01-89$ & $\cdots$ & $-\cdot$ & $\cdots$ & $\cdots$ & $\cdots$ & $\cdots$ & $\cdots$ & $\cdots$ & $-\cdot$ & $\cdots$ \\
\hline & $08-01-89$ & $\cdots$ & $\cdots$ & $\cdots$ & $\cdots$ & $\cdots$ & $\cdots$ & $\cdots$ & $\cdots$ & $\cdots$ & $\cdots$ \\
\hline & $08-18-89$ & $\cdots$ & $\cdots$ & $-\cdot$ & $\cdots$ & $\cdots$ & $\cdots$ & $\cdots$ & $\cdots$ & $\cdots$ & $\cdots$ \\
\hline & $08-18-89$ & $\cdots$ & $\cdots$ & $\cdots$ & $\cdots$ & $\because$ & $\because$ & $\because$ & $\cdots$ & $\because$ & $\cdots$ \\
\hline & $09-06-89$ & $\cdots$ & -. & -- & $\cdots$ & 8.6 & $<10$ & 560 & 2 & $<10$ & $<2$ \\
\hline & $09-06-89$ & $\cdots$ & $\cdots$ & -- & $\cdots$ & $\cdots$ & -. & $\cdots$ & $\cdots$ & $\cdots$ & - \\
\hline & $09-06-89$ & $\cdots$ & $\cdots$ & -- & $\cdots$ & 8.6 & $<10$ & 550 & 2 & $<10$ & $<2$ \\
\hline & $09-06-89$ & $\cdots$ & $\cdots$ & $\cdots$ & $\cdots$ & $\cdots$ & $\cdots$ & $\cdots$ & $\cdots$ & $\cdots$ & $\cdots$ \\
\hline & $09-06-89$ & -- & $\cdots$ & - & $\cdots$ & 8.3 & $<10$ & 570 & 2 & $<10$ & $<2$ \\
\hline & $09-06-89$ & $\cdots$ & -- & -- & $\cdots$ & $-\cdot$ & $\cdots$ & $\cdots$ & -- & $\cdots$ & $\cdots$ \\
\hline & $02-21-90$ & $\cdots$ & $\cdots$ & $\cdots$ & $\cdots$ & $\cdots$ & -- & $\cdots$ & $\cdots$ & $\cdots$ & $\cdots$ \\
\hline & $03-06-90$ & $\cdots$ & $\cdots$ & $\cdots$ & $\cdots$ & $\cdots$ & $\cdots$ & $\cdots$ & $\cdots$ & $\cdots$ & $\cdots$ \\
\hline & $07-11-90$ & $\cdots$ & $-\cdot$ & -- & $\cdots$ & $\cdots$ & $\cdots$ & $\cdots$ & $\cdots$ & $\cdots$ & $\cdots$ \\
\hline & $07-11-90$ & $\cdots$ & $\cdots$ & $\cdot-$ & $\cdots$ & 10 & 10 & 550 & 2 & $<10$ & $<2$ \\
\hline & $07-11-90$ & $\cdots$ & $\cdots$ & -- & $\cdots$ & $\cdots$ & -- & $\cdots$ & -- & $\cdots$ & $\cdots$ \\
\hline & $07-16-90$ & $\cdots$ & $\because \cdot$ & $\cdots$ & $\cdots$ & $\cdots$ & $\cdots$ & $\cdots$ & $\cdots$ & $\cdots$ & $\cdots$ \\
\hline & $08-15-90$ & 1.4 & .40 & 1.5 & .40 & 7.7 & $<10$ & 610 & 2 & $<10$ & $<2$ \\
\hline & $08-15-90$ & $\cdots$ & $\cdots$ & $\cdots$ & $\cdots$ & -- & $\cdots$ & $\cdots$ & $\cdots$ & $\cdots$ & $\cdots$ \\
\hline & $08-15-90$ & $\cdots$ & $\cdots$ & $\cdots$ & $\cdots$ & 9.3 & $<10$ & 580 & 2 & $<10$ & $<2$ \\
\hline & $08-15-90$ & $\cdots$ & $\ddot{\theta}$ & $\because$ & 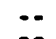 & -- & $\because$ & -- & $\because$ & 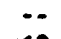 & $\cdots$ \\
\hline & $08-15-90$ & 2.2 & .27 & 2.3 & .29 & 9.6 & $<10$ & 560 & 2 & $<10$ & $<2$ \\
\hline & $08-16-90$ & $\cdots$ & -. & $\cdots$ & $\cdots$ & 10 & $<10$ & 500 & 2 & $<10$ & $<2$ \\
\hline & $08-16-90$ & $\cdots$ & $\cdots$ & $\cdots$ & $\cdots$ & $\cdots$ & $\cdots$ & $\cdots$ & $\cdots$ & $\cdots$ & $\cdots$ \\
\hline & $09-05-90$ & $\cdots$ & $\cdots$ & $\cdots$ & $\cdots$ & $\cdots$ & $\cdots$ & $\cdots$ & $\cdots$ & $\cdots$ & $\cdots$ \\
\hline & $10-19-90$ & $\cdots$ & $\cdots$ & $\cdots$ & $\cdots$ & $\cdots$ & $\cdots$ & $\cdots$ & $\cdots$ & -- & $\cdots$ \\
\hline & $10-20-90$ & $\cdots$ & $\cdots$ & $\cdots$ & -. & 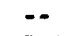 & -. & $\cdots$ & $\cdots$ & $\cdots$ & $\cdots$ \\
\hline & $10-20-90$ & 1.7 & .22 & 1.5 & .21 & 5.7 & $<10$ & 660 & 1 & $<10$ & $<2$ \\
\hline & $01-07-91$ & $\cdots$ & -. & -. & $-\cdot$ & $\cdots$ & $\cdots$ & - & $\cdots$ & $\cdots$ & $\cdots$ \\
\hline & $01-16-91$ & $\cdots$ & $\cdots$ & $\cdots$ & $\cdots$ & $\cdots$ & $\cdots$ & $\cdots$ & $\cdots$ & $\cdots$ & $\cdots$ \\
\hline & $02-09-91$ & $\cdots$ & $\cdots$ & $\cdots$ & $\cdots$ & $\cdots$ & $\cdots$ & $\cdots$ & $\cdots$ & $-\cdot$ & $\cdots$ \\
\hline & $03-05-91$ & $\cdots$ & -. & $\cdots$ & $\cdots$ & $\cdots$ & -- & $\cdots$ & $\cdots$ & $\cdots$ & $\cdots$ \\
\hline & $06-12-91$ & $\cdots$ & $\cdots$ & -- & $\cdots$ & $\cdots$ & -. & $\cdots$ & $\cdots$ & $\cdots$ & $\cdots$ \\
\hline & $08-08-91$ & -. & -- & $\cdots$ & - & $\cdots$ & -- & - & $\cdots$ & -- & $\cdots$ \\
\hline & $08-27-91$ & $\cdots$ & $\cdots$ & $\cdots$ & $\cdots$ & $\cdots$ & $\cdots$ & $\cdots$ & $\cdots$ & $\cdots$ & $\cdots$ \\
\hline & $08-27-91$ & $\cdots$ & $\cdots$ & $\cdots$ & $\cdots$ & $\cdots$ & $\cdots$ & $\cdots$ & -- & -- & $\cdots$ \\
\hline & $08-27-91$ & $\cdots$ & $\cdots$ & $\cdots$ & $\cdots$ & $\cdots$ & -- & $\ldots$ & $\cdots$ & $\cdots$ & $\cdots$ \\
\hline
\end{tabular}


SURFACE-MATER DATA-Continued

CHEMICAL ANALYSES-Continued

\begin{tabular}{|c|c|c|c|c|c|c|c|c|c|c|}
\hline $\begin{array}{l}\text { STATION } \\
\text { NUMBER }\end{array}$ & DATE & 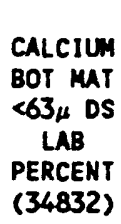 & 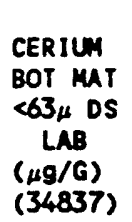 & $\begin{array}{c}\text { CHRO- } \\
\text { MIUA } \\
\text { BOT MAT } \\
<63 \mu \text { DS } \\
\text { LAB } \\
(\mu g / G) \\
(34842)\end{array}$ & $\begin{array}{c}\text { COBALT } \\
\text { BOT MAT } \\
\angle 63_{\mu} \text { DS } \\
\text { LAB } \\
(\mu g / G) \\
(34847)\end{array}$ & $\begin{array}{c}\text { COPPER } \\
\text { BOT MAT } \\
\angle 63_{\mu} \text { DS } \\
\text { LAB } \\
(\mu 9 / G) \\
(34852)\end{array}$ & $\begin{array}{c}\text { EURO- } \\
\text { PIUN } \\
\text { BOT MAT } \\
\angle 63_{\mu} \text { DS } \\
\text { LAB } \\
(\mu 9 / G) \\
(34857)\end{array}$ & $\begin{array}{c}\text { GALLIUN } \\
\text { BOT MAT } \\
\angle 63 \mu \text { DS } \\
\text { LAB } \\
(\mu 9 / G) \\
(34862)\end{array}$ & $\begin{array}{c}\text { COLD } \\
\text { BOT MAT } \\
\angle 63 \mu \text { DS } \\
\text { LAB } \\
(\mu g / G) \\
(34872)\end{array}$ & $\begin{array}{c}\text { HOLAIUN } \\
\text { BOT MAT } \\
\angle 63 \mu \text { DS } \\
\text { LAB } \\
(\mu 9 / G) \\
(34877)\end{array}$ \\
\hline
\end{tabular}

PUERCO RIVER MEAR CHAMBERS, AZ-Continued

$09396100 \quad 02-15-89$
$08-01-89$
$08-01-89$
$08-01-89$
$08-01-89$
$08-01-89$
$08-01-89$
$08-01-89$
$08-01-89$
$08-01-89$
$08-18-89$
$08-18-89$
$09-06-89$
$09-06-89$
$09-06-89$
$09-06-89$
$09-06-89$
$09-06-89$
$02-21-90$
$03-06-90$
$07-11-90$
$07-11-90$
$07-11-90$
$07-16-90$
$08-15-90$
$08-15-90$
$08-15-90$
$08-15-90$
$08-15-90$
$08-16-90$
$08-16-90$
$09-05-90$
$10-19-90$
$10-20-90$
$10-20-90$
$01-07-91$
$01-16-91$
$02-09-91$
$03-05-91$
$06-12-91$
$08-08-91$
$08-27-91$
$08-27-91$
$08-27-91$

\begin{tabular}{|c|c|c|c|}
\hline$\ldots$ & -. & - & -. \\
\hline . & -. & $\cdots$ & -. \\
\hline$\cdots$ & $\cdots$ & $\cdots$ & $\cdots$ \\
\hline$\cdots$ & $\cdots$ & $\cdots$ & $\cdots$ \\
\hline - & -. & -. & - \\
\hline - & -. & -- & $\cdots$ \\
\hline$\cdots$ & -. & $\cdots$ & $\ldots$ \\
\hline$\cdots$ & $\cdots$ & - & - \\
\hline$\cdots$ & $\cdots$ & $\cdots$ & - \\
\hline-- & 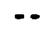 & $-\cdot$ & $\because$ \\
\hline$\cdots$ & - & $\cdots$ & 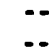 \\
\hline 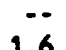 & $\because \overline{0}$ & $\ddot{B}$ & $\ddot{12}$ \\
\hline $\begin{array}{r}1.0 \\
\ldots\end{array}$ & $\begin{array}{l}78 \\
\cdots\end{array}$ & 45 & 16 \\
\hline 1.6 & 78 & 45 & 12 \\
\hline -. & $\cdots$ & -. & 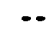 \\
\hline 1.5 & $\pi$ & 47 & 12 \\
\hline$\cdots$ & $\cdots$ & $\cdots$ & -. \\
\hline - & $\cdots$ & - & $\cdots$ \\
\hline$\cdots$ & $\cdots$ & $\cdots$ & $\cdots$ \\
\hline$\because$ & $\ddot{B}$ & 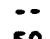 & 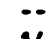 \\
\hline 2.2 & 86 & 50 & 14 \\
\hline$\ldots$ & $\ldots$ & .. & $\cdots$ \\
\hline 2.1 & 70 & 45 & 12 \\
\hline - & - & -. & -. \\
\hline 1.8 & 78 & 50 & 14 \\
\hline -. & $\cdots$ & -. & -. \\
\hline $\begin{array}{l}1.7 \\
1.9\end{array}$ & $\frac{83}{75}$ & $\begin{array}{l}50 \\
52\end{array}$ & $\begin{array}{l}13 \\
14\end{array}$ \\
\hline$\cdots$ & - & $\cdots$ & $\cdots$ \\
\hline$\cdots$ & $\cdots$ & $\cdots$ & $\cdots$ \\
\hline$\cdots$ & - & $\cdots$ & -- \\
\hline$\because$ & $\because$ & 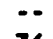 & $\ddot{\theta}$ \\
\hline 1.9 & 57 & 36 & 8 \\
\hline - & - & -. & -. \\
\hline - & $\cdots$ & -. & -. \\
\hline$\therefore$ & $\cdots$ & $\cdots$ & $\cdots$ \\
\hline-- & $\cdots$ & $\cdots$ & $\cdots$ \\
\hline 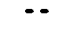 & $\cdots$ & $\cdots$ & $\cdots$ \\
\hline$\cdots$ & $\cdots$ & $\cdots$ & $\cdots$ \\
\hline$\cdots$ & $\cdots$ & $\cdots$ & $\bullet$ \\
\hline$\cdots$ & 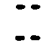 & 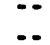 & - \\
\hline
\end{tabular}

\begin{tabular}{|c|c|c|c|c|}
\hline$\cdots$ & -. & $\cdots$ & -. & .. \\
\hline$\cdots$ & -- & $\cdots$ & $\cdots$ & - \\
\hline$\cdots$ & $\cdots$ & $\cdots$ & $\cdots$ & -. \\
\hline - & -. & - & -. & - \\
\hline$\cdots$ & $\cdots$ & $\cdots$ & $\cdots$ & - \\
\hline$\cdots$ & $\cdots$ & $\cdots$ & $\cdots$ & $\cdots$ \\
\hline$\cdots$ & $\cdots$ & $\cdots$ & $\cdots$ & $\cdots$ \\
\hline$\because$ & $\because$ & $\because$ & $\because$ & $\cdots$ \\
\hline .. & $\cdots$ & $\cdots$ & 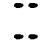 & 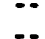 \\
\hline$\cdots$ & .. & .. & -. & .. \\
\hline - & -. & $\ldots$ & .. & .. \\
\hline 25 & $<2$ & 21 & $<8$ & $<4$ \\
\hline$\cdots$ & $\cdots$ & $\cdots$ & -- & - \\
\hline 23 & $<2$ & 21 & $<8$ & $<4$ \\
\hline$\because$ & $\cdots$ & $\because$ & $\cdots$ & $\cdots$ \\
\hline 22 & $<2$ & 20 & $<8$ & $<4$ \\
\hline$\cdots$ & -- & $\cdots$ & $\cdots$ & -- \\
\hline$\cdots$ & $\cdots$ & $\cdots$ & $\cdots$ & $\cdots$ \\
\hline - & $\cdots$ & $\cdots$ & $\cdots$ & $\cdots$ \\
\hline 25 & $<2$ & 24 & 8 & 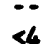 \\
\hline$\cdots$ & 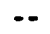 & $\cdots$ & $\cdots$ & .. \\
\hline$\cdots$ & -. & - & $\cdots$ & .. \\
\hline 22 & $<2$ & 17 & $<8$ & $<4$ \\
\hline$\cdots$ & $\cdots$ & $\cdots$ & $\cdots$ & $\cdots$ \\
\hline 24 & $<2$ & 22 & $<8$ & $<4$ \\
\hline$\cdots$ & $\cdots$ & $\cdots$ & $\cdots$ & -. \\
\hline $\begin{array}{l}23 \\
23\end{array}$ & $\begin{array}{r}2 \\
<2\end{array}$ & $\begin{array}{l}22 \\
23\end{array}$ & $\begin{array}{l}88 \\
<8\end{array}$ & $\begin{array}{l}<4 \\
<4\end{array}$ \\
\hline$\cdots$ & $\cdots$ & $\cdots$ & $\cdots$ & -. \\
\hline$\cdots$ & $\cdots$ & $\cdots$ & -. & $\cdots$ \\
\hline$\cdots$ & $\cdots$ & - & $\cdots$ & - \\
\hline$\cdots$ & $\cdots$ & $\cdots$ & $\cdots$ & $\cdots$ \\
\hline 17 & $<2$ & 13 & 88 & $<4$ \\
\hline$\cdots$ & $\cdots$ & $\cdots$ & $\cdots$ & $\cdots$ \\
\hline$\cdots$ & $\cdots$ & $\cdots$ & $\cdots$ & $\cdots$ \\
\hline$\cdots$ & $\cdots$ & $\cdots$ & $\cdots$ & $\cdots$ \\
\hline$\cdots$ & $\cdots$ & $\because$ & $\cdots$ & $\cdots$ \\
\hline$\cdots$ & $\cdots$ & $\cdots$ & $\cdots$ & $\cdots$ \\
\hline$\cdots$ & $\cdots$ & $\because$ & $\cdots$ & $\cdots$ \\
\hline$\cdots$ & $\cdots$ & $\because$ & $\because$ & $\because$ \\
\hline$\ldots$ & $\ldots$ & $\ldots$ & . & 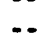 \\
\hline
\end{tabular}


SURFACE-WATER DATA-Cont inued

CHEMICAL ANALYSES-Continued

STATION

MUMBER

$093 \% 100$
02-15-89

08-01-89

08-01-89

08-01-89

08-01-89

08-01-89

08-01-89

08-01-89

08-01-89

08-01-89

08-18-89

08-18-89

09-06-89

09-06-89

09-06-89

09-06-89

09-06-89

09-06-89

02-21-90

03-06-90

07-11-90

07-11-90

07-11-90

07-16-90

08-15-90

08-15-90

08-15-90

08-15-90

08-15-90

08-16-90

08-16-90

09-05-90

10-19-90

10-20-90

10-20-90

01-07-91

01-16-91

02-09-91

03-05-91

06-12-91

08-08-91

08-27-91

08-27-91

08-27-91

\begin{tabular}{|c|c|c|c|c|c|c|c|c|}
\hline $\begin{array}{c}\text { IRON } \\
\text { BOT MAT } \\
\angle 63_{\mu} \text { DS } \\
\text { LAB } \\
\text { PERCENT } \\
\text { (34882) }\end{array}$ & $\begin{array}{c}\text { LANTHA- } \\
\text { NUA } \\
\text { BOT MAT } \\
\angle 63 \mu \text { DS } \\
\text { LAB } \\
(\mu g / G) \\
(34887)\end{array}$ & $\begin{array}{c}\text { LEAD } \\
\text { BOT MAT } \\
\angle 63_{\mu} \text { DS } \\
\text { LAB } \\
(\mu \mathrm{g} / \mathrm{G}) \\
(34892)\end{array}$ & $\begin{array}{c}\text { LITHIUH } \\
\text { BOT MAT } \\
\angle 63_{\mu} \text { DS } \\
\text { LAB } \\
(\mu g / G) \\
(34897)\end{array}$ & $\begin{array}{l}\text { MAGNE- } \\
\text { SIUN } \\
\text { BOT MAT } \\
\text { C63H DS } \\
\text { LAB } \\
\text { PERCENT } \\
(34902)\end{array}$ & $\begin{array}{l}\text { MANGA- } \\
\text { NESE } \\
\text { BOT MAT } \\
\angle 63 \mu \text { DS } \\
\text { LAB } \\
(\mu g / G) \\
(34907)\end{array}$ & $\begin{array}{c}\text { MOLYB- } \\
\text { DENUM } \\
\text { BOT MAT } \\
<63_{\mu} \text { DS } \\
\text { LAB } \\
(\mu g / G) \\
(34917)\end{array}$ & $\begin{array}{l}\text { NEOOYM- } \\
\text { IUM } \\
\text { BOT MAT } \\
\angle 63 \mu \text { DS } \\
\text { LAB } \\
\text { (HO/G) } \\
(34922)\end{array}$ & $\begin{array}{c}\text { NICKEL } \\
\text { BOT MAT } \\
\text { C63 DS } \\
\text { LAB } \\
(\mu 9 / G) \\
(34927)\end{array}$ \\
\hline
\end{tabular}

PUERCO RIVER MEAR CHAMBERS, AZ-Continued

\begin{tabular}{|c|c|c|c|c|c|c|c|c|}
\hline- & - & -. & -- & -. & . & -. & .. & $\ldots$ \\
\hline$\cdots$ & -- & -. & $\cdots$ & -- & -- & -- & -- & -- \\
\hline$\cdots$ & -. & $\cdots$ & -. & $\cdots$ & $\cdots$ & -. & $\cdots$ & -. \\
\hline$\cdots$ & -. & $\cdots$ & -- & $\cdots$ & $\cdots$ & -- & -- & -- \\
\hline$\cdots$ & -. & $\cdots$ & $\cdots$ & $\cdots$ & - & -. & -- & -- \\
\hline$\cdots$ & $\cdots$ & $\cdots$ & $\cdots$ & $\cdots$ & -. & -. & $\cdots$ & -- \\
\hline$\cdots$ & -. & $\cdots$ & $\cdots$ & $\cdots$ & $\cdots$ & -- & $\cdots$ & $\cdots$ \\
\hline$\cdots$ & $\cdots$ & $\cdots$ & $\cdots$ & $\cdots$ & $\cdots$ & $\cdots$ & -- & - \\
\hline$\because$ & $\cdots$ & $\cdots$ & $\cdots$ & $\because$ & $\cdots$ & $\cdots$ & $\cdots$ & $\cdots$ \\
\hline 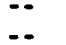 & 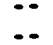 & $\ldots$ & $\ldots$ & $\cdots$ & 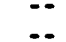 & 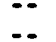 & 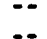 & $\cdots$ \\
\hline-- & $\ldots$ & -. & $\ldots$ & $\ldots$ & .. & .. & .. & .. \\
\hline 3.0 & 42 & 22 & 36 & .89 & 390 & $<2$ & 35 & 17 \\
\hline$\cdots$ & -- & $=$ & -- & -. & -. & -- & -. & - \\
\hline 3.0 & 41 & 22 & 36 & .87 & 380 & $<2$ & 36 & 18 \\
\hline$\cdots$ & .- & $\ldots$ & $=$ & $\ldots$ & - & $\ldots$ & - & $\ldots$ \\
\hline 2.9 & 41 & 23 & 35 & .85 & 380 & $<2$ & 34 & 18 \\
\hline$\cdots$ & $\cdots$ & $\cdots$ & $\cdots$ & $\cdots$ & $\because$ & $\cdots$ & $\cdots$ & $\cdots$ \\
\hline$\cdots$ & -. & $\cdots$ & -. & $\cdots$ & $\cdots$ & -. & -- & - \\
\hline$\cdots$ & -. & $\cdots$ & $\cdots$ & $\cdots$ & -- & $\cdots$ & $\cdots$ & $\cdots$ \\
\hline$\because$ & 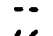 & $\ddot{\theta}$ & $\because$ & $\because$ & -- & 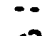 & $\ddot{z}$ & $\ddot{M}$ \\
\hline 3.8 & 46 & 27 & 46 & 1.3 & 450 & $<2$ & 39 & 20 \\
\hline$\cdots$ & 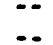 & $\cdots$ & 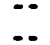 & $\cdots$ & 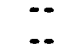 & 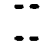 & 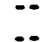 & $\cdots$ \\
\hline$=0$ & 38 & 20 & 34 & 1.0 & 450 & $<2$ & $\ddot{31}$ & 19 \\
\hline$\therefore$ & .. & $\cdots$ & -. & $\cdots$ & $\cdots$ & $\ldots$ & $\because$ & $\ldots$ \\
\hline 3.5 & 42 & 23 & 41 & 1.1 & 430 & $<2$ & 36 & 17 \\
\hline$\cdots$ & -- & $\cdots$ & $\cdots$ & $\ldots$ & - & $\ldots$ & $\cdots$ & $\therefore$ \\
\hline $\begin{array}{l}3.4 \\
3.8\end{array}$ & $\begin{array}{l}45 \\
42\end{array}$ & $\begin{array}{l}22 \\
20\end{array}$ & $\begin{array}{l}41 \\
45\end{array}$ & $\begin{array}{l}1.0 \\
1.3\end{array}$ & $\begin{array}{l}420 \\
470\end{array}$ & $\begin{array}{l}<2 \\
<2\end{array}$ & $\begin{array}{l}38 \\
33\end{array}$ & $\begin{array}{l}18 \\
21\end{array}$ \\
\hline- & -- & $\cdots$ & $\cdots$ & $\cdots$ & $\cdots$ & - & -. & $\cdots$ \\
\hline$-\cdot$ & -- & $\cdots$ & $\cdots$ & $-\bullet$ & $\cdots$ & $\cdots$ & $-\cdot$ & 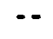 \\
\hline -. & -- & $\cdots$ & -- & $\cdots$ & -- & $\cdots$ & -- & $\cdots$ \\
\hline$\because$ & $\ddot{z}$ & $\ddot{10}$ & 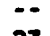 & 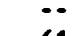 & $\ddot{0}$ & $\ddot{n}$ & $\ddot{a}$ & $\ddot{z}$ \\
\hline 1.9 & 32 & 18 & 23 & .61 & 350 & $<2$ & 24 & 11 \\
\hline$\cdots$ & $\cdots$ & $\because$ & 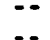 & $\because$ & 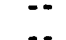 & $\cdots$ & $\cdots$ & 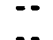 \\
\hline$\cdots$ & $\cdots$ & $\because$ & 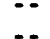 & $\because$ & $\because$ & $\cdots$ & $\because$ & $\cdots$ \\
\hline$\cdots$ & $=-$ & $\ldots$ & $\ldots$ & $\because$ & $\ldots$ & - & $\therefore$ & $\cdots$ \\
\hline$\ldots$ & .. & $\ldots$ & $\ldots$ & $\ldots$ & $\ldots$ & $\ldots$ & $\ldots$ & - \\
\hline .. & - & $\ldots$ & -. & -. & .- & .- & .. & .. \\
\hline- & -. & - & -. & - & - & - & -. & .. \\
\hline -. & -. & $\cdots$ & $\cdots$ & - & -. & -. & $\cdots$ & -- \\
\hline$\cdots$ & -. & - & $\cdots$ & - & $\cdots$ & $\cdots$ & $\cdots$ & -. \\
\hline
\end{tabular}


SURFACE-WATER DATA-Cont inued

CHEMICAL AMALYSES-Cont inued

\begin{tabular}{|c|c|c|c|c|c|c|c|c|c|c|}
\hline & & NIOBIUN & $\begin{array}{l}\text { PHOS- } \\
\text { PHORUS }\end{array}$ & $\begin{array}{l}\text { Potas- } \\
\text { sIUN }\end{array}$ & $\begin{array}{l}\text { SCAN- } \\
\text { DIUN }\end{array}$ & SILVER & soolus & $\begin{array}{l}\text { STRON- } \\
\text { TIUN }\end{array}$ & $\begin{array}{l}\text { TANTA- } \\
\text { LUN }\end{array}$ & THORIUN \\
\hline $\begin{array}{l}\text { TATION } \\
\text { UBER }\end{array}$ & DATE & $\begin{array}{c}\text { BOT MAT } \\
\angle 63 \mu \text { DS } \\
\text { LAB } \\
(\mu g / G) \\
(34932)\end{array}$ & $\begin{array}{l}\text { BOT MAT } \\
<63 \mu \text { DS } \\
\text { LAB } \\
\text { PERCENT } \\
\text { (34937) }\end{array}$ & $\begin{array}{l}\text { BOT MT } \\
\angle 63 \mu \text { DS } \\
\text { LAS } \\
\text { PERCENT } \\
\text { (34942) }\end{array}$ & $\begin{array}{c}\text { BOT MAT } \\
\angle 63 \mu \text { DS } \\
\text { LAB } \\
(\mu \sigma / G) \\
(34947)\end{array}$ & $\begin{array}{c}\text { BOT KAT } \\
<63 \mu \text { DS } \\
L A B \\
(\mu 9 / G) \\
(34957)\end{array}$ & $\begin{array}{l}\text { BOT MAT } \\
\angle 63 \mu \text { DS } \\
\text { LAB } \\
\text { PERCENT } \\
\text { (34962) }\end{array}$ & $\begin{array}{c}\text { BOT MAT } \\
\angle 63_{\mu} \text { DS } \\
\text { LAB } \\
(\mu 9 / G) \\
(34967)\end{array}$ & $\begin{array}{c}\text { BOT MAT } \\
\angle 63 \mu \text { DS } \\
L A B \\
(\mu \sigma / G) \\
(34977)\end{array}$ & $\begin{array}{c}\text { BOT MAT } \\
\angle 63_{\mu} \text { DS } \\
\text { LAB } \\
(\mu g / G) \\
(34982)\end{array}$ \\
\hline
\end{tabular}

09396100

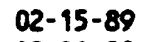

$08-01-89$

$08-01-89$

08-01-89

08-01-89

08-01-89

08-01-89

08-01-89

08-01-89

08-01-89

08-18-89

08-18-89

09-06-89

09-06-89

09-06-89

09-06-89

09-06-89

09-06-89

02-21-90

03-06-90

07-11-90

$07-11-90$

$07-11-90$

07-16-90

08-15-90

08-15-90

$08-15-90$

08- 15-90

$08-15-90$

08-16-90

08- 16-90

09-05-90

10-19-90

10-20-90

10-20-90

01-07-91

01-16-91

02-09-91

03-05-91

06-12-91

08-08-91

08-27-91

08-27-91

08-27-91

PUERCO RIVER MEAR CHAMBERS, AZ-Continued

\begin{tabular}{|c|c|c|c|c|c|c|c|c|}
\hline -. & .. & .. & .. & -. & -. & -- & -. & -. \\
\hline-- & -- & -. & $\cdots$ & -- & -. & -- & -- & -. \\
\hline$\because$ & -- & $\cdots$ & $\cdots$ & -- & -- & -- & $\because$ & -- \\
\hline-- & -- & -. & $\cdots$ & $\cdots$ & -- & -- & $\because \cdot$ & -- \\
\hline$\because$ & -- & $\cdots$ & $\cdots$ & $\cdots$ & $\cdots$ & $\cdots$ & -. & -- \\
\hline $\begin{array}{l}-- \\
-\end{array}$ & $\because$ & $\cdots$ & $\ddot{-}$ & -- & -- & -- & $\because$ & 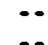 \\
\hline$\because$ & $\ddot{\because}$ & $\ddot{--}$ & $\ddot{0}$ & $\cdots$ & $\because$ & $\ddot{-}$ & $\ddot{-}$ & $\because$ \\
\hline$\because$ & -. & .. & .. & $\therefore$ & $\because$ & $\therefore$ & $\therefore$ & 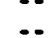 \\
\hline-- & -- & -. & .. & -- & -. & -. & -- & -- \\
\hline-- & -- & -. & -. & -- & -- & $\cdots$ & -. & -. \\
\hline 14 & .05 & 1.9 & 12 & $<4$ & .46 & 170 & $<40$ & 13 \\
\hline -. & $\cdots$ & 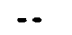 & 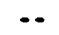 & $\because$ & -. & - & -. & $\therefore$ \\
\hline 13 & .05 & 1.9 & 12 & $<4$ & .45 & 170 & $<40$ & 15 \\
\hline$\because$ & $=$ & 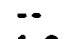 & $\ddot{\ddot{n}}$ & $\cdots$ & 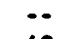 & $\because$ & $\because$ & $\because$ \\
\hline 13 & .05 & 1.9 & 12 & $<4$ & .48 & 170 & $<40$ & 14 \\
\hline -. & -. & $\cdots$ & $\cdots$ & $\cdots$ & -. & $\cdots$ & 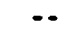 & .. \\
\hline-- & $\cdots$ & $\cdots$ & $\cdots$ & $\cdots$ & -- & $\cdots$ & -. & -- \\
\hline 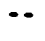 & -- & -. & $\cdots$ & $\because$ & $-\cdot$ & -- & -. & -- \\
\hline$\ddot{12}$ & $\ddot{0}$ & $\ddot{g}$ & $\ddot{\mu}$ & $\ddot{\theta}$ & 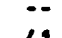 & $\ddot{\theta}$ & $\ddot{10}$ & $\because$ \\
\hline $\begin{array}{l}12 \\
-\end{array}$ & .07 & 2.0 & 14 & 4 & .41 & 210 & $<40$ & 16 \\
\hline -. & -. & -. & .. & -. & -. & -. & -. & -. \\
\hline 9 & .05 & 2.0 & 11 & $<4$ & .55 & 180 & $<40$ & 13 \\
\hline$\because$ & $\ddot{n}$ & 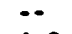 & -- & $\because$ & -. & $\cdots$ & $\ddot{z}$ & -- \\
\hline 9 & .05 & 1.9 & 16 & $<4$ & .40 & 190 & $<40$ & 15 \\
\hline 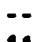 & $\ddot{\ddot{x}}$ & $\because$ & $\ddot{a r}$ & $\because$ & $\ddot{x}$ & $\ddot{\ddot{O}}$ & $\ddot{ }$ & 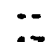 \\
\hline 11 & .05 & 1.9 & 15 & $<4$ & .36 & 190 & $<40$ & 17 \\
\hline 11 & .05 & 1.9 & 16 & $<4$ & .29 & 200 & $<40$ & 15 \\
\hline-- & -. & $\because$ & $\cdots$ & -- & $\cdots$ & -- & $-\cdot$ & -. \\
\hline$\cdots$ & -- & -- & $\cdots$ & $\cdots$ & -- & -- & -- & $\cdots$ \\
\hline$\because$ & -. & $\because$ & $\cdots$ & $\cdots$ & $\cdots$ & $\cdots$ & $\cdots$ & $\cdots$ \\
\hline-- & $\because$ & $\because-$ & $\cdots$ & -. & -- & $\cdots$ & $\cdots$ & .. \\
\hline 6 & .04 & 2.0 & 7 & $<4$ & .81 & 170 & $<40$ & 10 \\
\hline$\cdots$ & -- & -- & $\cdots$ & $\cdots$ & $\cdots$ & $\because$ & $\cdots$ & $\cdots$ \\
\hline$\ldots$ & $\cdots$ & -. & -- & $\cdots$ & $\cdots$ & $\because$ & $\because$ & $\cdots$ \\
\hline$\because$ & $\cdots$ & -. & -. & $\cdots$ & $-\cdot$ & -- & $\cdots$ & $\cdots$ \\
\hline .. & $\because$ & 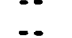 & 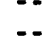 & $\ldots$ & $\because$ & $\cdots$ & $\because$ & 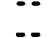 \\
\hline & . & -- & -. & -. & -- & -. & .. & .. \\
\hline$\cdots$ & -- & $\cdots$ & $\cdots$ & $\cdots$ & -. & -. & .. & -. \\
\hline$\cdots$ & $\cdots$ & $\cdots$ & $\cdots$ & $\cdots$ & $\because$ & $\cdots$ & $\cdots$ & $\cdots$ \\
\hline$\cdots$ & -. & -- & $\cdots$ & $\cdots$ & $-\cdot$ & - & $\cdots$ & -. \\
\hline
\end{tabular}


CHEMICAL AKALYSES-Continued

STATION

MUMBER

DATE

\begin{tabular}{|c|c|c|c|c|c|c|c|c|}
\hline $\begin{array}{l}\text { SED. } \\
\text { SUSP. } \\
\text { FALL } \\
\text { DIAN. } \\
\text { FINER } \\
\text { THAN } \\
002 \text { MM } \\
\text { (70337) }\end{array}$ & $\begin{array}{l}\text { SED. } \\
\text { SUSP. } \\
\text { FALL } \\
\text { DINA. } \\
\times \text { FINER } \\
\text { THAN } \\
.004 \text {.M } \\
\text { (70338) }\end{array}$ & $\begin{array}{l}\text { OINAER } \\
\text { THAN } \\
.008 \text { min } \\
\text { (70339) }\end{array}$ & $\begin{array}{l}\text { SED. } \\
\text { SUSP. } \\
\text { FALL } \\
\text { DINA. } \\
\times \text { FINER } \\
\text { THAN } \\
.016 \text { mM } \\
(70340)\end{array}$ & $\begin{array}{l}\text { SED. } \\
\text { SUSP. } \\
\text { FALL } \\
\text { DINM. } \\
\times \text { FINER } \\
\text { THAN } \\
.031 \text { M } \\
\text { (70341) }\end{array}$ & $\begin{array}{r}\times 11 \\
T H \\
.062 \\
(70\end{array}$ & $\begin{array}{l}\text { PP. } \\
\dot{L} \\
\text { IM. } \\
\text { IER } \\
\text { W. }\end{array}$ & $\begin{array}{l}\text { SP. } \\
\text { IM. } \\
\text { IER } \\
\text { IN }\end{array}$ & $\begin{array}{l}\text { SP. } \\
\text { IM. } \\
\text { IN. } \\
\text { IN }\end{array}$ \\
\hline
\end{tabular}

PUERCO RIVER MEAR ChaMbers, AZ-Continued

$09396100 \quad 02-15-89$
$08-01-89$
$08-01-89$
$08-01-89$
$08-01-89$
$08-01-89$
$08-01-89$
$08-01-89$
$08-01-89$
$08-01-89$
$08-18-89$
$08-18-89$
$09-06-89$
$09-06-89$
$09-06-89$
$09-06-89$
$09-06-89$
$09-06-89$
$02-21-90$
$03-06-90$
$07-11-90$
$07-11-90$
$07-11-90$
$07-16-90$
$08-15-90$
$08-15-90$
$08-15-90$
$08-15-90$
$08-15-90$
$08-16-90$
$08-16-90$
$09-05-90$
$10-19-90$
$10-20-90$
$10-20-90$
$01-07-91$
$01-16-91$
$02-09-91$
$03-05-91$
$06-12-91$
$08-08-91$
$08-27-91$
$08-27-91$
$08-27-91$

\begin{tabular}{|c|c|c|c|}
\hline -. & . & - & $\cdots$ \\
\hline$\cdots$ & $\cdots$ & - & $\cdots$ \\
\hline$\cdots$ & $\cdots$ & $\cdots$ & $\cdots$ \\
\hline$\cdots$ & $\cdots$ & $\cdots$ & $\cdots$ \\
\hline$\cdots$ & $\cdots$ & $\cdots$ & -. \\
\hline$\cdots$ & $\cdots$ & -. & $\cdots$ \\
\hline$\cdots$ & $\cdots$ & $\cdots$ & $\cdots$ \\
\hline$\cdots$ & $\cdots$ & $\cdots$ & $\cdots$ \\
\hline$\cdots$ & $\cdots$ & $\cdots$ & $\cdots$ \\
\hline$\cdots$ & $\cdots$ & $\cdots$ & $\cdots$ \\
\hline$\cdots$ & $\cdots$ & $\cdots$ & - \\
\hline$\ldots$ & $\ldots$ & .. & $\ldots$ \\
\hline -- & $\ldots$ & .- & .. \\
\hline 45 & 55 & 65 & 75 \\
\hline$\cdots$ & $\cdots$ & $\cdots$ & $\cdots$ \\
\hline 43 & 51 & 61 & 69 \\
\hline$\cdots$ & $\cdots$ & $\cdots$ & $\cdots$ \\
\hline$\cdots$ & $\cdots$ & $\cdots$ & $\cdots$ \\
\hline$\cdots$ & $\cdots$ & $\cdots$ & $\cdots$ \\
\hline$\cdots$ & $\cdots$ & $\cdots$ & $\cdots$ \\
\hline $\begin{array}{l}53 \\
48\end{array}$ & $\begin{array}{l}63 \\
57\end{array}$ & $\begin{array}{l}72 \\
66\end{array}$ & $\begin{array}{l}79 \\
72\end{array}$ \\
\hline$\cdots$ & $\cdots$ & $\cdots$ & $\cdots$ \\
\hline$\cdots$ & -. & $\cdots$ & $\cdots$ \\
\hline$\cdots$ & $\cdots$ & $\cdots$ & $\cdots$ \\
\hline$\cdots$ & $\cdots$ & $\cdots$ & $\cdots$ \\
\hline$\cdots$ & $\cdots$ & $\cdots$ & $\cdots$ \\
\hline$\cdots$ & $\cdots$ & $\cdots$ & $\cdots$ \\
\hline$\cdots$ & $\cdots$ & $\cdots$ & $\cdots$ \\
\hline- & 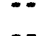 & $\cdots$ & $\cdots$ \\
\hline$\because$ & 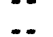 & 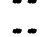 & $\ldots$ \\
\hline . & $\ldots$ & .. & $\ldots$ \\
\hline . & . & $\ldots$ & $\ldots$ \\
\hline - & -. & $\cdots$ & - \\
\hline - & $\cdots$ & $\cdots$ & $\cdots$ \\
\hline- & $\cdots$ & $\cdots$ & $\cdots$ \\
\hline- & $\cdots$ & $\cdots$ & $\cdots$ \\
\hline 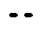 & $\cdots$ & $\cdots$ & $\cdots$ \\
\hline 62 & 76 & 78 & 88 \\
\hline- & $\cdots$ & $\cdots$ & $\cdots$ \\
\hline 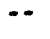 & $\cdots$ & $\cdots$ & $\cdots$ \\
\hline$\cdots$ & $\cdots$ & $\cdots$ & $\cdots$ \\
\hline
\end{tabular}

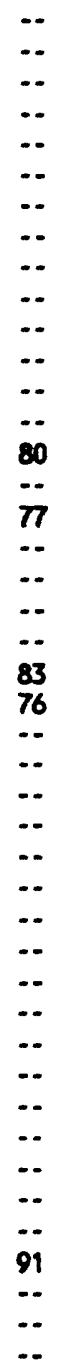

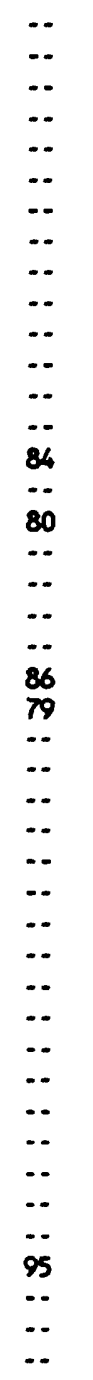

\begin{tabular}{|c|c|c|}
\hline$\cdots$ & $\cdots$ & $\cdots$ \\
\hline$\cdots$ & $\cdots$ & $\cdots$ \\
\hline$\cdots$ & $\cdots$ & $\cdots$ \\
\hline$\cdots$ & $\cdots$ & $\cdots$ \\
\hline$\cdots$ & $\cdots$ & $\cdots$ \\
\hline$\cdots$ & $\cdots$ & $\cdots$ \\
\hline$\cdots$ & $\cdots$ & $\cdots$ \\
\hline$\cdots$ & $\cdots$ & $\cdots$ \\
\hline$\cdots$ & $\cdots$ & $\cdots$ \\
\hline$\because$ & $\cdots$ & $\because$ \\
\hline$\cdots$ & $\because$ & $\cdots$ \\
\hline$\because$ & $\ldots$ & $\ldots$ \\
\hline$\ddot{m}$ & - & .. \\
\hline 92 & 100 & 100 \\
\hline 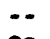 & 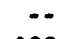 & $\cdots$ \\
\hline 92 & 100 & $\cdots$ \\
\hline$\cdots$ & $\cdots$ & $\cdots$ \\
\hline$\cdots$ & $\cdots$ & $\because$ \\
\hline$\cdots$ & $\cdots$ & $\cdots$ \\
\hline 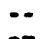 & $\ddot{m}$ & 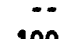 \\
\hline $\begin{array}{l}93 \\
90\end{array}$ & $\begin{array}{l}99 \\
99\end{array}$ & $\begin{array}{l}100 \\
100\end{array}$ \\
\hline$\cdots$ & $\cdots$ & $\cdots$ \\
\hline$\cdots$ & $\cdots$ & $\cdots$ \\
\hline$\cdots$ & $\cdots$ & $\cdots$ \\
\hline$\cdots$ & $\cdots$ & $\cdots$ \\
\hline$-\cdot$ & $\cdots$ & $\cdots$ \\
\hline$\because$ & 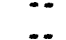 & $\cdots$ \\
\hline$\because$ & 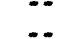 & $\because$ \\
\hline$\ldots$ & $\cdots$ & $\ldots$ \\
\hline -. & $\ldots$ & .. \\
\hline$\cdots$ & $\cdots$ & -. \\
\hline$\cdots$ & $\cdots$ & $\cdots$ \\
\hline$-\cdot$ & $\cdots$ & - \\
\hline$\cdots$ & $\cdots$ & $\cdots$ \\
\hline -- & $\cdots$ & $\cdots$ \\
\hline$\because$ & $\cdots$ & $\cdots$ \\
\hline$\because$ & $\because$ & $\cdots$ \\
\hline 99 & 100 & $\cdots$ \\
\hline$\cdots$ & $\because$ & $\cdots$ \\
\hline$\cdots$ & $\because$ & $\cdots$ \\
\hline
\end{tabular}


SURFACE-WATER DATA-Cont inued

CHEMICAL ANALYSES-Cont inued

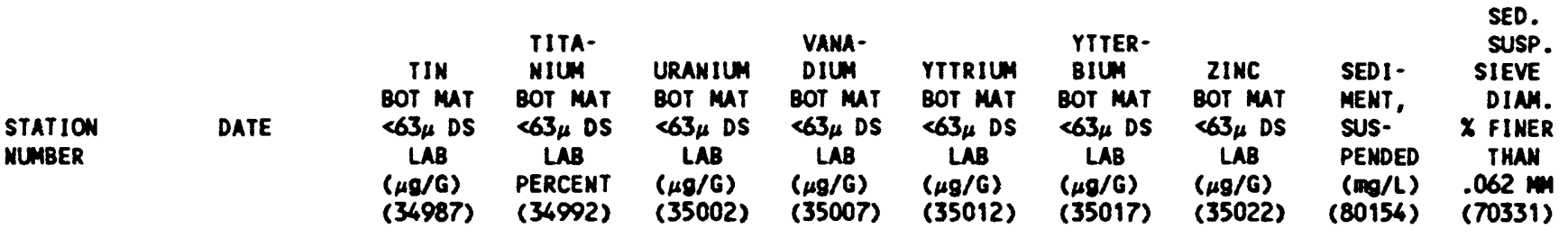

PUERCO RIVER NEAR ChAMBERS, AZ-Cont inued

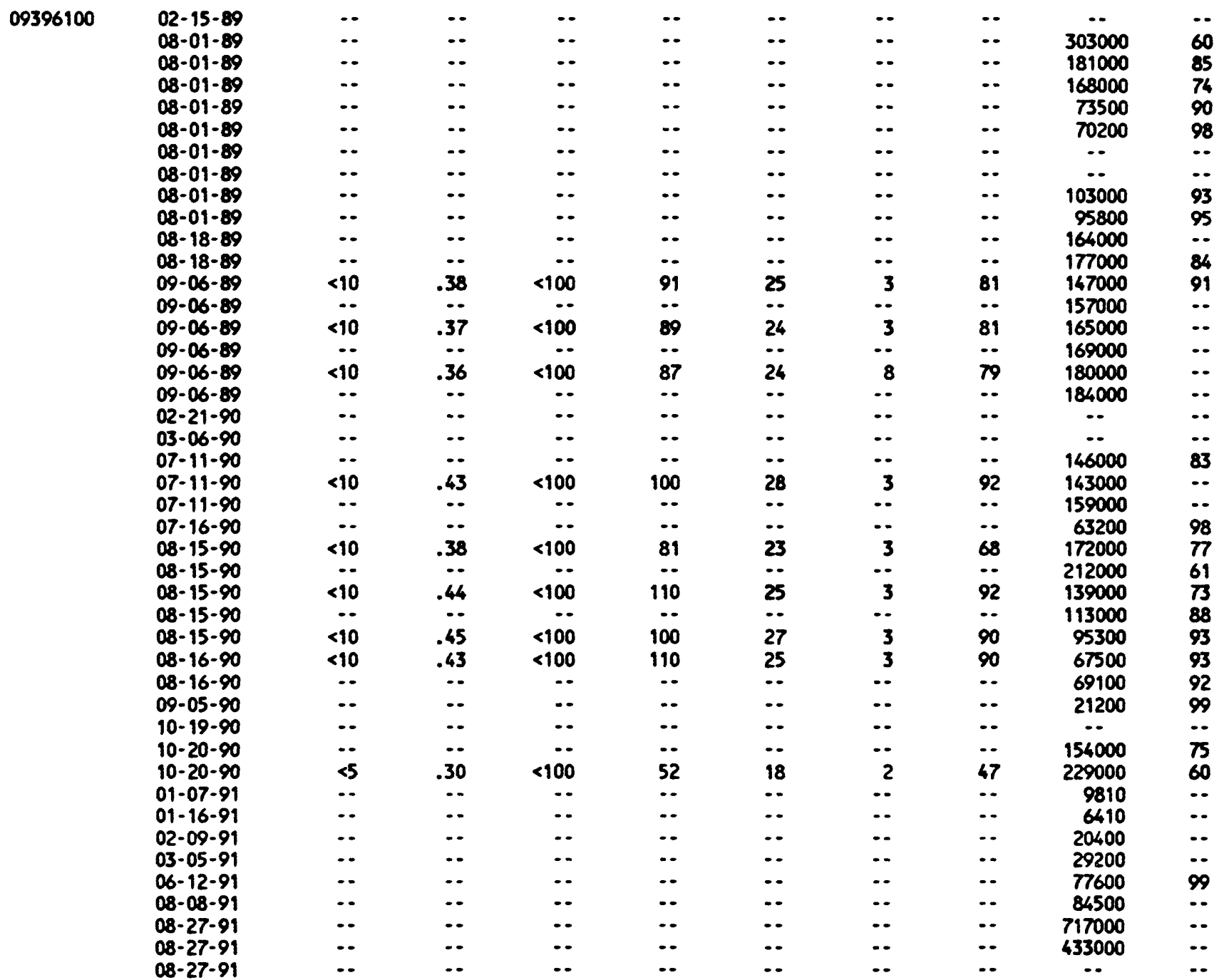


SURFACE-MATER DATA-Continued

CHEMICAL ANALYSES-Continued
STATION

MUNBER

09386950
STATION MAME

ZUNI RIVER ABOVE BLACKROCK RESEVOIR
DATE

19-06-88 1510

01-25-89 1300

03-08-89 $\quad 1545$

03-22-89 1145

$04-91-89 \quad 1655$

07-26-89 0110

07-26-89 0190

07-26-89 0140

07-26-89 0200

07-26-89 0220

07-26-89 0240

07-26-89 0320

07-26-89 0400

07-26-89 0600

07-26-89 0640

07-26-89 0720

07-26-89 0800

07-26-89 0840

07-26-89 $\quad 1600$

$19-14-89 \quad 1450$

$09-04-90 \quad 1300$

$03-19-90 \quad 1530$

09-25-90 1315

12-05-90 1030

02-26-91 1500

$04-04-91 \quad 1520$

04-04-91 1520

04-04-91 $\quad 1720$

$04-04-91 \quad 1930$

04-04-91 2120

04-04-91 2320

04-05-91 0120

04-05-91 0320

04-05-91 0520

04-05-91 0720

04-05-91 0920

04-05-91 1120

04-05-91 1403

$04-05-91 \quad 1430$

05-14-91 1030

09-06-91 0915
LATITIDE LONGITUDE

$35^{\circ} 06^{\prime} 03^{\prime \prime N} \quad 108^{\circ} 45^{\prime} 00^{\circ \mathrm{m}}$ 
SURFACE-WATER DATA-Cont inued

CHEMICAL ANALYSES-Cont inued

\begin{tabular}{|c|c|c|c|c|c|c|c|c|c|c|}
\hline $\begin{array}{l}\text { STATION } \\
\text { NUMBER }\end{array}$ & DATE & $\begin{array}{c}\text { ALTITUDE } \\
\text { OF LAND } \\
\text { SURFACE } \\
\text { DATUM } \\
\text { (Eeters } \\
\text { above } \\
\text { NGVD) } \\
\text { (72000) }\end{array}$ & $\begin{array}{l}\text { SAM- } \\
\text { PLING } \\
\text { METHOD, } \\
\text { COOES } \\
\text { (82398) }\end{array}$ & $\begin{array}{l}\text { TEMPER- } \\
\text { ATURE } \\
\text { WATER } \\
\left({ }^{\circ} \mathrm{C}\right) \\
(00010)\end{array}$ & $\begin{array}{l}\text { DIS- } \\
\text { CHARGE, } \\
\text { IN } \\
\text { CUBIC } \\
\text { METERS } \\
\text { PER } \\
\text { SECOND } \\
(00060)\end{array}$ & $\begin{array}{l}\text { DIS- } \\
\text { CHARGE, } \\
\text { INST. } \\
\text { CUBIC } \\
\text { METERS } \\
\text { PER } \\
\text { SECOND } \\
\text { (00061) }\end{array}$ & $\begin{array}{c}\text { GAGE } \\
\text { HEIGHT } \\
\text { (neters) } \\
\text { (00065) }\end{array}$ & $\begin{array}{l}\text { TUR- } \\
\text { B1D- } \\
\text { ITY } \\
\text { (NTU) } \\
\text { (00076) }\end{array}$ & $\begin{array}{l}\text { SPE- } \\
\text { CIFIC } \\
\text { CON- } \\
\text { DUCT- } \\
\text { ANCE } \\
\text { (uS/CA) } \\
(00095)\end{array}$ & $\begin{array}{l}\text { SPE- } \\
\text { CIFIC } \\
\text { CON- } \\
\text { DUCT- } \\
\text { ANCE } \\
\text { LAB } \\
(\mu S / C \mathrm{CA}) \\
(90095)\end{array}$ \\
\hline
\end{tabular}

ZUNI RIVER MEAR BLACKROCK RESEVOIR-Continued

\begin{tabular}{|c|c|c|c|c|c|c|c|c|c|}
\hline 09386950 & $\begin{array}{l}11-06-88 \\
01-25-89 \\
03-08-89 \\
03-22-89 \\
04-11-89 \\
07-26-89 \\
07-26-89 \\
07-26-89 \\
07-26-89 \\
07-26-89 \\
07-26-89 \\
07-26-89 \\
07-26-89 \\
07-26-89 \\
07-26-89 \\
07-26-89 \\
07-26-89 \\
07-26-89 \\
07-26-89 \\
11-14-89 \\
01-04-90 \\
03-19-90 \\
09-25-90 \\
12-05-90 \\
02-26-91 \\
04-04-91 \\
04-04-91 \\
04-04-91 \\
04-04-91 \\
04-04-91 \\
04-04-91 \\
04-05-91 \\
04-05-91 \\
04-05-91 \\
04-05-91 \\
04-05-99 \\
04-05-91 \\
04-05-91 \\
04-05-91 \\
05-14-91 \\
09-06-91\end{array}$ & $\begin{array}{l}-. \\
70 \\
70 \\
70 \\
50 \\
50 \\
50 \\
50 \\
50 \\
50 \\
50 \\
50 \\
50 \\
50 \\
50 \\
50 \\
50 \\
10 \\
\cdots \\
-- \\
-- \\
\cdots \\
\cdots \\
-- \\
50 \\
\cdots \\
50 \\
50 \\
50 \\
50 \\
50 \\
50 \\
50 \\
50 \\
50 \\
50 \\
50 \\
20 \\
\cdots \\
10\end{array}$ & 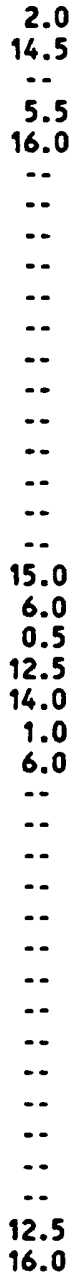 & $\begin{array}{r}. . \\
. . \\
. . \\
. . \\
5.7 \\
9.1 \\
21.4 \\
18.2 \\
15.2 \\
13.8 \\
9.5 \\
7.4 \\
3.4 \\
3.6 \\
3.2 \\
2.7 \\
2.4 \\
. . \\
. . \\
. . \\
. . \\
. . \\
. . \\
. . \\
1.7 \\
.- \\
2.1 \\
2.3 \\
2.5 \\
2.9 \\
3.1 \\
3.2 \\
3.4 \\
3.4 \\
3.4 \\
3.4 \\
4.0 \\
. . \\
. . \\
. .\end{array}$ & 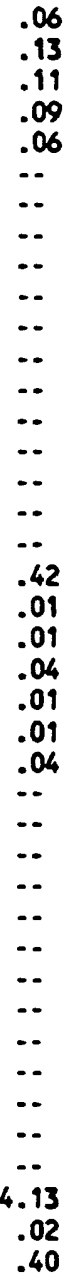 & $\begin{array}{l}. . \\
. . \\
.87 \\
.85 \\
.80 \\
1.25 \\
1.26 \\
1.53 \\
1.48 \\
1.42 \\
1.39 \\
1.30 \\
1.25 \\
1.11 \\
1.12 \\
1.10 \\
1.09 \\
1.07 \\
1.00 \\
. .- \\
. . \\
. . \\
. . \\
. .- \\
. . \\
1.04 \\
.-. \\
1.06 \\
1.07 \\
1.08 \\
1.09 \\
1.10 \\
1.10 \\
1.11 \\
1.11 \\
1.11 \\
1.11 \\
1.14 \\
1.14 \\
. . \\
.93\end{array}$ & 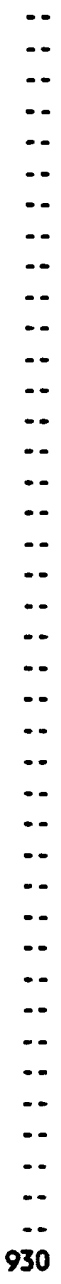 & $\begin{array}{c}650 \\
-. \\
680 \\
-- \\
605 \\
472 \\
-\therefore \\
419 \\
-. \\
300 \\
287 \\
270 \\
242 \\
243 \\
243 \\
230 \\
224 \\
227 \\
220 \\
900 \\
-. \\
730 \\
365 \\
810 \\
710 \\
780 \\
\cdots \\
790 \\
575 \\
550 \\
510 \\
505 \\
500 \\
480 \\
480 \\
490 \\
420 \\
490 \\
491 \\
710 \\
340\end{array}$ & 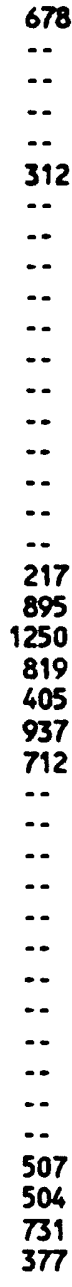 \\
\hline
\end{tabular}


SURFACE-UATER DATA-Cont inued

CHEMICAL ANALYSES- Continued

\begin{tabular}{|c|c|c|c|c|c|c|c|c|c|c|}
\hline $\begin{array}{l}\text { STATION } \\
\text { MUMBER }\end{array}$ & DATE & $\begin{array}{c}\text { OXYGEN, } \\
\text { DIS- } \\
\text { SOLVED } \\
\text { (mg/L) } \\
(00300)\end{array}$ & $\begin{array}{l}\text { PH } \\
\text { WATER } \\
\text { UHOLE } \\
\text { FIELD } \\
\text { (STAND- } \\
\text { ARD } \\
\text { UNITS) } \\
\text { (00400) }\end{array}$ & $\begin{array}{l}\text { PH } \\
\text { WATER } \\
\text { WHOLE } \\
\text { LAB } \\
\text { (STAND- } \\
\text { ARD } \\
\text { UNITS) } \\
\text { (00403) }\end{array}$ & $\begin{array}{l}\text { ALKA- } \\
\text { LINITY } \\
\text { WAT DIS } \\
\text { FIX END } \\
\text { FIELD } \\
\text { WO/L A8 } \\
\text { CaCO3 } \\
(39036)\end{array}$ & $\begin{array}{l}\text { ALKA- } \\
\text { LINITY } \\
\text { WAT DIS } \\
\text { TOT IT } \\
\text { FIELD } \\
\text { M/L as } \\
\text { CaCO3 } \\
\text { (39086) }\end{array}$ & $\begin{array}{c}\text { ALKA- } \\
\text { LINITY } \\
\text { LAB } \\
(\mathrm{mg} / L \\
\text { as } \\
\text { CaCO3) } \\
(90410)\end{array}$ & $\begin{array}{l}\text { CAR- } \\
\text { BONATE } \\
\text { WATER } \\
\text { DIS IT } \\
\text { FIELD } \\
\text { Mg/L as } \\
\text { CO3 } \\
(00452)\end{array}$ & $\begin{array}{l}\text { BICAR- } \\
\text { BONATE } \\
\text { WATER } \\
\text { DIS IT } \\
\text { FIELD } \\
\text { m/L OS } \\
\text { HCO3 } \\
\text { (00453) }\end{array}$ & $\begin{array}{l}\text { SOLIDS, } \\
\text { RESIDUE } \\
\text { AT } 180^{\circ} \mathrm{C} \\
\text { DIS- } \\
\text { SOLVED } \\
(\mathrm{mg} / \mathrm{L}) \\
(70300)\end{array}$ \\
\hline
\end{tabular}

ZUNI RIVER MEAR BLACKROCK RESEVOIR-Continued

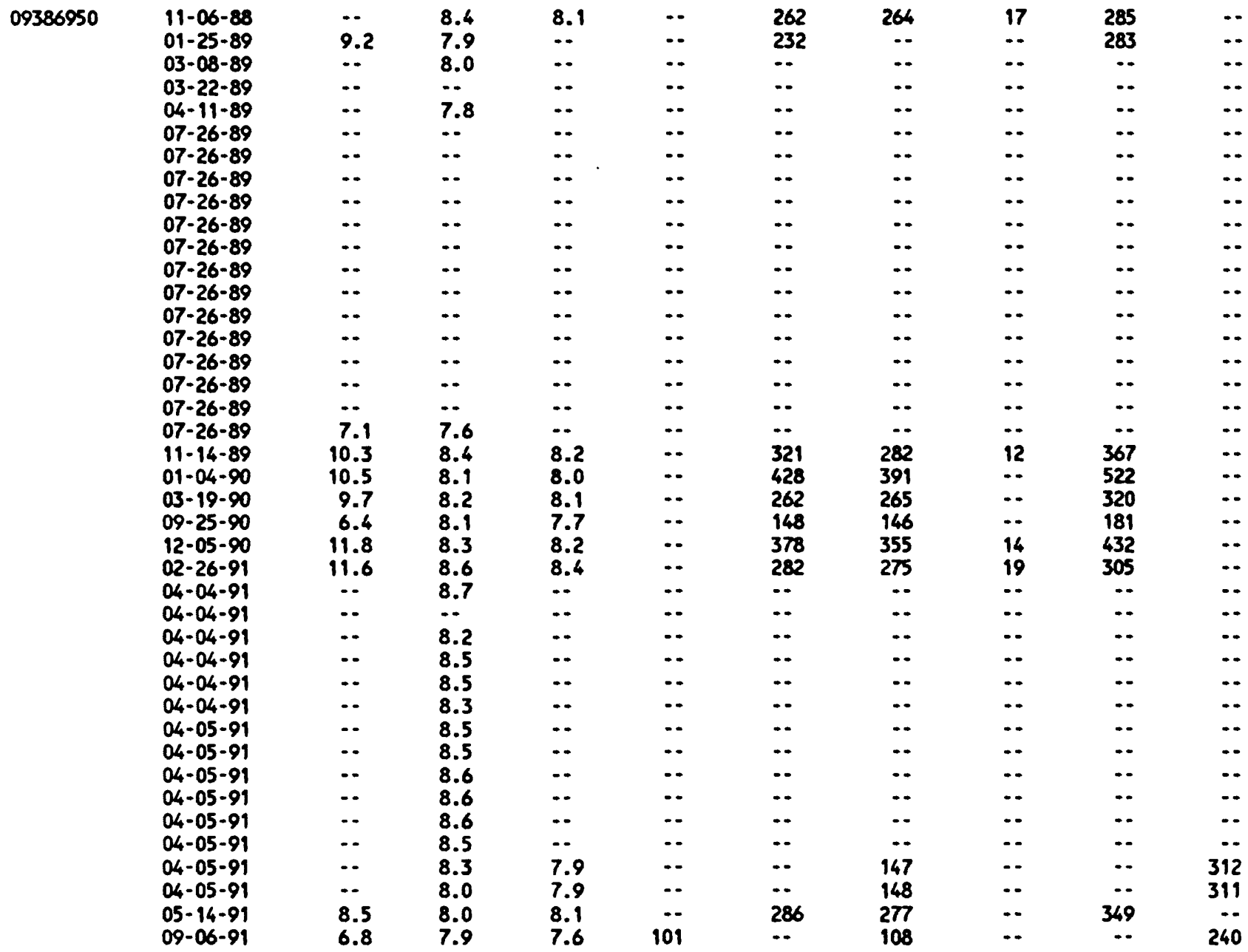


SURFACE-HATER DATA-Continued

CHEMICAL ANALYSES-Continued

\begin{tabular}{|c|c|c|c|c|c|c|c|c|c|c|}
\hline $\begin{array}{l}\text { STATION } \\
\text { MUMBER }\end{array}$ & DATE & $\begin{array}{l}\text { SOLIIDS, } \\
\text { SUM OF } \\
\text { CONSTI- } \\
\text { TUENTS, } \\
\text { DIS- } \\
\text { SOLVED } \\
\text { (m./L) } \\
\text { ( } 70301)\end{array}$ & $\begin{array}{c}\text { SOLIDS, } \\
\text { DIS- } \\
\text { SOLVED } \\
\text { (metric } \\
\text { tons } \\
\text { per } \\
\text { dey) } \\
\text { (70302) }\end{array}$ & $\begin{array}{l}\text { HARD- } \\
\text { NESS } \\
\text { TOTAL } \\
\text { (mo/L } \\
\text { as } \\
\text { Coco3) } \\
(00900)\end{array}$ & $\begin{array}{c}\text { CALCIUA } \\
\text { DIS- } \\
\text { SOLVED } \\
\text { (mo/l } \\
\text { as Ca) } \\
(00915)\end{array}$ & $\begin{array}{l}\text { MAGNE- } \\
\text { SIUN, } \\
\text { DIS- } \\
\text { SOLVED } \\
\text { (mo/L } \\
\text { as Mg) } \\
(00925)\end{array}$ & $\begin{array}{l}\text { SODIUH, } \\
\text { DIS- } \\
\text { SOLVED } \\
(\mathrm{mg} / \mathrm{L} \\
\text { as } \mathrm{Na}) \\
(00930)\end{array}$ & $\begin{array}{l}\text { SOOIUA } \\
\text { ADSORP- } \\
\text { TION } \\
\text { RATIO } \\
\text { (00931) }\end{array}$ & $\begin{array}{l}\text { SODIUH } \\
\text { PERCENT } \\
\text { (00932) }\end{array}$ & $\begin{array}{l}\text { POTAS- } \\
\text { SIUA, } \\
\text { DIS- } \\
\text { SOL VED } \\
\text { (mo/L } \\
\text { os K) } \\
\text { (00935) }\end{array}$ \\
\hline
\end{tabular}

ZUNI RIVER MEAR BLACKROCK RESEVOIR-Continued

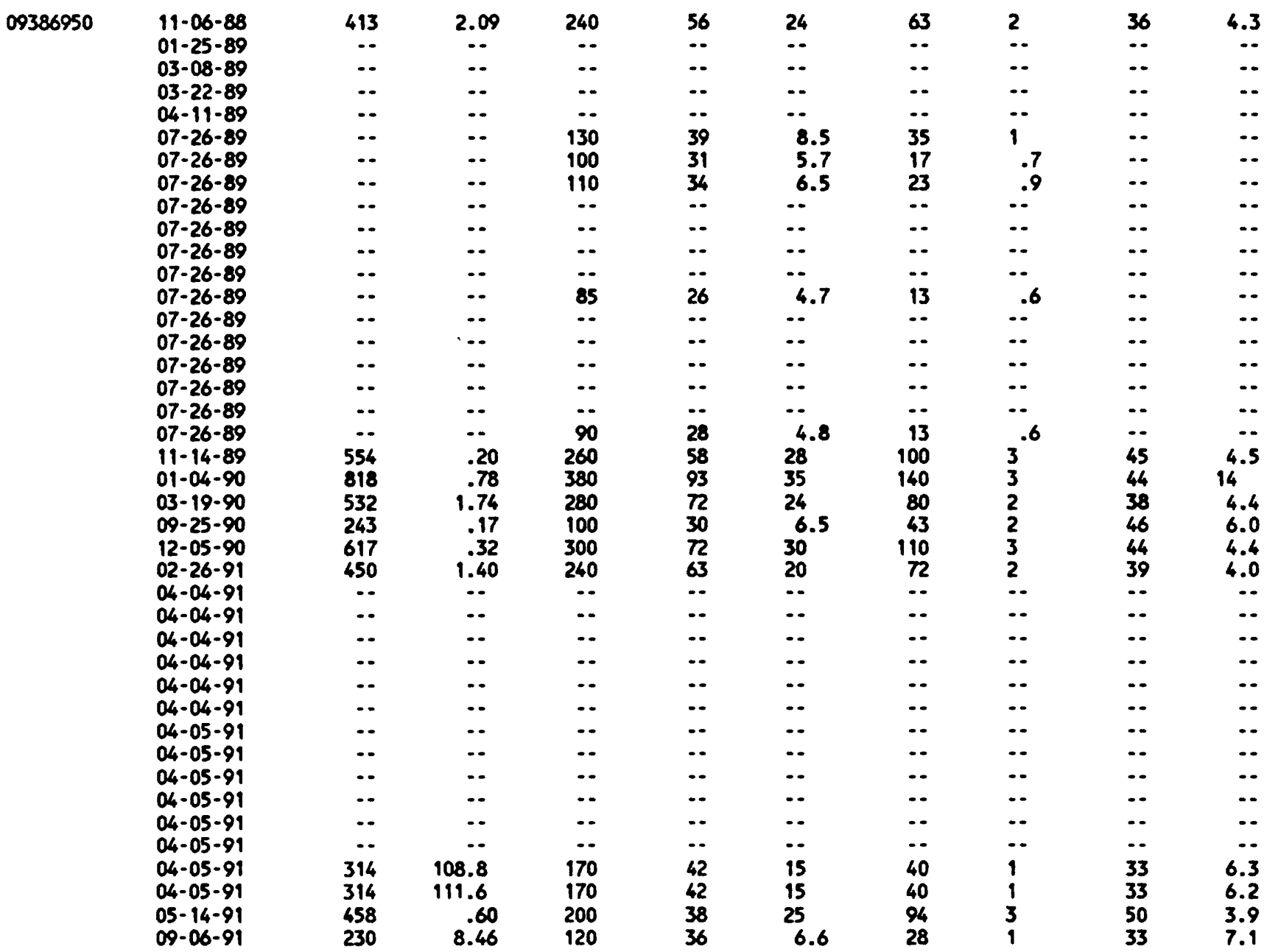


SURFACE-WATER DATA-Continued

CHEMICAL ANALYSES-Continued

STATION

NUMBER

DATE

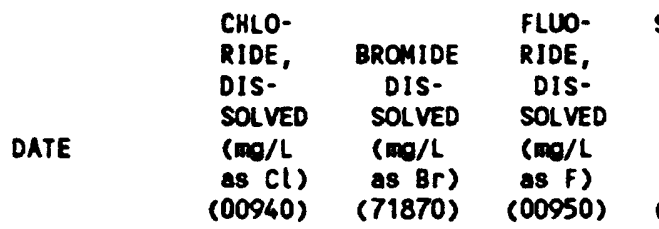

ZUNI RIVER NEAR BLACKROCK RESEVOIR-Continued

$09386950 \quad 11-06-88$
$01-25-89$
$03-08-89$
$03-22-89$
$04-19-89$
$07-26-89$
$07-26-89$
$07-26-89$
$07-26-89$
$07-26-89$
$07-26-89$
$07-26-89$
$07-26-89$
$07-26-89$
$07-26-89$
$07-26-89$
$07-26-89$
$07-26-89$
$07-26-89$
$11-14-89$
$01-04-90$
$03-19-90$
$09-25-90$
$12-05-90$
$02-26-91$
$04-04-91$
$04-04-91$
$04-04-91$
$04-04-91$
$04-04-91$
$04-04-91$
$04-05-91$
$04-05-91$
$06-05-91$
$04-05-91$
$04-05-91$
$04-05-91$
$04-05-91$
$06-05-91$
$05-14-91$
$09-06-91$

\begin{tabular}{|c|c|c|}
\hline 16 & -. & .30 \\
\hline$\cdots$ & $\cdots$ & $\cdots$ \\
\hline$\cdots$ & $\cdots$ & $\cdots$ \\
\hline$\cdots$ & $\cdots$ & $\cdots$ \\
\hline$\cdots$ & $\cdots$ & $\cdots$ \\
\hline$\cdots$ & $\cdots$ & $\cdots$ \\
\hline$\cdots$ & $\cdots$ & $\cdots$ \\
\hline$\cdots$ & $\cdots$ & $\cdots$ \\
\hline$\cdots$ & $\cdots$ & $\cdots$ \\
\hline$\because$ & 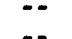 & $\cdots$ \\
\hline$\cdots$ & $\cdots$ & $\ldots$ \\
\hline$\ldots$ & $\ldots$ & .. \\
\hline .. & .. & 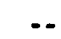 \\
\hline$\cdots$ & $\cdots$ & -. \\
\hline$\cdots$ & $\cdots$ & $\cdots$ \\
\hline$\cdots$ & - & .. \\
\hline -. & $\cdots$ & $\cdots$ \\
\hline$\cdots$ & $\cdots$ & $\cdots$ \\
\hline 29 & $\cdots$ & .40 \\
\hline 46 & $\cdots$ & .50 \\
\hline 20 & - & .20 \\
\hline 16 & - & .40 \\
\hline 29 & $\cdots$ & .20 \\
\hline 23 & $\cdots$ & .30 \\
\hline$\cdots$ & $\cdots$ & $\cdots$ \\
\hline$\cdots$ & $\cdots$ & $\cdots$ \\
\hline$\cdots$ & $\cdots$ & $\cdots$ \\
\hline$\cdots$ & $\cdots$ & $\cdots$ \\
\hline$\cdots$ & $\because$ & $\because$ \\
\hline 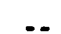 & $\ldots$ & .- \\
\hline . & .. & $\ldots$ \\
\hline .. & .. & $\cdots$ \\
\hline -. & -- & $\cdots$ \\
\hline 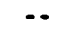 & $\cdots$ & $\cdots$ \\
\hline & $\cdots$ & $\cdots$ \\
\hline $\begin{array}{l}16 \\
13\end{array}$ & $\begin{array}{l}.070 \\
.080\end{array}$ & $\begin{array}{l}.30 \\
.30\end{array}$ \\
\hline 25 & -. & .40 \\
\hline 11 & .030 & .40 \\
\hline
\end{tabular}

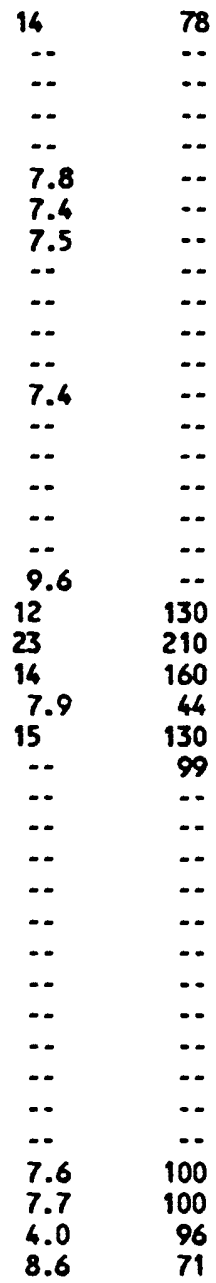

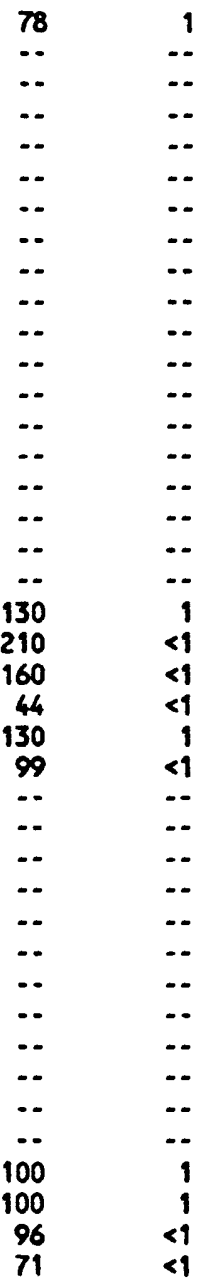

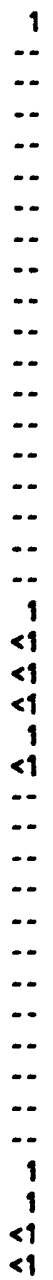

\begin{tabular}{|c|c|c|}
\hline 1 & - & -. \\
\hline$\cdots$ & - & -- \\
\hline$\cdots$ & $\cdots$ & - \\
\hline$\cdots$ & $\cdots$ & $\cdots$ \\
\hline$\cdots$ & 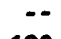 & $\because$ \\
\hline$\cdots$ & 190 & $<.5$ \\
\hline$\cdots$ & 160 & $<.5$ \\
\hline 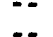 & 160 & $<.5$ \\
\hline$\ldots$ & $\ldots$ & $\ldots$ \\
\hline$\ldots$ & $\ldots$ & $\ldots$ \\
\hline - & - & $\cdots$ \\
\hline -. & 120 & $<.5$ \\
\hline$\cdots$ & $\ldots$ & -. \\
\hline$\cdots$ & $\cdots$ & -. \\
\hline$\cdots$ & $\cdots$ & $\cdots$ \\
\hline$\cdots$ & $\cdots$ & $\cdots$ \\
\hline$\cdots$ & $\cdots$ & $\because$ \\
\hline 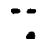 & 95 & $<.5$ \\
\hline $\begin{array}{r}1 \\
<1\end{array}$ & $\ldots$ & $\ddot{\cdots}$ \\
\hline$i$ & $\ldots$ & .. \\
\hline 1 & - & - \\
\hline$<1$ & $\cdots$ & $\cdots$ \\
\hline$<1$ & $\cdots$ & $\cdots$ \\
\hline$\cdots$ & $\cdots$ & -. \\
\hline$\cdots$ & $\cdots$ & $\because$ \\
\hline -. & -- & $\because$ \\
\hline$\cdots$ & $\cdots$ & $\because$ \\
\hline$\cdots$ & $\cdots$ & $\because$ \\
\hline$\cdots$ & $\cdots$ & $\cdots$ \\
\hline$\cdots$ & 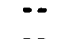 & $\cdots$ \\
\hline$\cdots$ & $\because$ & $\because$ \\
\hline$\ldots$ & $\cdots$ & $\because$ \\
\hline . & $\ldots$ & .. \\
\hline$\cdots$ & -. & -. \\
\hline$\cdots$ & $\pi$ & $<.5$ \\
\hline$\because$ & 76 & $<.5$ \\
\hline$<1$ & 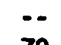 & 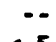 \\
\hline -- & 70 & .5 \\
\hline
\end{tabular}


SURFACE-WATER DATA-Cont inued

CHEMICAL AHALYSES-Cont inued

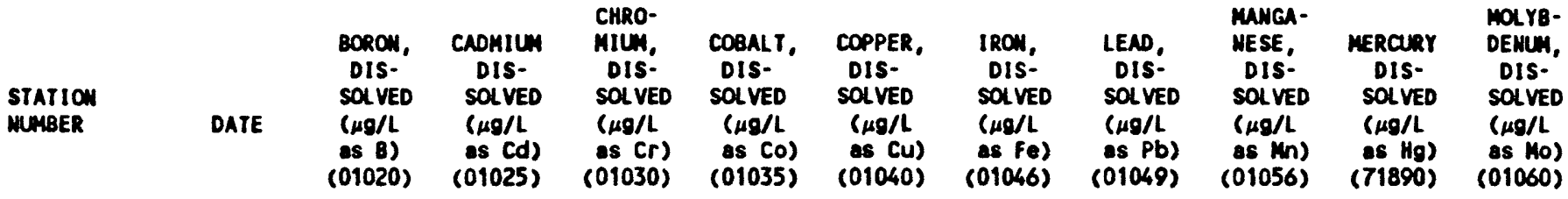

\begin{tabular}{|c|c|c|c|c|c|c|c|c|c|c|c|}
\hline 09386950 & $11-06-88$ & 90 & 2.0 & $<1$ & $\cdots$ & $<1$ & 13 & $<5$ & 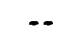 & $<.1$ & $\cdots$ \\
\hline & $01-25-89$ & - & $\cdots$ & -- & $\cdots$ & $\cdots$ & $\cdots$ & $\cdots$ & $\cdots$ & $\cdots$ & $\cdots$ \\
\hline & $03-08-89$ & $\cdots$ & $-\infty$ & $\cdots$ & $\cdots$ & $\cdots$ & - & - & $\cdots$ & $\cdots$ & $\cdots$ \\
\hline & $03-22-89$ & - & $\ldots$ & $\cdots$ & - & $\cdots$ & $\cdots$ & -. & $\cdots$ & $\cdots$ & $\cdots$ \\
\hline & $04-11-89$ & - & $\cdots$ & $\cdots$ & $\cdots$ & $\cdots$ & $\cdots$ & $\cdots$ & -- & $\cdots$ & $\cdots$ \\
\hline & $07-26-89$ & - & $<1.0$ & $<5$ & $<3$ & $<10$ & 41 & 104 & 7304 & $\cdots$ & $<10$ \\
\hline & $07-26-89$ & $\cdots$ & $<9.0$ & $<5$ & $<3$ & 10 & 40 & $<10 i$ & 510 & $\cdots$ & $<10$ \\
\hline & $07-26-89$ & $-\infty$ & $<1.0$ & $<5$ & $<3$ & $<10$ & 49 & 201 & $610\}$ & $\cdots$ & $<10$ \\
\hline & $07-26-89$ & $\cdots$ & $\cdots$ & $\cdots$ & $\cdots$ & $\cdots$ & $\cdots$ & $\cdots$ & $\cdots$ & $\cdots$ & $\cdots$ \\
\hline & $07-26-89$ & $\cdots$ & $\cdots$ & $\cdots$ & $\cdots$ & $\cdots$ & $\cdots$ & $\cdots$ & $\cdots$ & $\cdots$ & $\cdots$ \\
\hline & $07-26-89$ & $\cdots$ & $\cdots$ & $\cdots$ & -- & $-\infty$ & -- & $\cdots$ & $\cdots$ & $\cdots$ & $\cdots$ \\
\hline & $07-26-89$ & $\cdots$ & 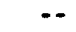 & $\cdots$ & $\cdots$ & $\cdots$ & $\cdots$ & - & $\cdots$ & $\cdots$ & $\cdots$ \\
\hline & $07-26-89$ & $\cdots$ & $<1.0$ & $<5$ & $<3$ & $<10$ & 23 & $<101$ & 4701 & $\cdots$ & $<10$ \\
\hline & $07-26-89$ & $\cdots$ & $\cdots$ & $\cdots$ & $\cdots$ & $\cdots$ & $\cdots$ & $\cdots$ & $\cdots$ & $\cdots$ & - \\
\hline & $07-26-89$ & -- & $\cdots$ & $\cdots$ & $\cdots$ & $\cdots$ & $\cdots$ & $\cdots$ & $\cdots$ & $\cdots$ & $\cdots$ \\
\hline & $07-26-89$ & $\cdots$ & $\cdots$ & $\cdots$ & $\cdots$ & $\cdots$ & $\cdots$ & $\cdots$ & $\cdots$ & $\cdots$ & 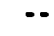 \\
\hline & $07-26-89$ & -- & $\cdots$ & $\cdots$ & $\cdots$ & $\cdots$ & $\cdots$ & $\cdots$ & $\cdots$ & $\cdots$ & $\cdots$ \\
\hline & $07-26-89$ & $\cdots$ & $\cdots$ & $\cdots$ & 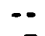 & $\because$ & $\cdots$ & $\because$ & $\because$ & $\cdots$ & $-\infty$ \\
\hline & $07-26-89$ & $=$ & $<1.0$ & $<5$ & $<$ & $<10$ & 47 & $\times 101$ & 31 & $\cdots$ & $<10$ \\
\hline & $11-14-89$ & 120 & $<1.0$ & $<1$ & $\cdots$ & 3 & 14 & $<1$ & $\cdots$ & $<.1$ & $\cdots$ \\
\hline & $01-04-90$ & 140 & $<9.0$ & 1 & $\cdots$ & $<10$ & 26 & $<101$ & $\cdots$ & $<.1$ & $\cdots$ \\
\hline & $03-19-90$ & 90 & $<1.0$ & $<5$ & $\cdots$ & $<10$ & 10 & $<101$ & $\cdots$ & $<.1$ & $\cdots$ \\
\hline & $09-25-90$ & $\begin{array}{l}200 \\
120\end{array}$ & $<1.0$ & $<$ & $\cdots$ & 3 & 85 & $<1$ & $\cdots$ & $<.9$ & $\cdots$ \\
\hline & $02.26-91$ & 70 & $<1.0$ & $<1$ & $\ldots$ & 1 & 12 & 1 & $\ldots$ & -1 & $\cdots$ \\
\hline & $04-04-91$ & $\ldots$ & $\cdots$ & - & $\ldots$ & .. & $\ldots$ & $\cdots$ & $\ldots$ & $\ldots$ & $\ldots$ \\
\hline & $04-04-91$ & -. & $\cdots$ & $\cdots$ & 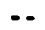 & $\cdots$ & 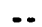 & 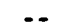 & $\ldots$ & $\ldots$ & - \\
\hline & $04-04-91$ & $\ldots$ & .. & -- & $\ldots$ & -. & - & $\ldots$ & & & \\
\hline & $m-2-0$ & $\ldots$ & 0 & & & & & 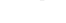 & - & . & 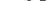 \\
\hline & & & & & - & - & 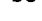 & $\cdots$ & $\cdots$ & $\cdots$ & $\cdots$ \\
\hline & $0,-04-91$ & $\cdots$ & $\cdots$ & $\cdots$ & $\cdots$ & $\cdots$ & $\cdots$ & $\cdots$ & $\cdots$ & $\cdots$ & $\cdots$ \\
\hline & $04-04-91$ & $\cdots$ & $\cdots$ & $\cdots$ & $\cdots$ & $-\infty$ & 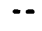 & $\cdots$ & $\cdots$ & $\cdots$ & $\cdots$ \\
\hline & $04-05-91$ & $\cdots$ & $\cdots$ & $\cdots$ & $-\infty$ & $-\infty$ & $\cdots$ & $\cdots$ & $\cdots$ & $\cdots$ & $\cdots$ \\
\hline & $04-05-91$ & $=$ & -- & $\cdots$ & -- & $=$ & $\cdots$ & -- & -- & $\cdots$ & $\cdots$ \\
\hline & $04-05-91$ & $\cdots$ & $\cdots$ & $\cdots$ & $\cdots$ & -- & - & $-\infty$ & $\cdots$ & $\because$ & $\cdots$ \\
\hline & $04-05-91$ & -. & - & $\cdots$ & $-\infty$ & -- & $\cdots$ & $\cdots$ & $\cdots$ & $\cdots$ & - \\
\hline & $04-05-91$ & $=-$ & $\cdots$ & $\cdots$ & $\cdots$ & $\cdots$ & $\cdots$ & $\cdots$ & $\cdots$ & $\cdots$ & $\cdots$ \\
\hline & $04-05-91$ & 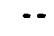 & $\cdots$ & $\cdots$ & $\cdots$ & $\cdots$ & $\cdots$ & $\because$ & $\cdots$ & $\cdots$ & $\cdots$ \\
\hline & $04-05-91$ & 60 & $<1.0$ & $<5$ & $<3$ & $<10$ & 10 & $<10 i$ & $<1$ & $\cdots$ & $<10$ \\
\hline & $04-05-91$ & 60 & $<1.0$ & $<5$ & $<3$ & $<10$ & 10 & $<10 i$ & 1 & $\because$ & $<10$ \\
\hline & $05-14-91$ & 120 & $<1.0$ & $<1$ & $\because$ & $<1$ & 11 & 1 & $\because$ & .1 & $\because$ \\
\hline & $09-06$ & 70 & .0 & $<5$ & $<3$ & $<10$ & 74 & $<101$ & $<1$ & $-\infty$ & $<10$ \\
\hline
\end{tabular}


SURFACE-MATER DATA-Cont inued

CHEMICAL AMALYSES-Continued

STATION

MUMBER

09386950

\begin{tabular}{|c|c|c|c|}
\hline $\begin{array}{l}11-06-88 \\
01-25-89\end{array}$ & $\cdots$ & $\ldots$ & 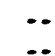 \\
\hline $\begin{array}{l}01-25-89 \\
03-08-89\end{array}$ & $\cdots$ & $\cdots$ & .- \\
\hline $03-22-89$ & .. & -. & .- \\
\hline $04-11-89$ & .. & -. & .. \\
\hline $\begin{array}{l}07-26-89 \\
07-26-89 \\
07-26-89\end{array}$ & $\begin{array}{l}<10 \\
<10 \\
<10\end{array}$ & $\begin{array}{r}1.0 \\
1.0 \\
<1.0\end{array}$ & $\begin{array}{l}300 \\
220 \\
250\end{array}$ \\
\hline $07-26-89$ & $\cdots$ & $\ldots$ & $\cdots$ \\
\hline $07-26-89$ & .. & $\cdots$ & -. \\
\hline $07-26-89$ & $\cdots$ & -. & .. \\
\hline $07-26-89$ & .. & -. & .. \\
\hline $07-26-89$ & $<10$ & 2.0 & 180 \\
\hline $07-26-89$ & $\cdots$ & $\cdots$ & -. \\
\hline $07-26-89$ & $\cdots$ & $\cdots$ & -. \\
\hline $07-26-89$ & .. & $\cdots$ & -. \\
\hline $07-26-89$ & .. & .. & . \\
\hline $07-26-89$ & $\cdots$ & $\cdots$ & -. \\
\hline $07-26-89$ & $<10$ & $<1.0$ & 180 \\
\hline $11-14-89$ & $\cdots$ & $\cdots$ & $\cdots$ \\
\hline $01-04-90$ & $\cdots$ & $\cdots$ & -. \\
\hline $03-19-90$ & $\cdots$ & $\cdots$ & $\cdots$ \\
\hline $09-25-90$ & -. & $\cdots$ & -. \\
\hline $12-05-90$ & $\cdots$ & $\cdots$ & 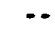 \\
\hline $02-26-91$ & $\cdots$ & - & $\cdots$ \\
\hline $04-04-91$ & $\cdots$ & $\cdots$ & $\cdots$ \\
\hline $04-04-91$ & $\cdots$ & -- & $\cdots$ \\
\hline $04-04-91$ & $\cdots$ & $\cdots$ & -. \\
\hline-91 & $\cdots$ & $\cdots$ & -. \\
\hline $04-04-91$ & $-\cdot$ & $\cdots$ & $\cdots$ \\
\hline $04-04-91$ & $\cdots$ & $\cdots$ & $-\cdot$ \\
\hline $04-05-91$ & $\cdots$ & $\cdots$ & -. \\
\hline $04-05-91$ & $-\cdot$ & $\cdots$ & -. \\
\hline $04-05-91$ & $\cdots$ & $\cdots$ & $\cdots$ \\
\hline $04-05-91$ & -. & -. & $\cdots$ \\
\hline $04-05-91$ & $\cdots$ & $\cdots$ & $\cdots$ \\
\hline $04-05-91$ & $\cdots$ & .. & -. \\
\hline $04-05-9 i$ & $<10$ & $<1.0$ & 370 \\
\hline $04-05-91$ & $<10$ & $<1.0$ & 370 \\
\hline $05-16-91$ & -- & $\cdots$ & $\cdots$ \\
\hline $09-0$ & $<10$ & $<1.0$ & 300 \\
\hline
\end{tabular}

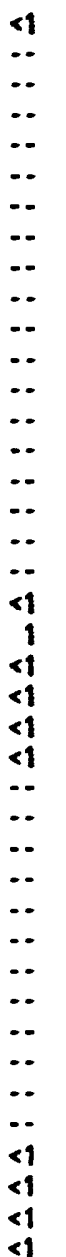

\begin{tabular}{|c|c|c|}
\hline$<1$ & $\cdots$ & $\cdots$ \\
\hline$\cdots$ & $\cdots$ & $\ldots$ \\
\hline$\cdots$ & $\cdots$ & -. \\
\hline$\cdots$ & $\cdots$ & $\cdots$ \\
\hline$\cdots$ & $\cdots$ & -. \\
\hline$\cdots$ & 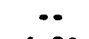 & $\cdots$ \\
\hline$\cdots$ & -1.20 & 52 \\
\hline$\cdots$ & $\cdots$ & $\cdots$ \\
\hline$\cdots$ & $\cdots$ & $\cdots$ \\
\hline$\cdots$ & $\cdots$ & $\cdots$ \\
\hline$\cdots$ & $\cdots$ & $\cdots$ \\
\hline$\cdots$ & $\cdots$ & $\cdots$ \\
\hline$\cdots$ & $\cdots$ & 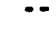 \\
\hline$\because$ & $\because$ & $\because$ \\
\hline .. & 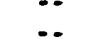 & 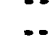 \\
\hline -. & .. & .- \\
\hline$\cdots$ & .. & $\cdots$ \\
\hline$\cdots$ & .. & -. \\
\hline$<1$ & - & $\cdots$ \\
\hline 1 & $\cdots$ & $\cdots$ \\
\hline$<1$ & $\cdots$ & .. \\
\hline$<1$ & $\ldots$ & $\cdots$ \\
\hline$<1$ & $\cdots$ & $\cdots$ \\
\hline$<1$ & - & $\ldots$ \\
\hline$\cdots$ & $\cdots$ & $\cdots$ \\
\hline$\cdots$ & $\cdots$ & - \\
\hline$\cdots$ & $\cdots$ & $\cdots$ \\
\hline$\because$ & $\because$ & $\because$ \\
\hline$\because$ & $\because$ & $\cdots$ \\
\hline .. & $\ldots$ & 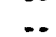 \\
\hline$\cdots$ & . & 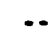 \\
\hline$\cdots$ & $\cdots$ & $\cdots$ \\
\hline- & $\cdots$ & - \\
\hline- & $\because$ & $\therefore$ \\
\hline$\cdots$ & $\cdots$ & $\cdots$ \\
\hline- & $\cdots$ & $\because$ \\
\hline$\ddot{1}$ & $\cdots$ & $\because$ \\
\hline & $\ldots$ & $=$ \\
\hline
\end{tabular}


SURFACE-WATER DATA-Contínued

CHEMICAL AKALYSES-Cont inued

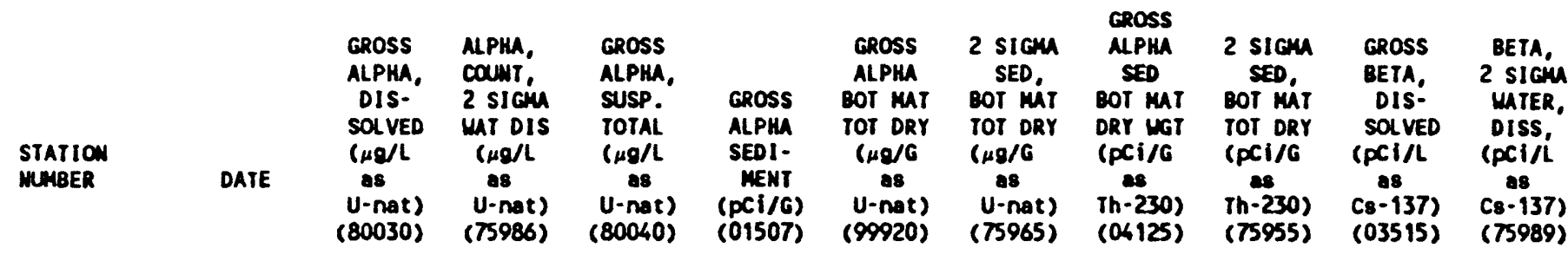

ZUI RIVER NEAR BLACKROCK RESEVIR-Continued

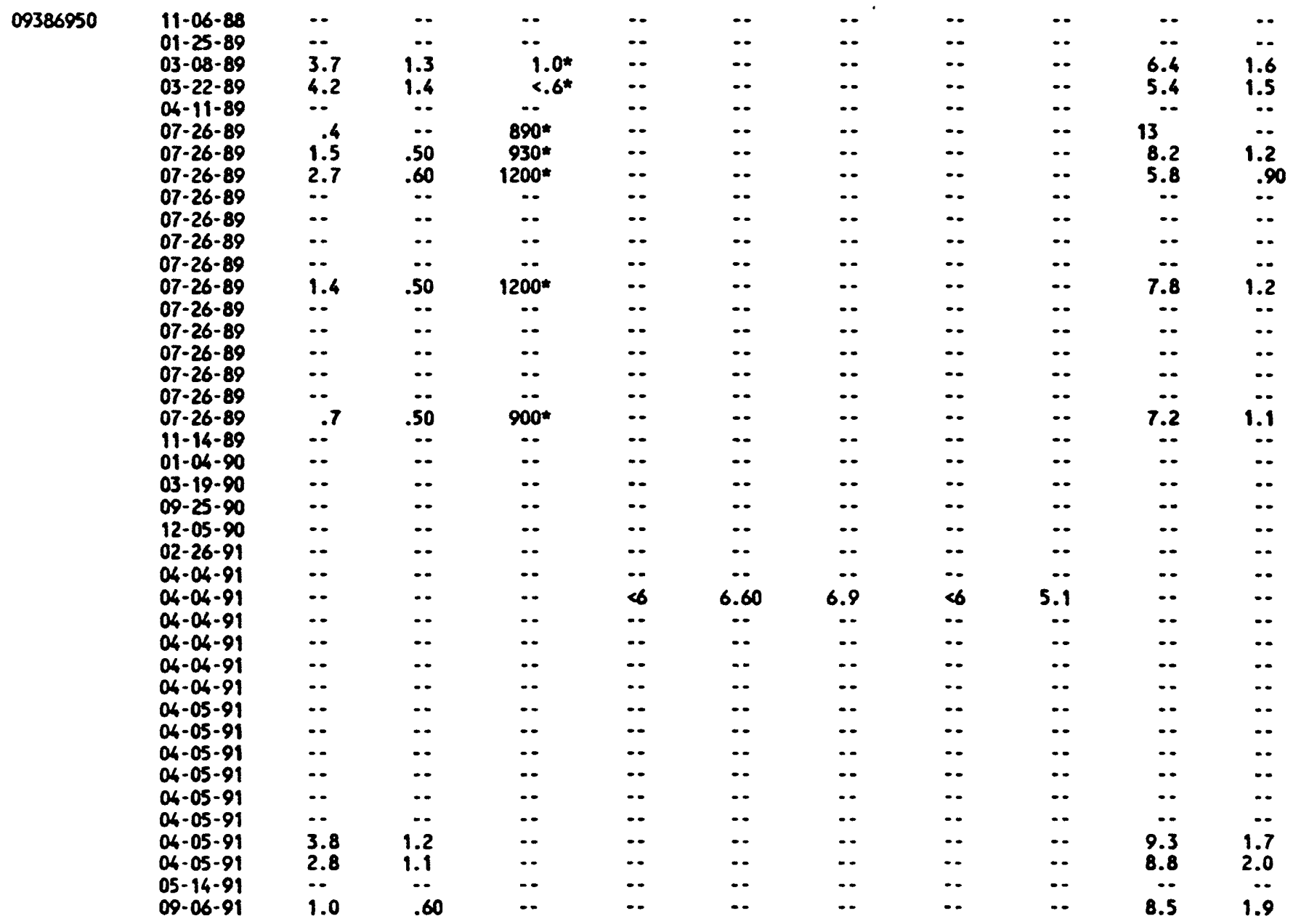




\begin{tabular}{|c|c|c|c|c|c|c|c|c|c|c|c|}
\hline & & & & $\begin{array}{l}\text { URFACE-WI } \\
\text { HEMICAL }\end{array}$ & $\begin{array}{l}\text { ER DATA- } \\
\text { ALYSES-C }\end{array}$ & $\begin{array}{l}\text { Continued } \\
\text { ont inued }\end{array}$ & & & & & \\
\hline $\begin{array}{l}\text { STATIOW } \\
\text { MUABER }\end{array}$ & DATE & $\begin{array}{c}\text { GROSS } \\
\text { BETA, } \\
\text { SUSP. } \\
\text { TOTAL } \\
\text { (PCi/L } \\
\text { As } \\
\text { Os-137) } \\
(03516)\end{array}$ & $\begin{array}{l}\text { GROSS } \\
\text { BETA, } \\
\text { DISS. } \\
\text { (PCi/L } \\
\text { As } \\
S r-90 / \\
r-90) \\
(80050)\end{array}$ & $\begin{array}{l}\text { BETA, } \\
2 \text { SIGUA } \\
\text { HATER, } \\
\text { DISS, } \\
\text { (PCi/L } \\
28 \\
S r-90 / \\
\text { S-90) } \\
r-90) \\
(75988)\end{array}$ & $\begin{array}{l}\text { GROSS } \\
\text { BETA, } \\
\text { SUSP, } \\
\text { TOTAi } \\
\text { (pCi/L } \\
\text { Q8 } \\
S r-90 / \\
r-90) \\
(80060)\end{array}$ & $\begin{array}{c}\text { BETA } \\
2 \text { SIGU } \\
\text { SED, SUSP, } \\
\text { TOT DRY } \\
\text { (PCI/G } \\
\text { as } \\
\text { Sr-90/ } \\
Y-90) \\
(76005)\end{array}$ & $\begin{array}{l}\text { GROSS } \\
\text { BETA, } \\
\text { BOI MAI } \\
\text { TOT DRY } \\
\text { (PCi/G } \\
\text { \&s } \\
S r-90 / \\
Y-90) \\
(04102)\end{array}$ & $\begin{array}{l}\text { BETA } \\
2 \text { SIGIU } \\
\text { BOT MUT } \\
\text { TOT DRY } \\
\text { Sr-90/ } \\
\text { Y-90 } \\
(P C i / G) \\
(75966)\end{array}$ & $\begin{array}{l}\text { GROSS } \\
\text { BETA } \\
\text { BOT MMT } \\
\text { TOT DRY } \\
\text { (PCII/ } \\
\text { os } \\
\text { C8-137) } \\
(99922)\end{array}$ & $\begin{array}{c}\text { BETA } \\
2 \text { SIGM } \\
\text { BOT MAT } \\
\text { TOT DRY } \\
\text { (PCi/G } \\
\text { Qs } \\
\left.C_{8}-137\right) \\
(99923)\end{array}$ & $\begin{array}{l}\text { Ra-226 } \\
\text { SED, } \\
\text { SUSP, } \\
\text { TOTAL, } \\
\text { DRY WGi } \\
\text { (PCi/G) } \\
\text { (75944) }\end{array}$ \\
\hline & & & ZUNI RII & R MEAR BL & CKROCK RE & SEVOIR - CON & tinued & & & & \\
\hline 09386950 & $11-06-88$ & -. & .. & -. &.- & -- & .- & .. & .. & .. & .. \\
\hline 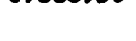 & $01-25-89$ & -. & -- & -. & -. & -- & -- & -. & .. & .. & .- \\
\hline & $03-08-89$ & $1.1 *$ & 4.7 & 1.2 & $1.1 *$ & .70 & $-\cdot$ & $\cdots$ & -. & $-\cdot$ & $\cdot-$ \\
\hline & $03-22-89$ & $.9 *$ & 4.0 & 1.1 & $.9 *$ & .60 & -. & $-\cdot$ & $-\cdot$ & $-\cdot$ & -. \\
\hline & $04-11-89$ & $\because-$ & $\cdots$ & $\cdots$ & $\because$ & -- & $\cdots$ & -- & $\cdot-$ & $\cdots$ & $\cdots$ \\
\hline & $07-26-89$ & $1300 *$ & 10 & $\because$ & $1200 *$ & $\ddot{-}$ & $\because$ & 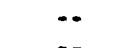 & -. & $\because$ & $-\cdot$ \\
\hline & $07-26-89$ & $520^{*}$ & 6.8 & 1.0 & $480 *$ & 69 & -. & -- & -- & $-\cdot$ & $\cdots$ \\
\hline & $07-26-89$ & $910=$ & 5.2 & .80 & $840^{*}$ & 110 & -. & -. & -- & $-\cdot$ & $\cdots$ \\
\hline & $07-26-89$ & $\cdots$ & - & -- &.- & -. & -- & -- & -. & $\cdot-$ & -- \\
\hline & $07-26-89$ & -. & $\cdot \cdot$ & -- & $-\cdot$ & -- & -- & $\cdots$ & -. & $-\cdot$ & $\cdot$. \\
\hline & $07-26-89$ & -- & -. & $\cdot-$ & $\cdots$ & $-\cdot$ & $\cdot-$ & -- & -. & $\cdot-$ & -- \\
\hline & $07-26-89$ & $-\cdot$ & -- & -. & -. & -- & -. & -. & -. & -. & .. \\
\hline & $07-26-89$ & $380 *$ & 6.3 & .90 & 410* & 45 & -. & $-\cdot$ & -. & -- & -. \\
\hline & $07-26-89$ & $-\cdot$ & $\cdots$ & -- & -. & -- & 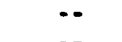 & -- & $\cdot-$ & $-\cdot$ & $\cdots$ \\
\hline & $07-26-89$ & -- & $-\cdot$ & $\cdot \cdot$ & .. & -- & -. & -. & $-\cdot$ & -. & $\cdots$ \\
\hline & $07-26-89$ & $\cdot-$ & -. & $-\cdot$ & .. & -. & -. & $\cdots$ & -. & -. & $\cdot \cdot$ \\
\hline & $07-26-89$ & $\cdot-$ & -- & $-\cdot$ & -- & $-\cdot$ & -. & -- & -- & $-\cdot$ & $-\cdot$ \\
\hline & $07-26-89$ & $\because$ & $\because$ & - & $\because$ & -- & -- & $-\cdot$ & -. & $\cdot-$ & $\cdots$ \\
\hline & $07-26-89$ & $150^{*}$ & 5.8 & .90 & $160^{*}$ & 23 & $\cdot-$ & 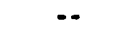 & -- & -- & -. \\
\hline & $11-16-89$ & -. & $\cdots$ & -- & $\cdots$ & $\cdots$ & $\cdot \cdot$ & -- & -- & .. & $\cdots$ \\
\hline & $01-04-90$ & -. & $\cdot-$ & $-\cdot$ & -. & $-\cdot$ & -- & $-\cdot$ & -- & $\cdots$ & $\cdots$ \\
\hline & $03-19-90$ & $\cdots$ & -- & -- & -- & $-\cdot$ & $\cdot-$ & -- & $-\cdot$ & -- & $\cdot \cdot$ \\
\hline & $09-25.90$ & -- & -- & -- & $-\cdot$ & -- & $\cdot \cdot$ & -- & -- & -- & -. \\
\hline & $12.05-90$ & -. & -- & $-\cdot$ & $\cdots$ & $\cdot \cdot$ & $\cdot-$ & $\cdot-$ & -- & -- & -. \\
\hline & $02-26-91$ & .. & $\cdot-$ & $-\cdot$ & -. & $-\cdot$ & $\cdot-$ & $\cdots$ & -. & -- & -. \\
\hline & $04-04-91$ & $\cdot \cdot$ & $\cdots$ &.- & $\cdots$ & -- & $\ddot{n}$ & $\because$ & 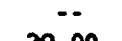 & -- & $\ddot{\theta}$ \\
\hline & $04-04-91$ & -. & $\cdot-$ & -. & -. & $-\cdot$ & 21 & 6.6 & 29.00 & 6.55 & 1.0 \\
\hline & $04-04-91$ & -. & -. & -. & -. & $\cdot-$ & .. & $\cdots$ & $\cdots$ & $-\cdot$ & $\cdots$ \\
\hline & $04-04-91$ & -. & $-\cdot$ & .. & -. & -. & -. & -. & $-\cdot$ & $\cdots$ & $\cdot-$ \\
\hline & $04-04-91$ & -. & $\cdot-$ & $\cdots$ & -. & $-\cdot$ & -. & -. & -. & $-\cdot$ & $\cdot \cdot$ \\
\hline & $04-04-91$ & $\cdots$ & -. & $\cdot-$ & -. & $-\cdot$ & $\cdot-$ & -. & -- & $-\cdot$ & $\cdot \cdot$ \\
\hline & $04-05-91$ & -. & -. & -. & $-\cdot$ & $\cdot-$ & $\cdot-$ & -. & $-\cdot$ & $\cdots$ & -. \\
\hline & $04-05-91$ & $-\cdot$ & $\cdot-$ & $\cdots$ & -. & -- & -. & $\cdot-$ & -- & -. & $\cdots$ \\
\hline & $04-05-91$ & -- & -. & -. & -. & -- & -. & -. & -. & .. & -. \\
\hline & $04-05-91$ & -. & -- & -- & -. & -. & .. & .. & -. & $-\cdot$ & -. \\
\hline & $04-05-91$ & -- & -. & -. & -- & -. & -. & -. & -. & -. & -. \\
\hline & $04-05-91$ & -. & $\because$ & $\because$ & -. & -- & -. & .. & $\cdots$ & -. & -. \\
\hline & $04-05-91$ & $-\cdot$ & 7.0 & 1.3 & $\cdots$ & $\cdot \cdot$ & $\cdot \cdot$ & $\cdot \cdot$ & $\cdot \cdot$ & $\cdots$ & -. \\
\hline & $04-05-91$ & -. & 6.2 & 1.1 & -. & $-\cdot$ & $\cdot-$ & $\cdot \cdot$ & $-\cdot$ & -. & $\cdot \cdot$ \\
\hline & $05-14-91$ & -- & $\therefore$ & $\because$ & $-\cdot$ & -. & $\cdot-$ & $\cdot-$ & $-\cdot$ & $-\cdot$ & $\cdots$ \\
\hline & $09-06-91$ & -. & 7.0 & 1.6 & -. & -. & -. & -. & -. & -- & .. \\
\hline
\end{tabular}


SURFACE-WATER DATA-Cont inued

CHEMICAL AHALYSES-Cont inued

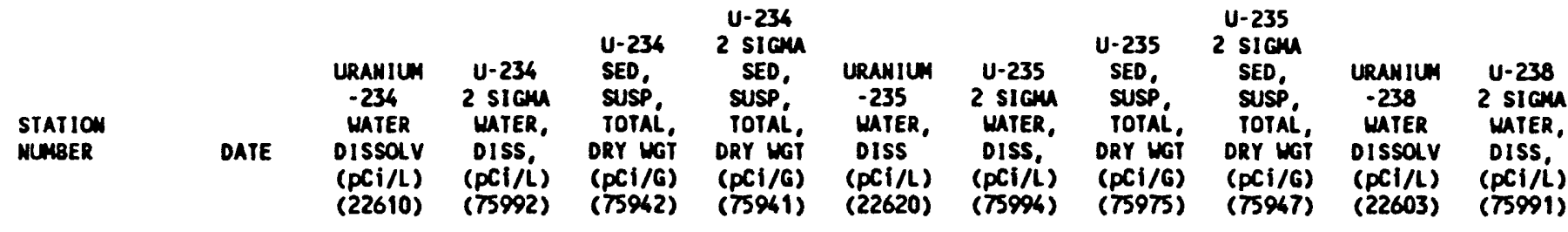

ZUNI RIVER NEAR BLACKROCK RESEVOIR-Continued

\begin{tabular}{|c|c|c|c|c|c|c|c|c|c|c|c|}
\hline \multirow[t]{40}{*}{09386950} & $\begin{array}{l}11-06-88 \\
01-25-89\end{array}$ & .. & 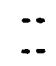 & $\cdots$ & $\cdots$ & -. & -. & -. & $\cdots$ & $\therefore$ & 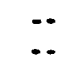 \\
\hline & $03-08-89$ & -. & $\ldots$ & $\ldots$ & -- & .. & -. & -. & .. & -. & $\cdots$ \\
\hline & $03-22-89$ & -. & $\cdots$ & -- & - & $\cdots$ & $\cdots$ & -. & -. & .. & $\cdots$ \\
\hline & $06-11-89$ & .. & $\cdots$ & $\cdots$ & $\cdots$ & $\cdots$ & $\cdots$ & $\cdots$ & $\cdots$ & $\cdots$ & $-\cdot$ \\
\hline & $07-26-89$ & $\cdots$ & $\cdots$ & $\cdots$ & $\cdots$ & $\cdots$ & $\cdots$ & $\cdots$ & $\cdots$ & $\cdots$ & $\cdots$ \\
\hline & $07-26-89$ & $\cdots$ & $\cdots$ & $\cdots$ & $\cdots$ & $\cdots$ & $\cdots$ & $\cdots$ & $\cdots$ & $\cdots$ & $\cdots$ \\
\hline & $07-26-89$ & $\cdots$ & $\cdots$ & $\cdots$ & $\cdots$ & -- & -- & $\cdots$ & $\cdots$ & $\cdots$ & $\cdots$ \\
\hline & $07-26-89$ & $\cdots$ & $\cdots$ & $-\cdot$ & -- & -- & -- & $\because$ & -- & $\cdots$ & $\cdots$ \\
\hline & $07-26-89$ & $\cdots$ & $\cdots$ & -- & -- & -- & $\cdots$ & $\cdots$ & $-\cdot$ & $\cdots$ & -- \\
\hline & $07-26-89$ & -. & $\cdots$ & -- & -- & -- & -- & - & $\cdots$ & $-\cdot$ & -- \\
\hline & $07-26-89$ & $\cdots$ & $\cdots$ & -- & $\cdots$ & $\cdots$ & $\cdots$ & $\cdots$ & $\cdots$ & -. & $\cdots$ \\
\hline & $07-26-89$ & $\cdots$ & $\cdots$ & -- & -- & -- & $\cdots$ & $\cdots$ & $\cdots$ & -- & -- \\
\hline & $07-26-89$ & $\cdots$ & $\cdots$ & $\cdots$ & -- & $\cdots$ & $-\cdot$ & $\cdots$ & $\cdots$ & $\cdots$ & -- \\
\hline & $07-26-89$ & $\cdots$ & $\cdots$ & $\cdots$ & $\cdots$ & $\cdots$ & $\cdots$ & -- & $\cdots$ & $\cdots$ & 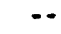 \\
\hline & $07-26-89$ & $\cdots$ & $\cdots$ & -- & $\cdots$ & $\cdots$ & -- & $\cdots$ & $\cdots$ & $\cdots$ & $-\cdot$ \\
\hline & $07-26-89$ & $\cdots$ & $\cdots$ & -- & $\cdots$ & $\cdots$ & $\cdots$ & -- & $\cdots$ & $\cdots$ & -- \\
\hline & $07-26-89$ & $\cdots$ & $\cdots$ & $\cdots$ & -- & -- & $-\cdot$ & $\cdots$ & $\cdots$ & $\cdots$ & -- \\
\hline & $07-26-89$ & $\cdots$ & $\cdots$ & -- & -- & $\cdots$ & $\cdots$ & $\cdots$ & $\cdots$ & $\cdots$ & -- \\
\hline & $11-14-89$ & $\cdots$ & $\cdots$ & $\cdots$ & $\cdots$ & $\cdots$ & $\cdots$ & $\cdots$ & $\cdots$ & $=$ & -- \\
\hline & $01-06-90$ & $\cdots$ & $\cdots$ & $\cdots$ & - & $\cdots$ & $\cdots$ & $\cdots$ & $\cdots$ & $\cdots$ & $-\cdot$ \\
\hline & $03-19-90$ & $\cdots$ & $\cdots$ & $\cdots$ & $\cdots$ & $\cdots$ & -- & -- & $\cdots$ & -. & $\cdots$ \\
\hline & $09-25-90$ & $\cdots$ & $\cdots$ & $\cdots$ & -- & $\cdots$ & -- & -- & $\cdots$ & $\cdots$ & $\cdots$ \\
\hline & $12-05-90$ & $\cdots$ & $\cdots$ & -- & -- & $\cdots$ & -- & $\cdots$ & -- & -- & $\cdots$ \\
\hline & $02-26-91$ & $\cdots$ & -- & -- & -- & $\cdots$ & $\cdots$ & -- & $\cdots$ & $\cdots$ & -- \\
\hline & $04-04-91$ & $\cdots$ & $\cdots$ & $\cdots$ & -- & $\cdots$ & - & $\cdots$ & $\cdots$ & .. & -. \\
\hline & $04-04-91$ & $\cdots$ & $\cdots$ & .9 & .10 & $\cdots$ & $\cdots$ & $<.1$ & ND & $\cdots$ & - \\
\hline & $04-04-91$ & $-\cdot$ & $\cdots$ & -- & $=-$ & $\cdots$ & $-\cdot$ & $\cdots$ & $\cdots$ & $\cdots$ & $\cdots$ \\
\hline & $06-04-91$ & $\cdots$ & $\cdots$ & $-\cdot$ & $\cdots$ & $\cdots$ & -- & $\cdots$ & $\cdots$ & $\cdots$ & $-\cdot$ \\
\hline & $04-04-91$ & $\cdots$ & $\cdots$ & $\cdots$ & $\cdots$ & $\cdots$ & $\cdots$ & $\cdots$ & $\cdots$ & $\cdots$ & $\cdots$ \\
\hline & $06-04-91$ & $\cdots$ & $\cdots$ & $\cdots$ & $\cdots$ & $\cdots$ & -- & -- & $\cdots$ & $\cdots$ & $\cdots$ \\
\hline & $06-05-91$ & -. & -- & $\cdots$ & -- & -- & -- & $\cdots$ & $\cdots$ &.- & $-\cdot$ \\
\hline & $06-05-91$ & $\cdots$ & $\cdots$ & $\cdots$ & $\cdots$ & $\cdots$ & -- & $\cdots$ & $\cdots$ & $\cdots$ & $\cdots$ \\
\hline & $04-05-91$ & $\cdots$ & $-\cdots$ & $\cdots$ & -- & -- & -- & $\cdots$ & $\cdots$ & $-\cdot$ & $\cdots$ \\
\hline & $06-05-91$ & $\cdots$ & $\cdots$ & $\cdots$ & -- & $\cdot-$ & $-\cdot$ & $\cdots$ & $\cdots$ & $\cdots$ & $\cdots$ \\
\hline & $06-05-91$ & $\cdots$ & $\cdots$ & $\cdots$ & -- & $\cdots$ & $\cdots$ & $\cdots$ & $\cdots$ & $\cdots$ & $\cdots$ \\
\hline & $04-05-91$ & $\cdots$ & - & $\cdots$ & -- & $\cdots$ & -- & $\cdots$ & $\cdots$ & -. & $\cdots$ \\
\hline & $06-05-91$ & $\cdots$ & $\cdots$ & 1.3 & .20 & $\cdots$ & $\cdots$ & $<.1$ & no & $\cdots$ & $\cdots$ \\
\hline & $06-05-$ & $\cdots$ & $-\cdot$ & 1.1 & .10 & $\cdots$ & $\cdots$ & $<.1$ & ND & $\cdots$ & $\cdots$ \\
\hline & $05-14-91$ & $\cdots$ & $\cdots$ & $\cdots$ & $\cdots$ & $\cdots$ & $\cdots$ & $\cdots$ & $\cdots$ & $\cdots$ & -- \\
\hline & $09-06$ & .40 & $<.1$ & 1.3 & .30 & $<.1$ & No & ND & NO & .30 & $<.06$ \\
\hline
\end{tabular}


SURFACE-MATER DATA-Continued

CHEMICAL AMALYSES-Continued

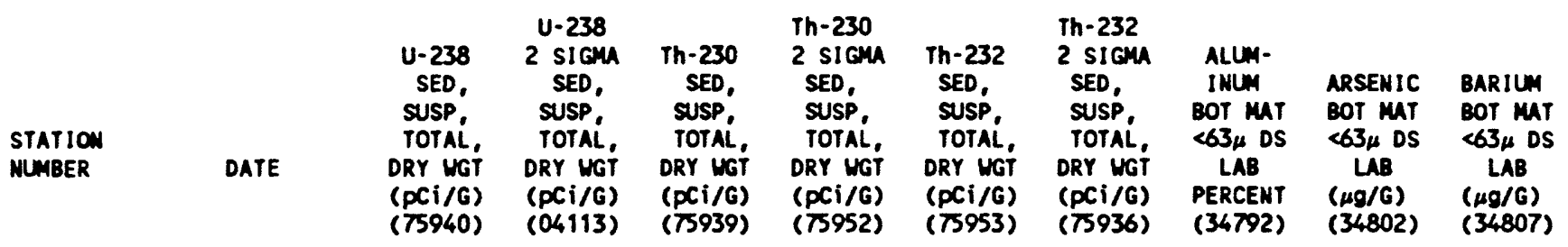

ZUNI RIVER MEAR BLACKROCK RESEVIR-Continued

$09386950 \quad$
$11-06-88$
$01-25-89$
$03-08-89$
$03-22-89$
$04-11-89$
$07-26-89$
$07-26-89$
$07-26-89$
$07-26-89$
$07-26-89$
$07-26-89$
$07-26-89$
$07-26-89$
$07-26-89$
$07-26-89$
$07-26-89$
$07-26-89$
$07-26-89$
$07-26-89$
$11-14-89$
$01-04-90$
$03-19-90$
$09-25-90$
$12-05-90$
$02-26-91$
$04-04-91$
$04-04-91$
$04-04-91$
$04-04-91$
$04-04-91$
$04-04-91$
$04-05-91$
$04-05-91$
$04-05-91$
$04-05-91$
$04-05-91$
$04-05-91$
$04-05-91$
$04-05-91$
$05-14-91$
$09-06-91$

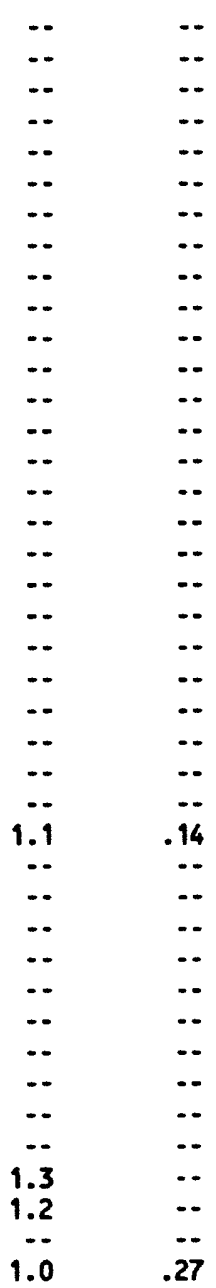

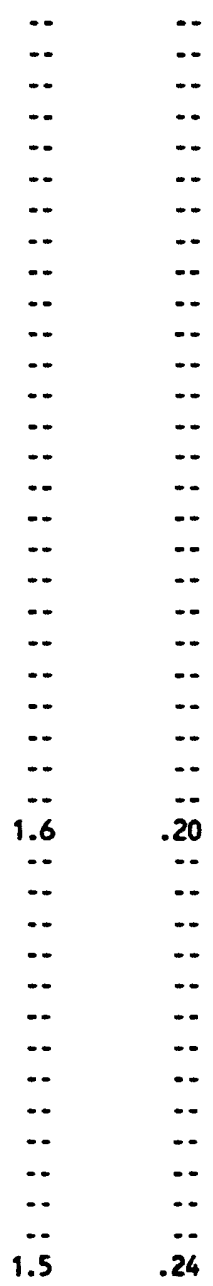

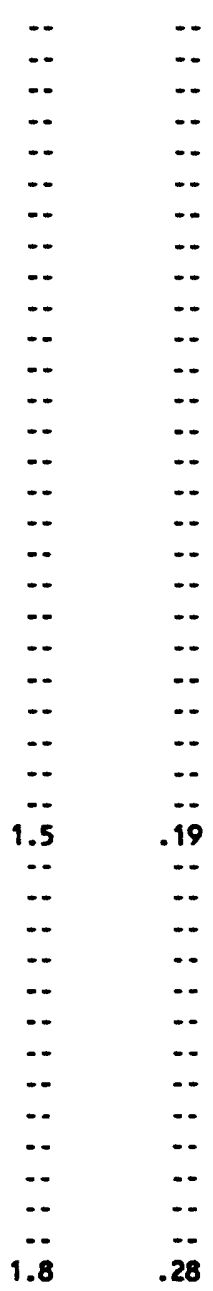

\begin{tabular}{|c|c|c|}
\hline - & - & - \\
\hline$\cdots$ & $\cdots$ & - \\
\hline$\cdots$ & $\cdots$ & $\cdots$ \\
\hline$\cdots$ & - & - \\
\hline 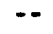 & $\cdots$ & $\cdots$ \\
\hline $\begin{array}{l}10 \\
11 \\
10\end{array}$ & $\begin{array}{r}<10 \\
10 \\
<20\end{array}$ & $\begin{array}{l}540 \\
560 \\
560\end{array}$ \\
\hline$\ldots$ & $\ldots$ & $\ldots$ \\
\hline 11 & 10 & 570 \\
\hline$\cdots$ & $\cdots$ & -- \\
\hline$\cdots$ & $\cdots$ & $\cdots$ \\
\hline 11 & $<20$ & 550 \\
\hline$\cdots$ & $\cdots$ & $\cdots$ \\
\hline$\cdots$ & $\cdots$ & $\cdots$ \\
\hline$\cdots$ & $\cdots$ & $\because$ \\
\hline 12 & 10 & 550 \\
\hline 12 & $<10$ & 540 \\
\hline$\cdots$ & $\cdots$ & -- \\
\hline$\cdots$ & $\cdots$ & -. \\
\hline$\cdots$ & $\cdots$ & -. \\
\hline$\cdots$ & 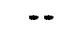 & - \\
\hline- & $\cdots$ & - \\
\hline$\cdots$ & $\cdots$ & $\cdots$ \\
\hline$\cdots$ & $\cdots$ & $\cdots$ \\
\hline$\cdots$ & $\cdots$ & $\cdots$ \\
\hline$\cdots$ & $\cdots$ & -. \\
\hline$\cdots$ & $\cdots$ & $-\cdot$ \\
\hline$\cdots$ & $\because$ & $\because$ \\
\hline$\cdots$ & $\because$ & $\cdots$ \\
\hline$\ldots$ & $\bar{~}$ & $\ddot{-}$ \\
\hline$\ldots$ & .. & .. \\
\hline$\cdots$ & - & -. \\
\hline -. & $\cdots$ & .. \\
\hline -- & -. & -. \\
\hline$\cdots$ & - & .. \\
\hline$\cdots$ & -- & -. \\
\hline$\cdots$ & $\cdots$ & $\cdots$ \\
\hline$\cdots$ & $\cdots$ & $\cdots$ \\
\hline
\end{tabular}


SURFACE-WATER DATA-Cont imued

CKEMICAL ANALYSES-Cont inued

\begin{tabular}{|c|c|c|c|c|c|c|c|c|c|c|}
\hline & & $\begin{array}{l}\text { BERYL- } \\
\text { LIUY }\end{array}$ & BISMUTK & CADMIUM & CALCIUN & CERIUM & $\begin{array}{l}\text { ChRO- } \\
\text { MIUN }\end{array}$ & COBALT & COPPER & $\begin{array}{l}\text { EURO- } \\
\text { PIUA }\end{array}$ \\
\hline $\begin{array}{l}\text { STATION } \\
\text { NUMBER }\end{array}$ & DATE & $\begin{array}{c}\text { BOT MAT } \\
<63 \mu \text { DS } \\
\text { LAB } \\
(\mu g / G) \\
(34812)\end{array}$ & 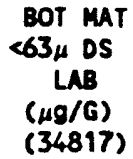 & 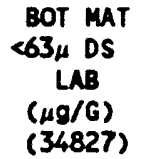 & $\begin{array}{c}\text { BOT MAT } \\
\text { <63H DS } \\
\text { LAB } \\
\text { PERCENT } \\
\text { (34832) }\end{array}$ & $\begin{array}{c}\text { BOT MAT } \\
<63 \mu \text { DS } \\
\text { LAB } \\
(\mu 9 / G) \\
(34837)\end{array}$ & $\begin{array}{c}\text { BOT MAT } \\
<63 \mu \text { DS } \\
\text { LAB } \\
(\mu g / G) \\
(34842)\end{array}$ & $\begin{array}{c}\text { BOT MAT } \\
<63 \mu \text { DS } \\
\text { LAB } \\
(\mu 9 / G) \\
(34847)\end{array}$ & 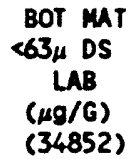 & $\begin{array}{c}\text { BOT MAT } \\
<63 \mu \text { DS } \\
\text { LAB } \\
(\mu g / G) \\
(34857)\end{array}$ \\
\hline
\end{tabular}

ZUNI RIVER NEAR BLACKROCK RESEVOIR-Continued

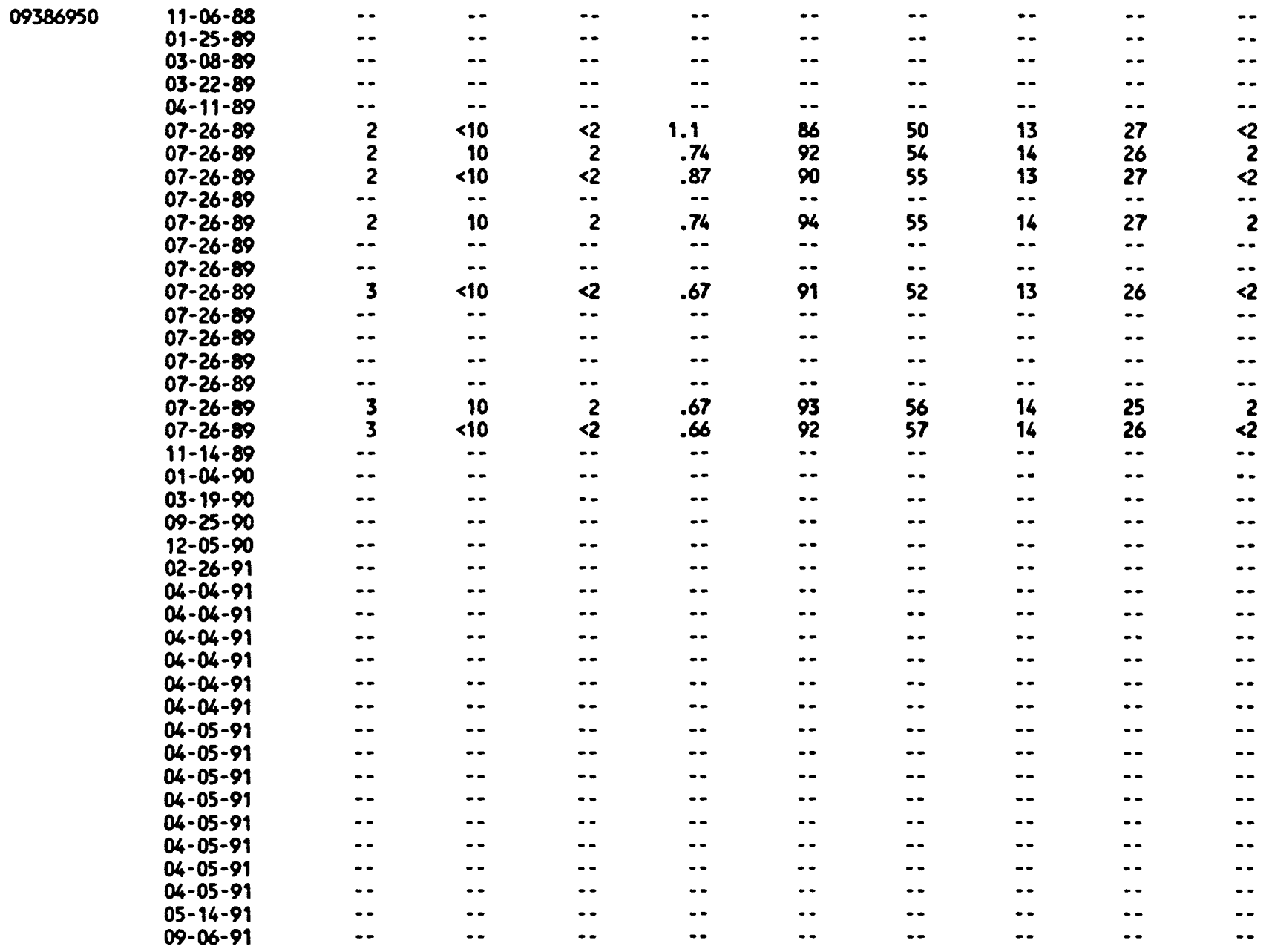


SURFACE-WATER DATA-Cont inued

CHEMICAL ANALYSES-Cont inued

STATION

NUMBER

OATE

$\begin{array}{cc}\text { GALLIUN } & \text { GOLD } \\ \text { BOT MAT } & 80 T \text { MAT } \\ \angle 63 \mu \text { DS } & \angle 63 \mu \text { DS } \\ \text { LAB } & \text { LAB } \\ (\mu g / G) & (\mu 9 / 6) \\ (34862) & (34872)\end{array}$

HOLMIUA
BOT MAT
$<63_{\mu}$ OS
LAB
$(\mu g / G)$
$(34877)$

IRON
BOT MAT
$\angle 63 \mu$ DS
LAB
PERCENT
(34882)

LANTHA-

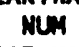

BUT

$<63 \mu$ OS

LAB

$(\mu \mathrm{g} / \mathrm{G})$

(34887)

LEAD

LITHIUM

MAGNE-

SIUA

BOT MAT

$\angle 63 \mu$ OS $<63 \mu$ OS

LAB

( $\mu \rho / G)$

(34892)

LAB

$(\mu g / G)$

(34897)

LAB

PERCENT

(34902)

ZUNI RIVER NEAR BLACKROCK RESEVIR-Continued

$09386950 \quad \begin{aligned} & 11-06-88 \\ & 01-25-89 \\ & 03-08-89 \\ & 03-22-89 \\ & 04-11-89 \\ & 07-26-89 \\ & 07-26-89 \\ & 07-26-89 \\ & 07-26-89 \\ & 07-26-89 \\ & 07-26-89 \\ & 07-26-89 \\ & 07-26-89 \\ & 07-26-89 \\ & 07-26-89 \\ & 07-26-89 \\ & 07-26-89 \\ & 07-26-89 \\ & 07-26-89 \\ & 11-14-89 \\ & 01-04-90 \\ & 03-19-90 \\ & 09-25-90 \\ & 12-05-90 \\ & 02-26-91 \\ & 04-04-91 \\ & 04-04-91 \\ & 04-04-91 \\ & 04-04-91 \\ & 04-04-91 \\ & 04-04-91 \\ & 04-05-91 \\ & 04-05-91 \\ & 04-05-91 \\ & 04-05-91 \\ & 04-05-91 \\ & 04-05-91 \\ & 04-05-91 \\ & 04-05-91 \\ & 05-14-91 \\ & 09-06-91 \\ & \end{aligned}$

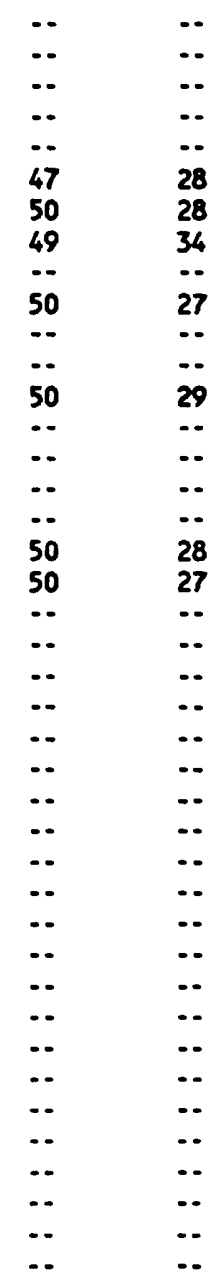

\begin{tabular}{|c|c|c|}
\hline - & - & .. \\
\hline$\cdots$ & $\cdots$ & $\cdots$ \\
\hline$\cdots$ & $\cdots$ & $\cdots$ \\
\hline$\cdots$ & $\cdots$ & $\cdots$ \\
\hline$\because$ & $\cdots$ & $\cdots$ \\
\hline $\begin{array}{l}41 \\
43\end{array}$ & $\begin{array}{r}.84 \\
.80\end{array}$ & $\begin{array}{l}380 \\
360\end{array}$ \\
\hline 42 & .82 & 390 \\
\hline 42 & .79 & 370 \\
\hline$\cdots$ & - & $\cdots$ \\
\hline$\cdots$ & $\cdots$ & - \\
\hline 44 & $<.80$ & 360 \\
\hline$\cdots$ & $\cdots$ & - \\
\hline$\cdots$ & $\cdots$ & $\cdots$ \\
\hline$\cdots$ & $\cdots$ & $\cdots$ \\
\hline$\cdots$ & $\cdots$ & - \\
\hline $\begin{array}{l}46 \\
47\end{array}$ & $\begin{array}{l}.83 \\
.85\end{array}$ & $\begin{array}{l}340 \\
340\end{array}$ \\
\hline$\cdots$ & $\cdots$ & 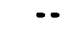 \\
\hline$\cdots$ & 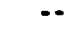 & -. \\
\hline$\cdots$ & $\cdots$ & $\cdots$ \\
\hline$\cdots$ & $\cdots$ & $\cdots$ \\
\hline$\cdots$ & -- & $\cdots$ \\
\hline$\because$ & -- & $-\cdot$ \\
\hline$\cdots$ & $\cdots$ & $\cdots$ \\
\hline$\cdots$ & $\cdots$ & $\cdots$ \\
\hline$\cdots$ & $\cdots$ & $\cdots$ \\
\hline 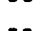 & $\because$ & $\cdots$ \\
\hline- & $\theta$ & . \\
\hline .. & $\ldots$ & \\
\hline$\cdots$ & .- & 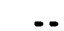 \\
\hline$\cdots$ & -. & $\because$ \\
\hline$\cdots$ & $\cdots$ & $\cdots$ \\
\hline$-\cdot$ & $-\cdot$ & $\cdots$ \\
\hline$\cdots$ & $\cdots$ & - \\
\hline$\cdots$ & $\cdots$ & $\cdots$ \\
\hline$\cdots$ & $\cdots$ & - \\
\hline 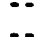 & $\cdots$ & $\cdots$ \\
\hline$\cdots$ & - & 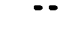 \\
\hline
\end{tabular}


STATION

MUMBER

DATE

\begin{tabular}{|c|c|c|c|c|c|c|c|c|}
\hline $\begin{array}{l}\text { MOLYB- } \\
\text { DENUM }\end{array}$ & NEOO YM- & ICKE & 10810 & $\begin{array}{l}\text { PHOS- } \\
\text { PHORUS }\end{array}$ & POTAS- & $\begin{array}{l}\text { SCAN- } \\
\text { DIUM }\end{array}$ & $511 \mathrm{VE}$ & SODIUM \\
\hline $\begin{array}{c}\text { BOT MAT } \\
\angle 63 \mu \text { DS } \\
\text { LAB } \\
(\mu g / G) \\
(34917)\end{array}$ & $\begin{array}{c}B O T \text { MAT } \\
\angle 63 \mu \text { DS } \\
\text { LAB } \\
(\mu g / G) \\
(34922)\end{array}$ & $\begin{array}{c}B O T \text { MAT } \\
\angle 63_{\mu} \text { DS } \\
L A B \\
(\mu g / G) \\
(34927)\end{array}$ & $\begin{array}{c}\text { BOT MAT } \\
\angle 63 \mu \text { DS } \\
\text { LAB } \\
(\mu g / G) \\
(34932)\end{array}$ & $\begin{array}{c}\text { BOT MAT } \\
\text { C63 }{ }_{\mu} \text { DS } \\
\text { LAB } \\
\text { PERCENT } \\
\text { (34937) }\end{array}$ & $\begin{array}{c}\text { BOT MAT } \\
\angle 63 \mu \text { DS } \\
\text { LAB } \\
\text { PERCENT } \\
\text { (34942) }\end{array}$ & $\begin{array}{c}B O T \text { MAT } \\
\angle 63 \mu \text { DS } \\
L A B \\
(\mu g / G) \\
(34947)\end{array}$ & $\begin{array}{c}\text { BOT MAT } \\
<63 \mu \text { DS } \\
\text { LAB } \\
(\mu g / G) \\
(34957)\end{array}$ & 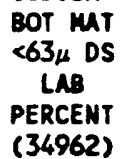 \\
\hline
\end{tabular}

ZUWI RIVER NEAR BLACKROCK RESEVOIR-Continued

$09386950 \quad$
$11-06-88$
$01-25-89$
$03-08-89$
$03-22-89$
$04-11-89$
$07-26-89$
$07-26-89$
$07-26-89$
$07-26-89$
$07-26-89$
$07-26-89$
$07-26-89$
$07-26-89$
$07-26-89$
$07-26-89$
$07-26-89$
$07-26-89$
$07-26-89$
$07-26-89$
$11-14-89$
$01-04-90$
$03-19-90$
$09-25-90$
$12-05-90$
$02-26-91$
$04-04-91$
$04-04-91$
$04-04-91$
$04-04-91$
$04-04-91$
$04-04-91$
$04-05-91$
$04-05-91$
$04-05-91$
$04-05-91$
$04-05-91$
$04-05-91$
$04-05-91$
$04-05-91$
$05-14-91$
$09-06-91$

\begin{tabular}{|c|c|c|c|c|c|}
\hline$\cdots$ & $\cdots$ & $\cdots$ & $\ldots$ & - & -. \\
\hline$\cdots$ & $\cdots$ & $\cdots$ & $\cdots$ & $\cdots$ & $\cdots$ \\
\hline$\cdots$ & $\cdots$ & $\cdots$ & $\cdots$ & $\cdots$ & $\cdots$ \\
\hline$\cdots$ & $\ldots$ & $\cdots$ & 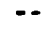 & $\cdots$ & -. \\
\hline$\cdots$ & 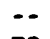 & 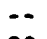 & 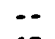 & 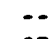 & $\cdots$ \\
\hline $\begin{array}{r}<2 \\
2 \\
<2\end{array}$ & $\begin{array}{l}39 \\
40 \\
40\end{array}$ & $\begin{array}{l}20 \\
20 \\
18\end{array}$ & $\begin{array}{l}15 \\
17 \\
18\end{array}$ & $\begin{array}{l}.05 \\
.05 \\
.05\end{array}$ & $\begin{array}{l}1.8 \\
1.8 \\
1.8\end{array}$ \\
\hline$\ldots$ & $\cdots$ & $\cdots$ & .. & - & -. \\
\hline 2 & 40 & 18 & 16 & .05 & 1.8 \\
\hline$\cdots$ & $\cdots$ & $\cdots$ & $\cdots$ & $\cdots$ & $\cdots$ \\
\hline$\cdots$ & $\cdots$ & 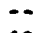 & $\cdots$ & $\cdots$ & $\cdots$ \\
\hline$<2$ & 41 & 19 & 17 & .05 & 1.8 \\
\hline$\cdots$ & $\cdots$ & $\cdots$ & $\cdots$ & $\cdots$ & $\because$ \\
\hline$\cdots$ & $\cdots$ & $\cdots$ & $\cdots$ & $\cdots$ & $\cdots$ \\
\hline$\cdots$ & $\cdots$ & $\cdots$ & a & 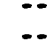 & $\ldots$ \\
\hline$\cdots$ & $\ddot{B}$ & 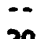 & 17 & 05 & 8 \\
\hline $\begin{array}{r}2 \\
<2\end{array}$ & $\begin{array}{l}40 \\
39\end{array}$ & $\begin{array}{l}20 \\
22\end{array}$ & $\begin{array}{l}17 \\
17\end{array}$ & $\begin{array}{l}.05 \\
.05\end{array}$ & 1.8 \\
\hline$\cdots$ & $\cdots$ & $\cdots$ & $\cdots$ & $\cdots$ & $\cdots$ \\
\hline$\cdots$ & -. & $\cdots$ & $\cdots$ & $\cdots$ & $\cdots$ \\
\hline$\cdots$ & $\cdots$ & $\cdots$ & $\cdots$ & -. & $\cdots$ \\
\hline$\cdots$ & $\cdots$ & $\cdots$ & $\cdots$ & $\cdots$ & $\cdots$ \\
\hline$\cdots$ & $\cdots$ & $\cdots$ & $\cdots$ & $\cdots$ & $\cdots$ \\
\hline$\cdots$ & $\cdots$ & $\cdots$ & $\cdots$ & $\cdots$ & $\cdots$ \\
\hline$\cdots$ & $\cdots$ & $\cdots$ & $\cdots$ & $\cdots$ & $\cdots$ \\
\hline$\cdots$ & $\cdots$ & $\cdots$ & $\cdots$ & $\cdots$ & $\cdots$ \\
\hline 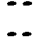 & $\ldots$ & $\ldots$ & $\cdots$ & $\cdots$ & $\because$ \\
\hline - & .. & $\ldots$ & -. & $\ldots$ & $\ldots$ \\
\hline - & .. & - & -. & .. & .. \\
\hline -. & -. & -. & - & $\ldots$ & .. \\
\hline - & $\cdots$ & $\cdots$ & - & $\cdots$ & -. \\
\hline$\cdots$ & - & $\cdots$ & - & $\cdots$ & - \\
\hline$\cdots$ & $\cdots$ & $\cdots$ & $\cdots$ & $\cdots$ & $\cdots$ \\
\hline$\cdots$ & - & $\cdots$ & $\cdots$ & $\cdots$ & $\cdots$ \\
\hline$\cdots$ & $\cdots$ & $\cdots$ & $\cdots$ & $\cdots$ & $\cdots$ \\
\hline$\cdots$ & $\cdots$ & $\cdots$ & $\cdots$ & $\cdots$ & $\cdots$ \\
\hline$\cdots$ & $\cdots$ & $\cdots$ & $\cdots$ & $\cdots$ & $\cdots$ \\
\hline$\cdots$ & $\cdots$ & $\because$ & $\cdots$ & $\cdots$ & $\cdots$ \\
\hline$\cdots$ & $\cdots$ & $\cdots$ & $\cdots$ & - & \\
\hline
\end{tabular}

\begin{tabular}{|c|c|c|}
\hline$\cdots$ & -. & -. \\
\hline$\cdots$ & $\cdots$ & $\cdots$ \\
\hline$\cdots$ & .. & $\cdots$ \\
\hline$\cdots$ & .. & - \\
\hline$\cdots$ & -. & $\ldots$ \\
\hline $\begin{array}{l}14 \\
15\end{array}$ & $<4$ & $\begin{array}{r}.30 \\
.24\end{array}$ \\
\hline 15 & $<4$ & \\
\hline$\cdots$ & -. & $\ldots$ \\
\hline 15 & 2 & .28 \\
\hline$\cdots$ & $\cdots$ & $\cdots$ \\
\hline$\cdots$ & -. & $\cdots$ \\
\hline 16 & $<4$ & .20 \\
\hline$\cdots$ & -. & $\ldots$ \\
\hline$\cdots$ & -. & $\cdots$ \\
\hline$\cdots$ & .. & - \\
\hline$\cdots$ & -. & $\cdots$ \\
\hline $\begin{array}{l}16 \\
17\end{array}$ & $\begin{array}{r}2 \\
<4\end{array}$ & $\begin{array}{l}.16 \\
.12\end{array}$ \\
\hline$\cdots$ & $\cdots$ & $\cdots$ \\
\hline$\cdots$ & -. & $\cdots$ \\
\hline$\cdots$ & $\cdots$ & $\cdots$ \\
\hline$\cdots$ & -. & $\cdots$ \\
\hline$\cdots$ & $\cdots$ & $\cdots$ \\
\hline$\cdots$ & $\cdots$ & $\cdots$ \\
\hline$\ldots$ & 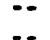 & $\because$ \\
\hline$\ldots$ & $\ldots$ & -1 \\
\hline - & .. & $\ldots$ \\
\hline$\cdots$ & .. & .. \\
\hline$\cdots$ & -. & $\cdots$ \\
\hline$\cdots$ & -. & $\cdots$ \\
\hline$\cdots$ & $\cdots$ & $\cdots$ \\
\hline$\cdots$ & $\cdots$ & $\cdots$ \\
\hline$\cdots$ & $\cdots$ & - \\
\hline$\cdots$ & $\cdots$ & $\cdots$ \\
\hline$\cdots$ & $\cdots$ & $\cdots$ \\
\hline$\because$ & $\cdots$ & $\cdots$ \\
\hline$\cdots$ & $\cdots$ & $\cdots$ \\
\hline$\cdots$ & $\ldots$ & $\ldots$ \\
\hline
\end{tabular}


STATION

NUMBER

DATE

\begin{tabular}{|c|c|c|c|c|c|c|c|c|}
\hline $\begin{array}{c}\text { STRON- } \\
\text { TIUN } \\
\text { BOT MAT } \\
<63 \mu \text { DS } \\
\text { LAB } \\
(\mu 9 / G) \\
(34967)\end{array}$ & $\begin{array}{l}\text { TAHTA- } \\
\text { LUH } \\
\text { BOT MAT } \\
\text { C63H DS } \\
\text { LAB } \\
(\mu 9 / G) \\
(34977)\end{array}$ & 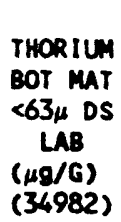 & $\begin{array}{c}\text { TIN } \\
\text { BOT MAT } \\
<63 \mu \text { DS } \\
L A B \\
(\mu g / G) \\
(34987)\end{array}$ & 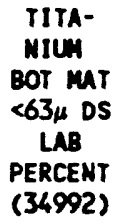 & $\begin{array}{c}\text { URANIUA } \\
\text { BOT MAT } \\
\angle 63_{\mu} \text { DS } \\
\text { LAB } \\
(\mu g / G) \\
(35002)\end{array}$ & $\begin{array}{c}\text { VANA- } \\
\text { OIUN } \\
\text { BOT MAT } \\
<63 \mu \text { DS } \\
\text { LAB } \\
(\mu g / G) \\
(35007)\end{array}$ & 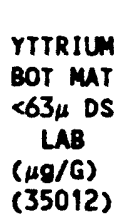 & $\begin{array}{c}\text { YTTER- } \\
\text { BIUM } \\
\text { BOT MAT } \\
<63 \mu \text { DS } \\
\text { LAB } \\
(\mu g / G) \\
(35017)\end{array}$ \\
\hline
\end{tabular}

ZUWI RIVER NEAR BLACKROCK RESEVOIR-Continued

\begin{tabular}{|c|c|c|c|c|c|c|c|c|c|c|}
\hline 09386950 & $\begin{array}{l}11-06-88 \\
01-25-89\end{array}$ & $\ldots$ & -- & -. & $\begin{array}{l}-- \\
\cdots\end{array}$ & -- & -- & -. & -. & 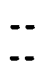 \\
\hline & $03-08-89$ & -- & -- & $\ldots$ & $\ldots$ & - & -- & -- & -- & -- \\
\hline & $03-22-89$ & .. & - & -. & .. & -. & -. & -- & - & -- \\
\hline & $04-11-89$ & -. & $\cdots$ & -. & -- & -- & -- & -- & -- & -- \\
\hline & $07-26-89$ & 120 & $<40$ & 17 & $<10$ & .47 & $<100$ & 100 & 29 & 3 \\
\hline & $07-26-89$ & 110 & 40 & 17 & 10 & .49 & 100 & 110 & 29 & 3 \\
\hline & $07-26-89$ & 110 & $<40$ & 17 & $<10$ & .49 & $<100$ & 110 & 29 & 3 \\
\hline & $07-26-89$ & -- & -- & .. & -- & -- & -- & -- & -- & -- \\
\hline & $07-26-89$ & 110 & 40 & 18 & 10 & .50 & 100 & 110 & 30 & 3 \\
\hline & $07-26-89$ & $\cdots$ & -- & $\cdots$ & $\cdots$ & -. & -- & $\cdots$ & -- & $\cdots$ \\
\hline & $07-26-89$ & -- & -- & -. & -- & $\cdots$ & $=$ & $\cdots$ & -- & - \\
\hline & $07-26-89$ & 100 & $<40$ & 18 & $<10$ & .49 & $<100$ & 110 & 30 & 3 \\
\hline & $07-26-89$ & - & -- & $\cdots$ & -- &.- & -- & - & -- & $\cdots$ \\
\hline & $07-26-89$ &.- &.- & $\cdots$ & -- & -- & -- & $\cdots$ & -- & $\cdots$ \\
\hline & $07-26-89$ & $\cdots$ & -- & $\cdots$ & -- & $\cdots$ & -- & -- & -- & $=-$ \\
\hline & $07-26-89$ & $=$ & $=$ & $\cdots$ & -- & 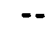 & -- & $\cdots$ & -- & $\cdots$ \\
\hline & $\begin{array}{l}07-26-89 \\
07-26-89\end{array}$ & $\begin{array}{l}100 \\
100\end{array}$ & $\begin{array}{r}40 \\
<40\end{array}$ & $\begin{array}{l}18 \\
-.\end{array}$ & $\begin{array}{r}10 \\
<10\end{array}$ & $\begin{array}{l}.50 \\
.49\end{array}$ & $\begin{array}{r}100 \\
<100\end{array}$ & $\begin{array}{l}120 \\
110\end{array}$ & $\begin{array}{l}30 \\
29\end{array}$ & $\begin{array}{l}3 \\
3\end{array}$ \\
\hline & $11-14-89$ & $=$ & $\therefore-$ & - & -- & - & $=-$ & -- & $\cdots$ & -- \\
\hline & $01-04-90$ & $=-$ & -- & $\cdots$ & -- & $=-$ & -- & $\cdots$ & -- & $\ldots$ \\
\hline & $03-19-90$ & $\ldots$ & -- & $\cdots$ & $=-$ & -- & -. & -- & -- & $\cdots$ \\
\hline & $09-25-90$ & $\cdots$ & -- & $\cdots$ & $=$ & -- & $\cdots$ & $\cdots$ & -- & $\cdots$ \\
\hline & $12-05-90$ & $\cdots$ & -- & $\cdots$ & -- & -- & $\cdots$ & $\cdots$ & -- & $\cdots$ \\
\hline & $02-26-91$ & $\cdots$ & -- & $\cdots$ & $\cdots$ & -- & $\cdots$ & -- & -- & $\cdots$ \\
\hline & $04-04-91$ & -- & -- & $\cdots$ & -- & $\cdots$ & $\cdots$ & -- & -- & - \\
\hline & $04-04-91$ & -- & -- & $\cdots$ & -- & -- & -- & -- & -. & $\cdots$ \\
\hline & $04-04-91$ & -- & $\cdots$ & $\cdots$ & -- & -- & -- & $\cdots$ & $\cdots$ & $\cdots$ \\
\hline & $04-04-91$ &.- & $\cdots$ & $\cdots$ & $\cdots$ & $\cdots$ & $=$ & -- & -. & $\cdots$ \\
\hline & $04-04-91$ & -- & -- & $\cdots$ & -- & -- & -- & -- & -. & $\cdots$ \\
\hline & $04-04-91$ & $\cdots$ & $-\cdot$ & $\cdots$ & $\cdots$ & $\cdots$ & $\cdots$ & -- & $\cdots$ & -- \\
\hline & $04-05-91$ & $=$ & -- & $\cdots$ & $=$ & -- & -- & -- & $\cdots$ & $-\cdot$ \\
\hline & $04-05-91$ & -- & -- & $\cdots$ & $=-$ & -- & $=$ & $\cdots$ & $\cdots$ & -- \\
\hline & $04-05-91$ & -- & -- & - & -- & $\cdots$ & - & $=-$ & -- & -. \\
\hline & $04-05-91$ & $\cdots$ & - & $\cdots$ & $\cdots$ & .. & $\ldots$ & $\cdots$ & $\ldots$ & -. \\
\hline & $04-05-91$ & $\cdots$ & - & $\cdots$ & $\cdots$ & -. & $\cdots$ & -- & .. & $\cdots$ \\
\hline & $04-05-91$ & $\cdots$ & $\cdots$ & $\cdots$ & $\cdots$ & $\cdots$ & -. & $\cdots$ & $\cdots$ & $\cdots$ \\
\hline & $04-05-91$ & $\cdots$ & -- & $\cdots$ & $\cdots$ & $\cdots$ & $\cdots$ & -- & $\cdots$ & $\cdots$ \\
\hline & $04-05-91$ & $\cdots$ & $-\cdot$ & $\cdots$ & $\cdots$ & -- & $\cdots$ & $\cdots$ & $\cdots$ & $\cdots$ \\
\hline & $05-14-91$ & $\cdots$ & - & $\cdots$ & $\cdots$ & -- & $-\cdot$ & $\cdots$ & -. & - \\
\hline & $09-06-91$ & - & $\cdots$ & $\cdots$ & $=-$ & $\cdots$ & $\ldots$ & -- & .. & - \\
\hline
\end{tabular}


SURFACE-MATER DATA-Cont inued

CHEMICAL AMALYSES-Cont inued

STATION

MUMBER

DATE

$11-06-88$

$01-25-89$

$03-08-89$

03-22-89

$04-11-89$

$07-26-89$

$07-26-89$

07-26-89

$07-26-89$

07-26-89

$07-26-89$

07-26-89

$07-26-89$

07-26-89

07-26-89

07-26-89

07-26-89

07-26-89

$07-26-89$

$11-14-89$

$01-04-90$

03-19-90

09-25-90

12-05-90

02-26-91

04-04-91

04-04-91

04-04-91

04-04-91

04-04-91

04-04-91

04-05-91

04-05-91

04-05-91

04-05-91

04-05-91

04-05-91

04-05-91

04-05-91

05-14-91

09-06-91

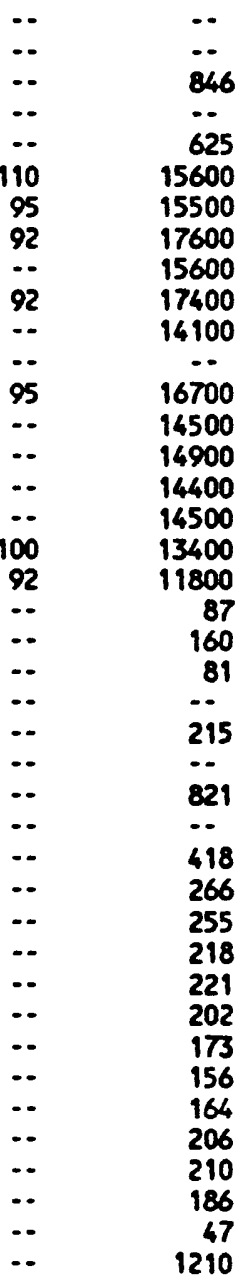

ZUWI RIVER MEAR BLACKROCK RESEVOIR-COntinued

SED. $\quad$ SED. $\quad$ SED. $\quad$ SED. SED.

SUSP. SUSP. SUSP. SUSP. SUSP. SUSP. SIEVE FALL FALL FALL FALL FALL

$\times$ FIMER $\times$ DINA. DINM. DIAM. THAN $\begin{array}{llllll}(70331) & (70337) & (70338) & (70340) & (70342) & (70343)\end{array}$ 
SURFACE-HATER DATA-Cont inued

CHEMICAL ANALYSES-Cont inued

\begin{tabular}{|c|c|c|c|c|c|}
\hline $\begin{array}{l}\text { STATION } \\
\text { MUMBER }\end{array}$ & STATION RANE & DATE & TIME & LATITUDE & LONGITUDE \\
\hline 09394500 & LITTLE COLORADO RIVER AT WOOORUFF, ARIZONA & $\begin{array}{l}03-14-89 \\
07-23-89 \\
07-23-89 \\
07-23-89 \\
07-23-89 \\
07-23-89 \\
07-23-89 \\
07-23-89 \\
07-23-89 \\
07-23-89 \\
07-23-89 \\
07-23-89 \\
07-23-89 \\
07-23-89 \\
07-23-89 \\
07-23-89 \\
07-23-89 \\
07-23-89 \\
07-23-89 \\
07-23-89 \\
07-23-89 \\
07-23-89 \\
07-23-89 \\
07-23-89 \\
07-23-89 \\
07-23-89 \\
07-23-89 \\
07-23-89 \\
07-23-89 \\
08-18-89 \\
08-18-89 \\
08-18-89 \\
08-18-89 \\
08-18-89 \\
08-18-89 \\
08-18-89 \\
08-18-89 \\
08-18-89 \\
08-18-89 \\
08-18-89 \\
08-18-89 \\
08-19-89 \\
08-19-89 \\
08-19-89 \\
08-19-89\end{array}$ & $\begin{array}{l}1520 \\
\cdots \\
0810 \\
0850 \\
0910 \\
0911 \\
0930 \\
0950 \\
1010 \\
1011 \\
1030 \\
1050 \\
1110 \\
1130 \\
1131 \\
1150 \\
1210 \\
1230 \\
1231 \\
1250 \\
1310 \\
1330 \\
1331 \\
1350 \\
1610 \\
1510 \\
1511 \\
1512 \\
1513 \\
10 \\
1500 \\
1740 \\
1741 \\
1830 \\
1930 \\
2030 \\
2031 \\
2130 \\
2230 \\
2231 \\
2232 \\
1410 \\
1415 \\
1423 \\
1428\end{array}$ & $34 \cdot 46 \cdot 5811 \mathrm{~N}$ & $110^{\circ} 02^{\prime} 37^{m y}$ \\
\hline
\end{tabular}


SURFACE-WATER DATA-Cont inued

CHEAICAL ANALYSES-Cont inued

\begin{tabular}{|c|c|c|c|c|c|c|c|c|c|c|}
\hline $\begin{array}{l}\text { STATION } \\
\text { MUNBER }\end{array}$ & DATE & $\begin{array}{c}\text { ALTITUDE } \\
\text { OF LAND } \\
\text { SURFACE } \\
\text { DATUN } \\
\text { (METERS } \\
\text { ABOVE } \\
\text { NGVD) } \\
\text { (72000) }\end{array}$ & $\begin{array}{l}\text { SNM- } \\
\text { PLING } \\
\text { METHOD, } \\
\text { COOES } \\
(82398)\end{array}$ & $\begin{array}{l}\text { TEMPER- } \\
\text { ATURE } \\
\text { WATER } \\
\left({ }^{\circ} \mathrm{C}\right) \\
(00010)\end{array}$ & $\begin{array}{l}\text { DIS- } \\
\text { CHARGE, } \\
\text { INST. } \\
\text { CUBIC } \\
\text { METERS } \\
\text { PER } \\
\text { SECOND } \\
(00061)\end{array}$ & $\begin{array}{l}\text { CAGE } \\
\text { HEIGHT } \\
\text { (METERS) } \\
\text { (00065) }\end{array}$ & $\begin{array}{l}\text { SPE- } \\
\text { CIFIC } \\
\text { CON- } \\
\text { DUCT- } \\
\text { ANCE } \\
\text { LAB } \\
\text { (mS/Cn) } \\
(900 \% 5)\end{array}$ & $\begin{array}{c}\text { PH } \\
\text { WATER } \\
\text { WHOLE } \\
\text { LAB } \\
\text { (STAND- } \\
\text { ARD } \\
\text { UNITS) } \\
\text { (OO403) }\end{array}$ & $\begin{array}{l}\text { NITRO- } \\
\text { GEN, } \\
\text { NO2+NO3 } \\
\text { DIS- } \\
\text { SOLVED } \\
(\mathrm{mg} / L \\
\text { as N) } \\
(00631)\end{array}$ & $\begin{array}{l}\text { HARD- } \\
\text { NESS } \\
\text { TOTAL } \\
\text { (ng/L } \\
\text { as } \\
\text { Cacos) } \\
(00900)\end{array}$ \\
\hline
\end{tabular}

LITTLE COLORADO RIVER AT WOOORUFF, ARIZONA-COnt inued

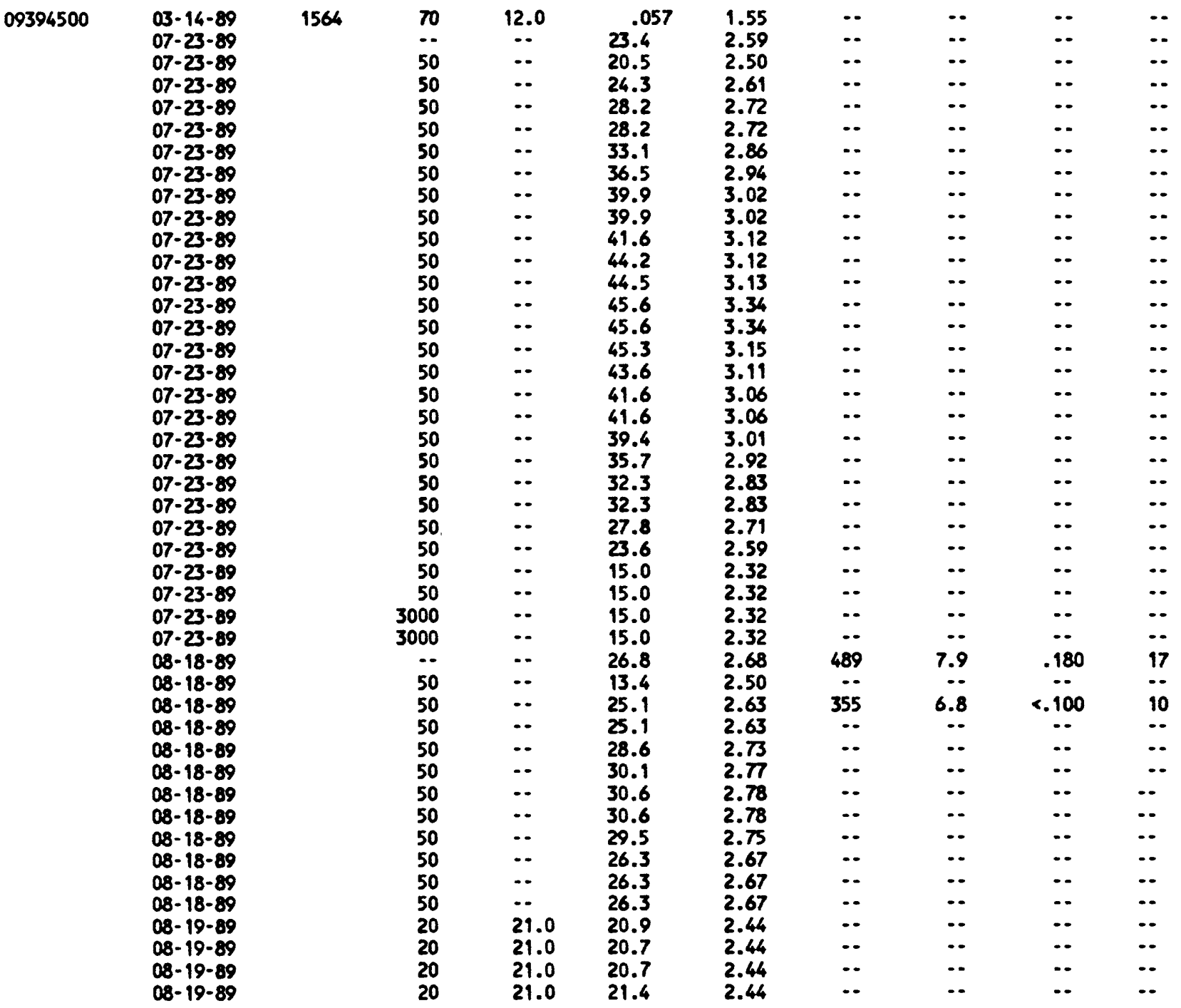


CHEMICAL AMALYSES-Continued

STATION

MUMBER

09394500

CALCIUN
DIS-
SOLVED
DATE $(\mathrm{mg} / \mathrm{L}$
$\mathrm{as} \mathrm{Ca})$
$(00 \mathrm{C} 15)$
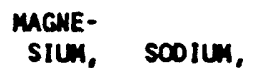

SOLVED SOLVED

(mo/L

SOLVED

as $\mathrm{Mg}$ )

(mos $/ \mathrm{Ma})$

(00930)

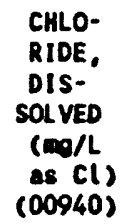
BROMIOE
DIS-
SOLVED
$(m / L$
as Br)
$(71870)$

$\begin{array}{cc}\text { FLLO- } & \text { SILICA, } \\ \text { RIDE, } & \text { DIS- } \\ \text { DIS- } & \text { SOLVED } \\ \text { SOLVED } & (\mathrm{mO} / L \\ (\mathrm{mO} / L & \text { as } \\ \text { as F) } & \text { Si02) } \\ (00950) & (00955)\end{array}$

LITILE COLORADO RIVER AT WOOORUFF, ARIZOMA-Continued

\begin{tabular}{|c|c|c|c|c|c|c|c|c|c|c|}
\hline $03-14-89$ & $\cdots$ & $\cdots$ & $\cdots$ & - & $-\cdot$ & $\cdots$ & $\cdots$ & -- & $\cdots$ & $\cdots$ \\
\hline $07-23-89$ & $\cdots$ & $\cdots$ & $\cdots$ & -. & $\cdots$ & $\cdots$ & $\cdots$ & $\cdots$ & $-\cdot$ & $-\cdot$ \\
\hline $07-23-89$ & $\cdots$ & $\cdots$ & $\cdots$ & $\cdots$ & $\cdots$ & $\cdots$ & $\cdots$ & $-\cdot$ & $-\cdot$ & $-\cdot$ \\
\hline $07-23-89$ & $\cdots$ & $\cdots$ & $\cdots$ & -. & $\cdots$ & $\cdots$ & -. & $\cdots$ & $\cdots$ & .. \\
\hline $07-23-89$ & -. & $\cdots$ & $\cdots$ & $\cdots$ & $\cdots$ & $\cdots$ & $\cdots$ & $\cdots$ & $\cdots$ & $\cdots$ \\
\hline $07-23-89$ & $\cdots$ & $\cdots$ & $\cdots$ & .. & $\cdots$ & $\cdots$ & -. & $\cdots$ & $\cdots$ & -. \\
\hline $07-23-89$ & $\cdots$ & $\cdots$ & $\cdots$ & -- & $\cdots$ & $\cdots$ & -. & $-\cdot$ & $\cdots$ & .. \\
\hline $07-23-89$ & $\cdots$ & $\cdots$ & $\cdots$ & $\cdots$ & $\cdots$ & $\cdots$ & $\cdots$ & $\cdots$ & $\cdots$ & $\cdots$ \\
\hline $07-23-89$ & $\cdots$ & -. & $\cdots$ & - & $\cdots$ & $\cdots$ & $\cdots$ & -. & $\cdots$ & -. \\
\hline $07-23-89$ & $\cdots$ & $\cdots$ & $\cdots$ & $\cdots$ & $\cdots$ & $\cdots$ & $\cdots$ & $\cdots$ & $\cdots$ & $\cdots$ \\
\hline $07-23-89$ & $\cdots$ & $\cdots$ & $\cdots$ & $\cdots$ & $\cdots$ & $\cdots$ & $\cdots$ & $\cdots$ & $\cdots$ & -. \\
\hline $07-23-89$ & $\cdots$ & -. & .. & -. & $\cdots$ & 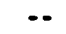 & -. & $\cdots$ & $\cdots$ & -. \\
\hline $07-23-89$ & $\cdots$ & $\cdots$ & $\cdots$ & $\cdots$ & $\cdots$ & $\cdots$ & $\cdots$ & $\cdots$ & $\cdots$ & $\cdots$ \\
\hline $07-23-89$ & $\cdots$ & $\cdots$ & $\cdots$ & $-\cdot$ & $\cdots$ & $\cdots$ & $\cdots$ & $\cdots$ & $\cdots$ & $\cdots$ \\
\hline $07-23-89$ & $\cdots$ & $\cdots$ & $\cdots$ & $\cdots$ & $\cdots$ & $\cdots$ & $\cdots$ & $\cdots$ & $\cdots$ & $\cdots$ \\
\hline $07-23-89$ & $\cdots$ & -. & -. & -. & $\cdots$ & -. & $\cdots$ & -. & $\cdots$ & -. \\
\hline $07-23-89$ & $\cdots$ & $\cdots$ & $\cdots$ & $\cdots$ & $\cdots$ & $\cdots$ & $\cdots$ & $\cdots$ & $\cdots$ & $\cdots$ \\
\hline $07-23-89$ & $\cdots$ & $\cdots$ & $\cdots$ & $\cdots$ & $\cdots$ & $\cdots$ & $\cdots$ & $\cdots$ & $\cdots$ & $\cdots$ \\
\hline $07-23-89$ & $\cdots$ & $\cdots$ & $\cdots$ & $-\cdot$ & $\cdots$ & $\cdots$ & $\cdots$ & $\cdots$ & $\cdots$ & -. \\
\hline $07-23-89$ & $\cdots$ & $\cdots$ & $\cdots$ & $\cdots$ & $\cdots$ & $\cdots$ & $\cdots$ & $\cdots$ & $\cdots$ & -. \\
\hline $07-23-89$ & $\cdots$ & $\cdots$ & $\cdots$ & $\cdots$ & $\cdots$ & $\cdots$ & $\cdots$ & $\cdots$ & $\cdots$ & $\cdots$ \\
\hline $07-23-89$ & $\cdots$ & $\cdots$ & $\cdots$ & -. & $\cdots$ & $\cdots$ & $\cdots$ & $\cdots$ & $\cdots$ & -. \\
\hline $07-23-89$ & $\cdots$ & $\cdots$ & $\cdots$ & $\cdots$ & $\cdots$ & $\cdots$ & $\cdots$ & $\cdots$ & $\cdots$ & $\cdots$ \\
\hline $07-23-89$ & $\cdots$ & $\cdots$ & $\cdots$ & $-\cdot$ & $\cdots$ & $\cdots$ &.- & $\cdots$ & $\cdots$ & .. \\
\hline $07-23-89$ & $\cdots$ & $\cdots$ & $\cdots$ & -- & $\cdots$ & $\cdots$ & $\cdots$ & $\cdots$ & $\cdots$ & $\cdots$ \\
\hline $07-23-89$ & $\cdots$ & $\cdots$ & $\cdots$ & $\cdots$ & $\cdots$ & $\cdots$ & $\cdots$ & $\cdots$ & $\cdots$ & .. \\
\hline $07-23-89$ & $\cdots$ & -- & $\cdots$ & -- & -- & $\cdots$ & $\cdots$ & $\cdots$ & $\cdots$ & .. \\
\hline $07-23-89$ & $\cdots$ & $\cdots$ & $\cdots$ & $\cdots$ & $\cdots$ & $\cdots$ & $\cdots$ & $\cdots$ & $\cdots$ & -. \\
\hline $07-23-89$ & $\cdots$ & $-\cdot$ & $\cdots$ & $\cdots$ & $\cdots$ & $\cdots$ & $\cdots$ & $\cdots$ & $\cdots$ & $\cdots$ \\
\hline $08-18-89$ & 3.6 & 2.0 & 100 & 10 & 92 & 1.4 & 21 & .15 & .60 & 18 \\
\hline $08-18-89$ & $\cdots$ & $\cdots$ & $\cdots$ & -- & $\cdots$ & $-\cdot$ & $\cdots$ & $\cdots$ & $\cdots$ & $\cdots$ \\
\hline $08-18-89$ & 1.7 & 1.3 & 84 & 12 & 94 & 1.9 & 21 & $\cdots$ & .60 & 25 \\
\hline $08-18-89$ & -. & $-\cdot$ & $\cdots$ & -. & -. & -. & -. & $\cdots$ & $\cdots$ & $\cdots$ \\
\hline $08-18-89$ & $\cdots$ & $\cdots$ & $\cdots$ & $\cdots$ & $\cdots$ & $\cdots$ & $\cdots$ & $\cdots$ & $\cdots$ & .. \\
\hline $08-18-89$ & $\cdots$ & $\cdots$ & $\cdots$ & $\cdots$ & $\cdots$ & $\cdots$ & $\cdots$ & $\cdots$ & $\cdots$ & $\cdots$ \\
\hline $08-18-89$ & -- & $\cdots$ & $\cdots$ & $\cdots$ & $\cdots$ & $\cdots$ & $\cdots$ & $\cdots$ & $\cdots$ & $\cdots$ \\
\hline $08-18-89$ & $\cdots$ & $\cdots$ & $\cdots$ & $\cdots$ & $\cdots$ & $\cdots$ & $\cdots$ & $\cdots$ & $\cdots$ & $\cdots$ \\
\hline $08-18-89$ & $\cdots$ & $\cdots$ & $\cdots$ & $\cdots$ & $\cdots$ & $\cdots$ & -. & $\cdots$ & $\cdots$ & -. \\
\hline $08-18-89$ & $\cdots$ & $\cdots$ & $\cdots$ & $\cdots$ & $\cdots$ & $\cdots$ & $\cdots$ & $\cdots$ & $\cdots$ & $\cdots$ \\
\hline $08-18-89$ & $\cdots$ & $\cdots$ & $-\cdot$ & -. & $\cdots$ & $\cdots$ & $\cdots$ & $\cdots$ & $\cdots$ & $\cdots$ \\
\hline $08-18-89$ & $\cdots$ & $\cdots$ & $\cdots$ & $\cdots$ & $\cdots$ & $\cdots$ & $\cdots$ & $\cdots$ & $\cdots$ & $\cdots$ \\
\hline $08-19-89$ & $\cdots$ & $\cdots$ & $-\cdot$ & $\cdots$ & $\cdots$ & $\cdot \cdot$ & $\cdots$ & $\cdots$ & $\cdots$ & $\cdots$ \\
\hline $08-19-89$ & $\cdots$ & $\cdots$ & $\cdots$ & $\cdots$ & $\cdots$ & $\cdots$ & $\cdots$ & $\cdots$ & $\cdots$ & -- \\
\hline $08-19-89$ & $\cdots$ & $\cdots$ & $\cdots$ & $\cdots$ & $\cdots$ & $\cdots$ & $\cdots$ & $\cdots$ & $\cdots$ & $\cdots$ \\
\hline $08-19-89$ & $\cdots$ & $\cdots$ & $\cdots$ & $\cdots$ & $\cdots$ & $\cdots$ & $\cdots$ & $\cdots$ & $\cdots$ & $\cdots$ \\
\hline
\end{tabular}


SURFACE-WATER DATA-Continued

CHEMICAL AMALYSES-Continued

\begin{tabular}{|c|c|c|c|c|c|c|c|c|c|c|c|}
\hline MBER & DATE & $\begin{array}{l}\text { SULFATE } \\
\text { DIS- } \\
\text { SOL VED } \\
(\mathrm{mo} / L \\
\text { es SO4) } \\
(00945)\end{array}$ & $\begin{array}{l}\text { BARIUK, } \\
\text { DIS- } \\
\text { SOLVED } \\
\text { ( } \mu 9 / L \\
\text { Es B8) } \\
(01005)\end{array}$ & $\begin{array}{l}\text { BERYL- } \\
\text { LIUN, } \\
\text { DIS- } \\
\text { SOLVED } \\
(\mu g / L \\
\text { as Be) } \\
(01010)\end{array}$ & $\begin{array}{c}\text { CADMILY } \\
\text { DIS- } \\
\text { SOLVED } \\
(\mu g / L \\
88 \mathrm{Cd}) \\
(01025)\end{array}$ & $\begin{array}{l}\text { CHRO- } \\
\text { MIUN, } \\
\text { DIS- } \\
\text { SOLVED } \\
(\mu g / L \\
\text { as Cr) } \\
(01030)\end{array}$ & $\begin{array}{c}\text { COBALT, } \\
\text { DIS- } \\
\text { SOLVED } \\
(\mu g / L \\
\text { B8 Co) } \\
(01035)\end{array}$ & $\begin{array}{l}\text { COPPER, } \\
\text { DIS- } \\
\text { SOLVED } \\
(\mu g / L \\
\text { OS CU) } \\
(01040)\end{array}$ & $\begin{array}{l}\text { IROH, } \\
\text { DIS- } \\
\text { SOLVED } \\
\text { ( } \mu g / L \\
\text { Os Fe) } \\
(01046)\end{array}$ & $\begin{array}{l}\text { LEAD, } \\
\text { DIS- } \\
\text { SOLVED } \\
\text { ( } \mu Q / L \\
\text { AS Pb) } \\
(01049)\end{array}$ & $\begin{array}{l}\text { MNAGA- } \\
\text { MESE, } \\
\text { DIS- } \\
\text { SOLVED } \\
(\mu g / L \\
\text { os Mn) } \\
(01056)\end{array}$ \\
\hline
\end{tabular}

LITTLE COLORADO RIVER AT WOOORUFF, ARIZOMA-Continued

\begin{tabular}{|c|c|c|c|c|c|c|c|c|c|c|c|}
\hline \multirow[t]{44}{*}{09394500} & $\begin{array}{l}03-14-89 \\
07-23-89\end{array}$ & $\ddot{-}$ & $\begin{array}{l}-. \\
\ldots\end{array}$ & 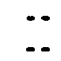 & 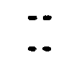 & -- & -. & $\because$ & 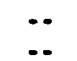 & 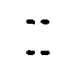 & 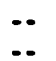 \\
\hline & $07-23-89$ & $\cdots$ & .- & $\ldots$ & $\cdots$ & -. & .. & -- & $\ldots$ &.- & $\ldots$ \\
\hline & $07-23-89$ & -. & .. & -- & -. & -. & .. & - & - & .- & .. \\
\hline & $07-23-89$ & $\cdots$ & .. & -- & -- & $\cdots$ & $\cdots$ & -- & -- & $\cdots$ & -- \\
\hline & $07-23-89$ & $\cdots$ & -. & - & $\cdots$ & $\cdots$ & - & -- & -. & $\cdots$ & $\cdots$ \\
\hline & $07-23-89$ & -- &.- & $\cdots$ & -- & $\cdots$ & -- & -- & -- & -- & $\cdots$ \\
\hline & $07-23-89$ & -- & -. & -- & -- &.- & -. & -- & -- & -- & -- \\
\hline & $07-23-89$ & $\cdots$ & .. & $\cdots$ & -- & -- & - & $=$ & -- & $\cdots$ & -. \\
\hline & $07-23-89$ & -. & -. & -. & -. & $\cdots$ &.- & $\cdots$ & -- & -. & -- \\
\hline & $07-23-89$ & -- & -- & -- & -- & $\cdots$ & $\cdots$ & $\because$ & $-\cdot$ & $\cdots$ & -. \\
\hline & $07-23-89$ & $\cdots$ & $\cdots$ & $\cdots$ & $-\cdot$ & $\cdots$ & -- & -- & $\cdots$ & -- & $\cdots$ \\
\hline & $07-23-89$ & -- &.- & $\cdots$ & $\cdots$ & $\cdots$ & $\cdots$ & $\cdots$ & 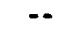 & $\cdots$ &.- \\
\hline & $07-23-89$ & $\cdots$ & -- & $\cdots$ & $\cdot-$ & -- & $\cdots$ & $\cdots$ & $\cdots$ & $\cdot-$ & $\cdots$ \\
\hline & $07-23-89$ & $\cdots$ &.- & $\cdots$ & -- & -- & -. & $\cdots$ & -. & -- & -. \\
\hline & $07-23-89$ & $\cdots$ & $\cdots$ & $\cdots$ & $\cdots$ & $\cdots$ & $\cdots$ & $\cdots$ & $\cdots$ & $\cdots$ & $\cdots$ \\
\hline & $07-23-89$ & $\cdots$ & $\cdots$ & $\cdots$ & $\cdots$ & $\cdots$ & $\cdots$ & $\cdots$ & $-\cdot$ & $\cdots$ & -- \\
\hline & $07-23-89$ & -. & -. & - & -- & -- & -- & - & -- & -- & - \\
\hline & $07-23-89$ & -- & $\cdots$ & $-\cdot$ & -- & -- & - & -- & -- & $-\cdot$ & $-\cdot$ \\
\hline & $07-23-89$ & -- & .. & -- & -- & $\cdots$ & -. & -- & -. & - & - \\
\hline & $07-23-89$ & $\cdots$ & $\cdots$ & $\cdots$ & $\cdots$ & $\cdots$ & $\cdots$ & $\cdots$ & $\cdots$ & $\cdots$ & $\cdots$ \\
\hline & $07-23-89$ & $\cdots$ & $\cdots$ & $\cdots$ & -- & $\cdots$ & -- & $\cdots$ & $\cdots$ & $\cdots$ & -. \\
\hline & $07-23-89$ & $\cdots$ & $\cdots$ & -- & - & -- & $\cdots$ & $\cdots$ & -- & $\cdots$ & -- \\
\hline & $07-23-89$ & $\cdots$ & $\cdots$ & $\cdots$ & $\because$ & $\cdots$ & $\cdots$ & $\cdots$ & $\cdots$ & -- & $-\cdot$ \\
\hline & $07-23-89$ & $\cdots$ & $\cdots$ & -- & -- & -- & $\cdots$ &.- & -. & -- & -- \\
\hline & $07-23-89$ & - & -- & -- & $\cdots$ & $\cdots$ & - & $\cdots$ & -- & $\cdots$ & - \\
\hline & $07-23-89$ &.- & .. & $\cdots$ & $\cdots$ & -- & -. & - & -- & -. & $\cdots$ \\
\hline & $07-23-89$ & -- & .. & $\cdots$ & $\cdots$ & -. & $\cdots$ & $\cdots$ & $\cdots$ & $\cdots$ & $-\cdot$ \\
\hline & $07-23-89$ & -- & - & -- & $\cdots$ & $\because$ & $\cdots$ & 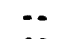 & 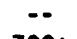 & 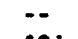 & $\because$ \\
\hline & $08-18-89$ & 50 & 33 & $<.5$ & $<1.0$ & $<5$ & $<3$ & $<10$ & 300 & $<10 i$ & 13 \\
\hline & $08-18-89$ & $\cdots$ & $\cdots$ & - & $\cdots$ & $\cdots$ & $\cdots$ & -- & -- & $\cdots$ & -- \\
\hline & 08-18-89 & 28 & 63 & $<.5$ & $<1.0$ & $<5$ & $<3$ & 10 & 9601 & $<10 i$ & 531 \\
\hline & $08-18-89$ & $\cdots$ & $\cdots$ & $\cdots$ & $\cdots$ & $\cdots$ & $\cdots$ & $\cdots$ & $\cdots$ & $\cdots$ & $\cdots$ \\
\hline & $08-18-89$ & - & -. & $\cdots$ & $-\cdot$ & $\cdots$ & -. & -- & -- & $\cdots$ & $\cdots$ \\
\hline & $08-18-89$ & $\cdots$ & $\cdots$ & $=$ & $\cdots$ & $\cdots$ & -- & -- & $\cdots$ & $\cdots$ & $\cdots$ \\
\hline & $08-18-89$ & $\cdots$ & -. & $\cdots$ & $\cdots$ & $\cdots$ & - & $\cdots$ & $\cdots$ & $\cdots$ & -. \\
\hline & $08-18-89$ & $\cdots$ & $\cdots$ & $\cdots$ & $\cdots$ & $\cdots$ & $\cdots$ & $\cdots$ & $\cdots$ & $\cdots$ & $\cdots$ \\
\hline & $08-18-89$ & $\cdots$ & $\cdots$ & $\cdots$ & $\cdots$ & $\cdots$ & -. &.- & $\cdots$ & $-\cdot$ & $\cdots$ \\
\hline & $08-18-89$ & -- & $\cdots$ & -- & $\cdots$ & -- & -- & -- & -- & $\cdots$ & $\cdots$ \\
\hline & $08-18-89$ & -- & -- & $\cdots$ & -- & -- & $\cdots$ & $\cdots$ & -- & $\cdots$ & $\cdots$ \\
\hline & $08-18-89$ & -- & $\cdots$ & - & $\cdots$ & -- & - & -- & $\cdots$ & $\cdots$ & $\cdots$ \\
\hline & $08-19-89$ & -- & -- & $\cdots$ & $\cdots$ & -- & -- & $\cdots$ & $\cdots$ & $\cdots$ & $\cdots$ \\
\hline & $08-19-89$ & $\cdots$ & $\cdots$ & $\cdots$ & $\cdots$ & -- & -- & $\cdots$ & -- & $\cdots$ & $\cdots$ \\
\hline & $08-19-89$ & -- & -- & $\cdots$ & $\cdots$ & -- & $\cdots$ & $\cdots$ & $\cdots$ & $\cdots$ & -- \\
\hline & $08-19-89$ & -. & -- & $\cdots$ & $\cdots$ & -- & $\cdots$ & $\cdot-$ & -- & $\cdots$ & $\cdots$ \\
\hline
\end{tabular}


SURFACE-MATER DATA-Cont ínued

CHEMICAL ANALYSES-Continued

SIATIOM

MUMBER

\begin{abstract}
09394500
\end{abstract}
LITTLE COLORADO RIVER AT HOOORUFF, ARIZONA-Continued

\begin{tabular}{|c|c|c|c|c|c|c|c|c|c|c|}
\hline $03-14-89$ & -. & .. & -. & .. & -. & -. & .. & .. & 2.9 & .60 \\
\hline $07-23-89$ & $\cdots$ & $\cdots$ & .. & $\cdots$ & $\cdots$ & .. & .. & .. & $12 t$ & 2.2 \\
\hline $07-23-89$ & $\cdots$ & $\cdots$ & -. & $\cdots$ & $\cdots$ & $\cdots$ & $\cdots$ & -. & $\because$ & -. \\
\hline $07-23-89$ & -. &.- & -. & $\cdots$ & -. & -. & -. & .. & -- & -. \\
\hline $07-23-89$ & $\cdots$ & -. & .. & -. & $\cdots$ & .. & -. & -. & 3.2 & .70 \\
\hline $07-23-89$ & $\cdots$ & -. & -. & $\cdots$ & $\cdots$ & $\cdots$ & -. & -. & .. & .. \\
\hline $07-23-89$ & $\cdots$ & $\cdots$ & .. & $\cdots$ & $\cdots$ & $\cdots$ & $\cdots$ & $\cdots$ & $\cdots$ & $\cdots$ \\
\hline $07-23-89$ & $\cdots$ & $\cdots$ & .. & $\cdots$ & $\cdots$ & -. & $\cdots$ & $\cdots$ & -. & $\cdot \cdot$ \\
\hline $07-23-89$ & $\cdots$ & $\cdots$ & -. & $\cdots$ & $\cdots$ & $\cdots$ & $\cdots$ & -. & -. & .. \\
\hline $07-23-89$ & .. & -. & -. & .. & $\cdots$ & -. & $\cdots$ & -. & -. & -. \\
\hline $07-23-89$ & -. & -. & .. & $\cdots$ & $\cdots$ & $\cdots$ & $\cdots$ & $-\cdot$ & $\cdots$ & -. \\
\hline $07-23-89$ & $\cdots$ & -. & $\cdots$ & $\cdots$ & $\cdots$ & -. & $\cdots$ & -. & $\cdots$ & -. \\
\hline $07-23-89$ & -. & -. & .. & .. & $\cdots$ & .. & .. & -. & .. & -. \\
\hline $07-23-89$ & $\cdot-$ & $\cdots$ & -. & $\cdots$ & $\cdots$ & -. & $\cdots$ & $-\cdot$ & 1.4 & .90 \\
\hline $07-23-89$ & $\cdot-$ & $\cdots$ & $\cdot \cdot$ & $\cdots$ & $\cdots$ & $\cdots$ & $\cdots$ & $\cdots$ & $\cdots$ & $\cdot-$ \\
\hline $07-23-89$ & $\cdot \cdot$ & $\cdot \cdot$ & $\cdots$ & $\cdots$ & $\cdots$ & $\cdots$ & -. & $\cdots$ & .. & -. \\
\hline $07-23-89$ & $\cdots$ & $\cdots$ & -. & $\cdots$ & $\cdots$ & $\cdots$ & -. & -. & $\cdots$ & .. \\
\hline $07-23-89$ & $\cdots$ & $\cdots$ & -. & $\cdots$ & $\cdots$ & -. & $\cdots$ & $\cdots$ & -. & $-\cdot$ \\
\hline $07-23-89$ & .. & -. & .. & -. & -. & .. & .. & -- & .. & .. \\
\hline $07-23-89$ & $\cdots$ & $\cdots$ & .. & $\cdot \cdot$ & $\cdots$ & $\cdots$ & -. & $\cdots$ & .. & -. \\
\hline $07-23-89$ & $\cdots$ & $\cdots$ & $\cdots$ & $\cdots$ & $\cdots$ & -. & $\cdots$ & -. & .. & .. \\
\hline $07-23-89$ & .. & $\ldots$ & .. & .. & $\cdots$ & .. & .. & -- & 3.3 & 1.9 \\
\hline $07-23-89$ & $\cdots$ & $\cdot \cdot$ & $\cdots$ & $\cdots$ & $\cdots$ & -. & $\cdots$ & $\cdots$ & $\cdots$ & $\cdots$ \\
\hline $07-23-89$ & $\cdots$ & -. & .. & .. &.- & .. & -. &.- & -. & .. \\
\hline $07-23-89$ & $\cdots$ & $\cdots$ & -. & $\cdots$ & $\cdots$ & $\cdots$ & $\cdots$ & $\cdots$ & -. & -. \\
\hline $07-23-89$ & $\cdots$ &.- & $\cdots$ & -. & .. & .. & -. &.- & -. & -. \\
\hline $07-23-89$ & $\cdots$ & $\cdots$ & -. & $\cdots$ & $\cdots$ & .. & -. & $\cdots$ & -. & $\cdots$ \\
\hline $07-23-89$ & -- & $\cdots$ & -. & .. & .. & .. & .. & $\cdots$ & .. & .. \\
\hline $07-23-89$ & $\because$ & $\because$ & -- & $\because-$ & $\because$ & $\because \cdot$ & $\because$ & $\cdots$ & -. & -. \\
\hline $08-18-89$ & $<10$ & $<10$ & $<1.0$ & 38 & 50 & 12 & 7 & $\cdots$ & $23 t$ & 4.2 \\
\hline $08-18-89$ & -. & -. & -. & .. & -. & $\cdots$ & $\cdot$. & $\cdots$ & $\therefore$ & $\because$. \\
\hline $08-18-89$ & $<10$ & $<10$ & $<1.0$ & 28 & 59 & 26 & 8 & 5.00 & $12 t$ & 3.2 \\
\hline $08-18-89$ & -. & $\cdots$ & $\cdots$ & $\cdots$ & $\cdots$ & -. & $\cdots$ & -. & $\therefore$ & $\cdots$ \\
\hline $08-18-89$ & $\cdots$ & $\cdots$ & .. & $\cdots$ & $\cdots$ & $\cdot \cdot$ & $\cdots$ & -. & $\cdot \cdot$ & .. \\
\hline $08-18-89$ & $\cdots$ & $\cdots$ & -. & -. & -. & $\cdots$ & $\cdot$. & -. & .. & .. \\
\hline $08-18-89$ & $\cdots$ & $\cdots$ & -. & .. & -. & -. & -. & .. & $22 t$ & 4.7 \\
\hline $08-18-89$ & $\cdots$ & $\cdots$ & -. & -. & $\cdots$ & $\cdots$ & $\cdots$ & $\cdot-$ & $\therefore$ & $\cdots$ \\
\hline $08-18-89$ & $\cdot-$ & $\cdots$ & -. & $\cdots$ & $\cdots$ & $\cdots$ & $\cdots$ & -. & $\cdots$ & $\cdots$ \\
\hline $08-18-89$ & $\cdots$ & $\cdots$ & .. & $\cdots$ & $\cdots$ & $\cdots$ & $\cdots$ & -. & 7.1 & 1.7 \\
\hline $08-18-89$ & $\cdots$ & $\cdots$ & -. & .. & $\cdots$ & $\cdot \cdot$ & $\cdots$ & -. & $\because$ & $\cdots$ \\
\hline $08-18-89$ & $\cdots$ & $\cdots$ & - & -. & $\cdots$ & $\cdots$ & $\cdots$ & -. & .. & -. \\
\hline $08-19-89$ & $\cdots$ & $-\cdot$ & $-\cdot$ & $\cdots$ & $\cdots$ & $\cdots$ & $\cdots$ & $\cdots$ & -. & -. \\
\hline $08-19-89$ & $\cdots$ & $\cdots$ & $\cdots$ & $\cdots$ & $\cdots$ & $\cdots$ & $\cdots$ & -. & $-\cdot$ & $\cdots$ \\
\hline $08-19-89$ & $\cdots$ & $\cdots$ & -. & $\cdots$ & $\cdots$ & $\cdots$ & $\cdots$ & -. & -. & $\cdots$ \\
\hline $08-19-89$ & $\cdots$ & $\cdots$ & $\cdots$ & $\cdots$ & $\cdots$ & $\cdots$ & -. & $\cdots$ & -. & $\cdots$ \\
\hline
\end{tabular}


SURFACE-WATER DATA-Cont inued

CHEMICAL ANALYSES-Cont inued

STATION

NUMBER

DATE

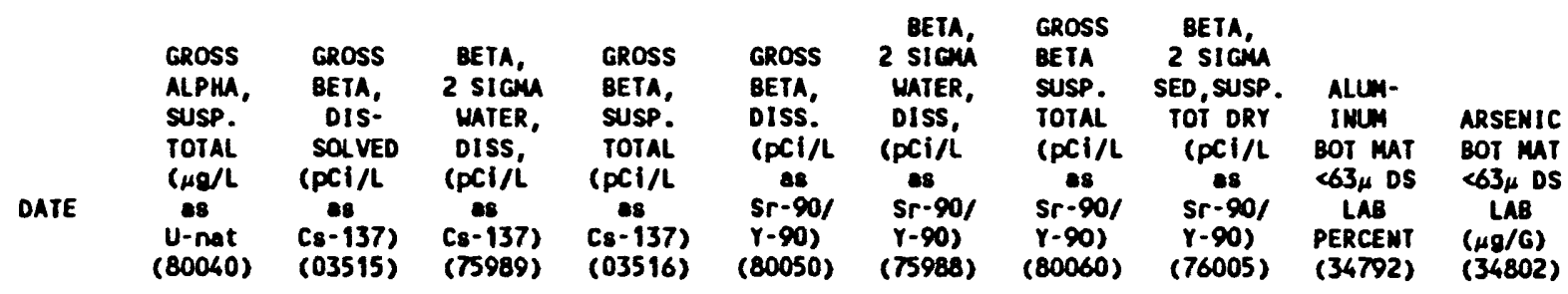

09394500

$03-14-89$
$07-23-89$
$07-23-89$
$07-23-89$
$07-23-89$
$07-23-89$
$07-23-89$
$07-23-89$
$07-23-89$
$07-23-89$
$07-23-89$
$07-23-89$
$07-23-89$
$07-23-89$
$07-23-89$
$07-23-89$
$07-23-89$
$07-23-89$
$07-23-89$
$07-23-89$
$07-23-89$

LITTLE COLORADO RIVER AT WOODRUFF, ARIZOHA-Continued

$07-23-89$

07-23-89

07-23-89

07-23-89

07-23-89

07-23-89

07-23-89

07-23-89

08-18-89

08-18-89

08-18-89

08-18-89

08-18-89

08-18-89

08-18-89

08-18-89

08-18-89

08-18-89

08-18-89

08-18-89

08-19-89

08-19-89

08-19-89

08-19-89

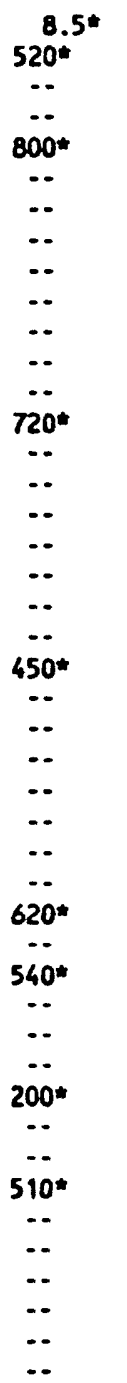

\begin{tabular}{|c|c|c|}
\hline $\begin{array}{l}4.9 \\
2.4\end{array}$ & $\begin{array}{l}0.80 \\
1.1\end{array}$ & $1100^{6.4 *}$ \\
\hline$\cdots$ & $\cdots$ & $\cdots$ \\
\hline$\because$ & $\because$ & $\because$ \\
\hline 12 & 2.1 & 1300 \\
\hline$\cdots$ & $\cdots$ & $\cdots$ \\
\hline$\because$ & $\cdots$ & $\because$ \\
\hline$\cdots$ & $\cdots$ & $\because$ \\
\hline$\cdots$ & $\cdots$ & $\cdots$ \\
\hline$\cdots$ & $\cdots$ & $\cdots$ \\
\hline$\cdots$ & $\cdots$ & $\cdots$ \\
\hline$\cdots$ & $\cdots$ & $\because$ \\
\hline$\because$ & $\because$ & - \\
\hline$<.6$ & 1.5 & $\begin{array}{c}1200 \\
\ldots\end{array}$ \\
\hline$\ldots$ & $\cdots$ & $\ldots$ \\
\hline$\ldots$ & $\ldots$ & .. \\
\hline$\cdots$ & $\cdots$ & $\cdots$ \\
\hline -. & $\cdots$ & $\cdots$ \\
\hline - & $\cdots$ & $\cdots$ \\
\hline$\because$ & $\because$ & $\because$ \\
\hline 1.8 & 1.6 & $1100 *$ \\
\hline$\because$ & $\because$ & $\because$ \\
\hline$\cdots$ & $\cdots$ & $\cdots$ \\
\hline 0 & $\cdots$ & $\ldots$ \\
\hline . & .. & $\ldots$ \\
\hline 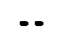 & - & - \\
\hline 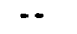 & $\cdots$ & $\cdots$ \\
\hline 3.1 & 1.0 & 1200 \\
\hline$\because$ & $\cdots$ & $\because$ \\
\hline 3.9 & 1.4 & $1700 *$ \\
\hline$\cdots$ & $\because$ & $\because$ \\
\hline- & $\cdots$ & $\cdots$ \\
\hline 6.0 & 1.3 & $1500 *$ \\
\hline- & 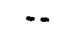 & - \\
\hline -. & $\cdots$ & $\cdots$ \\
\hline 5.0 & 1.1 & $1100 *$ \\
\hline 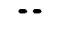 & $\cdots$ & $-\cdot$ \\
\hline . & $\cdots$ & $\because$ \\
\hline$\cdots$ & - & - \\
\hline$\cdots$ & $\cdots$ & $\cdots$ \\
\hline & $\because$ & $\cdots$ \\
\hline
\end{tabular}

4.

2.

9.

9.8

-.

-

-

$\cdots$

$\because$

$<$

-

$\cdots$

-

-.

1.

-.

‥

-

-

2.8

2.8

3.4

-.

-

$5.4 \quad 1.2$

$\begin{array}{ll}5.4 & 1.2 \\ -. & -.\end{array}$

4.3

1.0

-.

$\cdots$

-.

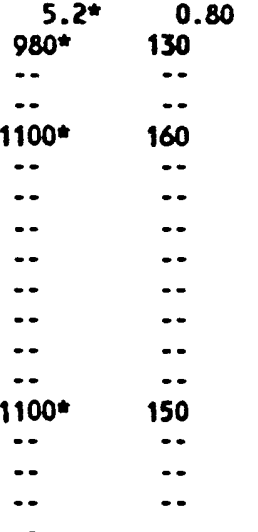

-.

$\because$

-.

$970 * \quad 140$

-.

-.

-.

-.

$-$

$1000 * \quad 150$

$\ddot{1500} \quad 240$

$\begin{array}{ll}1500 & 240 \\ \cdots & \cdots\end{array}$

-.

$1300 * \quad 190$

$\therefore$

$1000 * \quad 140$

$\begin{array}{ll}1000 & 140 \\ \cdots & \cdots \\ \cdots & \cdots \\ \cdots & \cdots \\ \cdots & \cdots\end{array}$

$\ddot{8} \quad \ddot{0}$

$\begin{array}{ll}8.1 & \\ -. & \end{array}$

-.

$\cdots$

-. $\quad \cdots$

-.

$8.3<10$

$\begin{array}{ll}8.3 & < \\ \cdots & -.\end{array}$

-. $\quad$ -

$\cdots$

-. $\quad \cdots$

-.

-

8.110

-.

$\cdots$

-

$\begin{array}{lll}- & \\ - & \ldots\end{array}$

-.

8,40

$8.4<10$

$\begin{array}{ll}-. & - \\ -. & -\end{array}$

$\begin{array}{ll}\cdots & \cdots\end{array}$

$\begin{array}{ll}7.2 & <10 \\ -- & -10\end{array}$

$7.1<10$

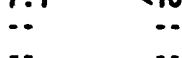

$\cdots$

$\cdots$

-

-.

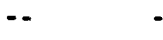

$\begin{array}{lll}- & - \\ \cdots & -\end{array}$

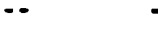

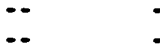

-

$\begin{array}{ll}- & \\ \cdots & -\end{array}$ 
SURFACE-WATER DATA-Continued

CHEMICAL AMALYSES-Continued

\begin{tabular}{|c|c|c|c|c|c|c|c|c|c|c|c|}
\hline $\begin{array}{l}\text { STATION } \\
\text { NUMBER }\end{array}$ & DATE & 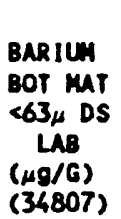 & $\begin{array}{l}\text { BERYL- } \\
\text { LIUH } \\
\text { BOT MAT } \\
\angle 63 \mu \text { DS } \\
\text { LAB } \\
(\mu g / G) \\
(34812)\end{array}$ & 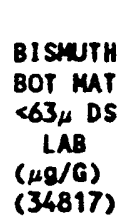 & $\begin{array}{c}\text { CADMIUA } \\
\text { BOT MAT } \\
<63_{\mu} \text { DS } \\
\text { LAB } \\
(\mu g / G) \\
(34827)\end{array}$ & 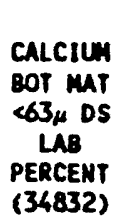 & $\begin{array}{c}\text { CERIUH } \\
\text { BOT MAT } \\
<63 \mu \text { DS } \\
\text { LAB } \\
(\mu g / G) \\
(34837)\end{array}$ & 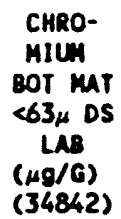 & 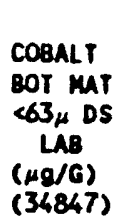 & $\begin{array}{l}\text { COPPER } \\
\text { BOT MAT } \\
\angle 63 \mu \text { DS } \\
\text { LAB } \\
(\mu g / G) \\
(34852)\end{array}$ & $\begin{array}{c}\text { EURO- } \\
\text { PIUN } \\
\text { BOT MAT } \\
\angle 63 \mu \text { DS } \\
\text { LAB } \\
(\mu 9 / G) \\
(34857)\end{array}$ \\
\hline
\end{tabular}

\begin{tabular}{|c|c|c|c|c|c|c|c|c|c|c|c|}
\hline 09394500 & $\begin{array}{l}03-14-89 \\
07-23-89\end{array}$ & $\ddot{740}$ & $\because$ & $\therefore$ & $\ddot{<}$ & 4.7 & 67 & $\ddot{64}$ & $\ddot{16}$ & $\ddot{31}$ & $\ddot{<2}$ \\
\hline & $07-23-89$ & -. & $\therefore$ & $\ldots$ & $\therefore$ & $\ldots$ & $\therefore$ & $\therefore$ & $\ldots$ & $\ldots$ & $\therefore$ \\
\hline & $07-23-89$ & -- & $\ldots$ & -- & $\cdots$ & $\ldots$ & -. & -. & .. & $\ldots$ & -. \\
\hline & $07-23-89$ & $\cdots$ & $\cdots$ & $\cdots$ & $\cdots$ & -- & $\cdots$ & $\cdots$ & $\cdots$ & -- & $\cdots$ \\
\hline & $07-23-89$ & -- & $\cdots$ & - & $\cdots$ & $\cdots$ & $\cdots$ & -. & $\cdots$ & $-\cdot$ & $\cdots$ \\
\hline & $07-23-89$ & -. & $\cdots$ & $-\cdot$ & $\cdots$ & -- & $-\cdot$ & -. & $\cdots$ & -. & $\cdots$ \\
\hline & $07-23-89$ & -. & $\cdots$ & $\cdots$ & $\cdots$ & $\cdots$ & $\cdots$ & $\cdots$ & $\cdots$ & -. & -. \\
\hline & $07-23-89$ & 660 & 2 & $<10$ & $<2$ & 4.7 & 60 & 61 & 15 & 32 & $<2$ \\
\hline & $07-23-89$ & $\cdots$ & $\cdots$ & $\cdots$ & $\cdots$ & $\cdots$ & $\cdots$ & $\cdots$ & $\cdots$ & $\cdots$ & $\cdots$ \\
\hline & $07-23-89$ & $\cdots$ & $\cdots$ & $\cdots$ & $\cdots$ & $\cdots$ & $\cdots$ & $\cdots$ & $\cdots$ & -- & $\cdots$ \\
\hline & $07-23-89$ & $\cdots$ & $\cdots$ & $\cdots$ & $\cdots$ & $\cdots$ & $\cdots$ & $\cdots$ & $\cdots$ & $\cdots$ & - \\
\hline & $07-23-89$ & -. & $\cdots$ & -- & $\cdots$ & $\cdots$ & $\cdots$ & $\cdots$ & $\cdots$ & -- & $\cdots$ \\
\hline & $07-23-89$ & $\cdots$ & $\cdots$ & $\cdots$ & $\cdots$ & $\cdots$ & $\cdots$ & $\cdots$ & $\cdots$ & $\cdots$ & $\cdots$ \\
\hline & $07-23-89$ & $\cdots$ & $\cdots$ & $\cdots$ & $\cdots$ & $\cdots$ & $\cdots$ & $\cdots$ & $\cdots$ & $\cdots$ & $\cdots$ \\
\hline & $07-23-89$ & $\cdots$ & $\cdots$ & $\cdots$ & $\cdots$ & $\cdots$ & $\cdots$ & $\cdots$ & $\cdots$ & $\cdots$ & $\cdots$ \\
\hline & $07-23-89$ & $-\cdot$ & $\cdots$ & $\cdots$ & $\cdots$ & $\cdots$ & $\cdots$ & $\cdots$ & $\cdots$ & $\cdots$ & 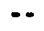 \\
\hline & $07-23-89$ & 740 & 2 & $<10$ & $<2$ & 4.7 & 67 & 64 & 16 & 31 & $<2$ \\
\hline & $07-23-89$ & $\cdots$ & $\cdots$ & $\cdots$ & $\cdots$ & $\cdots$ & $\cdots$ & $\cdots$ & $\cdots$ & $\cdots$ & $\cdots$ \\
\hline & $07-23-89$ & $\cdots$ & $\cdots$ & $\cdots$ & $\cdots$ & $\cdots$ & $\cdots$ & $\cdots$ & $\cdots$ & $\cdots$ & $\cdots$ \\
\hline & $07-23-89$ & $\cdots$ & $\cdots$ & $\cdots$ & $\cdots$ & $\cdots$ & $\cdots$ & $\cdots$ & $\cdots$ & $\cdots$ & $\cdots$ \\
\hline & $07-23-89$ & $\cdots$ & $\cdots$ & $\cdots$ & $\cdots$ & $\cdots$ & $\cdots$ & $\cdots$ & $\cdots$ & -- & $\cdots$ \\
\hline & $07-23-89$ & $\cdots$ & $\cdots$ & $\cdots$ & $\cdots$ & $\cdots$ & $\cdots$ & $\cdots$ & $\cdots$ & $\cdots$ & $\cdots$ \\
\hline & $07-23-89$ & -- & $\cdots$ & $\cdots$ & -. & $\cdots$ & -- & $\cdots$ & $\cdots$ & -. & $\cdots$ \\
\hline & $07-23-89$ & $\cdots$ & $\because$ & $\cdots$ & $\cdots$ & $\cdots$ & $\cdots$ & $\cdots$ & $\cdots$ & $\cdots$ & $\cdots$ \\
\hline & $07-23-89$ & 670 & 2 & $<10$ & $<2$ & 4.7 & 69 & 63 & 16 & 30 & $<2$ \\
\hline & $07-23-89$ & $\cdots$ & $\cdots$ & $\cdots$ & $\cdots$ & $\cdots$ & $\cdots$ & $\cdots$ & $\cdots$ & $\cdots$ & $\cdots$ \\
\hline & $07-23-89$ & -- & $\cdots$ & $\cdots$ & $\cdots$ & $\cdots$ & $\cdots$ & $\cdots$ & $\cdots$ & $\cdots$ & $\cdots$ \\
\hline & $07-23-89$ & $-\cdot$ & $\cdots$ & $\cdots$ & $\cdots$ & $\cdots$ & $\cdots$ & $\cdots$ & $\cdots$ & -. & $\bullet$ \\
\hline & $08-18-89$ & 570 & 2 & $<10$ & $<2$ & 3.8 & 60 & 45 & 12 & 23 & $<2$ \\
\hline & $08-18-89$ & $\cdots$ & $\cdots$ & $\cdots$ & $\cdots$ & $\cdots$ & $\because$ & $\because$ & $\because$ & $\cdots$ & $\cdots$ \\
\hline & $08-18-89$ & 560 & 2 & $<10$ & $<2$ & 3.9 & 62 & 41 & 11 & 21 & $<2$ \\
\hline & $08-18-89$ & $\cdots$ & $\cdots$ & $\cdots$ & $\cdots$ & $\cdots$ & $\cdots$ & $\cdots$ & $\cdots$ & $\cdots$ & $\cdots$ \\
\hline & 08-18-89 & $\cdots$ & $-\cdot$ & $\cdots$ & $\cdots$ & $\cdots$ & $\cdots$ & $\cdots$ & $\cdots$ & $\cdots$ & $\cdots$ \\
\hline & $08-18-89$ & $\cdots$ & $\cdots$ & -- & $\cdots$ & $\cdots$ & $\cdots$ & $\cdots$ & $\cdots$ & $\cdots$ & $\cdots$ \\
\hline & $08-18-89$ & $\cdots$ & $\cdots$ & -- & $\cdots$ & $\cdots$ & $\cdots$ & -- & $\cdot-$ & $\cdots$ & $\cdots$ \\
\hline & $08-18-89$ & $\cdots$ & $\cdots$ & -- & $\cdots$ & $\because$ & $\cdots$ & $\cdots$ & $\cdots$ & $\cdots$ & $\cdots$ \\
\hline & $08-18-89$ & $\cdots$ & $\cdots$ & $-\cdot$ & $\cdots$ & $\cdots$ & $\cdots$ & $\cdots$ & -- & $\cdots$ & $\cdots$ \\
\hline & $08-18-89$ & $\cdots$ & $\cdots$ & $\cdots$ & $\cdots$ & -- & $\cdots$ & $\cdots$ & $\cdots$ & $\cdots$ & $\cdots$ \\
\hline & 08-18-89 & $\cdots$ & $\cdots$ & $\cdots$ & $\cdots$ & $\cdots$ & $\cdots$ & $\cdots$ & $\cdots$ & $\cdots$ & $\cdots$ \\
\hline & $08-18-89$ & $\cdots$ & $\cdots$ & $\cdots$ & $\cdots$ & -- & $\cdots$ & $\cdots$ & $\cdots$ & $\cdots$ & $\cdot$ \\
\hline & $08-19-89$ & $\cdots$ & $\cdots$ & $\cdots$ & $\cdots$ & $-\cdot$ & $\cdots$ & $\cdots$ & $\cdots$ & $\cdots$ & $\cdots$ \\
\hline & $08-19-89$ & $\cdots$ & $\cdots$ & $\cdots$ & $\cdots$ & $\cdots$ & $\cdots$ & $\cdots$ & $\cdots$ & $\cdots$ & $\bullet$ \\
\hline & $08-19-89$ & -- & $\cdots$ & $\cdots$ & -- & $-\cdot$ & $\cdots$ & $\cdots$ & $\cdots$ & $\cdots$ & $=$ \\
\hline & $08-19-89$ & -- & $\cdots$ & $\cdots$ & $\cdots$ & $\cdots$ & $\cdots$ & $\cdots$ & $\cdots$ & $\cdots$ & $\cdots$ \\
\hline
\end{tabular}


SURFACE-HATER DATA-Cont Inued

CHEMICAL AKALYSES-Continued

\begin{tabular}{|c|c|c|c|c|c|c|c|c|c|c|c|}
\hline $\begin{array}{l}\text { STATION } \\
\text { VUWBER }\end{array}$ & DATE & $\begin{array}{c}\text { GALLIUA } \\
\text { BOT MAT } \\
\angle 63_{\mu} \text { DS } \\
\text { LAB } \\
(\mu g / G) \\
(34862)\end{array}$ & $\begin{array}{c}\text { COLD } \\
\text { BOT MAT } \\
\angle 63 \mu \mathrm{DS} \\
\text { LAB } \\
(\mu \sigma / G) \\
(34872)\end{array}$ & $\begin{array}{c}\text { HOLMIUA } \\
\text { BOT MAT } \\
\angle 63_{\mu} \text { DS } \\
\text { LAB } \\
(\mu g / G) \\
(34877)\end{array}$ & $\begin{array}{l}\text { IRON } \\
\text { BOT MAT } \\
\angle 63 \mu \text { DS } \\
\text { LAB } \\
\text { PERCENT } \\
\text { (34882) }\end{array}$ & $\begin{array}{l}\text { LANTHA- } \\
\text { MUM } \\
\text { BOT MAT } \\
\angle 63_{\mu} \text { DS } \\
\text { LAB } \\
(\mu g / G) \\
(34887)\end{array}$ & $\begin{array}{c}\text { LEAD } \\
\text { BOT MAT } \\
\angle 63_{\mu} \text { DS } \\
\text { LAB } \\
(\mu \sigma / G) \\
(34892)\end{array}$ & $\begin{array}{c}\text { LITHIUH } \\
\text { BOT MAT } \\
\angle 63_{\mu} \text { DS } \\
\text { LAB } \\
(\mu 9 / G) \\
(34897)\end{array}$ & $\begin{array}{l}\text { MAGNE- } \\
\text { SIUH } \\
\text { BOT MAT } \\
\angle 63 \mu \text { DS } \\
\text { LAB } \\
\text { PERCENT } \\
\text { (34902) }\end{array}$ & $\begin{array}{l}\text { MANGA- } \\
\text { NESE } \\
\text { BOT MAT } \\
\angle 63_{\mu} \text { DS } \\
\text { LAB } \\
(\mu g / G) \\
(34907)\end{array}$ & $\begin{array}{c}\text { MOLYB- } \\
\text { DENUA } \\
\text { BOT MAT } \\
\angle 63 \mu \text { DS } \\
\text { LAB } \\
(\mu g / G) \\
(34917)\end{array}$ \\
\hline
\end{tabular}

\begin{tabular}{|c|c|c|c|c|c|c|c|c|c|c|c|}
\hline 09394500 & $\begin{array}{l}03-14-89 \\
07-23-89\end{array}$ & $\ddot{20}$ & $\ddot{8}$ & $\ddot{4}$ & 3.6 & $\ddot{36}$ & $\ddot{24}$ & $\ddot{47}$ & $\ddot{2.1}$ & $\ddot{660}$ & $\ddot{<}$ \\
\hline & $07-23-89$ & $\therefore$ & $\therefore$ & $\therefore$ & $\ldots$ & .. & $\because$ & $\because$ & $\because$ & 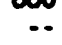 & $<2$ \\
\hline & $07-23-89$ & -. & .. & -. & -. & $\cdots$ & -. & $\cdots$ & -- & -. & . \\
\hline & $07-23-89$ &.- & -. & -. & -. & -- & -. & -. & .. & .. & .. \\
\hline & $07-23-89$ & $\cdots$ & -. & -. & -. & $-\cdot$ & -. & $\cdots$ & -. & -. & -. \\
\hline & $07-23-89$ & $\cdots$ & $\cdots$ & -. & -. & $\cdots$ & $\cdot \cdot$ & $\cdots$ & -. & $\cdots$ & - \\
\hline & $07-23-89$ & $\cdots$ & .- & -. & -. & .. & .. &.- & .. & .. & - \\
\hline & $07-23-89$ & 21 & $<8$ & $<4$ & 3.6 & 36 & 24 & 47 & 2.1 & 680 & $<2$ \\
\hline & $07-23-89$ & $\cdots$ & -. & $-\cdot$ & -. & -- & $\cdots$ & $\cdots$ & -. & -. & $\because$ \\
\hline & $07-23-89$ & $\cdots$ & -. & -. & -. & $\cdots$ & .. & $\cdots$ & -. & -. & -. \\
\hline & $07-23-89$ & $\cdots$ & -. & -. & -. & -- & $\cdot-$ & $\cdots$ & -. & -- & - \\
\hline & $07-23-89$ & $\because \cdot$ & -. & -. & -. & -- & .• & $\cdots$ & -. & -. & - \\
\hline & $07-23-89$ & $\cdots$ & -. & -. & -. & .. & .. & -. & -. & -. & - \\
\hline & $07-23-89$ & $\cdots$ & -. & $\cdot-$ & -. & $\cdot \cdot$ & -. & $-\cdot$ & -. & -- & - \\
\hline & $07-23-89$ & $\cdots$ & -. & $\cdots$ &.- & -- & $\cdot \cdot$ & $-\cdot$ & -. & $-\cdot$ & . \\
\hline & $07-23-89$ & $\because$ & $-\cdot$ & $\because$ & $\because$ & $\because-$ & $\because-$ & $\because$ & -. & -- & \\
\hline & $07-23-89$ & 20 & $<8$ & $<4$ & 3.6 & 36 & 24 & 47 & 2.1 & 660 & $<2$ \\
\hline & $07-23-89$ & $\cdots$ & .. & $\cdots$ & $\cdots$ & -. & $\cdots$ & $\because$ & $\cdots$ & $\cdots$ & .- \\
\hline & $07-23-89$ & $\cdots$ & -. & -. & -. & -- & .. & -- & $\cdots$ & -. & - \\
\hline & $07-23-89$ & $\cdots$ & -. & -. & -. & -. & -. & $\cdot \cdot$ & -. & -- & \\
\hline & $07-23-89$ & $\because \cdot$ & -- & -. & -- &.- & -. & -. & -- & -. & $\cdot \cdot$ \\
\hline & $07-23-89$ & $\cdots$ & $\cdots$ & $\cdots$ & -. & -- & $\cdots$ & $\cdots$ & $-\cdot$ & -- & \\
\hline & $07-23-89$ & $\cdots$ & -. & $\cdots$ & -. & -- & $\cdot \cdot$ & $\cdots$ & $\cdots$ & -. & - \\
\hline & $07-23-89$ & -. & -. & -. & -. & -. & $\ddot{-}$ & $\because$ & $\cdot \cdot$ & -- & .. \\
\hline & $07-23-89$ & 20 & $<8$ & $<4$ & 3.7 & 36 & 24 & 48 & 2.1 & 690 & $<2$ \\
\hline & $07-23-89$ & $\cdots$ & -. & $\cdots$ & -. & $\cdot-$ & -. & 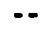 & $\cdots$ & $\cdot \cdot$ & \\
\hline & $07-23-89$ & $\cdots$ & -. & $\cdots$ & -. & $\cdots$ & $\cdots$ & -- & $\cdots$ & -- & - \\
\hline & $07-23-89$ & $\cdot-$ & $-\cdot$ & -. & -. & 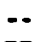 & -. & 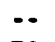 & -. & $\cdots$ & \\
\hline & $08-18-89$ & 17 & $<8$ & $<4$ & 2.7 & 33 & 18 & 30 & 1.5 & 660 & $<2$ \\
\hline & $08-18-89$ & $\therefore$ & .. & .. & $\ldots$ & $\because$ & $\therefore$ & $\cdots$ & $\because$ & 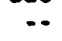 & $\therefore$ \\
\hline & $08 \cdot 18-89$ & 17 & $<8$ & $<4$ & 2.6 & 34 & 18 & 28 & 1.5 & 690 & $<2$ \\
\hline & $08-18-89$ & $\cdots$ & -- & $\cdots$ & -- & $\cdots$ & -. & -- & $\cdots$ & $\cdot \cdot$ & - \\
\hline & $08-18-89$ & $\cdot-$ & -. & $\cdots$ & -. & -. & -. & $\cdots$ & -. & -. & . \\
\hline & $08-18-89$ & $\cdots$ & -. & $\cdots$ & -. & $\cdots$ & -. & $\cdots$ & $\cdots$ & -- & - \\
\hline & $08-18-89$ & $\cdot-$ & -. & $-\cdot$ & -. & -. & $\cdots$ & $\cdots$ & -. & -. & - \\
\hline & $08-18-89$ & $-\cdot$ & .. & $\cdots$ & -. & $\cdots$ & $\cdots$ & $\cdots$ & -. & -. & . \\
\hline & $08-18-89$ & $\cdot-$ & -- & -. & -- & -. & $\cdots$ & $-\cdot$ & -- & -. & \\
\hline & $08-18-89$ & $-\cdot$ & $\cdots$ & -. & -. & $\cdots$ & $\cdots$ & $\cdots$ & $-\cdot$ & -. & - \\
\hline & $08-18-89$ & $\cdots$ & -. & -. & -. & -. & -. & $\cdots$ & -. & -. & - \\
\hline & $08-18-89$ & $\cdots$ & $\cdots$ & $\cdots$ & -. & $\cdots$ & $\cdots$ & $\cdots$ & $-\cdot$ & -. & - \\
\hline & $08-19-89$ & $\cdots$ & $\cdots$ & $\cdots$ & -. & $\cdot \cdot$ & $\cdot \cdot$ & $\cdots$ & 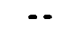 & -. & \\
\hline & $08-19-89$ & $\cdot \cdot$ & -. & $-\cdot$ & -. & $-\cdot$ & -. & $\cdots$ & $-\cdot$ & -. & \\
\hline & $08-19-89$ & .. & -. & -. & -. & -. & -. & -. & $\cdots$ & -. & \\
\hline & -89 & -. &.- & -. & $\cdots$ & -- & -. & -. & -. & -. & \\
\hline
\end{tabular}


SURFACE-WATER DATA-Continued

CHEMICAL AMALYSES-Cont inued

\begin{tabular}{|c|c|c|c|c|c|c|c|c|c|c|c|}
\hline $\begin{array}{l}\text { TATION } \\
\text { UMBER }\end{array}$ & DATE & $\begin{array}{l}\text { NEOOYM- } \\
\text { IUH } \\
\text { BOT MAT } \\
\angle 63 \mu \text { DS } \\
\text { LAB } \\
(\mu \sigma / G) \\
(34922)\end{array}$ & $\begin{array}{c}\text { NICKEL } \\
\text { BOT MAT } \\
\angle 63 \mu \text { DS } \\
\text { LAB } \\
(\mu g / G) \\
(34927)\end{array}$ & $\begin{array}{c}\text { MIOBIUN } \\
\text { BOT MAT } \\
\angle 63_{\mu} \text { DS } \\
\text { LAB } \\
(\mu g / G) \\
(34932)\end{array}$ & $\begin{array}{l}\text { PHOS- } \\
\text { PHORUS } \\
\text { BOT MAT } \\
\angle 63 \mu \text { DS } \\
\text { LAB } \\
\text { PERCENT } \\
\text { (34937) }\end{array}$ & $\begin{array}{l}\text { POTAS- } \\
\text { SIUA } \\
\text { BOT MAT } \\
\angle 63 \mu \text { DS } \\
\text { LAB } \\
\text { PERCENT } \\
\text { (34942) }\end{array}$ & $\begin{array}{c}\text { SCAN- } \\
\text { DIUN } \\
\text { BOT MAT } \\
\angle 63 \mu \text { DS } \\
\text { LAB } \\
(\mu 9 / G) \\
(34947)\end{array}$ & $\begin{array}{c}\text { SILVER } \\
\text { BOT MAT } \\
\angle 63_{\mu} \text { DS } \\
\text { LAB } \\
(\mu \mathrm{g} / \mathrm{G}) \\
(34957)\end{array}$ & $\begin{array}{l}\text { SOOIUN } \\
\text { BOT MAT } \\
\angle 63 \mu \text { DS } \\
\text { LAB } \\
\text { PERCENT } \\
\text { (34962) }\end{array}$ & 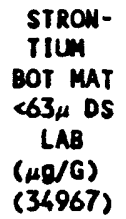 & $\begin{array}{c}\text { TANTA- } \\
\text { LUN } \\
\text { BOT MAT } \\
\angle 63 \mu \text { DS } \\
\text { LAB } \\
(\mu 9 / G) \\
(34977)\end{array}$ \\
\hline
\end{tabular}

LITTLE COLORADO RIVER AT WOOORUFF, ARIZOMA-Continued

\begin{tabular}{|c|c|c|c|c|c|c|c|c|c|c|c|}
\hline \multirow[t]{44}{*}{09394500} & $\begin{array}{l}03-14-89 \\
07-23-89\end{array}$ & $\overline{33}$ & 31 & 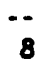 & .07 & 2.4 & $\ddot{13}$ & -8 & .17 & $\ddot{170}$ & $<40$ \\
\hline & $07-23-89$ & .. & $\cdots$ & $\cdots$ & -. & -- & $\cdots$ & $\cdots$ & $\cdots$ & -. & -. \\
\hline & $07-23-89$ & -- & $\cdots$ & $\cdots$ & -- & $\cdots$ & $\cdots$ & $\cdots$ & $\cdots$ & -- & - \\
\hline & $07-23-89$ & $\cdots$ & $\cdots$ & $\cdots$ & $\cdots$ & $\cdots$ & $\cdots$ & $\cdots$ & -- & $\cdots$ & $\cdots$ \\
\hline & $07-23-89$ & $\cdots$ & $\cdots$ & $\cdots$ & $\cdots$ & $\cdots$ & $\cdots$ & $\cdots$ & -- & $\cdots$ & -- \\
\hline & $07-23-89$ & $-\cdot$ & $\cdots$ & $\cdots$ & $\cdots$ & $\cdots$ & $\cdots$ & $\cdots$ & $\cdots$ & $\cdots$ & $-\cdot$ \\
\hline & $07-23-89$ & $\because$ & $\cdots$ & $\cdots$ & -- & $-\cdot$ & $\because$ & $\cdots$ & $\cdots$ & $\cdots$ & -- \\
\hline & $07-23-89$ & 34 & 32 & 9 & .07 & 2.5 & 13 & $<4$ & .19 & 180 & $<40$ \\
\hline & $07-23-89$ & $\cdots$ & $\cdots$ & $\cdots$ & $\cdots$ & -- & $\cdots$ & $\cdots$ & - & $\cdots$ & -- \\
\hline & $07-23-89$ & $\cdots$ & $\cdots$ & $\cdots$ & -- & -- & $\cdots$ & -- & -- & -- & $-\cdot$ \\
\hline & 07-23-89 & -- & $\cdots$ & $\cdots$ & $\cdots$ & $\cdots$ & -- & -- & $-\cdot$ & $-\cdot$ & -- \\
\hline & $07-23-89$ & $\cdots$ & $\cdots$ & $\cdots$ & $\cdots$ & $\cdots$ & $\cdots$ & $\cdots$ & $\cdots$ & $\cdots$ & $\cdots$ \\
\hline & $07-23-89$ & $\cdots$ & $\cdots$ & $\cdots$ & $-\cdot$ & $\cdots$ & $\because$ & $\cdots$ & $-\cdot$ & -- & $\cdots$ \\
\hline & $07-23-89$ & $-\cdot$ & -- & -- & -- & -- & $\cdots$ & $\cdots$ & -- & -- & $\cdots$ \\
\hline & $07-23-89$ & $\cdots$ & -- & $\cdots$ & -- & $\cdots$ & -- & -- & -- & -- & $\cdots$ \\
\hline & $07-23-89$ & $\because$ & $\cdots$ & $\cdots$ & $\because$ & -- & $\because$ & -- & $\because$ & -- & -- \\
\hline & $07-23-89$ & 33 & 31 & 8 & .07 & 2.4 & 13 & 4 & .17 & 170 & $<40$ \\
\hline & $07-23-89$ & 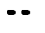 & -- & $\because$ & -- & $\cdots$ & $\cdots$ & -- & $\cdots$ & -- & $\cdots$ \\
\hline & $07-23-89$ & -- & $\cdots$ & $\cdots$ & -- & -- & $\cdots$ & $\cdots$ & -- & $\cdots$ & $\cdots$ \\
\hline & $07-23-89$ & $\cdots$ & $\cdots$ & $\cdots$ & -- & $\cdots$ & -- & $\cdots$ & $-\cdot$ & -- & $\cdots$ \\
\hline & $07-23-89$ & $\cdots$ & -- & -- & -- & -- & -- & -- & -- & $-\cdot$ & -- \\
\hline & $07-23-89$ & $\cdots$ & -- & -- & $\cdots$ & $\cdots$ & $\cdots$ & -- & $\cdots$ & $-\cdot$ & -- \\
\hline & $07-23-89$ & $\cdots$ & $\cdots$ & -- & -- & $\cdots$ & -- & $\cdots$ & -- & -- & -- \\
\hline & $07-23-89$ & $\cdots$ & -- & -- & -- & $\cdots$ & -- & $\cdots$ & $\cdots$ & $\cdots$ & $\cdots$ \\
\hline & $07-23-89$ & 35 & 30 & 8 & .07 & 2.5 & 13 & $<4$ & .18 & 170 & $<40$ \\
\hline & $07-23-89$ & $\cdots$ & $\cdots$ & -- & $\cdot-$ & -- & -- & $\cdots$ & -- & -- & $\cdots$ \\
\hline & $07-23-89$ & $\cdots$ & $\cdots$ & -- & -- & -- & $\cdots$ & $\cdots$ & $-\cdot$ & $-\cdot$ & -- \\
\hline & $07-23-89$ & -- & $\cdots$ & $\because$ & $\because$ & $\cdots$ & $\because$ & $\cdots$ & -- & -- & -- \\
\hline & $08-18-89$ & 30 & 21 & 5 & .05 & 1.6 & 10 & $<4$ & .57 & 270 & $<40$ \\
\hline & $08-18-89$ & $\cdots$ & $\cdots$ & $\cdots$ & -- & $\cdots$ & -- & $\cdots$ & $\cdots$ & -- & $\cdots$ \\
\hline & 08-18-89 & 31 & 19 & 7 & .05 & 1.6 & 9 & $<4$ & .59 & 280 & $<40$ \\
\hline & $08-18-89$ & -- & $\cdots$ & $\cdots$ & $\cdots$ & $\cdots$ & $\cdots$ & $\cdots$ & $\cdots$ & $\cdots$ & $\cdots$ \\
\hline & $08-18-89$ & -- & $\cdots$ & $\cdots$ & -- & - & $\cdots$ & -- & -- & -- &.- \\
\hline & 08-18-89 & -- & $\cdots$ & $\cdots$ & $\cdots$ & $\cdots$ & $\cdots$ & $\cdots$ & -- & $\cdots$ & $\cdots$ \\
\hline & $08-18-89$ & $\cdots$ & $\cdots$ & $\cdots$ & $\cdots$ & $\cdots$ & $\cdots$ & $\cdots$ & $\cdots$ & -. & $-\cdot$ \\
\hline & 08-18-89 & $-\cdot$ & $\cdots$ & $\cdots$ & $\cdots$ & $\cdots$ & $\cdots$ & $\cdots$ & $\cdots$ & $\cdots$ & $\cdots$ \\
\hline & $08-18-89$ & $\cdot-$ & $\cdots$ & $\cdot-$ & $-\cdot$ & $\cdots$ & $\cdots$ & $\cdots$ & $\cdots$ & $\cdots$ & $\cdots$ \\
\hline & 08-18-89 & $-\cdot$ & $\cdots$ & $\cdots$ & $\cdots$ & $\cdots$ & $\cdots$ & $\cdots$ & $\cdots$ & -- & -- \\
\hline & 08-18-89 & $\cdots$ & $\cdots$ & -- & -- & $\cdots$ & $\cdots$ & $\cdots$ & -- & $-\cdot$ & $\cdots$ \\
\hline & 08-18-89 & $\cdots$ & $\cdots$ & -- & $\cdots$ & $\cdots$ & $\cdots$ & $\cdots$ & -- & -- & $\cdots$ \\
\hline & $08-19-89$ & $\cdots$ & $\cdots$ & -- & $\cdots$ & $\cdots$ & $\cdots$ & $\cdots$ & -- & -- & -- \\
\hline & $08-19-89$ & $\cdots$ & $\cdots$ & -- & $\cdots$ & -- & -- & $\cdots$ & -- & $\cdots$ & -- \\
\hline & 08-19-89 & $-\cdot$ & $\cdots$ & -- & -- & -- & $\cdots$ & -- & -- & -- & $\cdots$ \\
\hline & $08-19-89$ & -. & $\cdots$ & -- & -- & -- & -- & $\cdots$ & -- & -- & -- \\
\hline
\end{tabular}


CHEMICAL ANALYSES-Cont inued

\begin{tabular}{|c|c|c|c|c|c|c|c|c|c|c|}
\hline $\begin{array}{l}\text { STATION } \\
\text { NUABER }\end{array}$ & DATE & $\begin{array}{c}\text { THORIUM } \\
\text { 8OT MAT } \\
\text { C63 } \mu \text { DS } \\
\text { LAB } \\
(\mu g / G) \\
(34982)\end{array}$ & $\begin{array}{c}\text { TIN } \\
\text { BOT MAT } \\
\angle 63_{\mu} \text { DS } \\
\text { LAB } \\
(\mu g / G) \\
(34987)\end{array}$ & $\begin{array}{l}\text { TITA- } \\
\text { NIUM } \\
\text { BOT MAT } \\
\angle 63 \mu \text { DS } \\
\text { LAB } \\
\text { PERCENT } \\
\text { (34992) }\end{array}$ & $\begin{array}{c}\text { URANIUN } \\
\text { BOT MAT } \\
\angle 63_{\mu} \text { DS } \\
\text { LAB } \\
(\mu g / G) \\
(35002)\end{array}$ & $\begin{array}{l}\text { VANA- } \\
\text { DIUA } \\
\text { BOT MAT } \\
\angle 63 \mu \text { DS } \\
\text { LAB } \\
(\mu g / G) \\
(35007)\end{array}$ & $\begin{array}{c}\text { YTTRIUA } \\
\text { BOT MAT } \\
\angle 63_{\mu} \text { DS } \\
\text { LAB } \\
(\mu g / G) \\
(35012)\end{array}$ & $\begin{array}{l}\text { YTTER- } \\
\text { BILA } \\
\text { BOT MAT } \\
<63 \mu \text { DS } \\
\text { LAB } \\
(\mu g / G) \\
(35017)\end{array}$ & $\begin{array}{c}21 N C \\
80 T M A T \\
\angle 63 \mu \text { DS } \\
\text { LAB } \\
(\mu g / G) \\
(35022)\end{array}$ & $\begin{array}{l}\text { SEDI - } \\
\text { MENT, } \\
\text { SUS- } \\
\text { PENDED } \\
(m g / L) \\
(80154)\end{array}$ \\
\hline
\end{tabular}

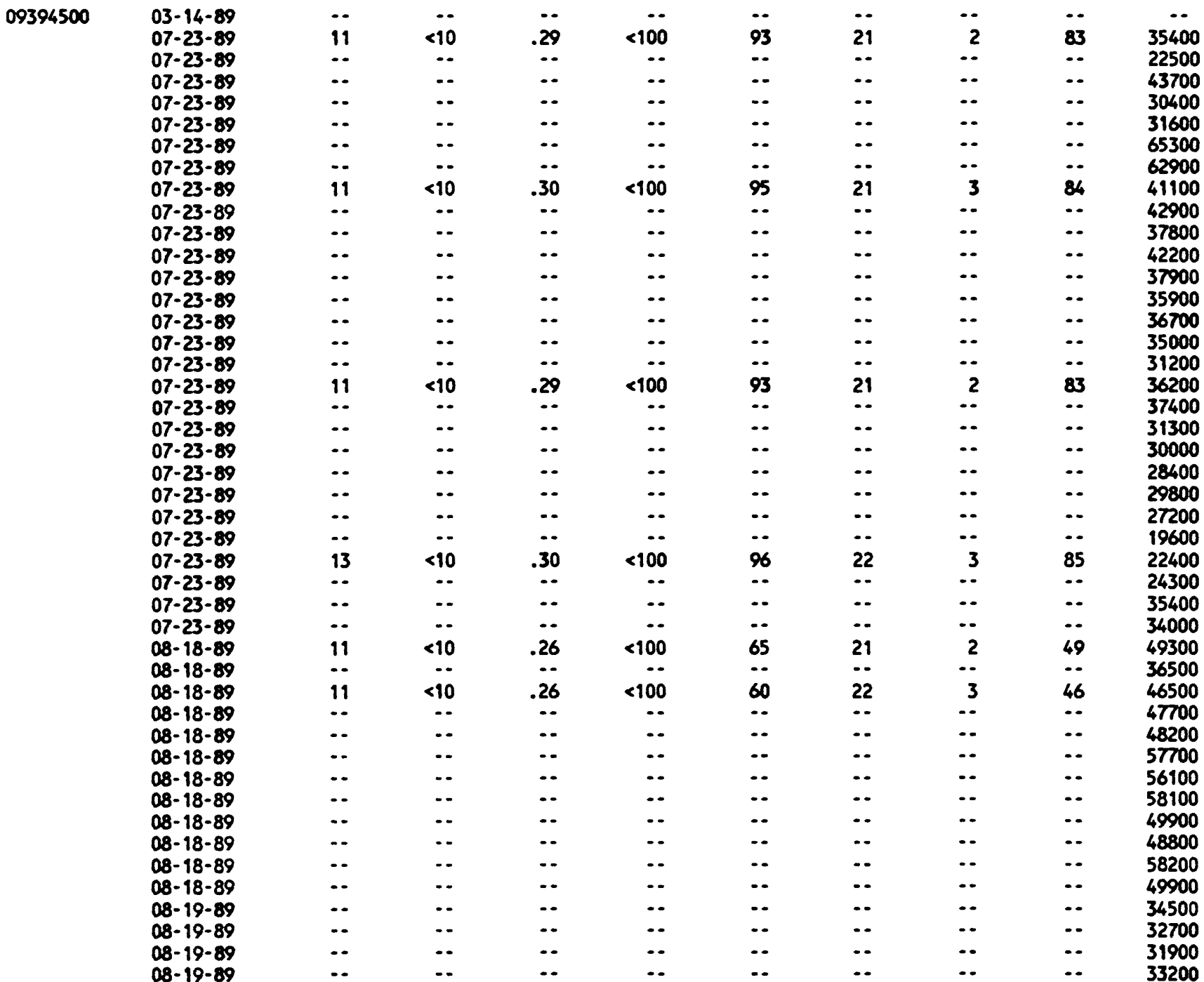


CHEMICAL AHALYSES-Continued

STATIOM

NUMBER

DATE

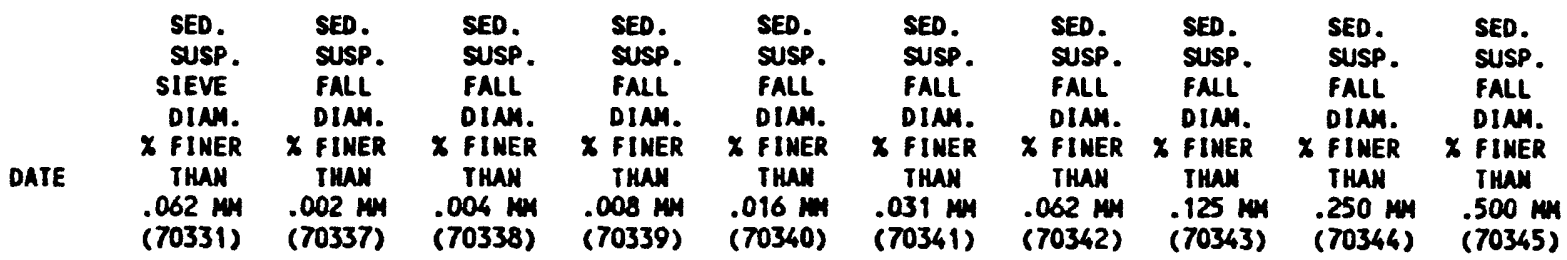

LITTLE COLORADO RIVER AT WOODRUFF, ARIZOUA-Cont inued

\begin{tabular}{|c|c|}
\hline 09394500 & $\begin{array}{l}03-14-89 \\
07-23-89 \\
07-23-89 \\
07-23-89 \\
07-23-89 \\
07-23-89 \\
07-23-89 \\
07-23-89 \\
07-23-89 \\
07-23-89 \\
07-23-89 \\
07-23-89 \\
07-23-89 \\
07-23-89 \\
07-23-89 \\
07-23-89 \\
07-23-89 \\
07-23-89 \\
07-23-89 \\
07-23-89 \\
07-23-89 \\
07-23-89 \\
07-23-89 \\
07-23-89 \\
07-23-89 \\
07-23-89 \\
07-23-89 \\
07-23-89 \\
07-23-89 \\
08-18-89 \\
08-18-19-89 \\
08-19-89 \\
08-18-89 \\
08-18-89 \\
08-18-89 \\
08-18-89 \\
08-18-89 \\
08-18-89 \\
08-18-89 \\
08-89 \\
08-89 \\
07\end{array}$ \\
\hline
\end{tabular}

\begin{tabular}{|c|c|}
\hline$\cdots$ & $\ldots$ \\
\hline 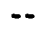 & $\cdots$ \\
\hline$\Rightarrow$ & 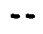 \\
\hline$\cdots$ & 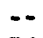 \\
\hline 43 & 56 \\
\hline -. & $\cdots$ \\
\hline- & $\because$ \\
\hline 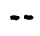 & $\cdots$ \\
\hline$\cdots$ & $\cdots$ \\
\hline$\cdots$ & $\because$ \\
\hline 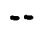 & $\cdots$ \\
\hline- & $\ldots$ \\
\hline - & $\cdots$ \\
\hline 41 & 54 \\
\hline$\cdots$ & -- \\
\hline$\cdots$ & $\cdots$ \\
\hline 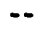 & $\cdots$ \\
\hline$\cdots$ & $\cdots$ \\
\hline- & $\cdots$ \\
\hline- & $\cdots$ \\
\hline$\because$ & $\because$ \\
\hline 41 & 54 \\
\hline$\cdots$ & $\cdots$ \\
\hline 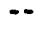 & $\cdots$ \\
\hline-- & $\cdots$ \\
\hline$\cdots$ & 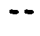 \\
\hline$\cdots$ & 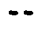 \\
\hline$\cdots$ & $\cdots$ \\
\hline$\cdots$ & $\cdots$ \\
\hline$\cdots$ & $\cdots$ \\
\hline$\cdots$ & $\cdots$ \\
\hline$\cdots$ & $\cdots$ \\
\hline$\cdots$ & $\cdots$ \\
\hline$\cdots$ & $\cdots$ \\
\hline$\cdots$ & $\cdots$ \\
\hline$\cdots$ & $\cdots$ \\
\hline$\cdots$ & $\cdots$ \\
\hline$\cdots$ & $\cdots$ \\
\hline$\cdots$ & $\cdots$ \\
\hline$\cdots$ & $\cdots$ \\
\hline$\cdots$ & $\because$ \\
\hline$\because$ & $\because$ \\
\hline$\ldots$ & $\ldots$ \\
\hline$\ldots$ & \\
\hline
\end{tabular}

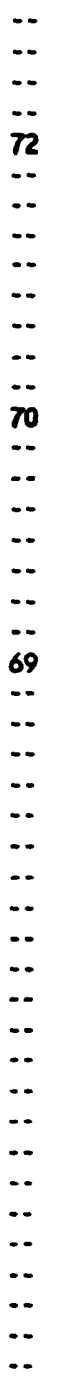

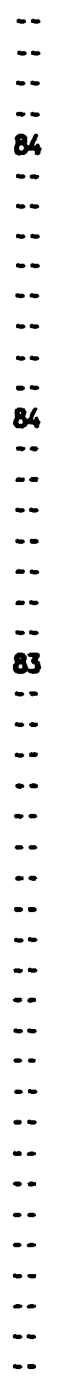

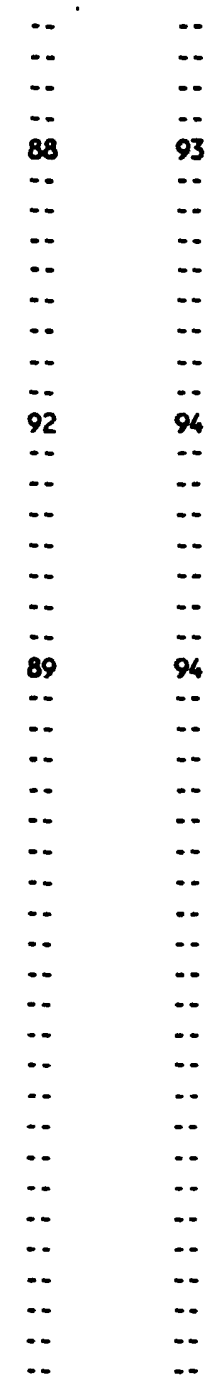

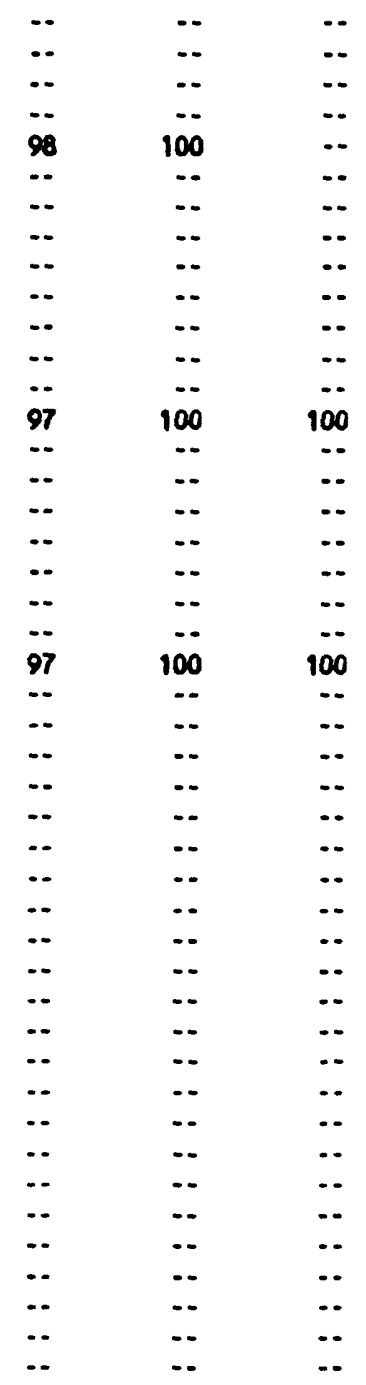


SURFACE-HATER DATA-Continued

CHEMICAL AMALYSES-Contimed
STATION

NUMBER

09394500
STATION NAME

LITTLE COLORADO RIVER AT WOODRUFF, ARIZONA
DATE TIME LATITLOE LONGITLDE

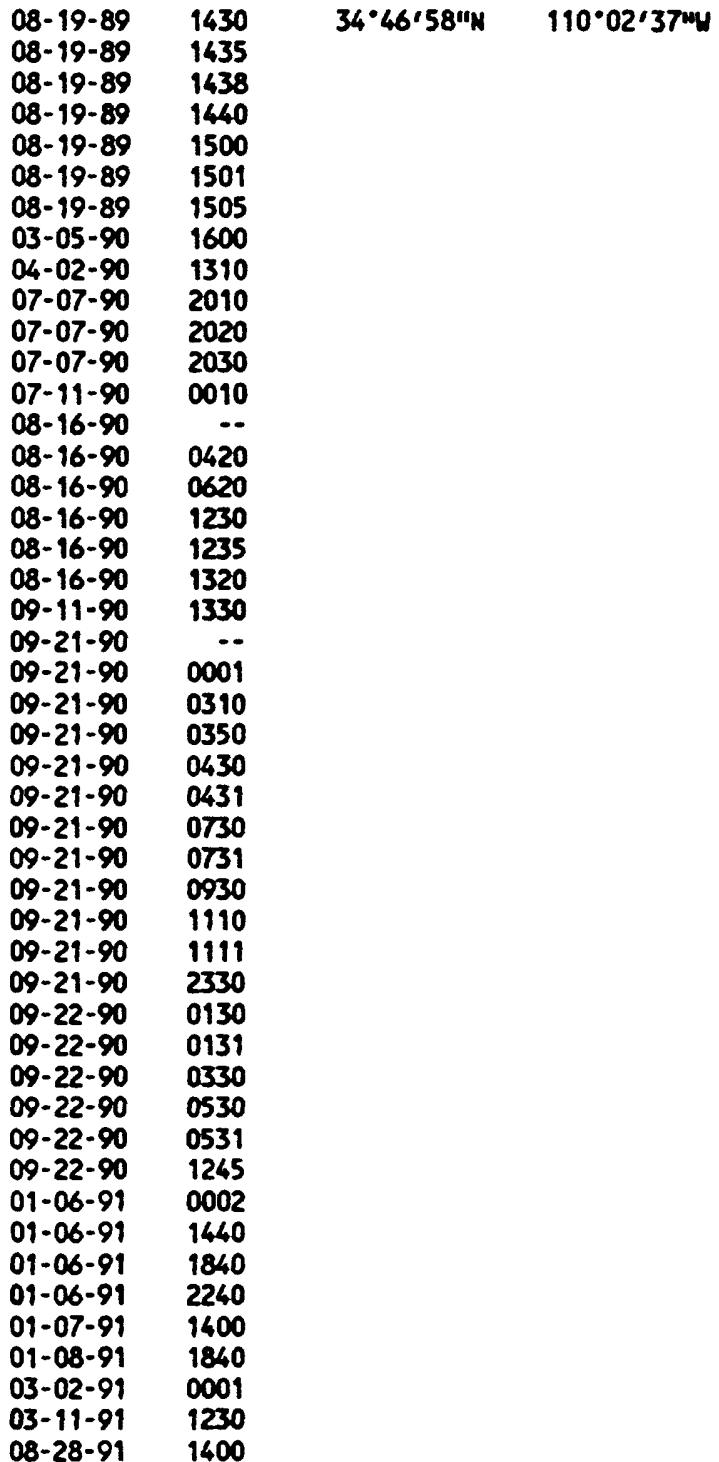


SURFACE-UATER DATA-Cont inued

CHEMICAL AMLYSES-Cont inued

\begin{tabular}{|c|c|c|c|c|c|c|c|c|c|c|}
\hline $\begin{array}{l}\text { STATION } \\
\text { MUMBER }\end{array}$ & DATE & $\begin{array}{c}\text { SAN- } \\
\text { PLING } \\
\text { METHOD, } \\
\text { CODES } \\
\text { (82398) }\end{array}$ & $\begin{array}{l}\text { STREAM } \\
\text { HIDTH } \\
\text { (METERS) } \\
\text { (00004) }\end{array}$ & $\begin{array}{c}\text { TEMPER- } \\
\text { ATURE } \\
\text { WATER } \\
(\cdot \mathrm{C}) \\
(00010)\end{array}$ & $\begin{array}{l}\text { DIS- } \\
\text { CHARGE, } \\
\text { INST. } \\
\text { CUBIC } \\
\text { METERS } \\
\text { PER } \\
\text { SECOND } \\
\text { (00061) }\end{array}$ & $\begin{array}{l}\text { GAGE } \\
\text { MEIGHT } \\
\text { (METERS) } \\
\text { (00065) }\end{array}$ & $\begin{array}{c}\text { SPE- } \\
\text { CIFIC } \\
\text { CON- } \\
\text { DUCT- } \\
\text { ANCE } \\
\text { ( } \mathrm{HS} / \mathrm{Cm}) \\
(00095)\end{array}$ & $\begin{array}{l}\text { SPE- } \\
\text { CIFIC } \\
\text { CON- } \\
\text { DUCT- } \\
\text { ANCE } \\
\text { LAB } \\
(\mu S / \mathrm{cm}) \\
(90095)\end{array}$ & $\begin{array}{c}\text { OXYGEN, } \\
\text { DIS- } \\
\text { SOLVED } \\
\text { (mg/L) } \\
(00300)\end{array}$ & $\begin{array}{l}\text { PH } \\
\text { WATER } \\
\text { WHOLE } \\
\text { FIELD } \\
\text { (STAND- } \\
\text { ARD } \\
\text { UNITS) } \\
\text { (00400) }\end{array}$ \\
\hline
\end{tabular}

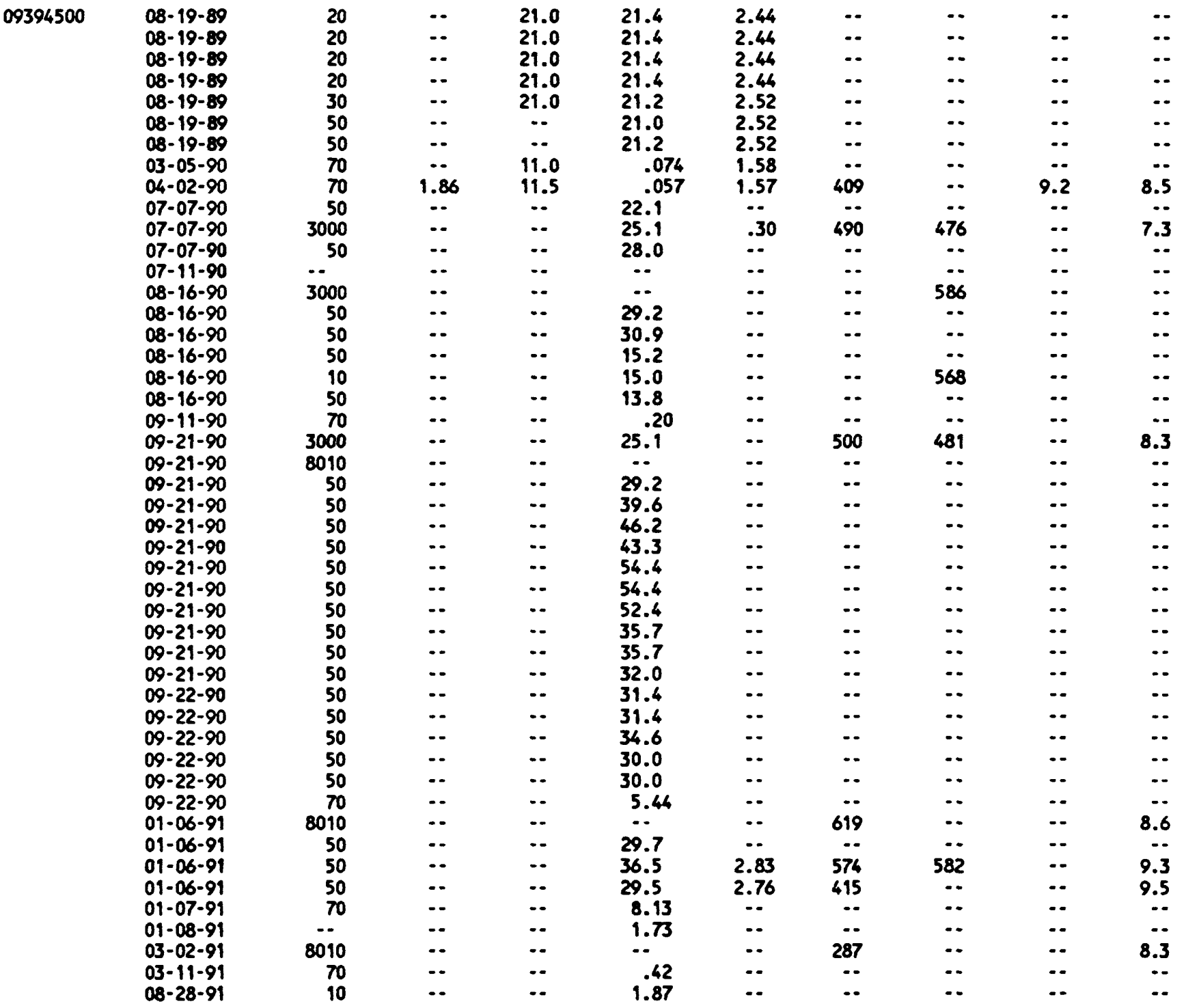


CHPMICAL ARAYSES-Continued

STATIOF

IUMBER

DAIE

CAR-

\begin{tabular}{|c|c|c|c|c|c|c|c|c|c|}
\hline $\begin{array}{c}\text { PB } \\
\text { WATER } \\
\text { WBOLE } \\
\text { LAB } \\
\text { (STAND- } \\
\text { ARD } \\
\text { UNITS) } \\
\text { (00403) }\end{array}$ & $\begin{array}{l}\text { ALKA- } \\
\text { LIMITY } \\
\text { WAI DIS } \\
\text { FIX ERDD } \\
\text { FIELD } \\
\text { CECO3 } \\
(\text { (mS/L) } \\
(39036)\end{array}$ & $\begin{array}{c}\text { ALKA - } \\
\text { LINITY } \\
\text { LAB } \\
\text { (ms/L } \\
\text { As } \\
\text { Caco3) } \\
(90410)\end{array}$ & $\begin{array}{l}\text { ATE } \\
\text { WATER } \\
\text { DIS IT } \\
\text { FIELD } \\
\text { (mE/L } \\
\text { As } \\
\text { COS) } \\
(00452)\end{array}$ & $\begin{array}{l}\text { SOLIDS, } \\
\text { RESIDUEE } \\
\text { AT } 180^{\circ} \mathrm{C} \\
\text { DIS- } \\
\text { SOLVED } \\
(\mathrm{ms} / \mathrm{L}) \\
(70300)\end{array}$ & $\begin{array}{l}\text { SOLIDS, } \\
\text { SUM OP } \\
\text { CONSTI- } \\
\text { TUEATS, } \\
\text { DIS- } \\
\text { SOLVED } \\
\text { (ms/L) } \\
(70301)\end{array}$ & $\begin{array}{c}\text { SOLIDS, } \\
\text { DIS- } \\
\text { SOLVED } \\
\text { (motric } \\
\text { tons } \\
\text { por } \\
\text { dey) } \\
(70302)\end{array}$ & $\begin{array}{l}\text { BARD- } \\
\text { KESS } \\
\text { TOTAL } \\
\text { (m\&/L } \\
\text { es } \\
\text { Ceco3) } \\
(00900)\end{array}$ & $\begin{array}{l}\text { CALCIUM } \\
\text { DIS- } \\
\text { SOLVED } \\
\text { (ms/L } \\
\text { as Ca) } \\
\text { (00815) }\end{array}$ & $\begin{array}{l}\text { MAGIE- } \\
\text { SIUA, } \\
\text { DIS- } \\
\text { SOLVED } \\
\text { (m8/L } \\
\text { As Ms) } \\
(00925)\end{array}$ \\
\hline
\end{tabular}

LITILE COLORADO RIVER AT WOODRUFE, ARIZONA-Continued

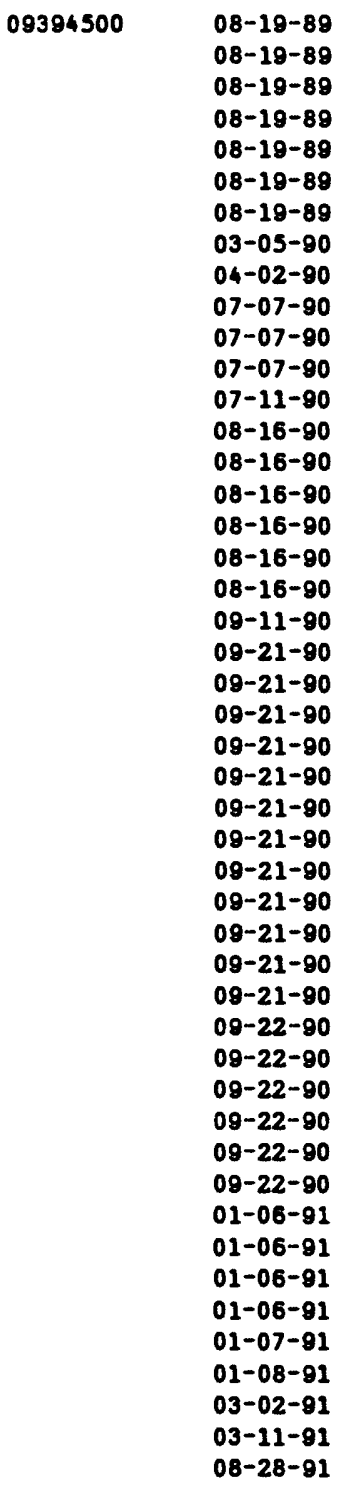

\begin{tabular}{|c|c|c|}
\hline-- & -- & -- \\
\hline-- & -- & -- \\
\hline- & -- & -- \\
\hline-- & -- & -- \\
\hline-- & -- & -- \\
\hline-- & -- & - \\
\hline-- & -- & -- \\
\hline- & -- & - \\
\hline-- & 134 & -- \\
\hline-- & -- & -- \\
\hline 7.6 & -- & 655 \\
\hline-- & -- & -- \\
\hline-- & -- & -- \\
\hline 8.8 & -- & -- \\
\hline-- & -- & -- \\
\hline-- & -- & -- \\
\hline-- & -- & -- \\
\hline 8.9 & -- & -- \\
\hline-- & -- & -- \\
\hline-- & -- & - \\
\hline 8.5 & -- & 161 \\
\hline-- & -- & -- \\
\hline-- & -- & -- \\
\hline-- & -- & -- \\
\hline-- & -- & -- \\
\hline-- & -- & -- \\
\hline-- & -- & -- \\
\hline-- & -- & -- \\
\hline-- & -- & -- \\
\hline-- & -- & -- \\
\hline-- & -- & -- \\
\hline-- & -- & - \\
\hline-- & -- & -- \\
\hline-- & -- & -- \\
\hline-- & -- & -- \\
\hline-- & -- & -- \\
\hline-- & -- & -- \\
\hline$-\infty$ & -- & -- \\
\hline-- & -- & -- \\
\hline-- & -- & -- \\
\hline 8.9 & 130 & 165 \\
\hline-- & -- & -- \\
\hline-- & -- & -- \\
\hline-- & -- & -- \\
\hline-- & -- & -- \\
\hline-- & -- & -- \\
\hline- & - & \\
\hline
\end{tabular}

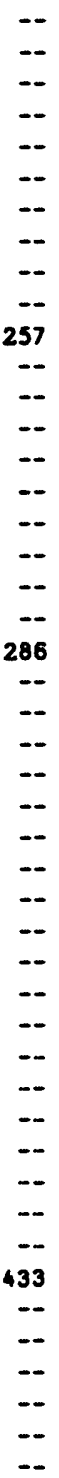

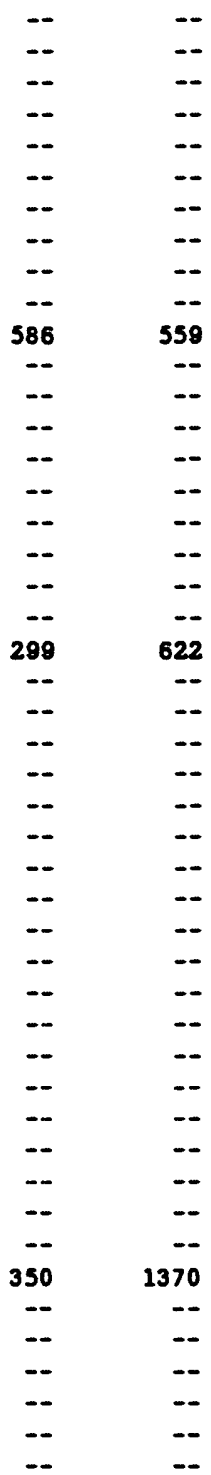

\begin{tabular}{|c|c|c|}
\hline-- & - & -- \\
\hline- & -- & -- \\
\hline-- & $\cdots$ & -- \\
\hline- & -- & -- \\
\hline-- & -- & $\cdots$ \\
\hline-- & -- & -- \\
\hline-- & - & - \\
\hline-- & -- & -- \\
\hline-- & -- & -- \\
\hline- & -- & -- \\
\hline 130 & 43 & 6.4 \\
\hline-- & -- & -- \\
\hline-- & -- & -- \\
\hline 7 & 1.3 & .92 \\
\hline-- & -- & -- \\
\hline- & - & -- \\
\hline-- & -- & -- \\
\hline 12 & 2.5 & 1.3 \\
\hline- & - & $\cdots$ \\
\hline-- & -- & -- \\
\hline 21 & 6.6 & 1.1 \\
\hline-- & -- & -- \\
\hline-- & -- & -- \\
\hline- & - & -- \\
\hline-- & -- & -- \\
\hline-- & -- & -- \\
\hline-- & $\cdots$ & -- \\
\hline$\cdots$ & $\cdots$ & $\cdots$ \\
\hline- & - & -- \\
\hline$\overline{-1}$ & -- & -- \\
\hline- & 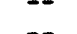 & - \\
\hline -- & $\ldots$ & $\ldots$ \\
\hline-- & -- &.- \\
\hline-- & -- & -- \\
\hline-- & -- & -- \\
\hline-- & -- & -- \\
\hline-- & -- & -- \\
\hline-- & -- & -- \\
\hline-- & - & -- \\
\hline 12 & 3.4 & .88 \\
\hline-- & -- & -- \\
\hline- & -- & -- \\
\hline-- & -- & -- \\
\hline 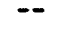 & -- & -- \\
\hline- & -- & -- \\
\hline- & & \\
\hline
\end{tabular}


SURFACE-WATER DATA-Cont inued

CHEMICAL AMALYSES-Continued

\begin{tabular}{|c|c|c|c|c|c|c|c|c|c|c|}
\hline $\begin{array}{l}\text { STATION } \\
\text { NUNBER }\end{array}$ & DATE & $\begin{array}{l}\text { SODIUA, } \\
\text { DIS- } \\
\text { SOLVED } \\
(m / L \\
\text { as Ma) } \\
(00930)\end{array}$ & $\begin{array}{l}\text { SOOIUA } \\
\text { ADSORP- } \\
\text { TION } \\
\text { RATIO } \\
\text { (00931) }\end{array}$ & $\begin{array}{l}\text { SOOIUN } \\
\text { PERCENT } \\
(00932)\end{array}$ & $\begin{array}{l}\text { POTAS- } \\
\text { SIUN, } \\
\text { DIS- } \\
\text { SOLVED } \\
(m / L \\
\text { es K) } \\
(00935)\end{array}$ & $\begin{array}{l}\text { CHLO- } \\
\text { RIDE, } \\
\text { DIS- } \\
\text { SOLVED } \\
(m 9 / L \\
\text { OS Cl) } \\
(00940)\end{array}$ & $\begin{array}{l}\text { BROMIDE } \\
\text { DIS- } \\
\text { SOLVED } \\
\text { (mg/L } \\
\text { es 8r) } \\
\text { (71870) }\end{array}$ & $\begin{array}{l}\text { FLUO- } \\
\text { RIDE, } \\
\text { DIS- } \\
\text { SOLVED } \\
(m / L \\
\text { OS F) } \\
(00950)\end{array}$ & $\begin{array}{l}\text { SILICA, } \\
\text { DIS- } \\
\text { SOLVED } \\
\text { (mg/L } \\
\text { os } \\
\text { sio2) } \\
(00955)\end{array}$ & $\begin{array}{l}\text { SULFATE } \\
\text { DIS- } \\
\text { SOLVED } \\
\text { (aO/L } \\
\text { as SO4) } \\
(00945)\end{array}$ \\
\hline
\end{tabular}

LITTLE COLORADO RIVER AT HOOORUFF, ARIZONA-Cont inued

\begin{tabular}{|c|c|}
\hline 09394500 & $\begin{array}{l}08-19-89 \\
08-19-89 \\
08-19-89 \\
08-19-89 \\
08-19-89 \\
08-19-89 \\
08-19-89 \\
03-05-90 \\
04-02-90 \\
07-07-90 \\
07-07-90 \\
07-07-90 \\
07-11-90 \\
08-16-90 \\
08-16-90 \\
08-16-90 \\
08-16-90 \\
08-16-90 \\
08-16-90 \\
09-11-90 \\
09-21-90 \\
09-21-90 \\
09-21-90 \\
09-21-90 \\
09-21-90 \\
09-21-90 \\
09-21-90 \\
09-21-90 \\
09-21-90 \\
09-21-90 \\
01-08-91-90 \\
03-11-91 \\
08-28-91\end{array}$ \\
\hline
\end{tabular}

\begin{tabular}{|c|c|}
\hline$\cdots$ & 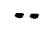 \\
\hline$\ldots$ & $\cdots$ \\
\hline 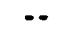 & - \\
\hline$\because$ & $\ldots$ \\
\hline$\ldots$ & $\cdots$ \\
\hline$\ldots$ & $\ldots$ \\
\hline$\ldots$ & $\cdots$ \\
\hline$\cdots$ & $\cdots$ \\
\hline$\cdots$ & $\cdots$ \\
\hline$=$ & $\because$ \\
\hline 34 & 1 \\
\hline$\ldots$ & $\cdots$ \\
\hline$\cdots$ & $\cdots$ \\
\hline 100 & 16 \\
\hline$\ldots$ & $\cdots$ \\
\hline$\cdots$ & $\cdots$ \\
\hline$\cdots$ & 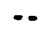 \\
\hline 110 & 16 \\
\hline - & $=$ \\
\hline- & $\cdots$ \\
\hline \%6 & 9 \\
\hline-- & 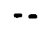 \\
\hline$\cdots$ & $\cdots$ \\
\hline$\cdots$ & $\cdots$ \\
\hline$\cdots$ & $\cdots$ \\
\hline$=$ & $\cdots$ \\
\hline$\cdots$ & $\cdots$ \\
\hline$\cdots$ & - \\
\hline$\cdots$ & $\cdots$ \\
\hline$-\infty$ & $\cdots$ \\
\hline$\cdots$ & $\cdots$ \\
\hline$\cdots$ & $\cdots$ \\
\hline$\cdots$ & $\cdots$ \\
\hline$\cdots$ & $\cdots$ \\
\hline$\cdots$ & $\cdots$ \\
\hline$\cdots$ & $\cdots$ \\
\hline$\cdots$ & $\cdots$ \\
\hline$\cdots$ & $\cdots$ \\
\hline$\cdots$ & $\cdots$ \\
\hline 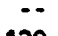 & $\because$ \\
\hline 120 & 15 \\
\hline- & $\cdots$ \\
\hline$\cdots$ & $\cdots$ \\
\hline$\cdots$ & $\cdots$ \\
\hline-- & $\cdots$ \\
\hline$\cdots$ & $\cdots$ \\
\hline$\cdots$ & $\cdots$ \\
\hline
\end{tabular}

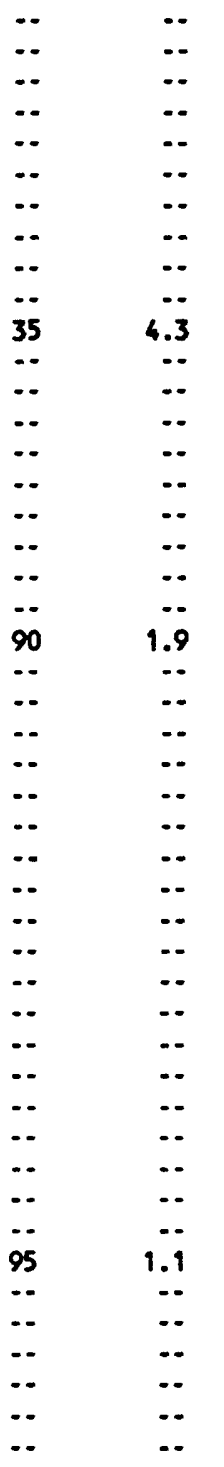

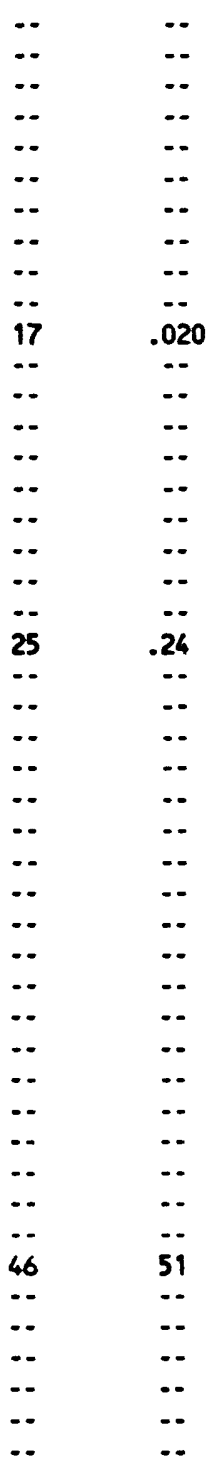

\begin{tabular}{|c|c|c|}
\hline -. & -. & $\cdots$ \\
\hline$\cdots$ & $\cdots$ & $\cdots$ \\
\hline$\because$ & $\cdots$ & $\cdots$ \\
\hline$\therefore$ & $\because$ & $\ddot{-}$ \\
\hline$\cdots$ & $\cdots$ & -. \\
\hline$\because$ & $\cdots$ & -- \\
\hline$\because$ & 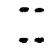 & $\because$ \\
\hline -. & .. & .. \\
\hline .30 & 14 & 73 \\
\hline 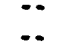 & $\because-$ & $\because$ \\
\hline .. & 32 & .. \\
\hline$\cdots$ & $\cdots$ & $\cdots$ \\
\hline 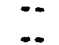 & 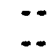 & $\because$ \\
\hline$\cdots$ & 38 & -. \\
\hline$\because$ & -. & $\cdots$ \\
\hline 40 & $\ddot{9}$ & $\because \overline{0}$ \\
\hline$\because$ & $\ldots$ & .. \\
\hline$\cdots$ & -. & $\cdots$ \\
\hline$\cdots$ & $\because$ & $-\cdot$ \\
\hline$\therefore$ & $\therefore$ & $\because$. \\
\hline$\because$ & $\cdots$ & -- \\
\hline 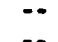 & $\cdots$ & -. \\
\hline$\cdots$ & $\ddot{-}$ & $\because$ \\
\hline -. & -. & -- \\
\hline$\cdots$ & $\cdots$ & -. \\
\hline$\cdots$ & 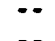 & $\cdots$ \\
\hline$\therefore$ & 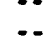 & $\therefore$ \\
\hline 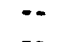 & -- & -- \\
\hline - & -- & -- \\
\hline 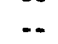 & $\because$ & $\therefore$ \\
\hline$\because$ & -. & -. \\
\hline .40 & 18 & 60 \\
\hline$\because$ & $\because$ & $\quad \therefore$ \\
\hline -. & -. & .. \\
\hline$\because$ & $\because$ & $\cdots$ \\
\hline 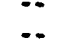 & $\because$ & $\because$ \\
\hline
\end{tabular}


SURFACE-WATER DATA-Continued

CHEMICAL ANALYSES-Cont inued

STATION

MUMBER

09394500

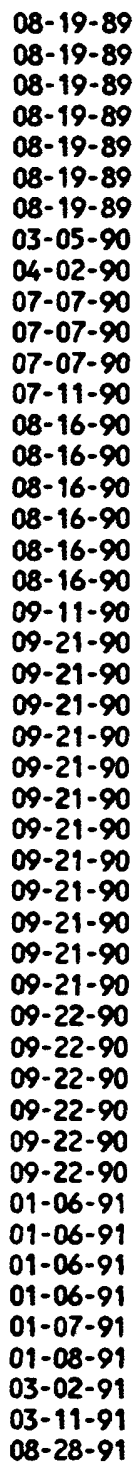

08-19-89

$08-19-89$
$08-19-89$

08-19-89

08-19-89

08-19-89

$03-05-90$

04-02-90

07-07-90

$07-07-90$

$07-11-90$

$08-16-90$

$08-16-90$

$08-16-90$

08-16-90

$08-16-90$

$09-11-90$

09-21-90

09-21-90

$09-21-90$

$09-21-90$

$09-21-90$

$09-21-90$

$09-21-90$

09-21-90

$09-22-90$

09-22-90

09-22-90

09-22-90

$09-22-90$

$01-06-91$

01-06-91

01-06-91

$01-06-91$

01-07-91

03-02-91

08-28-91
LITTLE COLORADO RIVER AT WOOORUFF, ARIZOWA-Continued

\begin{tabular}{|c|c|c|c|c|c|c|c|c|}
\hline $\begin{array}{c}\text { ARSENIC } \\
\text { DIS- } \\
\text { SOLVED } \\
(\mu g / L \\
\text { as AS) } \\
(01000)\end{array}$ & $\begin{array}{l}\text { BARIUH, } \\
\text { DIS- } \\
\text { SOLVED } \\
(\mu g / L \\
\text { as Ba) } \\
(01005)\end{array}$ & $\begin{array}{l}\text { BERYL- } \\
\text { LIUM, } \\
\text { DIS- } \\
\text { SOLVED } \\
\text { ( } \mu g / L \\
\text { as Be) } \\
(01010)\end{array}$ & $\begin{array}{l}\text { BORON, } \\
\text { DIS- } \\
\text { SOLVED } \\
(\mu g / L \\
\text { as B) } \\
(01020)\end{array}$ & $\begin{array}{c}\text { CADMIUH } \\
\text { DIS- } \\
\text { SOLVED } \\
\text { ( } \mu g / L \\
\text { as Cd) } \\
(01025)\end{array}$ & $\begin{array}{c}\text { CHRO- } \\
\text { MIUH, } \\
\text { DIS- } \\
\text { SOLVED } \\
(\mu g / L \\
\text { as Cr) } \\
(01030)\end{array}$ & $\begin{array}{l}\text { COBALT, } \\
\text { DIS- } \\
\text { SOLVED } \\
(\mu g / L \\
\text { as CO }) \\
(01035)\end{array}$ & $\begin{array}{l}\text { COPPER, } \\
\text { DIS- } \\
\text { SOLVED } \\
(\mu g / L \\
\text { as CU) } \\
(01040)\end{array}$ & $\begin{array}{l}\text { IRON, } \\
\text { DIS- } \\
\text { SOLVED } \\
(\mu 9 / L \\
\text { as Fe) } \\
(01046)\end{array}$ \\
\hline
\end{tabular}
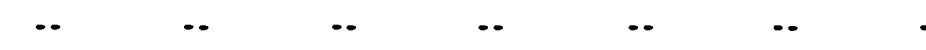

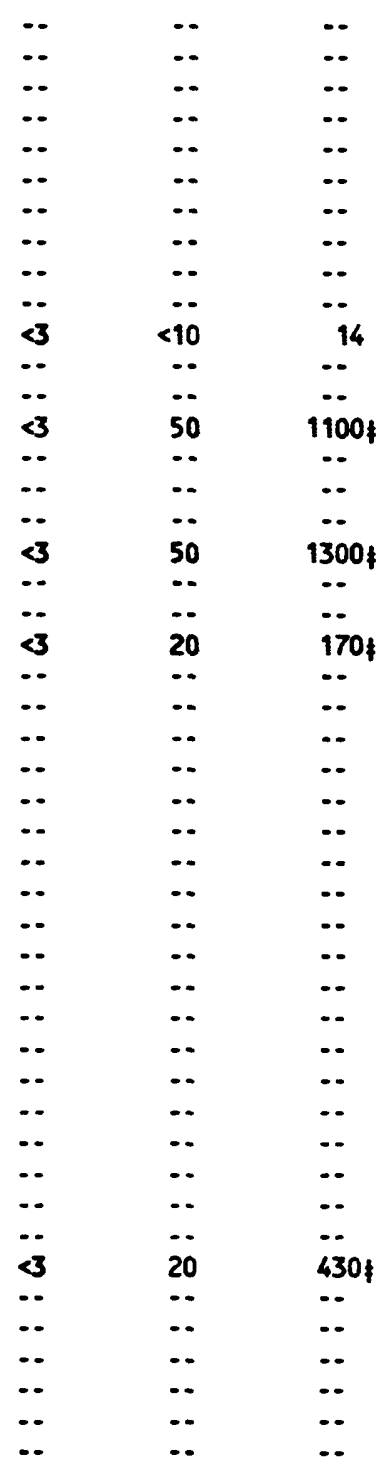


SURFACE-WATER DATA-Cont inued

CHEMICAL ANALYSES-Cont inued

STATION

NUMBER
DATE

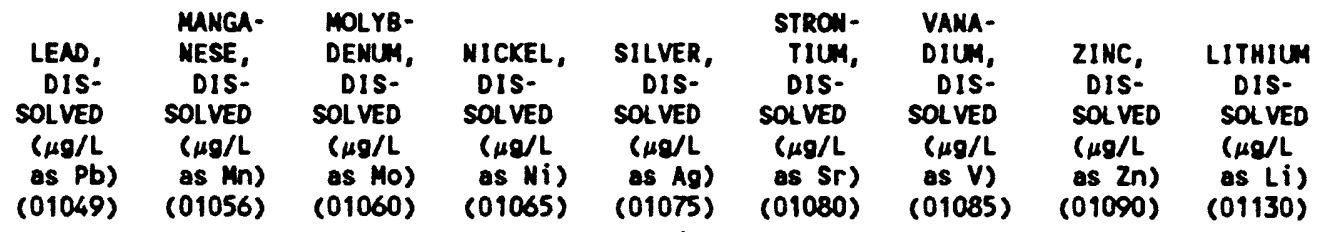

LITTLE COLORADO RIVER AT WOOORUFF, ARI2ONA-Contínued

\begin{tabular}{|c|c|}
\hline 09394500 & $\begin{array}{l}08-19-89 \\
08-19-89 \\
08-19-89 \\
08-19-89 \\
08-19-89 \\
08-19-89 \\
08-19-89 \\
03-05-90 \\
04-02-90 \\
07-07-90 \\
07-07-90 \\
07-07-90 \\
07-11-90 \\
08-16-90 \\
08-16-90 \\
08-16-90 \\
08-16-90 \\
08-16-90 \\
08-16-90 \\
09-11-90 \\
09-21-90 \\
09-21-90 \\
09-21-90 \\
09-21-90 \\
09-21-90 \\
09-21-90 \\
09-21-90 \\
09-21-90 \\
09-21-90 \\
09-21-90 \\
01-08-08-91-91 \\
03-11-91 \\
09-28-91\end{array}$ \\
\hline
\end{tabular}

\begin{tabular}{|c|c|c|}
\hline - & $\cdots$ & $\cdots$ \\
\hline$\cdots$ & $\cdots$ & $\cdots$ \\
\hline-- & $\cdots$ & $\cdots$ \\
\hline$\cdots$ & $\cdots$ & $\cdots$ \\
\hline - & $\cdots$ & $\cdots$ \\
\hline - & $\cdots$ & $\cdots$ \\
\hline$\cdots$ & $\cdots$ & $\cdots$ \\
\hline$\cdots$ & $\cdots$ & -- \\
\hline$\cdots$ & $\cdots$ & $\cdots$ \\
\hline$\ddot{0}$ & $\cdots$ & 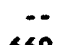 \\
\hline$<10$ & $<9.0$ & 660 \\
\hline$\cdots$ & $\cdots$ & $\cdots$ \\
\hline-- & $\cdots$ & $\cdots$ \\
\hline$<10$ & 1.0 & 23 \\
\hline$\cdots$ & $\cdots$ & $\cdots$ \\
\hline$\cdots$ & $\cdots$ & $\cdots$ \\
\hline-- & $\cdots$ & $\cdots$ \\
\hline$<10$ & $<1.0$ & 40 \\
\hline$\cdots$ & $\cdots$ & $\cdots$ \\
\hline$\cdots$ & $\cdots$ & -- \\
\hline$<10$ & $<1.0$ & 140 \\
\hline$-\infty$ & $\cdots$ & -- \\
\hline$\cdots$ & $\cdots$ & $\cdots$ \\
\hline-- & $\cdots$ & $\cdots$ \\
\hline$\cdots$ & $\cdots$ & -- \\
\hline$\cdots$ & $\cdots$ & $\cdots$ \\
\hline-- & $\cdots$ & $\cdots$ \\
\hline$\cdots$ & $\cdots$ & $\cdots$ \\
\hline$\cdots$ & $\cdots$ & $\cdots$ \\
\hline$\cdots$ & $\cdots$ & $\cdots$ \\
\hline$\cdots$ & $\cdots$ & $\cdots$ \\
\hline$\cdots$ & $\cdots$ & $\cdots$ \\
\hline$\cdots$ & $\cdots$ & $\cdots$ \\
\hline$\cdots$ & $\cdots$ & $\cdots$ \\
\hline$\cdots$ & $\cdots$ & $\cdots$ \\
\hline$\cdots$ & $\cdots$ & $\cdots$ \\
\hline$\cdots$ & $\cdots$ & $\cdots$ \\
\hline$\cdots$ & $\cdots$ & -- \\
\hline$\cdots$ & $\cdots$ & $\cdots$ \\
\hline$\cdots$ & $\cdots$ & -- \\
\hline$<10$ & $<1.0$ & 88 \\
\hline$\cdots$ & $\cdots$ & $\cdots$ \\
\hline$\cdots$ & $\cdots$ & $\cdots$ \\
\hline$\cdots$ & $\cdots$ & $\cdots$ \\
\hline$\cdots$ & $\cdots$ & $\cdots$ \\
\hline$\cdots$ & $\cdots$ & $\cdots$ \\
\hline$\cdots$ & $\cdots$ & $\cdots$ \\
\hline
\end{tabular}


SURFACE-WATER DATA-Cont inued

CHEMICAL ANALYSES-Cont inued

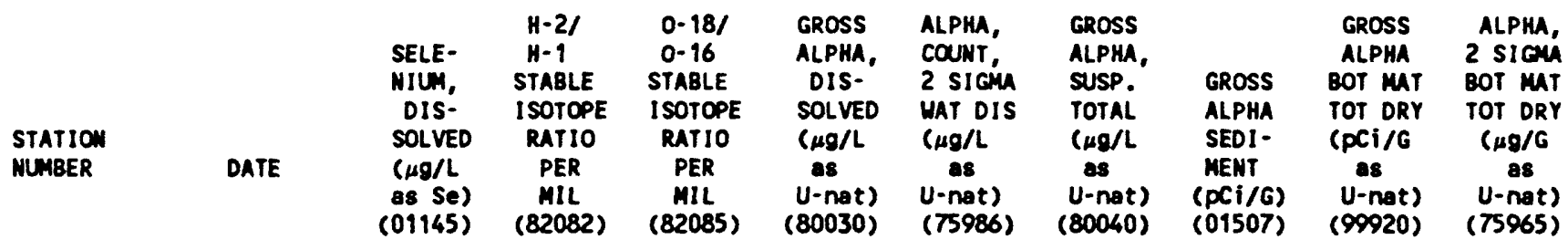

\begin{tabular}{|c|c|}
\hline 09394500 & $\begin{array}{l}08-19-89 \\
08-19-89 \\
08-19-89 \\
08-19-89 \\
08-19-89 \\
08-19-89 \\
08-19-89 \\
03-05-90 \\
04-02-90 \\
07-07-90 \\
07-07-90 \\
07-07-90 \\
07-11-90 \\
08-16-90 \\
08-16-90 \\
08-16-90 \\
08-16-90 \\
08-16-90 \\
08-16-90 \\
09-11-90 \\
09-21-90 \\
09-21-90 \\
09-21-90 \\
09-21-90 \\
09-21-90 \\
09-21-90 \\
09-21-90 \\
09-21-90 \\
09-21-90 \\
09-21-90 \\
09-21-90 \\
09-21-90 \\
09-22-90 \\
01-07-02-91 \\
03-11-91 \\
08-28-91 \\
09-22-90 \\
09-22-90 \\
09-22-90 \\
09-22-90 \\
01-06-91 \\
01-06-91 \\
01-91\end{array}$ \\
\hline
\end{tabular}

LITTLE COLORADO RIVER AT WOOORUFF, ARI 2ONA-Cont inued

\begin{tabular}{|c|c|c|c|c|c|c|c|}
\hline -. & -. & -. & -. & -. & $\cdots$ & .. & -. \\
\hline -. & $-\cdot$ & -. & -. & -. & $\cdots$ & -. & .. \\
\hline -. & $\because$ & $\cdots$ & $\because$ & $\ddot{-}$ & $\cdots$ & -・ & -. \\
\hline 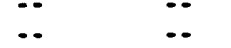 & 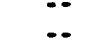 & 4.0 & $1 . \overline{3}$ & $380 *$ & $\because$ & $\because$ & $\because$ \\
\hline -. & .. & 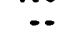 & -. & $\cdots$ & -. & .. & .. \\
\hline$\cdots$ & -. & $<.6$ & .40 & $460^{*}$ & $\cdot \cdot$ & $\cdots$ & -. \\
\hline$\because$ & 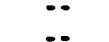 & $\because$ & $\because$ & $\because$ & $\because$ & $\because$ & $\because-$ \\
\hline$\because$ & $\ddot{-.}$ & 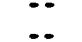 & 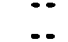 & 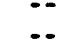 & $\because$ & $\because$ & 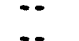 \\
\hline$<9$ & .. & 3.9 & 1.5 & $380 *$ & .. & .. & .. \\
\hline$\cdots$ & -. & -. & $\cdots$ & $\cdots$ & $\cdots$ & -. & $\cdots$ \\
\hline$\cdots$ & $\cdots$ & $\cdots$ & $\cdots$ & $\cdots$ & $\cdots$ & $\cdots$ & .. \\
\hline-82.0 & -11.80 & $\cdots$ & $\cdots$ & $\cdots$ & $\cdots$ & $\cdots$ & $\cdots$ \\
\hline$\ddot{. .}$ & $\because$ & $\cdots$ & $\cdots$ & $\cdots$ & $\because$ & 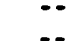 & $\cdots$ \\
\hline$\because$ & $\because$ & .. & $\because$ & $\because$ & $\ddot{a}$ & 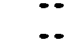 & $\because$ \\
\hline-83.5 & -11.70 & -. & .. & -. & $<6$ & 6.6 & 9.98 \\
\hline$\cdot-$ & $\cdot-$ & -. & $\cdots$ & $\cdots$ & $\cdots$ & $\cdots$ & -. \\
\hline$\cdots$ & -. & -. & -. & $\cdots$ & $\cdots$ & -. & -. \\
\hline$<1$ & 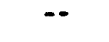 & $\cdots$ & $\cdots$ & $\cdots$ & $\cdots$ & $\cdots$ & $\cdots$ \\
\hline$\ddot{0}$ & $\because$ & $\because$ & $\because$ & $\because$ & $\because$ & 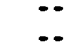 & 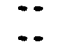 \\
\hline -. & .. & .. & -. & -. & $\cdots$ & -. & .. \\
\hline$\cdots$ & -. & $\cdots$ & $\cdots$ & $\cdots$ & $\cdots$ & -. & .. \\
\hline 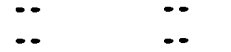 & $\because$ & $\ddot{-}$ & $\because$ & $\because-$ & $\because-$ & $\ddot{-}$ & $\ddot{-.}$ \\
\hline .. & .. & .. & -. & .. & .. & .. & .. \\
\hline$\cdots$ & -. & $\cdots$ & $\cdots$ & $\cdots$ & $\cdots$ & $\cdots$ & -. \\
\hline$\cdots$ & $\cdots$ & $\cdots$ & $\cdots$ & $\cdots$ & $\cdots$ & $\cdots$ & $\cdots$ \\
\hline$\cdots$ & -. & $\cdots$ & $\cdots$ & $\cdots$ & $\cdots$ & $\cdots$ & $\cdots$ \\
\hline$\cdots$ & $\because$. & $\because$. & $\because$ & 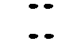 & $\because$ & $\because$ & $\because$. \\
\hline .. & .. & -. & -. & .. & .. & .. & .. \\
\hline .. & -. & $\cdots$ & $\cdots$ & -. & $\cdots$ & $\cdots$ & -. \\
\hline 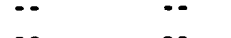 & $\cdots$ & $\cdots$ & $\cdots$ & $\cdots$ & $\cdots$ & $\cdots$ & $\cdots$ \\
\hline$\ddot{.}$ & $\because \cdot$ & $\because$ & $\cdots$ & -. & $\cdots$ & & $\cdots$ \\
\hline .. & .. & .. & .- & .. & .. & .. &.- \\
\hline$\because$ & 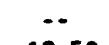 & -. & -. & -. & -. & .. & .. \\
\hline-142.0 & -18.50 & $11 t$ & 2.9 & -. & 9 & 12.0 & 9.40 \\
\hline$\cdots$ & $\cdots$ & $\cdots$ & $\cdots$ & .. & $\cdots$ & $\cdots$ & $\cdots$ \\
\hline$\cdots$ & $\cdots$ & $\cdots$ & $\cdots$ & $\cdots$ & $\cdots$ & $\cdots$ & $\cdots$ \\
\hline$\ddot{-90.5}$ & $\ddot{2}$ & $\cdots$ & $\cdots$ & $\cdots$ & $\cdots$ & $\cdots$ & $\cdots$ \\
\hline $\begin{array}{l}-Y 0.3 \\
-.\end{array}$ & $\begin{array}{c}-12.20 \\
\ldots .\end{array}$ & $\therefore$ & .. & $\therefore$ & .. & 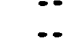 & $\because-$ \\
\hline$\cdots$ & -. & -. & -. & .. & -. & .. & .. \\
\hline
\end{tabular}


SURFACE-HATER DATA-Cont inued

CHEMICAL ANALYSES - Cont inued

STATION

MUMBER

DATE

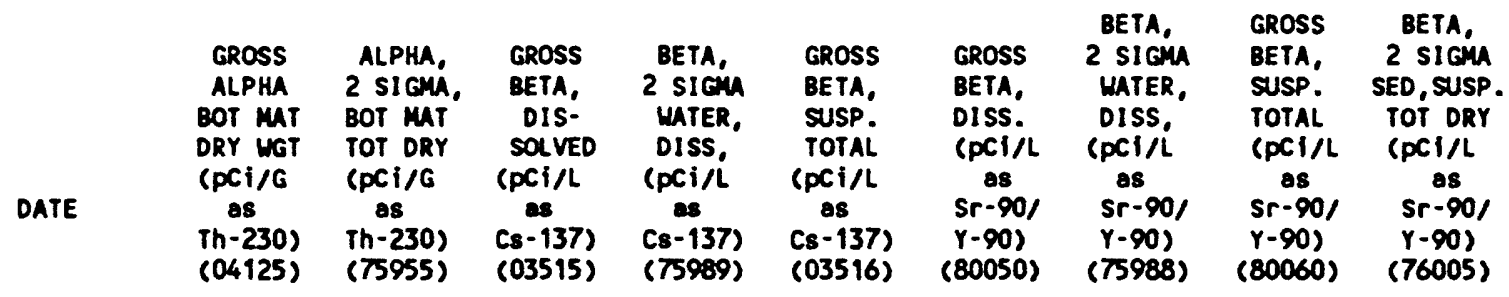

LITTLE COLORADO RIVER AT WOOORUFF, ARIZOWA-COntinued

$09394500 \quad 08-19-89$
$08-19-89$
$08-19-89$
$08-19-89$
$08-19-89$
$08-19-89$
$08-19-89$
$03-05-90$
$04-02-90$
$07-07-90$
$07-07-90$
$07-07-90$
$07-11-90$
$08-16-90$
$08-16-90$
$08-16-90$
$08-16-90$
$08-16-90$
$08-16-90$
$09-11-90$
$09-21-90$
$09-21-90$
$09-21-90$
$09-21-90$
$09-21-90$
$09-21-90$
$09-21-90$
$09-21-90$
$09-21-90$
$09-21-90$
$09-21-90$
$09-21-90$
$09-22-90$
$09-22-90$
$09-22-90$
$09-22-90$
$09-22-90$
$09-22-90$
$01-06-91$
$01-06-91$
$01-06-91$
$01-06-91$
$01-07-91$
$01-08-91$
$03-02-91$
$03-11-91$
$08-28-91$

\begin{tabular}{|c|c|c|}
\hline -- & $\cdots$ & - \\
\hline$\cdots$ & $\cdots$ & - \\
\hline- & - & $\cdots$ \\
\hline -- & - & -- \\
\hline - & -- & 1.5 \\
\hline -- & $\cdots$ & - \\
\hline$\cdots$ & 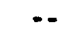 & 4.6 \\
\hline-- & - & $\cdots$ \\
\hline$\cdots$ & $\cdots$ & $\cdots$ \\
\hline$\cdots$ & $\cdots$ & $\cdots$ \\
\hline$\cdots$ & $\cdots$ & 7.3 \\
\hline$\cdots$ & $\cdots$ & $\cdots$ \\
\hline$\because$ & $\because$ & $\cdots$ \\
\hline$\because$ & $\because$ & $\because$ \\
\hline-- & $\ldots$ & -. \\
\hline- & - & - \\
\hline 4 & 6.4 & -. \\
\hline - & $=$ & $\cdots$ \\
\hline-- & $\cdots$ & $\cdots$ \\
\hline$\because$ & $\because$ & $\cdots$ \\
\hline$\because$ & $\cdots$ & $\cdots$ \\
\hline-- & $=$ & $\cdots$ \\
\hline$=$ & -- & $\cdots$ \\
\hline$\because$ & $\cdots$ & -- \\
\hline-- & $\because$ & $\cdots$ \\
\hline$\because$ & $\because$ & $\cdots$ \\
\hline$=$ & $\cdots$ & -- \\
\hline - & -. & -- \\
\hline- & $\cdots$ & $\cdots$ \\
\hline-- & - & $\cdots$ \\
\hline-- & $\cdots$ & $\cdots$ \\
\hline$\cdots$ & $\cdots$ & $\cdots$ \\
\hline$\cdots$ & $\cdots$ & $\cdots$ \\
\hline$\cdots$ & -- & $\cdots$ \\
\hline$\cdot-$ & $\cdots$ & $\cdots$ \\
\hline$-\cdot$ & $\cdots$ & $\cdots$ \\
\hline-- & $\because$ & $\cdots$ \\
\hline$\overline{0}$ & 79 & 30 \\
\hline$\therefore$ & $\begin{array}{l}7.2 \\
-.\end{array}$ & $\begin{array}{l}3.0 \\
. .\end{array}$ \\
\hline - & -. & -. \\
\hline-- & - & -- \\
\hline-- & -- & - \\
\hline-- & - & $\cdots$ \\
\hline$\cdots$ & $\cdots$ & $\cdots$ \\
\hline
\end{tabular}

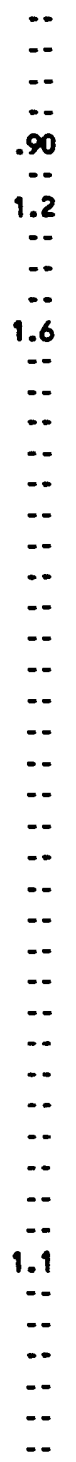

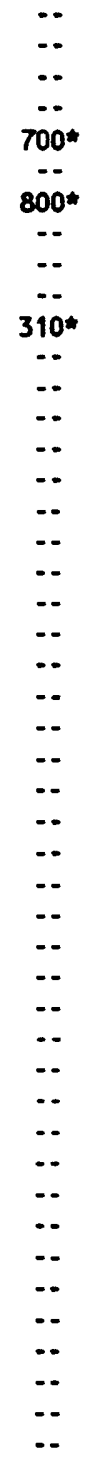

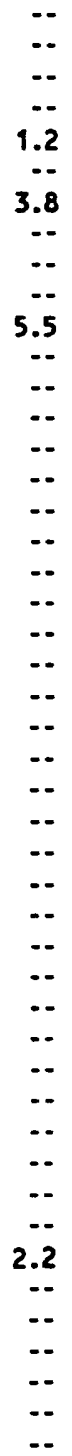

\begin{tabular}{|c|c|c|}
\hline -. & $\cdots$ & $\cdots$ \\
\hline -- & - & $\cdots$ \\
\hline-- & - & $\cdots$ \\
\hline -- & -. & $\cdots$ \\
\hline .70 & $650 *$ & 89 \\
\hline -. & $\cdots$ & 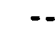 \\
\hline 1.0 & $690^{\circ}$ & 110 \\
\hline$\cdots$ & $\cdots$ & $\cdots$ \\
\hline$=$ & $\cdots$ & $\cdots$ \\
\hline 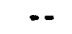 & - & $\cdots$ \\
\hline 1.2 & $280^{*}$ & $\pi 5$ \\
\hline -- & $\cdots$ & $\cdots$ \\
\hline -. & $\cdots$ & $\cdots$ \\
\hline -. & $\cdots$ & $\cdots$ \\
\hline -- & -- & $\cdots$ \\
\hline -- & $\cdots$ & $\cdots$ \\
\hline -- & 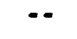 & $\cdots$ \\
\hline-- & -- & -- \\
\hline -- & -- & $\cdots$ \\
\hline 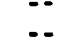 & $\ldots$ & $\because$ \\
\hline -. & $\therefore$ & . \\
\hline -. & -- & $\ldots$ \\
\hline- & -. & $=$ \\
\hline$\cdots$ & -- & $=$ \\
\hline -- & - & -- \\
\hline -- & -- & $\cdots$ \\
\hline-- & -- & $\cdots$ \\
\hline-- & $-\cdot$ & -- \\
\hline-- & $-\cdot$ & -- \\
\hline-- & $\cdots$ & $\cdots$ \\
\hline-- & -- & -- \\
\hline-- & $\because$ & $\because$ \\
\hline$\ldots$ & $\cdots$ & $\cdots$ \\
\hline .. & $\ldots$ & . \\
\hline -. & - & - \\
\hline-- & - & -- \\
\hline -. & $\cdots$ & -- \\
\hline 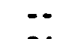 & $\cdots$ & - \\
\hline .86 & 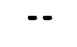 & $\because$ \\
\hline 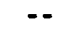 & -- & - \\
\hline$\ddot{--}$ & $=$ & -. \\
\hline- & - & 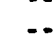 \\
\hline$\cdots$ & -- & \\
\hline-- & -- & \\
\hline
\end{tabular}


STATION

MUMBER

DATE

\begin{tabular}{|c|c|c|c|c|c|c|c|c|}
\hline $\begin{array}{l}\text { GROSS } \\
\text { BETA, } \\
\text { BOT MAT } \\
\text { TOT DRY } \\
\text { (PCi/G } \\
\text { as } \\
\text { Sr-90/ } \\
Y-90) \\
(04102)\end{array}$ & $\begin{array}{c}\text { BETA, } \\
2 \text { SIGMA } \\
\text { BOT MAT } \\
\text { TOT DRY } \\
\text { (PCi/G } \\
\text { as } \\
\text { Sr-90/ } \\
Y-90) \\
(75966)\end{array}$ & $\begin{array}{c}\text { GROSS } \\
\text { BETA, } \\
\text { BOT MAT } \\
\text { TOT DRY } \\
\text { (PCi/G } \\
\text { as } \\
\text { Cs-137) } \\
(99922)\end{array}$ & $\begin{array}{l}\text { BETA, } \\
2 \text { SIGIA } \\
\text { BOT MUT } \\
\text { TOT ORY } \\
\text { (pCi/G } \\
\text { \&s } \\
\text { Cs-137) } \\
(99923)\end{array}$ & $\begin{array}{l}\text { Cs- } 937 \\
\text { SOIL, } \\
\text { TOTAL, } \\
\text { (pCi/G) } \\
(76007)\end{array}$ & $\begin{array}{l}\text { Cs-137 } \\
2 \text { SIGA } \\
\text { SOIL, } \\
\text { TOTAL, } \\
\text { DRY WGT } \\
\text { (pCi/G) } \\
\text { (04103) }\end{array}$ & $\begin{array}{l}\text { Ra-226 } \\
\text { SED, } \\
\text { SUSP, } \\
\text { TOTAL, } \\
\text { DRY WGT } \\
\text { (PCi/G) } \\
\text { (75944) }\end{array}$ & $\begin{array}{l}\text { U-234 } \\
\text { SED, } \\
\text { SUSP, } \\
\text { TOTAL, } \\
\text { DRY WGT } \\
\text { (PCi/G) } \\
\text { (75942) }\end{array}$ & $\begin{array}{l}\text { U-234 } \\
2 \text { SIGMA } \\
\text { SED, } \\
\text { SUSP, } \\
\text { TOTAL, } \\
\text { DRY WGT } \\
\text { (PCi/G) } \\
\text { (75941) }\end{array}$ \\
\hline
\end{tabular}

LITTLE COLORADO RIVER AT WOOORUFF, ARIZOMA-Continued

\begin{tabular}{|c|c|c|c|c|c|c|c|c|c|c|}
\hline \multirow[t]{46}{*}{09394500} & $\begin{array}{l}08-19-89 \\
08-19-89\end{array}$ & -. & 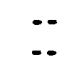 & $\ldots$ & $\cdots$ & 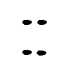 & -. & $\ldots$ & -. & $\begin{array}{l}- \\
\cdots\end{array}$ \\
\hline & $08-19-89$ & .. & $\ldots$ & $\ldots$ & .- & $\ldots$ & -- & $\ldots$ & -- & .. \\
\hline & $08-19-89$ & -. & $\cdots$ & - & -. & -. & -. & -- & $\ldots$ & -. \\
\hline & $08-19-89$ & -. & $\cdots$ & $\ldots$ & -- & .13 & .040 & - & .. & -. \\
\hline & $08-19-89$ & $\cdots$ & $\cdots$ & $\cdots$ & $\cdots$ & -. & - & $\cdots$ & .. & -. \\
\hline & $08-19-89$ & $\cdots$ & -- & $\cdots$ & $\cdots$ & $\cdots$ & -- & $\cdots$ & $\cdots$ & -. \\
\hline & $03-05-90$ & $\cdots$ & $\cdots$ & $\cdots$ & $\cdots$ & $\cdots$ & $\cdots$ & $\cdots$ & $\cdots$ & $\cdots$ \\
\hline & $04-02-90$ & $\cdots$ & $\cdots$ & $\cdots$ & $\cdots$ & $\cdots$ & $\cdots$ & $\cdots$ & $\cdots$ & $\cdots$ \\
\hline & $07-07-90$ & $\cdots$ & $\cdots$ & $\cdots$ & $\cdots$ & $\cdots$ & $\cdots$ & $\cdots$ & $\cdots$ & $\cdots$ \\
\hline & $07-07-90$ & $\cdots$ & $\cdots$ & $\cdots$ & $\cdots$ & $\cdots$ & $-\cdot$ & -- & $\cdots$ & $\cdots$ \\
\hline & $07-07-90$ & $\cdots$ & $\cdots$ & $\cdots$ & $\cdots$ & $\because$ & $\because$ & $\cdots$ & -- & $-\cdot$ \\
\hline & $07-11-90$ & $\cdots$ & $\cdots$ & $-\cdot$ & $\cdots$ & .22 & .070 & $\cdots$ & $\cdots$ & -- \\
\hline & $08-16-90$ & $\cdots$ & $\cdots$ & $\cdots$ & $\cdots$ & $\cdots$ & $\cdots$ & $\cdots$ & $\cdots$ & $\cdots$ \\
\hline & $08-16-90$ & $\cdots$ & $\cdots$ & $\cdots$ & $\cdots$ & $\cdots$ & $\cdots$ & $\cdots$ & $-\cdot$ & -- \\
\hline & $08-16-90$ & $\cdots$ & $\cdots$ & $\cdots$ & $\cdots$ & .17 & .060 & $\cdots$ & $\cdots$ & $\cdots$ \\
\hline & $08-16-90$ & $\cdots$ & $\cdots$ & $\cdots$ & $\cdots$ & $\cdots$ & -- & $\cdots$ & $\cdots$ & $\cdots$ \\
\hline & $08-16-90$ & 25 & 5.5 & 31.70 & 5.50 & -- & $\cdots$ & 1.1 & 1.2 & .30 \\
\hline & $08-16-90$ & $\cdots$ & $\cdots$ & $\cdots$ & $\cdots$ & $\cdots$ & $\cdots$ & $\cdots$ & $\cdots$ & $\cdots$ \\
\hline & $09-11-90$ & $\cdots$ & $\cdots$ & $\because$ & $\cdots$ & $\cdots$ & $\cdots$ & $\cdots$ & -- & $\cdots$ \\
\hline & $09-29-90$ & $\cdots$ & $\cdots$ & $\cdots$ & $\cdots$ & $\cdots$ & $\cdots$ & $\cdots$ & $\cdots$ & $\cdots$ \\
\hline & $09-29-90$ & $\cdots$ & $\cdots$ & $\cdots$ & $\cdots$ & $\cdots$ & $\cdots$ & $\cdots$ & -- & $\cdots$ \\
\hline & $09-21-90$ & $\cdots$ & $\cdots$ & $\cdots$ & $\cdots$ & $\cdots$ & -- & $\cdots$ & -- & $\cdots$ \\
\hline & $09-21-90$ & $\cdots$ & $\cdots$ & $\cdots$ & -- & $\cdots$ & $\cdots$ & $\cdots$ & $\cdots$ & $\cdots$ \\
\hline & $09-29-90$ & $\cdots$ & $\cdots$ & -. & -- & $\cdots$ & $\cdots$ & $\cdots$ & $-\cdot$ & $\cdots$ \\
\hline & $09-29-90$ & $\cdots$ & $\cdots$ & $\cdots$ & $\cdots$ & $\cdots$ & $\cdots$ & $\cdots$ & $\cdots$ & $\cdots$ \\
\hline & $09-29-90$ & $\cdots$ & $\cdots$ & $\cdots$ & $\cdots$ & $\cdots$ & $\cdots$ & $\cdots$ & $\cdots$ & $\cdots$ \\
\hline & $09-21-90$ & $\cdots$ & $\cdots$ & $\cdots$ & $\cdots$ & $\cdots$ & $\cdots$ & $\cdots$ & $\cdots$ & $\cdots$ \\
\hline & $09-21-90$ & $\cdots$ & $\cdots$ & $\cdots$ & $\cdots$ & $\cdots$ & $\cdots$ & $\cdots$ & $\cdots$ & $\cdots$ \\
\hline & $09-21-90$ & $\cdots$ & $\cdots$ & $\cdots$ & 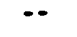 & $\cdots$ & $\cdots$ & $\cdots$ & -- & $\cdots$ \\
\hline & $09-21-90$ & $\cdots$ & $\cdots$ & $\cdots$ & $\cdots$ & $\cdots$ & $\cdots$ & $\cdots$ & $\cdots$ & $\cdots$ \\
\hline & $09-21-90$ & $\cdots$ & $\cdots$ & $\cdots$ & $\cdots$ & $\cdots$ & $\cdots$ & $\cdots$ & $\cdots$ & $\cdots$ \\
\hline & $09-22-90$ & -. & $\cdots$ & $\cdots$ & $-\cdot$ & $\cdots$ & -. & $\cdots$ & $\cdots$ & $\cdots$ \\
\hline & $09-22-90$ & $\cdots$ & $\cdots$ & $\cdots$ & $\cdots$ & $\cdots$ & $\cdots$ & $\cdots$ & $\cdots$ & $\cdots$ \\
\hline & $09-22-90$ & $\cdots$ & $\cdots$ & $\cdots$ & $\cdots$ & $\cdots$ & $\cdots$ & $\cdots$ & $\cdots$ & $\cdots$ \\
\hline & $09-22-90$ & $\cdots$ & $\cdots$ & $\cdots$ & $\cdots$ & $\cdots$ & $\cdots$ & $\cdots$ & $\cdots$ & $\cdots$ \\
\hline & $09-22-90$ & $\cdots$ & $\cdots$ & $\cdots$ & $\cdots$ & $\cdots$ & $\cdots$ & $\cdots$ & $\cdots$ & $\cdots$ \\
\hline & $09-22-90$ & $\cdots$ & $\cdots$ & $\cdots$ & $\cdots$ & $\cdots$ & $\cdots$ & $\cdots$ & $\cdots$ & -. \\
\hline & $09-06-91$ & $\cdots$ & $\cdots$ & $\cdots$ & $\cdots$ & $\cdots$ & $\cdots$ & $\cdots$ & $\cdots$ & -. \\
\hline & $01-06-91$ & $\because$ & $\because$ & $\cdots$ & $\because$ & $\cdots$ & $\cdots$ & $\because$ & $\cdots$ & $\because$ \\
\hline & $01-06-91$ & 18 & 4.6 & 24.00 & 4.62 & $\cdots$ & $\cdots$ & .9 & .8 & .15 \\
\hline & $09-06-99$ & $\cdots$ & $\cdots$ & $\cdots$ & $\cdots$ & $\cdots$ & $\cdots$ & $\cdots$ & $\cdots$ & $\cdots$ \\
\hline & $01-07-91$ & $\cdots$ & $\cdots$ & $\cdots$ & -. & $\cdots$ & 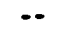 & $\cdots$ & -. & -- \\
\hline & $09-08-91$ & $\cdots$ & $\cdots$ & $\cdots$ & -. & .08 & .050 & $\cdots$ & -- & $\cdots$ \\
\hline & $03-02-99$ & .. & -- & .. & -- & $\ldots$ & -. & $\cdots$ & -. & -. \\
\hline & $03-11-91$ & $\cdots$ & -- & $\cdots$ & -. & $\cdots$ & $\cdots$ & $\cdots$ & -. & $\cdots$ \\
\hline & $08-28-91$ & $\cdots$ & -- & -- & 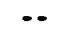 & $\cdots$ & -. & $\cdots$ & -. & $\cdots$ \\
\hline
\end{tabular}


SURFACE-WATER DATA-Continued

CHEMICAL ANALYSES-Continued

STATION

nUMBER

DATE

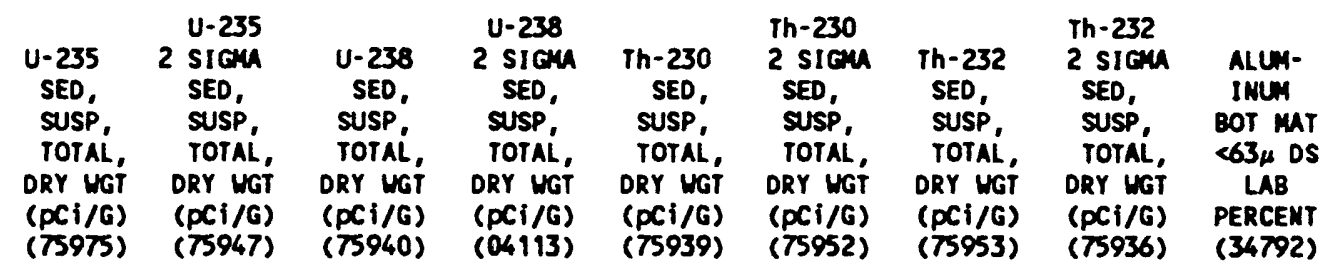

$0939500 \quad 08-19-89$
$08-19-89$
$08-19-89$
$08-19-89$
$08-19-89$
$08-19-89$
$08-19-89$
$03-05-90$
$04-02-90$
$07-07-90$
$07-07-90$
$07-07-90$
$07-11-90$
$08-16-90$
$08-16-90$
$08-16-90$
$08-16-90$
$08-16-90$
$08-16-90$
$09-11-90$
$09-21-90$
$09-21-90$
$09-21-90$
$09-21-90$
$09-21-90$
$09-21-90$
$09-21-90$
$09-21-90$
$09-21-90$
$09-21-90$
$09-21-90$
$09-21-90$
$09-22-90$
$09-22-90$
$09-22-90$
$09-22-90$
$09-22-90$
$09-22-90$
$01-06-91$
$01-06-91$
$01-06-91$
$01-06-91$
$01-07-91$
$01-08-91$
$03-02-91$
$03-11-91$
$08-28-91$

LITTLE COLORADO RIVER AT WOOORUFF, ARIZONA-Continued

\begin{tabular}{|c|c|c|c|c|c|c|c|c|}
\hline .. & -. & $\cdots$ & -. & -. & -. & -- & -. & $\cdots$ \\
\hline . & -- & $\cdots$ & -. & -. & - & $-\cdot$ & - & -. \\
\hline -- & -- & - & -. & -. & -. & -- & $\cdots$ & -. \\
\hline - & $\cdots$ & $\cdots$ & - & -- & $\cdots$ & $\cdots$ & $\cdots$ & $-\cdot$ \\
\hline$\cdots$ & $\cdots$ & $\cdots$ & $\cdots$ & $\cdots$ & $\cdots$ & $\cdots$ & $\cdots$ & -. \\
\hline 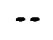 & -. & -. & -. & -. & -. & -. & -. & .. \\
\hline$\cdots$ & -. & $\cdots$ & -- & $\cdots$ & - & -- & -. & -. \\
\hline$\cdots$ & -. & $\cdots$ & $\cdots$ & -- & -- & $\cdots$ & $\cdots$ & -- \\
\hline$\cdots$ & $\cdots$ & $\cdots$ & $\cdots$ & $\cdots$ & $\cdots$ & $\cdots$ & $-\cdot$ & $-\cdot$ \\
\hline$\cdots$ & -- & $\cdots$ & $\cdots$ & $\cdots$ & $\cdots$ & $\because$ & $\cdots$ & $\because$ \\
\hline$\cdots$ & $\cdots$ & $\cdots$ & $\cdots$ & $\cdots$ & $\cdots$ & $\cdots$ & $\cdots$ & 8.2 \\
\hline$\because$ & $\cdots$ & $\cdots$ & $\cdots$ & $\cdots$ & $\cdots$ & $-\cdot$ & $\because$ & $\cdots$ \\
\hline$\because$ & 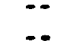 & 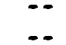 & $\cdots$ & 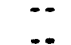 & 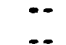 & $\because$ & 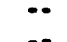 & $\because$ \\
\hline$\ldots$ & $\therefore$ & $\ldots$ & $\therefore$ & $\ldots$ & $\ldots$ & $\because$ & $\because$ & $\begin{array}{r}8.7 \\
\ldots\end{array}$ \\
\hline$\ldots$ & -. & $\cdots$ & -- & -. & .- & -. & .. & .. \\
\hline$\ldots$ & -. & .. & .. & $\ldots$ & .- & .. & -. & 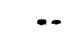 \\
\hline$<.1$ & NO & 1.0 & .23 & 1.0 & .30 & 1.3 & .30 & 9.3 \\
\hline$\cdots$ & 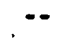 & $\cdots$ & $\cdots$ & $\cdots$ & $\cdots$ & $\cdots$ & $\cdots$ & -. \\
\hline - & $\cdots$ & - & -- & 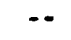 & -. & $\ldots$ & -- & - \\
\hline - & $\cdots$ & $\cdots$ & -. & $\cdots$ & $\cdots$ & -. & -. & 8.2 \\
\hline$\cdots$ & $\cdots$ & $\cdots$ & -- & $\cdots$ & - & -. & $\cdots$ & $\cdots$ \\
\hline$\cdots$ & $\cdots$ & $\cdots$ & -- & $\cdots$ & $\cdots$ & $\cdots$ & $\cdots$ & $\cdots$ \\
\hline$\cdots$ & $\cdots$ & $\cdots$ & $\cdots$ & $\cdots$ & $\cdots$ & $\cdots$ & $\cdots$ & $\cdots$ \\
\hline$\cdots$ & $\cdots$ & $\cdots$ & $\cdots$ & $\cdots$ & $\because$ & $\cdots$ & $\cdots$ & $\cdots$ \\
\hline 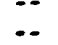 & $\because$ & $\because$ & $\because$ & $\because$ & $\because$ & 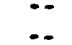 & 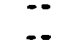 & 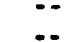 \\
\hline .. & $\ldots$ & .. & $\ldots$ & $\ldots$ & .. & $\ldots$ & $\ldots$ & $\ldots$ \\
\hline -. & -. & -. & - & -. & -. & -. & -. & .. \\
\hline-- & -. & -. & $\ldots$ & -. & -. & - & .. & $\ldots$ \\
\hline -. & - & -. & $\cdots$ & $\cdots$ & -. & - & -. & $\cdots$ \\
\hline -. & $\cdots$ & -. & $\cdots$ & $\cdots$ & -- & $\cdots$ & $\cdots$ & -. \\
\hline$\cdots$ & $\cdots$ & -- & $\cdots$ & $\cdots$ & -. & $\cdots$ & -. & .. \\
\hline$\cdots$ & $\cdots$ & -- & $\cdots$ & $\cdots$ & -. & $\cdots$ & -. & -. \\
\hline-- & $\cdots$ & $\cdots$ & $\cdots$ & $\cdots$ & -- & $\cdots$ & $\cdots$ & 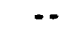 \\
\hline -- & $\cdots$ & $\cdots$ & $\cdots$ & $\cdots$ & $-\cdot$ & -. & -. & - \\
\hline$\cdots$ & $\cdots$ & -- & $\cdots$ & $\cdots$ & $\cdots$ & $\cdots$ & $\cdots$ & $\cdots$ \\
\hline 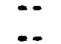 & $\cdots$ & $\because$ & $\cdots$ & $\cdots$ & -- & $\cdots$ & $\cdots$ & -. \\
\hline$\therefore$ & $\cdots$ & $\cdots$ & $\because$ & - & 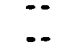 & 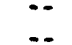 & 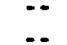 & $\cdots$ \\
\hline$<.1$ & .02 & .9 & .16 & 1.2 & .18 & 1.3 & .18 & 8.0 \\
\hline-- & - & -. & $\cdots$ & $\cdots$ & -. & $\cdots$ & - & -. \\
\hline-- & -- & -- & $\cdots$ & $\cdots$ & -. & $\cdots$ & .. & 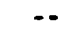 \\
\hline -. & $\cdots$ & $\cdots$ & $\cdots$ & $\cdots$ & -- & -- & 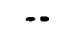 & $\cdots$ \\
\hline -. & - & -- & $\cdots$ & $\cdots$ & -- & $\cdots$ & $-\infty$ & $\cdots$ \\
\hline -. & $\cdots$ & -. & $\cdots$ & -- & $-\cdot$ & $\cdots$ & $\cdots$ & $\cdots$ \\
\hline$\cdots$ & -- & -. & $\cdots$ & $\cdots$ & -. & $\cdots$ & -. & \\
\hline
\end{tabular}


Chemical aMaLYSES-Cont inued

\begin{tabular}{|c|c|c|c|c|c|c|c|c|c|c|}
\hline $\begin{array}{l}\text { STATION } \\
\text { MUABER }\end{array}$ & DATE & $\begin{array}{c}\text { ARSENIC } \\
\text { BOT MAT } \\
<63 \mu \text { DS } \\
\text { LAB } \\
(\mu g / G) \\
(34802)\end{array}$ & $\begin{array}{l}\text { BARIUM } \\
\text { BOT MAT } \\
\angle 63 \mu \text { DS } \\
\text { LAB } \\
(\mu g / G) \\
(34807)\end{array}$ & $\begin{array}{l}\text { BERYL- } \\
\text { LIUM } \\
\text { BOT } \mathrm{MAT} \\
\angle 63_{\mu} \text { DS } \\
\text { LAB } \\
(\mu g / G) \\
(34812)\end{array}$ & $\begin{array}{c}\text { BISIUTH } \\
\text { BOT } \mu A T \\
\angle 63_{\mu} \text { DS } \\
\text { LAB } \\
(\mu g / G) \\
(34817)\end{array}$ & $\begin{array}{c}\text { CADMIUA } \\
\text { BOT MAT } \\
\angle 63_{\mu} \text { DS } \\
\text { LAB } \\
(\mu g / G) \\
(34827)\end{array}$ & $\begin{array}{l}\text { CALCIUH } \\
\text { BOT MAT } \\
\angle 63 \mu \text { DS } \\
\text { LAB } \\
\text { PERCENT } \\
\text { (34832) }\end{array}$ & $\begin{array}{c}\text { CERIUA } \\
\text { BOT } M A T \\
\angle 63 \mu \text { DS } \\
\text { LAB } \\
(\mu g / G) \\
(34837)\end{array}$ & $\begin{array}{l}\text { CHRO- } \\
\text { MIUA } \\
\text { BOT MAT } \\
\angle 63_{\mu} \text { DS } \\
\text { LAB } \\
(\mu g / G) \\
(34842)\end{array}$ & $\begin{array}{c}\text { COBALT } \\
\text { BOT } M A T \\
\angle 63 \mu \text { DS } \\
\text { LAB } \\
(\mu g / G) \\
(34847)\end{array}$ \\
\hline
\end{tabular}

LITTLE COLORADO RIVER AT WOOORUFF, ARIZOMA-Continued

\begin{tabular}{|c|c|c|c|c|c|c|c|c|c|c|}
\hline 09394500 & $\begin{array}{l}08-19-89 \\
08-19-89\end{array}$ & $\cdots$ & $\begin{array}{l}\cdots \\
\cdots\end{array}$ & -. & - & -. & $\cdots$ & -. & -. & 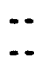 \\
\hline & $08-19-89$ & -. & -. & -. & -. & .. & -. & -. & .. & $\ldots$ \\
\hline & $08-19-89$ & $\cdots$ & -. & $\cdots$ & $\cdots$ & -. & -. & -. & - & -- \\
\hline & $08-19-89$ & $\cdots$ & $\cdots$ & $\cdots$ & $\cdots$ & -. & $\cdots$ & -. & -. & $\cdots$ \\
\hline & $08-19-89$ & - & $\cdots$ & $\cdots$ & $\cdots$ & $\cdots$ & $\cdots$ & -. & -- & $\cdots$ \\
\hline & $08-19-89$ & $\cdots$ & $\cdots$ & $\cdots$ & $\cdots$ & $\cdots$ & $\cdots$ & $\cdots$ & $\cdots$ & $\cdots$ \\
\hline & $03-05-90$ & $\cdots$ & $\cdots$ & $\cdots$ & $\cdots$ & $\cdots$ & $\cdots$ & $\cdots$ & -- & $\cdots$ \\
\hline & $04-02-90$ & $\cdots$ & $\cdots$ & $\cdots$ & $\cdots$ & -. & $\cdots$ & $\cdots$ & $\cdots$ & - \\
\hline & $07-07-90$ & - & $\cdots$ & $\cdots$ & -- & $-\cdot$ & $\cdots$ & -- & -- & - \\
\hline & $07-07-90$ & $<10$ & 670 & 2 & $<10$ & $<2$ & 4.5 & 66 & 49 & 15 \\
\hline & $07-07-90$ & $\cdots$ & $\cdots$ & $\cdots$ & $\cdots$ & $\cdots$ & $\cdots$ & $\cdots$ & $\cdots$ & $\cdots$ \\
\hline & $07-11-90$ & $\cdots$ & $\cdots$ & $\cdots$ & $\cdots$ & - & $\cdots$ & $\cdots$ & $\cdots$ & $\cdots$ \\
\hline & $08-16-90$ & $<10$ & 450 & 2 & $<10$ & $<2$ & 2.1 & 58 & 38 & 13 \\
\hline & $08-16-90$ & $\cdots$ & $\cdots$ & $\cdots$ & $\cdots$ & $\cdots$ & $\cdots$ & $\cdots$ & $\cdots$ & $\cdots$ \\
\hline & $08-16-90$ & -- & $\cdots$ & $\cdots$ & $\cdots$ & $\cdots$ & $\cdots$ & $\cdots$ & $\cdots$ & $\cdots$ \\
\hline & $08-16-90$ & - & $-\cdot$ & - & $\because$ & - & $\cdots$ & $\cdots$ &.- & $\cdots$ \\
\hline & $08-16-90$ & $<10$ & 430 & 2 & $<10$ & $<2$ & 1.6 & 56 & 39 & 13 \\
\hline & $08-16-90$ & $\cdots$ & $\cdots$ & $\cdots$ & $\cdots$ & $\cdots$ & $\cdots$ & $\cdots$ & $\cdots$ & $\cdots$ \\
\hline & $09-11-90$ & $\cdots$ & $\cdots$ & $\cdots$ & $\cdots$ & $\cdots$ & $\cdots$ & $\cdots$ & $\cdots$ & $\cdots$ \\
\hline & $09-29-90$ & $<10$ & 580 & 2 & $<10$ & $<2$ & 3.6 & 58 & 53 & 14 \\
\hline & $09-29-90$ & $\cdots$ & $\cdots$ & $\cdots$ & $\cdots$ & -- & $\cdots$ & $\cdots$ & $\cdots$ & $\cdots$ \\
\hline & $09-29-90$ & $\cdots$ & $\cdots$ & $\cdots$ & $\cdots$ & $\cdots$ & $\cdots$ & $\cdots$ & $\cdots$ & $\cdots$ \\
\hline & $09-21-90$ & $\cdots$ & $-\cdot$ & - & $\because-$ & $\cdots$ & $\cdots$ & $\cdots$ & $-\cdot$ & $\cdots$ \\
\hline & $09-21-90$ & $\cdots$ & $\cdots$ & $\cdots$ & $\cdots$ & -- & $\cdots$ & $\cdots$ & -- & $\cdots$ \\
\hline & $09-21-90$ & $\cdots$ & $\cdots$ & $\cdots$ & $\cdots$ & $\cdots$ & $\cdots$ & $\cdots$ & $\cdots$ & $\cdots$ \\
\hline & $09-21-90$ & $\cdots$ & -- & $\cdots$ & $\cdots$ & $\cdots$ & $\cdots$ & $\cdots$ & $\cdots$ & $\cdots$ \\
\hline & $09-21-90$ & $\cdots$ & $\cdots$ & $\cdots$ & $\cdots$ & $\cdots$ & $\cdots$ & $\cdots$ & $\cdots$ & $\cdots$ \\
\hline & $09-21-90$ & $\cdots$ & $\cdots$ & $\cdots$ & $\cdots$ & $\cdots$ & $\cdots$ & $\cdots$ & $\cdots$ & $\cdots$ \\
\hline & $09-21-90$ & $\cdots$ & -- & $\cdots$ & $\cdots$ & $\cdots$ & $\cdots$ & -. & $\cdots$ & $\cdots$ \\
\hline & $09-21-90$ & $\cdots$ & $\cdots$ & $\cdots$ & $\cdots$ & $\cdots$ & $\cdots$ & $\cdots$ & $\cdot-$ & $\cdots$ \\
\hline & $09-21-90$ & $\cdots$ & -- & - & $-\cdot$ & $\cdots$ & $\cdots$ & $\cdots$ & $\cdots$ & $\cdots$ \\
\hline & $09-22-90$ & $\cdots$ & $\cdots$ & $\cdots$ & $\cdots$ & $\cdots$ & $\cdots$ & $\cdots$ & $\cdots$ & $\cdots$ \\
\hline & $09-22-90$ & $\cdots$ & $\cdots$ & $\cdots$ & $\cdots$ & $\cdots$ & $\cdots$ & $\cdots$ & $\cdots$ & $\cdots$ \\
\hline & $09-22-90$ & $\cdots$ & $\cdots$ & $\cdots$ & $\cdots$ & $\cdots$ & -- & $\cdots$ & $\cdots$ & $\cdots$ \\
\hline & $09-22-90$ & $\cdots$ & $\cdots$ & $\cdots$ & $\cdots$ & $\cdots$ & $\cdots$ & $\cdots$ & $\cdots$ & $\cdots$ \\
\hline & $09-22-90$ & - & -- & $\cdots$ & $\cdots$ & $\cdots$ & $\cdots$ & $\cdots$ & $\cdots$ & $\cdots$ \\
\hline & $09-22-90$ & $\cdots$ & $\cdots$ & - & $\cdots$ & $\cdots$ & $\cdots$ & $\cdots$ & $\cdots$ & $\cdots$ \\
\hline & $01-06-91$ & $\cdots$ & $\cdot-$ & $\cdots$ & $\cdots$ & $\cdots$ & $\cdots$ & $\cdots$ & $\cdots$ & $\cdots$ \\
\hline & $01-06-91$ & $\cdots$ & $-\cdot$ & $\cdots$ & -. & $\cdots$ & $\cdots$ & $\cdots$ & $\cdots$ & $\cdots$ \\
\hline & $01-06-91$ & $<10$ & 500 & 2 & $<10$ & $<2$ & 3.0 & 64 & 50 & 12 \\
\hline & $01-06-91$ & $\cdots$ & -- & $\cdots$ & $\cdots$ & $\cdots$ & $\cdots$ & $\cdots$ & $\cdots$ & $\cdots$ \\
\hline & $01-07-91$ & $\cdots$ & $\cdots$ & $\cdots$ & $\cdots$ & $\cdots$ & $\cdots$ & $\cdots$ & $\cdots$ & $\cdots$ \\
\hline & $01-08-91$ & $\cdots$ & $-\cdot$ & $\cdots$ & $\cdots$ & -- & $\cdots$ & $\cdots$ & $\cdots$ & $\cdots$ \\
\hline & $03-02-91$ & $\cdots$ & $-\cdot$ & $\cdots$ & 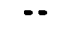 & $\cdots$ & $\cdots$ & $\cdots$ & $\cdots$ & $\cdots$ \\
\hline & $03-11-91$ & $\cdots$ & -. & $\cdots$ & $\cdots$ & $\cdots$ & $\cdots$ & $\cdots$ & $-\cdot$ & $\cdots$ \\
\hline & $08-28-91$ & - & $\cdots$ & $\cdots$ & $\cdots$ & $\cdots$ & $\cdots$ & $\cdots$ & $\cdots$ & . \\
\hline
\end{tabular}


SURFACE-MATER DATA-Cont inued

CHEMICAL ANALYSES-Continued

\begin{tabular}{|c|c|c|c|c|c|c|c|c|c|c|}
\hline $\begin{array}{l}\text { STATION } \\
\text { NUMBER }\end{array}$ & DATE & $\begin{array}{c}\text { COPPER } \\
\text { BOT MAT } \\
\angle 63_{\mu} \text { DS } \\
\text { LAB } \\
(\mu g / 6) \\
(34852)\end{array}$ & $\begin{array}{c}\text { EURO- } \\
\text { PIUH } \\
\text { BOT MAT } \\
\angle 63 \mu \text { DS } \\
\text { LAB } \\
(\mu g / 6) \\
(34857)\end{array}$ & $\begin{array}{c}\text { GALLIUA } \\
\text { BOT MAT } \\
\angle 63_{\mu} \text { DS } \\
\text { LAB } \\
(\mu g / G) \\
(34862)\end{array}$ & $\begin{array}{c}\text { COLD } \\
\text { BOT MAT } \\
\angle 63_{\mu} \text { DS } \\
\text { LAB } \\
(\mu g / 6) \\
(34872)\end{array}$ & $\begin{array}{c}\text { HOLMIUA } \\
\text { BOT MAT } \\
\angle 63_{\mu} \text { DS } \\
\text { LAB } \\
(\mu g / G) \\
(34877)\end{array}$ & $\begin{array}{l}\text { IRON } \\
\text { BOT MAT } \\
\angle 63_{\mu} \text { DS } \\
\text { LAB } \\
\text { PERCENT } \\
\text { (34882) }\end{array}$ & $\begin{array}{c}\text { LATHA- } \\
\text { MUM } \\
\text { 80T MAT } \\
\angle 63_{\mu} \text { DS } \\
\text { LAB } \\
(\mu g / G) \\
(34887)\end{array}$ & $\begin{array}{c}\text { LEAD } \\
\text { BOT MAT } \\
\angle 63_{\mu} \text { DS } \\
\text { LAB } \\
(\mu g / G) \\
(34892)\end{array}$ & $\begin{array}{c}\text { LITHIUN } \\
80 T \text { MAT } \\
\angle 63 \mu \text { DS } \\
\text { LAB } \\
(\mu g / 6) \\
(34897)\end{array}$ \\
\hline
\end{tabular}

$09394500 \quad 08-19-89$
$08-19-89$
$08-19-89$
$08-19-89$
$08-19-89$
$08-19-89$
$08-19-89$
$03-05-90$
$04-02-90$
$07-07-90$
$07-07-90$
$07-07-90$
$07-11-90$
$08-16-90$
$08-16-90$
$08-16-90$
$08-16-90$
$08-16-90$
$08-16-90$
$09-11-90$
$09-21-90$
$09-21-90$
$09-21-90$
$09-21-90$
$09-21-90$
$09-21-90$
$09-21-90$
$09-21-90$
$09-21-90$
$09-21-90$
$09-21-90$
$09-21-90$
$09-22-90$
$09-22-90$
$09-22-90$
$09-22-90$
$09-22-90$
$09-22-90$
$01-06-91$
$01-06-91$
$01-06-91$
$01-06-91$
$01-07-91$
$01-08-91$
$03-02-91$
$03-11-91$
$08-28-91$

LITTLE COLORADO RIVER AT HOOORUFF, ARIZOMA-COntinued

\begin{tabular}{|c|c|c|c|c|c|c|c|c|}
\hline$\cdots$ & $\cdots$ & $\cdots$ & $\cdots$ & $\cdots$ & -. & $\cdots$ & $\cdots$ & -. \\
\hline$\cdots$ & $\cdots$ & $\cdots$ & $\cdots$ & $\cdots$ & -- & $\cdots$ & $\cdots$ & $\cdots$ \\
\hline$\cdots$ & $\cdots$ & $\cdots$ & $\cdots$ & $\cdots$ & $\cdots$ & $\cdots$ & $\cdots$ & -. \\
\hline$\cdots$ & $\cdots$ & $\cdots$ & $\cdots$ & $\cdots$ & -- & $\cdots$ & $\cdots$ & -. \\
\hline$\cdots$ & $\cdots$ & $\cdots$ & $\cdots$ & $\cdots$ & $\cdots$ & $\cdots$ & $\cdots$ & $\cdots$ \\
\hline$\because$ & $\cdots$ & $\cdots$ & $\cdots$ & -- & $\cdots$ & $\cdots$ & $\cdots$ & $\cdots$ \\
\hline$\cdots$ & $\cdots$ & $\cdots$ & $\cdots$ & $\cdots$ & $\cdots$ & $\cdots$ & $\cdots$ & $\cdots$ \\
\hline$\cdots$ & $\cdots$ & $\cdots$ & $\cdots$ & $\cdots$ & $\cdot-$ & $\cdots$ & $\cdots$ & $\cdots$ \\
\hline$\cdots$ & $\cdots$ & $\cdots$ & $\cdots$ & $\cdots$ & $\cdots$ & $\cdots$ & $\cdots$ & $\cdots$ \\
\hline 29 & $<2$ & $\ddot{18}$ & 88 & $\ddot{<4}$ & $\ddot{3.5}$ & $\ddot{38}$ & $\ddot{28}$ & $\ddot{42}$ \\
\hline -. & -. & -. & $\cdots$ & -. & -. & - & $\ldots$ & $\begin{array}{l}42 \\
\ldots-\end{array}$ \\
\hline$\cdots$ & $\cdots$ & $\cdots$ & $\cdots$ & $\cdots$ & $\cdots$ & $\cdots$ & $\cdots$ & -. \\
\hline 16 & $<2$ & 19 & $<8$ & $<4$ & 3.2 & 32 & 16 & 32 \\
\hline$\cdots$ & $\cdots$ & $\cdots$ & $\cdots$ & -- & $\cdots$ & $\cdots$ & $\cdots$ & $\cdots$ \\
\hline$\cdots$ & $\cdots$ & $\cdots$ & $\cdots$ & $\cdots$ & $\cdots$ & -. & $\cdots$ & $\cdots$ \\
\hline$\cdots$ & $\cdots$ & $\cdots$ & $\cdots$ & $\cdots$ & $\cdots$ & $\cdots$ & $\cdots$ & $\cdots$ \\
\hline 18 & $<2$ & 21 & $<8$ & $<4$ & 3.4 & 31 & 17 & 33 \\
\hline$\cdots$ & $\cdots$ & $\cdots$ & $\cdots$ & $\cdots$ & $\cdots$ & $\cdots$ & $\cdots$ & $\cdots$ \\
\hline$\cdots$ & $\cdots$ & $\cdots$ & $\cdots$ & $\cdots$ & $\cdots$ & $\cdots$ & $\cdots$ & -. \\
\hline 26 & $<2$ & 18 & $<8$ & $<4$ & 3.3 & 36 & 21 & 38 \\
\hline$\cdots$ & $\cdots$ & $\cdots$ & $\cdots$ & $\cdots$ & 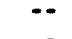 & $\cdots$ & $\cdots$ & $\cdots$ \\
\hline -- & $\cdots$ & $\cdots$ & $\cdots$ & $\cdots$ & $\cdots$ & $\cdots$ & $\because-$ & $\cdots$ \\
\hline$\cdots$ & $\cdots$ & 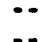 & $\cdots$ & $\cdots$ & $\because$ & $\cdots$ & $\cdots$ & $\cdots$ \\
\hline$\cdots$ & $\cdots$ & 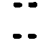 & $\ldots$ & $\ddot{\cdots}$ & $\because$ & $\ldots$ & $\ldots$ & 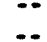 \\
\hline$\cdots$ & $\cdots$ & $\ldots$ & $\ldots$ & $\cdots$ & & $\ldots$ & 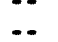 & $\ldots$ \\
\hline$\cdots$ & $\ldots$ & .. & $\ldots$ & $\ldots$ & .. & $\ldots$ & $\ldots$ & .. \\
\hline .. & - & -. & $\ldots$ & .. & -. & .. & $\ldots$ & .. \\
\hline -. & $\cdots$ & $\cdots$ & $\cdots$ & -. & - & - & $\cdots$ & .. \\
\hline - & $\cdots$ & $\cdots$ & $\cdots$ & -. & -- & .. & -. & .. \\
\hline -- & $\cdots$ & $\cdots$ & $\cdots$ & $\cdots$ & -. & $\cdots$ & - & $\cdots$ \\
\hline$\cdots$ & $\cdots$ & $\cdots$ & $\cdots$ & $\cdots$ & -- & $\cdots$ & $\cdots$ & $\cdots$ \\
\hline$\cdots$ & $\cdots$ & $\cdots$ & $\cdots$ & $\cdots$ & $\cdots$ & $\cdots$ & $\cdots$ & $\because$ \\
\hline$\cdots$ & $\cdots$ & $\cdots$ & $\cdots$ & $\cdots$ & $\cdots$ & $\cdots$ & $\cdots$ &. \\
\hline$\cdots$ & $\cdots$ & $\because$ & $\cdots$ & $\because$ & $-\cdot$ & 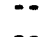 & $\cdots$ & $\cdot$ \\
\hline$\cdots$ & 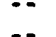 & $\cdots$ & $\cdots$ & $\because$ & $\because$ & 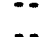 & $\cdots$ & - \\
\hline$\because$ & $\cdots$ & $\cdots$ & 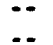 & $\because$ & $\because$ & $\cdots$ & 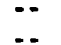 & $\because$ \\
\hline$\because$ & $\ldots$ & .. & 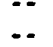 & $\cdots$ & 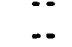 & $\ldots$ & 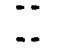 & 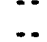 \\
\hline 20 & $<2$ & 19 & 48 & $<4$ & 3.0 & 34 & 17 & 31 \\
\hline -. & $\cdots$ & $\cdots$ & $\cdots$ & $\cdots$ & $\cdots$ & -. & $\cdots$ & $\cdots$ \\
\hline$\cdots$ & $\cdots$ & $\cdots$ & $\cdots$ & $\cdots$ & - & -. & 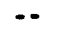 & - \\
\hline$\cdots$ & $\cdots$ & $\cdots$ & $\cdots$ & $\cdots$ & $\cdots$ & $\cdots$ & $\cdots$ & 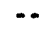 \\
\hline$\cdots$ & $\cdots$ & $\cdots$ & $\cdots$ & $\cdots$ & $\cdots$ & $\cdots$ & $\cdots$ & 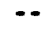 \\
\hline$\cdots$ & $\cdots$ & $\cdots$ & $\cdots$ & $\cdots$ & $\cdots$ & $\cdots$ & $\cdots$ & \\
\hline & $\cdots$ & $\cdots$ & $\cdots$ & $\cdots$ & 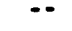 & $\cdots$ & $\cdots$ & \\
\hline
\end{tabular}


SURFACE-WATER DATA-Continued

CHEMICAL AMALYSES-Continued

\begin{tabular}{|c|c|c|c|c|c|c|c|c|c|c|}
\hline $\begin{array}{l}\text { TATION } \\
\text { UMBER }\end{array}$ & DATE & $\begin{array}{l}\text { MAGNE- } \\
\text { SIUA } \\
\text { BOT MAT } \\
\text { C63H DS } \\
\text { LAB } \\
\text { PERCENT } \\
\text { (34902) }\end{array}$ & $\begin{array}{l}\text { MANGA- } \\
\text { NESE } \\
\text { BOT NAT } \\
\angle 63 \mu \text { DS } \\
\text { LAB } \\
(\mu \sigma / G) \\
(34907)\end{array}$ & $\begin{array}{c}\text { MOLYB- } \\
\text { DENUN } \\
\text { BOT MAT } \\
\angle 63 \mu \text { DS } \\
\text { LAB } \\
(\mu g / G) \\
(34917)\end{array}$ & $\begin{array}{l}\text { MECOYH- } \\
\text { IUN } \\
\text { BOT MAT } \\
\angle 63 \mu \text { DS } \\
\text { LAB } \\
(\mu g / G) \\
(34922)\end{array}$ & $\begin{array}{l}\text { NICKEL } \\
\text { BOT MAT } \\
\angle 63 \mu \text { DS } \\
\text { LAB } \\
(\mu \sigma / G) \\
(34927)\end{array}$ & $\begin{array}{c}\text { MIOBIUN } \\
\text { BOT MAT } \\
\angle 63 \mu \text { DS } \\
\text { LAB } \\
(\mu g / G) \\
(34932)\end{array}$ & $\begin{array}{l}\text { PHOS- } \\
\text { PHORUS } \\
\text { BOT MAT } \\
\angle 63_{\mu} \text { DS } \\
\text { LAB } \\
\text { PERCENT } \\
\text { (34937) }\end{array}$ & $\begin{array}{l}\text { POTAS- } \\
\text { SIUN } \\
\text { BOT MAT } \\
\angle 63 \mu \text { DS } \\
\text { LAB } \\
\text { PERCENT } \\
(34942)\end{array}$ & $\begin{array}{c}\text { SCAN- } \\
\text { DIUN } \\
\text { BOT MTT } \\
663_{\mu} \text { DS } \\
\text { LA8 } \\
(\mu 9 / G) \\
(34947)\end{array}$ \\
\hline
\end{tabular}

$09394500 \quad 08-19-89$
$08-19-89$
$08-19-89$
$08-19-89$
$08-19-89$
$08-19-89$
$08-19-89$
$03-05-90$
$04-02-90$
$07-07-90$
$07-07-90$
$07-07-90$
$07-11-90$
$08-16-90$
$08-16-90$
$08-16-90$
$08-16-90$
$08-16-90$
$08-16-90$
$09-11-90$
$09-21-90$
$09-21-90$
$09-21-90$
$09-21-90$
$09-21-90$
$09-21-90$
$09-21-90$
$09-21-90$
$09-21-90$
$09-21-90$
$09-21-90$
$09-21-90$
$09-22-90$
$09-22-90$
$09-22-90$
$09-22-90$
$09-22-90$
$09-22-90$
$01-06-91$
$01-06-91$
$01-06-91$
$01-06-91$
$01-07-91$
$01-08-91$
$03-02-91$
$03-11-91$
$08-28-91$

LITTLE COLORADO RIVER AT WOOORUFF, ARIZONA-COntinued

\begin{tabular}{|c|c|c|c|c|c|c|c|c|}
\hline$\cdots$ & - & $\cdots$ & $\cdots$ & - & - & - & $\cdots$ & $\cdots$ \\
\hline$\cdots$ & $\cdots$ & $\cdots$ & $\cdots$ & $\cdots$ & -. & $\cdots$ & $\cdots$ & $\cdots$ \\
\hline$\cdots$ & - & $\cdots$ & $\cdots$ & - & -- & $\cdots$ & $\cdots$ & $\cdots$ \\
\hline$\cdots$ & $\cdots$ & $\cdots$ & $\cdots$ & -. & -. & $\cdots$ & $\cdots$ & $\cdots$ \\
\hline$\cdots$ & $\cdots$ & $\cdots$ & $\cdots$ & $\cdots$ & $\cdots$ & -- & $\cdots$ & $\cdots$ \\
\hline$\cdots$ & $\cdots$ & $\cdots$ & $\cdots$ & $\cdots$ & $\cdots$ & -- & $\cdots$ & $\cdots$ \\
\hline$\cdots$ & $\cdots$ & $\cdots$ & $\cdots$ & $\cdots$ & $\cdots$ & $\cdots$ & $\cdots$ & $\cdots$ \\
\hline$\cdots$ & $\cdots$ & $\cdots$ & $\cdots$ & $\cdots$ & $\cdots$ & $\because$ & $\because$ & $\cdots$ \\
\hline$\because$ & $\because$ & $\ldots$ & 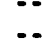 & $\ldots$ & $\cdots$ & $\cdots$ & $\because$ & $\because$ \\
\hline 2.0 & 770 & $<2$ & 31 & 22 & 8 & .08 & 2.3 & 13 \\
\hline$\cdots$ & $\cdots$ & $\cdots$ & -. & -. & -. & $\because$ & $\cdots$ & $\cdots$ \\
\hline$\cdots$ & - & $\cdots$ & - & -- & -- & -- & $\cdots$ & 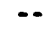 \\
\hline 1.8 & 520 & $<2$ & 26 & 19 & 8 & .04 & 1.5 & 12 \\
\hline$\cdots$ & $\cdots$ & -. & $\cdots$ & -. & -. & $\cdots$ & $\cdots$ & $\cdots$ \\
\hline$\cdots$ & $\cdots$ & $\cdots$ & -. & -. & $\cdots$ & $\cdots$ & $\cdots$ & $\cdots$ \\
\hline$\cdots$ & $\cdots$ & $\cdots$ & 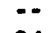 & $\cdots$ & $\cdots$ & $\cdots$ & $\because$ & $\cdots$ \\
\hline 1.9 & 480 & $<2$ & 26 & 26 & 9 & .04 & 1.5 & 13 \\
\hline$\cdots$ & $\cdots$ & $\cdots$ & $\cdots$ & $\cdots$ & $\cdots$ & $\cdots$ & - & $\cdots$ \\
\hline$\because$ & 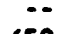 & $\cdots$ & $\ddot{a}$ & $\ddot{n}$ & 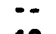 & $\ddot{n}$ & $\cdots$ & $\because$ \\
\hline 1.8 & 650 & $<2$ & 28 & 24 & 10 & .06 & 1.9 & 12 \\
\hline$\cdots$ & $\ldots$ & $\because$ & $\cdots$ & $\cdots$ & $\cdots$ & $\cdots$ & $\because$ & $\because$ \\
\hline$\ldots$ & $\ldots$ & 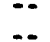 & $\ldots$ & $\ldots$ & $\ldots$ & $\ldots$ & $\ldots$ & -8 \\
\hline -. & -. & -. & -. & .. & .. & -. & - & 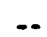 \\
\hline$\cdots$ & -. & -. & $\ldots$ & .. & -. & $\ldots$ & -. & - \\
\hline - & -. & -. & -. & .. & -. & $\ldots$ & . & 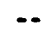 \\
\hline$\cdots$ & -. & -. & -. & -. & -. & - & - & .. \\
\hline$\cdots$ & $\cdots$ & -. & $\cdots$ & $\cdots$ & -. & $\cdots$ & - & -. \\
\hline$\cdots$ & $\cdots$ & $\cdots$ & $\cdots$ & $\cdots$ & -- & $\cdots$ & - & -. \\
\hline$\cdots$ & 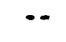 & - & -- & - & $\cdots$ & $\cdots$ & -- & -. \\
\hline$\cdots$ & $\cdots$ & $\cdots$ & $\cdots$ & $\cdots$ & $\cdots$ & $\cdots$ & $\cdots$ & - \\
\hline$\cdots$ & $\cdots$ & $\cdots$ & -- & $\cdots$ & -. & $\cdots$ & -- & - \\
\hline$\cdots$ & -- & $\cdots$ & -- & -. & -. & $\cdots$ & $\cdots$ & $\cdots$ \\
\hline$\cdots$ & $\cdots$ & $\cdots$ & -. & $\cdots$ & -. & $\cdots$ & - & - \\
\hline$\cdots$ & $\cdots$ & -- & $\cdots$ & $\cdots$ & $\cdots$ & $\cdots$ & $\cdots$ & $\cdots$ \\
\hline - & $\cdots$ & $\cdots$ & $\cdots$ & $\cdots$ & $\cdots$ & $\cdots$ & $\cdots$ & $\cdots$ \\
\hline$\cdots$ & $\cdots$ & $\cdots$ & $\cdots$ & $\cdots$ & $\cdots$ & $\cdots$ & $\cdots$ & -- \\
\hline- & $\cdots$ & $\cdots$ & $\cdots$ & $\cdots$ & $\cdots$ & - & $\cdots$ & $\cdots$ \\
\hline$\because$ & $\ddot{3}$ & 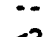 & $\ddot{m}$ & $\bar{x}$ & 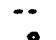 & $\ddot{a r}$ & $\because$ & 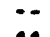 \\
\hline 1.7 & 630 & $<2$ & 28 & 23 & 8 & .05 & 1.5 & 11 \\
\hline$\cdots$ & $\because$ & $\cdots$ & $\cdots$ & 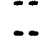 & $\because-$ & 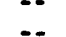 & $\therefore$ & $\cdots$ \\
\hline - & $\ldots$ & $\ldots$ & $\ldots$ & $\ldots$ & $\ldots$ & $\ldots$ & $\cdots$ & $\cdots$ \\
\hline .. & .. & .. & $\ldots$ & .. & $\ldots$ & $\ldots$ & $\ldots$ & 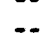 \\
\hline$\bullet$ & $\cdots$ & $\cdots$ & $\cdots$ & $\ldots$ & - & -. & $\ldots$ & \\
\hline & & $\cdots$ & - & - & - & $\cdots$ & 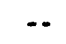 & \\
\hline
\end{tabular}


MUMBER

STATION

DAte

$08-19-89$

09394500

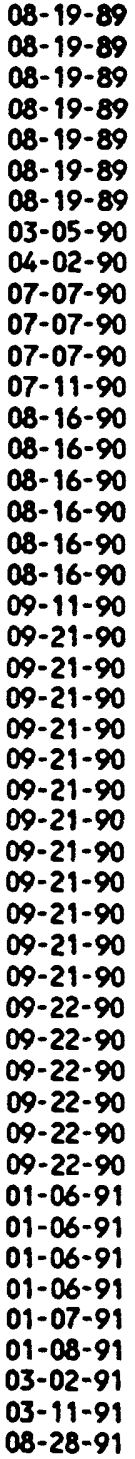

\begin{tabular}{|c|c|c|c|c|c|c|c|c|}
\hline $\begin{array}{l}\text { SILVER } \\
\text { BOT MAT } \\
\angle 63 \mu \text { DS } \\
\text { LAB } \\
(\mu \sigma / G) \\
(34957)\end{array}$ & $\begin{array}{l}\text { SODIUA } \\
\text { BOT MAT } \\
\angle 63_{\mu} \text { DS } \\
\text { LAB } \\
\text { PERCENT } \\
\text { (34962) }\end{array}$ & $\begin{array}{c}\text { STRON- } \\
\text { TIUM } \\
\text { BOT MAT } \\
\angle 63 \mu \text { DS } \\
\text { LAB } \\
(\mu g / G) \\
(34967)\end{array}$ & $\begin{array}{l}\text { TANTA- } \\
\text { LUM } \\
\text { BOT MAT } \\
<63 \mu \text { DS } \\
\text { LAB } \\
(\mu 9 / G) \\
(34977)\end{array}$ & $\begin{array}{c}\text { THORIUN } \\
\text { BOT MAT } \\
\angle 63 \mu \text { DS } \\
\text { LAB } \\
(\mu \sigma / G) \\
(34982)\end{array}$ & $\begin{array}{c}\text { TIM } \\
80 T \text { MAT } \\
\angle 63_{\mu} \text { DS } \\
\text { LAB } \\
(\mu g / G) \\
(34987)\end{array}$ & $\begin{array}{l}\text { TITA- } \\
\text { HIUM } \\
\text { BOT KAT } \\
\angle 63 \mu \text { DS } \\
\text { LAB } \\
\text { PERCENT } \\
\text { (34992) }\end{array}$ & $\begin{array}{c}\text { URANIUM } \\
\text { BOT MAT } \\
\angle 63_{\mu} \text { DS } \\
\text { LAB } \\
(\mu \sigma / G) \\
(35002)\end{array}$ & $\begin{array}{c}\text { VAMA- } \\
\text { DIUM } \\
\text { BOT MAT } \\
<63 \mu \text { DS } \\
\text { LAB } \\
(\mu 9 / G) \\
(35007)\end{array}$ \\
\hline
\end{tabular}

LITTLE COLORADO RIVER AT WOOORUFF, ARIZONA-Continued

\begin{tabular}{|c|c|c|c|c|c|c|c|c|}
\hline - & $\cdots$ & $\cdots$ & $\cdots$ & $\cdots$ & $\cdots$ & $\cdots$ & $\cdots$ & $\cdots$ \\
\hline$\cdots$ & $\cdots$ & $\cdots$ & $\cdots$ & $\cdots$ & $\cdots$ & $\cdots$ & $\cdots$ & $\cdots$ \\
\hline .. & $\cdots$ & $\cdots$ & -- & -. & -- & - & $\cdots$ & $\cdots$ \\
\hline - & -. & - & -. & .. & -. & - & - & $\cdots$ \\
\hline -. & $\ldots$ & . & - & -. & -. & - & $\cdots$ & - \\
\hline -. & -. & -. & $\ldots$ & -. & -. & - & $\cdots$ & $\cdots$ \\
\hline$\cdots$ & $\cdots$ & $\cdots$ & $\cdots$ & -. & -. & $\cdots$ & $\cdots$ & $\cdots$ \\
\hline$\cdots$ & $\cdots$ & $\cdots$ & $\cdots$ & $\cdots$ & $\cdots$ & $\cdots$ & $\cdots$ & $\cdots$ \\
\hline$\ldots$ & $\cdots$ & $\cdots$ & -. & -. & - & .. & $\cdots$ & $\cdots$ \\
\hline$\cdots$ & $\cdots$ & $\because$ & 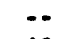 & - & $\cdots$ & $\cdots$ & $\cdots$ & 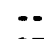 \\
\hline$<4$ & .24 & 190 & $<40$ & 13 & $<10$ & .33 & $<100$ & 87 \\
\hline - & $\cdots$ & .. & $\cdots$ & -. & -. & $\cdots$ & $\cdots$ & $\cdots$ \\
\hline .. & -. & $\cdots$ & -. & -. & .. & .. & -. & .. \\
\hline$<4$ & .65 & 350 & $<40$ & 12 & $<10$ & .31 & $<100$ & 73 \\
\hline 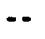 & $\cdots$ & $\cdots$ & -. & .. & -- & $\cdots$ & -. & $\cdots$ \\
\hline$\cdots$ & $\cdots$ & -. & $\cdots$ & $\cdots$ & $\cdots$ & $\cdots$ & $\cdots$ & $\cdots$ \\
\hline - & $\cdots$ & $\cdots$ & -. & -. & $\cdots$ & -. & $\cdots$ & - \\
\hline$<4$ & .62 & 370 & $<40$ & 13 & $<10$ & .30 & $<100$ & 76 \\
\hline$\ldots$ & $\cdots$ & - & -. & $\ldots$ & -. & .. & $\cdots$ & . \\
\hline .. & $\ldots$ & .. & .. & .. & -. & -. & - & - \\
\hline$<4$ & .38 & 270 & $<40$ & 12 & $<5$ & .29 & $<100$ & 80 \\
\hline-- & $\cdots$ & $\cdots$ & $\cdots$ & $\cdots$ & $\cdots$ & $\cdots$ & $\cdots$ & -. \\
\hline- & $\cdots$ & $\cdots$ & $\cdots$ & $\cdots$ & -. & $\cdots$ & $\cdots$ & $\cdots$ \\
\hline$\cdots$ & $\cdots$ & $\cdots$ & -. & $\cdots$ & $\cdots$ & -. & $\cdots$ & -. \\
\hline$\cdots$ & $\cdots$ & $\cdots$ & -- & $\cdots$ & $\cdots$ & -- & $\cdots$ & $\cdots$ \\
\hline - & $\cdots$ & 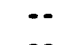 & $\cdots$ & $\cdots$ & $\because$ & 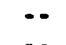 & $\cdots$ & $\cdots$ \\
\hline-- & $\cdots$ & $\cdots$ & -. & $\cdots$ & $-\cdot$ & $\because$ & $\cdots$ & $\cdots$ \\
\hline$\cdots$ & $\cdots$ & $-\cdot$ & -- & $\cdots$ & -- & -. & $\cdots$ & $\cdots$ \\
\hline$\therefore$ & $\cdots$ & 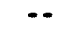 & $\cdots$ & $\cdots$ & $\cdots$ & -- & $\cdots$ & $\cdots$ \\
\hline$\cdots$ & $\cdots$ & $\cdots$ & $\cdots$ & $\cdots$ & $\because$ & - & $\cdots$ & $\cdots$ \\
\hline-- & $\cdots$ & $\cdots$ & - & $\cdots$ & 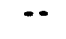 & $\cdots$ & $\cdots$ & $\cdots$ \\
\hline$\cdots$ & $\cdots$ & $\cdots$ & - & $\cdots$ & $\cdots$ & $\cdots$ & $\cdots$ & $\cdots$ \\
\hline$\cdots$ & $\cdots$ & $\cdots$ & $\cdots$ & $\cdots$ & $\cdots$ & $\cdots$ & $\cdots$ & $\cdots$ \\
\hline$\cdots$ & $\cdots$ & $\because$ & $\because$ & $\cdots$ & $\because$ & $\because$ & $\cdots$ & $\cdots$ \\
\hline$\cdots$ & $\cdots$ & $\because$ & $\cdots$ & $\cdots$ & $\because$ & $\cdots$ & $\cdots$ & $\cdots$ \\
\hline$\ldots$ & $\ldots$ & .. & $\ldots$ & .. & $\therefore$ & $\therefore$ & $\cdots$ & $\ldots$ \\
\hline -. & $\cdots$ & $\cdots$ & .. & $\cdots$ & -. & -. & -. & - \\
\hline -- & $\cdots$ & - & - & -. & -. & -. & -. & -. \\
\hline-- & $\cdots$ & - & -. & $\cdots$ & .. & -. & $\cdots$ & -- \\
\hline$<4$ & .70 & 330 & $<40$ & 12 & $<5$ & .33 & $<100$ & 73 \\
\hline - & $\cdots$ & $\cdots$ & - & $\cdots$ & -. & - & $\cdots$ & - \\
\hline$\cdots$ & $\cdots$ & $\cdots$ & $-\cdot$ & $\cdots$ & -- & $\cdots$ & $\cdots$ & 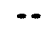 \\
\hline$-\cdot$ & $\cdots$ & $\cdots$ & $\cdots$ & $\cdots$ & -. & $-\cdot$ & $\cdots$ & $-\cdot$ \\
\hline$-\cdot$ & $\cdots$ & -- & $-\cdot$ & $\cdots$ & -- & $\cdot-$ & $\cdots$ & $\cdots$ \\
\hline 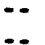 & $\cdots$ & $\because$ & $\because$ & 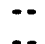 & $\because$ & -- & $\cdots$ & - \\
\hline
\end{tabular}


CHEMICAL ANALYSES-Cont inued

STATION
MUNBER DATE

09394500

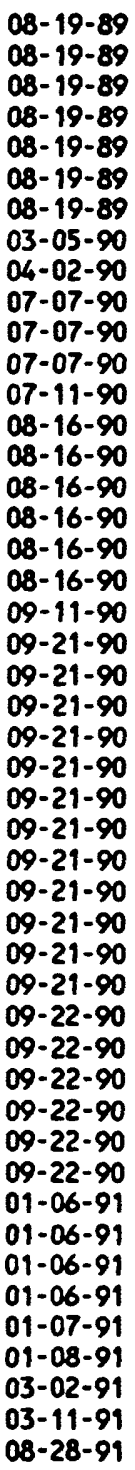

YTTER-

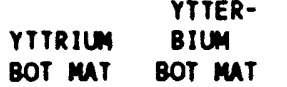

$\angle 63 \mu$ DS

LAB

( $\mu g / G)$

$663_{\mu}$ DS

LAB

$(\mu g / G)$

(35017)
ZINC

BOT MT

$\angle 63_{\mu}$ DS

LAB

$(\mu 9 / G)$

(35022)

$\begin{array}{cccc}\text { SED. } & \text { SED. } & \text { SED. } & \text { SED. } \\ \text { SUSP. } & \text { SUSP. } & \text { SUSP. } & \text { SUSP. } \\ \text { SIEVE } & \text { SIEVE } & \text { SIEVE } & \text { SIEVE } \\ \text { DINM. } & \text { DIAM. } & \text { DINM. } & \text { DINM. } \\ \times \text { FINER } & \times \text { FINER } & \times \text { FINER } & \times \text { FINER } \\ \text { THAN } & \text { THAN } & \text { THAN } & \text { THAN } \\ .062 & .125 \text { m } & .250 \text { MM } & .500 \text { M } \\ (70331) & (70332) & (70333) & (70334)\end{array}$

LITTLE COLORADO RIVER AT WOOORUFF, ARIZOWA-CONtinued

\begin{tabular}{|c|c|c|c|}
\hline 93 & $\cdots$ & -- & $\cdots$ \\
\hline 93 & $\cdots$ & - & -. \\
\hline 93 & $\cdots$ & $\cdots$ & $\cdots$ \\
\hline 93 & $\cdots$ & -- & $\cdots$ \\
\hline 86 & $\cdots$ & -- & $\cdots$ \\
\hline$\cdots$ & $\cdots$ & -- & - \\
\hline$\ddot{\theta}$ & $\cdots$ & - & $\cdots$ \\
\hline 97 & $-\cdot$ & -- & $\cdots$ \\
\hline 94 & $\because$ & -- & $-\infty$ \\
\hline $\begin{array}{l}94 \\
94\end{array}$ & 100 & 100 & $\ldots$ \\
\hline 94 & - & $\ldots$ & . \\
\hline$\cdots$ & - & -- & $\ldots$ \\
\hline- & $\cdots$ & $\cdots$ & $\ldots$ \\
\hline 89 & $\cdots$ & -- & $\cdots$ \\
\hline 87 & $\cdots$ & $\because$ & $\cdots$ \\
\hline $\begin{array}{l}89 \\
98\end{array}$ & $\begin{array}{l}95 \\
99 \\
97\end{array}$ & $\begin{array}{r}99 \\
100\end{array}$ & $\begin{array}{l}100 \\
100\end{array}$ \\
\hline 92 & 97 & 100 & 100 \\
\hline 100 & $\because$ & $\cdots$ & $\because$ \\
\hline$\therefore$ & 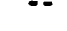 & 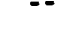 & $\cdots$ \\
\hline- & $\cdots$ & 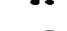 & $=-$ \\
\hline 90 & $\ldots$ & $\ldots$ & 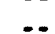 \\
\hline$\cdots$ & -. & .- & 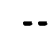 \\
\hline - & $\cdots$ & -- & $\cdots$ \\
\hline 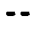 & $\cdots$ & -- & $\cdots$ \\
\hline$\cdots$ & -- & -- & $\ldots$ \\
\hline 86 & -- & $\cdots$ & $\cdots$ \\
\hline$\cdots$ & -- & $\cdots$ & 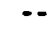 \\
\hline 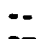 & -- & -- & -- \\
\hline 97 & -- & $=$ & 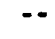 \\
\hline$\cdots$ & $\cdots$ & $\cdots$ & - \\
\hline 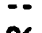 & $\cdots$ & $\cdots$ & 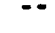 \\
\hline 96 & -- & $\cdots$ & $\cdots$ \\
\hline$\because$ & $\because-$ & $\cdots$ & \\
\hline 97 & .. & .. & . \\
\hline -. & -- & -. & 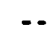 \\
\hline$\cdots$ & -- & -- & \\
\hline 86 & -- & $\cdots$ & 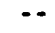 \\
\hline-- & -- & -. & \\
\hline-- & - & - & \\
\hline$\cdots$ & -- & -- & \\
\hline$\cdots$ & -- & $\cdots$ & 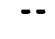 \\
\hline-- & $\ddot{-}$ & $\because-$ & \\
\hline$\cdots$ & $\cdots$ & $\cdots$ & \\
\hline
\end{tabular}


STATION

MUMBER

DATE

08- 19-89

08-19-89

08-19-89

08-19-89

08-19-89

08-19-89

08-19-89

03-05-90

04-02-90

07-07-90

07-07-90

07-07-90

$07-11-90$

08- $16-90$

08-16-90

08-16-90

08-16-90

08-16-90

08-16-90

$09-11-90$

$09-21-90$

$09-21-90$

$09-21-90$

$09-21-90$

$09-21-90$

09-21-90

$09-21-90$

$09-21-90$

$09-21-90$

$09-21-90$

$09-21-90$

$09-21-90$

09-22-90

09-22-90

$09-22-90$

09-22-90

09-22-90

09-22-90

01-06-91

01-06-91

01-06-91

01-06-91

01-07-91

01-08-91

03-02-91

03-11-91

08-28-91

CHEMICAL ANALYSES-Continued

\begin{tabular}{|c|c|c|c|c|c|c|c|c|}
\hline $\begin{array}{l}\text { SED. } \\
\text { SUSP. } \\
\text { FALL } \\
\text { DIAM. } \\
\times \text { FINER } \\
\text { THAN } \\
.002 \mathrm{mM} \\
\text { (70337) }\end{array}$ & $\begin{array}{c}\text { SED. } \\
\text { SUSP. } \\
\text { FALL } \\
\text { DIAM. } \\
\times \text { FINER } \\
\text { THAN } \\
.004 \text { M } \\
\text { (70338) }\end{array}$ & $\begin{array}{l}\text { SED. } \\
\text { SUSP. } \\
\text { FALL } \\
\text { DINM. } \\
\times \text { FINER } \\
\text { THAN } \\
\text {.008 mM } \\
\text { (70339) }\end{array}$ & $\begin{array}{l}\text { SED. } \\
\text { SUSP. } \\
\text { FALL } \\
\text { OIAM. } \\
\times \text { FINER } \\
\text { THAN } \\
.016 \text { mA } \\
\text { (70340) }\end{array}$ & $\begin{array}{l}\text { SED. } \\
\text { SUSP. } \\
\text { FALL } \\
\text { DIAM. } \\
\times \text { FINER } \\
\text { THAN } \\
.031 \mathrm{MM} \\
\text { (70341) }\end{array}$ & $\begin{array}{l}\text { SED. } \\
\text { SUSP. } \\
\text { FALL } \\
\text { DIAA. } \\
\times \text { FINER } \\
\text { THAN } \\
.062 \text { mM } \\
\text { (70342) }\end{array}$ & $\begin{array}{l}\text { SED. } \\
\text { SUSP. } \\
\text { FALL } \\
\text { DINM. } \\
\times \text { FINER } \\
\text { THN } \\
\text {.125 MM } \\
\text { (70343) }\end{array}$ & $\begin{array}{c}\text { SED. } \\
\text { SUSP. } \\
\text { FALL } \\
\text { DIAM. } \\
\times \text { FINER } \\
\text { THAN } \\
.250 \text { m } \\
(70344)\end{array}$ & $\begin{array}{c}\text { SED } \\
\text { SUSP. } \\
\text { FALL } \\
\text { OIAN. } \\
\times \text { FINER } \\
\text { THAN } \\
.500 \\
\text { (70345) }\end{array}$ \\
\hline
\end{tabular}

LITTLE COLORADO RIVER AT WOOORUFF, ARIZONA-Continued

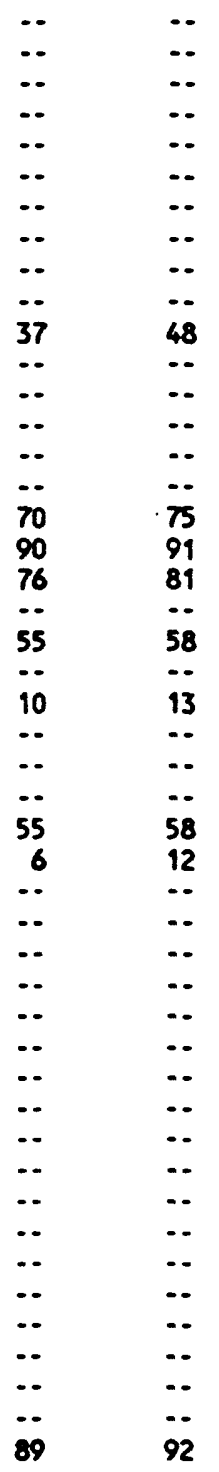

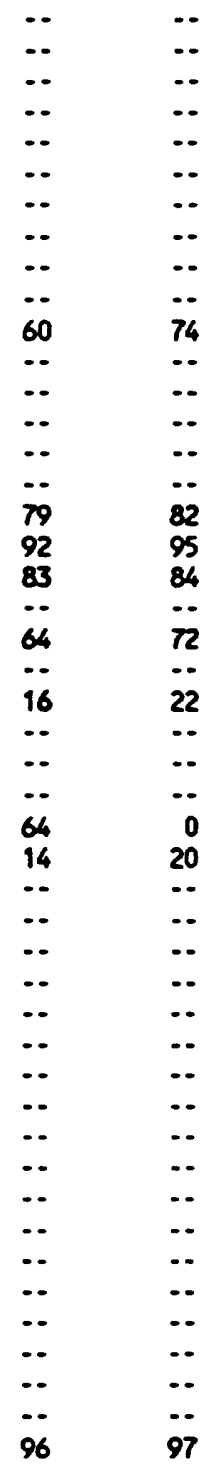

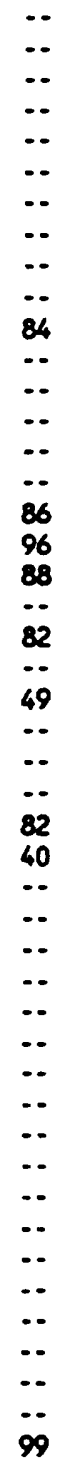

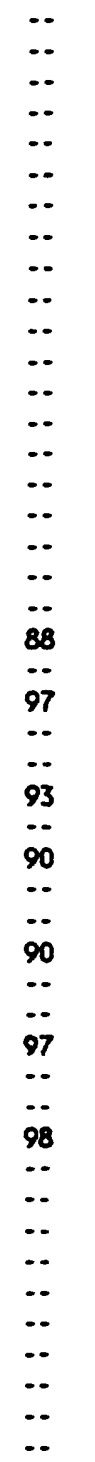

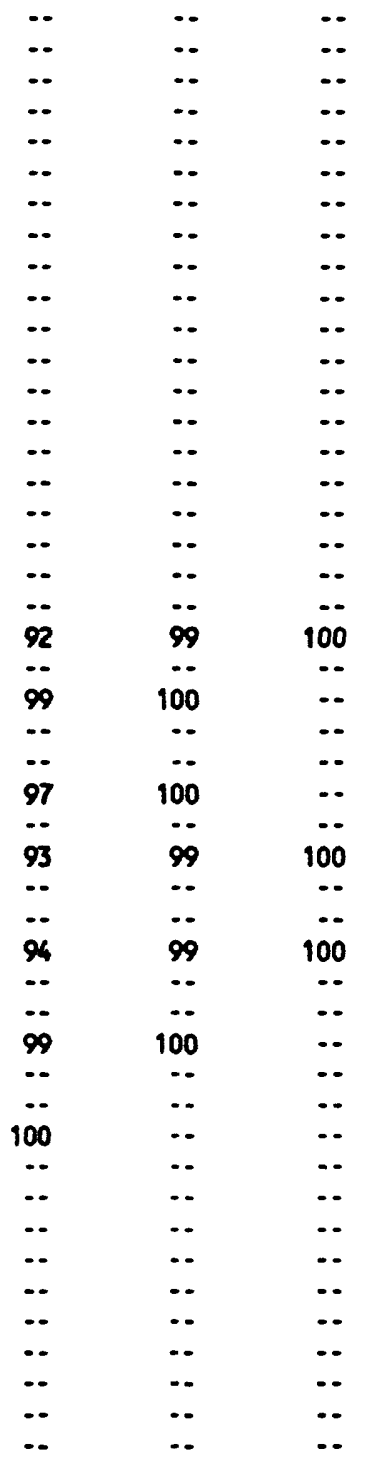


SURFACE-WATER DATA-Cont inued

CHEMICAL AMALYSES - Cont inued

STATION

MUMBER

09397300
STATION MAME

LITTLE COLORADO RIVER MEAR JOSEPH CITY, ARIZOMA
02-17-89

03-15-89

03-27-89

$07-23-89$

07-23-89

$07-23-89$

07-23-89

$07-24-89$

07-24-89

$07-24-89$

07-24-89

07-26-89

07-26-89

07-26-89

$07-26-89$

07-26-89

07-26-89

$07-26-89$

07-26-89

07-26-89

07-26-89

07-26-89

07-26-89

07-27-89

08-18-89

08-18-89

08-18-89

08-18-89

08-18-89

08-18-89

08-19-89

08-19-89

08-19-89

08-19-89

03-05-90

07-08-90

07-08-90

07-08-90

07-08-90
TIME

1300

1145

1300

1550

1551

1630

1631

1045

1046

1050

1051

0630

0730

0731

0950

095

1010

1019

1120

1310

1311

1820

1821

1345

1630

1631

1850

1851

2140

2141

0010

0210

0440

0800

1300

0140

0200

0220

0240 
SURFACE-WATER DATA-Continued

CHEMICAL ANALYSES-Continued

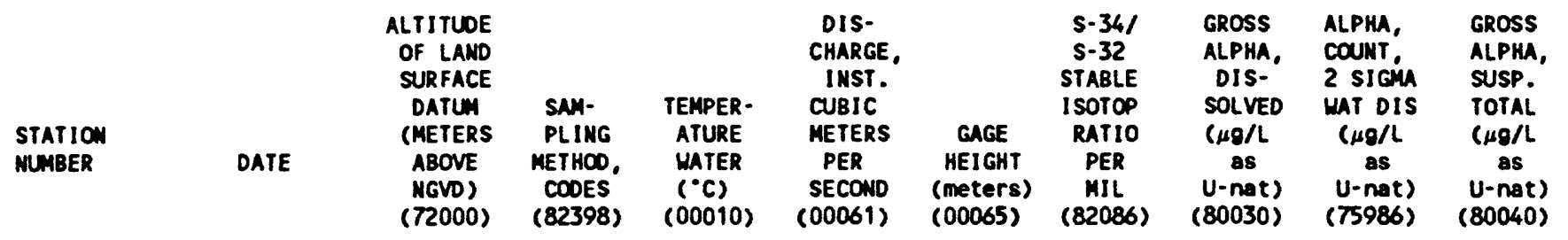

LITTLE COLORADO RIVER NEAR JOSEPH CITY, AZ-Continued

\begin{tabular}{|c|c|c|c|c|c|c|c|c|c|c|}
\hline 09397300 & $\begin{array}{l}02-17-89 \\
03-15-89 \\
03-27-89 \\
07-23-89 \\
07-23-89 \\
07-23-89 \\
07-23-89 \\
07-24-89 \\
07-24-89 \\
07-24-89 \\
07-24-89 \\
07-26-89 \\
07-26-89 \\
07-26-89 \\
07-26-89 \\
07-26-89 \\
07-26-89 \\
07-26-89 \\
07-26-89 \\
07-26-89 \\
07-26-89 \\
07-26-89 \\
07-26-89 \\
07-27-89 \\
08-18-89 \\
08-18-89 \\
08-18-89 \\
08-18-89 \\
08-18-89 \\
08-18-89 \\
08-19-89 \\
08-19-89 \\
08-19-89 \\
08-19-89 \\
03-05-90 \\
07-08-90 \\
07-08-90 \\
07-08-90 \\
07-08-90\end{array}$ & 1533 & $\begin{array}{l}70 \\
70 \\
70 \\
50 \\
50 \\
50 \\
50 \\
70 \\
70 \\
50 \\
50 \\
50 \\
50 \\
50 \\
50 \\
50 \\
50 \\
50 \\
50 \\
50 \\
50 \\
50 \\
50 \\
10 \\
50 \\
50 \\
50 \\
50 \\
50 \\
50 \\
50 \\
50 \\
50 \\
50 \\
70 \\
50 \\
50 \\
50 \\
50\end{array}$ & 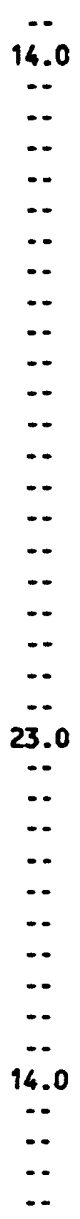 & $\begin{array}{l}E .9 \\
.2 \\
3.5 \\
70 \\
70 \\
70 \\
30 \\
8.9 \\
8.9 \\
8.9 \\
8.9 \\
70.5 \\
70.5 \\
70.5 \\
60.3 \\
60.3 \\
47.3 \\
47.3 \\
38.2 \\
35.4 \\
35.4 \\
42.8 \\
42.8 \\
15.9 \\
185.5 \\
185.5 \\
144.4 \\
144.4 \\
110.4 \\
110.4 \\
118.1 \\
106.8 \\
86.1 \\
64.0 \\
5.27 \\
56.9 \\
57.8 \\
59.5 \\
\end{array}$ & $\begin{array}{l}.73 \\
.57 \\
.87 \\
1.10 \\
1.10 \\
1.10 \\
. . \\
.83 \\
.83 \\
.83 \\
.83 \\
1.10 \\
1.10 \\
1.10 \\
1.07 \\
1.07 \\
1.02 \\
1.02 \\
.99 \\
.98 \\
.98 \\
1.00 \\
1.00 \\
.88 \\
1.49 \\
1.49 \\
1.34 \\
1.34 \\
1.23 \\
1.23 \\
1.26 \\
1.22 \\
1.15 \\
1.08 \\
.66 \\
1.07 \\
. . \\
. . \\
. . .\end{array}$ & 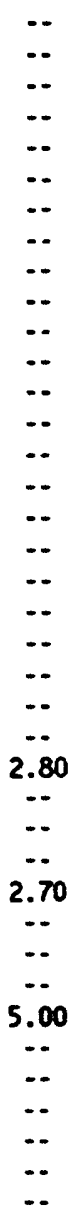 & 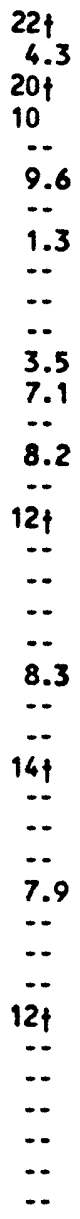 & 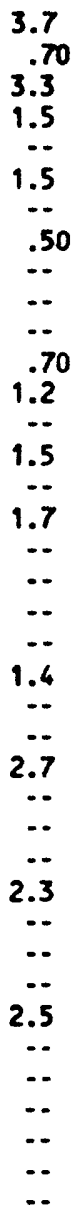 & 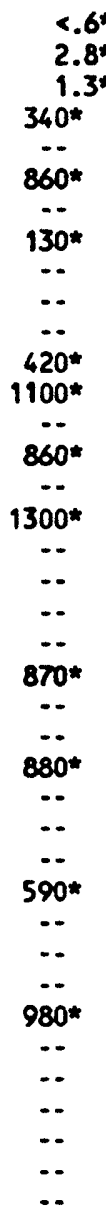 \\
\hline
\end{tabular}




\begin{tabular}{|c|c|c|c|c|c|c|c|c|c|c|}
\hline \multicolumn{11}{|c|}{ SURFACE-WATER DATA-Continued } \\
\hline \multicolumn{11}{|c|}{ CHEMICAL AMALYSES-Cont inued } \\
\hline $\begin{array}{l}\text { STATION } \\
\text { NUMBER }\end{array}$ & DATE & $\begin{array}{c}\text { GROSS } \\
\text { BETA, } \\
\text { DIS- } \\
\text { SOLVED } \\
\text { (pCi/L } \\
\text { as } \\
\text { Cs-137) } \\
(03515)\end{array}$ & $\begin{array}{c}\text { BETA, } \\
2 \text { SIGMA } \\
\text { WATER, } \\
\text { DISS, } \\
\text { (PCi/L } \\
\text { as } \\
\text { Cs-137) } \\
\text { (75989) }\end{array}$ & $\begin{array}{c}\text { GROSS } \\
\text { BETA, } \\
\text { SUSP. } \\
\text { IOTAL } \\
\text { (PCi/L } \\
\text { as } \\
\text { Cs-137) } \\
(03516)\end{array}$ & $\begin{array}{c}\text { GROSS } \\
\text { BETA, } \\
\text { DISS. } \\
\text { (PCi/L } \\
\text { as } \\
S r-90 / \\
Y-90) \\
(80050)\end{array}$ & $\begin{array}{l}\text { BETA } \\
2 \text { SIGIA } \\
\text { WATER, } \\
\text { DISS. } \\
\text { (PCi/L } \\
\text { as } \\
\text { Sr-90/ } \\
\text { Y-90) } \\
(75988)\end{array}$ & $\begin{array}{c}\text { GROSS } \\
\text { BETA, } \\
\text { SUSP. } \\
\text { TOTAL } \\
(P C i / L \\
88 \\
S r-90 / \\
Y-90) \\
(80060)\end{array}$ & $\begin{array}{c}\text { BETA, } \\
2 \text { SIGM } \\
\text { SED, SUSP. } \\
\text { TOT DRY } \\
\text { (PCi/G } \\
\text { Os } \\
\text { Sr-90/ } \\
Y-90) \\
(76005)\end{array}$ & $\begin{array}{c}\text { Cs-137 } \\
\text { SOIL, } \\
\text { TOTAL, } \\
\text { (pCi/G) } \\
\text { (76007) }\end{array}$ & $\begin{array}{c}\text { Cs- } 137 \\
2 \text { SIGMA } \\
\text { SOIL, } \\
\text { TOTAL, } \\
\text { DRY WGT } \\
\text { (PCi/G) } \\
\text { (04103) }\end{array}$ \\
\hline
\end{tabular}

LITTLE COLORADO RIVER NEAR JOSEPH CITY, AZ-Continued

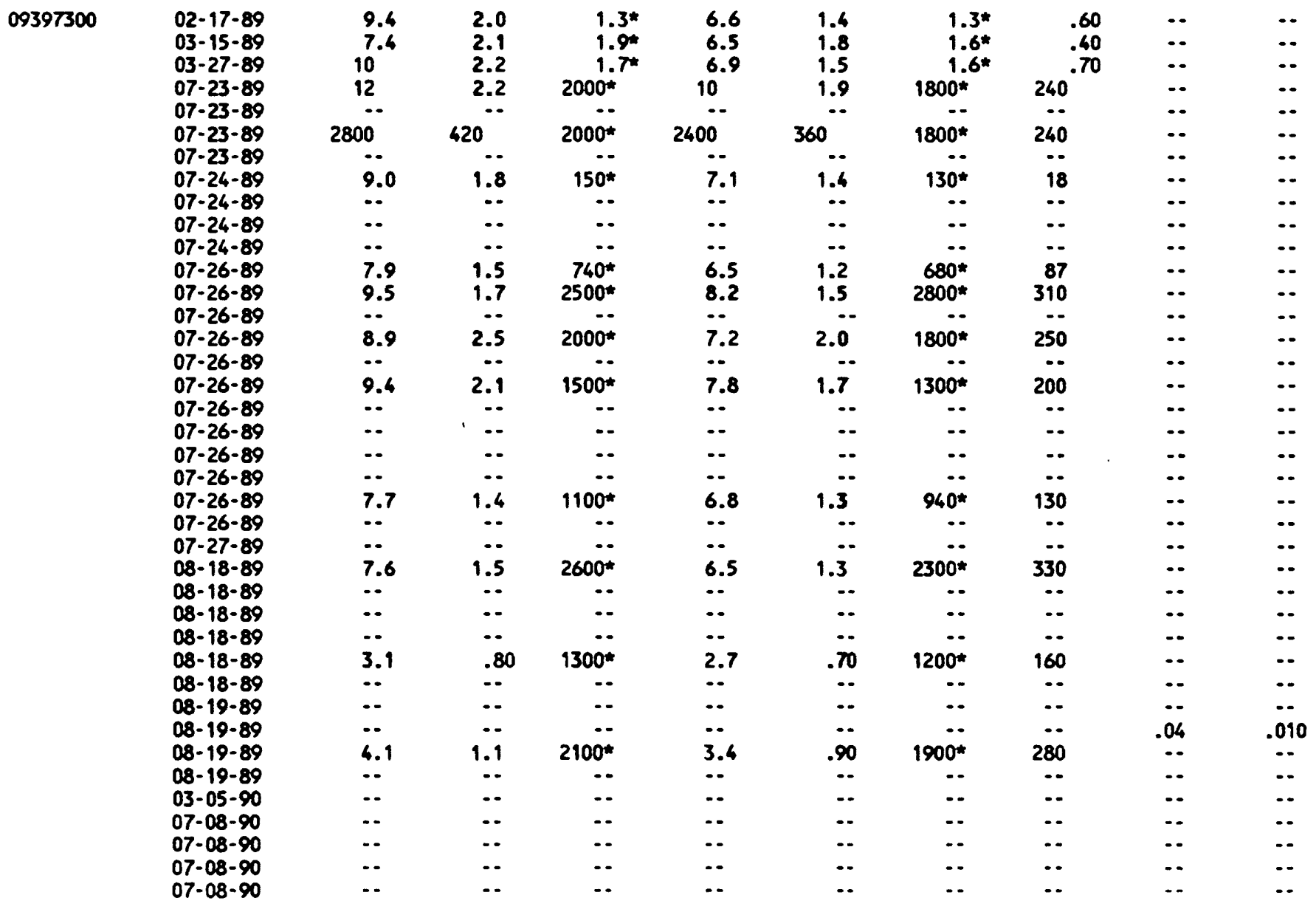


STATION

MUMBER

DATE

02-17-89

03-15-89

$03-27-89$

07-23-89

07-23-89

07-23-89

$07-23-89$

$07-24-89$

07-24-89

07-24-89

$07-24-89$

$07-26-89$

$07-26-89$

07-26-89

$07-26-89$

$07-26-89$

$07-26-89$

$07-26-89$

$07-26-89$

$07-26-89$

07-26-89

07-26-89

07-26-89

07-27-89

08-18-89

08-18-89

08-18-89

08-18-89

08-18-89

08-18-89

08-19-89

08-19-89

08-19-89

08-19-89

03-05-90

07-08-90

07-08-90

07-08-90

07-08-90

\begin{tabular}{|c|c|c|c|c|c|c|c|c|}
\hline $\begin{array}{l}\text { ALUA- } \\
\text { INUN } \\
\text { BOT MAT } \\
\angle 63 \mu \text { DS } \\
\text { LAB } \\
\text { PERCENT } \\
\text { (34792) }\end{array}$ & $\begin{array}{c}\text { ARSENIC } \\
\text { BOT MAT } \\
\angle 63 \mu \text { DS } \\
\text { LAB } \\
(\mu g / G) \\
(34802)\end{array}$ & $\begin{array}{l}\text { BARIUN } \\
\text { BOT } M A T \\
\angle 63 \mu \text { DS } \\
\text { LAB } \\
(\mu g / G) \\
(34807)\end{array}$ & $\begin{array}{l}\text { BERYL- } \\
\text { LIUN } \\
\text { BOT } M A T \\
\angle 63_{\mu} \text { DS } \\
\text { LAB } \\
(\mu g / G) \\
(34812)\end{array}$ & $\begin{array}{c}\text { BISAUTH } \\
\text { BOT MAT } \\
\angle 63 \mu \text { DS } \\
\text { LAB } \\
(\mu g / G) \\
(34817)\end{array}$ & $\begin{array}{c}\text { CADHIUM } \\
\text { BOT MAT } \\
\angle 63 \mu \text { OS } \\
\text { LAB } \\
(\mu g / 6) \\
(34827)\end{array}$ & $\begin{array}{l}\text { CALCIUM } \\
\text { BOT MAT } \\
\angle 63 \mu \text { DS } \\
\text { LAB } \\
\text { PERCENT } \\
\text { (34832) }\end{array}$ & $\begin{array}{l}\text { CERIUH } \\
\text { BOT MAT } \\
\angle 63_{\mu} \text { DS } \\
\text { LAB } \\
(\mu g / G) \\
(34837)\end{array}$ & $\begin{array}{c}\text { CHRO- } \\
\text { MIUA } \\
\text { BOT MAT } \\
\angle 63 \mu \text { DS } \\
\text { LAB } \\
(\mu g / G) \\
(34842)\end{array}$ \\
\hline
\end{tabular}

LITTLE COLORADO RIVER MEAR JOSEPH CITY, AZ-Contimued

\begin{tabular}{|c|c|c|c|c|c|c|c|c|}
\hline -. & -- & - & -. & -- & -- & -. & - & -. \\
\hline$\cdots$ & -- & -- & $\cdots$ & -- & -- & -- & $\cdots$ & -- \\
\hline -. & -- & -- & -. & -- & -- & - & -. & - \\
\hline -. & -- & $\cdots$ & $\cdots$ & $\cdots$ & -- & $\cdots$ & $\cdots$ & $\cdots$ \\
\hline -. & -- & -- & $\cdots$ & $\cdots$ & $\cdots$ & $\cdots$ & $\cdots$ & $\cdots$ \\
\hline$\cdots$ & $\cdots$ & $\cdots$ & $\cdots$ & $\cdots$ & $\cdots$ & $\cdots$ & $\cdots$ & $\cdots$ \\
\hline$\ldots$ & 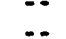 & $=$ & $\because$ & $\because$ & $\because-$ & $\because$ & $\cdots$ & $\cdots$ \\
\hline -. & $\therefore$ & $\therefore$ & $\therefore$ & $\ldots$ & $\because-$ & $\therefore$ & $\ldots$ & -. \\
\hline -- & -- & -- & .. & -- & -. & -. & $\ldots$ & .. \\
\hline-- & -- & -- & -. & .. & .. & -- & .. & .. \\
\hline-- & -- & -- & $\cdots$ & -- & -. & -- & -. & -. \\
\hline -- & -- & -- & $\cdots$ & -- & -- & -- & $\cdots$ & $\cdots$ \\
\hline-- & -- & -- & - & -- & - & -- & $\cdots$ & -. \\
\hline-- & $\because$ & $\because$ & $\cdots$ & $\because$ & -- & -- & $\cdots$ & -- \\
\hline-- & -- & -- & -- & -- & -- & -- & -- & -- \\
\hline-- & -- & $\cdots$ & $\cdots$ & -- & -- & -- & $\cdots$ & 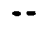 \\
\hline- & $\cdots$ & $\cdots$ & $\cdots$ & $\because$ & $\cdots$ & $\cdots$ & $\cdots$ & $\cdots$ \\
\hline$-\overline{-}$ & $\because$ & 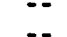 & $\cdots$ & $\because$ & $\cdots$ & $\because$ & $\cdots$ & $\cdots$ \\
\hline .- & $\because$ & $\cdots$ & 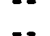 & 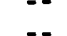 & 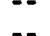 & $\because$ & $\because$ & $\because$ \\
\hline -- & $\ldots$ & $\ldots$ & $\ldots$ & - & $\ldots$ & $\ldots$ & $\ldots$ & $\cdots$ \\
\hline -. & .. & - & -. & -. & .. & -. & .. & .- \\
\hline -. & - & -. & .. & -. & .. & -. & .. & .. \\
\hline 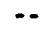 & -- & -- & -. & -- & $\cdots$ & -. & . & -. \\
\hline$-\cdot$ & -. & -- & $\cdots$ & -- & -. & -- & $\cdots$ & $\cdots$ \\
\hline$\cdots$ & -- & -- & $\cdots$ & -- & $\cdots$ & -- & $\cdots$ & -- \\
\hline -- & -- & - & $\cdots$ & $\cdots$ & -- & -- & -. & -- \\
\hline 7.1 & $<10$ & 570 & 2 & $<10$ & $<2$ & 4.3 & 70 & 54 \\
\hline- & - & $\cdots$ & $\cdots$ & - & - & $\cdots$ & $\cdots$ & $\cdots$ \\
\hline$\cdots$ & -- & -- & $\cdots$ & $=$ & $\cdots$ & $-\cdot$ & -- & -- \\
\hline -. & $\cdots$ & $\cdot-$ & $\cdots$ & $\cdots$ & $\cdots$ & $\cdots$ & $\cdots$ & $\cdots$ \\
\hline-- & $\cdots$ & $-\cdot$ & $\cdots$ & $=$ & $\cdots$ & -- & $\cdots$ & $\cdots$ \\
\hline$\cdots$ & $\cdots$ & $\cdots$ & $\ddot{-}$ & $\because$ & $\ddot{-}$ & 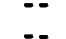 & $\ddot{-}$ & -- \\
\hline-- & 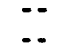 & 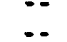 & 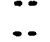 & $\because$ & $\cdots$ & $=-$ & 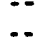 & -. \\
\hline 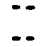 & $\ldots$ & $\ldots$ & .. & $\therefore$ & $\ldots$ & $=$ & $\cdots$ & $\ldots$ \\
\hline .. & $\ldots$ & -. & .. & .. & -. & -- & $\ldots$ & .. \\
\hline - & $\cdots$ & - & $\cdots$ & .. & -. & $\cdots$ & & \\
\hline
\end{tabular}


SURFACE-WATER DATA-Continued

CHEMICAL ANALYSES-Cont inued

STATION

NUMBER

DATE

\begin{tabular}{|c|c|c|c|c|c|c|c|c|}
\hline $\begin{array}{c}\text { COBALT } \\
\text { BOT MAT } \\
\angle 63 \mu \text { DS } \\
\text { LAB } \\
(\mu 9 / G) \\
(34847)\end{array}$ & $\begin{array}{c}\text { COPPER } \\
\text { BOT MAT } \\
\angle 63 \mu \text { DS } \\
\text { LAB } \\
(\mu g / G) \\
(34852)\end{array}$ & $\begin{array}{c}\text { EURO- } \\
\text { PIUM } \\
\text { BOT MAT } \\
\angle 63 \mu \text { DS } \\
\text { LAB } \\
(\mu 9 / G) \\
(34857)\end{array}$ & 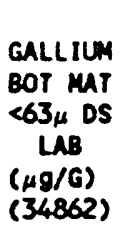 & $\begin{array}{c}\text { COLD } \\
\text { BOT MAT } \\
\angle 63 \mu \text { DS } \\
\text { LAB } \\
(\mu g / G) \\
(34872)\end{array}$ & $\begin{array}{c}\text { HOLMIUA } \\
\text { BOT MAT } \\
\angle 63 \mu \text { DS } \\
\text { LAB } \\
(\mu g / G) \\
(34877)\end{array}$ & $\begin{array}{l}\text { IRON } \\
\text { BOT MAT } \\
\angle 63_{\mu} \text { DS } \\
\text { LAB } \\
\text { PERCENT } \\
\text { (34882) }\end{array}$ & $\begin{array}{c}\text { LANTHA- } \\
\text { NUM } \\
\text { BOT MAT } \\
\angle 63 \mu \text { DS } \\
\text { LAB } \\
(\mu g / G) \\
(34887)\end{array}$ & $\begin{array}{c}\text { LEAD } \\
\text { BOT MAT } \\
\angle 63 \mu \text { DS } \\
\text { LAB } \\
(\mu g / G) \\
(34892)\end{array}$ \\
\hline
\end{tabular}

LITTLE COLORADO RIVER MEAR JOSEPH CITY, AZ-Cont inued

$09397300 \quad 02-17-89$
$03-15-89$
$03-27-89$
$07-23-89$
$07-23-89$
$07-23-89$
$07-23-89$
$07-24-89$
$07-24-89$
$07-26-89$
$07-24-89$
$07-26-89$
$07-26-89$
$07-26-89$
$07-26-89$
$07-26-89$
$07-26-89$
$07-26-89$
$07-26-89$
$07-26-89$
$07-26-89$
$07-26-89$
$07-26-89$
$07-27-89$
$08-18-89$
$08-18-89$
$08-18-89$
$08-18-89$
$08-18-89$
$08-18-89$
$08-19-89$
$08-19-89$
$08-19-89$
$08-19-89$
$03-05-90$
$07-08-90$
$07-08-90$
$07-08-90$
$07-08-90$

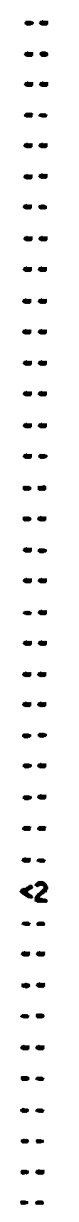

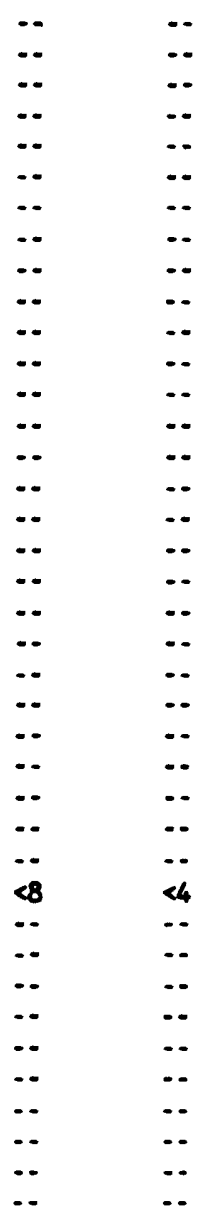


SURFACE-HATER DATA-Contínued

CHEHICAL AKALYSES-Cont inued

STATION

MUMBER

DATE

02-17-89

03-15-89

03-27-89

07-23-89

07-23-89

07-23-89

07-23-89

07-24-89

07-24-89

07-24-89

07-24-89

07-26-89

07-26-89

07-26-89

07-26-89

07-26-89

07-26-89

07-26-89

07-26-89

07-26-89

07-26-89

07-26-89

07-26-89

07-27-89

08-18-89

08-18-89

08-18-89

08-18-89

08-18-89

08-18-89

08-19-89

08-19-89

08-19-89

08-19-89

03-05-90

07-08-90

07-08-90

07-08-90

07-08-90

\begin{tabular}{|c|c|c|c|c|c|c|c|}
\hline $\begin{array}{c}\text { LITHIUN } \\
\text { BOT MAT } \\
\angle 63 \mu \text { OS } \\
\text { LAB } \\
(\mu g / G) \\
(34897)\end{array}$ & $\begin{array}{l}\text { MGNE- } \\
\text { SIUA } \\
\text { BOT MAT } \\
\angle 63 \mu \text { DS } \\
\text { LAB } \\
\text { PERCENT } \\
\text { (34902) }\end{array}$ & $\begin{array}{c}\text { MANGA- } \\
\text { MESE } \\
\text { BOT MAT } \\
\angle 63 \mu \text { DS } \\
\text { LAB } \\
(\mu 9 / G) \\
(34907)\end{array}$ & $\begin{array}{c}\text { MOLYB- } \\
\text { DENUA } \\
\text { BOT MT } \\
\text { C63H DS } \\
\text { LAB } \\
(\mu 9 / G) \\
(34917)\end{array}$ & 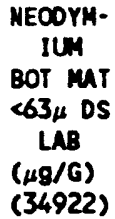 & $\begin{array}{c}\text { NICKEL } \\
\text { BOT MAT } \\
\angle 63_{\mu} \text { DS } \\
\text { LAB } \\
(\mu g / G) \\
(34927)\end{array}$ & $\begin{array}{c}\text { NIOBIUH } \\
\text { BOT MAT } \\
<63 \mu \text { DS } \\
\text { LAB } \\
(\mu g / G) \\
(34932)\end{array}$ & $\begin{array}{l}\text { PHOS- } \\
\text { PHORUS } \\
\text { BOT MAT } \\
<63 \mu \text { OS } \\
\text { LAB } \\
\text { PERCENT } \\
\text { (34937) }\end{array}$ \\
\hline
\end{tabular}

LITTLE COLORADO RIVER MEAR JOSEPH CITY, AZ-COntinUEd

\begin{tabular}{|c|c|c|c|}
\hline$\cdots$ & $\cdots$ & $\cdots$ & - \\
\hline - & $\cdots$ & - & - \\
\hline$\cdots$ & $\cdots$ & $\cdots$ & $\cdots$ \\
\hline$\cdots$ & $\cdots$ & $\cdots$ & $\cdots$ \\
\hline$\cdots$ & $\cdots$ & -- & $\cdots$ \\
\hline$\cdots$ & $\cdots$ & $\cdots$ & $\cdots$ \\
\hline - & $\cdots$ & - & - \\
\hline$\cdots$ & $\cdots$ & $\cdots$ & $\cdots$ \\
\hline$\cdots$ & $\cdots$ & $\cdots$ & $\cdots$ \\
\hline$\cdots$ & $\cdots$ & $\cdots$ & $\cdots$ \\
\hline$\cdots$ & $\cdots$ & $\cdots$ & $\cdots$ \\
\hline$\cdots$ & $\cdots$ & $\cdots$ & $\cdots$ \\
\hline$\cdots$ & $\cdots$ & $\cdots$ & $\cdots$ \\
\hline$\cdots$ & $\cdots$ & $\cdots$ & $\cdots$ \\
\hline$\because$ & $\because$ & $\because$ & $\cdots$ \\
\hline$\because$ & $\because$ & $\because$ & 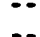 \\
\hline$\ldots$ & $\ldots$ & $\ldots$ & .. \\
\hline .. & .. & .. & .. \\
\hline . & .. & .- & .. \\
\hline -- & - & - & .. \\
\hline$\cdots$ & -- & $\cdots$ & $\cdots$ \\
\hline$\cdots$ & $\cdots$ & $\cdots$ & $\cdots$ \\
\hline$\cdots$ & $\cdots$ & $\cdots$ & $\cdots$ \\
\hline$\cdots$ & $\cdots$ & $\cdots$ & $\cdots$ \\
\hline$\cdots$ & $\cdots$ & -. & $\cdots$ \\
\hline$\cdots$ & $\cdots$ & $\cdots$ & $\cdots$ \\
\hline 34 & $\because 4$ & $\overline{630}$ & $\because$ \\
\hline $\begin{array}{l}54 \\
\ldots\end{array}$ & 1.4 & 030 & $<2$ \\
\hline .. & $\ldots$ & $\ldots$ & $\ldots$ \\
\hline$\ldots$ & $\ldots$ & .. & $\ldots$ \\
\hline -. & .. & $\ldots$ & $\ldots$ \\
\hline -- & $\ldots$ & .. & - \\
\hline$\cdots$ & $\cdots$ & $\cdots$ & $\cdots$ \\
\hline -. & $\cdots$ & $\cdots$ & $\cdots$ \\
\hline-- & $\cdots$ & $-\cdot$ & $\cdots$ \\
\hline-- & $\cdots$ & - & $\cdots$ \\
\hline-- & $\cdots$ & $\cdots$ & \\
\hline
\end{tabular}

\begin{tabular}{|c|c|c|}
\hline$\cdots$ & - & $\ldots$ \\
\hline$\cdots$ & $\cdots$ & $\cdots$ \\
\hline$\cdots$ & $\cdots$ & $\cdots$ \\
\hline$\cdots$ & $\cdots$ & $\cdots$ \\
\hline$\cdots$ & $\cdots$ & $\cdots$ \\
\hline$\therefore$ & $\cdots$ & $\cdots$ \\
\hline$\cdots$ & $\cdots$ & $\cdots$ \\
\hline$\because$ & $\because$ & $\cdots$ \\
\hline - & $\ldots$ & 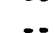 \\
\hline$\ldots$ & .. & $\ldots$ \\
\hline - & .. & .. \\
\hline$\cdots$ & -. & $\ldots$ \\
\hline - & -. & . \\
\hline$\cdots$ & $\cdots$ & $\cdots$ \\
\hline$\cdots$ & -. & $\cdots$ \\
\hline$\cdots$ & $\cdots$ & $\cdots$ \\
\hline$\cdots$ & $\cdots$ & $\cdots$ \\
\hline$\cdots$ & $\cdots$ & $\cdots$ \\
\hline$\because$ & $\cdots$ & $\because$ \\
\hline$\because$ & 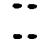 & 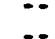 \\
\hline 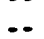 & $\ldots$ & $\cdots$ \\
\hline . & .. & .. \\
\hline$\cdots$ & -. & $\ldots$ \\
\hline$\cdots$ & $\cdots$ & $\cdots$ \\
\hline$\cdots$ & $\cdots$ & $\cdots$ \\
\hline$\because$ & $\cdots$ & $\cdots$ \\
\hline 24 & 10 & .06 \\
\hline- & $\cdots$ & $\cdots$ \\
\hline - & $\cdots$ & $\cdots$ \\
\hline- & $\cdots$ & $\cdots$ \\
\hline- & $\cdots$ & $\cdots$ \\
\hline 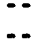 & $\cdots$ & $\cdots$ \\
\hline- & $\because$ & $\cdots$ \\
\hline- & $\cdots$ & $\because$ \\
\hline$\therefore$ & $\ldots$ & $\ldots$ \\
\hline & - & $\ldots$ \\
\hline
\end{tabular}


SURFACE-MATER DATA-Cont inued

CHEMICAL ANALYSES-Continued

STATION

MUMBER

DATE

02-17-89

$03-15-89$

03-27-89

$07-23-89$

07-23-89

07-23-89

07-23-89

$07-24-89$

$07-24-89$

$07-24-89$

$07-24-89$

07-26-89

07-26-89

07-26-89

$07-26-89$

07-26-89

07-26-89

07-26-89

$07-26-89$

07-26-89

07-26-89

07-26-89

07-26-89

07-27-89

08-18-89

08-18-89

08-18-89

08-18-89

08-18-89

08-18-89

08-19-89

08-19-89

08-19-89

08-19-89

03-05-90

$07-08-90$

07-08-90

07-08-90

07-08-90

\begin{tabular}{|c|c|c|c|c|c|c|c|}
\hline $\begin{array}{l}\text { POTAS- } \\
\text { SIUN } \\
\text { BOT MAT } \\
\angle 63_{\mu} \text { OS } \\
\text { LAB } \\
\text { PERCENT } \\
\text { (34942) }\end{array}$ & $\begin{array}{c}\text { SCAN- } \\
\text { DIUN } \\
\text { BOT MAT } \\
\angle 63 \mu \text { DS } \\
\text { LAB } \\
(\mu g / G) \\
(34947)\end{array}$ & $\begin{array}{c}\text { SILVER } \\
\text { BOT MAT } \\
\angle 63 \mu \text { DS } \\
\text { LAB } \\
(\mu g / G) \\
(34957)\end{array}$ & $\begin{array}{l}\text { SOOIUN } \\
\text { BOT MAT } \\
\angle 63 \mu \text { DS } \\
\text { LAB } \\
\text { PERCENT } \\
\text { (34962) }\end{array}$ & $\begin{array}{c}\text { STRON- } \\
\text { TIUA } \\
\text { BOT MAT } \\
\angle 63 \mu \text { DS } \\
\text { LAB } \\
(\mu g / G) \\
(34967)\end{array}$ & 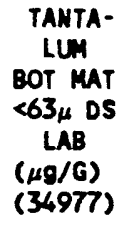 & $\begin{array}{c}\text { THORIUN } \\
\text { BOT MAT } \\
\angle 63 \mu \text { DS } \\
\text { LAB } \\
(\mu g / G) \\
(34982)\end{array}$ & $\begin{array}{c}\text { TIN } \\
\text { BOT MAT } \\
<63 \mu \text { DS } \\
\text { LAB } \\
(\mu g / G) \\
(34987)\end{array}$ \\
\hline
\end{tabular}

LITTLE COLORADO RIVER MEAR JOSEPH CITY, AZ-Continued

\begin{tabular}{|c|c|c|c|c|c|c|c|}
\hline$\cdots$ & $\cdots$ & $\cdots$ & $\cdots$ & -- & -- & $\cdots$ & -- \\
\hline -. & $\cdots$ & $\cdots$ & $\cdots$ & $\cdots$ & $\cdots$ & $\cdots$ & -. \\
\hline$\cdots$ & $\cdots$ & $\cdots$ & $\cdots$ & $\cdots$ & $\cdots$ & $\cdots$ & $\cdots$ \\
\hline$\cdots$ & $\cdots$ & $\cdots$ & $\cdots$ & $\cdots$ & $\cdots$ & $\cdots$ & $\cdots$ \\
\hline$\cdots$ & 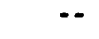 & -- & $\cdots$ & $-\cdot$ & -- & - & - \\
\hline$\cdots$ & $\cdots$ & 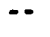 & $\cdots$ & - & -- & -- & - \\
\hline$\cdots$ & $\cdots$ & $\cdots$ & $\cdots$ & $\cdots$ & $\cdots$ & $\cdots$ & -- \\
\hline$\cdots$ & $\cdots$ & $\cdots$ & $\cdots$ & $\cdots$ & $\because$ & $\cdots$ & $\cdots$ \\
\hline 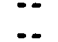 & $\ldots$ & 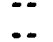 & 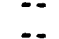 & $\because$ & $\because$ & 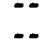 & $\because-$ \\
\hline$\ldots$ & $\ldots$ & $\ldots$ & $\ldots$ & $\therefore$ & 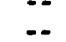 & $\ldots$ & -. \\
\hline -. & .. & .. & .. & -. & .- & -. & .. \\
\hline - & -. & -- & $\cdots$ & -- & $\because$ & -- & -. \\
\hline -. &,$\quad \cdots$ & $\cdots$ & $\cdots$ & 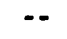 & -- & - & -- \\
\hline -. & $\cdots$ & $\cdots$ & $\cdots$ & - & $\cdots$ & -- & -. \\
\hline$\cdots$ & $\cdots$ & $\cdots$ & $\cdots$ & $\cdots$ & $\cdots$ & $\cdots$ & $\cdots$ \\
\hline-- & $-\cdot$ & -- & $\cdots$ & $=$ & -- & - & $\cdots$ \\
\hline-- & $-\cdot$ & $\cdots$ & $\cdots$ & $\cdots$ & -- & -- & $\cdots$ \\
\hline$\cdots$ & $\cdots$ & $\cdots$ & $\cdots$ & $\cdots$ & -- & $\cdots$ & $\cdots$ \\
\hline$\cdots$ & $\cdots$ & $\cdots$ & $\cdots$ & $\cdots$ & -- & $-\cdot$ & $\cdots$ \\
\hline$\because$ & $\because$ & $\because$ & $\cdots$ & $\cdots$ & $\because$ & $\cdots$ & 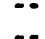 \\
\hline$\ldots$ & .. & $\ldots$ & $\ldots$ & $\ldots$ & $\because$ & $\because$ & .. \\
\hline$\ldots$ & .. & .. & $\ldots$ & $\ldots$ & $\ldots$ & $\ldots$ & $\ldots$ \\
\hline - & .. & -. & - & .. & .. & $\ldots$ & .. \\
\hline -. & -- & -- & -. & - & .. & .. & .. \\
\hline- & - & $-\cdot$ & $\cdots$ & $\cdots$ & -. & -. & -. \\
\hline$\because$ & $\because$ & $\cdots$ & 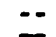 & -. & -- & $\cdots$ & -. \\
\hline 1.6 & 10 & $<4$ & .75 & 310 & $<40$ & 11 & 31 \\
\hline$\cdots$ & -- & $\cdots$ & $\cdots$ & $\cdots$ & -- & $\cdots$ & $\cdots$ \\
\hline$\cdots$ & -- & $\cdots$ & $\cdots$ & $\cdots$ & $\cdots$ & $\cdots$ & $\cdots$ \\
\hline$\cdots$ & $\cdots$ & $\cdots$ & $\cdots$ & $\cdots$ & $\cdots$ & $\cdots$ & $\cdots$ \\
\hline$\cdots$ & $\cdots$ & $\cdots$ & $\cdots$ & $\cdots$ & $\cdots$ & $\cdots$ & - \\
\hline$\cdots$ & $\cdots$ & $\cdots$ & $\because$ & $\cdots$ & $\cdots$ & $\cdots$ & $\cdots$ \\
\hline$\cdots$ & $\because$ & $\ddot{-}$ & - & $\cdots$ & $\because$ & $\ddot{-}$ & $\cdots$ \\
\hline$\ldots$ & 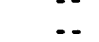 & $\ldots$ & $\ldots$ & $\cdots$ & $\because$ & .. & -. \\
\hline -. & -. & -. & - & - & .. & $\ldots$ & .. \\
\hline - & $\cdots$ & $\cdots$ & $\cdots$ & - &.- & $\cdots$ & 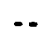 \\
\hline
\end{tabular}


SURFACE-WATER DATA-Continued

CHEMICAL AMALYSES-Continued

STATION

MUMBER

DATE

\begin{tabular}{|c|c|c|c|c|c|c|}
\hline $\begin{array}{l}\text { TITA- } \\
\text { NIUA } \\
\text { BOT MAT } \\
\angle 63_{\mu} \text { DS } \\
\text { LAB } \\
\text { PERCENT } \\
\text { (34992) }\end{array}$ & $\begin{array}{l}\text { URANIUN } \\
\text { BOT MAT } \\
\angle 63 \mu \text { DS } \\
\text { LAB } \\
(\mu g / G) \\
(35002)\end{array}$ & $\begin{array}{c}\text { VAMA- } \\
\text { DIUM } \\
\text { BOT MAT } \\
\angle 63_{\mu} \text { DS } \\
\text { LAB } \\
(\mu g / G) \\
(35007)\end{array}$ & $\begin{array}{c}\text { YTTRIUA } \\
\text { BOT MAT } \\
\angle 63 \mu \text { DS } \\
\text { LAB } \\
(\mu g / G) \\
(35012)\end{array}$ & $\begin{array}{l}\text { YTTER- } \\
\text { BIUN } \\
\text { BOT MAT } \\
\angle 63 \mu \text { DS } \\
\text { LAB } \\
(\mu 9 / G) \\
(35017)\end{array}$ & $\begin{array}{c}\text { ZINC } \\
\text { BOT MAT } \\
\angle 63 \mu \text { DS } \\
\text { LAB } \\
(\mu g / G) \\
(35022)\end{array}$ & $\begin{array}{l}\text { SED 1- } \\
\text { MENT, } \\
\text { SUS- } \\
\text { PENDED } \\
\text { (mo/L) } \\
(80154)\end{array}$ \\
\hline
\end{tabular}

LITTLE COLORADO RIVER MEAR JOSEPH CITY, AZ-COntinued

$09397300 \quad 02-17-89$
$03-15-89$
$03-27-89$
$07-23-89$
$07-23-89$
$07-23-89$
$07-23-89$
$07-24-89$
$07-24-89$
$07-24-89$
$07-24-89$
$07-26-89$
$07-26-89$
$07-26-89$
$07-26-89$
$07-26-89$
$07-26-89$
$07-26-89$
$07-26-89$
$07-26-89$
$07-26-89$
$07-26-89$
$07-26-89$
$07-27-89$
$08-18-89$
$08-18-89$
$08-18-89$
$08-18-89$
$08-18-89$
$08-18-89$
$08-19-89$
$08-19-89$
$08-19-89$
$08-19-89$
$03-05-90$
$07-08-90$
$07-08-90$
$07-08-90$
$07-08-90$

\begin{tabular}{|c|c|}
\hline$\cdots$ & - \\
\hline$\cdots$ & $\cdots$ \\
\hline$-\cdot$ & $\cdots$ \\
\hline$\cdots$ & -- \\
\hline$\cdots$ & $\cdots$ \\
\hline$\cdots$ & $\cdots$ \\
\hline$\ldots$ & $\because$ \\
\hline .. & $\ldots$ \\
\hline -. & $\ldots$ \\
\hline$\cdots$ & . \\
\hline$=$ & $\ldots$ \\
\hline 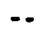 & $\ldots$ \\
\hline- & $\cdots$ \\
\hline$\cdots$ & $\cdots$ \\
\hline$\cdots$ & -. \\
\hline$\cdots$ & $\cdot-$ \\
\hline$\cdots$ & -- \\
\hline$\because$ & $\cdots$ \\
\hline 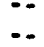 & - \\
\hline -. & $\ldots$ \\
\hline -. & -. \\
\hline - & .. \\
\hline -- & -. \\
\hline - & $\cdots$ \\
\hline -. & $\cdots$ \\
\hline$\ddot{z}$ & $-\overline{-}$ \\
\hline .34 & $<100$ \\
\hline$\cdots$ & $\cdots$ \\
\hline 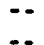 & $\cdots$ \\
\hline$\cdots$ & -. \\
\hline -. & -. \\
\hline$\cdots$ & $\cdots$ \\
\hline$\cdots$ & 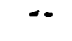 \\
\hline$\cdots$ & $\cdots$ \\
\hline$\cdots$ & - \\
\hline
\end{tabular}

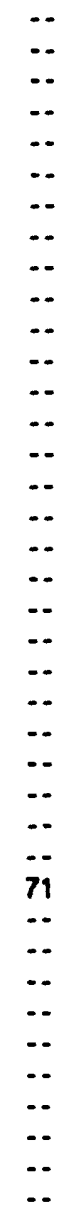

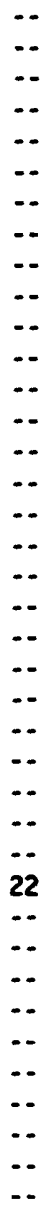

\section{$\cdots$}

-

-

-

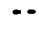

$\cdots$

$\cdots$

$-\infty$

$\cdots$

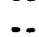

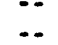

-.

$\cdots$

$\cdots$

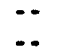

-

$+$

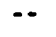

$-$

$\cdots$

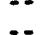

$\cdots$

-.

$-\cdots$

2

-.

$\cdots$

$\cdots$

$\cdots$

$+-$

-

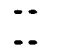

$\cdots$

-.

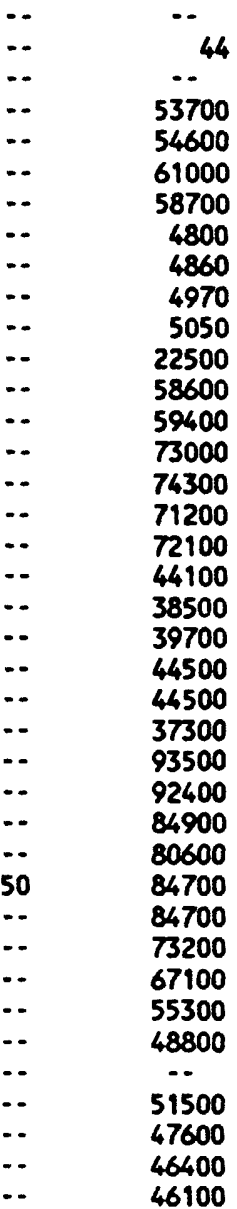


STATION

MUMBER

09397300
OATE
SURFACE-WATER DATA-Cont inued

CHEMICAL ANALYSES-Cont inued

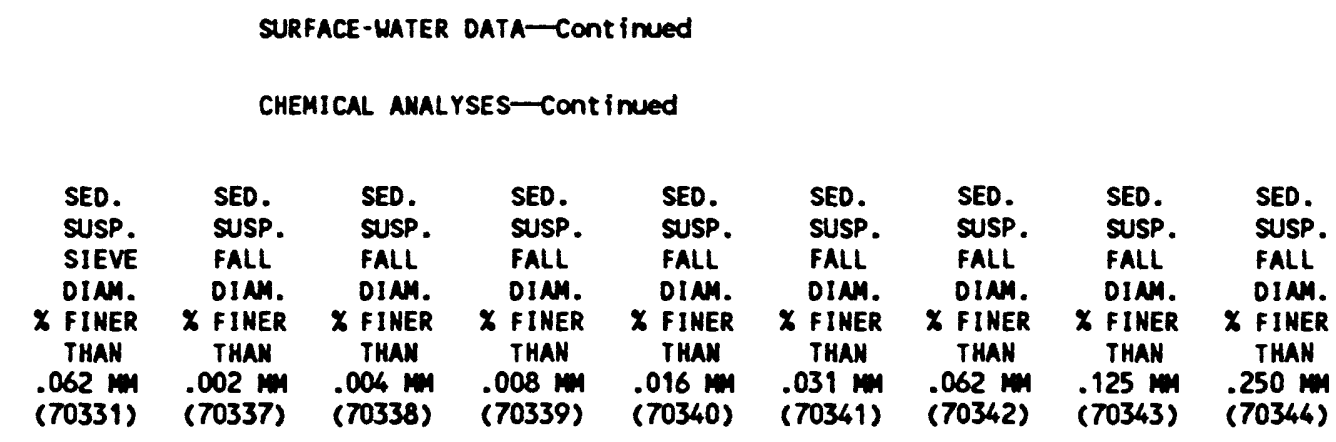

LITTLE COLORADO RIVER MEAR JOSEPH CITY, AZ-Continued

$02-17-89$
$03-15-89$
$03-27-89$
$07-23-89$
$07-23-89$
$07-23-89$
$07-23-89$
$07-24-89$
$07-24-89$
$07-24-89$
$07-24-89$
$07-26-89$
$07-26-89$
$07-26-89$
$07-26-89$
$07-26-89$
$07-26-89$
$07-26-89$
$07-26-89$
$07-26-89$
$07-26-89$
$07-26-89$
$07-26-89$
$07-27-89$
$08-18-89$
$08-18-89$
$08-18-89$
$08-18-89$
$08-18-89$
$08-18-89$
$08-19-89$
$08-19-89$
$08-19-89$
$08-19-89$
$03-05-90$
$07-08-90$
$07-08-90$
$07-08-90$
$07-08-90$
0

\begin{tabular}{|c|c|c|}
\hline - & - & $\cdots$ \\
\hline 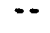 & $\cdots$ & $\cdots$ \\
\hline$\cdots$ & $\cdots$ & $\cdots$ \\
\hline 99 & $\cdots$ & $\cdots$ \\
\hline$\because$ & $\cdots$ & $\cdots$ \\
\hline 98 & $\cdots$ & $\cdots$ \\
\hline$\because$ & $\cdots$ & $\cdots$ \\
\hline 9 & $\cdots$ & $\because$ \\
\hline 97 & $\because$ & $\because$ \\
\hline$\cdots$ & $\cdots$ & $\cdots$ \\
\hline$\ddot{07}$ & - & $\ldots$ \\
\hline $\begin{array}{l}97 \\
95\end{array}$ & $\ldots$ & $\cdots$ \\
\hline - & - & $\cdots$ \\
\hline 98 & - & $\cdots$ \\
\hline$\cdots$ & $\cdots$ & $\cdots$ \\
\hline 98 & $\cdots$ & $\cdots$ \\
\hline$\cdots$ & $\cdots$ & $\cdots$ \\
\hline 98 & $\cdots$ & $\cdots$ \\
\hline 97 & $\cdots$ & $\cdots$ \\
\hline$\cdots$ & $\cdots$ & $\cdots$ \\
\hline$\cdots$ & $\cdots$ & $\because$ \\
\hline 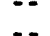 & $\ddot{0}$ & $\ddot{\theta}$ \\
\hline 77 & $\begin{array}{l}0 y \\
--\end{array}$ & $\begin{array}{l}\infty< \\
--\end{array}$ \\
\hline -. & $\ldots$ & -. \\
\hline 78 & - & $\cdots$ \\
\hline$\therefore$ & $\cdots$ & $\cdots$ \\
\hline$\therefore$ & $\cdots$ & $\cdots$ \\
\hline$\cdots$ & $\cdots$ & $\cdots$ \\
\hline$\because$ & $\cdots$ & $\cdots$ \\
\hline$\because$ & $\cdots$ & $\cdots$ \\
\hline 85 & $\cdots$ & $\cdots$ \\
\hline$\cdots$ & $\cdots$ & $\cdots$ \\
\hline$\ddot{0}$ & $\cdots$ & $\cdots$ \\
\hline $\begin{array}{l}97 \\
96\end{array}$ & 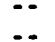 & $\because$ \\
\hline 97 & -. & $\ldots$ \\
\hline 94 & .. & - \\
\hline
\end{tabular}

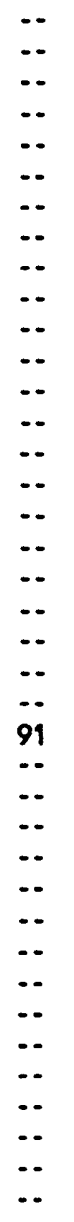

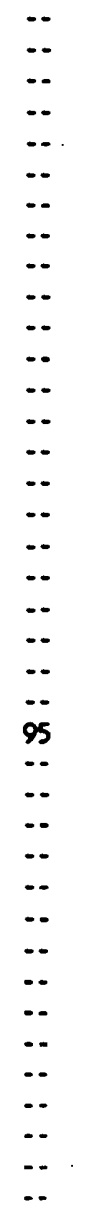


SURFACE-WATER DATA-Cont inued

CHEMICAL ANALYSES-Cont inued

STATION

MUBER

STATION NAME

LATITUDE

LONGITTDE

09397300

LITTLE COLORADO RIVER NEAR JOSEPH CITY, ARIZOMA

07-08-90 0440

07-08-90 0620

$07-14-90 \quad 1730$

$07-14-90 \quad 2150$

$07-14-90 \quad 2340$

$07-15-90 \quad 0750$

$07-16-90 \quad 0150$

$07-16-90 \quad 1610$

08-16-90 $\quad 1645$

$08-16-90 \quad 1750$

09-01-90 ‥

$09-01-90 \quad 1820$

09-01-90 $\quad 1930$

09-01-90 2110

09-01-90 2150

09-05-90 1200

09-11-90 $\quad 1130$

$09-21-90$-.

09-21-90 0550

$09-21-90 \quad 0700$

09-21-90 0710

$09-21-90 \quad 0830$

$09-21-90 \quad 0850$

$09-21-90 \quad 1020$

09-21-90 $\quad 1110$

$09-21-90 \quad 1130$

09-21-90 1230

09-21-90 1630

09-21-90 1740

09-22-90 $\quad 1200$

12-18-90 1525

01-06-91 ‥

01-06-91 0002

01-07-91 1620

01-15-91 1540

08-01-91 1130

08-01-91 1145

08-01-91 1230

08-08-99 1630

08-28-91 $\quad 1740$

08-28-91 1745

$34 \cdot 56 \cdot 591 \mathrm{~N} \quad 110 \cdot 20 \cdot 24 \mathrm{MH}$

09-06-91 0250 


\begin{tabular}{|c|c|c|c|c|c|c|c|c|c|c|}
\hline $\begin{array}{l}\text { STATION } \\
\text { MUMBER }\end{array}$ & DATE & $\begin{array}{l}\text { SAM- } \\
\text { PLIING } \\
\text { METHOD, } \\
\text { COOES } \\
(82398)\end{array}$ & $\begin{array}{l}\text { STREAK } \\
\text { NIDTH } \\
\text { (METERS) } \\
(00004)\end{array}$ & $\begin{array}{c}\text { TEMPER- } \\
\text { ATURE } \\
\text { WATER } \\
\left({ }^{\circ} \mathrm{C}\right) \\
(00010)\end{array}$ & $\begin{array}{l}\text { DIS- } \\
\text { CHARGE, } \\
\text { INST. } \\
\text { CUBIC } \\
\text { METERS } \\
\text { PER } \\
\text { SECOND } \\
\text { (00061) }\end{array}$ & $\begin{array}{c}\text { GAGE } \\
\text { HEIGHT } \\
\text { (meters) } \\
\text { (00065) }\end{array}$ & $\begin{array}{c}\text { SPE- } \\
\text { CIFIC } \\
\text { CON- } \\
\text { DUCT- } \\
\text { ANCE } \\
(\mu S / C D) \\
(00095)\end{array}$ & $\begin{array}{l}\text { SPE- } \\
\text { CIFIC } \\
\text { CON- } \\
\text { DUCT- } \\
\text { ANCE } \\
\text { LAB } \\
(\mu S / \mathrm{Cm}) \\
(90095)\end{array}$ & $\begin{array}{c}\text { OXYGEN, } \\
\text { DIS- } \\
\text { SOLVED } \\
\text { (mo/L) } \\
(00300)\end{array}$ & $\begin{array}{l}\text { PH } \\
\text { WATER } \\
\text { WHOLE } \\
\text { FIELD } \\
\text { (STAND- } \\
\text { ARD } \\
\text { UNITS) } \\
\text { (00400) }\end{array}$ \\
\hline
\end{tabular}

$09397300 \quad 07-08-90$
$07-08-90$
$07-14-90$
$07-14-90$
$07-14-90$
$07-15-90$
$07-16-90$
$07-16-90$
$08-16-90$
$08-16-90$
$09-01-90$
$09-01-90$
$09-01-90$
$09-01-90$
$09-01-90$
$09-05-90$
$09-11-90$
$09-21-90$
$09-21-90$
$09-21-90$
$09-21-90$
$09-21-90$
$09-21-90$
$09-21-90$
$09-21-90$
$09-21-90$
$09-21-90$
$09-21-90$
$09-21-90$
$09-22-90$
$12-18-90$
$01-06-91$
$01-06-91$
$01-07-91$
$01-15-91$
$08-01-91$
$08-01-91$
$08-01-91$
$08-08-91$
$08-28-91$
$08-28-91$
$09-06-91$

LITTLE COLORADO RIVER MEAR JOSEPH CITY, AZ-Continued

\begin{tabular}{|c|c|c|c|c|c|c|c|c|}
\hline 50 & -- & -- & 67.4 & 1.11 & -- & $=$ & -- & $\cdots$ \\
\hline 50 & -- & -- & 50.4 & $=$ & $\cdots$ & $\cdots$ & $\cdots$ & $=$ \\
\hline 50 & $\cdots$ & $\cdots$ & 100.8 & 1.23 & $\cdots$ & 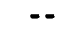 & $\cdots$ & $\cdots$ \\
\hline 50 & - & $\cdots$ & 35.1 & -- & $\cdots$ & $\cdots$ & 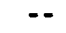 & $\cdots$ \\
\hline 50 & -- & $\cdots$ & 28.6 & -- & $\cdots$ & -- & -- & -- \\
\hline 50 & $\cdots$ & $\cdots$ & 28.3 & -- & $\cdots$ & $\cdots$ & -- & - \\
\hline 50 & $\cdots$ & $\cdots$ & 31.7 & -- & -- & -- & $\cdots$ & -- \\
\hline 70 & -- & $\cdots$ & 8.9 & $\ddot{\theta}$ & $\cdots$ & $\ddot{-}$ & -- & -- \\
\hline 10 & -- & -- & 27.2 & .94 & $\cdots$ & 709 & $\cdots$ & -- \\
\hline 50 & -- & $\cdots$ & 22.4 & .94 & $\cdots$ & 719 & -- & -- \\
\hline 3000 & $\cdots$ & -- & -- & $\cdots$ & $\cdots$ & 446 & -- & -- \\
\hline 50 & -- & $\cdots$ & 90.1 & -- & $\cdots$ & $\cdots$ & -- & $\cdots$ \\
\hline 50 & $\cdots$ & -- & 59.4 & -- & -- & $\because$ & -- & -- \\
\hline 50 & $\cdots$ & -- & 35.1 & -- & $\cdots$ & -- & $\cdots$ & $\cdots$ \\
\hline 50 & $\cdots$ & -- & 35.1 & $\because$ & -- & $=$ & $\cdots$ & $\cdots$ \\
\hline 70 & $\cdots$ & $\cdots$ & 6.7 & .81 & -- & -- & $\cdots$ & $\cdots$ \\
\hline 70 & $\cdots$ & $\cdots$ & .57 & .70 & $\cdots$ & $\cdots$ & -- & -- \\
\hline 3000 & - & $\cdots$ & 28.6 & .94 & 592 & 598 & -- & 8.3 \\
\hline 50 & $\cdots$ & -- & 50.7 & $\because$ & $\cdots$ & -- & $\cdots$ & $\cdots$ \\
\hline 50 & $\cdots$ & -- & 29.7 & .95 & -- & -- & -- & $\cdots$ \\
\hline 50 & $\cdots$ & -- & 30.6 & .95 & -- & -- & -- & $\cdots$ \\
\hline 50 & $=$ & -- & 36.8 & $\cdots$ & $\cdots$ & $\cdots$ & $-\cdot$ & -- \\
\hline 50 & -- & $\cdots$ & 40.0 & $\because$ & $\cdots$ & $\cdots$ & $\cdots$ & $\cdots$ \\
\hline 50 & $\because$ & -- & 35.1 & .98 & $\because$ & $\cdots$ & $\cdots$ & $\cdots$ \\
\hline 50 & $\cdots$ & -- & 38.8 & -- & $\cdots$ & $\cdots$ & -- & -- \\
\hline 50 & -- & -- & 36.0 & -- & -- & -- & -- & -- \\
\hline 50 & -- & $=-$ & 35.1 & -- & -- & -- & -- & $\cdots$ \\
\hline 50 & -- & -- & 35.1 & $-\cdot$ & $\cdots$ & -- & $\cdots$ & -- \\
\hline 50 & -- & -- & 29.7 & $\cdot-$ & $\cdots$ & $\cdots$ & -- & $\cdots$ \\
\hline 70 & $\cdots$ & -- & 34.0 & .97 & -- & $-\cdot$ & $\cdots$ & -. \\
\hline 70 & $\cdots$ & -- & .91 & -- & $\cdots$ & -- & $\cdots$ & -. \\
\hline 8010 & $\because$ & -- & -- & $\cdots$ & 871 & $\because$ & -- & $\cdots$ \\
\hline 8010 & $\cdots$ & -- & $\cdots$ & $\cdots$ & 812 & $\cdots$ & -- & 8.8 \\
\hline 70 & $\cdots$ & $=$ & 22.6 & .91 & 518 & 559 & $\cdots$ & 9.3 \\
\hline 70 & $\cdots$ & 7.0 & E.85 & -- & $\cdots$ & $\cdots$ & $\cdots$ & $\cdots$ \\
\hline 50 & $\cdots$ & -- & 2.5 & .77 & 439 & -- & $\cdots$ & 8.0 \\
\hline 10 & 21.3 & 23.0 & 2.3 & .76 & 408 & 446 & 6.7 & 7.8 \\
\hline 50 & $\cdots$ & $\cdots$ & 2.2 & .76 & 414 & $\cdots$ & $\cdots$ & 8.0 \\
\hline 50 & -- & -- & 7.7 & .85 & 1360 & $\cdots$ & $\cdots$ & 7.5 \\
\hline 50 & $\cdots$ & $\cdots$ & 6.4 & .81 & $\cdots$ & -- & $\cdots$ & $\cdots$ \\
\hline 50 & $\cdots$ & $\because$ & $\cdots$ & 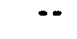 & $\cdots$ & $\cdots$ & $\cdots$ & $\because$ \\
\hline 5 & -- & - & -- & -. & -- & -- & $\cdots$ & 7.9 \\
\hline
\end{tabular}


CHEMICAL AMALYSES-Cont inued

STATION

MUMBER

DATE

\begin{tabular}{|c|c|c|c|c|c|c|c|c|}
\hline $\begin{array}{l}\text { PH } \\
\text { WATER } \\
\text { WHOLE } \\
\text { LAB } \\
\text { STAND- } \\
\text { NRD } \\
\text { WNITS) }\end{array}$ & $\begin{array}{l}\text { FIX END } \\
\text { FIELL } \\
\text { CaCO3 } \\
(\operatorname{mo/L} / L) \\
(39036)\end{array}$ & $\begin{array}{l}\text { ALKA- } \\
\text { LINITY } \\
\text { WAT DIS } \\
\text { TOT IT } \\
\text { FIELO } \\
\text { MO/L \& } \\
\text { CaCO3 } \\
(39086)\end{array}$ & $\begin{array}{l}\text { ALKA- } \\
\text { LINITY } \\
\text { LAB } \\
\text { (mg/L } \\
\text { os } \\
\text { Caco3) } \\
(90410)\end{array}$ & $\begin{array}{l}\text { BICAR- } \\
\text { BONATE } \\
\text { WATER } \\
\text { DIS IT } \\
\text { FIELD } \\
\text { mo/L as } \\
\text { HCO3 } \\
(00453)\end{array}$ & $\begin{array}{l}\text { SOLI } \\
\text { RESI } \\
\text { AT } 18 \\
\text { OIS } \\
\text { SOLV } \\
(\mathrm{mol} / \\
(703\end{array}$ & $\begin{array}{l}\text { TUE } \\
0 \\
\text { SO } \\
\text { (m. } \\
\text { C70 }\end{array}$ & $\begin{array}{l}\text { DS, } \\
\text { ED } \\
\text { ic } \\
0 \\
12)\end{array}$ & $\begin{array}{l}\text { O- } \\
\text { iAA } \\
\text { ED } \\
\text { i } \\
\text { 8) }\end{array}$ \\
\hline
\end{tabular}

LITTLE COLORADO RIVER MEAR JOSEPH CITY, AZ-Continued

$09397300 \quad 07-08-90$
$07-08-90$
$07-14-90$
$07-14-90$
$07-14-90$
$07-15-90$
$07-16-90$
$07-16-90$
$08-16-90$
$08-16-90$
$09-01-90$
$09-01-90$
$09-01-90$
$09-01-90$
$09-01-90$
$09-05-90$
$09-11-90$
$09-21-90$
$09-21-90$
$09-21-90$
$09-21-90$
$09-21-90$
$09-21-90$
$09-21-90$
$09-21-90$
$09-21-90$
$09-21-90$
$09-21-90$
$09-21-90$
$09-22-90$
$12-18-90$
$01-06-91$
$01-06-91$
$01-07-91$
$01-15-91$
$08-01-91$
$08-01-91$
$08-01-91$
$08-08-91$
$08-28-91$
$08-28-91$
$09-06-91$

\begin{tabular}{|c|c|c|c|c|c|}
\hline$\cdots$ & $\cdots$ & 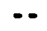 & $\cdots$ & -. & $\ldots$ \\
\hline$\cdots$ & $\cdots$ & .. & $\cdots$ & $\cdots$ & $\cdots$ \\
\hline-- & $\cdots$ & $\cdots$ & -- & -- & -. \\
\hline-- & $\cdots$ & $\cdots$ & $\cdots$ & -- & $-\cdot$ \\
\hline$\cdots$ & $\cdots$ & $\cdots$ & -- & -- & - \\
\hline$\cdots$ & $\cdots$ & $\cdots$ & $\cdots$ & -- & 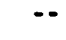 \\
\hline$\cdots$ & $\cdots$ & $\cdots$ & $\cdots$ & $\cdots$ & $\cdots$ \\
\hline 8.1 & $\cdots$ & $\cdots$ & $\ddot{י}$ & $\cdots$ & $\ddot{m}$ \\
\hline $\begin{array}{l}8.1 \\
8.1\end{array}$ & 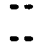 & 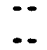 & $\begin{array}{l}239 \\
246\end{array}$ & -- & 390 \\
\hline 7.8 & .. & .. & $\begin{array}{l}240 \\
132\end{array}$ & .. & $\begin{array}{l}405 \\
265\end{array}$ \\
\hline$\cdots$ & $\cdots$ & $\cdots$ & $\cdots$ & -. & $\ldots$ \\
\hline-- & $\cdots$ & $\cdots$ & $\cdots$ & -. & $\cdots$ \\
\hline-- & $\cdots$ & $\cdots$ & $\cdots$ & $\cdots$ & -- \\
\hline-- & -- & $\cdots$ & $\cdots$ & $\cdots$ & 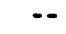 \\
\hline-- & -- & $\cdots$ & -. & $\cdots$ & $\cdots$ \\
\hline -- & $\cdots$ & $\cdots$ & $\cdots$ & -. & - \\
\hline 8.4 & -- & $-\cdot$ & 152 & $\cdot-$ & 356 \\
\hline$\cdots$ & $\cdots$ & $\cdots$ & $\cdots$ & $\cdots$ & $\cdots$ \\
\hline$\cdots$ & $\cdots$ & $\cdots$ & $\because$ & $-\cdot$ & $\cdots$ \\
\hline -- & $\cdots$ & $\cdots$ & $\cdots$ & $\cdots$ & -- \\
\hline -. & $\ldots$ & $\cdots$ & $\ldots$ & -- & - \\
\hline -. & .. & .. & .. & -. & 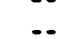 \\
\hline -. & - & .. & .. & -. & 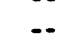 \\
\hline- & -. & .. & .- & .. & . \\
\hline-- & $\cdots$ & -. & -- & -. & 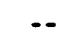 \\
\hline-- & $\cdots$ & .. & -- & -. & .. \\
\hline$-\cdot$ & $\cdots$ & -. & -- & -. & -. \\
\hline$\cdots$ & $\cdots$ & $\cdots$ & $\cdots$ & $\cdots$ & . \\
\hline$\cdots$ & $\cdots$ & -- & $\cdots$ & $\cdots$ & - \\
\hline$\cdots$ & 9 & $\cdots$ & $\cdots$ & $\cdots$ & -- \\
\hline$\because$ & $\cdots$ & $\cdots$ & $\ddot{0}$ & $\cdots$ & $\ddot{m}$ \\
\hline 8.9 & $\cdots$ & $\cdots$ & 147 & $\cdots$ & 379 \\
\hline$\cdot-$ & $\cdots$ & 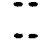 & $\cdots$ & 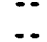 & $\cdots$ \\
\hline$\because 0$ & 71 & 71 & $\ldots$ & 88 & $\cdots$ \\
\hline $\begin{array}{l}7.8 \\
--8\end{array}$ & $\therefore$ & $\ldots$ & $\ldots$ & $\infty$ & $\cdots$ \\
\hline$\ddot{-}$ & 7 & -. & $\ldots$ & .. & $\cdots$ \\
\hline 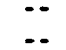 & $\therefore$ & -. & .. & .. & .. \\
\hline.- & -. & -- & -- & -. & . \\
\hline$\cdots$ & -. & -. & -. & -. & \\
\hline
\end{tabular}

\begin{tabular}{|c|c|c|}
\hline$\cdots$ & -. & -- \\
\hline$\cdots$ & 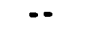 & $\cdots$ \\
\hline-- & $\cdots$ & $\cdots$ \\
\hline$\cdots$ & $\cdots$ & $\cdots$ \\
\hline$\cdots$ & -- & $\cdots$ \\
\hline$\cdots$ & $-\cdot$ & -. \\
\hline$\cdots$ & $\cdots$ & $\cdots$ \\
\hline$\ddot{0}$ & -- & $\cdots$ \\
\hline $\begin{array}{l}410 \\
430\end{array}$ & $\begin{array}{l}916 \\
784\end{array}$ & 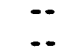 \\
\hline 269 & -. & -. \\
\hline$\cdots$ & -- & $\cdots$ \\
\hline$\cdots$ & -- & $\cdots$ \\
\hline$\cdots$ & $\cdots$ & $\cdots$ \\
\hline$\cdots$ & - & $\cdots$ \\
\hline$\cdots$ & -- & $\cdots$ \\
\hline$\because$ & $\because$ & $\cdots$ \\
\hline 361 & 881 & $\cdots$ \\
\hline$\cdots$ & $\cdots$ & $\cdots$ \\
\hline$\because$ & $\because$ & $\because$ \\
\hline$\cdots$ & 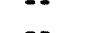 & $\because$ \\
\hline 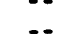 & 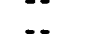 & 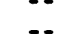 \\
\hline 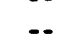 & - & - \\
\hline & -. & $\ldots$ \\
\hline . & -. & .- \\
\hline 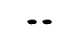 & -- & -. \\
\hline$\cdots$ & -- & - \\
\hline$-\cdot$ & $\cdots$ & $\cdots$ \\
\hline- & 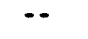 & $\cdots$ \\
\hline & -- & $\cdots$ \\
\hline & $\cdots$ & $\cdots$ \\
\hline$\because$ & $\because$ & $\cdots$ \\
\hline 319 & 733 & $\cdots$ \\
\hline$\cdots$ & -- & $\cdots$ \\
\hline$\ddot{265}$ & $\overline{53}, 2$ & .070 \\
\hline 265 & 53.2 & $\begin{array}{c}.070 \\
. .\end{array}$ \\
\hline$\cdots$ & $\ldots$ & $\ldots$ \\
\hline 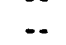 & $\ldots$ & .- \\
\hline - & $\ldots$ & - \\
\hline-- & -- & $-\cdot$ \\
\hline
\end{tabular}


CHEMICAL ANALYSES-Cont inued

\begin{tabular}{|c|c|c|c|c|c|c|c|c|c|c|}
\hline $\begin{array}{l}\text { STATION } \\
\text { NUMBER }\end{array}$ & DATE & $\begin{array}{l}\text { NITRO- } \\
\text { GEN, } \\
\text { NITRITE } \\
\text { DIS- } \\
\text { SOLVED } \\
\text { (HS/L } \\
\text { AS N) } \\
\text { (00613) }\end{array}$ & $\begin{array}{l}\text { NITRO- } \\
\text { GEN, } \\
\text { NITRATE } \\
\text { DIS- } \\
\text { SOLVED } \\
\text { (MS/L } \\
\text { aS N) } \\
(00618)\end{array}$ & $\begin{array}{c}\text { KITRO- } \\
\text { GEN, } \\
\text { MO2+NO3 } \\
\text { DIS- } \\
\text { SOLVED } \\
\text { (mg/L } \\
\text { AS N) } \\
\text { (00631) }\end{array}$ & $\begin{array}{l}\text { MITRO- } \\
\text { GEN, } \\
\text { NITRATE } \\
\text { DIS- } \\
\text { SOLVED } \\
\text { (MN/L } \\
\text { as NO3) } \\
\text { (71851) }\end{array}$ & $\begin{array}{c}\text { NITRO- } \\
\text { GEN, } \\
\text { NITRITE } \\
\text { DIS- } \\
\text { SOLVED } \\
\text { (Mg/L } \\
\text { as NO2) } \\
\text { (71856) }\end{array}$ & $\begin{array}{l}\text { MITRO- } \\
\text { GEN,AN- } \\
\text { MONIA + } \\
\text { ORGANIC } \\
\text { TOTAL } \\
(\mathrm{mg} / L \\
\text { es N) } \\
(00625)\end{array}$ & $\begin{array}{l}\text { PHOS- } \\
\text { PHORUS } \\
\text { DIS- } \\
\text { SOLVED } \\
\text { (mg/L } \\
\text { as P) } \\
(00666)\end{array}$ & $\begin{array}{l}\text { PHOS- } \\
\text { PHORUS } \\
\text { TOTAL } \\
\text { (mg/L } \\
\text { as P) } \\
(00665)\end{array}$ & $\begin{array}{l}\text { PHOS- } \\
\text { PHORUS } \\
\text { ORTHO, } \\
\text { DIS- } \\
\text { SOLVED } \\
\text { (mg/L } \\
\text { as P) } \\
(00679)\end{array}$ \\
\hline
\end{tabular}

LITTLE COLORADO RIVER NEAR JOSEPH CITY, AZ-Continued

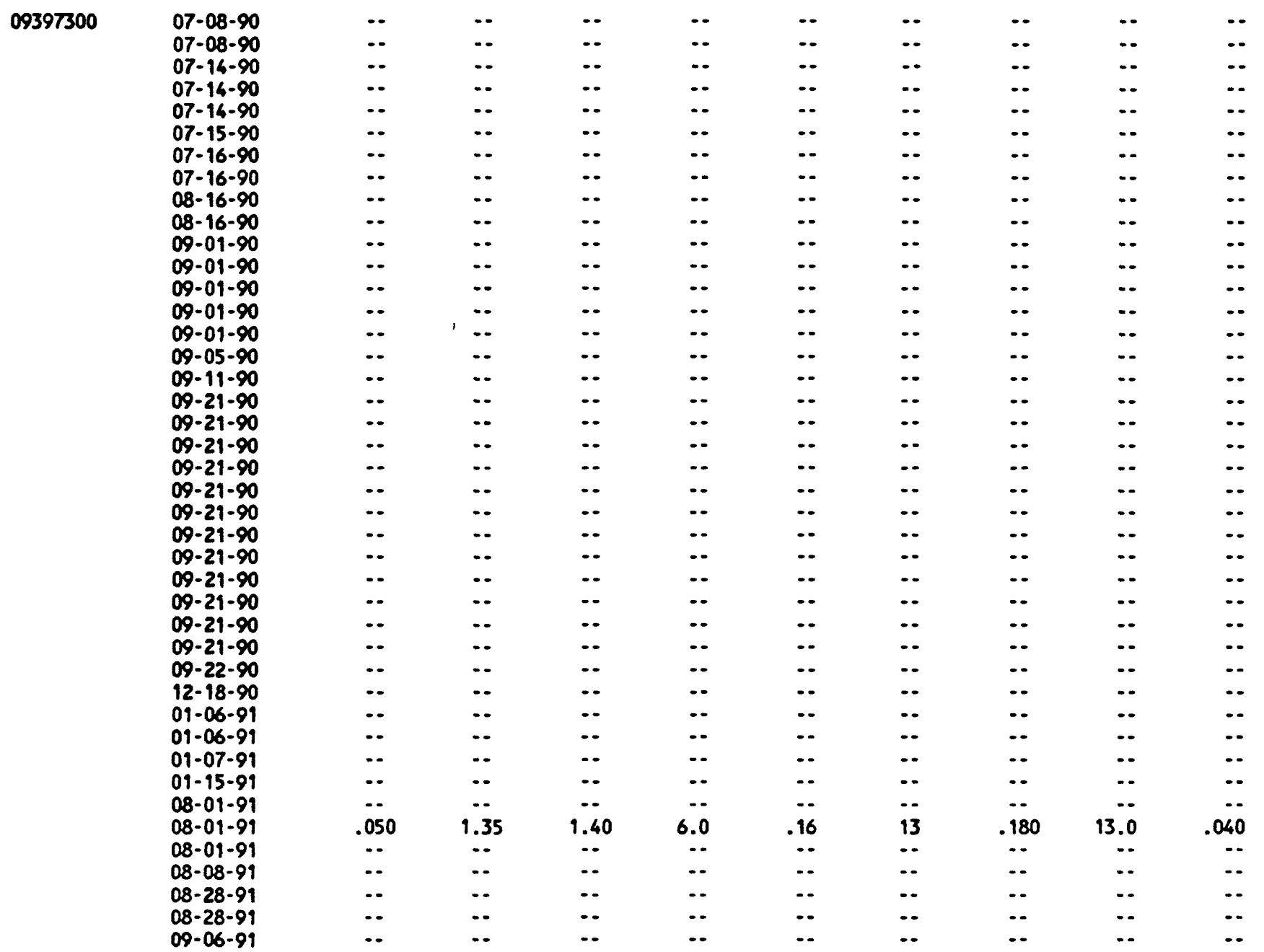


SURFACE-WATER DATA-Cont inued

CHEMICAL AMALYSES-Continued

STATION

NUMBER

DATE

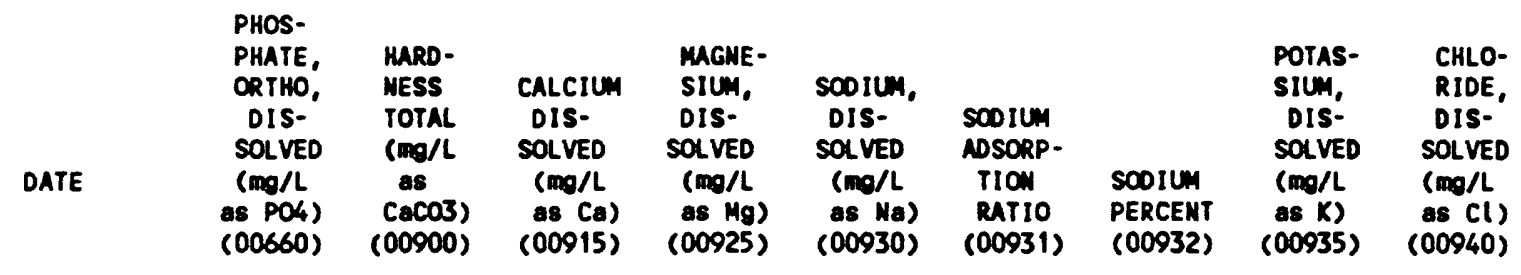

$09397300 \quad 07-08-90$
$07-08-90$
$07-14-90$
$07-14-90$
$07-14-90$
$07-15-90$
$07-16-90$
$07-16-90$
$08-16-90$
$08-16-90$
$09-01-90$
$09-01-90$
$09-01-90$
$09-01-90$
$09-01-90$
$09-05-90$
$09-11-90$
$09-21-90$
$09-21-90$
$09-21-90$
$09-21-90$
$09-21-90$
$09-21-90$
$09-21-90$
$09-21-90$
$09-21-90$
$09-21-90$
$09-21-90$
$09-21-90$
$09-22-90$
$12-18-90$
$01-06-91$
$01-06-91$
$01-07-91$
$01-15-91$
$08-01-91$
$08-01-91$
$08-01-91$
$08-08-91$
$08-28-91$
$08-28-91$
$09-06-91$

LITTLE COLORADO RIVER MEAR JOSEPH CITY, AZ-Continued

\begin{tabular}{|c|c|c|c|c|c|c|c|c|}
\hline$\cdots$ & -- & $\cdots$ & $\cdots$ & -. & - & $\cdots$ & $\cdots$ & -. \\
\hline$\cdots$ & $\cdots$ & $\cdots$ & $\cdots$ & -- & $\cdots$ & $\cdots$ & -- & -. \\
\hline -. & $\cdots$ & $\cdots$ & - & $\cdots$ & $\cdots$ & -. & $\cdots$ & $\cdots$ \\
\hline - & $\cdots$ & -. & $\cdots$ & $\cdots$ & $\cdots$ & $\cdots$ & $\cdots$ & $\cdots$ \\
\hline$\cdots$ & $\cdots$ & -- & -. & -. & $\cdots$ & $\cdots$ & -. & $\cdots$ \\
\hline$\cdots$ & -. & $\cdots$ & $\cdots$ & -. & $\cdots$ & $\cdots$ & $\cdots$ & $\cdots$ \\
\hline$\cdots$ & 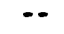 & $\cdots$ & $\cdots$ & $\cdots$ & $\cdots$ & $\cdots$ & $\cdots$ & $\cdots$ \\
\hline - & 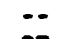 & $\because$ & $\because$ & $\because$ & $\cdots$ & 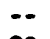 & 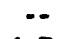 & 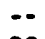 \\
\hline $\begin{array}{l}\ldots \\
\ldots \\
\ldots\end{array}$ & $\begin{array}{r}23 \\
25 \\
100\end{array}$ & $\begin{array}{r}7.5 \\
7.6 \\
32\end{array}$ & $\begin{array}{l}1.0 \\
1.3 \\
5.0\end{array}$ & $\begin{array}{r}130 \\
130 \\
41\end{array}$ & $\begin{array}{r}12 \\
11 \\
?\end{array}$ & $\begin{array}{l}92 \\
91 \\
46\end{array}$ & $\begin{array}{l}1.7 \\
1.8 \\
3.5\end{array}$ & $\begin{array}{l}29 \\
32 \\
15\end{array}$ \\
\hline .. & -- & $\cdots$ & -. & - & $\cdots$ & - & -. & $\cdots$ \\
\hline -. & $\cdots$ & $\cdots$ & $\cdots$ & $\cdots$ & $\cdots$ & $\cdots$ & -- & $\cdots$ \\
\hline -. & -- & $\cdots$ & $\cdots$ & -- & $\cdots$ & $\cdots$ & -- & $\cdots$ \\
\hline$\cdots$ & $\cdots$ & $\cdots$ & $\cdots$ & - & $\cdots$ & $\cdots$ & $\because$ & -- \\
\hline$\cdots$ & $\cdots$ & $\cdots$ & $\cdots$ & -- & $\cdots$ & $\cdots$ & $\because$ & $\cdots$ \\
\hline$\cdots$ & $\ddot{\theta}$ & $\because$ & $\because$ & $\ddot{0}$ & $\ddot{B}$ & $\ddot{m}$ & $\because$ & $\ddot{B}$ \\
\hline -. & 26 & 8.3 & 1.1 & 120 & 10 & 90 & 2.0 & 42 \\
\hline$\cdots$ & $\cdots$ & $\cdots$ & $\cdots$ & $\cdots$ & $\cdots$ & $\cdots$ & $\cdots$ & $\cdots$ \\
\hline$\cdots$ & $\therefore$ & $\cdots$ & $\cdots$ & $\cdots$ & $\cdots$ & $\cdots$ & $\cdots$ & $\cdots$ \\
\hline$\cdots$ & -- & $\cdots$ & $\cdots$ & - & $\cdots$ & $\cdots$ & -- & $\cdots$ \\
\hline$\cdots$ & $\cdots$ & $\cdots$ & 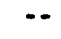 & $\cdots$ & $\cdots$ & -- & $\cdots$ & $\cdots$ \\
\hline$\cdots$ & -- & $\cdots$ & $\cdots$ & -- & $\cdots$ & $\cdots$ & -- & $\cdots$ \\
\hline$\cdots$ & $\cdots$ & $\cdots$ & $\cdots$ & $\because$ & $\cdots$ & $\cdots$ & $\cdots$ & $\cdots$ \\
\hline$\cdots$ & -- & $\cdots$ & $\cdots$ & -- & $\cdots$ & $\cdots$ & -- & $\cdots$ \\
\hline$\cdots$ & $\cdots$ & $\cdots$ & $\cdots$ & $\cdots$ & $\cdots$ & $\cdots$ & $\cdots$ & $\cdots$ \\
\hline$\cdots$ & $\cdots$ & $\cdots$ & $\cdots$ & $\cdots$ & $\cdots$ & $\cdots$ & $\cdots$ & $\cdots$ \\
\hline -. & $\cdots$ & $\cdots$ & $\cdots$ & $\therefore$ & $\cdots$ & $\cdots$ & $\cdots$ & - \\
\hline$\cdots$ & $-\cdot$ & $\cdots$ & $\cdots$ & $-\cdot$ & $\cdots$ & $\cdots$ & $\cdots$ & $\cdots$ \\
\hline$\cdots$ & $\cdots$ & $\cdots$ & $\cdots$ & $\cdots$ & $\cdots$ & $\cdots$ & $\cdots$ & - \\
\hline$\cdots$ & $\cdots$ & $\cdots$ & $\cdots$ & -- & $\cdots$ & $\because$ & $\cdots$ & $\because$ \\
\hline$\ldots$ & $\ldots$ & $\because$ & $\ldots$ & $\therefore$ & $\ldots$ & $\ldots$ & $\therefore$ & $\because$ \\
\hline - & 11 & 2.6 & 1.1 & 110 & 14 & 95 & 1.4 & 34 \\
\hline$\cdots$ & $\cdots$ & $\cdots$ & $\cdots$ & -. & $\cdots$ & $\cdots$ & -. & $\cdots$ \\
\hline - & -. & - & -- & -. & $\cdots$ & -. & -. & $\cdots$ \\
\hline .12 & 100 & 29 & 7.6 & 45 & 2 & 47 & 5.7 & 37 \\
\hline$\cdots$ & $\cdots$ & $\cdots$ & $\cdots$ & $\cdots$ & $\cdots$ & $\cdots$ & -. & $\cdots$ \\
\hline$\cdots$ & $\cdots$ & $\cdots$ & $\cdots$ & $\cdots$ & $\cdots$ & $\because$ & $\cdots$ & $\cdots$ \\
\hline 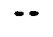 & $\cdots$ & $\cdots$ & -- & $\cdots$ & $\cdots$ & - & $\cdots$ & $\cdots$ \\
\hline$\cdots$ & 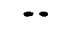 & -- & $\cdots$ & $\cdots$ & $\cdots$ & -- & 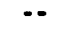 & $\cdots$ \\
\hline$\cdots$ & $\cdots$ & $\cdots$ & $\cdots$ & $\cdots$ & $\cdots$ & $\cdots$ & $\cdots$ & \\
\hline
\end{tabular}


CHEMICAL AKALYSES-Cont inued

STATION

MUMBER

DATE

$\begin{array}{cc} & \text { FLUO- } \\ \text { BRONIDE } & \text { RIDE, } \\ \text { DIS- } & \text { DIS- } \\ \text { SOLVED } & \text { SOLVED } \\ (\mathrm{mg} / L & (\mathrm{mg} / \mathrm{L} \\ \text { AS Br) } & \text { as F) } \\ (71870) & (00950)\end{array}$

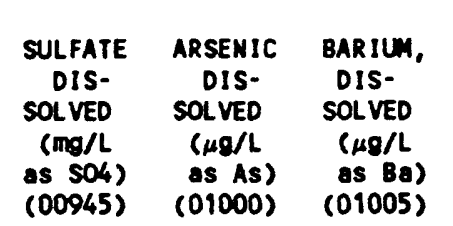

(00945)
BERYL-

LIUN,

SOLVED

$(\mu \mathrm{g} / \mathrm{L}$

as Be)

(01010)
BORON, CADMIUN

( $\mu \mathrm{g} / \mathrm{L}$

as B)

(01020)
DIS-

SOLVED

$(\mu \mathrm{g} / \mathrm{L}$

as Cd)

(01025)

LITTLE COLORADO RIVER NEAR JOSEPH CITY, AZ-ContinuEd

$09397300 \quad 07-08-90$
$07-08-90$
$07-14-90$
$07-14-90$
$07-14-90$
$07-15-90$
$07-16-90$
$07-16-90$
$08-16-90$
$08-16-90$
$09-01-90$
$09-01-90$
$09-01-90$
$09-01-90$
$09-01-90$
$09-05-90$
$09-11-90$
$09-21-90$
$09-21-90$
$09-21-90$
$09-21-90$
$09-21-90$
$09-21-90$
$09-21-90$
$09-21-90$
$09-21-90$
$09-21-90$
$09-21-90$
$09-21-90$
$09-22-90$
$12-18-90$
$01-06-91$
$01-06-91$
$01-07-91$
$01-15-91$
$08-01-91$
$08-01-91$
$08-01-91$
$08-08-91$
$08-28-91$
$08-28-91$
$09-06-91$

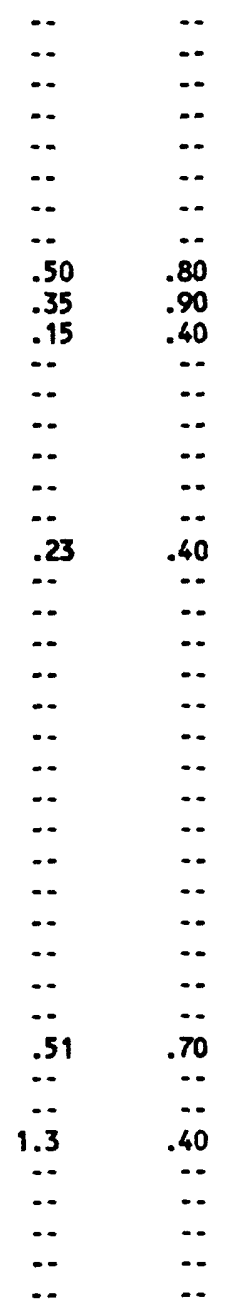

\begin{tabular}{|c|c|}
\hline - & - \\
\hline$\cdots$ & -. \\
\hline - & $\cdots$ \\
\hline -. & - \\
\hline -- & 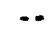 \\
\hline$\cdots$ & - \\
\hline - & - \\
\hline$\cdots$ & - \\
\hline $\begin{array}{c}12 \\
15 \\
8.3\end{array}$ & $\begin{array}{l}84 \\
93 \\
83\end{array}$ \\
\hline$\ldots$ & - \\
\hline$\ldots$ & - \\
\hline - & - \\
\hline -. & - \\
\hline -. & - \\
\hline$\cdots$ & $\cdots$ \\
\hline 11 & 84 \\
\hline$\cdots$ & $\cdots$ \\
\hline$\cdots$ & - \\
\hline$\cdots$ & $\cdots$ \\
\hline$\cdots$ & $\cdots$ \\
\hline$\cdots$ & $\cdots$ \\
\hline$\cdots$ & $\cdots$ \\
\hline$\cdots$ & $\cdots$ \\
\hline$\because$ & $\ldots$ \\
\hline$\ldots$ & . \\
\hline - & - \\
\hline$\cdots$ & - \\
\hline$\cdots$ & $\cdots$ \\
\hline - & $\cdots$ \\
\hline$\because$ & $\because$ \\
\hline 26 & 53 \\
\hline - & $\cdots$ \\
\hline$\ddot{25}$ & $\ddot{2}$ \\
\hline 25 & 62 \\
\hline$\ldots$ & $\ldots$ \\
\hline$\cdots$ & - \\
\hline$\cdots$ & $\cdots$ \\
\hline$\cdots$ & - \\
\hline
\end{tabular}

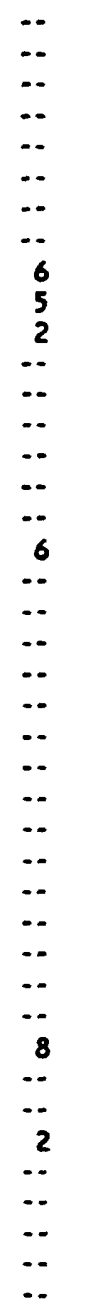

-
-
-
-
-
-
-
-
31
25
80
-
-
-
-
-
-
46
--
-
-
-
-
-
-
-
-
-
-
-
-
-
-
49
-
100
-
-
-
-
-

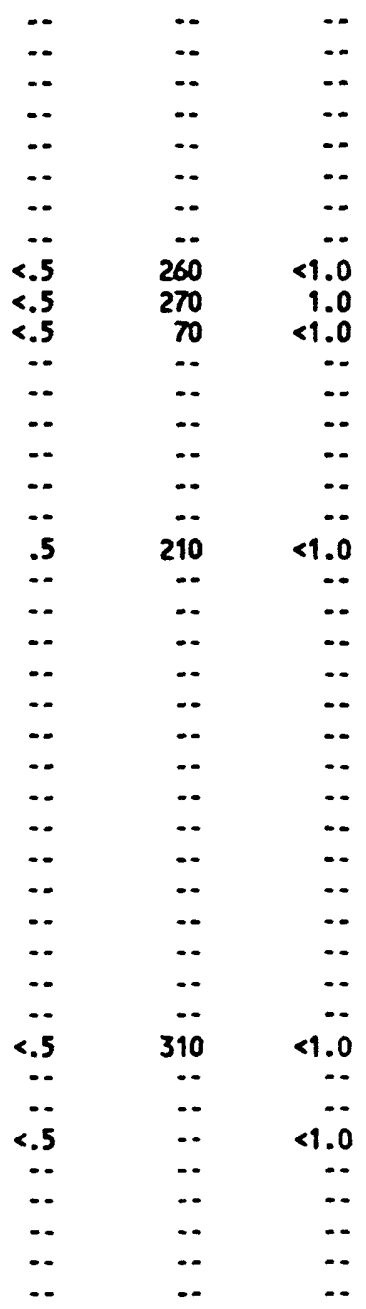


STATION

NUMBER

DATE

\begin{tabular}{|c|c|c|c|c|c|c|c|c|c|}
\hline ATE & $\begin{array}{l}\text { CHRO- } \\
\text { MIUM, } \\
\text { DIS- } \\
\text { SOLVED } \\
\text { ( } \mu g / L \\
\text { AS Cr) } \\
(01030)\end{array}$ & $\begin{array}{l}\text { COBALT, } \\
\text { DIS- } \\
\text { SOLVED } \\
\text { ( } \mu g / L \\
\text { as Co }) \\
(01035)\end{array}$ & $\begin{array}{l}\text { COPPER, } \\
\text { DIS- } \\
\text { SOLVED } \\
\text { ( } \mu g / L \\
\text { as Cu) } \\
(01040)\end{array}$ & $\begin{array}{l}\text { IRON, } \\
\text { DIS- } \\
\text { SOLVED } \\
\text { ( } \mu g / L \\
\text { as Fe) } \\
(01046)\end{array}$ & $\begin{array}{l}\text { LEND, } \\
\text { DIS- } \\
\text { SOLVED } \\
\text { ( } \mu g / L \\
\text { as Pb) } \\
(01049)\end{array}$ & $\begin{array}{l}\text { MANCA- } \\
\text { NESE, } \\
\text { DIS- } \\
\text { SOLVED } \\
\text { ( } \mu Q / L \\
\text { as } \mathrm{Hn}) \\
(01056)\end{array}$ & $\begin{array}{l}\text { MOLYB- } \\
\text { DENUM, } \\
\text { DIS- } \\
\text { SOLVED } \\
(\mu g / L \\
\text { as Mo) } \\
(01060)\end{array}$ & $\begin{array}{l}\text { NICKEL, } \\
\text { DIS- } \\
\text { SOLVED } \\
\text { ( } \mu g / L \\
\text { as } N i) \\
(01065)\end{array}$ & $\begin{array}{l}\text { SILVER, } \\
\text { OIS- } \\
\text { SOLVED } \\
\text { ( } \mu g / L \\
\text { as Ag) } \\
\text { (01075) }\end{array}$ \\
\hline
\end{tabular}

LITTLE COLORADO RIVER NEAR JOSEPH CITY, AZ-Continued

\begin{tabular}{|c|c|c|c|c|c|c|c|c|c|c|}
\hline 09397300 & $07-08-90$ & $\ddot{a}$ & $\ddot{-.}$ & $\ddot{. .}$ & $\begin{array}{l}- \\
\therefore\end{array}$ & $\begin{array}{l}\ldots \\
\ldots\end{array}$ & $\begin{array}{l}\ldots \\
\ldots-\end{array}$ & 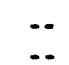 & 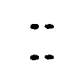 & 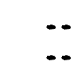 \\
\hline & $\begin{array}{l}07-08-90 \\
07-14-90\end{array}$ & $\because-$ & $\because \cdot$ & $\because$. & $\begin{array}{l}-. \\
-.\end{array}$ & $\because$ & $\begin{array}{l}-. \\
-.\end{array}$ & $\because-$ & $\because$. & $\because$ \\
\hline & $07-14-90$ & $\therefore$ & .. & -. & -. & -. & -. & -. & $\therefore$ & $\because$ \\
\hline & $07-14-90$ & .. & $\cdots$ & -. & -- & $\cdots$ & -- & -. & $\ldots$ & .. \\
\hline & $07-15-90$ & $\cdots$ & -. & -. & -. & -. & -. & .. & -. & .. \\
\hline & $07-16-90$ & $\cdots$ & $\cdots$ & $\cdots$ & $\cdots$ &.- & $-\cdot$ & $\cdots$ & $\cdots$ & $\cdot \cdot$ \\
\hline & $07-16-90$ & $\cdots$ & $\cdots$ & $\cdots$ & $\cdots$ & $\because$ & -- & $\cdots$ & -. & -. \\
\hline & $08-16-90$ & $<5$ & 3 & 10 & 87 & $<10 \mathrm{i}$ & 3 & $<10$ & $<10$ & 2.0 \\
\hline & $08-16-90$ & $<5$ & $<3$ & 40 & $500 \notin$ & $<10 \mathrm{i}$ & 17 & $<10$ & $<10$ & 1.0 \\
\hline & $09-01-90$ & $<5$ & $<3$ & $<10$ & $80^{\circ}$ & $<10 i$ & 280 ; & $<10$ & $<10$ & $<1.0$ \\
\hline & $09-01-90$ & $\because$ & $\because$ & $\because$ & $\because$ & $\because$ & 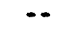 & -. & $\cdots$ & $\cdots$ \\
\hline & $09-01-90$ & $\cdots$ & $\cdots$ & $\cdots$ & $\cdots$ & $\cdots$ & $\cdots$ & $\cdots$ & $\cdots$ & $\cdots$ \\
\hline & $09-01-90$ & $\cdots$ & $\cdots$ & $\cdot-$ & -. & -. & $\cdots$ & $\cdots$ & $\cdots$ & -. \\
\hline & $09-01-90$ & $\cdots$ & $\cdots$ & $\cdots$ & $\cdots$ & $\cdots$ & 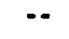 & $\cdots$ & $\cdots$ & -. \\
\hline & $09-05-90$ & $\cdots$ & $\cdots$ & $\cdots$ & $\cdots$ & $\cdots$ & $\cdots$ & $\cdots$ & $\cdots$ & -. \\
\hline & $09-11-90$ & $\cdots$ & $\because$ & $\because$ & $\because$ & $\because$ & $\because$ & 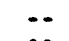 & $\cdots$ & - \\
\hline & $09-21-90$ & $<5$ & 3 & $<10$ & 84 & $<10 i$ & 5 & $<10$ & $<10$ & $<1.0$ \\
\hline & $09-21-90$ & $\cdots$ & $\cdots$ & $\cdots$ & -. & -. & $\cdots$ & $\cdots$ & $\cdots$ & -. \\
\hline & $09-21-90$ & $\cdots$ & -. & -. & -. & -. & -. & -. & -. & -. \\
\hline & $09-21-90$ & $\cdots$ & -- & -- & -. & -. & -. & -. & -. & -. \\
\hline & $09-21-90$ & -. & .. & -. & -. & -. & -. & -. & .. & -. \\
\hline & $09-21-90$ & $\cdots$ & $-\cdot$ & $-\cdot$ & -. & -. & -. & $\cdots$ & -. & -. \\
\hline & $09-21-90$ & $\cdots$ & $\cdots$ & -. & -. & $-\cdot$ & -. & -. & -. & -. \\
\hline & $09-21-90$ & $\cdots$ & $-\cdot$ & -. & -. & -. & -. & -. & $\cdots$ & -. \\
\hline & $09-21-90$ & $\cdots$ & $\cdots$ & $\cdots$ & $\cdots$ & $\cdots$ & 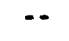 & $\cdots$ & $\cdots$ & -. \\
\hline & $09-21-90$ & $\cdots$ & $\cdots$ & -. & $\cdots$ & -. & -. & $\cdots$ & $\cdots$ & -. \\
\hline & $09-21-90$ & $\cdots$ & $\cdots$ & $\cdots$ & $\cdots$ & $\cdots$ & $\cdots$ & $\cdots$ & $\cdots$ & -. \\
\hline & $09-21-90$ & -. & -. & .. & .. & -. & -. & -. & -. & -. \\
\hline & $09-22-90$ & $\cdots$ & $\cdots$ & $\cdots$ & $\cdots$ & .. & -. & -. & -. & -. \\
\hline & $12-18-90$ & $\cdots$ & $\cdots$ & $\cdots$ & $\cdots$ & $\cdots$ & $\cdots$ & $\cdots$ & $\cdots$ & -- \\
\hline & $01-06-91$ & $\cdot \cdot$ & -- & -. & -. & -. & -. & -. & -. & -. \\
\hline & $01-06-91$ & $\cdots$ & $-\cdot$ & -. & -. & $\cdots$ & -. & -. & -. & -. \\
\hline & $01-07-91$ & $<5$ & 3 & 20 & $1000 \mid$ & $<10 i$ & 23 & $<10$ & $<10$ & $<1.0$ \\
\hline & $01-15-91$ & -. & -. & $\cdots$ & $\cdots$ & $\cdots$ & $\cdots$ & $\cdots$ & $\cdots$ & $\cdots$ \\
\hline & $08-01-91$ & $-\cdot$ & $\cdots$ & $\cdots$ & $\cdots$ & $\cdots$ & -. & $-\cdot$ & -- & -. \\
\hline & 08-01-91 & $<5$ & $<3$ & 10 & $2100 \notin$ & $<10 i$ & 36 & $<10$ & $<10$ & $<1.0$ \\
\hline & $08-01-91$ & -. & $\ldots$ & .. & $\ldots$ & -. & .. & -. & -. & $\ldots$ \\
\hline & $08-08-91$ & -. & $\cdots$ & $-\cdot$ & -. & $\cdots$ & -. & -. & -- & -- \\
\hline & $08-28-91$ & $\cdots$ & $\cdots$ & -. & -. & -- & -. & $\cdots$ & -. & $\cdots$ \\
\hline & $08-28-91$ & -. & $\cdots$ & -. & -. & $\cdots$ & -. & -. & -. & $\ldots$ \\
\hline & $09-06-91$ & -. & -. & -. & -. & -. & -. & -. & -. & -. \\
\hline
\end{tabular}




\section{STATION}

NUABER

DATE

\begin{tabular}{|c|c|c|c|c|c|c|c|c|c|}
\hline ATE & $\begin{array}{l}\text { STRON- } \\
\text { TIUH, } \\
\text { DIS- } \\
\text { SOLVED } \\
\text { ( } \mu \mathrm{g} / \mathrm{L} \\
\text { as Sr) } \\
(01080)\end{array}$ & $\begin{array}{l}\text { VANA- } \\
\text { DIUN, } \\
\text { DIS- } \\
\text { SOLVED } \\
(\mu g / L \\
\text { as V) } \\
(01085)\end{array}$ & $\begin{array}{l}\text { ZINC, } \\
\text { DIS- } \\
\text { SOLVED } \\
(\mu 9 / L \\
\text { as Zn) } \\
(01090)\end{array}$ & $\begin{array}{l}\text { LITHIUN } \\
\text { DIS- } \\
\text { SOLVED } \\
(\mu g / L \\
\text { as Li) } \\
(01130)\end{array}$ & $\begin{array}{l}\text { SELE- } \\
\text { NIUH, } \\
\text { DIS- } \\
\text { SOLVED } \\
\text { ( } \mu g / L \\
\text { as SE) } \\
\text { (01145) }\end{array}$ & $\begin{array}{l}\text { H-2I } \\
\text { H-1 } \\
\text { STABLE } \\
\text { ISOTOPE } \\
\text { RATIO } \\
\text { PER } \\
\text { HIL } \\
(82082)\end{array}$ & $\begin{array}{c}0-18 / \\
\text { O-16 } \\
\text { STABLE } \\
\text { I SOTOPE } \\
\text { RATIO } \\
\text { PER } \\
\text { MIL } \\
(82085)\end{array}$ & $\begin{array}{l}\text { GROSS } \\
\text { ALPHA, } \\
\text { DIS- } \\
\text { SOLVED } \\
\text { ( } \mu g / L \\
\text { as } \\
U-n a t) \\
(80030)\end{array}$ & $\begin{array}{l}\text { ALPHA, } \\
\text { COUNT, } \\
2 \text { SIGIA } \\
\text { WAT DIS } \\
\text { ( } \mu g / L \\
\text { as } \\
\text { U-nat) } \\
\text { (75986) }\end{array}$ \\
\hline
\end{tabular}

LITTLE COLORADO RIVER MEAR JOSEPH CITY, AZ-Continued

$09397300 \quad 07-08-90$
$07-08-90$
$07-14-90$
$07-14-90$
$07-14-90$
$07-15-90$
$07-16-90$
$07-16-90$
$08-16-90$
$08-16-90$
$09-01-90$
$09-01-90$
$09-01-90$
$09-01-90$
$09-01-90$
$09-05-90$
$09-11-90$
$09-21-90$
$09-21-90$
$09-21-90$
$09-21-90$
$09-21-90$
$09-21-90$
$09-21-90$
$09-21-90$
$09-21-90$
$09-21-90$
$09-21-90$
$09-21-90$
$09-22-90$
$12-18-90$
$01-06-91$
$01-06-91$
$01-07-91$
$01-15-91$
$08-01-91$
$08-01-91$
$08-01-91$
$08-08-91$
$08-28-91$
$08-28-91$
$09-06-91$

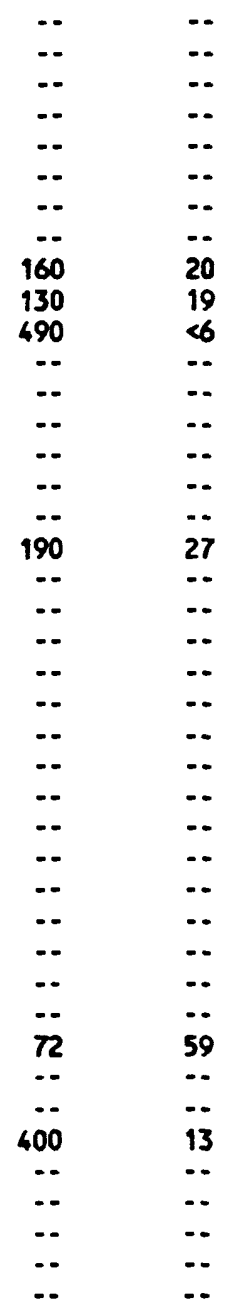

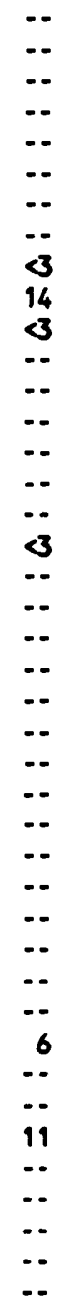

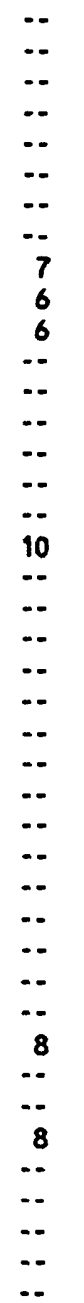

\begin{tabular}{|c|c|c|}
\hline- & $\cdots$ & -- \\
\hline$\cdots$ & $\cdots$ & -- \\
\hline$\cdots$ & -. & $\cdots$ \\
\hline-- & $\cdots$ & $\cdots$ \\
\hline-- & $\cdots$ & - \\
\hline$\cdots$ & $-\cdot$ & -- \\
\hline- & $\cdots$ & -- \\
\hline 2 & -85.5 & -12.15 \\
\hline 1 & -83.5 & -12.05 \\
\hline$<1$ & -20.0 & -4.05 \\
\hline$\cdots$ & $\cdots$ & $\cdots$ \\
\hline-- & $\cdots$ & $\cdots$ \\
\hline 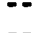 & $\cdots$ & $\cdots$ \\
\hline 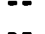 & $\because$ & $\cdots$ \\
\hline .. & $\ldots$ & $\ldots$ \\
\hline$<1$ & -. & .. \\
\hline$\cdots$ & -. & - \\
\hline$\cdots$ & $\cdots$ & - \\
\hline$\cdots$ & $\cdots$ & $\cdots$ \\
\hline$\cdots$ & $\cdots$ & $\cdots$ \\
\hline-- & -- & -- \\
\hline$\cdots$ & -- & -- \\
\hline- & $\cdots$ & -- \\
\hline$\cdots$ & $\cdots$ & $\cdots$ \\
\hline$\cdots$ & $\cdots$ & $\cdots$ \\
\hline$\cdots$ & - & $\because$ \\
\hline & -. & 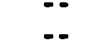 \\
\hline- & $\ldots$ & $\cdots$ \\
\hline- & -133.0 & -17.15 \\
\hline-- & - & - \\
\hline$<1$ & $\cdots$ & $\cdots$ \\
\hline-- & $\cdots$ & - \\
\hline$\because$ & -81.5 & $\begin{array}{l}-11.50 \\
-11.50\end{array}$ \\
\hline $\begin{array}{l}<1 \\
\therefore-\end{array}$ & $\begin{array}{l}-81.0 \\
-81.0\end{array}$ & $\begin{array}{l}-11.50 \\
-11.50\end{array}$ \\
\hline & -81.0 & -11.50 \\
\hline & $\cdots$ & $\cdots$ \\
\hline & $\because$ & $=$ \\
\hline
\end{tabular}




\begin{tabular}{|c|c|c|c|c|c|c|c|c|c|c|}
\hline \multicolumn{11}{|c|}{ SURFACE-MATER DATA-Cont inued } \\
\hline \multicolumn{11}{|c|}{ CHEMICAL AMALYSES-Cont inued } \\
\hline $\begin{array}{l}\text { STATION } \\
\text { MUMBER }\end{array}$ & DATE & $\begin{array}{c}\text { GROSS } \\
\text { ALPHA } \\
\text { SEDI- } \\
\text { MENT } \\
\text { (pCi/G) } \\
\text { (01507) }\end{array}$ & $\begin{array}{c}\text { GROSS } \\
\text { ALPMA } \\
\text { BOT MAT } \\
\text { TOT DRY } \\
\text { (pCi/G } \\
\text { as } \\
\text { U-nat) } \\
\text { (99920) }\end{array}$ & $\begin{array}{c}\text { ALPHA, } \\
2 \text { SIGMA } \\
\text { BOT MAT } \\
\text { TOT DRY } \\
\text { ( } \mu g / G \\
\text { as } \\
U-\text { nat) } \\
\text { (75965) }\end{array}$ & $\begin{array}{l}\text { GROSS } \\
\text { ALPHA } \\
\text { BOT MAT } \\
\text { DRY WGT } \\
\text { (PCi/G } \\
\text { As } \\
\text { Th-230) } \\
\text { (04125) }\end{array}$ & $\begin{array}{l}\text { ALPHA, } \\
2 \text { SIGWA } \\
\text { BOT MAT } \\
\text { TOT DRY } \\
\text { (PCi/G } \\
\text { as } \\
\text { Th-230) } \\
\text { (75955) }\end{array}$ & $\begin{array}{l}\text { GROSS } \\
\text { BETA, } \\
\text { DIS- } \\
\text { SOLVED } \\
\text { (PCi/L } \\
\text { as } \\
\text { Cs-137) } \\
(03515)\end{array}$ & $\begin{array}{l}\text { BETA, } \\
2 \text { SICWA } \\
\text { WATER, } \\
\text { DISS, } \\
\text { (pCi/L } \\
\text { as } \\
\text { Cs-137) } \\
\text { (75989) }\end{array}$ & $\begin{array}{c}\text { GROSS } \\
\text { BETA, } \\
\text { DISS. } \\
\text { (pCi/L } \\
\text { as } \\
S r-90 / \\
Y-90) \\
(80050)\end{array}$ & $\begin{array}{c}2 \text { SIGMA } \\
\text { WATER } \\
\text { DISS. } \\
\text { (PCi/L } \\
\text { as } \\
\text { Sr-90/ } \\
Y-90) \\
(75988)\end{array}$ \\
\hline
\end{tabular}

$09397300 \quad 07-08-90$
$07-08-90$
$07-14-90$
$07-14-90$
$07-14-90$
$07-15-90$
$07-16-90$
$07-16-90$
$08-16-90$
$08-16-90$
$09-01-90$
$09-01-90$
$09-01-90$
$09-01-90$
$09-01-90$
$09-05-90$
$09-11-90$
$09-21-90$
$09-21-90$
$09-21-90$
$09-21-90$
$09-21-90$
$09-21-90$
$09-21-90$
$09-21-90$
$09-21-90$
$09-21-90$
$09-21-90$
$09-21-90$
$09-22-90$
$12-18-90$
$01-06-91$
$01-06-91$
$01-07-91$
$01-15-91$
$08-01-91$
$08-01-91$
$08-01-91$
$08-08-91$
$08-28-91$
$08-28-91$
$09-06-91$

LITTLE COLORADO RIVER MEAR JOSEPH CITY, AZ-Cont inuEd

\begin{tabular}{|c|c|c|c|c|c|c|c|c|}
\hline$-\cdot$ & $\cdots$ & -. & $\cdots$ & -- & $\cdots$ & $\cdots$ & $\cdots$ & -- \\
\hline$\because$ & $\cdots$ & $\because$ & $\cdots$ & $\because$ & $\cdots$ & $\cdots$ & $\cdots$ & $-\cdot$ \\
\hline$<6$ & 6.74 & 7.1 & 5 & 5.3 & $\cdots$ & $\cdots$ & $\cdots$ & $\cdots$ \\
\hline$\cdots$ & $\cdots$ & $\cdots$ & $\cdots$ & $\cdots$ & $\cdots$ & $\cdots$ & $\cdots$ & $\cdots$ \\
\hline$\cdots$ & $\because$ & $\cdots$ & $\cdots$ & $\cdots$ & $\cdots$ & $\cdots$ & $\cdots$ & $\cdots$ \\
\hline$-\cdot$ & $\cdots$ & $\cdot-$ & $\cdot-$ & $\cdots$ & $\cdots$ & $\cdots$ & $\cdots$ & $\cdots$ \\
\hline$\cdots$ & $\cdots$ & $\cdots$ & $\cdots$ & $\cdots$ & $\cdots$ & $\cdots$ & $\cdots$ & $\cdots$ \\
\hline$\because$ & $\because$ & $\because$ & $\because$ & $\because$ & $\cdots$ & $\cdots$ & $\cdots$ & $\cdots$ \\
\hline$<6$ & 5.76 & 9.1 & 4 & 5.8 & $\cdots$ & $\cdots$ & $\cdots$ & $\cdots$ \\
\hline$<6$ & 5.20 & 8.0 & 4 & 5.9 & $\cdots$ & $\cdots$ & $\cdots$ & $\cdots$ \\
\hline$\cdots$ & $\cdots$ & $-\cdot$ & $\cdots$ & -- & $\cdots$ & -- & $\because$ & $\cdots$ \\
\hline-- & -- & 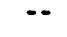 & $\cdots$ & $\cdots$ & $\cdots$ & $\cdots$ & $\cdots$ & $\cdots$ \\
\hline$\cdots$ & $\cdots$ & $\because$ & $\cdots$ & -- & $\cdots$ & $\cdots$ & $\cdots$ & $\cdots$ \\
\hline$\cdots$ & $\cdots$ & $\cdots$ & $\cdots$ & $\cdots$ & $\cdots$ & $\cdots$ & $\cdots$ & $\cdots$ \\
\hline$\cdots$ & $\cdots$ & $\cdots$ & $\cdots$ & $\cdots$ & $\cdots$ & $\cdots$ & $\cdots$ & 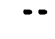 \\
\hline$\cdots$ & $\cdots$ & $\because$ & $\because$ & $\because$ & $\because$ & $\because$ & $\cdots$ & $\cdots$ \\
\hline$\cdots$ & $\because$ & $\cdots$ & $\because$ & $\because-$ & $\cdots$ & $\cdots$ & $\because$ & $\cdots$ \\
\hline$\ldots$ & $\ldots$ & $\ldots$ & $\ldots$ & $\because$ & $\ldots$ & $\ldots$ & $\cdots$ & $\ldots$ \\
\hline .. & - & .. & .. & .. & $\therefore$ & $\ldots$ & $\ldots$ & $\cdots$ \\
\hline$\cdots$ & $\cdots$ & - & $\cdots$ & -. & .. & .. & $\ldots$ & $\ldots$ \\
\hline$\cdots$ & -- & - & $\cdots$ & $\cdots$ & -. & -. & - & $\ldots$ \\
\hline$\cdots$ & $\cdots$ & $\cdots$ & $\cdots$ & - & $\cdots$ & $\cdots$ & -. & $\cdots$ \\
\hline$\cdots$ & -- & $-\cdot$ & $\cdots$ & $\cdots$ & $\cdots$ & $\cdots$ & $\cdots$ & $\cdots$ \\
\hline$\cdots$ & $\cdots$ & $-\cdot$ & $\cdots$ & $-\cdot$ & $\cdots$ & -- & - & - \\
\hline$\cdots$ & $\cdots$ & -- & $\cdots$ & -- & $\cdots$ & $\cdots$ & $\cdots$ & $\cdots$ \\
\hline$-\cdot$ & $\cdots$ & $-\cdot$ & $\cdots$ & $-\cdot$ & $=$ & $\cdots$ & $\cdots$ & $\cdots$ \\
\hline-- & $\cdots$ & $-\cdot$ & $\cdots$ & $-\cdot$ & $\cdots$ & -- & $\cdots$ & $\cdots$ \\
\hline$\because$ & $\cdots$ & $\cdots$ & $\cdots$ & $\cdots$ & $\cdots$ & $\cdots$ & $\cdots$ & - \\
\hline$\cdots$ & $\because$ & $\because$ & $\cdots$ & $\cdots$ & $\cdots$ & $\cdots$ & $\cdots$ & $=$ \\
\hline$\because$ & $\because$ & $\because$ & $\because$ & $\because$ & $\cdots$ & $\because$ & $\cdots$ & $\cdots$ \\
\hline 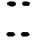 & 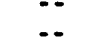 & 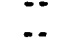 & $\because$ & $\therefore$ & $\cdots$ & $\cdots$ & $\because$ & $\cdots$ \\
\hline 7 & 10.00 & 9.0 & 7 & 5.8 & 6.6 & 1.8 & 5.0 & 1.4 \\
\hline$-\cdot$ & $\cdots$ & $-\cdot$ & $\cdots$ & $\cdots$ & $\cdots$ & $\cdots$ & $\cdots$ & - \\
\hline-- & $\cdots$ & $\cdots$ & $\cdots$ & $\cdots$ & $\cdots$ & -. & -. & $\cdots$ \\
\hline$\cdots$ & $\cdots$ & $-\cdot$ & $\cdots$ & $\cdot-$ & $\cdots$ & $\cdots$ & $\cdots$ & $\cdots$ \\
\hline$-\cdot$ & $\cdots$ & -. & $\cdots$ & $\cdots$ & $\cdots$ & $\cdots$ & $\cdots$ & . \\
\hline$\cdots$ & $\cdots$ & $\cdots$ & $\cdots$ & $\cdots$ & $\cdots$ & $\cdots$ & $\cdots$ & -. \\
\hline$-\cdot$ & $\cdots$ & $-\cdot$ & $\cdots$ & $-\cdot$ & $\cdots$ & $\cdots$ & $\because$ & $-\cdot$ \\
\hline$\because$ & $\because$ & $\because$ & $\cdots$ & $\because$ & $\cdots$ & $\because$ & $\cdots$ & 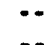 \\
\hline$\cdots$ & $\cdots$ & $\cdots$ & $\cdots$ & $\cdots$ & $\cdots$ & $\cdots$ & $\cdots$ & \\
\hline
\end{tabular}


SURFACE-WATER DATA-Cont inued

CHEMICAL AMALYSES-Cont inued

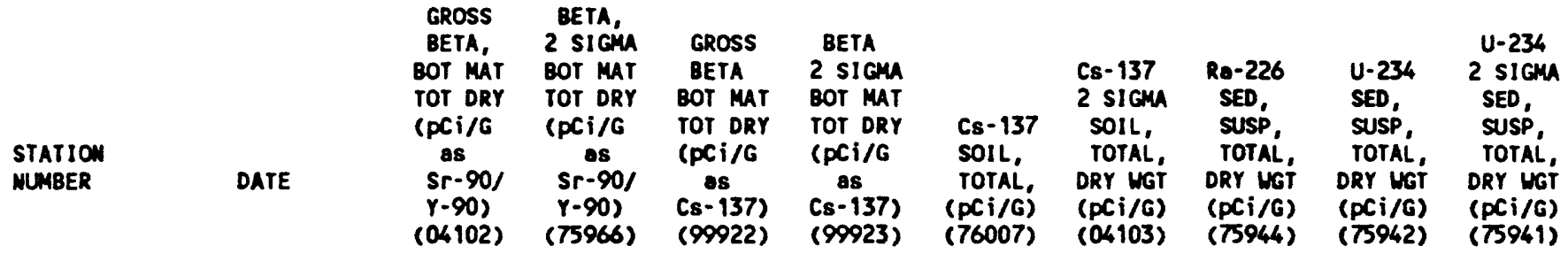

$09397300 \quad 07-08-90$
$07-08-90$
$07-14-90$
$07-14-90$
$07-14-90$
$07-15-90$
$07-16-90$
$07-16-90$
$08-16-90$
$08-16-90$
$09-01-90$
$09-01-90$
$09-01-90$
$09-01-90$
$09-01-90$
$09-05-90$
$09-11-90$
$09-21-90$
$09-21-90$
$09-21-90$
$09-21-90$
$09-21-90$
$09-21-90$
$09-21-90$
$09-21-90$
$09-21-90$
$09-21-90$
$09-21-90$
$09-21-90$
$09-22-90$
$12-18-90$
$01-06-91$
$01-06-91$
$01-07-91$
$01-15-91$
$08-01-91$
$08-01-91$
$08-01-91$
$08-91$
$09-91$
09

LITTLE COLORADO RIVER NEAR JOSEPH CITY, AZ-Continued

\begin{tabular}{|c|c|c|c|c|c|c|c|c|}
\hline -. & $\cdots$ & $\ldots$ & $\ldots$ & $\ldots$ & $\ldots$ & $\cdots$ & $\cdots$ & $\ldots$ \\
\hline$\cdots$ & $\cdots$ & $\cdots$ & $\cdots$ & $\cdots$ & $\cdots$ & $\cdots$ & $\cdots$ & $\cdots$ \\
\hline 16 & 5.4 & 21.70 & 5.37 & $\cdots$ & $\cdots$ & .9 & 1.0 & .10 \\
\hline$\cdots$ & $\cdots$ & $\cdots$ & $\ldots$ & $\cdots$ & $\cdots$ & $\cdots$ & $\cdots$ & $\cdots$ \\
\hline$\cdots$ & $\cdots$ & $\cdots$ & $\cdots$ & $\cdots$ & $\cdots$ & $\cdots$ & $\cdots$ & $\cdots$ \\
\hline$\cdots$ & $\cdots$ & $\cdots$ & $\cdots$ & $\cdots$ & $\cdots$ & $\cdots$ & $\cdots$ & $\cdots$ \\
\hline$\cdots$ & $\cdots$ & $\cdots$ & $\cdots$ & $\cdots$ & $\cdots$ & $\cdots$ & 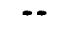 & $\cdots$ \\
\hline 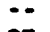 & -- & $\cdots$ & $\cdots$ & $\cdots$ & $\cdots$ & $\cdots$ & $\cdots$ & $\because$ \\
\hline $\begin{array}{l}23 \\
21\end{array}$ & $\begin{array}{l}5.4 \\
5.1\end{array}$ & $\begin{array}{l}29.70 \\
27.00\end{array}$ & $\begin{array}{l}5.35 \\
5.13\end{array}$ & $\cdots$ & $\cdots$ & $\begin{array}{l}1.4 \\
1.3\end{array}$ & $\begin{array}{l}1.4 \\
1.2\end{array}$ & $\begin{array}{l}.30 \\
.30\end{array}$ \\
\hline$\cdots$ & - & $\cdots$ & $\cdots$ & $\cdots$ & $\cdots$ & $\because$ & $\cdots$ & - \\
\hline$\cdots$ & $\cdots$ & 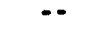 & $\cdots$ & $\cdots$ & $\cdots$ & $\cdots$ & $\cdots$ & $\cdots$ \\
\hline$\cdots$ & $\cdots$ & $\cdots$ & $\cdots$ & $\cdots$ & $\cdots$ & $\cdots$ & $\cdots$ & $\cdots$ \\
\hline$\cdots$ & $\cdots$ & $\cdots$ & $\cdots$ & $\cdots$ & 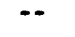 & $\cdots$ & $\cdots$ & $\cdots$ \\
\hline$\cdots$ & $\cdots$ & $\cdots$ & $\cdots$ & $\cdots$ & $\cdots$ & $\cdots$ & $\cdots$ & $\cdots$ \\
\hline$\cdots$ & $\cdots$ & $\cdots$ & $\cdots$ & $\cdots$ & $\cdots$ & $\cdots$ & $\cdots$ & $\cdots$ \\
\hline$\cdots$ & $\cdots$ & $\cdots$ & $\cdots$ & $\cdots$ & $\cdots$ & $\cdots$ & $\cdots$ & $-i$ \\
\hline$\cdots$ & $\cdots$ & $\cdots$ & $\cdots$ & $\cdots$ & $\cdots$ & $\cdots$ & $\cdots$ & $\therefore$ \\
\hline$\cdots$ & $\cdots$ & $\cdots$ & $\cdots$ & $\cdots$ & $\cdots$ & $\cdots$ & $\cdots$ & $\cdots$ \\
\hline$\cdots$ & $\cdots$ & $\cdots$ & $\cdots$ & $\cdots$ & $\cdots$ & $\cdots$ & $\cdots$ & $\cdots$ \\
\hline$\cdots$ & $\cdots$ & $\cdots$ & $\cdots$ & $\cdots$ & $\cdots$ & $\cdots$ & $\cdots$ & $\cdots$ \\
\hline$\cdots$ & 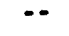 & $\cdots$ & $\cdots$ & $\cdots$ & $\cdots$ & $\cdots$ & $\cdots$ & $\cdots$ \\
\hline$\cdots$ & $\cdots$ & $\cdots$ & $\cdots$ & $\cdots$ & $\cdots$ & $\cdots$ & $\cdots$ & $\cdots$ \\
\hline$\cdots$ & $\cdots$ & $\cdots$ & $\cdots$ & $\cdots$ & $\cdots$ & $\cdots$ & $\cdots$ & $\cdots$ \\
\hline$\cdots$ & $\cdots$ & $\cdots$ & $\cdots$ & $\cdots$ & $\cdots$ & $\cdots$ & $\cdots$ & $\cdots$ \\
\hline$\cdots$ & $\cdots$ & $\cdots$ & $\cdots$ & $\cdots$ & $\cdots$ & $\cdots$ & $\cdots$ & $\cdots$ \\
\hline$\cdots$ & $\cdots$ & $\cdots$ & $\cdots$ & $\cdots$ & $\cdots$ & $\cdots$ & $\cdots$ & $\cdots$ \\
\hline$\cdots$ & $\cdots$ & $\cdots$ & $\cdots$ & $\cdots$ & $\cdots$ & $\cdots$ & $\cdots$ & $\cdots$ \\
\hline$\cdots$ & $\cdots$ & $\cdots$ & $\cdots$ & $\cdots$ & $\cdots$ & $\cdots$ & $\cdots$ & $\cdots$ \\
\hline$\cdots$ & $\cdots$ & $\cdots$ & $\cdots$ & $\cdots$ & $\cdots$ & $\cdots$ & $\cdots$ & $\cdots$ \\
\hline$\cdots$ & $\cdots$ & $\cdots$ & $\cdots$ & 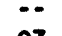 & 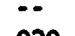 & $\cdots$ & $\cdots$ & $\cdots$ \\
\hline$\cdots$ & $\cdots$ & $\cdots$ & $\cdots$ & .03 & .020 & $\cdots$ & $\cdots$ & $\cdots$ \\
\hline$\because$ & $\cdots$ & $\cdots$ & $\cdots$ & $\cdots$ & $\cdots$ & $\cdots$ & $\cdots$ & $\because$ \\
\hline 22 & 5.1 & 28.00 & 5.12 & $\cdots$ & $\cdots$ & 1.1 & .9 & .13 \\
\hline$\cdots$ & $\cdots$ & $\cdots$ & $\cdots$ & $\cdots$ & $\cdots$ & $\cdots$ & $\cdots$ & $\cdots$ \\
\hline$\cdots$ & $\cdots$ & $\cdots$ & $\cdots$ & $\cdots$ & $\cdots$ & $\cdots$ & $\cdots$ & $\cdots$ \\
\hline$\cdots$ & $\cdots$ & $\cdots$ & $\cdots$ & $\cdots$ & $\cdots$ & $\cdots$ & $\cdots$ & $\cdots$ \\
\hline$\cdots$ & $\cdots$ & $\cdots$ & $\cdots$ & 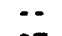 & $\because$ & $\cdots$ & -- & $=-$ \\
\hline$\cdots$ & $\cdots$ & $\cdots$ & $\cdots$ & .07 & .010 & $\cdots$ & $\cdots$ & $\cdots$ \\
\hline$\cdots$ & $\cdots$ & $\cdots$ & $\cdots$ & $\cdots$ & $\cdots$ & $\cdots$ & $\cdots$ & $\cdots$ \\
\hline$\cdots$ & $\cdots$ & $\cdots$ & $\cdots$ & $-\infty$ & $\cdots$ & $\cdots$ & $\cdots$ & - \\
\hline & $\cdots$ & $\because$ & $\because$ & $\cdots$ & $\cdots$ & $\cdots$ & $\cdots$ & - \\
\hline
\end{tabular}


STATION

MUABER

DATE

07-08-90

07-08-90

$07-14-90$

07-14-90

07-14-90

07-15-90

$07-16-90$

07-16-90

08-16-90

08-16-90

09-01-90

09-01-90

09-01-90

09-01-90

09-01-90

09-05-90

$09-11-90$

09-21-90

$09-21-90$

$09-21-90$

09-21-90

$09-21-90$

09-21-90

09-21-90

09-21-90

09-21-90

$09-21-90$

09-21-90

09-21-90

09-22-90

12-18-90

01-06-91

01-06-91

01-07-91

01-15-91

08-01-91

08-01-91

08-01-91

08-08-91

08-28-91

08-28-91

09-06-91

SURFACE-WATER DATA-Cont inued

CHEMICAL AMALYSES-Continued

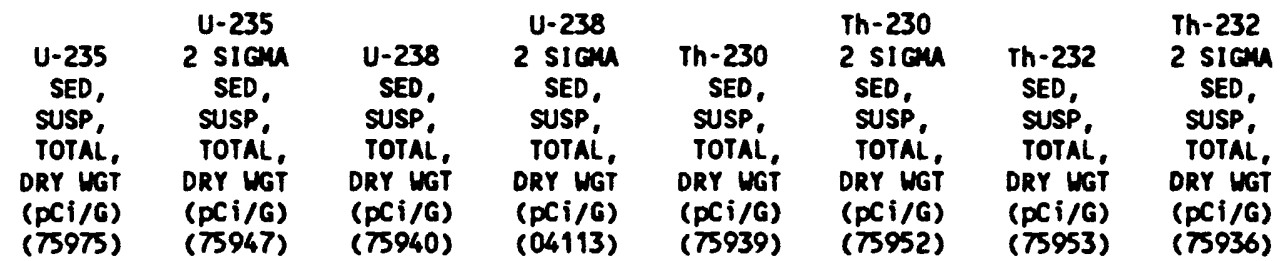

LITTLE COLORADO RIVER MEAR JOSEPH CITY, AZ-Continued

\begin{tabular}{|c|c|c|c|c|c|c|c|}
\hline -. & -. & -. & -. & -. & -- & -. & -- \\
\hline & -. & -1 & & 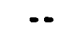 & 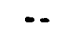 & 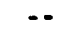 & \\
\hline$<.1$ & ND & 1.0 & .13 & 1.2 & .18 & 1.1 & .16 \\
\hline -. & $\cdots$ & -- & - & $\cdots$ & $\cdots$ & $\therefore$ & -. \\
\hline .. & $\because$ & $\cdots$ & $\cdots$ & $\cdots$ & $\cdots$ & $\cdots$ & 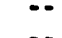 \\
\hline$n$ & 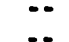 & $\ddot{*}$ & 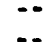 & $\because$ & $\because$ & 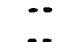 & $\because$ \\
\hline & $\ldots$ & .. & .. & .. & .. & .. & . \\
\hline$<.1$ & ND & 1.1 & .24 & 1.3 & .30 & 1.6 & .40 \\
\hline$<.1$ & ND & 1.0 & .23 & 1.2 & .30 & 1.4 & .30 \\
\hline$-\cdot$ & $\cdots$ & $\cdots$ & $\cdots$ & $\because$ & $\cdots$ & $\cdots$ & $\cdots$ \\
\hline$\cdots$ & $\cdots$ & -. & -. & - & -. &.- & $\cdots$ \\
\hline & $\cdots$ & $\cdots$ & -- & $\cdots$ & $\cdots$ & $\cdots$ & $\cdots$ \\
\hline & $\cdots$ & $\cdots$ & $\cdots$ & $\cdots$ & $\cdots$ & $\because$ & $\cdots$ \\
\hline$\cdots$ & $\because$ & $\cdots$ & $\cdots$ & $\cdots$ & $\cdots$ & $\cdots$ & -. \\
\hline-0 & & $\cdots$ & $\cdots$ & & $\cdots$ & $\cdots$ & $\cdots$ \\
\hline$\ldots$ & $n$ & & 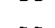 & 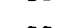 & 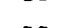 & $\cdots$ & $\cdots$ \\
\hline & -- & -. & -. & .. & -. & -. & .. \\
\hline & -- & -- & -. & -. & -. & -- & -. \\
\hline$\because$ & $\cdots$ & $\cdots$ & $\cdots$ & $\cdots$ & -. & -. & -. \\
\hline & $\cdots$ & $\cdots$ & $\cdots$ & $\cdots$ & $\cdots$ & -. & $\cdots$ \\
\hline & $\cdots$ & $\cdots$ & $\cdots$ & 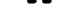 & 0 & $\cdots$ & $\cdots$ \\
\hline & 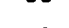 & $\cdots$ & $\cdots$ & 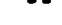 & $\cdots$ & & $\cdots$ \\
\hline & $\cdots$ & $\cdots$ & $\cdots$ & $\cdots$ & - & $\cdots$ & $\cdots$ \\
\hline & .. & .. & .. & .. & .. & .. & $\therefore$ \\
\hline E- & -. & .. & -. & -. & -. & .. & -. \\
\hline$\ldots$ & -- & -- & -- & $-\cdot$ & -. & -. & -- \\
\hline & $\cdots$ & $\cdots$ & $\cdots$ & $\cdots$ & $\cdots$ & $\cdots$ & $\cdots$ \\
\hline & $\cdots$ & $\cdots$ & $\cdots$ & $\cdots$ & $\cdots$ & $\cdots$ & -- \\
\hline 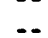 & $\therefore$ & $\because$ & -- & 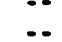 & $\because$ & $\because$ & 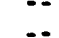 \\
\hline$<.1$ & .02 & 1.0 & .14 & 1.2 & .18 & 1.2 & .19 \\
\hline . & . & 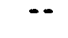 & . & 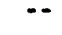 & . & . & $\cdots$ \\
\hline & $\cdots$ & $\cdots$ & $\cdots$ & $\cdots$ & $\cdots$ & $\cdots$ & $\cdots$ \\
\hline & 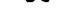 & 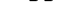 & 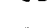 & 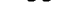 & . & $\cdots$ & \\
\hline & .. & -. & -. & -. & -. & .- & \\
\hline & $\cdots$ & $\cdots$ & 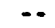 & $\cdots$ & -. & -. & - \\
\hline & $\cdots$ & $\cdots$ & $\cdots$ & $\cdots$ & $\cdots$ & $\cdots$ & $\cdots$ \\
\hline & $\because$ & $\cdots$ & -. & $\cdots$ & -. & $\cdots$ & $\ldots$ \\
\hline
\end{tabular}


SURFACE-HATER DATA-Cont inued

CHEMICAL ANALYSES-Cont inued

\begin{tabular}{|c|c|c|c|c|c|c|c|c|c|c|}
\hline & & $\begin{array}{l}\text { ALUN- } \\
\text { IMUN }\end{array}$ & ARSENIC & BARIUN & $\begin{array}{l}\text { BERYL- } \\
\text { LIUM }\end{array}$ & BISIUTH & CADMIUN & CALCIUM & CERIUA & $\begin{array}{l}\text { CHRO- } \\
\text { AIUM }\end{array}$ \\
\hline $\begin{array}{l}\text { STATION } \\
\text { NUMBER }\end{array}$ & DATE & $\begin{array}{l}\text { BOT MAT } \\
\text { C63 } \mu \text { DS } \\
\text { LAB } \\
\text { PERCENT } \\
\text { (34792) }\end{array}$ & $\begin{array}{c}\text { BOT MT } \\
<63 \mu \text { DS } \\
\text { LAB } \\
(\mu \sigma / G) \\
(34802)\end{array}$ & $\begin{array}{c}\text { BOT MAT } \\
\angle 63_{\mu} \text { DS } \\
L A B \\
(\mu \sigma / G) \\
(34807)\end{array}$ & $\begin{array}{c}\text { BOT MAT } \\
\angle 63 \mu \text { DS } \\
\text { LAB } \\
(\mu 9 / G) \\
(34812)\end{array}$ & $\begin{array}{c}\text { BOT MAT } \\
\angle 63_{\mu} \text { DS } \\
\text { LAB } \\
(\mu 9 / G) \\
(34817)\end{array}$ & $\begin{array}{c}\text { BOT MAT } \\
\angle 63 \mu \text { DS } \\
L A B \\
(\mu 9 / G) \\
(34827)\end{array}$ & $\begin{array}{l}\text { BOT MAT } \\
\angle 63 \mu \text { DS } \\
\text { LAB } \\
\text { PERCENT } \\
\text { (34832) }\end{array}$ & $\begin{array}{c}\text { BOT MT } \\
<63 \mu \text { DS } \\
\text { LAB } \\
(\mu g / G) \\
(34837)\end{array}$ & $\begin{array}{c}\text { BOT MAT } \\
<63 \mu \text { DS } \\
\text { LAB } \\
(\mu 9 / G) \\
(34842)\end{array}$ \\
\hline
\end{tabular}

LITTLE COLORADO RIVER MEAR JOSEPH CITY, AZ-Continued

\begin{tabular}{|c|c|}
\hline 09397300 & $\begin{array}{l}07-08-90 \\
07-08-90 \\
07-14-90 \\
07-14-90 \\
07-14-90 \\
07-15-90 \\
07-16-90 \\
07-16-90 \\
08-16-90 \\
08-16-90 \\
09-01-90 \\
09-01-90 \\
09-01-90 \\
09-01-90 \\
09-01-90 \\
09-05-90 \\
09-11-90 \\
09-21-90 \\
09-21-90 \\
09-21-90 \\
09-21-90 \\
09-21-90 \\
09-21-90 \\
09-21-90 \\
09-21-90 \\
09-21-90 \\
09-21-90 \\
09-21-90 \\
09-21-90 \\
09-22-90 \\
12-18-90 \\
01-06-91 \\
01-06-91 \\
01-07-91 \\
01-15-91 \\
08-01-91 \\
08-01-91 \\
08-01-91 \\
08-08-91 \\
08-28-91 \\
08-28-91 \\
09-06-91\end{array}$ \\
\hline
\end{tabular}

\begin{tabular}{|c|c|c|c|c|}
\hline 8.5 & $<10$ & 520 & 2 & $<10$ \\
\hline - & 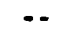 & $=$ & $\cdots$ & $\cdots$ \\
\hline 7.1 & $<10$ & 600 & 2 & $<10$ \\
\hline -. & $\cdots$ & -- & $\ldots$ & - \\
\hline-- & $\cdots$ & $\cdots$ & $\ldots$ & 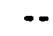 \\
\hline-- & - & - & - & -- \\
\hline$\cdots$ & $\cdots$ & - & $\cdots$ & -. \\
\hline.- & - & -- & $=$ & $=$ \\
\hline $\begin{array}{l}9.9 \\
9.8 \\
7.7\end{array}$ & $\begin{array}{r}<10 \\
\times 10 \\
\times 10\end{array}$ & $\begin{array}{l}510 \\
520 \\
650\end{array}$ & $\begin{array}{l}2 \\
2 \\
2\end{array}$ & $\begin{array}{l}<10 \\
<10 \\
<10\end{array}$ \\
\hline$\cdots$ & $\cdots$ & $\cdots$ & $\cdots$ & - \\
\hline$=-$ & $=-$ & $\cdots$ & $\cdots$ & $=$ \\
\hline-- & $\cdots$ & $\cdots$ & -- & - \\
\hline-- & $=$ & -- & $=$ & 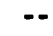 \\
\hline$\ldots$ &.- & $\cdots$ & $\cdots$ & $\cdots$ \\
\hline-- & $\ldots$ & $\cdots$ & $\cdots$ & - \\
\hline 8.1 & $<10$ & 570 & 2 & $<10$ \\
\hline-- & -- & $-\infty$ & $\cdots$ & - \\
\hline-- & $\cdots$ & -- & $\ldots$ & $=$ \\
\hline-- & -- & $\cdots$ & $\ldots$ & - \\
\hline-- & $\cdots$ & $\cdots$ & $=$ & 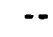 \\
\hline$\cdots$ & -- & -- & $\ldots$ & -- \\
\hline$\cdots$ & $-\infty$ & $\cdots$ & $\cdots$ & $-\infty$ \\
\hline-- & -- & $\cdots$ & $\cdots$ & $\cdots$ \\
\hline$\cdots$ & -- & $\cdots$ & $\cdots$ & - \\
\hline$\cdots$ & -- & -- & -- & $\cdots$ \\
\hline-- & $\cdots$ & $\cdots$ & -- & $\cdots$ \\
\hline$=$ & $\cdots$ & $\cdots$ & -- & -- \\
\hline$\cdots$ & $\cdots$ & $=$ & - & $\cdots$ \\
\hline$\cdots$ & $\cdots$ & $\cdots$ & $\ldots$ & $\ldots$ \\
\hline 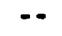 & -- & $\cdots$ & $\cdots$ & $=$ \\
\hline$\cdots$ & $=$ & -- & -- & $=$ \\
\hline 8.7 & $<10$ & 440 & 2 & $<10$ \\
\hline-- & $\cdots$ & $\cdots$ & $\cdots$ & $\cdots$ \\
\hline$\cdots$ & $\cdots$ & -- & $\cdots$ & $=$ \\
\hline$=$ & $\cdots$ & -- & - & $\cdots$ \\
\hline-- & $\cdots$ & $\cdots$ & $\cdots$ & $=$ \\
\hline$\cdots$ & $\cdots$ & $\cdots$ & - & $=$ \\
\hline-- & $\cdots$ & $\cdots$ & $\cdots$ & $\cdots$ \\
\hline$\cdots$ & $\cdots$ & $\cdots$ & -- & $\cdots$ \\
\hline$\cdots$ & $-\theta_{0}$ & $-\theta_{0}$ & - & \\
\hline
\end{tabular}

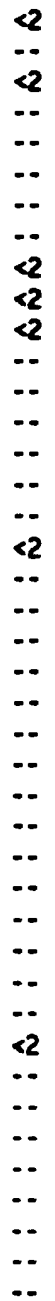

\begin{tabular}{|c|c|}
\hline 2.9 & 65 \\
\hline 2.4 & 65 \\
\hline$\cdots$ & $\cdots$ \\
\hline$\cdots$ & -. \\
\hline$\because$ & $=$ \\
\hline 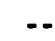 & -. \\
\hline $\begin{array}{l}1.9 \\
2.0 \\
3.5\end{array}$ & $\begin{array}{l}70 \\
71 \\
65\end{array}$ \\
\hline$\because$ & $\cdots$ \\
\hline .. & 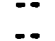 \\
\hline$\cdots$ & - \\
\hline$\cdots$ & -- \\
\hline 3.1 & 58 \\
\hline -. & $\cdots$ \\
\hline$\because$ & $\ddot{-}$ \\
\hline .. & -. \\
\hline$\cdots$ & $\cdots$ \\
\hline$\cdots$ & 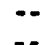 \\
\hline -. & $\because$ \\
\hline -- & $\cdots$ \\
\hline$\cdots$ & $\cdots$ \\
\hline 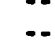 & 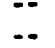 \\
\hline - & $\cdots$ \\
\hline$\cdots$ & $\ddot{-}$ \\
\hline 2.0 & 55 \\
\hline 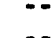 & $\cdots$ \\
\hline & .. \\
\hline & -. \\
\hline & $\cdots$ \\
\hline 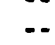 & $\because$. \\
\hline & . \\
\hline
\end{tabular}


SURFACE-HATER DATA-Cont inued

CHEMICAL ANALYSES-Cont inued

\begin{tabular}{|c|c|c|c|c|c|c|c|c|c|c|}
\hline $\begin{array}{l}\text { ATION } \\
\text { MBERR }\end{array}$ & DATE & $\begin{array}{c}\text { COBALT } \\
\text { BOT MUT } \\
\angle 63_{\mu} \text { DS } \\
L A B \\
(\mu g / G) \\
(34847)\end{array}$ & $\begin{array}{l}\text { COPPER } \\
\text { BOT MUT } \\
\angle 63_{\mu} \text { DS } \\
\text { LAB } \\
(\mu g / G) \\
(34852)\end{array}$ & $\begin{array}{c}\text { EURO- } \\
\text { PIUN } \\
\text { BOT MAT } \\
\angle 63 \mu \text { DS } \\
\text { LAB } \\
(\mu g / G) \\
(34857)\end{array}$ & $\begin{array}{c}\text { GALLIUN } \\
\text { BOT MAT } \\
\angle 63 \mu \text { DS } \\
\text { LAB } \\
(\mu 9 / G) \\
(34862)\end{array}$ & $\begin{array}{l}\text { COLD } \\
\text { BOT MUT } \\
<63 \mu \text { DS } \\
\text { LAB } \\
(\mu g / G) \\
(34872)\end{array}$ & 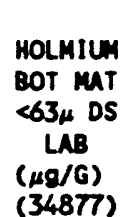 & $\begin{array}{l}\text { IROW } \\
\text { BOT MUT } \\
\text { C63H DS } \\
\text { LAB } \\
\text { PERCENT } \\
(34882)\end{array}$ & $\begin{array}{c}\text { LANTHA- } \\
\text { NUM } \\
\text { BOT MAT } \\
\angle 63_{\mu} \text { DS } \\
\text { LAB } \\
(\mu g / G) \\
(34887)\end{array}$ & $\begin{array}{l}\text { LEAD } \\
\text { BOT MAT } \\
\angle 63_{\mu} \text { DS } \\
\text { LAB } \\
(\mu g / G) \\
(34892)\end{array}$ \\
\hline
\end{tabular}

LITTLE COLORADO RIVER MEAR JOSEPH CITY, AZ-Continued

$09397300 \quad 07-08-90$
$07-08-90$
$07-14-90$
$07-14-90$
$07-14-90$
$07-15-90$
$07-16-90$
$07-16-90$
$08-16-90$
$08-16-90$
$09-01-90$
$09-01-90$
$09-01-90$
$09-01-90$
$09-01-90$
$09-05-90$
$09-11-90$
$09-21-90$
$09-21-90$
$09-21-90$
$09-21-90$
$09-21-90$
$09-21-90$
$09-21-90$
$09-21-90$
$09-21-90$
$09-21-90$
$09-21-90$
$09-21-90$
$09-22-90$
$12-18-90$
$01-06-91$
$01-06-91$
$01-07-91$
$01-15-91$
$08-01-91$
$08-01-91$
$08-01-91$
$08-08-91$
$08-28-91$
$08-28-91$
$09-06-91$

01

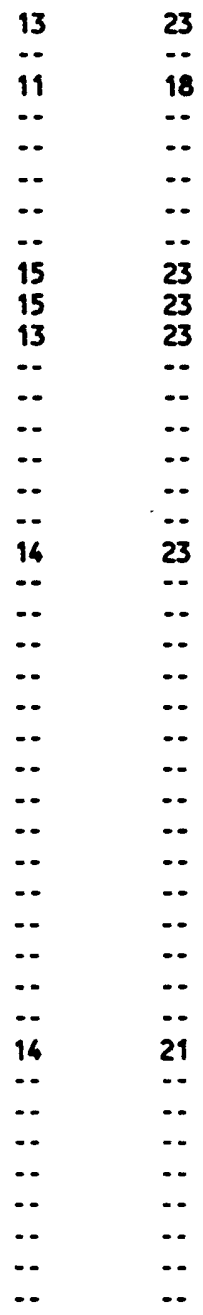

\begin{tabular}{|c|c|c|}
\hline$<2$ & & \\
\hline$\cdots$ & & \\
\hline$<2$ & & \\
\hline-- & & \\
\hline$\cdots$ & & \\
\hline 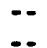 & & \\
\hline 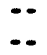 & & \\
\hline$<2$ & & \\
\hline $\begin{array}{l}<2 \\
<2\end{array}$ & & \\
\hline$\cdots$ & & \\
\hline$\cdots$ & & \\
\hline$\cdots$ & & \\
\hline$\because$ & & \\
\hline$\cdots$ & & \\
\hline$<2$ & & \\
\hline$\cdots$ & & \\
\hline - & & \\
\hline-- & & \\
\hline-- & & \\
\hline$\cdots$ & & \\
\hline$\cdots$ & & \\
\hline-- & & \\
\hline 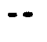 & & \\
\hline$\cdots$ & & \\
\hline$\because$ & & \\
\hline$\because$ & & \\
\hline$\cdots$ & & \\
\hline$\ldots$ & & \\
\hline - & & \\
\hline$<2$ & & \\
\hline$\cdots$ & & \\
\hline$\cdots$ & & \\
\hline$\cdots$ & & \\
\hline$\cdots$ & & \\
\hline$\cdots$ & & \\
\hline$\because$ & & \\
\hline$=$ & & \\
\hline
\end{tabular}

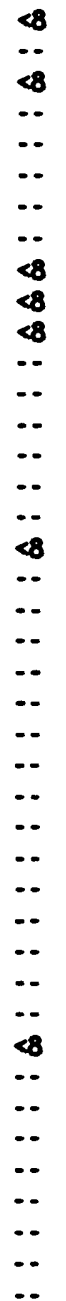

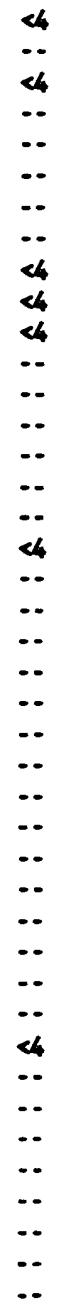

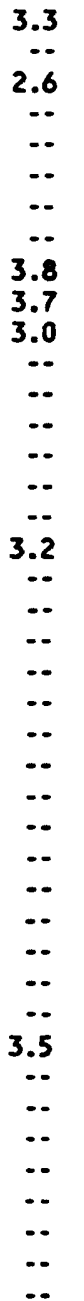

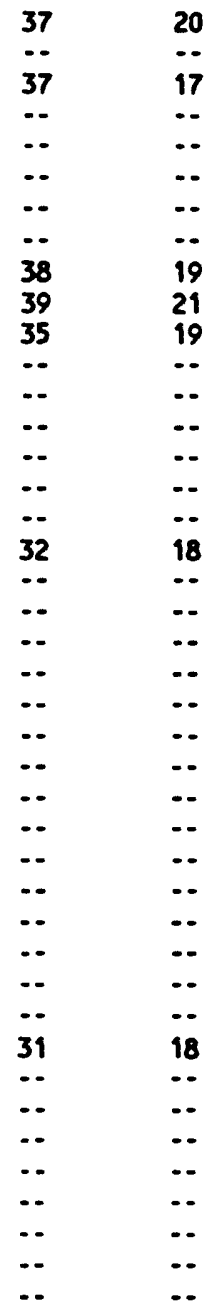


SURFACE-WATER DATA-Continued

CHEMICAL ANALYSES-Cont inued

\begin{tabular}{|c|c|c|c|c|c|c|c|c|c|}
\hline $\begin{array}{l}\text { STATION } \\
\text { MUNBER }\end{array}$ & DATE & $\begin{array}{l}\text { LITHIUN } \\
\text { BOT MAT } \\
\angle 63 \mu \text { DS } \\
\text { LAB } \\
(\mu g / G) \\
(34897)\end{array}$ & $\begin{array}{l}\text { MAGNE- } \\
\text { SIUN } \\
\text { BOT MAT } \\
\angle 63 \mu \text { DS } \\
\text { LAB } \\
\text { PERCENT } \\
\text { (34902) }\end{array}$ & $\begin{array}{l}\text { MANA- } \\
\text { NESE } \\
\text { BOT MAT } \\
\angle 63_{\mu} \text { DS } \\
\text { LAB } \\
(\mu 9 / G) \\
(34907)\end{array}$ & $\begin{array}{l}\text { MOLY- } \\
\text { DENUN } \\
\text { BOT MAT } \\
\angle 63 \mu \text { DS } \\
\text { LAB } \\
(\mu 9 / G) \\
(34917)\end{array}$ & $\begin{array}{l}\text { NECOYM- } \\
\text { IUN } \\
\text { BOT MAT } \\
\angle 63_{\mu} \text { DS } \\
\text { LAB } \\
(\mu g / G) \\
(34922)\end{array}$ & $\begin{array}{l}\text { NICKEL } \\
\text { BOT MAT } \\
\angle 63 \mu \text { DS } \\
\text { LAB } \\
(\mu 9 / G) \\
(34927)\end{array}$ & 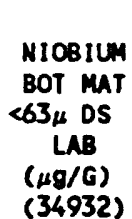 & $\begin{array}{l}\text { PHOS- } \\
\text { PHORUS } \\
\text { BOT MAT } \\
\text { C63 } \mu \text { DS } \\
\text { LAB } \\
\text { PERCENT } \\
\text { (34937) }\end{array}$ \\
\hline
\end{tabular}

09397300

$07-08-90$

07-08-90

07-14-90

$07-14-90$

07-14-90

07-15-90

07-16-90

07-16-90

08-16-90

08-16-90

09-01-90

09-01-90

09-01-90

09-01-90

09-01-90

09-05-90

$09-11-90$

09-21-90

09-21-90

09-21-90

09-21-90

09-21-90

$09-21-90$

09-21-90

09-21-90

09-21-90

09-21-90

09-21-90

$09-21-90$

09-22-90

12-18-90

01-06-91

01-06-91

01-07-91

01-15-91

08-01-91

08-01-91

08-01-91

08-08-91

08-28-91

08-28-91

09-06-91

LITTLE COLORADO RIVER NEAR JOSEPH CITY, AZ-CONtinued

\begin{tabular}{|c|c|c|}
\hline 34 & 1.6 & 580 \\
\hline$\ddot{31}$ & .94 & 440 \\
\hline$\therefore$ & 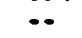 & $\because$ \\
\hline .. & .. & 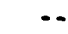 \\
\hline$-\cdot$ & -- & $\cdots$ \\
\hline$\because$ & $\cdots$ & $\cdots$ \\
\hline 43 & 1.6 & 520 \\
\hline 43 & 1.5 & $\begin{array}{l}520 \\
550\end{array}$ \\
\hline & 1.5 & \\
\hline -- & .. & .. \\
\hline- & -. & $\cdots$ \\
\hline$\bullet$ & $\cdots$ & $\cdots$ \\
\hline$\because$ & $\because$ & $\because$ \\
\hline 37 & 1.7 & 580 \\
\hline -. & -. & 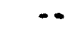 \\
\hline$\cdots$ & $\because$ & $\because$ \\
\hline$\cdots$ & .. & .. \\
\hline -- & -. & - \\
\hline 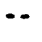 & $\cdots$ & $\cdots$ \\
\hline -. & -. & - \\
\hline$\because$ & $\because$ & $\because$ \\
\hline .. & .. & .. \\
\hline-- & -. & $\ldots$ \\
\hline$\because$ & $\because$ & $\because$ \\
\hline$\therefore$ & $\because$ & $\because$ \\
\hline$\cdots$ & .. & \\
\hline 39 & 1.8 & 500 \\
\hline -. & ב- & .. \\
\hline .. & .. & -. \\
\hline & $\cdots$ & $\ldots$ \\
\hline & 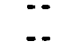 & $\because$ \\
\hline & -. & .. \\
\hline$\cdots$ & -. & $\ldots$ \\
\hline
\end{tabular}

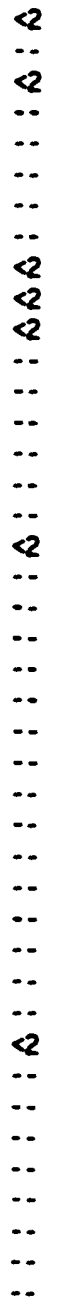

30

30

21

-

-.

$\cdots$

$\cdots$

-.

31

32

30 
SURFACE-UATER DATA-Continued

CHEMICAL ANALYSES-Cont inued

STATION

MUABER

DATE

07-08-90

07-08-90

$07-14-90$

07-14-90

07-14-90

07-15-90

07-16-90

07- $16-90$

08-16-90

08-16-90

09-01-90

09-01-90

09-01-90

09-01-90

09-01-90

09-05-90

09-11-90

09-21-90

09-21-90

09-21-90

09-21-90

09-21-90

09-21-90

09-21-90

09-21-90

09-21-90

$09-21-90$

09-21-90

09-21-90

09-22-90

12-18-90

01-06-91

$01-06-91$

01-07-91

01-15-91

08-01-91

08-01-91

08-01-91

08-08-91

08-28-91

08-28-91

09-06-91

\begin{tabular}{|c|c|c|c|c|c|c|c|}
\hline $\begin{array}{l}\text { POTAS- } \\
\text { SIUA } \\
\text { BOT MAT } \\
\text { } 63 \mu \text { DS } \\
\text { LAB } \\
\text { PERCENT } \\
\text { (34942) }\end{array}$ & $\begin{array}{c}\text { SCAN- } \\
\text { DIUA } \\
\text { BOT MAT } \\
\text { } 63 \mu \text { DS } \\
\text { LAB } \\
(\mu 9 / G) \\
(34947)\end{array}$ & $\begin{array}{c}\text { SILVER } \\
\text { BOT MAT } \\
\angle 63 \mu \text { DS } \\
\text { LAB } \\
(\mu g / G) \\
(34957)\end{array}$ & $\begin{array}{l}\text { SOOIUN } \\
\text { BOT MAT } \\
\text { <63 }{ }^{\prime} \text { DS } \\
\text { LAB } \\
\text { PERCENT } \\
\text { (34962) }\end{array}$ & 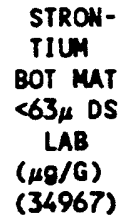 & $\begin{array}{c}\text { TANA - } \\
\text { LUN } \\
\text { BOT MT } \\
<63 \mu \text { DS } \\
\text { LAB } \\
(\mu g / G) \\
(34977)\end{array}$ & $\begin{array}{c}\text { THORIUN } \\
\text { BOT MAT } \\
\angle 63 \mu \text { DS } \\
\text { LAB } \\
(\mu g / G) \\
(34982)\end{array}$ & $\begin{array}{c}\text { TIN } \\
\text { BOT MAT } \\
\angle 63_{\mu} \text { DS } \\
\text { LAB } \\
(\mu g / G) \\
(34987)\end{array}$ \\
\hline
\end{tabular}

LITTLE COLORADO RIVER MEAR JOSEPH CITY, AZ-Continued

\begin{tabular}{|c|c|c|c|c|c|c|c|}
\hline 1.8 & 12 & $<4$ & .47 & 270 & $<40$ & 13 & $<10$ \\
\hline-- & -- & $\because$ & 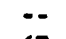 & 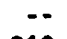 & $=-$ & $\ddot{\theta}$ & 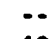 \\
\hline 1.7 & 9 & $<4$ & .63 & 210 & $<40$ & 12 & $<10$ \\
\hline$\cdots$ & $\cdots$ & $\cdots$ & $\cdots$ & -- & $\cdots$ & -- & -- \\
\hline$-\cdot$ & $\cdots$ & $\cdots$ & -- & $\cdots$ & -- & 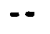 &.- \\
\hline-- & -- & $\cdots$ & 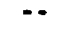 & -- & -- & -- & -- \\
\hline$=-$ & $\cdots$ & $\because$ & -- & $\cdots$ & -- & -- & $\cdots$ \\
\hline$\because$ & 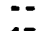 & $\because$ & 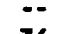 & $=$ & 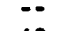 & $\because-$ & $\because$ \\
\hline $\begin{array}{l}1.8 \\
1.8 \\
2.1\end{array}$ & $\begin{array}{l}15 \\
15 \\
12\end{array}$ & $\begin{array}{l}<4 \\
<4 \\
<4\end{array}$ & $\begin{array}{l}.36 \\
.40 \\
.48\end{array}$ & $\begin{array}{l}280 \\
280 \\
190\end{array}$ & $\begin{array}{l}<40 \\
<40 \\
<40\end{array}$ & $\begin{array}{l}14 \\
14 \\
11\end{array}$ & $\begin{array}{l}<10 \\
<10 \\
<10\end{array}$ \\
\hline$\cdots$ & $\cdots$ & $\cdots$ & $\cdots$ & -- & $\cdots$ & $\cdots$ & $\cdots$ \\
\hline$\cdots$ & $-\cdot$ & $\because$ & $\cdots$ & $\cdots$ & $\cdots$ & $\cdots$ & $\cdots$ \\
\hline$\because$ & $\cdots$ & $\cdots$ & $\cdots$ & -- & $\because$ & -- & -- \\
\hline- & $\cdots$ & $\cdots$ & $\cdots$ & $\cdots$ & $\cdots$ & $\cdots$ & $=-$ \\
\hline 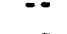 & $\cdots$ & $\cdots$ & 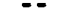 & $\cdots$ & - & $\cdots$ & -- \\
\hline$\cdots$ & -- & $\cdots$ & -- & -- & -- & $\because$ & 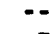 \\
\hline 1.9 & 12 & $<4$ & .47 & 260 & $<40$ & 13 & $<5$ \\
\hline-- & $\cdots$ & $\cdots$ & -- & -- & 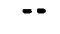 & -- & $\because$ \\
\hline$\cdots$ & $\cdots$ & $\cdots$ & - & -- & -- & $\cdots$ & $\cdots$ \\
\hline$\cdots$ & $\cdots$ & $\because$ & - & $=$ & $\cdots$ & -- & - \\
\hline- & $\cdots$ & $\because$ & $\because$ & $\cdots$ & $\because$ & $\cdots$ & - \\
\hline$\cdots$ & $\cdots$ & 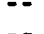 & $\cdots$ & $\because$ & $\cdots$ & $\because$ & $\cdots$ \\
\hline 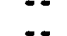 & $\cdots$ & $\because$ & 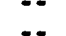 & $\cdots$ & $\because$ & $\cdots$ & $\cdots$ \\
\hline 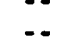 & 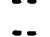 & - & $\ldots$ & $\because$ & $\because$ & $\because$ & $\cdots$ \\
\hline -. & .- & .. & .. & .. & .. & - & $\ldots$ \\
\hline- & $\cdots$ & $\cdots$ & $\cdots$ & $\cdots$ & $\cdots$ & - & - \\
\hline-- & $-\cdot$ & $\cdots$ & -. & - & $\because$ & -- & - \\
\hline-- & $\cdots$ & - & - & $\because$ & $\cdots$ & - & - \\
\hline-- & $\cdots$ & $\cdots$ & -. & -- & $\because$ & $\because$ & -- \\
\hline$\cdots$ & -- & $\cdots$ & - & -- & 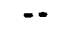 & -- & - \\
\hline- & $\because$ & $\because$ & -. & -- & -. & $=$ & $-\cdot$ \\
\hline 1.7 & 13 & $<4$ & .63 & 350 & $<40$ & 11 & $<5$ \\
\hline- & $\cdots$ & $\because$ & - & $=$ & $=-$ & $\cdots$ & $\cdots$ \\
\hline & $\cdots$ & - & $\cdots$ & $\because$ & $\because$ & $\cdots$ & - \\
\hline- & $\because$ & -- & - & $\cdots$ & $\because$ & $\because$ & - \\
\hline & $\ldots$ & $\ldots$ & 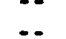 & 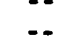 & . & $\cdots$ & 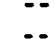 \\
\hline$\because$ & $\ldots$ & $\ldots$ & .. & $\ldots$ & $\ldots$ & 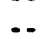 & 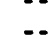 \\
\hline - & $\cdots$ & -- & -. & 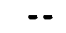 & - & $\cdots$ & .. \\
\hline & -- & -- & -- & & 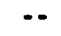 & 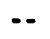 & \\
\hline
\end{tabular}


SURFACE-WATER DATA-Cont inued

CHEMICAL ANALYSES-Continued

STATION

MUABER

09397300
DATE

$07-08-90$
$07-08-90$
$07-14-90$
$07-14-90$
$07-14-90$
$07-15-90$
$07-16-90$
$07-16-90$
$08-16-90$
$08-16-90$
$09-01-90$
$09-01-90$
$09-01-90$
$09-01-90$
$09-01-90$
$09-05-90$
$09-11-90$
$09-21-90$
$09-21-90$
$09-21-90$
$09-21-90$
$09-21-90$
$09-21-90$
$09-21-90$
$09-21-90$
$09-21-90$
$09-21-90$
$09-21-90$
$09-21-90$
$09-22-90$
$12-18-90$
$01-06-91$
$01-06-91$
$01-07-91$
$01-15-91$
$08-01-91$
$08-01-91$
$08-01-91$
$08-08-91$
$08-28-91$
$08-28-91$
$09-06-91$

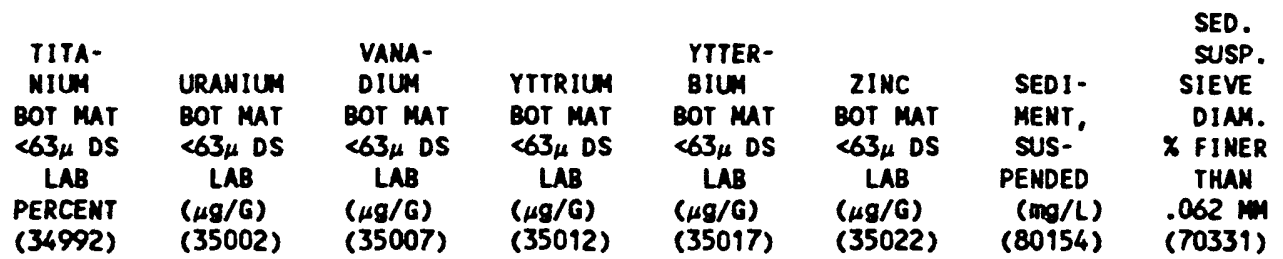

LITTLE COLORADO RIVER NEAR JOSEPH CITY, AZ-CONTIMUEd

\begin{tabular}{|c|c|c|c|c|c|c|c|}
\hline .33 & $<100$ & 76 & 24 & 2 & 58 & 45600 & 90 \\
\hline$\cdots$ & -- & $=$ & 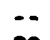 & -- & 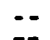 & 49500 & 97 \\
\hline .30 & $<100$ & 72 & 22 & 2 & 55 & 178000 & 93 \\
\hline -. & $\cdots$ & $=$ & -- & -. & - & 238000 & 71 \\
\hline- & $\cdots$ & - & -. & - & -. & 226000 & 73 \\
\hline - & - & $\cdots$ & .. & $=$ & -. & 173000 & 82 \\
\hline$\cdots$ & $\cdots$ & $\cdots$ & -. & $\cdots$ & -. & 56400 & 91 \\
\hline - & - & $\cdots$ & $\cdots$ & $\cdots$ & -. & 96900 & 98 \\
\hline .41 & $<100$ & 100 & 24 & 3 & 78 & 51300 & 97 \\
\hline .40 & $<100$ & 100 & 25 & 3 & 78 & 64500 & 86 \\
\hline .35 & $<100$ & 84 & 21 & 2 & 71 & 44800 & 84 \\
\hline -- & - & $\cdots$ & $\cdots$ & $\cdots$ & $\cdots$ & 64000 & 92 \\
\hline$\cdots$ & $\cdots$ & $\cdots$ & $\cdots$ & $\cdots$ &.- & 46200 & 85 \\
\hline$=$ & $\cdots$ & $\cdots$ & -. & - & -. & 37400 & 84 \\
\hline$\cdots$ & -. & $\cdots$ & $\cdots$ & $\cdots$ & -. & 31300 & 85 \\
\hline$\cdots$ & - & $\cdots$ & $\cdots$ & $=$ & $\cdots$ & 42900 & 100 \\
\hline-- & $\cdots$ & 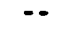 & $\cdots$ & -- & $\cdots$ & 87400 & 100 \\
\hline .29 & $<100$ & 80 & 19 & 2 & 67 & 46800 & $\cdots$ \\
\hline - & $\cdots$ & $\cdots$ & $\cdots$ & $\cdots$ & $\cdots$ & 57900 & $\cdots$ \\
\hline -. & -. & $\cdots$ & $\cdots$ & $\cdots$ & $\cdots$ & 54300 & 97 \\
\hline -. & $\cdots$ & $\cdots$ & -. & -. & $-\cdot$ & 59700 & 93 \\
\hline -. & $\cdots$ & $\cdots$ & $\cdots$ & -- & $\cdots$ & 54300 & 7 \\
\hline -- & $\cdots$ & $\cdots$ & $\cdots$ & $\cdots$ & $\cdots$ & 59700 & 3 \\
\hline -. & $\cdots$ & $\cdots$ & $\cdots$ & $\cdots$ & $\cdots$ & 45800 & 93 \\
\hline- & $\cdots$ & $\cdots$ & -- & -- & $\cdots$ & 52300 & 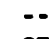 \\
\hline -. & .. & - & -. & -. & -. & 45800 & 93 \\
\hline-- & -- & $\cdots$ & $\cdots$ & $\cdots$ & -. & 43900 & $\cdots$ \\
\hline-- & -. & -- & $\cdots$ & -- & -. & 41400 & -- \\
\hline - & $\ldots$ & $\cdots$ & $\cdots$ & $\cdots$ & $\cdots$ & 38400 & $\cdots$ \\
\hline- & -. & $=-$ & $\cdots$ & -- & -. & 27500 & 91 \\
\hline .. & $\cdots$ & $\cdots$ & $\cdots$ & $\cdots$ & $\cdots$ & 31900 & $\cdots$ \\
\hline$\cdots$ & $\cdots$ & $\cdots$ & $\cdots$ & $\cdots$ & $\cdots$ & $\cdots$ & $\cdots$ \\
\hline - & $\cdots$ & $-\cdots$ & $\cdots$ & $\cdots$ & $\cdots$ & $\cdots$ & $\cdots$ \\
\hline .35 & $<100$ & 82 & 19 & 2 & 58 & 17100 & 89 \\
\hline - & $\cdots$ & $\cdots$ & -. & $\cdots$ & -. & 4050 & $\cdots$ \\
\hline$\cdots$ & -. & $\cdots$ & $\cdots$ & - & $\cdots$ & 18400 & 96 \\
\hline$\cdots$ & $\cdots$ & $\cdots$ & $\cdots$ & $\cdots$ & $\cdots$ & 17700 & $\cdots$ \\
\hline$\cdots$ & $\cdots$ & -. & $-\cdot$ & $\cdots$ & $\cdots$ & 16300 & $\phi$ \\
\hline$\cdots$ & $\cdots$ & $\cdots$ & $\cdots$ & $\cdots$ & $\cdots$ & 143000 & 86 \\
\hline$\cdots$ & $\cdots$ & $\cdots$ & $\cdots$ & $\cdots$ & $\cdots$ & 203000 & 60 \\
\hline-- & $\cdots$ & - & $\cdots$ & $\cdots$ & $\cdots$ & 135000 & 91 \\
\hline -. & $\cdots$ & $\cdots$ & $\cdots$ & $\cdots$ & - & 31400 & 78 \\
\hline
\end{tabular}


SURFACE-HATER DATA-Cont inued

\section{CHEMICAL ANALYSES-Continued}

STATION

NUMBER

DATE

\begin{tabular}{|c|c|c|c|c|c|c|c|c|}
\hline $\begin{array}{l}\text { SED. } \\
\text { SUSP. } \\
\text { FALL } \\
\text { DINM. } \\
\times \text { FIMER } \\
\text { THAN } \\
.002 \\
\text { (70337) }\end{array}$ & $\begin{array}{l}\text { SED. } \\
\text { SUSP. } \\
\text { FALL } \\
\text { DINM. } \\
\times \text { FINER } \\
\text { THAN } \\
.004 \text {. } \\
\text { (70338) }\end{array}$ & $\begin{array}{l}\text { SED. } \\
\text { SUSP. } \\
\text { FALL } \\
\text { DINM. } \\
\times \text { FINER } \\
\text { THAN } \\
.008 \text { MM } \\
\text { (70339) }\end{array}$ & $\begin{array}{l}\text { SED. } \\
\text { SUSP. } \\
\text { FALL } \\
\text { DINM. } \\
\times \text { FINER } \\
\text { THAN } \\
\text { TH } \\
\text { O16 MM } \\
(70340)\end{array}$ & $\begin{array}{l}\text { SED. } \\
\text { SUSP. } \\
\text { FALL } \\
\text { OINH. } \\
\times \text { FINER } \\
\text { THAN } \\
.031 \text { MN } \\
\text { (70341) }\end{array}$ & $\begin{array}{l}\text { SED. } \\
\text { SUSP. } \\
\text { FALL } \\
\text { DINH. } \\
\times \text { FINER } \\
\text { THAN } \\
.062 \text { MM } \\
\text { (70342) }\end{array}$ & $\begin{array}{l}\text { SED. } \\
\text { SUSP. } \\
\text { FALL } \\
\text { DINM. } \\
\times \text { FINER } \\
\text { THAN } \\
\text { I 125 MM } \\
\text { (70343) }\end{array}$ & $\begin{array}{l}\text { SED. } \\
\text { SUSP. } \\
\text { FALL } \\
\text { DINM. } \\
\times \text { FINER } \\
\text { THAN } \\
.250 \text { MM } \\
\text { (70344) }\end{array}$ & $\begin{array}{c}\text { SED. } \\
\text { SUSP. } \\
\text { FALL } \\
\text { DINM. } \\
\times \text { FINER } \\
\text { TKAN } \\
\text { 500 } \\
\text { (70345) }\end{array}$ \\
\hline
\end{tabular}

LITTLE COLORADO RIVER NEAR JOSEPH CITY, AZ-Continued

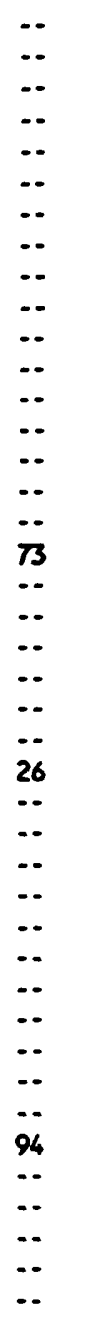

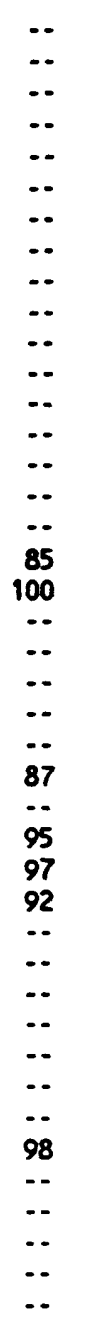

\begin{tabular}{|c|c|c|}
\hline-- & $\cdots$ & $\cdots$ \\
\hline$\because$ & $\cdots$ & $\cdots$ \\
\hline$\cdots$ & $\cdots$ & $\cdots$ \\
\hline-- & 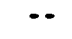 & $\cdots$ \\
\hline$\cdots$ & $\cdots$ & $\cdots$ \\
\hline$\therefore$ & $\cdots$ & $\cdots$ \\
\hline$\cdots$ & -- & -. \\
\hline$\cdots$ & -- & $=$ \\
\hline$\cdots$ & $-\cdot$ & $\cdots$ \\
\hline$\because$ & $\because$ & $\cdots$ \\
\hline$\therefore$ & $\because$ & $\because$ \\
\hline .. & .. & $\ldots$ \\
\hline -. & .. & .. \\
\hline - & - & $\cdots$ \\
\hline-- & -- & - \\
\hline 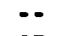 & 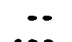 & $\cdots$ \\
\hline 95 & 100 & $\cdots$ \\
\hline$\cdots$ & $\cdots$ & $\cdots$ \\
\hline -. & $\cdots$ & $\cdots$ \\
\hline$\because$ & $\cdots$ & $\cdots$ \\
\hline$\because$ & 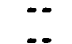 & $\because$ \\
\hline$\therefore$ & $\because$ & $\cdots$ \\
\hline 96 & 99 & 100 \\
\hline$\because$ & $\cdots$ & -. \\
\hline 98 & 100 & $\cdots$ \\
\hline 100 & $\cdots$ & - \\
\hline 98 & 100 & $\cdots$ \\
\hline -. & - & $\cdots$ \\
\hline$-\cdot$ & - & $\cdots$ \\
\hline$\cdots$ & $\cdots$ & $\cdots$ \\
\hline$\cdots$ & $\cdots$ & $\cdots$ \\
\hline$\cdots$ & $\cdots$ & $\cdots$ \\
\hline$\cdots$ & $\cdots$ & $\because$ \\
\hline$\ddot{\phi}$ & 100 & $\because$ \\
\hline-- & - & .. \\
\hline-- & $=-$ & .. \\
\hline-- & $\cdots$ & - \\
\hline$\cdots$ & $\cdots$ & -. \\
\hline$\cdots$ & $\cdots$ & \\
\hline
\end{tabular}




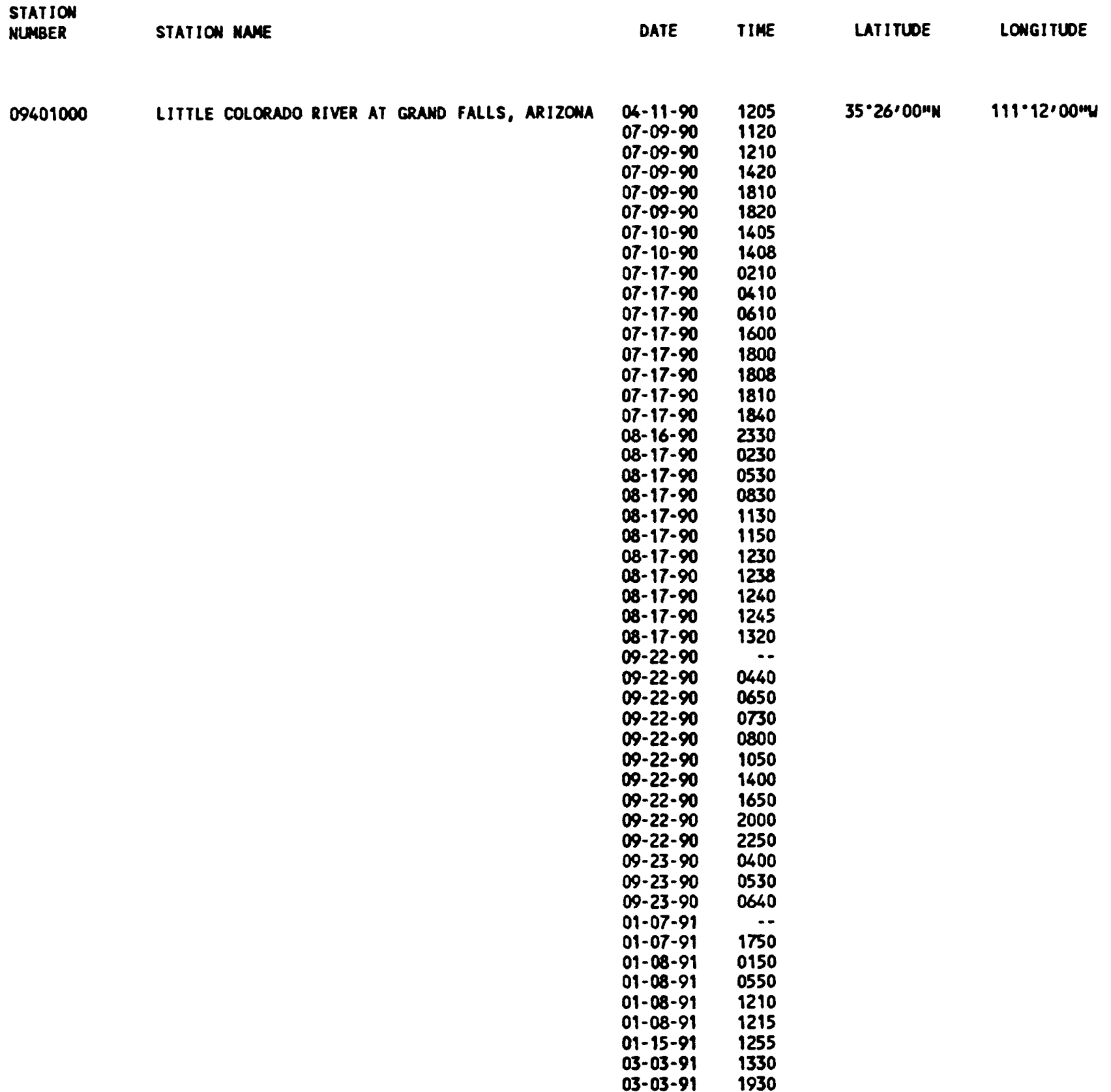


SURFACE-WATER DATA-Cont inued

CHEMICAL ANALYSES-Cont inued

\begin{tabular}{|c|c|c|c|c|c|c|c|c|c|c|}
\hline $\begin{array}{l}\text { STATION } \\
\text { NUMBER }\end{array}$ & DATE & $\begin{array}{c}\text { ALTITUDE } \\
\text { OF LAND } \\
\text { SURFACE } \\
\text { DATUM } \\
\text { (meters } \\
\text { above } \\
\text { NGVD) } \\
\text { (72000) }\end{array}$ & $\begin{array}{l}\text { SAM- } \\
\text { PLING } \\
\text { METHOD, } \\
\text { CODES } \\
(82398)\end{array}$ & $\begin{array}{l}\text { STRENM } \\
\text { UIDTH } \\
\text { (meters) } \\
\text { (00004) }\end{array}$ & $\begin{array}{l}\text { TEMPER- } \\
\text { ATURE } \\
\text { WATER } \\
\text { ('C) } \\
\text { (00010) }\end{array}$ & $\begin{array}{l}\text { DIS- } \\
\text { CHARGE, } \\
\text { INST. } \\
\text { CUBIC } \\
\text { METERS } \\
\text { PER } \\
\text { SECOND } \\
\text { (00061) }\end{array}$ & $\begin{array}{l}\text { GAGE } \\
\text { HEIGHT } \\
\text { (meters) } \\
\text { (00065) }\end{array}$ & $\begin{array}{l}\text { SPE- } \\
\text { CIFIC } \\
\text { CON- } \\
\text { OUCT- } \\
\text { ANCE } \\
(\mu S / C m) \\
(00095)\end{array}$ & $\begin{array}{l}\text { SPE- } \\
\text { CIFIC } \\
\text { CON- } \\
\text { OUCT- } \\
\text { ANCE } \\
\text { LAS } \\
(\mu S / \mathrm{Cm}) \\
(90095)\end{array}$ & $\begin{array}{c}\text { OXYGEN, } \\
\text { DIS- } \\
\text { SOLVED } \\
\text { (mg/L) } \\
\text { (00300) }\end{array}$ \\
\hline
\end{tabular}

LITTLE COLORADO RIVER AT GRAND FALLS, AZ-Continued

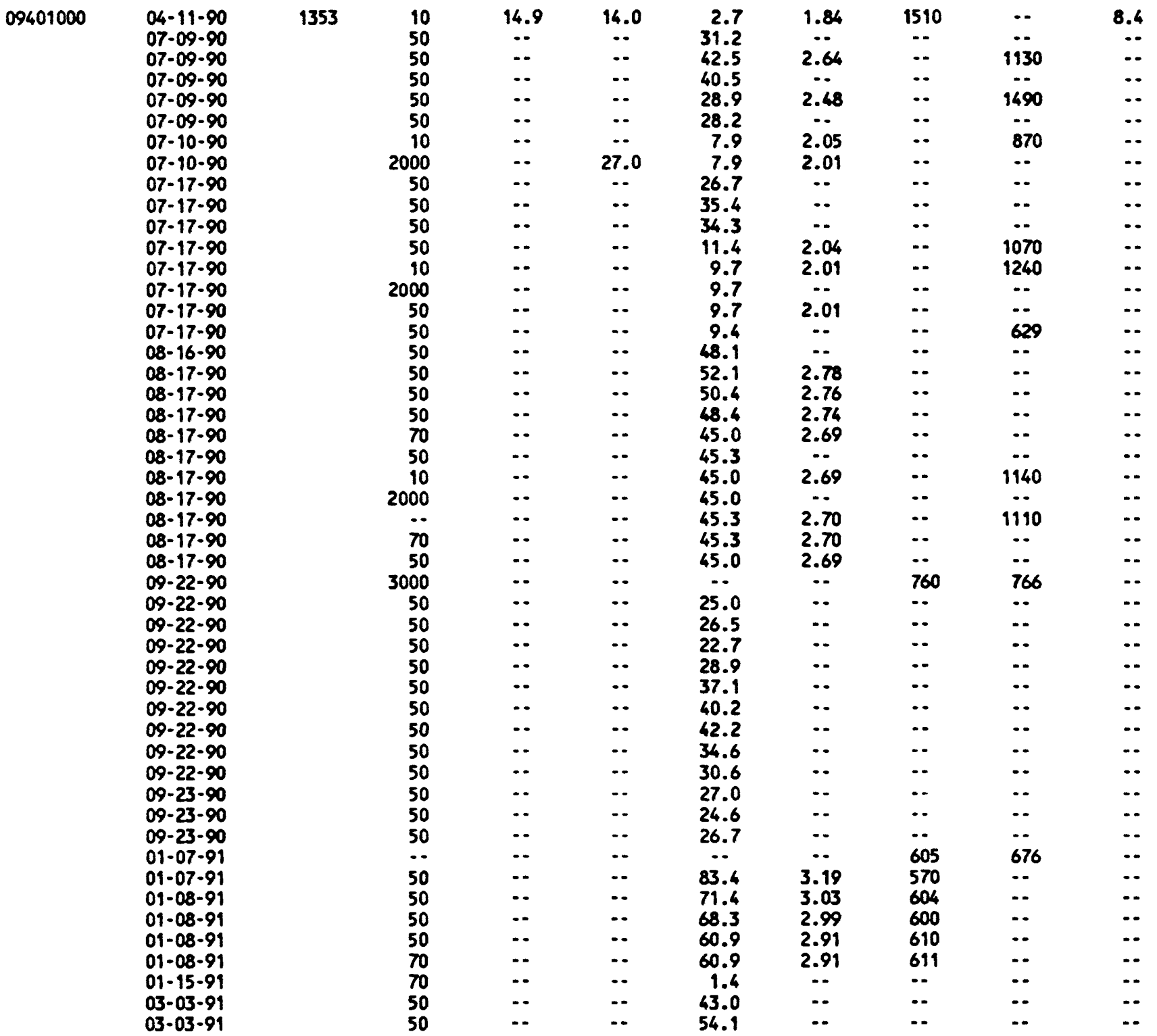


SURFACE-WATER DATA-Cont inued

CHEMICAL ANALYSES-Cont inued

STATION

NUMBER

$09401000 \quad 04-11-90$
$07-09-90$
$07-09-90$
$07-09-90$
$07-09-90$
$07-09-90$
$07-10-90$
$07-10-90$
$07-17-90$
$07-17-90$
$07-17-90$
$07-17-90$
$07-17-90$
$07-17-90$
$07-17-90$
$07-17-90$
$08-16-90$
$08-17-90$
$08-17-90$
$08-17-90$
$08-17-90$
$08-17-90$
$08-17-90$
$08-17-90$
$08-17-90$
$08-17-90$
$08-17-90$
$09-22-90$
$09-22-90$
$09-22-90$
$09-22-90$
$09-22-90$
$09-22-90$
$09-22-90$
$09-22-90$
$09-22-90$
$09-22-90$
$09-23-90$
$09-23-90$
$09-23-90$
$01-07-91$
$01-07-91$
$01-08-91$
$01-08-91$
$01-08-91$
$01-08-91$
$01-15-91$
$03-03-91$
$03-03-91$

\begin{tabular}{|c|c|c|c|c|c|c|c|c|}
\hline $\begin{array}{l}\text { PH } \\
\text { WATER } \\
\text { WHOLE } \\
\text { FIELD } \\
\text { (STAND- } \\
\text { ARD } \\
\text { UNITS) } \\
\text { (00400) }\end{array}$ & $\begin{array}{l}\text { PH } \\
\text { WATER } \\
\text { WHOLE } \\
\text { LAB } \\
\text { (STAND- } \\
\text { ARD } \\
\text { UNITS) } \\
\text { (00403) }\end{array}$ & $\begin{array}{l}\text { ALKA- } \\
\text { LINITY } \\
\text { WAT DIS } \\
\text { FIX END } \\
\text { FIELD } \\
\text { CaCO3 } \\
(\text { mo/L) } \\
(39036)\end{array}$ & $\begin{array}{l}\text { ALKA- } \\
\text { LINITY } \\
\text { LAB } \\
\text { (mg/L } \\
\text { AS } \\
\text { CaCO3) } \\
(90410)\end{array}$ & $\begin{array}{l}\text { CAR- } \\
\text { BONATE } \\
\text { WATER } \\
\text { DIS IT } \\
\text { FIELD } \\
\text { COS AS } \\
\text { COS } \\
(00452)\end{array}$ & $\begin{array}{l}\text { BICAR- } \\
\text { BONATE } \\
\text { UATER } \\
\text { OIS IT } \\
\text { FIELO } \\
\text { WO/L AS } \\
\text { HCO3 } \\
(00453)\end{array}$ & $\begin{array}{l}\text { SOLIDS, } \\
\text { RESIDUE } \\
\text { AT } 180^{\circ} \mathrm{C} \\
\text { DIS- } \\
\text { SOLVED } \\
(\mathrm{mO} / L) \\
(70300)\end{array}$ & $\begin{array}{l}\text { SOLIDS, } \\
\text { SUN OF } \\
\text { CONSTI- } \\
\text { TUENTS, } \\
\text { DIS- } \\
\text { SOLVED } \\
(\text { mo/L) } \\
(70301)\end{array}$ & $\begin{array}{l}\text { SOLIDS, } \\
\text { DIS- } \\
\text { SOLVED } \\
\text { (tons } \\
\text { per } \\
\text { day) } \\
\text { (70302) }\end{array}$ \\
\hline
\end{tabular}

LITTLE COLORADO RIVER AT GRAND FALLS, AZ-Continued

\begin{tabular}{|c|c|c|c|c|c|c|c|c|}
\hline 8.5 & - & 130 & - & 4 & 151 & -. & $\cdots$ & $\cdots$ \\
\hline$\cdots$ & $\cdots$ & -. & - & $\cdots$ & $\cdots$ & - & $\cdots$ & $\cdots$ \\
\hline$\cdots$ & 8.1 & $\cdots$ & 135 & - & - & 574 & 591 & 2104 \\
\hline$\cdots$ & - & $\cdots$ & $\cdots$ & $\cdots$ & $\cdots$ & $\cdots$ & $\cdots$ & $\cdots$ \\
\hline -. & 7.8 & - & 135 & $\cdots$ & $\cdots$ & 1360 & 686 & 3401 \\
\hline$\cdots$ & $\cdots$ & $\cdots$ & $\cdots$ & $\cdots$ & $\cdots$ & $\cdots$ & $\cdots$ & $\cdots$ \\
\hline - & 8.1 & $\cdots$ & 186 & $\cdots$ & - - & 527 & 508 & 359 \\
\hline - & $\cdots$ & $\cdots$ & -- & $\cdots$ & - & $\cdots$ & $\cdots$ & $\cdots$ \\
\hline - & - & 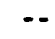 & -. & - & -- & - & - & - \\
\hline- & .. & $\cdots$ & -. & $\cdots$ & $\cdots$ & $\cdots$ & - & $\cdots$ \\
\hline-- & $\cdots$ & - & $\cdots$ & $\cdots$ & $\cdots$ & $\cdots$ & $\cdots$ & $\cdots$ \\
\hline$\cdots$ & 7.8 & $\cdots$ & 191 & $\cdots$ & -- & 642 & 604 & 635 \\
\hline-- & 7.8 & $=$ & 300 & -- & $\cdots$ & 652 & 692 & 544 \\
\hline$\cdots$ & $\because$ & -- & $\cdots$ & $\cdots$ & $\cdots$ & $\cdots$ & $\cdots$ & $\cdots$ \\
\hline 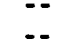 & 89 & -- & 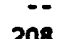 & $\cdots$ & $\cdots$ & $\ddot{27}$ & 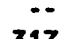 & -- \\
\hline$\because$ & 8.1 & $\ddot{-}$ & $\begin{array}{c}208 \\
\ldots-\end{array}$ & $\because$ & $\because$ & $\begin{array}{r}276 \\
\ldots-\end{array}$ & $\begin{array}{r}317 \\
\ldots\end{array}$ & $\begin{array}{r}225 \\
\cdots\end{array}$ \\
\hline .- & .. & -. & .. & .. & .. & -. & $\ldots$ & -. \\
\hline$\ldots$ & - & - & - & - & $\ldots$ & $\ldots$ & $\cdots$ & . \\
\hline$\cdots$ & - & - & - & -. & $\ldots$ & - & -. & .. \\
\hline$\cdots$ & $\cdots$ & $\cdots$ & $\cdots$ & $\cdots$ & $\cdots$ & $\cdots$ & $\cdots$ & $\cdots$ \\
\hline$\cdots$ & $\cdots$ & $\cdots$ & $\cdots$ & $\cdots$ & $\cdots$ & $\cdots$ & $\cdots$ & $\cdots$ \\
\hline- & 7.7 & $\cdots$ & 275 & - & - & 608 & 681 & 2367 \\
\hline-- & $\cdots$ & $\cdots$ & $\because$ & $\cdots$ & - & $\cdots$ & $\cdots$ & -- \\
\hline$\cdots$ & 7.8 & - & 265 & $\cdots$ & $\cdots$ & 616 & 654 & 2413 \\
\hline$\cdots$ & $\cdots$ & - & $\cdots$ & $\cdots$ & $\cdots$ & $\cdots$ & $\cdots$ & $\cdots$ \\
\hline$\because$ & 2 & 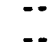 & $\ddot{0}$ & $\cdots$ & $\cdots$ & 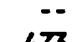 & 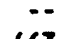 & $\cdots$ \\
\hline 8.0 & 8.2 & 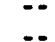 & 189 & $\because$ & $\because$ & 473 & 463 & $\cdots$ \\
\hline$\ldots$ & $\ldots$ & $\ldots$ & $\because$ & $\cdots$ & $\ldots$ & $\cdots$ & $\cdots$ & $\cdots$ \\
\hline .. & $\ldots$ & .. & $\ldots$ & .. & $\ldots$ & $\ldots$ & $\ldots$ & $\ldots$ \\
\hline - & $\ldots$ & .. & $\ldots$ & $\ldots$ & $\ldots$ & $\ldots$ & $\ldots$ & $\ldots$ \\
\hline$\cdots$ & - & .. & .. & . & .. & $\ldots$ & $\ldots$ & $\ldots$ \\
\hline -. & - & -. & .. & $\ldots$ & $\ldots$ & .. & $\ldots$ & $\ldots$ \\
\hline - & $\cdots$ & $\cdots$ & .. & $\cdots$ & $\cdots$ & $\cdots$ & .. & $\cdots$ \\
\hline 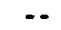 & - & $\cdots$ & $\cdots$ & $\cdots$ & .. & .. & .. & - \\
\hline .. & - & $\cdots$ & -. & $\cdots$ & $\cdots$ & - & - & $\cdots$ \\
\hline$\cdots$ & $\cdots$ & - & -. & -. & - & -- & - & $\cdots$ \\
\hline$\cdots$ & $\cdots$ & $\cdots$ & $\cdots$ & $\cdots$ & $\cdots$ & $\cdots$ & $\cdots$ & - \\
\hline$=$ & - & - & $\cdots$ & $\cdots$ & - & $\cdots$ & - & $\cdots$ \\
\hline 8.7 & 8.3 & $\cdots$ & 184 & - & $\cdots$ & 392 & 396 & $\cdots$ \\
\hline 8.7 & - & - & $\cdots$ & $\cdots$ & $\cdots$ & $\cdots$ & $\cdots$ & $\cdots$ \\
\hline 8.8 & $\cdots$ & $\cdots$ & $\cdots$ & $\cdots$ & $\cdots$ & $\cdots$ & $\cdots$ & $\cdots$ \\
\hline 8.8 & -- & $\cdots$ & $\cdots$ & $\cdots$ & $\cdots$ & $\cdots$ & $\cdots$ & . \\
\hline 8.8 & $\cdots$ & $\cdots$ & $\cdots$ & $\cdots$ & $\cdots$ & $\cdots$ & $\cdots$ & -0 \\
\hline 8.6 & $\cdots$ & $\cdots$ & $\cdots$ & $\cdots$ & $\cdots$ & $\cdots$ & $\cdots$ & $\cdots$ \\
\hline$\cdots$ & $\cdots$ & $\cdots$ & $\cdots$ & $\cdots$ & 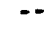 & $\cdots$ & $\cdots$ & 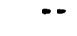 \\
\hline -. & $=$ & $\cdots$ & $\cdots$ & $\cdots$ & $\cdots$ & $\cdots$ & $\cdots$ & $\cdots$ \\
\hline- & -- & - & & -. & -- & & - & \\
\hline
\end{tabular}


SURFACE-WATER DATA-Cont imued

CHEMICAL ANALYSES-Continued

\begin{tabular}{|c|c|c|c|c|c|c|c|c|c|c|}
\hline $\begin{array}{l}\text { STATION } \\
\text { MUMBER }\end{array}$ & DATE & $\begin{array}{l}\text { NITRO- } \\
\text { GEN, } \\
\text { MANONIA } \\
\text { DIS- } \\
\text { SOLVED } \\
\text { (MA/L } \\
\text { OS N) } \\
\text { (00608) }\end{array}$ & $\begin{array}{c}\text { NITRO- } \\
\text { GEN, } \\
\text { NITRITE } \\
\text { DIS- } \\
\text { SOLVED } \\
(\mathrm{m} / \mathrm{L} \\
\text { Os N) } \\
(00613)\end{array}$ & $\begin{array}{l}\text { NITRO- } \\
\text { GEN, } \\
\text { NITRATE } \\
\text { DIS- } \\
\text { SOLVED } \\
(m / L / L \\
\text { as N) } \\
(00618)\end{array}$ & $\begin{array}{l}\text { NITRO- } \\
\text { GEN, } \\
\text { NO2+NO3 } \\
\text { D1S- } \\
\text { SOLVED } \\
\text { (mo/L } \\
\text { As N) } \\
(00631)\end{array}$ & $\begin{array}{l}\text { NITRO- } \\
\text { GEN, } \\
\text { NITRATE } \\
\text { DIS- } \\
\text { SOLVED } \\
\text { (MA/L } \\
\text { as NO3) } \\
\text { (71851) }\end{array}$ & $\begin{array}{c}\text { NITRO- } \\
\text { GEN, } \\
\text { NITRITE } \\
\text { DIS- } \\
\text { SOLVED } \\
\text { (mo/L } \\
\text { as NO2) } \\
\text { (71856) }\end{array}$ & $\begin{array}{l}\text { NITRO- } \\
\text { GEN,NM- } \\
\text { MONIA + } \\
\text { ORGANIC } \\
\text { TOTAL } \\
\text { (mO/L } \\
\text { OS N) } \\
(00625)\end{array}$ & $\begin{array}{l}\text { PHOS- } \\
\text { PHORUS } \\
\text { DIS- } \\
\text { SOLVED } \\
\text { (m./L } \\
\text { as P) } \\
(00666)\end{array}$ & $\begin{array}{l}\text { PHOS- } \\
\text { PHORUS } \\
\text { TOTAL } \\
\text { (mo/L } \\
\text { as P) } \\
\text { (00665) }\end{array}$ \\
\hline
\end{tabular}

LITTLE COLORADO RIVER AT GRAND FALLS, AZ-Continued

\begin{tabular}{|c|c|c|c|c|c|c|c|c|c|c|}
\hline & $\begin{array}{l}04-11-90 \\
07-09-90\end{array}$ & $\begin{array}{l}\cdots \\
\cdots\end{array}$ & & & & $\begin{array}{l}\cdots \\
\ldots\end{array}$ & -. & $\because$ & & $\because$ \\
\hline & $\begin{array}{l}07-09-90 \\
07-09-90\end{array}$ & $\therefore$ & $\because$ & $\because$ & $\cdots$ & $\because$ & $\ldots$ & $\because$ & $\cdots$ & $\begin{array}{l}\text {.- } \\
\text { - }\end{array}$ \\
\hline & $07-09-90$ & $\cdots$ & 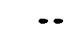 & $\cdots$ & -- & -. & .. & $\ldots$ & $\ldots$ & $\because$ \\
\hline & $07-09-90$ & -- & -. & -- & .. & .. & .. & $\ldots$ & $\cdots$ & $\because$ \\
\hline & $07-09-90$ & .. & -. & .. & .. & .. & $\ldots$ & $\ldots$ & $\cdots$ & 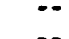 \\
\hline & $07-10-90$ & .830 & .020 & .880 & .900 & 3.9 & .07 & 23 & $\ddot{200}$ & $\because$ \\
\hline & $07-10-90$ & .. & -. & $\ldots$ & -. & .. & $\because$ & $\ldots$ & .220 & 18.0 \\
\hline & $07-17-90$ & -. & .- & -. & -. & .. & $\ldots$ & $\ldots$ & $\cdots$ & $\because$ \\
\hline & $07-17-90$ & -. &.- & -- &.- & -. & .. & .. & $\ldots$ & $\ldots$ \\
\hline & $07-17-90$ & -- & -- & $-\cdot$ & -- & -- & .. & -. & .. & $\ldots$ \\
\hline & $07-17-90$ & $\cdots$ & $-\cdot$ & $\cdots$ & $\cdots$ & $\cdots$ & -- & $\cdots$ & -. & .. \\
\hline & $07-17-90$ & $\cdots$ & -- & $\cdots$ & $\cdots$ & $\cdots$ & $\cdots$ & $\cdots$ & $\cdots$ & -. \\
\hline & $07-17-90$ & $\cdots$ & $\cdots$ & $\cdots$ & $\cdots$ & $\cdots$ & $\cdots$ & $\cdots$ & $\cdots$ &.- \\
\hline & $07-17-90$ & $\cdots$ & $\cdots$ & $\cdots$ & $\cdots$ & $\cdots$ & $\cdots$ & $\cdots$ & $\cdots$ & -. \\
\hline & $07-17-90$ & -- & -- & $\cdots$ & $\because \cdot$ & $\cdots$ & $\cdots$ & $\cdots$ & $\cdots$ & $\cdots$ \\
\hline & $08-16-90$ & $\cdots$ & $\cdots$ & $\cdots$ & $\because$ & -- & $\cdots$ & $\cdots$ & $\cdots$ & $\cdots$ \\
\hline & $08-17-90$ & $\cdots$ & $\cdots$ & $\cdots$ & $\cdots$ & $\cdots$ & $\cdots$ & $\cdots$ & $\cdots$ & $\cdots$ \\
\hline & $08-17-90$ & $\cdots$ & $\cdots$ & $\cdots$ & $\cdots$ & $\cdots$ & $\cdots$ & $\cdots$ & $\cdots$ & $\cdots$ \\
\hline & $08-17-90$ & $\cdots$ & $\cdots$ & $\cdots$ & $\because$ & $\cdots$ & $\cdots$ & $\cdots$ & $\cdots$ & $\cdots$ \\
\hline & $08-17-90$ & $\cdots$ & $\cdots$ & $\cdots$ & $\cdots$ & $\cdots$ & $\cdots$ & $\cdots$ & $\cdots$ & $\cdots$ \\
\hline & $08-17-90$ & $\cdots$ & $\cdots$ & $\cdots$ & $\cdots$ & $\cdots$ & $\cdots$ & $\cdots$ & $\cdots$ & $\cdots$ \\
\hline & $08-17-90$ & $\cdots$ & $\because$ & $\because$ & $\because$ & $\because$ & $\because$ & $\cdots$ & $\cdots$ & $\cdots$ \\
\hline & $08-17-90$ & $\because$ & $\because$ & $\because$ & $\because$ & -- & $\because$ & $\because$ & $\because$ & $\cdots$ \\
\hline & $08-17-90$ & $\because$ & $\cdots$ & $\cdots$ & $\cdots$ & $\cdots$ & $\cdots$ & $\cdots$ & $\cdots$ & $\cdots$ \\
\hline & $08-17-90$ & $\cdots$ & $\cdots$ & $\cdots$ & $\cdots$ & $\cdots$ & $\cdots$ & $\cdots$ & $\cdots$ & $\cdots$ \\
\hline & $08-17-90$ & $\cdots$ & $\cdots$ & $\cdots$ & $\cdots$ & $\cdots$ & $\cdots$ & $\cdots$ & $\cdots$ & $\cdots$ \\
\hline & $09-22-90$ & $\cdots$ & $\cdots$ & $\cdots$ & $\cdots$ & $\cdots$ & $\cdots$ & $\cdots$ & $\cdots$ & $\cdots$ \\
\hline & $09-22-90$ & $\cdots$ & $\cdots$ & $\cdots$ & $\cdots$ & $\cdots$ & $\cdots$ & $\cdots$ & $\cdots$ & $\cdots$ \\
\hline & $09-22-90$ & $\cdots$ & $\cdots$ & $\cdots$ & $\cdots$ & $\cdots$ & $\cdots$ & $\cdots$ & $\cdots$ & $\cdots$ \\
\hline & $09-22-90$ & $\because$ & $\cdots$ & $-\cdot$ & $\cdots$ & $\because$ & $\because$ & $\cdots$ & $\cdots$ & $\cdots$ \\
\hline & $09-22-90$ & $\therefore$ & $\cdots$ & $\because$ & $\cdots$ & $\because$ & $\cdots$ & $\because$ & 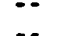 & $\because$ \\
\hline & $\begin{array}{l}09-22-90 \\
09-22-90\end{array}$ & .. & .. & .. & $\ldots$ & .. & $\ldots$ & $\therefore$ & $\ldots$ & $\cdots$ \\
\hline & $09-22-90$ & $-\cdot$ & .. & -. & -. &.- & .. & .- & $\ldots$ & $\ldots$ \\
\hline & $09-22-90$ & $\cdots$ & $\cdots$ & $\cdots$ & 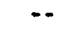 & -. & -. & -. & .- & .. \\
\hline & $09-22-90$ & $\cdots$ & $-\cdot$ & $\cdots$ & $\cdots$ & $-\cdot$ & $\cdots$ & $\ldots$ & -. & -. \\
\hline & $09-23-90$ & $\cdots$ & $\cdots$ & $\cdots$ & $\cdots$ & $\cdots$ & -. & $\cdots$ & -- & .. \\
\hline & $09-23-90$ & $\cdots$ & $\cdots$ & $\cdots$ & -- & $\cdots$ & $\cdots$ & $\cdots$ & .. & -. \\
\hline & $09-23-90$ & -- & $\cdots$ & $\cdots$ & $\cdots$ & $\cdots$ & -- & $\cdots$ & $\cdots$ & -. \\
\hline & $01-07-91$ & $\cdots$ & $\cdots$ & $\cdots$ & $\cdots$ & $\cdots$ & $\cdots$ & $\cdots$ & $\cdots$ & $\cdots$ \\
\hline & $01-07-91$ & $\cdots$ & $\cdots$ & $\cdots$ & $-\cdot$ & $\cdots$ & $\cdots$ & $\cdots$ & $\cdots$ & -. \\
\hline & $01-08-91$ & $\cdots$ & $\cdots$ & $\cdots$ & $\cdots$ & $\cdots$ & $\cdots$ & $\cdots$ & $\cdots$ & $\cdots$ \\
\hline & $01-08-91$ & $\cdots$ & $\cdots$ & $\cdots$ & $\cdots$ & $\cdots$ & $\cdots$ & $\cdots$ & $\cdots$ & $\cdots$ \\
\hline & $01-08-91$ & $\cdots$ & $\cdots$ & $\cdots$ & $\cdots$ & $\cdots$ & $\cdots$ & $\cdots$ & $\cdots$ & $\cdots$ \\
\hline & $01-08-91$ & $\cdots$ & $\cdots$ & $\cdots$ & $\cdots$ & $\cdots$ & $\cdots$ & $\cdots$ & $\cdots$ & $\cdots$ \\
\hline & $01-15-91$ & $\cdots$ & $\cdots$ & $\cdots$ & $\cdots$ & $\cdots$ & $\cdots$ & $\cdots$ & $\cdots$ & $\cdots$ \\
\hline & $03-03-91$ & $\cdots$ & $\cdots$ & $\cdots$ & $\cdots$ & $\cdots$ & $\cdots$ & $\cdots$ & $\cdots$ & $\cdots$ \\
\hline 09401000 & 03 & $\cdots$ & $\cdots$ & $\cdots$ & $\cdots$ & $\cdots$ & $\cdots$ & $\cdots$ & $\cdots$ & $\cdots$ \\
\hline
\end{tabular}


SURFACE-HATER DATA-Cont inued

CHEMICAL ARALYSES-Cont inued

\begin{tabular}{|c|c|c|c|c|c|c|c|c|c|c|c|}
\hline $\begin{array}{l}\text { STATION } \\
\text { MUNBER }\end{array}$ & DATE & $\begin{array}{l}\text { PHOS- } \\
\text { PHORUS } \\
\text { ORTHO, } \\
\text { DIS- } \\
\text { SOLVED } \\
\text { (mg/L } \\
\text { as P) } \\
\text { (00671) }\end{array}$ & $\begin{array}{l}\text { PHOS- } \\
\text { PHATE, } \\
\text { ORTHO, } \\
\text { DIS- } \\
\text { SOLVEO } \\
\text { (Mg/L } \\
\text { as PO4) } \\
(00660)\end{array}$ & $\begin{array}{l}\text { CARBON, } \\
\text { ORGANIC } \\
\text { TOTAL } \\
\text { (mg/L } \\
\text { as C) } \\
\text { (00680) }\end{array}$ & $\begin{array}{l}\text { HARD- } \\
\text { NESS } \\
\text { TOTAL } \\
\text { (mg/L } \\
\text { as } \\
\text { Caco3) } \\
(00900)\end{array}$ & $\begin{array}{c}\text { CALCIUN } \\
\text { DIS- } \\
\text { SOLVED } \\
\text { (mg/L } \\
\text { as Ca) } \\
\text { (00915) }\end{array}$ & $\begin{array}{l}\text { MAGNE- } \\
\text { SIUN, } \\
\text { DIS- } \\
\text { SOLVED } \\
\text { (mg/L } \\
\text { as Mg) } \\
\text { (00925) }\end{array}$ & $\begin{array}{l}\text { SOOIUH, } \\
\text { DIS- } \\
\text { SOLVED } \\
\text { (mg/L } \\
\text { as } \mathrm{Na}) \\
(00930)\end{array}$ & $\begin{array}{l}\text { SOOILH } \\
\text { ADSORP- } \\
\text { TION } \\
\text { RATIO } \\
\text { (00931) }\end{array}$ & $\begin{array}{l}\text { SOOILH } \\
\text { PERCENT } \\
\text { (00932) }\end{array}$ & $\begin{array}{l}\text { POTAS- } \\
\text { SIUH, } \\
\text { DIS- } \\
\text { SOLVED } \\
\text { (mo/L } \\
\text { OS K) } \\
(00935)\end{array}$ \\
\hline
\end{tabular}

LITTLE COLORADO RIVER AT GRAND FALLS, AZ-Continued

\begin{tabular}{|c|c|c|c|c|c|c|c|c|c|c|c|}
\hline 09401000 & $\begin{array}{l}04-11-90 \\
07-09-90\end{array}$ & $\ldots$ & $\cdots$ & - & 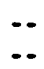 & $\because$ & $\therefore$ & $\begin{array}{l}\cdots \\
\cdots\end{array}$ & 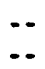 & $\because$ & $\because$ \\
\hline & $07-09-90$ & .. & $\ldots$ & $\cdots$ & 46 & 13 & 3.1 & 210 & 14 & 90 & 2.6 \\
\hline & $07-09-90$ & $\cdots$ & $\cdots$ & $\cdots$ & $\cdots$ & $\ldots$ & $\ldots$ & $\ldots$ & $\therefore$ & $\ldots$ & $\ldots$ \\
\hline & $07-09-90$ & $\cdots$ & $\cdots$ & $\cdots$ & 61 & 18 & 3.8 & 220 & 12 & 88 & 3.3 \\
\hline & $07-09-90$ & $\cdots$ & $\cdots$ & $\cdots$ & $\cdots$ & $\cdots$ & $\cdots$ & - & $\cdots$ & $\cdots$ & -- \\
\hline & $07-10-90$ & .080 & .25 & 62 & 39 & 12 & 2.0 & 170 & 12 & 90 & 2.3 \\
\hline & $07-10-90$ & -. & $\cdots$ & -. & $\cdots$ & $\cdots$ & $\cdots$ & $\cdots$ & $\cdots$ & $\cdots$ & $\cdots$ \\
\hline & $07-17-90$ & $\cdots$ & $\cdots$ & $\cdots$ & $\cdots$ & $\cdots$ & $\cdots$ & $\cdots$ & $\cdots$ & $\cdots$ & - \\
\hline & $07-17-90$ & $\cdots$ & $\cdots$ & $\cdots$ & $\cdots$ & $\cdots$ & $\cdots$ & $\cdots$ & $\cdots$ & $\cdots$ & - \\
\hline & $07-17-90$ & $\cdots$ & $\cdots$ & $\cdots$ & $\cdots$ & $\cdots$ & $\cdots$ & -- & $\cdots$ & $\cdots$ & $\cdots$ \\
\hline & $\begin{array}{l}07-17-90 \\
07-17-90\end{array}$ & $\ldots$ & $\because-$ & $\ddot{-.}$ & $\begin{array}{l}51 \\
62\end{array}$ & $\begin{array}{l}15 \\
19\end{array}$ & $\begin{array}{l}3.2 \\
3.3\end{array}$ & $\begin{array}{l}190 \\
200\end{array}$ & 12 & $\begin{array}{l}88 \\
87\end{array}$ & 3.3 \\
\hline & $07-17-90$ & $\cdots$ & $\ldots$ & .. & $\ldots$ & $\ldots$ & 3.5 & $\ldots$ & $\ldots$ & $\ldots$ & 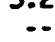 \\
\hline & $07-17-90$ & $\cdots$ & $\cdots$ & $\cdots$ & $\cdots$ & $\cdots$ & -. & $\cdots$ & .. & .. & .. \\
\hline & $07-17-90$ & $\cdots$ & $\cdots$ & $\cdots$ & 29 & 9.1 & 1.4 & 84 & 7 & 85 & 2.9 \\
\hline & $08-16-90$ & $\cdots$ & - & $\cdots$ & $\cdots$ & $\cdots$ & -- & $\cdots$ & $\cdots$ & $\ldots$ & $\ldots$ \\
\hline & $08-17-90$ & $\cdots$ & $\cdots$ & $\cdots$ & $\cdots$ & $\cdots$ & $\ldots$ & $\cdots$ & $\ldots$ & -. & $\cdots$ \\
\hline & $08-17-90$ & $\cdots$ & $\cdots$ & $\cdots$ & $\cdots$ & $\cdots$ & $\cdots$ & $\cdots$ & $\cdots$ & $\cdots$ & - \\
\hline & $08-17-90$ & $\cdots$ & $\cdots$ & $\cdots$ & $\cdots$ & $\cdots$ & $\cdots$ & -- & $\cdots$ & $\cdots$ & - \\
\hline & $08-17-90$ & $\cdots$ & $\cdots$ & $\cdots$ & $\cdots$ & $\cdots$ & $\cdots$ & $\cdots$ & $\cdots$ & $\cdots$ & 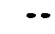 \\
\hline & $08-17-90$ & $\cdots$ & - & $\cdots$ & $\cdots$ & $\cdots$ & -. & -- & $\cdots$ & $\cdots$ & $\because$ \\
\hline & $08-17-90$ & $\cdots$ & $\cdots$ & $\cdots$ & 76 & 24 & 3.7 & 200 & 10 & 84 & 3.8 \\
\hline & $08-17-90$ & $\cdots$ & $\cdots$ & $\cdots$ & $\cdots$ & $\cdots$ & $\cdots$ & -- & $\cdots$ & $\cdots$ & -- \\
\hline & $08-17-90$ & $\cdots$ & $\cdots$ & $\cdots$ & 73 & 23 & 3.6 & 190 & 10 & 84 & 3.3 \\
\hline & $08-17-90$ & $\cdots$ & $\cdots$ & $\cdots$ & $\cdots$ & $\cdots$ & $\cdots$ & $\cdots$ & $\cdots$ & $\cdots$ & - \\
\hline & $08-17-90$ & $\cdots$ & $\cdots$ & $\cdots$ & $\cdots$ & $\cdots$ & $\cdots$ & $\cdots$ & $\cdots$ & $\cdots$ & $\cdots$ \\
\hline & $09-22-90$ & $\cdots$ & $\cdots$ & $\cdots$ & 45 & 14 & 2.3 & 150 & 10 & 87 & 2.8 \\
\hline & $09-22-90$ & $\cdots$ & $\cdots$ & $\cdots$ & $\cdots$ & $\cdots$ & $\cdots$ & $-\cdot$ & $\cdots$ & $\cdots$ & $\cdots$ \\
\hline & $09-22-90$ & $\cdots$ & $\cdots$ & $\cdots$ & $\cdots$ & $\cdots$ & $\cdots$ & $\cdots$ & $\cdots$ & $\cdots$ & - \\
\hline & $09-22-90$ & $\cdots$ & $\cdots$ & $\cdots$ & $\cdots$ & $\cdots$ & $\cdots$ & $\cdots$ & $\cdots$ & $\cdots$ & $\cdots$ \\
\hline & $09-22-90$ & $\cdots$ & $\cdots$ & -- & $\cdots$ & $\cdots$ & $\cdots$ & $\cdots$ & $\cdots$ & $\cdots$ & - \\
\hline & $09-22-90$ & $\cdots$ & $\cdots$ & $\cdots$ & $\cdots$ & $\cdots$ & $\cdots$ & $\cdots$ & $\cdots$ & $\cdots$ & 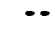 \\
\hline & $09-22-90$ & $\cdots$ & -. & $\cdots$ & $\cdots$ & $\cdots$ & -. & $\cdots$ & $\cdots$ & $\cdots$ & $\cdots$ \\
\hline & $09-22-90$ & $\cdots$ & $\cdots$ & $\cdots$ & $\cdots$ & $\cdots$ & $-\cdot$ & -- & $\cdots$ & $\cdots$ & $\cdots$ \\
\hline & $09-22-90$ & $\cdots$ & - & $\cdots$ & $\cdots$ & $\cdots$ & $\cdots$ &.- & $\cdots$ & $-\cdot$ & -- \\
\hline & $09-22-90$ & $\cdots$ & $\cdots$ & $\cdots$ & $\cdots$ & $\cdots$ & $\cdots$ & -- & -- & $\cdots$ & -- \\
\hline & $09-23-90$ & $\cdots$ & $\cdots$ & $\cdots$ & $\cdots$ & $\cdots$ & $\cdots$ & -- & $\cdots$ & $\cdots$ & $\cdots$ \\
\hline & $09-23-90$ & $\cdots$ & $\cdots$ & $\cdots$ & -- & $\cdots$ & $\cdots$ & $\cdots$ & $\cdots$ & $\cdots$ & - \\
\hline & $09-23-90$ & -- & $\cdots$ & $\cdots$ & $\cdots$ & $\cdots$ & $\cdots$ & -- & -- & $\cdots$ & $\cdots$ \\
\hline & $01-07-91$ & $\cdots$ & $\cdots$ & $\cdots$ & 16 & 4.9 & .91 & 140 & 15 & 94 & 1.5 \\
\hline & $01-07-91$ & $\cdots$ & $\cdots$ & $\cdots$ & $\cdots$ & $\cdots$ & $\cdots$ & $-\cdot$ & $\cdots$ & $\cdots$ & $\cdots$ \\
\hline & $01-08-91$ & $\cdots$ & $\cdots$ & $\cdots$ & $\cdots$ & $\cdots$ & $\cdots$ & $\cdots$ & $\cdots$ & $\cdots$ & - \\
\hline & $01-08-91$ & $\cdots$ & $\cdots$ & $\cdots$ & $\cdots$ & $\cdots$ & $\cdots$ & $\cdots$ & $\cdots$ & $\cdots$ & - \\
\hline & & $\cdots$ & $\cdots$ & $\cdots$ & $\cdots$ & $\cdots$ & $\cdots$ & $\cdots$ & $\cdots$ & $\cdots$ & - \\
\hline & $01-0$ & $\cdots$ & $\cdots$ & $\cdots$ & $\cdots$ & $\cdots$ & $\cdots$ & $\cdots$ & $\cdots$ & $\cdots$ & - \\
\hline & $01-15-91$ & $\cdots$ & $\cdots$ & $\cdots$ & $\cdots$ & $\cdots$ & $\cdots$ & $\cdots$ & $\cdots$ & $\cdots$ & - \\
\hline & $03-03-91$ & $\cdots$ & $\cdots$ & $\cdots$ & $\cdots$ & $\cdots$ & $\cdots$ & $\cdots$ & $\cdots$ & $\cdots$ & - \\
\hline & $03-03-91$ & $\ldots$ & $\cdots$ & $\cdots$ & $\cdots$ & $\cdots$ & $\cdots$ & - & $\cdots$ & $\cdots$ & - \\
\hline
\end{tabular}


SURFACE-WATER DATA-Cont inued

CHEAICAL ANALYSES-Continued

STATION

MUMBER

DATE

\begin{tabular}{|c|c|c|c|c|c|c|c|c|c|}
\hline ATE & $\begin{array}{l}\text { CHLO- } \\
\text { RIDE, } \\
\text { DIS- } \\
\text { SOLVEO } \\
\text { (mg/L } \\
\text { as Cl) } \\
(00940)\end{array}$ & $\begin{array}{l}\text { BROMIDE } \\
\text { OIS- } \\
\text { SOLVED } \\
\text { (mg/L } \\
\text { as Br) } \\
(71870)\end{array}$ & $\begin{array}{l}\text { FLUO- } \\
\text { RIDE, } \\
\text { OIS- } \\
\text { SOLVED } \\
\text { (mg/L } \\
\text { as F) } \\
(00950)\end{array}$ & $\begin{array}{l}\text { SILICA, } \\
\text { OIS- } \\
\text { SOLVEO } \\
\text { (mg/L } \\
\text { as } \\
\text { si02) } \\
(00955)\end{array}$ & $\begin{array}{l}\text { SULFATE } \\
\text { OIS- } \\
\text { SOLVED } \\
\text { (mg/L } \\
\text { As SO4) } \\
(00945)\end{array}$ & $\begin{array}{l}\text { ARSENIC } \\
\text { DIS- } \\
\text { SOLVEO } \\
(\mu g / L \\
\text { as As) } \\
(01000)\end{array}$ & $\begin{array}{l}\text { BARIUH, } \\
\text { OIS- } \\
\text { SOLVED } \\
\text { ( } \mu g / L \\
\text { os Ba) } \\
(01005)\end{array}$ & $\begin{array}{c}\text { BERYL- } \\
\text { LIUH, } \\
\text { DIS- } \\
\text { SOLVED } \\
(\mu \mathrm{g} / L \\
\text { as Be) } \\
(01010)\end{array}$ & $\begin{array}{c}\text { BORON, } \\
\text { DIS- } \\
\text { SOLVED } \\
\text { ( } \mu \mathrm{g} / \mathrm{L} \\
\text { as B) } \\
(01020)\end{array}$ \\
\hline
\end{tabular}

LITTLE COLORADO RIVER AT GRANO FALLS, AZ-Continued

\begin{tabular}{|c|c|c|c|c|c|c|c|c|c|c|}
\hline 09401000 & $\begin{array}{l}04-11-90 \\
07-09-90\end{array}$ & $\because-$ & -. & -. & -. & $\cdots$ & 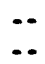 & 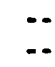 & $\cdots$ & $\ldots$ \\
\hline & $07-09-90$ & 180 & .050 & .70 & 26 & 7 & 10 & 170 & $<.5$ & 490 \\
\hline & $07-09-90$ & -- & -- & $\cdots$ & - & -- & - & $\cdots$ & $\cdots$ & \\
\hline & $07-09-90$ & 240 & .030 & .10 & 21 & 97 & 6 & 200 & $<.5$ & 290 \\
\hline & $07-09-90$ & $\cdots$ & - & -. & -. & -. & -- & -. & $\cdots$ & . \\
\hline & $07-10-90$ & 110 & .090 & .70 & 15 & 78 & 8 & 120 & $<.5$ & 470 \\
\hline & $07-10-90$ & $\cdots$ & $\cdots$ & -. & $\ldots$ &.- & -. & -. & - & $\cdots$ \\
\hline & $07-17-90$ & -- & -. & -. & $\cdots$ & -- & $\cdots$ & -. & $\ldots$ & 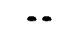 \\
\hline & $07-17-90$ & $\cdots$ & $\cdots$ & - & $\cdots$ & -- & $\cdots$ & -. & -- & $\because$ \\
\hline & $07-17-90$ & $\cdots$ & $\cdots$ & $\cdots$ & $\cdots$ & $\cdots$ & -- & $\cdots$ & $\cdots$ & $\cdots$ \\
\hline & $\begin{array}{l}07-17-90 \\
07-17-90\end{array}$ & $\begin{array}{l}120 \\
120\end{array}$ & $\begin{array}{l}.070 \\
.080\end{array}$ & .80 & 16 & 140 & 3 & $\begin{array}{l}160 \\
150\end{array}$ & $<.5$ & $\begin{array}{l}360 \\
370\end{array}$ \\
\hline & $07-17-90$ & $\begin{array}{c}120 \\
\ldots\end{array}$ & .000 & .90 & $\begin{array}{l}14 \\
--\end{array}$ & $\begin{array}{l}150 \\
\ldots\end{array}$ & 3 & $\begin{array}{l}150 \\
. .\end{array}$ & $<.5$ & $\begin{array}{l}370 \\
\ldots\end{array}$ \\
\hline & $07-17-90$ & $\cdots$ & $\cdots$ & $\ldots$ & .. & $\ldots$ & $\ldots$ & $\ldots$ & $\ldots$ & . \\
\hline & $07-17-90$ & 12 & .85 & .60 & 14 & 67 & 5 & 11 & $<.5$ & 120 \\
\hline & $08-16-90$ & $\cdots$ & -. & .. & -- & -- & -. & $\therefore$ & -. & \\
\hline & $08-17-90$ & 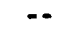 & $\cdots$ & $=$ & $\cdots$ & -- & $\cdots$ & .- & -. & 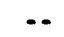 \\
\hline & $08-17-90$ & - & -. & -- & $\cdots$ & $-\cdot$ & -. & -. & $\cdots$ & 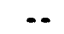 \\
\hline & $08-17-90$ & $\cdots$ & $\cdots$ & -. & $=$ & -- & $-\cdot$ & - & $\cdots$ & -1 \\
\hline & $08-17-90$ & $\cdots$ & $\therefore$ & $=$ & -- & -- & $\cdots$ & -- & $\cdots$ & \\
\hline & $08-17-90$ & $\cdots$ & $\cdots$ & $\ldots$ & $\cdots$ & -. & $\cdots$ & -. & $\cdots$ & \\
\hline & $08-17-90$ & 81 & .32 & .60 & 12 & 190 & 3 & 130 & $<.5$ & 310 \\
\hline & $08-17-90$ & $\cdots$ & $\because$ & $\cdots$ & -- & $\cdots$ & $\cdots$ & $\cdots$ & $\cdots$ & 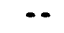 \\
\hline & $08-17-90$ & 79 & .060 & .70 & 14 & 180 & 2 & 30 & $<.5$ & 320 \\
\hline & $08-17-90$ & $\cdots$ & $\cdots$ & $\cdots$ & $\cdots$ & $\cdots$ & $\cdots$ & $\cdots$ & $\cdots$ & $\cdots$ \\
\hline & $08-17-90$ & $\cdots$ & $\cdots$ & $\cdots$ & $\cdots$ & $\cdots$ & $\cdots$ & $\cdots$ & $\cdots$ & \\
\hline & $09-22-90$ & 56 & .080 & .70 & 13 & 110 & 4 & 120 & $<.5$ & 330 \\
\hline & $09-22-90$ & $\cdots$ & $\cdots$ & $\cdots$ & $\cdots$ & $\cdots$ & $\cdots$ & $\cdots$ & $\cdots$ & 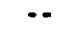 \\
\hline & $09-22-90$ & $\cdots$ & $\cdots$ & -- & -- & $\cdots$ & $\cdots$ & $\cdots$ & $\cdots$ & 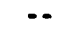 \\
\hline & $09-22-90$ & $\cdots$ & $\cdots$ & $\cdots$ & $\cdots$ & $\cdots$ & $\cdots$ & $\cdots$ & $\cdots$ & $\bullet$ \\
\hline & $09-22-90$ & $\cdots$ & $\cdots$ & $\cdots$ & $\cdots$ & $\cdots$ & $\cdots$ & -- & $\cdots$ & $\cdots$ \\
\hline & $09-22-90$ & $\cdots$ & $\cdots$ & -- & $\cdots$ & $-\cdot$ & $\cdots$ & $\cdots$ & $\cdots$ & $\cdots$ \\
\hline & $09-22-90$ & $\cdots$ & $\cdots$ & $\cdots$ & $\cdots$ & $\cdots$ & $\cdots$ & $\cdots$ & $\cdots$ & $\cdots$ \\
\hline & $09-22-90$ & $\cdots$ & $-\cdot$ & $\cdots$ & $\cdots$ & $\cdots$ & $\cdots$ & $\cdots$ & $\cdots$ & $\ldots$ \\
\hline & $09-22-90$ & -- & $\cdots$ & -- & $\cdots$ & $\cdots$ & $\cdots$ & $\cdots$ & $\cdots$ & 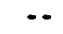 \\
\hline & $09-22-90$ & $\cdots$ & $\cdots$ & $\cdots$ & $\cdots$ & $\cdots$ & $\cdots$ & $\cdots$ & $\cdots$ & \\
\hline & $09-23-90$ & -- & $\cdots$ & - & $\cdots$ & -- & $\cdots$ & $\cdots$ & $\cdots$ & - \\
\hline & $09-23-90$ & $\cdots$ & $\cdots$ & $-\cdot$ & $\cdots$ & $\cdots$ & $\cdots$ & $\cdots$ & $\cdots$ & \\
\hline & $09-23-90$ & $\cdots$ & $\cdots$ & $\cdots$ & $\cdots$ & $\cdots$ & $\cdots$ & $\cdots$ & $\cdots$ & $\cdots$ \\
\hline & $01-07-91$ & 71 & .49 & .50 & 13 & 53 & 7 & 30 & $<.5$ & 260 \\
\hline & $01-07-91$ & $\cdots$ & $\cdots$ & $\cdots$ & $\cdots$ & $\cdots$ & $\cdots$ & $\cdots$ & $\cdots$ & . \\
\hline & $01-08-91$ & $\cdots$ & $\cdots$ & -- & $\cdots$ & $\cdots$ & $\cdots$ & $\cdots$ & $\cdots$ & 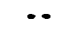 \\
\hline & $01-08-91$ & $\cdots$ & $\cdots$ & $\cdots$ & $\cdots$ & $\cdots$ & $\cdots$ & $\cdots$ & $\cdots$ & - \\
\hline & $01-08-91$ & $\cdots$ & $\cdots$ & $\cdots$ & $\cdots$ & -. & $\cdots$ & $\cdots$ & $\cdots$ & \\
\hline & $01-08-91$ & $\cdots$ & $\cdots$ & - & $\cdots$ & $\cdots$ & $-\cdot$ & -- & $\cdots$ & $\bullet$ \\
\hline & $01-15-91$ & $\cdots$ & -- & -- & $\cdots$ & -- & $\cdots$ & $\cdots$ & $\cdots$ & \\
\hline & $03-03-91$ & $\cdots$ & -. & $\cdots$ & $\cdots$ & $\cdots$ & $\cdots$ & $\cdots$ & $\cdots$ & \\
\hline & $03-03-$ & $\cdots$ & $\ldots$ & -- & $\cdots$ & $\ldots$ & $\ldots$ & $\cdots$ & $\ldots$ & \\
\hline
\end{tabular}




\begin{tabular}{|c|c|c|c|c|c|c|c|c|c|c|}
\hline $\begin{array}{l}\text { TATION } \\
\text { NBBER }\end{array}$ & DATE & $\begin{array}{c}\text { CADMIUM } \\
\text { DIS- } \\
\text { SOLVED } \\
\text { ( } \mu 9 / L \\
\text { as Cd) } \\
\text { (01025) }\end{array}$ & $\begin{array}{l}\text { CHRO- } \\
\text { MIUM, } \\
\text { DIS- } \\
\text { SOLVED } \\
\text { ( } \mu g / L \\
\text { as Cr) } \\
(01030)\end{array}$ & $\begin{array}{l}\text { COBALT, } \\
\text { DIS- } \\
\text { SOLVED } \\
\text { ( } \mu g / L \\
\text { as Co) } \\
(01035)\end{array}$ & $\begin{array}{l}\text { COPPER, } \\
\text { DIS- } \\
\text { SOLVED } \\
\text { ( } \mu g / L \\
\text { as CU) } \\
(01040)\end{array}$ & $\begin{array}{c}\text { IRON, } \\
\text { DIS- } \\
\text { SOLVED } \\
\text { ( } \mu 9 / L \\
\text { as Fe) } \\
(01046)\end{array}$ & $\begin{array}{l}\text { LEAD, } \\
\text { DIS- } \\
\text { SOLVED } \\
(\mu g / L \\
\text { AS Pb) } \\
(01049)\end{array}$ & $\begin{array}{l}\text { MANGA- } \\
\text { NESE, } \\
\text { DIS- } \\
\text { SOLVED } \\
\text { ( } \mu g / L \\
\text { as } M n) \\
(01056)\end{array}$ & $\begin{array}{l}\text { MOLYB- } \\
\text { DENUM, } \\
\text { DIS- } \\
\text { SOLVED } \\
(\mu g / L \\
\text { as MO) } \\
(01060)\end{array}$ & $\begin{array}{l}\text { NICKEL, } \\
\text { DIS- } \\
\text { SOLVED } \\
\text { ( } \mu g / L \\
\text { as Ni) } \\
\text { (01065) }\end{array}$ \\
\hline
\end{tabular}

\begin{tabular}{|c|c|c|c|c|c|c|c|c|c|c|}
\hline 09401000 & $04-11-90$ & $\because$ & $\because-$ & 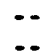 & $\ddot{-.}$ & $\because-$ & $\therefore$ & $\because-$ & $\ddot{-.}$ & $\because$ \\
\hline & $\begin{array}{l}07-09-90 \\
07-09-90\end{array}$ & $<1.0$ & $<5$ & 3 & $<10$ & 800 & $<\ddot{10 i}$ & $\ddot{64 t}$ & $<\ddot{0}$ & $<\ddot{10}$ \\
\hline & $07-09-90$ & & $\therefore$ & $\ldots$ & $\cdots$ & .. & .. & .. & $\therefore$ & \\
\hline & $07-09-90$ & $<1.0$ & $<5$ & $<3$ & $<10$ & 690 & $<10 i$ & 684 & $<10$ & $<10$ \\
\hline & $07-09-90$ & $\because$ & $\because$ & $\because$ & $\ddot{x}$ & 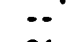 & $\because$ & $\because$ & 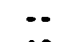 & $\because$ \\
\hline & $07-10-90$ & 1.0 & $<5$ & 3 & $<10$ & 96 & $<10 i$ & 17 & $<10$ & $<10$ \\
\hline & $07-10-90$ & $\cdots$ & -. & $\cdots$ & $\cdots$ & $\cdots$ & $\cdots$ & $\cdots$ & $\cdots$ & -. \\
\hline & $07-17-90$ & $\cdots$ & -. & $\cdots$ & -. & $\cdots$ & -. & $\cdots$ & $\cdots$ & -. \\
\hline & $07-17-90$ & -. & $\cdots$ & $\cdots$ & -. & -. & -. & $\cdots$ & -. & -. \\
\hline & $07-17-90$ & $\cdots$ & $\cdots$ & $\because$ & $\because$ & $\cdots$ & $\cdots$ & $\cdots$ & $\cdots$ & -. \\
\hline & $\begin{array}{l}07-17-90 \\
07-17-90\end{array}$ & $\begin{array}{l}2.0 \\
1.0\end{array}$ & $\begin{array}{l}<5 \\
<5\end{array}$ & $<3$ & $\begin{array}{l}<10 \\
<10\end{array}$ & $\begin{array}{l}130 \\
100\end{array}$ & $\begin{array}{l}<10 i \\
<10 i\end{array}$ & $\begin{array}{l}39 \\
38\end{array}$ & $\begin{array}{l}<10 \\
<10\end{array}$ & $\begin{array}{l}<10 \\
<10\end{array}$ \\
\hline & $07-17-90$ & $\because \cdot$ & $\cdots$ & $\cdots$ & $\cdots$ & -. & -. & $\cdot \cdot$ & $\cdots$ & -. \\
\hline & $07-17-90$ & $\because$ & $\because$ & $\because$ & $\ddot{0}$ & $\ddot{m}$ & $\because$ & $\ddot{z}$ & 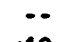 & $\because$ \\
\hline & $07-17-90$ & $<1.0$ & $<5$ & $<3$ & 50 & 120 & $10 i$ & $63 t$ & $<10$ & $<10$ \\
\hline & $08-16-90$ & -. & -. & $\cdots$ & -. & -. & -. & $\cdots$ & 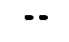 & $\cdots$ \\
\hline & $08-17-90$ & $\cdots$ & $\cdots$ & $\cdots$ & 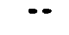 & $\cdots$ & $\cdots$ & $\cdots$ & $\cdots$ & $\cdots$ \\
\hline & $08-17-90$ & $\cdots$ & $\cdots$ & $\cdots$ & $\cdots$ & $\cdots$ & $\cdots$ & $\cdots$ & $\cdots$ & $\cdots$ \\
\hline & $08-17-90$ & $\cdots$ & $\cdots$ & $\cdots$ & $\cdots$ & $\cdots$ & $\cdots$ & $\cdots$ & $\cdots$ & $\cdots$ \\
\hline & $08-17-90$ & $\cdots$ & $\cdots$ & $\cdots$ & $\cdots$ & -. & $\cdots$ & $\cdots$ & $\cdots$ & $\cdots$ \\
\hline & $08-17-90$ & $\ddot{0}$ & 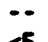 & $\ddot{z}$ & $\ddot{\theta}$ & $\ddot{0}$ & $\ddot{0}$ & $\ddot{z}$ & $\ddot{\theta a}$ & $\ddot{0}$ \\
\hline & $08-17-90$ & $<1.0$ & $<5$ & $<$ & $<10$ & 86 & $<10 i$ & 34 & $<10$ & $<10$ \\
\hline & $08-17-90$ & $\cdots$ & $\cdots$ & $\cdots$ & $\because$ & $\cdots$ & $\because$ & $\cdots$ & $\because$ & 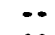 \\
\hline & $08-17-90$ & $<1.0$ & $<5$ & $<3$ & 70 & 180 & $<10 i$ & 11 & $<10$ & $<10$ \\
\hline & $08-17-90$ & $\cdots$ & $\cdots$ & $\cdots$ & $\cdots$ & -. & -. & $\cdots$ & $-\cdot$ & $\cdots$ \\
\hline & $08-17-90$ & $\cdots$ & $\because$ & $\cdots$ & 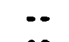 & $\because$ & $\because$ & $\because$ & $\because$ & -. \\
\hline & $09-22-90$ & $<1.0$ & $<5$ & $<3$ & $<10$ & 87 & $<10 i$ & 2 & $<10$ & $<10$ \\
\hline & $09-22-90$ & $\cdots$ & $\cdots$ & $\cdots$ & $\cdots$ & $\cdots$ & $\cdots$ & -. & $\cdots$ & $\because$ \\
\hline & $09-22-90$ & -. & $\cdots$ & $\cdots$ & $\cdot-$ & $\cdots$ & $\cdots$ & -. & $\cdots$ & $\cdots$ \\
\hline & $09-22-90$ & $\cdots$ & $\cdots$ & $\cdots$ & $\cdots$ & $\cdots$ & -. & -. & $\cdots$ & -- \\
\hline & $09-22-90$ & $\cdots$ & $\cdots$ & $\cdots$ & $\cdots$ & $\cdots$ & -・ & ". & $\cdots$ & $\cdots$ \\
\hline & $09-22-90$ & $\cdots$ & $\cdots$ & $\cdots$ & $\because$ & $\cdots$ & $\cdots$ & $\cdot \cdot$ & $\cdots$ & $\cdots$ \\
\hline & $09-22-90$ & $\cdots$ & $\cdots$ & $\cdots$ & $\cdots$ & $\cdots$ & $\cdots$ & -. & $\cdots$ & $\cdots$ \\
\hline & $09-22-90$ & -. & $\cdots$ & $\cdots$ & $\cdots$ & - & $\cdots$ & -. & $\cdots$ & $\cdots$ \\
\hline & $09-22-90$ & $\cdots$ & $\cdots$ & $\cdots$ & $\cdot \cdot$ & -. & $\cdot-$ & -. & $\cdots$ & $\cdots$ \\
\hline & $09-22-90$ & -. & $\cdots$ & $-\cdot$ & $\cdots$ & -. & $-\cdot$ & -- & $\cdots$ & $\cdots$ \\
\hline & $09-23-90$ & $\cdots$ & $\cdots$ & $\cdots$ & $\cdots$ & $\cdots$ & $\cdots$ & $\cdots$ & $\cdots$ & $\cdots$ \\
\hline & $09-23-90$ & $\cdots$ & $\cdots$ & $\cdots$ & $\cdots$ & 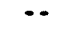 & -- & $\cdots$ & $\cdots$ & -・ \\
\hline & $09-23-90$ & -- & $\cdots$ & $\cdots$ & $\cdots$ & -. & $\because-$ & $\because \cdot$ & $\because$ & $\cdots$ \\
\hline & $01-07-91$ & $<1.0$ & $<5$ & $<3$ & 10 & 250 & $<10 i$ & 5 & $<10$ & $<10$ \\
\hline & $01-07-91$ & -. & $\cdots$ & $\cdots$ & $\cdots$ & $\cdots$ & -. & $\cdots$ & $\cdots$ & $\cdots$ \\
\hline & $01-08-91$ & $\cdots$ & $\cdots$ & $\cdots$ & $\cdots$ & $\cdots$ & -. & -. & $\cdots$ & $\cdots$ \\
\hline & $01-08-91$ & $\cdots$ & $\cdots$ & $\cdots$ & $\cdot \cdot$ & -. & $\cdots$ & $\cdots$ & -. & $\cdots$ \\
\hline & $01-08-91$ & $\cdots$ & $\ldots$ & $\cdots$ & $\cdots$ & $\cdots$ & $\cdots$ & $\cdots$ & $\cdots$ & $\cdots$ \\
\hline & $01-08-91$ & -. & $\cdots$ & $\cdots$ & $\cdots$ & $\cdots$ & $\cdots$ & $\cdots$ & $\cdots$ & $\cdots$ \\
\hline & $01-15-91$ & $\cdots$ & $\cdots$ & $\cdots$ & $\cdots$ & $\cdots$ & $\cdots$ & $\cdots$ & 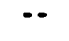 & -. \\
\hline & $03-03-91$ & -. & $\cdots$ & $\cdots$ & $\cdots$ & $\cdots$ & $\cdots$ & $\cdots$ & $\cdots$ & $\cdots$ \\
\hline & $03-03-91$ & $\because$ & $\cdots$ & $\cdots$ & $\cdots$ & $\cdots$ & $\cdots$ & $\cdots$ & $\cdots$ & $\cdots$ \\
\hline
\end{tabular}


SURFACE-MATER DATA - Cont ímued

CHEMICAL AMALYSES- Cont inved

\begin{tabular}{|c|c|c|c|c|c|c|c|c|c|c|c|}
\hline $\begin{array}{l}\text { STATION } \\
\text { MUABER }\end{array}$ & DATE & $\begin{array}{c}\text { GROSS } \\
\text { ALPHA, } \\
\text { SUSP. } \\
\text { TOTAL } \\
\text { ( } \mu g / L \\
\text { as } \\
\text { U-nat) } \\
(80040)\end{array}$ & $\begin{array}{c}\text { GROSS } \\
\text { ALPHA } \\
\text { SEDI- } \\
\text { MENT } \\
\text { (pCi/G) } \\
\text { (01507) }\end{array}$ & $\begin{array}{c}\text { GROSS } \\
\text { ALPHA } \\
\text { BOT MAT } \\
\text { TOT DRY } \\
\text { (pCi/G } \\
\text { as } \\
U-n a t) \\
(99920)\end{array}$ & $\begin{array}{l}\text { ALPHA, } \\
2 \text { SIGHA } \\
\text { BOT MAT, } \\
\text { TOT DRY } \\
\text { ( } 9 g / G \\
\text { as } \\
\text { U-nat) } \\
(75965)\end{array}$ & $\begin{array}{c}\text { GROSS } \\
\text { ALPHA } \\
\text { BOT MAT } \\
\text { ORY WGT } \\
\text { (PCI/G } \\
\text { As } \\
\text { Th-230) } \\
(04125)\end{array}$ & $\begin{array}{c}\text { ALPHA } \\
2 \text { SIGA } \\
\text { BOI MAT } \\
\text { TOI DRY } \\
\text { (pCi/G } \\
\text { es } \\
\text { Th-230) } \\
(75955)\end{array}$ & $\begin{array}{c}\text { CROSS } \\
\text { BETA, } \\
\text { DIS- } \\
\text { SOLVED } \\
\text { (PCI/L } \\
\text { as } \\
\text { Cs-137) } \\
(03515)\end{array}$ & $\begin{array}{c}\text { CETA, } \\
2 \text { SIGH } \\
\text { UATER, } \\
\text { DISS, } \\
\text { (PCI/L } \\
\text { As } \\
\text { Cs-137) } \\
\text { (75989) }\end{array}$ & $\begin{array}{c}\text { GROSS } \\
\text { BETA, } \\
\text { SUSP. } \\
\text { TOTAL } \\
\text { (PCI/L } \\
\text { os } \\
\text { C8-137) } \\
(03516)\end{array}$ & $\begin{array}{c}\text { GROSS } \\
\text { BETA, } \\
\text { DISS. } \\
\text { (pCi/L } \\
88 \\
S r-90) \\
\gamma-90) \\
(80050)\end{array}$ \\
\hline
\end{tabular}

09401000

\begin{tabular}{|c|c|c|c|c|}
\hline $\begin{array}{l}04-11-90 \\
07-09-90\end{array}$ & $\cdots$ & $\cdots$ & $\cdots$ & $\ldots$ \\
\hline $\begin{array}{l}07-09-90 \\
07-09-90\end{array}$ & 1100 & $\cdots$ & $\cdots$ & $\cdots$ \\
\hline $\begin{array}{l}07-09-90 \\
07-09-90\end{array}$ & .. & .. & $\ldots$ & $\ldots$ \\
\hline $07-09-90$ & 1400 & .. & $\ldots$ & $\ldots$ \\
\hline $07-09-90$ & 0 & .. & $\cdots$ & $\ldots$ \\
\hline $07-10-90$ & $120 *$ & $\cdots$ & $\cdots$ & $\cdots$ \\
\hline $07-10-90$ & $\cdots$ & $\cdots$ & $\cdots$ & $\cdots$ \\
\hline $07-17-90$ & $\cdots$ & $\cdots$ & $\cdots$ & $\cdots$ \\
\hline $07-17-90$ & $\cdots$ & $\cdots$ & $\cdots$ & $\cdots$ \\
\hline $07-17-90$ & $\cdots$ & $\cdots$ & $\cdots$ & $\cdots$ \\
\hline $07-17-90$ & $1600^{*}$ & $\cdots$ & $\cdots$ & $\cdots$ \\
\hline $07-17-90$ & $4900^{*}$ & 9 & 12.20 & 9.1 \\
\hline $07-17-90$ & $\cdots$ & $\cdots$ & $\cdots$ & $\cdots$ \\
\hline $07-17-90$ & $\cdots$ & $\cdots$ & $\cdots$ & $\cdots$ \\
\hline $07-17-90$ & $940 *$ & 9 & 11.90 & 8.8 \\
\hline $08-16-90$ & $\cdots$ & $\cdots$ & $\cdots$ & $\cdots$ \\
\hline $08-17-90$ & $\cdots$ & $\cdots$ & $\cdots$ & $\cdots$ \\
\hline $08-17-90$ & $\cdots$ & $\cdots$ & $\cdots$ & $\cdots$ \\
\hline $08-17-90$ & $\cdots$ & $\cdots$ & - & $\cdots$ \\
\hline $08-17-90$ & -- & $\cdots$ & $\cdots$ & $\cdots$ \\
\hline $08-17-90$ & $\cdots$ & $\because$ & $\cdots$ & $\cdots$ \\
\hline $08-17-90$ & $\cdots$ & 10 & 16.10 & 12 \\
\hline $08-17-90$ & $\cdots$ & $\cdots$ & $\cdots$ & $\cdots$ \\
\hline $08-17-90$ & $\cdots$ & $\cdots$ & $\cdots$ & $\cdots$ \\
\hline $08-17-90$ & $\cdots$ & $\cdots$ & $\cdots$ & $\cdots$ \\
\hline $08-17-90$ & 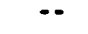 & $\cdots$ & $\cdots$ & $\cdots$ \\
\hline $09-22-90$ & $\cdots$ & $\cdots$ & $\cdots$ & $\cdots$ \\
\hline $09-22-90$ & $\cdots$ & $\cdots$ & $\cdots$ & $\cdots$ \\
\hline $09-22-90$ & $\cdots$ & $\cdots$ & $\cdots$ & $\cdots$ \\
\hline $09-22-90$ & $\cdots$ & $\cdots$ & $\cdots$ & $\cdots$ \\
\hline $09-22-90$ & -. & $\cdots$ & $\cdots$ & $\cdots$ \\
\hline $09-22-90$ & $\cdots$ & $\cdots$ & $\cdots$ & $\cdots$ \\
\hline $09-22-90$ & $\cdots$ & $\cdots$ & $\cdots$ & $\cdots$ \\
\hline $09-22-90$ & $\cdots$ & $\cdots$ & -. & $\cdots$ \\
\hline $09-22-90$ & $\cdots$ & $\cdots$ & -. & - \\
\hline $09-22-90$ & -. & $\cdots$ & -. & - \\
\hline $09-23-90$ & $\cdots$ & $\cdots$ & $\cdots$ & $\cdots$ \\
\hline $09-23-90$ & $\cdots$ & $\cdots$ & $\cdots$ & $\cdots$ \\
\hline $09-23-90$ & - & $\cdots$ & $\cdots$ & $\cdots$ \\
\hline $01-07-91$ & -. & 13 & 18.00 & 10 \\
\hline $01-07-91$ & $\cdots$ & $\cdots$ & $\cdots$ & $\cdots$ \\
\hline 01-08-91 & $\cdots$ & $\cdots$ & $\cdots$ & $\cdots$ \\
\hline $01-08-91$ & $\cdots$ & $\cdots$ & $\cdots$ & $\cdots$ \\
\hline $01-08-91$ & $\cdots$ & $\cdots$ & $\cdots$ & $\cdots$ \\
\hline $01-08-91$ & $\cdots$ & $\cdots$ & $\cdots$ & $\cdots$ \\
\hline $01-15-91$ & $\cdots$ & $\cdots$ & $\cdots$ & $\cdots$ \\
\hline $03-03-91$ & $\cdots$ & $\cdots$ & $\cdots$ & $\cdots$ \\
\hline $03-03-91$ & $\cdots$ & $\cdots$ & $\ldots$ & $\cdots$ \\
\hline
\end{tabular}

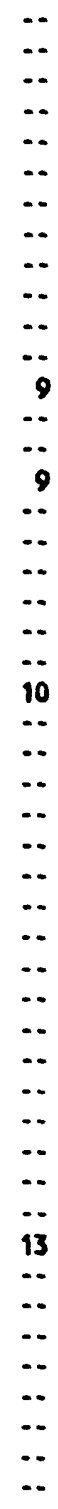

\begin{tabular}{|c|c|c|c|}
\hline 0 & $\cdots$ & -. & $\cdots$ \\
\hline$\cdots$ & $\cdots$ & $\cdots$ & $-\cdot$ \\
\hline 8.8 & 2.5 & $810^{*}$ & 6.7 \\
\hline -. & -. & -. & -. \\
\hline 11 & 3.0 & $1000 *$ & 8.5 \\
\hline - & $\cdots$ & $\cdots$ & -. \\
\hline 6.7 & 1.7 & $96 *$ & 5.0 \\
\hline$\cdots$ & $\cdots$ & $\cdots$ & $-\cdot$ \\
\hline$\cdots$ & $\cdots$ & $\cdots$ & $\cdots$ \\
\hline$\cdots$ & $\cdots$ & $\cdots$ & $\cdots$ \\
\hline 81 & $\ddot{3}$ & - & $\ddot{0}$ \\
\hline $10^{8.7}$ & $\begin{array}{l}2.3 \\
2.7\end{array}$ & $2200 *$ & $\begin{array}{l}6.0 \\
7.7\end{array}$ \\
\hline$\cdots$ & $\cdots$ & $\cdots$ & $\cdots$ \\
\hline$\cdots$ & $\cdots$ & $\cdots$ & $\cdots$ \\
\hline 7.4 & 1.6 & $490^{\circ}$ & 5.6 \\
\hline$\because-$ & $\cdots$ & $\cdots$ & $\cdots$ \\
\hline$\ldots$ & 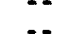 & $\cdots$ & $\because$ \\
\hline .. & $\ldots$ & $\ldots$ & .. \\
\hline .. & $\ldots$ & $\ldots$ & .. \\
\hline -. & $\cdots$ & $\ldots$ & $\cdots$ \\
\hline$\cdots$ & $\cdots$ & $\cdots$ & $\cdots$ \\
\hline - & $\cdots$ & $\ldots$ & $\cdots$ \\
\hline$\cdots$ & - & $\cdots$ & $\cdots$ \\
\hline$\cdots$ & $\cdots$ & $\cdots$ & $\cdots$ \\
\hline$\cdots$ & $\cdots$ & $\cdots$ & $\cdots$ \\
\hline$\cdots$ & $\cdots$ & $\cdots$ & $\cdots$ \\
\hline$\cdots$ & $\cdots$ & $\cdots$ & $\cdots$ \\
\hline$\cdots$ & $\cdots$ & $\cdots$ & $\cdot$ \\
\hline$\cdots$ & $\cdots$ & $\cdots$ & $\cdots$ \\
\hline$\ldots$ & $\because$ & $\cdots$ & $\cdots$ \\
\hline$\cdots$ & $\therefore$ & $\ldots$ & $\cdots$ \\
\hline -. & .. & .. & . \\
\hline$\cdots$ & -. & $\ldots$ & .. \\
\hline 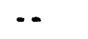 & -. & . & .. \\
\hline -. & -. & $\cdots$ & $\cdots$ \\
\hline$\cdots$ & $\cdots$ & $\cdots$ & $\cdots$ \\
\hline- & -. & .. & .. \\
\hline 7.5 & 1.8 & $\cdots$ & 5.6 \\
\hline$\cdots$ & $\cdots$ & $\cdots$ & $\cdots$ \\
\hline$\cdots$ & $\cdots$ & $\cdots$ & 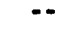 \\
\hline$\cdots$ & $\cdots$ & $\cdots$ & $\cdots$ \\
\hline$\cdots$ & $\cdots$ & $\cdots$ & \\
\hline$\cdots$ & $\cdots$ & $\cdots$ & 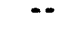 \\
\hline$\cdots$ & $\because$ & $\cdots$ & 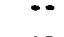 \\
\hline & $\ldots$ & $\cdots$ & .. \\
\hline
\end{tabular}


SURFACE-WATER DATA-Cont Inued

CHEMICAL AKALYSES-Continued

STATION

MUABER

BETA,
2 SICUA
WATER,
DISS,
(pCI/L
Os
DATE $\quad$ Sr-90/
$\gamma-90)$
$(75988)$

$\begin{array}{ll}\text { GROSS } & \text { BETA, } \\ \text { BETA, } & 2 \text { SIGMA } \\ \text { SUSP, } & \text { SED, SUSP } \\ \text { TOTAL } & \text { TOT DRY } \\ \text { (PCI/L } & \text { (PCI/G }\end{array}$

GROSS BETA BETA, 2 SIGM BOT MAT BOT MAT TOT DRY TOT DRY (PCi/G (pCi/G

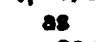
Sr-90/ $(1-90)$
$(80060)$
(76005) $\begin{array}{ccc}88 & 88 & 88 \\ s r-90 / & s r-90 / & s r-90 /\end{array}$
GROSS BETA,

BOT MAT BOT MAT

TOT DRY TOT DRY

SPCi/G $\quad$ PCI/G

88 as

(8-137) $\quad(8-137)$

(99922)

C8-137
soll.
TOTAL,
(pci/G)
(76007)

C8-137

SOIL SED,

TOTAL, TOTAL,

DRY WGT ORY WG

(pCi/G) (pCi/G)

(04103) (75944)

LITTLE COLORADO RIVER AT GRAMD FALLS, AZ-Continued

\begin{tabular}{|c|c|c|c|c|}
\hline 09401000 & $\begin{array}{l}04-11-90 \\
07-09-90 \\
07-09-90 \\
07-09-90 \\
07-09-90 \\
07-09-90 \\
07-10-90 \\
07-10-90 \\
07-17-90 \\
07-17-90 \\
07-17-90 \\
07-17-90 \\
07-17-90 \\
07-17-90 \\
07-17-90 \\
07-17-90 \\
08-16-90 \\
08-17-90 \\
08-17-90 \\
08-17-90 \\
08-17-90 \\
08-17-90 \\
08-17-90 \\
08-17-90 \\
08-17-90 \\
08-17-90 \\
08-17-90 \\
09-22-90 \\
09-22-90 \\
09-22-90 \\
09-22-90 \\
09-22-90 \\
09-22-90 \\
09-22-90 \\
09-22-90 \\
09-22-90 \\
09-22-90 \\
09-23-90 \\
09-23-90 \\
09-23-90 \\
01-07-91 \\
01-07-91 \\
01-08-91 \\
01-08-91 \\
01-08-91 \\
01-08-91 \\
01-15-91 \\
03-03-91 \\
03-03-91\end{array}$ & 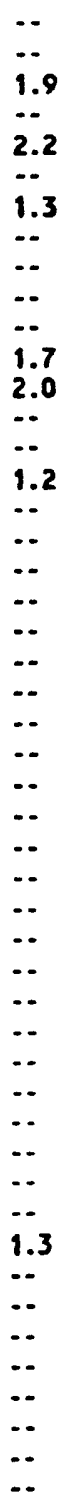 & 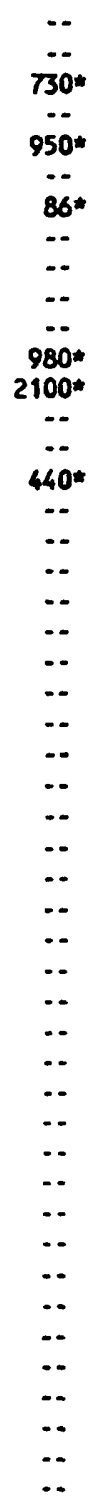 & 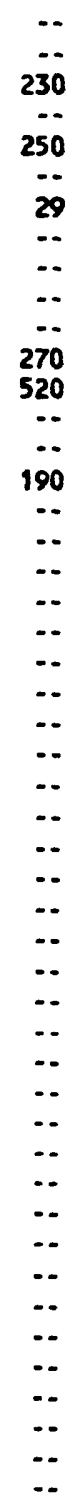 \\
\hline
\end{tabular}

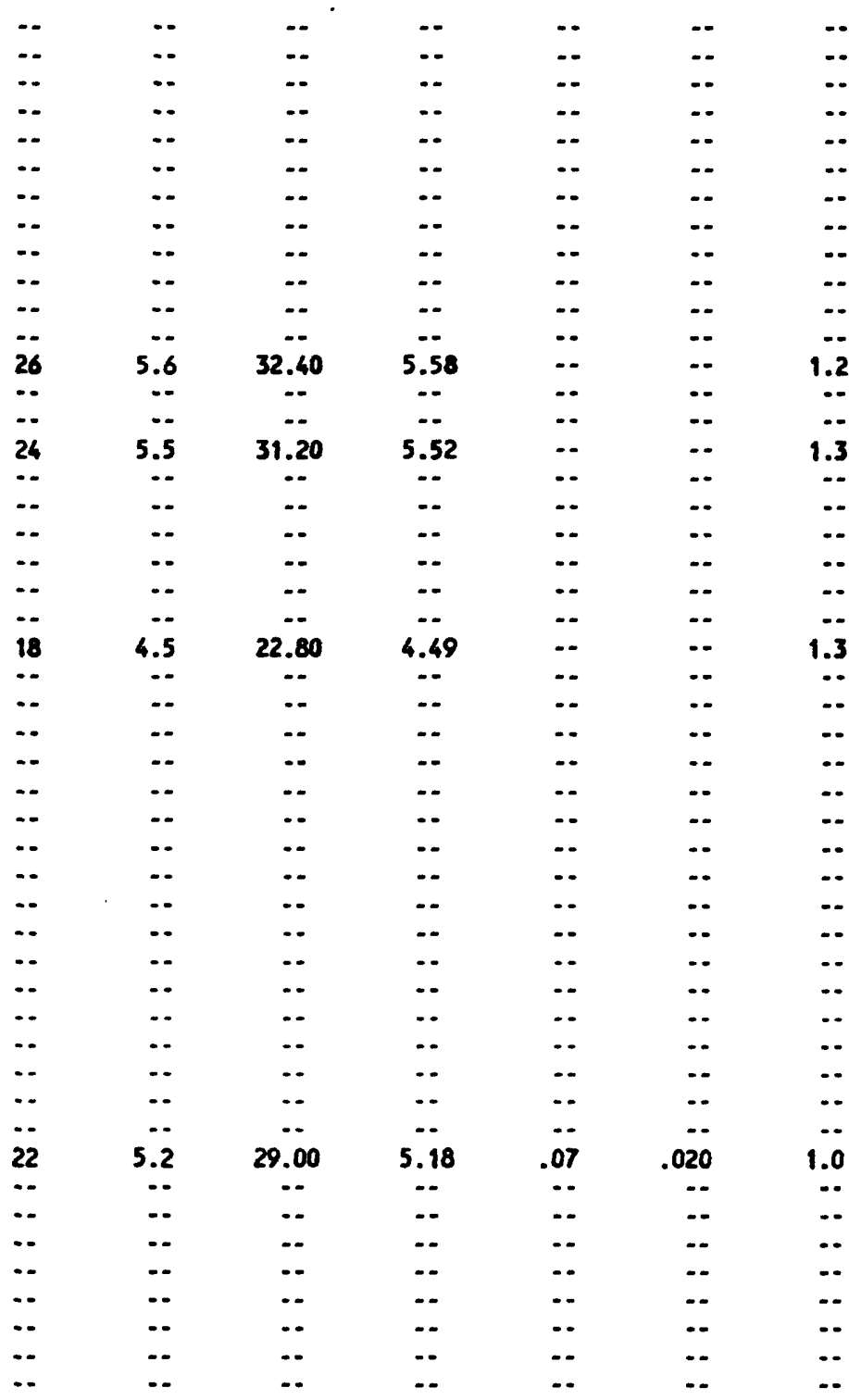


SURFACE-MATER DATA-Continued

CHEAICAL ANALYSES-Continued

\begin{tabular}{|c|c|c|c|c|c|c|c|c|c|c|c|}
\hline & & & $U-234$ & & U-235 & & $U-238$ & & & Th-230 & \\
\hline TATION & & $\begin{array}{c}\text { U-234 } \\
\text { SED, } \\
\text { SUSP, } \\
\text { TOTAL. }\end{array}$ & $\begin{array}{l}2 \text { SICM } \\
\text { SED, } \\
\text { SUSP. } \\
\text { TOTAL. }\end{array}$ & $\begin{array}{c}\text { U-235 } \\
\text { SED, } \\
\text { SUSP, } \\
\text { TOTAL }\end{array}$ & $\begin{array}{l}2 \text { SICM } \\
\text { SED, } \\
\text { SUSP. } \\
\text { TOTAL. }\end{array}$ & $\begin{array}{l}\text { U-238 } \\
\text { SED, } \\
\text { SUSP, } \\
\text { TOTAL. }\end{array}$ & $\begin{array}{l}2 \text { SICM } \\
\text { SED, } \\
\text { SUSP, } \\
\text { TOTAL. }\end{array}$ & $\begin{array}{l}\text { URANIUN } \\
\text { MATURAL } \\
\text { DIS- } \\
\text { SOLVED }\end{array}$ & $\begin{array}{c}\text { Th-230 } \\
\text { SED, } \\
\text { SUSP, } \\
\text { TOTAL }\end{array}$ & $\begin{array}{l}2 \text { SIGM } \\
\text { SED, } \\
\text { SUSP, } \\
\text { TOTAL. }\end{array}$ & $\begin{array}{l}\text { Th-232 } \\
\text { SED, } \\
\text { SUSP, } \\
\text { TOTAL. }\end{array}$ \\
\hline UABER & DATE & $\begin{array}{l}\text { DRY WGT } \\
\text { (pCi/G) } \\
\text { (75942) }\end{array}$ & $\begin{array}{l}\text { DRY WGT } \\
\text { (pCi/G) } \\
(75941)\end{array}$ & $\begin{array}{l}\text { DRY WGT } \\
\text { (pCi/G) } \\
(75975)\end{array}$ & $\begin{array}{l}\text { ORY UGT } \\
\text { (pCi/G) } \\
(75947)\end{array}$ & $\begin{array}{l}\text { DRY WGT } \\
\text { (PCi/G) } \\
(75940)\end{array}$ & $\begin{array}{l}\text { ORY UGT } \\
\text { (pCi/G) } \\
(04113)\end{array}$ & $\begin{array}{c}(\mu q / L \\
a 8 U) \\
(22703)\end{array}$ & $\begin{array}{l}\text { DRY UGT } \\
\text { (pCi/G) } \\
(75939)\end{array}$ & $\begin{array}{l}\text { DRY UGi } \\
\text { (pCi/G) } \\
(75952)\end{array}$ & $\begin{array}{l}\text { DRY UGT } \\
\text { (pCi/G) } \\
\text { (75953) }\end{array}$ \\
\hline
\end{tabular}

LITTLE COLORADO RIVER AT GRAMD FALLS, AZ-Contimued

\begin{tabular}{|c|c|c|c|c|c|c|c|c|c|c|c|}
\hline 09401000 & $\begin{array}{l}04-11-90 \\
07-00-90\end{array}$ & $\cdots$ & $\cdots$ & $\cdots$ & $\cdots$ & $\cdots$ & $\cdots$ & $\ldots$ & $\ldots$ & $\ldots$ & $\cdots$ \\
\hline & 07-09-90 & $\cdots$ & $\cdots$ & $\cdots$ & $\cdots$ & $\cdots$ & $\cdots$ & $\cdots$ & $-\infty$ & $\cdots$ & $\cdots$ \\
\hline & $07-09-90$ & $\cdots$ & $\cdots$ & $\cdots$ & $\cdots$ & $\cdots$ & $\cdots$ & $-\infty$ & $\cdots$ & $\cdots$ & $\cdots$ \\
\hline & $07-09-90$ & $\cdots$ & $\cdots$ & $\cdots$ & $\cdots$ & $\cdots$ & - & $\cdots$ & $\cdots$ & - & $\cdots$ \\
\hline & $07-09-90$ & -- & $\cdots$ & $\cdots$ & $\cdots$ & $\cdots$ & $\cdots$ & $\cdots$ & 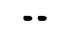 & $\cdots$ & $\ldots$ \\
\hline & $07-09-90$ & -- & $\cdots$ & $\cdots$ & $\cdots$ & $\cdots$ & $\cdots$ & $-\infty$ & $\cdots$ & $\ldots$ & $\cdots$ \\
\hline & $07-10-90$ & -. & $\ldots$ & $\cdots$ & $\cdots$ & $\ldots$ & $\cdots$ & 9.2 & $\ldots$ & $\cdots$ & $\ldots$ \\
\hline & $07-10-90$ & -- & - & $\cdots$ & $\cdots$ & $-\infty$ & -. & $\ldots$ & $\cdots$ & $\cdots$ & $\ldots$ \\
\hline & $07-17-90$ & $\cdots$ & $\bullet$ & $\cdots$ & $\cdots$ & $\ldots$ & $-\infty$ & $\cdots$ & $\ldots$ & $-\infty$ & $-\infty$ \\
\hline & $07-17-90$ &.- & $\ldots$ & $\cdots$ & $\cdots$ & $\ldots$ & -. & $\cdots$ & $\cdots$ & $\cdots$ & $\ldots$ \\
\hline & $07-17-90$ & $-\infty$ & $\cdots$ & $\cdots$ & $\cdots$ & $\cdots$ & $\cdots$ &.- & $\cdots$ & $\ldots$ & $\ldots$ \\
\hline & $07-17-90$ & $\cdots$ & $\ldots$ & $\cdots$ & $\cdots$ & $\ldots$ & -- & $\cdots$ & $\cdots$ & $\cdots$ & -. \\
\hline & $07-17-90$ & 1.2 & .20 & $<.1$ & MD & 1.3 & .26 & $\cdots$ & 1.2 & .30 & 1.4 \\
\hline & $07-17-90$ & -- & $\cdots$ & 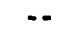 & $\cdots$ & $\cdots$ & -- & $-\infty$ & $\cdots$ & $\cdots$ & $\cdots$ \\
\hline & $07-17-90$ & $\cdots$ & -. & $\cdots$ & $\cdots$ & $\cdots$ & $\cdots$ & $\cdots$ & $\cdots$ & $\ldots$ & $\cdots$ \\
\hline & $07-17-90$ & 1.1 & .20 & .1 & ND & 1.0 & .22 & $\cdots$ & 1.6 & .40 & 1.6 \\
\hline & $08-16-90$ & $\cdots$ & $\cdots$ & $\cdots$ & $\cdots$ & $\cdots$ & $\cdots$ & 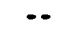 & $\cdots$ & $-\infty$ & - \\
\hline & $08-17-90$ & $\ldots$ & $\cdots$ & $\cdots$ & - & -- & -. & $\ldots$ & $\cdots$ & $\ldots$ & $\ldots$ \\
\hline & $08-17-90$ & $\cdots$ & $\cdots$ & $\cdots$ & $\cdots$ & $\ldots$ & -. & $\cdots$ & - & $\ldots$ & $\cdots$ \\
\hline & $08-17-90$ & $\cdots$ & $\cdots$ & $\cdots$ & -- & $\ldots$ & $\cdots$ & $\cdots$ & $\ldots$ & $\ldots$ & $\cdots$ \\
\hline & $08-17-90$ & $\ldots$ & .. & $\cdots$ & - & $\cdots$ & -. & $\ldots$ & $\ldots$ & $\ldots$ & $\cdots$ \\
\hline & $08-17-90$ & $\ldots$ & . & $\cdots$ & - & $-\infty$ & - & $\ldots$ & $-\infty$ & $\ldots$ & $\ldots$ \\
\hline & $08-17-90$ & 1.3 & .30 & $<.1$ & MD & 1.5 & .29 & $\cdots$ & 1.5 & .30 & 1.5 \\
\hline & $08-17-90$ & -- & $\ldots$ & $\cdots$ & $\cdots$ & $\ldots$ & -. & $\ldots$ & - & 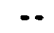 & $\cdots$ \\
\hline & $08-17-90$ & $\ldots$ & $\ldots$ & $\cdots$ & $\ldots$ & $-\infty$ & - & $\ldots$ & $\ldots$ & $-\infty$ & $\ldots$ \\
\hline & $08-17-90$ &.- & $\cdots$ & $\cdots$ & $\cdots$ & -- & $\cdots$ & $\ldots$ & $\cdots$ & $\cdots$ & $\cdots$ \\
\hline & $08-17-90$ & $\ldots$ & $\ldots$ & $\cdots$ & $\ldots$ & 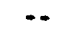 & - & $\cdots$ & $\ldots$ & $\ldots$ & $\ldots$ \\
\hline & $09-22-90$ & $\cdots$ & $\cdots$ & $\cdots$ & $\cdots$ & $\cdots$ & $\cdots$ & $=$ & $\cdots$ & $\cdots$ & $\cdots$ \\
\hline & $09-22-90$ & $\ldots$ & $\ldots$ & - & .. & $\cdots$ & $\ldots$ & $\ldots$ & $\ldots$ & $\ldots$ & $\ldots$ \\
\hline & $09-22 \cdot 90$ & -- & $\ldots$ & $\ldots$ & -. & $\ldots$ & $\cdots$ & $\cdots$ & $\ldots$ & $\ldots$ & $\ldots$ \\
\hline & $09-22-90$ & $\ldots$ & 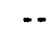 & .. & - & $\cdots$ & - & $\ldots$ & $\ldots$ & $\ldots$ & $\ldots$ \\
\hline & $09-22-90$ & $\cdots$ & $\cdots$ & $\cdots$ & $\ldots$ & $\ldots$ & $\cdots$ & $\ldots$ & $\ldots$ & $\ldots$ & $\cdots$ \\
\hline & $09-22-90$ & $\ldots$ & $\cdots$ & - & - & $\ldots$ & - & $\ldots$ & $\ldots$ & $\ldots$ & $\cdots$ \\
\hline & $09-22-90$ & $\cdots$ & $\cdots$ & $\cdots$ & $\cdots$ & $\ldots$ & $\cdots$ & $\ldots$ & $\ldots$ & $\ldots$ & $\ldots$ \\
\hline & $09-22-90$ & $\ldots$ & $\ldots$ & $\cdots$ & - & -- & -. & $\ldots$ & $\ldots$ & $\ldots$ & .. \\
\hline & $09-22-90$ & $\cdots$ & -. & $\cdots$ & - & $\ldots$ & $\cdots$ & 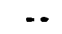 & $\ldots$ & $\ldots$ & $\ldots$ \\
\hline & $09-22-90$ & $\cdots$ & $\cdots$ & $\cdots$ & $\cdots$ & 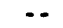 & - & $\cdots$ & .. & $\ldots$ & $\cdots$ \\
\hline & $09-23-90$ & -- & - & $\cdots$ & - & $\cdots$ & .. & $\ldots$ & $\cdots$ & $\ldots$ & $\ldots$ \\
\hline & $09-23-90$ & $\cdots$ & .. & $\cdots$ & - & 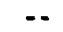 & -. & $\ldots$ & $\cdots$ & $\ldots$ & $\cdots$ \\
\hline & $09-23-90$ & -- & $\ldots$ & $\cdots$ & - & $\cdots$ & -- & $\ldots$ & $\cdots$ & $\ldots$ & $\ldots$ \\
\hline & $01-07-91$ & .9 & .13 & $<.1$ & .02 & 1.1 & .15 & $\cdots$ & 1.5 & .22 & 1.5 \\
\hline & $01-0$ & -- & $\ldots$ & $\cdots$ & $\cdots$ & $-\infty$ & $\cdots$ & $=$ & $\cdots$ & 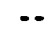 & $\therefore$ \\
\hline & $01-08-91$ & $\cdots$ & $\cdots$ & - & $\cdots$ & $\cdots$ & $\cdots$ & $\cdots$ & $\cdots$ & $-\infty$ & $\cdots$ \\
\hline & $01-0$ & $\ldots$ & $\ldots$ & $\cdots$ & 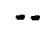 & $-\infty$ & $\ldots$ & $\ldots$ & $\ldots$ & $\ldots$ & $\ldots$ \\
\hline & $01-08-91$ & -- & $\ldots$ & $\cdots$ & $\cdots$ & $\cdots$ & $\cdots$ & $\cdots$ & $\rightarrow$ & $\ldots$ & $\ldots$ \\
\hline & $01-08-91$ & $\cdots$ & $\cdots$ & $\cdots$ & $\cdots$ & $\cdots$ & $\infty$ & $\ldots$ & $\cdots$ & $\ldots$ & $\ldots$ \\
\hline & $01-15-91$ & $\cdots$ & $\cdots$ & $\cdots$ & - & $\cdots$ & $\cdots$ & 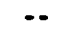 & $\cdots$ & $\cdots$ & $\rightarrow$ \\
\hline & $03-03-91$ & $=-$ & $\cdots$ & $\cdots$ & $\cdots$ & $\cdots$ & $\ldots$ & $\cdots$ & $\cdots$ & $\infty$ & $\cdots$ \\
\hline & & $\cdots$ & $\cdots$ & $\cdots$ & $\cdots$ & $\cdots$ & $\ldots$ & 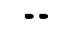 & -. & $\ldots$ & $\cdots$ \\
\hline
\end{tabular}


SURFACE-MATER DATA-Cont inued

CHEMICAL NKALYSES-Continued

\begin{tabular}{|c|c|c|c|c|c|c|c|c|c|c|c|}
\hline $\begin{array}{l}\text { STATION } \\
\text { MUABER }\end{array}$ & DATE & $\begin{array}{l}\text { Th-232 } \\
2 \text { SIGU } \\
\text { SED, } \\
\text { SUSP, } \\
\text { TOTAL, } \\
\text { ORY WGi } \\
\text { (pCi/G) } \\
\text { (75936) }\end{array}$ & $\begin{array}{l}\text { ALUH- } \\
\text { INUM } \\
\text { BOT MAT } \\
\angle 63_{\mu} \text { DS } \\
\text { LAB } \\
\text { PERCENT } \\
\text { (34792) }\end{array}$ & $\begin{array}{c}\text { ARSENIC } \\
\text { BOT MAT } \\
\angle 63 \mu \text { DS } \\
\text { LAB } \\
(\mu g / G) \\
(34802)\end{array}$ & $\begin{array}{l}\text { BARIINA } \\
\text { BOT MAT } \\
\angle 63 \mu \text { DS } \\
\text { LAB } \\
(\mu g / G) \\
(34807)\end{array}$ & $\begin{array}{c}\text { BERYL- } \\
\text { LIUN } \\
\text { BOT MAT } \\
\angle 63 \mu \text { DS } \\
\text { LAB } \\
(\mu g / G) \\
(34812)\end{array}$ & $\begin{array}{c}\text { BISWUTH } \\
\text { BOT MAT } \\
\angle 63 \mu \text { OS } \\
\text { LAB } \\
(\mu q / G) \\
(34817)\end{array}$ & $\begin{array}{c}\text { CADMIUM } \\
\text { BOT MAT } \\
\angle 63 \mu \text { OS } \\
\text { LAB } \\
(\mu g / G) \\
(34827)\end{array}$ & $\begin{array}{l}\text { CALCIUN } \\
\text { BOT MAT } \\
\angle 63 \mu \text { OS } \\
\text { LAB } \\
\text { PERCENT } \\
\text { (34832) }\end{array}$ & $\begin{array}{l}\text { CERIUN } \\
\text { BOT MAT } \\
\angle 63 \mu \text { OS } \\
\text { LAB } \\
(\mu g / G) \\
(34837)\end{array}$ & $\begin{array}{l}\text { CHRO- } \\
\text { HIIN } \\
\text { BOT MAT } \\
663 \mu \text { DS } \\
\text { LAB } \\
(\mu g / G) \\
(34842)\end{array}$ \\
\hline
\end{tabular}

LITILE COLORADO RIVER AT GRAND FALLS, AZ-Continued

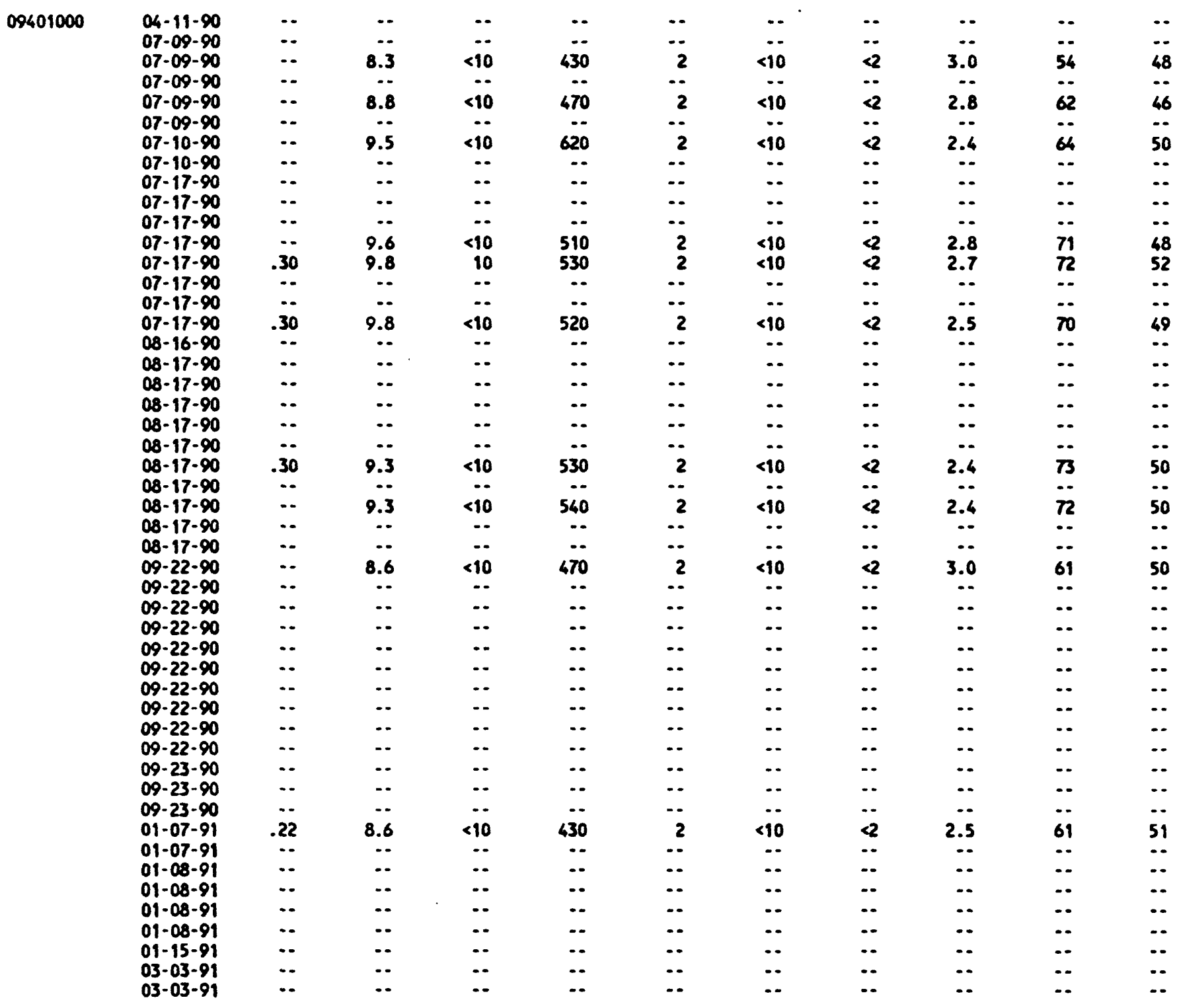


SURFACE-UATER DATA-Cont inued

CHEMICAL AMALYSES-cont inued

\begin{tabular}{|c|c|c|c|c|c|c|c|c|c|c|c|}
\hline $\begin{array}{l}\text { TATION } \\
\text { UMBER }\end{array}$ & DATE & $\begin{array}{c}\text { COBALT } \\
\text { BOT MAT } \\
\angle 63_{\mu} \text { DS } \\
\text { LAB } \\
(\mu g / G) \\
(34847)\end{array}$ & $\begin{array}{c}\text { COPPER } \\
80 T M A T \\
\angle 63_{\mu} \text { DS } \\
L A B \\
(\mu g / G) \\
(34852)\end{array}$ & $\begin{array}{l}\text { EURO- } \\
\text { PIUN } \\
\text { BOT MAT } \\
\text { C63н DS } \\
\text { LAB } \\
(\mu g / G) \\
(34857)\end{array}$ & $\begin{array}{c}\text { GALLIUN } \\
\text { BOT MAT } \\
\angle 63 \mu \text { DS } \\
\text { LAB } \\
(\mu g / G) \\
(34862)\end{array}$ & $\begin{array}{c}\text { COLD } \\
\text { BOT MAT } \\
\angle 63 \mu \mathrm{DS} \\
\text { LAB } \\
(\mu \mathrm{g} / \mathrm{G}) \\
(34872)\end{array}$ & 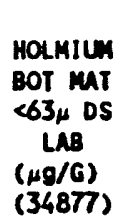 & $\begin{array}{l}\text { IRON } \\
\text { BOT MAT } \\
\angle 63_{\text {W OS }} \\
\text { LAB } \\
\text { PERCENT } \\
\text { (34882) }\end{array}$ & $\begin{array}{l}\text { LANTHA- } \\
\text { MU } \\
\text { Bot MAT } \\
\angle 63 \mu \text { DS } \\
\text { LAB } \\
(\mu g / G) \\
(34887)\end{array}$ & $\begin{array}{c}\text { LEAD } \\
\text { BOT MAT } \\
\angle 63_{\mu} \text { DS } \\
\text { LAB } \\
(\mu g / G) \\
(34892)\end{array}$ & $\begin{array}{c}\text { LITHIUN } \\
\text { BOT MAT } \\
\angle 63_{\mu} \text { DS } \\
\text { LAB } \\
(\mu g / G) \\
(34897)\end{array}$ \\
\hline
\end{tabular}

LITTLE COLORADO RIVER AT GRUD FALLS, AZ-Continued

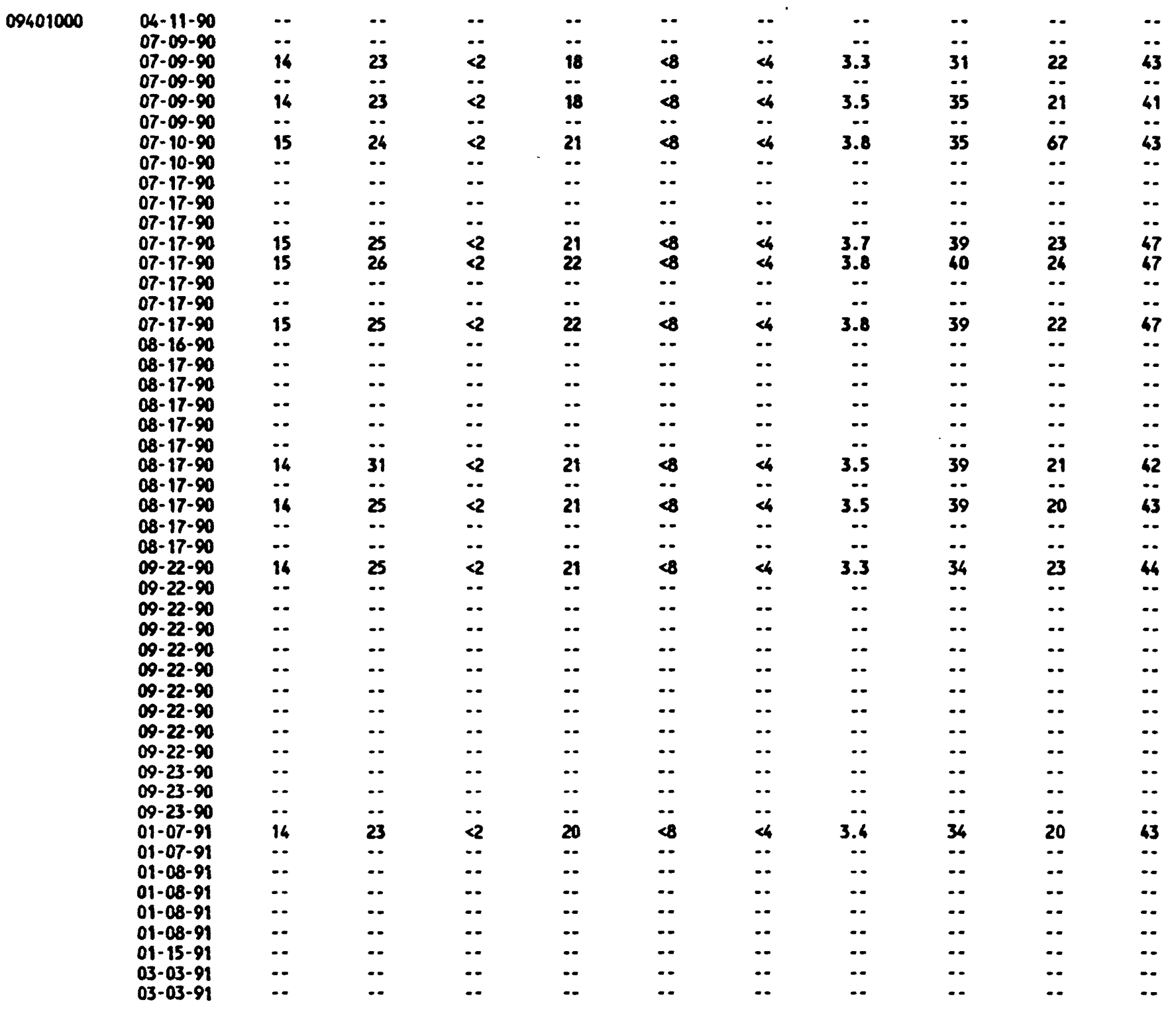


SURFACE-WATER DATA-Continued

CHEMICAL AMALYSES-Continued

STATION

MUABER
DATE

$04-11-90$
$07-09-90$

$07-09-90$

07-09-90

$07-09-90$

07-09-90

$07-10-90$

$07-10-90$

$07-17-90$

$07-17-90$

$07-17-90$

$07-17-90$

$07-17-90$

$07-17-90$

$07-17-90$

$07-17-90$

$08-16-90$

$08-17-90$

$08-17-90$

$08-17-90$

$08-17-90$

$08-17-90$

$08-17-90$

$08-17-90$

$08-17-90$

$08-17-90$

$08-17-90$

09-22-90

$09-22-90$

09-22-90

09-22-90

09-22-90

09-22-90

09-22-90

09-22-90

09-22-90

09-22-90

09-23-90

09-23-90

$09-23-90$

01-07-91

$01-07-91$

$01-08-91$

01-08-91

01-08-91

01-08-91

01-15-91

03-03-91

03-03-91

\begin{tabular}{|c|c|c|c|c|c|c|c|c|}
\hline $\begin{array}{l}\text { MAGNE- } \\
\text { SIUA } \\
\text { BOT MAT } \\
\angle 63 \mu \text { DS } \\
\text { LAB } \\
\text { PERCENT } \\
\text { (34902) }\end{array}$ & $\begin{array}{c}\text { MANGA- } \\
\text { NESE } \\
\text { BOT MAT } \\
<63 \mu \text { DS } \\
\text { LAB } \\
(\mu g / G) \\
(34907)\end{array}$ & $\begin{array}{c}\text { MOLYB- } \\
\text { DENUM } \\
\text { BOT MAT } \\
\angle 63_{\mu} \text { DS } \\
\text { LAB } \\
(\mu 9 / G) \\
(34917)\end{array}$ & $\begin{array}{l}\text { NECOYM- } \\
\text { IUM } \\
\text { BOT MAT } \\
\angle 63 \mu \text { DS } \\
\text { LAB } \\
(\mu 9 / G) \\
(34922)\end{array}$ & $\begin{array}{l}\text { NICKEL } \\
\text { BOT MMT } \\
\angle 63 \mu \text { DS } \\
\text { LAB } \\
(\mu g / G) \\
(34927)\end{array}$ & $\begin{array}{c}\text { NLOBIUN } \\
\text { BOT MTT } \\
\angle 63 \mu \text { DS } \\
\text { LAB } \\
(\mu g / G) \\
(34932)\end{array}$ & $\begin{array}{l}\text { PHOS- } \\
\text { PHORUS } \\
\text { BOT MAT } \\
\angle 63 \mu \text { DS } \\
\text { LAB } \\
\text { PERCENT } \\
\text { (34937) }\end{array}$ & $\begin{array}{l}\text { POTAS- } \\
\text { SIUM } \\
\text { BOT MAT } \\
\angle 63_{\mu} \text { OS } \\
\text { LAB } \\
\text { PERCENT } \\
\text { (34942) }\end{array}$ & $\begin{array}{c}\text { SCAN- } \\
\text { DIUA } \\
80 T \text { MAT } \\
\angle 63 \mu \text { DS } \\
\text { LAB } \\
(\mu 9 / G) \\
(34947)\end{array}$ \\
\hline
\end{tabular}

LITTLE COLORADO RIVER AT GRAND FALLS, AZ-Continued

\begin{tabular}{|c|c|c|c|c|c|c|c|c|}
\hline$\cdots$ & $\cdots$ & -. & .. & .. & .. & .. & -. & -. \\
\hline$\cdots$ & $\cdots$ & $\cdots$ & $\cdots$ & - & -. & -- & - & - \\
\hline 1.9 & 480 & $<2$ & 25 & 22 & 8 & .07 & 1.8 & 12 \\
\hline$\cdots$ & $\cdots$ & - & - & .. & -. & $\cdots$ & $\cdots$ & - \\
\hline 1.8 & 540 & $<2$ & 28 & 23 & 10 & .06 & 1.9 & 12 \\
\hline$\cdots$ & 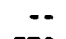 & $\cdots$ & 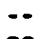 & 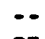 & $\because$ & 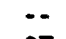 & $\cdots$ & 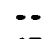 \\
\hline 2.0 & 530 & $<2$ & 29 & 25 & 10 & .07 & 2.0 & 13 \\
\hline$\cdots$ & $\cdots$ & $\cdots$ & $\cdots$ & $\cdots$ & $\cdots$ & $\cdots$ & $\cdots$ & $\cdots$ \\
\hline$\cdots$ & $\cdots$ & $\cdots$ & $\because$ & $\cdots$ & $\cdots$ & $\cdots$ & $\cdots$ & $\cdots$ \\
\hline$\cdots$ & $\cdots$ & $\cdots$ & $\cdots$ & $\cdots$ & $\cdots$ & $\cdots$ & $\cdots$ & $\cdots$ \\
\hline$\because$ & $\because$ & $\cdots$ & $\because$ & $\because$ & $\because$ & $\because$ & $\cdots$ & -. \\
\hline $\begin{array}{l}1.7 \\
1.7\end{array}$ & $\begin{array}{l}530 \\
530\end{array}$ & $\begin{array}{l}<2 \\
<2\end{array}$ & $\begin{array}{l}31 \\
33\end{array}$ & $\begin{array}{l}24 \\
23\end{array}$ & $\begin{array}{l}10 \\
10\end{array}$ & $\begin{array}{l}.07 \\
.07\end{array}$ & $\begin{array}{l}1.9 \\
1.9\end{array}$ & $\begin{array}{l}13 \\
14\end{array}$ \\
\hline - & $\cdots$ & $\cdots$ & $\cdots$ & .. & -- & -. & $\cdots$ & - \\
\hline$\cdots$ & $\because$ & $\cdots$ & $\because$ & 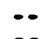 & $\cdots$ & $\cdots$ & -. & -. \\
\hline 1.6 & 520 & $<2$ & 33 & 22 & 11 & .06 & 1.9 & 14 \\
\hline$\cdots$ & $\cdots$ & $\cdots$ & $\cdots$ & $\cdots$ & $\cdots$ & $\cdots$ & $\cdots$ & $\cdots$ \\
\hline$\cdots$ & $\because$ & $\cdots$ & $\cdots$ & $\cdots$ & $\cdots$ & $\cdots$ & $\cdots$ & $\cdots$ \\
\hline$\cdots$ & $\cdots$ & $\cdots$ & $\cdots$ & $\cdots$ & -- & -- & $\cdots$ & $\cdots$ \\
\hline$\cdots$ & $\cdots$ & $\cdots$ & $\cdots$ & $\cdots$ & $\cdots$ & $\cdots$ & $\cdots$ & $\cdots$ \\
\hline$\cdots$ & $\because$ & $\because$ & $\because$ & 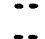 & 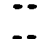 & $\because$ & $\because$ & $\cdots$ \\
\hline 1.5 & 540 & $<2$ & 32 & 20 & 10 & .05 & 1.8 & 14 \\
\hline$\therefore$ & $\therefore$ & $\therefore$ & $\therefore$ & $\therefore$ & $\therefore$ & $\therefore$ & $\therefore$ & $\therefore$ \\
\hline 1.5 & 550 & $<2$ & 31 & 17 & 10 & .05 & 1.8 & 14 \\
\hline$\cdots$ & $\cdots$ & $\cdots$ & $\cdots$ & $\cdots$ & $\cdots$ & $-\cdot$ & $\cdots$ & $\cdots$ \\
\hline - & - & -. & - & -. & -. & -. & - & . \\
\hline 1.7 & 530 & $<2$ & 29 & 23 & 9 & .06 & 2.0 & 13 \\
\hline$\cdots$ & $\cdots$ & $\cdots$ & $\cdots$ & $\cdots$ & $\cdots$ & $\cdots$ & $\cdots$ & -. \\
\hline$\cdots$ & $\cdots$ & $\cdots$ & $\cdots$ & $\cdots$ & $\cdots$ & $\cdots$ & $\cdots$ & $\cdots$ \\
\hline$\cdots$ & $\cdots$ & $\cdots$ & $\cdots$ & $\cdots$ & $\cdots$ & $\cdots$ & $\cdots$ & $\cdots$ \\
\hline$\cdots$ & $\cdots$ & $\cdots$ & $\cdots$ & $\cdots$ & $\cdots$ & 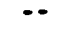 & $\cdots$ & $\cdots$ \\
\hline$\cdots$ & $\cdots$ & $\cdots$ & $\cdots$ & $\cdots$ & $\cdots$ & 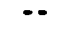 & $\cdots$ & $\cdots$ \\
\hline$\cdots$ & $\cdots$ & $\cdots$ & $\cdots$ & $\cdots$ & -- & $-\cdot$ & $\cdots$ & $\cdots$ \\
\hline$\cdots$ & $\because$ & $\cdots$ & $\cdots$ & $\cdots$ & $\cdots$ & $\cdots$ & $\cdots$ & $\cdots$ \\
\hline$\cdots$ & $\cdots$ & $\because$ & $\because$ & $\cdots$ & $\cdots$ & $\because$ & - & $\cdots$ \\
\hline -. & $\ldots$ & .. & $\ldots$ & $\ldots$ & $\ldots$ & - & $\ldots$ & $\ldots$ \\
\hline .. & .. & .. & .. & .. & -. & .- & .. &. \\
\hline -. & - & -. & -. & .. & .. & .. & .- & -. \\
\hline 1.8 & 520 & $<2$ & 28 & 25 & 9 & .06 & 1.8 & 13 \\
\hline$\cdots$ & $\cdots$ & $\cdots$ & $\cdots$ & $\cdots$ & $\cdots$ & - & $\cdots$ & $\cdots$ \\
\hline$\cdots$ & $\cdots$ & $\cdots$ & $\cdots$ & $\cdots$ & $\cdots$ & 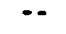 & $\cdots$ & $\cdots$ \\
\hline$\cdots$ & $\cdots$ & $\cdots$ & $\cdots$ & $\cdots$ & $\cdots$ & $\cdots$ & $\because$ & $\cdots$ \\
\hline$\cdots$ & $\cdots$ & $\cdots$ & $\cdots$ & $\cdots$ & $\cdots$ & $\cdots$ & $\cdots$ & $\cdots$ \\
\hline$\cdots$ & $\cdots$ & $\cdots$ & $\cdots$ & $\cdots$ & $\cdots$ & - & $\cdots$ & $\cdots$ \\
\hline$\cdots$ & $\cdots$ & $\cdots$ & $\cdots$ & $\cdots$ & $\cdots$ & $\cdots$ & $\cdots$ & 0 \\
\hline$\cdots$ & $\cdots$ & $\cdots$ & $\cdots$ & $\cdots$ & $\cdots$ & $\cdots$ & $\cdots$ & $\cdots$ \\
\hline$\cdots$ & - & $\cdots$ & $\cdots$ & & $\cdots$ & $\cdots$ & & \\
\hline
\end{tabular}


STATION

MUMBER
DATE

$04-11-90$

07-09-90

07-09-90

07-09-90

07-09-90

07-09-90

07-10-90

07-10-90

07-17-90

07-17-90

07-17-90

07-17-90

07-17-90

07-17-90

07-17-90

07-17-90

08-16-90

08-17-90

08-17-90

08-17-90

08-17-90

08-17-90

08-17-90

08-17-90

08-17-90

08-17-90

08-17-90

09-22-90

09-22-90

09-22-90

09-22-90

09-22-90

09-22-90

09-22-90

09-22-90

$09-22-90$

09-22-90

09-23-90

09-23-90

09-23-90

01-07-91

01-07-91

01-08-91

01-08-91

01-08-91

01-08-91

01-15-91

03-03-91

03-03-91

\begin{tabular}{|c|c|c|c|c|c|c|c|c|}
\hline $\begin{array}{l}\text { SILVER } \\
\text { BOT MAT } \\
\angle 63 \mu \text { OS } \\
\text { LAB } \\
(\mu 9 / G) \\
(34957)\end{array}$ & $\begin{array}{l}\text { SOOILA } \\
\text { BOT MAT } \\
\angle 63 \mu \text { OS } \\
\text { LAB } \\
\text { PERCENT } \\
\text { (34962) }\end{array}$ & $\begin{array}{l}\text { STRON- } \\
\text { TIUW } \\
\text { BOT MAT } \\
\angle 63_{\mu} \text { OS } \\
\text { LAB } \\
(\mu 9 / G) \\
(34967)\end{array}$ & $\begin{array}{c}\text { TANTA- } \\
\text { LUM } \\
\text { BOT MAT } \\
\angle 63_{\mu} \text { DS } \\
\text { LAB } \\
(\mu 9 / G) \\
(34977)\end{array}$ & $\begin{array}{c}\text { THORIUH } \\
\text { BOT MAT } \\
\angle 63_{\mu} \text { OS } \\
\text { LAB } \\
(\mu 9 / G) \\
(34982)\end{array}$ & $\begin{array}{c}\text { TIN } \\
\text { BOT NAT } \\
\angle 63_{\mu} \text { DS } \\
\text { LAB } \\
(\mu \sigma / G) \\
(34987)\end{array}$ & $\begin{array}{l}\text { TITA- } \\
\text { NIUH } \\
\text { BOT MAT } \\
\angle 63 \mu \text { DS } \\
\text { LAB } \\
\text { PERCENT } \\
\text { (34992) }\end{array}$ & $\begin{array}{c}\text { URANIUN } \\
\text { BOT MAT } \\
\text { C63H OS } \\
\text { LAB } \\
(\mu g / G) \\
(35002)\end{array}$ & 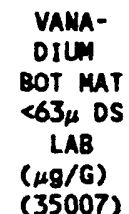 \\
\hline
\end{tabular}

LITTLE COLORADO RIVER AT GRANO FALLS, AZ-Contimued

\begin{tabular}{|c|c|c|c|c|c|c|c|c|}
\hline -. & -- & -- & -- & -- & -- & -- & $\cdots$ & $\cdots$ \\
\hline-- & -- & $=$ & 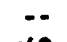 & 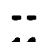 & 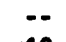 & $\ddot{z}$ & $\ddot{-}$ & $=$ \\
\hline$<4$ & .60 & 350 & $<40$ & 11 & $<10$ & .33 & $<100$ & 77 \\
\hline-- & -- & -- & -- & $\cdots$ & $\cdots$ & $\cdots$ & - & $\cdots$ \\
\hline$<4$ & .52 & 310 & $<40$ & 12 & $<10$ & .35 & $<100$ & 82 \\
\hline$\cdots$ & 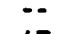 & $=$ & -- & 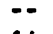 & $\because-$ & $=$ & -- & $\because$ \\
\hline$<4$ & .47 & 330 & $<40$ & 14 & $<10$ & .36 & $<100$ & 88 \\
\hline-- & $\cdots$ & -- & -- & $\cdots$ & -- & -- & -- & - \\
\hline$\cdots$ & $\cdots$ & $\cdots$ & $\cdots$ & $\cdots$ & 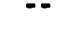 & 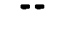 & $\cdots$ & $\cdots$ \\
\hline 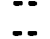 & $\begin{array}{l}-- \\
--\end{array}$ & $\because-$ & $\begin{array}{l}-- \\
--\end{array}$ & $\because$ & $\because$ & $\because$ & $=$ & $\because$ \\
\hline$<4$ & .46 & 320 & $<40$ & 14 & $<10$ & .39 & $<100$ & 94 \\
\hline$<4$ & .45 & 310 & $<40$ & 14 & $<10$ & .39 & $<100$ & 96 \\
\hline$\cdots$ & -- & -- & -- & $\cdots$ & $\cdots$ & -- & $\cdots$ & $\cdots$ \\
\hline-- & -- & -- & -- & -- & -- & -- & -- & - \\
\hline$<4$ & .42 & 300 & $<40$ & 14 & $<10$ & .39 & $<100$ & 96 \\
\hline$\cdots$ & -- & $\cdots$ & -. & - & -- & 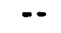 & -- & - \\
\hline -- & -- & -. & $\cdots$ & $\cdots$ & - & -. & $\cdots$ & $\cdots$ \\
\hline$-\cdot$ & $\cdots$ & $\cdots$ & -- & $\cdots$ & -- & $-\cdot$ & -- & - \\
\hline$-\cdot$ & -- & $=$ & $=-$ & $\cdots$ & -- & -- & $=$ & 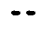 \\
\hline$\cdots$ & $\cdots$ & -- & -- & $=-$ & $\cdots$ & -- & -- & - \\
\hline$\overline{-}$ & $\ddot{\theta}$ & $\bar{m}$ & $\ddot{n}$ & 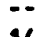 & 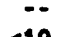 & 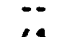 & $\ddot{n}$ & $\cdots$ \\
\hline $\begin{array}{l}4 \\
--\end{array}$ & .42 & $\begin{array}{r}270 \\
\ldots\end{array}$ & $\begin{array}{r}<40 \\
\ldots-\end{array}$ & $\begin{array}{l}16 \\
-.\end{array}$ & $<10$ & .41 & $<100$ & 97 \\
\hline$<4$ & .42 & 270 & $<40$ & 14 & $<10$ & .40 & $<100$ & 97 \\
\hline$\cdots$ & $\cdots$ & $\cdots$ & 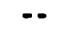 & - & - & -. & - & -- \\
\hline$\cdots$ & $\cdots$ & -. & -- & -- & -- & -- & -- & -. \\
\hline$<4$ & .49 & 300 & $<40$ & $<4$ & $<5$ & .34 & $<100$ & 85 \\
\hline$\cdots$ & $\cdots$ & -- & $\cdots$ & -- & -- & -- & $\cdots$ & -- \\
\hline$\cdots$ & $\cdots$ & $\cdots$ & -- & $\cdots$ & $\therefore$ & -- & -- & - \\
\hline$\cdots$ & $\cdots$ & - & $\cdots$ & -- & - & -- & -- & $\cdots$ \\
\hline-- & $\cdots$ & $\cdots$ & -- & $\cdots$ & $\cdots$ & -- & $\cdots$ & $\cdots$ \\
\hline$\cdots$ & $\cdots$ & $\cdots$ & $\cdots$ & $\cdots$ & $\cdots$ & $\cdots$ & $\cdots$ & - \\
\hline$\cdots$ & $\cdots$ & $\cdots$ & $\cdots$ & $\cdots$ & $\cdots$ & $\cdots$ & $\cdots$ & - \\
\hline$\cdots$ & $\cdots$ & $\cdots$ & $\because$ & $\cdots$ & $\cdots$ & $\cdots$ & -- & $\because$ \\
\hline$\because$ & $\because$ & $\because$ & $\because$ & $\cdots$ & $\because$ & $\because$ & $\cdots$ & $\cdots$ \\
\hline$\ldots$ & $\cdots$ & $\therefore$ & 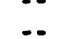 & $\ldots$ & 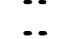 & 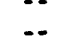 & $\therefore$ & $\cdots$ \\
\hline .. & -. & . & $\ldots$ & .. & .. & - & $\ldots$ & .. \\
\hline -. & $\cdots$ & -. & -. & -. & .. & -- & .. & 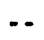 \\
\hline$<4$ & .54 & 340 & $<40$ & 13 & $<5$ & .36 & $<100$ & 84 \\
\hline$\cdots$ & $\cdots$ & $\cdots$ & -- & $\cdots$ & -. & -. & 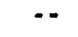 & $\cdots$ \\
\hline$\cdots$ & $\cdots$ & -- & -- & $\cdots$ & - & -- & -. & $\cdots$ \\
\hline$\cdots$ & -- & -- & $\cdots$ & $\cdots$ & $\cdots$ & -- & -- & 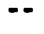 \\
\hline$\cdots$ & $\cdots$ & $\cdots$ & $\cdots$ & $\cdots$ & -- & -- & -- & 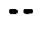 \\
\hline$\cdots$ & $\cdots$ & $=$ & $=$ & $=$ & $=-$ & -- & -- & \\
\hline$\cdots$ & $\cdots$ & -- & -- & $\because$ & $\cdots$ & $\because$ & $\cdots$ & \\
\hline$\cdots$ & $\cdots$ & $\cdots$ & $\cdots$ & $\cdots$ & $\cdots$ & $\cdots$ & -- & \\
\hline$\cdots$ & -1 & -- & -- & -- & -- & -- & -- & \\
\hline
\end{tabular}


STATION

MUABER

DATE

$04-11-90$

$07-09-90$

07-09-90

$07-09-90$

$07-09-90$

$07-09-90$

07-10-90

$07-10-90$

$07-17-90$

$07-17-90$

$07-17-90$

$07-17-90$

$07-17-90$

$07-17-90$

$07-17-90$

07-17-90

08-16-90

$08-17-90$

$08-17-90$

$08-17-90$

08-17-90

08-17-90

08-17-90

08-17-90

08-17-90

08-17-90

08-17-90

09-22-90

09-22-90

09-22-90

09-22-90

09-22-90

$09-22-90$

09-22-90

09-22-90

09-22-90

09-22-90

09-23-90

09-23-90

09-23-90

01-07-91

01-07-91

01-08-91

01-08-91

01-08-91

01-08-91

01-15-91

03-03-91

03-03-91

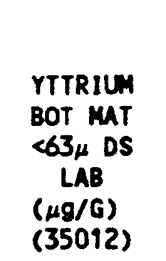

\begin{tabular}{|c|c|c|c|c|c|}
\hline $\begin{array}{l}\text { SEDI - } \\
\text { MENT, } \\
\text { SUS- } \\
\text { PENDED } \\
\text { (mg/l) } \\
(80154)\end{array}$ & $\begin{array}{l}\text { SED. } \\
\text { SUSP. } \\
\text { SIEVE } \\
\text { DIAH. } \\
\times \text { FINER } \\
\text { THAN } \\
\text { OS2 } \\
\text { (70331) }\end{array}$ & $\begin{array}{l}\text { SED. } \\
\text { SUSP. } \\
\text { SIEVE } \\
\text { DINH. } \\
\times \text { FINER } \\
\text { THAN } \\
\text {.125 MA } \\
(70332)\end{array}$ & $\begin{array}{l}\text { SED. } \\
\text { SUSP. } \\
\text { SIEVE } \\
\text { DINA. } \\
\times \text { FINER } \\
\text { THAN } \\
\text {-250 MM } \\
\text { (70333) }\end{array}$ & $\begin{array}{l}\text { SED. } \\
\text { SUSP. } \\
\text { SIEVE } \\
\text { DIAM. } \\
\times \text { FINER } \\
\text { THAN } \\
\text { S00 MM } \\
\text { (70334) }\end{array}$ & $\begin{array}{l}\text { SED. } \\
\text { SUSP. } \\
\text { SIEVE } \\
\text { DINM. } \\
\times \text { FINER } \\
\text { THAN } \\
1.00 \text { M } \\
\text { (70335) }\end{array}$ \\
\hline
\end{tabular}

LITTLE COLORADO RIVER AT GRAND FALLS, AZ-Continued

\begin{tabular}{|c|c|c|c|}
\hline$=$ & -. & -. & $\ldots$ \\
\hline$\cdots$ & $\cdots$ & -- & 95500 \\
\hline 20 & 2 & 56 & 79500 \\
\hline- & -- & $=$ & 63500 \\
\hline 23 & 2 & 60 & 60000 \\
\hline-- & $\cdots$ & $\cdots$ & 52500 \\
\hline 23 & 2 & 87 & 51900 \\
\hline- & -- & - & 49300 \\
\hline$\cdots$ & -- & $\cdots$ & 164000 \\
\hline$\cdots$ & -- & $\cdots$ & 147000 \\
\hline-- & $\because$ & $=$ & 129000 \\
\hline $\begin{array}{l}24 \\
25\end{array}$ & $\begin{array}{l}3 \\
3\end{array}$ & $\begin{array}{l}74 \\
77\end{array}$ & $\begin{array}{l}77100 \\
85100\end{array}$ \\
\hline$\cdots$ & $\cdots$ & -- & 81800 \\
\hline- & $\cdots$ & $\cdots$ & 82300 \\
\hline 25 & 3 & 79 & 87400 \\
\hline$\cdots$ & $\cdots$ & -- & 84200 \\
\hline$\cdots$ & $-\cdot$ & - & 100000 \\
\hline$\cdots$ & $\cdots$ & $\cdots$ & 97900 \\
\hline$=-$ & $\cdots$ & $\cdots$ & 109000 \\
\hline$\because$ & $\because$ & $=$ & 93000 \\
\hline 25 & 2 & 7 & 97900 \\
\hline$=$ & $\ldots$ & 10 & 00300 \\
\hline 25 & 3 & 75 & $E 92300$ \\
\hline - & $\cdots$ & -- & 92100 \\
\hline - & -- & $\cdots$ & 99700 \\
\hline 20 & 2 & 69 & 69100 \\
\hline$\cdots$ & $\cdots$ & $\cdots$ & 59600 \\
\hline$\cdots$ & -- & $\cdots$ & 63900 \\
\hline-- & $\cdots$ & $\cdots$ & 65600 \\
\hline$\cdots$ & $\cdots$ & $\cdots$ & 75700 \\
\hline$\cdots$ & $\cdots$ & $\cdots$ & 81600 \\
\hline$\because$ & $\because$ & $\cdots$ & 75700 \\
\hline$\cdots$ & $\cdots$ & $\cdots$ & 63100 \\
\hline$\cdots$ & $\cdots$ & $\cdots$ & 65100 \\
\hline$\cdots$ & -- & $\cdots$ & 60900 \\
\hline$\cdots$ & $\cdots$ & $\cdots$ & 53000 \\
\hline$\cdots$ & -- & $\cdots$ & 18400 \\
\hline 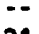 & $\because$ & $\cdots$ & 52500 \\
\hline 21 & 2 & 62 & 21700 \\
\hline$\because$ & $\cdots$ & $\cdots$ & 43500 \\
\hline$\because$ & $\cdots$ & $\because$ & 49400 \\
\hline$\ldots$ & $\ldots$ & 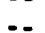 & 43000 \\
\hline$\cdots$ & .. & -. & 39900 \\
\hline$=-$ & -. & - & 16500 \\
\hline$\cdot$ & -. & $=$ & 30000 \\
\hline & -- & -- & 27000 \\
\hline
\end{tabular}

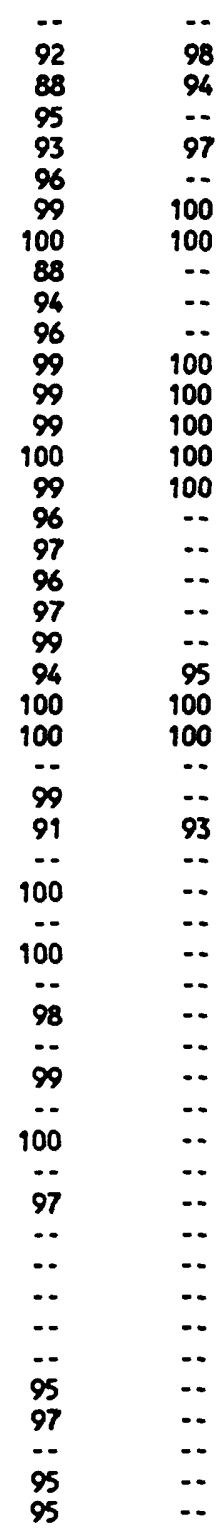

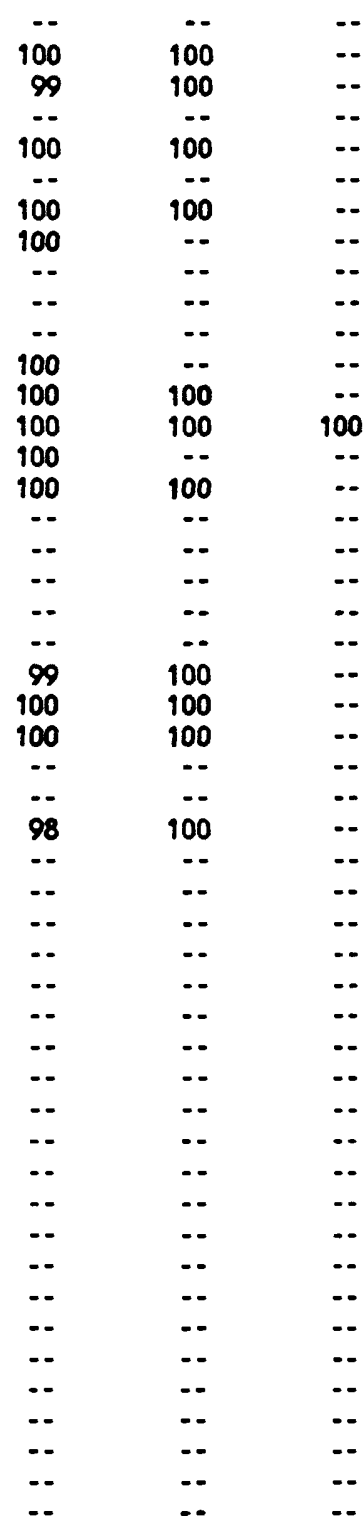


STATION

NUMBER

$09401000 \quad 04-11-90$
$07-09-90$
$07-09-90$
$07-09-90$
$07-09-90$
$07-09-90$
$07-10-90$
$07-10-90$
$07-17-90$
$07-17-90$
$07-17-90$
$07-17-90$
$07-17-90$
$07-17-90$
$07-17-90$
$07-17-90$
$08-16-90$
$08-17-90$
$08-17-90$
$08-17-90$
$08-17-90$
$08-17-90$
$08-17-90$
$08-17-90$
$08-17-90$
$08-17-90$
$08-17-90$
$09-22-90$
$09-22-90$
$09-22-90$
$09-22-90$
$09-22-90$
$09-22-90$
$09-22-90$
$09-22-90$
$09-22-90$
$09-22-90$
$09-23-90$
$09-23-90$
$09-23-90$
$01-07-91$
$01-07-91$
$01-08-91$
$01-08-91$
$01-08-91$
$01-08-91$
$01-15-91$
$03-03-91$
$03-03-91$

\begin{tabular}{|c|c|c|c|c|c|c|c|c|}
\hline $\begin{array}{l}\text { SED. } \\
\text { SUSP. } \\
\text { FALL } \\
\text { DIAN. } \\
\times \text { FINER } \\
\text { THAN } \\
.002 \text { M } \\
\text { (70337) }\end{array}$ & $\begin{array}{l}\text { SED. } \\
\text { SUSP. } \\
\text { FALL } \\
\text { DIAN. } \\
\times \text { FINER } \\
\text { THAN } \\
\text {.004 MM } \\
\text { (70338) }\end{array}$ & $\begin{array}{l}\text { SED. } \\
\text { SUSP. } \\
\text { FALL } \\
\text { DINM. } \\
\times \text { FINER } \\
\text { THAN } \\
\text {.008 m1 } \\
\text { (70339) }\end{array}$ & $\begin{array}{l}\text { SED. } \\
\text { SUSP. } \\
\text { FALL } \\
\text { DINH. } \\
\times \text { FINER } \\
\text { THAN } \\
.016 \\
\text { (70340) }\end{array}$ & $\begin{array}{l}\text { SED. } \\
\text { SUSP. } \\
\text { FALL } \\
\text { DIAM. } \\
\times \text { FINER } \\
\text { THAN } \\
.031 \text { IM } \\
\text { (70341) }\end{array}$ & $\begin{array}{l}\text { SED. } \\
\text { SUSP. } \\
\text { FALL } \\
\text { DINH. } \\
\times \text { FINER } \\
\text { THAN } \\
\text {.062 MM } \\
\text { (70342) }\end{array}$ & $\begin{array}{l}\text { SED. } \\
\text { SUSP. } \\
\text { FALL } \\
\text { DIAN. } \\
\times \text { FINER } \\
\text { THAN } \\
\text {.125 mM } \\
\text { (70343) }\end{array}$ & $\begin{array}{l}\text { SED. } \\
\text { SUSP. } \\
\text { FALL } \\
\text { DIAM. } \\
\times \text { FINER } \\
\text { THAN } \\
\text {.250 } \\
\text { (70344) }\end{array}$ & $\begin{array}{l}\text { SED. } \\
\text { SUSP. } \\
\text { FALL } \\
\text { DIAM. } \\
\times \text { FINER } \\
\text { THAN } \\
.500 \text { m1 } \\
\text { (70345) }\end{array}$ \\
\hline
\end{tabular}

LITTLE COLORADO RIVER AT GRAND FALLS, AZ-Continued

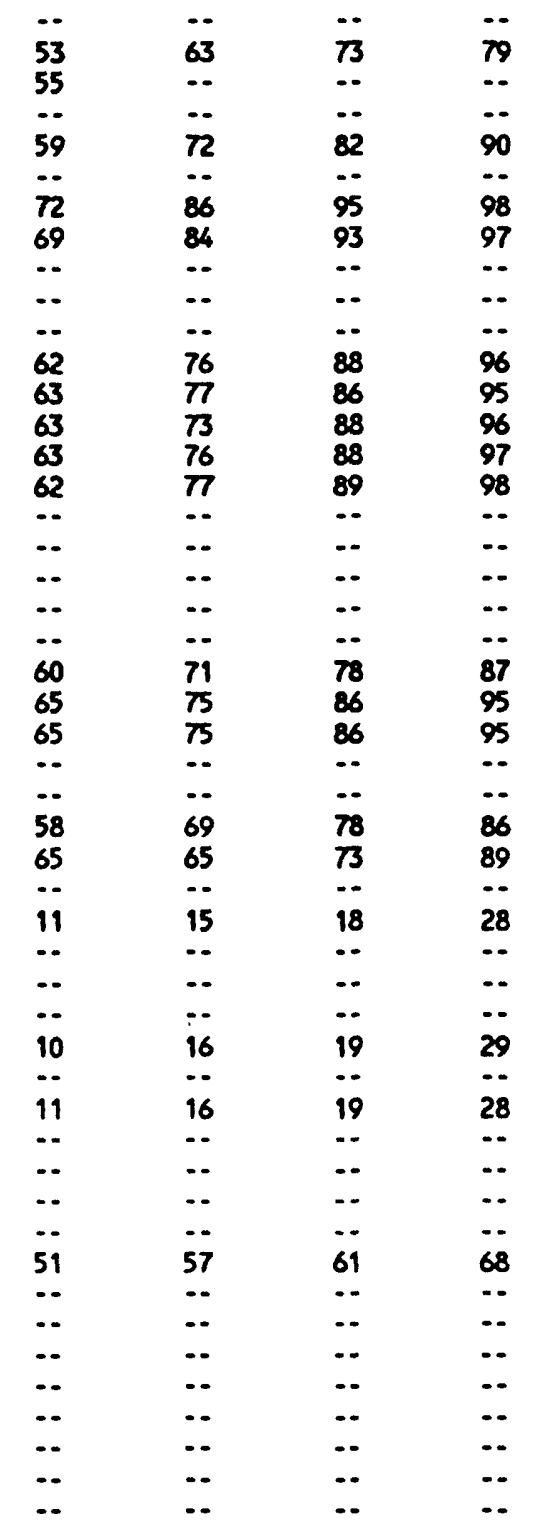

\begin{tabular}{|c|c|c|c|}
\hline -. & - & -. & - \\
\hline$\cdots$ & $\cdots$ & $\cdots$ & $\cdots$ \\
\hline$\cdots$ & $\cdots$ & $\cdots$ & -. \\
\hline-- & $\cdots$ & $\cdots$ & $\cdots$ \\
\hline$\cdots$ & $\cdots$ & $\cdots$ & $\cdots$ \\
\hline$\cdots$ & $\cdots$ & $\cdots$ & $\cdots$ \\
\hline$\cdots$ & $\cdots$ & $\cdots$ & 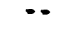 \\
\hline$\cdots$ & $\cdots$ & $\cdots$ & $\cdots$ \\
\hline$\cdots$ & $\cdots$ & $\cdots$ & $\cdots$ \\
\hline$\cdots$ & $\cdots$ & $\cdots$ & $\cdots$ \\
\hline 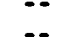 & 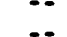 & $\because$ & $\because$ \\
\hline .- & $\ldots$ & $\ldots$ & .. \\
\hline .. & $\ldots$ & .. & $\ldots$ \\
\hline -. & -. & .- & $\ldots$ \\
\hline 100 & 100 & 100 & -. \\
\hline$\cdots$ & $\cdots$ & $\cdots$ & $\cdots$ \\
\hline -. & $\cdots$ & $\cdots$ & - \\
\hline- & $\cdots$ & $\cdots$ & $\cdots$ \\
\hline$\cdots$ & $\cdots$ & $\cdots$ & $\cdots$ \\
\hline$-\cdot$ & $\cdots$ & $\cdots$ & $\cdots$ \\
\hline$\cdots$ & $\cdots$ & $\because$ & $\cdots$ \\
\hline$\because$ & $\cdots$ & $\because$ & $\because$ \\
\hline$\therefore$ & $\ldots$ & $\therefore$ & $\therefore$ \\
\hline .- & $\ldots$ & .. & .. \\
\hline .- & $\ldots$ & .- & .. \\
\hline 97 & 98 & 100 & $\cdots$ \\
\hline 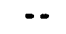 & $\cdots$ & $\cdots$ & $\because$ \\
\hline 99 & 100 & $\cdots$ & $\cdots$ \\
\hline$\cdots$ & $\cdots$ & $\cdots$ & $\cdots$ \\
\hline 99 & 100 & -- & $\cdots$ \\
\hline$\ldots$ & -. & $\cdots$ & .. \\
\hline 97 & 99 & 99 & 100 \\
\hline 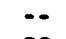 & 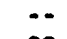 & 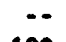 & $\cdots$ \\
\hline 98 & 9 & 100 & $\cdots$ \\
\hline 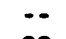 & $\ddot{0}$ & -- & $\cdots$ \\
\hline 99 & 100 & $\ddot{-}$ & 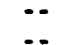 \\
\hline$\ddot{\infty}$ & $\ddot{0}$ & 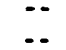 & 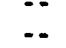 \\
\hline $\begin{array}{l}99 \\
75\end{array}$ & $\begin{array}{r}100 \\
86\end{array}$ & 98 & 100 \\
\hline$\therefore$ & $\cdots$ & $\cdots$ & $\cdots$ \\
\hline$\cdots$ & $\cdots$ & 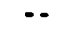 & $\cdots$ \\
\hline$\cdots$ & $\cdots$ & $\cdots$ & - \\
\hline$\cdots$ & $\cdots$ & 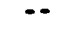 & 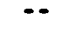 \\
\hline- & $\cdots$ & $\cdots$ & $\cdots$ \\
\hline$\cdots$ & $\cdots$ & $\cdots$ & $\cdots$ \\
\hline$\cdots$ & $\cdots$ & $\cdots$ & $=$ \\
\hline & & & \\
\hline
\end{tabular}


SURFACE-WATER DATA-Cont inued

CHEMICAL AKALYSES-Continued

\section{STATION}

MUBER

09401000
STATION MAME

LITTLE COLORADO RIVER AT GRAND FALLS, ARIZOMA
DATE

TIME

LATITUDE

LONGITUDE

03-04-91 0130

03-04-91 0730

03-04-91 1330

03-04-91 1930

03-05-91 -.

03-05-91 0130

03-05-91 1300

03-05-91 1038

03-08-99 0730

03-08-91 $\quad 1140$

03-08-91 1310

03-08-91 1750

03-08-91 1920

03-09-91 0100

03-09-91 0230

$03-09-91 \quad 0330$

04-04-91 0700

04-04-91 $\quad 1640$

04-05-91 0100

04-05-91 1920

04-05-91 1020

04-06-91 0500

04-06-91 1640

$04-09-99 \quad 0030$

$04-09-91 \quad 0140$

04-09-91 0220

$04-09-91 \quad 0340$

04-09-91 0440

04-09-91 1230

$04-10-91 \quad 0100$

$04-10-91 \quad 0140$

04-10-91 0200

$04-10-91 \quad 0320$

04-10-91 1920

04-10-91 2010

$04-11-91 \quad 0210$

$04-11-91 \quad 0810$

$04-11-91 \quad 0950$

05-01-91 1245

05-01-91 1255

05-09-91 1315

05-09-91 1315

09-06-91 1455

09-09-91 1445 
SURFACE-HATER DATA-Cont inued

CHEMICAL ANALYSES-Cont inued

\begin{tabular}{|c|c|c|c|c|c|c|c|c|c|c|}
\hline $\begin{array}{l}\text { STATION } \\
\text { MUNBER }\end{array}$ & DATE & $\begin{array}{c}\text { SAH- } \\
\text { PLING } \\
\text { METHOD, } \\
\text { COOES } \\
(82398)\end{array}$ & $\begin{array}{l}\text { STREAM } \\
\text { WIDTH } \\
\text { (meters) } \\
\text { (00004) }\end{array}$ & $\begin{array}{c}\text { TEMPER- } \\
\text { ATURE } \\
\text { HATER } \\
\left({ }^{\circ} \mathrm{C}\right) \\
(00010)\end{array}$ & $\begin{array}{l}\text { DIS- } \\
\text { CKARGE, } \\
\text { INST. } \\
\text { CUBIC } \\
\text { METERS } \\
\text { PER } \\
\text { SECOND } \\
\text { (00061) }\end{array}$ & $\begin{array}{l}\text { GAGE } \\
\text { HEIGHT } \\
\text { (meters) } \\
\text { (00065) }\end{array}$ & $\begin{array}{c}\text { SPE- } \\
\text { CIFIC } \\
\text { CON- } \\
\text { DUCT- } \\
\text { ANCE } \\
\text { (14S/Cm) } \\
(00095)\end{array}$ & $\begin{array}{l}\text { SPE- } \\
\text { CIFIC } \\
\text { CON- } \\
\text { DUCT- } \\
\text { ANCE } \\
\text { LAB } \\
(\mu S / \mathrm{cm}) \\
(90095)\end{array}$ & $\begin{array}{l}\text { OXYGEN, } \\
\text { DIS- } \\
\text { SOLVED } \\
(m / L) \\
(00300)\end{array}$ & $\begin{array}{l}\text { PH } \\
\text { WATER } \\
\text { WHOLE } \\
\text { FIELD } \\
\text { (STAND- } \\
\text { ARD } \\
\text { UNITS) } \\
\text { (00400) }\end{array}$ \\
\hline
\end{tabular}

LITTLE COLORADO RIVER AT GRANO FALLS, AZ-Continued

$09401000 \quad 03-04-91$
$03-04-91$
$03-04-91$
$03-04-91$
$03-05-91$
$03-05-91$
$03-05-99$
$03-05-91$
$03-08-91$
$03-08-91$
$03-08-91$
$03-08-91$
$03-08-91$
$03-09-91$
$03-09-91$
$03-09-91$
$04-04-91$
$04-04-91$
$04-05-91$
$04-05-91$
$04-05-91$
$04-06-91$
$04-06-91$
$04-09-91$
$04-09-91$
$04-09-91$
$04-09-91$
$04-09-91$
$04-09-91$
$04-10-91$
$04-10-91$
$04-10-91$
$04-10-91$
$04-90-91$
$04-10-91$
$04-11-91$
$04-11-91$
$04-11-91$
$05-01-91$
$05-01-91$
$05-09-91$
$05-09-91$
$09-06-91$
$09-06-91$

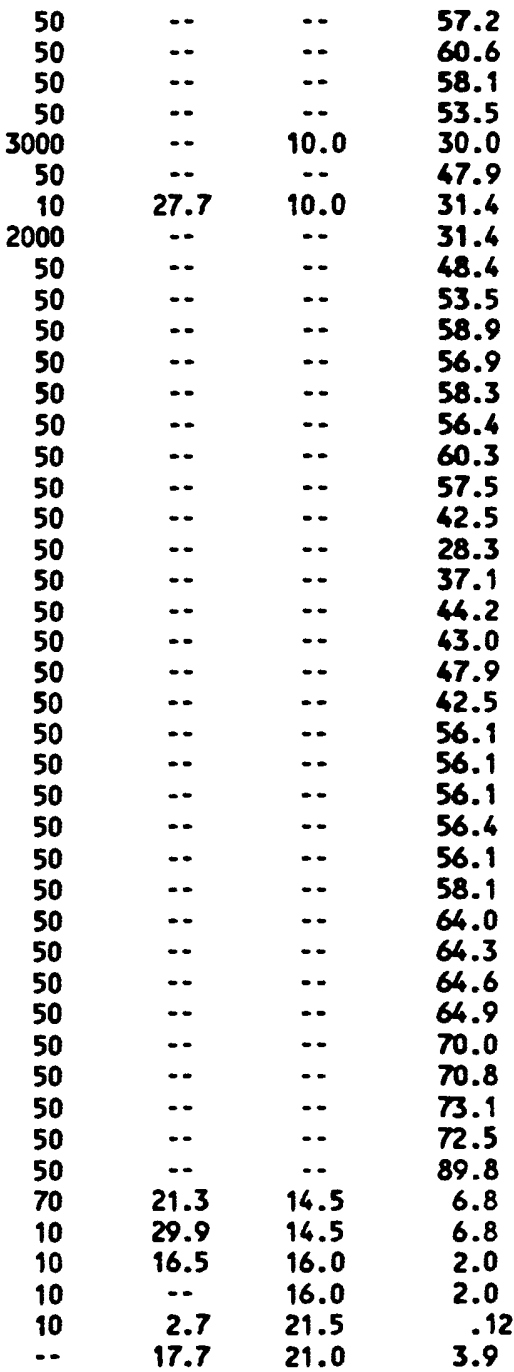

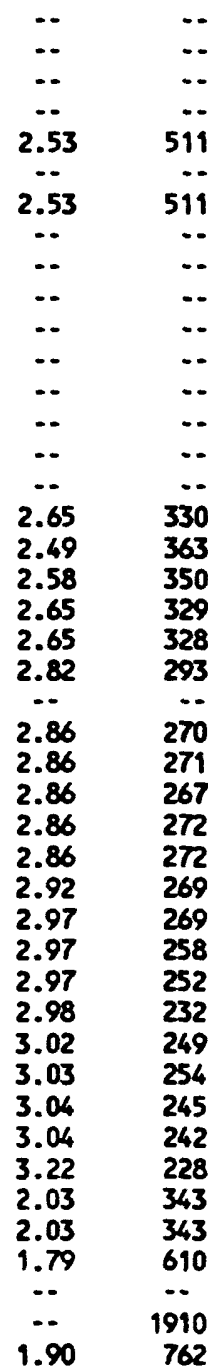

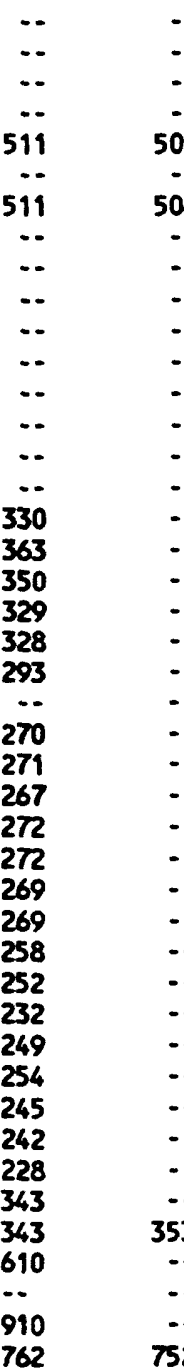

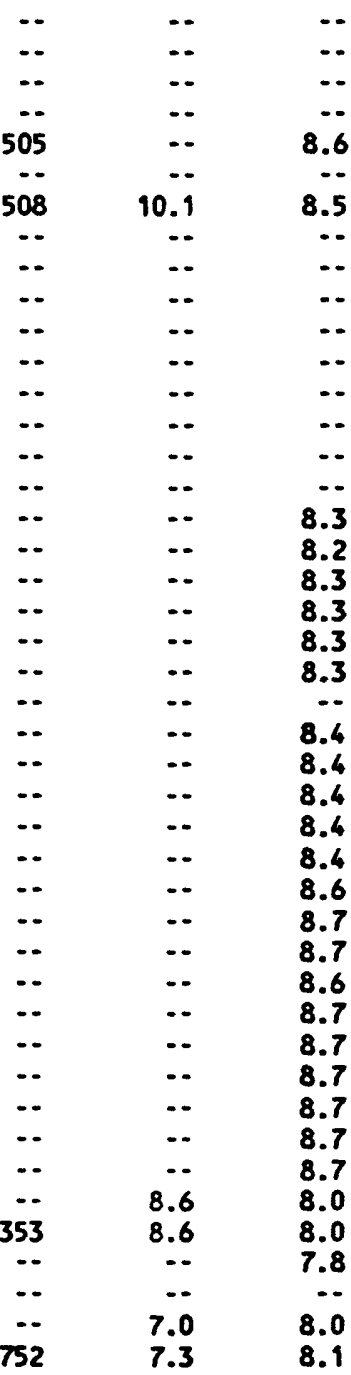


SURFACE-WATER DATA-Cont inued

CHEMICAL ANALYSES-Cont inued

STATION

MUMBER

09401000
DATE

03-04-91

03-04-91

03-04-91

03-04-91

03-05-91

03-05-91

03-05-91

03-05-91

03-08-91

03-08-91

03-08-91

03-08-91

03-08-91

03-09-91

03-09-91

03-09-91

04-04-91

$04-04-91$

04-05-91

$04-05-91$

04-05-91

04-06-91

04-06-91

04-09-91

04-09-91

04-09-91

04-09-91

04-09-91

04-09-91

04-10-91

04-10-91

04-10-91

04-10-91

04-10-91

04-10-91

04-11-91

$04-11-91$

04-11-91

$05-01-91$

05-01-91

05-09-91

05-09-91

09-06-91

09-09-91

\begin{tabular}{|c|c|c|c|c|c|c|c|c|}
\hline $\begin{array}{l}\text { PH } \\
\text { WATER } \\
\text { WHOLE } \\
\text { LAB } \\
\text { (STAND- } \\
\text { ARD } \\
\text { UN1TS) } \\
\text { (00403) }\end{array}$ & $\begin{array}{l}\text { ALKA- } \\
\text { LINITY } \\
\text { WAT DIS } \\
\text { FIX ENO } \\
\text { FIELD } \\
\text { CaCO3 } \\
(\mathrm{mg} / \mathrm{L}) \\
(39036)\end{array}$ & $\begin{array}{l}\text { ALKA- } \\
\text { LINITY } \\
\text { WAT DIS } \\
\text { TOT IT } \\
\text { FIELD } \\
\text { Cal as } \\
\text { CaCO3 } \\
\text { (39086) }\end{array}$ & $\begin{array}{l}\text { ALKA- } \\
\text { LINITY } \\
\text { LAB } \\
\text { (mg/L } \\
\text { as } \\
\text { CaCO3) } \\
(90410)\end{array}$ & $\begin{array}{l}\text { BICAR- } \\
\text { BONATE } \\
\text { HATER } \\
\text { OIS IT } \\
\text { FIELD } \\
\text { mg/L \&S } \\
\text { HCO3 } \\
(00453)\end{array}$ & 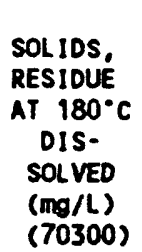 & $\begin{array}{l}\text { SOLIDS, } \\
\text { SUA OF } \\
\text { CONSTI - } \\
\text { TUENTS, } \\
\text { DIS- } \\
\text { SOL VED } \\
\text { (mg/L) } \\
(70301)\end{array}$ & $\begin{array}{l}\text { SOLIDS, } \\
\text { DIS- } \\
\text { SOLVED } \\
\text { (metric } \\
\text { tons } \\
\text { per } \\
\text { day) } \\
(70302)\end{array}$ & $\begin{array}{l}\text { NITRO- } \\
\text { GEN, } \\
\text { MMONIA } \\
\text { DIS- } \\
\text { SOLVED } \\
\text { (mg/L } \\
\text { as N) } \\
(00608)\end{array}$ \\
\hline
\end{tabular}

LITTLE COLORADO RIVER AT GRAMD FALLS, AZ-Continued

\begin{tabular}{|c|c|c|c|c|c|c|c|c|}
\hline -. & .. & $\cdots$ & $\cdots$ & $\cdots$ & $\cdots$ & $\cdots$ & $\ldots$ & $\ldots$ \\
\hline$\cdots$ & $\cdots$ & $\cdots$ & $\cdots$ & -- & $\cdots$ & $\cdots$ & .. & .. \\
\hline -. & - & - & $\cdots$ & $\cdots$ & $\cdots$ & $\cdots$ & -- & $\cdots$ \\
\hline$\cdots$ & $\cdots$ & $\cdots$ & $\cdots$ & $\cdots$ & $\cdots$ & $\cdots$ & $\cdots$ & $\cdots$ \\
\hline 8.3 & 90 & -. & 127 & $\cdots$ & 299 & 294 & 856 & . \\
\hline - & -. & $\cdots$ & -. & $\cdots$ & $\cdots$ & $\cdots$ & $\cdots$ & -. \\
\hline 8.2 & 90 & $\cdots$ & 130 & - & 300 & 311 & 899 & -. \\
\hline$\cdots$ & -. & $\cdots$ & $\cdots$ & $\cdots$ & $\cdots$ & $\cdots$ & $\cdots$ & $\cdots$ \\
\hline - & -. & $\cdots$ & $\cdots$ & $\cdots$ & $\cdots$ & $\cdots$ & -- & -. \\
\hline$\cdots$ & $\cdots$ & $\cdots$ & $\cdots$ & $\cdots$ & $\cdots$ & $\cdots$ & $\cdots$ & $\cdots$ \\
\hline$\cdots$ & -. & $\cdots$ & $\cdots$ & $\cdots$ & $\cdots$ & $\ldots$ & $\cdots$ & .. \\
\hline$\cdots$ & $\cdots$ & $\cdots$ & $\cdots$ & $\cdots$ & $\cdots$ & $\cdots$ & $\cdots$ & - \\
\hline$\cdots$ & $\cdots$ & $\cdots$ & $\cdots$ & $\cdots$ & $\cdots$ & $\cdots$ & $\cdots$ & $\cdots$ \\
\hline$\cdots$ & $\cdots$ & $\cdots$ & $\cdots$ & $\cdots$ & $\cdots$ & $\cdots$ & $\cdots$ & $\cdots$ \\
\hline$\cdots$ & $\cdots$ & $\cdots$ & 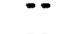 & $\cdots$ & $\because$ & $\because$ & $\cdots$ & $\cdots$ \\
\hline$\cdots$ & $\cdots$ & $\cdots$ & $\cdots$ & 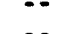 & $\because$ & $\because$ & $\because$ & $\cdots$ \\
\hline .. & $\ldots$ & $\ldots$ & $\ldots$ & $\ldots$ & $\ldots$ & $\cdots$ & $\cdots$ & $\cdots$ \\
\hline .. & .. & $\ldots$ & .. & .. & .. & .. & .. & $\ldots$ \\
\hline -. & .. & -. & .. & .. & .. & -. & -. & .. \\
\hline .. & $\ldots$ & $\cdots$ & -. & $\cdots$ & $\cdots$ & $\cdots$ & - & $\ldots$ \\
\hline -. & -. & $\cdots$ & $\cdots$ & $\cdots$ & $\cdots$ & $\cdots$ & -. & $\cdots$ \\
\hline$\cdots$ & $\cdots$ & $\cdots$ & -- & $\cdots$ & $\cdots$ & $\cdots$ & $\cdots$ & $\cdots$ \\
\hline$\cdots$ & $\cdots$ & $\cdots$ & $\cdots$ & $\cdots$ & $\cdots$ & $\because$ & $\cdots$ & -- \\
\hline$\cdots$ & $\cdots$ & $\cdots$ & $\cdots$ & $\cdots$ & $\cdots$ & $\cdots$ & $-\cdot$ & $\cdots$ \\
\hline$\cdots$ & $\cdots$ & $\cdots$ & $\cdots$ & $\cdots$ & $\cdots$ & $\cdots$ & $-\cdot$ & -- \\
\hline$\cdots$ & $\cdots$ & $\cdots$ & $\cdots$ & $\because$ & $\cdots$ & - & $\cdots$ & - \\
\hline$\cdots$ & $\cdots$ & $\cdots$ & $\cdots$ & $\cdots$ & $\because$ & $\cdots$ & $\cdots$ & $\cdots$ \\
\hline$\cdots$ & $\cdots$ & $\because$ & $\cdots$ & $\cdots$ & $\cdots$ & $\cdots$ & $\cdots$ & $\cdots$ \\
\hline$\ldots$ & $\cdots$ & $\because$ & $\because$ & $\because$ & $\because$ & 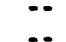 & $\because$ & $\cdots$ \\
\hline 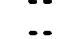 & $\ldots$ & $\ldots$ & $\cdots$ & $\ldots$ & $\ldots$ & $\ldots$ & $\ldots$ & $\ldots$ \\
\hline .. & .. & $\ldots$ & .. & $\ldots$ & $\ldots$ & $\ldots$ & .. & .. \\
\hline -. & -. & -. & .. & .. & .. & -. & .. & .. \\
\hline -. & $\cdots$ & $\cdots$ & -. & .. & $\ldots$ & - & -. & -. \\
\hline -. & $\cdots$ & - & -. & $\cdots$ & - & $\cdots$ & -. & -. \\
\hline$\cdots$ & $\cdots$ & $\cdots$ & $\cdots$ & $\cdots$ & $\cdots$ & - & 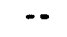 & $\cdots$ \\
\hline$\cdots$ & $\cdots$ & $\cdots$ & $\cdots$ & $\cdots$ & $\cdots$ & $\cdots$ & $\cdots$ & $\cdots$ \\
\hline -. & 50 & $\because$ & -. & 69 & $\cdots$ & 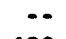 & 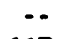 & $\cdots$ \\
\hline 8.4 & 50 & 63 & 65 & 61 & $\cdots$ & 180 & 117 & $\cdots$ \\
\hline$\cdots$ & $\cdots$ & $\cdots$ & $\cdots$ & $\cdots$ & $\cdots$ & $\cdots$ & $\cdots$ & $\cdots$ \\
\hline- & $\cdots$ & $\because$ & $\cdots$ & די & $\cdots$ & $\because$ & $\cdots$ & $\because$ \\
\hline 8.2 & $\cdots$ & $\begin{array}{l}156 \\
159\end{array}$ & $\cdots$ & $\begin{array}{l}193 \\
184\end{array}$ & 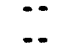 & 427 & 159 & .070 \\
\hline
\end{tabular}




\section{SURFACE-WATER DATA-Cont inued \\ CHEMICAL ANALYSES-Continued}

\begin{tabular}{|c|c|c|c|c|c|c|c|c|c|c|}
\hline $\begin{array}{l}\text { STATION } \\
\text { MUMBER }\end{array}$ & DATE & $\begin{array}{c}\text { NITRO- } \\
\text { GEN, } \\
\text { MITRITE } \\
\text { DIS- } \\
\text { SOLVED } \\
\text { (mg/L } \\
\text { os N) } \\
(00613)\end{array}$ & $\begin{array}{c}\text { NITRO- } \\
\text { GEN, } \\
\text { NO2+NO3 } \\
\text { DIS- } \\
\text { SOLVED } \\
\text { (mo/L } \\
\text { as M) } \\
(00631)\end{array}$ & $\begin{array}{l}\text { MITRO- } \\
\text { GEN,NM- } \\
\text { MONIA + } \\
\text { ORGANIC } \\
\text { TOTAL } \\
(\text { Mo/L } \\
\text { Bs N) } \\
(00625)\end{array}$ & $\begin{array}{l}\text { PHOS- } \\
\text { PHORUS } \\
\text { DIS- } \\
\text { SOLVED } \\
\text { (mo/L } \\
\text { Os P) } \\
(00666)\end{array}$ & $\begin{array}{l}\text { PHOS- } \\
\text { PHORUS } \\
\text { TOTAL } \\
\text { (mo/L } \\
\text { os P) } \\
(00665)\end{array}$ & $\begin{array}{l}\text { PHOS- } \\
\text { PHORUS } \\
\text { ORTHO, } \\
\text { DIS- } \\
\text { SOL VED } \\
\text { (mg/L } \\
\text { os P) } \\
(00671 \text { ) }\end{array}$ & $\begin{array}{l}\text { PHOS- } \\
\text { PHATE, } \\
\text { ORTHO, } \\
\text { DIS- } \\
\text { SOLVED } \\
\text { (mo/L } \\
\text { os POL) } \\
\text { (0OS60) }\end{array}$ & $\begin{array}{l}\text { CARBOW, } \\
\text { ORGANIC } \\
\text { TOTAL } \\
\text { (mo/L } \\
\text { as C) } \\
(00680)\end{array}$ & $\begin{array}{l}\text { HARD- } \\
\text { MESS } \\
\text { TOTAL } \\
\text { (mo/L } \\
\text { os } \\
\text { Caco3) } \\
(00900)\end{array}$ \\
\hline
\end{tabular}

LITTLE COLORADO RIVER AT GRAD FALLS, AZ-Continued

$09401000 \quad 03-04-91$
$03-04-91$
$03-04-91$
$03-04-91$
$03-05-91$
$03-05-91$
$03-05-91$
$03-05-91$
$03-08-91$
$03-08-91$
$03-08-91$
$03-08-91$
$03-08-91$
$03-09-91$
$03-09-91$
$03-09-91$
$04-04-91$
$04-04-91$
$04-05-91$
$04-05-91$
$04-05-91$
$04-06-91$
$04-06-91$
$04-09-91$
$04-09-91$
$04-09-91$
$04-09-91$
$04-09-91$
$04-09-91$
$04-10-91$
$04-10-91$
$04-10-91$
$04-10-91$
$04-10-91$
$04-10-91$
$04-11-91$
$04-11-91$
$04-11-91$
$05-01-91$
$05-01-91$
$05-09-91$
$05-09-91$
$09-06-91$
$09-09-91$

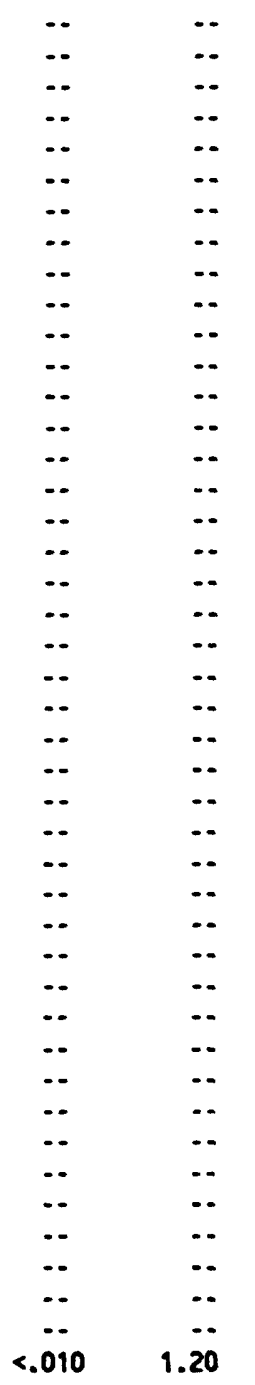

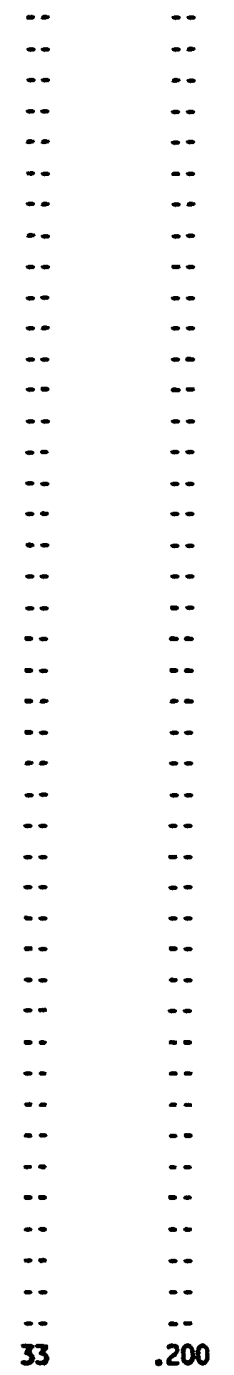

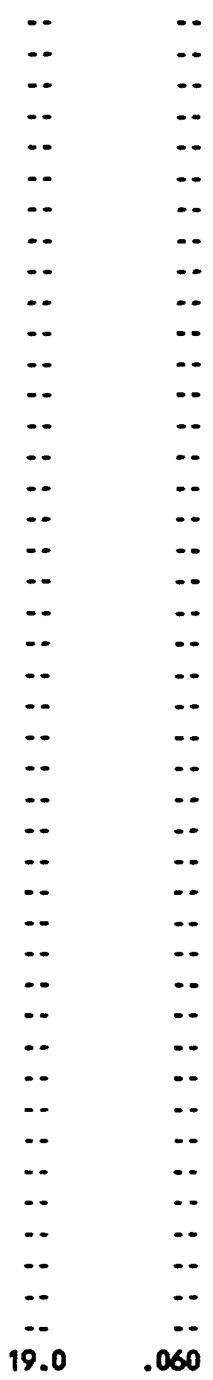

\begin{tabular}{|c|c|}
\hline$\cdots$ & $\cdots$ \\
\hline$\cdots$ & $\cdots$ \\
\hline$\overline{-}$ & $\because-$ \\
\hline$\cdots$ & 93 \\
\hline$\cdots$ & $\therefore$ \\
\hline$\cdots$ & 96 \\
\hline$\because$ & 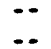 \\
\hline .. & $\ldots$ \\
\hline$\cdots$ & $\cdots$ \\
\hline$\because$ & $\ddot{\cdots}$ \\
\hline$\therefore$ & .. \\
\hline$\cdots$ & - \\
\hline$\ddot{-}$ & $\because$ \\
\hline$\therefore$ & 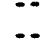 \\
\hline$\cdots$ & .. \\
\hline$\cdots$ & $\cdots$ \\
\hline$\because$ & $\because$ \\
\hline -. & -. \\
\hline -- & -. \\
\hline 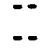 & $\ddot{-}$ \\
\hline$-\cdot$ & $\cdots$ \\
\hline$\cdots$ & $\cdots$ \\
\hline$\cdots$ & 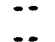 \\
\hline .. & -. \\
\hline -. & $\cdots$ \\
\hline - & $\cdots$ \\
\hline$\because$. & $\because$ \\
\hline 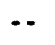 & .. \\
\hline - & $\cdots$ \\
\hline$\cdots$ & $\because$ \\
\hline$\therefore$ & .. \\
\hline$\because$ & $\cdots$ \\
\hline & $\begin{array}{l}\cdots \\
-\end{array}$ \\
\hline 18 & $\ldots$ \\
\hline
\end{tabular}


SURFACE-MATER DATA-Cont inued

CHEMICAL AMALYSES-Contínued

STATION

MUMBER

DATE

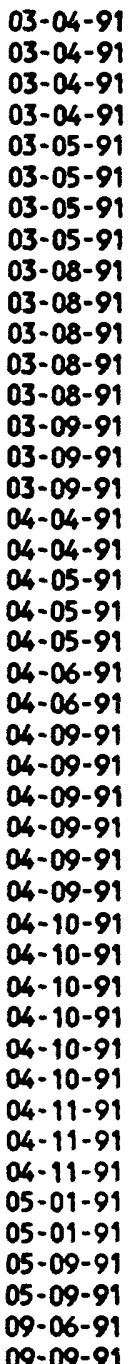

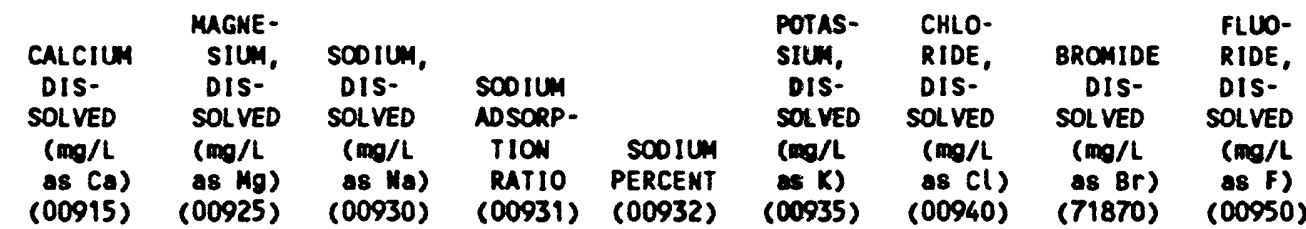

LITTLE COLORADO RIVER AT GRAND FALLS, AZ-Continued

$09401000 \quad 03-04-91$
$03-04-91$
$03-04-91$
$03-04-91$
$03-05-91$
$03-05-91$
$03-05-91$
$03-05-91$
$03-08-91$
$03-08-91$
$03-08-91$
$03-08-91$
$03-08-91$
$03-09-91$
$03-09-91$
$03-09-91$
$04-04-91$
$04-04-91$
$04-05-91$
$04-05-91$
$04-05-91$
$04-06-91$
$04-06-91$
$04-09-91$
$04-09-91$
$04-09-91$
$04-09-91$
$04-09-91$
$04-09-91$
$04-10-91$
$04-10-91$
$04-10-91$
$04-10-91$
$04-10-91$
$04-10-91$
$04-11-91$
$04-11-91$
$04-11-91$
$05-01-91$
$05-01-91$
$05-09-91$
$05-09-91$
$09-06-91$
$09-09-91$

\begin{tabular}{|c|c|c|c|c|c|c|c|c|}
\hline-- & -- & -. & -- & -. & -. & -- & -- & - \\
\hline-- & -- & -. & -- & -- &.- & - & - & - \\
\hline -- & -. & -. & -- & $\ldots$ & $\cdots$ & - & $\cdots$ & $\cdots$ \\
\hline -. & -- & 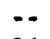 & - & -- & - & $=$ & - & -. \\
\hline 6.7 & 1.4 & 96 & 9 & 90 & 1.5 & 50 & .30 & .40 \\
\hline$=$ & $\cdots$ & $\cdots$ & -- & $\cdots$ & -- & -- & $\because$ & -- \\
\hline 7.1 & 2.5 & 94 & 8 & 87 & 2.0 & 48 & .29 & .40 \\
\hline-- & $-\cdot$ & - & -- & 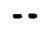 & $-\cdot$ & - & -- & -- \\
\hline$\cdots$ & $\cdots$ & $\cdots$ & -- & -- & 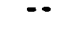 & -- & -- & -- \\
\hline$\cdots$ & $\because$ & $\cdots$ & -- & -- & -- & 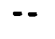 & $\cdots$ & -- \\
\hline$\because$ & $=$ & - & -- & 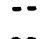 & -- & $\cdots$ & $\cdots$ & $\cdots$ \\
\hline$\because$ & $\because$ & $\because$ & $\because$ & $\cdots$ & - & $\overline{-}$ & -- & - \\
\hline - & $\ldots$ & $\ldots$ & $\ldots$ & $\ldots$ & -- & $\ldots$ & - & $\cdots$ \\
\hline$\cdots$ & .. & $\ldots$ & -- & .- & -. & -. & .. & -. \\
\hline 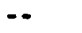 & -- & -- & -. & $\cdots$ & -- & -. & .. & -. \\
\hline -. & $\cdots$ & -- & $\cdots$ & -- & -- & - & -. & - \\
\hline$\cdots$ & $\cdots$ & -- & $\cdots$ & $\cdots$ & $-\cdot$ & -- & -- & -- \\
\hline$\cdots$ & $\cdots$ & -- & $\cdots$ & 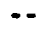 & -- & $\cdots$ & -- & $\cdots$ \\
\hline$\cdots$ & -- & $\cdots$ & -- & $\cdots$ & -- & $\cdots$ & $-\cdot$ & $\cdots$ \\
\hline$\cdots$ & -- & $\cdots$ & $=$ & -- & $\cdots$ & $\cdots$ & -- & $=$ \\
\hline$\cdots$ & -- & -- & $\cdots$ & $\cdots$ & $\cdots$ & -- & $\cdots$ & $\cdots$ \\
\hline$\because$ & -- & -- & -- & -- & -- & $=$ & -- & -- \\
\hline$\because$ & 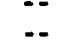 & -- & $\therefore$ & 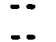 & $\because$ & 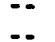 & $\because$ & $=-$ \\
\hline$\ldots$ & -. & $\ldots$ & $\ldots$ & $\ldots$ & .- & $\ldots$ & $\ldots$ & $\ldots$ \\
\hline - & - & -- & -- & $\cdots$ & -. & .. & .. & .- \\
\hline -- & -- & -- & 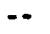 & -- & $-\cdot$ & $\cdots$ & -. & .. \\
\hline$\cdots$ & 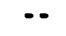 & -- & $\cdots$ & $\cdots$ & -- & -. & -- & -- \\
\hline-- & -- & -. & -- & $\cdots$ & -- & -- & -- & -. \\
\hline-- & -- & $\cdots$ & -- & $\cdots$ & -- & $\cdots$ & -- & -. \\
\hline-- & -- & - & $-\cdot$ & $\cdots$ & $=-$ & -- & $\cdots$ & -. \\
\hline$\cdots$ & -- & $\cdots$ & $\cdots$ & $\cdots$ & $\cdots$ & $\cdots$ & $\cdots$ & $\cdots$ \\
\hline-- & -- & $\cdots$ & $-\cdot$ & -- & $-\cdot$ & -. & -- & -. \\
\hline$\cdots$ & -- & $\cdots$ & $\cdots$ & -- & -- & $\cdots$ & -- & $\cdots$ \\
\hline - & $\cdots$ & $\cdots$ & $\cdots$ & $\cdots$ & $\cdots$ & $\cdots$ & $\cdots$ & $\cdots$ \\
\hline$\cdots$ & - & $\because$ & $\cdots$ & -- & $\cdots$ & $\cdots$ & $\cdots$ & $\cdots$ \\
\hline 15 & 3.1 & 49 & 3 & $\cdots$ & $\therefore$ & $\cdots$ & $\because$ & $\cdots$ \\
\hline 15 & 2.9 & 48 & 3 & 67 & 1.2 & 59 & .. & .10 \\
\hline- & -- & $\cdots$ & $\cdots$ & $\cdots$ & -- & $\cdots$ & $\cdots$ & $\cdots$ \\
\hline.- & -- & - & -- & $\cdots$ & -. & -- & -- & $\cdots$ \\
\hline 9.3 & 1.9 & $\ddot{i n}$ & $\ddot{\theta}$ & 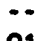 & $\because$ & $\ddot{x}$ & $\ddot{c}$ & 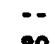 \\
\hline Y.5 & 1.9 & 150 & 12 & 91 & 2.3 & 75 & 1.5 & 80 \\
\hline
\end{tabular}


SURFACE - MATER DATA-Cont inued

CHEMICAL AKALYSES-Continued

STATION

NUMBER

09401000
$03-04-91$

$03-04-91$

03-04-91

03-04-91

03-05-91

03-05-91

03-05-91

03-05-91

03-08-91

03-08-91

03-08-91

03-08-91

03-08-91

03-09-91

$03-09-91$

03-09-91

$04-04-91$

$04-04-91$

$04-05-91$

04-05-91

$04-05-91$

04-06-91

04-06-91

04-09-91

04-09-91

04-09-91

04-09-91

04-09-91

04-09-91

04-10-91

04-10-91

$04-10-91$

$04-10-91$

$04-10-91$

$04-10-91$

04-11-91

$04-11-91$

04-11-91

05-01-91

05-01-91

05-09-91

05-09-91

09-06-91

09-09-91

\begin{tabular}{|c|c|c|c|c|c|c|c|c|}
\hline $\begin{array}{l}\text { SILICA, } \\
\text { DIS- } \\
\text { SOLVED } \\
\text { (mg/L } \\
\text { as } \\
\text { sio2) } \\
(00955)\end{array}$ & $\begin{array}{c}\text { SULFATE } \\
\text { DIS- } \\
\text { SOLVED } \\
\text { (mg/l } \\
\text { as SO4) } \\
\text { (00945) }\end{array}$ & $\begin{array}{c}\text { ARSENIC } \\
\text { DIS- } \\
\text { SOLVED } \\
(\mu g / L \\
\text { as As) } \\
(01000)\end{array}$ & $\begin{array}{l}\text { BARIUH, } \\
\text { DIS- } \\
\text { SOLVED } \\
\text { ( } \mu g / L \\
\text { as Ba) } \\
\text { (01005) }\end{array}$ & $\begin{array}{l}\text { BERYL- } \\
\text { LIUH, } \\
\text { OIS- } \\
\text { SOLVED } \\
(\mu g / L \\
\text { as Be) } \\
(01010)\end{array}$ & $\begin{array}{c}\text { BORON, } \\
\text { OIS- } \\
\text { SOLVED } \\
(\mu g / L \\
\text { as B) } \\
(01020)\end{array}$ & $\begin{array}{c}\text { CADHIUM } \\
\text { DIS- } \\
\text { SOLVED } \\
\text { ( } \mu 9 / L \\
\text { as Cd) } \\
(01025)\end{array}$ & $\begin{array}{l}\text { CHRO- } \\
\text { HIUY, } \\
\text { DIS- } \\
\text { SOLVED } \\
\text { ( } \mu g / L \\
\text { as Cr) } \\
(01030)\end{array}$ & $\begin{array}{c}\text { COBALT, } \\
\text { DIS- } \\
\text { SOLVED } \\
(\mu g / L \\
\text { as CO) } \\
(01035)\end{array}$ \\
\hline
\end{tabular}

LITTLE COLORADO RIVER AT GRAND FALLS, AZ-contimued

\begin{tabular}{|c|c|c|c|c|c|c|c|c|}
\hline$\cdots$ & $\cdots$ & $\cdots$ & -. & $\cdots$ & $\cdots$ & $\cdots$ & $\cdots$ & $\cdots$ \\
\hline$\cdots$ & $\cdots$ & $\cdots$ & $\cdots$ & $\cdots$ & $\cdots$ & $\cdots$ & $\cdots$ & $\cdots$ \\
\hline$\cdots$ & $\cdots$ & $\cdots$ & $\cdots$ & $\cdots$ & $\cdots$ & $\cdots$ & $\cdots$ & $\cdots$ \\
\hline$\cdots$ & $\cdots$ & $\cdots$ & $\cdots$ & $\cdots$ & $\cdots$ & $\cdots$ & $\cdots$ & - \\
\hline 12 & 49 & 3 & 13 & $<.5$ & 120 & $<1.0$ & $<5$ & $<3$ \\
\hline .. & 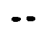 & -. & . & $\cdots$ & $\cdots$ & .. & $\cdots$ & - \\
\hline 30 & 46 & 3 & 19 & $<.5$ & 120 & $<1.0$ & $<5$ & $<3$ \\
\hline$\cdots$ & $\cdots$ & $\cdots$ & - & $\cdots$ & $\cdots$ & $\cdots$ & $\cdots$ & - \\
\hline$\cdots$ & $\cdots$ & $\cdots$ & $\cdots$ & $\cdots$ & $\cdots$ & $\cdots$ & $\cdots$ & $\cdots$ \\
\hline$\cdots$ & $\cdots$ & $\cdots$ & $\cdots$ & $\cdots$ & $\cdots$ & $\cdots$ & $\cdots$ & - \\
\hline$\cdots$ & $\cdots$ & $\cdots$ & $\cdots$ & $\cdots$ & -- & $\cdots$ & $\cdots$ & $\cdots$ \\
\hline$\cdots$ & $\cdots$ & $\cdots$ & $\cdots$ & $\cdots$ & $\cdots$ & $\cdots$ & $\cdots$ & $\cdots$ \\
\hline$\cdots$ & $\cdots$ & $\cdots$ & $\cdots$ & $\cdots$ & $\cdots$ & $\cdots$ & $\cdots$ & $\cdots$ \\
\hline$\cdots$ & $\cdots$ & $\cdots$ & $\cdots$ & $\cdots$ & $\cdots$ & $\cdots$ & $\cdots$ & $\cdots$ \\
\hline$\cdots$ & $\cdots$ & $\cdots$ & $\cdots$ & $\cdots$ & $\cdots$ & $\cdots$ & $\cdots$ & $\cdots$ \\
\hline$\cdots$ & $\cdots$ & $\cdots$ & - & $\cdots$ & $\cdots$ & $\cdots$ & $\cdots$ & $\cdots$ \\
\hline$\cdots$ & $\cdots$ & $\cdots$ & $\cdots$ & $\cdots$ & $\cdots$ & $\cdots$ & $\cdots$ & $\cdots$ \\
\hline$\cdots$ & $\cdots$ & $\cdots$ & $\cdots$ & $\cdots$ & $\cdots$ & $\cdots$ & $\cdots$ & $\cdots$ \\
\hline$\cdots$ & $\cdots$ & $\cdots$ & -- & $\cdots$ & $\cdots$ & $\cdots$ & $\cdots$ & - \\
\hline$\cdots$ & $\cdots$ & $\cdots$ & $\cdots$ & $\cdots$ & $\cdots$ & $\cdots$ & $\cdots$ & - \\
\hline$\cdots$ & $\cdots$ & $\cdots$ & $\cdots$ & $\cdots$ & -- & $\cdots$ & $\cdots$ & - \\
\hline$\because$ & $\because$ & $\because$ & $\because$ & $\because$ & $\cdots$ & $\because$ & $\because$ & $\cdots$ \\
\hline$\ldots$ & $\because$ & $\therefore$ & $\ldots$ & $\because$ & $\because$ & $\because$ & 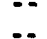 & - \\
\hline .. & .. & $\ldots$ & $\ldots$ & $\ldots$ & $\ldots$ & $\ldots$ & $\ldots$ & $\ldots$ \\
\hline$\cdots$ & .. & -. & -. & $\ldots$ & $\ldots$ & .. & .. & .. \\
\hline$\cdots$ & -. & -. & - & -. & -. & -. & -. & 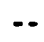 \\
\hline$\cdots$ & $\cdots$ & -. & $\cdots$ & $\cdots$ & $\cdots$ & $\cdots$ & $\cdots$ & 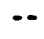 \\
\hline$\cdots$ & $\cdots$ & $\cdots$ & $\cdots$ & $\cdots$ & $\cdots$ & $\cdots$ & $\cdots$ & $\cdots$ \\
\hline$\cdots$ & $\cdots$ & $\cdots$ & $\cdots$ & $\cdots$ & $\cdots$ & $\cdots$ & $\cdots$ & $\cdots$ \\
\hline$\cdots$ & $\cdots$ & $\cdots$ & $\cdots$ & $\cdots$ & $\cdots$ & $\cdots$ & $\cdots$ & $\cdots$ \\
\hline$\cdots$ & $\cdots$ & $\cdots$ & $\cdots$ & $\cdots$ & $\cdots$ & $\cdots$ & $\cdots$ & - \\
\hline$\cdots$ & $\cdots$ & $\cdots$ & $\cdots$ & $\cdots$ & $\because$ & $\cdots$ & $\cdots$ & \\
\hline$\cdots$ & $\cdots$ & $\cdots$ & $\cdots$ & $\cdots$ & $\cdots$ & $\cdots$ & $\cdots$ & - \\
\hline$\cdots$ & 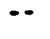 & $\cdots$ & $\cdots$ & $\cdots$ & $\cdots$ & $\because$ & $\cdots$ & $\cdots$ \\
\hline$\cdots$ & $\cdots$ & $\because$ & 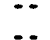 & $\because$ & $\because$ & $\because$ & $\because$ & 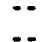 \\
\hline$\cdots$ & $\because$ & 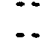 & $\cdots$ & $\cdots$ & $\cdots$ & $\cdots$ & 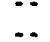 & - \\
\hline 6.4 & $\because$ & $\therefore$ & 33 & $<.5$ & .. & $<1.0$ & $<5$ & $<3$ \\
\hline 5.4 & 18 & -. & $\cdots$ & -. & 20 & -. & $\cdots$ & .. \\
\hline$\cdots$ & $\cdots$ & $\cdots$ & $\cdots$ & $\cdots$ & $\cdots$ & $\cdots$ & $\cdots$ & \\
\hline$\cdots$ & $\cdots$ & $\cdots$ & $\cdots$ & $\cdots$ & $\cdots$ & $\cdots$ & $\cdots$ & \\
\hline$\cdots$ & 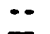 & $\cdots$ & $\cdots$ & $\cdots$ & $\cdots$ & $\because$ & $\because$ & \\
\hline 15 & 75 & 6 & 32 & $<.5$ & $\cdots$ & $<1.0$ & $<5$ & \\
\hline
\end{tabular}




\section{STATION}

MUMBER

09401000

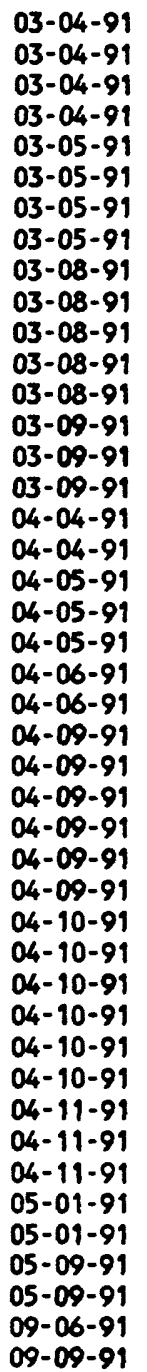

DATE

\begin{tabular}{|c|c|c|c|c|c|c|c|c|c|}
\hline ATE & $\begin{array}{c}\text { COPPER, } \\
\text { DIS- } \\
\text { SOLVED } \\
(\mu g / L \\
\text { As CU) } \\
(01040)\end{array}$ & $\begin{array}{l}\text { IRON, } \\
\text { DIS- } \\
\text { SOLVED } \\
\text { ( } \mu \text { g/L } \\
\text { as Fe) } \\
(01046)\end{array}$ & $\begin{array}{l}\text { LEAD, } \\
\text { DIS- } \\
\text { SOLVED } \\
\text { ( } \mu g / L \\
\text { OS Pb) } \\
(01049)\end{array}$ & $\begin{array}{l}\text { MANGA- } \\
\text { NESE, } \\
\text { DIS- } \\
\text { SOLVED } \\
\text { ( } \mu 9 / L \\
\text { as Mn) } \\
(01056)\end{array}$ & $\begin{array}{c}\text { MOLYB- } \\
\text { DENUY, } \\
\text { DIS- } \\
\text { SOLVED } \\
(\mu g / L \\
\text { as MO) } \\
(01060)\end{array}$ & $\begin{array}{l}\text { NICKEL, } \\
\text { DIS- } \\
\text { SOLVED } \\
\text { ( } \mu g / L \\
\text { as Ni) } \\
(01065)\end{array}$ & $\begin{array}{c}\text { SILVER, } \\
\text { DIS- } \\
\text { SOLVED } \\
\text { ( } \mu g / L \\
\text { IS Ag) } \\
\text { (01075) }\end{array}$ & $\begin{array}{c}\text { STRON- } \\
\text { TIUM, } \\
\text { DIS- } \\
\text { SOLVED } \\
\text { ( } \mu g / L \\
\text { as SR) } \\
(01080)\end{array}$ & $\begin{array}{l}\text { VANA- } \\
\text { DIUA, } \\
\text { DIS- } \\
\text { SOLVED } \\
\text { ( } \mu g / L \\
\text { As V) } \\
\text { (01085) }\end{array}$ \\
\hline
\end{tabular}

LITTLE COLORADO RIVER AT GRAND FALLS, AZ-Contimued

\begin{tabular}{|c|c|c|c|c|c|c|c|c|}
\hline$\cdots$ & -- & $\cdots$ & -- & -- & -- & $\cdots$ & -- & -- \\
\hline$\cdots$ & 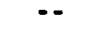 & $\cdots$ & $\cdots$ & -- & $\cdots$ & $\cdots$ & $\cdots$ & - \\
\hline -. & $\cdots$ & $\cdots$ & -- & $\cdots$ & -- & $-\cdot$ & -- & $\cdots$ \\
\hline$\because$ & $\because$ & $\cdots$ & $\cdots$ & $=-$ & $=$ & $=-$ & $=$ & -. \\
\hline 10 & $500 \$$ & $<10 i$ & 5 & $<10$ & $<10$ & $<1.0$ & 170 & 10 \\
\hline - & -- & $\cdots$ & $\cdots$ & - & - & -- & -- & - \\
\hline 40 & $2200\}$ & $<10 i$ & 24 & $<10$ & $<10$ & $<1.0$ & 160 & 15 \\
\hline$\cdots$ & $\cdots$ & $\cdots$ & $\cdots$ & $=$ & 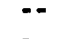 & $=$ & $\because$ & $\cdots$ \\
\hline$\cdots$ & $\cdots$ & $\because$ & $\cdots$ & -- & $\cdots$ & -- & $\cdots$ & $\cdots$ \\
\hline$\cdots$ & $\cdots$ & $\because$ & -- & $\cdots$ & $\cdots$ & $\cdots$ & $\cdots$ & $\cdots$ \\
\hline 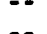 & $\because$ & - & - & -- & -- & -- & $\because$ & - \\
\hline .. & $\ldots$ & $\cdots$ & $\therefore$ & $\ldots$ & $\ldots$ & 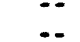 & $\cdots$ & $\cdots$ \\
\hline -- & -. & $\ldots$ & .. & .- & -. & -- & $\ldots$ & .. \\
\hline-- & $\ldots$ & $\cdots$ & -- & -- & -- & -- & -- & -. \\
\hline$\cdots$ & - & -- & - & -- & -. & -- & $\because$ & -. \\
\hline$\cdots$ & -- & -- & -- & $\cdots$ & -- & -- & -- & $\cdots$ \\
\hline$\cdots$ & $\cdots$ & $\cdots$ & $-\cdot$ & -- & -- & -- & -- & $\cdots$ \\
\hline$\cdots$ & -- & $\cdots$ & $\because$ & -- & -- & $-\cdot$ & -- & $\cdots$ \\
\hline$-\cdot$ & $-\cdot$ & $\cdots$ & $-\cdot$ & -- & $-\cdot$ & $\cdots$ & $\cdots$ & - \\
\hline$\cdots$ & $\cdots$ & $\cdots$ & $\cdots$ & $\cdots$ & $\cdots$ & $\cdots$ & $\cdots$ & $\cdots$ \\
\hline$\cdots$ & $\because$ & $\because$ & $\cdots$ & $\because$ & $\because$ & $\because$ & $\because$ & $\cdots$ \\
\hline 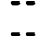 & $\because$ & $\because$ & $\because$ & - & $\because$ & $\because$ & -- & $=-$ \\
\hline$\ldots$ & $\ldots$ & $\ldots$ & $\ldots$ & 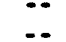 & -- & 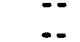 & -- & $=$ \\
\hline -. & $\ldots$ & $\ldots$ & .. & - & - & $\ldots$ & $\ldots$ & -. \\
\hline$\cdots$ & -- & -- & $\cdots$ & -- & -- & -- & $\cdots$ & - \\
\hline$-\cdot$ & $=$ & - & $-\cdot$ & -- & -- & -- & - & $\cdots$ \\
\hline- & $\cdots$ & $\cdots$ & - & $=-$ & $\cdots$ & - & - & $\cdots$ \\
\hline-- & -- & $\cdots$ & $\cdots$ & -- & -- & -- & $\cdots$ & $\cdot$ \\
\hline-- & -- & $\cdots$ & $\cdots$ & $\cdots$ & -- & -- & -- & $\cdots$ \\
\hline$\because$ & $\because$ & $\because$ & $\cdots$ & -- & -- & -- & -- & -- \\
\hline$\cdots$ & $\cdots$ & $\cdots$ & $-\cdot$ & -- & -- & -- & -- & - \\
\hline -. & $\cdots$ & $\cdots$ & $\cdots$ & $\cdots$ & $\cdots$ & $\cdots$ & -- & - \\
\hline$\cdots$ & $\cdots$ & $\cdots$ & $\cdots$ & $\cdots$ & $\cdots$ & $\cdots$ & $\cdots$ & - \\
\hline$\because$ & $\cdots$ & $\cdots$ & $\cdots$ & $\cdots$ & $\cdots$ & $\cdots$ & $\cdots$ & - \\
\hline$\cdots$ & $\cdots$ & $\because$ & $\because$ & $\because$ & $\cdots$ & $\cdots$ & $\because$ & 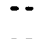 \\
\hline 10 & 160 & $<10 i$ & 5 & $<10$ & $<10$ & $<1.0$ & 360 & $<6$ \\
\hline$\cdots$ & 50 & $\cdots$ & 2 & -. & -. & - & -. & $\ldots$ \\
\hline$\cdots$ & $\cdots$ & $\cdots$ & -- & -- & $-\cdot$ & $-\cdot$ & $\cdots$ & 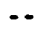 \\
\hline$\cdots$ & -- & $\cdots$ & -- & -- & -- & -- & -- & \\
\hline 10 & 59 & $\because$ & $\overline{2}$ & $\ddot{-}$ & $\because-$ & $=$ & $=-$ & 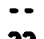 \\
\hline 10 & 51 & $<10 i$ & 2 & $<10$ & $<10$ & $<1.0$ & 230 & 22 \\
\hline
\end{tabular}


SURFACE-WATER DATA-Cont inued

CHEMICAL ANALYSES-Cont inued

STATION

MUMBER

09401000

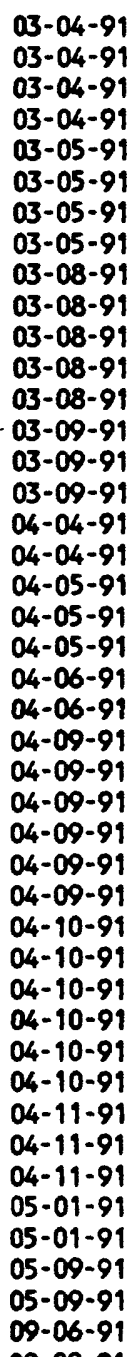

DATE

$\begin{array}{ccccc} & & & \text { SELE- } & \\ \text { ZINC, } & \text { LITHIUN } & \text { NIUN, } & \text { GROSS } \\ \text { DIS- } & \text { DIS- } & \text { DIS- } & \text { ALPHA } \\ \text { SOLVED } & \text { SOLVED } & \text { SOLVED } & \text { SEDI- } \\ \text { DATE } & (\mu g / L & (\mu g / L & (\mu 9 / L & \text { MENT } \\ & 882 n) & \text { AS Li) } & \text { SS SE }) & (p C i / G) \\ & (01090) & (01130) & (01145) & (01507)\end{array}$

GROSS

BETA,

ALPHA 2 SIGU ALPHA 2 SIGA BOT MAT
BOT MAT BOT MAT BOT MAT BOT MAT TOT DRY

TOT DRY TOT DRY DRY WGT TOT DRY (PCI/G

$(\mu g / G \quad(\mu g / G \quad$ (pCi/G (pCi)G

$\begin{array}{ccccc}\text { is } & \text { 88 } & 88 & 88 & 5 r-90 / \\ U-n a t) & U-n a t) & T h-230) & T h-230) & \gamma-90)\end{array}$

$\begin{array}{lllll}(99920) & (75965) & (04125) & \text { (75955) } & (04102)\end{array}$

LITTLE COLORADO RIVER AT GRAND FALLS, AZ-Continued

\begin{tabular}{|c|c|c|c|c|c|c|}
\hline$\cdots$ & $\cdots$ & $\cdots$ & -. & -. & $\cdots$ & -. \\
\hline$\cdots$ & $\cdots$ & -- & $\cdots$ & $\cdots$ & $\cdots$ & -. \\
\hline$\because$ & 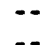 & $\because$ & $\cdots$ & 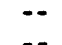 & 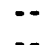 & $\because$ \\
\hline 7 & $<1$ & $<6$ & 7.830 & 8.8 & 6 & 6.3 \\
\hline$\therefore$ & $\therefore$ & $\therefore$ & -. & 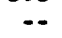 & $\ldots$ &.. \\
\hline 25 & 1 & $<6$ & 5.170 & 7.2 & 3 & 4.6 \\
\hline 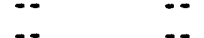 & $\cdots$ & $\cdots$ & $\cdots$ & $\cdots$ & $\cdots$ & -• \\
\hline$\cdots$ & $\cdots$ & $\cdots$ & $\because$ & -- & -. & -. \\
\hline$\cdots$ & $\cdots$ & $\cdots$ & $\cdots$ & $\cdots$ & $\cdots$ & $-\cdot$ \\
\hline$\ldots$ & .. & $\therefore$ & $\ldots$ & $\because$ & $\ldots$ & $\because$ \\
\hline -. & -. & -. & -. & -. & -. & .. \\
\hline -- & -. & $\cdots$ & $\cdot-$ & $-\cdot$ & -. & -. \\
\hline$\cdots$ & $\cdots$ & $\cdots$ & $\cdots$ & $\cdots$ & $\cdots$ & $-\cdot$ \\
\hline$\because$ & $\cdots$ & $\cdots$ & $-\cdot$ & $\because \cdot$ & $\cdots$ & $\because$ \\
\hline .. & .. & .. & $\therefore$ & $\because$ & $\because$. & $\because$ \\
\hline -. & -. & -. & -. & -. & -. & -. \\
\hline$\cdots$ & $\cdots$ & $\cdots$ & $\cdots$ & $\cdots$ & $\cdots$ & $-\cdot$ \\
\hline .. & .. & .. & .. & .. & .- & .. \\
\hline -. & .. & .. & .. & .. & .. & -. \\
\hline$\because$ & -. & $\cdots$ & -. & $\cdots$ & $\cdots$ & $\cdots$ \\
\hline .. & .. & .. & $\therefore$ & 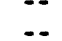 & $\because$ & - \\
\hline -- & -. & -. & -. & -. & .. & -. \\
\hline$\cdots$ & $\cdots$ & $\cdots$ & -. & $\cdots$ & $\cdots$ & -. \\
\hline$\cdots$ & $\cdots$ & $\cdots$ & $\cdots$ & $\cdots$ & $\cdots$ & $\cdot-$ \\
\hline$\cdots$ & 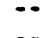 & $\cdots$ & $\ddot{*}$ & $\because$ & $\because$ & $\because$ \\
\hline .. & .- & .. & $\therefore$ & .. & $\therefore$ & $\therefore$ \\
\hline -. & -- & -. & -. & $\cdots$ & $\cdots$ & -. \\
\hline$\cdots$ & -. & $\cdots$ & $\cdots$ & $\cdots$ & $\cdots$ & -. \\
\hline -- & .. & 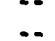 & 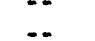 & $\because$ & $\ddot{-}$ & $\ddot{-}$ \\
\hline - & -. & -. & -- & $\because$ & .. & .. \\
\hline.- & -. & -. & .. & $\therefore$ & -. & -. \\
\hline$<4$ & $\cdots$ & $\cdots$ & $\cdots$ & $\cdots$ & -. & $\cdots$ \\
\hline- & $\cdots$ & - & $\cdots$ & -- & $\because$ & -. \\
\hline$\because-$ & 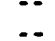 & $\ddot{-}$ & $\because$ & 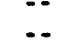 & $\because$ & $\ddot{\ddot{-}}$ \\
\hline$\cdots$ & -- & -. & -. & -. & -. & -. \\
\hline 10 & 1 & $\cdots$ & $\cdots$ & -. & $\cdots$ &.- \\
\hline
\end{tabular}




\begin{tabular}{|c|c|c|c|c|c|c|c|c|c|c|}
\hline \multicolumn{11}{|c|}{ SURFACE-WATER DATA-Cont inued } \\
\hline \multicolumn{11}{|c|}{ CHEMICAL AKALYSES-Cont inued } \\
\hline $\begin{array}{l}\text { STATION } \\
\text { NUMBER }\end{array}$ & DATE & $\begin{array}{l}2 \text { SIGM } \\
\text { BOT MAT } \\
\text { TOT DRY } \\
\text { (pCi/G } \\
\text { as } \\
S r-90 / \\
Y-90) \\
(75966)\end{array}$ & $\begin{array}{l}\text { GROSS } \\
\text { BETA } \\
\text { BOT MAT } \\
\text { TOT DRY } \\
\text { (PCi/G } \\
\text { As } \\
\text { Cs-137) } \\
(99922)\end{array}$ & $\begin{array}{l}\text { BETA, } \\
2 \text { SIGIA } \\
\text { BOT MAT } \\
\text { TOT DRY } \\
\text { (PCI/G } \\
\text { as } \\
\text { Cs-137) } \\
(99923)\end{array}$ & $\begin{array}{l}\text { URANIUM } \\
\text { - } 234 \\
\text { WATER } \\
\text { DISSOLV } \\
\text { (PCi/L) } \\
\text { (22610) }\end{array}$ & $\begin{array}{l}\text { U-234 } \\
2 \text { SIGWA } \\
\text { WATER, } \\
\text { DISS, } \\
\text { (PCi/L) } \\
\text { (7T992) }\end{array}$ & $\begin{array}{l}\text { U-234 } \\
\text { SED, } \\
\text { SUSP, } \\
\text { TOTAL, } \\
\text { DRY WGT } \\
\text { (PCi/G) } \\
\text { (TS942) }\end{array}$ & $\begin{array}{l}\text { U-234 } \\
2 \text { SIGA } \\
\text { SED, } \\
\text { SUSP, } \\
\text { TOTAL, } \\
\text { DRY WGT } \\
\text { (PCi/G) } \\
\text { (75941) }\end{array}$ & $\begin{array}{l}\text { URANIUM } \\
\text {-235 } \\
\text { WATER, } \\
\text { DISS } \\
\text { (pCi/L) } \\
\text { (22620) }\end{array}$ & $\begin{array}{l}\text { U-235 } \\
2 \text { SIGMA } \\
\text { WATER, } \\
\text { DISS, } \\
\text { (PCi/L) } \\
\text { (TS994) }\end{array}$ \\
\hline
\end{tabular}

\begin{tabular}{|c|c|c|c|c|c|c|c|c|c|c|}
\hline \multirow[t]{43}{*}{09401000} & $03-04-91$ & $-\cdot$ & -- & -- & -- & -- & & -- & -- & $\begin{array}{l}-. \\
.-\end{array}$ \\
\hline & $03-04-91$ & - & $\therefore$ & 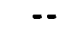 & -- & -- & $\cdots$ & -- & $-\cdot$ & $\because \cdot$ \\
\hline & $03-04-91$ & $-\cdot$ & -- & $-\cdot$ & -- & $\cdots$ & $\cdots$ & -- & -- & $\cdots$ \\
\hline & $03-04-91$ & $\because$ & $26 . \overline{80}$ & $\because$ & $\because$ & $\because$ & $\because$ & 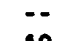 & $\because$ & 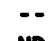 \\
\hline & $\begin{array}{l}03-05-91 \\
03-05-91\end{array}$ & $\begin{array}{c}5.0 \\
.-\end{array}$ & 26.80 & $\begin{array}{c}5.01 \\
.-\end{array}$ & 2.5 & .3 & 1.1 & $\begin{array}{l}.10 \\
.-\end{array}$ & $<.1$ & ND \\
\hline & $\begin{array}{l}03-05-91 \\
03-05-91\end{array}$ & 4.5 & 22.40 & 4.45 & $2 . \overline{3}$ & 3 & 1.1 & .20 & $<.9$ & $\overline{\text { ND }}$ \\
\hline & 03-05-91 & - & - & -- & 2.5 & $\because$ & $\because:-$ & 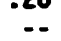 & $\because$. & $\ldots$ \\
\hline & $03-08-91$ & -- & -- & -- & -- & -- & $\cdots$ & $-\cdot$ & $-\cdot$ & -. \\
\hline & $03-08-91$ & $\cdots$ & $-\cdot$ & -- & -- & -- & -- & -- & $-\cdot$ & -- \\
\hline & 03-08-91 & -- & $-\cdot$ & $-\cdot$ & $\cdots$ & $\cdots$ & -- & $\cdot \cdot$ & -- & $-\cdot$ \\
\hline & 03-08-91 & $\cdots$ & -- & -- & -. & $\cdots$ & $-\cdot$ & $-\cdot$ & $-\cdot$ & -- \\
\hline & $03-08-91$ & $\cdots$ & -- & $-\cdot$ & $\cdots$ & -- & $\cdots$ & $\cdot-$ & -- & -. \\
\hline & $03-09-91$ & $\cdots$ & $\cdots$ & $\cdots$ & $\cdots$ & $\cdots$ & $\cdots$ & $\cdots$ & $\cdots$ & $-\cdot$ \\
\hline & 03-09-91 & -- & -- & -- & $-\cdot$ & -- & $\cdots$ & $-\cdot$ & $\cdots$ & -- \\
\hline & 03-09-91 & -- & -- & $-\cdot$ & -- & $\cdots$ & -. & $\cdots$ & $\cdot-$ & -- \\
\hline & $04-04-91$ & -- & $\cdots$ & -- & $\cdot-$ & $\cdots$ & $\cdot-$ & -- & -. & -- \\
\hline & $04-04-91$ & $-\cdot$ & -- & -- & $\cdots$ & $\cdots$ & -- & $\cdot-$ & $-\cdot$ & -- \\
\hline & $04-05-91$ & -- & -- & -- & -- & $\cdots$ & $\cdots$ & -- & $\cdot-$ & -- \\
\hline & $04-05-91$ & -- & $\cdots$ & $-\cdot$ & $\cdots$ & $\cdots$ & $\cdots$ & $-\cdot$ & $-\cdot$ & $\cdots$ \\
\hline & $04-05-91$ & -- & -. & -- & $-\cdot$ & $\cdots$ & 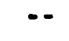 & $\cdots$ & -- & -- \\
\hline & $04-06-91$ & $\cdots$ & -- & $-\cdot$ & -- & $\cdots$ & -. & $\cdots$ & $\cdots$ & $\cdots$ \\
\hline & $04-06-91$ & -- & -. & -- & -- & -- & $-\cdot$ & $-\cdot$ & $-\cdot$ & -. \\
\hline & $04-09-91$ & -- & -- & -- & -- & $\cdots$ & $\cdots$ & $\cdots$ & $\cdots$ & -- \\
\hline & $04-09-91$ & -- & $\because$ & -- & $-\cdot$ & $-\cdot$ & -- & $-\cdot$ & $-\cdot$ & -- \\
\hline & $04-09-91$ & -- & -- & -- & -- & -- & -- & $-\cdot$ & -. & -- \\
\hline & $04-09-91$ & -- & -- & -- & $-\cdot$ & $\cdots$ & $\cdots$ & $\cdots$ & $-\cdot$ & -- \\
\hline & $04-09-91$ & $-\cdot$ & $-\cdot$ & -- & $-\cdot$ & $\cdots$ & -- & $\cdots$ & -- & $\cdots$ \\
\hline & $04-09-99$ & $-\cdot$ & $-\cdot$ & $\cdot-$ & -- & $-\cdot$ & $\cdots$ & -. & $-\cdot$ & $-\cdot$ \\
\hline & $04-10-91$ & -- & , & -- & $\cdots$ & $\cdots$ & $\cdots$ & $\cdots$ & -. & $\cdots$ \\
\hline & $04-10-91$ & $-\cdot$ & $\because$ & $-\cdot$ & $\cdots$ & $\cdot \cdot$ & $-\cdot$ & -・ & -・ & $\because$ \\
\hline & $04-10-91$ & $-\cdot$ & -- & $\because$ & -- & $\cdots$ & $-\cdot$ & $\cdot-$ & $-\cdot$ & -- \\
\hline & $04-10-91$ & -- & -- & $\cdots$ & -- & $-\cdot$ & -- & -- & $-\cdot$ & $\cdot$ \\
\hline & $04-10-91$ & $\cdots$ & -- & $-\cdot$ & $\cdot-$ & $\cdots$ & -- & -- & -- & $-\cdot$ \\
\hline & $04-10-91$ & $-\cdot$ & -- & $-\cdot$ & $\cdots$ & $\cdots$ & -- & $\cdots$ & $\cdots$ & $\cdots$ \\
\hline & $04-19-91$ & $\cdots$ & -- & -. & $\cdots$ & $\cdots$ & -- & $\cdots$ & $\cdots$ & -- \\
\hline & $04-11-91$ & $\cdots$ & -- & $\cdots$ & $\cdots$ & $\cdots$ & $\cdots$ & $-\cdot$ & $\cdot-$ & $\cdot-$ \\
\hline & $04-11-91$ & $-\cdot$ & -- & -. & $\cdots$ & -. & $\cdots$ & -. & $-\cdot$ & -- \\
\hline & 05-01-91 & -. & $\cdots$ & $\cdots$ & -. & $\cdots$ & $\cdots$ & -. & -. & - \\
\hline & 05-01-91 & -- & -- & $\cdots$ & $\because$ & $\cdots$ & -- & -- & -. & 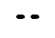 \\
\hline & $05-09-91$ & $\cdots$ & $\cdots$ & -. & $\cdots$ & -. & $\cdots$ & $\cdots$ & -. & -. \\
\hline & $05-09-91$ & $\cdots$ & $-\cdot$ & 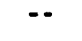 & -- & $\cdots$ & $\cdots$ & $\cdot \cdot$ & -- & 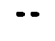 \\
\hline & 09-06-91 & $-\cdot$ & -- & -- & $\because-$ & $\cdots$ & $\cdots$ & -- & $\cdots$ & -- \\
\hline & 09-09-91 & -- & -- & $\cdots$ & 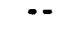 & -- & $\cdots$ & -- & $\cdots$ & - \\
\hline
\end{tabular}


CHEMICAL AKALYSES-Continued

STATION

NUMBER

\begin{tabular}{|c|c|}
\hline 09401000 & $\begin{array}{l}03-04-91 \\
03-04-91 \\
03-04-91 \\
03-04-91 \\
03-05-91 \\
03-05-91 \\
03-05-91 \\
03-05-91 \\
03-08-91 \\
03-08-91 \\
03-08-91 \\
03-08-91 \\
03-08-91 \\
03-09-91 \\
03-09-91 \\
03-09-91 \\
04-04-91 \\
04-04-91 \\
04-05-91 \\
04-05-91 \\
04-05-91 \\
04-06-91 \\
04-06-91 \\
04-09-91 \\
04-09-91 \\
04-09-91 \\
04-09-91 \\
04-09-91 \\
04-09-91 \\
04-10-91 \\
04-10-91 \\
04-10-91 \\
04-10-91 \\
04-10-91 \\
04-10-91 \\
04-11-91 \\
04-11-91 \\
04-11-91 \\
05-01-91 \\
05-01-91 \\
05-09-91 \\
05-09-91 \\
09-06-91 \\
09-09-91\end{array}$ \\
\hline
\end{tabular}

\begin{tabular}{|c|c|c|c|c|c|c|c|}
\hline & $U-235$ & & & & $U-238$ & & Th-230 \\
\hline $\begin{array}{l}\text { U-235 } \\
\text { SEO, } \\
\text { SUSP, } \\
\text { TOTAL, }\end{array}$ & $\begin{array}{l}2 \text { SIEA } \\
\text { SEO, } \\
\text { SUSP, } \\
\text { TOTAL, }\end{array}$ & $\begin{array}{l}\text { URANIUN } \\
-238 \\
\text { MATER }\end{array}$ & $\begin{array}{l}\text { U-238 } \\
2 \text { SIGU } \\
\text { WATER, }\end{array}$ & $\begin{array}{c}\text { U-238 } \\
\text { SED, } \\
\text { SUSP, } \\
\text { TOTAL, }\end{array}$ & $\begin{array}{c}2 \text { SICH } \\
\text { SED, } \\
\text { SUSP, } \\
\text { TOTAL, }\end{array}$ & $\begin{array}{c}\text { Th-230 } \\
\text { SED, } \\
\text { SUSP, } \\
\text { TOTAL, }\end{array}$ & $\begin{array}{l}2 \text { SI EUA } \\
\text { SED, } \\
\text { SUSP. } \\
\text { TOTAL, }\end{array}$ \\
\hline $\begin{array}{l}\text { DRY WGT } \\
\text { (PCi/G) } \\
\text { ( } 75975)\end{array}$ & $\begin{array}{l}\text { DRY WGT } \\
\text { (PCi/G) } \\
(75947)\end{array}$ & $\begin{array}{l}\text { DISSOLV } \\
(p C i / L) \\
(22603)\end{array}$ & $\begin{array}{l}\text { DISS, } \\
\text { (pCi/L) } \\
\text { (75991) }\end{array}$ & $\begin{array}{l}\text { DRY WGT } \\
(\mathrm{PCi} / G) \\
(75940)\end{array}$ & $\begin{array}{l}\text { DRY WGT } \\
\text { (PCi/G) } \\
(04113)\end{array}$ & $\begin{array}{l}\text { DRY WGT } \\
\text { (PCi/G) } \\
(75939)\end{array}$ & $\begin{array}{l}\text { DRY WGT } \\
\text { (PCi/G) } \\
\text { (75952) }\end{array}$ \\
\hline
\end{tabular}

LITTLE COLORADO RIVER AT GRAND FALLS, AZ-Continued

\begin{tabular}{|c|c|c|c|c|c|c|c|}
\hline .. & .. & .. & .. & .. & -. & .. & .. \\
\hline -. & -. & -. & .. & -. & .. & .. & .. \\
\hline$\because$ & 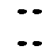 & 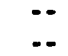 & 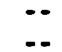 & 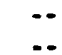 & $\ddot{. .}$ & 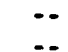 & 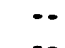 \\
\hline$<.1$ & ND & 1.7 & .20 & 1.2 & .015 & 1.4 & 19 \\
\hline$\because$ & $\cdots$ & $\because$ & $\cdots$ & -. & $\therefore$ & $\therefore$ & \\
\hline$<.1$ & ND & 1.5 & .20 & 1.1 & .16 & 1.5 & .21 \\
\hline$\because$. & 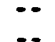 & $\because$ & $\because$ & $\because$ & $\cdots$ & $\cdots$ & $\cdots$ \\
\hline .. & $\ddot{\because}$ & 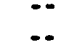 & $\because$ & $\ddot{-}$ & $\because-$ & $\because$ & $\because$ \\
\hline -. & -. & .. & .. & .. & .. & .. & $\therefore$ \\
\hline$\because$ & $\cdots$ & -. & -. & -. & $\cdots$ & -. & .. \\
\hline$\because$ & $\cdots$ & $\because$ & $\because$ & $\because$ & $\cdots$ & $\cdots$ & -. \\
\hline .. & .. & $\because$ & $\because$ & $\because$ & $\because$ & 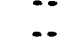 & 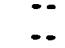 \\
\hline -. & -. & -. & . & .. & - & $\cdots$ & .. \\
\hline -- & $\cdots$ & $\because$ & $\cdots$ & -. & $\cdots$ & $\cdots$ & 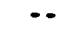 \\
\hline$\because$ & $\because$ & $\because$ & $\because$ & 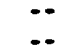 & $\because:$ & 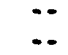 & 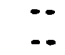 \\
\hline -. & $\cdots$ & .. & .. & .. & .. & $\cdots$ & $\therefore$ \\
\hline -. & $\because$ & $\cdots$ & -. & -. & -. & $\cdots$ & -. \\
\hline 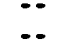 & $\because$. & 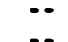 & $\because$ & 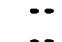 & 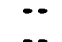 & $\because$ & -. \\
\hline$\cdots$ & $\therefore$ & .. & $\cdots$ & $\ddot{\therefore}$ & $\because$. & 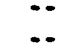 & $\because$ \\
\hline -. & $\cdots$ & -. & .. & .. & .. & 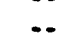 & $\ddot{0}$ \\
\hline$\cdots$ & $\cdots$ & $\cdots$ & $\cdots$ & -. & -. & $\cdots$ & .. \\
\hline 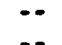 & $\because$ & $\because$ & $\because$ & -. & $\cdots$ & $\cdots$ & -. \\
\hline$\therefore$ & $\because$ & $\because$ & $\because$. & $\because$ & $\because-$ & 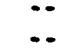 & $\because$ \\
\hline -. & -. & .. & .. & .. & .. & .. & .. \\
\hline -. & $\cdots$ & -. & -. & -. & $\cdots$ & $\cdots$ & -. \\
\hline$\cdots$ & $\because$ & $\begin{array}{l}\cdots \\
\cdots\end{array}$ & $\because:$ & 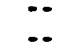 & $\because$. & $\because$ & $\because$ \\
\hline . & .. & .. & .. & $\therefore$ & $\therefore$ & $\cdots$ & $\because$ \\
\hline- & $\cdots$ & -. & -. & -. & -. & $\cdots$ & .. \\
\hline$\because$ & $\because$. & $\because-$ & $\because$. & $\because$ & $\because$ & $\because$ & $\because$ \\
\hline - & - & $\because$ & $\because$. & 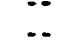 & $\cdots$ & $\because$ & -. \\
\hline- & -. & -. & -. & .. & -. & $\cdots$ & -. \\
\hline$\cdots$ & $\cdots$ & $\cdot-$ & $\cdots$ & -. & 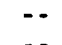 & $\cdots$ & $\because$ \\
\hline 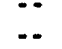 & $\therefore$ & 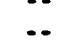 & $\because$. & $\because$ & $\therefore$ & $\therefore$ & $\because$. \\
\hline - & $\cdots$ & -. & -. & -. & $\cdots$ & - & -. \\
\hline & $\cdots$ & $\cdots$ & -. & -. & $\cdots$ & - & \\
\hline
\end{tabular}


SURFACE-MATER DATA-Cont inued

CHEMICAL AKALYSES-Continued

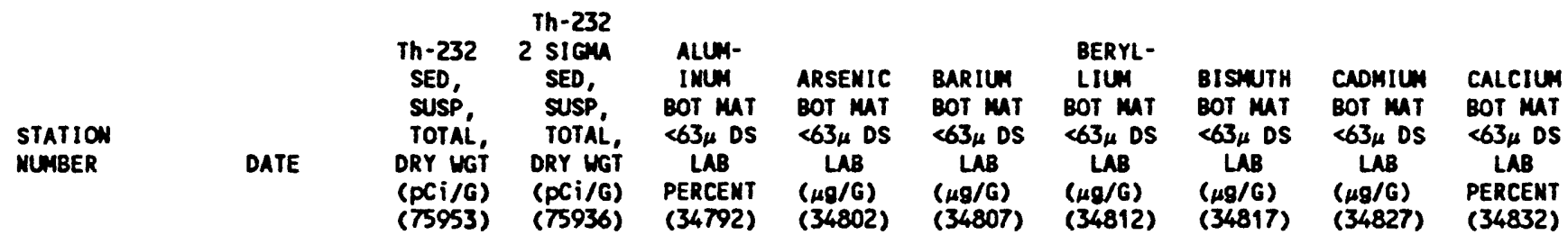

LITTLE COLORADO RIVER AT GRAND FALLS, AZ-Continued

\begin{tabular}{|c|c|c|c|c|c|c|c|c|c|c|}
\hline \multirow[t]{43}{*}{09401000} & $03-04-91$ & $\because$ & $\because$. & $\because$ & $\begin{array}{l}-. \\
\end{array}$ & $\because$. & $\because-$ & $\because$. & $\ddot{-.}$ & - \\
\hline & $\begin{array}{l}03-04-91 \\
03-04-91\end{array}$ & $\because$ & .. & .. & .. & .. & $\ldots$ & $\because$ & $\cdots$ & \\
\hline & $03-04-91$ & -. & -. & -. & $\cdots$ & -. & .. & .. & -. & .. \\
\hline & 03-05-91 & 1.5 & .20 & -. & -. & -- & .. & .. & .. & .. \\
\hline & $03-05-91$ & -- & $\cdots$ & -. & -. & $\cdots$ & $\cdots$ & -. & $\cdots$ & -. \\
\hline & $03-05-91$ & 1.3 & .18 & 5.9 & $<10$ & 660 & 1 & $<10$ & $<2$ & 4.5 \\
\hline & 03-05-91 & $\cdot-$ & $\cdot \cdot$ & $\cdots$ & -. & -- & $\cdots$ & $\cdots$ & $\cdots$ & $\cdots$ \\
\hline & 03-08-91 & $\cdots$ & $\cdots$ & $\cdots$ & $\cdots$ & $\cdots$ & $\cdots$ & $\cdots$ & $\cdots$ & $\because$ \\
\hline & $03-08-91$ & $\cdots$ & $\cdots$ & $\cdots$ & -. & $-\cdot$ & $\cdots$ & $\cdots$ & $\cdots$ &.- \\
\hline & $03-08-91$ & $\cdots$ & $\cdots$ & $\cdots$ & $\cdots$ & $\cdots$ & $\cdots$ & $\cdots$ & $\cdots$ & $\cdots$ \\
\hline & $03-08-91$ & $\cdot-$ & $\cdots$ & $\cdots$ & $\cdots$ & $\cdots$ & $\cdots$ & $\cdots$ & $\cdots$ & $\cdots$ \\
\hline & 03-08-91 & -. & $\cdots$ & $\cdots$ & $\cdots$ & $\cdots$ & $\cdots$ & $\cdots$ & $\cdots$ & $\cdots$ \\
\hline & 03-09-91 & $\cdots$ & $\cdots$ & $\cdots$ & $\cdots$ & $\cdots$ & $\cdots$ & $\cdots$ & $\cdots$ & $\cdots$ \\
\hline & $03-09-91$ & $\cdots$ & $\cdots$ & -. & $\cdots$ & $\cdots$ & $\cdots$ & $\cdots$ & $\cdots$ & - \\
\hline & 03-09-91 & $\cdots$ & $\cdots$ & $\cdots$ & $\cdot-$ & $\cdot-$ & $\cdots$ & $\cdots$ & $-\cdot$ & $\cdots$ \\
\hline & $04-04-91$ & $\cdots$ & $\cdots$ & $\cdots$ & $\cdots$ & $\cdots$ & $\cdots$ & $\cdots$ & $\cdots$ & $\cdots$ \\
\hline & $04-04-91$ & $\cdots$ & $\cdots$ & $\cdots$ & $\cdots$ & $\cdots$ & $\cdots$ & $\cdots$ & $\cdots$ & $\cdots$ \\
\hline & $04-05-91$ & $\cdots$ & $\cdots$ & -. & $\cdots$ & $\cdots$ & $\cdots$ & $\cdots$ & $\cdots$ & $\cdots$ \\
\hline & $04-05-91$ & -. & $\cdots$ & -. & $\cdots$ & -- & $\cdots$ & $\cdots$ & $\cdots$ & -. \\
\hline & $04-05-91$ & $-\cdot$ & $\cdots$ & $\cdots$ & $\cdots$ & $\cdot-$ & $\cdots$ & $\cdots$ & $\cdots$ & $\cdots$ \\
\hline & $04-06-91$ & $\cdots$ & $\cdots$ & $\cdots$ & $\cdots$ & $\cdots$ & $\cdots$ & $\cdots$ & $\cdots$ & $\cdots$ \\
\hline & $04-06-91$ & $\cdots$ & $\cdots$ & $\cdots$ & $\cdots$ & -- & $\cdots$ & $\cdots$ & $\cdots$ & $\cdots$ \\
\hline & $04-09-91$ & $\cdots$ & $\cdots$ & $\cdots$ & $\cdots$ & $\cdot-$ & $\cdots$ & $\cdots$ & $\cdots$ & $\because$ \\
\hline & $04-09-91$ & $\cdots$ & -- & $\cdots$ & $\cdots$ & $\cdots$ & $\cdots$ & $\cdots$ & $\cdots$ & $\cdots$ \\
\hline & $04-09-91$ & -. & $\cdots$ & $\cdots$ & $\cdots$ & $\cdots$ & $\cdots$ & $\cdots$ & $\cdots$ & $\cdots$ \\
\hline & $04-09-91$ & $\cdots$ & $\cdot-$ & $\cdots$ & $\cdots$ & $\cdots$ & $\cdots$ & $\cdots$ & $\cdots$ & $\cdots$ \\
\hline & $04-09-91$ & $\cdots$ & $-\cdot$ & $\cdots$ & $\cdots$ & $\because$ & $\cdots$ & $\cdots$ & $\cdots$ & $\cdots$ \\
\hline & $04-09-91$ & $\cdots$ & $\cdots$ & $\cdots$ & $\cdots$ & $\cdot \cdot$ & $\cdots$ & $\cdots$ & $\cdots$ & $\cdots$ \\
\hline & $04-10-91$ & $\cdots$ & $\cdots$ & $\cdots$ & $\cdots$ & $\cdot-$ & $\cdots$ & $\cdots$ & $\cdots$ & - \\
\hline & $04-10-91$ & $\cdots$ & $\cdot-$ & $\cdots$ & $-\cdot$ & -- & -- & $\cdots$ & $\cdots$ & $\cdots$ \\
\hline & $04-10-91$ & $\cdots$ & -- & $\cdots$ & $\cdot-$ & $\cdot \cdot$ & -- & $\cdots$ & $\cdots$ & $\cdots$ \\
\hline & $04-10-91$ & $\cdots$ & -. & $\cdots$ & $\cdots$ & -. & -- & $\cdots$ & $\cdots$ & $\cdots$ \\
\hline & $04-10-91$ & -- & -- & -- & -- & -. & -- & $\cdots$ & $\cdots$ & $\cdots$ \\
\hline & $04-10-91$ & $\cdots$ & $\cdots$ & -- & -- & $\cdot-$ & $\cdots$ & $\cdots$ & $\cdots$ & $\cdots$ \\
\hline & $04-11-91$ & -- & -. & -. & $\cdot-$ & $\cdot \cdot$ & $\cdots$ & $\cdots$ & $\cdots$ & $\cdots$ \\
\hline & $04-11-91$ & -. & -. & -. & $\cdot \cdot$ & -. & $\cdots$ & $\cdots$ & $\cdots$ & $\cdots$ \\
\hline & $04-11-91$ & $\cdots$ & $\cdots$ & $-\cdot$ & -- & -. & $\cdots$ & $\cdots$ & $\cdots$ & $\cdots$ \\
\hline & $05-01-91$ & $\cdots$ & -. & -. & $\cdot-$ & -. & $\cdots$ & $\cdots$ & $\cdots$ & $\cdots$ \\
\hline & $05-01-91$ & -. & $\cdots$ & -- & $\cdots$ & -. & -. & $\cdots$ & $\cdots$ & $\cdots$ \\
\hline & $05-09-91$ & -- & $\cdots$ & $\cdots$ & $\cdots$ & 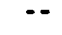 & $\cdots$ & $\cdots$ & $\cdots$ & $\cdots$ \\
\hline & $05-09-91$ & $\cdots$ & $\cdots$ & $\cdots$ & -- & -- & $\cdots$ & $\cdots$ & $\cdots$ & -- \\
\hline & 09-06-91 & $\cdots$ & $-\cdot$ & $\cdot-$ & $\cdot-$ & $\cdots$ & $\cdot-$ & $\cdots$ & $\cdot-$ & $\cdots$ \\
\hline & $09-09-91$ & $\cdots$ & -. & $\cdots$ & $\cdots$ & -- & $\cdots$ & $\cdots$ & $\cdots$ & $\cdots$ \\
\hline
\end{tabular}


URFACE-WATER DATA-Continued

CHEMICAL ANALYSES-Continued

STATION

MUMBER

DATE

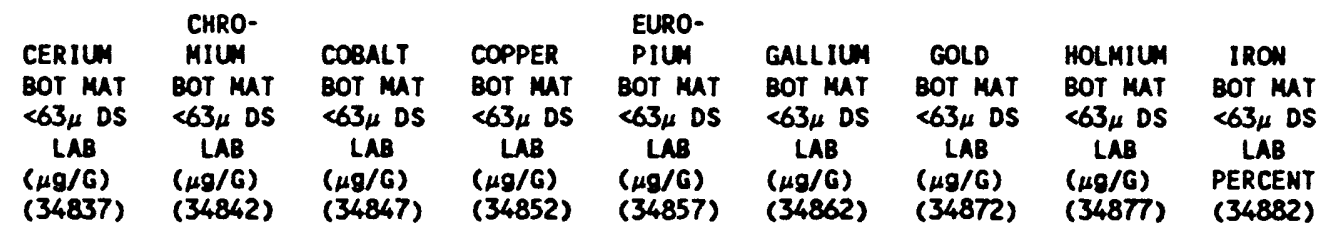

LITTLE COLORADO RIVER AT GRAND FALLS, AZ-Cont inued

$09401000 \quad 03-04-91$
$03-04-91$
$03-04-91$
$03-04-91$
$03-05-91$
$03-05-91$
$03-05-91$
$03-05-91$
$03-08-91$
$03-08-91$
$03-08-91$
$03-08-91$
$03-08-91$
$03-09-91$
$03-09-91$
$03-09-91$
$04-04-91$
$04-04-91$
$04-05-91$
$04-05-91$
$04-05-91$
$04-06-91$
$04-06-91$
$04-09-91$
$04-09-91$
$04-09-91$
$04-09-91$
$04-09-91$
$04-09-91$
$04-10-91$
$04-10-91$
$04-10-91$
$04-10-91$
$04-10-91$
$04-10-91$
$04-11-91$
$04-11-91$
$04-11-91$
$05-01-91$
$05-01-91$
$05-09-91$
$05-09-91$
$09-06-91$
$09-09-91$

\begin{tabular}{|c|c|}
\hline$\cdots$ & .. \\
\hline - & .. \\
\hline$\cdots$ & .. \\
\hline$\cdots$ & -. \\
\hline$\cdots$ & -- \\
\hline$\because$ & 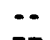 \\
\hline 60 & 37 \\
\hline$\cdots$ & $\cdots$ \\
\hline$\cdots$ & $\cdots$ \\
\hline$\cdots$ & 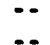 \\
\hline$\ldots$ & $\because$ \\
\hline$\cdots$ & ‥ \\
\hline .. & .. \\
\hline - & - \\
\hline- & $\cdots$ \\
\hline$\cdots$ & -. \\
\hline$\cdots$ & $\cdots$ \\
\hline$\cdots$ & $\cdots$ \\
\hline$\cdots$ & - \\
\hline$\cdots$ & $\cdots$ \\
\hline$\cdots$ & $\cdots$ \\
\hline$\cdots$ & "- \\
\hline .. & $\ldots$ \\
\hline$\cdots$ & $\cdots$ \\
\hline .. & $\cdots$ \\
\hline -. & $\cdots$ \\
\hline -. & -. \\
\hline -. & -. \\
\hline$\cdots$ & $\cdots$ \\
\hline$\cdots$ & $\cdots$ \\
\hline$\cdots$ & $\cdots$ \\
\hline$\cdots$ & $\cdots$ \\
\hline$\cdots$ & $\cdots$ \\
\hline .. & -. \\
\hline$\cdots$ & -- \\
\hline 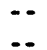 & - \\
\hline$\ldots$ & \\
\hline -. & $\cdots$ \\
\hline & \\
\hline
\end{tabular}

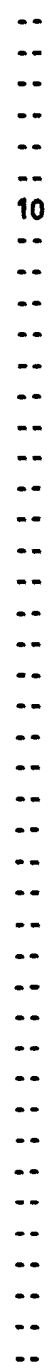

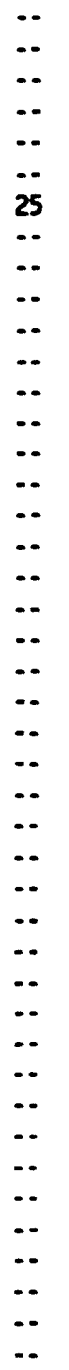

\begin{tabular}{|c|c|}
\hline$\cdots$ & -. \\
\hline$\cdots$ & $\cdots$ \\
\hline$\cdots$ & $\cdots$ \\
\hline$\cdots$ & $\cdots$ \\
\hline$\cdots$ & $\cdots$ \\
\hline 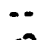 & 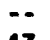 \\
\hline$<2$ & 13 \\
\hline$\cdots$ & $\because$ \\
\hline$\cdots$ & $\cdots$ \\
\hline$\cdots$ & $\because$ \\
\hline$\cdots$ & $\ldots$ \\
\hline$\ldots$ & .. \\
\hline$\cdots$ & .. \\
\hline$\cdots$ & $\cdots$ \\
\hline$\cdots$ & $\cdots$ \\
\hline$\cdots$ & $=-$ \\
\hline$\cdots$ & $\cdots$ \\
\hline$\cdots$ & $\cdots$ \\
\hline 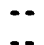 & 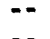 \\
\hline$\cdots$ & 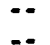 \\
\hline 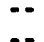 & 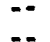 \\
\hline$\cdots$ & 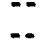 \\
\hline .. & -. \\
\hline - & $\cdots$ \\
\hline -. & $\cdots$ \\
\hline$\cdots$ & $\cdots$ \\
\hline$\cdots$ & $\cdots$ \\
\hline 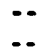 & $\cdots$ \\
\hline$\cdots$ & 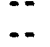 \\
\hline -. & 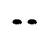 \\
\hline$\cdots$ & $\cdots$ \\
\hline$\cdots$ & $\cdots$ \\
\hline$\cdots$ & $\cdots$ \\
\hline$\cdots$ & - \\
\hline -- & - \\
\hline -. & - \\
\hline$\cdots$ & $\cdots$ \\
\hline$\cdots$ & 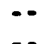 \\
\hline$\cdots$ & \\
\hline
\end{tabular}

\begin{tabular}{|c|c|c|}
\hline$\cdots$ & $\cdots$ & $\cdots$ \\
\hline-- & $\cdots$ & $\cdots$ \\
\hline$\cdots$ & $\cdots$ & -- \\
\hline$\cdots$ & -. & $\cdots$ \\
\hline$\cdots$ & $\cdots$ & $\ldots$ \\
\hline$\because$ & $\cdots$ & $\cdots$ \\
\hline$<8$ & $<4$ & 2.2 \\
\hline$\cdots$ & $\cdots$ & $\cdots$ \\
\hline$\cdots$ & $\cdots$ & $\cdots$ \\
\hline$\cdots$ & $\because$ & $\cdots$ \\
\hline$\cdots$ & $\because$ & $\cdots$ \\
\hline$\because$ & $\because$ & 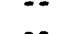 \\
\hline$\ldots$ & $\ldots$ & .. \\
\hline$\cdots$ & .. & $\ldots$ \\
\hline -. & $=$ & $\cdots$ \\
\hline$\cdots$ & -. & $\cdots$ \\
\hline$\cdots$ & $\cdots$ & $\cdots$ \\
\hline$\cdots$ & $=$ & $\cdots$ \\
\hline$\cdots$ & $\cdots$ & $\cdots$ \\
\hline$\cdots$ & $\cdots$ & $\cdots$ \\
\hline$\cdots$ & $\cdots$ & $\cdots$ \\
\hline$\cdots$ & $\cdots$ & $\because$ \\
\hline$\ldots$ & $\cdots$ & $\because$ \\
\hline$\ldots$ & $\ldots$ & $\cdots$ \\
\hline$\ldots$ & $\ldots$ & $\ldots$ \\
\hline -- & .. & .. \\
\hline$\cdots$ & .. & . \\
\hline$\cdots$ & $\cdots$ & 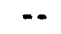 \\
\hline$\cdots$ & $\cdots$ & $\cdots$ \\
\hline -. & $\cdots$ & $\cdots$ \\
\hline$\cdots$ & $\cdots$ & $\therefore$ \\
\hline$\cdots$ & -- & 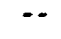 \\
\hline$\cdots$ & $\cdots$ & $\cdots$ \\
\hline$\cdots$ & $\cdots$ & $\cdots$ \\
\hline$\cdots$ & $\cdots$ & $\cdots$ \\
\hline 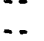 & $\cdots$ & $\overline{-}$ \\
\hline$\ldots$ & -. & \\
\hline -. & $\cdots$ & $\ldots$ \\
\hline$\cdots$ & $\cdots$ & . \\
\hline$\cdots$ & $\cdots$ & $\cdots$ \\
\hline 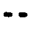 & $\cdots$ & . \\
\hline
\end{tabular}


SURFACE-WATER DATA-Cont inued

CHEMICAL ANALYSES-Cont inued

\begin{tabular}{|c|c|c|c|c|c|c|c|c|c|c|}
\hline & & $\begin{array}{l}\text { LANTHA- } \\
\text { NUN }\end{array}$ & LEAD & LITHIUN & $\begin{array}{l}\text { MAGNE- } \\
\text { SIUN }\end{array}$ & $\begin{array}{l}\text { MANGA- } \\
\text { NESE }\end{array}$ & $\begin{array}{l}\text { MOLYB- } \\
\text { DENUN }\end{array}$ & $\begin{array}{l}\text { NEOOYM- } \\
\text { IUN }\end{array}$ & NICKEL & NIOBIUN \\
\hline $\begin{array}{l}\text { STATION } \\
\text { NUMBER }\end{array}$ & DATE & $\begin{array}{c}\text { BOT MAT } \\
\angle 63 \mu \text { DS } \\
\text { LAB } \\
(\mu g / G) \\
(34887)\end{array}$ & $\begin{array}{c}\text { BOT MAT } \\
<63 \mu \text { DS } \\
\text { LAB } \\
(\mu \sigma / G) \\
(34892)\end{array}$ & $\begin{array}{c}\text { BOT MAT } \\
<63 \mu \text { DS } \\
\text { LAB } \\
(\mu 9 / 6) \\
(34897)\end{array}$ & $\begin{array}{l}\text { BOT MAT } \\
\angle 63 \mu \text { DS } \\
\text { LAS } \\
\text { PERCENT } \\
\text { (34902) }\end{array}$ & $\begin{array}{c}\text { BOT MAT } \\
<63 \mu \text { DS } \\
\text { LAB } \\
(\mu g / G) \\
(34907)\end{array}$ & $\begin{array}{c}\text { BOT MAT } \\
\angle 63 \mu \text { DS } \\
\text { LAB } \\
(\mu 9 / G) \\
(34917)\end{array}$ & $\begin{array}{c}\text { BOT MAT } \\
\angle 63 \mu \text { DS } \\
\text { LAB } \\
(\mu \sigma / G) \\
(34922)\end{array}$ & $\begin{array}{c}\text { BOT MAT } \\
\angle 63_{\mu} \text { DS } \\
\text { LAB } \\
(\mu g / G) \\
(34927)\end{array}$ & $\begin{array}{c}\text { BOT MAT } \\
\angle 63_{\mu} \text { DS } \\
\text { LAB } \\
(\mu \sigma / G) \\
(34932)\end{array}$ \\
\hline
\end{tabular}

LITTLE COLORADO RIVER AT GRAD FALLS, AZ-Continued

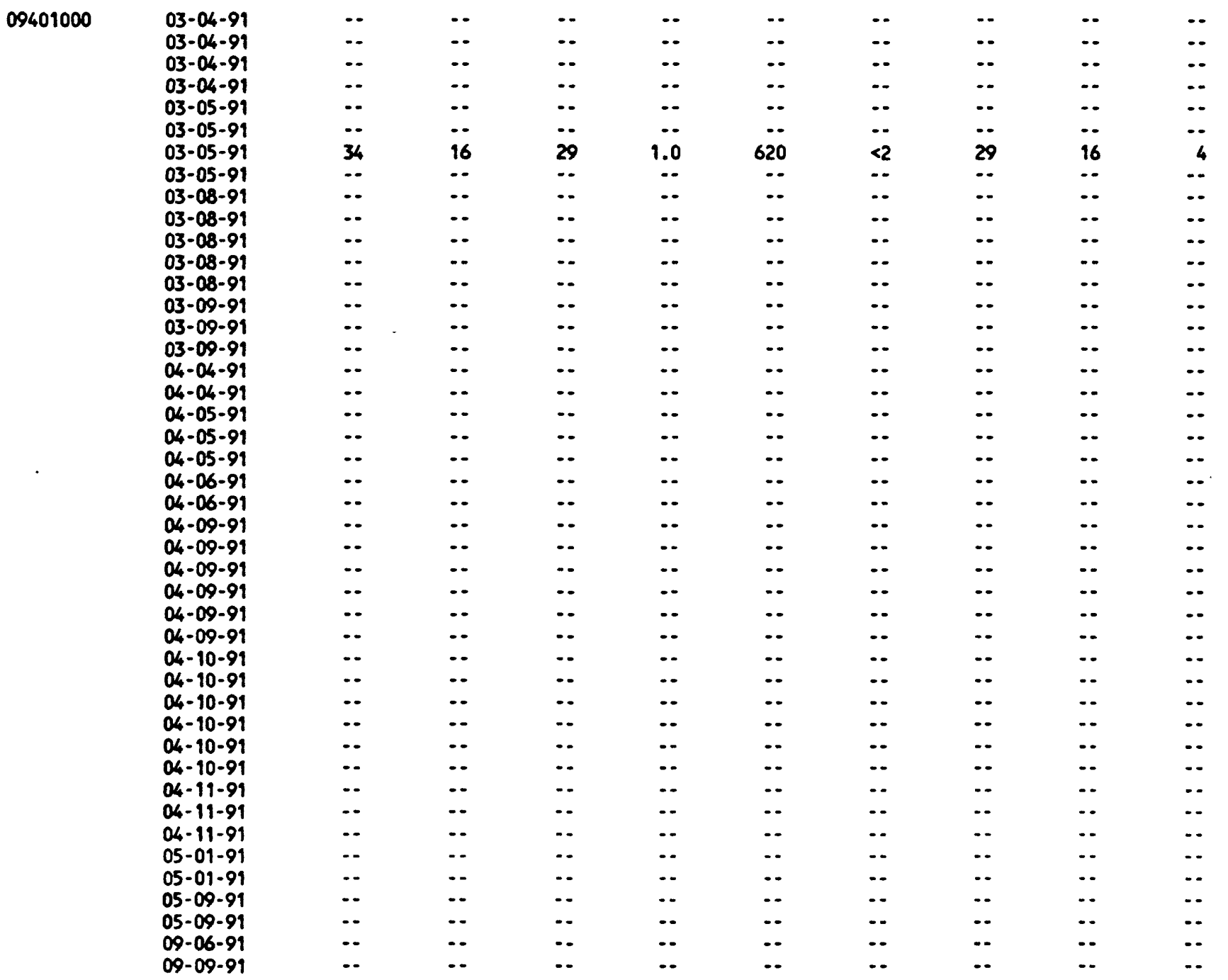


SURFACE-WATER DATA-Cont inued

CHEMICAL ANALYSES-Cont inued

\begin{tabular}{|c|c|c|c|c|c|c|c|c|c|c|}
\hline & & $\begin{array}{l}\text { PHOS- } \\
\text { PHORUS }\end{array}$ & $\begin{array}{l}\text { POTAS- } \\
\text { SIUN }\end{array}$ & $\begin{array}{l}\text { SCAN- } \\
\text { DIUN }\end{array}$ & SILVER & SoDIUN & $\begin{array}{l}\text { STRON- } \\
\text { TIUN }\end{array}$ & $\begin{array}{l}\text { TANTA- } \\
\text { LUN }\end{array}$ & THORIUN & TIN \\
\hline $\begin{array}{l}\text { STATION } \\
\text { NUABER }\end{array}$ & DATE & $\begin{array}{c}\text { BOT MAT } \\
\angle 63 \mu \text { DS } \\
\text { LAB } \\
\text { PERCENT } \\
\text { (34937) }\end{array}$ & $\begin{array}{l}\text { BOT MT } \\
\angle 63 \mu \text { DS } \\
\text { LAB } \\
\text { PERCENT } \\
\text { (34942) }\end{array}$ & $\begin{array}{c}\text { BOT MT } \\
\angle 63 \mu \text { DS } \\
\text { LAB } \\
(\mu g / G) \\
(34947)\end{array}$ & $\begin{array}{c}\text { BOT MT } \\
\angle 63 \mu \text { DS } \\
\text { LAB } \\
(\mu g / G) \\
(34957)\end{array}$ & $\begin{array}{l}\text { BOT MT } \\
\angle 63 \mu \text { DS } \\
\text { LAB } \\
\text { PERCENT } \\
\text { (34962) }\end{array}$ & $\begin{array}{c}\text { BOT MT } \\
\angle 63_{\mu} \text { DS } \\
\text { LAB } \\
(\mu g / G) \\
(34967)\end{array}$ & $\begin{array}{c}\text { BOT MT } \\
\angle 63 \mu \text { DS } \\
\text { LAB } \\
(\mu g / G) \\
(34977)\end{array}$ & $\begin{array}{c}\text { BOT MT } \\
\angle 63 \mu \text { DS } \\
\text { LAB } \\
(\mu g / G) \\
(34982)\end{array}$ & $\begin{array}{c}\text { BOT MT } \\
\angle 63 \mu \text { DS } \\
\text { LAB } \\
(\mu g / G) \\
(34987)\end{array}$ \\
\hline
\end{tabular}

$09401000 \quad 03-04-91$
$03-04-91$
$03-04-91$
$03-04-91$
$03-05-91$
$03-05-91$
$03-05-91$
$03-05-91$
$03-08-91$
$03-08-91$
$03-08-91$
$03-08-91$
$03-08-91$
$03-09-91$
$03-09-91$
$03-09-91$
$04-04-91$
$04-04-91$
$04-05-91$
$04-05-91$
$04-05-91$
$04-06-91$
$04-06-91$
$04-09-91$
$04-09-91$
$04-09-91$
$04-09-91$
$04-09-91$
$04-09-91$
$04-10-91$
$04-10-91$
$04-10-91$
$04-10-91$
$04-10-91$
$04-10-91$
$04-11-91$
$04-11-91$
$04-91-91$
$05-01-91$
$05-01-91$
$05-09-91$
$09-09-91$
$09-91$
$03-91$

LITTLE COLORADO RIVER AT GRAND FALLS, AZ-Cont inued

\begin{tabular}{|c|c|c|c|c|c|c|c|c|}
\hline$\cdots$ & $\cdots$ & $\cdots$ & $\cdots$ & $\cdots$ & $\cdots$ & $\cdots$ & $\cdots$ & $\ldots$ \\
\hline$\cdots$ & $\cdots$ & $\cdots$ & $\cdots$ & $\cdots$ & $\cdots$ & $\cdots$ & $\cdots$ & $\cdots$ \\
\hline$\cdots$ & $\cdots$ & $\cdots$ & $\cdots$ & $\cdots$ & $\cdots$ & $\cdots$ & - & $\cdots$ \\
\hline$\cdots$ & $\cdots$ & $\cdots$ & $\cdots$ & $\cdots$ & $\cdots$ & $\cdots$ & $-\infty$ & $\cdots$ \\
\hline$\cdots$ & $\cdots$ & $\cdots$ & $\cdots$ & $\cdots$ & $\cdots$ & $\cdots$ & $\cdots$ & $\cdots$ \\
\hline$\cdots$ & $\cdots$ & $\cdots$ & $\cdots$ & $\cdots$ & 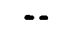 & $\cdots$ & $\cdots$ & - \\
\hline 05 & 1.7 & 8 & $<4$ & .91 & 270 & $<40$ & 9 & $<5$ \\
\hline- & -- & $\cdots$ & -- & $\cdots$ & $\cdots$ & $\cdots$ & $\cdots$ & $\ldots$ \\
\hline$\cdots$ & $\cdots$ & $\cdots$ & $\cdots$ & $\cdots$ & $\cdots$ & $\cdots$ & -- & $\ldots$ \\
\hline- & $\cdots$ & $=$ & -- & $\cdots$ & $\cdots$ & $\cdots$ & $\cdots$ & $\cdots$ \\
\hline$\cdots$ & $\cdots$ & $\cdots$ & $\cdots$ & $\cdots$ & $\cdots$ & $\cdots$ & $\cdots$ & $\cdots$ \\
\hline-- & $\cdots$ & $\cdots$ & $-\infty$ & $\cdots$ & $\cdots$ & $\cdots$ & $-\infty$ & $\cdots$ \\
\hline-- & $\cdots$ & $=$ & $\cdots$ & $\cdots$ & $\cdots$ & $\cdots$ & $\cdots$ & $\cdots$ \\
\hline$\cdots$ & $\cdots$ & -- & $\cdots$ & $\cdots$ & $\cdots$ & $\cdots$ & $\cdots$ & $\cdots$ \\
\hline$\cdots$ & $\cdots$ & $\cdots$ & $\cdots$ & $\cdots$ & $\cdots$ & -- & $\cdots$ & $\cdots$ \\
\hline$\cdots$ & $\cdots$ & $\cdots$ & $\cdots$ & $\cdots$ & $\cdots$ & $\cdots$ & $\cdots$ & - \\
\hline$\cdots$ & $\cdots$ & $\cdots$ & $\cdots$ & $\cdots$ & $\cdots$ & $\cdots$ & -- & $\cdots$ \\
\hline$\cdots$ & $\cdots$ & $\cdots$ & $\cdots$ & $\cdots$ & $\cdots$ & -- & $\cdots$ & $\cdots$ \\
\hline$\infty$ & $\cdots$ & $\cdots$ & $\cdots$ & $\cdots$ & $\cdots$ & $\cdots$ & $\cdots$ & $\cdots$ \\
\hline$\cdots$ & $\cdots$ & $\cdots$ & $\cdots$ & $\cdots$ & $\cdots$ & $\cdots$ & -- & $\cdots$ \\
\hline$\cdots$ & -- & $\cdots$ & $\cdots$ & $\cdots$ & $\cdots$ & - & - & $\cdots$ \\
\hline-- & $\cdots$ & $\cdots$ & $\cdots$ & $\cdots$ & $\cdots$ & -- & $\cdots$ & - \\
\hline$\cdots$ & $\cdots$ & $\cdots$ & $\cdots$ & $\cdots$ & $\cdots$ & $\cdots$ & $\cdots$ & $\cdots$ \\
\hline$\cdots$ & $\cdots$ & - & $\cdots$ & $\cdots$ & $\cdots$ & -- & $\cdots$ & $\cdots$ \\
\hline$\cdots$ & $\cdots$ & $\cdots$ & $\cdots$ & $\cdots$ & - & - & $\cdots$ & $\cdots$ \\
\hline$\cdots$ & $\cdots$ & -- & $\cdots$ & $\cdots$ & $\cdots$ & -- & $\cdots$ & $\cdots$ \\
\hline$\cdots$ & $\cdots$ & $\cdots$ & $\cdots$ & $\cdots$ & $\cdots$ & $\cdots$ & $\cdots$ & - \\
\hline$\cdots$ & $\cdots$ & $\cdots$ & $\cdots$ & $\cdots$ & $\cdots$ & $\cdots$ & $\cdots$ & $\cdots$ \\
\hline$\cdots$ & $\cdots$ & $\cdots$ & $\cdots$ & $\cdots$ & $\cdots$ & $\cdots$ & $\cdots$ & $\cdots$ \\
\hline$\cdots$ & $\cdots$ & $\cdots$ & $\cdots$ & $\cdots$ & $\cdots$ & $\cdots$ & $\cdots$ & $\cdots$ \\
\hline$\cdots$ & $\cdots$ & $\cdots$ & $\cdots$ & $\cdots$ & $\cdots$ & $\cdots$ & $\cdots$ & $\cdots$ \\
\hline$\ldots$ & $\cdots$ & $\cdots$ & $\cdots$ & $\cdots$ & $\cdots$ & $\cdots$ & $\cdots$ & $\cdots$ \\
\hline$\cdots$ & $\cdots$ & $=$ & $\cdots$ & $\cdots$ & $\cdots$ & $\cdots$ & $\cdots$ & - \\
\hline$\cdots$ & $\cdots$ & $\cdots$ & $\cdots$ & $\cdots$ & $\cdots$ & $\cdots$ & $\cdots$ & $\cdots$ \\
\hline$\cdots$ & $\cdots$ & $\cdots$ & $\cdots$ & $\cdots$ & $\cdots$ & $\cdots$ & $\cdots$ & $\cdots$ \\
\hline$\cdots$ & $\cdots$ & $\cdots$ & $\cdots$ & $\cdots$ & $\cdots$ & $\cdots$ & $\cdots$ & $\cdots$ \\
\hline$\cdots$ & $\cdots$ & $\cdots$ & $\cdots$ & $\cdots$ & $\cdots$ & $\cdots$ & $\cdots$ & $\ldots$ \\
\hline$\cdots$ & $\cdots$ & $\cdots$ & $\cdots$ & $\cdots$ & $\cdots$ & $\cdots$ & $\cdots$ & $\cdots$ \\
\hline$\cdots$ & $\cdots$ & $\cdots$ & $\cdots$ & $\cdots$ & $\cdots$ & $\cdots$ & $\cdots$ & - \\
\hline$\cdots$ & $\cdots$ & $\cdots$ & $\cdots$ & $\cdots$ & - & $\cdots$ & $\cdots$ & $\cdots$ \\
\hline$\cdots$ & $\cdots$ & $\cdots$ & $\cdots$ & $\cdots$ & $\cdots$ & $\cdots$ & $\cdots$ & $\cdots$ \\
\hline$\cdots$ & $\because$ & $\cdots$ & $\cdots$ & $\cdots$ & $\cdots$ & $\cdots$ & $\cdots$ & $\cdots$ \\
\hline$\cdots$ & $\because$ & $\cdots$ & $\cdots$ & $\cdots$ & $\cdots$ & $\cdots$ & $\cdots$ & $\cdots$ \\
\hline- & -- & $\cdots$ & $\cdots$ & $\cdots$ & $\cdots$ & $\cdots$ & $\because$ & \\
\hline
\end{tabular}


SURFACE-WATER DATA-Cont inued

CHEMICAL AKALYSES-Cont inued

STATION

MUMBER
DATE

03-04-91

$03-04-91$

$03-04-91$

03-04-91

03-05-91

03-05-91

03-05-91

03-05-91

03-08-91

03-08-91

03-08-91

03-08-91

03-08-91

03-09-91

03-09-91

03-09-91

$04-04-91$

$04-04-91$

04-05-91

04-05-91

04-05-91

04-06-91

04-06-91

04-09-91

04-09-91

04-09-91

04-09-91

04-09-91

04-09-91

04-10-91

04-10-91

04-10-91

04-10-91

04-10-91

04-10-91

04-11-91

04-11-91

04-11-91

05-01-91

05-01-91

05-09-91

05-09-91

09-06-91

$09-09-91$
SED.

\begin{tabular}{|c|c|c|c|c|c|c|}
\hline $\begin{array}{l}\text { TITA- } \\
\text { NIUN } \\
\text { BOT MAT } \\
\angle 63 \mu \text { DS } \\
\text { LAB } \\
\text { PERCENT } \\
\text { (34992) }\end{array}$ & $\begin{array}{c}\text { URANIUA } \\
\text { BOT MAT } \\
\angle 63 \mu \text { DS } \\
\text { LAB } \\
(\mu g / G) \\
(35002)\end{array}$ & $\begin{array}{l}\text { VANA- } \\
\text { OIUN } \\
\text { BOT NAT } \\
\angle 63 \mu \text { DS } \\
\text { LAB } \\
(\mu g / G) \\
(35007)\end{array}$ & $\begin{array}{c}\text { YTTRIUA } \\
\text { BOT MAT } \\
\angle 63 \mu \text { DS } \\
\text { LAB } \\
(\mu g / G) \\
(35012)\end{array}$ & $\begin{array}{c}\text { YTTER- } \\
\text { BIUN } \\
\text { BOT MAT } \\
<63 \mu \text { DS } \\
\text { LAB } \\
(\mu g / G) \\
(35017)\end{array}$ & $\begin{array}{c}\text { 2INC } \\
\text { BOT MAT } \\
\angle 63 \mu \text { DS } \\
\text { LAB } \\
(\mu g / G) \\
(35022)\end{array}$ & $\begin{array}{l}\text { SEDI- } \\
\text { MENT, } \\
\text { SUS- } \\
\text { PENDED } \\
(\mathrm{mg} / \mathrm{L}) \\
(80154)\end{array}$ \\
\hline
\end{tabular}

LITTLE COLORADO RIVER AT GRAND FALLS, AZ-cont inued

\begin{tabular}{|c|c|c|c|c|c|c|c|}
\hline -- & $\cdots$ & - & $\cdots$ & $\cdots$ & $\cdots$ & 25800 & 89 \\
\hline -- & $\cdots$ & -. & -. & -- & -. & 33100 & 95 \\
\hline$\cdots$ & - & $\cdots$ & $\cdots$ & $\cdots$ & $\cdots$ & 32300 & 95 \\
\hline$\cdots$ & $\cdots$ & $\cdots$ & - & $\cdots$ & $\cdots$ & 26600 & 95 \\
\hline$\cdots$ & $\cdots$ & $\cdots$ & $\cdots$ & $\cdots$ & -- & 21100 & $\cdots$ \\
\hline$\because$ & $\because$ & $\because$ & 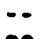 & $\because$ & $\because$ & 26600 & 87 \\
\hline .27 & $<100$ & 59 & 20 & 2 & 45 & 22500 & 91 \\
\hline-- & $\cdots$ & $\cdots$ & $\cdots$ & $\cdots$ & $\cdots$ & 22600 & - \\
\hline -. & $\cdots$ & -. & $\cdots$ & $\cdots$ & $\cdots$ & 17200 & 87 \\
\hline$\cdots$ & $\cdots$ & $\cdots$ & $\cdots$ & $\cdots$ & $\cdots$ & 15500 & 85 \\
\hline$\cdots$ & $\cdots$ & $\cdots$ & $\cdots$ & $\cdots$ & $\cdots$ & 15600 & 82 \\
\hline$\cdots$ & $\cdots$ & $\cdots$ & $\cdots$ & -. & $\cdots$ & 14000 & 85 \\
\hline$\cdots$ & $\therefore$ & $\cdots$ & $\cdots$ & $\cdots$ & $\cdots$ & 15300 & 80 \\
\hline$\cdots$ & $\because$ & $\cdots$ & $\cdots$ & 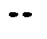 & $\cdots$ & 20100 & 88 \\
\hline 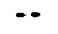 & $\cdots$ & $\cdots$ & $\cdots$ & $\cdots$ & $\cdots$ & 15700 & 92 \\
\hline$\cdots$ & $\cdots$ & $\cdots$ & $\cdots$ & $\cdots$ & $\cdots$ & 17400 & 89 \\
\hline$\cdots$ & $\cdots$ & $=$ & $\cdots$ & $\cdots$ & $\cdots$ & 17100 & 81 \\
\hline$\cdots$ & -- & $\cdots$ & $\cdots$ & $-\cdot$ & $\cdots$ & 12800 & $\cdots$ \\
\hline$\cdots$ & $\cdots$ & $\cdots$ & $\cdots$ & $\cdots$ & -- & 15900 & $\cdots$ \\
\hline-- & $\cdots$ & $=$ & $\because \cdot$ & $-\cdot$ & - & 12900 & $\cdots$ \\
\hline$\cdots$ & $\cdots$ & $\cdots$ & $\cdots$ & -. & $\cdots$ & 12800 & $\cdots$ \\
\hline$\cdots$ & $\cdots$ & $\cdots$ & $\cdots$ & $\cdots$ & $\cdots$ & 11300 & $\cdots$ \\
\hline$\cdots$ & $\cdots$ & $\cdots$ & $\cdots$ & $\cdots$ & -. & 11300 & $\because$ \\
\hline$\cdots$ & $\cdots$ & $-\cdot$ & $\cdots$ & $=$ & $\cdots$ & 16000 & 80 \\
\hline$-\cdot$ & $\cdots$ & $-\cdot$ & $-\cdot$ & $\cdots$ & $\cdots$ & 17000 & $\cdots$ \\
\hline$\cdots$ & $\cdots$ & $\cdots$ & $\cdots$ & $\cdots$ & $\cdots$ & 13900 & $\cdots$ \\
\hline$\cdots$ & $\because-$ & $\cdots$ & $\cdots$ & $\cdots$ & $\cdots$ & 10400 & $\because$ \\
\hline$-\cdot$ & $\cdots$ & $\cdots$ & $\cdots$ & $\cdots$ & $\cdots$ & 14000 & 72 \\
\hline$\cdots$ & $\cdots$ & $\cdots$ & $\cdots$ & $\cdots$ & $\cdots$ & 10100 & $\cdots$ \\
\hline$\cdots$ & $\cdots$ & -- & $\cdots$ & -. & $\cdots$ & 12100 & -. \\
\hline$\cdots$ & $\cdots$ & $\cdots$ & -- & $\cdots$ & $\cdots$ & 14200 & -- \\
\hline$\cdots$ & $\cdots$ & $\cdots$ & $\cdots$ & -. & $\cdots$ & 9270 & $-\cdot$ \\
\hline$\cdots$ & $\cdots$ & $\cdots$ & $\cdots$ & -- & -- & 10200 & -. \\
\hline$\cdots$ & $\cdots$ & $\cdots$ & $\cdots$ & $\cdots$ & $\cdots$ & 7060 & $\cdots$ \\
\hline$\cdots$ & $\cdots$ & $\cdots$ & $\cdots$ & $\cdots$ & $\cdots$ & 11900 & -- \\
\hline 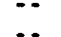 & $\therefore$ & $\ldots$ & $\because$ &.- & $\therefore$ & 15600 & $\because$ \\
\hline$\ldots$ & .. & .. & .. & .. & $\ldots$ & 11000 & 33 \\
\hline .. & - & -. & -. & -. & -. & $\begin{array}{c}\angle 9000 \\
\ldots\end{array}$ & $\therefore$ \\
\hline -. & -. & -. & -. & .. & .. & 2500 & 91 \\
\hline$\cdots$ & -- & .. & -. & -. & -. & 1320 & 38 \\
\hline$\cdots$ & $\cdots$ & $\cdots$ & $\cdots$ & $\cdots$ & -- & 1320 & 38 \\
\hline -. & $\cdots$ & $\cdots$ & $\cdots$ & $\cdots$ & $\cdots$ & 53900 & 100 \\
\hline$\cdots$ & -- & $\cdots$ & $-\cdot$ & $\cdots$ & $\cdots$ & 56900 & \\
\hline
\end{tabular}


STATION

NUMBER

09401000
SURFACE-WATER DATA-Cont inued

CHEMICAL ANALYSES-Cont inued

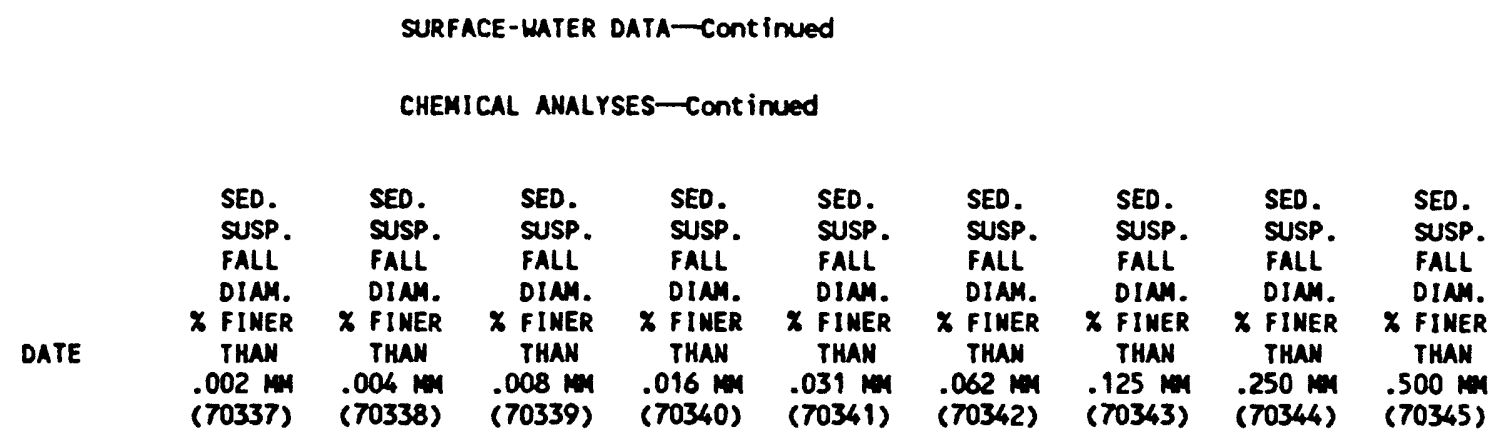

LITTLE COLORADO RIVER AT GRAMD FALLS, AZ-Continued

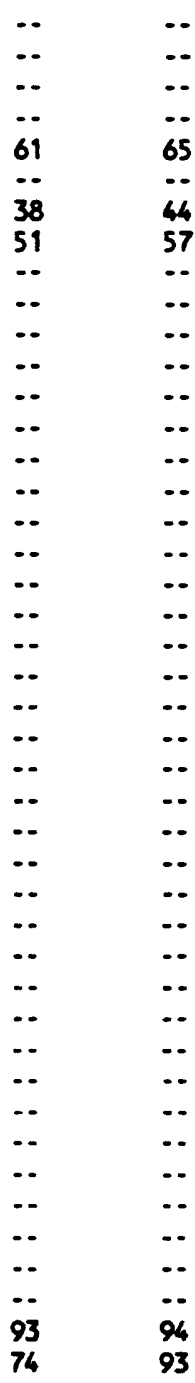

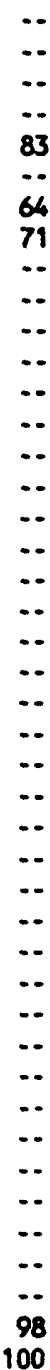

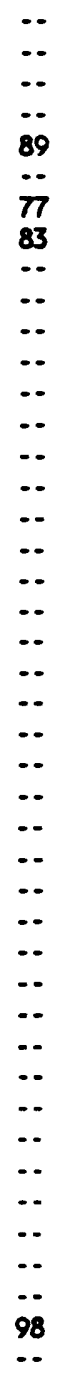

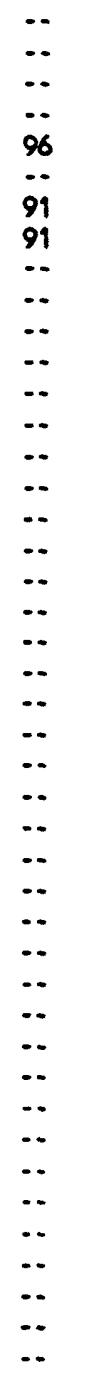

\begin{tabular}{|c|c|c|}
\hline - & $\cdots$ & -. \\
\hline - & 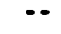 & $\cdots$ \\
\hline$\cdots$ & $\because$ & $\cdots$ \\
\hline$\because$ & $\cdots$ & $\cdots$ \\
\hline 100 & $\cdots$ & $\cdots$ \\
\hline$\cdots$ & $\ddot{m}$ & 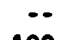 \\
\hline $\begin{array}{l}98 \\
99\end{array}$ & $\begin{array}{r}99 \\
100\end{array}$ & 100 \\
\hline$\cdots$ & -- & $\cdots$ \\
\hline$\cdots$ & $\because$ & $\cdots$ \\
\hline$\cdots$ & $\cdots$ & $\cdots$ \\
\hline$\cdots$ & $\cdots$ & $\cdots$ \\
\hline$\cdots$ & $=$ & $\cdots$ \\
\hline$\cdots$ & $\cdots$ & $\cdots$ \\
\hline$\cdots$ & $\cdots$ & $\cdots$ \\
\hline$\because$ & $\because$ & 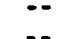 \\
\hline$\ldots$ & $\ldots$ & $\ldots$ \\
\hline$\ldots$ & $\ldots$ & $\ldots$ \\
\hline$\ldots$ & $\ldots$ & .. \\
\hline-- & $\cdots$ & - \\
\hline$\cdots$ & - & $\cdots$ \\
\hline$\cdots$ & $\cdots$ & $\cdots$ \\
\hline$\cdots$ & -- & $\because$ \\
\hline$\cdots$ & $\cdots$ & $\cdots$ \\
\hline$\cdots$ & - & $\cdots$ \\
\hline$\cdots$ & $\cdots$ & $\cdots$ \\
\hline$\because$ & $\because$ & $\because$ \\
\hline$\cdots$ & $\because$ & $\because$ \\
\hline$\ldots$ & $\ldots$ & $\therefore$ \\
\hline - & $\ldots$ & $\ldots$ \\
\hline - & .. & 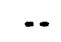 \\
\hline$\ldots$ & .. & $\ldots$ \\
\hline$\cdots$ & - & - \\
\hline$\cdots$ & -. & $\cdots$ \\
\hline$\cdots$ & - & $\cdots$ \\
\hline-- & - & $\cdots$ \\
\hline-- & $=$ & $\cdots$ \\
\hline$\cdots$ & -- & $\cdots$ \\
\hline$\cdots$ & $\because$ & $\cdots$ \\
\hline$\cdots$ & $\because$ & $\because$ \\
\hline & - & $\ldots$ \\
\hline
\end{tabular}


SURFACE WATER-Continued

CHEMICAL AHALYSES-Cont inued

\begin{tabular}{|c|c|c|c|c|c|}
\hline $\begin{array}{l}\text { STATION } \\
\text { MUABER }\end{array}$ & STATION MAME & DATE & TIME & LATITUDE & LONGITUDE \\
\hline 09402000 & LITTLE COLORADO RIVER AT CAMERON, ARIZONA & $\begin{array}{l}02-22-90 \\
04-13-90 \\
07-08-90 \\
07-12-90 \\
07-12-90 \\
07-23-90 \\
07-23-90 \\
08-19-90 \\
08-19-90 \\
08-21-90 \\
08-23-90 \\
09-12-90 \\
09-18-90 \\
09-18-90 \\
09-19-90 \\
09-19-90 \\
09-19-90 \\
09-20-90 \\
09-20-90 \\
09-20-90 \\
09-20-90 \\
09-21-90 \\
09-24-90 \\
09-24-90 \\
12-18-90 \\
01-07-91 \\
01-07-91 \\
01-08-91 \\
02-12-91 \\
03-07-91 \\
05-02-91 \\
08-30-91 \\
09-05-91\end{array}$ & $\begin{array}{l}1325 \\
1240 \\
1740 \\
1230 \\
1530 \\
1840 \\
1845 \\
1245 \\
1248 \\
1330 \\
1330 \\
1440 \\
1230 \\
1810 \\
\cdots \\
0440 \\
1640 \\
\cdots \\
0740 \\
1340 \\
2240 \\
0440 \\
0130 \\
0230 \\
1310 \\
1410 \\
2030 \\
1530 \\
1330 \\
1400 \\
1315 \\
1230 \\
1300\end{array}$ & $35 \cdot 55 \cdot 35 \mathrm{mN}$ & $111 \cdot 34 \cdot 00 \mathrm{my}$ \\
\hline 353730108312001 & PIPELINE ARROYO & $\begin{array}{l}08-14-90 \\
08-15-90 \\
08-15-90\end{array}$ & $\begin{array}{l}1449 \\
0010 \\
1330\end{array}$ & $35 \cdot 37 \cdot 30^{\prime \prime N}$ & $108 \cdot 31 \cdot 2004$ \\
\hline 352450108592401 & MANUELITO WASH, U-59 & $\begin{array}{l}08-16-90 \\
10-19-90 \\
08-08-91 \\
08-16-91 \\
08-16-91\end{array}$ & $\begin{array}{c}0010 \\
0010 \\
0010 \\
\therefore \\
2100\end{array}$ & $35 \cdot 24 \cdot 50^{\prime \prime N}$ & $108^{\circ} 59 \cdot 24^{\prime \prime 4}$ \\
\hline 09397300 & LEROUX WASH MEAR HOLBROOK, ARIZOMA & $\begin{array}{l}07-19-90 \\
12-20-90\end{array}$ & $\begin{array}{l}0010 \\
1300\end{array}$ & $34^{\circ} 54 \cdot 18^{\prime \prime N}$ & $110^{\circ} 12 \cdot 03^{\prime} 4$ \\
\hline
\end{tabular}


SURFACE-WATER DATA-Cont inued

CHEMICAL ANALYSES-Continued

STATION

NUMBER

09402000

02-22-90

$04-13-90$

07-08-90

07-12-90

$07-12-90$

07-23-90

07-23-90

$08-19-90$

08-19-90

08-21-90

08-23-90

09-12-90

09-18-90

09-18-90

09-19-90

$09-19-90$

09-19-90

09-20-90

09-20-90

09-20-90

09-20-90

09-21-90

09-24-90

09-24-90

12-18-90

01-07-91

01-07-91

01-08-91

02-12-91

03-07-91

05-02-91

08-30-91

09-05-91

353730108312001

08-14-90

$08-15-90$

08-15-90

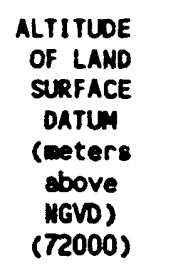

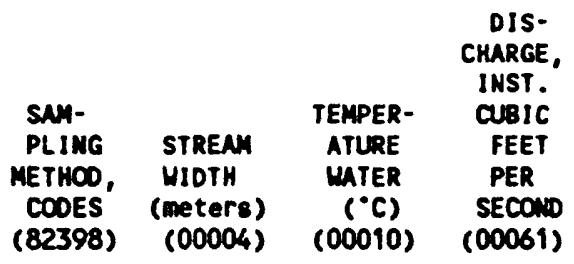

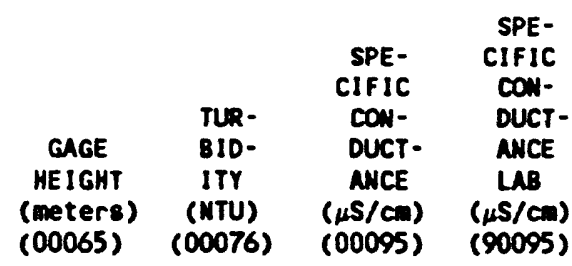

LITTLE COLORADO RIVER AT CAMERON, AZ-Continued

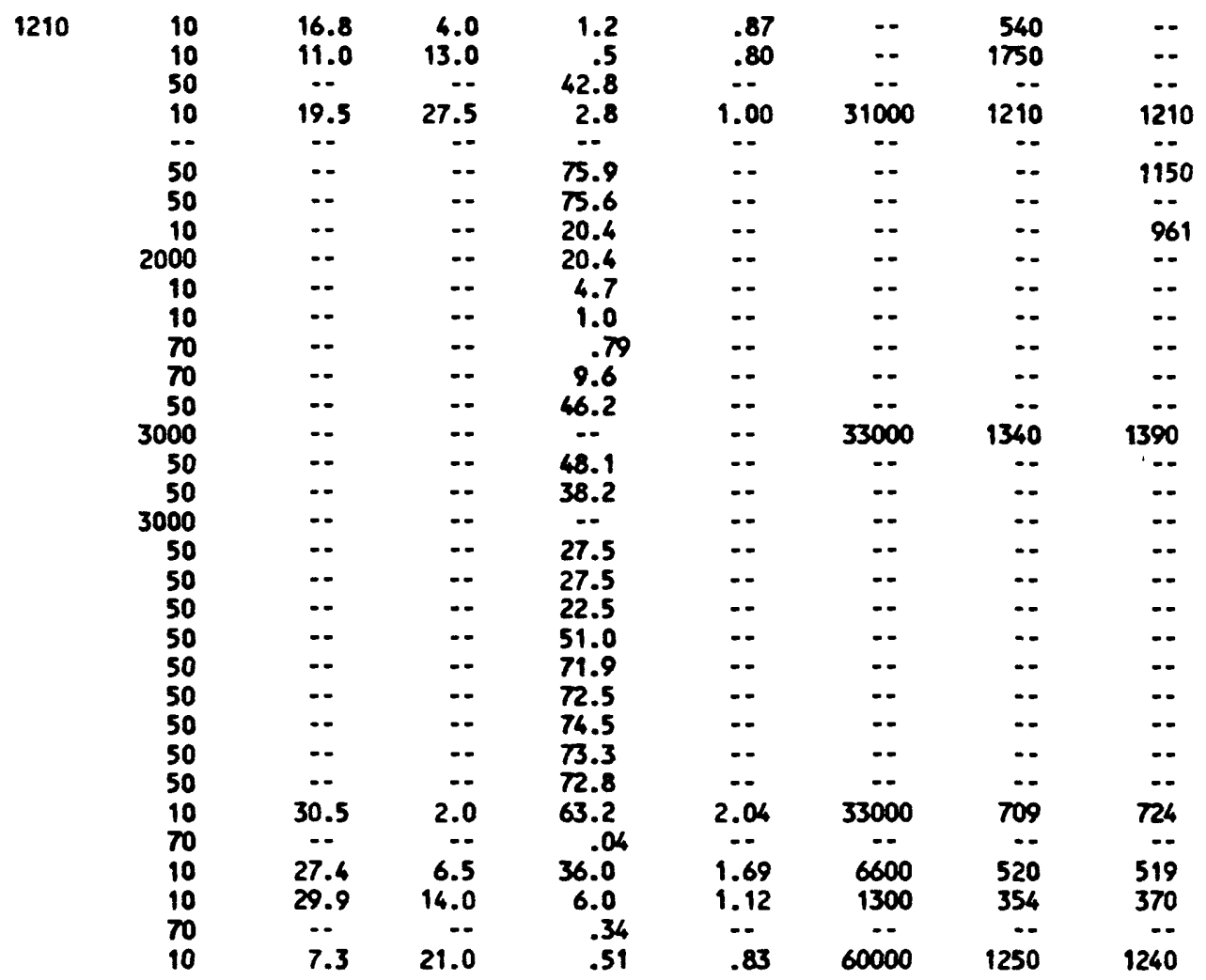

PIPELINE ARROYO-Continued

2070

$\begin{array}{llll}- & \cdots & \cdots & \cdots \\ -- & \cdots & -- & \cdots \\ 50 & \cdots & -- & \cdots\end{array}$

$\cdots$
-

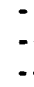

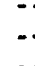

$\cdots$ 793

MANUELITO MASH, U-59-Continued

$\begin{array}{ll}352450108592401 & 08-16-90 \\ 10-19-90 \\ 08-08-91 \\ 08-16-91 \\ 08-16-91\end{array}$

$\begin{array}{llll}-- & -- & -- & - \\ -- & - & -- & - \\ -- & -- & -- & - \\ -- & -- & -- & - \\ -- & -- & -- & -\end{array}$

LEROUX MASK MEAR MOLBROOK, ARIZOMA-Contimued

09397300

30

$\because$. $\because$ 


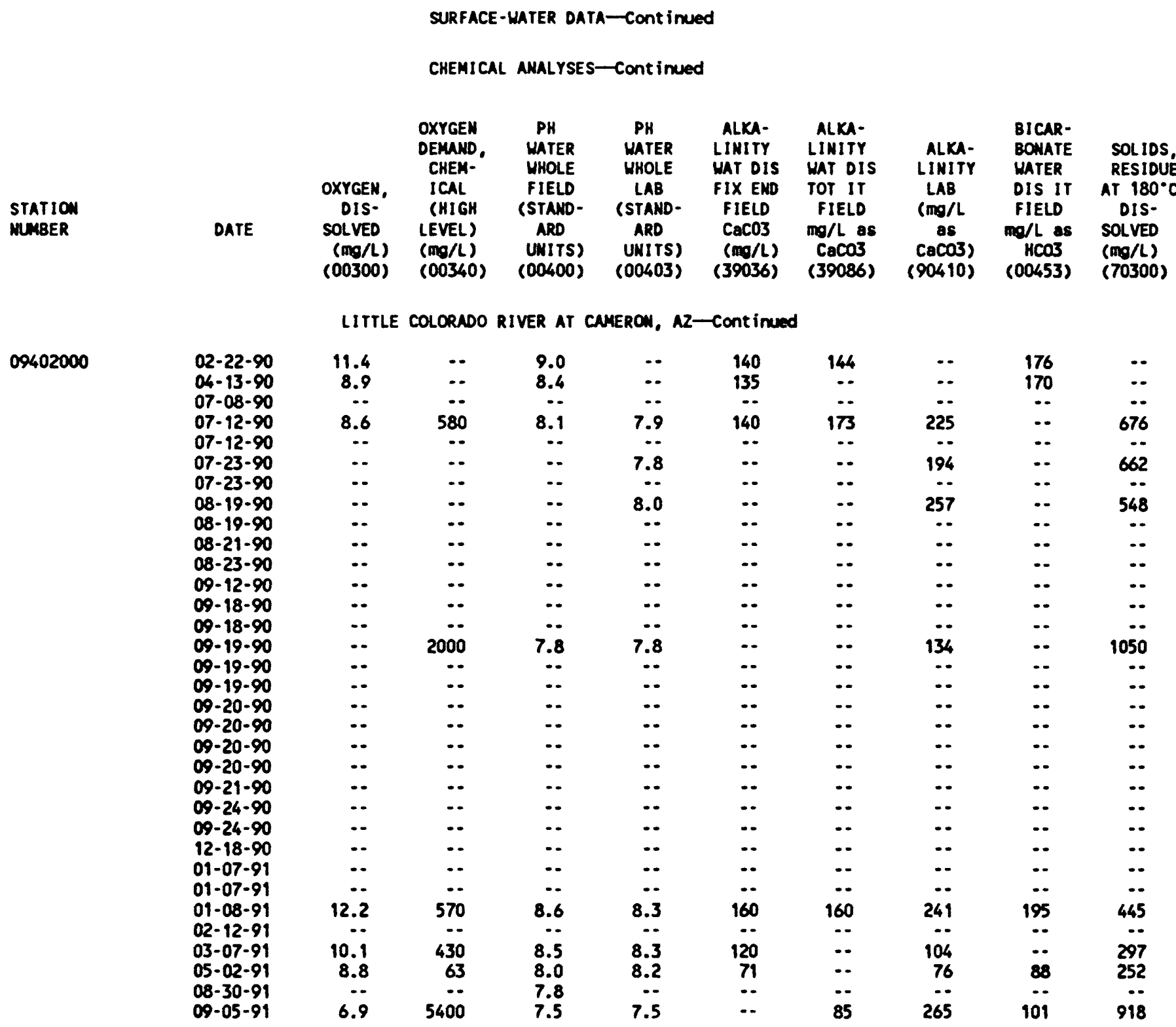

$353730108312001 \quad 08-14-90$ $08-15-90$ 08-15-90
08-16-90 $10-19-90$ 08-08-91 08-16-91 08-16-91
LEROUX WASH NEAR HOLBROOK, ARIZONA-Continued

MANUELITO WASH, U-59-Cont inued

$\begin{array}{lllllllll}\ldots & \ldots & \ldots & \ldots & \ldots & \ldots & \ldots \\ \ldots & \ldots & \ldots & \ldots & \ldots & \ldots & \ldots & \ldots & \ldots \\ \ldots & \ldots & \ldots & \ldots & \ldots & \ldots & \ldots & \ldots & \ldots \\ \ldots & \ldots & \ldots & \ldots & \ldots & \ldots & \ldots\end{array}$

PIPELINE ARROYO-Continued

\begin{tabular}{|c|c|c|c|c|c|c|c|}
\hline$\cdots$ & $\cdots$ & $\cdots$ & $\cdots$ & $\cdots$ & $\cdots$ & $\cdots$ & .. \\
\hline -. & -. & $\cdots$ & $\cdots$ & $\cdots$ & -- & -. & -- \\
\hline -. & -. & 7.8 & $\cdots$ & $\cdots$ & 176 & -. & 573 \\
\hline
\end{tabular}


STATION

MUABER

09402000

353730108312001

$08-14-90$

$08-15-90$

08-15-90
$02-22-90$

$04-13-90$

07-08-90

07-12-90

$07-12-90$

07-23-90

$07-23-90$

08-19-90

08-19-90

08-21-90

$08-23-90$

$09-12-90$

09-18-90

09-18-90

$09-19-90$

09-19-90

$09-19-90$

09-20-90

09-20-90

09-20-90

09-20-90

09-21-90

09-24-90

$09-24-90$

$12-18-90$

01-07-91

01-07-91

$01-08-91$

02-12-91

03-07-91

05-02-91

08-30-91

09-05-91

SURFACE-WATER DATA-Continued

CHEMICAL AKALYSES-Cont inued

\begin{tabular}{|c|c|c|c|c|c|c|c|c|}
\hline $\begin{array}{l}\text { SOLIDS, } \\
\text { SUH OF } \\
\text { CONSTI- } \\
\text { TUENTS, } \\
\text { DIS- } \\
\text { SOLVED } \\
(\mathrm{mD} / \mathrm{L}) \\
(70301)\end{array}$ & $\begin{array}{l}\text { SOLIDS, } \\
\text { DIS- } \\
\text { SOLVED } \\
\text { (tons } \\
\text { per } \\
\text { day) } \\
\text { (70302) }\end{array}$ & $\begin{array}{l}\text { RESIDUE } \\
\text { TOTAL } \\
\text { AT } 10^{\circ} \mathrm{C} \\
\text { SUS- } \\
\text { PENDED } \\
(\mathrm{mg} / \mathrm{L}) \\
(00530)\end{array}$ & $\begin{array}{l}\text { NITRO- } \\
\text { GEN, } \\
\text { AMNONIA } \\
\text { DIS- } \\
\text { SOLVED } \\
\text { (mO/L } \\
\text { OS N) } \\
\text { (00608) }\end{array}$ & $\begin{array}{l}\text { WITRO- } \\
\text { GEN, } \\
\text { NITRITE } \\
\text { DIS- } \\
\text { SOLVED } \\
\text { (mo/L } \\
\text { OS N) } \\
\text { (00613) }\end{array}$ & $\begin{array}{l}\text { MITRO- } \\
\text { GEN, } \\
\text { WITRATE } \\
\text { DIS- } \\
\text { SOLVED } \\
(\text { OO/L } \\
\text { OS N) } \\
(00618)\end{array}$ & $\begin{array}{c}\text { MITRO- } \\
\text { GEN, } \\
\text { MO2+NO3 } \\
\text { OIS- } \\
\text { SOLVED } \\
\text { (mo/L } \\
\text { as N) } \\
(00631)\end{array}$ & $\begin{array}{c}\text { MITRO- } \\
\text { GEN, } \\
\text { MITRATE } \\
\text { DIS- } \\
\text { SOLVED } \\
\text { (mo/L } \\
\text { as NO3) } \\
\text { (71851) }\end{array}$ & $\begin{array}{c}\text { NITRO- } \\
\text { GEN, } \\
\text { NITRITE } \\
\text { DIS- } \\
\text { SOLVED } \\
\text { (mo/L } \\
\text { as MO2) } \\
\text { (71856) }\end{array}$ \\
\hline
\end{tabular}

LITTLE COLORADO RIVER AT CAMERON, AZ-Continued

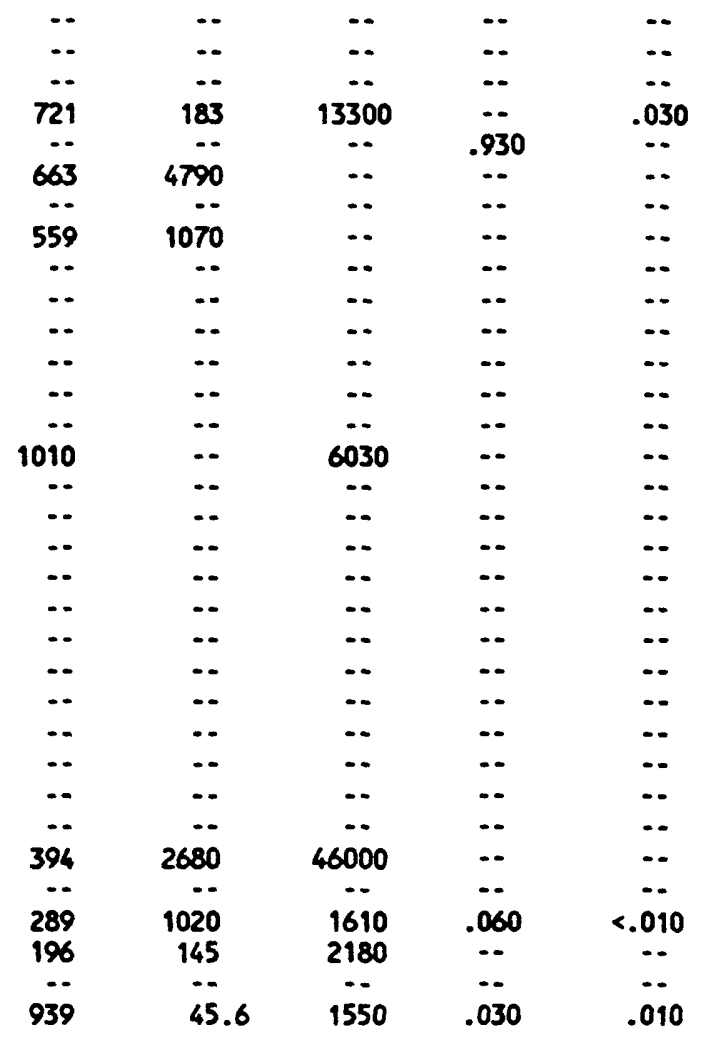

PIPELINE ARROYO-Continued
MAUELITO WASH, U-59-Cont inued

352450108592401

$08-16-90$

$10-19-90$

08-08-91

$08-16-91$

08-16-91

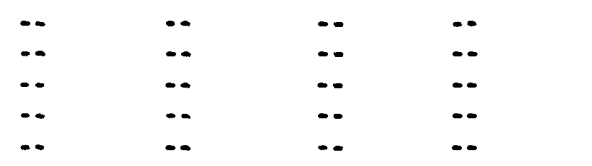

LEROUX WASH MEAR HOLBROOK, ARIZOWA-Continued

\begin{tabular}{|c|c|c|c|}
\hline -. & -. & -. & $\cdots$ \\
\hline$\cdots$ & $\cdots$ & $\cdots$ & $\because$ \\
\hline 1.07 & 1.10 & 4.7 & .10 \\
\hline$\cdots$ & $\cdots$ & $\cdots$ & -. \\
\hline$\because$ & $\because$ & $\because$ & $\because$ \\
\hline -. & .. & .. & .. \\
\hline$\cdots$ & -. & -. & -. \\
\hline$\cdots$ & $\because$ & 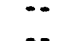 & 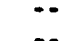 \\
\hline .. & .. & $\because$ & $\because$ \\
\hline$\cdots$ & -. & -. & .. \\
\hline$\cdots$ & -- & -. & $\cdots$ \\
\hline$\ldots$ & .. & $\because$ & $\ddot{-}$ \\
\hline -. & -. & .. & -. \\
\hline 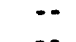 & $\because$ & $\because$ & $\because$ \\
\hline$\because$ & $\because$ & $\cdots$ & $\ddot{-.}$ \\
\hline$\because$ & $\cdots$ & -. & .. \\
\hline$\because$ & $\cdots$ & $\cdots$ & $\cdot-$ \\
\hline$\because$ & $\because$ & $\because$ & $\because$ \\
\hline - & -. & .. & .. \\
\hline - & -. & -. & $\cdots$ \\
\hline$\cdots$ & $\ddot{~}$ & $\because$ & $\because$ \\
\hline - & .. & .. & .. \\
\hline -. & .430 & -. & -. \\
\hline $\begin{array}{l}\cdots \\
-.\end{array}$ & $\cdots$ & $\ldots$ & 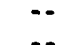 \\
\hline 8.59 & 8.60 & 38 & .03 \\
\hline
\end{tabular}

530

$$
\begin{aligned}
& 07-19-90 \\
& 12-20-90
\end{aligned}
$$

09397300 


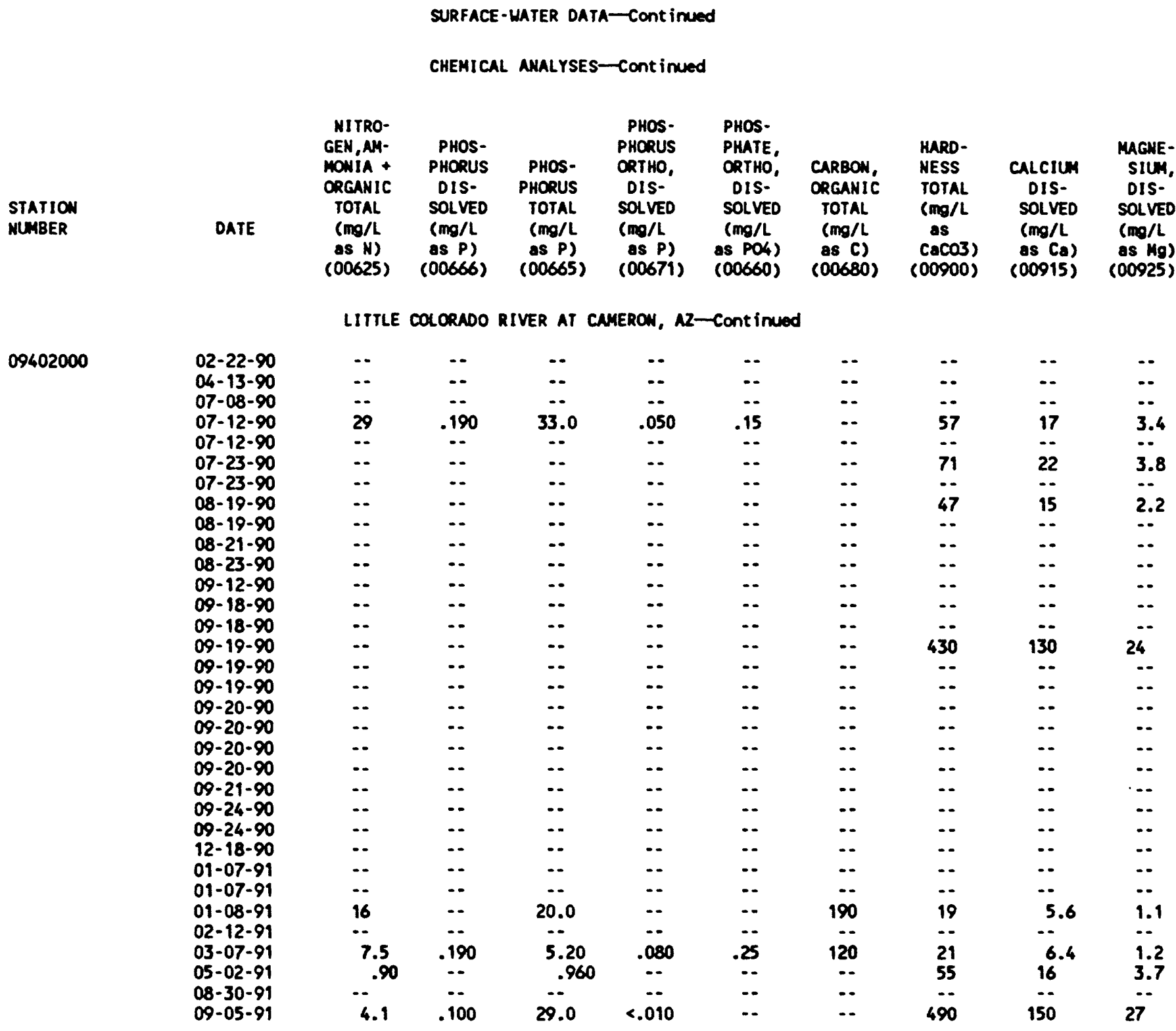

$353730108312001 \quad 08-14-90$

$08-15-90$

08-15-90
352450108592401

08-16-90

$10-19-90$

08-08-91

$08-16-91$

08-16-91

\section{PIPELINE ARROYo-Continued}

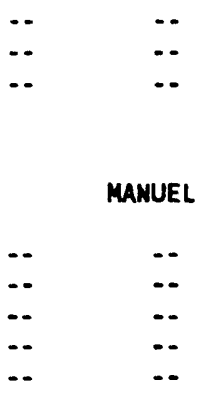

LEROXX WASH NEAR HOLBROOK, ARIZOM-Continued 
SURFACE-WATER DATA-Continued

CHEMICAL AKALYSES-Continued

\begin{tabular}{|c|c|c|c|c|c|c|c|c|c|c|}
\hline $\begin{array}{l}\text { STATION } \\
\text { MUMBER }\end{array}$ & DATE & $\begin{array}{c}\text { SOOIUN, } \\
\text { DIs- } \\
\text { SOLVED } \\
\text { (mo/L } \\
\text { as Ha) } \\
(00930)\end{array}$ & $\begin{array}{l}\text { SOOIUM } \\
\text { ADSORP- } \\
\text { TION } \\
\text { RATIO } \\
\text { (00931) }\end{array}$ & $\begin{array}{l}\text { SODIUN } \\
\text { PERCEN } \\
\text { (00932) }\end{array}$ & $\begin{array}{l}\text { POIAS- } \\
\text { SIUW, } \\
\text { DIS- } \\
\text { SOLVED } \\
\text { (mg/L } \\
\text { os K) } \\
(00935)\end{array}$ & $\begin{array}{l}\text { CHLO- } \\
\text { RIDE, } \\
\text { OIS- } \\
\text { SOLVED } \\
\text { (mo/L } \\
\text { as Cl) } \\
(00940)\end{array}$ & $\begin{array}{c}\text { BROWIDE } \\
\text { DIS- } \\
\text { SOLVED } \\
\text { (mo/L } \\
\text { os Br Br) } \\
(71870)\end{array}$ & $\begin{array}{l}\text { FLUO- } \\
\text { RIDE, } \\
\text { DIS- } \\
\text { SOLVED } \\
\text { (mo/L } \\
\text { os F) } \\
(00950)\end{array}$ & $\begin{array}{l}\text { SILICA, } \\
\text { DIS- } \\
\text { SOLVED } \\
\text { (mg/L } \\
\text { as } \\
\text { siog) } \\
(00955)\end{array}$ & $\begin{array}{c}\text { SULFATE } \\
\text { DIS- } \\
\text { SOLVED } \\
\text { (me/L } \\
\text { as Sol) } \\
\text { (00945) }\end{array}$ \\
\hline \multicolumn{11}{|c|}{ LITTLE COLORADO RIVER AT CAMERON, AZ-Continued } \\
\hline \multirow[t]{32}{*}{09402000} & $02-22-90$ & .. & -. & -. & .. & -. & .. & .. & -. & .. \\
\hline & $04-13-90$ & -. & -. & -. & .. & .. & .. & .. & .. & .. \\
\hline & $07-08-90$ & 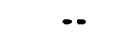 & $\cdots$ & -. & .. & -. & .. & -. & .. & .. \\
\hline & $07-12-90$ & 230 & 13 & 89 & 3.8 & 190 & .37 & .70 & 23 & 110 \\
\hline & $07-12-90$ & $\therefore$ & $\because$ & $\cdots$ & $\cdots$ & $\cdots$ & $\cdots$ & $\cdots$ & $\cdots$ & $\cdots$ \\
\hline & $07-23-90$ & 210 & 11 & 86 & 3.2 & 120 & .14 & .70 & 16 & 170 \\
\hline & $07-23-90$ & $\ddot{a}$ & $\because$ & $\because$ & $\because \cdot$ & $\because$ & $\because$ & $\because$ & $\because$ & $\cdots$ \\
\hline & $08-19-90$ & 170 & 11 & 88 & 2.6 & 72 & .040 & .60 & 12 & 130 \\
\hline & $08-19-90$ & -. & $\cdots$ & $\cdots$ & -. & $\cdot-$ & $\cdots$ & $\cdots$ & $\cdots$ & $\cdots$ \\
\hline & $08-21-90$ & $\cdots$ & $\cdots$ & $\cdots$ & $\cdots$ & $\cdots$ & $\cdot \cdot$ & $\cdots$ & $\cdots$ & -. \\
\hline & $08-23-90$ & -. & $\cdots$ & $\cdots$ & $\cdots$ & $\cdots$ & -. & $\cdots$ &.- & -. \\
\hline & $09-12-90$ & -. & $\cdots$ & $\cdots$ & $\cdots$ & $\cdot-$ & -. & $\cdots$ & $\cdots$ & $\cdot \cdot$ \\
\hline & $09-18-90$ & -. & $\cdots$ & $\cdots$ & $\cdots$ & -. & -. & -. & -. & -. \\
\hline & $09-18-90$ & .. & -. & $\cdots$ & $\cdots$ & -. & -. & -. & .. & .. \\
\hline & $09-19-90$ & 140 & 3 & 41 & 6.5 & 30 & .030 & .50 & 10 & 590 \\
\hline & $09-19-90$ & -. & $\cdots$ & $\cdots$ & $\cdots$ & $\cdots$ & $\cdots$ & $\cdots$ & $\cdots$ & -. \\
\hline & $09-19-90$ & -. & $\cdots$ & $\cdots$ & $\cdots$ & $\because \cdot$ & 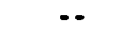 & $\cdots$ & $\cdots$ & -. \\
\hline & $09-20-90$ & $\cdot-$ & -. & -. & $\cdots$ & $\cdots$ & -. & .. & -. & .. \\
\hline & $09-20-90$ & -. & $\cdots$ & $\cdots$ & -. & -. & -. & $\cdots$ & $\cdots$ & -. \\
\hline & $09-20-90$ & -. & $\cdots$ & $\cdots$ & $\cdot$. & -. & $\cdots$ & -. & $\cdots$ & -. \\
\hline & $09-20-90$ & -. & $\cdots$ & $\cdots$ & $\cdots$ & -. & -. & -. & $\cdots$ & -. \\
\hline & $09-21-90$ & $\cdot \cdot$ & $\cdots$ & $\cdots$ & $\cdots$ & $\cdots$ & $\cdots$ & -. & $\cdots$ & -. \\
\hline & $09-24-90$ & $\cdot-$ & -. & $\cdots$ & -. & $\cdot \cdot$ & -. & -. & $\cdots$ & -. \\
\hline & $09-24-90$ & -. & $\cdots$ & $\cdots$ & $\cdots$ & $\cdots$ & -. & $\cdots$ & $\cdots$ & $\cdot \cdot$ \\
\hline & $12-18-90$ & .. & $\cdots$ & $\cdots$ & $\cdots$ & -. & -. & -. & -. & -. \\
\hline & $01-07-91$ & -. & -. & $\cdots$ & $\cdots$ & $\cdot-$ & $\cdots$ & $\cdots$ & $\cdots$ & -. \\
\hline & $01-07-91$ & $\because$ & $\because$ & $\ddot{\theta}$ & $\cdots$ & $\because$ & $\cdots$ & $\ddot{m}$ & $\because$ & $\because-$ \\
\hline & $01-08-91$ & 140 & 14 & 93 & 2.1 & 68 & 2.0 & .70 & 11 & 67 \\
\hline & $02-12-91$ & $\cdots$ & $\cdots$ & 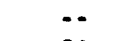 & $\cdots$ & $\cdots$ & $\because \cdot$ & $\cdots$ & $\cdots$ & -. \\
\hline & $03-07-91$ & $\begin{array}{r}100 \\
50\end{array}$ & 10 & 91 & 1.5 & 51 & .70 & .50 & 8.1 & 55 \\
\hline & $\begin{array}{l}05-02-91 \\
08-30-91\end{array}$ & $\begin{array}{l}50 \\
\cdots\end{array}$ &.- & 32 & $\begin{array}{l}1.7 \\
\ldots\end{array}$ & 38 & $\ddot{-.}$ & .10 & 6.3 & $\underline{17}$ \\
\hline & $\begin{array}{l}08-30-91 \\
09-05-91\end{array}$ & 86 & 2 & 27 & 9.8 & 23 & .39 & .70 & 12 & 540 \\
\hline
\end{tabular}

353730108312001

08-14-90 $08-15-90$ $08-15-90$
08-16-90 $10-19-90$ 08-08-91 $08-16-91$ 08-16-91
352450108592401
$07-19-90$

$12-20-90$

\section{PIPELINE ARROYO-Continued}

\begin{tabular}{|c|c|c|c|c|c|c|c|c|}
\hline -. & -. & $\cdots$ & -. & -. & .. & - & .. & -. \\
\hline$\cdots$ & $\cdots$ & $\cdots$ & $\cdots$ & $\cdots$ & $\cdots$ & -. & -. & $\because$ \\
\hline 29 & .5 & 11 & 7.4 & 8.3 & .040 & .50 & 12 & 240 \\
\hline
\end{tabular}

09397300 
SURFACE-WATER DATA-Cont inued

CHEMICAL AMALYSES-Contimued

STATION

MUMBER

09402000
$02-22-90$

$04-13-90$

$07-08-90$

07-12-90

07-12-90

07-23-90

07-23-90

08-19-90

08-19-90

08-21-90

08-23-90

$09-12-90$

$09-18-90$

09-18-90

$09-19-90$

09-19-90

$09-19-90$

09-20-90

09-20-90

$09-20-90$

09-20-90

09-21-90

$09-24-90$

$09-24-90$

12-18-90

01-07-91

01-07-91

01-08-91

02-12-91

03-07-91

05-02-91

08-30-91

09-05-91

$353730108312001 \quad \begin{aligned} & 08-14-90 \\ & 08-15-90\end{aligned}$

08-15-90

\begin{tabular}{|c|c|c|c|c|c|c|c|c|}
\hline $\begin{array}{l}\text { ARSENIC } \\
\text { OIS- } \\
\text { SOLVED } \\
(\mu g / L \\
\text { OS AS) } \\
(01000)\end{array}$ & $\begin{array}{l}\text { ARSENIC } \\
\text { TOTAL } \\
\text { ( } \mu g / L \\
\text { As As) } \\
(01002)\end{array}$ & $\begin{array}{l}\text { BARILM, } \\
\text { DIS- } \\
\text { SOLVED } \\
\text { ( } \mu g / L \\
\text { as Ba) } \\
(01005)\end{array}$ & $\begin{array}{l}\text { BERYL- } \\
\text { LIUH, } \\
\text { DIS- } \\
\text { SOLVED } \\
(\mu g / L \\
\text { OS BE) } \\
\text { (01010) }\end{array}$ & $\begin{array}{l}\text { BORON, } \\
\text { DIS- } \\
\text { SOIVED } \\
(\mu g / L \\
\text { AS B) } \\
(01020)\end{array}$ & $\begin{array}{c}\text { CADHIL } \\
\text { DIS- } \\
\text { SOLVED } \\
(\mu g / L \\
\text { as Cd) } \\
\text { (01025) }\end{array}$ & $\begin{array}{c}\text { CHRO- } \\
\text { MIUH, } \\
\text { DIS- } \\
\text { SOLVED } \\
(\mu g / L \\
\text { OS Cr) } \\
(01030)\end{array}$ & $\begin{array}{l}\text { COBALT, } \\
\text { OIS- } \\
\text { SOLVED } \\
(\mu g / L \\
\text { as CO) } \\
(01035)\end{array}$ & $\begin{array}{c}\text { COPPER, } \\
\text { DIS- } \\
\text { SOLVEO } \\
\text { ( } \mu \mathrm{g} / \mathrm{L} \\
\text { as Cu) } \\
(01040)\end{array}$ \\
\hline
\end{tabular}

LITTLE COLORADO RIVER AT CNMERON, AZ-Continued

\begin{tabular}{|c|c|c|c|c|c|c|c|c|}
\hline$\cdots$ & $\cdots$ & -. & -. & $\cdots$ & $\cdots$ & -- & $\cdots$ & -- \\
\hline$\cdots$ & $\cdots$ & $\cdots$ & $\cdots$ & $\cdots$ & $\therefore$ & $\cdots$ & $\cdots$ & $\cdots$ \\
\hline$\cdots$ & $\cdots$ & $\cdots$ & $\cdots$ & $\cdots$ & -- & $\cdots$ & $\cdots$ & $\cdots$ \\
\hline 5 & 10 & 240 & $<.5$ & 490 & 2.0 & 2 & $<3$ & 7 \\
\hline$\cdots$ & $\cdots$ & $\cdots$ & $\cdots$ & $\cdots$ & -- & $\cdots$ & $\cdots$ & $\cdots$ \\
\hline 3 & $\cdots$ & 170 & $<.5$ & 370 & 2.0 & $<5$ & $<3$ & $<10$ \\
\hline$\cdots$ & $\cdots$ & $\because$ & $\cdots$ & $\cdots$ & $\cdots$ & $\cdots$ & $\cdots$ & $\cdots$ \\
\hline 4 & $\cdots$ & 130 & $<.5$ & 290 & $<1.0$ & $<5$ & $<3$ & $<10$ \\
\hline$\cdots$ & $\cdots$ & $\cdots$ & $\cdots$ & $\cdots$ & $\cdots$ & $\cdots$ & - & -- \\
\hline$\cdots$ & $\cdots$ & $\cdots$ & $\cdots$ & $\cdots$ & $\cdots$ & $\cdots$ & $\cdots$ & $\cdots$ \\
\hline$\cdots$ & $\cdots$ & $\cdots$ & $\cdots$ & $\cdots$ & $\cdots$ & $\cdots$ & $\cdots$ & $\cdots$ \\
\hline$\cdots$ & $\because$ & $\cdots$ & $\cdots$ & $\because$ & $\because$ & $\because$ & $\because$ & 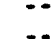 \\
\hline$\ldots$ & $\therefore$ & $\ldots$ & $\ldots$ & $\cdots$ & $\because$ & $\cdots$ & 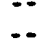 & $\ldots$ \\
\hline$<1$ & 27 & 160 & $<.5$ & 160 & $<1.0$ & $<5$ & $<3$ & $<10$ \\
\hline$\cdots$ & $\cdots$ & $\cdots$ & $=$ & $\cdots$ & $\cdots$ & $\cdots$ & $\cdots$ & $\cdots$ \\
\hline$\cdots$ & $\cdots$ & $-\cdot$ & $\cdots$ & $-\cdot$ & $\cdots$ & $\cdots$ & -. & $\cdots$ \\
\hline$\cdots$ & $\cdots$ & $\cdots$ & $\cdots$ & $\cdots$ & $\cdots$ & $\cdots$ & -- & $\cdots$ \\
\hline$\cdots$ & $\cdots$ & $\cdots$ & $\cdots$ & -- & -. & $\cdots$ & -. & $\cdots$ \\
\hline$\cdots$ & $\cdots$ & -- & $\cdots$ & $\cdots$ & $\cdots$ & $\cdots$ & -. & $\cdots$ \\
\hline$\cdots$ & $\cdots$ & $\cdots$ & $\cdots$ & $\cdots$ & $\cdots$ & $\cdots$ & $\cdots$ & $\cdots$ \\
\hline$\cdots$ & $\because$ & $\cdots$ & $\cdots$ & $\cdots$ & -- & $\cdots$ & $\cdots$ & $\cdots$ \\
\hline$\cdots$ & $\cdots$ & $\cdots$ & $\cdots$ & $\cdots$ & $\cdots$ & $\cdots$ & $\cdots$ & $\cdots$ \\
\hline$\cdots$ & $\cdots$ & -- & $\cdots$ & $\cdots$ & $\because$ & 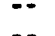 & $\cdots$ & $\cdots$ \\
\hline$\ldots$ & $\cdots$ & $\therefore$ & $\ldots$ & $\ldots$ & $\because$ & $\ldots$ & $\therefore$ & $\ldots$ \\
\hline -. & -- & .. & .. & $\ldots$ & .. & $\ldots$ & .. & .. \\
\hline 5 & 12 & 16 & $<.5$ & 260 & $<1.0$ & $<5$ & $<3$ & 20 \\
\hline -. & -. & $\cdots$ & $\cdots$ & -. & -. & $\cdots$ & -- & $\cdots$ \\
\hline $\begin{array}{l}2 \\
1\end{array}$ & $\begin{array}{r}11 \\
5\end{array}$ & $\begin{array}{l}25 \\
77\end{array}$ & $\begin{array}{c}<.5 \\
\therefore\end{array}$ & $\begin{array}{l}110 \\
130\end{array}$ & $\begin{array}{l}<1.0 \\
<1.0\end{array}$ & $\begin{array}{l}<5 \\
<9\end{array}$ & $\begin{array}{l}<3 \\
\therefore-\end{array}$ & $\begin{array}{r}10 \\
2\end{array}$ \\
\hline$\because$ & 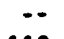 & 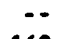 & $\because$ & $\because$ & $\cdots$ & $\cdots$ & $\because$ & $\because$ \\
\hline 2 & 110 & 160 & $<.5$ & 140 & $<1.0$ & $<1$ & $<3$ & 11 \\
\hline
\end{tabular}

PIPELIME ARROYO-Continued

\begin{tabular}{|c|c|c|c|c|c|c|c|c|}
\hline - & -- & $\cdots$ & $\cdots$ & $\cdots$ & -- & - & -. & - \\
\hline$\ldots$ & $\cdots$ & $\cdots$ & $\cdots$ & $\cdots$ & -. & $\cdots$ & $\cdots$ & \\
\hline & $\cdots$ & 120 & $<.5$ & 110 & 1.0 & $<5$ & 7 & $<10$ \\
\hline
\end{tabular}

MANUELITO HASH, U-59-Continued

$352450108592401 \quad 08-16-90$ 10-19-90 08-08-91 08-16-91 08-16-91

\begin{tabular}{|c|c|}
\hline 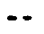 & -- \\
\hline$\cdots$ & $\cdots$ \\
\hline$\cdots$ & $\cdots$ \\
\hline$\cdots$ & $\cdots$ \\
\hline
\end{tabular}

LEROUX WASH MEAR HOLBROOK, ARIZONA-Cont inued

09397300 
SURFACE-WATER DATA-Cont inued

CHEMICAL AMALYSES - Cont inued

STATION

NUMBER

09402000

353730108312001

$08-14-90$

$08-15-90$

$08-15-90$
$02-22-90$
$04-13-90$

$07-08-90$

$07-12-90$

$07-12-90$

07-23-90

$07-23-90$

$08-19-90$

$08-19-90$

$08-21-90$

$08-23-90$

$09-12-90$

$09-18-90$

$09-18-90$

$09-19-90$

$09-19-90$

$09-19-90$

$09-20-90$

$09-20-90$

$09-20-90$

$09-21-90$

$09-24-90$

$09-24-90$

$12-18-90$

$01-07-91$

$01-07-91$

$01-08-91$

$02-12-91$

$03-07-91$

$05-02-91$

$08-30-91$

$09-05-91$

\begin{tabular}{|c|c|c|c|c|c|c|c|c|}
\hline $\begin{array}{l}\text { IRON, } \\
\text { DIS- } \\
\text { SOLVED } \\
\text { ( } \mu \sigma / L \\
\text { as Fe) } \\
(01046)\end{array}$ & $\begin{array}{l}\text { LEND, } \\
\text { DIS- } \\
\text { SOLVED } \\
\text { ( } \mu S / L \\
\text { as Pb) } \\
(01049)\end{array}$ & $\begin{array}{c}\text { MANGA- } \\
\text { NESE, } \\
\text { DIS- } \\
\text { SOLVED } \\
(\mu g / L) \\
\text { as Mn) } \\
(01056)\end{array}$ & $\begin{array}{c}\text { MOLYB- } \\
\text { DENUM, } \\
\text { DIS- } \\
\text { SOLVED } \\
(\mu g / L \\
\text { as MO) } \\
(01060)\end{array}$ & $\begin{array}{l}\text { NICKEL, } \\
\text { DIS- } \\
\text { SOLVED } \\
\text { ( } \mu g / 1 \\
\text { as Ni) } \\
(01065)\end{array}$ & $\begin{array}{l}\text { SILVER, } \\
\text { DIS- } \\
\text { SOLVED } \\
\text { ( } \mu g / L \\
\text { as Ag) } \\
(01075)\end{array}$ & $\begin{array}{l}\text { STRON- } \\
\text { TIUM, } \\
\text { DIS- } \\
\text { SOLVED } \\
(\mu g / L \\
\text { as Sr) } \\
(01080)\end{array}$ & $\begin{array}{l}\text { VANA- } \\
\text { DIUM, } \\
\text { DIS- } \\
\text { SOLVED } \\
(\mu g / L \\
\text { OS V) } \\
(01085)\end{array}$ & $\begin{array}{l}\text { ZINC, } \\
\text { DIS- } \\
\text { SOL VED } \\
(\mu 0 / L \\
\text { as } \mathrm{Zn}) \\
(01090)\end{array}$ \\
\hline
\end{tabular}

LITTLE COLORADO RIVER AT CAMERON, AZ-Continued

\begin{tabular}{|c|c|c|c|c|c|c|c|c|}
\hline - & $\cdots$ & - & $\ldots$ & - & $\cdots$ & - & $\ldots$ & - \\
\hline$\cdots$ & $\cdots$ & $\cdots$ & $\cdots$ & $\cdots$ & $\cdots$ & - & -. & - \\
\hline$\because$ & $\cdots$ & $\cdots$ & $\cdots$ & $\cdots$ & $\cdots$ & $\therefore$ & $\cdots$ & $\cdots$ \\
\hline 610 & 3 & 25 & $<10$ & $<10$ & $<1.0$ & 470 & 24 & 72 \\
\hline 200 & $\because$ & 70 & $\because$ & 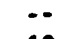 & $\because$ & $\because$ & 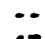 & 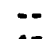 \\
\hline 120 & $<10$ & 61 & $<10$ & $<10$ & $<1.0$ & 540 & 13 & 15 \\
\hline$\because$ & $\because$ & $\because$ & $\ddot{B}$ & $\ddot{B}$ & $\because$ & 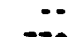 & $\because$ & $\because$ \\
\hline 100 & $<10$ & 7 & $<10$ & $<10$ & 2.0 & 330 & 14 & 8 \\
\hline$\cdots$ & $\cdots$ & $\cdots$ & $\cdots$ & $\cdots$ & $\cdots$ & $\cdots$ & $\cdots$ & $\cdots$ \\
\hline$\cdots$ & $\cdots$ & $\cdots$ & $\cdots$ & $\cdots$ & $\cdots$ & $\cdots$ & $\cdots$ & -. \\
\hline$\cdots$ & $\cdots$ & $\cdots$ & $\cdots$ & $\cdots$ & $\cdots$ & $\cdots$ & $\cdots$ & $\cdots$ \\
\hline$\cdots$ & $\cdots$ & $\cdots$ & $\cdots$ & $\cdots$ & $\cdots$ & $\cdots$ & $\cdots$ & $\cdots$ \\
\hline$\cdots$ & $\cdots$ & $\cdots$ & $\cdots$ & $\cdots$ & $\cdots$ & $\cdots$ & - & $\cdots$ \\
\hline$\because$ & $\ddot{\theta}$ & 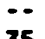 & $\ddot{0}$ & $\ddot{\theta}$ & $\because$ & $\ddot{0}$ & 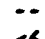 & $\ddot{-}$ \\
\hline 11 & $<10$ & 35 & $<10$ & $<10$ & $<1.0$ & 2100 & $<6$ & $<3$ \\
\hline$\because$ & $\cdots$ & $\cdots$ & $\cdots$ & $\because$ & $\because$ & $\because$ & $\cdots$ & $\cdots$ \\
\hline$\ldots$ & $\ldots$ & $\ldots$ & $\ldots$ & $\ldots$ & $\cdots$ & $\cdots$ & $\cdots$ & $\because$ \\
\hline$\ldots$ & $\ldots$ & $\ldots$ & . & $\ldots$ & .. & $\ldots$ & .. & $\ldots$ \\
\hline .. & $\cdots$ & $\ldots$ & - & $\ldots$ & $\ldots$ & $\ldots$ & $\ldots$ & .. \\
\hline -. & $\cdots$ & - & $\cdots$ & $\cdots$ & $\cdots$ & .. & -. & .. \\
\hline$\cdots$ & $\cdots$ & - & $\cdots$ & $\ldots$ & $\ldots$ & . & .. & .. \\
\hline 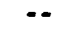 & $\cdots$ & - & $\cdots$ & $\cdots$ & $\cdots$ & $\ldots$ & - & .. \\
\hline$\cdots$ & $\cdots$ & $\cdots$ & $\cdots$ & $\cdots$ & $\cdots$ & $\cdots$ & $\cdots$ & .. \\
\hline$\cdots$ & $\cdots$ & $\cdots$ & $\cdots$ & $\cdots$ & $\cdots$ & $\cdots$ & $\cdots$ & $\cdots$ \\
\hline$\cdots$ & $\cdots$ & $\cdots$ & $\cdots$ & $\cdots$ & $\cdots$ & $\cdots$ & $\cdots$ & $\cdots$ \\
\hline$\cdots$ & $\cdots$ & $\cdots$ & $\cdots$ & - & $\cdots$ & 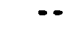 & .. & 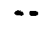 \\
\hline 130 & $<10$ & 5 & 10 & $<10$ & $<1.0$ & 150 & 16 & 3 \\
\hline$\cdots$ & $\cdots$ & $\cdots$ & $\cdots$ & $\because$ & $\cdots$ & $\cdots$ & $\cdots$ & 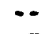 \\
\hline $\begin{array}{r}160 \\
10\end{array}$ & $\begin{array}{r}<10 \\
<1\end{array}$ & $\begin{array}{l}2 \\
2\end{array}$ & $\begin{array}{r}<10 \\
\ldots\end{array}$ & $\begin{array}{r}<10 \\
\ldots\end{array}$ & $\begin{array}{l}<1.0 \\
<1.0\end{array}$ & $\begin{array}{r}160 \\
\ldots\end{array}$ & $\begin{array}{r}8 \\
-.\end{array}$ & $\begin{array}{l}<3 \\
<3\end{array}$ \\
\hline$\cdots$ & . & . & .. & .. & $\ldots$ & 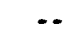 & .. & . \\
\hline 18 & $<1$ & 1 & $<10$ & $<10$ & $<1.0$ & 1600 & $<6$ & 3 \\
\hline
\end{tabular}

PIPELINE ARROYO-Cont inued

\begin{tabular}{|c|c|c|c|c|c|c|c|}
\hline -. & $\cdots$ & $\cdots$ & -- & $\cdots$ & -. & $\cdots$ & .. \\
\hline- & $\therefore$ & $\cdots$ & - & -. & -. & -- & -. \\
\hline & $<10$ & 1600 & $<10$ & $<10$ & $<1.0$ & 820 & $<6$ \\
\hline
\end{tabular}

MAKUELITO MASK, U-59-Cont inued

$\begin{array}{ll}352450108592401 & 08-16-90 \\ 10-19-90 \\ 08-08-91 \\ 08-16-91 \\ 08-16-91\end{array}$

$\begin{array}{lll}\ldots & \ldots & \ldots \\ \ldots & \ldots & \ldots \\ \ldots & \ldots & \ldots \\ \ldots & \ldots & \ldots\end{array}$

LEROUX WASH MEAR HOLBROOK, ARIZOWA-Continued

09397300

$07-19-90$

$12-20-90$ 
SURFACE-WATER DATA-Cont inued

CHEMICAL ANALYSES-Cont imued

STATION

MUMBER

09402000

353730108312001

08- $14-90$

08-15-90

08-15-90
$02-22-90$
$04-13-90$

07-08-90

07-12-90

$07-12-90$

$07-23-90$

07-23-90

$08-19-90$

$08-19-90$

08-21-90

08-23-90

09-12-90

$09-18-90$

09-18-90

$09-19-90$

$09-19-90$

09-20-90

09-20-90

09-20-90

09-20-90

09-21-90

09-24-90

09-24-90

$12-18-90$

01-07-91

01-07-91

01-08-91

02-12-91

03-07-91

05-02-91

08-30-91

09-05-91
LITTLE COLORADO RIVER AT CAMERON, AZ-Contínued $\begin{array}{ccc}\text { GROSS } & \text { ALPHA, } & \text { GROSS } \\ \text { ALPHA, } & \text { COUNT, } & \text { ALPHA, } \\ \text { DIS- } & 2 \text { SIGMA } & \text { SUSP. } \\ \text { SOLVED } & \text { WAT OIS } & \text { TOTAL } \\ (\mu g / L & (\mu g / L & (\mu g / L \\ \text { as } & \text { as } & \text { as } \\ \text { U-nat) } & U \text {-nat) } & U-n a t) \\ (80030) & (75986) & (80040)\end{array}$

\begin{tabular}{|c|c|c|c|c|c|c|c|c|c|}
\hline $\begin{array}{l}\text { ANTI- } \\
\text { MOWY, } \\
\text { TOTAL } \\
\text { ( } \mu \mathrm{g} / \mathrm{L} \\
\text { es Sb) } \\
(01097)\end{array}$ & $\begin{array}{l}\text { LITHIUN } \\
\text { DIS- } \\
\text { SOLVED } \\
\text { ( } \mu g / L \\
\text { OS Li) } \\
(01130)\end{array}$ & $\begin{array}{l}\text { SELE- } \\
\text { NIUN, } \\
\text { DIS- } \\
\text { SOLVED } \\
\text { ( } \mu 9 / 1 \\
\text { as SE) } \\
\text { (01145) }\end{array}$ & $\begin{array}{l}\text { SELE- } \\
\text { NIUN, } \\
\text { TOTAL } \\
\text { ( } \mu \text { g/L } \\
\text { as Se) } \\
\text { (01147) }\end{array}$ & $\begin{array}{c}\text { H-2I } \\
\text { H-1 } \\
\text { STABLE } \\
\text { I SOTOPE } \\
\text { RATIO } \\
\text { PER } \\
\text { MIL } \\
\text { (82082) }\end{array}$ & $\begin{array}{c}\text { O-18/ } \\
\text { O-16 } \\
\text { STABLE } \\
\text { ISOTOPE } \\
\text { RATIO } \\
\text { PER } \\
\text { MIL } \\
(82085)\end{array}$ & $\begin{array}{l}\text { TRITIUN } \\
\text { TOTAL } \\
\text { as } \\
(p C i / L) \\
(07000)\end{array}$ & $\begin{array}{c}\text { GROSS } \\
\text { ALPHA, } \\
\text { DIS- } \\
\text { SOLVED } \\
\text { ( } \mu g / L \\
\text { as } \\
\text { U-nat) } \\
(80030)\end{array}$ & $\begin{array}{l}\text { ALPHA, } \\
\text { COUNT, } \\
2 \text { SICMA } \\
\text { WAT DIS } \\
\text { ( } \mu g / L \\
\text { as } \\
U-n a t) \\
(75986)\end{array}$ & $\begin{array}{c}\text { GROSS } \\
\text { ALPHA, } \\
\text { SUSP. } \\
\text { TOTAL } \\
\text { ( } \mu g / L \\
\text { as } \\
\text { U-nat) } \\
(80040)\end{array}$ \\
\hline
\end{tabular}

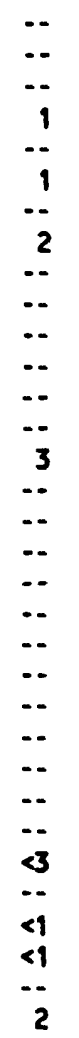

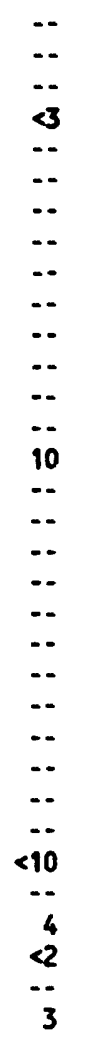

\begin{tabular}{|c|c|c|c|}
\hline$\cdots$ & -- & $=$ & $\cdots$ \\
\hline-- & $\cdots$ & $\cdots$ & $\cdots$ \\
\hline$\cdots$ & $\cdots$ & $\cdots$ & $\cdots$ \\
\hline$\cdots$ & -. & -- & $\cdots$ \\
\hline$\cdots$ & $\cdots$ & $\cdots$ & $\cdots$ \\
\hline$\cdots$ & 15 & 2.8 & 2000 \\
\hline$\cdots$ & $\cdots$ & $\cdots$ & $\cdots$ \\
\hline$\cdots$ & $\cdots$ & $\cdots$ & $\cdots$ \\
\hline$\cdots$ & $\cdots$ & $\cdots$ & $\cdots$ \\
\hline$\cdots$ & $\cdots$ & $\cdots$ & $\cdots$ \\
\hline 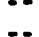 & $\cdots$ & $\cdots$ & $\because$ \\
\hline$\ldots$ & $\ldots$ & $\cdots$ & $\cdots$ \\
\hline - & .. & $\ldots$ & $\ldots$ \\
\hline -- & -. & - & - \\
\hline$\cdots$ & -. & -- & -. \\
\hline$\cdots$ & -. & $\cdots$ & $\cdots$ \\
\hline$\cdots$ & $\cdots$ & $\cdots$ & $\cdots$ \\
\hline$\cdots$ & -- & $\cdots$ & $\cdots$ \\
\hline 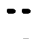 & $\cdots$ & $\cdots$ & $\cdots$ \\
\hline$\cdots$ & $\cdots$ & -- & $\cdots$ \\
\hline$\cdots$ & $\cdots$ & $\because$ & -- \\
\hline$\ldots$ & $\cdots$ & $\because$ & $\cdots$ \\
\hline$\ldots$ & 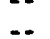 & 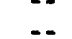 & $\cdots$ \\
\hline - & .. & .. & $\ldots$ \\
\hline - & -- & $\cdots$ & -. \\
\hline$\cdots$ & 18 & 3.6 & -. \\
\hline$\cdots$ & $\cdots$ & $\cdots$ & $\cdots$ \\
\hline$\cdots$ & $\cdot-$ & -- & $\cdots$ \\
\hline-- & $\cdots$ & $-\cdot$ & $\cdots$ \\
\hline 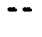 & $\cdots$ & $-\cdot$ & -- \\
\hline 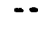 & $\cdots$ & $\cdots$ & $\cdots$ \\
\hline
\end{tabular}

\section{PIPELINE ARROYO-Continued}

$\begin{array}{llllllllll}\ldots & \ldots & \ldots & \ldots & \ldots & \ldots & \ldots & \ldots & \ldots & \ldots \\ -. & -. & -. & -. & -. & -. & -. & \ldots & \ldots & \ldots \\ -. & 17 & 2 & -- & -90.5 & -13.25 & 22 & \ldots & \ldots & \ldots\end{array}$

MUNUELITO WASH, U-59-Continued

352450108592401

$08-16-90$

$10-19-90$ 08-08-91

08-16-91

08-16-91

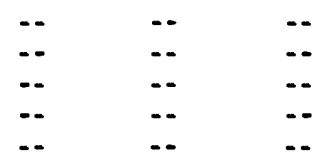

LEROUX WASH MEAR HOLBROOK, ARIZONA-Continued
09397300

07-19-90 $12-20-90$ 


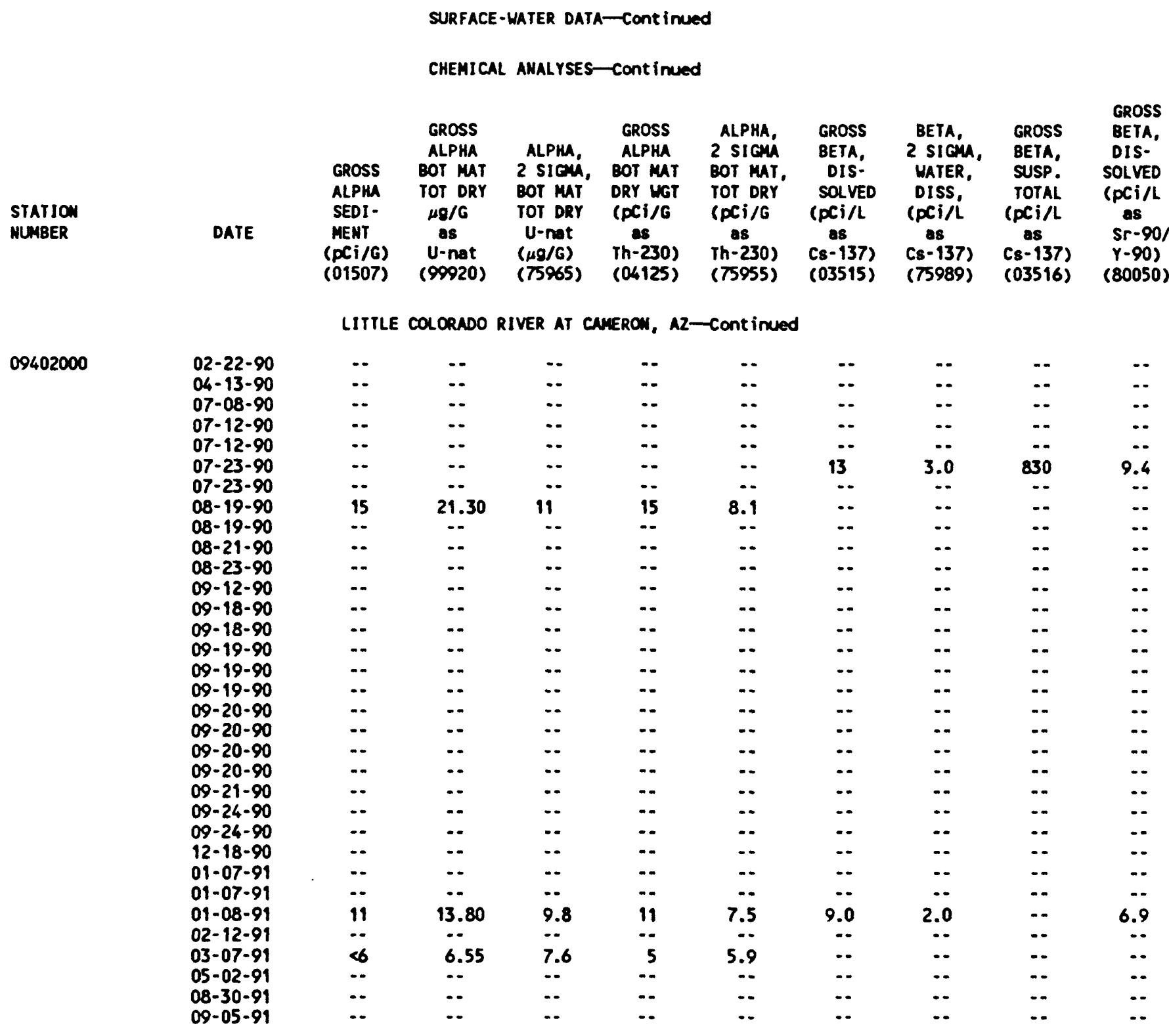

353730108312001

$08-14-90$ $08-15-90$ $08-15-90$
352450108592401
PIPELINE ARROYo-Continued

\begin{tabular}{|c|c|c|c|c|c|c|c|c|}
\hline .. & -- & -. & $\cdots$ & -. & $\cdots$ & - & $\ldots$ & $\cdots$ \\
\hline$\cdots$ & $\cdots$ & $\cdots$ & $\cdots$ & $\cdots$ & $\cdots$ & $\cdots$ & $\cdots$ & $\cdots$ \\
\hline -. & - & -. & $\ldots$ & - & .. & .. & - & \\
\hline
\end{tabular}

MANUELITO WASH, U-59-Continued

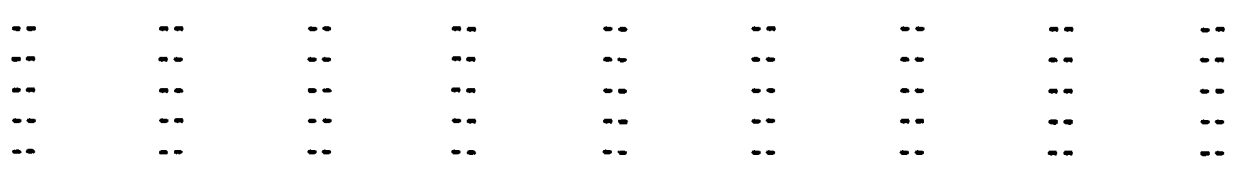

09397300

$07-19-90$ $12-20-90$

LEROUX WASH NEAR HOLBROOK, ARIZONA-COnt inuEd 
STATION

MUMBER

09402000

02-22-90

04-13-90

07-08-90

07-12-90

07-12-90

07-23-90

07-23-90

08-19-90

$08-19-90$

08-21-90

08-23-90

09-12-90

09-18-90

09-18-90

09-19-90

09-19-90

09-19-90

09-20-90

09-20-90

09-20-90

09-20-90

09-21-90

09-24-90

09-24-90

12-18-90

01-07-91

01-07-91

01-08-91

02-12-91

03-07-91

05-02-91

08-30-91

09-05-91
SURFACE-WATER DATA-Cont inued

CHEHICAL AMALYSES-CONT InUEd

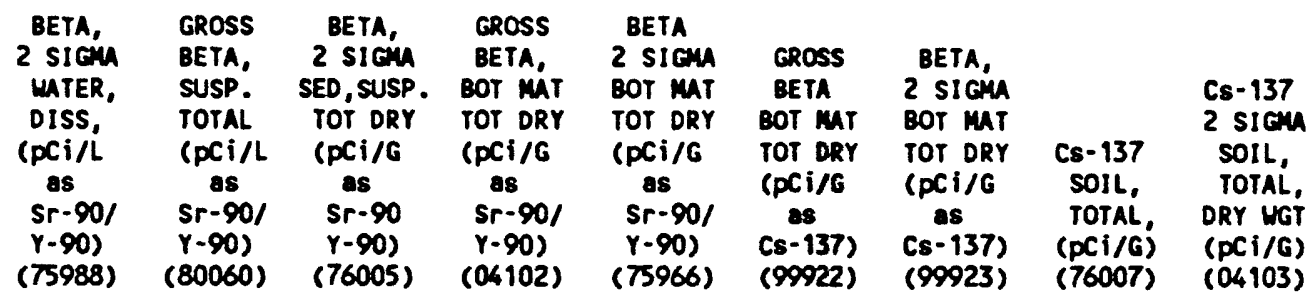

LITTLE COLORADO RIVER AT CAMERON, AZ-Continued

\begin{tabular}{|c|c|c|c|c|c|c|c|c|}
\hline$\cdots$ & $\cdots$ & $-\cdot$ & -. & -- & -- & -- & $\cdots$ & -- \\
\hline-- & -- & $\cdots$ & $\cdots$ & -- & -- & -- & $\cdots$ & - \\
\hline$\cdots$ & $\cdots$ & -- & $\cdots$ & $\cdots$ & $\cdots$ & $\cdots$ & -. & -- \\
\hline$\cdots$ & -- & -- & $\cdots$ & -- & $\cdots$ & $-\cdot$ & $\cdots$ & $\cdots$ \\
\hline$=-$ & $=-$ & -- & - & -- & $\cdots$ & $-\cdot$ & $-\cdot$ & $\cdots$ \\
\hline 2.2 & 750 & 240 & $\cdots$ & $\because$ & $\cdots$ & $\cdots$ & $-\cdot$ & $\cdots$ \\
\hline$\cdots$ & $-\cdot$ & -- & $\ddot{2}$ & $\because$ & $\cdots$ & $-\overline{1}$ & $\cdots$ & $\cdots$ \\
\hline$\cdots$ & $\cdots$ & $-\cdot$ & 23 & 5.4 & 29.70 & 5.41 & $\cdots$ & $\cdots$ \\
\hline-- & $\cdots$ & $-\cdot$ & $\cdots$ & 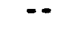 & -- & $\cdots$ & $\cdots$ & -- \\
\hline$\cdots$ & $\cdots$ & -- & $\cdots$ & -- & $\cdots$ & $\because$ & $\cdots$ & $\cdots$ \\
\hline-- & $\cdots$ & $\cdots$ & $\cdots$ & $\cdots$ & $\cdots$ & -- & $\cdots$ & -- \\
\hline 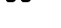 & 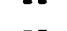 & -- & $\cdots$ & $\cdots$ & $\cdots$ & $\cdots$ & $\cdots$ & $\because$ \\
\hline - & $\ldots$ & - & $\ldots$ & 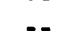 & -8 & . & -8 & $\cdots$ \\
\hline .- & $\ldots$ & .- & .. & .- & $=$ & $\ldots$ & .. & - \\
\hline - & -. & -- & -. & .- & -- & .- & ... & ..- \\
\hline.- & $\cdots$ & -- & -- & -- & -- & -- & $\cdots$ & .- \\
\hline-- & $\cdots$ & -- & -- & -- & $\cdots$ & -- & -. & .- \\
\hline$\cdots$ & $\cdots$ & -. & - & -- & -- & $\cdots$ & -. & -- \\
\hline-- & $\cdots$ & -- & $\cdots$ & $-\cdot$ & $\cdots$ & $\cdots$ & $\cdots$ & $\cdots$ \\
\hline- & -- & -- & $\cdots$ & $\cdots$ & $\cdots$ & -- & $\cdots$ & $\cdots$ \\
\hline$=-$ & -- & $-\cdot$ & $\cdots$ & $\cdots$ & $\cdots$ & -- & $\cdots$ & -- \\
\hline$\cdots$ & $\cdots$ & -- & $\cdots$ & $\cdots$ & $\cdots$ & $\cdots$ & $\cdots$ & $\cdots$ \\
\hline$\cdots$ & $\cdots$ & $\cdots$ & $\cdots$ & $\cdots$ & $\cdots$ & $\cdots$ & $\cdots$ & $\cdots$ \\
\hline$\because-$ & $\because$ & $\because$ & -- & - & $=$ & -- & $\because$ & $\cdots$ \\
\hline$=-$ & -- & $\because$ & $\ldots$ & $\begin{array}{l}\cdots \\
--\end{array}$ & 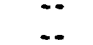 & $\because$ & $\because$ & $\because-$ \\
\hline 1.5 & - & .. & 8 & 3.0 & 10.10 & 3.04 & .17 & .040 \\
\hline$\cdots$ & $\cdots$ & -. & $\cdots$ & -- & 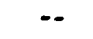 & $\cdots$ & $\cdots$ & $\cdots$ \\
\hline-- & $\cdots$ & -. & 20 & 4.8 & 25.10 & 4.76 & $\therefore$ & $\cdots$ \\
\hline$\cdots$ & $\cdots$ & -- & -- & $-\cdot$ & $\cdots$ & -- & 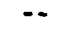 &.- \\
\hline$\cdots$ & $\cdots$ & -- & $\cdots$ & $\cdots$ & -- & $\cdots$ & $\because$ & $\cdots$ \\
\hline$\cdots$ & - & $\cdots$ & - & -- & $\cdots$ & $-\cdot$ & $\cdots$ & \\
\hline
\end{tabular}

PIPELINE ARROYO-Continued

$353730108312001 \quad 08-14-90$ $08-15-90$ 08-15-90
352450108592401

08-16-90 $10-19-90$ 08-08-91 08-16-91 08-16-91

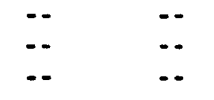

MAUELITO WSH, U-59-Cont inued

$\begin{array}{lllllllll}\ldots & \ldots & \ldots & \ldots & \ldots & \ldots & .03 & .010 \\ \ldots & \ldots & \ldots & \ldots & \ldots & -- & \ldots & .15 & .020 \\ \ldots & \ldots & \ldots & \ldots & -. & \ldots & -. & .01 & .010 \\ \ldots & \ldots & \ldots & \ldots & \ldots & \ldots & \ldots & \ldots\end{array}$

LEROUX WASH MEAR HOLBROOK, ARIZONA-Continued 
SURFACE-WATER DATA-Cont inued

CHEHICAL ANALYSES-Cont inued

STATION

MUMBER

09402000

353730108312001

$08-14-90$

$08-15-90$

$08-15-90$
352450108592401

08- $16-90$

$10-19-90$

08-08-91

08-16-91

08-16-91

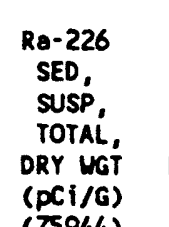

$\begin{array}{cc}\text { URANIUN } & \text { U-234 } \\ \text {-234 } & 2 \text { SIGMA } \\ \text { WATER } & \text { WATER, } \\ \text { DISSOLV } & \text { DISS, } \\ \text { (pCI/L) } & (\text { CI /L) } \\ (22610) & (75992)\end{array}$

U.234

2 SIGU

SED, URANIUN U-235

SUSP,

TOTAL,

DRY WGT

(PCi/G)

(75941)
-2352 SIEN

MATER, MATER,

DISS

(pCi/L)

(22620)
DISS,

$(p C i / L)$

(75994)
U-235

SED,

SUSP,

TOTAL,

DRY WGT

(pCi/G)

(75975)
U.235

2 sign

SED, SUSP TOTAL, DRY WGT $(\mathrm{PCi} / \mathrm{G})$ (75947)

\section{LITTLE COLORADO RIVER AT CAMERON, AZ-Cont inued}

\begin{tabular}{|c|c|c|c|c|c|c|c|c|}
\hline$\cdots$ & $\cdots$ & $\cdots$ & $\cdots$ & $\cdots$ & $\cdots$ & $\cdots$ & $\cdots$ & -. \\
\hline$\cdots$ & $\cdots$ & $\cdots$ & $\cdots$ & $\cdots$ & $\cdots$ & $\cdots$ & $\cdots$ & $\cdots$ \\
\hline$\cdots$ & $\cdots$ & $\cdots$ & $\cdots$ & $\cdots$ & $\cdots$ & $\cdots$ & $\cdots$ & $\cdots$ \\
\hline$\cdots$ & $\cdots$ & $\cdots$ & $\cdots$ & $\cdots$ & $\cdots$ & $\cdots$ & $\cdots$ & $\cdots$ \\
\hline$\cdots$ & $\cdots$ & $\cdots$ & -- & $\cdots$ & $\cdots$ & $\cdots$ & $\cdots$ & $\cdots$ \\
\hline$\because$ & $\cdots$ & $\cdots$ & $\cdots$ & $\cdots$ & $\cdots$ & $\cdots$ & $\cdots$ & $\cdots$ \\
\hline$\because$ & $\cdots$ & $\cdots$ & $\because$ & $\ddot{*}$ & $\cdots$ & $\cdots$ & $\because$ & $\because$ \\
\hline 1.3 & $\cdots$ & $\cdots$ & 1.0 & .20 & $\cdots$ & $\cdots$ & $<.1$ & ND \\
\hline$\cdots$ & $\cdots$ & $\cdots$ & $\cdots$ & $\cdots$ & $\cdots$ & $\cdots$ & $\because$ & $\cdots$ \\
\hline$\because$ & $\ldots$ & $\therefore$ & $\ldots$ & $\because$ & $\because$ & $\because$ & $\because$ & $\cdots$ \\
\hline$\ldots$ & $\ldots$ & $\ldots$ & $\ldots$ & $\ldots$ & $\ldots$ & $\therefore$ & $\cdots$ & $\cdots$ \\
\hline - & - & .. & .. & $\ldots$ & $\ldots$ & .. & .. & .. \\
\hline$\cdots$ & $\cdots$ & $\cdots$ & $\cdots$ & $\cdots$ & $\cdots$ & -. & .. & $\cdots$ \\
\hline$\cdots$ & $\cdots$ & $\cdots$ & $\cdots$ & $\cdots$ & $\cdots$ & -. & .. & $\cdots$ \\
\hline$\cdots$ & $\cdots$ & $\cdots$ & $\cdots$ & $\cdots$ & $\cdots$ & $\cdots$ & $\cdots$ & $\cdots$ \\
\hline$\cdots$ & $\cdots$ & $\cdots$ & $\cdots$ & $\cdots$ & $\cdots$ & $\cdots$ & $\cdots$ & $\cdots$ \\
\hline$\cdots$ & $\cdots$ & $\cdots$ & $\cdots$ & $\cdots$ & $\cdots$ & $\cdots$ & $\cdots$ & $\cdots$ \\
\hline$\cdots$ & $\cdots$ & $\cdots$ & $\cdots$ & $\cdots$ & $\cdots$ & $\cdots$ & $\cdots$ & $\because$ \\
\hline$\cdots$ & $\cdots$ & $\cdots$ & $\cdots$ & $\cdots$ & $\cdots$ & -. & $\cdots$ & $\cdots$ \\
\hline$\cdots$ & $\cdots$ & $\cdots$ & $\cdots$ & $\cdots$ & $\cdots$ & $\cdots$ & $\cdots$ & $\cdots$ \\
\hline$\cdots$ & $\cdots$ & $\cdots$ & $\cdots$ & $\cdots$ & $\cdots$ & $\cdots$ & $\cdots$ & $\cdots$ \\
\hline$\cdots$ & $\cdots$ & $\cdots$ & $\cdots$ & $\cdots$ & $\cdots$ & $\cdots$ & $\cdots$ & $\cdots$ \\
\hline - & $\cdots$ & $\cdots$ & $\cdots$ & $\cdots$ & $\cdots$ & $\cdots$ & $\cdots$ & $\cdots$ \\
\hline$\cdots$ & $\cdots$ & $\cdots$ & $\cdots$ & $\cdots$ & $\cdots$ & -- & $\cdots$ & \\
\hline$\cdots$ & $\cdots$ & $\cdots$ & $\cdots$ & $\cdots$ & $\cdots$ & $\cdots$ & $\cdots$ & 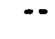 \\
\hline$\because$ & $\cdots$ & $\because$ & $\because$ & $\ddot{45}$ & $\cdots$ & $\cdots$ & $\because$ & $\ddot{m}$ \\
\hline 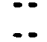 & $\because$ & $\because$ & $\begin{array}{r}1.0 \\
\ldots .\end{array}$ & .15 & 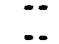 & 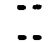 & $<.1$ & .03 \\
\hline$\cdots$ & 2.1 & .2 & .8 & .10 & $<.1$ & ND & $<.1$ & ND \\
\hline 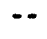 & $\cdots$ & $\cdots$ & $\cdots$ & $\cdots$ & - & -. & $\cdots$ & 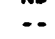 \\
\hline$\cdots$ & $\cdots$ & $\cdots$ & $\cdots$ & $\cdots$ & -. & $\cdots$ & $\cdots$ & \\
\hline & $\cdots$ & $\cdots$ & $\cdots$ & - & $\cdots$ & $\cdots$ & .. & \\
\hline
\end{tabular}

PIPELINE ARROYO-Cont inued

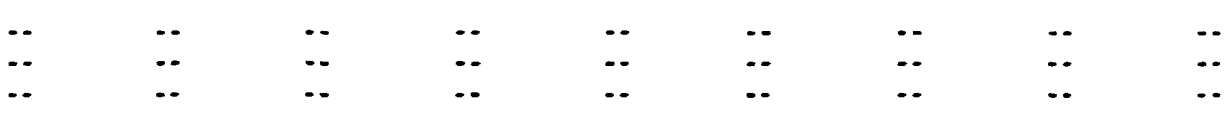

MANUELITO WASH, U-59-Cont inued

\begin{tabular}{|c|c|c|c|c|c|c|c|c|}
\hline$\cdots$ & -. & -. & $\cdots$ & $\cdots$ & $\cdots$ & $\cdots$ & $\cdots$ & $\cdots$ \\
\hline$\cdots$ & $\cdots$ & - & $\cdots$ & $\cdots$ & $\cdots$ & $\cdots$ & $\cdots$ & $\cdots$ \\
\hline - & -. & .. & $\cdots$ & $\cdots$ & 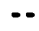 & - & $\cdots$ & $=0$ \\
\hline .8 & $\cdots$ & - & .8 & .10 & $\cdots$ & $\cdots$ & $<.1$ & NI \\
\hline
\end{tabular}

LEROUX WASH MEAR HOLBROOK, ARIZONA-Cont inued

09397300

$07-19-90$

$12-20-90$ 
CHEMICAL ANALYSES-Continued

STATION

MUMBER

09402000

35373010831200

08-14-90

$08-15-90$

08-15-90
$02-22-90$

$04-13-90$

$07-08-90$

$07-12-90$

$07-12-90$

$07-23-90$

$07-23-90$

08-19-90

$08-19-90$

$08-21-90$

$08-23-90$

$09-12-90$

$09-18-90$

$09-18-90$

$09-19-90$

09-19-90

$09-19-90$

$09-20-90$

09-20-90

$09-20-90$

$09-20-90$

$09-21-90$

$09-24-90$

$09-24-90$

12-18-90

1-07-91

$01-07-91$

01-08-91

02-12-91

03-07-91

05-02-91

08-30-91

09-05-91

\begin{tabular}{|c|c|c|c|c|c|c|c|c|}
\hline & & & & & & & & \\
\hline $\begin{array}{l}\text { URANIUN } \\
\text { - } 238 \\
\text { WATER } \\
\text { OISSOLV } \\
\text { (PCi/L) } \\
(22603)\end{array}$ & $\begin{array}{c}\text { U-238 } \\
2 \text { SIEU } \\
\text { WATER, } \\
\text { DISS, } \\
\text { (PCI/L) } \\
\text { (75991) }\end{array}$ & $\begin{array}{c}\text { U-238 } \\
\text { SED, } \\
\text { SUSP, } \\
\text { TOTAL, } \\
\text { ORY WGT } \\
\text { (PCI/G) } \\
\text { (7S940) }\end{array}$ & $\begin{array}{l}2 \text { SIGMA } \\
\text { SED. } \\
\text { SUSP. } \\
\text { TOTAL, } \\
\text { ORY WGT } \\
\text { (PCI/G) } \\
\text { (04113) }\end{array}$ & $\begin{array}{l}\text { Th-230 } \\
\text { SED, } \\
\text { SUSP, } \\
\text { TOTAL, } \\
\text { DRY WGT } \\
\text { (PCi/G) } \\
\text { (TS939) }\end{array}$ & $\begin{array}{l}2 \text { SICH } \\
\text { SED, } \\
\text { SUSP. } \\
\text { TOTAL, } \\
\text { DRY HGT } \\
\text { (PCI/G) } \\
\text { (TS952) }\end{array}$ & $\begin{array}{l}\text { Th-232 } \\
\text { SED, } \\
\text { SUSP, } \\
\text { TOTAL, } \\
\text { DRY WGT } \\
\text { (PCi/G) } \\
\text { (TS953) }\end{array}$ & $\begin{array}{l}2 \text { SICM } \\
\text { SED, } \\
\text { SUSP, } \\
\text { TOTAL, } \\
\text { ORY WGT } \\
\text { (PCi/G) } \\
\text { (T5936) }\end{array}$ & $\begin{array}{l}\text { ALUN- } \\
\text { INUM } \\
\text { BOT MAT } \\
\angle 63 \mu \text { DS } \\
\text { LAB } \\
\text { PERCENT } \\
\text { (34792) }\end{array}$ \\
\hline
\end{tabular}

\section{LITTLE COLORADO RIVER AT CAMERON, AZ-Cont ínued}

\begin{tabular}{|c|c|c|c|c|c|c|c|c|}
\hline -. & -. & -- & -. & -. & -. & -. & -. & -. \\
\hline$\cdots$ & -. & $\cdots$ & $\cdots$ & -. & $\cdots$ & $\cdots$ & - & -. \\
\hline$\cdots$ & $\cdots$ & $\cdots$ & $\cdots$ & $\because$ & $\cdots$ & $\cdots$ & $\cdots$ & $\because$ \\
\hline$\cdots$ & -. & $\cdots$ & $\cdots$ & $\because$ & $\cdots$ & $\cdots$ & $\cdots$ & 9.9 \\
\hline$\ddot{.-}$ & $\ddot{\ddot{n}}$ & $\because$ & $\because$ & 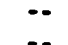 & $\because$ & $\because$ & $\because$ & $\because$ \\
\hline$\because$ & $\cdots$ & $\because$ & $\because$ & $\because$ & $\because$ & $\because$ & $\because$ & 9.2 \\
\hline -. & .. & 1.1 & .23 & 1.2 & .30 & 1.7 & .40 & 9.4 \\
\hline -. & -. & $\cdots$ & $\cdots$ & $\cdots$ & $\cdots$ & $\cdots$ & $\cdots$ & - \\
\hline$\because$ & $\cdots$ & 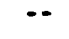 & $\cdots$ & $\cdots$ & $\cdots$ & -. & -. & -. \\
\hline 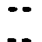 & 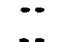 & $\because$ & $\because$ & $\because$ & $\because$ & $\cdots$ & $\cdots$ & -. \\
\hline 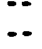 & $\because$. & $\because$ & 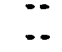 & 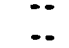 & $\ddot{\circ}$ & $\because$ & $\ddot{-}$ & $\ddot{-}$ \\
\hline$\cdots$ & -. & -. & -. & -. & .. & .. & -. & .. \\
\hline 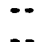 & 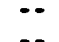 & 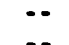 & 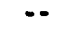 & $\because$ & $\cdots$ & 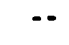 & -. & 9.0 \\
\hline$\because$ & $\because-$ & $\because$ & $\because$ & $\because$ & $\ddot{*}$ & 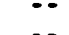 & $\cdots$ & $\cdots$ \\
\hline -. & -. & .. & .. & .. & $\because$ & $\because$ & 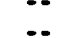 & $\because$ \\
\hline$\cdots$ & $\cdots$ & - & -. & -. & -. & .. & -. & .. \\
\hline$\cdots$ & $\cdots$ & $\cdots$ & $\cdots$ & -. & $\cdots$ & $\cdots$ & -. & -. \\
\hline$\because$ & 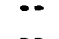 & $\cdots$ & $\because$ & -・ & $\because$ & $\because$ & 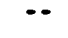 & $\cdots$ \\
\hline .. & .. & .. & $\ldots$ & -. & $\therefore$ & $\ldots$ & $\therefore$ & $\therefore$ \\
\hline$\cdots$ & -. & -. & -. & $\because$ & $\cdots$ & $\cdots$ & - & .. \\
\hline$\cdots$ & $\cdots$ & $\because$ & $\cdots$ & -. & $\cdots$ & $\cdots$ & $\therefore$ & -. \\
\hline$\cdots$ & $\because-$ & $\because$ & $\because$ & $\because$ & $\because$ & $\because$ & $\ddot{\ddot{\prime}}$ & $\ddot{0}$ \\
\hline -. & .. & 1.0 & .02 & 1.4 & .19 & 1.5 & .20 & 7.8 \\
\hline$\cdots$ & $\ddot{m}$ & $\cdots$ & $\cdots$ & $\cdots$ & - & $\cdots$ & - & \\
\hline 1.5 & .20 & .9 & .12 & 1.2 & .16 & 1.2 & .17 & 5.0 \\
\hline$\cdots$ & .. & .. & .. & .. & .. & .. & -. & $\cdots$ \\
\hline$\ldots$ & -. & $\ldots$ & -. & -. & $\cdots$ & $\cdots$ & 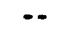 & .. \\
\hline
\end{tabular}

PIPELINE ARROYO-Continued

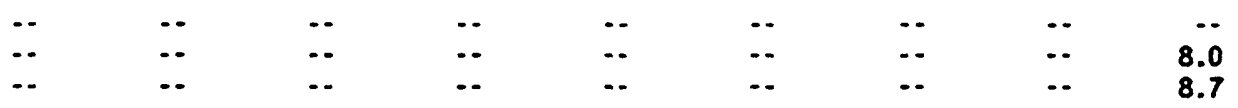

MANUELITO WASH, U-59-Continued

352450108592401

08-16-90

$10-19-90$

08-08-91

$08-16-91$

08-16-91

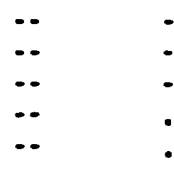

$\begin{array}{ll}\ldots & \ldots \\ \ldots & \ldots \\ .- & \ldots \\ .9 & .12 \\ .8 & .10\end{array}$

$\cdots$
$\cdots$
2.0
.8

$\begin{array}{ccc}\ldots & \ldots & \ldots \\ \ldots & \ldots & 7.0 \\ . . & \ldots & \ldots \\ 1.6 & <.21 & \cdots \\ .7 & <.11 & -.\end{array}$

LEROUX WASH NEAR HOLBROOK, ARIZOMA-Continued 
CHERICAL ANALYSES-Continued

STATION

MUMBER

09402000

353730108312001

$08-14-90$

$08-15-90$

08-15-90
$02-22-90$

$04-13-90$

07-08-90

$07-12-90$

$07-12-90$

$07-23-90$

$07-23-90$

$08-19-90$

$08-19-90$

$08-21-90$

08-23-90

$09-12-90$

$09-18-90$

$09-18-90$

$09-19-90$

$09-19-90$

$09-20-90$

$09-20-90$

$09-20-90$

$09-20-90$

$09-21-90$

$09-24-90$

$09-24-90$

12-18-90

01-07-91

$01-07-91$

01-08-91

$02-12-91$

03-07-91

05-02-91

08-30-91

09-05-91
$09-19-90$

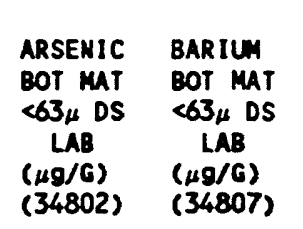

$\begin{array}{cc}\text { BERYL- } & \\ \text { LIUH } & \text { BISNUTH } \\ \text { BOT MAT } & \text { BOT MAT } \\ \angle 63_{\mu} \text { DS } & \angle 63_{\mu} \text { DS } \\ \text { LAB } & \text { LAB } \\ (\mu g / G) & (\mu g / G) \\ (34812) & (34817)\end{array}$

CAOMIUN

$\angle 63 \mu$ DS

LAB

$(\mu g / G)$

(34827)

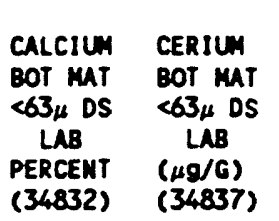

CHRO-

MIUM

BOT MAT

LAB LAB

$(\mu g / G)$

(34842)

LITTLE COLORADO RIVER AT CAMERON, AZ-Continued

\begin{tabular}{|c|c|c|c|}
\hline$\cdots$ & -. & $\cdots$ & .. \\
\hline$\ldots$ & $\ldots$ & -. & -. \\
\hline .- & .. & -. & \\
\hline$<10$ & 400 & 3 & $<10$ \\
\hline$\therefore$ & $\ldots$ & $\therefore$ & -. \\
\hline$<10$ & 520 & 2 & $<10$ \\
\hline - & $\cdots$ & 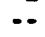 & $\ldots$ \\
\hline$<10$ & 520 & 2 & $<10$ \\
\hline$\therefore$ & $\ldots$ & $\ldots$ & $\ldots$ \\
\hline .. & .. & .. & .. \\
\hline .- & $\ldots$ & .. & .. \\
\hline -. & $\ldots$ & .. & .. \\
\hline - & - & $\cdots$ & - \\
\hline$\ldots$ & .. & .. & .. \\
\hline$<10$ & 480 & 2 & $<10$ \\
\hline$\cdots$ & - & -. & -. \\
\hline$\cdots$ & $\cdots$ & $\cdots$ & -- \\
\hline$\cdots$ & $\cdots$ & -. & -. \\
\hline$\cdots$ & $\cdots$ & $\cdots$ & $-\cdot$ \\
\hline$\cdots$ & $\cdots$ & $\cdots$ & $\cdots$ \\
\hline$\cdots$ & $\cdots$ & $\cdots$ & $\cdots$ \\
\hline$\ldots$ & $\cdots$ & $\ldots$ & $\ldots$ \\
\hline$\ldots$ & $\ldots$ & $\ldots$ & $\therefore$ \\
\hline$\cdots$ & $\cdots$ & -. & .. \\
\hline$\cdots$ & $\cdots$ & $\cdots$ & .. \\
\hline -. & $\cdots$ & -. & - \\
\hline$<10$ & 480 & 2 & $<10$ \\
\hline$\cdots$ & - & $\cdots$ & - \\
\hline$<10$ & 650 & 1 & $<10$ \\
\hline$\cdots$ & $\cdots$ & $\cdots$ & $\cdots$ \\
\hline$\cdots$ & $\because$ & $\because$ & $\because$ \\
\hline
\end{tabular}

\begin{tabular}{|c|c|}
\hline -. & - \\
\hline$\cdots$ & $\cdots$ \\
\hline$\because$ & $\because$ \\
\hline$<2$ & 1.9 \\
\hline$\cdots$ & $\cdots$ \\
\hline$<2$ & 2.6 \\
\hline -. & - \\
\hline$<2$ & 2.3 \\
\hline 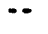 & $\cdots$ \\
\hline$\cdots$ & $\cdots$ \\
\hline$\cdots$ & $\cdots$ \\
\hline$\cdots$ & $\cdots$ \\
\hline$\cdots$ & $\cdots$ \\
\hline 2 & 3 \\
\hline$\therefore$ & $\ldots$ \\
\hline$\cdots$ & $\cdots$ \\
\hline - & -- \\
\hline - & -. \\
\hline$\cdots$ & $\cdots$ \\
\hline 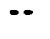 & $\cdots$ \\
\hline$\cdots$ & $\cdots$ \\
\hline$\cdots$ & $\cdots$ \\
\hline$\cdots$ & $\cdots$ \\
\hline$\cdots$ & $\cdots$ \\
\hline$\cdots$ & $\cdots$ \\
\hline$<2$ & 2.7 \\
\hline$\because$ & $\cdots$ \\
\hline$<2$ & 4.2 \\
\hline$\cdots$ & $\cdots$ \\
\hline$\cdots$ & $\cdots$ \\
\hline
\end{tabular}

PIPELINE ARROYO-Continued

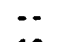

$<10$

$<10$

$\begin{array}{rrr}-- & \cdots & \cdots \\ 650 & 2 & <10 \\ 580 & 2 & <10\end{array}$

$<2$
$<2$

1.9
.96

93

76
43

10

MANUELITO WASH, U-59-Cont inued

352450108592401

08-16-90

$10-19-90$

08-08-91

08-16-91

08-16-91

$\begin{array}{cccc}\ldots & \ldots & \ldots & \ldots \\ <10 & 640 & 2 & <10 \\ \ldots & \ldots & \ldots & \ldots \\ \ldots & \ldots & \ldots & \ldots \\ \ldots & \ldots & \ldots & \ldots\end{array}$

LEROUX WASH MEAR HOLBROOK, ARIZOMA-COnt inued

09397300

07-19-90

$12-20-90$ 
SURFACE-WATER DATA-COntinued

CHEMICAL AMALYSES-Continued

STATION

MUMBER

DATE

$02-22-90$

04-13-90

07-08-90

07-12-90

07-12-90

07-23-90

07-23-90

08-19-90

08-19-90

08-21-90

08-23-90

$09-12-90$

09-18-90

09-18-90

09-19-90

09-19-90

09-19-90

09-20-90

09-20-90

09-20-90

09-20-90

09-21-90

09-24-90

09-24-90

12-18-90

01-07-91

01-07-91

01-08-91

02-12-91

03-07-91

05-02-91

08-30-91

09-05-91

$\begin{array}{cc} & \text { EURO- } \\ \text { COPPER } & \text { PIUM } \\ \text { BOT MAT } & 80 T \text { MAT } \\ \angle 63 \mu \text { DS } & \angle 63 \mu \text { DS } \\ \text { LAB } & \text { LAB } \\ (\mu g / G) & (\mu g / G) \\ (34852) & (34857)\end{array}$

GALLIU

COLD $<63 \mu$ DS

LAB

( $\mu \mathrm{g} / \mathrm{G})$

(34862)
$80 T$ MAT

LAB

( $\mu g / G)$

(34872)

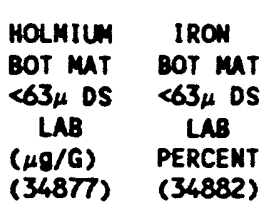

LANTHA-

MUN

BOT MAT

$\angle 63 \mu$ DS

LAB

$(\mu g / G)$

(34887)
LEAD

BOT MAT BOT

$\angle 63 \mu$ DS $\angle 63 \mu$ DS

LAB LAB

( $\mu \mathrm{g} / \mathrm{G}) \quad(\mu \mathrm{g} / \mathrm{G})$

(34892) (34897)

LITTLE COLORADO RIVER AT CAMERON, AZ-Continued

\begin{tabular}{|c|c|c|c|c|c|c|c|}
\hline$\cdots$ & -- & -- & -- & $\cdots$ & $=$ & -- & -- \\
\hline$\cdots$ & - & -- & -- & $\cdots$ & $\cdots$ & -- & $\cdots$ \\
\hline -. & -- & -- & -- & - & 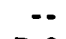 & 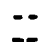 & $\ddot{-}$ \\
\hline 23 & $<2$ & 22 & $<8$ & $<4$ & 3.8 & 35 & 22 \\
\hline 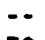 & 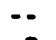 & $\ddot{m}$ & 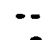 & $\because$ & $\because$ & 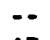 & 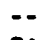 \\
\hline 30 & $<2$ & 20 & $<8$ & $<4$ & 3.5 & 43 & 24 \\
\hline$\because$ & 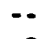 & $=$ & $\cdots$ & $\cdots$ & $\cdots$ & -- & $\ddot{\theta}$ \\
\hline 27 & $<2$ & 21 & $<8$ & $<4$ & 3.5 & 40 & 21 \\
\hline$\cdots$ & -- & $\cdots$ & $\cdots$ & $\cdots$ & $\cdots$ & - & $\cdots$ \\
\hline$\cdots$ & -- & $\cdots$ & $\cdots$ & $\cdots$ & $\cdots$ & $\cdots$ & $\cdots$ \\
\hline$\cdots$ & $\cdots$ & $\cdots$ & $\cdots$ & $\cdots$ & $\cdots$ & $\cdots$ & $\cdots$ \\
\hline$-\bullet$ & $\cdots$ & $\cdots$ & $\cdots$ & $\because$ & $\cdots$ & $\cdots$ & $\cdots$ \\
\hline$\cdots$ & $=$ & $\cdots$ & $\cdots$ & $\cdots$ & $\cdots$ & -- & $\cdots$ \\
\hline$\ddot{z}$ & $\bar{r}$ & $\ddot{20}$ & $<8$ & $\ddot{<4}$ & 3.2 & 45 & 21 \\
\hline 27 & $<2$ & $\begin{array}{l}22 \\
\ldots\end{array}$ & $\begin{array}{l}\mathbf{0} \\
--\end{array}$ & 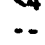 & $\begin{array}{r}3.2 \\
.-\end{array}$ & $\begin{array}{l}45 \\
--\end{array}$ & $\begin{array}{l}21 \\
--\end{array}$ \\
\hline$\ldots$ & $\because$ & -. & -- & - & .- & -. & -. \\
\hline - & - & -. & -. & $\cdots$ & .- & -- & - \\
\hline - & $\cdots$ & $\cdots$ & $\cdots$ & $\cdots$ & $\cdots$ & -. & -. \\
\hline$\cdots$ & -- & -- & -- & $\cdots$ & $\cdots$ & - & - \\
\hline$\cdots$ & - & -- & -- & $\cdots$ & $\cdots$ & - & $\cdots$ \\
\hline- & - & $\cdots$ & -. & -. & -- & -. & - \\
\hline - & $\cdots$ & $\cdots$ & -. & $\cdots$ & -- & -- & $\cdots$ \\
\hline -. & $\cdots$ & -- & $\cdots$ & $\cdots$ & -- & -- & -- \\
\hline-- & -- & $-\cdot$ & $\cdots$ & $\cdots$ & $\cdots$ & -- & $\cdots$ \\
\hline$\cdots$ & $\cdots$ & -- & $\cdots$ & $\because$ & -- & - & $\cdots$ \\
\hline$\because$ & $\cdots$ & -- & $\cdots$ & 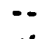 & -- & $=$ & $=-$ \\
\hline 22 & $<2$ & 18 & $<8$ & $<4$ & 3.0 & 33 & 19 \\
\hline$\overline{-}$ & -- & 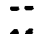 & $\overline{-}$ & $\because$ & $\because$ & $\ddot{-}$ & $\because$ \\
\hline 18 & $<2$ & 11 & $<8$ & $<4$ & 1.7 & 28 & 15 \\
\hline-- & $\because$ & $\because-$ & $\cdots$ & $\cdots$ & -- & 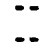 & $\because$ \\
\hline$\because$ & $\ldots$ & -. & - & 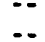 & 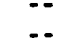 & 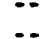 & $\cdots$ \\
\hline
\end{tabular}

PIPELINE ARROYO-Continued

$08-14-90$

08-15-90

08-15-90
353730108312001

08-16-90

$10-19-90$

08-08-91

08-16-91

08-16-91
22

$\begin{array}{lll}-- & -. & -- \\ <2 & 20 & <8 \\ <2 & 19 & <8\end{array}$

48

$\cdots$
$<4$

2.6

30
48

23

31

MANUELITO MASH, U-59-Continued

\begin{tabular}{|c|c|c|c|c|c|c|c|c|}
\hline 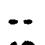 & $=$ & 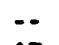 & - & $=$ & - & -- & 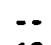 & 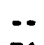 \\
\hline 19 & $<2$ & 17 & $<8$ & $<4$ & 2.8 & 41 & 18 & 34 \\
\hline$\cdots$ & $\cdots$ & $\cdots$ & -- & -- & - & -- & -- & 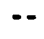 \\
\hline 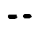 & -- & - & - & - & - & -- & -. & \\
\hline- & 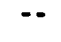 & -- & $\cdots$ & -- & $-\cdot$ & $\cdots$ & - & \\
\hline
\end{tabular}

LEROUX WASH NEAR HOLBROOK, ARIZOWA-CONtinued

09397300

07-19-90

$12-20-90$

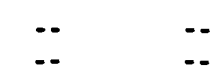


SURFACE-MATER DATA-Cont inued

CHEMICAL AMALYSES-continued

STATION

MUMBER

09402000

$02-22-90$

$04-13-90$

$07-08-90$

$07-12-90$

$07-12-90$

$07-23-90$

$07-23-90$

$08-19-90$

$08-19-90$

$08-21-90$

$08-23-90$

$09-12-90$

$09-18-90$

$09-18-90$

$09-19-90$

$09-19-90$

$09-19-90$

$09-20-90$

$09-20-90$

09-20-90

09-20-90

09-21-90

$09-24-90$

09-24-90

12-18-90

01-07-91

01-07-91

01-08-91

02-12-91

03-07-91

05-02-91

08-30-91

09-05-91
353730108312001

08- $14-90$

$08-15-90$

08- $15-90$

\begin{tabular}{|c|c|c|c|c|c|c|c|c|}
\hline $\begin{array}{l}\text { MAGNE- } \\
\text { SIUN } \\
\text { BOT MAT } \\
\angle 63 \mu \text { DS } \\
\text { LAB } \\
\text { PERCENT } \\
(34902)\end{array}$ & $\begin{array}{l}\text { MNNGA- } \\
\text { NESE } \\
\text { BOT MAT } \\
\angle 63_{\mu} \text { DS } \\
\text { LAB } \\
(\mu g / G) \\
(34907)\end{array}$ & $\begin{array}{c}\text { MOLYB- } \\
\text { DEMUA } \\
\text { BOT MAT } \\
\angle 63_{\mu} \text { DS } \\
\text { LAB } \\
(\mu g / G) \\
(34917)\end{array}$ & $\begin{array}{l}\text { NEOOYM- } \\
\text { IUN } \\
\text { BOT MAT } \\
\angle 63_{\mu} \text { DS } \\
\text { LAB } \\
(\mu g / G) \\
(34922)\end{array}$ & $\begin{array}{c}\text { NICKEL } \\
\text { BOT MAT } \\
\angle 63_{\mu} \text { OS } \\
\text { LAB } \\
(\mu g / G) \\
(34927)\end{array}$ & $\begin{array}{c}\text { NIOBIUN } \\
\text { BOT MAT } \\
\angle 63_{\mu} \text { DS } \\
\text { LAB } \\
(\mu g / G) \\
(34932)\end{array}$ & $\begin{array}{l}\text { PHOS- } \\
\text { PHORUS } \\
\text { BOT MAT } \\
\angle 63_{\mu} \text { DS } \\
\text { LAB } \\
\text { PERCENT } \\
(34937)\end{array}$ & $\begin{array}{l}\text { POTAS- } \\
\text { SIUN } \\
\text { BOT MAT } \\
\angle 63 \mu \text { DS } \\
\text { LAB } \\
\text { PERCENT } \\
\text { (34942) }\end{array}$ & $\begin{array}{c}\text { SCAN- } \\
\text { DIUH } \\
\text { BOT MAT } \\
\angle 63_{\mu} \text { DS } \\
\angle A B \\
(\mu 9 / G) \\
(34947)\end{array}$ \\
\hline
\end{tabular}

LITTLE COLORADO RIVER AT CAMERON, AZ-COnt inuEd

\begin{tabular}{|c|c|c|c|c|c|c|c|c|}
\hline -. & $\cdots$ & $\cdots$ & $\cdots$ & $\cdots$ & $\cdots$ & $\cdots$ & -- & $\cdots$ \\
\hline -. & $\cdots$ & $\cdots$ & $\cdots$ & $\cdots$ & $\cdots$ & -- & $\cdots$ & $\cdots$ \\
\hline$\cdots$ & $\because$ & $\cdots$ & $\ddot{r}$ & $\ddot{m}$ & 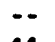 & $\ddot{0}$ & 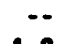 & $\ddot{\theta}$ \\
\hline 1.9 & 510 & $<2$ & 30 & 22 & 11 & .06 & 1.8 & 16 \\
\hline$\because$ & 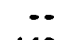 & $\cdots$ & $\because$ & $\because$ & -- & 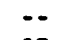 & $\cdots$ & . \\
\hline 1.3 & 460 & $<2$ & 35 & 16 & 11 & .05 & 1.9 & 12 \\
\hline$\cdots$ & $\cdots$ & $\ldots$ & $\cdots$ & $\cdots$ & $\cdots$ & - & $\cdots$ & -. \\
\hline 1.5 & 530 & $<2$ & 33 & 19 & 10 & .05 & 1.8 & 16 \\
\hline$\cdots$ & $\cdots$ & $\cdots$ & $\cdots$ & $\cdots$ & $\cdots$ & $\cdots$ & $\cdots$ & $\cdots$ \\
\hline$\cdots$ & $\cdots$ & $\cdots$ & $\cdots$ & $\cdots$ & $\cdots$ & $\cdots$ & $\cdots$ & - \\
\hline$\cdots$ & $\cdots$ & $\cdots$ & $\cdots$ & $\cdots$ & $\cdots$ & -- & $\cdots$ & 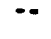 \\
\hline$\because$ & $\because$ & $\because$ & $\because$ & $\because$ & $\cdots$ & $\because$ & $\because$ & $\because$ \\
\hline$\ldots$ & $\ldots$ & $\ldots$ & $\because$ & $\because$ & $\ldots$ & 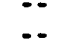 & $\because$ & $\ldots$ \\
\hline 1.3 & 430 & $<2$ & 39 & 22 & 12 & .05 & 1.9 & 13 \\
\hline$\cdots$ & $\cdots$ & $\cdots$ & $\cdots$ & $\cdots$ & $\cdots$ & -- & $\cdots$ & $\cdots$ \\
\hline$\cdots$ & $\cdots$ & $\cdots$ & $\cdots$ & - & $\cdots$ & -. & 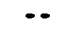 & 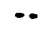 \\
\hline$\cdots$ & $\cdots$ & $\cdots$ & $\cdots$ & -. & $\cdots$ & $\cdots$ & $\cdots$ & - \\
\hline$\cdots$ & $\cdots$ & $\cdots$ & $\cdots$ & $\cdots$ & $\cdots$ & $\cdots$ & $\cdots$ & 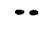 \\
\hline$\cdots$ & $\cdots$ & $\cdots$ & $\cdots$ & $\cdots$ & $\cdots$ & $\cdots$ & $\cdots$ & 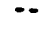 \\
\hline$\cdots$ & $\cdots$ & $\cdots$ & $\cdots$ & $\cdots$ & $\cdots$ & $\cdots$ & $\cdots$ & 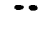 \\
\hline$\cdots$ & $\cdots$ & $\cdots$ & $\cdots$ & $\cdots$ & $\cdots$ & $\cdots$ & $\cdots$ & \\
\hline$\cdots$ & $\cdots$ & $\cdots$ & $\because$ & $\because$ & $\cdots$ & $\cdots$ & $\because$ & 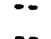 \\
\hline$\cdots$ & $\because$ & 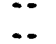 & $\because$ & $\because$ & $\because$ & $\cdots$ & $\because$ & $\cdots$ \\
\hline$\therefore$ & $\therefore$ & $\ldots$ & $\ldots$ & $\ldots$ & $\ldots$ & $\cdots$ & $\because$ & 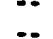 \\
\hline -. & -. & .. & - & -. & $\ldots$ & $\ldots$ & .. & . \\
\hline 1.5 & 490 & $<2$ & 27 & 21 & 8 & .06 & 1.8 & 11 \\
\hline$\cdots$ & -. & $\cdots$ & -. & - & $\cdots$ & - & $\therefore$ & 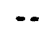 \\
\hline .83 & 530 & $<2$ & 22 & 11 & $<4$ & .04 & 1.9 & 0 \\
\hline$\cdots$ & $\cdots$ & $\cdots$ & $\cdots$ & 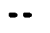 & $\cdots$ & $\cdots$ & -- & $\because$ \\
\hline$\cdots$ & $\cdots$ & $\cdots$ & $\cdots$ & $\cdots$ & $\cdots$ & $\cdots$ & $\cdots$ & \\
\hline$\cdots$ & $\cdots$ & 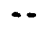 & $\cdots$ & $\therefore$ & $\cdots$ & 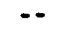 & $\cdots$ & \\
\hline
\end{tabular}

PIPELINE ARROYO-Continued

$\begin{array}{lllllllll}. . & \ldots & \ldots & \ldots & \ldots & \ldots & \ldots & \ldots & \ldots \\ .66 & 280 & <2 & 40 & 17 & 14 & .05 & 2.1 & 11 \\ .71 & 290 & <2 & 40 & 14 & 11 & .05 & 1.9 & 13\end{array}$

MANUELITO WASH, U-59-Continued

$352450108592401 \quad 08-16-90$ $10-19-90$ $08-08-91$ 08-16-91 08-16-91

$\begin{array}{ll}\because- & \ldots \\ .94 & 330 \\ \ldots & \ldots \\ \ldots & \ldots\end{array}$

$\cdots$
$<2$
$\cdots$
$\cdots$

LEROUX WASH NEAR HOLBROOK, ARIZONA-CONt inued

09397300

$07-19-90$

$12-20-90$ 
SURFACE-WATER DATA-Continued

CHEMICAL AMALYSES-Continued

STATION

NUMBER

DATE
353730108312001

$08-14-90$ $08-15-90$ 08-15-90

\begin{tabular}{|c|c|c|c|c|c|c|c|c|}
\hline $\begin{array}{l}\text { SILVER } \\
\text { BOT MAT } \\
\angle 63_{\mu} \text { DS } \\
\text { LAB } \\
(\mu 9 / G) \\
(34957)\end{array}$ & $\begin{array}{l}\text { SOOIUN } \\
\text { BOT MAT } \\
\angle 63_{\mu} \text { DS } \\
\text { LAB } \\
\text { PERCENT } \\
(3 \angle 962)\end{array}$ & $\begin{array}{l}\text { STRON- } \\
\text { TIUA } \\
\text { BOT MAT } \\
\text { C63 DS } \\
\text { LAB } \\
(\mu g / G) \\
(36967)\end{array}$ & $\begin{array}{l}\text { TANTA- } \\
\text { LUA } \\
\text { BOT MAT } \\
\text { <63 } \mu \text { DS } \\
\text { LAB } \\
(\mu g / G) \\
(34977)\end{array}$ & 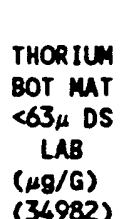 & $\begin{array}{c}\text { TIN } \\
\text { BOT MAT } \\
\angle 63_{\mu} \text { DS } \\
\text { LAB } \\
(\mu g / G) \\
(34987)\end{array}$ & $\begin{array}{l}\text { TITA- } \\
\text { NIUA } \\
\text { BOT MAT } \\
863 \mu \text { DS } \\
\text { LAB } \\
\text { PERCENT } \\
\text { (3K992) }\end{array}$ & $\begin{array}{c}\text { URANIUN } \\
\text { BOT HAT } \\
\text { C63, DS } \\
\text { LAB } \\
(\mu g / G) \\
(35002)\end{array}$ & $\begin{array}{c}\text { VAMA- } \\
\text { DIUN } \\
\text { BOT MAT } \\
\angle 63_{\mu} \text { DS } \\
\text { LAB } \\
(\mu g / G) \\
(35007)\end{array}$ \\
\hline
\end{tabular}

LITTLE COLORADO RIVER AT CAMERON, AZ-cont inued

\begin{tabular}{|c|c|c|c|c|c|c|c|c|}
\hline - & -. & - & $\cdots$ & -. & $\ldots$ & $\cdots$ & - & -. \\
\hline$\cdots$ & $\cdots$ & $\cdots$ & -. & $\cdots$ & $-\cdot$ & $\cdots$ & -- & $\cdots$ \\
\hline$\cdots$ & $\cdots$ & -. & $\cdots$ & $\cdots$ & -. & $\cdots$ & -. & -. \\
\hline$<4$ & .46 & 340 & $<40$ & 14 & $<10$ & .34 & $<100$ & 87 \\
\hline$\because$ & $\ddot{-}$ & 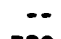 & $\cdots$ & 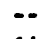 & 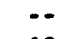 & $\because$ & 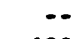 &.- \\
\hline$<4$ & .38 & 320 & $<40$ & 14 & $<10$ & .35 & $<100$ & 81 \\
\hline$\because$ & $\because$ & $\because$ & 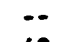 & $\ddot{\theta}$ & $\because$ & 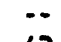 & 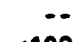 & 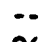 \\
\hline$<4$ & .41 & 280 & $<40$ & 15 & $<10$ & .42 & $<100$ & 96 \\
\hline$\cdots$ & $\cdots$ & $\cdots$ & $\cdots$ & $\cdots$ & $\cdots$ & $\cdots$ & -- & $\cdots$ \\
\hline$\cdots$ & $\cdots$ & $\cdots$ & $\cdots$ & $\cdots$ & -- & $\cdots$ & $\cdots$ & $\cdots$ \\
\hline$\cdots$ & $\cdots$ & $\cdots$ & $\cdots$ & $\cdots$ & $\cdots$ & $\cdots$ & $\cdots$ & $\because$ \\
\hline$\cdots$ & $\cdots$ & $\cdots$ & $\cdots$ & $\cdots$ & $\cdots$ & $\cdots$ & $\cdots$ & 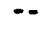 \\
\hline$\cdots$ & $\because$ & $\cdots$ & $\cdots$ & $\cdots$ & $\cdots$ & $\because$ & $\cdots$ & 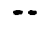 \\
\hline 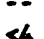 & 37 & $\ddot{2}$ & $\ddot{n}$ & 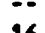 & $\bar{F}$ & $\ddot{7}$ & $\ddot{n}$ & - \\
\hline 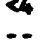 & .38 & 250 & $<40$ & 16 & $<$ & .37 & $<100$ & 90 \\
\hline .. & .. & $\ldots$ & .. & $\ldots$ & $\ldots$ & $\ldots$ & $\ldots$ & . \\
\hline$\cdots$ & $\ldots$ & .. & $\ldots$ & .. & $\ldots$ & $\ldots$ & .. & 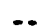 \\
\hline -. & $\ldots$ & - & $\ldots$ & .. & -. & $\cdots$ & .. & 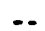 \\
\hline -- & -- & .. & - & -. & -. & $\because$ & .. & - \\
\hline$\cdots$ & -- & $\cdots$ & - & - & -. & $\cdots$ & -. & $\because$ \\
\hline -- & -- & $\cdots$ & -- & $\cdots$ & -- & $\cdots$ & -. & $\cdot$ \\
\hline-- & $\cdots$ & -- & -- & $\cdots$ & $-\cdot$ & -- & - & - \\
\hline -. & $\cdots$ & -. & $\cdots$ & $\cdots$ & $\cdots$ & $\cdots$ & $\cdots$ & 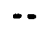 \\
\hline$\cdots$ & -- & -. & -- & $\cdots$ & $\cdots$ & $\cdots$ & $-\cdot$ & - \\
\hline -- & $\cdots$ & $\cdots$ & $\cdots$ & $\cdots$ & -- & $\cdots$ & -- & - \\
\hline$\cdots$ & $\cdots$ & -- & $\cdots$ & $\cdots$ & $\cdots$ & $\cdots$ & $\cdots$ & \\
\hline$<4$ & .61 & 290 & $<40$ & 11 & $<5$ & .33 & $<100$ & 74 \\
\hline$\cdots$ & $\cdots$ & $\cdots$ & $\cdots$ & $\cdots$ & $-\cdot$ & $\cdots$ & -. & $\cdots$ \\
\hline$<4$ & .98 & 230 & $<40$ & 7 & $<5$ & .22 & $<100$ & 44 \\
\hline-- & $-\cdot$ & $\cdots$ & $\cdots$ & $\cdots$ & $\cdots$ & $\cdots$ & $\cdots$ & \\
\hline$\cdots$ & $\cdots$ & $\cdots$ & $\cdots$ & $\cdots$ & $-\cdot$ & $\cdots$ & $-\cdot$ & \\
\hline$\because$ & $\cdots$ & $\cdots$ & $\cdots$ & $\cdots$ & $-\cdot$ & $\cdots$ & $-\cdot$ & \\
\hline
\end{tabular}

PIPELINE ARROYO-Continued

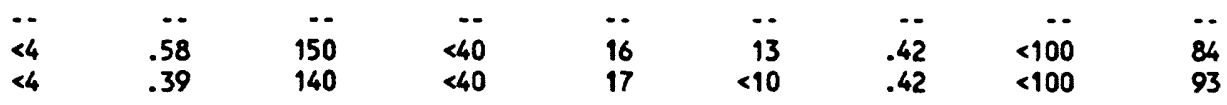

MANUELITO MASH, U-59-Continued

352450108592401

08-16-90 $10-19-90$ 08-08-91 08-16-91 08-16-91

$\begin{array}{ccccc}\ldots & \ldots & \ldots & \ldots & \ldots \\ <4 & .69 & 210 & <40 & 12 \\ -. & \ldots & \ldots & \ldots & \ldots \\ \ldots & \ldots & \ldots & \ldots & \ldots\end{array}$

LEROUX WASH MEAR HOLBROOK, ARIZONA-Continued 
SURFACE-WATER DATA-Cont inued

CHEMICAL ANALYSES-Cont inued

STATION

NUMBER

09402000

353730108312001

$08-14-90$ $08-15-90$ $08-15-90$
$02-22-90$

$04-13-90$

$07-08-90$

$07-12-90$

$07-12-90$

$07-23-90$

$07-23-90$

08-19-90

08-19-90

$08-21-90$

08-23-90

$09-12-90$

$09-18-90$

09-18-90

$09-19-90$

$09-19-90$

$09-19-90$

$09-20-90$

09-20-90

$09-20-90$

09-20-90

$09-21-90$

$09-24-90$

$09-24-90$

12-18-90

$01-07-91$

$01-07-91$

01-08-91

02-12-91

03-07-91

05-02-91

08-30-91

09-05-91
$08-16-90$ $10-19-90$ 08-08-91 08-16-91 $08-16-91$
352450108592401

\begin{tabular}{|c|c|c|c|c|c|c|c|}
\hline $\begin{array}{l}\text { YTTRIUA } \\
\text { BOT MAT } \\
\angle 63 \mu \text { OS } \\
\text { LAB } \\
(\mu \mathrm{g} / \mathrm{G}) \\
(35012)\end{array}$ & $\begin{array}{c}\text { YTTER- } \\
\text { BILA } \\
\text { BOT MAT } \\
<63 \mu \text { DS } \\
\text { LAB } \\
(\mu g / G) \\
(35017)\end{array}$ & $\begin{array}{c}\text { 2INC } \\
\text { BOT MAT } \\
<63 \mu \text { DS } \\
\text { LAB } \\
(\mu g / G) \\
(35022)\end{array}$ & $\begin{array}{l}\text { SEDI - } \\
\text { MENT, } \\
\text { SUS- } \\
\text { PENDED } \\
(\mathrm{mg} / \mathrm{l}) \\
(80154)\end{array}$ & $\begin{array}{l}\text { SED. } \\
\text { SUSP. } \\
\text { SIEVE } \\
\text { DIAN. } \\
\text { X FINER } \\
\text { THAN } \\
\text {.062 } \\
(70331)\end{array}$ & $\begin{array}{l}\text { SED. } \\
\text { SUSP. } \\
\text { SIEVE } \\
\text { DINH. } \\
\times \text { FINER } \\
\text { THAN } \\
\text {-125 MM } \\
\text { (70332) }\end{array}$ & $\begin{array}{l}\text { SED. } \\
\text { SUSP. } \\
\text { SIEVE } \\
\text { DINM. } \\
\times \text { FINER } \\
\text { THAN } \\
.250 \text { M } \\
\text { (70333) }\end{array}$ & $\begin{array}{l}\text { SED. } \\
\text { SUSP. } \\
\text { SIEVE } \\
\text { DINA. } \\
\times \text { FINER } \\
\text { THAN } \\
.500 \\
(70334)\end{array}$ \\
\hline
\end{tabular}

LITTLE COLORADO RIVER AT CAMERON, AZ-Continued

\begin{tabular}{|c|c|c|c|}
\hline -. & -. & - & -. \\
\hline$\cdots$ & -. & -. & - \\
\hline -. & -. & -. & 62900 \\
\hline 24 & 3 & 66 & 67000 \\
\hline$\cdots$ & -. & -. & $\cdots$ \\
\hline 25 & 3 & 67 & 25000 \\
\hline -- & -. & -. & 26500 \\
\hline 25 & 3 & 75 & 78000 \\
\hline-- & -- & -. & 75100 \\
\hline-- & $\cdots$ & -. & 88200 \\
\hline - & -. & -. & 89500 \\
\hline-- & -- & -. & 118000 \\
\hline-- & -- & - & 116000 \\
\hline -- & -. & -. & 125000 \\
\hline 25 & 2 & 91 & 98900 \\
\hline-- & -. & -. & 67700 \\
\hline-- & $\cdots$ & - & 97100 \\
\hline-- & - & -. & 84100 \\
\hline-- & -. & -. & 121000 \\
\hline -. & -. & -. & 118000 \\
\hline -. & - & - & 98300 \\
\hline-- & -. & -. & 139000 \\
\hline-- & $\cdots$ & -. & 64900 \\
\hline-- & -- & - & 73400 \\
\hline-- & -- & - & 87800 \\
\hline -. & -. & -- & 50400 \\
\hline -- & -. & -. & 72000 \\
\hline 20 & 2 & 57 & 85500 \\
\hline-- &.- & - & 111 \\
\hline 18 & 2 & 36 & 46100 \\
\hline -. & 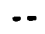 & - & 4000 \\
\hline -. & -. & - & 91200 \\
\hline -. & .. & -. & 139000 \\
\hline
\end{tabular}

\begin{tabular}{|c|c|c|}
\hline - & -- & - \\
\hline -. & -- & -- \\
\hline$\cdots$ & -- & -- \\
\hline$\cdots$ & -- & -- \\
\hline$\cdots$ & $\because$ & -. \\
\hline 97 & 100 & 100 \\
\hline $\begin{array}{l}97 \\
00\end{array}$ & 100 & 100 \\
\hline $\begin{array}{l}99 \\
\infty\end{array}$ & 100 & 100 \\
\hline 99 & 100 & 100 \\
\hline$\cdots$ & -- & $\cdots$ \\
\hline$\cdots$ & $-\cdot$ & - \\
\hline$\cdots$ & -- & - \\
\hline$\cdots$ & -- & $\cdots$ \\
\hline$\cdots$ & $\cdots$ & -- \\
\hline$\cdots$ & $\cdots$ & $\cdots$ \\
\hline 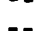 & 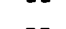 & $\cdots$ \\
\hline$\ldots$ & $\ldots$ & . \\
\hline - & -. & .. \\
\hline - & -. & $\cdots$ \\
\hline- & - & - \\
\hline$\cdots$ & -- & $\cdots$ \\
\hline-- & -- & $\cdots$ \\
\hline$\cdots$ & -- & $\cdots$ \\
\hline-- & -- & $\cdots$ \\
\hline$\cdots$ & $=$ & $\cdots$ \\
\hline 7 & & \\
\hline $\begin{array}{l}71 \\
-.-\end{array}$ & $\begin{array}{l}84 \\
--\end{array}$ & $\begin{array}{l}97 \\
-.\end{array}$ \\
\hline 79 & 90 & 99 \\
\hline-- & -- & 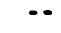 \\
\hline 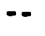 & $-\cdot$ & 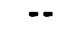 \\
\hline$=$ & $\cdots$ & \\
\hline
\end{tabular}

PIPELINE ARROYO-Continued

$\begin{array}{llllllll}\ldots & \ldots & \ldots & \ldots & \ldots & \ldots & \ldots & \ldots \\ 26 & 3 & 78 & \ldots & \ldots & \ldots & \ldots & \ldots \\ 26 & 3 & 83 & \ldots & \ldots & \ldots & \ldots & \ldots\end{array}$

MNUELITO WASH, U-59-Cont inued

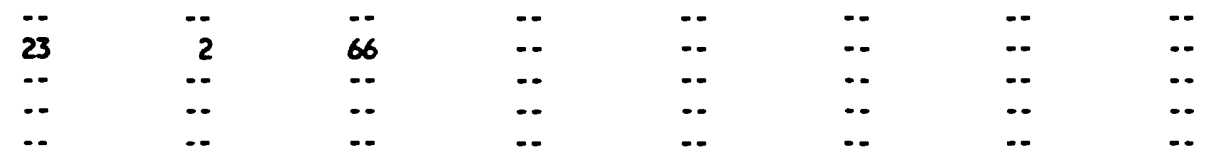

LEROXX MASH MEAR HOLBROOK, ARIZOWA-COnt inued

09397300

6650

100 
SURFACE-WATER DATA-Cont inued

CHEMICAL AMALYSES-Continued

STATION

MUABER

DATE

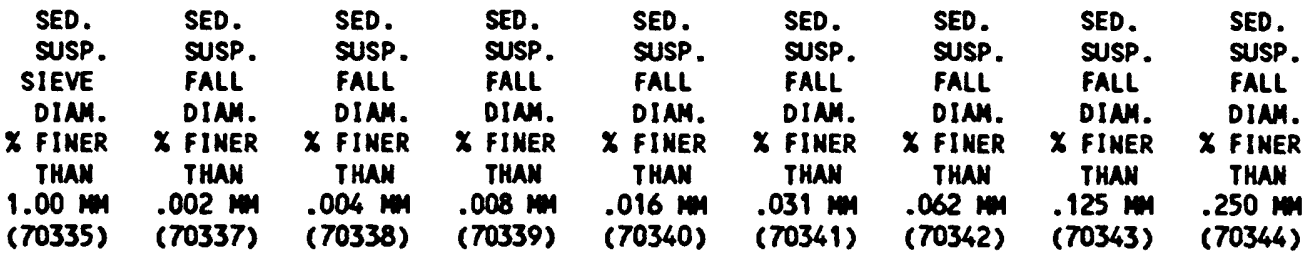

LITTLE COLORADO RIVER AT CAMERON, AZ-Continued

09402000

353730108312001

$08-14-90$ $08-15-90$ $08-15-90$
352450108592401

08-16-90 $10-19-90$ 08-08-91 08-16-91 08-16-91

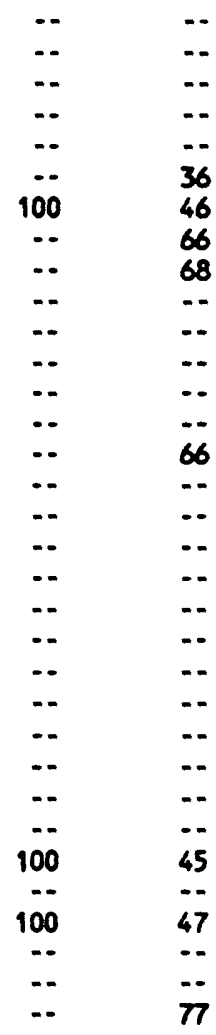

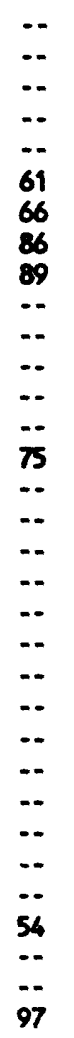

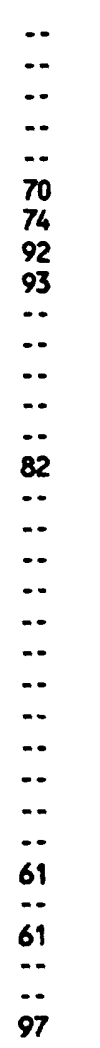

PIPELINE ARROYO-Continued

$\begin{array}{lllllllll}\ldots & \ldots & \ldots & \ldots & \ldots & \ldots & \ldots & \ldots & \ldots \\ \ldots & - & - & \ldots & \ldots & \ldots & \ldots & \ldots & \ldots \\ \ldots & \ldots & -- & \ldots & \ldots & \ldots & \ldots & \ldots & \ldots\end{array}$

MANUELITO UASH, U-59-Continued

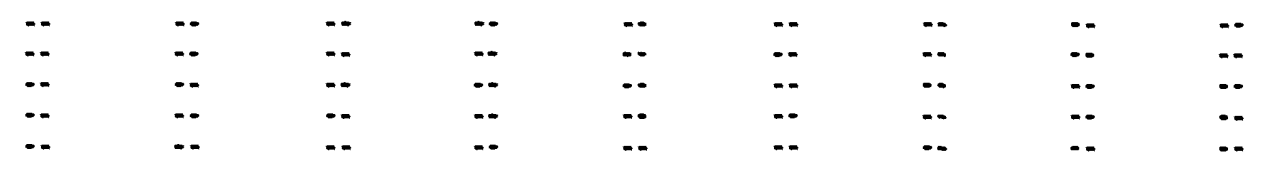

LEROUX WASH NEAR HOLBROOK, ARIZOMA-Continued

09397300

LEROXX UASH MEAR HOLBROOK, ARIZOUh-Continued 


\begin{tabular}{|c|c|c|c|c|c|c|}
\hline STATION MUMBER & STATION MAME & DATE & TIME & & LATITUDE & LONGI TUDE \\
\hline 353156108362301 & $\begin{array}{l}\text { SOUTH FORK PUERCO RIVER AT ROUTE } 566 \\
\text { BRIDGE, NEH MEXICO }\end{array}$ & $05-17-90$ & 1200 & & $35^{\circ} 31 \cdot 56^{\mathrm{mN}}$ & $108 \cdot 36 \cdot 23 \cdot \mathrm{W}$ \\
\hline 353727108312401 & PIPELIME ARROYO U.59 & $\begin{array}{l}08-14-90 \\
08-14-90 \\
08-14-90\end{array}$ & $\begin{array}{l}1353 \\
1420 \\
1738\end{array}$ & & $35 \cdot 37 \cdot 27{ }^{n N}$ & $108^{\circ} 31 \cdot 24^{\prime \prime W}$ \\
\hline 353151108361301 & SOUTH FORK PUERCO U-59 & $\begin{array}{l}10-19-90 \\
08-15-91\end{array}$ & $\begin{array}{l}0010 \\
1030\end{array}$ & & $35 \cdot 31 \cdot 51$ WN & $108 \cdot 36 \cdot 13^{114}$ \\
\hline 352359107382110 & SAN MATEO & $05-09-90$ & 1538 & & $35 \cdot 23 \cdot 59^{\prime \prime N}$ & $107 \cdot 38^{\prime} 21^{\prime \prime 4}$ \\
\hline 353535107112701 & CHICO ARROYO & $05-18-90$ & 1400 & & $35 \cdot 35 \cdot 35^{\prime \prime} \mathrm{N}$ & $107 \cdot 11 \cdot 37 \cdot w$ \\
\hline 354020107043302 & RIO PUERCO & $\begin{array}{l}05-18-90 \\
08-18-90\end{array}$ & $\begin{array}{l}1200 \\
0010\end{array}$ & & $35 \cdot 40 \cdot 20^{\prime \prime N}$ & $107 \cdot 04 \cdot 33^{m W}$ \\
\hline 353104108490201 & GALLUP SEWAGE TREATMENT PLANT & $\begin{array}{l}03-27-89 \\
03-08-90 \\
03-09-90 \\
08-03-90\end{array}$ & $\begin{array}{l}1700 \\
0815 \\
0730 \\
0920\end{array}$ & & $35 \cdot 31 \cdot 04 \mathrm{wN}$ & $108^{\circ} 49 \cdot 02^{\prime 1} \mathrm{~W}$ \\
\hline 353056108504402 & BRIDGE 83 & $\begin{array}{l}03-31-89 \\
08-03-90 \\
10-16-90\end{array}$ & $\begin{array}{l}1630 \\
0725 \\
0800\end{array}$ & & $35 \cdot 31 \cdot 00$ "N & $108 \cdot 46 \cdot 0014 \mathrm{~W}$ \\
\hline 351942109041402 & PUERCO RIVER AT LUPTON WELL CLUSTER & $10-16-90$ & 1400 & & $35^{\circ} 19 \cdot 42^{\prime \prime N}$ & $109 \cdot 04 \cdot 14114$ \\
\hline 351933109041901 & PUERCO RIVER AT LUPTON, ROUTE 66 BRIDGE & $03-08-90$ & 1200 & & $35 \cdot 19 \cdot 33 \cdot \mathrm{N}$ & $109 \cdot 04 \cdot 19 \cdot 1 \mathrm{~W}$ \\
\hline $\begin{array}{l}345351110094402 \\
09 \cdot 44^{\prime \prime M}\end{array}$ & HOLBROOK SURFACE-WATER DATA & \multicolumn{2}{|c|}{$05-15-90$} & 0900 & \multicolumn{2}{|c|}{$34 \cdot 53 \cdot 51 " N$} \\
\hline \multirow{2}{*}{$\begin{array}{l}351527109161902 \\
16 \cdot 19^{M W}\end{array}$} & QUERINO ROAD SURFACE-MATER DATA & \multicolumn{2}{|c|}{$04-04-89$} & 1700 & \multirow{2}{*}{\multicolumn{2}{|c|}{$35 \cdot 15 \cdot 27 \times N$}} \\
\hline & & $03-08-90$ & 1510 & & & \\
\hline 351244109194901 & PUERCO RIVER AT SAMDERS, ARIZOWA & $03-09-90$ & 1630 & & $35 \cdot 12 \cdot 44^{m N}$ & $109 \cdot 19$ \\
\hline
\end{tabular}


SURFACE-MATER DATA-Continued

CHEMICAL AMALYSES-Continued

\begin{tabular}{|c|c|c|c|c|c|c|c|c|c|}
\hline STATION MAME & DATE & $\begin{array}{c}\text { ALTITUDE } \\
\text { OF LAND } \\
\text { SURFACE } \\
\text { DATUN } \\
\text { (METERS } \\
\text { ABOVE } \\
\text { NGVD) } \\
\text { (72000) }\end{array}$ & $\begin{array}{l}\text { SAN- } \\
\text { PLIMG } \\
\text { METHOD, } \\
\text { COOES } \\
\text { (82398) }\end{array}$ & $\begin{array}{c}\text { TEMPER- } \\
\text { ATURE } \\
\text { WATER } \\
\left({ }^{\circ} \mathrm{C}\right) \\
(00010)\end{array}$ & $\begin{array}{l}\text { FLOW } \\
\text { RATE, } \\
\text { INSTAN- } \\
\text { TANEOWS } \\
\text { (LITERS/ } \\
\text { SEC) } \\
\text { (00059) }\end{array}$ & $\begin{array}{l}\text { DIS- } \\
\text { CHARGE, } \\
\text { INST. } \\
\text { CUBIC } \\
\text { METERS } \\
\text { PER } \\
\text { SECOND } \\
\text { (00061) }\end{array}$ & $\begin{array}{c}\text { TUR- } \\
\text { BID- } \\
\text { ITY } \\
\text { (NTU) } \\
\text { (00076) }\end{array}$ & $\begin{array}{l}\text { OXID- } \\
\text { ATION } \\
\text { RED- } \\
\text { UCTION } \\
\text { POTEN- } \\
\text { TIAL } \\
\text { (IIV) } \\
(00090)\end{array}$ & 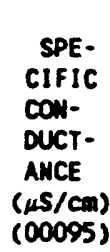 \\
\hline
\end{tabular}

MISCELLAKEOUS SURFACE-WATER DATA SITES-Continued

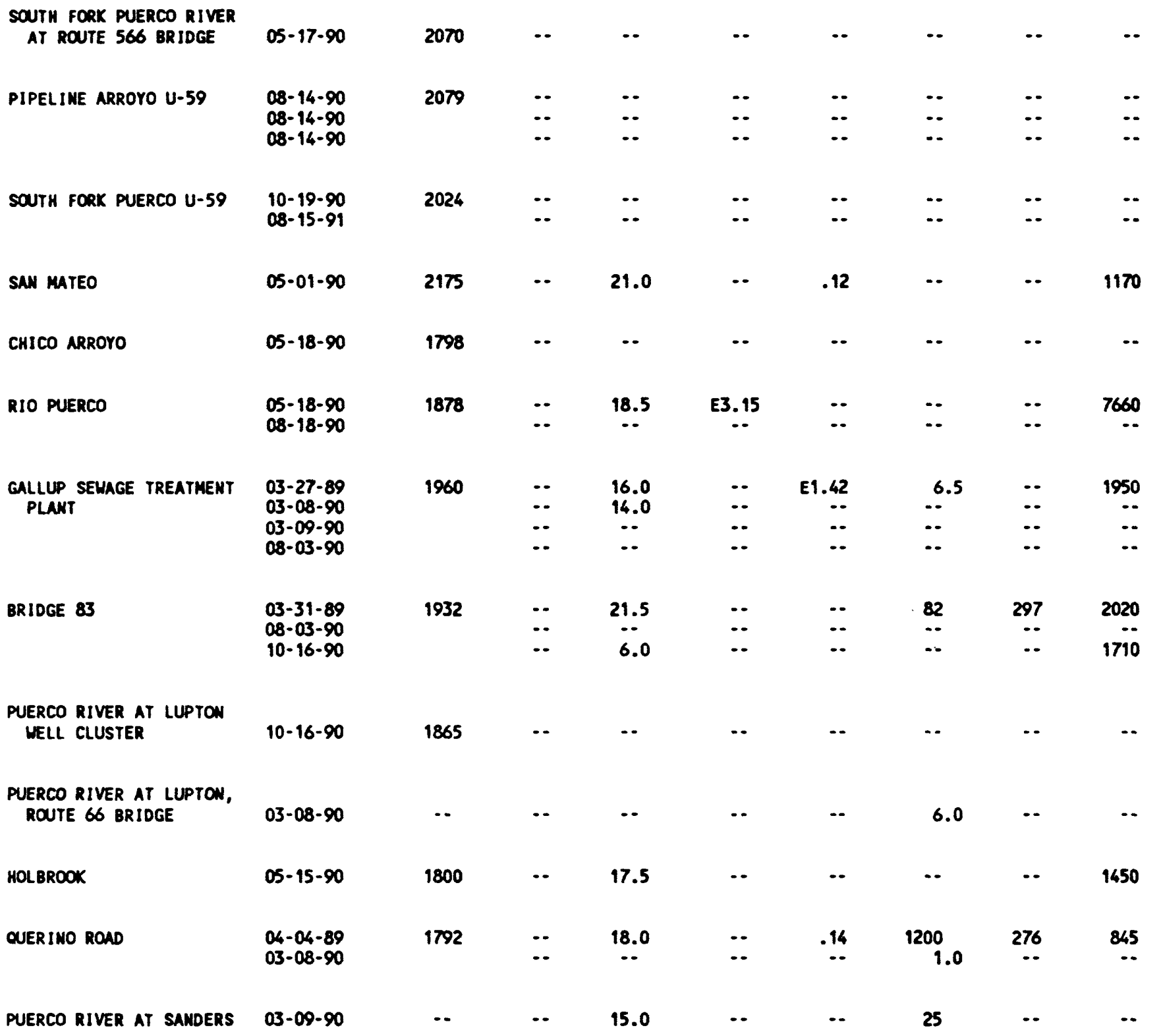




\begin{tabular}{|c|c|c|c|c|c|c|c|c|c|}
\hline \multicolumn{10}{|c|}{ SURFACE-WATER DATA-Cont inued } \\
\hline \multicolumn{10}{|c|}{ CHEMICAL ANALYSES-Cont inued } \\
\hline STATION MAME & DATE & $\begin{array}{l}\text { SPE- } \\
\text { CIFIC } \\
\text { CON- } \\
\text { DUCT- } \\
\text { ANCE } \\
\text { LAB } \\
(\mu S / \mathrm{Cm}) \\
(90095)\end{array}$ & $\begin{array}{l}\text { OXYGEN, } \\
\text { DIS- } \\
\text { SOLVED } \\
(\text { OOdL } / \text { ) } \\
(00300)\end{array}$ & $\begin{array}{l}\text { OXYGEN } \\
\text { DEMAND, } \\
\text { CHEM- } \\
\text { ICAL } \\
\text { (HIGH } \\
\text { LEVEL) } \\
\text { (mO/L) } \\
(00340)\end{array}$ & $\begin{array}{l}\text { PH } \\
\text { WATER } \\
\text { WHOLE } \\
\text { FIELD } \\
\text { (STAND- } \\
\text { ARD } \\
\text { UNITS) } \\
\text { (00400) }\end{array}$ & $\begin{array}{l}\text { PH } \\
\text { WATER } \\
\text { WHOLE } \\
\text { LAB } \\
\text { (STAND- } \\
\text { NRD } \\
\text { UNITS) } \\
\text { (00403) }\end{array}$ & $\begin{array}{l}\text { ALKA- } \\
\text { LINITY } \\
\text { WAT DIS } \\
\text { FIX END } \\
\text { FIELD } \\
\text { CaCO3 } \\
(\mathrm{mg} / \mathrm{L}) \\
(39036)\end{array}$ & $\begin{array}{l}\text { ALKA- } \\
\text { LINITY } \\
\text { WAT DIS } \\
\text { TOT IT } \\
\text { FIELD } \\
\text { WO/L as } \\
\text { Caco3 } \\
(39086)\end{array}$ & $\begin{array}{l}\text { ALKA- } \\
\text { LINITY } \\
\text { LAB } \\
\text { (mo/L } \\
\text { as } \\
\text { Caco3) } \\
(90410)\end{array}$ \\
\hline \multicolumn{10}{|c|}{ MISCELLANEOUS SURFACE-HATER DATA SITES-Continued } \\
\hline $\begin{array}{l}\text { SOUTH FORK PUERCO RIVER } \\
\text { AT ROUTE } 566 \text { BRIDGE }\end{array}$ & $05-17-90$ & -- & -- & $-\cdot$ & -- & -- & -- & $\cdots$ & -- \\
\hline PIPELINE ARROYO U-59 & $\begin{array}{l}08-14-90 \\
08-14-90 \\
08-14-90\end{array}$ & $\begin{array}{l}\cdots \\
\cdots \\
\cdots\end{array}$ & $\begin{array}{l}-- \\
-- \\
\cdots\end{array}$ & $\begin{array}{l}-- \\
-- \\
--\end{array}$ & $\begin{array}{l}-- \\
\cdots \\
\cdots\end{array}$ & $\begin{array}{l}-- \\
--\end{array}$ & $\begin{array}{l}-- \\
\cdots \\
\cdots\end{array}$ & $\begin{array}{l}\cdots \\
\cdots \\
\cdots\end{array}$ & $\begin{array}{l}-. \\
\cdots \\
\cdots\end{array}$ \\
\hline SOUTH FORK PUERCO U-59 & $\begin{array}{l}10-19-90 \\
08-15-91\end{array}$ & $\begin{array}{l}-- \\
--\end{array}$ & $\begin{array}{l}-. \\
-.\end{array}$ & $\begin{array}{l}-- \\
--\end{array}$ & $\begin{array}{l}-- \\
\cdots\end{array}$ & -- & $\begin{array}{l}-- \\
--\end{array}$ & $\begin{array}{l}-- \\
\cdots\end{array}$ & $\begin{array}{l}-- \\
-.\end{array}$ \\
\hline SAN MATEO & $05-01-90$ & 1140 & 6.4 & -- & 8.9 & 8.8 & 240 & 244 & -- \\
\hline CHICO ARROYO & $05-18-90$ & 2900 & $\cdots$ & -- & $\cdots$ & 8.4 & -- & $\cdots$ & 389 \\
\hline RIO PUERCO & $\begin{array}{l}05-18-90 \\
08-18-90\end{array}$ & $\begin{array}{r}689 \\
--\end{array}$ & $\begin{array}{r}6.5 \\
-.\end{array}$ & $\begin{array}{ll}-- \\
--\end{array}$ & $\begin{array}{l}8.1 \\
-.\end{array}$ & 8.0 & -- & $\begin{array}{c}167 \\
\cdots\end{array}$ & $\begin{array}{l}85 \\
--\end{array}$ \\
\hline $\begin{array}{l}\text { GALLUP SELAGE TREATMENT } \\
\text { PLANT }\end{array}$ & $\begin{array}{l}03-27-89 \\
03-08-90 \\
03-09-90 \\
08-03-90\end{array}$ & $\begin{array}{c}1990 \\
\ldots \\
1760\end{array}$ & $\begin{array}{c}6.4 \\
-. \\
-. \\
-.\end{array}$ & $\begin{array}{c}110 \\
\ldots \\
\ldots \\
--\end{array}$ & $\begin{array}{c}7.6 \\
\ldots \\
\ldots \\
\ldots\end{array}$ & $\begin{array}{c}7.5 \\
\ldots \\
-. \\
7.4\end{array}$ & $\begin{array}{c}410 \\
\ldots \\
\ldots \\
--\end{array}$ & $\begin{array}{c}408 \\
\ldots \\
-. \\
-.\end{array}$ & $\begin{array}{r}413 \\
\ldots \\
280\end{array}$ \\
\hline BRIDGE 83 & $\begin{array}{l}03-31-89 \\
08-03-90 \\
10-16-90\end{array}$ & $\begin{array}{l}1960 \\
1790 \\
1760\end{array}$ & $\begin{array}{r}8.3 \\
-. \\
9.0\end{array}$ & $\begin{array}{l}84 \\
-- \\
--\end{array}$ & $\begin{array}{l}\ldots \\
.0\end{array}$ & $\begin{array}{l}7.6 \\
7.5 \\
7.2\end{array}$ & $\begin{array}{c}430 \\
-- \\
231\end{array}$ & $\begin{array}{l}-- \\
--\end{array}$ & $\begin{array}{c}412 \\
270 \\
\cdots\end{array}$ \\
\hline $\begin{array}{l}\text { PUERCO RIVER AT LUPTON } \\
\text { WELL CLUSTER }\end{array}$ & $10-16-90$ & $\cdots$ & -- & -- & $\cdots$ & 8.4 & -- & -- & $\cdots$ \\
\hline $\begin{array}{l}\text { PUERCO RIVER AT LUPTON, } \\
\text { ROUTE } 66 \text { BRIDGE }\end{array}$ & $03.08 \cdot 90$ & $\cdots$ & $\cdots$ & $\cdots$ & $\cdots$ & 7.8 & $\cdots$ & $\cdots$ & 278 \\
\hline HOLBROOK & $05-15-90$ & 1460 & E7.0 & -- & 8.6 & 8.4 & -- & -. & 189 \\
\hline OUERINO ROAD & $\begin{array}{l}04-04-89 \\
03-08-90\end{array}$ & $\begin{aligned} 845 \\
-.\end{aligned}$ & $\begin{array}{r}6.9 \\
-.\end{array}$ & $\begin{array}{l}28 \\
--\end{array}$ & $\begin{array}{c}8.2 \\
-.-\end{array}$ & $\begin{array}{l}8.2 \\
8.0\end{array}$ & 220 & 216 & $\begin{array}{l}208 \\
265\end{array}$ \\
\hline PUERCO RIVER AT SANDERS & $03-09-90$ & 1760 & -- & -- & -- & 7.9 & -- & $\ldots$ & 260 \\
\hline
\end{tabular}




\begin{tabular}{|c|c|c|c|c|c|c|c|c|c|}
\hline \multicolumn{10}{|c|}{ SURFACE-WATER OATA-Cont inued } \\
\hline \multicolumn{10}{|c|}{ CHEMICAL ANALYSES-Cont inued } \\
\hline STATION MNE & OATE & $\begin{array}{c}\text { CAR- } \\
\text { BONATE } \\
\text { WATER } \\
\text { OIS IT } \\
\text { FIELD } \\
\text { Mg/L as } \\
\text { CO3 } \\
(00452)\end{array}$ & $\begin{array}{l}\text { BICAR- } \\
\text { BONATE } \\
\text { WATER } \\
\text { OIS IT } \\
\text { FIELD } \\
\mathrm{mg/L} \text { as } \\
\text { HCO3 } \\
(00453)\end{array}$ & $\begin{array}{l}\text { SOLIOS, } \\
\text { RESIOUE } \\
\text { AT } 180^{\circ} \mathrm{C} \\
\text { OIS- } \\
\text { SOLVED } \\
(\mathrm{mg} / \mathrm{L}) \\
(70300)\end{array}$ & $\begin{array}{l}\text { SOLIOS, } \\
\text { SUM OF } \\
\text { CONSTI- } \\
\text { TUENTS, } \\
\text { DIS- } \\
\text { SOLVED } \\
\text { (mg/L) } \\
(70301)\end{array}$ & $\begin{array}{l}\text { SOLIOS, } \\
\text { OIS- } \\
\text { SOLVED } \\
\text { (metric } \\
\text { tons } \\
\text { per } \\
\text { day) } \\
(70302)\end{array}$ & $\begin{array}{l}\text { NITRO- } \\
\text { GEN, } \\
\text { NMONIA } \\
\text { OIS- } \\
\text { SOLVED } \\
\text { (mg/L } \\
\text { as N) } \\
\text { (00608) }\end{array}$ & $\begin{array}{l}\text { NITRO- } \\
\text { GEN, } \\
\text { NO2+NO3 } \\
\text { OIS- } \\
\text { SOLVED } \\
\text { (mo/L } \\
\text { as N) } \\
(00631)\end{array}$ & $\begin{array}{l}\text { NITRO- } \\
\text { GEN,AN- } \\
\text { MONIA - } \\
\text { ORGANIC } \\
\text { TOTAL } \\
\text { (MG/L } \\
\text { OS N) } \\
\text { (00625) }\end{array}$ \\
\hline \multicolumn{10}{|c|}{ MISCELLAMEOUS SURFACE-HATER DATA SITES-Continued } \\
\hline $\begin{array}{l}\text { SOUTH FORK PUERCO RIVER } \\
\text { AT ROUTE } 566 \text { BRIDGE }\end{array}$ & $05-17-90$ & $\cdots$ & $\cdots$ & $\cdots$ & $\cdots$ & $\cdots$ & $\cdots$ & $\cdot-$ & - \\
\hline PIPELINE ARROYO U-59 & $\begin{array}{l}08-16-90 \\
08-14-90 \\
08-16-90\end{array}$ & $\begin{array}{l}\cdots \\
\cdots \\
\cdots\end{array}$ & $\begin{array}{l}\cdots \\
\cdots \\
\cdots\end{array}$ & $\begin{array}{l}\cdots \\
\cdots \\
\cdots\end{array}$ & $\begin{array}{l}\cdots \\
\cdots \\
\cdots\end{array}$ & $\begin{array}{l}\cdots \\
\cdots \\
\cdots\end{array}$ & $\begin{array}{l}\cdots \\
\cdots \\
\cdots\end{array}$ & $\begin{array}{l}\cdots \\
\cdots \\
\cdots\end{array}$ & $\begin{array}{l}\cdots \\
\cdots \\
\cdots\end{array}$ \\
\hline SOUTH FORK PUERCO U-59 & $\begin{array}{l}10-19-90 \\
08-15-91\end{array}$ & $\cdots$ & $\begin{array}{l}\cdots \\
\cdots\end{array}$ & $\begin{array}{l}\cdots \\
\cdots\end{array}$ & $\begin{array}{l}\cdots \\
--\end{array}$ & $\begin{array}{l}\cdots \\
--\end{array}$ & $\cdots$ & $\begin{array}{l}\cdots \\
\cdots\end{array}$ & $\cdots$ \\
\hline SAN MATEO & $05-01-90$ & 22 & 254 & $\cdots$ & 717 & 7.54 & $\cdots$ & $<.100$ & -- \\
\hline CHICO ARROYO & $05-18-90$ & $-\cdot$ & -- & -- & $\cdots$ & $-\cdot$ & -- & -- & -- \\
\hline RIO PUERCO & $\begin{array}{l}05-18-90 \\
08-18-90\end{array}$ & $\begin{array}{l}\cdots \\
\therefore\end{array}$ & 204 & $\begin{array}{ll}-- \\
--\end{array}$ & $\begin{array}{l}537 \\
\cdots\end{array}$ & $\because-$ & $\begin{array}{ll}-\cdot \\
\therefore\end{array}$ & $\therefore$ & $\because-$ \\
\hline $\begin{array}{l}\text { GALLUP SEWAGE TREATMENT } \\
\text { PLANT }\end{array}$ & $\begin{array}{l}03-27-89 \\
03-08-90 \\
03-09-90 \\
08-03-90\end{array}$ & $\begin{array}{l}\cdots \\
\cdots \\
\cdots\end{array}$ & $\begin{array}{c}497 \\
-. \\
\ldots \\
-.\end{array}$ & $\begin{array}{c}1210 \\
\ldots \\
\cdots \\
1040\end{array}$ & $\begin{array}{c}1230 \\
\ldots \\
\ldots \\
\ldots\end{array}$ & $\begin{array}{l}-- \\
\cdots \\
\cdots\end{array}$ & $\begin{array}{l}1.60 \\
\cdots \\
-- \\
--\end{array}$ & $\begin{array}{c}<.100 \\
\cdots \\
\cdots \\
\cdots\end{array}$ & $\begin{array}{c}39 \\
\ldots \\
-- \\
\ldots\end{array}$ \\
\hline BRIDGE 83 & $\begin{array}{l}03-31-89 \\
08-03-90 \\
10-16-90\end{array}$ & $\begin{array}{l}\cdots \\
\cdots\end{array}$ & $\begin{array}{l}\cdots \\
\cdots \\
\cdots\end{array}$ & $\begin{array}{c}1230 \\
1050 \\
=\end{array}$ & $\begin{array}{c}1310 \\
\ldots \\
\ldots\end{array}$ & $\begin{array}{l}\cdots \\
\cdots \\
\cdots\end{array}$ & $\begin{array}{c}24.0 \\
\ldots \\
\ldots\end{array}$ & $\begin{array}{l}.290 \\
=- \\
-\end{array}$ & $\begin{array}{c}29 \\
\cdots \\
\cdots\end{array}$ \\
\hline $\begin{array}{l}\text { PUERCO RIVER AT LUPTON } \\
\text { WELL CLUSTER }\end{array}$ & $10-16-90$ & $\cdots$ & $\cdots$ & $\cdots$ & $\because$ & $\because$ & $\cdots$ & $\cdots$ & $\cdots$ \\
\hline $\begin{array}{l}\text { PUERCO RIVER AT LUPTON, } \\
\text { ROUTE } 66 \text { BRIDGE }\end{array}$ & $03-08-90$ & $\cdots$ & -- & 1250 & $\cdots$ & $\because$ & $\cdots$ & -- & -- \\
\hline HOL BRCOK & $05-15-90$ & $\cdots$ & $\cdots$ & $\cdots$ & 1210 & $\cdots$ & $<.002$ & $<.010$ & -. \\
\hline OUERINO ROAD & $\begin{array}{l}04-04-89 \\
03-08-90\end{array}$ & $\begin{array}{ll}-- \\
--\end{array}$ & $\begin{array}{c}229 \\
-\cdot\end{array}$ & $\begin{array}{r}536 \\
1190\end{array}$ & $\begin{array}{ll}499 \\
\cdots\end{array}$ & $\begin{array}{c}6.57 \\
\cdots\end{array}$ & .050 & 1.90 & 1.0 \\
\hline PUERCO RIVER AT SAMDERS & $03-09-90$ & $\cdots$ & $\cdots$ & 1190 & -- & $\cdots$ &.- & $\cdots$ & -. \\
\hline
\end{tabular}




\begin{tabular}{|c|c|c|c|c|c|c|c|c|c|}
\hline & & SURF & ACE-WATER & ATA-Cont & nued & & & & \\
\hline & & CHEM & ICAL ANALY & ES-Cont i & ved & & & & \\
\hline STATIOW MNME & DATE & $\begin{array}{l}\text { PHOS- } \\
\text { PHORUS } \\
\text { DIS- } \\
\text { SOLVED } \\
\text { (mg/L } \\
\text { as P) } \\
\text { (OOS66) }\end{array}$ & $\begin{array}{l}\text { PHOS- } \\
\text { PHORUS } \\
\text { TOTAL } \\
\text { (mo/L } \\
\text { as P) } \\
\text { (00665) }\end{array}$ & $\begin{array}{l}\text { PHOS- } \\
\text { PHORUS } \\
\text { ORTHO, } \\
\text { DIS- } \\
\text { SOLVED } \\
\text { (mo/L } \\
\text { as P) } \\
(00671)\end{array}$ & $\begin{array}{l}\text { PHOS- } \\
\text { PHATE, } \\
\text { ORTHO, } \\
\text { DIS- } \\
\text { SOLVED } \\
\text { (MG/L } \\
\text { as PO4) } \\
(00660)\end{array}$ & $\begin{array}{l}\text { CARBON, } \\
\text { ORGANIC } \\
\text { DIS- } \\
\text { SOLVED } \\
\text { (mg/L } \\
\text { OS C) } \\
\text { (OOGBi) }\end{array}$ & $\begin{array}{l}\text { CARBOW, } \\
\text { ORGANIC } \\
\text { TOTAL } \\
\text { (mo/L } \\
\text { as C) } \\
(00680)\end{array}$ & $\begin{array}{l}\text { MARD- } \\
\text { NESS } \\
\text { TOTAL } \\
\text { (mg/L } \\
\text { as } \\
\text { Caco3) } \\
\text { (00900) }\end{array}$ & $\begin{array}{l}\text { CALCIUW } \\
\text { DIS- } \\
\text { SOLVED } \\
\text { (mill } \\
\text { os Ca) } \\
\text { (00915) }\end{array}$ \\
\hline & & LLANEOUS & SURFACE-WA & ER DATA $S$ & TES-Cont & nued & & & \\
\hline $\begin{array}{l}\text { SOUTH FORK PUERCO RIVER } \\
\text { AT ROUTE S66 BRIDGE }\end{array}$ & $05-17-90$ & $\because$ & $\cdots$ & $\cdots$ & $\cdots$ & $\cdots$ & $\cdots$ & $\cdots$ & $\cdots$ \\
\hline PIPELINE ARROYO U-59 & $\begin{array}{l}08-14-90 \\
08-14-90 \\
08-14-90\end{array}$ & $\begin{array}{l}\because \\
\because\end{array}$ & $\begin{array}{l}\because- \\
-\cdot\end{array}$ & 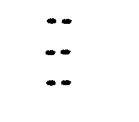 & 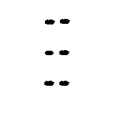 & $\begin{array}{l}\ddot{-} \\
\ddot{-}\end{array}$ & $\begin{array}{l}\because- \\
--\end{array}$ & $\begin{array}{l}\ddot{-} \\
\ddot{-}\end{array}$ & 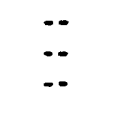 \\
\hline SOUTH FORK PUERCO U-59 & $\begin{array}{l}10-19-90 \\
08-15-91\end{array}$ & $\begin{array}{l}\cdots \\
\cdots\end{array}$ & $\because-$ & $\ddot{-}$ & $\begin{array}{l}\cdots \\
\cdots\end{array}$ & $\begin{array}{l}\cdots \\
\cdots\end{array}$ & $\ddot{-}$ & $\begin{array}{l}\cdots \\
\cdots\end{array}$ & 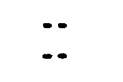 \\
\hline SAN MATEO & $05-01-90$ & $\cdots$ & -- & $\cdots$ & $\cdots$ & $\cdots$ & $\cdots$ & 25 & 8.0 \\
\hline CHICO ARROYO & $05-18-90$ & $\cdots$ & $\cdots$ & $\cdots$ & $\cdots$ & $\cdots$ & $\cdots$ & 220 & 48 \\
\hline RIO PUERCO & $\begin{array}{l}05-18-90 \\
08-18-90\end{array}$ & $\because$ & $\because$ & $\ddot{-}$ & $\because$ & $\ddot{-}$ & $\ddot{-}$ & $\begin{array}{l}230 \\
\cdots\end{array}$ & $\begin{array}{l}65 \\
-\end{array}$ \\
\hline $\begin{array}{l}\text { GALLUP SEMAGE TREATMENT } \\
\text { PLANT }\end{array}$ & $\begin{array}{l}03-27-89 \\
03-08-90 \\
03-09-90 \\
08-03-90\end{array}$ & $\begin{array}{c}8.90 \\
\ldots \\
\cdots \\
\cdots\end{array}$ & $\begin{array}{c}11.0 \\
\ldots \\
\cdots \\
-.\end{array}$ & $\begin{array}{c}1.20 \\
\cdots \\
\cdots \\
-.\end{array}$ & $\begin{array}{l}3.7 \\
-: \\
-\cdot \\
-\cdot\end{array}$ & $\begin{array}{l}8.8 \\
-- \\
-- \\
--\end{array}$ & $\begin{array}{l}36 \\
\cdots \\
\cdots \\
\cdots\end{array}$ & $\begin{array}{l}78 \\
\cdots- \\
\cdots \\
\therefore-\end{array}$ & $\begin{array}{l}21 \\
-- \\
-- \\
--\end{array}$ \\
\hline BRIDGE 83 & $\begin{array}{l}03-31-89 \\
08-03-90 \\
10-16-90\end{array}$ & $\begin{array}{c}8.10 \\
\cdots \\
\cdots\end{array}$ & $\begin{array}{c}8.40 \\
\cdots \\
\cdots\end{array}$ & $\begin{array}{c}6.20 \\
\cdots \\
-\cdot\end{array}$ & $\begin{array}{l}19 \\
\cdots\end{array}$ & $\begin{array}{l}15 \\
\cdots \\
\cdots\end{array}$ & $\begin{array}{l}33 \\
\because- \\
\cdots\end{array}$ & $\begin{array}{l}83 \\
\because- \\
--\end{array}$ & $\begin{array}{l}23 \\
\cdots \\
\cdots\end{array}$ \\
\hline $\begin{array}{l}\text { PUERCO RIVER AT LUPTON } \\
\text { WELL CLUSTER }\end{array}$ & $10-16-90$ & $\cdots$ & $\cdots$ & $\cdots$ & $\cdots$ & $\cdots$ & $\cdots$ & $\cdots$ & $\cdots$ \\
\hline $\begin{array}{l}\text { PUERCO RIVER AT LUPTON, } \\
\text { ROUTE } 66 \text { BRIDGE }\end{array}$ & $03-08-90$ & $\cdots$ & $\cdots$ & $\cdot \cdot$ & $\cdots$ & $\cdots$ & $\cdot \cdot$ & $\cdot-$ & 52 \\
\hline HOLBROOK & $05-15-90$ & $\cdots$ & $\cdots$ & .001 & ND & 3.4 & $\cdots$ & 310 & 68 \\
\hline QUERINO ROND & $\begin{array}{l}04-04-89 \\
03-08-90\end{array}$ & .340 & .360 & .280 & $\therefore .86$ & $\begin{array}{l}8.7 \\
--\end{array}$ & $\begin{array}{l}27 \\
-\cdots\end{array}$ & 240 & $\begin{array}{l}63 \\
63\end{array}$ \\
\hline PUERCO RIVER AT SANDERS & $03-09-90$ & $\cdots$ & $\cdot-$ & $\cdots$ & $\cdots$ & $\cdots$ & $\cdots$ & $\cdots$ & 64 \\
\hline
\end{tabular}




\section{SURFACE-WATER DATA-Cont inued \\ CHEMICAL ANALYSES-Cont inued}

\begin{tabular}{|c|c|c|c|c|c|c|c|c|c|}
\hline STATION NAME & DATE & $\begin{array}{l}\text { MAGE- } \\
\text { SIUM, } \\
\text { DIS- } \\
\text { SOLVED } \\
\text { (mg/L } \\
\text { as Mg) } \\
(00925)\end{array}$ & $\begin{array}{l}\text { SODIUA, } \\
\text { DIS- } \\
\text { SOLVED } \\
\text { (mg/L } \\
\text { as Na) } \\
(00930)\end{array}$ & $\begin{array}{l}\text { SOOIUN } \\
\text { ADSORP- } \\
\text { TION } \\
\text { RATIO } \\
\text { (00931) }\end{array}$ & $\begin{array}{l}\text { SOOIUN } \\
\text { PERCENT } \\
\text { (00932) }\end{array}$ & $\begin{array}{l}\text { POTAS- } \\
\text { SIUH, } \\
\text { DIS- } \\
\text { SOLVED } \\
\text { (m9/L } \\
\text { Bs K) } \\
(00935)\end{array}$ & $\begin{array}{l}\text { CHLO- } \\
\text { RIDE, } \\
\text { DIS- } \\
\text { SOLVED } \\
(\mathrm{mg} / \mathrm{L} \\
\text { as Cl) } \\
(00940)\end{array}$ & $\begin{array}{c}\text { BROHIDE } \\
\text { OIS- } \\
\text { SOLVED } \\
\text { (mg/L } \\
\text { as Br) } \\
(71870)\end{array}$ & $\begin{array}{l}\text { FLUO- } \\
\text { RIDE, } \\
\text { DIS- } \\
\text { SOLVED } \\
\text { (mg/L } \\
\text { O8 F) } \\
\text { (00950) }\end{array}$ \\
\hline
\end{tabular}

MISCELLANEQUS SURFACE-WATER DATA SITES-Continued

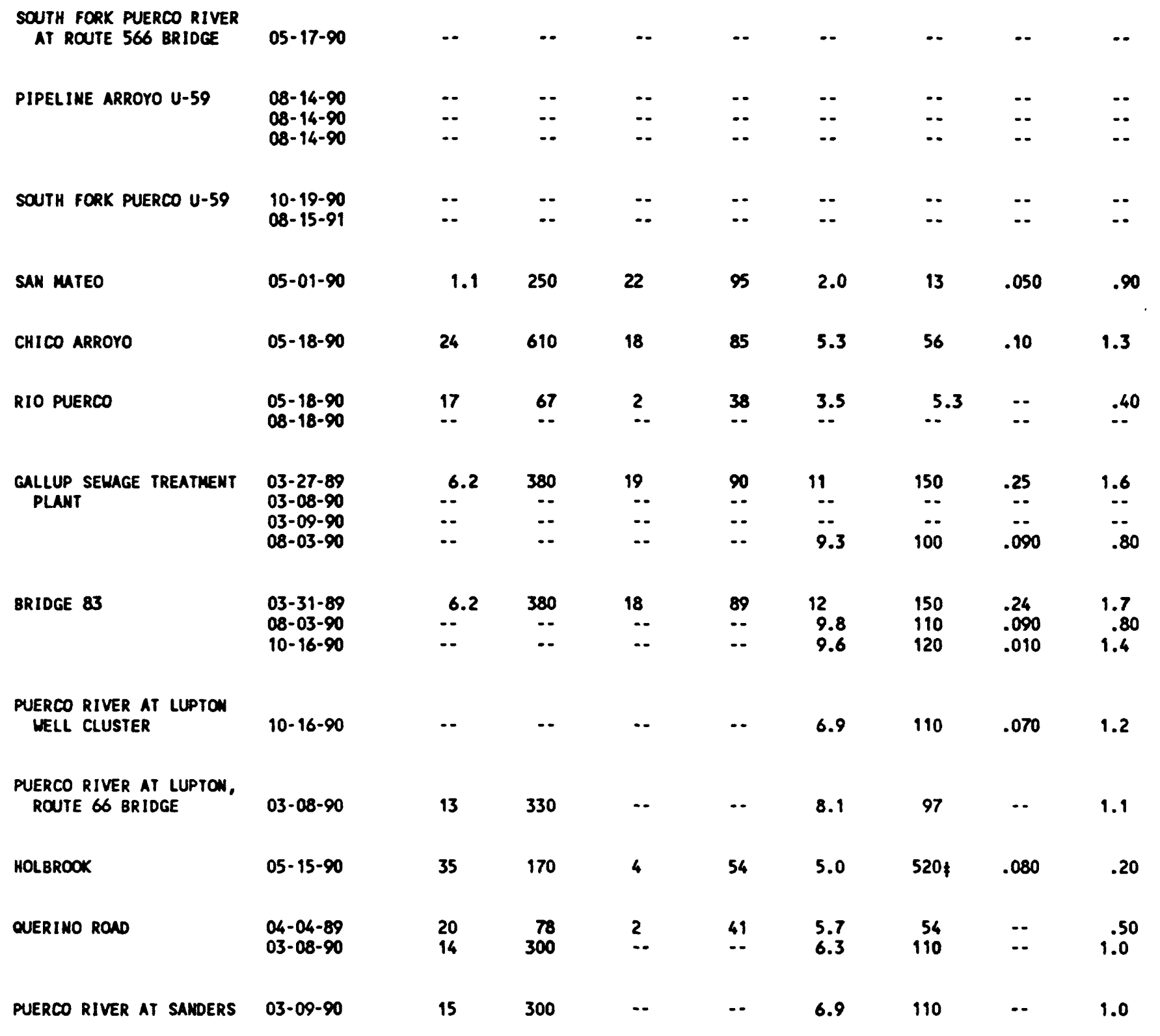




\section{SURFACE-MATER DATA-Cont inued \\ CHEMICAL AMALYSES-Continued}

\begin{tabular}{|c|c|c|c|c|c|c|c|c|c|}
\hline STATION MAME & DATE & $\begin{array}{c}\text { SILICA, } \\
\text { DIS- } \\
\text { SOLVED } \\
\text { (mo/L } \\
\text { as } \\
\text { si02) } \\
(00955)\end{array}$ & $\begin{array}{l}\text { SULFATE } \\
\text { DIS- } \\
\text { SOLVED } \\
\text { (mo/l } \\
\text { as SO4) } \\
\text { (00945) }\end{array}$ & $\begin{array}{c}\text { ARSENIC } \\
\text { DIS- } \\
\text { SOLVED } \\
\text { ( } \mu g / L \\
\text { AS AS) } \\
(01000)\end{array}$ & $\begin{array}{l}\text { BARIUH, } \\
\text { DIS- } \\
\text { SOLVED } \\
(\mu g / L \\
\text { AS Ba) } \\
(01005)\end{array}$ & $\begin{array}{l}\text { BERYL- } \\
\text { LIUN, } \\
\text { DIS- } \\
\text { SOLVED } \\
\text { ( } \mu 9 / L \\
\text { as Be) } \\
(01010)\end{array}$ & $\begin{array}{l}\text { BORON, } \\
\text { DIS- } \\
\text { SOLVED } \\
(\mu g / L \\
\text { As B) } \\
(01020)\end{array}$ & $\begin{array}{l}\text { CADKIUA } \\
\text { DIS- } \\
\text { SOLVED } \\
\text { ( } \mu g / L \\
\text { As Cd) } \\
\text { (01025) }\end{array}$ & $\begin{array}{l}\text { CHRO- } \\
\text { MIUA, } \\
\text { DIS- } \\
\text { SOLVED } \\
(\mu g / L \\
\text { OS Cr) } \\
(01030)\end{array}$ \\
\hline
\end{tabular}

miscellamequS sURfaCe-mater DATA SITES-Continued

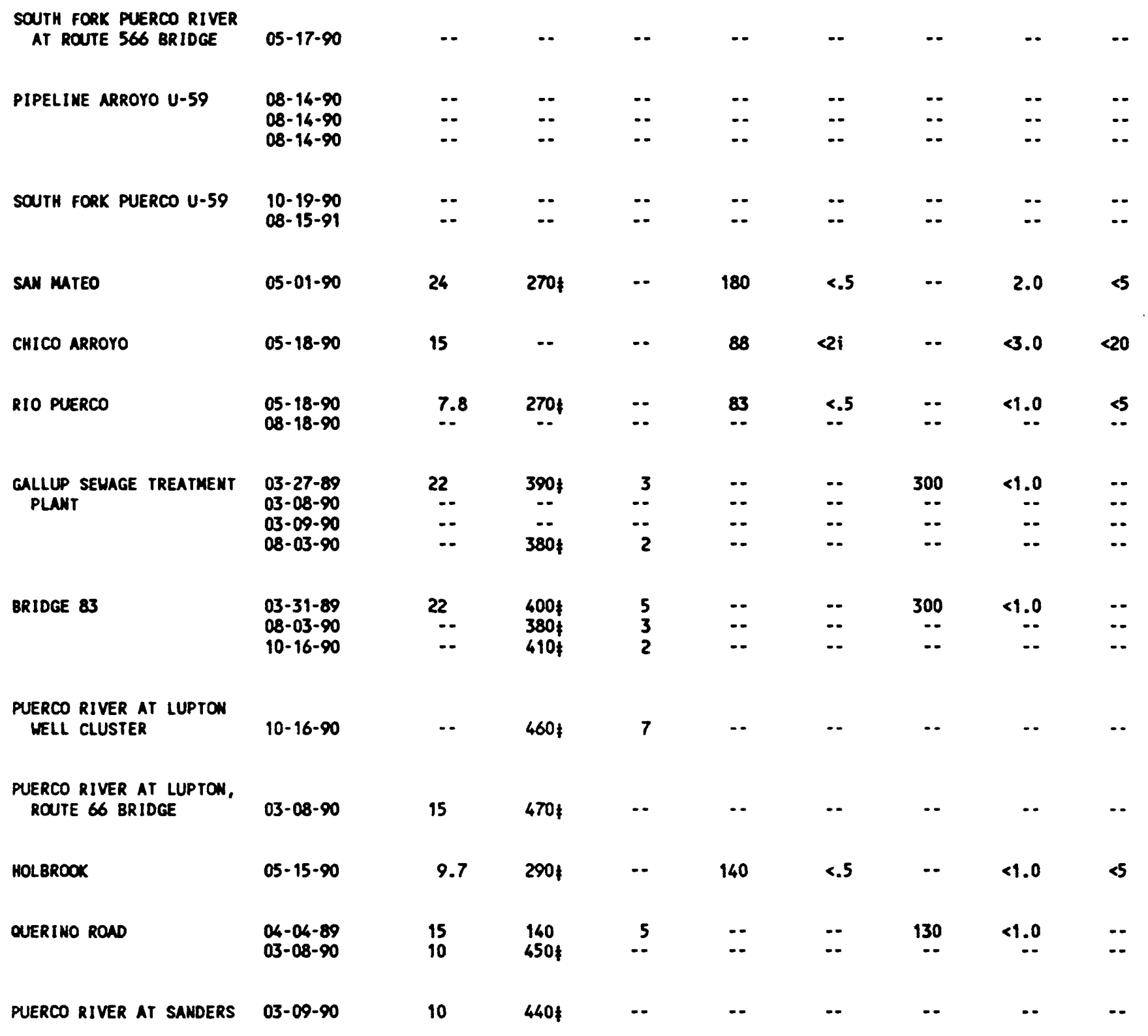


STATION RAME

DATE

SOUTH FORK PUERCO RIVER
AT ROUTE 566 BRIDGE

PIPELINE ARROYO U-59

$08-14-90$

$08-14-90$

$08-14-90$

SOUTH FORK PUERCO U-59

10-19-90 $05-17-90$

SAN MATEO

$05-09-90$

CHICO ARROYO

RIO PUERCO

GALLUP SEMAGE TREATMENT PLANT

BRIDGE 83

PUERCO RIVER AT LUPTON WELL CLUSTER

PUERCO RIVER AT LUPTON, ROUTE 66 BRIDGE

HOLBROOK

OUERINO ROAD

$04-04-89$ 03-08-90

PUERCO RIVER AT SANDERS
CHRO-

\begin{tabular}{|c|c|c|c|c|c|c|c|}
\hline $\begin{array}{c}\text { MIUN, } \\
\text { HEXA- } \\
\text { VALENT, } \\
\text { DIS. } \\
(\mu g / L \\
\text { as Cr) } \\
(01032)\end{array}$ & $\begin{array}{c}\text { COBALT, } \\
\text { DIS- } \\
\text { SOLVED } \\
(\mu g / L \\
\text { O8 CO) } \\
(01035)\end{array}$ & $\begin{array}{l}\text { COPPER, } \\
\text { DIS- } \\
\text { SOLVED } \\
(\mu g / L \\
\text { as Cu) } \\
(01040)\end{array}$ & $\begin{array}{l}\text { IRON, } \\
\text { DIS- } \\
\text { SOLVED } \\
(\mu g / L \\
\text { as Fe) } \\
(01046)\end{array}$ & $\begin{array}{l}\text { LEAD, } \\
\text { DIS- } \\
\text { SOLVED } \\
(\mu g / L \\
\text { as Pb) } \\
(01049)\end{array}$ & $\begin{array}{l}\text { MANGA- } \\
\text { NESE, } \\
\text { DIS- } \\
\text { SOLVED } \\
(\mu g / L \\
\text { as Nn) } \\
(01056)\end{array}$ & $\begin{array}{c}\text { MERCLRY } \\
\text { DIS- } \\
\text { SOLVED } \\
\text { ( } \mu \mathrm{g} / \mathrm{L} \\
\text { OS } \mathrm{HS}) \\
(71890)\end{array}$ & $\begin{array}{c}\text { MOLYB- } \\
\text { DENUN, } \\
\text { DIS- } \\
\text { SOLVED } \\
\text { ( } \mu \mathrm{g} / \mathrm{L} \\
\text { O8 MO) } \\
(01060)\end{array}$ \\
\hline
\end{tabular}

MISCELLANEOUS SURFACE-WATER DATA SITES-Continued 


\section{SURFACE-HATER DATA-Cont inued}

CHEMICAL ANALYSES-Continued

STATION WHAE

DATE

$05-17-90$

ROUTE 566 BRIDGE

PIPELINE ARROYO U-59

$08-14-90$

$08-14-90$

$08-14-90$

SOUTH FORK PUERCO U-59

$10-19-90$

08-15-91

SAN MATEO

CHICO ARROYO

RIO PUERCO

GALLUP SEMAGE TREATMENT PLANT

BRIDGE 83

03-31-89 $08-03-90$ $10-16-90$

PUERCO RIVER AT LUPTON WELL CLUSTER

PUERCO RIVER AT LUPTON, ROUTE 66 BRIDGE

HOLBROOK

QUERIMO ROAD

PUERCO RIVER AT SAMDERS

$05-01-90$

$05-18-90$
$08-18-90$

$03-27-89$

$03-08-90$

$03-09-90$

08-03-90

$10-16-90$

03-08-90

$05-15-90$ $03-08-90$

$03-09-90$
$<10$

3.0

30

$<1.0 \quad 1100$

$\begin{array}{rr}<10 & <1.0 \\ \cdots & -\end{array}$

$\begin{array}{ll}<1 & \ldots \\ -- & \ldots \\ -- & \quad- \\ -- & -\end{array}$

$5 \quad \ldots$

$\begin{array}{ll}5 & \cdots \\ \therefore & \cdots \\ - & \cdots\end{array}$

$<10<1.0$

790

$<6$

6

27

$04-04-89$

$\begin{array}{lll}2 & -- & 730 \\ - & -- & --\end{array}$

$\begin{array}{ll}-. & 9 \\ -- & \quad-\end{array}$
SELENIUN, DISSOLVED $(\mu \mathrm{g} / \mathrm{L}$ as Se) (01145)

MISCELLANEOUS SURFACE-HATER DATA SITES-Cont inued 


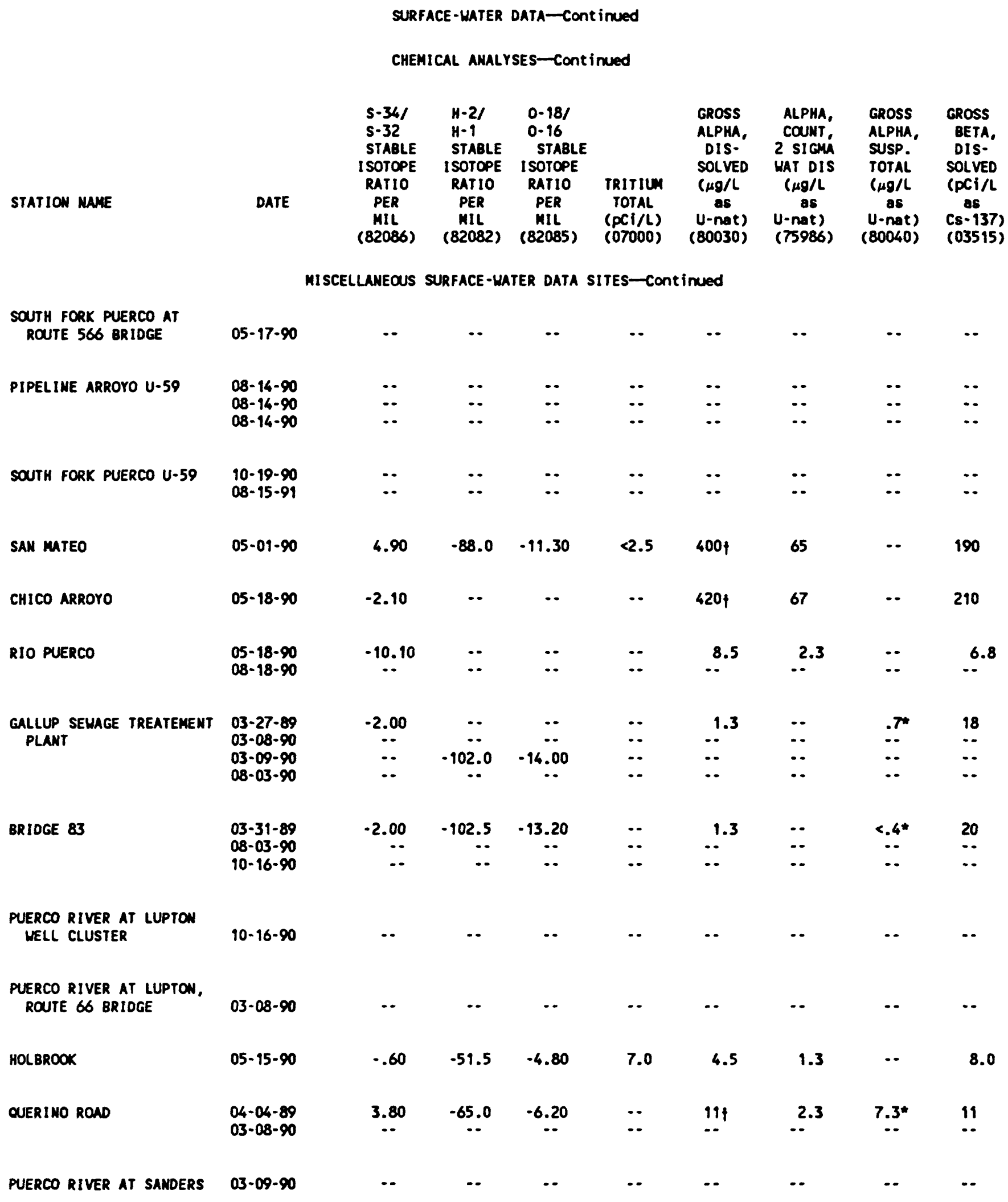




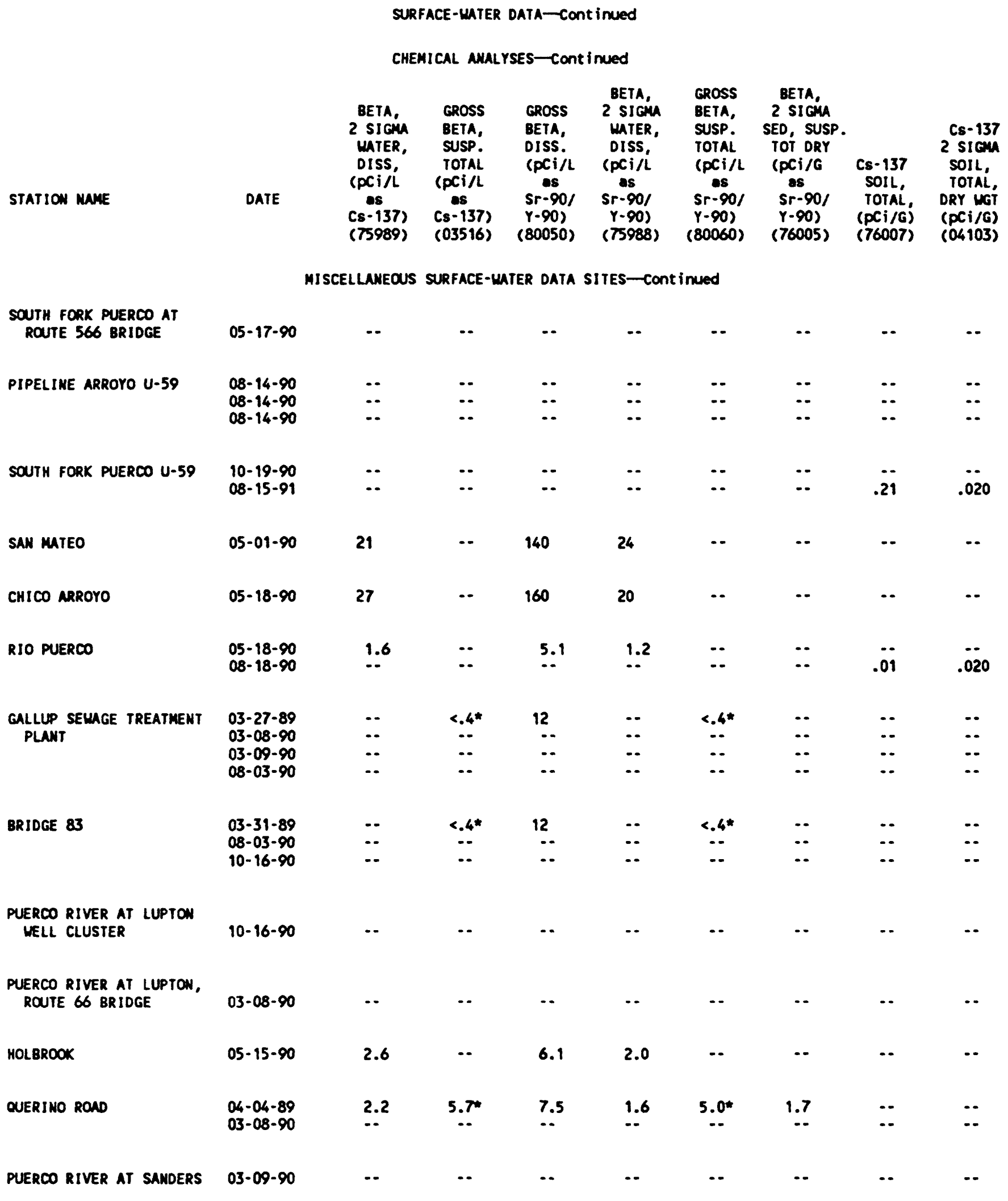




\section{SURFACE-MAIER DATA-Cont inued}

CHEMICAL AMALYSES-Continued

\begin{tabular}{|c|c|c|c|c|c|c|c|c|c|}
\hline STATION MAME & DATE & $\begin{array}{l}\text { RA-226 } \\
\text { SED, } \\
\text { SUSP, } \\
\text { TOTAL, } \\
\text { ORY WGT } \\
\text { (PCi/G) } \\
\text { (75944) }\end{array}$ & $\begin{array}{l}\text { URANIUN } \\
\text {-234 } \\
\text { MUTER } \\
\text { OISSOLV } \\
\text { (PCi/L) } \\
(22610)\end{array}$ & $\begin{array}{l}\text { U-234 } \\
2 \text { SIGMA } \\
\text { WATER, } \\
\text { O1SS, } \\
\text { (pCi/L) } \\
\text { (75992) }\end{array}$ & $\begin{array}{l}\text { U-234 } \\
\text { SED, } \\
\text { SUSP, } \\
\text { TOTAL, } \\
\text { DRY WGT } \\
\text { (PCi/G) } \\
\text { (75942) }\end{array}$ & $\begin{array}{l}\text { U-234, } \\
2 \text { SIGW } \\
\text { SED, } \\
\text { SUSP, } \\
\text { TOTAL, } \\
\text { DRY WGI } \\
\text { (PCI/G) } \\
\text { (TS941) }\end{array}$ & $\begin{array}{l}\text { URANIIN } \\
\text {-235 } \\
\text { MATER, } \\
\text { DISS } \\
\text { (PCi/L) } \\
(22620)\end{array}$ & $\begin{array}{l}\text { U-235 } \\
2 \text { SIGMA } \\
\text { HATER, } \\
\text { DISS, } \\
\text { (PCi/L) } \\
\text { (75994) }\end{array}$ & $\begin{array}{c}\text { U-235 } \\
\text { SED, } \\
\text { SUSP, } \\
\text { TOTAL, } \\
\text { DRY WG } \\
\text { (PCi/G) } \\
\text { (TS9TS. }\end{array}$ \\
\hline \multicolumn{10}{|c|}{ MISCELLANEOUS SURFACE-LATER DATA SITES-Continued } \\
\hline $\begin{array}{l}\text { SOUTH FORK PUERCD AT } \\
\text { ROUTE S66 BRIDGE }\end{array}$ & $05-17-90$ & $\cdots$ & $\cdots$ & $\cdots$ & 1.7 & .40 & $\cdots$ & $\cdots$ & $<.1$ \\
\hline PIPELINE ARROYO U-59 & $\begin{array}{l}08-14-90 \\
08-14-90 \\
08-14-90\end{array}$ & $\begin{array}{l}1.8 \\
1.2 \\
1.8\end{array}$ & $\begin{array}{l}\because- \\
-.\end{array}$ & $\begin{array}{l}\because . \\
\because-\end{array}$ & $\begin{array}{l}1.6 \\
1.7 \\
1.8\end{array}$ & $\begin{array}{l}.20 \\
.20 \\
.20\end{array}$ & $\begin{array}{l}\because- \\
\cdots\end{array}$ & $\begin{array}{l}\because- \\
\because-\end{array}$ & $\begin{array}{l}\text { ND } \\
<.1 \\
<.1\end{array}$ \\
\hline SOUTH FORK PUERCO U-59 & $\begin{array}{l}10-19-90 \\
08-15-91\end{array}$ & $\ddot{1.9}$ & $\begin{array}{l}-\cdot \\
-\cdot\end{array}$ & $\because \cdot$ & $\ddot{1.0}$ &.$\ddot{10}$ & $\because \cdot$ & $\because$ & $<.1$ \\
\hline SAN MATEO & $05-01-90$ & -. & 150 & 22 & $\because$ & $\cdots$ & 1.1 & .80 & $\cdots$ \\
\hline CHICO ARROYO & $05-18-90$ & $\cdot \cdot$ & 170 & 31 & 2.9 & .70 & 5.8 & 1.3 & $<.1$ \\
\hline RIO PUERCO & $\begin{array}{l}05-18-90 \\
08-18-90\end{array}$ & $\because$ & 2.8 & $\therefore$ & $\because$ & $\ddot{-}$ & $<.1$ & $\begin{array}{l}\text { ND } \\
\because-\end{array}$ & $\because$ \\
\hline $\begin{array}{l}\text { GALLUP SEMAGE TREATMENT } \\
\text { PLANT }\end{array}$ & $\begin{array}{l}03-27-89 \\
03-08-90 \\
03-09-90 \\
08-03-90\end{array}$ & $\begin{array}{l}-. \\
- \\
-\cdot\end{array}$ & $\begin{array}{l}\cdots \\
\therefore \\
\therefore\end{array}$ & $\begin{array}{l}\because . \\
\because \\
\therefore\end{array}$ & $\begin{array}{l}\because . \\
\because \\
\therefore\end{array}$ & $\begin{array}{l}\because . \\
\ddot{-} \\
\cdots\end{array}$ & $\begin{array}{l}\because . \\
.4 \\
\because-\end{array}$ & $\begin{array}{l}\because . \\
\because \\
-\end{array}$ & $\begin{array}{l}\cdots \\
\cdots \\
\cdots \\
\cdots\end{array}$ \\
\hline BRIDGE 83 & $\begin{array}{l}03-31-89 \\
08-03-90 \\
10-16-90\end{array}$ & $\begin{array}{l}-\cdot \\
-- \\
-\cdot\end{array}$ & $\begin{array}{l}\because . \\
\because .\end{array}$ & $\begin{array}{l}\because \cdot \\
\because-\end{array}$ & $\begin{array}{l}\because \cdot \\
\therefore\end{array}$ & $\begin{array}{l}\because \cdot \\
\because \\
-\end{array}$ & $\begin{array}{l}\cdots \\
\cdots\end{array}$ & $\begin{array}{l}\because- \\
\because-\end{array}$ & $\begin{array}{l}\because- \\
\because-\end{array}$ \\
\hline $\begin{array}{l}\text { PUERCO RIVER AT LUPTON } \\
\text { WELL CLUSTER }\end{array}$ & $10-16-90$ & $\cdots$ & $\cdots$ & $\cdots$ & $\cdots$ & $\cdots$ & $\cdots$ & $\cdots$ & $\cdots$ \\
\hline $\begin{array}{l}\text { PUERCO RIVER AT LUPTOW, } \\
\text { ROUTE } 66 \text { BRIDGE }\end{array}$ & $03-08-90$ & $\cdots$ & 3.7 & .7 & $\cdots$ & $\cdots$ & .3 & .20 & $\cdots$ \\
\hline HOLBROOK & $05-15-90$ & $\cdots$ & 1.8 & .2 & $\cdots$ & $\cdots$ & $<.1$ & ND & $\cdots$ \\
\hline QUERINO ROAD & $\begin{array}{l}04-04-89 \\
03-08-90\end{array}$ & $\begin{array}{l}\because- \\
\because-\end{array}$ & $\begin{array}{l}4.3 \\
5.3\end{array}$ & $\begin{array}{l}.7 \\
.8\end{array}$ & $\because$ & $\because$ & $\begin{array}{l}.3 \\
.6\end{array}$ & $\begin{array}{l}.20 \\
.20\end{array}$ & $\because$ \\
\hline PUERCO RIVER A & $03-09-90$ & $\cdots$ & 6.5 & 1.1 & $\cdots$ & $\cdots$ & .3 & .20 & $\cdots$ \\
\hline
\end{tabular}




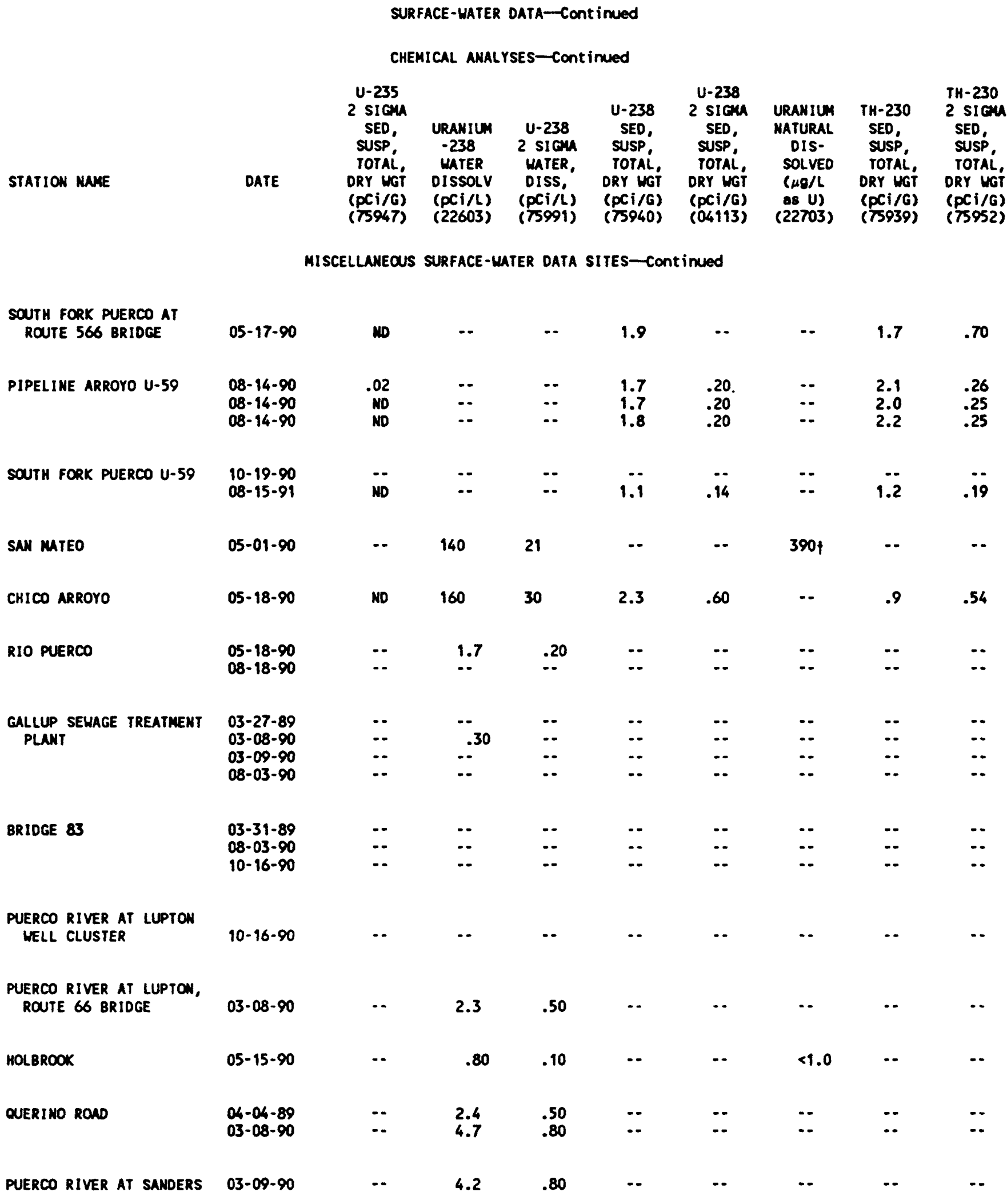




\begin{tabular}{|c|c|c|c|c|c|c|c|c|c|}
\hline \multicolumn{10}{|c|}{ SURFACE-HATER OATA-Continued } \\
\hline \multicolumn{10}{|c|}{ CHEMICAL ANALYSES-Cont inued } \\
\hline $\begin{array}{l}\text { STATION } \\
\text { MUMBER }\end{array}$ & DATE & $\begin{array}{l}\text { TH-232 } \\
\text { SED, } \\
\text { SUSP. } \\
\text { TOTAL, } \\
\text { ORY WGI } \\
\text { (PCi/G) } \\
\text { (75953) }\end{array}$ & $\begin{array}{l}\text { Th-232 } \\
2 \text { SIGMM, } \\
\text { SED, SUSP. } \\
\text { TOTAL, } \\
\text { ORY WGI } \\
(\text { PCi/G) } \\
\text { (75936) }\end{array}$ & $\begin{array}{l}\text { ALUM- } \\
\text { IMUM } \\
\text { BOT MMT } \\
\text { C63 }{ }^{\prime} \text { DS } \\
\text { LAB } \\
\text { PERCENT } \\
(34792)\end{array}$ & $\begin{array}{l}\text { ARSENIC } \\
\text { BOT MAT } \\
<63_{\mu} \text { OS } \\
\text { LAB } \\
(\mu 9 / G) \\
(34802)\end{array}$ & $\begin{array}{l}\text { BARIUM } \\
\text { BOT MAT } \\
\angle 63_{\mu} \text { OS } \\
\text { LAB } \\
(\mu 9 / G) \\
(34807)\end{array}$ & $\begin{array}{c}\text { BERYL- } \\
\text { LIUM } \\
\text { BOT MAT } \\
\angle 63 \mu \text { OS } \\
\text { LAB } \\
(\mu g / G) \\
(34812)\end{array}$ & $\begin{array}{l}81 \text { BINTH } \\
\text { BOT MAT } \\
\angle 63 \mu \text { OS } \\
\text { LAB } \\
(\mu g / G) \\
(34817)\end{array}$ & $\begin{array}{l}\text { CADMIUN } \\
\text { BOT MAT } \\
\angle 63 \mu \text { DS } \\
\text { LAB } \\
(\mu 9 / G) \\
(34827)\end{array}$ \\
\hline \multicolumn{10}{|c|}{ MISCELLANEOUS SURFACE- WATER OATA SITES-Continued } \\
\hline $\begin{array}{l}\text { SOUTH FORK PUERCO AT } \\
\text { ROUTE } 566 \text { BRIDGE }\end{array}$ & $05-17-90$ & 1.7 & .70 & $\cdots$ & $\cdots$ & -- & $\cdots$ & $\cdots$ & $\cdots$ \\
\hline PIPELINE ARROYO U-59 & $\begin{array}{l}08-14-90 \\
08-14-90 \\
08-14-90\end{array}$ & $\begin{array}{l}1.5 \\
1.6 \\
1.8\end{array}$ & $\begin{array}{l}.20 \\
.21 \\
.22\end{array}$ & $\begin{array}{l}\because . \\
\because-\end{array}$ & $\begin{array}{l}\because- \\
\because-\end{array}$ & $\begin{array}{l}\because . \\
\because-\end{array}$ & $\begin{array}{l}\because . \\
\because-\end{array}$ & $\begin{array}{l}\because \\
\cdots\end{array}$ & 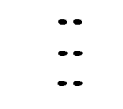 \\
\hline SOUTH FORK PUERCO U-59 & $\begin{array}{l}10-19-90 \\
08-15-91\end{array}$ & $\ddot{1.0}$ &.$\ddot{17}$ & $\begin{array}{l}7.2 \\
-.\end{array}$ & $<10$ & 640 & $\begin{array}{l}2 \\
\therefore\end{array}$ & $<10$ & $<2$ \\
\hline SAN MUTEO & $05-01-90$ & $\cdots$ & $\cdots$ & -. & $\cdots$ & -. & -. & $\cdots$ & -. \\
\hline CHICO ARROYO & $05-18-90$ & 1.1 & .56 & $\cdots$ & $\cdots$ & $\cdots$ & $\cdots$ & $\cdots$ & $\cdots$ \\
\hline RIO PUERCO & $\begin{array}{l}05-18-90 \\
08-18-90\end{array}$ & $\begin{array}{ll}\because- \\
-\cdot\end{array}$ & $\because \cdot$ & $\because$ & $\because$ & $\because$ & $\because$ & $\because$ & $\because$ \\
\hline $\begin{array}{l}\text { GALLLP SEMAGE TREATMENT } \\
\text { PLANT }\end{array}$ & $\begin{array}{l}03-27-89 \\
03-08-90 \\
03-09-90 \\
08-03-90\end{array}$ & $\begin{array}{l}- \\
\because \\
\because- \\
-\cdot\end{array}$ & $\begin{array}{l}\because . \\
\because \\
\because-\end{array}$ & $\begin{array}{l}\because \\
\because- \\
\because-\end{array}$ & $\begin{array}{l}\because \\
\because \\
\because-\end{array}$ & $\begin{array}{l}\because . \\
\because \\
\because-\end{array}$ & $\begin{array}{l}\because . \\
\because \\
\because \\
-\end{array}$ & $\begin{array}{l}\because \\
\because \\
\therefore\end{array}$ & $\begin{array}{l}. . \\
\because \\
\because .\end{array}$ \\
\hline BRIOGE 83 & $\begin{array}{l}03-31-89 \\
08-03-90 \\
10-16-90\end{array}$ & $\begin{array}{l}-. \\
\because- \\
\cdots\end{array}$ & $\begin{array}{l}\because . \\
\cdots \\
\cdots\end{array}$ & $\begin{array}{l}-. \\
\therefore \\
\therefore\end{array}$ & $\begin{array}{l}\because \\
\because- \\
\cdots\end{array}$ & $\begin{array}{l}\because \\
\because-\end{array}$ & $\begin{array}{l}\because- \\
\because-\end{array}$ & $\begin{array}{l}- \\
\therefore \\
\therefore\end{array}$ & $\begin{array}{l}\because \\
\because-\end{array}$ \\
\hline $\begin{array}{l}\text { PUERCO RIVER AT LUPTON } \\
\text { WELL CLUSTER }\end{array}$ & $10-16-90$ & $\cdots$ & $\cdots$ & $\cdots$ & $\cdots$ & $\cdots$ & $\cdots$ & $\cdots$ & $\cdots$ \\
\hline $\begin{array}{l}\text { PUERCO RIVER AT LUPTOW, } \\
\text { ROUTE } 66 \text { BRIOGE }\end{array}$ & $03-08-90$ & $-\cdot$ & $\cdots$ & -. & $\cdots$ & $\cdots$ & $\cdots$ & $\cdots$ & $\cdot-$ \\
\hline HOLBROOK & $05-15-90$ & -. & -. & -. & $\cdots$ & -. & -. & -. & -. \\
\hline QUERINO ROAD & $\begin{array}{l}04-04-89 \\
03-08-90\end{array}$ & $\ddot{-.}$ & $\because$ & $\ddot{-}$ & $\begin{array}{l}\cdots \\
\cdots\end{array}$ & $\begin{array}{ll}\because- \\
\cdots\end{array}$ & $\begin{array}{l}-- \\
--\end{array}$ & $\ddot{-}$ & $\ddot{-}$ \\
\hline PUERCO RIVER AT SAMDER & $03-09-90$ & -. & -. & -. & -. & $\cdots$ & -. & -. & -. \\
\hline
\end{tabular}




\begin{tabular}{|c|c|c|c|c|c|c|c|c|c|}
\hline \multicolumn{10}{|c|}{ SURFACE-WATER DATA-Cont Inued } \\
\hline \multicolumn{10}{|c|}{ CHEMICAL AMALYSES-Continued } \\
\hline $\begin{array}{l}\text { STATION } \\
\text { NUMBER }\end{array}$ & DATE & $\begin{array}{l}\text { CALCIUN } \\
\text { BOT MAT } \\
\angle 63_{\mu} \text { DS } \\
\text { LAB } \\
\text { PERCENT } \\
\text { (34832) }\end{array}$ & $\begin{array}{c}\text { CERIUH } \\
\text { BOT MAT } \\
\angle 63_{\mu} \text { DS } \\
\text { LAB } \\
(\mu 8 / G) \\
(34837)\end{array}$ & $\begin{array}{l}\text { CHRO- } \\
\text { MIUN } \\
\text { BOT MAT } \\
\angle 63_{\mu} \text { DS } \\
\text { LAB } \\
(\mu g / G) \\
(34842)\end{array}$ & $\begin{array}{c}\text { COBALT } \\
\text { BOT MAT } \\
\angle 63 \mu \text { DS } \\
\text { LAB } \\
(\mu g / G) \\
(34847)\end{array}$ & $\begin{array}{l}\text { COPPER } \\
\text { BOT MAT } \\
\angle 63_{\mu} \text { DS } \\
\text { LAB } \\
(\mu g / G) \\
(34852)\end{array}$ & $\begin{array}{l}\text { EURO- } \\
\text { PIUN } \\
\text { BOT MAT } \\
\text { C63H DS } \\
\text { LAB } \\
(\mu g / G) \\
(34857)\end{array}$ & $\begin{array}{c}\text { GALLIUA } \\
\text { BOT MAT } \\
\angle 63_{\mu} \text { DS } \\
\text { LAB } \\
(\mu g / G) \\
(34862)\end{array}$ & $\begin{array}{c}\text { COLD } \\
\text { BOT MAT } \\
\angle 63_{\mu} \text { DS } \\
\text { LAB } \\
(\mu g / G) \\
(34872)\end{array}$ \\
\hline \multicolumn{10}{|c|}{ MISCELLANEOUS SURFACE-WATER DATA SITES-Continued } \\
\hline $\begin{array}{l}\text { SOUTH FORK PUERCO AT } \\
\text { ROUTE } 566 \text { BRIDGE }\end{array}$ & $05-17-90$ & $\cdots$ & $\cdots$ & $\cdots$ & $\cdots$ & $\cdots$ & $\cdot-$ & $\cdots$ & $\cdots$ \\
\hline PIPELINE ARROYO U-59 & $\begin{array}{l}08-14-90 \\
08-14-90 \\
08-14-90\end{array}$ & $\begin{array}{l}\cdots \\
\cdots \\
\cdots\end{array}$ & $\begin{array}{l}\cdots \\
\cdots \\
\cdots\end{array}$ & $\begin{array}{l}\cdots \\
\cdots \\
\cdots\end{array}$ & $\begin{array}{l}\cdots \\
\cdots \\
\cdots\end{array}$ & $\begin{array}{l}\cdots \\
\cdots \\
\cdots\end{array}$ & $\begin{array}{l}\cdots \\
\cdots \\
\cdots\end{array}$ & $\begin{array}{l}\cdots \\
\cdots \\
\cdots\end{array}$ & $\begin{array}{l}\cdots \\
\cdots \\
\cdots\end{array}$ \\
\hline SOUTH FORK PUERCO U-59 & $\begin{array}{l}10-19-90 \\
08-15-91\end{array}$ & $\begin{array}{c}1.8 \\
-.\end{array}$ & $\begin{array}{l}79 \\
\cdots\end{array}$ & $\begin{array}{l}43 \\
--\end{array}$ & $\begin{array}{l}11 \\
--\end{array}$ & $\begin{array}{l}20 \\
--\end{array}$ & $<2$ & $\begin{array}{l}16 \\
--\end{array}$ & $\begin{array}{l}<8 \\
--\end{array}$ \\
\hline SAN MATEO & $05-01-90$ & $\cdots$ & $\cdots$ & $\cdots$ & $\cdots$ & $\cdots$ & $\cdots$ & $\cdots$ & $\cdots$ \\
\hline CHICO ARROYO & $05-18-90$ & $\cdots$ & $\cdots$ & $\cdots$ & $\cdots$ & $\cdots$ & $\cdots$ & $\cdots$ & $\cdots$ \\
\hline RIO PUERCO & $\begin{array}{l}05-18-90 \\
08-18-90\end{array}$ & $\cdots$ & $\cdots$ & $\cdots$ & $\cdots$ & 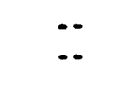 & $\cdots$ & $\cdots$ & $\cdots$ \\
\hline $\begin{array}{l}\text { GALLUP SEMAGE TREATMENT } \\
\text { PLANT }\end{array}$ & $\begin{array}{l}03-27-89 \\
03-08-90 \\
03-09-90 \\
08-03-90\end{array}$ & $\begin{array}{l}1 \\
- \\
\ldots \\
\ldots \\
--\end{array}$ & $\begin{array}{l}\cdots \\
\cdots \\
--\end{array}$ & $\begin{array}{l}\cdots \\
\ldots \\
\cdots \\
\cdots\end{array}$ & $\begin{array}{l}-. \\
-- \\
\cdots \\
--\end{array}$ & $\begin{array}{l}\cdots \\
\cdots \\
\cdots \\
\cdots\end{array}$ & $\begin{array}{l}\cdots \\
-- \\
\cdots \\
\cdots\end{array}$ & $\begin{array}{l}\cdots \\
\cdots \\
\cdots \\
\cdots\end{array}$ & $\begin{array}{l}\cdots \\
\cdots \\
\cdots\end{array}$ \\
\hline BRIDGE 83 & $\begin{array}{l}03-31-89 \\
08-03-90 \\
10-16-90\end{array}$ & $\begin{array}{l}\cdots \\
\cdots \\
\cdots\end{array}$ & $\begin{array}{l}\cdots \\
\cdots \\
--\end{array}$ & $\begin{array}{l}\cdots \\
\cdots\end{array}$ & $\begin{array}{l}\cdots \\
\cdots \\
\cdots\end{array}$ & $\begin{array}{l}-. \\
\cdots \\
--\end{array}$ & $\begin{array}{l}\cdots \\
\cdots \\
\cdots\end{array}$ & $\begin{array}{l}\cdots \\
\cdots \\
\cdots\end{array}$ & $\begin{array}{l}\cdots \\
\cdots\end{array}$ \\
\hline $\begin{array}{l}\text { PUERCO RIVER AT LUPTON } \\
\text { WELL CLUSTER }\end{array}$ & $10-16-90$ & $\cdots$ & $\cdots$ & $\cdots$ & $\cdots$ & $\cdots$ & $\cdots$ & $\cdots$ & $\cdots$ \\
\hline $\begin{array}{l}\text { PUERCO RIVER AT LUPTON, } \\
\text { ROUTE } 66 \text { BRIOGE }\end{array}$ & $03-08-90$ & $\cdots$ & $\cdots$ & $\cdots$ & $\cdots$ & $\cdots$ & $\cdots$ & $\cdots$ & $\cdots$ \\
\hline HOLBROOK & $05-15-90$ & $\cdots$ & $\cdots$ & $\cdots$ & $\cdots$ & 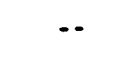 & $\cdots$ & $\cdots$ & $\cdots$ \\
\hline QUERINO ROND & $\begin{array}{l}04-04-89 \\
03-08-90\end{array}$ & $\ddot{--}$ & 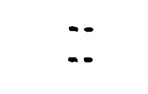 & 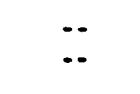 & 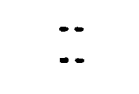 & $\begin{array}{l}-- \\
--\end{array}$ & $\begin{array}{l}\cdots \\
\cdots\end{array}$ & $\begin{array}{l}-- \\
\cdots\end{array}$ & $\begin{array}{l}\cdots \\
\cdots\end{array}$ \\
\hline PUERCO RIVER AT SANDERS & $03-09-90$ & $\cdots$ & $\cdots$ & $\cdots$ & $\cdots$ & $\cdots$ & $\cdots$ & $\cdots$ & $\cdots$ \\
\hline
\end{tabular}


CHEMICAL aNALYSES-Continued

STATION

NUMBER

SOUTH FORK PUERCO AT ROUTE 566 BRIDGE

PIPELINE ARROYO U-59

$08-14-90$

SOUTH FORK PUERCO U-59

SAN MATEO

CHICO ARROYO

RIO PUERCO

GALLUP SEWAGE TREATMENT PLANT

BRIDGE 83

$$
\begin{aligned}
& \text { PUERCO RIVER AT LUPTON } \\
& \text { UELL CLUSTER } \\
& \text { PUERCO RIVER AT LUPTON, } \\
& \text { ROUTE } 66 \text { BRIOGE }
\end{aligned}
$$

HOLBROOK

QUERINO ROND

PUERCO RIVER AT SANDERS
$08-14-90$

$08-14-90$

$10-19-90$ 08-15-91

05-01-90

$05-17-90$

$05-18-90$

05-18-90

$08-18-90$

03-27-89

03-08-90

03-09-90

$08-03-90$

03-31-89

$08-03-90$

$10-16-90$

$10-16-90$

$03-08-90$

\begin{tabular}{|c|c|c|c|c|c|c|c|c|c|}
\hline ATE & 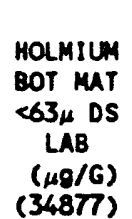 & 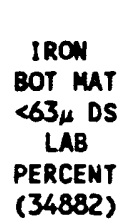 & $\begin{array}{c}\text { LANTKA- } \\
\text { NUA } \\
\text { BOT MAT } \\
\angle 63_{\mu} \text { DS } \\
\text { LAB } \\
(\mu g / G) \\
(34887)\end{array}$ & $\begin{array}{c}\text { LEAD } \\
\text { BOT MAT } \\
\angle 63_{\mu} \text { DS } \\
\text { LAB } \\
(\mu 9 / G) \\
(34892)\end{array}$ & 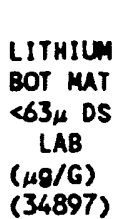 & $\begin{array}{l}\text { MAGNE- } \\
\text { SIUM } \\
\text { BOT MAT } \\
\angle 63 \mu \text { DS } \\
\text { LAB } \\
\text { PERCENT } \\
\text { (34902) }\end{array}$ & $\begin{array}{l}\text { MANGA- } \\
\text { NESE } \\
\text { BOT MAT } \\
<63_{\mu} \text { DS } \\
\text { LAB } \\
(\mu 9 / G) \\
(34907)\end{array}$ & $\begin{array}{c}\text { MOLYB- } \\
\text { DENUM } \\
\text { BOT MAT } \\
\angle 63_{\mu} \text { DS } \\
\text { LAB } \\
(\mu \sigma / G) \\
(34917)\end{array}$ & $\begin{array}{c}\text { MEOOYM- } \\
\text { IUM } \\
\text { BOT MT } \\
\angle 63_{\mu} \text { DS } \\
\text { LAB } \\
(\mu g / G) \\
(34922)\end{array}$ \\
\hline
\end{tabular}

$05-15-90$

$04-04-89$ 03-08-90

$03-09-90$
MISCELLANEOUS SURFACE-WATER DATA SITES-Continued

$\begin{array}{lll}- & \ldots & \ldots \\ \cdots & \ldots & \ldots \\ \ldots & \ldots & \end{array}$

$\begin{array}{ccc}<4 & 2.4 & 42 \\ -- & -. & -\end{array}$

20

29

.71

360

$<2 \quad 32$

$-\cdot$

$-$

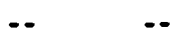

$\begin{array}{lll}\cdots & - & \ldots \\ - & \ldots & \ldots\end{array}$

$\begin{array}{ll}1 & \\ \cdots & \cdots \\ \cdots & \cdots \\ \cdots & \cdots\end{array}$

$\begin{array}{lll}\ldots & \ldots & \ldots \\ \cdots & \ldots & - \\ \cdots & \ldots & -\end{array}$

-.

-- 
STATION

MUMBER
SURFACE-WATER DATA-Cont inued

CHEMICAL AMALYSES-Contirued

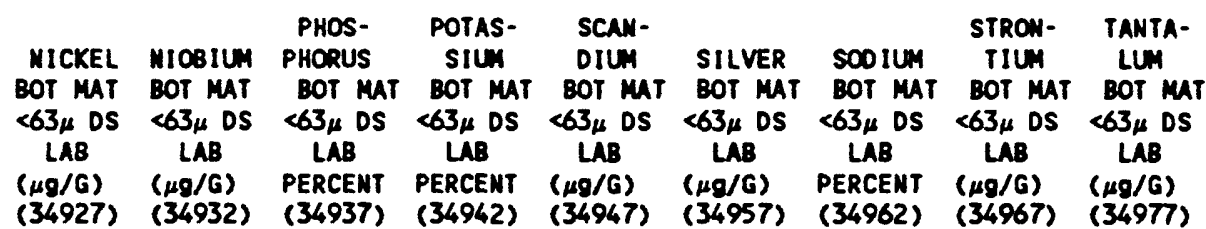

MISCELLANEOUS SURFACE-WATER DATA SITES-Continued

SOUTH FORK PUERCO AT

ROUTE 566 BRIDGE

PIPELIME ARROYO U-59

$08-14-90$

$08-14-90$

$08-14-90$

SOUTK FORK PUERCO U-59

$10-19-90$

08-15-91

SAM MATEO

$05-01-90$

CHICO ARROYO

RIO PUERCO

GALLUP SEWAGE TREATMENT PLANT

BRIDGE 83

PUERCO RIVER AT LUPTON

WELL CLUSTER

PUERCO RIVER AT LUPTON, ROUTE 66 BRIDGE

HOLBROOK

QUERIMO ROAD

PUERCO RIVER AT SAMDERS
$05-18-90$

05-18-90 08-18-90

03-27-89

03-08-90

03-09-90

03-31-89

08-03-90

$10-16-90$

$10-16-90$

$03-08-90$

$05-15-90$

$04-04-89$

03-08-90

03-09-90
08-03-90

$\begin{array}{ll}\ldots & \ldots \\ \cdots & \cdots \\ \cdots & \cdots\end{array}$

$\begin{array}{lll}14 & 12 & .05\end{array}$

$10 \quad \cdots$

$\begin{array}{ccc}.7 & 170 & 40 \\ \therefore & \therefore & \end{array}$

$+\quad \quad-$

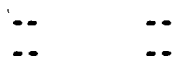

$\begin{array}{lll}\ldots & \cdots & - \\ - & \cdots & - \\ - & \cdots & - \\ - & \cdots & -\end{array}$

$\begin{array}{lll}\ldots & \ldots & \ldots \\ -- & \ldots & \ldots \\ - & \ldots & \ldots\end{array}$

$\cdots$

-

$\cdots$
$\cdots$

$\cdots$
$\cdots$

$\cdots$

$\cdots$

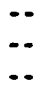

$-\cdot$
$\cdots$
$\cdots$ 
STATION

MUNBER

DATE

$05-17-90$

$$
\text { ROUTE } 566 \text { BRIDGE }
$$

PIPELINE ARROYO U-59

08-14-90

$08-14-90$

08-14-90

SOUTH FORK PUERCO U-59

$10-19-90$ 08-15-91

SAN MUTEO

CHICO ARROYO

RIO PUERCO

gALLUP SEWAGE TREATMENT PLANT

BRIDGE 83

$03-31-89$

08-03-90

$10-16-90$

PUERCO RIVER AT LUPTON WELL CLUSTER

PUERCO RIVER AT LUPTON, ROUTE 66 BRIDGE

03-08-90

HOLBROOK

$05-15-90$

QUERINO ROND

$04-04-89$ 03-08-90

PUERCO RIVER AT SANDERS 03-09-90

$10-16-90$

$03-08-90$

08-03-90
SURFACE-MATER DATA-Continued

CHEMICAL ANALYSES-Continued

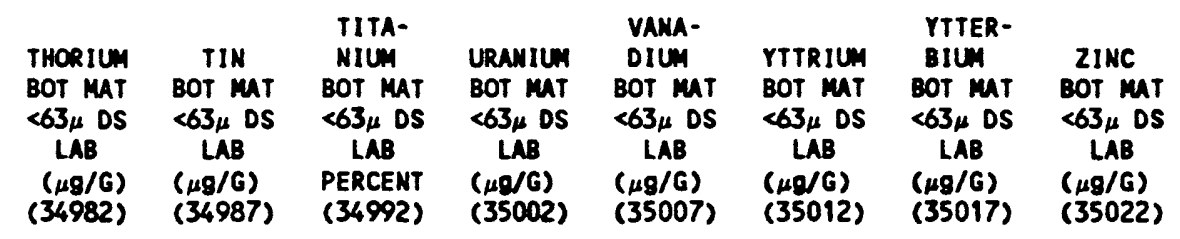

MISCELLANEOUS SURFACE-WATER DATA SITES-Cont inued

$11 \quad<5$

$<5$

.42

$<100$

75

23

3

67 


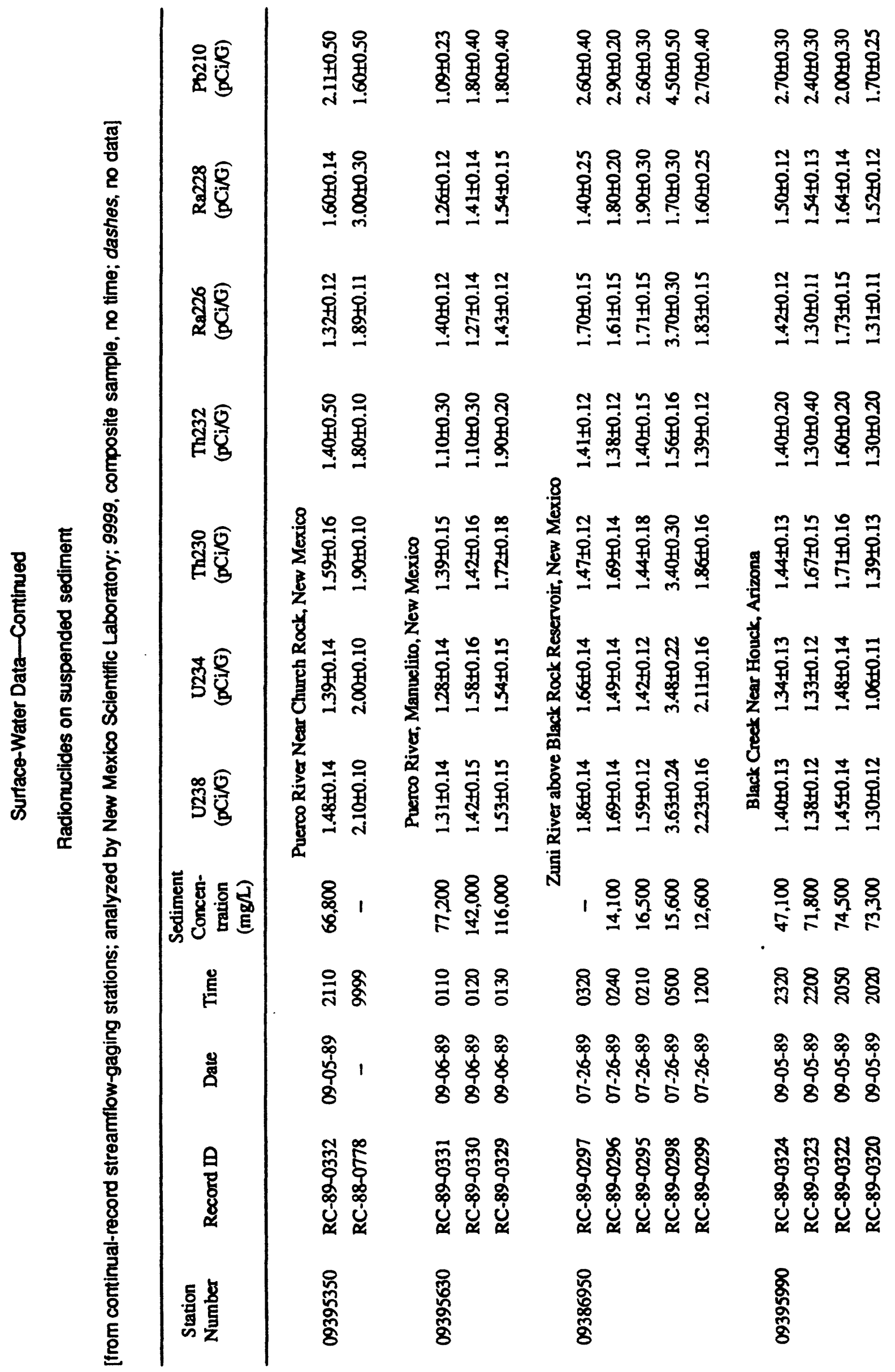




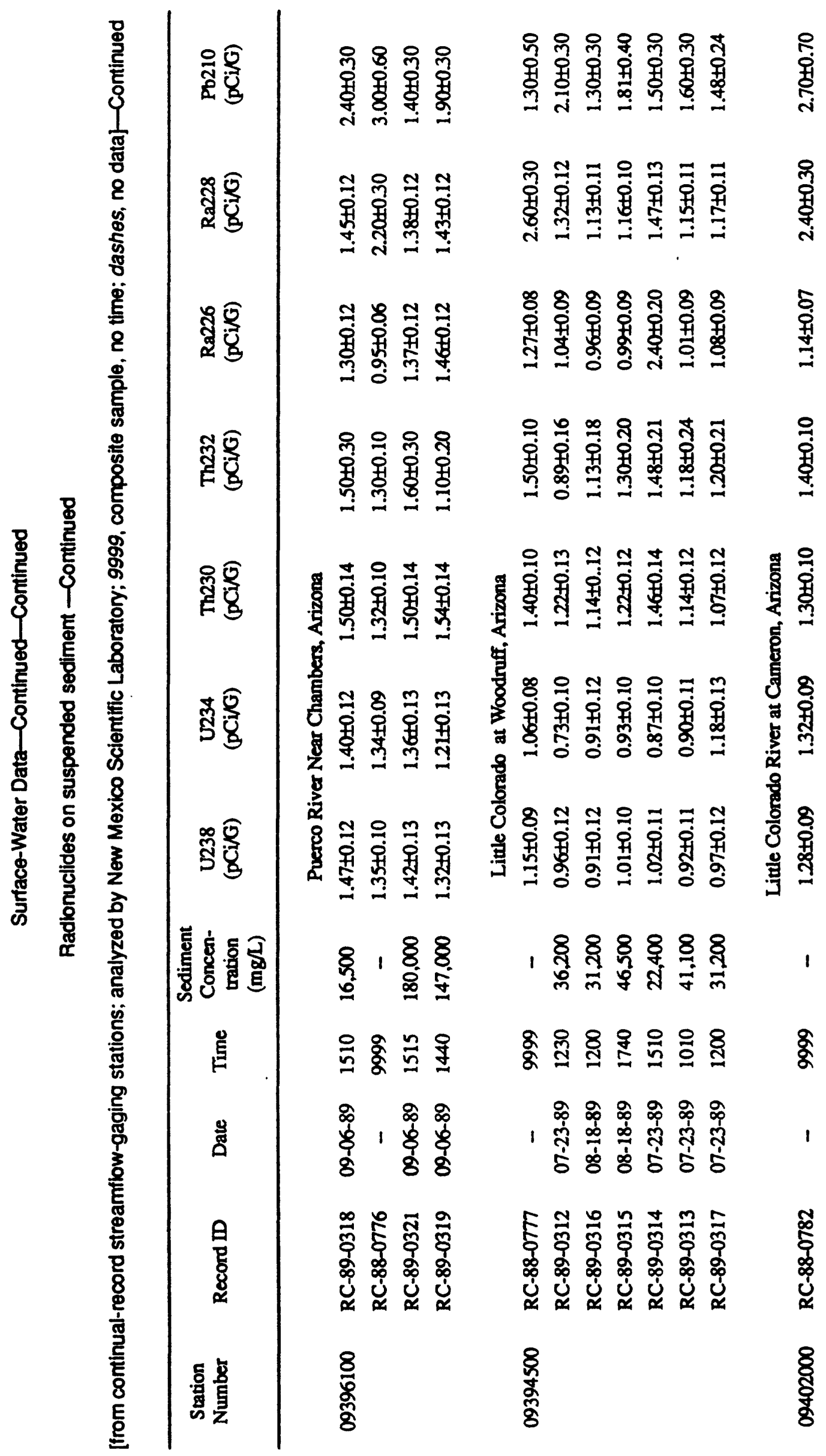


PRECIPITATION DATA

09395350 PUERCO RIVER NEAR CHURCH ROCK, NM

RAINFALL ACCUMULATED (MILLIMETERS), WATER YEAR MAY 1989 TO SEPTEMBER 1989

DAILY SUM VALUES

\begin{tabular}{|c|c|c|c|c|c|c|c|c|c|c|c|c|}
\hline DAY & OCT & NOV & DEC & JAN & FEB & MAR & APR & Mar & JUW & JUL & AUG & SEP \\
\hline $\begin{array}{l}1 \\
2 \\
3 \\
4 \\
5\end{array}$ & $\begin{array}{l}\cdots \\
\cdots \\
\cdots \\
\cdots \\
\cdots\end{array}$ & $\begin{array}{l}\cdots \\
\cdots \\
\cdots \\
\cdots \\
\cdots\end{array}$ & $\begin{array}{c}\cdots . \\
\cdots \\
\cdots \cdot \\
\cdots\end{array}$ & $\begin{array}{c}\cdots \\
\cdots \\
\cdots \\
\cdots \\
\cdots\end{array}$ & $\begin{array}{l}\cdots \\
\cdots \\
\cdots \\
-- \\
--\end{array}$ & $\begin{array}{l}\cdots \\
\cdots \\
\cdots \\
\cdots \\
\cdots\end{array}$ & $\begin{array}{l}\cdots \\
\cdots \\
\cdots \\
\cdots- \\
\cdots\end{array}$ & $\begin{array}{r}.00 \\
.00 \\
.00 \\
1.27 \\
.00\end{array}$ & $\begin{array}{l}.00 \\
.00 \\
.00 \\
.00 \\
.00\end{array}$ & $\begin{array}{l}.00 \\
.00 \\
.00 \\
.00 \\
.00\end{array}$ & $\begin{array}{r}8.64 \\
.00 \\
.00 \\
.00 \\
.00\end{array}$ & $\begin{array}{l}.00 \\
.00 \\
.00 \\
.00 \\
.00\end{array}$ \\
\hline $\begin{array}{r}6 \\
7 \\
8 \\
9 \\
10\end{array}$ & $\begin{array}{l}\ldots . \\
\cdots- \\
\cdots \\
\cdots \\
\cdots\end{array}$ & $\begin{array}{l}\cdots . \\
\cdots \\
\cdots \\
\cdots \\
\cdots\end{array}$ & $\begin{array}{l}\cdots \\
\cdots \\
\cdots \cdot \\
\cdots \\
\cdots\end{array}$ & $\begin{array}{l}\cdots \\
\cdots \\
\cdots \\
\cdots \\
\cdots\end{array}$ & $\begin{array}{l}\cdots \\
\cdots \\
\cdots- \\
\cdots- \\
\cdots\end{array}$ & $\begin{array}{l}\cdots \\
\cdots \\
\cdots \\
\cdots \\
\cdots\end{array}$ & $\begin{array}{l}\cdots \\
\cdots \\
\cdots \\
\cdots \\
\cdots-\end{array}$ & $\begin{array}{l}.00 \\
.00 \\
.00 \\
.00 \\
.00\end{array}$ & $\begin{array}{r}.00 \\
1.52 \\
.00 \\
.00 \\
.00\end{array}$ & $\begin{array}{l}.00 \\
.00 \\
.00 \\
.00 \\
.00\end{array}$ & $\begin{array}{r}.00 \\
.00 \\
.00 \\
2.03 \\
.00\end{array}$ & $\begin{array}{l}.00 \\
.00 \\
.00 \\
.00 \\
.00\end{array}$ \\
\hline $\begin{array}{l}11 \\
12 \\
13 \\
14 \\
15\end{array}$ & $\begin{array}{l}\cdots \\
\cdots \\
\cdots \\
\cdots \\
\cdots \\
\cdots\end{array}$ & $\begin{array}{l}\cdots \\
\cdots \\
\cdots \\
\cdots \\
\cdots\end{array}$ & $\begin{array}{l}\cdots \\
\cdots \\
\cdots \cdot \\
\cdots \\
\cdots\end{array}$ & $\begin{array}{l}\cdots \\
\cdots \\
\cdots \\
\cdots- \\
\cdots\end{array}$ & $\begin{array}{l}\cdots \\
\cdots \\
\cdots \\
\cdots \\
\cdots\end{array}$ & $\begin{array}{l}\cdots \\
\cdots \\
\cdots \\
\cdots \\
\cdots\end{array}$ & $\begin{array}{l}\cdots \\
\cdots \\
\cdots \\
\cdots- \\
\cdots \\
\cdots\end{array}$ & $\begin{array}{l}.00 \\
.51 \\
.25 \\
.00 \\
.00\end{array}$ & $\begin{array}{l}.00 \\
.00 \\
.00 \\
.00 \\
.00\end{array}$ & $\begin{array}{l}.00 \\
.00 \\
.00 \\
.00 \\
.00\end{array}$ & $\begin{array}{l}.00 \\
.00 \\
.00 \\
.25 \\
.00\end{array}$ & $\begin{array}{l}.00 \\
.00 \\
.00 \\
.00 \\
.00\end{array}$ \\
\hline $\begin{array}{l}16 \\
17 \\
18 \\
19 \\
20\end{array}$ & $\begin{array}{l}\cdots \\
\cdots \\
\cdots- \\
\cdots \\
\cdots\end{array}$ & $\begin{array}{l}\cdots \\
\cdots \\
\cdots \\
\cdots \\
\cdots\end{array}$ & $\begin{array}{l}\cdots \\
\cdots \\
\cdots \cdot \\
\cdots-\end{array}$ & $\begin{array}{l}-. \\
\cdots- \\
\cdots- \\
\cdots- \\
--\end{array}$ & $\begin{array}{l}\cdots \\
\cdots \\
\cdots \\
\cdots \\
\cdots\end{array}$ & $\begin{array}{l}\cdots \\
\cdots \\
\cdots \\
\cdots \\
\cdots\end{array}$ & $\begin{array}{l}\cdots \\
\cdots \\
\cdots- \\
\cdots- \\
\cdots\end{array}$ & $\begin{array}{l}6.35 \\
.00 \\
.00 \\
.00 \\
.00\end{array}$ & $\begin{array}{l}.00 \\
.00 \\
.00 \\
.00 \\
.00\end{array}$ & $\begin{array}{l}.00 \\
.00 \\
.00 \\
.00 \\
.00\end{array}$ & $\begin{array}{r}.00 \\
.00 \\
10.16 \\
2.54 \\
.00\end{array}$ & $\begin{array}{l}.00 \\
.00 \\
.00 \\
.76 \\
.00\end{array}$ \\
\hline $\begin{array}{l}21 \\
22 \\
23 \\
24 \\
25\end{array}$ & $\begin{array}{l}\cdots \\
\cdots \\
\cdots \\
\cdots \\
\cdots\end{array}$ & $\begin{array}{l}\cdots \\
\cdots \\
\cdots- \\
\cdots- \\
\cdots\end{array}$ & $\begin{array}{l}\cdots \cdot \\
\cdots . \\
\cdots-. \\
\cdots\end{array}$ & $\begin{array}{l}\cdots \\
\cdots \\
\cdots \\
\cdots \\
\cdots\end{array}$ & $\begin{array}{l}\cdots \\
\cdots \\
\cdots \\
\cdots- \\
\cdots\end{array}$ & $\begin{array}{l}\cdots \\
\cdots \\
\cdots \\
\cdots \\
\cdots\end{array}$ & $\begin{array}{l}\cdots \\
\cdots \\
\cdots \\
\cdots \\
\cdots\end{array}$ & $\begin{array}{l}.00 \\
.00 \\
.00 \\
.00 \\
.00\end{array}$ & $\begin{array}{l}.00 \\
.00 \\
.00 \\
.00 \\
.00\end{array}$ & $\begin{array}{r}.00 \\
1.52 \\
3.30 \\
6.60 \\
14.99\end{array}$ & $\begin{array}{r}1.27 \\
.00 \\
.00 \\
.00 \\
.00\end{array}$ & $\begin{array}{l}.00 \\
.00 \\
.00 \\
.00 \\
.00\end{array}$ \\
\hline $\begin{array}{l}26 \\
27 \\
28 \\
29 \\
30 \\
31\end{array}$ & $\begin{array}{l}\cdots- \\
\cdots \cdot \\
\cdots- \\
\cdots- \\
\cdots-\end{array}$ & $\begin{array}{l}-\cdot- \\
-- \\
-- \\
-- \\
---\end{array}$ & $\begin{array}{l}\cdots \\
\cdots \\
\cdots \cdot \\
\cdots \\
\cdots\end{array}$ & $\begin{array}{l}\cdots \cdot \\
\cdots \\
\cdots \cdot \\
\cdots- \\
\cdots \\
\cdots\end{array}$ & $\begin{array}{l}\cdots \\
\cdots \\
\cdots- \\
\cdots \\
\cdots \\
\cdots\end{array}$ & $\begin{array}{c}\cdots \\
\cdots \\
\cdots \\
\cdots \\
\cdots \\
\cdots\end{array}$ & $\begin{array}{c}\cdots \\
\cdots \\
\cdots \\
\cdots \\
\cdots \\
\cdots\end{array}$ & $\begin{array}{l}.00 \\
.00 \\
.00 \\
.00 \\
.00 \\
.00\end{array}$ & $\begin{array}{l}.00 \\
.00 \\
.00 \\
.00 \\
.00 \\
-.-\end{array}$ & $\begin{array}{l}.25 \\
.00 \\
.00 \\
.51 \\
.00 \\
.00\end{array}$ & $\begin{array}{l}.00 \\
.00 \\
.00 \\
.00 \\
.00 \\
.00\end{array}$ & $\begin{array}{l}.00 \\
.00 \\
.00 \\
.00 \\
.00 \\
. .\end{array}$ \\
\hline
\end{tabular}


PRECIPITATION DATA-Continued

09395350 PUERCO RIVER MEAR CHURCH ROCK, MH-Cont inued

RAIMFALL ACCUMLATED (MILLIMETERS), WATER YEAR OCTOBER 1989 TO SEPTEMBER 1990 DAILY SUM VALUES

\begin{tabular}{|c|c|c|c|c|c|c|c|c|c|c|c|c|}
\hline DAY & OCT & NOV & DEC & JAK & FEB & MAR & APR & mar & JUN & JUL & AUG & SEP \\
\hline $\begin{array}{l}1 \\
2 \\
3 \\
4 \\
5\end{array}$ & $\begin{array}{r}.00 \\
.00 \\
2.03 \\
13.72 \\
1.02\end{array}$ & $\begin{array}{l}.00 \\
.00 \\
.00 \\
.00 \\
.00\end{array}$ & $\begin{array}{l}.00 \\
.00 \\
.00 \\
.00 \\
.00\end{array}$ & $\begin{array}{l}.00 \\
.00 \\
.00 \\
.00 \\
.00\end{array}$ & $\begin{array}{r}.00 \\
1.52 \\
.76 \\
.00 \\
1.52\end{array}$ & $\begin{array}{l}.00 \\
.00 \\
.76 \\
.00 \\
.00\end{array}$ & $\begin{array}{r}.25 \\
.00 \\
.00 \\
.00 \\
7.37\end{array}$ & $\begin{array}{r}16.00 \\
12.45 \\
4.32 \\
.00 \\
.00\end{array}$ & $\begin{array}{l}.00 \\
.00 \\
.00 \\
.00 \\
.00\end{array}$ & $\begin{array}{r}.00 \\
11.94 \\
.00 \\
.00 \\
2.29\end{array}$ & $\begin{array}{r}.00 \\
.00 \\
.00 \\
.00 \\
6.60\end{array}$ & $\begin{array}{r}1.02 \\
.00 \\
.00 \\
8.89 \\
5.33\end{array}$ \\
\hline $\begin{array}{r}6 \\
7 \\
8 \\
9 \\
10\end{array}$ & $\begin{array}{l}.00 \\
.00 \\
.00 \\
.00 \\
.00\end{array}$ & $\begin{array}{l}.00 \\
.00 \\
.00 \\
.00 \\
.00\end{array}$ & $\begin{array}{l}.00 \\
.00 \\
.00 \\
.00 \\
.00\end{array}$ & $\begin{array}{l}.00 \\
.00 \\
.00 \\
.00 \\
.00\end{array}$ & $\begin{array}{r}.00 \\
.00 \\
2.54 \\
.00 \\
.00\end{array}$ & $\begin{array}{r}1.78 \\
.00 \\
.00 \\
.00 \\
4.06\end{array}$ & $\begin{array}{l}.00 \\
.00 \\
.51 \\
.00 \\
.00\end{array}$ & $\begin{array}{l}.00 \\
.00 \\
.00 \\
.00 \\
.00\end{array}$ & $\begin{array}{r}.00 \\
.00 \\
.00 \\
.25 \\
4.57\end{array}$ & $\begin{array}{r}.00 \\
6.35 \\
1.02 \\
.76 \\
.00\end{array}$ & $\begin{array}{l}.76 \\
.00 \\
.00 \\
.00 \\
.00\end{array}$ & $\begin{array}{l}.00 \\
.00 \\
.00 \\
.00\end{array}$ \\
\hline $\begin{array}{l}11 \\
12 \\
13 \\
14 \\
15\end{array}$ & $\begin{array}{l}.00 \\
.00 \\
.00 \\
.00 \\
.00\end{array}$ & $\begin{array}{l}.00 \\
.00 \\
.00 \\
.00 \\
.00\end{array}$ & $\begin{array}{l}.00 \\
.00 \\
.00 \\
.00 \\
.00\end{array}$ & $\begin{array}{l}.00 \\
.00 \\
.25 \\
.00 \\
.00\end{array}$ & $\begin{array}{l}.00 \\
.00 \\
.00 \\
.00 \\
.00\end{array}$ & $\begin{array}{r}4.32 \\
.25 \\
.51 \\
.51 \\
1.02\end{array}$ & $\begin{array}{l}.00 \\
.00 \\
.00 \\
.00 \\
.00\end{array}$ & $\begin{array}{l}.00 \\
.00 \\
.00 \\
.00 \\
.00\end{array}$ & $\begin{array}{l}.00 \\
.00 \\
.00 \\
.00 \\
.00\end{array}$ & $\begin{array}{r}2.79 \\
.00 \\
9.14 \\
.51 \\
.00\end{array}$ & $\begin{array}{r}1.27 \\
.25 \\
6.60 \\
6.10 \\
4.06\end{array}$ & $\begin{array}{l}.00 \\
.00 \\
.00 \\
.00 \\
.00\end{array}$ \\
\hline $\begin{array}{l}16 \\
17 \\
18 \\
19 \\
20\end{array}$ & $\begin{array}{r}.00 \\
.00 \\
.00 \\
.00 \\
6.35\end{array}$ & $\begin{array}{l}.00 \\
.00 \\
.00 \\
.00 \\
.00\end{array}$ & $\begin{array}{r}1.52 \\
.00 \\
.00 \\
.00 \\
.00\end{array}$ & $\begin{array}{l}.00 \\
.00 \\
.00 \\
.25 \\
. . .\end{array}$ & $\begin{array}{r}.25 \\
.00 \\
.00 \\
.00 \\
1.02\end{array}$ & $\begin{array}{l}.00 \\
.00 \\
.00 \\
.00 \\
.00\end{array}$ & $\begin{array}{r}.00 \\
4.83 \\
1.02 \\
.25 \\
.00\end{array}$ & $\begin{array}{l}.00 \\
.00 \\
.00 \\
.00 \\
.00\end{array}$ & $\begin{array}{l}.00 \\
.00 \\
.00 \\
.00 \\
.00\end{array}$ & $\begin{array}{r}.00 \\
3.05 \\
.25 \\
.00 \\
.00\end{array}$ & $\begin{array}{r}1.27 \\
2.29 \\
.00 \\
.00 \\
6.60\end{array}$ & $\begin{array}{r}.25 \\
.00 \\
7.62 \\
.25 \\
3.81\end{array}$ \\
\hline $\begin{array}{l}21 \\
22 \\
23 \\
24 \\
25\end{array}$ & $\begin{array}{l}.51 \\
.00 \\
.00 \\
.00 \\
.00\end{array}$ & $\begin{array}{l}.00 \\
.00 \\
.00 \\
.00 \\
.00\end{array}$ & $\begin{array}{l}.00 \\
.00 \\
.00 \\
.00 \\
.00\end{array}$ & $\begin{array}{l}. . . \\
.00 \\
.00 \\
.00\end{array}$ & $\begin{array}{l}.00 \\
.00 \\
.00 \\
.00 \\
.00\end{array}$ & $\begin{array}{l}.00 \\
.00 \\
.00 \\
.00 \\
.00\end{array}$ & $\begin{array}{r}.00 \\
.00 \\
.00 \\
2.54 \\
1.02\end{array}$ & $\begin{array}{l}.00 \\
.00 \\
.00 \\
.00 \\
.00\end{array}$ & $\begin{array}{l}.00 \\
.00 \\
.00 \\
.00 \\
.00\end{array}$ & $\begin{array}{r}.00 \\
.00 \\
1.78 \\
.76 \\
.00\end{array}$ & $\begin{array}{l}.00 \\
.00 \\
.00 \\
.00 \\
.00\end{array}$ & $\begin{array}{r}.25 \\
6.35 \\
.25 \\
.00 \\
.00\end{array}$ \\
\hline $\begin{array}{l}26 \\
27 \\
28 \\
29 \\
30 \\
31\end{array}$ & $\begin{array}{l}.00 \\
.00 \\
.00 \\
.00 \\
.00 \\
.00\end{array}$ & $\begin{array}{l}.00 \\
.00 \\
.00 \\
.00 \\
.00 \\
. . .\end{array}$ & $\begin{array}{r}.00 \\
.00 \\
.00 \\
1.27 \\
.25 \\
.00\end{array}$ & $\begin{array}{l}.00 \\
.00 \\
.00 \\
.00 \\
.00 \\
.00\end{array}$ & $\begin{array}{l}.00 \\
.00 \\
.00 \\
\ldots . \\
\ldots . \\
\ldots\end{array}$ & $\begin{array}{l}.00 \\
.00 \\
.51 \\
.25 \\
.00 \\
.00\end{array}$ & $\begin{array}{l}.00 \\
.00 \\
.00 \\
.00 \\
.25 \\
. . .\end{array}$ & $\begin{array}{l}.00 \\
.00 \\
.00 \\
.76 \\
.00 \\
.00\end{array}$ & $\begin{array}{r}.00 \\
.00 \\
.00 \\
.00 \\
2.54 \\
. . .\end{array}$ & $\begin{array}{l}.00 \\
.00 \\
.00 \\
.00 \\
.00 \\
.00\end{array}$ & $\begin{array}{l}.00 \\
.00 \\
.00 \\
.00 \\
.00 \\
.00\end{array}$ & $\begin{array}{l}.00 \\
.00 \\
.76 \\
.00 \\
.00 \\
. .-\end{array}$ \\
\hline
\end{tabular}


09395350 PUERCO RIVER MEAR CHURCH ROCK, MM-Continued

RAINFALL ACCUMULATED (MILLIMETERS), WATER YEAR OCTOBER 1990 TO SEPTEMBER 1991 DAILY SUM VALUES

\begin{tabular}{|c|c|c|c|c|c|c|c|c|c|c|c|c|}
\hline DAY & OCT & NOV & DEC & JAN & FEB & MAR & APR & MAY & JUW & JUL & AUG & SEP \\
\hline $\begin{array}{l}1 \\
2 \\
3 \\
4 \\
5\end{array}$ & $\begin{array}{r}8.13 \\
.00 \\
.00 \\
.00 \\
.00\end{array}$ & $\begin{array}{r}.00 \\
6.10 \\
3.81 \\
2.54 \\
.25\end{array}$ & $\begin{array}{l}.00 \\
.00 \\
.00 \\
.00 \\
.00\end{array}$ & $\begin{array}{r}.00 \\
.00 \\
1.52 \\
5.08 \\
.00\end{array}$ & $\begin{array}{l}.00 \\
.00 \\
.00 \\
.00 \\
.00\end{array}$ & $\begin{array}{r}16.00 \\
4.57 \\
.00 \\
.00 \\
.00\end{array}$ & $\begin{array}{l}.00 \\
.00 \\
.00 \\
.00 \\
.00\end{array}$ & $\begin{array}{l}.00 \\
.00 \\
.00 \\
.00 \\
.00\end{array}$ & $\begin{array}{r}.00 \\
1.52 \\
.00 \\
.00 \\
.00\end{array}$ & $\begin{array}{l}.00 \\
.00 \\
.00 \\
.00 \\
.00\end{array}$ & $\begin{array}{r}2.29 \\
2.29 \\
.25 \\
.25 \\
4.32\end{array}$ & $\begin{array}{r}.51 \\
.00 \\
.00 \\
1.02 \\
4.06\end{array}$ \\
\hline $\begin{array}{r}6 \\
7 \\
8 \\
9 \\
10\end{array}$ & $\begin{array}{r}.00 \\
3.56 \\
.25 \\
.00 \\
.00\end{array}$ & $\begin{array}{r}.00 \\
.51 \\
3.56 \\
.00 \\
.25\end{array}$ & $\begin{array}{l}.00 \\
.00 \\
.00 \\
.00 \\
.00\end{array}$ & $\begin{array}{r}.25 \\
5.08 \\
.00 \\
.00 \\
.00\end{array}$ & $\begin{array}{l}.00 \\
.00 \\
.25 \\
.00 \\
.00\end{array}$ & $\begin{array}{l}.00 \\
.00 \\
.00 \\
.00 \\
.00\end{array}$ & $\begin{array}{l}.00 \\
.00 \\
.00 \\
.00 \\
.00\end{array}$ & $\begin{array}{l}.00 \\
.00 \\
.00 \\
.00 \\
.00\end{array}$ & $\begin{array}{r}.00 \\
.00 \\
.00 \\
.00 \\
2.03\end{array}$ & $\begin{array}{r}.00 \\
.00 \\
8.89 \\
.00 \\
.00\end{array}$ & $\begin{array}{r}.51 \\
.00 \\
.00 \\
.25 \\
3.30\end{array}$ & $\begin{array}{r}1.78 \\
.00\end{array}$ \\
\hline $\begin{array}{l}11 \\
12 \\
13 \\
16 \\
15\end{array}$ & $\begin{array}{l}.00 \\
.00 \\
.00 \\
.00 \\
.00\end{array}$ & $\begin{array}{l}.00 \\
.00 \\
.00 \\
.00 \\
.00\end{array}$ & $\begin{array}{r}.00 \\
7.62 \\
5.59 \\
.00 \\
.00\end{array}$ & $\begin{array}{l}.00 \\
.00 \\
.00 \\
.00 \\
.00\end{array}$ & $\begin{array}{l}.00 \\
.00 \\
.00 \\
.00 \\
.00\end{array}$ & $\begin{array}{l}.00 \\
.00 \\
.00 \\
.00 \\
.00\end{array}$ & $\begin{array}{l}.00 \\
.00 \\
.25 \\
.00 \\
.00\end{array}$ & $\begin{array}{l}.00 \\
.00 \\
.00 \\
.00 \\
.00\end{array}$ & $\begin{array}{r}11.68 \\
2.79 \\
.00 \\
.00 \\
.00\end{array}$ & $\begin{array}{l}.25 \\
.51 \\
.00 \\
.00 \\
.00\end{array}$ & $\begin{array}{r}2.79 \\
.51 \\
.00 \\
.00 \\
3.05\end{array}$ & .0 \\
\hline $\begin{array}{l}16 \\
17 \\
18 \\
19 \\
20\end{array}$ & $\begin{array}{r}.00 \\
.00 \\
.00 \\
17.27 \\
.51\end{array}$ & $\begin{array}{r}.00 \\
.00 \\
.00 \\
.00 \\
2.79\end{array}$ & $\begin{array}{r}.51 \\
.00 \\
.76 \\
1.02 \\
.00\end{array}$ & $\begin{array}{r}1.78 \\
2.03 \\
.00 \\
.00 \\
.00\end{array}$ & $\begin{array}{l}1.52 \\
1.02 \\
.00 \\
.00 \\
.00\end{array}$ & $\begin{array}{r}3.05 \\
.00 \\
.00 \\
.00 \\
.00\end{array}$ & $\begin{array}{l}.00 \\
.00 \\
.00 \\
.00 \\
.00\end{array}$ & $\begin{array}{l}.00 \\
.00 \\
.00 \\
.00 \\
.00\end{array}$ & $\begin{array}{l}.00 \\
.00 \\
.00 \\
.00 \\
.00\end{array}$ & $\begin{array}{r}1.27 \\
.51 \\
2.79 \\
.25 \\
1.52\end{array}$ & $\begin{array}{r}.25 \\
1.78 \\
2.79 \\
.00 \\
.00\end{array}$ & .0 \\
\hline $\begin{array}{l}21 \\
22 \\
23 \\
24 \\
25\end{array}$ & $\begin{array}{l}.00 \\
.00 \\
.00 \\
.00 \\
.00\end{array}$ & $\begin{array}{l}.00 \\
.00 \\
.00 \\
.00 \\
.00\end{array}$ & $\begin{array}{l}.00 \\
.00 \\
.00 \\
.00 \\
.00\end{array}$ & $\begin{array}{r}1.02 \\
.00 \\
1.52 \\
.51 \\
.00\end{array}$ & $\begin{array}{l}.00 \\
.00 \\
.00 \\
.00 \\
.00\end{array}$ & $\begin{array}{l}.76 \\
.00 \\
.00 \\
.00 \\
.00\end{array}$ & $\begin{array}{l}.00 \\
.00 \\
.00 \\
.00 \\
.00\end{array}$ & $\begin{array}{l}.00 \\
.00 \\
.00 \\
.00 \\
.00\end{array}$ & $\begin{array}{l}.00 \\
.00 \\
.00 \\
.00 \\
.00\end{array}$ & $\begin{array}{l}.25 \\
2.29 \\
1.78 \\
4.57 \\
.00\end{array}$ & $\begin{array}{l}.00 \\
.00 \\
.00 \\
.00 \\
.00\end{array}$ & .0 \\
\hline $\begin{array}{l}26 \\
27 \\
28 \\
29 \\
30 \\
31\end{array}$ & $\begin{array}{l}.00 \\
.00 \\
.00 \\
.00 \\
.00 \\
.00\end{array}$ & $\begin{array}{r}.76 \\
1.02 \\
.00 \\
.00 \\
.00 \\
. . .\end{array}$ & $\begin{array}{r}.00 \\
.25 \\
3.81 \\
2.56 \\
.00 \\
.76\end{array}$ & $\begin{array}{l}.00 \\
.00 \\
.00 \\
.00 \\
.00 \\
.00\end{array}$ & $\begin{array}{r}.00 \\
.00 \\
2.29 \\
\ldots .- \\
\ldots .-\end{array}$ & $\begin{array}{r}4.06 \\
.00 \\
5.08 \\
.51 \\
.00 \\
.00\end{array}$ & $\begin{array}{r}5.33 \\
.00 \\
.00 \\
.00 \\
.00 \\
\ldots . .\end{array}$ & $\begin{array}{l}.00 \\
.00 \\
.00 \\
.00 \\
.00 \\
1.78\end{array}$ & $\begin{array}{l}.00 \\
.00 \\
.00 \\
.00 \\
.00 \\
. .-\end{array}$ & $\begin{array}{r}.00 \\
.00 \\
7.11 \\
1.52 \\
.25 \\
3.81\end{array}$ & $\begin{array}{l}.51 \\
.25 \\
.00 \\
.00 \\
.00 \\
.00\end{array}$ & . \\
\hline
\end{tabular}


PRECIPITATION DATA-CONtinued

09395630 PUERCO RIVER NEAR MANUELITO, NH

RAINFALL ACCUNULATED (HILLIMETERS), MATER YEAR MAY 1989 TO SEPTEMBER 1989 DAILY SUM VALUES

\begin{tabular}{|c|c|c|c|c|c|c|c|c|c|c|c|c|}
\hline DAY & OCT & NOV & DEC & JAN & FEB & MAR & APR & MAY & JUN & JUL & AUG & SEP \\
\hline $\begin{array}{l}1 \\
2 \\
3 \\
4 \\
5\end{array}$ & $\begin{array}{l}\ldots- \\
\ldots- \\
\ldots \\
\ldots \\
\ldots\end{array}$ & $\begin{array}{l}\ldots- \\
\ldots- \\
\ldots- \\
-\ldots \\
-\ldots\end{array}$ & $\begin{array}{l}\ldots \\
\ldots- \\
\ldots- \\
\ldots- \\
\ldots-\end{array}$ & $\begin{array}{l}\ldots \\
\ldots \\
\ldots \\
\ldots \\
\ldots\end{array}$ & $\begin{array}{l}\ldots . \\
\ldots- \\
\cdots- \\
-. . \\
-.\end{array}$ & $\begin{array}{l}\ldots- \\
\ldots \\
\ldots \\
\ldots \\
\ldots\end{array}$ & $\begin{array}{l}\ldots \\
\ldots \\
\ldots- \\
\ldots \\
\ldots\end{array}$ & $\begin{array}{l}. .0 \\
.00 \\
.00 \\
.00 \\
.00\end{array}$ & $\begin{array}{l}.00 \\
.00 \\
.00 \\
.00 \\
.00\end{array}$ & $\begin{array}{l}.00 \\
.00 \\
.00 \\
.00 \\
.00\end{array}$ & $\begin{array}{l}.25 \\
.00 \\
.00 \\
.00 \\
.00\end{array}$ & $\begin{array}{l}.00 \\
.00 \\
.25 \\
.00 \\
.00\end{array}$ \\
\hline $\begin{array}{r}6 \\
7 \\
8 \\
9 \\
10\end{array}$ & $\begin{array}{l}\ldots \\
\ldots \\
\ldots \\
\ldots \\
\ldots\end{array}$ & $\begin{array}{l}\ldots \\
\ldots \\
\ldots \\
\ldots- \\
\ldots\end{array}$ & $\begin{array}{l}\ldots \\
\ldots \\
\cdots \\
\cdots \\
\cdots\end{array}$ & $\begin{array}{l}\ldots \\
\ldots \\
\ldots \\
\ldots \\
\ldots\end{array}$ & $\begin{array}{l}\ldots . \\
\ldots \\
\ldots \\
\ldots \\
\ldots\end{array}$ & $\begin{array}{l}\ldots \\
\ldots \\
\ldots \\
\ldots \\
\cdots\end{array}$ & $\begin{array}{l}\ldots \\
\ldots \\
\ldots \\
\ldots\end{array}$ & $\begin{array}{l}.00 \\
.00 \\
.00 \\
.00 \\
.00\end{array}$ & $\begin{array}{l}.00 \\
.00 \\
.00 \\
.00 \\
.00\end{array}$ & $\begin{array}{l}.00 \\
.00 \\
.00 \\
.00 \\
.00\end{array}$ & $\begin{array}{l}.00 \\
.00 \\
.00 \\
.00 \\
.00\end{array}$ & $\begin{array}{l}.00 \\
.00 \\
.00 \\
.00 \\
.00\end{array}$ \\
\hline $\begin{array}{l}11 \\
12 \\
13 \\
14 \\
15\end{array}$ & $\begin{array}{l}-.- \\
--. \\
--- \\
--- \\
-.-\end{array}$ & $\begin{array}{l}\ldots- \\
\ldots \\
-\ldots \\
-.- \\
-.\end{array}$ & $\begin{array}{l}\ldots- \\
\ldots- \\
\ldots- \\
\cdots- \\
\cdots-\end{array}$ & $\begin{array}{l}\cdots- \\
-- \\
\cdots \\
\cdots- \\
\cdots\end{array}$ & $\begin{array}{l}\cdots \\
\cdots \\
\cdots \\
\cdots \\
\cdots\end{array}$ & $\begin{array}{l}\ldots- \\
\ldots- \\
\cdots \\
\cdots \\
\cdots\end{array}$ & $\begin{array}{l}\cdots- \\
\cdots- \\
\cdots- \\
\cdots-\end{array}$ & $\begin{array}{l}.00 \\
.00 \\
.00 \\
.00 \\
.00\end{array}$ & $\begin{array}{l}.00 \\
.00 \\
.00 \\
.00 \\
.00\end{array}$ & $\begin{array}{r}3.56 \\
.00 \\
.00 \\
.00 \\
.00\end{array}$ & $\begin{array}{r}.00 \\
.00 \\
.00 \\
2.54 \\
.00\end{array}$ & $\begin{array}{l}.00 \\
.00 \\
.00 \\
.00 \\
.00\end{array}$ \\
\hline $\begin{array}{l}16 \\
17 \\
18 \\
19 \\
20\end{array}$ & $\begin{array}{l}\ldots- \\
\ldots- \\
-\ldots \\
-\ldots \\
-.-\end{array}$ & $\begin{array}{l}\ldots- \\
\ldots \\
\ldots \\
\ldots \\
\ldots\end{array}$ & $\begin{array}{l}\ldots- \\
\ldots- \\
\ldots- \\
\ldots \\
\ldots\end{array}$ & $\begin{array}{l}\ldots- \\
\ldots \\
\ldots \\
\ldots \\
\ldots\end{array}$ & $\begin{array}{l}\ldots- \\
\ldots- \\
\ldots- \\
\ldots \\
\ldots\end{array}$ & $\begin{array}{l}\ldots \\
\ldots \\
\ldots \\
\ldots \\
\ldots\end{array}$ & $\begin{array}{l}\cdots- \\
\cdots \\
\cdots \\
\cdots \\
\ldots-\end{array}$ & $\begin{array}{l}.00 \\
.00 \\
.00 \\
.00 \\
.00\end{array}$ & $\begin{array}{l}.00 \\
.00 \\
.00 \\
.00 \\
.00\end{array}$ & $\begin{array}{l}.00 \\
.00 \\
.00 \\
.00 \\
.00\end{array}$ & $\begin{array}{r}.00 \\
.00 \\
13.97 \\
2.03 \\
.00\end{array}$ & $\begin{array}{r}.76 \\
.25 \\
.00 \\
2.54 \\
.00\end{array}$ \\
\hline $\begin{array}{l}21 \\
22 \\
23 \\
24 \\
25\end{array}$ & $\begin{array}{l}\ldots- \\
\ldots- \\
\ldots- \\
\ldots- \\
\ldots-\end{array}$ & $\begin{array}{l}\ldots- \\
\ldots- \\
\ldots- \\
\ldots \\
\ldots\end{array}$ & $\begin{array}{l}\ldots- \\
\ldots- \\
\ldots- \\
\ldots \\
\ldots\end{array}$ & $\begin{array}{l}\ldots \\
\ldots \\
\ldots \\
\ldots \\
\ldots\end{array}$ & $\begin{array}{l}\ldots . \\
\ldots- \\
\ldots- \\
\cdots \\
\cdots\end{array}$ & $\begin{array}{l}\ldots \\
\ldots \\
\ldots \\
\ldots \\
\ldots\end{array}$ & $\begin{array}{l}\ldots- \\
\cdots- \\
\cdots- \\
\cdots-\end{array}$ & $\begin{array}{l}.00 \\
.00 \\
.00 \\
.00 \\
.00\end{array}$ & $\begin{array}{l}.00 \\
.00 \\
.00 \\
.00 \\
.00\end{array}$ & $\begin{array}{r}.00 \\
.51 \\
.25 \\
.25 \\
6.10\end{array}$ & $\begin{array}{l}.00 \\
.00 \\
.00 \\
.00 \\
.00\end{array}$ & $\begin{array}{l}.00 \\
.00 \\
.00 \\
.00 \\
.00\end{array}$ \\
\hline $\begin{array}{l}26 \\
27 \\
28 \\
29 \\
30 \\
31\end{array}$ & $\begin{array}{l}\ldots- \\
\ldots \\
\ldots- \\
\ldots- \\
\ldots- \\
\ldots\end{array}$ & $\begin{array}{l}\ldots \\
\ldots \\
\ldots \\
\ldots \\
\ldots \\
\ldots\end{array}$ & $\begin{array}{l}\ldots- \\
\ldots \\
\ldots- \\
\ldots \\
\ldots- \\
\ldots\end{array}$ & $\begin{array}{l}\ldots- \\
\ldots- \\
\ldots- \\
\ldots- \\
\ldots \\
\ldots\end{array}$ & $\begin{array}{l}\ldots \\
\ldots \\
\ldots \\
\ldots \\
\ldots \\
\ldots\end{array}$ & $\begin{array}{l}\ldots- \\
\ldots- \\
\ldots- \\
\ldots- \\
\ldots- \\
\ldots\end{array}$ & $\begin{array}{l}\ldots- \\
\ldots . \\
\ldots- \\
\ldots- \\
\ldots\end{array}$ & $\begin{array}{l}.00 \\
.00 \\
.00 \\
.00 \\
.00 \\
.00\end{array}$ & $\begin{array}{r}.00 \\
.00 \\
.00 \\
9.02 \\
.00 \\
\ldots .\end{array}$ & $\begin{array}{r}.00 \\
11.43 \\
.25 \\
.00 \\
.00 \\
2.03\end{array}$ & $\begin{array}{l}.00 \\
.00 \\
.00 \\
.00 \\
.00 \\
.00\end{array}$ & $\begin{array}{l}.00 \\
.00 \\
.00 \\
.00 \\
.00 \\
. . .\end{array}$ \\
\hline
\end{tabular}


PRECIPITATION DATA-Continued

09395630 PUERCO RIVER MEAR MANUEL1TO, NM-Continued

RAINFALL ACCUNLATED (HILLIMETERS), UATER YEAR OCTOBER 1989 TO SEPTEMBER 1990 DAILY SUM VALUES

\begin{tabular}{|c|c|c|c|c|c|c|c|c|c|c|c|c|}
\hline DAY & OCT & NOV & DEC & JAN & FEB & MR & APR & maY & JuH & JUL & AUG & SEP \\
\hline $\begin{array}{l}1 \\
2 \\
3 \\
4 \\
5\end{array}$ & $\begin{array}{l}.00 \\
.00 \\
.00 \\
.51 \\
.00\end{array}$ & $\begin{array}{l}.00 \\
.00 \\
.00 \\
.00 \\
.00\end{array}$ & $\begin{array}{l}.00 \\
.00 \\
.00 \\
.00 \\
.00\end{array}$ & $\begin{array}{l}.00 \\
.00 \\
.25 \\
.00 \\
.25\end{array}$ & $\begin{array}{r}.51 \\
1.02 \\
.00 \\
.00 \\
.00\end{array}$ & $\begin{array}{l}.00 \\
.00 \\
.25 \\
.51 \\
.25\end{array}$ & $\begin{array}{r}.51 \\
.00 \\
.00 \\
.00 \\
1.02\end{array}$ & $\begin{array}{r}.76 \\
4.06 \\
.25 \\
.00 \\
.00\end{array}$ & $\begin{array}{l}.00 \\
.00 \\
.00 \\
.00 \\
.00\end{array}$ & $\begin{array}{l}.00 \\
.00 \\
.00 \\
.00 \\
.76\end{array}$ & $\begin{array}{l}.00 \\
.00 \\
.00 \\
.00 \\
.00\end{array}$ & $\begin{array}{l}.00 \\
.00 \\
.00 \\
.00 \\
.76\end{array}$ \\
\hline $\begin{array}{r}6 \\
7 \\
8 \\
9 \\
10\end{array}$ & $\begin{array}{l}.00 \\
.00 \\
.00 \\
.00 \\
.00\end{array}$ & $\begin{array}{l}.00 \\
.00 \\
.00 \\
.00 \\
.00\end{array}$ & $\begin{array}{r}1.27 \\
.00 \\
.00 \\
.00 \\
.00\end{array}$ & $\begin{array}{l}.00 \\
.00 \\
.00 \\
.00 \\
.00\end{array}$ & $\begin{array}{l}.00 \\
.00 \\
1.27 \\
.00 \\
.00\end{array}$ & $\begin{array}{l}.25 \\
.00 \\
.00 \\
.00 \\
1.52\end{array}$ & $\begin{array}{l}.00 \\
.00 \\
.25 \\
.00 \\
.00\end{array}$ & $\begin{array}{l}.00 \\
.00 \\
.00 \\
.00 \\
.00\end{array}$ & $\begin{array}{l}.00 \\
.00 \\
.00 \\
.00 \\
.76\end{array}$ & $\begin{array}{l}.00 \\
.51 \\
.51 \\
.76 \\
.00\end{array}$ & $\begin{array}{l}.00 \\
.00 \\
.00 \\
.00 \\
.51\end{array}$ & $\begin{array}{l}.25 \\
.00 \\
.25 \\
.00 \\
.00\end{array}$ \\
\hline $\begin{array}{l}11 \\
12 \\
13 \\
14 \\
15\end{array}$ & $\begin{array}{l}.00 \\
.00 \\
.00 \\
.00 \\
.00\end{array}$ & $\begin{array}{l}.00 \\
.00 \\
.00 \\
.00 \\
.00\end{array}$ & $\begin{array}{l}.00 \\
.00 \\
.00 \\
.00 \\
.00\end{array}$ & $\begin{array}{l}.00 \\
.00 \\
.00 \\
.00 \\
.00\end{array}$ & $\begin{array}{l}.00 \\
.00 \\
.00 \\
.00 \\
.00\end{array}$ & $\begin{array}{l}.25 \\
.76 \\
.00 \\
.51 \\
.00\end{array}$ & $\begin{array}{l}.00 \\
.00 \\
.00 \\
.00 \\
.00\end{array}$ & $\begin{array}{l}.00 \\
.00 \\
.00 \\
.00 \\
.00\end{array}$ & $\begin{array}{l}.00 \\
.00 \\
.00 \\
.00 \\
.00\end{array}$ & $\begin{array}{r}.00 \\
.25 \\
1.27 \\
.25 \\
.00\end{array}$ & $\begin{array}{r}.00 \\
.51 \\
1.78 \\
2.03 \\
1.78\end{array}$ & $\begin{array}{l}.00 \\
.00 \\
.00 \\
.00 \\
.00\end{array}$ \\
\hline $\begin{array}{l}16 \\
17 \\
18 \\
19 \\
20\end{array}$ & $\begin{array}{l}.00 \\
.00 \\
.00 \\
.00 \\
.51\end{array}$ & $\begin{array}{l}.00 \\
.00 \\
.00 \\
.00 \\
.00\end{array}$ & $\begin{array}{l}.25 \\
.00 \\
.00 \\
.00 \\
.00\end{array}$ & $\begin{array}{r}.00 \\
.00 \\
.00 \\
.00 \\
1.02\end{array}$ & $\begin{array}{l}.51 \\
.00 \\
.00 \\
.00 \\
.51\end{array}$ & $\begin{array}{l}.00 \\
.00 \\
.00 \\
.00 \\
.00\end{array}$ & $\begin{array}{l}.00 \\
.25 \\
.00 \\
.00 \\
.00\end{array}$ & $\begin{array}{l}.00 \\
.00 \\
.00 \\
.00 \\
.00\end{array}$ & $\begin{array}{l}.00 \\
.00 \\
.00 \\
.00 \\
.00\end{array}$ & $\begin{array}{l}.00 \\
.00 \\
.25 \\
.25 \\
.00\end{array}$ & $\begin{array}{r}2.54 \\
.00 \\
.00 \\
.00 \\
1.52\end{array}$ & $\begin{array}{r}2.79 \\
.00 \\
1.78 \\
.00 \\
2.79\end{array}$ \\
\hline $\begin{array}{l}21 \\
22 \\
23 \\
24 \\
25\end{array}$ & $\begin{array}{l}.25 \\
.00 \\
.00 \\
.00 \\
.00\end{array}$ & $\begin{array}{l}.00 \\
.00 \\
.00 \\
.00 \\
.00\end{array}$ & $\begin{array}{l}.25 \\
.00 \\
.00 \\
.00 \\
.00\end{array}$ & $\begin{array}{l}.00 \\
.00 \\
.00 \\
.00 \\
.00\end{array}$ & $\begin{array}{l}.00 \\
.00 \\
.00 \\
.00 \\
.00\end{array}$ & $\begin{array}{l}.00 \\
.00 \\
.00 \\
.00 \\
.00\end{array}$ & $\begin{array}{r}.00 \\
.00 \\
.00 \\
1.78 \\
.25\end{array}$ & $\begin{array}{l}.00 \\
.00 \\
.00 \\
.00 \\
.00\end{array}$ & $\begin{array}{l}.00 \\
.00 \\
.00 \\
.00 \\
.00\end{array}$ & $\begin{array}{l}.00 \\
.00 \\
.76 \\
.25 \\
.00\end{array}$ & $\begin{array}{l}.00 \\
.00 \\
.00 \\
.00 \\
.00\end{array}$ & $\begin{array}{l}.51 \\
3.81 \\
1.52 \\
.00 \\
.00\end{array}$ \\
\hline $\begin{array}{l}26 \\
27 \\
28 \\
29 \\
30 \\
31\end{array}$ & $\begin{array}{l}.00 \\
.00 \\
.00 \\
.00 \\
.00 \\
.00\end{array}$ & $\begin{array}{l}.00 \\
.00 \\
.00 \\
.00 \\
.51 \\
\ldots . .\end{array}$ & $\begin{array}{l}.00 \\
.00 \\
.00 \\
.51 \\
.00 \\
.00\end{array}$ & $\begin{array}{l}.00 \\
.00 \\
.00 \\
.00 \\
.00 \\
.00\end{array}$ & $\begin{array}{l}.00 \\
.00 \\
.76 \\
\ldots . \\
\ldots . \\
\ldots\end{array}$ & $\begin{array}{r}.00 \\
.00 \\
.00 \\
1.02 \\
.51 \\
.00\end{array}$ & $\begin{array}{l}.00 \\
.00 \\
.00 \\
.00 \\
.00 \\
. .-\end{array}$ & $\begin{array}{l}.00 \\
.00 \\
.00 \\
.51 \\
.00 \\
.00\end{array}$ & $\begin{array}{l}.00 \\
.00 \\
.00 \\
.00 \\
.00 \\
. . .\end{array}$ & $\begin{array}{l}.00 \\
.00 \\
.00 \\
.00 \\
.00 \\
.00\end{array}$ & $\begin{array}{l}.00 \\
.00 \\
.00 \\
.00 \\
.00 \\
.00\end{array}$ & $\begin{array}{l}.00 \\
.76 \\
.51 \\
.25\end{array}$ \\
\hline
\end{tabular}


PRECIPITATION DATA-Cont inued

09395630 PUERCO RIVER NEAR MANUELITO, MH-Continued

RAINFALL ACCUMUATED (MILLIMETERS), WATER YEAR OCTOBER 1990 TO SEPTEMBER 1991 DAILY SUM VALUES

\begin{tabular}{|c|c|c|c|c|c|c|c|c|c|c|c|c|}
\hline DAY & OCT & NOV & DEC & JAN & FEB & MAR & APR & MAY & JUN & JUL & AUG & SEP \\
\hline $\begin{array}{l}1 \\
2 \\
3 \\
4 \\
5\end{array}$ & $\begin{array}{l}.25 \\
.00 \\
.00 \\
.00 \\
.00\end{array}$ & $\begin{array}{r}.25 \\
2.79 \\
4.32 \\
.00 \\
.00\end{array}$ & $\begin{array}{l}.00 \\
.00 \\
.00 \\
.00 \\
.00\end{array}$ & $\begin{array}{r}.00 \\
.00 \\
1.02 \\
3.30 \\
.00\end{array}$ & $\begin{array}{l}.00 \\
.00 \\
.00 \\
.00 \\
.00\end{array}$ & $\begin{array}{r}4.57 \\
.51 \\
.00 \\
.00 \\
.51\end{array}$ & $\begin{array}{l}.00 \\
.00 \\
.00 \\
.00 \\
.00\end{array}$ & $\begin{array}{l}.00 \\
.00 \\
.00 \\
.00 \\
.00\end{array}$ & $\begin{array}{l}.00 \\
.00 \\
.00 \\
.00 \\
.00\end{array}$ & $\begin{array}{l}.00 \\
.00 \\
.00 \\
.00 \\
.00\end{array}$ & $\begin{array}{r}1.52 \\
.76 \\
2.03 \\
.00 \\
4.57\end{array}$ & $\begin{array}{r}.00 \\
.00 \\
.00 \\
8.64 \\
1.27\end{array}$ \\
\hline $\begin{array}{r}6 \\
7 \\
8 \\
9 \\
10\end{array}$ & $\begin{array}{r}.00 \\
1.52 \\
.00 \\
.00 \\
.00\end{array}$ & $\begin{array}{r}.00 \\
.00 \\
1.02 \\
.00 \\
.00\end{array}$ & $\begin{array}{l}.00 \\
.00 \\
.00 \\
.00 \\
.00\end{array}$ & $\begin{array}{l}.76 \\
.00 \\
.00 \\
.00 \\
.00\end{array}$ & $\begin{array}{l}.00 \\
.00 \\
.25 \\
.00 \\
.00\end{array}$ & $\begin{array}{l}.00 \\
.00 \\
.00 \\
.00 \\
.00\end{array}$ & $\begin{array}{l}.00 \\
.00 \\
.00 \\
.00 \\
.00\end{array}$ & $\begin{array}{l}.00 \\
.00 \\
.00 \\
.00 \\
.00\end{array}$ & $\begin{array}{l}.00 \\
.00 \\
.00 \\
.00 \\
.00\end{array}$ & $\begin{array}{l}.00 \\
.00 \\
.00 \\
.00 \\
.00\end{array}$ & $\begin{array}{r}1.27 \\
.00 \\
.00 \\
.00 \\
.25\end{array}$ & $\begin{array}{r}1.52 \\
.00 \\
.00 \\
.00 \\
.00\end{array}$ \\
\hline $\begin{array}{l}11 \\
12 \\
13 \\
14 \\
15\end{array}$ & $\begin{array}{l}.00 \\
.00 \\
.00 \\
.00 \\
.00\end{array}$ & $\begin{array}{l}.00 \\
.00 \\
.00 \\
.00 \\
.00\end{array}$ & $\begin{array}{l}.00 \\
2.03 \\
1.52 \\
.00 \\
.00\end{array}$ & $\begin{array}{l}.00 \\
.00 \\
.00 \\
.00 \\
.00\end{array}$ & $\begin{array}{l}.00 \\
.00 \\
.00 \\
.00 \\
.00\end{array}$ & $\begin{array}{l}.00 \\
.00 \\
.00 \\
.51 \\
.51\end{array}$ & $\begin{array}{l}.00 \\
.00 \\
.00 \\
.00 \\
.00\end{array}$ & $\begin{array}{l}.00 \\
.00 \\
.00 \\
.00 \\
.00\end{array}$ & $\begin{array}{r}14.73 \\
.25 \\
.76 \\
.00 \\
.00\end{array}$ & $\begin{array}{l}.00 \\
.00 \\
.00 \\
.00 \\
.00\end{array}$ & $\begin{array}{r}.76 \\
.00 \\
.00 \\
.00 \\
3.30\end{array}$ & $\begin{array}{l}.00 \\
.00 \\
.00 \\
.00 \\
.00\end{array}$ \\
\hline $\begin{array}{l}16 \\
17 \\
18 \\
19 \\
20\end{array}$ & $\begin{array}{r}.00 \\
.00 \\
.00 \\
5.08 \\
.25\end{array}$ & $\begin{array}{l}.00 \\
.00 \\
.00 \\
.00 \\
1.02\end{array}$ & $\begin{array}{l}.51 \\
.00 \\
.51 \\
.76 \\
.00\end{array}$ & $\begin{array}{l}.51 \\
.00 \\
.00 \\
.00 \\
.00\end{array}$ & $\begin{array}{l}1.27 \\
1.78 \\
.00 \\
.00 \\
.00\end{array}$ & $\begin{array}{r}1.52 \\
.00 \\
.00 \\
.51 \\
.25\end{array}$ & $\begin{array}{l}.00 \\
.00 \\
.00 \\
.00 \\
.00\end{array}$ & $\begin{array}{l}.00 \\
.00 \\
.00 \\
.00 \\
.00\end{array}$ & $\begin{array}{l}.00 \\
.00 \\
.00 \\
.00 \\
.00\end{array}$ & $\begin{array}{r}1.02 \\
6.60 \\
.00 \\
.00 \\
2.56\end{array}$ & $\begin{array}{r}.00 \\
.00 \\
1.52 \\
.00 \\
.00\end{array}$ & $\begin{array}{l}.00 \\
.00 \\
.00 \\
.00 \\
.00\end{array}$ \\
\hline $\begin{array}{l}21 \\
22 \\
23 \\
24 \\
25\end{array}$ & $\begin{array}{l}.00 \\
.00 \\
.00 \\
.00 \\
.00\end{array}$ & $\begin{array}{l}.00 \\
.00 \\
.00 \\
.00 \\
.00\end{array}$ & $\begin{array}{l}.00 \\
.00 \\
.00 \\
.00 \\
.00\end{array}$ & $\begin{array}{l}.76 \\
.25 \\
.00 \\
.00 \\
.00\end{array}$ & $\begin{array}{l}.00 \\
.00 \\
.00 \\
.00 \\
.00\end{array}$ & $\begin{array}{l}.00 \\
.51 \\
.00 \\
.00 \\
.00\end{array}$ & $\begin{array}{l}.00 \\
.00 \\
.00 \\
.00 \\
.00\end{array}$ & $\begin{array}{l}.00 \\
.00 \\
.00 \\
.00 \\
.00\end{array}$ & $\begin{array}{l}.00 \\
.00 \\
.00 \\
.00 \\
.00\end{array}$ & $\begin{array}{l}.00 \\
.00 \\
.00 \\
1.27 \\
1.27\end{array}$ & $\begin{array}{l}.00 \\
.00 \\
.00 \\
3.05 \\
2.29\end{array}$ & $\begin{array}{l}.00 \\
.00 \\
.00 \\
.00 \\
.00\end{array}$ \\
\hline $\begin{array}{l}26 \\
27 \\
28 \\
29 \\
30 \\
31\end{array}$ & $\begin{array}{l}.00 \\
.00 \\
.00 \\
.00 \\
.00 \\
.00\end{array}$ & $\begin{array}{r}1.02 \\
.25 \\
.00 \\
.00 \\
.00 \\
. . .\end{array}$ & $\begin{array}{r}.00 \\
.51 \\
3.81 \\
1.02 \\
.00 \\
.25\end{array}$ & $\begin{array}{l}.00 \\
.00 \\
.00 \\
.25 \\
.00 \\
.00\end{array}$ & $\begin{array}{r}.00 \\
.00 \\
2.03 \\
. . . \\
\ldots .- \\
\ldots .\end{array}$ & $\begin{array}{r}.51 \\
1.02 \\
.25 \\
.25 \\
.00 \\
.00\end{array}$ & $\begin{array}{r}4.06 \\
.00 \\
.00 \\
.00 \\
.00 \\
\ldots .\end{array}$ & $\begin{array}{l}.00 \\
.00 \\
.00 \\
.00 \\
.00 \\
.76\end{array}$ & $\begin{array}{l}.00 \\
.00 \\
.00 \\
.00 \\
.00 \\
\ldots . .\end{array}$ & $\begin{array}{r}2.79 \\
.25 \\
.00 \\
.51 \\
.00 \\
.51\end{array}$ & $\begin{array}{l}.51 \\
.00 \\
.00 \\
.00 \\
.00 \\
.25\end{array}$ & $\begin{array}{l}.00 \\
.00 \\
.00 \\
.00 \\
.00 \\
. .-\end{array}$ \\
\hline
\end{tabular}


PRECIPITATION DATA-Cont inued

09395990 BLACK CREEK NEAR HOUCK, AZ

RAINFALL ACCUMLATED (MILLIMETERS), APRIL 1989 TO SEPTEMBER 1989 DAILY SUM VALUES

\begin{tabular}{|c|c|c|c|c|c|c|c|c|c|c|c|c|}
\hline DAY & OCT & NOV & DEC & JAN & FEB & MAR & APR & MAY & JUN & JUL & AUG & SEP \\
\hline $\begin{array}{l}1 \\
2 \\
3 \\
4 \\
5\end{array}$ & $\begin{array}{l}\ldots \\
\ldots \\
\ldots \\
\ldots \\
\ldots\end{array}$ & $\begin{array}{l}\ldots \\
\ldots \\
\ldots \\
\ldots \\
\ldots\end{array}$ & $\begin{array}{l}\ldots \\
\ldots \\
\ldots \\
\ldots \\
\ldots\end{array}$ & $\begin{array}{l}\ldots \\
\ldots \\
\ldots \\
\ldots \\
\ldots\end{array}$ & $\begin{array}{l}\ldots \\
\ldots \\
\ldots \\
\ldots \\
\ldots\end{array}$ & $\begin{array}{l}\ldots \\
\ldots \\
\ldots \\
\ldots \\
\ldots\end{array}$ & $\begin{array}{l}\ldots \\
\ldots \\
\ldots \\
\ldots \\
\ldots\end{array}$ & $\begin{array}{l}.00 \\
.00 \\
.00 \\
.00 \\
.00\end{array}$ & $\begin{array}{l}.00 \\
.00 \\
.00 \\
.00 \\
.00\end{array}$ & $\begin{array}{l}.00 \\
.00 \\
.00 \\
.00 \\
.00\end{array}$ & $\begin{array}{r}1.52 \\
.00 \\
.00 \\
.00 \\
.00\end{array}$ & $\begin{array}{r}.00 \\
.00 \\
1.78 \\
.25 \\
.00\end{array}$ \\
\hline $\begin{array}{r}6 \\
7 \\
8 \\
9 \\
10\end{array}$ & $\begin{array}{l}\ldots \\
\ldots \\
\ldots \\
\ldots \\
\ldots\end{array}$ & $\begin{array}{l}\ldots \\
\ldots \\
\ldots \\
\ldots \\
\ldots\end{array}$ & $\begin{array}{l}\ldots \\
\ldots \\
\ldots \\
\ldots \\
\ldots\end{array}$ & $\begin{array}{l}\ldots \\
\ldots \\
\ldots \\
\cdots \\
\cdots\end{array}$ & $\begin{array}{l}\ldots \\
\ldots \\
\ldots \\
\ldots \\
\cdots\end{array}$ & $\begin{array}{l}\ldots \\
\ldots \\
\ldots \\
\ldots \\
\ldots\end{array}$ & $\begin{array}{l}\ldots \\
\ldots \\
\ldots \\
\ldots\end{array}$ & $\begin{array}{l}.00 \\
.00 \\
.00 \\
.51 \\
.00\end{array}$ & $\begin{array}{l}.00 \\
.00 \\
.00 \\
.00 \\
.00\end{array}$ & $\begin{array}{l}.00 \\
.00 \\
.00 \\
.00 \\
.00\end{array}$ & $\begin{array}{r}.00 \\
.00 \\
3.56 \\
.00 \\
.00\end{array}$ & $\begin{array}{l}.00 \\
.00 \\
.00 \\
.00 \\
.00\end{array}$ \\
\hline $\begin{array}{l}11 \\
12 \\
13 \\
14 \\
15\end{array}$ & $\begin{array}{l}\ldots \\
\ldots \\
\ldots \\
\ldots \\
\ldots\end{array}$ & $\begin{array}{l}\ldots \\
\ldots \\
\ldots \\
\ldots \\
\ldots\end{array}$ & $\begin{array}{l}\ldots \\
\ldots \\
\cdots \\
\cdots \\
\cdots\end{array}$ & $\begin{array}{l}\ldots \\
\ldots \\
\ldots \\
\cdots \\
\cdots\end{array}$ & $\begin{array}{l}\ldots \\
\ldots \\
\ldots \\
\ldots \\
\ldots\end{array}$ & $\begin{array}{l}\ldots \\
\ldots \\
\ldots \\
\ldots \\
\ldots\end{array}$ & $\begin{array}{l}\ldots \\
\ldots \\
\ldots \\
\ldots \\
\ldots\end{array}$ & $\begin{array}{l}.00 \\
.00 \\
.00 \\
.00 \\
.00\end{array}$ & $\begin{array}{l}.00 \\
.00 \\
.25 \\
.00 \\
.00\end{array}$ & $\begin{array}{l}.00 \\
.00 \\
.00 \\
.00 \\
.00\end{array}$ & $\begin{array}{l}.00 \\
.00 \\
.00 \\
.00 \\
.00\end{array}$ & $\begin{array}{l}.00 \\
.00 \\
.00 \\
.00 \\
.00\end{array}$ \\
\hline $\begin{array}{l}16 \\
17 \\
18 \\
19 \\
20\end{array}$ & $\begin{array}{l}\ldots \\
\ldots \\
\cdots \\
\cdots \\
\cdots\end{array}$ & $\begin{array}{l}\ldots \\
\ldots \\
\ldots \\
\ldots\end{array}$ & $\begin{array}{l}\ldots \\
\ldots \\
\cdots \\
\cdots \\
\cdots\end{array}$ & $\begin{array}{l}\ldots \\
\ldots \\
\ldots \\
\ldots \\
\ldots\end{array}$ & $\begin{array}{l}\ldots \\
\ldots \\
\ldots \\
\ldots \\
\ldots\end{array}$ & $\begin{array}{l}\ldots \\
\ldots \\
\ldots \\
\ldots \\
\ldots\end{array}$ & $\begin{array}{l}\cdots \\
.00 \\
.00 \\
.00\end{array}$ & $\begin{array}{l}1.52 \\
.00 \\
.00 \\
.00 \\
.00\end{array}$ & $\begin{array}{l}.00 \\
.00 \\
.00 \\
.00 \\
.00\end{array}$ & $\begin{array}{l}.00 \\
.00 \\
.00 \\
.00 \\
.00\end{array}$ & $\begin{array}{r}.00 \\
4.06 \\
18.03 \\
.76 \\
.00\end{array}$ & $\begin{array}{l}.00 \\
.00 \\
.00 \\
.00 \\
.00\end{array}$ \\
\hline $\begin{array}{l}21 \\
22 \\
23 \\
24 \\
25\end{array}$ & $\begin{array}{l}\ldots \\
\cdots \\
\cdots \\
\cdots \\
\cdots\end{array}$ & $\begin{array}{l}\ldots \\
\cdots \\
\cdots \\
\cdots\end{array}$ & $\begin{array}{l}\ldots \\
\ldots \\
\cdots \\
\cdots \\
\cdots\end{array}$ & $\begin{array}{l}\ldots \\
\ldots \\
\ldots \\
\ldots\end{array}$ & $\begin{array}{l}\ldots \\
\ldots \\
\ldots \\
\ldots \\
\ldots\end{array}$ & $\begin{array}{l}\ldots \\
\ldots \\
\ldots \\
\ldots \\
\ldots\end{array}$ & $\begin{array}{l}.00 \\
.00 \\
.00 \\
.00 \\
.00\end{array}$ & $\begin{array}{l}.00 \\
.00 \\
.00 \\
.00 \\
.00\end{array}$ & $\begin{array}{l}.00 \\
.00 \\
.00 \\
.00 \\
.00\end{array}$ & $\begin{array}{l}.00 \\
.00 \\
.00 \\
.00 \\
.00\end{array}$ & $\begin{array}{l}.00 \\
.00 \\
.00 \\
.00 \\
.00\end{array}$ & $\begin{array}{l}.00 \\
.00 \\
.00 \\
.00 \\
.00\end{array}$ \\
\hline $\begin{array}{l}26 \\
27 \\
28 \\
29 \\
30 \\
31\end{array}$ & $\begin{array}{l}\ldots \\
\ldots \\
\ldots \\
\cdots \\
\cdots \\
\cdots\end{array}$ & $\begin{array}{l}\ldots \\
\ldots \\
\ldots \\
\ldots \\
\cdots\end{array}$ & $\begin{array}{l}\cdots \\
\cdots \\
\cdots \\
\cdots \\
\cdots\end{array}$ & $\begin{array}{l}\ldots \\
\ldots \\
\ldots \\
\ldots \\
\ldots \\
\ldots\end{array}$ & $\begin{array}{l}\ldots \\
\ldots \\
\ldots \\
\ldots \\
\ldots\end{array}$ & $\begin{array}{c}\ldots \\
\ldots \\
\ldots \\
\ldots \\
\ldots \\
\ldots\end{array}$ & $\begin{array}{l}.00 \\
.00 \\
.00 \\
.00 \\
.00 \\
. . .\end{array}$ & $\begin{array}{l}.00 \\
.00 \\
.00 \\
.00 \\
.00 \\
.00\end{array}$ & $\begin{array}{l}.00 \\
.00 \\
.00 \\
.00 \\
.00 \\
\ldots\end{array}$ & $\begin{array}{l}.00 \\
.00 \\
.00 \\
.00 \\
.00 \\
.00\end{array}$ & $\begin{array}{l}.00 \\
.00 \\
.00 \\
.00 \\
.00 \\
.00\end{array}$ & $\begin{array}{l}.00 \\
.00 \\
.00 \\
.00 \\
.00 \\
. .\end{array}$ \\
\hline
\end{tabular}


PRECIPITATION DATA-Cont inued

09395990 BLACK CREEK NEAR HOUCK, AZ-Cont inued

RAINFALL ACCUMUATED (MILLIMETERS), WATER YEAR OCTOBER 1989 TO SEPTEMBER 1990 DAILY SUM VALUES

\begin{tabular}{|c|c|c|c|c|c|c|c|c|c|c|c|c|}
\hline DAY & OCT & NOV & DEC & JAN & FEB & MAR & $A P R$ & MAY & JUN & JUL & AUG & SEP \\
\hline $\begin{array}{l}1 \\
2 \\
3 \\
4 \\
5\end{array}$ & $\begin{array}{r}.00 \\
.00 \\
4.57 \\
11.43 \\
.00\end{array}$ & $\begin{array}{l}.00 \\
.00 \\
.00 \\
.00 \\
.00\end{array}$ & $\begin{array}{l}.00 \\
.00 \\
.00 \\
.00 \\
.00\end{array}$ & $\begin{array}{l}.00 \\
.00 \\
.25 \\
.51 \\
.00\end{array}$ & $\begin{array}{r}.76 \\
4.06 \\
.00 \\
.00 \\
.00\end{array}$ & $\begin{array}{r}.00 \\
.00 \\
1.52 \\
.00 \\
.00\end{array}$ & $\begin{array}{r}.00 \\
.00 \\
.00 \\
.00 \\
3.81\end{array}$ & $\begin{array}{r}1.27 \\
3.81 \\
2.54 \\
.00 \\
.00\end{array}$ & $\begin{array}{l}.00 \\
.00 \\
.00 \\
.00 \\
.00\end{array}$ & $\begin{array}{l}.00 \\
.00 \\
.00 \\
.00 \\
.00\end{array}$ & $\begin{array}{l}.00 \\
.00 \\
.00 \\
.00 \\
.76\end{array}$ & $\begin{array}{r}.00 \\
.00 \\
2.79 \\
1.52 \\
23.11\end{array}$ \\
\hline $\begin{array}{r}6 \\
7 \\
8 \\
9 \\
10\end{array}$ & $\begin{array}{l}.00 \\
.00 \\
.00 \\
.00 \\
.00\end{array}$ & $\begin{array}{l}.00 \\
.00 \\
.00 \\
.00 \\
.00\end{array}$ & $\begin{array}{l}.00 \\
.00 \\
.00 \\
.00 \\
.00\end{array}$ & $\begin{array}{l}.00 \\
.00 \\
.00 \\
.00 \\
.00\end{array}$ & $\begin{array}{r}.00 \\
.00 \\
2.54 \\
.00 \\
.00\end{array}$ & $\begin{array}{r}.51 \\
.00 \\
.00 \\
.00 \\
3.81\end{array}$ & $\begin{array}{r}.00 \\
.00 \\
1.27 \\
.00 \\
.00\end{array}$ & $\begin{array}{l}.00 \\
.00 \\
.00 \\
.00 \\
.00\end{array}$ & $\begin{array}{r}.00 \\
.00 \\
.00 \\
.00 \\
3.05\end{array}$ & $\begin{array}{r}.00 \\
5.59 \\
5.84 \\
.25 \\
1.02\end{array}$ & $\begin{array}{l}.00 \\
.00 \\
.00 \\
.00 \\
1.02\end{array}$ & $\begin{array}{r}12.45 \\
.00 \\
.00 \\
.00 \\
.00\end{array}$ \\
\hline $\begin{array}{l}11 \\
12 \\
13 \\
14 \\
15\end{array}$ & $\begin{array}{l}.00 \\
.00 \\
.00 \\
.00 \\
.00\end{array}$ & $\begin{array}{l}.00 \\
.00 \\
.00 \\
.00 \\
.00\end{array}$ & $\begin{array}{l}.00 \\
.00 \\
.00 \\
.00 \\
.00\end{array}$ & $\begin{array}{l}.00 \\
.00 \\
.00 \\
.00 \\
.00\end{array}$ & $\begin{array}{l}.00 \\
.00 \\
.00 \\
.00 \\
.00\end{array}$ & $\begin{array}{r}.25 \\
.00 \\
1.02 \\
.00 \\
.00\end{array}$ & $\begin{array}{l}.00 \\
.00 \\
.00 \\
.00 \\
.00\end{array}$ & $\begin{array}{l}.00 \\
.00 \\
.00 \\
.00 \\
.00\end{array}$ & $\begin{array}{l}.00 \\
.00 \\
.00 \\
.00 \\
.00\end{array}$ & $\begin{array}{l}.25 \\
.00 \\
.76 \\
.00 \\
.00\end{array}$ & $\begin{array}{r}.00 \\
.25 \\
7.37 \\
11.94 \\
6.86\end{array}$ & $\begin{array}{l}.00 \\
.00 \\
.00 \\
.00 \\
.00\end{array}$ \\
\hline $\begin{array}{l}16 \\
17 \\
18 \\
19 \\
20\end{array}$ & $\begin{array}{l}.00 \\
.00 \\
.00 \\
.00 \\
6.10\end{array}$ & $\begin{array}{l}.00 \\
.00 \\
.00 \\
.00 \\
.00\end{array}$ & $\begin{array}{l}.00 \\
.00 \\
.00 \\
.00 \\
.00\end{array}$ & $\begin{array}{r}.00 \\
.00 \\
.00 \\
.00 \\
5.08\end{array}$ & $\begin{array}{r}.00 \\
.00 \\
.00 \\
.00 \\
1.78\end{array}$ & $\begin{array}{l}.00 \\
.00 \\
.00 \\
.00 \\
.00\end{array}$ & $\begin{array}{l}.00 \\
.00 \\
.00 \\
.00 \\
.00\end{array}$ & $\begin{array}{l}.00 \\
.00 \\
.00 \\
.00 \\
.00\end{array}$ & $\begin{array}{l}.00 \\
.00 \\
.00 \\
.00 \\
.00\end{array}$ & $\begin{array}{l}.00 \\
.00 \\
.51 \\
.00 \\
.00\end{array}$ & $\begin{array}{r}.51 \\
10.67 \\
.00 \\
.00 \\
.00\end{array}$ & $\begin{array}{r}2.03 \\
.51 \\
5.08 \\
.76 \\
9.14\end{array}$ \\
\hline $\begin{array}{l}21 \\
22 \\
23 \\
24 \\
25\end{array}$ & $\begin{array}{l}.76 \\
.00 \\
.00 \\
.00 \\
.00\end{array}$ & $\begin{array}{l}.00 \\
.00 \\
.00 \\
.00 \\
.00\end{array}$ & $\begin{array}{l}.00 \\
.00 \\
.00 \\
.00 \\
.00\end{array}$ & $\begin{array}{r}3.05 \\
.00 \\
.25 \\
.00 \\
.00\end{array}$ & $\begin{array}{l}.25 \\
.00 \\
.25 \\
.00 \\
.00\end{array}$ & $\begin{array}{l}.00 \\
.00 \\
.00 \\
.00 \\
.00\end{array}$ & $\begin{array}{l}.00 \\
.00 \\
.00 \\
.76 \\
1.02\end{array}$ & $\begin{array}{l}.00 \\
.00 \\
.00 \\
.00 \\
.00\end{array}$ & $\begin{array}{l}.00 \\
.00 \\
.00 \\
.00 \\
.00\end{array}$ & $\begin{array}{l}.00 \\
.00 \\
.00 \\
.00 \\
.00\end{array}$ & $\begin{array}{l}.00 \\
.00 \\
.00 \\
.00 \\
.00\end{array}$ & $\begin{array}{r}.51 \\
8.64 \\
2.29 \\
.00 \\
.00\end{array}$ \\
\hline $\begin{array}{l}26 \\
27 \\
28 \\
29 \\
30 \\
31\end{array}$ & $\begin{array}{l}.00 \\
.00 \\
.00 \\
.00 \\
.00 \\
.00\end{array}$ & $\begin{array}{l}.00 \\
.51 \\
.00 \\
.00 \\
.00 \\
. . .\end{array}$ & $\begin{array}{r}.00 \\
.00 \\
.00 \\
3.05 \\
.00 \\
.00\end{array}$ & $\begin{array}{l}.00 \\
.00 \\
.00 \\
.00 \\
.00 \\
.00\end{array}$ & $\begin{array}{r}.00 \\
.00 \\
3.56 \\
\ldots . \\
\ldots \\
\ldots\end{array}$ & $\begin{array}{l}.00 \\
.00 \\
.00 \\
.25 \\
.00 \\
.00\end{array}$ & $\begin{array}{l}.00 \\
.00 \\
.00 \\
.00 \\
.00 \\
.--\end{array}$ & $\begin{array}{r}.00 \\
.00 \\
.00 \\
2.79 \\
.00 \\
.00\end{array}$ & $\begin{array}{l}.00 \\
.00 \\
.00 \\
.00 \\
.00 \\
-.-\end{array}$ & $\begin{array}{r}.00 \\
.00 \\
.00 \\
.00 \\
.00 \\
1.52\end{array}$ & $\begin{array}{l}.00 \\
.00 \\
.00 \\
.00 \\
.00 \\
.00\end{array}$ & $\begin{array}{r}.00 \\
1.02 \\
1.27 \\
.00 \\
.00 \\
. .-\end{array}$ \\
\hline
\end{tabular}


PRECIPITATION DATA-Continued

09395990 BLACK CREEK NEAR HOUCK, A2-Continued

RAINFALL ACCUMLATED (MILLIMETERS), MATER YEAR OCTOBER 1990 TO SEPTEMBER 1991 DAILY SUM VALUES

\begin{tabular}{|c|c|c|c|c|c|c|c|c|c|c|c|c|}
\hline DAY & OCT & NOV & DEC & JAN & FEB & MAR & APR & MAY & JUN & JUL & AUG & SEP \\
\hline $\begin{array}{l}1 \\
2 \\
3 \\
4 \\
5\end{array}$ & $\begin{array}{r}3.56 \\
.25 \\
.00 \\
.00 \\
.00\end{array}$ & $\begin{array}{r}.00 \\
10.92 \\
3.56 \\
.25 \\
.00\end{array}$ & $\begin{array}{l}.00 \\
.00 \\
.00 \\
.00 \\
.00\end{array}$ & $\begin{array}{l}\ldots \\
\ldots \\
\ldots \\
\cdots \\
\ldots-\end{array}$ & $\begin{array}{l}\ldots \\
\ldots \\
\ldots \\
\ldots \\
\ldots\end{array}$ & $\begin{array}{r}15.24 \\
9.65 \\
.00 \\
.00 \\
.25\end{array}$ & $\begin{array}{l}.00 \\
.00 \\
.00 \\
.00 \\
.00\end{array}$ & $\begin{array}{l}.00 \\
.00 \\
.00 \\
.00 \\
.00\end{array}$ & $\begin{array}{r}1.52 \\
.00 \\
.00 \\
.00 \\
.00\end{array}$ & $\begin{array}{r}.00 \\
.00 \\
.00 \\
1.27 \\
.00\end{array}$ & $\begin{array}{r}7.37 \\
.25 \\
5.59 \\
1.02 \\
.76\end{array}$ & $\begin{array}{r}.00 \\
.00 \\
.00 \\
2.79 \\
9.40\end{array}$ \\
\hline $\begin{array}{r}6 \\
7 \\
8 \\
9 \\
10\end{array}$ & $\begin{array}{l}.00 \\
.00 \\
.00 \\
.00 \\
.00\end{array}$ & $\begin{array}{r}.00 \\
8.13 \\
.00 \\
.00 \\
.00\end{array}$ & $\begin{array}{l}.00 \\
.00 \\
.00 \\
.00 \\
.00\end{array}$ & $\begin{array}{l}\ldots \\
\ldots \\
\ldots- \\
\ldots- \\
\ldots\end{array}$ & $\begin{array}{l}\ldots \\
\ldots \\
\ldots \\
\ldots \\
\ldots\end{array}$ & $\begin{array}{l}.00 \\
.00 \\
.00 \\
.00 \\
.00\end{array}$ & $\begin{array}{l}.00 \\
.00 \\
.00 \\
.00 \\
.00\end{array}$ & $\begin{array}{l}.00 \\
.00 \\
.00 \\
.00 \\
.00\end{array}$ & $\begin{array}{l}.00 \\
.00 \\
.00 \\
.00 \\
3.81\end{array}$ & $\begin{array}{r}1.27 \\
4.06 \\
2.79 \\
.25 \\
.00\end{array}$ & $\begin{array}{r}3.56 \\
.00 \\
.00 \\
.51 \\
.00\end{array}$ & $\begin{array}{r}1.02 \\
1.27 \\
.00 \\
.00 \\
1.02\end{array}$ \\
\hline $\begin{array}{l}11 \\
12 \\
13 \\
14 \\
15\end{array}$ & $\begin{array}{l}.00 \\
.00 \\
.00 \\
.00 \\
.00\end{array}$ & $\begin{array}{l}.00 \\
.00 \\
.00 \\
.00 \\
.00\end{array}$ & $\begin{array}{l}.00 \\
.00 \\
.00 \\
.00 \\
.00\end{array}$ & $\begin{array}{l}\ldots \\
\ldots \\
\ldots \\
\ldots \\
\ldots\end{array}$ & $\begin{array}{l}\ldots \\
\ldots \\
\ldots \\
\ldots \\
\ldots\end{array}$ & $\begin{array}{r}.00 \\
.00 \\
.00 \\
1.52 \\
.51\end{array}$ & $\begin{array}{l}.00 \\
.00 \\
.00 \\
.00 \\
.00\end{array}$ & $\begin{array}{l}.00 \\
.00 \\
.00 \\
.00 \\
.00\end{array}$ & $\begin{array}{r}11.94 \\
4.32 \\
2.03 \\
4.57 \\
.76\end{array}$ & $\begin{array}{r}.00 \\
13.97 \\
.00 \\
.25 \\
.76\end{array}$ & $\begin{array}{r}.00 \\
.00 \\
.00 \\
2.29 \\
.00\end{array}$ & $\begin{array}{r}.00 \\
1.52 \\
.00 \\
.00 \\
.00\end{array}$ \\
\hline $\begin{array}{l}16 \\
17 \\
18 \\
19 \\
20\end{array}$ & $\begin{array}{r}.00 \\
.00 \\
.00 \\
12.95 \\
.51\end{array}$ & $\begin{array}{l}.00 \\
.00 \\
.00 \\
.00 \\
1.52\end{array}$ & $\begin{array}{l}.00 \\
.00 \\
.00 \\
. .- \\
. . .\end{array}$ & $\begin{array}{l}\ldots \\
\ldots \\
\ldots \\
\ldots \\
\ldots\end{array}$ & $\begin{array}{l}\ldots \\
\ldots \\
\ldots \\
\ldots \\
\ldots\end{array}$ & $\begin{array}{r}2.79 \\
.25 \\
.00 \\
.00 \\
.25\end{array}$ & $\begin{array}{l}.00 \\
.00 \\
.00 \\
.00 \\
.00\end{array}$ & $\begin{array}{l}.00 \\
.00 \\
.00 \\
.00 \\
.00\end{array}$ & $\begin{array}{l}.00 \\
.00 \\
.00 \\
.00 \\
.00\end{array}$ & $\begin{array}{l}.25 \\
.00 \\
.00 \\
.51 \\
.00\end{array}$ & $\begin{array}{r}.51 \\
.76 \\
1.02 \\
.00 \\
.00\end{array}$ & $\begin{array}{l}.00 \\
.00 \\
.00 \\
.00 \\
.00\end{array}$ \\
\hline $\begin{array}{l}21 \\
22 \\
23 \\
24 \\
25\end{array}$ & $\begin{array}{l}.00 \\
.00 \\
.00 \\
.00 \\
.00\end{array}$ & $\begin{array}{l}.00 \\
.00 \\
.00 \\
.00 \\
.00\end{array}$ & $\begin{array}{l}\ldots \\
\ldots \\
\ldots \\
\ldots \\
\ldots\end{array}$ & $\begin{array}{l}\ldots \\
\ldots \\
\ldots \\
\ldots \\
\ldots\end{array}$ & $\begin{array}{l}\ldots \\
\ldots \\
\ldots \\
\ldots\end{array}$ & $\begin{array}{r}2.54 \\
3.30 \\
.00 \\
.00 \\
.00\end{array}$ & $\begin{array}{l}.00 \\
.00 \\
.00 \\
.00 \\
.00\end{array}$ & $\begin{array}{l}.00 \\
.00 \\
.00 \\
.00 \\
.00\end{array}$ & $\begin{array}{l}.00 \\
.00 \\
.00 \\
.00 \\
.00\end{array}$ & $\begin{array}{r}1.52 \\
.00 \\
.00 \\
6.10 \\
1.52\end{array}$ & $\begin{array}{r}.00 \\
.00 \\
.00 \\
3.30 \\
.00\end{array}$ & $\begin{array}{r}.00 \\
.00 \\
1.27 \\
2.29 \\
.00\end{array}$ \\
\hline $\begin{array}{l}26 \\
27 \\
28 \\
29 \\
30 \\
31\end{array}$ & $\begin{array}{l}.00 \\
.00 \\
.00 \\
.00 \\
.00 \\
.00\end{array}$ & $\begin{array}{r}3.05 \\
.51 \\
.00 \\
.00 \\
.00 \\
. .-\end{array}$ & $\begin{array}{l}\ldots \\
\ldots \\
\ldots \\
\ldots \\
\ldots \\
\ldots\end{array}$ & $\begin{array}{l}\ldots \\
\ldots \\
\ldots \\
\ldots \\
\ldots \\
\ldots\end{array}$ & $\begin{array}{r}\ldots \\
.00 \\
5.08 \\
\ldots \\
\ldots \\
\ldots\end{array}$ & $\begin{array}{r}.76 \\
.25 \\
7.87 \\
.00 \\
.00 \\
.00\end{array}$ & $\begin{array}{r}5.08 \\
.00 \\
.00 \\
.00 \\
.00 \\
. . .\end{array}$ & $\begin{array}{l}.00 \\
.00 \\
.00 \\
.00 \\
.00 \\
7.11\end{array}$ & $\begin{array}{l}.00 \\
.00 \\
.00 \\
.00 \\
.00 \\
\ldots .\end{array}$ & $\begin{array}{r}.51 \\
.00 \\
.76 \\
11.94 \\
.00 \\
1.78\end{array}$ & $\begin{array}{l}.00 \\
.00 \\
.00 \\
.00 \\
.00 \\
.51\end{array}$ & $\begin{array}{l}.00 \\
.00 \\
.00 \\
.00 \\
.76 \\
. . .\end{array}$ \\
\hline
\end{tabular}


PRECIPITATION DATA-Continued

09396100 PUERCO RIVER MEAR CHAMBERS, AZ

RAINFALL ACCUMLATED (MILLIMETERS), APRIL 1989 TO SEPTEMBER 1989 DAILY SUM VALUES

\begin{tabular}{|c|c|c|c|c|c|c|c|c|c|c|c|c|}
\hline DAY & OCT & NOV & DEC & JAM & FEB & MAR & APR & MaY & JUN & JUL & AUG & SEP \\
\hline $\begin{array}{l}1 \\
2 \\
3 \\
4 \\
5\end{array}$ & $\begin{array}{l}\ldots \\
\ldots \\
\ldots \\
\ldots \\
\ldots\end{array}$ & $\begin{array}{l}\ldots \\
\ldots \\
\ldots \\
\ldots\end{array}$ & $\begin{array}{l}\ldots \\
\ldots \\
\ldots \\
\ldots \\
\ldots\end{array}$ & $\begin{array}{l}\ldots \\
\ldots \\
\ldots \\
\ldots \\
\ldots\end{array}$ & $\begin{array}{l}\ldots \\
\ldots \\
\ldots \\
\ldots \\
\ldots\end{array}$ & $\begin{array}{l}\ldots \\
\ldots \\
\ldots \\
\ldots \\
\ldots\end{array}$ & $\begin{array}{l}\ldots \\
\ldots \\
\ldots \\
\ldots \\
\ldots\end{array}$ & $\begin{array}{l}.00 \\
.00 \\
.00 \\
.00 \\
.00\end{array}$ & $\begin{array}{l}.00 \\
.00 \\
.00 \\
.00 \\
.00\end{array}$ & $\begin{array}{l}.00 \\
.00 \\
.00 \\
.00 \\
.00\end{array}$ & $\begin{array}{l}.00 \\
.00 \\
.25 \\
.00 \\
.00\end{array}$ & $\begin{array}{r}.00 \\
.00 \\
1.78 \\
.00 \\
.00\end{array}$ \\
\hline $\begin{array}{r}6 \\
7 \\
8 \\
9 \\
10\end{array}$ & $\begin{array}{l}\ldots \\
\ldots \\
\ldots \\
\ldots \\
\ldots\end{array}$ & $\begin{array}{l}\ldots \\
\ldots \\
\ldots \\
\ldots\end{array}$ & $\begin{array}{l}\ldots \\
\ldots \\
\ldots \\
\ldots\end{array}$ & $\begin{array}{l}\ldots . \\
\ldots \\
\ldots \\
\ldots \\
\ldots\end{array}$ & $\begin{array}{l}\ldots \\
\ldots \\
\ldots \\
\ldots \\
\ldots\end{array}$ & $\begin{array}{l}\ldots \\
\ldots \\
\ldots \\
\ldots \\
\ldots\end{array}$ & $\begin{array}{l}\ldots \\
\ldots \\
\ldots \\
\ldots \\
\ldots\end{array}$ & $\begin{array}{l}.00 \\
.00 \\
.00 \\
.00 \\
.00\end{array}$ & $\begin{array}{l}.00 \\
.00 \\
.00 \\
.00 \\
.00\end{array}$ & $\begin{array}{r}.00 \\
.25 \\
.00 \\
18.80 \\
.00\end{array}$ & $\begin{array}{l}.00 \\
.00 \\
.00 \\
.00 \\
.00\end{array}$ & $\begin{array}{l}.00 \\
.00 \\
.00 \\
.00 \\
.00\end{array}$ \\
\hline $\begin{array}{l}11 \\
12 \\
13 \\
14 \\
15\end{array}$ & $\begin{array}{l}\ldots \\
\ldots \\
\ldots \\
\ldots \\
\ldots\end{array}$ & $\begin{array}{l}\ldots \\
\ldots \\
\ldots \\
\ldots \\
\ldots\end{array}$ & $\begin{array}{l}\ldots \\
\ldots \\
\ldots \\
\ldots\end{array}$ & $\begin{array}{l}\ldots \\
\ldots \\
\ldots \\
\ldots \\
\ldots\end{array}$ & $\begin{array}{l}\ldots \\
\ldots \\
\ldots \\
\ldots \\
\ldots\end{array}$ & $\begin{array}{l}\ldots \\
\ldots \\
\ldots \\
\ldots \\
\ldots\end{array}$ & $\begin{array}{l}\ldots \\
\ldots \\
. .00 \\
.00\end{array}$ & $\begin{array}{l}.00 \\
.00 \\
.00 \\
.00 \\
.00\end{array}$ & $\begin{array}{r}.00 \\
2.54 \\
.00 \\
.00 \\
1.27\end{array}$ & $\begin{array}{l}.25 \\
.00 \\
.00 \\
.00 \\
.00\end{array}$ & $\begin{array}{l}.00 \\
.00 \\
.00 \\
.00 \\
.00\end{array}$ & $\begin{array}{l}.00 \\
.00 \\
.00 \\
.00 \\
.00\end{array}$ \\
\hline $\begin{array}{l}16 \\
17 \\
18 \\
19 \\
20\end{array}$ & $\begin{array}{l}\ldots \\
\ldots \\
\ldots \\
\ldots\end{array}$ & $\begin{array}{l}\ldots \\
\ldots \\
\ldots \\
\ldots\end{array}$ & $\begin{array}{l}\ldots \\
\ldots \\
\ldots \\
\ldots\end{array}$ & $\begin{array}{l}\ldots \\
\ldots \\
\ldots \\
\ldots\end{array}$ & $\begin{array}{l}\ldots \\
\ldots \\
\ldots \\
\ldots\end{array}$ & $\begin{array}{l}\ldots \\
\ldots \\
\ldots \\
\ldots \\
\ldots\end{array}$ & $\begin{array}{l}.00 \\
.00 \\
.00 \\
.00 \\
.00\end{array}$ & $\begin{array}{l}7.87 \\
.00 \\
.00 \\
.00 \\
.00\end{array}$ & $\begin{array}{l}.00 \\
.00 \\
.00 \\
.00 \\
.00\end{array}$ & $\begin{array}{l}.25 \\
.00 \\
.00 \\
.00 \\
.00\end{array}$ & $\begin{array}{r}.00 \\
2.03 \\
32.77 \\
2.03 \\
.00\end{array}$ & $\begin{array}{l}.00 \\
.00 \\
.00 \\
.00 \\
.00\end{array}$ \\
\hline $\begin{array}{l}21 \\
22 \\
23 \\
24 \\
25\end{array}$ & $\begin{array}{l}\ldots \\
\ldots \\
\ldots \\
\ldots\end{array}$ & $\begin{array}{l}\ldots \\
\ldots \\
\ldots \\
\ldots\end{array}$ & $\begin{array}{l}\ldots \\
\ldots \\
\ldots \\
\ldots \\
\ldots\end{array}$ & $\begin{array}{l}\ldots \\
\ldots \\
\ldots \\
\ldots\end{array}$ & $\begin{array}{l}\ldots \\
\ldots \\
\ldots \\
\ldots \\
\ldots\end{array}$ & $\begin{array}{l}\ldots \\
\ldots \\
\ldots \\
\ldots \\
\ldots\end{array}$ & $\begin{array}{l}.00 \\
.00 \\
.00 \\
.00 \\
.00\end{array}$ & $\begin{array}{l}.00 \\
.00 \\
.00 \\
.00 \\
.00\end{array}$ & $\begin{array}{l}.00 \\
.00 \\
.00 \\
.00 \\
.00\end{array}$ & $\begin{array}{r}.00 \\
.00 \\
.25 \\
.00 \\
7.19\end{array}$ & $\begin{array}{l}.00 \\
.00 \\
.00 \\
.00 \\
.00\end{array}$ & $\begin{array}{l}.00 \\
.00 \\
.00 \\
.00 \\
.00\end{array}$ \\
\hline $\begin{array}{l}26 \\
27 \\
28 \\
29 \\
30 \\
31\end{array}$ & $\begin{array}{l}\ldots \\
\ldots \\
\ldots \\
\ldots \\
\ldots \\
\ldots\end{array}$ & $\begin{array}{l}\ldots \\
\ldots \\
\ldots \\
\ldots \\
\ldots \\
\ldots\end{array}$ & $\begin{array}{l}\ldots \\
\ldots \\
\ldots \\
\ldots \\
\ldots \\
\ldots\end{array}$ & $\begin{array}{l}\ldots \\
\ldots \\
\ldots \\
\ldots \\
\ldots\end{array}$ & $\begin{array}{l}\ldots \\
\ldots \\
\ldots \\
\ldots \\
\ldots \\
\ldots\end{array}$ & $\begin{array}{l}\ldots \\
\ldots \\
\ldots \\
\ldots \\
\ldots \\
\ldots\end{array}$ & $\begin{array}{l}.00 \\
.00 \\
.00 \\
.00 \\
.00 \\
\ldots . .\end{array}$ & $\begin{array}{l}.00 \\
.00 \\
.00 \\
.00 \\
.00 \\
.00\end{array}$ & $\begin{array}{r}.00 \\
.00 \\
1.27 \\
.00 \\
.00 \\
. .-\end{array}$ & $\begin{array}{l}.51 \\
3.81 \\
1.02 \\
.51 \\
.00 \\
.00\end{array}$ & $\begin{array}{l}.00 \\
.00 \\
.00 \\
.00 \\
.00 \\
.00\end{array}$ & $\begin{array}{l}.00 \\
.00 \\
.00 \\
.00 \\
.00 \\
. . .\end{array}$ \\
\hline
\end{tabular}


PRECIPITATION DATA-Continued

09396100 PUERCO RIVER NEAR ChAMBERS, AZ-Cont inued

RAINFALL ACCUMLATED (MILLIMETERS), WATER YEAR OCTOBER 1989 TO SEPTEMBER 1990 DAILY SUM VALUES

\begin{tabular}{|c|c|c|c|c|c|c|c|c|c|c|c|c|}
\hline DAY & OCT & NOV & DEC & $\mathbf{J A N}$ & FEB & MAR & APR & MAY & JUN & JUL & AUG & SEP \\
\hline $\begin{array}{l}1 \\
2 \\
3 \\
4 \\
5\end{array}$ & $\begin{array}{r}.00 \\
.00 \\
5.59 \\
9.65 \\
.51\end{array}$ & $\begin{array}{l}.00 \\
.00 \\
.00 \\
.00 \\
.00\end{array}$ & $\begin{array}{l}.00 \\
.00 \\
.00 \\
.00 \\
.00\end{array}$ & $\begin{array}{l}.00 \\
.00 \\
.00 \\
.00 \\
.00\end{array}$ & $\begin{array}{r}.00 \\
4.83 \\
.25 \\
.00 \\
.00\end{array}$ & $\begin{array}{l}.25 \\
.00 \\
.51 \\
.00 \\
.25\end{array}$ & $\begin{array}{r}.25 \\
.00 \\
.00 \\
.00 \\
3.05\end{array}$ & $\begin{array}{r}.00 \\
2.03 \\
1.27 \\
.00 \\
.00\end{array}$ & $\begin{array}{l}.00 \\
.00 \\
.00 \\
.00 \\
.00\end{array}$ & $\begin{array}{l}.00 \\
.00 \\
.00 \\
.00 \\
.00\end{array}$ & $\begin{array}{l}.00 \\
.00 \\
.00 \\
.00 \\
.00\end{array}$ & $\begin{array}{l}.00 \\
.76 \\
.00 \\
.00 \\
.00\end{array}$ \\
\hline $\begin{array}{r}6 \\
7 \\
8 \\
9 \\
10\end{array}$ & $\begin{array}{l}.25 \\
.00 \\
.00 \\
.00 \\
.00\end{array}$ & $\begin{array}{l}.00 \\
.00 \\
.00 \\
.00 \\
.00\end{array}$ & $\begin{array}{l}.00 \\
.00 \\
.00 \\
.00 \\
.00\end{array}$ & $\begin{array}{l}.00 \\
.00 \\
.00 \\
.00 \\
.00\end{array}$ & $\begin{array}{r}.00 \\
.00 \\
2.79 \\
.00 \\
.00\end{array}$ & $\begin{array}{l}.00 \\
.00 \\
.00 \\
.00 \\
3.56\end{array}$ & $\begin{array}{l}.00 \\
.76 \\
.51 \\
.00 \\
.00\end{array}$ & $\begin{array}{l}.00 \\
.00 \\
.00 \\
.00 \\
.00\end{array}$ & $\begin{array}{r}.00 \\
.00 \\
.00 \\
.00 \\
1.52\end{array}$ & $\begin{array}{r}.00 \\
10.16 \\
3.56 \\
.51 \\
.00\end{array}$ & $\begin{array}{r}.51 \\
.00 \\
.25 \\
3.30 \\
.00\end{array}$ & $\begin{array}{l}.76 \\
.00 \\
.00 \\
.00 \\
.00\end{array}$ \\
\hline $\begin{array}{l}11 \\
12 \\
13 \\
14 \\
15\end{array}$ & $\begin{array}{l}.00 \\
.00 \\
.00 \\
.00 \\
.00\end{array}$ & $\begin{array}{l}.00 \\
.00 \\
.00 \\
.00 \\
.00\end{array}$ & $\begin{array}{l}.00 \\
.00 \\
.00 \\
.00 \\
.00\end{array}$ & $\begin{array}{l}.00 \\
.00 \\
.00 \\
.00 \\
.25\end{array}$ & $\begin{array}{l}.00 \\
.00 \\
.00 \\
.00 \\
.00\end{array}$ & $\begin{array}{l}.25 \\
.25 \\
.25 \\
.51 \\
.00\end{array}$ & $\begin{array}{l}.00 \\
.00 \\
.00 \\
.00 \\
.00\end{array}$ & $\begin{array}{l}.00 \\
.00 \\
.00 \\
.00 \\
.00\end{array}$ & $\begin{array}{l}.00 \\
.00 \\
.00 \\
.00 \\
.00\end{array}$ & $\begin{array}{r}.00 \\
.00 \\
1.52 \\
6.35 \\
.00\end{array}$ & $\begin{array}{l}.00 \\
.00 \\
6.60 \\
4.57 \\
1.78\end{array}$ & $\begin{array}{l}.00 \\
.00 \\
.00 \\
.00 \\
.00\end{array}$ \\
\hline $\begin{array}{l}16 \\
17 \\
18 \\
19 \\
20\end{array}$ & $\begin{array}{r}.00 \\
.00 \\
.00 \\
.00 \\
8.89\end{array}$ & $\begin{array}{l}.00 \\
.00 \\
.00 \\
.00 \\
.00\end{array}$ & $\begin{array}{l}.00 \\
.00 \\
.00 \\
.00 \\
.00\end{array}$ & $\begin{array}{l}.00 \\
.00 \\
.00 \\
.25 \\
.00\end{array}$ & $\begin{array}{r}.00 \\
.00 \\
.00 \\
.00 \\
1.52\end{array}$ & $\begin{array}{l}.00 \\
.00 \\
.00 \\
.00 \\
.00\end{array}$ & $\begin{array}{l}.00 \\
.00 \\
.00 \\
.00 \\
.00\end{array}$ & $\begin{array}{l}.00 \\
.00 \\
.00 \\
.00 \\
.00\end{array}$ & $\begin{array}{l}.00 \\
.00 \\
.00 \\
.00 \\
.00\end{array}$ & $\begin{array}{l}.51 \\
.00 \\
.00 \\
.25 \\
.00\end{array}$ & $\begin{array}{r}2.29 \\
.25 \\
.00 \\
.00 \\
.00\end{array}$ & $\begin{array}{r}.00 \\
5.08 \\
4.32 \\
.25 \\
14.22\end{array}$ \\
\hline $\begin{array}{l}21 \\
22 \\
23 \\
24 \\
25\end{array}$ & $\begin{array}{r}1.27 \\
.00 \\
.00 \\
.00 \\
.00\end{array}$ & $\begin{array}{r}.00 \\
.00 \\
.00 \\
.00 \\
.00\end{array}$ & $\begin{array}{l}.00 \\
.00 \\
.00 \\
.00 \\
.00\end{array}$ & $\begin{array}{l}.00 \\
.00 \\
.00 \\
.00 \\
.00\end{array}$ & $\begin{array}{l}.00 \\
.00 \\
.00 \\
.00 \\
.00\end{array}$ & $\begin{array}{l}.00 \\
.00 \\
.00 \\
.00 \\
.00\end{array}$ & $\begin{array}{r}.00 \\
.00 \\
.00 \\
1.27 \\
1.52\end{array}$ & $\begin{array}{l}.00 \\
.00 \\
.00 \\
.00 \\
.00\end{array}$ & $\begin{array}{l}.00 \\
.00 \\
.00 \\
.00 \\
.00\end{array}$ & $\begin{array}{r}.00 \\
.00 \\
.00 \\
.00 \\
.00\end{array}$ & $\begin{array}{r}.00 \\
.00 \\
.00 \\
.00 \\
.00\end{array}$ & $\begin{array}{r}.25 \\
8.38 \\
2.29 \\
.00 \\
.00\end{array}$ \\
\hline $\begin{array}{l}26 \\
27 \\
28 \\
29 \\
30 \\
31\end{array}$ & $\begin{array}{l}.00 \\
.00 \\
.00 \\
.00 \\
.00 \\
.00\end{array}$ & $\begin{array}{l}.00 \\
.00 \\
.00 \\
.00 \\
.00 \\
\ldots . .\end{array}$ & $\begin{array}{r}.00 \\
.00 \\
.00 \\
4.32 \\
.00 \\
.00\end{array}$ & $\begin{array}{l}.00 \\
.00 \\
.00 \\
.00 \\
.00 \\
.00\end{array}$ & $\begin{array}{r}.00 \\
.25 \\
5.08 \\
\ldots \\
\ldots \\
\ldots\end{array}$ & $\begin{array}{l}.00 \\
.00 \\
.00 \\
.25 \\
.00 \\
.00\end{array}$ & $\begin{array}{l}.00 \\
.00 \\
.00 \\
.00 \\
.00 \\
. . .\end{array}$ & $\begin{array}{r}.00 \\
.00 \\
.00 \\
2.79 \\
.00 \\
.00\end{array}$ & $\begin{array}{l}.00 \\
.00 \\
.00 \\
.00 \\
.00 \\
. . .\end{array}$ & $\begin{array}{r}.00 \\
.00 \\
.00 \\
.00 \\
.00 \\
3.05\end{array}$ & $\begin{array}{l}.00 \\
.00 \\
.00 \\
.00 \\
.00 \\
.00\end{array}$ & $\begin{array}{l}.00 \\
.00 \\
.00 \\
.00 \\
.51 \\
. . .\end{array}$ \\
\hline
\end{tabular}


09396100 PUERCO RIVER NEAR CHAMBERS, AZ-Continued

RAINFALL ACCUMLATED (MILLIMETERS), WATER YEAR OCTOBER 1990 TO SEPTEMBER 1991 DAILY SUM VALUES

\begin{tabular}{|c|c|c|c|c|c|c|c|c|c|c|c|c|}
\hline DAY & OCT & NOV & DEC & JAN & FEB & MAR & APR & MAY & JUN & JUL & AUG & SEP \\
\hline $\begin{array}{l}1 \\
2 \\
3 \\
4 \\
5\end{array}$ & $\begin{array}{r}2.29 \\
.00 \\
.00 \\
.00 \\
.00\end{array}$ & $\begin{array}{r}.00 \\
9.40 \\
3.56 \\
.00 \\
.00\end{array}$ & $\begin{array}{l}.00 \\
.00 \\
.00 \\
.00 \\
.00\end{array}$ & $\begin{array}{l}\ldots \\
\ldots \\
\ldots \\
\ldots \\
\ldots\end{array}$ & $\begin{array}{l}.00 \\
.00 \\
.00 \\
.00 \\
.00\end{array}$ & $\begin{array}{r}6.10 \\
11.68 \\
.00 \\
.00 \\
.00\end{array}$ & $\begin{array}{l}.00 \\
.00 \\
.00 \\
.00 \\
.00\end{array}$ & $\begin{array}{l}.00 \\
.00 \\
.00 \\
.00 \\
.00\end{array}$ & $\begin{array}{l}.00 \\
.00 \\
.00 \\
.00 \\
.00\end{array}$ & $\begin{array}{l}.00 \\
.00 \\
.00 \\
.00 \\
.00\end{array}$ & $\begin{array}{l}.51 \\
.00 \\
.25 \\
.00 \\
.00\end{array}$ & $\begin{array}{r}.00 \\
.00 \\
.00 \\
.00 \\
13.72\end{array}$ \\
\hline $\begin{array}{r}6 \\
7 \\
8 \\
9 \\
10\end{array}$ & $\begin{array}{l}.00 \\
.00 \\
.00 \\
.00 \\
.00\end{array}$ & $\begin{array}{l}.00 \\
4.06 \\
.00 \\
.00 \\
.00\end{array}$ & $\begin{array}{l}.00 \\
.00 \\
.00 \\
.00 \\
.00\end{array}$ & $\begin{array}{r}\ldots \\
\ldots . \\
.00 \\
.76 \\
2.54\end{array}$ & $\begin{array}{l}.00 \\
.00 \\
.00 \\
.00 \\
.00\end{array}$ & $\begin{array}{l}.00 \\
.00 \\
.00 \\
.00 \\
.00\end{array}$ & $\begin{array}{l}.00 \\
.00 \\
.00 \\
.00 \\
.00\end{array}$ & $\begin{array}{l}.00 \\
.00 \\
.00 \\
.00 \\
.00\end{array}$ & $\begin{array}{l}.00 \\
.00 \\
.00 \\
.00 \\
.76\end{array}$ & $\begin{array}{r}.00 \\
.76 \\
2.79 \\
.00 \\
.00\end{array}$ & $\begin{array}{l}.00 \\
.00 \\
.00 \\
.00 \\
.00\end{array}$ & $\begin{array}{r}1.27 \\
.00 \\
.00 \\
.00 \\
.00\end{array}$ \\
\hline $\begin{array}{l}11 \\
12 \\
13 \\
14 \\
15\end{array}$ & $\begin{array}{l}.00 \\
.00 \\
.00 \\
.00 \\
.00\end{array}$ & $\begin{array}{l}.00 \\
.00 \\
.00 \\
.00 \\
.00\end{array}$ & $\begin{array}{r}.00 \\
7.37 \\
3.05 \\
.00 \\
3.30\end{array}$ & $\begin{array}{l}.25 \\
.00 \\
.00 \\
.00 \\
.00\end{array}$ & $\begin{array}{l}.00 \\
.00 \\
.00 \\
.00 \\
.00\end{array}$ & $\begin{array}{l}.00 \\
.00 \\
.00 \\
.76 \\
.00\end{array}$ & $\begin{array}{l}.00 \\
.00 \\
.00 \\
.00 \\
.00\end{array}$ & $\begin{array}{l}.00 \\
.00 \\
.00 \\
.00 \\
.00\end{array}$ & $\begin{array}{l}3.30 \\
1.52 \\
.00 \\
.76 \\
.00\end{array}$ & $\begin{array}{l}.00 \\
.25 \\
.00 \\
.00 \\
.25\end{array}$ & $\begin{array}{l}.00 \\
.00 \\
.00 \\
.00 \\
.00\end{array}$ & $\begin{array}{l}.00 \\
.00 \\
.00 \\
.00 \\
.00\end{array}$ \\
\hline $\begin{array}{l}16 \\
17 \\
18 \\
19 \\
20\end{array}$ & $\begin{array}{r}.00 \\
.00 \\
.00 \\
13.72 \\
.00\end{array}$ & $\begin{array}{l}.00 \\
.00 \\
.00 \\
.00 \\
.00\end{array}$ & $\begin{array}{r}16.51 \\
.00 \\
.00 \\
1.78 \\
.00\end{array}$ & $\begin{array}{l}.51 \\
.00 \\
.00 \\
.00 \\
.00\end{array}$ & $\begin{array}{l}.00 \\
.51 \\
.00 \\
.00 \\
.00\end{array}$ & $\begin{array}{l}.00 \\
.00 \\
.00 \\
.76 \\
.00\end{array}$ & $\begin{array}{l}.00 \\
.00 \\
.00 \\
.00 \\
.00\end{array}$ & $\begin{array}{l}.00 \\
.00 \\
.00 \\
.00 \\
.00\end{array}$ & $\begin{array}{l}.00 \\
.00 \\
.00 \\
.00 \\
.00\end{array}$ & $\begin{array}{r}.00 \\
.00 \\
.00 \\
.00 \\
4.57\end{array}$ & $\begin{array}{l}.00 \\
.00 \\
.00 \\
.00 \\
.00\end{array}$ & $\begin{array}{l}.00 \\
.00 \\
.00 \\
.00 \\
.00\end{array}$ \\
\hline $\begin{array}{l}21 \\
22 \\
23 \\
24 \\
25\end{array}$ & $\begin{array}{l}.00 \\
.00 \\
.00 \\
.00 \\
.00\end{array}$ & $\begin{array}{l}.00 \\
.00 \\
.00 \\
.00 \\
.00\end{array}$ & $\begin{array}{l}.00 \\
.00 \\
.00 \\
\ldots . \\
\ldots .\end{array}$ & $\begin{array}{r}2.03 \\
.00 \\
.00 \\
.00 \\
.00\end{array}$ & $\begin{array}{l}.00 \\
.00 \\
.00 \\
.00 \\
.00\end{array}$ & $\begin{array}{l}.00 \\
.76 \\
.00 \\
.00 \\
.00\end{array}$ & $\begin{array}{l}.00 \\
.00 \\
.00 \\
.00 \\
.00\end{array}$ & $\begin{array}{l}.00 \\
.00 \\
.00 \\
.00 \\
.00\end{array}$ & $\begin{array}{l}.00 \\
.00 \\
.00 \\
.00 \\
.00\end{array}$ & $\begin{array}{r}.00 \\
.00 \\
1.78 \\
6.10 \\
.51\end{array}$ & $\begin{array}{r}.00 \\
.00 \\
.00 \\
5.33 \\
.00\end{array}$ & $\begin{array}{l}.00 \\
.00 \\
.00 \\
.00 \\
.00\end{array}$ \\
\hline $\begin{array}{l}26 \\
27 \\
28 \\
29 \\
30 \\
31\end{array}$ & $\begin{array}{l}.00 \\
.00 \\
.00 \\
.00 \\
.00 \\
.00\end{array}$ & $\begin{array}{r}2.03 \\
.00 \\
.00 \\
.00 \\
.00 \\
\ldots . .\end{array}$ & $\begin{array}{l}\ldots . \\
\ldots . \\
\ldots . \\
\ldots- \\
\ldots .\end{array}$ & $\begin{array}{l}.00 \\
.00 \\
.00 \\
.00 \\
.00 \\
.00\end{array}$ & $\begin{array}{r}.00 \\
.00 \\
6.86 \\
\ldots . . \\
\ldots .\end{array}$ & $\begin{array}{r}.25 \\
.00 \\
1.27 \\
.00 \\
.00 \\
.00\end{array}$ & $\begin{array}{l}.25 \\
.00 \\
.00 \\
.00 \\
.00 \\
. . .\end{array}$ & $\begin{array}{l}.00 \\
.00 \\
.00 \\
.00 \\
.00 \\
.25\end{array}$ & $\begin{array}{l}.00 \\
.00 \\
.00 \\
.00 \\
.00 \\
. . .\end{array}$ & $\begin{array}{l}.00 \\
.00 \\
.00 \\
.00 \\
.00 \\
.00\end{array}$ & $\begin{array}{r}1.27 \\
.00 \\
1.78 \\
.00 \\
.00 \\
.00\end{array}$ & $\begin{array}{l}.00 \\
.25 \\
.00 \\
.00 \\
.00 \\
. . .\end{array}$ \\
\hline
\end{tabular}


PRECIPITATION DATA-Continued

09386950 ZUNI RIVER ABOVE BLACK ROCK RESERVOIR, MM

RAINFALL ACCUNULATED (MILLIMETERS), MY 1989 TO SEPTEMBER 1989

DAILY SUM VALUES

\begin{tabular}{|c|c|c|c|c|c|c|c|c|c|c|c|c|}
\hline DAY & OCT & Nov & DEC & JAN & FEB & MUR & APR & mar & JUN & JUL & AUG & SEP \\
\hline $\begin{array}{l}1 \\
2 \\
3 \\
4 \\
5\end{array}$ & $\begin{array}{c}\ldots . \\
\cdots \\
\cdots \\
\cdots \\
\cdots\end{array}$ & $\begin{array}{c}\ldots \\
\ldots \\
\ldots \\
\ldots \\
\ldots\end{array}$ & $\begin{array}{c}\cdots \\
\cdots \\
\cdots \\
\cdots \\
\cdots\end{array}$ & $\begin{array}{c}\ldots . \\
\cdots \\
\cdots \cdot \\
\cdots\end{array}$ & $\begin{array}{l}\ldots \\
\cdots \\
\cdots \\
\cdots \\
\cdots\end{array}$ & $\begin{array}{l}\ldots . \\
\cdots \\
\cdots \\
\cdots \\
\cdots\end{array}$ & $\begin{array}{l}\cdots \\
\cdots \\
\cdots \\
\cdots \\
\cdots\end{array}$ & $\begin{array}{l}. . \\
.00 \\
.00 \\
.00 \\
.00\end{array}$ & $\begin{array}{l}.00 \\
.00 \\
.00 \\
.00 \\
.00\end{array}$ & $\begin{array}{l}.00 \\
.00 \\
.00 \\
.00 \\
.00\end{array}$ & $\begin{array}{r}2.29 \\
.00 \\
1.02 \\
.00 \\
.00\end{array}$ & $\begin{array}{l}.00 \\
.00 \\
.00 \\
.00 \\
2.54\end{array}$ \\
\hline $\begin{array}{r}6 \\
7 \\
8 \\
9 \\
10\end{array}$ & $\begin{array}{c}\ldots . \\
\cdots \\
\cdots- \\
\cdots \\
\cdots\end{array}$ & $\begin{array}{l}\cdots \\
\cdots \\
\cdots \\
\cdots \\
\cdots\end{array}$ & $\begin{array}{l}\cdots \\
\cdots \\
\cdots \\
\cdots \\
\cdots\end{array}$ & $\begin{array}{c}\ldots . \\
\cdots \\
\cdots \\
\cdots\end{array}$ & $\begin{array}{l}\cdots \\
\cdots \\
\cdots- \\
\cdots- \\
-.\end{array}$ & $\begin{array}{l}\ldots \\
\cdots \\
\cdots \\
\cdots \\
\cdots\end{array}$ & $\begin{array}{l}\cdots \\
\cdots \\
\cdots \\
\cdots \\
\cdots\end{array}$ & $\begin{array}{l}.00 \\
.00 \\
.00 \\
.00 \\
.00\end{array}$ & $\begin{array}{l}.00 \\
.00 \\
.00 \\
.00 \\
.00\end{array}$ & $\begin{array}{l}.00 \\
.00 \\
.00 \\
.00 \\
.00\end{array}$ & $\begin{array}{r}.00 \\
.00 \\
1.52 \\
.00 \\
.00\end{array}$ & $\begin{array}{l}.00 \\
.00 \\
.00 \\
.00 \\
.00\end{array}$ \\
\hline $\begin{array}{l}11 \\
12 \\
13 \\
14 \\
15\end{array}$ & $\begin{array}{c}-.- \\
-. \\
-- \\
-- \\
--\end{array}$ & $\begin{array}{l}\cdots \\
\cdots \\
\cdots \\
\cdots \\
\cdots\end{array}$ & $\begin{array}{l}\ldots- \\
\cdots \\
\cdots \\
\cdots\end{array}$ & $\begin{array}{l}\ldots . \\
\cdots \\
\cdots \\
\cdots\end{array}$ & $\begin{array}{l}\cdots \\
-.- \\
-- \\
-- \\
--\end{array}$ & $\begin{array}{l}\ldots . \\
\cdots \\
\cdots \\
\cdots \\
\cdots\end{array}$ & $\begin{array}{l}-\cdot- \\
\cdots- \\
\cdots- \\
\cdots- \\
-\cdot\end{array}$ & $\begin{array}{l}.00 \\
.00 \\
.00 \\
.00 \\
.00\end{array}$ & $\begin{array}{l}.00 \\
.00 \\
.00 \\
.00 \\
.00\end{array}$ & $\begin{array}{l}.76 \\
.00 \\
.00 \\
.00 \\
.00\end{array}$ & $\begin{array}{l}.00 \\
.00 \\
.00 \\
.00 \\
.00\end{array}$ & $\begin{array}{l}.00 \\
.00 \\
.00 \\
.00 \\
.00\end{array}$ \\
\hline $\begin{array}{l}16 \\
17 \\
18 \\
19 \\
20\end{array}$ & $\begin{array}{c}-.- \\
\cdots- \\
\cdots- \\
-. .\end{array}$ & $\begin{array}{c}\cdots \\
\cdots \\
\cdots \\
\cdots \\
\cdots\end{array}$ & $\begin{array}{l}\ldots \\
\cdots \\
\cdots \\
\cdots \\
\cdots\end{array}$ & $\begin{array}{l}\cdots \\
\cdots \\
\cdots \cdot \\
\cdots \\
\cdots\end{array}$ & $\begin{array}{c}\cdots \\
\cdots- \\
\cdots \\
\cdots \\
\cdots\end{array}$ & $\begin{array}{l}\cdots \\
\cdots \\
\cdots \\
\cdots \\
\cdots\end{array}$ & $\begin{array}{l}\cdots- \\
\cdots- \\
\cdots- \\
\cdots \\
\cdots\end{array}$ & $\begin{array}{l}.00 \\
.00 \\
.00 \\
.00 \\
.00\end{array}$ & $\begin{array}{l}.00 \\
.00 \\
.00 \\
.00 \\
.00\end{array}$ & $\begin{array}{l}.00 \\
.00 \\
.00 \\
.00 \\
.00\end{array}$ & $\begin{array}{r}8.64 \\
.00 \\
13.72 \\
.00 \\
.00\end{array}$ & $\begin{array}{l}.00 \\
.00 \\
.00 \\
.00 \\
.00\end{array}$ \\
\hline $\begin{array}{l}21 \\
22 \\
23 \\
24 \\
25\end{array}$ & $\begin{array}{c}\cdots \cdot \\
\cdots \\
\cdots \\
\cdots \\
\cdots\end{array}$ & $\begin{array}{l}\ldots \\
\cdots \\
\cdots \\
\cdots \\
\cdots\end{array}$ & $\begin{array}{l}\cdots \\
\cdots \\
\cdots \\
\cdots \\
\cdots\end{array}$ & $\begin{array}{l}\cdots \\
\cdots \\
\cdots \\
\cdots\end{array}$ & $\begin{array}{l}\cdots \\
\cdots \\
\cdots \\
\cdots \\
\cdots\end{array}$ & $\begin{array}{l}\ldots . \\
\cdots \\
\cdots \cdot \\
\cdots \\
\cdots\end{array}$ & $\begin{array}{l}\ldots \\
\cdots \\
\cdots \\
\cdots \\
\cdots\end{array}$ & $\begin{array}{l}.00 \\
.00 \\
.00 \\
.00 \\
.00\end{array}$ & $\begin{array}{l}.00 \\
.00 \\
.00 \\
.00 \\
.00\end{array}$ & $\begin{array}{r}.00 \\
29.72 \\
2.54 \\
.76 \\
18.80\end{array}$ & $\begin{array}{l}1.78 \\
.00 \\
.00 \\
.00 \\
.00\end{array}$ & $\begin{array}{l}.00 \\
.00 \\
.00 \\
.00 \\
.00\end{array}$ \\
\hline $\begin{array}{l}26 \\
27 \\
28 \\
29 \\
30 \\
31\end{array}$ & $\begin{array}{c}\ldots . \\
\cdots . \\
\cdots . \\
\cdots \\
\cdots\end{array}$ & $\begin{array}{c}\cdots \\
\cdots \\
\cdots- \\
\cdots \\
\cdots \\
\cdots\end{array}$ & $\begin{array}{l}\cdots . \\
\cdots . \\
\cdots \cdot \\
\cdots \\
\cdots-\end{array}$ & $\begin{array}{l}\ldots . \\
\cdots \\
\cdots \\
\cdots \\
\cdots\end{array}$ & $\begin{array}{c}\ldots . \\
\cdots . \\
\cdots . \\
\cdots \\
\cdots \\
\cdots\end{array}$ & $\begin{array}{l}\ldots . \\
\cdots \\
\cdots \\
\cdots \\
\cdots \\
\cdots\end{array}$ & $\begin{array}{c}\cdots \\
\cdots \cdot \\
\cdots \\
\cdots \\
\cdots \\
\cdots\end{array}$ & $\begin{array}{l}.00 \\
.00 \\
.00 \\
.00 \\
.00 \\
.00\end{array}$ & $\begin{array}{r}.00 \\
.00 \\
.00 \\
1.27 \\
.00 \\
. .\end{array}$ & $\begin{array}{r}.00 \\
.00 \\
.25 \\
.51 \\
.00 \\
11.94\end{array}$ & $\begin{array}{l}.00 \\
.00 \\
.00 \\
.00 \\
.00 \\
.00\end{array}$ & $\begin{array}{r}.00 \\
3.81 \\
.00 \\
.00 \\
.00 \\
. . .\end{array}$ \\
\hline
\end{tabular}


PRECIPITATION DATA-Continued

09386950 ZUNI RIVER ABOVE BLACK ROCK RESERVOIR, NH-Cont inued

RAINFALL ACCUNULATED (MILLIMETERS), WATER YEAR OCTOBER 1989 TO SEPTEMBER 1990 DAILY SUM VALUES

\begin{tabular}{|c|c|c|c|c|c|c|c|c|c|c|c|c|}
\hline DAY & OCT & NOV & DEC & JAN & FEB & MAR & APR & MAY & JUN & JUL & AUG & SEP \\
\hline $\begin{array}{l}1 \\
2 \\
3 \\
4 \\
5\end{array}$ & $\begin{array}{r}.00 \\
.00 \\
6.86 \\
13.97 \\
3.05\end{array}$ & $\begin{array}{l}.00 \\
.00 \\
.00 \\
.00 \\
.00\end{array}$ & $\begin{array}{l}.00 \\
.00 \\
.00 \\
.00 \\
.00\end{array}$ & $\begin{array}{l}.00 \\
.00 \\
.00 \\
.00 \\
.00\end{array}$ & $\begin{array}{r}.00 \\
1.78 \\
.00 \\
.00 \\
.51\end{array}$ & $\begin{array}{r}.00 \\
.00 \\
2.03 \\
.00 \\
.00\end{array}$ & $\begin{array}{r}2.03 \\
1.02 \\
.00 \\
.00 \\
3.81\end{array}$ & $\begin{array}{r}3.81 \\
10.92 \\
6.60 \\
.00 \\
.00\end{array}$ & $\begin{array}{l}.00 \\
.00 \\
.00 \\
.00 \\
.00\end{array}$ & $\begin{array}{l}.00 \\
.00 \\
.00 \\
.00 \\
.00\end{array}$ & $\begin{array}{r}1.02 \\
.00 \\
.00 \\
.00 \\
.00\end{array}$ & $\begin{array}{r}2.54 \\
.25 \\
.76 \\
3.05 \\
1.02\end{array}$ \\
\hline $\begin{array}{r}6 \\
7 \\
8 \\
9 \\
10\end{array}$ & $\begin{array}{l}.00 \\
.00 \\
.00 \\
.00 \\
.00\end{array}$ & $\begin{array}{l}.00 \\
.00 \\
.00 \\
.00 \\
.00\end{array}$ & $\begin{array}{l}.00 \\
.00 \\
.00 \\
.00 \\
.00\end{array}$ & $\begin{array}{l}.00 \\
.00 \\
.00 \\
.00 \\
.00\end{array}$ & $\begin{array}{r}1.27 \\
.00 \\
2.54 \\
2.03 \\
.00\end{array}$ & $\begin{array}{r}2.03 \\
.00 \\
.00 \\
.00 \\
12.45\end{array}$ & $\begin{array}{r}.00 \\
.76 \\
1.52 \\
.00 \\
.00\end{array}$ & $\begin{array}{l}.00 \\
.00 \\
.00 \\
.00 \\
.00\end{array}$ & $\begin{array}{l}.00 \\
.00 \\
.00 \\
.00 \\
6.10\end{array}$ & $\begin{array}{r}.51 \\
.51 \\
.00 \\
13.21 \\
.00\end{array}$ & $\begin{array}{r}.00 \\
.00 \\
.00 \\
.00 \\
2.29\end{array}$ & $\begin{array}{r}.00 \\
.25 \\
8.89 \\
.00 \\
.00\end{array}$ \\
\hline $\begin{array}{l}11 \\
12 \\
13 \\
14 \\
15\end{array}$ & $\begin{array}{l}.00 \\
.00 \\
.00 \\
.00 \\
.00\end{array}$ & $\begin{array}{l}.00 \\
.00 \\
.00 \\
.00 \\
.00\end{array}$ & $\begin{array}{l}.00 \\
.00 \\
.00 \\
.00 \\
.00\end{array}$ & $\begin{array}{l}.00 \\
.00 \\
.00 \\
.00 \\
.00\end{array}$ & $\begin{array}{l}.00 \\
.00 \\
.00 \\
.00 \\
.00\end{array}$ & $\begin{array}{r}4.83 \\
.00 \\
.00 \\
.00 \\
.00\end{array}$ & $\begin{array}{l}.00 \\
.00 \\
.00 \\
.00 \\
.00\end{array}$ & $\begin{array}{l}.00 \\
.00 \\
.00 \\
.00 \\
.00\end{array}$ & $\begin{array}{l}.00 \\
.00 \\
.00 \\
.00 \\
.00\end{array}$ & $\begin{array}{r}.00 \\
.00 \\
2.29 \\
4.06 \\
.00\end{array}$ & $\begin{array}{r}.00 \\
.00 \\
15.24 \\
16.51 \\
6.60\end{array}$ & $\begin{array}{l}.00 \\
.00 \\
.00 \\
.00 \\
.00\end{array}$ \\
\hline $\begin{array}{l}16 \\
17 \\
18 \\
19 \\
20\end{array}$ & $\begin{array}{l}.00 \\
.00 \\
.00 \\
.00 \\
8.13\end{array}$ & $\begin{array}{l}.00 \\
.00 \\
.00 \\
.00 \\
.00\end{array}$ & $\begin{array}{l}.00 \\
.00 \\
.00 \\
.00 \\
.00\end{array}$ & $\begin{array}{l}.00 \\
.00 \\
.00 \\
.00 \\
.25\end{array}$ & $\begin{array}{l}.00 \\
.00 \\
.00 \\
.00 \\
.00\end{array}$ & $\begin{array}{l}.00 \\
.00 \\
.00 \\
.00 \\
.00\end{array}$ & $\begin{array}{l}.00 \\
.00 \\
.00 \\
.00 \\
.00\end{array}$ & $\begin{array}{l}.00 \\
.00 \\
.00 \\
.00 \\
.00\end{array}$ & $\begin{array}{l}.00 \\
.00 \\
.00 \\
.00 \\
.00\end{array}$ & $\begin{array}{r}.00 \\
.00 \\
.51 \\
.51 \\
1.78\end{array}$ & $\begin{array}{r}2.03 \\
9.65 \\
.00 \\
.00 \\
3.56\end{array}$ & $\begin{array}{r}.00 \\
.00 \\
6.10 \\
.00 \\
3.30\end{array}$ \\
\hline $\begin{array}{l}21 \\
22 \\
23 \\
24 \\
25\end{array}$ & $\begin{array}{l}.00 \\
.00 \\
.00 \\
.00 \\
.00\end{array}$ & $\begin{array}{l}.00 \\
.00 \\
.00 \\
.00 \\
.00\end{array}$ & $\begin{array}{l}.00 \\
.00 \\
.00 \\
.00 \\
.00\end{array}$ & $\begin{array}{l}.00 \\
.00 \\
.00 \\
.00 \\
.00\end{array}$ & $\begin{array}{r}1.52 \\
.00 \\
.00 \\
.00 \\
.00\end{array}$ & $\begin{array}{l}.00 \\
.00 \\
.00 \\
.00 \\
.00\end{array}$ & $\begin{array}{l}.00 \\
.00 \\
.00 \\
1.78 \\
4.06\end{array}$ & $\begin{array}{l}.00 \\
.00 \\
.00 \\
.00 \\
.00\end{array}$ & $\begin{array}{l}.00 \\
.00 \\
.00 \\
.00 \\
.00\end{array}$ & $\begin{array}{l}.00 \\
.00 \\
.00 \\
.00 \\
.00\end{array}$ & $\begin{array}{l}.00 \\
.00 \\
.00 \\
.00 \\
.00\end{array}$ & $\begin{array}{r}1.78 \\
14.22 \\
2.03 \\
.00 \\
.00\end{array}$ \\
\hline $\begin{array}{l}26 \\
27 \\
28 \\
29 \\
30 \\
31\end{array}$ & $\begin{array}{l}.00 \\
.00 \\
.00 \\
.00 \\
.00 \\
.00\end{array}$ & $\begin{array}{r}.00 \\
.00 \\
.00 \\
.00 \\
1.02 \\
. \ldots\end{array}$ & $\begin{array}{l}.00 \\
.00 \\
.00 \\
.76 \\
.00 \\
.00\end{array}$ & $\begin{array}{l}.00 \\
.00 \\
.00 \\
.00 \\
.00 \\
.00\end{array}$ & $\begin{array}{r}.00 \\
.00 \\
2.54 \\
\ldots . \\
\ldots \\
\ldots\end{array}$ & $\begin{array}{r}.00 \\
.00 \\
.00 \\
.76 \\
4.83 \\
.00\end{array}$ & $\begin{array}{l}.25 \\
.00 \\
.00 \\
.00 \\
.00 \\
\ldots . .\end{array}$ & $\begin{array}{r}.00 \\
.00 \\
.00 \\
3.05 \\
.00 \\
.00\end{array}$ & $\begin{array}{r}.00 \\
.00 \\
.00 \\
.00 \\
1.78 \\
\ldots\end{array}$ & $\begin{array}{l}.00 \\
.00 \\
.00 \\
.00 \\
.25 \\
.00\end{array}$ & $\begin{array}{l}.00 \\
.00 \\
.00 \\
.00 \\
.00 \\
3.30\end{array}$ & $\begin{array}{r}.00 \\
.00 \\
2.54 \\
.00 \\
4.32 \\
\ldots . .\end{array}$ \\
\hline
\end{tabular}


PRECIPITATION DATA-Continued

09386950 ZUNI RIVER ABOVE BLACK ROCK RESERVOIR, WH-Continued

RAINFALL ACCUMLATED (MILLIMETERS), MATER YEAR OCTOBER 1990 TO SEPTEMBER 1991 DAILY SUM VALUES

\begin{tabular}{|c|c|c|c|c|c|c|c|c|c|c|c|c|}
\hline DAY & OCT & NOV & DEC & JAN & FEB & MAR & APR & MAY & JUN & JUL & AUG & SEP \\
\hline $\begin{array}{l}1 \\
2 \\
3 \\
4 \\
5\end{array}$ & $\begin{array}{r}4.32 \\
.00 \\
.00 \\
.00 \\
.00\end{array}$ & $\begin{array}{r}.76 \\
10.67 \\
.00 \\
.51 \\
.00\end{array}$ & $\begin{array}{l}.00 \\
.00 \\
.00 \\
.00 \\
.00\end{array}$ & $\begin{array}{l}.00 \\
.00 \\
.00 \\
.25 \\
.51\end{array}$ & $\begin{array}{l}.25 \\
.00 \\
.00 \\
.00 \\
.00\end{array}$ & $\begin{array}{r}13.21 \\
5.84 \\
.00 \\
.00 \\
2.54\end{array}$ & $\begin{array}{l}.00 \\
.00 \\
.00 \\
.00 \\
.00\end{array}$ & $\begin{array}{l}.00 \\
.00 \\
.00 \\
.00 \\
.00\end{array}$ & $\begin{array}{r}.00 \\
2.29 \\
.00 \\
.00 \\
.00\end{array}$ & $\begin{array}{l}.00 \\
.00 \\
.00 \\
.00 \\
.00\end{array}$ & $\begin{array}{r}4.06 \\
3.56 \\
.51 \\
.00 \\
1.27\end{array}$ & $\begin{array}{r}.00 \\
.00 \\
.00 \\
2.29 \\
3.56\end{array}$ \\
\hline $\begin{array}{r}6 \\
7 \\
8 \\
9 \\
10\end{array}$ & $\begin{array}{l}.00 \\
.00 \\
.00 \\
.00 \\
.00\end{array}$ & $\begin{array}{l}.00 \\
.00 \\
.51 \\
.00 \\
.00\end{array}$ & $\begin{array}{l}.00 \\
.00 \\
.00 \\
.00 \\
.00\end{array}$ & $\begin{array}{r}10.16 \\
.00 \\
.00 \\
.00 \\
2.79\end{array}$ & $\begin{array}{l}.00 \\
.00 \\
.00 \\
.00 \\
.00\end{array}$ & $\begin{array}{l}.00 \\
.00 \\
.00 \\
.00 \\
.00\end{array}$ & $\begin{array}{l}.00 \\
.00 \\
.00 \\
.00 \\
.00\end{array}$ & $\begin{array}{l}.00 \\
.00 \\
.00 \\
.00 \\
.00\end{array}$ & $\begin{array}{r}.00 \\
.00 \\
.00 \\
.00 \\
1.52\end{array}$ & $\begin{array}{r}.00 \\
.00 \\
1.52 \\
.00 \\
.00\end{array}$ & $\begin{array}{r}8.64 \\
.00 \\
.00 \\
1.52 \\
1.27\end{array}$ & $\begin{array}{l}.00 \\
.00 \\
.00 \\
.00 \\
.00\end{array}$ \\
\hline $\begin{array}{l}11 \\
12 \\
13 \\
14 \\
15\end{array}$ & $\begin{array}{l}.00 \\
.00 \\
.00 \\
.00 \\
.00\end{array}$ & $\begin{array}{l}.00 \\
.00 \\
.00 \\
.00 \\
.00\end{array}$ & $\begin{array}{r}.00 \\
8.38 \\
3.30 \\
.00 \\
2.54\end{array}$ & $\begin{array}{l}.00 \\
.00 \\
.00 \\
.00 \\
.00\end{array}$ & $\begin{array}{l}.00 \\
.00 \\
.00 \\
.00 \\
.00\end{array}$ & $\begin{array}{l}.00 \\
.00 \\
.00 \\
.00 \\
.25\end{array}$ & $\begin{array}{l}.00 \\
.00 \\
.00 \\
.00 \\
.00\end{array}$ & $\begin{array}{l}.00 \\
.00 \\
.00 \\
.00 \\
.00\end{array}$ & $\begin{array}{r}10.41 \\
1.27 \\
.51 \\
1.02 \\
.00\end{array}$ & $\begin{array}{r}.00 \\
8.38 \\
.00 \\
.00 \\
1.02\end{array}$ & $\begin{array}{r}.00 \\
.00 \\
.00 \\
6.86 \\
12.70\end{array}$ & $\begin{array}{l}.00 \\
.00 \\
.00 \\
.00 \\
.00\end{array}$ \\
\hline $\begin{array}{l}16 \\
17 \\
18 \\
19 \\
20\end{array}$ & $\begin{array}{r}.00 \\
.00 \\
.00 \\
8.64 \\
5.08\end{array}$ & $\begin{array}{l}.00 \\
.00 \\
.00 \\
.00 \\
.00\end{array}$ & $\begin{array}{r}13.72 \\
.00 \\
.00 \\
1.78 \\
.00\end{array}$ & $\begin{array}{l}.00 \\
.00 \\
.00 \\
.00 \\
.00\end{array}$ & $\begin{array}{r}.25 \\
1.27 \\
.00 \\
.00 \\
.00\end{array}$ & $\begin{array}{l}.00 \\
.51 \\
.00 \\
.00 \\
.00\end{array}$ & $\begin{array}{l}.00 \\
.00 \\
.00 \\
.00 \\
.00\end{array}$ & $\begin{array}{l}.00 \\
.00 \\
.00 \\
.00 \\
.00\end{array}$ & $\begin{array}{l}.00 \\
.00 \\
.00 \\
.00 \\
.00\end{array}$ & $\begin{array}{r}.00 \\
.00 \\
.76 \\
.00 \\
2.79\end{array}$ & $\begin{array}{l}.51 \\
.00 \\
.00 \\
.00 \\
.00\end{array}$ & $\begin{array}{l}.00 \\
.00 \\
.00 \\
.00 \\
.00\end{array}$ \\
\hline $\begin{array}{l}21 \\
22 \\
23 \\
24 \\
25\end{array}$ & $\begin{array}{l}.00 \\
.00 \\
.00 \\
.00 \\
.00\end{array}$ & $\begin{array}{l}.00 \\
.00 \\
.00 \\
.00 \\
.00\end{array}$ & $\begin{array}{l}.00 \\
.00 \\
.00 \\
.00 \\
.00\end{array}$ & $\begin{array}{l}.00 \\
.00 \\
.00 \\
.00 \\
.00\end{array}$ & $\begin{array}{l}.00 \\
.00 \\
.00 \\
.00 \\
.00\end{array}$ & $\begin{array}{r}.25 \\
1.78 \\
.00 \\
.00 \\
.00\end{array}$ & $\begin{array}{l}.00 \\
.00 \\
.00 \\
.00 \\
.00\end{array}$ & $\begin{array}{l}.00 \\
.00 \\
.00 \\
.00 \\
.00\end{array}$ & $\begin{array}{r}.00 \\
.00 \\
.00 \\
4.06 \\
.00\end{array}$ & $\begin{array}{r}.00 \\
.00 \\
.25 \\
1.02 \\
1.27\end{array}$ & $\begin{array}{r}.00 \\
.00 \\
.00 \\
.51 \\
3.05\end{array}$ & $\begin{array}{l}.00 \\
.00 \\
.00 \\
.00 \\
.00\end{array}$ \\
\hline $\begin{array}{l}26 \\
27 \\
28 \\
29 \\
30 \\
31\end{array}$ & $\begin{array}{l}.00 \\
.00 \\
.00 \\
.00 \\
.00 \\
.00\end{array}$ & $\begin{array}{r}1.27 \\
.76 \\
.00 \\
.00 \\
.00 \\
\ldots .-\end{array}$ & $\begin{array}{r}.00 \\
.00 \\
3.30 \\
.00 \\
.00 \\
.00\end{array}$ & $\begin{array}{l}.00 \\
.00 \\
.00 \\
.00 \\
.00 \\
.00\end{array}$ & $\begin{array}{r}.00 \\
.00 \\
5.33 \\
\ldots \\
\ldots \\
\ldots\end{array}$ & $\begin{array}{r}2.29 \\
.25 \\
2.03 \\
.00 \\
.00 \\
.00\end{array}$ & $\begin{array}{l}.51 \\
.00 \\
.00 \\
.00 \\
.00 \\
. . .\end{array}$ & $\begin{array}{l}.00 \\
.00 \\
.00 \\
.00 \\
.00 \\
3.30\end{array}$ & $\begin{array}{r}.00 \\
.00 \\
.00 \\
1.52 \\
.00 \\
. .\end{array}$ & $\begin{array}{l}.00 \\
.00 \\
.00 \\
.00 \\
.00 \\
4.57\end{array}$ & $\begin{array}{r}7.37 \\
.00 \\
.00 \\
.76 \\
.00 \\
.00\end{array}$ & $\begin{array}{l}.00 \\
.00 \\
.00 \\
.00 \\
.00 \\
\cdots\end{array}$ \\
\hline
\end{tabular}


PRECIPITATION DATA-Cont inued

09394500 LITTLE COLORADO RIVER AT WOOORUFF, AZ

RAINFALL ACCUMLATED (MILLIMETERS), WATER YEAR JUME 1989 TO SEPTEMBER 1989

DAILY SUM VALLUES

\begin{tabular}{|c|c|c|c|c|c|c|c|c|c|c|c|c|}
\hline DAY & OCT & NOV & DEC & JAN & FEB & MAR & APR & Mur & JUN & JUL & AUG & SEP \\
\hline $\begin{array}{l}1 \\
2 \\
3 \\
4 \\
5\end{array}$ & $\begin{array}{l}\ldots- \\
\ldots- \\
\ldots- \\
\ldots- \\
\ldots\end{array}$ & $\begin{array}{l}\ldots . \\
\ldots \\
\ldots \\
\cdots \\
\cdots\end{array}$ & $\begin{array}{l}\ldots- \\
\ldots- \\
\ldots- \\
\ldots \\
\ldots\end{array}$ & $\begin{array}{l}\ldots \\
\ldots \\
\ldots \\
\ldots \\
\cdots\end{array}$ & $\begin{array}{l}\ldots \\
\ldots \\
\ldots- \\
\cdots \\
\cdots\end{array}$ & $\begin{array}{l}\ldots \\
\ldots \\
\ldots \\
\ldots \\
\ldots\end{array}$ & $\begin{array}{l}\ldots \\
\ldots \\
\ldots- \\
\ldots- \\
\ldots\end{array}$ & $\begin{array}{l}\ldots \\
\ldots \\
\ldots \\
\ldots \\
\cdots\end{array}$ & $\begin{array}{l}.00 \\
.00 \\
.00 \\
.00 \\
.00\end{array}$ & $\begin{array}{l}.00 \\
.00 \\
.00 \\
.00 \\
.00\end{array}$ & $\begin{array}{r}.00 \\
.00 \\
2.29 \\
.25 \\
.00\end{array}$ & $\begin{array}{r}.00 \\
.00 \\
4.06 \\
1.02 \\
.00\end{array}$ \\
\hline $\begin{array}{r}6 \\
7 \\
8 \\
9 \\
10\end{array}$ & $\begin{array}{l}\ldots \\
\ldots \\
\ldots- \\
\ldots- \\
\ldots\end{array}$ & $\begin{array}{l}\ldots- \\
\ldots- \\
\ldots- \\
\ldots- \\
\ldots\end{array}$ & $\begin{array}{l}\ldots . \\
\ldots \\
\ldots- \\
\ldots-\end{array}$ & $\begin{array}{l}\ldots- \\
\ldots- \\
\ldots- \\
\cdots \\
-\ldots\end{array}$ & $\begin{array}{l}\ldots \\
\ldots \\
\ldots \\
\ldots \\
\ldots\end{array}$ & $\begin{array}{l}\ldots \\
\ldots \\
\ldots- \\
\ldots-\end{array}$ & $\begin{array}{l}\ldots \\
\ldots \\
\ldots \\
\ldots \\
\ldots\end{array}$ & $\begin{array}{l}\ldots \\
\ldots- \\
\ldots- \\
\ldots \\
\ldots\end{array}$ & $\begin{array}{l}.00 \\
.00 \\
.00 \\
.00 \\
.00\end{array}$ & $\begin{array}{r}.00 \\
.00 \\
.00 \\
4.32 \\
1.27\end{array}$ & $\begin{array}{l}.00 \\
.00 \\
.00 \\
.51 \\
.00\end{array}$ & $\begin{array}{l}.00 \\
.00 \\
.00 \\
.00 \\
.00\end{array}$ \\
\hline $\begin{array}{l}11 \\
12 \\
13 \\
14 \\
15\end{array}$ & $\begin{array}{l}\ldots- \\
\ldots- \\
\ldots- \\
\ldots-\end{array}$ & $\begin{array}{l}\ldots \\
\ldots- \\
\ldots \\
\ldots \\
\cdots\end{array}$ & $\begin{array}{l}\ldots- \\
\ldots- \\
\ldots \\
\ldots \\
\ldots-\end{array}$ & $\begin{array}{l}\ldots- \\
\ldots- \\
\ldots- \\
\ldots- \\
\ldots-\end{array}$ & $\begin{array}{l}\ldots \\
\ldots \\
\ldots- \\
\ldots- \\
\ldots-\end{array}$ & $\begin{array}{l}\ldots- \\
\ldots- \\
\ldots \\
\ldots- \\
\ldots-\end{array}$ & $\begin{array}{l}\ldots- \\
\ldots- \\
\ldots \\
\ldots \\
\ldots-\end{array}$ & $\begin{array}{l}\ldots \\
\ldots \\
\ldots \\
\ldots \\
\ldots\end{array}$ & $\begin{array}{l}.00 \\
.51 \\
.00 \\
.00 \\
.00\end{array}$ & $\begin{array}{l}.00 \\
.00 \\
.00 \\
.00 \\
.00\end{array}$ & $\begin{array}{l}.25 \\
.00 \\
.00 \\
.00 \\
.00\end{array}$ & $\begin{array}{l}.00 \\
.00 \\
.00 \\
.00 \\
.00\end{array}$ \\
\hline $\begin{array}{l}16 \\
17 \\
18 \\
19 \\
20\end{array}$ & $\begin{array}{l}\ldots- \\
\ldots- \\
\ldots \\
\ldots \\
\ldots\end{array}$ & $\begin{array}{l}\ldots- \\
\ldots . \\
-.- \\
\ldots\end{array}$ & $\begin{array}{l}\ldots . \\
\ldots- \\
\ldots- \\
\ldots-\end{array}$ & $\begin{array}{l}\ldots- \\
\ldots \\
\ldots \\
\ldots- \\
\ldots\end{array}$ & $\begin{array}{l}\ldots . \\
\ldots \\
-- \\
\cdots- \\
-.-\end{array}$ & $\begin{array}{l}\ldots- \\
\ldots \\
\ldots- \\
\ldots \\
\ldots\end{array}$ & $\begin{array}{l}\ldots- \\
\ldots- \\
\ldots- \\
\ldots-\end{array}$ & $\begin{array}{l}\ldots \\
\ldots \\
\ldots- \\
\ldots- \\
\ldots\end{array}$ & $\begin{array}{l}.00 \\
.00 \\
.00 \\
.00 \\
.00\end{array}$ & $\begin{array}{r}4.06 \\
.00 \\
.00 \\
.00 \\
.00\end{array}$ & $\begin{array}{r}.00 \\
.00 \\
28.45 \\
8.13 \\
.00\end{array}$ & $\begin{array}{l}.00 \\
.00 \\
.00 \\
.00 \\
.00\end{array}$ \\
\hline $\begin{array}{l}21 \\
22 \\
23 \\
24 \\
25\end{array}$ & $\begin{array}{l}\ldots- \\
\ldots \\
\ldots- \\
\ldots- \\
\ldots-\end{array}$ & $\begin{array}{l}\ldots- \\
\ldots- \\
\cdots \\
\cdots \\
-.-\end{array}$ & $\begin{array}{l}\ldots- \\
\ldots- \\
\ldots- \\
\cdots \\
-\end{array}$ & $\begin{array}{l}\ldots- \\
\ldots- \\
\ldots- \\
\ldots- \\
\ldots-\end{array}$ & $\begin{array}{l}\ldots- \\
\ldots- \\
\ldots- \\
\cdots \\
--\end{array}$ & $\begin{array}{l}\ldots- \\
\ldots- \\
\ldots- \\
-\ldots \\
-.-\end{array}$ & $\begin{array}{l}\ldots- \\
\ldots- \\
\ldots- \\
\cdots \\
\cdots\end{array}$ & $\begin{array}{l}\ldots- \\
\ldots- \\
\ldots- \\
\ldots- \\
\cdots\end{array}$ & $\begin{array}{l}.00 \\
.00 \\
.00 \\
.00 \\
.00\end{array}$ & $\begin{array}{r}.76 \\
.76 \\
.25 \\
1.27 \\
3.05\end{array}$ & $\begin{array}{l}.00 \\
.00 \\
.00 \\
.00 \\
.00\end{array}$ & $\begin{array}{l}.00 \\
.00 \\
.00 \\
.00 \\
.00\end{array}$ \\
\hline $\begin{array}{l}26 \\
27 \\
28 \\
29 \\
30 \\
31\end{array}$ & $\begin{array}{l}\ldots \\
\ldots \\
\ldots \\
\cdots \\
\cdots \\
\ldots\end{array}$ & $\begin{array}{l}\ldots- \\
\ldots- \\
\ldots \\
\cdots \\
\cdots\end{array}$ & $\begin{array}{l}\ldots \\
\ldots \\
\ldots \\
\ldots \\
\cdots \\
\cdots\end{array}$ & $\begin{array}{l}\cdots \\
\cdots \\
\cdots \\
\cdots \\
\cdots \\
\cdots\end{array}$ & $\begin{array}{c}\cdots- \\
\cdots \\
\ldots \\
\ldots \\
\ldots \\
\ldots\end{array}$ & $\begin{array}{l}\ldots \\
\ldots \\
\cdots \\
\cdots \\
\cdots \\
\cdots\end{array}$ & $\begin{array}{l}\cdots \\
\cdots \\
\cdots \\
\cdots \\
\cdots \\
\cdots\end{array}$ & $\begin{array}{l}\cdots \\
\cdots \\
\cdots \\
\cdots \\
\cdots \\
\cdots\end{array}$ & $\begin{array}{l}.00 \\
.00 \\
.00 \\
.00 \\
.00 \\
. .\end{array}$ & $\begin{array}{r}2.79 \\
.00 \\
.00 \\
.00 \\
.00 \\
5.33\end{array}$ & $\begin{array}{l}.00 \\
.00 \\
.00 \\
.00 \\
.00 \\
.00\end{array}$ & $\begin{array}{l}.00 \\
.00 \\
.00 \\
.00 \\
.25 \\
\ldots\end{array}$ \\
\hline
\end{tabular}


PRECIPITATION DATA-Continued

09394500 LITTLE COLORADO RIVER AT WOOORUFF, AZ-Continued

RAINFALL ACCUMLATED (MILLIMETERS), WATER YEAR OCTOBER 1989 TO SEPTEMBER 1990 DAILY SUA VALUES

\begin{tabular}{|c|c|c|c|c|c|c|c|c|c|c|c|c|}
\hline DAY & OCT & NOV & DEC & JAN & FEB & MAR & APR & MAY & JUN & JUL & AUG & SEP \\
\hline $\begin{array}{l}1 \\
2 \\
3 \\
4 \\
5\end{array}$ & $\begin{array}{r}.00 \\
.00 \\
.00 \\
5.33 \\
1.02\end{array}$ & $\begin{array}{l}.00 \\
.00 \\
.00 \\
.00 \\
.00\end{array}$ & $\begin{array}{l}.00 \\
.00 \\
.00 \\
.00 \\
.00\end{array}$ & $\begin{array}{l}.00 \\
.00 \\
.00 \\
.00 \\
.00\end{array}$ & $\begin{array}{r}.00 \\
.00 \\
3.05 \\
.51 \\
1.02\end{array}$ & $\begin{array}{l}.00 \\
.00 \\
.00 \\
.00 \\
.00\end{array}$ & $\begin{array}{l}.00 \\
.00 \\
.00 \\
.00 \\
.00\end{array}$ & $\begin{array}{r}1.52 \\
2.03 \\
.00 \\
.00 \\
.00\end{array}$ & $\begin{array}{l}.00 \\
.00 \\
.00 \\
.00 \\
.00\end{array}$ & $\begin{array}{r}.00 \\
13.97 \\
.00 \\
.00 \\
.00\end{array}$ & $\begin{array}{l}.00 \\
.00 \\
.00 \\
.00 \\
.00\end{array}$ & $\begin{array}{r}9.65 \\
.00 \\
.00 \\
1.27 \\
.00\end{array}$ \\
\hline $\begin{array}{r}6 \\
7 \\
8 \\
9 \\
10\end{array}$ & $\begin{array}{l}.00 \\
.00 \\
.00 \\
.00 \\
.00\end{array}$ & $\begin{array}{l}.00 \\
.00 \\
.00 \\
.00 \\
.00\end{array}$ & $\begin{array}{l}.00 \\
.00 \\
.00 \\
.00 \\
.00\end{array}$ & $\begin{array}{l}.00 \\
.00 \\
.00 \\
.00 \\
.00\end{array}$ & $\begin{array}{l}.00 \\
.00 \\
.00 \\
.00 \\
.00\end{array}$ & $\begin{array}{l}.00 \\
.00 \\
.00 \\
.00 \\
.25\end{array}$ & $\begin{array}{r}.00 \\
2.79 \\
.00 \\
.00 \\
.00\end{array}$ & $\begin{array}{l}.00 \\
.00 \\
.00 \\
.00 \\
.00\end{array}$ & $\begin{array}{r}.00 \\
.00 \\
.00 \\
.00 \\
3.30\end{array}$ & $\begin{array}{r}1.78 \\
13.21 \\
6.60 \\
.76 \\
.51\end{array}$ & $\begin{array}{r}.00 \\
.00 \\
3.30 \\
1.52 \\
.00\end{array}$ & $\begin{array}{l}.00 \\
.00 \\
.00 \\
.00 \\
.00\end{array}$ \\
\hline $\begin{array}{l}11 \\
12 \\
13 \\
14 \\
15\end{array}$ & $\begin{array}{l}.00 \\
.00 \\
.00 \\
.00 \\
.00\end{array}$ & $\begin{array}{l}.00 \\
.00 \\
.00 \\
.00 \\
.00\end{array}$ & $\begin{array}{l}.00 \\
.00 \\
.00 \\
.00 \\
.00\end{array}$ & $\begin{array}{l}.00 \\
.00 \\
.00 \\
.51 \\
.00\end{array}$ & $\begin{array}{l}.00 \\
.00 \\
.00 \\
.00 \\
.00\end{array}$ & $\begin{array}{r}.25 \\
.00 \\
1.27 \\
.25 \\
.00\end{array}$ & $\begin{array}{l}.00 \\
.00 \\
.00 \\
.00 \\
.00\end{array}$ & $\begin{array}{l}.00 \\
.00 \\
.00 \\
.00 \\
.00\end{array}$ & $\begin{array}{l}.00 \\
.00 \\
.00 \\
.00 \\
.00\end{array}$ & $\begin{array}{r}.00 \\
.00 \\
.00 \\
4.06 \\
.00\end{array}$ & $\begin{array}{r}.00 \\
2.79 \\
.76 \\
7.62 \\
8.64\end{array}$ & $\begin{array}{l}.00 \\
.00 \\
.00 \\
.00 \\
.00\end{array}$ \\
\hline $\begin{array}{l}16 \\
17 \\
18 \\
19 \\
20\end{array}$ & $\begin{array}{l}.00 \\
.00 \\
.00 \\
.00 \\
.25\end{array}$ & $\begin{array}{l}.00 \\
.00 \\
.00 \\
.00 \\
.25\end{array}$ & $\begin{array}{l}.00 \\
.00 \\
.00 \\
.00 \\
.00\end{array}$ & $\begin{array}{l}.00 \\
.00 \\
.00 \\
.00 \\
.00\end{array}$ & $\begin{array}{r}.00 \\
.00 \\
.00 \\
1.27 \\
.25\end{array}$ & $\begin{array}{l}.00 \\
.00 \\
.00 \\
.00 \\
.00\end{array}$ & $\begin{array}{l}.00 \\
.00 \\
.00 \\
.00 \\
.00\end{array}$ & $\begin{array}{l}.00 \\
.00 \\
.00 \\
.00 \\
.00\end{array}$ & $\begin{array}{l}.00 \\
.00 \\
.00 \\
.00 \\
.00\end{array}$ & $\begin{array}{l}.00 \\
.76 \\
.00 \\
.00 \\
.51\end{array}$ & $\begin{array}{r}1.27 \\
.00 \\
.00 \\
.00 \\
.00\end{array}$ & $\begin{array}{r}1.52 \\
.51 \\
6.35 \\
.76 \\
22.86\end{array}$ \\
\hline $\begin{array}{l}21 \\
22 \\
23 \\
24 \\
25\end{array}$ & $\begin{array}{r}2.03 \\
.00 \\
.00 \\
.00 \\
.00\end{array}$ & $\begin{array}{l}.00 \\
.00 \\
.00 \\
.00 \\
.00\end{array}$ & $\begin{array}{l}.00 \\
.00 \\
.00 \\
.00 \\
.00\end{array}$ & $\begin{array}{l}.00 \\
.00 \\
.00 \\
.00 \\
.00\end{array}$ & $\begin{array}{l}.00 \\
.00 \\
.00 \\
.00 \\
.00\end{array}$ & $\begin{array}{l}.00 \\
.00 \\
.00 \\
.00 \\
.00\end{array}$ & $\begin{array}{r}.00 \\
.00 \\
.00 \\
6.35 \\
.25\end{array}$ & $\begin{array}{l}.00 \\
.00 \\
.00 \\
.00 \\
.00\end{array}$ & $\begin{array}{l}.00 \\
.00 \\
.00 \\
.00 \\
.00\end{array}$ & $\begin{array}{l}.00 \\
.00 \\
.76 \\
.00 \\
.00\end{array}$ & $\begin{array}{l}.00 \\
.00 \\
.00 \\
.00 \\
.00\end{array}$ & $\begin{array}{r}1.02 \\
4.57 \\
.51 \\
.00 \\
.00\end{array}$ \\
\hline $\begin{array}{l}26 \\
27 \\
28 \\
29 \\
30 \\
31\end{array}$ & $\begin{array}{l}.00 \\
.00 \\
.00 \\
.00 \\
.00 \\
.00\end{array}$ & $\begin{array}{l}.00 \\
.00 \\
.00 \\
.00 \\
.00 \\
. .\end{array}$ & $\begin{array}{l}.00 \\
.00 \\
.00 \\
7.62 \\
.00 \\
.00\end{array}$ & $\begin{array}{l}.00 \\
.00 \\
.00 \\
.00 \\
.00 \\
.00\end{array}$ & $\begin{array}{l}.00 \\
.00 \\
.00 \\
. . \\
\ldots . \\
\ldots .\end{array}$ & $\begin{array}{l}.00 \\
.00 \\
.00 \\
.00 \\
.25 \\
.00\end{array}$ & $\begin{array}{l}.00 \\
.00 \\
.00 \\
.00 \\
.00 \\
. . .\end{array}$ & $\begin{array}{r}.00 \\
.00 \\
.00 \\
1.02 \\
.00 \\
.00\end{array}$ & $\begin{array}{l}.00 \\
.00 \\
.00 \\
.00 \\
.00 \\
\cdots\end{array}$ & $\begin{array}{l}.00 \\
.00 \\
.00 \\
.00 \\
.00 \\
.00\end{array}$ & $\begin{array}{r}.00 \\
.00 \\
.00 \\
.00 \\
4.06 \\
.25\end{array}$ & $\begin{array}{l}.00 \\
.00 \\
.00 \\
.00 \\
.00 \\
. . .\end{array}$ \\
\hline
\end{tabular}


09394500 LITTLE COLORADO RIVER AT WOOORUFF, AZ-Continued

RAINFALL ACCUMULATED (MILLIMETERS), WATER YEAR OCTOBER 1990 TO SEPTEMBER 1991

DAILY SUM VALUES

\begin{tabular}{|c|c|c|c|c|c|c|c|c|c|c|c|c|}
\hline DAY & OCT & NOV & DEC & JAN & FEB & MAR & APR & maY & JUN & JUL & AUG & SEP \\
\hline $\begin{array}{l}1 \\
2 \\
3 \\
4 \\
5\end{array}$ & $\begin{array}{r}1.27 \\
3.05 \\
.00 \\
.00 \\
.00\end{array}$ & $\begin{array}{r}.00 \\
19.81 \\
5.08 \\
.00 \\
.00\end{array}$ & $\begin{array}{l}.00 \\
.00 \\
.00 \\
.00 \\
.00\end{array}$ & $\begin{array}{r}.00 \\
.00 \\
.76 \\
.25 \\
8.13\end{array}$ & $\begin{array}{l}.00 \\
.00 \\
.00 \\
.00 \\
.00\end{array}$ & $\begin{array}{r}.76 \\
4.06 \\
.00 \\
.00 \\
.00\end{array}$ & $\begin{array}{l}.00 \\
.00 \\
.00 \\
.00 \\
.00\end{array}$ & $\begin{array}{l}.00 \\
.00 \\
.00 \\
.00 \\
.00\end{array}$ & $\begin{array}{r}2.54 \\
.25 \\
.00 \\
.00 \\
.00\end{array}$ & $\begin{array}{l}.00 \\
.00 \\
.00 \\
.00 \\
.00\end{array}$ & $\begin{array}{r}.00 \\
.00 \\
.76 \\
3.05 \\
.00\end{array}$ & $\begin{array}{r}.00 \\
.00 \\
.00 \\
.00 \\
7.11\end{array}$ \\
\hline $\begin{array}{r}6 \\
7 \\
8 \\
9 \\
10\end{array}$ & $\begin{array}{l}.00 \\
.00 \\
.00 \\
.00 \\
.00\end{array}$ & $\begin{array}{r}.00 \\
4.83 \\
.00 \\
.00 \\
.00\end{array}$ & $\begin{array}{l}.00 \\
.00 \\
.00 \\
.00 \\
.00\end{array}$ & $\begin{array}{r}12.95 \\
.00 \\
.00 \\
.00 \\
.00\end{array}$ & $\begin{array}{l}.00 \\
.00 \\
.00 \\
.00 \\
.00\end{array}$ & $\begin{array}{l}.00 \\
.00 \\
.00 \\
.00 \\
.00\end{array}$ & $\begin{array}{l}.00 \\
.00 \\
.00 \\
.00 \\
.00\end{array}$ & $\begin{array}{l}.00 \\
.00 \\
.00 \\
.00 \\
.00\end{array}$ & $\begin{array}{l}.00 \\
.00 \\
.00 \\
.00 \\
.00\end{array}$ & $\begin{array}{r}2.29 \\
.00 \\
2.54 \\
.00 \\
.00\end{array}$ & $\begin{array}{l}.25 \\
.00 \\
.00 \\
.25 \\
.76\end{array}$ & $\begin{array}{l}.25 \\
.00 \\
.00 \\
.00 \\
.00\end{array}$ \\
\hline $\begin{array}{l}11 \\
12 \\
13 \\
14 \\
15\end{array}$ & $\begin{array}{l}.00 \\
.00 \\
.00 \\
.00 \\
.00\end{array}$ & $\begin{array}{l}.00 \\
.00 \\
.00 \\
.00 \\
.00\end{array}$ & $\begin{array}{r}.00 \\
3.81 \\
.25 \\
.00 \\
4.57\end{array}$ & $\begin{array}{l}.00 \\
.00 \\
.00 \\
.00 \\
.00\end{array}$ & $\begin{array}{l}.00 \\
.00 \\
.00 \\
.00 \\
.00\end{array}$ & $\begin{array}{l}.00 \\
.00 \\
.00 \\
.00 \\
.00\end{array}$ & $\begin{array}{l}.00 \\
.00 \\
.00 \\
.00 \\
.00\end{array}$ & $\begin{array}{l}.00 \\
.00 \\
.00 \\
.00 \\
.00\end{array}$ & $\begin{array}{l}2.79 \\
1.02 \\
1.78 \\
.00 \\
.00\end{array}$ & $\begin{array}{l}.00 \\
.00 \\
.00 \\
.00 \\
.00\end{array}$ & $\begin{array}{l}.25 \\
.00 \\
.00 \\
.00 \\
.00\end{array}$ & $\begin{array}{l}.00 \\
.00 \\
.00 \\
.00 \\
.00\end{array}$ \\
\hline $\begin{array}{l}16 \\
17 \\
18 \\
19 \\
20\end{array}$ & $\begin{array}{r}.00 \\
.00 \\
.00 \\
.00 \\
4.32\end{array}$ & $\begin{array}{l}.00 \\
.00 \\
.00 \\
.00 \\
.00\end{array}$ & $\begin{array}{r}4.57 \\
.00 \\
.00 \\
.00 \\
1.78\end{array}$ & $\begin{array}{l}.00 \\
.00 \\
.00 \\
.00 \\
.00\end{array}$ & $\begin{array}{l}.00 \\
.51 \\
.00 \\
.00 \\
.00\end{array}$ & $\begin{array}{r}.00 \\
.00 \\
.00 \\
2.29 \\
3.05\end{array}$ & $\begin{array}{l}.00 \\
.00 \\
.00 \\
.00 \\
.00\end{array}$ & $\begin{array}{l}.00 \\
.00 \\
.00 \\
.00 \\
.00\end{array}$ & $\begin{array}{l}.00 \\
.00 \\
.00 \\
.00 \\
.00\end{array}$ & $\begin{array}{r}.00 \\
.00 \\
.00 \\
.00 \\
5.08\end{array}$ & $\begin{array}{l}.00 \\
.25 \\
.00 \\
.00 \\
.00\end{array}$ & $\begin{array}{l}.00 \\
.00 \\
.00 \\
.00 \\
.00\end{array}$ \\
\hline $\begin{array}{l}21 \\
22 \\
23 \\
24 \\
25\end{array}$ & $\begin{array}{l}.00 \\
.00 \\
.00 \\
.00 \\
.00\end{array}$ & $\begin{array}{l}.00 \\
.00 \\
.00 \\
.00 \\
.00\end{array}$ & $\begin{array}{l}.00 \\
.00 \\
.00 \\
.00 \\
.00\end{array}$ & $\begin{array}{l}.25 \\
.00 \\
.00 \\
.00 \\
.00\end{array}$ & $\begin{array}{l}.00 \\
.00 \\
.00 \\
.00 \\
.00\end{array}$ & $\begin{array}{r}1.52 \\
.00 \\
.00 \\
.00 \\
.00\end{array}$ & $\begin{array}{l}.00 \\
.00 \\
.00 \\
.00 \\
.00\end{array}$ & $\begin{array}{l}.00 \\
.00 \\
.00 \\
.00 \\
.00\end{array}$ & $\begin{array}{l}.00 \\
.00 \\
.00 \\
.00 \\
.00\end{array}$ & $\begin{array}{l}1.27 \\
.00 \\
.00 \\
.76 \\
.00\end{array}$ & $\begin{array}{r}.00 \\
.00 \\
5.59 \\
.25 \\
.00\end{array}$ & $\begin{array}{r}.00 \\
3.56 \\
2.29 \\
.00 \\
.00\end{array}$ \\
\hline $\begin{array}{l}26 \\
27 \\
28 \\
29 \\
30 \\
31\end{array}$ & $\begin{array}{l}.00 \\
.00 \\
.00 \\
.00 \\
.00 \\
.00\end{array}$ & $\begin{array}{r}4.83 \\
.00 \\
.00 \\
.00 \\
.00 \\
\ldots .\end{array}$ & $\begin{array}{r}.00 \\
.00 \\
6.35 \\
.00 \\
.00 \\
.00\end{array}$ & $\begin{array}{l}.00 \\
.00 \\
.00 \\
.00 \\
.00 \\
.00\end{array}$ & $\begin{array}{r}.00 \\
.00 \\
6.60 \\
\ldots . \\
\ldots . \\
\ldots\end{array}$ & $\begin{array}{r}4.06 \\
.00 \\
.25 \\
.00 \\
.00 \\
.00\end{array}$ & $\begin{array}{l}.00 \\
.00 \\
.00 \\
.00 \\
.00 \\
\ldots . .\end{array}$ & $\begin{array}{l}.00 \\
.00 \\
.00 \\
.00 \\
.00 \\
6.35\end{array}$ & $\begin{array}{l}.00 \\
.00 \\
.00 \\
.00 \\
.00 \\
. . .\end{array}$ & $\begin{array}{l}.00 \\
.00 \\
.00 \\
.00 \\
.00 \\
.00\end{array}$ & $\begin{array}{r}.00 \\
.00 \\
.00 \\
.00 \\
2.03 \\
.00\end{array}$ & $\begin{array}{l}.00 \\
.00 \\
.00 \\
.00 \\
.00 \\
\ldots . .\end{array}$ \\
\hline
\end{tabular}


PRECIPITATION DATA-Continued

09397300 LITTLE COLORADO RIVER MEAR JOSEPH CITY, AZ

RAINFALL ACCUMLATED (MILLIMETERS), MATER YEAR OCTOBER 1988 TO SEPTEMBER 1989

DAILY SUM VALUES

\begin{tabular}{|c|c|c|c|c|c|c|c|c|c|c|c|c|}
\hline DAY & OCT & NOW & DEC & JAN & FEB & MAR & APR & MAY & JUN & JUL & AUG & SEP \\
\hline $\begin{array}{l}1 \\
2 \\
3 \\
6 \\
5\end{array}$ & $\begin{array}{l}.00 \\
.00 \\
.00 \\
.25 \\
.00\end{array}$ & $\begin{array}{l}.00 \\
.00 \\
.00 \\
.00 \\
.00\end{array}$ & $\begin{array}{l}.00 \\
.00 \\
.00 \\
.00 \\
.00\end{array}$ & $\begin{array}{r}.00 \\
.00 \\
.00 \\
8.13 \\
.00\end{array}$ & $\begin{array}{l}.00 \\
.00 \\
.00 \\
.00 \\
.00\end{array}$ & $\begin{array}{l}\ldots \\
\ldots \\
\ldots \\
\ldots\end{array}$ & $\begin{array}{l}\ldots \\
\ldots \\
\ldots \\
\ldots \\
\ldots\end{array}$ & $\begin{array}{l}.00 \\
.00 \\
.00 \\
.00 \\
.00\end{array}$ & $\begin{array}{l}.00 \\
.00 \\
.00 \\
.00 \\
.00\end{array}$ & $\begin{array}{l}.00 \\
.00 \\
.00 \\
.00 \\
.00\end{array}$ & $\begin{array}{r}19.05 \\
.00 \\
26.42 \\
.00 \\
.00\end{array}$ & $\begin{array}{l}.00 \\
.00 \\
.00 \\
.51 \\
.00\end{array}$ \\
\hline $\begin{array}{r}6 \\
7 \\
8 \\
9 \\
10\end{array}$ & $\begin{array}{l}.00 \\
.00 \\
.00 \\
.00 \\
.00\end{array}$ & $\begin{array}{l}.00 \\
.00 \\
.00 \\
.00 \\
.00\end{array}$ & $\begin{array}{l}.00 \\
.00 \\
.00 \\
.00 \\
.00\end{array}$ & $\begin{array}{l}.00 \\
.00 \\
.00 \\
.00 \\
.00\end{array}$ & $\begin{array}{l}.00 \\
.00 \\
.00 \\
.25 \\
.00\end{array}$ & $\begin{array}{l}\ldots \\
\ldots \\
\ldots- \\
\ldots- \\
\ldots\end{array}$ & $\begin{array}{l}\ldots \\
\ldots \\
\ldots \\
\ldots \\
\ldots\end{array}$ & $\begin{array}{l}.00 \\
.00 \\
.00 \\
.00 \\
.00\end{array}$ & $\begin{array}{l}.00 \\
.00 \\
.00 \\
.00 \\
.00\end{array}$ & $\begin{array}{l}.00 \\
.00 \\
.00 \\
.00 \\
.76\end{array}$ & $\begin{array}{l}.00 \\
.00 \\
.00 \\
.76 \\
.00\end{array}$ & $\begin{array}{l}.00 \\
.00 \\
.00 \\
.00 \\
.00\end{array}$ \\
\hline $\begin{array}{l}11 \\
12 \\
13 \\
14 \\
15\end{array}$ & $\begin{array}{r}.00 \\
.00 \\
.00 \\
.00 \\
13.97\end{array}$ & $\begin{array}{r}.00 \\
.00 \\
.00 \\
2.54 \\
.00\end{array}$ & $\begin{array}{l}.00 \\
.00 \\
.00 \\
.00 \\
.00\end{array}$ & $\begin{array}{l}.00 \\
.00 \\
.00 \\
.00 \\
.00\end{array}$ & $\begin{array}{l}.00 \\
.00 \\
.25 \\
.00 \\
.00\end{array}$ & $\begin{array}{l}\ldots \\
\ldots \\
\ldots \\
\ldots \\
\ldots\end{array}$ & $\begin{array}{l}\ldots \\
\ldots \\
\ldots \\
\ldots \\
\ldots\end{array}$ & $\begin{array}{l}.00 \\
1.52 \\
1.02 \\
.00 \\
.00\end{array}$ & $\begin{array}{r}.00 \\
2.29 \\
.00 \\
.00 \\
.00\end{array}$ & $\begin{array}{r}16.26 \\
.00 \\
.00 \\
.00 \\
.00\end{array}$ & $\begin{array}{l}.00 \\
.00 \\
.00 \\
.00 \\
.00\end{array}$ & $\begin{array}{l}.00 \\
.00 \\
.00 \\
.00 \\
.00\end{array}$ \\
\hline $\begin{array}{l}16 \\
17 \\
18 \\
19 \\
20\end{array}$ & $\begin{array}{l}.00 \\
.00 \\
.00 \\
.00 \\
.00\end{array}$ & $\begin{array}{r}.00 \\
.00 \\
3.56 \\
.00 \\
.25\end{array}$ & $\begin{array}{l}.00 \\
.00 \\
.00 \\
.00 \\
.00\end{array}$ & $\begin{array}{l}.00 \\
.00 \\
.00 \\
.00 \\
.00\end{array}$ & $\begin{array}{l}.00 \\
.00 \\
.00 \\
.00 \\
.00\end{array}$ & $\begin{array}{l}\ldots \\
\ldots \\
\ldots \\
\ldots \\
\ldots\end{array}$ & $\begin{array}{l}\ldots \\
\ldots \\
\ldots \\
\ldots \\
\ldots\end{array}$ & $\begin{array}{l}.00 \\
.00 \\
.00 \\
.00 \\
.00\end{array}$ & $\begin{array}{l}.00 \\
.00 \\
.00 \\
.00 \\
.00\end{array}$ & $\begin{array}{l}.00 \\
.00 \\
.00 \\
.00 \\
.25\end{array}$ & $\begin{array}{r}.00 \\
1.02 \\
8.38 \\
.51 \\
.25\end{array}$ & $\begin{array}{l}.00 \\
.00 \\
.00 \\
.00 \\
.00\end{array}$ \\
\hline $\begin{array}{l}21 \\
22 \\
23 \\
24 \\
25\end{array}$ & $\begin{array}{l}.00 \\
.00 \\
.00 \\
.00 \\
.00\end{array}$ & $\begin{array}{r}.00 \\
.00 \\
.00 \\
.76 \\
3.05\end{array}$ & $\begin{array}{l}.00 \\
.00 \\
.00 \\
.00 \\
.76\end{array}$ & $\begin{array}{l}.00 \\
.00 \\
.00 \\
.51 \\
.00\end{array}$ & $\begin{array}{l}.00 \\
.00 \\
.00 \\
.00 \\
.00\end{array}$ & $\begin{array}{l}\ldots \\
\ldots- \\
\ldots \\
\ldots\end{array}$ & $\begin{array}{l}.00 \\
.00 \\
.00 \\
.00\end{array}$ & $\begin{array}{l}.00 \\
.00 \\
.00 \\
.00 \\
.00\end{array}$ & $\begin{array}{l}.00 \\
.00 \\
.00 \\
.00 \\
.00\end{array}$ & $\begin{array}{r}1.27 \\
.76 \\
.25 \\
1.02 \\
16.26\end{array}$ & $\begin{array}{l}.00 \\
.00 \\
.00 \\
.00 \\
.00\end{array}$ & $\begin{array}{l}.00 \\
.00 \\
.00 \\
.00 \\
.00\end{array}$ \\
\hline $\begin{array}{l}26 \\
27 \\
28 \\
29 \\
30 \\
31\end{array}$ & $\begin{array}{l}.00 \\
.00 \\
.00 \\
.00 \\
.00 \\
.00\end{array}$ & $\begin{array}{l}.00 \\
.00 \\
.00 \\
.00 \\
.00 \\
. . .\end{array}$ & $\begin{array}{l}.51 \\
.00 \\
.00 \\
.00 \\
.00 \\
.00\end{array}$ & $\begin{array}{l}.00 \\
.00 \\
.25 \\
.00 \\
.00 \\
.00\end{array}$ & $\begin{array}{l}.00 \\
.00 \\
.00 \\
\ldots . \\
\ldots . \\
\ldots\end{array}$ & $\begin{array}{l}\ldots . \\
\ldots \\
\ldots \\
\ldots \\
\ldots\end{array}$ & $\begin{array}{l}.00 \\
.00 \\
.00 \\
.00 \\
.00 \\
. . .\end{array}$ & $\begin{array}{l}.00 \\
.00 \\
.00 \\
.00 \\
.00 \\
.00\end{array}$ & $\begin{array}{l}.00 \\
.00 \\
.00 \\
.00 \\
.00 \\
. . .\end{array}$ & $\begin{array}{r}5.33 \\
.25 \\
6.10 \\
.00 \\
5.33 \\
2.56\end{array}$ & $\begin{array}{l}.00 \\
.00 \\
.00 \\
.00 \\
.00 \\
.00\end{array}$ & $\begin{array}{l}.00 \\
.00 \\
.00 \\
.00 \\
.00 \\
. . .\end{array}$ \\
\hline
\end{tabular}


PRECIPITATION DATA-Cont inued

09397300 LITTLE COLORADO RIVER MEAR JOSEPH CITY, AZ-Continued

RAINFALL ACCUMULATED (MILLIMETERS), WATER YEAR OCTOBER 1989 TO SEPTEMBER 1990 DAILY SUM VALUES

\begin{tabular}{|c|c|c|c|c|c|c|c|c|c|c|c|c|}
\hline DAY & $\mathbf{O C T}$ & NOV & DEC & JAN & FEB & MAR & APR & maY & JUN & JUL & AUG & SEP \\
\hline $\begin{array}{l}1 \\
2 \\
3 \\
4 \\
5\end{array}$ & $\begin{array}{l}.00 \\
.00 \\
.00 \\
.00 \\
.00\end{array}$ & $\begin{array}{l}.00 \\
.00 \\
.00 \\
.00 \\
.00\end{array}$ & $\begin{array}{l}.00 \\
.00 \\
.00 \\
.00 \\
.00\end{array}$ & $\begin{array}{l}.00 \\
.25 \\
.00 \\
.00 \\
.00\end{array}$ & $\begin{array}{r}1.02 \\
3.81 \\
.25 \\
.00 \\
1.78\end{array}$ & $\begin{array}{l}.00 \\
.00 \\
.00 \\
.00 \\
.00\end{array}$ & $\begin{array}{l}.00 \\
.00 \\
.00 \\
.00 \\
.00\end{array}$ & $\begin{array}{l}.00 \\
.25 \\
.00 \\
.00 \\
.00\end{array}$ & $\begin{array}{l}.00 \\
.00 \\
.00 \\
.00 \\
.00\end{array}$ & $\begin{array}{l}.00 \\
.76 \\
.00 \\
.00 \\
.00\end{array}$ & $\begin{array}{l}.00 \\
.00 \\
.00 \\
.00 \\
.00\end{array}$ & $\begin{array}{r}4.57 \\
.51 \\
.00 \\
.00 \\
.51\end{array}$ \\
\hline $\begin{array}{r}6 \\
7 \\
8 \\
9 \\
10\end{array}$ & $\begin{array}{l}.00 \\
.00 \\
.00 \\
.00 \\
.00\end{array}$ & $\begin{array}{l}.00 \\
.00 \\
.00 \\
.00 \\
.00\end{array}$ & $\begin{array}{l}.00 \\
.00 \\
.00 \\
.00 \\
.00\end{array}$ & $\begin{array}{l}.00 \\
.00 \\
.00 \\
.00 \\
.00\end{array}$ & $\begin{array}{l}.00 \\
.00 \\
.00 \\
.00 \\
.00\end{array}$ & $\begin{array}{l}.00 \\
.00 \\
.00 \\
.00 \\
.00\end{array}$ & $\begin{array}{l}.00 \\
.51 \\
.00 \\
.00 \\
.00\end{array}$ & $\begin{array}{l}.00 \\
.00 \\
.00 \\
.00 \\
.00\end{array}$ & $\begin{array}{r}.00 \\
.00 \\
.00 \\
1.78 \\
.25\end{array}$ & $\begin{array}{r}.51 \\
8.38 \\
1.27 \\
.00 \\
.00\end{array}$ & $\begin{array}{l}.25 \\
.00 \\
.00 \\
.00 \\
.25\end{array}$ & $\begin{array}{l}.00 \\
.00 \\
.00 \\
.00 \\
.00\end{array}$ \\
\hline $\begin{array}{l}11 \\
12 \\
13 \\
14 \\
15\end{array}$ & $\begin{array}{l}.00 \\
.00 \\
.00 \\
.00 \\
.00\end{array}$ & $\begin{array}{l}.00 \\
.00 \\
.00 \\
.00 \\
.00\end{array}$ & $\begin{array}{l}.00 \\
.00 \\
.00 \\
.00 \\
.00\end{array}$ & $\begin{array}{r}.00 \\
.00 \\
.00 \\
.00 \\
1.27\end{array}$ & $\begin{array}{l}.00 \\
.00 \\
.00 \\
.00 \\
.00\end{array}$ & $\begin{array}{r}.00 \\
.51 \\
3.30 \\
.25 \\
.00\end{array}$ & $\begin{array}{l}.00 \\
.00 \\
.00 \\
.00 \\
.00\end{array}$ & $\begin{array}{l}.00 \\
.00 \\
.00 \\
.00 \\
.00\end{array}$ & $\begin{array}{l}.00 \\
.00 \\
.00 \\
.00 \\
.00\end{array}$ & $\begin{array}{r}.00 \\
.00 \\
.00 \\
.76 \\
1.52\end{array}$ & $\begin{array}{r}.00 \\
.00 \\
2.03 \\
1.27 \\
14.73\end{array}$ & $\begin{array}{l}.00 \\
.00 \\
.00 \\
.00 \\
.00\end{array}$ \\
\hline $\begin{array}{l}16 \\
17 \\
18 \\
19 \\
20\end{array}$ & $\begin{array}{l}.00 \\
.00 \\
.00 \\
.00 \\
.00\end{array}$ & $\begin{array}{l}.00 \\
.00 \\
.00 \\
.00 \\
.00\end{array}$ & $\begin{array}{l}.00 \\
.00 \\
.00 \\
.00 \\
.00\end{array}$ & $\begin{array}{l}.00 \\
.00 \\
.00 \\
.00 \\
.00\end{array}$ & $\begin{array}{r}.00 \\
.00 \\
.00 \\
2.54 \\
1.27\end{array}$ & $\begin{array}{l}.00 \\
.00 \\
.00 \\
.00 \\
.00\end{array}$ & $\begin{array}{l}.00 \\
.00 \\
.76 \\
.00 \\
.00\end{array}$ & $\begin{array}{l}.00 \\
.00 \\
.00 \\
.00 \\
.00\end{array}$ & $\begin{array}{l}.00 \\
.00 \\
.00 \\
.00 \\
.00\end{array}$ & $\begin{array}{l}.00 \\
.00 \\
.00 \\
.00 \\
.00\end{array}$ & $\begin{array}{r}1.52 \\
.00 \\
.00 \\
.00 \\
.00\end{array}$ & $\begin{array}{l}.00 \\
.00 \\
.00 \\
.00 \\
.00\end{array}$ \\
\hline $\begin{array}{l}21 \\
22 \\
23 \\
24 \\
25\end{array}$ & $\begin{array}{r}3.56 \\
.00 \\
.00 \\
.00 \\
.00\end{array}$ & $\begin{array}{r}1.02 \\
.00 \\
.00 \\
.00 \\
.00\end{array}$ & $\begin{array}{l}.00 \\
.00 \\
.00 \\
.00 \\
.00\end{array}$ & $\begin{array}{l}.00 \\
.00 \\
.00 \\
.00 \\
.00\end{array}$ & $\begin{array}{l}.00 \\
.00 \\
.00 \\
.00 \\
.00\end{array}$ & $\begin{array}{l}.00 \\
.00 \\
.00 \\
.00 \\
.00\end{array}$ & $\begin{array}{r}.00 \\
.00 \\
.00 \\
4.32 \\
.25\end{array}$ & $\begin{array}{l}.00 \\
.00 \\
.00 \\
.00 \\
.00\end{array}$ & $\begin{array}{l}.00 \\
.00 \\
.00 \\
.00 \\
.00\end{array}$ & $\begin{array}{l}.00 \\
.00 \\
.00 \\
.00 \\
.00\end{array}$ & $\begin{array}{l}.00 \\
.00 \\
.00 \\
.00 \\
.00\end{array}$ & $\begin{array}{l}.00 \\
.00 \\
.00 \\
.00 \\
.00\end{array}$ \\
\hline $\begin{array}{l}26 \\
27 \\
28 \\
29 \\
30 \\
31\end{array}$ & $\begin{array}{l}.00 \\
.00 \\
.00 \\
.00 \\
.00 \\
.00\end{array}$ & $\begin{array}{l}.00 \\
.00 \\
.00 \\
.00 \\
.00 \\
\ldots .-\end{array}$ & $\begin{array}{r}.00 \\
.00 \\
.00 \\
6.60 \\
.00 \\
.00\end{array}$ & $\begin{array}{l}.00 \\
.00 \\
.00 \\
.00 \\
.00 \\
.00\end{array}$ & $\begin{array}{l}.51 \\
.25 \\
.00 \\
. . . \\
. .- \\
. . .\end{array}$ & $\begin{array}{l}.00 \\
.00 \\
.00 \\
.00 \\
.25 \\
.00\end{array}$ & $\begin{array}{l}.00 \\
.00 \\
.00 \\
.00 \\
.00 \\
. .-\end{array}$ & $\begin{array}{r}.00 \\
.00 \\
.00 \\
1.02 \\
1.52 \\
.00\end{array}$ & $\begin{array}{l}.00 \\
.00 \\
.00 \\
.00 \\
.00 \\
. . .\end{array}$ & $\begin{array}{l}.00 \\
.00 \\
.00 \\
.00 \\
.00 \\
.00\end{array}$ & $\begin{array}{l}.00 \\
.00 \\
.00 \\
.00 \\
.25 \\
.76\end{array}$ & $\begin{array}{l}.00 \\
.00 \\
.00 \\
.00 \\
.00 \\
. . .\end{array}$ \\
\hline
\end{tabular}


PRECIPITATION DATA-Continued

09397300 LITTLE COLORADO RIVER MEAR JOSEPH CITY, AZ-Continued

RAINFALL ACCUMLATED (MILLIMETERS), MATER YEAR OCTOBER 1990 TO SEPTEMBER 1991 DAILY SUM VALUES

\begin{tabular}{|c|c|c|c|c|c|c|c|c|c|c|c|c|}
\hline DAY & OCt & nov & DEC & JAN & FEB & MAR & APR & MAY & JUN & JUL & Nus & SEP \\
\hline $\begin{array}{l}1 \\
2 \\
3 \\
4 \\
5\end{array}$ & $\begin{array}{l}.00 \\
.25 \\
.00 \\
.00 \\
.00\end{array}$ & $\begin{array}{r}.00 \\
3.05 \\
4.32 \\
1.78 \\
.25\end{array}$ & $\begin{array}{l}.00 \\
.00 \\
.00 \\
.00 \\
.00\end{array}$ & $\begin{array}{r}.00 \\
.00 \\
1.02 \\
1.02 \\
4.06\end{array}$ & $\begin{array}{l}.00 \\
.00 \\
.00 \\
.00 \\
.00\end{array}$ & $\begin{array}{r}3.56 \\
5.33 \\
.00 \\
.00 \\
.00\end{array}$ & $\begin{array}{l}.00 \\
.00 \\
.00 \\
.00 \\
.00\end{array}$ & $\begin{array}{l}.00 \\
.00 \\
.00 \\
.00 \\
.00\end{array}$ & $\begin{array}{r}3.30 \\
.51 \\
.00 \\
.00 \\
.00\end{array}$ & $\begin{array}{l}.00 \\
.00 \\
.00 \\
.00 \\
.00\end{array}$ & $\begin{array}{l}.00 \\
.00 \\
.00 \\
.00 \\
.51\end{array}$ & $\begin{array}{l}.00 \\
.00 \\
.00 \\
.00 \\
.00\end{array}$ \\
\hline $\begin{array}{r}6 \\
7 \\
8 \\
9 \\
10\end{array}$ & $\begin{array}{l}.00 \\
.00 \\
.00 \\
.00 \\
.00\end{array}$ & $\begin{array}{l}.00 \\
.76 \\
.00 \\
.00 \\
.00\end{array}$ & $\begin{array}{l}.00 \\
.00 \\
.00 \\
.00 \\
.00\end{array}$ & $\begin{array}{r}11.18 \\
.00 \\
.00 \\
.00 \\
.00\end{array}$ & $\begin{array}{l}.00 \\
.00 \\
.00 \\
.00 \\
.00\end{array}$ & $\begin{array}{l}.00 \\
.00 \\
.00 \\
.00 \\
.00\end{array}$ & $\begin{array}{l}.00 \\
.00 \\
.00 \\
.00 \\
.00\end{array}$ & $\begin{array}{l}.00 \\
.00 \\
.00 \\
.00 \\
.00\end{array}$ & $\begin{array}{l}.00 \\
.00 \\
.00 \\
.00 \\
.00\end{array}$ & $\begin{array}{l}.00 \\
.00 \\
.00 \\
.00 \\
.00\end{array}$ & $\begin{array}{l}.00 \\
.00 \\
.00 \\
.00 \\
.00\end{array}$ & $\begin{array}{r}.00 \\
.25 \\
.51 \\
1.02 \\
.00\end{array}$ \\
\hline $\begin{array}{l}11 \\
12 \\
13 \\
14 \\
15\end{array}$ & $\begin{array}{l}.00 \\
.00 \\
.00 \\
.00 \\
.00\end{array}$ & $\begin{array}{l}.00 \\
.00 \\
.00 \\
.25 \\
.00\end{array}$ & $\begin{array}{r}.00 \\
5.59 \\
.00 \\
.00 \\
4.32\end{array}$ & $\begin{array}{l}.25 \\
.00 \\
.00 \\
.25 \\
.00\end{array}$ & $\begin{array}{l}.00 \\
.00 \\
.00 \\
.00 \\
.00\end{array}$ & $\begin{array}{l}.00 \\
.00 \\
.00 \\
.59 \\
.00\end{array}$ & $\begin{array}{l}.00 \\
.00 \\
.00 \\
.00 \\
.00\end{array}$ & $\begin{array}{l}.00 \\
.00 \\
.00 \\
.00 \\
.00\end{array}$ & $\begin{array}{r}2.79 \\
.76 \\
.00 \\
.00 \\
.00\end{array}$ & $\begin{array}{l}.00 \\
.00 \\
.00 \\
.00 \\
.00\end{array}$ & $\begin{array}{l}.25 \\
.00 \\
.00 \\
.00 \\
.00\end{array}$ & $\begin{array}{l}.00 \\
.00 \\
.00 \\
.00 \\
.00\end{array}$ \\
\hline $\begin{array}{l}16 \\
17 \\
18 \\
19 \\
20\end{array}$ & $\begin{array}{l}.00 \\
.00 \\
.00 \\
.00 \\
.00\end{array}$ & $\begin{array}{l}.00 \\
.00 \\
.00 \\
.00 \\
.00\end{array}$ & $\begin{array}{r}2.79 \\
.00 \\
.00 \\
.00 \\
.51\end{array}$ & $\begin{array}{l}.00 \\
.00 \\
.00 \\
.00 \\
.00\end{array}$ & $\begin{array}{l}.00 \\
.51 \\
.00 \\
.00 \\
.00\end{array}$ & $\begin{array}{l}.00 \\
.00 \\
.00 \\
.76 \\
.51\end{array}$ & $\begin{array}{l}.00 \\
.00 \\
.00 \\
.00 \\
.00\end{array}$ & $\begin{array}{l}.00 \\
.00 \\
.00 \\
.00 \\
.00\end{array}$ & $\begin{array}{l}.00 \\
.00 \\
.00 \\
.00 \\
.00\end{array}$ & $\begin{array}{l}.00 \\
.00 \\
.00 \\
.00 \\
.00\end{array}$ & $\begin{array}{l}.00 \\
.00 \\
.00 \\
.00 \\
.00\end{array}$ & $\begin{array}{l}.00 \\
.00 \\
.00 \\
.00 \\
.00\end{array}$ \\
\hline $\begin{array}{l}21 \\
22 \\
23 \\
24 \\
25\end{array}$ & $\begin{array}{l}.51 \\
.76 \\
.00 \\
.00 \\
.00\end{array}$ & $\begin{array}{l}.00 \\
.00 \\
.00 \\
.00 \\
.00\end{array}$ & $\begin{array}{r}.00 \\
1.27 \\
.25 \\
.00 \\
.00\end{array}$ & $\begin{array}{l}.76 \\
.00 \\
.25 \\
.00 \\
.00\end{array}$ & $\begin{array}{l}.00 \\
.00 \\
.00 \\
.00 \\
.00\end{array}$ & $\begin{array}{l}.00 \\
.00 \\
.00 \\
.00 \\
.00\end{array}$ & $\begin{array}{l}.00 \\
.00 \\
.00 \\
.00 \\
.00\end{array}$ & $\begin{array}{l}.00 \\
.00 \\
.00 \\
.00 \\
.00\end{array}$ & $\begin{array}{l}.00 \\
.00 \\
.00 \\
.00 \\
.00\end{array}$ & $\begin{array}{l}.00 \\
.00 \\
.00 \\
.00 \\
.00\end{array}$ & $\begin{array}{l}.00 \\
.00 \\
.00 \\
.00 \\
.00\end{array}$ & $\begin{array}{l}.00 \\
.00 \\
.00 \\
.00 \\
.00\end{array}$ \\
\hline $\begin{array}{l}26 \\
27 \\
28 \\
29 \\
30 \\
31\end{array}$ & $\begin{array}{l}.00 \\
.00 \\
.00 \\
.00 \\
.00 \\
.00\end{array}$ & $\begin{array}{r}3.30 \\
.00 \\
.00 \\
.00 \\
.00 \\
. . .\end{array}$ & $\begin{array}{r}.25 \\
.00 \\
2.54 \\
.00 \\
.00 \\
.00\end{array}$ & $\begin{array}{l}.00 \\
.00 \\
.00 \\
.00 \\
.00 \\
.00\end{array}$ & $\begin{array}{r}.00 \\
.00 \\
3.81 \\
\ldots .- \\
\ldots \\
\ldots\end{array}$ & $\begin{array}{r}.51 \\
.51 \\
1.78 \\
.00 \\
.00 \\
.00\end{array}$ & $\begin{array}{l}.00 \\
.00 \\
.00 \\
.00 \\
.00 \\
. .-\end{array}$ & $\begin{array}{r}.00 \\
.00 \\
.00 \\
.00 \\
.00 \\
1.78\end{array}$ & $\begin{array}{l}.00 \\
.00 \\
.00 \\
.00 \\
.00 \\
. . .\end{array}$ & $\begin{array}{l}.00 \\
.00 \\
.00 \\
.00 \\
.00 \\
.00\end{array}$ & $\begin{array}{l}.00 \\
.25 \\
.00 \\
.00 \\
.00 \\
.00\end{array}$ & $\begin{array}{l}.00 \\
.00 \\
.00 \\
.00 \\
.00 \\
. .-\end{array}$ \\
\hline
\end{tabular}




\section{PRECIPITATION DATA-Continued \\ 09401000 LITTLE COLORADO RIVER AT GRAND FALLS, AZ \\ RAINFALL ACCUMLATED (MILLIMETERS), DECEMBER 1989 TO SEPTEMBER 1990 \\ DAILY SUA VALUES}

\begin{tabular}{|c|c|c|c|c|c|c|c|c|c|c|c|c|}
\hline DAY & OCT & NOV & DEC & JAN & FEB & MAR & APR & MAY & JUN & JUL & AUG & SEP \\
\hline $\begin{array}{l}1 \\
2 \\
3 \\
4 \\
5\end{array}$ & $\begin{array}{l}\ldots- \\
\ldots- \\
\ldots- \\
\ldots- \\
\ldots-\end{array}$ & $\begin{array}{l}\ldots- \\
\ldots- \\
\ldots \\
\ldots- \\
-\ldots\end{array}$ & $\begin{array}{l}\cdots \\
\cdots \\
\cdots \\
\cdots \\
\cdots\end{array}$ & $\begin{array}{l}.00 \\
.00 \\
.00 \\
.00 \\
.00\end{array}$ & $\begin{array}{l}.00 \\
.00 \\
.00 \\
.00 \\
.00\end{array}$ & $\begin{array}{l}.00 \\
.00 \\
.00 \\
.00 \\
.00\end{array}$ & $\begin{array}{l}\ldots- \\
\ldots- \\
\ldots- \\
\ldots- \\
\ldots\end{array}$ & $\begin{array}{l}.00 \\
.25 \\
.00 \\
.00 \\
.00\end{array}$ & $\begin{array}{l}.00 \\
.00 \\
.00 \\
.00 \\
.00\end{array}$ & $\begin{array}{r}.00 \\
3.05 \\
1.52 \\
.00 \\
.00\end{array}$ & $\begin{array}{r}.00 \\
1.02 \\
.00 \\
.00 \\
.00\end{array}$ & $\begin{array}{r}.51 \\
.25 \\
1.52 \\
.00 \\
.00\end{array}$ \\
\hline $\begin{array}{r}6 \\
7 \\
8 \\
9 \\
10\end{array}$ & $\begin{array}{l}-- \\
-- \\
- \\
\cdots \\
\cdots\end{array}$ & $\begin{array}{l}\ldots \\
\ldots- \\
\ldots \\
\ldots \\
\cdots\end{array}$ & $\begin{array}{l}\ldots \\
\cdots \\
\cdots \\
\cdots \\
\cdots\end{array}$ & $\begin{array}{l}.00 \\
.00 \\
.00 \\
.00 \\
.00\end{array}$ & $\begin{array}{l}.00 \\
.00 \\
.00 \\
.00 \\
.00\end{array}$ & $\begin{array}{l}.00 \\
.00 \\
.00 \\
.00 \\
.00\end{array}$ & $\begin{array}{l}\ldots- \\
\ldots \\
\cdots \\
\cdots \\
\cdots\end{array}$ & $\begin{array}{l}.00 \\
.00 \\
.00 \\
.00 \\
.00\end{array}$ & $\begin{array}{l}.00 \\
.00 \\
.00 \\
.00 \\
.51\end{array}$ & $\begin{array}{r}.00 \\
2.54 \\
.00 \\
.00 \\
.51\end{array}$ & $\begin{array}{l}.00 \\
.00 \\
.00 \\
.00 \\
.00\end{array}$ & $\begin{array}{r}5.08 \\
.00 \\
.00 \\
.00 \\
.00\end{array}$ \\
\hline $\begin{array}{l}11 \\
12 \\
13 \\
14 \\
15\end{array}$ & $\begin{array}{l}\cdots \\
\ldots- \\
\cdots \\
\cdots \\
\cdots\end{array}$ & $\begin{array}{l}\ldots \\
\ldots \\
\ldots \\
\ldots\end{array}$ & $\begin{array}{l}\ldots \\
\ldots \\
\ldots \\
\cdots\end{array}$ & $\begin{array}{l}.00 \\
.00 \\
.00 \\
.00 \\
2.79\end{array}$ & $\begin{array}{r}.00 \\
.00 \\
.00 \\
1.02 \\
.00\end{array}$ & $\begin{array}{l}.00 \\
.00 \\
.25 \\
.25 \\
. .-\end{array}$ & $\begin{array}{l}\ldots- \\
\ldots \\
\ldots \\
\ldots \\
\ldots\end{array}$ & $\begin{array}{l}.00 \\
.00 \\
.00 \\
.00 \\
.00\end{array}$ & $\begin{array}{l}.00 \\
.00 \\
.00 \\
.00 \\
.00\end{array}$ & $\begin{array}{l}.00 \\
.00 \\
.00 \\
.00 \\
.00\end{array}$ & $\begin{array}{r}.00 \\
.00 \\
.00 \\
4.06 \\
3.56\end{array}$ & $\begin{array}{l}.00 \\
.00 \\
.00 \\
.00 \\
.00\end{array}$ \\
\hline $\begin{array}{l}16 \\
17 \\
18 \\
19 \\
20\end{array}$ & $\begin{array}{l}\ldots \\
\ldots \\
\ldots \\
\cdots \\
\cdots\end{array}$ & $\begin{array}{l}\ldots \\
\ldots \\
\ldots \\
\ldots\end{array}$ & $\begin{array}{l}\ldots \\
\ldots \\
. . \\
.00 \\
.00\end{array}$ & $\begin{array}{l}.25 \\
.00 \\
.00 \\
.00 \\
.00\end{array}$ & $\begin{array}{r}.00 \\
.00 \\
.00 \\
10.16 \\
4.83\end{array}$ & $\begin{array}{l}\ldots \\
\ldots \\
\ldots \\
\ldots \\
\ldots\end{array}$ & $\begin{array}{l}\ldots \\
\ldots \\
\ldots \\
\cdots \\
\cdots\end{array}$ & $\begin{array}{l}.00 \\
.00 \\
.00 \\
.00 \\
.00\end{array}$ & $\begin{array}{l}.00 \\
.00 \\
.00 \\
.00 \\
.00\end{array}$ & $\begin{array}{l}.00 \\
.00 \\
.51 \\
.00 \\
.00\end{array}$ & $\begin{array}{l}1.27 \\
1.02 \\
.00 \\
.00 \\
.00\end{array}$ & $\begin{array}{r}8.64 \\
.25 \\
13.97 \\
.00 \\
1.78\end{array}$ \\
\hline $\begin{array}{l}21 \\
22 \\
23 \\
24 \\
25\end{array}$ & $\begin{array}{l}\ldots \\
\ldots- \\
\cdots- \\
\cdots \\
\cdots\end{array}$ & $\begin{array}{l}\ldots- \\
\ldots- \\
\ldots- \\
\cdots- \\
\cdots-\end{array}$ & $\begin{array}{l}.00 \\
.00 \\
.00 \\
.00 \\
.00\end{array}$ & $\begin{array}{l}.00 \\
.00 \\
.00 \\
.00 \\
.00\end{array}$ & $\begin{array}{l}.00 \\
.00 \\
.00 \\
.00 \\
.00\end{array}$ & $\begin{array}{l}\ldots- \\
\ldots \\
\ldots \\
\ldots \\
\ldots\end{array}$ & $\begin{array}{r}.00 \\
.00 \\
3.30 \\
.00\end{array}$ & $\begin{array}{l}.00 \\
.00 \\
.00 \\
.00 \\
.00\end{array}$ & $\begin{array}{l}.00 \\
.00 \\
.00 \\
.00 \\
.00\end{array}$ & $\begin{array}{r}3.05 \\
.00 \\
4.32 \\
.00 \\
.00\end{array}$ & $\begin{array}{l}.00 \\
.00 \\
.00 \\
.00 \\
.00\end{array}$ & $\begin{array}{r}2.54 \\
.00 \\
.00 \\
.00 \\
.00\end{array}$ \\
\hline $\begin{array}{l}26 \\
27 \\
28 \\
29 \\
30 \\
31\end{array}$ & $\begin{array}{l}\cdots \\
\cdots \\
\cdots \\
\cdots \\
\cdots \\
\cdots\end{array}$ & $\begin{array}{l}\ldots- \\
\cdots \\
\cdots \\
\cdots \\
\cdots- \\
\cdots-\end{array}$ & $\begin{array}{r}.00 \\
.00 \\
.00 \\
11.43 \\
.00 \\
.00\end{array}$ & $\begin{array}{l}.00 \\
.00 \\
.00 \\
.00 \\
.00 \\
.00\end{array}$ & $\begin{array}{l}.25 \\
.00 \\
.00 \\
\cdots . \\
\cdots . \\
.-\end{array}$ & $\begin{array}{l}\ldots \\
\ldots \\
\ldots \\
\ldots \\
\ldots \\
\ldots\end{array}$ & $\begin{array}{l}.00 \\
.00 \\
.00 \\
.00 \\
.25 \\
. . .\end{array}$ & $\begin{array}{l}.00 \\
.00 \\
.25 \\
.00 \\
.00 \\
.00\end{array}$ & $\begin{array}{l}.00 \\
.00 \\
.00 \\
.00 \\
.00 \\
\cdots . .\end{array}$ & $\begin{array}{l}.00 \\
.00 \\
.00 \\
.00 \\
.00 \\
.00\end{array}$ & $\begin{array}{l}.00 \\
.00 \\
.00 \\
.00 \\
.00 \\
1.78\end{array}$ & $\begin{array}{l}.00 \\
.00 \\
.00 \\
.00 \\
.00 \\
. .-\end{array}$ \\
\hline
\end{tabular}


PRECIPITATION DATA-Cont inued

09401000 LITTLE COLORADO RIVER AT GRAND FALLS, AZ-cont inued

RAINFALL ACCUMULATED (MILLIMETERS), WATER YEAR OCTOBER 1990 TO SEPTEMBER 1991 DAILY SUM VALUES

\begin{tabular}{|c|c|c|c|c|c|c|c|c|c|c|c|c|}
\hline DAY & OCT & NOV & DEC & JAN & FEB & MR & APR & MAY & JUN & JUL & AUG & SEP \\
\hline $\begin{array}{l}1 \\
2 \\
3 \\
4 \\
5\end{array}$ & $\begin{array}{l}.00 \\
.00 \\
.00 \\
.00 \\
.00\end{array}$ & $\begin{array}{r}.00 \\
2.29 \\
1.52 \\
.25 \\
.00\end{array}$ & $\begin{array}{l}.00 \\
.00 \\
.00 \\
.00 \\
.00\end{array}$ & $\begin{array}{r}.00 \\
.00 \\
.00 \\
9.14 \\
.25\end{array}$ & $\begin{array}{l}.00 \\
.00 \\
.00 \\
.00 \\
.00\end{array}$ & $\begin{array}{r}10.16 \\
.00 \\
.00 \\
.00 \\
.00\end{array}$ & $\begin{array}{l}.00 \\
.00 \\
.00 \\
.00 \\
.00\end{array}$ & $\begin{array}{l}.00 \\
.00 \\
.00 \\
.00 \\
.00\end{array}$ & $\begin{array}{r}5.84 \\
.00 \\
.00 \\
.00 \\
.00\end{array}$ & $\begin{array}{l}.00 \\
.00 \\
.00 \\
.00 \\
.00\end{array}$ & $\begin{array}{r}13.72 \\
.00 \\
.00 \\
.00 \\
1.27\end{array}$ & $\begin{array}{l}1.52 \\
.00 \\
.00 \\
.00 \\
.00\end{array}$ \\
\hline $\begin{array}{r}6 \\
7 \\
8 \\
9 \\
10\end{array}$ & $\begin{array}{l}.00 \\
.00 \\
.00 \\
.00 \\
.00\end{array}$ & $\begin{array}{l}.00 \\
.00 \\
.00 \\
.00 \\
.00\end{array}$ & $\begin{array}{l}.00 \\
.00 \\
.00 \\
.00 \\
.00\end{array}$ & $\begin{array}{l}.00 \\
.00 \\
.00 \\
.00 \\
.00\end{array}$ & $\begin{array}{l}.00 \\
.00 \\
.25 \\
.00 \\
.00\end{array}$ & $\begin{array}{l}.00 \\
.00 \\
.00 \\
.00 \\
.00\end{array}$ & $\begin{array}{l}.00 \\
.00 \\
.00 \\
.00 \\
.00\end{array}$ & $\begin{array}{l}.00 \\
.00 \\
.00 \\
.00 \\
.00\end{array}$ & $\begin{array}{l}.00 \\
.00 \\
.00 \\
.00 \\
.00\end{array}$ & $\begin{array}{r}.00 \\
.00 \\
.00 \\
3.81 \\
.00\end{array}$ & $\begin{array}{r}5.59 \\
.00 \\
.00 \\
.51 \\
.00\end{array}$ & $\begin{array}{l}.00 \\
.00 \\
.00 \\
.00 \\
.00\end{array}$ \\
\hline $\begin{array}{l}11 \\
12 \\
13 \\
14 \\
15\end{array}$ & $\begin{array}{l}.00 \\
.00 \\
.00 \\
.00 \\
.00\end{array}$ & $\begin{array}{l}.00 \\
.00 \\
.00 \\
.00 \\
.00\end{array}$ & $\begin{array}{l}.00 \\
.00 \\
.00 \\
.00 \\
.00\end{array}$ & $\begin{array}{l}.00 \\
.00 \\
.00 \\
.00 \\
.00\end{array}$ & $\begin{array}{l}.00 \\
.00 \\
.00 \\
.00 \\
.00\end{array}$ & $\begin{array}{l}.00 \\
.00 \\
.00 \\
.00 \\
.00\end{array}$ & $\begin{array}{l}.00 \\
.00 \\
.00 \\
.00 \\
3.05\end{array}$ & $\begin{array}{l}.00 \\
.00 \\
.00 \\
.00 \\
.00\end{array}$ & $\begin{array}{l}.00 \\
.00 \\
.25 \\
.00 \\
.00\end{array}$ & $\begin{array}{l}.00 \\
.00 \\
.00 \\
.00 \\
.00\end{array}$ & $\begin{array}{r}.00 \\
3.30 \\
.00 \\
.76 \\
4.57\end{array}$ & $\begin{array}{l}.00 \\
.00 \\
.00 \\
.00 \\
.00\end{array}$ \\
\hline $\begin{array}{l}16 \\
17 \\
18 \\
19 \\
20\end{array}$ & $\begin{array}{l}.00 \\
.00 \\
.00 \\
.00 \\
.00\end{array}$ & $\begin{array}{l}.00 \\
.00 \\
.00 \\
.00 \\
.00\end{array}$ & $\begin{array}{r}2.54 \\
.76 \\
.00 \\
.00 \\
.00\end{array}$ & $\begin{array}{l}.00 \\
.00 \\
.00 \\
.00 \\
.00\end{array}$ & $\begin{array}{l}.00 \\
.00 \\
.00 \\
.00 \\
.00\end{array}$ & $\begin{array}{r}1.78 \\
.00 \\
.00 \\
.00 \\
1.52\end{array}$ & $\begin{array}{l}.00 \\
.00 \\
.00 \\
.00 \\
.00\end{array}$ & $\begin{array}{l}.00 \\
.00 \\
.00 \\
.00 \\
.00\end{array}$ & $\begin{array}{l}.00 \\
.00 \\
.00 \\
.00 \\
.00\end{array}$ & $\begin{array}{r}.00 \\
.00 \\
3.05 \\
.00 \\
10.67\end{array}$ & $\begin{array}{l}.00 \\
.00 \\
.51 \\
.00 \\
.00\end{array}$ & $\begin{array}{l}.00 \\
.00 \\
.00 \\
.00 \\
.00\end{array}$ \\
\hline $\begin{array}{l}21 \\
22 \\
23 \\
24 \\
25\end{array}$ & $\begin{array}{l}.00 \\
.00 \\
.00 \\
.00 \\
.00\end{array}$ & $\begin{array}{l}.00 \\
.00 \\
.00 \\
.00 \\
.00\end{array}$ & $\begin{array}{l}.00 \\
.00 \\
.00 \\
.00 \\
.00\end{array}$ & $\begin{array}{l}.00 \\
.00 \\
.00 \\
.00 \\
.00\end{array}$ & $\begin{array}{l}.00 \\
.00 \\
.00 \\
.00 \\
.00\end{array}$ & $\begin{array}{l}.00 \\
.00 \\
.00 \\
.00 \\
.00\end{array}$ & $\begin{array}{l}.00 \\
.00 \\
.00 \\
.00 \\
.00\end{array}$ & $\begin{array}{l}.00 \\
.00 \\
.00 \\
.00 \\
.00\end{array}$ & $\begin{array}{l}.00 \\
.00 \\
.00 \\
.00 \\
.00\end{array}$ & $\begin{array}{l}.00 \\
.00 \\
.00 \\
.51 \\
.51\end{array}$ & $\begin{array}{l}.00 \\
.00 \\
.00 \\
.25 \\
.25\end{array}$ & $\begin{array}{l}.00 \\
.00 \\
.00 \\
.00 \\
.00\end{array}$ \\
\hline $\begin{array}{l}26 \\
27 \\
28 \\
29 \\
30 \\
31\end{array}$ & $\begin{array}{l}.00 \\
.00 \\
.00 \\
.00 \\
.00 \\
.00\end{array}$ & $\begin{array}{r}2.29 \\
.00 \\
.00 \\
.00 \\
.00 \\
.--\end{array}$ & $\begin{array}{l}.00 \\
.00 \\
.25 \\
.00 \\
.00 \\
.00\end{array}$ & $\begin{array}{l}.00 \\
.00 \\
.00 \\
.00 \\
.00 \\
.00\end{array}$ & $\begin{array}{r}.00 \\
.00 \\
4.83 \\
\ldots . \\
\ldots . \\
. .\end{array}$ & $\begin{array}{r}3.30 \\
.00 \\
1.02 \\
.00 \\
.00 \\
.00\end{array}$ & $\begin{array}{l}.00 \\
.00 \\
.00 \\
.00 \\
.00 \\
. .-\end{array}$ & $\begin{array}{l}.00 \\
.00 \\
.00 \\
.00 \\
.00 \\
.00\end{array}$ & $\begin{array}{l}.00 \\
.00 \\
.00 \\
.00 \\
.00 \\
\cdots . .\end{array}$ & $\begin{array}{l}.00 \\
.00 \\
.00 \\
.00 \\
.00 \\
1.27\end{array}$ & $\begin{array}{l}.00 \\
.00 \\
.00 \\
.00 \\
.25 \\
.76\end{array}$ & $\begin{array}{l}.00 \\
.00 \\
.51 \\
.00 \\
.00 \\
. .\end{array}$ \\
\hline
\end{tabular}




\section{PRECIPITATION DATA-Cont inued \\ 09402000 LITTLE COLORADO RIVER NEAR CAMERON, AZ \\ RAinfAll ACCUMLATEd (MILLIMETERS), DECEMBER 1989 TO SEPTEMBER 1990 \\ DAILY SUN VALUES}

\begin{tabular}{|c|c|c|c|c|c|c|c|c|c|c|c|c|}
\hline DAY & OCT & NOV & DEC & JAN & FEB & MAR & APR & MAY & JUN & JUL & AUG & SEP \\
\hline $\begin{array}{l}1 \\
2 \\
3 \\
4 \\
5\end{array}$ & $\begin{array}{l}\ldots \\
\ldots \\
\ldots \\
\ldots \\
\ldots\end{array}$ & $\begin{array}{l}\cdots \\
\cdots \\
\cdots \\
\cdots \\
\cdots\end{array}$ & $\begin{array}{l}\ldots \\
\ldots \\
\ldots \\
\ldots \\
.00\end{array}$ & $\begin{array}{r}.00 \\
.76 \\
1.52 \\
.00 \\
.00\end{array}$ & $\begin{array}{l}.00 \\
.00 \\
.00 \\
.00 \\
.00\end{array}$ & $\begin{array}{l}.00 \\
.00 \\
.25 \\
.00 \\
.00\end{array}$ & $\begin{array}{r}.25 \\
.00 \\
.00 \\
1.78 \\
.00\end{array}$ & $\begin{array}{r}2.29 \\
.00 \\
.00 \\
.00 \\
.00\end{array}$ & $\begin{array}{l}.00 \\
.00 \\
.00 \\
.00 \\
.00\end{array}$ & $\begin{array}{l}.00 \\
.00 \\
.00 \\
.00 \\
.00\end{array}$ & $\begin{array}{r}.00 \\
3.81 \\
.00 \\
.00 \\
.00\end{array}$ & $\begin{array}{r}3.56 \\
6.86 \\
.00 \\
.00 \\
.51\end{array}$ \\
\hline $\begin{array}{r}6 \\
7 \\
8 \\
9 \\
10\end{array}$ & $\begin{array}{l}\ldots- \\
\ldots- \\
\ldots- \\
\ldots- \\
\ldots-\end{array}$ & $\begin{array}{l}\ldots \\
\ldots \\
\ldots \\
\cdots\end{array}$ & $\begin{array}{l}.00 \\
.00 \\
.00 \\
.00 \\
.00\end{array}$ & $\begin{array}{l}.00 \\
.00 \\
.00 \\
.00 \\
.00\end{array}$ & $\begin{array}{l}.00 \\
.00 \\
.00 \\
.00 \\
.00\end{array}$ & $\begin{array}{l}.00 \\
.00 \\
.00 \\
.00 \\
.00\end{array}$ & $\begin{array}{l}.00 \\
.00 \\
.00 \\
.00 \\
.00\end{array}$ & $\begin{array}{l}.00 \\
.00 \\
.00 \\
.00 \\
.00\end{array}$ & $\begin{array}{l}.00 \\
.00 \\
.00 \\
.00 \\
4.06\end{array}$ & $\begin{array}{r}2.54 \\
7.62 \\
.00 \\
.00 \\
.00\end{array}$ & $\begin{array}{l}.00 \\
.00 \\
.00 \\
.00 \\
.00\end{array}$ & $\begin{array}{l}.00 \\
.00 \\
.00 \\
.00 \\
.00\end{array}$ \\
\hline $\begin{array}{l}11 \\
12 \\
13 \\
14 \\
15\end{array}$ & $\begin{array}{l}\ldots . \\
\ldots \\
\ldots \\
\ldots \\
\ldots\end{array}$ & $\begin{array}{l}\cdots \\
\cdots \\
\cdots \\
\cdots \\
\cdots-\end{array}$ & $\begin{array}{l}.00 \\
.00 \\
.00 \\
.00 \\
.00\end{array}$ & $\begin{array}{l}.00 \\
.00 \\
.00 \\
.00 \\
.00\end{array}$ & $\begin{array}{l}.00 \\
.00 \\
.00 \\
.00 \\
.00\end{array}$ & $\begin{array}{r}.00 \\
2.03 \\
.00 \\
.00 \\
.00\end{array}$ & $\begin{array}{l}.00 \\
.00 \\
.00 \\
.00 \\
.00\end{array}$ & $\begin{array}{l}.00 \\
.00 \\
.00 \\
.00 \\
.00\end{array}$ & $\begin{array}{l}.00 \\
.00 \\
.00 \\
.00 \\
.00\end{array}$ & $\begin{array}{l}.00 \\
.00 \\
.00 \\
.00 \\
.00\end{array}$ & $\begin{array}{r}.00 \\
.00 \\
.00 \\
1.52 \\
6.86\end{array}$ & $\begin{array}{l}.00 \\
.00 \\
.00 \\
.00 \\
.00\end{array}$ \\
\hline $\begin{array}{l}16 \\
17 \\
18 \\
19 \\
20\end{array}$ & $\begin{array}{l}\ldots \\
\ldots \\
\ldots \\
\ldots \\
\ldots\end{array}$ & $\begin{array}{l}\ldots \\
\ldots \\
\ldots \\
\cdots \\
\cdots\end{array}$ & $\begin{array}{l}.00 \\
.00 \\
.00 \\
.00 \\
.00\end{array}$ & $\begin{array}{r}.00 \\
.00 \\
.00 \\
9.91 \\
.00\end{array}$ & $\begin{array}{r}.00 \\
.00 \\
.25 \\
13.21 \\
.00\end{array}$ & $\begin{array}{l}.00 \\
.00 \\
.00 \\
.00 \\
.00\end{array}$ & $\begin{array}{r}.00 \\
.00 \\
2.29 \\
.00 \\
.00\end{array}$ & $\begin{array}{l}.00 \\
.00 \\
.00 \\
.00 \\
.00\end{array}$ & $\begin{array}{l}.00 \\
.00 \\
.00 \\
.00 \\
.00\end{array}$ & $\begin{array}{l}.00 \\
.00 \\
.00 \\
.00 \\
.00\end{array}$ & $\begin{array}{r}4.32 \\
.00 \\
.00 \\
.00 \\
.00\end{array}$ & $\begin{array}{r}3.05 \\
.00 \\
13.97 \\
.25 \\
3.30\end{array}$ \\
\hline $\begin{array}{l}21 \\
22 \\
23 \\
24 \\
25\end{array}$ & $\begin{array}{l}\ldots \\
\ldots \\
\ldots \\
\ldots \\
\ldots\end{array}$ & $\begin{array}{l}\ldots \\
\ldots \\
\ldots \\
\cdots \\
\cdots\end{array}$ & $\begin{array}{l}.00 \\
.00 \\
.00 \\
.00 \\
.00\end{array}$ & $\begin{array}{l}.00 \\
.00 \\
.00 \\
.00 \\
.00\end{array}$ & $\begin{array}{l}.00 \\
.00 \\
.00 \\
.00 \\
.00\end{array}$ & $\begin{array}{l}.00 \\
.00 \\
.00 \\
.00 \\
.00\end{array}$ & $\begin{array}{r}.00 \\
.00 \\
.00 \\
3.81 \\
1.27\end{array}$ & $\begin{array}{l}.00 \\
.00 \\
.00 \\
.00 \\
.00\end{array}$ & $\begin{array}{l}.00 \\
.00 \\
.00 \\
.00 \\
.51\end{array}$ & $\begin{array}{r}.00 \\
.00 \\
34.54 \\
.00 \\
.00\end{array}$ & $\begin{array}{l}.00 \\
.00 \\
.00 \\
.00 \\
.00\end{array}$ & $\begin{array}{r}.25 \\
.25 \\
3.56 \\
.00 \\
.00\end{array}$ \\
\hline $\begin{array}{l}26 \\
27 \\
28 \\
29 \\
30 \\
31\end{array}$ & $\begin{array}{l}\ldots \\
\ldots \\
\ldots \\
\ldots \\
\ldots \\
\ldots\end{array}$ & $\begin{array}{l}\ldots- \\
\ldots \\
\ldots \\
\ldots \\
\ldots \\
\ldots\end{array}$ & $\begin{array}{r}.00 \\
.00 \\
.00 \\
10.41 \\
.00 \\
.00\end{array}$ & $\begin{array}{l}.00 \\
.00 \\
.00 \\
.00 \\
.00 \\
.00\end{array}$ & $\begin{array}{l}.00 \\
.00 \\
.25 \\
\ldots . \\
\ldots . \\
\ldots .\end{array}$ & $\begin{array}{r}.00 \\
.00 \\
.00 \\
1.52 \\
.00 \\
3.81\end{array}$ & $\begin{array}{r}.00 \\
.00 \\
.00 \\
.00 \\
8.38 \\
\ldots . .\end{array}$ & $\begin{array}{l}.00 \\
.00 \\
.00 \\
.00 \\
.00 \\
.00\end{array}$ & $\begin{array}{l}.00 \\
.00 \\
.00 \\
.00 \\
.00 \\
\ldots . .\end{array}$ & $\begin{array}{l}.00 \\
.00 \\
.00 \\
.00 \\
.00 \\
.00\end{array}$ & $\begin{array}{l}.00 \\
.00 \\
.00 \\
.00 \\
.00 \\
.00\end{array}$ & $\begin{array}{l}.00 \\
.00 \\
.00 \\
.00 \\
.00 \\
. .-\end{array}$ \\
\hline
\end{tabular}


PRECIPITATION DATA-Continued

09402000 LITTLE COLORADO RIVER NEAR CAMERON, AZ-Continued

RAINFALL ACCMULATED (MILLIMETERS), WATER YEAR OCTOBER 1990 TO SEPTEMBER 1991 DAILY SUM VALUES

\begin{tabular}{|c|c|c|c|c|c|c|c|c|c|c|c|c|}
\hline DAY & OCT & NOV & DEC & JAH & FEB & MAR & APR & MAY & JUN & JUL & AUG & SEP \\
\hline $\begin{array}{l}1 \\
2 \\
3 \\
4 \\
5\end{array}$ & $\begin{array}{r}.76 \\
1.02 \\
.00 \\
.00 \\
.00\end{array}$ & $\begin{array}{l}.00 \\
.00 \\
.00 \\
.00 \\
.00\end{array}$ & $\begin{array}{l}.00 \\
.00 \\
.00 \\
.00 \\
.00\end{array}$ & $\begin{array}{r}.00 \\
.00 \\
.00 \\
12.19 \\
.25\end{array}$ & $\begin{array}{l}.00 \\
.00 \\
.00 \\
.00 \\
.00\end{array}$ & $\begin{array}{r}5.59 \\
.00 \\
.00 \\
.00 \\
.00\end{array}$ & $\begin{array}{l}.00 \\
.00 \\
.00 \\
.00 \\
.00\end{array}$ & $\begin{array}{l}.00 \\
.00 \\
.00 \\
.00 \\
.00\end{array}$ & $\begin{array}{l}.00 \\
.00 \\
.00 \\
.00 \\
.00\end{array}$ & $\begin{array}{l}.00 \\
.00 \\
.00 \\
.00 \\
.00\end{array}$ & $\begin{array}{l}.00 \\
.00 \\
.00 \\
.00 \\
.00\end{array}$ & $\begin{array}{r}3.81 \\
.00 \\
.00 \\
.25 \\
.25\end{array}$ \\
\hline $\begin{array}{r}6 \\
7 \\
8 \\
9 \\
10\end{array}$ & $\begin{array}{l}.00 \\
.00 \\
.00 \\
.00 \\
.00\end{array}$ & $\begin{array}{r}3.30 \\
1.78 \\
.00 \\
.00 \\
.00\end{array}$ & $\begin{array}{l}.00 \\
.00 \\
.00 \\
.00 \\
.00\end{array}$ & $\begin{array}{l}.00 \\
.00 \\
.00 \\
.00 \\
.00\end{array}$ & $\begin{array}{l}.00 \\
.00 \\
.00 \\
.00 \\
.00\end{array}$ & $\begin{array}{l}.00 \\
.00 \\
.00 \\
.00 \\
.00\end{array}$ & $\begin{array}{l}.00 \\
.00 \\
.00 \\
.00 \\
.00\end{array}$ & $\begin{array}{l}.00 \\
.00 \\
.00 \\
.00 \\
.00\end{array}$ & $\begin{array}{l}.00 \\
.00 \\
.00 \\
.00 \\
.00\end{array}$ & $\begin{array}{l}.00 \\
.00 \\
.00 \\
.00 \\
.00\end{array}$ & $\begin{array}{l}.00 \\
.00 \\
.00 \\
.00 \\
.00\end{array}$ & $\begin{array}{l}.25 \\
.00 \\
.00 \\
.00 \\
.00\end{array}$ \\
\hline $\begin{array}{l}11 \\
12 \\
13 \\
14 \\
15\end{array}$ & $\begin{array}{l}.00 \\
.00 \\
.00 \\
.00 \\
.00\end{array}$ & $\begin{array}{l}.00 \\
.00 \\
.00 \\
.00 \\
.00\end{array}$ & $\begin{array}{l}.00 \\
.51 \\
.00 \\
.00 \\
.00\end{array}$ & $\begin{array}{l}.00 \\
.00 \\
.00 \\
.00 \\
.25\end{array}$ & $\begin{array}{l}.00 \\
.00 \\
.00 \\
.00 \\
.00\end{array}$ & $\begin{array}{r}.00 \\
.00 \\
.00 \\
.00 \\
1.78\end{array}$ & $\begin{array}{l}.00 \\
.00 \\
.00 \\
.00 \\
.00\end{array}$ & $\begin{array}{l}.00 \\
.00 \\
.00 \\
.00 \\
.00\end{array}$ & $\begin{array}{l}.00 \\
.00 \\
.00 \\
.00 \\
.00\end{array}$ & $\begin{array}{l}.00 \\
.76 \\
.00 \\
.00 \\
.00\end{array}$ & $\begin{array}{l}.25 \\
.00 \\
.00 \\
.00 \\
.00\end{array}$ & $\begin{array}{l}.00 \\
.00 \\
.00 \\
.00 \\
.00\end{array}$ \\
\hline $\begin{array}{l}16 \\
17 \\
18 \\
19 \\
20\end{array}$ & $\begin{array}{r}.00 \\
.00 \\
.00 \\
1.78 \\
.00\end{array}$ & $\begin{array}{l}.00 \\
.00 \\
.00 \\
.00 \\
.00\end{array}$ & $\begin{array}{r}2.54 \\
11.18 \\
.76 \\
.76 \\
.51\end{array}$ & $\begin{array}{l}.00 \\
.00 \\
.00 \\
.00 \\
.00\end{array}$ & $\begin{array}{l}.00 \\
.00 \\
.00 \\
.00 \\
.00\end{array}$ & $\begin{array}{r}12.95 \\
.00 \\
.00 \\
.00 \\
.51\end{array}$ & $\begin{array}{l}.00 \\
.00 \\
.00 \\
.00 \\
.00\end{array}$ & $\begin{array}{l}.00 \\
.00 \\
.00 \\
.00 \\
.00\end{array}$ & $\begin{array}{l}.00 \\
.00 \\
.00 \\
.00 \\
.00\end{array}$ & $\begin{array}{r}.00 \\
.00 \\
.25 \\
.00 \\
4.06\end{array}$ & $\begin{array}{r}.00 \\
.00 \\
1.27 \\
.00 \\
.00\end{array}$ & $\begin{array}{l}.00 \\
.00 \\
.00 \\
.00 \\
.00\end{array}$ \\
\hline $\begin{array}{l}21 \\
22 \\
23 \\
24 \\
25\end{array}$ & $\begin{array}{l}.00 \\
.00 \\
.00 \\
.00 \\
.00\end{array}$ & $\begin{array}{l}.00 \\
.00 \\
.00 \\
.00 \\
.00\end{array}$ & $\begin{array}{l}.00 \\
.00 \\
.00 \\
.00 \\
.00\end{array}$ & $\begin{array}{l}.00 \\
.00 \\
.00 \\
.00 \\
.00\end{array}$ & $\begin{array}{l}.00 \\
.00 \\
.00 \\
.00 \\
.00\end{array}$ & $\begin{array}{l}.00 \\
.00 \\
.00 \\
.00 \\
.00\end{array}$ & $\begin{array}{l}.00 \\
.00 \\
.00 \\
.00 \\
.00\end{array}$ & $\begin{array}{l}.00 \\
.00 \\
.00 \\
.00 \\
.00\end{array}$ & $\begin{array}{l}.00 \\
.00 \\
.00 \\
.00 \\
.00\end{array}$ & $\begin{array}{r}.02 \\
.00 \\
.00 \\
1.02 \\
17.53\end{array}$ & $\begin{array}{l}.00 \\
.00 \\
.00 \\
.00 \\
.00\end{array}$ & $\begin{array}{l}.00 \\
.00 \\
.00 \\
.00 \\
.00\end{array}$ \\
\hline $\begin{array}{l}26 \\
27 \\
28 \\
29 \\
30 \\
31\end{array}$ & $\begin{array}{l}.00 \\
.00 \\
.00 \\
.00 \\
.00 \\
.00\end{array}$ & $\begin{array}{l}.51 \\
.00 \\
.00 \\
.00 \\
.00 \\
-.-\end{array}$ & $\begin{array}{l}.00 \\
.00 \\
.00 \\
.00 \\
.00 \\
.00\end{array}$ & $\begin{array}{l}.00 \\
.00 \\
.00 \\
.00 \\
.00 \\
.00\end{array}$ & $\begin{array}{r}.00 \\
.00 \\
1.78 \\
-.- \\
-.- \\
-.-\end{array}$ & $\begin{array}{r}13.46 \\
4.57 \\
1.78 \\
.00 \\
.00 \\
.00\end{array}$ & $\begin{array}{l}.00 \\
.00 \\
.00 \\
.00 \\
.00 \\
\cdots .-\end{array}$ & $\begin{array}{l}.00 \\
.00 \\
.00 \\
.00 \\
.00 \\
.76\end{array}$ & $\begin{array}{l}.00 \\
.00 \\
.00 \\
.00 \\
.00 \\
. . .\end{array}$ & $\begin{array}{l}.011 \\
.09 \\
.00 \\
.00 \\
.00 \\
.00\end{array}$ & $\begin{array}{r}4.5 \% \\
.00 \\
.00 \\
.00 \\
.00 \\
.51\end{array}$ & $\begin{array}{l}.00 \\
.00 \\
.00 \\
.00 \\
.00 \\
. .\end{array}$ \\
\hline
\end{tabular}

